\title{
UC-NRLF
}

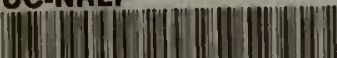

Tham

c ट $790 \quad 414$

ger

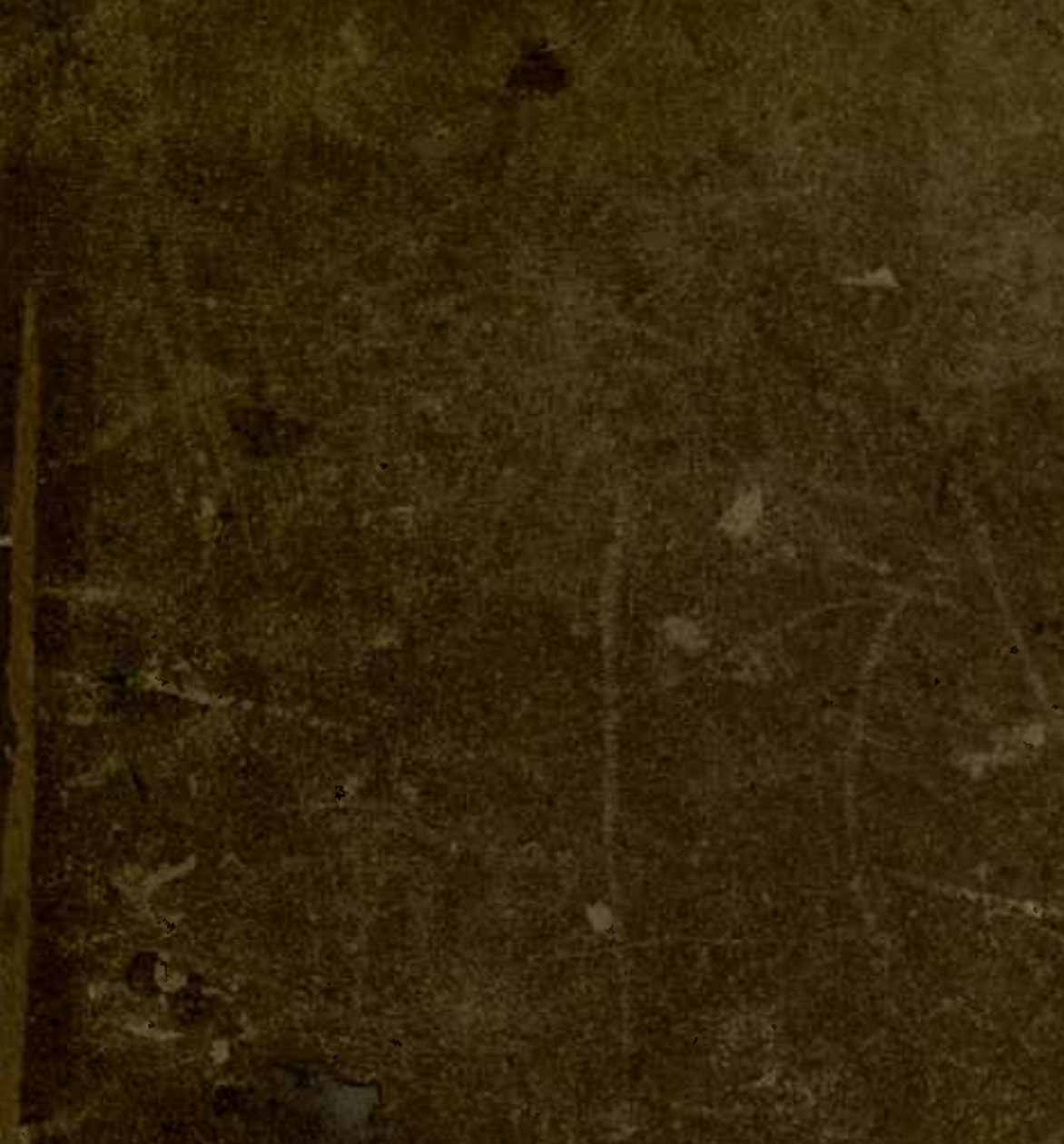



s.

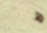

- 2 

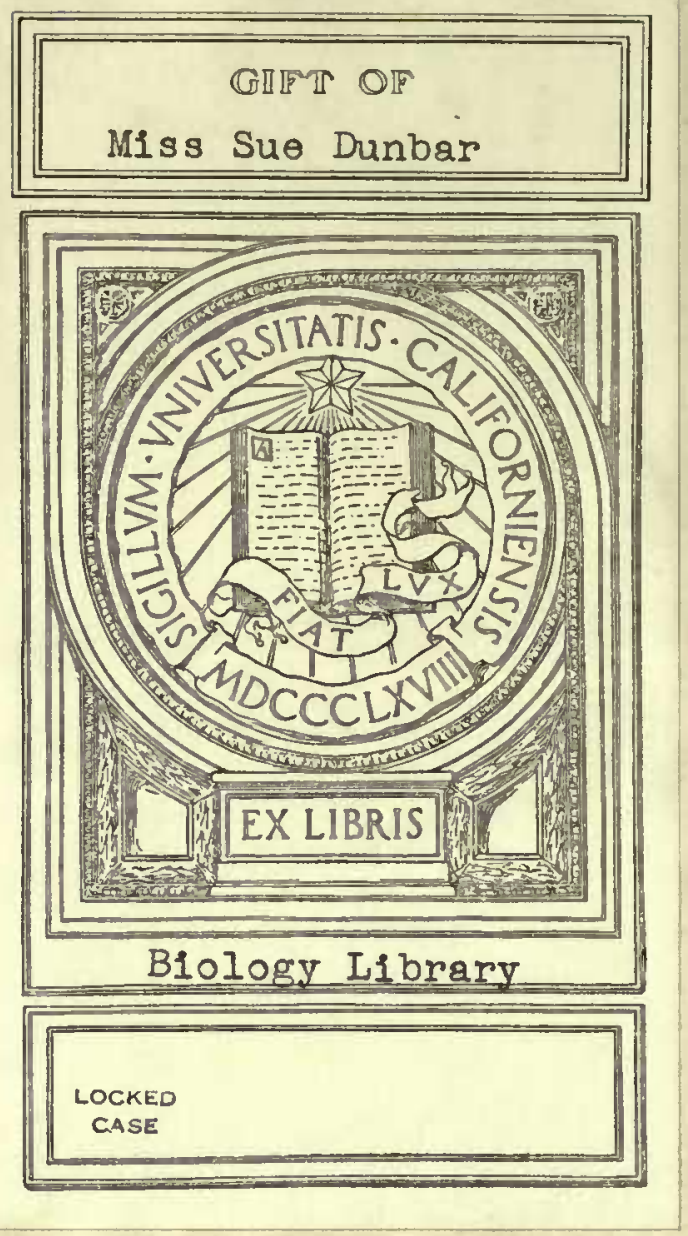





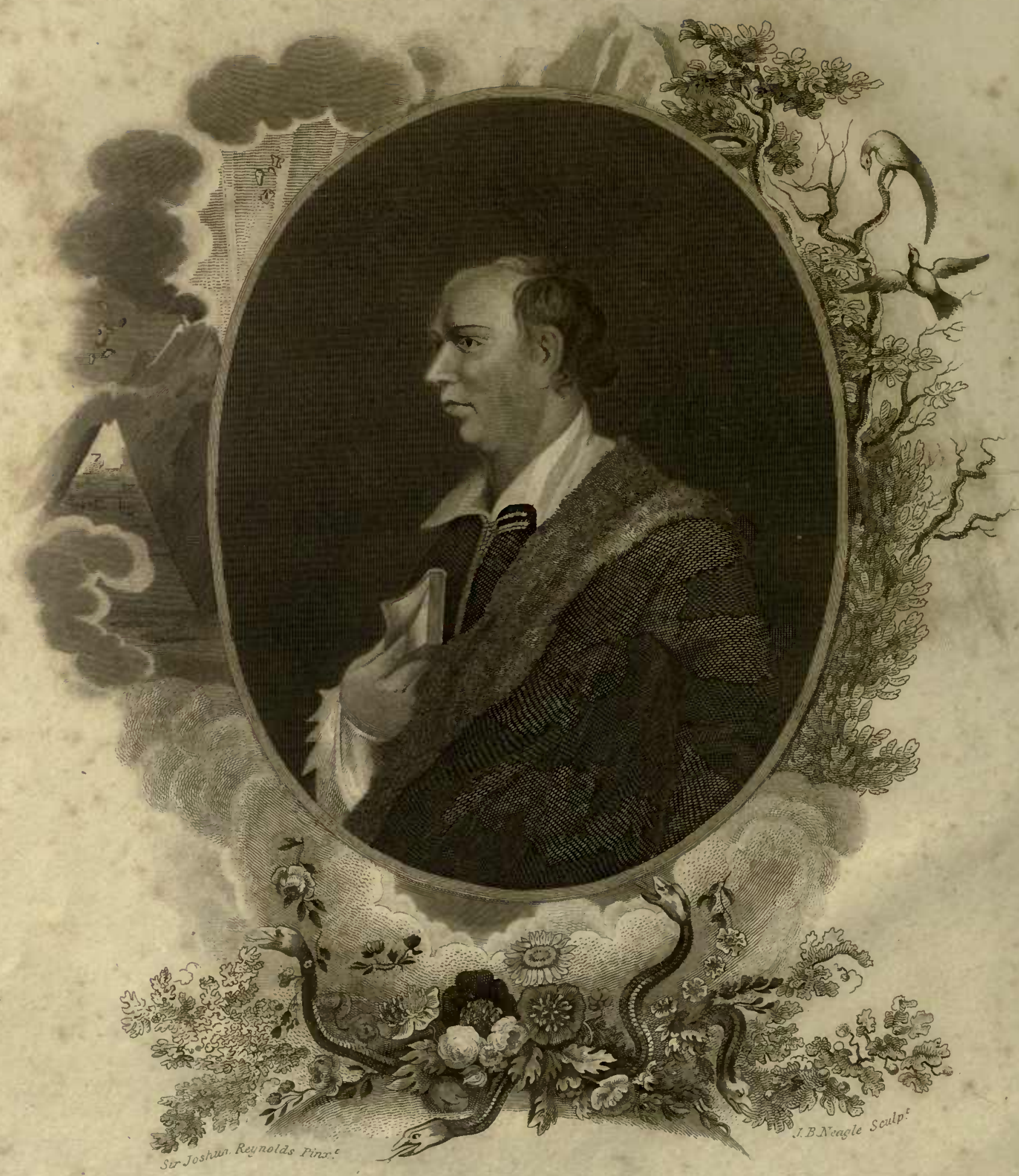




\section{HISTORY OF THE EARTH,}

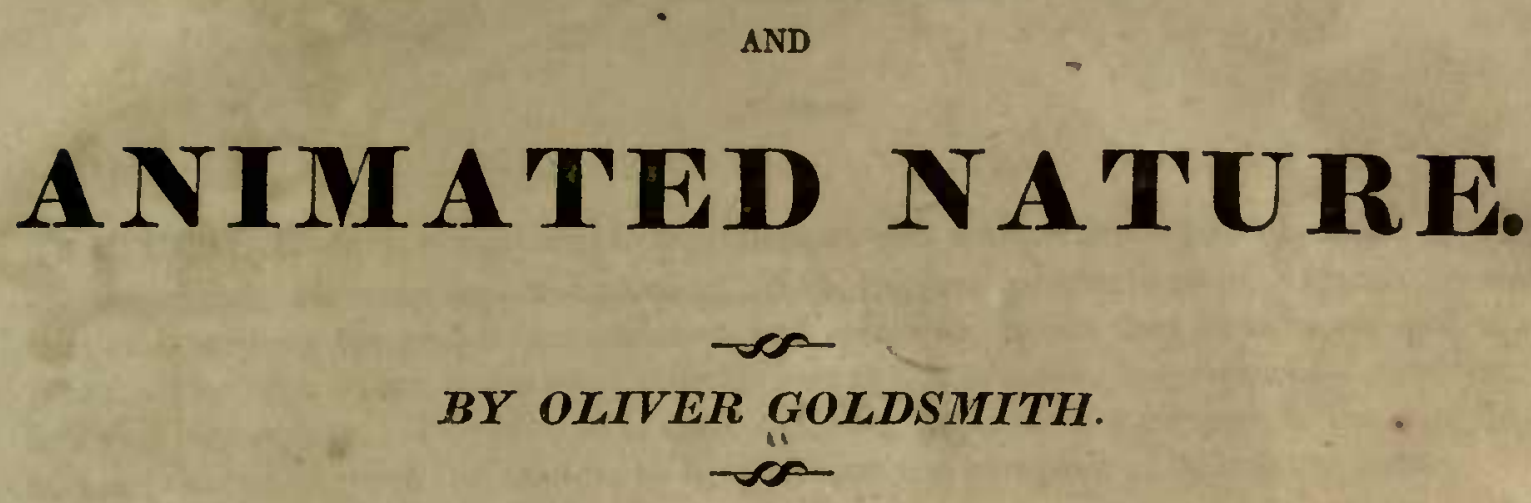

TO WHICH ARE ADDED,

\section{THE LIFE OF THE AUTHOR, HIS DESERTED VILLAGE,}

TRAVELLER, MISCELLANIES, \&c. \&c.

Adiet, sweet bard! to each fine feeling true, Thy virtues many, and thy fuibles few ;

Those forn'd to eharm e'en vicious mint's-and these

With harmless mirtl the soeial soul to please.

Another's woe thy heart could always melt;

None gave more free-for nove more deeply felt.

Sweet bard, adicu : thy own harmoniuus lays

Have sculptur'd out thy manument of praise

Xes, these survive to time's remotest day:

Whlle drops the bust, and boastful tombs decay.

Reader, if number'd In the muse's train,

Go, tune the lyre, and imitate bis atrain:

But, If no poet thou, reverse the plan;

Depart in peace, and imitate the man.

IN ONE YOLUME.

EMBELLISHED WITII $\Lambda$ SERIES OF BEAUTIFUL AND APPROPRIATE

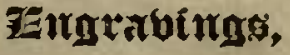

DESIGNED AND EXECUTED BY THE FIRST ARTISTS.

NEW-YORK :

PRINTED AND PUBLISHED BY THOMAS KINNERSLEY, OPPOSITE THE MANHATTAN BANK, BROADWAY.

1825. 


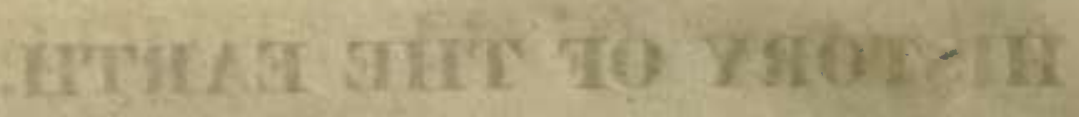

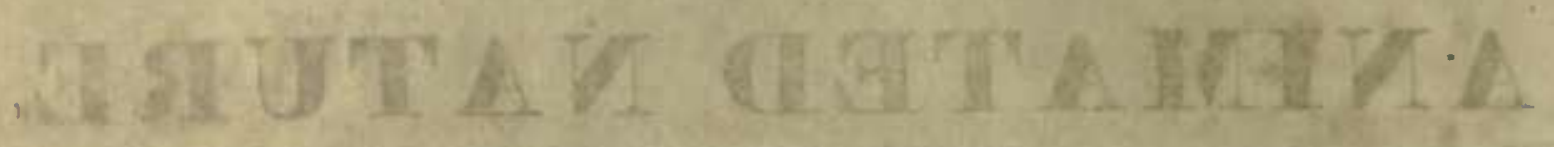

Regunitoditwo - Barkagy

$3+\frac{1}{2}$ 
$\mathbf{N}$

ATURAL History, considered in its utmost extent, comprehends two objects. First, that of discovering, ascertaining, and naming, all the various productions of Nature. Secondly, that of describing the properties, manners, and relations, which they bear to us, and to each other. The first, which is the most difficult part of this science, is systematical, dry, mechanical and incomplete. The second is more amusing, exhibits new pictures to the imagination, and improves our relish for existence, by widening the prospect of nature around us.

Both, however, are necessary to those who would understand this pleasing science in its utmost extent. The first care of every inquirer, no doubt, should be, to see, to visit, and examine, every object, before he pretends to inspect its habitudes or its history. From seeing and observing the thing itself, he is most naturally led to speculate upon its uses, its delights, or its inconveniences.

Numberless obstructions, however, are found in this part of his pursuit, that frustrate his diligence and retard his curiosity. The objects in nature are so many, and even those of the same kind are exhibited in sucl a variety of forms, that the inquirer finds himself lost in the exuberance before him, and, like a man who attempts to count the stars, unassisted by art, his powers are all distracted in barren superfluity.

To remedy this embarrassment, artificial systems have been devised, which grouping into masses those parts of nature more nearly resembling each other, refer the inquirer for the name of the single object he desires to know, to some one of those general distributions, where it is to be found by further examination.

If, for instance, a man should in his walks meet with an animal, the name, and consequently the history, of which he desires to know, he is taught by systematic writers of natural history to examine its most obvious qualities, whether a quadruped, a bird, a fish, or an insect. Having determined it, for explanation sake, to be an insect, he examines whether it has wings; if he finds it possessed of these, he is taught to examine whether it has two or four; if possessed of four, he is taught to observe whether the two upper wings are of a slielly hardness, and serve as cases to those under them; if he finds the wings composed in this manner, he is then taught to pronounce that this insect is one of the beetle kind: of the beetle kind, there are three different classes distinguished from each other by their feelers; he examines the inseet before him, and finds that the feelers are clavated or knobbed at the ends; of beetles, with feelers thus formed, there are ten kinds; and among those he is taught to look for the precise name of that which is before him. If, for instance, the knob be divided at the ends, and the 
belly be streaked with white, it is no other than the Dor, or the May-bug; an aninal, the noxious qualities of which give it a very distinguished rank in the history of the insect creation. In this manner a system of natural history may, in some measure, be compared to a dictionary of words. Both are solely intended to explain the names of things; but with this difference, that in the dietionary of words we are led from the name of the thing to its definition; whereas in the system of natural history, we are led from the definition to find out the name.

Such are the efforts of writers, who have composed their works with great labour and ingenuity, to direct the learner in his progress through nature, and to inform him of the name of every animal, plant, or fossil substance, that he happens to meet with: but it would be only deceiving the reader to conceal the truth, which is, that books alone can never teach hm this art in perfection; and the solitary student can never succeed. Without a master, and a previous knowledge of many of the objects of nature, his book will only serve to confound and disgust him. Few of the individual plants or animals, that he may happen to meet with, are in that precise state of health, or that exact period of vegetation, fiom whence their descriptions were taken. Perhaps he meets the plant only witl leaves, but the systematic writer has described it in flower. Perhaps he meets the bird before it has moulted its first feathers, while the systematic description was made in its state of full perfection. He thus ranges without an instructor, confused, and with sickening curiosity, from subject to subject, till at last he gives up the pursuit, in the multiplicity of his disappointments.

Some practice, therefore, much instruction, and diligent reading, are requisite to make a ready and expert naturalist, who shall be able, even by the help of a system, to find out the name of every object he meets with. But when this tedious, though requisite, part of study is attained, nothing but delight and variety attend the rest of his journcy. Wherever he travels, like a man in a country where he has many friends, he meets with nothing but acquaintances and allurements in all the stages of his way. The merc uninformed spectator passes on in gloomy solitude; but the naturalist; in every plant, in every insect, and every pebble, finds something to entertain his curiosity, and excite his speculation.

From hence it appears, that a system may be considered as a dictionary in the study of nature. The ancients, however, who have written most delightfully on this subject, seem entirely to have rejected those humble and mechanical helps to science. They contented themsclves with seizing upon the great outlines of history, and passing over what was common, as not worth the detail; they only dwelt upon what was new, great, and surprising, and sometimes even warmed the imagination at the expense of truth. Such of the moderns as revived this science in Europe, undertook the task more methodically, though not in a manner so pleasing. Aldrovandus, Gesner, and Jolnnson, seemed desirous of uniting the entertaining and rich descriptions of the ancients with the dry and systematic arrangement, of which they were the first projectors. This attempt, however, was extremely imperfect, as the great variety of nature was, as yet, but very inadequately known. Nevertheless, by attempting to carry on both objects at once, first directing us to the name of the thing, and then giving the detail of its history, they drew out their works into a tedious and unreasonable length; and thus mixing incompatible aims, they have left their labours rather to be occasionally consulted, than read with delight, by posterity 
The later moderns, with that good sense which they have carried into every other part of science, have taken a different method in cultivating natural history. They have been content to give, not only the brevity, but also the dry and disgusting air of a dictionary, to their systems. Ray, Klein, Brisson, and Linnæus, have luad only one aim, that of pointing out the object in nature, of discovering its name, and where it was to be found in those authors that treated of it in a more prolix and satisfactory manner. Thus natural history, at present, is carried on in two distinct and separate channels; the one serving to lead us to the thing, the other conveying the history of the thing, as supposing it already known.

The following Natural History is written with only such an attention to system as serves to remove the reader's embarrassments, and allure lim to procecd. It can make no pretensions in directing him to the name of every object he meets with; that belongs to works of a different kind, and written with very different aims. It will fully answer my design, if the reader, being already possessed of the name of any animal, shall find here a short, though satisfactory, history of its habitudes, its subsistence, its manners, its friendships, and hostilities. My aim has been to carry on just as much method as was sufficient to shorten my descriptions by generalizing them, and never to follow order where the art of writing, which is but another name for good sense, informed me that it would only contribute to the reader's embarrassment.

Still, however, the reader will perceive that I have formed a kind of system in the history of every part of animated nature, directing inyself by the great obvious distiuctions that she herself scems to have made; which, though too few to point exactly to the name, are yet sufficient to illuminate the subject, and remove the reader's perplexity. Mr. Buffon, indeed, who bas brought greater talents to this part of learning than any other man, lias alinost entirely rejected method in classing quadrupeds. This, with great deference to such a character, appears to me running into the opposite extreme; and, as some moderns have of late spent much time, great pains, and some learning, all to very little purpose, in systematic arrangement, he seems so much disgusted by their trifling, but ostentatious efforts, that he describes his animals almost in the order they happen to come before him. This want of method seems to be a fault; but he can lose little by a criticisin which every dull man can make, or by an error in arrangement, from which the dullest are most usually free.

In other respects, as far as this able philosopher has gone, I have taken him for my guide. The warmth of his style, and the brilliancy of his imagination, are inimitable. Leaving him, therefore, withont a rival in these, and only availing myself of his information, I have been content to describe things in my own way; and though many of the materials are taken from him, yet I have added, retrenched, and altered, as I thought proper. It was my intention at one time, whenever I differed from him, to have mentioned it at the bottom of the page; but this occurred so often, that I soon found it would look like envy, and might perhaps convict me of those very errors which I was wanting to lay upon him. I have, therefore, as being every way his debtor, concealed my dissent, where my opinion was different; but wherever I borrow from hin, I take care at the bottom of the page to express my obligations. But though my obligations to this writer are many, they extend to but the smallest part of the work, as he has hitherto completed only the history of quadrupeds. I was, therefore, left to my own reading alone, to make out the history of birds, fishes, and insects, of which the arrangement was so diffxo. 1. 
cult, and the necessary information so widely diffused, and so obscurely related when found, that it proved by much the most laborious part of the undertaking. Thus having made use of Mr. Buffon's lights in the first part of the work, I may with some share of confidence recommend it to the public. But what shall I say to that part, where I have been entirely left without his assistance? As I would affect neither modesty nor confidence, it will be sufficient to say, that my reading upon this part of the subject has been very extensive; and that I have taxed my scanty circumstances in procuring books, which are on this subject, of all others, the most expensive. In consequence of this industry, I here offer a work to the public, of a kind which has never been attempted in ours, or any other modern language, that I know of. The ancients, indeed, and Pliny in particular, have anticipated me in the present manner of treating natural history. Like those historians who describe the events of a campaign, they have not condescended to give the private particulars of every individual that formed the army ; they were content with characterizing the generals, and describing their operations, while they left it to meaner hands to carry the muster-roll. I have followed their manner, rejecting the numerous fables which they adopted, and adding the improvements of the moderns, which are so numerous, that they actually make up the bulk of natural history.

The delight which I found in reading Pliny, first inspired me with the idea of a work of this nature. Having a taste rather classical than scientific, and having but little employed myself in turning over the dry labours of modern system-makers, my earliest intention was to translate this agreeable writer, and by the help of a commentary to make my work as amusing as I could. Let us dignify natural history never so much with the grave appellation of an useful science, yet still we must confess, that it is the occupation of the idle and the speculative, more than of the busy and the ambitious part of mankind. My intention, therefore, was to treat what I then conceived to be an idle subject, in an idle manner; and not to hedge round plain and simple narratives with hard words, accumulated distinctions, ostentatious learning, and disquisitions that produced no conviction. Upon the appearance, however, of Mr. Buffon's work, I dropped my former plan, and adopted the present, being convinced, by his manner, that the best imitation of the ancients was to write from our own feelings, and to imitate nature.

It will be my chief pride, therefore, if this work may be found an innocent amusement for those who have nothing else to employ them, or who require a relaxation from labour. Professed naturalists will, no doubt, find it superficial; and yet I should hope that even these will discover hints and remarks, gleaned from various reading, not wholly trite or elementary. I would wish for their approbation. But my chief ambition is to drag up the obscure and gloomy learning of the cell to open inspection, to strip it from its garb of austerity, and to show the beauties of that form, which only the industrious and the inquisitive have been hitherto permitted to approach. 


\section{CONTENTS.}

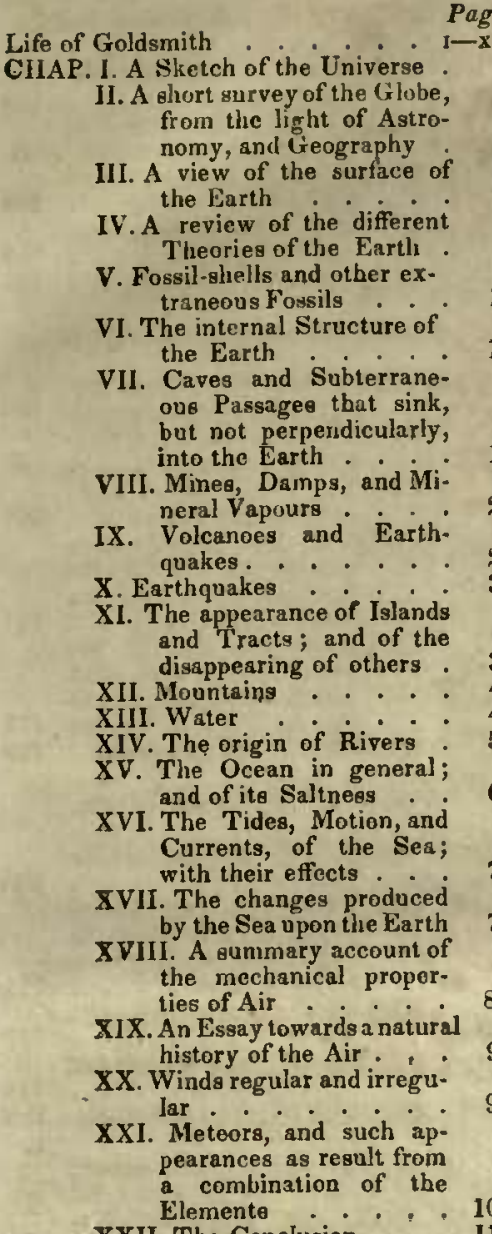

XXII. The Conclusion : 117

ANIMALS,

GHAP. XXIII. A comparison of Aninals with the inferior ranks of Creation

XXIV. The generation of Animals XXV. The Infancy of $\dot{M a n}: 133$ XXVI. Puberty . . . . 138 XXVI1. The Age of Monhood 140 XXVIII. Sleep and Hunger . 153 XXIX. Seeing , . . . . 159

XXX. Hearing . . . 164

XXXI. Smelling, Feeling, and

XXXII. Old Age and Death :

XXXIII. The Varieties in the Human Race

XXXIV. Monetere, 'Waxworks, \&c. . . . .

XXXVI. Aninıls : : : : 198

XXXVII. Quadrupeds in general, compered to Man .

ITIMALS OF THE HORSE XIND.

EHAP. XXXVIII. The Horse
CHAP. XXXIX. The Ass

$X L$. The Zebra

RUMINATING ANIMALS

CHAP. XLI. Introduction XLII. The Cow Kind The Buffalo

XLIII. Animals of the Sheep and Goat. Kind.

The Sheep....241

The Goat and its numerous Varjetics : : 245

The Gazclles 250

XI.IV. The Musk Animal : 255

XLV. Animals of the Deer

Kind Follow-Deer : : : 257
The

The Roe-buck . : : 267

The Elk . . . . . . 269

The Rein-Deer : * : 272

QUADRUPEDS OF THE HOG KIND.

CHAP. XLVI. Introduction . . . 279

The Wild Bosr . . . . ib.

The Hog . . . . 280

XLVII. The Peccary, or Tajacu 282

XLVIII. The Capibara, or Cabiai. . . 284

XLIX. The Babyrouessa, or Indian Ilog. . . . 285

CARNIYOROUS ANIMALS.

CHAP. L. Animals of the Cat Kind . 288 The Lion . . . . . . 292 The Tiger . . . 297 The Panther and the Leo.

pard
LI. Animals of the Dog Kind 307 The Wolf ? . . 317

The Fox. . . . 322

The Jacka! . . . . . 325

The Isatis . . . . . 326

The Hywa $\cdot \dot{*} \cdot 327$

LII. Animals of the WeaseI Kind . . . 328

The Ermine, or Stoat : 330

The Ferret . . : 332

The Pole-cat . . 333

The Martin . . . . 334

The Sable . : $: 336$

The Ichneumon . . 337

The Stinkards. . . . 333

The Genet. . : : 340

The Civet . . . . ib

The Glutton . . . 342

ANIMALS OF THE IIARE KIND.

Introduction . . . 345

The Hare . . . . $i b$

The Rabbit : : $: 349$

The Squirrel $: 351$

The Flying Squirrel. : 354

Tlie Marmout . . . : 355

The Agouti

The Pacs . . . . . 359

The Guinea-pig : : 360

ANIMALE OF THE RAT AND HEDQEHOQ KINDS.

CHAP. LIII. The Rat Kind . . 363 The Great Rat : : * ib.
CHAP. LIII. The Dormouse . . Page. The Musk-Rat : 367

The Cricetus . . . . 368

The Lening . . : 369

The Mole

LIV.The Hedgehog, or Prickly Kind . . 373

The Tanrec and Tendrac: 374

The Percupine . . . . 375

LV. Quadrupeds covered with seales or shells instead of hair . . . . . 377

The Pangolin : : 378

The Arnadillo, or Tatou . 380

LVI. Animals of the Rat Kind 382

LVII. Amplibious Quadrupeds $3 \& 6$

The Otter . . . . ib.

The Beaver . . . : 389

The Seal $: 392$

The Morse . . . . 395

The Manati . . . . 396

THE MONKEY KIND, THE ELEPHANT, RHINOCEnos, do.

CHAP. LVIII. Animals of the Menkey Kind 398

The Ouran Outang . . 398

The Baboon $: 404$

The Monkey . . . 400

The Maki : : 412

The Oppossum and its Kinds 413

LIX. The Elephant . . 416

LX. The Rhinoceros : . 425

LXI. The Hippopotamns : $\quad 427$

LXII. The Camelopard . . . 4:9

LXIII. The Camel and the

Dromedary. 430

LXIV. The Lama : . . 483

LXV. The Nyl-ghau $: \div 435$

LXVI. The Bear 436

LXVII. The Badger . . , . 438

LXVIII. The Tapir : 439

LXIX. The Racoon.

LXX. The Coatimondi . . 440

LXXI. The Ant-Bear : 44

LXXII. The Sloth 442

LXXIII. The Jerboa : : 444

\section{BIRDS,}

OF BIRDS IN GEVERAT

CIIAP. LXXIV. Introduction . . . 448

LXXV. The generation, nest-

ling, and incubation of Birds 454

LXXV1. The division of Birds 459

LXXVII. The Ostrich . 462

LXXVIH. The Emu . . 466

LXXIX. The Cassowary 467

LXXX. The Dodo ... : 469

RAPACIOUE BIRNS.

CIIAP. LXXXI. Rapacious Birds , . 471 LXXXII. Thie Eagle, \&c.. : 473

LXXXIII. The Condor of Amerieg

LXXXIV The Vultoin $47 \%$

I,XXXV. The Falcon Kind $4=6$

LXXXVI. The Buteher-Bird 486

LXXXVII. Rapacious Birds of the Owl Kind.

488

DIRDS OF THE POULTRY KIND.

CIIAP. LXXXVIII. Birds of the Poul. try Kind 


\section{CHAP. LXXXIX. The Cock}

XC. The Peacock

XCI. The T'urkey

XClI. The Pheasant

XCIII. The Pintada, or Guinea llen ..... XCIV. The Bustard : : 504

XCV. The Grous . . . 505

XCVI. The Partridge : . 507

XCVII. The Quail . . 509

BIRDS OF THE PIE KIND.

CHAP. XCVIII. Birds of the Pie Kind 511 XCIX. The Raven and the Crow 512 C. The Magpie . . . . 516 cl. The Woodpecker : . 519 CII. The Bird of Paradise . : 522 CIII. The Cuckoo . . . 523 CIV. The Parrot . . . 525 CV. The Pigeon . . . 529

BIRDS OF THE SPARROW KIND.

CHAP. CVI. Birds of the Sparrow Kind 533 CVII. The Thruslı, \&c . . 539 CVIII. The Nightingale, \&c. . 540 CIX. The Canary-Bird, \&c. . 544 CX. The Swallow ... 546 CXI. The Humming-Bird . . 548

BIRDS OF THE CRANE KIND.

CHAP. CXII. Birds of the Crane Kind in general *. . * 551 CXIII. The Crane . . . 552 CXIV. The Stork . . . 556 CXV. The Balearic and other Forcign Cranes . . . 557 CXVI. The Hcron, \&c. - . 559

CXVIJ. The Bittern . . . . 502

CXVIII. The Spoonbill. : $56{ }^{\circ}$

CXIX. The Flamingo . . 564

CXX. The Avosetta and the Corrira A. . .

CXXI. Sinall Birds of the Crane Kind. $\cdot$.

CXXII. The Water Hen and the Coot . . . . 572

\section{WATER-FOWL.}

CHAP. CXXIII. Water-Fowl in general

CXXIV. The Pelican

574

CXXV The Albatross

CXXVI. The Corniorant . . 580

CXXVII. The Gannet . : 582

CXXVIII. Smaller Gulls and . Petrels . CXXIX. The Penguin Kind : 587 CXXX. The Auk, Puffin, Sc. 589 CXXXI. Birds of the Goose Kind

CXXXII. The Swan : 593 CXXXIII. The Goose, \&c. : 596 CXXXIV. The Duck, \&cc. . 597 CXXXV. The King-Fisher . GU2

FISHES IN GENERAL.

CHAP. CXXXVI. Introduction CXXXVI1. Cetaccous Fislses in CXXXVIII. The Whale

CIIAP. CXXXIX. The Narwhalo . Pagé CXL. The Caclualot, \&c. : 623 CXL1. The Dolphin, tho Grampus, and the porpoise, Sic.

621

CARTILAGINOUS FISHES.

CHAP. CXLII. Cartilaginous Fishes in ceneral

CXLIII. Cartilaginous Fisies of the Shark Kind

CXLIV. Cartilaginous Flatfish of the Ray Kind .

CXLV. The Lamprey, Rc.

CXLVI. The Sturgeon, \&c. .

CXLVII. Anomalous Cartilaginous Fishes.

\section{SPIYOUS FISIIES.}

CHAP. CXL VIII. The Division of Spinous Fishes

SEct. I. Prickly-finned Fishes

Sect. IJ. Soft-finned Fisles

CXLIX. Spinous Fishes

627

629

632

638

CRUSTACEOUS AND TESTACEOUS FISHES.

CHAP. CL. TheDivisionof Shell-Fish 662 CLI. Crustaceous Animals of the Lobster Kind.

CLII. The Tortoise and its Kinds 669 CLIII. The Shell of 'Testaceous Fishes . . . .

CLIV. Turbinated Shell-fisls of the Snail Kind . 681

CLV. Bivalved Shell-fish, or Shells of the Oyster Kind 687

CLVI. Multivalvo Shell-fish 693

FROGS, LIZARDS, AND SERPENTS

FROGS AND TOADS.

CHAP. CLVII. Frogs and Toads in

CLVIIJ. The Frog and its Va: rieties . . . ib.

CLIX. The Toad and itsV arieties 702 THE ZIZARD EIND.

CHAP. CLX. Lizards in general . . 709 CLXI. The Crocodile, and its Affinities

CLXJI. The Salamander : 7 I7

CLXIII. The Chamelion, the Iguana, and Lizards of different Kinds

SERPENTS, \&C.

CLXIV. Serpents in general . . . 723 CLXV. Venomous Serpents in gencral . . . 732

CLXVI. Serpents withont venom 739

\section{INSECTS.}

INSECTS OF THE FIRST ORDER.

CHAP. CLXVII. Insects in general 743 CLXVIII. Insects without wings 746 CLXIX. The Spider and its Varicties
CHAP. CLXX. Tho Flea

CLXXI. The Louse and its Varieties ${ }^{\circ} \cdot{ }^{\circ}$ CLXXII. The Bug and its Variaties

CLXXIII. The Woodiouse and its Varieties

CLXXIV. The Monceulus, or Arborescent Water-flea

CLXXV. The Scorpion and its Varieties

CLXXVI. The Soolopendra and Gally-worm

CLXXVII. The Leech

Page

$75 \%$

753

756

758

ib.

739

762

INSECTS OF THE SECOND ORDEF

CHAP. CLXXVIII. The Second Order of Insects in general

CLXXIX. The Libella, or Dragon-fly

CLXXX. The Formica Leo, or Lion-Ant

CLXXXI. The Grasshopper the Locust, the Cicada, the Cricket, and the MoleCricket

CLXXXIJ. The Earwig, the Froth Insect, and some others belonging to the Second Order of Insects

CLXXXIII. The Ephenera

INSECTS OF THE THIRD ORDER.

CIIAP. CLXXXIV. Catcrpillars in gencral XV. The Transforma-

CLXXXV. The Transformato its corresponding Butterfly or Moth . . .

CLXXXVI. Butterfies and Moths ......

CLXXXVII. The Enemies of the Catcrpillar ..

CLXXXVIII. The Silkworm

INSECTS OF THE FOURTH ORDER.

CHAP. CLXXXIX. The Fourth Order of Insects in general 800

CLXL. The Bee . . . ib. CLXLI. The Wasp : 809 CLXLII. The Ichneumon Fly 813 CLXLIII. The Ant . . 814

CIXLIV. The Beetle and its Varieties . . . . 818

CLXLV. The Gnat and Tipula 825 THE ZOOPHYTES.

CHAP. CI.XLVI. Zoopliytes in general . . . . 828 CLXLVII. Worms : 829 CLXLVIII. The Star-fish * 832 CLXLIX The Polypus . 833 CC. Lythophytes and Sponges 837

\section{POETRY.}

Traveller ...... . 843

Deserted Village . : 850

Hermit . . . . . 855

Logicians Refuted : : 858

Esays $\quad 859-880$ 


\section{THE LIFE}

\section{OF

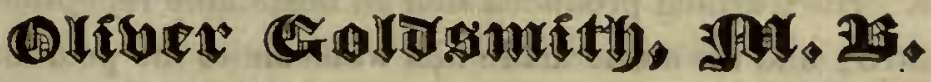

"THE life of a Scholar," Dr. Goldsmith has remarked, "seldom abounds with adventure: " his fame is acquired in solitude; and the historian, who only views him at a distance, must " be content with a dry detail of actions by which he is scarce distinguished from the rest of "mankind: but we are fond of talking of those who have given us pleasure; not that we have "any thing important to say, but because the subject is pleasing."

Oliver Goldsmith, son of the Reverend Charles Goldsmith, was born at Elphin, in the county of Roscommon, in Ireland, in the year 1729. His father had four sons, of whom Oliver was the third. After being well instructed in the classics, at the school of Mr. Hughes, he was admitted a sizer in Trinity College, Dublin, on the 11th of June, 1744. While he resided there, he exhibited no specimens of that genius, which, in maturer years, raised his character so high. On the 27 th of February, 1749, O. S. (two years after the regular time,) he obtained the degree of Bachelor of Arts. Soon after he turned his thoughts to the pro. fession of physic; and, after attending some courses of anatomy in Dublin, proceeded to Edinburgh, in the year 1751 , where he studied the several branches of medicine under the different professors in that university. His beneficent disposition soon involved him in unexpected difficulties; and he was obliged precipitately to leave Scotland, in consequence of haviug engaged himself to pay a considerable sum of money for a fellow student.

The beginning of the year 1754, he arrived at Sunderland, near Newcastle, where he was arrested at the suit of one Barclay, a taylor in Edinburgh, to whom he had given security for his friend. By the good offices of Laughlin Maclane, Esq. and Dr. Sleigh, who were then in 
the college, he was soon delivered out of the hands of the bailiff, and took his passage on board a Dutch ship to Rotterdam, where, after a short stay, he proceeded to Brussels. He then visited great part of Flanders; and, after passing some time at Strasbourg and Louvain, where he obtained a degree of Bachelor in Plyssic, he accompanied an English geutleman to Genera.

It is undoubtedly a fact, that this ingenious unfortunate man made most part of his tour on foot. He had left England with very little money; and being of a philosophic turn, and at that time possessing a body capable of sustammg every fatigue, and a heart not easily terrified by danger, he became an enthusiast to the design he lad formed of seeing the manners of different countries. He had some knowledge of the French language, and of music: he played tolerably well on the German flute; which, from amusement, became, at some times, the means of subsistence. His learning produced him an hospitable reception at most of the religious houses he visited; and his music made him welcome to the peasants of Flanders and Germany. "Whenever I approached a peasant's house towards night-fall," he used to say, "I played one of my most merry tunes, and that generally procured me not only a lodging, but subsistence for the next day: but, in truth," (his constant expression,) "I must own, whenever I attempted to entertain persons of a higher rank, they always thought my performance odious, and never made me any return for my endeavours to please them."

On his arrival at Geneva, he was recommended as a proper person for a travelling tutor to a young man, who had been unexpectedly left a considerable sum of money by his uncle Mr. S. ******. This youth, who was articled to an attorney, on the receipt of his fortune determined to see the world.

During Goldsmith's continuance in Switzerland, he assiduously cultivatesl his poetical talent, of which he had given some striking proofs at the college of Edinburgh. It was from heisce he sent the first sketch of his delightful epistle, called the Traveller, to his brother Henry, a clergyman in Ireland, who, giving up fame and fortune, had retired with an amiable wife to happiness and obscurity, on an income of only forty pounds a year. The great affection Goldsmith bore for this brother, is expressed in the poem before mentioned, and gives a striking picture of his situation.

From Geneva Mr. Goldsmith and his pupil proceeded to the south of France, where the young man, upon some disagreement with his preceptor, paid him the small part of his salary which was due, and embarked at Marseilles for Eugland. Our wanderer was left once more upon the world at large, and passed through a number of difficulties in traversing the greatest part of France. At length his curiosity being gratified, he bent his course towards England, and arrived at Dover, the beginning of the winter, in the year $\mathbf{3 7 5 8 .}$

His finances were so low on his return to England, that he with difficully got to the metropolis, his whole stock of cash amounting to no more than a few half-pence. An entire strangel in London, his mind was filled with the most gloomy reflections in consequence of his embar- 
rassed situation. He applied to several apothecaries, in hopes of being received in the capacity of a journeyman; but his broad Irish accent, and the uncouthness of his appearance, occasioned him to meet with insult from most of the medical tribe. The next day, however, a chymist, near Fish-street, struck with his forlorn condition, and the simplicity of his manner, took him into his laboratory, where he continued till he discovered that his old friend Dr. Sleigh was in London. "It was Sunday," said Goldsmith, "when I paid him a visit ; and it is to be supposed, in my best clothes. Sleigh scarcely knew me: such is the tax the unfortunate pay to pivelty. However, when be did recollect me, I found his heart as warm as ever; and he shared his purse and his friendship with me during his continuance in London." Goldsmith, unwilling to be a burden to his friend, a short time after, eagerly embraced an offer which was made him to assist the late Rev. Dr. Milner, in instructing the young gentlemen at the Academy at Peckham; and acquitted himself greatly to the Doctor's satisfaction for a short time; but, having obtained some reputation by the criticisms he had written in the Monthly Review, Mr. Griffith, the principal proprietor, engaged lim in the compilation of it; and resolving to pursue the profession of writing, he returned to London, as the mart where abilities of every kind were sure of meeting distinction and reward. Here he determined to adopt a plan of the strictest economy, and, at the close of the year 1759, took lodgings in Green-Arbour-Court, in the Old Baily, where he wrote several ingenious pieces. His first works were The Bee, a weekly pampliet; and An Inquiry into the present State of Polite Learning in Europe. The late Mr. Newberry, who, at that time, gave great encouragement to men of literary abilities, became a kind of patron to Goldsmith, and introduced him as one of the writers in the Public Ledger," in which his Citizen of the World originally appeared, under title of "Chinese Letlers."

Through the generosi $y$ of Mr. Newherry, for whom he had written and compiled a variety of pieces, or, in other terms, had held the "pen of a ready writer," our Author was enabled to shift his quarters from Green-Arbour-Court to Wine-Office-Court, in Fleet-street, where he put the finishing stroke to his Vicar of Wakffild. Having conciliated the esteem of Dr. Johnson by that passport to the human heart, flattery, the Colossus of Literature gave so strong a recommendation of Goldsmill's Novel, that the Author obtained sixty pounds for the copy; a sum far beyond his expectation, as he candidly acknowledged to a literary friend. It was, however, a very seasonable relief, as it extricated our Author from many embarrassments un-

(a) During this time (according to another account) he wrote for the British Magazine, of which Dr. Smollett was then editor, most of those Esrays and Tales, which he afterwards collecled and published in a separate volume. He also wrote occasionally for the Critical Review; and it was the meril which he discovered in criticising a despicable translation of Ovid's Fasti, hy a pedantic schoolmaster, and his Inquiry into the present State of Learning in Europe, which first introduced him to the acquaintance of Dr. Smollett, who recommended him to several literati, and to most of the booksellers by whom he was afterwards patronized. 
derr which he then laboured. But as Goldsmith's reputation as a writer was not yet establisl.ed, the bookseller was doubtful of the success of the Novel, and he kept the manuscript by him till the Traveller appeared, when he published it with great advantage.

Among many other persons of distinction who were desirous to know him, was the Duke of Northumberland, and the circumstance that attended his introduction to that nobleman, is worthy of being related, in order to show a striking trait of his character. "I was invited," said the Doctor, "by my friend Percy, to wait upon the Duke, in consequence of the satisfaction he had received from the perusal of one of my productions. I dressed myself in the best manner I could, and, after studying some compliments I thought necessary on such an occasion, proceeded to Northumberland house, and acquainted the servants that I had particular business with his Grace. They showed me into an anti-chamber, where, after waiting some time, a gentleman, very elegantly dressed, made his appearance. Taking him for the Duke, I delivered all the fine things I had composed, in order to compliment him on the honour he had done me; when, to my great astonishment, he told me I had mistaken him for his master, who would see me immediately. At that instant the Duke came into the apartment; and I vas so confounded on the occasion, that I wanted words barely sufficient to express the sense i entertained of the Duke's politeness, and went away exceedingly chagrined at the blunder I had committed."

The Doctor, at the time of this visit, was much embarrassed in his circumstances; but, vaiil of the honour done him, was continually mentioning it. One of those ingeniols executors of the law, a bailiff, who had a writ against him, determined to turn this circumstance to his own advantage. He wrote him a letter, that he was steward to a nobleman who was charmed with reading his last production, and had ordered him to desire the Doctor to appoint a place where he might have the honour of meeting him, to conduct him to his Lordship. The vanity of poor Goldsmith immediately swallowed the bait : he appointed the British Coffeehouse, to which he was accompanied by his friend Mr. Hamilton, the printer of the Critical Review, who in vain remonstrated on the singularity of the application. On entering the coffec-room, the hailiff paid his respects to the Doctor, and desired that he might have the honour of immediately attending him. They had scarce entered Pall-Mall, in their way to his Lorlship, when the bailiff produced his writ. Mr. Hamilton generously paid the money, and redeemed the Doctor from captivily.

Dr. Goldsmith, in 1765, produced his poem of the Traveller, which obtained the commendation of Dr. Johnson, who candidly acknowledged, "that there had not been so fine a Poen since the time of Pope." But such was his diffidence, that he kept the manuscript by him some years; nor could he be prevailed on to publish it, till persuaded by Dr. Johnson, who furnished him with some ideas for its enlargenent.

This Poem, in consequence of the reception it met with from the public, enhanced his 
literary character with the booksellers, and introduced him to the notice of several persons eminent for their rank and superior talents, as Lord Nugent, Sir Joshua Reynolds, Dr. Nugent, Beauclerc, Mr. Dyer, \&c. These distinguished characters were entertained with his conversation, and highly pleased with his blunders : at the same time they admired the elegance of his poems and simplicity of the man. He published, the same year, a Collection of Essays, which had previously appeared in the newspapers, magazines, and other periodical publications. But The Vicar of Wakefield, published in $\mathbf{1 7 6 6}$, established his reputation as a Novelist.

Goldsmith's finances augmented with his fame, and enabled him to live in a superior style; for, soon after the publication of his Traveller, he changed his lodgings in Wine-Office-Court for a set of chambers in the Inner Temple; and at the same time, in conjunction with Mr. Bott, a literary friend, took a country house on the Edgware Road, for the benefit of the air, and the convenience of retirement. He gave this little mansion the jocular appellation of the Shoemaker's Paradise, being built in a fantastic style by its original possessor, who was one of the craft.

In this rural retirement he wrote his History of England, in a Series of Letters from a Nobleman to his Son; and, as an incontestible proof of the merit of this production, it was generally supposed to have come from the pen of Lord Lyttleton, one of the most elegant writers of his time: and it may be further observed, to enhance the reputation of the work, that it was never disavowed by that Noble Lord to any of his most intimate friends. It had a very extensive sale, and was introduced into many seminaries of learning as a most useful guide to the study of Euglish history.

It was a true observation with the Doctor, that "of all his compilations, his Sclection of . English Poetry showed most the heart of the profession." To furnish copy for this work, it required no invention, and but little thought: he had only to mark with a pencil the particular passages for the printer, so that he easily acquired two hundred pounds; but then he observed, lest the premium should be deemed more than a compensation for the labour, "that a man shows his judgment in these selections; and he may be often twenty years of his life in cul. tivating that judgment."

His Comedy of the Good-natured Man was produced at Covent-Garden Theatre in 1768, which, though it exhibited strong marks of genius, and keen observations on men and manners. did not at first meet with that applause which was due to its merit. The bailiff scene was. generally reprobated, though the characters were well drawn; but, to comply, however, with the taste of the town, the scene was afterwarls greatly abridgeci. Many parts were highly applauded, as possessing great conic genius, and particularly that of Cronker, a character truly original, excellently conceived by the Anthor, and highly supported by Shuter, the most popular comedian of his day. The manner of his reading the incendiary leiter in the fourth sct, and the expression of the different passions by which he was agitated, produced shouts 
of applause. Goldsmith himself was so transported with the actiug of Shuter, that he expressed his gratitude to him before the whole company, assuring him, "he lad exceeded his own idea of the character, and that the fue comic riclness of his colouring made it almost appear as new to him as to any other person in the house." Dr. Johnson, as a to'sen of his friendship for the Author, wrote the prologue.

The production of this comedy added considerably to his purse, as, from the profits of his three nights, and the sale of the copy, he acquired the sum of five hundred pounds, which, with an additional sum he had reserved out of the product of a Roman History, in 2 vols. 8 vo. and an History of England, 4 vols. 8vo. he was enabled to descend from the attic story, he occupied in the Inner Temple, and take possession of a spacious suit of chambers in Brook-Court, Middle Temple, which he purchased at no less a sum than four hundred pounds. He was at the further charge of furnishing his chambers in an elegant manner, fitting up a handsone library, and procuring every article, convenient and ornamental, that was proper for the accommodation of a man who stood ligh in the republic of letters, and whose talents were re. warded in a degree proportionate to their merit.

But this improvement in his circumstances, and manner of living, by no means compensated for the mortification he underwent from the verysevere strictures of some rigid critics on his comedy. Sentimental writing was the prevailing taste of the town, with which a comedy, called False Delicacy, written by Kelly, abounded; and being got up at the Theatre in Drury Lane, under the superintendance of Mr. Garrick, it met with such general approbation, that it was performed for several successive nights with unbounded applause, and bore away the palm from Goldsmith's comedy, which came out much at the same time at the other theatre. False Delicacy became so popular a piece, that ten thonsand copies were sold in the course of only one season; and the booksellers concerned in the property, as a token of their acknowledgment of the merit of the comedy, apparent from its extraordinary sale, presented Kelly with a piece of plate of considerable value, and gave an elegant entertainment to him and his friends. These circumstances irritated the feelings of Goldsmith to so violent a degree, as to dissolve the bands of friendship between Kelly and him; for though, in every other instance, he bore a near resemblance to his own character of the Good Natured Man, yet, in literary fame, he "could bear no rival near his throne." Had not his countryman and fellow bard aspired at rivalship, had he been modestly content to move in an humbler sphere, he might not only have retained his friendship, but commanded his purse; but, as emphatically expressed by the same author from, whom we cited the last quotation; "To contend for the bow of Ulysses; this was a fault ; that way envy lay."

There is a humorous anecdote related of Goldsmith concerning a periodical publication in which he was jointly concerned with Dr. Kenrick, Bickerstan, and others. The publication son dropped; upon which a friend remarked that it was a very short-lived production, and 
had died a very extraordinary sudden death. common case; it died of too many Doctors."

"Not at all, Sir," said Goldsmith; "a very

But Goldsmith, soon disgusted with such trivial pursuits, applied himself to nobler subjects, and produced a highly finished Poem, called The Deserted Village. The bookseller gave lim a note of a hundred guineas for the copy, which Goldsmith returned, saying to a friend, "It is too much; it is more than the honest bookseller can afford, or the piece is worth." He estimated the value according to the following conputation; "That it was near five shillings a couplet, which was more than any bookseller could afford, or, indeed, any modern poetry was worth:" but the sale was so rapid, that the bookseller, with the greatest pleasure, soon paid him the hundred guineas, with acknowledgment for the generosity be had evinced upon the occasion.

The author addresses this Poem to his friend Sir Joshua Reynolds. He writes in the character of a native of a country village, to which he gives the name of Auburn, and which he pathetically addresses. He then proceeds to contrast the innocence and happiness of a sim. ple and a natural state with the miseries and vices that have been introduced by polished life, and gives the following beautiful apostrophe to retirement:

O blest retirement! friend to life's decline,

Retrents from care, that never must be mine;

How blest is he who crowns, in shades like these,

A youth of labour with an age of ease;

Who quits a world where strong temptations try,

And, since 'tis hard to combat, learus to fly!

For him no wretches, born to work and weep,

Explore the mine, or tempt the dangerous deep;
No surly porter stands in guilty state,

To spurn imploring famine from the gare;

But on he moves to meet his latter end,

Angels around befriending virtue's friend;

Sinks to the grave with unperceiv'd decay,

While resignation gently slopes the way;

And all his prospeets brightening to the last,

His heaven commences ere the world bo past!'

The description of the parish priest (probably intended for a character of his brother Henry) would have done honour to any poet of any age. In this description the simile of the bird teaching her young to fly, and of the mountain that rises above the storm, are not easily to be paralleled. The rest of the poem consists of the character of the village school-master, and a cescription of the village ale-house; both drawn with admirable propriety and force; a descant on the mischiefs of luxury and wealth; the variety of artificial pleasures; the mise. ries of those who, for want of employment at lome, are driven to settle new colonies abroad; and concludes with the following beautiful apostrophe to poetry:

and thou, sweet poetry! thou loveliest maid, itill first to fly where sensual joys invade; Infit, in these degenerate times of slame, To eatch the heart, or strike for honest fame; Dear charming nymph! neglected and decried,
My shame in crowds, my solitary pride;

Thou source of all my bliss, and all iny wne, That found'st me poor at first, and keep'st ine so; Thou guide, hy which the robler arts excel, Thou nurse of every virtue, fare thee well,

The Doctor did not reap a profit from his poetical labours equal to those of his prose. I he 
Earl of Lisburne, whose classical taste is well known, one day at a dinner of the Royal Academicians, lamented to the Doctor his neglecting the muses, and inquired of him why he forsook poetry, in which he was sure of charming his readers, to compile histories and write novels? The Doctor replied, 'My Lord, by courting the muses I shall starve; but by my other labours, I eat, drink, have good clothes, and enjoy the luxuries of life.'

This finished Poem was by no means a hasty production; it occupied two years in composing; and was the effect of the most minute observation, during an excursion of between four and five years. Soon after the appearance of this work, he paid a tribute to the merit of Dr. Parnell, in a Life prefixed to a new Edition of that elegant writer's "Poems on several occasions;" a work that does honour to the head and heart of the author.

The next Comedy the Doctor produced was in the year 1772: it was called, She Stoops to Conquer, and proved more successful than the Good-natured Man. Colman, who was then manager of Covent-Garden Theatre, and had given incontestible proofs of dramatic genius in the production of various excellent pieces, was greatly mistaken in his judgment of this romedy, which he thought too farcical, and bad consigned to condemnation at the time of its last rehearsal. Indeed, the performers, in general, coincided with the manager in opinion. The piece, however, notwithstanding the sentence pronounced by that acknowledged critic, was received with great applausc, to his mortification, and the exultation of the author, who was not a little piqued at the critic from the following circumstance.

The first night of the performance of his comedy, Goldsmith did not come to the house till it approached the close, having been ruminating in St. James's Park on the very important decision of the fate of his piece then pending; and such were his anxiety, and appreliension of its failure, that he was with great difficulty prevailed on to repair to the theatre, on the suggestion of a friend, who pointed out the necessity of his presence, in order to take cognizance of any passages that might appear objectionable, for the purpose of omission, or alteration in the repetition of the performance. Our Author, with an expectation suspended between hope and fear, had scarcely entered the passage that leads to the stage, than his ears were shock ed at a hiss, which proceedel from the audience, as a token of thcir disapprobation of the farcical supposition of Mrs. Hardcastle's being so palpably deluded, as to conceive herself at the distance of fifty miles from her house, when she was not at the distance of fifty yards. Such was the tremor and agitation of the Doctor on this unwelcome salute, that, running up to the manager, he exclaimed, "What's that?" Pshaw! Doctor," replied Colman, in a sarcastic tone, "don't be terrified at squibs, when we have been sitting these two hours upon a barrel of gunpowder." Goldsmith's pride was so hurt by the poignancy of this remark, that the friend-lip which had before subsisted between the Manager and the Author was dissolved for life.

The success of the comedy of She Stoops to Conquer produced a most illiberal personal at- 
tack on the author in one of the public prints. Enraged at this abusive publication, Dr. Goldsmith repaired to the house of the publisher, and, after remonstrating on the malignity of this attack on his character, began to apply his cane to the shoulders of the publisher, who, making a powerful resistance, from being the defensive soon became the offensive combatant. Dr. Kenrick, who was sitting in a private room of the publisher's, hearing a noise in the shop, came in, put an end to the fight, and conveycd the Doctor to a coach. The papers instantly teemed with fiesh abuse on the impropriety of the Doctor's attempting to beat a person in his own house, on which, in the Daily Advertiser of Wednesday, March 31, 177.3, he inserted the following address.

'TO THE PUBLIC.

'Lest it may be supposed that I have been willing to correct in others an abuse of which I have been guilty myself, I beg leave to declare, that, in all my life, I never wrote, or dictated, a single paragraph, letter, or essay, in a newspaper, except a few moral essays, under the character of a Chinese, about ten years ago, in the Ledger; and a letter, to which I signed my name, in the St. James's Chronicle. If the liberty of the press therefore has been abused, I have had no hand in it.

'I have always considered the press as the protector of our freedom, as a watchful guardian, capable of uniting the weak against the encroachments of power. What concerns the public, most properly admits of a public discussion. But of late, the press has turned from defending public interest, to making inroads upon private life; from combating the strong, to overwhelming the feeble. No condition is now too obscure for its abuse, and the protector is become the tyrant of the people. In this manner the freedom of the press is beginning to sow the seeds of its own dissolution; the great must oppose it from principle, and the weak from fear; till, at last, every rank of mankind shall be found to give up its benefits, content with security from its insults.

'How to put a stop to this licentiousness, by which all are indiscriminately abused, and by which vice consequently escapes in the general censure, I am unable to tell; all I could wish is, that, as the law gives us no protection against the injury, so it should give calumniators no shelter after having provoked correction. The insults which we receive before the public, by being more open, are the more distressing; by treating them with silent contempt, we do not pay a sufficient deference to the opinion of the world. By recurring to legal redress, we too oflen expose the weakness of the law, which only serves to increase our mortification by failing to relieve us. In short, every man should singly consider himself as a guardian of the liberty of the press, and, as far as his influence can extend, should endeavour to prevent its licentiousness becoming at last the grave of its freedom. 
The profits arising from his two comedies were estimated at $£ 1300$, rating the Good-natured Man at $£ 500$, and She Stoops to Conquer at $£ 800$, which, with the product of other works, amounted, as is asserted upon a good authority, to $£ 1800$; but, through a profuse liberality to indigent authors, and particularly those of his own country, who played on his credulity, together with the effects of a habit he had contracted for gaming, he found himsclf, at the close of that very year, not in a state of enjoyment of a pleasing prospect before him, but enveloped in the glooin of despondency, and all the perplexities of debt, accumulated by his own indiscretion.

It is remarkable, that, about this time, our Author altered his mode of address; he rejected the title of Doctor, and assumed that of plain Mr. Goldsmith. This innovation has been attributed to various causes. Some supposed he then formed a resolution never to engage as a practical professor in the healing art; others imagiued that he conceived the important appellation of Doctor, and the grave deportment attached to the character, incompatible with the man of fashion, to which he had the vanity to aspire; but, whatever might be his motive, he could not throw off the title, which the world imposed on him to the day of his death, and which is annexed to his memory at the present day; though he never obtained a degree superior to that of Bachelor of Physic.

Though Goldsmith was indiscreet, he was, at the same time, industrious; and, though his genius was lively and fertile, he frequently submitted to the dull task of compilation. He had previously written Histories of England, Greece, and Rome; and afterwards undertook, and finished, a work, entitled, An History of the Earth and Animated Nature,

His last production, Retaliation, though not intended for public view, but merely his own private amusement, and that of a few particular friends, exhibits strong marks of genuine humour. It originated from some jokes of festive merriment on the Author's person and dialect, in a club of literary friends, where good nature was sometimes sacrificed at the shrine of wit and sarcasm; and as Goldsmith could not disguise his feelings upon the occasion he, was called upon for retaliation, which be produced the very next club meeting.

It may not be so accurate as his other poetical productions, as he did not revise it, or live to finish it in the manner he intended; yet high eulogiums have been passed on it by some of the first characters in the learned world, and it has obtained a place in most of the editions of the English Poets.

Our Author now approached the period of his dissolution. He had been frequently attack: ed for some years with a strangury, and the embarrassed state of his affairs aggravated the violence of the disorder, which, with the agitation of his mind, brought on a nervous fever, 
that operated in so great a degree, that he exhibited signs of despair, and even a disgust with life itself.

Finding his disorder rapidly increase, he sent for Mr. Hawes, his apothecary, as well as intimate friend, to whom he related the symptoms of his malady. He told him he had taken two ounces of ipecacuanla wine as an emetic; and expressed a great desire of making trial of Dr. James's fever powders, which he desired him to send him. The apothecary represented to his patient the impropriety of taking this medicine at that time; but no argument could prevail with him to relinquish his intention; so that Mr. Hawes, apprehensive of the fatal consequences of his putting this rash resolve into execution, in order to divert him from it, requested permission to send for Doctor Fordyce, who attended immediately, on receiving the message.

Doctor Fordyce, of whose medical abilities Goldsmith always expressed the highest sense, corroborated the opinion of the apothecary, and used every argument to dissuade him from taking the powders; but, deaf to all the remonstrances of his physician and friend, he fatally persisted in his resolution; and when the apothecary visited him the following day, and inquired of him how he did, he fetched a deep sigh, and said, in a dejected tone, "He wished he had taken his friendly advice last night." Doctor Fordyce, alarmed at the dangerous symptoms which the disorder indicated, thought it necessary to call in the advice of another physician; and accordingly proposed sending for Doctor Turton, of whom he knew Goldsmith had a great opinion. The proposal was acceded to; a servant was immediately despatched with a message; and, on his arrival, the two doctors assisted at a consultation, which they continued regularly every day till the disorder put a period to the existence of their patient, on the fourth day of April, 1774, in the 45th year of his age.

His friends, who were very numerous and respectable, had determined to bury him in Westminster-abbey : his pall was to have heen supported by Lord Shelburne, Lord Louth, Sir Joshua Reynolds, the Honourable Mr. Beauclerc, Mr. Edmund Burke, and Mr. Garrick; but, from some unaccountable circumstances, this design was dropped; and his remains were privately deposited in the Temple burial-ground, on Satırday, the 9th of April; when Mr. Hugh Kelly, Messrs. John and Robert Day, Mr. Palmer, Mr. Etherington, and Mr. Hawes, gentlemen who had been his, fricuds in tife, attended his corpse as mourners, and paid the last tribute to his memory.

A subscription, however, was afterwards raised by his friends, to defray the expense of a marble monument, which was placed in Westminster-abbey, between Gay's monument and the Duke of Argyle's, in the Poet's corner, with the following Latin inscription, written by bis friend Dr. Samuel Johnson: 


\section{OLIVARI GOLDSMITI,}

Poetæe, Physici, Historici, qui nullum fere scribendi genus non tetigit,

nullun quod ietigit non ornavit;

sive risus esșent movendi, sive lacrymæ,

affectuum potens, at lenis dominator;

iugenio sublimis, vividus, versatilis ;

oratione grandis, nitidus, venustus;

hoc inonumento memoriain coluit

sodalium amor,

amicorum fides,

lectorum veneratio.

Natus Hibernia, Forniæ Loufordiensts,

in loco cui nomen Pallas,

Nov. xxix. MDCCXXXI.

Eblanse literis institutus, obiit Londini,

April ir. MLCCLXXIV.

\section{Translation.}

This monument is raised to the memory of

OLIVER NOLDSMITH,

Poet, Natural Philosopher, and Historian, who left no species of writing untouched, or unadorned by his pen,

whether to move laughter, or draw tears :

he was a powerful master over the affections,

though at the same time, a gentle tyraut;

$$
\text { of a genius }
$$

at once sublime, lively, and equal to every subject:

in expression at once noble, pure, and delicate.

His memory will last as long as society retains affection,

friendship is not void of honour,

and reading wants not her admirers.

He was born in the kingdom of Ireland, at Fernes, in the province of Leinster,

Where Pallas had set her name, Nov. 29, 1731.

He was educated at Dublin, and died in London, April 4, 1774.

We insert the following lines, in verse and prose, written by a friend immediately after his death, as they were deemed faithful transcripts of his character.

Here rests, from the cares of the world and his pen, A poet, whose like we shall scarce meet again; Who, though form'd in an age when corruption ran high,

And folly alone seem'd with folly to vie;

Wheri geuius, with traffic too commonly train'd, Recounted her merits by what she had gain'd;

Yet spurn'd at those walks of debasement and pelf,

And in poverty's spite dar'd to think for himself.

Thus fiee'd from those fetters the muses of bind,

He wrote from the heart to the hearts of mankind ;

And such was the prevalent force of his song,

Sex, ages, and parties, he drew in a throng.

The lovers-'twas theirs to esteem and commend, For his Hermit had prov'd bin their tutor and friend :

The statesmen, bis politic passions on fire,

Ackiowledg'd repose fron the charms of his lyre.

The moralist too had a feel for his rlyymes,

For his Essays were curbs on the rage of the times;

Nay, the critic, all school'd in grammatical sense,

Who look'd in the glow of description for sense;
Reform'd as he read, fell a dupe to his art, And confess'd by his eyes what he felt at his heart.

Yet, blest with original powers like these, His principal force was on paper to pleasc;

Like a fleet-footed hunter, thougb first in the chace, On the road of plain sense he oft slacken'd his pace; Whilst dullness and cunning, by whipping and goring, Their hard-footed hackneys paraded before him ; Compounded likewise of sucl prinitive parts, That his manncrs alone would have gain'd him our hearts.

So simple in truth, so ingenuously kind, So ready to fecl for the wants of inankind; Yet praise but an author of popular quill, His flux of philanthropy quickly stood still; Transform'd from himself, he grew meanly severe, And rail'd at those talents he ought not to fear.

Such then were lis foibles; but though thcy were such As shadow'd the picture a little too much, The style was all graceful, expressive and grand, And the whole the result of a masterly hand. 
The prosaic eulogium which follows, does the highest honour to his character, both literary and personal.

"In an age when genius and learning are too generally sacrificed to the purposes of ambition and avarice, it is the consolation of virtue, as well as its friends, that they can commemorate the name of Goldsmith as a shining example to the contrary.

" Early compelled (like many of the greatest men) into the service of the muses, he never once permitted his necessities to have the least improper influence on his conduct; but, knowing and respecting the honourable line of his profession, he made no farther use of fiction, than to set off the dignity of truth; and in this he succeeded so happily, that his writings stamp him no less the man of genius, than the universal friend of mankind.

"Such is the outline of his poetical character, which, perhaps, will be remembered, whilst the first rate poets of this country have any monuments left them. But, alas! his noble and inmortal part, the good man, is only consigned to the short-lived memory of those who are left to lament his death.

"Having naturally a powerful bias on his mind to the cause of virtue, he was cheerful and indefatigable in every pursuit of it; warm in his friendship, gentle in his manners, and in every act of charity and benevolence, "the very milk of human nature." Nay, even his foibles, and little weaknesses of temper, may be said rather to simplify than degrade his understanding; for, thongh there may be many instances adduced, to prove he was no man of the world, most of those instances would attest the unadulterated purity of his heart. One who esteemed the kindness and friendship of such a man, as forming a principal part of the happiness of his life, pays this last sincere and grateful tribute to his memory."

The esteem in which our Author was held by Dr. Johnson, is evident from the following passage, extracted from a letter of the Doctor to Mr. Boswell, soon after his demise. "Of poor dear Dr. Goldsmith there is little to be told, more than the papers have made public. He died of a fever, made, I am afraid, more violent by uneasiness of mind. His debts began to be heavy, and all his resources were exhausted. Sir Joshua Reynolds is of opinion, that he owed no less than two thousand pounds. Was ever poet so trusted before?"

To so high a degree of literary fane did Goldsmillı arrive, that the product of his writings in general is said to have amounted, in the course of fourteen years, to more than $£ 8000$, but this sum was dissipnted by an improsident liberality without discrimination of objects, and other foibles incidental to mankind, which our Author could not see in himself; or, if be could see, wanted resolution to correct. But with these foibles he possessed many virtues, and those particularly of humanity and benevolence, which disposed him to do all the good within his power; so that he lived respected, and died lamented.

"The perse, of Goldsmith," (says Mr. Boswell, in his Life of Dr. Johnson,) "was short; his countenance coarse and vulgar"; his deportment that of a scholar, awkwardly affecting the 
complete gentleman. No man had the art of displaying, with more advantage as a writer, whatever literary acquisitions lie made. His mind resembled a fertile but thin soil ; there was a quick but not a strong vegetation of whatever chanced to be thrown upon it. No deep root could be struck. The oak of the forest did not grow there; but the elegant shrubbery, and the fragrant parterre, appeared in gay succession. It has been generally circulated, and believed, that he was a mere fool in conversation. In allusion to this, Mr. Horatio Walpole, who admired his writings, said, he was "an inspired idiot;" and Garrick describes him as one:

\section{for shoriness call'd Noll, \\ Who wrote like an angel, and talk'd like pour Prill.}

But, in reality, these descriptions are greatly exaggerated. He had, no doubt, a more than common share of that hurry of ideas, which we often find in bis countrymen, and which sometimes introduces a laughable confusion in expressing them. He was very much what the French call un et vurdie; and from vanity, and an eager desire of being conspicuous wherever he was, he frequently talked carelessly, without any knowledge of the subject, or even without thought. Those who were any ways distinguished, excited envy in him to so ridiculous an excess, that the instances of it are hardly credible. He, I am told, had no settled system of any sort, so that his conduct must not be too strictly criticised; but his affections were social and generous; and when he had money, he bestowed it liberally. His desires of imaginary consequence frequently predominated over his attention to truth.

In the opinion of many of the literati, Goldsmith rivalled in prose writing, and even surpassed, Dr. Johnson. His prose has been admitted as the model of perfection, and the standard of the English language. Dr. Johnson says, "Goldsmith was a man of such variety of powers, and such felicity of performance, that he seemed to excel in whatever he attempted; a man who had the art of being minute without tediousness, and general without confusion; whose language was capacious without exuberance; exact without restraint ; and easy without weakness."

The most admired of his prosaic writings are the Vicar of Wakefield, Essays, Letters from a Nobleman to his Son, and Life of Parnell.

With respect to the Vicar of Wakefield, it is certainly a composition which has justly merited the applause of all discerning persons as one of the best novels in the English language. The diction is chaste, correct, and elegant. The characters are drawn to the life; and the scenes it exhibits are ingeniously variegated with humour and sentiment. The hero of the piece displays the most shining virtues that can adorn relative and social life; sincere in his professions, lumane and generous in his disposition, he is himself a pattern of the character he represents, enforcing that excellent maxim, that example is more powerful than precept. 
His wife is drawn as possessing many laudable qualifications; and her prevailing passion for external parade is an inoffensive foible, calculated rather to excite our mirth than incur our censure. The character of Olivia, the Vicar's eldest daughter, is contrasted with that of Sophia, the younger; the one being represented as of a disposition gay and volatile, the other as rather grave and steady; though neither of them seems to have indulged their peculiar propensity beyond the bounds of moderation.

Upon a review of this excellent production, it may be truly said, that it inculcates the purest lessons of morality and virtue, free from the rigid laws of stoicism, and adapted to attract the esteem and observation of every ingenious mind. It excites not a thought that can be injurious in its tendency, nor breaths an idea that can offend the chastest ear; or, as it has been expressed, the language is such as "angels might have heard, and virgins told." The writer, who suggested this pleasing idea, observes further, that, "if we do not always admire his knowledge or extensive philosophy, we feel the benevolence of his heart, and are charmed with the purity of its principles. If we do not follow, with awful reverence, the majesty of his reason, or the dignity of the long-extended period, we at least catch a pleasing sentiment in a natural and unaffected style."

Goldsmith's merit, as a poet, is universally acknowledged. His writings partake rather of the elegance and lyarmony of Pope, than the grandeur and sublimity of Milton; and, as we observed before, from the authority of Dr. Johnson, he rivals every writer of verse since the death of Pope; and it is to be lamented that his poetical productions are not more numerous; for though lis ideas flowed rapidly, he arranged them with great caution, and occupied much time in polishing his periods, and harmonizing his numbers:

His most favourite Poems are the Traveller, Deserted Village, Hermit, and Retaliation. These productions may justly be ranked with the most admired works in English Poetry.

The Traveller delights us with a display of charming imagery, refined ideas, and happy expression. The characteristics of the different nations are strongly marked, and the predilection of each inhabitant in favour of his own ingeniously described.

The Deserted Village is generally admired: the characters are drawn from the life. The descriptions are lively and picturesque; and the whole appears so easy and natural, as to bear the semblance of historical truth more thall poetical fiction,

The Hormit holds equal estimation with the rest of his poetical productions; and its beauties did not fail to attract the notice of the artist. The subject is delineated in a masterly manner by the pencil of Mr. Kirk, to which anple justice is done by the engraving of Mr. Anker Smith; and, through the united skill of those ingenious artists, produces a very chaste and elegant vignette.

His last poem of Retaliation, to which we have before adverted, is replete with humour, free 
xyi LIFE OF GOLDSMITH.

from spleen, and forcibly exhibits the prominent features of the several characters to which it alludes. Dr. Johnson, as reported by Mr. Boswell, sums up his literary character in the following concise manner. "Take him [Goldsmith] as a Poet, his Traveller is a very fine performance, and so is his Deserted Village, were it not sometimes too much the echo of his Traveller. Whether we takc him as a poet, as a comic writer. or as an historian, he stands in the first class." 


\section{HISTORY OF THE EARTH.}

\section{CHAPTER 1.}

\section{A SKETCH OF THE UNIVERSE.}

$\mathbf{T}$ HE world may be considered as one vast mansion, where man has becn admitted to enjoy, to admire, and to be grateful. The first desires of savage nature are merely to gratify the importunities of sensual appetite, and to neglect the contemplation of things, barely satisfied with their enjoyment: the beauties of nature, and all the wonders of creation, have but little charms for a being taken up in obviating the wants of the day, and anxious for precarious subsistence.

Philosophers, therefore, who liave testified such surprise at the want of euriosity in the ignorant, seem not to consider that they are usually employed in making provisions of a more important nature; in providing rather for the necessities than the amusements of life. It is not till our more pressing wants are sufficiently supplied, that we can attend to the calls of curiosity; so that in every age scientific refinement has been the latest effort of human industry.

But human curiosity, though at first slowly excited, being at last possessed of leisure for indulging its propensity, becomes one of the greatest amusements of life, and gives higher satisfactions than what even the senses can afford. A man of this disposition turns all nature into a magnificent theatre, replcte with objects of wonder and surprise, and fitted up chiefly for his happiness and entertainment: he industriously examines all things, from the minutest insect to the most finished animal; and, when his limited organs can no longer make the disquisition, he sends out his imagination upon new inquiries.

Nothing, therefore, can be more august and striking than the idea which his reason, aided by lis imagination, furnishes of the universe around him. Astronomers tell us, that this earth which we inhabit forms but a very minute part in that great assemblage of bodies of which the world is composed. It is a million of times less than the sun, by which it is enlightened. The planets also, which, like it, are subordinate to the sun's influence, exceed the earth a thousand times in magnitude. These, which were at first supposed to wander in the heavens without any fixed path, and that took their name from their apparent deviations, have long been found to perform their circuits with great exactness and strict regularity. They have been discovered as forming, with our earth, a system of bodies circulating round the sun, all obedient to one law, and impelled by one common influence.

Modern philosophy has taught us to believe, that, when the great Author of nature began the work of creation, he chose to operate by second causes; and that, suspending the constant exertion of his power, he cndued matter with a quality, by which the universal economy of nature might be con- 
tinued without his immediate assistance. This quality is called attraction; a sort of approximating influence, which all bodies, whether terrestrial or cclestial, are found to possess; and which in all increases as the quantity of matter in each increases. The sun, by far the greatest body in our system, is, of consequence, possessed of much the greatest share of this attracting power; and all the planets, of which our earth is one, arc, of course, entirely subject to its superior influence. Were this power, therefore, left uncontrolled by any other, the sun must quickly have attracted all the bodies of our celestial system to itself; but it is cqually counteracted by another power of equal efficacy; namely, a progressive force, which each planet received when it was impelled forward by the divine Architect, upon its first formation. The heavenly bodies of our system being thus acted upon by two opposing powers; namely, by that of attraction, which draws them towards the sun; and that of impulsion, which drives them straight forward into the great void of space; they pursue a track between these contrary directions; and each, like a stone whirled about in a sling, obeying two opposite forces, circulates round its great centre of heat and motion.

In this manner, therefore, is the harmony of our planetary system preserved. The sun, in the midst, gives heat, and light, and circular motion, to the planets which surround it : Mercury, Venus, the Earth, Mars, Jupiter, Saturn, and Herschel, or the Georgium Sidus, perform their constant circuits at different distances, each taking up a time to complete its revolutions proportioned to the greatuess of the circle which it is to describe. 'The lesser planets also, which are attendants upon some of the greater, are subject to the same laws; they circulate with the same exactness; and are, in the saine manner, influenced by their respective centres of motion.

Besides those bodies which make a part of our peculiar system, and which may be said to reside within its great circumference, there are others that frequently come among us, from the most distant tracts of space, and that scem like dangerous intruders upon the beautiful simplicity of nature. These are Concts, wliose appearance was once so terrible to mankind; and the theory of which is so little understood at present: all we know is, that their number is much greater than that of the planets; and that, like these, they roll in orbits, in some measure obedient to solar influence. Astronomers have endeavoured to calculate the returning periods of many of them; but experience has not, as yet, confirmed the veracity of their investigations. Indeed, who can tell, when those wanderers have made their exeursions into other worlds and distant systems, what obstacles may be found to oppose their progress, to accelerate their motions, or retard their return?

But what we have hitherto attempted to sketch, is but a small part of that great fabric in which the Deity has thought proper to manifest his wisdom and omuipotence. There are multitudes of other bodies, dispersed over the face of the heavens, that lie too remote for cxamination: these have no motion, such as the planets are found to possess, and arc therefore called fixed stars; and from theer cxtreme brilliancy, and their immense distance, plilosophers have been induced to suppose them to be suns, resembling that which enlivens our system. As the imagination also, once excited, is seldom content to stop, it has furnished each with an attendant system of planets belonging to itself; and has even induced sume to deplore the fate of those systems, whose imagined suns, which sometimes happens, have become no longer visible.

But conjectures of this kind, which no reasoning can ascertain, nor experiment reach, are rather amusing than useful. Though we see the greatness and wisdom of the Deity in all the sceming worlds that surround us, it is our chief concern to trace him in that which we inhabit. The cxamination of the earth, the wonders of its contrivance, the history of its advantages, or of the seeming defects in its formation, are the proper business of the natural historian. A description of this earth, its animals, vegetables, and mincrals, is the most delightful entertainment the mind can be furnished with, as it is the most interesting and useful. I would beg leave, therefore. to conclude these common-place speculations, with an observation which, I hope, is not entirely so.

An use, hitherlo not wuch insisted upon, that may result from the contemplation of ce- 
lestial magnificence, is, that it will teach us to make an allowance for the apparent irregularities we find below. Whenever we can examine the works of the Deity at a proper point of distance, so as to take in the whole of his design, we see nothing but uniformity, beauty, and precision. The hearens present us with a plan, which, though inexpressibly magnificent, is yet regular beyond the power of invention. Whenever. therefore, we find any apparent defects in the earth, which we are about to consider, instead of attempting to reason oursclves into an opinion that they are beautiful, it will be wiser to say, that we do not behold them at the proper point of distance, and that our eye is laid too close to the objects, to take in the regularity of their connexion. In short, we may conclude, that God, who is regular in his GREAT productions, acts with equal uniformity in the LITTLE.

\section{CHAPTER I.}

\section{A SHORT SURVEY OF THE GLOBE, FROM THE LIGHT OF ASTRONOMY AND GEOGRAPHY.}

ALL the sciences are in some measure linked with each other, and before the one is ended, the other begins. In a natural history, therefore, of the earth, we must begin with a short account of its situation and form, as given us by astronomers and geographers : it will be sufficient, however, upon this occasion, just to hint to the imagination, what they, by the most abstract reasonings, have forced upon the understanding. The earth which we inhabit is, as has been said before, one of those bodies which circulate in our solar system; it is placed at a happy middle distance from the centre; and even seems, in this respect, privileged beyond all other planets that depend upon our great luminary for their support. Less distant from the sun than Herschel, or the Georgium Sidus, Saturn, Jupiter, and Mars, and yet less parched up than Venus and Mereury, that are situate too near the violence of its power, the earth scems in a peculiar manner to share the bounty of the Creator: it is not, therefore, without reason, that mankind consider themselves as the peculiar objects of his providence and regard.

Besides that motion which the earth has round the sun, the circuit of which is performed in a year, it has another upon its own axle, which it performs in twenty-four hours. Thus, like a chariot-wheel, it has a compound motion; for while it goes forward on its journey, it is all the while turning upon itself. From the first of these two arise the grateful vicissitude of the seasons; from the second, that of day and night.

It may be also readily conceived, that a body thus whecling in circles will most probably be itself a sphere. The earth, beyond all possibility of doubt, is found to be so. Whenever its shadow happens to fall upon the moon, in an eclipse, it appears to be always circular, in whatever position it is projected : and it is easy to prove, that a body which in every position makes a circular shadow, must itself be round. The rotundity of the earth may be also proved from the meeting of two ships at sea: the topmasts of each are the first parts that are discovered by both, the under parts being hidden by the convexity of the globe which rises between them. The ships, in this instance, may be resembled to two men who approach each other on the opposite sides of a hill: their heads will first be seen, and gradually as they come nearer they will come entirely into view.

However, though the earth's figure is said to be spherical, we ought only to conceive it as being nearly so. It has been found in the last age to be rather flatted at both poles, so that its form is commonly resembled to that of a turnip. The cause of this swelling of the equator is ascribed to the greater rapidity of the motion with which the parts of the earth are there carried round ; and which, consequently, endeavouring to fly off, act in opposition to central attraction. The twirling of a mop may 
serve as an homely illustration; which, as cvery one has seen, spreads and grows broader in the niddle as it continues to be turned round.

As the carth receives light and motion from the sun, so it derives much of its warmth and power of regetation from the same bencficent source. However, the different parts of the globe participate of these advantages in very different proportions, and accordingly put on very different appearances; a polar prospect, and a landscape at the equator, are as opposite in their appearances as in their situation.

'The polar regions, that receive the solar beams iu a very oblique direction, and continue for one half of the year in night, receive but few of the genial comforts which other parts of the world enjoy. Nothing can be more mouruful or hideous than the picture which travellers present of those wretched regions. The ground, "which is rocky and barren, rears itself in every place in lofty mountains and inaccessible cliffs, and meets the mariner's eye at even forty leagues from shore These precipices, frightful in themselves, receive an additional horror from being constantly covered with ice and snow, which daily seern to accumulate, and fill all the valleys with increasing desolation. The few rocks and cliffs that are bare of snow, look at a distance of a dark brown colour, and quite naked. Upon a nearer approach, however, they are found replete with many different veins of coloured stone, here and there spread over with a little earth, and a scanty portion of grass and heath. The internal parts of the country are still more desolate and deterring. In wandering through these solitudes, some plains appear covered with ice, that, at first glance, seem to promise the traveller an easy journey. But these are even more formidable and more unpassable than the mountains themselves, being cleft with dreadful chasms, and every where abounding with pits that threaten certain destruction. The seas that surround these inhospitable coasts are still more astonishing, being covered with flakes of tloating ice, that spread like extensive fields, or that rise out of the water like enormous mountains. These,

- Crantz's History of Greenland, p. 3.

bIbid. p. $22 . \quad$ Ibid. p. 27. which are composed of materials as clear and transparent as glass, ${ }^{c}$ assume many strange and fantastic appearances. Some of them look like churches or castles, with pointed turrets ; some like ships in full sail; and people liave often given themselves the fruitless toil to attempt piloting the imaginary vessels into harbour. There are still others that appear like large islands, with plains, valleys, and hills, which often rear their heads two hundred yards above the level of the sea ; and although the height of these be amazing, yet their depth beneath is still more so; some of them being found to sink three hundred fathom under water.

The earth presents a very different appearance at the equator, where the sun-beams, darting directly downwards, burn up the lighter soils into extensive sandy deserts, or quicken all the moister tracts with incredible vegetation. In these regious, almost all the saine inconveniences are felt from the proximity of the sun, that in the former were endured from its absence The deserts are entirely barren, except where they are found to produce serpents, and that in such quantities, that some extensive plains seem almost entirely covered with them."

It not unfrequently happens also, that this dry soil, which is so parched and comminuted by the force of the sun, rises with the smallest breeze of wind; and the sands being composed of parts almost as small as those of water, they assume a similar appearance, rolling onward in waves like those of a troubled sea, and overwhelining all they meet with inevitable destruction. On the other hand, those tracts which are fertile, teem with vegetation even to a noxious degree. The grass rises to such a height as often to require burning; the forests are impassable from underwoods, and so matted above, that even the sun, fierce as it is, can seldom penetrate. These are so thick as scarcely to be extirpated; for the tops being so bound together by the climbing plants that grow round them, though an hundred should be cut at the bottom, yet no one would fall, as they mutually support eacb otlier. In these dark and tan-

d Adanson's Description of Senegal.

e Linuxi Amanit. vol. vi. p. 67. 
gled forests, beasts of various kinds, insects in astonishing abundance, and serpents of surprising magnitude, find a quiet retreat from man, and are seldoin disturbed except by each other.

In this manner the extremes of our globe seem equally unfitted for the comforts and conveniences of life: and although the imagination may find an awful pleasure in contemplating the frightful precipices of Greenland, or the luxurious verdure of Africa, yet true happiness can only be found in the more moderate climates, where the gifts of nature may be enjoyed, without incurring danger in obtaining them.

It is in the temperate zone, therefore, that all the arts of improving nature, and refining upon happiness, have been invented: and this part of the earth is, more properly speaking, the theatre of natural history. Although there be millions of animals and vegetables in the unexplored forests under the line, yet most of these may for ever continue unknown, as curiosity is there repressed by surrounding danger: But it is otherwise in these delightful regions which we inhabit, and where this art has had its beginning. Among us there is scarce a shrub, a flower, or an insect, without its particular history; scarce a plant that could be useful, which has not been propagated; nor a weed that could be noxious, which has not been pointed out.

\section{CHAPTER III.}

\section{A VIEW OF THE SURFACE OF THE EARTH.}

WHEN we take a slight survey of the surface of our globe, a thousand objects offer themselves, which, though long known, yet still demand our curiosity. The most obvious beauty that every where strikes the eye is the verdant covering of the earth, which is formed by an happy mixture of herbs and trees of various magnitudes and uses. It has been often remarked, that no colour refreshes the sight so much as green: and it may be added, as a further proof of the assertion, that the inhabitants of those places where the fields are continually white with snow, generally become blind long before the usual course of nature.

This advantage, which arises from the verdure of the fields, is not a little improved by their agreeable inequalities. There are scarcely two natural landscapes that offer prospects entirely resembling each other; their risings and depressions, their hills and valleys. are never entirely the same, but always offer something new to entertain and refresh the imagination.

But to increase the beanties of the face of nature, the landscape is enlivened by springs and lakes, and intersected by rivulets. These lend a brightness to the prospect; give motion and coolness to the air; and, what is much more important, furnish health and sub. sistence to animated nature.

Such are the most obvious and tranquil objects that every where offer: but there are objects of a more awful and magnificent kind; the Mountain rising above the clouds, and topt with snow; the River pouring down its sides, increasing as it runs, and losing itself, at last, in the ocean; the Ocean spreading its immense sheet of waters over one half of the globe, swelling and subsiding at well known intervals, and forming a communication between the most distant parts of the earth.

If we leave those objects that seem to be natural to our eartl, and keep the same constant tenor, we are presented with the great irregularities of nature: the burning mountain; the abrupt precipice; the unfathomable cavern; the headlong cataract; and the rapid whirlpool.

If we carry our curiosity a little further, 
and descend to the objects immediately below the surface of the globe, we shall there find wonders still as amazing. We first perceive the earth for the most part lying in regular beds or layers, every bed growing thicker in proportion as it lies deeper, and its contents more compact and heavy. We shall find, almost wherever we make our subterranean inquiry, an amazing number of shells that once belonged to aquatic animals. Here and there, at a distance from the sea, beds of oyster-shells, several yards thick, and many miles over; sometimes testaceous substances of various kinds on the tops of mountains, and often in the heart of the hardest marble. These, which are dug up by the peasants in every country, are regarded with little curiosity; for being so very common, they are considered as substances entirely terrene. But it is otherwise with the inquirer after nature, who finds them, not only in shape but in substance, every way resembling those that are found in the sea; and be, therefore, is at a loss to account for their removal.

Yet not one part of nature alone, but all her productions and varieties, become the object of the speculative man's inquiry : he takes different views of nature from the inattentive spectator; and scarcely an appearance, how common soever, but affords matter for his contemplation: he inquires how and why the surface of the earth has those risings and depressions which most men call natural; he demands in what manner the mountains were formed, and in what consists their uses; he asks from whence springs arise, and how rivers flow round the convexity of the globe; he enters into an examination of the ebbings and flowings; and the other wonders, of the deep; he acquaints himself with the irregularities of nature, and endeavours to investigate their causes; by which, at least, he will become better versed in their history. The internal structure of the globe becomes an object of his curiosity; and, although his inquiries can fathom but a very little way, yet, if possessed with a spirit of theory, his imagination will supply the rest. He will endeavour to account for the situation of the marine fossils

\footnotetext{
a Buffon, Woodward, Burnet, Whiston, Kirclier, Bourquat, Leibuitz, Steno, Ray, \&c.
}

that are found in the earth, and for the appearance of the different beds of which it is composed. These have been the inquiries that have splendidly employed many of the philosophers of the last and present age, ${ }^{2}$ and, to a certain degree, they must be serviceable. But the worst of it is, that, as speculations amuse the writer more than facts, they may be often carried to an extravagant length; and that time may be spent in reasoning upon nature, which might be more usefully employed in writing her history.

Too mucl speculation in natural history is certainly wrong; but there is a defect of an opposite nature that does much more prejudice; namely, that of silencing all inquiry, by alleging the benefits we receive from a thing, instead of investigating the cause of its production. If $I$ inquire how a mountain came to be formed; such a reasoner, enumerating its benefits, answers, because God knew it would be useful. If I demand the cause of an earthquake, he finds some good produced by it, and alleges that as the cause of its explosion. Thus such an inquirer has constantly some ready reason for every appearance in nature, which serves to swell his periods, and give splendour to his declamation; every thing about him is, on some account or other, declared to be good; and he thinks it presumption to scrutinize into its defects, or to endeavour to imagine how it might be better. Such writers, and there are many such, add very little to the advancement of knowledge. It is finely remarked by Bacon, that the investigation of final causes is a barren study; and, like a virgin dedicated to the Deity, brings forth nothing. In fact, those men who want to compel every appearance and every irregularity in nature into our service, and expatiate on their benefits, combat that very morality which they would seem to promote. God has permitted thousands of natural evils to exist in the world, because it is by their intervention that man is capable of moral evil; and he has permitted that we should be subjeet to moral evil, that we might do something to deserve eternal happiness, by showing that we had rectitude to avoid it.

Investigatio causarum finalium sterilis est, et veluti virgo Deo dedicata, nil parit. 


\section{CHAPTER IV.}

\section{A REVIEW OF THE DIFFERENT THEORIES OF THE EARTH.}

HUMAN invention has been exercised for several ages to account for the various irregularities of the earth. While those philosophers, mentioned in the last chapter, see nothing but beauty, symmetry, and order; there are others, who look upon the gloomy side of naturc, enlarge on its defects, and seem to consider the earth, on which they tread, as one scene of extensive desolation. ${ }^{a}$ Beneath its surface they observe minerals and waters confusedly jumbled together; its different beds of earth irregularly lying upon each other; mountains rising from places that once were level; ${ }^{b}$ and hills sinking into valleys; whole regions swallowed by the sea, and others again rising out of its bosom. All these they suppose to be but a few of the changes that have been wrought in our globe; and they send out the imagination to describe its primeval state of beauty.

Of those who have written theories describing the mamer of the original formation of the earth, or accounting for its present appearances, the most celebrated are Burnet, Whiston, Woodward, and Buffon. As speculation is endless, so it is not to be wondered that all these differ from each other, and give opposite accounts of the several changes, which they suppose our earth to have undergone. As the systems of each have had their admirers, it is, in some measure, incumbent upon the natural historian to be acquainted, at least, with their outlines; and, indeed, to know what others have even dreamed in matters of science, is very useful, as it may often prevent us from indulging similar delusions ourselves, which we should never have adopted, but because we take them to be wholly our own. However, as entering into a detail of these theories is rather furnishing a history of opinions than things, I will endeavour to be as concise as I can.

The first who formed this amusement of earth-making into system, was the celebrated

- Buffon's Second Discourse.

No. 2.
Thomas Burnet, a man of polite learning and rapid imagination. His Sacred Theory, as he calls it, describing the changes which the earth has undergone, or shall hereafter undergo, is well known for the warmth with which it is imagined, and the weakness with which it is reasoned; for the elegance of its style, and the meanness of its philosophy. "The earth," says he, "before the deluge, was very differently formed from what it is at present : it was at first a fluid mass; a chaos composed of various substances, differing both in density and figure: those which were most heavy sunk to the centre, and formed in the middle of our globe a hard solid body; those of a lighter nature remained next; and the waters, which were lighter still, swam upon its surface, and covered the earth on every side. The air, and all those fluids which were lighter than water, floated upon this also; and in the same manner encompassed the globe; so that between the surrounding body of waters, and the circumambient air, there was formed a cont of oil, and other unctuous substances, lighter than water. However, as the air was still extremely impure, and must have carried up with it many of those earthy particles with whicl it once was intimately blended, it soon began to defecate, and to depose these particles upon the oily surface already mentioned, which soon uniting, the earth and oil formed that crust, which soon became an habitable surface, giving life to vegetation, and dwelling to animals.

"This imaginary antediluvian abode was very different from what we see it at present. The earth was light and rich; and formed of a substance entirely adapted to the feeble state of incipient vegetation; it was an uniform plain, every where covered with verdure; without mountains, without seas, or the smallest inequalities. It had no difference of seasons, for its equator was in the plane of the ecliptic, or, in otherwords, it turned direct-

\footnotetext{
b Senec, Quast. lib. vi. cap. 21
} 
ly opposite to the sun, so that it enjoyed one perpetual and luxuriant spring. However, this delightilul face of nature did not long continue in the same state; for, after a time, it began to crack and open in fissures; a circumstance which always succeeds when the sun exhales the moisture from rich or marshy situations. The crimes of mankind had been for some time preparing to draw down the wrath of Heaven; and they, at length, induced the Deity to defer repairing these breaches in nature. Thus the chasms of the earth every day becane wider, and, at length, they penetrated to the great abyss of waters; and the whole earth, in a manner, fell in. Then ensued a total disorder in the uniform beauty of the first creation, the terrene surface of the globe being broken down: as it sunk the waters gushed out in its place; the deluge became universal; all inankind, except eight persons, were destroyed, and their posterity condemned to toil upon the ruins of desolated nature."

It only remains to mention the manner in which he relieves the earth from this universal wreck, which would seem to be as diflicult as even its first formation: "These great masses of earth falling into the abyss, drew down with them vast quantities also of air ; and, by dashing against each other, and breaking into small parts by the repeated violence of the shock, they, at length, left between them large cavities, filled with nothing but air. These cavities naturally offered a bed to receive the influent waters; and in proportion as they filled, the face of the earth became once more visible. The higher parts of its broken surface, now become the tops of inountains, were the first that appeared; the plains soon after came forward, and, at length, the whole globe was delivered from the waters, except the places in the lowest situations; so that the ocean and the seas are still a part of the ancient abyss, that have not had a place to return. Islands and rocks are fragments of the earth's former crust; kingdoms and continents are larger masses of its broken substance; and all the inequalities that are to be found on the surface of the present earth, are owing to the accidental confusion into which both earth and waters were then thrown."

The next theorist was Woodward, who, in his Essay towards a Natural History of the Earth, which was only designed to precede a greater work, has endeavoured to give a more rational account of its appearances; and was, in fact, snuch better furmshed for such an undertaking than any of his predecessors, being one of the most assiduous naturalists of his time. His little book, therefore, contains many important facts, relative to natural history, although his system may be weak and groundless.

He begins by asserting that all terrene substances are disposed in beds of various natures, lying horizontally one over the other, somewhat like the coats of an onion; that they are replete with shells, and other productions of the sea; these shells being found in the deepest cavities, and on the tops of the highest mountains. From these observations, which are warranted by experience, be proceeds to observe, that these shells and extraneous fossils are not productions of the earth, but are all actual remains of those animals which they are known to resemble; that all the beds of the earth lie under each other, in the order of their.specific gravity; and that they are disposed as if they had been left there by subsiding waters. All these assertions he alfirms with much earnestuess, although daily experience contradicts him in some of them; particularly we find layers of stone often over the lightest soils, and the softest earth under the hardest bodies. However, having taken it for granted, that all the layers of the earth are found in the order of their specific gravity, the lightest at the top, and the heaviest next the centre, he consequently asserts, and it will not improbably follow, that all the substances of which the earth is composed were once in an actual state of dissolution. This universal dissolution he takes to have happened at the time of the flood. He supposes, that at that time a body of water, which was then in the centre of the earth, uniting with that which was found on the surface, so far separated the terrene parts as to mix all together in one fluid mass; the contents of which afterwarls sinking according to their respective gravities, produced the present appearances of the earth. Being aware, however, of an objection, that fossil substances are not found dissolved, he exempts them from 
this universal dissolution, and, for that purpose, endeavours to show that the parts of aninals have a stronger cohesion than those of minerals; and that, while even the hardest rocks may be dissolved, bones and shells may still continue entire.

So much for Woodward: but of all the systems which were published respecting the earth's formation, that of Whiston was most applauded, and most opposed. Nor need we wonder: for being supported with all the parade of deep calculation, it awed the ignorant, and produced the approbation of such as would be thought otherwise; as it implied a knowledge of abstruse learuing, to be even thought capable of comprehending what the writer aimed at. In fact, it is not easy to divest this theory of its mathematical garb: but those who have had leisure, have found the result of our philosopher's reasoning to be thus: He supposes the earth to have been originally a comet; and he considers the history of the creation, as given us in scripture, to have its commencement just when it was, by the hand of the Creator, more regularly placed as a planet in our solar system. Before that time he supposes it to have been a globe without beauty or proportion; a world in disorder; subject to all the vicissitudes which comets endure; some of which have been found, at different times, a thousand times hotter than melted iron; at others, a thousand times colder than ice. These alterations of heat and cold, continually melting and freezing the surface of the earth, he supposes to have produced, to a certain depth, a chaos entirely resembling that described by the poets, surrounding the solid contents of the earth, which still continued unchanged in the midst, making a great burning globe of more than two thousand leagues in diameter. This surrounding chaos, however, was far from being solid : he resembles it to a dense though fluid atmosphere, composed of substances mingled, agitated, and shocked against each other; and in this disorder he describes the earth to have been just at the eve of creation.

But upon its orbit being then changed, when it was more regularly whecled round the sun, every thing took its proper place; every part of the surrounding fluid then fell into a situation, in proportion as it was light or heavy.
The middle, or central part, which always remaiued unchanged, still continued so, retaining a part of that heat which it received in its primeval approaches towards the sun; which heat, he calculates, may continue for about six thousand years. Next to this fell the heavier parts of the chaotic atmosphere, which serve to sustain the lighter: but as in descending they could not entirely be separated from many watery parts, with which they were intimately mixed, they drew down a part of these also with them; and these could not mount again after the surface of the earth was consolidated : they, therefore, surrounded the heavy first-descending parts in the same manner as these surround the central globe. Thus the entire body of the earth is composed internally of a great burning globe: next which is placed a heavy terrene substance, that encompasses it; round which also is circumfused a body of water. Upon this body of water, the crust of earth, which we inhabit, is placed: so that, according to him, the globe is composed of a number of coats, or shells, one within the other, all of different densities. The body of the earth being thus formed, the air, which is the lightest substance of all, surrounded its surface; and the beams of the sun, darting through, produced that light which, we are told, first obeyed the Creator's command.

The whole economy of the creation being thus adjusted, it only remained to account for the risings and depressions on the surface of the earth, with the other seeming irregularities of its present appearance. The hills and valleys are considered by him as formed by their pressing upon the internal fluid, which sustains the outward shell of earth, with greater or less weight: those parts of the earth which are heaviest sink into the subjacent fluid more deeply, and become valleys; those that are lightest, rise higher upon the earth's șurface, and are called mountains.

Such was the face of nature before the deluge: the earth was then more fertile and populous than it is at present; the life of man and animals was extended to ten times its present duration; and all these advantages arose from the superior heat of the central globe, which ever since has been cooling. As its heat was then in full power, the genial principle was also much greater than at present; 
vegetation and animal increase were carried on with more vigour; and all nature secmed teeming with the seeds of life. But these physical advantages were only produetive of moral evil; the warmth which invigorated the body inereased the passions and appetites of the mind; and, as man became more powerful, he grew less innocent. It was found necessary to punish this depravity; and all living creatures were overwhelmed by the deluge in universal destruction.

This deluge, which simple believers are willing to ascribe to a miracle, philosophers have long been desirous to account for by natural causes; they have proved that the earth could never supply from any reservoir towards its centre, nor the atmosphere by any discliarge from:above, such a quantity of water as would cover the surface of the globe to a certain deptl over the tops of our highest mountains. Where, therefore, was all this water to be found? Whiston luas found enough, and more than a suffieiency, in the tail of a comet; for he seems to allot comets a very active part in the great operations of nature.

He calculates, with great seeming preeision, the year, the month, and the day of the week, on which this comet (which has paid the earth some visits since, though at a kinder distance) involved our globe in its tail. The tail he supposed to be a vaporous fluid substanee, exhaled from the body of the comet by the extreme heat of the sun, and increasing in proportion at it approached that great lisminary. It was in this that our globe was involved at the time of the deluge; and, as the earth still acted by its natural attraction, it drew to itself all the watery vapours which were in the comet's tail; and the internal waters being also at the same time let loose, in a very short space the tops of the highest mountains were laid under the deep.

The punishment of the deluge being thus completed, and all the guilty destroyed, the earth, which had been broken by the eruption of the internal waters, was also enlarged by it; so that, upon the comet's recess, there was found room sufficient in the internal abyss for the recess of the superfluous waters; whither they all retired, and left the earth uncovered, but in some respects changed, particularly in its figure, which, from being round, was now become oblate. In this universal wreck of nature, Noah survived, by a variety of happy causes, to re-people the earth, and to give birth to a race of men slow in believing illimagined theories of the earth.

After so many theories of th: earth which have been published, applauded, answered, and forgotten, Mr. Buffon ventured to add one more to the number. This philosopher was, in every respect, better qualified than any of lis predecessors for such an attempt, being furnished with more materials, having a brighter imagination to find new proofs, and abetter style to clothe them in. However, if one so ill qualified as I am may judge, this seems the weakest part of his admirable work; and I could wish that he had been content with giving us facts instead of systems; that, instead of being a reasoner, he had contented himself with being merely an historian

He begins his system by making a distinction between the first part of it and the last; the one being founded only on conjecture, the other depending entirely upon actual observation. The latter part of his theory may, therefore, be true, though the former should be found erroneous.

"The planets," says he, "and the earth among the number, might liave been formerly (he only offers this as conjecture) a part of the body of the sun, and adherent to its substance. In this situation, a comet falling in upon that great body, might have given it such a shock, and so shaken its whole frame, that some of its particles might have been driven off like streaming sparkles from redhot iron; and each of these streams of fire, small as they were in comparison of the sun, might have been large enough to have made an earth as great, nay, many times greater, than ours. So that in this manner the planets, together with the globe which we inhabit, might have been driven off from the body of the sun by an impulsive force: in this manner also they would continue to recede from it for ever, were they not drawn back by its superior power of attraction; and thus, by the combination of the two motions, they are wheeled round in circles.

"Being in this manner detached at a distance from the body of the sun, the planets, from having been at first globes of liquid fire, 
gradually became cool. The carth also, having been impelled obliquely forward, received a rotatory motion upon its avis at the very instant of its formation; and this motion being greatest at the equator, the parts there acting against the force of gravity, they must have swollen out, and given the earth an oblate or flatted figure.

"As to its internal substance, our globe, having once belonged to the sun, it continues to be an uniform mass of melted matter, very probably vitrified in its primeval fusion. But its surface is very differently composed. Having been in the beginning heated to a degree equal to, if not greater, than what comets are found to sustain; like them it had an atmosphere of vapours floating round it, and which, cooling by degrees, condensed and subsided upon its surface. These vapours formed, according to their different densities, the earth, the water, and the air; the heavier parts falling first, and the lighter remaining still suspended."

Thus far our philosopher is, at least, as much a system-maker as Whiston or Burnet; and, indeed, he fights his way with great perseverance and ingenuity, through a thousand objections that naturally arise. Having, at last, got upon the earth, he supposes hinself on firmer ground, and goes forward with greater security. Turning his attention to the present appearance of things upon this globe, he pronounces from the view, that the whole earth was at first under water. This water he supposes to have been the lighter parts of its former evaporation, which, while the earthy particles sunk downwards by their natural gravity, floated on the surface, and covered it for a considerable space of time.

"The surface of the earth," says he," "must have been in the beginning much less solid than it is at present; and, consequently, the same causes which at this day produce but very slight changes, must then, upon so complying a substance, have had very considerable effects. We have no reason to doubt but that it was then covered with the waters of the sea; and that those waters were above the tops of our highest mountains : since, even in such elevated situations, we find shells and

- Theorie de la Terre, vol. i. p. 111. other marine productions in very great abundance. It appears also that the sea continued for a considerable time upon the face of the earth : for as these layers of shells are found so very frequent at such great depths, and in such prodigious quantities, it seems impossible for such numbers to have been supported all alive at one time; so that they must have been brought there by successive depositions. These shells also are found in the bodies of the hardest rocks, where they could not liave been deposited, all at once, at the time of the deluge, or at any such instant revolution; since that would be to suppose, that all the rocks in which they are found, were, at that instant, in a state of dissolution, which would be absurd to assert. The sea, therefore, deposited them wheresoever they are now to be found, and that by slow and successive degrees.

"It will appear also, that the sea covered the whole earth, from the appearance of its layers, which lying regularly one above the other, seem all to resemble the sediment form. ed at different times by the ocean. Hence, by the irregular force of its wares, and its currents driving the bottom into sand. banks, mountains must have been gradually formed within this universal covering of waters; and these successively raising their heads above its surface, must, in time, have formed the highest ridges of mountains upon land, together with continents, islands, and low grounds, all in their turns. This opinion will receive additional weight by considering, that in those parts of the earth where the pow: er of the occan is greatest, the inequalitics on the surface of the earth are highest. The ocean's power is greatest at the equator; where its winds and tides are most constant; and, in fact, the mountains at the equator are found to be higher than in any other part of the world. The sea, therefore, has produced the principal changes in our earth: rivers, volcanoes, earthquakes, storms, and rain, having made but slight alterations, and only such as have affected the globe to very inconsiderable depths."

This is but a very slight sketch of $\mathrm{Mr}$. Buffon's theory of the earth; a theory which he has much more powerfully supported, than happily invented; and it would be needless to 
take up the reader's time from the pursuit of truth in the discussion of plausibilities. In fact, a thousand questions inight be asked this most ingenious philosopher, which he would not find it easy to answer; but such is the lot of humanity, that a single Goth can in one day destroy the fabric which Casars were employed an age in erecting. We inight ask, How mountains, which are composed of the most compact and ponderous substances, should be the first whose parts the sea began to remove? We might ask, How fossil-wood is found deeper even than shells? which argues, that trees grew upon the places he supposes once to have been covered witl the ocean. But we hope this excellent man is better enployed than to think of gratifying the petulance of incredulity, by answering endless objections.

\section{CHAPTER V. \\ OF FOSSIL-SHELLS, AND OTIIER EXTRANEOUS FOSSILS.}

WE may affirm of Mr. Buffon, that which has been said of the chymists of old; though he may have failed in attaining his principal aim, of establishing a theory, yet he has brought together such a multitude of facts relative to the history of the earth, and the nature of its fossil productions, that curiosity finds ample compensation, even while it feels the want of conviction.

Before, therefore, I enter upon the deseription of those parts of the earth which seem more naturally to fall within the subject, it will not be improper to give a short history of those animal productions that are found in such quantities, either upon its surface, or at different depths below it. They denand our curiosity; and, indeed, there is nothing in natural history that has afforded more scope for doubt, conjecture, and speculation. Whatever depths of the earth we examine, or at whatever distance within land we seek, we most commonly find a number of fossil-shells, which being coinpared with others from the sea, of known kinds, are found to be exactly of a similar shape and nature." They are found at the very bottom of quarries and mines, in the retired and inmost parts of the most firm and solid rocks, upon the tops of even the highest hills and mountains, as well as in the valleys and plains; and this not in one country alone, but in all places where there is any digging for marble, chalk, or any other terrestrial mat-

\footnotetext{
- Woodward's Essay towards a Natural History, p 16.
}

ters, that are so compact as to fence off the external injuries of the air, and thus preserve these shells from decay.

These marine substances, so commonly diffused, and so generally to be inet with, were for a long time considered by philosophers as productions, not of the sea, but of the earth. "As we find that spars," said they, "always shoot into peculiar shapes, so these seeming suails, cockles, and mussel-shells, are only sportive forms that nature assumes amongst others of its mineral varieties: they have the shape of fish, indeed, but they have always been terrestrial substances."

With this plausible solution mankind were for a long time content : but upon closer inquiry, they were obliged to alter their opinion. It was found that these shells had in every re. spect the properties of animal, and not of mineral nature. They were found exactly of the same weight with their fellow shells upon shore. They answered all the rhymical trials in the same manner as sea-shells do. Their parts, when dissolved, had the same appearance to view, the same smell and taste. They had the same effects in medicine, when inwardly administered; and, in a word, were so exactly conformable to marine bodies, that they had all the accidental concretions growing to them, (such as pearls, corals, and smaller shells,) which are found in shells just gathered on the shore. 'They were, there-

b Lowthorp's Abridgment, Phil. Trans. vol. ii. p. 426. 
fore, from these considerations, given back to the sea; but the wonder was, how to account for their coming so far from their own natural element upon lind. ${ }^{\mathrm{a}}$

As this naturally gave rise to many conjectures, it is not to be wondered that sone anong them have been very extraordinary. An Italian, qunted by Mr. Bufron, supposes them to have been deposited in the earth at the time of the erusades, by the pilgrims who returned from Jerusalem; who gathering them upon the sea-shore, in their return carried them to their different places of habitation. But this conjecturer seems to have but a very inadequate idea of their numbers. At Touraine, in France, more than a hundred miles from the sea, there is a plain of about nine leagues long, and as many loroad, whence the peasants of the country supply theinselves with inarl for manuring their lands. They seldom dig deeper than twenty feet; and the whole plain is composed of the same materials, which are shells of various kinds, without the smallest portion of eartl between them. Here then is a large space, in which are deposited millions of tons of shells, that pilgrims could not have collected, though their whole employment had been nothing else. England is furnished with its beds, which, though not quite so extensive, yet are equally wonderful. "Near Reading, in Berkshire, for many succeeding generations, a continued body of oyster-shells has been found through the whole circumference of five or six acres of ground. The foundation of these shells is a hard rocky chalk; and above this chalk, the oyster-sliells lie in a bed of green sand, upon a level, as nigh as can possibly be judged, and about two feet thickness." ${ }^{\circ b}$ These shells are in their natural state, but they were found also petrified, and almost in equal abundance $e^{\circ}$ in all the Alpine rocks, in the Pyrenees, on the hills of France, England, and Flanders. Even in all quarries from whence marble is dug, if the rocks be split perpendicularly downwards, petrified shells and other marine substances will be plainly discerned.

"About a quarter of a mile from the river Medway, in the county of Kent, after the

Woodward, p. 43

- Phil. Trans. vol. ii. p. 427. Buffon, vol. i. p. 407 . taking off the coping of a piece of ground there, the workinen eame to a blue nuarble, which continued for three feet and a half deep, or inore, and then beneath appeared a hard floor, or pavement, composed of petrified shells erowded closely together. This layer was about an inch deep, and several yards over; and it could be walked upon as upon a beach. These stones, of which it was composed, (the describer supposes them to have always been stones, ) were either wreathed as snails, or bivalvular like coekles. The wreathed kinds were about the size of a hazel-nut, and were filled with a stony substanec of the colour of marl; and they themsclves, also, till they were washed, were of the same colour; but when eleaned, they appeared of the colour of bezoar, and of the sanne polish. After boiling in water they became whitish, and left a chalkiness upon the fingers." $d$

In several parts of Asia and Afriea, travellers have observed these shells in great abundance. In the mountains of Castravan, which lie above the city Barut, they quarry out a white stone, every part of which contains petrified fishes in great numbers, and of surprising diversity. They also seem to continue in such prescrvation, that their fins, seales, and all the minutest distinctions of their make, can be perfeetly discerned."

From all these instances we may conelude, that fossils are very numerous; and, indeed, independent of their situation, they afford no small entertainment to observe them as preserved in the eabinets of the eurious. The varieties of their kinds are astonishing. Most of the sca-shells which are known, and many others to which we are entirely strangers, are to be seen either in their natural state, or in various degrees of petrifaction.' In the place of some we have mere spar, or stone, exactly expressing all the lineaments of animals, as having been wholly formed from them. For. it has happened, that the shells dissolving by very slow degrees, and the matter having nicely and exactly filled all the cavities within, this matter, after the shells have perished, has preserved exactly and regularly the whole

¿ Phil. Trans. p. 426.

- Buffon, vol. i. p. 408. 1 Hill, p. 646. 
print of their internal surface. Of these there are various kinds found in our pits; many of them resembling those of our own shores; and many others that are only to be found on the coasts of other countries. There are some shells resembling those that are never stranded upon our coasts; ${ }^{a}$ but always remain in the deep: and many more there are which we can assimulate with no shells that are known amongst us. But we find not only shells in our pits, but also fishes and corals in great abundance; together with almost every sort of marine production.

It is extraordinary enough, however, that the common red coral, though so very frequent at sea, is scarcely seen in the fossil world; nor is there any account of its having ever been met with. But to compensate for this, there are all the kinds of the white coral now known, and many other kinds of that substance with which we are unacquainted. Of animals there are various parts: the vertebræ of whales, and the mouths of lesser fishes; these, with teeth also of various kinds, are found in the cabinets of the curious; where they receive long Greek names, which it is neither the intention nor the province of this work to enumerate. Indeed, few readers would think themselves much improved, should I proceed with enumerating the various classes of the Conicthyodontes, Polyleptoginglimi, or the Orthoceratites. These names, which mean no great matter when they are explained, may serve to guide in the furnishing a cabinet; but they are of very little service in furnishing the page of instructive history.

From all these instances we see in what abundance petrifactions are to be found; and, indeed, Mr. Buffon, to whose accounts we have added some, has not been sparing in the variety of his quotations, concerning the places where they are mostly to be found. However, I am surprised that he should have omitted the mention of one, which, in some measure, more than any of the rest, would have served to strengthen his theory. We are informed, by almost every traveller ${ }^{e}$ that has described the pyramids of Egypt, that one of them is entirely built of a kind of free-stone, in which these petrified shells are found in great abundance. This being the case, it may be conjectured, as we have accounts of these pyramids among the earliest records of mankind, and of their being built so long before the age of Herodotus, who lived but fifteen hundred years after the flood, that even the Egyptian priests could tell neither the time nor the cause of their erection; I say, it may be conjectured that they were erected but a short time after the flood. It is not very likely, therefore, that the marine substances found in one of them, had time to be formed into a part of the solid stone, either during the deluge, or immediately after it; and, consequently, their petrifaction must have been before that period. And this is the opinion Mr. Buffon lias so stremuously endeavoured to maintain; having given specious reasons to prove, that such shells were laid in the beds where they are now found, not only before the deluge, but even antecedent to the formation of man, at the time when the whole earth, as he supposes, was buried bencath a covering of waters.

But while there are many reasons to persuade us that these extraneous fossils liave been deposited by the sea, there is one fact that will abundantly serve to convince us, that the earth was habitable, if not inhabited, before these marine substances came to be thus deposited. For we find fossil-trees, which no doubt once grew upon the earth, as deep, and as much in the body of solid rocks, as these sluellz are found to be. Some of these fallen trees also have lain at least as long, if not longer, in the earth, than the shells, as they have been found sunk deep in a marly substance, composed of decayed shells, and other marine productions. Mr. Buffon has proved, that fossil-shells could not have been deposited in such quantities all at once by the flood; and I think, from the above instance, it is pretty plain, that, howsoever they were deposited, the earth was covered with trees before their deposition; and, consequently, that the sea could not have made a very permanent stay. How then shall we account for these extraordinary appearances in nature? A suspension of all assent is

$$
\text { - Littorales. " "Pelagii. }
$$

\footnotetext{
c Ilasselquist, Sandys.
} 
certainly the first, although the most mortifying conduct. For my own part, were I to offer a conjecture, (and all that has been said upon this subjeet is but conjecture, ) instead of supposing them to be the remains of animals belonging to the sea, I would consider them rather as bred in the numerous freshwater lakes, that in primeval times covered the face of uncultivated nature. Some of these shells we know to belong to fresh waters; some can be assimilated to none of the marine shells now known;" why, therefore, may we not as well ascribe the production of all to fresh waters, where we do not find them, as we do that of the latter to the sea only, where we never find them?

We know that lakes, and lands also, have produced animals that are now no longer existing; why, therefore, might not these fossil productions be among the number? I grant that this is making a very harsh supposition: but I cannot avoid thinking, that it is not attended with so many embarrassments as some of the former, and that it is much easier to believe that these shells were bred in fresh water, than that the sea had for a long time covered the tops of the highest mountains.

\section{CHAPTER VI.}

\section{OF THE INTERNAL STRUCTURE OF THE EARTH.}

HAVING, in some measure, got free from the regions of conjecture, let us now proceed to a description of the earth as we find it by examination, and observe its internal composition, as far as it has been the subject of experience, or exposed to human inquiry. These inquiries, indeed, have been carried but to a very little depth below its surface, and even in that disquisition men have been conducted more by motives of avarice than of curiosity. The deepest mine, which is that at Cotteberg in Hungary, ${ }^{\mathrm{b}}$ reaches not more than three thousand feet deep; but what proportion does that bear to the depth of the terrestrial globe, down to the centre, which is above four thousand miles? All, therefore, that has been said of the earth, to a deeper degree, is merely fabulous or conjectural: we may suppose with one, that it is a globe of glass ; with another, a sphere of heated iron; ${ }^{\mathrm{d}}$ with a third, a great mass of waters ; ${ }^{e}$ and with a fourth, one dreadful volcano:' but let us at the same time show our conciousness, that all these are but suppositions.

Upon examining the earth, where it has been opened to any depth, the first thing that

a Hill's Fossils, p. 41.
' Buffon. d Whiston. occuirs, is the different layers or beds of which it is composed; these all lying horizontally one over the other, like the leaves of a book, and each of them composed of materials that increase in weight in proportion as they lie deeper. This is, in general, the disposition of the different materials, where the earth seems to have remained unmolested; but this order is frequently inverted; and we cannot tell whether from its original formation, or from accidental causes. Of different substances, thus disposed, the far greatest part of our globe consists, from its surface downwards to the greatest depths we ever dig or mine. ${ }^{\mathrm{g}}$

The first layer, most commonly found at the surface, is that light coat of blackish mould, which is called by some garden earth. Witl this the earth is every where invested, unless it be washed off by rains, or removed by some other external violence. This seems to lave been formed from animal and vegetable bodies decaying, and thus turning into its substance. It also serves again as a storehouse, from whence animal and vegetable nature are renewed; and thus are all vital

\footnotetext{
- Burnet. $\quad$ Kircher

g Woodivard, p. 9
} 
blessings continued with unceasing circulation. This earth, however, is uot to be supposed entirely pure, but is mixed with much stony and gravelly matter, from the layers lying immediately beneath it. It generally happens, that the soil is fertile in proportion to the quantity that this putrefied mould bears to the gravelly mixture; and as the former predominates, so far is the vegetation upon it more luxuriant. It is this external covering that supplies man with all the true riches he cnjoys. He may bring up gold and jewels from greater depths; but they are merely the toys of a capricious being, things upon which he lias placed an imaginary value, and for which fools alone part with the more substantial blessings of life. "It is this earth," says Pliny, "that, like a kind mother, receives us at our birth, and sustains us when born." It is this alone, of all the elements around us, that is never found an enemy to man. The body of waters deluge him with rains, oppress him with hail, and drown him with inundations. The air rushes in storms, prepares the tempest, or lights up the volcano; but the earth, gentle and indulgent, ever subservient to the wants of man, spreads his walks with flowers, and his table with plenty; returns with interest every good committed to her care; and though she produces the poison, she still supplies the antidote; though constantly teased more to furnish the luxuries of man than his necessities, yet, even to the last, she continues her kind indulgence, and, whel life is over, she piously covers his remains in her bosom.

This external and fruitful layer which covers the earth, is, as was said, in a state of continual change. Vegetables, which are naturally fixed and rooted to the same place, receive their adventitious nourishment from the surrounding earth and water; animals, which change from place to place, are supported by these, or by each other. Both, however, having for a time enjoyed a life adapted to their nature, give back to the earth those spoils, which they had borrowed for a very short space, yet still to be quickened again into fresh existence. But the deposits they make are of very dissimilar kinds,

a Plinii Historia Naturalis, lib. ii. cap. 63. and the earth is very differently enriched by their continuance; those countries, that have for a long time supported men and other animals, having been observed to becoine every day more barren; while, on the contrary, those desolate places, in which vegetables only are abundantly produced, are known to be possessed of amaziug fertility. "In regions which are uninhabited," says Mr. Buffon, "where the forests are not cut down, and where animals do not feed upon the plants, the bed of vegetable earth is constantly increasing. In all woods, and even in those which are often cut, there is a layer of earth, of six or eight inches thick, which has been formed by the leaves, branches, and bark, which fall and rot upon the ground. I have frequently observed on a Roman way, which crosses Burgundy for a long extent, that there is a bed of black earth, of more than a foot thick, gathered over the stony pavement, on which several trees, of a very considerable size, are supported. This l have found to be nothing else than an earth formed by decayed leaves and branches, which have been converted by time into a black soil. Now, as vegetables draw much more of their nourishment from the air and water than they do from the earth, it must follow, that in rotting upon the ground, they must give more to the soil than they have taken from it. Hence, therefore, in woods kept a long time without cutting, the soil below increases to a considerable depth; and such we actually find the soil in those American wilds, where the forests have been undisturbed for ages. But it is otherwise where men and animals have long subsisted: for as they make a considerable consumption of wood and plants, both for firing and other uses, they take more from the earth than they return to it; it follows, therefore, that the bed of vegetable earth, in an irhahited country, must be always diminishing; and must at length resemble the soil of Arabia Petrea, and other provinces of the East, which having been long inhabited, are now become plains of salt and sand; the fixed salt always remaining, while the other volatile parts have flown away."

If from this external surface we descend

Buffon, vol. i. p. 353. 
deeper, and view the earth cut perpendicularly downwards, either in the banks of great rivers, or steepy sca-shores, or, going still deeper, if we observe it in quarries or inines, we shill find its layers regularly disposed in their proper order. We must not expect, however, to find them of the same kind or thickness in every place, as they difier in different soils and situations. Sometimes marl is seen to be over sand, and sometimes under it. The most common disposition is, that under the first earth is found gravel or sand, then clay or marl, then chalk or coal, inarbles, ores, sands, gravels; and thus an alteruation of these substances, each growing more dense as it sinks deeper. The clay, for instance, found at the depth of a hundred feet, is usually more heavy than that found not far from the surface. In a well which was dug at Amsterdam, to the depth of two hundred and thirty feet, the following substances were found in succession: seven feet of vegetable earth, nine of turf, nine of soft clay, eight of sand, four of earth, ten of clay, four of earth, ten of sand, two of clay, four of white sand, one of soft earth, fourteen of sand, eight of clay mixed with sand, four of sea-sand mixed with shells, then a hundred and two feet of soft clay, and then thirty-one feet of sand.

In a well dug at Marly, to the depth of a hundred feet, Mr. Buffon gives us a still inore exact enumeration of its layers of earth. "Thirteen of a reddish gravel, two of gravel mingled with a vitrifiable sand, three of mud or slime, two of marl, four of marly stone, five of marl in dust mixed with vitrifiable sand, six of very fine vitrifiable sand, three of earthy marl, three of hard marl, one of gravel, one of eglautine, a stone of the hardness and grain of marble, one of gravelly marl, one of stony marl, one of a coarser kind of stony marl, two of a coarser kind still, one of vitrifiable sand inixed with fossil-shells, two of fine gravel, three of stony marl, one of coarse powdered marl, one of stone calcinable like marble, three of gray sand, two of white sand, one of red sand streaked with white, eight of gray sand with shells, three of very fine sand, three of a hard gray stone, lour of red sand streaked

- Varenius, as quoted by Mr. Buffon, p. 358 with white, three of white sand, and ffteen of reddish vitrifiable sand.

In this manuer the earth is every where found in beds over beds; and, what is still re markable, each of them, as far as it extends always maintains exactly the same thickuess It is found also, that as we proceed to considerable deptlis, every layer grows thicker. Thus in the adduced instances we might have observed, that the last layer was fifteen feet thick, while inost of the others were not above eight; and this inight liave gone much deeper, for aught we can tell, as before they got through it the workmen ceased digging

These layers are sometimes very extensive, and often are found to spread over a space of some leagues in circumference. But it must not be supposed that they are uniformly continued over the whole globe without any interruption: on the contrary, they are ever, at sinall intervals, cracked through as it were by perpendicular fissures; the earth resembling, in this respect, the muddy bottom of a pond, from whence the water has been dried off by the sun, and thus gaping in several chinks, which descend in a direction perpendicular to its surface. These fissures are many times found empty, but oftener closed up with adventitious substances, that the rain, or some other accidental causes, have conveyed to fill their cavities. Their openings are not less different than their contents, some being not above half an inch wide, some a foot, and some several hundred yards asunder; which last form those dreadful chasms that are to be found in the Alps, at the edge of which the traveller stands dreading to look down at the immeasurable gulf below. These amazing clefts are well known to such as have passed thesemountains, where a chasm frequently presents itself several hundred feet deep, and as many over, at the edge of which the way lies. It often happens also, that the road leads along the bottom, and then the spectator observes on each side frightful precipices several hundred yards above him; the sides of which correspond so exactly with each other, that they evidently secm torn asunder.

But these cliasms, to be found in the Alps, are nothing to what Ovalle tells us are to be seen in the Andes. These amazing mountains, in comparison of which the former are 
but little hills, have their fissures in proportion to their greatness. In some places they are a mile wide, and deep in proportion; and there are some others, that, running under ground, in extent resemble a province.

Of this kind also is that cavern called $\mathrm{El}$ denhole, in Derbyshire, which Dr. Plott tells us was sounded by a line of eight and twenty hundred feet, without finding the bottom, or meeting with water : and yet the mouth at the top is not above forty yards over. ${ }^{\text {. }}$ This immeasurable cavern runs perpendicularly downward; and the sides of it seem to tally so plainly as to show that they once were united. Those who come to visit the place, generally procure stones to be thrown into its mouth; and these are heard for several minutes, falling and striking against the sides of the cavern, producing a sound that resembles distant thunder, dying away as the stone goes deeper.

Of this kind also is that dreadful cavern described by Elian; his account of which the reader may not have met with." "In the country of the Arrian Indians, is to be seen an amazing chasm, which is called, The Gulf of Pluto. The depth and the recesses of this horrid place are as extensive as they are unknown. Neither the natives, nor the curious who visit it, are able to tell how it was first made, or to what depths it descends. The Indians continually drive thither great multitudes of animals, more than three thousand at a time, of different kinds, sheep, horses, and goats: and, with all absurd superstition, force them into the cavity, from whence they never return. Their several sounds, however, are heard as they descend; the bleating of sheep, the lowing of oxen, and the neighing of horses, issuing up to the mouth of the cavern. Nor do these sounds cease, as the place is continually furnished with a fresh supply."

\footnotetext{
- Plil. Trans. vol. ii. p. 370
}

There are many more of these dreadful perpendicular fissures in different parts of the eartl ; with accounts of which Kircher, Gaffarellus, and others, who have given histories of the wonders of the subterranean world, abundantly supply us. The generality of readers, however, will consider them with less astonishment when they are informed of their being common all over the earth; that in every field, in every quarry, these perpendicular fissures are to be found, either still gaping, or filled with matter that has accidentally closed their interstices. The inattentive spectator neglects the inquiry, but their being common is partly the cause that excites the philosopher's attention to them; the irregularities of nature lue is often content to let pass unexamined; but when a constant and a common appearance presents itself, every return of the object is a fresh call to his curiosity; and the chink in the next quarry becomes as great a matter of wonder as the chasm in Eldenhole. Philosophers liave long, therefore, endcavoured to find out the cause of these perpendicular fissures, which our own countrymen, Woodward and Ray, were the first that found to be so common and universal. Mr. Buffon supposes them to be cracks made by the sun, in drying up the earth, immediately after its emersion from the deep.

The heat of the sun is very probably a principal cause; but it is not right to ascribe to one only, what we find may be the result of many. Earthquakes, severe frosts, bursting waters, and storms tearing up the roots of trees, have, in our own times, produced them; and to this variety of causes we must, at present, be content to assign those that have happened before we had opportunities for observation.

b Eliani Var. Hist. lib. xvi. cap. 16. 


\section{CHAPTER VH.}

\section{OF CAVES AND SUBTERRANEOUS PASSAGES THAT SINK, BUT NOT PER- PENDICULARLY, IN'TO THE EARTH.}

IN surveying the subterranean wonders of the globe, besides those fissures that descend perpendieularly, we frequently find others that descend but a little way, and then spread themselves often to a great extent below the surface. Many of these caverns, it must be confessed, may be the production of art and human industry; retreats made to protect the oppressed, or shelter the spoiler. The famous labyrinth of Candia, for instance, is supposed to be entirely the work of art. Mr. Tournefort assures us, that it bears the impression of human industry, and that great pains have been bestowed upon its formation. The stone-quarry of Maestricht is evidently made by labour: carts enter at its mouth, and load within, then return, and discharge their freight into boats that lie on the brink of the river Maese. This quarry is so large, that forty thousand people may take shelter in it: and it in general serves for this purpose, when armies march that way; becoming then an impregnable retreat to the people that live thereabout. Nothing can be more beautiful than this cavern, when lighted up with torches: for there are thousands of square pillars, in large level walks, about twenty feet high; and all wrought with much neatness and regularity. In this vast grotto there is very little rubbish; which shows both the goodness of the stone and the carefulness of the workmen. To add to its beauty, there also are, in various parts of it, little pools of water, for the convenience of the men and cattle. It is remarkable also, that no droppings are seen to fall from the roof, nor are the walks any way wet under foot, except in cases of great rains, where the water gets in by the air-shafts. The salt-mines in Poland are still more spacious than these. Some of the catacombs, both in Egypt and Italy, are said to be very extensive. But no part of the world has a greater number of artificial ca-

- Phil. Trans. vol. ii. p. 368.

No. 3. verns that Spain, which were made to serve as retreats to the Christians against the fury of the Moors, when the latter conquered that country. However, an account of the works of art does not properly belong to a natural history. It will be enough to observe, that though caverns be found in every country, far the greatest part of them have been fashioned by the hand of nature only. Their size is found beyond the power of man to have effected, and their forms but ill adapted to the conveniences of a human habitation. In some places, indeed, we find mankind 'still make use of them as houses; particularly in those countries where the climate is very severe; but in general they are deserted by every race of meaner animals, except the bat: these nocturnal solitary creatures are usually the only inhabitants; and these only in such whose descent is sloping, or, at least, not directly perpendicular.

There is scarcely a country in the world without its natural caverns; and many new ones are discovered every day. Of those in England, Oakey-hole, the Devil's-hole, and Penpark-hole, have been often described. The' former, which lies on the south side of Mendip-hills, within a mile of the town of Wells, is much resorted to by travellers. To conceive a just idea of this, we must imagine a precipice of more than a bundred yards high, on the side of a mountain which shelves away a mile above it. In this is an opening not very large, into which you enter, going along upon a rocky uneven pavement, sometimes ascending, and sometimes descending. The roof of it, as you advance, grows higher: and, in some places, is fifty feet from the floor. In some places, however, it is so low, that a man must stoop to pass. It extends itself, in length, about two hundred yards: and from every part of the roof and the floor, there are formed sparry concretions of various

\footnotetext{
b Phil. Traus. vol. ii. p. 368.
} 
figures, that by strong imaginations have been likened to men, lions, and organs. At the farthest part of this cavern rises a stream of water, well stored with fish, large enough to turn a mill, and which discharges itself near the entrance.

Penpark-hole, in Gloucestershire, is almost as remarkable as the former. Captain Sturmy descended into this by a rope, twenty-five fathoms perpendicular, and at the bottom found a very large vault in the shape of a horse-shoe. The floors consisted of a kind of white stone enamelled with lead ore, and the pendant rocks were glazed with spar. Walking forward on this stony pavement, for some time, he came to a great river, twenty fathoms broad, and eight fathoms deep; and having been informed that it ebbed and flowed with the sea, he remained in this gloomy abode for five hours, to make an exact observation. He did not find, however, any alteration whatsoever in its appearance. But his curiosity was ill requited; for it cost this unfortunate gentleman his life: immediately after his return he was seized with an unusual and violent headach, which threw him into a fever, of which he died soon after.

But of all the subterranean caverns now known, the grotto of Antiparos is the most remarkable, as well for its extent as for the beauty of its sparry incrustations. This celebrated cavern was first discovered by one Magni, an Italian traveller, about an hundred years ago, at Antiparos, an inconsiderable island of the Archipelago." The account he gives of it is long and inflated, but upon the whole amusing. "Having been informed," says he, "by the natives of Paros, that in the little island of Antiparos, which lies about two miles from the former, of a gigantic statue that was to be seen at the mouth of a cavern in that place, it was resolved that we (the French consul and himself) should pay it a visit. In pursuance of this resolution, after we had landed on the island, and walked about four miles through the midst of beautiful plains, and sloping woodlands, we at length came to a little hill, on the side of

\footnotetext{
- Kircher Mund. sub. 112. I have translated a part of Kircher's description, rather than Tournefort's, as the latter was written to support an hypothesis.
}

which yawned a most horrid cavern, that with its gloom at first struck us with terror, and almost repressed curiosity. Recovering the first surprise, however, we entered boldly; and had not proceeded above twenty paces, when the supposed statue of the giant presented itself to our view. We quickly perceived, that what the ignorant natives had been terrified at as a giant, was nothing more than a sparry concretion, formed by the water dropping from the roof of the cave, and by degrees hardening into a figure that their fears had formed into a monster. Incited by this extraordinary appearance, we were induced to proceed still farther, in quest of new adventures in this subterranean abode. As we proceeded, new wonders offered themselves; the spars formed into trees and shrubs presented a kind of petrified grove; some white, some green; and all receding in due perspective. They struck us with the more amazement, as we knew them to be mere productions of Nature, who, hitherto in solitude, had, in her playful moments, dressed the scene as if for her own amusement.

"But we had as yet seen but a few of the wonders of the place; and were introduced only into the portico of this amazing temple. In one corner of this half-illuminated recess, there appeared an opening of about three feet wide, which seemed to lead to a place totally dark, and that, one of the natives assured us, contained nothing more than a reservoir of water. Upon this we tried, by throwing down some stones, which rumbling along the sides of the descent for some time, the sound seemed at last quashed in a bed of water. In order, however, to be more certain, we sent in a Levantine mariner, who, by the promise of a good reward, with a flambeaux in his hand, ventured into this narrow aperture. After continuing within it for about a quarter of an hour, he returned, carrying some beautiful pieces of white spar in his hand, which art could neither imitate nor equal. Upon being informed by him that the place was full of these beautiful incrustations, I ventured in once more with him for about fifty paces, anxiously and cautiously descending by a steep and dangerous way. Finding, however, that we came to a precipice which led into a spacious amphitheatre, if I may so call it, 
still deeper than any other part, we returned, and being provided with a ladder, flambeaux, and other things to expedite our descent, our whole company, man by man, ventured into the same opening, and descending one after another, we at last saw ourselves altogether in the most magnificent part of the cavern.

"Our candles being now all lighted up, and the whole place completelyilluminated, never could the eye be presented with a more glittering, or a more magnificent scene. The roof all hung with solid icicles, transparent as glass, yet solid as marble. The eye could scarcely reach the lofty and noble ceiling; the sides were regularly formed with spars; and the whole presented the idea of a magnificent theatre, illuminated with an immense profusion of lights. The floor consisted of solid marble; and in several places magnificent columns, thrones, altars, and other objects, appeared, as if nature had designed to mock the curiosities of art. Our voices, upon speaking or singing, were redoubled to an astonishing loudness; and upon the firing of a gun, the noise and reverberations were almost deafening. In the midst of this grand amphitheatre rose a concretion of about fifteen feet high, that, in some measure, resembled an altar; from which, taking the hint, we caused mass to be celebrated there. The beautiful columns that shot up round the altar, appeared like candlesticks; and many other natural objects represented the customary ornaments of this sacrament.

"Below even this spacious grotto there seemed another cavern; down which I ventured with my former mariner, and descended about fifty paces by means of a rope. I at last arrived at a small spot of level ground, where the bottom appeared different from that of the amphitheatre, being composed of a soft clay, yielding to the pressure, and in which I thrust a stick to about six feet deep. In this, however, as above, numbers of the most beautiful crystals were formed, one of which particularly resembled a table. Upon our egress from this amazing cavern, we per- ceived a Greek inscription upon a rock at the mouth, but so obliterated by time, that we could not read it. It seemed to import, that one Antipater, in the time of Alexander, had come thither; but whether he had penetrated into the depths of the cavern, he does not think fit to inform us."

Such is the account of this beautiful scene, as communicated in a letter to Kircher. We have another, and a more copious description of it, by Tournefort, which is in every body's hands; but I have given the above, both because it was communicated by the first discoverer, and because it is a simple narrative of facts, without any reasoning upon them. According to Tournefort's account, indeed, we might conclude, from the rapid growth of the spars in this grotto, that it must every year be growing narrower, and that it must in time be choked up with them entirely; but no such thing has happened hitherto, and the grotto at this day continues as spacious as we ever knew it.

This is not a place for inquiry into the seeming vegetation of those stony substances, with which this and almost every cavern are incrusted: it is enough to observe, in general, that they are formed by an accumulation of that little gritty matter which is carried thither by the waters, and which in time acquires the hardness of marble. What in this place more imports us to know, is, how these amazing hollows in the earth came to be formed. And I think, in the three instances above mentioned, it is pretty evident, that their excavation has been owing to water. These finding subterraneous passages under the earth, and by long degrees hollowing the beds in which they flowed, the ground above them has slipped down closer to their surface, leaving the upper layers of the earth or stone still suspended; the ground that sinks upon the face of the waters forming the floor of the cavern; the ground or rock, that keeps suspended, forming the roof: and, indeed, there are but few of these caverns found without water, either within them, or near enough to point out their formation. 


\section{CHAPTER VIII.}

\section{OF MINES, DAMPS, AND MINERAL VAPOURS.}

THE caverns, which we have been describing, generally carry us but a very little way below the surface of the earth. Two hundred feet, at the utmost, is as much as the lowest of them is found to sink. The perpendicular fissures run much deeper; but few persons have been bold enough to venture down to their deepest recesses; and some few who have tried, have been able to bring back no tidings of the place, for unfortunately they left their lives below. The excavations of art have conducted us much farther into the bowels of the globe. Some mines in Hungary are known to be a thousand yards perpendicular downwards; and I have been informed, by good authority, of a coal-mine in the north of England, an hundred yards deeper still.

It is beside our present purpose to inquire into the peculiar contrivance and construction of these, which more properly belongs to the history of fossils. It will be sufficient to observe in this place, that as we descend into the mines, the various layers of eartl are seen as we have already described them; and in some of these are always found the metals or minerals for which the mine has been dug. Thus frequently gold is found dispersed and mixed with clay and gravel;" sometimes it is mingled with other metallic bodies, stones, or bitumens ;" and sometimes united with that most obstinate of all sulustances, platina, from which scarce any art can separate it. Silver is sonctimes found quite pure ; ${ }^{c}$ sometimes mixed with other substances and minerals. Copper is found in beds mixed with various substances, marbles, sulphurs, and pyrites. Tin, the ore of which is heavier than that of any other metal, is generally found mixed with every kind of matter: lead is also equally common; and iron we well know can be extracted from all the substances upon earth.

\footnotetext{
- Ulloa, vol. ii. p. 470.

b Ulloa, ibid.

c Macquer's Chymistry, vol. i. p. 316 .
}

The variety of substances which are thus found in the bowels of the earth, in their native state, have a very different appearance from what they are afterwards taught to assume by human industry. The richest metals are very often less glittering and splendid than the most useless marcasites; and the basest ores are generally the most beautiful to the eye.

This variety of substances, which compose the internal parts of our globe, is productive of equal varieties, both above and below its surface. The combination of the different minerals with each other, the heats which arise from their mixture, the vapours they diffuse, the fires which they generate, or the colds which they sometimes produce, are all either noxious or salutary to man; so that in this great elaboratory of nature, a thousand benefits and calamities are forging, of which we are wholly unconscious; and it is happy for us that we are so.

Upon our descent into mines of considerable depth, the cold seems to increase from the mouth as we descend ; but after passing very low down, we begin by degrees to come into a warmer air, which sensibly grows hotter as we go deeper, till, at last, the labourers can scarcely bear any covering as they continue working.

This diffcrence in the air was supposed by Boyle to proceed from magazines of fire that lay nearer the centre, and that diffused their heat to the adjacent regions. But we now know that it may be ascribed to more obvious causes. In some mines, the composition of the earth all around is of such a nature, that, upon the admission of water or air, it frequently becomes hot, and often bursts out into eruptions. Besides this, as the external air cannot readily reach the bottom, or be renewed there, an observable heat is per-

\footnotetext{
d Hill's Fossils, p. 628.

- Boyle, vol. iii. p. 232.
} 
ccived below, without the necessity of recurring to the central heat for an explanation.

Hence, therefore, there are two principal causes of the warmth at the bottom of mines: the heat of the substances of which the sides are composed; and the want of renovation in the air below. Any sulphureous substance, mixed with iron, produces a very great heat, by the admission of water. If, for instance, a quantity of sulphur be mixed with a proportionable share of iron filings, and both kncaded together into a soft paste, with water, they will soon grow hot, and at last produce a flame. This experiment, produced by art, is very commonly effected within the bowels of the earth by nature. Sulphurs and irons are intimately blended together, and want only the mixture of water or air to excite their heat; and this, when once raised, is communicated to all bodies that lie within the sphere of their operation. Those beautiful minerals called marcasites and pyrites, are often of this composition; and where ver they are found, either by imbibing the moisture of the air, or having been by any means combined with water, they render the mine considerably hot. ${ }^{\circ}$

The want of fresh air also, at these depths, is, as we have said, another reason for their being found much hotter. Indeed, without the assistance of art, the bottom of most mines would, from this cause, be insupportable. To remedy this inconvenience, the miners are often obliged to sink, at some convenient distance from the mouth of the pit where they are at work, another pit, which joins the former below, and which, in Derbyshire, is called an air-shaft. Through this the air circulates; and thus the workmen are enabled to breathe freely at the botton of the place; which becomes, as Mr. Boyle aflirıns, very commodious for respiration, and also very temperate as to heat and cold.' Mr. Locke, however, who has left us an account of the Mendip mines, seems to present a different picture. "The descent into these is exceedinglydifficult and dangerous; for they are not sunk like wells, perpendicnlarly, but as the crannies of the rocks happen to run. The constant method is to swing down

\footnotetext{
- Kircher Mund. Subt. vol. ii. p. 216.

- Boyle, vol, iii. p. 23 S.
}

by a rope placed under the arms, and clamber along by applying both feet and hands to the sides of the narrow passage. The air is conveyed into them through a little passage that runs along the sides from the top, where they set up some turfs, on the lee-side of the hole, to catch and force it down. These turfs being removed to the windy side, or laid over the mouth of the hole, the miners below presently want breath, and faint; and if sweetsmelling flowers chance to be placed there, they immediately lose their fragrancy, and stink like carrion." An air so putrefying can never be very commodious for respiration.

Indeed, if we examine the complexion of most miners, we shall be very well able to form a judgment of the unwholesomeness of the place where they are confined. Their pale and sallow looks show how much the air is damaged by passing through those deep and winding ways, that are rendered humid by damps, or warmed with noxious exhalations. But although every mine is unwholesome, all are not equally so. Coal-mines are generally less noxious than those of tin; tin than those of copper; but none are so dreadfully destructive as those of quicksilver. At the mines near the village of Idra, nothing can adequately describe the deplorable infirmities of such as fill the hospital there; emaciated and crippled; every limb contracted or convulsed, and some in a manner transpiring quicksilver at every pore. There

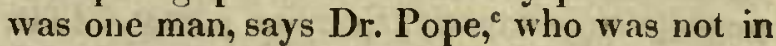
the mines above half a year, and yet wliose body was so impregnated with this mineral, that putting a piece of brass money in his mouth, or rubbing it between his fingers, it immediately became as white as if it had been washed over with quicksilver. In this manner all the workmen are killed sooner or later; first becoming paralytic, and then dying consumptive: and all this they sustain for the trifling reward of seven pence a day.

But these metallic mines are not so noxious from their own vapours, as from those of the substances with which the ores are usually united, such as arsenic, cinnabar, bitumen, or vitriol. From the fumes of these, variously

- Phil. Trans. vol. ii. p. 578. 
combined, and kept inclosed, are produced those various dainps, that put on so many dreadful forms, and are usually so fatal. Sometimes those noxious vapour's are perceived by the delightful fragrance of their smell, somewhat resembling the pea-blossom in bloom, from whence one kind of damp has its name. The miners are not deceived, however, by its flattering appearances; but as they lave thus timely notice of its coming, they avoid it while it continues, which is generally during the whole summer scason. Another shows its approach by the burning of the candles, which seem to collect their flame into a globe of light, and thus gradually lessen, till they are quite extinguished. From this, also, the miners frequently escape; however, such as have the misfortune to be caught in it, eitlier swoon away, and are suffocated, or slowly recover in excessive agonies. Here also is a third, called the fulminating damp, much more dangerous than either of the former, as it strikes down all before it like a flash of gunpowder, without giving any warning of its approach. But there is another, more deadly than all the rest, which is found in those places where the vapour has been long confined, and has been, by some accident, set free. The air rushing out from theuce, always goes upon deadly errands; and scarce any escape to describe the symptoms of its operations.

Some colliers in Scotland, working ncar an old mine that had been long closed up, happened, inadvertently, to open a hole into it, from the pit where they were then employed. By great good fortune, they at that time, perceived their error, and instantly fled for their lives. The next day, however, they were resolved to renew their work in the same pit, and eiglit of them ventured down, without any great apprehensions; but they had scarcely got to the bottom of the stairs that led to the pit, but, coming within the vapour, they all instantly dropped down read, as if they had been shot. Amongst these unfortunate poor men, there was one whose wife was informed he ivas stifled in the mine; and, as he happened to be next the entrance, she so far ventured down as to see where he lay. As she approached the place, the sight of her

* Phil. Trans. vol. ii. p. 375. husband inspired her with a desire to rescue lim, if possible, from that dreadful situation; though a little refection might liave shown ber it was then too late. But nothing could deter her; she ventured forward, and had scarce touched him with her band, when the damp prevailed, and the misguided, but faithful creature, fell dead by his side.

Thus, the vapours found beneath the surface of the carth are very various in their effects upon the constitution: and they are not less in their appearances. There are many kinds that seeningly are no way prejudicial to bealth, but in which the workmen breathe freely; and yet in these, if a lighted candle be introduced, they inmediately take fire, and the whole cavern at once becomes one furnace of flame. In mines, therefore, subject to damps of this kind, they are obliged to have recourse to a very peculiar contrivance to supply suffcient light for their operations. This is by a great wheel; the circumference of which is beset with flints, which striking against steels placed for that purpose at the extremity, a stream of fire is produced, which affords light enough, and yet which does not set fire to the mineral vapour.

Of this kind are the vapours of tlue mines about Bristol : on the contrary, in other mines, a single spark struck out from the collision of flint and steel, would set the whole shaft in a flame. In such, therefore, every precaution is used to avoid a collision; the workmen making use only of wooden instruments in digging; and being cautious, before they enter the mine, to take out even the nails from their shoes. Whence this strange difference slould arise, that the vapours of some mines catch fire with a spark, and others only with a flame, is a question that we nust be content to leave in obscurity, till we know more of the nature both of mineral vapour and of fire This only we may observe, that gunpowder will readily fre with a spark, but not with the flame of a candle; on tlue other hand, spirits of wine will flame with a candle, but not with a spark: but even liere the cause of this difference as yet remains a secret.

As from this account of mines, it appears that the interual parts of the globe are filled with vapours of various kinds, it is not surprising that they should, at different times, 
reach the surface, and there put on rarious appearances. In fact, much of the salubrity, and much of the unwholesomeness, of climates and soils, is to be ascribed to these vapours, which make their way from the bowels of the earth upwards, and refiesh or taint the air with their exbalations. Salt mines, being naturally cold," send forth a degree of coldness to the external air, to comfort and refresh it : on the contrary, metallic mines are known, not only to warm it with their exhalations, but often to destroy all kinds of vegetation by their volatile corrosive fumes. In some mines, dense vapours are plainly perceived issuing from their mouths, and seusibly warm to the touch. In some places, neither snow nor ice will continue on the ground that covers a mine; and over others' the fields are found destitute of verdure." The inhabitants, also, are rendered dreadfully sensible of these subterraneous exhalations, being affected with such a variety of evils proceeding entirely from this cause, that books bave been professedly written upon this class of disorders.

Nor are these vapours, which thus escape to the surface of the earth, entirely unconfined; for they are frequently, in a manner, circumscribed to a spot. The grotto Del Cane, near Naples, is an instance of this; the noxious effects of which have made that cavern so very famous. This grotto, which has so much employed the attention of travellers, lies within four miles of "Naples, and is situated near a large lake of clear wholesome water." Nothing can exceed the beauty of the landscape which this lake affords; being surrounded with hills covered with forests of the most beautiful verdure, and the whole bearing a kind of amphitheatrical appearance. However, this region, beautiful as it appears, is almost entirely uninhabited; the few peasants that necessity compels to reside there, looking quite consumptive and ghastly, from the poisonous exhalations that rise from the earth. The famous grotto lies on the side of a hill, near which place a peasant resides, who keeps a number of dogs for the purpose of showing the experiment to the curious. These poor animals always seem perfectly sensible of the approach of a stranger, and endeavour to get out of the way. However, their at- tempts being perceived, they are taken and brought to the grotto; the noxious effects of which they have so frequently experienced. Upon entering this place, which is a little cave, or hole rather, dug into the hill, about eight feet high, and twelve feet long, the observer can see no visible inark of $i t s$ pestilential vapour; only to about a foot from the bottom, the wall seems to be tinged with a colour resembling that which is given by stagnant waters. When the dog, this poor philosophical martyr, as some have called him, is held above this mark, he does not seem to feel the smallest inconvenience; but when his head is thrust down lower, he struggles to get free for a little; but in the space of four or five minutes he seems to lose all sensation, and is taken out seemingly without life. Being plunged in the neighbouring lake, he quickly recovers, and is permitted to run home, seemingly without the smallest injury.

This vapour, which thus for a time suffocates, is of the humid kind, as it extinguishes a torch, and sullies a looking-glass; but there are other vapours perfectly inflammable, and that only require the approach of a candle to set them blazing. Of this kind was the burning well at Brosely, which is now stopped up; the vapour of which, when a candle was brought within about a foot of the surface of the water, caught flame like spirits of wine, and continued blazing for several hours after. Of this kind, also, are the perpetual fires in the kingdom of Persia. In that province, where the worshippers of fire hold their chief mysteries, the whole surface of the earth, for some extent, seems impregnated with inflammable vapours. A reed stuck into the ground continues to burn like a flambeau; a hole made beneath the surface of the earth, instantly becomes a furnace, answering all the purposes of a culinary fire. There they make lime by merely burying the stones in the earth; and watch with veneration the appearances of a flame that has not been extinguished for times immemorial. How different are inen in various climates! This deluded people worship these vapours as a deity, which in other parts of the world are considered as one of the greatest evils. 


\section{CHAPTER IX.}

\section{OF VOLCANOES AND EARTHQUAKES.}

MINES and caverns, as we have said, reach but a very little way under the surface of the earth, and we have hitherto had no opportunities of exploring further. Without all doubt, the wonders that are still unknown surpass those that liave been represented, as there are depths of thousands of miles which are hidden from our inquiry. The only tidings we have from those unfathomable regions are by means of volcanoes, those burning mountains that seem to discharge their materials from the lowest abysses of the earth. ${ }^{2}$ A volcano may be considered as a cannon of immense size, the mouth of which is often near two miles in circumference. From this dreadful aperture are discharged torrents of flame and sulphur, and rivers of melted metal. Whole clouds of smoke and ashes, with rocks of enormous size, are discharged to many miles distance; so that the force of the most powerful artillery, is but as a breeze agitating a feather in comparison. In the deluge of fire and melted matter which runs down the sides of the mountain, whole cities are sometimes swallowed up and consumed. Those rivers of liquid fire are sometimes two hundred feet deep; and, when they harden, frequently form considerable hills. Nor is the danger of these confined to the eruption only: but the force of the internal fire struggling for vent, frequently produces earthquakes through the whole region where the volcano is situated. So dreadful have been these appearances, that men's terrors have added new horrors to the scene, and they have regarded as prodigies, what we know to be the result of natural causes. Some philosophers have considered them as vents communicating with the fires of the centre; and the ignorant, as the mouths of hell itself. Astonishment produces fear, and fear superstition: the inhabitants of Iceland believe the bellowings of Hecla are nothing else but the

- Buffor, vol. i. p. 291. cries of the damned, and that its eruptions are contrived to increase their tortures.

But if we regard this astonishing scene of terror with a more tranquil and inquisitive eye, we shall find that these conflagrations are produced by very obvious and natural causes. We have already been apprised of the various mineral substances in the bosom of the earth, and their aptness to burst out into flames. Marcasites and pyrites, in particular, by being humified with water or air, contract this heat, and often endeavour to expand with irresistible explosion. These, therefore, being lodged in the depths of the earth, or in the bosom of mountains, and being either washed by the accidental influx of waters below, or fanned by air, insinuating itself through perpendicular fissures from above, take fire at first by only heaving in earthquakes, but at lengtl by bursting through every obstacle, and making their dreadful discharge in a volcano.

These volcanoes are found in all parts of the earth: In Europe there are three that are very remarkable; Atna in Sicily, Vesuvius in Italy, and Hecla in Iceland. Ftna has been a volcano for ages immemorial. Its eruptions are very violent, and its discharge has been known to cover the earth eighty-six feet deep. In the year.1537, an eruption of this mountain produced an earthquake through the whole island for twelve days, overturned many houses, and at last formed a new aperture, which overwhelmed all within five leagues round. The cinders thrown up were driven even into Italy, and its burnings were seen at Malta, at the distance of sixty leagues. "There is nothing more awful," says Kircher, "than the eruptions of this mountain, nor nothing more dangerous than attempting to examine its appearances, even long after the eruption has ceased. As we attempt to clamber up its steepy sides, every step we take upward, the feet sink back half way. Upon arriving near the summit, ashes and snow, with an ill- 
assorted conjunction, present nothing but objects of desolation. Nor is this the worst, for, as all places are covered over, many caverns are entirely hidden from the sight, into which, if the inquirer happens to fall, he sinks to the bottom, and meets inevitable destruction. Upon coming to the edge of the great crater, nothing ean sufficiently represent the tremendous magnificence of the scene. A gulf two miles over, and so deep that no bottom can be seen; on the sides pyramidical rocks starting out between apertures that emit smoke and flane; all this accompanied with a sound that never ceases, louder than thunder, strikes the bold with horror, and the religious with reneration for HIм that has power to control its burnings."

In the descriptions of Vesuvius or Hecla, we shall find seareely any thing but a repetition of the same terrible objects, but rather lessened, as these mountains are not so large as the former. The crater of Vesurius is but a mile across, according to the same author; whereas that of Etna is two. On this particular, however, we must place no dependence, as these caverns every day alter; being lessened by the mountain s sinking in at one eruption, and cnlarged by the fury of another. It is not one of the least remarkable particulars respecting Vesuvius, that Pliny the naturalist was suffocated in one of its eruptions; for his curiosity impelling him too near, he found himself involved in smoke and cinders when it was too late to retire; and his companions hardly escaped to give an account of the misfortune. It was in that dreadful eruption that the city of Herculaneum was overwhelmed; the ruins of which have lately been discovered at sixty feet distance below the surface, and, what is still more remarkable, forty feet below the bed of the sea. One of the most remarkable eruptions of this mountain was in the year 1707, which is finely described by Valetta; a part of whose description I shall beg leave to translate.

"Towards the latter end of sunmer, in the year 1707 , the mount Vésuvius, that had for a long time been silent, now began to give some signs of commotion. Little more than internal murmurs at first were heard, that seemed to contend within the lowest depths of the mountain; no flame, nor even any smoke, was as yet seen. Soon after some smoke appeared by day, and a flame by night, which seemed to brighten all the campania. At intervals, also, it shot off substances with a sound very like that of artillery, but which, even at so great a distance as we were at, infinitely exceeded them in greatness. Soon after it began to throw up ashes, which becoming the sport of the winds, fell at great distances, and some many miles. To this succeeded showers of stones, which killed inany of the inhabitants of the valley, but made a dreadful ravage among the cattle. Soon after a torrent of burning matter began to roll down the sides of the mountain, at first with a slow and gentle motion, but soon with increased celerity. The matter thus poured out, when cold, seemed upon inspection to be of vitrified earth, the whole united into a mass of more than stony hardness. But what was particularly obscrvable was, that upon the whole surface of these melted materials, a light spongy stone seemed to float, while the lower body was of the hardest substance of which our roads are usually made. Hitherto there were no appearances but what had been often remarked before; but on the third or fourth day, seeming flashes of lightning were shot forth from the mouth of the mountain, with a noise far exceeding the loudest thunder. These flashes, in colour and brightness, resembled what we usually sec in tempests, but they assumed a more twisted and serpentine form. After this followed such clonds of sinoke and ashes, that the whole city of Naples, in the midst of the day, was involved in nocturnal darkness, and the nearest friends were unable to distinguish each other in this frightful gloom. If any person attempted to stir out without torch-light, the was obliged to return, and every part of the city was filled with supplications and terror. Àt length, after a continuance of some hours, about one o'clock at inidnight, the wind blowing from the north, the stars began to be seen; the heavens, though it was night, liegan to grow brighter; and the cruptions, after a continuance of fifteen days, to lessen. 'The torrent of melted matter was secn to extend from the mountain down to the shore; the people began to return to their former dwellings, and the whole face of nature to resume its former appearance." 
The famous Bishop Berkley gives an account of one of these eruptions in a manner something different from the former." "In the year 1717, and the middle of April, with much difficulty $I$ reached the top of Mount Vesuvius, in which I saw a vast aperture full of smoke, which hindered me from seeing its depth and figure. I heard within that horrid gulf certain extraordinary sounds, which seemed to proceed from the bowels of the mountain, a sort of murmuring, sighing, dashing sound; and, between whiles, a noise like that of thunder or cantion, with a clattering like that of tiles falling from the tops of houses into the streets. Sometimes, as the wind changed, the sinoke grew thinner, discovering a very ruddy flame, and the circumference of the crater streaked with red and several shades of yellow. After an hour's stay, the smoke, being moved by the wind, gave us short and partial prospects of the great hollow; in the flat bottom of which $I$ could discern two furnaces almost contiguous; that on the left seeming about three yards over, glowing with ruddy flame, and throwing up red-hot stones with a hideous noise, which, as they fell back, caused the clattering already taken notice of.-May 8; in the morning, I ascended the top of Vesuvius a second time; and found a different face of things. The smoke ascending upright, gave a full prospect of the crater, which, as I could judge, was about a mile in circumference, and a hundred yards deep. A conical mount had been formed, since my last visit, in the middle of the bottom, which I could see was made by the stones, thrown up and fallen back again into the crater. In this new hill remained the two furnaces already mentioned. The one was seen to throw up every three or four minutes, with a dreadful sound, a vast number of red-hot stones, at least three hundred feet higher than my head, as I stood upon the brink; but as there was no wind, they fell perpendicularly back from whence they had been discharged. The other was filled with red-hot liquid matter, like that in the furnace of a glass-house, raging and working like the waves of the sea, with a short abrupt noise. This matter would sometimes boil over, and

\footnotetext{
- Phil. Trans, vol. ii. p. 209.
}

run down the side of the conical hill, appearing at first red hot, but changing colour as it hardened and cooled. Had the wind driven in our faces, we had been in no small danger of stifling by the sulphureous smoke, or being killed by the masses of melted minerals that were shot from the bottom. But as the wind was favourable, I had an opportunity of surveying this amazing scene for above an hour and a half together. On the fifth of June, after a horrid noise, the mountain was seen at Naples to work over; and, about three days after, its thunders were renewed so, that not only the windows in the city, but all the houses, shook. From that time it continued to overflow, and sometimes at night were seen columns of fire shooting upward from its summit. On the tenth, when all was thought to be over, the mountain again renewed its terrors, roaring and raging most violently. One cannot form a juster idea of the noise, in the most violent fits of it, than by imagining a mixed sound made up of the raging of a tempest, the murmur of a troubled sea, and the roaring of thunder and artillery, confused all together. Though we heard this at a distance of twelve miles, yet it was very terrible. I therefore resolved to approach nearer to the mountain; and, accordingly, three or four of us got into a boat, and were set ashore at a little town situated at the foot of the mountain. From thence we rode about four or five miles, before we came to the torrent of fire that was descending from the side of the volcano; and here the roaring grew exceedingly loud and terrible as we approached. I observed a mixture of colours in the cloud, above the crater, green, yellow, red, and blue. There was likewise a ruddy dismal light in the air, over that tract where the burning river flowed. These circumstances, set off and augmented by the horror of the night, made a scene the most uncommon and astonishing I ever saw; which still increased as we approached the burning river: Imagine a vast torrent of liquid fire, rolling from the top down the side of the mountain, and with irresistible fury bearing down and consuming vines, olives, and houses; and divided into different channels, according to the inequalities of the mountain. The largest stream seemed half a mile broad 
at least, and five niles long. I walked so far before my companions up the mountain, along the side of the river of fire, that I was obliged to retire in great haste, the sulphureous stream having surprised me, and almost taken away my breath. During our return, which was about three o'clock in the morning, the roaring of the mountain was heard all the way, while we observed it throwing up huge spouts of fire and burning stones, which, falling, resembled the stars in a rocket. Sometimes I observed two or three distinct columns of flame, and sometimes one only, that was large enough to fill the whole crater. These burning columns, and fiery stones, seemed to be shot a thousand feet perpendicular above the summit of the volcano; and in this manner the mountain continued raging for six or eight days after. On the 18 th of the same month, the whole appearance ended, and the mountain remained perfectly quiet, without any visible smoke or flame.

The matter which is found to roll down from the mouth of all volcanoes in general, resembles the dross that is thrown from a smith's forge. But it is different, perhaps, in various parts of the globe; for, as we have already said, there is not a quarter of the world that has not its volcanoes. In Asia, particularly in the islands of the Indian Ocean, there are many. One of the most famous is that of Albouras, near Mount Taurus, the summit of which is continually on fire, and covers the whole adjacent country with ashes. In the island of Ternate there is a volcano, which, some travellers assert, burns most furiously in the times of the equinoxes, because of the winds which then contribute to increase the flames. In the Molucco islands there are many burning mountains; they are also seen in Japan, and the islands adjacent; and in Java and Sumatra, as well as in other of the Philippine islands. In Africa there is a cavern, near Fez, which continually sends forth either smoke or flames. In the Cape de Verde islands, one of them, called the Island del Fuego; continually burns; and the Portuguese, who frequently attempted a settlement there, have as often been obliged to desist. The Peak of Teneriffe is, as every one knows, a volcano, that seldom desists from eruptions. But, of all parts of the earth,
America is the place where those dreadful irregularities of nature are the most conspicuous. Vesuvius, and Itrna itself, are but mere fireworks in comparison to the burning mountains of the Andes; which, as they are the highest mountains of the world, so also are they the most formidable for their eruptions. The mountain of Arequipa in Peru, is one of the most cclebrated; Carassa, and Malahallo, are very considerable; but that of Cotopaxi, in the province of Quito, exceeds any thing we have hitherto read or heard of. The mountain of Cotopaxi, as described by Ulloa, is more than tliree miles perpendicular from the sea; and it became a volcano at the time of the Spaniards' first arrival in that country. A new eruption of it happened in the year 1743, having been some days preceded by' a continual roaring in its bowels. The sound of one of these mountains is not, like that of the volcanoes in Europe, confined to a province, but is heard at a hundred and fifty miles distance." "An aperture was made in the summit of this immense mountain; and three more about equal heights near the mid-' dle of its declivity, which was at that time buried under prodigious masses of snow. 'The' ignited substances ejected on that occasion, mixed with a prodigious quantity of ice and snow, melting amidst the flames, were carried down with such astonishing rapidity, that in an instant the valley from Callo to Latucunga was overflowed; and besides its ravages in bearing down the houses of the Indians, and other poor inhabitants, great numbers of people lost their lives. The river of Latucunga was the channel of this terrible flood; till being too small for receiving such a prodigious current, it overflowed the adjacent country, like a vast lake, near the town, and carried away all the buildings within its reach. The inhabitants retired into a spot of higher ground behind the town, of which those parts which stood within the limits of the current were totally destroyed. The dread of still greater devastations did not subside for three days; during which the volcano ejected cinders, while torrents of melted ice and snow poured down its sides. The eruption lasted several days, and was accompanied with ter-

\footnotetext{
alloa, vol. i. p. $442 . \quad$ Ulloa, vol. i. p. 442.
} 
rible roarings of the wind, rushing through the volcano, still louder than the former rumblings in its bowels. At last all was quiet, neither fire nor smoke to be scen, nor noise to be heard; till, in the ensuing year, the flames again appeared with recruited violence, forcing their passage through several other parts of the mountain, so that in clear nights the flames being reflected by the transparent ice, formed an awfully magnificent illumination."

Such is the appearance and the effect of those fires which proceed from the more inward recesses of the earth : for that they generally come from deeper regions than inan has hitherto explored, I cannot avoid thinking, contrary to the opinion of Mr. Buffon, who supposes them rooted but a very little way below the bed of the mountain. "We can neversuppose," says this great naturalist, "that these substances are ejected from any great distance below, if we only consider the great force already required to fling them up to such vast heights above the mouth of the inountain; if we consider the substances thrown up, which we shall find upon inspection to be the same with those of the mountain below ; if we take into our consideration, that air is always necessary to keep up the flame; but, most of all, if we attend to one circumstance, which is, that if these substances were exploded from a vast depth below, the same force required to shoot them up so high, would act against the sióes of the volcano, and tear the whole mountain in pieces." To all this spe- cious reasoning, particular answers might be easily given ; as, that the length of the funnel increases the force of the explosion; that the sides of the funnel are actually often burst with the great violence of the flame; that air may be supposed at depths at least as far as the perpendicular fissures descend. But the best answer is a well-known fact; namely, that the quantity of matter discharged from Etıa alone, is supposed, upon a moderate computation, to exceed twenty times the original bulk of the mountain." "The greatest part of Sicily seems covered with its eruptions.

The inlabitants of Catanea have found. at the distance of several miles, streets and houses sixty feet deep, overwhelmed by the lava or matler it has discliarged. But what is still more remarkable, the walls of these very houses have been built of materials evidently thrown up by the mountain. The inference from all this is very obvious; that the matter thus exploded cannot belong to the mountain itself, otherwise it would have been quickly consumed; it cannot be derived from moderate depths, since its amazing quantity evinees, that all the places near the bottom must have long since been exhausted; nor can it have an extensive, and, if I may so call it, a superficial spread, for then the country round would be quickly undermined; it must, therefore, be supplied from the deeper regions of the earth; those undiscovered tracts where the Deity performs his wonders in solitude, satisfied with self-approbation!

\section{CHAPTER X.}

\section{OF EARTHQUAKES.}

HAVING given the theory of rolcanoes, we have in some measure given also that of earthquakes. They both seem to proceed from the same cause, only with this difference, that the fury of the voleano is spent in the eruption; that of an earthquake spreads

\footnotetext{
- Kircher, Mund. Subt. vol. i. p. 202.
}

wider, and acts more fatally by being confincd. The volcano only affrights a province; earthquakes have laid whole kingdoms in ruin.

Philosophers ${ }^{b}$ have taken some pains to distinguish between tlie various kinds of earth-

\footnotetext{
bristotle, Agricola, Buffon.
} 
quakes, such as the tremulous, the pulsative, the perpendicular, and the inclined; but these are rather the distinctions of art than of nature, mere accidental differences arising from the situation of the country or of the cause. If, for instance, the confined fire acts directly under a province or a town, it will heave the carth perpendicularly upward, and produce a perpendicular earthquake. If it acts at a distance, it will raise that tract obliquely, and thus the inhabitants will perceive an inclined one.

Nor does it seem to me that there is much greater reason for Mr. Buffon's distinction of earthquakes; one kind of which he supposes to be produced by fire in the manner of volcanoes, and confined but to a very narrow circumference. 'The other kind he ascribes to the struggles of confined air, expanded by heat in the bowels of the earth, and eideavouring to get free. For how do these two causes differ? Fire is an agent of no power whatsoever without air. It is the air, which being at first compressed, and then dilated in a cannon, that drives the ball with such force. It is the air struggling for vent in a volcano, that throws up its contents to such vast heights. In short, it is the air confined in the lowels of the earth, and acquiring elasticity by heat, that produces all those appearances which are generally aseribed to the operation of fire. When, therefore, we are told that there are two causes of earthquakes, we only learn that a greater or smaller quantity of heat produces those terrible effects; for air is the only active operator in either.

Sume philosophers, however, have been willing to give the air as great a share in producing these terrible efforts as they could; and, magnilying its powers, have called in but a very moderate degree of heat to put it in action. Although experience tell us that the earth is full of inflaminable materials. and that fires are produced wherever we descend; althongh it tells us that those countries where there are volcanoes, are most subject to earthquakes; yet they step out of their way, and so find a new solution. These only allow but just heat enough to produce the most dreadful phenomena, and, backing their assertions with

* Buffon, vol. ii. p. 328.

No. 4. long calculations, give theory an air of demonstration. Mr. Amontons ${ }^{b}$ has been particularly sparing of the internal heat in this respect; and has shown, perhaps accurately enough, that a very moderate degrce of heat may suflice to give the air amazing powers of expansion.

It is amazing enough, however, to trace the progress of a philosophical fancy let loose in imaginary speculations. They run thus: "A very moderate degree of heat may bring the air into a condition capable of producing earthquakes; for the air, at the depth of forty-three thousand five hundred and twentyeight fathom below the surface of the earth, becomes almost as heavy as quicksilver. 'This, however, is but a very slight depth in comparison of the distance to the centre, and is scarcely a seventicth part of the way. The air, therefore, at the centre, must be infinitely heavier than mercury, or any body that we know of. This granted, we shall take something more, and say, that it is very probable there is nothing but air at the centre. Now let us suppose this air heated, by some means, even to the degree of boiling water, (as we have proved that the density of the air is here very great,) its elasticity must be in proportion; a heat, therefore, which at the surface of the earth would have produced but a slight expansive force, must, at the centre, produce one very extraordinary, and, in short, be perfectly irresistible. Hence, this force may, with great ease, produce earthquakes; and, if increased, it may convulse the globe; it may (by only adding figures enough to the calculation) destroy the solar system, and even the fixed stars themselves." These reveries generally produce nothing; for, as I have ever olsserved, increased calculations, while they scem to tire the memory, give the reasoning faculty perfect repose.

However, as earthquakes are the most formidable ministers of nature, it is not to be wondered that a multitude of writers have been curiously employed in their consideration. Woodward has ascribed the cause to a stoppage of the waters below the earth's surface by some accident. These being thus accumulated, and yet acted upon by fires,

b Memoires de I'Academie de Sciences, An. 1703. 
which he supposes still deeper, both contribute to heave up the eartl upon their bosom. This, he thinks, accounts for the lakes of water produced in an earthquake, as well as for the fires that sometimes burst from the earth's surface upon those dreadful occasions. There are others who have supposed that the earth may be itself the cause of its own convulsions. "When," say they, "the root or basis of some large tract is worn away by a fluid underneath, the earth sinking therein, its weight occasions a tremour of the adjacent parts, sometimes producing a noise, and sometimes an inundation of water." Not to tire the reader with a history of opinions instead of facts, some have ascribed them to electricity, and some to the same causes that produce thunder.

It would be tedious, therefore, to give all the various opinions that have employed the speculative on this subject. The activity of the internal heat seems alone sufficient to account for every appearance that attends these tremendous irregularities of nature. To conceive this distinctly, let us suppose, at some vast distance under the earth, large quantities of inflammable matter, pyrites, bitumens, and marcasites, disposed, and only waiting for the aspersion of water, or the humidity of the air, to put their fires in motion: at last, this dreadful mixture arrives; waters find their way into those depths, through the perpendicular fissures; or air insinuates itself through the same minute apertures: instantly new appearances ensue; those substances, which for ages before lay dormant, now conccive new apparent qualities; they grow hot, produce new air, and only want room for expansion. However, the narrow apertures by which the air or water had at first admission, are now closed up; yet as new air is continually generated, and as the heat every moment gives this air new elasticity, it at length bursts, and dilates all round; and, in its struggles to get free, throws all above it into similar convulsions. Thus an earthquake is produced, more or less extensive, according to the depth or the greatness of the cause.

But before we proceed with the causes, let us take a short view of the appearances which

A Plin. Lib. ii. cap. 86. have attended the most remarkable earthquakes. By these we shall see how far the theorist corresponds with the historian. The greatest we find in antiquity is that mentioned by Pliny, ${ }^{a}$ in which twelve cities in Asia Minor were swallowed up in one night: he tells us also of another, near the lake Thrasymene, which was not perceived by the armies of the Carthaginians and Romans, that were then engaged near that lake, although it shook the greatest part of Italy. In another place he gives the following account of an earthquake of an extraordinary kind. "When Lucius Marcus and Sextus Julius were consuls, there appeared a very strange prodigy of the earth, (as I have read in the book of Atruscan discipline,) which happened in the province of Mutina. Two mountains shocked against each other, approaching and retiring with the most dreadful noise. They, at the same time, and in the midst of the day, appeared to cast forth fire and smoke, while a vast number of Roman knights and travellers from the Atmilian Way, stood and continued amazed spectators. Several towns were destroyed by this shock; and all the animals that were near them were killed." In the times of Trajan, the city of Antioch, and a great part of the adjacent country, was buricd by an carthquake. About three hundred years after, in the times of Justinian, it was once more destroyed, together with forty thousand inhabitants; and, after an interval of sixty years, the same ill-fated city was a third time overturned, with the loss of not less than sixty thousand souls. In the year 1182, most of the cities of Syria, and the kingdom of Jerusalem, were destroyed by the same accident. In the year 1594, the Italian historians describe an earthquake at Puteoli, which caused the sea to retire two hundred yards from its former bed.

But one of those most particularly described in history, is that of the year 1693; the damages of which were chiefly felt in Sicily, but its motion perceived in Germany, France, and England. It extended to a circumference of two thousand six hiundred leagues; chiefly affecting the sea-coast and great rivers; inore perceivable also upon the moun-

blin. lib. iii. cap. 85. 
tains than in the valleys. Its motions were so rapid, that those who lay at their length were tossed from side to side, as upon a rolling billow." The walls were dashed fiom their foundations; and no less than fifty-four cities, with an incredible number of villages, were either destroyed or greatly damaged. The city of Catanea, in particular, was utterly overthrown. A traveller, who was on his way thither, at the distance of some miles, perceived a black cloud, like night, hanging over the place. The sea, all of a sudden, began to roar; Mount Atna to send forth great spires of flame; and soon after a shock ensued, with a noise as if all the artillery in the world had been at once discharged. Our traveller, being obliged to alight instantly, felt himself raised a foot from the ground; and turning his eyes to the city, he, with amazement, saw nothing but a thick cloud of dust in the air. The birds flew about astonished; the sun was darkened; the beasts ran howling from the lills; and although the shock did not continue above three minutes, yet near nineteen thousand of the inhabitants of Sicily perished in the ruins. Catanea, to which city the describer was travelling, seemed the principal seene of riin; its plaee only was to be found; and not a footstep of its former magnificence was to be seen remaining.

The earthicuake which happened in Jamaica, in 1692 , was very terrible, and its description sufficiently minute. "In two minutes' time it destroyed the town of Port Royal, and sunk the houses in a gulf forty fathoms deep. It was attended with a hollow rumbling noise, like that of thunder; and; in less than a minute, three parts of the houses, and their inhabitants, were all sunk quite under water. While they were thus swallowed up on one side of the street, on the other the horses were thrown into heaps; the sand of the streets rising like the waves of the sea, lifting up those that stood upon it, and immediately overwhelming them in pits. All the wells discharged their waters with the most vehement agitation. The sea felt an equal share of turbulence, and, bursting over its mounds, deluged all that came in its way.

- Phil. Trans.
The fissures of the earth were, in some places, so great, that one of the streets appeared twice as broad as formerly. In many places, however, it opened and closed again, and continued this agitation for some time. Of these openings, two or three hundred might be seen at a time; in some whereof the people were swallowed up; in others, the earth closing, caught them by the middle, and thus crushed them instantly to death. Other openings, still more dreadful than the rest, swallowed up whole streets; and others, more formidable, spouted up whole eataracts of water, drowning such as the earthquake had spared. The whole was attended with the most noisome stench; while the thundering of the distant falling mountains, the whole sky overcast with a dusky gloom, and the crash of falling habitations, gave unspeakable horror to the scene. After this dreadful calamity was over, the whole island seemed converted into a scene of desolation; scarcely a planter's house was lelt standing; almost all were swallowed up; houses, people, trees, shared one universal ruin; and in their places appeared great pools of water, which, when dried up by the sun, left only a plain of barren sand, without any vestige of former inhabitants. Most of the rivers, during the earthquake, were stopped up by the falling in of the mountains; and it was not till after some time that they made themselves new channels. The mountains seemed particularly attacked by the force of the shock; and it was supposed that the principal seat of the concussion was among them. Those who were saved got on board ships in the harbour, where many remained above two months; the shocks continuing, during that interval, with more or less violence every day."

As this description seems to exhibit all the appearances that usually make up the catalogue of terrors belonging to an earthquake, I will suppress the detail of that which happened at Lisbon in our own times, and which is too recent to require a description. In fact, there are few particulars in the accounts of those who were present at that scene of desolation, that we have not more minutely and accurately transmitted to us by former wr1ters, whose narratives I have for that reason preferred. I will therefore close this descrip- 
tion of human calamities with the account of the dreadful earthquake at Calabria, in 1638. It is related by the celebrated $\mathrm{Fa}$ ther Kircher, as it happened while he was on his journcy to visit Mount Aitna. and the rest of the wonders that lie towards the south of Italy. I need scarcely inform the reader, that Kircher is considered, by scholars, as one of the greatest prodigies of learning.

"Having hired a boat, in company with four more, two friars of the order of St. Francis, and two seculars, we launched, on the twenty-fourth of March, from the harbour of Messina, in Sicily, and arrived the same day at the promontory of Pelorus. Our destination was for the city of Euphæmia, in Calabria, where we had some business to transact, and where we designed to tarry for some time. However, Providence seemed willing to cross our design; for we were obliged to continue for three days at Pelorus, upon account of the weather; and though we often put out to sea, yet we were as often driven back. At length, however, wearied with the delay, we resolyed to prosecute our voyage; and, although the sea seemed more than usually agitated, yet we ventured forward. The gulf of Charybdis, which we approached, seemed whirled round in such a manner, as to forin a vast hollow, verging to a point in the centre. Proceeding onward, and turning my eyes to Atua, I saw it cast forth large volumes of smoke, of mountainous sizes, which entirely covered the whole island, and blotted out the very shores from my view. This, together with the dreadful noise, and the sulphureous stench, which was strongly perceived, filled ine with apprehensions that some more dreadful calamity was impending. The sea itself seemed to wear a very unusual appearance; those who have seen a lake in a violent sliower of rain covered all over with bubbles, will conceive some idea of its agitations. My surprise was still increased by the calmuess and serenity of the weather; not a breeze, not a cloud, which might be supposcil to put all nature thus into motion. I therefore warned my companions that an cartl:quake was appioaching; and, after some time, making for the shore with all possible diligence, we landed at Tropæ, happy and thankful for having escaped the threatening dangers of the sea.

"But our triumpls at land were of short duration; for we had scarcely arrived at the Jesuits' College in that city, when our ears were stunned with a horrid sound, resembling that of an infinite number of chariots driven fiercely forward, the wheels rattling, and the thongs cracking. Soon after this, a most dreadful earthquake ensued, so that the whole tract upon which we stood seemed to vibrate, as if we were in the scale of a balance that continued wavering. This motion, however, soon grew more violent; and being no longer able to keep my legs, I was thrown prostrate upon the ground. In the mean time, the universal ruin round me redoubled my amazement. The crash of falling houses, the tottering of towers, and the groans of the dying, all contributed to raise my terror and despair. On every side of me l saw nothing but a scene of ruin, and danger threatening wherever I should fly. I cominended myself to God, as my last great refuge. At that hour, Ohow vain was every sublunary happiness! wealth, honour, empire, wisdom, all mere useless sounds, and as empty as the bubbles in the deep. Just standing on the threshold of eternity, nothing but God was my pleasure; and the nearer I approached, I only loved him the inore.-After some time, however, finding that I remained unhurt amidst the general concussion, I resolved to venture for safety, and running asfast as I could, reached the shore, but almost terrified out of my reason. I did not search long here till I found the boat in which I had landed, and my companions also, whose terrors were even greater than mine. Our meeting was not of that kind where every one is desirous of telling his own happy escape; it was all silence, and a gloomy dread of impending terrors.

"Leaving this seat of desolation, we prosecuted our voyage along the coast, and the next day came to Rochetta, where we landed, although the earth still continued in violent agitations. But we were scarcely arrived at our inn, when we were once more obliged to return to the boat, and in about half an hour we saw the greatest part of the town, and the inn at which we had set up, dashed to the ground, and burying all its inbabitants beneath its ruins. 
"In this manner, proceeding onward in our little ressel, finding no safety at land, and yet, from the smallness of our boat, having but a very dangerous continuance at sea, we at length landed at Lopizium, a castle midway between Tropx and Euphomia, the city to which, as I said before, we were bound. Here, wherever I turned my eyes, nothing but scenes of ruin and horror appeared; towns and castles levelled to the ground; Strombalo, though at sixty miles distance, belehing forth flanes in an unusual manner, and with a noise which I could distinctly hear. But my attention was quickly turued from more remote to contiguous danger. The rumbling sound of an approaching earthquake, which we by this time were grown acquainted with, alarmed us for the consequences; it every moment seemed to grow louder, and to approach more near. The place on which we stood now began to shake most dreadfully, so that being unable to stand, iny companious and I caught hold of whatever slirub grew next us, and supporied ourselves in that manner.

"After some time, this violent paroxysm ceasing, we again stood up, in order to prosecute our royage to Eupharnia, that lay within sight. In the mean time, while we were preparing for this purpose, I turned my eyes towards the city, but could sce only a frightful dark cloud that seemed to rest upon the place. 'This the more surprised lis, as the weather was so very serene. We waited, therefore, till the cloud was passed away; then turning to look for the city, it was totally surk. Wonderful to tell! nothing but a dismal and putrid lake was to be seen where it stood. We looked about to find some one that could tell us of its sad catastrophe, but could see none! All was become a melancholy solitude! a scene of hideous desolation! Thus proceeding pensively along, in quest of some human being that could give us some little information, we at length saw a boy sitting by the shore, and appearing stupified with terror. Of him, therefore, we inquired concerming the fate of the city, but he could not be induced to give us an answer. We entreated him with every expression of tenderness and pity to tell ns: but his senses were quite wrapt up in the contemplation of the danger he had escaped. We offered him some victuals, but he seemed to loathe the sight. We still persisted in our oflices of kindness; but he only pointed to the place of the city, like one out of his senses; and then running up into the woods, was never lieard of after. Such was the fate of the city of Euploxmia! and as we continued our melancholy course along the shore, the whole coast, for the space of two hundred miles, presented nothing but the remains of cities, and men.scattered, without an habitation, over the ficlds. Proceeding thus along, we at length ended our distressful voyage by arriving at Naples, after luaving escaped a thousand dangers both at sea and land."

The reader, I hope, will excuse me for this long translation from a favourite writer, and that the sooncr, as it contains some particulars relative to carthquakes not to be found elsewhere. Frow the whole of these accounts we may gather, that the most concornitant circumstances are these:

A rumbling sound before the earthquake. This proceeds from the air or fire, or both, forcing their way through the chasms of the carth, and cndeavouring to get free; which is also heard in rolcanoes.

A violent agitation or heaving of the sea, sometimes before and sometimes after that at land. This agitation is only a similar effect produced on the waters with that at land, and may be called, for the sake of perspicuity. a seci-quake; and this also is produced by volcanoes.

A spouting up of waters to great heights. It is not easy to describe the manner in which this is performed: but volcanoes also perform the same; Vesurius being known frequently to cject a vast body of water.

A rocking of the earth to and fro, and sometimes a perpendicular bouncing, if it may be so called, of the same. This differcnce clicfly arises from the situation of the place with respect to the suhterranean fire. Directly under, it lifts; at a farther distance, it rocks.

Some earthquakes seem to travel onward, and are felt in different countries at different hours the same day. This arises from the great shock being given to the earth at one place, and that being communicated onward 
by an undulatory motion, successively affects different regions in its progress; as the blow given by a stone falling in a lake, is not perceived at the shores till some time after the first concussion.

The shock is sometimes instantaneous, like the explosion of gunpowder; and sometimes tremulous, and continuing for several minutes. The riearer the place where the shock is first given, the more instantaneours and simple it appears. At a greater distance, the earth redoubles the first blow with a sort of vibratory continuation.

As waters have generally so great a share in producing earthquakes, it is not to be wondered that they should generally follow those breaches made by the force of fire, and appear in the great chasms which the eartlyquake has opened.

These are soine of the most remarkable phenomena of earthquakes, presenting a frightful assemblage of the inost terrible eflects of air, eartl, fire, and water.

The valley of Solfatara, near Naples, seens to exhibit, in a minuter degree, whatever is seen of this horrible kind on the great theatre of nature. This plain, which is about twelve hundred feet long, and a thousand broad, is embosomed in mountains, and has in the middle of it a lake of noisome blackish water, covered with a bitumen, that floats upon its surface. In every part of this plain, caverns appear smoking with sulphur, and often emitting flames. The earth, wherever we walk over it, trembles beneatl the feet. Noises of flames, and the hissing of waters, are heard at the bottom. The water sometinges spouts up eight or ten feet high. The most noisome funies, foetid water, and sulphureous vapours, offend the smell. A stone thrown into any of the caverns, is ejected again with considerable violence. These appearances generally prevail when the sea is any way disturbed; and the whole seems to exhibit the appearance of an earthquake in miniature. However, in this sinaller scene of wonders, as well as in the greater, there are many appearances for which, perhaps, we shall never aecount; and many questions may be asked, which no conjectures can thoroughly resolve. It was the fault of the philosopliers of the last age, to be more inquisitive after the causes of things than alter the lhings themselves. They seemed to think that a confession of ignorance cancelled their claims to wisdom; they, therefore, had a solution for every demand.But the present age has grown, if not more inquisitive, at least more modest; and none are now ashamed of that ignorance which labour can neither remedy nor remove.

\section{CHAPTER XI.}

\section{OF THE APPEARANCE OF NEW ISLANDS AND TRACTS; AND OF THE DISAPPEARING OF OTHERS.}

HITHERTO we have taken a survey only of the evils which are produced by subterranean fires, but we have inentioned notling of the benefits they may possibly produce. They may be of use in warming and cherishing the ground, in promoting vegetation, and giving a more exquisite flavour to the productions of the earth. The imagination of a person who has never been out of our 'own mild region, can scarcely reach to that luxuriant beauty with which all nature appears clothed in those very countries that we have but just now described as desolated by eartlquakes, and undermined by subterranean fires. It must be granted, therefore, that though in those regions they have a greater share in the danger:, they have also a larger proportion in the benefits of nature.

But there is another advantage arising from subterranean fires, which, though hitherto disregarded by man, yet may one day become serviceable to him; I mean, that while 
they are found to swallow $v$ p cities and plains in one place, they are also known to produce promontories and islands in another. We have many instances of islands being thus formed in the midst of the sea, which, though for a long time barren, have afterwards become fruitful seats of happiness and ind ustry.

New islands are formed in two ways; either suddenly, by the action of subterraneous fires; or more slowly, by the deposition of mud, carried down by rivers, and stopped by some accident. ${ }^{a}$ With respect particularly to the first, ancient historians, and modern travellers, give us such accounts as we can have no room to doubt of. Seneca assures us, that in his time the island of Therasia appeared unexpectedly to some mariners, as they were employed in another pursuit. Pliny assures us, that thirteen islands in the Mediterranean appeared at once emerging from the water; the cause of which lie ascribes rather to the retiring of the sea in those parts, than to any subterraneous elevation. However, he mentions the island of Hiera, near that of Therasia, as formed by subterraneous explosions; and adds to his list several others formed in the same manner. In one of which he relates that fish in great abundance were found, and that all those who ate of them died shortly after.

"On the twenty-fourth of May," in the year 1707 , a slight earthquake was perceived at Santorin; and the day following, at sunrising, an object was seen by the inhabitants of that island, at two or three miles distance at sea, which appeared like a floating rock. Some persons, desirous either of gain, or incited by curiosity, went there, and found, even while they stood upon this rock, that it seemed to rise beneath their feet. They perceived also, that its surface was covered with punice-stones and oysters, which it had raised from the bottom. Every day after, until the fourteenth of June, this rock seemed considerably to increase; and then was found to be half a mile round, and about thirty feet above the sea. The earth of which it was composed seemed whitish, with a small proportion of clay. Soon after this the sea again

\footnotetext{
Buffon, vol. ii. p. 343.

Hist. de l'Acad. an. 1708, p. 23.

- Justin, lib. $\mathrm{xxx}$. cap. 4 .
}

appeared troubled, and steams arose which were very offensive to the inhabitants of Santorin. But on the sixteenth of the succeeding month, seventeen or eighteen rocks more were seen to rise out of the sea, and at length to join together. All this was accompanied with the most terrible noise, and fires which proceeded from the island that was newly formed. The whole mass, however, of all this new-formed earth, uniting, increased every day, both in height and breadth, and, by the force of explosions, cast forth rocks to seven miles distance. This continued to bear the same dreadful appearances till the month of November in the same year; and it is at present a volcano, which sometimes renews its explosions. It is about three miles in circumference; and more than from thirty-five to forty feet high."

It seems extraordinary, that, about this place in particular, islands have appeared at different times, particularly that of Hicra, mentioned above, which has received considerable additions in succeeding ages. Justin tells us, ${ }^{\mathrm{c}}$ that at the time the Macedonians were at war with the Romans, a new island appeared between those of Theramenes and Therasia, by means of an earthquake. We are told that this became half as large again about a thousand years after, another island rising up by its side, and joining to it, so as scarcely at present to be distinguished from the former.

A new island was formed in the year 1720 , near that of Tercera, near the continent of Africa, by the same causes. In the beginning of December, at night, there was a terrible earthquake at that place, and the top of a new island appeared, which cast forth smoke in vast quantities. The pilot of a ship, who approached it, sonnded on one side of this island, and could not find ground at sixty fathom: at the other side the sea was totally tinged of a different colour, exhibiting a mixture of white, blue, and green; and was very shallow. This island, on its first appearance, was larger than it is at present; for it has since that time sunk in such a manner, as to be scarcely above water."

In the spring of 1783 , a volcanic island was formed about 30 miles trom the south-west point of Iceland. The discoverer, Captain Von Loweuhorn, in the Dauish service. 
A traveller, whom these appcarances could not avoid affecting, speaks of them in this manner:" "What can be more surprising than to see fire not only break out of the bowels of the earth, but also to make itself a passage through the waters of the sea! What cail be more extraordinary, or foreign to our common notions of things, than to see the bottom of the sea rise up into a mountain above the water, and become so firm an island as to be able to resist the violence of the greatest storms! I know that subterraneous fires, when pent in a narrow passage, are able to raise up a mass of earth as large as an island : but that this should be done in so regular and exact a manner that the water of the sea should not be able to penetrate and extinguish those fires; that after having made so many passages, they should retain force enough to raise the earth; and, in fine, after having been extinguished, that the mass of earth should not fall down, or sink again with its own weight, but still remain in a manner suspended over the great arch below! This is what to me seems more surprising than any thing that has been related of Mount Ætna, Vesuvius, or any other volcano."

Such are his sentiments: however, there are few of these appearances any way more extraordinary than those attending volcanoes and earthquakes in general. We are not more to be surprised that inflammable substances should be found beneath the bottom of the 6ea, than at similar depths at land. These have all the force of fire, giving expansion to air, and tending to raise the earth at the bottom of the sea, till it at length heaves above water. These marine volcanoes are not so frequent; for, if we may judge of the usual procedure of nature, it must very often happen, that before the bottom of the sea is elevated above the surface, a chasin is opened in it, and then the water pressing in, extinguishes the volcano before it has time to pro-

who arrived just at the time of the first eruption, when smoke and flames ascended out of the sea, relates that no island or any land conld be seen, from which these flames could originate. No wonder, then, that he fell into the greatest consteruation, when, as he expresses himself, he saw the waves on fire. The following year the Danish gevernment directed, that all ships bound to Iccland should examine the new-formed island; but su entirely duce its effects. This extinction, however, is not effected without very great resistance from the fire beneath. The water, upon dashing into the caveru, is very probably at first ejected back with great violence; and thus some of those amazing water-spouts are secn, which have so often astonished the mariner, and excited curiosity. But of these in their place.

Besides the production of those islands by the action of fire, there are others, as was said, produced by rivers or seas carrying mud, earth, and such like substances, along with their currents; and at last depositing them in some particular place. At the mouths of most great rivers, there are to be scen banks, thus formed by the sand and mud carricd down with the stream, which have rested at that place, where the force of the current is diminished by its junction with the sea. These banks, by slow degrees, increase at the bot tom of the decp: the water in those places, is at first found by mariners to grow more shallow; the bank soon heaves up above the surface; it is considered, for a while, as a tract of useless and barren sand; but the seeds of some of the more hardy vegetables are driven thither by the wind, take root, and thus binding the sandy surface, the whole spot is clothed in time with a beautiful verdure. In this manner there are delightful and inhabited islands at the mouths of many rivers, particularly the Nile, the $\mathrm{Po}$, the Mississippi, the Ganges, and the Senegal. There has been, in the memory of man, a beautiful and large island formed in this manner at the mouth of the river Nanquin, in China, made from depositions of mud at its opening : it is not less than sixty miles long, and aloout twenty broad. La Loubere informs "1s," in his voyage to Siam, that these sand-banks increase every day, at the mouths of all the great rivers in Asia : and hence, he asserts, that the navigation up these rivers becomes

had it vanished, that none of them either saw or could discover the smallest trace of $\mathrm{jt}$. However, towards the end of the next year, a Danish ship of war, of 64 guns, was wrecked on this rock; which is now no longer visible, but remains a most dangerous rock, nearly level with the surface of the water.

a Phil. Trans. vol. v. p. 197.

b Lettres Curieuses et Edifiantes, sec. xi. p. 234. 
every day more difficult, and will, at one timc or other, be totally obstructed. The same may be remarked with regard to the Wolga, which has at present seventy openings into the Caspian sea; and of the Danube, which has seven into the Euxine. We have had an instance of the formation of a new island not very long since at the mouth of the Humber, in England. "It is yet within the memory of man," says the relater," "since it begail to raise its head above the ocean. It began its appearance at low water, for the space of a few hours, and was buried again till the next tide's retreat. Thus successively it lived and died, until the year 1666, when it began to maintain its ground against the insult of the wares, and then first invited the aid of human industry. A bank was thrown about its rising grounds, and being thus defended from the incursions of the sea, it became firm and solid, and, in a short time, afforded good pasturage for cattle. It is about nine miles in circumference, and is worth to the proprietor about eight hundred pounds a year." It would be endless to mention all the islands that have been thus formed, and the advantages that have been derived from them. However, it is frequently found, that new islands may often be considered as only turning. the rivers from their former beds; so that in proportion as land is gained at one part, it is lost by the overflowing of some other.

Little, therefore, is gained by such accession; nor is there mueh more hy the new islands which are sometimes formed from the spoils of the continent. Mariners assure us, that there are sometimes whole plains unrooted from the main lands, by tloods and teinpests. These being carried out to sea, with all their trees and animals upon them, are frequently seen floating in the ocean, and exhibiting a surprising appearance of rural tranquillity in the midst of danger. The greatest part, however, having the earth at their roots at length washed away, are dispersed, and their animals drowned; but now and then some are found to brave the fury of the ocean, till being stuck either among rocks or sands, they again take firm footing, and become perinanent islands.

Phil. Trans, vol. iv. p. 251.
As different causes have thus concurred to produce new islands, so we have accounts of others, that the same causes have contributed to destroy. We have already seen the power of earthquakes exerted in sinking whole cities, and leaving lakes in their room. There have been islands, and regions also, that have shared the same fate; and have sunk with their inhabitants never more to be heard of Thus Pausanias tells us of all island called Chryses, that was sunk near Lemnos. Plin: mentions several; among others, the island of Cea, for thirty miles, having been washed away, with several thousands of its inhabitants. But of all the noted devastations of this kind, the total submersion of the island of Atalantis, as mentioned by Plato, has been most the subject of speculation. Mankind, in general, now consider the wliole of his description as an ingenious fable; but when fables are grown famous by time and authority, they become an agreeable, if not a necessary, part of literary information.

"About nine thousand years are passed," says Plato, " since the island of Atalantis was in being. The priests of Egypt were well acquainted with it; and the first heroes of Athens gained much glory in their wars with the inhabitants. This island was as large as Asia Minor and Syria united; and was situated beyond the Pillars of Hercules, in the Aflantic ocean. The beauty of the buildings, and the fertility of the soil, were far beyond ary thing a inodern imagination can conceise: gold and ivory were every where common: and the fruits of the earth offered themselves without cultivation. The arts and the courage of the inhabitants, were not inferior to the happiness of their situation; and they were frequently known to make conquests, and overrun the continents of Europe and Asia." The imagination of the poetical philosopher riots in the description of the natural and acquired advantages, which they long enjoyed in this charming region. "If," says he, "we compare that country to our own, ours will appear a mere wasted skeleton, when opposed to it. Their mountains, to the very tops, were clothed with fertility, and poured down rivers to enrich the plains below."

- Pausanias, 1. 8. in Arcad. p. 509. 
However, all these beauties and benefits were destroyed in one day by an earthquake sinking the earth, and the sea overwhelming it. At present not the sinallest vestiges of such an island are to be found; Plato remains as the only authority for its existence; and philosophers dispute about its situation. It is not for me to enter into the controversy, when there appears but little probability to support the fact; and, indeed, it would be useless to run back nine thousand years in search of dificulties, as we are surrounded with objects that more closely affect us, and that demand admiration at our very doors. When I consider, as Lactantius suggests, the various vicissitudes of nature; lands swallowed by yawning earthquakes, or overwhelmed in the deep; rivers and lakes disappearing, or dried away; mountains levelled into plains; and plains swelling up into mountains; I cannot help regarding this earth as a place of every little stability; as a transient abode of still more transitory beings.

\section{CHAPTER XII.}

\section{OF MOUNTAINS.}

HAVING at last, in some measure, emerged from the deeps of the earth, we come to a scene of greater splendour; the contemplation of its external appearance. In this survey, its mountains are the first objects that strike the imagination, and excite our curiosity. There is not, perhaps, any thing in all nature that impresses an unaccustomed spectator with such ideas of awful solemnity, as these immense piles of Nature's erecting, that scem to mock the minuteness of human magnificence.

In countries where there are nothing but plains, the smallest elevations are apt to excite wonder. In Holland, which is all a flat, they show a little ridge of hills, near the seaside, which Boerhaave generally marked out to his pupils, as being mountains of no small consideration. What would be the sensations of such an auditory, could they at once be presented with a view of the heights and precipices of the Alps or the Andes! Even among us in England, we have no adequate ideas of a mountain prospect; our hills are generally sloping from the plain, and clothed to the very top with verdure : we can scarcely, therefore, lift our imaginations to those inmense piles, whose tops peep up behind intervening clouds, sharp and precipitate, and reach to heights that huinan avarice or curiosity have never been able to ascend.
We, in this part of the world, are not, for that reason, so immediately interested in the question which has so long been agitated among philosophers, concerning what gave rise to these inequalities on the surface of the globe. In our own happy region, we gencratly see no inequalities but such as contribute to use and leanty; and we therefore are amazed at a question, inquiring how such necessary inequalities came to be formed, and seeming to express a wonder how the globe comes to be so beautiful as we find it. But though with us there may be no great cause for such a demand, yet in those places where mountains deform the face of nature, where they pour down cataracts, or give fury to tempests, there seems to be good reason forinquiry eitherinto their causes or their uses. It has been, therefore, asked by many, in what manner mountains have come to be formed; or for what uses they are designed?

To satisfy curiosity in these respects, much reasoning has been employed, and very little knowledge propagated. With regard to the first part of the demand, the manner in which mountaing were formed, we have already seen the conjectures of different philosophers on that head. One supposing that they were formed from the earth's hroken shell at the tine of the deluge; another, that they existed from the creation, and only acquired their 
deformities in process of time; a third, that they owed their original to earthquakes; and still a fourth, with much more plausibility than the rest, ascribing them entirely to the fluctuations of the deep, which he supposes in the beginning to have covered the whole earth. Such as are pleased with disquisitions of this kind, may consult Burnet, Whiston, Woodward, or Buffon. Nor would l be thought to decry any mental amusements, that at worst keep us innocently cinployed; but, for my own part, I cannot help wondering how the opposite demand has never come to be made; and why philosophers have never asked how we come to have plains? Plains are sometimes more prejudicial to man than mountains. Upon plains, an inundation has greater power; the beains of the sun are often collected there with suffocating fierceness; they are sometimes found desert for several liundred miles together, as in the country east of the Caspian sea, although otherwise fruitful, merely because there are no risings or depressions to form reservoirs, or collect the smallest rivulet of water. 'The most rational answer, therefore, why either mountains or plains were formed, seems to be that they were thus fashioned by the hand of Wisdom, in order that pain and pleasure should be so contiguous, as that morality might be exercised either in bearing the one, or communicating the other.

Indeed, the more I consider this dispute respecting the formation of mountains, the more I ain struck with the futility of the question. 'There is neither a straight line, nor an exact superficies, in all nature. If we consider a circle, even with mathematical precision, we shall find it formed of a number of small right lines, joining at augles together. These angles, therefore, may be considered in a circle as mountains are upon our globe; and to demand the reason for the one being monntainous, or the other angular, is only to ask, why a circle is a circle, or a globe is a globe. In short, if there be no surface without inequality in nature, why should we be surprised that the earth has such? It has often been said, that the inequalities of its surface are searce distinguishable, if compared to its magnitude; and I think we have every reason to be content with the answer.
Some, however, have avoided the difficulty by urging the final cause. They allege, that mountains have been formed merely beeause they are useful to man. This carries the inquirer but a part of the way; for no one con affirm, that in all places they are useful. The contrary is known, by horrid experience, in those valleys that are subject to their influence. However, as the utility of any part of our earthly habitation is a very pleasing and flattering speculation to every philosopher, it is not to be wondered that much has been said to prove the usefulness of these. For this purpose many conjectures have been made, that have receired a degree of assent even beyond their evidence; for men were unwilling to become more miserably wise.

It has been alleged, as one principal advantage that we derive from them, that they serve, like hoops or ribs, to strengthen our earth, and to bind it together. In consequence of this theory, Kircher has given us a map of the earth, in this manner hooped with its mountains; which might have a much more solid foundation, did it entirely corres. pond with truth.

Others have found a different use for them, especially when they run surrounding our globe; which is, that they stop the vapours which are continually travelling from the equator to the poles; for these being urged by the heat of the sun, from the warm regions of the line, must all be accumulated at the poles, if they were not stopped in their way by those high ridges of mountains which cross their direction. But an answer to this may be, that all the great mountains in America lie lengthwise, and therefore do not cross their direction.

But to leave these remote advantages, others assert, that not only the animal but vegetable part of the creation would perish for want of convenient humidity, were it not for their friendly assistance. Their summits are, by these, supposed to arrest, as it were, the vapours which float in the regions of the air. Their large inflections and channels are considered as so many basons prepared for the reception of those thick vapours, and impetuous rains, which descend into thein. The huge caverns beneath are so many magazines or conservatories of water for the peculiar 
service of man; and those orifices by which the water is discharged upon the plain, are so situated as to enrich and render them fruitful, instead of returning through subterraneons channels to the sea, after the performance of a tedious and fruitless circulation. ${ }^{a}$

However this be, certain it is, that alınost all our great rivers find their source among mountains; and, in general, the more extensive the mountain, the greater the river: thus the river Amazon, the greatest in the world, has its source anong the Andes, which are the highest mountains on the globe; the river Niger travels a long course of several hundred miles from the mountains of the Moon, the highest in all Africa; and the Danube and the Rhine proceed from the $\Lambda \mathrm{lps}$, which are probably the highest mountains of Europe.

It needs scarcely be said, that, with respect to height, there are many sizes of mountains, from the gently rising upland, to the tall craggy precipice. The appearance is in general different in those of different magnitudes. The first are clothed with verdure to the very tops, and only seem to ascend to improve our prospects, or supply us with a purer air: but the lofty mountains of the other class have a very different aspect. At a distance their tops are seen, in wary ridges, of the very colour of the clouds, and only to be distinguished from them by their figure; which, as I have said, resembles the billows of the sea. ${ }^{b}$ As we approach, the mountain assumes a deeper colour; it gathers upon the sky, and seems to hide half the horizon behind it. Its summits also are becone more distinct, and appear with a broken and perpendicular line. What at first seemed a single hill, is now found to be a chain of continued molintains, whose tops running along in ridges, are embosomed in each other; so that the curvatures of one are fitted to the prominences of the opposite side, and form a winding valley between, often of several miles in extent; and all the way continuing nearly of the same breadth.

Nothing can be finer, or more exact, than Mr. Pope's description of a traveller straining up the Alps. Every mountain he comes to

- Nature Displayed, vol. iii. p. 88 .

- Lettres Philosophiques sur la Formation, \&r. p. 106. he thinks will be the last; he finds, however. an unexpected hill rise before him; and that being scaled, he finds the lighest summit almost at as great a distance as before. Upon quitting the plain, he might have left a green and fertile soil, and a climate warm and pleasing. As he ascends, the ground assumes a more russet colour; the grass becomes more mossy, and the weather more moderate. Still as he ascends, the weather becomes more cold, and the earth more barren. In this dreary passage he is often entertained with a little valley of surprising verdure, caused by the reflected lieat of the sun collected into a narrow spot on the surrounding heights. But it much more frequently happens that he sees only frightful precipices beneath, and lakes of amazing depths; from whence rivers are formed, and fountains derive their original. On those places next the highiest summits, regetation is scarcely carried on; here and there a few plants of the most hardy kind appear. The air is intolerably cold; either continually refrigerated with frosts, or disturbed with tempests. All the ground here wears an eternal covering of ice, and snows that seem constantly accmunlating. Upon emerging from this war of the elements, he ascends into a purer and serener region, where vegetation is entirely ceased; where the precipices, composed entirely of rocks, rise perpendicularly above him; while he views beneath him all the combat of the elements; clouds at his feet, and thunders darting upwards from their bosoms below. A thousand meteors, which are never seen on the plain, present themselves. Circular rainbows ; mock suns; the shadow of the mountain projected "1pon the body of the air $;^{\mathrm{e}}$ and the traveller's own image, reflected as in a looking-glass, upon the opposite cloud.'

Such are, in general, the wonders that present themselves to a traveller in his journey either over the $\Lambda$ lps or the Andes. But we must not suppose that this picture exhibits cither a constant or an invariable likeness of those stupendous lieights. Indeed, nothing can he more capricions or irregular than the forms of many of them. The tops of some

\footnotetext{
e Tilloa, vol. i. d Ibid.

e Phil. Trans, vol. v. p. 152.
}

PUloa, vol. : 
run in ridges for a considerable length, without interruption; in others, the line seems indented by great valleys to an amazing depth. Soinetimes a solitary and a single mountain rises from the bosom of the plain; and sometimes extensive plains, and even provinces, as those of Saroy and Quito, are found embosomed near tops of mountains. In general, however, those countriesthat are most mountainous, are the most barren and uninhabitable.

If we compare the heights of mountains with each other, we shall lind that the greatest and highest are found under the line. ${ }^{\mathrm{a}}$ It is thought by some, that the rapidity of the earth's notion in these parts, together with the greatness of the tides there, may have thrown up those stupendous masses of earth. But, be the cause as it may, it is a remarkable fact, that the inequalities of the earth's surface are greatest there. Near the poles, the earth, indeed, is craggy and uneven enough; but the heights of the mountains there are very inconsiderable. On the contrary, at the equator, where nature seems to sport in the amazing size of all her productions, the plains are extensive, and the mountains remarkably lofty. Some of them are known to rise three miles perpendicular above the bed of the ocean.

To enumerate the most remarkable of these, according to their size, we shall begin with the Andes, of which we have an excellent deseription by Ulloa, who went thither by command of the king of Spain, in company with the French Academicians, to ineasure a degree of the meridian. His journcy up these mountains is too curious not to give an extract from it.

After many incommodious days sailing up the river Guayaquil, he arrived at Caracol, a town situated at the foot of the Andes. Nothing could exceed the inconveniences which he experienced in this voyage, from the tlies and moschetoes, (an animal resembling our gint.) "We were the whole day," says he, "in continual motion to keep them off; but at night our torments were excessive. Our gloves, indeed, were some defence to our hrands; but our faces were entirely exposed;

n Bufion, passim.

so. 5 . nór were our clothes a sufficient defence for the rest of our bodies; for their stings penetrating through the cloth, caused a very painful and fiery itching. One night, in coming to an anchor near a large and hand some house that was uninhabited, we had no sooner seated ourselves in it, than we were attacked on all sides by swarms of moschetoes, so that it was impossible to have one moment's quiet. Those who had covered themselves with clothes made for this purpose, found not the smallest defence; wherefore, hoping to find some relief in the open fields, we ventured out, though in danger of suffering in a more terrible manner from the serpents. But both places were equally obnoxious. On quitting this inhospitable retreat, we the next night took up our quarters in a house that was inhabited; the host of which being informed of the terrible manner we had past the night be-* fore, gravely told us, that the house we so greatly complained of, had been forsaken on account of its being the purgatory of a soul. But we had more reason to believe that it was quitted on account of its being the purgatory of the body. After having journeyed for upwards of three days, through boggy roads, in which the mules at every step sunk up to their bellies, we began at length to perceive an alteration in the climate; and having been long accustomed to heat, we now began to feel it grow sensibly colder:

"It is remarkable, that at 'Tariguagua we often sce instances of the effects of two opposite temperatures, in two persons happening to meet; one of them leaving the plains below, and the other descending from the mountain. The former thinks the cold so severe, that he wraps himself up in all the garments he can procure; while the latter finds the heat so great, that he is scarce able to bear any clothes whatsoever. The one thinks the water so cold, that he avoids being sprinkled by it; the other is so delighted with its warmth, that he uses it as a bath. Nor is the case very different in the same person, who experiences the same diversity of sensation upon his journey up, and upon his return. This difference only proceeds trom the change naturally felt at leaving a climate to which one has been accustomed, and coming into another of an opposite temperiture. 
- The ruggedness of the road from Tariguagua, leading up the mountain, is not easily described. In some parts, the declivity is so great, that the mules can scarcely keep their footing; and in others, the acclivity is equally difficult. The trouble of having people going before to mend the road, the pains arising from the many falls and bruises, and the being constantly wet to the skin, might be supported, were not these inconveniences augmented by the sight of such frightful precipices, and deep abysses, as musi fill the mind with ceaseless terror. 'There are some places where the road is so stecp, and yct so narrow, that the mules are obliged to slide down, without making any use of their feet whatsoever. On one side of the rider, in this situation, rises an eminence of several hundred yards; and on the other, an abyss of equal depth; so that if he in the least checks his mule, so as to destroy the equilibrium, they both must unavoidably perish.

"After having travelled about nine days in this manner, slowly winding along the side of the mountain, we began to find the whole country covered with an hoar frost; and an hut, in which we lay, had ice on it. Having escaped many perils, we at length, after a journey of fifteen days, arrived upon the plain, on the extremity of which stands the city of Quito, the capital of one of the inost charming regions upon earth. Here, in the centre of the torrid zone, the beat is not only very tolerable, but in some places the cold also is painful. Here they enjoy all the temperature and advantages of perpetual spring; their fields being always covered with verdure, and enamelled with flowers of the most lively colours. However, although this betiutiful region be higher than any other country in the world, and although it took up so many days of painful journey in the ascent, it is still overlooked by tremendous mountains; their sides covered with snow, and yet flaming with volcanoes at the top. These seemed piled one upon the other, and rise to a most astonishing height, with great coldness. However, at a determined point above the surface of the sea, the congelation is found at the same height in all the mountains. Those parts which are not subject to a continual frost, have here and there growing upon then a rush, resembling the genista, but much more soft and flexible. Towards the extremity of the part where the rush grows, and the cold begins to increase, is found a vegetable, with a round bulbous head, which, when dried, becomes of amazing elasticity. Higher up, the earth is entirely bare of regetation, and scems covered with etemal snow. The most remarkable mountains arc, that of $\mathrm{Co}$ topaxi, (already described as a volcano, Chimborazo, and Pinchincha. Cotopaxi is more than three geographical miles above the surface of the sea: the rest are not much inferior. On the top of the latter was ny station for measuring a degree of the meridian; where I sufiered particular hardships, from the intenseness of the cold, and the violence of the storms. The sky round was, in general, involved in thick fogs, which, when they cleared away, and the elonds, by their gravity, moved nearer to the surlace of the earth, they appeared surrounding the foot of the mountain, at a vast distance below, like a sea, encompassing an island in the midst of it. When this happened, the horrid noises of tempests were heard from beneath, then discharging themselves on Quito, and the neighbouring country. I saw the lightnings issue from the clonds, and heard the thmoler's roll far beneath me. All this tine, while the tempest was raging below, the mountain top, where I was placed, enjoyed a delightful serenity; the wind was abated; the sky clear; and the enlivening rays of the sum moderated the severity of the cold. However, this was of no very long duration, for the wind returned with all its violence, and with such velocity as to dazzle the sigit; whilst iny fears were increased by the dreadful concussions of the precipice, and the fall of chormous rocks; the only sounds that were heard in this firightful situation."

Such is the animated pieture of these moun tains, as given us by this ingenious Spaniard: and I believe the reader will wish that I had made the quotation still longer. A passage. over the Alps, or a journey across the Pyrenees, appear pelty trips or excursions in the comparison; and yet these are the most lofty mountains we know of in Europe.

If we compare the Alps with the mountains already described, we shall find them but lit- 
tle more than one half of the height of the former. The Andes, upon being measured by the barometer, are found above three thousand one hundred and thirty-six toises or fathoms above the surface of the sea. ${ }^{a}$ Whereas the highest point of the Alps is not above sixteen hundred. The one, in other words, is above three miles high; the other about a mile and a half. The highest mountains in Asia are Mount Taurus, Mount Immaus, Mount Caucasus, and the mountains of Japan. Of these, none equals the Andes in height; although Mount Caucasus, which is the highest of them, makes very near approaches. Father Verbiest tells of a mountain in China, which he measured, and found a mile and a half high.' In Africa, the mountains of the Mloon, famous for giving source to the Niger and the Nile, are rather more noted than known. Of the Peak of Teneriffe, one of the Canary Islands that lie off this coast, we have more certain information. In the year 1727 , it was visited by a company of English merchants, who travelled up to the top, where they observed its height, and the volcano on its very summit. ${ }^{\text {. They found it }}$ a heap of mountains, the highest of which rises over the rest like a sugar-loaf, and gives a name to the whole mass. It is computed to be a mile and a half perpendicular from the surface of the sea. Kircher gives us an estimate of the heights of most of the other great mountains in the world; but as he has taken his calculations in general from the ancients, or from modern travellers, who had not the art of measuring them, they are quite incredible. The art of taking the heights of places by the barometer, is a $11 \mathrm{cw}$ and ingenious invention. As the air grows lighter as we ascend, the fluid in the tube rises in due proportion: thus the instrument being properly marked, gives the height with a tolerable degree of exactness; at least enough to satisfy curiosity.

Few of our great mountains have been estimated in this manner; travellers having, perhaps, been deterred, by a supposed impossibility of breathing at the top. However, it has been invariably found, that the air in the highest that our modern travellers have

- Ulloa, vol. i. p. 442 ascended, is not at all too fine for respiration. At the top of the Peak of Teneriffe, there was found no other inconvenicnce from the air, except its coldness; at the top of the Andes, there was no difficulty of breathing perceived. The accounts, therefore, of those who have asserted that they were unable to breathe, although at much less heights, are greatly to be suspected. In fact, it is very natural for mankind to paint those obstacles as insurmountable, which they themselves have not had the fortitude or perseverance to surmount.

The difficulty and danger of ascending to the tops of mountains, proceeds from other causes, not the thinness of the air. For instance, some of the summits of the Alps have never yet been visited by man. But the reason is, that they rise with such a rugged and precipitate ascent, that they are utterly inaccessible. In some places they appear like a great wall of six or seven hundred feet high; in others, there stick out enormous rocks, that hang upon the brow of the steep, and every moment threaten destruction to the traveller below.

In this manner almost all the tops of the highest mountains are bare and pointed. And this naturally proceeds from their being so continually assaulted by thunders and tempests. All the earthy substances with which they might have been once covered, have for a'ges been washed away from their summits; and nothing is left remaining but immense rocks, which no tempest has hitherto been able to destroy.

Nevertheless, time is every day, and every hour, making depredations; and huge fragments are seen tumbling down the precipice, either loosened from the summit by frost or rains, or struck down by lightning. Nothing can exhibit a more terrible picture than one of these enormous rocks, commonly larger than a house, falling from its height, with a noise louder than thunder, and rolling down the side of the mountain. Doctor Plot tells us of one in particular, which being loosened from its bed, tumbled down the precipice, and was partly shattered into a thousand pieces. Notwithstanding, one of the largest frag- 
meuts of the same, still preserving its motion, travelled over the plain below, crossed a rivulet in the midst, and at last stopped on the other side of the bank! These fragments, as was said, arc often struck off by lightning, and sometimes undermined by rains; but the most usual manner in which they are disunited fiom the mountain, is by frost: the rains insinuating between the interstices of the mountain, continue there until there comes a frost, and then, when couverted into ice, the water swells with an irresistible force, and produces the same effect as gunpowder, splitting the most solid rocks, and thus shattering the summits of the mountain.

But not rocks alone, but whole mountains are, by various causes, disunited from each other. We see in many parts of the Alps, amazing clefts, the sides of which so exactly correspond with the opposite, that no doubt can be made of their having been once joined together. At Cajeta, in Italy, a mountain was split in this manner by an earthquake; and there is a passage opened through it, that appears as if elaborately donc by the industry of man. In the Andes these brcaches are frequently seen. That at Thermopyle, in Greece, has been long famous. The mountain of the Troglodytes, in Arabia, has thus a passage through it: and that in Savoy, which nature began, and which Victor Amadeus completed, is an instance of the same kind.

We have accounts of some of these disruptions, immediately after their happening. "In the month of Junc," in the year 1714, a part of the mountain of Diableret, in the district of Valais, in France, suddenly fell down between

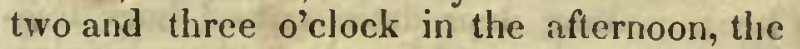
weather being very calm and serene. It was of a conical figure, and destroyed fiftyfive cottages in the fall. Fifteen persons, together with about a hundred beasts, were also crus!ed beneath its ruins, which covered an extent of a good league square. The dust it occasioned iustantly covered all the neighbourhood in darkness. The heaps of rubbish were more than three hundred feet high. They stopped the current of a river that ran along the plain, which is now formed into several new and deep lakes. There

- Buffon, vol. ii. p. 364. appeared, through the winole of this rubbish, none of those substances that scemed to mdicate that this disruption liad been by means of subterraneous tires. Most probably, the base of this rocky mountain was rotted and decayed; and thus fell, without any extrancous violence." In the same manner, in the year 1618, the town of Pleurs, in France, was buried bencath a rocky mountain, at the foot of which it was situated.

These accidents, and many more that might be enumerated of the sane kind, have been produced by various causes; by earthquakes, as in the mountain at Cajeta; or by being $\mathrm{d} c$ cayed at the bottom, as at Diableret. But the most general way is, by the foundation of one part of the mountain being hollowed by waters, and thus wanting a support, lyreaking from the other. Thus it generally has becil found in the great chasms in the $A \mathrm{lps}$; and thus it almost always is known in those disruptions of lills, which are known ly the name of land-slips. These are nothing more than the slidings down of a higher piece of ground, disrooted from its situation by subterraneous inundations, and settling itsclf upon the plain below.

There is not an appearance in all nature that so much astonished our ancestors, as these land-slips. In fact, to behold a large upland with its houses, its corn, and cattle, at once loosened from its place, and floating, as it were, upon the subjacent water; to behold it quitting its ancicnt situation, and travelling forward like a ship in quest of new adventures; this is certainly one of the most extraordinary appearances that can be imagined; and to a people, ignorant of the powers of nature, might well be considered as a prodigy. Accordingly, we find all our old historians incritioning it as an omen of approaching calamities. In this more enlightencel age, howcrer, its cause is very well known; and, instead of cxciting ominous apprchensions in the populace, it only gives rise to some very ridiculous law-suits annong them, about whose the property slınll be; whether the land which has thus slipt shall belong to the original possessor, or to him upon whose grounds it has encroached and settled. What las

b Hist. de l' $\Lambda$ cademie des Sciences, p. 4. an. 1715. 
been the determination of the judges, is not so well kiown, but the circumstances of the slips have been minutely and exactly described.

In the lands of Slatberg, in the kingdom of Iccland, there stood a declivity, gradually ascending for near half a mile. In the year 1713 , and on the 10th of March, the inhabitants perceived a crack on its side, somewhat like a furrow made with a plough, which they imputed to the effects of lightning, as there had been thunder the night before. However, on the evening of the same day, they were surprised to hear an hidcous confused noise issuing all round from the side of the hill; and their curiosity being raised, they resorted to the place. There, to their amazement, they found the earth, for near tive acres, all ii! gentle motion, and slidiug down the hill upon the subjacent plain. This motion continued the remaining part of the day, and the whole night; hor did the noise cease during the whole time; proceeding, probably, from the attrition of the ground beneath. The day following, however, this strange journey down the hill censed entirely ; and above an acre of the meadow below was found covered with what before composed a part of the declivity.

However, these slips, when a whole mountain's side seems to descend, happen but very varely. There are some of another kind, however, much more common; and, as they are always sudden, much more dangerous. These are snow-slips, well kuown, and greatly dreaded by travellers. It often happens, th.t when snow has long been accumulated on the tops and on the sides of mountains, it is horne down the precipice, either hy means of tempests, or its own melting. At first, when loosened, the rolume in Inotion is but small; but gathers as it continues to roll; and, by the time it has reached the habitable parts of the mountain, is generally grown of enormous bulk. Wherever it rolls, it levels al! things

Phil. Trans. vol. iv. p. 250. in its way; or buries them in unavoidable destruction. Instead of rolling, it sometines is found to slicle along from the top; yet eve: thus it is generally as fatal as before. Nerertheless, we have had an instance, a few years ago, of a small family in Germany, that lived for above a fortnight beneath one of these snow-slips. Although they were buried, during that whole time, in utter darknesi, and under a bed of some hundred feet deep, yet they were luckily taken out alive; the weight of the snow being supported by a beam that kept up the roof; and nourishment being supplied them by the milk of an ass, if I remember right, that was buried under the same ruin.

But it is not the parts alone that are thus found to subside, whole mountains have been known totally to disappear. Pliny tells us, that in his own time the lofty mountain of Cybotus, together with the city of Eurites, were swallowed by an earthquake. The same fate, he says, attended Phlegium, one of the highest mountains in Ethiopia; which, after one night's concussion, was never seen more. In more modern times, a very noted mountain in the Mlolucca islands, known by the name of the Pcak, and remarkable for being seen at a vely great distance from sea, was swallowed by an earthquake; and nothing but a lake was left in the place where it stood. Thus, while storms and tempests are levelled agaiust mountains above, earthquakes and waters are undermining them below. All our histories talk of their destruction; and very few new ones (if we except mount Cencre, and one or two such heaps of cinders, ) aro produced. If mountains, therefore, were of such great utility, as some plilosophers make them, to mankind, it would be a very melancholy consideration that such benefits were diminishing every day. But the truth is, the valleys are fertilized by that earth which is washed from their sides; and the plains become richer, in proportion as the mountains decay.

\footnotetext{
- Plin. lib. ii. cap. 93.
} 


\section{CHAPTER XII.}

\section{OF WATER.}

IN contemplating nature, we shall often find the same substances possessed of contrary qualities, and producing opposite effects. Air, which liquefies one substance, dries up another. That fire which is seen to burn up the desert, is often found, in other places, to assist the luxuriance of vegetation; and water, which, next to fire, is the most fluid substance upon earth, nevertheless gives all other bodies their firmness and durability; so that every element seems to be a powerful servant, capable either of good or ill, and only awaiting external direction, to become the friend or the enemy of mankind. These opposite qualities, in this substance in particular, have not failed to excite the admiration and inquiry of the curious.

That water is the inost fluid penetrating body, next to fire, and the most difficult to confine, is incontestably proved by a variety of experiments. A vessel through which water cannot pass, may be said to retain any thing. It may be objected, indeed, that syrups, oils, and honey, leak through some vessels that water cannot pass through; but this is lar from being the result of the greater tenuity and fineness of their parts; it is owing to the rosin wherewith the wood of such vessels abounds, which oils and syrups have a power of dissolving; so that these fluids, instead of finding their way, may more properly be said to eat their way through the vessels that contain them. However, water will at last find its way even through these; for it is known to ascape through vessels of every substance, glass only cxcepted. Other bodies may be found to make their way out more readily indeed; as air, when it finds a vent, will escape at once; and quicksilver, because of its weight, quickly penetrates through whatever chinky vessel confines it: but water, though it operates more slowly, yet always finds a more certain issue. $\Lambda \mathrm{s}$, for instance, it, is well known that air will not pass through leather; which water will very readily penetrate. Air also may be retained in a bladder; but water will quickly ooze through. And those who drive this to the greatest degree of precision, pretend to say, that it will pass through pores ten times smaller than air can do. Be this as it may, we are very certain that its parts are so small that they lave been actually driven through the pores of gold. This has been proved by the famous $\mathrm{F}$ lorentine experiment, in which a quantity of water was shut up in a hollow ball of gold, and then pressed with a huge force by screws, during which the fluid was seen to ooze out through the pores of the metal, and to stand, like a dew, upon its surface.

As water is thus penetrating, and its parts thus minute, it may easily be supposed that they enter into the composition of all bodies, vegetable, animal, and fossil. This every chymist's experience convinces him of; and the mixture is the more obvious, as it can always be separated, by a gentle heat, from those substances with which it had been united. Fire, as was said, will penetrate where water cannot pass; but then it is not so easily to be separated. But there is scarce any substance from which its water cannot be divorced. The parings or filings of lead, tin, and antimony, by distillation, yield water plentifully: the hardest stones, sea-salt, nitre, vitriol, and sulphur, are found to consist chicfly of water; into which they resolve by force of fire. "All birds, beasts, and fishes," says Newton, "insects, trees, and vegetables, witl their parts, grow from water; and, by putrefaction, return to water again." In short, almost every substance that we sce, owes its texture and firmness to the parts of water that mix with its earth; and, deprived of this fluid, it becomes a mass of shapeless dust and ashes.

From hence we see, as was above hinted, that this most fluid body, when mixed with others, gives them consistence and form. Water, by being mixed with earth or ashes, and formed into a vessel, when baked before the 
fire, becomes a coppel, remarkable for this, that it will bear the utmost force of the hottest furnace that art can contrive. So the Chinese earth, of which porcelain is made, is nothing more than an artificial composition of earth and water, united by heat; and which a ureater degree of heat could easily separate. 'Thus we see a body, extremely fluid of itself, in some measure assuming a new nature, by being united with others: we see a body, whose fluid and dissolving qualities are so obvious, giving consistence and hardness to all the substances of the earth.

From considerations of this kind, Thales, and many of the ancient philosophers, held that all things were made of water. In order to confirm this opinion, Helmont made an experiment, by divesting a quantity of earth of all its oils and salts, and then putting this earth, so prepared, into an earthen pot, which nothing but rain-water could enter, and planting a willow therein; this vegetable, so planted, grew up to a considerable height and bulk, merely from the accidental aspersion of rain-water; while the earth, in which it was planted, received no sensible diminution. From this experiment, he concluded, that water was the only nourishment of the vegetable tribe; and that vegetables, being the nourishment of animals, all organized substances, therefore, owed their support and being only to water. But this has been said by Woodward to be a mistake: for he shows, that water being impregnated with earthy particles, is only the conveyer of such substances into the pores of vegetables, rather than an increaser of them by its own bulk: and likewise, that water is ever found to afford so much less nourishnent, in proportion as it is purified by distillation. A plant in distilled water will not grow so fast as in water not distilled: and if the same be distilled three or four times over, the plant will scarcely grow at all, or receive any nourishment from it. So that water, as such, does not seem the proper nourishment of vegetables, but only the vehicle thereof, which contains the nutritious particles, and carries them through all parts of

- IIill's History of Fossils.

b Ilermetically sealing a glass vessel, means no more than leesting the muth of the phial red hot; and thus, the plant. Water, in its pure state, may suffice to extend or swell the parts of a plant, but affords vegetable matter in a moderate proportion.

However this be, it is agreed on all sides, that water, such as we find it, is far from being a pure simple substance. The most genuine we know is mixed with exhalations and dissolutions of various kinds; and no expedient that has been hitherto discovered, is capable of purifying it entirely. If we filter and distil it a thousand times, according to Boerhaave, it will still depose a sediment: and by repeating the process we may evaporate it entirely away, but can never totally remove its impurities. Some, however, assert, that water, properly distilled, will have no sediment ; and that the little white speck which is found at the bottom of the still, is a substance that enters from without. Kircher used to show in his Museum, a phiali of water, that had been kept for fifty years, hermetically sealed ; during which it had deposed no sediment, but continued as transparent as when first it was put in. How far, therefore, it may be brought to a state of purity by distillation, is unknown; but we very well know, that all such water as we every where see, is a bed in which plants, minerals, and animals, are all found confusedly floating together.

Raill-water, which is a fluid of Nature's own distilling, and which has been raised so high by evaporation, is nevertheless a very mixed and impure substance. Exhalations of all kinds, whether salts, sulphurs, or metals, make a part of its substance, and tend to increase its weight. If we gatier the water that falls, after a thunder-clap, in a sultry summer's day, and let it settle, we shall find a real salt sticking at the bottom. In winter, however, its inpure mixtures are fewer, bit still may be separated by distillation. But as to that which is generally caught pouring from the tops of houses, it is particularly foul, being impregnated with the smoke of the chimneys, the vapour of the slates or tiles, and with other impuritios that birds and animals may have deposited there. Besides, though it should be

when the glass is become pliant, squeezing the mouth together with a pair of pincers, and then twisling it six or seven times round, which effectually closes it up. 
supposed free from all these, it is mixed with is quantity of air, which, after being kept for sone time, will be seen to separate.

Spring-water is next in point of purity. 'This, according to Dr. Halley, is collected from the air itself; which being sated with water, and coming to be condensed by the eveniug's cold, is driven against the tops of the mountains, where being condensed and collected, it trickles down by the sides, into the cavities of the earth; and running for a while underground, bubbles up in fountains upon the plain. This having made but a short circulation, has generally had no long time to dissolve or imbibe any foreign substances by the way.

River-water is generally more foul than the former. Wherever the stream flows, it receives a tincture from its channel. Plants, mincrals, and animals, all contribute to add to its impurities: so that such as live at the mouths of great rivers, are generally subject to all those disorders which contaminated and unwholesome waters are known to produce. Of all the river-water in the world, that of the Indus and the Thames is said to be the most light and wholesome.

The most impure fresh water that we know, is that of stagnating pools and lakes, shich, in summer, may be more properly considered as a jelly of floating insects, than a collection of water. In this, millions of little reptiles, undisturbed by any current, which might crush their frames to picces, breed and engender. The whole tecms with shapeless life, and only grows more fruitful by increasing putrefaction.

Of the purity of all these waters, the lightness, and not the transparency, ought to be the test. Water may be extremely cle ar and beautiful to the eye, and yet very much impregnated with inineral particles. In fact, sea-water is the most transparent of any, and yet it is well known to contain a large mixture of salt and bitumen. On the contrary, those waters which are lightest, have the fewest dissolutions floating in them; and inay, therefore, be the most useful for all the purposes of life. But, after all, though much has been said upon this subject, and although waters have been weighed with great assiduity, to determine their degree of salubrity, yet neither this, nor thein curdling with soap, nor any other philosophical standard whatsoever, will answer the purposes of true information. Experience alone ought to determine the useful or noxious qualities of every spring; and experience assures us, that diflerent kinds of water are adapted to different constitutions. An incontesiable proof of this, are the many medicinal springs throughout the world, whose peculiar benefits are known to the natives of their respective countries. These are of various kinds, according to the different minerals with which they are impregnated; hot, saline, sulphureous, bituminous, and oily. But the account of these will come most properly under that of the several minerals by which they are produced.

After all, therefore, we must be contented with but an impure mixture for our daily beverage. And yet, perhaps, this very mixture may often be more serviceable to our health than that of a purer kind. We know that it is so with regard to vegetables: and why not, also, in general, to man? Be this as it will, if we are desirous of having water in its greatest purity, we are ordered, by the curious in this particular, to distil it from snow, gathered upon the tops of the highest mountains, and to take none but the outer and superficial part thereof. This we must be satisfied to call pure water; but even this is far short of the pure unmixed philosophical element; which, in reality, is no where to be found.

As water is thus mixed with foreign matter, and often the repository of minute animals, or vegctable seeds, we need not be surprised that, when carried to sea, it is always found to putrefy. But we must not suppose that it is the element itself which thus grows putrid and offensive, but the substances with which it is impregnated. It is true, the utmost precautions are taken to destroy all vegetable and animal substances that may have previously been lodged in it, by boiling; but, notwithstanding this, there are some that will still survive the operation, and others that find their way during the time of its stowage. Seamen, therefore, assure us, that their water is generally found to putrefy twice, at least, and sometimes three times, in a long voyage. In about a month after $i t$ has been at sea, when the bung is taken out of the cask, it sends up a noismue and dangerous vapour, which 
would take fire upon the application of a candle." The whole body of the water then is found replete with little worm-like insects, that float, with great briskness, through all its parts. These generally live for about a couple of days; and then dying, by depositing their spoils, for awhile increase the putrefaction. After a time, the heavier parts of these sinking to the bottom, the lighter float in a scum, at the top; and this is what mariners call, the water's purging itself. There is still, however, another race of insects, which are bred, very probably, from the spoils of the former; and produce, after some time, similar appearances: these dying, the water is then thought to change no more. However, it very often happens, especially in hot climates, that nothing can drive these nauseous insects from the ship's store of water. They often increase to a very disagreeable and frightful size, so as to deter the mariner, though parching with thirst, from tasting that cup which they have contaminated.

This water, as thus described, therefore, is a very different fluid from that simple elementary substance upon which philosophical theories have been founded; and concerning the nature of which there have been so many disputes. Elementary water is no way compounded; but is without taste, smell, or colour; and incapable of being discerned by any of the senses, except the touch. This is the famous dissolvent of the chymists, into which, as they have boasted, they can reduce all bodies; and which makes up all other substances, only by putting on a different disguise. In some forms, it is fluid, transparent, and evasive of the touch; in others, hard, firm, and elastic. In some, it is stiffened by cold; in others, dissolved by fire. According to them, it only assumes external shapes from accidental causes; but the mountain is as inuch a body of water, as the cake of ice that melts on its brow; and even the philosopher himself is composed of the same materials with the cloud or meteor which he contemplates.

Speculation seldom rests when it begins. Others, disallowing the universality of this substance, will not allow that in a state of na-

\footnotetext{
- Phil. Trans. vol. v. part ii. p. 71 .
}

ture there is any such thing as water at all. "What assumes the appearance," say they, " is nothing more than melted ice. Ice is the real element of Nature's making; and when found in a state of fluidity, it is then in a state of violence. All substances are naturally hard; but some more readily melt with heat than others. It requires a great heat to melt iron; a smaller heat will melt copper; silver, gold, tin, and lead, melt with smaller still; ice, which is a body like the rest, melts with a very moderate warmth; and quicksilver melts with the smallest warmth of all. Water, therefore, is but ice kept in continual fusion; and still returning to its former state, when the heat is taken away." Between these opposite opinions, the controversy has been carried on with great ardour, and much has been written on both sides; and yet, when we come to examine the debate, it will probably terminate in this question, whether cold or heat first began their operations upon water? This is a fact of very little importance, if known; and, what is more, it is a fact we can never know.

Indeed, if we examine into the operations of cold and heat upon water, we shall find that they produce somewhat similar effects. Water dilates in its bulk, by heat, to a very considerable degree; and, what is more extraordinary, it is likewise dilated by cold in the same manner.

If water be placed over a fire, it grows gradually larger in bulk, as it becomes hot, until it begins to boil; after which no art can either increase its bulk or its heat. By increasing the fire, indeed, it may be more quickly evaporated away; but its heat and its bulk still continue the same. By the expanding of this fluid, by heat, philosophers have found a way to determine the warmth or the coldness of other bodies; for if put into a glass tube, by its swelling and rising, it shows the quantity of heat in the body to which it is applied; and by its contracting and sinking, it shows the absence of the same. Instead of using water in this instrument, which is called a thermometer, they now make use of spirit of wine, which is not apt to freeze, and which is endued even with a greater expansion, by heat, than water. The instrument consists of nothing more than a hollow ball of glass, with a 
long tube growing out of it. This being partly filled with spirits of wine tinctured red, so as to be seen when it rises, the ball is plunged into boiling water, which making the spirit within expand and rise in the tube, the water marks the greatest height to which it ascends; at this point the tube is to be broken off; and then hermetrically sealed, by melting the glass with a blow-pipe; a scale being placed by the side, completes the thermometer. Now as the fluid expands or condenses with heat or cold, it will rise and fall in the tube in proportion; and the degrec or quantity of ascent or descent will be seen in the scale.

No lire, as was said, can make water hotter, after it begins to boil. We can, therefore, at any time be sure of an equable certain heat; which is that of boiling water, which is invariably the same. The certainty of such a heat is not less useful than the instrument that measures it. It affords a standard, fixed degree of heat over the whole world; boiling water being as hot in Greenland as upon the coast of Guinea. One fire is more intense than another; of heat there are various degrees; but boiling water is a heat every where the same, and easily procurable.

As heat thus expands water, so cold, when it is violent enough to freeze the same, produces exactly the same effect, and expands it likewise. Thus water is acted upon in the same manner by two opposite qualitics; being dilated by both. As a proof that it is dilated by cold, we have only to observe the ice floating on the surface of a pond, which it would not do were it not dilated, and grown more bulky, by freezing, than the water which remains unfroze. Mr. Boyle, however, put the matter past a doubt, by a varicty of experiments." Having poured a proper quantity of water into a strong earthen vessel, he exposed it, uncovered, to the open air, in frosty nights; and observed, that continually the ice reached higher than the water before it was frozen. He filled also a tube with water, and stopped both ends with wax: the water, when frozen, was found to push out the stopples from both ends; and a rod of ice apyeared at each end of the tube, which showed how much it was swollen by the cold within.

- Boyle, vol. i. p. 610.
From hence, therefore, we may be very certain of the cold dilating of the water; and expericnce also shows that the force of this expansion has been found as great as any which heat has been found to produce. The touch-hole of a strong guu-barrel being stopped, and a plug of iron forcibly driven into the muzzle, after the barrel liad been filled with water, it was placed in a mixture of ice. and salt; the plug, though soldered to the barrel, at first gave way, but being fixed in more firmly, within a quarter of an hour the gun-barrel burst with a loud noise, and blew up the cover of the box wherein it lay. Such is its force in an ordinary experiment. But it has been known to burst cannons, filled with water, and then left to freeze; for the cold congealing the water, and the ice swelling, it became irresistible. The bursting of rocks by frost, which is frequent in the northern climates, and is sometimes seen in our own, is an equal proof of the expansion of congealed water. For having by some means insinuated itself into the body of the rock, it has remained there till the cold was sufficient to affect it by congelation. But when once frozen, no obstacle is able to confine it from dilating; and, if it cannot otherwise find room, the rock must burst asunder.

This alteration in the bulk of water might have served as a proof that it was capable of being compressed into a narrower space than it occupied before; but, till of late, water was held to be incompressible. The general opinion was, that no art whatsoever could squeeze it into a narrower compass; that no power on earth, for instance, could force a pint of water into a vessel that held an hair's. breadth less than a pint. And this, said they, appears from the famous Florentine experiment; where the water, rather than suffer a compressure, was seen to oozc through the pores of the solid metal; and, at length, making a cleft in the side, spun out with great vehemence. But later trials have proved that water is very compressible, and partakes of that elasticity which every other body possesses in some degree. Indeed, had not mankind been dazzled by the brilliancy of one inconclusive experiment, there were numerous reasons to convince them of its lıaving the same properties with other substances. Ice, 
which is water in another state, is very elastic. A stone, flung slantingly along the surface of a pond, bounds from the water several times; which shows it to be elastic also. But the trials of Mr. Canton have put this past all doubt; which being somewhat similar to those of the great Boyle, who pressed it with weights properly applied, carry sufficient conviction.

What has been hitherto related, is chiefly applicable to the element of water alone; but its fluidity is a property that it possesses in common with several other substances, in other respects greatly differing from it. That quality which gives rise to the definition of the fluid, namely, that its parts are in a continual intestine motion, seems extremely applicable to water. What the shapes of those parts are, it would be vain to attempt to discover. Every trial only shows the futility of the attempt; all we find is, that they are extremely minute; and that they roll over each other with the greatest ease. Some, indeed, from this property alone, have not hesitated to pronounce them globular; and we have, in all our hydrostatical books, pictures of these little globes in a state of sliding and rolling orer each other. But all this is merely the work of imagination; we know that substances of any kind, reduced very small, assume a fluid appearance, somewhat resembling that of water. Mr. Boyle, after finely powdering and sifting a little dry powder of plaister of Paris, put it in a vessel over the fire, where it soon began to boil like water, exhibiting all the motions and appearances of a boiling liquor. Although but a powder, the parts of which we know are very different from each other, and just as aceident has formed them, yet it heaved in great waves like water. Upon agitation, a heavy body will sink to the bottom, and a light one emerge to the top. There is no reason, then, to suppose the figure of the parts of water round, since we see their fluidity very well imitated by a composition, the parts of which are of various forms and sizes. The shape of the parts of water, therefore, we must be content to continue ignorant of. All we know is, that earth, air, and fire, conduce to separate the parts from each other.

Earthy substances divide the parts from each other, and keep them asunder. This division may be so great, that the water will entirely lose its fluidity thereby. Mud, potter's clay, and dried bricks, are but so many different combinations of earth and water: each substance in which the parts of water are most separated from each other, appearing to be the most dry. In some substances, indeed, where the parts of water are greatly divided, as in porcelain, for instance, it is no easy matter to recover and bring them together again; but they continue in a manner fixed and united to the manufactured clay. This circumstance led Doctor Cheney into a very peculiar train of thinking. He suspected that the quantity of water, on the surface of the earth, was daily decreasing. For, says he, some parts of it are continually joined to vegetable, animal, and mineral substances, which no art can again recover. United with these, the water loses its fluidity; for if, continues he, we separate a few particles of any fluid, and fasten them to a solid body, or keep them asunder, they will be fluid no longer. To produce fluidity, a considerable number of such particles are required; but here they are close, and destitute of their natural properties. Thus, according to him, the world is growing every day harder and harder, and the earth firmer and firmer; and there may come a time when every object around us may be stiffened in universal frigidity! However, we have causes enough of anxiety in this world already, not to add this preposterous coneern to the number.

That air also contributes to divide the parts of water, we can have no manner of doubt; some have even disputed whether water be not capable of being turned into air. However, though this cannot be allowed, it must be granted, that it may be turned into a substance which greatly resembles air (as we have seen in the experiment of the rolipile) with all its properties; except that, by cold, this new-made air may be condensed again into water.

But of all the substances which tend to divide the parts of water, fire is the most powerful. Water, when heated into steam, acquires such force, and the parts of it tend to fly off from each other with such violence, that no earthly substance we know of is strong enough to confine them. A single drop of 
water, converted into steam, has been found capable of raising a weight of twenty tons; and would have raised twenty thousand, were the vessel confining it sufficiently strong, and the fire below increased in proportion.

From this easy yielding of its parts to external pressure, arises the art of determining the specific gravity of bodies by plunging them in water; with many other useful discoveries in that part of natural philosophy, called hydrostatics. The laws of this science, which Archimedes began, and Pascal, with some other of the moderns, have much improved, rather belongs to experimental than to natural history. However, I will take leave to mention some of the most striking paradoxes in this branch of science, which are as well confirmed by experiment, as rendered universal by theory. It would, indeed, be unpardonable, while discoursing on the properties of water, to omitgiving some account of the manner in which it sustains such immense bulks as we see flating upon its soft and yielding surface: how some bodies, that are known to sink at one time, swim with ease, if their surface be enlarged: how the heaviest body, even gold itself, may be made to swim upon water; and how the lightest, such as cork, shall remain sunk at the bottom: how the pouring in of a single quart of water, will burst a hogshead hooped with iron: and how it ascends, in pipes, from the valley, to travel over the mountain: these are circumstances that are at first surprising; but, upon a slight consideration, lose their wonder.

"In order to conceive the manner in which all these wonders are effected, we must begin by observing that water is possessed of an invariable property, which has not hitherto been mentioned; that of always keeping its surface level and even. Winds, indeed, may raise it into waves, or art spurt it up in fountains; but ever, when left to itself, it sinks into a smooth even surface, of which no one part is higher than another. If I should pour water, for instance, into the arm of a pipe of the shape of the letter $U$, the fluid would rise in the other arm just to the same height; be-

- In the above sketch, the manner of demonstrating used by Monsieur D'A lembert is made use of, as the most obvious, and the most satisfactory. Vide Essai sur, \&ec. cause, otherwise, it would not find its lerel, which it invariably maintains. A pipe bending from one hill down into the valley, and rising by another, may be considered as a tube of this kind, in which the water, sinking in one arm, rises to maintain its level in the other. Upon this principle all water-pipes depend; which can never raise the water higher than the fountain from which they proceed.

Again, let us suppose for a moment, that the arms of the pipe already mentioned, may be made long or short at pleasure; and let us still further suppose, that there is some obstacle at the bottom of it, which prevents the water poured into one arm, from rising in the other. Now it is evident, that this obstacle at the bottom will sustain a pressure from the water in one arm, equal to what would make it rise in the other; and this pressure will be great, in proportion as the arm filled with water is tall. We may, therefore, generally conclude, that the bottom of every vessel is pressed by a force, in proportion to the height of the water in that vessel. For instance, if the vessel filled with water be forty feet high, the bottom of that vessel will sustain such a pressure as would raise the same water forty feet high, which is very great. From hence we see how extremely apt our pipes, that convey water to the city, are to burst; for descending from a hill of more than forty feet high, they are pressed by the water contained in them, with a force equal to what would raise it to more than forty feet high; and that this is sometimes able to burst a wooden pipe, we can have no room to doubt of.

Still recurring to our pipe, let us suppose one of its arms ten times as thick as the other; this will produce no effect whatsoever upon the obstacle below, which we supposed hindering its rise in the other arm; because, how thick soever the pipe may be, its contents would only rise to its own level; and it will, therefore, press the obstacle with a force equal thereto. - We may, therefore, universally conclude, that the bottom of any vessel is pressed by its water, not as it is broad or narrow, but in proportion as it is ligh. Thus the water contained in a vessel not thicker than my finger, presses its bottom as forcibly as the water contained in an hogshead of an 
equal height; and, if we made holes in the bottoms of both, the water would burst out as forceful from the one as the other. Hence we may, with great case, burst an hogshead with a single quart of water; and it has been often done. We have only, ${ }^{a}$ for this, to place an hogshead on one end, filled with water: we then bore a hole in its top, into which we plant a narrow tin pipe, of about thirty feet high: by pouring a quart of water into this, at the top, as it continues to rise higher in the pipe, it will press more forcibly on the bottom and sides of the hogshead below, and at last burst it.

Still returning to our simple instrument of demonstration. If we suppose the obstacle at the bottom of the pipe to be moveable, so as that the force of the water can push it up into the other arm; such a body as quicksilver, for instance. Now, it is evident, that the weight of water weighing down upon this quicksilver in one arm, will at last press it up in the other arm; and will continue to press it upwards, until the fluid in both arms be upon a par. So that here we actually see quicksilver, the heaviest substance in the world, except'gold and platina, floating upon a water, which is but a very light substance.

When we see water thus capable of sustaining quicksilver, we need not be surprised that it is capable of floating much lighter substances, ships, animals, or timber. When any thing floats upon water, we always see that a part of it sinks in the same. A cork, a ship, a buoy, each buries itself in a bed on the surface of the water; this bed may be considered as so much water displaced; the water will, therefore, lose so much of its own weight, as is equal to the weight of that bed of water which it displaces. If the body be heavier than a similar bulk of water, it will sink; if lighter, it sill swim. Universally, therefore, a body plunged in water, loses as much of its weight as is equal to the weight of a body of water of its own bulk. Some light bodies, therefore, such as cork, lose much of their weight, and therefore swim ; other more ponderous bodies sink, because they are heavier than their bulk of water.

Upon this simple theorem entirely depends

- Nollet's Lectures.

No. 6. the art of weighing metals hydrostatically. I have a guinea, for instance, and desire to know whether it be pure gold; I have weighed it in the usual way with another guinea, and find it exactly of the same weight, but still 1 have some suspicion, from its greater bulk, that it is not pure. In order to determine this, I have nothing more to do than to weigh it in water with that same guinea that I know to be good, and of the same weight; and this will instantly show the difference; for the true ponderous metal will sink, and the false bulky one will be sustained in proportion to the greatness of its surface. Those whose business it is to examine the purity of metals, have a balance made for this purpose, by which they can precisely determine which is most ponderous, or, as it is expressed, which has the greatest specific gravity. Seventy-one pound and a half of quicksilver, is found to be equal in bulk to a hundred pound weight of gold. In the same proportion sixty of lead, fifty-four of silver, fortyseven of copper, forty-five of brass, forty-two of iron, and thirty-nine of tin, are each equal to an hundred pound of the same most ponderous of all metals.

This method of precisety determining the parity of gold, by weighing in water, was first discovered by Archimedes, to whom mankind have been indebted for many useful discoveries. Hiero, king of Sicily, having sent a certain quantity of gold to be made into a crown, the workman, it seems, kept a part for his own use, and supplied the deficiency with a baser metal. His fraud was suspected by the king, but could not be detected; till he applied to Archimedes, who weighed the crown in water; and, by this method, informed the king of the quantity of gold which was taken away.

It has been said, that all fluids endeavour to preserve their level; and, likewise, that a body pressing on the surface, tended to destroy that level. From hence, therefore, it will ensily be inferred, that the deeper any hody sinks, the greater will be the resistance of the depressed fluid beneath. It will be asked, thereforc, as the resistance increases in proportion as the body descends, how comes the body, after it lias got a certain way, to sink at all? The answer is obvious: 
From the fluid above pressing it down with almost as great a force as the fluid beneath presses it up. Take away, by any art, the pressure of the fluid from above, and let only the resistance of the fluid from below be suffered to act, and after the body is gone down very deep, the resistance will be insuperable. To give an instance: A small hole opens in the bottom of a ship at sea, forty feet we will suppose below the surface of the water; through this the water bursts up with great violence; I attempt to stop it with $m y$ hand, but it pushes the hand violently away. Here the hand is, in fact, a body attempting to sink upon water, at a depth of forty feet, with the pressure from above taken away. The water, therefore, will overcome my strength; and will continue to burst in till it has got to its level: if I should then dive into the hold, and clap my hand upon the opening, as before, I should perceive no force acting against my hand at all; for the water above presses the hand as much down against the hole, as the water without presses it upward. For this reason, also, when we dive to the bottom of the water, we sustain a very great pressure from above, it is true, but it is counteracted by the pressure from below; and the whole acting uniformly on the surface of the body, wraps us close round without injury.

As I have deviated thus far, I will just mention one or two properties more, which water, and all such like fluids, is found to possess.

a This phenomenon, which has so long embarrassed philosophers, is easily soluble upon the principle, that the attraction between the particles of glass and water is greater than the attraction between the particles of water themselves: for, if a glass tube be held parallel to the Irorizon, and a drop of water be applied to the under side of the tube, it will adhere to it: nor will it fall from the
And, first, their ascending in vessels which are emptied of air, as in our common pumps for instance. The air, however, being the agent in this case, we must previously examine its properties, before we undertake the explanation. The other property to be mentioned is, that of their ascending in small capillary tubes. This is one of the most extraordinary and inscrutable appearances in nature. Glass tubes may be drawn, by means of a lamp, as fine as a hair; still preserving their hollow within. If one of these be planted in a vessel of water, or spirit of wine, the liquor will immediately be seen to ascend; and it will rise higher, in proportion as the tube is smaller; a foot, two feet, and more. How does this come to pass? Is the air the cause? No: the liquor rises, although the air be taken away. Is attraction the cause? No: for quicksilver does not ascend, which it otherwise would. Many have been the theories of experimental philosophers to explain this property. Such as are fond of travelling in the regions of conjecture, may consult Hawksbee, Morgan, Jurin, or Watson, who have examined the subject with great minuteness. Hitherto, however, nothing but doubts, instead of knowledge, have been the result of their inquiries. It will not, therefore, become us to enter into the minuteness of the inquiry, when we have so many greater wonders to call our attention away.

glass, till its bulk and gravity are so far increased as to overbalance the attraction of the glass. Hence it is easy to conceive, lrow seusibly such a power must act on the surface of a fluid not viscid, as water, contained within the cavity of a small glass tube; as also that the quantity of the fluid raised, will be as the surface of the bore which it - fills, that is, as the diameter of the tube. 


\section{CHAPTER XIV.}

\section{OF THE ORIGIN OF RIVERS.}

"THE sun ariseth, and the sun goeth down, and pants for the place from whence he arose. All things are filled with labour, and man cannot utter it. All rivers run into the sea, yet the sea is not full. Unto the place whence the rivers come, thither they return again. The eye is not satisfied with seeing, nor the ear with hearing." " Thus speaks the wisest of the Jews. And at so early a period was the curiosity of man employed in observing these great circulations of nature. Every cye attempted to explain those appearances; and every philosopher who has long thought upon the subject, seems to give a peculiar solution. The inquiry whence rivers are produced; whence they derive those unceasing stores of water, which continually enrich the world with fertility and verdure; has been variously considered, and divided the opinions of mankind more than any other topic in natural history.

In this contest the various champions may be classed under two leaders; Mr. De la Hire, who contends that rivers must be supplied from the sea, strained through the pores of the earth ; and Dr. Halley, who has endeavoured to demonstrate that the clouds alone are sufficient for the supply. Both sides have brought in mathematics to their aid; and have shown that long and laborious calculations can at any time be made to obscure both sides of a question.

De la Hire begins his proofs, that rainwater, evaporated from the sea, is insufficient for the production of rivers; by showing that rain never penetrates the surface of the earth above sixteen inches. From thence he infers, that it is impossible for it, in many cases, to sink so as to be found at such considerable depths below. Rain-water, he grants, is often seen to mix with rivers, and to swell their currents; but a much greater part of it eva-

Ecclesiastes, chap. i. ver. 5, 7, 8 .

b Hist. de l'Acad. 1713, p. 56 . porates. "In fact," continues he, "if we suppose the earth every where covered with water, evaporation alone would be sufficient to carry off two feet nine inches of it in a year: and yet we very well know, that scarcely nineteen inches of rain-water falls in that time; so that evaporation would carry off a much greater quantity than is ever known to descend. The small quantity of rain-water that falls is, therefore, but barely sufficient for the purposes of regetation. Two leaves of a fig-tree have been found, by experiment, to imbibe from the earth, in five hours and a half, two ounces of water. This implies the great quantity of fluid that must be exhausted in the maintenance of one single plant. Add to this, that the waters of the river Rungis will, by calculation, rise to fifty inches; and the whole country from whence they are suppliedn, ever receives fifty inches in the year by rain. Besides this, there are many salt springs, which are known to procecd immediately from the sea, and are subject to its flux and reflux. In short, wherever we dig beneath the surface of the earth, except in a very few instances, water is to be found : and it is by this subterrancous water that springs and rivers, nay, a great part of vegetation itself, is supported. It is this subterraneous water which is raised into steam, by the internal heat of the earth, that feeds plants. It is this subterraneous water that distils through interstices; and there, cooling, forms fountains. It is this, that by the addition of rains, is increased into rivers, and pours plenty over the whole earth."

On the other side of the question, ${ }^{\circ}$ it is asserted, that the vapours which are exhaled from the sea, and driven by the winds upon land, are more than sufficient to supply not only plants with moisture, but also to furnish a sufficiency of water to the greatest rivers.

c Phil. Trans. vol. ii. p. 12.8. 
For this purpose, an estimate has heen made of the quantity of water emptied at the mouths of the greatest rivers; and of the quantity also raised from the sea by evaporation; and it has been found, that the latter by far exceeds the former. This calculation was made by Mr. Marriotte. By him it was found, upon receiving such rain as fell in a year, in a proper vessel fitted for that purpose, that, one year with another, there might fall about twenty inches of water upon the surface of the earth, throughout Europe. It was also computed that the river Seine, from its source to the city of Paris, might cover an extent of ground, that would supply it annually with above seven millions of cubic feet of this water, formed by evaporation. But upon computing the quantity which passed through the arches of one of its bridges in a year, it was found to amount only to two hundred and eighty millions of cubic feet, which is not above the sixth part of the former number. Hence it appears, that this river may receive a supply, brought to it by the evaporated waters of the sea, six times greater than what it gives back to the sea by its current; and, therefore, evaporation is more than sufficient for maintaining the greatest rivers, and supplying the purposes also of vegetation.

In this manner, the sea supplies sufficient humidity to the air, for furnishing the earth with all necessary moisture. One part of its vapours fall upon its own bosom, before they arrive upon land. Another part is arrested by the sides of mountains, and is compelled, by the rising stream of air, to mount upward towards the summits. Here it is presently precipitated, dripping down by the cramies of the stone. In some places, entering into the caverns of the mountain, it gathers in those receptacles, which being once filled, all the rest overflows; and breaking out by the sides of the hills, forms single springs. Many of these run down by the valleys or guts between the ridges of the mountain, and, coming to unite, form little rivulets or brooks; many of these meeting. in one common valley, and gaining the plain ground, being grown less rapid, become a river; and many of

- Phil. Trans. vol. ii. p. 128. these uniting, malke such vast bodies of water, as the Rhine, the Rhone, and the Danube.

There is still a third part, which falls upon the lower grounds, and furnishes plants with their wonted supply. But the circulation does not rest even here; for it is again exhaled into vapour by the action of the sun; and afterwards returned to that great mass of waters whence it first arose. "This," adds Dr. Halley, "seems the most reasonable hypothesis; and much more likely to be true, than that of those who derive all springs from the filtering of the sea-waters, through certain imaginary tubes or passages within the earth ; since it is well known that the greatest rivers have their most copious fountains the most remote from the sea."

This secms the most general opinion; and yet, after all, it is still pressed with great difliculties; and there is still room to look out for a better theory. The perpetuity of many springs, which always yield the same quantity when the least rain or vapour is afforded, as well as when the greatest, is a strong objection. Derham ${ }^{b}$ mentions a spring at Upminster, which he could never perceive by his eye to be diminished, in the greatest droughts, even when all the ponds in the country, as well as an adjoining brook, have been di'y for several inonths together. In the rainy seasons, also, it was never overflowed; except sometimes, perhaps, for an hour or so, upon the immission of the external rains. He, therefore, justly enough concludes, that had this spring its origin from rain or vapour, there would be found an increase or decrease of its water, corresponding to the causes of its production.

Thus the reader, after having been tossed from one hypothesis to another, must at last be content to settle in conscious ignorance. All that has been written upon this subject, affords him rather something to say, than something to think; something rather for others than for himself. Varenius, indeed, although he is at a loss for the origin of rivers, is by no means so as to their formation. He is pretty positive that all rivers are artificial. He boldly asserts, that their channels have been originally formed by the industry of man.

- Derham Physico-Theol. 
His reasons are, that when a new spring breaks forth, the water does not make itself a new channel, but spreads over the adjacent land. "Thus," says he, "men are obliged to direct its course; or, otherwise, Nature would never have found one." He enumerates many rivers that are certainly known, from history, to have been dug by men. He alleges, that no salt-water rivers are found, because men did not want salt-water; and as for salt, that was procurable at less expense than digging a river for it. However, it costs a speculative man but a small expense of thinking to form such an hypothesis. It may, perhaps, engross the reader's patience to detain him longer upon it.

Nevertheless, though Philosophy be thus ignorant, as to the production of rivers, yet the laws of their motion, and the nature of their currents, have been very well explained. The Italians have particularly distinguished themselves in this respect; and it is chiefly to them that we are indebted for the improvement."

All rivers have their source either in mountains, or elevated lakes; and it is in their descent from these that they acquire that velocity which maintains their future current. At first their course is generally rapid and headlong; but it is retarded in its journey, by the continual friction against its banks, by the many obstacles it meets to divert its stream, and by the plains generally becoming more level as it approaches towards the sea.

If this acquired velocity be quite spent, and the plain through which the river passes is entirely level; it will, notwithstanding, still continue to run, from the perpendicular pressure of the water, which is always in exact proportion to the depth. This perpendicular pressure is nothing more than the weight of the upper waters pressing the lower out of their places; and, consequently, driving them forward, as they cannot recede against the stream. As this pressure is greatest in the deepest parts of the river, so we generally find the middle of the stream most rapid; both because it has the greatest motion thus communicated by the pressure, and

- S. Guglielmini della Natura de Fiumi, passim.

Ibid. the fewest obstructions from the banks on either side.

Rivers thus set into motion are almost always found to make their own beds. Where they find the bed elevated, they wear its substance away, and deposit the sediment in the next hollow, so as in time to make the bottom of their channels even. On the other hand, the water is continually gnawing and eating away the banks on each side; and this with more force as the current happens to strike more directly against them. $\mathrm{Br}$ these means it always has a tendency to render tinem more straight and parallel to its own course. Thus it continues to rectify its banks, and enlarge its bed ; and, consequently, to diminish the force of its stream, till there becomes an equilibrium between the force of the water, and the resistance of its banks, upon which both will remain without any further mutation. And it is happy for man that bounds are thus put to the erosion of the earth by water; and that we find all rivers only dig and widen themselves but to a certain degree. ${ }^{b}$

In those plains ${ }^{c}$ and large valleys where great rivers flow, the bed of the river is usually lower than any part of the valley. But it often happens, that the surface of the water is higher than many of the grounds that are adjacent to the banks of the stream. If, after inundations, we take a view of some river's, we shall find their banks appear above water, at a time that all the adjacent valley is overflowed. This proceeds from the frequent deposition of mud, and such like substances, upon the banks, by the rivers frequently overflowing; and thus, by degrees, they become elevated above the plain; and the water is often seen higher also.

Rivers, as every one has seen, are always broadest at the mouth, and grow narrower towards their source. But what is less known, and probably more deserving curiosity, is, that they run in a more direct channel as they immediately leave their sources; and that their sinnosities and turnings become more numerous as they proceed. It is a certain sign among the savages of North .America,

c Buffon, de Fleuves, passim. vol. ï. 
that they are near the sea, when they find the rivers winding, and every now and then changing their direction. And this is even now beeome an indication to the Europeans themselves, in their journeys through those trackless forests. As those sinuosities, therefore, increase as the river approaches the sea, it is not to be wondered at that they sometimes divide, and thus disembogue by different channels. The Danube disemlogues into the Euxine by seven mouths; the Nile by the same number; and the Wolga by seventy.

The currents $\mathrm{s}^{\mathrm{a}}$ of rivers are to be estimated very differently from the manner in which those writers, who have given us mathematieal theories on this subject, represent them. 'They found their calculations upon the surface being a perfect plain from one bank to the other: but this is not the actual state of nature; for rivers, in general, rise in the middle; and this convexity is greatest in proportion as the rapidity of the stream is greater. Any person, to be convinced of this, need only lay his eye, as nearly as he can, on a level with the stream, and looking across to the opposite bank, he will perceive the river in the midst to be elevated considerably above what it is at the edges. This rising, in some rivers, is often found to be three feet high; and is ever increased in proportion to the rapidity of the strean. In this case, the water in the midst of the current, loses a part of its weight, from the velocity of its motion; while that at the sides, for the contrary reason, sinks lower. It sometimes, however, happens, that this appearance is reversed; for when tides are found to flow up with violence against the natural current of the water, the greatest rapidity is then found at the sides of the river, as the water there least resists the influx from the sea. On those occasions, therefore, the river presents a concave rather than a convex surface; and, as in the former case, the middle waters rose in a ridge, in this case they sink in a furrow.

The stream of all rivers is more rapid in proportion as its channel is diminished. For instance, it will be much swifter where it is

aufon, de Fleuves, passim. vol. ij. ten yards broad, than where it is twenty, for the force behind still pushing the water forward, when it comes to the narrow part, it must make up by velocity what it wants in room.

It often happens that the stream of a river is opposed by one of its jutting banks, by an island in the midst, the arches of a bridge, or some such obstacle. This produces not unfrequently a back current; and the water having passed the arch with great velocity, pushes the water on each side of its direct current. This produces a side current, tending to the bank; and not unfrequently a whirlpool; in which a large body of waters are circulated in a kind of eavity, sinking down in the middle. The central point of the whirlpool is always lowest, because it has the least motion; tho other parts are supported, in some measure, by the violence of theirs, and consequently rise higher as their motion is greater; so that towards the extremity of the whirlpool, must be higher than towards the centre.

If the stream of a river be stopped at the surface, and yet be free below; for instance, if it be laid over by a bridge of boats, there will then be a double current; the water at the surface will flow back, while that at the bottom will proceed with increased velocity. It often happens that the current at the bottom is swifter than at the top, when, upon violent land-floods, the weight of waters towards the source presses the waters at the bottom, before it has had time to communicate its motion to the surface. However, in all other cases, the surface of the stream is swifter than the bottom, as it is not retarded by rubbing over the bed of the river.

It might be supposed that bridges, dams, and other obstacles in the current of a river, would retard its velocity. But the difference they make is very inconsiderable. The water, by these stoppages, gets an elevation above the object; which, when it has surmounted, it gives a velocity that recompenses the former delay. Islands and turnings also retard the course of the stream but very inconsiderably; any cause which diminishes the quantity of the water, most sensibly diminishes the force and the velocity of the stream. 
An increase" of water in the bed of the liver always increases its rapidity; except in cases of inundation. The instant the river lias overflowed its banks, the velocity of its current is always turned that way, and the inundation is pereeived to continue for some days; which it would not otherwise do, if, as soon as the cause was discontinued, it acquired its former rapidity.

A violent storm, that sets directly up against the course of the stream, will always retard, and sometimes entirely stop its course. I have seen an instance of this, when the bed of a large river was left entirely dry for some hours, and fish were caught among the stones at the bottom.

Inundations are generally greater towards the source of rivers than farther down; because the current is generally swifter below than above; and that for the reasons already assigned.

A little river ${ }^{b}$ may be received into a large one, without augmenting either its width or depth. This, which at first view seems a paradox, is yet very casily accounted for. The little river, in this case, only goes towards increasing the swiftuess of the larger, and putting its dormant waters into motion. In this manner the Venetian branch of the Po was pushed on by the Ferrarese branch and that of Penaro, without any enlargement of its breadth or depth from these accessions.

A river tending to enter another, either perpendicularly, or in an opposite direction, will be diverted by degrees from that direction; and be obliged to make itself a more favourable entrance downward, and more conspiring with the stream of the former.

The union of two rivers into one, makes it flow the swifter; since the same quantity of water, instead of rubbing against four shores, now only rubs against two. And, besides, the current being deeper, bccomes, of consequence, more fitted for motion.

With respect to the places from whence rivers proceed, it may be taken for a general rule, that the largest ${ }^{c}$ and highest mountains supply the greatest and most extensive rivers. It may also be remarked, in whatever direction the ridge of the mountain runs, the river

\footnotetext{
- Buffon, vol. ii. p. 62. G Guglielmini.
}

takes an opposite course. If the mountain, for instance, stretclies from north to south, the river runs from east to west; and so contrariwise. These are somc of the most generally received opinions with regard to the course of rivers; lowever, they are liable to many exceptions; and nothing but an actual knowledge of each particular river can furnish us with an exact theory of its current.

The largest rivers of Europe are, first, the Wolga, which is about six hundred and fifty leagues in length, extending from Reschow to Astrachan. It is remarkable of this river. that it abounds with water during the summer months of May and June; but all the rest of the year is so shallow as scarce to cover its bottom, or allow a passage for loaded vessels that trade up its stream. It was up this river that the English attempted to trade into Persia, in which they were so unhappily disappointed, in the year 1741. The next in order is the Danube. The course of this is about four hundred and fifty leagues, from the mountains of Switzerland to the Black Sea. It is so deep between Buda and Belgrade, that the Turks and Christians have fleets of men of war upon it; which frequently en: gaged during the last war between the Ottomans and the Austrians: however, it is unnavigable further down, by reason of its cataracts, which prevent its commerce into the Black Sea. The Don, or Tanais, which is four hundred leagues from the source of that branch of it called the Softna, to its mouth in the Euxine Sea. In one. part of its course, it approaches near the Wolga; and Peter the Great had actually begun a canal, by which he intended joining those two rivers; but this he did not live to finish. The Nieper, or Boristhenes, which rises in the middle of Muscovy, and runs a course of three hundred and fifty leagues, to empty itself into the Black Sea. The Old Cossacks inhabit the banks and islands of this river; and frequently cross the Black Sea, to plunder the maritime places on the coasts of Turkey. The Dwina, which takes its rise in a province of the same name in Russia, that runs a course of three hundred leagues, and disembogues into the White Sea, a little below Archangel.

c Doctor Halley. 
The largest rivers of $A$ sia are, the Hohanho, in China, which is eight hundred and fifty leagues in length, computing from its source at Raja Ribron, to its mouth in the gulf of Changi. The Jenisca of Tartaly, about eight hundred leagues in length, from the lake Sclinga, to the Icy Sea. This river is, by some, supposed to supply most of that great quantity of drift wood which is seen floating in the seas near the Arctic circle. The Oby, of five hundred leagues, running from the lake of Kila into the Northern Sea. The Amour, in Eastern Tartary, whose course is about five hundred and seventy-five leagues, from its source to its entrance into the sca of Kamtschatka. The Kiam, in China, fire hundred and fifty leagues in length. The Ganges, one of the most noted rivers in the world, and about as long as the former. It rises in the mountains which separate India from Tartary ; and running through the dominions of the Great Mogul, discharges itself by several mouths into the bay of Bengal. It is not only esteemed by the Indians for the depth and pureness of its stream, but for a supposed sanctity which they believe to be in its waters. It is visited annually by several hundred thousand pilgrims, who pay their devotions to the river as to a god: for savage simplicity is always known to mistake the blessings of the Deity, for the Deity himself. They carry their dying friends from distant countries, to cxpire on its banks; and to be buried in its stream. The water is lowest in April or May; but the rains beginning to fall soon after, the flat country is overflowed for several miles, till about the end of September; the waters then begin to retire, leaving a prolific sediment behind, that enriches the soil, and, in a few days time, gives a luxuriance to vegetation, beyond what cau be conceived by an European. Next to this may be reckoned the still more celebrated river Euphrates. This rises from two sources, northward of the city Erzerum, in 'Turcomania, and unites about three days' journey below the same; from whence, after performing a course of five hundred leagues, it falls into the gulf of Persia, fifty miles below the city of Bassora in Arabia. The river Indus is extended, from its source to its discharge into the Arabian Sea, four hundred leagues.
The largest rivers of Africa are, the Senegal. which runs a course of not less than eleven hundred leagues, comprehending the Niger, which some have supposed to fall into it. However, later accounts seem to affirm that the Niger is lost in the sands, about three hundred miles up from the western coasts of Africa. Be this as it may, the Senegal is well known to be navigable for more than three hundred leagues up the country; and how much higher it may reach is not yet discovered, as the dreadful fatality of the inland parts of Africa, not only deters curiosity, but even avarice, which is a much stronger passion. At the end of last war, of fifty Englishmen that werc sent to the factory at Galam, a place taken from the French, and nine hundred miles up the river, only one returned to tell the fate of his companions, who were destroyed by the climate. The celebrated river Nile is said to be ninc hundred and seventy leagues, from its source among the Monntains of the Moon, in Upper Athiopia, to its opening into the Meditcrranean Sea. The sources of this river wele considered as inscrutable by the ancients; and the causes of its periodical inundation wer: equally unknown. They have both becn ascertained by the missionaries who have travelled into the interior parts of Athiopia. The Nile takes its rise in the kingdom of Gojam, ${ }^{2}$ from a small aperture on the top of a mountain, which, though not above a foot and a half over, yet was unfathomable. This fountain, when arrived at the foot of the mountain, expands into a river; and being joined by others, forms a lake thirty leagues long, and as many broad; from this, its channel, in some measure, winds back to the country where it first began ; from thence, precipitating by frightful cataracts, it travels through a variety of desert regions, equally formidable, such as Amhara, Olaca, Damot, and Xaoa. Upon its arrival in the kingdom of Upper Egypt, it runs through a rocky channel, which some late travellers have mistaken for its cataracts. In the beginning of its course, it receives many lesser rivers into it; and Pliny was mistaken in saying that it reccived none. In the beginning also of its course, it has many

Kircher, Mund. Subt. vol. ii. p. 72. 
windings; but, for above three hundred leagues from the sea, runs in a direct line. Its annual overflowings arise from a very obvious cause, which is almost universal with the great rivers that take their source near the fine. The rainy season, which is periodical in those climates, floods the rivers; and as this always happens in our summer, so the Nile is at that time overflown. From these inundations, the inhabitants of Egypt derive lappiness and plenty; and, when the river loes not arise to its accustomed heights, they prepare for an indifferent harvest. It begins to overflow about the seventeenth of June; it generally continues to augment for forty days, and decreases in about as many more. 'The time of increase and decrease, however, is much more inconsiderable now than it was among the ancients. Herodotus informs us, that it was a hundred days rising, and as many falling; which shows that the inundation was inuch greater at that time than at present. Mr. Buffon ${ }^{2}$ has ascribed the present diminution, as well to the lessening of the Mountains of the Moon, by their substance having so long been washed down with the stream, as to the rising of the earth in Egypt, that has for so many ages received this extraneous supply. But we do not find, by the buildings that have remained since the times of the ancients, that the earth is much raised since then. Besides the Nile in Africa, we may reckon the Zara, and the Coanza, from the greatness of whose openings into the sea, and the rapidity of whose streams, we form an estimate of the great distance from whence they come. Their courses, however, are spent in watering deserts and savage countries, whose poverty or fierceness have kept strangers away.

But of all parts of the world, America, as its exhibits the most lofty mountains, so also it supplies the largest rivers. The foremost of these is the great river Amazon, which, from its source in the lake of Lauricocha, to its discharge into the Western Ocean, performs a course of more than twelve hundred leagues. ${ }^{b}$ The breadtl and depth of this river are answerable to its vast length; and, where its width is most contracted, its depth

- Buffon, vol. ii. p. 82. is augmented in proportion. So great is the body of its waters, that other rivers, though before the objects of admiration, are lost in its bosom. It proceeds, after their junction, with its usual appearance, without any visible change in its breadth or rapidity; and, if we may so express it, remains great without ostentation. In some places it displays its whole magnificence, dividing into several large branches, and encompassing a multitude of islands; and, at length, discharging itself into the ocean, by a channel of a hundred and fifty miles broad. Another river, that may almost rival the former, is the St. Lawrence, in Canada, which rising in the lake Assiniboils, passes from one lake to another, from Christinaux to Alempigo; from thence to lake Superior; thence to the lake Hurons; to lake Erie; to lake Ontario; and, at last, after a course of nine hundred leagues, pours their collected waters into the Atlantic Ocean. The river Mississippi is of more than seven luundred leagues in length, beginning at its source near the lake Assiniboils, and ending at its opening into the gulf of Mexico. The river Plate runs a length of more than eight hundred leagues from its source in the river Parana, to its mouth. The river Oroonoko is seven hundred and fifty leagues in length, from its source near Pasto, to its discharge into the Atlantic Ocean.

Such is the amazing length of the greatest rivers; and even in some of these, the most remote sources very probably yet continue unknown. In fact, if we consider the number of rivers which they receive, and the little acquaintance we have with the regions through which they run, it is not to be wondered at that geographers are divided concerning the sources of most of them. As among a number of roots by which nourishment is conveyed to a stately tree, it is difficult to determine precisely that by which the tree. is chiefly supplied; so among the many branches of a great river, it is equally difficult to tell which is the original. Hence it may easily bappen, that a similar branch is taken for the capital stream; and its runnings are pursued, and delineated, in prejudice of some other branch that better deserved the name

b Ulloa, vol. i. p. 388. 
and the description. In this manner, ${ }^{a}$ in Europe, the Danube is known to receive thirty lesser rivers ; the Wolga, thirty-two or thirtythree. In Asia, the Holuanho receives thirtyfive; the Jenisca above sixty; the Oby as many; the Amour about forty; the Nanquin receives thirty rivers; the Ganges twenty; and the Euphrates about eleven. In Africa, the Senegal receives more than twenty rivers; the Nile receives not one for five hundred leagues upwards, and then only twelve or thirteen. In America, the river Amazon receives above sixty, and those very considerable; the river St. Lawrence about forty, counting those which fall into its lakes; the Mississippi receives forty; and the river Plate above fifty.

I mentioned the inundation's of the Ganges and the Nile; but almost every other great river, whose source lies within the tropics, have their stated inundations also. The river Pegu has been called, by travellers, the Indian Nile, because of the similar overflowings of its stream: this it does to an extent of thirty leagues on each side; and so fertilizes the soil, that the inhabitants send great quantities of rice into other countries, and have still abundance for their own consumption. The river Senegal has likewise its inundations, which cover the whole flat country of Negroland, begiuning and ending much about the same time with those of the Nile; as, in fact, both rivers rise from the same mountains. But the difference between the effects of the inundations in each river is remarkable: in the one, it distributes health and plenty; in the other, diseases, famine, and death. The inhabitants along the torrid coasts of the Senegal, can reccive no benefit from any additional manure the river may carry down to their soil, which is by nature more than sufficiently luxuriant; or, even if they could, they have not industry to turn it to any advantage. The banks, therefore, of the rivers, lie uncultivated, overgrown with rank and noxious herbage, and infested with thousands of animals of various malignity. Every new flood only tends to increase the rankness of the soil, and to provide fresh shelter for the creatures that infest it. If the flood continues

\footnotetext{
- Buffop, vol. ii. p. 74.
}

but a few days longer than usual, the impiovident inhabitants, who are driven up in the higher grounds, want provisions, and a famine ensues. When the river begins to return into its channel, the humidity and heat of the air are equally fatal; and the carcases of infinite numbers of animals, swept away by the inundation, putrefying in the sun, produce a stench that is almost insupportable. But even the luxuriance of the vegetation becomes a nuisance. I have been assured, by persons of veracity who have been up the river Senegal, that there are some plants growing along the coast, the smell of which is so powerful, that it is hardly to be endured. It is certain, that all the sailors and soldiers who have been at any of our factories there, ascribe the unwholesomeness of the voyage up the stream, to the vegetable vapour. However this be, the inundations of the rivers in this wretched part of the globe, contribute scarcely any advantage, if we except the beauty of the prospects which they afford. These, indeed, are finished beyond the utmost reach of art: a spacious glassy river, with its banks here and there fringed to the very surface by the mangrove-tree that grows down into the water, presents itself to view. Lofty forests of various colours, with openings between, carpeted with green plants, and the most gaudy flowers; beasts and animals of various kinds, that stand upon the banks of the river, and, with a sort of wild curiosity, survey the mariners as they pass, contribute to heighten the scenc. This is the sketch of an African prospect; which delights the eye, cven while it clestroys the constitution.

Besides these annually periodical inundations, there are many rivers that overflow at much shorter intervals. Thus most of those in Peru and Chili have scarcely any motion by night; but upon the appearance of the morning sun, they resume their former rapidity: this proceeds from the mountain snows, which, melting with the heat, increase the stream, and continue to drive on the current while the sun continues to dissolve them. Some rivers also flow. with an even, steady current, from their source to the sea; others flow with greater rapidity, their stream being poured down in a cataract, or swallowed by the sands, before they reach the sea. 
The rivers of those countries that have been least inhabited, are usually more rocky, uneven, and broken into vaterfalls or cataracts, than those where the industry of man has been more prevalent. Wherever man comes, nature puts on a milder appearance: the terrible and the sublime are exchanged for the gentle and the useful; the cataract is sloped away into a placid stream; and the banks become more smooth and even." It must have required ages to render the Rhone or the Loire navigable; their heds must have been cleaned and directed; their inequalities removed; and, by a long course of industry, nature must have been taught to conspire with the desires of her controller. Every one's experience must have supplied instances of rivers thus being made to flow more evenly, and more beneficially to mankind; but there are some whose currents are so rapid, and falls so precipitate, that no art can obviate, and that must for ever remain as amazing instances of incorrigible nature.

Of this kind are the cataracts of the Rhine; one of which I have seen exhibit a very strange appearance; it was that at Schaffhausen, which was frozen quite across, and the water stood in columns where the cataract liad formerly fallen. The Nile, as was said; has its cataracts. The river Vologda, in Russia, lias two. The river Zara, in Africa, has one near its source. The river Velino, in Italy, has a cataract of above a hundred and fifty feet perpendicular. Near the city of Gottenburgh," in Sweden, the river rushes down from a prodigious high precipice into a deep pit, with a terrible noise, and such dreadful force, that those trees designed for the masts of ships, which are floated down the river, are usually turned upside down in their fall, and often are shattered to pieces, by being dashed against the surface of the water in the pit; this occurs if the masts fall sideways upon the water; but if they fall endways, they dive so far under water that they disappear for a quarter of an hour, or more: the pit into which they are thus plunged has been often sounded with a line of some hundred fathoms long, but no ground has been found hitherto. There is also a cata-

- Bufion vol. ii. p. 90 . ract àt Powerscourt, in Ireland, in which, if I am rightly informed, the water falls three hundred feet perpendicular; which is a greater descent than that of any other cataract in any part of the world. There is a cataract at Albany. in the province of New York, which pours its stream fifty feet perpendicular But of all the cataracts in the world, that of Niagara, in Canada, if we con.. sider the great body of water that falls, must be allowed to be the greatest, and the most astouishing

This amazing fall of water is made by the river St. Lawrence, in its passage from the lake Erie into the lake Ontario. We have already said that St. Lawrence was one of the largest rivers in the world; and yet the whole of its waters are here poured down by a fall of a hundred and fifty feet perpendicular. It is not easy to bring the imagination to correspond with the greatness of the scene; a river extremely deep and rapid, and that serves to drain the waters of almost all North America into the Atlantic ocean, is here poured precipitately down a ledge of rocks, that rise like a wall, across the whole bed of its stream. The width of the river, a little above, is near three quarters of a mile broad, and the rocks, where it grows narrower, are four hundred yards over. Their direction is not straight across, but hollowing inwards like a horse-shoe; so that the cataract, which bends to the shape of the obstacle, rounding inwards, presents a kind of theatre the most tremendous in nature. Just in the middle of this circular wall of waters, a little island, that has braved the fury of the current, presents one of its points, and divides the stream at top into two; but it unites again long before it has got to the bottom. The noise of the fall is heard at several leagues distance; and the fury of the waters at the bottom of their fall is inconceivable. The dashing produces a mist that rises to the very clouds; and that produces a most beautiful rainlow; when the sun shines. It may casily be conceived, that such a cataract quite destroys the navigation of the stream; and yet some Indian canoes, as it is said, have been known to venture down it with safety.

b Phil. Trans. vol. ii. p. 325. 
Of those rivers that lose themselves in the sands, or are swallowed up by chasms in the earth, we have various information. What we are told by the ancients, of the river Alpheus, in Arcadia, that sinks into the ground, and rises again near Syracuse, in Sicily, where it takes the name of Arethusa, is rather more known than credited. But we have better information with respect to the river Tigris being lost in this manner under Mount Taurus; of the Guadilquiver in Spain, being buried in the sands; of the river Greatah, in Yorkshire, rumning underground, and rising again; and even of the great Rhine itself. a part of which is no doubt lost in the sands, a little above Leyden. But it ought to be observed of this river, that by much the greatest part arrives at the ocean: for, although the ancient channel which fell into the sea a little to the west of that city, be now entirely choked up, yet there are still a number of small canals, that carry a great body of waters to the sea : and besides, it has also two very large openings, the Lech, and the Waal, below Rotterdam, by which it einpties itself abundantly.

Be this as it will, nothing is more common in sultry and sandy deserts, than rivers being thus either lost in the sands, or entirely dried up by the sun. And hence we see, that under the Line, the small rivers are but few; for such little streams as are common in Europe, and which with us receive the name of rivers, would quickly evaporate, in those parching and extensive deserts. It is even confidently asserted, that the great river Niger is thus lost before it reaches the ocean;

- Krantz's History of Greenland, vol. i. p. 41. and that its supposed mouths, the Gambia, and the Senegal, are distinct rivers, that come a vast way from the interior parts of the country. It appears that the rivers under the Line are large; but it is otherwise at the Poles," where they must necessarily be small. In that desolate region, as the mountains are covered with perpetual ice, which melts but little, or not at all, the springs and rivulets are furnished with a very small supply. Here, therefore, man and beast would perish, and die for thirst, if Providence had not ordered, that in the hardest winter, thaws should intervene, which deposit a small quan. tity of snow-water in pools under the ice; and from this source the wretched inhabitants drain a scanty beverage.

Thus, whatever quarter of the globe we turn to, we shall find new reasons to be satisfied with that part of it in which we reside. Our rivers furnish all the plenty of the African'stream, without its inundation; they have all the coolness of the Polar rivulet, with a more constant supply; they may want the terrible magnificence of huge cataracts, or extensive lakes, but they are more navigable, and more transparent; though less deep and rapid than the rivers of the torrid zone, they are more manageable, and only wait the will of man to take their direction. The rivers of the torrid zone, like the monarchs of the country, rule with despotic tyranny, profuse in their bounties, and ungovernable in their rage. The rivers of Europe, like their kings, are the friends, and not the oppressors of the people ; bounded by known limits, and abridged in the power of doing ill, directed by human sagacity, and only at freedom to distribute happiness and plenty. 


\section{CHAPTER XV.}

\section{OF THE OCEAN IN GENERAL; AND OF ITS SALTNESS.}

IF we look upon a map of the world, we shall find that the ocean occupies considerably more of the globe, than the land is found to do. This immense body of waters is diffused round both the Old and New Continent, to the south; and may surround them also to the north, for what we know, but the ice in those regions has stopped our inquiries. Although the ocean, properly speaking, is but one extensive sheet of waters, continued over every part of the globe, without interruption, and although no part of it is dirided from the rest, yet geographers have distinguished it by different naines; as the Atlantic or Western Ocean, the Northern Ocean, the Southern Ocean, the Pacific Ocean, and the Indian Ocean. Others have divided it differently, and given other names; as the Frozen Ocean, the Inferior Ocean, or the American Ocean. But all these being arbitrary distinctions, and not of Nature's making, the naturalist may consider them with indifference.

In this vast receptacle, almost all the rivers of the earth ultimately terminate; nor do such great supplies seem to increase its stores; for it is neither apparently swollen by their tribute, nor diminished by their failure; it still continues the same. Indeed, what is the quantity of water of all the rivers and lakes in the world, compared to that contained in this great receptacle ?a If we should offer to make a rude estimate, we shall find that all the rivers in the world, flowing into the bed of the sea, with a continuance of their present stores, would take up at least eight hundred years to fill it to its present height. For, supposing the sea to be eightyfive millions of square miles in extent, and a quarter of a mile upon an average in depth, this, upon calculation, will gire above twenty-one millions of cubic miles of water, as the contents of the whole ocean. Now, to esti-

- Buffon, vol. ii. p. 70 .

No. 7 . mate the quantity of water which all the rivers supply, take any one of them; the Po, for instance, the quantity of whose discharge into the sea, is known to be one cubic mile of water in twenty-six days. Now it will be found, upon a rude computation, from the quantity of ground the Po, with its influent streams, covers, that all the the rivers of the world furnish about two thousand times that quantity of water. In the space of a year, therefore, they will have discharged into the sea about twenty-six thousand cubic miles of water; and not till eight hundred years, will they have discharged as much water as is contained in the sea at present. I have not. troubled the reader with the odd numbers, lest he should imagine I was giving precision to a subjeet that is incapable of it.

Thus great is the assemblage of waters diffused round our habitable globe; and yet, immeasurable as they seem, they are mostly rendered subservient to the necessities and the conveniences of so little a being as man. Nevertheless, if it should be asked whether they be made for him alone, the question is not easily resolved. Some philosophers have perceired so much analogy to man in the formation of the ocean, that they have not hesitated to assert its being made for him alone. The distribution of land and water, say they, is admirable ; the one being laid against the other so skilfully, that there is a just equipoise of the whole globe. Thus the Northeru Ocean balances against the Southern; and the New Continent is an exact counterweight to the Old. As to any ob jection from the ocean's occupying too large a share of the globe, they contend, that there could not have been a smaller surface employed to supply the earth with a due share of evaporation. On the other hand, some take the gloomy side of the question; they

b Derham's Physico-Theol. 
either magnify its apparent defects; or assert, that ${ }^{b}$ what secms defects to us, may be real beauties to some wiser order of beings. They observe, that multitudes of animals are concealed in the ocean, and but a small part of thein are known; the rest, therefore, they fail not to say, were certainly made for their own benefit, and not for ours. How far cither of these opinions be just, I will not presume to determine; but of this we are certain, that God has endowed us with abilities to turn this great extent of waters to our own advantage. He has made these things, perhaps, for other uses; but he has given us faculties to convert them to our own. This much agitated question, therefore, seems to terminate here. We shall never know whether the things of this world have been made for our use; but we very well know that we have been made to enjoy them. Let us then boldly affirm, that the earth, and all its wonders, are ours; since we are furnished with powers to force them into our service. Man is the lord of all the sublunary creation; the howling savage, the winding serpent, with all the untameable and rebellious offspring of nature, are clestroyed in the contest, or driven to a distance from his habitations. 'The extensive and tempestuous ocean, instead of limiting or dividing his power, only serves to assist his industry, and enlarge the sphere of his enjoyments. Its billows, and its monsters, instead of presenting a scene of terror, only call up the coulage of this little intrepid being; and the greatest danger that man now fears on the deep, is from his fellow-creatures. Indeed, when I consider the human race as Nature has formed them, there is but very little of the habitable globe that seems made for them. But when I consider them as accumulating the experience of ages, in commanding the carth, there is nothing so great, or so terrible. What a poor contemptible being is the naked savage, standing on the beach of the ocean, and trembling at its tumults! How little capable is he of converting its terrors into benefits; or of saying, behold an eleunent made wholly for my enjoyment! He considers it as an angry deity, and pays it

- Burnet's Theory, passim. the homage of submission. But it is very different when he has exercised his mental powers; when he has learnt to find his own superiority, and to malze it subservient to his commands. It is then that his dignity begins to appear, and that the true Deity is justly praised for having been mindful of man; for having given him the earth for his habitation, and the sea for an inheritance.

This power which man has obtained over the occan, was at first enjoyed in common, and none pretended to a right in tirat element where all seemed intruders. The sea. therefore, was open to all till the time of the emperor Justinian. His successor Leo granted such as were in possession of the shore the sole right of fishing before their respective territories. The Thracian Bosphorus was the first that was thus appropriated; and from that time it has been the struggle of most of the powers of Europe to obtain an exclusive right in this element. The republic of Venice claims the Adriatic. The Danes are in possession of the Baltic. But the English have a more extensive claim to the cnpire of all the seas encompassing the kingdoms of England, Scotland, and Ireland; and although these have been long contested, yet they are now considered as their indisputable property. Every one know's that the great power of the nation is exerted on this element; and that the instant England ceases to be superior upon the ocean, its safety begins to be precarious.

It is in some measure owing to our dependance upon the sea, and to our commerce there, that we are so well acquainted with its extent and figure. The bays, gulfs, currents, and shallows of the ocean, are much better known and examined than the provinces and kingdoms of the earth itself. The hopes of acquiring wealth by commerce, has carried man to much greater length than the desire of gaining information could have done. In consequence of this, there is scarcely a strait or a harbour, scarcely a rock or a quicksand, scarcely an inflexion of the shore, or the jutting of a promontory, that has not been minutely described. But as these present very little entertainment to the imagination, or de-

\footnotetext{
bope's Ethic Epistle, passim.
} 
light to any but those whose pursuits are lucrative, they need not be dwelt upon here. While the merchant and the mariner are solicitous in describing currents and soundings, the naturalist is employed in observing wonders, though not so beneficial, yet to him of a much more important nature. The saltness of the sea secms to be foremost.

Whence the sea has derived that peculiar bitterish saltness which we find in it, appears, by Aristotle, to have exercised the curiosity of naturalists in all ages. He supposed (and mankind were for ages content with the solution) that the sun continually raised diy saline exhalations from the earth, and deposited them upon the sea; and hence, say his followers, the waters of the sea are more salt at top than at bottom. But, unfortunately for this opinion, neither of the facts is true. Seasalt is not to be raised by the vapours of the sun; and sea-water is not salter at the top than at the bottom. Father Bohours is of opinion that the Creator gave the waters of the ocean their saltness at the beginning; not only to prevent their corruption, but to enable them to bear greater burthens. But their saltness does not prevent their corruption; for stagnant sea-water, like fresh, soon grows putrid : and, as for their bearing greater burthens, fresh waters answer all the purposes of navigation quite as well. The established opinion, therefore, is that of Boyle, who supposes, "that the sea's saltness is supplied not only from rocks or masses of salt at the bottom of the sca, but also from the salt which the rains and rivers, and other waters, dissolve in their passage through many parts of the earth, and at length carry with them to the sea." But as there is a difference in the taste of rock-salt found at land, and that dissolved in the walers of the ocean, this may be produced by the plenty of nitrous and bituminous bodies that, with the salts, are likewise washed into that great receptacle. These substances being thus once carried to the sea, must for ever remain there; for they do not rise by evaporation, so as to be returned back from whence they came. Nothing but the fresh waters of the sea rise in vapours; and all the saltness remains behind. Hence

a Boyle, vol. iii. p. 221. it follows, that every year the sea must become more and more salt; and this speculation Doctor Halley carries so far as to lay down a method of finding out the age of the world by the saltness of its waters. "For if it be observed," says he, "what quantity of salt is at present contained in a certain weight. of water, taken up from the Caspian Sea, for example, and, after some centuries, what greater quantity of salt is contained in the same weight of water taken from the same place: we may conclude, that in proportion as the saltness has increased in a certain time, so much must it have increased before that time; and we may thus, by the rule of proportion, make an estimate of the whole timc wherein the water would acquire the degree of saltness it should be then nossessed of." All this may be fine; however, an experiment, begun in this century, which is not to be completed till some centuries hence, is rather a little mortifying to modern curiosity : and, I am induced to think, the inhabitants round the Caspian Sea will not be apt to undertake the inquiry.

This saltness is found to prevail in every part of the ocean; and as much at the surface as at the bottom. It is also found in all those seas that communicate with the ocean; but rather in a less degree.

The great lakes, likewise, that have no ontlets nor communication with the ocean, are found to be salt: but some of them in less proportion. On the contrary, all those lakes through which rivers run into the sea, however extensive they be, are, notwithstanding very fresh: for the rivers do not deposite their salts in the bed of the lake, but carry them, with their currents, into the ocean. Thus the lakes Ontario and Erie, in North America, although for magnitude they may be considered as inland seas, are, nevertheless, freshwater lakes; and kept so by the river St. Lawrence, which passes through them. But those lakes that have no communication with the sea, nor any rivers going out, although they be less than the former, are, however, always salt. Thus, that which goes by the name of the Dead Sea, though very small, when compared to those already mentioned,

b Phil. Trans. vol. v. p. 218 , 
is so excecdingly salt, that its waters scem scarcely capable of dissolving any inore. The lakes of Mexico, and of Titicaca, in Peru, though of no great extent, are, nevertheless, salt; and both for the same reason.

Those who are willing to turn all things to the best, have not failed to consider this saltness of the sea as a peculiar blessing from Providence, in order to keep so great an element sweet and wholesome. What foundation there may be in the remark, I will not pretend to determine; but we shall shortly find a much better cause for its being kept sweet, namely, its motion.

On the other hand, there have been many who have considered the subject in a different light, and have tried every endeavour to make salt-water fresh, so as to supply the wants of mariners in long voyages, or when exhausted of their ordinary stores. At first it was supposed simple distillation would do; but it was soon found that the bitter part of ilse water still kept mixed. It was then tried by uniting salt of tartar with sea-water, and distilling both; but here the expense was greater than the advantage. Calcined bones were next thought of; but a hogshead of calcined bones, carried to sea, would take up as much room as a hogshead of water, and was more hard to be obtained. In this state, therefore, have the attempts to sweeten seawater rested; the chymist satisfied with the reality of his invention; and the mariner convinced of its being useless. I cannot, therefore, avoid mentioning a kind of succedaneum which has been lately conceived to answer the purposes of fresh water, when inariners are quite exhausted. It is well known, the persons who go into a warm bath, come out several ounces lipavier than they went in; their bodies laving imbibed a correspondent quantity of water. This more particularly happens, if they have been previousjy debarred from drinking, or go in with a violent thirst; which they quickly find quenehed, and their spirits restored. It was supposed, that in case of a total failure of fresh-water at sea, a warm bath might be made of sea-water, for the use of mariners; and that their pores would thus imbibe the fuid, without any of its salts, which would be seen to crystallize on the surface of their bodies. In this manner, it is supposed, a sufficient quantity of moisture may be procured to sustain life, till time or accident furnish a more copious supply.

But, however this be, the saltness of the sea can by no means be considered as a principal cause in preserving its waters from putrefaction. The ocean has its currents, like livers, which circulate its contents round the globe; and these may be said to be the great agents that keep it sweet and wholesome. Its saltness alone would, by no means, answer this purpose: and some liave even imagined that the various substances with whicl it is mixed, rather tend to promote putrescence than impede it. Sir Robert Hawkins, one of our most enlightened navigators, gives the following account of a calm, in which the sea continuing for some time without motion, began to assume a very formidable appearance. "Were it not," says he, "for the moving of the sea, by the force of winds, tides, and currents, it would corrupt all the world. The experiment of this I saw in the year 1590 , lying with a fleet about the islands of Azores, almost six inonths; tlie greatest part of which time we were becalned. Upon which all the sea became so replenished with several sorts of jellies, and forms of serpents, adders, and snakes, as seemed wonderful: some green, some black, some yellow, some white, some of divers colours, and many of them had life; and some there were a yard and a half, and two yards long; which had I not seen, I could hardly have believed. And hereof are witnesses all the company of the ships which were then present: so that hardly a man could draw a bucket of water clear of some corruption. In which voyage, towards the end thereof, many of every ship fell sick, and began to die apace. But the speedy passage into our country was a remedy to the crazed, and a preservative for those that were not touched."

This shows, abundantly, how little the sea's saltness was capable of preserving it from putrefaction: but, to put the matter beyond all doubt, Mr. Boyle kept a quantity of seawater; taken up in the English Channel, for some time barrelled up; and, in the space of a few weeks, it began to acquire a fetid 
smell : he was also assured, by one of his acquaintance, who was becalmed for twelve or fourteen days in the Indian sea, that the water, for want of motion, began to stink; and that had it continued much longer, the stench would probably have poisoned him. It is the motion, therefore, and not the saltness of the sea, that preserves it in its present state of salubrity; and this, very probably, by dashing and breaking in pieces the rudiments, if I may so call them, of the various animals that would otherwise breed there, and putrefy.

There are some advantages, however, which are derised from the saltness of the sea. Its waters beng evaporated, furnish that salt which is use? ror domestic purposes; and, although in some places it is made from springs, and, ir: otners, dug out of mines, yet the greatest quantity is made only from the sca. That which is called bay-salt, (from its coming to us by the Bay of Biscay,) is a stronger kind, made by evaporation in the sun: that called common salt, is evaporated in pans over the fire, and is of a much inferior quality to the former.

Another benefit arising from the quantity of salt dissolved in the sea, is, that it thus becomes heavier, and, consequently, more bmoyant. Mr. Boyle, who examined the difference between sea-water and fresh, found that the former appeared to be about a fortyfifth part heavier than the latter. Those, also, who have had opportunities of bathing in the sea, pretend to have experienced a much greater ease in swimming there, than in fresh-water. However, as we see they have only a forty-fifth part more of their weight sustained by it, I am apt to doubt whether so minute a difference can be practically perceivable. Be this as it may, as sea-water alters in its weight from fresh, so it is found also to differ from itself in different parts of the ocean. In general, it is perceived to be heavier, and consequently salter, the nearer we approach the Line."

But there is an advantage arising from the saltness of the waters of the sea, much greater than what has been yet mentioned; which is,

- Boyle, vol. iii. p. 222.

Phil. Trans. vol. ji. p. 297. c Macrobius. that their congelation is thus retarded. Some, indeed, have gone so far as to say, that ${ }^{\circ}$ seawater never freezes: but this is an assertion contradicted by experience. However, it is certain that it requires a much greater degree of cold to freeze it than fresh-water; so that, while rivers and springs are seen converted into one solid body of ice, the sea is always fit for navigation, and no way affected by the coldness of the severest winter. It is, therefore, one of the greatest blessings we derive from this element, that when at land all the stores of Nature are locked up from us, we find the sea ever open to our necessities, and patient of the hand of industry.

But it must not be supposed, because in our temperate climate we never see the sea frozen, that it is in the same manner open in every part of it. A very little aequaintance with the accounts of inariners, must have informed us, that at the polar regions it is embarrassed with mountains, and moving sheets of ice, that often render it impassable. These tremendous floats are of different magnitudes; sometimes rising more than a thousand fee' above the surface of the water ;" sometimes diffused into plains of above two hundred leagues in length; and, in many parts, sixty or eighty broad. They are usually divided by fissures; one piece following another so close, that a person may step from one to the other. Sometimes mountains are seen rising amidst these plains, and presenting the appearance of a variegated landscape, with hills and valleys, houses, churches, and towers. These are appearances in which all naturalists are agreed; but the great contest is respecting their formation. Mr. Buffon asserts, ${ }^{e}$ that they are formed from fresh-water alone; which congealing at the mouths of great rivers, accumulate those huge masses that disturb navigation. However, this great naturalist seems not to have been aware that there are two sorts of ice floating in these seas; the fiat ice, and the mountain ice: the one formed of sea-water only, the other of fresh. . $^{\text {. }}$

The flat, or driving ice, is entirely composed of sea-water; which, upon dissolution,

d Krantz's History of Greenland, vol. j. p. 31 ,

- Buffon, vol. ii. p.91. , Krantz. 
is found to be salt; and is readilydistinguislied from the mountain or fresh-water ice, by its whiteness, and want of transparency. This ice is much more terrible to mariners than that which rises up in lumps: a ship can avoid the one, as it is seen at a distance; but it often gets in among the other, which sometimes closing, crushes it to pieces. This, which manifestly has a different origin from the fresh-water ice, may perhaps have been produced in the Icy Sea, beneatli the Pole; or along the coasts of Spitzberg, or Nova Zembla.

The mountain-ice, as was said, is different in every respect, being formed of fiesh-water, and appearing lard and transparent; it is generally of a pale green colour, though some pieces are of a beautiful sky blue; many large masses, also, appear gray; and some black. If exsmined more ncarly, they are found to be incorporated with earth, stones, and brushwood, washed from the shore. On these also are sometimes found, not only earth, but nests with hirds' eggs, at several hundred miles from land. The generality of these, though almost totally fiesh, have, nevertheless, a thick crust of salt-water frozen upon them, probably from the power that ice has sometimes to produce ice. Such mountains as are bere described, are most usually seen at spring-time, and after a violent storm, driving out to sea, where they at first terrify the mariner, and are soon after dashed to pieces by the continual washing of the waves; or driven into the warmer regions of the south, there to be melted away. They sometimes, however, strike back upon their native shores, where they seem to take root at the feet of mountains; and, as Martius tells us, are sometimes higher than the mountains themselves. Those seen by him were blue, full of clefts and carities made by the rain, and crowned with snow, which alternately thawing and freezing every ycar, augmented their size. These, composed of materials more solid than that driving at sea, presented a variety of agrecable figures to the cye, that, with a little help from fancy, assumed the appearance of trees in blossom; the inside of churches, with arches, pillars, and winlows; and the blue coloured rays, darting from within, presented the resemblance of a glory. If we inquire into the origin and formation of these, which, as we sec, are very different from the former, I think we have a very satisfactory account of them in Krantz's History of Grecnland; and I will take leave to give the passage, with a very few alterations. "These mountains of ice," says he, "are not salt, like the sea-water, but sweet; and, therefore, can be formed no where except on the mountains, in rivers, in caverns, and against the hills near the sea-shore. The mountains of Greenland are so high, that the snow which falls upon them, particularly on the north side, is, in one night's time, wholly converted into ice: they also contain clefts and cavities, where the sun seldom or never injects his rays: besides these, are projections, or landing places, on the declivities of the steepest hills, where the rain and snowwater lodge, and quickly congeal. When now the accumulated flakes of snow slide down, or fall with the rain from the eminences above on these prominences; or, when here and there a mountain-spring comes rolling down to such a lodging place, where the ice has already scated itself, they all freeze, and add their tribute to it. This, by degrees, waxes to a body of ice, that can no more be overpowered by the sun; and which, though it may indecd, at certain scasons, diminish by a thaw, yet, upon the whole, through annual acquisitions, it assumes an annual growth. Such a body of ice is often prominent far over the rocks. It does not melt on the upper surface, but underneath; and often cracks into many larger or smaller elefts, from whence the thawed water trickles out. By this it becomes, at last, so weak, that being overloaded with its own ponderous bulk it breaks loose and tumbles down the rocks with a terrible crash. Where it happens to overhang a precipice on the shore, it plunges into the dcep with a shock like thunder: and with such an agitation of the water, as will overset a boat at some distance, as many a poor Greenlander has fatally experienced." Thus are these amazingice mountains launched forth to sca, and found floating in the waters round both thePoles. It is these that have hindered mariners from discovering the extensive countries that lie round the South Pole: and that probably block up the pas sage to China by the Nortl. 
I will conclude this chapter with one effect more, produced by the saltness of the sea; which is, the luminous appearance of its waves in the nightit. All who have been spectators of a sea by night, a little ruffled with winds, seldom fail of observing its fiery brightness. In "some places it shimes as far as the eye can reach; at other times, only when the waves boom against the side of the vessel, or the oar dashes into the water. Some seas shine often; others more seldom; some, ever when particular winds blow; and others, within a narrow compass; a long tract of light being seen along the surface, whilst all the rest is hid in total darkness. It is not easy to account for these extraordi- nary appearances: some have supposed that a number of luminous insects produced the effect, and this is in reality sometimes the case; in general, however, they have every resemblance to that light produced by electricity; and, probably, arise from the agitation and dashing of the saline partieles of the fluid against each other. But the manner in which this is done, (for we can produce nothing similar by any experiments hitherto made,) remains for some happier accident to discover. Our progress in the knowledge of Nature is slow; and it is a mortifying consideration, that we are hitherto more indebted for suceess to chance than industry.

\section{$-9000$}

\section{CHAPTER XVI.}

\section{OF THE TIDES, MOTION, AND CURRENTS OF THE SEA; WITH THEIR EFFECTS.}

IT was said, in the former chapter, that the waters of the sea were kept sweet by their motion, without which they would soon putrefy, and spread universal infection. If we look for final causes, here, indeed, we have a great and an obvious one that presents itself before us. Had the sea been made without motion, and resembling a pool of stagnant water, the nobler races of animaled nature would shortly be at an end. Nothing would then be left alive but swarms of ill-formed creatures, with scarcely more than vegetable life; and subsisting by putrefaction. Were this extensive bed of waters entirely quiescent, millions of the smaller reptile kinds would there find a proper retreat to breed and multiply in; they would find there no agitation, no concussion in the parts of the fluid to crush their feeble frames, or to force them from the places where they were bred; there they would multiply in security and ease, enjoy a short life, and putrefying, thus again give nourishment to numberless other, as little worthy of existence as themselves.

\footnotetext{
- Boyle, vol. i. p. 294.
}

But the motion of this great element effectually destroys the number of these viler creatures; its currents and its tides produce continual agitations, the shock of which they are not able to endure; the parts of the fluid rub against each other, destroy all viscidities; and the ocean, if I may so express it, acquires health by exercise.

The most obvious motion of the sea, and the most generally acknowledged, is that of its tides. This element is observed to flow for certain hours, from south towards the north; in which motion or flux, which lasts about six hours, the sea gradually swells; so that entering the mouths of rivers, it drives back the river waters to their heads. After a contiuual flux of six hours, the sea seems to rest for a quarter of an hour; and then begins to ebb, or retire back again, from north to south, for six hours more; in which time the waters sinking, the rivers resume their natural course. After a seeming pause of a quarter of an hour, the sea again begins to flow as before : and thus it has alternately risen and fallen, twice a dav, since the creation. 
This amazing appearance did not fail to excite the curiosity, as it did the wonder of the ancients. After some wild conjectures of the earliest philosophers, it became well known, in the time of Pliny, that the tides were entirely under the influence, in a small degree, of the sun; but in a mucl greater, of the moon. It was found that there was a flux and reflux of the sea, in the space of twelve hours fifty minutes, which is exactly the time of a lunar day. It was observed, that whenever the moon was in the meridian, or, in other words, as nearly as possible over any part of the sea, that the sea flowed to that part, and made a tide there; on the contrary, it was found, that when the moon left the meridian, the sea began to flow back again from whence it came; and there might be said to ebb. Thus far the waters of the sea seemed very regularly to attend the motions of the moon. But it appeared, likewise, that when the moon was in the opposite meridian, as far off on the other side of the globe, that there was a tide on this side also; so that the moon produced two tides, one by her greatest approach to us; and another by her greatest distance from us : in other words, the moon, in once going round the earth, produced two tides, always at the same time; one on the part of the globe directly under her; and the other, on the part of the globe directly opposite.

Mankind continued for several ages content with knowing the general cause of these wonders, hopeless of discovering the particular manner of the moon's operation. Kepler was the first who conjectured that attraction was the principal cause; asserting, that the sphere of the moon's operation extended to the earth, and drew up its waters. The precise manner in which this is done, was discovered by Newton.

The moon has been found, like all the rest of the planets, to attract, and to be attracted by the earth. This attraction prevails throughout our whole planetary system. The more matter there is contained in any body, the more it attracts: and its influence decreases in proportion as the distance, when squared, increases. This being premised, lot us see what must ensue upon supposing tle moon in the meridian of any tract of the sea. The surface of the water immediately under the moon is nearer the moon than any other part of the globe is ; and, therefore, must be more subjeet to its attraction than the waters any where else. The waters will, therefore, be attracted by the moon, and rise in a heap; whose eminence will be the highest where the attraction is greatest. In order to form this eminence, it is obvious that the surface, as well as the depths, will be agitated; and that wherever the water runs from one part, succeeding waters must run to fill up the space it has left. Thus the waters of the sea, running from all parts, to attend the motion of the moon, produce the flowing of the tide; and it is high tide at that part wherever the moon comes over it, or to its meridian.

But when the moon travels onward, and ceases to point over the place where the waters were just risen, the cause here of their rising ceasing to operate, they will flow back by their natural gravity, into the lower parts from whence they had travelled; and this retiring of the waters will form the ebbing of the sea.

Thus the first part of the demonstration is obvious; since, in general, it requires no great sagacity to conceive that the waters nearest the moon are most attracted, or raised highest by the moon. But the other part of the demonstration, namely, how there come to be high tides at the same time, on the opposite side of the globe, and where the waters are farthest from the moon, is not so easy to conceive. To comprehend this, it must be observed, that the part of the earth and its waters that are farthest from the moon are the parts of all others that are least attracted by the moon: it must also be observed, that all the waters, when the moon is on the opposite side of the earth, must be attracted by it in the same direction that the earth itself attracts them; that is, if I may so say, quite throngh the body of the earth, towards the moon itself. This, therefore, being conceived, it is plain that those waters which are farthest from the moon, will have less weight than those of any other part, on the same side of the globe; because the moon's attraction, which conspires with the carth's attraction, is there least. Now; there- 
fore, the waters farthest from the moon, having less weight, and being lightest, will be pressed on all sides, by those that, having more attraction, are heavier; they will be pressed, I say, on all sides; and the heavier waters flowing in, will make them swell and rise in an eminence directly opposite to that on the other side of the globe, caused by the more immediate influence of the moon.

In this manner the moon, in one diurnal revolution, produces two tides; one raised im-mediately under the sphere of its influence, and the other directly opposite to it. As the moon travels, this vast body of waters rears upward, as if to watch its motions; and pursues the same constant rotation. However, in this great work of raising the tides, the sun has no small share; it produces its own tides constantly every day, just as the moon does, but in much less degree, because the sun is at an immensely greater distance. Thus there are solar tides, and lunar tides. Whien the forces of these two great luminaries concur, which they always do when they are either in the same, or in opposite parts of the heavens, they jointly proiluce a much greater tide, than when they are so situated in the hearens, as each to make peculiar tides of their own. To express the very same thing technically; in the conjunctions and oppositions of the sun and moon, the attraction of the sun conspires with the attraction of the moon; by which means the high spring tides are formed. But in the quadratures of the sun and moon, the water raised by the one is depressed by the other; and hence the lower neap-tides have their production. In a word, the tides are greatest in the syzigies, and least in the quadratures.

This theory well understood, and the astronomical terms previously known, it may readily be brought to explain the various appearances of the tides, if the earth were covered with a deep sea, and the waters uninfluenced by shoals, currents, straits, or tempests. But in every part of the sea, near the shores, the geographer must come in to correct the calculations of the astronomer. For, by reason of the shallowness of some places, and the narrowness of the straits in others, there arises a great diversity in the effect, not to be accounted for without an exact knowledge of all the circumstances of the place. In the great depths of the ocean, for instance, a very slow and imperceptible motion of the whole body of water will suflice. to raise its surface several feet ligh; but if the sane increase of water is to be conveyed through a narrow chamel, it must rush through it with the most impetuous rapidity. 'l'hus, in the English Channel, and the German Ocean, the tide is found to flow strongest in those places that are narrowest; the same quantity of water being, in this case. driven through a smaller passage. It is often seen, therefore, pouring through a strait with great force; and, by its rapidity, considerably raised above the surface of that part of the ocean into which it runs.

This shallowness and narrowness in many parts of the sea, give also rise to a peculiarity in the tides of some parts of the world. For in many places, and in our own seas in particular, the greatest swell of the tide is not while the moon is in its meridian height, and directly over the place, but some time after it has declined from thence. The sea, in this case, being obstructed, pursues the moon with what despatch it can, but does not arrive with all its waters till long after the moon has ceased to operate. Lastly, from this shallowness of the sea, and from its being obstructed by shoals and straits, we may account for the Mediterranean, the Baltic, and the Black Sea, having no sensible tides. These, though to us they seem very extensive, are not however large enough to be affected by the influence of the moon; and as to their communication with the ocean, through such narrow inlets, it is impossible in a few hours they should receive and re. turn water enough to raise or depress them in any considerable degree.

In general we may observe, that all tides are much higher, and more considerable in the torrid zone, than in the rest of the ocean; the sea in those parts being generally deep$\mathrm{er}$, and less affected by changeable winds, or winding shores." The greatest tide we know of, is that at the mouth of the river Indus, where the water rises thirty feet in height.

a Bufion, vol. ii. p. 187. 
How great, therefore, must have been the amazement of Alexander's soldiers at so strange an appearance! They who always before had been accustomed only to the scarcely perceptible risings of the Mediterranean, or the minute intunescence of the Black Sea, when made at once spectators of a river rising and falling thirty feet in a few hours, must no doubt have felt the most extreme awe, and, as we are told, a mixture of curiosity and apprehension. The tides are also remarkably high on the coast of Malay, in the straits of Sunda, in the Red Sea, at the mouth of the river St. Lawrence, along the coasts of China and Japan, at Panama, and in the gulf of Bengal. The tides of Tonquin, however, are the most remarkable in the world. In this part there is but one tide, and one ebb, in twenty-four hours; whereas, as we have said before, in other places there are two. Besides, there, twice in each month there is no tide at all, when the moon is near the equinoctial, the water being for some time quite stagnant. These, with some other odd appearances attending the same phænomena, were considered by many as inscrutable; but Sir Isaac Newton, with peculiar sagacity, adjudged them to arise from the concurrence of two tides, one from the South Sea, and the other from the Indian Ocean. Of each of these tides there come successively two every day; two at one time greater, and two at another that are less. The time between the arrival of the two greater, is considered by him as high tide; the time between the two lesser, as ebb. In short, with this clue, that grcat mathematician solved every appearance, and so established his theory, as to silence every opposer.

This lluctuation of the sea from the tides, produces another, and more constant rotation of its waters, from the east to the west, in this respect following the course of the moon. This may be considered as one great and general current of the waters of the sea; and although it be not every where distinguishable, it is nevertheless every where cxistent, except when opposed by some particular current or eddy, produced by partial and local causes. This tendency of the sea

- Quintus Curtius. towards the west is plainly perceivable in all the great straits of the ocean; as, for in stance, in those of Magellan, where the tide. running in from the east, rises twenty feei high, and continues flowing six hours: whereas the ebb continues but two hours, and the current is directed to the west This proves that the flux is not equal to the reflux; and that from both results a motion of the sea westward, which is more powerful during the time of the flux than the reflux.

But this motion westward has been sensibly observed by navigators, in their passage back from India to Madagascar, and so on to Africa. In the great Pacific Ocean also it is very perceivable: but the places where it is most obvious, are, as was said, in those straits which join one ocean to another. In the straits between the Maldivia islands, in the gulf of Mexico, between Cuba and Jucatan. In the straits of the gulf of Paria, the motion is so violent, that it hath received the appellation of the Dragon's Mouth. Northward in the sea of Canada, in Waigat's straits, in the straits of Java, and, in short, in every strait where the ocean on one part pours into the ocean on the other. In this manner, therefore, is the sca carried with an unceasing circulation round the globe; and, at the same time that its waters are pushed back and forward with the tide, they have thus a progressive current to the west, which though less observal le, is not the less real.

Besides these two general motions of the sea, there are others which are particular to many parts of it, and are called currents. These are found to run in all directions, east, west, north, and south; being formed, as was said above, by various causes; the prominence of the shores, the narrowness of the straits, the variations of the wind, and the inequalities at the bottom. These, though no great object to the philosopher, as their causes are generally local and obvious, are nevertheless of the most material consequence to the mariner; and, without a knowledge of which, he could never succeed. It often has happened, that when a ship has unknowingly got into one of these, cvery thing seems to go forward with success, the mariners suppose themselves every hour approaching their wished-for port, the wind fills 
their sails, and the ship's prow seems to divide the water; but, at last, by miserable experience they find, that instead of going forward, they have been all the time receding. The business of currents, therefore, makes a considerable article in navigation; and the direction of their stream, and their rapidity has been carefully set down. This some do by the observation of the surface of the current; or by the driving of the froth along the shore; or by throwing out what is called the log-line, with a buoy made for that purpose; and by the direction and motion of this, they judge of the setting, and the rapidity of the current.

These currents are generally found to be most violent under the equator, where indeed all the motions of the occan are most perceivable. Along the coasts of Guinea, if a ship happens to overshoot the mouth of any river it is bound to, the current prevents its return; so that it is obliged to steer out to sea, and take a very large compass, in order to correct the former mistake. These set in a contrary direction to the general motion of the sea westward; and that so strongly, that a passage which with the current is made in two days, is with difficulty performed in six weeks against it. However, they do not extend above twenty leagues from the coast: and ships going to the East Indies, take care not to come within the sphere of their action. At Sumatra, the currents, which are extremely rapid, run from south to north; there are also strong currents between Madagascar and the Cape of Good Hope. On the western coasts of America, the current always runs from the south to the north, where a south wind, continually blowing, most probably occasions this phrnomenon. But the currents that are most remarkable, and those continually flowing, into the Mediterranean sea, both from the ocean by the straits of Gibralter, and at its other extremity, from the Euxine sea by the Archipelago. This is one of the most extraordinary appearances in nature, this large sea receiving not only the numerous rivers that fall into it, such as the Nile, the Rhone, and the Po, but also a very great influx from the Euxine sea on one part, and the Ocean on the other. At the same time, it is seen to return none of those waters it is thus known to receive: ontlets running from it there are none; no river's but such as bring it fresh supplies; no straits but what are constantly pouring their waters into it. It has therefore been the wonder of mankind in every age, how and by what means this vast concour'se of waters are disposed of; or how this sea, which is always receiving, and never returning, is no way fuller than before. In order to account for this, some have said, that the water was re-conveyed by subterraneous passages into the Red Sea. ${ }^{2}$ There is a story told of an Arabian caliph, who caught a dolphin in this sea, admiring the beauty of which, he let it go again, having previously marked it by a ring of iron. Some time after a dolphin was caught in the Red Sea, and quickly known by the ring to be the same that had been taken in the Mediterranean before. Such, however, as have not been willing to found their opinions upon a story, have attempted to account for the disposal of the waters of the Mediterranean by evaporation. For this purpose they have entered into long calculations upon the extent of its surface, and the quantity of water that would be raised from such a surface in a year. They then compute how much water runs in by its rivers and straits in that time; and find, that the quantity exhausted by evaporation greatly exceeds the quantity supplied by rivers and seas. This solution, no doubt, would be satisfactory, did not the Ocean, and the Euxine, evaporate as well as the Mediterranean: and as these are subject to the same drain, it must follow, that all the seas will in this respect be upon a par; and, therefore, there must be some other cause for this unperceived drain, and continual supply. This seems to be satisfactorily enough accounted for by Dr. Smith, who supposes an under current running through the straits of Gibraltar to carry out as much water into the Ocean, as the upper current continually carries in from it. To confirm this, he observes, that nearer home, between the north and south .oreland, the tide is known to run one way at top, and the ebb another way at bottom. This double current he also confirms by an expen-

\footnotetext{
aircher Mund. Subt. vol. 1.
} 
ment communicated to him by an able seaman, who being with one of the king's frigates in the Baltic, found he went with his boat into the mid-streain, and was carried violently by the current; upon which a basket was sunk, with a large cannon ball, to a certain depth of water, which gave a check to the boat's motion; as the basket sunk still lower, the boat was driven by the force of the water below against the upper current; and the lower the basket was let down, the stronger the under current was found, and the quicker was the boat's motion against the upper stream, which seemed not to be above four fathom deep. Hence we may readily infer, that the same cause inay operate at the straits of Gibraltar; and that while the Mediterranean seems replenishing at top, it may be emptying at bottom.

The number of the currents at sea are inpossible to be recounted, nor, indeed, are they always known; new ones are daily produced by a variety of causes, and as quickly disappear. When a regular current is opposed by another in a narrow strait, or where the bottom of the sea is very uneven, a whirlpool is often formed. These were formerly considered as the most formidable obstructions to navigation, and the ancient poets and historians speak of them with terror; they are described as swallowing up ships, and dashing them against the rocks at the bottom: apprehension did no sail to add imaginary terrors to the description, and placed at the centre of the whirlpool a dreadful den, fraught with monsters, whose howlings served to add new horrors to the dashings of the deep. Mankind at present, however, view these eddies of the sea with very little apprehension; and some have wondered how the ancients could have so much overcharged their descriptions. But all this is very naturally accounted for. In those times when navigation was in its infancy, and the slightest concussion of the waves generally sent the poor adventurer to the bottom, it is not to be wondered at that he was terrified at the violent agitations in one of these. When his little ship, but-ill fitted for opposing the fury of the sen, was got within the vortex, there was then no possibility of ever returning. To add to the fatality, they were alvays near the shore; and along the shore was the only place where this ill-provided mariner durst venture to sail. These were therefore dreadful impediments to his navigation; for if he attempted to pass between them and the shore, he was sometimes sucked in by the eddy; and if he attempted to avoid them out at sca, he was often sunk by the storm. But in our time, and in our present improved state of navigation, Charybdis, and the Euripus, with all the other irregular currents of the Mediterranean, are no longer formidable. Mr. Addison, not attending to this train of thinking, upon passing through the straits of Sicily, was surprised at the litthe there was of terror in the present appearance of Scylla and Charybdis; and seems to be of opinion, that their agitations are much diminished since the times of antiquity. In fact, from the reasons above, all the wonders of the Mediterranean Sea are deseribed in much higher colours than they merit, to us who are acquainted with the more magnificent terrors of the Ocean. The Mediterranean is one of the smoothest and most gentle seas in the world; its tides are scarcely perceivable, except in the gulf of Venice, and shipwrecks are less known there than in any other part of the world.

It is in the Ocean, therefore, that these. whirlpools are particularly dangerous, where the tides are violent, and the tempests fierce. To mention only one, that called the Maelstroom, upon the coasts of Norway, which is considered as the most dreadful and voracious in the world. . The name it has received from the natives, signifies the navel of the sea, since they suppose that a great share of the water of the sea is sucked up and discharged by its vortex. A minute description of the internal parts is not to be expected, since none who were there ever returned to bring back information. The body of the waters that form this whirlpool, are extended in a circle above thirteen miles in circumference. In the midst of this stands a rock, against which the tide in its ebb is clashed with inconceivable fury. At this time it instantly-swallows up all things that come within the sphere of its violence, trees, timber,

aircher Mund. Subt. vol. i. p. 156 . 
and shipping. No skill in the mariner, nor strength of rowing, can work an escape : the sailor at the helm finds the ship at first go in a current opposite to his intentions ; his vesscl's motion, though slow in the beginning, becomes every moment more rapid; it goes round in eireles still narrower and narrower, till at last it is dashed against the rocks, and instantly disappears; nor is it secn again for six hours: till the tide flowing, it is vomited forth with the same violence with which it was drawn in. The noise of this dreadful vortex still farther contributes to increase its terror, which, with the dashing of the waters, and the dreadful valley, if it may be so called, caused by their circulation, makes one of the most tremendous objects in nature.

\section{CHAPTER XVI.}

\section{OF THE CHANGES PRODUCED BY THE SEA UPON THE EARTH.}

FROM what has been said, as well of the earth as of the sea, they both appear to be in continual fluctuation. The earth, the common promptuary that supplies subsistenee to men, animals, and vegetables, is continually furnishing its stores to their support.

But the matter which is thus derived from it, is soon restored and laid down again to be prepared for fresh mutations. The transmigration of souls is no doubt false and whimsical; but nothing can be more certain than the transmigration of bodies: the spoils of the meanest reptile may go to the formation of a prince; - and, on the contrary, as the poet has it, the body of Cæesar may be employed in stopping a beer-barrel. From this, and other causes, therefore, the earth is in continual change. Its interual fires, the deviation of its rivers, and the falling of its mountains, are daily altering its surface; and geography can scarcely recolleet the lakes and the valleys that history once described.

But these changes are nothing to the instability of the ocean. It would seem that inquietude was as natural to it as its fluidity. It is first scen with a constant and equable motion going towards the west; the tides then interrupt this progression, and for a time drive the waters in a contrary direction; beside thesc agitations, the currents act their part in a smaller sphere, being generally greatest where the other motions of the sea are least; namely, nearest the shore: the winds also contribute their share in this uni- versal fluctuation : so that searcely any part of the sea is wholly seen to stagnate.

Nil enim quiescit, undis impellitur unda, Et spiritus et calor toto se corpore miscent.

As this great element is thus changed, and continually labouring internally, it may be readily supposed that it produces correspondent changes upon its shores, and those parts of the earth subject to its influence. In fact, it is every day making considerable alterations, either by overflowing its shores in one place, or deserting them in others : by covering over whole tracts of country, that were cultivated and peopled, at one time; or by leaving its bed to be appropriated to the purposes of vegetation, and to supply a new theatre for human industry at another.

In this struggle between the earth and the sea for dominion, the greatest number of our shores seem to defy the whole rage of the waves, both by their height, and the rocky materials of which they are composed. The coasts of Italy, for instance, are bordered with rocks of marble of different kinds, the quarries of which may easily be distinguished at a distance from sea, and appear like perpendicular columns of the most beautiful kinds of marble, ranged along the shore. In general, the coasts of France, from Brest to Bordeaux, are composed of rocks; as are also those of Spain and England, which de-

\footnotetext{
2. Buffon, vol. ii.p. 199.
} 
fend the land, and only are interrupted here and there to give an egress to rivers, and to grait the conveniences of bays and harbours to our shipping. It may be in general remarked, that wherever the sea is most violent and furious, there the boldest shores, and of the most compact materials, are found to oppose it. There are many shores several hundred feet perpendicular, against which the sea, when swollen with tides, or storms, rises and beats with inconceivable fury. In the Orkneys, where the shores are thus formed, it sometimes, when agitated by a storm, rises two hundred feet perpendicular, and dashes up its spray, together with sand, and other substances that compose its bottom, upon land, like showers of rain.

Hence, therefore, we may conceive how the violence of the sea, and the boldness of the shore, may be said to have made each other. Where the sea meets no obstacles, it spreads its waters with a gentle intumescence, till all its power is destroyed, by wanting depth to aid the motion. But when its progress is checked in the midst, by the prominence of rocks, or the abrupt elevation of the land, it dashes with all the force of its depth against the obstacle, and forms, by its repented violence, that abruptness of the shore which confines its impetuosity. Where the sea is extremely deep, or very much vexed by tempests, it is no small obstacle that can confine its rage; and for this reason we see the boldest shores projected against the deepest waters; all less impediments having long before been surmounted and washed away. Perhaps of all the shores in the world, there is not one so ligh as that on the west of St. Kilda, which, upon a late admeasurement, ${ }^{b}$ was found to be six hundred fathom perpendicular above the surface of the sea. Here, also, the sea is deep, turbulent, and stormy; so that it requires great force in the shore to oppose its violence. In many parts of the world, and particularly upon the coasts of the East Indies, the shores, though not high above water, are generally very deep, and consequently the wares roll against the land with great weight and irregularity. This rising of the waves against the shore, is

* Buffon, vol. ii. p. 191. Description of St. Kilda. called by mariners the surf of the sea; and in shipwrecks is generally fatal to such as attempt to swim on shore. In this case, no dexterity in the swimmer, no float he can use, neither swimıning girdle nor cork jacket will save him; the weight of the superincumbent waves breaks upon him at once, and crushes lim with certain ruin. Some few of the natives, however, have the art of swimming and of navigating their little boats near those shores, where an European is sure of instant destruction.

In places where the force of the sea is less violent, or its tides less rapid, the shores are generally seen to descend with a more gradual declivity. Over these, the waters of the tide steal by almost imperceptible degrees, covering them for a large extent, and leaving them bare on its recess. Upon these shores, as was said, the sea seldom beats with any great violence, as a large wave has not depth sufficient to float it onwards; so that here only are to be seen gentle surges making calmly towards land, and lessening as they approach. As the sea, in the former description, is generally seen to present prospects of tumult and uproar, here it more usually exhibits a scene of repose and tranquil beauty. Its waters, which when surveyed from the precipice, afforded a muddy greenish hue, arising from their depth and position to the eye, ${ }^{c}$ when regarded from a shelving shore, wear the colour of the sky, and seem rising to meet it. The deafening noise of the deep sea is here converted into gentle murmurs; instead of the water's dashing against the face of the rock, it advances and recedes, still going forward, but with just force enough to push its weeds and shells, by insensible approaches, to the shore.

There are other shores, beside those already described, which either have been raised by art to oppose the sea's approaches, or, from the sea's gaining ground, are threatened with imminent destruction. The sea's being thus seen to give and take away lands at pleasure, is, without question, one of the most extraordinary considerations in all natural history. In some places it is seen to obtain the superiority by slow and certain

' Newton's Optics, p. 163-167. 
approaches; or to burst in at once, and overwhelm all things in undistinguished destruction; in other places it departs from its shores, and where its waters have been known to rage, it leaves fields covered with the most beautiful verdure.

'The formation of new lands, by the sea's continually bringing its sediment to one place, and by the accumulation of its sands in another, is easily conceived. We have had many instances of this in England. The island of Oxney, which is adjacent to Romney marsh, was produced in this manner. This had for a long time been a low level, continually in danger of being overflown by the river Rother; but the sea, by its depositions, has gradually raised the bottom of the river, while it has hollowed the mouth; so that the one is sufficiently secured from inundations, and the other is deep enough to admit ships of considerable burthen. 'The like also may be seen at that bank called the Dogger-sands; where two tides meet, and which thus receives new increase every day, so that in time the place seems to promise fair for being habitable earth. On many parts of the coasts of France, England, Holland, Germany, and Prussia, the sea has been sensibly known to retire. ${ }^{2}$ Hubert Thomas asserts, in his Description of the country of Liege, that the sea formerly encompassed the city of Tongres, which, however, is at present thirty-five leagues distant from it : this assertion he supports by many strong reasons; and among others, by the iron rings fixed in the walls of the town, for fastening the ships that came into the port. In Italy there is a considerable piece of ground gained at the mouth of the river Arno; and Ravenna, that once stood by the sea side, is now eonsiderably removed from it. But we need scarcely mention these, when we find that the whole republic of Holland seems to be a conquest upon the sea, and in a manner rescued from its bosom. The surface of the earth, in this country, is below the level of the bed of the sea: and I remember, upon approaching the coast, to have looked down upon it from the sea, as into a valley; however, it is every day rising higher by the depositions made

\footnotetext{
Bufton, vol. vi. p. 424.
}

upon it by the sea, the Rhine, and the Meuse ; and those parts which fornerly admitted large men of war, are now known to be too shallow to receive ships of very moderate. burthen.b The province of Jucatan, a peninsula in the gulf of Mexico, was formerly a part of the sea; this tract, which stretches out into the ocean, a hundred leagues, and which is above thirty broad, is every where, at a moderate depth below the surface, composed of shells, which evince that its land once formed the bed of the sea. In France, the town of Aigues Mortes was a port in the times of St. Louis, which is now removed more than four miles from the sea. Psalmodi, in the same kingdom, was an island in the year 815 , but is now more than six miles from the shore. All along the coasts of Norfolk, I am very well assured, that in the memory of man, the sea has gained fifty yards in some places, and has lost as much in others.

Thus numerous, therefore, are the inslances of new lands having been produced from the sea, which, as we see, is brought about two different ways : first, by the waters raising banks of sand and mud where their sediment is deposited : and secondly, by their relinquishing the shore entirely, and leaving it unoccupied to the industry of man.

But as the sea has been thus known to re. cede from some lands, so has it, by fatal experience, been found to encroach upon others; and, probably, these depredations on one part of the shore, may account for their dereliction from another; for the current which rested upon some certain bank, having got an egress in some other place, it no longer presses upon its former bed, but pours all its stream into the new entrance, so that every inundation of the sea may be attended with some correspondent dereliction of another shore.

However this be, we have numerous histories of the sea's inundations, and its burying whole provinces in its bosom. Many countries that have been thus destroyed bear. melancholy witness to the truth of history; and show the tops of their houses, and the spires of their steeples, still standing at the

\footnotetext{
b Buffon, vol. vi. p. 424
} 
bottom of the water. One of the most considerable inmudations we have in history, is that which happened in the reign of IIenry I. which overllowed the estates of the Earl Godwin, and forms now that bank called the Goodwin Sands: In the year 1546, a similar irruption of the sea destroyed a hundred thousand persons in the territory of Dort; and yet a greatel number round Dullart. In Friezland, and Zealand, there were inore than three hundred villages overwhelmed; 'and their remains continue still visible at the hottom of the water in a clear day. The Baltic Sea has, by slow degrees, covered a large part of Pomerania; and, among others, destroyed and overwhelmed the famous port of Vineta. In the same manner, the Norwegian Sea has formed several little islands from the main land, and still daily advances upon the continent. The German Sea has advanced upon the shores of Holland, near Catt; so that the ruins of an ancient citadel of the Romans, which was formerly built upon this coast, are now actually under water. To these accidents several more might be added; our own historians, and those of other countries; abound with them; almost every flat shore of any extent being able to show something that it has lost, or something that it has gained from the sea.

There are some shores on which the sea has made temporary depredations; where it has overflowed, and after remaining perhaps some ages, it has again retired of its own accord, or been driven back by the industry of man." There are many lands in Norway, Scotland, and the Maldivia islands, that are at one time covered with water, and at another free. The country round the Isle of Ely, in the times of Bede, about a thousand years ago, was one of the most delightful spots in the whole kingdom. It was not only richly cultivated, and produced all the necessaries of life, but grapes also that afforded excellent wine. Thie accounts of that time are copious in the description of its verdure and fertility; its rich pastures, covered with flowers and herbage; its beautiful shades, and wholesome air. But the sea breaking in upon the land, overwhelmed the whole coun-

- Buffan, vol. ii. p. 425. try, took possession of the soil, and totally destroyed one of the most fertile valleys in the world. Its air, from being dry and healthful, from that time became most unwholesome, and clogged with vapours; and the small part of the country that, by being higher than the rest, escaped the deluge, was soon rendered uninhabitable, from its noxious vapours. Thus this country continued under water for some centuries; till, at last, the sea, by the same caprice which had prompted its invasions, began to abandon the earth in like manner. It has continued for some ages to relinquish its former conquests; and although the inhabitants can neither boast the longevity, nor the luxuries of their former preoccupants, yet they find ample means of subsistence; and if they happen to survive the first years of their residence there, they are often known to arrive at a good old age.

But although history be silent as to many other inundations of the like kind, where the sea has overfowed the country, and afterwards retired, yet we have numberless testimonies of another nature, that prove it beyond the possibility of a doubt: I mean those numerous trees that are found buried at considerable depths in places where either rivers or the sea has accidentally overflown. ${ }^{b}$ At the inouth of the river Ness, near Bringes, in Flanders, at the depth of fifty feet, are found great quantities of trees lying as close to each other as they do in a wood: the trunks, the branches, and the leaves, are in such perfect preservation, that the particular kind of each tree may instantly be known. About five hundred years ago, this very ground was known to have been covered by the sea; nor is there any history or tradition of its having been dry ground, which we can have no doubt must have been the case. Thus we see a country flourishing in verdure, producing large forests, and trees of various kinds, overwhelmed by the sea. We see this element depositing ity sediment to a height of fifty feet; and its waters must, therefore, have risen much higher. We see the same, after it has thus overwhelmed and sunk the land so deep beneath its slime, capriciously

b Buffon, vol. ii. p. 403. 
retiring from the same coasts, and leaving that habitable once inore, which it had formerly destroyed. All this is wonderful; and, perhaps, instead of attempting to inquire after the cause, which has hitherto been inserutable, it will best become us to rest satisfied with admiration.

At the city of Modena in Italy, and about four miles round it, wherever it is dug, when the worknien arrive at the depth of sixty-three feet, they come to a bed of chalk, which they bore with an augre five foet deep: they then withdraw from the pit, before the augre is removed, and upon its cxtraction, the water bursts up through the aperture with great violence, and quickly fills this new-made well, which continues full, and is affected neither by rains nor droughts. But that which is most remarkable in this operation, is the layers of earth as we descend. At the depth of fourteen feet, are found the ruins of an ancient city, paved streets, houses, floors, and different pieces of Mosaic. Under this is found a solid earth, that would indnce one to think had never been removed; however, under it is found a solt oozy earth, made up of vegetables; and at twenty-six feet depth, large trees entire, such as walnut-trees, with the walnuts still sticking on the stem, and their leaves and branches in exact preservation. At twenty-cight feet deep, a soft chalk is found, mixed with a vast quantity of shells; and this bed is eleven feet thick. Under this, vegetables are found again, with leaves and branches of trees as beforc; and thus alternately chalk and vegetable earth to the depth of sixty-three feet. These are the layers wherever the workmen attempt to bore; while in many of them, they also find pieces of charcoal, bones, and bits of iron. From this description, therefore, it appears, that this country has been alternately overflowed and deserted by the sea, one age after another: nor were these overflowings and retirings of trifling depth, or of short continuance. When the sea burst in, it must have been a long time in overwhelming the branches of the fallen forest with its sediments; and still longer in forming a regular bed of shells eleven feet over them. It must have, therefore, taken an age, at least, to make any one of these layers; and we may conclude, that it must have been many ages employed in the production of them all. The land, also, upon being deserted, must have had time to grow compact, to gather fresh fertility, and to be drained of its waters before it could be disposed to vegetation; or before its trees could have shot forth again to maturity.

We have instances nearer home of the same kind, given us in the Philosophical Transactions; one of them by Mr. Derham. An inundation of the sea at Dagenham, in Essex, laying bare a part of the adjacent pasture, for above two hundred feet wide, and, in some places, twenty deep, it discovered a number of trees that had lain there for many ages before; these trees, by laying long under ground, were become black and hard, and their fibres so tough, that one might as easily break a wire, as any of thein: they lay so thick in the place where they were found, that in many parts he could step from one to another: he conceived, also, that not only all the adjacent marshes, for several hundred acres, were covered underneath with such timber, but also the marshes along the mouth of the Thames, for several miles. The meeting with these trees, at such depths, he ascribes to the sediment of the river, and the tides, which constantly washing over them, have always left some part of their substance behind, so as, by repeated alluvions, to work a bed of vegetable earth over them, to the beight at which he found it.

The levels of Hatfield-Chace, in Yorkshire, a tract of above eighteen thousand acres, which was yearly overflown, was renuced to arable and pasture land, by one Sir Cornelins Vermusden, a Dutchman. At the bottom of this wide extent, are found millions of the roots and bodies of trees, of such as this island either formerly did, or does at present produce. The roots of all stand in their proper postures; and by them, as thick as ever they could grow, the respective trunks of each, some above thirty yards long. The oaks, some of which have been sold for fifteen pounds apiece, are as black as ebony, very lasting, and close grained. The ash-trees are as soft as earth, and are commonly cut in pieces by the workmen's spades, and as soon as flung up into the open air, turn to dust. But all the rest, even the willows 
themselves, which are softer than the ash, preserve their substance and texture to this very day. Some of the firs appear to have vegetated, even after they were fallen, and to have, from their branches, struck up large trees, as great as the parent trunk. It is observable, that many of these trees have been burnt, some quite through, some on one side, some have been found chopped and squared, others riven with great wooden wedges, all sufficiently manifesting, that the country which was deluged, had formerly been inhabited. Near a great root of one tree were found eight coins of the Roman emperors; and in some places, the marks of the ridge and furrow were plainly perceivable, which testified that the ground had formerly been patient of cultivation.

The learned naturalist who has given this description," has pretty plainly evinced, that this forest, in particular, must have been thus levelled by the Romans; and that the falling of the trees must have contributed to the accumulation of the waters. "The Romans," says he, "when the Britons fled, always pursued them into the fortresses of low woods, and miry forests: in these the wild natives found shelter; and, when opportunity offered, issued out, and fell upon thcir invaders without mercy. In this manner, the Romans were at length so harassed, that orders were issued out for cutting down all the woods and forests in Britain. In order to effect this, and destroy the enemy the easier, they set fire to the woods composed of pines, and other inflammable timber, which spreading, the conflagration destroyed not only the forest, but infinite numbers of the wretched inhabitants who had taken shelter therein. When the pine-trees had thus done what mischief they could, the Romans then brought their army nearer, and, with whole legions of the captive Britons, cut down most of the trees that were yet left standing; leaving only here and there some great trees untouched, as monuments of their fury. These, unneedful of their labour, being destitute of the-support of the underwood, and of their neighbouring trees, were easily overthrown by the winds, and, without interruption, remained on the places where they

- Phil. Trans. vol. jv. part ii. p. 214. happened to fall. The forest thus fallen, must necessarily have stopped up the currents, both from land and sea; and turned into great lakes, what were before but temporary streams. The working of the waters here, the consumption and decay of rotten boughs and branches, and the vast increase of watermoss which flourishes upon marshy grounds, soon formed a covering over the trunks of the fallen trees, and raised the earth several feet above its former level. The earth thus every day swelling, by a continual increase from the sediment of the waters, and by the lightness of the vegetable substances of which it was composed, soon overtopt the waters by which this intumescence was at first effected; so that it entirely got rid of its inundations, or only demanded a slight assistance from man for that purpose." This may be the origin of all bogs, which are formed by the putrefaction of vegetable substances, mixed with the mud and slime deposited by waters, and at length acquiring a sufficient consistency.

From this we see what powerful effects the sea is capable of producing upon its shores, either by overflowing some or deserting others; by altering the direction of these, and rendering those craggy and precipitate, which before were shelving. But the influence it has upon these is nothing to that which it has upon that great body of earth which forms its bottom. It is at the bottom of the sen that the greatest wonders are performed, and the most rapid changes are produced; it is there that the motion of the tides and the currents have their whole force, and agitate the substances of which their bed is composed. But all these are almost wholly hid from human curiosity: the miracles of the deep are performed in secret; and we have but little information from its abysses, except what we receive by inspection at very shallow depths, or by the plummet, or from divers, who are known to descend from twenty to thirty fathom."

The eye can reach but a very short way into the depths of the sea; and that only when its surface is glassy and serene. In many seas it perceives nothing but a bright

6 Pliil. Trans. vol. iv. part ii.p. $10^{\circ}$ 
sandy plain at bottom, extending for several hundred miles, without an intervening object. But in others, particularly in the Red Sea, it is very different: the whole bottom of this extensive bed of waters is, literally speaking, a forest of sub-marine plants, and corals formed by insects for their habitation, sometimes branching out to a great extent. Here are seen the madrepores, the sponges, mosses, seamushrooms, and other marine productions, covering every part of the bottom; so that some have even supposed the sea to have taken its name from the colour of its plants below. However, these plants are by no means peculiar to this sea, as they are found in grcat quantities in the Persian gulf, along the coast of Africa, and those of Provence and Catalonia.

The bottoin of unany parts of the sea near America presents a very different, though a very beautiful appearance. This is covered with regetables, which make it look as green as a meadow, and beneath are seen thousands of turtles, and other sea-animals, feeding thereon.

In order to extend our knowledge of the sea to greater deptlis, recourse has been had to the plumnet; which is generally made of a lump of lead of about forty pounds weight, fastened to a cord. ${ }^{2}$ This, however, only answers in moderate depths; for when a deep sea is to be sounded, the matter of which the cord is composed, being lighter than the water, floats upon it, and when let down to a considerable depth, its length so increases its surface, that it is often suflicient to prevent the lead from sinking; so that this may be the reason why some parts of the sea are said to have no bottom.

In general, we learn from the plummet, that the bottom of the sea is tolerably even where it has been examined; and that the farther from the shore, the sea is in general the deeper. Notwithstanding, in the midst of a great and unfathomable ocean, we often find an island raising its head, and singly braving its fury. Such islands may be considered as the mountains of the deep; and, could we for a moment imagine the waters of the ocean removed, or dried away, we

\footnotetext{
- Boyle, vol. ii.p 5.
}

should probably find the inequalities of its bed resembling those that are found at land. Here extensive plains; there valleys; and, in many places, mountains of amazing height. M. Buache has actually given us a map of that part of its bottom, which lies between Africa and America, taken from the several soundings of mariners : in it we find the same uncven surface that we do upon land, the same eminences, and the same depressions. In such an imaginary prospect, however, there would be this difference, that as the tops of landmountains appear the nost barren and rocky, the tops of sea-mountains would be found the most verdant and fruitful.

The plummet, which thus gives us some idea of the inequalities of the bottom, leares us totally in the dark as to every other particular; recourse, therefore, has been had to divers: these, either being bred up in this dangerous way of life, and accustomed to remain some time under water without breathing, or assist. ed by means of a diving-bell, have been able to return some confused and uncertain accounts of the places below. In the great divingbell improved by Dr. Halley, which was large enough to contain five men, and was supplied with fresh air by buckets, that alternately rose and fell, they descended fifty fathom. In this huge machine, which was let down. from the mast of the ship, the doctor limself went down to the bottom, where, when the sea was clear, and especially when the sun shone, he could see perfectly well to write or read, and much more to take up any thing that was underneath: at other times, when the water was troubled and thick, it was as dark as night below, so that he was obliged to keep a candle lighted at the bottom. But there is one thing very remarkable; that the water, which from above was usually seen of a green colour, when looked at from below; appeared to him of a very different one, casting a redness upon one of his hands, like that of damask roses ${ }^{b}$-a proof of the sea's taking its colour not from any thing floating in it, but from the different reflexions of the rays of light. Upon the whole, the accounts we have received from the bottom, by this contrivance, are but few. We learn from it, and from 
divers in general, that while the surface of the sea may be deformed by tempests, it is usually calm and temperate below; ; $^{\text {that some }}$ divers who have gone down when the weather was calm, and eame up when it was tempestuous, were surprised at their not perceiving the change at the bottom. This, however, must not be supposed to obtain with regard to the tides and the currents, as they are seen constantly shifting their bottom; taking their bed with great violence from one place, and depositing it upon another. We are informed, also, by divers, that the sea grows colder in proportion as they descend to the bottom; that as far as the sun's rays pierce, it is influenced by their warmth; but lower, the cold becomes almost intolerable. A person of quality, who had been himself a diver, as Mr. Boyle informs us, declared, that though he seldom descended above three or four fathoms, yet he found it so much colder than near the top, that he could not well endure it; and that being let down in a great diving-bell, although the water could not immediately touch him, he found the air extremely cold upon his first arrival at the bottoin.

From divers also we learn, that the sea, in many places, is filled with rocks at bottom; and that, among their clefts, and upon their sides, various substances sprout forward, which are either really vegetable, or the nests of insects, increased to some magnitude. Some of these assume the shape of beautiful flowers; and though soft, when taken up, soon harden, and are kept in the cabinets of the curious.

But of all those divers who have brought us information fiom the bottom of the deep, the famous Nicola Pesce, whose performances are told us by Kircher, is the most celebrated. I will not so much as pretend to vouch for the veracity of Kircher's account, which he assures us he had from the archives of the kings of Sicily; but it may serve to enliven a heavy chapter. "In the times of Frederic, king of Sicily, there lived a celebrated diver, whose name was Nicolas, and who, from his amazing skill in swimming, and his perseverance under water, was surnamed the Fish. This man had, from his infancy, been used to

Boyle, vol. iii. p. 242. the sea; and earned his scanty subsistence by diving for corals and oysters; which he sold to the villagers on shore. His long acquaintance with the sea, at last, brought it to be almost his natural element. He frequently was known to spend five days in the milst of the waves, without any other provisions than the fish which he caught there, and ate raw. He often swan over from Sicily to Calabria, a tempestuous and dangerous passage, carrying letters from the king. He was frequently known to swin among the gulfs of the Lipari islands, no way apprehensive of danger.

"Some mariners out at sea, one day observed something at some distance from them, which they regarded as a sea-monster; but, upon its approach, it was known to be Nicolas, whom they took into their slip. When they asked him whither he was going in so stormy and rough a sea, and at such a distance from land, he showed them a packet of letters, which he was carrying to one of the towns of Italy, exactly done up in a leather bag, in such a manner as that they could not be wetted by the sea. He kept them thus company for some time on their voyage, conversing and asking questions; and after eating a hearty meal with them, he took his leave, and jumping into the sea, pursued his voyage alone.

"In order to aid these powers of enduring in the deep, nature seemed to have assisted him in a very extraordinary manner; for the spaces between his fingers and toes were webbed, as in a goose; and his chest became so very capacious, that he could take in, at one inspiration, as much breath as would serve him for a whole day.

"The account of so extraordinary a person did not fail to reach the king himself; who, aetuated by the general curiosity, ordered that Nicolas should be brought before him. It was no easy matter to find $\mathrm{Ni}$ colas, who generally spent his time in the solitudes of the deep; but at last, however, after much searching, he was found, and brought before his majesty. The curiosity of this monarch had been-long excited by the accounts he had heard of the bottom of the gulf of Clarybdis; he therefore conceived that it would be a proper opportunity 
to have more certain information; and commanded our poor diver to examine the bottom of this dreadful whirlpool: as an incitement to his obedience, he ordered a golden cup to be flung into it. Nicolas was not insensible of the danger to which he was exposed; dangers best known only to himself; and he therefore presumed to remonstrate: but the hopes of the reward, the desire of pleasing the king, and the pleasure of showing his skill, at last prevailed. He instantly jumped into the gulf, and was swallowed as instantly up in its bosom. He continued for three quarters of an hour below ; during which time the king and his attendants remained upon shore anxious for his fate; but he at last appeared, buffeting upon the surface, holding the cup in triumph in one hand, and making his way good among the waves with the other. It may be supposed he was received with applause, upon his arrival on shore; the cup was made the reward of his adventure; the king ordered him to be taken proper care of; and, as he was somewhat fatigued and debilitated by his labour, after a hearty meal he was put to bed, and permitted to refresh himself by sleeping.

"When his spirits were thus restored, he was again bronght to satisfy the king's curiosity with a narrative of the wonders he had seen; and his account was to the following effect :-He would never, he said, have obey- ed the king's commands, had he been apprized of half the dangers that were before him. There were four things, he said, that rendered the gulf dreadful, not only to men, but even to the fishes themselves: first, the force of the water bursting up from the bottom, which requires great strength to resist; secondly, the abruptness of the rocks, that on everyside threatened destruction; thirdly, the force of the whirlpool, dashing against those rocks; and fourthly, the number and magnitude of the polypous fish, some of which appeared as large as a man, and which, every where sticking against the rocks, projected their fibrous arms to entangle lim. Being asked how he was able so readily to find the cup that had been thrown in, he replied, that it happened to be llung by the waves into the cavity of a rock, against which he himself was urged in his descent. This account, however, did not satisfy the king's curiosity: being requested to venture once more into the gulf for further discoveries, he at first refused; but the king, desirous of having the most exact information possible of all things to be found in the gulf, repeated his solicitations; and, to give them still greater weight, produced a larger cup than the former, and added also a purse of gold. Upon these considerations, the unfortunate Pessacola once again plunged into the whirlpool, and was never heard of more."

\section{CHAPTER XVII.}

\section{A SUMMARY ACCOUNT OF THE MECHANICAL PROPERTIES OF AIR.}

HAVING described the earth and the sea, we now ascend into that fluid which surrounds them both; and which, in some measure, supports and supplies all animated nature. As, upon viewing the bottom of the ocean from its surface, we see an infinity of animals moving therein, and seeking food; so, were some superior being to regard the earth at a proper distance, he might consider us in the same light : he might, from his superior station, behold a number of busy little beings, immersed in the ærial fluid, that every where surrounds them, and sedulously employed in procuring the means of subsistence. This fluid, though too fine for the gross perception of its inhabitants, might, to his nicer organs of sight, be very visible; and, while he at once saw into its operations, he might smile at the varieties of human conjecture concerning it : he might readily discern, perhaps, the height above the surface of the earth to which this fluid atmosphere reaches: he might exactly 
determine the peculiar form of its parts which gives it the spring or elasticity with which it is endued: be might distinguish which of its parts were pure incorruptible air, and which only made for a little time to assume the appearance, so as to be quickly returned back to the element from whence it came. But as for us, who are immersed at the bottom of this gulf, we must be contented with a more confined knowledge; and, wanting a proper point of prospect, remain satisfied with a combinalion of the effects.

One of the first things that our senses inform us of is, that although the air is too fine for our sight, it is very obvious to our touch. Although we cannot see the wind contained in a bladder, we can very readily fecl its resistance; and though the hurricane may want colour, we often fatally experience that it does not want force. We liave equal experience of the air's spring or elasticity: the bladder, when pressed, returns again, upon the pressure being taken away; a bottle, when filled, often bursts, from the spring of air which is included.

So far the slightest experience reaches; but, by carrying experiment a little farther, we learn that air also is heavy : a round glass vessel being emptied of its air, and accurately weighed, has been found lighter than when it was weighed with the air in it. Upon computing the superior weight of the full vessel, a cubic foot of air is found to weigh something more than an ounce.

From this experiment, therefore, we learn, that the earth, and all things upon its surface, are every where covered with a pondcrous fluid, which rising very high over our heads, must be proportionably heavy. For instance, as in the sea, a man at the depth of twenty feet sustains a greater weight of water, than a man at the depth of but ten feet; so will a man at the bottom of a valley have a greater weight of air over him, than a man on the top of a mountain.

From hence we may conclude, that we sustain a very great weight of air; and although, like men walking at the bottom of the sea, we cannot feel the weight which presses equally round us, yet the pressure is not the less real. As in morals, we seldom know the blessings that surround us till we are deprived of them; so here we do not perceive the weight of the ambient fluid till a a part of it is taken away. If, by any means, we contrive to take away the pressure of the air from any one part of our bodies, we are soon made sensible of the weight upon the other parts. Thus, if we elap our hand upon the mouth of a vessel from whence the air has been taken away, there will thus be air on one side, and none on the other; upon which we shall instantly find the hand violently sucked inwards; which is nothing more than the weight of the air upon the back of the hand that forces it into the space which is empty below.

As, by this experiment, we perceive that the air presses with great weight upon every thing on the surface of the earth, so by other experiments we learn the exact weight with which it presses. First, if the air be exhausted out of any vessel, a drinking vessel for instance, ${ }^{\mathrm{a}}$ and this vessel be set with the mouth downwards in water, the water will rise up into the empty space, and fill the inverted glass; for the external air will, in this ease, press up the water where there is no weight to resist; as, one part of a bed being pressed, makes the other parts, that have no weight upon them, rise. In this case, as was said, the water being pressed without, will rise in the glass; and would continue to rise (if the empty glass were tall enough) thirtytwo feet high. In fact, there have been pipes made purposely for this experiment of above thirty-two feet high; in which, upon being exbausted, the water has always risen to the height of thirty-two feet: there it has always rested, and never ascended higher. From this, therefore, we learn, that the weight of the air which presses up the water, is equal to a pillar or column of water which is thirtytwo feet high; as it is just able to raise such a column, and no more. In other words, the surface of the earth is every where covered with a weight of air, which is equivalent to a covering of thirty-two feet deep of water; or to a weight of twenty-nine inehes and a half of quicksilver, which is known to be just as heavy as the former.

a This may be done by burning a bit of paper in the same, aud tlien quickly turning it down upon the water. 
Thus we see that the air at the surface of the earth is just as heavy as thirty-two feet of water, or twenty-nine inches and a half of quicksilver; and it is easily found, by computation, that to raise water thirty-two feet will require a weight of fifteen pounds upon every square inch. Now, if we are fond of computations, we have only to calculate how many square inches are in the surface of an ordinary human body, and allowing every inch to sustain fifteen pounds, we may amaze ourselves at the weight of air we sustain. It has been computed, and found, that our ordinary load of air amounts to within a little of forty thousand pounds: this is wonderful! but wondering is not the way to grow wise.

Notwithstanding this be our ordinary load, and our usual supply, there are at different times very great variations. The air is not, like water, equally heavy at all seasons; but sometimes is lighter and sometimes more heavy. It is sometimes more compressed, and sometimes more elastic or springy, which produces the same effects as an inerease of its weight. The air which at one time raises water thirty-two feet in the tube, and quicksilver twenty-nine inches, will not at another raise the one to thirty feet, or the other to twenty-six inches. This makes, therefore, a very great difference in the weight we sustain; and we are actually known, by computation, to earry at one time four thousand pounds of air more than at another.

The reason of this surprising difference in the weight of air, is either owing to its pressure from above, or to an inerease of vapour floating in it. Its increased pressure is the consequence of its spring or elastieity, which cold and heat sensibly affect, and are continually ehanging.

This elasticity of the air is one of its most amazing properties; and to which it should seem nothing ean set bounds. A body of air that may be contained in a nut-shell, may easily, with heat, be dilated into a sphere of unknown dimensions. On the contrary, the air contained in a house, may be compressed into a cavity not larger than the eye of a needle. In short, no bounds can be set to its confinement or expansion; at least, experiment has hitherto found its attempts indefinite. In every situation, it retains its elasticity; and the more elosely we compress it, the more strongly does it resist the pressure. If to the increasing the elasticity on one side by compression, we increase it on the other side by heat, the force of both soon beeomes irresistible; and a certain French philosopleer supposed, that air thus confined, and expanding, was sufficient for the explo. sion of a world.

Many instruments have been formed to measure and determine these different properties of the air; and which serve several useful purposes. The barometer serves to measure its weight; to tell us wben it is heavier, and when lighter. It is composed of a glass tube or pipe, of about thirty inches in length, closed up at one end: this tube is then filled with quicksilver; this done, the maker, clapping his finger upon the open end, inverts the tube, and plunges the open end, finger and all, into a bason of quicksilver, and then takes his finger away: now the quicksilver in the tube will, by its own weight, endeavour to descend into that in the bason; but the external air, pressing on the surface of the quicksilver in the bason without, and no air bcing in the tube at top, the quicksilver will continue in the tube, being pressed up, as was said, by the air, on the surface of the bason below. The height at which it is known to stand in the tube, is usually about twenty-nine inches, when the air is heavy; but not above twenty-six, when the air is very light. Thus, by this instrument we can, with some exactness, determine the weight of the air; and, of consequence, tell before-hand the changes of the weather. Before fine dry weather, the air is cliarged with a variety of vapours, which float in it unseen, and render it extremely heavy, so that it presses up the quicksilver ; or, in other words, the barometer rises. In moist, rainy weather, the vapours are washed down, or there is not heat sufficient for them to lise: so that the air is then sensibly lighter, and presses up the quicksilver with less force; or, in other words, the barometer is seen to fall. Our constitutions seem also to correspond with the changes of the weather-glass; they are braced, strong, and vigorous, with

- Monsieur Amontons. 
a large body of air upon them; they are languid, relaxed, and feeble, when the air is light, and refuses to give our fibres their proper tone.

But although the barometcr thus measures the weight of the air with exactness enough for the general purposes of life, yet it is often affected with a thousand irregularities, that no exactness in the instrument can remedy, nor no theory account for. When high winds blow, the quicksilver generally is low ; it rises higher in cold weather than in warm; and is usually higher at morning and evening than at inid-day: it generally descends lower after rain than it was before it. There are also frequent changes in the air, without any sensible alteration in the barometer.

As the barometer is thus used in predicting the changes of the weather, so it is also serviceable in measuring the heights of nountains, which mathematicians cannot so readily do : for as, the higher we ascend from the surface of the earth, the air becomes lighter, so the quicksilver in the barometer will descend in proportion. It is found to sink at the rate of the tenth part of an inch for every ninety feet we ascend; so that in going up a mountain, if I find the quicksilver fallen an inch, I conclude that I am got upon an ascent of near nine hundred feet higl. In this there has been found some variation; into a detail of which, it is not the business of a natural historian to enter.

In order to determine the elasticity of air, the wind-gun has been invented, which is an instrument variously made; but in all upon the principle of compressing a large quantity of air into a tube, in which there is an ivory ball, and then giving the compressed elastic air free power to act, and drive the ball as directed. The ball thus driven, will picrce a thick board; and will be as fatal, at small distances, as if driven with gunpowder. I do not know whether ever tho force of this instrument has been assisted by means of heat; certain I am, that this, which could be very easily contrived by means of phosphorus, or any other hot substance applied to the barrel, would give such a force as I doubt whether gunpowder itself could produce.

The air-pump is an instrument contrived to exhaust the air from round a vessel adapt- ed to that purpose, called a receiver. This method of exluausting, is contrived in the simple instrument, by a piston, like that of a syringe, going down into the ressel, and thus pushing out its air; which, by means of a valve, is prevented from returning into the vessel again. But this, like all other complicated instruments, will be better understood by a minute inspection, than an hour's description : it may suflice here to observe, that by depriving animals, and other substances, of all air, it shows us what the benefits and effects of air are in sustaining life, or promoting vegetation.

The digester is an instrument of still more extraordinary effects than any of the former; and sufficiently discovers the amazing force of air, when its elasticity is augmented by fire. A common tea-kettle, if the spout were closed up, and the lid put firmly down, would serve to become a digester, if strong enough. But the instrument used for this purpose is a strong metal pot, with a lid to screw close on, so that, when down, no air can get in or return: into this pot meat and bones are put, with a small quantity of water, and then the lid screwed close; a lighted lamp is put undernenth, and, what is very extraordinary, (yet equally true, ) in six or eight minutes the whole mass, bones and all, are dissolved into a jelly; so great is the force and elasticity of the air contained within, struggling to escape, and breaking in pieces all the substances with which it is mixed. Care, however, must be taken not to heat this instrument too violently; for then the inclosed air would become irresistible, and burst the whole, with perhaps a fatal explosion.

There are numberless other useful instruments made to depend on the weight, the elasticity, or the fluidity, of the air, which do not come within the plan of the present work; the design of which is not to give an account of the inventions that have been made for determining the nature and properties of air, but a mere narrative of its effects. The description of the pump, the forcingpump, the fire-engine, the steam-engine, the syphon, and many others, belong not to the naturalist, but the experimental philosopher: the one gives a history of Nature, as he finds she presents berself to him; and he draws 
the obvious picture: the other pursues her with close investigation, tortures her by experiment to give up her secrets, and measures her latent qualities with laborious precision. Much more, therefore, might be said of the mechanical effects of air, and of the conjectures that have been made respecting the form of its parts; how some have supposed them to resemble little hoops coiled up in a spring; others, like flecces of wool; others, that the parts are endued with a repulsive quality, by which, when squeezed together, they endeavour to fly off, and recede from each other. We might have given the disputes relative to the height to which this body of air extends above us, and con- ccrning which there is no agreement. We might have inquired how much of the air we breathe is elementary, and not reducible to any other substance; and of what density it would become, if it were supposed to be continued down to the centre of the earth. At that place we might, with the help of figures, and a bold imagination, have shown it twenty thousand times heavier than its bulk of gold. We might also prove it millions of times purer than upon earth, when raised to the surface of the atmosphere. But these speculations do not belong to natural history; and they have hitherte produced no great advantages in that branch of science to which they more properly appertain.

\section{Chapter XIX.}

\section{AN ESSAY TOWARDS A NATURAL HISTORY OF THE AIR.}

A LATE eminent philosopher has considered our atmosphere as one large chymical vessel, in which an infinite number of various operations are constantly performing. In it all the bodies of the earth are continually sending up a part of their substance by evaporation, to mix in this great alembic, and to float a while in common. Here minerals, from their lowest depths, ascend in noxious, or in warm vapours, to make a part of the general mass; seas, rivers, and subterranean springs, furnish their copious supplies; plants receive and return their share; and animals, that by living upon, consume this generalstore, are found to give it back in greater quantities when they die." The air, therefore, that we breathe, and upon which we subsist, bear's very little resemblance to that pure elementary body which was described in the last chapter; and which is rather a substance that may be conceived, than experienced to exist. Air, such as we find it, is one of the most compounded bodies in all nature. Water may be reduced to a fluid every way resembling air, by heat; which,

- Boyle, vol. ii. p. 593.

so. $9 \& 10$. by cold, becomes water again. Every thing we see gives off its parts to the air, and has a little floating atmosphere of its own round it. The rose is encompassed with a sphere of its own odorous particles; while the nightshade infects the air with a scent of a more ungrateful nature. The perfume of musk flies off in such abundance, that the quantity remaining becomes sensibly lighter by the loss. A thousand substances that escape all our senses we know to be there ; the poiverful emanations of the load-stone, the effluvia of electricity, the rays of light, and the insinuations of fire. Such are the various substances through which we move, and which we are constantly taking in at every pore, and returning again with imperceptible discharge!

This great solution, or mixture of all earthly bodies, is continually operating upon itself; which, perhaps, may be the cause of its unceasing motion: but it operates still more visibly upon such grosser substances as are exposed to its influence; for scarcely any substance is found capable of resisting the corrodingqualities of the air. The air, say the chymists, is a chaos furnished with all kinds 
of salts and menstruums; and, therefore, it is capable of dissolving all kinds of bodies. It is well known, that copper and iron are quickly covered, and eaten with rust; and that, in the climates near the equator, no art can keep them clean. In those dreary countries, the instruments, knives and keys, that are kept in the pocket, are nevertheless quickly incrusted; and the great guns, with every precaution, after some years, become useless. Stones, as being less hard, may be readily supposed to be more easily soluble. The marble of which the noble monuments of Italian antiquity are composed, although in one of the finest climates in the world, show the impressions which have been made upon them by the air. In many places they seem worm-eaten by time; and, in others, they appear crumbling into dust. Gold alone seems to be exempted from this general state of dissolution; it is never found to contract rust, though exposed never so long: the reason of this seems to be, that sea-salt, which is the only menstruum eapable of acting upon, and dissolving gold, is but very little mixed with the air; for salt being a very fixed body, and not apt to volatilize, and rise with heat, there is but a small proportion of it in the atmosphere. In the elaboratories, and shops, however, where salt is mucl used, and the air is impregnated with it, gold is found to rust as well as other metals.

Bodies of a softer nature are obviously destroyed by the air." Mr. Boyle says, that silks brought to Jamaica, will, if there exposed to the air, rot, even while they preserve their colour; but if kept therefrom, they both retain their strength and gloss. The same happens in Brazil, where their clothes, which are black, soon turn of an iron colour; though, in the shops, they preserve their proper hue. In these tropical climates also, such are the putrescent qualities of the air, that white sugar will sometimes be full of maggots. Drugs and plaisters lose their virtue, and become verminous. In some places they are obliged to expose their sweetmeats by day in the sun, otherwise the night air would quickly cause them to putrefy. On the contrary, in the cold arctic regions, ani-

- Buffon, vol. iii. p. 62. mal substances, during their winter, are never known to putrefy; and meat may be kept for months without any salt whatsoever. This experiment happily succeeded with the eight Englishmen that were accidentally left upon the inhospitable coasts of Greenland, at a place where seven Dutehmen had perished but a few years before; for killing some reindeer for their subsistence, and having no salt to preserve the flesh, to their great surprise they soon found it did not want any, as it remained sweet during their eight months continuance upon that shore.

These powers, with which air is endued over unorganized substances, are exerted in a still stronger manner over plants, animals of an inferior nature, and, lastly, over man hinself. Most of the beauty, and the luxuriance of vegetation, is well known to be derived from the benign influence of the air; and every plant seems to have its favourite climate, not less than its proper soil. The lower ranks of animals, also, seem formed for their respective climates, in which only they can live. Man alone seems the child of every climate, and capable of existing in all. However, this peculiar privilege does not exempt him from the influences of the air; he is as much subject to its malignity as the meanest insect or vegetable.

With regard to plants, air is so absolutely necessary for their life and preservation, that they will not vegetate in an exhausted receiver. All plants have witlin them a quantity of air, which supports and agitates their juices. They are continually imbibing fresh nutriment from the air, to increase this store, and to supply the wants which they sustain from evaporation. When, therefore, the external air is drawn from them, they are no longer able to subsist. Even that quantity of air which they before were possessed of, escapes through their pores, into the exhausted receiver; and as this continues to be pumped away, they become languid, grow flaccid, and die. However, the plant or flower thus ceasing to vegetate, is kept, by being secured from the external air, a much longer time sweet than it would have continued, had it been openly exposed.

Buffon, vol. iii. p. 68 , 
That air which is so necessary to the life of vegetables, is still more so to that of animals; there are none found, how seemingly torpid soever, that do not require their needful supply. Fishes themselves will not live in water from whence the air is exhausted; and it is generally supposed that they die in frozen ponds, from the want of this necessary to animal existence. Many have been the animals that idle curiosity has tortured in the prison of a receiver, merely to observe the manner of their dying. We shall, from a thousand instances, produce that of the viper, as it is known to be one of the most vivacious reptiles in the world; and as we shall feel but little compassion for its tortures. Mr. Boyle took a new-caught viper, and shutting it up into a small receiver, began to pump away the air." "At first, upon the air's being drawn away, it began to swell; some time after he had done pumping, it began to gape, and open its jaws; being thus compelled to open its jaws, it once more resumed its former laukness; it then began to move up and down within, as if to scek for air, and after a while foamed a little, leaving the foam sticking to the inside of the glass; soon after, the body and neck grew prodigiously tumid, and a blister appeared upon its back; an hour and a half after the receiver was exhausted, the distended viper moved, and gave manifest signs of life; the jaws remained quite distended; as it were from beneath the epiglottis, came the black tongue, and reached beyond it; but the animal seemed, by its posture, not to have any life; the mouth also was grown blackish within; and in this situation it continued for twenty-tliree hours. But upon the air's being re-admitted, the viper's mouth was presently closed, and soon after opened again; and for some time those motions continued, which argued the remains of life." Such is the fate of the most insignificant or minute reptile that can be thus included. Mites, fleas, and even the little eels that are found swimming in vinegar, die for want of air. Not only these, but the eggs of these animals, will not produce in vacuo, but require air to bring them to perfection.

As in this manner air is necessary to their

Boyle's Physico-Mechan. Exper. passim. subsistence, so also it must be of a proper kind, and not impregnated with foreign mixtures. That factitious air which is pumped from plants or fluids, is generally, in a short time, fatal to them. Mr. Boyle has given us many experiments to this purpose. After having shown that all vegetable, and most. mineral substances, properly prepared, may afford air, by being placed in an exhausted receiver, and this in such quantities, that some have thought it a new substance, made by the alteration which the mineral or plant has undergone by the texture of its parts being loosened in the operation-having shown, I say, that this air may be drawn in great quantities from vegetable, animal, or mineral substances, such as apples, cherries, amber burnt, or hartshorn ${ }^{b}-$ he included a frog in artificial air, produced from paste; in seven minutes space it suffered convulsions, and at last lay still, and being taken out, recovered no motion at all, but was dead. A bird inclosed in artificial air, from raisins, died in a quarter of a minute, and never stirred more. A snail was put into the receiver, with air of paste; in four minutes it ceased to move, and was dead, although it had survived in vacuo for several hours: so that factitious air proved a greater enemy to animals than even a vacuum itself.

Air also may be impregnated with fumes that are instantly fatal to animals. The fumes of hot iron, copper, or any other heated metal, blown into the place where an animal is confined, instantly destroy it. We have already mentioned the vapours in the grotto Del Cane suffocating a dog. The ancients even supposed, that these animals, as they always ran with their noses to the ground, were the first that felt any infection. In short, it should seem that the predominance of any one vapour, from any body, how wholesome soever in itself, becomes infectious; and that we owe the salubrity of the air to the variety of its mixture.

But there is no animal whose frame is more sensibly affected by the changes of the air than man. It is true, he can endure a greater variety of climates than the lower orders generally are able to do; but it is

- Boyle's Physico-Mechan, vol. ii. p. 598. 
rather by the means which he has discovered of obviating their effects, than by the apparent strength of his constitution. Most other animals can bear cold or hunger better, endure greater fatigues in proportion, and are satisfied with shorter repose. The variations of the climate, therefore, would probably affect them the less, if they had the same means or skill in providing against the severities of the change. However this be, the body of man is an instrument much more nicely sensible of the variations of the air, than any of those which his own art has produced; for his frame alone seems to unite all their properties, being invigorated by the weight of the air, relaxed by its moisture, enfeebled by its heat, and stiffened by its frigidity.

But it is chiefly by the predominance of some peculiar vapour, that the air becomes unfit for human support. It is often found, by dreadful experience, to enter into the constitution, to mix with its juices, and to putrefy the whole inass of blood. The nervous system is not less affected by its operations; palsies and vertigoes are caused by its damps; and a still more fatal train of distempers by its exhalations. In order that the air should be wholesome, it is necessary, as we have seen, that it should not be of one kind, but the compound of several substances; and the more various the composition, to all appearance the more salubrious. A man, therefore, who continues in one place, is not so likely to enjoy this wholesome variety, as he who changes his situation; and, if I may so express it, instead of waiting for a renovation of air, walks forward to meet its arrival. This mere motion, independent even of the benefits of exercise, becomes wholesome, by thus supplying a great variety of that healthful fluid by which we are sustained.

A thousand accidents are found to increase these bodies of vapour, that make one place more or less wholesome than another. Heat may raise them in too great quantities; and cold may stagnate them. Minerals may give off their effluvia in such proportion as to keep away all other kind of air; vegetables may render the air unwholesome by their supply; and animal putrefaction seems to furnish a quantity of vapour, at least as noxious as any of the former. All these united, generally make up the mass of respiration, and are, when mixed together, harmless; but any one of them, for a long time singly predominant, becomes at length fatal.

The effects of heat in producing a noxious quality in the air, are well known. Those torrid regions under the Line are always unwholesome. At Senegal, I am told, the natives consider forty as a very advanced time of life, and generally die of old age at fifty. At Carthagena, ${ }^{,}$in America, where the heat of the hottest day ever known in Europe is continual, where, during their winter season, thesedreadful heats are united with a continual succession of thunder, rain, and tempests, arising from their intenseness, the wan and livid complexions of the inhabitants might make strangers suspect that they were just recovered from some dreadful distemper; the actions of the natives are conformable to their colour; in all their motions there is somewhat relaxed and languid; the heat of the climate even affects their specch, which is soft and slow, and their words generally broken. Travellers from Europe retain their strength and ruddy colour in that climate, possibly for three or four nonths; but afterwards suffer such decays in both, that they are no longer to be distinguished from the inhabitants by their complexion. However, this languid and spiritless existence is frequently drawled on sometimes even to eighty. Young persons are generally most affected by the heat of climate, which spares the more aged; but all, upon their arrival on the coasts, are suljject to the saine train of fatal disorders. Few nations have experienced the mortality of these coasts, so much as our own; in our unsuccessful attack upon Carthagena, more than three parts of our army were destroyed by the climate alone; and those that returned from that fatal expedition, found their former vigour irretrievably gone. In our more fortunate expedition, which gave us the Havannah, we had little reason to boast of our success; instead of a third, not a fifth part of the army were left survivors of

- Ulloa, vol. i. p. 42. 
their victory, the climate being an enemy that even heroes canuot conquer.

The distempers that thus proceed from the cruel malignity of those climates are many; that, for instance, called the Chapotonadas, carries off a multitude of people; and extremely thins the crews of European ships, whom gain tempts into those inhospitable regions. The nature of this distemper is but little known, being caused in some persons by cold, in others by indigestion. But its effects are far from being obscure; it is generally fatal in three or four days: upon its seizing the patient, it brings on what is there called the black vomit, which is the sad symptom after which none are ever found to recover. Some, when the vomit attacks them, are seized with a delirium, that, were they not tied down, they would tear themselves to pieces, and thus expire in the midst of this furious paroxysm. This disorder, in milder climates, takes the name of the bilious fever, and is attended with milder symptoms, but very dangerous in all.

There are many other disorders incident to the human body, that seem the offspring of heat; but to mention no other, that very lassitude which prevails in all the tropical climates, may be considered as a disease. The inhabitants of India," says a modern philosopher, sustain an unceasing languor, from the heats of their climate; and are torpid in the midst of profusion. For this reason, the great Disposer of Nature has clothed their country with trees of an amazing height, whose shade might defend them from the beams of the sun; and whose continual freshness might, in some measure, temperate their fierceness. From thesc shades, therefore, the air receives refreshing moisture, and animals a cooling protection. The whole race of savage animals retire, in the midst of the day, to the very centre of the forests, not so much to avoid their enemy man, as to find a defence against the raging heats of the season. 'This advantage, which arises from shades in torrid climates, may probably afford a solution for that extraordinary circumstance related by Boyle, which he imputes to

\footnotetext{
- Linnæi Amœnitates, vol.v. p. 444.
}

a different cause. In the island of Ternate, belonging to the Dutch, a place that had been long celebrated for its beauty and healthfulness, the clove-trees grew in such plenty, that they in some measure lessened their own value: for this reason, the Dutch re solved to cut down the forests, and thus to raise the price of the commodity; but they had soon reason to repent of their avarice; for such a change ensued, by cutting down the trees, that the whole island, from being healthy and delightful, having lost its charming shades, became extremely sickly, and has actually continued so to this day. Boerhaave considered heat so prejudicial to health, that he was never seen to go near a fire.

An opposite set of calamities are the consequence, in climates where the air is condensed by cold. In such places, all that train of distempers which are known to arise from obstructed perspiration, are very common; ${ }^{b}$ eruptions, boils, scurvy, and a loathsome leprosy, that covers the whole body with a scurf, and white putrid ulcers. These disorders also are infections; and, while they thus banish the patient from society, they generally accompany him to the grave. The men of those climates seldom attain to the age of fifty; but the women, who do not lead such laborious lives, are found to live longer.

The antumnal complaints which attend a wet summer, indicate the dangers of a moist air. The long continuance of an east wind also, shows the prejudice of a dry one. Mineral exhalations, when copious, are every where known to be fatal; and although we probably owe the increase and luxuriance of vegetation to a moderate degree of their warmth, yet the natives of those countries where there are mines in plenty, but too often experience the noxious effects of their vicinity. Those trades also that deal in the preparations of metals of all kinds, are always unwholesome; and the workmen, after some time, are generally seen to labour under palsies, and other nervous complaints. The vapours from some vegetable substances, are well known to be attended with dangerous effects. The shade of the machinel tree, in

" Krantz's History of Greenland, vol. i. p. 235. 
America, is said to be fatal ; as was that of the juniper, if we may credit the ancients. Those who walk through fields of poppies, or in any manner prepare those flowers for making opium, are very sensibly affected with the drowsiness they occasion. A physician of Mr. Boyle's acquaintance, causing a large quantity of black hellebore to be pounded in a mortar, most of the persons who were in the room, and especially the person who pounded it, were purged by it, and some of them strongly. He also gathered a certain plant in Ireland, which the person who beat it in a mortar, and the physician who was standing near, were so strongly affected by, that their hands and faces swelled to an enormous size, and continued tumid for a long time after.

But neither mineral nor vegetable steams are so dangerous to the constitution, as those proceeding from animal substances, putrefying either by disease or death. The effluvia that come from diseased bodies, propagate that frightful catalogue of disorders which are called infectious. The parts which compose vegetable vapours, and mineral exhalations, seem gross and heavy, in comparison of these volatile vapours, that go to great distances, and have been described as spreading desolation over the whole earth. They fly every where; penetrate every where; and the vapours that fly from a single discase, soon render it epidemic.

The plague is the first upon the list in this class of human calamities. From whence this scourge of mall's presumption may have its beginning, is not well known; but we well know that it is propagated by infection. Whatever be the general state of the atmosphere, we learn, from expcrience, that the noxious vapours, though but singly introduced at first, taint the air by degrees: every person infected, tends to add to the growing malignity; and, as the disorder becomes more general, the putrescence of the air becomes more noxious, so that the symptoms are aggravated by continuance. When it is said that the origin of this disorder is unknown, it implies, that the air seems to be but little employed in first producing it. There are some countries, even in the midst of Africa, that we learn have never been infected with it; but continue, for centuries, unmolested. On the contrary, there are others, that are generally visited once a year, as in Egypt, which, nevertheless, seems peculiarly blessed with the serenity and temperature of its climate. In the former countries, which are of vast extent, and many of them very populous, every thing should seem to dispose the air to make the plague continual among them. The great heats of the climate, the unwholesomeness of the food, the sloth and dirt of the inhabitants, but, above all, the bloody battles which are continually fought among them, after which heaps of dead bodies are left unburied, and exposed to putrefaction. All these one might think would be apt to bring the plague among them; and yet, nevertheless, we are assured, by Leo Africanus, that in Numidia the plague is not known once in a hundred years; and that in Negroland, it is not known at all. This dreadful disorder, therefore, must have its rise, not from any previous disposition of the air, but from some particular cause, beginning with one individual, and extending the malignity, by communication, till at last the air becomes actually tainted by the generality of the infection.

The plague which spread itself over the whole world, in the year 1346 , as we are told by Mezeray, was so contagious, that scarcely a village, or even a house, escaped being infected by it. Before it had reached Europe, it had been for two years travelling from the great kingdom of Cathay, where it began by a vapour most horridly fetid; this broke out of the earth like a subterranean fire, and upon the first instant of its eruption, consumed and desolated above two hundred leagues of that country, even to the trees and stones.

In that great plague which desolated the city of London; in the year 1665, a pious and learned schoolmaster of Mr. Boyle's acquaintance, who ventured to stay in the city, and took upon him the humane office of visiting the sick and the dying, who had been deserted by better physicians, averred, that being once called to a poor woman who had buried her children of the plague, he found the room where she lay so little that it scarcely could hold any more than the bed whereon she was stretched. However, in this wretched abode, beside her, in an open 
coffin, her husband lay, who had some time before died of the same lisease; and whom she, poor creature, soon followed. But what showed the peculiar malignity of the air, thus suffering from animal putrefaction, was, that the contagious steams had produced spots on the very wall of their wretched apartment: and Mr. Boyle's own study, which was contiguous to a pest-house, was also spotted in the same frightful manner. Happily for mankind, this disorder, for more than a century, has not been known in our island; and, for this last age, has abated much of its violence, even in those countries where it is most common. Diseases, like empires, have their revolutions; and those which for a while were the scourge of mankind, sink unheard of, to give place to new ones, more dreadful, as being less understnod.

For this revolution in disorders, which has employed the speculation of many, Mr. Boyle accounts in the following manner: "Since," says he, "there want not causes in the bowels of the earth to make considerable changes amongst the materials that nature has plentifully treasured up in those magazincs, and as those noxious steams are abundantly supplied to the surface, it may not seem improbable, that in this great variety some may be found capable of affecting the human frame in -a particular manner, and thus of producing new diseases. The duration of these may be greater or less, according to the lastingness of those subterraneous causes that produced them. On which account, it need be no wonder that some diseases have but a short duration, and vanish not long after they appear; whilst others may continue longer, as having under ground more settled and durable causes to maintain them."

From the recital of this train of mischiefs produced by the air upon minerals, plants, animals, and man himself, a gloomy mind may be apt to dread this indulgent nurse of nature as a cruel and an inexorable stepmother: but it is far otherwise; and, although we are sometimes injured, yet almost all the comforts and blessings of life spring from its propitious influence. It would be needless to observe, that it is absolutely necessary for

\footnotetext{
- Keil, Robinson.
}

the support of our lives; for of this, every moment's experience assures us. But how it contributes to this support, is not so readily comprehended. All allow it to be a friend, to whose benefits we are constantly obliged: and yet, to this hour, philosophers are divided as to the nature of the obligation. The dispute is, whether the air is only useful by its weight to force our juices into circulation ;" or, whether, by containing a peculiar spirit, it mixes with the blood in our vessels, and acts like a spur to their industry. ${ }^{b}$ Perhaps it may exert both these useful offices at the same time. Its weight may give the blood its progressive motion, through the larger vessels of the body; and its admixture with it cause those contractions of all the vessels, which serve to force it still more strongly forward, through the minutest channels of the circulation. Be this as it may, it is well known, that that part of our blood which has just received the influx of the air in our bodies, is of a very different colour from that which has almost performed its circuit. It has been found, that the arterial blood, which has been immediately mixed with the air in the lungs, and, if I may so express it, is just beginning its journey through the body, is of a fine florid scarlet colour; while, on the contrary, the blood of the reins, that is returning from having performed its duty, is of a blackish crimson liue. Whence this difference of colour should proceed, is not well understood; we only know the fact, that this florid colour is communicated by the air; and we are well convinced, that this air has been admitted into the blood for very useful purposes.

Besides this vital principal in animals, the air also gives life and body to flame. A candle quickly goes out in at exhausted receiver; for having soon consumed the quantity of air, it then expires for want of a fresh supply. There has been a flame contrived that will burn under water; but none has yet been found that will continue to burn without air. Gunpowder, which is the most catching and powerful fire we know, will not go off in an exhausted receiver; nay, if a train of gunpowder be laid, so as that one part may be fired in the open air, yet the other part in vacuo

b Whytt upon Vital and Involuntary Motions. 
will remain untouched, and unconsumed. Wood also set on fire, immediately goes out, and its flame ceases, upon removing the air; for something is then wanting to press the body of the fire against that of the fuel, and to prevent the too speedy diffusion of the flame. We frequently see cooks, and others, whose business it is to keep up strong fires, take proper precautions to exclude the beams of the sun from shining upon them, which effectually puts them out. 'This they are apt to ascribe to a wrong cause; namely, the operation of the light; but the real fact is, that the warmth of the sun-beams lessens and dissipates the body of the air that goes to feed the flame; and the fire, of consequence, languishes for want of a necessary supply.

The air, while it thus kindles fire into flame, is notwithstanding found to moderate the rays of light, to dissipate their violence, and to spread an uniform lustre over every object. Were the beams of the sun to dart directly upon us, without passing through this protecting medium, they would either burn us up at once, or blind us with their effulgence. But by going through the air, they are reflected, refracted, and turned from their direct course, a thousand different ways; and thus are more evenly diffused over the face of nature.

Among the other necessary benefits the air is of to us, one of the principal is its conveyance of sound. Even the vibrations of a bell, which have the loudest effect that we know of, cease to be heard, when under the receiver of an air-pump. Thus all the pleasures we receive from conversation with each other, or from music, depend entirely upon the air.

Odours likewise are diffused only by the means of air; without this fluid to swim in, they would for ever remain torpid in their respective substances; and the rose would affect us with as little sensations of pleasure, as the thorn on which it grew.

Those who are willing to augment the catalogue of the benefits we receive from this element, assert also, that tastes themselves would be insipid, were it not that the air presses their parts upon the nerves of the tongue and palate, so as to produce their grateful effects. Thus, continue they, upon the tops of high mountains, as on the Peak of Teneriffe, the most poignant bodies, as pepper, ginger, salt, and spice, have no sensible taste, for want of their particles being thus sent home to the sensory. But we owe the air sufficient obligations, not to be studious of admitting this among the number: in fact, all substances have their taste, as well" on the tops of mountains, as in the bottom of the valley; and I have been one of many, who have ate a very savoury dinner on the Alps.

It is sufficient, therefore, that we regard the air as the parent of health and vegetation; as a kind dispenser of light and warmth ; and as the conveyer of sounds and odours. This is an element of which avarice will not deprive us; and which power cannot monopolize. The treasures of the earth, the verdure of the fields, and even the refreshments of the stream, are too often seen going only to assist the luxuries of the great; while the less fortunate part of mankind stand humble spectators of their encroachments. But the air no limitations can bound, nor any land-marks restrain. In this benign element, all mankind can boast an equal possession; and for this we all have equal obligations to Heaven. We consume a part of it, for our own sustenance, while we live; and, when we die, our putrefying bodies give back the supply, which, during life, we had accumulated from the general mass. 


\section{CHAPTER XX.}

\section{OF WINDS, IRREGULAR AND REGULAR.}

WIND is a current of air. Experimental philosophers produce an artificial wind, by an instrument called an eolipile. This is nothing more than a hollow copper ball, with a long pipe; a tea-kettle might be readily made into one, if it were entirely closed at the lid, and the spont left open; through this spout it is to be filled with water, and then set upon the fire, by which means it produces a violent blast, like wind, which continues while there is any water remaining in the instrument. In this manner water is converted into a rushing air; which, if caught as it goes out, and left to cool, is again quickly converted into its former element. Besides this, as was mentioned in the former chapter, almost every substance contains some portions of air. Vegetables, or the bodies of animals left to putrefy, produce it in a very copious manner. But it is not only seen thus escaping from bodies, but it may be very easily made to enter into them. A quantity of air may be compressed into water, so as to be intimately blended with it. It finds-a much easier admission into wine, or any fermented liquor; and an easier still, into spirits of wine. Some salts suck up the air in such quantities, that they are made sensibly heavicr thereby, and often are melted by its moisture. In this manner, most bodics, bcing found either capable of receiving or affording it, we are not to be surprised at those streams of air that are continually flecting round the globe. Minerals, vegetables, and animals, contribute to increase the current; and are sending off their constant supplies. These, as they are differently affected by cold or heat, by mixture or putrefaction, all yicld diferent quantities of air at different times; and the loudest tempests, and most rapid -rwirlwinds, are formed from their united contributions.

The sun is the principal instrument in rarefying the juices of plants, so as to give an escape to their imprisoned air ; it is also equally operative in promoting the putrefaction of animals. Mineral exhalations are more frequently raised by subterranean lseat. The moon, the other planets, the seasons, are all combined in producing these effects in a smaller degree. Mountiuins give a direction to the courses of the air. Fires carry a current of air along their body. Night and day alternately chill and warm the earth, and produce an alternate current of its vapours. These, and many other causes, may be assigned for the variety and the activity of the winds, their continual change, and uncertain duration.

With us on land, as the wind proceeds from so many causes, and mects such a variety of obstacles, there can be but little hopes of ever bringing its motions to conform to theory; or of foretelling how it may blow a minute to come. The great Bacon, indeed, was of opinion, that by a close and regular history of the winds, continued for a number of ages together, and the particulars of each observation reduced to general maxims, we might at last come to understand the variations of this capricious element; and that we could foretell the certainty of a wind, with as much case as we now forctell the return of an eclipse. Indeed, his own beginnings in this arduous undertaking, scem to spcak the possibility of its success; but, unhappily for mankind, this investigation is the work of ages, and we want a Bacon to direct the process.

To be able, therefore, with any plausibility, to account for the variations of the wind upon land, is not to be at present expected; and to understand any thing of their nature, we must have recourse to those places where they are more permanent and steady. This uniformity and steadiness we are chiefly to expect upon the ocean. There, where there is no varicty of substances to furnish the air with various and inconstant supplies; where there are no mountains to direct the course of its current, but where all is extensirely 
uniform and even; in such a place, the wind arising from a simple cause, must have but one simple motion. In fact, we find it so. There are many parts of the world where the winds, that with us are so uncertain, pay their stated visits. In some places they are found to blow one way by day, and another by night; in others, for one half of the year, they go in a direction contrary to their former course: but, what is more extraordinary still, there are some places where the winds never change, but for ever blow the same way. This is particularly found to obtain between the tropies in the Atlantic and Athiopic oceans; as well as in the great Pacific sea.

Few things can appear more extraordinary to a person who has never been out of our variable latitudes, than this steady wind, that for ever sits in the sail, sending the vessel forward; and as effectually preventing its return. He who has been taught to consider that nothing in the world is so variable as the winds, must certainly be surprised to find a place where there is notling more uniform. With us their inconstancy has become a proverb; with the natives of those distant climates they may talk of a friend or a mistress as fixed and unchangeable as the winds, and mean a compliment by the comparison. When our ships are once arrived into the proper latitudes of the great Pacific ocean, the mariner forgets the helm, and his skill becomes almost uscless: neither storms nor tempests are known to deform the glassy bosom of that immense sheet of waters; a gentle breeze, that for ever blows in the same direction, rests upon the canvass, and speeds the navigator. In the space of six wecks, ships are thus known to cross an immense oceail, that takes more than so many months to return. Upon returning, the trade-wind, which has been propitious, is then avoided; the mariner is generally obliged to steer into the northern Jatitudes, and to take the advantige of every casual wind that offers, to assist him into port. This wind, which blows with such constancy one way, is known to prevail not only in the Pacific ocean, but also in the Atlantic, between the coasts of Guinea and Brazil; and, likewise, in the Athiopic ocenn. This seems to be the great universal wind, blowing from the east to the west, that pre- vails in all the extensive oceans, where the land does not frequently break the general current. Were the whole surface of the globe an ocean, there would probably be but this one wind, for ever blowing from the east, and pursuing the motions of the sun westward. All the other winds seem subordinate to this; and inany of them are made from the deviations of its current. To form, therefore, any conception relative to the variations of the wind in general, it is proper to begin with that which never varies.

There have been many theories to explain this invariable motion of the winds; among the rest, we camnot omit that of Dr. Lyster, for its strangeness. "The sea," says he, " in those latitudes, is generally covered over with green weeds, for a great extent; and the air produced from the vegetable perspiration of these, produces the trade-wind." The theory of Cartesius was not quite so absurd. He alleged, that the earth went round faster than its atmosphere at the equator; so that its motion, from west to east, gave the atmosphere an imaginary one from east to west : and thus an east wind was eternally seen to prevail. Rejecting those arbitrary opinions, conceived without force, and asserted without proof, Dr. Halley has given one more plausible; which secms to be the reigning system of the day.

To conceive his opinion clearly, let us for a moment suppose the whole surface of the earth to be an ocean, and the air encompassing it on every side, without motion. Now it is evident, that that part of the air which lies directly under the beams of the sun, will be rarefied; and if the sun remained for ever in the same place, there would be a great vacuity in the air, if I may so express it, beneath the place where the sun stood. The sun moving forward from east to west, this vacuity will follow too, and still be made under it. But while it goes on to make new vacuities, the air will rush in to fill up those the sun has already made; in other words, as it is still travelling forward, the air will continually be rushing in behind, and pursue its motions from east to west. In this manner the air is put into motion by day; and by night the parts continue to impel each other, till the next return of the sun, that gives a new force to the circulation. 
In this manner is explained the constant east wind that is found blowing round the globe, near the cquator. But it is also known, that as we recede from the equator on either side, we come into a trade-wind, that continually blows from the poles, from the north on one side, or the south on the other, both directing towards the equator. This also proceeds from a similar cause with the former; for the air being more rarefied in those places over which the sun more directly darts its rays, the currents will come both from the north and the south, to fill up the intermediate vacuity.

These two motions, namely, the general one from east to west, and the more particular one from both the poles, will account for all the phænomena of trade-winds; which, if the whole surface of the globe were sea, would undoubtedly be constant, and for ever continue to blow in one direction. But there are a thousand circumstances to break these air-currents into smaller ones; to drive them back against their general course; to raise or depress them; to condense them into storms; or to whirl them in eddies. In consequence of this, regard must be often had to the nature of the soil, the position of the high mountains, the course of the rivers, and even to the luxuriance of vegetation.

If a country, lying directly under the sun, be very flat and sandy, and if the land be low and extensive, the heats occasioned by the reflection of the sun-beams, produces a very great rarefaction of the air. The deserts of Africa, which are conformable to this description, are scarcely ever fasıned by a breath of wind by day; but the burning sun is continually seen blazing in intolerable splendour above them. For this reason, all along the coasts of Guinea, the wind is always perceived blowing in upon land, in order to fill up the vacuity caused by the sun's operation. In those shores, therefore, the wind blows in a contrary direction to that of its general current; and is constantly found setting in from the west.

From the same cause it happens, that those constant calms, attended with deluges of rain, are found in the same part of the ocean. For this tract being placed in the middle, between the westerly winds blowing on the coast of Guinea, and the easterly trade-winds that move at some distance from shore, in a contrary direction, the tendency of that part of the air that lies between these two opposite currents, is indifferent to either, and so rests between both in torpid serenity; and the weight of the incumbent atmosphere, being dirninished by the continual contrary winds blowing from hence, it is unable to keep the vapours suspended that are copiously borne thither; so that they fall in continual ruins.

But it is not to be supposed, that any theory can account for all the phænomena of even those winds that are known to he inost regular. Instead of a complete system of the trade-winds, we must rather be content with an imperfect history. These, as was said, being the result of a combination of effects, assume as great a variety as the causes producing them are various.

Besides the great general wind above mentioned, in those parts of the Atlantic that lie under the temperate zone, a north wind prevails constantly during the months of October, November, December, and January. These, therefore, are the most favourable months for embarking for the East Indies, in order to take the benefit of these winds, for crossing the Line: and it has been often found, by experience, that those who had set sail five months before, were not in the least farther advanced in their voyage, than those who waited for the favourable wind. During the winter of Nova Zembla, and the other arctic countries, a north wind reigns almost continually. In the Cape de Verde islands, a south wind prevails during the month of July. At the Cape of Good Hope, a northwest wind blows during the month of September. There are also regular winds, produced by various causes, upon land. The ancient Greeks were the first who observed a constant breeze, produced by the melting of the snows, in some ligh neighbouring countries. This was perceived in Greece, Thrace, Macedonia, and the Egean sea. The same kind of winds are now remarked in the kingd om of Congo, and the most soutliern parts of Africa. The flux and reflux of

- Buffion, vol. ii. p. 230. 
the sea also produces some regular winds, that serve the purposes of trade; and, in general, it may be observed, that wherever there is a strong current of water, there is a current of air that seems to attend it.

Besides these wiurls that are found to blow in one direction, there are, as was said before, others that blow for eertain months of the year, one way, and the rest of the year the contrary way : these are called the monsoons, from a famous pilot of that name, who first used them in navigation with success." In all that part of the ocean that lies between Africa and India, the east winds begin at the month of January, and continue till about the commencement of June. In the month of August or September, the contrary dircetion takes place; and the west winds prevail for three or four months. The interval betwe ?n these winds, that is to sny, from the end of June to the beginning of August, there is no fixed wind; but the sea is usually tossed by violent tempests, proceeding from the north. These winds are always subject to their greatest variationis as they approach the land; so that, on one side of the great peninsula of India, the coasts are, for near half the year, harassed by violent hurricanes, and northern tempests; while, on the opposite side, and all along the coasts of Coromandel, these dreadful tempests are wholly unknown. At Java and Ceylon, a west wind begins to reign in the month of September; but, at fifteen degrees of south latitude, this wind is found to be lost; and the great general trade-wind from the east is perceived to prevail. On the contrary, at Cochin, in China, the west wind begins at Mareh; so that these monsoons prevail, at different seasons, throughout the Indies. So that the mariner takes one part of the year to go from Java to the Moluecas; another from Cochin to Molucea: another from Molucca to China; and still another to direct him from China to Japan.

There are winds also that may be considered as peculiar to certain coasts; for example, the sonth wind is almost constant upon the coasts of Chili and Peru; western winds almost constantly prevail on the coast

- Varenii Geographia Generalis, cap. 20. of Terra Magellanica; and in the environs of the Straits Le Miaire. On the coasts of Malabar, north and north-west winds prevail eontinually; along the coast of Guinea, the north-west wind is also very frequent; and, at a distance from the coasts, the north-east is always found prevailing. From the beginning of November to the end of December, a west wind prevails on the coasts of Japan; and, during the whole winter, no ships can leave the port of Cochin, on account of the impetuosity of the winds that set upon the coast. 'These blow with such vehemence, that the ports are entirely choked up with sand, and even boats are not able to enter. However, the east winds that prevail for the other half of the year, clear the mouths of their harbours from the accumulations of the preceding winter, and set the confined ships at liberty. At the Straits of Babelmandel there is a south wind that periodically returns, and which is always followed by a north-east.

Besides winds thus peculiar to certain coasts, there are others fonid to prevail on all the coasts, in warm climates, which, during one part of the day, blow from the shore, and, during another part of it, blow from the sea. The sea-breeze, in those countries, as Dampier observes, commonly rises in the morning, about nine, proceeding slowly, in a fine small black curl, upon the surface of the water, and making its way to refiesh the shore. It is gentle at first, hut increases gradually till twelve, then insensibly sinks away, and is totally hushed at five. Upon its ceasing, the land-breeze begins to take its turn, which increases till twelve at night, and is succeeded, in the morning, by the sea-breeze again. Without all doubt, nothing could have been more fortunate for the inhabitants of the warm countries, where those breezes blow, than this alternate refreshment, which they feel at those seasons when it is most wanted. The heat, on some coasts, would be insupportable, were it not for such a supply of air, when the sun has rarefied all that which lay more immediately under the coast. The sea-breeze temperates the heat of the sun by day; and the land-breeze corrects the malignity of the dews and vapours by night. Where these breezes, therefore, pre- 
vail, (and they are very common, the inhabitants enjoy a share of health and happiness, unknown to those that live much farther up the country, or such as live in similar latitudes without this advantage. The cause of these obviously seems to arise from the rarefaetion of the air by the sun, as their duration continues with its appearance, and alters when it goes down. The sun, it is observed, equally diffusing his beams upon land and sea, the land, being a more solid body than the water, receives a greater quantity of heat, and reflects it more strongly. Being thus, therefore, heated to a greater degree than the waters, it, of consequence, drives the air from land out to sea: but, its influence being removed, the air returns to fill up the former vacuity. Such is the usnal method of accounting for this phænomenon; but, unSortunately, these sea and land-breezes are risitants that come at all hours. On the coasts of Malabar, the land-breezes begin at midnight, and continue till noon; then the sea-breezes take their turn, and continue till midnight. While, again, at Congo, the land-breezes begin at five, and continue till uine the next day.

But, if the cause of these be so inscrutable, that are, as we see, tolerably regular in their visitations, what shall we say to the winds of our own climate, that are continually shifting, and incapable of rest? Some general causes may be assigned, which nothing but particular experience can apply. And, in the first place, it may be observed, that clouds and heat, and, in short, whatever either increases the density or the elasticity of the air, in any one place, will produce a wind there: for the increased activity of the air thus pressing more powerfully on the parts of it that are adjacent, will drive them forward; and thus go on, in a current, till the whole comes to an equality.

In this manner, as a denser air produces a wind, on the one hand; so will any accident, that contributes to lighten the air, produce it on the other: for, a lighter air may be considered as a vacuity into which the neighbouring air will rush : and hence it happens, that when the barometer marks a peculiar

- Buffon, vol. ii. p. 252. lightness in the air, it is no wonder that it foretells a storm.

The winds, upon large waters, are genorally more regular than those upon land. The wind at sea generally blows with an even steady gale; the wind, at land, puffs by intervals, increasing its strength, and remitting it, without any apparent cause. This, in a great measure, inay be owing to the many moun tains, towers, or trees, that it meets in its way, all contributing either to turn it from its course, or interrupt its passage.

The east wind blows more constantly than any other, and for an obvious reason: all other winds are, in some measure, deviations from it, and partly may owe their origin thereto. It is generally, likewise, the most powerful, and for the same reason.

There are often double currents of the air. While the wind blows one way, we frequently see the clouds move another. This is generally the case before thunder; for it is well known that the thunder cloud always moves against the wind: the cause of this surprising appearance has hitherto remained a secret. From hence we inay conclude, that weathercocks only inform us of that current of the air, which is near the surface of the earth; but are often erroneous with regard to the upper regions; and, in fact, Derham has often found them erroneous.

Winds are generally more powerful on elevated situations than on the plain, because their progress is interrupted by fewer obstacles. In proportion as we ascend the heights of a mountain, the violence of the weather seems to increase, until we have got above the region of storms, where all is usually calm and serene. Sometimes, however, the storms rise even to the tops of the highest mountains; as we learn from those who have been on the Andes, and as we are convinced by the deep snows that crown cven the highest.

Winds blowing from the sea are generally moister, and more attended with rains, than those which blow over extensive tracts of land: for the sea gives off more vapours to the air, and these are rolled forward upon land, by the winds blowing from thence. ${ }^{b}$ For

b Derham's Physiço-Theol. 
this reason, our easterly winds that blow from the continent, are dry, compared with those that blow from the surface of the ocean, with which we are surrounded on every other quarter.

In general the winds are more boisterous in spring and autumu than at other seasons: for that being the time of high tides, the sea Inay communicate a part of its motions to the winds. The sun and moon, also, which then have a greater effect upon the waters, may also have some influence upon the winds : for, there being a great body of air surrounding the globe, which, if condensed into water, would cover it to the depth of thirty-two feet, it is evident that the sun and moon will, to a proportionable degree, affect the atmosphere, and make a tide of air. This tide will be scarcely perceivable, indeed; but, without doubt, it actually exists; and may contribute to increase the vernal and autumnal storms, which are then known to prevail.

Upon narrowing the passage through which the air is driven, both the density and the swiftness of the wind is increased. For, as currents of water flow with greater force and rapidity by narrowing their chanuels; so also will a current of air, driven through a contracted space, grow more violent and irresistible. Hence we find those dreadful storms that prevail in the defiles of mountains, where the wind, pushing from behind through a narrow channel, at once increases in speed and density, levelling, or tearing up, every obstacle that rises to obstruct its passage.

Winds reflected from the sides of mountains and towers, are often found to be more forceful than those in direct progression. This we frequently pereeive near lofty buildings, such as churches or steeples, where winds are generally known to prevail, and that much more powerfilly than at some distance. The air, in this case, by striking against the side of the building, acquires additional density, and, therefore, blows with more force.

These differing degrees of density, which the air is found to possess, sufliciently show that the force of the winds do not depend upon their velocity alone; so that those instruments called anemometers, which are made to measure the velocity of the wind, will by no means give us certain information of the force of the storm. In order to estimate this with exactness, we ought to know its density; which also these are not calculated to discover. For this reason we often see storms, with very powerful effeets, that do not seem to show any great speed; and, on the contrary, we see these wind-measurers go round with great swiftness, when scarcely any damage has followed from the storm.

Such is the nature and the inconstancy of the irregnlar winds, with which we are best acquainted. But their effects are much more formidable in those climates near the tropics, where they are often found to break in upon the steady course of the trade-winds, and to mark their passage with destruction. With us the tempest is but rarely known, and its ravages are registered as an uncommon calamity; but in the countries that lie between the tropies, and for a good space beyond them, its visits are frequent, and its effects are anticipated. In these regions the winds vary their terrors; sometimes involving all things in a suffocating heat; sometimes mixing all the elements of fire, air, earth, and water, together; sometimes, with a momentary swiftness, passing over the face of the country, and destroying all things in their passage; and sometimes raising whole sandy deserts in one country, to deposite them upon some other. We have little reason, therefore, to envy these climates the luxuriance of their soil, or the brightuess of their skies. Our own muddy atmosphere, that wraps us round in obscurity, though it fails to gild our prospects with sunshine, or our groves with fruitage, nevertheless answers the call of industry. They may boast of a plentiful, but precarious, harvest; while, with us, the labourer toils in a certain expectation of a moderate, but a happy return.

In Egypt, a kingdom so noted for its fertility and the brightness of its atmosphere, during summer, the south winds are so hot, that they almost stop respiration; besides which, they are charged with such quantities of sand, that they sometimes darken the air, as with a thick cloud. These sands are so fine, and driven with such violence, that they

\footnotetext{
aufon, vol. ii. p. 258.
} 
penetrate every where, even into chests, be they shut never so closely. If these winds happen to continue for any length of timc, they produce epidemic diseases, and are often followed by a great mortality. It is also found to rain but very seldom in that country: however, the want of showers is richly compensated by the copiousness of their dews, which grently tend to promote vegetation.

In Persia, the winter begins in November, and continues till March. The cold at that time is intense enough to congeal the water; and snow falls in abundance upon their mountains. During the months of March and April, winds arise, that blow with great force, and seem to usher in the heats of sumner. These return again in autumn, with some violence; witlout, however, producing any dreadful effects. But, during their summer, all along the coasts of the Persian Gulf, a very dangerous wind prevails, which the natives call the Sameyel, still more dreadful and burning than that of Egypt, and attended with instant and fatal effects. This terrible blast, which was, perhaps, the pestilence of the ancients, instantly kills all those that it involves in its passage. What its malignity consists in, none can tell, as none have ever survived its effects, to give information. It frequently, as I am told, assumes a visible form, and darts, in a kind of bluish vapour, along the surface of the country. The natives, not only of Persia, but of Arabia, talk of its effects with terror; and their poets have not failed to heighten them with the assistance of imagination. They have described it as under the conduct of a minister of vengeance, who governs its terrors, and raises, or depresses it, as he thinks proper. ${ }^{\mathrm{a}}$ These deadly winds are also known along the coasts of India, at Negapatam, Masulipatam, and Petapoli. But, luckily for mankind, the shortness of their duration diminishes the injuries that might ensuc from their malignity.

The Cape of Good Hope, as well as many islands in the West-Indies, are famous for their hurricanes, and that extraordinary kind of clond which is said to produce them. This cloud, which is the forerunner of an approaching hurricanc, appears, when first scen,

- Herbelot, Bibliotheque Oriental. like a small black spot, on the verge of the horizon; and is called, by sailors, the bull's eye, from being seen so minute at a vast distance. All this time a perfect calm reigns over the sea and land, while the cloud grows gradually broader as it approaches. At length, coming to the place where its fury is to fall, it invests the whole horizon with darkness. During all the time of its approach, an hollow murmur is heard in the cavities of the mountains; and beasts and animals, sensible of its approach, are seen running over the fields, to seek for shelter. Nothing can be more terrible than its violence when it begins. The houses in those countries, which are made of timber, the better to resist its fury, bend to the blast like osiers, and again recover their rectitude. The sun, which but a moment before blazed with meridian splendour, is totally shut out; and a midnight darkness prevails, except that the air is incessantly illuminated with gleams of lightning, by which one can easily see to read. The rain falls, at the same time, in torrents; and its descent has been resembled to what pours from the spouts of our houses after a violent shower. These hurricanes are not less offensive to the sense of smelling also, and never come without leaving the most noisome stench behind them. If the seamen also lay by their wet clothes, for twenty-four hours, they are all found swarming with little white naggots, that were brought with the hurricane. Our first mariners, when they visited these regions, were ignorant of its effects, and the signs of its approach; their ships, therefore, were dashed to the bottom at the first onset; and numberless were the wrecks which the hurricane occasioned. But, at present, being forewarned of its approach, they strip their masts of all their sails, and thus patiently abide its fury. These hurricanes are common in all the tropical climates. Un the coasts of Guinea they have frequently three or four in a day, that thus shut out the heavens for a little space; and, when past, leave all again in former splendour. They chiefly prevail, on that coast, in the intervals of the trade winds; the appronch of which clears the air of its incteors, and gives these mortal showcrs that little degree of wholesomeness which they possess. They chicfly obtain 
there during the months of April and May; they are known at Loango from January to April; on the opposite coast of Africa, the hurricane season begins in May; and, in general, whenever a trade-wind begins to cease, these irregular tempests are found to exert their füry.

All this is terrible: but there is a tempest, known in those climates, more formidable than any we have hitherto been describing, which is called, by the Spaniards, a Tornado. As the former was seen arriving from one part of the heavens, and making a line of destruction; so the winds in this seem to blow from every quarter, and settle upon one destined place, with such fury, that nothing can resist their vehemence. When they have all met in their central spot, then the whirlwind begins with circular rapidity. The splsere every moment widens, as it continues to turn, and catches every object that lies within its attraction. This also, like the former, is preceded by a flattering calm; the air is every where hushed; and the sea is as smooth as polished glass : however, as its effects are more dreadful than those of the ordinary hurricane, the mariner tries all the power of his skill to avoid it; which, if he fails of doing, there is the greatest danger of his going to the bottom. All along the coasts of Guinea, beginning about two degrees north of the line, and so downward, lengthwise, for about a thousand miles, and as many broad, the ocean is unnavigable on account of these tornadoes. In this torrid region there reign unceasing tornadoes, or continual calms; among which, whatever ship is so unhappy as to fall, is totally deprived of all power of escaping. In this dreadful repose of all the elements, the solitary vessel is obliged to continue, without a single breeze to assist the mariner's wishes, except those whirlwinds, which only serve to increase his calamity. At present, therefore, this part of the ocean is totally avoided; and, although there may be much gold along the coasts of that part of Africa, to tempt avarice, yet there is something much more dreadful than the fabled dragon of antiquity, to guard the treasure. As the internal parts of that country are totally unknown to travellers, from their burning sands and extensive deserts, so here we find a vast tract of ocean, lying off its shores, equally unvisited by the mariner.

But of all these terrible tempests that deform the face of Nature, and repress human presumption, the sandy tempests of Arabia and Africa are the most terrible, and strike the imagination most strongly. To conceive a proper idea of these, we are by no means to suppose them resembling those whirlwinds of dust that we sometimes see scattering in in our air, and spriukling their contents upon our roads or meadows. The sand-storm of Africa exhibits a very different appearance. As the sand of which the whirlwind is composed is excessively fine, and almost resembles the parts of water, its motion entirely resembles that of a fluid; and the whole plain seems to float onward, like a slow iuundation. The body of sand thus rolling, is deep enough to bury houses and palaces in its bosom: travellers, who are crossing those extensive deserts, perceive its approach at a distance; and, in genera' have time to avoid it, or turn out of its way, as it generally extends but to a moderate breadth. However, when it is extremely rapid, or very extensive, as sometimes is the case, no swiftness, no art, can avail; nothing then remains, but to meet death with fortitude, and submit to be buried alive with resignation.

It is happy for us of Britain, that we have no such calamity to fear; for, from this, even some parts of Europe are not entirely free. We have an account given us, in the History of the French Academy, of a miserable town in France, that is constantly in danger of being buried under a similar inundation; with which I will take leave to close this chapter. "In the neighbourbood of St. Paulde Leon, in Lower Brittany," there lies a tract of country along the sca-side, which before the year 1666 was inhabited, but now lies deserted, by reason of the sands which cover it, to the height of twenty feet; and which every year advance more and more inland, and gain ground continually. From the time mentioned above, the sand has buried more than six leagues of the comntry inward; and it is now but half a league from the town of $\mathrm{St}$. Paul; so that, in all appearance, the inha-

- Histoire de l'Academie des Sciences, an. 1722. 
bitants must be obliged to abandon it entirely.

In the country that has been overwhelmed, there are still to be seen the tops of some steeples peeping through the sand, and nany chimneys that still remain above the sandy ocean. The inhabitants, however, had sufficient time to escape; but being deprived of their little all, they had no other resource but begging for their subsistence. This calamity chiefly owes its advancement to a north, or an east wind, raising the sand, which is extremely fue, in such great quantities, and with such velocity, that $M$. Deslandes, who gave the account, says, that while he was walking near the place, during a moderate breeze of wind, he was obliged, from time to time, to shake the sand from his clothes and his hat, on which it was lodged in great quantities, and made them too heavy to be easily borne. Still further, when the wind was violent, it drove the sand across a little arm of the sea, into the town of Roscoff, and covered the streets of that place two feet deep; so that they have been obliged to carry it off in carts. It may also be observed, that there are several particles of iron mixed with the sand, which are readily affected by the loadstone. The part of the coast that furnishes these sands, is a tract of about four leagues in length; and is upon a level with the sea at high-ivater. 'The shore lies in such a manner as to leave its sands subject only to the north and east winds, that bear them farther up the shore. It is easy to conceive how the same sand that has at one time been borne a short way inland, may, by some succeeding and stronger blast, be carried up much higher; and thus the whole may continue advaneing forward, deluging the plain, and totally destroying its fertility. At the same time, the sea, from whence this deluge of sand proceeds, may furnish it in inexhaustible quantities. This unhappy country, thus so overwlielmed in so singular a manner, may well justify what the ancients and the moderns have reported concerning those tempests of sand in Africa, that are said to destroy villages, and even armies in their bosom."

\section{CHAPTER XXI.}

\section{OF METEORS, AND SUCH APPEARANCES AS RESULT FROM A COMBINATION OF THE ELEMENTS.}

IN proportion as the substances of nature are more compounded and combined, their appearances become more inexplicable and amazing. The properties of water have been very nearly ascertained. Many of the qualities of air, earth, and fire, have been discovered and estimated; but when these come to be united by nature, they often produce a result which no artificial combinations can imitate: and we stand surprised,that although we are possessed of all those substances which nature makes use of, she shows herself a much more various operator than the most skilful chemist ever appeared to be. Every cloud that moves, and every shower that falls, serves to mortify the philosopher's pride, and to show him hidden qualities in air and water, that he finds it difficult to explain. Dews, hail, snow, and thunder, are not less difficult for being more common. Indeed, when we reflect on the manner in which nature performs any one of these operations, our wonder increases. To see water, which is heavier than air, rising in air, and then falling in a form so very different from that in which it rose; to see the same fluid at one time descending in the form of hail, at another in that of snow; to see two elouds, by dashing against each other, producing an electrical fire, which no watery composition that we know of can effect; these, I say, serve sufficiently to excite our wonder; and still the nr)re, in proportion as the objects are ever pressing on our curiosity. Much, $2 \mathrm{~A}$ 
however, has been written concerning the manner in which nature operates in these productions; as nothing is so ungrateful to mankind as hopeless ignorance.

And first, with regard to the manner in which water evaporates, and rises to form clouds, much has been advaneed, and many theories devised. All water, ${ }^{\mathrm{B}}$ say some, has a quantity of air mixed with it; and the heat of the sun darting down, disengages the particles of this air from the grosser fluid; the sun's rays being reflected back froin the water, carry back with thein those bubbles of air and water, which, being lighter than the condensed air, will ascend till they meet with a inore rareficd air; and they will then stand suspended. Experience, however, proves nothing of all this. Particles of air or fire, are not thus known to aseend with a thin eoat of water; and, in fact, we know that the little particles of steam are solid drops of water. But, besides this, water is known to evaporate more powerfully in the severest frost, than when the air is noderately warm." Dr. Hamilton, therefore, of the university of Dublin, rejecting this theory, has endeavoured to establish another. According to him, as aqua-fortis is a menstruum that dissolves iron, and keeps it mixed in the fluid; as aqua-regia is a menstruum that dissolves gold; or as water dissolves salts to a certain quantity, so air is a menstruum that corrodes and dissolves a certain quantity of water, and keeps it suspended above. But however ingenious this may be, it can hardly be adınitted : as we know by Mariotte's experiment, ${ }^{c}$ that if water and air be inclosed together, instead of the air's acting as a menstruum upon the water, the water will act as a menstruum upon the air, and take it all up. We know also, that of two bodies, that which is most fluid and penetrating, is most likely to be the menstruum of the other; but water is more fluid and penetrating than air, and therefore the most likely of the two to be the menstruum. We know that all bodies are more speedily acted upon, the more their parts are brought into contact with the menstruum that dissolves them; but water, in-

- Spectacle de la Nature, vol. iii.

b Memoires de l'Academie des Sciences, an. 1705. closed with compressed air, is not the more diminished thereby. ${ }^{d}$ In short, we know that cold, which diminishes the force of other menstruums, is often found to promote evaporation. In this variety of opinion and uncertainty of conjecture, 1 eannot avoid thinking that a theory of evaporation may be formed upon very simple and obvious principles, and embarrassed, as far as I can conceive, with very few objections.

We know that a repelling power prevails in nature, not less than an attractive one. This repulsion prevails strongly between the body of fire and that of water. If I plunge the end of a red-hot bar of iron into a vessel of water, the fluid rises, and large drops of it fly up in all manner of direetions, every part bubbling and steaning until the iron be cold. Why may we not for a moment compare the rays of the sill, darted direetly upon the surface of the water, to so many bars of red-hot iron, each bar indeed infinitely small, but not the less poweriul? In this case, wherever a ray of fire darts, the water, from its repulsive quality, will be driven on all sides; and, of consequence, as in the case of the bar of iron, a part of it will rise. The parts thus rising, however, will be extremely sinall; as the ray that darts is extremely so. The assemblage of the rays darting upon the water is this manner, will cause it to rise in a light thin steam above the surface; and as the parts of this steam are extremely minute, they will be lighter than air, and consequently float upon it. There is no need for supposing them bubbles, of water filled with fire; for any substance, even gold itself, will float on air, if its parts be made small enough; or; in other words, if its surface be suffieiently increased. This water, thus disengaged from the general mass, will be still farther attenuated and broken by the reflected rays, and consequently more adapted for ascending.

From this plain account, every appearance in evaporation may be easily deduced. The quantity of heat increases evaporation, because it raises a greater quantity of stenm. The quantity of wind increases cvaporation; for, by waving the surface of the water, it tlius

c Marione, de la Nature de l'Air, p. 97, 106.

a See Boyle's Works, vol. ii. p. 619. 
exposes a greater surface to the vaporating rays. A dry frost, in some measure, assists the quantity of evaporation; as the quantity of rays are found to be no way diminished thereby. Moist weather alone prevents evaporition; for the rays being absorbed, refracted, and broken, by the intervening moisture, before they arrive at the surface, cannot produce the effect; and the vapour will rise in a small proportion.

Thus far we have accounted for the ascent of vapours; but to account for their falling again is attended with rather more difficulty. We have already observed, that the particles of vapour, disengaged from the surface of the water, will be broken and attenuated in their ascent, by the reflected, and even the direct rays, that happen to strike upon their minute surfaces. They will, therefore, continue to ascend, till they rise above the operation of the reflected rays, which reaches but to a certain height above the surface of the earth. Being arrived at this region, which is cold for want of reflected heat, they will be condensed, and suspended in the form of elouds. Some vapours, that ascend to great heights, will be frozen into snow; others, that are condensed lower down, will put on the appearance of a mist, which we find the clouds to be when we ascend among them, as they hang along the sides of a mountain. These clouds of snow and rain, being blown about by winds, are either entirely scattered and dispersed above, or they are still more condensed by motion, like a snow-ball, that grows more Iarge and solid as it continues to roll. At last, therefore, they will become too weighty for the air which first raised them to sustain; and they will descend with their excess of weight, either in snow or rain. But, as they will fall precipitately, when they begin to descend, the air, in some measure, will resist the falling: for, as the descending fluid gathers velocity in its precipitation, the air will increase its resistance to it, and the water will, therefore, be thus broken into rain; as we see that water which falls from the tops of houses, though it begins in a spout, separates into drops before it has got to the bottom. Were it not for this happy interposition of the air, between us and the water falling from a considerable height above us, a drop of rain might fall with dangerous force, and a hailstone might strike us with fatal rapidity.

In this manner, cvaporation is produced by day; hut when the sun goes down, a part of that vapour which his rays had excited, being no longer broken, and atteuu ated by the reflecting rays, it will become heavier than the air, even before it has reached the clouds; and it will, therefore, fall back in dews, which differ only from rain in descending before they have had time to condense into a visible form.

Hail, the Cartesians say, is a frozen cloud, half melted, and frozen again in its descent. A hoar frost is but a frozen dew. Lightning we know to be an electrical flash, produced by the opposition of two elouds: and thunder to be the sound proceeding from the same, continued by an echo reverberated among them. It would be to very little purpose to attempt explaining exactly how these wonders are effected; we have as yet but little insight into the manner in which these meteors are found to operate upon each other; and, therefore, we must be contented with a detail rather of their effects than their causes.

In our own gentle elimate, where nature wears the mildest and kindest aspeet, every meteor seems to befriend us. With us, rains fall in refreshing showers, to enliven our fields, and to paint the landscape with a more vivid beauty. Snows cover the earth, to preserve its tender vegetables from the inclemency of the departing winter. The dews descend with such an imperceptible fall as no way injures the constitution. Even thunder is seldom injurious; and it is often wished for by the husbandman, to clear the air, and to kill numberless insects that are noxious to vegetation. Hail is the most injurious meteor that is known in our climate; but it seldom visits us with violence, and then its fury is but transient.

One of the most dreadful storms we hear of ${ }^{a}$ was that of Hertfordshire, in the year 1697. It began by thunder and lightning, which continued for some hours, when suddenly a black cloud came forward, against the wind, and marked its passage with de-

- Phil. Trans. vol. ii. p. 147. 
vastation. The hailstones which it poured down, being measured, were found to be many of thein fourteen inches round, and, consequently, as large as a bowling-green ball. Wherever it came, every plantation fell before it; it tore up the ground, split great oaks, and other trees, without nuinber; the fields of rye were cut down, as if levelled with a scythe; wheat, oats, and barley, suffered the same damage. The inhabitants found but a precarious shelter, even in their houses, their tiles and windows being broke by the violence of the hailstones, which, by the force with which they came, seemed to have descended froin a great height. The birds, in this universal wreck, vainly tried to escape by light ; pigeons, crows, rooks, and many more of the smaller and feebler kinds, were brought down. An unhappy young man, who had not time to take shelter, was killed; one of his eyes was struck out of his head, and his body was all over black with the bruises; another lad just time to escape, but not without the most imminent danger, his body being bruised all over. But what is most extraordinary, all this fell within the compass of a mile.

Mezeray, in his history of France, tells us of a shower of hail much more terrible, which happened in the year 1510, when the French monarch invaded Italy. There was, for a time, a horrid darkness, thicker than that of midnight, which continued till the terrors of mankind were changed to still more terrible objects, by thunder and lightning breaking the gloom, and bringing on such a shower of hail, as no history of humani calamities could equal. These hailstones were of a bluish colour, and some of them weighed not less than a hundred pounds. A noisome vapour of sulphur attended the storm. All the birds and beasts of the country were entirely destroyed. Numbers of the human race suffered the same fate. But what is still more extraordinary, the fishes found no protection from their native element; but we: equal sufferers in the general calamity.

These, however, are terror's that are seldom exerted in our mild climates. They only serve to mark the page of history with wonder; and stand as admonitions to mankind of the various stores of punishment in the hands of the Deity, which his power can treasure up, and his mercy can suspend. In the temperate zones, therefore, meteors are rarely found thus terrible; but between the tropics, and near the poles, they assume very dreadful and various appearances. In those inclement regions, where cold and heat exert their chief power, meteors seem peculiarly to have fixed their residence. They are seen there in a thousand terrifying forms, astonishing to Europeans, yet disregarded by the natives, from their frequency. The wonders of air, fire, and water, are there combined, to produce the most tremendous effects; and to sport with the labours and ap. prehensions of mankind. Lightuings, that flash wilhout noise; hurricanes, that tear up the earth; clouds, that all at once pour down their contents, and produce an instant deluge; mock suıs; northern lights, that illuninate half the hemisphere; circular rainbows; halos; fleeting balls of fire; clouds, reflecting back the images of things on earth, like mirrors; and water-spouts, that burst from the sea, to join with the mists that hang inmediately above them. These are but a part of the phrenomena that are common in those countries; and from many of which our own climate is, in a great measure, exempted.

'The meteors of the torrid zone are different from those that are found near the polar circles; and it may readily be supposed, that in those countries where the sun exerts the greatest force in raising vapours of all kinds, there should be the greatest quantity of meteors. Upon the approach of the winter months, as they are called, under the Line, which usually begin about May, the sky, from a fiery brightness, begins to be overcast, and the whole horizon seems wrapt in a muddy cloud. Mists and vapours still continue to rise; and the air, which so lately before was clear and elastic, now becomes humid, obscure, and stifling: the fogs becone so thick, that the light of the sun seems, in a manner, excluded; nor would its presence be known, but for the intense and sulfocating heat of its beams, which dart through the gloom, and, instead of dissipating, ouly serve to incrione the mist.

Aler this preparation, there follows al most continual succession of thunder, rain, and tempests. During this dreadful scason, 
the streets of cities flow like rivers; and the whole country wears the appearance of an occan. The inhabitants often make use of this opportunity to lay in a stock of fresh water, for the rest of the year; as the same cause which pours down the deluge at one season, denies the kindly shower at another. The thunder which attends the fall of these rains, is much more terrible than that we are generally acquainted with. With us the flash is seen at some distance, and the noise shortly after ensues; our thunder generally rolls on one quarter of the sky, and one stroke pursues another. But here it is otherwise; the whole sky seems illuminated with unremitted tl ishes of lightning; 'every part of the air sceins productive of its own thunders; and every cloud produces its own shock. The strokes come so thick, that the inliabitants can scarcely mark the intervals; butall is one unremitted roar of elementary confusion. It should seem, however, that the lightning of those countries is not so fatal, or so dangerous, as with us; since, in this case, the torrid zone would be uninhabitable.

When these terrors have ceased, with which, however, the natives are familiar, meteors of another kind begin to make their appearance. The intense beams of the sun, darting upon stagnant waters, that generally cover the surface of the country, raise vapours of various kinds. Floating bodies of fire, which assume different names, rather from their accidental forms, than from any real difference between them, are seen without surprise. The draco volans, or flying dragon, as it is called; the ignis fatuus, or wandering fire; the fires of St. Helmo, or the mariner's light, are every where frequent; and of these we have numberless descriptions. "As I was riding in Jamaica," says Mr. Barbham, " one morning from my habitation, situated about three miles north-west from Jago de la Vega, I saw a ball of fire, appearing to me of the bigness of a bomb, swiftly falling down with a great blaze. At first I thought it fell into the town; but when I came nearer, I saw inany people gathered together, a little to the southward, in the savanna, to whom I rode up, to inquire the cause of their meeting: they were admiring, as I found, the ground's being strangely broke up and plough- ed by a ball of fire; which, as they said, fell down there. I observed there were many holes in the ground; one in the middle, of the bigness of a man's head, and five or six smaller round about it, of the bigness of one's fist, and so deep as not to be fathomed by such implements as were at hand. It was observed also, that all the green herbage was burnt up, near the holes; and there continued a strong smell of sulphur near the place, for some time after."

Ulloa gives an account of one of a similar kind, at Quito." "About nine at night," says he, "a globe of fire appeared to rise from the side of the mountain Pichinca, and so large, that it spread a light over all the part of the city facing that mountain. The house where I lodged looking that way, J was surprised with an extraordinary light, darting through the crevices of the window-shutters. On this appearance, and the bustle of the people in the street, I hastened to the window, and came time ellough to see $i t$, in the middle of its career; which continued from west to south, till I lost sight of it, being intercepted by a mountain, that lay between me and it. It was round; and its apparent diameter about a foot. I observed it to rise from the sides of Pichinca; although, to judge from its course, it was behind that mountain where this congeries of inflammable matter was kindled. In the first half of its visible course, it emitted a prodigious effulgence, then it began gradually to grow dim; so that, upon its disappearing behind the intervening mountain, its light was very faint."

Meteors of this kind are very frequently seen between the tropics; but they sometimes, also, visit the more temperate regions of Europe. We have the description of a very extraordinary one, given us by Montanari, that serves to show to what great heights, ill our atmosphere, these vapour's are found to ascend. In the year 1676 , a great globe of fire was seen at Bononia, in Italy, about three quarters of an hour after sun-set. It passed westward, with a most rapid course, and at the rate of not less than a hundred and sixty miles in a minute, which is mucl swifter than the force of a camon-ball, and,

\footnotetext{
- Ulloa, vol. i. p. 41.
} 
at last, stood over the Adriatic sea. In its course it crossed over all Italy ; and, by computation, it could not have been less than thirty-eight miles above the surface of the earth. In the whole line of its course, wherever it approached, the inhabitants below could distinctly hear it, with a hissing noise, resembling that of a fire-work. Having passed away to sea, towards Corsica, it was heard, at last, to go off with a most violent explosion, much louder than that of a cannon : and, immediately after, another noise was heard, like the rattling of a great cart upon a stony pavement; which was, probably, nothing more than the echo of the former sound. Its magnitude, when at Bononia, appeared twice as long as the moon, one way, and as broad the other; so that, considering its height, it could not have been less than a nile long, and half a mile broad. From the height at which this was seen, and there being no volcano on that quarter of the world from whence it came, it is more than probable that this terrible globe was kindled on some part of the contrary side of the globe, in those regions of vapours which we have been just describing; and thus, rising above the air, and passing in a course opposite to that of the earth's motion, in this manner it acquired its amazing rapidity.

To these meteors, common enough southward, we will add one more of a very uncommon kind, which was seen by Ulloa, at Quito, in Peru; the beauty of which will, in some measure, serve to relieve us, after the description of those hideous ones preceding. "At day break," says he, "the whole mountain of Pambamarca, where we then resided, was encompassed with very thick clouds; which the rising of the sun dispersed so far, as to leave only some vapours; too fine to be seen. On the side opposite to the rising sun, and about ten fathoms distant from the place where we were standing, we saw, as in a looking-glass, each his own image; the head being as it were, the centre of three circular rainbows, one without the other, and just near enough to each other as that the colours of the internal verged upon those more external; while round all was a circle of white, but with a greater space betwcen. In this manner these circles were erected, like a mirror, before us ; and as we moved, they moved, in disposition and order. But what is most remarkable, though we wcre six in number, every one saw the phænomemou with regard to himself, and not that relating to others. The diameter of the arches grallually altered, as the sun rose above the horizon; and the whole, after continuing a long time, insensibly faded away. In the beginning, the diameter of the inward iris, taken from its last colour, was about five degrees and a half; and that of the white arch, which surrounded the rest, was not less than sixty-seven degrees. At the beginning of the phrenomenon, the arches seemed of an oval, or elliptical figure, like the disk of the sun ; and afterwards becane perfectly circular. Each of these was of a red colour, bordered with an orange; and the last bordered by a bright yellow, which altered into a straw colour, and this turued to a green; but, in all, the external colour remaincd red." Such is the description of one of the most beautiful illusions that has ever been seen in nature. This alone seems to have combined all the splendours of optics in one view: To understand the manner, therefore, low this phænomenon was produced, would require a perfect knowledge of optics; which it is not our present province to enter upon. It will be sufficient, therefore, only to observe, that all these appearances arise from the density of the cloud, together with its uncommon and peculiar situation, with respect to the spectator and the sun. It may be observed, that but one of these three rainbows was real, the rest being only reflections thereof. It may also be observed, that whenever the spectator stands between the sun and a cloud of falling rain, a rainbow is seen, which is nothing more than the reflection of the different coloured rays of light from the bosom of the cloud. If, for instaıce, we take a glass globe, filled with water, and hang it up before us opposite the sun, in many situations it will appear transparent ; but if it is raised higher, or sidewnys, to an angle of forty-five degrees, it will at first appear red; altered a very little higher, yellow; then green, then blue, thien vislet colnur: in slort, it will assume sucerssively all the colours of the rainbow; lut, if rais d higher still, it will becone transparent again. A falling shower may be considered as an infinite gumber of these little transparent globes, assuning different colours, hy being placed at their proper heights. The rest of the shower will 
appear transparent, and no part of it will seem coloured; but such as are at angles of forty-five degrees from the eye, forty-five degrees upward, forty-five degrees on cach side, and forty-five degrees downward, did not the plane of the earth prevent us. We therefore see only an arch of the rainbow, the lower part being cut offfrom our sight by the earth's interposition. However, upon the tops of very high mountains, circular rainbows are seen, because we can see to an angle of fortyfive degrees downward, as well as upward, or sideways, and therefore we take in the rainbow's complete circle.

In those forlorn regions round the poles, the meteors, though of another kind, are not less numerous and alarming. When the winter begins, and the cold prepares to set in, the same misty appearance which is produced in the southern climates by the heat, is there produced by the contrary extreme. ${ }^{a}$ The sea smokes like an oven, and a fog arises, which mariners call the frost smoke. This cutting mist commonly raises blisters on several parts of the body; and, as soon as it is wafted to some colder part of the atmosphere, it freezes to little icy particles, which are driven by the wind, and creates such an intense cold on land, that the limbs of the inhabitants are sometimes frozen, and drop off.

There, also, halos, or luminous circles round the moon, are oftener seen than in any other part of the earth, being formed by the frost sinoke; although the air otherwise seems to be elear. A lunar rainbow also is often seen there, though somewhat different from that which is common with us; as it appears of a pale white, striped with gray. In these countries also, the aurora borealis streams with peculiar lustre, and variety of colours. In Greenland it generally arises in the east, and darts its sportive fires, with variegated beauty, over the whole horizon. Its appearance is almost constant in winter; and at those seasons when the sun departs, to return no more for half a year, this meteor kindiy rises to supply its beams, and affords sufficient light for all the purposes of existence. However, in the very midst of their

\footnotetext{
- Paul Egede's History of Greenland.
}

tedious night, the inhabitants are not entirely forsaken. The tops of the mountains are often seen painted with the red rays of the sun; and the poor Greenlander from thence begins to date his chronology. It would appear whimsical to read a Greenland calendar, in which we might be told, That one of their chiefs, having lived forty days, died, at last, of a good old age; and that lis widow continued for half a day to deplore his loss, with great fidelity, before she admitted a second husband.

The meteors of the day, in these countries, are not less extaordinary than those of the night: mock surs are often reflected upon an opposite cloud; and the ignorant spectator fancies that there are often three or four real suns in the firmament at the same time. In this splendid appearance the real sun is always readily known by its superior brightness, every reflection being seell with diminished splendour. The solar rainbow there, is often seen different from ours. Instead of a plcasing variety of colours, it appears of a pale white, edged with a stripe of dusky yellow; the whole being reflected from the bosom of a frozen cloud.

But, of all the meteors which mock the imagination with an appearance of reality, those strange illusions that are seen there, in fine serene weather, are the most extraordinary and entertaining. "Nothing," says Krantz," ever surprised me more, than on a fine warm summer, s day, to perceive the islands that lie four leagues west of our shore, putting on a form quite different from what they are known to have. As I stood gazing upon them, they appeared at first infinitely greater than what they naturally are; and seemed as if I viewed them through a large magnifying glass. They were not thus only made larger, but brought nearer to me. I plainly deseried every stone upon the land, and all the furrows filled with iee, as if I stood close by. When this illusion had lasted for a while, the prospect seemed to break up, and a new scene of wonder to present itself. The island seemed to travel to the sliore, and represented a wood, or a tall cut liedge. The scene then shifted, and showed the appearance of all sorts of curious figures; as ships with sails, strcamers, and flags; antique 
clevated castles, with decayed turrets; and a thousand forms, for which fancy, found a resemblance in nature. When the eye had been satisfied with gazing, the whole group of riches seemed to rise in air, and at length vanish into nothing. At such times the weather is quiteserene and clear; but compressed with such subtle vapours, as it is in very hot weather; and these appearing between the eye and the object, give it all that variety of appearances which glasses of different refrangibilities would have done." Mr. Krantz observes, that commonly a couple of hours afterwards, a gentle west wind and a visible mist follow, which put an end to this lusus naturce.

It were easy to swell this catalogue of meteors with the names of many others, both in our own clinate and in other parts of the world. Such as falling stars, which are thought to be no more than unctuous vapours, raised from the earth to small heights, and continuing to shine till that matter which first raised and supported them, being burnt out, they fall back again to the earth, with extinguished flame. Burning spears, which are a peculiar kind of aurora borealis; bloody rains, which are said to be the excrements of an inseet, that at that time has been raised into the air. Showers of stones, fishes, and ivy-berries, at first, no doubt, raised into the air by tempests in one country, and falling at some considerable distance, in the manner of rain, to astonish another. But ornitting these, of which we know little more than what is thus briefly mentioned, I will conclude this chapter with the description of a water-spout; a most surprising phrenomenon; not less dreadful to mariners, than astonishing to the observer of nature.

These spouts are seen very commonly in the tropical seas, and sometimes in our own. Those seen by Tournefort, in the Mediterranean, he has described as follows: "The first of these," says this great botanist, "that we saw, was about a musket-shot from our ship. There we perceived the water began to boil, and to rise about a foot above its level. The water was agitated and whitish; and, above its surface, there seemed to stand a smoke, such as might be imagined to come from wet straw before it begins to blaze. It made a sort of a murmuring sound, like that of a torrent heart at a distance, mixed, at the same time, with a hissing noise, like that of a serpent: shortly after, we perceived a column of this smoke rise up to the clouds, at the same time whirling about with great rapidity. It appeared to be as thick as one's finger; and the former sound still continued. When this disappeared, after lasting for about eight minutes, upon turning to the opposite quarter of the sky, we perceived another, which began in the manner of the former; presently after, a third appeared in the west; and instantly beside it still another arose. The most distant of these three could not be above a musket-shot from the ship. They all continued like so many heaps of wet straw set on fire, that continued to smoke, and to make the same noise as before. We soon after perceived each, with its respective canal, mounting up in the clouds, and spreading where it touched; the cloud, like the mouth of a trumpet, making a figure, to express it intelligibly, as if the tail of an animal were pulled at one end by a weight. These canals were of a whitish colour, and so tinged, as I suppose, by the water which was contained in them; for, previous to this, they were apparently empty, and of the colour of transparent glass. These canals were not straight, but bent in some parts, and far from being perpendicular, but rising in their clouds with a very inclined ascent. But what is very particular, the cloud to which one of them was pointed happening to be driven by the wind, the spout still continued to follow its motion, without being broken; and passing behind one of the others, the spouts crossed each other, in the form of a St. Andrew's cross. In the beginning they were all about as thick as one's finger, except at the top, where they were broader, and two of them disappeared; but shortly after, the last of the three increased considerably; and its canal, which was at first so small, soon became as thick as a man's arm, then as his leg, and, at last, thicker than his whole body. We saw distinetly, through this transparent body, the water, which rose up with a kind of spiral motion; and it sometimes diminished a little of its thickness, and again resumed the same; sometimes widening at top, and sometimes at bottom; exactly 
resembling a gut filled with water, pressed with the fingers, to make the fluid rise, or fall; and I am well convinced that this alteration in the spout was caused by the wind, which pressed the cloud, and impelled it to give up its contents. After some time its bulk was so diminished as to be no thicker than a man's arm again ; and thus, swelling and diminishing, it at last became very small. In the end, I observed the sea which was raised about it to resume its level by degrees, and the end of the canal that touched it to become as small as if it had been tied round with a cord; and this contiumed till the light, striking through the cloud, took away the view. I still, however, continued to look, expecting that its parts would join again, as I had before seen in one of the others, in which the spout was more than once broken, and yet again came together; but I was disappointed, for the spout appeared no more."

Many have been the solutions offered for this surprising appearance. Mr. Buffon supposes the spout, here described, to proceed from the operation of fire, beneath the bed of the sea; as the waters at the surface are thus seen agitated. However, the solution of Dr. Stuart is not divested of probability; who thinks it may be accounted for by suction, as in the application of a cupping-glass to the skin.

Wherever spouts of this kind are seen, they are extremely dreaded by mariners; for if they happen to fall upon a ship, they most commonly dash it to the bottom. But, if the ship be large enough to sustain the deluge, they are at least sure to destroy its sails and rigging, and render it unfit for sailing. It is said that vessels of any force usually fire their guns at them, loaden with a bar of iron; anil if so happy as to strike them, the water is instantly seen to fall from them, with a dreadful noise, though without any farther mischief.

I am at a loss whether we ought to reckon these spouts called typhons, which are sometimes seen at land, of the same kind with those so often described by mariners at sea, as they seem to differ in several respects. That, for instance, observed at Hattield, in Yorkshire, in $\mathbf{1 6 8 7}$, as it is described by the person who oaw it, secms rather to have been a whirlwind than a water-spout. The season in พо. $11 \& 12$. which it appeared was very dry, the weather extremely hot, and the air very cloudy. After the wind had blown for some time with considerable force, and condensed the black clouds one upon another, a great whirling of the air ensued; upon which the centre of the clouds, every now and then, darted down in the shape of a thick long black pipe; in which the relator could distinctly view a motion, like that of a screw, continually screwing up to itself, as it were, whatever it happened to touch. In its progress it moved slowly over a grove of young trees, which it violently bent in a circular motion. Going forward to a barn, it in a minute stript it of all the thatch, and filled the whole air with the same. As it came near the relator, he perceived that its blackness proceeded from a gyration of the clouds, by contrary winds meeting in a point, or a centre; and where the greatest force was exerted, there darting down, like an Archimedes' screw, to suck up all that came in its way. Another which he saw, some time after, was attended with still more terrible effects; levelling or tearing up great oak-trees, catching up the birds in its vortex, and dashing them against the ground. In this manner it proceeded with an audible whirling noise, like that of a mill; and at length dissolved, after having done much mischief.

But we must still continue to suspend our assent as to the nature even of these land spouts, since they have been sometimes found to drop, in a great column of water, at once upon the earth, and produce an instant inundation, which could not readily have happened had they been caused by the gyration of a whirlwind only. Indeed, every conjecture regarding these meteors, seems to me entirely unsatisfactory. They sometimes appear in the calmest weather at sea, of which I have been an eye-witness; and, therefore, these are not caused by a whirlwind. They are alivays capped by a cloud; and, therefore, are not likely to proceed from fires at the loottom. 'Tliey change place; and, therefore, suction seems impracticable. In short, we still want facts, upon "which to build a rational theory ; and, instead of knowledge, we

- Phil. Trans. vol. iv. p. 108. 
must be contented with admiration. To be well acquainted with the appearances of nature, even though we are ignorant of their causes, often constitutes the most useful wisdom. ${ }^{\mathrm{a}}$

[But among all the wonders that have lately cngaged the attention of the philosopher and the chemist, is the circumstance, that after the explosion of these luminous meteors, heavy stones, varying in bulk and number, have almost constantly fallen from them to the earth. Credibility in a fact, for which not even a conjectural cause in the remotest degree probable could be assigned, was for some time suspended: but the proofs are now so numerous, and of such respectable authority, that it can no longer be doubted.

In the year 1794, Dr. Chaldni published a dissertation on this subject; and two years afterwards Mr. King produced a still inore complete collection of exumples, both ancient and modern, many of them supported by such evidence, that even scepticism could no longer refuse its consent. Mr. Howard, in the Philosophical Transactions for 1802, published an admirable treatise, endeavouring to throw all possible light upon a subject so singular and interesting. He not only collected all the recent and well-authenticated accounts of the fall of the stony bodies, and examined the evidence of their truth, but procured specimens of the stones which were said to have fallen in different places, compared them together, and suljected them to

[ Dr. Franklin supposes a water-spout and a whilwind to proceed from the same cause : a fluid moving from all points horizontally tuwards a centre, must at that centre either mount or descend. If a hole lee opened in the middle of llie bottom of a tub filled with water, the water will flow from all sides to the centrc, and then descend in a whirl: but the air flowing on or near the surface of land or water, from all sides towards a centre, must at that centre ascend, because the land or water will hinder descent.

The lower region of the air is often more heated, and so more rarefied, than the upper, and consequently speeifically lighter: if therefore a large tract of land or sea, unsheltered by clouds, and unrufled by wind, become violently heated and rarefied, so that the lower region become lighter than the superincumbent upper one, the heated lighter air will ascend like smoke up a chininey; and as this rising cannot operate through the whole tract at once, becanse that would leave too extensive a vacuum, the rising will begin in that culumn which happens to be most rarefied; and the warm air will flow horizontally chemical analysis. It may here be proper to give a few of the more recent instances, with the testimonies upon which they rest.

In July, 1794, about twelve stones fell near Sienna in Tuscany, as related by the Earl of Bristol. December 13, 1795, a large stone of tifty-six pounds weight, fell at Wold cottage in Yorkshire, and is described by captain Topham. February 19, 1796, a stone of ten pounds weight fell in Portugal, an account of which is given by Mr. Southey. December 19,1798 , showers of stones fell at Benares in the East Indies, upon the testimony of J.Lloyd Williams, Esq. A pril26, 1803, according to M. Fourcroy, several stones, from ten to fourteen pounds weight, fell near L'Aigle in Normandy.

In corroboration of these facts, it appears, that whether they have fallen in England, France, Italy, Germany, or India, they are all composed of the same ingredients, all resemble each other, and completely differ from any other kuown stone. Sometimes the stones continue luminous till they sink into the earth, but most commonly their luminousness disappears at the time of explosion; but they are always found hot. Their size differs from a few ounces to several tons; they are usually of a roundish form, and always covered with a black crust. When broken they appear of an ashy-gray colour, and of a granular texture, like a coarse sand-stone, and have an earthy stuell.

A stone which fell in Yorkshire, deprived as much as possible of its metallic particles,

from all parts of this column, where the several currents ineeting, a whirl or eddy is nalurally formed, ascending by a spiral motion, in the same manner as water descends spirally through the hole in the tub.

If the vacuum passes over water, the water may rise in a body or culumn to the heiglut of about 32 feet; and this whirl of air may be as invisible as air itself. As the whirl weakens, the tube may apparently separate in the middle; the column of water subsiding, the superior condensed part drawing up to the cloud. The tube or whirl of air may nevertlieless remain entire, the middle only becoining invisible, as not containing any visible matter.

The author has, frequently, in a fine calm summer's day, when the sun luas been very hot, and the atmosphere unruffled by winds, secu slieaves of corn, bay-cocks, and other nuveable substances, suddenly lifted up with a circular motion, and carried to a considerable distance: and in a blazing fire, where the llame and smoke are carried up through a small chimney, if a piece of paper or other very light substance be put into the flame, it will be lifted up the chimney with a spiral motion.] 
according to Mr. Howard, produced from one hundrel and fifty grains, seventy-five of siliceous earth, thirty-seven of magnesia, forty-eight of oxyde, or calx of iron, and two of oxyde, or calx of nickell; leaving an excess from its original weight of twelve grains, owing to the oxydation of the metallic bodics.

Various conjectures have been made, to account for their appearance; but such is the obscurity of the subject, that no opinion in the slightest degree probable has yet been advanced. It was at first supposed, that they had been thrown out of volcanoes, but the iminense distance from all volcanoes renders this opinion of little value. Chaldni endeavoured to prove, that the meteors from which they fell, were bodies floating in space, unconnected with any planetary system, attracted by the earth in their progress, and kindied by their rapid motion in the atmosphere. Laplace suggests the probability of their having been thrown off by the volcanoes of the moon; but the meteors which almost always accompany them, and the swiftness of their horizontal motion, persuade us to reject this opinion. Sir William Hamilton, and Mr. King, with greater probability consider them as concretions actually formed in the atmosphere.

In addition to these, the showers of sulphur which arc related to have occasionally fallen, and the vast masses of iron found in South America, and Siberia, are supposed to have their origin from the same causes: for it is a singular coincidence, that these pieces of iron contain nickell, which has never been known to be present in real native iron.

Upon the whole, we can only look with ignorant astonishment, and at present consider these stony and metallic masses as fragments of meteoric fire-balls, which have burst in the atmosphere, the origin and causes of which must be left to the accumulated wisdom and inquiry of future ages.]

\section{CHAPTER XXII.}

\section{THE CONCLUSION.}

HAVING thus gone through a particular description of the earth, let us now pause for a moment, to contemplate the great picture before us. The universe may be considered as the palace in which the Deity resides; and this earth as one of its apartments. In this, all the meaner races of animated nature mechanically obey him; and stand ready to exccute his commands without hesitation. Mall alone is found refractory; he is the only being endued with a power of contradicting these mandates. The Deity was pleased to exert superior power in creating him a superior being; a being cndued with a choice of good and evil ; and capable, in some measure, of co-operating witl his own intentions. Man, therefore, may be considered as a limited creature, endued with powers imitative of those residing in the Deity. He is thrown into a world that stands in need of his help; and has bcen granted a power of producing harmony from partial confusion.

If, therefore, we consider the earth as allotted for our habitation, we shall find that much has been given us to enjoy, and much to amend; that we have anple reasons for our gratitude, and still more for our industry. In those great outlines of nature, to which art cannot reach, and where our greatest efforts must have been ineffectual, God himself has finished these with amazing grandeur and beauty. Our beneficent Father has considered these parts of nature as peculiarly his own; as parts which no creature could have skill or strength to amend: and, therefore, made them incapable of alteration, or of more perfect regularity. The heavens and the firmament show the wisdom and the glory of the Workman. Astronomers, who are best skilled in the symmetry of systems, can find nothing there that they can alter for the bet$2 B^{*}$ 
ter. God made these perfect, because no subordinate being could correct their defects.

When, therefore, we survey nature on this side, nothing can be more splendid, more correct, or amazing. We there behold a Deity residing in the midst of an universe, infinitely extended every way, animating all, and cheering the vacuity with his presence! We behold an immense and shapeless mass of matter, formed into worlds by his power, and dispersed at intervals, to which even the imagination cannot travel! In this great theatre of his glory, a thousand suns, like our own, animate their respective systems, appearing and vanishing at divine command. We behold our own bright luminary, fixed in the centre of its system, wheeling its planets in times proportioned to their clistances, and at once dispensing light, heat, and action. The earth also is seen with its twofold motion; producing, by the one, the change of seasons; and, by the other, the grateful vicissitudes of day and night. With what silent magnificence is all this performed! with what seeming ease! The works of art are exerted with interrupted force; and their noisy progress discovers the obstructions they receive: but the carth, with a silent steady rotation, successively presents every part of its bosom to the sun; at once imbibing nourishment and light from that parent of vegetation and fertility.

But not only provisions of heat and light are thus supplied, but its whole surface is covered with a transparent atmosphere, that turns with its motion, and guards it from external injury. The rays of the sun are thus broken into a genial warmth; and, while the surface is assisted, a gentle heat is produced in the bowels of the earth, which contributes to cover it with verdure. Waters also are supplied in healthful abundance, to support life, and assist vegetation. Mountains arise, to diversify the prospect, and give a current to the stream. Seas extend from one continent to the other, replenished with animals that may be turned to human support; and also serving to enrich the earth with a suf- ficiency of vapour. Breezes fly along the surface of the fields, to promote health and vegetation. The coolness of the evening invites to rest; and the freshness of the inorning renews for labour.

Such are the delights of the habitation that has beell assigned to man; without any one of these, he must have been wretched; and none of these could his own industry have supplied. But while many of his wants are thus kindly furnished on the one hand, there are numberless inconveniences to excite his industry on the other. This habitation, though provided with all the conveniences of air, pasturage, and water, is but a desert place, without human cultivation. The lowest animal finds more conveniences in the wilds of nature than he who boasts himself their lord. The whirlwind, the inundation, and all the asperities of the air, are peculiarly terrible to man, who knows their consequences, and, at a distance, dreads their approach. The earth itself, where human art has not pervaded, puts on a frightful gloomy appearance. The forests are dark and tangled; the meadows overgrown with rank weeds; and the brooks stray without a determined channel. Nature, that has been kind to every lower order of beings, has been quite neglectful with regard to him; to the savage uncontriving man the earth is an abode of desolation, where his shelter is insufficient, and his food precarious.

A world thus furnished with advantages on one side, and inconveniences on the other, is the proper abode of reason, is the fittest to exercise the industry of a free and a thinking creature. These evils, which art can remedy, and prescience guard against, are a proper call for the exertion of his faculties; and they tend still more to assimilate him to his Creator. God beholds with pleasure that being which he has made, converting the wretchedness of his natural situation into a theatre of triumph; bringing all the headlong tribes of nature into subjection to his will; and producing that order and uniformity upon earth, of which his own heavenly fabric is so bright an example. 


\section{Of สntma!ม.}

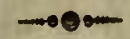

\section{CHAPTER XXII.}

\section{A COMPARISON OF ANIMALS WITH THE INFERIOR RANKS OF CREATION.}

HAVING given an account of the earth in general, and the advantages and inconveniences with which it abounds, we now come to consider it more minutely. Having described the habitation, we are naturally led to i:iquire after the inhabitants. Amidst the infinitely different productions which the earth offers, and with which it is every where covered, animals hold the first rank; as well because of the finer formation of their parts, as of their superior power. The vegetable, which is fixed to one spot, and obliged to wait for its accidental supplies of nourishment, may be considered as the prisoner of nature. Unable to correct the disadvantages of its situation, or to shield itself from the dangers that surround it, every object that has motion may be its destroyer.

But animals are endowed with powers of motion and defence. The greatest part are capable, by changing place, of commanding nature; and of thus obliging her to furnish that nourishment which is most agreeable to their state. Those few that are fixed to one spot, even in this seemingly helpless situation, are, inevertheless, protected from external injury by a hard shelly covering; which they often can close at pleasure, and thus defend themselves from every assault. And here, I think, we may draw the line between the animal and vegetable kingdoms. Every animal, by soine means or other, finds protection froun injury; either from its force, or courage, its swiftness, or cunning. Some are protected by hiding in convenient places; and others by taking refuge in a hard resisting shell. But vegetables are totally unprotectod; they are exposed to every assailant, and patiently submissive in every attack. In a word, an animal is an organized being, that is in some measure provided for its own security ; a vegetable is destitute of every protec. tion.

But though it is very easy, without the help of definitions, to distinguish a plant from an animal, yet both possess many properties so much alike, that the two kingdoms, as they are called, seemed mixed with each other. Hence, it frequently puzzles the naturalist to tell exactly where animal life begins, and vegetative terminates: nor, indeed, is it easy to re-solve, whether some objects offered to view be of the lowest of the animal, or the highest of the vegetable races. The sensitive plant, that moves at the touch, seems to have as much perception as the fresh-water polypus, that is possessed of a still slower share of motion. Besides, the sensitive plant will not reproduce upon cutting in pieces, which the polypus is known to do; so that the vegetable production seems to have the superiority. But, notwithstanding this, the polypus hunts for its food, as most other animals do. It changes its situation; and, therefore, possesses a power of choosing its food, or retreating from danger. Still, therefore, the animal kingdom is far removed above the vegetable; and its lowest denizen is possessed of very great privileges, when compared with the plants with which it is often surrounded.

However, both classes have many resemblances, by which they are raised above the unorganized and inert masses of nature. Minerals are mere inactive, insensible bodies, entirely motionless of themselves, and waiting some external force to alter their forms, 
or their properties. But it is otherwise with animals and vegetables; these are endued with life and vigonr; they have their state of improvement and decay; they are capable of reproducing their kinds; they grow from seeds in some, and from cuttings in others; they seem all possessed of sensation, in a greater or less degree; they both have their enmities and affections; and, as some animals are, by nature, impelled to violence, so some plants are found to exterminate all others, and make a wilderuess of the places round them. As the lion makes a desert of the forest where it resides, thus no other plant will grow under the shade of the inanchineeltree. Thus, also, that plant, in the West Indies, called caraguata, clings round whatever tree it happens to approach: there it quickly gains the ascendant; and, loading the tree with a verdure not its own, keeps away that nourishment designed to feed the trunk; and, at last, entirely destroys its supporter. As all animals are ultimately supported upon vegetables, so vegetables are greatly propagated, by being made a part of animal food. Birds distribute the seeds wherever they fly, and quadrupeds prune them into greater luxuriance. By these means the quantity of food, in a state of nature, is kept equal to the number of the consumers; and, lest some of the weaker ranks of animals should find nothing for their support, but all the provisions be devoured by the strong, different vegetables are appropriated to different appetites. If, transgressing this rule, the stronger ranks should invade the rights of the weak, and, breaking through all regard to appetite, should make an indiscriminate use of every vegetable, nature then punishes the transgression, and poison marks the crime as capital.

If, again, we compare vegetables and animals, with respect to the places where they are found, we shall find them bearing a still stronger similitude. The vegetables that grow in a dry and sunny soil, are strong and vigorous, though not luxuriant; so, also, are the animals of such a climate. Those, on the contrary, that are the joint product of heat and moisture, are luxuriant and tender; and the animals assimilating to the vegetable food, on which they ultimately subsist, are much larger in sucl places than in others. Thus, in the internal parts of South America and Africa, where the sun usually scorches all above, while inundations cover all below, the insects, reptiles, and other animals, grow to a prodigious size: the earth-worm of America is often a yard in length, and as thick as a walking cane; the boiguacu, which is the largest of the serpent kind, is sometimes forty feet in length; the bats, in those countries, are as big as a rabbit; the toads are bigger than a duck; and their spiders are as large as a sparrow. On the contrary, in the cold frozen regions of the north, where vegetable nature is stinted of its growth, the few animals in those climates partake of the diminution; all the wild animals, except the bear, are much smaller than in milder countries; and such of the domestic kinds as are carried thither, quickly degenerate, and grow. less. Their very insects are of the minute kinds, their bees and spiders being not half so large as those in the temperate zone.

The similitude between vegetables and animals is no where more obvious than in those that belong to the ocean, where the nature of one is admirably adapted to the necessities of the other. This element, it is well known, has its vegetables, and its insects that feed upon them in great abundance. Over many tracts of the sea, a weed is seen floating, which covers the surface, and gives the resemblance of a green and extensive meadow. On the under side of these unstable plants, millions of little animals are found, adapted to their situation. For, as their ground, if I may so express it, lies over their heads, their feet are placed upon their backs; and, as land animals have their legs below their bodies, these have them above. At land also, most animals are furnished with eyes to see their food; but at sea, almost all the reptile kinds are without eyes, which might only give them prospects of danger at a time when unprovided with the means of escaping it. ${ }^{2}$

Thus, in all places, we perceive an obvious similitude between the animals and the vegetables of every region. In general, however, the most perfect races have the least

- Linnæi Amonitates, vol. v. p. 68. 
similitude to the vegetable productions on which they are ultimately fed; while, on the contrary, the meaner the animal, the more local it is found to be, and the more it is influenced by the varieties of the soil where it resides. Many of the more humble reptile kinds are not only confined to one country, but also to a plant; nay, even to a leaf. Upon that they subsist; increase with its vegetation, and seem to decay as it declines. They are merely the circumscribed inhabitants of a single vegetable: take them from that, and they instantly die; being entirely assimilated to the plant they feed on, assuming its colour, and even its medicinal properties. For this reason, there are infinite numbers of the meaner animals that we have never an opportunity of seeing in this part of the world; they are incapable of living separate from their kindred vegetables, which grow only in a certain climate.

Such animals as are formed more perfect, lead a life of less dependance; and some kinds are found to subsist in many parts of the world at the same time. But, of all the races of animated nature, man is the least affected by the soil where he resides, and least influenced by the variations of vegetable sustenance: equally unaffected by the luxuriance of the warm climates, or the sterility of the poles, he has spread his habitations over the whole earth; and finds subsistence as well amidst the ice of the north as the burning deserts under the Line. All creatures of an inferior nature, as has been said, have peculiar propensities to peculiar climates; they are circumscribed to zones, and confined to territories, where their proper food is found in the greatest abundance; but man may be called the animal of every climate, and suffers but very gradual alterations from the nature of any situation.

As to animals of a meaner rank, whom man compels to attend him in his migrations, these being obliged to live in a kind of constraint, and upon vegetable food, often different from that of their native soil, they very soon alter their natures with the nature of their nourishment, assimilate to the vegetables upon which they are fed, and thus assume very different habits as well as appearances. Thus man, unaffected himself, alters and directs the nature of other animals at his pleasure; increases their strength for his delight, or their patience for his necessities.

This power of altering the appearances of things, seems to have been given him for very wise purposes. The Deity, when he made the earth, was willing to give his favoured creature many opponents, that might at once exercise his virtues, and call forth his latent abilities. Hence we find, in those wide uncultivated wildernesses, where man, in his savage state, owns inferior strength, and the beasts claim divided dominion, that the whole forest swarms with noxious animals and vegetables; animals, as yet undescribed, and vegctables which want a name. In those recesses, nature seems rather lavish than magnificent in bestowing life. The trees are usually of the largest kinds, covered round with parasite plants, and interwoven at the tops with eacl other. The boughs, both above and below, are peopled with various generations; some of which have never been upon the ground, and others have newier stirred from the branches on which they were produced. In this manner millions of minute and loathsome creatures pursue a round of uninterrupted existence, and enjoy a life scarcely superior to vegetation. At the same time, the vegetables in those places are of the larger kinds, while the animal race is of the smaller: but man has altered this disposition of nature; having, in a great measure, levelled the extensive forests, cultivated the softer and finer vegetables, destroyed the numberless tribes of minute and noxious animals, and taken every method to increase a numerous breed of the larger kinds. He thus has exercised a severe control ; unpeopled nature, to embellish it ; and diminished the size of the vegetable, in order to improve that of the animal kingdom.

To subdue the earth to his own use was, and ought to be, the aim of man; which was only to be done by increasing the number of plants, and diminishing that of animals: to multiply existence, alone was that of the Deity. For this reason, we find, in a state of nature, that animal life is increased to the greatest quantity possible; and, we can scarcely form a system that could add to its numbers. First, plants or trees are pro- 
vided by nature, of the largest kinds; and, consequently, the nourishing surface is thus extended. In the second place, there are animals peculiar to every part of the vegetable, so that no part of it is lost. But the greatest possible increase of life would still be deficient, were there not other animals that lived upon animals; and these are, themselves, in turn, food for some other greater and stronger set of creatures. Were all animals to live upon vegetables alone, thousands would be extinct that now have existence, as the quantity of their provision would shortly fail. But, as things are wisely constituted, one animal now supports another; and thus, all take up less room than they would by living on the same food; as, to make use of a similar instance, a greater number of people may be crowded into the same space, if each is made to bear his fellow upon his shoulders.

To diminish the number of animals, and increase that of vegetables, has been the general scope of human industry; and, if we compare the utility of the kinds, with respect to man, we shall find, that of the vast variety in the animal kingdom, but very few are serviceable to him; and, in the vegetable, but very few are entirely noxious. How small a part of the insect tribes, for instance, are beneficial to mankind, and what numbers are injurious! In some countries they almost darken the air : a candle cannot be lighted without their instantly flying upon it, and putting out the flame. ${ }^{a}$ The closest recesses are no safeguard from their annoyance; and the most beautiful landscapes of nature only serve to invite their rapacity. As these are injurious, from their multitudes, so most of the larger kinds are equally dreadful to him, from their courage and ferocity. In the most uncultivated parts of the forest these maintain an undisputed empire; and man invades

- Ulloa's Description of Guayaquil. their retreats with terror. These are dreadful; and there are still more which are utterly useless to him, that serve to take up the room which more beneficial creatures might possess; and incommode him, rather with their numbers than their enmities. Thus, in a catalogue of land-animals, that amounts to more than twenty thousand, we can scarcely reckon up a hundred that are ally way useful to him; the rest being either all his open or his secret enemies, immediately attacking him in person, or intruding upon that food he has appropriated to himself. Vegetables, on the contrary, though existing in greater variety, are but few of them noxious. The most deadly poisons are often of great use in medicine; and even those plants that only seen to cumber the ground, serve for food to that race of animals which he has taken into friendship or protection. The smaller tribes of vegetables, in particular, are cultivated, as contributing either to his necessities or amusement; so that vegetable life is as much promoted by human industry, as animal life is controlled and diminished.

Hence it was not without a long struggle, and various combinations of experience and art, that man acquired his present dominion. Almost every good that he possesses was the result of the contest; for, every day, as he was contending, he was growing more wise; and patience and fortitude were the fruits of his industry.

Hence, also, we see the necessity of some animals living upon each other, to fill up the plan of Providence; and we may, consequently, infer the expediency of man's living upon all. Both animals and vegetables seem equally fitted to his appetites; and were any religious or moral motives to restrain him from taking away life, upon any account, he would only thus give existence to a variety of beings made to prey upon each other; and, instead of preventing, multiply mutual destruction. 


\section{Chapter XXIV.}

\section{OF THE GENERATION OF ANIMALS.}

BEFORE we survey animals in their state of maturity, and perforining the functions adapted to their respective natures, method requires that we should consider them in the more early periods of their existence. There has been a time when the proudest and the noblest animal was a partaker of the same imbecility with the meanest reptile; and, while yet a candidate for existence, equally helpless and contemptible. In their incipient state, all are upon a footing; the insect and the philosopher being equally insensible, clogged with matter, and unconscious of existence. Where then are we to begin with the history of those beings, that make such a distinguished figure in the creation? $\mathrm{Or}$, where lie those peculiar characters in the parts that go to make up animated naturethat mark one animal as destined to creep in the dust, and another to glitter on the throne?

This has been a subject that has employed the curiosity of all ages, and the plitosophers of every age have attempted the solution. In tracing nature to her most lidden recesses, she becomes too minute or obscure for our inspection; so that we find it impossible to mark her first differences, to discover the point where animal life begins, or the cause that conduces to set it in motion. We know little more than that the greatest number of animals require the concurrence of a male and female to reproduce their kind; and that these, distinctly and invariably, are found to beget creatures of their own species. Curiosity has, therefore, been active in trying to discover the immediate result of this union; how far either sex contributes to the bestowing animal life, and whether it be to the male or female that we are most indebted for the privilege of our existence.

Hippocrates has supposed that fecundity proceeded from the mixture of the seminal liquor of both sexes, each of which equally contributes to the formation of the incipient animal. Aristotle, on the other hand, would have the seminal liquor in the male alone to contribute to this purpose, while the female supplied the proper nourishment for its support. Such were the opinions of these fathers of philosophy; and these continued to be adopted by the naturalists and schoolmen of succeeding ages, with blind veneration. At length, Steno and Harvey, taking anatony for their guide, gave mankind a nearer view of nature just advancing into animation. These perceived, in all such animals as produced their young alive, two glandular bodies, near the womb, resembling that ovary, or eluster of small eggs, which is found in fowls; and from the analogy between both, they gave these also the name of ovaria, These, as they resembled eggs, they naturally concluded had the same offices; and, therefore, they were induced to think that all animals, of what kind soever, were produced from eggs. At first, however, there was some altereation raised against this system: for, as these ovaria were separate froin the womb, it was objected that they could not be any way instrumental in replenishing that organ, with which they did not communicate. But, upon more minute inspection, Fallopius, the anatomist, perceived two tulullar vessels depending from the womb, which, like the horns of a snail, had a power of erecting themselves, of embraciug the ovaria, and of receiving the eggs, in order to be fecundated by the seminal liquor. This diseovery seemed, for a long time after, to fix the opinions of philosophers. The doctrine of Hippocrates was re-established, and the chief business of generation was ascribed to the female. This was for a long time the established opinion of the schools; but Leuwenhoeck, once more, shook the whole system, and produced a new schism among the lovers of speculation. Upon examining the seminal liquor of a great variety of male animals with microscopes, which helped his sight more than that of any of his successors, he perceived. $2 \mathrm{C}$ 
therein infinite numbers of little living creatures, like tadpoles, very brisk, and floating in the fluid with a seeming voluntary motion. Each of these, therefore, was thought to be the rudiments of an animal, similar to that from which it was produced; and this only required a reception from the female, together with proper nourishment, to complete its growth. The business of gencration was now, therefore, given back to the male a second time, by many; while others suspended their assent, and chose rather to confess ignorance than to embrace error."

In this manner has the dispute continued for several ages, some accidental discovery serving, at intervals, to renew the debate, and revive curiosity. It was a subject where speculation could find much room to display itself; and Mr. Buffon, who loved to speculate, would not omit such an opportunity of giving scope to his propensity. According to this most pleasing of all naturalists, the inicroscopediscovers that the seminal liquor, not only of males, but of females also, abounds in these moving little animals, which have been mentioned above, and that they appear equally brisk in either fluid. These he takes not to be real animals, but organical particles, which, being simple, cannot be said to be organized themselves, but go to the composition of all organized bodies whatsoever; in the same manner as a tooth, in the wheel of a watch, cannot be called either the wheel or the watch, and yet contributes to the sum of the machine. These organical particles are, according to him, diffused throughout all nature, and to be found not only in the seminal. liquor, but in most other fluids in the parts of vegetables, and all parts of animated nature. As they happen, therefore, to be differently applied, they serve to constitute a part of the animal, or the vegetable, whose growth they serve to increase, while the superfluity is thrown off in the seminal liquor of both sexes, for the reproduction of other animals or vegetables of the same species. These particles assume different figures, according to the receptacle into which they enter; falling into the womb, they unite into a foetus; beneath the bark of a tree they pul-

- Bonnet Considerations sui les Corps Organises. lulate into branches; and, in short, the same particles that first formed the animal in the womb, contribute to increase its growth when brought forth."

To this system it has been objected, that it is impossible to conceive organical substances without being organized; and that, if divested of organization themselves, they could never make an organized body, as an infinity of circles could never make a triangle. It has been objected, that it is more difficult to conceive the transformation of these organical particles, than even that of the animal, whose growth we are inquiring after; and this system, therefore, atteinpts to explain one obscure thing by another still more obscure.

But an objection, still stronger than these, has been advanced by an ingenious countryman of our own; who asserts, that these little animals, which thus appear swimming and sporting in almost every fluid we examine with a microscope, are not real living particles, but some of the more opaque parts of the fluid, that are thus increased in size, and seem to have a much greater motion than they have in reality. For the motion being magnified with the object, the smallest degree of it will seem very considerable; and a being almost at rest may, by these means, be apparently put into violent action. Thus, for instance, if we look upon the sails of a windinill moving at a distance, they appear to go very slow; but, if 'we approach them, and thus magnify their bulk to our eye, they go round with great rapidity. A microscope, in the same manner, serves to bring our eye close to the object, and thus to enlarge it; and not only increase the magnitude of its parts, but of its motion. Hence, therefore, it would follow, that these organical particles, that are said to constitute the bulk of living nature, are but mere optical illusions; and the system founded on them must, like them, be illusive.

These, and many other objections, have been made to this system; which, instead of enlightening the mind, serve only to show, that too close a pursuit of nature very often leads to uncertainty. Happily, however, for

- Mr. Buffon. 
inankind, the most intricate inquiries are generally the most uscless. Instead, therefore, of balancing accounts between the sexes, and at teinpting to ascertain to which the business of generation most properly belongs, it will be more instructive, as well as anusing, to begin witl animal nature, from its carliest retirements, and evanescent outlines, and pursue the incipient creature through all its changes in the womb, till it arrives into open day.

The usual distinction of animals, with respect to their manner of geucration, has been into the oviparous and viviparous kinds; or, in other words, into those that bring forth an egg, which is afterwards hatched into life, and those that bring forth their young alive and perfect. In one of these two ways all animals were supposed to have been produced, and all other kinds of generation were supposed imaginary or erroneous. But later discoveries have taught us to be more cautious in making general conclusions, and have even induced many to doubt whether animal life may not be produced merely from putrefaction."

Indecd, the infinite number of creatures that putrid substances seem to give birth to, and the variety of little insects seen floating in liquors, by the microscope, appear to favour this opinion. But, however this may be, the former method of classing animals can now by no means be admitted, as we find many animals that are produced neither from the womb, nor from the shell, but merely from cuttings; so that to multiply life in some creatures, it is sufticient only to multiply the dissection. This being the simplest method of generation, and that in which life seems to require the smallest preparation for its existtence, I will begin witl it, and so proceed to the two other kinds, from the meanest to the most elaborate.

The earth-worm, the millepedes, the seaworm, and many marine insects, may be multiplied by being cut in pieces; but the polypus is noted for its amazing fertility; and from hence it will be proper to take the description. The structure of the polypus may be compared to the finger of a glove, open at one end, and closed at the other. The

\footnotetext{
- Bonnet Consid. p. 100.
}

closed end represents the tail of the polypus, with which it serves to fix itself to any suhstance it happens to be upon; the open end may be compared to the mouth; and, if we conceive six or eight small strings issuing from this end, we shall have a proper idea of its arms, which it can ercet, lengthen, and contract, at pleasure, like the horns of a snail. This creature is very voracious, and makes use of its arms as a fisherman does of his net, to catch and entangle such little animals as happen to come within its rcach. It lengthens these arms several inches, keeps them separated from each other, and thus occupies a large space in the water, in which it resides. These arms, when extended, are as fine as threads of silk, and have a most exquisite degree of feeling. If a small worm happens to get within the sphere of their activity, it is quickly entangled by one of these arms, and, soon after, the other arms come to its aid; these all together shortening, the worm is drawn into the animal's mouth, and quickly devoured, colouring the body as it is swallowed. Thus much is necessary to be observed of this animal's method of living, to show that it is not of the vegetable tribe, but a real animal, performing the functions which other animals are found to perform, and endued with powers that many of them are destitute of. But what is most extraordinary remains yet to be told; for, if examined with a microscope, there are seen several little specks, like buds, that seem to pullulate from different parts of its body; and these soon after appear to be young polypi, and, like the large polypus, begin to cast their little arms about for prey, in the same manner. Whatever they happen to ensnare is devoured, and gives a colour not only to their own bodies, but to that of the parent; so that the same food is digested, and serves for the nourishment of both. The food of the little one passes into the large polypus, and colours its body; and this, in its turn, digests, and swallows its food to pass into theirs. In this manner every polypus has a new colony sprouting from its body; and these new ones, even while attached to the parent animal, become parents themselves, having a smaller colony also budding from them; all, at the same time, busily employed in seeking for 
their prey, and the food of any one of them serving for the nourishment, and eirculating through the bodies, of all the rest. This society, however, is every hour dissolving; those newly produced are seen at intervals to leave the body of the large polypus, and beeome, shortly after, the head of a beginning colony themselves.

In this manner the polypus multiplies naturally; but one may take a much readier and shorter way to inerease them, and this only by cutting them in pieees. Though cut into thousands of parts, eaeh part still retains its vivacious qualities, and each shortly becomes a distinct and complete polypus; whether cut lengthways or crossways, it is all the same: this extraordinary ereature seems a gainer by our endeavours, and inultiplies by apparent destruction. The experiment has been tried, tines without number, and still attended with the same success. Here, therefore, naturalists, who have been blamed for the cruelty of their experiments upon living animals, may now boast of their increasing animal life, instead of destroying it. The production of the polypus is a kind of philosophical generation. The famons Sir Thomas Brown hoped one day to be able to produce children by the same method as trees are produced: the polypus is multiplied in this manner; and every philosopher may thus, if he please, boast of a very uumerous, though, I should suppose, a very useless progeny.

This method of generation, from cuttings, may be considered as the most simple kind, and is a strong instance of the little pains nature takes in the formation of her lower and humbler productions. As the removal of these from inanimate into animal existence is but small, there are but few preparations made for their journey. No organs of generation seem provided, no womb to receive, no shell to protect them in their state of transition. The little reptile is quickly fitted for all the offices of its humble sphere, and, in a very short time, arrives at the height of its contemptible perfection.

The next generation is of those animals that we see produced from the egg. In this manner all birds, most fishes, and many of the insect tribes, are brought forth. An egg may be considered as a womb, detached from the body of the parent animal, in which the embryo is but just beginning to be formed. It may be regarded as a kind of incomplete delivery, in which the aninal is disburthened of its young before its perfect formation. Fishes and insects, indeed, most usually commit the care of their eggs to hazard; but birds, which are more perfectly formed, are found to hateh them into maturity by the warmth of their bodies. However, any other heat, of the same temperature, would answer the end as well; for either the warmth of the sun, or of a stove, is equally efficacious in bringing the animal in the egg to perfection. In this respect, therefore, we may consider generation from the egg as inferior to that in which the animal is brought forth alive. Nature has taken care of the viviparous anj$\mathrm{mal}$ in every stage of its existence. That force which separates it from the parent, separates it from life; and the embryo is shielded with unceasing protection till it arrives at exclusion. But it is different with the little animal in the egg; often totally negleeted by the parent, and always separable from it, every accident may retard its growtlı, or even destroy its existence. Besides, art or aceident, also, may bring this animal to a state of perfeetion; so that it can never be considered as a complete work of nature, in which so much is left for accident to finish or destroy.

But, however inferior this kind of generation may be, the observation of it will afford great insight into that of nobler animals, as we can here wateh the progress of the growing embryo in every period of its existence, and eateh it in those very moments when it first seems stealing into motion. Malpighi and Haller have been particularly industrious on this subject; and, with a patience almost equalling that of the sitting hen, have attended incubation in all its stages. From them, therefore, we have an amazing history of the chicken in the egg, and of its advances into complete formation.

It would be methodically tedions to describe those parts of the egg which are well known, and obvious; such as its shell, its white, and its yolk; but the disposition of these is not so apparent. Immediately under 
the shell lies that common membrane, or skin, which lines it on the inside, adhering closely to it every where, except at the broad end, where a little cavity is left, that is filled with air, which increases as the animal within grows larger. Under this membrane are contained two whites, though seeming to us to be only one, each wrapped up in a membrane of its own, one white within the other. In the midst of all is the yolk, wrapped round likewise in its own membrane. At each end of this are two ligaments, called chalazx, which are, as it were, the poles of this microcosm, being white dense substances, made from the membranes, and serving to keep the white and the yolk in their places. It was the opinion of Mr. Derham, that they served also for another purpose; for a line being drawn from one ligament to the other, would not pass directly through the middle of the yolk, but rather towards one side, and would divide the yolk into two unequal parts, by which means these ligaments served to keep the smallest side of the yolk always uppermost ; and in this part he supposed the cicatricula, or first speck of life, to reside; which, by being uppermost, and consequently next the hen, would be thus in the warmest situation. But this is rather fanciful than true, the incipient animal being found in all situations, and not particularly influenced by any." The cicatricula, which is the part where the animal first begins to show signs of life, is not unlike a vetch, or a lentil, lying on one side of the yolk, and within its membrane. All these contribute to the little animal's convenience or support; the outer membranes and ligaments, preserve the fluids in their proper places; the white serves as nourishment; and the yolk, with its membranes, after a time, becomes a part of the animal's body. This is the description of a hen's egg, and answers to that of all others, how large or how small soever.

Previous to putting the eggs to the hen, our philosophers first examined the cicatricula, or little spot, already mentioned; and which may be considered as the most important part of the egg. This was found, in those that were impregnated by the cock, to

- Haller.

Ibid. be large; but in those laid without the cock, very simall. It was found by the microscope, to be a kind of bag, containing a transparent liquor, in the midst of which the embryo was seen to reside. The embryo resembled a composition of little threads, which the warmth of future incubation tended to enlarge, by varying and liquefying the other fluids contained within the shell, and thus pressing them either into the pores or tubes of their substance.

Upon placing the eggs in a proper warmth, ${ }^{\circ}$ either under the sun, or in a stove, after six hours the vital speck begins to dilate, like the pupil of the eye. The head of the chicken is distinctly seen, with the back-bone, something resembling a tadpole, floating in its ambient fluid, but as yet seeming to assume none of the functions of animal life. In about six hours more the little animal is seen more distinctly; the head becomes more plainly visible, and the vertebræe of the back more easily perceivable. All these signs of preparation for life are increased in six hours more: and, at the end of twenty-four hours, the ribs begin to take their places, the neck begins to lengthen, and the head to turn to one side.

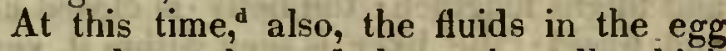
seem to have changed place; the yolk, which was before in the centre of the shell, approaches nearer to the broad end. The watery part of the white is, in some measure, evaporated through the shell, and the grosser part sinks to the small end. The little animal appears to turn towards the part of the broad end, in which a cavity has been described, and with its yolk seems to adhere to the membrane there. At the end of forty hours the great work of life seems fairly begun, and the animal plainly appears to move; the back-bone, which is of a whitish colour, thickens; the head is turned still more on one side; the first rudiments of the eyes begin to appear, the heart beats, and the blood begins already to circulate. The parts, however, as yet are fluid; but, by degrees, become more and more tenacious, and harden into a kind of jelly. At the end of two days, the liquor, in which the chicken swims, seems to increase; the head appears with two little bladders in 
the place of eyes; the leart beats in the manner of every embryo where the blood does not circulate through the lungs. In about fourteen hou's after this, the chicken is grown more strong; its head, however, is still bent downwards; the veins and arteries begin to branch, in order to form the brain; and the spinal marrow is seen stretching along the back-bone. In three days, the whole body of the chicken appears bent; the head, with its two eye-balls, with their different humours, now distinctly appear; and five other vesicles are seen, which soon unite to form the rudiments of the brain. The outlines also of the thighs and wings begin to be scen, and the body begins to gather flesh. At the end of the fourth day, the vesicles that go to form the brain approach each other; the wings and thighs appear more solid; the whole body is covered with a jelly-like flesh; the heart, that was hitherto exposed, is now covered up within the body, by a very thin transparent membrane ; and, at the same time, the umbilical vessels, that unite the animal to the yolk, now appear to come forth from the abdomen. After the fifth and sixth days, the vessels of the brain begin to be covered over; the wings and thighs lengthen; the belly is closed up, and tumid; the liver is seen within it, very distinctly, not yet grown red, but of a very dusky white; both the ventricles of the heart are discerned, as if they were two separate hearts, beating distinctly; the whole body of the animal is covered over ; and the traces of the incipient feathers are already to be seen. The seventh day, the head appears very large; the brain is covered entirely over; the bill begins to appear betwixt the eyes; and the wings, the thighs, and the legs, have acquired their perfect figure." Hitherto, however, the animal appears as if it had two hodies; the yolk is joined to it by the umbilical vessels that come from the belly; and is furnished with its vessels, through which the blood circulates, as through the rest of the body of the chicken, making a bulk greater than that of the animal itself. But towards the end of incubation, the umbilical vessels shorten the yolk, and with it the intestines are thrust up into the body of the chicken, by. the action of

- Haller. the muscles of the belly; and the two bodies are thus formed into one. During this state, all the organs are found to perforn their secretions; the bile is found to be separated, as in grown animals; but it is fluid, transparent, and without bitteruess: and the chicken then also appears to have lungs. On the tenth, the muscles of the wings appear, and the feathers begin to push out. On the eleventh, the heart, which hitherto had appeared divided, begins to unite; the arteries which belong to it join into it, like the fingers into the palm of the hand. All these appearances only come more into view, because the fluids the vessels liad hitherto seereted were more transparent; but as the colour of the fluids deepen, their operations and circulations are more distinctly seen. As the animal thus, by the eleventh day completely formed, begins to gather strength, it becomes more uneasy in its situation, and exerts its animal powers with increasing foree. For some time before it is able to break the shell in which it is imprisoned, it is heard to chirrup, receiving a sufficient quantity of air for this purpose, from that cavity which lies between the membrane and the shell, and which must contain air to resist the external pressure. At length, upon the twentieth day, in some birds sooner, and later in others, the inclosed animal breaks the sliell within which it has been confined, with its beak; and, by repeated efforts, at last procures its enlargement.

From this little history we perceive, that those parts which are most conducive to life, are the first that are begun: the head, and the back-bone, which no doubt inclose the brain, and the spinal marrow, though both are too limpid to be discerned, are the first that are seen to exist: the beating of the heart is perceived soon after: the less noble parts seem to spring from these; the wings, the thighs, the feet, and, lastly, the bill. Whatever, therefore, the animal has double, or whatever it can live without the use of, these are latest in production: Nature first sedulously applying to the formation of the nobler organs, without which life would be of short continuanee, and would be begun in vain.

The resemblance between the beginning animal in the egg, and the embryo in the womb, is very striking; and this similitude has in- 
duced many to assert, that all animals are produced from eggs, in the same manner. 'They consider an egg excluded from the body by some, and separated into the womb by others, to be actions merely of one kind; with this only difference, that the nourishment of the one is kept within the body of the parent, and increases as the embryo happens to want the supply; the nourishment of the other is prepared all at once, and sent out with the beginning animal, as entirely sufficient for its future support. But leaving this to the discussion of anatomists, let us proceed rather with facts than dissertations; and as we have seen the progress of an oriparous animal, or one produced from the shell, let us likewise trace that of a viviparous animal, which is brought forth alive. In this investigation, Graaf has, with a degree of patience characteristic of his nation, attended the progress and increase of various animals in the womb, and minutely marked the changes they undergo. Having dissected a rabbit, half an hour after impregnation, he perceived the horns of the womb, that go to embrace and communicate with the ovary, to be more red than before; but no other change in the rest of the parts. Having dissected another, six hours after, he perceived the follicules, or the membrane covering the eggs contained in the ovary, to become reddish. In a rabbit dissected after twenty-four hours, he perceived, in one of the ovaries, three follicules, and, in the other, five, that were changed; being become, from transparent, dark and reddish. In one dissected after three days, he perceived the horns of the womb very strictly to embrace the ovaries; and he observed three of the follicules in one of them, much longer and harder than before: pursuing his inquisition, he also found two of the eggs actually separated into the horns of the womb, and eacli about the size of a grain of mustard-seed; these little eggs were each of them inclosed in a double membrane, the inner parts being filled with a very limpid liquor. After four days, he found, in one of the ovaries, four, and in the other, five follicules, emptied of their eggs: and in the horus correspondent to these, he found all equal number of eggs thus separated: these eggrs were now grown larger than betore, and somewhat of the size of sparrow- shot. In five days, thie eggs were grown to the size of duck-shot, and could be blown from the part of the womb where they were, by the breath. In seven days, these eggs were found of the size of a pistol-bullet, ench covered with its double membrane, and these much more distinct than before. In nine days, having examined the liquor contained in one of these eggs, he found it, from a limpid colour, less fluid, to have got a light cloud floating upon it. In ten days, this cloud began to thicken, and to form an oblong body, of the figure of a little worm : and, in twelve days, the figure of the embryo was distinctly to be perceived, and even its parts came into view. In the region of the breast he perceived two bloody specks; and two more, that appeared whitish. Fourtcen days after impregnation, the head of the embryo was become large and transparent, the eyes prominent, the mouth open, and the rudiments of the ears beginning to appear; the back-bone, of a whitislı colour, was bent towards the breast; the two bloody specks being now considerably increased, appeared to be nothing less than the outlines of the two ventricles of the heart; and the two whitish specks on each side, now appeared to be the rudiments of the lungs; towards the region of the belly, the liver began to be seen, of a reddish colour: and a little intricate mass, like ravelled thread, discerned, which soon appeared to be the stomach and the intestines: the legs soon after began to be seen, and to assume their natural positions: and from that time forth, all the parts being formed, every day only served to develope them still more, until the thirty-first day, when the rabbit brought forth her young, completely fitted for the purposes of their humble happiness.

Having thus scen the stages of generation in the meaner animals, let us take a view of its progress in man; and trace the feeble beginnings of our own existence. An account of the lowliness of our own origin, if it cannot amuse, will at least serve to humble us; and it may take from our pride, though it fails to gratify our curiosity. We cannot here trace the variations of the beginning animal, as in the former instances; for the opportunities of inspection are but few and accidental : for this reason, we must be content often to fill 
up the blanks of our history with conjecture. And, first, we are entirely ignorant of the state of the infant in the womb, immediately after conception; but we have good reason to believe that it proceeds, as in most other animals, from the egg. ${ }^{2}$ Anatomists inform us, that four days after conception, there is found in the womb an oval substance, about the size of a small pea, but longer one way than the other ; this little body is formed by an extremely fine menbrane, inclosing a liquor a good deal resembling the white of an egg: in this may, even then, be perceived, several small fibres, united together, which forın the first rudiments of the embryo. Beside these, are seen another set of fibres, which soon after become the placenta, or that body by whicl the animal is supplied with nourishment.

Seven days after conception, we can readily distinguish, by the eye, the first lineaments of the child in the womb. However, they are as yet without form ; showing, at the end of seven days, pretty much such an appearance as that of the chicken after four and twenty hours, being a small jelly-like mass, yet exhibiting the rudiments of the head; the trunk is barely visible: there likewise is to be discerned a small assemblage of fibres issuing from the body of the infant, which afterwards become the bloodvessels that convey nourishment from the placenta to the child, while inclosed in the womb.

Fifteen days after conception, the liead becomes distinctly visible, and even the most prominent fcatures of the visage begin to appear. The nose is a little elevated : there are two black specks in the place of eyes; and two little holes, where the ears are aiterwards seen. The body of the embryo also is grown larger; and both above and below, are seen two little protuberances, which mark the places from whence the arms and thighs are to proceed. The length of the whole body, at this time, is less than half an incl.

At the end of three weeks, the body has received very little increase; but the legs and feet, with the hands and arms, are become apparent. The growth of the arms is nore speedy than that of the legs; and the fingers are sooner separated than the toes. About this time the internal parts are found, upon

\footnotetext{
- This history of the child in the womb is translated from Mr. Buffon, with soine alterations.
}

dissection, to become distinguishable. The places of the bones are marked by small threadlike substances, that are yet more fluid even than a jelly. Among them, the ribs are distinguishable, like threads also, disposed on each side of the spine; and even the fingers and toes scarcely exceed hairs in thickness.

In a month, the embryo is an inch long; the body is bent forward, a situation which it almost always assumes in the womb, either because a posture of this kind is the most easy, or because it takes up the least room. The human figure is now no longer doubtful; every part of the face is distinguishable; the body is sketched out; the bowels are to be distinguished as thrcads; the bones are still quite soft, but in some places beginning to assume a greater rigidity; the blood-vessels that go to the placenta, which, as was said, contributes to the child's nourishment, are plainly seen issuing from the navel, (bcing therefore called the umbilical vessels,) and going to spread themselves upon the placenta. According to Hippocrates, the male einbryo developes sooner than the female : he adds, that, at the end of thirty days, the parts of the body of the male are distinguishable; while those of the female are not equally so till ten days after.

In six weeks, the embryo is grown two inches long; the human figure begins to grow every day more perfect; the head being still much larger, in proportion to the rest of the body ; and the motion of the heart is perceived almost by the eye. It has been seen to beat in an embryo of filty days old, a long time after it had been taken out of the womb.

In two monilis, the embryo is more than two inches in length. The ossification is perceivable in the arms and thighs, and in the point of the chin, the under jaw being greatly advanced before the upper. 'These parts, however, may as yet be considered as bony points, rather than as bones. The umbilical vessels, which before went side by side, are now begun to be twisted, like a rope, one over the other, and go to join with the placenta, which, as yet, is but small.

In three months, the embryo is above three inches long, and weighs about three ounces. Hippocrates observes, that not till then the mother perceives the child's notion : and he adds, that in female children, the motion is not cbservable till the end of four months. How- 
over, this is no general rule, as there are women who assert, that they pereeivet themselves to be quiek with child, as their expression is, at the end of two months; so that this quickness seens rather to arise from the proportion between the child's strength and the mother's sensi'sility, than from any determinate period of time. At all times, however, the child is equally alive; and, consequently, those juries of inatrons, that are to deterinine upon the preguancy of eriminals, should not inquire whether the woman be quick, but whether she be with chill; if the latter be perceivable, the former follows of course.

Four months and a half after conception, the embryo is from six to seven inches long. All the parts are so augmented, that even their proportions are now distinguishable. The very uails begin to appear upon the fingers and toes: and the stomach and intestines already begin to perforin their functions of receiving and digesting. In the stomach is found a liquor similar to that in which the embryo floats; in one part of the intestines, a milky substance; and, in the other, an excrementitious. There is found, also, a small quantity of bile in the gall blidder; and some urine in its own proper receptacle. By this tiıne, also, the posture of the embryo scems to be determined. The head is bent forward, so that the chin seems to rest upon its breast; the knees are raised up towards the head, and the legs bent backward, somewhat resembling the posture of those wlio sit on their haunches. Sonnetimes the knees are raised so higli as to touch the clieeks, and the feet are crossed over each other; the arms are laid upon the breast, whilc one of the hands, and often both, touch the visage; sometines the hands are shut, and sometimes also the arms are found hanging down by the hody. These are the most usual postures which the embryo assunes; but these it is frequently known to elange; and it is owing to these alterations that the mother so frequently feels those twitches, which are usually attended with pain.

'The embryo, thus situated, is furnished by nature with all things proper for its support; and, as it increases in size, its nourishment also is found to increase with it. As soon as it first begins to grow in the womb, that receptacle, from being very sinall, grows larger; and, what is more surprising, thicker every day.
The sides of a bladder, as we know, the more they are distended, the more they become thin. But here, the larger the womb grows, the more it appears to thicken. Within this the embryo is still farther involved in two membranes, called the chorion and amnios; and floats in a thin transparent fluid, upon which it seems, in some ineasure, to sulisist. However, the great storehouse, from whence its chief nourishment is supplied, is called the placenta; a red substance somewliat resembling a sponge, that adheres to the inside of the womb, and communicates, by the umbilical vessels, with the embryo. These umbilical vessels, which consist of a vein and two arterics, issue from the navel of the ehild, and are branched out upon the placenta; where they, in fact, seem to form its substance; and, if I may so express it, to suck up their nourishment from the womb, and the fluids contained therein. The blood thus received from the womb, by the placenta, and communicated by the umbilical vein to the body of the embryo, is conveyed to the heart; where, without ever passing into the lungs, as in the born infant, it takes a shorter course; for, entering the right auricle of the heart, instead of passing up into the pulmonary artery, it seems to break this partition, and goes directly through the body of the heart, by an opening called the foramen ovale, and from thence to the aorta, or great artery; by which it is driven into all parts of the body. Thus we see the placenta, in some measure, supllying the place of lungs; for, as the little animal call receive no air by inspiration, the lungs are therefore useless. But we see the placenta converting the fluid of the romb into blood, and sending it, by the umbilical rein, to the heart; from whence it is despatched by a quicker and shorter circulation through the whole frame.

In this manner the embryo reposes in the womb; supplied with that nourishment which is fitted to its necessities, and furnished with those organs that are adapted to its situation. As its sensations are but few, its wants are in the same proportion; and it is probable that a slcep, with scarcely any intervals, marks the earliest period of luuman life.

As the little creature, however, gathers streng th and size, it scems to beeome more wakeful and uneasy; even in the womb it begins to feel the want of something it does not possess; a sensation that seems cocval with man's nature, 
and never leaves him till he dies. The embryo even then begins to struggle for a state more marked by pleasure and pain, and, from about the sixth month, begins to give the mother warning of the greater pain she is yet to endure. The continuation of pregnancy, in woman, is usually nine months; but there have been many instances when the.child has lived that was born at seven; and some are found to continue pregnant a month above the usual time. When the appointed time approaches, the infant, that has for some months been giving painful proofs of its existence, now begins to increase its efforts for liberty. The head is applied downward, to the aperture of the womb, and by reiterated efforts it cndeavours to extend the same: these cndeavours produce the pain which all women in labour fecl in some degree; those of strong constitutions the least, those most weakly the most severely; since we learn, that the women of Africa always deliver themselves, and are well a few hours after; while those of Europe require assistance, and recover more slowly. Thus the infant, still continuing to push with its head forward, by the repetition of its endeavours, at last succeeds, and issues into life. The blood, which had hitherto passed through the heart, now takes a wider circuit; and the foramen ovale closes; the lungs, that had till this time been inactive, now first begin their functions; the air rushes in to distend then!; and this produces the first sensation of pain, which the infant expresses by a shriek; so that the beginning of our lives, as well as the end, is marked with anguish."

From comparing these accounts, we perceive that the most laboured generation is the most perfect; and that the animal which, in proportion to its bulk, takes the longest time for production, is always the most complete when finished. Of all others, man seems the slowest in coming into life, as he is the slowest in coming to perfection; other animals, of the same bulk, seldom remain in the womb above six months, while he continues nine; and even after his birth appcars more than any other to have his state of imbecility prolonged.

We may observe also, that that generation is the most complete in which the fewcst animals are produced : Nature, loy attending to

a Bonnet Contemplate. de la Nature, vol. i. p. 212. the production of one at a time, seems to exert all her efforts in bringing it to perfection; but, where this attention is divided, the animals so produced cone into the world with partial advantages. In this manner twins are never, at least while infints, so large or so strong as those that come singly into the world; each having, in some measure, robbed the other of its right; as that support, which Nature meant for one, has been prodigally divided.

In this manner, as those animals are the best that are produced singly, so we find that the noblest animals are ever the least fruitful. These are seen usually to bring forth but one at a time, and to place all their attention upon that alone. On the other hand, all the oviparous kinds produce in amazing plenty; and even the lower tribes of viviparous animals increase in a seeming proportion to their ninuteness and imperfection. Nature seens lavish of life in the lower orders of the creation; and, as if she meant them entirely for the use of the nobler races, she appears to have bestowed greater pains in multiplying the number than in completing the kind. In this manner, while the elephant and the horse bring forth but one at a time, the spider and the bectle are seen to produce a thousand: and even among the smaller quadrupeds, all the inferior kinds are extreinely fertile; any onc of these being found, in a very few months, to become the parent of a numerous progeny.

In this manner, thcrcfore, the smallest animals multiply in the greatest proportion; and we have reason to thank Providence, that the most formidable animals are the least fruitful. Had the lion and the tiger the same degree of fecundity with the rabbit or the rat, all the arts of man would be unable to oppose these fierce invaders; and we should soon perceive them become the tyrants of those who claim the lordship of the creation. But Heaven, in this respect, has wisely consulted the advantage of all. It has opposed to man only such enemies as he has art and strength to conquer; and, as large animals require proportional supplies, Nature was unwilling to give new life, where it, in some measure, denied the necessary means of subsistence.

In consequence of this pre-established order, the animals that are endowed with the most perfect methods of generation, and bring forth 
but one at a time, seldom begin to procreate till they have almost acquired their full growth. On the other hand, those which hring forth many, engender before they have arrived at half their natural size. The horse and the bull, come almost to perfectiou before they begin to generate; the hog and the rabhit, scarcely leave the teat before they become parents themselves. In whatever light, therefore, we consider this subject, we shall find that all creatures approach most to perfection, swhose ge- neration most nearly resembles that of man. The reptile produced from cutting, is but one degree above the vegetable. The animal produced from the egg, is a step higher in the seale of existence: that class of animals which are brought forth alive, are still more exalted. Of these, such as bring forth one at a time are the most complete; and foremost of these stands man, the great master of all, who seems to have united the perfections of all the rest in his formation.

\section{CHAPTER XXV.}

\section{THE INFANCY OF MAN.}

WHEN we take a survey of the various classes of animals, and examine their strength, their beanty, or their structure, we shall find man to possess most of those advantages united, which the rest enjoy partially. Infinitely superior to all others in the powers of the understanding, he is also superior to them in the fitness and proportions of his form. He would, indeed, have been one of the most miserable beings upon earth, if with a sentient mind he was so formed as to be incapable of oheying its impulse: but nature has otherwise provided; as with the most extcnsive intellects to command, she has furnished him with a body the best fitted for obedience.

In infancy, ${ }^{a}$ however, that mind, and this body, form the most helpless union in all animated naturc ; and, if any thing can give us a picture of complete imbecility, it is a man when just come into the world. The infant just born, stands in need of all things, without the power of procuring any. The lower races of animals, upon being produced, are active, vigorous, and capable of self-support; but the infant is obliged to wait in helpless expectation, and its cries are its only aid to procure subsistence.

An infant just born may be said to come from one element into another ; for, from the watery fluid in which it was surrounded, it now inmerges into air ; and its first cries seem

- Buffon, vol. iv. p. 173. to inuply how greatly it regrets the change. How much longer it could have continued in a state of almost total insensibility, in the womb, is impossible to tell; but it is very probable that it could remain there some hours more. In order to throw some light upon this subject, Mr. Buffon so placed a pregnant bitch as that her puppies were brought forth in warm water, in which he kept them above half an hour at a time. However, he saw no change in the animals, thus newly brought forth ; they continued the whole time vigorous; and, during the whole time, it is very probable that the blood circulated through the same channels through which it passed while they continued in the womb.

Almost all animals have their eyes closed, ${ }^{b}$ for some days after being brought into the world. The infant opens them the instant of its birth. However, it seems to keep them fixed and idle; they want that lustre which they acquire by degrees; and if they liappen to move, it is rather an accidental gaze than an exertion of the act of seeing. The light alone seems to make the greatest impression upon them. The eyes of infants are sometimes found turned to the place where it is strongest ; and the pupil is seen to dilate and diminish, as in grown persons, in proportion to the quantity it receives. But still, the infant is incapable of distinguishing objects ; the sense of

b Buffon, vol. iv. p. 173. 
seeing, like the rest of the senses, requires a habit before it becomes any way serviceable. All the senses must be compared with each other, and nuust be made to correct the defects of one another, before they can give just information. It is probable, therefore, thrat if the inlant could express its own sensations, it would give a very extaordinary description of the illusions which it suffers from them. The sight might, perhaps, be represented as inverting objects, or multiplying them; the hearing, instead of conveying one uniform tone, niight be said to bring up an interrupted succession of noises ; and the touch apparently would divide one body into as many as there are fingers that grasped it. But all these errors are lost in one coinmon confused idea of existence; aud it is happy for the infant, that it then can make but very little use of its senses, when they could serve only to bring it false information.

If there be any distinct sensations, those of pain seem to be much more fiequent and stronger than those of pleasurc. The infant's cries are sufficient indications of the uneasinesses it must, at every interval, enclure; while, in the beginuing, it has got no external marks to testily its satisfactions. It is not till after forty days that it is seen to smile; and not till that time also the tears begin to appear, its former expressions of uueasiness being always without them. As to any other marks of the passions, the infant being as yet almost without them, it can express none of them in its visage; which, except in the act of crying and laughing, is fixed in a sectled serenity. All the other parts of the body seem equally reluxed and fecble; its motions are uncertain, and its postures without choice; it is unable to stand upright; its hams are yet bent, from the habit which it received from its position in the womb; it has not strength enough in its arms to stretch thein forward, unuch less to grasp any thing with its hands; it rests just in the posture it is laid; and, if abandoned, must continue in the same position.

Nevertheless, though this be the description of infuncy among mankind in general, there are countries and races, ainong whom infancy does not seem marked with such utter imbecility, but where the children, not long after they are born, appear possessed of a greater share of self-support. The children of Negroes have a surprising degrec of this premature industry: they are able to walk at two months; or, at least, to move from one place to another: they also hang to the mother's back without any assistance, and seize the breast over her shoulder, continuing in this posture till she thinks proper to lay them down. This is very different in the children of our countries, that seldom are able to walk under a twelvemonth.

The skin of children newly brought fortl is always red, proceeding from its transparency, by which the blood beneath appear's more conspicuous. Some say that this redness is greatest in those children that are afterwards about to have the finest complexions; and it appears reasonable that it should be so, since the thinnest skins are always the fairest. The size of a new-horn infant is generally about twenty inches, and its weight about twelve pounds. The hoad is large, and all the members delicate, soft, and pulfy. These appearances alter with its age; as it grows older, the head becomes less in proportion to the rest of the body; the flesh hardens; the bones that before birth grew very thick in proportion, now lengthen by degrees, and the human figure inore and more acquires its due dimensions. In such children, however, as are but feeble or sickly, the head always continues too big for the body; the hends of dwarfs being extremely large in proportion.

lufants, when newly born, pass most of their ti'ne in sleeping, and awake with crying, excited either by sensations of pain, or of hunger. Man, when come to maturity, but rarcly feels the want of food, as eating twice or tirice in the four-and-twenty hours, is known to suffice the most voracious: but the infant inay be considered as a little glutton, whose only pleasure consists in its appetite: and this, except when it slecps, it is never easy withont satisfying. Thus nature has adapted dilferent desires to the different perionds of life; each as it seems nuost necessary for hunan support or succession. While the animal is yet firrning, lunger excites it to that supply which is necessury for its growth; when it is conpletely formed, a different appetite takes place, that incites it to communicate existence. These two desires lake up the whole attention at different periods, but are 
very seldom found to prevail strongly togegether in the same age; one pleasure ever serving to repress the other: and, if we find a person of full age, placing a principal part of his happiness in the nature and quantity of his food, we have strong reasons to suspect, that with respect to his other appetites, he still retains a part of the imbecility of his childhood.

It is extraordinary, however, that infants, who are thus more voracious than grown persons, are nevertheless more capable of sustaining hunger. We have several instances, in accidental cases of famine, in which the child has bcen known to survive the parent; and seen clinging to the breast of its dead mother. Their little bodies also are more patient of cold; and we have similar instances of the mother's perishing in the snow, while the infant has been found alive beside her. However, if we examine the internal structure of infants, we shall find an obvious reason for both these advantages. Their bloodvessels are known to be much larger than in adults; and their nerves much thicker and softer : thus, being furnished with a more copious quantity of juices, both of the nervous and sanguinary kinds, the infant finds a tem porary sustenance in this superfluity, and does not expire till both are exhausted. The circulation also being larger and quicker, supplies it with proportionable warmth, so that it is more capable of resisting the accidental rigours of the weather.

The first nourishment of infants is well known to be the mother's milk; and, what is remarkable, the infant has milk in its own breasts, which may be squeezed out by compression: this nourishment becomes less grateful as the child gathers strength; and perhaps, also, more unwholesome. However, in cold countries, which are unfavourable to propagation, and where the female has seldom above three or four children at the most, during her life, she continues to suckle the child for four or five years together. In this manner the mothers of Canada and Greenland are often seen suckling two or three children, of different ages, at a time.

The life of infants is very precarious, till the age of three or four, from which time it becomes more secure; and when a child ar- rives at its seventh year, it is then considered as a more certain life, as Mr. Buffon asserts, than at any other age whatever. It appears, from Simson's Tables, that of a certain number of children born at the same time, a fourth part are found dead at the end of the first year; more than one third at the end of the sccond; and, at least, half, at the end of the third: so that those who live to be above three years old, are indulged a longer term than half the rest of their fellow creatures. Nevertheless, life, at that period, may be considered as mere animal existence; and rather a preparation for, than an enjoyment of those satisfactions, both of mind and body, that make life of real value: and hence it is more natural for mankind to deplore a fellow creature, cut off in the bloom of life, than one dying in early infancy. The one, by living up to youth, and thus wading through the disadvantageous parts of existence, seems to have earned a short continuance of its enjoyments; the infant, on the contrary, has served but a short apprenticeship to pain; and, when taken away, may be considered as rescued from a long continuance of misery.

There is something very remarkable in the growth of the human body. The embryo in the womb continues to increase still inore and more, till it is born. On the other hand, the child's growth is less every year till the time of pubcrty, when it seems to start up of a sudden. Thus, for instance, the embryo, which is an inch long, in the first month, grows but one inch and a quarter in the second; it then grows one and a half in the third; two and a half in the fourth; and in this manner it keeps increasing, till, in the last month of its continuance, it is actually found to grow four inches; and, in the whole, about eighteen inches long. But it is otherwise with the child when born: if we suppose it eighteen inches at that time, it grows, in the first year, six or seven inches; in the second year, it grows but four inches; in the third year about three; and so on, at the rate of about an inch and a half, or two inches, each year, till the time of puberty, when nature seems to make one great last effort to complete her work, and unfold the whole animal machine.

\footnotetext{
aufion, vol. iv. p. 173.
} 
The growth of the mind in children seems to correspond with that of the body. The comparative progress of the understanding is greater in infants than in children of three or four years old. If we only reflect a moment on the amazing acquisitions that an infant makes in the first and second years of life, we shall have much cause for wonder. Being sent into a world where every thing is new and unknown, the first months of life are spent in a kind of torpid amazement; an attention distracted by the multiplicity of objects that press to be known. The first labour, therefore, of the little learner is, to correct the illusions of the senses, to distinguish one object from another, and to exert the memory, so as to know them again. In this manner a child of a year old has already made a thousand experiments; all which it has properly ranged, and distinctly remembers. Light, heat, fire, sweets, and bitters, sounds soft or terrible, are all distinguished at the end of a very few months. Besides this, every person the child knows, every individual object it becomes fond of, its rattles, or its bells, may be all considered as so many new lessons to the young mind, with which it has not become acquainted, without repeated exertions of the understanding. At this period of life, the knowledge of every individual object cannot be acquired without the same effort which, when grown up, is employed upon the most abstract idea: every thing the child hears or sees, all the marks and characters of nature, are as much unknown, and require the same attention to attain, as if the reader were set to understand the characters of an Ethiopic manuscript: and yet, we see in how short a time the little studept begins to understand them all, and to give evident marks of early industry.

It is very amusing to pursue the young mind, while employed in its first attainments. At about a year old, the same necessities that first engaged its faculties, increase, as its acquaintance with nature enlarges. Its sudies, therefore, if I may use the expression, are no way relaxed; for, having experienced what gave pleasure at one time, it desires a repetition of it from the same object; and, in order to obtain this, that object must be pointed out; here, therefore, a new necessity arises, which, very often, neither its little arts nor importunities can remove; so that the child is at last obliged to set about naming the objects it desires to possess or avoid. In beginning to speak, which is usually about a year old, children find a thousand difficulties. It is not without repeated trials that they come to pronounce any one of the letters ; nor without an effort of the memory, that they can retain them. For this reason, we frequently see them attempting a sound which they had learned, but forgot; and when they have failed, I have often seen their attempt attended with apparent confusion. The letters soonest learned, are those which are most easily formed; thus A and B require an obvious disposition of the organs, and their pronunciation is consequently soou attained. $\mathrm{Z}$ and $\mathrm{R}$, which require a more complicated position, are learned with greater difficulty. And this may, perhaps, be the reason why the children in some countries speak sooner than in others; for the letters mostly occurring in the language of one country, being such as are of easy pronunciation, that language is of course more easily attained. In this manner the children of the Italians are said to speak sooner than those of the Germans; the language of the one being sinooth and open; that of the other, crowded with consonants, and extrcmely guttural.

But be this as it will, in all countries children are found able to express the greatest part of their wants by the time they arrive at two years old; and from the moment the necessity of learning new words ceases, they relax their industry. It is then that the mind, like the body, seems every year to make slow advances; and, in order to spur up attention, many systems of education have been contrived.

Almost every philosopher, who has written on the education of children, has been willing to point out a method of his own, chiefly professing to ad vance the health, and improve the intellects at the same time. These are usually found to begin with finding nothing right in the common practice; and by urging a total reformation. In consequence of this, nothing can be more wild or imaginary than their various systems of improvement. Some will have the children every day plunged in 
cold water, in order tostrengthen their bodies; they will have them converse with the servants in nothing but the Latin langunge, in order to strengthen their minds; every hour of the day must be appointed for its own studies, and the child must learn to make these very studies an amusement; till about the age of ten or eleven it becomes a prodigy of premature improvement. Quite opposite to this, we have others, whom the courtesy of mankind also calls philosophers: and they will have the child learn nothing till the age of ten or eleven, at which the former has attained so mnch perfection; with them the mind is to be kept empty, until it has a proper distinction of some metaphysical ideas about truth; and the promising pupil is debarred the use of even his own faculties, lest they should conduct him into prejudice and error. In this manner, some men, whom fashion has celebrated for profound and fine thinkers, have given their hazarded and untried conjectures, upon one of the most important subjects in the world, and the most interesting to humanity. When men speculate at liberty upon innate ideas, or the abstracted distinctions between will and power, they may be permitted to enjoy their systems at pleasure, as they are harmless, although they may be wrong; but when they allege that children are to be every day plunged in cold water, and, whatever be their constitutions, indiscriminately inured to cold and moisture; that they are to be kept wet in the feet, to prevent their catching cold; and never to be corrected when young, for fear of breakiug their spirits when old; these are such noxious errors, that all reasonable men should endeavour to oppose them. Many have been the children whom these opinions, begun in speculation, have injured or destroyed in practice; and I have seen many a little philosophical martyr, whom I wished, but was unable to relieve.

If any system be therefore necessary, it is one that would serve to show a very plain point; that very little system is necessary. The natural and common course of education is in every respect the best; I mean that in which the child is permitted to play among its little equals, fron whose similar instructions it often gains the most useful stores of knowledge. A child is not idle because it is playing about the fields, or pursuing a butterlly; it is all this time storing its mind with objects, upon the nature, the properties, and the relations of which future curiosity may speculate.

I have ever found it a vain task to try to make a child's learning its amusement; nor do I see what good end it would answer, were it actually attained. The child, as was said, ought to have its share of play, and it will be benefited thereby; and for every reason also it ought tohave its share of labour. The mind, by early labour, will be thus accustomed to fatigues and subordination; and whatever be the person's future employment in life, he will be better fitted to endure it: he will be thus enabled to support the drudgeries of office with content; or to fill up the vacancies of life with variety. The child, therefore, should by times be put to its duty; and be taught to know, that the task is to be done, or the purishment to be endured. I do not object against alluring it to duty by reward; but we well know, that the mind will be more strongly stimulated by pain; and both may, upon some occasions, take their turn to operate. In this manner, a child, by playing with its equals abroad, and labouring with them at school, will acquire more health and knowledge, than by being bred up under the wing of any speculative system-maker; and will be thus qualified for a life of activity and obedience. It is true, indeed, that when educated in this manner, the boy may not be so seemingly sensible and forward as one bred up under solitary instruction; and, perhaps, this early forwardness is more engaging than useful. It is well known, that many of those children who have been such prodigies of literature before ten, have not made an adequate progress to twenty. It should seem, that they only began learning manly things before their time; and, while others were busied in picking up that knowledge adapted to their age and curiosity, these were forced upon subjects unsuited to their years; and, upon that account alone, appearing extraordinary. The stock of knowledge in both may be equal; but with this difference, that each is yet to learn what the other knows.

But whatever may have been the acquisitions of children at ten or twelve, their great- 
est and most rapid progress, is made when they arrive near the age of puberty. It is then that all the powers of nature seem at work in strengthening the inind, and completing the body; the youth acquires courage, and the virgin modesty; the mind, with new sensations, assumes new powers; it conceives with grea- terforce, and remembers with greater tenacity. About this time, therefore, which is various in different countries, more is learned inone year than in any two of the preceding; and on this age, in particular, the greatest weight of instruction ought to be thrown.

\section{CHAPTER XXVI.}

\section{OF PUBERTY.}

IT has been often said, that the season of youth is the season of pleasures : but this can only be true in savage countries, where but little preparation is made for the perfection of human nature; and where the mind has but a very small part in the enjoyment. It is otherwise in those places where nature is carried to the highest pitch of refinement, in which this season of the greatest sensual delight is wisely made subservient to the succeeding and more rational one of manhood. Youth, with us, is but a scene of preparation; a drama, upon the right conduct of which all future happiness is to depend. The youth who follows his appetites, too soon seizes the cup, before it has received its best ingredients; and, by anticipating his pleasures, robs the remaining parts of life of their share; so that his eagerness only produces a manhood of imbecility, and an age of pain.

The time of puberty is different in various countries, and always more late in men than in women. In the warm countries of India, the women are marriageable at nine or ten, and the men at twelve or thirteen. It is also different in cities, where the inhabitants lead a more soft, luxurious life, from the country, where they work harder, and fare less delicately. Its symptoms are seldom alike in different persons; but it is usually known by a swelling of the breasts in one sex, and a roughness of the roice in the other. At this season, also, the women seem to acquire new beauty, while the men lose all that delicate effeminacy of countenance which they had when boys.

All countries, in proportion as they are ci- vilized or barbarous, improve or degrade the nuptial satisfaction. In those miserable regions, where strength makes the only law, the stronger sex exerts its power, and becomes the tyrant over the weaker: while the inhabitant of Negroland is indolently taking his pleasure in the fields, his wife is obliged to till the grounds, that serve for theirmutual support. It is thus in all barbarous countries, where the men throw all the laborious duties of life upon the women; and, regardless of beauty, put the softer sex to those employments that must effectually destroy it.

But, in countries that are half barharous, particularly wherever Mahometanism prevails, the men run into the very opposite extreme. Equally brutal with the former, they exert their tyranny over the weaker sex, and consider that half of the human creation as merely made to be subservient to the depraved desires of the other. The chief, and, indeed, the only aim of an Asiatic, is to be possessed of many womer; and to be able to furnish a seraglio, is the only tendency of his am bition. As the savage was totally regardless of beauty, he, on the contrary, prizes it too highly; he excludes the person who is possessed of such personal attractions from any share in the duties or employments of life; and, as if willing to engross all beauty to himself, increases the number of his captives in proportion to the progress of his fortune. In this manner he vainly expects to augment his satisfactions, by sceking from many that happiness which he ought to look for in the society of one alone. He lives a gloomy tyrant, 
amidst wretches of his own making; he fecls none of those endearments which spring from affection, none of those delicacies which arise from knowledge. His mistresses, being shut out from the world, and totally ignorant of all that passes there, have no arts to entertain his mind, or crilm his anxieties; the day passes with them in sullen silence, or languid repose; appetite can furnish but few opportunities of varying the scene; and all that falls beyond it must be irksome expectation.

From this avarice of women, if I may be allowed to express it so, has proceeded that jealousy and suspieion which ever attends the miser: hence those low and barbarous methods of keeping the women of those countries guarded, and of making and procuring eunuchs to attend them. These unhappy creatures are of two kinds, the white and the black. The white are generally made in the country where they reside, being but partly deprived of the marks of virility; the black are generally brought from the interior parts of Africa, and are made entirely bare. These are chiefly chosen for their deformity; the thicker the lips, the flatter the nose, and the more black the teeth, the more valuable the eunuch; so that the vile jealousy of mankind here inverts the order of Nature; and the poor wretch finds himself valued in proportion to his deficiencies. In Italy, where this barbarous custom is still retained, and eunuchs are made in order to improve the voice, the laws are severely aimed against such practice; so that bcing entirely prohibited, none but the poorest, and most abandoned of the people, still secretly practise it upon their children. Of those served in this manner, not one in ten is found to become a singer; but such is the luxurious folly of the times, that the success of one amply compensates for the failure of the rest. 'It is very difficult to account for the alterations whieh castration makes in the voice, and the other parts of the body. The eunuch is shaped differently from others. His legs are of an equal thickness above and below; his knees weak; his shoulders narrow ; and his beard thin and downy. In this manner his person is rendered more deformed; but his desires, as I am told, still continue the sarne; and actually, in Asia, some of them are found to have their seraglios, as No. $13 \& 14$. well as their masters. Even in our country. we have an instance of a very fine woman being married to one of them, whose appearance was the most unpromising; and, what is more extraordinary still, I am told, that this couple continue perfectly happy in each other's society.

The mere necessities of life seem the only aim of the savage; the sensual pleasures are the only study of the semi-barbarian; but the refinement of sensuality, by reason, is the boast of real politeness. Among the merely barbarous nations, such as the natives of Madagascar, or the inhabitants of Congo, nothing is desired so ardently as to prostitute their wives, or daughters, to strangers, for the most trifling advantages; they will account it a dishonour not to be among. the foremost who are thus received into favour: on the other hand, the Mahometan keeps his wife faithful, by confining her person; and would instantly put her to death, if he but suspected her chastity. With the politer inhabitants of Europe both these barbarous extremes are avoided; the woman's person is left free, and no constraint is imposed but upon her affections. The passion of love, which may be considered as the nice conduct of ruder desire, is only known, and practised in this part of the world; so that what other nations guard as their right, the more delicate European is contented to ask as a favour. In this manner, the concurrence of mutual appetite contributes to increase mutual satisfaction; and the power on one side of refusing, makes every blessing more grateful when obtained by the other. In barbarous countries, woman is considered merely as an useful slave; in such as are somewhat more refined, she is regarded as a desirable toy ; in countries entirely polished, she enjoys juster privileges, the wife being considered as an useful friend, and an agreea ble mistress. Her nind is still more prized than her person; and without the improvement of both, she can never expect to become truly agreeable; for her good sense alone can preserve what she has gained by her beauty.

Female beauty, as was said, is always seen to improve about the age of puberty: but if we should attempt to define in what this beauty consists, or what constitutes its perfection, $2 \mathrm{E}$ 
we should find nothing more difficult to determine. Every country has its peculiar way of thinking, in this respeet; and even the same country thinks differently at different times. The ancients had a very different taste from what prevails at present. The eye-brows joining in the middle was considered as a very peculiar grace by 'Tibullus, in the enumeration of the charms of his inistress. Narrow foreheads were approved of, and scarcely any of the Roman ladies, that are celebrated for their other perfections, but are also praised for the redness of their hair. The nose also of the Grecian Venus, was such as would appear at present an actual deformity; as it fell in a straight line from the forehead, without the smallest sinking between the eyes; without which we never see a face at present.

Among the moderns, every country seems to have peculiar ideas of beauty." The Persians admire large eye-brows, joining in the middle; the edges and corners of the eyes are tinctured with black, and the size of the head is increased by a great variety of bandages, formed into a turban. In some parts of India, black teeth and white hair are desired with ardour; and one of the principal employments of the women of Thibet, is to redden the teeth with herbs, and to make their hair white by a certain preparation. The passion for coloured teeth obtains also in China and Japan; where, to complete their idea of beauty, the object of desire must have little eyes, nearly closed, feet extremely small, and $a$ waist far from being shapely. There

aufon. are some nations of the American Indians that flatten the heads of their children, by keeping them, while young, squeezed between two boards, so as to make the visage much larger than it would naturally be. Others flatten the head at top; and others make it as round as they possibly can. The inkabitants along the western coasts of Africa have a very extraordinary taste for beauty. A flat nose, thick lips, and a jet black complexion, are there the most indulgent gifts of Nature. Such, indeed, they are all, in some degree, found to possess. However, they take care, by art, to increase the natural deformities, as they should seem to us; and they have many additional methods of rendering their persons stillmore frightfully pleasing. "The whole body and visage is often scarred with a variety of monstrous figures; which is not done without great pain, and repeated incision; and even sometimes parts of the body are cut away. But it would be endless to remark the various arts which caprice, or custom, has employed to distort and disfigure the body, in order to render it more pleasing: in fact, every nation, how barbarous soever, seems unsatisfied with the human figure, as Nature has left it, and has its peculiar arts of heightening beauty. Painting, powdering, cutting, boring the nose and the ears, lengthening the one and depressing the other, are arts practised in many countries; and, in some degree, admired in all. These arts might have been at first introduced to hide epidemic deformities : custom, by degrees, reconciles them to the view; till, from looking upon them with indifference, the eye at length begins to gaze with pleasure.

\section{CHAPTER XXVI. OF THE AGE OF MANHOOD.}

THE human body attains to its full height during the age of puberty; or, at least, a short time after. Some young people are found to cease growing at fourteen or fifteen; others continue their growth till two or three and twenty. During this period they are all of

b This chapter is translated from Mr. Buffon, whose description is very excellent. Whatever I have added. is a slender make; their thighs and legs small, and the muscular parts are yet unfilled. But, by degrees, the fleshy fibres augment; the muscles swell, and assume their figure; the limbs become proportioned, and rounder; and before the age of thirty, the body in men

marked by inverted commas, "thus." And in whatever trifling points I have differed, the nntes will warve in shne 
has acquired the most perfect symmetry. In women, the body arrives at perfection much sooner, as they arrive at the age of maturity more early; the muscles, and all the other parts being weaker, less compact and solid, than those of man, they require less time in coming to perfection; and, as they are less in size, that size is sooner completed. Hence the persons of women are found to be as complete at twenty, as those of men are found to be at thirty.

The body of a well-shaped man ought to be square; the muscles should be expressed with boldness, and the lines of the face strongly marked. In the woman, all the muscles should be rounder, the lines softer, and the features more delicate. Strength and majesty belong to the man, grace and softness are the peculiar embellishments of the other sex. In both, every part of their form declares their sovereignty over other creatures. Man supports his body crect; his attitude is that of command; and his face, which is turned towards the heavens, displays the dignity of his station. The image of lis soul is painted in his visage; and the. excellence of his nature penetrates through the material form in which it is enclosed. His majestic port, his sedate and resolute step, announce the nobleness of his rank. He touches the earth only with his extremity; and beholds it as if at a disdainful distance. His arms are not given hin, as to other creatures, for pillars of support; nor docs he lose, by rendering them callous against the ground, that delicacy of touch which furnishes him with so many of his enjoyments. His hands are made for very different purposes; to second every intention of his will, and to perfect the gifts of Nature.

When the soul is at rest, all the features of the visage seem settled in a state of profound tranquillity. Their proportion, their union, and their luarmony, secm to mark the sweet serenity of the mind, and give a true information of what passes within. But, when the soul is excited, the human visage becomes a living picture; where the passions are expressed with as inuch delicacy as energy, where every motion is designed by some correspondent feature, where every impression anticipates the will, and betrays those hidden agitations, that he would often wish to conceal.

It is particularly in the eyes that the passions are painted; and in which we may most readily discover their beginning. The eye scems to belong to the soul more than any other organ; it seems to participate of all its emotions; as well the most soft and tender, as the most tumultuous and forceful. It not only receives, but transmits them by sympathy: the observing eye of one catches the secret fire from another; and the passion thus often becomes general.

Such persons as are short-sighted labour under a particular disadvantage in this respect. They are, in a manner, entirely cut off from the language of the eyes; and this gives an air of stupidity to the face, which often produces very unfavourable prepossessions. However intelligent we find such persons to be, we can scarcely be brought back from our first prejudice, and often continue in the first erroneous opinion. In this manner we are too much induced to judge of men by their physiognomy; and having, perhaps, at first, caught up our judgments prematurely, they mechanically influence us all our lives after. This extends even to the very colour, or the cut of pcople's clothes; and we should, for this reason, be carcful, even in such trifling particulars, since they go to make up a part of the total judgment which those we converse with may form to our advantage.

The vivacity, or the languid motion of the eyes, give the strongest marks to physiognomy; and their colour contributes still more to enforce the expression. The different colours of the eye are the dark hazle, the light hazle, the green, the blue, and gray, the whitish gray, "and also the red." These different colours arise from the different colours of the little muscles that serve to contract the pupil; " and they are very often found to change colour with disorder and with age."

The most ordinary colours are the hazle and the blue, and very often both these colours are found in the eycs of the same person. Those cyes which are called black are only of the dark hazle, which may be easily seen unon closer inspection; liowever, those 2 E* 
eycs are reckonel the most beautiful where the sharle is the decpest; and either in these, or the bluc eyes, the fire, which gives its finest expression to the eyc, is more distinguishable in proportion to the darkness of the tint. For this reason, the black eyes, as they are called, have the greatest vivacity; hut, probably, the blue have the most powerful effect in beauty, as they reflect a greater rariety of lights, being composed of more various colours.

This variety, which is found in the colour of the eyes, is peculiar to man, and one or two other kinds of animals; but, in general, the colour in any one individual is the same in all the rest. The eyes of oxen are brown; those of sheep of a water-colour; those of goats are gray: "and it may also be, in general, remarked, that the eyes of most white animals are red; thus the rabbit, the ferret, and, even in the human race, the white Moor, all have their eyes of a red colour."

Although the eye, when put into motion, seems to be drawn on one side, yet it only moves round the centre; by which its coloured part moves nearer or farther from the angle of the eye-lids, or is elevated or depressed. The distance between the eyes is less in man than in any other animal; and in some of them it is so great, that it is impossible that they should ever view the same object witl both eyes at once, unless it be very far off. "This, however, in them, is rather an advantage than an inconvenience, as they are thus able to watch round them, aud guard against the dangers of their precarious situation."

Next to the eyes, the features, which most give a character to the face, are the eye-brows; which being, in some measure, more apparent than the other features, are most readily distinguisherl at a distance. "Le Brun, in giving a painter directions, with regard to the passions, places the principal expression of the face in the eye-brows. From their cle vation and depression, most of the furious pas. sions are characterized; and such as have this feature extremely. moveable, are usually known to have an expressive face. By mearis of these we can imitate all the other passions, as they are raised or depressed at command; the rest of the features are generally fixed; or, when put into motion, they do not obey the will: the mouth and eyes, in an actor, for instance, may, hy being violently distorted, give a very different expression from what he would intend; but the eye-brows can scarcely be exerted improperly ; their being raised, denotes all those passions which pride or pleasure inspire; and their depression marks those which are the effects of contemplation and pain; and such who have this feature, therefore, most at command, are often found to excel as actors."

The eye-lashes have an effect, in giving expression to the eye, particularly when long and close: they soften its glances, and improve its sweetness. Man and apes are the only animals that have eye-lashes both upon the upper and lower lids; all other animals want them on the lid below.

The eye-lids serve to guard the ball of the eye, and to furnish it with a proper moisture. The upper lid rises and falls; the lower has scarcely any motion; and although their being mored depends on the will, yet it often happens that the will is unable to keep them open, when sleep or fatigue oppresses the mind. In birds and amphibious quadrupeds, the lower lid alone has motion; fishes and insects have no eye-lids whatsoever.

The foreliead makes a large part of the face, and a part which chiefly contributes to its beauty. It ought to be justly proportioned; neither too round nor too llat; neither too narrow nor too low; and the hair should come thick upon its extremities. It is known to every body how much the hair tends to improve the face; and how much the being bald serves to take away from beauty. The lighest part of the head is that which becomes bald the soonest, as well as that part which lies immediately above the temples. The hair under the temples, and at the back of the head, is very seldom known to fail, "and women are much less apt to become bald than inen. Mir. Buffon seems to think they never become bald at all; but we have too many instances of the contrary among us, not to contradict very casily the assertion. Of all parts or appendages of the body, the hair is that which is found most different, in different climates; and often not only contributes to mark the country, but also the disposition of 
the man. It is, in general, thickest where the constitution is strongest; and more glossy, and beautiful, where the health is most permanent. The ancients held the hair to be a sort of excrement, produced like the nails; the part next the root pushing out that immediately contiguous. But the moderus have found that every hair may be truly said to live, to receive nutriment, to fill and distend itself, like the other parts of the body. 'The roots, they observe, do not turn gray sooner than the extremities, but the whole hair changes colour at once; and we have many instances of persons who have grown gray in one night's time." Each hair, if viewed with a microscope, is found to consist of five or six lesser ones, all wrapped up in one common covering; it appears knotted, like some sorts of grass, and sends forth branches at the joints. It is bulbous at the root, by which it imbibes its moisture from the body: and it is split at the points; so that a single hair, at its end, resembles a brush. Whatever be the size or the shape of the pore, through which the hair issues, it accommodates itself to the same; being either thick, as they are large; small, as they are less; round, triangular, and variously formed, as the pores happen to be various. 'The hair takes its colour from the juices flowing through it; and it is found that this colour differs in different tribes and races of people. The Americans and the Asiatics have their hair black, thick, straight, and shining. The inhabitants of the torrid climates of Africa have it black, short, and woolly. The people of Scandinavia have it red, long, and curled; and those of our own, and the neighbouring countries, are found with hair of various colours. However, it is supposed by many, that every man resembles in his disposition the inhabitants of those countries whom he resembles in the colour and the nature of his hair; so that the black are said, like the Asiatics, to be grave and acute; the red, like the Gothic nations, to be choleric and bold. However this may be, the length and the strength of the hair is a gencral mark of a good constitution; and, as that hair which is strongest is most commonly curled, so curled hair is generally regarded among us as a

\footnotetext{
- Mr. Buffon says, that the hair begins to grow gray at the points; but the fact is olherwise.

'Mr. Buftion is of this opinion. Ile says, that the up.
}

beauty. The Greeks, however, had a very different idea of beauty in this respect; and seem to have taken one of their peculiar national distinctions from the length and the straightness of the hair."

The nose is the most prominent feature in the face; but, as it has scarcely any motion, and that only in the strongest passions, it rather adds to the beauty than to the expression of the countenance. "However, I am told, by the skilful in this branch of knowledge, that wide nostrils add a great deal to the bold and resolute air of the countenance; and where they are narrow, though it may constitute beauty, it seldom improves expression." The form of the nose, and its advanced position, are peculiar to the human visage alone Other animals, for the most part, have nostrils, with a partition between them; but none of them have an elevated nose. Apes themselves have scarcely any thing else of this feature but the nostrils; the rest of the feature lying flat upon the visage, and scarcely higher than the cheek-bones. "Among all the tribes of the savage also, the nose is very flat; and I have seen a Tartar who had scarcely any thing else but two holes through which to breathe."

The mouth and lips, next to the eyes, are found to have the greatest expression. The passions have great power over this part of the face; and the mouth marks its different degrees by its different forms. The organ of speech still more animates this part, and gives it more life than any other feature in the countenance. The ruby colour of the lips, and the white cuamel of the tecth, give it such a superiority over every other feature, that it seems to make the principal object of our regards. In fact, the whole attention is fixed upon the lips of the speaker: however rapid his diseourse, however valious the subject, the mouth takes correspondent situations; and deaf men have been often found to sce the force of those reasonings which they could not hear, understanding every word as it was spoken.

"The under jaw in man possesses a great variety of motions; while the upper has been thought, by many, to be quite immoveable.

per jaw is immoveable in all animals. However, the par: rot is an obvious exceprion; and so is man limself, as shown above. 
However, that it moves in man, a very casy experiment will suffice to convince us. If we keep the head fixed, with any thing between our teeth, the edge of a table for instance, and then open our mouths, we shall find that both jaws recede from it at the same time; the upper jaw rises, the lower falls, and the table remains untouched between them. The upper jaw has motion as well as the under; and, what is remarkable, it has its proper muscles behind the head for thus raising and depressing it. Whenever, therefore, we eat, both jaws move at the same time, though very unequally; for the whole head moving with the upper jaw, of which it makes a part, its motions are thus less observable." In the luuman embryo, the under jaw is very much advanced before the upper. "In the adult, it hangs a good deal more backward; and those whose upper and under row of teeth are equally prominent, and strike directly against each other, are what the painters call under-hung; and they consider this as a great defect in beauty. The under jaw in a Chinese face falls greatly more backward than with us; and, I am told, the difference is half an inch, when the mouth is shut naturally." In instances of the most violent passion, the under jaw has often an involuntary quivering motion; and often, also, a state of languor produces another, which is that of yawning. "Every one knows how very sympathetic this kind of languid motion is ; and that for one person to yawn, is sufficient to set all the rest of the company a yawning. A ridiculous instance of this was commonly practised upon the famous M'Laurin, one of the professors at Edinburgh. He was very subject to have his jaw dislocated; so that when he opened his mouth wider than ordinary, or when he yawned, he could not shut it again. In the inidst of his harangues, therefore, if any of his pupils began to be tired of his lecture, he had only to gape or yawn, and the professor instantly caught the sympathetic affection; so that he thus continued to stand specchless, with his mouth wide open, till his servant, from the next room, was called in to set his jaw again."

When the mind reflects with regret upon

- Mr. Buffon says, that both jaws, in a perfect face, should be on a level: but this is denied by the best painters. some good unatlained or lost, it fecls an internalemotion, which acting upon the diapliragm, and that upon the lungs, produces a sigh; this, when the mind is strongly affected, is repeated; sorrow succeeds these first cmotions, and tears are often seen to follow: sobbing is the sigh still more invigorated; and lamentation, or crying, proceeds from the continuance of the plaintive tone of the voice, which scems to implore pity. "There is yet a silent agony, in which the mind appears to disdain all external help, and broods over its distresses with gloomy reserve. 'This is the most dangerous state of mind : accidents or friendship may lessen the louder kinds of grief ; but all remedies for this must be had from within; and there despair too often finds the most deadly enemy."

Laughter is a sound of the voice, interrupted and pursued for some continuance. The muscles of the belly, and the diaphragm, are employed in the slightest exertions; but those of the ribs are strongly agitated in the louder; and the head sometimes is thrown backward, in order to raise them with greater ease. The smile is often an indication of kindness and good-will : it is also often used as a mark of contempt and ridicule.

Blushing proceeds from different passions; being produced by shame, anger, pride, and joy. Paleness is often also the effect of anger; and almost ever attendant on fright and fear. These alterations in the colour of the countenance are entirely involuntary; all the other expressions of the passions are, in some small degree, under control; but blushing and paleness betray our secret purposes; and we might as well attempt to stop them, as the circulation of the blood, by which they are caused.

The whole head, as well as the features of the face, takes peculiar attitudes from its pas sions: it bends forward, to express humility, shame, or sorrow; it is turned to one side in languor or in pity; it is thrown with the chin forward in alrogance and pride; erect in self-conceit and obstinacy; it is thrown backwards in astonishment; and combines its mution to the one side and the other, to express

[b Since the publication of this work, the editor has been credibly informed, that the professor had not the defect here mentioned.] 
contempt, ridicule, anger, and resentment. "Painters, whose study leads to the contemplation of external forms, are much more adequate judges of these than any naturalist can be; and it is with these a general remark, that no one passion is regularly expressed on different countenances in the same manner; but that grief often sits upon the face like joy; and pride assumes the air of passion. It would be vain, therefore, in words, to express their general effect, since they are often as rarious as the countenances they sit upon; and in making this distinction nicely, lies all the skill of the physiognomist. In being able to distinguish what part of the face is marked by nature, and what by the mind; what part has been originally formed, and what is made by habit, constitutes this science, upon which the ancients so much valued themselves, and which we at prescnt so little regard. Some, however, of the most acute men among us, have paid great attention to this art; and, by long practice, have been able to give some character of every person whose face they examined. Montaigne is well known to have disliked those men who shut one eye in looking upon any object; and Fielding asserts, that he never knew a person with a steady glavering smile, but he found him a rogue. However, most of these observations, tending to a discovery of the mind by the face, are merely capricions; and Nature has kindly lid our hearts from each other, to keep us in good humour with our fellow-creatures."

The parts of the head which give the least expression to the face, are the ears; and they are generally found hidden under the hair. These, which are immoveable, and make so small an appearance in man, are very distinguishing features in quadrupeds. They serve in them as the principal marks of the passions; the ears discover their joys or their terrors, with tolerable pecision; and denote all their internal agitations. The smallest cars, in men, are said to be most beautiful; but the largest are found the best for hearing. There are some savage nations who bore their ears, and so draw that part down, that the tips of the ears are seen to rest upon their shoulders.

Thestrange variety of the different customs of men, appears still more extravagant in their manner of wearing their beards. Some, and among others the " $T$ urks, cut the hair off their. heads, and let their beards grow. The Europeans, on the contrary, shave their beards. and wear their hair. The Negroes shave their heads in figures at one time, in stars at another, in the manner of friars; and still more commonly in alternate stripes; and their little boys are shaved in the same manner. The Talapoins, of Siam, shave the heads and the eye-brows of such children as are committed to their care. Every nation seems to have entertained different prejudices, at different times, in favour of one part or another of the beard. Some have admired the hair upon the cheeks on each side, as we see with some low-bred men among ourselves, who want to be fine. Some like the hair lower down; some choose it curled; and others like it straight. "Some have cut it into a peak; and others shave all but the whisker. This particular part of the beard was highly prized among the Spaniards; till of late, a man without whiskers was considered as unfit for company; and where Nature had denied them, Art took care to supply the deficiency. We are told of a Spanish general who, when he borrowed a large sum of money from the Venetians, pawned his whisker, which he afterwards took proper care to release. Kingson assures us, that a considerable part of the religion of the Tartars consists in the management of their whiskers; and that they waged a long and bloody war with the Persians, declaring them infidels, merely because they would not give their whiskers the orthodox cut. The kings of Persia carried the care of their beards to a ridiculous excess, when they chose to wear them matted with gold thread: and even the kings of France, of the first races, had them knotted and buttoned with gold. But of all nations, the Americans take the greatest pains in cut ting their hair, and plucking their beards. The under part of the beard, and all but the whisker, they take care to pluck up by the roots, so that many have supposed them to have no luair naturally growing on that part : and even Linnaus has fallen into that mistakc. Their hair is also cut into bands; and no small care employed in adjusting the whisker. In fact, we have a very wrong idea of savage finery; and are apt to suppose that, like the 
beasts of the forest, they rise, and are dressed with a shake: but the reverse is true; for no birth-night beauty takes more time or pains in the adorning her person than they. I remember, when the Cherokee kings were over here, that I have waited for three hours during the time they were dressing. They never would venture to make their appearance till they had gone through the tedious ceremonies of the toilet; they had their boxes of oil and ochre, their fat. and their perfumes, like the most effeminate beau, and generally took up four hours in dressing, before they considered themselves as fit to be seen. We must not, therefore, consider a delicacy in point of dress, as a mark of refinement, since savages are much more difficult in this particular, than the most fashionable or tawdry European. The more barbarous the people, the fonder of finery. In Europe, the lustre of jewels, and the splendour of the most brilliant colours, are generally given up to women, or to the weakest part of the other sex, who are willing to be contemptibly fine: but in Asia, these trifling fineries are eagerly sought after by every condition of men; and, as the proverb has it, we find the richest jewels in an AEthiop's ear. The passion for glittering ornaments, is still stronger among the absolute barbarians, who often exchange their whole stock of provisions, and whatever else they happen to be possessed of, with our seamen, for a glass-bead, or a looking-glass."

Although fashions have arisen in different countries from fancy and caprice, these, when they become general, deserve examination. Mankind have always considered it as a matter of moment, and they will ever continue desirous of drawing the attention of each other, by such ornaments as mark the riches, the power, or the courage of the wearer. The value of those shining stones which have at all times been considered as precious ornaments, is entirely founded upon their scarceness or their brilliancy. It is the same likewise with respect to those shining metals, the weight of which is so little regarded, when spread over our clothes. These ornaments are rather designed to draw the attention of others, than to add to any enjoyments of our own; and few there are that these ornaments will not serve to dazzle, and who can coolly distinguish between the metal and the man. All things rare and brilliant will, therefore, ever continue to be fashionable, while men derive greater advantage from opulence than virtue; while the means of appearing considerable arc more easily acquired, than the title to be considered. The first impression we generally make, arises from our dress; and this varies, in conformity to our inclinations, and the manner in which we desire to be considered. The modest man, or he who would wish to be thought so, desires to show the simplicity of his mind by the plainness of his dress; the vain man, on the contrary, takes a pleasure in displaying his superiority, "and is willing to incur the spectator's dislike, so he does but excite his attention."

Another point of view which men have in dressing, is to increase the size of their figure; and to take up more room in the world than Nature seems to have allotted them. We desire to swell out our clothes by the stiffiess of art, and raise our heels, while we add to the largeness of our heads. How bulky soever our dress may be, our vanities are still more bulky. The largeness of the doctor's wig arises from the same pride with the smallness of the beau's queue. Both want to have the size of their understanding measured by the size of their beads.

There are some modes that seem to have a more reasonable origin, which is to hide or to lessen the defects of Nature. To take men altogether, there are many more deformed and plain, than beautiful and shapely. The former, as being the most numerous, give law to fashion; and their laws are generally such as are made in their own favour. The women begin to colour their cheeks with red, when the natural roses are faded; and the younger are obliged to subınit, though not compelled by the same necessity. In all parts of the world, this custom prevails inore or less; and powdering and frizzing the hair, though not so general, seems to have arisen from a similar control.

But leaving the draperies of the human picture, let us return to the figure, unadorned by art. Man's head, whether considered externally or interually, is differently formed fiom that of all other animals, the monkey-kind only excepted, in which there is a striking 
similitude. There are some differences, however, which we shall take notice of in another place. The bodies of all quadruped animals are covered with hair; but the head of man seems the part most adorned; and that more abundantly than in any other animal.

There is a very great variety in the teeth of all animals; some have them above and below; others have them in the under jaw only; in some tley stand separate from each other; while in some they are continued and united. The palate of some fishes is nothing clse but a bony plate studded with points, which perform the offices of teeth. All these substances, in every animal, derive their origin from the nerves; the substance of the nerves hardens by being exposed to the air; and the nerves that terminate in the mouth, being thus exposed, acquire a bony solidity. In this manner, the tecth and nails are formed in man; and in this manner, also, the beak, the hoofs, the horns, and the talons, of other animals, are found to be produced.

The neck supports the head, and unites it to the body. This part is much more considerable in the generality of quadrupeds, than iu man. But fishes, and other animals that want lungs similar to ours, have no neck whatsoever. Birds, in general, have the neck longer than any other kind of animals: those of them, which have short claws, have also short necks; those, on the contrary, that have them long, are found to have the neck in proportion. "In men, there is a lump upon the wind-pipe, formed by the thyroid cartilage, which is not to be seen in women; an Arabian fable says, that this is a part of the original apple, that has stuck in the man's throat by the way, but that the woman swallowed her part of it down."

The human breast is outwardly formed in a very different manner from that of other animals. It is larger in proportion to the size of the body; and none but man, and such animals as make use of their fore feet as hands, such as monkeys, bats, and squirrels, and such quadrupeds as climb trees, are found to have those bones called the clavicles, or, as we usually term them, the collar-bones."

\footnotetext{
Mr. Buffon says, that none but inonkeys have then ;
} but this is an oversight.
The breasts in women are larger than in men; however, they seem formed in the same manner; and, sometimes, milk is found in the breasts of men, as well as in those of women. Among animals, there is a great variety in this part of the body. The teats of some, as in the ape and the elephant, are like those of men, being but two, and placed on each side of the breast. The teats of the bear amount to four. The sheep has but two, placed between the hinder legs. Other animals, such as the bitch and the sow, have them all along the belly; and, as they produce many young, they have a great many teats for their support. The form also of the teats varies in different animals; and, in the same animal, at different ages. The bosom in females, seems to unite all our ideas of beauty, where the outline is continually changing, and the gradatious are soft and regular.

"The graceful fall of the shoulders, both in man and woman, constitute no small part of beauty. In apes, though otherwise made like us, the shoulders are high, and drawn up on each side towards the ears. In man they fall by a gentle declivity; and the more so, in proportion to the beauty of lis form. In fact, being high-shouldered, is not without reason considered as a deformity, for we find very sickly persons are always so; and people, when dying, are ever seen with their shoulders drawn up in a surprising manner. The muscles that serve to raise the ribs, mostly rise near the shoulders: and the ligher we raise the shoulders, we the more easily raise the ribs likewise. It liappens, therefore, in the sickly and the dying, who do not breathe witlıout labour, that to raise the ribs, they are obliged to call in the assistance of the shoulders; and thus their bodies assume, from ha: bit, that form which they are so frequently obliged to assume. Women with child also, are usually seen to be high-shouldered; for the weight of the inferior parts drawing down the ribs, they are obliged to use every effort to elevate them, and thus they raise the shoulders of course. During pregnancy, also, the shape, not only of the shoulders, but also of the breast, and even the features of the face, are greatly altered: for the whole upper forepart of the body is covered with a broad thin skin, called the myoides; which being, at 
that time, drawn down, it also draws down with it the skin, and, consequently, the feasures of the face. By these means the visage takes a particular form; the lower eye-lids, and the corners of the mouth, are drawn downwards; so that the eyes are enlarged, and the mouth lengthened; and women, in these circumstances, are said, by the midwives, to be all nouth and eyes."

The arms of men but very little resemble the fore feet of quadrupeds, and much less the wings of birds. The ape is the only animal that is possessed of hands and arms; but these are much more rudely fashioned, and with less exact proportion, than in men; " the thumb not being so well opposed to the rest of the fingers, in their hands, as in ours."

The form of the back is not much different in mant from that of other quadruped animals, only that the reins are more muscular in him, and stronger. The buttock, however, in man, is different from that of all other animals whatsoever. What goes by that name, in other creatures, is only the upper part of the thigh; man being the only animal that supports himself perfectly erect, the largeness of this part is owing to the peculiarity of his position.

Man's feet, also, are different from those of all other animals, those even of apes not excepted. The foot of the ape is rather a kind of awkward hand; its toes, or rather fingers, are long, and that of the middle longest of all. This foot also wants the heel, as in man; the sole is narrower, and less adapted to maintain the equilibrium of the body in walking, dancing, or running.

The nails are less in man than in any other animal. If they were much longer than the extremities of the fingers, they would rather be prejudicial than serviceable, and obstruct the management of the hand. Such savages as let them grow long, make use of them in flaying animals, in tearing their flesh, and such like purposes; however, though their nails are considerably larger than ours, they are by no means to be compared to the hoofs or the claws of other animals. "They may sometimes be seen longer, indeed, than the claws of any animal whatsoever; as we learn that the nails of some of the learned men in China are longer than their fingers. But these want that solidity which might give force to their exertions; and could never, in a state of nature, have served them for annoyance or defence."

There is little known exactly with regard to the proportion of the human figure; and the beauty of the best statues is better conceived by observing than by measuring them. 'The statues of antiquity, which were at first copied after the human form, are now become the models of it; nor is there one man found whose person approaches to those inimitable performances, that have thus, in one figure, united the perfections of many. It is sufficient to say that, from being at first models, they are now become originals; and are used to correct the deviations in that form from whence they were taken. I will not, however, pretend to give the proportions of the human body, as taken from these, there being nothing more arbitrary, and which good painters themselves so much contemn. Some, for instance, who have studied after these, divide the body into ten times the lengtl of the face, and others into eight. Some pretend to tell us, that there is a similitude of proportion in different parts of the body. Thus, that the hand is the length of the face; the thumb the length of the nose; the space between the eyes is the breadth of an eye; that the breadth of the thigh, at thickest, is double that of the thickest part of the leg, and treble the smallest; that the arms extended, are as long as the figure is high; that the legs and thighs are half the length of the figure. All this, however, is extremely arbitrary; and the excellence of a shape, or the beauty of a statue, results from the attitude and position of the whole, rather than any established measurements, begun without experience, and adopted by caprice. In general, it may be remarked, that the proportions alter in every age, and are obriously different in the two sexes. In women, the shoulders are narrower, and the neck proportionably longer, than in men. The hips also are considerably larger, and the thiglis much shorter, than in men. 'These proportions, however, vary greatly at different ages. In infancy, the upper parts of the body are much larger than the lower; the legs and thighs do not constitute any thing like half the height of the whole figure: in 
proportion as the child increases in age, the inferior parts are found to lengthen; so that the body is not equally divided until it has acquired its full growth.

The size of men varies considerably. Men are said to be tall who are from five fect eight inches to six feet high. The middle stature is from five feet five to five fect eight: and those are said to be of small stature who fall under these measures. "However, it ought to be remarked, that the same person is always taller when he arises in the morning, than upon going to bed at night; and sometimes there is an inch differenee; and 1 lave seen more. Few persons are sensible of this remarkable variation; and $\mathrm{l}$ am told, it was first perceired, in England, by a recruiting officer. He often found that those men whom he had enlisted for soldiers, and answered to the appointed standard at one time, fell short of it when they came to be mcasured before the colonel, at the head-quarters. This diminution in their size proceeded from the different times of the day, and the different states of the body, when they happened to be measured. If, as was said, they were measured in the morning, after the night's refreshment, they were found to be commonly half an inch, and very often a whole inch, taller than if measured after the fatigues of the day; if they were measured when fresh in the country, and before a long fatiguing mareh to the regiment, they were found to be an inch taller than when they arrived at their journey's end. All this is now well known among those who reeruit for the army, and the reason of this difference of stature is obvious. Between all the joints of the back-bone, which is composed of several pieces, there is a glutinous liquor deposited, which serves, like oil in a machine, to give the parts an easy play upon each other. This lubricating liquor, or synovia, as the anatomists call it, is poured in during the season of repose, and is consumed by exercise and employment; so that in a body, after hard labour, there is searce any of it remaining; but all the joints grow stiff, and their motion becomes hard and painful. It is from hence, therefore, that the body diminishes in stature. For this moisture being drained away from betwcen the numerous joints of the back-bone, they lie closer upon each other; and their whole length is thus very sensibly diminished; but sleep, by restoring the fluid again, swells the spaces between the joints, and the whole is extended to its former dimensions.

"As the human body is thius often found to differ from itself in size, so it is found to differ in its weight also; and the same person, without any apparent cause, is found to be heavice at one time than another. If, after having eaten a hearty dimner, or having drunk hard, the person should find himself thus heavier, it would appear no way extraordinary; but the fact is, the body is very often found heavier some hours after eating a hearty meal than immediately succeeding it. If, for instance, a person, fatigued by a day's hard labour, should eat a plentiful supper, and then get himself weighed upon going to bed; after slceping soundly, if he is again weighed, he will tind himself considerably ,heavier thain before; and this difference is often found to amount to a pound, or sometimes to a pound and a half. From whence his adventitious weight is derived is not easy to conceive; the body, during the whole night, appears rather plentifully perspiring than imbibing any fluid, rather losing than gaining moisture: however, we have no reason to doubt, but that either by the lungs, or perhaps, by a peeuliar set of pores, it is all this time inhaling a quantity of fluid, which thus increases the weight of the whole body, upon being weighed the next morning."

Although the human body is externally more dclicate than any of the quadruped kind, it is, notwithstanding, extremely muscular; and, perhaps, for its size, stronger than that of any other animal. If we should otrer to compare the strength of the lion with that of man, we should cousider that the claws of this animal, give us a false idea of its power; we ascribe to its force what is only the effeets of its arms. Those which man has reeeived from Nature are not offensive; happy had Art never furnished him with any more terrible than those which arm the paws of the lion!

aroin the experiment also, the lenrned may gather upon what a weak foundaion the whole doctrine of Sanctorian perspiration is built: but this disquisition inore properly belongs to medicine than natural history. 
But there is another manner of comparing the strength of man with that of other animils ; namely, by the weights which either can carry. We are assured that the porters of Coustantinople carry burdens of nine hunlred pounds weight. Mr. Desaguliers tells us of a man, who by distributing weiglits in such a manner, as that every part of his body bore its share, was thus able to raise a weight of two thousand pounds. A lorse, which is about seven times our bulk, would be thus able to raise a weight of fourtcen thousand pounds, if its strength were in the same proportion. ${ }^{b}$ "But, the truth is, a horse will not carry upon its back above a weight of two or three hundred pounds; while a man, of confessedly inferior strength, is thus able to support two thousand. Whence comes this seeming superiority? The answer is obvious. Because the load upon the man's slioulders is placed to the greatest advantage ; while, upon the lıorse's back, it is placed at the greatest disadvantage. Let us suppose, for a moment, the man standing as upright as possible, under the great load above mentioned. It is obvious, that all the bones of his body may be compared to a pillar supporting a building, and that his muscles have scarce any share in this dangerous duty. However, they are not entirely inactive; as man, let him stand never so upright, will laare some bending in different parts of his body. The museles, therefore, give the bones some assistance, and that with the greatest possible advantage. In this manner, a man has been found to support two thousand weight; but may be capable of supporting a still greater. The manner in which this is done, is by strapping the load round the shoulders of the person who is to bear it, by a machine something like that by which milk vessels or waterbuckets are carried. The load being thus placed on a scaffold, on each side, contrived for that purpose, and the man standing erect in the midst, all parts of the scaffold, except that where the man stands, are made to sink; and thus the man maintaining his position, the load, whatever it is, becomes suspended, and the column of his bones may be fairly said to support it. If, lowever, lie should but ever so little give way, he nust inevitably drop;

Mfr. Buffon calls it a better manner; but this is not the case. and no power of his can raise the weights again. But the case is very different with regard to a load laid upon a lıorse. The column of the bones there lies a different way; and a weight of five hundred pounds, as I am told, would break the back of the strongest lorse that could be found. The great force of a horse, and other quadrupeds, is exerted when the load is in such a position as that the column of the bones can be properly applied, which is lengtiw wise. When, therefore, we are to estimate the comparative strength of a horse, we are not to try what he can carry, but what he can draw ; and, in this case, his amazing superiority over man is easily discerned; for onc horse can draw a load that ten men cannot move. And, in some cases, it happens that a draft-horse draws the better for being somewhat loaded; for, as the peasants say, the load upon the back keeps him the better to the ground."

There is still another way of estimating human strength, by the perseverance and agility of our motions. Men, who are exercised in running, outstrip liorses; or, at least, hold their speed for a longer continuance. In a journey, also, a man will walk down a horse; and, after they liave both continued to proceed for several days, the horse will be quite tired, and the man will be fresher than in the beginning. The king's nessengers of Ispahan, who are runners by profession, go thirty-six leagues in fourteen hours. Travellers assure us, that the Hottentots outstrip lions in the chase; and that the savages, who bunt the elk, pursue with such speed, that they at last tire down and take it. We are told many very surprising things of the great swiftness of the savages, and of the long journeys they undertake, on foot, through the most craggy mountains, where there are no paths to direct, nor houses to entertain them. They are said to perform a journey of twelve luundred leagues in less than six weeks. "But notwithstanding what travellers report of this matter, I have been assured, from many of our officers and soldiers, who compared their own swiftness with that of the native Americans, during the last war, that although the savages held out, and, as the phrase is, had better bottoms, yet, for a

b Mr. Buffon carries this subject no farther; and thus far, without explanation, it is erroneous. 
spurt, the Englishmen were more nimble and speedy."

Neverthcless, in general, civilized man is ignorant of his own powers : he is ignorant how much he loses by effeminacy; and what might be acquired by habit and exercise. Here and there, indeed, men are found among us of extraordinary strength; but that strength, for want of opportunity, is seldom called into exertion. "A Anong the ancients it was a quality of much greater use than at present ; as in war, the same inan that hadl strength sufficient to carry the heaviest armour, had strength sufficient also to strike the most fatal blow. In this case, his strength was at once his protection and his power. We ought not to be surprised, therefore, when we hear of onc man terrible to an army, and irresistible in his career, as we find some generals represented in ancient history. But we may be very certain that this prowess was exaggerated by flattery, and exalted by terror. An age of ignorance is ever an age of wonder. At such times, mankind, having no just ideas of the human powers, are willing rather to represent what they wish, than what they know; and exalt human strength, to fill up the whole sphere of their limited conceptions. Great strength is an accidental thing; two or three in a country may possess it; and these may have a claim to heroism. But what may lead us to doubt of the veracity of these accounts is, that the heroes of antiquity are represented as the sons of lreroes; their amazing strength is delivered down from father to son; and this we know to be contrary to the course of nature. Strength is not hereditary, although titles are: and I am very much induced to believe, that this great tribe of heroes, who are all represented as the descendants of heroes, are more obliged to their titles than to their strength, for their characters. With regard to the shining characters in Homer, they are all represented as princes, and as the sons of princes; while we are told of scarce any share. of prowess in the meaner men of the army; who are only brought into the field for these to protect, or to slaughter. But nothing can be more unlikely than that those men, who were bred in the luxury of courts, should be strong; while the whole body of the people, who received a plainer and simpler education, should be comparatively weak. Nothing can be more contrary to the general laws of nature, than that all the sons of heroes should thus inherit not only the kingdoms, but the strength of their forefathers; and we may conclucle, that they owe the greatest share of their imputed strength rather to the dignity of their stations than the foree of their arms; and, like all fortunate princes, their flatterers happened to be believed. In later ages, indeed, we have some accomts of amazing strength, which we can have no reason to doubt of. But in these, nature is found to pursue her ordinary course; and we find their strength accidental. We find these strong men among the lowest of the people, and gradually rising into notice, as this superiority had more opportunity of being seen. Of this number was the Roman tribune, who went by the name of the second Achilles; who, with his own hand, is said to have killed, at different times, three hundred of the enemy; and when treacherously set upon, by twentyfive of his own countrynien, although then past his sixtieth year, killed fourteen of them before he was slain. Of this number was Milo, who, when he stood upright, could not be forced out of his place. Pliny tells us of one Athanatus, who walked across the stage at Rome, loaded with a breastplate weighing five hundred pounds, and buskins of the same weight. But of all the procligies of strength, of whom we have any accounts in Roman history, Maximin, the emperor, is to be reckoned the foremost. Whatever we are told relative to him is well attested; his character was too exalted not to be thoroughly known; and that very strength, for which he was celebrated, at last procured him no less a reward than the empire of the world. Maximin was above nine feet in height, and the best proportioned man in the whole empire. He was by birth a Thracian; and, from being a simple herdsman, rose through the gradations of office, until he came to be emperor of Rome. The first opportunity he had of exerting hisstrength, was in the presence of all the citizens, in the theatre, where he overthrew twelve of the strongest men in wrestling, and outstript two of the fleetest horses in running, all in one day. He could draw a chariot loaden, that two strong horses could not move: he could break a horse's jaw with a blow of his fist, and its thigh with a kick. In war he was always foremost and invincible: happy had it been 
for him and his subjects if, from being formidable to his enemies, he had not become still more so to his subjects; he reigned, for some time, with all the world his enemy; all mankind wishing him dead, yet none daring to strike the hlow. As if fortune had resolved that through life he should continue unconquerable, he was killed at last by his own soldiers while he was sleeping. We have many other instances, in later ages, of very great strength, and not fewcr of amazing swifuess; but these, merely corporeal perfections, are now considered as of small advantage, either in war or in peace. The invention of gunpowder has, in some measure, levelled all force to one standard; and lras wrought a total change in martial education through all parts of the world. In peace also the invention of new machines every day, and the applieation of the strength of the lower animals to the purposes of life, have rendered human strength less valuable. The boast of corporeal force is, therefore, consigned to savage nations, where those arts not being introduced, it may still be needful; but, in more polite countries, few will be proud of that strength which other animals can be taught to exert to as useful purposes as they.

"If we compare the largeness and thickness of orr muscles with those of any other animal, we shall find that, in this respect, we have the advantage; and if strength, or swiftness, depended upon the quantity of muscular flesh slone, I believe that, in this respect, we should be nore active and powerful than any other. But this is not the case; a great deal more than the size of the muscles goes to eonstitute activity or force; and it is not he who has the thickest legs that can make the best use of them. Those, therefore, who have written elaborate treatises on muscular force, and have estimated the strength of animals by the thickness of their muscles, have been employed to very little purpose. It is in general observed, that thin and raw-boned mell are always stronger and more powerful, than such as are seemingly more muscular; as in the former all the parts have better room for their exertions."

Women want much of the strength of men; and, in some countries, the stronger sex have availed themselves of this superiority, in cruelly and tyrannically enslaving those who were made with equal pretensions to a share in all the advantages life can bestow. Savage nations olblige their women to a life of continual labour ; upon them rest all the drudgeries of domestic duty; while the husband, indolently reclined in his hammock, is first served from the firuits of her industry. From this negligent situation he is seldom roused, except by the calls of appetite, when it is necessary, either hy fishing or hunting, to make a variety in his entertainments. A savage has no idea of taking pleasure in exereise; he is surprised to see an European walk forward for his anusement, and then return back again. As for his part, he could be contented to remain for ever in the same situation, perfectly satisfied with sensual pleasures and undisturbed repose. The women of these countries are the greatest slaves upon earth: scusible of their weakness; and unable to resist, they are obliged to suffer those hardships which are naturally inflicted by such as have been taught that mothing but corporeal force ought to give pre-eminence. It is not, therefore, till after some degree of refinement, that women are treated with lenity; and not till the highest degree of politeness, that they are permitted to share in all the privileges of man. The first inspulse of savage nature is to confirm their slavery; the next of half barbarous nations, is to appropriate their beauty; and that of the perfectly polite, to engage their affections. In civilized countries, therefore, womien have united the force of modesty to the power of their natural charms; and thus obtain that superiority over the mind, which they are unable to extort by their strength. 


\section{CHAPTER XXVII.}

\section{OF SLEEP AND HUNGER.}

AS man, in all the privileges he enjoys, and the powers he is invested with, has a superiority over all other animals, so, in his necessities, lie seems inferior to the meanest of them all. Nature has brought him intolife with a greater variety of wants and infir nities than the rest of her crentures, unarmed in the midst of enemics. The lion has natural arms; the brar natural clothing; but man is destitute of all such advantages; and, from the superiority of his mind alone, he is to supply the deficiency. The number of his wants, however, were merely given, in order to multiply the number of his enjoyments; since the possibility of being deprived of any good, teaches him the value of its nossession. Were man born with those advantages which he learns to possess by industry, he would very probably enjoy them with a blunter relish; it is by being naked, that he knows the value of a covering; it is by being exposed to the weather, that he learns the coniforts of an habitation. Every want thus becomes a means of pleasure, in the redressing; and the animal that has most desires, may be said to be capable of the greatest varicty of happiness.

Beside the thousand imaginary wants peculiar to man, there are two, which he has in common with all other animals; and which he feels in a more necessary manner than they. These are the wants of sleep and hunger. Every animal that we are acquainted with, seems to endure the want of these with much less injury to health than man; and some are most surprisingly patient in sustaining both. The little domestic animals that we keep about IIs, may often set a lesson of calm resignation, in supporting want and watchfulness, to the boasted philosopher. They receive their pittance at unecrtain intervals, and wait its coming with cheerful expectation. We have instances of the dog and the cat living in this manner, without food, for screral days; and yet still preserving their attachment to the tyrant that oppresscs them; still ready to exert their little services for his amusenent or defence. But the patience of these is nothing, to what the animals of the forest endurc. As these mostly live upon accidental carnage, so they are often known to remain withont food for several weeks together. Nature, kindly solicitous for their support, has also contracted their stomachs, to suit them for their precarious way of living: and kindly, while it abridges the banguet, lessens the necessity of providing for it. But the meaner tribes of animals are nade still more capable of sustaining life without food, many of them remaining in a state of torpid indifference, till their prey approaches, whicn they junp upon and seize it. In this mamner the snake, or the spider, continue, for several months together, to subsist upon a single meal; and some of the butterfly kinds live upon little or nothing. But it is very different with man: his wants daily make their importunate demands ; and it is known, that lie cannot continue to live nany days without cating, drinking, and slecping.

Hunger is a much more powerful enemy to man than watchfulness, and kills him nuch suoner. It may be considered as a disorder that food removes; and that would quickly be fatal, withont its proper antidote. In fact, it is so terrible to man, that to avoid it he even encounters certain death; and, rather than endure its tortures, exchanges them for immediate destruction. However, by what I have been told, it is much more dreadful in its approaches, than in its continuance; and the pains of a famishing wretch decrease, as his strength diminishes. In the beginning, the desire of food is dreadful indeed, as we know by experience, for there are fecw who have not in some degree, felt its approaches. But, after the first or second day, its tortures become less terrible, and a total insensibility at length comes kindly in to the poor wretch's assistance. I have talked with the captain of a ship, who was one of six that endured it in its extremities; and who was the only person that had not lost his 
senses, when they received accidental relief. He assured me, his pains, at first, were so great, as to be often tempted to eat a part of one of the men who died; and which the rest of his crew actually for some time lived upon: he said, that during the continuance of this paroxysm, he found his pains insupportable; and was desirous, at one time, of anticipating that death which he thought inevitable: but his pains, he said, gradually decreased after the sixth day, (for they had water in the ship, which kept them alive so long, and then lie was in a state rather of languor than desire; nor did he much wish for food, except when he saw others eating; and that for a while revived his appetite, though with diminished importunity. The latter part of the time, when his health was almost destroyed, a thousand strange images rose upon his nind; and every one of his senses began to bring him wrong information. The most fragrant perfumes appeared to him to have a foetid smell; and every thing he looked at took a greenish hue, and sometimes a ycllow. When he was presented with food by the ship's company that took him and his men up, four of whom died shortly after, he could not help looking upon it with loathing, instead of desire; and it was not till after four days, that his stomach was brought to its natural tone, when the violence of his appetite returued, with a sort of canine eagerness.

Thus dreadful are the effects of hunger; and yet when we come to assign the cause that produces them, we find the subject involved in doubt and intricacy. This longing eagerness is, no doubt, given for a very obvious purpose; that of replenishing the body, wasted by fatigue and perspiration. Were not men stimulated by such a pressing monitor, they might be apt to pursue other amusements, with a perseverance beyond their power; and forget the useful hours of refreshment, in those more tempting ones of pleasure. But hunger makes a deniand that will not be refused; and, indeed, the generality of mankind seldom await the call.

Hunger has been supposed by some to arise from the rubbing of the coats of the stomach against each other, without having any intervening substance to prevent their painful attrition. Others have imagined, that its juices, wanting their necessary supply, turn acrid, or, as some say, pungent; and thus fret its internal coats, so as to produce a train of the most uneasy sensations. Boerhaave, who established his reputation in physic, by uniting the conjectures of all those that preceded him, ascribes hunger to the united effect of both these causes; and asserts, that the pungency of the gastric juices, and the attrition of its coats against each other, cause those pains, which nothing but food can remove. These juices continuing still to be separated in the stomach, and every moment becoming more acrid, mix with the blond, and infect the circulation: the circulation being thus contaminated, becomes weaker, and more contracted ; and the whole nervous frame sympathizing, an hectic fever, and sometimes madness, is produced; in which state the faint wretch expires. In this manner, the man who dies of hunger, may be said to be poisoned by the juices of his own body; and is destroyed less by the want of nourishment, than by the vitiated qualities of that which he had already taken.

However this may be, we have but few instances of men dying, except at sea, of absolute hunger. The decline of those unhappy creatures who are destitute of food, at land, being nore slow and unperceived. These, from often being in need, and as often receiving an accidental supply, pass their lives between surfeiting and repining; and their constitution is impaired by insensible degrees. Man is unfit for a state of precarious expectation. That share of provident precaution which incites him to lay up stores for a distant day, becomes his torment, when totally unprovided against an immediate call. The lower race of animals, when satisfied, for the instant moment, are perfectly happy : but it is otherwise with man ; his mind anticipates distress, and feels the pangs of want even before it arrests lim. Thus the mind being continually luarassed by the situation, it at length influences the constitution, and unfits it for all its functions. Some cruel disorder, bnt no way like humger, seizes the unhappy sufferer; so that almost all those men who have thus long lived by chance, and whose every day may be considered as an happy escape from famine, are known at last to die in reality of a disorder caused by hunger; but which, in the common language, is often called a broken heart. Some of these I have known myself, when very little able to relieve thein : and I have been told, 
by a very active and worthy magistrate, that the number of such as die in London for want, is much greater than one wonld imaginc-1 think lic talked of two thousand in a year!

But how numerous soever those who dic of hunger may be, many times greater, on the other hand, are the number of those who die by repletion. It is not the province of the present page to speculate, with the physician, upon the danger of surfeits; or, with the moralist, upon the nauseousness of gluttony: it will only be proper to observe, that as nothing is so prejudicial to health as hunger by constraint, so nothing is more beneficial to the constitution than voluntary abstinence. It was not without reason that religion enjoined this duty; since it answered the double purpose of restoring the health oppressed by luxury, and diminished the consumption of provisions, so that a part might come to the poor. It should be the business of the legislature, therefore, to enforce this divine precept; and thus, by restraining one part of mankind in the use of their superfluities, to consult for the benefit of those who want the necessaries of life. The injunctions for abstinence are strict over the whole Continent ; and where rigorously observed even among ourselves, for a long time after the Reformation. Queen Elizabeth, by giving her commands upon this head the air of a political injunction, lessened, in a great measure, and in my opinion very unwisely, the religious force of the obligation. She enjoined that her subjects should fast from fiesh on Fridays and Saturdays ; but at the same time declared, that this was not commanded from motives of religion, as if there were any differences in meats, but merely to favour the consumption of fish, and thus to multiply the number of marincrs; and also to spare the stock of sheep, which might be more beneficial in another way. In this manner the injunction defeated its own force; and this most salutary law became no longer binding, when it was supposed to come purely from man. How far it may be enjoined in the Scriptures, I will not take upon me to say; but this may be asserted, that if the utmost benefit to the individual, and the most extensive advantage to society, serve to mark any institution as of Heavcn, this of abstinence inay be reckoned among the foremost.

Were we to give an history of the various benefits that have arisen from this command, and how conducive it has bcen to long life, the instances would fatigue with their inultiplicity. It is surprising to what a great age the primitive Christians of the East, who retired from pcrsecution in the deserts of Arabia, continucd to live, in all the bloom of health, and yet all the rigours of abstemious discipline. Their common allowance, as we are told, for four and twenty hours, was twelve ounces of bread, and nothing but water. On this simple beverage, St. Anthony is said to have lived a hundred and five years; James, the hermit, an hundred and four; Arsenius, tutor to the emperor Arcadius, an hundred and twenty; St. Epiphanius, an hundred and fiftecn; Simeon, an hundred and twelve; and Rombald, an hundred and twenty. In this manner did these boly temperate men live to at extreme old age, kept cheerful by strong hopcs, and healthful by moderate labour.

Abstinence, which is thus voluntary, may be much more easily supported than constrained lhunger. Man is said to live without food for seven days; which is the usual limit assigned him ; and, perhaps, in a state of constraint, this is the longest time he can survive the want of it. But in cases of voluntary abstinence, of sickness, or sleeping, he has been known to live much longer.

In the records of the Tower, there is an account of a Scotchman, imprisoned for felony, who for the space of six weeks took not the least sustenance, being exactly watched during the whole time; and for this he received the king's pardon.

When the American Indians undertake long journeys, and when, consequently, a stock of provisions sufficient to support them the whole way, would be more than they could carry ; in order to obviate this inconvenience, instead of carrying the necessary quantity, they contrive a method of palliating their hunger, by swallowing pills, made of calcined shells and tobacco. These pills take away all appctite, by producing a temporary disorder in the stomach; and, no doubt, the frequent repetition of this wretched expedient must at last be fatal. By these means, however, they continue several days without eating, cheerfully bearing such extremes of fatigue and watching, as would quickly destroy men bred up in a greater state of delicacy. For those arts by which we learn to obviate our necesșities, do not 
fail to unfit us for their accidental encounter.

Upon the ivhole, therefore, nan is less able to support hunger than any'other animal ; and he is not better qualified to support a state of watchfulness. Indeed, sleep seems much more necessary to him, than to any other creature: as, when awake, he may be said to exhaust a greater proportion of the nervous fluid; and, consequently, to stand in need of an adequate supply. Other animals, when most aivake, are but little removed from a state of slumber; their feeble faculties, imprisoncd in matter, and rather exerted by impulse than deliberation, require sleep, rather as a cessation from motion, than from thinking. But it is otherwise with man; his ideas, fatigued with their various excursions, demand a cessation, not less than the body, from toil: and he is the only creature that seems to require sleep from double motives; not less for the refreshment of the mental, than of the bodily frame.

There are some lower animals, indeed, that seem to spend the greatest part of their lives in sleep; but, properly speaking, the sleep of such may be considered as a kind of death; and their waking, a resurrection. Flies, and insects, are said to be asleep, at a time that all the vital motions have ceased, without respiration, without any circulation of their juices; if cut in pieces, they do not awakc, nor does any fluid ooze out at the wound. These may be considered rather as congealed than as sleeping animals; and their rest, during winter, rather as a cessation from life, than a necessary refreshment; but in the ligher races of animals, whose blood is not thus congealed, and thaved by heat, these all bear the want of sleep inucli better than man; and some of them continue a long time without seeming to take any refreshment from it whatsoever.

But man is more feeble; he requires its due return; and if it fails to pay the accustomed visit, his whole frame is in a short time tlirown into disorder: his appetite ceases; his spirits are dejected; his pulse beconies quicker and harder ; and his mind, abridged of its slumbering visions, begins to adopt waking dreams. A thousand strange phantoms arise, which come and go without his will; these, which are transient in the beginning, at last take firm possession of the mind, which yields to their dominion, and after a long struggle, runs into confirmed madness. In that horrid state, the mind may be considered as a city without walls, open to every insult, and paying homage to every invader; every idea that then starts with any force, becomes a reality; and the reason, over futigued with its former importunities, makes no head against the tyrannical invasion, but submits to it from mere imbecility.

But it is happy for mankind, that this state of inquietude is seldom driven to an extreme; and that there are medicines which seldom fail to give relief. However, man finds it more difficult than any other animal to procure sleep: and some are obliged to court its approaches for several hours together, before they incline to rest. It is in rain that all light is excluded; that all sounds are removed; that warmth and softness conspire to invite it; the restless and busy mind still retains its former activity; and Reason, that wishes to lay down the reins, in spite of herself, is obliged to maintain them. In this disagreeable state, the mind passes from thought to thought, willing to lose the distinctness of perception, by increasing the multitude of the images. At last, wlien the approaches of sleep are near, every object of the imagination begins to mix with that next it; their outlines become, in a manner, rounder; a part of their distinctions fade away; and sleep, that ensues, fashions out a drcam from the remainder.

If then it should be asked from what cause this state of repose proceeds, or in what manner sleep thus binds us for several hours together? I must fairly conféss my ignorance; although it is easy to tell what philosophers say upon the subject. Sleep, says one of them, consists in a scarcity of spirits, by which the orifices or pores of the nerves in the brain, through which the spirits used to flow into the nerves, being no longer kept open by the frequency of the spirit3, shut of themselves; thus the nerves, wanting a new supply of spirits, become lax, and unfit to convey any impression to the brain. All this, however, is explaining a very great obscurity by somewhat more obscure; leaving. therefore, those spirits to open and shut the en-

\footnotetext{
- Rohault.
} 
trances to the brain, let us be contented with simply enumerating the effects of sleep upon the human constitution.

In sleep, the whole nervous frame is relased, while the heart and the lungs seen more forcibly exerted. This fuller circulation produces also a swelling of the muscles, as they always find who sleep with ligatures on any part of their body. This increased circulation also, may be considered as a kind of exercise, which is continued through the frame; and by this, the perspiration becomes more copious, although the appetite for food is entirely taken away. T'oo much sleep dulls the appreheusion, weakens the memory, and unfits the body for labour. On the contrary, sleep too much abridged, emaciates the firame, produces melancholy, and consumes the constitution. It requires some care, therefore, to regulate the quantity of sleep, and just to take as much as will completely restore nature, without oppressing it. The poor, as Otway says, sleep little; forced by their situation, to lengthen out their labour to their necessities, they liave but a short interval for this pleasing refreshment; and I have ever been of opinion, that bodily labour demands a less quantity of sleep than mental. Labourers and artizans are generally satisfied with about seven hours; but I have known some sclıolars who usually slept nine, and perceived their faculties no way impaired by oversleeping.

The famous Philip Barrettiere, who was consilered as a prodigy of learning at the age of fourteen, was known to sleep regularly twelve hours in the twenty-four; the extreme activity of his mind, when awake, in some measure called for an adequate alternation of repose : and, I am apt to think, that when students stint themselves in this particular, they lessen the waking porrers of the imagination, and weaken its most strenuous exertions. Animals that seldom think, as was said, can very easily dispense with sleep; and of inen, such as think least, will, very probably, be satisfied with the smallest share. A life of study, it is well known, unfits the body for receiving this gentle refreshment; the approaches of sleep are driven of by thinking: when, therefore, it comes at last, we should not be too ready to interrupt its continuance. Sleep is, indeed, to some, a very agreeable period of their existence: and it has been a question in the schools, Which was most happy, the man who was a beggar by night, and a king by day; or he who was a beggar by day, and a king by night? It is given in favour of the nightly monarch, by him who first started the question: "For the dream," says he, "gives the full enjoyment of the dignity, without its attendant inconveniences; while, on the other hand, the king, who supposes himself degraded, feels all the misery of his fallen fortune, without trying to find the comforts of his humble situation. Thus, by day, both states have their peculiar distresses: but, by night, the exalted beggar is perfectly blessed, and the king conpletely miserable." All this, however, is rather fanciful than just; the pleasure dreans can give us, seldon reaches to our waking pitch of happiness: the mind often in the midst of its highest visionary satisfactions, demands of itself, whether it does not owe them to a dream; and lirequently awakes with the reply.

But it is seldom, except in cases of the highest delight, or the most extreme uneasiness, that the mind has power thus to disengage itself from the dominion of fancy. In the ordinary course of its operations, it submits to those numberless fantastic images that succeed each other, and which, like many of our waking thoughts, are generally forgotten. Of these, however, if any, by their oddity, or their continuance, affect us. strongly, they are then remembered; and there have been some who felt their impressions so strongly, as to mistake them for realities, and to rank them annong the past actions of their lives.

There are others upon whom dreams seen to have a very different effect; and who, without seeming to remember their impressions the next morning, have yet shown, by their actions during sleep, that they were very powerfully impelled by their dominion. We have numberless instances of such persons who, while asleep, have performed many of the ordinary duties to which they had been accustomed when waking; and, with a ridiculous industry, have completed by night, what they failed doing by day. We are told, in the German Epheinerides, of a young stu- 
dent, who being enjoined a severe exercise by his tutor, went to bed, despairing of accomplishing it. 'The next moruing awaking, to his great surprise, he found the task fairly written out, and finished in his own handwriting.

He was at first, as the account has it, induced to ascribe this strange production to the operations of all infernal agent; but his tutor, willing to examine the affair to the bottom, set him another exercise, still more severe than the former, and took precautions to observe his conduct the whole night. The young gentleman, upon being so severely tasked, felt the same inquietude that he had done on the former occasion; went to bed gloomy and pensive, pondering on the next day's duty, and, after some time, fell asleep. But shortly after, his tutor, who continued to observe him from a place that was concealed, was surprised to see him get up, and very deliberately go to the table; where he took out pen, ink, and paper, drew himself a chair, and sat very methodically to thinking: it seems, that his being asleep, only served to strengthen the powers of his imagination; for he very quickly and easily went throngh the task assigned him; put his chair aside, and then returned to bed to take out the rest of his nap. What credit we are to give to this account, I will not pretend to determine; but this may be said, that the book from whence it was taken, has some good marks of veracity; for it is very learned, and very dull; and is written in a country noted, if not for truth, at least for want of invention.

The ridiculous story of Arlotto is well known, who has had a volume written, containing a narrative of the actions of his life, not one of which was performed while he was awake. He was an Italian Franciscan friar, extremely rigid in his manners, and remarkably devout and learned in his daily conversation. By night, however, and during his sleep, he played a very different character from what he did by day, and was often detected in very atrocious crimes. He was at one time detected in actually attempting a rape, and did not awake till the next morning, when he was surprised to find limself in the hands of justice. His brothers of the convent often watched him while he went very deli- berately into the chapel, and there attempted to commit sacrilege. 'They sometimes permitted him to carry the clualice and the vestments away into his own chamber, and the next morning amused themselves at the poor man's consternation for what he had done. But of all his sleeping transgressions, that was the most ridiculous, in which lue was called to pray for the soul of a person departed. Arlotto, after having devoutly performed his duty, retired to a chamber which was shown him, to rest; but there he had no sooner fallen asleep, than he began to reflect that the dead body had got a ring upon one of the fingers, which might be useful to him: accordingly, with a pious resolution of stealing it, he went down, undressed as he was, into a room full of women, and, with great composure, endeavoured to seize the ring. The consequence was, that he was taken before the inquisition for witchcraft; and the poor creature had like to have been condemued, till his peculiar character accidentally came to be known: however, he was ordered to remain for the rest of life in his own convent, and upon no account whatsoever to stir abroad.

What are we to say to such actions as these? or how account for this operation of the mind in dreaming? It should seem, that the imagination, by day, as well as by night, is always employed; and that often, against our wills, it intrudes, where it is least commanded or desired. While awake, and in health, this busy principle cannot much delude us: it may build castles in the air, and raise a thousand phantoms before us; but we have every one of the senses alive to bear testimony to its falschood. Our eyes show us that the prospect is not present; our hearing and our touch depose against its reality; and our taste and smelling are equally vigilent in detecting the imposture. Reason, therefore, at once gives judgment upon the cause, and the vagrant intruder, Imagination, is imprisoned, or banished from the mind. But in sleep it is otherwise; having, as much as possible, put our senses from their duty, having closed the eyes from seeing, and the ears, taste, and smelling, from their peculiar functions, and having dininished even the tonch itself, by all the arts of softness, the 
imagination is then left to riot at large, and to lead the understanding without an opposer. Every incursive idea then becomes a reality ; and the mind, not having one power that can prove the illusion, takes them for truths. As in madness, the senses, from struggling with the imagination, are at length forced to submit; so, in sleep, they seem for a while sooth- ed into the like subnission: the smallest violence exerted upon any one of them, however, rouses all the rest in their mutual dcfence; and the imagination, that had for a while told its thousand falsehoods, is totally driven away, or only permitted to pass under the custody of such as are every moment ready to detect its imposition.

\section{CHAPTER XXIX.}

\section{OF SEEING.}

"HAVING mentioned the senses as correcting the errors of the insagination, and as forcing it, in some measure, to bring us just information, it will naturally follow, that we slould examine the nature of those senses themselves: we shall thus be enabled to see how far they also impose on us, and how far they contribute to correct each other. Let it be observed, however, that in this we arc neither giving a treatise of optics or phonics, but a history of our own perceptions: and to those we chiefly confine ourselves."

The eyes very soon begin to be formed in the human embryo, and in the chicken also.

Of all the parts which the animal has double, the eyes are produced the soonest, and appear the most prominent. It is true, indeed, that in viviparous animals, and particularly in man, they are not so large in proportion, at first, as in the oviparous kinds; nevertheless, they are more speedily dcveloped, when they begin to appear, than any other parts of the body. It is the same with the organ of hearing; the little bones that compose the internal parts of the ear are entirely formed before the other bones, though much larger, hare acquired any part of their growth or solidity. Hence it appears, that those parts of the body which are furnished with the greatest quan-

- This chapter is taken from Mr. Buffon. I believe the reader will readily excuse any apology; and, perhaps, may wish that I had taken this liberty much more frequently. What $I$ add is marked, as in a former instance, with inverted commas. tity of nerves, are the first in forming. Thus the brain and the spinal-marrow, are the first seen begun in the embryo; and, in general, it may be said, that wherever the nerves go, or send their branches in great numbers, there the parts are soonest begun, and the most com. pletely finished.

If we examine the eyes of a child some hours, or even some days, after its birth, it will be easily discerned that it as yct makes no use of them. The humours of the organ not having acquired a sufficient consistence, the rays of light strike but confusedly upon the retina, or expansion of nerves at the back of the eye. It is not till about a month after they are born, that children fix them upon objects; for, before that time, they turn them indiscriminately every where, without appearing to be affected by any. At six or seven weeks old, they plainly discover a choice in the objects of their attention; they fix their eyes upon the most brilliant colours, and seem peculiarly desirous of turning them towards the light. Hitherto, however, they only seem to fortify the organ for seeing distinctly ; but they have still many illusions to correct.

The first great error in vision is, that the eye inverts every object : and it in reality appears to the child, until the touch has served to undeceive it, turned upside down. A second error in vision is, that every object appears double. The same object forms itself distinctly upon each eye ; and is consequently seen twice. This error, also, can only be 
corrected by the touc! 1 ; and although, in reality, every object we see appears iuverted and double, yet the judgment and habit have so often corrected the sense, that we no longer submit to its imposition, but see every object in its just position, the very instant it appears. Were we, therefore, deprived of fceling, our eyes would not only misrepresent the situation, but also the number of all things around us.

To convince us that we see objects inverted, we have only to observe the manuer in which images are represented, coming through a small hole, in a darkened room. If such a small hole be made in a dark room, so that no light can come in, but through it, all the objects without will be painted on the wall behind, but in an inverted position, their lieads downwards. For as all the rays which pass from the different parts of the object without, cannot enter the hole in the same extent which they had in leaving the object; since, if so, they would require the aperture to be as large as the object; and, as each part, and every point of the object, sends forth the image of itself on cvery side, and the rays, which form these images, pass from all points of the object as from so many centres, so such only can pass through the sinall aperture as come in opposite directions. Thus the little aperture becomes a centre for the entire object; through which the rays from the upper parts, as well as from the lower parts of it, pass in converging directions; and, consequently, they must cross each other, in the central point, and thus paint the objects behind, upon the wall, in an inverted position.

It is, in like manner, easy to conceive, that we see all objects double, whatever our present sensations may seem to tell us to the contrary. For to convince us of this, we have only to compare the situation of any one object on shutting one eye, and then compare the same situation by shutting the other. If, for instance, we hold up a finger, and shut the right eye, we shall find it hide a certain part of the room; if again reshutting the other eye, we shall find that part of the room visilble, and the finger seeming to cover a part of the room that had been visible before. If we open both eyes, however, the part covered Fill appear to lie between the two extremes.
But the truth is, we see the object our finger had covered, one image of it to the right, and the other to the left; but, from habit, suppose that we see but one inage placed between both; our sense of feeling having corrected the errors of sight. And thus, also, if instead of two eyes we had two hundred, we sliould, at first, fancy the objects increased in proportion, until one sense had corrected the errors of alsother.

"The having two eyes might thus be said to be rather an inconvenience than a benefit; since one eye would ankwer the purposes of sight as well, and be less liable to illusion. But it is otherwise; two cyes greatly contribute, il not to distinct, at least to extensive vision. ${ }^{a}$ When an object is placed at a moderate distance, by the means of both eyes we see a larger share of it than we possibly could with one; the right eye seeing a greater portion of its right side, and the left eye of its corresponding side. Thus both eyes, in some measure, see round the object; and it is this that gives it, in nature, that bold relievo, or swelling, with which they appear; and which 10 painting, how exquisite socver, can attain to. The painter must be contented with shading on a flat surface; but the eyes, in observing nature, do not beliold the shading only, but a part of the figure also, that lies beliind those very sluadings, which gives it that swelling, which painters so ardently desire, but can never fully imitatc.

"There is another defect, which either of the eyes, taken singly, would have, but which is corrected, by having the organ double. In either eye there is a point, which has no vision whatsoever; so that if one of them ouly is einployed in seeing, there is a part of the object to which it is always totally blind. 'This is that part of the optiv: nerve where its vein and artery run; which being jnsensible, that point of the object that is painted there must continue unseen. To be convinced of this we have only to try a rery easy experiment. If we take three black patches, and stick them upon a white wall, about a foot distant from each other, each about as high as the eye that is to observe them; then retiring six or seven feet back, and shutting one

\footnotetext{
* Leonardo da Vinci.
} 
cye, by trying for some time, we shall find, that while we distinctly behold the black spots that are to the riglit and left, that which is in the middle remains totally unseen. Or, in other words, when we bring that part of the cye, where the optic artery runs, to fall upon the object, it will then become invisible. This defect. however, in cither eye, is always corrected by both, since the part of the object that is unseen by one, will be very distinctly perceived by the other."

Beside the former defects, we can have no idea of distances from the sight, without the help of touch. Naturally every object we see appears to be within our eyes; and a child, who has as yet made but little use of the sense of feeling, must suppose that every thing it sees makes a part of itself. Such objects are only seen more or less bulky as they approach, or recede from its eyes; so that a tly that is near will appear larger than an $o x$ at a distance. It is experience alone that can rectify this mistake; and a long acquaintance with the real size of every object, quickly assures us of the distance at which it is seen. 'The last man in a file of soldiers appears in reality inuch less, perhaps ten times more diminutive, than the man next to us; however, we do not perceive this difference, but continue to think him of equal stature; for the numbers we have seen thus lessened by distance, and have found, by repeated experience, to be of the natural size when we come closer, instantly correct the sense, and every object is perceived with nearly its natural proportion. But it is otherwise, if we observe objects in such situations as we lave not had sufficient experience to correct the errors of the eye; if, for instance, we look at men from the top of a ligh steeple, they, in that case, appear very much diminished, as we have not had a habit of correcting the sense in that position.

Although a small degree of reflection will serve to convince us of the truth of these positions, it may not be amiss to strengthen them by an authority which cannot be disputed. Mr. Cheselden having couched a boy of thirteen for a cataract, who had hitherto been blind, and thus at once having restored him to sight, curiously marked the progress of his mind upon that occasion. This youth, though he had been till then incapable of seeing, yet was not totally blind, but could tell day from night, as persons in his situation always unay. He conld also, with a strong light, distinguish black from white, and either from the vivid colour of scarlet: however, he saw nothing of the form of bodies; and, without a bright light, not even colours themselves. He was, at first, couched only in one of his eyes; and when he saw for the first time, he was so far from judging of distances, that he supposed his cye touched every objeet tha. he saw, in the same manner as his hands might be said to feel them. The objects that were most agrecable to him were such as were of plain surfaces and regular figures: though he could as yet make no judgment whatever of their different forms, nor give a reason why one pleased him more than another. Although he could form some idea of colours during his state of blindness, yet that was not sufficient to direct him at present; and he could scarcely be persuaded that the colour's he now saw were the same with those he had formerly conceived such erroneous ideas of. He delighted most in green; but black objects, as if giving him an idea of his former blindness, lie regarded with horror. He had, as was said, no idea of forms; and was unable to distinguish one object from another, though never so different. When those things were shown him, which he had been formerly familiarized to by his feeling, he bcheld them with earnestness, in order to remember them a second time: but as he had too many to recollect at once, he forgot the greatest number; and for one he could tell, after seeing, there was a thousand he was totally unacquainted with. He was very much surprised to find, that those things and persons he loved best, were not the most beautiful to be seen; and even testified displeasure in not finding his parents so handsome as he conceived them to be. It was near two months before he could find that a picture resembled a solid body. Till then he only considered it as a flat surface, variously shadowed; but when he began to perceive that these kind of shadings actually represented human beings, he then began to examine, by his touch, whether they had not the usual qualities of such bodies, and was mreatly surprised to find, what 
- he expected a very unequal surface, to be smooth and even. "He was then shown a miniature-picture of lis father, which was contained in his mother's watcl-case, and he readily perceived the resemblance; but asked, with great astonishment, how so large a face could be contained in so small a compass? It seemed as strange to him as if a bushel was contained in a pint ressel. At first he could bear but a very small quantity of light, and he saw crery object much greater than the life; but, in proportion as he saw objects that were really large, he seemed to think the former were diminished; and although he knew the chamber where he was contaiued in the house, yet, until he saw the latter, he could not be brought to conceive how a house could be larger than a chamber. Before the operation, he had no great expectations from the pleasure he should receive from a new sense; lie was only excited by the hopes of being able to read and write; he said, for instance, that he could hare no greater pleasure in walking in the garden with his sight, than he had without it, for he walked there at his ease, and was acquainted with all the walks. He remarked also, with great justice, that his former blindness gave him one advantage over the rest of mankind, which was that of being able to walk in the night with confidence and security. But when he began to make use of his new sense, he seemed transported beyond measure. He said, that every new object was a new source of delight, and that lis pleasure was so great as to be past expression.

About a year after, he was brought to Epsom, where there is a very fine prospect, with which he seemed greatly charmed; and he called the landscape before him a new method of seeing. He was couched in the other eye, a year after the former, and the operation succeeded equally well: when he saw with both eyes, he said that objects appeared to hin twice as large as when he saw but with one; however, he did not see them doubled, or, at least, he showed no marks as if le saw them so. Mr. Cheselden mentions ininstances of many more that were restored to sight in this manner; they all seemed to concur in their perceptions with this youth; and ther all secmed narticularly -embarrassed in learning how to direct their cyes to the ob. jects they wished to observe.

In this manner it is that our feeling corrects the sense of seeing, and that objects which appear of very different sizes at different distances, are all reduced, by experience, to their natural standard. "But not the feeling only, but also the colour and brightness of the object, contributes, in some measure, to assist us in forming an idea of the distance at which it appears. ${ }^{2}$ Those which we see most strongly marked with light and sluade, we readily know to be nearer than those on which the colours are more faintly spread, and that, in some measure, take a part of their hue from the air between us and them.-Bright objects also are seen at a greater distance than such as are obscure, and, most probably, for this reason, that being less similar in colour, to the air which interposes, their impressions are less effaced by it, and they continue more distinctly visible. 'Thus a black and distant object is not seen so far off as a bright and glittering one, and a fire by night is seen much farther off than by day."

The power of seeing objects at a distance is very rarely equal in both eyes. When this inequality is in any great degree, the person so circumstanced then makes use only of one eye, shutting that which sees the least, and employing the other with all its power. And hence proceeds that awkward look which is known by the name of strabism.

There are many reasous to induce us to think that such as are near-sighted see objects larger than other persons; and yet the contrary is most certainly true, for they sce them less. Mr. Buffon informs us that he himself is short-sighted, and that his left eye is stronger than his right. He has very frequently experienced, upon looking at any object, such as the letters of a book, that they appear less to the weakest eye; and that when he places the book, so as that the letters appear double, the images of the left eye, which is strongest, are greater than those of the right, which is the most fecble. He has examined several others, who were in similar circumstances, and

ar. Buffon gives a different theory, for which I must refer the reader to the original. That I have given, I take to be easy and satisfactory enough. 
has always found that the best eye saw every object the largest. This he ascribes to habit; for near-sighted people being accustomed to come close to the object, and view but a small part of it at a time, the habit ensues, when the whole of an object is seen, and it appears less to them than to others.

Infants, having their eyes less than those of adults, must see objects also smaller in proportion. For the image formed on the back of the eye will be large, as the eye is capacious; and infants, having it not so great, cannot have so large a picture of the object. This may be a reason also why they are unable to see so distinctly, or at such distances, as persons arrired at maturity.

Old men, on the contrary, see bodies close to them very indistinctly, but bodies at a great distance from them with more precision; and this may happen from an alteration in the coats, or, perhaps, humours of the eye ; and not, as is supposed, from their diminution. The eornea, for instance, may become too rigid to adapt itself, and take a proper convexity for seeing minute objects; and its rery flatness will be sufficient to fit it for distant vision.

When we cast our eyes upon an object extremely brilliant, or when we fix and detain them too long upon the same object, the organ is hurt and fatigued, its vision becomes indistinct, and the innage of the body which has thus too violently, or too perseveringly employed us, is painted upon every thing we look at, and mixes with every object that occurs. "And this is an obvious consequence of the eye taking in too much light, either immediately, or by reflection. Every body exposed to the light, for a time, drinks in a quantity of its rays, which being brought into darkness, it cannot instantly discharge. Thus the hand, if it be exposed to broad day-light for some time, and then immediately snatched into a dark room, will appear still luninous: and it will be some time before it is totally darkened. It is thus with the eye; which, either by an instant gaze at the sun, or a steady continuance upon some less brilliant object, has taken in too much light; its humours are, for a while, unfit for vision, until that be discharged, and room made for rays of a milder nature." How dangerous the looking upon bright and luminous objects is to the No. $15 \& 16$ sight, may be easily secn, from such as live in countries covered for most part of the year with snow, who become generally blind before their time. Travellers who cross these countries are obliged to wear a crape before their faces, to save their eyes, which would otherwise be rendered totally unserviceable; and it is equally dangerous in the sandy plains of Africa. 'The reflection of the light is there so strong, that it is impossible to sustain the effeet without incurring the danger of losing one's sight entirely. Such persons, therefore, as read or write for any continuance, should choose a moderate light, in order to save their eyes; and although it may seem insuffieient at first, the eye will accustom itself to the shade, by degrees, and be less liurt by the want of light than the excess.

"It is, indeed, surprising how far the eye can accommodate itself to darkness, and make the best of a gloomy situation. When first taken from the light, and brought into a dark room, all things disappear; or, if any thing is seen, it is only the remaining radiations that still continue in the eye. But, after a very little time, when these are spent, the eye takes the advantage of the smallest ray that happens to enter; and this alone would, in time, serve for many of the purposes of life. There was a gentleman of great courage and understanding, who was a major under King Charles 1.; this unfortunate man, sharing in his master's misfortunes, and being forced abroad, ventured at Madrid to do his king a signal service; but unluckily failed in the attempt. In consequence of this, he was instantly ordered to a dark and dismal dungeon, into which the light never entered, and into which there was no opening but by a hole at the top, down which the keeper put his provisious, and presently closed it again on the other side. In this manner the unfortunate loyalist continued for some weeks, distressed and disconsolate; but at last he began to think he saw some little glimmering of light. This internal dawn seemed to increase from time to time, so that he could not only discover the parts of his bed, and such other large objects, but, at length, he even began to perceive tlie mice that frequented lis cell; and saw them as they ran about the floor, eating the crumbs of bread that happen- 
ed to fafl. After some months' confinement he was at last set free; but such was the effect of the darkness upon him, that he could not, for some days, venture to leave his dungeon, but was obliged to accustom himself by degrees to the light of the day.

\section{CHAPTER XXX.}

\section{OF IIFARING."}

AS the sense of hearing, as well as of sight, gives us notice of remote objects, so, like that, it is subject to similar errors, being capable of imposing on us upon all occasions, where we cannot rectify it by the sense of feeling. We can have from it no distinct intellignnce of the distance from whence a sounding body is heard; a great noise far off, and a small one very near, produce the same sensation; and unless we receive information from some other sense, we can never distinctly tell whether the sound be a great or a small one. It is not till we have learned, by experience, that the particular sound which is heard, is of a peculiar kind; then we can judge of the distance froin whence we hear it. When we know the tone of the bell, we can then judge how far it is from us.

Every body that strikes against another produces a sound, which is simple, and but one in bodies which are not elastic, but which is often repeated in such as are. If we strike a bell, or a stretched string, for instance, which are both elastic, a single blow produces a sound, which is repeated by the undulations of the sonorous body, and which is multiplied as often as it happens to undulate or vibrate. These undulations each strike their own peculiar blow; but they succeed so fast, one behind the other, that the ear supposes them one continued sound; whereas, in reality, they make many. A person who should, for the first time, hear the toll of the bell, would very probably be able to distinguish these breaks of sound; and, in fact, we can readily ourselves perceive an intention and premission in the sound.

In this manner, sounding bodies are of two

a This chapter is taken from Mr. Buflou, except where marked by inverted commas. kinds; those unelastic ones, which, being struck, return but a single sound; and those more elastic, returning a succession of sounds; which uniting together, form a tone. This tone may be considered as a great number of sounds, all produced one after the other, by the same body, as we find in a bell, or the string of a harpsichord, which continues to sound for some tine atter it is struck. A continuing tone may also be produced from a non-elastic body, by repeating the blow quick and often, as when we beat a drum, or when we draw a bow along the string of a fiddle.

Considering the subject in this light, if we should multiply the number of blows, or repeat them at quicker intervals upon the sounding body, as upon the drum, for instance, it is evident that this will have no effect in altering the tone; it will only make it either more even, or more distinct. But it is otherwise, if we increase the force of the blow: if we strike the body with double weight, this will produce a tone twice as loud as the former. If, for instance, I strike a table with a switch, this will be very.different from the sound produced by striking it with a cudgel. Hence, therefore, we may infer, that all bodies give a louder and a graver tone, not in proportion to the number of times they are struck, but in proportion to the force that strikes them. And, if this be so, those philosophers who make the tone of a sonorous body, of a bell, or the string of a harpsichord, for instance, to depend upon the number only of its vibrations, and not the force, have mistaken what is only an effect for a cause. A bell, or an elastic string, can only be considered as a drum beaten; and the frequency of the blows can make no alteration whatever in the tone. The largest bells, and the longest 
and thickest strings, have the most forceful vibrations; and, t!lerefore, their tones are the most loud and the most grave.

To know the maner in which sounds thus produced become pleasing, it must be observed, no one continuing tone, how loud and swelling soever, can give us satisfaction; we must have a succession of them, and those in the most pleasing proportion. The nature of this proportion may be thus conceived. If we strike a body incapable of vibration with a double force, or, what amounts to the sane thing, with a double mass of matter, it will produce a sound that will be doubly grave. Music has been said, by the ancients, to have been first invented from blows of different hammers on an anvil. Suppose then we strike an anvil with a hammer of one pound weight, and again with a hammer of two pounds, it is plain that the two-pound hammer will produce a sound twice as grave as the former. But if we strike with a two-poind hammer, and then with a three-ponnd. it is evident that the latter will produce a sound one-third more grave than the former. If we strike the anvil with a three-pound hammer, and then with a four-pound, it will likewise follow that the latter will be a quarter part more grave than the former. Now, in the comparing between all those sounds, it is obvious that the difference between one and two is more easily perceived, than between two and three, three and four, or any numbers succeeding in the sane proportion. The succession of sounds will be, therefore, pleasing in proportion to the ease with which they may be distinguished. That sound which is double the former, or, in other words, the octave to the preceding tone, will, of all others, be the most pleasing harmony. The next to that which is as two to three, or, in other words, the thir l, will be most agreeable. And thus, universally, those sounds whose difference may be most easily compared, are the most agreeable.

"Musicians, therefore, have contented themselves with seven different proportions of sound, which are called notes, and which sufficiently answer all the purposes of pleasure. Not but that they inight adopt a greater diversity of proportions; and some have actually done so; but, in these, the differences of the proportion are so imperceptible, that the ear is rather fatigued than pleased in making the distinction. In order, however, to give variety, they have admitted half tones: but in all the countries where music is yet in its infancy, they have rejected such; and they can find music in none but the obvious ones. The Chinese, for instance, have neither flats nor sharps in their music; but the intervals between their other notes, are in the same proportion with ours.

"Many more barbarous nations have their peculiar instruments of music; and, what is remarkable, the proportion between theirnotes is in all the same as in ours. This is not the place for entering into the nature of these sounds, their effects upon the air, or their consonances witheach other. Wearenotnow giving a history of sound, but of huinan perception.

"All countries are pleased with music; and if they have not skill enough to produce harmony, at least they scem willing to substitute noise. Without all question, noise alone is sufficient to operate powerfully on the spirits; and, if the mind be already predisposed to joy, I have seldom found noise fail of increasing it into rapture. The mind feels a kind of distracted pleasure in such powerful sounds, braces up every nerve, and riots in the excess. But, as in the eye, an immediate gaze upon the sun will disturb the organs, so, in the ear, a loud unexpected noise disorders the whole frame, and sometimes disturbs the sense ever alter. The mind must have tine to prepare lor the expected shock, and to give its organs the proper tension for its arrival.

"Musical sounds, however, seem of a different kind. Those are generally most pleasing which are most unexpected. It is not from bracing up the nerves, but from the grateful succession of the sounds, that these become so charming. There are few, how indifferent soerer, but have at times felt their pleasing impressions; and, perhaps, even those who have stood out against the powerful persuasion of sounds, only wanted the proper tume, or the proper instrument, to allure them.

"The ancients give us a thousand strange. instances of the effects of music upon men and animals. The story of Arion's harp, that gathered the dolphins to the ship's side, is well 
known; and what is remarkable, Schotteus assures us, ${ }^{2}$ that he saw a sinilar instance of fishes being allured by music. They tell us of diseases that have been cured, unchastity corrccted, seditions quelled, passions removed, and sometimes excited even to madness. Dr. Wallis lias endeavoured to account for these surprising effects, by ascribing them to the novelty of the art. For my own part, I can scarcely hesitate to impute them to the exaggeration of the writers. They are as hyperbolical in the effects of their oratory; and yet, we well know, there is nothing in the orations which they have left us, capable of exciting madness, or of raising the mind to that ungovernable degree of fury which they describe. As they liave exaggerated, therefore, in one instance, we may naturally suppose that they have done the same in the other; and, indeed, from the few remains we have of their music, collected by Meibornius, one might be apt to suppose there was nothing very powerful in what is lost. Nor does any one of the ancient instruments, such as we see them represented in statues, appear comparable to our fiddle.

"However this be, we have many odd accounts, not only among them, but the moderns, of the power of music; and it must not be denied, but that, on some particular occasions, musical sounds may have a very powerful effect. I have seen all the horses and cows in a field, where there were above a hundred, gathered round a person that was blowing a French horn, and seeming to testify an awkward kind of satisfaction. Dogs are well known to be very sensible of different tones in music; and I have sometimes heard them sustain a very ridiculous part in a concert, where their assistance was neither expected nor desired.

"We are told of Henry IV. of Deımark, that being one day desirous of trying in person whether a musician, who boasted that he could excite men to madness, was not an impostor, he submitted to the operation of his skill : but the consequence was much more terrible than he expected; for, becoming actually mad, he killed four of lis atten-

a Quod oculis meis spectavi. Schotti Magic. univeralis, pars. ii. lib. 1. p. 26. dants in the midst of his transports. A contrary effect of music we have, ${ }^{,}$in the cure of a madnan of Alais, in France, by music. This manl, who was a dancing-master, after a fever of five days, grew furious, and so ungovernable that his hands were obliged to be tied to his sides: what at first was rage, in a short time was converted into silent melancholy, which no arts could exhilarate, nor no medicines remove. In this sullen and dejected state, an old acquaintance accidentally came to inquire after his health; he found him sitting up in bed, tied, and totally regardless of every external object around him. Happening, however, to take up a fiddle that lay in the room, and touching a favourite air, the poor madınan instantly seemed to brighten up at the sound; from a recumbent posture, he began to sit up ; and, as the musician continued playing, the patient seemed desirous of dancing to the sound: but he was tied, and incapable of leaving his bed, so that he could only humour the tune with his head, and those parts of his arms which were at liberty. Thus the other continued playing, and the dancing-inaster practised his own art, as far as he able, for about a quarter of an hour, when suddenly falling into a deep sleep, in which his disorder caine to a crisis, he awaked perfectly recovered.

"A thousand other instances might be added, equally true : let it suffice to add one more, which is not true ; I mean that of the tarantula. Every person who has been in Italy now well knows, that the bite of this animal, and its being cured by music, is all a deception. When strangers come into that part of the country, the country peoplc are ready enough to take money for dancing to the tarantula. A friend of mine had a servant who suffered bimself to be bit; the wound, which was little larger than the puncture of a pin, was uneasy for a few hours, and then became well without any farther assistance. Some of the country people however, still make tolerable livelihood of the credulity of strangers, as the musician finds his account in it not less than the dancer."

Sounds, like light, are not only extensively

b Olai Magni, 1. 15. hist. c. 28. 2708. p. 22. 
diffused, but are frequently reflected. The laws of this reflection, it is true, are not as well understood as those of light; all we know is, that sound is principally reflected by hard bodies; and their being hollow; also, sometimes increases the reverberation. "No art, however, can make an echo; and some who have bestowed great labour and expense upon such a project, have only erected shapeless buildings, whose silence was a mortifying lecture upon their presumption."

The internal cavity of the ear scems to be fitted up for the purpose of cchoing sound with the greatest precision. This part is fashioned out in the temporal bone, like a cavern cut into a rock. "In this the sound is repeated and articulated; and, as some anatomists tell us, (for we have as yet but very little knowledge on this subject,) is beaten against the tympanum, or drum of the ear, which moves four little bones joined thereto; and these move and agitate the internal air which lies on the other side; and lastly, this air strikes and affects the auditory nerves, which carry the sound to the brain."

One of the most common disorders in old age is deafness; which probably proceeds from the rigidity of the nerves in the labyrinth of the ear. This disorder, also, sometimes proceeds from a stoppage of the wax, whicl art may easily remedy. In order to know whether the defect be an internal or an external one, let the deaf person put a repeating watch into his moutin, and if he hears it strike, he may be assured that his disorder proceeds from an external cause, and is, in some measure, curable: "for there is a passage from the ears into the mouth, by what anatomists call the eustachian tube; and, by this passage, people often hear sounds, when they are utterly without hearing through the larger channel: and this also is the reason that we often see persons who listen with great attention, hearken with their mouths open, in order to catch all the sound at every aperture."

It often happens, that persons hear differently with one ear from the other; and it is generally found that these have what is called, by inusicians, a bad ear. Mr. Buffon, who has made many trials upon persons of this kind, always found that their defect in judgiing properly of sounds proceeded from the inequality of their ears; and receiving by both, at the same time, unequal sensations, they form an unjust idea. In this manner, as those people hear false, they also, without knowing it, sing false. Those persons also frequently deceive themselves with regard to the side from whence the sound comes, generally supposing the noise to come on the part of the best ear.

Such as are lard of hearing, find the same advantage in the trumpet made for this purpose, that short-sighted persons do from glasses. 'These trumpets might be easily improved so as to increase sounds, in the same manner that the telescope does objects; however, they could be used to advantage only in a place of solitude and stillness, as the neighbouring sounds would mix with the more distant, and the whole would produce in the ear nothing but tumult and confusion.

Hearing is a much more necessary sense to man than to animals. With these it is only a warning against danger, or an encouragement to mutual assistance. In man, it is the source of most of his pleasure; and without which the rest of his serses would be of little benefit. A man born deaf, nust necessarily be dumb; and bis whole sphere of knowledge must be bounded only by sensual objects. We have an instance of a young man, who, being born deaf, was restored at the age of twenty-four to perfect hearing: the account is given in the Memoirs of the Academy of Sciences, 1703, page 18.

A young man, of the town of Chartres; between the age of twenty-three and twentyfour, the son of a tradesman, and deaf and dumb from his birth, began to speak all of a sudden, to the great astonishment of the whole town. He gave them to understand, that about three or four months before, he had heard the sound of the bells for the first time, and was greatly surprised at this new and unknown sensation. After some time, a kind of water issued from his left ear, and he then heard perfectly well with both. During these three months, he was sedulously employed in listening without saying a word, and accustoming himself to speak softly (so as not to be heard) the words pronounced by others. He laboured hard also in perfecting limself 
in the pronunciation, and in the ideas attaclsed to every sound. At length, having supposed himself qualified to break silence, he declared, that he could now speak, although as yet but imperfectly. Soon after, some able divines questioned hin concerning his ileas of his past state; and principally with respect to God, his soul, the morality or turpitude of actions. The young man, however, had not driven his solitary speculations into that channel. He had gone to mass indeed with his parents, and learned to sign himself with the cross, to kneel down and assume all the grimaces of a man that was praying; but he did all this without any manner of knowledge of the intention or the cause; he saw others do the like, and that was enough for him; he knew nothing even of death, and it never entered into his head; he led a life of pure animal instinct; entirely taken up with sensible objects, and such as were present, he did not seem even to make as many reflections upon these, as might reasonably be expected from his improving situation; and yet the young man was not in want of understanding; but the understanding of a man deprived of all commerce with others, is so very confined, that the mind is in some measure totally under the control of its immediate sensations.

Notwithstanding, it is very possible to communicate ideas to deaf men, which they previously wanted, and even give them very precise notions of some abstract subjects, by means of signs and of letters. A person born deaf, miay, by time, and sufficient pains, be taught to write and read, to speak, and by the motions of the lips, to understand what is said to him; however, it is probable that, as most of the motions of speech are made within the mouth by the tongue, the knowledge from the motion of the lips is but very confined : "nevertheless, I have conversed with a gentleman thus taught, and in all the commonly occurring questions, and the usual salutations, he was ready enough, merely by attending to the motion of the lips alone. When I ventured to speak for a short continuance, he was totally at a loss, although he understond the subject, when written, extremely well." Persons taught ill this nıanner, were at first eonsidered as prodigies; but there have been so many instances of success of late, and so many are skilful in the art of instructing in this way, that though still a matter of some curiosity, it ceases to be an object of wonder.

\section{CHAPTER XXXI.}

\section{OF SMELLING, FEELING, AND TASTING.}

AN animal may be said to fill up that sphere which he ean reach by his senses; and is actually large in proportion to the sphere to which its organ extends. By sight, man's enjoyments are diffused into a wide circle ; that of hearing, though less widely diffused, nevertheless extends his powers; the sense of smelling is more contracted still; and the taste and touch arc the most confined of all. Thus man enjoys very distant objects but with one sense only; more nearly he brings two senses at once to bear upon them; his sense of smelling assists the other two, at its own distance; and of such objects, as a man, he may be said to be in perfect possession.

Each sense, however, the more it acts at a distance, the more eapable it is of making com- binations; and is, consequently, the more improveable. Refined imaginations, and men of strong minds, take more pleasure, therefore, in improving the delights of the distant senses, than in elyjoying such as are scarce capable of improvenient.

By combining the objects of the extensive senses, all the arts of poetry, painting, and harmony, have been discovered; but the closer senses, if I may so call them, such as sinelling, tasting, and touching, are, in some measure, as simple as they are limited, and adnit of little variety. The man of imagination makes a great and artificial happiness by the pleasure of altering and combining; the sensualist just stops whcre he hegan, and cultivates only those pleasures which he canıot improve. The sen 
sualist is contented with those enjoyments that are already made to his hand; but the man of pleasure is best pleased with growing happiness.

Of all the senses, perhaps, there is not one in which man is more inferior to other animals than in that of smelling. With man, it is a sense that acts in a narrow sphere, and disgusts almost as frequently as it gives him pleasure. With many other aninals it is diffused to a very great extent; and never seems to offend them. Dogs not only trace the steps of other animals, but also discover them by the scent at a very great distance; and while they are thus exquisitely ensible of all smells, they seem no way disgusted by any.

But, although this sense is, in general, so very inferior in man, it is much stronger in those nations that abstain from animal food, than ainong Europeans. The Bramins of India have a power of smelling, as I am informed, equal to what it is in most other creatures. They can smell the water which they drink, that to us seems quite inodorons; and have a word, in their language, which denotes a country of fine water. We are told also, that the negroes of the Antilles, by the smell alone, can distinguish between the footsteps of a Frenchman and a negro. It is possible, therefore, that we may dull this irgan by our luxurious way of living; and sacrifice to the pleasures of taste, those which might be received from perfume.

However, it is a sense that we can, in some measure, dispense with; and I have known many that wanted it cntirely, with but very little inconvenience from its loss. In a state of nature it is said to be useful in guiding us to proper nourishinent, and deterring us from that which is unwholesome; but, in our present situation, such information is but little wanted; and, indeed, but little attended to. In fact, the sense of sinelling gives us very often false intelligence. Many things that have a disagreeable odour, are, nevertheless, wholesome and pleasant to the taste; and such as make eating an art, scldom think a meal fit to please the appetite, till it begins to offend the nose. On the other hand. there are many things that smell most gratefully, and yet are noxious, or fatal to the constitution. Some physicians think that perfumes ingeneral are un wholesome; that they relax the nerves, produce head-aches, and even retard digestion. The manchineel apple, which is known to be deadly poison, is possessed of the most grateful oduur. Some of those mineral vapours that are often found fatal in the stomach, smell like the swcetest flowers, and continue thus to flatter till they destroy. This sense, therefore, as it shonld scem, was never meant to direct us in the choice of food, but appears rather as an attendaut than a necessary pleasure.

Indeed, if we examine the natives of different countries, or even different natives of the same, we shall find no pleasure in which they differ so widely as that of smelling. Some persons are pleased with the smell of a rose; while I have known others that could not abide to have it approach them. The savage nations are highly delighted with the smell of assufoetidla, which is to us the most nauseous stink in nature. It would in a manner seem that our delight in perfumes was made by habit; and that a very little industry could bring us totally to invert the perception of odours.

Thus much is certain, that many bodies which at one distance are an agrcenble perfume, when nearer are a most ungratefiul odour. Musk and anbergrise, in small quantities, are considered by most persons as highly fragrant; and yet, when in larger masses, their scent is insufferable. From a mixture of two bodies, each whereof is, of itself, void of all smell, a very powerful smell may be drawn. Thus, by grinding quick-lime with sal-ammoniac, may be produced a very foetid mixture. On the contrary, from a mixture of two bodies, that are separately disagreeable, a very pleasant aromatic odour may be gained. A mixture of aqua-fortis with spirit of wine produces this effect. But not only the alterations of bodies by each other, but the smallest change in us, makes a very great alteration in this sense, and frequently deprives us of it totally. A slight cold often hinders us from smelling; and as often ehanges the nature of odours. Some persons, from disorder, retain an incurable aversion to those smells which most pleased them before: and nuany have been known to have an antipathy to some animals, whose presence they instantly perceived by the sunell. From all this, therefore, the sense of smelling appears to be an uncertain monitor, easily disordered, and not much missed when totally wanting. 
The sense most nearly allied to smelling is that of tasting. This, some have been willing to consider nuerely as a nicer kind of touch, and have undertaken to account, in a very mechanical manner, for the difference of savours. "Such bodies," said they," as are pointed, happening to be applied to the papillac of the tongue, exeite a very powerful sensation, and give us the idea of saltness. Such, on the contrary, as are of a rounder figure, slide smoothly along the papilla, and are perceived to be sweet." In this manner they lave with minute labour, gone through the variety of imagined forms in bodies, and have given them as iunagiuary effects. All we can precisely determine upon the nature of tastes is, that the bodies to be tasted must be either somewhat moistened, or, in sonie measure, dissolved by the saliva, before they can produce a proper sensation: when both the tongue itself and the body to be tasted are extremely dry, no taste whatever ensues. The sensation is then changed ; and the tongue instead of tasting, can only be sairl, like any other part of the body, to feel the object.

It is for this reason that clildren have a stronger relish of tastes than those who are more advanced in life. This organ with them, from the greater moisture of their bodies, is kept in greater perfection; and is, consequently, better adapted to perform its functions. Every person remembers how gieat a pleasure he found in siveets, while a child; but his taste growing more obtuse with age, he is obliged to use artificial means to excite it. It is then that he is found to call in the assistance of poignant sauces, and strong relishes of salts and aromaties; all which the delicacy of his tender organ in childhood. was unable to endure. His taste grows callous to the natural relishes, and is artificially formed to others more unnatural ; so that the highest epicure may be said to have the most depraved taste; as it is owing to the bluntness of his organ, that he is obliger to have recourse to such a variety of expedients to gratify his appetite.

As smells are often rendered agreeable by habit, so also tastes may be. Tobacco and coffee, so pleasing to many, are yet, at first, very disagreeable to all. It is not without perseverance that we begin to havea relish for thenı; we force nature so long, that what was constraint in the beginning, at last becomes inclination.
The grossest, and yet the most useful of all the senses, is that of feeling. We are often seen to survive under the loss of the rest; but of this we can never be totally deprived, but with life. Although this sense is diffused over all parts of the body, yet it most frequently happens that those parts which are most exercised in tonching, acquire the greatest degree of accuracy. 'Thus the fingers, by long liabit, become greater masters in the art than any other, even where the sensation is inore delicate and fine. ${ }^{2}$ It is from this habit, therefore, and their peculiar formation, and not as is supposed, from their being furnished with a greater quantity of nerves, that the fingers are thus perfectly qualified to judge of forms. Blind men, who are obliged to use them much oftener, have this sense much finer; so that the delicacy of the touch arises rather from the habit of constantly employing the fingers, than from any fancied nervousness in theil conformation.

All animals that are furnished with hands" seem to have more understanding than others. Monkeys have so many actions like those of men, that they appear to have similar ideas of the form of bodies. All other creatures, deprived of liands, can have no distinct ideas of the shape of the objects by which they are surrounded, as they want this organ, which serves to examine and measure their forms, their risings, and depressions. $\Lambda$ quadruped, probably, conceives as erroneous an idea of any thing near him, as a child would of a rock or a mountain that it beheld at a distance.

It may be for this reason, that we often see them frighted at things with which they ought to be better acquainted. Fishes, whose bodies are covered with scales, and who have no organs for feeling, must be the most stupid of all animals. Serpents, that are likewise destitute, are yet, by winding round several bodies, better capable of judging of their form. All these, however, can have but very imperfect ideas from feeling; and we have already seen, when deprived of this sense, how little the rest of the senses are to be relied on.

The feeling, therefore, is the guardian, the judge, and the examiner of all the rest of the senses. It establishes their information, and detects their errors. All the other seuses are altered by time, and contradict their former

- Buffon, vol. vi. p. 80 .

b Ibid. vol. vi. p. 82 . 
evidence; but the touch still continues the same; and, though extremely confined in its operations, yet it is never found to deceive. The universe, to a man who had only used the rest of his senses, would be but a scene of illusion; every object misrepresented, and all its propertics unknown. Mr. Buffon has in1agined a man just newly brought into existence, describing the illusion of his first sensations, and pointing out the steps by which he arrived at reality. He considers him as just created, and awaking amidst the productions of nature; and, to animate the narrative still more strongly, has made his philosoplical man a speaker. The reader will no doubt recollect Adam's speech in Milton as being similar. All that I can say to obviate the iniputation of plagiarism is, that the one treats the subject more as a poet, the other more as a philosopher. The philusopher's man describes his first sensations in the following manner. ${ }^{\mathrm{a}}$

I well remenber that joyful anxious moment when I first became acquainted with my own existence. I was quite ignorant of what 1 was, how I was produced, or from whence I came. I opened my eyes; what an addition to my surprise! the light of the day, the azure vault of heaven, the verdure of the eartl, the crystal of the waters, all employed ine at once, and animated and filled me with inexpressible delight. I at first imagined that all those objects were within me, and made a part of myself.

Impressed with this idea, I turned my cyes to the sun; its splendour dazzled and overpowered me: I shut them once more; and, to my great concern, I supposed that during this short interval of darkness, I was again returning to nothing.

Afllicted, seizerl witl astonishment, I pondered a monent on this great change, when I heard a variety of unexpected sounds. The whistling of the wind, and the melody of the groves, formed a concert, the soft cadence of which sunk upon my soul. I listened for some time, and was persuaded tliat all this music was within me.

Quite occupied with this new kind of existence, I had alrearly forgotten the light, which was my first inlet into life; when I once more opened my eycs, and found myself again in possession of my former liappiness. The gra-

\footnotetext{
- Buffon, vol. vi. p. 88 .
}

tification of the two senses at once, was a pleasure too great for utterance.

I tumed my cyes upon a thousand various oljects; I soon found that I could lose them, ancl restore them at will; and amused myself more at leisure with a repetition of this newmade power.

I now began to gaze without emotion, and to henrken with tranquillity, when a light breeze, the freshness of which cliarmed ine, wafter its perfumes to my sense of smelling, and gave me such satisfaction as even increased my self-love.

Agitated, roused by the various pleasures of my new existence, I instantly arose, and perccived myself moved along, as if by some unknown and secret power.

I had scarcely proceeded forward, wheı the novelty of my situation once more rendered me inmoveable. My surprise returned; I supposed that every object around me liad been in motion; I gave to them that agitation which I produced by changing place; and the whole creation scened once nore in disorder.

I lifted my hand to my head; I touched $\mathrm{my}$ forehead; I felt my whole frame: I then supposed that my hand was the principal organ of my existence; all its informations were distinct and perfect, and so superior to the senses I had yet experienced, that I cmployed myself for some time in repeating its enjoyments; every part of my person I touched, secmed to touch my hand in turn; and gave back sensation for sensation.

I soon found that this faculty was expanded over the whole surface of iny body; and I now first began to perceive the limits of my existence, which 1 had in the beginning supposed spread over all the oljects I saw.

Upon casting my eyes upon my loody, and surveying my own form, 1 thought it greater than all the objects that surrounded me. I gazed upon my person with pleasure; I examined the formation of my liand, and all its motions; it secmed to ne large or little in proportion as I approached it to my eyes; I brought it very near, and it then hid alinost every other object from my sight. I began soon, lowever, to find that my sight gave ne uncertain information, and resolved to depend upon my feeling for l'edress.

This preraution was of the utmost service; I renewed my motions, and walked forward 
with my face turned towards the heavens. I happened to strike lightly against a palm-tree, and this renewed my surprise : I laid my hand on this strange body ; it seemed replete with new wonders, for it did not return mie sensation for sensation, as my former feclings had done. 1 perceived that there was something external, and which did not make a part of my own existence.

I now, therefore, resolved to touch whatever I saw, and vainly attempted to touch the sun; I stretched forth iny arm, and felt ouly yielding air : at every effort, I fell from one surprise into another, for every object appeared equally near me; and it was not till after an infinity of trials, that I found some objects farther removed than the rest.

Amazed with the illusions, and the uncertainty of my state, I sat down beneath a tree; the most beautiful fruits hung upon it, within niy reach ; I stretched forth my hand, and they instantly separated from the branch. I was proud of bcing able to grasp a substance without me; I held them up, and their weight appeared to me like an animated power that endeavoured to draw them to the enrth. I found a pleasure in conquering their resistance.

I held them near my eye ; I considered thcir form and beauty; their fragrance still unore allured me to bring them nearer'; I approached them to my lips, and drank in their odours; the perfume invited my sense of tasting, and 1 soon tried a new sense-How new! how exquisite! Hitherto I had tasted only of pleasure; but now it was lnxury. The power of tasting gave me the idea of possession.

Flattered with this new acquisition, I continued its excercise, till an agrecalble languor stealing upon my mind, I felt all my limbs become heavy, and all my desires suspended. My sensations were now no longer vivid and distinct; but seemed to lose every object, and presented only feeble images, confusedly marked. At that instant I sunk upon the flowery bank, and slumber seized me. All now scemed once more lost to me. It was then as if I was returning to my former nothing. How long my sleep continued, I cannot tell; as I yet had no perception of time. My awaking appeared like a second birth ; and $I$ then perceived that I had ceased for a time to exist. This produced a new sensation of fear; and from this interruption in life, I began to conclude that I was not formed to exist for ever.

In this state of doubt and perplexity, I began to harbour new suspicions; and to fear that sleep had robbed me of some of my late powers; when turning on one side, to resolve iny doubts, what was my amazement, to bchold another being like myself, stretched by my side! New ideas now began to arise; new passions, as yet unperceived, with fears and pleasures, all took possession of my mind, and prompted iny curiosity: love served to complete that happiness which was begun in the individual; and every sense was gratified in all its varieties.

\section{CHAPTER XXXII.}

\section{OF OLD AGE AND DEATH.}

EVERY thing in nature has its improvement and decay. The human form is no sooner arrived at its state of perfection, than it begins to decline. The alteration is at first insensible; and often several years are elapsed before we find ourselves grown old. The news of this disagreeable change too generally comes from without; and we Iearn from

\footnotetext{
This chapter is taken from Mr. Buffon, except where it is marked by inverted commas.
}

others that we grow old, before we are willing to believe the report.

When the body has come to its full height, and is extended into its just dimensions; it then also begins to receive an additional bulk, which rather loads than assists it. This is formed from fat; which generally at the age of thirtyfive, or forty, covers all the muscles, and interrupts their activity. Every action is then performed with greater labour, and the increase of size only serves as a forerunner of decay. 
The bones, also, become every day more solic. In the embryo they are as soft almost as the muscles of the flesh; but by degrees they harden, and acquire their natural vigour; but still, however, the circulation is carried on through them, and, how hard soever the bones may seem, yet the blood holds its current through them, as through all other parts of the body. Of this we may be convinced, by an experiment, which was first accidentally discovered by our ingenious countryman Mr. Belcher. Perceiving at a friend's house, that the bones of hogs, which were fed upon madder, were red, he tried it upon various animals by mixing this root with their usual food; and he found that it tinctured the bones in all; an evident demonstration that the juices of the body had a circulation through the bones. He fed some animals alternately upon madder and their common food, for some time, and he found their bones tinctured with alternate layers, in conformity to their manner of living. From all this he naturally concluded, that the blood circulated through the bones, as it does through every other part of the body; and that, how solid soever they seemed, yet, like the softest parts, they were furnished through all their substance, with their proper cailals. Nevertheless, these canals are of very different capacities, during the different stages of life. In infancy they are capacious; and the blood flows almost as frecly through the bones as through any other part of the body : in manhood their size is greatly diminished; their vessels are almost imperceptible; and the circulation through them is proportionably slow. But, in the decline of life, the blood which flows through the bones, no longer contributing to their growth, must necessarily serve to increase their hardness. The channels that every where run throngh the human frame, may be compared to those pipes that we every where see crusted on the inside, by the water, for a long continuance, running through them. Both every day grow less and less, by the smatl rigid particles which are deposited within them. Thus as the vessels are by degrees diminished, the juiees also, which were necessary for the circulation through them, are diminished in proportion; till at length, in old age, those props of the lumian frame are not only more solid, but more brittle.

The cartilages, or gristles, which may be considered as bones beginuing to be formed, grow also more rigid. The juices circulating through then, for there is a circulation through all parts of the body, every day contribute to render them harder; so that these substances, which, in youth, are elastic and pliant, in age isecome hard and bony. As these cartilages are generally placed near the joints, the motion of the joints also must, of consequence, beconie more difficult. Thus, in old age, every action of the body is performed with labour: and the cartilages, formerly so supple, will now sooner break than bend.

"As the cartilages acquire hardness, and unfit the joints for motion, so also that mucous liquor, which is always separated between the joints, and which serves, like oil to a hinge, to give them an easy and ready play, is now grown more scanty. It becomes thicker, and more clammy, more unfit for answering the purposes of motim ; and from thence, in old age, every joint is not only stiff, but awkward. At every motion this clammy liquor is heard to crack; and it is not without the greatest effort of the muscles that its resistance is overconie. I have seen an old person, who never moved a single joint, that did not thus give notice of the violence done to it."

The membranes that cover the bones, the joints, and the rest of the body, become, as we grow old, nore dense and more dry. Those which surround the bones, soon cease to be dnctile. 'The filures, of which the muscles or' flesh is composed, become every day more rigid; and while to the touch the body seems, as we advance in years, to grow softer, it is, in reality increasing in lardness. It is the skin, anil not the flesh, that we fecl upon'such occasions. The fat, and the flabbiness of that, seems to give an appearance of softness, which the flesh itself is very far from having. There are few can doubt this, after trying the difference between the flesh of young and old animals. The first is soft and tender, the last is hard and dry.

The skin is the only part of the body that age does not contribute to harden. That stretches to every degree of tension; and we have horrid instances of its pliancy, in many disorders incident to humanity. In youth 
therefore, while the body is vigorous and increasing, it still gives way to its growth. But, although it thus adapts itself to our increase, it does not in the same manner conform to our decay. The skin, which, in youth was filled and glossy, when the body begins to decline has not elasticity enough to shrink entirely with its diminution. It hangs, therefore, in wrinkles, which no art can remove. The wrinkles of the body, in general, proceed from this cause. But those of the face scem to procecd from another; namely, from the many varieties of positions into which it is put by the speech, the food, or the passions. Every grimace, and every passion, wrinkles up the visage into different forms. These are visible enough in young persons: but what at first was accidental or transitory, becomes unalterably fixed in the visage as it grows older. "From hence we may conclude, that a freedom from passions not only adds to the happiness of the mind, but preserves the beauty of the face; and the person that has not felt their intuence, is less strongly marked by the decays of nature."

Hence, therefore, as we advance in age, the bones, the cartilages, the membranes, the flesh, the skin, and every fibre of the body, become more solid, more brittle, and more dry. Every part shrinks, every motion becomes more slow : the circulation of the fluids is performed with less freedom; perspiration diminishes; the secretions alter; the digestion becomes slow and laborious: and the juices no longer serving to convey their accustomed nourishment, those parts may be said to live no longer when the circulation ceases. Thus the body dies by little and little; all its functions are diminished by degrees; life is driven from one part of the frame to another; universal rigidity prevails; and death at last seizes upon the little that is left.

As the bones, the cartilages, the muscles, and all other parts of the body, are softer in women than in men, these parts must, of consequence, require a longer time to come to that hardness which hastens death. Women, therefore, ought to be a longer time in growing old than men; and this is actually the case. If we consult the tables which have been drawn up respecting bunan life, we shall find that, after a certain age, they are more long- lived than men, all other circumstances the same. A woman of sixty has a better chance than a man of the same age to live till eighty. Upon the whole, we may infer, that such persons as have been slow in coming up to maturity, will also be slow in growing old; and this holds as well with regard to other animals as to man.

The whole duration of the life of either vegetables or animals, may be, in some measure, determined from their manner of coming to maturity. The tree, or the animal, which takes but a short time to increase to its utmost pitch, perishes much sooner than such as are less premature. In both the increase upwards is first accomplished; and not till they have acquired their greatest degree of height do they begin to spread in bulk. Mau grows in stature till about the age of seventeen; but his body is not completely develoved tillabout thirty. Dogs, on the other hand, are at their utmost size in a year, and become as bulky as they usually are in another. However, Inan, who is so long in growing, continues to live fourscore, or a hundred years; but the dog seldom above twelve or thirteen. In general, also, it may be said, that large animals live longer than little ones, as they usually take a longer time to grow. But in all animals, one thing is equally certain, that they carry the cause of their own decay about them; and that their deaths are necessary and inevitable. The prospects which some visionaries have formed of perpetuating life by remedies, have been often enough proved false by their own example. Such unaccountable schemes would, therefore, have died with them, had not the love of life always augmented our credulity.

When the body is naturally well formed, it is possible to lengthen out the period of life for some years by minagement. Temperance in diet is often found conducive to this end. The famous Cornaro, who lived to above a hundred years, although his constitution was naturally feeble, is a strong instance of the benefit of an abstemious life. Moderation in the passions also may contribute to extend the term of our existence. "Fontenelle, the cclebrated writer. was naturally of a very weak and delicate babit of body. He was affected by the smallest irregularities; and had frequently suffered severe fits of illness from the slightest causes. But the remarkable equality of his temper, and 
his seeming want of passion, lengthened out his life to above a hundred. It was remarkable of him, that nothing could vex or make him uneasy; every occurrence seemed equally pleasing; and no event, however unfortunate, seemed to come unexpected." However, the term of life can be prolonged but for a very little time by any art we can use. We are told of men who have lived beyond the ordinary duration of human existence; such as Parr, who lived to a hundred and forty-four; and Jenkins, to a bundred and sixty-five; yet these men used no peculiar arts to prolong life; on the contrary, it appears that these, as well as other's, remarkable for their longevity, were peasants accustomed to the greatest fatigues, who had no settled rules of diet, but who often indulged in accidental excesses. Indeed, if we consider that the European, the Negro, the Chinese, and the American, the civilized man and the savage, the rich and the ponr, the inhabitant of the city and of the country, though all so different in other respects, are yet entirely sinilar in the period allotted them for living; if we consider that neither the difference of race, of climate, of nourishment, of convenience, or of soil, makes any difference in the term of life; if we consider that those men who live upon raw flesh, or dried fishes, upon sago, or rice, upon cassava, or upon roots, nevertheless live as lning as those who are fed upon bread and meat; we shall readily be brought to acknowledge, that the duration of life depends neither upon habit, customs, or the quintity of food; we shall confess, that nothing can change the laws of that mechanism which regulates the number of our years, and which can chiefly be affected only by long fasting, or great excess.

If there be any difference in the different periods of man's existence, it ought principally to be ascribed to the quality of the air. It has been observed, that in elevated situations there have been found more old people than in those that were low. The mountains of Scotland, Wales, Auvergne, and Switzerland, have furnished more instances of extreme old age, than the plains of Holland, Flanders, Germany, or Poland. But, in general, the duration of life is nearly the same in most countries. Man, if not cut off by accidental diseases, is often found to live to ninety or a hundred ycars. Our ancestors did not live beyond that date: and, since the times of David, this term has undergone little alteration.

If we be asked, how in the beginning men lived so much longer than at present, and by what means their lives were extended to nine hundred and thirty, or even nine hundred and sixty years; it may be answered, that the productions of the earth, upon which they fed, might be of a different nature at that time from what they are at present. "It may be answered, that the term was abridged loy $\mathrm{Di}$ vine command, in order to keep the earth from being overstocked with human inhabitants; since, if every person were now to live and generate for nine liundred years, mankind would be increased to such a degree, that there wonld be no room for subsistence: so that the plan of Providence would be altered; which is seen not to produce life without providing a proper supply."

But to whatever extent life may be prolonged, or however some may have delayed the effects of age, death is the certain goal to which all are hastening. All the causes of decay which have been mentioned contribute to bring on this dreaded dissolution. However, nature approaches to this awful period by slow and imperceptible degrees; life is consumed day after day; and some one of our faculties, or vital principles, is every hour dying before the rest; so that death is only the last shade in the pieture; and it is probable that man suffers a greater change in going from youth to age, than from age into the grave. When we first begin to live, our lives may scarcely be said to be our own; as the child grows, life increases in the same proportion; and is at its height in the prime of manhood. But as soon as the body begins to decrease, life decreases also; for as the human frame diminishes, and its juices circulate in sinaller quantity, life diminishes and circulates with less rigour; so that as we begin to live by degrees, we begin to die in the same manner.

Why then should we fear death, if our lives have been sueh as not to make eternity dreadful? Why should we fear that moment, which is prepared by a thousand other moments of the same kind? the first pangs of sickness being probably greater than the last struggles of departure. Death, in most persons, is as 
calmly endured as the disorder that brings it on. If we inquire from those whose business it is to attend the sick and the dying, we shall fiod that, except in a very few acute cases, where the patient dies in agonies, the greatest number die quictly, and seemingly without pain: and even the agonies of the former rather terrify the spectators than torment the patient; for how inany have we not seen who have bcen accidentally relieved from this extremity, and yet had no memory of what they then endured? In fact, they had ceased to live during that time when they ceased to have sensation; and their pains were only those of which they had an idea.

The greatest number of mankind die, therefore, without sensation; and of those few that still preserve their faculties entire to the last moment, therc is scarcely one of them that does not also preserve the hopes of still outliving his disorder. Nature, for the happiness of man, has rendered this sentiment strouger than his reason. A person dying of an incurable disorder, which he must know to be so, by frequent examples of his case; which he perccives to be so by the inquietude of all around him, by the tears of his friends, and the departure or the face of the physician, is, nevertheless, still in hopes of getting over it. His interest is so great, that he only attends to his own representations; the judgment of others is considered as a hasty conclusion; and while death every moment makes new inroads upon his constitution, and destroys life in some part, hope still seems to escape the universal ruin, and is the last that submits to the blow.

Cast your eyes upon a sick man, who has a hundred times told you that he felt himself dying, that he was convinced he could not recover, and that he was ready to expire; examine what passes on his visage, when, through zcal or indiscretion, any one comes to tell him that his end is at hand. Yon will sce him change, like one who is told an unexpected picce of news. He now appears not to have thoroughly believed what he had bcen telling you himself: he doubted much; and his fears were greater than his hopes; but he still had some fecble expectations of living, and would not lave seen the approaclies of death, unless he had been alarin- ed by the mistaken assiduity of his attendants.

Death, therefore, is not that terrible thing which we suppose it to be. It is a spectre which frights us at a distance, but which disappears when we come to approach it more closely. Our ideas of its terrors are conceived in prejudice, and dressed up by fancy: we regard it not only as the greatest misfortune, but as also an evil accompanied with the most excruciating tortures; we have even increased our apprehensions, by reasoning on the extent of our sufferings. "It must be dreadful," say some, "since it is sufficient to separate the soul from the body : it must be long, since our sufferings are proportioned to the succession of our ideas; and these being painful, must succeed cach other with extreme rapidity." In this manner has false philosophy laboured to augment the miseries of our nature; and to aggravate that period which $\mathrm{Na}$ ture has kindly covered with insensibility. Ncither the mind nor the body can suffer these calamities : the mind is, at that time, mostly without ideas; and the body too much enfeebled to be capable of perceiving its pain. A very acute pain produces either death or fainting, which is a state similar to death: the body can suffer but to a certain degree; if the torture become excessive, it destroys itself; and the mind ccases to perceive, when the body can no longer endure.

In this manner, excessive pain admits of no reflection: and wherever there are any signs of it, we may be sure that the sufferings of the patient are no greater than what we ourselves may have remembered to endurc.

But, in the article of death, we have many instances in which the dying person has shown that very reflection which presupposes an absence of the greatest pain; and, consequently, that pang which ends life cannot even be so great as those which have preceded. Thus, when Charles XII. was shot at the siege of Frederickshall, he was seen to clap his hand on the hilt of his sword; and although the blow was great enongh to terminate one of the boldest and bravest lives in the world, yet it was not painful enough to destroy reflection. He perceived himself attacked; he reflected that he onght to defend himself; and his body obcyed the impulse of his mind, 
even in the last extremity. Thus it is the prejuclice of persons in health, and not the body in pain, that makes us suffer from the approach of death; we have all our lives contracted a habit of making out excessive pleasures and paius; and nothing but repeated experience shows us how seldom the onc ean be suffered, or the other enjoyed to the utmost.

If there be any thing necessary to confirm what we have said concerning the gradual cessation of life, or the insensible approaches of our end, nothing can more effectually prove it than the uncertainty of the signs of death. If we consult what Winslow or Bruhier have said upon this sulject, we shall be convinced, that between life and death the shade is so very undistingnishable, that even all the powers of art can scarcely determine where the one ends, and the other begins. The colour of the visage, the warmth of the body, the suppleness of the joints, are but uncertain sigus of life still subsisting; while, on the contrary, the paleness of the complexion, the coldness of the body, the stiffness of the extremities, the cessation of all motion, and the total insensibility of the parts, are but uncertain marks of death begun. In the same manner, also, with regard to the pulse and the breathing, these motions are often so kept muder, that it is impossible to perceive them. By approaching a looking-glass to the mouth of the person supposed to be dead, people often expect to find whether he breathes or not. But this is a very uncertain experiment: the glass is frequently sullied by the vapour of the dead man's body; and olten the person is still alive, although the glass is no way tarnished. In the same manner, neither burning nor scarifying, neither noises in the ears nor pungent spirits applied to the nostrils, give certain signs of the discontinuance of life; and there are many instances of persons who have endured them all, and afterwards recovered without any external assistance, to the astonishment of the spectators. How careful, therefore, should we be, before we commit those who are dearest to us to the grave, to be well assured of their departure : experience, justice, humanity, all persuade us not to hasten the funerals of our friends, but to keep their bodies unburied, until we have certain signs of their real decease.

\section{CHAPTER XXXIII.}

\section{OF THE VARIETIES IN THE HUMAN RACE.}

HITHERTO we have compared man with other animals; we now come to compare men with each other. We have hitherto considered him as an individual, endowed with excellencies above the rest of the creation; we now come to consider the advantages which men have over men, and the various kinds with which our earth is inllabited.

If we compare the minute differences of mankind, there is scarce one nation upon the earth that entirely resembles another; and there may be said to be as many different kinds of men as there are countries inhabited. One polished nation does not differ more from another, than the merest savages do from those savages that lie even contiguous to them; and it frequently happens that a river, or a mountain, divides two barbarous tribes that a re milike each other in manners, customs, features, and complexion. But these differences, however perceivable, do not form such distinctions as come within a general picture of the varieties of mankind. Custom,accident, or fashion, may produce considerable alterations in neiglibouring nations; their being derived from ancestors of a different climate, or complexion, may contribute to inake accidental distinctions, which every day grow less; and it may be said, that two neighbouring nations, how unlike soever at first, will assimilate by degrees; and by long continuance, the difference between them will at last become almost inperceptible. It is not, therefore, between contiguous nations we are to 
look for any strong marked varieties in the human species: it is by comparing the inhabitants of opposite climates and distant countries; those who live within the polar circles, with those beneath the equator; those that live on one side of the globe, with those that occupy the other.

Of all animals, the differences between mankind are the smallest. Of the lower races of creatures, the changes are so great as often entirely to disguise the natural animal, and to distort, or to disfigure, its shape. But the chief differences in man are rather taken from the tincture of his skin than the variety of his figure: as in all climates he preserves his erect deportment, and the marked superiority of his form. If we look round the world, there seem to be not above six $x^{\mathrm{a}}$ distinct varieties in the human species, each of which is strongly marked, and speaks the kind seldom to have mixed with any other. But there is nothing in the shape, nothing in the faculties, that shows their coming from different originals; and the varieties of climate, of nourishment, and custom, are sufficient to produce every change.

The first distinct race of men is found round the polar regions. The Laplanders, the Esquimaux Indians, the Samoid Tartars, the inhabitants of Nova Zembla, the Borandians, the Greenlanders, and the natives of Kamtschatka, may beconsidered as one peculiar race of people, all greatly resembling each other in their stature, their complexion, their customs, and their ignorance. These nations being under a rigorous climate, where the productions of nature are but few, and the provisions coarse and unwholesome, their bodies have shrunk to the nature of their food; and their complexions have suffered, from cold, almost a similar change to what heat is known to produce; their colour being a deep brown, in some places inclining to actual blackness. These, therefore, in general, are found to be a race of short stature and old shape, with countenances as savage as their manners are barbarous. The visage in these countries, is large and broad, the nose flat and short, the eyes of a yellowish brown, inclining

I have taken four of these varieties from Linnaus; those of the Laplanders and Tartars from Mr. Buffun. to blackness, the eye-lids drawn towards the temples, the cheek-bones extremely high, the mouth very large, the lips thick and turned outwards, the voice thin and squeaking, the head large, the hair black and straight, the colour of the skin of a dark grayish. ${ }^{b}$ Thcy are short in stature, the generality not being above four feet high, and the tallest not above five. Among all these nations the women are as deformed as the men, and resemble them so nearly, that one cannot at first distinguish the sexes among them.

These nations not only resemble each other in their deformity, their dwarfishness, the colour of their hair and eyes, but they have, in a great measure, the same inclinations, and the same manners, being all equally rude, superstitious, and stupid. The Danish Laplanders have a large black cat, to which they communicate their secrets, and consult in all their affairs. Among the Swedish Laplanders there is in every family a drum for consulting the devil; and although these nations are robust and nimble, yet they are so cowardly that they never can be brought into the field. Gustavus Adolphus attempted to form a regiment of Laplanders, but he found it impossible to accomplish his design; for it should seem that they can live only in their own country, and in their own manner. They make use of skates, which are made of fir, of near three feet long, and half a foot broad; these are pointed, and raised before, and tied to the foot by straps of leather. With these they skate on the icy snow, and with such velocity, that they very easily overtake the swiftest animals. They make use also of a pole, pointed with iron at one end, and rounded at the other. This pole serves to push them along, to direct their course, to support them from falling, to stop the impetuosity of their motion, and to kill that game which they have overtaken. Upon these skates they descend the steepest mountains, and scale the most craggy precipices; and, in these exercises, the women are not less skilful than the men. They have all the use of the bow and arrow, which seems to be a contrivance common to all barbarous nations; and which,

b Krantz. 
however, at first, required no small skill to invent. They launch a javelin, also, with great force, and some say, that they can hit a mark, no larger than a crown, at thirty yards distance, and with such force as would pierce a man through. They are all hunters; and particularly pursue the ermine, the fox, the ounce, and the martin, for the sake of their skins. These they barter, with their southern neighbours, for brandy and tobacco; both which they are fond of to excess. Their food is principally dried fish, the flesh of rein-deer and bears. Their bread is composed of the bones of fishes, pounded and mixed with the inside tender bark of the pine-tree. Their drink is train oil or brandy; and, when deprived of these, water, in which juniper berries have been infused. With regard to their morals, they have all the virtues of simplicity, and all the vices of iguorance. They offer their wives and daughters to strangers; and seem to think it a particular honour if their offer be accepted. They have no idea of religion, or a Supreme Being; the greatest number of them are idolaters; and their supcrstition is as profound as their worship is contemptible. Wretched and ignorant as they are, yet they do not want pride; they set themselves far above the rest of mankind; and Krantz assures us, that when the Greenlanders are got together, nothing is so customary among thein as to turn the Europeans into ridicule. They are obliged, indeed, to yield them the preeminence in understanding and mechanicarts; but they do not know how to set any value upon these. Thry therefore count themselves the only civilized and well-bred people in the world; and it is common with them, when they see a quiet or a modest stranger, to say that he is almost as well bred as a Greenlander.

From this description, therefore, this whole race of people may be considered as distinct from any other. Their long continuance in a climate the most inhospitable, their being obliged to subsist on food the most coarse and ill prepared, the savageness of their manners, and their laborious lives, all have contributed to shorten their stature, and to deform their bodies." In proportion as we approach towards the north pole, the size of the natives

- Ellis`s Voyage, p. 256. appears to diminish, growing less and less as we advance higher, till we come to those latitudes that are destitute of all inhabitants whatsoever.

The wretched natives of these climates seem fitted by nature to endure the rigours of their situation. As their food is but scanty and precarious, their patience in hunger is amazing." A man, who has eaten nothing for four days, can manage his little canoc in the most furious waves, and calmlysubsist in the midst of a tempest, that would quickly dash an European boat to pieces. Their strength is not less amazing than their patience; a woman among them will carry a piece of timber, or a stone, near double the weight of what an European can lift. Their bodies are of a dark gray all over; and their faces brown, or olive. The tincture of their skins partly scems to arise from their dirty manner of living, being generally daubed with train-oil ; and partly from the rigours of climate, as the sudden alterations of cold and raw air in winter, and of burning heats in summer, shade their conplexions by degrees, till, in a succession of generations, they at last become alınost black. As the countries in which they reside are the most barren, so the natives seem the most barbarous of any part of the earth. Their more southem neighbours of America, treat them with the same.scorn that a polished nation would treat a savage one; and we may readily judge of the rudeness of those manners, which even a native of Canada can think more barbarous than his own.

But the gradations of nature are imperceptible; and, while the north is peopled with such miscrable inhabitants, there are here and there to be found, upon the edges of these regions, people of a larger stature, and completer figure. A whole race of the dwarfish breed is often found to come down from the north, and settle more to the southward; and, on the contrary, it sometimes happens that southern nations are seen higher up, in the midst of these diminutive tribes, where they have continued for time immemorial. Thus the Ostiac Tartars seem to be a race that have travelled down from the north, and to be originally sprung from the minute savages

brantz, p. 134. vol. i. 
we have been describing. There are also Norwegians and Finlanders, of proper stature, who are seen to inhabit in latitudes higher even than Lapland. These, however, are but accidental migrations, and serve as shades to mnite the distinct varieties of mankind.

The second great variety in the human species, seems to be that of the Tartar race; from whence, probably, the little men we have been describing originally proceeded. The Tartar country, taken in general, comprehends the greatest part of Asia ; and is, consequent$l y$, a general name given to a number of nations, of various forms and complexions. But, however they scem to differ from each other, they all agrce in being very unlike the people of any other country. All these nations have the upper part of the visage very broad, and wriukled even while yet in their youth. Their noses are short and flat, their eyes little, and sunk in their heads; and, in some of them, they are seen five or six inches asunder. Their cheek-bones are high, the lower part of their visage narrow, the chin long and advanced forward, their teeth of an enormous size, and growing separate from each other; their eyebrows thick, large, and covering their eyes; their eyclids thick, the face broad and flat, the complexion olive coloured, and the hair black. They are of a middle size, extremely strong, and very robust. They have but little beard, which grows straggling on the chin. They have large thighs, and short legs. The ugliest of all are the Calmucks, in whose appearance there seems to be something frightful. They all lead an erratic life, remaining under tents of hair, or skins. They live upon horse flesh, and that of camels, either raw or a little sodden between the horse and the saddle. They eat also fish dried in the sun. Their most usual drink is wares' milk, fermented with millet ground into meal. 'They all have the head shaven, except a lock of hair on the top, which they let grow sufficiently long to form into tresses, on each side of the face. The women, who are as ugly as the men, wear their hair, which they bind up with bits of copper, and other ornaments of a like nature. The majority of these nations have no religion, no settled notions of morality, no decency of behaviour. They are cliefly robbers; and the natives of Dagestan, who live near their more polished neighbours, make a traffic of 'Tartar slaves who have bcen stolen, and sell them to the Turks and the Persians. Their chief riches consist in horses, of which perhaps there are more in Tartary than in any other part of the world. The natives are taught by custom to live in the same place with their horses, they are continually employed in managing them, and at last bring them to such great obedience, that the horse seems actually to understand the rider's intention.

To this race of men, also, we must refer the Chinese and the Japanese, however different they seem in their manners and ceremonies. It is the form of the body that we are now principally considering ; and there is, between these countries, a surprising resemblance. It is in general allowed, that the Chinese have broad faces, small eyes, flat noses, and scarce any beard; that they are broad and square shouldered, and rather less in stature than Europeans. These are marks common to them and the Tartars, and they may, therefore, be considered as being derived from the same original. "I have observed," says Chardin, "that in all the pcople from the east and the north of the Caspian sea, to the peninsula of Malacca, that the lines of the face, and the formation of the visage. is the same. This has induced me to believe, that all these nations are derived from the same original, however different either their complexions or their manners may appear: for as to the complexion, that proceeds entirely from the climate and the food; and as to the manners, these are generally the result of their different degrees of wealth or power." That they come from one stock, is evident also from this, that the Tartars who settle in China, quickly resemble the Chinese; and, on the contrary, the Chinese who settle in Tartary, soon assume the figure and the manners of the Tartars.

The Japanese so much resemble the Chinese, that one cannot hesitate to rank them in the same ćlass. They only differ in being rather browner, as they inhabit a nore southern clinate. They are, in general, described as of a brown complexion, a short stature, a broad flat face, a very little beard, and black 
hair. Their customs and ceremonies are nearly the same; their ideas of beauty similar; and their artificial deformities of blackening the teeth, and bandaging the feet, entirely alike in both countries. They both, therefore, proceed from the same stock; and although they differ very much from their brutal progenitors, yet they owe their civilization wholly to the mildiness of the clinate in which they reside, and to the peculiar fertility of the soil. To this tribe, also, we may refer the Cochin Chinese, the Siamese, the Tonquinese, and the inhabitants of Arracan, Laos, and Pegu, who, though all differing from the Chinese and each other, mevertheless have too strong a resemblance not to betray their common original.

Another, which makes the third variety in the human species, is, that of the southern Asiatics; the form of whose features and persons may be easily distinguished from those of the Tartar races. 'The nations that inhabit the peninsula of India, seem to be the principal stock fiom whence the inhabitants of the islands that lie scattered in the Indian ocean have been peopled. They are, in general, of a slender shape, with long straight black hair, and often with Roman noses. Thus they resemble the Europeans in stature and features; but greatly differ in colour and habit of body. The Indians are of an olive colour, and, in the more southern parts, quite black; although the word Mogul, in their langunge, signifies a white man. 'The women are extremely delicate, and bathe very often; they are of an olive colour, as well as the men: their legs and thighs are long, and their bodies short, which is the opposite to what is scen among the women of Europe. They are, as I am assured, by no ineans so fruitful as the European women; but they feel the pains of child-birth with much less sensibility, and are generally up and well the day following. In fact, these pains scem greatest in all countries where the women are most delieate, or the constitution enfeebled by luxury or indolence. The women of savage nations seem, in a great measure, exempt from painful labours; and even the hard-working wives of the peasants among ourselves, have this advantage from a life ofindustry, that their childbearing is less painful. Over all India, the children arrive sooner at maturity, than with us of Europe. They often marry and consuminate, the busband at ten years old, and the wife at eight; and they frequently have children at that age. However, the women who are mothers so soon, cease bearing before they are arrived at thirty; and at that time they appear wrinkled, and seem marked with all the deformities of age. The Indians have long been remarkable for their cowardice and effeminacy; every conqueror, that has attempted the invasion of their country, having succeeded. The warmth of the climate entirely influences their manners; they are slothful, submissive, and luxurious; satisfied with sensual happiness alone, they find no pleasure in thinking; and contented with slavery, they are ready to obey any master. Many tribes among them eat nothing that has life; they are fearful of killing the meanest insect; and have even erected hospitals for the maintenance of all kinds of vermin. The Asiatic dress is a loose flowing garment, rather fitted for the purposes of peace and indolence, than of industry or war. The vigour of the Asiatics is, in general, conformable to their dress and nourishment; fed upon rice, and clothed in effeminate silk vestments, their soldiers are unable to oppose the onset of an European army ; and from the times of Alexander to the present day, we have scarcely any instances of their success in arms. Upon the whole, therefore, they may be considered as a feeble race of sensualists, too dull to find rapture in any pleasures, and too indolent to turn their gravity into wisdom. To this class we may refer the Persians, and Arabians, and, in general, the inhabitants of the islands that lie scattered in the Indian ocean.

The fourth striking variety in the human species, is to be found among the negroes of Africa. This gloomy race of mankind is found to blacken all the southern parts of Africa, from eighteen degrees north of the line, to its extreme termination at the Cape of Good Hope. I know it is said, that the Caffies, who inhabit the southern extremity of that large continent, are not to be ranked among the negro race: however, the difference between them, in point of colour and features, is so sinall, that they may very easily be grouped in this general picture; and in the one or $2 \mathrm{~K}^{*}$ 
two that I have seen, I could not perceive the smallest difference. Each of the negro nations, it must be owned, differ from each other; they have their peculiar countries for beauty, like us; and different nations, as in Europe, pride themselves upon the regularity of their features. Those of Guinea, for instance, are extremely ugly, and have an insupportable scent; those of Mosambique are reckoned beautiful, and have no ill smell whatsocver. The negroes, in general, are of a black colour, with a smooth soft skin. This smoothness proceeds from the downy softuess of the hair which grows upon it; the strength of which gives a roughness to the feel, in those of a white complexion. Their, skins, therefore, have a velvet smonthness, and seem less braced upon the muscles than ours. The hair of their heads differs entirely from what we are accustomed to, being soft, woolly, and short. The beard also, partakes of the same qualities; but in this it differs, that it soon turns gray, which the hair is seldom found to do; so that several are seen with white beards, and black hair, at the same time. Their eyes are generally of a deep hazel; their noses that and short; their lips thick and tumid; and their teeth of an ivory whiteness. This, their only beauty, however, is set off by the colour of their skin; the contrast between the black and white being the more observable. It is false to say that their features are deformed by art; since, in the negro children born in European countries, the same deformities are seen to prevail; the same flatness in the nose; and the same prominence in the lips. They are, in general, said to be well shaped; but of such as I have seen, I never found one that might be justly called so; their legs being mostly ill formed, and commonly bending outward on the shin-bone. But it is not only in those parts of their bodies that are obvious, that they are disproportioned; those parts which among us are usually concealed by dress, with them are large and languid. ${ }^{2}$ The women's breasts, after hearing one child, hang down below the navel; and it is customary with them to suckle the child at their hacks, by throwing the breasts over the shoulder.

a Limmens, in prina linen sua, faminas Africanas depingit sicut aliquid deforme in parte genitali gestantes, quod sinum pudoris nuncupat. $\Lambda$ ttamen nilil differunt a
As their persons are thus naturally deformed, at least to our imaginations, their minds are equally incapable of strong exertions. The climate seems to relax their mental powers still more than those of the body; they are, therefore, in general, found to be stupid, indolent, and mischievous. The Arabians themselves, many eolonies of whom have migrated southward into the inostinland parts of Africa, seem to have degenerated from their ancestors; forgetting their ancient learning, and losing their beauty, they have become a race scarcely any way distinguishable from the original natives. Nor does it seem to have fared otherwise with the Portuguese, who about two centuries ago, settled along this coast. They also are become almost as black as the negroes, and are said by some to be even more barbarous.

The inhabitants of America make a fifth race, as different from all the rest in colour, as they are distinet in habitation. The natives of America (except in the northern extremity, where they resemble the Laplanders.) are of a red or copper colour; and although, in the old world, different climates produce a variety of complexions and customs, the natives of the new continent seem to resemble each other in almost every respect. They are all nearly of one colour; all have black thick straight hair, and thin black beards; which, however, they take care to pluck out by the roots. They have, in general, flat noses, with high cheek-bones, and small eyes; and these deformities of nature they endeavour to increase by art: they flatten the nose, and often the whole head of their children, while the bones are yet susceptible of every impression. They paint the body and face of various colours, and consider the hair upon any part of it, except the head, as a deformity which they are careful to eradicate. Their limbs are generally slighter made than those of the Europeans; and, I am assured, they are far from being so strong. All these savages seem to be cowardly; they seldom are known to face their enemies in the field, but fall upon them at an advantage; and the greatness of their fears serves to increase the rigours of their

nostratibus in hae parte nizi quod labia pudenda sint aliq'antulum tumidiora. In hominibus etiam penis est longior et multo laxior. 
cruelty. The wants which they often sustain, make them surprisingly patient in adversity: distress, by being grown familiar, becomes less terrible; so that their patience is less the result of fortitude than of custom. They have all a serious air, although they seldom think; and, however cruel to their enemies, are kind and just to each other. In short, the customs of savage nations in every country are almost the same; a wild, independent, and precarious life, produces a peculiar train of virtues and vices: and patience and hospitality, indolence and rapacity, content aud sincerity, are found not less among the natives of America, that all the barbarous nations of the globe.

The sixth and last variety of the human species, is that of the Europeans, and the nations bordering on them. In this class we may reckon the Georgians, Cireassians, and Mingrelians, the inhabitants of Asia Minor, and the northern parts of Africa, together with a part of those countries which lie northwest of the Caspian sea. The inhabitants of these countries differ a good deal from each other; but they generally agree in the colour of their bodies, the beauty of their complexions, the largeness of their limbs, and the vigour of their understandings. Those arts which might have had their invention among the other races of mankind, have come to perfection there. In harbarous countries the inhabitants go either naked, or are awkwardly clothed in furs or feathers; in countries semibarbarous, the robes are loose and flowing; but here the clothing is less made for show than expedition, and unites, as much as possible, the extremes of ornament and despatch.

To one or other of these classes we may refer the people of every country: and as each nation has been less visited by strangers, or has had less commerce with the rest of mankind, we find their persons and their manners more strongly impressed with one or other of the characters mentioned above. On the contrary, in those places where trade lias long flourished, or where enemies have made many incursions, the races are usually found blended, and properly fall beneath no one character. Thus, in the islands of the Indian ocean, where a trade has been carried on for time immemorial, the inhabitants appear to be a mixture of all the nations upon the earth; white, olive, brown, and black men, are all seen living together in the same city, and propagate a inixed breed, that can be referred to none of the classes into which naturalists have thought proper to divide mankind.

Of all the colours by which mankind is diversified, it is easy to perceive, that ours is not only most beautiful to the eye, but the inost advantageous. The fair complexion seems, if I may so express it, as a transparent covering to the soul; all the variations of the passions, every expression of joy or sorrow, flows to the cheek, and, without language, marks the mind. In the slightest change of liealth also the colour of the European face is the most exact index, and often teaches us to prevent those disorders that we do not as yet perceive: not but that the African black, and the Asiatic olive complexions, admit of their alterations also; but these are neither so distinct, nor so visible, as with us; and in some countries the colour of the visage is never found to change; but the face continues in the same settled shade in shame and in sicknoss, in anger and despair.

The colour, therefore, most natural to man, ought to be that which is most becoming; and it is found, that, in all regions, the children are born fair, or at least red, and that they grow more black, or tawny, as they advance in age. It should seem, consequently, that man is naturally white; since the same causes that darken the complexion in infauts, may have originally operated, in slower degrees: in blackening whole nations. We could, therefore, readily account for the blackness of different nations, did we not sec the Amerieans, who live under the line, as well as the natives of Negroland, of a red colour, and but a very small shade darker than the natives of the northern latitudes, in the same continent. For this reason, some have sought for other causes of blackness than the elinate; and have endeavoured to prove that the blacks are a race of people bred from one man, who was marked with accidental blackıess. This, however, is but mere ungrounded conjecture: and, although the Americans are not so dark as the negroes, yet we must still continue in the ancient opinion, that the deepness of the colour proceeds from the excessive heat of 
the climate. For, if we compare the heats of Africa with those of America, we shall find they bear no proportion to each other. In America, all that part of the continent, which lies under the line, is cool and pleasant, either shaded by mountains, or refreshed by breezes from the sea. But in Africa, the wide tract of country that lies under the line is very extensive, and the soil sandy; the reflection of the sun, therefore, from so large a surface of earth, is almost intolerable ; and it is not to be wondered at, that the inhabitants should bear, in their looks, the marks of the inhospitable climate. In America, the country is but thinly inhabited; and the more torrid tracts are generally left desert by theinhabitants; for which reason they are not so deeply tinged by the beams of the sun. But in Africa the whole face of the country is fully peopled; and the natives are obliged to endure their situation, without a power of migration. It is there, consequently, that they are in a manner tied down to feel all the severity of the heat; and their complexions take the darkest hue they are capable of receiving. We need not, therefore, have recourse to any imaginary propagation, from persons accidentally black, since the climate is a cause obvious and sufficient to produce the effect.

In fact, if we examine the complexion of different countries, we shall find them darken in proportion to the heat of their climate; and the shades gradually to deepen as they approach the line. Some nations, indeed, may be found not so much tinged by the sun as others, although they lie nearer the line. But this ever proceeds from some accidental causes; either from the country lying higher, and consequently being colder; or from the natives bathing oftener, and leading a more civilized life. In general, it may be asserted, that as we approach the line, we find the inhabitants of each country grow browner, until the colour deepens into perfect blackness. Thus, taking our standard from the whitest race of people, and beginning with our own country, which, I believe, bids fairest for the pre-cminence, we shall find the French, who are more southern, a slight shade deeper than we; going farther down, the Spaniards are browner than the French; the inhabitants of $\mathrm{Fez}$ darker than they; and the natives of Ne- groland the darkest of all In what manner the sun produces this effect, and how thesame luminary which whitens wax and linen, should darken the human complexion, is not easy to conceive. Sir Thomas Brown first supposed, that a mucous substance, which had something of a vitriolic quality, settled under the reticular membrane, and grew darker with heat. Others have supposed that the blackness lay in the epidermis, or scarf-skin, which was burnt up like leather. But nothing has been satisfactorily discovered upon the subject; it is sufficient that we are assured of the fact; and that we have no doubt of the sun's tinging the complexion in proportion to its vicinity.

But we are not to suppose that the sun is the only cause of darkening the skin; the wind, extreme cold, hard labour, or coarse and sparing nourishinent, are all found to contribute to this effect. We find the peasants of every country, who are most exposed to the weather, a shade darker than the higher ranks of people. The savage inhabitants of all places are exposed still more, and therefore contract a still deeper hue ; and this will account for the tawny colour of the North American Indians. Although they live in a climate the same, or even more northerly than ours, yet they are found to be of complexions very different from those of Europe. But it must be considered, that they live continually exposed to the sun; that they use many methods to darken their skins by art, painting them with red ochre, and anointing them with the fat of bears. Had they taken, for a succession of several generations, the same precautions to brighten their colour that an European does, it is very probable that they would in time come to have similar complexions, and, perhaps, dispute the prize of beauty.

The extremity of coll is not less productive of a tawny complexion than that of heat. The natives of the aretic circle, as was observed, are alt brown: and those that lie most to the north are alinost entirely black. In this manner both extremes are unfavourable to the human form and colour, and the same effects are produced under the poles that are found at the line.

With regard to the slature of different countries, that secms chichly to result from the 
nature of the food, and the quantity of the supply. Not but that the severity of heat or cold, may, in some measure, diminish the growth, and produce a dwarfishness of make. But, in general, the food is the great agent in producing this effect; where that is supplied in large quantities, and where its quality is wholesome and nutrimental, the inhabitants are generally seen above the ordinary stature. On the contrary, where it is afforded in a sparing quantity, or very coarse, and void of nourishment in its kind, the inhabitants degenerate, and sink below the ordinary size of mankind. In this respect they resemble other animals, whose bodies, by proper feeding, may be greatly augmented. An ox, on the fertile plains of India, grows to a size four times as large as the diminutive animal of the same kind bred in the Alps. The horses bred in the plains are larger than those of the mountain. So it is with man; the inhabitants of the valley are usually found taller than those of the hill; the natives of the Highlands of Scotland, for instance, are short, broad, and hardy; those of the Lowlands are tall and sliapely. The inhabitants of Greenland, who live upon dried fish and seals, are less than those of Gambia, or Senegal, where Nature supplies them with vegetable and animal abundance.

The form of the face seems rather to he the result of custom. Nations who have long considered some artificial deformity as beautiful, who have industriously lessened the feet, or flattened the nose, by degrees begin to receive the impression they are taught to assume; and Nature, in a course of ages, shapes itself to the constraint, and assumes hereditary deformity. We find nothing more common in births, than for children to inherit sometimes even the accidental deformities of their parents. We have many instances of squinting in thefather,which lie received from fright or habit, communicated to the offspring; and $l$ myself have seen a child distinctly marked with a scar, similar to one the father had received in battle. In this manner, accidental deformities may become natural ones; and by assiduity may be continued, and even increased, through successive generations. From this, therefore, may have arisen the small eyes and long ears of the Tartar and Chinese na- tions. From hence originally may have come the flat noses of the blacks, and the flat heads of the American Indians.

In this slight survey, therefore, I think we may see that all the variations in the human figure, as far as they differ from our own, are produced either by the rigour of the climate, the bad quality or the scantiness of the provisions, or by the savage customs of the country. They are actual marks of the degeneracy in the human form; and we may consider the European figure and colour as standards to which to refer all other varieties, and with which to compare them. In proportion as the Tartar or American approaches nearer to European beauty, we consider the race as less degenerated; in proportion as he differs more widely, he has made greater deviations from his original form.

That we have all sprung from one common. parent we are taught, both by reason and religion, to believe; and we have good reason also to think that the Europeans resemble him more than any of the rest of his children. However, it must not be concealed that the olive-coloured Asiatic, and even the jet-black negro, claim this honour of hereditary resemblance; and assert, that white men are mere deviations from original perfection. Odd as this opinion may seem, they have Linnæus, the celebrated naturalist, on their side: who supposes man a native of the tropical climates, and only a sojourner more to the north. But, not to enter into a controversy upon a matter of a very remote speculation, I think one argument alone will suffice to prove the contrary, and show that the white man is the original source from whence the other varieties have sprung. We have frequently seen white children produced from black parents, but have never seen a black offspring the production of two whites. From hence we may conclude, that whiteness is the colour to which mankind naturally tends : for, as in the tulip, the parent stock is known by all the artificial varieties breaking into it; so in mall, that colour must be original which never alters, and to which all the rest are accidentally seen to change. I have seen in London, at different times, two white negroes, the issue of black parents, that served to convince me of the truth of this theory. I had before been taught 
to believe that the whiteness of the negro's skin was a disease, a kind of milky whiteness, that might be called rather a leprous crust than a natural complexion. I was taught to suppose, that the numberless white negroes found in various parts of Africa, the white men that go by the name of Chacrelas, in the East Indies, and the white Americans, near the Isthmus of Darien, in the. West Indies, were all as so many diseased persons, and even more deformed than the blackest of the natives. But, upon examining that negro which was last shown in London, I found the colour to be exactly like that of an European; the visage white and ruddy, and the lips of the proper redness. However, there were sufficient marks to convince me of its descent. The hair was white and woolly, and very unlike any thing I had seen before. The iris of the eye was yellow, inelining to red; the nose was flat, exactly resembling that of a negro; and the lips thick and prominent. No doubt, therefore, remained of the child's having been born of negro parents: and the person who showed it had attestations to conviuce the most incredulous. From this, then, we see that the variations of the negro colour is into whiteness, whereas the white are never found to have a race of negro children. Upon the whole, therefore, all thuse clianges which the African, the Asiatic, or the American, undergo, are but accidental deformities, which a kinder climate, better nourishment, or more civilized manners, would, in a course of centuries, very probably remove.

\section{CHAPTER XXXIV.}

\section{OF MONSTERS.}

HITHERTO I have only spoken of those varieties in the human species, that are common to whole nations; but there are varieties of another kind, which are only found in the individual; and being more rarely seen, are therefore called monstrous. If we examine into the varieties of distorted nature, there is scarcely a limb of the body, or a feature in the face, that has not suffered some reprobation, either from art or nature; being enlarged or diminished, lengthened or wrested, from its due proportion. Liınæus, after having given a catalogue of monsters, particularly adds, the flat heads of Canada, the long heads of the Chinese, and the slender waists of the women of Europe, who, by strait lacing, take such pains to destroy their health, through a mistaken desire to improve their beauty. It be-

\footnotetext{
ainnæi Syst. vol. i. p. 29. Monorchides ut minus fertiles.

b Vide Phil. Trans. passim. Miscellan. Curioss. Johan. Baptist. Wenck. Dissertatio Physica an ex virilis huınani seminis cum brutali per nefarium coitum commixtione, aut vicissiın ex bruti maris cum inuliebri hunano scıninis commixtione possit verus homo generari. Vide etiam, Johnstoni Thaumatographia Naturalis. Vide Adalberri Disquisitio Physica ostenti duorutn puerorum unus quo-
}

longs more to the physician than the naturalist to attend to these minute deformities; and indeed it is a melancholy contemplation to speculate upon a catalogue of calanities, inflicted by unpitying Nature, or brought upon us by our own caprice. Some, however, are fond of such accounts; and there have been books filled with nothing else. To these, therefore, I refer the reader; who may be better pleased with accounts of men with two heads, or without any head, of children joined in the middle, of bones turned into flesl, or flesh converted into bones, than I am. ${ }^{b}$ It is sufficient here to observe, that every day's experience must have shown us miserable instances of this kind produced by nature or affectation; calamilities that no pity can soften, or assiduity relieve.

rum dente aureo, alter eum capite giganteo Bilux spectabantur. A man without lungs and stomach, Journal de Scavans, 1682, p. 301 ; another without any brain, Andreas Caroli Nemorabilia, p. 167, an. 1676; another without any head, Giornale di Roma, anno 1675, p. 26; another without any arms, New Memoirs of Literature, vol. iv. p. 446. In short, the variety of these accounts is almost infinite; and, perhaps, their use is as much circunscribed as their variety is extensive 
Passing over, therefore, every other account, I shall only mention the famousinstance quoted by Father Malbranche, upon which. he founds his beautiful theory of monstrous productions. A woman of Paris, the wife of a tradesman, went to see a criminal broke alive upon the wheel, at the place of public cxecution. She was at that time two months advanced in her pregnaucy, and no way subjeet to any disorders to aflect the child in her womb. She was, however, of a tender habit of boly; and, though led by curiosity to this horrid spectacle, very easily moved to pity and compassion. She felt, therefore, all those strong emotions which so terrible a sight must naturally inspire; shuddered at every blow the criminal received, and almost swooned at bis cries. Upon returning from this scene of blood, she continued for some days pensive, and her imagination still wrought upon the spectacle she had lately seen. After some time, however, sheseemed perfectly recovered from her fright, and had almost forgotten her former uneasiness. When the time of her delivery approached, she seemed no ways mindful of her former terrors, nor were her pains in labour more than usual in such circumstances. But what was the annazement of her friends and assistants when the child came into the world! It was found that every limb in its body was broken like those of the malefactor, and just in the same place. This poor infant, that had suffered the pains of life even before its coming into the world, did not die, but lived in an hospital in Paris, for twenty years after, a wretched instance of the supposed powers of imagination in the nother, of altering and distorting the infant in the womb. 'The manner in which Malbranche reasons upon this fact, is as follows: the Creator has established such a sympathy between the sereral parts of nature, that we are led not only to imitate each other, but also to partake in the same affections and desires. The animal spirits are thus earried to the respective parts of the body, to perform the same actions which we sce others perform, to receive in some measure their wounds, and take part in their sufferings. Experience tells us, that if we look attentively on any person severely beaten, or sorely wounded, the spirits immediately flow into those parts of the body which No. $17 \& 18$. correspond to those we see in pain. The more delicate the coustitution, the more it is thus affected; the spirits making a stronger impression on the fibres of a weakly habit than of a robust one. Strong vigorous men see an execution withont much concern, while women of nicer texture are struck with horror and concern. 'I'his sensibility in them must, of consequence, be communicated to all parts of their body; and as the fibres of the child in the womb are incomparably finer than those of the mother, the course of the animal spirits must consequently produce greater alterations. Hence, every stroke given to the criminal forcibly struck the imagination of the woman ; and, by a kind of counter-stroke, the delicate tender frame of the child.

Such is the reasoning of an ingenious man upon a fact, the veracity of which many have since called in question. ${ }^{\mathrm{a}}$ They have allowed, indeed, that such a child might have been produced, but have denied the cause 'of its deformity. "How could the imagination of the mother," say they, "produce such dreadful effects upon her child? She has no communication with the infant; she scarcely touches it in any part; quite unaffected with her concerns, it sleeps in security, in a manner secluded by a fluid in which it swims, from her that bears it. With what a variety of deformities," say they, "would all mankind be marked, if all the vain and capricious desires of the mother were thus readily written upon the body of the child!" Yet, notwithstanding this plausible way of reasoning, I cannot avoid giving some credit to the variety of instances I have either read or seen upon this subject. If it be a prejudice, it is as old as the days of Aristotle, and to this day as strongly believed by the generality of mankind as ever. It does not admit of a reason; aud, indeed, I can give none, even why the child should, in any respect, resemble the father or the mother. The fact we generally find to be so.. But why it should take the particular print of the father's features in the womb is as hard to conceive, as why it should be effected by the mother's imagination. We all know what a strong effect the imagination

- Buffon, vol iv. p. 9. 
has on those parts in particular, without being able to assign a cause how this effect is produced; and why the imagination may not produce the same effect in marking the child that it does in forming it, I see no reason. Those persons whose employment it is to rear up pigeons of different colours can breed them, as their expression is, to a feather. In fact, by properly pairing them, they can give what colour they will to any feather, in any part of the body. Were we to reason upon this fact, what could we say? Might it not be asserted, that the egg, being distinct from the body of the female, cannot be influenced by it? Might it not be plausibly said, that there is no similitude between any part of the egg and any particular feather which we expect to propagate; and yet, for all this, the fact is known to be true, and what no speculation can invalidate. In the same manner, a thousand various instances assure us, that the child in the womb is sometimes marked by the strong affections of the mother: how this is performed we know not; we only see the effect, without any connection between it and the cause. The best physicians liave allowed it; and have been satislied to submit to the experience of a number of ages; but many disbelieve it, because they expect a reason for every effect. This, however, is very hard to be given, while it is very easy to appear wise by pretending incredulity.

Among the nuinber of monsters, dwarfs and giants are usually reckoned; though not, pcrhaps, with the strictest propriety, since they are no way different from the rest of mankind, except in stature. It is a dispute, however, about words; and, therefore, scarcely worth contending about. But there is a dispute, of a more curious nature, on this subject ; namely, whether there are races of people thus very diminutive, or vastly large; or whether they be merely accidental varieties, that now and then are seen in a country, in a few persons, whose bodies some external cause has contributed to lessen or enlarge.

With regard to men of diminutive stature, all antiquity has been unanimous in asserting their national existence. Homer was the first who has given us an account of the pigmy nation contending with the cranes; and what puctical license might be supposed to exag- gerate, Athenæus has attempted seriously to confirm by historical assertion." If we attend to these, we must believe that, in the internal parts of Africa, there are whole nations of pigmy beings, not more than a foot in stature, who continually wage an unequal war with the birds and beasts that inhabit the plains in which they reside. Some of the ancients, however, and Strabo in particular, have supposed all these accounts to be fabulous; and have been more inclined to think this supposed nation of pigmies nothing more than a species of apes, well known to be numerous in that part of the world. With this opinion the moderns have all concurred ; and that diminutive race, which was described as human, has been long degraded into a class of animals that resemble us but very imperfectly.

The existence, therefore, of a pigmy race of mankind being founded in error, or in fable, we can expect to find men of diminutive stature only by accident, among men of the ordinary size. Of these accidental dwarfs, every country, and almost every village, can produce numerous instances. There was a time when these unfavoured children of $\mathrm{Na}$ ture were the peculiar favourites of the great; and no prince or nobleman thought himself completely attended unless he had a dwarf among the number of his doinestics. These poor little men were kept to be laughed at; or to raise the barbarous pleasure of their masters, by their contrasted inferiority. Even in England, as late as the tines of King James I. the court was at one time furnished with a dwarf, a giant, and a jester; these the king often took a pleasure in opposing to each other, and often fomented quarrels among them, in order to be a concealed spectator of their animosity. It was a particular entertainment of the courtiers at that time to see little Jeffrey, for so the dwarf was called, ride round the lists, expecting his antagonist; and discovering, in his actions, all the marks of contemptible resolution.

It was in the same spirit, that Peter of Russia, in the year 1710 , celebrated a marriage of dwarfs. This monarch, though raised by his native genius far above a barbarian, twas, nevertheless, still many degrees removed from

Athenæus, ix. 390. 
actual refinement. His pleasures, thereforc, were of the vulgar kind; and this was among the number. Upon a certain day, which he lsal ordered to be proclaimed several months before, he invited the whole body of his courtiers, and all the foreign ambassadors, to be present at the inarriage of a pigmy man and woman. The preparations for this wedding were not only very grand, but executed in a style of barbarous ridicule. He ordered that all the dware men and women, within two hundred miles, should repair to the capital; and also insisted that they should be present at the ceremony. For this purpose he supplied them with proper rehicles; but so contrived it, that one horse was seen carrying in a dozen of them into the city at once, while the mob followed, shouting and laughing, from behind. Some of them were at first unwilling to obey an order which they knew was calculated to turn them into ridicule, and did not come : but lie soon obliged them to obey; and, as a punishment, enjoined, that they should wait upon the rest at dinner. The whole company of dwarfs amounted to seventy, besides the bride and bridegroom, who were richly adorned, and in the extremity of the fashion. For this little company in miniature, every thing was suitably provided; a low table, small plates, little glasses, and, in short, every thing was so fitted as if all things had been dwindled to their own standard. It was his great pleasure to see their gravity and their pride; the contention of the women for places, and the men for superiority. This point he attempted to adjust, by ordering that the most diminutive should take the lead; but this bred disputes, for none would then consent to sit foremost. All this, however, being at last settled, dancing followed the dimner, and the ball was opened with a minuet by the bridegroom, who measured exactly three feet two inches high. In the end, matters were so contrived, that this little company, who met together in gloomy pride, and unwilling to be pleased, being at last familiarized to laughter, joined in the diversion, and became, as the journalist has it," extremely sprightly and entertaining.

- Die dench wurdige. Iwerg. Hockweit, \&c. Lipsia, 1713, vol. viii. p. 102. seq.
But whatever may be the entertaininent such guests might afford when mited, I never found a dwarf capable of affording any when alone. I have sometimes conversed with some of these that were exhibited at our fairs about Town, and have ever found their intellects as contracted as their persons. They, in general, seemed to me to have faculties very much resembling those of children, and their desires likewise of the same kind; being diverted with the same sports, and best pleased with such companions. Of all those 1 have seen, which may amount to five or six, the little man, whose name was Coan, that died lately at Chelsea, was the nost irtelligent and sprightly. I have heard him and the giant, who sang at the theatres, sustain a very ridiculous due:, to which they were taught to give great spirit. But this mirth, and seeming sagacity, were but assumed. He had, by long habit, been taught to look cheerful upon the approach of company; and his conversation was but the mere etiquette of a person that had been used to receive visiters. When driven out of his walk, nothing could be more stupid or ignorant, nothing more dejected or forlorn. But we have a complete history of a dwarf, very accurately related by Mr. Daubenton, in his part of the Histoire Naturelle; which I will here take leave to translate.

This dwarf, whose name was Baby, was well known, having spent the greatest part of his life at Lunenville, in the palace of Stanislaus, the titular king of Poland. He was born near the village of Plaisne, in France, in the year 1741. His father and mother were peasants, both of good constitutions, and inured to a life of husbandry and labour. Baby, when born, weighed but a pound and a quarter. We are not informed of the dimensions of his body at that time; but we may conjecture they were very small, as he was presented on a plate to be baptized, and for a long time lay in a slipper. His mouth, although proportioned to the rest of his body, was not, at that time, large enough to take in the nipple; and he was, therefore, obliged to be suckled by a she-goat that was in the house; and that served as a nurse, attending to his cries with a kind of maternal fondness. He began to articulate some words when eighteen months old; and at two years he was able to walk 
alone. He was then fitted with shoes that were about an inch and a half long. He was attacked with several acute disorders; but the small-pox was the only one which left any marks behind it. Until he was six years old, he eat no other food but pulse, potatoes, and bacon. His father and mother were, from their poverty, incapable of affording him any better nourishment; and his education was little better than his food, being bred up among the rustics of the place. At six years old he was about fifteen inches high ; and his whole body weighed but thirteen pounds. Notwithstanding this, he was well proportioned, and handsome; his health was good, but his understanding scarcely passed the bounds of instinct. It was at that time that the king of Poland, having heard of such a curiosity, had him conveyed to Lunenville, gave him the name of Baby, and kept him in his palace.

Baby, having thus quitted the hard condition of a peasant, to enjoy all the comforts and conveniences of life, seemed to receive no alteration from his new way of living, either in mind or person. He preserved the goodness of his constitution till about the age of sixteen, but his body seemed to increase very slowly during the whole time; and his stupidity was such, that all instructions were lost in improving his understanding. He could never be brought to have any sense of religion, nor even to show the least signs of a reasoning faculty: They attempted to teach him dancing and music, but in vain : he never could make any thing of music ; and as for dancing, although he beat time tolerably exact, yet he could never remember the figure, but while his dancing master stood by to direct his motions. Notwithstanding, a inind thus destitute of understanding was not without its passions; anger and jealousy harassed it at times; nor was be without desires of another nature.

At the age of sixteen, Baby was twenty-nine inches tall; at this he rested; but having thus arrived at his acme, the alterations of puberty, or rather, perhaps, of old age, came fast upon him. From being very beautiful, the poor little creature now became quite deformed; his strength quite forsook him; his backbone began to bend; his head hung forward; his legs grew weak; one of his shoulders turned awry; and hisnose grew disproportionably large. With his strength, his natural spirits also forsook him; and, by the time he was twenty, he was grown feeble, decrepit, and marked with the strongest impressions of old age. It had been before remarked by some, that he would die of old age before he arrived at thirty; and, in fact, by the time he was twenty-two, he could scarcely walk a hundred paces, being worn out with the multiplicity of his years, and bent under the burden of protracted life. In this year he died: a cold, attended with a slight fever, threw him into a kind of lethargy, which had a few momentary intervals; but he could scarcely be brought to speak. However, it is asserted. that in the five last years in his life he showed a clearer understanding than in his times of best health: but at length he died, after enduring great agonies, in the twenty-second year of his age.

Opposite to this accidental diminution of the human race, is that of its extraordinary magnitude. Concerning the reality of a nation of giants, there have been many disputes among the learned. Some have affirmed the probability of such a race; and others, as warmly have denied the possibility of their existence. But it is not from any speculative reasonings, upon a subject of this kind, that information is to be obtained; it is not from the disputes of the scholar, but the labours of the enterprising, that we are to be instructed in this inquiry. Indeed, nothing can be more absurd, than what some learned men have advanced upon this subject. It is very unlikely, says Grew, that there should either be dwarfs or giants; or if such, they cannot be fitted for the usual enjoyment of life and reason. Had man been born a dwarf, he could not have been a reasonable creature: for to that end, he must have a jolt head, and then he would not have body and blood enough to supply his brain with spirits; or if he had a small head, proportionable to his body, there would not be brain enough for conducting life. But it is still worse with giants; and there could never have been a nation of such, for there would not be food enough found in any country to sustain them; or, if there were beasts sufficient for this purpose, there would not be grass enough for their maintenance. But what is still more, add others, giants could 
never be able to support the weiglit of their own bodies; since a man of ten feet higlı, nust be eight times as heavy as one of the ordinary stature; whereas he lias but twice the size of muscles to support such a burden: and, consequently, would be overloaded with the weight of his own body. Such are the theories upon this subject; and they require no other answer, but that experience proves them both to be false: dwarfs are found capable of life and reason; and giants are seen to carry their own bodies. We have several accounts firom mariners, that a nation of giants actually exists; and mere speculation should never induce us to doubt their veracity.

Ferdinand Magellan was the first who discovered this race of people along the coast towards the extremity of South America. Magellan was a Portuguese, of noble extraction; who having long behaved with great lravery, under Albuquerque, the conqueror of India, lie was treated with neglect by the court, upon lis return. Applying, therefore, to the king of Spain, he was intrusted with the command of five ships, to subduc the Molucea islands; upen one of which he was slain. It was in his voyage thither, that he happened to winter in St. Julian's Bay, an American harbour, forty-nine degrees south of the line. In this desolate region, wherc nothing was seen but objects of terror, where neither trees nor verdure drest the face of the conntry, they remained for some months without sceing any human creature. They had judged the country to be utterly uninhabitable; when one day, they saw approaching, as if he had been dropt from the clouds, a man of enormons stature, dancing and singing, and putting dust upon his head, as they supposed, in token of peace. 'This overture for friendship was, by Magellan's command, quickly answered by the rest of his men; and the giant approaching, testificl every inark of astonishment and surprise. He was so tall, that the Spaniards only reaclied his uvaist; his face was broad, his colour brown, and painted over with a varicty of tints; eacl cheek had the resemblance of a heart clrawn upon it; his liair was approaching to whiteness; he was clothed in skins, and armed with a bow. Being treated with kindness, and dismissed with some trifling presents, le soon returned with many more of the same stature; two of whom the mariners decoyed on ship- board: nothing could be niore gentle than they were in the beginning; they considered the fetters that were preparing for them as ornaments, and played with them like children with their toys; but when they found for what purpose they were intended, they instantly exerted their amazing strength, and broke them in pieces with a very easy effort. This account, witl a variety of other circumstances, has been confirmed by succeeding travellers: Herrara, Sebald, Wert, Oliver Van Noort, and Janes le Maire, all correspond in affirming the fact, although they differ in many particulars of their respective descriptions. The last voyager we have lıad, that luas seen this enormous race, is Commodore Byron. I lave talked with the person who first gave the relation of that royage, aud who was the carpenter of the Commiodorc's slip; lie was a sensible, understanding man, and I bclieve extremely faithful. By him, therefole, I was assured, in the most solemn manner, of the truth of his relation; and this account has since been confirmed by onc or two publications; in all which the particulars are pretty nearly the same: One of the circumstances which most puzzled me to reconcilc to probability, was that of the horses, on which they are clescribed as riding down to the shore. IVe know the Amcrican liorse to be of European breed; and, in sonse measure, to be dcgenerated from the original. I was at a loss, therefore, to account how a horse of not more than fourteen liands high, was capable of carrying a man of nine feet; or, in other words, an animal almost as large as jtself. But the wonder will cease, when we consider, that so small a beast as an ass, will carry a man of ordinary size tolerably well; and the proportion between this and the former instance is nearly exact. We can no longer, therefore, refuse our assent to the existence of this gigantic race of mankiud: in what manner they are propagaterl, or under what regulations they live, is a subject that remains for future investigation. It should appear, however, that they are a wandering uation, changing thcir abode with the course of the sun, and shifting their situation, for the convenience of food, climatc, or pasture. ${ }^{2}$

This race of giants are described as possessed

a Later voyagcrs have not confirmed this account, in some particulars. 
of great strength; and, no doubt, they must be very different front those accidental giants that are to be seen in different parts of Europe. Stature, with these, scenıs rather their infirmity than their pride; and adds to their burden, without increasing their strength. Of those I have seen, the generality were ill formed and unhealthful; weak in their persons, or incapable of exerting what strength they were possessed of. The same defects of understanding that attended those of suppressed stature, were found in those who were thus overgrown: they were heavy, phlegmatic, stupid, and inclined to sadness. Their numbers, however, are but few ; and it is thus kindly ordered by Providence, that as the middle stature is the best fitted for liappiness, so the middle ranks of mankind are produced in the greatest variety.

However, mankind scems naturally to have a respect for nicn of extraordinary stature; and it has been a supposition of long standing, that our ancestors were much taller, as well as much more beautiful, than we. This has been, illdecd, a theme of poctical declamation from the beginning; and man was scarcely forned, when lie began to deplore an imaginary decay. Nothing is more natural than this progress of the mind, in looking up to antiquity with reverential wonder. Having been accustomed to compare the wisdon of our father's with our own, in early imbecility, the impression of their superiority remains when they no longer exist, and when we cease to be inferior. Thus the men of every age consider the past as wiser than the present; and the reverence seems to accumulate as our imaginations ascend. For this reason, we allow remote antiquity many advantages, without disputing their title: the inhabitants of uncivilized countries represent them as taller and stronger; and the people of a more polished nation, as more healthy and more wise. Nevertheless, these attributes secm to be only the prejudices of ingenuous minds; a kind of gratitude, which we hope in turn to receive from posterity. The ordinary stature of men, Mr. Derhanı observes, is, in all probability, the same now as at the beginning. The oldest measure we have of the luuman figure, is in the monument of Cheops, in the first pyramid of Egypt. This must have subsisted many liundred years before the times of Homer, who is the first that deplores the decay. This monument, however, scarcely exceeds the measure of our ordinary coffins : the cavity is no more than six feet long, two feet wide, and deep in about the same pioportion. Several mumnies also, of a very carly age, are found to be only of the ordinary stature; and show that, for these thrce thousand years at least, men have not suffered the least diminution. We have many corroborating proofs of this, in the ancient picces of armour which are dug up in different parts of Europe. The brass liclmet dug up at Medauro, fits one of our men, and yet is allowed to have been left there at the overthrow of Asdrubal. Some of our finest antique statues, which we learn from Pliny and others to be exactly as big as the life, still continue to this day, remaining monuments of the superior excellence of their workmen indecd, but not of the superiority of their stature. We may conclude, therefore, that men have been in all ages pretty much of the same size they are at present; and that the only difference must have been accidental, or perhaps national.

As to the superjor beauty of our ancestors, it is not easy to make the comparison: beauty secms a very uncertain charm; and frequently is less in the object, than in the eye of the beholder. Were a modern lady's face forıned exactly like the Venus of Medicis, or the Sleeping Vestal, she would scarcely be considered beautiful, except by the lovers of antiquity, whom of all her admirers perhaps she would be least desirous of pleasing. It is true, that we have some disorders among us that disfigure the features, and from which the ancients were exenıpt; but it is equally truc, that we want some wliich were common among them, and which were equally deforming. As for their intellectual powers, these also were probably the same as ours: we excel them in the sciences, which may be considered as a history of accumulated experience; and they excel us in the poetic arts, as they liad the first rifling of all the striking images of Nature. 


\section{CHAP'TER XXXV.}

\section{OF MUMMIES, WAX-IVORKS, \&c.}

"MAN" is not content with the usual term of life, but he is willing to lengthen out his existence by art; and although he cannot prevent death, he tries to obviate his dissolution. It is natural to attempt to preserve even the most trifling relics of what has long given us pleasure; nor does the mind separate from the body, without a wish, that even the wretched heap of dust it leaves behind may yet be remembered. The embalming, practised in various nations, probably had its rise in this fond desire : an urn filled with ashes, among the Romans, served as a pledge of continuing affection; and even the grassy graves in our own church-yards, are raised above the surface, with the desire that the body below should not be wholly forgotten. The soul, ardent after eternity for itself, is willing to procure, even for the body, a prolonged duration."

But of all nations, the Egyptians carried this art to the highest perfection: as it was a principle of their religion, to suppose the soul continued only coeval to the duration of the body, they tried every art to extend the life of the one by preventing the dissolution of the other. In this practice they were exercised from the earliest ages; and the mummies they have embalmed in this manuer, continue in great numbers to the present day. We are told, in Genesis, that Joseph seeing his father expire, gave orders to his physicians to embalin the body, which they execnted in the compass of forty days, the usual time of embalming. Herodotus also, the most ancient of the profane historians, gives us a copious detail of this art, as it was practised, in his time, among the Egyptians. There are certain men among them, says he, who practise embalming as a trade; which they perform with all expedition possible. In the first place, they draw out the brain througif the

\footnotetext{
- This chapter I have, in a great measure, trknslated from Mr. Daubenton. Whatever is acided from others, is marked with inverted commas.
}

nostrils, with irons adapted to this purpose; and in proportion as they evacuate it in this manner, they fill up the cavity with aromatics: they next cul open the belly, near the sides, with a sharpened stone, and take out the entrails, which they cleanse, and wash in palm oil; having performed this operation, they roll them in aromatic powder, fill them with myrrh, cassia, and other perfumes, except incense; and replace them, sewing up the body again. After these precautions, they salt the body with nitre, and keep it in the salting-place for seventy days, it not being permitted to preserve it so any longer. When the seventy days are accomplished, and the body washed once more, they swathe it in bands made of linen, which have-been dipt in a gum the Egyptians use instead of salt. When the friends lave taken back the body, they make a hollow trough, something like the shape of a man, in which they place the body; and this they enclose in a box, preserving the whole as a most precious relic, placed against the wall. Such are the ceremonies used with regard to the rich. As for those who are contented with a humbler preparation, they treat them as follows: they fill a syringe with an odoriferous liquor extracted from the cedartrec, and, without making any incision, inject it up the body of the deceased, and then keep it in nitre, as long as in the former case. When the time is expired, they evacuate the body of the cedar liquor which had been injected ; and such is the effect of this operation, that the liquor dissolves the intestines, and brings them away: the nitre also serves to eat away the flesh, and leaves only the skin and the bones remaining. This done, the body is returned to the friends, and the embalmer takes no farther trouble about it. The third method of embalming those of the meanest condition, is merely by purging and cleansing the intestines by frequent injections, and preserving the body for a similar term in nitre, at the end of which it is restored to the relations. 
Diodorus Siculus also makes mention of the manner in which these embalmings are performed. According to him, there were several officers appointed for this purpose; the first of them, who was ealled the scribe, marked those parts of the body, on the left side, which were to be opened; the cutter made the incision; and one of those that were to salt it drew out all the bowels, except the heart and the kidneys; another washed them in palm wine and odoriferous liquors; afterwards they anointed for above thirty days with cedar, gum, myrrh, cinnamon, and other perfumes. These aromatics preserved the body entire for a long time, and gave a rery agreeable odour. It was not in the least disfigured by this preparation; after which it was returned to the relations, who kept it in a coffin, placed upright against a wall.

Most of the modern writers who have treated on this subject, have inerely repeated what has been said by Herodotus; and if they add any thing of their own, it is but merely from conjecture. Dumont observes, that it is very probable, that aloes, bitumen, and cinnamon, make a principal part of the composition which is used on this occasion: he adds, that, after embalming, the body is put into a coffin, made of the sycamore-tree, which is alınost incorruptible. Mr. Grew lemarks, that in an Egyptian mummy, in the possession of the Royal Society, the preparation was so penetrating as to enter into the very substance of the bones, and rendered them so black, that they scemed to have been burnt. From this he is induced to believe, that the Egyptians had a custom of embalming their dead, by boiling them in a kind of liquid preparation, until all the aqueous parts of the body were exhaled away; and until the oily or gummy matter had penetrated throughout. He proposes, in consequence of this, a method of macerating, and afterwards of boiling, the body in oil of walnut.

I aun, for my own part, of opinion, that there were several ways of preserving dead bodies fiom putrefaction; and that this would be no difficult matter, since different uations have all succeeded in the attempt. We have an example of this kind among the Guanches, the ancient inhabitants of the island of Teneriff. Those who survired the general dc- struction of this people by the Spaniards, when they conquered this island, informed them, that the art of embalming was still preserved there; and that there was a tribe of priests among them possessed of the secret, which they kept concealed as a sacred mystery. As the grealest part of the nation was destroyed, the Spaniards could not arrive at a complete knowledge of this art; they only found out a tow of the particulars. Having taken out the bowels, they washed the body several times in a lec, made of the dried bark of the pine-tree, warmed, during the suminer, by the sun, or by a stove in the winter. They afterwards anointed it with butter, or the fat of bears, which they had previously boiled with odoriferous herbs, such as sage and lavender. After this unction, they suffered the body to dry; and then repeated the operation as often as it was necessary, until the whole substance was impregnated with the preparation. When it was become very light, it was then a certain sign that it was fit and properly prepared. They then rolled it up in the dried skins of goats; which, when they had a mind to save expense, they suffered to remain with the hair still growing upon them. Purchas assures us, that he has seen mummies of this kind in London; and mentions the name of a gentleman who had seen several of them in the island of Teneriff, which were supposed to have been two thousand years old ; but without any certain proofs of such great antiquity. This people, who probably came first from the coasts of Africa, might have learned this art from the Egyptians, as there was a traffic carried on from thence into the most internal parts of Africa.

Father Acosta and Garcilasso de la Vega make no doubt but that the Peruvians understood the art of preserving their dead for a very long space of time. They assert their having seen the bodies of several incas, that were perfectly preserved. They still preserved their hair and their cye-brows; but they had eyes inade of gold, put in the places of those taken out. They were clothed in their usual habits, and seated in the manner of the lndians, their arms placed on their breasts. Garcilasso touched one of their fingers, and found it apparently as hard as wood; and the whole body was not heavy enough to over 
burden a weak man, who should attempt to curly it away. Acosta presimes that these bodies were embalued with a bitumen, of which the Indians knew the properties. Garcilisso, however, is of a different opinion, as he satw nothing bituminous about them ; but he confesses that he di I not exaunine then very particulurly; and he regrets his not having inguired imo the methods used for that purpose. He adds, that being a Peruvian, his countrymen would not have scrupled to inform lim of the secret, if they reaily liad it still among them.

Garcilasso, thus being ignorant of the secret, makes use of some inductions to throw light upon the subject; he asserts, that the air is so dry and so colit at Cusco, that flesh dries there like woot, without corrupting; and he is of opinion, that they dried the body in snow before they applied the bitumen: he adds, that in the times of the incas, they uaually dried the flesh which was designed for the use of the army ; and that, when it had lost its humidity, it "nisht be kept without salt, or any other preparation.

It is said, that at Spitzbergen, which lies within the aretic circle, and consequently in the coldest climate, bodies never corrupt, nor suffer any apparent alteration, even thongh buried for thirty years. Nothing corrmits or putrefies in that climate; the wood which has been employed in buildling those houses where the train-oil is separated, appears as fresh as the day it was lirst cut.

If excessive cold, therefore, be thus capable of preserving bodies from corruption, it is not less certain that a great degrec of diyness, produced by heat, produces the same eff.et. It is well known that the men and animals that are buried in the sands of Arabia quickly dry up, and continue in preservation for several ages, as if they had been actually cmbalmed. It has often happened, that whole caravans have perished in crossing those deserts, either by the burning winds that infest them, on by the sands which are raised by the tempest, and overwh tm every creature in certain ruin. The bodies of those persons are preserved entire; and they are often found in this condition by so ue accidental passenger. Many authors, both ancient and modern, make mention of such mummies as these; and Shaw says, that he has been assured that numbers of men, as well as other animals, have been thus preserved, for times immemorial, in the burning sands of Saibah, which is a place, he supposes, situate between liasem and liggypt.

The corruption of dead bodies bcing entirely caused by the formentation of the humours, whatever is capable of hindering or retarding this fermentation, will contribute to their meservation. Both heat and cold, though so contrary in themselves, produce similar effects in this particnlar, by drying up the liunours. The cold in condensing and thickening them, and the heat in evaporating then before they have time to act upon the solids. But it is necessary that these extremes should be constant; for if they succeed each other so as that cold shall follow heat, or dryness humidity, it mast then necessarily happen that corrup ion must ensue. However, in temperate clinats, there are natural canses capable of preserving dead bodies; among which we may reckon the quality of the earth in which they are buricel. If the earth be drying and astringralt, it will inbibe the humidity of the borly; and it may probably be for this reason that the borlies huried in the monastery of the Cordeliers, at 'Thoulouse, do not putrely, but dry in such a manner that they may be lifted up by one arm.

The gums, resins, and bitumens, with which dead bodies are cmbalmed, kiep off the inpressions which they would else receive from the alteration of the temperature of the air; and still more, if a hody thus prepared be placed in a dry or burning sand, the most powerful means will be united for its preservation. We are not to be surprised, therefore, at $w$ hat we are told by Chardin, of the comutry of Chorosan, in Persia. The bodies which have been previonsly embalmed, and buried in the sands of that country, as he assures us, are fount to petrefy, or, in other words, to become extremely hard, and are preserved for sevral ages. It is asserted, that sume of them have continued for a thousand years.

'The Egyptians, as has been mentioned ahove, swathed the body with linen bands, and enclosed it in a coffu: however, it is probable that, with all these precautions, they would not have continued till now, if the tombs, or pits, in which they were placed, had not been clug in a dry chalky soil, which was not susceptible of humidity; and whieh was besides covered over with a dry sand of scveral feet thickness. 
The sepulclires of the ancient Egyptians subsist to this day. Most travellers who have been in Egypt have described those of ancient mummies, and have seen the mumnies interred there. These catacombsare within two leagues of the ruins of the city, nine leagues from Grand Cairo, and about two miles from the village of Zaccara. They extend from thence to the Pyramids of Pharaoh, which are about eight miles distant. These sepulchres lie in a field, covered with a fine running sand, of a yellowish colour. The country is dry and hilly; the entrance of the tombs is cholied up with sand; there are many open, but several more that are still concealer. The inhabitants of the neighbouring village have no other commerce, or nethod of subsisting, but by secking out mumnies, and selling them to such strangers as happen to be at Grand Cairo. This commerce, some years ago, was not only a very common, but a very gainful one. A complete mumuny ivas of ten solu for twenty pounds: but it must not be supposed that it was bought at such a high price fiom a mere passion for antiquity; there were much more powerful motives for this traffic. Mummy, at that time, made a considerable article in medicine; and a thousand imaginary virtues were ascribed to it, for the cure of most disorlers, particularly of the paralytic kind. 'There was no shop, therefore, without mummy in it ; and no physician thought he had properly treated his patient without adding this to his prescription. Induced by the general repute, in which this supposed drug was at that time, several Jews, both of Italy and France, found out the art of imitating mummy so exactly, that they, for a long time, deceived all Europe. This they did hy dryiny dead boclies in ovens, after having prepared them with myrrh, aloes, and bitumen. Still, however, the request for mummies contimued, and a variety of cures were daily ascribed to them. At length, Paræus wrote a treatise on their total inefficacy in physic; and showed their abuse in loading the stomach, to the exclusion of more eflicacious medicines. From that tine, therefore, their reputation began to decline; the Jews discontinued their connterfeits, and the trade returned entire to the Enyptians, when it was no longer of value. The industry of seehing after mumnies is now totally relaxed, their price merely arbitrary, and just what the curious are willing to give.
In seeking for mummies, they first clear away the sand, which they may do for weeks together, without finding what is wanted. Upon coming to a little square opening of about eighteen feet in depth, they descend into it, by holes for the feet, placed at proper intervals, and there they are sure of finding what they seek for. These caves, or wells, as they call them, are hollowed out of a white fiee-stone, which is found in all this country, a few fect below the covering of sand. When one gets to the bottom of these, which are sometimes forty feet below the surface, there are several square openings on each side, into passages of ten or fiftren feet wide, and these lead to chamber's of fifteen or twenty feet square. These are all hewn out of the rock; and in each of the catacombs are to be found several of these apartments, communicating with each other. 'They extend a great way under ground, so as to be under the city of Menphis, and in a manner to undermine its emvirons.

In some of the chambers, the walls are adomed with figures and hieroglyphics; in others, the mummies are found in tombs round the apartment hollowed out in the rock. 'These tombs are upright, and cut into the shape of a man, with his aruss stretched out. There are others found, and these in the greatest number, in wooden-coffins, or in cloths covered with bitumen. These coffins, or wrappers, are covered all over with a variety of ormaments. There are some of them painted, and adorned with figures, such as that of Death, and the leaden seals, on which several characters are engraven. Some of these coffins are carved into the human shape; but the head alone is distinguishable: the rest of the body is all of a piece, and terminated by a pedestal, while there are some with their arms hanging down; and it is by these inarks that the bodies of persons of rank are distinguished from those of the meaner order. These are generally finmd lying on the floor, without any profusion of ornaments; and in some chanbers the mummies are found indiscriminately piled upon each other, and buried in the sancl.

Many mummies are found lying on their backs; their heads turned to the north, and their hands placel on the belly. 'The bands of linen, with which these were swatherl, are found to be more than a thonsand yards loug; and, of consequence, the number of circum- 
volutions they make about the body must have been amaziug. These were performed by beginning at the head, and ending at the feet; but they contrived it so as to avoid covering the face. However, when the face is entirely uncovered, it moulders jnto dust immediately upon the admission of the air. When, therefore, it is preserved entire, a slight covering of cloth is so disposed over it, that the shape of the eyes, the nose, and the mouth, are seen under it. Some mummies have been found with a long beard, and hair that reached down to the mid-leg, nails of a surprising length, and some gilt, or at least painted of a gold colour. Some are found with bands upon the breast, covered with hieroglyphics, ingold, silver, or in green; and some with tutelary idols, and other figures of jasper, within their body. A piece of gold also has often been found under their tongues, of about two pistoles value; and, for this reason, the Arabians spoil all the munmies they meet with, in order to get at the gold.

But although art, or accident, has thus been found to preserve dead bodies entire, it must by no means be supposed that it is capable of preserving the exact form and lineanents of the deceased person. Those bodies which are found dried away in the deserts, or in some particular church-yards, are totally deformed, and scarcely any lineaments remain of their external structure. Nor are the mummics preserved by embalming, in a better condition. The flesh is dried away, hardened, and hidden under a variety of bandages; the bowels, as we have seen, are totally removed; and from hence, in the most perfect of them, we see only a shapeless mass of skin discoloured; and even the features scarcely distinguishable. The art is, therefore, an effort rather of preserving the substance than the likeness of the deceased; and has, consequently, not been brought to its highest pitch of perfection. It appears from a mummy, not long since dug up in France, that the art of embalning was more completely mnderstoorl in the western world than even in Egypt. This mummy, which was dug up at Auvergne, was an amazing instance of their skill, and is one of the most curious relics in the art of preservation. As some pensants, in that part of the world, were digging in a field, near Rion, witl.- in about twenty-six paces of the highway, between that and the river Artiers, they discovered a tomb, about a loot and a hall beneath the surface. It was composed only of two stones; one of which formed the bodly of the sepulchre, and the other the cover. This tomb was of free-stone, seven feet and a half long, three feet and a half broad, and about three feet high. It was of rude workmanship; the cover had been polished, but was without figure or inscription: within this tomb was placed a leaden-coffin, four feet seven inches long, fourteen inches broad, and fifteen high. It was not made coffin-fashion, but oblong. like a box, equally broad at both ends, and covered with a licl that fitted on like a snuffbox, without a linge. This cover had two holes in it, each of about two inches long, and very narrow, filled with a substance resembling butter; but for what purpose intended remains unknown. Within this coffin was a mummy, in the highest and most perfect preservation. The internal sides of the coffin were filled with an aromatic substance, mingled with clay. Round the mummy was wrapped a coarse cloth, in form of a uapkin; under this were two shirts, or shrouds, of the most exquisite texture ; beneath these a banrage, which covered all parts of the body, like an infant in swaddling-clothes; still under this general bandage there was another, which went particularly round the extremities, the hands, and the legs. The head was covered with two caps; the feet and hands were without any particular bandages; and the whole body was covered with an aromatic: substance an inch thick. When these were removed, and the body exposed naked to view, nothing could be more astonishing than the preservation of the whole, and the exact resemblance it bore to a body that had been dead a day or two before. It appeared well proportioned, except that the head was rather large, and the feet small. The skin had all the pliancy and colour of a body lately dead : the visage, however, was of a brownish hue. The belly yielded to the touch; all the joints were flexible, except those of the legs and feet ; the fingers stretched forth of themselves when bent inwarls. The nails still continued entire; and all the marks of the joints, both in the fingers, the palms of the hands, and the 
soles of the feet, remained perfeetly visible. The bones of the arms and legs were soft and pliant; but, on the contrary, those of the skull preserved their rigidity; the hair, which only covered the back of the head, was of a chesnut eolour, and about two inches long. The pericranium at top was separated from the skull by an incision, in order to open it for the introdueing proper aromatics in the place of the brain, where they were found mixed with clay. The teeth, the tongue, and the ears, were all preserved in perfect form. 'The intestines were not taken out of the body, but remained pliant and entire, as in a fresh subject; and the breast was made to rise and fall like a pair of bellows. The embalming preparation had a very strong and pungent smell, which the body preserved for more than a month after it was exposed to the air. This odour was perceived wherever the mummy was laid; although it remained there but a very short time, it was even pretended that the peasants of the neighbouring villages were incommoded by it. If onc touched either the mummy, or any part of the preparation, the hands smelled of it for several hours after, although washed with water, spirit of wine, or vinegar. This mummy, having remained exposed for some months to the curiosity of the public, began to suffer some mutilations. A part of the skin of the forehead was cut off; the teeth were drawn out, and some attempts were made to pull away the tongue. It was, therefore, put into a glass-ease, and shortly after transmitted to the king of France's cabinet at Paris.
There are many reasons to believe this te be the body of a person of the highest dis. tinction : however, no marks remain to assure us either of the quality of the person, or the time of his decease. There are only to be scen some irregular figures on the coflin; one of which represents a kind of star. There were also some singular characters upon the bandages, which were totally defaced by those who had toru them away. However, it should seem that it had remained for several ages in this state, since the first years immediately suceeeding the interment, are usually those in which the body is most liable to decay. It appears also to be a inuch more perfect inethod of embalming than that of the Egyptians; as in this the flesh continues with its natural elasticity and colour, the bowels remaiu entire, and the joints have almost the pliancy which they had when the person was alive. Upon the whole, it is probable that a much less tedious preparation than that used by the Egyptians would have sufficed to keep the body from putrefaction; and that an injection of petreoleum inwardly, and a layer of asphaltum without, would have sufficed to have made a mummy; and it is remarkable that Auvergne, where this was found, affords these two substances in sufficient plenty. This art, therefore, might be brought to greater perfection than it has arrived at hitherto, were the art worth preserving. But mankind have long since grown wiser in this respect; and think it unnecessary to keep by them a deformed carease, which, instead of aiding their magnificence, must only serve to mortify their pride.

\section{CHAPTER XXXVI.}

\section{OF ANIMALS}

LEAVING man, we now descend to the lower ranks of animated nature, and prepare to examine the life, manners, and characters, of these our huinble partuers in the creation. But, in such a wonderful variety as is diffused around us, where shall we begin? The number of beings endued with life, as well as we, seems, at first view, infinite. Not only the forest, the waters, the air, teems with animals of various kinds; but almost every vegetable, every lcaf, has millions of minute inhabitants, each of which fill up the circle of its alloted life, and some are found objects of the greatest euriosity. In this sceming exuberance of 
animals, it is natural for ignorance to lie down in hopeless uncertainty, and to declare what requires labour to particularize to be utterly inscrutable. It is otherwise, however, with the active and searching mind; no way intimidated with the immense variety, it begins the task of numbering, grouping, and classing, all the varrous kinds that fall within its notice; finds every day new relations between the several parts of the creation; acquires the art of considering several at a time under one point of view; and, at last, begins to find that the variety is neither so great nor so inscrutable as was at first imagined. As in a clear night, the number of the stars secms infinite; yet, if we sedulously attend to each in its place, and regularly elass them, they will soon be found to diminish, and come within a very scanty computation.

Method is one of the principal helps in natural history, and without it very little progress can be made in this science. It is by that alone we can hope to dissipate the glare, if I may so express it, which arises from a multiplicity of objects at once presenting themselves to the view. It is method that fixes the attention to one point, and learls it, by slow and certain degrees, to leave no part of nature unobserved.

All naturalists, therefore, have been very careful in adopting some method of elassing or grouping the several parts of nature; and some have written books of natural history with no other view. These methodical divisions some have treated with contémpt, ${ }^{\mathrm{a}}$ not considering that books, in general, are written with opposite views; some to be read, and some only to be occasionly consulted. The inethodists in natural history, seem to be content with the latter advantage; and have sacrificed to order alone, all the delights of the subject, all the arts of heightening, awakening, or continuing curiosity. But they certainly have the same use in science, that a dictionary has in language; but with this difference, that in a dictionary we proceed from the name to the definition; in a system of natural history, we proceed from the definition to find out the thing. Without the aid of system, nature must still have lain undistinguish-

Mr. Buffon in his Introduction, \&c. ed, like furniture in a lumber-room: every thing we wish for is there indeed, but we know not where to find it. If, for instance, in a morning excursion, I find a plant, or an insect, the name of which I desire to learn; or, perbaps, am curious to know whether already known; in this inquiry I can expect information only from one of these systems, which being eouched in a methodical form, quickly direets ine to what I seck for. Thus we will suppose that our inquirer has net with a spider, and that he has never seen such an inseet before. He is taught by the writer of a system" to examine whether it has wings, and lie finds it has none. He, therefore, is to look for it annong the wingless insects, or the Aptera, as Linneus calls them: he then is to see whether the head and breast make one part of the body, or are disunited; he funds they make one: he is then to reckon the number of feet and eyes, and he finds that it has eight of each. 'The insect, therefore, must be cither a scorpion or a spider; but he lastly examines its feclers, which he finds clavated, or clubbed; and, by all these marks, be at last discovers it to be a spider, Of spiders, there are forty-seven sorts; and, by reading the description of each, the inquirer will learn the name of that which he desires to know. With the name of the insect, he is also directed to those authors that have given any account of it, and the page where that account is to be found; by this means he may know at once what has been said of that animal by others, and what there is of novelty in the result of his own researches.

From hence it will appear how useful those systems in natural history are to the inquirer; but, having given them all their merit. it would be wrong not to observe, that they have, in general, been very much abused. Their authors, in general, seem to think that they are improvers of natural history, when in reality they are but guides; they seem to boast that they are adding to our knowledge, while they are only arranging it. These authors, also, seem to think that the reading of their works and systems is the best method to attain a knowledge of nature; but setting aside the impossibility of getting through whole volumes

- Linnæus. 
of a dry long catalogue, the multiplicity of whose contents is too great for even the strongest memory, such works rather tell us the names than the history of the creature we desire to inquire after. In these dreary pages, every insect or plant, that has a name, makes as distinguished a figure as the most wonderful, or the most useful. The true end of studying nature is to make a just selection, to find those parts of it that most conduce to our pleasure or convenience, and to leave the rest in neglect. But these systems, employing the same degree of attention upon all, give us no opportunities of knowing which most deserves attention; and he who has made his knowledge from such systems only, has his memory crowded with a number of trifling, or minute particulars, which it should be his business and his labour to forget. These books, as was said before, are useful to be consulted, but they are very unnecessary to be read; no inquirer intonature should be without one of them; and, without any doubt, Linnaeus deserves the preference.

One fault more, in almost all these systematic writers, and that which leads me to the subject of the present chapter, is, that seeing the necessity of methodical distribution in some parts of nature, they have introduced it into all. Finding the utility of arranging plants, birds, or insects, they have arranged quadrupeds also with the same assiduity; and although the number of these is so few as not to exceed two hundred, ${ }^{a}$ they have darkened the subject with distinctions and divisions, which only serve to puzzle and perplex. All method is only useful in giving perspicuity, where the subject is either dark or copious : but with regard to quadrupeds, the number is but few; many of them we are well acquainted with by habit; and the rest may very readily be known, without any method. In treating of such, therefore, it would be useless to confound the reader with a multiplicity of divisions: as quadrupeds are conspicuous enough to obtain the second rank in nature, it becomes us to be acquainted with, at least, the names of them all. However, as there

a In Dr. Shaw's General Zoology, the number of quadrupeds, not including the cetaceous and seal tribes, amount to five hundred and twelve, besides their varieties. are naturalists who have gained a name from the excellence of their methods in classing these animals, some readers may desire to have a knowledge of what has been laborionsly invented for their instruction. I will just take leave, therefore, to mention the most applauded methods of classing animals, as adopted by Ray, Klein, and Linnæus; for it often happens, that the terms which have been long used in a science, though frivolous, become, by prescription, a part of the science itself.

Ray, after Aristotle, divides all animals into two kinds; those which have blood, and those which are bloodless. In the last class, he places all the inseet tribes. The former he divides into such as breathe throngh the lungs, and such as breathe through gills: these last comprehend the fishes. In those which breathe throngh the lungs, some have the heart composed of two ventricles, and some have it of one. Of the last are all animals of the cetaceous kind, all oviparous quadrupeds, and serpents. Of those that have two ventricles, some are oviparous, which are the birds; and some viviparous, which are quadrupeds. The quadrupeds he divides into such as have a hoof, and such as are claw-footed. Those with the hoof, he divides into such as have it undivided, such as have it cloven, and such as have the hoof divided into more parts, as the rhinoceros, and hippopotamus. Animals with the cloven boof, he divides into such as chew the cud, as the cow, and the sheep; and such as are not ruminant, as the hog. He divides those animals that chew the cud, into four kinds: the first have hollow horns, which they never shed, as the cow; the second is of a less species, and is of the sheep kind; the third is of the goat kind; and the last, which have solid horns, and shed them annually, are of the deer kind. Coming to the claw-footed animals, he finds some with large claws, resembling the fingers of the humail hand; and these he makes the ape kind. Of the others, some have the foot divided in two, and have a claw to each division; these are the camel kind. The elephant makes a kind by itself, as its claws are covered over by a skin. The rest of the numerous tribe of claw-footed animals he divides into two kinds; the analogons, or such as resemble each other; and the anomalous, which differ from the rest. 
The analogous claw-footed animals are of two kinds; they have more than two cutting teeth in each jaw, such as the lion and thedog, which are carnivorous; or they have but two cutting teeth in each jaw, and these are chiefly fed upon vegetables. The carnivorous kinds are divided into the great and the little. The great carnivorous animals are divided into such as have a short snout, as the cat and the lion; and such as have it long and pointed, as the dog and the, wolf. The little claw-footed carnivorous aninals differ from the great, in having a proportionably smaller head, and a slender body, that fits them for creeping into holes, in pursuit of their prey, like worms; and they are therefore called the vermin kind.

We see, from this sketch of division and subdivision, how a subject, extremely delightful and amusing in itself, may be darkened and rendered disgusting. But, notwithstanding, Ray seems to be one of the most sinple distributors; and his method is still, and not without reason, adopted by many. Such as have been at the trouble to learn this method, will certainly find it useful; nor would we be thought, in the least, to take from its merits; all we contend for is, that the same information may be obtained by a pleasanter and an easier method.

If was the great success of Ray's method, that soon after produced such a variety of attempts in the same manner; but almost all less simple, and more obscure. Mr. Klein's method is briefly as follows: he makes the power of changing place the characteristic mark of animals in general; and he takes their distinctions from their aptitude and fitness for such a change. Some change place by means of feet, or some similar contrivance; others have wings and feet: some can change place only in water, and have only fins: some go upon earth, without any feet at all: some change place, by moving their shell: and some move only at a certain time of the year. Of such, however, as do not move at all, he takes no notice. The quadrupeds that move chiefly by means of four feet upon land he divides into two orders. The first are the hoofed kind; and the second, the claw kind. Each of these orders is divided into four families. The first family of the hoofed kind, are the single hoofed, such as the horse, ass, drc. The second family are such as have the hoof cloven into two parts, such as the cow, de. The third family have the hoof divided into three parts; and in this family is found only the rhinoceros. 'The fourth family have the loof divided into five parts; and in this is only to be found the elephant. With respect to the clawed kind, the first family comprehends those that have but two claws on each foot, as the camel; the second family have three claws; the thirl, four; and the fourth, five. This inethod of taking the distinctions of animals from the organs of motion, is ingenious; but is, at the same time, incomplete; and, besides, the divisions into which it must necessarily fall, is inadequate; since, for instance, in his family with two claws, there is but one animal; whereas, in his family with five claws, there are above a hundred.

Brisson, who has laboured this subject with great accuracy, divides animated nature into nine classes; namely, quadrupeds; cetaceous animals, or those of the whale kind; birds ; reptiles, or those of the serpent kind; cartilaginous fishes; spinous fishes; shelled animals; insects; and worms. He divides the quadrupeds into eighteen orders; and takes their distinctions from the number and form of their teetl.

But of all those whose systems have been adopted and admired, Limnæus is the foremost; as, with a studied brevity, his system comprehends the greatest variety in the smallest space.

According to hin, the first distinction of animals is to be taken from their internal structure. Some have the heart with two ventricles, and hot red blood; namely, quadrupeds and birds. The quadrupeds are viviparous, and the birds oviparous.

Some have the heart with but one ventricle, and cold red blood; namely, anphibia and fishes. The amphibia are furnished with lungs; the fishes with gills.

Some hare the heart with one rentricle, and cold white serum; namely, insects and worms: the insects have feclers; and the worms, lolder's.

The distinctions of quadrupeds, or animals with paps, as he calls them, are taken from their teeth. He divides them into seven 
orders; to which he gives nanes that are not easy of translation: Primates, or principles, with four cutting teeth in each jaw ; Bruta, or brutes, with no cutting tecth; Feræ, or wild beasts, with gencrally six cutting tecth in each jaw; Glires, or dornice, with two cutting teeth, both above and below ; Pecora, or cattle, with many cutting teeth above, and none below; Bellux, or beasts, with the fore-tecth blunt; Cete, or those of the whale kind, with cartilaginous tecth. I have but just sketched out this system, as being, in its own nature, the closest abridgment: it would take volumes to dilate it to its proper length. The names of the different animals, and their classes, alone make two thick octavo volumes; and yet nothing is given lout the slightest description of each. I have omitted all criticism also upon the accuracy of the preceding systems : this has been done both by $B$ uffon and Daubenton, not with less truth than humour; for they had too unuch good sense not to see the absurdity of multiplying the terms of science to no cnd, and disappointitig our curiosity rather with a catalogie of nature's varietics, than a history of nature.

Insteal, therefore, of taxing the memory and teazing the patience with such a variety of divisions and subdivisions, I will take leave to class the productions of nature in the mast obvious, though not in the most accurate. manuer. In natural history, of all other sciences, there is the lenst danger of obscurity. In morals, or in metaphysics, every definition must be precise, because those sciences are built upon definitions; but it is otherwise in those subjects where the exhibition of the object itself is always capable of correcting the error. Thus it may often happen, that in a lax system of natural history, a creature may be ranked among quadrupeds that belongs more properly to the fish or the insect classes. But that can produce very little confusion, and every reader can thus make a system the most agreeable to his own imagrination. It will be of no inanner of consequence whether we call a bird or an insect a quadruped, if we are careful in marking all its distinctions : the uncertainty in reasoning, or thinking, that these approximations of the different kinds of animals produce, is but very small, and happens but very rarely: whereas the labour that naturalists have been at to keep the kinds asunder, has been excessive. This, in general, his given birth to that variety of systems which we have just mentioned, each of which scems to be almost as good as the preceding.

Taking, therefore, this latitude, and using methorl only where it contributes to conciseness or perspicuity, we shall divide animated nature into four elasses; namely, Qnadrupeds, Birds, Fishes, and lnsects. All these secm in general pretty well distinguished fiom each other by nature; yet there are several instances in which we can scarcely tell whether it is a bird or a quadruped that we are about to examine; whether it is a fish or an insect that offers to our curiosity. Nature is varied by inperceptihle gradations, so that no line can be drawu between any two classes of its productions, and no definition made to comprehend them all. However, the distinctions between these classes are sufficiently marked, and their encroachments upon cach other are so rare, that it will be suificient particularly to apprize the reader when they happen to be blended.

There are many quadrupeds that we are well acquainted with; and of those we do not know, we shall form the most clear and distinct conceptions, by being told whercin they differ, and whercin they resemble those with which we are familiar. Each class of quadrupeds may be ranged under soine one of the domestic kinds, that may serve for the inodel hy which we are to form some kind of idea of the rest. Thus we may say that a tiger is of the cat kind, a wolf of the dog kind, because there are some rude resemblances between each; and a person who has never secn the wild animals, will have some incomplete knowledge of their figure from the tame ones. On the contrary, I will not, as some systematic

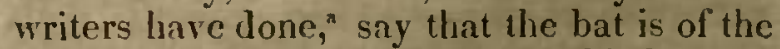
liuman kind, or a hog of the horse kind, merely because there is some resemblance in their teeth, or their paps. For although this resemblance may be striking enough, yet a person who has never scen a bat or a hog, will never form any just conception of either, by being told of this minute sinilitude. In short, the

a Jinnexi Syst. 
method in classing quadrupeds should be taken from their most striking resemblances; and where these do not offer, we shall not force the similitude, but leave the animal to be described as a solitary species. The number of quadrupeds is so few, that indeed, without any method whatever, there is no great danger of confusion.

All quadrupeds, the number of which, according to Buffon, amounts to but two hundred, nay be classed in the following manner.

First, those of the Horse kind. This class contains the Horse, the Ass, and the Zebra. Of these none have horns, and their hoof is of one solid piece.

The second class are those of the Cow kind; comprehending the Urus, the Buffalo, the Bison, and the Bonassus. These have cloven hoofs, and chew the cud.

The third class is that of the Sheep kind; with cloven hoofs, and chewing the cud like the former. In this is comprehended the Sheep, the Goat, the Lama, the Vigogne, the Gazella, the Guinea Deer, and all of a similar form.

The fourth class is that of the Deer kind, with cloven hoofs, and with solid horns, that are shed every year. This class contains the Elk, the Rein-deer, the Stag, the Buck, the Roe-buck, and the Axis.

The fifth class comprehends all those of the Hog kind, the Peccari, and the Babyrouessa.

The sixth class is, that numeraus one of the Cat kind. This comprelsends the Cat, the Lion, the Panther, the Leopard, the Jaguar, the Cougar, the Jaguarette, the Lynx, the Ounce, and the Catamountain. These are all carnivorous, and furnished with crooked claws, which they can sheath and unsheath at pleasure.

The seventh class is that of the Dog kind, carnivorous, and furnished with claws like the former, but which they cannot sheath. This class comprehends the Dog, the Wolf, the Fox, the Jackal, the Isatis, the Hyæna, the Ciret, the Gibet, and the Genet.

The eighth class is that of the Weasel kind, with a long small body, with five toes, or claws, on each foot; the first of them separated from the rest like a thumb. This comprehends the Weasel, the Martin, the Pole-cat, the Fer- ret, the Mangoust, the Vansire, the Erinine, with all the varieties of the American Moufettes.

The ninth class is that of the Rabbit kind, with two large cutting teeth in each jaw. This comprehends the Rabbit, the Hare, the Guinea-pig, all the various species of the Squirrel, the Dormouse, the Marmotte, the Rat, the Mouse, the Agouti, the Paca, the Aperea, and the Tapeti.

The tenth class is that of the Hedge-hog kind, with elaw-feet, and covered with prickles; comprehending the Hedge-hog and the Porcupine, the Couando and the Urson.

The eleventh class is that of the Tortoise kind, covered with a shell, or scales. This comprehends the Tortoise, the Pangolin, and the Phataguin.

The twelith is that of the Otter, or amphibious kind; comprehending the Otter, the Beaver, the Desman, the Morse, and the Seal.

The thirteenth class is that of the Ape and Monkey kinds, with hands, and feet resembling hands.

The fourteenth class is that of winged quardrupeds, or the Bat kind; containing the Bat, the Flying Squirrel, and some other varieties.

The animals which seem to approach no other kind, either in nature or in form, but tn make each a distiuct species in itself, are the following: the Elephant, the Rhinoceros, the Hippopotamus, the Camelopard, the Camel, the Bear, the Badger, the Tapir, the Cabrai, the Coati, the Ant-bear, the Tatou, and, lastly, the Sloth.

All other quadrupeds, whose names are not set down, will be found among some of the above mentioned classes, and referred to that which they most resemble. When, therefore, we are at a loss to know the name of any particular animal, by examining which of the known kinds it most resembles, either in shape, or in hoofs, or claws, and then cxamining the particular description, we shall be able to discorer not only its name, but its history. I have already said, that all methods of this kind are merely arbitrary, and that Nature makes no exact distinction between her productions. It is hard, for instance, to tell whether we ought to refer the civet to the dog or the cat kind; but, if we know the exact history of the civet, it is no great matter $2 \mathrm{~N}$ 
to which kind we shall judge it to bear the greatest resemblance. It is enough, that a distribution of this kind excites in us some rude outlines of the make, or some marked similitudes in the nature of these animals; but to know them with any precision, no system, or even description, will serve, since the animal itself, or a good print of it, must be seen, and its listory be read at length, before it can be said to be known. To pretend to say that we have an idea of a quadruped, because we can tell the number or the make of its teeth, or its paps, is as absurd as if we should pretend to distinguish men by the buttons of their clothes. Indeed it often happens that the quadruped itself can be but seldom seen; that many of the more rare kinds do not come into Europe above once in an age, and some of them have never been able to bear the removal: in such a case, therefore, there is no other substitute but a good print of the animal, to give an idea of its figure; for no description whatsoever can answer this purpose so well. Mr. Locke, with his usual good sense, has observed, that a drawing of the animal, taken from the life, is one of the best' methods of advancing natural history; and yet, most of our modern systematic writers are content rather with describing. Descriptions, no doubt, will go snme way towards giving an idea of the figure of an animal; but they are certainly much the longest way about, and, as they are usualiy managed, much the most obscure. In a drawing we can, at a single glance, gather more instruction than by a day's painful investigation of methodical systems, where we are told the proportions with great exactness, and yet remain ignorant of the totality. In fact, this method of describing all things is a fault that has infected many of our books, that treat on the meaner arts, for this last age. They attempt to teach by words, what is ouly to be learnt by practice and inspection. Most of our dictionaries, and bodies of arts and sciences, are guilty of this error. Suppose, for instance, it be requisite to mention the manner of making shoes, it is plain that all the verbal instructions in the wor'd will never give an adequate idea of this humble art, or teach a man to become a shoemaker. A day or two in a shoemaker's shop will answer the end better than a whole folio of instruction, which only serves to oppress the learner with the weight of its pretended importance. We have lately scen a laborious work carried on at Paris, with this only intent, of teaching all the trades by description: however, the design at first blush seems to be ill considered; and it is probable that very few advantages will be derived from so laborious an undertaking. With regard to the descriptions in natural history, these, without all question, under the direction of good sense, are necessary; but still they shonld be kept within proper bounds; and, where a thing may be much more easily shown than described, the exhibition should ever precede the account.

\section{CHAPTER XXXVII.}

\section{OF QUADRUPEDS IN GENERAL, COMPARED TO MAN}

UPON comparing the various animals of the globe with each other, we shall find that quadrupeds demand the rank immediately next ourselves; and, consequently, come first in consideration. The similitude between the structure of their bodies and ours, those instincts which they enjoy in a superior degree to the rest, their constant services, or their unceasing hostilities, all render them the foremost objects of our curiosity, the most interesting parts of animated uature. These, however, although now so completely subdued, very probably, in the beginning, were nearer upon an equality with us, and disputed the possession of the earth. Man, while yet savage himself, was but ill qualified to civilize the forest. While yet naked, unarmed, and without shelter, every wild beast was a for- 
midable rival; and the destrnction of such was the first employment of heroes. But when he began to multiply, and arts to accumulate, he soon cleared the plains of the most noxious of these his rivals; a part was taken under his protection and care, while the rest found a precarious refuge in the burning desert, or the howling wilderness.

From being rivals, quadrupeds have now become the assistants of man; upon them he devolves the most laborious employments, and tinds in them patient and humble coadjutors, ready to obey, and content witis the smallest retribution. It was not, however, without long and repeated efforts that the independent spirit of these animals was broken; for the savage freedom, in wild animals, is generally found to pass down through several generations before it is totally sub. dued. Those cats and dogs that are taken from a state of natural wildness in the forest, still transmit their fierceness to their young; and, however concealed in general, it breaks out upon several occasions. Thus the assiduity and application of man in bringing them up, not only alters their disposition, but their very forms; and the difference between animals in a state of nature and domestic tameness, is so considerable, that Mr. Buffon has taken this as a principal distinction in classing them.

In taking a cursory view of the form of quadrupeds, we may easily perceive, that of all the ranks of animated nature, they bear the uearest resemblance to man. This similitude will be found more striking when, erecting themselves on their hinder feet, they are taught to walk forward in an upright posture. We then see that all their extremities in a manner correspond with ours, and present us with a rude initation of our own. In some of the ape kind the resemblance is so striking, that anatomists are puzzled to find in what part of the human body man's superiority consists; and scarcely any lut the metaphysician can draw the line that divides them.

But if we compare their internal structure with our own, the likeness will be found still to increase, and we shall perceive many advantages they enjoy in common with us, above the lower tribes of nature. Like us, they are placed above the class of birds, by bringing forth their young alive; like us, they are placed above the class of fishes, by breatling through the lungs; like us, they are placed above the class of insects, by having red blood circulating throngh their veins; and, lastly, like us, they are different from almost all the other classes of animated nature, being either wholly or partly covered with hair. Thus nearly are we represented, in point of conformation, to the class of animals inmediately below us; and this shows what little reason we have to be proud of our persons alone, to the perfection of which quadrupeds make such very near approaches.

The similitude of quadrupeds to man obtains also in the fixedness of their nature, and their being less apt to be changed by the influence of climate or food, than the lower ranks of nature. ${ }^{a}$ Birds are found very apt to alter both in colour and size; fishes likewise still more; insects may be quickly brought to change and adapt themselves to the climate; and if we descend to plants, which may be allowed to have a kind of living existence, their kinds may be surprisingly and readily altered, and taught to assume new forms. The figure of every animal may be considered as a kind of drapery, which it may be made to put on or off by human assiduity: in man, the drapery is almost invariable; in quadrupeds, it admits of some variation; and the variety may be made greater still, as we descend to the inferior classes of aninal existence.

Quadrupeds, although they are thus strongly marked, and in generil divided from the various kinds around them, yet some of them are often of so equivocal a nature, that it is hard to tell whether they ought to be ranked in the quadruped cliss. or degraded to those below them. If, for instance, we were to marshal the whole group of animals ronind man, placing the most perfect next him, and those most equivocal near the elasses they most approach, we should find it difficult, after the principal had taken their stations near him, where to place many that lic at the outskirts of this phalanx. The bat makes a near approach to the ærial tribe, and might, by

\footnotetext{
a Buffon, vol. xviii. p. 179.
} 
some, be reckoned among the birds. The porcupine has not less pretensions to that class, being covered with quills, and showing that birds are not the only part of nature that are furnished with such a defence. The armadillo might be referred to the tribe of insects or snails, being, like them, covered with a shell; the seal and the morse night be ranked among the fishes, like them being furnished with fins, and almost constantly resilling in the same element. All these, the farther they recede from the human figure, become less perfect, and may be considered as the lowest kinds of that class to which we have referred them.

But althongh the variety in quadrupeds is thus great, they all seem well adapter to the stations in which they are placed. There is scarcely one of them, how rudely shaped soever, that is not formed to cnjoy a state of happiness fitted to its nature. All its deformities are only relative to us, but all its enjoyments are peculiarly its own. We may superficially suppose the sloth, that takes up months in climbing a single tree, or the mole, whose cyes are too small for distant vision, are wretched and helpless creatures: but it is probable that their life, with respect to themselves, is a life of luxury; the most pleasing foud is easily obtained; and as they are abridged in one pleasure, it may be doubled in those which remain. Quadrupeds, and all the lower kinds of animals, have, at worst, but the torments of immediate evil to encounter, and this is but transient and accidental: Inan has two sources of calamity, that which he foresees, as well as that which he feels; so that, if his reward were to be in this life alone, then, indeed, would he be, of all beings, the most wretched.

The heads of quadrupeds, though differing from each other, are, in general, adapted to their way of living. In some it is sharp, the better to fit the animal for turning up the earth in which its food lies. In some it is long, in oriter to give a greater room for the olfactory nerves, as in dogs, who are to hunt and find out their prey by the scent. In others it is short and thick, as in the lion, to increase the strength of the jaw, and to fit it the better for combat. In quadrupeds that feed upon grass, they are enabled to hold down their heads to the ground, by a strong tendinons ligament, that runs from the head to the mildle of the back. This serves to raise the head, although it has been held to the ground for several hours, withont any labour, or any assistance from the muscles of the neck.

The teeth of all animals are entirely fitted to the nature of their food. Those of such as live upon flesh differ in every respect from such as live upon vegetables. In the latter they seen entirely made for gathering and bruising their simple food, being edged before, and fitted for cutting; but broad towards the back of the jaw, and fitted for pounding. In the carnivorous kinds, they are sharp before, and fitted rather for holding than dividing. In the one, the teeth serve as grindstunes; in the other, as weapons of defence: in both, howeser, the surface of those teeth which serve fol grinding are unequal; the cavities and risings fitting those of the opposite, so as to tally exactly when the jaws are brought together. These inequalities better serve for connminuting the food; bit they become smooth with age; and, for this reason, old animals take a fonger tine to chew their food than such as are in the vigour of life.

Their legs are not better fitted than their teeth to their respective wants or enjoyments. In some they are made for strength only, and to support a vast unwieldly frane, without much flexibility or beautiful proportion. Thus the legs of the elephant, the rhinoceros, and the sea-horse, resemble pillars: were they made smaller, they woukd be unfit to support the body ; were they endowed with grenter flexibility, or swiftness, that would be needless, as they do not pursue other animals for food; and, conscious of their own superior strength, there are none that they deign to avoid. Deers, hares, and other creatures, that are to find safety only in flight, lave their legs made entirely for speed; they are slender and nervous. Were it not for this advantage, every carnivorous animal would soon make them a prey, and their races would be entirely extinguished. But, in the present state of nature, the nieans of safety are rather superior to those of offence; and the pursuing animal must owe success only to patience, perseverance, and industry. The feet of some, that live upon fish alone, are made for swimming. The tors of these animals are joined together with membrases, being web-footed like a goose or a duck, by which they swim with great ranility. Those animals that lead a life of hostility, and live 
upon others, have their fect armed with sharp claws, which some can sheath and unsheath at will. 'Those, on the contrary, who lead peaceful lives, have generally hoofs, which scrvesome as weapons of defence; and which, in all, are better fitted for traversing extensive tracts of rugged country than the claw-foot of their pursuers.

The stomach is generally proportioned to the quality of the animal's food, or the ease with which it is obtained. In those that live upon flesh, and such nourishing substances, it is small and glandular, affording such juices as are best adapted to digest its contents; their intestines also are short, and without fatness. On the contrary, such animals as feed entirely upon vegetables, have the stomach very large; and those who chew the cud have no less than four stomachs, all which serve as so many laboratories, to prepare and turn their coarse food into proper nourishment. In Africa, where the plants afford greater nourishment than in our temperate climates, several animals, that with us have four stomachs, have there but two." However, in all animals the size of the intestines is proportioned to the nature of the food: where that is furnished in large quantities, the stomach dilates to answer the increase. In domestic auimals, that are plentifully supplied, it is large; in the wild auimals, that live precariously, it is much more contracted, and the intestines are much shorter.

In this manner, all animals are fitted by nature to fill up some peculiar station. The greatest animals are made for an iuoffensive life, to range the plains and the forest without injuring others; to live upon the productions of the earth, the grass of the field, or the tender branches of trees. These, secure in their own strength, neither fly from any other quadrupeds, nor yet attack them: Nature, to the grentest strength, has added the most gentle and harmless dispositions: without this, those enormous creatures would be more than a match for all the rest of the creation; for what devastation might not ensue, were the elephant, or the rhinoceros, or the buffilo, as fierce and as mischievous as the tiger or the rat? In order to oppose these larger animals,

- Buffon. and in some measure to prevent their exuberance, there is a species of the carnivorous kind, of inferior strength indeed, but of greater activity and cuming. The lion and the tiger generally watch for the larger kinds of prey, attack them at some disadvantage, and commonly jump upon them by surprise. None of the carnivorous kinds, except the dog alone, will inake a voluntary attack, but with the odds on their side. They are all cowards by nature, and usually eatch their prey by a bound from some lurking-place, seldom attempting to invade thein openly; for the larger beasts are too powerful for them, and the smallet too swift.

A lion does not willingly attack a horse; and then only when compelled by the keenest hunger. The combats between a lion and a horse are frequent enough in Italy; where they are both enclosed in a kind of amphitheatre, fitted for that purpose. The lion always approaches wheeling about, while the horse presents his hinder parts to the enemy. The lion in this manner goes round and round, still narrowing his circle, till be comes to the proper distance to make his spring; just at the time the lion springs, the horse lashes with both legs from behind, and, in general, the oddls are in his favour; it more often happening that the lion is stunned, and struck motionless by the blow, than that he effects his jump between the horse's shoulders. If the lion is stumed, and left sprawling, the horse escapes, without attempting to improve his victory; but if the lion succeeds, he sticks to his prey, and tears the horse in pieces in a very short time.

But it is not among the larger animals of the forest alone, that these hostilities are carried on; there is a minuter, and a still more treacherous contest, between the lower ranks of quadrupeds. The pasther hunts for the sheep and the goat; the catamonntain for the hare or the rabbit; and the wild cat for the squirrel or the mouse. In proportion as each carnivorous animal wants strength, it uses all the assistance of patience, assiduity, and cunuing. However, the arts of these to pursue, are not so great as the tricks of their prey to escape; so that the power of destruction in one class, is inferior to the power of safety in the other. Were this otherwise, the forest 
would soon be dispeopled of the feebler races of animals; and beasts of prey themselves would want, at one time, that subsistence which they lavishly destroyed at another.

Few wild animals seek their prey in the day-time; they are then generally deterred by their fears of man in the inhabited countries, and by the excessive heat of the sun in those extensive forests that lie towards the south, and in which they reigu the undisputed tyrants. As soon as the morning, therefore, appears, the caruivorous animals retire to their dens; and the elephant, the horse, the deer, and all the hare kinds, those inoffensive tenants of the plain, make their appearance. But again, at night-fall, the state of hostility begins; the whole forest then echoes to a variety of different howlings. Nothing can be more terrible than an African landscape at the close of evening; the deeptoned roarings of the lion; the shriller yellings of the tiger; the jackal, pursuing by the scent, and barking like a dog; the hyana, with a note peculiarly solitary and dreadful; but, above all, the hissing of the various kinds of serpents, that then begin their call, and, as I am assured, make a inuch louder symphony than the birds in our groves in a morning.

Beasts of prey seldom devour each other; nor can any thing but the greatest degree of hunger induce them to it. What they chiefly seek after, is the deer, or the goat; those harmless creatures, that secm inade to embellish nature. These are either pursued or surprised, and afford the most agreeable repast to their destroyers. The most usual method with even the fiercest animals, is to hide and crouch near some path frequented by their prey; or some water where cattle come to drink; and seize them at once with a bound. The lion and the tiger leap twenty feet at a spring; and this, rather than their swiftness or strength, is what they have most to depend upon for a supply. There is scarcely one of the deer or hare kind, that is not very easily capable of escaping them byits swiftness; so that whenever any of these fall a prey, it must be owing to their own inattention.

But there is another class of the carnivorous kind, that hunt by the scent, and which it is much more difficult to escape. It is re- markable, that all animals of this kind pursue in a pack; and encourage each other by their mutual cries. The jackal, the syagnsh, the wolf, and the dog, are of this kind; they pursue with patience rather than swiftness; their prey flies first, and leaves them for miles belind; but they keep on with a constant steady pace, and excite each other by a general spirit of industry and emulation, till at last they share the common plunder. But it too often happens, that the larger beasts of prey, when they hear a cry of this kind begun, pursue the pack, and when they have hunted down the animal, come in and monopolize the spoil. This has given rise to the report of the jackal's being the lion's provider; when the reality is, that the jackal hunts for itself, and the lion is an unwelcome intruder upon the fruit of his toil.

Nevertheless, with all the powers which carnivorous animals are possessed of, they generally lead a life of famine and fatigue. Their prey has such a variety of methods for escaping, that they sometimes continue without food for a fortnight logether: but nature has endowed them with a degree of patience equal to the severity of their state; so that as their subsistence is precarious, their appetites are complying. They usually seize their prey with a roar, either of seeming delight, or perhaps to terrify it from resistance. They frequently devour it, bones and all, in the most ravenous manner; and then retire to their dens, continuing inactive, till the calls of hunger again excite their courage and industry. But as all their methods of pursuit are counteracted by the arts of evasion, they often continue to range without success, supporting a state of famine for several days, nay, sometimes, weeks together. Of their prey, some find protection in holes, in which nature has directed them to bury themselves; some find safety by swiftness; and such as are possessed of neither of these advantages, generally herd together, and endeavour to repel invasion by united force. The very sheep, which to us seem so defenceless, are by no means so in a state of nature; they are furnished with arms of defence, and a very great degree of swiftness; but they are still further assisted by their spirit of mutual defence: the females fall into the centre; and 
the males, forming a ring round them, oppose their horns to the assailants.

Some animals, that feer upon fruits which are to be found only at one time of the year, fill their holes with several sorts of plants, which enable them to lie concealed during the hard frosts of the winter, contented with their prison, since it affords then plenty and protection. These holes are dug with so much art, that there seems the design of an architect in the formation. There are usually two apertures, by one of which the little inhabitant can always escape, when the enemy is in possession of the other. Many creatures are equally careful of avoiding their enemies, by placing a centinel to warn them of the approach of danger. These generally perform this duty by turns; and they know how to punish such as have neglected their post, or have been unmindful of the common safety. Such are a part of the efforts that the weaker races of quadrupeds exert to avoid thcir invaders; and, in general, they are attended with success. The arts of instinct are most commonly found an overmatch for the invasions of instinct. Man is the only creature against whom all their little tricks cannot prevail. Wherever he has spread his dominion, scarcely any flight can save, or any retreat harbour; wherever he comes, terror seems to follow, and all society ceases among the inferior tenants of the plain; their union against him can yield them no protection, and their cunning is but weakness. In their fellow-brutes, they have an enemy whom they can oppose with an equality of advantage; they can oppose fraud or swiftness to force, or numbers to invasion; but what can be done against such an enemy as man, who finds them out though unseen; and though remote, destroys them? Wherever he comes, all the contest among the meaner ranks seem to be at an end, or is carried on only by surprise. Such as he has thought proper to protect, have calmly submitted to his protection; such as he has found it convenient to destroy, carry on an unequal war, and their numbers are cvery day decreasing.

The wild animal is subject to few alterations; and, in a state of savage nature, continues for ages the same, in size, shape, and colour. But it is otherwise when subdued, and taken under the protection of man; its external form, and even its internal structure, are altered by human assiduity : and this is one of the first and greatest causes of the variety that we see aniong the several quadrupeds of the same species. Man appears to have changed the very nature of domestic animals, by cultivation and care. A domestic animal is a slave that seems to have few other desires but such as man is willing to allow it. Humble, patient, resigned, and attentive, it fills up the duties of its station; ready for labonr, and content with subsistence.

Almost all domestic animals seem to bear the marks of servitude strong upon them. All the varietics in their colour, all the fineness and length of their hair, together with the depending length of their ears, seem to have arisen from a long continuance of domestic slavery. What an immense variety is there to be found in the ordinary race of dogs and horses! the principal differences of which have been effected by the industry of man, so adapting the food, the treatment, the labour, and the climate, that Nature seems almost to have forgotten her original design; and the tanie animal no longer bears any resemblance to its ancestors in the woods around him.

In this manuer, nature is under a kind of constraint, in those animals we have taught to live in a state of servitude near us. 'The savage animals preserve the marks of their first formation; their colours are generally the same; a rough dusky brown, or a tawny, seem almost their only varieties. But it is otherwise in the tame; their colours are various, and their forms different from cacl other. The nature of the climate indeed operates upon all; but more particularly on these. That nourishment which is prepared by the hand of man, not adapted to their appetites, but to suit his own convenience; that climate, the rigours of which he can soften; and that employment to which they are sometimes assigned; producc a number of distinctions that are not to be found among the savage animals. These, at first, were accidental, but in time became hereditary; and a new race of artificial monsters are propagated, rather to answer the purposes of human pleasure than their own convenience. In short, their very appetites may be changed; and those that feed only upon grass may be rendered carnivorous. I have seen a shecp that would eat flesh, and a horse that was fond of oysters. 
But not their appetites, or their figure alone, but their very dispositions, and their natural sagacity, are altered by the vicinity of man. In those coumtries where men have seldom intruded, some animals have been found, cstablished in a kind of civil state of society. Remote from the tyrauny of man, they seem to have a spirit of mutual benevolence, and mutual friendship. The beavers, in those distant solitudes, are known to build like architects, and rule like citizens. The habitations that these have been seen to erect, exceed the houses of the human inhabitants of the same country, both in neatness and convenience. But as soon as man intrudes upon their society, they scem impressed with the terrors of their inferior situation, their spirit of society ceases, the bond is dissolved, and every animal looks for safety in solitude, and there tries all its little industry to shift only for itself.

Next to human influence, the climate seems to have the strongest effects both upon the nature and the form of quadrupeds. As in man we have seen some alterations produced by the variety of his situation; so in the lower ranks, that are more subject to variation, the influence of clinate is more rearlily perceived. As these are inore nearly attached to the eartl, and in a manner connected to the soil; as they have none of the arts of shiclding off the inclemency of the weather, or softening the rigours of the sun, they are conscquently more changed by its variations. In gencral it may be remarked, that the colder the country, the larger and the warmer is the fur of each animal; it bcing wisely provided by Nature, that the inhabitant should be adapted to the rigours of its situation. Thus the fox and wolf, which in temperate climates have but short hair, have a fine long fur in the frozen regions near the pole. On the contrary, those dogs which with us have long hair, when carried to Guinea or Angola, in a sliort time cast their thick covering, and assume alighter dress, and one more adapted to the warmth of the country. The beaver, and the crminc, which are found in the greatest plenty in the cold regions, are rcmarkable for the warmth and delicacy of their furs; while the elcphant, and the rhinoceros, that are natives of the line, lave scarcely any hair. Not but that liuman industry can, in some measure, co-operite with, or repress, the effects of climate in this par- ticular. It is well known what alterations are prodaced by proper carr, in the sheep's fleece, in different parts of our own country; and the same industry is pursued with a like success in Syria, where many of their animals are clothed with a long and beautiful hair, which they take care to improve, as they work it into that stuff called camblet, so well known in different parts of Europe.

The disposition of the animal secms also not less marked by the climate than the figure. The same causes tliat seem to have rendered the human inhabitants of the rigorous climates savage and ignorant, have also operated upon their animals. Both at the line and the pole, the wild quadrupeds are fierce and untameable. In these latitudes, their savage dispositions having not been quelled hy any efforts from man, and being still farther stimulated by the severity of the weather, they continue fierce and untractable. Most of the attempts which have hitherto been made to tame the wild beasts brought home from the pole or the equator, have proved ineffectual. They are gentle and harmless enough while youug; but as they grow up, they acquire thicir natural ferocity, and snap at the hand that feeds them. It may indeed, in general, be asserted, that in all countries where the men are most barbarous, the beasts are most fierce and cruel : and this is but a natural consequence of the struggle between unan and the more savage animals of the forest; for in proportion as he is weak and timid, they must be bold and intrusive; in proportion as his dominion is lout feebly supported, their rapacity must be more obnoxious. In the extensive countries, therefore, lying round the pole, or beneath the line, the quadrupeds are fierce and formidable. Africa has ever been remarked for the brutality of its mucn, and the fierceness of its animals: its lions and its leopards are not less terrible than its crocodiles and its serpents; their dispositions seem entirely marked with the rigours of the climate, and bcing bred in an extreme of heat, they show a peculiar ferocity, that ncither the force of man can conquer, uor his arts allay. However, it is happy for the wretched inhabitants of thuse clinates, that its most formidable animuls are all solitary ones; that they lave not learnt the art of unitiug, to oppress mankind; but ench depending on its own strength, invades without any assistant. 
The food also is another cause of the vapiety which we find among quadrupeds of the same kind. Thus the beasts which feed in the valley are generally larger than those which glean a scanty subsistence on the mountain. Such as live in the warm climates, where the plants are much larger and moresucculent than with us, are equally remarkable for their bulk. The ox fed in the plains of Indostan, is much larger than that which is more liardily maintained on the side of the Alps. 'The deserts of Africa, where the plants are extremely nourishing, produce the largest and fiercest animals; and, perhaps for a contrary reason, America is found not to produce such large animals as are seen in the ancient continent. But, whatever be the reason, the fact is certain, that while America exceeds us in the size of its reptiles of all kinds, it is far inferior in its quadruped productions. Thus, for instance; the largest animal of that country is the tapir, which can by no ineans be compared to the elephant of Africa. Its beasts of prey, 'also, are divested of that strength and courage which is so dangerous in this part of the world. The American lion, tiger, and leopard, if such diminutive creatures deserve these names, are neither so fierce nor so valiant as those of Africa and Avia. The tiger-of Bengal has been seen to measure twelve feet in length, without including the tail: whereas the American tiger seldom exceds three. This difference obtains still more in the other animals of that country, so that some have been of opinion that all quall rupeds in Southern America are of a different species from those most resembling them in the old world; and that there are none which are common to both, but such as have entered America by the north; and which, being able to bear the rigours of the frozen pole, have travelled from the ancient continent, by that passage, into the new. Thus the bear, the wolf, the elk, the stag, the fox, and the beaver, are known to the inhabitants as well of North America as of Russia; while most of the various kinds to the southward, in both continents, bear no resemblance to each other. Upon the whole, such as peculiarly belong to the new continent are without any marks of the quadruped

\footnotetext{
a Buffon.
}

No. $19 \& 20$. perfection. They are almost wholly destitute of the power of defence; they have neither formidable teeth, horns, or tail; their figure is awkward, and their limbs ill proportioned. Some among them, such as the ant-bear and the sloth, appear so miserably formed, as scarcely to have the power of inoving and eating. They, seemingly, drag out a miserable and languid existence in the most desert solitude; and would quickly have been destroyed in a contry where there were inhabitants, or powerfil beasts to oppose them.

But if the yuadrupeds of the new continent be less, they are fonnd in much greater abundance; for it is a rule that obtains throngh uature, that the smaliest animals multiply the fastest. The goat, imported firom Europe to South America, soon begius to degenerate; but as it grows less it becomes more prolific; and, instead of one kid at a time, or two at the most, it generally produces live, and sometimes more. What there is in the fond, or the climate, that produces this change, we have not been able to learn; we might be apt to ascribe it to the lieat, but that on the African coast, where it is still hotter, this rule does not obtain; for the goat, instead of degenerating there, seems rather to improve.

However, the rule is general among all quadrupeds, that those which are large and formidable produce but few at a tine; while such as are mean and contemptible are $\mathrm{ex}$ tremely prolific. The lion, or tiger, have seldom above two cubs at a litter; while the cat; that is of a similar nature, is usually seen to have five or six. In this mamner, the lower tribes become extremely numcrous; and, but for this surprising fecundity, from their natural weakness they would quickly be extirpated. The breed of mice, for instance, would have long since been blotted from the eartl, were the mouse as slow in production as the elephant. But it has been wisely provided, that such animals as can make but little resistance, should at least have a means of repairing the destruction, which they must often suffer, by their quick reproduction; that they should increase even among cnemies, and multiply under the hand of the destroyer. On the other hand, it has as wisely been ordered by Providence, that the larger kinds should produce but slowly; otherwise, as they 20 
require proportional supplies from nature, they would quickly consume their own store; and, of consequence, many of them would soon perish through want; so that life would thus be given without the necessary means of subsistence. In a word, Providence has most wisely balanced the strength of the great against the weakness of the little. Since it was necessary that some should be great and others mean, since it was expedient that some should live upon others, it has assisted the wcakness of one by granting it fruitfinlness; and diminished the number of the other by infecundity.

In consequence of this provision, the larger creatures, which bring forth few at a time, scldom begin to generate till they have nearly acquired their full growth. On the contrary, those which bring many, reproduce before they have arrived at their natural size. Thus the horse and the bull are nearly at their best before they begin to breed; the hog and the rabbit scarcely leave the teat before they become parents in turn. Almost all animals likewise continue the time of their pregnancy in proportion to their size. The mare continues eleven months with foal, the cow nine, the wolf five, and the bitch nine weeks. In all, the intermediate litters are the most fruitful; the first and the last generally producing the fewest in number, and the worst of the kind.

Whatever be the natural disposition of animals at other times, they all acquire new courage when they consider themselves as defending their young. No terrors can then drive them from the post of duty; the mildest begin to exert their little force, and resist the most formidable enemy. Where resistance is hopeless, they then incur cvery danger, in order to rescue their young by flight, and retard their own expedition by providing for their little ones. When the female oppossum, an animal of America, is pursued, she iustantly takes her young into a false belly, with which nature has supplied her, and carries them off, or dies in the cndeavour. I have been lately assured of a she-fox, which, when hunted, took her cub in her mouth, and run for several miles without quitting it, until at last she was forced to leave it behind, upon the approach of a mastiff, as she ran through a farmer's yard.
But, if at this period the mildest animals acquire new fierceness, how formidable must those be that subsist by rapine! At such times, no obstacles can stop their ravage, nor no threats can terrify; the lioness then scems more hardy than even the lion himself. She attacks men and beasts indiscriminately, and carries all she can overeome reeking to her cubs, whom she thus early accustoms toslaughter. Milk, in the carnivorous animals, is much more sparing than in others; and it may be for this reason that all such earry home their prey alive, that, in feeding their young, its blood inay supply the deficiencies of nature, and serve instead of that milk with which they are so sparingly supplied.

Nature, that has thus given them courage to defend their young, has given them instinct to choose the proper times of copulation, so as to bring forth when the provision suited to each kind is to be found in the greatest plenty. The wolf, for instance, couples in November, so that the time of pregnancy continuing five months, it may have its young in April. The mare, who goes eleven months, admits the horse in sunimer, in order to foal about the beginning of May. On the contrary, those animals which lay up provisions for the winter, such as the beaver and the marmotte, couple in the latter end of autumn, so as to have their young about January, against which season they have provided a very comfortable store. These seasons for coupling, however, among some of the domestic kinds, are generally in consequence of the quantity of provisions with which they are at any time supplied. Thus we may, by feeding any of these animals, and keeping off the rigour of the climate, make them breed whenever we please. In this manner those contrive who produce lambs all the year round.

The choice of situation in bringing forth is also very remarkable. In most of the rapacious kinds, the female takes the utmost precautions to hide the place of her retreat from the male; who otherwise, whien pressed by hunger, would be apt to devour her cubs. She seldom, therefore, strays far trom the den, and never approaches it while he is in view, nor visits him again till her young are capable of providing for themselves. Such animals as are of tender constitutions take the 
utmost care to provide a place of warmth, as well as safety, for their young; the rapacious kinds bring forth in the thickest woods; those that ehew the cud, with the various tribes of the vermin kind, choose some hiding place in the neighbourhood of man. Some dig holes in the ground; some choose the hollow of a tree; and all the amphibious kinds bring up their young near the water, and accustom them betimes to their proper element.

Thus Nature seems kindly careful lor the protection of the meanest of her creatures: but there is one class of quadrupeds that seems entirely left to chance, that no parent stands forth to protect, nor no instructor leads, to teach the arts of subsistence. These are the quadrupeds that are brought forth from the egg, such as the lizard, the tortoise, and the crocodile. The fecundity of all other animals compared with these is sterility itself. These bring forth above two hundred at a time; but, as the offspring is more numerous, the parental care is less exerted. Thus the numerous brood of eggs are, without farther solicitude, buried in the warm sands of the shore, and the heat of the sun alone is left to bring them to perfection. "To this perfection they arrive almost as soon as disengaged from the shell. Most of them, without any other guide than instinct, immediately make to the water. In their passage thither, they have numberless enemies to fear. The birds of prey that haunt the shore, the beasts that accidentally come there, and eren the animals that give them birth, are known, with a strange rapacity, to thin their numbers as well as the rest.

But it is kindly ordered by Providence, that these animals, which are mostly noxious, should thus have many destroyers: were it not for this, by their extreme fecundity, they would soon over-run the earth, and cumber all our plains with deformity.

["Thus throughout the whole economy of nature we may trace displays of infinite wisdom, even in regulating the impulses of instinetive power, and in governing its annual or varied tides. A mere system of organized matter, without any independent and intelligent cause, could nerer have communicated to itself that prescience which the numerous tribes of animals exhibit; and to ascribe the visible phenomena to chance, is to invest a mere abstract idea with attributes, which, even human knowledge, refined by all the light which philosophy imparts, is scarcely able to comprehend. And even if we allow chance to have been the primitive cause of existence, and of the varied phenomena connected with it, we must ascribe to it that eternity of being which Atheism denies to the intelligent Creator; unless we conceive that chance, by chance, has begotten chance throughout an infinite series in past duration. The absurdity of such a supposition it would be folly to pursue.

"That many things appear inexplicable in the economy and overruling Providence of God, will be most readily allowed. In every department, shadows, and obscurities, veil from human penetration a considerable portion of his ways. In the vast chain of being, a few links only are open to human inspection; and even these the dimness of our bodily organs and mental powers will not permit us fully to explore. Sometimes even those links which we perceive are not immediately connected together; and at other times, mists, minuteness, and distance, lay an embargo upon our faculties. It is thus that the parts with which we are surrounded, are intercepted and concealed from our discernment, while the chain itself, stretching into another world, can only be discovered by that light, which. in futurity, eteruity shall impart.

"In the structure and organs of animals, there is an adaptation for certain ends which the most superficial observer can hardly fail to observe. Adaptation implies design, and this involves some being or power capable ol forming the design, and calculating upon issues, which no combination of accidents has in any known case ever yet produced. The evidences of wisdom which are scattered over the surface of our globe, speak in a language that must be heard even by the most careless and inattentive; and the animal world presents us with a noble compendium of facts, that are constantly exposed to the scrutiny of every eye. Of these, Dr. Goldsmith has furnished a grand exlibition; and the condition of that reader is not to be envied, who, after perusing his Natural History, can close his book, and deliberately think there is no God."] 


\section{AMIMAES OF THE HORSE ISIND.}

\section{$\rightarrow \infty 00$ \\ CHAPTER XXXVII. \\ OF THE HORSE.}

\begin{abstract}
ANIMALS of the horse kind deserve a place next to man, in a listory of nature.
\end{abstract} Their activity, their strength, their usefulness, and their beauty, all contribute to render them the principal oljects of our curiosity and care; a race of creatures in whose welfare we are interested next to our own.

Of all the quadruped animals, the horse seems the most beantiful: the noble largeness of his form, the glossy smonthness of his skin, the graceful ease of his motions, and the exact symmetry of his shape, have taught us to regard him as the first, and as the most perfectly formed ; and yet, what is extraordinary enough, if we examine him internally, his structure will be found the most different from that of man of all other quarrupeds whatsoever. As the ape approaches us the nearest in internal conformation, so the horse is the

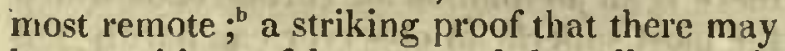
be oppositions of beauty, and that all grace is not to be referred to one standard.

To have an idea of this noble animal in his

as it may happen, that in a description where it is the aim ratler to insert what is not usually known, than all that is known, some of the more obvious particulars may be omitted; I will take leave to subjoin in the notes the characteristic marks of each animal, as given us by Linnxus. "The loorse, with six cutting teeth before, and single-hoofed; a a native of Europe and the East, (but I believe rather of Africa;) a generous, proud, and stroug animal; fit either for the draught, the course, or tho road: he is delighted with woods; he takes care of lise. hinder parts; defends himself from the flies with his tail; scratches his fellow; defends his young; calls by neighing; sleeps after niglit-fall; fights by kicking, and by biting also; rolls on the ground when he sweats; eats the grass cluser tlan the ox; distributes the seed by dunging; wants a gall-bladder; never vomits; the foal is produced native simplicity, we are not to look for him in the pastures or the stables, to which he lias been consigned by man; but in those wild and extensive plains where he has been originally produced; where he ranges without control, and riots in all the variety of luxurious nature. In this state of happy independence, he disdains the assistance of man, which only tends to servitude. In those boundless tracts, whether of Africa or New Spain, where he runs at liberty, he seems no way incommoded with the inconveniences to which he is subject in Europe. The continual verdure of the fields supplies his wants; and the climate, that never knows a winter, suits his constitution, which naturally secms adlapted to heat. His enemies of the forest are but few, for none but the greater kinds will venture to attack him : any one of these he is singly able to overcome; while, at the sanse time, he is content to find safety in society; for the wild horses of those countries always herd together.

In these countries, therefore, the horses are

with the feet stretched out; he is injured by being struck on the ear: upon the stiffle; by being caught by the nose in barnacles; by luaving his teeth ruhhed with tallow; by the herb padus; by the herb phalandria; by the cruculio; by the conops. His diseases are different in different countries. A consımption of the ethmoid bones of the nose, called the glanders, is with us the most infectious and fatal. He eats hemlock without injury. The mare goes witl foal 290 days. The placenta is not fixed. He acquires not the canine teeth till the age of five years.

[ ${ }^{n}$ In South America is found a horse wluose hoofs are divided, like those of a ruminant quadruped. In its geneçal appearance, size, and colour, it resembles the ass, but has the voice and cars of a horse, and has no basids crossing the shoulders. It is very wild, swift, and strong.]

${ }^{b}$ Histoire Naturelle, Daubenton, vol. vii. p. 374. 
often seen feeding in droves of five or six hundred. As they do not carry on war against any other race of animals, they are satisfied to remain entirely upon the defensive. The pastures on which they live, satisfy all their appetites, and all other precantions are purely for their security, in case of a surprise. As they are never attacked but at a clisadvantage, whenever they sleep in the forests, they have always one among their number that stands as centinel, to give notice of any approaching danger; and this office they take by turns. If a man approaches them while they are feeding by day, their centinel walks up boldly near lim, as if to examine his strength, or to intinidate him from proceeding; but as the man approaches within pistol-shot, the centinel then thinks it high time to alarm his fellows; this he does by a loud kind of snorting, upon which they all take the signal, and fly off with the speed of the wind; their faithful centinel hringing up the rear. ${ }^{\text {' }}$

It is not easy to say from what country the horse came originally. It should seem that the colder climates do not agree with his constitution; for although he is found almost in them all, yet his form is altered there, and he is found at once diminutive and ill-shaped. We have the testimony of the ancients that there were wild horses once in Europe; at present, however, they are totally brought under subjection; and even those which are found in Anerica are of a Spanish breed, which being sent thither upon its first discovery, have since become wild, and have spread over all the south of that vast continent almost to the straits of Magellan. These, in general, are a small breed, of about fourteen hands high. They have thick jaws and clumsy joints; their ears and neck also are long; they are easily tamed; for the horse, by nature, is a gentle complying creature, and resists rather from fear than obstinacy. - They are caught by a kind of noose, and then held fast by the legs, and tied to a tree, where they are left for two days without food or drink. By that time they begin to grow nıanageable; and in some weeks they become as tame as if they had never been in a state of wildness. If, by any accident, they are once more set at liberty, they never become wild again, but know their masters, and

a Dictionnaire Universelle des Animaux, p. 19. come to their call. Some of the buccaneers have often been agreeably surprised, after a long absence, to see their faithful horses once more present themselves, with their usual assiduity ; and come up, with fond submission, to receive the rein.

These American horses, however, cannot properly be ranked among the wild races, since they were originally bred from such as were tane. It is not in the new, but the old world, that we are to look for this animal in a true state of nature; in the extensive deserts of Africa, in Arabia, and those wide-spread comntries that separate Tartary from the more southern nations. Vast droves of these animals are seen wild among the Tartars; they are of a snall breed, extrenely swift, and very readily evade their pursuers. As they go togethel, they will not adnit of any strange animals among them, though even of their own kind. Whenever they find a tame horse attempting to associate with them, they instantly gather round him, and soon oblige him to seek safety by flight. There are vast numbers also of wild horses to the north of China, but they are of a weak, timid breed; small of stature, and useless in war.

At the Cape of Good Hope there are mumbers of horses in a state of nature, but small, vicious, and untameable. They are found wild also in several other parts of Africa ; but the wretched inhabitants of that country either want the art to tame them, or seen ignorant of their uses. It is common with the negroes, who are carried over from thence to America, when they first see a horse, to testify both terror and surprise. These poor men secm not to have any knowledge of such a creature ; and, though the horse is probably a native of their own country, they have let all the rest of mankind enjoy the benefit of his services, without turning them to any advantage at home. In some parts of Africa, therefore, where the horse runs wild, the natives seem to consider him rather in the light of a dainty for food, than a useful creature, capable of assisting them cither in war or in labour : riding seems a refinement that the natives of Angola or Caffraria have not as yet been able to attend to ; and whenever they catch a horse, it is only with an intent to eat him.

Labat, tom. vii. 
But of all countries in the world, where the horse runs wild, Arabia produces the most beautiful breed, the most generous, swift, and persevering. They are found, though not in great numbers, in the deserts of that country; and the natives use every stratagem to take them. Although they are active and beautiful, yet they are not so large as those that are bred up tame; they are of a brown colour, their mane and tail very short, and the hair black and tufted." Their swiftness is incredible: the attempt to pursue them in the usual manner of the chase, with dogs, would be entirely fruitless. Such is the rapidity of their flight, that they are instantly out of view, and the dogs themselves give up the vain pursuit. The only method, therefore, of taking them, is by traps hidden in the sand, which entangling their feet, the hunter at length comes up, and either kills them, or carries them home alive. If the horse be young, he is considered among the Arabians as a very great delicacy; and they feast upon him while any part is found remaining: but if, from his shape or vigour, he promises to be serviceable in his more noble capacity, they take the usual methods of taming him, by fatigue and hunger, and he soon becomes a useful domestic animal.

The usual manner of trying their swiftness is by hunting the ostrich : the horse is the only animal whose speed is comparable to that of this creature, which is found in the sandy plains, with which those countries abound. The instant the ostrich perceives itself aimed at, it makes to the mountains, while the horseman pursues with all the swiftness possible, and endeavours to cut off its retreat. The chase then continues along the plain, while the ostrich makes use of both legs and wings to assist its motion. However, a horse of the first speed is able to outrun it; so that the poor animal is then obliged to have recourse to art to elude the hunter, by frequently turning: at length, finding all escape hopeless, it hides its head wherever it can, and suffers itself tamely to be taken. If the horse, in a trial of this kind, shows great speed, and is not readily tired, his price becomes proportionably great, and there are some horses valued at a thousand ducats.

- Marm Descript de l'Afrique, lib. i. p. 51.
But the horses thus caught, or trained in this manner, are at present but very few : the value of Arabian horses, all over the world, has, in a great measure, thinned the deserts of the wild breed; and there are very few to be found in those countries, except such as are tame. The Arabians, as we are told by historians, first began the management of horses in the time of Shaque Ishmael. Before that, they wandered wild along the face of the country neglected and uscless; but the natives then first began to tame their ficrceness, and to improve their beauty; so that at present they possess a race of the most beautiful horses in the world, with which thicy drive a trade, and furnish the stables of princes at immense prices.

There is scarcely an Arabian, how poor soever, but is provided with his horse. ${ }^{.}$They, in general, make use of mares in their ordinary excursions; experience having taught them that they support fatigue, thirst, and hunger, better than the horses are found to do. Thiey are also less vicious, of a gentler nature, and are not so apt to neigh. They are more liarmless also among themselves, not so apt to kick or hurt each other, but remain whole days together without the least mischief. The Turks, on the contrary, are not fond of mares; and the Arabianssell them such horses as they do not choose to keep for stallions at home. They preserve the pedigree of their horses with great care, and lor several ages back. They know their alliances, and all their genea$\log y$; they distinguish the races by different names, and divide them into three classes. The first is that of the nobles, the ancient breed and unadulterated on either side; the sccond is that of the horses of the ancient race, but adulterated; and the third is that of the common and inferior kind: the last they sell at a low price; but those of the first elass, and even of the second, amongst which are found liorses of equal value to the former, are sold extremely dear. They know, by long experience, the race of a liorse by his appearance; they can tell the name, the surname, the colour, and the marks properly belonging to each. When they are not possessed of stallions of the noble race themselves,

Buffor. 
for their mares, they borrow from their neighbours, paying a proper price, as with us, and receive a written attestation of the whole. In this attestation is contained the name of the horse and the mare, and their respective genealogies. When the mare has produced her fonl, new witnesses are called, and a new attestation signed, in which are described the marks of the foal, and the day noted when it was brought forth. These attestationsincrease the value of the horse; and they are given to the persoll who buys him. The most ordinary mare of this race sells for five hundred crowns; there are many that sell for a thonsand; and some of the very finest kinds for fourteen or fifteen hundred pounds. As the Arabians have no other house but a tent to live in, this also serves them for a stable; so that the mare, the foal, the husband, the wife, and the children, lie all together indiscriminately: the little children are often seen upon the body or the neck of the mare, while these continue inoffensive and harmless, permitting them thus to play with and caress them without any injury. The Arabians never beat their horses; they treat them gently; they speak to them, and seem to hold a discourse; they use them as friends; they never attempt to increase their speed by the whip, nor spur them, but in cases of necessity. However, when this happens, they set off with amazing swiftness; they leap over obstacles with as much agility as a buck; and if the rider happens to fall, they are so manageable that they stand still in the midst of their most rapid career. The Arabian horses are of a middle size, easy in their motions, and rather inclined to leanness than fat. They are regularly dressed every morning and evening, and with such eare that the smallest roughness is not left upon their skins. They wash the legs, the mane, and the tail, which they never cut; and which they seldom comb, lest they should thin the hair. They give them nothing to eat during the day; they only give them to drink once or twice; and at sun-set they hang a bag to their beads, in which there is about half a bushel of clean barley. They contiuue eating the whole night, and the bag is again taken away the next morning. They are turned out to pasture in the beginning of March, when the grass is pretty high, and at which time the mares are given to the stallion. When the spring is past, they take them again from pasture, and they get neither grass nor hay during the rest of the year; barley is their only food, except now and then a little straw. 'The mane of the foal is always clipped when about a year or eighteen months old, in order to make it stronger and thicker. They begin to break thein at two years old, or two years and a half at farthest; they nerer saddle or bridle them till at that age; and then they are always kept ready saddled at the door of the tent, from morning till sun-set, in order to be prepared against any surprise. They at present seem sensible of the great advantage their horses are to the country; there is a law, therefore, that prohibits the exportation of the mares; and such stallions as are brought into England are generally purcliased on the eastern shores of Africa, and come round to us by the Cape of Good Hope. They are in general less in stature than our own, being not above fourteen, or fourteen hands and a half high: their motions are much more graceful and swifter than of our own horses; but, nevertheless, their speed is far from being equal; they run higher from the ground; their stroke is not so long and close; and they are far inferior in bottom. Still, how. ever, they must be considered as the first and finest breed in the world, and that from which all others have derived their principal qualifications. It is even probable that Arabia is the original countl'y of horses; since there, instead of crossing the brecd, they take every precaution to keep it entire. In other countries they must continually change the races, or their horses would soon degenerate; but there the same blood has passed down throught a long succession, without any diminution either of force or beauty.

The race of Arabian horses has spread itself into Barbary, among the Moors, and has even extended across that extensive continent to the western shores of Africa. Among the negroes of Gambia and Sencgal, the chiefs of the country are possessed of horses, which, though little, are very beautiful, and extremely manageable. Instend of barley, they are fed in those countries with maise bruised and reduced into meal, and mixed up with milk when they design to fatten them. These are 
considered as next to the Arabian horses, both for swiftness and beauty; but they are rather still smaller than the former. The Italiaus have a peculiar sport, in which horses of this brecd run against each other. They have no riders, but saddles so formed as to flap against the horses' sides as they move, and thus to spur them forward. They are set to run in a kind of railed walk, about a mile long, out of which they never attempt to escape; but when they once set forward, they never stop, although the walk from one end to the other is covered with a crowd of spectators, which opens and gives way as the horses approach. Our horses would scarcely, in this manner, face a crowd, and continue theirspeed without a rider, through the midst of a multitude; and, indeed, it is a little surprising how in such a place the horses find their own way. However, what our English horses may want in sagacity, they make up by their swiftness; and it has been found upon computation, that their speed is nearly one-fourth greater, even carrying a rider, than that of the swiftest Barb without onc.

The Arabian breed has been diffused into Egypt as well as Barbary, and intoPersia also; where, as we are told by Marcns Paulus, there are studs of ten thousand white mares all together, very fleet, and with the hoof so hard that shoeing is unnecessary. In these countries, they in general give their liorses the same treatment that they give in Arabia, except that they litter them upon a bed of their own dung, dried in the sum, and then reduced to powder. When this, which isspread under the horse about five inches thick, is moistened, they dry it again, and spread it as before. The horses of these countries a good deal rescmble each other. They are usually of a slender make; their legs fine, bony, and far apart; a thin mane; a fine clest; a beautiful head; the ear small and well pointed; the shoulder thin; the side rounded, without any unsightly prominence ; the croup is a little of the longest, and the tail is generally set high. The race of horses, however, is much degenerated in Numidia; the natives having been disconraged from keeping the breed up by the Turks, who seize "ipon all the good horses, without paying the owners the smallest gratuity for their care in bringing them up.
The Tingitanians and Egyptians have now, therefore, the fame of rearing the finest horses, both for size and beauly. The smalle'st of these last are usually sixteen hauds high; and all of them shaped, as they express it, with the elegance of an antelope.

Next to the Barb, travellers generally rank the Spanish genette. These horses, like the former, are little, but extremely swift and beautiful. The head is something of the largest; the mane thick ; the ears long, but well pointcd; the eyes filled with fire; the shoulder thickish, and the breast full and large. The croup round and large; the legs beautiful, and without hair; the pastern a little of the longest, as in the Barb, and the hoof rather too high. Nevertheless, they move with great ease, and carry themselves extremely well. Their most usual colour is black, or a dark bay. They seldom or never have white legs, or white snip. The Spaniards, who have a groundless aversion to these marks, never breed from such as have them. They arc all branded on the buttock with the owner's name; and those of the province of Andalusia pass for the best. These are said to possess courage, obedience, grace, and spirit, in a greater degree than even the Barb; and for this reason they have been preferred as warhorses to those of any other country.

The Italian horses were once more beautiful than they are at present, for they have greatly neglected the breed. Nevertheless, there are still found some beautiful horses among them, particularly among the Neapolitans, who chielly use them for the draught. In general, they have large heads and thick necks. They are also restive, and consequently unmanageable. These faults, however, are recompensed by the largeness of their size, by their spirit, and the beauty of their motion. They are cxcellent for show, and have a peculiar aptitude to prance.

The Danish horses are of such an excellent size, and so strong a make, that they are preferred to all others for the dranght. There are some of them perfectly well shaped; but this is but seldom secu, for in general they are found to have a thick neck, heary shoulders, long and hollow back, and a narrow croup: however, they all move well, and are found excellent both for parade and war. They are 
of all colours, and often of whimsical ones, some being streaked like the tiger, or mottled like the leopard.

The German horses are originally from Arabian and Barbary stocks: nevertheless, they appear to be sinall and ill-shaped: it is said also, that they are weak and washy, with tender hoofs. The Hungarian horses, on the other hand, are excellent for the draught, as well as the saddle. The Hussars, who use them in war, usually slit their nostrils; which is done, as it is said, to prevent their neighing, but, perhaps, without any real foundation.

The Dutch breed is good for the draught, and is generally used for that purpose over Europe: the best come from the province of Friezland. The Flauders' horses are much inferior to the former; the have most commonly large heads, flat feet, and swollen legs; which are an essential blemish in horses of this kind.

The French horses are of various kinds; but they have few that are good. The best horses of that country come from Limosin; they have a strong resemblance to the Barb, and, like them, they are excellent for the chase; but they are slow in coining to perfection: they are to be carefully rreated while young, and must not he backed till they are eight years old. Normandy furvishes the next best; which, though not so good for the chase, are yet better for war. In general, the French hoirses have the fault of being heavy shouldered, which is opposite to the fault of the Barb, which is too thin in the shoulder, and is, consequently, apt to be shoulder-slipt.

Having mentioned the horses most usually known in Eiırope, we pass on to those of nore distant countries, of whinse horses we can only judge hy report. We mentioned the wild horses of Anrerica. Such as are tame, if we may credit the latest reports, ${ }^{2}$ are admirable. Great numbers of these are bred up to the chase, and are chiefly kept for this purpose, particularly at Quito. The hunters, as Ulloa informs us, are divided into two classes; one part on foot, the other nol horseback : the business of the footmen is to rouse the deer; and that of the horsemen, to hunt it down. They all, at break of day, repair to the place appointed, which is generally on the summit of a hill, with

- Ulloa's Voyage, vol. i. p. 464. every man his greyhound. The horsemen place theniselves on the highest peaks; whilst those on foot range the precipices, making an hideous noise, in order to start the deer. Thus the company extend themselves three or four leagues, or more, according to their numbers. On starting any game, the horse which first perceives it, sets off, and the rider, being unable to guide or stop him, pursues the chase, sonetimes down such a steep slope, that a man on foot, with the greatest care, could hardly keep his legs; from thence he flies up a dangerous ascent, or along the side of a mountain; so that a person not used to this exercise would think it much safer to throw hinıself out of the saddle, than commit his life to the precipitate ardour of his horse. The other horses, which join in the chase, do not wait for the riders to animate them; they set forward immediately upon seeing another at full speed; and it becomes prudence in the rider to give them their way, and at the same time to let them feel the spur, to carry him over the precipices. These horses are backed and exercised to this method of hunting; and their usual pace is trotting.

There are said to be very goot horses in the islands of the Archipelago. Those of Crete were in great reputation among the ancients for their swiftness and force; however, at present they are but little used, even in the country itself, because of the unevenness of the ground, which is there very rocky and mountainous. The original horses of Morocco are much smaller than the Arabian breed; however, they are very swift and vigorous. In Turkey there are to be found horses of almost all races : Arabians, Tartars, Hungarians, and those natural to the place. The latter are very beautiful and elegant; they have a great deal of fire, swiftness, and management ; but they are not able to support fatigue: they eat little; they are easily heated; and they have skius so sensible, that they can scarcely bear the rubbing of the stirrup. The Persian horses are, in general, the most beautiful and most valuable of all thic East. The pastures in the plains of Media, Persepolis, Ardebil, and Derbent, are excellent for the purpose of rearing them; and there were bred in those places vast numbers, by order of the government of Persia, while that country was under any government. Pietro della Valle prefers the horses of Persia to those of Italy; and informs us, that they are in gene- 
ral of a middle size; and although some are found even of the sinallest stature, yet that does not impair their beauty or their strength ; yet, in soine places, they are found of a very good size, and as large as the English saddle-horses are generally found to be: they have all a thin head, a fine crest, a narrow breast, small ears well placed, the legs fine, the hoof hard, and the croup beautiful; they are docile, spirited; nimble, hardy, courageous, and capable of supporting very great fatigue; they run very swiftly, without being easily fatigued ; they are strong, and easily nourished, being only supplied with barley and chopped straw; they are put to grass only for six weeks in the spring; they have always the tail at full length, and there is no such thing as geldings among the number; they are defended from the air, as in England, by body-cloths; they attend them with the most punctual exactness; and they are rid generally in a snaffle, without spurs. Great numbers of these are every year transported into Turkey, but chielly into the East Indies : however, after all, travellers agree that they are not to be compared to the Arabian horses, either for courage, force, or beauty; and that the latter are eagerly sought, even in Persia.

The horses of India are of a very indifferent kind, being weak and washy. Those which are used by the grandees of the country come from Persia and Arabia; they are fed with a snuall quantity of hay during the day; and at night they have boiled peas, mixed with sugar and butter, instead of oats or barley: this nourishinent supnorts them, and gives them strength; otherwise they would soon sink and degenerate. Those naturally belonging to the country, are very small and vicious. Some are so very little, that Taverner reports, that the young Mogul prince, at the age of seven or eight, rode one of those little hor'ses, that was not much larger than a greyhound: and it is not loug since one of these was brought over into this country as a present to our Queen, that measures no more than nine hands high: and is not much larger than a common mastiff. It would see!n, that cliruates excessively hot are unfavourable to this animal. In this manner, the horses of the Gold-coast, and of Guinea, are extremely little, but very manageable. It is a common exercise with the grandees of that country, who are excellent horsemen, to dart out their lances before them upon full gallop, and to catch them again before they come to the ground. They have a sport also on horseback, that requires great dexterity in the rider, and a great sliare of activity in the horse: they strike off a ball, with a battledore, while they are upon a full gallop, and pursuing it, strike it again before it comes to the ground; and this they continue for a nile together, striking sometines to the right, and sometimes to the left, with amazing speed and agility.

The horses of China are as indifferent as those of India : they arc weak, little, ill-shaped, and cowardly. Those of Corea are not above three feet high; almost all the breed there are made geldings, and are so timorous, that they can be rendered no way serviceable in war; so that it may be said, that the Tartar horses werc properly the conquerors of China. These, indeed, are very serviceable in war, and although but of a middle size, yet they are surprisingly patient, vigorous, swift, and bold; their hoofs are extremely hard, though rather too narrow; their heads are fine, but rather ton little; the neck is long and stiff; the legs of the longest; and yet, with all these faults, they are found to be an excellent brced. The Tartars live with their horses pretty much in the same manner as the Arabians do; they begin to back them at the age of scven or eight months, placing their children upon them, who manage them even at that early age. By these meaus they break them by little and little, till at last, about the age of six or scven years, they are capable of enduring anızing hardships. Thus they have been known to march two or three days without once stopping; to continue five or six, without eating any thing except a handful of grass at every eight hours; and, besides, to remain without drinking for four and twenty hours. These horses, which are so vigorous in their own country, lose all their strength when they are brought into China or the Indies; but they thrive pretty well in Persia and Turkey. The race of little Tartars towards the north have also a breed of little horses, wlich they set such a value upon, that it is forbidden to sell then to strangers : these horses have the very same qualities with those of the larger kind; which they prohably derive from a similar treatment. There are also very fine horses in Circassia and Mirnglelia. There are sone greatly, esteemed in the 
Ukraine, in Walachia, Poland, and Sweden; but we have no particular accounts of thcir excellencies or defects.

If we consult the ancients on the nature and qualities of the horses of different countries, we learn that the Grecian horses, and particularly those of Thessaly, had the reputation of being excellent for war; that those of Achaia were the largest that were known; that the most beautiful came from Egypt, which bred great numbers; that the horses of Ethiopia were not in esteem, from the heat of the country; that Arabia and Africa furnished very beautiful horses, and very fit for the course; that those of Italy, and particularly of Apulia, were very good; that in Sicily, Capadocia, Syria, Armenia, Media, and Persia, there were excellent horses, equally esteemed for their speed and vigour; that those of Sardinia and Corsica, thongh small, were spirited and courageous; that those of Spain resembled the Parthian horses, in being very well adapted for war; that in Walachia and Transylvania, there were horses with bushy tails, and manes hanging down to the ground, which, nevertheless, were extremely swift and active; that the Danish horses were good leapers; those of Scandinavia, though little; were well shaped, and possessed of great agility; that the Flanders' breed was strong; that the Gaulish horses were good for carrying burdens; that the German breeds were so bad, so diminutive, and ill-shaped, that no use could be made of them; that the Swiss and Hungarian horses were good; and, lastly, that those of India were very diminutive and feeble.

Such are the different accounts we have of the various races of horses in different parts of the world. I have hitherto omitted making mention of one particular breed, more excellent than any that either the ancients or moderus have produced; and that is our own. It is not without great assiduity, and unceasing application, that the English horses are now become superior to those of any other part of the world, for size, strength, swiftness, and beauty. It was not without great attention, and repeated trials of all the best horses in different parts of the world, that we have been thus successful in improving the breed of this animal; so that the English horses are now capable of performing what no others ever could attain to. By a judicious inixture of the several kinds, by the happy difference of our soils, and by our superior skill in management, we have brought this animal to its highest perfection. An English horse, therefore, is now known to excel the Arabian in size and swiftness, to be more durable than the Barb, and more hardy than the Persian. An ordinary racer is known to go at the rate of a mile in t two minutes: and we had one instance, in the admirable Childers, of still greater rapidity. He has been frequently known to move above eighty-two feet and a lialf in a second, or almost a mile in a minute: he has also run round the course of Newmarket, which is very little less than four miles, in six minutes and forty seconds. But what is surprising, few horses bave been since found that ever could equal him: and those of his breed have been remarkably deficient.

However this be, no horses can any way equal our own, either in point of swiftness or strength; and these are the qualifications our horsemen seem cliefly to value. For this reason, when the French, or other foreigners, describe our breed, they all mention, as a fault, the awkward and ungainly motion of our horses; they allow them to be very good indeed, but they will not grant them an easy or an elegant carriage. But these writers do not consider that this seeming want of grace is entirely the result of our manner of breaking them. We consult only speed and despatch in this animal's motions; the French and other nations are more anxious for parade and spirit. For this reason, we always throw our liorses forward, while they put them upon their haunches: we give them an easy swift gait of going, that covers a great deal of ground; they, on the contrary, throw them back, giving them a more showy appearance indeed, but one infinitely less useful. The fault of our mainner of breaking is, that the horse is sometimes apt to fall forward: the French managed-horse never falls before, but more usually on one side : and for this reason the rider wears stiff boots, to guard his legs against such accidents. However, it would be a very

- See Buffon's account of our horses. 
easy matter to give our horses all that grace which foreigners a re so foud of; but it would certainly take from their swiftuess and Jurability.

But in what degree of contempt soever foreigners might formerly have held our horses, they have for some time perceived their error, and our English hunters are considered as the noblest and the most useful horses in the world. Our geldings are, therefore, sent over to the continent in great numbers, and sell at very great prices; as for our mares and stallions, there is a law prohibiting their exportation; and one similar to this is said to have obtained even as carly as the times of Athelstau, who prohibited their exportation, except where designed as presents.

Roger de Belegme, created Enrl of Shrewsbury by William the Conqueror, ${ }^{a}$ is the first who is recorded to have nade attenuts (owards the mending our native brecrl. If introduced Spanish stallions into lis istate at Powisland in Wales, firom which that part of the country was for many ages alter lamous for a swift and generous race of horses: however, at that time strength and swilucss were more regarded than beauty; the horses' shapes, in time of action, being entirely lid loy a coat of armour, which the knights then ustially put upon them, ejther by ivay of ornament or defence.

The number of our hoises in London aloue, in the time of King Stephen, is said to have amounted to twenty thousand. However, long after, in the times of Queen Elizabetls, the whole kingdom could not supply two thousand horses to iorm our cavalry. At preselıt, the former numbers seem revived; so that, in the late war, we furnished out above thirteen thousand horsemen; and could, if hard pushed, supply above four times that number. How far this great iucrease of horses among us may be beneficial, or otherwise, is not the proper business of the present page to discuss; but certain it is, that wherc horscs increase ill too great a degree, men must diminish proportionably; as that food which goes to supply

\footnotetext{
a Britislı Zoology, vol. i. p. 4. To this work I am indebted for several particular with regard to the uative animals of this islaud.
}

the one, might very easily be converted into nourishment to serve the other. But, perhaps, it may be speculinting too remotely, to argue for the diminution of their mumbers upon this principle, since every manufacture we export into other countries, takes up loom, and nay have necupied that place, which, in a state of greater simplicity, might have given birth and subsistence to mankind, and have added to population.

Be this as it will, as we have been at such expense and trouble to procure an excellent breed of horses, it is not now to he explected that we should decline the advantages arising from it, just when in our possession. It may be, therefore, the nost pmilent measure in our legishature, to encouragre the luroed as an useful banch of commoner, and a natumal ilefence to the counury. But how tar this (mol is answered by the breediug "I) of racers, is what most persons, versed in this sulject, ale very apt to questim. 'They ascret, that tire ruming-horse,

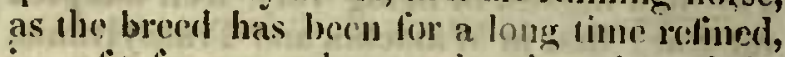
is mufit for any othere service thith that of the course, being tox slight cither los the road, the chase, or the combat; and his joints so clelicatcly imitel, as to render him sulject to the suallest accidents. They, thereline, conclucle, that less enconragenent given to racing, would be a means of turning us fiom breeding rather tir swiftness than strengtlı; and that we should thus be again famuus for our strong liunters, which, they say, arc wearing out liom among us.

How far this may be fact, I will not take upon me to determine, being but little versed in a subject that does not properly come within the compass of natural bistory. Instead, therefore, of farther expatiating on this wellknown animal's qualifications, upon which many volumes might easily be written, I will content myself with just meutioning the description of Canserarius, in which he professes to unite all the perfections which a horse ought to be possessed of. "It must," says he, "have three parts like those of a woman; the breast must be broad, the hips round, and the mane long: it must in three things resemble a lion; its countenance must be ficree, its courage must be great, and its fury irresistible : it must have three things belonging to the sheep; the nose, gentleness, and patience: it must have 
three of a decr; head, leg, and skin : it nust liave three of a wolf; throat, neck, and hearing: it Inust have three of a fox ; ear, tail, and trot : three of a serpent ; memory, sight, and flexibility : and, lastly, three of a hare; lunning, walking, and perseverance."

\section{CHAP'TER XXXIX.}

\section{OF THE ASS."}

ALTHOUGH this animal is very easily distinguished from the horse at first sight, yet, upon a closer inspection, the similitude between them is very striking. They liave both a similar outline in the external parts; the same conformation within. One would be led, from the great resemblance there is between them, to sinpose then of the same species; and that the ass was only a horse degeneratel: however, they are perfectly distinct, and there is an inseparable line drawn between them, for the mule they produce is barren. This scems to be the barrier between every species of animals; this keeps them asunder, and prescrves the unities of their form. If the mule, or the monster, bred between two animals, whose form nearly approaches, is no longer fertile, we may then conclude, that these animals, however resembling, are of different kinds. Nature has providently stopped the fruitfulness of these illforined productions, in order to preserve the form of every animal uncontaminated: were it not for this, the races would quickly be mixed with each other; no one kind would preserve its original perfection; cvery creature would quickly degenerate; and the world would be stocked with imperfection and deformity.

The horse and the as 3 , therefore, though so nearly approaching in form, are of two distinct kinds, different in their natures; and were there but one of each kind, both races would

It is a curious natural fact, that the horse has the singular property of breathing through the nostril only, and not through the mouth; for, in the severest exercise, the mouth is never seen open, unless the lower jaw be brought down violently by the force of the bit. This may account for the great dilatation of the nostrils after hard running.

In those vast desert regions, in the most southern parts of Siberia, is found a horse differing in several particulars from the common horse, already described. It is said to live in small herds of about twenty each, having then be extinguished. Their shapes and their halsits may, indeel, loc very ucarly alike; but were is something in every animal, besides its conformation or way of life, that determines its specilic nature. Thus there is much greater resemblance between the horse and the ass, than hetween the sheeje and the goat; anil yet the latter produce an animal that is by no neens liarren; but which quickly repmoduces an offspring resenbling the sheep; while the imule of the former is marked with cermain sterility. The goat and the slreep may be thercfore said to be of one kind, although sor much unlike in figure; while the horse aud the ass are perfectly distinct, though so closely resentbling. It has, indeed, been said by Aristotle, that their male is sometimes prolific; this, however, has not been confirmed by any other testimony, although there has elapsed a period of near two thousand ycars to collect the evidence.

But what tends to put the subject out of dispute, is, that the two animals are found in a state of nature entirely different. The onager, or wild ass, is seen in still greater abundance than the wild horse; and the peculiarities of its kind are more distinctly marked than in those of the tame one. Harl it been a horse degenerated, the likeness would be stronger between them, the higher we went to the original stock from whence both have been supposed to be sprung. The wild animals of both kinds would, in such a case, resemble each other,

the manners of the common wild horse, but far exceeding it in swiftness. Its head is large, and forehead flat; and its tecth are only thirty-eight in number. But the most singular mark of difference is, that the tail is slender, like that of the cow, and destitute of hair for half its length; the lower part only being covered with a long ash-coloured hair.

b Many parts of this account are extracted from Daubenton and Buffon; which I mention here, to avoid troubling the reader with a multiplicity of quotations. 
inuch more than those of the tame kind, upon whom art has, for a succession of ages, been exercising all its force, and producing strange habits and new alterations. The contrary, however, obtains, and the wild ass is even more assinine, if I may so express it, than that bred in a state of domestic servitude; and has even a natural aversion to the horse, as the reader will shortly learn.

The wild ass has, by some writers, been confounded with the zebra, but very improperly, for they are of a very different species. The wild ass is not streaked like the zcbra, nor is his shape so beautiful; his figure is pretty much the same as that of the common ass, except that he is of a brighter colour, and has a white list running from his head to his tail. This animal is found wild in many islands of the Archipelago, particularly in that of Cerigo.! There are many wild asses in the deserts of Lybia and Numidia, that run with such amazing swiftness, that scarcely even the coursers of the country can overtake them. When they see a man, they set up a horrid braying, and stop short all together, till he approaches near them; they then, as if by common consent, fly off with great speed; and it is upon such occasions that they generally fall into the traps which are previously prepared to catch them. The natives take them chiefly upon account of their flesh, which they esteem as delicious eating; and for their skins, of which that kind of leather is made which is called shagreen.

Olearius relates, that the monarch of Persia invited him on a certain day to be present at an entertainment of a very peculiar nature, which was exhibited in a small building, near the palace, resembling a theatre. After a collation of fruits and sweetmeats, more than thirty of these wild asses were driven into the arca, among which the monarch discharged 'several shot, and some arrows, and in which he was imitated by some of the rest of his attendants. The asses, finding themselves wounded, and no way of escaping, instantly began to attack each other, biting with great fierceness, and braying terribly. In this manner they continued their mutual animosity, while the arrows were poured in from above, until they were all killed: upon which they were ordered to be taken, and sent to the king's kitchen at Ispahan. The Persians esteem the flesh of this animal so bighly, that its delicacy is even become a proverb among them. What may be the taste of wild ass's flesh, we are unable to say; but ccrtain it is, that the flesh of the tame ass is the worst that can be obtained, being drier, more tough, and more disagreeable, than horse-flesh. Galen even says that it is very unwholesome. Yet we should not judge hastily upon the different tastes of different people, in the preference they give to certain meats. The climate produces very great changes in the tenderness and the savour of several viands: that beef, for instance, which is so juicy and good in England, is extremely tough and dry when killed under the line; on the contrary, that pork, which is with us so unpalatable in summer, in the warmer latitudes, where it is always hotter than here, is the finest eating they have, and much preferable to any hog's flesh in Europe.

The ass, like the horse, was originally imported into America by the Spaniards, and afterwards by other nations. That country seems to have been peculiarly favourable to this race of animals; and, where they have run wild, they have multiplied in such numbers, that in some places they are become a nuisance. In the kingdom of Quito, the owners of the grounds where they are bred, suffer all persons to take away as many as they can, on paying a small acknowledgment, in proportion to the number of days their sport lasts. They catch them in the following manner. A number of persons go on horseback, and are attended by Indians on foot: when arrived at the proper places, they form a circle, in order to drive them into some valley; where, at full speed, they throw the noose, and endeavour to halter them. Those creatures, finding themselves enclosed, make very furious efforts to escape; and, if only one forces his way through, they all follow with an irresistible impetuosity. However, when noosed, the hunters throw them down, and secure them with fetters, and thus leave them till the chase is over. Then, in order to bring them away with greater facility, they pair them with tame beasts of the same kind; but this is not easily performed, for they are so remarkably fierce that they often hurt the 
persons who undertake to manage them. They have all the swiftness of horses, and neither declivities nor precipices can retard their career. When attacked, they defend themselves with their heels and mouth with such activity, that, without slackeniug their pace, they often maim their pursuers. But the inost remarkable property in these creatures is, that, after carrying their first load, their celerity leaves them, their dangerous ferocity is lost, and they soon contract the stupid look and dulness peculiar to the assinine species. It is also observable, that these creatures will not permit a horse to live among them. They always feed together; and if a horse happens to stray into the place where they graze, they all fall upon him; and, without giving him the liberty of flying, they bite and kick him till they leave him for dead upon the spot."

Such is this animal in its natural state, swift, fierce, and formidable: but, in the state of tameness, the ass presents a very different picture; the moment his native liberty is repressed, he seems entirely to give up all claims to freedom; and he assumes a patience and submission even humbler than his situation. He is, in a state of tameness, the most gentle and quiet of all animals. He suffers with constancy, and, perhaps, with courage, all the illtreatment that cruelty and caprice are pleased to inflict. He is temperate with regard to the quantity and the quality of his provision. He is contented with the most neglected weeds; and makes his humble repast upon what the horse and other animals leave behind. If he gives the preference to any vegetable, it is to the plantain; for which he is often seen to neglect every other herb in the pasture: but he is chiefly delicate with respect to his water; he drinks only at the clearest brooks, and chiefly those to which he has been accustomed. He drinks as soberly as he eats; and never, like the horse, dips his nose into the stream. As he is seldom saddled, he frequently rolls himself upon the grass; and lies down, for this purpose, as often as he has an opportunity, without minding what becomes of his burden. He never rolls, like the horse, in the mud; he even fears to wet his feet; and

- Ulloa, vol. i. p. 316. turns out of his way to avoid the dirty parts of a road.

When very young, the ass is sprightly, and even tolerably handsome; but he soon loses these qualifications, either by age or bad treatment, and he becomes slow, stupid, and headstrong. He seems to show no ardour, except for the female, having been often known to die after the covering. The sheass is not less fond of her young than the male is of her; and we are assurcd that she will cross fire and water to protect or rcjoin it. This animal is sometimes not less attached to his owner; by whom he is too often abused. He scents him at a distance, and distinguishes him from others in a crowd; he knows the ways he has passed, and the places where he inhabits.

When overloaded, the ass shows the injustice of his master, by hanging down his head and lowering his ears; when he is too hard pressed, he opens his mouth and draws back his lips, in a very disagreeable manner. If his eyes are covered he will not stir a step; and, if he is laid down in such a manner, that one eye is covered with the grass while the other is hidden with a stone, or whatever is next at hand, he will continue fixed in the same situation, and he will not so much as attempt to rise to free himself from those slight impediments. He walks, trots, and gallops, like a horse; but, although he sets out very freely at first, yet he is soon tired; and then no beating will make him mend his pace. It is in vain that his unmerciful rider exerts his whip or his cudgel; the poor little animal bears it all with patience, and without a groan; and, conscious of his own imbecility, does not offer even to move.

Notwithstanding the stupid heaviness of his air, he may be educated with as much ease as any other animal; arid several have been brought up to perform, and exhibit as a show. Ingeneral, however, the poor animal is entirely neglected. Man despises this humble useful creature, whose efforts are exerted to please him, and whose services are too cheaply purchased. The horse is the only favourite, and upon him alone all expense and labour are bestowed. He is fed, attended, and stabled, while the ass is abandoned to the cruelty of the lowest rustics, or even to the sport of chil- 
dren; and, instead of gaining by the lessons he receives, is always a loser. He is conducted along by blows ; he is insulted by unnecessary stripes; he is overloaded by the lazy; and, being generally the property of the poor, he shares with them in their wants and their distresses. Thus this faithful animal, which, were there no horses, would be the first of the quadruped kind in our esteem, is now considered as nothing: his properties and qualifications being found in a higher degree elsewhere, he is entirely disregarded; and, from being the second, he is degraded into one of the most useless of the domestic quadrupeds.

For this reason, very little care has been taken to improve the breed; it is suffered to degenerate; and it is probable, that of all other animals this alone is rendered feebler and more diminutive, by being in a state of domestic servitude. The horse, the cow, and thesheep, are rendered larger by the assiduity of man; the ass is suffered to dwindle every generation, and particularly in England, where it is probable that, but for the medicinal qualities of its milk, the whole species would have ere now been extinguished. Nevertheless, we have good reasons to believe, that, were the same care bestowed on the ass that is spent upon the horse, were the same industry used in crossing the breed and improving it, we should see the ass become, from his present mean state, a very portly and serviceable animal; we should find him rival the horse in some of his perfections, and exceed him in others. The ass, bulk for bulk, is stronger than the horse; is more sure-footed; and though more slow in his motions, he is much less apt to start out of the way.

The Spaniards, of all people in Europe, seem alone to be acquainted with the value of the ass. They take all proper precautions to improve the breed; and I have seen a jack-ass, from that country, above fifteen liands high. This animal, however, seems originally a native of Arabia. A warm climate is known to produce the largest and the best; their size and spirit decline in proportion as they advance into colder regions.

Though now so common in all parts of England, the ass was entirely lost among us during the reign of Queen Elizabeth. Ho- lingshead informs us that our land did yield no asses." However, there are accounts of their being common in England before that time. In Sweden, they are at present a sort of rarity; nor does it appear by the last history of Norway, that they have yet reached that country. It is in the hotter climates alone that we are to look for the original of this serviceable creature. In Guinea, they are larger and more beautiful than even the horses of the same country. In Persia, they have two kinds; one of which is used for burdens, being slow and heavy; the other, which is kept for the saddle, being smooth, stately, and nimble. They are managed as horses, only that the rider sits nearer the crupper, and they are taught to amble like them. They generally cleave their nostrils to give them more room for breathing, and many of these are sold for forty or fifty pounds.

The ass is a much more hardy animal than the horse, and liable to fewer diseases. Of all animals covered with hair, he is the least subject to vermin, for he has no lice, probably owing to the dryness and the hardness of his skin. Like the horse, he is three or four years in coming to perfection; he lives till twenty or twenty-five; sleeps much less than the horse; and never lies down for that purpose, unless very much tired. The she-ass goes above eleven months with young, and never brings forth more than one at a time. The mule may be engendered either between a horse and a she-ass, or between a jack-ass and a mare. The latter breed is every way preferable, being larger, stronger, and better shaped. It is not yet well known whether the animal called the Gimerro be one of these kinds; or, as is asserted, bred between the ass and the bull. While naturalists affirm the impossibility of this mixture, the natives of the alpine countries, where this animal is bred, as strongly insist upon its reality. The common mule is very healthy, and will live above thirty years, being found very serviceable in carrying burdeus, particularly in mountainous and stony places, where horses are not so sure-footed. The size and strength of our asses is at present greatly improved by the importation of Spanish jack-asses; and it is

\footnotetext{
* British Zoology, vol. i. p. 11.
} 
probable we may come in time to equal the Spaniards in breeding them, where it is not uncommon to give fifty or sixty guineas for a mule; and, indeed, in some mountainous countries, the inhabitants cannot well do without them. Their manner of going down the precipices of the Alps, or the Andes, is very extraordinary; and with it we will conclude their history. In these passages, on one side, are steep eminences, and, on the other, frightful abysses; and, as they generally follow the direction of the mountain, the road, instead of lying in a level, forms at every little distance steep declivities, of several hundred yards downward. These can only be descended by mules; and the animal itself seems sensible of the danger, and the caution that is to be used in such descents. When they come to the edge of one of these descents, they stop, without being checked by the rider; and, if he inadvertently attempts to spur them on, they continue immoveable. They seem all this time ruminating on the danger that lies before them, and preparing themselves for the encounter. They not only attentively view the road, but tremble and snort at the danger. Having prepared for the descent, they place their fore-feet in a posture as if they were stopping themselves; they then also put their hinder-feet together, but a little forward, as if they were going to lie down. In this attitude, having taken as it were a survey of the road, they slide down with the swiftuess of a meteor. In the mean time, all the rider has to do is to keep himself fast on the saddle, without checking the rein, for the least motion is sufficient to disorder the equilibrium of the mule; in which case they both unavoidably perish. But their address, in this rapid descent, is truly wonderful; for, in their swiftest motion, when they seem to have lost all government of themselves, they follow exactly the different windings of the road, as if they had previously settled in their. minds the route they were to follow, and taken every precaution for their safety. In this journey, the natives, who are placed along the sides of the mountains, and hold by the roots of the trees, animate the beast wilh shouts, and encourage him to perseverance. Some mules, after being long used to these journeys, acquire a kind of reputation for their safety and skill; and their value rises in proportion to their fame."

\section{CHAPTER XL.}

\section{OF THE ZEBRA.}

THERE are but three animals of the horse kind. The horse, which is the most stately and courageous: the ass, which is the most patient and humble: and the zebra, which is the most beautiful, but at the same time the wildest animal in nature. Nothing can exceed the delicate regularity of this creature's colour, or the lustrous smoothness of its skin; but, on the other hand, nothing can be more timid or more untamealule.

It is chiefly a native of the southern parts of Africa; and there are whole herds of them often seen feeding in those extensive plains that lie towards the Cape of Good Hope. However, their watchfulness is such, that they will suffer nothing to come near them, and their swiftness so great, that they readily leave every pursuer far behind. The zebra, in shape, rather resembles the mule than the horse or the ass. It is rather less than the former, and yet larger than the latter. Its ears are not so long as those of the ass, and yet not so small as in the horse kind. Like the ass, its head is large, its back straight, its legs finely placed, and its tail tufted at the end; like the horse, its skin is smooth and close, and its hind quarters round and fleshy. But its greatest beauty lies in the amazing regularity and elegance of its colours. In the male, they are white and brown; in the

- Ulloa, vol.i. 
female, white and black. These colours are disposed in alternate stripes over the whole body, and with such exactness and symmetry, that ane would think Nature had employed the rule and compass to paint them. These stripes, which, like so many ribbands, are laid all over its body, are narrow, parallel, and exactly separated from each other. It is not here as in other party-coloured animals, where the tints are blended into each other; every stripe here is perfectly distinct, and preserves its colour round the body, or the limb, without any diminution. In this manner are the head, the body, the thighs, the legs, and even the tail and the ears, beautifully streaked, so that at a little distance one would be apt ti suppose that the animal was dressed out by art, and not thus admirably adorned by nature.

In the male zebra, the head is striped with fine bands of black and white, which in a manner centre in the forehead. The ears are variegated with a white and dusky brown. The neck has broad stripes of the same dark brown running round it, leaving narrow white stripes between. The body is striped also across the back with broad bands, leaving narrower spaces of white between them, and ending in points at the sides of the belly, which is white, except a black line pectinated on each side, reaching from between the fore-legs, along the middle of the belly, two-thirds of its lerigth. There is a line of separation between the trunk of the body and the hinder quarters, on each side; behind which, on the rump, is a plat of narrow stripes, joined together by a stripe down the middle, to the end of the tail. The colours are different in the female; and in none the stripes seem entirely to agree in form, but in all they are equally distinct; the hair equally smooth and fire; the white shining and unmixed; and the black, or brown, thick and lustrous.

Such is the beauty of this creature, that it seems by nature fitted to satisfy the pride and the pleasure of man; and formed to be taken into his service. Hitherto, however, it appears to have disdained servitude, and neither force nor kinduess have been able to wean it from its native independence and ferocity. But this wildness might, perhaps, in time be surmounted : and it is probable, the horse and the ass, when first taken from the forest, were equally obstinate, fierce, and unmanageable. Mr. Buffou informs us that the zebra, from which he took his description, could never be entirely mastered, notwithstanding all the efforts which were tried to tame it. They continued, indeed, to mount it, but then with such precautions as evidently showed its fierceness; for two men were obliged to hold the reins, while the third ventured upon its back; and even then it attempted to kick whenever it perceived any person approaching. That which is now in the Queen's menagerie, at Buckingham-Gate, is even more vicious than the former; and the keeper who shows it, takes care to inform the spectators of its ungovernable nature. Upon my attempting to approach it, it seemed quite terrified, and was preparing to kick, appearing as wild as if just caught, although taken extremely young, and used with the utmost indulgence. Yet still it is most probable that this animal, by time and assiduity, could be brought under subjection. As it resembles the horse in form, without all doubt it has a similitude of nature, and only requires the efforts of an industrious and skilful nation, to be added to the number of our domestics. It is not now known what were the pains and dangers which were first undergone to reclaim the breed of horses from savage ferocity; these, no doubt, made an equal opposition; but, by being opposed by an industrious and enterprising race of mankind, their spirit was at last subdued, and their freedom restrained. It is otherwise with regard to the zebra; it is the native of countries where the human inhabitants are but little raised above the quadruped. The natives of Angola, or Caffraria, have no other idea of advantage from horses but as they are good for food; neither the fine stature of the Arabian courser, nor the delicate colourings of the zebra, have any allurements to a race of people, who only consider the quantity of flesh, and not its conformation. The delicacy of the zebra's shape, or the painted elegance of its form, are no more regarded by such, than by the lion that makes it his prey. For this reason, therefore, the zebra may hitherto have continued wild, because it is the native of a couutry where there have been no successive efforts made to reclaim it. All 
pursuits that have been hitherto instituted against it, were rather against its life than its liberty : the animal has thus been long taught to consider man as its most mortal enemy; and it is not to be wondered that it refuses to yield obedience where it has so seldom experienced mercy. There is a kind of knowledge in all animals, that I have often considered with amazement; which is, that they seen perfectly to know their encmies, and to avoid them. Instinct, incleed, may teach the deer to fly from the lion; or the mouse to avoid the cat; but what is the principle that teaches the dog to atrack the dog-butcher wherever he sees him? In China, where the killing and dressing dogs is a trade, whenever one of these people moves out, all the dogs of the village, or the street, are sure to be after him. This 1 should hardly have believed, but that I have seen more than one instance of it among ourselves. I have seen a poor fellow, who made a practice of stealing and killing dogs for their skins, pursued in full cry for three or four streets together, by all the bolder breed of dogs, while the weaker flew from his presence with affright. How these animals could thus fund out their enemy, and pursue him, appears, I own, unaccountable; but such is the fact; and it not only obtains in dogs, but in several other animals, though perhaps to a less degree. This, very probably, may have been, in some measure, a cause that has hitherto kept the zebra in its state of natural wildness; and in which it may continue, till kinder treatment shall have reconciled it to its pursuers.

It is very likely, therefore, as a more civilized people are now placed at the Cape of Good Hope, which is the chicf place where this animal is found, that we may have them tamed anả rendered serviceable. Nor is its extraordinary beauty the only motive we have for wishing this animal among the number of our dependents: its swiftness is said to surpass that of all others; so that the speed of a zebra is become a proverb among the Spaniards and Portuguese. It stands better upon its legs also than a horse ; and is, consequently, stronger in proportion. Thus, if by proper care we improved the breed, as we have in other instances, we should probably in time to come lave a race as large as the horse, as fleet, as strang, and much more beautiful.

The zebra, as was said, is chiefly a native of the Cape of Good Hope. It is also found in the kinglom of Angola; and, as we are assured by Lopez, in several provinces also of Barbary. In those boundless forests it has nothing to restrain its liberty; it is too shy to be caught in traps, and, thercfore, seldom taken alive. It would seem, therefore, that none of them have ever been brought into Europe, that were caught sufficiently young, so as to be untinctured by their original state of wildness. The Portuguese, indeed, pretend that they have been able to tame them, and that they have sent four from Africa to Lishon, which were so far brought under, as to diaw the King's coach : they add, that the person who sent them over, had the office of notary conferred upon him for his reward, which was to remain to him and his posterity for ever: but I do not find this confirmed by any person who says he saw them. Of those which were sent to Brazil, not one could be tamed; they would permit one man only to approach them; they were tied up very short; and one of them, which had by some means got loose, actually killed his groom, having bitten him to death." Notwithstanding this, I believe, were the zebra taken up very young, and properly treated, it might be rendered as tame as another animal; and Merolla, who saw many of them, asserts, that, when tamed, which he speaks of as being common enough, they are not less estimable for their swiftness than their beauty.

This animal, which is neither to be found in Europe, Asia, or America, is nevertheless very easily fed. That which came over into England some years ago, would eat almost any thing, such as bread, meat, and tobacco; that which is now among us, subsists entirely upon hay. As it so nearly resembles the hor'se and the ass in structure, so it probably brings forth annually as they do. The noise they make is neither like that of a horse or an ass, but more resembling the confused barking of a mastiff dog. In the two which I saw, there was a circumstance that seems to have escaped naturalists; which is, that the skin hangs loose below the jaw upon the neck, in a kind of dewlap, which takes away nuch from the general beauty. But whether this be a natural

Dapper. Pyrard. tom. ii. p. 376.

$2 Q^{*}$ 
or accidental blemish, I will not take upon me to determine.

These animals are often sent as presents to the princes of the East. We are told, that one of the governors of Batavia gave a zebra, which had been sent to him from Africa, to the Emperor of Japan, for which he received,

a Navendorf.

b In addition to these species may be mentioned the Quagga. This animal, which used to be confounded with the zebra, is now acknowledged to he quite distinct. It inhabits the same parts of Africa as the zebra, but is always found in separate lierds, never associating with it. It is about the same size as the zebra, but less elegant in its shape and marks; and is of a much more docile na- as an equivalent for the company, a present, to the value of sixty thousand crowns. ${ }^{\text {" }}$ Teller also relates, that the Great Mogul gave two thousand ducats for one of them. And it is frequent with the Atrican ambassalors to the court of Constantinople, to bring some of these animals with them, as presents for the Grand Signior.

ture ; the Dutcl 2 colonists at the Cape having been said to tame them, and use them for the draught and saddle. Its general colonr is of a ferruginous tinge, with brown stripes. These stripes, however, are fewer in number than those of the zebra, and inuch less elegantly disposed, there being seldom any on the haunches, shoulders, and legs; and, on the hinder parts, they gradually diminish into spots. 


\section{OF RUMTINATITIG ANTMATS.}

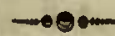

\section{CHAPTER XLI.}

\section{INTRODUCTION.}

OF all animals, those that chew the cud are the most harmless, and the most easily tamed. As they live entirely upon vegetables, it is neither their interest nor their pleasure to make war upon the rest of the brute creation; content with the pastures where they are placed, they seldom desire to change, while they are furnished with a proper supply; and, fearing nothing from each other, they generally go in herds for their mutual security. All the fiercest of the carnivorous kinds seek their food in gloomy solitude; these, on the contrary, range together; the very meanest of them are found to unite in each other's defence; and the hare itself is a gregarious animal, in those countries where it has no other enemies but the beasts of the forests to guard against.

As the food of ruminant animals is entirely of the vegetable kind, and as this is very easily procured, so these animals seem naturally more indolent and less artful than those of the carnivorous kinds ; and as their appetites are more simple, their instincts seem to be less capable of variation. The fox or the wolf are for ever prowling; their long habits of want give them a degree of sharpness and cunning; their life is a continued scene of stratagem and escape : but the patient ox, or the deer, enjoy the repast that nature has abundantly provided; certain of subsistence, and content with security.

As nature has furnished these animals with

All quadrupeds that chew the cud have suet instead of the soft fat of other animals; iand they have.the awkward habit af:rising, when in a recumbent posture, upon stheir hiud legsffirst. A. cow, when-she rises from the,grouni, an appetite for such coarse and simple nutriment, so she has cularged the capacity of the intestines, to take in a greater supply. In the carnivorous kinds, as their food is nourishing and juicy, their stomachs are but small, and their intestines short; but in these, whose pasture is coarse, and where much must be accumulated before any quantity of nourishment can be obtained, their stomachs are large and numerous, and their intestincs long and muscular. The bowels of a ruminating animal may be considered as an elaboratory, with vessels in it, fitted for various transmutations. It requires a long and tedious process before grass can be transmuted into flesh; and for this purpose, nature, in general, has furnished such animals as feed upon grass with four stomachs, through which the food successively passes and undergoes the proper separations. ${ }^{2}$

Of the four stomachs with which ruminant animals are furnished, the first is called the paunch, which receives the food after it has been slightly chewed; the second is called the honcycomb, and is properly nothing more than a continuation of the former : these two, which are very capacious, the animal fills as fast as it can, and then lies down to ruminate; which may be properly considered as a kind of vomiting without effort or pain. The two stomachs above mentioned being filled with as much as they can contain, and the grass, which was slightly chewed, beginning to swell

places herself on the fore-knees, and then lifts up the whole hinder parts. A horse springs up first an his ,fore-legs, and then rises up his hinder, parte. This una be orirg ito the different conformation of the stomech. 
with the heat of the situation, it dilates the stomachs, and these again contract upon their contents. The aliment, thus squeezed, has but two passages to escape at; one into the third stomach, which is very narrow ; and the other back, by the gullet, into the mouth, which is wider. The greatest quantity, therefore, is driven back, through the largest aperture, into the mouth, to be chewed a second time; while a small part, and that only the most liquid, is driven into the third stomach, through the orifice which is so small. The food which is driven to the mouth, and chewed a second time, is thus rendered more soft and moist, and becomes at last liquid enough to pass into the conduit that goes to the third stomach, where it undergoes a still farther comminution. In this stomach, which is called the manifold, from the number of its leaves, all which tend to promote digestion, the grass has the appearance of hoiled spinage, but not yet sufficiently reduced, so as to make a part of the animal's nourishment; it requires the operation of the fourth stomach for this purpose, where it undergoes a complete maceration, and is separated to be turned into chyle.

But nature has not been less careful in another respect, in fitting the intestines of these animals for their food. In the carnivorous kinds they are thin and lean; but in ruminating animals they are strong, fleshy, and well covered with fat. Every precaution seems taken that can help their digestion: their stomach is strong and muscular, the more readily to act upon its contents; their intestines are lined with fat, the better to preserve their warmth; and they are extended to a much greater length, so as to extract every part of that nourishment which their vegetable food so scantily supplies.

In this manner are all quadrupeds of the cow, the sheep, or the deer kind, seen to ruminate; being thus furnished with four stomachs, for the macerating of their food. These, therefore, may most properly be called the ruminant kinds; although there are many others that have this quality in a less observable degree. The rhinoceros, the camel, the horse, the rabbit, the marmotte, and the squirrel, all cliew the cud by intervals, although they are not furnished with stomachs like the former. But not these alone, there are numberless other animals that appear to ruminate; not only birds, but fishes and insects. Among birds are the pelican, the stork, the heron, the pigeon, and the turtle; these have a power of disgorging their food to feed their young. Among fishes are lobsters, crabs, and that fish called the dorado. The salmon also is said to be of this number: and, if we may believe Ovid, the scarus likewise; of which he says,

Of all the fish that graze beneath the flood,

He only ruminates his former food.

Of insects, the ruminating tribe is still larger; the mole, the cricket, the wasp, the drone, the bee, the grasshopper, and the beetle. All these animals either actually chew the cud, or secm at least to ruminate. They have the stomach composed of muscular fibres, by means whereof the food is ground up and down, in the same manner as in those which are particularly distinguished by the appellation of ruminants.

But not these alone; men themselves have been often known to ruminate, and some even with pleasure. The accounts of these calamities, for such I must consider them, incident to our fellow-creatures, are not very pleasant to read: yet I must transcribe a short one, as given us by Slare, in the Philosophical Transactions, as it may, in some measure, show the satisfaction which the lower tribes of animals enjoy while they ruminate. The man in question was a citizen of Bristol, of about twenty years of age, and, what seemed more extraordinary still, of a ruminating family, for his father was frequently subject to the same infirmity, or amusement, as he himself perhaps would call it. This young man usually began to cliew his meat over again within about a quarter of an hour after eating. His ruminating after a full meal generally lasted about an hour and a half; nor could lie sleep until this task was performed. The victuals, upon the return, tasted even more pleasantly than at first; and returned as if they had been beaten up in a mortar. If lie ate a variety of things, that which he ate first came up again first; and if this return was interrupted for any time,

- At conira herbosa pisces laxantur arena, Ut scarus epastus solus qui ruminant escas. 
it produced sickness and disorder, and he was never well till it relurned. Instances of this kind, however, are rare and accidental; and it is happy for mankind that they are so. Of -all other animals, we spend the least time in eating; this is one of the great distinctions between us and the brute ereation; and eating is a pleasure of so low a kind, that none but such as are nearly allied to the quadruped, desire its prolongation.

\section{CHAPTER XIII.}

\section{OF QUADRUPEDS OF THE COW KIND.}

OF all ruminant animals, those of the cow kind deserve the first rank, both for their size, their beauty, and their services. The borse is more properly an animal belonging to the rich; the slicep chiefly thrives in a flock, and requires attendauce ; but the cow is more especially the poor man's pride, his riclies, and his support. There are many of our peasantry that have no other possession but a cow; and even of the advantages resulting from this most useful creature, the poor are but the nominal possessors. Its flesh they canıot pretend to taste, since then their whole riches are at ouce destroyed; its calf they are obliged to fatten for sale, since veal is a delicacy they conld not make any pretensions to; its very milk is wrought into butter and cheese for the tables of their masters; while they have no share, even in their own possession, but the choice of their market. 1 cannot bear to hear the rich crying out for liberty while they thus starve their fellow-creatures, and feed them up with an imaginary good, while they monopolize the real benefits of nature.

In those countries where the men are under better subordination, this excellent animal is of more general advantage. In Germany, Poland, and Switzerland, every peasant keeps two or three cows, not for the benefit of his master, but for himself. The meanest of the peasants there kills one cow at least for his own table, which he salts and hangs up, and thus preserves as a delicacy all the year round. There is scarcely a cottage in those countries that is not hung round

\footnotetext{
" The animals of this kind have the horns hollow,
} anooth, turned outwards and forwards, in a semicircular with these marks of hospitality; and whics often make the owner better contented with liunger, since he has it in his power to be luxurious when he thinks proper. A piece of beef hung up there is considered as an elegant piece of furniture, whieh, though seldom touched, at least argues the possessor's opulence and ease. But it is very different, for some years past, in this conntry, where our lower rustics at least are utterly unable to purchase meat any part of the year, and by them even butter is considered as an article of extravagance.

The climate and pasture of Great Britain, however, are excellently adapted to this animal's moderate nature; and the verdure and the fertility of our plains arc perfectly suited to the manner of its feeding; for wanting the upper fore-teeth, it loves to graze on a ligh rich pasture. This animal seems but little regardful of the quality of its food, provided it be supplied in sufficient abund ance; it makes no particular distinetion in the choice of its herbage, but indiseriminately and hastily devours the proper quantity. For this reason, in our pastures, where the grass is rather high than succulent, more flourishing than nutritious, the cow thrives admirably; and there is no part of Europe where the tame animal grows larger, yields more milk, or more readily fattens, than with us.

Our pastures supply them with abundance, and they in return enrich the pasture; for, of all animals, the cow secms to give back more than it takes from the soil. The horse

form; in the lower jaw there are eight front teeth, but none in the upper: and there are no tusks in either. 
and the sheep are known, in a course of years, to impoverish the ground. The land where they have fed becomes weedy, and the vegetables coarse and unpalatable; on the contrary, the pasture where the cow has been bred, acquires a finer, softer surface, and becomes every year more beautiful and even. The reason is, that the horse being furnished with fore-teeth in the upper jaw, nips the grass closely, and therefore only chooses that which is the most delicate and tender; the sheep also, though with respect to its teeth formed like the cow, only bites the most succulent parts of the herbage : these animals, therefore, leave all the high weeds standing; and while they cut the finer grass too closely, suffer the ranker herbage to vegetate and overrun the pasture. But it is otherwise with the cow: as its teeth cannot come so close to the ground as those of the horse, nor so readily as those of the sheep, which are less, it is obliged to feed upon the tallest vegetables that offer; thus it eats them all down, and in time, levels the surface of the pasture.

The age of the cow is known by the teeth and horns. This animal is furnished with eight cutting teeth in the lower jaw; at the age of ten months the two iniddlemost of these fall out, and are replaced by others that are not so white, but broader; at the age of sixteen months the two next milk-white teeth fall out likewise, and others come up in their room; thus, at the end of every six months, the creature loses and gains, till at the age of three years all the cutting-teeth are renewed, and then they are long, pretty white, and equal; but in proportion as the animal advances in years, they become irregular and black, their inequalities become smoother, and the animal less capable of chewing its food. Thus the cow often declines from this single cause; for as it is obliged to eat a great deal to support life, and as the smoothness of the teeth makes the difficulty of chewing great, a sufficient quantity of food cannot be supplied to the stomach. Thus the poor animal sinks in the midst of plenty, and every year grows leaner and leaner till it dies.

The lorns are another and. a surer method of determining this animal's age. At three years old, it sheds its horns, and new ones arise in their place, which continue as long as it lives; at four years of age, the cow has small pointed, neat sinooth horns, thickest near the head; at five, the horns become larger, and are marked round with the former year's growth. Thus, while the animal contimues to live, the horus continue to lengthen; and every year a new ring is added at the root; so that allowing three years before their appearance, and then reckoning the number of rings, we have, in both together, the animal's age exactly.

As we have indisputably the best breed of horned cattle of any in Europe, so it was not without the same assiduity that we came to excel in these, as in our horses. The breed of cows has been eitirely improved by a foreign mixture, properly adapted to supply the imperfections of our own. Such as are purely British are far inferior in size to those on many parts of the continent; but those which we have thus improved by far excel all others. Our Lincolnshire kind derive their size from the Holstein breed: and the large hornless cattle that are bred in some parts of England, canne originally from Poland. We werc once famous for a wild breed of these animals, but these have long since been worn out; and perhaps no kingdom in Europe can furnish so few wild animals of all kinds as our own. Cultivation and agriculture are sure to banish these wherever they are found; and every addition a country receives from art. drives away those animals that are only fitted for a state of nature.

Of all quadrupeds, the cow seems most liable to alteration from its pasture. In the different parts of our own country we easily perceive the great varieties produced among these animals, by the richuess or poverty of the soil. In some they grow to a great bulk; and I have seen an ox sixteen hands high, which is taller than the general run of our horses. In others, they appear as diminutive; being not so large as an ass. The breed of the Isle of Man, and inost parts of Scotland, is much less in general than in England or Ireland: they are differently shaped also, the dewlap being much smaller, and, as the expression is, the beast has more of the ewe neck. This, till some years ago, was considered in cattle as a deformity; and the cow was chosen, according to Virgil's direction, 
with a large dewlap: however, at present, it is the universal opinion, that the cow wants in udder what it has in neck; and the larger the dewlap, the smaller is the quantity of its milk. Our graziers now, therefore, endeavour to mix the two breeds; the large Holstein with the small northern; and from both results that fine milch breed, which excels the cattle of any other part of the world.

This difference, arising from pasture, is more observable in other countries than in our own. The cow kind is to be found in almost every part of the world, large in proportion to the richness of the pasture; and small as the animal is stinted in its food. Thus Africa is remarkable for the largest and the smallest cattle of this kind; as is also India, Poland, Switzerland, and several other parts of Europe. Among the Eluth Tartars, where the pastures are remarkably rich and nourishing, the cow becomes so large that he must be a tall man who can reach the tip of its shoulder. On the contrary, in France, where the animal is stinted in its food, and driven from the most flourishing pastures, it greatly degenerates.

But the differences in the size of this animal are not so remarkable as those which are found in its form, its hair, and its horns. The difference is so very extraordinary in many of them, that they have been even considered as a different kind of creature, and names have been given them as a distinet species, when in reality they are all the same. In this manner the urus and the bison have been considered, from the variety in their make, to be distinct in their production; but they are all, in fact, the descendants of one common stock, as they have that ccrtain mark of unity, they breed and propagate aunong each other. Naturalists have, therefore, laboured under an obvious error, when, because of the extreme bulk of the urus. or becausc of the luinp upon the back of the bison, they assigned them different places in the creation, and separated a class of animals which was really united. It is true, the horse and the ass do not differ so much in form, as the cow and the bison; nevertheless, the former are distinct animals, as their breed is marked with sterility; the

\footnotetext{
- Buffon, vol. xxiii. ø. 78 .

No. $21 \& 22$.
}

latter are animals of the same kind, as their breed is fruitful, and a race of animals is produced, in which the hump belonging to the bison is soon worn away. The diflerences, therefore, between the cow, the urus, and the bison, are merely accidental. The same caprice in nature that has given horns to some cows, and denied them to others, may also have given the bison a hump, or increased the bulk of the urus; it may have given the one a mane, or denied a sufficiency of hair to the other.

But before we proceed farther, it may be proper to describe these varieties, which have been thus taken for distinct kinds. ${ }^{b}$ The urus, or wild bull, is chiefly to be met with in the province of Lithuania; and grows to a size that scarcely any other animal, except the elephant, is found to equal. It is quite black, except a stripe mixed with white, that runs from the neck to the tail, along the top of the back; the horns are short, thick, and strong; the eyes are fierce and fiery; the forehead is adorned with a kind of garland of black curled hair, and some of them are found to have beards of the same; the neck is short and strong; and the skin has an odour of musk. The female, though not so big as the male, exceeds the largest of our bulls in size; nevertheless, her udder and teats are so small, that they can scarcely be perceived. Upon the whole, however, this auimal resembles the tame one very exactly, except in some trifling varieties, which his state of wildness, or the richness of the pastures where he is found, may easily have produced.

The bison, which is another variety of the cow kind, differs from the rest, in having a lump between its shoulders. These animals are of various kind; some very large, others as diminutively little. In general, to regard this animal's fore-parts, he has somewhat the look of a lion, with a long shaggy mane, and a beard under his chin; his head is little, his eyes red and fiery, with a furious look; the forehead is large, and the horns so big, and so far asunder, that three men might often sit between them. On the middle of the back there grows a bunch almost as high as that of a camel, covered with hair, and which is con.

\footnotetext{
b This description is chiefly taken from Klein.
} $2 \mathbf{R}$ 
sidered as a great delicacy by those that hunt him. There is no pursuing him with safety, except in forests where there are trees large enough to hide the hunters. He is generally taken by pit-falls: the inhabitants of those countries where be is found wild, digging holes in the ground, and covering them over with boughs of trees and grass; then provoking the bison to pursue them, they get on the opposite side of the pit-fall, while the furious animal, running head foremost, falls into the pit prepared for him, and is there quickly overcome and slain.

Besides these real distinctions in the cow kind, there have been many others inade, that appear to be in name only. Thus the bonasus, of which naturalists have given us long descriptions, is supposed by Klein and Buffon to be no more than another name for the bison, as the descriptions given of them by the ancients coincide. The bubalus also of the ancients, which some have supposed to belong to the cow kind, Buffon places among the lower class of ruıninant quadrupeds, as it inost resembles them in size, shape, and the figure of its horns. Of all the varieties, therelore, of the cow kind, there are but two that are really distinct; namely, the cow and the buffalo: these two are separated by nature; they seem to bear an antipathy to each other; they avoid each other, and may be considered as much removed as the horse is from the ass or the zebra. When, therefore, we have described the varieties of the cow kind, we shall pass on to the buffilo, which, being a different animal, requires a separate history.

There is scarcely a part of the world, as was said before, in which the cow is not found in some one of its varieties; either large, like the urus, or humped, as the bison; with straight horns, or bending, inverted backwards, or turning sideways to the cheek, like those of the ram; and, in many countries, they are found without any horns whatsoever. But, to be more particular, beginning at the north, the few kine which subsist in Iceland, are without horns, although of the same race originally with ours. The size of these is rather relative to the goodness of the pasture, than the warmth or colduess of the climate. The Dutch frequently bring great quantities of lean cattle from Denmark, which they fatten on their own rich grounds. These are in general of a larger size than their own natural breed; and they fattell very easily. The cattle of the Ukraine, where the pasture is excellent, become very fat, and are considered as one of the largest breeds of Europe. In Switzerland, where the mountains are covered with rich nourishing herbage, which is entirely reserved for their kine, these anjmals grow to a very large size. On the contrary, in France, where they get no other grass but what is thought unfit for horses, they dwindle and grow lean. In some parts of Spain the cow grows to a good size : those wild bulls, however, which they pride themselves so much in combating, are a very mean despicable little animal, and somewhat shaped like one of our cows, with uothing of that peculiar stermness of aspect for which our bulls are remarkable. In Barbary, and the provinces of Africa, where the ground is dry, and the pasturage short, the cows are of a very small breed, and give milk in proportion. On the contrary, in Ethiopia, they are of a prodigious bigness. The same holds in Persia and Tartary; where, in some places, they are very small, and, in others, of an amazing stature. It is thus, in almost every part of the world, this animal is found to correspond in size to the quantity of its provision.

If we examine the form of these animals, as they are found tame, in different regions, we shall find, that the breed of the urus, or those without a hump, chiefly occupies the cold and the temperate zones, and is not so much dispersed towards the south. On the contrary, the breed of the bison, or the animal with a hump, is found in all the southern parts of the world; throughout the vast continent of India; throughout Africa, from mount Atlas to the Cape of Good Hope. In all these countries, the bison seems chiefly to prevail : where they are found to have a smooth solt hair, are very nimble of foot, and in some measure supply the want of horses. The bison breed is also more expert and docile than ours; many of them, when they carry burdens, bend their knees to take them up, or set them down : they are treated, therefore, hy the natives of those countries, with a degree of tenderness and care equal to their utility; and the respect for them in India has degenerated 
even into blind adoration. But it is among the Hottentots where these animals are eliefly esteemerl, as being inore than commonly serviccable. They are their fellow domestics, the companions of their pleasures and fatigues; the cow is at once the Hottentot's protector and servant, assists him in attending his flocks, and guarling them against every invader: while the sheep are grazing, the faithful backely, as this kind of cow is ealled, stands or grazes beside them; still, however, attentive to the looks of its master, the backely flies round the field, herds in the sheep that are straying, obliges them to keep within proper linits, and shows no mercy to robbers, or even strangers, who attempt to plunder. But it is not the plunderers of the fluck alone, but even the eneusies of the nation, that these backelies are taught to eombat. Every arny of Hottentots is furnished with a proper luerd of these, which are let loose against the enemy, when the occasion is most convenient. Being thus sent forward, they ov:rurn all before them; they strike every opposer drown with their horns, and trample upon then with their feet; and thus often proceure their masters an easy victory, even belore they have attenupted to strike a blow. An animal so serviceable, it may be supposed, is not withont its reward. The backely lives in the same cottage with its master, and, by long habit, gains an affection for him; and in proportion as the man approaches to the brute, so the brute seenis to attain even to some share of human sagacity. The Hottentot and his backely thus mutually assist each other; and when the latter happens to die, a new one is chosen to succeed him, by a counsel of the oll men of the village. The new backely is then joined with one of the veterans of his own kind, from whom he learns his art, becomes sucial and diligent, and is taken for life into luman friendship and protection.

The bisons, or cows with a hump, are found to differ very much from each other in the several parts of the world where they are found. The wild nnes of this kind, as with $\mathrm{ns}$, are much larger than the tame. Some have horus, and some are withoint any; some have them depressed, and some raised in such a manner that they are used as weapons of annoyance or defence; some are extremely large, and others among them, such as the zebu, nr Barbary cow, are very small. They are all, however, equally docile and gentle when tamed; aud, in general, furnishel ivith a fine lustruus soft hair, more beautiful than that of our own breed; their lump is also of different sizes, in some weighing fiom forty to fifty pounds, in others less: it is not, however, to be considered as a part necessarily belonging to the animal; and probably it night be cut away without much injury : it resembles a gristly fat; and, as I am assured, cuts and tastes somewhat like a dressed udder. The bisons of Malabar, Abyssinia, and Madagnsear, are of the great kind, as the pastures there are plentiful. Those of Arabia Petrea, and most parts of Africa, are small, and of the zebu or little kind. In Ameriea, especially towards the north, the bison is well known. The American bison, lowever, is found to be rather less than that of the ancient continent; its hair is longer and thicker, its beard more reniarkahle, and its hide more lustrons and soft. There are many of them brought up tame in Carolina; however, their wild dispositions still seem to contiume, for they break through all fences to get into the corn-ficlds, and lead the whole tame herd after them, wherever they penetrate. They breed also with the tame kinds originally brought over from Europe; and thus produce a race peculiar to that country.

From all this it appears, ${ }^{\text {a that naturalists }}$ have given various names to animals in reality the same, and only differing in some few aceidental circumstances. The wild cow and the tame, the animal belonging to Europe, and that of Asia, Africa, and America, the bonasus and the urus, the bison and the zebu, are all one and the same, propagate among each other, and, in the course of a few generations, the hump wears away, and scarcely any vestiges of savage fierceness are found to remain. Of all animals, therefore, except man alone, the cow secms most extensively propagated. Its nature seems equally capable of the rigours of heat and cold. It is an inliabitant as well of the frozen fields of Iceland, as the burning deserts of Lybia. It seems an ancient iumate in every climate, domestic and tame in those countries which have been civilized, savage and wild in the countries which are less peopled, but capable of being made useful in all; able

- Buffon, vol. xxiii. p. 130. 
to defend itself in a state of nature against the most powerful enemy of the forest; and only subordiuate to man, whose force it has experienced, and whose aid it at last seems to require. However wild the calves are, which are taken from the dam in a savage state, either in Africa or Asia, they soon become humble, patient, and familiar; and man may be considered in those countries, as almost helpless without their assistance. Other animals preserve their nature or their form with inflexible perseverance; but these, in every respect, suit themselves to the appetites and conveniences of mankind; and as their shapes are found to alter, so also does their nature; in no animal is there seen a greater variety of kinds, and in none a more liumble and pliant disposition.

\section{THE BUFFALO.}

IF we should compare the shape of our common cow with that of the bison, the difference will appear very great. The shaggy mane of the latter, the beard, the curled forehead, the inverted liorns, the broad breast, and the narrow hinder parts, give it the appearance rather of a lion than a cow; and fit it more for a state of war with mankind, than a state of servitude. Yet, notwithstanding these appearances, both animals are found to be the same; or at least so nearly allied, that they breed among each other, and propagate a race that continues the kind.

On the other hand, if we compare the buffalo with our common cow, no two animals can be more nearly alike, either in their form or their nature; both equally submissive to the yoke, both often living under the same roof, and employed in the same domestic services; the malse and the turn of their bodies so much alike, that it requires a close attention to distinguish them: and yet, after all this, no two animals can be more distinct, or seem to have stronger antipathies to each other. ${ }^{a}$ Were there but one of each kind remaining, it is probable the race of both would shortly be extinct. However, such is the fixed aversion formed between these creatures, that the cow refuses to breed with the buffalo, which it nearly resembles; while it is known to propagate with

\footnotetext{
- Buffon.
}

the bison, to which it has, in point of form, but a very distant similitude.

The buffalo is, upon the whole, by no means so beantiful a creature as the cow ; his figure is more clumsy and awkwrird; his air is wilder; and he carries his head lower, and nearer the ground; his limbs are less fleshy, and his tail more naked of hair; his body is shorter and thicker than that of the cow kind; his legs are higher; his head smaller; his horns not so round, black, and compressed, with a bunch of curled hair hanging down between them: his skin is also harder and thicker, more black and less furnished with hair; his flesh, which is hard and blackish, is not only disagreealle to the raste, but likewise to thit smell. The milk of the female is by no means so goorl as that of the cow; it is however produced in great abundance. In the warm countries, a!most all their cheese is made of the milk of the buffalo; and they supply butter also in larye quantities. The veal of the young buffalo is not better eating than the beef of the old. The hide of this animal seems to be the most valuable thing he furnishes. The leather made of it is well known for its thickness, softness, and impenetrability. As these animals are, in general, larger and stronger than the cow, they are usefully employed in agriculture. They are used in drawing hurdens, and sometimes in carrying them; being guided by a ring, which is thrust through their nose. Two buffaloes yoked in a waggon, are said to draw more than four strong horses; as their heads and necks are naturally bent downward, they are thus better fitted for the draught, and the whole weight of their bodies is applied to the carriage that is to be drawn forward.

From the size and bulk of the buffalo, we may be easily led to conclude that he is a native of the warmer climates. The largest quadrupeds are generally found in the torrid zone; and the buffalo is inferior, in point of size, only to the elephant, the rhinoceros, or the hippopotamus. The camelopard or the camel may indeed be taller, but they ure neither so long, nor near so corpulent. Accordingly, we find this animal wild in many parts of India; and tamed also, wherever the natives have occasion for his services. The wild buffaloes are very dangerous animals, and are often found to gore travellers to death, and then trample them with their feet, until they have entirely mangled 
the whole body: however, in the woods they are not so much to be feared as in the plains, because in the violence of their pursuit their large horus are apt to be entangled in the branches of the trees, which gives those who have beel surprised by them time to escape the danger. There is scarcely any other method of avoiding their pursuit; they run with great swiftness; they overturn a tree of mo. derate growth; and are such swimmers, as to cross the largest rivers without any difficulty. In this mamer, like all other large animals of the torrid zone, they are very fond of the water; and, in the midst of their pursuit, often plunge in, in order to cool themselves. The negroes of Guinen, and the Indians of Malabar, where buffaloes are in great abundance, take great delight in hunting and destroying them: however, they never attempt to face the buffalo openly; but, generally climbing up the tree, shoot at him from thence, and do not come down till they find they have effectually despatched him. When they are taned, no animal can be more patient or humble; and though by no means so docile as the cow kind, yet they go through domestic drudgeries with more strength and perseverance.

Althongh these animals be chiefly found in the torrid zone, yet they are bred in several parts of Europe, particularly in Italy, where they make the food and the riches of the poor. The female produces but one at a time, in the saine manner as the cow; but they are very different in the times of gestation; for the cow, as we know, goes but nime months; whereas the buffalo continues pregnant for twelve. They are all afraid of fire; and, perhaps, in consequence of this, have an aversion to red colours, that resemble the colour of flame: it is said, that in those countries where they are found in plenty, no person dares to dress in scarlet. In general they are inoffensive animals, if undisturbed; as indeed all those which feed upon grass are found to be; but when they are wounded, or when even but fired at, nothing then can stop their fury; they then turn up the ground with their fore-feet, bellow much louder and more terribly than the bull, and make at the object of their resentment with ungovernable rage. It is happy, in such circumstances, if the person they pursue has a wall to escape over, or some such obstacle; otherwise they soon overtake, and instantly destroy him. It is remarkable, however, that although their horns are so very formidable, they in general thake more use of their feet in combat, and rather tread their enemies to death than gore them.

Having thus gone through the history of these animals, it may be proper to observe, that no names lave been more indiscriminately used than those of the bull, the urus, the bison, and the buffalo. It therefore becomes such as would have distinct ideas of each, to be careful in separating the kinds, the one from the other, allowing the cow for the standard of all. 'The urus, whether of the large enormous kind of Lithuania, or the smaller race of Spain, whether with long or short horns, whether with or without long hair in the forehead, is every way the same with what our common breed was before they were taken from the forest, and reduced to a state of servitude. The bison, and all its varieties, which are known by a hump between the shoulders, is also to be ranked in the same class. This animal, whether with crooked or with straight horns, whether they be turned towards the cheek, or totally wanting, whether it be large or diminntive, whatever be its colour, or whatever the length of its hair, whether called the bonasus by some, or the bubalus by others, is but a variety of the cow kind, with whom it breeds, and with whom of consequence it has the closest connexion. Lastly, the buffalo, though shaped much more like the cow, is a distinct kind by itself, that never mixes with any of the former; that goes twelve months with young, whereas the cow goes but nine; that testifies an aversion to the latter; and, though bred under the same roof, or feeding in the same pasture, has always kept separate: and makes a distinct race in all parts of the world. These two kinds are supposed to be the only real varieties in the cow kind, of which naturalists have given so many varieties. With respect to some circumstances inentioned by travellers, such as that of many kinds defending themselves by voiding their dung against their pursuers; this is a practice which they have in common with other timid creatures when pursued, and arises rather from fear than a desire of defence. 
The musky smell also by which some have been distinguished, is found common to many of these kinds, in a state of nature; and does not properly make the characteristic marks of any. The particular kind of noise also, which some of them are known to make, which rather resembles grunting than bellowing or lowing, is but a savage variety, which many wild animals have, and yet lose when brought into a state of tameness. For these reasons, Mr. Buffon, whom I have followed in this description, is of opinion, that the zebu, or little African cow, and the grunting, or Siberian cow, are but different races of the bison; as the shape of the horns, or the length of the hair, are never properly characteristic marks of any animal, but are found to vary with climate, food, and cultivation.

In this manner the number of animals of the cow kind, which naturalists have extended to eight or ten sorts, are reduced to two; and as the utmost deference is paid to the opinion of Mr. Buffon in this particular, I have taken him for my guide. Nevertheless, there is an animal of the cow kind, which neither he, nor any other naturalist that I know of, has hitherto described, yet which makes a very distinct class, and may be added as a third species.

This animal was shown some years ago in London, and seemed to unite many of the characteristics of the cow and the hog; having the head, the horns, and the tail, of the former; with the bristles, the colour, and the grunting, of the latter. It was about the size of an ass, but broader and thicker; the colour resem- bling that of a hog, and the hair bristly, as in that animal. The hair upon the body was thin, as in the hog; and a row of bristles ran along the spine, rather shorter and softer than in the hog kind. The head was rather larger than that of a cow; the teeth were entirely resembling those of that animal, and the tongue was rough in like manner. It fed upon hay ; and consequently its internal conformation must have resembled that of the cow kind more than the hog, whose food is always chosen of a kind more succulent. The eyes were placed in the head as with the cow, and were pretty nearly of the same colour; the horns were black and flattish, but bent rather backwards to the neek, as in the goat kind; the neck was short and thick, and the back rather rising in the middle; it was cloven-footed, like the cow, without those hinder claws that are found in the hog kinds. But the greatest variety of all in this extraordinary creature, which was a female, was, that it had but two teats, and consequently, in that respect, resembled neither of the kinds to which, in other circumstances, it bore so strong a similitude. Whether this animal was a distinct kind, or a monster, I will not prelend to say. it was shown under the name of the bonasus; and it was said, by the person who showed it, to have come from India: but no credit is to be given to interested ignorance; the person only wanted to make the animal appear as extraordinary as possible; and I believe would scarcely scruplea lie or two to increase that wonder in us, by which he found the means of living.

\section{CHAPTER XLIII.}

\section{OF ANIMALS OF THE SHEEP AND GOAT KIND.}

AS no two animals are found entirely the same, so it is not to be expected that any two races of animals should exactly correspond in

\footnotetext{
In the sheep kird the horns are bollow, wrinkled, perennial, bent backwards and outwards, into a circular or spiral form, and generally placed at the sides of the head; in the lower jaw there are eight front teeth, but none in the upper; there are no canine teeth in either. In the
}

every particular. The goat and the sheep are apparently different in the form of their bodies, in their covering, and in their horns. They

goat the horns are hollow, rough, compressed, and rise somewhat erect from the top of the head, and bend backwards; there are eight front teptl in the lower jatw, none in the upper, and no canine teeth in either; the chin $i$ bearded. 


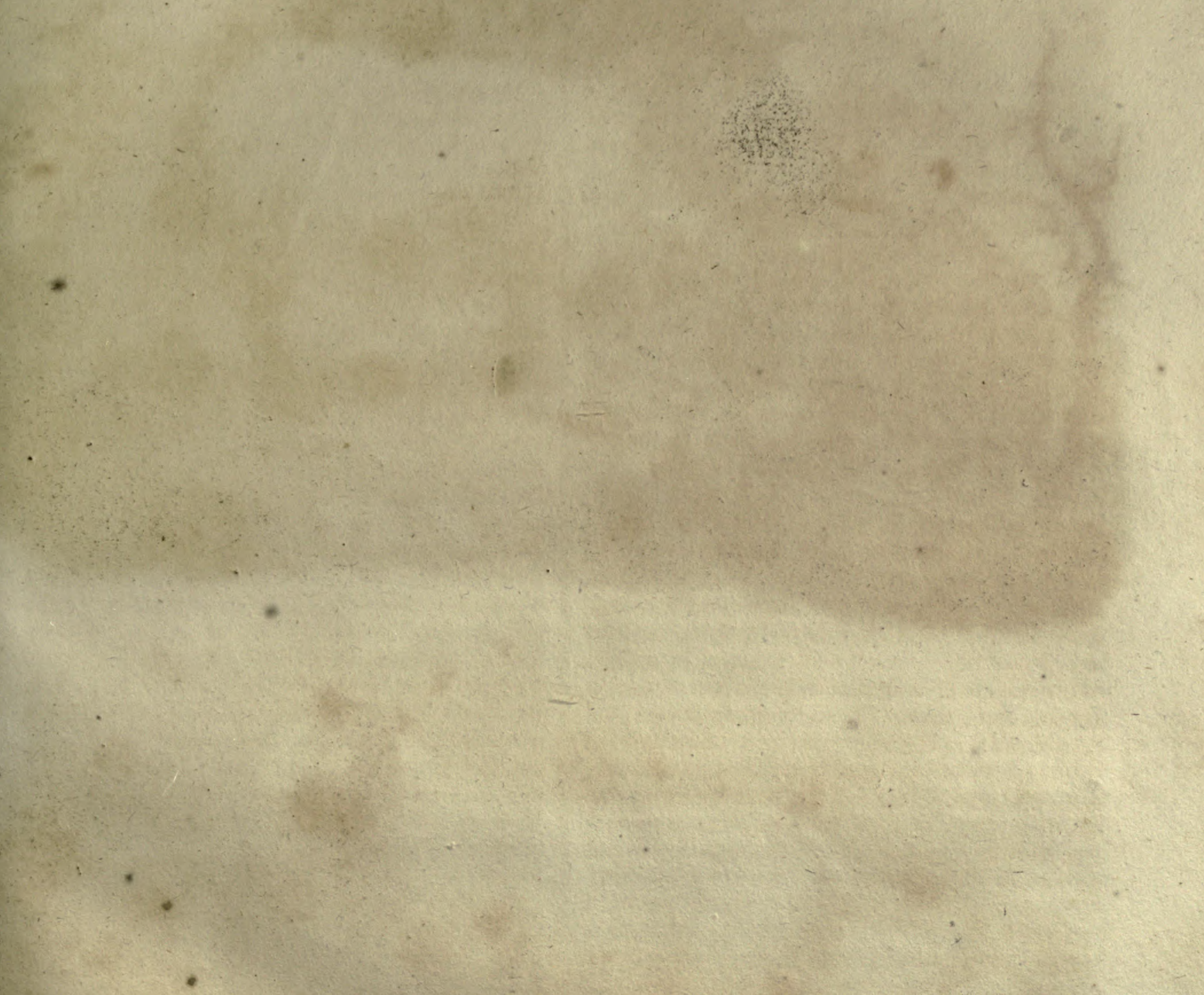




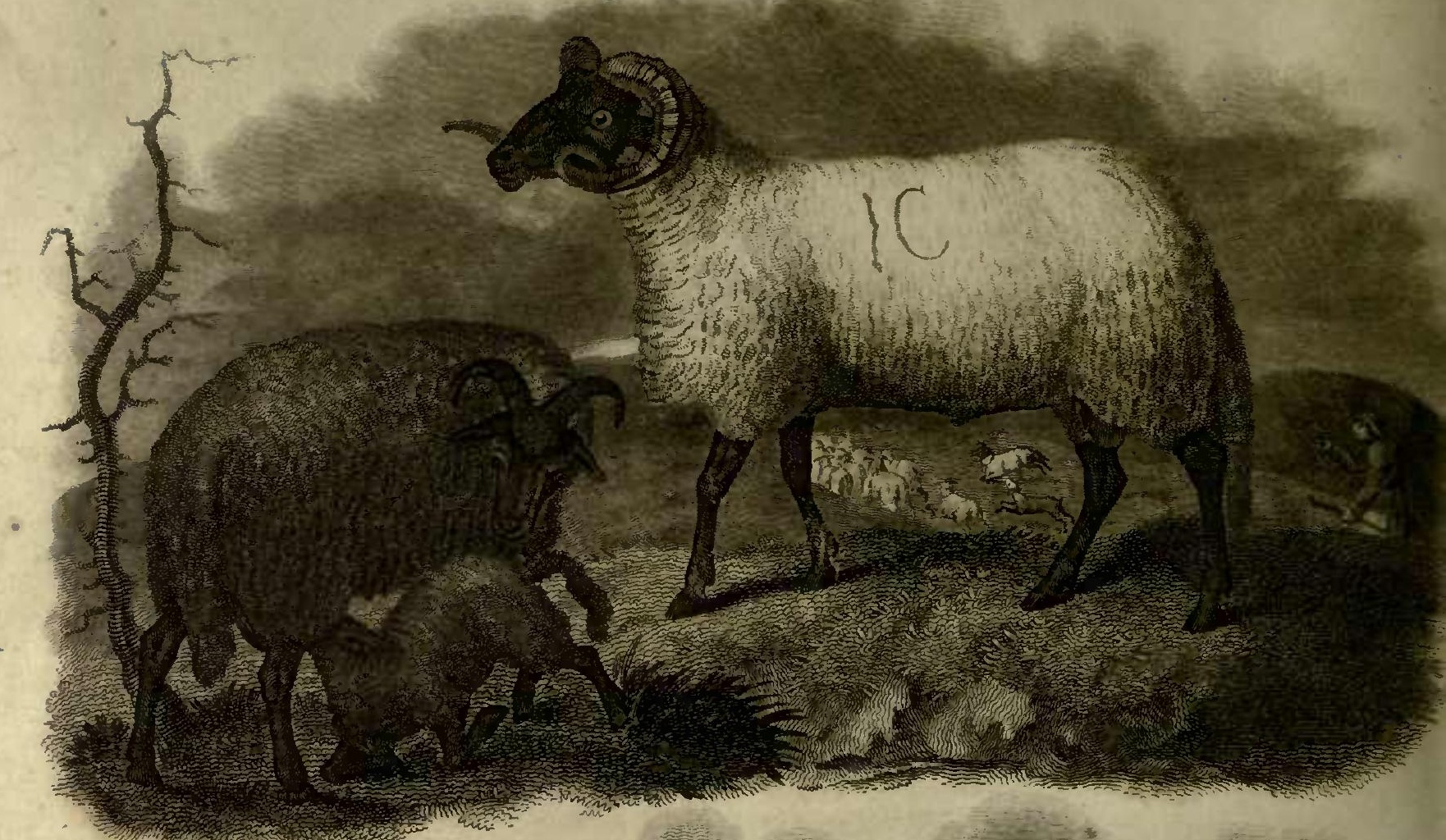

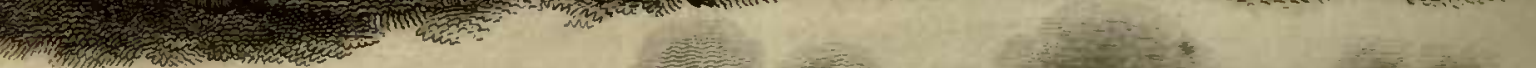

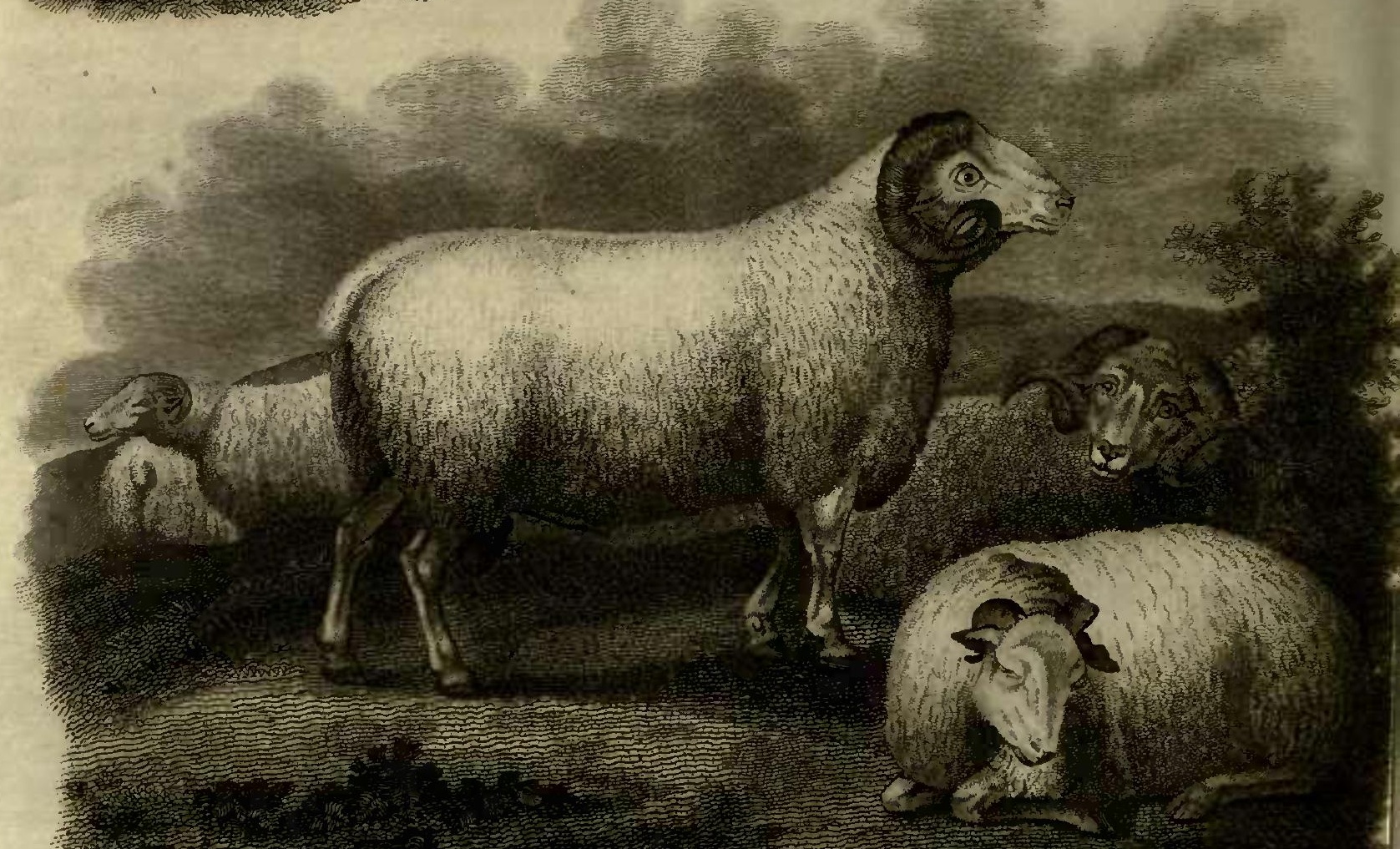


may, from hence, be considered as two different kinds, with regard to all coininon and domestic purposes. But if we cone to extmine them closer, and observe their internal consfor:nation, notwo animals can be more alike; their feet, their four stomachs, their suet, their appctitia, all are entirely the saine, and show the similitude between them; but what makes a much stronger commexion is, that they propngate with each other. The buck-goat is found to produce with the ewe an animal that, in two or tirce generations, returis to the sheep, and sceins to retain no marks of its ancient progenitor." The sheep and the goat, therefore, may be considered as belonging to one family; and were the whole races reduced to one of each, they would quickly replenish the earth with their kind.

If we we examine the sheep and goat internally, we shall find, as was said, that their conformation is entirely the same; nor is their structure very remote from that of the cow kind, which they resemble in their hoofs, and in their chewing the cud. Indeed, all ruminant animals are internally very much alike. The goat, the sheep, or the deer, exhibit to the eye of the anatomist the same parts in miniature which the cow or the bison exhilbited in the great. But the differences between those animals are, nevertheless, sufficiently apparent. Nature has obviously marked the distinctions between the cow and the sheep kind, by their form anil size; and they are also distinguished from those of the deer kind, by never shedding the horns. Indeed, the furm and figure of these animals, if there were nothing else, would seldom fail of guiding us to the kirsd; and we might alınost upon sight tell which belongs to the deer kind, and which are to be degraded into that of the goat. However, the annually shedding the horns in the deer, and the permaneuce in the sheep, draws a pretty exact line between the kinds; so that we may hold to this distinction only, and define the sheep and goat kind as ruminant animals of a smaller size, that never shed their horns.

If we consider these harmless and useful animuls in one point of view, we shall find that both have been Ing reclaimed, and brought into a stite of domestic servitude. Both scem to require protection from man; and are, in

\footnotetext{
- Buffon, passim.
}

some measure, pleased with his society. The shecp, indeed, is the more serviceable creature of the two ; but the goat has more sensibility and attachment. The attenling "lpon both was once the employment of the wisest and the best of men; and those have heen cver supposed the happiest $t i$ nes in which these harmless creatures were considered as the chicf objects of human attention. In the earliest ages, the goat seemed rather the greater favourite; and, indeed, it continues such, in some commtries, to this day among the poor. However, the sheep has long since become the princinal object of human care; while the goat is disregarded by the gencrality of mankind, or become the possession only of the lowest of the people. The sheep, therefore, and its varieties, nray be considered first; and the goat, with all those of its kind, will then properly follow

\section{THE SHEEP.}

Those animals that take refuge under the protection of inan, in a few geueraitons become indolent and helpless. Having lost the habit of self-defence, they seem to lose also the instincts of nature. The sheep, in its present domestic state, is, of all animals, the nost defenceless and inoffensive. With its liberty, it seems to have been deprived of its swiftness and cunning; and what in the ass might rather be called patience, in the sheep appears to be stupidity. With 110 one quality to fit it for self-preservation, it makes vain efforts at all. Without swiftness, it endeavours to fly ; and without strength, sometimes offers to oppose. But these feeble attempts racher incite than repress the insults of every enemy; and the dog follows the flock with greater delight upon seeing them fly, and attacks them with unore fierceness upon their unsupported attempts at resistance. Indeed, they run together in florks rather with the hopes of losing their single danger in the crowd, than of uniting to repress the attack by numbers. The sheep, therefore, were it exposed it its present state to struggle with its uatural enenies of the forest, would soon be extirpated. Loaded with a lieavy flece, deprived of the defence of its horns, and rendered heavy, slow, and feeble, it can have no other safety than what it finds from nıan. 
This animal is now, therefore, obliged to rely solely upon that art for protection, to which it orivinally owes its degradation.

But we are not to impute to nature the formation of an animal so utterly unprovided against its enemies, and so unfit for defence. 'The moufflon, which is the sheep in a savage state, is a bold, fleet creature, able to escape from the greater animals by its swiftness, or to oppose the smaller kinds with the arms it has received from nature. It is by human art alone that the sheep lias become the tardy defenceless creature we find it. Every race of quadrupeds might easily be corrupted by the sanse allurements by which the sheep has been thus debilitated and lepressed. While undisturbed, and properly supplied, none are found to set any bounds to their appetite. They all pursue their food while able, and continue to graze, till they often die of disorders occasioned by too much fatness. But it is very different with them in a state of nature: they are in the forest surrounded by dangers, and alarmed with unceasing hostilities; they are pursued every hour from one tract of country to another ; and spend a great part of their time in attempts to avoid their enemies. Thus constantly exercised, and continually practising all the arts of defence and escape, the animal at once preserves its life and native independence, together with its swiftness, and the sleuder agility of its form.

The sheep, in its servile state, seems to be divested of all inclinations of its own; and of all animals it appears the most stupid. Every quadruped has a peculiar turn of countenance, a physiognomy, if we may so call it, that generally marks its nature. The sheep seems to have none of those traits that betoken either courage or cunning; its large eyes, separated from each other, its ears sticking out on each side, and its narrow nostrils, all testify the extreme simplicity of this creature; and the position of its horns also, show that nature designed the sheep rather for flight than combat. It appears a large mass of flesh, supported upon four sinall straight legs, ill fitted for carrying such a burden; its motions are awkward, it is easily fatigued, and often sinks under the weight of its own corpulency. In proportion as these marks of human transformation are ino'e numerous, the a nimal becomes more helpless and stupid. Those which live upon a more fertile pasture, and grow fat, become entirely feeble; those that want horns ale found niore dull and heavy than the rest ; those whose fleeces are longest and finest are most subject to a variety of disorders; and, in short, whatever changes have been wrought in this animal by the industry of man are entirely calculated for human advantage, and not for that of the creature itself. It might require a succession of ages before the sheep could be restored to its primitive state of activity, so as to become a match for its pursuers of the forest.

The goat, which it resembles in so many other respects, is much its superior. The one has its particular attaclıment, sees danger, and generally contrives to escape it; but the other is timid without a cause, and secure when real danger approaches. Nor is the sheep, when bred up tame in the house, and familiarized with its keepers, less obstinately absurd: from being dull and timid, it then acquires a degree of pert familiarity; buts with its head, becones inischievous, and shows itself every way unworthy of being singled out from the rest of the flock. Thus it seems rather formed for slavery than friendship; and framed more for the necessities than the amusenents of man= kind. There is but one instance in which the sheep show's any attachment to its keeper; and that is seen rather on the continent than among us in Great Britain. IVhat I allude to is, their following the sound of the shepherd's pipe. Before I had seen them trained in this manner I had no conception of those descriptions in the old pastoral poets, of the shepherd leading his flock from one country to another. As I had been used only to see these harmless creatures driven before their keepers, I supposed that all the rest was but invention; but in niany parts of the Alps, and even some provinces of France, the shepherd and his pipe are still continued with true antique sinuplicity. The flock is regularly penned every evening, to preserve them from the wolf; and the shepherd returns homeward at sun-set with his sheep following him, and seemingly pleased with the sound of the pipe, which is blown with a reed, and resembles the chanter of a bagpipe. In this manner, in those countries that still continue poor, the Arcadian life is

naubenton upon the Sheep 
preserved in all its former purity ; but in countries where a greater inequality of condition prevails, the shepherd is generally some poor wretcl, who attends a flock from which he is to derive no benefits, anul only guards those lixuries which he is not fated to share.

It does not appear, froin early writers, that the sheep was bred in Britain ; and it was not till several ages after this animal was cultivated, that the woollen manufacture was carried on among us." That valuable branch of business lay for a considerable time in foreign hands; and we were obliged to import the cloth manufactured from our own materials. There were, notwithstanding, many unavailing efforts among our kings to introduce and preserve the manufacture at home. Henry the Second, by a patent granted to the weavers in London, directed, that if any cloth was found made of a mixture of Spanish wool, it should be burned by the mayor. Such edicts, at length, although but sliwly, operated towards the estahlishing this trade annong us. The Flemings, who at the revival of arts possessed the art of cloth-working in a superior degrec, were invited to settle here; and soon after foreign cloth was prohibited from being worn in England. In the times of Queen Elizabeth this manufacture received every encouragenent; and many of the inhalsitants of the Netherlands being then forced, by the tyranny of Spain, to take refinge in this country, they improved us in those arts, in which we at present excel the rest of the world. Every art, however, has its rise, its meridinn, and its decline; and it is supposed by many, that the wonllen manufacture has, for some time, been decaying amongst us. The cloth now made is thought to be much worse than that of some years past; being neither so firm nor fine; neither so nuch courted abroad, nor so serviceable at home.

No country, however, produces such sheep as England; either with larger fleeces, or better adapted for the business of clothing. Those of Spain, indced, are finer, and we generally require some of their wool to work up with our own: but the weight of a Spanish fleece is no way comparable to one of Lincoln or Warwickshire; and, in those counties it is no uncommon thing to give fifty guineas for a ram.

a British Zoology, vol. i. p. 23.

- Lisle's Husbandry, vol. ii. p. 155.
The sheep without horns are counted the best sort, because a great part of the aniual's nourishment is supposed to go up into the horns. ${ }^{b}$ Sheep, like other runinant animals, want the upper fore-teeth; but have eight in the lower jaw : two of these drop, and are replaced at two years old; four of them are replaced at three years old; and all at four. The new teeth are easily known from the rest, by their freshness and whiteness. There are some breeds, however, in England, that yever cliange their teeth at all; these the shepherds call the leather-mouthed cattle; and, as their teeth are thus long wcaring, they are generally supposed to grow old a year or two before the rest.: The sheep brings forth one or two at a time; and sometimes three or four. The first lainb of an ewe is generally pot-bellied, short and thick, and of less value than those of a second or third production; the third being supposed the best of all. They bear their young five months; and, by being housed, they bring forth at any time of the year.

But this animal, in its domestic state, is too well known to require a detail of its peculiar hahits, or of the arts which have been used to improve the breed. Indeed, in the eye of an observer of nature, every art which tends to render the creature more helpless and uscless to itself, may be considered rather as an iujury than an improvement; and if we are to lonk for this animal in its noblest state, we must seek for it in the African desert, or the extensive plains of Siberia. Among the degenerate descendants of the wild sheep, there have been so many changes wrought, as entirely to disguist the kind, and often to mislead the observer. The variety is so great, that scarcely any two countries have their sheep of the same kind; but there is found a manifest difference in all, either in the size, the covering, the shape, or the horns.

The woolly sheep, ${ }^{d}$ as it is scen among us, is found only in Europe, and some of the temperate provinces of Asia. When transported into warmer countries, either into Florida or Guinea, it loses its wool, and assumes a covering fitted to the climate, becoming hairy and rough; it there also loses its fertility, and its flesh no longer has the same flavour. In the same manner, in the very cold countries, it

c Lisle's Husbandry, vol. ii. p. 155.

d Buffon, vol. xxiii. p. 168 . 
seems equally helpless and a stranger; it still requires the unceasing attention of mankind for its preservation; and although it is found to subsist, as well in Greenland as in Guinea, yet it seems a natural inhabitant of neither.

Of the domestic kinds to be found in the different parts of the world, besides our own, which is common in Europe, the first variety is to be seen in Iceland, Muscory, and the coldest climates of the north. This, which may be called the Iccland sheep, resembles our breed in the form of the body and the tail; but differs in a very extraordinary manner in the number of the luorns; being generally found to have four, and sometimes even eight, growing from different parts of the forehead. These are large and formidable; and the animal seems thus fitted by nature for a state of war: however, it is of the nature of the rest of its kind, being mild, gentle, and timid. Its wool is very different also from that of the common shecp, being long, smooth, and hairy. Its colour is of a dark brown; and under its outward coat of hair it has an internal covering, that rather resembles fur than wool, being fine, short, and soft.

The second variety to be found in this animal, is that of the broad-tailed sheep, so common in Tartary, Arabia, Persia, Barbary, Syria, and Egypt. This sheep is only remarkable for its large and heary tail, which is often found to wcigh from twenty to thirty pounds. It sometimes grows a foot broad, and is obliged to be supported by a small kind of board, that goes upon wheels. This tail is not covered underneath with wool, like the upper part, but is bare; and the natives, who consider it as a very great delicacy, are very careful in attending and preserving it from injury. Mr. Buffon supposes that the fat which falls into the caul in our sheep, goes in these to furnish the tail; and that the rest of the body is from thence deprived of fat in proportion. With regard to their fleeces, in the temperate climates, they are, as in our own breed, soft and woolly; but in the warmer latitudes, they are hairy: yet in both they preserve the enomnous size of their tails.

The third observable variety is that of the sheep called strepsicheros. This animal is a

- Krantz. native of the islands of the Archipelago, and only differs from our shecp, in having straight horns, surrounded with a spiral fiuriow.

The last variety is that of the Guinea shecp, which is generally found in all the tropical climates, both of Africa and the East Indies. They are of a large size, with a rough hairy skin, short horns, and ears hanging down, with a kind of dewlap under the chin. They differ greatly in form from the rest, and might be considered as animals of another kind, were they not known to breed with our sheep. These, of all the domestic kinds, scem to approach the nearest to the state of nature. They are larger, stronger, and swifter, than the common race; and, consequently, better fitted for a precarious forest life. However, they seem to rely, like the rest, on man for support; being entirely of a domestic nature, and subsisting only in the warmer climates.

Such are the varieties of this animal, which have been reduced into a state of domestic servitude. These are all capable of producing among each other; all the peculiarities of their form have been made by climate and human cultivation; and none of them seem sufficiently independent to live in a state of savage nature. They are, therefore, to be considered as a degenerate race, formed by the hand of man, and propagated merely for his benefit. At the same time, while man thus cultivates the domestic kinds, he drives away and destroys the savage race, which are less beneficial, and more headstrong. These, therefore, are to be found in but a very small number, in the most uncultivated countries, where they have been able to subsist by their native swiftness and strength. It is in the more uncultivated parts of Greece, Sardinia, Corsica, and particularly in the deserts of Tartary, that the moufflon is to be found, that bears all the marks of being the primitive race; and that has been actually known to breed with the donestic animal.

The mouflon, or musmon, though covered with hair, bears a stronger similitude to the ram, than to any other animal: like the ram, it has the eyes placed near the horns; and its ears are shorter than those of the goat; it also resembles the ram in its horns, and in all the particular contours of its form. The horns also are alike; they are of a yellow colour; 
they have three sides, as in the ram, and bend backwards in the same manner behind the cars; the muzzle and the inside of the ears, are of a whitish colour, tinctured with yellow; the other parts of the face are of a brownish gray. The general colour of the hair over the body is of a brown, approaching to that of the red deer. The inside of the thighs and the belly are of a white, tinctured with yellow. The form, upon the whole, seems more made for agility and strength than that of the common sheep; and the moufflon is actually found to live in a savage state, and maintain itself, either by force or swiftness, against all the animals that live by rapine. Such is its extreme speed, that many have been inclined rather to rank it among the deer kind, than the sheep. But in this they are deceived, as the musmon has a mark that entirely distinguishes it from that species, being known never to shed its horns. In some these are scen to grow to a surprising size; many of them measuring, in their convolutions, above two ells long. They are of a yellow colour, as was said; but the older the animal grows, the darker the horms become: with these they often maintain very furious battles between each other; and sometimes they are found broken off in such a manner, that the small animals of the forest creep into the cavity for shelter. ${ }^{a}$ When the musmon is seen standing on the plain, his fore-legs are always straight, while his hinder legs seem bent under lifm; but in cases of more active necessity, this seeming deformity is removed, and he moves with great swiftness and agility. The female very much resembles the male of this species, but that she is less, and her horns also are never seen to grow to that prodigious size they are of in the wild ram. Such is the sheep in its savage state; a bold, noble, and beautifil animal: but it is not the most beautiful creatures that are always found most useful to man. Human industry has therefore destroyed its grace, to improve its utility.

THE GOAT, AND ITS NUMEROUS VARIETIES.

There are some domestieanimals that scem as auxiliaries to the more useful sorts; and

a Gimelin, as quoted by Buffon. that, by ceasing to be the first, are considered as nothing. We have seen the services of the ass slighted, because inferior to those of the horse; and, in the same manner, those of the goat are held cheap, because the sheep so far exceeds it. Were the horse or the sheep removed from nature, the inferior kinds would then be invaluable; and the same arts would probably be bestowed in perfecting their kinds, that the higher order of animals have experienced. But in their present neglected state, they vary but little from the wild animals of the same kind: man has left them their primitive habits and forms; and the less they owe to his assiduity, the more they receive from nature.

The goat seems, in every respect, more fitted for a life of savage liberty than the sheep. ${ }^{6}$ It is naturally more lively, and more possessed with animal instinct. It easily attaches it-. self to man, and seems sensible of his caresses. It is also stronger and swifter, more courageous, and more playful, lively, capricious, and vagrant: it is not easily confined to its flock, but chooses its own pastures, and loves to stray remote from the rest. It chiefly delights in climbing precipices, in going to the very edge of danger; it is often seen suspended upon an eminence hanging over the sea, upon a very little base, and even sleeps there in security. Nature has, in some measure, fitted it for traversing these declivities with ease; the hoof is hollow underneath, with sharp edges, so that it walks as securely on the ridge of a house, as on the level ground. It is a hardy animal, and very easily sustained; for which reason it is chicfly the property of the poor, who have no pastures with which to supply it. Happily, however, it seems better pleased with the neglected wild, than the cultivated ficlds of art; it chooses the healthy mountain, or the shrubby rock; its favourite food is the tops of boughs, or the tender bark of young trees; it seems less afraid of immoderate heat, and bears the warm clinates better than the sheep; it sleeps exposed to the sun, and seems to enjoy its warmest fervors; neither is it terrified at the storm, or incommoded by the rain; immoderate cold alone scems to affect it, and is said to produce a

b Bufou. 
vertigo, with which this animal is sometimes incommoded. The inconstancy of its nature is perceivable in the irregularity of its gait; it goes forward, stops, runs, approaches, flies, merely from caprice, and with no other seeming reason than the extreme vivacity of its disposition.

There are proofs of this animal's being naturally the friend of man; and that the goat seldom resunes its primeval wildıess, when once reduced into a state of servitude. In the year 1698, an English vessel happening to touch at the island of Bonavista, two negroes came, and offered the sailors as many goats as they chose to take away. Upon the captain's expressing his astonishment at this offer, the negroes assured him that there were but twelve persons in the island, and that the gonts were multiplied in such a manner as even to become a nuisance: they added, that instead of giving any trouble to catch them, they followed the few inhabitants that were left with a sort of obstinacy, and rather became importunate with their tameness.

The goat produces but two at a time, and three at the most. But in the warmer climates, although the animal degenerates, and grows less, yet it becomes more fruitlinl, being generally found to bring forth three, four, and tive, at a single delivery. The buck is capable of propagating at the age of one year, and the female at sevell mouths; however, the fruits of this premature generation are weak and defective; and their best loreeding-time is generally delayed till the age of two years, or eighteen mouths at least. One buck is sulficient for a hundred and lifty goats; his appetites are excessive : but this ardour brings onl a speedy decay, so that he is enervated in four years at most, and even becones old hefore lie reaches his seventh year. The goat, like the sheep, continues five months with young; and, in some places, bears twice a year.

'The milk of the goat is sweet, nourishling, and medicinal; not so apt to curdle upon the stomach as that of the cow: and, therefore, preferable to those whose digestion is but weak. The peruliarity of this animal's lood gives the milk a llavour diflerent from that either of the cow or the slieep; for as it generally feeds upon shrubby pastures, and healthy mountains, there is an agreeable mildness in! the taste, very pleasing to such as are fond of that aliment. In several parts of lreland, and the highlands of Scotland, the goat makes the chief possession of the inhabitants. On those mountaiıs, where no other useful animal could find subsistence, the goat continues to glean a sufficient living, and supplies the hardy natives with what they consider as varied luxury. They lie upon beds made of their skins, which are soft, clean, and wholesome; they live upon their milk, with oatbread; they convert a part of it into butter, and some into cheese: the flesh, indeed, they seldom taste of, as it is a delicacy which they find too expensive; however, the kid is considered, even by the city epicure, as a great rarity ; and the flesh of the goal, when properly prepared, is ranked by sone as no way inferior to velison. In this manner, even in the wilclest solitudes, the poor find comforts of which the rich do not think it worth their while to dispossess them: in these inountainous retreats, where the landscape presents only a scenc of rocks, heaths, and shrubs, that speak the wretcheducss of the soil, these simple people have their feasts aud their pleasures; their faithliul tlock of gontsattends them to these awful solitudes, and furnishes them with all the necessaries of life; while their remote siluation happily keeps them ignorant of greater luxury.

As these auimals are apt to stray from the flock, 110 man cau attend above lifty of them at a time. They are fattence in the same manuer as sheep; but, taking every precaution, their thesh is never so good or so sweet, in our climate, as that of multon. It is otherwise between the tropies. The mutton there becomes flabliy and lean, while the flesh of the goat rather secms to improve: and in some places the latter is cultivated in preference to the former: We, therefore, find this animal in alınost crery part of the world, as it seens fitted for the necessities of man in both extrenes. Towarde the north, where the pasture is conise and harren, the goat is fitted to find a scanty subsistence: between the tropies, where the lieat is excessive, the goat is fitted to hear the climate, and its flesh is found to improve.

Onc of the most remarkable varietics we 
find in the goat is in that of Natolia. The Natolian goat, or, as Mr. Buffon calls it, the goat of Angora, has the ears longer than ours, and broader in proportion. The male has horns of about the saine length with the goat of Europe, but black, and turned very differently, going out horizontally on each side of the head, and twisted round in the manner of a cork-screw. The horns of the female are shorter, and encircle the car somewhat like those of the ram. They are of a dazzling white colour, and in all the hair is very long, thick, fine, and glossy; which, indeed, is the case with almost all the animals of Syria. There are a great number of these animals about Angora, where the inhabitants drive a trade with their hair, which is sold either raw, or manufactured, into all parts of Europe. Nothing can exceed the beauty of the stuffs which are made from the hair of almost all the animals of that country. These are well known among us by the name of camlet.

A second variety is the Assyrian goat, of Gesner, which is somewhat larger than ours, with ears almost hanging down to the ground, and broad in proportion. ${ }^{\mathrm{a}}$ The horns, on the contrary, are not above two inches and a half long, black, and bending a little backwards. The hair is of a fox colour, and under the throat there are two excrescences, like the gills of a cock. These animals are chiefly kept round Aleppo for the sake of their milk. They are driven through the streets, and their milk is sold to the inhabitants as they pass along.

In the third variety may be reckoned the little goat of Africa, which is of the size of a kid, but the hair is as long as that of the ordinary breed. The horns, which do not exceed the length of a man's finger, are thick, and bend downwards so close to the head that they almost enter the skin.

There is an animal of this kind at the Cape of Good Hope, called the blue goat, which may be ranked as the fourth variety. It is in shape like the domestic, but much larger, being nearly of the size of a stag. Its hair is very short, and of a delightful blue; but it

a. Sonini assures us, that though the ears of this variety are much longer than those of the common goat, they never reach so low as the ground, nor, as has been reported, are they ever cropped. loses a great deal of its beauty when the ani$\mathrm{mal}$ is dead. It has a very long beard; but the horns are not so long in proportion as in other goats, being turned spirally, in the manner of a cork-screw. It has very long legs, but well proportioned; and the flesh is very well tasted, but lean. For this reason, in that plentiful country, it is chiefly killed upon account of its skin. It is a very shy animal, and seldom comes near the Dutch settlements; but they are found in great abundance in the more uncultivated parts of the country. Besides these, they are found in this extensive region of various colours, and many of them are spotted beautifully, with red, white, and brown.

In fine, the Juda goat resembles ours in most parts, except in size, it being much smaller. This animal is common in Guinea, Angola, and all along the coast of Africa; it is not much larger than the hare, but it is extremely fat, and its flesh admirably tasted. It is in that country universally preferred to mutton.

These animals seem all of one kind, with very trifling distinctions between them. It is true that they differ in some respects; such as having neither the same colour, hair, ears, or horns. But it ought to be considered as a rule in natural bistory, that neither the horns, the colour, the fineness or the length of the hair, nor the position of the ears, are to be considered as making an actual distinction in the kinds. These are accidental varieties, produced by climate and food, which are known to change even in the same animal, and give it a seeming difference of form. When we see the shapes, the inclinations, and the internal conformation of seemingly different creatures nearly the same; and, above all, when we see them producing among each other, we then have no hesitation in pronouncing the species, and asserting that these are of the goat kind, with which they are so materially connected.

But, although these are evidently known to belong to the goat kind, there are others nearly resembling the goat, of whose kindred we cannot be equally certain. These are such as being found in a state of nature, have not as yet been sufficiently subjected to human observation. Hence it is impossible to deter- 
mine with precision to which class they belong; whether they be animals of a particular kind, or merely the goat in its state of savage freedom. Were there but one of these wild animals, the inquiry would soon be cuded; and we might readily allow it for the parent stock; but, in the present case, there are two kinds that have almost equal pretensions to this honour; and the claims of which it has been found difficult to determine. The animals in question are the shammoy and the ibex. These both bear very near approaches to the goat in figure; have horns that never shed; and, at the same time, are more different from each other than from the animal in question. From which of these two sources our domestic goat is derived, is not easy to settle. Instead, therefore, of entering into the discussion, I will content myself with the result of $\mathrm{Mr}$. Buffon's inquiries. $\mathrm{He}$ is of opinion that the ibex is the principal souree; that our domestic goat is the immediate descendant; and that the shammoy is but a variety from that stock, a sort of collateral branch of the same family. His pruncipal reason for giving the preference to the ibex, is its having a more masculinc figure, large horns, and a large beard; whereas the shammoy wants these marks of primitive strength and wilduess. He supposes, therefore, in their original savage state, that our goat has taken after the male of the parent stock, and the shammoy after the female; and that this has produced a variety in these animals, even before they underwent human cultivation.

However this be, the two animals in question seem both well fitted for their precarious life, being extremely sivift, and capable of rumning with ease along the ledges of precipices, where even the wolf or the fox, though instigated by hunger, dare not pursue them. They are both natives of the Alps, the Pyrenees, and the mountains of Greece; there they propagate in vast numbers, and continue to exist in spite of the hunter and every beast of prey that is found incessantly to pursue them.

The ibex resembles the goat in the shape of its body; but differs in the horns, which are mich larger. They are bent backward, full of knots; and it is generally asserted that there is a knot added every year. There are some of these found, if we bclieve Bellonius, at least two yards long. The ibex has a large black beard, is of a brown colour, with a thick warm coat of hair. There is a streak of black runs along the top of the back; and the belly and back of the thighs are of a fawn colour.

The shammoy, though a wild animal, is very easily tamed, and docile; and to be found only in rocky and mountainous places. It is about the size of a domestic goat, and resembles one in many respects. It is most agree. ably lively, and active beyond expression. The shammoy's hair is short, like that of the doc; in spring it is of an ash colour, in autumn a dun colour, inclining to black, and in winter of a blackish brown. This animal is found in great plenty in the mountains of Dauphiny, of Piedmont, Savoy, Switzerland, and Germany. They are peaceful, gentle creatures, and live in society with each other. They are found in flocks of from four to fourscore, and even a hundred, dispersed upon the crags of the mountains. The large males are seen feeding detached from the rest, except in rutting time, when they approach the females, and drive away the young. The time of their coupling is from the beginning of September to the end of October; and they bring forth in April and March. The young keeps with the dam for about five months, and sometimes longer, if the hunters and the wolves do not separate them. It is asserted that they live between twenty and thirty years Their flesh is good to eat; and they are found to have ten or twelve pounds of suet, which far surpasses that of the gont in hardness and goodness. The shammoy has scarce any cry, as most animals are knewu to have; if it has any, it is a kind of feeble bleat, by which the parent calls its young. But in cases of danger, and when it is to warn the rest of the flock, it uses a hissing noise, which is heard at a great distance. For it is to be observed, that this creature is extemely vigilant, and has an eye the quickest and most piercing in vature. Its sinell also is not less distinguishing. When it sees its enemy distinctly, it stops for a moment; and then, if the person be near, in an instant after it flies off. In the

- Mr. Peroud's account, as quoted by Bufton 
same manner, by its smell, it can discover a man.at hall a leaure distance, and gives the earliest notice. Upon any alarm, therefore, or any apprehensious of danger, the shammoy begins his hissing note with such forec, that the roeks and the forests re-ccho to the sound. The first hiss continues as long as the time of one inspiration. In the beginning it is very sharp, and decper towards the close. The atrinal having, after this tirst alarm, reposed a moment, again looks round, and, perceiving the reality of its fears, continues to hiss by intervals, until it has spread the alarm to a very great distance. During this tine, it seems in the most violent agitation; it strikes the ground with its fore-foot, and somelimes with both : it bounds from rock to rock; it turns and looks round; it runs to the edge of the precipice; and, still perceiving the cuemy, flies with all its speed. The hissing of the male is much louder and sharper than that of the female; it is performed through the nose; and is properly no more than a very strong breath driven violently through a small aperture. The shammoy feeds upon the best herbage, and chooses the most delicate parts of the planits, the flower and the tender buds. It is not less delicate with regard to several aromatic herbs which grow upon the sides of the mountains. It drinks but very little while it feeds upon the succulent herbage, and chews the cud in the intervals of feeding. This animal is greatly admired for the beauty of its eyes, which are round and sparkling, and which mark the warmth of its constitution. Its head is furnished with two small horns, of about half a foot long, of a beautiful black, and rising from the forehead, almost betwixt the eyes. 'These, contrary to what they are found in other animals, instead of going backwards or sideways, jet out forward, and bend a little, at their extremities, backward, in a small circle, and end in a very sharp point. The ears are placed, in a very elegant manner, near the horns; and there are two stripes of black on each side of the face, the rest being of a whitish yellow, which never changes. The horn of this animal is often used as the head of a cane. Those of the female are less, and not so much bent; and some farriers are seen to blced cattle with them. These animals are so much incommoded by heat, that they are never found in summer, except in the caverns of rocks, amidst fragments of unmelted ice, under the shade of high and spreading trees, or of rough and hanging precipices, that face the north, and which keep off entirely the rays of the sulı. They go to pasture both morning and evening, and seldom during the heat of the day. They rum along the rocks with great ease and seeming indifference, and leap from one to another, so that no dogs are able to pursue them. There is nothing inore extraordinary than to see them climbing, and descending precipices, that to all other quadrupeds are inaccessible. They always mount or descend in an oblique direction; and throw themselves down a rock of thirty feet, and light with great security upon some excrescence or fragment, on the side of the precipice, which is just large enough to place their tect upon; they strike the rock, however, in their descent, with their feet, three or four times, to stop the velucity of their motion; and, when they have got upon their base below, they at once seem fixed and secure. In fact, to see them jump in this manner, they seem rather to have wings than legs: some, indeed, pretend to say, that they use their horns for climbing, but this wants confirmation. Certain it is that their legs alone are formed for this arduous employment, the hinder being rather longer than the former, and bending in such a manner, that when they descend upon them, they break the force of the fall. It is also asserted, that when they feed, one of them always stands as centinel; but how far this may be true is questionable. For certain, while they feed, there are some of them that keep continually grazing round the rest; but this is practised among all gregarious animals; so that when they see any danger, they warn the rest of the herd of its approach. During the rigours of winter, the shammoy sleeps in the thicker forests, and feeds upon the shrubs and the buds of the pine-tree. It sometimes turns up the snow with its foot, to look for herbage, and, where it is green, makes a delicions repast. 'The more craggy and uneven the forest, the more this animal is pleased with the abode, which thus adds to its becurity. The hunting the shaminoy is very laborious, and cxtieinely difficult. The most usual way is to hide be- 
lind the clefts of the rocks and shoot them. This, however, must be done with great precaution; the sportsinan must creep for a vast way upon his belly, in silence, and take also the advantage of the wind, which if it blow from him they would instantly perceive. When arrived at a proper distance, he then advances his piece, which is to be rifle-barrelled, and to carry one ball, and tries his fortune among them. Some also pursue this animal, as they do the stag, by placing proper persons at all the passages of a glade orvalley, and then sending in others to rouze the game. Dogs are quite useless in this chase, as they rather alarm than overtake. Nor is it without danger even to the men; for it often happens that when the animal finds itself overpressed, it drives at the hunter with its head, and often tumbles him down to the neighbouring precipice. This animal cannot go upon ice whensmooth; but if there be the least inequalities on its surface, it then bounds along in security, and quickly evades all pursuit.

The skin of the shammoy was once famous, when tanned, for its softness and warmth; at present, however, since the art of tanning has been brought to greater perfection, the leather called shammoy is made also from those of the tame goat, the sheep, and the deer. Many medicinal virtues also were said to reside in the blood, fat, gall, and the concretion sometimes found in the stomach of this animal, called the German bezoar. The fat, mixed with milk, was said to be good in ulcers of the lungs. The gall was said to be useful in strengthening the sight; the stone, which is generally about the size of a walnut, and blackish, was formerly in great request for having the same virtues with oriental bezoar. However, in the present enlightened state of physic, all these medicines are quite out of repute; and although we have the names of several medicines procurable from quadrupeds, yet, except the musk or hartshorn alone, I know of none in any degree of reputation. It is true, the fat, the urine, the beak, and even the dung of various animals, may be found efficacious, where better remedies are not to be had; but they are far surpassed by many at present in use, whose operations we know, and whose virtues are confirmed by repeated experience.
Such are the quadrupeds that more prculiarly belong to the goat kind. Each of these, in all probability, can engender and breed with the other; and were the whole race extinguished, except any two, these would be suffieient to replenish the world, and continue the kind. Nature, however, proceeds in her variations by slow and inseusible degrees, and scarce draws a firm, distinguished line between any two neighbouring races of animals whatsoever. Thus it is hard to discover where the sheep ends, and the goat begins; and we shall find it still harder to fix precisely the boundaries between the goat kind and the deer. In all transactions from one kind to the other, there are found to be a middle race of animals, that seem to partake of the nature of both, and that can precisely be referred to neither. That race of quadrupeds, called the gazelles, are of this kind; they are properly neither goat nor deer, and yet they have many of the marks of both; they make the shade between these two kinds, and fill up the chasm in nature.

\section{THE GAZELLES,}

ThE Gazelles, of which there are several kinds, can, with propriety, be referred neither to the goat nor the deer; and yet they partake of both natures. Like the goat, they have lollow horns that never fall, which is otherwise in the deer. They have a gallbladder, which is found in the goat and not in the deer; and, like that animal, they feed rather upon shrubs than grassy pasture. On the other hand, they resemble the raebuck in size and delicacy of form; they have deep pits under the eyes like that animal; they resemble the roebuck in the colour and nature of their hair; they resemble him in the bunches upon their legs, which only differ in being upon the fore-legs in these, and on the hind-legs in the other. They seem therefore, to be of a middle nature between these two kinds; or, to spenk with greater truth and precision, they form a distinct kind by themselves.

The distinguishing marks of this tribe of animals, by which they differ both from the goat and the deer, are these: their horns are 
made differently, being annulated or ringed round, at the same time that there are longitudinated depressions running from the bottom to the point. They have bunches of hair upon their fore-legs; they have a streak of black, red, or brown, running along the lower part of their sides, and three streaks of whitish hair in the internal side of the ear. These are characters that none of them are without; besides these, there are others which, in general, they are found to have, and which are more obvious to the beholder. Of all animals in the world, the gazclle has the most beautiful eye, extremely brilliant, and yet so meek, that all the eastern poets compare the eyes of their unistresses to those of this animal. A gazelle-eyed beauty is considered as the highest compliment that a lover can pay; and, indeed, the Greeks themselves thought it no inelegant piece of flattery to resemble the eyes of a beautiful woman to those of a cow. The gazelle, for the most part, is more delicately and finely limbed than even the roebuck; its hair is as short, but finer, and more glossy. Its hinder legs are longer than those before, as in the hare, which gives it greater security in ascending or descending steep places. Their swiftness is equal, if not superior, to that of the roe; but as the latter bounds forward, so these run along in an even uninterrupted course. Most of them are brown upon the back, white under the belly, with a black stripe separating those colours between. Their tail is of various lengths, but in all covered with pretty long hair; and their ears are beautiful, well-placed, and terminating in a point. They all have a cloven hoof, like the sheep; they all have permanent horns; and the female lias them smaller than the nuale.

Of these animals, Mr. Buffon makes twelve varieties; which, however, is much ferrer than what other naturalists have made them. The first is the gazella, properiy so called, which is of the size of the roebuck, and very much resembling it in all the proportions of its body, but entirely differing, as was said, in the nature and fashion of the horns, which are black and hollow, like those of the ram or the goat, and never fall. The second he calls the kevel, which is rather less than the former; its eyes also seem larger; and its horns, instead of being round, are flatted on the sides, as well in the male as the female. The third he calls the corin, which very much resembles the two former, but that it is still less than either. Its horns also are smaller in proportion, smoother than those of the other two, and the annular prominences belonging to the kind are scarce discernible, and may be rather called wrinkles than prominences. Some of these animals are often seen streaked like the tiger. These three are supposed to be of the same species. The fourth he calls the zeiran, the horns only of which he has seen; which, from their size, and the description of travellers, he supposes to belong to a larger kind of the gazelle, found in India and Persia, under that denomination.

The fifth he calls the koba, and the sixth the $k o b$; these two differ from each other only in size, the former being much larger than the latter. The muzzle of these animals is much longer than those of the ordinary gazelle; the liead is differently shaped, and they have no depressions under the eyes. The seventh he calls after its Egyptian name, the algazel; which is shaped pretty much like the ordinary gazelle, except that the horns are much longer, being generally three feet from the point to the insertion; wherens, in the common gazelle, they are not above a foot; they are smaller also, and straighter, till near the extremities, when they turn short, with a very sharp flexure: they are black and smooth, and the annular prominences are scarcely observable. The eighth is called the pazan; or, by some, the bezoar goat, which greatly resembles the former, except a small variety in their horns; and also with this difference, that as the algazel feeds upon the plains, this is only found in the mountains. They are both inhabitants of the same countries and climates; being found in Egypt, Arabia, and Persia. This last is the animal famous for that concretion in the intestines or stomach, called the oriental bezoar, which was once in such repute all over the world for its medicinal virtues. The word bezoar is supposed to take its name either from the pazan or pazar, which is the animal that produces it; or from a word in the Arabic language, which signifies antidote or counter-poison. It is a stone 
of a glazed blackish colour, found in the stomach, or the intestives of some animal, and brought over to us from the East-Indies. Like all other animal concretions, it is found to have a kind of nucleus, or hard substance within, upon which the external coatings were formed; for, upon being sawed through, it is seen to have layer over layer, as in an onion. This nucleus is of various kinds; sometimes the buds of a shrub, sometimes a piece of stone, and sometimes a marcasite. This stone is from the size of an acorn to that of a pigeon's egg; the larger the stone, the more valuable it is held; its price increasing, like that of a diamond. There was a time when a stone of four ounces sold in Europe for above two hundred pounds; but, at present, the price is greatly fallen, and they are in very little esteem. The bezoar is of various colours; sometimes of a blood colour, sometimes of a pale yellow, and of all the shades between these two. It is generally glossy, smooth, and has a fragrant smell, like that of ambergris, probably arising from the aromatic vegetables upon which the animal that produces it feeds. It has been given in vertigoes, epilepsies, palpitations of the heart, cholic, jaundice; and in those places, where the dearness and not the value of medicines is consulted, in almost every disorder incident to man. In all, perhaps, it is equally efficacious, acting only as an absorbent powder, and possessing virtues equal to common chalk, or crabs' claws. Judicious physicians have therefore discarded it; and this celebrated medicine is now chiefly consumed in countries where the knowledge of Nature has been but little advanced. When this medicine was in its highest reputation, many arts were used to adulterate it; and many countries endeavoured to find out a bezoar of their own. Thus we had Occidental bezoar, brought from America; German bezoar, which has been mentioned before; cow bezoar, and monkey bezoar. In fact, there is scarce an animal, except of the carnivorous kinds, that does not produce some of these concretions in the stomach, intestines, kidneys, bladder, and even in the heart. To these ignorance may impute virtues that they do not possess; experience has found but fow cures wrought by their efficacy : but it is well known, that they often prove fatal to the animal that bears them. These concretions are generally found in cows, by their practice of licking off their hair, which gathers in the stomach into the shape of a ball, acquires a surprising degree of hardness, and sometimes a polish like leather. They are often as large as a goose-egg: and when become too large to pass, block up the passage of the food, and the animal dies. The substance of these balls, however, is different from the bezoar mentioned above; being rather a concretion of bair than of stone. There is a bezoar found in the gall-bladder of a boar, and thence called hog bezoar, in very great esteem; but perhaps with as little justice as any of the former. In short, as we have already observed, there is scarce an animal, or scarce a part of their bodies, in which concretions are not forned; and it is more than probable, as Mr. Buffon justly remarks, that the bezoar so much in use formerly, was not the production of the pazar, or any one animal only, but that of the whole gazelle kind; who feeding upon odoriferous herbs and plants, gave this admirable fragrance to the accidental concretions which they were found to produce. As this medicine, however, is but little used at present, our curiosity is much abated as to the cause of its formation. To returu, therefore, to the varieties in the gazelle tribe, the ninth is called the ranguer, and is a native of Senegai. This differs somewhat in shape and colour f: om the rest; but particularly in the shape of its horns, which are straight near to the points, where they crook forward, pretty much in the same manner as in the shammoy they crook backward. The tenth variety of the gazelie is the antelope, so well known to the English, who have given it the name. This animal is of the size of a roe-buck, and resembles the gazelle in many particulars, but differs in otbers: it has deeper eye-pits than the former; the horns are formed differently also, being about sixteen inches long, almost touching each other at the bottom, and spreading as they rise, so as at their tips to be sixteen inches asunder. They have the annual prominences of their kind, but not so distinguishable as in the gazelle: however, they have a double flexure, which is very remarkable, and serves to distinguish them from all others of their kind. At the root 
they have a tuft of hair, which is longer than that of any part of the body. Like others of the same kind, the antelope is brown on the back, and white under the belly; but these colours are not separated by the black streak which is to be found in all the rest of the gazelle kinds. There are different sorts of this animal, some with larger horns than others, and others with less. The one which makes the eleventh variety in the gazelle kind, Mr. Buffon calls the lidme, which has very long horns; and the other, which is the twelfth and last, he calls the Indian antelope, the horns of which are very small.

To these may be added three or four varieties more, which is not easy to tell whether to refer to the goat or the gazelle, as they equally resemble both. The first of these is the bubalus, an animal that seems to partake of the mixed natures of the cow, the goat, and the deer. It rescmbles the stag in the size and the figure of its body, and particularly in the shape of its legs. But it has permanent horns, like the goat; and made entirely like those of the gazelle kind. It also resembles that animal in its way of living: however, it differs in the make of its head, being exactly like the cow in the length of its muzzle, and in the disposition of the bones of its skull; from which similitude it has taken its name. This animal has a narrow long head; the eyes are placed very high; the forelicad short and narrow; the horns permanent, about a foot long, black, thick, annulated, and the rings of the gazelle kind, remarkbly large; its shoulders are very high, and it has a kind of bunch on them, that terminates at the neck; the tail is about a foot long, and tufted with hair at the extremity. The hair of this animal is remarkable in being thinker at the middle than at the root: in all other quadrupeds, except the elk and this, the hair tapers off from the bottom to the point; but in these, each hair seems to swell in the middle, like a nine-pin. The bubalus also resembles the elk in size, and the colour of its skin ; but these are the only similitudes between them: as the one has a very large branching head of solid horns that are naturally deciduous, the other has black unbranching hollow horns that never fall. The bulsalus is common enough in Barbary, and luas often been called by the name of the barbary cow, from which animal it differs so widely. It partakes pretty much of the nature of the antelope; like that having the hair short, the hide black, the ears pointed, and the flesh good for food.

The second anomalous animal of the goatkind, Mr. Buffon calls the condoma. It is supposed to be equal in size to the largest stag, but with hollow horns, like those of the goat kind, and with varied flcxures, like those of the antelope. They are above three feet long; and at their extremities about two feet asunder. All along the back there runs a white list, which ends at the insertion of the tail ; another of the same colour crosses this, at the bottom of the neck, which it entirely surrounds : there are two more of the same kind running round the body, one behind the fore-legs, and the other running parallel to it before the hinder. The colour of the rest of the body is grayish, except the belly, which is white: it has also a long gray beard; and its legs, though long, are well proportioned.

The third that may be mentioned, he calls the guiba. It resembles the gazelles in every particular, except in the colour of the belly, which, as we have seen, is white in them, but in this is of a deep brown. Its horns also are not marked with annual prominences, but are smooth and polished. It is also remarkable for white lists, on a brown ground, that are disposed along the aninal's body, as if it were covered with harness. Like the former it is a native of Africa.

The African wild goat of Grimmius is the fourth. It is of a dark ash-colour; and in the middle of the head is a hairy tuft, standing upright ; on both sides, between tlue eyes and the nose, there are very deep cavities, greater than those of the other kinds, which contain a yellow oily liquor, which coagulates into a black substance, that has a smell between musk and civet. This being taken away, the liquor again runs out, and congulates, as before. These cavities have no conımunication with the cyes, and, consequently, this oozing substance can have nothing of the nature of tears.

To this we may add the chevrotin, or little guinea deer, which is the least of all cloven footed quadrupeds, and perhaps the most beau: tiful; its legs, at the smallest part, are not much thicker than the shank of a tobaccopipe; it is about seven inches high, and about twelve from the point of the nose to the inser- 
tion of the tail. It is the most delicately shaped animal in the world, being completely formed like a stag in mininture; except that its horus, when it has any, are more of the gazelle kind, being hollow and annulated in the same manner. It has two canine teeth in the upper jaw; in which respect it differs from all other animals of the goat or deer kind, and thus makes a species entirely distinct by itself. This wonderful animal's colour is not less pleasing; the hair, which is short and glossy, being in some of a beautiful yellow, except on the neck and belly, which is white. They are natives of India, Guinea, and the warm climates between the tropics; and are found in great plenty. But though they are amazingly swift for their size, yet the Negroes often overtake them in the pursuit, and knock them down with their sticks. They may be easily tamed, and then they become familiar and pleasing; but they are of such delicate constitutions, that they can bear 110 climate but the hottest; and they always perish with the rigours of ours, when they are brought over. The male in Guinea has horns: the female is without any; as are all the kinds of this animal, to be found either in Java or Ccylon, where they chiefly abound.

Such is the list of the gazelles; all which pretty nearly resemble the deer in form and delicacy of shape; but have the horns hollow, single, and permanent, like those of the goat. They properly fill up, as has been already observed, the interval between these two kinds of animals; so that it is difficult to tell where the goat ends, and the deer may be said to begin. If we compare the gazelles with each other, we shall find but very slight distinctions between them. The turn or the magnitude of the horns, the different spots on the skin, or a difference of size in each, are chiefly the marks by which their varieties are to be known; but their way of living, their nature, and their peculiar swiftness, all come under one description.

The gazelles are, in general, inhabitants of the warmer climates; and contribute, among other embellishments, to add beauty to those forests that are for ever green. They are often seen feeding in herds, on the sides of the mountain, or in the shade of the wroods; and fly all together, upon the smallest approaches of danger. They bound with such swiftness, and are so very shy, that dogs or men vainly attempt to pursue them. They traverse those precipices with ease and safety, which to every quadruped else are quite impracticable; nor can any animals but of the winged kind overtake them. Accordingly, in all those countries where they are chiefly found, they are pursued by falcons; and this admirable manner of hunting makes onc of the principal amusements of the upper ranks of people all over the East. The A rabians, Persians, and Turks, breed up for this purpose, that kind of hawk called the falcon gentle, with which, when properly trained, they go forth on horseback among the forests and the mountains, the falcon perching upon the hand of the hunter. Their expedition is conducted with profound silence; their dogs are taught to hang behind; while the men, on the fleetest coursers, look round for the game. Whenever they spy a gazelle at the proper distance, they point the falcon to its object, and encourage it to pursue. The falcon, with the swiftness of an arrow, flies to the animal, that, knowing its danger, endeavours, but too late, to escape. The falcon soon coming up with its prey, fixes its talons, one into the animal's cheek, the other into its throat, and deeply wounds it. On the other hand, the gazelle attempts to escape, but is generally wounded too deep to run far. The falcon clings with the utmost perseverance, nor ever leaves its prey till it fills; upon which the hunters from behind approaching, take up both, and reward the falcon with the blood of the spoil. They also teach the young ones by applying them to the dead animalis throat, and accustoming them betimes to fix upon that particular part ; for if it should happen that the falcon fixed upon any other part of the gazelle, either its back or its haunches, the animal would easily escape among the mountains, and the hunter wonld also lose his falcon. They sometimes also hunt these animals with the ounce. This carnivorous and fierce creature bcing made tame and domestic, generally sits on horseback behind the hunter, and remains there with the utmost composure, until the gazelle is shown; it is then that it exerts all its arts and fierceness; it does not at once fly at its prey, but approaches slyly, turning and winding about 
until it comes within the proper distance, when all at once it bounds upon the heedless animal, and instantly kills it, and sucks its blood. If, on the other hand, it misses its aim, it rests in its place, without attempting to pursue any farcher, but secms ashamed of its own inability.

There is still another way of taking the gazelle, which seems not so certain, nor so amusing as either of the former. A tame gazelle is bred up for this purpose, who is taught to join those of its kind, wherever it perceives them. When the hunter, therefore, perceives a herd of these together, he fixes a noose round the horns of the tame gazelle in such a manner, that if the rest but touch it, they arc en- tangled; and thus prepared, he sends his gazelle among the rest. The tame animal no sooner approaches, but the males of the herd instantly sally forth to oppose him; and, in butting with their horns, are caught in the noose. In this, both struggling for some time, fall together to the ground; and, at last, the hunter coming up, disengages the one, and kills the other. Upon the whole, however, these animals, whatever be the arts used to pursue them, are very difficult to be taken. As they are continually subject to alarms from carnivorous beasts, or from man, they keep chicfly in the most solitary and inaccessible places, and find their only protection from situations of the greatest danger.

\section{CHAPTER XLIV.}

\section{OF THE MUSK ANIMAL.}

THE more we search into nature, the more we shall fud how little she is known; and we shall more than once have occasion to find, that protracted inquiry is more apt to teach us modesty, than to produce inforination. Althongh the number and nature of quadrupeds at first glance seems very little known; yet, when we come to examine closer, we find sone with which we are very ptrially acquarat, and others that are utterly unknown. There is scarce a cabinet of the curious but what has the spoils of animals, or the horns or the hoofs of quadrupeds, which do not come within former descriptions. There is scarce a person whose trade is to dress or improve furs, but knows several creatures by their skins, which no naturalist has hitherto had notice of. But of all quadrupeds, there is none so justly the rejroach of natural historians, as that which bears the musk. This perfume, so well known to the elegant, and so very useful in the hands of the physician; a medicine that has for more than a century been imported from the East in great quantities, and during all that time has been inllproving in its reputation, is, nevertheless, so very litcle understood, that it remains a doubt whether the ani nal that produces it be a hog, an ox, a goat, or a deer.
When an animal with which we are so nearly connected, is so utterly unknown, how little must we know of many that are more remote and unserviceable! Yet naturalists proceed in the same train, enlarging their catalogues and their names, without endeavouring to find out the nature, and fix the precise history of those with which we are very partially acquainted. It is the spirit of the scholars of the present age to be fonder of increasing the bulk of our knowledge, than its utility; of extending their conquests, than of improving their empire.

The musk which comes to Europe, is bronght over in small bags, about the size of a pigeon's egg, which, whell cut open, appear to contain a kind of dusky, reddish substance, like coagulated blood, and which, in large quantities, has a very strong smell; but, when mixed and diffused, becomes a very agreeable perfume. Indeed, no substance now known in the world has a stronger or a more permanent smell. A grain of musk perfumes a whole room; ; and its odour continues for some days without diminution. But in a larger quantity it continues for ycars together ; and seems scarce wasted in its weight, although it has filled the atnosphere to a great distance with its parts. It is particularly used in mcdi- 
cine, in nervous and hysteric disorders; and is found in such cases to be the most powerful remedy now in use : however, the animal that furnishes this admirable medicine, has been very variously described, and is known but very imperfectly.

'The description given of this animal by Grew, is as follows: "The musk animal is properly neitler of the goat nor deer kind, for it has no liorns, and it is uncertain whether it runinates or not; however, it wants the foreteeth in the upper jaw, in the same manner as in runinating animals; but, at the sarne time, it has tusks like those of a log. It is three feet six inclies in length, from the head to the tail; and the head is above half a foot long. The fore-part of the head is like that of a grayhound; and the ears are three inclies long, and erect, like those of a rabbit; but the tail is not above two inches. It is cloven-footed, like beasts of the goat kind; the hair on the head and legs is half an inch long, on the belly an inch and a half, and on the back and buttocks three inches, and proportionably thicker than in any other animal. It is brown and white alternately, from the root to the point ; on the head and thighs it is brown, but under the belly and tail white, and a little curled, especially on the back and belly. On each side of the lower jaw, under the corners of the mouth, there is a tuft of thick hair, which is short and hard, and about three quarters of an inch long. The liair, in general, of this animal, is remarkable for its softness and fine texture; but what distinguishes it particularly are the tusks, which are an inch and a half long, and turn back in the form of a hook; and more particularly the bag which contains the musk, which is three inches long, two broad, and stands out fronı the belly an inch and a half. It is a very fearful animal, and, therefore, it has long ears; and the sense of hearing is so quick, that it can discover an enemy at a great distance."

After so Iong and circumstantial a description of this animal, its nature is but very little known; nor has any anatomist as yet examined its internal structure; or been able to inform us whether it be a ruminant animal, or one of the hog kind; how the musk is formed, or whether those bags in which it comes to us be really belonging to the animal, or al'e ouly the sophistications of the venders. Indeed, when we consider the inmense quantities of this substance which are consumed in Europe alone, not to mention the East, where it is in still greater repute than here, we can hardly suppose that any one animal can furnish the supply ; and particularly when it must be killed before the bag can be obtained. We are told, it is true, that the musk is often deposited hy the animal upon trees and stones, against which it rubs itself when the quantity becomes uneasy; but it is not in that form which we receive it, but always in what seems to be its own natural bladder. Of these, Taverner brought lome near two thousand in one year; and, as the animal is wild, so many must, during that space, have been hunted and taken. But as the creature is represented very shy, and as it is found but in some particular provinces of the East, the wonder is, low its bag should be so cheap, and firnished in such great plenty. The bag in common does not cost (if 1 do not forget) above a crowll by retail; and yet this is supposed the only one belonging to the animal; and for the obtaining of which, it must have been luunted and killed. The only way of solving this difficulty, is to suppose that these bags are, in a great measure, counterfeit, taken from some other animal, or from some part of the same, filled with its blood, and a very little of the perfume, but enough to impregnate the rest with a strong and permanent odlour. It comes to us from different parts of the East ; from China, Tonquin, Bengal, and often from Muscovy : that of Thibet is reckoned the best, and sells for fourteen shillings an ounce; that of Muscovy the worst, and sells but for three; the odour of this, though very strong at first, being quickly found to evaporate. Musk was some years ago in the lighest request as a perfume, and but little regarded as a medicine; but at present its reputation is tutally changed; and having been found of great benefit in pliysic, it is but little regarded for the purposes of elegance. It is thus that things which become necessary, cease to continue pleasing; and the consciousness of their use, destroys their power of administering delight. 


\section{CHAPTER XLV.}

\section{ANIMALS OF THE DEER KIND.}

IF we compare the stag and the bull, as to shape and form, no two animals can be more unlike; and yet, if we examne their internal structure, we shall find a striking similitude between them. Indeed, their differences, except to a nice observer, will scarcely be percrivable. All of the decr kind want the gallblıdder; their kidneys are formed differently ; their spleen is also proportionably larger; their tail is shorter; and their horns, which are soli.l, are renewed every year. Such are the slight internal discriminations betwe'n two animals, one of which is among the swiftest, and the other the heaviest of the brute creation.

The stag is one of those innocent and peaceable animals that seems made to embellish the forest, and animate the solitudes of nature. 'The casy elegance of his form, the lightness of his motions, those large branches that seem marle rather for the ornament of his hend than its defence, the size, the strength, and the swiftness of this beautiful creature, all sufficiently rank him ansong the first of quadrupeds, among the most noted objects of human curiosity.

The stag, or hart, whose female is called a hind, and the young a calf, differs in the size and in horus from a fallow-deer. He is much larger, and his horns are round; whereas in the fallow-kind they are broad and palınated. By these the animal's age is known. The first year the stag has no horns, but a horny excrescence, which is short, rough, and covered with a thin, hairy skin. The next year the horns are single and straight; the third year they have two antlers, three the fourth, four the fifth, and five the sixth; this number is not always certain, for sometimes there are more, and often less. When arrived at the sixth year, the antlers do not always increase; and although the number may amount to six or seven on each side, yet the auimal's age is then estimated rather from the size of the antJer's, and the thickness of the branch which sustains them, than from their variety. These horns, large as they scem, are, not withstanding, shed every year, and new ones conte in their place. The old horns are of a firm, solid texture, and usually employed in making handles for knives, and other domestic utensils. But while young, nothing can be more soft or tender; and the animal, as if conscious of his own imbecility at those times, instantly upon shedding his former horns, retires froin the rest of his fellows, and hides himself in solitudes and thickets, never venturing out to pasture, except by night. Duriug this time, which most usually happens in the spring, the new horns are very painful, and have. a quick sensibility of any external impression. The flies, also, are extremely troublesome to him. When the old horn is fallen off, the new does not begin immediately to appear; but the bones of the skull are seen covered only with a transparent periosteum or skin, which, as anatomists teach us, covers the bones of all animals. After a short time, however, this skin begins to swell, and to form a soft tunnour, which contains a great deal of blood, and which begins to be covered with a downy substance that has the feel of velvet, and appears nearly of the same colour with the rest of the animal's hair. This tumour every day buds forward from the point like the graft of a tree ; and, rising by degrees fiom the head, shoots out the antlers on either side, so that in a few days, in proportion as the animal is in conclition, the whole head is completed. However, as was said above, in the begimning, its consistence is very soft, and has a sort of bark, which is no more than a continuation of the integument of the skull. It is velveted and downy, and every where furnished with bloodvessels, that supply the growing horns with nourishinent. As they creep along the sides of the branches, the print is marked over the whole surface; and the larger the blood-vessels, the deeper these marks are found to be: from hence arises the incquality of the surface of the deel's horns; which, as we see, are furrowed all along the sides, the impressions diminishing towards the point, where the substance is as smooth and as solid as ivory. But it ought to be observed, that this substance, of which the horns are comvosed, begins to harden at the 
bottom while the upper part remains soft, and still continues growing; from whence it appears that the horns grow differently in deer from those of sheep or cows; in which they are always seen to increase from the bottom. However, when the whole head has received its full growth, the extremities then begin to acquire their solidity; the velvet covering, or bark, with its blood-vessels, dry up, and then begin to fall; and this the auimal hastens, by rubbing its antlers against every tree it meets. In this manner, the whole external surface being stripped off by degrees, at length the whole head acquires its complete hardness, expansion, and beauty.

It would be a vain task to inquire into the cause of the animal production of these horns; it is sufficient to observe, that if a stag be castrated when its horns are fallen off, they will never grow again; and, on the contrary, if the same operation is performed when they are on, they will never fall off. If only one of his testicles are taken out, he will want the horn on that side; if one of the testicles only be tied up, he will want the horn of the opposite side. The incrcase of their provision also tends to facilitate the growth and the expansion of the horus; and Mr. Buffon thinks it possible to retard their growth entirely by greatly retrenching their food. ${ }^{\mathrm{a}}$ As a proof of this, nothing can be more obvious than the difference between a stag bred in fertile pastures and undisturbed by the hunter, and one often pursued and ill-nourished. The former has his head expanded, his antlers numerous, and the branches thick; the latter has but few antlers, the traces of the bloodvessels upon them are but slight, and the expansion but little. The beauty and size of their horns, therefore, mark their strength and their vigour; such of them as are sickly, or have been wounded, never shooting out that magnificent profusion so much admired in this animal. Thus the horns may, in every respect, be resembled to a vegetable substance, grafted upon the head of an animal. Like a vegetable they grow from the extremities; like a vegetable they are for a while covered with a bark that nourishes them; like a ve-

\footnotetext{
a Buffon, vol. xi. p. 113.

b Mr. Buffon has supposed something like this. Vide passim.
}

getable they have their annual production and decay; and a strong imagination might suppose that the leafy productions on which the animal feeds, go once more to vegetate in his horns. ${ }^{b}$

The stag is usually a tivelvemonth old before the horns hegin to appear, and then a single branch is all that is seen for the year ensuing. About the begiming of spring, all of this kind are seen to shed their horns, which fall off of themselves; though sometimes the animal assists the efforts of nature, by rubbing them against a tree. It scldom happens that the branches on both sides fall off at the same time, there often being two or three days between the dropping of the one and the other. The old stags usually shed their horns first; which generally happens towards the latter end of February, or the beginning of March. Those of the second head, (namely, such as are between five and six years old,) shed their horus about the middle or latter end of March; those still younger, in the month of April; and the youngest of all, not till the middle, or the latter end of May; they generally shed them in pools of water, whither they retire from the heat; and this has given rise to the opinion of their always hiding their horns. These rules, though true in general, are yet subject to many variations; and universally it is known that a severe winter retards the shedding of the horns. The horus of the stag generally increase in thickness and in height from the second year of its age to the eighth. In this state of perfection they continue during the vigour of life; but as the animal grows old the horns feel the impressions of age, and shrink like the rest of the body. No branch bears nore than twenty or tiventy-two antlers even in the highest state of vigour; and the number is subject to great variety; for it happens that the stag at one year has either less or more than the year preceding, in proportion to the goodness of his pasture, or the continuance of his security, as these aninals seldom thrive when often roused by the hunters. The horns are also found to partake of the nature of the soil; in the more fertile pastures they are large and tender; on the contrary, in the barren soil, they are liard, stunted, and brittle. As soon as the stags have shed their horns, they separate from each other, and scek the plainer parts of the country, remote from every other aninal, which they 
are utterly unable to oppose. They then walk with their heads stooping down, to keep their horns from striking ayainst the branches of the trees above. In this state of imbecility they continuc near three months before their heads have acquired their full growth and solidity; and then, by rubbing them against the branches of every thicket, they at length clear them of the skin which had contributed to their growth and nourishment. It is said by some, that the horn takes the colour of the sap of the tree ayainst which it is rubbed; and that sone thus become red, when rubbed against the heath; and others brown, by rubbing against the oak; this, however, is a mistake, since stags kept in parks where there are no trees, have a variety in the colour of their horns, which cau be ascribed to nothing but nature. A short time after they have fumlished their horns, they begin to feel the impressions of the rut, or the desire of copnlation. The old ones are the most forward; and abont the end of Augnst, or the beginning of September, they quit their thickets, and return to tie mountnin in order to seek the hind, to whou they call with a loud trenendous note. At this time their neck is swolu; they appenr bold and furious : fly from country to country; strike with their horus against the trees and other obstacles, and continue restless and fierce until they liave found the fensale; who at lirst flies from them, but is at last compelleil and overtaken. When two stags contend for the same fomale, how timorous soever they may appear at other times, they then seem agitated with an uncommon degree of ardour. They paw up the earth, nienace each other with their horns, brllow with all their force, and striking in a desperate manner again $\mathrm{t}$ ench other, seem determined upon death or victory. This combat continues till one of thein is defeated or flies; and it often happens that the victor is obliged to fight several of those battles hefore it remains undisputed master of the field. The old ones are generally the conquerors upon these occasions, as they have more strength and greater courage; and these also are preferred by the hind to the young ones, as the latter are more fecble, and less ardent. However, they are all equally inconstant, keeping to the female but a few days, and then seeking out for another, not to be enjoyed, perhaps, without a repetition of their former danger.

พo. $23 \& 24$.
In this manner the stag continues to range from one to the other for about three weeks, the time the rut continues; during which he scarce eats, slecps, or rests, but continues to pursue, to combat, and to enjoy. At the end of this period of madıess, for such in this animal it seems to be, the creature that was before so fat, sleek, and glossy, becomes lean, feeble, and timid. He then retires from the herd to seek plenty and repose; lie frequents the side of the forest, and chooses the most nourishing pastures, remaining there till his strength is renewed. Thus is his whole life passed in the alternations of plenty and want, of corpulence and inanition, of health and sickness, without having lis constitution much affected by the violence of the change. As he is above five years coming to perfection, he lives about forty years; and it is a general rule, that every animal lives about seven or eight times the number of years which it continues to grow. What, therefore, is reported concerning the life of this animal, has arisen from the credulity of ignorance: some say, that a stag having been taken in France, with a collar, on which were written these words, "Cæsar hoc me donavit;" this was interpreted of Julius Casar; but it is not considered that Cresar is a general name for kings, and that one of the Emperors of Germany, who are always styled Casars, might have ordered the inscription.

This animal may differ in the term of his life according to the goodness of his pasture, or the undisturbed repose he happens to enjoy. These are adrantages that influence not only his age, but his size and his vigour. The stags of the plains, the valleys, and the little hills, which abound in corn and pasture, are much more corpulent and much taller than such as are bred on the rocky waste, or the heathy mountain. The latter are low, small, and meagre, incapable of going so swift as the former, although they are found to hold out much longer. They are also more artful in evading the hunters; their horns are generally black and short, while those of the lowland stags are reddish and flourishing; so that the animal seems to increase in beauty and stature in proportion to the goodness of the pasture, which he enjoys in security. The usual colour of the stag in England $2 \mathrm{U}$ 
was red; nevertheless, the greater number in other countries are brown. There are some few that are white; but these seem to have obtained this colour in a former state of domestic tameness. Of all the animals that are natives of this climate, there are none that have such a beautiful cye as the stag; it is sparkling, soft, and sensible. His senses of smelling and hearing are in no less perfection. When he is in the least alarmed, he lifts the head and erects the ears, standing for a few minutes as if in a listening posture. Whenever he ventures upon some unknown ground, or quits his native covering, he first stops at the skirt of the plain to examine all around; he next turns against the wind to examine by the sinell if there be any enemy approaching. If a person should happen to whistle or call out, at a distance, the stag is seen to stop short in his slow measured pace, and gazes upon the stranger with a kind of awkward admiration: if the cunning animal perceives neither dogs nor fire-arms preparing against him, he goes forward, quite unconcerned, and slowly proceeds without offering to fly. Man is not the enemy he is most afraid of; on the contrary, he seems to be delighted with the sound of the shepherd's pipe; and the hunters sometimes make use of that instrument to allure the poor animal to his destruction.

The stag eats slowly, and is very delicate in the choice of his pasture. When he has eaten a sufficiency, he then retires to the covert of some thicket to chew the cud in security. His rumination, however, seems performed with much greater difficulty than with the cow or sheep; for the grass is not returned from the first stomach without much straining, and a kind of hiccup, which is easily perceived during the whole time it continues. This may proceed from the grcater length of his neck and the narrowness of the passage, all those of the cow and the sheep kind having it much wider.

This animal's voice is much stronger, loud$\mathrm{er}$, and more tremulous, in proportion as he advances in age; in the time of rut it is even terrible. At that season he seems so trarisported with passion, that nothing obstructs his fury; and, when at bay, he keeps the dogs off with great intrepidity. Some years ago,
William Duke of Cumberland caused a tiger and a stag to be inclosed in the same area; and the stag made so bold a defence, that the tiger was at last obliged to fly. The stag seldom drinks in the winter, and still less in the spring, while the plants are tender and covered over with dew. It is in the heat of summer, and during the time of rut, that he is seen constantly frequenting the sides of rivers and lakes, as well to slake his thirst as to cool his ardour. Heswims with great ease and strength, and best at those times when he is fattest, his fat keeping him buoyant, like oil upon the surface of the water. During the time of rut he even ventures out to sea, and swims from onc island to another, although there may be some leagues distance between them.

The cry of the hind, or female, is not so - loud as that of the male, and is never excited but by apprehension for herself or her young. It need scarce be mentioned that she has no horns, or that she is more fecble and unfit for hunting than the male. IVhen once they have conceived, they separate from the males, and then they both herd apart. The time of gestation continues between eight and nine months, and they generally produce but one at a time. Their usual season for bringing forth is about the month of May, or the beginning of Inne, during which they take great care to hicle their young in the most obscure thickets. Nor is this precaution without reason, since almost every creature is then a formidable enemy. 'The eagle, the falcon the osprey, the wolf, the $\mathrm{dog}$, and all the rapacious family of the cat kind, are in continual employment to find out her retreat. But, what is more unnatural still, the stag himself is a prolessed cnemy, and she is obliged to use all her arts to conceal her young from him, as from the inost dangerous of her pursuers. At this season, therefore, the courage of the male scems transferred to the female; she defends her young against her less formidable opponents by force; and when pursued by the hunter, she ever offers herself to mislead him from the principal objects of her concern. Sho flies before the hounds for half the day, and then returns to her young, whose life she has thus preserved at the hazard of her own. The calf, for so the young of this animal is cal led, never quits the dam during the whole 
summer; and in winter, the hind, and all the malos under a year old, keep together, and asseinble in herds, which are more numerous in proportion as the season is more scvere. In the spring they separate; the hinds to bring forth, while none but the year olds remain together; these animals are, however, in general, fond of herding and grazing in company; it is danger or necessity alone that separates them.

The dangers they have to fear from other animals, are nothing when compared to those from man. The men of every age and nation have made the chase of the stag one of their most favourite pursuits; and those who first hunted from necessity, have continued it for amusement. In our own country, in particular, hunting was ever estcemed as one of the principal diversions of the great. ${ }^{\mathrm{a}}$ At first, indeed, the beasts of chase had the whole island for their range, and knew no other limits than those of the ocean.

'The Roman jurisprudence, which was formed on the manners of the first ages, established it as a law, that, as the natural right of things which have no master, belongs to the first possessor, wild beasts, birds, and fishes, are the property of whosoever could first take them. But the northern barbarians, who overran the Roman empire, bringing with them the strongest relish for this amusement, and, being now possessel of more easy means of subsistence from the lands they had conquered, their chiefs and leaders began to appropriate the right of hunting, and, instend of a natural right, to make it a royal one. When the Saxon kings, therefore, had established themselves in a heptarchy, the chases were reserved by each sovereign for his own particular amusement. Hunting and war, in those uncivilized ages, were the only employment of the great. Their active, but mucultivated minds, were susceptible of no pleasures but those of a violent kind, such as gave exercise to their bodies, and prevented the uneasiness of thinking. But as the Saxon kings only appropriated those lands to the business of the chase which were unoccupied before, so no individuals received any injury. But it was otherwise when the Norman kings

\footnotetext{
a British Zonlogy.
}

were settled upon the throne. The passion for bunting was then carricd to an excess, and every civil right was involved in general ruin. This ardour for hunting was stronger than the consideration of religion even in a superstitious age. The village communities, nay, even the most sacred edifices, were thrown down, and all turned into one vast waste, to make room for animals, the objects of a lawless tyrant's pleasure. Sanguinary laws were enacted to preserve the game; and, in the reigns of William Rufus and Henry I. it was less crimiual to destroy one of the human species than a beast of chase. Thus it continued while the Norman line filled the throne; but when the Saxon line was restored, under Henry II. the rigour of the forestlaws were softened. The barons also for a long time imitated the encroachments, as well as the amusements, of the monarchs; but when property became more equally divided, by the introduction of arts and industry, these extensive hunting grounds became more limited; and as tillageand husbandry increased, the beasts of chase were obliged to give way to others more useful to the community. Those vast tracts of land, before dedicated to hunting, were then contracted; and, in proportion as the useful arts gained ground, they protected and encouraged the labours of the industrious, and repressed the licentiousness of the sportsman. It is therefore, among the subjects of despotic government only, that these laws remain in full force; where large wastes lie uncultivated for the purpose of hunting; where the husbandman can find no protection from the invasions of his lord, or the continual depredations of those animals which he inakes the objects of his pleasure.

In the present cultivated state of this country, therefore, the stag is unknown in its wild natural state; and such of them as remain among us are kept, under the name of red derr, in parks among the fallow-deer. But they are become less common than formerly; its excessive viciousness, during the rutting season, and the badness of its flesh, inducing most people to part with the species. The few that still remain wild, are to be found on the moors that border on Cornwall and Devonshire; and in Ireland, on most of the large mountains of that country.

$2 \mathrm{U}^{*}$ 
In England, the hunting the stag and the buck are performed in the same manner; the animal is driven from some gentleman's park, and then hunted through the open country. But those who pursue the wild animal, have a much higher object, as well as a greater variety in the chase. To let loose a creature that was already in our possession, in order to catch it again, is, in my opinion, but a poor pursuit, as the reward, when obtained, is only what we before had given away. But to pursue an animal that owns no proprietor, and which he that first seizes may be said to possess, has something in it that seems at least more rational; this rewards the hunter for his toil, and seems to repay his industry. Besides, the superior strength and swiftness of the wild animal prolongs the amusement; it is possessed of more various arts to escape the hunter, and leads him to precipices where the danger ennobles the chase. In pursuing the animal let loose from a park, as it is unused to danger, it is but little versed in the stratagems of escape; the hunter follows as sure of overcoming, and feels none of those alterations of hope and fear which arise from the uncertainty of success. But it is otherwise with the mountain stag: having spent his whole life in a state of continual apprehension; having frequently been followed, and as frequently escaped, he knows every trick to mislead, to confound, or intimidate his pnrsuers; to stimulate their ardour, and enhance their success.

Those who hunt this animal have their peculiar terms for the different objects of their pursuit. The professors in every art take a pleasure in thus employing a language known only to themselves, and thus accumulate words which, to the ignorant, have the appearance of knowledge. In this manner, the stag is called the first year, a calf, or hind calf; the second year, a knobber; the third, a brock; the fourth, a stag-guard; the fifth, a stag; the sixth, a hart. The female is called a hind; the first year she is a calf; the second, a hearse; the third, a hind. This animal is said to harbour in the place where he resides. When be cries, he is said to bell; the print of lis hoof is called the slot; his tail is called the single; his excrement the fewmet; his horns are called his head: when simple, the first year, they are called broches; the third year, spcars; the fourth year, that part which bears the antlers is called the beam, and the little impressions upon its surface, glitters; those which rise from the crust of the beam are called pearls. The antlers also have distinct names; the first that branches off is called the antler; the second, the sur-antler; all the rest which grow afterwards, till you come to the top, which is called the crown, are called royal antlers; the little buds about the tops are called croches. The impression on the place where the stag has lain, is called the layer If it be in covert or a thicket, it is called his harbour. When a deer has passed into a thicket, leaving marks whereby his bulk may be guessed, it is called an entry. When they cast their heads, they are said to mew. When they rub their heads against trees, to bring off the peel of their horns, they are said to fray. When a stag bard hunted takes to swimining in the water, he is said to go sail; when he turns his head against the hounds, he is said to bay; and when the hounds pursue upon the scent, until they have unharboured the stag, they are said to draw on the slot.

Such are hut a few of the many terms used by hunters in pursuing of the stag, most of which are now laid aside, or in use only among the gamekeepers. The chase, however, is continued in many parts of the country where the red deer are preserved, and still makes the amusement of such as have not found out more liberal entertainments. In those few places where the animal is perfectly wild, the amusement, as was said above, is superior. The first great care of the hunter, when he leads out his hounds to the mountain side, where the deer are generally known to harbour, is to make choice of a proper stag to pursue. His ambition is to unharbour the largest and the boldest of the whole herd; and for this purpose he examines the track, if there be any, which if he finds long and large, be concludes, that it must have belonged to a stag, and not a hind, the print of whose foot is rounder. Those marks also which he leaves on trees, by the rubbing of his horns, show his size, and point him out as the proper object of pursuit. Now to serk out a stag in his lamnt, it is to he observed, that he changes his manner of feeding every month. 
From the conclusion of rutting-time, which is November, he feeds in heaths and broomy places. In December they herd together, and withdraw into the strength of the forests, to shelter theinselves from the severe weather, feeding on holm, elder-trees, and brambles. The three following months they leave herding, but keep four or five in a company, and venture out to the corners of the forest, where they feed on winter pasture, sometimes making their incursions into the neighbouring corn-fields, to feed upon the tender shoots, just as they peep above ground. In April and May they rest in thickets and shady places, and seldom venture forth unless roused by approaching danger. In September and October their annual ardour returns; and then they leave the thickets, boldly facing every danger, without any certain place for food or harbour. When, by a knowledge of these circumstances, the hunter has found out the residence, and the quality of his game, his next care is to uncouple and cast off his hounds in the pursuit: these no sooner perceive the timorous animal that flies before them, but they altogether open in full cry, pursuing rather by the scent than the view, encouraging each other to continue the chase, and tracing the flying aninal with the most amazing sagacity. The hunters also are not less ardent in their speed on horseback, cheering up the dogs, and directing them where to pursue. On the other hand, the stag, when unharboured, flies at first with the swiftness of the wind, leaving his pursuers several miles in the rear; and at length having gained his former coverts, and no longer hearing the cries of the dogs and men that he had just left behind, he stops, gazes round him, and seems to recover his natural tranquillity. But this calm is of short duration, for his inveterate pursuers slowly and securely trace him along, and be once more hears the approaching destruction from behind. He again, therefore, renews his efforts to escape, and again leaves his pursuers at almost the former distance; but this second effort makes him more feeble than before, and when they come up a second time, he is unable to outstrip them with equal velocity. The poor animal now, therefore, is obliged to have recourse to all bis little arts of escape, which sonetimes, though but seldom, avai him. In proportion as his strength fails him, the ardour of his pursuers is inflamed; he tracks more heavily on the ground, and this increasing the strength of the scent, redoubles the eries of the hounds, and enforces their speed. It is then that the stag seeks for refuge among the herd, and tries every artifice to put off some other head for his own. Sonnetimes he will send forth some little deer in his stead, in the mean time lying close himself, that the hounds may overshoot him. He will break into one thicket after another, to find decr, rousing them, gathering them logether, and endeavouring to put them upon the tracks he has made. His old companions, however, with a true spirit of ingratitude, now all forsake and shun hin with the most watelful industry, leaving the unhappy creature to take his fate by himself. Thus abandoned of his fellows, he again tries other arts, by donbling and crossing in some hard beaten highway, where the scent is least perceivable. He now also runs against the wind, not only to cool himself, but the better to hear the voice, and judge of the distanee, of his inplacable pursuers. It is now easily perceivable how sorely he is pressed, by his manuer of running, which, from the bounding, easy pace with which he began, is converted into a stiff and short manner of going; his mouth also is black and dry, without form on it; his tongue hangs out; and the tears, as some sny, are seen starting from his eyes. His last refuge, when every other method of safety has failed him, is to take the water, and to attempt an escape by crossing whatever lake or river he happens to approach. While swimming, he takes all possible care to keep in the middle of the stream, least, by touching the bough of a tree, or the herbage on the banks, he may give scent to the hounds. He is also ever found to swim against the stream; whence the huntsmen have made into a kind of proverb, That he that would his chase find, must up with the river and down with the wind. On this occasion too he will often cover himself under water, so as to show nothing but the tip of his nose. Every resource, and every art being at length exhausted, the poor creature tries the last remains of his strength, by boldly opposing those enemies he cannot escape; he therefore faces the dogs and men, threaterns with 
his horns, guards himself on every side, and for some time stands at bay. In this manner, quite desperate, lie furiously aims at the first dog or man that approaches; and it often happens that he does not die unrevenged. At that time, the more prudent, both of the dogs and men, seem willing to avoid him; but the whole pack quickly coming up, he is soon surrounded and brought down, and the huntsman winds a treble mort, as it is called, with his horn.

Such is the manner of pursuing this animal in England; but every country has a peculiar method of its own, adapted either to the nature of the climate, or the face of the soil. The ancient manner was very different from that practised at present; they used their dogs only to find out the game, but not to rouse it. Hence they were not curious as to the music of their hounds, or the composition of their pack ; the dog that opened before he had discovered his game, was held in no estimation. It was their usual manner silently to find out the animal's retreat, and surround it with nets and engines, then to drive him up with all their cries, and thus force him into the toils which they have previously prepared. In succeeding times the fashion seemed to alter; and particularly in Sicily, the manner of hunting was as follows. ${ }^{\mathrm{a}}$ The nobles and gentry being informed which way a herd of deer passed, gave notice to one another, and appointed a day of hunting. For this purpose, every one was to bring a cross-bow, or a long-bow, and a bundle of staves, shod with iron, the heads bored, with a cord passing through them all. Thus provided, they came to where the herd continued grazing, and casting themselves about in a large ring, surrounded the deer on every side. Then each taking his stand, unbound his faggot, set up his stake, and tied the end of the cord to that of his next neighbour, at the distance of about ten feet one from the other. Between each of these stakes was hung a bunch of crimson feathers, and so disposed, that with the least breath of wind they would whirl round, and preserve a sort of fluttering motion. This done, the persons who set up the staves withdrew, and hid themselves in the neighbour-

a Pier Hieroglyph. lib. vii. cap. vi. ing coverts: then the chief huntsman, entering with his hounds within the lines, roused the game with a fisll cry. The deer, frighted, and flying on all sides, upon approaching the lines, were scared away by the fluttering of the feathers, and wandered about within this artificial paling, still awed by the shining and fluttering plumage that encircled their retreat ; the huntsman, however, still pursuing, and calling every person by name, as he passed by their stand, commanded him to shoot the first, third, or sixth, as he pleased; and if any of then missed, or singled out another than that assigned him, it was considered as a most shameful mischance. In this manner, however, the whole herd was at last destroyed; and the day concluded with mirth and feasting.

The stags of China are of a particular kind, for they are no taller than a common house$\mathrm{dog}$; and hunting them is one of the principal diversions of the great. Their flesh, while young, is exceedingly good; but when they arrive at maturity, it begins to grow hard and tough: however, the tongue, the muzzle, and the ears, are in particular esteem among that luxurious people. Their manner of taking them is singular enough: they carry with them the heads of some of the females stuffed, and learn exactly to imitate their cry; upon this the male does not fail to appear, and looking on all sides, perceives the head, which is all that the hunter, who is himself concealed, discovers. Upon their nearer appronch the whole company rise, surround, and often take him alive.

There are very few varieties in the red deer of this country; and they are mostly found of the same size and colour. But it is otherwise in different parts of the world, where they are seen to differ in form, in size, in horns, and in colour.

The stag of Corsica is a very small animal, being not above half the size of those commoll among us. His body is short and thick, his legs short, and his hair of a dark brown.

There is in the forests of Germany, a kind of stag, named by the ancients the Tragelaphus, and which the natives call the bran deer, or the brown deer. This is of a darker colour than the common stag, of a lighter shade upon the belly, long hair upon the neck and 
throat, by which it appears bearded, like the goat.

There is also a very beautiful stag, which by some is said to be a native of Sardinia; but others (among whom is Mr. Buffon) are of opinion that it comes from Africa or the East-Indies. He calls it the axis, after Pliny; and considers it as making the shade between the stag and the fallow-deer. The horns of the axis are round, like those of the stag; but the form of its body entirely resembles that of the buck, and the size also is exactly the same. The hair is of four colours; namely, fallow, white, black, and gray. The white is predominant under the belly, on the inside of the thighs and the legs. Along the back there are two rows of spots in a right line; but those on other parts of the body are very irregular. A white line runs along each side of this animal, while the head and neck are gray. The tail is black above, and white beneath; and the hair upon it is six inches long.

Althongh there are but few individuals of the deer kind, yet the race seems diffused over all parts of the earth. The new continent of America, in which neither the sheep, the goat, nor the gazelle, have been originally bred, nevertheless produces stags, and other animals of the deer kind, in sullicient plenty. The Mexicans have a breed of white stags in their parks, which they call stags royal." The stags of Canada differ from ours in nothing except the size of the horns, which in them is greater; and the direction of the antlers, which rather turn back, than project forward, as in those of Europe. The same difference of size that obtains among our stags, is also to be seen in that country; and, as we are informed by Ruysch, the Americans have brought them into the same state of domestic tameness that we have our sheep, goats, or black cattle. They send them forth in the day-time to feed in the forests; and at night they return home with the herdsman who guards them. The inhabitants have no other milk but what the hind produces; and use no other cheese but what is made from thence. In this manner we find, that an animal which seems inade only for man's amuscment, may be easily brought to supply his necessities.

Buffon, vol, xii. p. 35 .
Nature has many stores of happiness and plenty in reserve, which ouly want the call of industry to he prosluced, and now remain as candidates for human approbation.

\section{THE FALLOW-DEER.}

No two animals can be more nearly allied than the stag and the fallow-deer. ${ }^{6}$ Alike in form, alike in disposition, in the superb furniture of their heads, in their swiftuess and timidity; and yet no two animals keep more distinct, or avoid each other with more fixed animosity. They are never seen to herd in the same place, they never engender together, or form a mixed breed; and eren in those countries where the stag is comınon, the buck seems to be entirely a stranger; in short, they both form distinct families; which, though so seemingly near, are still remote: and although with the same habitudes, yet retain an unalterable aversion. The fallowdeer, as they are much smaller, so they seem of a nature less robust, and less savage than those of the stag kind. They are found but rarely wild in the forests; they are, in general, bred up in parks, and kept for the purposes of hunting, or of luxury, their flesh being preferred to that of any other animal. It need scarce be mentioned, that the horns of the buck make its principal distinction, being broad and palmated; whereas those of the stag are in every part round. In the one, they are flatted and spread like the palm of the hand; in the other they grow like a tree, every branch being of the shape of the stem that bears it. The fallow-deer also has the tail longer, and the hair lighter than the stag; in other respects, they pretty near resemble one another.

The head of the buck, as of all other animals of this kind, is shed every year, and takes the usual time for repairing. The only difference between it and the stag is, that this change happens later in the buck; and its rutting-time, consequently, falls more into the winter. It is not found so furious at this senson as the former; nor does it so much exhaust itself by the violence of its ardour.

b Buffon, vol. xii. p. 36 . 
It does not quit its natural pastures in quest of the female, nor does it attack other animals with indiscriminate ferocity: however, the males combat for the female among each other; and it is not without many contests, that one buck is scen to become master of the whole herd. It often happens also, that an herd of fallow-deer is seen to divide into two parties, and engage each other with great ardour and obstinacy." - They both seem desirous of gaining some favourite spot of the park for pasture, and of driving the vanquished party into the coarser and more disagreeable parts. Each of these factions has its particular chief; namely, the two oldest and strongest of the herd. These lead on to the engagement; and the rest follow under their direction. Thesecombats a resingular enough, from the disposition and conduct which seems to regulate their mutual efforts. They attack with order, and support the assault with courage; they come to each other's assistance, they retire, they rally, and never give up the victory upon a single defeat. The combat is renewed for several days together; until at length the most feeble side is obliged to give way, and is content to escape to the most disagreeable part of the park, where only they can find safety and protection.

The fallow-deer is easily tamed, and feeds upon many things which the stag refuses. By this means it preserves its venison better; and even after rutting, it does not appear entirely exhausted. It continues almost in the same state through the whole year, although there are particular seasons when its flesh is chiefly in esteem. This animal also browzes closer than the stag; for which reason it is more prejudicial among young trees, which it often strips too close for recovery. The young deer eat much faster and more greedily than the old; they seek the female at their second year; and, like the stag, are fond of variety. The doe goes with young above eight months, like the hind; and commonly briugs forth one at a time: but they differ in this, that the buck comes to perfection at three, and lives till sixteen ; whereas the stag does not come to perfection till seven, and lives till forty.

a Buffon, vol. xii. p. 36 .
As this animal is a beast of chase, like the stag, so the hunters have invented a number of names relative to him. The buck is, the first year, called a fawn; the second, a pricket; the third, a sorel; the fourth, a sore; the filth, a buck of the first head; and the sixth, a great buck: the female is called a doe; the first year, a fawn; and the second, a tegg. The manner of hunting the buck is pretty much the same as that of stag-hunting, except that less skill is required in the latter. The buck is more easily roused; it is sufficient to judge by the view, and mark what grove or covert it enters, as it is not known to wauder far from thence; nor, like the stag, to change its layer, or place of repose. Wheu hard huited, it takes to some strong hold, or covert, with which it is acquainted, in the more gloomy parts of the wood, or the steeps of the inountain; not like the stag, flying before the hounds, nor crossing nor doubling, nor using any of the subtleties which the stag is accustomed to. It will take the water when sorely pressed, but seldom a great river; nor can it swim so long, nor so swiftly, as the former. In general, the strength, the cuming, and the courage of this animal, are inferior to those of the stag; and, consequently, it affords neither so long, so varions, nor so obstinate a chase : besides, being lighter, and not tracing so deeply, it leaves a less powerful and lasting scent, and the dogs in the pursuit are more frequently at a fault.

As the buck is a more delicate animal than the stag, so also it is subject to greater varieties. ${ }^{\circ}$ We have in England two varietics of the fallow-deer, which are said to be of foreign origin. The beautiful spotted kind, which is supposed to have been brought from Bengal; and the very deep brown sort, that are now so common in several parts of this kingdom. These were introduced by King James the First from Norway: for having observed their hardiness, and that they could endure the winter, even in that severe climate, without fodder, he brought over some of them into Scotland, and disposed of them among his chases. Since that time, they have multiplied in many parts of the British empire; and England is now become

b British Zoology. 
more famous for its venison, than any other country in the world. Whatever pains the French have takeil to rival us in this particular, the flesh of their fallow-deer, of which they keep but a few, has neither the fatness nor the flavour of that fed upon English pasture.

However, therc is scarce a country in Europe, except far to the northward, in which this animal is a stranger. The Spanish fallowdeer are as large as stags, but of a darker colour, and a more slender neck: their tails are louger than those of ours, they are black above, and white below. The Virginian deer are larger and stronger than ours, with great necks, and their colour inclinable to gray. Other kinds have the hoofs of their hind legs marked outwardly with a white spot: and their ears and tail much longer than the common. One of these has been seen full of white spots, with a black list down the middle of his back. In Guiaıla, a country of South America, according to Labat, there are deer without horns, which are much less than those of Europe, but resembling them in every other particular. They are very lively, light of course, and excessively fearful; their hair is of a reddish fallow, their heads are small and lean, their ears little, their necks long and arched, the tail short, and the sight piercing. When pursued, they fly into places where no other animal can follow them. The Negroes, who pursue them, stand to wateh for them in narrow paths, which lead to the brook, or the meadow where they feed; there waiting in the utmost silence, for the slightest sound will drive them away, the Negro, when he perceives the animal within reach, shoots, and is happy if he can bring down his game. Their flesh, though seldom fat, is considered as a great delicacy, and the hunter is well rewarded for his trouble.

\section{THE ROE-BUCK.}

THE roe-buck is the smallest of the deer kind known in our climate, and is now almost extinct among us, except in some parts of the Highlands of Seotland. It is generally about three feet long, and about two feet high. The horns are from eight to nine inches long, upright, round, and divided into only three bran-

No. $23 \& 24$. ches. The body is covered with very long hair, well adapted to the rigour of its mountainous abode. The lower part of each hair is ash colour; near the ends is a narrow bar of black, and the points are yellow. The hairs on the face are black, tipped with ash colour. The ears are long, their insides of a pale yellow, and covered with long hair. The spaces bordering on the eyes and mouth, are black. The chest, belly, and legs, and the inside of the thighs, are of a yellowish white; the rump is of a pure white, and the tail very short. The make of this little animal is very elegaut; and its swiftness equals its beauty. It differs from the fallow-deer, in having round horns, and not flatted like theirs. It differs from the stag, in its smaller size, and the proportionable paucity of its antlers : and it differs from all of the goat kind, as it annually sheds its head, and obtains a new one, which none of that kind are ever seen to do.

As the stag frequents the thickest forests, and the sides of the lighest mountains, the roe-buck, with humbler ambition, courts the shady thicket, and the rising slope. Although less in size, and far inferior in strength, to the stag, it is yet more beautiful, more active, and even more courageous. Its hair is always smooth, clean, and glossy; and it frequents only the driest places, and of the purest air. Though but a very little animal, as we have already observed, yet when its young is attacked, it faces even the stag himself, and often comes off victorious." All its motions are elegant and easy; it bounds without effort, and continues the course with but little fatigue. It is also possessed of more cunning in avoiding the hunter, is more difficult to pursue, and, although its seent is much stronger than that of the stag, it is more frequently found to make a good retreat. It is not with the roe-buck as with the stag, who never offers to use art until his strength is begiuning to decline; this more cunning animal, when it finds that its first efforts to escape are witlout suecess, returns upon its former track, again goes forward, and again returns, until, by its various windings, it has entirely confounded the scent, and joined the last emanations to those of its former course. It then,

a Buffon, vol. xii. p. 75 
by a bound, goes to one side, lies flat upon its belly, and permits the pack to pass by very near, without offering to stir.

But the roe-buck differs not only from the stag in superior cunning, but also in its natural appetites, its inclinations, and its whole habits of living. Instead of herding together, these animals live in separate families; the sire, the dam, and the young ones, associate together, and never admit a stranger into their little community. All others of the deer kind are inconstant in their affection; but the roe-buck never leaves its mate; and, as they have been generally bred up together from their first fawning, they conceive so strong an attachment, the male for the female, that they never after separate. Their rutting-season continues but fifteen days; from the latter end of October to about the middle of November. They are not at that time, like the stag, overloaded with fat; they have not that strong odour,which is perceived in all others of the deer kind; they have none of those furious excesses; nothing, in short, that alters their state: they only drive away their fawns upon these occasions; the buek forcing them to retire, in order to make room for a succeeding progeny; however, when the copulating season is over, the fawns return to their does, and remain with them some time longer: after which, they quit them entirely, in order to begin an independent family of their own. The female goes with young but five months and a half, which alone serves to distinguish this animal from all others of the deer kind, that continue pregnant more than eight. In this respect, she rather approaches more nearly to the goat kind; from which, howcver, this race is separated by the male's annually casting its horrs.

When the female is ready to bring forth, she seeks a retreat in the thickest part of the woods, being not less apprehensive of the buck, from whom she then separates, than of the wolf, the wild-cat, and almost every ravenous animal of the forest; she generally produces two at a time, and three hut very rarely. In about ten or twelve days these are able to follow the dam, except in cases of warm pursuit, when their strength is not equal to the fatigue. Upon such occasions, the tenlerness of the dam is very extraordinary; leav- ing them in the deepest thickets, she offers herself to the danger, flies before the hounds, and does all in lier power to lead them from the retreat where she has lodged her little ones. Such animals as are nearly upon her own level she boldly cncounters; attacks the stag, the wild-cat, and even the wolf; and while she has life, continues her efforts to protect her young. Yet all her cudeavours are often vain; about the month of May, which is her fawning time, there is a greater destruction among those animals than at any other season of the year. Numbers of the fawns are taken alive by the peasants; numbers are found out, and worried by the dogs; and still more by the wolf, which has always been their most iuveterate enemy. By these continual depredations upon this beautiful creature, the roe-buck is every day becoming scarcer; and the whole race in many countries is wholly worn out. They were once common in England; the huntsmen, who characterized only such beasts as they knew, have given names to the different kinds and ages as to the stag: thus they called it the first year a hind; the second, a gyrle; and the third, a.hemuse; but these names at present are utterly useless, since the animal no longer exists among us. Even in France, where it was once extremely common, it is now confined to a few pro. viuces; and it is probable that in an age or two the whole breed will be utterly extirpated. Mr. Buffon. indeed, observes, that in those districts where it is mostly found, it seems to maintain its usual plenty, and that the balance between its destruction and increase is held pretty even; however, the number in general is known to decrease; for wherever cultivation takes place, the beasts of nature are known to retire. Many animals that once flourished in the world inay now be extinct; and the descriptions of Aristotle and Pliny, though taken from life, may be considered as fabulous, as their archetypes are no longer existing.

The fawns continue to follow the deer eight or nine months in all; and, upon separating, their horns begin to appear simple, and without antlers, the first year, as in those of the stag kind." These they shed at the latter

\footnotetext{
a Buffon, vol. xii. p. 88 .
} 
end of autumn, and renew during the winter; differing in this from the stag, who sheds them in spring, and renews them in summer. When the roe-buck's head is completely furnished, it rubs the horns against the trees in the manner of the stag, and thus strips them of the rough skin and the blood-vessels, which no longer contribute to their nourishment and growth. When these fall, and new ones begin to appear, the roe-buck does not retire as the stag to the covert of the wood, but continues its usual haunts, only keeping down its head to avoid striking its horns against the branches of trees, the pain of which it seems to feel with exquisite sensibility. The stag, who sheds his horns in summer, is obliged to seek a retreat fronı the flies, that at that time greatly incommode him; but the roe-buck, who sheds them in winter, is under no such necessity ; and, consequently, does not separate from its little family, but keeps with the female all the year round. ${ }^{a}$

As the growth of the roe-buck, and its arrival at maturity, is much speedier than that of the stag, so its life is proportionably shorter. It seldom is found to extend above twelve or fifteen years; and, if kept tame, it does not live above six or.seven. It is an animal of a very delicate constitution, requiring variety of food, air, and exercise. It must be paircd with a female, and kept in a park of at least a hundred acres. They may easily be subdued, but never thoroughly tamed. No arts ean teach them to be familiar with the feeder, much less attached to him. They still preserve a part of their natural wildness, and are sulject to terrors without a eause. They sometimes, in attempting to escape, strike themselves with such force against the walls of their enelusure, that they break their limbs, and become utterly disabled. Whatever care is taken to tame them, they are never entirely to be relied on, as they have capricious fits of fierceness, and sometimes strike at those they dislike with a degree of foree that is very dangerous.

The ery of the roe-buck is neither so lond nor so frequent as that of the stag. The young ones have a particular nsanner of calling to the dam, which the hunters easily imitate, and often thus allure the fermale to her destruction. Upon some occasions also they become in a

a Buffon, vol. xii. p. 88 . manner intoxicated with their food, which, during the spring, is said to ferment in their stomachs, and they are then very easily taken. In summer they keep close under covert of the forest, and seldon venture out, except in violent heats, to drink at some river or fountain. In general, however, they are contented to slake their thirst with the dew that falls on the grass and the leaves of trees, and seldom risk their safety to satisfy their appetite. They delight chiefly in hilly grounds, preferring the tender branches and buds of trees to corn, or other vegetables; and it is universally allowed that the flesh of those between one and two years old is the greatest delicacy that is known. Perhaps, also, the scarceness of it enhances its flavour.

In America this animal is much more common than in Europe. With us there are but two known varieties; the red, which is the largest sort; and the brown, with a spot behind, which is less. But in the new continent the breed is extremely numerous, and the varieties in equal proportion. In Louisiana, where they are extremely common, they are much larger than in Europe, and the inhabitants live in a great measure upon its flesh, which tastes like mutton when well fatted. They are found also in Brasil, where they have the name of cugacu apara, only differing from ours in some slight deviations in the horns. This animal is also said to be common in China; although such as have deseribed it seem to confound it with the musk goat, which is of a quite different nature.

\section{THE ELK.}

We have hitherto been describing minute animals in comparison of the elk; the size of which, from eoncurrent testimony, appears to be equal to that of the elephant itself. It is an animal rather of the buck than the stag kind, as its horns are flatted towards the top; but it is far beyond both in stature, some of them being known to be above ten feet high. It is a native both of the old and new continent, being known in Europe under the name of the elk, and in America by that of the moose-deer. It is sometimes taken in the German and Russian forests, although seldom appearing; but it is extrcmely common in North America, where $2 \mathrm{X}^{*}$ 
the natives pursue, and track it in the snow. The accounts of this animal are extremely various; some describing it as being no higher than a horse, and others above twelve feet high.

As the stature of this creature makes its chief peculiarity, so it were to be wished that we could come to some precision upon that head. If we were to judge of its size by the horns, which are sometimes fortuitously dug up in many parts of Ireland, we should not be much amiss in ascribing them to an animal at least ten feet high. One of these I have seen, which was ten feet nine inches from one tip to the other. From such dimensions it is easy to perceive that it required an animal far beyond the size of a horse to support them. To bear a head with such extensive and heavy antlers, required no small degree of strength; and without all doubt the bulk of the body must have been proportionable to the size of the horns. I remember some years ago, to have seen a sinall moose-fleer, which was brought from America, by a gentleman of Ireland : it was about the size of a horse, and the horns were very little larger than those of a commion stag: this, therefore, serves to prove that the horns bear an exuct proportion to the animal's size; the small elk has but small horns; whereas those enornions ones, which we have described above, must have belonged to a proportionable creature. In all the more noble animils, nature observes a perfect syinmetry; and it is not to be supposed she fails in this single instance. We have no reason, therefore, to doubt the accounts of Jocelyn and Dudley, who affirm that they have been found fourteen spans; which at nine inches to a span, makes the animal almost eleven feet high. Others have extended their accounts to twelve and fourteen feet, which makes this creature one of the most formidable of the forest.

There is but very little difference between the European elk and the American monsedeer, as they are but varieties of the same animal. It nay be rather larger in America than with us; as in the forests of that unpeopled country, it receives less disturbance than in our owil. In all places, however, it is timorous and gentle ; content with its pasture, and never willing to disturb any other animal, when supplied itself. The European elk grows to above seven or eight feet high. In the year 1742, there was a female of this animal shown at Paris, which was caught in a forest of Red Russia, belonging to the Cham of Tartary ; it was then but young, and its height was even at that time six feet seven inches; but the describer observes, that it has since become much taller and thicker, so that we may suppose this foniale at least seven feet high. There have been no late opportunities of secing the male; but, by the rule of proportion, we nuay estimate his size at eight or nine feet at the least, which is about twice as high as an ordinary horse. The height, however, of the female, which was measured, was but six feet seven inches, Paris measure; or alnıst seven English feet high. It was ten feet from the tip of the nose to the insertion of the tail ; and eight feet round the body. The hair was very long and coarse, like that of a wild boar. The ears resembled those of a mule, and were a foot and a half long. The upper jaw was longer by six inclies than the lower; and, like other ruminating animals, it had no teeth, (cutting-teeth, I suppose the describer means.) It had a large beard under the throat, like a goat; and in the middle of the forchead, between the horns, there was a bone as large as an egg. The nostrils were four inches long on each side of the nouth. It made use of its fore-feet, as a defence against its enemies. Those who showed it, asserted that it ran with astonishing swiftness; and that it swam also with equal expedition, and was very fond of the water. 'They gave it thirty pounds of bread every day, besides hay, and it drank eight buckets of water. It was tame and familiar, and submissive enough to its kecper.

This description differs in many circumstances from that which we have of the moose, or American elk, which the French call the original. Of these there are two kinds, the common light gray moose, which is not very large; and the black moose, which grows to an enormous height. Mr. Duilley observes, that a doe or hind of the black nıose kind, of the fourth year, wanted but an inch of seven feet high. All, however, of both kinds, have flat, palmed horus, not unlike the fallow deer, only that the palm is much larger, having a short trunk at the head, and then immediately. spreading above a foot broad, with a kind of

a Dictionnaire Raisonee des Animaux, Au Nom, Elan. 
small antlers, like teeth on one of the edges. In this purticular, all of the elk kind agree; as well the European elk, as the gray and the black moose-deer.

The gray moose-deer is about the size of a horse; and, although it has large buttocks, its tail is not above an inch long. As, in all of this kind, the upper lip is nuch longer than the under, it is said that they continue to go backward as they feed. Their nostrils are so large that a man may thrust his hand in a considerable way; and their horns are as long as those of a stag, but, as was observed, much broader.

The black moose is the enormous animal mentioned above, from eight to twelve feet high. Jocelyn, who is the first English writer that mentions it, says, that it is a goodly creature, twelve feet high, with exceeding fair horns, that have broad palms, two fathoms from the top of one horn to another. He assures us that it is a creature, or rather a monster of superfluity, and nany times bigger than an English ox. 'This account is confirmed by Dudley; but he does not give so great an expansion to the horns, measuring them only thirty-one inches between one tip and the other; however, that such an extraordinary animal as Jocelyn describes, has actually existed, we can make no manner of doubt of, since there are horns common enough to be scen among us, twelve feet from one tip to the other.

These animals delight in cold countries, feeding upon grass in summer, and the bark of trees in winter. When the whole country is deeply covered with snow, the moose-deer herd together under the tall pine-trees, strip off the bark, and remain in that part of the forest while it yields them subsistence. It is at that time that the natives prepare to hunt them: and particularly when the sun begins to melt the snow by day, which is frozen again at night; for then the icy crust which covers the surface of the snow, is too weak to support so great a bulk, and only retards the animal's motion. When the Indians, therefore, pereeive a herd of these at a distance, they immediately prepare for their pursuit, which is not, as with us, the sport of an hour, but is attended with toil, difficulty, and danger." The timorous animal no somier observes its enemies approach, than it immediately endeavours to escape, but sinks

- Phil. Trans. vol. ii. p. 436. at every step it takes. Still, however, it pursues its way through a thousand obstacles: the snow, which is usually four feet deep, yields to its weight, and embarrasses its speed; the sharp ice wounds its feet; and its lofty horns are entangled in the branches of the forest, as it passes along. The trees, however, are broken down with ease; and wherever the moosedeer runs, it is perceived by the snapping off the branches of the trees, as thick as a man's thigh, with its horns. The chase lasts in this manner for the whole day; and sometimes he has been known to continue for two, nay three days together; for the pursuers are often not less excited by famine, than the pursued by fear. Their perseverance, lowever, generally succeeds; and the Indian who first comes near enough, darts his lance, with unerring aim, which stieks in the poor animal, and at first inereases its efforts to escape. In this manner the moose trots heavily on, (for that is its. usual pace, ) till its pursuers once more come up, and repeat their blow: upon this, it again summons up sufficient vigour to get a-liead; but, at last, quite tired, and spent witli loss of blood, it sinks, as the describer expresses it, like a ruined building, and makes the earth shake beneath its fall.

This animal, when killed, is a very valuable aequisition to the hunters. The flesh is very well tasted, and said to be very nourishing. The hide is strong, and so thick that it has been often known to turı a musket-ball ; bowever, it is soft and pliable, and, when tanned, the leather is extremely light, yet very lasting. The fur is a light gray in some, and blackish in others; and when viewed through a microscope, appears spongy like a bulrush, and is smaller at the roots and points than in the middle; for this reason, it lies very flat and smooth, and though beaten or abused never so much, it always returns to its former state. The horns also are not less useful, being applied to all the purposes for which hartshorn is beneficial: these are different in different animals; in some they resemble entirely those of the European elk, which spread into a broad palm, with small antlers on one of the edges; in others they have a branched brow-antler between the bur and the palm, which the German clk has not: and in this they entirely agree with those whose horns are frequently dug up in Ireland. This animal is said to be troubled with the ep:- 
lepsy, as it is often found to fall down when pursned, and thus becomes an easier prey ; for this reason, an imaginary virtue has been ascribed to the hinder hoof, which some have supposed to be a specific against all epileptic disorders. This, however, may be considered as a vulgar error; as well as that of its curing itself of this disorder by applying the hinder hoof behind the ear. After all, this animal is but very indifferently and confusedly described by travellers; each mixing his account with something false or trivial; often mistaking some other quadruped for the elk, and confounding its history. Thus some have mistaken it for the rein-deer, which, in every thing but size, it greatly resembles; some have supposed it to be the same with the tapurette, it entirely differs; some have described it as the common red American stag, which scarcely differs from our own; and, lastly, some have confounded it with the bubalus, which is more properly a gazelle of Africa.

\section{THE REIN-DEER.}

OF all animals of the deer kind, the reindeer is the most extraordinary and the most useful. It is a native of the icy regions of the north; and though many attempts have been made to accustom it to a inore southern climate, it shortly feels the influence of the change, and in a few months declines and dies. Nature seems to have fitted it entirely to answer the necessities of that hardy race of mankind that live near the pole. As these would find it inpossible to subsist among their barren snowy mountains without its aid, so this animal can live only there, when its assistance is mostabsolutely necessary. From it alone the natives of Lapland and Greenland supply most of their wants; it answers the purposes of a horse, to convey them and their scanty furniture from one mountain to another; it answers the purposes of a cow, in giving milk; and it answers the purposes of the sheep, in furnishing them with a warm, though an homely kind of clothing. From this quadruped alone, therefore, they receive as inany advantages as

\footnotetext{
a Condamine. b Dapper, Description de l'Afrique, p. 17.

c For the greatest part of this description of the rein-
}

we derive from three of our most useful creatures; so that Providence does not leave these poor outcasts entirely destitute, but gives them a faithful domestic, more patient and serviceable than any other in naturc.

The rein-deer resembles the American elk in the fashion of its horns. It is not easy in words to describe these minute differences; nor will the reader, perhaps, lave a distinct idea of the sirnilitude, when told that both have brow-antlers, very large, and hanging over their eyes, palmated towards the top, and bending forward like a bow. But here the similitude between these two animals ends; for, as the elk is much larger than the stag, so the rein-deer is much smaller. It is lower and stronger built than the stag; its legs are shorter and thicker, and its hoofs much broader than in that animal; its hair is much thicker and warmer; its horns much larger in proportion, and branching forward over its eyes; its ears are mucl larger; its pace is rather a trot than a bounding, and this it can continue for a whole day; its hoofs arc cloven and moveable, so that it spreads them abroad as it goes, to prevent its sinking in the snow. When it proceeds on a journey, it lays its great horns on its back, while there are two branches which always hang over its forehead, and almost covers its face. One thing seems peculiar to this animal and the elk; which is, that as they move along, their hoofs are heard to crack with a pretty loud noise. This arises from their manner of treading; for as they rest upon their cloven hoof, it sprears on the ground, and the two divisions separate from each other, but when they lift it, the divisions close again, and strike against each other with a crack. The female also of the rein-deer has horns as well as the male, by which the species is distinguished from all other animals of the deer kind whatsocver.

When the rein-deer first shed their coat of hair, they are brown; but in proportion as summer approaches, their hair begins to grow .whitish ; until, at last, they are nearly gray.* They are, however, always black about the eyes. The neck has long hair, hanging down, and coarser than upon any other part of the

deer, I am obliged to Mr. Hoffberg; upon whose authority, being a native of Sweden, and an experienced natsralist, we may confidently rely: 
body. The feet, just at the insertion of the hoof, are surrounded with a ring of white. The hair in general stands so thick over the whole body, that if one should attempt to separate it, the skin will no where appear uncovered: whenever it falls also, it is not seen to drop from the root, as in other quadrupeds, but seems broken short near the bottom; so that the lower part of the hair is seen growing, while the upper falls away. The horus of the female are made like those of the male, except that they are smaller and less branching. As in the rest of the deer kind, they sprout from the points; and also in the beginning are furnished with an hairy crust, which supports the blood-vessels of most exquisite sensibility. The rein-deer shed their horns, after rutting time, at the latter end of November; and they are not completely furnished againtill towards autumn. The female always retains bers till she brings forth, and then sheds them about the beginning of November. If she be barren, however, which is not unfrequently the case, she does not shed them till winter. The castration of the rein-deer does not prevent the shedding of their horus: those which are the strongest cast them early in winter; those which are more weakly not so soon. Thus, from all these circumstances, we see how greatly this animal differs from the common stag. The female of the rein-deer has borns, which the hind is never seen to have; the rein-deer, when castrated, renews its horns, which we are assured the stag never does: it differs not less in its habits and manner of living, being tame, submissive, and patient; while the stag is wild, capricious, and unmanageable.

The rein-deer, as was said, is naturally an inhabitant of the countries bordering on the arctic circle. It is not unknown to the natives of Siberia. The North Americans also hunt it under the nane of the caribou. But in Lapland, this animal is converted to the utmost advantage; and some herdsmen of that country are known to possess above a thousand in a single herd.

Lapland is divided into two districts, the momitainous and the woody. The mountainous part of the country is at best barren and bleak.excessively cold, and uninhabitable during the winter; still, however, it is the most desirable part of this frightful region, and is most thickly peopled during the summer. The natives generally reside on the declivity of the mountains, three or four cottages together, and lead a cheerful and social life. Upon the approach of winter, they are obliged to migrate into the plains below, each bringing down his whole herd, which often amounts to more than a thousand, and leading them where the pasture is in greatest plenty. The woody part of the country is much more desolate and hideous. The whole fice of nature there presents a frightful scene of trees without fruit, and plains without verdure. As far as the eye can reach, nothing is to be seen, even in the midst of summer, but barren fields, covered only with a moss, almost as white as snow; no grass, no flowery landscapes, only here and there a pine-tree, which may have escaped the frequent conflagrations by which the natives burn down their forests. But what is very extraordinary, as the whole surface of the country is clothed in white, so, on the contrary, the forests seem to the last degree dark and gloomy. While one kind of moss makes the fields look as if they were covered with snow, another kind blackens over all their trees, and even hides their verdure. This moss, however, which deforms the country, serves for its only support, as upon it alone the rein-deer can subsist. The inhabitants, who, during the summer, lived among the mountains, drive down their herds in winter, and people the plains and woods below. Such of the Laplanders as inhabit the woods and the plains all the year round, live remote from each other, and having been used to solitude, are melancholy, ignorant, and helpless. They are much poorer also than the mountaineers; for, while one of those is found to possess a thousand rein-deer at a time, none of these are ever known to rear the tenth part of that number. The rein-deer makes the riches of this people; and the cold mountainous parts of the country agree best with its constitution. It is for this reason, therefore, that the mountains of Lapland are preferred to the woods; and that many claim an exclusive right to the tops of hills, covered in almost eternal snow. As soon as the summer begins to appear, the Laplander, who had fed his rein-deer upon the lower grounds during the winter, then drives them up to the moun- 
tains, and leaves the woody country, and the low pasture, which at that season are truly deplorable. The gnats breed by the sun's heat in the marshy bottoms and the weedy lakes, with which the country abounds more than any other part of the world, are all upon the wing, and fill the whole air like clouds of dust in a dry windy day. The inhabitants, at that time, are obliged to daub their faces with pitch, mixed with milk, to shield their skins from their depredations: All places are then so greatly infested, that the poor natives can scarce open their mouths without fear of suffocation; the insects enter, from their numbers and minuteness, into the nostrils and the eyes, and do not leave the sufferer a moment at his ease. But they are chiefly enemies to the rein-deer: the horns of that animal being then in their tender state, and possessed of extreme sensibility, a famished cloud of insects instantly settle upon them, and drive the poor animal almost to distraction. In this extre. mity, there are but two remedies to which the quadruped, as well as its master, are obliged to have recourse. The one is, for both to take shelter near their cottage, where a large fire of tree-moss is prepared, which filling the whole place with smoke, keeps off the gnat, and thus by one inconvenience, expels a greater; the other is, to ascend to the highest summit of the mountains, where the air is too thin, and the weather too cold, for the guats to come. There the rein-deer are seen to continue the whole day, although without food, rather than to venture down to the lower parts, where they can have no defence against their unceasing persecutors. Besides the gnat, there is also a gadfly, that, during the summer season, is no less formidable to them. This insect is bred under their skins, where the egg has been deposited the preceding summer; and it is no sooner produced as a fly, than it again endeavours to deposite its eggs in some place similar to that from whence it came. Whenever, therefore, it appears flying over a herd of rein-deer, it puts the whole body, how numerous soever, into motion; they know their enemy, and do all they can, by tossing their horns, and running among each other, to terrify or avoid it. All their endeavours, however, are too generally without effect; the gadfly is seen to deposite its eggs, which bur- rowing under the skin, wound it in several places, and often bring on an incurable disorder. In the morning, therefore, as soon as the Lapland herdsman drives his deer to pasture, his grcatest care is to keep them from scaling the summits of the mountains where there is 110 food, but where they go merely to be at ease from the gnats and gadflies that are ever annoying them. At this time there is a strong contest between the dogs and the deer; the one endeavouring to climb up against the side of the hill, and to gain those summits that are covered in eternal snows; the other forcing them down, by barking and threatening, and, in a manner, compelling them into the places where their food is in the greatest plenty. There the men and dogs confine them; guarding them with the utmost precaution the whole day, and driving them home at the proper seasons for milking.

The female brings forth in the middle of May, and gives milk till about the middle of October. Every morning and evening, during the summer, the herdsman returns to the cottage with his deer to be milked, where the women previously loave kindled up a smoky fire, which effectually drives off the gnats, and keeps the rein-deer quiet while milking. The female furnishes about a pint, which, though thirner than that of the cow, is, nevertheless, sweeter, and more nourishing. This done, the herdsman drives them back to pasture; as he neither folds nor houses them, neither provides for their subsistence during the winter, nor improves their pasture by cultivation.

Upon the return of the winter, when the gnats and flies are no longer to be fearrd, the Laplander descends into the lower grounds; and as there are but few to dispute the possession of that desolate country, he has an extensive range to feed them in. Their chief, and almost their only food at that time, is the white moss already mentioned; which, from its being fed upon by this auimal, obtains the name of the lichen rangiferimus. This is of two kinds; the woody licheu, which covers almost all the desert parts of the country like snow; the other is black, and covers the branches of the trees in very great quantities. However unpleasing these may be to the spectator, the native esteems them as one of his choicest benefits, and the most indulgent gift 
of nature. While his fields are clother with moss, he euvies neither the fertility nor the verdure of the more southernlandscape; dressed up warmly in his deer-skin clothes, with shoes and gloves of the same materials, he drives his herds along the desert, fearless and at ease, ignorant of any higher luxury than what their milk and smoke-dried flesh affords him. Hardened to the climate, he sleeps in the midst of ice; or awaking, dozes away his time with tobacco; while his faithful dogs supply his place, and keep the herd from wandering. The deer, in the meantime, with instincts adapted to the soil, pursue their food, though covered in the deepest snow. They turn it up with their noses, like swinc; and, even though its surface be frozen and stifr, yet the hide is so hardened in that part, that they easily overcome the difficulty. It sometimes, however, happens, though but rarely, that the winter commences with rain, and a frost ensuing, covers the whole country with a glazed crust of ice. Then, indeed, both the rein-deer and the Laplander are undone; they have no provisions laid up in case of accident, and the only resource is to cut down the large pinetrees that are covered with moss, which furnishes but a scanty supply; so that the greatest part of the herd is then seen to perish without a possibility of assistance. It sometimes also happens, that even this supply is wanting; for the Laplander often burns down his woods, in order to improve and fertilize the soil which produces the moss, upon whick he feeds his cattle.

In this manner, the pastoral life is still continued near the pole; neither the coldness of the winter, nor the length of the nights; neither the wildness of the forests, nor the vagrant disposition of the herd, interrupt the even tenour of the Laplander's life. By night and day he is seen attending his favourite cattle, and remains unaffected, in a scason which would be speedy death to those bred up in a milder climate. He gives himself no uneasiness to house his herds, or to provide a winter subsistence for them; he is at the trouble neither of manuring his grounds, nor bringing in his harvest; he is not the hireling of another's luxury; all his labours are to obviate the necessities of his own situation; and these he undergoes with cheerfulness, as he is sure No. $23 \& 24$. to enjoy the fruits of his own industry. If, therefore, we compare the Laplander with the peasant of more southern climates, we shall have little reason to pity his situation; the climate in which he lives is rather terrible to us than to him; and as for the rest, he is blessed with liberty, plenty, and ease. The rein-decr alone supplies him with all the wants of life, and some of the conveniences; serving to show how many advantages nature is capable of supplying, when necessity gives the call. Thus the poor, little helpless native, who was originally, perhaps, driven by fear or famine into those inhospitable climates, would seem, at first view, to be the most wretched of mankind : but it is far otherwise; he looks round among the few wild animals that his barren country can maintain, and singles out one from among them, and that of a kind which the rest of mankind have not thought worth taking from a state of nature; this he cultivates, propagates, and multiplies; and from this alone derives every comfort that can soften the severity of his situation.

The rein-deer of this country are of two kinds, the wild and the tame. The wild are larger and stronger, but more mischicvous than the others. Their breed, however, is preferred to that of the tame; and the female of the latter is often sent into the woods, from whence she returns home impregnated by one of the wild kind. These are fitter for drawing the sledge, to which the Laplander accustoms them betimes, and yokes them to it by a strap, which goes round the neck, and comes down between their legs. The sledge is extremely light, and shod at the bottoin with the skin of a young deer, the hair turned to slide on the frozen snow. The person who sits on this, guides the animal with a cord, fastened round the horns, and encourages it to proceed with his voice, and drives it with a goad. Some of the wild breed, though by far the strongest, are yet found refractory. and often turn upon their drivers; who have then no other resource but to cover themselves with their sledge, and let the animal vent its fury upon that. But it is otherwise with thuse that are tame; no creature can be more ac. tive, patient, and willing: when hard pushed they will trot nine or ten Swedish miles, or between fifty and sixty English miles, at one $2 Y$ 
stretch. But, in such a case, the poor obedient creature fatigues itself to death, and, if not prevented by the Laplander, who kills it immediately, it will die a day or two after. In general, they can go about thirty miles without halting, and this without any great or dangerous efforts. This, which is the only manner of travelling in that country, can be performed only in winter, when the snow is glazed over with ice; and although it be a very speedy method of conveyance, yet it is inconvenient, dangerous, and troublesome.

In order to make these animals more obedient, and more generally serviceable, they castrate them: this operation the Laplanders perform with their teeth; these become sooner fat when taken from labour; and they are found to be stronger in drawing the sledge. There is usually one male left entire for every six females; these are in rut from the Feast of St. Matthew to about Michaelmas. At this time, their horns are thoroughly burnished, and their battles among each other are fierce and obstinate. The females do not begin to breed till they are two years old; and then they continue regularly breeding every year till they are superannuated. They go with young above eight months, and generally bring forth two at a time. The fondness of the dam for her young is very remarkable; it often happens that when they are separated from her, she will return from pasture, keep calling round the cottage for them, and will not desist until, dead or alive, they are brought and laid at her feet. They are at first of a light brown; but they become darker with age; and at last the old ones are of a brown, almost approaching to blackness. The young follow the dam for two or three years; but they do not acquire their full growth until four. They are then broke in, and managed for drawing the sledge; and they continue serviceable for four or five years Ionger. They never live above fifteen or sixteen years; and when they arrive at the proper age, the Laplander gencrally kills them for the sake of their skins and their flesh. 'T'his he performs by striking them on the back of the neck with his knife into the spinal marrow; upon which they instantly fall, and he then cuts the arteries that lead to the heart. and lets the blood discharge itself into the cavity of the breast.

There is scarce any part of this animal that is not converted to its peculiar uses. As soon as it begins to grow old, and some time before the rut, it is killed, and the flesh dried in the air. It is also sometimes hardened with smoke, and laid up for travelling provision, when the natives migrate from one part of the country to another. During the winter, the rein-deer are slaughtered as sheep with us; and every four persons in the family are allowed one rein-deer for their week's subsistence. In spring, they sparc the herd as much as they can, and live upon fresh fish. In summer, the milk and curd of the rein-deer makes their chief provision; and, in autumn, they live wholly upon fowls, which they kill with a cross-bow, or catch in springes. Nor is this so scanty an allowance; since, at that time, the sea-fowls come in such abundance that their ponds and springs are covered over. These are not so shy as with us, but yield themselves an easy prey. They are chiefly allured to those places by the swarms of gnats which infest the country during the summer, and now repay the former inconveniences, by inviting such numbers of birds as supply the natives with food a fourth part of the year, in great abundance.

The milk, when newly taken, is warmed in a caldron, and thickeried with remet; and then the curd is pressed into cheeses, which are little and well tasted. These are never found to breed mites as the cheese of other countries; probably because the mite-fly is not to be found in Lapland. The whey which remains is warmed up again, and becomes of a consistence as if thickened with the white of eggs. Upon this the Laplanders feed during the summer; it is pleasant and well tasted, but not very nourishing. As to butter, they very seldom make any, because the milk affords but a very small quantity, and this, both in taste and consistence, is more nearly resembling to suet. They never keep their milk till it turns sour; and do not dress it into the variety of dishes which the more southern countries are known to do. The only delicacy they make from it is with wood-sorrel. which being boiled up with it, and coarumating, the whole is put into casks, or deer 
skins, and kept under ground to be eaten in winter.

The skin is cren a more valuable part of this animal than either of the former. From that part of it which covered the head and fect, they make thcir strong snow-shoes with the hair on the outside. Of the other parts they compose their garments, which are cxtreinely warm, and which cover them all over. The hair of these also is on the outside; and they sometimes line them with the fur of the glutton, or some other warm-furred animal of that climate. These skins also serve them for beds. They spread them on each side of the fire, upon some leaves of the dwarf birchtree, and in this manner lie both soft and warm. Many garments made of the skin of the rein-deer are sold every year to the inhabitants of the morc southern parts of Europe; and they are found so serviceable in keeping out the cold, that even people of the first rank are known to wear them.

In short, no part of this animal is thrown away as useless. The blood is preserved in small casks, to make sauce with the marrow in spring. The horns are sold to be converted into glue. The sinews are dried, and divided so as to make the strongest kind of sewing thread, not unlike catgut. The tongucs, which are considered as a great delicacy, are dried, and sold into the more southern provinces. The intestines themselves are washed like our tripe, and in high esteem among the natives. Thus the Laplander finds all his necessities amply supplied from this single animal, and he who has a large herd of these animals has no idea of higher luxury.

But although the rein-deer be a very hardy and vigorous animal, it is not without its diseascs. I have already mentioned the pain it feels from the gnat, and the apprehensions it is under from the gadfly. Its hide is often found pierced in a hundred places, like a sieve, from this insect, and not a ferw die in their third year from this very cause. Their teats also are subject to cracking, so that blood comes instead of milk. They sometimes take a loathing for their food; and, instead of eating, stand still and chew the cud. They are also troubled with a vertigo, like the elk, and turn round often till they die.
The Laplander judges of their state by the manner of their turning. If they turn to the right, he judges their disorder but slight; if they turn to the left, he deems it incurable. The rein-decr are also subject to ulcers near the hoof, which unqualifies them for travelling, or keeping with the herd. But the most fatal disorder of all is that which the natives call the suddataka, which attacks this animal at all seasons of the year. The instant it is seized with this disease, it begins to breathe with great difficulty; its eyes begin to stare, and its nostrils to cxpand. It acquires also an unusual degree of ferocity, and attacks all it meets indiscriminately. Still, however, it continues to feed as if in health, but is not seen to chew the cud, and it lies down more frequently than before. In this manner it continues, every day consuming and growing more lean, till at last it dies from mere inanition: and not one of these that are attacked with this disorder are ever found to recover. Notwithstanding it is but very lately known in that part of the world; although, during the last ten or fifteen years, it has spoiled whole provinces of this necessary creature. It is contagious; and the moment the Laplander perceives any of his herd infected, he hastens to kill them immediately before it sprcads any farther. When examined internally, there is a frothy substance found in the brain, and round the lungs; the intestines are lax and flabby, and the spleen is diminished almost to nothing. The Laplander's only cure in all these disorders, is to anoint the animal's back with tar; if this does not suceeed, he considers the disease as beyond the power of art; and, with bis natural phlegm, submits to the severities of fortune.

Besides the internal maladies of this animal, there are some external eneınies which it has to fear. The bears now and then make depredations upon the herd; but of all their persecutors, the crctuare called the glutton is the most dangerous and the most successful. The war between these is carricd on not less in Lapland than in North America, where the rein-deer is called the carribou, and the glutton the carcajou. This animal, which is not above the size of a badger, waits whole wecks together for its prey, hid in the branches of some spreading tree; and when $2 \mathrm{Y}$ * 
the wild rein-deer passes underneath, it instantly drops down upon it, fixing its teeth and claws into the neck. just behind the horns. It is in vain that the wounded animal then flies for protection, that it rustles among the branches of the forest, the glutton still holds its former position, and, although it often loses a part of its skin and flesh, which are rubbed off against the trees, yet it still keeps fast, until its prey drops with fatigue and loss of blood. The deer has but one only method of escape, which is by jumping into the water; that element its enemy cannot endure; for, as we are told, it quits its hold immediately, and then thinks only of providing for its own proper security. 


\section{QUADRUPEDS OF THE HOG IETD.}

\section{$\rightarrow 00-$ \\ CHAPTER XLVI. \\ INTRODUCTION.}

ANIMALS of the hog kind seem to unite in themselves all those distinctions by which others are separated. They resemble those of the horse kind in the number of their teeth, which in all amount to forty-four, in the length of their head, and in having but a single stomach. They resemble the cow kind in their cloven hoofs and the position of their intestines; and they resemble those of the claw-footed kind in their appetite for flesh, in their not chewing the cud, and in their numerous progeny. 'Thus this species serves to fill up that chasm which is found between the carnivorous kinds and those that live upon grass; being possessed of the ravenous appetites of the one, and the inoffensive nature of the other. We may consider them, therefore, as of a middle nature, which we can refer lieither to the rapacious nor the peaceful kinds, and yet partaking somewhat of the nature of both. Like the rapacious kinds, they are found to have short intestines; their hoofs also, though cloven to the sight, will, upon anatomical inspection, appear to be supplied with bones like beast of prey; and the number of their teats also increase the similitude; on the other hand, in a natural state they live upon vegetables, and seldom seek after animal food, except when urged by necessity. They offend no other ani$\mathrm{mal}$ of the forest, at the same time that they are furnished with arms to terrify the bravest.

\section{THE WILD BOAR,}

WHrch is the original of all the varieties we find in this creature. is by no means so stupid nor so filthy an animal as that we have reduced to tameness; he is much smaller than the tame hog, and does not vary in his colour as those of the domestic kind do, but is always found of an iron gray, inclining to black; his snout is much longer than that of the tame hog, and the ears are shorter, round er, and black; of which colour are also the feet and the tail. He roots the ground in a different manner from the common hog; for as this turns up the earth in little spots here and there, so the wild boar ploughs it up like a furrow, and does irreparable damage in the cultivated lands of the farmer. The tusks also of this animal are larger than in the tame breed, some of them heing seen almost a foot long." These, as is well known, grow from both the under and upper jaw, bend upwards circularly, and are exceedingly sharp at the points. They differ from the tusks of the elephant in this, that they never fall; and it is remarkable of all the hog kind, that they never shed their teeth as other animals are seen to do. The tusks of the lower jaw are always the most to be dreaded, and are found to give very terrible wounds.

The wild boar can properly be called neither a solitary nor a gregarious animal. The three first years the whole litter follows the sow, and the family lives in a herd together. They are then called beasts of company, and unite their common forces against the invasions of the wolf, or the more formidable beasts of prey. Upon this their principal safety while young depends, for when attacked they give each other mutual assist-

a Buffon, vol. ix. p. 147. 
ance, calling to each other with a very lond and fierce note; the strongest face the danger; they form a ring, and the weakest fall into the centre. In this position few ravenous beasts dare venture to attack them, but pursue the chase where there is less resistance and danger. However, when the wild boar is come to a state of maturity, and when conscious of his own superior strength, he then walks the forest alone and fearless. At that time he dreads no single creature, nor does he turn out of his way even for man himself. He does not seek danger, and he does not much seem to avoid it.

This animal is therefore seldom attacked, but at a disadvantage, either by numbers, or when found sleeping by moon-light. The hunting the wild boar is one of the principal amusements of the nobility in those countries where it is to be found. The dogs provided for this sport are of the slow heavy kind. Those used for hunting the stag, or the roebuck, would be very improper, as they would too soon come up with their prey; and, instead of a chase, would only furnish out an engagement. A small mastiff is therefore chosen; nor are the hunters much mindful of the goodness of their nose, as the wild boar leaves so strong a scent, that it is impossible for them to mistake its course. They never hunt any but the largest and the oldest, which are known by their tracks. When the boar is rcared, as is the expression for driving him from his covert, he goes slowly and uniformly forward, not much afraid, nor very far before his pursuers. At the end of every half mile, or thereabouts, he turns round, stops till the hounds come up, and offers to attack them. These, on the other hand, knowing their danger, keep off, and bay him at a distance. After they have for a while gazed upon each other with mutual animosity, the boar again slowly goes on his course, and the dogs renew their pursuit. In this manner the charge is sustained, and the chase continues till the boar is quite tired, and refuses to go any farther. The dogs then attempt to close in upon him from behind; those which are young, fierce, and unaccustomed to the chase, are generally the foremost, and often lose their lives by their ardour. Those which are older and better trained are content to wait until the hunters come up, who strike at him with their spear's, and, after several blows, despatch or disable him. The instant the animal is killed, they cut off the testicles, which would otherwise give a taint to the flesh; and the huntsmen celebrate the victory with their horns.

\section{THE HOG,}

IN a natural state, is found to feed chiefly upon roots and vegetables; it seldom attacks any other animal, being content with such provisions as it procures without danger. Whatever animal happens to die in the forest, or is so wounded that it can make no resistance, becomes a prey to the hog, who seldom refuses animal food, how putrid soever, although it is never at the pains of taking or procuring it alive. For this reason, it seems a glutton rather by accident than choice, content with vegetable food, and only devouring flesh when pressed by necessity, and when it happens to offer. Indeed, if we behold the hog in its domestic state, it is the most sordid and brutal animal in nature." The awkwardness of its form seems to influence its appetites: and all its sensations are as gross as its shapes are unsightly. It seems possessed only of an insatiable desire of eating; and it seems to make choice only of what other animals find the most offensive. But we ought to consider that the hog with us is in an unnatural state, and that it is in a manner compelled to feed in this filthy manner from wanting that proper nourishment which it finds in the forest. When in a state of wildness, it is of all other quadrupeds the most delicate in the choice of what vegetable it shall feed on, and rejects a greater number than any of the rest. The cow, for instance, as we are assured by Linnæus, eats two hundred and seventy-six plants, and rejects two hundred and eighteen; the goat cats four hundred and forty-lline, and rejects a hundred and twenty-six; the sheep eats three hundred and eighty-seven, and rejects a hundred and forty-one; the horse eats two hundred and sixty-two, and rejects two hundred and twelve; but the hog, more

\footnotetext{
a Buffon, vol. ix. p. 14.
} 
nice in its provision than any of the former, eats but seventy-two plants, and rejects a hundred and seventy-one. The indelicacy of this animal is, therefore, rather in our apprehensions than in its nature; since we find it makes a very distinguishing choice in the quality of its food; and if it does not reject animal putrefaction, it may be because it is abridged in that food which is most wholesome and agreeable to it in a state of nature. This is certain, that its palate is not insensible to the difference of eatables; for, where it finds variety, it will reject the worst, with as distinguishing a taste as any other quadruped whatsocver." In the orchards of peachtrees in North America, where the hog has plenty of delicious food, it is observed, that it will reject the fruit that has lain but a few hours on the ground, and continue on the watch whole hours together for a fresh windfall.

However, the hog is naturally formed in a more inperfect manner than the other animals that we have rendered domestic around us, less active in its motions, less furnished with instinet in knowing what to pursue or aroid. Without attachment, and incapable of instruction, it continues, while it lives, an useless, or rather a rapacious dependent. The coarseness of its hair, and the thickness of its hide, together with the thick coat of fat that lies immediately under the skin, render it insensible to blows, or rough usnge. Mice have been known to burrow in the back of these animals while fattening in the sty, without their seeming to perceive it. Their other senses seem to be in tolerable perfection; they scent the hounds at a distance; and, as we have seen, they are not insensible in the choice of their provisions.

The hog is, ly nature, stupid, inactive, and drowsy; if undisturbed, it would sleep half its time; but it is frequently awaked by the calls of appetite, which when it has satisfied, it goes to rest again. Its whole life is thus a round of sleep and gluttony; and if supplied with sufficient food, it soon grows unifit even for its own existence; its flesh becomes a greater load than its legs are able to support, and it continues to feed lying down, or kneeling,

aritish Zoology, vol. i. p. 42. b Buffon. an helpless instance of indulged sensuality. The only time it seems to have passions of a more active nature, are, when it is incited by venery, or when the wind blows with any vehemence. Upon this occasion, it is so ngitated as to run violently towards its sty, screaming horribly at the same time, which secms to argue that it is naturally fond of a warn climate. It appears also to foresee the approach of bad weather, bringing straw to its sty in its nouth, preparing a bed, and hidiug itself from the impending storm. Nor is it less agitated when it hears any of its kind in distress: when a hog is caught in a gate, as is often the case, or when it suffers any of the usual domestic operations of ringing or spaying, all the rest are then seen to gather round it, to lend their fruitless assistance, and to sympathize with its sufferings. They have often also been known to gather round a dog that had teazed them, and kill him upon the spot.

Most of the diseases of this animal arise from intemperance; measles, imposthumes, and scrofulous swellings, are reckoned among the number. It is thought by some that they wallow in the mire to destroy a sort of louse, or insect, that is often found to infest them; however, they are generally known to live, whenso permitted, to eighteen or twenty years; and the females produce till the age of fifteen. As they produce from ten to twenty young at a litter, and that twice a year, we may easily compute how numerous they would shortly become, if not diminished by human industry. In the wild state they are less prolific; and the sow of the woods brings forth but once a year, probably because exhausted by rearing up her former numerous progeny.

It would be superfluous to d well longer upon the nature and qualities of an animal too well known to need a description: there are few, even in cities, who are unacquainted with its uses, its appetites, and way of living. The arts of fattening, rearing, guarding, and nanaging hogs, fall more properly under the $\operatorname{cog}$ nizance of the farmer than the naturalist; they make a branch of domestic economy, which, properly treated, may be cxtended to a great length; but the history of nature ought always to end where that of art begins. It will be sufficient, therefore, to observe, that the wild boar was formerly a native of our coun 
try, as appears from the laws of Hoeldda, the famous Welch legislator, who permitted his grand huntsman to chase that animal from the middle of November to the beginning of December. William the Conqueror also punished such as were convicted of killing the wild boar in his forests, with the loss of their eyes. At present, the whole wild breed is extinct; but no country makcs greater use of the tame kinds, as their flesh, which bears salt better than that of any other animal, makes a principal part of the provisions of the British navy.

As this animal is a native of almost every country, there are some varietics found in the species. That which we call the East India breed, is lower, less furnished with hair, is usually black, and has the belly almost touching the ground ; it is now common in England; it fattens more easily than the ordinary kinds, and makes better bacon.

There is a remarkable variety of this animal about Upsal, which is single-hoofed, like the horse; but in no other respect differing from the common kinds. The authority of Aristotle, who first made mention of this kind, has been often called into question; some have asserted, that such a quadruped never existed, because it happened not to fall within the sphere of their own confined observation; however, at present, the animal is too well known to admit of any doubt concerning it. The hog common in Guinea differs also in some things from our own; though shaped exactly as ours, it is of a reddish colour, with long ears, which end in a sharp point, and a tail which hangs down to the pastern; the whole body is covered with short red shining hair, without any bristles, but pretty long near the tail. Their flesh is said to be excellent, and they are vcry tame.

All these, from their near resemblance to the hog, may be considered as of the same species; the East lndian hog, we well know, breeds with the common kind; whether the same obtains between it, and those of Upsal and Guinea, we cannot directly affirm; but where the external similitude is so strong, we may be induced to believe that the appetites and habits are the same. It is true, we are told, that the Guinea breed will not mix with ours, but keep separate, and herd only together: however, this is no proof of their diversity, since every animal will prefer its own likeness in its mate; and they will then only mix with another sort, when deprived of the society of their own. These, therefore, we may consider as all of the hog kind; but there are other quadrupeds, that, in general, resemble this species, which, nevertheless, are very distinct from them. Travellers, indeed, from their general form, or from their habits and way of living, have been content to call these creatures hogs also; but upon a closer inspection, their differencesare found to be such as entirely to separate the kinds, and make each a distinct animal by itself.

\section{CHAPTER XLVII.}

\section{THE PECCARY, OR TAJACU.}

THAT animal which of all others most resembles the hog, and yet is of a formation very distinct from it, is called the peccary, or tajacu. It is a native of America, and found there, in such numbers, that they are seen in herds of several hundreds together, grazing among the woods, and inoffensive, except when offended.

The peccary, at first view, resembles a small hog; the form of its body, the shape of

- British Zoology, vol. i. p. 44. its head, the length of its snout, and the form of its legs, are entirely alike: however, when we come to examine it nearer, the differences begin to appear. The body is not so bulky ; its legs not so long; its bristles much thicker and stronger than those of the hog, resembling rather the quills of a porcupine, than hair; instead of a tail, it has only a little fleshy protuberance, which does not even cover its

- Ammenit. Acad. vol. v. p. 465. 
posteriors; but that which is still more extraordinary, and in which it differs from all other quadrupeds whatsoever, is, that it has got upon its back a lump, resembling the navel in other animals, which is found to separate a liquor of a very strong smell. The peccary is the only creature that has those kinds of glands which discharge the musky substance on that part of its body. Some have them under the belly, and others under the tail; but this creature, by a conformation peculiar to itself, lias them on its back. This lump, or navel, is situated on that part of the back which is over the hinder legs; it is, in general, so covered with long bristles, that it cannot be seen, except they be drawn aside. A small space then appears, that is almost bare, and only beset with a few short fine hairs. In the middle it rises like a lump; and in this there is an orifice, into which one may thrust a common goose quill. This hole or bag is not above an inch in depth; and round it, under the skin, are situated a number of sinall glands, which distil a whitish liquor, in colour and substance resembling that obtained from the civet animal. Perhaps it was this analogy, that led Dr. Tyson to say, that it smelt agreeably also, like that perfume. But this Mr. Buffon absolutely denies; affirming, that the smell is at every time, and in every proportion, strong and offensive, and to this I can add my own testimony, if that able naturalist should want a voucher.

But, to be more particular in the description of the other parts of this quadruped; the colour of the body is grizly, and beset with bristles, thicker and stronger than those of a common hog; though not near so thick as those of a porcupine, they resemble, in this respect, that they are variegated with black and white rings. The belly is almost bare; and the short bristles on the sides, gradually increase in length, as they approach the ridge of the back, where some are five inches long. On the head also between the ears, there is a large tuft of bristles that are chiefly black. The cars are about two inches and a half long, and stand upright; and the eyes resemble those of a common hog, only they are smaller. From the lower corner of the eye to the snout, is usually six inches; and the snout itself is like that of a hog's, though it is but small. One side No. $25 \& 26$. of the lower lip is generally smooth, by the rubbing of the tusk of the upper jaw. The feet and hoofs are perfectly like those of a common hog; but, as was already observed, it has no tail. There are some anatomical differences in its internal structure from that of the common hog. Dr. Tyson was led to suppose, that it had three stomachs; whereas the hog las but one: however, in this he was deceived, as Mr. Daubenton has plainly shown, that the stomach is only divided by two closings, which gives it the appearance as if divided into three; and there is no conformation that prevents the food in any part of it, from going or returning to any other.

The peccary may be tamed like the hog, and has pretty nearly the same habits and natural inclinations. It feeds upon the same aliments; its flesh, though drier and leaner than that of the hog, is pretty good eating; it is improved by castration; and, when killed, not only the parts of generation must be taken instantly away, but also the navel on the back, with all the glands that contribute to its supply. If this operation be deferred for only half an hour, the flesh becomes utterly unfit to be eaten.

The peccary is extremely numerous in all the parts of Southern America. They go in herds of two or three hundred together; and unite, like hogs, in each other's defence. They are particularly fierce when their young are attempted to be taken from them. They surround the plunderer, attack him without fear, and frequently make his life pay the forfeit of his rashness. When ally of the natives are pursued by a herd in this manner, they frequently climb a tree to aroid them 5 while the peccaries gather round the root, threaten with their tusks, and their rough bristles standing erect, as in the hog kind, they assume a very terrible appearance. In this manner they remain at the foot of the tree for hours together; while the hunter is obliged to wait patiently, and not without apprebensions, until they think fit to retire.

The peccary is rather fond of the mountainous parts of the country, than the lowlands; it seems to delight neither in the marsh. es nor the mud, like our hogs; it kceps among the woods, where it subsists upon wild fruits, roots, and vegetables ; it is also an unceasing 24 
enemy to the lizard, the toad, and all the serpent kinds, with which these uncultivated forests abound. As soou as it perceives a serpent, or a viper, it at once seizes it with its fore hoofs and teeth, skins it in an instant, and devours the flesh. This is often seen, and may, therefore, be readily credited : but as to its applying to a proper vegetable immediately after, as an antidote to the poison of the animal it had devoured, this part of the relation we may very well suspect. The flesh, neither of the toad nor viper, as every one kuows, are poisonous; and, therefore, there is no need of a remedy against their venom. Ray gives no credit to either part of the acconnt: however, we can have no reason to disbelieve that it feeds upon toads and serpents; it is only the muking use of a vegetable antidote that appears improbable, and which perhaps had its rise in the ignorance and credulity of the natives.

The peccary, like the hog, is very prolific; the young ones follow the dam, and do not separate till they have come to perfection. If taken at first, they are very easily tamed, and soon lose all their natural ferocity; however, they never show any remarkable signs of docility, but continue stupid and rude, without attachment, or even seeming to know the hand that feeds them. They only continue to do no inischief; and they may be permitted to run tame without apprehending any dan- gerous consequences. They seldom stray far from home; they return of themselves to the sty; and do not quarrel anong each other, except when they happen to be fed in common. At such times, they have an angry kind of growl, much stronger and harsher than that of a hog; but they are seldom heard to seream as the former; only now and then, when frighted, or irritated, they have an abrupt angry manner of blowing like the boar.

The peccary, though like the hog in so many various respects, is, nevertheless, a very distinct race, and will not $\mathrm{mlx}$, nor produce an intermediate breed. The European hog has been trarisplanted into America, and suffered to run wild among the woods; it is often seen to herd among a drove of peccaries, but never to breed from them. They may, therefore, be considered as two distinct creatures; the hog is the larger and the more useful animal; the peccary, more feeble and local; the hog subsists in most parts of the world, and in almost every climate; the peccary is a native of the warner regions, and cannot subsist in ours, without shelter and assistance. It is more than probable, however, that we could readily propagate the breed of this quadruped; and that, in two or three generations, it might be familiarized to our climate: but as it is inferior to the hog in every respect, so it would be needless to admit a new domestic, whose services are better supplied in the old.

\section{CHAPTER XLVII.}

\section{THE CAPIBARA, OR CABIAI.}

THERE are some quadrupeds so entirely different from any that weareacquainted with, that it is hard to find a well known animal to which to resemble them. In this case, we must be content to place them near such as they most approach in form and habits, so that the reader inay at once have some idea of the creature's shape or disposition, although, perhaps, an inadequate and a very confused one.

Upon that confused idea, however, it will be our business to work; to bring it, by degrees, to greater precision; to mark out the differences of form, and thus give the clearest notions that words can easily convey. The known animal is a kind of rude sketch of the figure we want to exhibit; from which, by degrees, we fashion out the shape of the creature we desire should be known; as a statuary seldom begins his work, till the rude outline of the figure is given by some other hand. In this manner, I have placed the ca 
pibara among the hog kind, merely because it is more like a hog than any other animal cominonly known, and yet, more closely examined, it will be found to differ in some of the most obvious particulars.

The capibara resembles a hog of about two years old, in the shape of its body, and the coarseness and colour of its hair. Like the hog, it has a thick short neek, and a rounded bristly back; like the hog, it is fond of the water and marslyy places, brings forth many at a time, and, like it, feeds upon animal and vegetable food. But, when examined more nearly, the differences are many and obvious. The head is longer, the eyes are larger, and the snout, instead of being rounded, as in the hog, is split like that of a rabbit or a hare, and furnished with thick strong whiskers; the mouth is not so wide, the number and the form of the teeth are different, for it is without tusks : like the peceary it wants a tail; and, unlike to all others of this kind, instead of a cloven hoof, it is in a manner web-footed, and thus entirely fitted for swinming, and living in the water. 'The hoofs before are divided into four parts; and those behind into three; between the divisions, there is a prolongation of the skin, so that the foot, when spread in swimming, can beat a greater surface of water.

As its feet are thus made for the water, so it is seen to delight entirely in that element; and some naturalists have called it the vaterhog for that reason. It is a native of South Anerica, and is chiefly seen frequenting the borders of lakes and rivers, like the otter. It seizes the fish upon which it preys, with its hoofs and teeth, and carries them to the edge of the lake, to devour them at its ease. It lives also upon fruits, corn, and sugar-eanes. As its feet are long and broad, it is often seen sitting up like a dog that is taught to beg. Its cry more nearly resembles the braying of an ass, than the grunting of a hog. It seldom goes out, except at night, and that always in company. It never ventures far from thesides of the river or the lake in which it preys; for as it runs ill, because of the length of its feet, and the shortness of its legs, so its only place of safety is the water, into which it immediately plunges when pursued, and keeps so long at the bottom, that the hunter can have no hopes of taking it there. The Capibara, even in a state of wildness, is of a gentle nature, and, when taken young, is easily tamed. It comes and goes at conmand, and evers shows an attachment to its keeper. Its flesh is said to be fat and tender, but, from the nature of its food, it has a fishy taste, like that of all those which are bred in the water. Its head, however, is said to be excellent; and in this it resembles the beaver, whose fore-parts taste like flesh, and the hinder like the fish it feeds on.

\section{CHAPTER XIX.}

\section{THE BABYROUESSA, OR INDIAN HOG.}

THE Babyrouessa is still more remote from the hog kind than the capibara; and yet most travellers who have described this animal, do not scruple to call it the hog of Borneo, which is an island in the East Indies, where it is principally to be found. Probably this animal's figure upon the whole most resembles that of the hog kind, and may have induced them to rank it among the number: however, when they come to its description, they represent it as having neither the hair, the bristles, the head, the stature, nor the tail of a hog. Its legs, we are told, are longer, its snout shorter, its body more slender, and somewhat resembling that of a stag; its hair is finer, of a gray colour, rather resembling wool than bristles, and its tail also tufted with the same. From these varieties, therefore, it can scarcely be called a hog; and, yet, in this class we must be content to rank it, until its form and nature come to be better known. What we at present principally distinguish it by, are four enormous tusks, that grow out of each jaw; the two largest from $2 \mathrm{Z}^{*}$ 
the upper, and the two smallest from the under. The jaw-bones of this extraordinary animal are found to be very thick and strong; from whence these monstrous tusks are seen to proceed, that distinguish it from all other quadrupeds whatsoever. The two that go from the lower jaw are not above a foot long, but those of the upper are above half a yard: as in the boar, they bend circularly, and the two lower stand in the jaw as they are seen to do in that animal; but the two upper rise from the upper jaw, rather like horns than teeth; and, bending upwards and backwards, sometimes have their points directed to the animal's eyes, and are often fatal by growing into them. Were it not that the babyrouessa has two such large teeth underneath, we miglit easily suppose the two upper to be horns; and, in fact, their sockets are directed upwards; for which reason, Dr. Grew was of that opinion. But as the teeth of both jaws are of the same consistence, and as they both grow out of sockets in the same manner, the analogy between both is too strong not to suppose them of the same nature. The upper teeth, when they leave the socket, immediatety pierce the upper lips of the animal, and grow as if they immediately went from its cheek. The tusks in both jaws are of a very fine ivory, smoother and whiter than that of the elephant, but not so hard or serviceable.

These enormous tusks give this animal a very formidable appearance; and yet it is thought to be much less dangerous than the wild boar." Like animals of the hog kind, they go together in a body, and are often seen in company with the wild boar, with which, however, they are never known to engender. They have a very strong scent, which discovers them to the hounds; and, when pursued, they growl dreadfully, often turning back upon the dogs, and wounding them with the tusks of the lower jaw, for those of the upper are rather an obstruction than a defence. They run much swifter than the boar, and have a more exquisite scent, winding the men and the dogsat a great distance. When liunted close$l y$, they generally plunge themselves into the sea, where they swim with great swiftness and facility, diving, and rising again at pleasure;

- Buffon, vol. xxv. p. 179. and in this manner they most frequently escape their pursuers. Although fierce and terrible when offended, yet they are peaceable and harmless when unimolested. They are easily tamed, and their flesh is good to be eaten; but it is said to putrefy in a very short time. They have a way of reposing themselves different from most other animals of the larger kind; which is by hitching one of their upper tusks on the branch of a tree, and then suffering their whole body to swing down at ease. Thus suspended from a tooth, they continue the whole uight quite secure, and out of the reach of such animals as hunt them for prey.

The babyrouessa, though by its teeth and tusks it seems fitted for a state of hostility, and probably is caruivorous, yet, nevertheless, seems chiefly to live upon vegetables and the leaves of trees. It seldom seeks to break into gardens, like the boar, in order to pillage the more succulent productions of human industry, but lives remote from mankind, content with coarser fare and security. It has been said, that it was only to be found in the island of Borneo, but this is a mistake, as it is well known in many other parts both of Asia and Africa, as at the Celebes, Estrila, Senegal, and Madagascar.

Such are the animals of the hog kind, which are not distinctly known; and even all these, as we see, have been but imperfectly examined or described. There are some others of which we have still more imperfect notices; such as the waree, a hog of the Isthmus of Darien, described by Wafer, with large tusks, small ears, and bristles like a coarse fur over all the body. This, however, may be the European hog, which has run wild in that part of the new world, as no other traveller has taken notice of the same. The Canary boar seems different from other animals of this kind, by the largeness of its tusks; and, as is judged from the skeleton, by the aperture of its nostrils, and the number of its grinders. I cannot conclude this account of those animals that are thus furnished with enormous tusks, without observing that there is a strong consent between these and the parts of genera. tion. When castrated, it is well known that

D Anderson's Natural History of Greenland. 
the tusks grow much smaller, and are scarce seen to appear without the lips; but what is still more remarkable, is, that in a boar, if the tusks by any accident or design be broke away, the animal abates of its fierceness and venery, and it produces nearly the same effect upon its constitution, as if castration had actually taken place. ${ }^{a}$

a Lisle's Husbandry, vol. ii. p. 329. 


\section{caringozous arrumatas.}

\section{CHAPTER L:}

\section{ANIMALS OF THE CAT KIND.}

WE have hitherto been describing a class of peaceful and harmless animals, that serve as the instruments of man's happiness, or, at least, that does not openly oppose him. We come now to a bloody and unrelenting tribe, that disdain to own his power, and carry on unceasing hostilities against him. All the class of the cat kind are chiefly distinguished by their sharp and formidable claws, which they can hide and extend at pleasure. They lead a solitary, ravenous life, neither uniting for their mutual defence, like vegetable feeders, nor for their mutual support, like those of the dog kind. The whole of this cruel and ferocious tribe seck their food alone; and, except at certain seasons, are even enemies to each other. The dog, the wolf, and the bear, are sometimes known to live upon vegetables or farinaceous food; but all of the cat kind, such as the lion, the tiger, the leopard, and the ounce, devour nothing but flesh, and starve upon any other provision.

They are, in general, fierce, rapacious, subthe, and cruel, unfit for society among each other, and incapable of adding to human happiness. However, it is probable that even the fiercest could be rendered domestic, if man thought the conquest worth tne trouble. Lions have been yoked to the chariots of conquerors, and tigers have been taught to tend those herds which they are known at present to destroy; but these services are not sufficient to recompense for the trouble of their keeping; so that ceasing to be useful, they continue to be noxious, and become rebellious subjects because not taken under equal protection with the rest of the brute creation.

Other tribes of animals are classed with difficulty ; having often but few points of resemblance; and, though alike in form, have different dispositions, and different appetites. But all those of the cat kind, although differing in size, or in colour, are yet nearly allied to each other; being equally fierce, rapacious, and artful; and he that has seen one has seen all. In other creatures there are many changes wrought by human assiduity ; the dog, the hog, or the sheep, are altered in their natures and fornıs, just as the necessities or the caprice of mankind have found fitting; but all of this kind are inflexible in their forms, and wear the print of their natural wildness strong upon them. The dogs or cows vary in different countries, but lions or tigers are still found the same; the very colour is nearly alike in all; and the slightest alterations are suficient to make a difference in the kinds, and to give the animal a different denomination.

The cat kind are not less remarkable for the sharpness and strength of their claws, which thrust forth from their sheath when they seize their prey, than for the shortness of their snout, the roundness of their head, and the large whiskers which grow on thc upper lip. Their teeth also, which amount to the number of thirty, are very formidable, but rather calculated for tearing their prey than for chewing it - for this reason they feed but slowly : and while they eat, generally continue growling, to deter others from taking a share. In the dog kind, the chief power lics in the under jaw, which is long, and furnished with muscles of amazing strength; but in these the greatest force lies in the claws, which are extended with great ease, and their gripe is so tenacious that nothing can open it. The hinder parts in all these animals are much weaker than those before; and they seem less made for strength than agility. Nor are they endued with the swiftness of most other aninals; but generally owe their subsistence rather to catching their prey by surprise than by hunting it fairly down. They all seize 
it with a bound, at the same time expressing th.ir fierce pleasure with a roar; and the first grisp generally disables the captive from all further resistince. With all these qualifications for slaughter, they nevertheless seem timid and cowardly, and seldom make an attack, like those of the dog kind, at a disadvantage: on the contrary, they fly when the force against them is superior, or even equal to their own; and the lion himself will not venture to make a second attempt, where he has been once repulsed with success. For this reason, in couniries that are tolerably inhabited, the lion is so covardly, that he is often scared away by the cries of women and children.

The cat, which is the smallest animal of this kind, is the only one that lias been taken under human protection, and may be considered as a faithless friend, brought to oppose a still more insidious enemy. ${ }^{a}$ It is, in fact, the only animal of this tribe whose services can more than recompense the trouble of their education, and whose strength is not sufficient to make its anger formidable. The lion, or the tiger, may easily be tamed, and rendered subservient to human command; but even iı their humblest, and most familiar moments, they are still dangerous; since their strength is such that the smallest fit of anger or caprice may have dreadful consequences. But the cat, though easily offended, and often capricious in her resentments, is not endowed with powers sufficient to do any great mischief. Of all animals, when young, there is none more prettily playful than the kitten; but it seems to lose this disposition as it grows old, and the innate treachery of its kind is then seen to prevail. From being naturally ravenous, education teaches it to disguise its appetites, and to watch the favourable moment of plunder; supple, insinuating, and artful, it has learned the arts of concealing its intentions till it can put them into execution ; when the opportunity offers, it at once scizes npon whatever it finds, flies off with it, and continues at a distance till it supposes its offence forgotten. The cat has only the appearance of attachment; and it may easily be perceived, by its timid approaches, and sile-long looks, that it either dreads its mitster, or distrusts his kindness; different

a This description is nearly translated from Mr. Bufion : what I have added is marked with inverted commas. from the dog, whose caresses are sincere, the cat is assiduous rither for its own pleasure, than to please ; and often gains confideuce, only to abuse it. 'The form of its body, and its temperament, correspond with its disposition ; active, cleanly, delicate, and volupruous, it loves its ease, and seeks the softest cushions to lie on. "Many of its habits, however, are rather the consequences of its formation, than the result of any perverseness in its disposition; it is timid and mistrustful, because its body is weak, and its skin tender; a blow hurts it infinitely more than it does a dog, whose hide is thick, and body nuscular; the long fur in which the cat is clothed, entirely disguises its shape, which, if seen naked, is long, feeble, and slender ; it is not to be wondered, therefore, that it appears much more fearful of chastisement than the dog, and often flies, even when no correction is intended. Being also the native of the warmer climates, as ivill be shown hereafier, it chooses the softest bed to lie on, which is always the warmest."

The cat goes with young fifty-six days, and seldom brings forth above five or six at a time. The female usually hides the place of her retreat from the inale, who is often found to devour her kittens. She feeds them for some weeks with her nuilk, and whatever sniall animal she can take by surprise, accustoming them betimes to rapine. Before they are a year old, they are fit to engender; the female seeks the male with cries; nor is their copulation performed without great pain, from the narrowness of the passage in the female. They live to about the age of ten years; and, during that period, they are extremely vivacious, suffering to be worried a long time before they die.

The young kittens are very playful and amusing; but their sport soon turns into malice, and they, from the beginning, show a disposition to cruclty ; they often look wistfully towards the cage, sit centinels at the moutl of a mouse-hole, and, in a sluort time, become more expert hunters, than if they had received the instruction of art. Indeed, their disposition is so incapable of constraint, that all instruction would be but thrown away. It is true, that we are told of the Greek nionks of the isle of Cyprus, teaching cats to liunt the scrpents with which the island is infested ; but this may be natural to the animal itself, and they might have fallen upon such a pursuit without any 
instruction. Whatever animal is much weaker than themselves, is to them an indiscriminate object of destruction. Birds, young rabbits, hares, rats, and mice, bats, moles, toads, and frogs, are all equally pursued; though not, perhaps, equally acceptable. The mouse seems to be their favourite game; and, although the cat has the sense of smelling in but a mean degree, it, nevertheless, knows those holes in which its prey resides. I have seen one of them patiently watch a whole day until the mouse appeared, and continue quite motionless until it came within reach, and then seized it with a jump. Of all the marks by which the cat discovers its natural malignity, that of playing and sporting with its little captive, before killing it outright, is the most flagrant.

The fixed inclination which they discover for this peculiar manner of pursuit, arises from the conformation of their eyes. The pupil in man, and in most other animals, is capable but of a small degree of contraction and dilatation; it enlarges a little in the dark, and contracts when the light pours in upon it in too great quantities. In the eyes of cats, lowever, this contraction and dilatation of the pupil, is so considerable, that the pupil, which by day-light appears narrow and small like the black of one's nail, by night expands over the whole surface of the cye-ball, and, as every one must have seen, their eyes seem on fire. By this peculiar conformation, their eyes see better in darkness than light; and the animal is thus better adapted for spying out and surprising its prey.

Although the cat is an inhabitant of our houses, yet it cannot properly be called a dependent; although perfectly tame, yet it acknowledges no obedience; on the contrary, it does only just what it thinks fit, and no art can control any of its inclinations. In general, it is but half tamed; and has its attachments rather to the place in which it resides, than to the inhabitant. If the inhabitant quits the house, the cat still remains; and if carried elsewhere, seems for a while bewildered with its new situation. It must take time to become acquainted with the holes and retreats in which its prey resides, with all the little labyrinths through which they often make good an escape.
The cat is particularly fearful of water, of cold, and of ill smells. It loves to keep in the sun, to get near the fire, and to rub itself against those who carry perfumes. It is excessively fond of some plants, such as valerian, marum, and cat-mint: against these it rubs, smells them at a distance, and, at last, if they be planted in a garden, wears them out.

This animal eats slowly, and with difficulty, as its teeth are rather made for tearing, than chewing its aliments. For this reason, it loves the most tender food, particularly fish, which it eats as well boiled as raw. Its sleeping is very light; and it often seems to sleep, the better to deceive its prey. When the cat walks, it treads very softly, and without the least noise; and as to the necessities of nature, it is cleanly to the last degree. Its fur also is usually sleek and glossy; and, for this reason, the hair is easily electrified, sending forth shining sparks, if rubbed in the dark.

"The wild cat breeds with the tame;" and, therefore, the latter may be considered only as a variety of the former: however, they differ in some particulars; the cal, in its savage state, is somewhat larger than the house-cat; and its fur being longer, gives it a greater appearance than it really has; its head is bigger, and face flatter; the teeth and claws much more formidable; its muscles very strong, as being formed for rapine; the tail is of a moderate length, but very thick and flat, marked with alternate bars of black and white, the end always black; the hips, and hind part of the lower joints of the leg, arealways black; the fur is very soft and fine: the general colour of these animals, in England, is a yellowish white, mixed with a deep gray. These colours, though they appear at first sight confusedly blended together, yet on a close inspection, will be found to be disposed like the streaks on the skin of the tiger, pointing from the back downwards, rising from a black list, that runs from the head, along the middle of the back, to the tail. This animal is found in our larger woods; and is the most destructive of the carnivorous kinds in this kingdom. It inhabits the most mountainous and woody parts of these islands, living mostly in trees, and feeding only by night. It often happens,

- British Zoology. 
that the females of the tame kind go into the woods to seek mates among the wild ones. It should secm, that these, however, are not original inhabitants of this kingdom, but were introduced first in a domestic state, and afterwards became wild in the woods, by ill usage or neglect. Certain it is, the cat was an animal much higher in esteem among our ancestors than it is at present. By the laws of Howel, the price of a kitten, before it could see, was to be a penny ; till it caught a mouse, two-pence; and when it commenced mouser, four-pence: it was required, besides, that it should be perfect in its senses of hearing and seeing, be a good mouser, have the claws whole, and be a good nurse. If it failed in any of these qualities, the seller was to forfeit to the buyer the third part of its value. If any one stole or killed the cat that guarded the prince's granary, he was to forfeit a milch ewe, its fleece and lamb, or as much wheat as when poured on the cat, suspended by the tail, (the head touching the floor,) would form a heap high enough to cover the tip of the former. From hence we discover, besides a picture of the simplicity of the times, a strong argument that cats were not naturally bred iil our forests. An animal that could have been so easily taken, could never have been rated so highly; and the precautions laid down to improve the breed, would have been superfluous, in a creature that multiplies to such an amazing degree.

"In our climate, we know but of one variety of the wild cat : and, from the accounts of travellers, we learn, that there are but very few differences in this quadruped in all parts of the world. The greatest difference, indeed, between the wild and the tame cat, is rather to be found internally than in their ontward form. Of all other quadrupeds, the wild cat is, perhaps, that whose intestines are proportionably the smallest and the shortest. The intestines of the sheep, for iustance, uuravelled out, and measured nccording to their length, will be found to be above thirty times the length of its body ; whereas, the wild cat's intestines being measured out, will not be found above three times the length of its body. This is a surprising difference; but we may account for it, from the nature of the food in the two animals; the one living upon vegeta-

No. $25 \& 26$. bles, which require a longer, and a more tedious preparation, before they can become a part of its body; the other, living upon flesh, which requires very little alteration, in order to be assimilated into the substance of the creature that feeds upon it. The one, therefore, wanted a long canal for properly digesting and straining its food; the other, but a short one, as the food is already prepared to pass the usual secretions: however, a difficulty still remains behind; the intestines of the wild cat are, by one-third, shorter than those of the tame. How can we account for this? If we say that the domestic cat, living upon more nourishing and more plentiful provision, has its intestines enlarged to the quantity with which it is supplied, we shall find this observation contradieted in the wild boar and the wolf, whose intestines are as long as those of the hog or the dog, though they lead a savage life, and, like the wild cat, are fed by precarious subsistence. The shortness, therefore, of the wild cat's intestines, is still unaceounted for; and most naturalists consider the difficulty as inextricable. We must leave it, therefore, as one of those difficulties which future observation or accident are most likely to discover.

This animal is one of those few which are common to the new continent, as well as the old. When Christopher Columbus first discovered that country, a hunter brought bim one, which he had discovered in the woods, which was of the ordinary size, the tail very long and thick. They were common also in Peru, although they were not rendered domestic. They are well known also in several parts of Africa, and many parts of Asia. In some of these countries they are of a peculiar colour, and inclining to blue. In Persia, Pietro dello Valle informs us, that there is a kind of cat, particularly in the province of Chorazan, of the figure and form of the ordinary one, but infinitely more beautiful in the lustre and colour of its skin. It is of a gray blue, without mixture, and is soft and shining as silk. The tail is very long, and covered with hair six inches long, which the animal throws upon its back, like the squirrel. These cats are well known in France; and have been brought over into England, under the name of the blue cat, which, however, is not their colour. 
Another variety of this animal is called by us the lion cat ; or, as others more properly term it, the cat of Angora. These are larger tlian the common car, and even than the wild one. Their hai, is much longer, and hangs about their head and neek, giving this crenture the appearance of a lion. Some of these are white, and others of a dun colour. These conie fiom Syria and Persia, two countries which are noted for giving a long soft hair to the animals which are bred in them. The sheep, the goats, the dogs, and the rabbits of Syria, are all remarkable for the fine glossy length and sofiness of their hair; but particularly the cat, whose nature seems to be so inflexible, conforms to the nature of the climate and soil, loses its savage colour, which it preserves almost in every other part of the world, and assumes the most beautiful appearance. There are some other varieties in this animal, but rather in colour than in for'm; and, in general, it may be remarked, that the cat, when carried into other countries, alters but very little, srill preserving its natural manners, habits, and conformation."

\section{THE LION.}

Tre influence of climate upon mankind is very sinall; ${ }^{2}$ he is found to subsist in all parts of the earth, as well under the frozen poles, as beneath the torrid zone: but in animals, the climate may be considered as congenial, and a kind of secoud nature. They almost all have their particular latitudes, beyond which they are unahle to subsist; either perishing with a moderate cold, or dying for want of a frozen air, even in a temperate climate. The rein-deer is never seen to depart from the icy fields of the north; and, on the contrary, the lion degencrates, when taken from beweath the line. The whole earth is the native country of man; but all inferior animals have each their own peculiar districts.

Most terrestrial animnals are found larger, fiercer, and stronger, in the warm, than in the cold or temperate climates. They are also more courageous and enterprising; all their dispositions seeming to partake of the ardour

a This description is principally taken from Mr. Buffon: such parts as are added from others, I have marked witl inverted commas. of their native soil. The lion, produced under the burning sun of Africa, is, of all others, the most terrible, the most undaunted. The w olf or the dog, instead of attempting to rival him, scarce deserve to attend his motions, or become his providers. Such, however, of these animals, as are bred in a more temperate clinate, or towards the tops of cold and lofty mountains, are far nıore gentle, or, to speak nuore properly, far less daugerous than those bred in the torrid valleys beneath. The lions of Mount Atlas, the tops of which are covered in eternal snows, have neither the strength nor the ferocity of the lions of Bildulgerid or Zaara, where the plains are covered with burning sands. It is particularly in these frightful deserts, that those enormous and terrible beasts are found, that seem to be the scourge and the terrur of the neighbouring kingdoms. Happily, indeed, the species is not very numerous; and it seems to be diminishing daily: for those who have travelled through these countries, assure us, that there are by no means so many there at present, as were known formerly; and $\mathrm{Mr}$. Shaw observes, that the Romans carried fity tines as many lions from Lyhia, in one year, to combat in their amphitheatros, as are to be found in the whole country at this tinc. The same remark is nade with regard to Turkey, to Persia, and the Indies; where the lions are found to diminish in their numbers every day. Nor is it difficult to assign the cause of this diminution: it is obvious that it cammot be owing to the increase of the force of other quadrupeds, since they are all iuferior to the lion, and, consequently, instend of lessening the number, only tend to increase the supplies on which they subsist; it must, therefore, be occasioned by the increase of mankind, who is the only animal in nature capable of making head against these tyrants of the forest, and preventing their increase. The arms even of a Hottentot or a Negro make them more than a match for this powerful creature; and th' $y$ seldom make the attack, without coning off victorious. Their usual manner is to find out his retreat, and with spears headed with iron, to provoke him to the combat: four men are considered as sufficiunt for this encounter; and he against whom the lion? flies, reccives him upon his spear, while the otlors attack lim behind ; the lion, finding himself wounded in the rear, turns that way, and thus gives the 


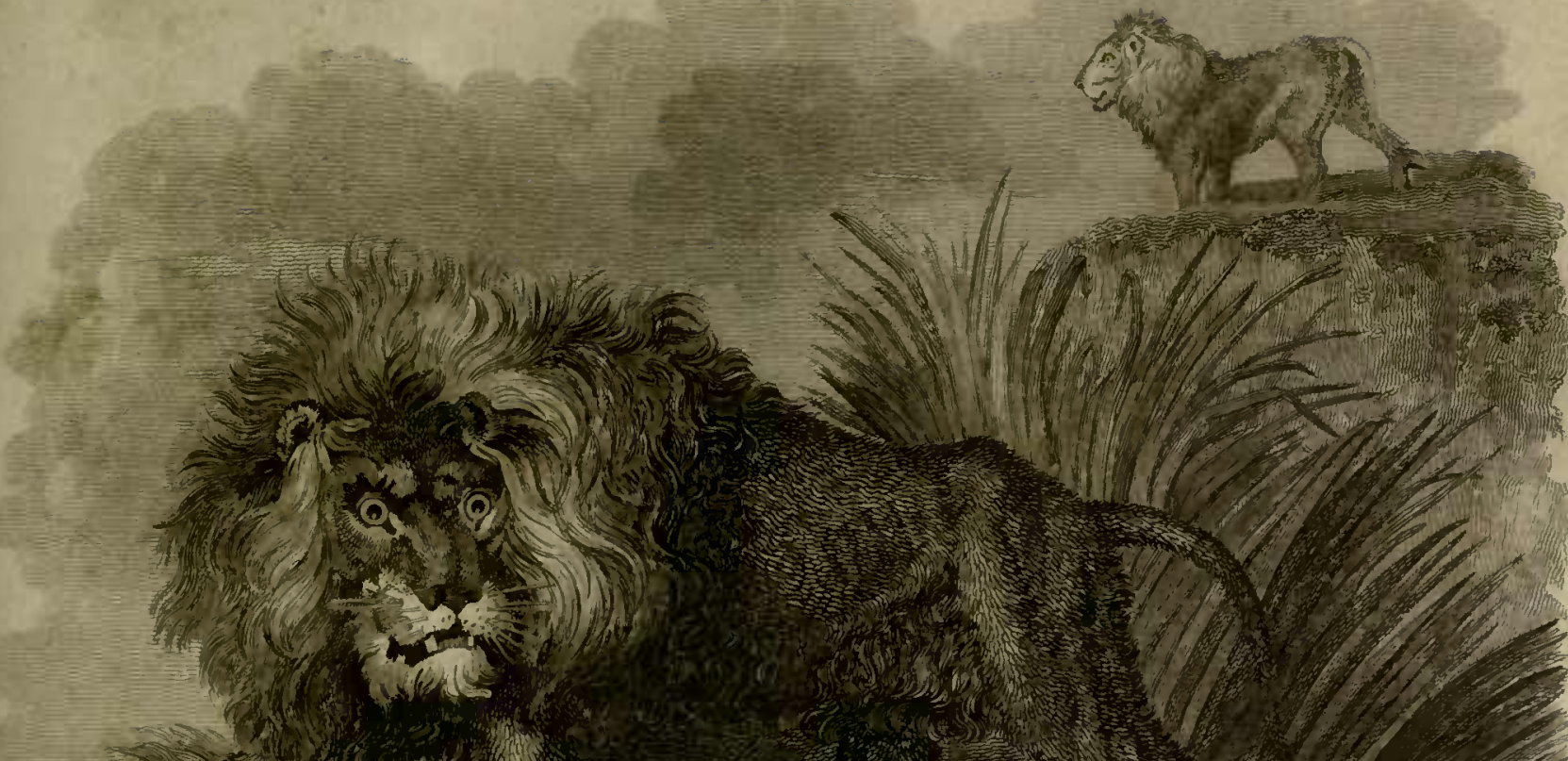

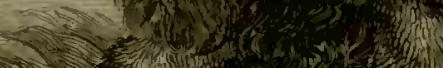

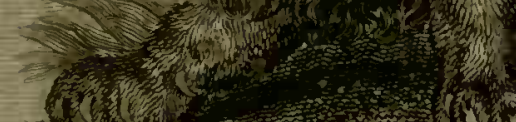

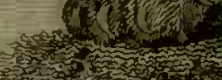

13) 30 ,

57.

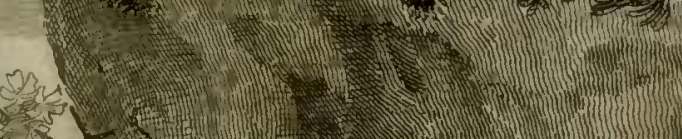

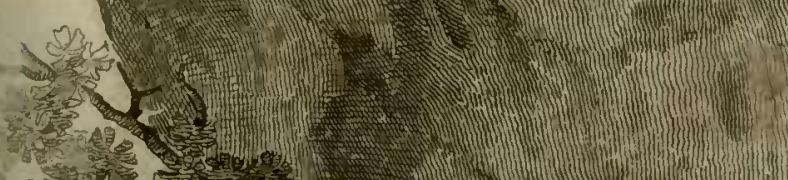
y

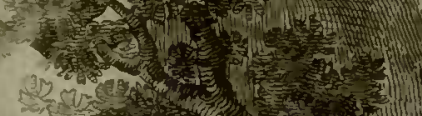

(n)

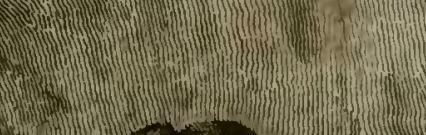

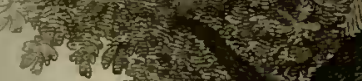

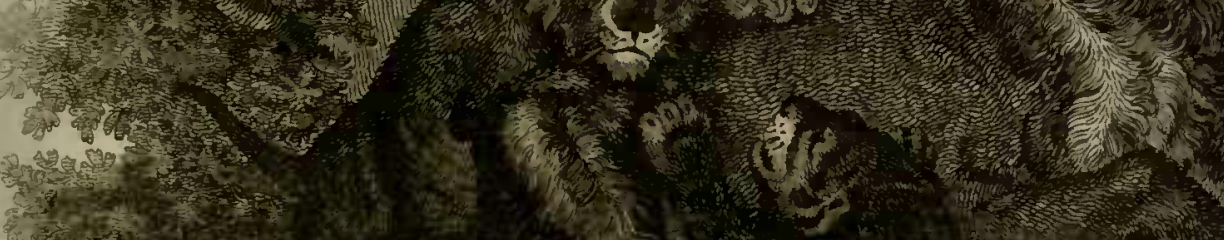

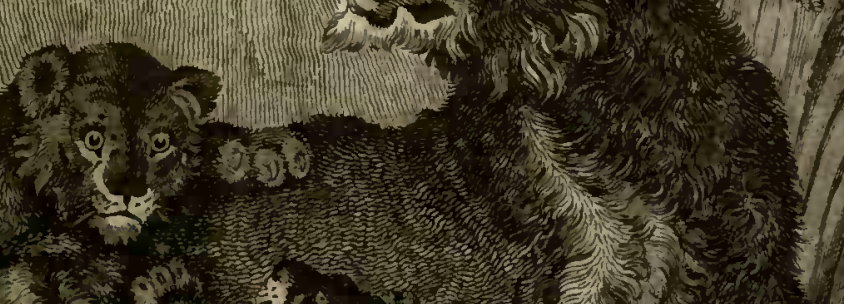

(n)

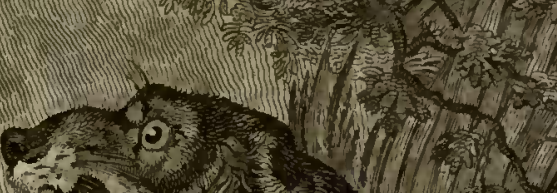

17
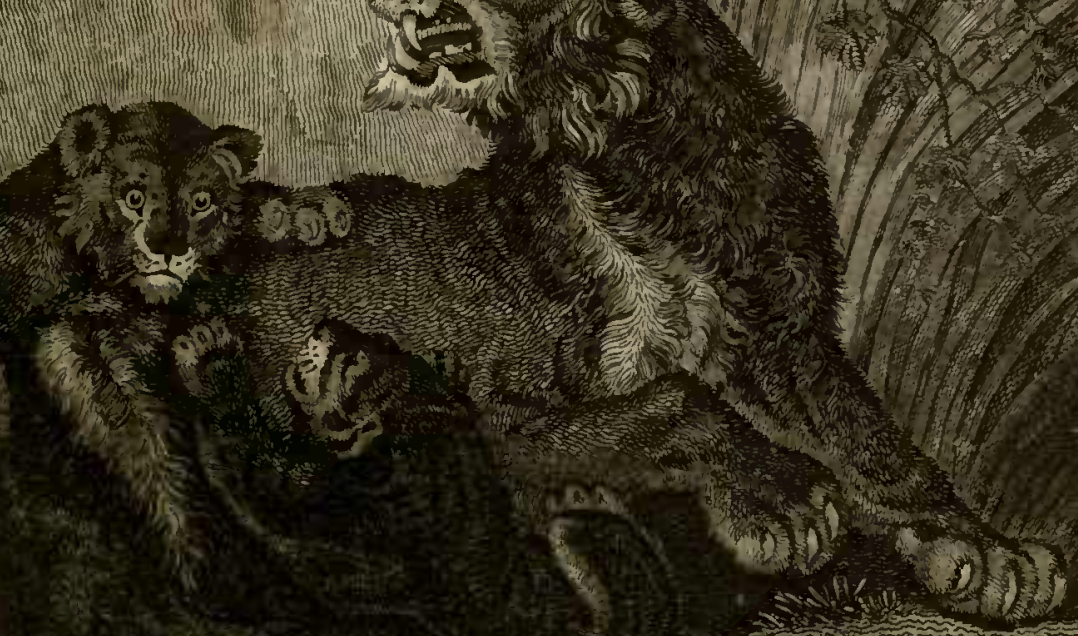

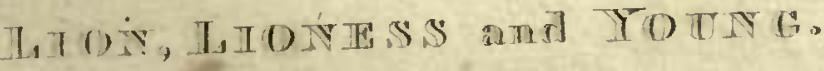

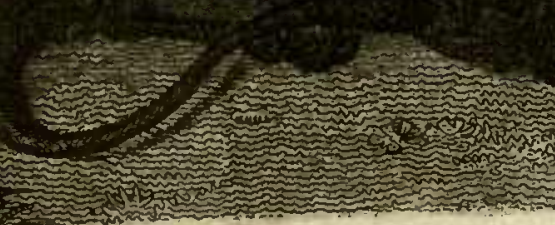


man he first attacked an opportunity to recover. In this manner they attack him on all sides; until, at last, they entirely disable, and then despatch him. This superiority in the numbers, and the arts of inan, that are sufficient to conquer the lion, serve also to enervate and discourage him; for he is brave only in proportion to the success of his former encounters. In the vast deserts of "Zaara, in the burning sands that lie between Mauritania, and Negroland, in the uninhabited countries that lie to the north of Catriaria, and, in ge neral, in all the deserts of Africa, where man has not fixed his habitation, the lions are found in great numbers, and preserve their natural courage and force. Accustomed to measure their strength with every animal they meet, the halit of conquering renders them intrepid and terrible. Having never experienced the dangerous arts and combinations of man, they have no apprehensions from his power. They boldly fice him, and seem to brave the force of his arms. Wounds rather serve to provoke their rage than repress their ardour. They are not daunted even with the opposition of numbers; a single lion of the desert often attacks an entire caravan; and, after an obstinate combat, when he finds himself overpowered, instead of flying, he continues to combat, retreating, and still facing the enemy till he dies. On the contrary, the lions which inhabit the peopled countries of Morocco or India, having become aequainted with human power, and experienced man's superiority, have lost all their courage, so as to be scared away with a shout; and seldom attack any but the unresisting flocks or herds, which even women and children are sufficient to protect.

This alteration in the lion's disposition sufficiently shows that he might easily be tamed, and admit of a certain degree of education. "In fact, nothing is more common than for the keepers of the wild beasts to play with this animal, to pull out his tongue, and even to chastise him without a cause. He seems to bear it all with the utmost composure; and we very rarely have instances of his revenging these unprovoked sallies of impertinent cruclty. However, when his anger is at last excited, the consequences are terrible. : Labat tells us of a gentleman who kept a lion in his chamber, and employed a servant to attend it ; who, as is usual, mixed his blows with caresses. This ill-judged association continued for some time; till one morning the gentleman was awakened by a noise in his room, which, at first, he could not tell the cause of; but, drawing the curtains, he perceived a horrid spectacle; the lion growling over the man's head, which he had separated from the body, and tossing it round the floor. He immediately, therefore, flew into the next room, called to the people without, and had the animal secured from doing further mischief." However, this single account is not sufficient to weigh against the many instances we every day see of this creature's gentleness and submission. He is often bred up with other domestic animals, and is seen to play innocently and familiarly among then; and, if ever it happens that his natural ferocity returns, it is seldom exerted against his benefactors. As his passions are strong, and his appetites vehement, one ought not to presume that the impressions of education will always prevail; so that it would be dangerous in such circumstances to suffer liim to remain too long without food, or to persist in irritating and abusing him : however, numberless accounts assure us that his anger is noble, his courage magnanimous, and his disposition grateful. He has been often seen to despise contemptible enemies, and pardon their insults, when it was in his power to punish them. He has been seen to spare the lives of such as were thrown to be devoured by him, to live peaceably with them, to afford them a part of his subsistence, and sometimes to want food himself rather than deprive them of that life which his generosity had spared.

It may also be said that the lion is not cruel, since he is so only from necessity, and never kills more than he consumes. When satiated, he is perfectly gentle; while the tiger, the wolf, and all the inferior kinds, such as the fox, the pole-cat, and the ferret, kill without remorse, are fierce without cause, and, by their indiscriminate slaughter, seem rather to satisfy their malignity than their hunger.

The outward form of the lion seems tospeak his internal generosity. His figure is striking, his look confident and bold, his gait proud, and his voice terrible. His stature is not overgrown, like that of the elephant, or rhinoceros; 
nor is his shape clumsy, like that of the hippopotamus, or the ox. It is compact, well proportioned, and sizeable; a pertect model of strength joined with agility. It is inuscular and bold, neither charged with fat nor unnecessary flesh. It is sufficient but to see him in order to be assured of his superior force. His large head surrounded with a dreadful mane; all those muscles that appear under the skin swelling with the slightest exertions; and the great breadth of his paws, with the thickness of his limbs, plainly evince that no other animal in the forest is capable of opposing him. He has a very broad face that, as some have imagined, resembles the human. It is surrounded with very long hair, which gives it a very majestic air. The top of the head, the temples, the cheeks, the under-jaw, the neck, the breast, the shoulder, the hinder part of the legs, and the belly, are furnished with it, while all the rest of the body is covered with a very short hair, of a tawny colour. "The length of the hair in many parts, and the shortness of it in others, serves a good deal to disguise this animal's real figure. The breast, for instance, appears very broad, but in reality it is as narrow and contracted in proportion as that of the generality of dogs and horses. For the same reason, the tail seems to be of an equal thickness from one end to the other, on account of the inequality of the hair with which it is encompassed; it being shorter near the insertion where the flesh and bones are large, and growing longer in proportion as its real thickness lessens towards the point, where it ends in a tuft. The hair about the neck and the breast is not different from that on the rest of the body, except in the length of it; nor is each hair pointed as in most other animals, but of an equal thickness from one end to the other. The neck is very strong, but not composed of one solid bone, as Aristotle has imagined; on the contrary, though very short and muscular, it has as many bones as the camel or the horse; for it is universal to all quadrupeds to have seven joints in the neck; and not one of them have either more or less. However, the muscles in the neck of the lion, that tie the bones together, are extremely strong, and have somewhat the appearance of bones; so that ancient authors, who have treated of this animal, have mistaken the whole for a single bone. The tongue is rough, and beset with prickles as hard as the cat's claws; these have the grain turned backwards; so that it is probable a lion, if it should attempt to lick a man's hand, as we are told it sometimes does, would tear off the skin. The eyes are always bright and fiery; nor even in death does this terrible look forsake them. In short, the structure of the paws, teeth, eyes, and tongue, are the same as in a cat; and also in the inward parts these two animals so nearly resemble each other, that the anatomist's chief distinction arises merely from the size."

The lion has, as was observed before, a large mane, which grows every year longer as the animal grows older: the lioness is without this ornament at every age. This mane is not coarse ar rough as in a horse, but composed of the same hair with the rest of the body, lengthened and shining. The mane, as well as the rest of the body, is of a yellow colour; nor is there ever any difference to be found in the colour of one lion from that of another. What the ancients might have said concerning black lions, or white, or streaked like the tiger, is not confirmed by modern experience; so that these varietics have never been seen, or exist no longer.

It is usually supposed that the lion is not possessed of the sense of sinelling in such perfection as most other animals. It is also observed, that too strong a light greatly incommodes him. This is more than probable from the formation of his eyes, which, like those of the cat, seem fitted for seeing best in the dark. For this reason, he seldom appears in open day, but ravages chiefly by night; and not only the lion, but all other animals of the cat kind, are kept off by the fires which the inhabitants light to preserve their herds and flocks; the brightuess of the flame dazzles their eyes, which are only fitted for seeing in the dark; and they are afraid to venture blindly into those places which they know to be filled with their enemies. "It is equally true of all this kind, that they hunt rather by the sight than the smell; and it sometimes happens that the lion pursues either the jackall or the wild dog, while they are huntirg upon the scent; and, when they have run the beast down, he comes in and monopolizes the spoil. From 
hence, probably, may have arisen the story of the lion's provider: these little industrious animals may often, it is true, provide a feast for the lion; but they have hunted merely for themselves, and he is an unwelcome intrider upon the fruits of their toil."

The lion, when hungry, boldly attacks all animals that come in his way; but, as he is very formidable, and as they all seek to avoid him, he is often obliged to hide, in order to take them by surprise. For this purpose he crouches on his belly, in some thicket, or among the long grass, which is found in many parts of the forest; in this retreat he continues, with patient expectation, until his prey comes within a proper distance, and he then springs after it, fifteen or twenty feet from him, and often seizes it at the first bound. If he misses the effort, and in two or three reiterated springs cannot seize his prey, he continues motionless for a time, seems to be very sensible of his disappointment, and waits for a more successful opportunity. In the deserts and forests, his most usual prey are the gazelles and the monkeys, with which the torrid regions abound. The latter he takes when they happen to be upon the ground, for he cannot climb trees like the cat or the tiger. He devours a great deal at a time, and generally fills himseif for two or three days to come. His teeth are so strong that he very easily breaks the bones, and swallows them with the rest of the body. It is reported that he sustains hunger a very long time, but thirst he cannot support in an equal degree, his temperament being extremely hot; some have even asserted that he is in a continual fever. He drinks as often as he meets with water, lapping it like a cat; which, as we know, drinks but slowly. He generally requires about fifteen pounds of raw flesh in a day; he prefers that of live animals, and particularly those which he has just killed. He seldom devours the bodies of animals when they hegin to putrefy ; and he chooses rather to hunt for a fresh spoil, than to return to that which he had half devoured before. However, though he usually feeds upon fresh provision, his breath is very offensive, and his urine insupportable.

The roaring of the lion is so loud, that when it is heard in the night, and re-echoed by the mountains, it resembles distant thun- der. This roar is his natural note; for when enraged he has a different growl, which is short, broken, and reiterated. The roar is a deep hollow growl, which he sends forth five or six times a day, particularly before rains. The cry of anger is much louder and more formidable. This is always excited by opposition; and upon these occasions, when the lion summons up all his terrors for the combat, nothing can be more terrible. He then lashes his sides with his long tail, which alone is strong enough to lay a man level. He moves his mane in every direction; it seems to rise and stand like bristles round his head; the skin and muscles of his face are all in agitation; his huge eye-brows half cover his glaring eye-balls; he discovers his teeth, which are formed rather for destruction than chewing his food; he shows his tongue covered with points, and extends his claws, which appear almost as long as a man's fingers. Prepared in this manner for war, there are few aninals that will venture to engage him; and even the boldest of the human kind are daunted at his approach. The elephant, the rhinoceros, the tiger, and the hippopotamns, are the only animals that are not afraid singly to make opposition.

"Nevertheless, neither the leopard nor the wild boar, if provoked, will shun the combat: they do not seek the lion to attack, but will not fly at his approach; they wait his onset, which he seldom makes unless compelled by hunger; they then exert all their strength, and are sometimes suecessful. We are told of the combat of a lion and a wild boar, in a meadow near Algiers, which continued for a long time with incredible obstinacy. At last, both were seen to fall by the wounds they had given each other; and the ground all about them was covered with their blood. These instances, however, are very rare, for the lion is in general the undisputed master of the forest. Man is the only creature that attacks him with almost certain success; with the assistance of dogs and horses, which are trained to the pursuit. These animals that, in a state of nature, would have fled from the presence of the lion, in an agony of consternation, when conscious of the assistance of man, become pursuers in their turn, and boldly hunt their natural tyrant. The dogs are 
always of the large breed; and the horses themselves, as Gesier assures us, must be of that sort called charossi, or lion-eyed, all others of this kind flying at the sight of the lion, and endeavouring to throw their riders. When the lion is roused, he recedes with a slow, proud motion; he never goes off directly forward, nor measures his paces equally, but takes all oblique course, going from one side to the other, and bounding rather than running. When the hunters approach him, they either shoot or throw their javelins; and in this manner disable him before he is attacked by the dogs, many of whom he would otherwise destroy. He is very vivacious, and is never killed at once, but continues to fight desperately even after he has received his mortal blow. He is also taken by pit-falls; the natives digging a deep hole in the ground, and covering it slightly over with sticks and earth; which, however, give way beneath his weight, and he sinks to the bottom, from whence he has no means of escape. But the most usual manner of taking this animal is while a cub, and incapable of resistance. The place near the den of the lioness is generally well known by the greatness of her depredations on that occasion; the natives, therefore, watch the time of her absence, and, aided by a swift horse, carry off her cubs; which they sell to strangers, or to the great men of their country."

The lion, while young and active, lives by hunting in the forest at the greatest distance from any human habitation; and seldom quits this retreat while able to subsist by his natural industry; but when he becomes old and unfit for the purposes of surprise, he boldly comes down into places more frequented, attacks the flocks and herds that take shelter near the habitation of the shepherd or the husbandman, and depends rather upon his courage than his address for support. It is remarkable, however, that when he makesone of these desperate sallies, if he finds men and quadrupeds in the same field, he only attacks the latter, and never meddles with men, unless they provoke him to engage. It isobserved that he prefers the flesh of camels to any other food; he is likewise said to be fond of that of young elephants ; these he often attacks before their trunk is yet grown; and, unless the old elephant comes to their assistance, he makes them an easy prey.

The lion is terrible upon all occasions, but particularly at those seasons when he is incited by desire, or when the female has brought forth. It is then that the lioness is seen followed by eight or ten males, who fight most bloody battles among each other, till one of them become victorious over all the rest. She is said to bring forth in spring, and to produce but once a year. "With respect to the time of gestation, naturalists have been divided, some asserting that the lioness went with young six months, and others but two. The time also of their growth and their age have hitherto been left in obscurity ; sone asserting that they acquired their full growth in three years, and others that they required a longer period to come to perfection; some saying (and among this number is Mr. Buffon) that they lived to but twenty, or twenty-two years at most; others making their lives even of shorter duration. All these doubts are now reduced to certainty; for we have had several of these animals bred in the Tower; so that the manner of their copulation, the time of their gestation, the number they bring forth, and the time they take to come to perfection, are all pretty well known. Although the lion emits his urine backwards, yet he couples in the ordinary manner; and, as was said before, his internal structure in almost every respect resembles that of a cat. The lioness, however, is upon these occasions particularly fierce, and often wounds the lion in a terrible manner. She goes with young, as I am assured by her keeper, no more than five months; the young ones, which are never more than two in number when brought forth, are about the size of a large pug $\mathrm{dog}$, harmless, pretty, and playful; they continuc the teat for tivelve months, and the animal is more than five years in coming to perfection. As to its age, from its imprisoned state, we can have no certainty; since it is very probable, that, being deprived of its natural climate, food, and exercise, its life must be very much abridged. However, naturalists have hitherto been greatly mistaken as to the length of its existence. The great he-lion, called Pompey, which died in the year 1760, was known to have been in the Tower for above seventy 



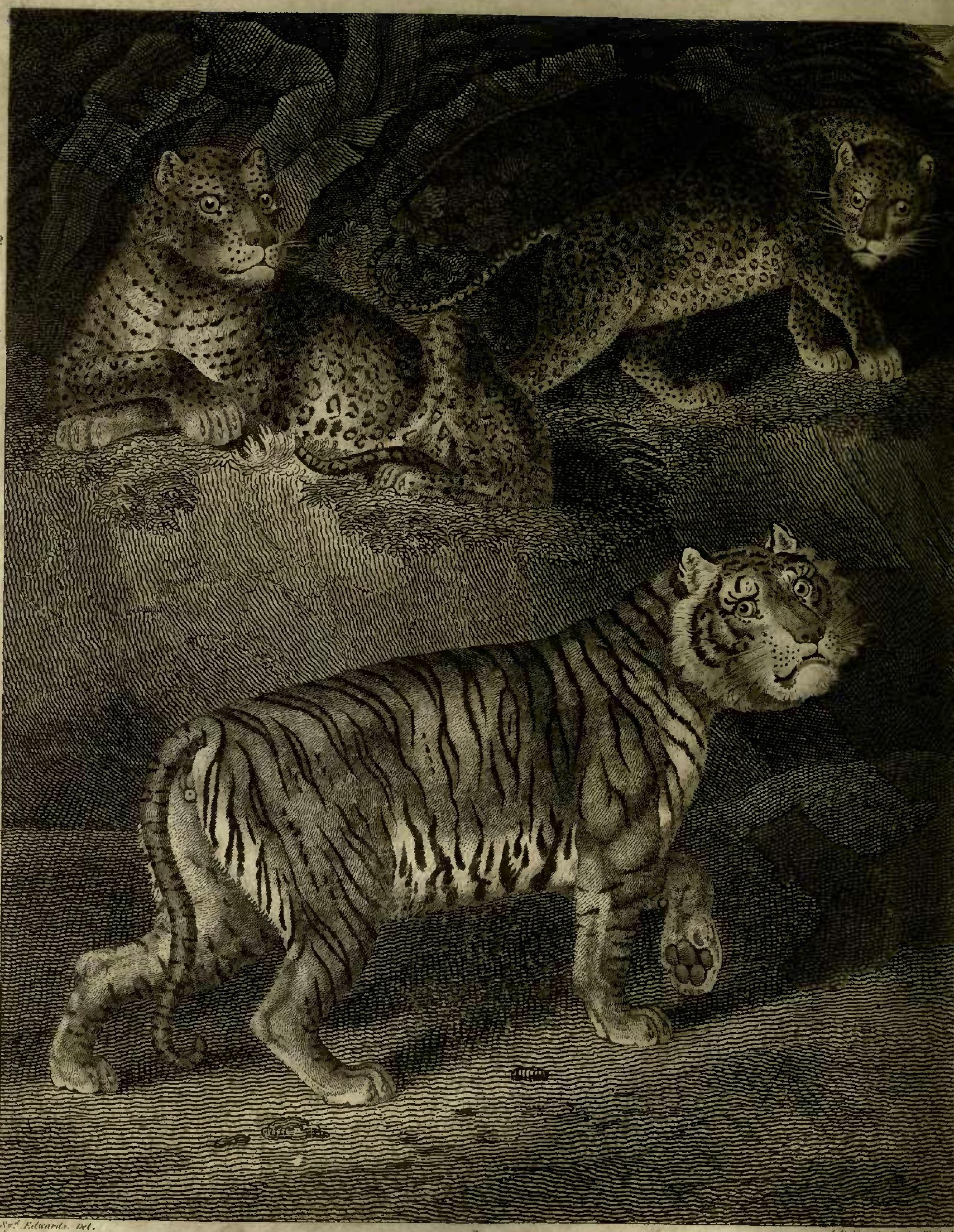

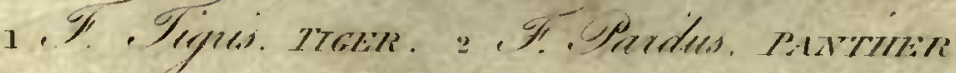

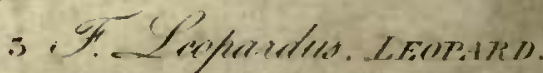


years; and one lately died there, which was brought from the river Gainbia, that died above sixty-three. The lion, therefore, is a very long-lived animal; and, very probably, in his native forests, his age exceeds even that of man himself."

In this animal, all the passions, even of the most gentle kind, are in excess, but particularly the attachment of the female to her young. The lioness, though naturally less strong, less courageous, and less mischievous than the lion, becomes terrible when she has got young ones to provide for. She then makes her incursions with even more intrepidity than the lion himself; she throws herself indiscriminately among men and other animals; destroys without distinction; loads herself with the spoil, and brings it home reeking to ber cubs, whom she accustoms betimes to cruelty and slaughter. She usually brings forth in the most retired and inaccessible places; and when.she fears to have her retreat discovered, often hides her tracks, by running back her ground, or by brushing them out with her tail. She sometimes also, when her apprehensions are great, transports them from one place to another; and, if obstructed, defends them with determined courage, and fights to the last.

The lion is chiefly an inhabitant of the torrid zone; and, as was said, is always most formidable there: nevertheless, he can subsist in more temperate climates; and there was a time when even the southern parts of Europe were infested by him. At present, he is only found in Africa and the East Indies; in some of which countries he grows to an enormous height. The lion of Bildulgerid is said to be nearly five feet high, and between nine and ten feet from the tip of the nose to the insertion of the tail. We have in the Tower, at present, one of above four feet high, that was brought from Morocco, which is the largest that for some time past has been seen in Europe. The ordinary size is between three and four feet; the female being in all her dimensions about one-third less than the male. There are no lions in Ainerica; the Puma, which has received the name of the American lion, is, when compared, a very contemptible animal, having neither the shape, the size, nor the mane of the lion; being known to be extremely cowardly, to climb trees for its prey, to subsist rather by its cunning than its courage, and to be inferior even to the animal that goes by the name of the American tiger. We ought not, therefore, to confound this little treacherous creature with the lion, which all the ancients have concurred in denominating the king of beasts, and which they have described as brave and merciful. "Indeed, the numerous accounts which they have given us of this animal's generosity and tenderness, show that there must be some foundation for the general belief of its good qualities; for mankind seldom err when they are all found to unite in the same story. However, perhaps, the caution of Aristophanes, the comic poet, is better followed in practice, who advises us to have nothing to do with this creature, but to let the lioness suckle her own whelps."

\section{THE TIGER.}

"THE ancients had a saying, That as the peacock is the most beautiful among birds, so is the tiger among quadrupeds." In fact, no quadruped can be more beautiful than this animal; the glossy smoothness of his hair, which lies much smoother, and shines with greater brightness than even that of the leopard; the extreme blackness of the streaks with which he is marked, and the hright yellow colour of the ground which they diversify, at oncestrike the beholder. To this beauty of colouring is added an extremely elegant form, much larger, indeed, than that of the leopard, but more slender, more delicate, and bespeaking the most extreme swiftness and agility. Unhappily, however, this animal's disposition is as mischievous as its form is admirable, as if Providence was willing to show the small value of beanty, by bestowing it on the most noxious of quadrupeds. We have at present one of these animals in the Tower, which to the view appears the most good-natured and harmless creature in the world; its physiognomy is far from fierce or angry; it has not

a Tantem antem prastat pulcluritudine tigris inter alias faras quantum inter volıcles pavo 
the commanding, stern countenance of the lion, but a gentle, placid air; yet, for all this, it is fierce and savage beyond measure; neither correction can terrify it, nor indulgence can tame.

The chief and most observable distinction in the tiger, and in which it differs from all others of the mottled kind, is in the shape of its colours, which run in streaks or bands in the same direction as his ribs, from the back down to the belly. The leopard, the panther, and the ounce, are all partly covered like this animal, but with this difference, that their colours are broken in spots all over the body; whereas, in the tiger they stretch lengthwise, and there is scarce a round spot to be found on his skin. Besides this, there are other observable distinctions: the tiger is much larger, and often found bigger than even the lion himself; it is much slenderer also in proportion to its size; its legs shorter, and its neck and body longer. In short, of all other animals, it most resembles the cat in shape; and, if we conceive the latter magnified to a very great degree, we shall have a tolerable idea of the former.

In classing carnivorous animals, we may place the lion foremost; ${ }^{\mathrm{n}}$ and immediately after him follows the tiger, which seems to partake of all the noxious qualities of the lion, without sharing any of his good ones. To pride, courage, and strength, the lion joins greatness, clemency, and generosity: but the tiger is fierce without provocation, and cruel without necessity. The lion seldom ravages except when excited by hunger; the tiger, on the contrary, though glutted with slaughter, is not satisfied, still continues the carnage, and seems to have its courage only inflamed by not finding resistance. In falling in among a flock or a herd, it gives no quarter, but levels all with indiscriminate cruelty, and scarce finds time to appease its appetite while intent upon satisfying the malignity of its nature. It thus becomes the scourge of the country where it is found; it fears neither the threats nor the opposition of mankind; the beasts, both wild and tame, fall equally a sacrifice to its insatiable fury; the young elephant and

\footnotetext{
- The remainder of this description is taken from $\mathrm{Mr}$ Buffon, except where marked with commas.
}

the rhinoceros become equally its prey, and it not unfrequently ventures to attack even the lion himself.

Happily for the rest of nature, that this animal is not common, and that the species is chiefly confined to the warmest provinces of the east. The tiger is found in Malabar, in Siam, in Bengal, and in all the countries which are inhabited by the elephant or the rhinoceros. Some even pretend that it has a friendship for, and often accompanies the latter, in order to devour its excrements, which scrve it as a purge. Be this as it will, there is no doubt but that they are often seen together at the sides of lakes and rivers; where they are probably both compelled to go by the thirst which, in that torrid climate, they must very often endure. It is likely enough also that they seldom make war upon each other, the rhinoceros being a peaceable animal, and the tiger knowing its strength too well to venture the cugagement. It is still more likely that the tiger finds this a very convenient situation, since it can there surprise a greater number of animals which are compelled thither from the same motives. In fact, it is generally known to lurk near such places where it has an opportunity of choosing its prey, or rather of multiplying its massacres. When it has killed one, it often goes to destroy others, swallowing their blood down at large draughts, and seeming rather glutted than satiated with its abundance.

However, when it has killed a large animal, such as a horse or a buffalo, it immediately begins to devour it on the spot, fearing to be disturbed. In order to feast at his ease, it carries off its prey to the forest, dragging it along with such ease, that the swiftness of its motion seems scarce retarded by the enormous load it sustains. From this alone, we may judge of its strength; but to have a more just idea of this particular, let us stop a moment to consider the dimensions of this most formidable creature. Some travellers have compared it for size to a horse, and others to a buffalo, while others have contented themselves with saying, that it is much larger than a lion. We lave recent accounts of this animal's magnitude that deserve the utmost confidence. Mr. Buffon has been assured by one of his friends, that he saw a tiger in the East 
Indies fifteen feet long. "Supposing that he means including the tail, this animal, allowing four feet for that, must have been eleven feet from the tip of the nose to the insertion of the tail. Indeed, that which is now in the Tower is not so large, being, as well as l could nueasure, six feet from the tip to the insertion, and the tail was three feet more. Like all the rest of its kind, its motions are irregular and desultory; it bounds rather than runs; and, like them, rather chooses to take its prey by surprise, than to be at the trouble of hunting it down." How large a leap it can take at once we may easily judge, by comparing what it might do, to what we sec so small an animal as the cat actually perform. The cat can leap several feet at a bound; and the tiger, who is ten times as long, can no doubt spring proportionably.

"The tiger is the only animal whose spirit seems untameable. Neither force nor constraint, neither violence nor flattery, can prevail in the least on its stubborn nature. The caresses of the keeper have no influence on their heart of iron; and time, instead of mollifying its disposition, only serves to increase its fierceness and unalignity. The tiger smaps at the hand that feeds it, as well as that by which it is cliastised; every object scems considered only as its proper prey, which it devours with a look; and, although confined by bars and chains, still makes fiuitless efforts, as if to show its malignity, when incapable of exerting its force."

To give a still more complete idea of the strength of this terrible creature, we shall quote a passage from Father Tachard, who was an eye witness of a combat between a tiger and three clephants at Siam. For this purpose, the king ordered a lofty pallisade to be built of bamboo cane, about a hundred feet square; and in the midst of this were three clephants appointed for combating the tiger. Their heads, and a part of their trunk were covered with a kind of armour, like a mask, which defended that part from the assaults of the fierce animal with which they were to engage. As soon, says this author, as we were arrived at the place, a tiger was brought forth from its den, of a size much larger than we had ever seen before. It was not at first let loose, but held with cords, so that one of No. $25 \& 26$. the elephants approaching, gave it threc or four terrible blow's with its trunk on the back, with such force, that the tiger was for some time stunned, and lay without motion, as if it had been dead. However, as soon as it was let loose, and at full liberty, although the first blows had greatly abated its fury, it made at the elephant with a loud shriek, and aimed at seizing his trunk. But the eleplant, wrinkling it up with great dexterity, received the tiger on his great teeth, and tossed it up into the air. This so discouraged the furious animal, that it no more ventured to approach the elephant, but made several circuits round the pallisade, often attempting to fly at the spectators. Shortly after, three elephants were sent against it, and they continued to strike it so terribly with their trunks, that it once more lay for dead; and they would certainly have killed it, had not there been a stop put to the combat.

From this account, we may readily judge of the strength of this animal, which, although reduced to captivity, and held by cords; though first disabled, and set alone against three, yet ventured to continue the engagement, and even that against animals covered and protected from its fury.

"Captain Hamilton informs us, that in the Sundal Raijah's dominions there are three sorts of tigers in the woods, and that the smallest are the fiercest. This is not above two feet high, appears to be extremely cunning. and delights in human flesh. The seconid kind is about three feet high, and hunts decr and wild hogs, besides the little animal which has been al ready described under the - name of the chevrotain, or Guinea deer. The tiger of the largest sort is above three feet and a half high: but, although endowed with greater powers, is, by no means, so rapacious as either of the former. This formidable animal, which is called the royal tigrer, (one of which we have at present in the Tower, does not seem so ravenous nor so dangerous, and is even more cowardly. A peasant in that country, as this traveller informs us, had a buffalo fallen into a quagmire, and while he went for assistance, there came a large tiger, that with its single strength drew forth the animal, which the united force of many men could not effect. When the people returned to the place, the 
first object they beheld was the tiger, who had thrown the buffulo over its shoulder, as a fox does a goose, and was carrying it away, with the feet upwards, towards its den; however, as soon as it saw the men, it let fall its prey, and instantly fled to the woods: but it had previously killed the buffalo, and sucked its blood; and, no doubt, the people were very well satisfied with its retreat. It may be observed, that some East Indian buffiloes weigh above a thousand pounds, which is twice as heavy as the ordinary run of our black cattle; so that from hence we may form a conception of the enormous strength of this rapacious animal, that could thus run off with a weight at least twice as great as that of itself.

"Were this animal as common as the panther, or even as the lion himself, thus furnished as it is with the power to destroy, and the appetite for slaughter, the country would be uninhabitable where it resides. But luckily the species is extremely scarce; and has been so since the earliest accounts we have had of the tiger. About the times of Angustus, we are assured by Pliny, that when panthers were brought to Rome by hundreds, a single tiger was colssidered as an extraordinary sight; and he tells us, that the emperor Claudius was able to procure four only; which shows how difficultly they were procured. The incredible fierceness of this animal may be, in some measure, the cause of the scarcity which was then at Rome, since it was the opinion of Varro, that the tiger was never taken alive:" but its being a native only of the East Indies, and that particularly of the warmer regions, it is not to be wondered that thespeciesshould be so few."

We may, therefore, consider the species of the true streaked tiger, as one of the scarcest of animals, and much less diffused than that of the lion. As to the number of its young, we have no certain accounts; however, it is said, that it brings forth four or five at a time. Although furious at all times, the female, upon this occasion, exceeds her usual rapacity; and, if lier young are taken from her, she pursues the spoiler with incredible rage; he, to save a part, is contented to lose a part, and drops

* Tigr is vivus capi ad huc non potuit. Var de ling. Lat. one of her cubs, with which she immediately returns to her den, and again pursues him; he then drops another, and by the time she has returned with that he generally escapes with the remainder. If she loses her young entirely, she then hecomes desperate, boldly approachies even the towns themselves, and commits incredible slaughter. The tiger expresses its resentment in the same manner with the lion; it moves the muscles and skin of its face, shows its teeth, and shrieks in the most frightful manner. Its note is very different from that of the lion; being rather a scream than a roar: and the ancients expressed it very well, when they said that, tigrides indomitce rancant rugiuntque leones.

The skin of these animals is much esteemed all over the east, particularly in China; the Mandarines cover their seats of justice in the public places with it, and convert it into coverings for cushions in winter. In Europe, these skins, though but seldom to be met with, are of no great value; those of the panther and the leopard being held in much greater estimation. This is all the little benefit we derive from this dreadful animal, of which so many falsehoods have been reported; as, that its sweat was poisonous, and the hair of its whiskers more dangerous than an envenomed arrow. But the real miscliefs which the tiger occasious while living are sufficient, without giving imaginary ones to the parts of its hody when dead. In fact, the lndians sometimes eat its flesh, and find it neither disagreeable nor unwholesome.

There is an animal of America, which is usually called the red tiger, but Mr. Buffon calls it the cougar, which, no doubt, is very different from the tiger of the east. Some, however, have thought proper to rank both together, and I will take leave to follow their example, merely because the cougar is more like a tiger in every thing, exeept the colour, than any other animal I know, having the head, the body, and the neck, shaped very much in the same manner. Of these slight differences, words would give but a very faint idea; it will be, therefore, sufficient to observe, that they are both equally slender, and are smaller where the neck joins the head, than others of the panther kind. There is one at present in the Tower; and it seemed to me, as well 
as I could see it throngh the bars, that were it properly streaked and coloured, it would in all things resemble a small tiger. It is, however, of a very different colour, being of a deep brown, and the tail very long and pointed. It is rather darker on the back; under the chin it is a little whitish, as also on the lower part of the belly.

Of all the American animals, this is the most formidable and mischievous; even their pretended lion not rxcepted : it is said there are several sorts of them; and, as well as I can remember, I have seen one or two here in England, both differing from the present, in size and conformation. It is, indeed, a vain endeavour to attempt to describe all the less obvious varieties in the cat kind. If we examine them minutely, we shall find the differences multiply upon us so much, that instead of a history, we shall only be paid with a catalogue of distinctions. Fron such of them as I have seen, within these last six years, I think I could add two animals of this species, that have not been bitherto described, .and with the names of which he that showed them was ntterly unaequainted. But it is a poor ambition, that of being eager to find out inew distinctions, or adding one noxious animal more, to a list that is already sufficiently numerous. Were the knowing a new variety to open an unknown history, or in the least to extend our knowledge, the inquiry would be then worth pursuing; but what signifies mentioning some trifling difference, and from thence becoming authors of a new name, when the difference might have originally proceeded either from climate, soil, or indiscriminate copulation?

The cougars are extremely common in South America; and, where the towns border upon the forest, these make frequent incursions by night into the midst of the streets, carrying off fowls, dogs, and other domestic creatures. They are, however, but weak and contemptible, compared to the'great tiger, being found unable to cope with a single man. The $\mathrm{Ne}$ groes and Indians are very dexterous in encountering them; and some, even for the sake of their skins, seek them in their retreats. The arms in this combat, seemingly so dangerous, are only a lance of two or three yards long, made of lieary wood, with the point har- dened in the fire; and a kind of scymitar, of about three quarters of a yard in length. Thus armed, they wait till the tiger makes an assault against the left hand, which holds the lance, and is wrapped up in a short cloak of baize. Sometimes the animal, aware of the danger, seems to decline the combat; but then its antagonist provokes it with a slight touch of the lance, in order, while he is defending himself, to strike a sure blow. As soon, therefore, as the creature feels the lance, it grasps it with one of its paws, and with the other strikes at the arm which holds it. Then it is that the person nimbly aims a blow with his scymitar, which he kept concealed, with the other hand, and hamstrings the creature, which immediately draws back enraged, but instantly returns to the charge. But then, receiving another stroke, it is totally deprived of the power of motion: and the combatant, killing it at his leisure, strips the skin, cuts off the head, and returns to his companions, displaying these as the trophies of his victory.

This animal, as we are assured, is often more successful against the crocodile; and it is the only quadruped in that part of the world, that is not afraid of thie engagement. It must be no unpleasant sight to observe, from a place of safety, this extraordinary combat, between animals so terrible and obnoxious to man. Such as have seen it, describe it in the following manner. When the tiger, inpelled by thirst, that seems continually to consume it, comes down to the river side to drink, the crocodile, which makes no distinction in its prey, lifts its head above water to seize it; the tiger, not less rapacious than the other, and unacquainted with the force of the enemy, boldly ventures to seize it, and plunges its claws into the eyes of the crocodile, which is the only vulnerable parts of its body: upon this the crocodile instantly dives under water, and the tiger goes down with him, for he will sooner die than let go its hold. In this manner the combat continues for some time, until the tiger is drowned, or escapes, as is sometimes the case, from its disabled enemy.

These animals are common in Guiana: They were formerly seen swimming over, in great numbers, into the island of Cayenne, to

- Buffon, vol. xix.p. 22. 
attack and ravage the flocks and lierds of the inhabitants. In the beginning, they were a terrible scourge to the infant eolony; but, by degrees, they were repulsed and destroyed, and are now seen no longer at that place. They are found in Brazil, in Paraguay, in the country of the Amazons, and in several other parts of South Anerica. They often climb trees in quest of prey, or to avoid their pursucrs. They are deterred by fire, like all other animals of the cat kind; or more properly speaking, they seldom venture near those places where they see it kindled, as they are always sure of their enemies being near, and their nocturnal eyes are dazzled by the brightness of the blaze. From the description of this animal, one would be hardly led to suppose, that its flesh was good for food; and yet we have several accounts which allege the fact, some asserting it to be superior even to mutton: however, what Monsieur Des Marchais observes, is most likely to be true; namely, That the most valuable part of this animal is its skin, and that its flesh is but indifferent eating, being generally lean, and usually having a strong fumet.

\section{THE PANTHER AND THE LEOPARD.}

WE have hitherto found no great diffieulty in distiuguishing one animal from another, each carrying its own peculiar marks, which, in some measure, serve to separate it from all the rest. But it is otherwise, when we come to these of the cat kind, that fill up the chasm between the tiger and the cat. The spots with which their skins are diversified, are, so various, and their size so equivocal, that it is no easy matter to distinguish the species, particularly as we have little else but the spots and the size to guide us in making the distinction. If we regard the figure and diversity of the spots, we shall find many varieties not taken notice of by any naturalist: if we are led by the sizc, we shall find an imperceptible gradation from the cat to the tiger. It would be vain, thercfore, to make as many varieties in these animals as we seedifferences in spots or stature; it will be sufficient to seize the most general distinctions, and leave the rest to such as are fond of more minute disquisitions.

Or all this tribe, whose skins are so beautifully spotied, and whose natures are so mischievous, the panther may be considered as the foremost. This animal has been by many naturalists mistaken for the tiger, and in fact, it approaches next to it in size, fierceness, and beauty. It is distinguished, however, by one obvious and leading elraracter; that of being spotted, not streaked; for, in this particular, the tiger differs from the panther, the leopurd, and almost all the inferior ranks of this mischievous family.

This animal, which Mr. Buffon calls simply the panther, Linnæus the pard, Gesuer the pardalis, and the modern Latins the lcopardus; this animal, I say, which goes by too many uames, and which the English have indiscriminately called by the riame of the panther or the leopard, may be considered as the largest of the kind, and is spotted in a manuer somewhat different from those that are smaller. As those spots, however, make the principal difference between it and the lesser animals, which it otherwise resembles inshape, sizc, disposition, and beauty, I will first show these slight distinctions, and mention the names each animal has received in consequence thercof; and then proceed to give their history together, still marking any peculiarity observable in one of the species, which is not found in the rest.

Next to the great panther, already mentioned, is the animal which Mr Buffon calls the LEOPARD, a name which he ackuowledges to be given arbitrarily, for the sake of distinction. Other naturalists have not much attended to the slight differences between this and the great panther, nor have they considered its discriminations as sufficient to entitle it to another name. It luas hitherto, therefore, gone under the name of the LEOPARD, Or PANTHER of Senegal, where it is eliefly found. The differenees between this aninal and the former are these: the large panther is often found to be six feet long, from the tip of the nose to the insertion of the tail; the panther of Senegal is not above four. The large panther is marked with spots in the manner of a rose, that is, five or six make a kind of eircle, and there is generally a large one in the mid- 
dle. The leopard of Senegal has a much more beautiful coat, the yellow is more brilliant, and the spots are smaller, and not disposed in rirgs but in clusters. As to the rest, they are both whitish under the belly; the tail in both is pretty long, but rather longer in proportion in the latter, than in the former. To these two animals, whose differences seem to be so very minute, we may add a third; namely, the JAGUAR, or PANTIIER of America. This, in cvery respect, resembles the two former, except in the disposition of its spots, and that its neck and head are rather streaked than spotted. The jaguar is also said to be lower upon its legs, and less than the leopard of Senegal. These three quadrupeds, as we see, have but very slight differences, and the principal distinction used by Mr. Buffon, is taken from the size; the first, as he says, is usually six fect long; the second, four feet; and the last, about three: however, it appears from the particular subjects of bis description, that the panther in his possession was not above three feet seven inches long; that the leopard's skin which he describes, was abont four; and that the jaguar, at two years old, was between two and three feet loug, which, when come to its full growth, would, no doubt, be four feet long, as well as the two former. From hence, therefore, we may conclude, that the size in these animals is not sufficient to make a distinction among them; and that those who called them all three by the indiscriminate uames of the lcopard and the panther, if not right, were at least excusable. Of those which are now to be seen in the Tower, the jaguar, or the American panther, is rather the largest of the three; and is by no means the contemptible animal which $\mathrm{Mr}$. Buffon describes it to be; the leopard is the least of them, and has, by some travellers, been supposed to be an animal produced between the panther and the ounce, an animal which resembles, but is less than any of the former. These three animals we may, therefore, rank together, as they agree pretty nearly in their robe, their size, their dispositions, and their ferocity.

We come next to an animal confessedly different from any of the former, being much smiller, and its colour more inclining to white. Its uane, however, in our language, has caus- ed no small confusion. It has been generally called by foreigners, the onza, or the ounce, and this name some of our own writers have thought proper to give it; but others of them, and these the most celebrated, such as Willoughby, have given this name to a different animal, with a short tail, and known to the ancients and moderus by the name of the hynx. I confess myself at a loss, in this case, whom to follow; the alteration of names should be always made with great caution, and never but in cases of necessity. If we follow Willoughby, there will be an animal of the panther kind, very distinguishable from all the rest, left without a name; and if we recede from him, it will serve to produce some confusion among all the numerous class of readers and writers who have taken him for their guide: however, as he seems himself to have been an innovator, the name of the lynx having been long adopted into our language before, it was unuecessary to give the animal that bore it another name, and to call that creature an ounce, which our old writers had been accustomed to know by the Latin appellation; for this reason, therefore, we may safely venture to take a name that has been long misapplied, from the lynx, and restore it to the animal in question. We will, therefore, call that animal of the panther kind, which is less. than the panther, and with a longer tail, the ounce; and the lyux may remain in possession of that name by which it was known among all our old English writers, as well as by all antiquity.

The ounce, or the onza of Linnaus, is much less than the panther, being not, at most, a bove three feet and a half long: however, its hair is much longer than that of the panther, and its tail still more so. The panther of four or five feet long, has a tail but of two feet, or two feet and a half. The ounce, which is but about three feet, has a tail often longer than the rest of its body. The colour of the ounce is also apparently different, being rather more inclining to a cream-colour, which is deeper on the back, and whiter towards the belly. The hair on the back is an inch and a lialf long; and that on the belly two inches and a half, which is much longer than that of the panther. Its spots are disposed pretty much in the same inanner as the large panther, ex- 
cept that on the haunches it is rather marked with stripes than with spots.

Descending to animals of this kind that are still smaller, we find the catamountain, which is the ocelot of Mr. Buffon, or the tiger-cat of most of those who exhibit as a show. It is less than the ounce, but its robe more beautifully variegated. It is an American animal, and is about two feet and a half in length, from the nose to the insertion of the tail. It is extremely like a cat, except that it is larger and slenderer, that its colours are more beautiful, and its tail rather shorter. The fur is of a reddish colour, the whole beautified with black spots, and streaks of different figures. They are long on the back, and round on the belly and paws. On the ears are black stripes, which run across; but, in other respects, they entirely resemble those of a cat. These colours, however, which naturalists have taken great pains minutely to describe, are by no means permanent, being differently disposed in different animals of the same species. I remember to have seen an animal of this size, but whether of this species I will not pretend to say, some years ago, that was entirely brown, and was said also to have come from America.

From this tribe of the cat kind, with spotted skins and a long tail, we come to another, with skins diversified in like manner, but with a shorter tail. The principal of these is the LYNX, the name by which the animal was known to Flian, among the ancients; and to all our old English writers among those of a more modern date. This name has been corrupted by the Portuguese into the word ouze; and this corruption has been adopted by Ray, who has improperly called this animal the ounce, after some of the foreign travellers. The first striking distinction between the lynx, and all those of the panther kind, is in its tail, which is at least half as short in proportion, and black at the extrenity. Its fur is much longer, the spots on the skin less vivid, and but confusedly mingled with the rest. Its ears are much longer, and tipped at the point with a black tuft of hair. The colour round the eyes is white; and the physiognomy nore placid and gentle. Each hair of this animal is of three different colours: the root is of a grayish brown; the middle red, or of an ash colour; and the ends white. This whitencss at the ends takes up so small a part of the particular hair, that it does not prevent us from seeing the principal colour, which is that in the middle part; so that it only makes the surface of the body appear as if it were silvered over: however, the hair of which the spots consist has no white at the ends, and at the roots it is not quite so black as the other part. This animal is not above the size of the ounce, but is rather stronger built, and it has but twentyeight tceth; whereas all the rest of the cat kind already mentioned have thirty.

Another animal of this kind is called the siagush, or, as Mr. Buffon names it, the caraCaL. It is a native of the East Indies, and resembles the lynx in size, in form, and even in the singularity of being tufted at the tips of the ears. However, the siagush differs in not being mottled as the lynx is ; its fur, or rather hair, is rougher and shorter; its tail is rather longer, its muzzle more lengthened; its pliysiognomy more fierce, and its nature more savage.

The third and last animal that need to be mentioned of this kind, is that which Mr. Buffon calls the SERval, and which he has first described. It is a native of Malabar, resembling the panther in its spots, but the lynx in the shortness of its tail, in its size, and in its strong built form.

These seem to be all the principal distinctions anong animals of the panther kind, from the largest of this tribe down to the doniestic cat, which is the smallest of all these fierce and nischievous varieties. In all, their nature seems pretty much the same; being equally ficrce, subtlc, cruel, and cowardly. The panther, including the leopard and the jaguar, or American panther, as they are the larg st, so also are they the most dangerous of this kind; for the whole race of cats are noxious in proportion to their power to do mischief. They inhabit the most torrid latitudes of India, Africa, and America, and have never been alle to multiply beyond the torrid zone. They are generally found in the thickest and the most entangled forests, and often near renıote habitations, where they watch to surprise all kinds of domestic animals. They very seldom attack man, even though provoked by him; they rather spem desirous of finding safety by flight, or by climbing trees, at which they are very expert. In this manner, also, they often pursue their prey, and, being expert at seizing 
it, as well above as below, they cause a vast destruction. Of all other animals, these are the most sullen, and, even to a proverb, untameable. They still preserve their fierce and treacherous spirit; and at those places where they are exposed to be secn anong others, we often observe that while their keeper is familiar with the lion or the bear, yet he is apprehensive of the large panther, and keeps it bound with the shortest chain.

As the ounce differs from these in figure and size, so also it seems to differ in disposition, being more mild, tractable, and tame. These we often see as harmless aud innocent as cats; and there is onc at present in the Tower with which the kecper plays without the smallest apprchension. I own I was not a little uneasy, at first, for the man, when he put his hand through the bars, and called the animal by its name; but I was a good deal surprised to see the creature, which one might suppose irritated by long confinement, come gently up to him, stroke his hand with its face, in the manner of a cat, and testify the utmost gentleness of disposition. The ounce, therefore, is remarkable for being easily tamed; and, in fact, it is employed all over the East for the purposes of hunting. Not, indeed, but the panthers themselves are sometimes used for this purpose, but they are never thoroughly subdued like the former, being usually brought to the field in a carriage, and kept chained and caged until they are shown the gazelle, or the leveret, which is their prey. 'This they pursue rather by three or four great springs than by running. If they seize it by this sudden effort, it finds no mercy; but if it escapes from this first effort, they never attempt to pursue, and appear quite disappointed and confounded at their mischance. It sometimes happens that they are so much enraged at it, that they attack even their employer, and his only resource to avoid their fury is to throw then some small pieces of meat, which he has brought with him for that purpose.

The ounce, however, is not so dangerous ; and is treated with more confilence and familiarity. It is usually brought to the field hood-winked behind one of the horsemen. When the game appears, the ounce is instantly uncovered, and shown where it lies; upon which the fierce creature darts like an arrow to the place, and seizes it at once, or, missing it, remains motionless on the place. It would be vain to attempt retrieving its disgrace, by continuing the pursuit; for, although it bounds with greater agility than most other animals, yet it is slow and awkward in running, and has no means of finding the animal it pursues by the smell, as is common among these of the dog kind. From hence, therefore, it appears how much superior the European method of hunting is to that of the Asiatic; since whatever amusement this exercise afforils must arise from the continuance of the chase, and from the fluctuation of doubt and expeciation, which raise and clepress the pursucrs by turns. All this an Asiatic hunter is deprived of ; and his greatest pleasure can scarcely be more than what among us is called coursing, in which the dog pursues the animal, and keeps it constantly in view.

But it must not be supposed that it is from choice the Asiatics use this method of chase; for, no doubt, were dogs serviccable among them as they are in Europe, they would be employed for the same purposes. But the fact is, that the extreme heat of the tropical climates produces such universal putrefaction, and sends up such various and powerful scerts, that dogs are at first bewildered in the cliase, and at last come to lose the delicacy of their scent entirely. They are, therefore, but little used in those warm countries ; and what could they avail in places where almost every other animal of the forest is stronger and more rapacious? The lion, the tiger, the panther, and the ounce, are all natural enemies to the $\mathrm{dog}$, and attack him wherever he appears with ungovernable fury. The breed, therefore, in those places, would quickly be destroyed; so that they are obliged to have recourse to those animals which are more fitted to serve them ; and thus convert the ounce to those purposes for which dogs are employed in Europe.

The catamountain, or ocelot, is one of the fiercest, and, for its size, one of the most destructive animals in the world. It is, as was before observed, a native of South America, and by no means capable of the same education as the ounce, which it more approaches in size than in disposition. Two of these, from whom Mr. Buffon has taken his description, svere brouglit over from Carthagena, and having been taken from the dam when very young, were afterwards suckled by a bitch. 
But, before they were three months old, they had strength and ingratitude enough to kill and devour their nurse. Their succeeding fierceness and malignity seemed to correspond with their first efforts; for no arts could tame or soften their natures; and while they continued in their cages, they still testified an unceasing disposition for slaughter. When their food was given them, the male alivays served himself before the female ventured to touch a bit; and it was not till he was satisfied that the other began. In their savage state, these animals are still more destructive; having great strength and agility, they very easily find and overtake their prey, which they pursue among the tops of the trees, as well as on the ground; but what renders them still more mischievous is, their unceasing appetite rather. for the blood than the flesl of their prey. They suck this with the greatest aridity, but frequently leave the carcase otherwise untouched, in order to pursue other animals for the blood in like manner. They generally continue on the tops of trees, like our wild cats, where they make their nest, and often bring forth their young. When they spy any aninal they can master, and there are but few in the forest but what are inferior, they dart down upon it with inevitable exactness.

The whole tribe of animals of the panther kind, with long tails, are chiefly inhabitants, as was said, of the torrid zone; but those of the short-tailed kind, and partienlarly the lynx, is principally found in the cold countries that are bordering on the pole. The lynx is chiefly to be met with in the north of Germany, Lithuania, Muscovy, Siberia, and North America. Those of the new continent, however, are rather smaller than in Europe, as is the case with almost all their quadrupeds; they are somewhat whiter also, hut in other respects there is scarce any difference to be found among them." This animal has been called by some lupus cervarius, or a creature compounded between a wolf and a stag; but for what reasoll is hard to guess; it no way resembles either in shape or in disposition. In its nature, it exactly resembles the cat, except that being bigger, and nearly two feet long, it is bolder and fiercer. Like the cat, it climbs trees, and seeks its prey by surprise; like the cat it is delicate and cleanly, covering its urine with its paws; and it rescmbles the wolf in nothing except its cry, which often deceive the hunters, and induces them to think they hear a wolf and not a lynx. This animal also is rather more delicate than the cat; and after having once feasted upon its prey, will never return to it again, but hunts the woods for another. From hence may have arisen the common report of the lynx having, of all other quadrupeds, the shortest memory. This, however, is not the only idle story that has been propagated of it: as of its seeing with such perspicuity, as to perceive objects through walls and mountains; as of having its urime of such a quality, as to harden, and becomea precious stone; with several others, propagated by ignorance or imposture.

The sIagush and the SERvaL are both so like all the rest of the cat kind in disposition, that it is but repeating the same account once more to give their distinct history. As the lynx is found only in cold countries, so the siagush is to be met with only in the warm tropical climates. It is used, in the same manner as the ounce, for hunting; but it seems to have a property which the other has not; namely, that of being able to overtake its prey by pursuing it. Whether this is performed by having a finer scent than the former, or greater swiftness, we are not informed; being only told that when it overtakes either the gazelle or the antelope, it leaps upon their backs, and, getting forward to their shoulders, scratches their eyes out, by which means they become an easy prey to the hunters. Some have called this animal the lion's provider; and it is said that when it calls him to pursue his prey, its voice very much resembles that of one man calling another. ${ }^{b}$ From hence we may conjecture that this animal pursues its prey in full cry, and that the lion only follows to partake or seize the spoil. The same account is given also of the jackal; and very probably it may be true, not only of these animals, but of some others, since it is natural enough to suppose that the lion will pursue whenever he is taught to discover his prey. We harl one of those animals a few years

b Thevenot, vol. ii. p. 114 . 


\section{$x^{2} \sin ^{2}$}

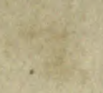

$c^{2}$

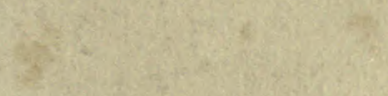

(6)

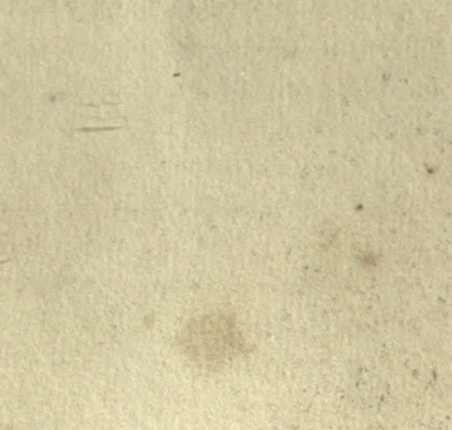

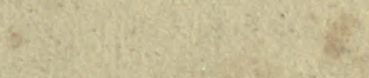

3

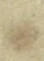

$(2,5)$

\section{7}

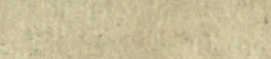

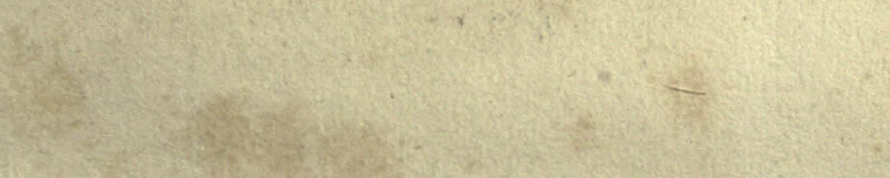

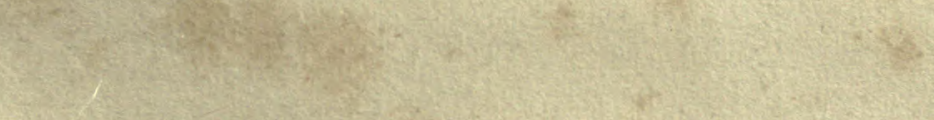

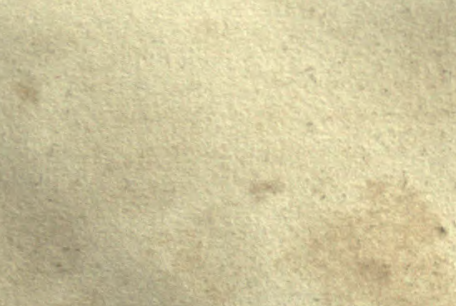

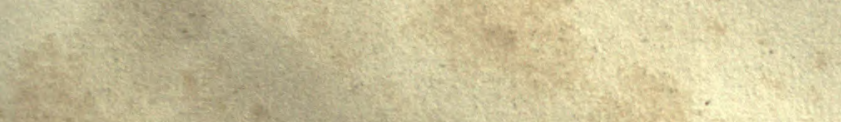<smiles>C1CC2CCC12</smiles>

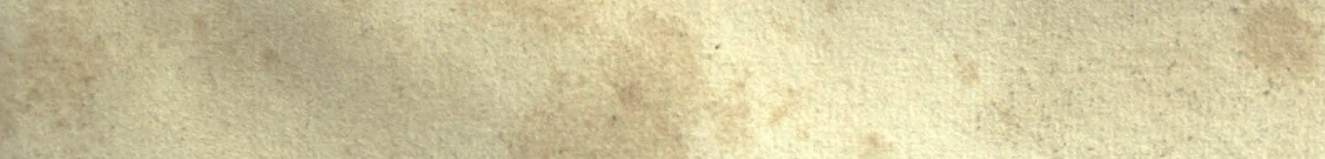

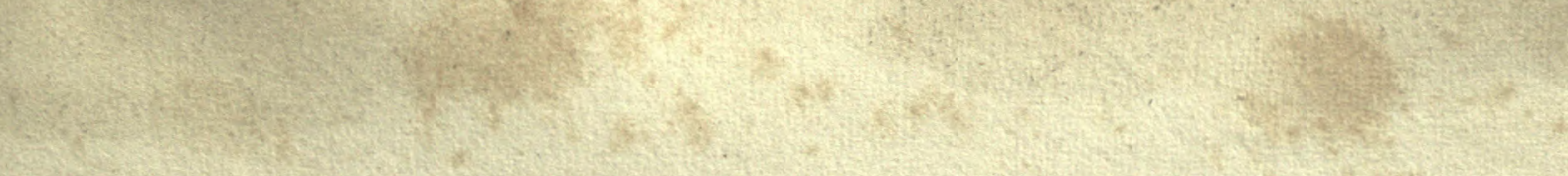



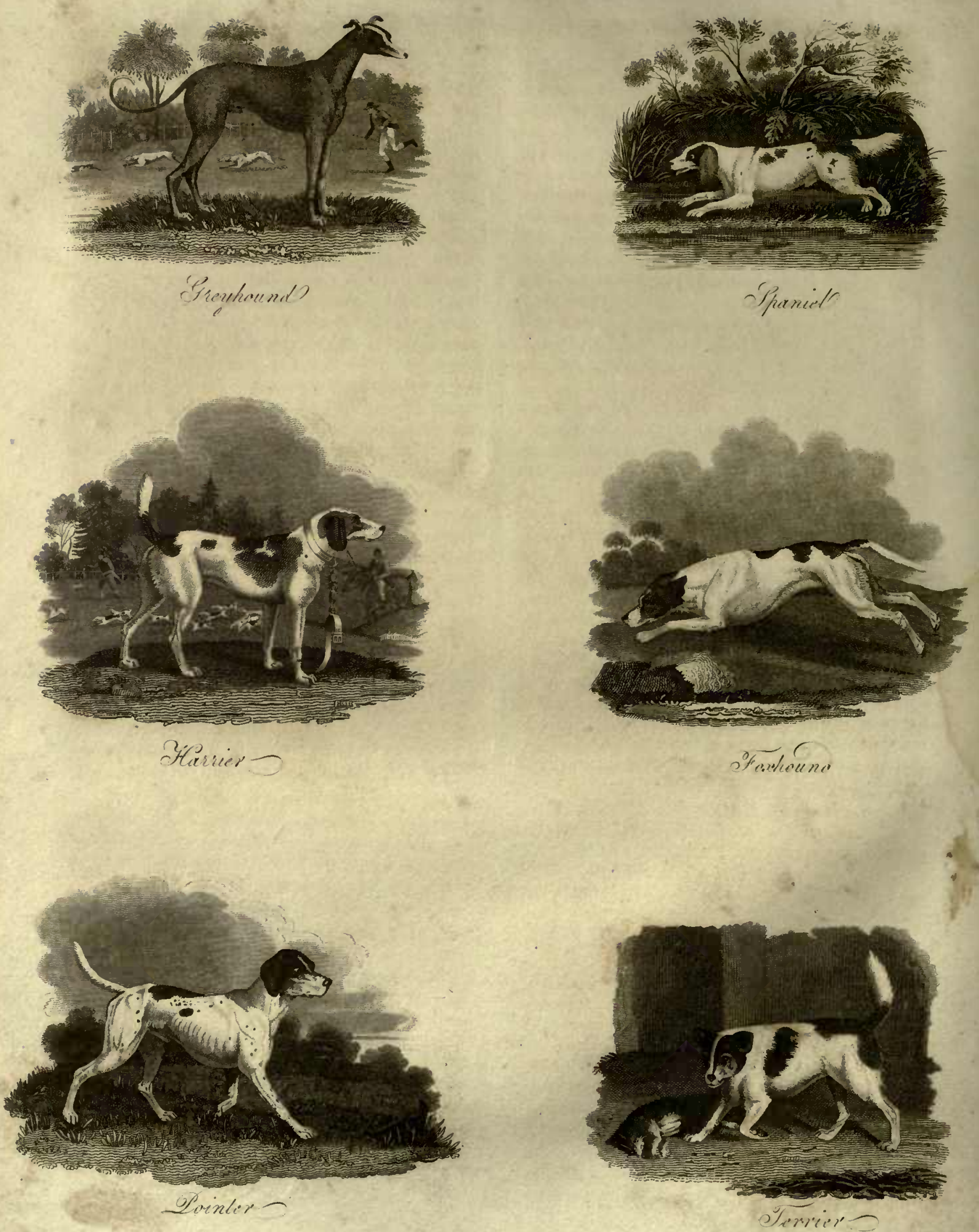
ago sent over from the East Indies, but it was not able to endure the change of climate, and it died in a very short time after it was brought to the Tower. Whether consumed by disease or not I cannot tell, but it seemed to be much slenderer than the cat or the lynx, and its ears were much longer; however, it is a very strong creature for its size, and has been known to

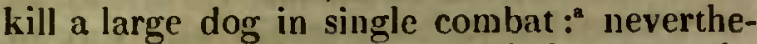
less, it is, like all of the cat kind, except the lion, remarkable for its cowardice, and will never, except in cases of necessity, attack an animal that is its equal in strength or activity. For this reason, when brought into the field, and put upon a service of danger, it obstinately refuses, and is alert only in the pursuit of animals that are too feeble for resistance, or too timid to exert their strength.

From what has been said of this capacious tribe, we perceive a similitude in the manners and dispositions of them all, from the lion to the cat. The similitude of their internal conformation is still more exact; the shortness of their intestines, the number of their teeth, and the structure of their paws. The first of this class is the lion, distinguishable from all the rest by his strength, his magnitude, and his mane. The second is the tiger, rather longer than the lion, but not so tall, and known by the streaks and the vivin beauty of its robe; ineluding also the American tiger or cougar; distinguishable by its size, next that of the tiger, its tawny colour, and its spots. The third is the panther and the leopard. The fourth is the ounce, not so large as any of the former, spotted like them, but distinguishable by the cream-coloured ground of its hair, and the great length of its tail, being above the length of its body. The fifth is the catamountain or tiger cat, less than the ounce, but differing particularly in having a shorter tail, and being streaked down the back like a tiger. The sixth is the short-tailed kind; namely, the lynx, of the size of the former, but with a short tail streaked, and the tips of its ears tufted with black. The seventh is the siagush, differing from the lynx in not being nottled like it, in not being so large, and in having the ears longer, though tipped with black, as before. The eighth is the serval, resensbling the lynx in its form, and the shortness of its tail ; streaked also like it, but not having the tips of his ears tufted. Lastly, the cat, wild and tame, with all its varieties; all less than any of the former, but, like them, cqually insidious, rapacious, and cruel.

This whole race may be considered as the most formidable encmy of mankind; there are others indeed stronger, but they are gentle, and never offering injury till injured: there are others more numerous, but they are more feeble, and rather look for safety by hiding from man, than opposing him. These are the only quadrupeds that make good their ground against him; and which may be said to keep some kingdoms of the earth in their own possession. How many extensive countries are there in Africa, where the wild beasts are so numerous, that man is deterred from living amongst them; reluctantly giving up to the lion and the leopard extensive tracts, that seem formed only for his delight and convenience!

\section{CHAPTER Li.}

\section{ANIMALS OF THE DOG KIND.}

THE second class of carnivornus quadrupeds may be denominated those of the dog kind. This class is neither so numerous nor so powerful as the former, and yet neither so treacherous, rapacious, or cowardly. This class may be principally distinguished by their

- Buffon.

No. $27 \& 28$. claws, which have no sheath, like those of the cat kind, but still continue at the point of each toc, without a capability of being stretcired forward or drawn back. The nose also, as well as the jaw, of all the dog kind, is longer than in the cat; the body is, in proportion, more strongly made, and covered with hair instead of fur. There are many internal dis$3 \mathrm{C}$ 
tinctions also; as in the intestines, which are much longer in the dog kind, than in those of the cat; the eye is not formed for night vision; and the olfactory nerves are diffused, in the dog kinds, upon a very extensive membrane within the skull.

If we compare the natural habitudes of this class with the former, we shall find that the dog kinds are not so solitary as those of the cat, but love to hunt in company, and encourage each other with their mutual cries. In this manuer the dog and the jackal pursuc their prey; and the wolf and fox, which are of this kind, though more solitary and silent among us, yet, in countries where less persecuted, and where they can more fearlessly display their natural incliusations, they are found to keep together in packs, and pursue their game with alternate howlings.

Animals of the dog kind want some of the advantages of the cat kind, and yet are possessed of others in which the latter are deficient. Upon observing their claws, is will easily be perceived that they cannot, like cats, pursue their prey up the sides of a tree, and continue the chase among the branches; their unmanageable claws cannot stick in the bark, and thus support the body up along the truuk, as we see the cat very easily perform: whenever, therefore, their prey flies up a tree from them, they can only follow it with their eyes, or watch its motions till hunger again brings it to the ground. For this reason, the proper prey of the dog kind, are only those animals, that, like themselves, are unfitted for climbing; the hare, the rabbit, the gazelle, or the roebuck.

As they are, in this respect, inferior to the cat, so they exceed it in the sense of smelling; by which alone they pursue their prey with certainty of success, wind it through all its mazes, and tire it down by perseverance. It often happens, however, in the savage state, that their prey is either too much diminished, or two wary to serve for a sufficient supply. In this case, when driven to an extremity, all the dog kinds can live for some time upon fruits and vegetables, which, if they do not please the appetite, at least serve to appease their hurger.

Of all this tribe, the dog has every reason to claim the preference, being the most intelligent of all known quadrupeds, and the acknow- ledged friend of mankind. The dog, independent of the beauty of his form, his vivacity, force, and swiftness, is possessed of all those internal qualifications that can conciliate the affections of man, and make the tyrant a protector. A natural share of courage, an angry and ferocious disposition, renders the dog, in its savage state, a formidable enemy to all other animals: but these readily give way to very different qualities in the domestic dog, whose only ambition seems the desire to please; he is seen to come crouching along, to lay his force, his courage, and all his useful talents, at the feet of his inaster; he waits his orders, to which he pays implicit obedience; he consults his looks, and a single glance is sufficient to put him in motion; he is more faithful even than the most hoasted anong men ; he is constant in his affections, friendly without interest, and grateful for the slightest favours; much more nindful of benefits received, than injuries offered, he is not driven off by unkindness; he still continues humble, submissive, and imploring; his only hope to be serviceable, his only terror to displease; he licks the hand that has been just lifted to strike him, and at last disarms resentment, by submissive perseverance.

More docile than man, more obedient than any other animal, he is not only instructed in a short time, but he also conforms to the dispositions and the manners of those who command him. He takes his tone from the house he inhabits; like the rest of the doniestics, he is disdainful among the great, and churlish among clowns. Always assiduous in serving his master, and only a friend to his friends, he is indifferent to all the rest, and declares himself openly against such as seem to be dependent like himself. He knows a beggar by his clothes, by his voice, or his gestures, and forbids his approach. When at night the guard of the house is committed to his care, he seems proud of the charge; he continues a watchful seutinel, he goes his rounds, scents strangers at a distance, and gives them warning of his beiug upon duty. If they attempt to break in upon his territories, he becones nıore fierce, flies at them, threatens, fights, and either conquers alone, or alarnis those who have most

a The rest of this description of the dog is taken from Mr. Buffou; what I have added, is marked as before. 
interest in coming to his assistance; however, when he has conquered, he quietly reposes upon the spoil, and abstains from what he has deterred others from abusing; giving thus at once a lesson of courage, temperance, and fidelity.

From hence we see of what importance this animal is to us in a state of nature. Supposing, for a moment, that the species had not existed, how could man, without the assistance of the dog, have been able to conquer, tame, and reduce to servitude, every other animal? How could he discover, chase, and destroy, those that were noxious to him? In order to be secure, and to become master of all Animated Nature, it was necessary for him to begin by making a friend of a part of them; to attach such of them to himself, by kindness and caresses, as seem fittest for obedience and active pursuit. Thus the first art employed by man, was in conciliating the favour of the $\mathrm{dog}$; and the fruits of this art were, the conquest and peaceable possession of the eurtl.

The generality of animals have greater agility, greater swiftness, and inore formidable arms, from nature, than man; their senses, and particularly that of sinelling, are far more perfect : they liaving gained, therefore, a new assistant, particularly one whose scent is so exquisite as that of the dog, was the gaining a new sense, a new faculty, which before was wanting. The machines and instruments which we have imagined for perfecting the rest of the senses, do not approach to that already prepared by nature, by which we are enabled to find out every animal, though unseen, and thus destroy the noxious, and use the serviceable.

The dog, thus useful in himself, taken into a participation of empire, exerts a degree of superiority over all animals that require human protection. The flock and the herd obey his voice more readily even than that of the shepherd or the herdsman; he conducts them, guards them, keeps them from capriciously seeking danger, and their enemies he considers as his own. Nor is he less useful in the pursuit; when the sound of the horn, or the voice of the huntsman calls him to the field, he testifies his pleasure by every little art, and pursues with perseverance those animals, which, when taken, he must not expect to divide. The desire of hunting is indeed natural to him, as well as to his master, since war and the chase are the only employment of savages. All animals that live upon flesh hunt by nature; the lion and the tiger, whose foree is so great that they are sure to conquer, hunt alone and witbout art; the wolf, the fox, and the wild-dog, hunt in packs, assists each other, and partake the spoil. But when education has perfected this talent in the domestie dog; when he has been taught by man to repress his ardour, to measure his motions, and not to exliaust his force by too sudden an exertion of it, he then hunts with method, and always with success.

"Although the wild dog, such as he was before he came under the protection of mankind, is at present utterly unknown, no such animal being now to be found in any part of the world; yet there are many that, from a domestic state, have turned savage, and entirely pursue the dictates of nature." In those deserted and uncultivated countries where the dog is found wild, they seem entirely to partake of the disposition of the wolf; they unite in large bodies, and attack the most formidable animals of the forest, the cougar, the panther, and the bison. In America, where they were originally brought by the Europeans, and a bandoned by their masters, they have multiplied to such a degree, that they spread in packs over the whole country, attack all other animals, and even man himself does not pass without insult. They are there treated in the same manner as all other carnivorous animals, and killed wherever they happen to come: however, they are easily tamed: when taken home, and treated with kinduess and lenity, they quickly become submissive and familiar, and continue faithfully attached to their masters. Different in this from the wolf or the fox, who, though taken never so young, are gentle only while cubs, and, as they grow older, give themselves up to their natural appetites of rapine and cruelty. In short, it may be asserted, that the dog is the only animal whose fidelity is unshaken; the only one who knows his master, and the friends of the family; the only one who instantly distinguishes a stranger; the only one who knows his name, and answers to the domestic call; the only one who seems 
to understand the nature of subordination, and secks assistance; the only one who, when he misses his master, testifies his loss by his complaints; the only one who, carried to a distant place, can fiud the way home; the only one whose natural talents are evident, and whose education is always successful.

In the same manner, as the dog is of the most complying disposition, so also is it the most susceptible of change in its form; the varieties of this animal being too many for even the most careful describer to mention. The climate, the food, and the education, all make strong impressions upon the animal, and produce alterations in its shape, its colour, its hair, its size, and in every thing but its nature. The same dog, taken from one climate and brought to another, secms to become another animal; but different breeds are as much separated, to all appearance, as any two animals the most distinct in nature. Nothing appears to continue constant with them, but their internal conformation; different in the figure of the body, in the length of the nose, in the shape of the head, in the length and the direction of the ears and tail, in the colour, the quality, and the quantity of the hair; in short, different in every thing but that make of the parts which serve to continue the species, and keep the animal distinct from all others. It is this peculiar conformation, this power of producing an animal that ean reproduce, that marks the kind, and approximates forms that at first sight seem never made for conjunction.

From this single consideration, therefore, we may at once pronounce all dogs to be of one kind; but which of them is the original of all the rest, which of them is the savage dog from whence such a variety of descendants have come down, is no easy matter to determine. We may easily, indeed, observe, that all those animals which are under the influence of man, are subject to great variations. Such as have been sufficiently independent, so as to choose their own climate, their own nourishment, and to pursue their own habitudes, preserve the original marks of nature, without much deviation; and it is probable, that the first of these is cven at this day very well represented in their descendants. But such as man has subdued, transported from one cli- mate to another, controlled in their manner of living, and their food, bave most probably been changed also in their forms; particularly the dog has felt these alterations more strongly than any other of the domestic kinds; for living more like man, he may be thus said to live more irregularly also, and, consequent$l y$, must have felt all those ehanges that such variety would uaturally produce. Some other causes also may be assigned for this variety in the species of the dog: as he is perpetually under the eye of his niaster, when accident has produced any singularity in its productions, man uses all his art to continue this peculiarity unchanged; either by breeding fiom such as had those singularities, or by destroying such as happened to want them; besides, as the dog produces much more frequently than some other animals, and lives a shorter time, so the chance for its varieties will be offered in greater proportion.

But which is the original animal, and which the artificial or aceidental variety, is a question which, as was said, is not easily resolved. If the internal structure of dogs of different sorts be compared with each other, it will be found, except in point of size, that in this respect they are exactly the same. This, therefore, affords no criterion. If other animals be compared with the dog internally, the wolf and the fox will be found to have the most perfect resemblance; it is probable, therefore, that the dog, which most ncarly resembles the wolf or the fox externally, is the original animal of its kind: for it is natural to suppose, that as the dog most nearly resembles them internally, so he may be near them in exter nal resemblance also, except where art or accident has altered his form. This being supposed, if we look among the number of varieties to be found in the dog, we shall not find one so like the wolf or the fox, as that which is called the shepherd's dog. This is that dog with long coarse hair on all parts except the nose, prieked ears, and a long nose, which is common enough among us, and receives his name from being principally used in guarding and attending on sheep. This seems to be the primitive animal of his kind; and we shall be the more confirmed in this opinion, if we attend to the different characters which climate produces in the animal, 
and the different races of dogs which are propagated in every country: and, in the first place, if we examine those countries which are still savage, or but half civilized, where it is most probable the dog, like his master, has received but few impressions from art, we shall find the shepherd's dog, or one very like him, still prevailing amongst them. The dogs that have run wild in America, and in Congo, approach this form. The dog of Sibcria, Lapland, and Iceland, of the Cape of Good Hope, of Madagascar, Madura, Calicut, and Malabar, have all a long nose, pricked ears, and resemble the shepherd's dog very nearly. In Guinea, the dor very speedily takes this form ; for, at the second or third generation, the animal forgets to bark, his ears and his tail become pointed, and his hair drops off, while a coarser, thimner kind comes in the place. This sort of dog is also to be found in the temperate climates in great abundance, particularly among those who, preferring usefulness to heauty, employ an animal that requires very little instruction to be serviceable. Notwithstanding this creature's defornity, his melancholy and savage air, he is superior to all the rest of his kind in instinct; and without any teaching, naturally takes to tending flocks, with an assiduity and vigilance that at once astonishes, and yet relieves his master.

In more polished and civilized places, the dog seems to partake of the universal refinement; and, like the men, becomes more beautiful, more majestic, and more capable of assuming an education foreign to his nature. The dogs of Albany, of Grecce, of Denmark, and of Ireland, are larger and stronger than those of any other kind. In France, Germany, Spain, and Italy, the dogs are of various kinds, like the men; and this variety seems formed by crossing the breed of such as are imported from various clines.

'The shepherd's dog may, therefore, be considered as the primitive stock from whence these varieties are all derived. He makes the stem of that genealogical tree which has been branched out into every part of the world. This aninal still continues pretty nearly in its original state among the poor in temperate climates; being transported into the colder regions, he grows less and mole ugly among the Laplanders; but becomes more perfect in Iceland, Russia, and Siberia, where the climate is less rigorous, and the people more civilized. Whatever differences there may be among the dogs of these countries, they are not very considerable, as they have all straight ears, long and thick hair, a savage aspect, and do not bark either so often or so loud as dogs of the more cultivated kind.

The shepherd's dog, transported into the temperate climates, and among people entirely civilized, such as England, France, and Germany, will be divested of his savage air, his pricked ears, his rough, long, and thick hair and, from the single influence of climate and food alone, will become either a matin, a mastiff, or a hound. These tluree seem the immediate descendants of the former; and from them the other varieties are produced.

The Hound, the Harrier, and the Beagle, seem all of the same kind; for although the bitch is covered but by one of them, yet in her litters are found puppies resembling all the three. This animal, transported into Spain or Barbary, where the hair of all quadrupeds become soft and long, will be there converted into the land-spaniel, and the water-spaniel, and these of different sizes.

The Gray Matin Hound, which is in the second branch, transported to the north, becomes the great Danish dog; and this, sent into the south, becomes the gray-hound, of different sizes. The same, transported into Ireland, the Ukraine, Tartary, Epirus, and Albania, becomes the great wolf-dog, known by the name of the Irish wolf-dog.

The MastifF, which is the third branch, and chiefly a wative of England, when transported into Denmark, becomes the little Danish dog; and this little Danish dog, sent into the tropical and warm climates, becomes the animal called the Turkisf Dog, without hair. All these races, with their varieties, are produced by the influence of climate, joined to the different food, education, and shelter, which they have received among mankind. All other kinds may be considered as mongrel races, produced by the concurrence of these, and found rather by crossing the breed than by attending to the individual. "As these are extremely numerous, and very different in different countries, it would be almost endless to mention the whole; besides, nothing but experience can ascertain the reality of these conjectures, although they have so much the appearance of 
probability ; and until that gives morc certain information, we must be excused from entering more minutely into the subject.

"With regard to the dogs of our country in particular, the varieties are very great, and the number every day increasing. And this must happen in a country so open by commerce to all others, and where wealth is apt to produce capricious predilection. Here the ugliest and the most useless of their kinds will be entertained merely for their singularity ; and, being insported only to be looked at, they will lose even that small degree of sagacity which they possessed in their natural climates. From this importation of foreign useless dogs, our own native breed is, I am informed, greatly degenerated, and the varieties now to be found in England nuch more numerous than they were in the times of Queen Elizabeth, when Doctor Caius attempted their natural history. Sonse of these he mentions are no longer to be found among us, although many have since been introduced, by no nieans so serviceable as those which have been suffered to decay.

"He divides the whole race into thrce kinds. The first is, the generous kind, which consists of the terrier, the harrier, and the blood-hound; the gaze-lound, the gray-hound, the leymmer, and the tumbler; all thesc are used for hunting. Then the spaniel, the setter, and the water-spaniel, or finder, were used for fowling ; and the spaniel gentle, or lap-dog, for amusement. The second is the farm kind ; consisting of the shepherd's dog and the mastiff. And the third is the mongrel kind; consisting of the wappe, the turnspit, and the dancer. To these varieties we may add at present, the bulldog, the Dutch mastiff, the harlequin, the pointer, and the Dane, with a variety of lap-dogs, which, as they are perfectly useless, may be considered as unworthy of a name.

"The Terrier is a small kind of hound," with rough hair, made use of to force the fox or the badger out of their holes; or rather to give notice, by their barking, in what part of their kennel the fox or badger resides, when the sportsmen intend to dig them out.

"The Harrier, as well as the beagle and the fox-hound, are used for hunting; of all other animals, they have the quickest and most distinguishing sense of smelling. The properly

- British Zoology. breeding, matching, and training these, make up the business of many men's lives.

"The Blood-hound was a dog of great use, and in high esteem aniong our ancestors. Its employ was to recover any game that had escaped from the liunter, or had been killed, and stolen out of the forest. But it was still more employed in hunting thieves and robbers by their footsteps. At that time, when the country was less peopled than at present, and when, consequently, the footsteps of one man were less crossed and obliterated by those of others, this animal was very serviceable in such pursuits; but at present, when the country is every where peopled, this variety is quite worn out; probably because it was found of less service than formerly.

"The Gaze-hound hunted, like our grayhounds, by the eye and not by the scent. It chased indifferently the fox, hare, or buck. It would select from the herd the fattest and fairest deer, pursuc it by the eye, and if lost recover it again with amazing sagacity. This species is now lost or unknown among us.

"The Gray-hound is very well known at present, and was formerly held in such estimation, that it was the peculiar companion of a gentleman; who, in the times of semi-barbarism, was known by his horse, his hawk, and his gray-hound. Persons under a certain rank of life are forbidden, by some late game-laws, from keeping this aninal; wherefore, to disguise it the better, they cut off its tail.

"The Leymmer is a species now unknown to us. It hunted both by scent and sight, and was led in a leyme or thong, from whence it received its name.

"The Tumbler was less than the hound, more scraggy, and had pricked cars; so that by the description it seems to answer to the modern lurcher. This took its prey by mere cunning, depending neither on the goodness of its nose nor its swiftness. If it cane into a warren, it neither barked nor ran on the rabbits; but scemingly inattentive, approached sufficiently ncar till it came within reach, and then seized them by a sudden spring.

"The Land Spaniel, which probably had its name from Spain, where it might have acquired the softness of its hair, is well known at present. There are two varieties of this kind; nanely, the Slater, used in hawking to spring the gaine; and the Setter, that crouches 
down when it scents the birds, till the net be drawn over them. I have read somewhere that the famous poet, Lord Surry, was the first who taught dogs to set; it being an amusement to this day only known in England.

"The Water-Spaniel was another species used in fowling. This seems to be the most docile of all the dog kind; and this docility is particularly owing to his natural attachment to man. Many otlier kinds will not bear correction; but this patient creature, though very fierce to strangers, seems unalterable in his affections; and blows and ill usage seem only to increase his regard.

"The Lap-dog, at the time of Doctor Caius, was of Maltese breed; at present it comes from different countries; in general, the more awkward or extraordinary these are, the more they are prized.

"The Shepherd's dog has been already mentioned, and as for the Mastiff he is too common to require a description. Doctor Caius tells us, that three of these were reckoned a match for a bear, and four for a lion. However, we are told that three of them overcame a lion in the time of King James the first; two of them being disabled in the combat, the third obliged the lion to seek for safety by flight.

"As to the last division, namely, of the Wappe, the Turnspit, and the Dancer, these were mongrels, of no certain shape, and made use of only to alarm the family, or, being taught a variety of tricks, were carried about as a show.

"With regard to those of later importation, the Bull-dog, as Mr. Buffon supposes, is a breed between the small Dane and the English mastiff. The large Dane is the tallest dog that is generally bred in England. It is somewhat between a mastiff and a gray-hound in shape, being more slender than the one and much stronger than the other. They are chicfly used rather for show than service, being neither good in the yard nor the ficld. The highest are most estcemed; and they generally cut off their ears to improve their figure, as some absurdly suppose. The harlequin is not much unlike the small Dane, being an useless animal, somewhat between an Italiau gray-hound and a Dutch mastiff. To these several others might be added, such as the pug-dog, the black breed, and the pointer; but, in fact, the varieties are so nume. rous as to fatigue even the most ardent curiosity."

Of these of the foreign kinds, I shall mention only three, which are more remarkable than any of the rest. The Lion-Dog greatly resembles that animal, in miniature, from whence it takes the name. The hair of the fore-part of its body is extremely long, while that of the hinder-part is as short. The nose is short, the tail long, and tufted at the point, so that in all these particulars it is entirely like the lion. However, it differs very much from that fierce animal in nature and disposition, being one of the smallest animals of its kind, extremely feeble, timid, and inactive. It comes originally from Malta, where it is found so small that women carry it about in their sleeves.

That animal falsely called the Turlish-dog, differs greatly from the rest of the kind, in being entirely without hair. The skin, which is perfectly bare, is of a flesh colour, with brown spots; and their figure, at first view, is rather disgusting. These seem to be of the small Danish breed, brought into a warn climate, and there, by a succession of generations, divested of their hair. For this reason, they are extremely chilly, and unable to endure the cold of our climate; and even in the midst of summer, they continue to shiver as we see men in a frosty day. Their spots are brown, as was said, well marked, and easily distinguishable in summer, but in the cold of winter they entirely disappear. They are called the Turkish breed, although brought from a much warmer climate; for some of them have been known to come from the warmest parts of Africa and the East Indies.

"The last variety, and the most wonderful of all that I shall mention, is the Great Irish Wolf-dog, that may be considered as the first of the canine species. This animal, which is very rare, even in the only country in the world where it is to be found, is rather kept for show than use, there being neither wolves nor any other formidable beasts of prey in Ireland, that secm to require so powerful an antagonist. The wolf-dog is therefore bred up in the houses of the great, or such gentlemen as choose to keep him as a curiosity, being 
neither good for hunting the hare, the fox, nor the stag, and equally unserviceable as a house dog. Nevertheless he is extremely beautiful and majestic to appearance, being the greatest of the $\log$ kind to be seen in the world. The largest of those I have seen, and I have seen above a dozen, was about four feet high, or as tall as a calf of a year old. He was made extremely like a gray-hound, but rather more robust, and inclining to the figure of the French matin, or the great Dane. His eye was mild, his colour white, and his nature seemed heavy and phlegmatic. This I ascribed to his having been bred up to a size beyond his nature; for we see in man, and all other animals, that such as are overgrown are neither so vigorous nor alert as those of a more moderate stature. The greatest pains have been taken with these to enlarge the breed, both by food and matching. This end was effectually obtained, indeed, for the size was cnormous; but, as it seemed to me, at the expense of the animal's fierceness,' vigilance, and sagacity. However, I was informed otherwise; the gentlemen who bred them assuring me that a mastiff would be nothing when opposed to one of them, who generally seized their antagonist by the back: he added, that they would worry the strongest bulldogs, in a few minutes, to death. But this strength did not appear either in their figure or their inclinations; they seemed rather more timid than the ordinary race of dogs; and their skin was much thinner, and consequently less fitted for combat. Whether, with these disadvantages they were capable, as I was told, of singly coping with bears, others may determine; however, they have but few opportunities, in their own country, of exerting their strength, as all wild carnivorous animals there are only of the vermin kind. Mr. Buffon seems to be of opinion that these are the true Molossian dogs of the ancients; he gives no reason for this opinion; and I am apt to think it ill-grounded. Not to trouble the reader with a tedious critical disquisition, which I have all along avoided, it will be sufficient to oberve, that Nemesianus, in giving directions for the choice of a bitch, advises to have one of Spartan or Molossian breed; and, among several other perfections, he says that the ears should be dependent, and fluctuate as she runs." This, however, is by no means the case with the Irish wolf-dog, whose ears resemble those of the gray-hound, and are far from fluctuating with the animal's motions. But of whatever kinds these dogs may be, whether known among the ancients, or whether produced by a later mixture, they are now almost quite worn away, and are very rarely to be met with even in lreland. If carried to other countries, they soon degenerate; and even at home, unless great care be taken, they quickly alter. They were once employed in clearing the island of wolves, which infested it in great plenty; but these being destroyed, the dogs also are wearing away, as if nature meant to blot out the species, when they had no longer any services to perform.

"In this manner several kinds of animals fade from the face of nature, that were once well known, but are now seen no longer. The enormous elk of the same kingdom, that, by its horns, could not have been less than eleven feet high, the wolf, and even the wolf-dog, are extinct, or only continued in such a manner as to prove their former plenty and existence. From bence it is probable, that many of the nobler kinds of dogs, of which the ancients have given us such beautiful descriptions, are now utterly unknown; since among the whole breed we have not one that will venture to engage the lion or the tiger in single combat. The English bull-dog is perhaps the bravest of the kind; but what are lis most boasted exploits to those mentioned of the Epirotic dogs by Pliny, or the Indian dogs by Elian. The latter gives us a description of a combat between a dog and a lion, which I will take leave to translate.

"When Alexander was pursuing his conquests in India, one of the principal men of that country was desirous of showing him the value of the dogs, which his country produced. Bringing his dog into the king's presence, he ordered a stag to be let loose before him, which the dog despised as an unworthy enemy, remained quite regardless of the animal, and never once stirred from his

a Elige tunc cursu facilem, facilenıque recursu, In Lacedamonio natam seu rure MolossoRenibus ampla satis validis, diductaque coxas Cuique nimis molles fluitent in cursibus aures. NEMESIAN. 
place. His master then ordered a wild boar to be set out; but the dog thought even this a despicable foe, and remained calm and regardless as before. He was next tried with a bear; but still despising his enemy, he only waited for an object more worthy of his courage and his force. At last they brought forth a tremendous lion, and then the dog acknowledged his antagonist, and prepared for combat. He instantly discovered a degree of ungovernable ardour; and, flying at the lion with fury, seized him by the throat, and totally disabled him from resistance. Upon this, the Indian, who was desirous of surprising the king, and knowing the constancy and bravery of his dog, ordered his tail to be cut off; which was casily performed as the bold animal was employed in holding the lion. He next ordered one of lis legs to be broken; which, however, did not in the least abate the dog's ardour, but he still kept his hold as before. Another leg was then broken; but the $\mathrm{dog}$, as if he had suffered no pain, only pressed the lion still the more. In this cruel manner, all his legs were cut off, without abating his courage; and at last, when even his head was separated from his body, the jaws seemed to keep their former hold. A sight so cruel did not fail to affect the king with very strong emotions, at once pitying the dog's fate, and admiring his fortitude. Upon which the Indian, seeing him thus moved, presented him with four dogs of the same kind, which, in some measure, alleviated his uneasiness for the loss of the former.

"The breed of dogs, however, in that country, is at present very much inferior to what this story seems to imply; since, in many places, instead of dogs, they have animals of the cat kind for hunting. In other places, also, this admirable and faithful animal, instead of being applied to his natural uses, is only kept to be eaten. All over China, there are dogbutchers, and shambles appointed for selling their flesh. In Canton, particularly, there is astreet appointed for that purpose; and, what is very extraordinary, wherever a dog-butcher appears, all the dogs of the place are sure to be in full icry after him; they know their enemy, and persecute him as far as they are able." Along the consts of Guinea, their flesh is esteemed a delicacy by the Negroes; and they No. $27 \& 28$. will give one of their cows for a dog. But, among this barbarous and brutal people, scarce any thing that has life comes amiss; and they may well take up with a dog, since they consider toads, lizards, and even the flesh of the tiger itself, as a dainty. It nay, perhaps, happen that the flesh of this aninial, which is so indifferent in the temperate climates, may assume a better quality in those which are more warm; but it is more than probable that the diversity is rather in man than in the flesh of the dog; since in the cold countries the flesh is caten with equal appetite by the savages; and they have their dogfeasts in the same manner as we have ours for venison.

In our climate, the wild animals that most approach the dog are the wolf and the fox; these, in their interual conformation, greatly resemble each other, and yet in their natures are very distinct. The ancients asserted that they bred together; and I am assured, by credible persons, that there are many animals in this country bred between a $\operatorname{dog}$ and $a$ fox. However, all the endeavours of Mr. Buffon to make them engender, as he assures us, were ineffectual. For this purpose, he bred up a young wolf, taken in the woods, at two months old, with a matin dog of the same age. They were shut up together, without any other, in a large yard, where they had a shelter for retiring. They neither of them knew any other individual of their kind, nor even any other man, but he who had the charge of feeding them. In this manner they were kept for three years; still with the same attention, and without constraining or tying them up. During the first year the young animals played with each other continually, and secmed to love each other very much. In the second year; they began to dispute about their victuals, although they were given more than they could use. The quarrel always began on the wolf's side. They were brought their food, which consisted of flesh and bones, upon a large wooden platter, which was laid on the ground. Just as it was put down, the wolf, instead of falling to the meat, began by driving off the dog; and took the platter in its teeth so expertly, that it let notling of what it contained fall upon the ground, and in this manner carried it off; but a the wolf could not 
entirely escape, it was frequently seen to run with the platter round the yard five or six times, still carrying it in a position that none of its contents could fall. In this manner it would continue ruming, only now and then stopping to take breath, until the dog coming up, the wolf would leave the victuals to attack him. The dog, however, was the stronger of the two, but as it was more gentle, in order to secure him from the wolf's attack, he had a collar put round his neck. In the third year, the quarrels of these ill-paired associates were more vehement, and their combats more frequent; the wolf, therefore, had a collar put about its neck, as well as the dog, who began to be more fierce and unmerciful. During the two first years, neither seemed to testify the least tendency towards engendering; and it was not till the end of the third, that the wolf, which was the female, showed the natural desire, but without abating either in its fierceness or obstinacy. This appetite rather increased than repressed their mutual animosity; they became every day more untractable and ferocious, and nothing was heard between them but the sounds of rage and resentment. They both, in less than three weeks, became remarkably lean, without ever approaching each other, but to combat. At length, their quarrels became so desperate, that the dog killed the wolf, who was become more weak and fecble; and he was soon after himself obliged to be killed, for, upon being set at liberty, he instantly flew upon every animal he met, fowls, dogs, and even men themselves not escaping his savage fury.

The same experiment was tried upon foxes, taken young, but with no better success; they were never found to engender with dogs; and our learued naturalist seems to be of opinion that their natures are too opposite ever to proroke mutual desire. One thing, however, must be remarked, that the animals on which he tried his experiments, were rather too old when taken, and had partly acquired their natural savage appetites, before they came into his possession. The wolf, as he acknowledges, was two or three months old before it was caught, and the foxes were taken in traps. It may, therefore, be casily supposed, that nothing conld ever after thoroughly tame those creatures that had been suckled in the wild state, and had caught all the habitudes of the dam. I have scen these animals, when taken earlier in the woods, become very tame; and, indeed, they rather were displeasing by being too familiar than too shy. It were to be wished that the experiment were tried upon such as these; and it is more than probable that it would procluce the desired success. Nevertheless, these experiments are sufficient to prove that neither the wolf nor the fox are of the same nature with the $\operatorname{dog}$, but each of a species perfectly distinet, and their joint produce most probably unfruitful.

The dog, when first whelped, is not a completely finished animal. In this kind, as in all the rest which bring forth many at a time, the young are not so perfect as in those which bring forth onc or two. They are always produced with the eyes closed, the lids being held together, not by sticking, but by a kind of thin membrane, which is torn as soon as the upper eye-lid becomes strong enough to raise it from the under. In general, their eyes are not opened till ten or twelve days old. During that time, the bones of the skull are not completed, the body is puffed up, the nose is short, and the whole form but ill-sketched out. In less than a month the puppy begins to use all its senses; and from thence makes hasty advances to its perfection. At the fourth month, the dog loses some of his teeth, as in other animals, and these are renewed by such as never fall. The number of these amount to forty-two, which is twelve more than is found in any of the cat kind, which are known never to have above thirty. The tecth of the dog being his great and only weapon, are formed in a manner much more serviceable than those of the former; and there is scarce any quadruped that has a greater facility in rending, cutting, or chewing its food. He cuts with his incisors, or fore-teeth, he loolds with his four great canine teeth, and he chews his meat with his grinders; these are fourteen in number, and so placed, that, when the jaws are shut, there remains a distance between them, so that the dog, by opening his mouth ever so wide, does not lose the power of his jaws. But it is otherwise in the cat kind, whose incisors, or cutting-teeth, are very small, and whose grinding-teeth when brought together, touch more closely than those of the dog, and, 
consequently, have less power. Thus, for instance, I can squeeze any thing more forcibly between my thumb and fore-finger, where the distance is greater, than between any other two fingers, whose distance from each other is less.

This animal is capable of reproducing at the age of twelve months," and goes nine weeks with young, and lives to about the age of twelve. Few quadrupeds are less delicate in their food; and yet there are many kinds of birds which the dog will not venture to touch. He is even known, although in a savage state, to abstain from injuring some, which one might suppose he had every reason to oppose. The dogs and the vultures which live wild about Grand Cairo in Egypt, (for the Mahometan law has expelled this useful animal from buman society,) continue together in a very sociable and friendly nanner: ${ }^{\circ}$ As they are both useful in devouring such carcasses as might otherwise putrefy, and thus infect the air, the inhahitants supply then with provisions every day, in order to keep them near the city. Upon these occasions, the quadrupeds and birds are often seen together, tearing the same piece of flesh, without the least enmity; on the contrary, they are known to live together with a kind of affection, and bring up their young in the same nest.

Although the dog is a voracious animal, yet he call bear hunger for a very long time. We have an instance, in the Memoirs of the Academy of Sciences, of this kind, in which a bitcl that had been forgotten in a countryhouse, lived forty days, without any other nourishment than the wool of a quile which she liad torn in pieces. It should seem that water is more necessary to the dog than food; lic drinks often, though not abundantly; and it is commonly believed, that when abridged in water, he runs mad. This dreadful malady, the consequences of which are so well known, is the greatest inconvenience that results from the keeping this faithful domestic. But it is a

a To this description I will beg leave to add a few particulars from Linnaus, as I find them in the original. " Vomitua gramiua purgatur ; cacat supra lapidem. Album grecum antisepticum summum. Mingit ad latus (llis, lowever, not till the animal is nine montlis old) cum hospite sape centies. Odorat anum alterius. Procis rixantibus crudelis. Menstruans coit cum variis. Alordet illa illos. Colıeret copula junctus."

b Ilasselquist Her. Palrestin. p. 232 disorder by no means so frequent as the terrors of the timorous would suppose; the dog has been often accused of madness, without a fair trial; and some persons have been supposed to receive their deaths from his bite, when either their own ill-grounded fears, or their natural disorders, were the true causc.

\section{THE WOLF.}

THE dog and the wolf are so very much alike internally, that the most expert anatomists can scarce perceive the difference; and it may be asserted also, that, externally, sonc dogs inore nearly rescmble the wolf than they do each other. It was this strong similitude that first led some naturalists to consider them as the same animal, and to look upon the wolf as the dog in its state of savage frecdom : however, this opinion is entertained no longer; the natural antipathy those two animals bear to each other; the longer time which the wolf goes with young than the dog, the one going over a hundred days, and the other not quite sixty ; the longer period of life in the former thais the latter, the wolf living twenty years, the dog not fifteen; all sufficiently poiut out a distinction, and draw a line that must for ever keep then asunder.

The wolf, from the tip of the nose to the insertion of the tail, is about three feet seven inches long, and about two feet five inches high; which shows lim to be larger than our great breed of mastiffs, which are seldom found to be above three feet by two. His colour is a mixture of black, brown, and gray, extremely rough and hard, but mixed towards the roots with a kind of ash-coloured fur. In comparing him to any of our well-known brecd of dogs, the great Dane or inongrel grayhound, for instance, he will appear to have the legs sholter, the head larger, the muzzle thicker, the eyes smaller, and more separated from cach other, and the ears shorter and straighter. He appears in every respect stronger than the dog; and the length of his hair contributes still more to his robust appearance. The feature which principally distinguishes the visage of the wolf from that of the dog is the eye, which opens slantingly upwards in the sanie direction with the nose; whereas, in the dog, it opens more at right angles with the nose, as in man. The 
tail, also, in this animal, is long and bushy; and he carries it rather more between his hind legs than the dog is seen to do. The colour of the eye-balls in the wolf are of a fiery green, and give his visage a fierce and formidable air, which his natural disposition does by no means contradict."

The wolf is one of those animals whose appetite for animal food is the most vehement; and whose means of satisfying this appetite are the most various. Nature has furnished him with strength, cunning, agility, and all those requisites which fit an animal for pursuing, overtaking, and conquering its prey; and yet, with all these, the wolf most frequently dies of hunger, for he is the declared enemy of man. Being long proscribed, and a reward offered for his head, he is obliged to fly from liuman habitations, and to live in the forest, where the few wild animals to be found there escape him either by their swiftncss or their art; or are supplied in too small a proportion to satisfy his rapacity. He is naturally dull and cowardly; but frequently disappointed, and, as often reduced to the verge of famine, he becomes ingenious from want, and couragcous from nccessity. When pressed with hunger, he braves danger, and comes to attack those animals which are undel the protection of man, particularly such as he can readily carry away, lambs, sheep, or even dogs theniselves, for all animal food becomes then equally agreeable. When this excursion has succeeded, he often returns to the charge, until having been wonnded, or hard pressed by the dogs or the shepherds, he hides himself by day in the thickest coverts, and only ventures out at night ; he then sallies forth over the country, keeps peering round the villages, carries off such animals as are not under protection, attacks the sheepfolds, scratches up and undermines the thresholds of doors where they are housed, enters furiously, and destroys all before he begins to fix upon and carry off his prey. Whien these sallies do not succeed, he then returins to the thickest part of the forest, content to pursue those smaller animals, which, even when taken, afford him but a scanty supply. He therc goes regularly to work,

a The rest of this history of the wolf is taken from Mr. Buffon; and I look upon it as a complete model for natural history. If I add or differ, I mark it as usual. follows by the scent, opens to the view, stilt keeps following, hopelcss himself of overtaking the prey, but expecting that some other wolf will come in to his assistance, and then content to share the spoil. At last, when his necessities are very urgent, he bollly faces certain destruction; he attacks women and children, and sometimes ventures even to fall upon men, becomes furions by his continual agitations, and ends his life in madness.

The wolf, as well externally as internally, so nearly resembles the dog, that he secins modelled upon the same plan; and yet he only offers the reverse of the model. If his form bc like, his nature is so different, that he only preserves the ill qualities of the dog, without any of his good ones. Indeed, they are so different in their dispositions, that no two animals can have a more perfect antipathy to each other. A young dog shudders at the sight of a wolf; he even shuns his scent, which, though unknown, is so repugnant to his nature, that he comes trembling to take protection near his master. A dog who is stronger, and who knows his strength, bristles up at the sight, testifies his animosity, attacks lim with courage, endeavours to put him to flight, and does all in his power to rid himself of a presence that is hateful to him. They never meet without either flying or fighting; fighting for life and death, and without mercy on either side. If the wolf is the stronger, he tears and and devours his prey: the dog, on the contrary, is more generous, and contents himself with his victory; he does not seem to think that the body of a dead enemy smells well; he leaves him where he falls, to serve as food for birds of prey, or for other wolves, since they devour each other; and when one wolf happens to be desperately wounded, the rest track him by his blood, and are sure to show him no mercy.

The dog, even in his savage state, is not cruel ; he is easily tamed, and coutinues firmly attached to his naster. The wolf, when taken young, becomes tame, but never has an attachment: Nature is stronger in him than education; he resumes with age his natura? dispositions, and returns as soon as he can to the woods from whence he was takcu. . Dogs, even of the dullest kinds, seek the company of other aninals; they are naturally disposed to follow and accompany other creatures besides 
themselves; and even by instinct, without any education, take to the care of flocks and herds. The wolf, on the contrary, is the enemy of all society; he does not even keep much company with those of his kind. When they are seen in packs together, it is not to be considered as a peaceful society, but a combination for war; they testify their hostile intentions by their loud howlings, and, by their fierceness, discover a project for attackiug some great unimal, such as a stag or a bull, or to destroy some more redoubtable watch-dog. The instant their military expedition is completed, their society is at an end; they then part, and each returns in silence to bis solitary retreat. There is not even any strong attachinents between the male and female; they seek each other only once a year, and remain but a few days together: they always couple in winter; at which time several males are seen following one female, and this association is still more bloody than the former: they dispute most cruelly, growl, bark, fight, and tear each other; and it sometimes happens that the majority kill the wolf, which has been chiefly preferred by the female. It is usual for the slie wolf to fly from them all with him she has chosen; and watehes this opportunity when the rest are asleep.

The season for coupling does not continue above twelve or fifteen days; and usually commences among the oldest, those which arc young being later in their desires. The males have no fixed time for engendlering, they pass from one female to the other, begimning at the end of Deeensber, and ending at the latter end of February. The time of pregnancy is about three months and a half; and the young wolves are found from the latter end of April to the beginning of July. The long continuance of the wolf's pregnancy is sufficient to make a distinetion between it and the clog, did not also the fiery fierceness of the eyes, the howl instead of barking, and the greater duration of its lile, leave no doubt of its being an animal of its own particular species. In other respects, hovever, they are entirely alike; the wolf couples exactly like the dog, the parts are formed in the same manner, and their separation hindered by the same cause. When the she wolves are near their time of bringing forth, they seek some very tufted spot, in the thickest part of the forests; in the middle of this they make a small opening, cutting away the thorns and briars with their teeth, and afterwards carry thither a great quantity of moss, which they form into a bed for their young ones. They generally bring forth five or six, and sometimes even to nine at a litter. The cubs are brought forth, like those of the bitch, with the cyes closed; the dam suckles them for some weeks, and teaches them betimes to eat flesh, which she prepares for them, by chewing it first herself. Some time after she brings them stronger food, hares, partridges, and birds yet alive. The young wolves begin by playing with them, and end by killing them. The dam then strips them of their feathers, tears them in pieces, and gives to each of them a share. They do not leave the den where they have been littered, till they are six weeks, or two months old. They then follow the old one, who leads them to drink to the trunk of some old tree, where the water has settled, or at some pool in the neighbourhood. If she apprehends any danger, she instantly conceals them in the first convenient place, or brings them back to their former retreat. In this manner they follow her for some nionths; when they are attacked, she defends them with all her strength, and more than usual ferocity. Although, at other times, more timorous than the male, at that season she becomes bold and fearless; willing perliaps to teach the young ones future courage by her own example. It is not till they are about ten or twelve inonths old, and until they have shed their first tecth, and completed the new, that she thinks them in a capacity to shift for themselves. Then when they have acquired arms from nature, and have learned inclustry and courage from her exaniple, she declines all future care of them, being again engaged in bringing up a new progeny.

The males and females are in a capacity to engender when two years old. It is probable that the females of this species, as well as of most others, are sooner completed than the males; but this is certain, that they never desire to copulate until their second winter ; from whence we may suppose that they live fifteen or tiventy years; for allowing three years for their complete growth, this multiplied by seven, gives them a life of twenty-one; most animals, as has been observed, living about seven times the number of years which they take 
to come to perfection. Of this, however, there is as yet no certainty, no more than of what huntsmen assert, that in all the litters there are more males than females. From them also we learn, that there are some of the males who attach themselves to the female, who accompany her during her gestation, until the time of bringing forth, when she hides the place of her retreat from the male, lest he should devour her cubs. But after this, when they are brought forth, that he then takes the same care of them as the female, carries them provisions, and, if the dam should happen to be killed, rears them up in her stead.

The wolf grows gray as he grows old, and his teeth wear, like those of most other animals, by using. He sleeps when his belly is full, or when he is fatigued, rather by day than night; and always, like the dog, is very easily waked. He drinks frequently; and in times of drought, when there is no water to be found in the trunks of old trees, or in the pools about the forest, he comes often, in the day, down to the brooks, or the lakes in the plain. Although very voracious, he supports hunger for a long time, and often lives four or five days without food, provided he be supplied with water.

The wolf has great strength, particularly in his fore parts, in the muscles of his neck and jaws. He carries off a sheep in his mouth without letting it touch the ground, and runs with it much swifter than the shepherds who pursue him; so that nothing but the dogs can overtake, and oblige him to quit his prey. He bites cruelly, and always with greater vehemence in proportion as he is least resisted; for he uses precautions with such animals as attempt to stand upon the defensive. He is cver cowardly, and never fights but when under a necessity of satisfying hunger; or making good his retreat. When he is wounded by a bullet, he is heard to cry out; and yet, when surrounded by the peasants, and attacked with clubs, he never howls as the dog under correction, but defends himself in silence, and dies as hard as he lived.

His nature is, in fact, more savage than that of the dog; he has less sensibility and greater strength. He travels, runs, and keeps plundering for whole days and nights together. $\mathrm{He}$ is in a manner indefatigable; and perhaps of all animals he is the most difficult to be hunted down. The dog is good natured and courageous; the wolf, though savage, is ever fearful. If he happens to be caught in a pitfall, he is for some time so frightened and astonished, that he may be killed without offering to resist, or taken alive without much danger. At that instant, one may clap a collar round his neck, muzzle him, and drag lim along, without his ever giving the least signs of anger or resentment. At all other times he has his senses in great perfection; his eye, his ear, and particularly his sense of smelling, which is even superior to the two former. He smells a carcass at more than a league's distance; healso perceives living animals a great way off, and follows them a long time upon the scent. Whenever he leaves the wood, he always takes care to go out against the wiud. When just come to its extremity, he stops to cxamine, by his smell, on all sides, the emanations that may come cither from his enemy or his prey, which he very nicely distinguishes. He prefers those animals which he kills limself to those he finds dead; and yet he does not disdain these when no better is to be had. He is particularly fond of human flesh; and perhaps, if he was sufficiently powerful, he would eat no other. Wolves have been seen following armies, and arriving in numbers upon the field of battle, where they devoured such dead bodies as were left upon the field, or but negligently interred. These, when once accustomed to human flesh, ever afterseek particularly toattack mankind, and choose to fall upon the shepherd rather than his flock. We have had a late instance of two or three of these keeping a whole province, for more than a month, in a continual alarm.

It sometimes happens that a whole country is called out to extirpate these most dangerous invaders. The lunting the wolf is a favourite diversion among the great of some countries; and it must be confessed it seems to be the most useful of any. These animals are distinguished by the huntsmen into the young wolf, the old wolf, and the great wolf. They are known by the prints of their feet; the older the wolf, the larger the track he leaves. That of the female is narrower and longer than those of the male. It is necessary 
to have a very good starter to put up the wolf; and it is even convenient to use every art to encourage him in his pursuit; for all dogs have a natural repugnance against this aninal, and are but cold in their endeavours. When the wolf is once put up, it is then proper to have 'grayhounds to let fly at him, in leashes, one after the other. The first leash is sent after him in the beginning, seconded by a man on horseback; the sceond are let loose about half a mile farther, and the third wh $n$ the rest of the dogs come up with, and begin to bait him. He for a long time keeps them off, stands his ground, threatens them on all sides, and often gets away; but usually the hunters arriving, coine in aid of the dogs, and help to despateh him with their cutlasses. When the animal is killed, the dogs testify no appetite to enjoy their victory, but leave him where he falls, a frightful spectacle, and even in death hideous.

The wolf is sometimes also hunted with harriers; but as he always goes straight forward, and often holds his speed for $\mathrm{a}_{\text {, whole }}$ day together, this kind of chase is tedious and disagreeable, at least if the harriers are not assisted by grayhounds, who may harass him at every view. Several other arts have been also used to takc and destroy this noxious animal. He is surrounded and wounded by men and large house-dogs; he is secured in traps; he is poisoned by carcasses, prepared and placed for that purpose, and is caught in pit-falls. "Gesner tell us of a friar, a woman, and a wolf, being taken in one of these, all in the same night. The woman lost her senses with the fright, the friar his reputatinn, and the wolf his life." All these disasters, however, do not prevent this animal's multiplying in great numbers, particularly in countries where the woods are plenty. France, Spain, and Italy, are greatly infested with them; but England, Ireland, and Scotland, are happily set free.

King Edgar is said to be the first who attempted to rid this kingdom of such disagreeable inmates, by commuting the punishment of certain crimes into the acceptance of a number of wolves', tongues for each criminal." However, some centuries after, these

5. British Zoology, p. 62. animals were again increased to such a degree, as to become the object of royal attention; accordingly Edward the First issued out his mandate to one Peter Corbet to superintend and assist in the destruction of them. They are said to have infested Ireland long after they were extirpated in Eng. land; however, the oldest men in that country remember nothing of these animals; and it is probable that there have been none there for more than a century past. Scotland also is totally free.

'The colour of this animal differs according to the different climates where it is bred, and often changes even in the same country. Beside the common wolves, which are found in France and Germany, there are others with thicker hair, inclining to yellow. These are more savage and less noxious than the former, neither approaching the flocks nor habitations, and living rather by the chase than rapine. In the northern climates there are found some quite black, and some white all over. The former are larger and stronger than those of any other kinds.

The species is very much diffused in every part of the world, being found in Asia, Africa, and in America, as well as Europe. The wolves of Senegal resemble those of France, except that they are larger and much fiercer than those of Europe. Those of Egypt are smaller than those of Grecce. In the east, the wolf is trained up for a show, being taught to dance and play tricks; and one of these thus educated often sells for four or five hundred crowns. "It is said that in Lapland the wolf will never attack a rein-deer that is seen haltered; for this wary animal, being well acquainted with the nature of a trap, suspects one whenever it perceives a rope. However, when he sees the deer entirely at liberty, he seldom fails to destroy it. "The wolf of North America is blacker and much less than those in other parts of the world, and approaches nearer in form to the dog than those of the ordinary kind. ${ }^{\circ}$ In fact, they were made use of as such by the savages till the Europeans introduced others; and even now, on the remoter shores, or the more inland parts of the country, the sa-

b Brooke's Natural History, vol. i. p. 198. 
rages still make use of these animals in hunting. They are very tame and gentle; and those of this kind that are wild, are neither so large nor so fierce as an European wolf, nor do they ever attack mankind. They go together in large packs by night to hunt the deer, which they do as well as any dogs in England; and it is confidently asserted that one of them is sufficient to run down a deer." Whenever they are seen along the banks of those rivers near which the wandering natives pitch their buts, it is taken for granted that the bison or the deer are not far off: and the savages affirm that the wolves come with the tidings, in order to have the garbage, after the animal has been killed by the hunters. Catesby adds a circumstance relative to these animals, which, if true, invalidates many of Mr. Buffon's observations in the foregoing history. He asserts, that these being the only dogs used by the Americans, before the arrival of the Europeans among them, they have since engendered together, and that their breed has become prolific; which proves the dog and the wolf to be of the same species. It were to be wished that this fact were better ascertained; we should then know to a certainty in what degree the dog and wolf resemble each other, as well in nature as in conformation; we might then, perhaps, be enabled to improve the breed of our dogs, by bringing them back to their native forms and instincts; we might, by crossing the strain, restore that race of those bold animals, which the ancients assure us were more than a match for the lion."

Howcver this animal may be useful in North America, the wolf of Europe is a very noxious animal, and scarce any thing belonging to him is good, except his skin. Of this the furriers make a covering that is warm and durable, though coarse and unsightly. His flesh is very indifferent, and seems to be disliked by all other animals, no other creature being known to eat wolf's flesh except the wolf himself. He breathes a most foetid vapour from his jaws, as his food is indiscriminate, often putrid, and seldom cleanly. In short, every way offensive, a savage aspect, a frightful howl, an unsupportable odour, a

a Dictionaire Raisonee. Loup. perverse disposition, fierce habits, he is hateful when living, and useless when dead.

\section{THE FOX.}

Tie Fox very exactly resembles the wolf and the dog internally; and although he differs greatly from both in size and carriage, yet when we come to examine his shapes minutely, there will appear to be very little difference in the description. Were, for instance, a painter to draw from a natural historian's exactest description the figure of a $\mathrm{dog}$, a wolf, and a fox, without having ever seen either, he would be very apt to confound all these animals together; or rather he would be unable to catch those peculiar outlines that no description can supply. Words will never give any person an exact idea of forms any way irregular; for although they be extremely just and precise, yet the numberless discriminations to be attended to will canfound each other, and we shall no more conceive the precise form, than we should be able to tell when one pebble more was added or taken away from a thousand. To conceive, therefore, how the fox differs in form from the wolf or the dog, it is necessary to see all three, or at least to supply the defects of description by examining the difference in a print.

The fox is of a slenderer make than the wolf, and not near so large; for as the former is above three feet and a half long, so the other is not above two feet three inches. The tail of the fox also is longer in proportion and more bushy; its nose is smaller and approaching more nearly to that of the grayhound, and its hair softer. On the other hand, it differs from the dog in having its eyes obliquely situated, like those of the wolf; its ears are directed also in the same manner as those of the wolf, and its head is equally large in proportion to its size. It differs still more from the dog in its strong offensive smell, which is peculiar to the species, and often the cause of their death. However, some are ignorantly of opinion that it will keep off infectious discases, and they preserve this animal near their habitations for that very purpose. 
The fox has since the beginning been famous for his cunning and his arts, and he partly merits his reputation." Without attempting to oppose either the dogs or the sheplerds, without attacking the flock, or alarming the village, he finds an easier way to subsist, and gains by his address what is denied to lis strength or courage. Patient and prudent, he waits the opportunity of depredation, and varies his conduct with every occasion. His whale study is his preservation; although nearly as indefatigable, and actually more swift than the wolf, he does not entirely trust to either, but makes limself an asylum, to which he retires in case of necessity; where he shelters himself from danger, and brings up his young.

As among men, those who lead a domestic life are mare civilized and more endued with wisdom than those who wander from place to place; so, in the inferior ranks of animated nature, the taking possession of a home supposes a degree of instinct which others are without.' The choice of the situation for this domicil, the art of making it convenient, of hiding its entrance, and securing it against more powerful animals, are all so many marks of superior skill and industry. The fox is furnished with both, and turns them to his advantage. He generally kceps his kemnel at the edge of the wood, and yet within an easy journey of some neighlubouring cottage. From thence he listens to the crowing of the cock, and the cackling of the domestic fowls. He scents them at a distance; he scizes his opportunity, conceals his approaches, creeps slily along, makes the attack, and seldom returns without his booty. If he be able to get into the yard, he begins by levelling all the poultry without remorse, and carrying off a part of the spoil, hides it at some convenient distance, and again returns to the charge. Taking off another fowl in the same manner, he hides that also, but not in the same place; and this he practises for several times together, until the approach of day, or the noise of the domestics, give him warning to retire. The same arts are practised when he finds birds entangled in springes laid for them by the fowler; the fox takes care to. be beforehand,

- Buffon, Renard. b Ibid. vo. $27 \& 28$. very expertly takes the bird out of the snare, hides it for three or four days, and knows very exactly when and where to return to avail himself of the hidden treasure. He is equally alert in seizing the young hares and rabbits before they have strength enough to escape him, and when the old ones are wounded and fatigued, he is sure to come upon them in their moments of distress, and to show them no mercy. In the same manner he funds out birds' nests, seizes the partridge and the quail while sitting, and destroys a large quantity of game. The wolf is most hurtful to the peasant, but the fox to the gentleman. In short, nothing that can be caten seems to come amiss; rats, mice, serpents, toads, and lizards. He will, when urged by liunger, eat vegetables and insects; and those that live near the sea-coasts will, for want of other food, eat crabs, shrimps, and shell-fish. The hedge$\mathrm{hog}$ in vain rolls itself up into a ball to oppose him, this determined glutton teases it until it is obliged to appear uncovered, and then he devours it. The wasp and the wild bee are-attacked with equal success. Although at first they fly out upon the inrader, and actually oblige him to retire, this is but for a few minutes, until he has rolled himself upon the ground, and thus crushed such as stick to lis skin; he then returns to the charge, and at last, liy perseverance, obliges them to abandon their combs; which he greedily devours, both wax and honey.

The chase of the fox requires less preparation than that of the wolf, and it is also more pleasant and amusing. As dogs have a natural repugnanee to pursue the wolf, so they are equally alert in following the fox; which they prefer even to the chase of the hare or the buck. The huntsmen, as upon other occasions, have their cant terms for every part of this chase. The fox the first year is called a $c u b$; the second, a fox; and the third an old fox; his tail is called the brush or drag, and his excrement the billiting. He is usually pursued by a large kind of harrier or hound, assisted by terriers, or a smaller brced, that follow him into lis kennel, and attack him therc. The instant he perceives himself pursued, he makes to his kennel, and takes refuge at the bottom of it, where for a while he loses the cry of his cnemies: but $3 \mathrm{E}$ 
the whole pack coming to the mouth, redouble their vehemence and rage, and the little terrier boldly ventures in. It often happens that the kennel is made under a rock, or among the roots of old trees: and in such cases the fox cannot be dug out, nor is the terrier able to contend with him at the bottom of his hole. By this contrivance he continues sccure; but when he can be dug out, the usual way is to carry him in a bag to some open country, and there set him loose before the hounds. The hounds and the men follow, barking and shouting wherever he runs; and the body being strongly employed, the mind has not time to make any reflection on the futility of the pursuit. What adds to this entertainment is the strong scent which the fox leaves, that always keeps up a full cry; although as his scent is stronger than that of the hare, it is much sooner evaporated. His shifts to escape when all retreat is cut off to his kennel, are various and surprising. Hc always chooses the most woody country, and takes those paths that are most embarrassed with thorns and briars. He does not double, nor use the unavailing shifts of the hare; but flies in a direct line before the hounds, though at no very great distance; manages his strength; takes to the low and plashy grounds, where the scent will be less apt to lie; and at last, when overtaken, he defends himself with desperate obstinacy, and fights in silence to the very last gasp.

The fox, though resembling the dog in many respects, is neveriheless rory distinct in his nature, refusing to engender with it; and though not testifying the antipathy of the wolf, yet discovering nothing more than indifference. This animal also brings forth fewer at a time than the $\mathrm{dog}$, and that but once a year. Its litter is generally from four to six, and seldom less than three. The female goes with young about six weeks, and scldom stirs out while pregnant, but makes a bed for her young, and takes every precaution to prepare for their production. When she finds the place of their retreat discovered, and that her young lave been disturbed during her absence, she removes them one after the other in her mouth, and endeavours to find them out a place of better security. A remarkable instance of this animal's parental affection happened while I was writing this history in the county of Essex. A she-fox that had, as it should scem, but one cub, was unkenuelled by a gentleman's hounds near Chelmstord, and hotly pursued. In such a case, when her own life was in imminent peril, one would think it was not a time to consult the safety of her young; however, the poor animal, braving every danger, rather than leave her cub behind to be worried by the dogs, took it up in her mouth, and ran with it in this mannes for some miles. At last, taking her way through a farmer's yard, she was assaulted by a mastiff, and at last obliged to drop her cub, which was taken up by the fariner. I was not displeased to hear that this faithful creature escaped the pursuit, and at last got off in safety. The cubs of the fox are born blind, like those of the dog; they are eighteen montlis or two years in coming to perfection, and live about twclve or fourteen years.

As the fox makes war upon all animals, so all others seem to make war upon him. The dog hunts him with peculiar acrimony; the wolf is still a greater and more necessitous enemy, who pursues him to his very retreat. Some pretend to say, that, to keep the wolf away, the fox lays at the mouth of its kennel a certain herb, to which the wolf has a particular aversion. This, which no doubt is a fable, at least shows that these two animals are as much enemies to each other as to all the rest of Animated Nature. But the fox is not hunted by quadrupeds alone; for the birds, who know him for their mortal enemy, attend him in his excursions, and give each other warning of their approaching danger. The daw, the magpie, and the blackbird conduct him along, perching on the hedges as hecreeps below, and, with their cries and notes of hostility, apprize all other animals to beware; a caution which they perfectly understand, and put into practice. The hunters themselves are often informed by the birds of the place of his retreat, and set the dogs into those thickets where they see them particularly noisy and querulous. So that it is the fate of this pretty plunderer to be detested by every rank of animals; all the weaker classes shun, and all the stronger pursuc him.

The fox, of all wild animals, is most subject to the influence of climate; and there are found 
as many varieties in this kind almost as in any of the domestic animals." The generality of foxes, as is well known, are red; but there are some, though not in England, of a grayish cast; and Mr. Buffon asserts, that the tip of the tail in all foxes is white; which, however, is not so in those of this country. There are only three varictics of this animal in Great Britain, and these are rather established upon a difference of size than of colour or form. The grayhound fox is the largest, tallest, and boldest; and will attack a grown sheep The mastiff fox is less, but more strongly built. The cur fox is the least and nost common; he lurks about hedges and ont-houses, and is the most pernicious of the three to the peasant and the farmer.

In the colder countries round the pole, the foxes are of all colours; black, blue, gray, iron gray, silver gray, white, white with red legs, white with black heads, white with the tip of the tail black, red with the throat and belly entirely white, and lastly, with a stripe of black running along the back, and another crossing it at the shoulders. ${ }^{b}$ The common kind, however, is more universally diffused than any of the former, being found in Europe, in the temperate climates of Asia, and also in America ; they are very rare in Africa, and in the countries lying urder the torrid zone. Those travellers who talk of having seen them at Calicut, and otluer parts of southern India, have mistaken the jackal for the fox. The fur of the white for is held in no great estimation, because the hair falls off. The blue fox skins are bought up with great avidity, from their scarceness; but the black fox skin is of all others the most estecmed, a single skin often selling for forty or fifty crowns. The hair of these is so disposed, that it is impossible to tell which way the grain lies; for if we hold the skin by the head, the hair hangs to the tail; and if we hold it by the tail, it hangs down equally smooth and even to the head. These are often made into men's mulfs, and are at once very beautiful and warm. In our temperate climate, however, furs are of very little service, there being scarce any weather so severe in England from which our ordinary clothes may not very well defend us.

a Buffon, Renard.

b Ibid.
THE JACKAL.

THE jackal is one of the most common wild animals in the East; and yet there is scarce any less known in Europe, or more confusedly described by natural historians. In general, we are assured that it resembles the fox in figure and disposition, but we are still ignorant of those nice distinctions by which it is known to be of a different species. It is said to be of the size of a middling dog, resembling the fox in the hinder parts, particularly the tail; and the wolf in the foreparts, especially the nose. Its legs are shorter than those of the fox, and its colour is of a briglit yellow, or sorrel, as we express it in horses. This is the reason it has been called in Latin the golden wolf; a name, however, which is entirely unknown in the countries where they are nost common.

The species of the jackal is diffused all over Asia, and is found also in most parts of Africa, seeming to take up the place of the wolf, which in those countries is not so common. There seem to be many varieties among then ; those of the warmest climates appear to be the largest, and their colour is rather of a reddislı brown, than of that beautiful yellow by which the smaller jackals are chicfly distinguished.

Although the species of the wolf approaches very near to that of the dog, yet the jackal seems to be placed between them; to the savage fierceness of the wolf, it adds the impudent familiarity of the $\mathrm{dog}^{\mathrm{e}}$ Its cry is a howl, mixed with barking, and a lamentation resembling that of human distress. It is more noisy in its pursuits even than the dog, and more voracious than the wolf. The jackal never goes alone, hut always in a pack of forty or fifty together. These unite regularly every day to Horni a combination against the rest of the forest. Nothing then can escape then ; they are content to take up with the smallest animals; and yet, when thus united, they have courage to face the largest. They seen very little afraid of mankind, but pursue their game to the very doors, without testifying either attachment or apprehension. They enter insolently into the shcep folds, the yards, and the stables, and, when they can find nothing elsc, devour the leather harness, boots, and shoes,

c Buffon, vol. xxvii. p. 52. 
and run off with what they had not time to swallow.

They not only attack the living but the dead. They scratch up with their feet the new-made graves, and devour the corpse how putrid soever. In those countries, therefore, where they abound, they are obliged to beat the earth over the grave, and mix it with thorns, to prevent the jackals from scraping it away. They always assist each other; as well in this enployment of exumation, as in that of the chase. While they are at this dreary work, they exhort each other by a most mournful cry, resembling that of children under chastisement; and when they have thus dug up the body, they share it amicably between them. These, like all other savage animals, when they have once tasted of human flesh, can never after refrain from pursuing mankind. They watch the burying-grounds, follow armies, and keep in the rear of caravans. They may be considered as the vulture of the quadruped kind; every thing that once had animal life, scems equally agreeable to them; the most putrid substances are greedily devoured; dried leather, and any thing that has been rubbed with grease, how insipid soever in itself, is sufficient to make the whole go down.

They hide themselves in holes by day, and seldom appear abroad till night-fall, when the jackal that has first hit upon the scent of some large beast gives notice to the rest by a howl, which it repeats as it runs; while all the rest that are within hearing, pack in to its assistance. The gazelle, or whatever other beast it may be, finding itself pursued, makes off towards the houses and the towns; hoping, by that means, to deter its pursuers fron following: but hunger gives the jackal the same degree of boldness that fear gives the gazelle, and it pursues even to the verge of the city, and often along the streets. The gazelle, however, by this uneans, most frequently escapes; for the inlabitants sallying out, often disturb the jackal in the chase; and as it hunts by the scent, when once driven off, it never recover's it again. In this manner we see how experience prompts the gazelle, which is naturally a very tiuid animal, and particularly fearful of man, to take refuge near him, considering him as the least dangerous enemy, and often cscaping by his assistance.

But man is not the only intruder upon the jackal's industry and pursuits. The lion, the tiger, and the panther, whose appetites are superior to their swiftness, attend to its call, and follow in silence at some distance behind." The jackal pursues the whole vight with unceasing assiduity, keeping up the cry, and with great perseverance at last tires down its prey ; but just at the moment it supposes itself going to share the fruits of its labour, the lion or the leopard comes in, satiates himself upon the spoil, and his poor provider nust be content with the bare carcass he leaves behind. It is not to be wondered at, therefore, if the jackal be voracious, since it so seldom has a sufficiency ; nor that it feeds on putrid substances, since it is not permitted to feast on what it has newly killed. Besides these enemies, the jackal has another to cope with, for between him and the dog there is an irreconcileable antipathy ; and they never part without an engagement. The Indian peasants often chase them as we do foxes; and have learned, by experience, when they have got a lion or a tiger in their rear. Upon such occasions they kecp their dogs close, as they would be no match for such formidable animals, and endeavour to put them to flight with their cries. When the lion is dismissed, they more casily cope with the jackal, who is as stupid as it is impudent, and seems much better fitted for pursuing than retreating. It sometimes happens that one of them steals silently into an out-house to seize the poultry, or devour the furniture, but hearing others in full cry at a distance, without thought, it instantly answers the call, and thus betrays its own depredations. The peasants sally out upon it, and the foolish animal finds, too late, that its instinct was too powerful for its safety.

\section{THE ISATIS.}

As the jackal is a sort of intermediate species between the dog and the wolf, so the isatis may be considered as placed between the dog and the fox. This animal has hitherto been supposed to be only a variety of the latter; but from the latest observations, there is no doubt of their being perfectly distinct. The

- Linnæi Systema, p. 60.

b In this description I have followed Mr. Buffon. 
isatis is very common in all the northern countries bordering upon the Icy Sea; and is seldom found, except in the coldest countries. It extremely resembles the fox, in the form of its body, and the length of its tail ; and a dog, in the make of its head, and the position of its eycs. The hair of these animals is softer than that of a common fox; some are blue, some are white at one season, and at another of a russet brown. Althongl the whole of its hair be two inches long, thick, tufted, and glossy, yet the under jaw is entirely without any, and the skin appears bare in that part.

This animal can bear only the coldest climates, and is chicfly seen along the coasts of the Icy Sea, and upon the banks of the great rivers that discharge thensselves thercin. It is chicfly fond of living in the open country, and seldom seen in the forest, being mostly found in the mountainous and naked regions of Norway, Siberia, and Lapland. It burrows like the fox; and, when with young, the female retires to her kennel, in the same manner as the fox is seen to do. These holes, which are very narrow, and extremely decp, have many outlets. They are kept very clean, and are bedded at the bottom with moss, for the animal to be more at its easc. Its manner of coupling, time of gestation, and number of young, are all similar to what is found in the fox; and it usually brings forth at the end of May or the beginning of June.

Such are the particulars in which this animal differs from those of the $\mathrm{dog} k$ ind, and in which it resembles them : but its most striking peculiarity remains still to be mentioned; namely, its changing its colour, and being seen at one time brown, and at another perfectly white. As was already said, some are naturally blue, and their colour never changes; but such as are to be white, are, when brought forth, of a yellow hue, which, in the beginning of September, is changed to white, all except along the top of the back, along which runs a stripe of brown, and another crossing it down the shoulders, at which time, the animal is called the crossed fox; however, this bruwn cross totally disappears before winter, and then the creature is all over white, and its fur is two inches long: this, about the beginning of May begins to fall; and the moulting is completed about the middle of July, when the isatis becomes brown once more. The fur of this animal is of no value, unless it be killed in winter.

\section{THE IY ENA.}

THE hyæna is the last animal I shall mention among those of the dog kind, which it, in many respects, resembles, although too strongly marked to be strictly reduced to any type. The hyana is nearly of the size of a wolf; and has some similitude to that animal in the shape of its head and body. The head, at first sight, does not appear to differ, except that the ears of the hyma are longer, and more without hair; but, upon observing more closely, we shall find the head broader, the nose flatter, and not so pointed. The eyes are not placed obliquely, but nore like those of a dog. The legs, particularly the hinder, are longer than those either of the dog or the volf, and different from all other quadrupeds, in having but four toes, as well on the fore-feet as on the hinder. Its hair is of a dirty grayish, marked with black, disposed in waves down its body. Its tail is short, with pretty long hair; and immediately under it, above the anus, there is an opening into a kind of glandular pouch, which separates a substance of the consistence, bnt not of the odour, of civet. 'This opening might have given rise to the error of the ancients, who asserted, that this animal was cvery year alternately male and female. Sucl are the more striking distinctions of the hyæna, as given 11 by naturalists; which, nevertheless, convey but a very confused idea of the peculiarity of its form. Its manner of holding the head secms remarkable; somewhat like a dog pursuing the scent, with the nose near the ground. The head being held thus low, the back appears elevated, like that of the hog, which, with a long bristly band of hair that runs all along, gives it a good deal the air of that animal; and, it is probable, that from this similitude it first took its nane; the word huoina being Grcek, and derived from hus, which significs a sow.

But no words can give an adequate idea of this animal's figure, deformity, and ficrceness; more savage and untameable than any other quadruped, it seems to be for cver in a state of rage or rapacity, for ever growling except when receiving its food. Its eyes then glisten, 
thic bristles of jts back all stand upright, its head hangs low, and yet its teeth appear; all which give it a most frightful aspect, which a dreadful howl tends to heighten. This, which I have often heard, is very peculiar: its beginning resembles the voice of a man moaning, and its latter part as if he were making a violent effort to vornit. As it is loud and frequent, it might, perhaps, have been sometimes mistaken for that of a human voice in distress, and have given rise to the accounts of the ancients, who tell us, that the hyæena makes its moan to attract unwary travellers, and then to destroy them: however this be, it seems the most untractable, and, for its size, the most terrible of all other quadrupeds; nor does its courage fall short of its ferocity; it defends itself against the lion, is a match for the panther, attacks the ounce, and seldom fails to conquer.

It is an obscene and solitary animal, to be found chiefly in the most desolate and uncultivated parts of the torrid zone, of which it is a native." It resides in the caverns of mountains, in the clefts of rocks, or in dens that it has formed for itself under the carth. Though taken never so young, it cannot be tamed; it lives by depredation, like the wolf, but is unch strouger, and more courageous. It sometimes attacks man, carrics off cattle, follows the flock, breaks open the sheep-cots by night, and ravages with insatiable voracity. Its eyes shine by night; and it is asserted, not without great appearance of truth, that it sces better by night than by day. When destitute of other provision, it scrapes up the graves, and devours the dead bodies, how putrid soever. To these dispositions, which are sufficiently noxious and formidable, the ancients have added numberless others, which are long since known to be fables: as, for instance, that the hyrena was male and female alternately; that having brought forth and suckled its young, it then changed sexes for a ycar, and became a malc. This, as was mentioned above, could only proceed from the opening under the tail, which all animals of this species are found to have; and which is found in the same manner in no other quadruped, except the badger. Therc is, in the weasel kind indeed, an opening, but it is lower down, and not placed above the anus, as in the badger and the hyæna. Some have said that this animal changes the colour of its hair at will; others, that a stone was found in its eye, which, put under a man's tongue, gave him the gift of prophecy ; somc have said that it had no joints in the neck, which, however, all quadrupeds are known to liave; and some, that the shadow of the hyana kept dogs from barking. These, among many other absurditics, have been asserted of this quadruped; and which I mention to show the natural disposition of mankind, to load those that are already but too guilty with accumulated reproach.

\section{CHAP'TER LII.}

\section{OF ANIMALS OF THE WEASEL KIND.}

HAVING described the bolder ranks of carnivorous animals, we now come to a uninuter and more feeble class, less formidable indeed than any of the former, but far nore numerous, and in proportion to their size, more active and enterprising. The weasel kind may be particularly distinguished from other carnivorous animals, by the length and slenderness of their bodics, which are so fitted as to wind, like worms, into very small openings, after

a Buffon. their prey; and hence also they have received the name of vermin, from their similitude to the worm in this particular. These animals differ from all the cat kind, in the formation and disposition of their claws, which, as in the dog kinds, they can neither draw nor extend at pleasure, as cats are known to do. They differ from the dog kind, in being clothed rather with fur than hair; and although somic variehes of the fox may resemble them in this parcular, yet the coat of the latter is longer, stronger, and always more resembling hair. 
Beside these distinctions, all animals of the weasel kind have glands placed near the anus, that either open into or beneath it, furnishing a substance that, in some, has the most offensive smell in nature, in others, the most pleasing perfune. All of this kind are still inore marked by their habitudes and dispositions, than their external form; cruel, voracious, and cowardly, they subsist only by theft, and find their chief protection in their minuteness. They are all, from the shortness of their legs, slow in pursuit; and, therefore, owe their support to their patience, assiduity, and cunning. As their prey is precarious, they live a long time without food; and if they happen to fall in where it is in plenty, they instantly destroy all about them before they begin to satisfy their appetite, and suck the blood of every animal before they begin to touch its flesh.

These are the marks common to this kind, all the species of which have a most striking resemblance to each other; and he that has seen one, in some measure, may be said to have seen all. The chief distinction in this numerous class of animals, is to be taken from the size; for no words can give the ininute irregularities of that outline by which one species is to be distinguished from that which is next it. I will begin, therefore, with the least and the best known of this kind, and still marking the size, will proceed gradually to larger and larger, until we come from the weasel to the glutton, which I take to be the largest of all. The weasel will serve as a model for all the rest; and, indeed, the points in which they differ from this little animal, are but very inconsiderable.

The wraser, ${ }^{a}$ as was said, is the smallest of this numerous tribe; its length not exceeding seven inches, from the tip of the nose to the insertion of the tail. This length, however, secms to be very great, if we compare it with the height of the animal, which is not above an inch and a halt: In measuring the wolf, we find him to be not asove once and a half as long as he is high; in obscrving the weasel, we find it near five times as long as it is high, which shows an amazing disproportion. The tail also, which is bushy, is two

a British Zoology, vol. i. p. 83. inches and a half long, and adds to the apparent length of this little animal's body. The colour of the weasel is of a bright red on the back and sides, but white under the throat and the belly. It has whiskers like a cat; and thirty-two teeth, which is two more than any of the cat kind; and these also seem better adapted for tearing and chewing, than those of the cat kind are. The eyes are litthe and black. The ears short, broad, and roundish; and liave a fold at the lower part, which makes them look as if they were double. Beneath the corners of the mouth, on each jaw, is a spot of brown.

This animal, though very diminutive to ap. pearance, is, nevertheless, a very formidable enemy to quadrupeds an hundred times its own size. It is very common and well known in most parts of this country; but seems held in very different estimation in different parts of it. In those places where sheep or lambs are bred, the weasel is a most noxious inmate, and every art is used to destroy it; on the contrary, in places where agriculture is chiefly followed, the weasel is considered as a friend that thins the number of such vermin as chictly live upon corn: however, in all places, it is one of the most untameable and untractable animals in the world. ${ }^{b}$ When kept in a cage, either for the putrposes of amnsement or inspection, it will not touch any part of its victuals while any body looks on. It keeps in a continual agitation, and seems frighted so much at the sight of mankind, that it will die, if not.permitted to hide itself from their presence. For this purpose, it must be provided, in its cage, with a sufficient quantity of wool or hay, in which it may conceal itself, and where it may carry whatever it has got to eat; which, however, it will not touch until it begins to putrefy. In this state it is seen to pass three parts of the day in sleeping; and reserves the night for its times of exercise and eating.

In its wild state, the night is likewise the time during which it may be properly said to live. At the approach of evening, it is seen stealing from its hole, and creeping about the farmer's yard for its prey. If it enters the place where poultry are kept, it never attacks

\footnotetext{
b Buffon, vol. xv. p. 37
} 
the cocks or the old hens, but immediately aims at the young ones. It does not eat its prey on the place, but, after killing it by a single bite near the head, and with a wound so small that the place can scarcely be perceired, it carries it off to its young, or its retreat. It also breaks and sucks the eggs, and sometimes kills the hen, that attempts to defend them. It is remarkably active; and, in a confined place, scarce any animal can escape it. It will run up the sides of walls with such facility, that no place is secure from it; and its body is so small, that there is scarce any hole but what it can wind through. During the summer, its excursions are more extensive; but in winter, it chiefly confines itself in barns and farm-yards, where it remains till spring, and where it brings forth its young. All this season it makes war upon the rats and mice, with still greater success than the cat; for being more active and slender, it pursues them into their holes, and, after a short resistance, destroys them. It creeps also into pigeon-holes, destroys the young, catches sparrows, and all kinds of small birds; and, if it has brought forth its young, hunts with still greater boldness and avidity. In summer, it ventures farther from the liouse; and particularly goes into those places where the rat, its chiefest prey, goes before it. Accordingly, it is found in the lower grounds, by the side of waters, near mills, and often is seen to hide its young in the hollow of a tree.

The female takes every precaution to make an easy bed for her little ones: she lines the bottom of her hole will grass, hay, leaves, and moss, and generally brings forth fiom three to five at a time. All animals of this, as well as those of the dog kind, bring forth their young with closed eyes: but they very soon acquire strength sufficient to follow the dam in her excursions, and assist in her projects of petty rapine. The weasel, like all others of its kind, does not run on equably, but moves by bounding; and when it climbs a tree, by a single spring it gets a good way from the ground. It jumps in the same manner upon its prey; and, having an extremely limber body, evades the attempts of much stronger animals to seize it.

This animal, like all of its kind, has a very strong smell; and that of the weasel is pecu- liarly foctid. This scent is very distinguishable in those creatures, when they void their excrement; for the glands which furnished this foetid substance, which is of the consistence of suct, open directly into the orifice of the anus, and taint the excrement with the strong effluvia. The weasel smells more strongly in summer than in winter; and more abominably when irritated or pursued, than when at its ease. It always preys in silence, and never has a cry except when struck, and then it has a rough kind of squeaking, which at once expresses resentment and pain. Its appetite for animal food never forsakes it; and it seems even to take a pleasure in the vicinity of putrefaction. Mr. Buffon tells us of one of them being found, with three young ones, in the carcass of a wolf that was grown putrid, and that liad been liung up, by the hind legs, as a terror to others. Into this horrid retreat the weasel thought proper to retire to bring forth her young; she had furnished the carity with hay, grass, and leaves; and the young were just brought forth when they were discovered by a peasant passing that way.

\section{THE ERMINE, OR STOAT}

NExT to the weasel in size, and perfectly alike in figure, is the ermine. The difference between this and the former animal is so very small, that many, and among the rest Limnæus, who gives but one description of both, have confounded the two kinds together. However, their differences are sufficient to induce later naturalists to suppose the two kinds distinct; and as their lights seem preferable, we choose to follow their descriptions."

The stoat, or ermine, differs from the weasel in size, being usually nine inches long; whereas the former is not much above six. The tail of the ermine is alivays tipped with black, and is longer in proportion to the body, and furnished with hair. The edges of the ears and the ends of the toes in this animal are of a yellowish white; and although it is of the same colour with the weasel, being of a lightish brown, and though both this animal,

a Buffon. British Zoology. 
as well as the weasel, in the most northern parts of Europe, changes its colour in winter, and hecomes white, yet even then the weasel may be easily distinguished from the ermine by the tip of the tail, which in the latter is always black.

It is well known that the fur of the ermine is the most valuable of any hitherto known ; and it is in winter only that this little animal has it of the proper colour and consistence. In summer, the erinine, as was said before, is brown, and it may at that time more properly be called the stoat. There are few so unacquainted with quadrupeds as not to perceive this change of colour in the lair, which in some degree ohtains in them all. The horse, the cow, and the goat, all manifestly change colour in the begimning of summer, the old long hair falling off, and a shorter coat of hair appearing in its room, generally of a darker colour, and yet more glossy. What obtains in our temperate climate, is seen to prevail still more strongly in those regions where the winters are long and severc, and the summers short and yet generally hot in an extreme degree. The animal has strength enough turing that scasun to throw off a warin coat of fur, which would but incommode it, and, continues for two or three months in a state somewhat resembling the ordinary quadrupeds of the milder climates. At the approacl of winter, however, the cold increasing, the coat of hair secus to thicken in propoltion ; from being coarse and short, it leugthens and grows fincr, while multimdes of smaller hair's grow up between the longer, thicken the coat, and give it all that warmth and softness which are so much valued in the furs of the northern animals.

It is no easy matter to account for this remarkable wainith of the furs of northern quadrupeds, ol how they come to be furnished with such an abundant covering. It is easy enough indeed, to say that nature fits them thus for the climate; and like an indulgent mother, when she exposes then to the rigour of an intemperate winter, supplies them with a covering against its inclemency. But this is only flourishing: it is not casy, I say, to tell how nature comes to furnish them in this manner. A few particulars on this subject are all that we yet know. It is observable among quadrupeds, as well as even among the human xo. $29 \& 30$. species itself, that a thin sparing dict is apt to produce hair ; children that have been ill fed, famished dogs and horses, are more hairy than others whose food has been more plentiful. This may, therefore, be one cause that the animals of the north, in winter, are more hairy than those of the milder climates. At that season, the whole country is covered with deep snow, and the provisions which these creatures are able to procure can bc but precarious and scanty. Its becoming fiuer inay also proceed from the severity of the cold, that contracts the pores of the skin, and the hair consequently takes the sliape of the aperture through which it grows, as wires are made smaller by being drawn through a smaller orifice. However this may be, all the auimils of the arctic climates may be said to have their winter and sunimer garments, pxcept very far to the north, as in Grecnland, where the cold is so continually intense and the food so scarce, that neither the bears nor foxes change colour. ${ }^{\mathrm{a}}$

The ermine, as was said, is remarkable among these for the softucss, the closeness, and the warmth of its fur. It is brown in summer, like the weasel, and changes colour before the winter is begun, becomilig a beautifal cream colour, all except the tip of the tail, as was said before, which still continues black. Mr. Daubenton had une of these brought him with its white winter fur, which he put into a cage and kept, in order to observe the manner of moulting its hair. He received it in the beginning of March; in a very short time it began to shed its coat, and a nixture of brown was scen to prevail among the white, so that at the ninth of the same month its head was nearly become of a reddish brown. Day after day this colour appeared to extend, at first along the neck and down the back, in the mainner of a stripe of about half an inch broad. The fore-part of the legs then assumed the same colour ; a part of the head, the thighs, and the tail, were the last that changed; but at the end of the month there was no white remaining, except on those parts which are always white in this species, particularly the throat and the belly. However, he had not the pleasure of sceing this animal resume its former whiteness, although he kept it for

a Krantz's History of Greenland, vol. i. p. 72. 3 F 
above two years; which, without doubt, was owing to its imprisoned state; this colour bing partly owing to its stinted food, and partly to the rigour of the season. During its state of confinement, this little auimal. always continued very wild and untractable; for ever in a state of violent agitation, except when asleep, which it often continued for three parts of the day. Except for its most disagreeable scent, it was an extremely pretty creature, its eyes sprightly, its physiognomy pleasant, and its motions so swift that the eye could scarce attend them. It was fed with eggs and flesh, but it always let them putrefy before it touched cither. As some of this kind are known to be fond of honey, it was tried to feed this animal with such food for a while; after having for three or four days deprived it of other food, it ate of this, and died shortly after ; a strong proof of its being a distinct species from the pole-cat or the martin, - who feed upon houry, but otherwise pretty much resemble the ernine iu their figure and dispositions.

In the north of Europe and Siberia their skins make a valuable article of commerce, and they are found there inuch more frequently than ainong us. In Siberia they burrow in the fields; and are taken in traps. baited with flesh. In Norway they are cither shot with blunt arrows, or taken in traps made of two flat stones, one being jropped with a stick, to which is fastened a baited string, and when the animals attempt to pull this way, the stone rlrops and crushes them to death. This animal is sometimes found white in Great Britain, and is then called a white weasel. Its furs, however, among us are of no value, having neither the thickness, the closeness, nor the whiteness of those which come from Siberia. The fur of the ermine, in every country, changes by time; for, as much of its beautiful whiteness is given it by certain arts known to the furriers, so its natural colour returns, and its former whiteness can never be restored again.

\section{THE FERRET.}

Tre animal next in size to the ermine, is the ferret; which is a kind of domestic in Europe, though said to be originally brought from Africa into Spain, which being a country abounding in rabbits, required an aninsal of this kind more than any other: however this be, it is not to be found at present among us, except in its domestic state; and it is chiefly kept tame, for the purposes of the warren.

The ferret is about one foot long, bcing nearly four inches longer than the weasel. It resembles that animal in the slenderness of its body, and the shortness of its legs; but its nose is sharper, and its body more slender, in proportion to its length. The ferret is commonly of a cream colour; but they are also found of all the colours of the weasel kind; white, blackish, brown, and party-coloured. Those that are of the whitish lind, have their eyes red, as is almost general with all animals entirely of that colour. But its principal distinction from the weasel, is the length of the hair on its tail, which is much longer in the ferret than the wcasel. Words will not well express the other distinctions; and what might take up a page in dull discrimination, a single glance of the eyc, when the animals themselves are presented, can discover.

As this animal is a native of the torrid zone, so it cannot bear the rigours of our climate without care and shelter; and it generally repays the trouble of its keeping, by its great agility in the warren. It is naturally such an eneny of the rabbit kind, that if a dead rabbit be presented to a young ferret, although it has never seen one before, it instantly attacks and bites it with an appearance of rapacity. If the rabbit be living, the ferret is still nore eager, seizes it by the neck, winds itself round it, and continues to suck its blood, till it be satiated.

Their chicf use in warrens is to enter the holes, and drive the rabbits into the nets that are prepared for them at the mouth. For this purpose, the ferret is muzzled ; otherwise, instead of driving out the rabbit, it wonld content itself with killing and sucking its blood at the bottom of the hole; but, by this contri. vance, being rendered unable to seize its prey, the rabbit escapes from its claws, and instantly makes to the mouth of the hole with such pre. cipitation, that it is inextricably entangled in the net, placed there for its reception. It often happens, however, that the ferret disengages itself of its muzzle, and shen it is nıost com monly lost, unl'ss it be dug out; for, finding all its wants satisfied in the warren, it never

2 Buffon. 
thinks of returning to the owner, but continues to lead a rapacious solitary life while the summer continues, and dies with the cold of the winter. In order to bring the ferret from his hole, the owners often burn straw and other substances at the mouth; they also beat above to terrify it; but this does not always succeed; for as there are often several issues to each hole, the ferret is affected neither by the noise nor the smoke, but continues secure at the bottom, sleeping the greatest part of the time, and waking only to satisfy the calls of hunger.

The female of this species, is sensibly less than the male, whom she seeks with great ardour, and, it is said, oftei diès without being admitted. They are usually kept in boxes, with wool, of which they make themselves a warm bed, that serves to defend them from the rigour of the climate. They sleep almost continually; and the instant they awake, they seem eager for food. They are usually fed with bread and milk. They breed twice a year. Some of them devour their young as soon as brought forth, and then. become fit for the male again. Their number is usually from five to six at a litter; and this is said to consist of more females than males. Upon the whole, this is an useful, but a disagreeable and offensive animal; its scent is foetid, its nature voracious, it is tame without any attachment, and such is its appetite for blood, that it has been known to attack and kill children in the cradle. It is very easy to be irritated; and, although at all times its smell is very offensive, it then is much more so; and its bite is very difficult of cure.

To the ferret kind we may add an animal which Mr. Buffon calls the vansire, the skin of which was sent him stuffed from Madagascar. It was thirteen inches long, a good deal resembling the ferret in figure, but differing in the number of its grinding tecth, which amounted to twelve; whereas in the ferret there are but eight: it differed also in colour, being of a dark brown, and exactly the same on all parts of its body. Of this animal, so nearly resembling the ferret, we have no other history but the mere description of its figure; and in a quadruped whose kind is so strong:

- Buffon. ly marked, perhaps this is sufficient to satisfy curiosity.

\section{THE POLECAT.}

THE Polecat is larger than the weasel, the ermine, or the ferret, being one foot five inches long; whereas the weasel is but six inches, the ermine nine, and the ferret eleven inches. It so much resembles the ferret in form, that some have been of opinion they were one and the same animal; nevertheless, there are a sufficient number of distinctions betwcen them: it is, in the first place, larger than the ferret; it is not quite so slender, and las a blunter nose; it differs also interually, having but fourteen ribs, whereas the ferret has fifteen; and wants one of the breast bones, which is found in the ferret: however, warreners assert, that the polecat will mix with the ferret; and they are sometimes obliged to procure an intercourse between these two animals, to improve the breed of the latter, which, by long confinement, is sometimes seen to abate of its rapacious disposition. Mr. Buffon denies that the ferret will admit the polecat; yet gives a variety, under the name of both animals, which may very probably be a spurious race between the two.

However this be, the polecat seems by much the more pleasing animal of the two; for although the long slender shape of all these vermin tribes gives them a very disagreeable appearance, yet the softness and colour of the hair in some of them atones for the defect, and renders them, if not pretty, at least not frightful. The polecat, for the most part, is of a deep chocolate colour; it is white about the mouth; the ears are short, rounded, and tipped with white; a little beyond the corners of the mouth a stripe begins, which runs backward, partly white and partly yellow: its hair, like that of all this class, is of two sorts, the long and the furry; but in this animal the two kinds are of different colours; the longest is black, and the shorter yellowish :b the throat, feet, and tail, are blacker than any other parts of the body; the claws are white underneath, and brown above; and its tail is about two inches and a half.

- Ray's Synopsis. 
It is very destructive to young game of all kinds ; but the rabbit seems to be its favourite prey: a single polecat is often sufficient to destroy a whole warren; for, with that insatiable thirst for blood which is natural to all the weasel kind, it kills much more than it can devour; and I have seen twenty rabbits at a time taken out dead, which they had destroyed, and that by a wound which was hardly perceptible. 'Their size, however, which is so much larger than the weasel, renders their retreats near houses much more precarious; although I have seen them burrow near a village, so as scarcely to be extirpated. But, in general, they resile in woods or thick brakes, making holes under ground of about two yards deep, commonly endiug among the roots of large trees, for greater sccurity. In winter they frequent houses, and make a common practice of robbing the hen-roost and the daijy.

The polecat is particularly destructive among pigeons, when it gets into a dove-liouse; without inaking so much noise as the weasel, it does a great deal more mischief; it despatches each with a single wound in the head; and, after killing a great number, and satiating itself with their blood, it then begins to think of carrying them home. This it carefully performs, going and returning, and bringing them one by one to its hole; but if it should happen that the opening by which it got into the dove-house be not large enough for the body of the pigeon to get through, this mischievous creature contents itself with carrying away the heads, and makes a most delicious feast upon the brains:

It is not less fond of honey; attacking the hives in winter, and forcing the bees away. It does not remove far from houses in winter, as its prey is not so easily found in the woods during that season. The female brings forth her young in summer, to the number of five or six at a time; these she soon trains to her own rapacious habits, supplying the want of milk, which no caruivorous quadruped has in plenty, with the blood of such arimals as she happens to seize. The fur of this animal is considered as soft and warm; yet it is in lessestimation than some of a much inferior kind,

- British Zoology, vol. i. p. 78.

b Buffon. from its offensive smell, which can never be wholly removed, or suppressed. The polecat seems to be an inhabitant of the temperate climates, ${ }^{c}$ scarce any being found towards the north, and but very few in the warmer latitudes. The species appear to be confined in Europe, from Poland to Italy. It is certain, that these animals are afraid of the cold, as they are often seen to come into houses in winter, and as their tracks are never found in the snow, near their retreats. It is probable, also, that they are afraid of heat, as they are but thinly scattered in the southern climates.

\section{THE MARTIN.}

Tirc Martin is a larger animal than any of the former, being generally eighteen inches long, and the tail ten more. It differs from 1he polecat, in being about four or five inches longer; its tril also is longer in proportion, and more bushy at the end; its nose is flatter; its cry is sharper and more piercing; its colours are more elegant; and, wluat still adds to their beauty, its scent is very unlike the former, instead of being offensive, is considered as a most pleasing perfumc. The martin, in short, is the most beautiful of all British beasts of prey : its head is small, and elegantly formed: its eyes lively; its ears are broad, rounded, and open; its back, its sides, and tail, are covered with a fine thick downy fur, with longer hair intermixed; the roots are ash colour. the middle of a bright cliesnut, the points black; the head is brown, with a slight cast of red; the legs, and upper sides of the feet, are of a chocolate colour; the palms, or under sides, are covered with a thick down, like that of the body; the feet are broad, the claws white, large, and sharp, well adapted for the purposes of climbing, but, as in others of the weasel kiud, incapable of being sheathed or unsheathed at pleasure; the throat and breast are white: the belly of the same colour with the back, but rather paler; the hair on the tail is very long, especially at the end, where it appears inuch thicker than near the insertion.

c Buffion. 
There is also a variety of this animal, called the yellow-breasied martin, which in no respect differs from the former, except that this has a ycllow breast, whereas the other has a white one: the colour of the body also is darker; and, as it lives more among trees than the other martin, its fur is more valuable, beautiful, and glossy. The former of these Mr. Buffon calls the fouine; the latter, simply the martin; and he supposes them to be a distinct species: but as they differ only in colour, it is unnecessary to embarrass history by a new distinction, where there is only so minute a difference.

Of all auimals of the weasel kind, the martin is the most pleasing; all its motions show great grace, as well as agility; and there is scarce an animal in our woods that will venture to oppose it. Quadrupeds five times as big are easily vanquished; the lare, the sheep, and even the wild cat itself, though much stronger, is not a match for the inartin: and although carnivorous animals are not fond of engaging each other, yet the wild cat and the martin seldom meet without a combat. Gesner tells us of one of this kind that he kept tame, which was extremely playful and pretty; it went among the houses of the neighbourhood, and alivays returned home when hungry: it was extremely fond of a dog that had been bred up with it, and used to play with it as cats are seen to play, lying on its back, and biting without anger or injury. That which was kept tame by Mr. Buffon, was not quite so social: it was divested of its ferocity, but continued without attachment; and was still so wild as to be obliged to be held by a chain. Whenever a cat appeared, it prepared for war: and if any of the poultry came within its reach, it flew upon them with avidity. Though it was tied by the middle of the body, it frequently escaped: at first it returned after some hours, but without seeming pleased, as if it only came to be fed; the next time it continued abroad longer; and, at last, went away without ever returning. It was a female, and was, when it went off, a year and a lialf old; and Mr. Buffon supposes it to have gone in quest of the male. It ate every thing that was given it, except salad or herbs; and it was remarkably fond of honey. It was remarked, that it drank often, and of- ten slept for two days together; and that, in like manner, it was often two or three days without sleeping. Before it went to sleep, it drew itself up into a round, hid its head, and covered it with its tail. When awake it was in continual agitation, and was obliged to be tied up, not less to prevent its attacking the poultry, than to hinder it from breaking whatever it came near, by the capricious wildness of its motions.

The yellow-breasted martin is much more common in France than in England; and yet even there this variety is much scarcer than that with the white breast. The latter kceps nearer houses and villages to make its petty ravages among the sheep and the poultry; the other keeps in the woods, and leads in every respect a savage life, building its nest on the tops of trees, and living upon such animals as are entirely wild like itself. About night-fall it usually quits its solitude to seck its prey, hunts after squirrels, rats, and rabbits; destroys great numbers of birds and their young, takes the eggs from the nest, and often removes them to its own without breaking. ${ }^{2}$ The instant the martin finds itself pursued by dogs, for which purpose there is a peculiar breed, that seem fit for this chase only, it immediately makes to its retreat, which is generally in the hollow of some tree, towards the top, and which it is impossible to come at without cutting it down. Their nest is generally the original tenement of the squirrel, which that little animal bestowed great pains in completing; but the martin having killed and dispossessed the little architect, takes possession of it for its own use, enlarges its dimensions, improves the softness of the bed, and in that retreat brings forth its young. Its litter is never above three or four at a time; they are brought forth with the eyes closed, as in all the rest of this kind, and very soon come to a state of perfection. The dam compensates for her own deficiency of milk, by bringing them eggs and live birds, accustoming them from the beginning to a life of carnage and rapine. When slie leads them from the nest into the woods, the birds at once distinguish their enemies, and attend them, as we before observed of the fox, with all the

\footnotetext{
arooke's Natural History.
} 
marks of alarm and animosity. Wherever the martin conducts her young, a flock of small birds are seen threatening and insulting her, alarming every thicket, and often directing the hunter in his pursuit. The martin is more common in North America than in any part of Europe. These animals are found in all the northern parts of the world, from Siberia to China and Canada. In every country they are hunted for their furs, which are very valuable, and chiefly so when taken in the beginning of winter. The most esteemed parts of the martin's skin is that part of it which is browner than the rest, and stretches along the back-bone. Above twelve thousand of these skins are annually imported into England from Hudson's Bay, and above thirty thousand from Canäda.

\section{THE SABLE.}

Most of the classes of the weasel kind would have continued utterly unknown and disregarded, were it not for their furs, which are finer, more glossy, and soft, than those of any other quadruped. Their dispositions are fierce and untameable; their scent generally offensive; and their figure disproportioned and unpleasing. The knowledge of one or two of them would, therefore, have sufficed curiosity; and the rest would probably have been confounded together under one common name, as things useless and uninteresting, had not their skins been coveted by the vain, and considered as capable of adding to human magnificence or beauty.

Of all these, however, the skin of the sable is the most coveted, and held in the highest esteem. It is of a brownish black; and the darker it is it becomes the more valuable. A single skin, though not above four inches broad, is often valued at ten or fifteen pounds; the fur differing from others in this, that it has no grain; so that rub it which way you will, it is equally smooth and unresisting. Nevertheless, though this little animal's robe was so much coveted by the great, its history till of late was but very little known; and we are obliged to Mr. Jonelin for the first accurate

- Regnard. description of its form and nature." From him we learn that the sable resembles the mar. tin in form and size, and the weasel in the number of its teeth; for it is to be observed, that whereas the martin has thirty-eight teeth, the weasel has but thirty-four; in this respect, therefore, the sable secms to make the shade between these two animals; being shaped like the one, and furnished with teeth like the other. It is also furnished with very large whiskers about the mouth; its feet are broad, and, as in the rest of its kind, furnished with five claws on each foot. These are its constant marks; but its fur, for which it is so much valued, is not always the same. Some of these species are of a dark brown over all the body, except the ears and the thront, where the hair is rather yellow ; others are more of a yellowish tincture, their cars and throat being also much paler. These, in both, are the colours they have in winter, and which they are seen to change in the beginning of the spring; the former becoming of a yellow brown, and the latter of a pale yellow. In other respects they resemble their kind, in vivacity, agility, and inquietude; in sleeping by day, and seeking their prey by night; in living upon smaller animals, and the disagreeable odour that chiefly characterizes their race.

They generally inhabit along the banks of rivers, in shady places, and in the thickest woods. They leap with great ease from tree to tree, and are said to be afraid of the sun, which tarnishes the lustre of their robes. They are chiefly hunted in winter for their skins, during which part of the year they are only in season. They are mostly found in Siberia, and but very few in any other country of the world; and this scarcity it is which enhances their value. The hunting of the sable chiefly falls to the lot of the condemned criminals, who are sent from Russia into these wild and extensive forests, that, for the greatest part of the year, are covered with snow; and, in this instance, as in many others, the luxuries and ornaments of the vain, are wrought out of the dangers and the miseries of the wretched. These are obliged to furnish a certain number of skins every year, and are

buffon, vol. xxvii. p. 113. 
punished if the proper quantity be not provided.

The sable is also killed by the Russian soldiers, who are sent into those parts to that end. They are taxed a certain number of skins yearly, like the former, and are obliged to shoot with only a single ball, to avoid spoiling the skin, or else with a cross-bow, and blunt arrows. As an encouragement to the hunters, they are allowed to share among themselves the surplus of those skins which they thus procure; and this, in the process of six or seven years, amounts to a very considerable sum. A colonel, during his seven years stay, gains about four thousand crowns for his share, and the conmon men six or seven hundred each for theirs.

\section{THE ICHNEUMON}

THE Ichneumon, which some have injudiciously denominated the cat of Pharaoh, is one of the boldest and most useful aninals of all the weasel kind. In the kingdom of Egypt, where it is chiefly bred, it is used for the same purposes that cats are in Europe, and is even more serviceable, as being more expert in eatching mice than they. This animal is usually of the size of the martin, and greatly resembles it in appearance, except that the hair, which is of a grisly black, is much rougher, and less downy. The tail, also, is not so bushy at the end; and each hair in particular has three or four colours, which are seen in different dispositions of its body. Under its rougher hairs, there is a softer fur of a brownish colour, the rough hair being about two inches long, but that of the muzzle extremely short, as likewise that on the legs and paws. However, being long since brought into a domestic state, therc are many varieties in this animal; some being much larger than the martin, others much less; some being of a lighter mixture of colours, and some being streaked in the manner of a cat.

The ichneumon, with all the strength of a cat, has more instinct and agility; a more universal appetite for carnage, and a greater variety of powers to procure it." Rats, mice,

a The rest of this description is extracted from Mr. Buffon, except where marked with commas. birds, serpents, lizards, and insects, are all equally pursued; it attacks evcry living thing which it is able to overcome, and indiscriminately preys on flesh of all kinds. Its courage is cqual to the veliemence of its appetites. It fears neither the force of the dog, nor the insidious malice of the cat; neither the claws of the vulture, nor the poison of the vipcr. It makes war upon all kinds of serpents with great avidity, seizes and kills them, how venomous soever they be; and, we are told, that when it begins to perceive the effects of their rage, it has recourse to a certain root, which the Indians call after its name, and assert to be an antidote for the bite of the asp or the viper.

But what this animal is particularly serviceable to the Egyptians for, is, that it discovers and destroys the eggs of the crocodilc. It also kills the young ones that have not as yet been able to reach the water; and, as fable usually goes hand in hand with truth, it : is said that the ichneumon sometimes enters the mouth of the crocodile, when it is found sleeping on the shorc, boldly attacks the enemy in the inside, and at length, when it has effectually destroyed it, it eats its way out again.

The ichneumon, when wild, generally resides along the banks of rivers; - and in times of inundation makes to the higher ground, often approaching inhabited places in quest of prey. It goes forward silently and cautiously, changing its manner of moving according to its necessities. Sometimes it carries the head high, shortens its body, and raises itself upon its legs; sometimes it lengthens itself, and seems to creep along the ground; it is often observed to sit upon its hind legs, like a dog when taught to beg; but more commonly it is seen to dart like an arrow upon its prey, and seize it with inevitable certainty. Its eyes are sprightly and full of fire, its physiognomy sensible, its body nimble, its tail long, and its hair rough and various. Like all of its kind, it has glands that open behind and furnish an odorous substance. Its nose is too sharp and its mouth too small to permit its seizing things that are large; however, it makes up by its courage and activity its want of arms; it easily strangles a cat though stronger and larger than itself; and oftèn fights with dogs, which, though never so bold, 
learn to dread the iclineumon as a formidable enemy. It also takes the water like the otter, and, as we are told, will continue under it much longer.

This animal grows fast and dies soon. It is found in great lumbers in all the southern parts of Asia, from Egypt to Java; and it is also found in Africa, particularly at the Cape of Good Hope. It is domestic, as was said, in Egypt, but in our colder climate, it is not easy to breed or maintain them, as they are not able to support the rigour of our winters. Nevertheless they take every precaution that instinct can dictate to keep themselves warm; they wrap themselves up into a ball, hiding the head between the legs, and in this manner continue to sleep all day long. "Seba had one sent him from the island of Ceylon, which he permitted to run for some months about the house. It was heavy and slothful by day, and often could not be awakened even with a blow; but it made up this indolence by its nocturnal activity, smelling about without either being wholly tame or wholly mischievous. It climbed up the walls and the trees with very great ease, and appeared extremely fond of spiders and worms, which it preferred, probably from their resemblance to serpents, its most natural food. - It was also particularly eager to scratch up holes in the ground; and this, added to its wildness and uncleanliness, obliged our naturalist to smother it in spirits in order to preserve, and added it to the rest of his collection."

This animal was one of those formerly worshipped by the Egyptians, who considered every thing that was serviceable to them as an emanation of the Deity, and worshipped such as the best representatives of God below. Indeed, if we consider the number of eggs which the crocodile lays in the sand at a time, which often amounts to three or four hundred, we have reason to admire this little animal's usefulness as well as industry in destroying them, since otherwise the crocodile might be produced in sufficient numbers to overrun the whole carth.

\section{THE STINKARDS.}

THIs is a name which our sájlors give to one or two animals of the weasel kind, which are chiefly found in America. All the weasel kind, as was already observed, have a very strong smell; some of them indeed approacliing to a perfume, but the greatest number most insupportably foetid. But the smell of our weasels, and ermines, and polecats, is fragrance itself when compared to that of the squash and the skink, which have been called the polccats of America. These two are found in different parts of America, both differing in colour and fur, but both obviously of the weasel kind, as appears not only from their figure and odour, but also from their disposition. The squash is about the size of a polecat, its hair of a deep brown, but principally differing from all of this kind in having only four toes on the feet before, whereas all ot her weasels have five. The skink, which I take to be Catesby's Virginia polecat, resembles a polecat in shape and size, but particularly differs in the length of its hair and colour. The hair is above three inches and a half long, and that at the end of the tail above four inches. The colour is partly black and partly white, variously disposed over the body, very glossy, long, and beautiful. There seem to be two varieties more of this animal, which $\mathrm{Mr}$. Buffon calls the conepate and the zorille. He supposes each to be a distinct species: but as they are both said to resemble the polecat in form, and both to be elothed with long fur of a black and white colour, it seems needless to make a distinction. The conepate resembles the skink in all things except in size, being smaller, and in the disposition of its colours, which are more exact, having five white stripes upon a black ground, running longitudinally from the head to the tail. The zorille resembles the skink, but is rather smaller and more beautifully coloured, its streaks of black and white being more distinct, and the colours of its tail being black at its insertion and white at the extremity; whereas in the skink they are all of one gray colour.

But whatever differences there may be in the figure or colour of these little animals, they all agree in one common affection, that of being intolerabiy foetid and loathsome. I have already observed that all the weasel kind have glands furnishing an odorous matter, near the anus, the conduits of which generally have their aperture just at its opening. 
That substance which is stored up in these receptacles, is in some of this kind, such as in the martin, already mentioned, and also in the genet and the civet, to be described hereafter, a inost grateful perfume; but in the weasel, the ermine, the ferret, and the polecat, it is extremely foetid and offensive. These glands in the animals now under consideration are much larger, and furnish a matter sublimed to a degree of putrescence, that is truly amazing. As to the perfumes of musk and civet, we know that a single grain will diffuse itself over a whole house, and continue for months to spread an agreeable odlour, without diminution. However, the perfume of the musk or the civet is nothing, either for strength or duration, to the insupportable odour of these. It is usually voided with their excrement; and if but a single drop happens to touch any part of a marn's garment, it is more than probable that he can never wear any part of it more.

In describing the effects produced by the excrement of these animals, we often hear of its raising this diabolical smell by its urine. However, of this I ain apt to doubt; and it should seem to me, that, as all the weasel kind have their excreinents so extremely fotid fiom the cause above mentioned, we may consider these also as being foetid from the same causes. Besides, they are not furnished with glands to give their urine such a sinell; and the analogy between them and the weasel kind being so strong in other respects, we may suppose they resemble each other in this. It has also been said that they take this method of ejecting their excrement to defend themselves against their pursuers; but it is much more probable that this ejection is the convulsive effect of terror, and that it serves as their defence without their own concurrence. Certain it is that they never smell thus horridly except when enraged or affrighted, for they are often kept tame about the houses of the planters of America without being very offensive.

The habitudes of all these animals are the same, living like all the rest of the weasel kind, as they prey upon smaller animals and birds' eggs. The squash, for instance, loursows like the polecat in the clefts of rocks, where it brings forth its young. It often steals xo. 29 \& 30. into farm-yards, and kills the poultry, eating only their brains. Nor is it safe to pursue or offend it, for then it calls up all its scents, which are its most powerful protection. At that time neither men nor dogs will offer to approach it; the scent is so strong that it reaches for half a mile round, and more near at hand is almost stifling. If the dogs continue to pursue, it does all in its power to escape, by getting up a tree, or by some such means; but if driven to an extremity, it then lets fly upon the hunters; and if it should happen that a drop of this fotid discharge falls in the eye, the person runs the risk of being blinded for ever."

The dogs themselves instantly abate of their ardour when they firid this extraordinary battery played off against them; they instantly turu tail, and leave the animal undisputed master of the field ; and no exhortations can ever bring them to rally. "In the year 1749," says Kalm, "one of these animals came near the farm where I lived. It was in winter time, during the night; and the dogs that were upon the watch, pursued it for some time, until it discharged against them. Although I was in my bed a good way off, I thought I should have been suffocated; and the cows and oxen, by their lowings, showed how much they were affected by the stench. About the end of the same year, another of these animals crept into our cellar, but did not exhale the smallest scent, because it was not disturbed. A foolish woman, however, who perceived it at night, by the shining of its eyes, killed it, and at that moment its stench began to spread. The whole cellar was filled with it to such a degree, that the woman kept her bed for several days after; and all the bread, meat, and other provisions, that were kept there, were so infected, that they were obliged to be thrown out of doors." Nevertheless, many of the planters and native Americans keep this animal tame about their houses: and seldom perceive any disagreeable scents, except it is injured or frighted. They are also known to eat its flesh, which some assert to be tolerable food; however, they take care to deprive it of those glands which are so horridly offensive.

- Voyage de Kalın, as quoted by Buffor, vol.xxvii. p.95. $3 \mathrm{G}$ 


\section{THE GENET.}

From the squash, which is the most offensive animal in nature, we come to the Genet, which is one of the most beautiful and pleasing. Instead of the horrid stench with which the former affects us, this has a most grateful odour; more faint than civet, but to some, for that reason, more agreeable. This animal is rather less than the martin; though there are genets of different sizes, and I have seen one rather larger. It also differs somewhat in the form of its body. It is not easy in words to give an idea of the distinction. It resembles all those of the weasel kind, in its length, compared to its height; it resembles them in having a soft, beautiful fur, in having its feet armed with claws that cannot be sheathed, and in its appetite for petty carnage. But then it differs from them in laving the nose much smaller and longer, rather resembling that of a fox than a weasel. The tail, also, instead of being bushy, tapers to a point, and is much longer; its ears are larger, and its paws smaller. As to its colours, and figure in general, the genet is spotted with black, upon a ground mixed with red and gray. It has two sorts of hair, the one shorter and softer, the other longer and stronger, but not above half an inch long on any part of its body except the tail. Its spots are distinct and separate upon the sides, but unite towards the back, and form black stripes, which run longitudinally from the neck backwards. It has also along the back a kind of mane or longish hair, which forms a black streak from the head to the tail, which last is marked with rings, alternately black and white, its whole length.

The genet, like all the rest of the weasel kinds, has glands, that separate a kind of perfume, resembling civet, but which soon flies off. These glands open differently from those of other animals of this kind; for, as the latter have their apertures just at the opening of the anus, these have their aperture immediately under it; so that the male seems, for this reason, to the superficial observer, to be of two sexes.

It resembles the martin very much in its habits and disposition; except, that it seems

- Buffon, vol. xix.p. 187. tamed much more easily. Belonius assures us, that he has seen them in the houses at Constantinople as tame as cats; and that they were permitted to run every where about, without doing the least mischief. For this reason they have been called the cats of Constantinople; although they have little else in common with that animal, except their skill in spying out and destroying vermin. Naturalists pretend that it inhabits only the moister grounds, and chiefly resides along the banks of rivers, having never been found in mountains, nor dry places. The species is not much diffused; it is not to be found in any part of Europe, except Spain and Turkey; it requires a warm climate to subsist and multiply in; and yet it is not to be found in the warmer regions either of India or Africa. From such as have seen its uses at Constalltinople, I learn, that it is one of the most beatltiful, cleanly, and industrious aninals in the world; that it keeps whatever house it is in perfectly free from mice and rats, which cannot endure its smell. Add to this, its nature is mild and gentle, its colours various and glossy, its fur valuable; and, upon the whole, it seems to be one of those animals that, with proper care, might be propagated amongst us, and might become one of the most serviceable of our domestics.

\section{THE CIVET.}

Proceeding from the smaller to the greater of this kind, we come, in the last place, to the Civet, which is much larger than any of the former; for as the martin is not above sixteen inches long, the civet is found to be above thirty. Mr. Buffon distinguishes this species into two kinds; one of which he calls the civet, and the other the zibet. The latter principally differs from the former in having the body longer and more slender, the nose smaller, the ears longer and broader: no mane or long hair runing down the back in the latter; and the tail is longer and better marked with rings of different colours, from one end to the other. These are the differences which have induced this great naturalist to suppose them animals of distinct species; and to allot each a separate descrip- 
tion. How tar future experience may confirm this conjecture, time must discover; but certain it is, that if such small varieties make a separate class, there may be many other animals equally entitled to peculiar distinction that are now classed together. We shall, therefore, content ourselves, at present, with considering, as former naturalists have done, these two merely as varieties of the same animal, and only altered in figure, by climate, food, or education.

The civet resembles animals of the weasel kind in the long slenderness of its body, the shortness of its legs, the odorous matter that exudes from the glands behind, the softness of its fur, the number of its claws, and their incapacity of being sheathed. It differs from them in being much larger than any hitherto described; in having the nose lengthened, so as to resemble that of the fox; the tail long, and tapering to a point; and its ears straight, like those of a cat. The colour of the civet varies; it is commonly ash, spotted with black; though it is whiter in the female, tending to yellow; and the spots are much larger, like those of a panther. 'The colour on the belly, and under the throat, is black; whereas the other parts of the body are black or streaked with gray. This aninal varies in its colour, being sometimes streaked, as in our kind of cats called tabbies. It has whiskers, like the rest of its kind ; and its eye is black and beautiful.

The opening of the pouch or bag, which is the receptacle of the civet, differs from that of the rest of the weasel kind, not opening into but under the anus. Besides this opening, which is large, there is still another lower down; but for what purposes designed, is not known. The pouch itself is about two inches and a half broad, and two long; its opening makes a chink, from the top downwards, that is about two inches and a half long; and it is covered on the edges and within, with short hair: when the two sides are drawn asunder, the inward cavity may be seen, large enough to hold a small pullet's egg; all around this are small glands, opening and furnishing that strong perfume which is so well known, and is found in this pouch, of the colour and consistence of pomatum. Those who make it their business to breed these animals for their perfume, usually take it from them twice or thrice a week, and sometimes oftener. The animal is kept in a long sort of a box, in which it cannot turn round. The person, therefore, opens this box behind, drags the animal backwards by the tail, keeps it in this position by a bar before, and, with a wooden spoon, takes the civet from the pouch, as carefully as he can; then lets the tail go, and shuts the box again. The perfume, thus procured, is put into a vessel, which he takes care to keepshut; and when a sufficient quantity is procured, it is sold to very great advantage.

The civet, ${ }^{\text {a }}$ although a native of the warmest climates, is found yet to live in temperate, and even cold countries, provided it be defended carefully from the injuries of the air. Wherefore, it is not only bred among the Turks, the Indians, and Africans, but great numbers of these animals are also bred in Holland, where this scraping people make no small gain of its perfume. The perfume of Amsterdam is reckoned the purest of any; the people of other countries adulterating it with gums, and other matters, which diminish its value, but increase its weight. The quantity which a single animal affords, generally depends upon its health and nourishment. It gives more in proportion as it is more delicately and abundantly fed. Raw flesh, hashed small, eggs, rice, birds, young fowls, and particularly fish, are the kinds of food the civet most delights in. These are to be changed and altered, to suit and entice its appetite, and continue its health. It gets but very little water; and although it drinks but rarely, yet it makes urine very frequently; and, upon such occasions, we cannot, as in other animals, distinguish the male from the female.

The perfume of the civet is so strong that it communicates itself to all parts of the animal's body; the fur is impregnated thereby, and the skin peuetrated to such a degree that it continues to preserve the odour for a long time after it is stript off. If a person be shut up with one of them in a close room, he cannot support the perfume, which is so copiously diffused. When the animal is irritated, as in all the weasel kind, its scent is much more violent than ordinary; and if it be tormented

a Buffon, vol. xix. 
80 as to make it sweat, this also is a strong perfume, and serves to adulterate or increase what is otherwise obtained from it. In general, it is sold in Holland for about fifty shillings an ounce : although, like all other commodities, its value alters in proportion to the demand. Civet must be chosen new, of a good consistence, a whitish colour, and a strong, disagreeable smell. There is still a very considerable traflic carried on from Bussorah, Calicut, and other places in India, where the animal that produces it is bred; from the Levant also, from Guinea, and especially from Brasil, in South America, although Mr. Buffon is of opinion that the animal is a native only of the Old Continent, and not to be found wild in the New. The best civet, however, is furnished, as was observed, by the Dutch, though not in such quantities at present as some years past, when this perfume was more in fastion. Civet is a much more grateful perfume than musk, to which it has some resemblance; and was some years ago used for the same purposes in medicine. But, at present, it is quite discontinued in prescription; and persons of taste or elegance seem to proscribe it even from the toilet. Perfumes, like dress, have their vicissitudes; musk was in peculiar repute, until displaced by civet; both gave ground, upon discovering the manner of preparing ambergris; and even this is now disused for the less powerful vegetable kinds of fragrance, spirits of lavender, or otter of roses.

As to the rest, the civet is said to be a wild fierce animal; and, although sometimes tamed, is never thoroughly familiar. Its teeth are strong and cutting, although its claws be feeble and inflexible. It is light and active, and lives by prey, as the rest of its kind, pursuing birds, and other small animals that it is able to overcome. They are sometimes seen stealing into the yards and outhouses, to seize upon the poultry: their cyes shine in the night, and it is very probable that they see better in the dark than by day. When they fail of animal food, they are found to subsist upon roots and fruits, and very seldom drink; for which reason they are never found near great waters. They breed very fast in their native climates, where the heat seems to conduce to their propagation; but in our temperate latitudes, al- though they furnish their perfume in great quantities, yet they are not found to multiply. A proof that their perfume has no analogy with their appetite for generation.

\section{THE GLUTTON.}

I wix. add but one animal more to this numerous class of the weasel kind; namely, the glutton; which, for several reasons, seems to belong to this tribe, and this only. We have hitherto had no precise description of this quadruped; some rescmbling it to a badger, some to a fox, and some to a hyæna. Linnaus places it among the weasels, from the similitude of its teeth; it should seem to me to resemble this animal still more, from the great length of its budy, and the shortuess of its legs, from the softuess of its fur, its disagreeable scent, and its insatiable appetite for animal food. Mr. Klein, who saw one of them, which was brought alive from Siberia, assures us, that it was about three feet long, and about a foot and a half high. If we compare these dimensions with those of otler animals, we shall find that they approach more nearly to the class we are at present describing than any other; and that the glutton may very justly be conceived under the form of a great, overgrown weasel. Its nose, its ears, its teeth, and its long bushy tail, are entirely similar; and as to what is said of its being rather corpulent than slender, it is most probable that those who described it thus, saw it after eating, at which time its belly, we are assured, is most monstrously distended : however, suspending all certainty upon this subject, I will take leave rather to follow Linnæus than Buffon, in describing this animal; and leave future experience to judge between them.

The glutton, which is so called from its vo. racious appetite, is an animal found as well in the north of Europe and Siberia, as in the northern parts of America, where it has the name of the carcajou. Anidst the variety of descriptions which have been given of it, no

- He says, it was an ell, eight inches long: I have, therefore, given its leagth, as supposing it to be a Flemish ell, which is twenty-seven inches. 
very just idea can be formed of its figure; and, indeed, some naturalists, anong whom was Ray, entirely doubted of its existence. From the best accounts, however, we have of it, the body is thick and long, the legs short; it is black along the back, and of a reddish brown on the sides ; its fur is held in the highest estimation, for its softness and beautiful gloss; the tail is bushy, like that of the weasel, but rather shorter; and its legs and claws are better fitted for climbing trees, than for running along the ground. Thus far it entirely resembles the weasel; and its manner of taking its prey is also by surprise, and not by pursuit.

Scarce any of the animals with short legs and long bodies pursue their prey; but, knowing their own incapacity to overtake it by swiftness, either creep upon it in its retreats, or wait in ambush and seize it with a bound. The glutton, from the make of its legs, and the length of its body, must be particularly slow: and, consequently, its only resource is in taking its prey by surprise. All the rest of the weasel kind, from the smallness of their size, are better. fitted for a life of insidious rapine than this; they can pursue their prey into its retreats, they can lurk unseen among the branches of trees, and hide themselves with ease under the leaves: but the glutton is too large to follow small prey into their retreats; nor would such, even if obtained, be sufficient to sustain it. For these reasons, therefore, this animal seems naturally compelled to the life for which it has long been remarkable. Its only resource is to climb a tree, which it does with great ease, and there it waits with patience until some large animal passes underneath, upon which it darts down with unerring certainty, and destroys it.

It is chiefly in North America that this voracious creature is seen lurking among the thick branches of trees, in order to surprise the deer, with which the exteusive forests of that part of the world abound. Endued with a degree of patience equal to its rapacity, the glutton singles out such trees as it observes marked by the teeth or the antlers of the deer; and is known to remain there watching for several days together. If it has fixed upon a wrong tree, and finds that the deer have either left that part of the country, or cautiously shun the place, it reluctantly descends, pursues the beaver to its retreat, or even ventures into the water, in pursuit of fishes. But if it happens that, by long attention, and keeping close, at last the elk or the rein-deer happens to pass that way, it at once darts down upon them, sticks its claws between their shoulders, and remains there unalterably firm. It is in vain that the large frighted animal increases its speed, or threatens with its branching horns; the glutton having taken possession of its post, nothing can drive it off; its enormous prey drives rapidly along amongst the thickest wood, rubs itself against the largest trees, and tears down the branches with its expanded horns; but still its insatiable foe sticks behind, eating its neck, and digging its passage to the great bloodvessels that lie in that part. Travellers who wander through those deserts, often see pieces of the glutton's skin sticking to the trees, against which it was rubbed by the deer. But the animal's voracity is greater than its feelings, and it never seizes without bringing down its prey. When, therefore, the deer, wounded and feeble with the loss of blood, falls, the glutton is seen to make up for its former abstinence by its present voracity. As it is not possessed of a feast of this kind every day, it resolves to lay in a store to scrve it for a good while to come. It is, indeed, amazing how much one of these animals can eat at a time! That which was seen by $\mathrm{Mr}$. Klein, although without exercise or air, although taken from its native climate, and enjoying but an indifferent state of health, was yet seen to eat thirteen pounds of flesh every day, and yet remain unsatisfied. We may, therefore, easily conceive how much more it must devour at once, after a long fast, of a food of its own procuring, and in the climate most natural to its constitution. We are told, accordingly, that from being a lank, thin animal, which it naturally is, it then gorges in such quantities, that its belly is distended, and its whole figure.seerns to alter. Thus voraciously it continues eating till, incapable of any other animal function, it lies totally torpid by the animal it has killed; and in this situation continues for two or threc days. In this loathsome and helpless state, it finds its 
chief protection from its horrid sme!l, which few animals care to come near;" so that it continues eating and sleeping till its prey be devoured, bones and all, and then it mounts a tree, in quest of another adventure.

The glutton, like many others of the weasel kind, seems to prefer the most putrid flesh to that newly killed; and such is the voraciousness of this hateful creature, that, if its swiftness and strength were equal to its rapacity, it would soon thin the forest of every other living creature. But, fortunately, it is so slow, that there is searce a quadruped that cannot escape it, except the beaver. 'This, therefore, it very frequently pursues upon land; but the beaver generally makes good its retreat by taking to the water, where the glutton has no chance to suceced. This pursuit only happens in summer; for in winter all that remains is to attack the beaver's house, as at that time it never stirs from hoine. This attack, however, seldom succeeds; for the beaver has a covert way bored under the ice, and the glutton has only the trouble and disappointment of sacking an erapty town.

A life of necessity generally produces a good fertile invention. The glutton, contlnually pressed by the call of appetite, and having neither swiftness nor activity to satisfy it, is obliged to make up by stratagem the defects of nature. It is often seen to examine the traps and the snares laid for other animals, in order to anticipate the fowlers. It is said to practise a thousand arts to procure its prey, to steal upon the retreats of the reindeer, the flesh of which animal it loves in preference to all others; to lie in wait for such animals as have been maimed by the hunters; to pursue the isatis while it is hunting for itself; and when that animal has run down its prey, to come in and seize upon the whole, and sometimes to devour even its poor provider; when these pursuits fail, even to dig

2 Linnæi Systema, p. 67. up the graves, and fall upon the bodies interred there, devouring them, bones and all. For these reasons, the natives of the countries where the glutton inhabits, hold it in utter detestation, and usually term it the vulture of quadrupeds. And yet, it is extraordinary enough, that, being so very obnoxious to man, it does not seem to fear him. ${ }^{b}$ We are told by Gemelin of one of these coming up boldly and calmly where there were several persons at work, without testifying the smallest apprehension, or attempting to run until it had received scveral blows, that at last totally disabled it. In all probability it came among them secking its prey; and, having been used to attack animals of inferior strength, it had no idea of a force superior to its own. The glutton, like all the rest of its kind, is a solitary animal; and is never seen in company except with its female, with which it couples in the midst of winter. The latter goes with young about four months, and brings forth two or three at a time. They bunow in holes as the weasel; and the male and female are generally found together, both equally resolute in defence of their young. Upon this occasion the boldest dogs arc afraid to approach them; they fight obstinately, and bite most eruelly. However, as they are unable to escape by flight, the hunters come to the assistance of the dogs, and easily overpower them. Their flesh, it may readily be supposed, is not fit to be eaten; but the skins amply recompense the hunters for their toil and danger. The fur has the most beautiful lustre that can be imagined, and is preferred betore all others, except that of the Siberian fox, or the sable. Among other peculiarities of this animal, Linnæus informs us, that it is very difficult to be skinned: but from what cause, whether its abominable stench, or the skin's tenacity to the flesh, he has not thought fit to inform us.

\footnotetext{
b Buffon. c Linnæi System. p. 67
} 


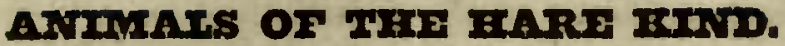

\section{$\rightarrow 00$ \\ INTRODUCTION.}

HAVING described in the last chapter a tribe of minute, fierce, rapacious animals, I come now to a race of minute animals of a more harmless and gentle kind, that, without being enemies to any, are preyed upon by all. As nature has fitted the former for liostility, so it has entirely formed the latter for evasion; and as the one kind subsist by their courage and activity, so the other find safety from their swiftness and their fears. The hare is the swiftest animal in the world for the time it continues; and few quadrupeds can overtake even the rabbit when it has but a short way to run. To this class also we may add the squirrel, somewhat resembling the hare and rabbit in its form and nature, and equally pretty, inoffensive, and pleasing.

If we were methodically to distinguish animals of the hare kind from all others, we might say that they have but two cutting teeth above and two below, that they are covered with a soft downy fur, and that they have a bushy tail. The combination of these marks might perhaps distinguish them tolerably well; whether from the rat, the beaver, the otter, or any other most nearly approaching in form. But, as I have declined all method that rather tend to embarrass history than enlighten it, I am contented to class these animals together for no very precise reason, but beeause I find a general resemblance between them in their natural habits, and in the shape of their heads and body. I call a squirrel an animal of the hare kind, because it is something like a hare. I call the paca of the same kind, merely because it is more like a rabbit than any other animal I know of. In short, it is fit to ereet some particular standard in the imagination of the reader, to refer him to some animal that he knows, in order to direct him in conceiv- ing the figure of such as he does not know. Still, however, he should be apprized that his knowledge will be defective without an examination of each particular species; and that saying an animal is of this or that particular. kind, is but a very trifling part of its history.

Animals of the hare kind, like all others that feed entirely upon vegetables, are inoffensive and timorous. As nature furnishes them with a most abundant supply, they have not that rapacity after food, remarkable in such as are often stinted in their provision. They are extremely active and amazingly swift, to which they chiefly owe their protection; for being the prey of every voracious animal, they are incessantly pursued. The hare, the rabbit, and the squirrel, are placed by Pyerius, in his Treatise of Ruminating Animals, among the number of those that chew the cud; but how far this may be true, I will not pretend to determine. Certain it is, that their lips continually move, whether sleeping or waking. Nevertheless, they ehew their meat very much before they swallow it, and for that reason I should suppose that it does not want a second mastication. All these animals use their fore-paws like hands; they are remarkably salacious, and are furnished by nature with more ample powers than most others for the business of propagation. They are so very prolific, that were they not thinned by the constant depredations made upon them by most other animals, they would quickly over-run the earth

\section{THE HARE.}

OF all these the hare is the largest, the most persecuted, and the most timorous; all 
its muscles are formed for swiftness ; and all its senses seem only given to direct its flight. It has very large prominent eyes, placed backwards in its head, so that it can almost see behind it as it runs. These are never wholly closed; but as the animal is continually upon the watch, it sleeps with them open. The ears are still more remarkable for their size; they are moveable, and capable of being directed to every quarter; so that the smallest sounds are readily received, and the animal's motions directed accordingly. The muscles of the body are very strong, and without fat, so that it may be said to carry no superfluous burden of flesh about it; the hinder feet are longer than the fore, which still adds to the rapidity of its motions; and almost all animals that are remarkable for their speed, except the horse, are formed in the same manner.

An animal so well formed for a life of escape might be supposed to enjoy a state of tolerable security; but as every rapacious creature is its enemy, it but very seldom lives out its natural term. Dogs of all kinds pursue it by instinct, and follow the hare more eagerly than any other animal. The cat and the weasel kinds are continually lying in ambush, and practising all their little arts to seize it; birds of prey are still more dangerous enemies, as against them no swiftness can avail, nor retreat secure; but man, an enemy far more powerful than all, prefers its flesh to that of other animals, and destroys greater numbers than all the rest. Thus pursued and persecuted on every side, the race would long since have been totally extirpated, did it not find a resource in its amazing fertility.

The hare multiplies exceedingly; it is in a state of engendering at a few months old; the female goes with young but thirty days, and generally brings forth three or four at a time. As soon as they have produced their young they are again ready for conception, and thus do not lose any time in continuing the breed. But they are in another respect fitted in an extraordinary manner for multiplying their kind; for the female, from the conformation of her womb, is often seen to bring forth, and yet to continue pregnant at the same time; or, in other words, to have

- Buffon, vol xiiti p. 12. young ones of different ages in her womb together. Other animals never reccive the male when pregnant, but bring forth their young at once. But it is frequently different with the hare; the female often, though already impregnated, admitting the male, and thus receiving a second impregnation. The reason of this extraordinary circumstance is, that the womb in these animals is divided in such a manner that it may be considered as a double organ, one side of which may be filled while the other remains empty. Thus these animals may be seen to couple at every period of their pregnancy, and even, while they are bringing forth young, laying the foundation of another brood.

The young of these animals are brought forth with their eyes open, and the dam suckles them for twenty days, after which they leave her, and seek out for themselves." From this we observe, that the education these animals receive is but trifling, and the family connexion but of a short duration. In the rapacious kinds the dam leads her young forth for months together; teaches them the art - of rapine; and, although she wants milk to supply them, yet keeps them under her care until they are able to hunt for themselves. But a long connexion of this kind would be very unnecessary as well as dangerous to the timid animals we are describing; their food is easily procured; and their associations, instead of protection, would only expose them to their pursuers. They seldom, however, separate far from each other, or from the place where they were produced; but make each a form at some distance, having a predilection rather for the place than each other's society. They feed during the night rather than by day, choosing the more tender blades of grass, and quenching their thirst with the dew. They live also upon roots, leaves, fruits, and corn, and prefer such plants as are furnished with a milky juice. They also strip the bark of trees during the winter, there being scarce any that they will not feed on, except the lime or the alder. They are particularly fond of birch, pinks, and parsley. When they are kept tame, they are fed with lettuce and other garden herbs; but the flesb

- Buffon, vol. xiii. p. 12. 
of such as are thus brought up is always indifferent.

They slcep or repose in their forms by day, and may be said to live only by night." It is then that they go forth to feed and couple. They do not pair, however, but in the ruttingséason, which begins in Fobruary; the inale pursues and discovers the female by the sagacity of its nose. They are then seen, by moonlight, playing, skipping, and pursuing each other; but the least motion, the slightest breeze, the falling of a leaf is sufficient to disturb their revels; they instantly fly off, and each takes a separate way.

As their limbs are made for running, they casily outstrip all other animals in the beginning; and could they preserve their speed, it would be impossible to overtake them; but as they exhaust their strength at their first efforts, and double back to the place they were started from, they are more easily taken than the fox, which is a much slower animal than they. As their hind legs are lnnger than the fore, they always choose to turn up hill, by which the speed of their pursuers is diminished, while theirs remain the same. Their nutions are also withont any noise, as they liave the sole of the foot furnished with hair; and they secin the only animals that have hair on the inside of their months.

They scldom live above seven or ejght years at the utinost ; they come to their full perfection in a year; and this multiplied by seven, as in other animals, gives the extent of theirlives. It is said, however, that the females live longer than the nuales: of this Mr. Buffon makes a doubt; but I am nssured that it is so. They pass their lives, in our climate, in solitude and silence; and they seldom are heard to cry. except when they are seized or wounded. Their voice is not so sharp as the note of some other animals, but more nearly approaching that of the squalling of a cliild. They are not so wild as their dispositions and their habits scem to indicate; but are of a complying nature, and easily susceptible of a kind of education. They are casily tamed. They even become fond and caressing, but they are incapable of attachment to any particular person, and never can be depended upon; for, thougl taken never so young, they regain their native

Buffon, vol, xiii. p. 12.

b Ibid.

No. $29 \& 30$. freedom at the first opportunity. As they have a remarkable good ear, and sit upon their hind legs, and use their fore-paws as hands, they have been taught to beat the drun, to dance to music, and go through the manual exercise.

But their natural instincts for their preservation are much more extraordinary tlan those artificial tricks that are taught them. They make thenıselves a form, particularly in those places where the colour of the grass niost resembles that of their skin; it is open to the sonth in winter, and to the north in summer. The hare, when it hears the hounds at a distance, flies for some time throngh a natural impulse, without managing its strength, or consulting any other neaus but speed for its safety. Having attained some hill or rising ground, and left the dogs so far behiud that it no longer hears their cries, it stops, rears on its hinder legs, and at length looks back to see if it has not lost its pursuers. But these, having once fallen upon the scent, pursure slowly and with united skill, and the poor animal soon again hears the fatal tidings of their approach. Sometimes when sore hunted it will start a fresh hare, and squat in the same form ; sometinses it will creep under the door of a sheepcot, and hide among the sheep; sometimes it will run anıong them, and no vigilance can drive it from the flock; some will enter holes like the rabbit, which the hunters call going to vault; some will go up one sille of the hedge and come down the other; and it has been known that a hare sorely hunted has got upon the top of a quick-set hedge, and run a good way thereon, by which it has effectially evaded the hounds. It is no unusual thing also for them to betake themselves to furze linslies, and to leap firom one to another, by which the dogs are frequently misled. However, the first doubling a hare makes is generally a key to all its future attempts of that kind, the latter being exactly like the former. The yonng hares tread heavier, and leave a stronger scent than the old, because their limbs are weaker; and the inore this forlorn creature tires, the heavier it treads, and the stronger is the scent it leaves. A buck, or male liare, is known by its choosing to run upon hard high-ways, feeding farther from the wood-sides, and making its doubling of a greater compass than the female. The male having made a turn or two about its form, frequently leads the lounds five 
or six miles on a stretch; but the female keeps close by some covert side, turns, crosses, and winds among the bushes like a rabbit, and seldom runs directly forward. In gencral, however, both male and female regulate their conduct according to the weather. In a moist day they hold by the highways more than at any other time, because the scent is then strongest upon the grass. If they come to the side of a grove or spring, they forhear to enter; but squat down by the side thereof until the hounds have overshot them; and then, turning along their former path, make to their old form, firom which they vainly hope for protection.

Hares are divided, loy the hunters, into mountain and measled hares. The former are more swift, vigorous, and have the flesin better tasted; the latter chiefly frequent the marshes, when hunted keep anong low grounds, and their flesh is moist, white, and flabby. When the male and ferralc kcep one particular spot, they will not suffer any strange hare to inake its furm in the same quarter, so that it is usually said, that the more you hunt, the more hares you shall have; for, having killed one hare, others come and take possession of its forin. Many of these animals are found to live in woods and thickets, but they are naturally fonder of the open country, and are constrained only by fear to take shelter in places that afford them neither a warm sun nor an agreeable pasture. They are, therefore, usually seen stealing out of the edges of the wood to taste the grass that grows shorter and sweeter in the open fields than under the shade of the trees; however, they seldom miss of being pursued; and every excursion is a new adventure. They are shot at by poachers; traced by thcir footsteps in the snow ; caught in springes; dogs, birds, and cats, are all combined against then; ants, snakes, and adders, drive them from their forms, especially in summer; even fleas, from which most other animals are free, persecute this poor creature; and, so valious are its enemics, that it is seldom permitted to reach cven that short term to which it is limited by nature.

The soil and climate have their influence upon this animal as well as on most others. In the countries bordering on the north pole, they bceosne white in winter, and are often seen in great troops of four or five hundred, running along the banks of the river Irtish, or the
Jenisca, and are white as the snow they tread on. They are caught in traps for the sake of their skins, which, on the spot, are sold for less than seven shillings a hundred. Their fur is well known to form a considerable article in the hat mannfacture; and wc accordingly import vast quantities of it from those countries where the hare abounds in such plenty. They are found also entirely black, but these in much less quantities than the former ; and even some have been seen with horns, though these but rarely. ${ }^{\mathrm{b}}$

The hares of the hot countries, particularly in Italy, Spain, and Barbary, are smaller than ours: those bred in the Milanese country are said to be the best in Europe. There is scarce a country where this animal is not to be found, from the torrid zone to the neighbourhood of the polar circle. The natives of Guinea knock them on the head as they cone down to the sides of the rivers to drink. They also surround the place where they are seen in numbers, and clattering a short stick, which every man carries, against that which the person next him carries, they diminish their circle gradually, till the hares are cooped up in the midst. They then altogether throw their sticks in among them, and with such deadly force, that they seldom fail of killing great numbers at a tinie. ${ }^{\text {. }}$

The flesh of this animal has been esteemed as a delicacy among some nations, and is held in detestation by others. The Jews, the ancient Britons, and the Mahometans, all considered it as an unclean animal, and religiously abstained from it. On the contrary, there are scarce any other people, however barbarous at present, that do not consider it as the most agreeable food. Fashion seems to preside and govern all the senses; what mankind at one time consider as beautiful, fragrant, or savoury, may at another time, or among other nations, be regarded as defornied, disgustful, or ill-tasted. That flesh which the ancient Romans so much adnired as to call it the food of the wise, was, among the Jews and the Druids, thought unfit to be eaten; and even the moderns, who, like the Romans, consider the flesh of this animal as a delicacy, have

a Klein. Disp. Qupdrup. p. 52. b Johnston de Quadrup. L. ii. C. 2 d Hist. Gen. des Voyages, tom. iv. p. 171. 
very different ideas as to dressing it. With us it is simply served up without inuch seasoning; but Apirius shows us the manner of dressing a hare in true Roman taste, with p rsley, rice, vinegar, cummin seed, and coriander.

\section{THE RABBIT.}

THE hare and the rabbit, though so very nearly resembling each other in form and disposition, are yet distinct kinds, as they refuse to mix with each other. Mr. Buffon bred up several of both kinds in the same place; but from being at first indifferent, they soon became enemies; and their combats were generally continued uotil one of them was disabled or destroyed. However, though these experiments were not attended with success, I am assured that nothing is more frequent than an animal bred between these two, but which, like the mule, is marked with sterility. Nay, it has been actually known that the rabbit couples with animals of a much more distant nature; and there is at present in the Museum at Brussels, a creature covered with feathers and hair, and said to be bred bctween a rabbit and a hen. The fecundity of the rabbit is still greater than that of the hare; and if we should calculate the produce from a single pair in one year, the number would be annazing. They breed seven times in a year, and bring eight young ones each time. On a supposition, therefore, that this happens regularly, at the end of four years, a couple of rabbits shall see a progeny of almost a million and a half. From hence we must justly apprehend being overstocked by their increase; but, happily for mankind, their enemies are numerous, and their nature inoffensive; so that their destruction bears a near proportion to their fertility.

But although their numbers be diminished by every beast and bird of prey, and still more by man himself, yet there is no danger of their extirpation. The hare is a poor, defenceless animal, that has nothing but its swiftness to depend on for safety ; its numbers are, therefore, every day decreasing; and in countries that are well peopled, the

- Vid. Apicii, \&c. species are so much kept under, that laws are inade for their preservation. Still, however, it is most likely that they will be at last totally destroyed; and, like the wolf or the elk in some countries, be only kept in remembrance. But it is otherwise with tlie rabbit, its fecundity being greater, and its means of safety more certain. The hare seems to have more various arts and instincts to escape its pursuers, by doubling, squatting, and winding; the rabbit has but one art of defence alone, but in that one finds safety; by making itself a hole, where it continues a great part of the day, and brceds up its young; there it continues secure from the fox, the hound, the kite, and every other enemy.

Nevertheless, though this retreat be safe and convenient, the rabbit does not seem to be naturally fond of keeping there. It loves the sunny field and the open pasture; it seems to be a chilly animal, and dislikes the coldness of its underground habitation. It is, therefore, continually out, when it does not fear disturbance; and the female often brings forth her young at a distance from the warren, in a bole, not above a foot deep at the most. There she suckles them for about a month, covering them over with moss and grass, whenever she goes to pasture, and scratching them up at her return. It has been said, indeed, that this shallow hole without the warren, is made lest the male should attack and destroy her young; but I have seen the male himself attend the young there, lead them out to feed, and conduct them back upon the return of the dam. This exterual retreat seems a kind of country house, at a distance from the general habitation; it is usually made near some spot of excellent pasture, or in the midst of a field of sprouting corn. To this both male and female often retire from the warren; lead their young by night to the food which lies so convenient, and, if not disturbed, continue there till they are grown up. There they fiud a greater variety of pasture than near the warren, which is generally eaten bare; and enjoy a warmer sun, by covering themselves up in a shallower hole. Whenever they are disturbed, they then forsake their retreat of pleasure for one of safety; they fly to the warren with their utmost speed; and if the way be short, $311 *$ 
there is scarce any dog, how swift soever, that can overtake them.

But it does not alivays happen that these animals are possessed of one of these external apartments; they most usually bring forth their young in the warren, hut always in a hole separate from the male. On these occasions, the female digs herself a hole, ${ }^{n}$ different from the ordinary one, by being more intricate; at the bottom of which she makes a more ample apartment. This done, she pulls off from her belly a good quantity of her hair, with which she makes a kind of bed for her young. During the two first days she never leaves them; and does not stir out but to procure nourishment, which she takes with the utmost despatch; in this manner suckling her young for near six weeks, until they are strong, and able to go abroad themselves. During all this tine, the male seldom visits their separate apartment; but when they are grown up, so as to come to the mouth of the hole, he then seems to acknowledge them as his offspring, lakes them between his paws, smooths their skin, and licks their eyes; all of them, one after the other, have an equal share in his caresses.

In this manner the rabbit, when wild, consults its pleasure and its safety : but those that are bred up tame, do not take the trouble of digging a hole, conscious of being already protected. It has also been observed, ${ }^{\mathrm{b}}$ that when people, to make a warren, stock it with tame rabbits, these animals, having been unaccustomed to the art of scraping a hole, continue exposed to the weather, and every other accident, without ever burrowing. Their immediate offspring also are equally regardless of their safety : and it is not till after two or three gencrations, that these animals begin to find the necessity and convenicnce of an asylum, and practise an art which they could only learn from nature.

Rabbits of the domestic breed, like all other animals that are under the protection of man, are of various colours; white, brown, black, and mouse-colour. The black are the most scarce; the brown, white, and mouse-colour, are in greater plenty. Most of the witd rabbits are of a brown, and it is the culour which prevails among the species; for in every nest of rabbits, whether the parents be black or

\footnotetext{
a Buffon. b Ibid.
}

white, there are some brown ones found of the number. But, in Fngland, there arc many warrens stocked with the mousc-colour kinds, which, some say, came originally from an island in the river Humber, and which still contiume their original colour, after a great number of successive gemerations. A gentlenian, who bred up tame rabbits for his anusement, gives the following account of their production: "I began," says he, "by having but one male and female only; the male was entirely white, and the female brown; but, in their posterity, the number of the brown by far exceeded those of any other colour: there were some white, some party-coloured, and somre black. It is surprising how much the descendants were obedient and submissive to their conumon parent; he was easily distinguished from the rest hy his superior whiteness; and, however numerous the other males were, this kept them all in subjection. Whenever they quarrelled among each other, cither for their fentales or provisions, as soon as he heard the noise he ran up to them with all despatch, and, upon his appearance, all was instantly reduced to peace and order. If he caught any of them in the fact, he instantly punished their, as an eximple to the rest. Another instance of his superiority was, that having accustomed them to come to me with the call of a whistle, the instant this signal was given, I saw him marshalling them up, leading them the foremost, and then suffering them all to file off before him."

The rabbit, though less than the liare, generally lives longer. As these animals pass the greater part of their lives in their burrow, where they continue at ease and unmolested, they have nothing to prevent the regularity of their health, or the due course of their nourishment. They are, therefore, generally found fatter than the hare; but their flesh is, notwitlstanding, much less delicate. That of the old oncs, in particular, is hard, tough, and dry; but it is said, that in warmer countries, they are better tasted. 'This nuy very well be, as the rabbit, though so very plentiful in Great Britain and Ireland, is, nevertheless, a native of the warmer clinıates: and has been originally imported into these kingroms from Spain. In that country, and in some of the islands in

c Mr. Moutier, as quoted by Mr. Buffon.

d Ibid. 
thic Mediterrancan, we are told that they once multiplied in such numbers as to prove the greatest nuisance to the natives. They at first demanded military aid to destroy them; but soon after they ealled in the assistanec of ferrets, which originally came from Africa, and these, with much more ease and expedition, contrived to lessen the calanity. In fact, rablits are found to love a warn climate, and to be incapable of bearing the cold of the north; so that in Sweden they are obliged to be littered in the houses. It is otherwise in all the tropical climates, where they are extremely common, and where they seldom burrow, as with us. The English counties that are most noted for these animals, are Lincolnshire, Norfolk, and Cambridgeshire. They delight in grounds of a sandy soil, which are warmer than those of clay ; and which also furnish a softer and finer pasture.

The tame rabbits are larger than the wild ones, from their taking more nourishment, and using less exercise; but their flesh is not so good, being more insipid and softer. In order to improve it, they are chiefly fed upon bran, and are stinted in their water ; for if indulged in too great plenty of moist food, they are apt, as the feeders express it, to grow rotten. The hair or fur is a very useful commodity, and is emplnyed in England for several purposes, as well when the skin is dressed with it on, as when it is pulled off. The skins, especially the white, are used for lining clothes, and are considered as a cheap initation of ermine. The skin of the male is usually preferred, as being the most lasting, but it is coarser; that on the belly in either sex, is the best and finest. But the clief use made of rabbit's fur, is in the manufacture of hats; it is always mixed, in certain proportions, with the fur of the beaver ; and it is said to give the latter more strength and consistence.

The Svrian rabbit, like all other animals bred in that country, is remarkable for the length of its hair; it falls along the sides in wavy wreaths, and is, in some places, curled at the end, like wool ; it is shed once a year in large masses; and it often happens that the rabbit, dragging a part of its robe on the ground, appears as if it had got another leg, or a longer tail. There are no rabbits naturally in America; however, those that have been carried from Europe, are found to multiply in the West India islands in great abundance. In other parts of that continent, they have animals that in some measure resemble the rabbits of Europe; and which most European travellers have often called hares or rabbits, as they happened to be large or small. Their giving them even the name will be a sufficient excuse for niy placing them among aninials of the hare kind; although they may differ in many of the most essential particulars. But before we go to the new continent, we will first examine such as bear even a distant resemblance to the hare kind at home.

\section{THE SQUIRREL.}

There are few readers that are not so well acquainted with the figure of a Squirrel as that of the rabbit ; but supposing it unknown to any, we might give them some idea of its form, by comparing it to a rabbit, with shorter cars, and a longer tail. The tail, indeed, is alone sufficient to distinguish it from all others, as it is extremely long, beautiful, and bushy, spreading like a fan, and which, when thrown up behind, covers the whole body. This serves the little animal for a double purpose; when erected, it serves, like an umbrella, as a secure protection from the injuries of the heat and cold; and when extended, it is very instrumental in promoting these vast leaps that the squirrel takes from tree to tree; nay, some assert that it answers still a third purpose, and when the squirrel takes to the water, which it sometimes does upon a picce of bark, that its tail serves it instead of a sail."

There are few wild animals in which therc are so many varieties as in the squirrel. The common squirrel is of the size of a small rabbit, and is rather of a more reddish brown.

The belly and breast are white; and the ears beautifully ornamented with long tufts of hair, of a deeper colour than that on the body. The eyes are large, black, and lively; the legs are sliort and muscular, like those of the rabbit; but the toes longer, and the claws sharper, so as to fit it for climbing. When it eats, or dresses itself, it sits erect, like the hare or rabbit, making use of its fore legs as hands; and chiefly resides in trees. The gray Vir-

\footnotetext{
a Klein.· Linnæus.
} 
sinian squirrel, which Mr. Buffon calls the petit gris, is larger than a rabbit, and of a grayish colour. Its body and limbs are thicker than those of the common squirrel; and its ears are shorter, and without tufts at the point. The upper part of the body, and external part of the legs, are of a fine whitish gray, with a beautiful red streak oneach side lengthways. The tail is covered with very long gray hair, variegated with black and white towards the extremity. This variety seems to be common to both continents; and in Sweden is seen to change colour in winter. The Barbary squirrel, of which Mr. Buffon makes three varieties, is of a mixed colour, between red and black. Along the sides there are white and brown lines, which render this animal very beautiful; but what still adds to its elegance is, that the belly is of a sky blue, surrounded with white. Some of these hold up the tail erect; and others throw it forward over their body. The Siberian white squirrel is of the size of a common squirrel. The Carolina black squirrel is much bigger than the former, and sometimes tipped with white at all the extremities. The Brasilian squirrel, which Mr. Buffon calls the coquallin, is a beautiful animal of this kind, and very remarkable for the variety of its colours. Its belly is of a bright yellow; its head and body variegated with white, black, brown, and orange colour. It wants the tufts at the extremity of its ears; and does not climb trees, as most of the kind are seen to do. To this list may be added the little ground squirrel of Carolina, of a reddish colour, and blackish stripes on each side; and like the former, not delighting in trees. Lastly, the squirrel of $\mathcal{N e w}_{\text {Spain, whieh is of }}$ a deep iron-gray colour, with seven longitudinal whitish streaks along the sides of the male, and five along those of the female. As for the flying squirrels, they are of a distinct kind, and shall be treated of by themselves.

These, which I suppose to be but a few of the numerous varieties of the squirrel, sufficiently serve to show how extensively this animal is diffused over all parts of the world. It is not to be supposed, bowever, that every variety is capable of sustaining every climate; for few animals are so tender, or so little able to endure a change of abode, as this. Those bred in the tropical climates, will only live near a warm sun; while, on the contrary, the squirrel of siberia will scarce endure the temperature of ours. These varieties do not only differ in their constitutions and colour, but in their dispositions also; for while some live on the tops of trees, others feed, like rabbits, on vegetables below. Whether any of these, so variously coloured, and so differently disposed, would breed among each other, we cannot tell: and since, therefore, we are left in uncertainty upon this point, we are at liberty either to consider each as distinct species by itself; or only a variety, that accident might have originally produced, and that the climate or soil might have continued. For my uwn part, as the original character of the squirrel is so strongly marked upon them all, I cannot help cotsidering them in the latter point of view; rather as the common descendants of one parent, than originally formed with such distinet similitudes.

The squirrel is a beautiful little animal;" which is but half savage; and which, from the gentleness and innocence of its manners, deserves our protection. It is neither carnivorous nor hurtful: its usual food is fruits, nuts, and acorns; it is cleanly, nimble, active, and industrious; its eyes are sparkling, and its physiognomy marked with meaning. It generally, like the hare and rabbit, sits up on its hinder legs; and uses the fore paws as hands; these have five claus or toes, as they are called, and one of them is separated from the rest like a thumb. This animal seems to approach the nature of birds, from its lightness, and surprising agility on the tops of trees. It seldom descends to the ground, except in case of storm, but jumps from one branch to another; feeds, in spring, on the buds and young shoots; in summer, on the ripening fruits; and particularly the young cones of the pine-tree. In autumn it has an extensive variety to feast upon; the acorn, the filbert, the cliesnut, and the wilding. This season of plenty, however, is not spent in idle enjoyment; the provident little animal gathers at that time its provisions for the winter; and cantiously foresees the season when the forest shall be stripped of its leaves and fruitage. Its nest is generally formed among the large

- Buffon. 
branches of a great tree, where they begin to fork of in small ones. After choosing the place where the timber begins to decay, and an hollow may the more easily be formed, the squirrel begins by making a kind of a level between the forks; and then bringing moss, twigs, and dry leaves, it binds them together with great art, so as to resist the most violent storm. This is covered up on all sides; and has but a single opening at top, which is just large enough to adinit the little animal; and this opening is itself defended from the weather by a kind of canopy, made in the fashion of a cone, so that it throws off the rain, though never so heavy. The nest thus formed, with a very little opening above, is, nevertheless, very commodious and roomy below; soft, well knit together, and every way convenient and warm. In this retreat the little animal brings forth its young, shelters itself from the scorching heat of the sun, which it seems to fear, and from the storms and inclemency of winter, which it is still less capable of supporting. Its provision of nuts and acorns is seldom in its nest, but in the hollows of the tree, laid up carefully together, and never touched but in cases of necessity. Thus one single tree serves for a retreat and a store-house; and without leaving it during the winter, the squirrel possesses all those enjoyments that its nature is capable of receiving. But it sometimes happens that its little mansion is attacked by a deadly and powerful foe. The martin goes often in quest of a retreat for its young, which it is incapable of making for itself; for this reason it fixes upon the nest of a squirrel, and, with double injustice, destroys the tenant, and then takes possession of the mansion.

However, this is a calamity that but seldom happens: and, of all other animals, the squirrel leads the most frolicsome, playful life, being surrounded with abundance, and having few enemies to fear. They are in heat early in the spring; when, as a modern naturalist says," it is very diverting to see the female feigning an escape from the pursuit of two or three inales, and to observe the various proofs which they give of their agility, which is then exerted in full force. Nature seems to have

- British Zoology. been particular in her formation of these animals for propagation: however, they seldom bring forth above four or five young at a time; and that but once a year. The time of their gestation seems to be about six weeks; they are pregnant in the beginning of April, and bring forth about the middle of May.

The squirrel is never found in the open fields, nor yet in copses or underwoods; it always keeps in the midst of the tallest trees, and, as much as possible, shuns the habitations of men. It is extremely watchful; if the tree in which it resides be but touched at the bottom, the squirrel instantly takes the alarm, quits its nest, at once flies off to another tree, and thus travels, with great ease, along the tops of the forest, until it finds itself perfectly out of danger. In this manner it continues for some hours at a distance from home, until the alarm be past away; and then it returns, by paths, that to all quadrupeds but itself, are utterly impassable. Its usual way of moving is by bounds; these it takes from one tree to another, at forty feet distance; and if at any time it is obliged to descend, it runs up the side of the next tree with amazing facility. It has an extremely sharp piercing note, which most usually expresses pain; it has another, more like the purring of a cat, which it employs when pleased; at least it appeared so in that from whence I have taken a part of this description.

In Lapland, and the extensive forests to the north, the squirrels are observed to change their habitation, and to remove in vast numbers from one country to another. In these migrations they are generally seen by thousands, travelling directly forward; while neither rocks, forests, nor even the broadest waters can stop their progress. What I am going to relate, appears so extraordinary, that were it not attested by numbers of the most credible historians, among whom are Klein and Linnæus, it might be rejected, with that scorn with which we treat imposture or credulity: however, nothing can be more true than, that when these animals, in their progress, meet with broad rivers, or extensive lakes, which abound in Lapland, they take a very extraordinary method of crossing them. Up. on approaching the banks, and perceiving the breadth of the water, they return, as if by com- 
mon consent, into the neighbouring forest, each in quest of a piece of bark, which answers all the purposes of boats for wafting them over. When the whole company are fitted in this manner, they boldly commit their little fleet to the waves; every squirrel sitting on its own piece of bark, and fanning the air with its tail, to drive the vessel to its desired port. In this orderly manner they set forward, and often cross lakes several miles broad. But it too often happens that the poor mariners are not aware of the dangers of their navigation; for although at the edge of the water it is generally calm, in the midst it is always more turbulent. There the slightest additional gust of wind oversets the little sailor and his vessel together. The whole navy, that but a few minutes before rode proudly and sccurely along, is now overturned, and a shipwreck of two or threc thousand sail ensues. This, which is so unfortunate for the little animal, is generally the most lucky accident in the world for the Laplander on the shore; who gathers up the dead bodies as they are thrown in by the waves, eats the flesh, and sells the skins for about a shilling the dozen."

The squirrel is easily tamed, and it is then a very familiar animal. It loves to lie warn, and will often creep into a man's pocket or his bosom. It is usually kept in a box, and fed with hazel nuts. Some find amusement in observing with what ease it bites the nut open and eats the kernel. In short, it is a pleasing pretty little domestic; and its tricks and habjtudes may serve to entertain a mind unequal to stronger operations.

\section{THE FLYING SQUIRREL.}

Mr. RAY was justly of opinion that the Flying Squirrel might more properly be said to be of the rat kind, because its fur is shorter than in other squirrels, and its colours also more nearly approach the former. However, as mankind have been content to class it among the squirrels, it is scarcely worth making a new distinction in its favour. This little animal, which is frequently brought over to England, is less than a common squirrel and bigger than a field mouse. Its skin is very

a Oeuvres de Regnard. soft, and elegantly adorned with a dark fur in some places, and light gray in others. It has large prominent black and very spark ling eyes, sunall ears, and very sharp teeth, with which it gnaws any thing quickly. When it does not leap, its tail, which is pretty enough, lies close to its back; but when it takes its spring, the tail is moved backwards and forwards from side to side. It is said to partake somewhat of the nature of the squirrel, of the rat, and of the dormouse; but that in which it is distinguished from all other animals, is its peculiar conformation for taking those leaps that almost look like flying. It is, indeed, anazing to see it at one bound dart above a liundred yards from one tree to another. They are assisted in this spring by a very pcculiar formation of the skin that extends from the fore-feet to the hinder; so that when the animal stretches its fore-legs forward and its hind-legs backward, this skin is spread out between them, somewhat like that between the legs of a bat. The surface of the body being thus increased, the little animal kec.ps buoyant in the air until the force of its first in pulsion is $\mathrm{ex}$ pired, and then it clescends. This skin, when the creature is at rest, or walking, comtinues wrinkled upon its sides; but when jts limbs are extended, it forms a kind of web between them of above an inch broad on cither side, and gives the whole body the appearance of a skin floating in the air. In this manner the flying squirrel changes place, not like a bird, by repeated strokes of its wings, but rather like a paper kite, supported by the expansion of the surface of its body; but with this difference, however, that, being natnrally heavier than the air, instead of mounting it descends ; and that jump, which upon the ground would not be above forty yards, wheri from a higher tree to a lower nay be above a hundred.

This little animal is morc common in America than in Europe, but not very commonly to be seen in either. It is lisually found, like the squirrel, on the tops of trees; but, though better fitted for leaping, it is of a more torpil disposition, and is sclion seen to exert its powers; so that it is ofien seized by the polecat and the martin. It is easily tamed, but apt to bicak away. whenever it finds an opportunity. It does not seem fond of nuts or alnonds, like other squirrels, but is chiefly pleased with the sprouts of the birch, and the 
cones of the pinc. It is fed in its tame state with bread and fruits; it generally slecps by day, and is always most active by niglit. Some naturalists gravely caution us not to let it get among our corn fields, where, they tell us, it will do a great deal of damage, by cropping the corn as soon as it begins to ear!

\section{THE MARMOUT.}

Fron the description of the squirrel and its varieties, we proceed to a different tribe of animals, no way indeed resembling the squirrel, but still something like the rablit aud the hare. We are to keep these two animals still in view as the centre of our comparison; as ohjects to which many others may bear some similitude, tbough they but little appioach each other. Among the hare kind is the Marmout, which naturalists have placed either among the loare kind or the rat kind, as it suited their respective systems. In fact, it bears no great resemblance to either; but of the two it approaches much nearer the hare, as well in the make of its head as in its size, in its bushy tail, and particularly in its chewing the cud, which alone is sufficient to determine our choice in giving it its present situation. How it ever came to be degraded into the rat or mouse I cannot conceive, for it no way resembles them in size, being near as big as a hare; or in its disposition, since no animal is more tractable nor more easily tamed.

The marmout is, as was said, almost as big as a hare, lut it is more corpulent than a cat, and has shorter legs. Its head pretty nearly resembles that of a hare, except that its ears are much shorter. It is clothed all over with very long hair, and a shorter fur below. These are of different colours, black and gray. The length of the hair gives the body the appearance of greater corpulence than it really has, and at the same time shorteus the feet, so that its belly seems touching the ground. Its tail is tufted and well furnished with hair, and it is carried in a straight direction with its body. It has five claws behind, and only four before. These it uses, as the squirrel does, to carry its food to its mouth; and it usually sits upon its

a He may easily be made tame; but he is apt to do a greatdeal of dainage in the corn fields, because he will crop the corn as soon as it begins to ear. Brooke's NAT. HIST. งo. $31 \& 32$. hinder parts to feed, in manner of that little animal.

The marmout is chiefly a native of the Alps ; and when taken young is tamed more ensily than any other wild animal, and almost as perfectly as any of those that are domestic.' It is readily taught to dance, to wicld a curlgel, and to obey the voice of its naster. L like the cat, it has an antipathy to the $\log$; and when it becomes familial to the family, and is sure of being supported by its master, it attacks and bites even the largest mastiff. From its squat, miscular make, it has great strength joined to great agility. It has four large cutting teeth, like all those of the hare kind, but it uses them to much more advantage, since in this animal they are very formidable weapons of defence. However, it is in general a very inoffensive animal; and, except its enmity to dogs, seems to live in friendship with every creaturc, unless when provoked. If not prevented, it is very apt to gnaw the furniture of a housc, and even to make holes through sooden partitions; from whence, perhaps, it has been compared to the rat. As its legs arr: very short, and made somewhat like those of a bear, it is often seen sitting up, and even walking on its hind legs in like manner; but with the fore-paws, as was said, it uses to feed itself in the manner of a squirrel. Like all of the hare kind, it runs much swifter up hill than down; it climbs trees with great ease, and runs up the clifts of rocks or the contiguous walls of houses with great facility. It is ludicrously said that the Savoyards, who are the only chimney-swecpers of Paris, have learned this art from the marmout, wlich is bred in the same country.

These animals eat indiscriminately of whatever is presented to them ; flesh, bread, fruits, herbs, roots, pulse, and insects. But they are particularly fond of milk and tutter. Although less inclined to petty thefts than the cat, yet they always try to steal into the dairy, where they lap up the milk like a cat, purring all the while like that animal, as an expression of their being pleased. As to the rest, milk is the only liquor they like. They seldom drink water, and refuse wine. When pleased or caressed, they often yelp like puppies; but

b Buffon, from whence the remainder of this description is taken. N. B. He takes it from Gesner, vol xvii. 
when irritated or frighted, they have a piercing note that hurts the hear. They are very cleanly animals, and like the cat retire upon nec:essary occa sions; but their bodies have a disagrecable scent, particularly in the heat of summer. This tinctures their flesh, which, being very fat and firm, would be very good, were not this flavour always found to predominate.

We have hitherto been describing affections in this animal which it has in common with many others; but we now come to one which particularly distinguishes it from all others of this kind, and, indeed, from every other quadruped, except the bat and the dormouse: this is its sleeping during the winter. The marmout, though a native of the highest mountains, and where the snow is never wholly melted, nevertheless seems to feel the influence of the cold more than any other, and in a manner has all its faculties chilled up in winter. This extraordinary suspension of life and motion for more than half the year, deserves our wonder, and excites our attention to consider the manner of such a temporary death, and the subsequent revival. But first to describe, before we attempt to discuss.

The marmout, usually at the end of September, or the beginning of October, prepares to fit up its habitation for the winter, from which it is never seen to issue till about the beginning or the middle of A pril. This animal's little retreat is made with great precaution, and fitted up with art. It is a hole on the side of a mountain, extremely deep, with a spacious apartment at the bottom, which is rather longer than it is broad. In this several marmouts can reside at the same time, without crowding each other, or injuring the air they breathe. The feet and claws of this animal seem made for digging; and, in fact, they burrow into the ground with amazing facility, scraping up the carth like a rabbit, and throwing back what they have thus loosened behind them. But the form of their hole is still more wonderful; it resembles the letter $\mathbf{Y}$; the two branches being two openings, which conduct into one channel and terminates in their general a partment that lies at the bottom. As the whole is made on the declivity of a mountain, there is no part of it on a level but the apartment at the end. One of the branches or openings issues out, sloping downwards; and this serves as a kind of sink or drain to the whole family, where they nake their excrements, and where the moisture of the place is drawn away. The other branch, on the contrary, slopes upwards, and this serves as their door upon which to go out and in. 'The apartment at the end is very warmly stuccoed round with moss and hay, of both which they make an ample provision during the summer. As this is a work of great labour, so it is undertaken in common; some cut the finest grass, others gather it, and others take their turns to drag it into their loole. Upon this occasion, as we are told, one of them lies on its back, permits the hay to be heaped upon its belly, keeps its paws upright to make greater room; and in this manner, laying still upon its back, it is dragged by the tail, hay and all, to their common retreat. This also some give as a reason for the hair being generally worn away on their backs, as is usually the case; however, a better reason for this may be assigned, for their continually rooting up holes, and passing through narrow openings. But, be this as it will, certain it is that they all live together, and work in common to make their habitation as suug and convenient as possible. In it they pass three parts of their lives; into it they retire when the storm is high; in it they continue while it rains; there they remain when apprehensive of danger, and never stir out except in fine weather, never going far from home even then. Whenerer they venture abroad, one is placed as a sentinel, sitting upon a lofty rock, while the rest amuse. themselves in playing along the green fields, are employed in cutting grass and making hay for their winter's convenience. Their trusty sentinel, when an enemy, a man, a dog, or a bird of prey approaches, apprizes its companions with a whistle, upon which they all make home, the sentinel limself bringing up the rear.

But it must not be supposed that this hay is designed for provision; on the contrary, it is always found in as great plenty in their holes at the end as at the beginning of winter; it is only sought for the convenience of their lodging, and the advantages of their young. As to provision, they seem kindly 
apprized by nature that during the winter they shall not want any, so that they make no preparations for food, though so diligently cmployed in fitting up their abode. As soon as they perceive the first approaches of the winter, during which their vital motions are to continue in some measure suspended, they labour very diligently to close up the two entrances of their habitation, which they effect with such solidity, that it is easier to dig up the earth any where else than where they have closed it. At that time they are very fat, and some of them are found to weigh above twenty pounds; they continue so for even three months more; but by degrees their flesh begins to waste, and they are usually very lean by the end of winter. When their refreat is opened, the whole family is then discovered, each rolled into a ball, and corered up under the hay. In this state they scem entirely lifeless; they may be taken away, and even killed without their testifying any great pain; and those who find them in this manner, carry them home in order to breed up the young and eat the old ones. A gradual and gentle warmth revives them; but they would die if too suddenly brought near the fire, or if their juices were too quickly liquefied.

Strictly speaking, says Mr. Buffon, these animals cannot be said to sleep during the winter; it may be called rather a torpor, a stagnation of all the faculties." This torpor is produced by the congelation of their blood, which is naturally much colder than that of all other quadrupeds. The isual heat of man and other animals is about thirty degrees above congelation; the heat of these is. not above ten degrees. Their interual heat is seldom greater than that of the temperature of the air. This has been often tried by plunging the ball of the thermometer into the body of a living dormouse, and it never rose beyond its usual pitch in air, and sometimes it sunk above a degree. It is not surprising, therefore, that these animals, whose blood is so cold naturally, should become torpid, when the external cold is too powerful for the small quantity of heat in their bodies, yet remaining; and this always happens when the ther-

aufon, vol. xvi. Loirs. mometer is not more than ten degrees above congelation. This coldness $\mathrm{Mr}$. Buffon has experienced in the blood of the bat, the dormouse, and the hedgehog, and with great justice he extends the analogy to the marmout, which, like the rest, is seen to sleep all the winter. This torpid state continues as long as the cause which produces it continues; and it is very probable that it might be lengthened out beyond its usual term, by artificially prolonging the cold; if, for instance, the animal were rolled up in wool, and placed in a cold cellar, nearly approaching to, but not quite so cold as an ice-house, for that would kill them outright, it would remain perhaps a whole year in its state of insensibility. However this be, if the heat of the air be above ten degrees, these animals are seen to revive; and, if it be continued in that degrec of temperature, they do not become torpid, but eat and sleep at proper intervals like all other quadrupeds whatever.

From the above account we may form some conception of the state in which these animals continue during the winter. As in some disorders where the circulation is extremely languid, the appetite is diminished in proportion, so in these the blood scarcely moving, or only moving in the greater vessels, they want no nourishment to repair what is worn away by its motions. They are seen, indeed, by slow degrees to become leaner in proportion to the slow attrition of their fluids; but this is not perceptible, except at the end of some months. Man is often known to gather nourishment from the ambient air; and these also inay in some measure be supplied in the same manner; and, having sufficient motion in their fluids to keep them from putrefaction, and just sufficient nourishment to supply the waste of their languid circulation, they continue ra ther feebly alive than sleeping.

These animals produce but once a year, and usually bring forth but three or four at a time. They grow very fast, and the extent of their lives is not above nine or ten years; so that the species is neither numerous nor very much diffused. They are chiefly found in the Alps, where they scem to prefer the brow of the highest mountains to the lowest ranges, and the sunny side to that in the shade. The inhabitants of the country where they 
chiefly reside, when they observe the hole, generally stay till winter before they think proper to open it; for if they begin too soon, the animal wakes, and as it has a surprising faculty of digging, makes its hole deeper in proportion as they follow. Such as kill it for food, use every art to improve the flesh, which is said to have a wild taste, and to cause vomitings." They, therefore, take away the fat, which is in great abundance, and salt the remainder, drying it somewhat in the manner of bacoll. Still, however, it is said to be very indifferent eating. This animal is fomnd in Poland under the denomination of the boback, entirely resembling that of the Alps, except that the latter has a toe more upon its forefoot than the former. It is found also in Siberia under the name of the jevraska, being rather smaller than either of the other two. Lastly, it is found in Canada by the appellation of the monax, differing only from the rest in having a bluish snout and a longer tail.

\section{TIE AGOUTI.}

Fros the marmost, which differs from the hare so much in the lengtlı of its fur, we go to the Agouti, another species equally differing in the shortness of its hair. These bear somc rude resemblance to the hare and the rabbit in their form and nıanner of living, but sufficiently differing to require a particular description. The first of these, and that the largest, as was hinted above, is called the agouti. This animal is found in great abundance in the southern parts of America, and has by some been called the rabbit of that continent. But, though in many respects it rescmbles the rabbit, yet still in many more it differs, and is, without all doubt, an animal peculiar to the new world only. The agouti is about the size of a rabbit, and has a head very much resembling it, except that the ears are very short in comparison. It resembles the rabbit also in the arched form of its back, in the hind legs being longer than the fore, and in having four great cutting teeth, two above and two below; but then it differs in the nature of its hair, which is not soft and downy as in the rabbit, but hard and bristly like that of a sucking pig, and of a reddish

a Dictionaire Raisonee, vol iii. p. 29. brown colour. It differs also in the tail, which is even shorter than in the rabbit, and entirely destitute of hair. Lastly, it differs in the number of its toes, having but three on the hinder feet, whereas the rabbit has five. All these distinctions, however, do not countervail against its general form, which resembles that of a rabbit, and most travellers have called it by that name.

As this aninal differs in form, it differs still more in habitudes and disposition. As it has the hair of a hog, so also it has its voraciousness. $^{b}$ It eats indiscriminately of all things; and, when satiated, hides the remainder, like the dog or the fox, for a future occasion. It takes a pleasure in gnawing and spoiling every thing it comes near. When irritated, its hair stands erect along the back, and, like the rabbit, it strikes the ground violently with its hind feet. It does not dig a hole in the ground, but burrows in the hollows of trees. Its ordinary food consists of the roots of the country, potatoes and yams, and such fruits as fall from the trees in autumn. It uses its forepaws, like the squirrel, to carry its food to its mouth: and as its hind feet are longer than the fore, it runs very swiftly upon plain ground or up a hill, but upon a descent it is in danger of falling. Its sight is excellent, and its hearing equals that of any other animal; whenever it is whistled to, it stops to hearken. The flesh of such as are fat and well fed is tolerable food, although it has a peculiar taste, and is a little tough. The French dress it like a sucking pig, as we learn from Mr. Buffon's account; but the English dress it with a pudding in its belly, like a hare. It is hunted by dogs; and whenever it has got into a sugar-ground, where the canes cover the place, it is easily overtaken, for it is embarrassed every step it takes, so that a man may easily conıe up with it without any other assistance. When in the open country, it usually runs with great swiftness before the dogs until it gains its retreat, within which it continues to hide, and nothing but filling the hole with snoke can force it out. For this purpose, the hunter burns faggots or straw at the entrance, and conducts the smoke in such a manuer that it fills the whole cavity. While this is doing, the poor little animal seems sensible of its danger, and begs for quarter

b Buffon. 
with a most plaintive cry, seldom quitting its hole till the uttnost extremity. At last, when half suffocated, it issues out, and trusts once more to its speed for protection. When still forced by the dogs, and incapable of making good a retreat, it turns upon the liunters, and with its hair bristling like a hog, and stauding upon its hind feet, it defends itself very obstinately. Sometines it bites the legs of those that attempt to take it, and will take out the piece wherever it fixes its tecth. ${ }^{\mathrm{n}}$

Its cry when disturbed or provoked resembles that of a sucking pig. If taken young, it is casily tamed, contiuues to play harmlessly about the house, and goes out and returns of its own accord. In a savage state it usually continues in the woods, and the fimale generally chooses the most obscure parts to bring forth her young. She there prepares a bed of leaves and dry grass, and generally brings forth two at a time. She breeds twice or thrice a year, and carries her young from one place to another, as convenience requires, in the manner of a cat. She generally lodges them, when three days old, in the hollow of a trec, suckling them but a very short time, for they soon come to perfection, and it sliould consequently follow that they soon grow old.

\section{THE PACA.}

THe Paca is an animal also of South America, very much resembling the former, and like it has received the name of the American rabbit, but with as little propriety. It is about the size of a hare, or rather larger, and in figure somewhat like a sucking pig, which it also resembles in its grunting and its manner of eating. It is, however, most like the agouti, although it differs in several particulars. Like the agouti, it is covered rather with coarse hair than a downy fur. But then it is beautifully marked along the sides with small ashcoloured spots, upon an amber coloured ground; whereas the agouti is pretty much of one reddish colour. The paca is rather more tlick and corpulent than the agouti; its nose is shorter, and its hind feet have five toes; whereas the agouti has but three. As to the rest, this animal bears some distant resem-

a Ray's Synop. blance to a rabbit, the ears are naked of hair, and somewhat sharp, the lower jaw is somewhat longer than the upper, the teeth, the shape of the head, and the size of it, are like to those of a rabbit. It has a short tail likewise, though not tufted; and its hinder legs are longer than the fore. It also burrows in the ground like that animal, and from this similitude alone travellers might have given it the name.

The paca does not make use of its forepaws, like the squirrel or the agouti, to carry its food to the inouth, but hunts for it on the ground, and roots like a hog. It is generally seen along the banks of rivers, and is only to be found in the moist and warm countries of South America. It is a very fat animal, and in this respect much preferable to the agouti, that is most cummonly found lean. It is eaten skin and all, like a young pig, and is considered as a great delicacy. Like the former little animal, it defends itself to the last extremity, and is very seldom taken alive. It is persecuted not only by man, but by every beast and bird of prey, who all watch its motions, and, if it ventures at any distance from its hole, are sure to seize it. But although the race of these little animals is thus continually destroyed, it finds some refuge in its hole, from the general combination; and breeds in such numbers, that the diminution is not perceptible.

To these animals may be added others, very similar, both in form and disposition; each known by its particular name in its native country, but which travellers have been contented to call rabbits or hares; of which we have but indistinct notice. The TAPETI, or the BRASILIAN RABBIT, is in shape like our English ones, but is much less, betng said to be not above twice the size of a dornıouse. It is reddish on the forehead, and a little whitish under the throat. It is remarkable for having 110 tail; but it has long ears and whiskers, like our rabbits, and black eyes. It does not burrow, like ours; but lives at large like the hare.

The APEREA is also called by some the BrASILIAN RABBIT, being an animal that seems to partake of the nature of a rabbit and a rat. The ears are like those of a rat, being short and round; but the other parts are like those of a rabbit, except that it has but three toes on the hinder legs like the agouti.

To these imperfect sketches of animals little 
known, others less known might be added; for as nature becomes more diminutive, her operations are less attentively regarded. I shall only, therefore, add one animal more to this class, and that very well known; I mean the Guinea-pig; which Brisson places among those of the rabbit kind; and as I do not know any other set of animals with which it can be so well compared, I will take leave to follow his example.

\section{THE GUINE A.PIG.}

ThE Guinea-pig is a native of the warmer climates; but has been so long rendered domestic, and so widely diffused, that it has now become common in every part of the world. There are few unacquainted with the figure of this. little animal ; in some places it is considered as the principal favourite; and is often found even to displace the lap-dog. It is less than a rabbit, and its legs are shorter; they are scarce seen, except when it moves; and the neck also is so short, that the head seems stuck upon the shoulders. The ears are short, thin, and transparent; the hair is like that of a sucking-pig, from whence it has taken the name; and it wants even the vestiges of a tail. In other respects, it has some similitude to the rabbit. When it moves, its body lengthens like that animal; and when it is at rest, it gathers op in the same manner. Its nose is formed with the rabbit lip, except that its nostrils are much farther asunder. Like all other animals in a domestic state, its colours are different; some are white, some are red, and others both red and white. It differs from the rabbit in the number of its toes, having four toes on the feet before, and but three on those behind. It strokes its head with the fore feet, like the rabbit; and, like it, sits upon the hind feet; for which purpose there is a naked callous skin on the back part of the legs and fect.

These animals are, of all others, the most helpless and inoffensive. ${ }^{n}$ They are scarce possessed of courage sufficient to defend themselves against the meanest of all quadrupeds,

- This history is partly taken from the Amænitates Academicer, vol. iv. p. 202. a mouse. Their only animosity is exerted against each other; for they will =ften fight very obstinately; and the stronger is often known to destroy the weaker. But against all other aggressors, their only remedy is patience and non-resistance. How, therefore, these animals in a savage state could contrive to protect themselves, I have not been able to learn; as they want strength, swiftness, and even the natural instinet so common to almost every other creature.

As to their manner of living among us, they owe their lives entirely to our unceasing protection. They must be constantly attended, shielded from the excessive colds of the winter, and secured against all other domestic animals, which are apt to attack them, from every motive, either of appetite, jealousy, or expericnce of their pusillanimous nature. Such, indeed, is their stupidity, that they suffer themselves to be devoured by the cats without resistance; and, differing from all other creatures, the female sees her young destroyed without once attempting to protect them. Their usual food is bran, parsley, or cabbage leaves; but there is scarce a vegetable cultivated in our gardens that they will not gladly devour. The carrot top is a pecnliar dainty; as also salad; and those who would preserve their healths, would do right to vary their food; for if they be continued on a kind too succulent or too dry, the effects are quickly perceived upon their constitutions. When fed upon recent vegetables, they seldom drink. But it often happens that, conlucted by nature, they seek drier food, when the former disagrees with them. They then gnaw clothes, paper, or whatever of this kind they ineet with; and on these occasions they are seen to drink like most other animals, which they do by lapping. They are chiefly fond of new milk; but in case of necessily, are content with water.

They move pretty much in the manner of rabbits, though not near so swiftly; and when confined in a room, seldom cross the floor, but generally keep along the wall. The male usually drives the female on before him, for they never move a-breast together, but constantly the one seems to tread in the footsteps of the preceding. They chiefly seek for the darkest recesses, and the most intri- 
cate retreats; where, if hay be spread as a bed for them, they continue to sleep together, and seldom venture out but when they suppose all interruption removed. On these occasions they act as rabbits; they swiftly move forward from their bed, stop at the entrance, listen, look round, and if they perceive the slightest approach of dauger, they run back with precipitation. In very cold weather, however, they are more active, and run about in order to keep themselves warm.

They are a very cleanly animal, and very different from those whose name they go by. If the young oncs happen to fall into the dirt, or be any other way discomposed, the feinale takes such an aversion to thein, that she never permits them to visit her more. Indeed, her whole employment, as well as that of the male, seems to consist in smoothing their skins, in disposing their hair, and improving its gloss. The male and female takes this oflice by turns; and when they have thus brushed up each other, they then bestow all their eoncern upon their young, taking particular care to make their hair lie smooth, and biting them if they appear refractory. As they are so solicitous for elegance themselves, the place where they are kept must be regularly cleaned, and a new bed of hay provided for them at least every wcek. Being natives of a warm climate, they are naturally chilly in ours; cleanliness, therefore, assists warmth, and expels moisture. They may be thus reared, without the aid of any artificial heat; but, in general, there is no keeping them from the fire in winter, if they be once perinitted to approach it.

When they go to sleep, they lie flat on their bellies, pretty much in their usual posture; except that they love to have their fore feet higher than their hinder. For this purpose they turn theinselves several times round before they lie down, to find the most convenient situation. They sleep like the hare, with their eyes half open; and continue extremely watcliful, if they suspect danger. The male and female are never seen both aslcep at the same time; but while he enjoys his repose, she remains upon the watch, silently continuing to guard him, and her head turned towards the place where he lies. When she supposes that he has had his turn, she then awakes him with a kind of murmur- ing noise, goes to him, forces him from his bed, and lies down in his place. He then performs the same good turn for her; and continues watehful till she also has done slecping.

These animals are exceedingly salacious. and generally are capable of coupling at six weeks old. 'The feinale never goes with young above five weeks; and usually brings forth from three to five at a time; and this not without pain. But what is very extraordinary, the female admits the male the very day she has brought forth, and beeomes again pregnant; so that their multiplication is astonishing. She suekles her young but about twelve or fifteen days; and during that time does not seem to know her own; for if the young of any other be brought, though much older, she never drives them away, but suffers them even to drain her, to the disadvantage of her own immediate offspring. 'They are produced with the eyes open, like all others of the hare kind; and in about twelve hours, equal even to the dam in agility. Although the dam has but two teats, yet she abundantly supplies them with milk; and they are also capable of feeding upon vegetables, almost from the very beginning. If the young ones are permitted to continue together, the stronger, as in all other societies, soon begins to govern the weak. Their contentions are often long and obstinate; and their jealousies very apparent. Their disputes are usually for the warmest place, or the most agreeable food. If one of them happens to be more fortunate in this respect than the rest, the strongest generally comes to dispossess it of its advantageons situation. Their manner of figliting, though terrible to them, is ridiculous enough to a spectator. One of them seizes the lair on the nape of the other's neek with its fore teeth, and attempts to tear it away; the other, to retaliate, turns its hinder parts to the eneiny, and kicks up behind like a horse, and with its hinder claws scratches the sides of its adversary; so that sometimes they cover each other with blood. When they contend in this manner, they gnash their teeth pretty loudly, and this is often a denunciation of mutual resentment.

These, though so formidable to each other, yet are the most timorous creatures upon earth, 
with respect to the rest of Animated Nature: a falling leaf disturbs them, and every animal overcomes them. From hence they are difficultly tamed; and will suffer none to approach them, except the person by whom they are fed. Their manner of eating is something like that of the rabbit; and, like it, they appear also to chew the cud. Although they seldom drink, they make water every minute. They grunt somewhat like a young pig; and have a more piercing note to express pain. In a word, they do no injury; but then, cxcent the plea- sure they afford the spectator, they are of very little benefit to mankind. Some, indeed, dress and eat them; but their flesh is indifferent food, and by no means a reward for the trouble of rearing them. This, perhaps, might be improved, by keeping them in a proper warren, and not suffering them to become domestic: however, the advantages that would result from this, would be few, and the trouble great; so that it is likely they would continue an useless, inoffensive dependent, rather propagated to satisfy caprice than to supply necessity. 


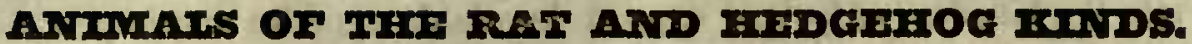

\section{CHAP'TER LIII.}

\section{THE RAT KIND.}

WERE it necessary to distinguish animals of the rat kind from all others, we might describe them as having two large cutting teeth, like the hare kind, in each jaw ; as covered with hair; and as not ruminating. These distinctions might serve to guide us, had. we not too near an acquaintance with this noxious race to be inistaken in their kind. Their numbers, their minuteness, their vicinity, their vast multiplication, all sufficiently contribute to press them uponour observation, and remind us of their existence. Indecd, if we look through the different ranks of animals, from the largest to the smallest, from the great elephant to the diminutive mouse, we shall find that we suffer greater injuries from the contemptible meanness of the one, than the formidable invasions of the other. Against the elephant, the rhinoceros, or the lion; we can oppose united strength; and by art make. up the deficiencies of natural power: these we have driven into their native solitudes, and obliged to continue at a distance, in the most inconvenient regions and unhealthful climates. But it is otherwise with the little teasing race I am now describing; no force can be exerted against their unresisting timidity ; no arts can diminish their amazing propagation; millions may be at once destroyed, and yet the breach be repaired in the space of a very few weeks; and, in proportion as nature has denied them force, it has supplied the defect by their fecundity.

\section{TIE GREAT RAT.}

THE animal best known at present, and in every respect the most mischievous, is the кo. 31 \& 32.
Great $R_{A T}$; which, though but a new comer into this country, has taken too secure a possession to be ever removed. This hateful and rapacious creature, though sometimes called the rat of Norway, is utterly unknown in all the northern countries, and, by the best accounts I can learn, comes originally from the Levant. Its first arrival, as I am assured, was upon the coasts of Ireland, in those ships that traded in provisions to Gibraltar; and perhaps we owe to a single pair of these animals, the numerous progeny that now infests the whole extent of the British Empire.

This animal, which is called by Mr. Buffon the surmalot, is in length about nine inches; its eyes are large and black; the colour of the head, and the whole upper part of the body, is of a light brown, mixed with a tawny and ash colour. The end of the nose, the throat, and belly, are of a dirty white, inclining to gray; the feet and legs are almost bare, and of a dirty pale flesh colour; the tail is as long as the body, covered with minute dusky scales mixed with a few hairs, and adds to the general deformity of its detestable figure. It is chiefly in the colour that this animal differs from the black rat, or the common rat, as it was once called : but now common no longer. This new invader, in a very few years after its arrival, found means to destroy almost the whole species, and to possess itself of their retreats.

But it was not against the black rat alone that its rapacity was directed; all other animals of inferior strength shared the same misfortunes. The contest with the black rat was of short continuance. As it was unable to contend, and had no holes to fly to for retreat, but where its voracious enemy could pursue, 
the whole race was soon extinguished. The frog also was an animal equally incapable of combat or defence. It had been designedly introduced into the kingdom of Ireland some years before the Norway rat; and it was seen to multiply amazingly. The inhabitants were pleased with the propagation of a harmless animal, that served to rid their fields of insects; and even the prejudices of the people were in its favour, as they supposed that the frog contributed to render their waters more wholesome. But the Norway rat soon put a stop to their increase; as these animals were of an amphibious nature, they pursued the frog to its lakes, and took it even in its own natural element. I am, therefore, assured, that the frog is once more almost extinct in that kingdom; and that the Norway rat, having no more enemies left there to destroy, is grown less numerous also.

We are not likely, therefore, to gain by the destruction of our old domestics, since they are replaced by such mischievous successors. The Norway rat has the same disposition to to injure us, with much greater power of mischief. It burrows in the banks of rivers, ponds, and ditches; and is every year known to do incredible damage to those mounds that are raised to conduct streams, or to prevent rivers from overflowing. In these holes, which it forms pretty near the edge of the water, it chiefly resides during the summer, where it lives upon smakl animals, fish, and corn. At the approach of winter, it comes nearer the farm houses; burrows in their corn, eats much, and damages still more than it consumes. But nothing that can be eaten seems to escape its voracity: It destroys rabbits, poultry, and all kinds of game; and, like the pole-cat, kills much more than it can carry away. It swims with great ease, dives with great celerity, and easily thins the fishpond. In short, scarce any of the feebler animals escape its rapacity, except the mouse, which shelters jtself in its little hole, where the Norway rat is too big to follow.

These animals frequently produce from fifteen to thirty at a time; ${ }^{\mathrm{a}}$ and usually briug forth three times a year. This great increase would quickly be found to over-run the whole

- Buffon, vol. xvii. p. 2. country, and render our assiduity to destroy them fruitless, were it not, happily for us, that they eat and destroy each other. The same insatiable appetite that impels them to indiscriminate carnage, also incites the strongest to devour the weakest, even of their own kind. The large male rat generally keeps in a hole by itself, and is dreaded by its own species. as the most formidable enemy. In this manner the number of these vermin is kept within due bounds; and when their increase becomes injurions to us, it is repressed by their own rapacity.

But beside their own enmities among each other, all the stronger carnivorous quadrupeds have natural antipathies against them. The dog, though he detests their flesh, yet openly declares his alacrity to pursue them; and attacks them with great animosity. Such as are trained up to killing these vermin, despatch them often with a single squeeze: but those dogs that show any hesitation, are sure to come off but indifferently; for the rat always takes the advantage of a inoment's delay, and instead of waiting for the attack, becomes the aggressor, seizing its pursuer by the lip, and inflicting a very painful and dangerous wound. From the inflammation, and other angry symptoms that attend this animal's bite, some have been led to think that it was in some measure venomous; but it is likely that the difficulty of the wound's healing, arises merely from its being deep and lacerated by the teeth, and is rather a consequence of the figure of the instruments that inflict it, than any venom they may be supposed to possess.

The cat is another formidable enemy of this kind; and yet the generality of our cats neither care to attack it, nor to feed upon it when killed. The cat is a more prudent hunter than the $d o g$, and will not be at the pains to take or combat with an enemy that is not likely to repay her time and danger. Some cats, how ever, will pursue and take the rat; though often not without an obstinate resistance. If hungry, the cat will sometimes eat the head; but, in general, she is merely content with her victory.

A foe much more dangerons to these vermin is the weasel. This animal pursues them with avidity, and being pretty nearly of their 
own size, follows them into their holes, wherc a desperate combat ensues. The strength of each is pretty near equal; but the arms are very different. The rat, furnished with four long tusks at the extremity of its jaw, rather snaps than bites; but the weasel, where it once fastens, holds, and continuing also to suck the blood at the same time, weakers its antagonist, and always obtains the victory. Mankind have contrived several other methods of destroying these noxious intruders; ferrets, traps, aud particularly poison; but of all other poisons, I am told that the nox vomica, ground and mixed with meal, is the most certain, as it is the least dangerous.

To this species I will subjoin, as a variety, the BLACK RAт. mentioned above, greatly resembling the former in figure, but very distinet in nature, as appears from their mutual antipathy. This animal was formerly as.mischievous as it was common; but at present it is almost utterly extirpated by the great rat, one malady often expelling another. It is become so scarce, that I do not remember ever to have seen one. It is said to be possessed of all the voracious and unnatural appetites of the former: though, as it is less, they may probably be less noxious. Its length is about seven inches; and the tail is near eight iuches long. The colour of the body is of a deep iron gray, bordering upon black, except the belly, which is of a dirty cincreous hue. They have propagated in America in great numbers, being originally introduced from Europe; and as they seem to keep their ground wherever they get footing, they are llow become the most noxious animals in that part of the world.

To this also we may subjoin the Black Water Rat; about the same size with the latter, with a lnrger head, a blunter nose, less eyes, and shorter ears, and the tip of its tail a little white. It was supposed by Ray to be web-footed; but this has been found to be a mistake, its toes pretty much resembling those of its kind. It never frequents houses; but is usually found on the banks of rivers, ditches, and ponds, where it burrows and breeds. It feeds on fish, frogs, and insects; and in some countries it is eat on fasting days.

\section{THE MOUSE.}

As animal equally mischievous, and equally well known with the former, is the Mouse. 'Timid, cautious, and active, all its dispositions are similar to those of the rat, except with fewer powers of doing mischief." Fearful by nature, but familiar from necessity, it attends upon mankind, and comes an unbidden guest to lis most delicate entertainments. Fear and necessity seem to regulate all its motions; it never lcaves its hole but to seek provision, and seldom ventures above a few paces from home. Different from the rat, it does not go from one house to another, unless it be forced; and as it is more easily satisfied, it does much less mischief.

Alınost all animals are tamed more difficultly in proportion to the cowardice of their natures. The truly bold and courageous easily become familiar, but those that are always fearful are ever suspicious. The mouse being the most feeble, and consequently the most timid of all quadrupeds, except the Guineapig, is never rendered thoroughly familiar; and, even though fed in a cage, retains its natural apprehensions. In fact, it is to these alone that it owes its security. ${ }^{b}$ No animal has more enemies, and few so iucapable of resistance. The owl, the cat, the suake, the hawk, the weasel, the rat itself, destroy this species by millions, and it only subsists by its amazing fecundity.

The mouse brings forth at all seasons, and several times in a year. Its usual number is from six to ten. These, in less than a fortnight are strong enough to run about and shift for themselves. They are chiefly found in farmers' yards, and among their corn, but are seldom in those ricks that are much infested with rats. They generally choose the south-west side of the rick, from whence most rain is expected; and from thence they often, of an evening, venture forth to drink the little drops either of rain or dew that hangs at the extremities of the straw. ${ }^{c}$ Aristotle gives us an idea of their prodigious fecundity, by. assuring us, that having put a mouse with

a Buffon, vol. xv. p. 145. b E volucribus hirundines sunt indociles, e terrestibus mures.-PLIN. . c Buffon, vol. xv. p. 147 . 
young into a vessel of corn, in some time after he found a hundred and twenty mice, all sprung from one original. The enrly growth of this animal implies also the short duration of its life, which scldom lasts above two or three years. This species is very much diffused, being found in almost all parts of the ancient continent, and having been exported to the ncw. a They are animals that, while they fear human society, closely attend it; and, although enemies to man, are never found but near those places where he has fixed his habitation. Numberless ways have been found for destroying them; and Gesner has minutely described the variety of traps hy which they are taken. Our Society for the Encouragement of Arts and Manufactures proposed a reward for the most ingenious contrivance for that purpose: and l obscrved alinost every candidate passing off descriptıons as inventions of his own. I thought it was cruel to detect the plagiarism, or frustrate the humble ambition of those who would be thought the inventors of a mouse-trap.

To this species, merely to avoud teazing the reader with a minute description of animals very inconsiderable and very nearly alike, I will add that of the LONG-TAILED FIELD Mouse, which is larger than the former, of a colour very nearly resembling the Norway rat, and chiefly found in fields and gardens. They are extremely voracious, and hurtful in gardens and young nurseries, where they are killed in great numbers. However, their fecundity quickly repairs the destruction.

Nearly resembling the former, but larger, (for it is six inches long,) is the short-TAILED FizLd Mousz; which, as its name implies, has the tail much shorter than the former, it being not above an inch and a half long, and endiug in a small tuft. Its colour is more inclining to that of the domestic mouse, the upper part being blackish, and the under of an ashcolour. 'This, as well as the former, are remarkable for laying up provision against winter: and Mr. Buffon assures us they sometimes have a store of above a bushel at a time.

We may add also the sHrew mouse to this species of minute animals, being about the

- Lisle's Husbandry, vol ui. p. 391. size of the domestic mouse, but differing great$1 y$ from it in the furm of its nose, which is very long and slender. The teeth also are of a very singular form, and twenty-eight in number; whereas the common number in the rat kind is usually not above sixteen. The two upper fore teeth are very sharp, and on each side of them there is a kind of wing or bcard, like that of an arrow, scarse visible but on a close inspection. The ott:r teeth are placed close together, being very small, and seeming scarce separated; so that with respect to this part of its formation, the animal has some resemblance to the viper. However, it is a very harmless little creature, doing scarce any injury. On the contrary, as it lives chiefly in the fields, and feeds more upon insects than corn, it may be considered rather as a friend than an enemy. It has a strong, disagreeable sinell, so that the cat, when it is killed, will refuse to eat it. It is said to bring four or five young at a time.

\section{THE DORMOUSE.}

These animals may be distinguished into three kinds; the GREATER DORMOUSE, which Mr. Buffon calls the LOIR; the MIDDLE, which he calls the LEROT; the LESS, which he denominates the nuscaroiv. They differ from cach other in size, the largest being equal to a rat, the least being no bigger than a mouse. They all differ from the rat in having the tail tufted with hair, in the manner of a squirrel, except that the squirrel's tail is flat, resembling a fan; and theirs round, resembling a brush. The lerot differs from the loir by having two black spots near the eyes; the muscardin differs from both in the whitish colour of its hair on the back. They all three agree in having black sparkling eyes, and the whiskers partly white and partly black. They agree in their being stupefied, like the marmout, during the winter, and in their hoarding up provisions to serve them in case of a temporary revival.

They inhabit the woods or very thick hedges, forming their nests in the hollow of some tree, or near the bottom of a close shrub, humbly content with continuing at the bottom, and never aspiring to sport. among the 


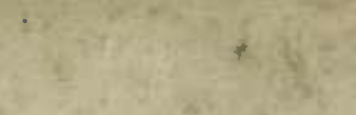

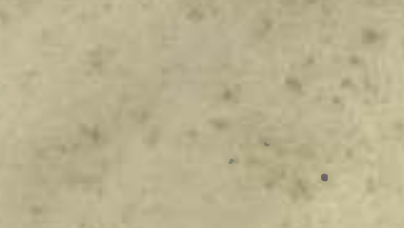

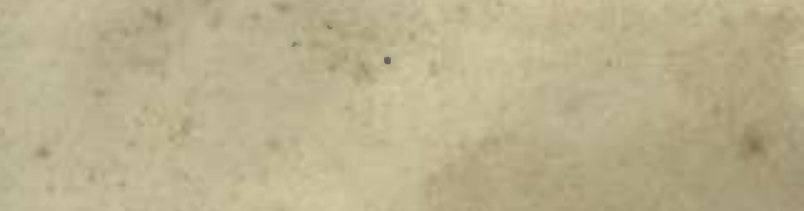

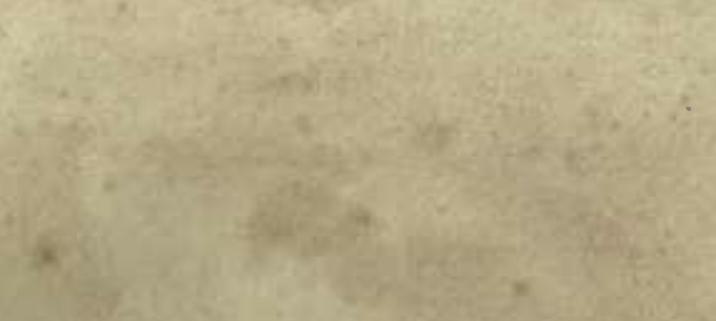

$$
\begin{aligned}
& \text { ki }
\end{aligned}
$$

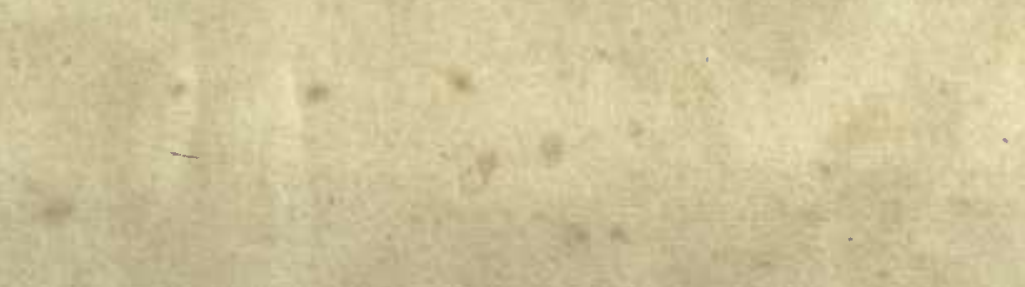

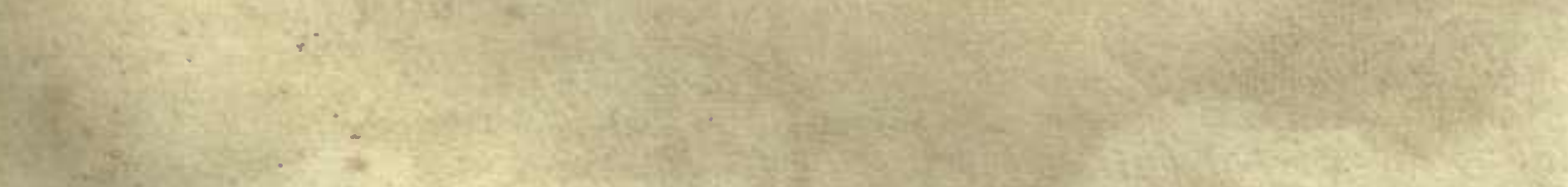

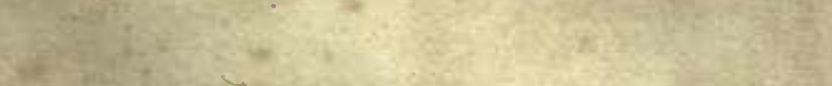

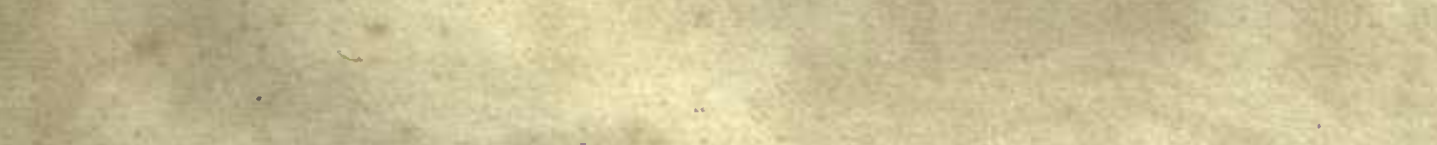

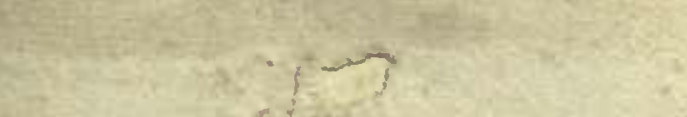

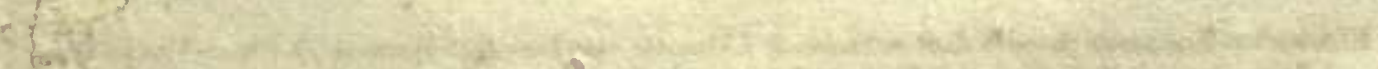
(8)

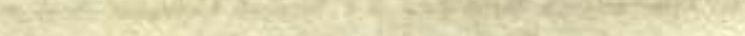




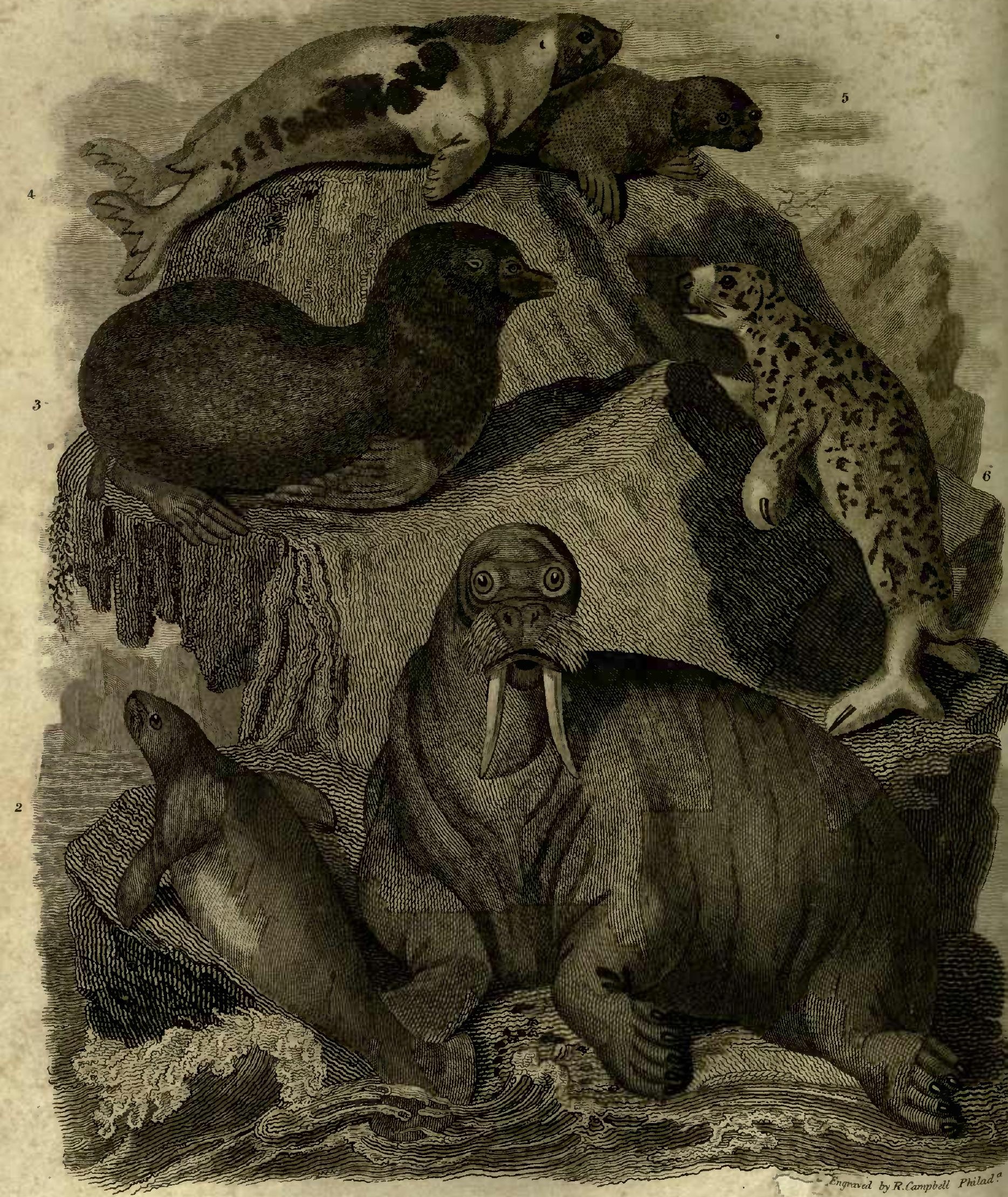

1Trichechus Rosmarus ArcticWalrus orMorse. 2.T.Manatus (var borealis) Manatns . 3.Phoca Ursina. Ursine Seal 4.P.Grenlandica Ilarp Seal.5.P.Vitutina Common Seal or Sea Calf. 6.P.Maculata. Spotted seal 
branches. Towards the approach of the cold season, they form a little magazine of nuts, beans, or acorns; and having laid in their hoard, shut themselves up with it for the winter. As soon as they feel the first advances of the cold, they prepare to lessen its effect, by rolling themselves up in a ball, and thus exposing the smallest surface to the weather. But it often happens that the warmth of a sunny day, or an accidental cliange fiom cold to heat, thaws their nearly stagnant fluids, and they revive. On such occasions they have thcir provisions laid in, and they have not far to seek for their support. In this manner tiey continue usually ssleep, but sometimes waking, for about five months in the year, seldom venturing from their retreats, and, consequently, but rarely seen. Their nests are lined with moss, grass, and dead leaves; they usually bring forth three or four young at a time, and that but once a year, in the spring.

\section{'CHE MUSK RAT.}

OF these animals of the rat kind, but with a inusky smell, there are also three distinctions, as of the former: the ONDATRA, the DESMAN, and the PILORI. The ondatia is a native of Canada, the desman of Lapland, and the pilori of the West India Islands. The ondatra differs from all others of its kind, in having the tail flatted and carried edge-ways. The desinan has a long extended snout, like the shrewmouse; and the pilori a short tail, as thick at one end as the other. They all resemble each other in being fond of the water, but particularly in that inusky odour from vhence they have taken their name.

Of these, the ondatra is the most remarkable, and has been the most minutely deseribed." "This animal is about the size of a small rabbit, but has the hair, the colour, and the tail of a rat, exeept that it is flatted on the sides, as mentioned above. But it is still more extraordinary upon other accounts, and different from all other unimals whatever. It is so formed that it can contract and enlarge its body at pleasure. It has a muscle like that of horses, by which they move their lides, lying immediately under the skin, and that furnish-

a Buton, vol. xx.p. 4 . ed with such a power of contraction, together with sueh an elasticity in the false ribs, that this animal can creep into a hole where others, seemingly much less, cannot follow. The female is remarkable also for two distinct apertures, one for urine, the other for propagation. The male is equally observable for a peculiarity of conformation; the nusky smell is much stronger at one particular season of the year than any other; and the marks of the sex seem to appear and disappear in the sanıe manuer.

The ondatra in some measure resembles the beaver in its uature and disposition. They both live in society during winter; they both form houses of two feet and a lialf wide, in which they reside several families together. In these they do not assemble to sleep as the inarmout, but purely to shelter themselves from the rigour of the season. However, they do not lay up inagazines of provision like the beaver; they only form a kind of covert-way to and round their dwelling, from whence they issur. to procure water and roots, upon which they subsist. During winter their houses are covered under a depth of eight or ten feet of snow ; so that they must lead but a cold, gloony, and necessitous life, during its continance. During summer they separate two by two, and feed upon the varicty of roots and vegetables that the season offers. They then become extremely fat, and are much sought after, as well for their flesh as their skins, which are very valuable. They then also acquire a very strong scent of musk, so pleasing to an Europeall, but which the savages of Canada cannot abide. What we admire as a perfume, they consider as a most abominable stench, and call one of their rivers, on the banks of which this animal is seen to burrow in nun?bers, by the name of the stinking river, as well as the rat itself, which is denominated by them the stinkard. This is a strange diversity among mankind; and, perhaps, may be ascribed to the different kinds of food among different nations. Such as chiefly feed upon rancid oils, and putrid flesh, will often mistake the nature of scents ; and, having been long used to ill smells, will, by habit, consider them as perfunes. Be this as it will, although these nations of northern savages consider the musk rat as intolerably foetid, they nevertheless regard it as very good eating, and, indeel, in 
this they imitate the epicures of Europe very exactly, whose taste seldom relishes a dish till the nose gives the strongest marks of disapprobation. As to the rest, this animal a good deal resembles the beaver in its habits and disposition ; but, as its instincts are less powerful, and its economy less exact, I will reserve for the description of that animal a part of what may be applicable to this.

\section{THE CRICETUS.}

The Cricctus, or German Rat, which Mr. Buffon calls the hamster, greatly resenibles the water rat in its size, small eyes, and the shortness of its tail. It differs in colour, being rather browner, like the Norway rat, with the belly and legs of a dirty yellow. But the marks by which it may be distinguished from all others are two pouclies, like those of a baboon, on each side of its jaw, under the skin, into which it can cram a large quantity of provision. These bags are oblong, and of the size, when filled, of a large walnut. They open into the mouth, and fall back along the neck to the shoulder. Into these the animal can thrust the surplus of those fruits or grains it gathers in the fields, such as wheat, peas, or acorns. When the immediate calls of hunger are satisfied, it then falls to filling these; and thus loaded with two great bunches on each side of the jaiv, it returns home to its hole to deposite the spoil as a store for the wintes. The size, the fecundity, and the voraciousness of this animal, render it one of the greatest pests in the countries where it is found, and every method is made use of to destroy it.

But although this animal is very noxious with respect to man, yet, considered with regard to those instincts which conduce to its ! own support and convenience, it deserves our admiration. ${ }^{2}$ Its hole offers a very curious object for contemplation, and shows a degree of skill superior to the rest of the rat kind. It consists of a varicty of apartments, fitted up for the different occasions of the little inhabitant. It is generally made on an inclining ground, und always has two entrances, one perpendicular, and the other oblique ; though, if there be more than one in a family, there

- Buffon, vol. xxvi. p. 159. are as many perpendicular holes as there are individuals below. The perpendicular hole is usually that through which they go in and out: the oblique serves to give a thorough air to keep the retreat clean, and, in case one hole is stopped, to give an exit at this. Within about a foot of the perpendicular hole, the animal makes two more, where are deposited the family's provisions. These are nuch more spacious than the former, and are large in proportion to the quantity of the store. Beside these, there is still another apartment, warmly lined with grass and straw, where the female brings forth her young; all these comminicate with each other, and all together take up a space of ten or twelve leet in dianeter. These animals furnish their store-houses with dry corn, well cleaned; they also lay in corn in the ear, and beans and peas in the pod. These, when occasion requires, they afterwards separate, carrying out the pods and empty ears by their oblique passage. They usually begin to lay in at the latter end of August; and, as each magazine is filled, they carefully cover up the mouth with earth, and that so neatly, that it is no easy matter to discover where the earth has been renioved. The only means of finding out their retreats are, therefore, to observe the oblique entrance, which generally has a surall quantity of earth before it; and this, though often several yards from their perpeudicular retreat, leads those that are skilled in the search to make the discovery. Many German peasants are known to make a livelihood by fiuding out and bringing off their hoards, which, in a fruitful season, often furnish two bushels of good grain in each apartment.

Like most others of the rat kind, they produce twice or thrice a year, and bring five or six at a time. Some years they appear in alarming numbers, at other tinies they are not so plentiful. The moist seasons assist their propagation; and it often happens on such years that their devastatious produce a famine all over the country. Happily, however, for mankind, these, like the rest of their kind, destroy each ather; and of two that Mr. Buffon kept in a cage, male and female, the latter killed and devoured the former. As to the rest, their fur is considered as very valuable; the natives are invited by rewards to destroy them; and the weasel kind seconds the wishes 
of government with great success. Although they are usually found brown on the back and white on the belly, yet many of them are observed to be gray, which may probably arise from the difference of age.

\section{THE LEMING.}

$H_{\text {Avivg considered various kinds of these }}$ noxious little animals that elude the indignation of mankind, and subsist by their number, not their strength, we come to a species more bold, more dangerous, and more numerous than any of the former. The leming, which is a native of Scandinavia, is often seen to pour down in myriads from the northern mountains, and, like a pestilence, destroys all the productions of the earth. It is described as being larger than a dormouse, with a bushy tail, though shorter. It is covered with thin hair of various colours. The extremity of the upper part of the head is black, as are likewise the neck and shoulders, but the rest of the body is reddish, intermixed with small black spots of various figures, as far as the tail, which is not above half an inch long. The eyes are little and black, the ears round and inclining towards the back, the legs before are short, and those behind longer, which gives it a great degree of swiftness. But what it is much more remarkable for than its figure are, its amazing fecundity and extraurdinary migrations.

In wet seasous, all of the rat kind are known to propagate more than in dry; but this species in particular is so assisted in multiplying by the moisture of the weather, that the inbabitants of Lapland sincerely believe that they drop from the clouds, and that the same magazines that furnish hail and snow pour the leming also upon them. In fact, after long rain, these animals set forward from their native momintains, and severnl millions in a troop deluge the whole plain with their numbers. They move, for the most part, in a square, marching forward by night, and lying still by day. Thus, like an animated torrent, they are often seen more than a mile loroad covering ${ }^{t /}$ sround, and

- Phil. Trans. vol ii. p. 872 . that so thick that the hindmost touches its leader. It is in vain that the poor inhabitant resists or attempts to stop their progress, they still keep inoving forward, and though thousands are destroyed, myriads are seen to succeed and make their destruction impracticable. They generally move in lines, whicls are about three feet from each other, and exactly parallel. Their march is always directed from the north-west to the south-east, and regularly conducted from the beginning. Wherever their motions are turned, nothing can stop them; they go directly forward, impelled by some strange power; and, from the time they first set out, they never once think of retreating. If a lake or a river happens to interrupt their progress, they all together take the water and swim over it; a fire, a deep well, or a torrent, does not turn them .out of their straight-lined direction; they boldly plunge into the flames, or leap down the well, and are sometimes seen climbing up on the other side. If they are interrupted by a boat across a river while they are swimming, they never aitempt to swim round it, but mount directly up its sides; and the boatmen. who know how vain resistance in such a case would be, calmly suffer the living torrent to pass over, which it does without further damage. If they meet with a stack of hay or corn that interrupts their passage, instead of going over it, they gnaw their way through ; if they are stopped by a house in their course, if they cannot go through it, they continue there till they die. It is happy, however, for mankind that they eat nothing that is prepared for human subsistence; they never enter a house to destroy the provisions, but are contented with eating every root and vegetable that they meet. If they happen to pass through a meadow, they destroy it in a very short time, and give it an appearance of being burnt up and strewed with ashes. If they are interrupted in their course, and a man should imprudently venture to altack one of them, the little anirnal is no way intimidated by the disparity of strength, but furiously flies up at its opponent, and, barking somewhat like a puppy, wherever it fastens does not easily quit the hold. If at last the leader be forced out of its line, which it defends as long as it can, and be separated from the rest of its 
kind, it sets up a plaintive cry, different from that of anger, and, as some pretend to say, gives itself a voluntary death, by hanging itself on the fork of a tree.

An enemy so numerous and destructive would quickly. render the countries where they appear utterly uninhabitable, did it not fortunately happen that the same rapacity that animates them to destroy the labuurs of mankind, at last impels them to destroy and devour each other. ${ }^{2}$ After committing incredible devastations, they are at last seen to separate into two armies, opposed with deadJy hatred, along the coast of the larger lakes and rivers. The Laplanders, who observe them thus drawn up to fight, instead of considering their mutual animosities as a happy riddance of the most dreadful pest, form ominous prognostics from the manner of their arrangement. They consider their combats as a presage of war, and expect an invasion from the Russians or the Swedes, as the sides next those kingdoms happen to conquer. The two divisions, however, continue their engagements and animosity until one party overcomes the other. From that time they utterly disappear, nor is it well known what becomes of either the conquerors or the conquered. Some suppose that they rush headlong into the sea, others that they kill themselves, as some are found hanging on the forked branches of a tree, and others still that they are destroyed by the young spring herbage. But the most probable opinion is, that, having devoured the vegetable productions of the country, and having nothing more to subsist on, they then fall to devouring each other; and, having habituated themselves to that kind of food, continue it. However this be, they are often found dead by thousands, and their carcasses have been known to infect the air for several miles round, so as to produce very malignant disorders. They seem also to infect the plants they have gnawed, for the cattle often die that afterwards feed in the places where they passed.

As to the rest, the male is larger and more beautifully spotted than the female. They are extremely prolific; and, what is extraordinary, their breeding does not hinder their

a Dictionaire Raisonee, vol. ii. p. 610. march; for some of them have been observed to carry one young one in their mouth and another on their back. They are greatly preyed upon by the ermine, and, as we are told, even by the rein-deer. The Swedes and Norwegians, who live by husbandry, consider an invasion from these vermin as a terrible visitation; but it is very different with respect to the Laplanders, who lead a vagrant life, and who, like the lemings themselves, if their provisions be destroyed in one part of the country, can easily retire to another. These are never so happy as when an army of lemings come down amongst them; for then they feast upon their flesh; which, though horrid food, and which, though even dogs and cats are known to detest, these little savages esteem very good eating, and devour greedily. They are glad of their arrival also upon another account, for they always expect a great plenty of game the year following, among those fields which the lemings have destroyed.

\section{THE MOLE.}

To these minute animals of the rat kind, a great part of whose lives is past in holes under ground, I will subjoin one little animal more, no way resembling the rat, except that its whole life is spent there. As we have seen some quadrupeds formed to crop the surface of the fields, and others to live upon the tops of trees, so the mole is formed to live wholly under the earth, as if nature meant that no place should be left wholly untenanted. Were we from our own sensations to pronounce upon the life of a quadruped that was never to appear above ground, but was always condemned to lunt for its prey underneath, obliged, whenever it removed from one place to another, to bore its way through a resisting body, we sliould be apt to assert that such an existence must be the most frightful and solitary in nature. However, in the present animal, though we find it condemned to all those seeming inconveniences, we sliall discover no signs of wretchedness or distress. No quadruped is fatter, none has a more sleek or glossy skin; and, though denied many advantages that most animals en- 
joy, it is most liberally possessed of others, which they have in a more scanty proportion.

This animal, so well known in England, is, however, utterly a stranger in other places, and particularly in Ireland. For such, therefore, as have never seen it, a short description will be necessary. And, in the first place, though somewhat of a size between the rat and the mouse, it no way resembles either, being an animal entirely of a singular 'sind, and perfectly unlike any other quadruped whatever. It is bigger than a mouse, with a coat of fine, short, glossy, black hair. Its nose is long and pointed, resembling that of a hog, but much longer. Its eyes are so small, that it is scarce possible to discern them. Instead of ears, it has only holes, in the place. Its neck is so short, that the head seems stuck upon the shoulders. The body is thick and round, terminating by a very small short tail, and its legs also are so very short, that the animal seems to lic flat on its belly. From under its belly, as it rests in this position, the four feet appear just as if they immediately grew ont of the body. Thus the animal appears to us at first view as a mass of flesh covered with a fine, shining, black skin, with a little head, and scarce any legs, eyes, or tail. On a close inspection, however, two little black points may be discerned, that are its eyes. The ancients, and some of the moderns, were of opinion that the animal was utterly blind; but Derham, by the help of a microscope, plainly discovered all the parts of the cye that are known in other animals, such as the pupil, the vitreous and crystalline humours. The fore legs appear very short and strong, and furnished with five claws to each. These are turned outwards and backwards, as the hands of a man when swimming. The hind legs are longer and weaker than the fore, being only used to assist its motions; whereas the others are continually employed in digging. The teeth are like those of a shrewinouse, and there are five on both sides of the upper jaw, which stand out; but those behind are aivided into points. The tongue is as large as the mouth will hold.

Such is the extraordinary figure and formation of this animal; which, if we compare with its manner of living, we shall find a ma-

No. $31 \& 32$. nifest attention in nature to adapt the one to the other. ${ }^{a} \quad A s$ it is allotted a subterraneous abode, the seeming defects of its formation vanish, or rather are turned to its advantage. The breadth, strength, and shortness of the fore feet, which are inclined outwards, aisswer the purposes of digging, serving to throw hack the earth with greater ease, and to pursue the worms and insects which are its prey: had they been longer, the falling in of the earth would have prevented the quick repetition of its strokes in viorking; or have obliged it to make a large hole in order to give room for their exertion. The form of the body is not less admirably contrived for its way of life. The fore part is thick, and very muscular, giving great strength to the action of the fore feet, enabling it to dig its way with amazing force and rapidity either to pursue its prey, or elude the search of the most active enemy. By its power of boring the earth, it quickly gets below the surface; and I have seen it, when let loose in the midst of a field, like the ghost on a theatre, instantly sink into the earth; and the most active labourer, with a spade, in vain attempted to pursue.

The smallness of its eyes, which induced the ancients to think it was blind, is, to this animal, a peculiar advantage. A small degree of vision is sufficient for a creature that is ever destined to live in darkness. A more extensive sight would only have served to show the horrors of its prison, while nature had denied it the means of an escape. Had this organ been larger, it would have been perpetually liable to injuries, by the falling of the earth into it; bui nature, to prevent that inconvenience, has not only made them very small, but very closely covered them with hair. Anatomists mention, beside these advantages, another that contributes to their security; namely, a certain muscle, by which the animal can draw back the eye whenever it is necessary or in danger.

As the eye is thus perfectly fitted to the animal's situation, so also are the senses of hearing and =melling. The first gives it notice of the most distant appearance of danger; the other directs it, in the midst of dark-

- British Zonlogy. 
ncss, to its fuod. The wants of a subterraneous animal can be but few : and these are sufficient to supply them : to eat, and to produce its kind, are the whole ensployment of such a life; and for both these purposes it is wonderfully adapted by nature. ${ }^{\text {a }}$

Thus admirably is this animal fitted for a life of darkness and solitude; with no appetites but what it can easily indulge, with no enemies but what it can easily evade or conquer. As soon as it has once buried itself in the earth, it seldom stirs out, unless forced by violent rains in summer, or when in pursuit of its prey, it happens to come too near the surface, and thus gets into the open air, which may be considered as its unnatural element. In gencral, it chooses the looser, softer grounds, bencath which it can travel with greater ease; in such also, it generally finds the greatest Jumber of worms and insects, upon which it chiefly preys. It is observed to be most active, and to cast up most earth, immediately before rain ; and, in winter, before a thaw : at those times the worms and insects begin to be in motion: and approach the surface, whither this industrious animal pursues them. On the contrary, in very dry weather, the mole seldom or never forms any lillocks; for then it is obliged to penetrate deeper after its prey, which at such seasons retire far in to the ground.

As the moles very seldom come above ground, they have few enemies; and very readily evade the pursuit of animals stronger and swifter than themselves. Their greatest calanity is an inundation; which, wherever it happens, they are seen in numbers attempting to save themselves by swimming, and using every effort to reach the higher grounds. The greatest part, however, perish, as well as their young, which remain in the holes behind. Were it not for such accidents, from their great fecundity, they would become extremely troublesome; and, as it is, in some places, they are considered by the farmer as his greatest pest. They conple towards the approach of spring; and their young are found about the beginning of May. They generally have four

a Testes habet maximos, parastatas amplissimas, novum corpus seminale ab his diversum ac separatum. Penem eliam facile omnium, in fallor, animalium longissimum, ex quibus colligere est maximam præ reliquis omnibus animalibus voluptatem in coilu, hoc abjeclum et vile animalculum sercipere ut habeant quod ipsi invideant qui in lioc supremas or five at a time; and it is easy to Ristinguish arnong other mole-hills, that in which the female has brought forth lier young. These are made with much greater art than the rest; and are usually larger. The female, in order to form this retreat, begius by ereeting the earth into a tolerable spacious apartuient, which is supported within by partitions, at proper distances, that prevent the ronf from falling. All round this she works, and heats the earth very firm, so as to make it capable of keeping out the rain, let it be never so violent. As the hillock, in which this apartment is thus formed, is raised above ground, the apartment itself is consequently above the level of the plain, and, therefore, less subject to accidental slight inumdations. The place being thus fitted, she then procures grass and dry leaves as a bed for her young. Therc they lie secure from wet, and she continues to make their retreat equally so from danger; for all round this hill of her own raising, are holes running into the earth, that part from the niddle apartment, like rays from a centre, and extend about fifteen feet in every direction : these resemble so many walks or chases, into which the animal makes her subterraneous excursions, and supplies her young with such roots or insects as she can provide: but they contribute still more to the general safety; for as the mole is very quick of hearing, the instant she perceives ber little habitation attacked, she takes to her burrow, and unless the earth be dug away by several men at once, she and her young always make a good retreat.

The mole is scarcely found, except in cultivated countries: the varieties are but few. That which is found in Virginia, resembles the common mole, except in colour, which is black, mixed with a deep purple. There are sonetimes white moles, seen particularly in Poland, rather larger than the former. As their skin is so very soft and beautiful, it is odd that it has not been turned to any advantage. Agricola tells us, that he saw hats made from it, the finest and the most beautiful that could be imagined.

vitæ suæ delicias collocant: Rsii Synops. Quadrup. p. 239. Huic opinioni assentitur D. Buffon, attamen non mihi apparet magnitudinem partiım tolem viluptatem augere Maribus enim salacissimis contrariuus obtinet.

b Buffon. 


\section{CHAP'TER LIV.}

\section{THE HEDGEHOG, OR PRICKLY KIND.}

ANIMALS of the Hedgehog kind require but very little accuracy to distinguish them from all others. That hair which serves the generality of quadrupeds for warmth and ornament, is partly wanting in these; while its place is supplied by sharp spines or prickles, that serve for their defence. This general characteristic, therefore, makes a much more obvious distinction than any that can be taken from their teeth or their claws. Nature, by this extraordinary peculiarity, seems to have separatel them in a very distinguished manner; so that, instead of classing the hedgehog among the moles, or the porcupine with the hare, as some have done, it is much mure natural and obvious to place them, and others approaching then, in this strange peculiarity, in a class by themselves; nor let it be supposed, that while I thus alter their arrangement, and separate them from animals with which they have been formerly combined, that I am destroying any sccret affinities that exist in nature. It is natural, indeed, for readers to suppose, when they see two such opposite animals as the hare and the porcupine assembled together in the same gromp, that there must be some material reason, some secret connexion, for thus joining animals so little resembling each other in appearance. But the reasins for this union were very slight, and merely arose from a similiturle in the fore tecth; no likeness in the interual conformation, no similitude in nature, in habitudes, or disposition; in short, nothing to fasten the link that combines them, but the similitude in the teeth: this, therefore, may be easily dispensed with; and, as was said, it will be nost proper to class them according to their most striking similituives.

The hedgehog, with an appenrance the most formidable, is yet one of the nost harmless animals in the world: unable or unwilling to offend, all its precautions are only directed to its own security; and it is armed with a thousand points, to keep off the eneny, but not to invade him. While other creatures trust to their force, their cunning, or their swiftness, this animal, destitute of all, has but one expedient for sufety; and from this alone it often finds protcetion. As soon as it perceives itself attacked, it withdraws all its vulnerable parts, rolls itself into a ball, and presents nothing but its defensive thorns to the enemy; thus, while it attempts to injure no other quadruped, they are equally incapable of injuring it : like those knights, we have somewhere read of, who were armed in such a mamer, that they could neither conquer others, nor be themselves overcome.

This animal is of two kinds; one with a nose like the snout of a hog; the other more short and blunt, like that of a dog. That with the muzzle of a dog is the most common, being about six inches in length, from the tip of the nose to the insertion of the tail. The tail is little more than an inch long; and so concealed by the spines, as to be scarce visible: the head, back, and sides, are covered with prickles; the nose, breast, and belly, are covered with fine soft hair ; ${ }^{a}$ the legs are short, of a dusky colour, and almost bare; the toes on each foot are five in number, long and separated; the prickles are about an inch in length, and very sharp pointed; their lower part is white, the middle black, and the points white: the eyes are small, and placed high in the head: the ears are round, pretty large, and naked; the month is small, but well furnished with teeth ; these, however, it only uses in chewing its fond, but neither in attacking or defending itself against other aninials. Its only reliance in cases of danger, is on its spines; the instant it perceives an enemy, it puts itself into a posture of defence, and keeps upon its guard until it supposes the danger over. On such occasions, it immediately alters its whole appearance: from its usual form, somewhat resem-

a Præputium propendens. Linnaci Syst. 75. And of the fenale he might have said, resupina copulatur.

3 L* 
bling a small animal, with a bunch on its back, the animal begins to bend its back, to lay its head upon its breast, to shut its eyes; to roll down the skin of its sides towards the legs, to draw these up, and lastly, to tuck them in every side, by drawing the skin still closer. In this form, which the hedgehog always puts on when disturbed, it no way resembles an aninual, but rather a roundish mass of prickles, impervious on every side. The shape of the animal thus rolled up, somewhat resembles a chesuut in the husk; there being, on one side, a kind of flat space, which is that on which the head and legs have been tucked in.

Such is the usual appearance of the hedgehog, upon the approach of any danger. Thus rolled up in a lump, it patiently waits till its enemy passes by, or is futigued with fruitless attempts to annoy it. 'The cat, the weasel, the ferret, and the martin, quickly decline the combat; and the dog himselt generally spends his time in empty menaces, rather than in effectual efforts. Every incrẹase of danger only increases the animal's precautions to keep on its guard; its assailant vainly attempts to bite, since he thus more frequently feels than inflicts a wound; he stands enraged and barking, and rolls it along with the paws; still, however, the hedgehog patiently submits to every indignity, but continues secure; and still more to disgust its eneny with the contest, sheds its urine, the smell of which is alone sutficient to send him avay. In this manner the dog, after barking for some time, leaves the hedgehog where he found him, who, perceiving the danger past, at length peeps out from its ball, and, if not interrupted, creeps slowly to its retreat.

The hedgehog, like most other wild animals, sleeps by day, and ventures out by night. It generally resides in small thickets, in bedges, or in ditches covered with bushes; there it makes a liole of about six or eight inches deep; and lies well wrapped up, in moss, grass, or lcaves. Its food is roots, fruits, worms, and insects. It is also said to suck cattle, and hurt their udders; but the smallness of its mouth will serve to clear it from this reproach. It is said also to be very hurtful in gardens and orchards, where It will roll itself in a heap of fruit, and so carry a large quantity away upon its prickles; but this imputation is as ill grounded as the former, since the spines are so disposed, that no fruit will stick upon them, even if we should try to fix them on. It rather appears to be a very serviceable animal, in ridding our ficlds of insects and worms, which are so prejudicial to vegetation.

Mr. Buffon, who kept the'se animals tame about his house, acquits them of the reproach of being mischievous in the garden, but then he accuses then of tricks, of which, from the torm and habits of this aninal, one would be never led to suspect them. "I have often," says he, "had the female ard hrl young brought me about the beginning of June: they are generally from three to five in number: they are white in the beginning, and only the marks of their spines appear: 1 was willing to rear some of them, and accordingly put the dam and her young into a tub, with abundant provision beside them; but the old animal, instead of suckling her young, devoured them all, one after another. On another occasion, an hedgehog that had made its way into the kirchen, discovered a little por, in which there was meat prepared for boiling; the mischievous animal drew out the meat, and left its excrements in the stead. I kept males and fenales in the same apartment, where they lived together, but never coupled. I permitted several of them to go about my garden, they did very little damage; and it was scarcely perceivable that they were there: they lived upon the fruits that fell from the trees; they dug the earth into shallow holes; they eat caterpillar's, beetles, and worms; they were also very fond of flesh, which they devoured boiled or raw."

They couple in spring, and bring forth about the beginning of sumner. They sleep during the winter, and what is said of their laying up provisions for that season, is consequently false. They at no time eat nuch, and can remain very long without any food whatsoever. Their blood is cold, like all other animals that sleep during the winter. Their flesh is not good for food; and their skins are converted to scarce any use, except to muzzle calves, to keep then from sucking.

\section{THE TANREC AND TENDRAC.}

ThE Tanrec and Tendrac, are two little animals described by Mr. Buffon, of the 



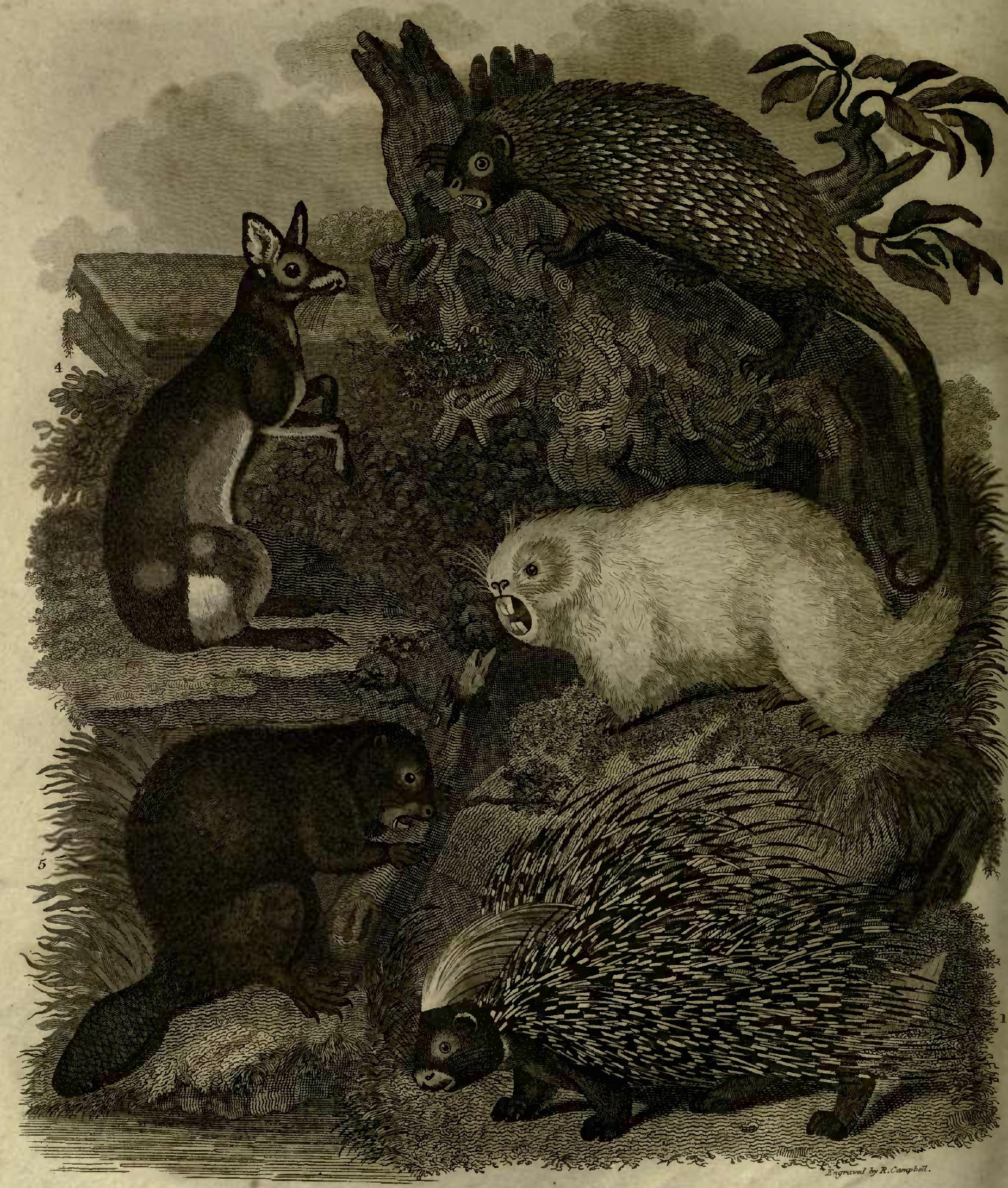

LHystrix Cristata, Common or Crested Poreupine. 
hedgehog kind; but yet sufficiently different from it, to constitute a different species. Like the hedgehog they are covered with prickles, though mixed in a greater proportion with hair; but unlike that animal, they do not defend themselves by rolling up in a ball. Their wanting this last property is alone sufficient to distinguish then from an animal in which it makes the most striking peculiarity: as also, that in the East lndies, where only they are found, the hedgehog exists separately also: a manifest proof that this animal is not a variety caused by the climate.

The tanrec is much less thain the hedgehog, being about the size of a inole, and covered with prickles, like that animal, except that they are shorter and smaller. The tendrac is still less than the former, and is defended only with prickles upon the head, the neck, and the shoulders; the rest being covered with a coarse hair, resembling a log's bristles. These little animals, whose legs are very short, move but slowly. They grunt like a hog; and wallow, like it, in the mire. They love to be near water, and spend more of their time there, than upon land. They are chiefly in creeks and harbours of salt water. They multiply in great numbers, make themselves holes in the ground, and sleep for several months. During this torpid state, their hairs (and I should also suppose their prickles) fall; and they are renewed upon their revival. They are usually very fat; and although their flesh be insipid, soft, and stringy, yet the Indians finil it to their taste, and consider it as a very great delicacy.

\section{THE PORCUPINE}

Trrose arms which the hedgehog possesses in miniature, the Porcupine has in a more enlarged degree. The short prickles of the hedgehog, are, in this animal, converted into shalis. In the one, the spines are about an inch long; in the other, a foot. The porcupine is about two feet long, and fifteen inches high. Like the hedgehog, it appear's a mass of misshapen flesh, covered with quills, from ten to fourteen inches long, resembling the

- Buffon vol. xxv. p. 254. barrel of a goose-quill in thickness, but tapering and sharp at both ends. These, whether considered separately or together, afford sufficient subject to detain curiosity. Each quill is thickest in the middle; and inserted into the aniual's skin, in the same inanner as feathers are found to grow upon birds. It is within-side spongy, like the top of a goosequill; and of ditlerent colours, being white and black alternately, from one end to the other. The biggest are often found fifteen inches long, and a quarter of au inch in diameter; extremely sharp, and capable of inflicting a mortal wound. They seem harder than common quills, being difficult to be cut, and solid at that end which is not fixed in the skin. If we examine them in common, as they grow upon the animal, they appear of two kinds; the one such as I have already described; the other, long, flexible, and slender, growing here and there among the former. There is still another sort of quills, that grow near the tail, white and transparent, like the writing quills, and that seem to be cut short at the end. All these quills, of whatever "kind, incline backwards, like the bristles of a hog; but when the animal is irritated, they rise, and stand upright, as bristles are seen to do.

Such is the formation of this quadruped, in those parts in which it differs from most others; as to the rest of its figure, the muzzle bears some resemblance to that of a hare, but black; the legs are very short, and the feet have five toes, both betore and behind; and these, as well as the belly, the head, and all other parts of the body, are covered with a sort of short hair, lile prickles, there being no part, except the ears and the sole of the foot, that is free from them: the ears are thinly covered with very fine hair; and are in shape like those of mankind: the eyes are small, like those of a hog, being only one-third of an inch from one corner to the other. After the skin is taken off, there appears a kind of paps on those parts of the body from whence the large quills proceed; these are about the size of a small pea, each answering to as many holes which appear on the outward surface of the skin, and which are about half an inch deep, like as many hollow pipes, wherein the quills are fixed, as in so many sheaths. 
This animal secms to partake very much of the nature of the hedgehog; having this formidable apparatus of armis rather to defend itself, than annoy the enemy, There have been, indeed, many naturalists who supposed that it was capable of discharging them at its foes, and killing at a great distance off. But this opinion has been entirely discredited of late; and it is now universally believed that its quills remain firmly fixed in the skin, and are then only shed when the animal mouls them, as birds do their feathers. It is true, we are told by Ellis, that a wolf at Hudson's Bay was found dead, with the quills of a porcupine fixed within its mouth; which might have very well happened, from the voraciousness of the former, and not the resentment of the latter. That rapacious creature, in the rage of appetite, might have attempted to devour the porcupine, quills and all, and very probably paid the forfeit by its life. However this be, of all the porcupines that have been brought into Europe, not one was ever seen to launch their quills; and yet the irritations they received were sufficient to have provoked their utmost indiguation. Of all the porcupines that Dr. Shaw observed in Africa, and hic saw numbers, not one ever attempted to dart its quills; their usual manner of delence being, to lie on one side, and when the enemy approaches very near, ly suddenly rising, to wound him with the points on the other.

It is probable, therefore, that the porcupine is seldom the aggressor; and when attacked by the bolder animals, it only directs its quills so as to keep always pointing towards the cnemy. These are an ample protection; and, as we are assured hy Kolben, at such times, even the lion himself will not venture to make an attack. Fron such, therefore, the porcupine can defend itself; and chiefly hunts for serpents, and all other reptiles, for subsistence. Travellers universally assure us, that between the serpent and the porcupine there exists an irreconcilable cumity, and that they never neet without a mortal engagement." ${ }^{*}$ The porcupiue, on these occasions, is saic to roll itself upon the serpent, and thus destroy and devour it. This may be true; while, what we are informed by Monsinur Sarrasin, of the porcupine of Canada chiefly sulısisting on vegeta-

a Bosman. Smitl. L. P. Vincent Marie, \&c. bles, may be equally so. Those which are brought to this commtry to be shown, are usually fed on bread, milk, and fruits ; but they will not refuse meat when it is offered them; and it is probable, they prefer it in a wild state, when it is to be had. ${ }^{b}$ The porcupine is also known to be extremely hurtful to gardens: and, where it enters, does incredible damage.

The Americans, who hunt this animal, assure us, that the porcupine lives from twelve to fifteen years. During the time of coupling, which is in the month of September, the males become very fierce and langerous, and often are seen to destroy cach other with their teeth. The fenale goes with young seven months, and brings forth but one at a time; this she suckles but about a month, and accustons it betimes to live, like herself, upon vegetablesand the bark of trees; she is very fierce in its defence; but, at other seasons, she is fearfil, tinid, and harmless. The porcupine never attempts to bite, nor any way to injure its pursuers; if hunted by a dug or a woll; it iustantly climbs up a tree, and continues there until it has wearied out the patience of its adversary; the wolf kuows by experiener, how firuitless it would be to wait ; he tlicrefore leaves the porcupine above, and sceks out lor a new adventure.

The porcupine does not escape so well from the Indian hunter, who engerly pursues it, in order to make enbroidery of its quills, and to eat its flesh. This, as we are cornmonly told, is very tolerable eating: however, we may expect wretched provisions when the savages are to be our caterers, for they eat every thing that has life. But they are very ingenious with regard to their embroidery: if I understand the accounts rightly, they die the quills of various colours, and then splitting them into slips, as we see in the making of a cane-rhair, they embroider with these their belts, baskets, and several other nccessary picces of furniture.

As to the rest, there are many things related concerning this aninual that are fabulous; but there are still many circumstimces morc, that yet remain to be known. It were curious to inquire whether this animal moults its quills when wild, for it is never seen to shed them in a domestic state; whether it sleeps all the winter, as we are told by some naturalists, which

\footnotetext{
b Bufion.
} 
we are sure it does not when brought into oul country ; and, lastly, whether its quills can be sent off with a shake; for no less a naturalist than Reaumur was of that opinion.

All that we can learn of an animal exposed as a show, or even by its lissection, is but merely its conformation; and that makes one of the least interesting parts of its history. We are naturally led, when presented with an extraordinary creature, to expect something extraordinary in its way of living, something uncomnon, and corresponding with its figure; but of this animal we know little with any precision, except what it offers in a state of captivity. In such a situation, that which I saw appeared to very little ailvantage: it was extremely dull and torpill, though very wakeful; and extremely voracious, though very capable of sustaining hunger; as averse to any attachnent, as to being tamed : it was kept in an iron cage, and the touching one of the bars was sufficient to excite its resentment, for its quills were instantly erected; and the poet was right in his epithet of fretful; for it appeared to me the most irascible creature upon carth.

The porcupines of America differ very inuch from that of the ancient continent, which we have been describing; and strictly speaking, may be considered as animals of a different species: however, from their being covered with quills, we will only add them as varieties of the former, since we know very little concerning them, except their difference of figure. They are of two kinds; the one called the couando; and the other, first named by $\mathrm{Mr}$.
Buffon, the urson: the one a native of the northern parts of America, the other of the south; and both differing from the former, in having long tails, whereas that has a very short one.

'The covando is much less than the porcupine; its quills are four times shorter, its snont more unlike that of a hare; its tail is long enough to catch hy the branches of trees, and hold by them. It may be easily tamed, and it is to be found chiefly in the southern parts of Ainerica; yet is ret wanting also in the northern.

The urson, which Mr. Buffon calls after our countryman Hudson, is a native of Hudson's Bay. The make of the body of this ani$\mathrm{mal}$ is not so round as that of the two former, but somewhat resembling the shape of a pig. It is covered with long bristly hair, with a shorter hair underneath; and under this the quills lie concealed very thick; they are white, with a brown point, and bearded, and the longest do not exceed four inches; they stick to the hand when the animal is stroked on the back; and likewisc, when the hand is taken away, they stick so fast as to follow it. They make their nest under the roots of great trees, sleep very much, and chiefly feed upon the bark of the juniper. In winter the snow serves then for drink; and in sumner they lap water, like a dog. They are very common in the country lying to the east of Hudson's Bay; and several of the trading Americans depend on them for food, at some seasons of the year.

\section{CHAPTER LV.}

\section{OF QUADRUPEDS COVERED WITH SCALES OR SHELLS INSTEAD OF HAIR.*}

WHEN we talk of a quadruped, the name seems to imply an animal covered with hair; when we mention a bird, it is natural to conceive a creature covered with feathers; when we hear of a fish, its scales are generally the

- This chapter is chielly extracted from Mr. Buffon, which 1 meution at once, to save the trouble of repeated quotation. first part that strikes our imagination. Nature, however, owns none of our distinctions; various in all her operations, she mixes her plans, groups her pictures, and excites our wonder, as well by her general laws as by her deviations. Quadrupeds, which we have considered as making the first general class in Animated Nature, and next to man the most dignified tenants of the earth, are yet, 
in many respccis, rclated to the classes bencath them, and do not in every respect, preserve their usual distinctions. - Their tirst character, which consists in having four feet, is common to the lizard kind as well as to them. The second prerogative, which is that of bringing forth living young, is found in the cetaceous tribe of fishes, and also in insects without number. Their third and last attribute, which seems more general and constant than the former, that of being covered with hair, is yet found in various other animals, and is deficient in quarupeds themselves. Thus we must be cautious of judging of the nature of animals from one single character, which is always found incomplete; for it often happens that three or four of the most general characters will not suffice. It must be by a general enumeration of the parts that we can determine precisely of the works of the creation; and instead of definitions, learn to describe. Had this method been followed, much of the disgust and the intricacy of history might have been avoided, and that time, which is now employed in combating error, laid out in the promoting of science.

Were we to judge of nature from definitions only, we should never be induced to suppose that there exister races of viviparous quadrupeds destitute of hair, aild firnished with scales and shells in their stend. However, nature, every way various, stipplies us with many instances of these cxtraordinary creatures; the old world has its quadrupeds covered with scales, and the new with a shell. In both, they resemble each other, as well in the strangeness of their appetites, as in their awkward conformation. Like animals but partially made up, and partaking of different natures, they want those instincts which animals formed but for onc element alone are found to possess. They seem to be a kind of strangers in nature; creatures taken from some other element, and capriciously thrown to find a precarious subsistence upon land.

\section{THE PANGOLIN.}

The pangolin, which has been usually called the scaly lizard, Mr. Buffon very judiciously restores to that denomination by which it is known in the countries wnere it is found. The calling it a lizard, he justly observes, might be apt to produce error, and occasion its being confounded with an animal which it resembles only in its general form, and in its being covered with scales. The lizard may bc considered as a reptile, produced from an egg; the pangolin is a quadruped, and brought forth alive, and perfectly formed. The lizard is all covered with the marks of scales; the pangolin bas scales neither on the throat, the breast, nur the belly. The scales of the lizard seem stuck upon the body even closer than those of fishes; the scales of the pangolin are on!y fixed at one and, and capable of being erceted, like those of the porcupine, at the will of the animal. The lizard is a defenceless creature; the pangolin can roll itself into a ball, like the hedgelıog, and presents the points of its scales to the enemy, which effectually defend it.

The pangolin, which is a native of the torrid climates of the ancient continent, is, of all other animals, the best prolected from external injury by nature. It is about three or four feet long; or, taking in the tail, from six to eight. Like the lizard, it has a small head, a very long nose, a short thick neck, a long borly, legs very short, and a tail extremely long, thick at the insertion, and terninating in a point. It has no teeth, but is armed with five toes ou each foot, with long white claws. But what it is chiefly distinguished by, is its scaly covering, which, ill some measure, hides all the proportions of its body. These scales defend the animal on all parts, except the under part of the head and neck. under the shoulders, the breast, the belly, and the inner side of the legs; all which parts are covered with a smooth, soft skin, without hair. Between the shells of this animal, at all the interstices, are seen hairs like bristles, brown at the extremity, and yellow towards the root. The scales of this extraordinary creature are of different sizes and different forms, and stuck upon the body somewhat like the leaves of an artichoke. The largest are found near the tail, which is covered with them like the rest of the body. These are above three inches broad, and about two inches long, thick in the middle and sharo at the edges, and terminated in a 
roundish point. They are extremcly hard, and their substance resembles that of horn. They are convexed on thc outside, and a little concave on the inner; one edge sticks in the skin, while the other laps over that immediatcly behind it. 'Those that cover the tail, conform to the shape of that part, being of a dusky brown colour, and so hard, when the animal has acquired its full growth, as to turn a musket-ball.

Thus armed, this animal fears nothing from the efforts of all other creatures, except man. The instant it perceives the approach of an enemy, it rolls itseli' up like the hedgehog, and presents no part but the cutting edges of its scales to the assailant. Its long tail, which, at first view, might be thought easily separable, serves still more to increase the animal's security. This is lapped round the rest of the body, and, being defended with shells even more cutting than any other part, the creature continucs in perfect security. Its shells are so large, so thick, and so pointed, that they repel every animal of prey; they make a coat of armour that wounds while it resists, and at once protects and threatens. The most cruel, the most famished quadruped of the forest, the tiger, the panther, and the hyæna, make vain attempts to force it. They tread upon, they roll it about, but all to no purpose; the pangolin remains safe within, while its invader almost always feels the reward of its rashness. The fox often destroys the hedgehog by pressing it with his weight, and thus obliges it to put forth its nose, which he instantly seizes, and soon after the whole body; but the scales of the pangolin effectually support it under any such weight, while nothing that the strongest animals are capable of doing can compel it to surrender. Man alone seems furuished with arms to conquer its obstinacy. The negroes of Africa, when they find it, bcat it to death with clubs, and consider its flesh as a very great delicacy.

But, although this animal be so formidahle in its appearance, there cannot be a more harmless, inoffensive creature when unmolested. It is even unqualified by nature to injure larger animals, if it had the disposition, for it has no teeth. It should seem that the bony matter, which goes in other animals to

No. $33 \& 34$. supply the teeth, is exhausted in this in supplying the scales that go to the covering of its body. Howcver this be, its life seems correspondent to its peculiar conformation. Incapable of being carnivorous, since it has no teeth, nor of subsisting on vegetables, which require much chewing, it lives entirely upon insects, for which nature has fitted it in a very extraordinary manner. As it has a long nose, so it may naturally be supposed to have a long tongue; but, to increasc its length still more, it is doubled in the mouth, so that when extended, it is shot out to above a quarter of a yard beyond the tip of the nose. This tongue is round, extremely red, and covered with an unctuous and slimy liquor; which gives it a shining hue. When the pangolin, therefore, approaches an ant-hill, for these are the insects on which it chiefly feeds, it lies down near it, concealing as much as possible the place of its retreat, and stretchjug out its long tongue among the ants, keeps it for some time quite immoveable. These little animals, allured by its appearance, and the unctuous substance with which it is smeared, instantly gather upon it in great numbers; and when the pangolini supposes a sufficiency, it quickly withdraws the tongue and swallows them at once. This peculiat. manner of hunting for its prey is repeated, either till it be satisfied, or till the ants, grown more cautious, will be allured to their destruction no. Jonger. It is against these noxious insects, therefore, that its only force or cunning is exerted; and were the Negroes but sufficiently sensible of its utility in alcstroying one of the greatest pests to their country, they would not be so cager to kill it. But it is the nature of savage men to pursue the immediate good, without being solicitous about the more distant benefit they remove. They, therefore, hunt this animal with the utmost avidity for its flesh; and as it is slow and unable to escape in art open place, they seldom fail of destroying it. However, it chiefly keeps in the most obscure parts of the forest, and digs itself a retreat in the clefts of rocks, where it brings forth its young, so that it is but rarely met with; and continues a solitary species, and an extraordinary instance of the varying of nature.

Of this animal, there is a variety which is $3 \mathrm{M}$ 
called the pritagis, much less than the former, being not above a foot long from the head to the tail, with shells differently formed, with its belly, breast, and throat covered with hair, iustead of a smooth skin, as in the former; but that by which it is peculiarly distinguished is the extent of its tail, which is above twice the length of its body. Both are found in the warm latitudes of the east, as well as in Africa; and, as their numbers are but few, it is to be supposed their fecundity is not great.

\section{THE ARMADILLO, OR TATOU.}

Havisg mentioned quadrupeds of the ancient continent covered with scales, we come next to quadrupeds of the new continent, covered with shells. It would seem that nature had reserved all the wonders of her power for these remote and thinly inhabited countries, where the men are savage, and the quadrupeds various. It would seem that she becomes more extraordinary in proportion as she retires from human inspection. But the real fact is, that wherever mankind are polished, or thickly planted, they soon rid the earth of these odd and half-formed productions, that in some measure encumber the soil. They soon disappear in a cultivated country, and continue to exist only in those remote deserts where they have no enemies but such as they are enabled to oppose.

The Armadillo is chiefly an inhabitant of South America; a peaceful, harmless creature, incapable of offending any other quadruped, and furnished with a peculiar covering for its own defence. The pangolin, described above, seems an inactive, helpless being, indebted for safety more to its patience than its power; but the armadillo is still more exposed and helpless. The pangolin is furnished with an arnour that wounds while it resists, and that is never attacked with impunity; but the armadillo is obliged to submit to every insult, without any power of repelling its enemy; it is attacked without danger, and is consequently liable to more various persecutions.

This animal being covered, like a tortoise, with a, shell, or rather a number of shells, its other proportions are not easily discerned. It appears, at first view, a round misshapen mass, with a long head, and a very large tail sticking out at either end, as if not of a piece with the rest of the body. It is of different sizes, firom a foot to three feet long, and covered with a shell divided into several pieces, that lap over each other like the plaits in a coat of armour, or in the tail of a lobster. The difference in the size of this animal, and also the different disposition and number of its plaits, have been considered as constituting so many species, each marked with its owu particular name. In all, however, the animal is partially covered with this natural coat of mail; the conformation of which affords one of the most striking curiosities in natural history. This shell, which in every respect resembles a bony substance, covers the head, the neck, the back, the sides, the rump, and the tail to the very point. The only parts to which it does not extend are, the throat, the breast, and the belly, which are covered with a white soft skin, somewhat resembling that of a fowl stripped of its feathers. If these naked parts be observed with attention, they will be found covered with the rudiments of shells, of the same substance with those which cover the back. The skin, even in the parts that are sofiest, seems to have a tendency to ossify; but a complete ossification takes place only on those parts. which have the least friction, and are the most exposed to the weather. The shell, which covers the upper part of the body, differs from that of the tortoise, in being composed of more pieces than one, which lie in bands over the body, and, as in the tail of the lobster, slide over each other, and are connected by a yellow membrane in the same manner. By this meains the animal has a motion in its back, and the armour gives way to its necessary inflections. These bands are of various numbers and sizes, and from them these animals have been distinguished into various kinds. In general, however, there are two large pieces that cover, one the shoulders and the other the rump. In the back, between these, the bands are placed in differeit numbers, that lap over each other, and give play to the whole. Besides their opening cross-ways, they also open down along the back, so that the animal can move in 
every direction. In some there are but three of these bands between the large pieces; in others there are six; in a third kind there are eight; in a fourth kind, nine; in a fifth kind, twelve; and, lastly, in the sixth kind there is but one large piece, which covers the shoulders, and the rest of the body is covered with bands all down to the tail. These shells are differently coloured in different kinds, but most usually they are of a dirty gray. This colour, in all, arises from another peculiar circumstance in their conformation, for the shell itself is covered with a softisls skin, which is smooth and transparent.

But, although these shells might easily defend this animal from a feeble enemy, yet they could make but a slight resistance against a more powerful antagonist; nature, therefore, has given the armadillo the same method of protecting itself with the hedgehog or the paugolin. The instant it perceives itself attacked, it withdraws the head under its shells, and lets nothing be seen but the tip of the nose; if the danger increase, the animal's precautions increase in proportion; it then tucks up its feet under its belly, unites its two extremities together, while the tail seems as a band to strengthen the connexion; and it thus becomes like a ball, a little flattish on each side. In this position it continues obstinately fixed, while the danger is near, and often long after it is over. In this situation it is tossed about at the pleasure of every other quadruped, and very little resembling a creature endowed with life and motion. Whenever the Indians take it, which is in this form, by laying it close to the fire, they soon oblige the poor animal to unfold itself, and to face a milder death to escape a more severe.

This animal is a native only of America, for they were utterly unknown before the discovery of that continent. It is an inoffensive, harmless creature, unless it finds the way into a garden, where it does a great deal of mischief, by eating the melons, the potatoes, and other vegetables. Although a native of the warmest parts of America, yet it bears the cold of our climate without any inconvenience. We have often seen them shown among other wild beasts, which is a proof they are not difficult to be brought over. Their motion seems to be a swift walk, but they can neither run, leap, nor climb trees; so that, if found in an open place, they have no metlod of escaping from their pursuers. Their ouly resource in such an extremity is to make towards their loole as fast as they can; or, if this be impracticable, to make a new hole before the enemy arrives. For this they require but a very few moments advantage; the mole itself does not burrow swifter than they can. For this purpose, they are furnished with claws extremely large, strong, and crooked, and usually four upon each foot. They are sometimes caught by the tail as they are making their way into the earth; but such is their resistance, and so difficult is it to draw them backward, that they leave their tail in the hand of their pursuer, and are very well contented to save their lives with its loss. The pursuers, sensible of this, never drag the tail with all their force, but hold it while another digs the ground about them, and thus these animals are taken alive. The instant the armadillo perceives itself in the power of its enemies, it bas but one last resource, to roll itsclf up, and thus patiently wait whatever tortures they think proper to inflict. The flesb of the smaller kinds is said to be delicate eating; so that we may suppose they receive no mercy. For this reason they are pursued with unceasing industry; and, although they burrow very deep in the earth, there have been many experlients used to force them out. The hunters sometimes contrive to fill the hole with smoke, which is often successful; they at other times force it by pouring in water. They also bring up a small kind of dogs to the chase that quickly overtake them, if at any distance from their burrow, and oblige them to roll themselves up in a ball, in which figure the hunters carry them home. If, however, the armadillo be near a precipice, it often escapes. by rulling itself up, and then tumbling down from rock to rock, without the least danger or inconvenience. They are sometimes taken in snares laid for them by the sides of rivers and low moist places, which they particularly frequent; and this methed, in general, succeeds better than any of the former, as their burrows are very deep, and they seldom stir out except in the night. At no time are they $3 \mathrm{M}^{*}$ 
found at any great distance from their retreats, so that it requires some patience and skill to intercept their retreat.

There are scarce any of these that do not root the ground, like a hog, in search of such roots as make a principal part of their food. They live also upon melons and other succulent vegetables, and all will eat flesh when they can get it. They frequent water and watery places, where they feed upon worms, small fish, and water insects. It is pretended that there is a kind of friendship between them and the rattle-snake, that they live peaceably and commodiously together, and are frequently found in the saine hole. This, however, may be a friendship of necessity to the armadillo; the rattle-snake takes possession of its retreats, which neither a re willing to quit, while each is incapable of injuring the other.

As to the rest, these animals, though they all resemble each other in the general character of being clothed with a shell. yet differ a good deal in their size, and in the parts into which their shell is divided. The first of this kind, which bas but three bands between the two large pieces that cover the back, is called the TATU APARA. I will not enter into an exact description of its figure, which, how well written soever, no imagiilation could exactly conceive; and the reader would be more fatigued to understand than I to write it. The tail is shorter in this than any other kind, being not more than two inches long, while the shell, taking all the pieces together, is a foot long and eight inches broad. The second is the tatou of Ray, or the encou-
BERT of Buffon; this is distinguished from the rest by six bands across the back; it is about the size of a pig of a month old, with a sinall long head and a very long tail, The third is the Tatuetre, furmished with eight bands, and not by a great deal so big as the former. Its tail is louger also, and its legs shorter in proportion. Its body, from the nose to the insertion of the tail, is about ten inches long, and the tail seven. The fourth is the PIG-HEADED ARMADILLO, with nine bauds. This is much larger than the former, being about two feet long from the nose to the tail. The fifth is the KABASSOU, or CATAPHRACTUS, with twelve binds, and still bigger than the former, or any other of its kind. This is often found above three feet long; but is never eaten as the rest are. The sixth is the WEASEL-HEADED ARmapillo, with eighteen bands, with a large piece before, and nothing but bands backward. This is above a foot long, and the tail five inches. Of all these, the kabassou and the encoubert are the largest; the rest are of a much sinaller kind. In the larger kinds, the shell is much more solid than in the others, and the flesh is much harder and unfit for the table. These are generally seen to reside in dry upland grounds, while the small species are al ways found in moist places, and in the neighbourhuod of brooks and rivers. They all roll themselves into a ball; but those whose bauds are fewest in number are least capable of covering themselves up completely. The tatu apara, for instance, when rolled up, presents two great interstices between its bands, by which it is very easily vulnerable, even by the feeblest of quadrupeds.

\section{CHAPTER LVI.}

\section{ANIMALS OF THE BAT KIND}

HAVING in the last chapter described a race of animals that unite the boundaries between quadrupeds and insects, I come in this to a very different class, that serve to fill up the chasm between quadrupeds and birds. Some naturalists, indeed, have found animals of the bat kind so much partaking of the nature of both, that they have bren at a loss in which rank to place them, and have doubted, in giving the history of the bat, whether it was a beast or a bird they were describing. These doubts, however, no longer exist; they 
are now universally made to take their place amoug quadrupels, to which their bringing forth their young alive, their hair, their teeth, as well as the rest of their habitudes and conformation, evidently entitle then. Pliny, Gesner, and Aldrovandus, who placed them among birds, did not consider that they wanted every character of that order of animals, except the power of flying. Indeed, when this animal is seen with an awkward and struggling motion, supporting itself in the air at the dusk of the evening, it presents in some measure the appearance of a bird; but naturalists, whose business it is to examine it more closely, to watch its habitudes, and inspect into its formation, are inexcusable for concurring in the mi take.

The bat in scarce any particular resembles the bird, except in its power of sustaining itsell in the air. It brings forth its young alive ; it suckles them; its mouth is furnished with teetl ; its lungs are formed like those of quadrupeds ; its intestines, and its skeleton, have a complete resemblance, and even are, in some measure, seen to resemble those of mankind.

The bat most common in England, is about the size of a mouse; or nearly two inches and a half long. The membranes that are usually called wings, are, properly speaking, an extension of the skin all round the body, except the head, which, when the animal flies, is kept stretched on every side, by the four interior toes of the fore feet, which are enormously long, and serve like masts that keep the canvas of a sail spread, and regulate its motions. ${ }^{\text {b }}$ The first toe is quite loose, and serves as a heel when the bat walks, or as a hook, when it would adhere to any thing. The hind feet are disengaged from the surrounding skin, and divided into five toes, somewhat resembling those of a mouse. The skin by which it flies is of a dusky colour. The body is covered with a short fur, of a mouse colour, tinged with red. The eyes are very small; the ears like those of a mouse.

This species of the bat is very common in England. It makes its first appearance early in summer, and begins its flight in the dusk of the evening. It principally frequents the sides of wood,, ylades, and shady walks; and is frequently observed to skim along the surface

- Penis propendens. of pieces of water. It pursues gnats, moths, and nocturnal insects of every kind. It feeds upon these; but will not refuse meat, whenever it can fund it. Its flight is a laborious, irregular movenent ; and if it happens to be interrupted in its course, it cannot readily prepare for a second elevation; so that if it strikes against any object, and falls to the ground, it is usually taken. It appears only in the most pleasant evenings, when its prey is generally abroad, and flies in pursuit with its mouth open. At other times it continues in its retreat ; the chink of a ruined building, or the hollow of a tree. Thus this little aninal, even in summer, sleeps the greatest part of its time, never venturing out by day-light, nor in rainy weather ; never hunting in quest of prey, but for a small part of the night, and then returning to its hole. But its short life is still more abridged by continuing in a torpid state during the winter. At the approach of the cold season, the bat prepares for its state of lifeless iuactivity, and seems rather to choose a place where it may continue safe from interruption, than where it may be warmly or conveniently lodged. For this reason it is usually seen hanging by its hooked claws to the roofs of caves, regardless of the eternal dainps that surround it. The bat seems the only animal that will venture to remain in these frightful subterranean abodes, where it continues in a torpid state, unaffected by every change of the weather. Such of this kind as are not provident enough to procure themselves a deep retreat, where the cold and heat selilom vary, are sometimes exposed to great inconveniences, for the weather often becomes so mild in the midst of winter as to warm them prematurely into life, and to allure them from their holes in quest of food, when nature has not provided a supply. These, therefore, have seldom strength to return; but, having exhausted themselves in a vain pursuit after insects which are not to be found, are destroyed by the owl, or any other animal that follows such petty prey.

The bat couples and brings forth in summer, generally from two to five at a time: of this I am certain, that I have found five young ones in a hole together; but whether they were the issue of one parent, I cannot tell. The female has but two nipples, and those

- British Zoology. 
forwara on the breast, as in the human kind. This was a sufficient motive for Limnæus to give it the title of a primas, to rank it in the same order with mankind; and to push this contemptible animal among the chiefs of the creation. Such arbitrary associations produce rather ridicule than instruction, and render even method contemptible; however, we are to forgive too strong an attachment to system in this able naturalist, since his application to the particular history of the animal counterbalances the defect."

From Linnzus we learn, that the female makes no nest for her young, as most birds and quadrupeds are known to do. She is barely content with the first hole she meets, where sticking herself by her hooks against the sides of her apartments she permits her young to hang at the nipple, and in this manner to continue for the first or second day. When, after some time, the dam begins to grow hungry, and find a necessity of stirring abroad, she takes her little ones and sticks them to the wall, in the manner she before hung herself; there they immoveably cling, and patiently wait till her return.

Thus far this animal seems closely allied to the quadruped race. Its similitude to that of birds is less striking. As nature has furnished birds with extremely strong pectoral muscles, to move the wings, and direct their flight, so has it also furnished this animal. As birds also have their legs weak, and unfit for the purposes of motion, the bat has its legs fashioned in the same manner, and is never seen to walk, or, more properly speaking, to push itself forward with its hind legs, but in cases of extreme necessity. The toes of the fore legs, or, if we may use the expression, its extremely long fingers, extend the web like a membrane that lies between them; and this, which is extremely thin, serves to lift the little body into the air: in this manner, by an unceasing percussion, much swifter than that of birds, the animal continues, and directs its flight; however, the great labour required in flying, soon fatigues it; for, unlike birds, which continue for days together upon the wing, the bat is tired in less than an hour, and then returns to its hole, satisfied

\footnotetext{
- Fauna Suecia, p. 8.
}

with its supply, to enjoy the darkness of its retreat.

If we consider the bat as it is seen in our own country, we shall find it a harmless, inoffensive creature. It is true that it now and then steals into a larder, and, like a mouse, commits its petty thefts upon the fattest parts of the bacon. But this happens seldom; the general tenor of its industry is employed in pursuing insects that are much more noxious to us than itself can possibly be; while its evening flight, and its unsteady wabbling motion, amuse the imagination, and add one figure more to the pleasing group of Alumated Nature.

The varieties of this animal, especially in our country, are but few; and the differences scarce worth enumeration. Naturalists mention the Long-eared Bat, much less than that generally seen, and witlı much longer ears; the Horse-shoe Bat, with an odd protuberance round its upper lip, somewhat in the form of a horse-shoe; the Rhinoceros Bat, with a horu growing from the nose, somewhat similar to that animal from whence it has the name. These, with several others, whose varieties are too numerous, and differences too minute for a detail, are all inoffensive, minute, and contemptible; incapable, from their size, of injuring mankind, and not sufficiently numerous much to incommode him. But there is a larger race of bats, found in the East and West Indies, that are truly formidable; each of these is singly a dangerous enemy, but when they unite in flocks, they then become dreadful. Were the inhabitants of the African coasts," says Des Marchais, to eat animals of the Bat kind, as they do in the East Indies, they would never want a supply of provisions. They are there in such numbers, that when they fly, they obscure the setting sun. In the morning, at peep of day, they are seen sticking upon the tops of the trees, and clinging to each other, like bees when they swarm; or like large clusters of cocoa. The Europeans often amuse themselves with shooting among this huge mass of living creatures, and observing their cmbarrassment when wounded. They sometimes enter the houses, and the Negroes are

b Des Marchais, vol. ii. p. 208. 
expcrt at killing them; but although thesc prople seem for ever hungry, yet they regard the bat with horror, and will not eat it, though ready to starve.

Of foreign bats, the largest we have any certain accounts of, is the Rousette, or the Grcat Bat of Madagascar. This formidable creature is near four feet broad, when the wings are extended; and a foot long, from the tip of the nose to the insertion of the rail. It resembles our bat in the form of its wings, in its manner of fying, and in its internal conformation. It differs from it in its cnormous size; in its colour, which is red, like that of a fox; in its head and nose also, which rescmble those of that animal, and which have induced some to call it the flying fox: it differs also in the number of its tceth; and in having a claw on the fore foot, which is wanting in ours. This formidable creature is found only in the ancicnt continent; particularly in Madagascar, along the coasts of Africa and Malabar, whicre it is usually seen about the size of a large hen. When they repose, they stick thenselves to the tops of the tallest trees, and hang with thcir heads downward. But when they are in motion, nothing can be more formidable: they are seen in clouds, darkening the air, as well by day as by night, destroying the ripe fruits of the country, and sometimes settling upon animals, and inan himself : they devour, indiscriminately, fruits, flesh, and insects, and drink the juice of the palm-tree: they are lieard at night in the forests at more than two miles distance, with a hoorrible din, but at the approach of day, they usually begin to retire; nothing is safe from their depredations; they destroy fowls and domestic animals, unless prescrved wilh the utmost care, and often fasten upon the inliabitants themselves, attack them in the face, and inflict very terrible wounds. In short, as some have already observed, the ancients scen to have taken their ideas of harpics from these fierce and voracious creatures, as they both concur in many parts of the description, being equally deformed, greedy, uncleanly, and cruel.

An aninal not so formidable, but still more mischievous than these, is the Anncrican Vampyre. This is still less than the former; but inore definrmed, and still more numerous. It is furnished with a horn like the rhinoceros bat; and its cars are extremely long. The other kinds generally resort to the forest, and the most deserted places; but these comc into towns and cities, and, after sun-set, when they begin to fly, cover the streets like a canopy. ${ }^{2}$ They are the common pest both of men and animals; they effectually destroy the one, and often distress the other. "They are," says Ulloa, "the most expert blood-letters in the world. The inhabitants of those warm latitudes being obliged, by the excessive heats, to leave open the doors and windows of the chambers where they sleep, the vampyres enter, and if they find any part of the body exposed, they never fail to fasten upon it. There they continue to suck the blood; and it often happens that the person dies under the operation. They insinuate their tooth into a vcin, with all the art of the most experienced surgcon, continuing to exhaust the body until they arc satiated. I have been assured," continues he, "by persons of the strictest veracity, that such an accident has happened to them; and that, had they not providentially awaked, their slecp would have been their passage into etcruity; having lost so large a quantity of blood as hardly to find strength to bind up the orifice. The reason why the puncture is not felt is, besides the great precaution with which it is made, the gentle refreshing agitation of the bat's wings, which contribute to increase sleep, and soften the pain."

The purport of this account has been confirmed by various other travellers; who all agree that this hat is possessed of a faculty of drawing the blood from persons sleeping; and thus often destroying them before they awakc. But still a very strong difficulty remains to be accounted for; the manner in which they inflict the wound. Ulloa, as has beell seell, supposes that it is done by a single tooth; but this we know to be impossible, since the animal cannot infix one tooth without all the rest accompanying its motions; the tecth of the bat kind being pretty even, and the mouth but sinall. Mr. Buffon therefore supposes the wound to be inflicted by the tongue; which, however, appears to me too large to. inflict an unpainful wound; and even less qualificd for that purpose than the teeth. Nor can the tongue, as Mr. Buffon seems to suppose, serve for the purposes of suction, since for this it

a Ulloa, vol.i. p. 58. 
must be hollow, like a syringe, which it is not found to be. I should therefore suppose, that the animal is endowed with a strong power of suction; and that, without inflicting any wound whatsoever, by continuing to draw, it enlarges the pores of the skin in such a manner that the blood at length passes, and that more freely the longer the operation is continued; so that, at last, when the bat goes off, the blood continues to flow. In confirmation of this opinion we are told, that where beasts have a thick skin, this animal cannot injure them; whereas, in horses, mules, and asses, they are very liable to be thus destroyed. As to the rest, these animals are considered as one of the great pests of South America; and often prevent the peopling of many parts of that continent : having destroyed at Barja, and several other places, such cattle as were brought there by the missionaries, in order to form a settlement.

\section{CHAPTER LVII.}

\section{OF AMPHIBIOUS QUADRUPEDS.}

THE gradations of nature from one class of beings to another are made by imperceptible deviations. As we saw in the foregoing chapters quadrupeds almost degraded into the insect tribe, or mounted among the inhabitants of the air, we are at present to observe their approach to fishes, to trace the degrees by which they become more unlike terrestrial animals, till the similitude of the fish prevails over that of the quadruped.

As in opposite armies the two bodies are distinct and separated from each other, while yet between them are various troops that plunder on both sides and are friends to neither; so between terrestrial and aquatic animals there are tribes that can scarce be referred to any rank, but lead an amphibious life between them. Sometimes in water, sometimes on land, they seem fitted for each element, and yet completely adapted to neither. Wanting the agility of quadrupeds upon land, and the perseverance of fishes in the deep, the variety of their powers only seems to diminish their force; and, though possessed of two different methods of living, they are more inconveniently provided than such as have but one.

All quadrupeds of this kind, though covered with hair in the usual manner, are furnished with membranes. between the toes, which assist their motion in the water. Their paws are broad and their legs short, by which they are more completely fitted for swimming; for, taking short strokes at a time, they make them oftener and with greater rapidity. Some, however, of these animals are more adupted to live in the water than others; but, as their power increases to live in the decp, their nnfitness for living upon land increases in the same proportion. Some, like the otter, resemble quadrupeds in every thing except in being in some measure web-footed; others depart still farther, in being, like the beaver, not only web-footed, but having the tail covered with scales, like those of a fish. Others depart yet farther, as the seal and the morse, by having the hind feet stuck to the body like fins; and others, as the lamentin, almost entirely resemble fishes, by having no hind feet whatsocver. Such are the gradations of the amphibious tribe. They all, however, get their living in the water, either by habit or conformation; they all continue a long time under water; they all consider that clement as their proper abode; whenever pressed by danger they fly to the water for security; and, when upon land, appear watchful, timorous, and unwieldy.

\section{THE OTTER.}

IN the first step of the progression from land to amphibious animals, we find the Otter, re- 
sembling those of the terrestrial kind in shape, hair, and internal conformation; resembling the aquatic tribes in its manner of living, and in having membranes between the toes to assist it in swimming. From this peculiar make of its feet, which are very short, it swims even faster than it runs, and can overtake fishes in their own element. The colour of this animal is brown ; and it is somewhat of the shape of an overgrown weasel, being long, slender, and soft-skinned. However, if we examine its figure in detail, we shall find it unlike any other animal hitherto described, and of such a shape as words can but weakly convey. Its usual length is about two feet long, from the tip of the nose to the insertion of the tail ; the head and nose are broad and flat; the mouth bears some similitude to that of a fish; the neck is short, and equal in thickness to the head; the body long; the tail broad at the insercion, but tapering off to a point at the end; the eyes are very small, and placed nearer the nose than usual in quadrupeds. The legs are very short, but renarkably strong, broad, and muscular. The joints are articulated so loosely, that the animal is capable of turning them quite back, and bringing them on line with the body, so as to perform the office of fins. Each foot is furnished with five toes, connected by strong broad webs like those of waterfowl. Thus nature, in every part, has had attention to the life of an animal whose food is fish, and whose haunts must necessarily be about water.

This voracious animal is never found but at the sides of lakes and rivers, but particularly the former, for it is seldom fond of fishing in a running stream, for the current of the water having more power upon it than the fishes it pursues, if it hunts against the stream, it swims too slow; and if with the stream, it overshoots its prey. However, when in rivers, it is always observed to swim against the stream, and to meet the fishes it preys upon rather than to pursue them. In lakes it destroys much more than it devours, and is often seen to spoil a pond in the space of a few nights. But the damage they do by destroying fish is not so great as their tearing in pieces the nets of the fishers, which they infalliby do whenever they happen to be entangled. The instant they find themselves caught, they go to work with their teeth, and in a few miNo. $33 \& 34$ nutes destroy nets of a very considerable value.

The otter has two different methods of fisling; the one, by catching its prey from the bottom upward, the other, by pursuing it into some little creek, and seizing it there. In the former case, as this animal has longer lungs than most other quadrupeds, upon taking in a quantity of air, it can remain for some minutes at the bottom; and whatever fish passes over at that time is certainly taken; for as the eyes of fish are placed so as not to see under them, the otter attacks them off their guard from below; and, seizing them at once by the belly, drags them on shore, where it often leaves them untouched, to continue the pursuit for hours together. The other method is chiefly practised in lakes and ponds, where there is no current; the fish thus taken are rather of the smaller kind, for the great ones will never be driven out of deep water.

In this manner, the otter usually lives during the sunımer, being furnished with a supply much greater than its consumption; killing for its amusement, and infecting the edges of the lake with quantities of dead fish, which it leaves there as trophies rather of its victory than its necessities. But in winter, when the lakes are frozen over, and the rivers pour with a rapid torrent, the otter is often greatly distressed for provisions; and is then obliged to live upon grass, weeds, and even the bark of trees. It then comes upon land, and, grown courageous from necessity, feeds upon terrestrial animals, rats, insects, and even sheep themselves. Nature, however, has given it the power of continuing a long time without food; and although, during that season, it is not rendered quite torpid, like the marmout or the dormouse, yet it keeps much nore within its retreat, which is usually the hollow of a bank, worn under by the water. There it often forms a kind of gallery, running for several yards along the edge of the water; so that when attacked at one end, it flies to the other, and often evades the fowler by plunging into the water at forty or fifty paces distant, while he expects to find it just before him.

We learn from Mr. Buffon, that this animal, in France, couples in winter, and brings forth in the beginning of spring. But it is certainly different with us, for its young are never found till the latter end of summer; and 1 
have frequently, when a boy, discovered their retreats, and pursued them at that season. I am, therefore, more inclined to follow the account given us of this animal by Mr. Lots, of the Academy of Stockholm, who assures us that it couples about the middle of summer, and brings forth at the end of nine weeks, generally three or four at a time. This, as well as the generality of his other remarks on this subject, agrecs so exactly with what I remember concerning it, that I will beg leave to take him for iny guide, assuring the reader that, however extraordinary the account may seem, I know it to be certainly true.

In the rivers and the lakes fiequented by the otter, the bottom is generally stony and uneven, with many trunks of trees, and long roots stretching underneath the water." The shore also is hollow and scooped inward by the waves. These are the places the otter chiefly chooses for its retreat; and there is scarce a stone which does not bear the mark of its residence, as upon them its excrements are always made. It is chiefly by this mark that its lurking places are known, as well as by the quantity of dead fish that are found lying here and there upon the banks of the water. To take the old ones alive is no easy task, as they are extremely strong, and there are few dogs that will dare to encounter them. They bite with great fierceness, and never let go their hold when they have once fasten$e d$. The best way, therefore, is to shoot them at once, as they never will be thoroughly tamed; and, if kept for the purposes of fishing, are always apt to take the first opportunity of escaping. But the young ones may be more easily taken, and converted to very useful purposes. The otter brings forth its young generally under the hollow banks, upon a bed of rushes, flags, or sinch weeds as the place affords it in the greatest quantities. I see in the British Zoology a description of its habitation, where that naturalist observes, "that it burrows under ground, on the banks of some river or lake, and always makes the entrance of its hole under water, then works up the surface of the earth, and there makes a minute orifice for the admission of air, and this little air-hole is often

a Journal Etranger, Juin. 1755. p. 14. found in the middle of some thicket." In some places this may be true, but I have never observed any such contrivance; the retreat, indeed, was always at the edge of the water, but it was only sheltered by the impending bank; aid the otter itself scemed to have but a small share in its formation. But be this as it nay, the young ones are always found at the edge of the water; and, if under the protection of her dam, she teaches them instantly to plunge, like herself, into the deep, and escape among the rushes or weeds that fringe the stream. At such times, therefore, it is very difficult to take them; for, though never so young, they swim with great rapidity, and in such a manner that no part of them is seen above water, except the tip of the nose. It is only when the dam is absent that they can be taken; and, in some places, there are dogs purposely trained for discovering their retreats. Whenever the dog comes to the place, he soon, by lis barking, shows that the otter is there; which, if there be an old one, instantly plunges into the water, and the young all follow. But, if the old one be absent, they continue terrified, and will not venture forth but under her guidance and protection. In this manner they are secured, and taken home alive, where they are carefully fed with small fish and water. In proportion, however, as they gather strength, they have milk mixed among their food, the quantity of their fish provision is retrenched, and that of vegetables is increased, until at length, they are fed wholly upon bread, which perfectly agrees with their constitution. The manner of training them up to bunt for fish requires not only assirluity but patience; however, their activity and use, when taught, greatly repays the trouble of teaching; and, perhaps, no other animal is more beneficial to his master. The usual way, is, first to learn them to fetch, as dogs are instructed; but, as they have not the same docility, so it requires inore art and experience to teach then. It is usually perlormed by accustoming them to take a truss stuffed with wool, of the shape of a fish, and made of leather, in their mouths, and to drop it at the word of command; to run after it when thrown forward, and to bring it to their master. From this they proceed to real fish, 
which are thrown dead into the water, and which they are taught to fetch from thence. From the dend they proceed to the live, until at last the animal is perfectly instructed in the whole art of fishing. An otter thus taught is a very valuable animal, and will catch fish enough to sustain not only itself but a whole family. I have seen one of these go to a gentleman's pond at the word of command, drive up the fish into a corner, and seizing upon the largest of the whole, bring it off, in its mouth, to its master.

Otters are to be met with in most parts of the world, and rather differ in size and colour from each other, than in habitudes or conformation." In North America, and Carolina, they are usually found white, inclining to yellow. The Brasilian otter is much larger than ours, with a roundish head, almost like a cat. The tail is shorter, being but five inches long; and the hair is soft, short, and black, except-on the head, where it is of a dark brown, with a yellowish spot under the throat.

\section{THE BEAVER.}

Is all countries, as man is civilized and improved, the lower ranks are repressed and degraded. ${ }^{b}$ Either reduced to servitude, or treated as rebels, all their societies are dissolved, and all their united talents rendered ineffectual. Their feeble arts quickly disappear, and nothing remains but their solitary instincts, or those foreign habitudes which they receive from human education. For this reason there remain no traces of their ancient talents and industry, except in those countries where man himself is a stranger; where, unvisited by his controlling power, for a long succession of ages, their little talents have had time to come to their limited perfection, and their common designs have been capable of being united.

The beaver seems to be now the only remaining monument of brutal society. From the result of its labours, which are still to be seen in the remote parts of America, we learn how far instinct can be aided by imitation. We from thence perceive to what a degree

\footnotetext{
Ray. b Buffon.
}

animals without language or reason, can concur for their mutual advantage, and attain by numbers those advantages which each in a state of solitude seems unfitted to possess.

If we examine the beaver merely as an individual, and unconnected with others of its kind, we shall find many other quadrupeds to exceed it in cunning, and almost all in the powers of annoyance and defence. The beaver, when taken from its fellows, and kept in a state of solitude or domestic tameness, appears to be a mild, gentle creature, familiar enough, but somewhat dull, and even. melancholy; without any violent passions or vehement appetites, moving but seldom, making no efforts to attain any good, except in gnawing the wall of its prison, in order to regain its freedom; yet this, however, without anger or precipation, but calm and indifferent to all about, without attachment or antipathies, neither seeking to offend, nor desiring to please. It appears inferior to the $\mathrm{dog}$ in those qualities which render animals of service to man; it seems made neither to serve, to command, nor to have connections with any other set of beings, and is only adapted for living among its kind. Its talents are entirely repressed in solitude, and are only brouglit out by society. When alone, it has but little industry, few tricks, and without cunning sufficient to guard it against the most obvious and bungling snares laid for it by the hunter. Far from attacking any other ani$\mathrm{mal}$, it is scarce possessed of the arts of defence. Preferring flight to combat, like all wild animals, it only resists when driven to an extremity, and fights only when its speed can no longer avail.

But this animal is rather more remarkable for the singularity of its conformation, than any intellectual superiorities it may be supposed, in a state of solitude, to possess. The beaver is the only creature among quadrupeds that has a flat broad tail, covered with scales, which serves as a rudder to direct its motions in the water. It is the sole quadruped that has membranes between the toes on the hind feet only, and none on the fore fect, which supply the place of hands, as in the squirrel. In short, it is the only animal that in its fore parts entirely resembles a quadruped, and in its hinder parts seems to ap$3 \mathrm{~N}^{*}$ 
proach the nature of fishes, by having a scaly tail. In other respects, it is about two feet long and near one foot high; it is somewhat shaped like a rat, except the tail, which, as has been observed, is flat and scaly, somewhat resembling a neat's tongue at the point. Its colour is of a light brown, the hair of two sorts; the one longer and coarser; the other soft, fine, short, and silky. The teeth are like those of a rat or a squirrel, but longer and stronger, and adinirably adapted to cutting timber or stripping bark, to which purposes they are constantly applied. One singularity more unay be mentioned iu its conformation; which is, that like birds, it has but one and the same vent for the ennission of its excrements and its urine; a strange peculiarity, but which anatomists leave us 110 room to doubt of.

The beavers begin to assemble about the months of June and July, to form a society that is to contiaue for the greatest part of the year. They arrive in numbers from every side, and generally form a company of above two hundred. The place of meeting is commonly the place where they fix their abode, and this is always by the side of some lake or river. If it be a lake in which the waters are always upon a level, they dispense with building a dam; but if it be a runuing stream, which is subject to floods and falls, they then set about building a dam, or pier, that crosses the river, so that it forms a dead water in that part which lies above and below. This dain, or pier, is often fourscore or a hundred feet loug, and ten or twelve feet thick at the base. If we compare the greatness of the work with the powers of the architect, it will appear enormous; but the solidity with which it is built is still more astonishing than its size. The part of the river over which this dam is usually built, is where it is most shallow, and where some great tree is found growing by the side of the stream. This they pitch upon as proper for making the principal part in their building; and, although it is often thicker than a man's body, they iustantly set about cutting it down. For this operation they have no other instrument but their teeth, which soon lay it level, and that also on the side they wish it to fall, which is always across the stream They then fall about cutting off the top branches, to make it lie close and even, aud serve as the principal beam of their fabric."

This dike, or causey, is sometimes ten, and sometimes twelve feet thick at the foundation. It descends in a declivity, or slope, on that side next the water, which gravitates upon the work in proportion to the height, and presses it with a prodigious force towards the earth. The opposite side is erected perpendicular, like our walls; and that declivity, which, at the bottom, or basis, is about twelve feet broad, diminishes towards the top, where it is no more than two feet broad, or thereabouts. The materials whereof this mole cousists, are wood and clay. The beavers cut, with surprising ease, large pieces of wood, some as thick as one's. arm or thigh, and about four, five, or six feet in length, or soinetimes more, according as the slope ascends. They drive one end of these stakes inco the ground, at a small distance one from the other, intermingling a few with them that are smaller and more pliant. As the water, however, would find a passage through the intervals or spaces between them, and leave the reservoir dry, they have recourse to a clay, which they know where to find, and with which they stop up all the cavities both within and without, so that the water is duly confined. They continue to raise the dike in proportion to the elevation of the water and the plenty which they have of it. They are conscions, likewise, that the conveyance of their materials by land would not be so easily accomplished as by water; and therefore they take the advantage of its increase, and swim with their mortar on their tails, and their.stakes between their teeth, to the places where there is most occasion for them. If their works are, either by the force of the water or the feet of the huntsmen, who run over them, in the least damnified, the breach is instantly made up; every nook and corner of the habitation is reviewed, and, with the utmost diligence and application, perfectly repaired. But when they find the huntsmen visit them too often, they work only in the night time, or else abandon their works entirely, and seek out for some safer situation.

a Spectacle de la Nature. 
The dikc, or molc, being thus completed, their next carc is to erect their several apartments, which are either round or oval, and divided into three stories, one raised above the other : the first below the level of the causcy, which is for the most part full of water; the other two above it. This little fabric is built in a very firm and substantial manner, on the edge of their reservoir, and always in such divisions or apartments as above mentioned; that, in case of the water's increase, they may move up a story higher, and be no ways incommoded. If they find any little island contiguous to their reservoir, they fix their mansion there, which is then more solid, and not so fiequently exposed to the overflowing of the water, in which they are not able to continue for any length of time. In case they cannot pitch upon so commodions a situation, they drive piles into the earth, in order to fence and fortify their habitation against the wind as well as the water. They make two apertures, at the bottom, to the stream; one is a passage to their bagnio, which they always kecp neat and clean; the other leads to that part of the building where every thing is conveyed, that will either soil or damage their upper apartments. They have a third opening, or doolway, much ligher, contrived for the prevention of their being shut up and confined, when the fiost and snow has closed the apertures of the lower floors. Sometimes they build their houses altogether upon dry land; but then they sink trenches five or' six feet deep, in order to descend into the water when they sce convenient. They make use of the same materials; and are equally industrious in the erection of their lodges, as their dikes. Their walls are perpendicular, and about two fect thick. As their teeth are more serviceable than saws, they cut off all the wood that projects beyond the wall. After this, when they have mixed up some clay and dry grass together, they work it into a kind of mortar, with which, by the help of their tails, they plaster all their works, both within and without.

The inside is vaulted, and is large enough for the reception of eight or ten beavers. In case it rises in an oval figure, it is for the generality above twelve feet long, and cight or ten feet broad. If the number of inliabitants inclease to fifteen, twenty, or thirty, the edifice is cnlarged in proportion. I have been credibly informed, that four hundred beavers have been discovered to reside in one large mansionhouse, divided into a vast number of apartments, that had a free comnumication one with another.

All these works, more especially in the northern parts, are finished in August, or Septemher at fartliest; at which tinie they begin to lay in their stores. During the summer they.are perfect epicures; and regale themselves every day on the choicest fruits and plants the country affords. Their provisions, indeed, in the winter season, principally consist of the wood of the birch, the plane, and some few other trees, which they steep in water, from time to time, in such quantities as are proportioned to the number of inhabitants. They cut down branches from three to ten feet in length. Those of the largest dimensions arc conveyed to their magazines by a whole. body of beavers; but the smallest by one only: cach of them, however, takes a different way, and has his proper walk assigned him, in order that no one labourer should interrupt another in the prosecution of his work. Their woodyards are larger or smaller, in proportion to the number in the family : and, according to the observation of some curious naturalists, the usual stock of timber, for the accommodation of ten beavers, consists of about thirty feet in a squarc surface, and ten in depth. These logs are not thrown up in one continued pile, but laid one across the other, with intervals, or small spaces between them, in order to take out, with the greater facility, but just such a quantity as they shall want for their immediate consumption, and those parcels only, which lic at the bottom in the water, and have been duly steeped. This timber is cut again into small particles, and conveyed to one of their largest lodges, where the whole family meet, to consume their respective dividends, which are made impartially, in even and equal portions. Sometimes they traverse the woods, and regale their young with a more novel and elegant entertainment.

Such as arc used to hunt these animals, kllow perfectly well that green wood is much more acceptable to them than that which is old and dry ; for which reason they plant a considerable quantity of it round their lodgemeuts; and as they come out to partake of it, they cither catch them in snares, or take them 
by surprise. In the winter, when the frosts are very severe, they sometimes break a large hole in the ice; and when the beavers resort thither for the benefit of a little fresh air, they either kill them with their hatchets, or cover them with a large substantial net. After this, they undermine and subvert the whole fabric; whereupon the beavers, in hopes to make their escape in the usual way, fly with the utmost precipitation to the water; and plunging into the aperture, fall directly into the net, and are inevitably taken.

\section{THE SEAL.}

Every step we proceed in the description of amphibious quadrupeds, we make nearer advances to the tribe of fishes. We first observed the otter with its feet webbed, and formed for an aquatic life; we next saw the beaver with the hinder parts covered with scales, resembling those of fishes; and we now come to a class of animals in which the shape and habitude of fishes still more apparently prevail, and whose internal conformation attaches thein very closely to the water. The seal, in general, resembles a quadruped in some respects, and a fish in others. The head is round, like that of a man; the nose broad, like that of the otter; the teeth like those of a dog; the eyes large and sparkling; no external ears, but holes that serve for that purpose; the neck is wcll proportioned, and of a moderate length; but the body thickest where the neck is joined to it. From thence the animal tapers down to the tail, growing all the way sinaller like a fish. The whole body is covered with a thick, bristly shining hair, which looks as if it were entirely rubbed over with oil; and thus far the quadruped prevails over the aquatic. But it is in the feet that this animal greatly differs from all the rest of the quadruped kind; for though furnished with the same number of bones with other quadrupeds, yet they are so stuck on the body, and so covered with a membrane, that they more resemble fins than feet; and might be taken for such, did not the claws with which they are pointed show their proper analogy. In the fore feet, or rather hands, all the arm and the cubit are hid under the skin, and nothing appears but the hand from the wrist downwards; so that if we inagine a child with its arms swathed down, and nothing appearing but its hands at ench side of the body, towards the breast, we may have some idea of the formation of this animal in that part. These hands are covered in a thick skin, which serves like a fin for swimming; and are distinguished by five claws, which are long, black, and piercing. As to the lind feet, they are. stretched out on cach side of the short tail, covered with a hairy skin like the former, and both together almost joining at the tail; the whole looks like the broad, flat tail of a fish; and, were it not for five claws which appear, might be considered as such. The dinensions of this animal are various, being found from four feet long to nine. They differ also in their colours; some being black, others spotted, some white, and many more yellow. It would, therefore, be almost endless to mention the varieties of this animal. Buffon describes three; and Krantz mentions five, all different from those described by the other. I might, were I fond of such honours, claim the merit of being a first describer myself; but, in fact, the varieties in this animal are so many, that were they all described, the catalogue would be as extensive as it would be useless and unentertaining. It is sufficient to observe, that they agree in the gencral external characters already mentioned, and internally in two or three more, which are so remarkable as to deserve peculiar attention.

It has been often remarked, that all animals are sagacious in proportion to the size of their brain. It has, in support of this opinion, been alleged, that man, with respect to his bulk, has, of all others, the largest. In pursuance of this assumption, some erroneous speculations have been formed. But, were the size of the brain to determine the quantity of the understanding, the seal would, of all other animals, be the most sagacious; for it has, in proportion, the largest brain of any, even man himself not cxcepted. However, this animal is possessed of but very few advantages over other quadrupeds; and the size of its brain furnishes it with few powers that contribute to its wisdom or its preservation 
This animal differs also in the formation of its tongue from all other quadrupeds. It is forked or slit at the end, like that of serpents; but for what purpose it is thus singularly contrived we are at a loss to know. We are much better informed with respect to a third singularity in its conformation, which is, that the foramen ovale in the heart is open. Those who are in the least acquainted with anatomy, know, that the veins uniting bring their blood to the heart, which sends it into the lungs, and from thence it returns to the heart again to be distributed through the whole body. Animals, however, belore they are born, make no use of their lungs; and therefore their blood, without entering their lungs, takes a shorter passage tlirough the very partition of the licart, from one of its chambers to the other, thus passing from the veins directly into those vessels that drive it through the whole fiane. But the moment the animal is brought forth, the passage through the partition, which passage is called the foramen ovale, closes up, and continues closed for ever; for the blood then takes its longest course through the lungs to return to the other chamber of the heart again. Now the seal's heart resembles that of an infant in the womb, for the foramen ovale never closes; ${ }^{*}$ and although the blood of this animal commonly circulates through the luugs, yet it can circulate without their assistance, as rwas observed above, by a shorter way. From hence, therefore, we see the manner in which this aninal is adlapted for continuing under water; for, being under no immediate necessity of breathing, the vital motions are still carried on while it continues at the bottons; so that it can pursue its prey in that element, and yet enjoy all the delights and advantages of ours.

The water is the seal's usual habitation, and whatever fish it can catch is its food. Though not equal in instinct and cumning to some terrestrial animals, it is greatly superior to the mute tenants of that clement in which it chiefly resides. Although it can continue for several minutes under water, yet it is not able, like fishes, to remain there for any length of time; and a seal may be drowned, like any

a I have followed the usual observations of naturalists with respect to the foramen ovalp in this animal: I have many reasons, however, to incline me to think that the other terrestrial animal. Thus it seems superior, in some respects, to the inhabitants of both elements, and inferior in many more. Although furnished with legs, it is in some measure deprived of all the advantages of them.b They are shut up within its body, while nothing appears but the extremities of them, and these furnished with very little notion, but to serve them as fins in the water. The hind feet, indeed, being turned back wards, are entircly useless upon land; so that when the animal is obliged to move, it drags itself forward like a reptile, and with an effort more painful. For this purpose it is obliged to use its fore feet, which, though very short, serve to give it such a degree of swiftness that a man cannot readily overtake it; and it runs towards the sea. As it is thus awkwardly formed for going upon land, it is seldom found at any distance firom the sea shore, but continues to bask upon the rocks; and, when disturbed, always plunges down at once to the bottom.

The scal is a social animal, and wherever it frequents numbers are generally seen together. They are found in every climate, but in the north and icy seas they are particularly nunierous. It is on those shores, which are less inliabited than ours, and where the fish resort in greater abundance, that they are seen hy thousands, like flocks of sheep, basking on the rocks, and suckling their young. There they keep watch like other gregarious animals; and, if an enemy appear, instantly plunge altogether into the water. In fine weather they more usually employ their time in fishing; and generally come on shore in tempests and storms. The seal seems the only animal that takes delight in these tremendous conflicts of nature. In the midst of thunders and torrents, when every other creature takes refuge from the fury of the clements, the seals are seen by thousands sporting along the shore, and delighted with the universal disorder! This, however, may arise from the sea being at that time too turbulent for them to reside in; and they may then particularly come upon land when unable to resist the shock of their more usual element.

As seals are gregarious, so they are also ani-

foramen is not entirely open. But this is not the place for a critical inquiry of this kind.

b Buffon. 
mals of passage, and perhaps the only quadrupeds that migrate from one part of the world to another. The generality of quadrupeds are contented with their native plains and forests, and seldom stray, exccpt when necessity or fcar impels them. But scals change their habitation; and are seen in vast multitudes directing their course from one continent to another." On the northern coasts of Greculand they are seen to retire in July, and to return again in September. This time it is supposed they go in pursuit of food. But they inake a second departure in March to cast their young, and return in the beginning of Jume, young ancl all, in a great body together, observing in their route a certain fixed time and track, likc lirols of passage. When they go upon this experlition, they are seen in great droves, for nuany days together, making towards the north, taking that part of the sea most frec limm ice, and going still forward into those scas where man cannot follow. II what namer they return, or by what passage, is utterly unknown; it is only observed, that when they leave the coasts to go upon this expedition, they are all extremely fat, but on their return, they come home excessively lcan.

The females, in our climate, bring forth in winter, and rear their young upon some sandbank, rock, or desolate island, at some distance from the continent. When they suckle their young they sit up on the hinder legs, while these, which are at first white, with woully hair, cling to the teats, of which there are four in number, near the navel.' In this manner the young continue in the place where they are brought forth, for twelve or fiftcen days; after which the dam brings then down to the water, and accustoms them to swim and get their food by their own industry. As each litter never exceeds above three or four, so the animal's cares are not much divided, and the education of her little ones is soon completed. In fact, the young arc particularly docile; they understand the mother's voice among the numerous bleatings of the rest of the old ones ; they mutually assist each other in danger, and are perfectly obedient to her call. Thus early accustomed to subjection, they continue to live in society, hunt and breed together, and have

- Krantz, vol. i. p. 129.

b Coeunt in littore resupinata femina. Lrv. Syst. a variety of tones by which they encourage to pursue or wain cach other of danger. Some compare their voices to the bleating of a flock of sheep, interrupted now and then by the barking of angry dogs, and sometimes the shriller notes of a cat. ${ }^{c}$ All along the shore, each has its own peculiar rock, of which it takes possession, and where it sleeps when fatigued with fishing, uninterrupted by any of the rest. The only season when their social spirit seems to forsake them, is that when they feel the influcuces of natural desire. 'They then fight most desperately; and the male that is victorious kecps all the females to himsclf. Their combats, on these occasions, are nianaged with great obstinacy, and yet great justice: two are nerer seen to fall upon one tugether; but each has its antagonist, and all fight an erjual battle, till onc alone becomes victoriuls.

We are not certainly informed how long the females contimue pregnant; but if we may judge from the time which intervenes betwcen their departure fron the Greenland coasts and thcir returu, they cannot go above seven or eight months at the farthest. How long this animal lives is also unknown: a genteman, whom 1 knew in Ireland, kept two of them, which he liad taken very young, in his house for ten years; and they appeared to have the marks of age at the time I saw them, for they were growu gray about the muzzle; and it is very probable they did not live many years longer. In their natural state the old ones are seen very fat and torpid, separated from the rest, and, as it should secm, incapable of procreation.

As their chief food is fish, so they are very expert at pursuing and catching it. In those places wlicre the herrings are seen in shoals, the seals frequent and destroy them by thousands. Whien the herring rritires, the seal is then obliged to hunt after fish that are stronger and more capable of evading the pursuit : however, they are very swift in deep waters, dive with great rapidity, and, while the spectator eyes the spot at which they disappear, they are seen to emerge at above a hundred yards distanee. The weaker fishes, thereforc, have no other means to cscaje their tyranny,

c Linnei Syst.

d British Zoology, vol. i. p. 75. 
but by darting into the shallows. The seal has been seen to pursue a mullet, which is a swift swimmer, and to turn it to and fro, in deep water, as a hound does a hare on land. The mullet has been seen trying every art of evasion; and at last swimming into shallow water, in hopes of escaping. There, however, the seal followed; so that the little animal had no other way left to escape, but to throw itself on one side, by which means it darted into shoaler water than it could have swam in with the belly undermost; and thus at last it got free.

As they are thus the tyrants of the element in which they chiefly reside, so they are not very fearful even upon land, except on those shores which are thickly inhabited, and from whence they have been frequently pursued. Along the desert coasts, where they are scldom interrupted by man, they seem to be very bold and courageous; if attacked with stones, like dogs, they bite such as are thrown against them; if encountered more closely, they make a desperate resistance, and, while they have any life, attempt to annoy their enemy. Some have been known, even while they were skinning, to turn round and seize their butchers; but they are generally despatched by a stunning blow on the nose. They usirally sleep soundly when not frequently disturbed; and that is the time when the hunters surprise them. The Europeans who go into the Greenland seas upon the whale-fishery, surround them with nets, and knock them on the head; but the Greenlanders, who are unprovided with so expensive an apparatus, destroy them in a different manner. One of these little men paddles away in his boat, and when he sees a seal asleep on the side of a rock, darts his lance, and that with such unerring aim, that it never fails to bury its point in the animal's side. The seal, feeling itself wounded, instantly plunges from the top of the rock, lance and all, into the sea, and dives to the bottom; but the lance has a bladder tied to one end, which keeps buoyant, and resists the animal's descent; so that every time the seal rises to the top of the water the Greenlander strikes it with his oar, until be at last despatches it. But in our climate, the seals are much more wary, and seldom suffer the hunters to come No. $33 \& 34$. near them. They are often seen upon the rocks of the Coruish coast, basking in the sun, or upon the inaccessible cliffs, left dry by the tide. There they continue, extremely watchful, and nes ersleep long without moving; seldom longer than a minute; for then they raise their heads, and if they sec no danger, they lie down again, raising and reclining their heads alternatcly, at intervals of about a minute each. The only method, therefore, that can be taken, is to shoot them: if they chance to escape, they hasten towards the deep, flinging stones and dirt behind them as they scramble along, and at the same tine expressing their pain, or their fears, by the most distressful cry ; if they happen to be overtaken, they make a vigorous resistance with their feet and teeth, till they are killed.

The seal is taken for the sake of its skin, and for the oil its fat yields. The former sells for about four shillings; and, when dressed, is very useful in covering trunks, making waistcoats, shot-pouches, and several other conveniences. The flesh of this animal formerly found place at the tables of the great. At a feast provided by Archbishop Neville, for Edward the Fourth, there were twelve seals and porpoises provided, among other extraordinary rarities.

As a variety of this animal, we may mention the sea-Lron, described in Anson's Voyages. This is much larger than any of the former; being from eleven to eighteen feet long. It is so fat that, when the skin is taken off, the blubber lies a foot thick all round the body. It seems to differ from the ordinary seal, not only in its size, but also in its food; for it is often scen to graze along the shore, and to feed upon the long grass that grows up along the edges of brooks. Its cry is very various, sometimes resembling the neighing of a horse, and sometimes the grunting of a hog. It may be regarded as the largest of the seal family.

\section{THE MORSE}

THE Morse is an animal of the seal kind; but differing from the rest, in a very particular formation of the teeth, having two large tusks 
growing from the upper jaw, shaped like those of an elephant, but directed downwards; whereas, in the elephant, they grow upright, like horns; it also wants the cutting leeth, both above and below: as to the rest, it pretty much reseinhles a seal, except that it is much larger, being from twelve to sixteen feet long. The morses are also generally seen to frequent the same places that seals are known to reside in; they have the same habitudes, the same advantaiges, and the same imperfections. There are, however, fewer varieties of the norse than the seal; and they are rarely found, $\mathrm{ex}$ cept in the frozen regions near the pole. They were formerly inore numerous than at presput; and the savage natives of the coasts of Greenland destroyed them in much greater quantities betore those seas were visited hy European ships upon the whale fishery, than now. Whether these animals have been since artually thinned by the fishers, or have removed to some more distant and unfequented shores, is not known; but certain it is, that the Greenlanders, who once had plenty, are now obliged to toil more assiduously for subsistence; and as the quantity of their provisions decrease, for they live mostly upon seals, the numbers of that poor people are every day diminishing. As to the teeth, they are generaliy from two to three feet long; and the ivory is much inore esteemed than that of the elephant, being whiter and harder. The fishers have been known formerly to kill three or four humdred at once; and along those shores where they chiefly frequented, their bones are still seen lying in prodigious quantitics. In this manner a supply of provisions, which would have supported the Greenland nation for ages, has been, in a few years, sacrificed to those who did not use them, but who sought them for the purposes of avarice and luxury!

\section{THE MANATI.}

WE come, in the last place, to an animal that terminates the boundary between quadrupeds and fishes. Instead of a creature preying amon: the deeps, and retiring upon land for repose or refreshment, we have here an animal that never leaves the water, and is enabled to live only there. It cannot be callerl a quadruped, as it has but two legs only: nor can it be called a fish, as it is covered with hair. In short, it forms the link that unites those two great tribes to each other; and may be indiscriminately called the last of bensts, or the first of fishes.

We hase seen the seal approaching nearly to the aquatic: tribes, by having its hind legs thrown back on each side of the tail, and form. ing something that resembled the tail of a fish; but upon examining the skeleton of that animal, its title to the rank of a quadruped was obscrved plainly to appear, having all the bones of the linder legs and feet as complete as any other animal whatsocver.

But we are now come to a creature that not ouly wants the external appearance of hinder legs, but, when examined internally, will be found to want them altogether. The manati is somewhat shaped in the heal and the hody like seal; it has also the fore legs or hands pretty much in the same manner, short and webbed, but with four claws only; these also are shorter in proportion than in the former animal, and placed nearer the head; so that they can scarcely assist its motions upon land. But it is in the hiuder parts that it chirfly cliffers from all others of the seal kind; for the tail is perfectly that of a fish, being spread ont broad like a faul, and wanting even the vestiges of those bones which make the legs and feet in others of its kind. The largest of these are about twenty-six feet in length; the skin is blarkish, very tongh and lard; when cut, as black as ebony ; and there are a few hairs scattered, like bristles, of about an inch long. The eyes are very small, in proportion to the animal's hearl; and the ear-holes, for it has no external ears, are so narrow as scarcely toadmit a jin's head. The tongue is so short, that some have pretended it has none at all; and the teeth are composed only of two solid white bones, running the whole length of both jaws, and formed merely for chewing, and not tearing its vegetable food. 'The female has breasts placed forward, like those of a woman; and she brings forth but one at a time: this she holds with her paws to her boson; there it sticks, and accompanies her wherever she gors.

This animal can searcely be called amphibious, as it never entirely liaves the water, only advancing the head out of the strean to reach the grass on the river sides. Its food is entirely upon vegetables; and, therefore, it is never 
found far in the open sea, but cliefly in the large rivers of South America; and often above two thousand miles from the ocean. It is also found in the seas near Kamtschatka, and feeds upon the weeds that grow near the shore. There are likewise level greens at the bottom of some of the Indian bays, and there the manaties are harmlessly seen grazing among turtles and other crustaceous fishes, neither giving nor fearing any disturbance. These auimals, when unmolested, keep together in large companies, and surround their young ones. ${ }^{a}$ They bring forth most commonly in autumn; and it is supposed they go with young eighteen months, for the time of generation is ill spring.

The manati has no voice nor cry, for the ouly noise it makes, is by fetching its breath. Its internal parts somewhat resemble those of a horse ; its intestines being longer, in proportion, than those of any other creature, the horse only excepted.

The fat of the manati, which lies under the skin, when exposed to the sun, has a fine smell

a Acta Petropolilana.

[To these atnphibious quadrupeds may be added that most extraordinary animal, the Duck-Bilacd Platypus, described by Dr. Shaw in his Naturalist's Miscellany. The body is depressed, and has some resemblance to that of an utter in ininature; and is covered with a soft beaverlike fur: but its most striking peculiarity is the strange and taste, and far exceeds the fat of any sea animal; it has this peculiar property, that the lieat of the sun will not spoil it, nor make it grow rancid; its taste is like the oil of sweet almonds; and it will serve very well, in all cases, instead of butter: any quantity may be taken inwardly with safety, for it has no other effect than keeping the body open. The fat of the tail is of a harder consistence; and, when boiled, is more delicate than the former. The lean is like beef, but more red; and may be kept a long while, in the hottest days, without tainting. It takes up a long time in boiling ; and, when done, eats like beef. The fat of the young ones is like pork; the lean is like veal ; and, upon the whole, it is very probable that this animal's flesh soniewhat resembles that of turtle; since they are fed in the same element, and upon the very sanie food. The turtle is a delicacy well known among us : our luxuries are not as yet sufficiently heightened to introduce the manati; which, if it could be brought over, might singly suffice for a whole corporation!

situation of its mouth or snout, exhibiting the perfect re semblance of the beak of a duck engrafted on the head of a quadruped; and so accurate is the similitude, that at first view it naturally excites the idea of some deceptive preparation by artificial means. It is a native of $\mathrm{New}$ Holland.] 


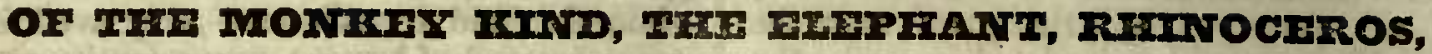

\author{
\&c. \&c.
}

\section{CHAPTER LVII.}

\section{ANIMALS OF THE MONKEY KIND.}

QUADRUPEDS may be considered as a numerous group, terminated on every side by some that but in part deserve the name. On one quarter we see a tribe covered with quills, or furnished with wings, that lift them anrong the inhalitants of the air; on another, we behold a diversity clotherl with scales and shells, to rank with insects; and still, on a third, we see them descending into the waters, to live among the mute tenants of that element. We now come to a numerous tribe that, leaviug the brute creation, seem to make approaches even to humanity; that bear an awkward resemblance of the human form, and discover some faint efforts at intellectual sagacity.

Animals of the monkey class are furnished with hands instead of paivs; their ears, eyes, eyelids, lips, and breasts, are like those of mankind; their internal conformation also bears some distant likeness; and the. whole offers a picture that may well mortify the pride of such as make their persons alone the principal object of their admiration. These approaches, however, are gradual; and sune bear the marks of this our boasted form more strongly than others.

In the Ape ${ }^{a}$ kind we see the whole external machine strongly impressed with the human

\footnotetext{
a Caubasson relates a laughable story of an ape, which became so attached to him, as to be desirous of accompanying him wherever he went. Once the animal secretly followed the father to church, where silently mounting on the top of the soundirg-board above the pulpit, he lay perfectly still till the sermon began. He then crept to the edge, and overlooking the preacher, initated all his gestures in so grotesque a mantser, that the whole congregation were unavoidably excited to laugh. The father, sulprised at this ill-timid levity, reproved his audience. The
}

likeness, and capable of the same exertions: these walk upright, want a tail, liave fleshy posteriors, have calves to their legs, and feet nearly like ours.

In the Baboon kind we perceive a more distant approach to the hunian forn ; the quidruped mixing in every part of the animal's figure : these generally go upon all-fours; but some, when upriglit, are as tall as a man; they have short tails, long snouts, and are possessed of brutal fierceness.

The Monkey kind are removed a step further: these are much less than the former, with tails as long, or longer, than their bodies, and flattish faces.

Listly, the Maki and Opossum kind, scem to lose all resemblance of the human figure, except in having hands; their noses are lengthened out, like those of quadrupeds, and every part of their bodies totally different from the human; however, as they grasp their food, or other objects, with one hand, which quadrupeds cannot do, this single similimde gives them an air of sagacity, to which they have scarcely any other pretensions.

From this slight survey, it may be easily seen that one general description will not serve for animals so very different from each other:

reproof failed in its effect, for the congregation still laughed, and the preacher in the warmtl of his zeal redoubled $\mathrm{l}$ is actions and his vociferations. These the ape so exactly imitated, that all respect for their pastor was swallowed up in the scene before them, and they burst out into a loud and continued roar of laughter. A firiend of the preacher at length pointing out to him the canse of this improper conduct, it was with tlue utınost difficulty he could conımand a serious countenance, while he ordered the servaints of the clunich to take the ape away. 
nevertheless, it would be fatiguing to the last degree, as their varieties are so numerous, and their differences so small, to go through a particular description of each. In this ease it will be best to give a history of the foremost in each class; at the same time marking the distinctions in every species. By this we shall a void a tedious repetition of similar characters, and consider the manncrs and the oddities of his fantastic tribe in general points of view; where we shall perceive how nearly they approach to the human figure, and how little they benefit by the approximation. The foremost of the Ape kind is

\section{THE OURAN OUTANG,}

OR WILD MAN OF THE WOODS.

Trus name seenus to have been given to various animals, agreeing in one conmmon character of walking upright, but coming from different countries, and of very different proportions and powers. The Troglodyte of Bontius, the DriLl of Purchas, and the PIGMY of Tyson, have all received this general nanse; and have been ranked, by some naturalists, under one general description. If we read the accounts of many remote travellers, under this name we are presented with a formidable animal, from six to eight feet high; if we examine the books of such as have described it nearer home, we find it a pigmy not above three. In this diversity we must be content to blend their various descriptions into one general account; observing, at the same time, that we have no reason to doubt ally of their relations, although we are puzzled which to follow.

The Ouran Outang, which of all other animals most nearly approaches to the human race, is seen of different sizes, from three to seven feet high. In general, however, its stature is less than that of a man; but its strength and agility much greater. Travellers, who have seen various kinds of these animals in their native solitudes, give us surprising relations of their foree, their swiftness, their address, and their ferocity: Naturalists, who have observed their form and manners at horne, have been as much struck with their patient, plinnt, imitative dispositions; with their appearance and conformation, so nearly human. Of the smallest sort of these animals we have had several, at different times, brought into this country, all nearly alike; but that observed by Dr. Tyson, is the best known, having been described with the greatest exactness.

The animal which was described by that learned physician, was brought from Angola in Africa, where it had been taken in the internal parts of the eountry, in company with a fenıale of the same kind, that died by the way. The body was covered with hair, which was of a coal-black colour, more resembliug human hair than that of brutes. It bore a still stronger similitude in its different lengths; for in those places where it is longest on the human species, it was also longest in this; as on the head, the upper lip, the chin, and the pubes. The face was like that of a man, the forehead larger, and the head round. The upper and lower jaw were not so prominent as in monkeys; but flat, like those of a man. The ears were like those of a man, in most respects; and the teeth had more resemblance to the human than those of any other ereature. The bending of the arms and legs swere just the same as in a man; and, in short, the animal, at first view, presented a figure entirely human.

In order to discover its differences, it was necessary to take a closer survey; and then the imperfections of its form began to appear. The first obvious difference was in the flatness of the nose; the next in the lowness of the forehead, and the wanting the prominence of the ehin. The ears were proportionably too large; the eyes too close to each other; and the interval between the nose and mouth too great. The borly and limbs differed, in the thighs being too short, and the arms too long; in the thumb being too little, and the palm of the hand too narrow. The feet also were rather more like hands than feet; and the animal, if we may judge from the figure, bent too much upon its haunches.

When this creature was examined anatomically, a surprising similitude was seen to prevail in its internal conformation. It differed from man in the number of its ribs, having thirteen; whereas, in man, there are but twelve. The vertebra of the neck also were shorter, the bones of the pelvis narrower, the orbits of the eyes were deeper, the kidneys were rounder, the urinary and gall bladders were longer and smaller, and the ureters of a 
different figure. Such were the principal distinctions between the internal parts of this animal and those of man; in almost every thing else they were entirely and exactly the same, and discovered an astonishing congruity. Indecd, many parts werc so much alike in conformation, that it might lave excited wonder how they were productive of such few advantages. The tongue, and all the organs of the voice, were the same, and yet the animal was dumb; the brain was formed in the same manner with that of man, and yet the creature wanted reason: an evident proof (as Mr. Buffon finely observes) that no dispositions of matter will give mind; and that the body, how nicely soever formed, is formed in vain, when there is not infused a soul to direct its operations.

Having thus taken a comparative view of this creature with man, what follows may be necessary to complete the general description. This animal was very hairy all behind, from the head downwards; and the hair so thick, that it covered the skin almost from being scen: but in all parts before, the hair was much thinner, the skin every where appeared, and in some places it was almost barc. When it went on all-fours, as it was sometimes seen to do, it appeared all hairy; when it went erect, it appeared beforc less hairy, and more like a man. Its hair, which in this particular animal was black, much more resembled that of men than the fur of brutes: for, in the latter, besides their long hair, there is usually a finer and a shorter intermixed; but in the ouran outang it was all of a kind; only about the pubes the hair was grayish, seemed longer, and somewhat diffcrent; as also on the upper lip and chin, where it was grayish, like the hair of a beard. The face, hands, and soles of the feet, were without hair; and so was most part of the forehead: but down the sides of the face the hair was thick, it being there alout an inch and a half long, which exceeded that on any other part of the body. In the palms of its hands were remarkable those lines which are usually taken notice of in palmistry; and, at the tips of the fingers, those spiral lines observed in man. The palms of the hands were as long as the soles of the fect; and the toes upon these were as long as the fingers; the middle toe was the longest of all, and the whole foot differed from the human. The hinder feet being thus formed as hands, the animal often used thein as such; and, on the contrary, now and then made use of its hands instead of fect. The breasts appeared small and shrivelled, but exactly like those of a man: the navel also appeared very fair, and in exact dispositions, being neiller harder nor more prominent than what is usually seen in children. Such is the description of this cxtraordinary creature; to which little lias been added by succeeding observers, except that the colour of the hair is often fond to vary: in that described by Edwards it was of a reddish brown.

From a picture so like that of the human species, we are naturally led to expect a corresponding mind; and it is certain, that such of these animals as have been shown in Europe, have discovered a degree of imitation beyond what any quadruped can arrive at.

That of Tyson was a gentle, fond, harmless creature. In its passage to England, those that it knew on ship-board, it would embrace with the greatest tenderuess, opening their bosoms, and clasping its hands about them. Monkeys of a lower species it held in utter aversion; it wonld always avoid the place where they were kept in the same vessel; and seemed to consider itself as a creature of higher extraction. After it was taken, and a little used to wear clothes, it grew very fond of them; a part it would put on without any help, and the rest it would carry in its hauds to some of the company, for their assistance. It would lie in a bed, place its head on the pillow, and pull the clothes upwards, as a man would do.

That which 'was seen by Edwards, and described by Buffon, showed even a superior degrce of sagacity. It walked, like all of its kind, upon two legs, even though it carried burdens. Its air was melancholy, and its deportment grave. Unlike the baboon or monkey, whose motions are violent and appetites capricious, who are fond of mischief, and obedient only from fear, this animal was slow in its motions, and a look was sufficient to kecp it in awe. I have seen it, says Mr. Buffon, give its hand to show the company to the door: I have secn it sit at table, unfold 
its napkin, wipe its lips, make use of the spoon and the fork to carry the victuals to its mouth, pour out its drink into a glass, touch glasses when invited, take a cup and saucer and lay them on the table, put in sugar, pour out its tea, leave it to cool before drinking, and all this without any other instigation than the signs or the command of its niaster, and often of its own accord. It was gentle and inoffensive; it even approached strangers with respect, and canc rather to receive caresses than to offer injuries. It was particularly fond of sugared comfits, which every body was ready to give it; and, as it had a defluxion upoit the breast, so much sugar contributed to increase the disorder, and shorten its life. It continued at Paris but one summer, and died in London. It ate indiscriminately of all thiugs, but it preferred dry and ripe fruits to all other aliments. It would drink wine, but in small quanticies, and gladly left it for milk, tea, or any other sweet liquor.

Such these animals appeared when brought into Europe. However, many of their $\mathrm{ex}$ traordinary habits were probably the result of education, and we are not told how long the instructions they received for this purpose were continued. But we learn from another account, that they take but a very short time to come to a great degree of imitative perfection. Mr. L. Brosse bought two young ones, that were but a year old, from a negro; and these at that early age cliscovered an astonishing power of initation." They even then sat at the table like men, ate of every thing without distinction, made use of their knife, spoon, and fork, both to eat their meat and help themselves. They drank winc and other liquors. When carried on ship-board they had signs for the cabin boys expressive of their wants; and whenever these neglected attendiug upon them as they desired, they instantly flew into a passion, seized thein by the arm, bit them, and kept them down. The male was sea-sick, and required attendance like a human creature; he was even twice bled in the arm, and every time afterwards, when he found himself out of order, he showed his arm, as desirous of being relieved by blceding.

Pyrard relites, that in the province of Sierra Leona, in Africa, there are a kind of apes,

as quoted by Buffon, vol. xxviii. p. 77 . called Baris, which are strong and muscular, and which, if properly instructed when young, serve as very useful domestics. They usually walk upright ; they pound at a mortar; they go to the river to fetch water, this they carry back in a little pitcher on their heads; but if care be not taken to receive the pitcher at their return, they let it fall to the ground, and then, secing it broken, they begin to lament and cry for their loss. Le Compte's account is much to the same purpose of an ape, which he saw in the Straits of Molucca. "It walked upon its two hind feet, which it bent a little, like a dog that had been taught to dance. It made use of its liands and arms as we do. Its visage was not nuch more disagreeable than that of a Hottentot; but the body was all over covered with a woolly hair of different colours. As to the rest, it cried like a cliild; all its outward actions were so like the liuman, and the passions so lively and significant, that dumb mien could scarcely better express their conceprions and desires. It had also that expression of passion or joy which we often see in children, stamping with its feet, and striking them against the ground, to show its spite, or when refused any thing it passionately longed for. Although these animals (continues he) are very big, for that I- saw was four feet. high, their nimbleness is incredible. It is a pleasurc beyond expression to see them run up the tackling of a ship, where they sometimes play as if they had a knack of vaulting peculiar to themselves, or as if they had been paid, like our rope-dancers, to divert the company. Sometimes, suspended by one arm, thiey poise theniselves, and then turn all of a sudden round about a rope, with as much quickness as a whcel, or a sling put into motion. Sometimes holding the rope successively with their long fingers, and, letting their whole body fall into the air, they run full speed from onc end to the other, and come back again with the samie swiftness. There is no posture but they imitate, nor motion but they perform, bending themselves like a bow, rolling like a bowl, lhanging by the hands, feet, and teeth, according to the different fancies with which their capricious inagination supplies them. But what is still more amazing than all, is their agility to fling themselves from one rope to another, though at thirty, forty, and fifty fcet distance." 
Such are the habitudes and the powers of the sinaller class of these extraordinary creatures; but we are presented with a very different picture in those of a larger stature and more muscular form. The little animals we have been describing, which are seldom found above four feet high, seem to partake of the nature of dwarfs among the human species, being gentle, assiduous, and playful, rather fitted to ainuse than terrify. But the gigantic races of the ouran outang, seen and described by travellers, are truly formidable; and in the gloomy forests, where they are only found, seem to hold undisputed dominion. Many of these are as tall or taller than a man; active, strong, and intrepid; cunning, lascivious, and cruel. This redoubtable rival of mankind is found in many parts of Africa, in the East Indies, in Madagascar, and in Borneo. ${ }^{.}$In the last of these places, the people of quality course him as we do the stag; and this sort of hunting is one of the favourite amusements of the king himself. This creature is extremely swift of foot, endowed with extraordinary strength, and runs with prodigious celerity. His skin is all hairy, his eyes sunk in his head, his countenance stern, his face tanned, and all his lineanients, though exactly human, harsh and blackened by the sun. In Africa this creature is even still more formidable. Battel calls him the pongo, and assures us that in all his proportions he resembles a man, except that he is much larger, even to a gigantic state. His face resembles that of a nian, the eyes deep sunk in the head, the hair on each side extremely long, the visage naked and without hair, as also the ears and the liands. The body is lightly covered, and scarcely differring from that of a man, except that there are no calves to the legs. Still, however, the animal is seen to walk upon his hinder legs, and in an erect posture. He sleeps under trees, and builds himself a hut, which serves to protect him against the sun and the rains of the tropical climates, of which he is a native. He lives only upon fruits, and is no way carnivorous. He cannot speak, although furnished with greater instinct than any other animal of the brute creation. When the negroes make a fire in the woods, this animal comes near and warms himself by the blaze. How-

- Le Compte's History of China. ever, he has not skill enough to keep the flame alive by feeding it with finel. They go together in companies, and if they happen to meet one of the human species remote from succour, they show him no mercy. They even attack the elephant, which they beat with their clubs, and oblige to leave that part of the forest which they claim as their own. It is impossible to take any of these dreadful ereatures alive, for they are so strong that ten men would not be a match for but one of them. None of this kind, therefore, are taken except when very young, and these but rarely, when the female happens to leave them behind; for in general they keep clung to the breast, and adhere both with legs and arms. From the sarne traveller we learn, that when one of these animals dies, the rest cover the body with a quantity of leaves and branches. They sometinues also show mercy to the human kind. A negro boy, that was taken by one of these, and carried into the woods, coutinued there a whole year, without receiving any injury. ${ }^{b}$ From another traveller we learn, that these animals often attempt to surprise the female negroes as they go into the wouds, and frequently keep them against their wills for the pleasure of their company, feeding them very plentifully all the time. He assures us, that he knew a woman of Loango that had lived among these animals for three years. They grow fiom six to seven feet high, and are of unequalled strength. They build sheds, and make use of clubs for their defence. Their faces are broad, their noses flat, their ears without a tip, their skins are more bright than that of a mulatto, and they are covered on many parts of the body with long and tawny coloured hair. Their belly is large, their heels flat, and yet rising behind. They sometimes walk upright, and sometimes upon allfours, when they are fantastically disposed.

From this description of the ouran outang, we perceive at what a distance the first animal of the brute creation is placed from the very lowest of the human species. Even in countries peopled with saviges, this creature is considered as a beast; and in those very places where we might suppose the smallest difference between them and mankind, the inhabitants hold it in the greatest contempt and

b Le Brosse, as quoted by Buffon, vol. xxviii. p. 70. 
detestation. In Borneo, where this animal has been said to come to its greatest perfection, the natives hunt it in the same manner as they pursue the elephant or the lion, while its resenublance to the human form procures it neither pity nor protection. The gradations of nature in the other parts of nature are minute and insensible; in the passage from quadrupeds to fishes we can scarcely tell where the quadruped ends and the fish begins; in the descent from beasts to insects we can hardly distinguish the steps of the progression; but in the ascent firom brutes to man, the line is strongly drawn, well marked, and unpassable. It is in vain that the ouran outang resembles man in form, or imitates many of his actions ; he still continues a wretched, helpless creature, pent up in the inost gloomy part of the forest, and, with regard to the provision for his own happiness, inferior even to the elephant or the beaver in sagacity. To us, indeed, this animal seems much wiser than it really is. As we have long been used to ineasure the sagacity of all actions by their similitude to our own, and not their fitness to the animal's way of living, we are pleased with the imitations of the ape, even though we know they are far from contributing to the convenience of its situation. An ape, or a quadruped, when under the trammels of human edication, may be an admirable olject for human curiosity, but is very little advanced by all its learning in the road to its own felicity. On the contrary, I have never seen any of these longinsiructed aninals that did not, by their melancholy air, appear sensible of the wretchedness of their situation. Its naarks of seeming sagacity were merely relative to us, and not to the animal; and all its boasted wisdom was merely of our own making.

There is, in fact, another circumstance relative to this animal, which ought not to be concealed. I have many reasons to believe that the niost perfect of the kind are prone, like the rest of the quadruped creation, and only owe their erect attitude to human education. Almost all the travellers who speak of thein, mention their going sometimes upon allfours, and sometimes erect. As their chief residence is among trees, they are without doubt usually seen erect while they arc climbing; hut it is more than probable that their efforts to escape upon the ground are by run-

No. $35 \& 36$. ning upon the hands and feet together. Schouten, who mentions their education, tells us that they are taken in traps, and taught in the beginning to walk upon their hind legs; which certainly implies that in a state of nature they run upon all-fours. Add to this, that, when we examine the palms of their hands and the soles of their feet, we find both equally callous and beaten; a certain proof that both have been equally used. In those hot countries, where the apes are known to reside, the soles of the negroes' feet, who go barefoot, are covered with a skin above an inch thick; while their hands are as soft as those of an European. Did the apes walk in the same manner, the same exercise would have furnished them with similar advantages, which is not the case. Besides all this, I have been assured by a very credible traveller, that these animials naturally run in the woods upon all-fours; and when they are taken, their hands are tied behind them, to teach them to walk upright. This attitude they learn after some time; and, thus instructed, they are sent into Europe to astonish the speculative with their near approaches to humanity, while it is never considered how much is natural, and how much has been acquired in the savage schools of Benin and Angola.

The animal next to these, and to be placed in the same elass, is the APE, properly so called, or the PIthf.Kos of the ancients. This is much less than the former, being not above a foot and a half high, but walks erect, is without a tail, and is easily tamed.

Of this kind also is the GıBBon, so called by Buffon, or the LONG-ARMED APE, which is a very extraordinary and remarkable creature. It is of different sizes, being from fout feet to two feet high. It walks erect, is without a tail, has a face rescmbling that of a man, with a circle of bushy hair all round the visage; its eyes are large, and sunk in its head; its face tanned, and its ears exactly proportioned. But that in which it chiefly differs from all others of the monkey tribe, is the extraordinary length of its arms, which when the animal stands erect are long enough to reach the ground; so that it can walk upon all-fours, and yet keep its erect posture at the same time. This anitnal, next to the ouran outang and the ape, most nearly resembles mankind, not only in form, but in gentle manners and $3 \mathbf{P}$ 
tractable disposition. It is a native of the East Indies, and particularly found along the coasts of Coromandel.

The last of the ape kind is the crocecprauUs, or the magot of Buffor. This animal wants a tail, like the former, although there is a small protuberance at that part, which yet is rather formed by the skin than the bone. It differs also in having a large callous red rump. The face is prominent, and approaches more to that of quadrupeds than of mas. The body is covered with a brownish hair, and yellow on the belly. It is about three feet and a half, or four feet high, and is a native of most parts of Africa and the East. As it recedes from man in its form, so also it appears different in its dispositions, being sulJen, vicious, and untractable."

\section{THE BABOON.}

Descending from the more perfect of the monkey kinds, we come to the Baboon and its varieties, a large, fierce, and formidable race, that, mixing the figure of the man and the quadruped in their conformation, seem to possess only the defects of both; the petulance of the one, and the ferocity of the other. These animals have a short tail; a prominent face; with canine teeth, larger than those of men; and callosities on the rump. In man the physiognomy may deceive, and the figure of the body does not always lead to the qualities of the mind; but in animals we may always judge of their dispositions by their looks, and form a just conjecture of their internal habits from their external form. If we compare the nature of the ape and the baboon by this easy rule, we shall at orice be led to pronounce that they greatly differ in their dispositions, and that the latter are infinitely more fierce, savage, and malicious, than the former. The ouran outang, that so nearly resembles man in its figure, approaches also nearest in the gentleness. of its manners and the pliancy of its temper. The cyno-

\footnotetext{
amnes femella hujusce et precedentium, ut et fere sequentium specierum, menstruali patiunter fluxu sicut in feminis.

b Buffon, vol. xxxviii. p. 183.
}

cephalus, that of all other apes is most nnlike man in form, and approaches nearer the dog in face, resembles also the brute in nature, being wild, restless, and impelled by a fretful impetuosity. But the baboon, who is still more remote, and resembles man only in having hands, who, from having a tail, a prominent face, and sharp claws, approaches more nearly to the savage tribe, is every way fierce, malicious, ignorant, and untractable.

The вAвоON, properly so called, is from three to four feet high, very strong built, with a thick body and limbs, and canine teeth, much longer than those of men. It has large callosities behind, which are quite uaked and red. Its tail is crooked and thick, and about seven or eight inches long. Its snout, for it can hardly be called a face, is long and thick, and on each side of its cheeks it has a pouch, into which, when satiated with eating, it puls the remainder of its provisions. It is covered with long thick hair, of a reddish brown colour, and pretty uniform over the whole body. It walks more commonly upon allfours than upright, and its hands as well as its feet are armed with long sharp claws, instead of the broad round nails of the ape kind.

An animal thus made for strength, and furnished with dangerous weapons, is found, in fact, to be one of the most formidable of the savage race in those countries where it is bred. It appears, in its native woods, to be impelled by two opposite passions; a hatred for the males of the human species, and a desire for womell. Were we assured of these strange oppositions in its dispositions from one testimony alone, the account might appear doubtful; but, as it comes from a variety of the most credible witnesses, we cannot refuse our assent. From them, therefore, we learn, that these animals will often assail women in a body, and force them into the woods, where they keep them against their will, and kill them when refractory. From the Chevalier Forbin we learn, that in Siam whole troops of these will often sally forth from their forests, and attack a village, when they know the men are engaged in their rice harvest. They are on such occasions actuated as well by desire as by hunger; and not only plunder the houses of whatever provisions they can find, but endeavour to force 
the women. These, however, as the Chevalier humorously relates, not at all liking either the manners or the figure of the paltry gallants, boldly stand on their defencr, and with clubs, or whatever other arms they can provide, instead of answering their caresses, oblige their ugly suitors to retreat; not, however, before they have damaged or plundered every thing eatable they can lay their hands on.

At the Cape of Good Hope, they are less formidable, but, to the best of their power, equally mischievous. They are there under a sort of natural discipline, and go about whatever they undertake with surprising skill and regularity. When they set about robbing an orchard or a vineyard, for they are extremely fond of grapes, apples, and ripe fruit, they do not go singly to work, but in large companies, and with preconcerted deliberation. On these occasions, a part of them enter the enclosure, while one is set to watch. The rest stand without the fence, and form a line reaching all the way from their fellows within, to their rendezvous without, which is generally in some craggy mountain. Every thing being thus disposed, the plunderers within the orchard throw the fruit to those that are without as fast as they can gather it; or, if the wall or hedge be high, to those that sit on the top; and these hand the plunder to those next them on the other side. Thus the fruit is pitched from one to another all along the line, till it is safely deposited at their head-quarters. They catch it as readily as the most skilful tennis-player can a ball; and while the business is going forward, which they conduct with great expedition, a most profound silence is observed among them. Their sentinel, during this whole time, continues upon the watch, extremely anxious and attentive; but, if he perceives any one coming, he instantly sets up a loud cry, and at this signal the whole company scamper off. Nor yet are they at any time willing to leave the place empty-handed; for if they be plundering a bed of melons, for instance, they go off with one in their mouths, one in their hands, and one under their arm. If the pursuit be hot, they drop first that from under their arm, then that from their hand; and, if it be continued, they at last let fall that which they had hitherto kept in their mouths. The natives of the Cape often take the young of these animals, and, feeding them with sheep and goat's milk, accustom them to guard their houses; which duty they perform with great punctuality. Those, however, that have been brought into Europe, are headstrong, rude, and untractable. Dogs and cats, when they have done any thing wrong, will run off; but these seem careless and insensible of the mischief they do; and I have seen one of them break a whole table of china, as it should seem by design, without appearing in the least conscious of having done auniss. It was not, however, in any respect so formidable as that described by $\mathrm{Mr}$. Buffon, of which he gives the following description: "It was not," says he, " extremely ugly, and yet it excited horror. It continually appeared in a state of savage ferocity, gnashing its teeth, flying at the spectators, and furiously restless. It was obliged to be confined in an iron cage, the bars of which it so forcibly attempted to break, that the spectators were struck with apprehension. It was a sturdy bold animal, whose short limbs and powerful exertions showed vast strength and agility. The long hair with which it was covered seemed to add to its apparent abilities; which, however, were in reality so great, that it could easily overcome a single man, unless armed. As to the rest, it for ever appeared excited by that passion which renders the mildest animals at intervals furious. Its lasciviousness was constant, and its satisfactions particular. Some others also of the monkey kind showed the same degree of impudence, and particularly in the presence of women; but, as they were less in size, their petulance was less obvious, and their insolence more easily corrected."

But however violent the desires of these animals may be, they are not found to breed in our climate. The female brings forth usually but one at a time, which she carries in her arms, and in a peculiar manner clinging to her breast. As to the rest, these animals are not at all carnivorous; they principally feed upon fruits, roots, and corn, and generally keep together in companies. The internal parts are more unlike those of man than of quadrupeds, particularly the liver, 
which is, like that of a dog, divided into six lobes. The lungs are more divided, the guts in reneral are shorter, and the kidneys rounder and flatter.

The largest of the baboon kind is the MANDRIL; an ugly, disgusting animal, with a tail shorter than the former, though of a much larger stature, being from four to five feet high. The muzzle is still longer than that of the preceding, it is of a bluish colour, and strongly marked with wrinkles, which give it a frightful appearance. But what renders it truly loathsome is, that from the nose there is always seen issuing a snot, which the animal takes care at intervals to lick off with its tongue, and swallow. It is a native of the Gold Coast ; it is said to walk more frequently erect than upon all-fours; and, when displeased, to weep like a child. There was one of them shown in England some years ago. It seemed tame, hut stupid, and had a method of opening its mouth and blowing at such as came too near.

The wanderow is a baboon rather less than the former, with the body less compact and muscular, and the hinder parts seemingly more feeble. The tail is from seven to eight inches long; the muzzle is prominent, as in the rest of this kind; but what particularly distinguishes it, is a large long white head of hair, together with a monstrous white beard, coarse, rough, and descending; the colour of the rest of the body being brown or black. As to the rest, in its savage state, it is equally. fierce with the others; but, with a proper education, it seems more tractable than most of its kind, and is chiefly seen in the woods of Ceylon and Malabar.

The maimon of Buffon, which Edwards calls the PIG-TAIL, is the last of the baboons, and in size rather approaches the monkey, being no larger than a cat. Its chief distinction, besides its prominent muzzle, like a baboon, is in the tail, which is about five or six inches long, and curled up like that of a hog; from which circumstance, peculiar to this animal, our English naturalist gave it the name. It is a native of Sumatra, and does not well endure the rigours of our climate. Edwards, however, kept one of them a year in London; and another of them happening at the saine time to be exposed in a show of beasts, he brought the two exiles together, to se if they would claim or acknowledge their kindred. The moment they came into each other's presence, they testified their mutual satisfaction, and seemed quite transported at the interview.

\section{THE MONKEY.}

The varieties in the larger tribes of the monkey kind are but few; in the ape we have seen but four, and in the baboon about as many. But when we come to the smaller class, the differences among them scem too tedious for enumeration. These, as was observed in the beginning, are all small in stature, and with loug tails, by which they are distinguished from the preceding. that entirely want the tail, or are large, and have but a short one. The varieties in the form and colour of dogs, or squirrels, is nothing to what are found among monkeys of the smaller kind. Bosman mentions above fifty sorts on the Gold Coast alone, and Smith confirms the account. Condamine asserts that it would take up a volume to describe the differences of these to be found along the river Amazon; and we are sure that every one of these is very different from those on the African coast. Naturalists, however, have undertaken to make a catalogue of their numbers; and they either transmit their descriptions from one to another, or only enumerate those few that have found their way to Europe, and have fallen within the narrow circle of their own observation. But, though it may be proper enough to describe such as fall under notice, it is certainly wrong to offer a scanty catalogue as complete, and to induce the reader to suppose he sees a picture of the whole group of these animals, when he is only presented with a small part of the number. Such, therefore, as are fond of the reputation of adding new descriptions to the stock of natural history, have here a wide, though surely a barren, field to enlarge in; and they will find it no difficult matter, by observing the various animals of this kind that are from time to time brought from their native coasts to this country, to indulge in description, and to ring the changes upon all the lechnical terms 
with which this most plensing science is obscured and rendered disgusting. For my own part, I will spare the reader and myself the trouble of entering into an elaborate description of each; content with observing once more, that their numbers are very great, and their differences very trifling. There is scarcely a country in the tropical climates that does not swarm with them, and scarcely a forest that is not inhabited by a race of monkeys distinct from all others. Every different wood along the coasts of Africa may be considered as a separate colony of monkeys, differing from those of the next district in colour, in size, and malicious mischief. It is indeed remarkable, that the monkeys of two cantons are never found to mix with each other, but rigorously to observe a separation: each forest produces only its own; and these guard their limits from the intrusion of all strangers of a different race from themselves. In this they somewhat resemble the human inhabitants of the savage nations among whom they are found, where the petty kingdoms are numerous, and their manners opposite. There, in the extent of a few miles, the traveller is presented with men speaking different languages, professing different religions, governed by different laws, and only resembling each other in their mutual animosity.

In general, monkeys of all kinds, being less than the baboon, are endued with less powers of doing mischief. Indeed, the ferocity of their nature seems to diminish with their size; and when taken wild in the woods, they are sooner tamed, and more easily taught to imitate man, than the former. More gentle than the baboon, and less grave and sullen than the ape, they soon begin to exert all their sportive mimicries, and are easily restrained by correction. But it must be confessed, that they will do nothing they are desired without beating; for, if their fears be entirely removed, they are the most insolent and headstrong animals in nature.

In their native woods they are not less the pests of man than of other auimals. The monkeys, says a traveller, ${ }^{,}$are in possession of every forest where they reside, and may be considered as the masters of the place.

a Description Ilistorique de Macacar, p. 51.
Neither the tiger, nor the lion itself, will renture to disputc the dominion, since these, from the tops of trees, continually carry on offensive war, and by their agility escape all possibility of pursuit. Nor have the birds less to fear from their continual depredations; for, as these harmless inhabitants of the wood usually build upon trees, the monkeys are for ever on the watch to find out and rob their nests; and such is their petulant delight in mischief, that they will fling their eggs against the ground, when they want appetite or inclination to devour them.

There is but one animal in all the forest that ventures to oppose the monkey, and that is the serpent. The larger snakes are often seen winding up the trees where the monkeys reside; and, when they happen to surprise them sleeping, swallow them whole, before the little animals have time to make a defence. In this manner, the two most mischievous kinds in all nature keep the whole forest between them; both equally formidable to each other, and for ever employed in mutual hostilities. The monkeys, in general, inhabit the tops of the trees, and the serpents cling to the branches nearer the bottom, and in this manner they are for ever seen near each other, like enemies in the same field of battle. Some travellers, indeed, have supposed that their vicinity rather argued their mutual friendship, and that they united in this manner to form an offensive league against all the rest of animated nature." "I have seen these monkeys," says Labat, "playing their gambols upon those very branches on which the snakes were reposing, and jumping over them without receiving any injury, although the serpents of that country were raturally vindictive, and always ready to bite whatever disturbed them." These gambols, however, were probably nothing more than the insults of an enemy that was conscious of its own safety; and the monkeys might have provoked the snake in the same maniser as we often see sparrows twitter at a cat. However this be, the forest is generally divided between them; and these woods, which nature seems to have emhellished with her richest magnificence, rather inspire terror than de-

b Labat, Relat. de l'Afriq. Occident, p. 317. 
light, and chiefly serve as retreats for mischief and malignity.

The enmity of these animals to mankind, is partly ridiculous, and partly formidable. They seem, says Le Comte and others, to have a peculiar instinet in discovering their foes, and are perfectly skilled, when attacked, in mutually defending and assisting each other. When a traveller enters among these woods, they consider him as an invader uporr their dominions, and all join to repel the intrusion. At first they survey him with a kind of insolent curiosity. They jump from branch to branch, pursue him as he goes along, and make a loud chattering, to call the rest of their companions together. They then begin their hostilities, by grinning, threatening, and flinging down the withered branches at him, which they break from the trees; they even take their excrements in their hands, and throw them at his head. Thus they attend him wherever he goes; jumping from tree to tree with such amazing swiftness, that the eye can scarcely attend their motions. Although they take the most desperate leaps, yet they are seldom seen to come to the ground, for they easily fasten upon the branches that break their fall, and stick, either by their hands, feet, or tail, wherever they touch. If one of them happens to be wounded, the rest assemble round, and clap their fingers into the wound, as if they were desirous of sounding its depth. If the blood flows in any quantity, some of them keep it shut up, while others get leaves, which they chew, and thrust into the opening: however extraordinary this may appear, it is asserted to be often seen, and to be strictly true. In this manner they wage a petulant, unequal war; and are often killed in numbers before they think proper to make a retreat. This they effect with the same precipitation with which they at first came together. In this retreat the young are seen clinging to the back of the female, with which she jumps away, seemingly unembarrassed by the burden.

The curiosity of the Europeans has, in some measure, induced the natives of the places where these animals reside, to catch or take them alive by every art they are able. The usual way in such case, is to shoot the female as she carries her young, and then both, of course, tumble to the ground. But even this is not easily performed; for if the animal be not killed outright, it will not fall; but clinging to some branch, continues, even when dead, its former grasp, and remains on the tree where it was shot, until it drops off by putrefaction : in this manner it is totally lost to the pursuer; for to attempt climbing the tree, to bring either it or the young one down, would probably be fatal, from the number of serpents that are hid among the branches. For this reason the sportsman always takes care to aim at the head; which, if he hits, the monkey falls directly to the ground; and the young one comes down at the same time, clinging to its dead parent.

The Europeans along the coasts of Guinea often go into the woods to shoot monkeys; and nothing pleases the negroes more than to see these animals drop, against which they have the greatest animosity. They consider them, and not without reason, as the most mischievous and tormenting creatures in the world; and are happy to see their numbers destroyed, upon a double account; as well because they dread their devastations, as because they love their flesh. The monkey, which is always skinned before it is eaten, when served up at a negro feast, looks so like a child, that an European is shocked at the very sight. The natives, however, who are not so nice, devour it as one of the highest delicacies; and assiduously attend our sportsmen, to profit by the spoil. But what they are chiefly astonished at, is to see our travellers carefully taking the young ones alive, while they leave them the old ones, that are certainly the most fit to be eaten. They cannot comprehend what advantage can arise to us from educating or keeping a little animal, that, by experience, they know to be equally fraught with tricks and mischief: some of them have even been led to suppose, that, with a kind of perverse affection, we love only creatures of the most mischievous kinds: and having seen us often buy young and tame monkeys, they have taken equal care to bring rats to our factors, offering them for sale, and greatly disappointed at finding no purchaser for so hopeful a commodity."

a Labat, Relat. de l'Afriq. Occident, p. 317 . 
The negrocs consider these animals as their greatest plague; and, indeed, they do incredible damage, when they cone in companies to lay waste a lield of Indian corn or rice, or a plantation of sugar-canes. They carry off as much as they are able; and they destroy ten times more than they bear away. Their manner of plundering is pretty much like that of the baboons, already mentioned, in a garden. One of them stands sentinel upon a tree, while the rest are plundering, carefully and cantiously turning on every side, but particularly to that on which there is the grentest danger: in the mean time, the rest of the spoiler's pursue their work with great silence and assiduity; they are not contented with the first blinde of corn, or the first cane that they happen to lay their hands on; they first pull up such as appear most alluring to the eye; they turn it round, examine, compare it with others, and, if they find it to their mind, stick it under one of their shoulders. When in this manner they have got their load, they begin to think of retrenting: but if it should happen that the owners of the field appear to interrupt their depredations, their faithful sentinel instantly gives notice, by crying out, Houp, houp, houp! which the rest perfectly understand, and all at once throwing down the corn they hold in their left hands, scamper off upon three legs, earrying the remainder in the right. If they are still botly pursued, they then are content to throw down their whole burden, and to take refuge among their woods, on the tops of which they remain in perfect security.

Were we to give faith to what some travellers assure us, of the government, policies, and subordination of thesc animals, we might perhaps be taxed with credulity; but we have no reason to doubt that they are under a kind of discipline, which they exercise among each other. They are generally secn to keep together in companies, to march in exact order, and to obcy the voice of some particular chieftain, remarkable for his size and gravity. One species of these, which Mr. Buffon ealls the ouarine, and which are reniarkable for the loudiuess and the distinctness of thicir voice, are still more so for the use to which they convert it. "I have frequently been a witness," says Margrave, "of their assemblies and deliberations. Fvery day, both morning and evening, the onarines assemble in the wools to receive instruction:. When all come together, one anong the number takes the higliest place on a tree, and makes a signal with his hand to the rest to sit round, in order to hearkes. As soon as he sees then placed, he begins his discourse, with so loud a voice, and yet m a manner so precipitate, that, to hear him at a distance, one would think the whole company were crying out at the same tine: lowever, dilring that time, one only is speaking; and all the rest observe the nost profound silence. When this has done, he nakes a sign with the land for the rest to reply' and at that instant they raise their voices together, until by another signal of the hand they are eıjoined silence. This they as readily obey; till, at last, the whole assembly breaks up, after hearing a repetition of the same preachment."

The chief food of the monkey tribe is finits, the bucls of trees, or succuleut roots and plants. They all, like man, seem fond of sweets; and particularly the pleasant juice of the palm-tree and the sugar-cane. With these the fertile regions in which they are bred seldom fail to supply them; but when it happens that these fail, or that more nourishing food becomes more agreeable, they eat insects and worms; and, sometimes, if near the coasts, desceurd to the sei-shore, where they eat oysters, crabs, and shell-fish. Their manner of managing an oyster is extráordinary enough; but it is too well attested to fail of our assent. As the oysters in the tropical elimates are generally larger than with us, the monkeys, when they go to the sea-side, pick up a stonc, and clap it between the opening shells; this preverits them from closing; and the monkey then eats the fish at his ease. They often also draw crals from the water, by putting their tail to the hole where that animal takes refuge, and the crab fastening upon it, they withdraw it with a jerk, and thus pull their prey upon shore. This habit of laying traps for other animals, makes them very cautious of being entrapped themselves; and I am assured, by many persons of eredit, that no snare, bow nicely baited soever, will take the monkey of the West 
India islands; for laving been accustomed to the cunning of man, it opposes its natural distrust to human artifice.

The monkey generally brings forth one at a time, and sometimes two. They are rarely found to breed when brought over into Europe; but of those that do, they exhibit a very striking picture of parental affection. The male and female are never tired of fondling their young one. They instruct it with no little assiduity ; and often severely correct it, if stubborn, or disinclined to profit by their example: they hand it from one to the other; and when the male has done showing his regard, the female takes her turn. When wild in the woods, the female, if she happens to have two, carries one on her back, and the other in her arms: that on her back clings very closely, clasping its hands round her neck, and its feet about her middle: when she wants to suckle it, she then alters their position; and that which has been fed gives place to the other, which she takes in her arms. It often happens that she is unable to leap from one tree to another, when thus loaden; and upon such occasions their dexterity is very surprising. The whole family form a kind of chain, locking tail in tail, or hand in hand, and one of them holding the branch above, the rest swing down, balancing to and fro, like a pendulum, until the undermost is enabled to catch hold of the lower branches of some neighbouring tree. When the hold is fixed below, the monkey lets go that which was above, and thus comes undermost in turn; but, creeping up along the cliain, attains the next branches, like the rest; and thus they all take possession of the tree, without ever coming to the ground.

When in a state of domestic tameness, those animals are very amusing, and often fill up a vacant hour, when other entertainment is wanting. There are few that are not acquainted with their various mimicries, and their capricious feats of activity. But it is generally in company with other animals of a more simple disposition that their tricks and superior instincts are shown; they seem to take a delight in tormenting them; and I have seen one of them amusing itself for hours together, in imposing upon the gravity of a cat. Erasmus tells us of a large monkey, kept by Sir Thomas More, that, one day diverting itself in his garden, where some tame rabbits were kept, played several of its usual pranks among them, while the rabbits scarcely well knew what to make of their new acquaintance: in the mean time, a weasel, that came for very different purposes than those of entertainment, was seen peering about the place in which the rabbits were fed, and endeavouring to make its way, by removing a board that closed their butch. While the monkey saw no danger, it continued a calın spectator of the enemy's efforts; but just when, by long labour, the weasel had effected its purpose, and had removed the board, the monkey stept in, and, with the utmost dexterity, fastened it again in its place; and the disappointed weasel was too much fatigued to renew its operations. 'To this I will only add what Father Carli, in his history of Angola, assures us to be true. In that horrid country, where be went to convert the savage natives to Christianity, and met with nothing but distress and disappointment; while his health was totally impaired by the raging heats of the climate, his patience exhansted by the obstinacy of the stupid natives, and his little provisions daily plundered, without redress, in such an exigency he found more faithful services from the inonkeys than the men; these he had taught to attend him, to guard him whilst sleeping against thieves and rats, to comb his head, to fetch his water; and, he asserts, that they were even more tractable than the human inhabitants of the place. It is indeed remarkable, that in those countries where the men are most barbarous and stupid, the brutes are most active and sagacious. It is in the torrid tracts, inhabited by barbarians, that such various animals are found with instinct so nearly approaching reason. The savages, both of Airica and America, accordingly suppose monkeys to be men; idle, slothful, rational heings; capable of speech and conversation; but obstinately dumb, for fear of being compelled to labour.

As of all savages, those of Africa are the most brutal, so, of all conntries, the monkeys of Africa are the most expert and entertaining. The monkeys of America are, in general, neither so sagacious nor so tractable, nor is their form so nearly approaching that of 
man. The monkeys of the new continent may be very easily distinguished from those of the old, by three marks. Those of the ancient continent are universally found to have a naked callous substance behind, upon which they sit; which those of America are entirely without: those also of the ancient continent have the nostrils differently formed, more resembling those of meu, the holes opcuing downward; whereas the American monkeys have them opening on each side: those of the ancient world have pouches on each side the jaw, into which they put their provisions ; which those of America are without: lastly, none of the monkeys of the ancient continent hang by the tail, which many of the American sorts are known to do. By these marks the monkcys of either continent may be readily distinguished from each other, and prized accordingly. The African monkey, as I am assured, requires a longer education, and mure correction, than that of America; but it is at last found capable of more various powers of imitation, and shows a greater degree of cunining and activity.

Mr. Buffon, who has examined the race of imitative bcings with greater accuracy than any other naturalist before him, makes but nine species of monkeys belonging to the ancient continent; and eleven belonging to the new. To all these he gives the names which they go by in their respective countries; which, undoubtedly, is the method least liable to error, and the most proper for imitation.

Of the monkeys of the ancient continent, the first he describes is the nocagvo; somewhat resembling a baboon in size, strength of body, and a hideous wrinkled visage : it differs, however, in having a very long tail, which is covered with tufted hair. It is a native of Congo.

The second is the PATAS, which is about the same size with the former; but differs in having a longer body, and a face less lideous: it is particularly remarkable for the colour of its hair, which is of a red, so brilliant, that the animal looks as if it were actually painted. It is usually brought from Senegal; and by some called the red African monkey.

The third of the ancient continent is the MaLBRouk; of which he supposes the monkey No. $35 \& 36$. which he calls the BoNET cursols to be a variety. The one is remarkable for a long tail, and long beard; the other, for a cap of hair that covers the crown of the head, from whence it takes the name. Both are natives of the East Indies; and the Bramins, who extend their charity to all the brute creation, have hospitals for such of them as happen to be sick, or otherwise disabled.

The fourth of this kind, is the nIANGABEY; it may be distinguished from all others by its eyelids, which are naked, and of a striking whiteness. It is a native of Madagascar.

The fifth is the MONa, or the cepHus of the ancients : it is distinguished by its colour, which is variegated with black and red; and its tail is of an ash colour, with spots on each side at its insertion. It is a native of the northern parts of Africa.

The sixth is the callitrix, or GREEN MONKEY of St. Iago; distinguished by its beautiful green colour on the back, its white breast and belly, and its black face.

The seventh is the moustoc, or white Nose; distinguished by the whiteness of its lips, from whence it has received its name, the rest of the face being of a deep blue. It is a native of the Gold Coast, and a very beautiful little animal.

The eighth is the TaLapoin; and may be distinguished as well by its beautiful variety of green, white, and yellow hair, as by that under the eyes being of a greater length than the rest. It is supposed to be a native of Africa and the East.

The ninth and last of the monkers of the ancient continent, is the nouc, so called in Cochin China, of which country it is a native. The douc seems to unite the characters of all the former together : with a long tail, like the monkey; of a size as large as the baboon; and with a flat face like the ape; it even resembles the American monkeys, in having no callosity on its posteriors. 'Thus it scems to form the shade by which the monkeys of one continent are linked with those of the other.

Next come the monkeys of the new continent; which, as has been said, differ from those of the old, in the make of their nostrils, in their having no callosity on their posteriors, and in their having no pouches on each 
side of the jaw. They differ also from each other, a part of them making no use of their tails to liang by; while others of them have the tail very strong and muscular; and serving by way of a fiftl luand to holl by. Those with muscular liolding tails, are called SAPAjous; those witl feeble useless tails, are callcd sAgorss. Of the sapajous there are five sorts: of the sagoins there are six.

The first of tie sapajous is the warive, or the BRAZILIAN GUARIBA. This monkey is as large as a fox, with black long liair, and remarkable for the louduess of its voice. It is the largest of the monkey kind to be found in America.

The second is the coartr; which may be distinguished from the rest by having 110 thumb, and consequently but four fingers on the two fore paws. The tail, however, supplies the defects of the hand; and with this the animal slings itself from one tree to another, with surprising rapidity.

The third is the sajou; distinguished from the rest of the sapajous by its yellowish, fleshcoloured face.

The fourtl is the sal. It is somewhat larger than the sajou, and has a broader muzzlc. It is called also the Bewailer, from its peculiar manner of lamenting when either threatened or beater.

The fifth and last of the sapajou kind, or monkeys that hold by the tail, is the samaki, or AURORA; which is the smallest and most beautilinl of all. It is of a fine orange colour, with two circles of thesh round the eyes. It is a very tender, delicate animal, and lield in high price.

Of the sagoins with feeble tails there are six kinds. The first and the largest, is the SAKI, or CAGUL; so remarkable for the length of the hair on its tail, that it luas been often termed the Fox-TAILED monkey. It is of different sizes; some being twice as large as others.

The second of this kind is the ramain; which is usually black, with the feet yellow. Some, however, are found all over brown, spotted with yellow.

The third is the wistitı; remarkable for the large tufts of hair upon its face, and its ammulated tail.

The fourtl is the MARIKINA; with a mane round the neck, and a bunch of hair at the end of the tail, like a lion.

The fifth is called the Incri with the face of a beautiful black, and white laair that descends on each side of the fice, like that of ınalı.

The last, least, and most beautiful of all is, the mico, an animal too curiously adorned not to demand a particular description; which is thus given of it by Mr. Condamine: "That," says he, "which the Governor of Para made me a present of, was the only one of its kind that was seen in the country. The hair on its body was of a beautifiul silver colour, brighter than that of the most vencrable humail hair; while the tail was of a deep brown, inclining to blackness. It had another singularity more remarkable than the former: its ears, its cheeks, and lips, were tinctured with so bright a vermilion, that one conld scarcely be led to suppose that it was natural. I kept it a year; and it was still alive. when I made this description of $\mathrm{it}$, almost within sight of the coasts of France: all I could then do was to preserve it in spirits of wine, which might serve to keep it in such a state as to slow that 1 did not in the least exaggerate in my description."

\section{OF THE MAKI.}

Trr: last of the monkey kind are the Makies; which have no other pretensious to be placed in this class, except that of liaving hambls like the former, and making use of them to climb trees, or to pluck their food. Animals of the hare kind, indeed; are often seen to feed themselves with their fore paws, but they can hold nothing in one of them singly, and are obliged to take up whatever they eat in both at once: but it is otherwise with the maki; as well as the monkey kinds, they seize their food with one hand, pretty mucl, like a man, and grasp it with great ease and firmuess. 'The maki, therefore, from this conformation in its luands both before and behind, approaches ncarly to the monkey kind; but in other respects, such as the make of the snout, the form of the ears, and the parts that distinguish the sexes, it entirely differs from them. There are many dif 


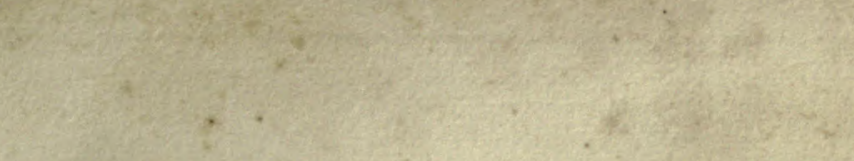

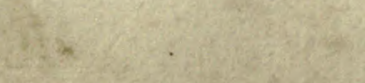

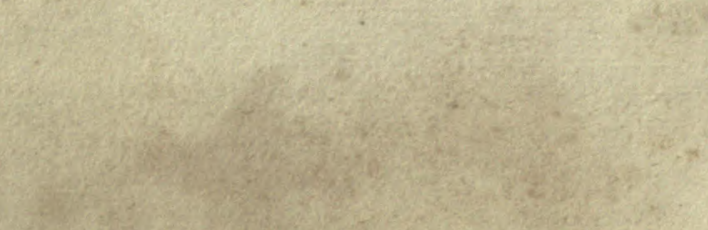

$\therefore$
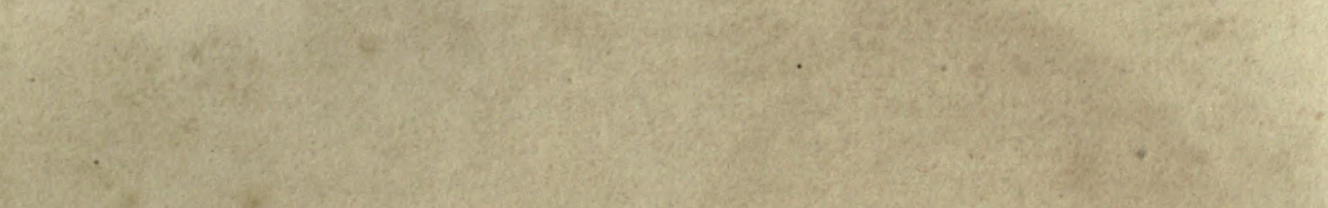

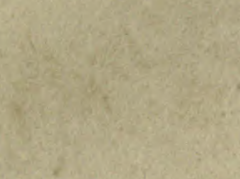

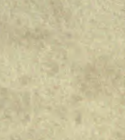

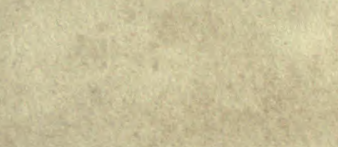

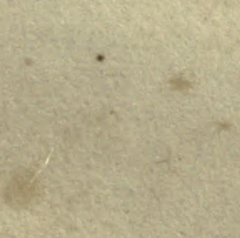

(3)

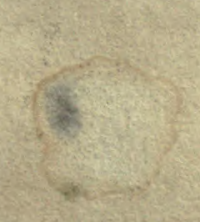

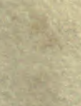
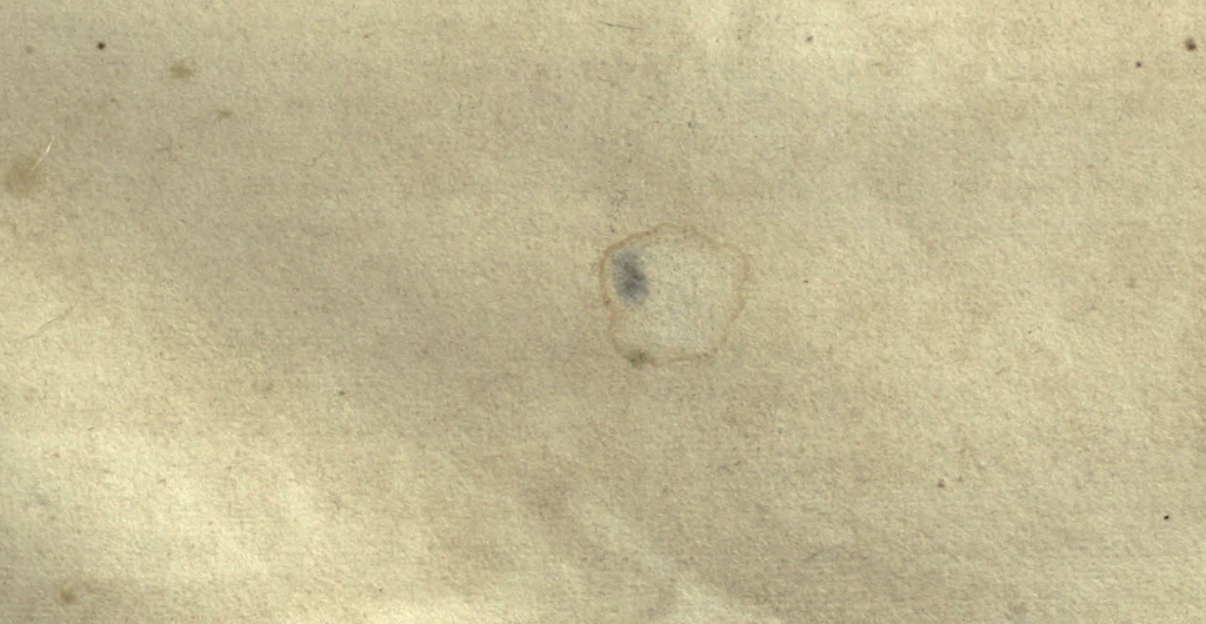

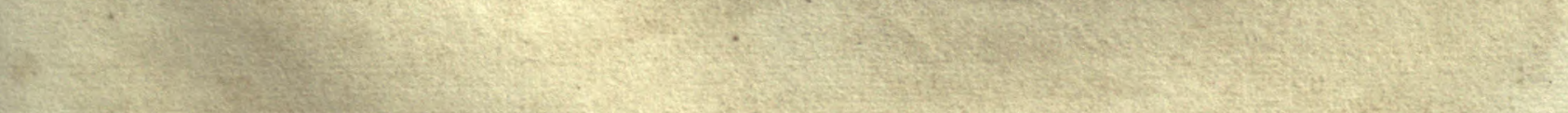

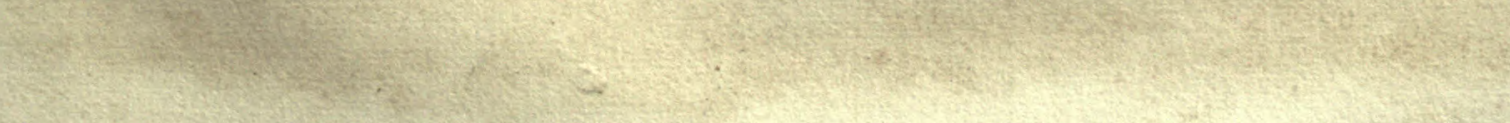

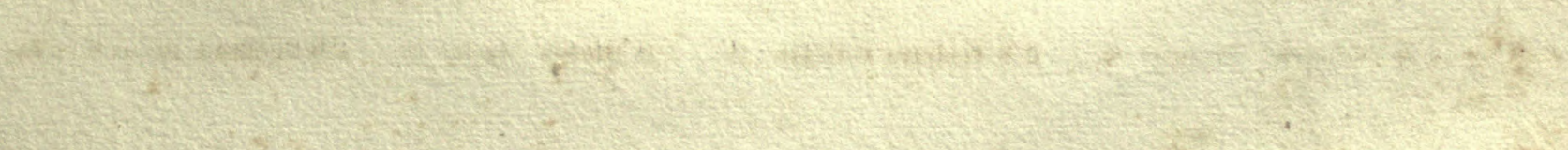




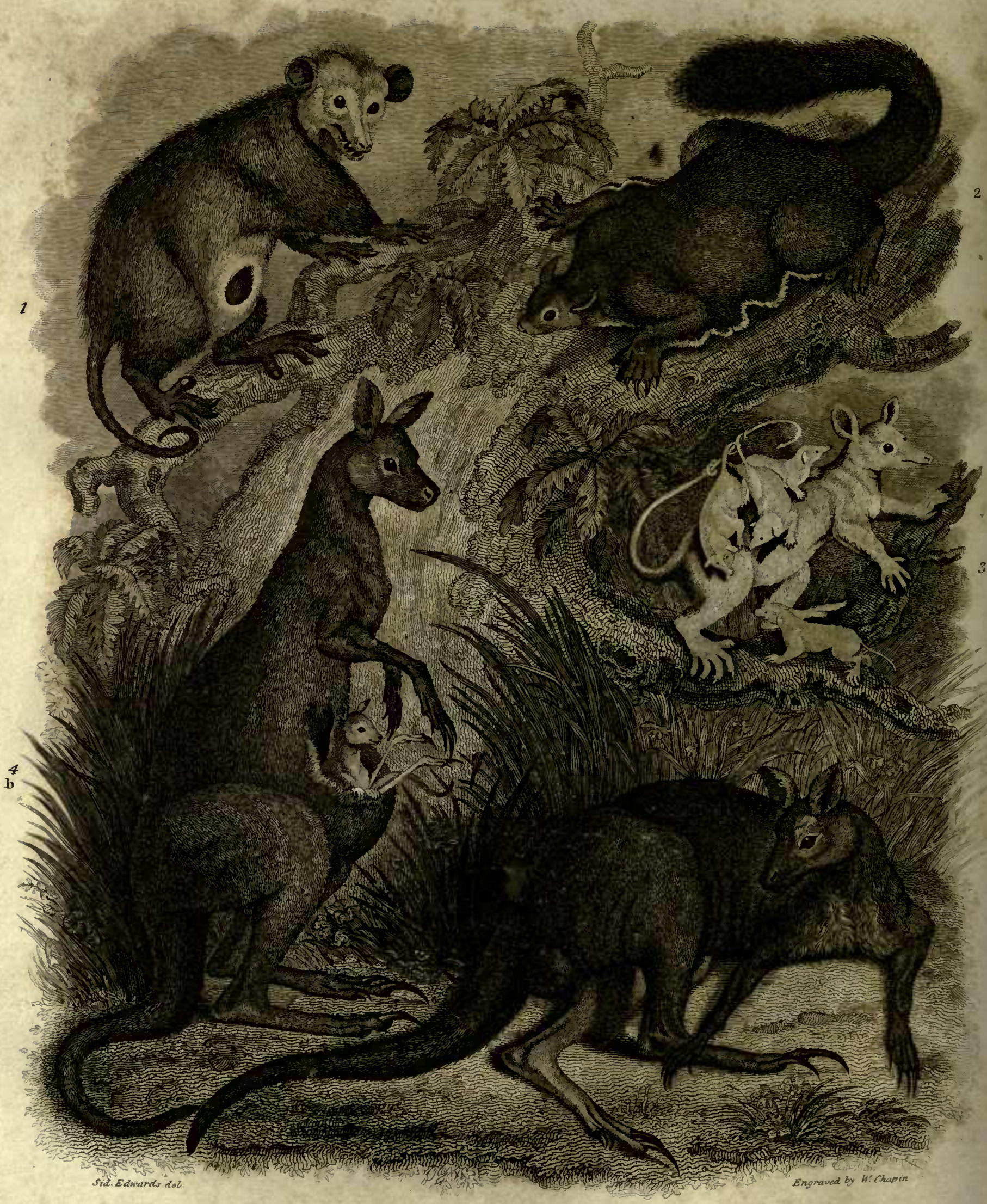

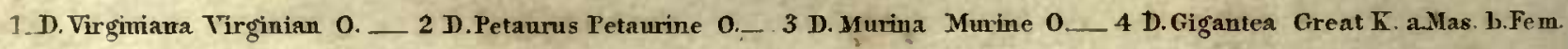


ferent kinds of these animals; all varying from each ollier in colour or size, but agreeing in the lsuman-like figure of their hands and feet, and in their long nose, which somewhat resembles that of a dog. As most of these are bred in the depths of the forest, we know little more concerning them than their figure. Their way of living, their power of pursuit and escape, can only be supposed, from the analogy of their conformation, somewhat to resemble those of the monkey.

The first of this kind is the mococo ; a beautiful animal, about the size of a common cat, but the body and limbs slenderer, and of a longer make. It has a very long tail, at least double the length of its body; it is covered with fur, and marked alternately with broad rings of black and white. But what it is chiefly rcinarkable for, besides the form of its hands and feet, is the largeness of its eyes, which are surrounded with a broad black space; and the length of the hinder legs, which by far exceed those before. When it sleeps, it brings its nose to its belly, and its tail over its head. When it plays, it uses a sort of galloping, with its tail raised over its back, which keeps continually in motion. The head is covered with dark ash-coloured hair; the back and sides with a red ash-colour, and not so dark as on the head; and the whole glossy, soft, and delicate, smooth to the touch, and standing almost upright like the pilc of velvet. It is a native of Madagascar; appears to be a harmless gentle animal; and though it resembles the monkey in many respects, yet it has neither its nalice nor its mischief: nevertheless, like the monkey, it scems to be always in motion; and moves, like all four-handed animals, in an oblique direction.

A second of this kind, which is also a native of Madagascar, is the Movgoz; which is less than the former; with a soft glossy robe, but a little curled. The nose also is thicker than that of the mococo; the eycs arc black, with orange-coloured circles round the pupil; and the tail is of one uniform colour. As to the rest, it is found of various colours; some being black, others brown; and its actions somewhat resemble those of a monkey.

The VARI is much larger than either of the former ; its hair is much longer, and it has a kind of ruff round the neck, consisting of very long hair, by which it may be casily distin- guished from the rest. It differs also in its disposition, which is fierce and savage; as also in the loudness of its voice, which somewhat resenbles the roaring of the lion. This also is a native of Madagascar.

To this tribe we may refer a little four-handed animal, of the island of Ceylon, which Mr. Buffon calls the LORI; very remarkable for the singularity of its figure. This is, of all other animals, the longest in proportion to its size; having nine vertebra in the loins; whereas other quadrupeds have only seven. The body appears still the longer by having no tail. In other respects, it resembles those of the maki kind; as well in its hands and feet, as in its snout, and in the glossy qualities of its hair. It is about the size of a squirrel; and appears to be a tame, harmless little animal.

\section{OF THE OPPOSSUM, AND ITS KINDS.}

To these four-handed animals of the ancient continent, we may add the four-handed animals of the ncw, that use their hands like the former, as well as their tails, and that fill up the chasm between the monkey tribe and the lower orders of the forest. As the maki kind in some measure seem to unite the fox and the monkey in their figure and size, so these secm to unite the monkey and the rat. They are all less than the former; they have long tails, almost bare of lair ; and their fur, as well as their shape, seems to place them near the rat kind. Some have accordingly ranked them in that class; but their being four-handed is a sufficicnt reason for placing them in the rear of the monkeys.

The first, and the most remarkable of this tribe, is the oppossum, an animal found both in North and South Amcrica, of the size of a small cat. The head resembles that of a fox; it has fifty teeth in all, but two great ones in the midst like those of a rat. The cyes are little, ronnd, clear, lively, and placed upright, the ears are long, broad, and transpar.nt, like those of the rat kind; its tail also increases the similitude, being round, long, a little hairy in the beginning, but quite naked towards the end. The fore legs are short, being about three inches long; while those behind are

a Bufion, vol. xxvi. p. 274.

$3 \mathrm{Q}$ 
about four. The feet arc like hands, each having five toes or fingers with white crooked nails, and rather longer, behind than before. But it is particular in this animal, that the thumb on the hinder legs wants a nail; whereas the fingers arc furnished with clawed nails as usual.

But that which distinguishes this animal from all others, and what has excited the wonder of mankind for more than two centuries, is the extraordinary conformation of its belly, as it is found to have a false womb, into which the young, when brought forth in the usual manner, creep, and continue for some days longer, to lodge and suckle securely. This bag, if we may so call it, being one of the most extraordinary things in natural history, requires a more minute description. Under the belly of the fenale is a kind of slit or upening, of alout three inches long; this opening is composed of a skin, which makes a bag internally, that is covered on the inside with hair, and in this bag are the teats of the female; and into it the young, when brought forth, retire, either to suckle or to escape from danger. This bag has a power of opening and shutting, at the will of the animal; and this is performed by means of several muscles, and two bones, that are fitted for this purpose, and that are peculiar to this animal only. These two bones are placed before the os pubis, to which they are joined at the base; they are about two inches long, and grow smaller and smaller to their extremities. These support the muscles that serve to open the bag, and give them a fixture. To these muscles there are antagonists, that serve in the same manner to shut the bag; and this they perform so exactly, that in the living animal the opening can scarcely be discerned, except when the sides are forcibly drawn asunder. The inside of this bag is furnished with glands, that exude a musky substance, which communicates to the flesh of the animal, and renders it unfit to be eaten. It is not to be supposed that this is the place where the young are conceived, as some have been led to imagine; for the oppossum has another womb, like that of the generality of animals, in which generation is performed in the ordinary manner. The bag we have been describing may rather be considered as a supplemental woinb. In the real womb, the little animal is partly brought to perfection; in the ordinary one, it receives a kind of additional incubation; and acquires, at last, strength cnough to follow the dan wherever she gocs. We have many reasons to suppose that the young of this animal are all brought forth prematurely, or before they have acquired that degree of perfection which is common in other quadrupeds. The little ones, when first produced, are in a mauner but half completed; and some travellers assert, that they are at that time not much larger than flies. We are assured also, that immediately on quitting the real womb, they creep into the false one; where they continue fixed to the teat, until they have strength sufficient to venture once once more into the open air, and share the fatigues of the parent. Ulloa assures us, that he has found five of these little creatures hidden in the belly of the dam three days after she was dead, still alive, and all clinging to the teat with great avidity. It is probable, therefore, that upon their first entering the false wornb, they seldom stir out from thence; but when more advanced, they venture forth several times in the day, and, at last, seldom make use of their retreat, except in cases of necessity or danger. Travellers are not agreed in their accounts of the time which these animals take to continue in the false. womb; some assure us they remain there for several weeks; and others, more precisely, mention a nonth. During this period of strange gestation, there is no difficulty in opening the bag in which they are concealed; they may be reckoned, examined, and handled, without much inconvenience; for they keep fixed to the teat, and cling there as firm as if they made a part of the body of the animal that bears them. When tlrey are grown stronger, they drop from the teat into the bag in which they are contained; and, at last, find their way out, in search of more copious subsistence. Still, however, the false belly serves them for a retreat, either when they want to sleep or to suckle, or when they are pursued by an enemy. The dain, on such occasions, opens her bag to receive them, which they enter,

-Pars formidine turpi

Scandunt rursus equum et nota conduntur in alvo.

The oppossum, when on the ground, is a slow, helpless animal; the formation of its 
hands are alone sufficient to slow itsincapacity of running with any degree of swiftness ; but, to counterbalance this inconveniessce, it climbs trees with great ease and expedition." It cliefly subsists upon birds; and lides annong the leaves of the trees, to seize them by surprise. It often also hangs by the tail, which is long and muscular; and, in this situation, for hours together, with the head downwards, it kceps watching for its prey. If any lesser animal, which it is able to overcome, passes underneatl, it drops upon it with deadly aim, and quickly devours it. By means of its tail, the oppossum also slings from one tree to another, humts insects, escapes its pursuers, and provides for its safety. It seems to be a creature that lives upon vegetables, as ivell as animal substances, roots, sugar-canes, the bark, and even the leaves, of trecs. It is easily tamed, but it is a disagreeable domestic, as well from its stupidity and figure, as its scent, which, however fragrant in small quantities, fails not to be ungrateful when copiously supplied.

An animal greatly resembling the former, ${ }^{b}$ is the MaRMOSE, which is found in the same continent. It seems ouly to differ in size, being less; and, instead of a bag to receive its young, has only two longitudinal folds near the thighs, within which the young, which are prematurely brought forth, as in the last iustance, continue to suckle. The young of these, when first produced, are not above the size of a bean; but continue sticking to the teat, until they have arrived at greater maturity.

The Cayopours is somewhat larger than the former, and a good deal resembling it in habits and figure, except that its suout is more pointed, its tail longer in proportion, and its colour different, being of an ush, somewliat inclining to yellow; however, I should suppose it to be only a variety of the former.

To this number we may add the pHatanGER, so called by Mr. Buffon; a good deal resembling the former, but distinguished by the fashion of its hinder hands; the thumb and fore-finger being joined together, except at the extrenities. This animal is about the size of a rat, and has, accordingly, by some, been called the rat of BURinam.

The last animal of this class is called, by

A. Buffon, vol. xxi. p. 174 .
Mr. Buffon, the tarsier. This extraordinary little animal resenbles the former, in liaving four hands, and a long tail ; but it differs very much in the extreme length of its hinder legs, which are longer than the rest of its whole body. The bones of that part of the foot called the tarsus, are likewise so very long, that from thence the animal has received its name: the tail is naked in the middle, and hairy only at both extremities : its hair is woolly, soft, and of a deep ash colour. As to the rest, it is tunknown from what country this animal was brought; but the naturalist from whom we have this description, supposes it to be a native of America.

From this general description of four-handed animals, we perceive what few advantages the brute creation derive from those organs, that, in man, are employed to so many great and useful purposes. They being able to pluck their food from the trees, the capacity of clinging among the branches, and at most of converting one of those branches into a weapon of offence, are the highest stretches of their sagacity, and the only use their hands have hitherto been employed in ; and yet some superficial men have asserted, that the hands alone are sufficient to vindicate the dominion of mankind over other animals; and that much of lis boasted reason, is nothing more than the result of his happier conformation: however, were this so, an ape or a monkey would in some instances be more rational than we; their fingers are smaller, and, in some of them, more finely formed than ours. To what a variety of purposes might they not be employed, if their powers were properly exerted! Those works which we, from the largeness of our fingers, are obliged to go clumsily about, one of these could very easily perform with the utmost exactness; and if the fineness of the hand assisted reason, an ape would be one of the most reasonable beings in the creation. But these admirably formed machines, are almost useless both to mankind and themselves; and contribute little nore to the happiness of animal life, than the paws of the lowest quadruped. They are supplied, indeed, with the organs; but they want the inind, to put them into action; it is that reasoning principle aloye, with which man has been endowed,

b Buffon, vol. xxi. p. 212. 
that can adapt seemingly opposite causes to concur in the same general design; and even where the organs are deficient, that can supply their place, by the intervention of assisting instruments. Where reason prevails, we find that it scarcely matters what the organs are that give it the direction ; the being furnished with that principle still goes forward, steadily, and uniformly successful; breaks through every obstacle, and becomes master of every enterprise. I have seen a man, without hands or

[Nearly allied to the last kind, in liaving a pouch for the security of its young, but differing in many other particulars, is the KANGuroo, a native of New Holland, first discovered by Captain Cook in the year 1770. Its size is at least that of a full-grown sheep; but there is a remarkable disproportion in its shape, the head and neck being very small, while the lower parts gradually. dilate to a very great size : the fore legs are hardly 19 inches long, while the hinder ones measure 3 feet 9 inches : accordingly, this animal's pace consists of vast springs or bounds, said legs, convert, by practice, his very stumps to the most convenient purposes; and with these clumsy instruments perform the most astonishing feats of dexterity. We may, therefore conclude, that it is the mind alone that gives a master to the creation; and that, if a bear or a horse were endowed with the same intellects that have been given to man, the hardness of a hoof, or the awkwardness of a paw, would be no obstacle to their advancenent in the arts of dominion, or of social felicity.

to exceed 9 feet in height and 20 in length. The tail is of such great strength as to be able to break a man's leg at a single blow. The young ones (of which the female is said to have only one at a time) at first hardly exceed an inch in length, and in the early periods of their growth reside entirely within the pouch of the dam. They feed on vegetables, drink by lapping, and burrow under ground. The Rat Kanguroo differs from the above, being only about the size of a rabbit, and is far less elegant and pleasing.?

\section{CHAPTER LIX.}

\section{OF THE ELEPHANT.}

HAVING gone through the description of those quadrupeds that, by resembling each other in some striking particular, admit of being grouped together, and considered under one point of view, we now come to those insulated sorts that bear no similitude with the rest, and that to be distinctly described must be separately considered.

The foremost of these, and in every respect the noblest quadruped in nature, is the elephant, not less remarkable for its size than its docility and understanding. All historians concur in giving it the character of the most sagacious animal next to man; and yet, were we to take our idea of its capacity from its outward appearance, we should be led to conceive very meanly of its abilities. The elephant, at first view, presents the spectator with an enormous mass of flesh that seems scarcely animated. Its huge body, covered with a callous hide, without hair; its large mis-shapen legs, that seem scarcely formed for motion; its little eyes, large ears, and long trunk ; all give it an air of extreme stupidity. But our prejudices will soon subside when we come to examine its history; they will even serve to increase our surprise, when we consider the various advantages it derives from so clunisy a conformation.

The clephant is seen from seven to no less than fifteen feet high. Whatever care we take to imagine a large aninal beforehand, yet the first sight of this huge creature never fails to strike us with astonishment, and in some neasure to exeeed our idea. Having been used to sinaller animals, we have scarcely any conception of its magnitude ; for a moving column of flesh, fourteen feet high, is an object so utterly different from those we are constantly presented with, that to be conceived it must be actually seen. Such, I own, were the suggestions that naturally arose to me when I first saw this animal, and yet for the sight of which I had taken eare to prepare my imagination. I found $m y$ ideas fall as short of its real size, as they did of its real figure; neither the pic- 
tures I had seen, nor the descriptions I had read, giving me adequate conceptions of either.

It would, therefore, be impossible to give an idea of this animal's figure by a description; which, even assisted by the art of the engraver, will but confusedly represent the original. In gencral it may be observed, that the forehead is very high ard rising, the ears very large and dependent, the eyes extremely small, the proboscis or trunk long, the body round and full, the back rising in an arch, and the whole aninal short in proportion to its height. The feet are round at the bottom; on each foot there are five flat horny risings, which scem to be the extremities of the toes, but do not appear outwardly. The hide is without hair, full of scratches and scars, which it receives in its passage through thick woods and thorny places. At the end of the tail there is a tuft of hair, a foot and a half long. The female is less than the inale, and the udder is between the fore legs. But a more accurate, as well as a more entertaining description of the parts, will naturally occur in the history of their uses.

Of all quadrupeds, the elephant is the strongest, as well as the largest ; and yet, in a state of nature, it is neither fierce nor formidable." Mild, peaceful, and brave, it never abuses its power or its strength, and only uses its force for its own protection, or that of its community. In its native deserts, the elephant is seldom seen alone, but appears to be a social, friendly creature. The oldest of the company conducts the band; that which is next in seniority brings up the rear. The young, the weak, and the sickly, fall into the centre; while the females carry their young, and keep them from falling by means of their trunks. They maintain this order only in dangerous marches, or when they desire to feed in cultivated grounds; they move with less precaution in the forests and solitudes; but without ever separating, or removing so far asunder as to be incapable of lending each other any requisite assistance. Nothing can be more formilable than a drove of elephants, as they appear at a distance in an African landscape ;

- I lave extracter the greatest part of this description from Mr. Buffon. Where I add, I mark with commas, "thus." wherever they march, the forests seem to fall before them ; in their passage, they bear down the branches upon which they feed; and if they enter into an enclosure, they destroy all the labours of the husbandman in a very short time. Their invasions are the more disagreeable, as there is no means of repelling them ; since it would require a small army to attack the whole drove when united. It now and then happens that one or two is found lingering behind the rest, and it is against these that the art and force of the hunters are united; but an attempt to molest the whole body would certainly be fatal. They go forward directly against him who offers the insult, strike him with their tusks, seize him with their trunks, fling him into the air, and then trample him to pieces under their fect. But they are thus dreadful only when offended; and do no manner of personal injury when suffered to feed without interruption. It is even said that they are mindful of injuries received; and, when once molested by man, seek all occasions for the future to be revenged; they smell him with their long trunks at a distance; follow him with all their speed upon the scent; and, though slow to appearance, they are soon able to come up with and destroy him.

In their natural state, they delight to live along the sides of rivers, to keep in the deepest vales, to refresh themselves in the most shady forests and watery places. They cannot live far from the water; and they always disturb it before they drink. They often fill their trunk with it, either to cool that organ, or to divert themselves by spurting it out like a fountain. They are equally distressed by the extremes of heat and cold ; and, to avoid the former, they frequently take shelter in the most obscure recesses of the forest, or often plunge into the water, and even swim from the continent into islands some leagues distant from the shore.

Their chief food is of the vegetable kind, for they loathe all kind of animal diet. When one among their number happens to light upon a spot of good pasture, he calls the rest, and invites them to share in the entertainment; but it must be a very copious pasture indeed that can supply the necessities of the whole band. As with their broad and heavy feet they sink deep wherever they go, they destro 
much more than they devour; so that they are frequently obliged to change their quarters, and to inigrate from one country to another. The Indians and negroes, who are often incommoded by such visitants, do all they can to keep them away, making loud noises, and large fires round their cultivated grounds: but these precautions do not always succeed; the elephants often break through their fences, destroy their whole harvest, and overturn their little habitations. When they have satisfied themselves, and trod down or devoured whatever lay in their way, they then retreat into the woods in the same orderly naanher in which they made their irruption.

Such are the habits of this animal, considered in a social light; and, if we regard it as an individual, we shall find its powers still more extraordinary. With a very awkward appearance, it possesses all the senses in great perfection, and is capable of applying them to more useful purposes than any other quadrnped. The elephant, as ive observed, has very small eyes, when compared to the enormous bulk of its body. But tlıough their minuteness may at first sight appear deformed, yet, when ive come to exanine them, they are seen to exhibit a variety of expression, and to discover the various sensations with which $j$ is moved. It turns them with attention and friendship to its master; it seems to reflect and deliberate; and as its passions slowly succeed each other, their vàrious workings are distiuctly seen.

The elephant is uot less remarkable for the excellence of its henring. Its ears are cxtrenely large, and greater in proportion than cven those of an ass. They are usually dependent; but it can readily raise and move them. They serve also to wipe its cyes, and to protect them against the dust and flies that night otherwise incommode then. It appears delighted with music, and very readily learns to beat time, to move in nicasure, and even to join its voice to the sound of the drum and the trumpet.

This animal's sense of smelling is not only exquisite, but it is in a great measure pleased with the same odours that delight mankind. The eleplsant gathers flowers with great pleasure and attention; it picks them up one by one, unites them into a nosegay, and seenis charmed with the perfume. The orange-flower seams to be particularly grateful, both to its sense of taste and smelling; it strips the tree of all its verdure, and eats every part of it, even to the branches themselves. It sceks in the meadows the most odoriferous plants to fred upon; and in the woods it prefers the cocoa, the banana, the palm, and the sago-tree, to all others. As the shoots of these are tender, and filled with pith, it eats not only the leaves and the fruits, but even the branches, the trunk, and the whole plant to the very roots.

But it is in the sense of touching that this animal excels all others of the brute creation, and perhaps even man himself. The organ of this sense lies wholly in the trunk, which is an instrunent peculiar to this anjmat, and that serves it for all the purposes of a hand. The trunk is, properly speaking, only the snout lengthened out to a great extent, hollow like a pipe, and ending in two openings, or nostrils, like those of a liog. An clephant of fourteen feet high has the trunk about eight feet long, and five feet and a half in circumference at the mouth, where it is thickest. It is hollow all along, but with a partition rumning from one end'of it to the other; so that though outwardly it appears like a single pipe, it is inwardly divided into two. This fleshy tube is composed of nerves and muscles, covered with a proper skin of a blackish colour, like that of the rest of the body. It is capable of heing moved in every direction, of being lengthencd and shortened, of being bent or straightened ; so pliant as to embrace any borly it is applied to, and yet so strong that nothing can be torn from the gripe. To aid the force of this grasp, there are several little cminences, like a caterpillar's feet, on the turlerside of this instrumcnt, which without doubt contrihute to the scnsibility of the touch, as well as to the firmuess of the hold. Through this trunk the animal breathes, drinks, and smells, as through a tubc; and at the very point of it, just above the nostrils, there is an extension of the skin, about five inches long, in the form of a finger, and which, in fact, answers all the purposes of one; for, with the rest of the extremity of the trunk, it is capable of assuming different forms at will, and consequently of being adapted to the ninutest olyjects. By means of this, the elephant can takc a pin from tle ground, untic the knots of a rope, unlock a door, and even write with a pen. "I have myself seen," says Æilian, "an clephant writing Latin characters on a 
board, in a very orderly manner, his keeper only showing him the figure of each letter. Wiile thus employed, the eyes might be observed studiously cast down upon the writing, and exhibiting an appearance of great skill and erudition." It sometimes happens that the olject is too lal'ge for the trunk to grasp; in such a case the elephant makes use of another expedient, as admirable as any of the former. It applies the extremity of the trunk to the surface of the object, and, sucking up its treath, lifts and sustains such a weight as the air in that case is capable of keeping suspended. In this manner this instrument is uscful in most of the purposes of life; it is an organ of smelling, of couching, and of suction; it not only provides for the animal's necessities and comforts, but it also serves for its ornament and defence.

But, though the elephant be thus admirably supplied by its trunk, yet, with respect to the rest of its conformation, it is unwieldly and helpless. The neck is so short that it can scarcely turn the head, and must wheel round in order to discover an enemy from behind. The hunters that attack it upon that quarter, generally thus escape the effects of its indignation; and find time to renew their assaults while the elephant is turning to face them. The legs are, indeed, not so inflexible as the neck, yet they are very stiff, and bend not withont difficulty. Those before seem to be longer than the hinder ; but, upon being measured, are found to be something shorter. The joints, by which they bend, are nearly in the middle, like the knee of a man; and the great bulk which they are to support makes their flexure ungainly. While the elephant is young, it bends the legs to lic down or to rise; but when it grows old, or sickly, this is not performed without human assistance, and it becones, consequently, so inconvenient, that the animal chooses to slecp standing. The feet, upon which these massy columns are supported, form a base scarcely broader than the lcgs they sustain. They are divided into five toes, which are covered beneath the skin, and none of which appear to the eye; a kind of protuberance like claws are only observed, which vary in number from three to five. The apparent claws vary; the intcrnal toes are constantly the same. The sole of the foot is furnished with a skin as thick and hard as พо. $35 \& 36$. horn, and which completely covers the whole under-part of the foot.

To the rest of the elephant's incumbrances may be added its enormous tusks, which are unserviceable for chewing, and are only weapous of defence. These, as the animal grows old, become so heavy, that it is sometimes obliged to make holes in the walls of its stall to rest them in, and ease itself of the fatigue of their support. It is well known to what an amazing size these tusks grow; they are two in number, proceeding from the upper jaw, and are sometimes found above six feet long. Some have supposed them to be rather the horns than the teeth of this animal; but, besides their greater similinde to bone than to horn, they have been indisputably found to grow fiom the upper jaw, and not from the frontal bones, as some liave thought proper to assert." Some also have asserted, that these tusks are shed in the saine manner as the stag sheds its horns; but it is very probable, from their solid consistence, and from their accidental defects, which often appears to be the effect of a slow decay, that they areas fixed as the teeth of other animals are geuerally found 10 lse. Certain it is that the elephant never sheds them in a domestic state, but keeps them till they become inconvenient and encumbersome to the last degree. An account of the uses to which these teeth are applied, and the manner of choosing the best ivory, bclongs rather to a bistory of the arts than of nature.

This animal is equally singular in other parts of its conformation; the lips and the tungue in other creatures serve to suck up and direct their drink or their food; but in the clephant they are totally inconvenient for such purposes; and it not only gathers its foorl winh its trunk, but supplies itself with watcr by the same means. When it eats hay, as 1 have seen it frequently, it takes up a small wisp of it with the trunk, turns and shapes it with that instrument for some time, and then directs it into the mouth, where it is chewerl by the grent grinding teeth, that are large in proportion to the bulk of the animal. This pacquet, when chewed, is swallowed, and never ruminated again, as in cows or sheep, the stomach and intestines of this creature more resembling

a See Mr. Daubenton's description of the skeleton of this animal. 
those of a horse. Its manner of drinking is equally extraordinary. For this purpose, the elephant dips the end of its trunk into the water, and sucks up just as much as fills that great fleshy tube completely. It then lifts up its head with the trunk full, and turning the point into its mouth, as if it intended to swallow trunk and all, it drives the point below the opening of the wind-pipe. The trunk being in this position, and still full of water, the elephant then blows strongly into it at the other end, which forces the water it contains into the throat; down which it is heard to pour with a loud gurgling noise, which continues till the whole is blown down. From this manner of drinking, some have been led into an opinion that the young elephant sucks with its trunk, and not with its mouth; this, however, is a fact which rio traveller has hitherto had an opportunity of seeing, and it must be referred to some future accident to determine."

The hide of the elephant is as remarkable as any other part. It is not covered over with hair, as in the generality of quadrupeds, but is nearly bare. Here and there indeed a few bristles are seen growing in the scars and wrinkles of the body, but very thinly scattered over the rest of the skin; but in general the head is dry, rough, and wrinkled, and resembling more the bark of an old tree than the skin of an animal. This grows thicker every year; and by a constant addition of substance, it at length contracts that disorder well known by the name of the elephantiasis, or Arabian leprosy; a disease to which man, as well as the elephant, is often subject. In order to prevent this, the Indians rub the elephant with oil, and frequently bathe it, to preserve its pliancy. To the inconveniences of this disorder is added another, arising from the great sensibility of those parts that are not callous. Upon these the flies settle in great abundance, and torment this animal unceasingly; to remedy which, the elephant tries all its arts; using not only its tail and trunk in the natural manner to keep them

a The young elephant, it is now known, dues not suck by the trunk, but by the inouth only, as in all other quadrupeds; during which the trunk of the young is thrown back over the head. It is, however, highly retsarkable, off, but eren takes the branch of a tree, or a bundle of hay, to strike them off with. When this fails, it often gathers up the dust with its trunk, and thus covers all the seusible places In this manner it has been seen to dust itselt several times a day, and particularly upon leaving the bath.

Water is as necessary to this animal as food itself. When in a state of nature, the elephant rarely quits the banks of the river, and often stands in water up to the belly. In a state of servitude, the lndians take equal care to provide a proper supply; they wash it with great address; they give it all the conveniences for lending assistance to itself; they sinooth the skin with a pumice-stone, and then rub it over with oils, essences, and odours.

It is not to be wondered at that an animal furnished with so many various advantages, both of strength, sagacity, and obedience, should be taken into the service of man. We accordingly find that the elephant, from time inninemorial, has been employed either for the purposes of labour, of war, or of ostentation; to increase the grandeur of eastern princes, or to extend their dominions. We have hitherto been describing this animal in its natural state; we now come to consider it in a different view, as taken from the forest, and reduced to human obedience. We are now to behold this brave harmless creature as learning a lesson from mankind, and instructed by him in all the arts of war, massacre, and devastation. We are now to behold this half-reasoning animal led into the field of battle, and wondering at those tumults and that madness which he is compelled to increase. The elephant is a native of Africa and Asia, being found neitler in Europe nor America. In Africa be still retains his natural liberty. The-savage inhabitants of that part of the world, instead of attempting to subdue this powerfnl creature to their necessities, are happy in being able to protect themselves from his fury. Formerly, indeed, during the splendour of the Carthaginian empire,

if what is related be true, that they do not attach themselves to their da!ns in particular, but suck indiscriminately the females of the whole herd. 
elephants were used in their wars; but this was only a transitory gleam of human power in that part of the globe; the natives of Afrien have long siace degenerated, and the elephant is only known among them from his devastations. However, there are no elephants in the northern parts of Africa at present, there being none found on this side of Mount Atlas. It is beyond the river Senegal that they are to be met with in great numbers, and so down to the Cape of Good Hope, as well as in the heart of the country. In this extensive region they appear to be more numerous than in any other part of the world. They are there less fearful of man: less retired into the heart of the forests, they seem to be scusible of his impotence and ignorance; and often come down to ravage his little labours. They treat him with the same haughty disdain which they show to other animals, and consider him as a mischiev ous little being, that fears to oppose them openly.

But although these animals are most plentiful in Africa, it is only in Asia that the greatest elephants are found, and rendered subservient to human command. In Africa, the largest do not exceed ten feet high; in Asia they are found from ten to fifteen. Their price increases in proportion to their size; and when they exceed a certain bulk, like jewels, their value then rises as the fancy is pleased to estimate.

The largest are entirely kept for the service of princes; and are maintained with the utmost magnificence, and at the greatest expense. The usual colour of the elephant, is a dusky black, but some are said to be white; and the price of one of these is inestinable. Such a one is peculiarly appropriated for the monarch's own riding; he is kept in a palace, attended by the nobles, and almost adored by the people." Some have said that these white elephants are larger - than the rest; ${ }^{b}$ others assert that they are less; and still others entirely doubt their existence.

As the art of war is but very little improved in Ásia, there are few princes of the East who do not procure and maintain as many

a P. Vincent Marie. b P. Tachard.

c Multis persuasum est elephantem non brutorum sed hominum more coire. Quod retro mingit non dubitatur. elephants as they are able, and place great confidence on their assistance in an engagement. For this purpose they are obliged to take them wild in their native forests, and tame them; for the elcphant never breeds in a state of servitude. It is one of the most striking peculiarities in this extraordinary creature, that his generative powers totally fail when he comes under the dominion of man; as if he seemed unwilling to propagate a race of slaves, to increase the pride of lis conqueror. There is, perhaps, no other quadruped that will not breed in its own native climate, if indulged with a moderate share of freedom; and we know that many of them will copulate in every climate. The elephant alone has never been seen to breed; and though he has been reduced under the obedience of man for ages, the duration of pregnancy in the female still remaius a secret. Aristotle, indeed, asserts, that she goes two years with young; that she continues to suckle her young for three years, and that she brings forth but one at a time: bit he does not inform us of the manner in which it was possible for him to have his information. From authorities equally doubtful, we learn, that the little one is about as large as a wild boar the instant it is brought forth; that its tusks do not yet appear; but that all the rest of its teeth are apparent; that at the age of six months, it is as large as an ox, and its tusks pretty well grown; and that it continues, in this manner, for near thirty years, advancing to maturity. All this is doubtful; but it is certain that, in order to recruit the numbers which are consumed in war, the princes of the East are every year obliged to send into the forests, and to use various methods to procure a fresh supply. Of all these numerous bands, there is not one that has not been originally wild; nor one that has not been forced into a state of subjection. Men themselves are often content to propagate a race of slaves, that pass down in this wretched state through successive generations: but the elephant, under subjection, is unalterably barren; perhaps from some physical canses, which are as yet unknown.

Sed ipse vidi marem hujusce speciei, in unstri regis stabulis, super fremellam itidem inclusam quadruqedum more silientem, pene paululum incurvato sed suff cienter recto 
The Indian princes having vainly endeavoured to multiply the breed of elephants, like that of other animals, have been at last content to separate the males from the females, to prevent those accesses of desire, which debilitated without multiplying the species. In order to take them wild in the woods, a spot of ground is fixed upon, which is surrounded with a strong palisade. This is made of the thickest and the strongest trees; and strengthened by cross bars which give firmness to the whole. The posts are fixed at such distances from each other, that a man can easily pass between them; there being only one great passage left open, through which an elephant can easily come; and which is so contrived as to shut behind, as soon as the beast is entered. To draw him into this enclosure, it is necessary tirst to find him out in the woods; and a female elephant is conducted along into the heart of the forest, where it is obliged by its keeper to cry out for the male. The male very readily answers the cry, and hastens to join her; which the keeper perceiving, obliges her to retreat, still repeating the same cry, until she leads the animal into the enclosure already described, which shuts the moment he is entered. Still, however, the female proceeds calling and inviting, while the male proceeds forward in the enclosure, which grows narrower all the way, and until the poor animal finds himself completely shut up, without the power of either advancing or retreating; the female in the mean time being let out by a private way, which she has been previously accustomed to. The wild elephant, upon seeing himself entrapped in this manner, instantly attempts to use violence; and, upon seeing the hunters, all his former desires ouly turn to fury. In the mean time, the hunters, having fixed him with cords, attempt to soften his indignation, by throwing buckets of water upon him in great quantities, rubbing the body with leaves, and pouring oil down his ears. Soon after, two tame elephants are brought, a male and a female, that caress the indignant animal with their-trunks; while they still continue pouring water to refresh it. At last a tame elephant is brought forward, of that number which is employed in instructing the new-comers, and an officer riding upon it, in order to show the late captive that it has nothing to tear. The hunters then open the enclosure; and while this creature leads the captive along, two more are joined on either side of it, and these compel it to submit. It is then tied by cords to a massy pillar, provided for that purpose, and suffered to remain in that position for about a day and a night, until its indignation be wholly subsided. The next day it begins to be somewhat submissive; and in a fortnight is completely tamed like the rest. The females are taken when accompanying the males; they often come into these enclosures, and they shortly after serve as decoys to the rest. But the method of taking the ele phant differs, according to the abilities of the hunter: the negroes of Africa, who hunt this animal merely for its flesh, are content to take it in pitfalls; and often to pursue it in the defiles of a mountain, where it cannot easily turn, and so wound it from behind till it falls.

The elcphant, when once tamed, becomes the most gentle aud obedient of all animals. It soon conceives an attachment for the person that attends it, caresses him, obeys him, and seems to anticipate his desires. In a short time it begins to comprehend several of the signs made to it, and even the different sounds of the voice; it perfectly distinguishes the tone of command from that of anger or approbation, and acts accordingly. It is seldom deceived in its master's voice; it receives his orders with attention, and executes them with prudence, eagerly, yet without precipitation. All its motions are regulated, and its actions seem to partake of its magnitude; being grave, majestic,and sccure. It is quickly taught to kneel down, to receive its rider; it caresses those it knows with its trunk; with this salutes such as it is ordered to distinguish, and with this, as with a hand, belps to take up a part of its load. It suffers itself to be arrayed in harness, and secms to take a pleasure in the finery of its trappings. It draws either chariots, cannon, or slipping, with surprising strength and perseverance; and this with a seeming satisfaction, provided that it be not beaten without a cause, and that its master appears pleased with its exertions.

The elephant's conductor is usually mounted upon its neck, and makes use of a rod of 
iron to guide it, wîtich is sometimes pointed, and at others bent into a hook. With this the animal is spurred forward, when dull or disobedient; but, in general, a word is sufficient to put the gentle creature into motion, especially when it is acquainted with its conductor. This acquaintance is often perfectly necessary; for the elephant frequently takes such an affection to its keeper, that it will obey no other: and it has been known to die for grief, when, in some sudden fit of madness, it has killed its conductor. We are told, that one of these, that was used by the French forces in India for the drawing their camnon, was promised, by the conductor, a reward for having performed some painful service; but being disappointed of its expectations, it slew him in a fury. The conductor's wife, who was a spectator of this shocking scene, could not restrain her madness and despair; but running with her two children in her arms, threw them at the elephant's feet, crying out, that since it had killed her husband, it might kill her and her cliildren also. The elepliant, seeing the children at its feet, instantly stopped, and moderating its fury, took up the eldest with its trunk, and placing him upon its neck, adopted him for its conductor, and obeyed him ever after with great punctuality.

But it is not for drawing burdens alone, that the elephants are serviceable in war; they are often brought into the ranks, and compelled to fight in the most dangerous parts of the field of battle. There was a time, indeed, in India, when they were much more used in war than at present. A century or two ago, a great part of the dependence of the general was upon the number and the expertness of his elephants; but of late, since war has been contented to adopt fatal instead of formidable arts, the elephant is little used, except for drawing cannon, or transporting provisions. The princes of the country are pleased to keep a few for ornament; or for the purposes of removing their seraglios: but they are seldom led into a field of battle, where they are unable to withstand the discharge of fire-arms, and have often been fornd to turn upon their employers. Still, however, they are used in war, in the more remote parts of the East; in Siam, in Cochin
China, in Tonquin, and Pegu. In all these places, they not only serve to swell the pomp of state, being adorned with all the barbarian splendour that those countries can bestow, but they are actually led into the field of battle, armed before with coats of mail, and loaded on the back each with a square tower, containing from five combatants to seven. Upon its neck sits the conductor, who goads the animal into the thickest ranks, and encourages it to increase the devastation; wherever it goes, nothing can withstand its fury; it levels the ranks with its immense bulk, flings such as oppose it into the air, or crushes them to death under its feet. In the mean time, those who are placed upon its back, combat as from an eminence, and fling down their weapons with double force, their weight being added to their velocity. Nothing, therefore, can be more dreadful, or more irresistible, than such a moving machine, to men unacquainted with the modern arts of war; the elephant thus armed and conducted, raging in the midst of the field of battle, inspires more terror than even those machines that destroy at a distance, and are often most fatal when most unseen. But this method of combating, is rather formidable that effectual; polished nations have ever been victorious over those semi-barbarous troops that have called in the elephant to their assistance, or attempted to gain a victory by merely astonishing their opposers. The Romans quickly learned the art of opening their ranks to admit the elephant, and thus separating it from assistance, quickly compelled its conductors to calm the animal's fury, and to submit. It sometimes also happened that the elephant became impatient of control ; and, instead of obeying its conductor, turned upon those forces it was employed to assist. In either case, there was a great deal of preparation to very little effect, for a single elephant is known to consume. as much as forty men in a day.

At present, therefore, they are chiefly employed in carrying, or drawing burdens, throughout the whole Peninsula of India; and no animal can be more fitted by nature for this employment. The strength of an elephant is equal to its bulk, for it can, with great eáse, draw a load that six horses could not remove; it can readily carry upon its 
back three or four thousand weight; upon its tusks alone it can support near a thousand: its force may also be estimated from the velocity of its motion, compared to the mass of its body. It can go, in its ordinary pace, as fast as a horse at an easy trot; and, when pushed, it can move as swiftly as a horse at full gallop. It can travel with ease fifty or sixty miles a day; and, when hard pressed, alnıost double that distance. It may be heard trotting on at a grcat distance; it is easy also to follow it by the track, which is deeply intpressed on the ground, and from fifteen to eighteen inches in diameter.

In India they are also put 10 other very disagrecable offices; for in some courts of the more barbarous princes, they are used as executioners : and this horrid task they perform with great dexterity: with their trunks they are seen to break every limb of the criminal at the word of command; they sometimes trample him to deatl, and sometimes impale him on their enormous tusks, as directed. In this the elephant is rather the servant of a cruel master than a voluntary tyrant, since no other animal of the forest is so naturally benevoleut and gentle; equally mindful of benefits as sensible of neglect, he contracts a friendship for his keeper, and obcys him even beyond his capacity.

In India, where they werc at one time employed in launching ships, a particular elephant was directed to force a very large vessel into the water: the work proved superior to its strength, but not to its endeavours; which, however, the keeper affected to despise. "Take away," says he, "that lazy beast, and bring another better fitted for service." The poor animal instantly upon this redoubled its efforts, fractured its skull, and died upon the spot.

In Delhi, an elephant, passing along the streets, put his trunk into a tailor's shop, where several people were at work. One of the persons of the sliop, desirous of some amusement, pricked the animal's trunk with his needle, and seemed highly delighted with this slight punishment. The elephant, however, passed on without any immediate signs of resentment; but coming to a puddle filled with dirty water, he filled his trunk, returned to the shop, and spurted the contents over all the finery upon which the tailors were then employed.
An elephant in Adsmeer, which often passed through the hazar or market, as lie went by a certain herb-woman, always received from her a nouthful of greens. Being one day scized with a periodical fit of madness, he broke his fetters, and rumning through the markst, put the crowd to flight, and among others, this woman, who in her haste forgot a little child at her stall. The elephant recollecting the spot where its benefactress was accustonied to sit, took up the infant gently in its trunk, and conveyed it to a place of safety.

At the Cape of Good Hope it is customary to hunt those animals for the sake of their teeth. Three horsemen, well mounted, and armed with lances, attack the elephant alternately, each relieving the other, as they see their companion pressed, till the beast is subdued. Three Dutchmen, brothers, who had made large fortunes by this business, determined to retire to Europe, and enjoy the fruits of their labours; but they resolved, one day before they went, to have a last chase, by way of amusement : they met with their ganie, and began their attack in the usual manner: but, unfortunately, one of their horses falling, happened to fling his rider; the inraged elephant instantly seized the unhappy huntsnian with his trunk, flung him up to a vast height in the air, and received him upon one of his tusks, as he fell; and then turning towards the other two brothers, as if it were with an aspect of revenge and insult, held out to then the impaled wretch, writhing in the agonies of deatl.

The teeth of the elephant are what produce the great tumity between him and mankind; but whether they are shed like the horus of the deer, or whether the aninial be killed to obtain them, is not yet perfectly known. All we lave as yet certain is, that the natives of Africa, from whence almost all our ivory comes, assure us, that they find the greatest part of it in their forests; nor would, say they, the teeth of an elephant recompense then for their trouble and danger in killing it: notwithstanding, the elepliauts which are tamed by man, are never known to shed their tusks; and from the hardness of their suhstance, they seem no way analogous to decrs' horns.

The teeth of the elephant are very often found in a fossil state. Some years ago, two great grinding teeth, and part of the tusk of 
an elephant, were discovered at the depth of forty-two yards in a lead-mine in Flintshire. ${ }^{2}$

The tusks of the Mammoth, so often found fossil in Siberia, and which are converted to the purposes of ivory, are generally supposed to belong to the elephant: however, the animal must liave been inuch larger in that country than it is found at present, as those tusks are often known to weigh four hundred pounds; while those that come from Africa seldom exceed two hundred and fifty. These enormous tusks are found lodged in the sandy banks of the Siherian rivers; and the natives pretend that they belong to an animal which is four times as large as the elephant.

There have lately been discovered several enormous skeletons, five or six fcet beneath the surface, on the banks of the Ohio, not remote from the river Miume, in America, seven hundred miles from the-sea coast. Some of the tusks are near seven feet long; one font nine inches in circumference at the base, and one foot near the point; the cavity at the root or base, niueteen inches deep. Besides their size, there are yet other differences: the tusks of the true elephant have sometimes a very slight lateral bend; these liave a larger twist, or spiral curve, towards the snaller end : but the great and specific difference consists in the shape of the grinding teeth; wlich, in these newly found, are fashioned like the teeth of a carnivorous animal ; not flat and ribbed transversely on their surface, like those of the modern elephant, but furnished with a double row of high and conic processes, as if intended to masticate, not to grind their food. A third difference is in the thigh-bone, which is of a great disproportionable thickness to that of the elephant ; and has also some other anatomical variations. These fossil bones have been also found in Peru and the Brazils; and, when cut and polished by the workers in ivory, appear, in every respect, similar. It is the opinion of Dr. Hunter, that they must have belonged to a larger animal than the elephant; and differing from it, in being carnivorous. But as yet this formidable creature has evaded our search; and, if indeed, such an animal exists, it is happy for man that it keeps at a distance; since wliat ravage might not be expected from a creature, endued with more than the strength of the elephant, and all the rapacity. of the tiger !

\section{CHAPTER LX.}

\section{OF THE RHINOCEROS.}

NEX'T to the elephant, the Rhinoceros is the most powerful of animals. It is usually found twelve feet long, from the tip of the nose to the insertion of the tail; from six to seven feet high; and the circumference of its body is nearly equal to its length. It is, therefore, equal to the elephant in bulk: and if it appears much smaller to the eye, the reason is, that its legs are much shorter. Words can convey but a very confused idea of this animal's shape; and yet there are few so remarkably formed: its head is furnished with a horn, growing from the snout, sometimes three feet and a haif long; and but for this, that part would have the appearance of the

- Pennant's Synopsis, p. 90. head of a hog; the upper lip, however, is much longer in proportion, ends in a point, is very pliable, serves to collect its food, and deliver it into the mouth: the ears are large, erect, and pointed; the eyes are small and piercing; the skin is naked, rough, knotty, and lying upon the body in folds, after a very peculiar fashion : there are two folds very remarkable; one above the shoulders, and another over the rump: the skin, which is of a dirty brown colour, is so thick as to turn the edge of a scimitar, and to resist a musket-ball; the belly hangs low; the legs are short, strong, and thick, and the lioofs divided into three parts, each pointing forward.

Such is the general outline of an animal that appears chiefly formidable from the horn 
growing from its snout; and formed rather for war, than with a propensity to engage. This horn is sometimes found from three to three feet and a half long, growing from the solid bone, and so disposed as to be managed to the greatest advantage. It is composed of the most solid substance; and pointed so as to inflict the most fatal wounds. The elephant, the boar, or the buffalo, are obliged to strike transversely with their weapons; but the rhinoceros employs all his force with every blow; so that the tiger will more willingly attack any other animal of the forest, than one whose strength is so justly employed. Indeed, there is no force which this terrible auinal has to apprehend: defended, on every side, by a thick horny hide, which the claws of the lion or the tiger are unable to pierce, and armed before with a weapon that even the elephant does not choose to oppose. The missionaries assure us, that the elephant is often found dead in the forests, pierced with the horn of a rhinoceros; and though it looks like wistom to doubt whatever they tell us, yet I cannot liclp giving credit to what they relate on this occasion, particularly when confirmed by Pliny. The combat between these two, the most formidable animals of the forest, must be very dreadful. Emanuel, king of Portugal, willing to try their strength, actually opposed them to each other; and the elephant was defeated.

But though the rhinoceros is thus formidable by nature, yet imagination has not failed to exert itself, in adding to its terrors. The scent is said to be most exquisite; and it is affirmed that it consorts with the tiger. It is reported also, that when it has overturned a man, or any other animal, it continues to lick the flesh quite from the bone with its tongue, which is said to be extremely rough. All this, howevel, is fabulous: the scent, if we may judge from the expansion of the olfactory nerves, is not greater than that of a hog, which we know to be indifferent ; it keeps company witl the tiger, only because they both frequent watery places in the burning climates where they are bred; and as to its rough tongue, that is so far from the truth, that no animal of near its size has so soft a onc. "I have often felt it myself," says Ladvocat, in his description of this animal; "it is smooth, soft, and small, like that of a dog; and to the feel it appears as if one passed the hand over velvet;
I have often scen ir lick a young man's face who kept it, and both seemed pleased with the action."

The rlinoceros which was slinwn at London in 1739, and described by Dr. Parsols, had been sent fiom Bengal. Though it was very young, not being above two years old, yet the charge of his carriage and food from India cost near a thousand pounds. It was fed with rice, sugar, and hay: it was daily supplied with seven pounds of rice, mixed with three of sugar, divided into tluree portions; it was given great quantities of hay and grass, which it chiefly preferred; its drink was water, which it took in great quantities. It was of a gentle disposition, and pernitred itself to be touched and handled by all visiters, never attempting inischief, except when abused, or when hungry; in such a case, there was no method of appeasing its fury, but by giving it something to eat. When angry, it would jump up agaiust the walls of its room witl great violence, and made many efforts to escape, but seldom attempted to attack its keep$\mathrm{er}$, and was always submissive to his threats. It had a peculiar cry, somewhat a mixture between the grunting of a hog and the bellowing of a calf.

The age of these animals is not well known; it is said by sonse, that they bring forth at three ycars old, and if we may reason from analogy, it is probable they seldom live till above twenty. That which was shown in London, was said by its keeper to be eighteen years old, and even at that age he pretended to consider it as a young one; however, it died shortly after, and that probably in the course of niture.

The rhinoceros is a native of the deserts of Asia and Africa, and is usually fonnd in those extensive forests that are frequented by the elephant and the lion. As it subsists entirely upon vegetable food, it is peaceful and harmless among its fellows of the brute creation; but, though it never provokes to combat, it equally disdains to fly. It is every way fitted for war, but rests content in the conciousness of its security. It is particularly fond of the prickly branches of trees, aud is seen to feed upon such thorny shrubs as would be dangerous to other animals, either to gather or to swallow. The prickly points of these, however, may only serve to give a poignant relish 


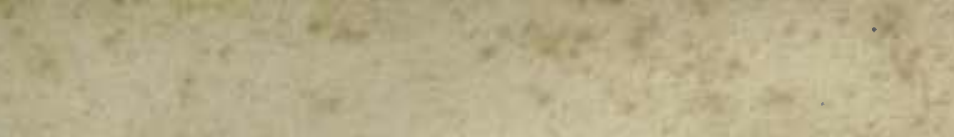

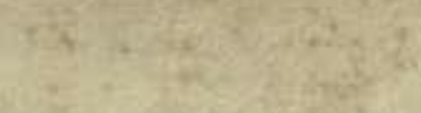

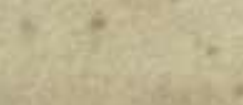

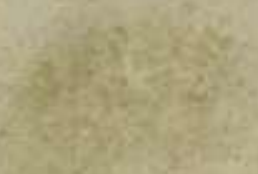

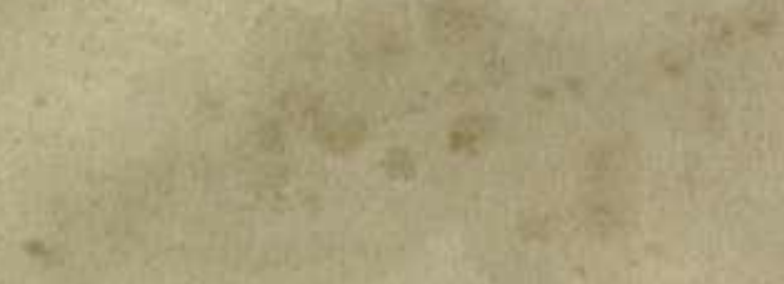

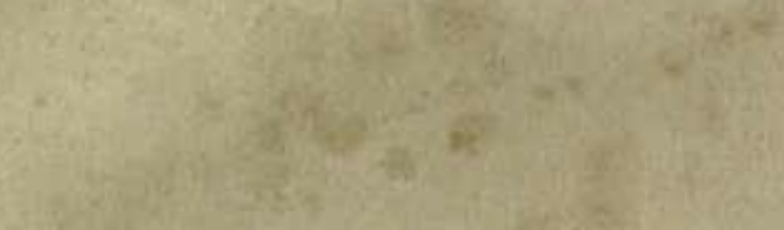

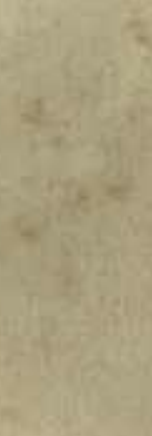

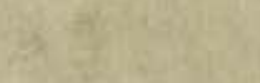

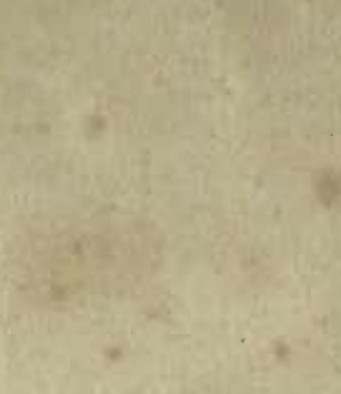

$$
\begin{aligned}
& \text { is. } \\
& 32 \\
& \text { then: } \\
& \text { (x) }
\end{aligned}
$$

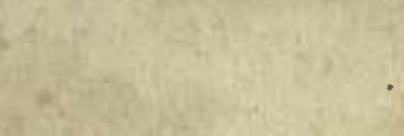

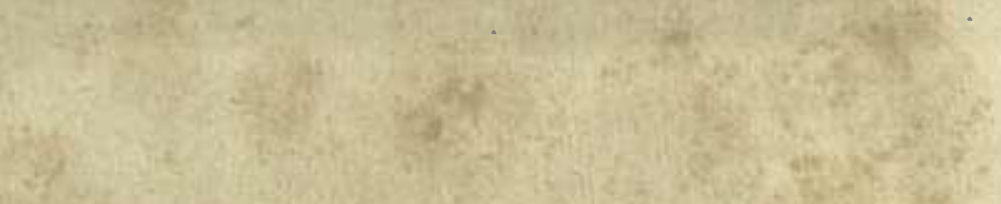

$$
\begin{aligned}
& \text { xials }
\end{aligned}
$$

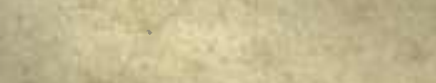

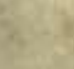

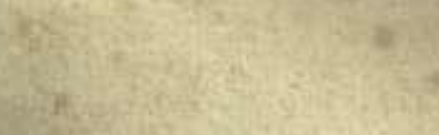

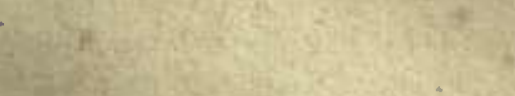

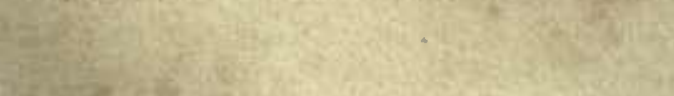

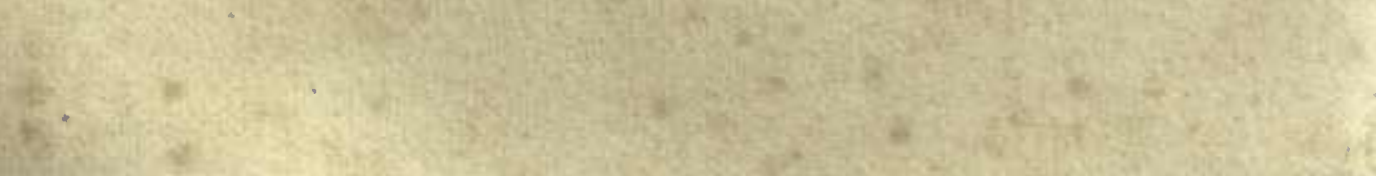

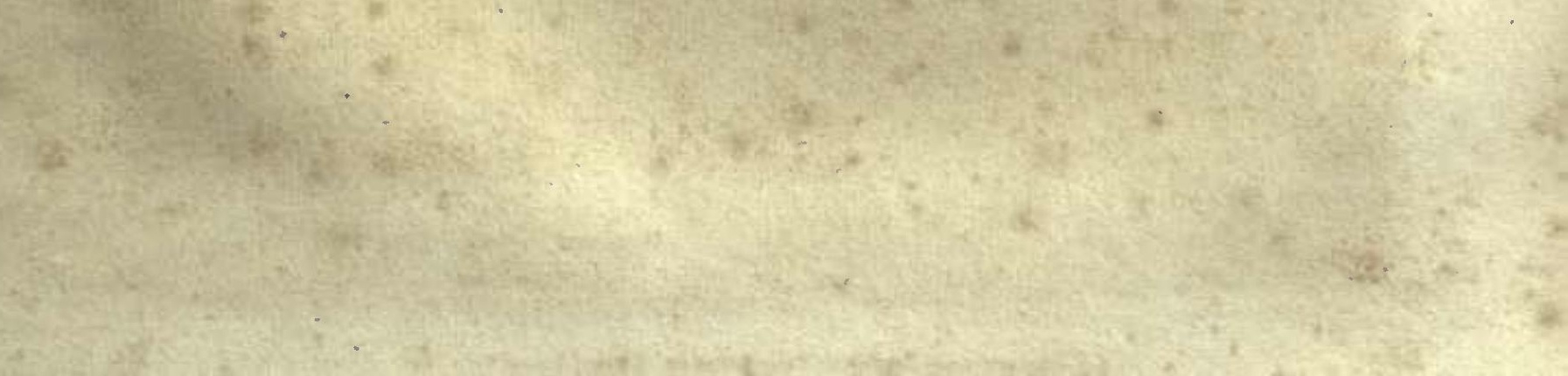



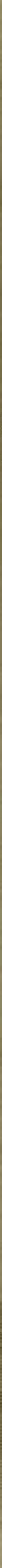
this aninual's palate, and may answer the same grateful ends in seasoning its banquet that spices do in heightening ours.

In some parts of the kinglom of Asia, where the natives are more desirous of appearing warlike than showing themselves brave, these animals are tamed, and led into the field to strike terror into the enemy; but they are always an unmanageable and restive animal, and probably more dangerous to the employers than those whoin they are brought to oppose.

The method of taking them, is chiefly watching them, till they are found either in some moist or marshy place, where, like hogs, they are fond of sleeping and wallowing. They then destroy the old one with fire arms; for no weapons that are thrown by the force of man are capable of entering this animal's hide. If, when the old one is destroyed, there happens to be a cub, they seize and tame it: these animals are sometimes taken in pit-falls, covered with green branches, laid in those paths which the rhinoceros makes in going from the forest to the river side.

There are some varieties in this animal, as in most others; some of them are found in Africa with a double horn, one growing above the other. This weapon, if considcred in itself, is one of the strongest and most dangerous that nature furnishes to any part of the animal creation. The horn is entirely solid, formed of the hardest bony substance, growing from the upper maxillary bone, by so strong an apophyse, as seemingly to make but one part with it. Many are the medicinal virtues that are ascribed to this horn, when taken in powder; but these qualitics have been attributed to it without any real foundation, and make only a small part of the many fables which this extraordinary animal has given rise to.

\section{CHAPTER LXI.}

\section{THE HIPPOPOTAMUS.}

THE hippopotanus is an animal as large, and not less formidable, than the rhinoceros; its legs are shorter, and its head rather more bulky than that of the animal last described. We have had but few opportunities in Europe of examining this formidable creature minutely; its dimensions, however, have been pretty well ascertained, by a description given us by Zerenghi, an Italian surgeon, who procured one of them to be killed on the banks of the river Nile. By his account it appears, that this terrible animal, which chiefly resides in the waters of that river, is above seventeen feet long, from the extrennity of the snout to the insertion of the tail; above sixteen feet in circumference round the body, and above seven feet high: the head is near four feet long. and above nine feet in circumference. The jaws open about two feet wide, and the cutting-teeth, of which it hath four in eacls jaw, are above a foot long.

Its feet in some mensure resemble those of the elephant, and are divided into four parts. The tail is short, flat, and pointed; the hide No. $37 \& 38$. is amazingly thick, and though not capable of turning a musket ball, is impenetrable to the blow of a sabre; the body is covered over with a few scattered hairs of a whitish colour. The whole figure of the animal is something between that of an ox and a hog, and its cry is something between the bellowing of the one and the grunting of the other.

This animal, however, though so terribly furnished for war, seems no way disposed to make use of its prodigious strength against an equal enemy ; it chiefly resides at the bottom of the great rivers and lakes of Africa, the Nile, the Niger, and the Zara; there it leads an indolent kind of life, and seems seldom disposed for action, except when exeited by the calls of hunger. Upon such occasions, three or four of them are often seen at the bottom of a river, near. some cataract, forming a kind of line, and seizing upon such fish as are forced down by the violence of the stream. In that element they pursue their prey with great swiftness and perseverance; 
they swim with much force, and remain at the bottom for thirty or forty minutes, without rising to take breath. They traverse the bottom of the stream, as if walking upon land, and make a terrible devastation where they find plenty of prey. But it often happens, that this animal's fishy lood is not supplied in sufficient abundance; it is then forced to come upon land, where it is an awkward and unwieldy stranger; it noves but slowly, and as it seldom lorsakes the margin of the river, it sinks at every step it takes; sometimes, however, it is forced by famine up into the higher grounds, where it commits drealful havoc among the plantations of the helpless natives, who see their possessions destroyed, without daring to resist their invader. Their chief method is by lighting fires, striking drums, and raising a cry to frighten it back to its favourite element; and as it is extremely timorous upon land, they generally succeed in their endeavours. But if they happen to wound, or otherwise irritate it too closely, it then becomes formidable to all that oppose it: it overturns whatever it meets, and brings forth all its strength, which it seemed not to have discovered before that dangerous occasion. It possesses the same inoffensive disposition in its favouritc element, that it is found to have upon land; it is never found to attack the mariners in their boats as they go up or down the stream; but should they inadvertently strike against it, or otberwise disturb its repose, there is much danger of its sending them at once to the bottom. "I have seen," says a mariner, as we find it in Dampier, "one of these animals open its jaw, and scizing a boat between its teeth, at once bite and sirsk it to the bottom. I have seen it, upon another occasion, place itself under one of our boats, and, rising under it, overset it, with six men who were in it; who, howcver, happily received no other injury." Such is the great strength of this animal; and from hence, probably, the imagination has been willing to match it in combat against others more fierce, and equally formidable. The crocodile and shark have been said to engage with it, and yield an easy victory; but as the shark is only found at sea, and the hippopotamus never ventures beyond the moutl of fresh-water rivers, it is most proba- ble that these engagements never occurred; it sometimes happens, indeed, that the princes of Africa amuse themselves witl combats, on their fresh-water lakes, between this and other formidable animals; but whether the rhinoceros or the crocodile are of this number, we have not been particularly informed. If this animal be attacked on land, and finding itself incapable of vengeance from the swiftness of its enemy, it immediately returns to the river, where it plunges in head foremost, and after a short time rises to the surface, loully bellowing, either to invite or intimidate the enemy; but though the negroes will venture to attack the shark or the crocodile in their natural element, and there destroy them, they are too well apprised of the force of the hippopotamus to engage it; this animal, therefore, continues the uncontrolled master of the river, and all others fly from its approach, or becoine an easy prey.

As the hippopotamus lives upon fish and vegetables, so it is probable the flesh of terrestrial animals may be equally grateful : the natives of Africa assert, that it has often been found to devour children and other creatures that it was able to surprise upon land; yet as it moves but slowly, almost every creature, endued with a common share of swiftuess, is able to escape it; and this animal, therefore, seldom ventures from the river side, but when pressed by the necessities of hunger, or of bringing forth its young.

The female al ways comes upon land to bring forth, and it is supposed that she seldom produces above one at a time. Upon this occasion, these animals are particularly timorous, and dread the approach of a terrestrial enemy; the instant the parent bears the slightest noise, it dashes into the stream, and the young one is seen to follow it with equal alacrity.

The young ones are said to be excellent eating; but the negroes, to whom nothing that has life comes amiss, fund an equal delicacy in the old. Dr. Pococke has seen their flesh sold in the shambles, like beef; and it is said, that their breast, in particular, is as delicate eating as veal. As for the rest, these animals are found in great numbers, and as they produce very fast, -their flesh might supply the countries where they are found, could those barbarous regions produce 


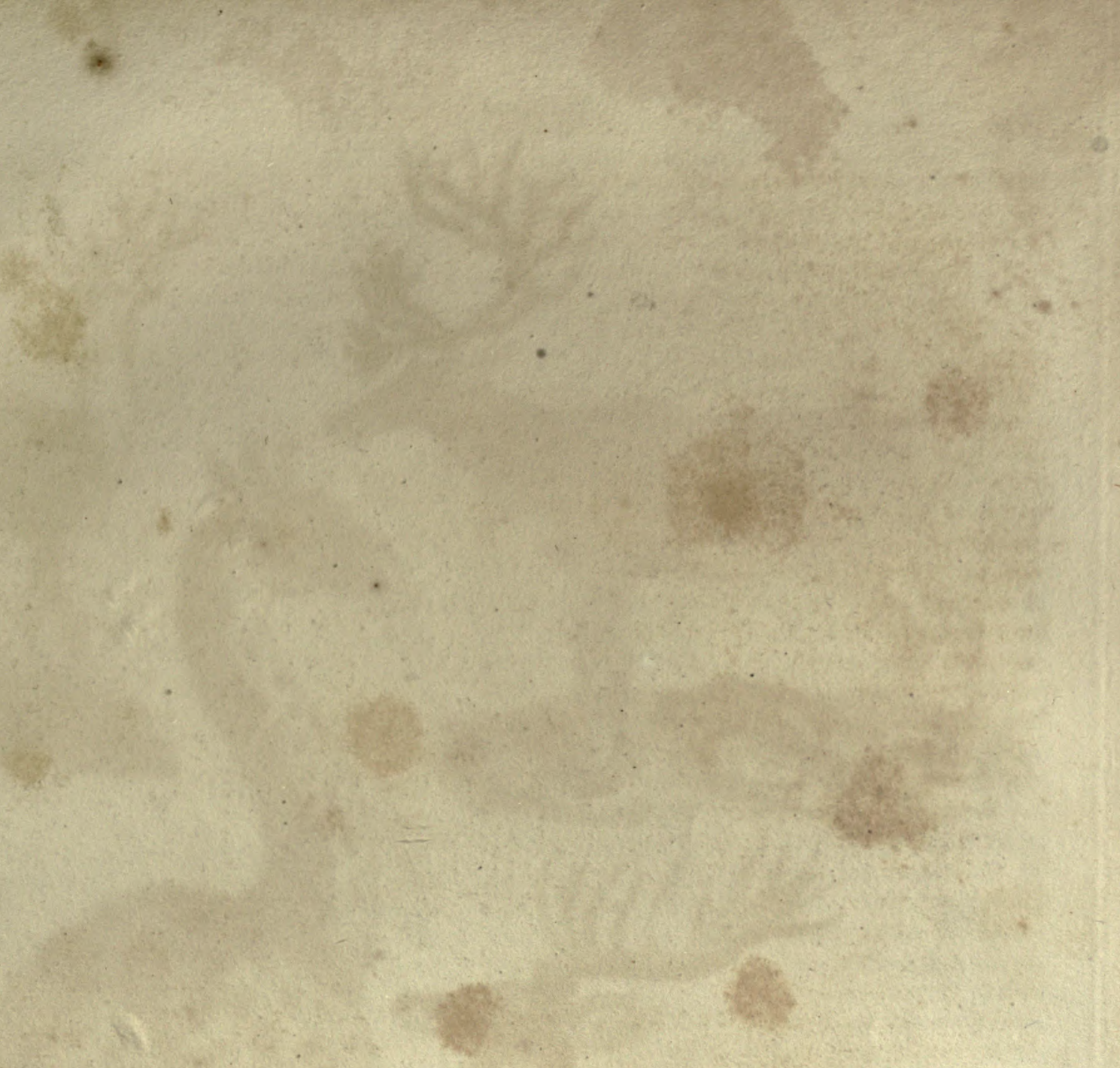

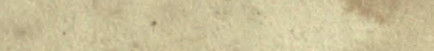

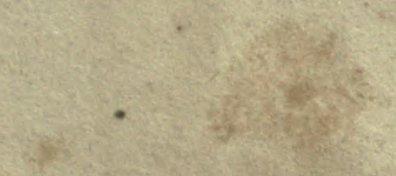

$$
\begin{aligned}
& \text { (3. }
\end{aligned}
$$

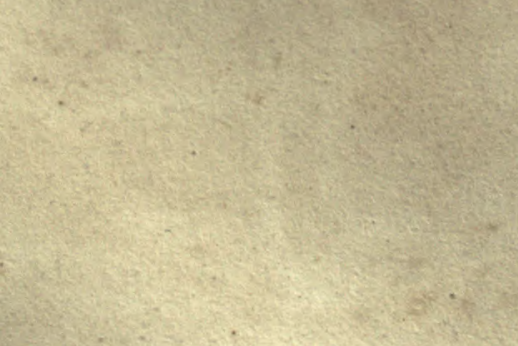

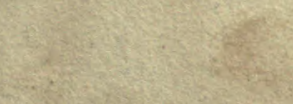
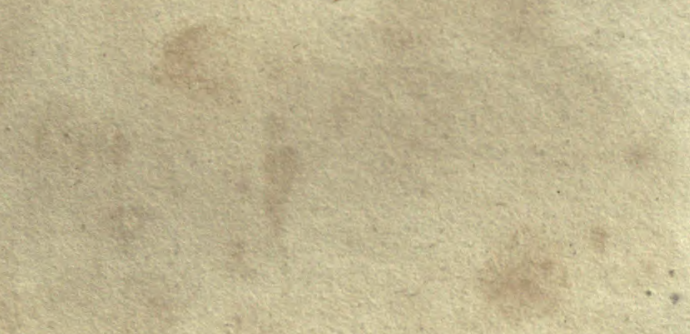

(i) $2=2$

28

Siterest

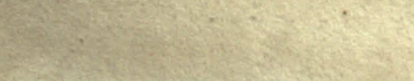

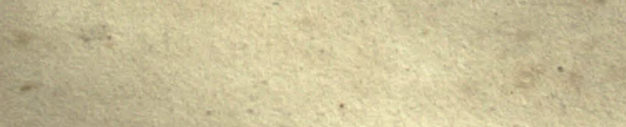

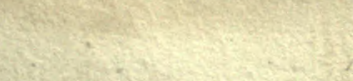




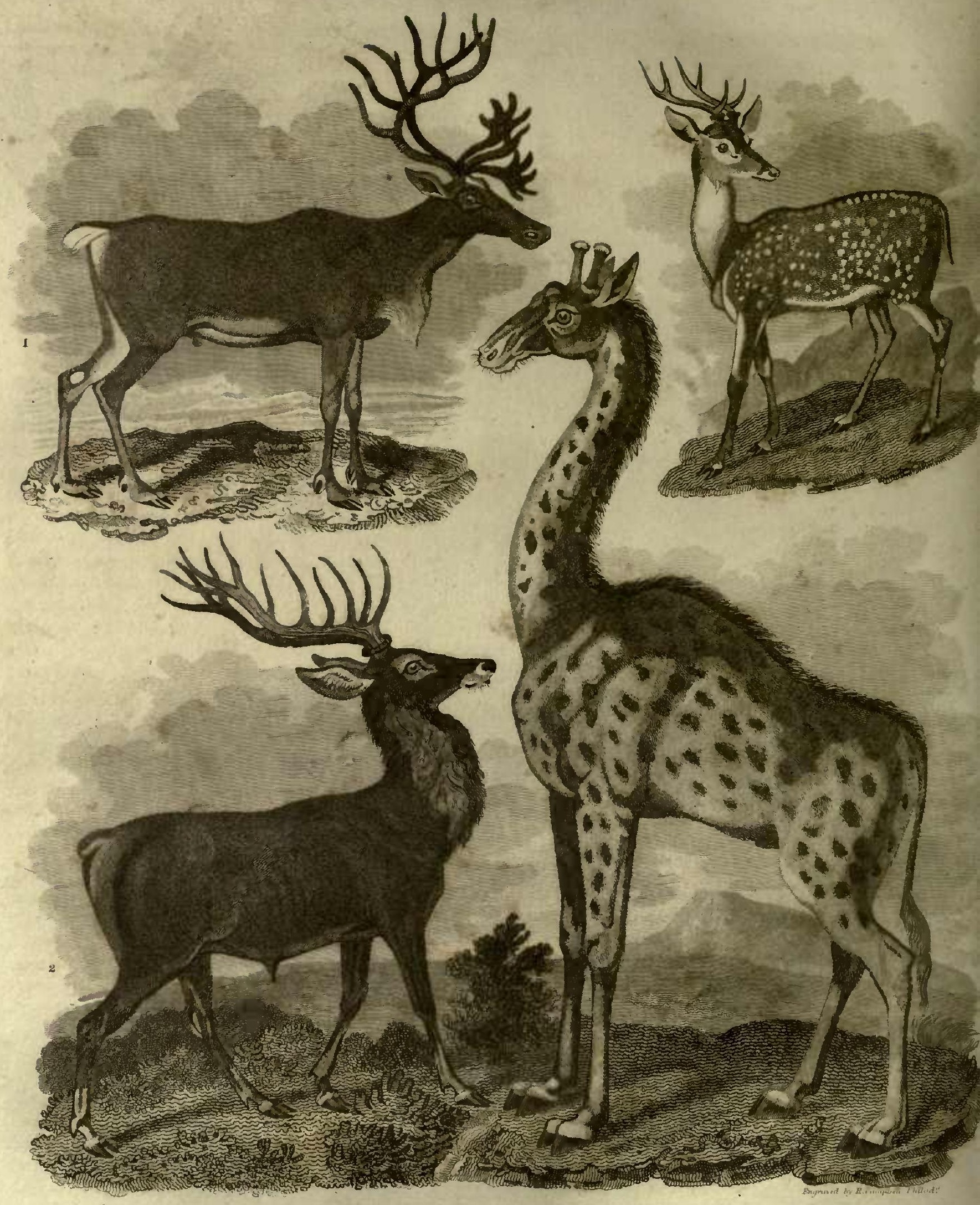

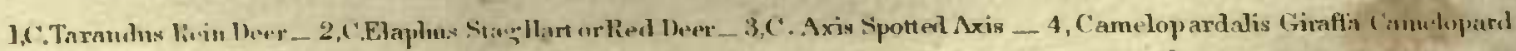


more expert huntsmen. It may be remarked, however, that this creature, which was onee in such plenty at the mouth of the Nile, is now wholly unknown in Lower Egypt, and is no where to be found in that river, except above the cataracts.

\section{CHAPTER LXII.}

\section{THE CAMELOPARD.}

WERE we to be told of an animal so tall, that a man on horseback could, with ease, ride under its belly, without stooping, we should hardly give credit to the relation; yet of this extraordinary size is the camelopard, an animal that inhabits the deserts of Africa, and the accounts of which are so well ascertained, that we cannot deny our assent to their authority. It is no easy matter to form an adequate idea of this creature's size, and the oddity of its formation. It exhibits somewhat the slender shape of the deer, or the camel, but destitute of their symmetry, or their easy power of motion. The head somewhat resembles that of the deer, with two round horns, near a foot long, and which, it is probable, it sheds as deer are found to do; it neck resembles that of a horse; its legs and feet those of the deer, but with this extraordinary differeuce, that the fore legs are near twice as long as the hinder. As these creatures have been found eighteen feet high, and ten from the ground to the top of the shoulder, so allowing three feet for the depth of the body, seven feet remains, which is high - errough to admit a man mounted on a middlesized horse. The hinder part, however, is much lower, so that when the animal appears standing, and at rest, it has somewhat the appearance of a $\operatorname{dog}$ sitting: and this formation of its legs gives it an awkward and a laborious motion. which, though swift, must yet be tiresome. For this reason, the camelopard is an animal very rarely found, and only finds refuge in the most internal desert regions of Afriea. The dimensions of a young one, as

- Laler naturalists sny, that this is a mistake, and assert, that as the neck is long and elcgant, and excecds the legs by at least four inches, besides the length of the head, it is they were accurately taken by a person who examined its skin, that was brought from the Cape of Good Hope, were found to be as follow: the length of the head was one foot eight inches; the beight of the fore leg, from the ground to the top of the shoulder, was ten feet; from the shoulder to the top of the head was seven; the height of the hind leg was eight feet five inches; and from the top of the shoulder to the insertion of the tail was just seven feet long.

No animal, either from its disposition, or its formation, seems less fitted for a state of natural hostility; its horns are blunt, and even knobbed at the ends; its teeth are made entirely for vegetable pasture; its skin is beautifully speckled with brown spots, upon a whitish ground; it is timorous and harmless, and, notwithstanding its great size, rather flies from, than resists, the slightest enemy; it partakes very much of the nature of the camel, which it so nearly resembles; it lives entircly upon vegetables, and when grazing is obliged to spread its lore legs very wide in order to reach its pasture $;^{\mathrm{a}}$ its motion is a kind of pace, two legs on each side moving at the same time, whereas in other animals they move transversely. It often lies down with its belly to the earth, and, like the camel, has a callous substance upon its breast, which, when reposed, defends it from injury. This animal was known to the ancients, but has been very rarely seen in Europe. One of them was sent from the enst to the Emperor of Germany, in the year 1559; but they have ofteil been seen tame at Grand Cairo in

evident that it can graze without difficulty, and is not obliged to kneel down, (as has been supposed) or spread asunder its legs, for that purpose. 
Egypt; and, I am told, there are two therc at present. When ancient Rome was in its splendour, Pompey exhibited at one time no less than ten upon the theatre. It was the barbarous pleasure of the people, at that time, to see the most terrible, and the most extraordinary animals, produced in combat against each other. The lion, the lynx, the tiger, the clephant, the hippopotamus, were all let loose promiscuously, and were seen to inflict indiscriminate destruction.

\section{CHAPTER LXIII.}

\section{THE CAMEL AND THE DROMEDARY:}

THESE names do not make two distinct kinds, but are only given to a variety of the same animal, which has, however, subsisted time immemorial. The principal, and perhaps the only sensible difference, by which those two races are distinguished, consists in this, that the camel has two bunches upon his back, whereas the dromedary has hut one; the latter, also, is neither so large, nor so strong, as the camel. These two races, however, produce with each other, and the mixed breed formed between them is considered the best, the most patient, and the most indefatigable of all the kind.

Of the two varieties, the dromedary is by far the most numerous, the camel being scarcely found, except in Turkey, and the countries of the Levant; while the other is found spread over all the deserts of Arabia, the southern parts of Africa, Persia, Tartary, and a great part of the eastern Indies. Thus, the one inhabits an immense tract of country, the other, in comparison, is confined to a province; the one inhabits the sultry countries of the Torrid Zone, the other delights in a warm, but not a burning climate; neither, however, can subsist, or propagate, in the variable climates towards the north; they seem formed for those countries, where shrubs are plenty, and water scarce; where they can travel along the sandy desert, without being impeded by rivers, and find food at expected distances; such a country is Arabia,

a These quadrupeds have six front teeth in the lower jaw, which are rather thin and broad: the canine teeth are a little remote from the rest; in the upper jaw there and this, of all others, seems the most adapted to the support and production of this animal.

The camel is the most temperate of all animals, and it can continue to travel several ditys without drinking. In those vast deserts, where the earth is every where dry and sandy, where there are neither birds nor beasts, neither iusects nor vegetables, where nothing is to be seen but lifls of sand and heaps of stone. there the canel travels, posting forward, without requiring either drink or pasture, and is often found six or seven days without any sustenance whatsoever. Its feet are formed for travelling upon sand, and utterly unfit for moist or marshy places; the inliabitants. therefore, find a most useful assistant in this animal, where no other could subsist, and by its means cross those deserts with safety, which would be unpassable by any other method of conveyance.

An animal, thus formed for a sandy and desert region, cannot be propagated in one of a different nature. Many vain efforts have been tried to propagate the camel in Spain; they have been transported into America, but have multiplied in neither. It is true, indeed, that they may be brought into these countries, and may, perhaps, be found to produce there; but the care of keeping them is so great, and the accidents to which they are exposed, from the changeableness of the clinate, are so many, that they cannot answer

are three, in the lower two: the upper lip divided; and there are no horns. 

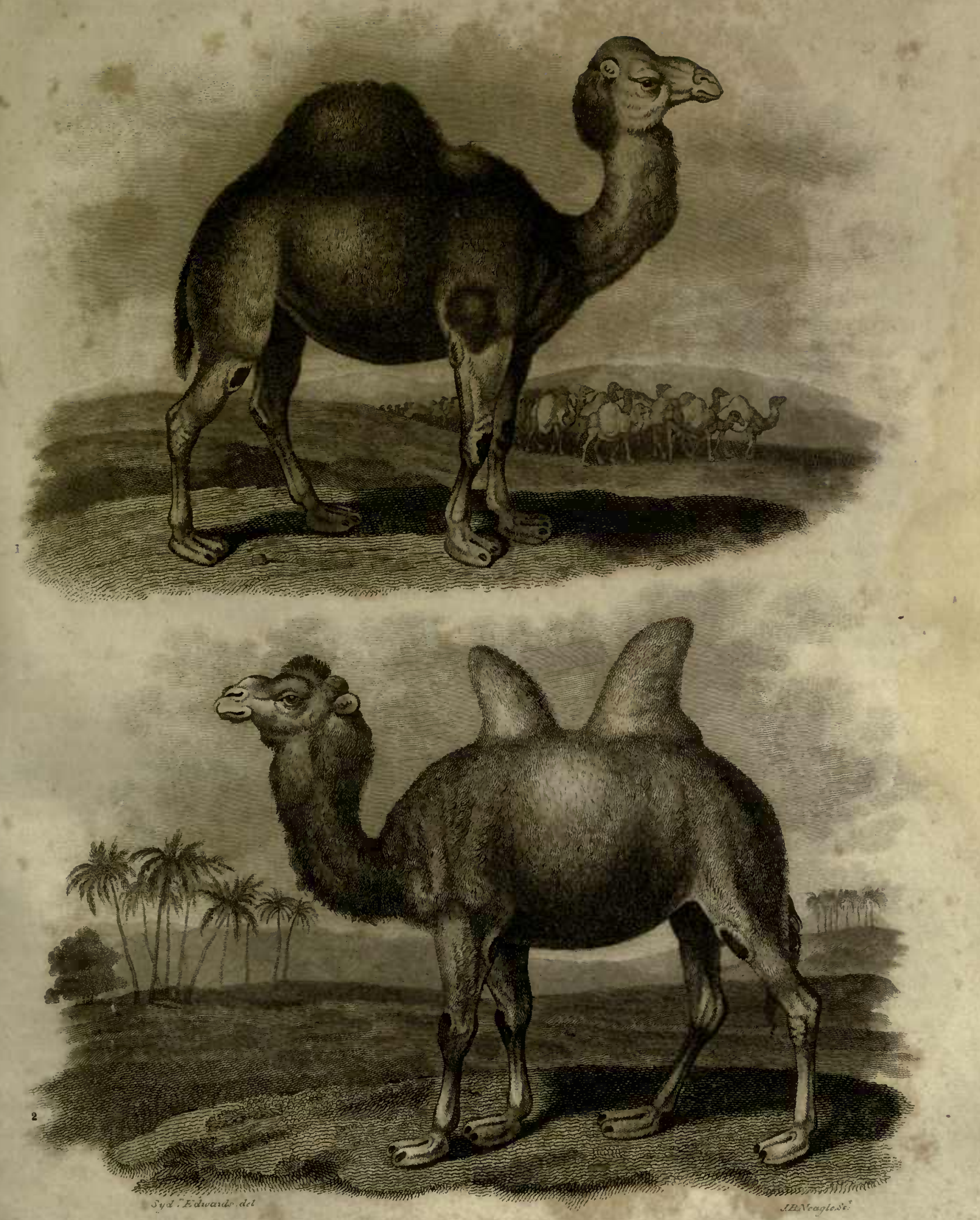

1.Camelus Dromedanus, Arabian Camel, or Dromedary. 2. Camelns bactriamus, Bactrian Camel. 


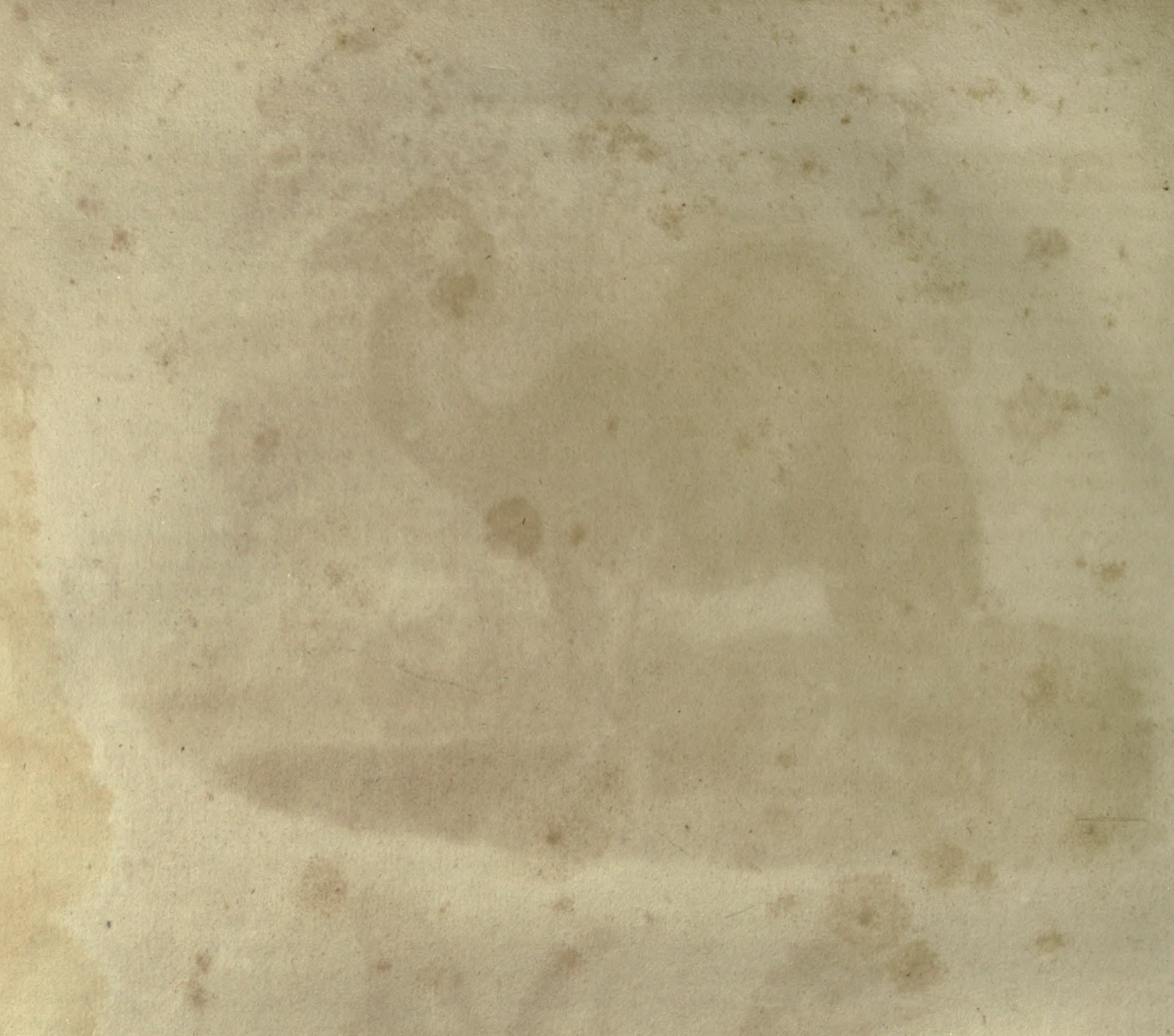

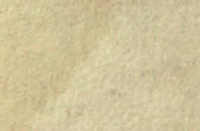
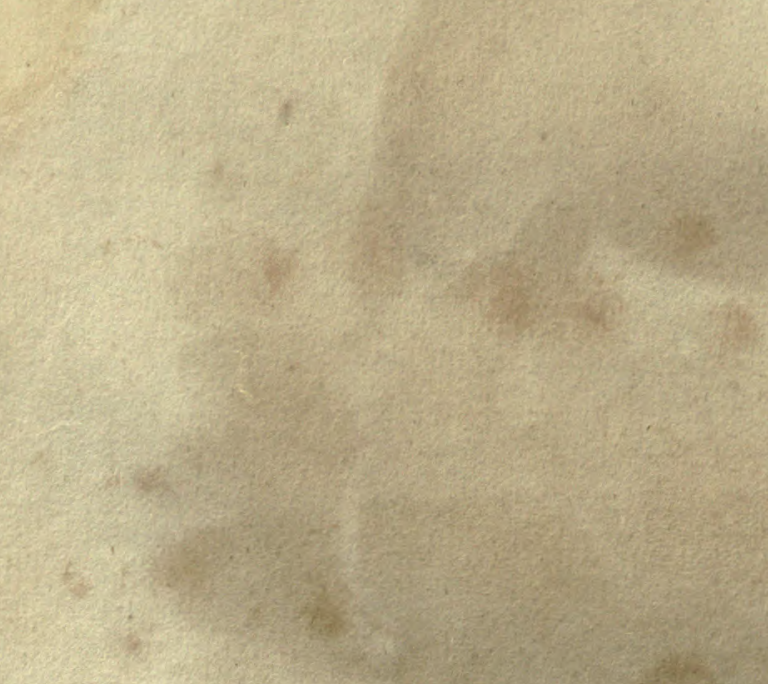
the care of keeping. In a few years also they are seen to d-generate; their strength and their patience forsake them; and instead of making the riches, they become the burden of their keepers.

But it is very different in Arabia, and those countries where the eamel is turned to useful purposes. It is there considered as a sacred animal, without whose help the natives could neither subsist, traffic, or travel; its milk makes a part of their nourishment; they feed upon its flesh, particularly when young; they clothe themselves with its hair, which it is seen to moult regularly once a year; and if they fear an invading enemy, their camels serve them in flight, and in a single day they are known to travel above a hundred miles. Thus, by means of the camel, an Arabian finds safety in his deserts; all the armies upon earth might be lust in the pursuit of a flying squadron of this country, mounted upon their camels, and taking refuge in solitudes, where nothing interposes to stop their flight, or to force them to wait the invader. Nothing can be more dreary than the aspect of these sandy plains, that seem entirely forsaken of life and vegetation : wherever the eye turns, nothing is presented but a steril and dusty soil, sometimes torn up by the winds, and moving in great waves along, which, when viewed from an eminence, resembles less the earth than the ocean; here and there a few shrubs appear, that only teach us to wish for the grove-that remind us of the shade in these sultry climates, without affording its refreshment: the return of morning, which, in other places. carries an idea of cheerfulness, here serves only to enlighten the endless and dreary waste, and to present the traveller wit' in unfinished prospect of his forlorn situation: yet in this chasm of nature, by the help of the camel, the Arabian finds safety and subsistence. There are here and there found spots of verdure, which, though remote from each other, are, in a manner, approximated by the labour and industry of the camel. Thus these deserts, which present the stranger with nothing but objects of danger and sterility, afford the inhabitant protection, food, and liberty. The Arabian lives independent and tranquil in the midst of his solitudes; and, instead of con- sidering the vast solitudes spread round him as a restraint upon his happiness, he is, by experience, taught to regard them as the rainparts of his freedom.

The camel is ensily instructed in the methods of taking up and supporting his burden; their legs, a few days after they are produced, are bent under their belly; they are in this manner loaded, and taught to rise; their burden is every day thus increased, by insensible degrees, till the aninal is capable of supporting a weight adequate to its force; the same care is taken in making them patient of hunger and thirst: while other animals receive their food at stated times, the camel is restrained for days together, and these intervals of famine are increased in proportion as the animal seems capable of sustaining them. By this method of education, they live five or six days withont food or water; and their stomach is formed most admirably by nature to fit them for long abstinence: besides the four stomachs, which all animals bave that chew the cud, (and the camel is of the number,) it lias a fifth stomach, which serves as a reservoir, to hold a greater quantity of water than the animal has an immediate occasion for. It is of a sufficient capacity to contain a large quantity of water, where the fluid remains without corrupting, or without being adulterated by the other aliments; when the camel finds itself pressed with thirst, it has here an easy resource for quenching it; it throws up a quantity of this water, by a simple contraction of the museles, into the other stomachs, and this serves to mascerate its dry and simple food; in this manner, as it drinks but seldom, it takes in a large quantity at a time, and travellers, when straitened for water, have been often known to kill their camels for that which they expected to find within them.

In Turkey, Persia, Arabia, Barbary, and Egypt, their whole commerce is carried on by means of camcls; and no carriage is more speedy, and none less expensive, in these countries. Merchants and travellers unite themselves into a body, furnished with camels, to secure themselves from the insulis of the robbers that jufest the countries in which they live. This assemblage is called a caravan, in which the numbers are sometimes 
known to amount to above ten thousand, and the number of camcls is often greater than those of the inen: each of these animals is loaded according to his strength, and he is so sensible of it himself, that when his burden is too great, he remains still upon his belly, the posture in which he was laden, refusing to rise, till his burden be lessened or taken away. In general, the large camels are capable of earrying a thousand weight, and sometimes twelve hundred; the dromedary, from six to seven. In these trading journeys they travel but slowly, their stages are generally regulated, and they seldom go above thirty, or at most about five and thirty miles a day. Every evening, when they arrive at a stage, which is usually some spot of verdure, where water and shrubs are in plenty, they are permitted to feed at liberty; they are then seen to eat as much in an hour, as will supply them for twenty-four; they seem to prefer the coarsest weeds to the softest pasture: the thistle, the nettle, the cassia, and other prickly vegetables, are their favourite food; but their drivers take care to supply them with a kind of paste composition, which serves as a more permanent nourishment.

As these animals have often gone the same track, they are said to know their way precisely, and to pursue their passage when their guides are utterly astray; when they come within a few miles of their baiting-place, in the evening, they sagaciously scent it at a distance, and inereasing their speed, are often seen to trot with vivacity to their stage.

The patience of this animal is most extraordinary; and it is probable, that its sufferings are great; for when it is loaded, it sends forth most lamentable cries, but never offers to resist the tyrant that oppresses it. At the slightest sign, it bends its knees and lies upon its belly, suffering itself to be loaded in this position; by this practice the burden is more easily laid upon it, than if lifted up while standing; at another sign it rises with its load, and the driver getting upon its back,

ar. Sonnini says, he bas sometimes seen them weary of the inparience of their riders, stop short, turn round their long necks to bite them, and utier cries of rage. In these circumstances the inan must be careful not to alight, between the two panniers, which, like hampers, are placed upon each side, he encourages the camel to proceed with his voice and with a song. In this manner the creature proceeds contentedly forward, with a slow uneasy walk, of about four miles an hour, and when it comes to its stage, lies down to be unloaded as before. ${ }^{\text {a }}$

Mr. Buffon seems to consider the camel to be the most domesticated of all other creatures, and to have more marks of the tyranny of man imprinted on its form. He is of opinion, that this animal is not now to be found in a state of nature; that the humps on its back, the callosities upon its breast and its legs, and even the great reservoir for water, are all marks of long servitude and domestic constraint. The deformities he supposes to be perpetuated by generation; and what at first was accident, at last becomes nature. However this be, the humps upon the back grow large in proportion as the animal is well fed, and if examined, they will be found composed of a substance not unlike the udder of a cow.

The inhabitants generally leave but one male to wait on ten females, the rest they castrate; and though they thus become weaker, they are more manageable and patient. The female receives the male in the same position as when these animals are loaded; she goes with young for about a year, and, like all other great animals, produces but one at a time. The camel's milk is abundant and nourishing, and mixed with water makes a principal part of the beverage of the Arabians. These animals begin to engender at three years of age, and they ordinarily live from forty to fifty years. The genital part of the male resembles that of the bull, but is placed pointing backwards, so that its urine seems to be ejected in the mamier of the female. This, as well as the dung, and almost every part of this animal, is converted to some useful purpose by the keepers. Of the urine, sal ammoniac is made; of the dung, litter for the horses, and fire for the purpose of dres-

as he would infallibly be torn to pieces; he must also refrain from striking his beast, as that would but increase his fury. 
sing their victuals. T!us, this animal alone seems to comprise within itself a variety of qualities, any one of which serves to render other quadrupeds absolutely necessary for the welfare of man: like the elephant, it is manageable and tame; like the horse, it gives the rider security; it carries greater hurdens than the ox or the mule, and its milk is furnished in as great abundance as that of the cow; the flesh of the young ones is supposed to be as delicate as veal; their hair is more beautiful, and nnore in request, than wool; while even of its very excrements no part is useless.

\section{CHAPTER LXIV.}

\section{THE LAMA.}

AS almost all the quadrupeds of America are smaller than the resembling ones of the ancient continent, so the Lama, which may be considered as the camel of the new world, is every way less than that of the old. This animal, like that described in the former chapter, stands high upon its legs, has a long neck, a small head, and resembles the camel, not only in its natural mildness, but its aptitude for servitude, its moderation, and its patience. The Americans early found out its useful qualities, and availed themselves of its labours: like the camel, it serves to carry goods over places inaccessible to other beasts of burden; like that, it is obedient to its driver; and often dies under, but never resists, his cruelty.

Of these animals, some are white, others black, but they are mostly brown; its face resembles that of the camel, and its height is about equal to that of an ass. They are not found in the ancient continent, but entirely belong to the new; nor are they found spread over all America, but are found chiefly upon those mountains that stretch from New Spain to the Straits of Magellan. They inhabit the highest regions of the globe, and seem to require purer air than animals of a lower situation are found to enjoy. Peru seems to be the place where they are found in greatest plenty. In Mexico they are introduced rather as curiosities than beasts of burden; but in Potosi, and other provinces of Peru, they make the chief riches of the Indians and Spaniards who rear them: their flesh is excellent food; their hair, or rather wool, may be spun into beautiful clothing; and they are capable, in the most rugged and dangerons ways, of carrying burdens, not exceeding a hundred weight, with the greatest safety. It is true, indeed, that they go but slowly, and seldom above fifteen miles a day; their tread is heavy, but sure; they descend precipices, and find footing among the most eraggy rocks, where even men can scarcely accompany them: they are, however, but feeble animals, and after four or five days' labour they are obliged to repose for a day or two. They are chiefly used in carrying the riches of the mines of Potosi ; and we are told that there are above three hundred thousand of these animals in actual employ.

This animal, as was said before, is above three feet high, and the neck is three feet long, the head is small and well proportioned, the eyes large, the nose long, the lips thick, the upper divided, and the lower a little depending; like all those animals that feed upon grass, it wants the upper cutting teeth; the ears are four inches long, and move with great agility; the tail is but five inches long, it is small, straight, and a little turned up at the end; it is cloven-footed like the ox, but it has a kind of spear-like appendage behind, which assists it in moving over precipices and rugged ways; the wool on the back is short, but long on the sides and the belly; it resembies the camel in the formation of the genital parts in the male, so that it makes urine backwards; it couples also in the same manner, and though it finds much difficnlty in the action, it is said to benuch inclined to venery. 
A whole day is often passed before this necessary husiness ean be completed, which is spent in growling, quarrelling, and spitting at each other; they seldom produce above one at a time, and their age never extends above ten or twelve year's at firthest.

Though the lama is no way comparable to the camel, either for size, strength, or perseverance, yet the Americans find a substitute in it, with which they seem perfectly contented. It appears formed for that indolent race of masters which it is obliged to serve; it requires no care, nor no expense in the attending or providing for its sustenance; it is supplied with a warm covering, and therefore does not require to be housed; satisfied with vegetables and grass, it wants neither corn nor hay to subsist it ; it is not less moderate in what it drinks, and exceeds even the camel in temperance. Indced, of all other creatures, it seems to require water least, as it is supplied by nature with saliva in such large quantities, that it spits it out on every occasion: this saliva seems to be the only offeusive weapon that the harmless creature has to testify its resentment. When overloaded or fatigued, and driven on by all the torturing acts of its keeper, it falls on its belly, and pours out against him a quan. tity of this fluid; which, though probably no way hurtful, the Indians are much afraid of. They say, that wherever it falls, it is of such an acrimonious nature, that it will either burn the skin, or cause very dangerous eruptions.

Such are these animals in their domestic state; but as they are found wild in very great numbers, they exhibit marks of great force and agility in their state of nature. 'The stag is scarcely more swift, or the goat or the shamoy a better climber. All its shapes are more delicate and strong; its colour is tarvny, and its wool is but short ; in their native forests, they are gregarious animals, and are often seen in flocks of two or three himdred at a time. When they perceive a stranger, they regard him at first with astonishment, without marking any fear or surprise; but shortly, as if by common consent, they snuff up the air, somewhat like horses, and at once, by a common flight, take refuge on the tops of the mountains; they are fonder of the northern than the southern side of the Andes; they often climb above the snowy tracts of the mountain, and seem vigorous in proportion to the colduess of their situation. The natives hunt the wild lama for the sake of its fleece. If the dogs surprise one upon the plain, they are generally successful; but if once the lama obtains the rocky precipice of the mountain, the hunters are obliged to desist in their pursuit.

The lama scems to be the largest of the camel kind in America; there are others, which are called GUANaCOES and PACOES, that are smaller and weaker, but endued with the same nature, and formed pretty much in the sanue manuer. They seem to bear the same proporions to each other, that the hurse does to the ass, and are employed with the same degree of subordination. The wool, however, of the paco, seems to bo the most valuable, and it is formed into stuffs not inferior to silk, either in price or beauty. The natural colour of the paco, is that of a dried rose leaf; the manufacturers seldom give its wool any other dye, but form it into quilts and carpets, which exceed those from the Levant. 'This manufacture forms a very considerable branch of commerce in South America, and probably, tor), might be extended to Europe, were the beanty and the durability of what is thus wrought up sufficiently known. 


\section{CHAPTER LXV.}

\section{THE NYL-GHAU.}

THIS animal, the name of which is pronounced nylgaw, is a native of India, and has but lately been imported into Europe; it seems to be of a middle nature, between the cow and the deer, and earries the appearance of both in its form. In its size, it is as much smaller than the one, as it is larger than the other; its body, horns, and tail, are not unlike those of a bull; and the head, neck, and legs, are very like those of a deer. The colour, in general, is ash or gray, from a mixture of black hairs and white; all along the ridge or edge of the neek, the hair is blacker, larger, and more erect, making a short, thin, and upright mane. Its horus are seven inches long; they are six inches round at the root; growing smaller by degrees, they terminate in a blunt point. The bluntness of these, together with the form of its head and neck, might incline us to suppose it was of the deer kind; but, as it never sheds its horns, it has a greater affinity to the cow.

From the disposition of that brought over to this country, which has been very accurately and minutely described by Dr. Hunter, their manuers are harmless and gentle. Although in its native wildness it is said to be fierce and vicious, this seemed pleased with every kind of familiarity, and always licked the hand that stroked or gave it bread, and never once attempted to use its horns offensively; it seemed to have much dependence on its organs of smell, and suuffed keenly, and with noise, whenever any person came within sight; it did so likewise when any food or drink was brought to it; and was so easily offended with smells, or so cautious,

This quadruped is a species of antelope : the loorns are inclining to a triangular form; and the feet are barred with black and white.

No. $37 \& 38$ that it would not taste the bread which was offered, when the hand happened to smell strong of turpentine. Its manner of fighting is very particular. It was observed at Lord Clive's, where two males were put into a little enclosure, that, while they were at a considerable distance from each other, they prepared for the attack, by falling upon their fore knees, then they shumled towards each other, with a quick pace, keeping still upon their fore knees; and when they were come within some yards, they made a spring, and darted against each other. The intrepidity and force with which they dart against any object, appeared by the strength with which one of them attempted to overturn a poor labourer, who unthinkingly stood on the outside of the pales of its enclosure. The nylghau, with the quiekness of lightning, darted against the wood-work with such violence, that he broke it to pieces, and broke off one of his horns close to the root, which occasioned the animal's death. At all the places in India, where we have settlements, they are considered as rarities, and brought from the distant interior parts of the country. The Emperor, sometimes, kills them in such numbers, as to distribute quarters of them to all his omrahs; which shows that they are internally wild and in plenty, and esteemed good and delicious food. The nyl-ghaus which have been brought to England, have been most, if not all of them, received from Surat or Bombay ; and they seem to be less uncommon in that part of India, than in Bengal; which gives room for a conjecture, that they may be indigenous perbaps in the province of Guzarat, one of the most western and most considerable of the Hindosten empire, lying to the northward of Surat, and stretching away to the Indian ocean. 


\title{
CHAP'TER LXVI.
}

\author{
THE BEAR:
}

OF the Bear there are three different kinds, the Brown Bear of the Alps, the Black Bear of North America, which is smaller, and the great Greenland or White Bear. These, though different in their forms, are no doubt of the same original, and owe their chief variations to food and climate. They have all the same habitudes, being equally carnivorous, treacherous, and cruel. It has been said, indeed, that the black bear of Anierica rejects animal food; but of the contrary I an certain, as I have often seen the young ones, which are brought over to London, prefer flesh to every kind of vegetable aliment.

The BRown BEAR is properly an inhabitant of the temperate climates; the black finds subsistence in the northern regions of Europe and America; while the great white bear takes refuge in the most icy climates, and lives where scarcely any other aniınal can find subsistence.

The brown bear is not only savage, but solitary; he takes refuge in the most unfrequ'nted parts, and the most dangerous precipices of uninhabited mountains. It chooses its den in the most gloomy parts of the forest, in some cavern that has been hollowed by time, or in the hollow of some old enormous trce. There it retires alone, and passes some months of the winter without provisions, or without ever stirring abroad. However, this animal is not entirely deprived of sensation, like the bat or the dormouse, but seems rather to subsist upon the exuberance of its former flesh, and only feels the calls of appetite, when the fat it had acquired in summer begins to be entirely wasted away. In this manner, when the bear retires to its den, to hide for the winter, it is extremely fat; but at the end of forty or fifty days,

a The animals of this kind, including the Racoon, Wolverene, Glutton, and Badger, have six front leeth in each jaw ; the two laieral ones of the lower jaw are longer than the rest, and lobed, and are likewise furnished with smaller or secondary teeth at their internal bases: the caune teeth are single; there are five or six grinders on each side; the first of which is placed close to the canine teeth: when it comes forth to seek for fresh nourıshment, it seems to have slept all its flesh away. It is a common report, that during this time they live by sucking their paws, which is a vulgar error that scarcely requires confutation. These solitary animals couple in autumin, but the time of gestation with the female is still unknown: the feniale takes great care to provide a proper retreat for her young; she secures them in the hollow of a rock, and provides a bed of hay in the warmest part of her den; she brings forth in winter, and the young ones begin to follow her in spring. The male and female by no means inhabit the same den; they have each their separate retreat, and seldom are seen together but upon the accesses of genial desire.

The voice of the bear is a kind of growl, interrupted with rage, which is ofen capriciously exerted; and though this animal seems gentle and placid to its master, when tamed, yet it is still to be distrusted and managerl with cantion, as it is often treacherous and resentful without a cause.

This animal is capable of some degree of instruction. There are few but have seen it dance in awk ward measures upon its hind fect, to the voice or the instrument of its leader; and it must be confessed that the dancer is often found to be the best performer of the two. I am told, that it is first taught to perform in this manner, by setting it upon hot plates of iron, and then playing to it, while in this uneasy situation.

The bear, when come to maturity, can never be tamed; it then continues in its native fierceness, and, though caged, still fornidably impotent, at the approach of its keeper flics to

the tongue is smooth; the snout projecting; and the eyes furnished with a nictitant or winking membrane. The soles of the feet are long, and extend to the heel; some use their fore paws as hands, and they are all able to climb trees in search of prey, or to avoid an enemy.

b Buffon. 
meet him. But notwithstanding the fierceness of this animal, the natives of those countries where it is found hunt it with great perseverance and alacrity. The least dangerous method of taking it is by intoxicating it, by throwing brandy upon honey, which it secms to be chicfly fond of, and seeks for in the hollow of trees. In Canada, where the BLACK BEARS are very common, and where their dens are made in trees that are hollow towards the top, they are taken by setting fire to their retreats, which are often above thirty feet from the ground. The old one is generally seen first to issue from her den, and is shot by the hunters. The young ones as they descend are caught in a noose, and are either kept, or killed for urovision. Their paws are said to be a great delicacy, and their hams are well enough known at the tables of the luxurious liere. Their fat also, which still preserves a certain degree of fluidity, is supposed to be an efficacious remedy in white or indolent tumors, though probably very little superior to hog's lard.

The wHite greEnLAND BEAR differs greatly, both in figure and dimensions, from those already described; and though it preserves in general the external form of its more southern kindred, yet it grows to above three times the size. The brown bear is seldom above six feet long; the white bear is often known from twelve to thirteen. The brown bear is made rather strong and sturdy, like the inastiff; the Greenland bear, thougl covered with very long hair, and apparently bulky, is nevertheless more slender, both as to the head, neck, aud body, and nore inclining to the shape of the grayhound. In short, all the variations of its figure and its colour, seem to proceed from the coldness of the climate where it resides, and the nature of the food it is supplied with.

The white bear seems the only animal that, by being placed in the coldest climate, grows larger than those that live in the temperate zones. All other species of aninated nature diminish as they approach the poles, and seem contracted in their size by the rigours of the ambient atmosphere; but the bear, being unmolested in these desolate climates, and meeting no animal but what he can easily conquer, fuiding also a sufficient supply of fishy provisions, grows to an enormous size; and as the lion is the tyrant of an African forest, so the bear remains undisputed master of the icy mountains in Spitzbergen aud Greenland. When our mariners laud upon those shores, in such parts as liave not been frequented before, the white bears come down to view them with an awkward curiosity; they approach slowly, seemiug undetermined whether to advance or retreat, and being naturally a timorous animal, they are only urged on by the conscious experience of their former victories; however, when they are shot at, or wounded, they endeavour to fly, or, finding that impracticable, they make a fierce and desperate resistance till they die. As they live upon fish and seals, their flesh is too strong for food, and the captors have nothing but the skin to reward them for the dangers incurred in the engagement.

The number of these animals that are found about the north pole, if we consider the scarcity there of all other terrestrial creatures, is very amazing. They are not only seen at land, but often on ice-floats, several leagues at sea. They are often transported in this mannel to the very shores of Iceland, where they no sooner land, but all the natives are in arms to receive them. It often happeus, that when a Greenlander and lis wife are paddling out at sea, by coming too near an icefloat, a white bear unexpectedly junıps into their boat, and if he does not overset it, sits calmly where he first came down, and, like a passenger, suffers himself to be rowed along. It is probable the poor little Grcenlander is not very fond of his new guest; however, he makes a virtue of necessity, and hospitably lows him to shore.

As this aninial lives chiefly upon fish, seals, and dead whales, it seldom removes far froun the shore. When forced by hunger, it often ventures into the deep, swims after seals, and devours whatever it can seize ; it is, however, Jut a bad swimmer, and is often luunted in this manner by boats till it is fatigued, and at last destroyed. It often happens that a battle ensues between a bear and a morse or a whale; but as the latter are more expert in their own element, they generally prove victorious. However, when the bear can find a young,whale, it repays him for the danger he incurs of meeting with the parent. 


\section{CHAPTER LXVI.}

\section{THE BADGER.}

THE Badger's legs are so short, that its belly seems to touch the ground; this, however, is but a deceitful appearance, as it is caused by the length of the hair, which is very long all over the body, and makes it scem much more bulky than it really is. It is a solitary stupid animal, that finds refuge remote from man, and digs itself a deep hole with great assiduity. It seems to avoid the light, and seldom quits its retreat by day, only stealing out at night to find subsistence. It burrows in the ground very easily, its legs being short and strong, and its claws stiff and horny. As it continues to bury itself, it throws the earth behind it to a great distance, and thus forms to itself a winding hole, at the bottom of which it remains in safety. As the for is not so expert at digging into the earth, it often takes possession of that which has been quitted by the badger; and, some say, forces it from its retreat, by laying its excrement at the mouth of the badger's hole.

This animal, however, is not long in making itself a new habitation, from which it seldom ventures far, as it flies but slowly, and can find safety only in the strength of its retreat. When it is surprised by the dogs at some distance from its hole, it then combats with desperate resolution; it falls upon its back, defends itself on every side, and seldom dies unrevenged in the midst of its enemies.

The badger, like the fox, is a carnivorous animal, and nothing that has life can come amiss to it. It sleeps the greatest part of its time, and thus, without being a voracious feeder, it still keeps fat, particularly in winter. They always keep their hole very clean; and when the female brings forth, she makes a comfortable warm bed of hay, at the bottom of her hole, for the reception of her young. She brings forth in summer, generally to the number of three or four, which she feeds at first with her inilk, and afterwards with such petty prey as she can surprise. She seizes the young rabbits in their warren, robs birds' nests, finds out where the wild bees have laid up their honey, and brings all to her expecting brood.

The young ones when taken are easily tamed, but the old still continue savage and incorrigible; the former, after a short time, play with the doys, follow their master about the house, but seem of all other animals the most fond of the fire. They often approach it so closely, that they burn themselves in a dangerous manner. They are sometimes also subject to the mange; and have a gland under their tail which scents pretty strongly. The poor of some countries eat their flesh; which though fat, is at best but rank and ill tasted. 


\section{CHAPTER LXVII.}

\section{THE TAPIR."}

THERE seems to be a rude, but an inferior resemblance, between many animals of the old and the new world. The cougar of America resembles the tiger in natural ferocity, though far inferior in its dinnensions. The lama bears some affinity to the camel, but is far behind it in strength and utility. The tapir may be considered as the hippopotamus of the new continent, but degraded both as to its size and feroeity.

This animal bears some distant resemblance in its form to a mule. It has a long snout, which it lengthens or contracts at pleasure. Its ears are small, loug, and pendent. Its neck and tail are short, and its claws strong and firm, of which it has four upon each foot.
Its skin is thick, and covered with brown hair; and the natives make shields of it, wlich cannot be pierced by an arrow.

This animal may, in some measure, be termed amphibious, as it chiefly resides in the water. It differs, however, from all others of this kind, in feeding entirely upon vegetables, and not making this element the place of its depredations. It feeds upon the pastures by the river-side, and as it is very timorous, the instant it hears the least noise, it plunges into the stream. They are greatly sought after by the natives, as their flesh is considered as a delicacy, and thought by some not inferins to beef.

\section{CHAPTER LXIX.}

\section{THE RACOON.}

THE Racoon, which some authors have called the Jamaica rat, is about the size of a small badger; its body is short and bulky; its fur is fine, long, and thick, blackish at the surface, and gray towards the bottom; the nose is rather shorter, and more pointed. than that of the fox; the eyes large and yellow; the teeth resembling those of a dog; the tail thick, but tapering towards a point, regularly marked with rings of black, and at least as long as the body; the fore feet are much shorter than the hinder, both armed with five

a The Tapir has ten front teeth in both jaws: the canine teeth are single in each jaw, and are bent inwards : there are five very broad grinders on each side in both jaws: the feet have three hoofs; but on the fore feet is an additional false or supplemeutary hoof. Its general attitude, when at rest, is sitting on its rump. It sleeps much by day, and when attacked by dogs makes a vigorous resist- sharp claws, with which, and his teeth, the animal makes a vigorous resistance. Like the squirrel, it makes use of its paws to hold its food while eating, but it differs from the monkey kind, which use but one hand on those occasions, whereas the racoon and the squirrel use both; as, wanting the thumb, their paws singly are unfit for grasping or holding. Though this animal be short and bulky, it is however very active; its pointed claws enable it to climb trees with great facility; it runs on the trunk with the same

ance. Its voice is a kind of whistle, so easily imitated, that in this manner it is frequenly trepanned. It produces but one young at a birth, of which it is very careful, leading it early to the water, to instruct it in swinming. It is gregarious, feeds by night on vegetables, and does not ruminate, as Mr. Bajon affirms. 
swiftness that it moves upon the plain, and sports amoug the most extreme branches with great agility, security, and ease; it moves forward chiefly by bounding, and though it proceeds in an oblique direction, it has speed enough most frequently to escape its pursuers.

This animal is a native of the southern parts of America, nor have any travellers mentioned its being found in the ancient contunent. But in the climates of which it is a mative, it is found in noxious abundance, partıcularly in Jamaica, where it keeps in the mountains, and where it often descends to feed upon the plantations of sugar-cane. The planters of these climates consider these animals as one of their greatest miseries; they have contrived various methods of destroying thein, yet still they propagate in such numbers that neither traps nor fire-arms can set them free; so that a swarm of these famished creatures are found to do more injury in a single night, than the lahours of a month can repair. But though, when wild, they are thus troublesome, in a state of tameness no animal is more harmless or anusing; they are capable of being instructed in various little amusing tricks. The racoon is playful and cleanly, and is very easily supported; it eats of every thing that is given it, and, if left to itself, no cat can be a better provider; it examines every corner, eats of all flesh, either boiled or raw, eggs, fruits, or corn; insects themselves cannot escape it, and, if left at liberty in a garden, it will feed upon snails, worms, and beetles; but it has a particular fondness for sweets of every kind, and to be possessed of these, in its wild state, it incurs every danger. Though it will eat its provisions dry, it will for choice dip them in water, if it lsappens to be in the way. It has one peculiarity which few otler animals have been found to possess-it drinks as well by lapping like the dog, as by sucking like the horse.

\section{CHAPTER LXX.}

\section{THE COATIMONDI.}

THE first peculiarity with which this animal strikes the spectator, is the extreme length of its snout, which, in some measure, resembles that of the hog, but elongated to a surprising degree, it bears some distant resemblance to the animal last described, except that the neek and the body are longer, the fur shorter, and the eyes smaller; but its principal distinction, as was said before, consists in the shape of its nose; the upper jaw being an inch longer than the lower, and the snout, which is moveable in every division, turning up at the end. Like the racoon, it sits up on the hinder legs with great ease, and, in this position, with both paws carries the food to its mouth.

This animal is very subject to eat its own tail, which is rather longer than its body: but this strange appetite is not peculiar to the coati alone; the mococo, and some of the monkey kinds, do the same, and seem to feel no pain in wounding a part of the body so remote from the centre of circulation.

It seems possessed of the same playful qualities, and indiscriminate appetites, with the animal described in the last chapter; if left at liberty in a state of tameness, it will pursue the poultry, and destroy every living thing that it has strength to conquer; though it is playful with its keeper, yet it seems obstinately bent against receiving any instruction, and neither threats nor caresses can induce it to practise any arts to which it is not naturally inclined. When it sleeps, it rolls itself up in a lump, and in that position often continues for fourteen or fifteen hours together. 


\section{CHAPTER LXXI.}

\section{THE ANT-BEAR.}

THERE are many animals that live upon ants in Africa and America; the pangolin or scaly lizard of Guinea may be considered among this number; but there are a greater variety in America, which make those minute insects their only subsistence. Though they are of different figures and sizes, yet, in general, they go under one common name of the ant-bear; the peculiar length and slenderness of their snout, their singular appetites, and their manner of taking their prey, striking us too strongly to attend to the minute lifferences of their size or form.

They have been classed by Mr. Buffon into the LARGER TAMANDUA, the SMALLER TAMANDUA, and the ANT-Eater. The longest of this kind is four feet long, from the tip of the snout to the insertion of the tail; their legs are short, and armed with four strong claws; their tail is long and tufted, and the animal often throws it on its baek like the squirrel. The second of this kind is not above eighteen inches long, the tail is without hair, and it sweeps the ground as the animal moves. The ANT-EATER, which is the third variety, is still smaller than either of the former, as it is not above seven inches from the tip of the snout to the insertion of the tail. The two former are of a brown dusky colour, but this of a beautiful reddish, mixed with yellow. Though they differ in figure, they all resemble each other in one peculiarity, which is the extreme slenderness of their snout, and the amazing length of their tongue.

The snout is produced in so disproportionate a manner, that the length of it makes near a fourth part of the whole figure. A horse has one of the longest heads of any animal we know, and yet the ant-bear has one above twice as long, in proportion to its body. The snout of this animal is almost round and cylindrical: it is extremely slender, and is scarcely thicker near the eyes than at its extremity. The mouth is very small, the nos- trils are very close to each other, the eyes are little in proportion to the length of the nose, the neck is short, the tongue is extremely long. slender, and flatted on both sides; this it keeps generally doubled up in the mouth, and is the only instrument by which it finds subsistence; for the whole of this tribe are entirely without teeth, and find safety only in the remoteness and security of their retreat.

If we examine through the various regions of the earth, we shall find that all the most active, sprightly, and useful quadrupeds, have been gathered round man, and either served his pleasures, or still maintained their independence by their vigilance, their cunning, or their industry. It is in the remote soliludes that we are to look for the helpless. the deformed, and the monstrous births of nature. These wretched animals being incapable of defending themselves, either by their agility or their natural arms, fall a prey to every creature that attacks them; they, therefore, retire for safety into the darkest forests, or the most desert mountains, where none of the bolder or swifter animals choose to reside.

It may well be supposed that an animal so helpless as the ant-bear is, with legs too short to fit it for flight, and unprovided with teeth to give it a power of resistance, is neither numerous, nor often seen; its retreats are in the most barren and uncultivated parts of South America. It is a native only of the new continent, and entirely unknown to the old. It lives chiefly in the woods, and lides itself under the fallen leaves. It seldom ventures from its retreat, and the industry of an hour supplies it with sufficient food for several days together. Its manner of procuring its prey is one of the most singular in all natural history: as its name implies, it lives entirely upon ants and insects ; these, in the countries where it is bred, are found in the greatest abundance, and often build themselves hills 
five or six feet high, where they live in community. When this animal approaches an ant-hill, it creeps slowly forward on its belly, taking every precaution to keep itself concealed, till it comes within a proper distance of the place where it intends to make its banquet; there lying closely along at its length, it thrusts forth its round red tongue, which is often two feet long, across the path of these busy insects, and there lets it lic motionless for several minutes together. The ants of that country, some of which are half an inch long, considering it as a piece of flesh accidentally thrown before them, come forth and swarm upon it in great numbers: but wherever they touch they stick; for this instrument is covered with a slimy fluid, which, like bird-lime, entangles every creature that lights upon it. Whien, therefore, the ant-bear has found a sufficient number for one morsel, it instantly draws in the tongue, and devours them all in a moment; after which it still continues in its position, practising the

[Besides the animal here described, are others of the same kind; the most remarkable of which are; the little Ant-eater, or Fourmiller, and the prickly Ant-eater of New Holland.

The former is singular for its having only two toes on the fore feet, armed with strong claws; and a tail which it is able to coil round the branches of trees, and hold fast by. The claws on the fore feet are extremely disproportionate; the outer one being very large, and the inner one much smaller. The whole animal is clothed in a beautiful, soft, curled, pale yellow fur. It is a native of Guiana. same arts until its hunger is entirely appeased; it then retires to its hiding-place once more, where it continues in indolent existence, till again excited by the calls of hunger.

Such is the luxurious life of a creature, that seems of all others the most helpless and deformed. It finds safety in its hiding-places from its enemies, and an ample supply in some neigh bouring ant-hill for all its appetites. As it only tries to avoid its pursuers, it is seldom discovered by them; yet helpless as this animal is, when driven to an extremity, though without teeth, it will fight with its claws with great obstinacy. With these arms alone, it has often been found to oppose the $\operatorname{dog}$, and even the jaguar. It throws itself upon its back, fastens upon its enemy with all its claws, sticks with great strength and perseverance, and even after killing his invader, which is sometimes the case, does not quit its hold, but remains fastened upon it with vindictive desperation.

The prickly Ant-eater is a short, roundish animal, with a long tubular mouth, and entirely covered over on the upper parts with strong sharp spines, resembling tliose of the Porcupine. Its tail is very short, and entirely concealed in the spines. The head, legs, and under parts of the body, are thickly covered with a dark-brown harsh hair. On its fore feet are five strong claws, and four on the hinder. In its mode of life it resembles the rest of its tribe, being generally found in the midst of some large ant-liill. When disturbed, it burrows with great strength and despatch under ground, during whicl exertion its body is lengthened out in a surprising manner.]

\section{CHAPTER LXXII.}

\section{THE SLOTH.}

OF the Sloth there are two different kinds, distinguished fram each other by their claws; the one, which in its native country is called the unan, having only two claws upon the fore feet, and being without a tail; the other, which is called the $\alpha i$, having a tail, and three claws upon each foot. The unan has the snout longer, the ears more apparent, and the fur very different from the other. It differs also in the number of its ribs, this having forty-six, while the ai has but twenty-eight. These differences, bowever, which though very apparent, have been but little regarded in the description of two animals which so strongly resemble each other in the general outlines of their figure, in their appetites, and their belpless formation.

They are both, therefore, described under 
the common appellation of the Sloth, and their liabitudes well deserve our wonder and curiosity. Nature seems cramped and constrained in their formation; other animals are often indolent fiom choice, these are slow from necessity. The ai, from which I shall take my description, and from which the other differs only in the slight particulars above mentioned, and in being ratler more active, is of about the size of a badger. Its fur is coarse and staring, somewhat rescmbling dried grass; the tail very short, and scarcely appearing; the mouth extended from ear to ear; the eye dull and heavy ; the feet armed with three claws each, and made so short, and set on so awk wardly, that a few paces is often the journey of a week; but though the feet are short, they are still longer than its legs, and these proceed from the body in such an oblique direction, that the sole of the foot seldom touches the ground. When the animal, therefore, is coinpelled to make a step forward, it scrapes on the back of the nails along the surface, and wheeling the limbs circularly about, yet still touching the ground, it at length places its foot in a progressive position; the other three limbs are all brought about with the same difficulty; and thus it is seen to move, not above three feet in an hour. In fact, this poor creature seldom changes place but by constraint, and when impelled by the severest stings of hunger.

The sloth seems to be the meanest and most ill-formed of all those animals that chew the cud; it lives entirely upon vegetable food, on the leaves, the fruit, and the flowers, of trees, and often even on the very bark, when nothing else is left on the tree for its subsistence. Like all other ruminant animals. it has four stomachs; and these requiring a large share of provision to supply them, it generally strips a tree of all its verdure in less than a fortnight. Still, however, it keeps aloft, unwilling to descend, while any thing remains that can serve it for food; it therefore falls to devouring the bark, and thus in a snort time kills the tree upon which it found itssupport. Thus destitute of provisions above, and crawling slowly from branch to branch in topes of finding something still left, it is at last obliged to encounter all the daugers that attend it below. Though it is formed by naso. $37 \& 38$. ture for climbing a tree with great pain and difficulty, yet it is utterly unable to descend; it therefore is obliged to drop from the branches to the ground, and as it is incapable of exerting itself to break the violence of its descent, it drops like a shapeless heavy mass, and feels no small shock in the fall. There, after remaining some time torpid, it prepares for a jouruey to some neighbouring tree; but this of all migrations is the most tedious, darigerous, and painful; it often takes a week in crawling to a tree not fifty yards distant; it moves with imperceptible slowness, and often baits by the way. All motions seem to torture it, every step it takes it sets forth a most plaintive melancholy cry, which, from some distant similitude to the human voice, excites a kind of disgust, mixed with pity. This plaintive sound seems its chief defence; few quadrupeds appear willing to interrupt its progress, either that the flesh is offensive, or that they are terrified at its cries. When at length they reach their destined tree, they mount it with much greater ease than when they moved upon the plain. They fall to with famished appetite, and, as before, destroy the very source that supplies them.

How far these may be considered as the unfinished productions of nature, I will not take upon me to determine; if we measure their happiness liy our sensations, nothing, it is certain, can be more miserable; but it is probable, considered with regard to themselves, they may have some stores of comfort unknown to us, which may set them upon a level with some other inferior ranks of the ereation; if a part of their life be exposed to pain and labour, it is compensated by a larger portion of plenty, indolence and safety. In fact, they are formed very differently from all other quadrupeds, and, it is probable, they have different enjoyments. Like birds, they have but one common vent for the purposes of propagation, excrement, and urine. Like the tortoise, which they resemble in the slowness of their motion, they continue to live some time after their nobler parts are wounded, or even taken away. They bear the marks of all those homely-formed animals, that, like rude machines, are not easily discomposed.

\section{$3 \mathrm{U}$}


Its note, according to Kircher, is an ascending and descending hexachord, which it utters only by night; its look is so pitcous, as to move compassion; it is also accompanied with tears, that dissuade every body from injuring so wretched a being. Its abstinence from food is remarkably powerful; one that had fastened itself by its fect to a pole, and was so suspended across two beams, remained forty days, without meat, drink, or sleep; the strength of its feet is so great, that whatsoever it seizes on cannot possibly be freed from its claws. A dog was let loose at the above mentioned animal, taken from the pole; after some time the sloth laid hold of the dog with its feet, and held him four days, till he perished with hunger.

[In addition to the two here mentioned, another, and by far the largest of its kind, has lately been introduced to the notice of naturalists from lndia. This animal approaches in size aud shape to that of the common bear, being clothed with a very long black shaggy hair. Its snout is a little elongated, and appears as if cut off at the end. The feet are all armed with five crooked pointed claws; and the tail is short, and hardly visible. In its motions, it was not, as in the others, slow and languid; but it appeared moderately lively, and made a kind of short abrupt roar when disturbed or irritated. It fed principally upon vegetables and milk, and was inuch delighted with honey and sweet things. It was said to burrow, and to have been dug out of its subterraneous retreat when first discovered.]

\section{CHAPTER LXXII.}

\section{THE JERBOA.}

THIS animal as little resembles a quadruped, as that which has been described in a former chapter. If we should suppose a bird, divested of its feathers, and walking upon its legs, it might give us some idea of its figure. It has four feet indeed, but in running, or resting, it never makes use of any bnt the hinder. The number of legs, however, do not much contribute to any animal's speed; and the jerboa, though, properly speaking, furnished but with two, is one of the swiftest creatures in the world.

a Pennant's Synopsis.

b These curious animals have two front teeth in each jaw; the fore legs are very short, and the hind legs very long; they have perfect collar bones. M. Sonnini, while he was in Egypt, fed for some time six of these animals in a large cage of iron wire. The very first night, they entirely gnawed asunder the upright and cross sticks of their prison; and he was under the necessity of having lhe inside of the cage lined with tin. They were fond of basking in the sun, and as soon as they were placed in the shade, they clung close to each other, and seemed to suffer from the privation of warmth. They did not usually sleep during the day. Though they had inuch agility in their moveinents, gentleness and iranquillity seeined to form their characier. They suffered theinselves to be
The jerboa is not above the size of a large rat, and its head is sloped somewhat in the manner of a rabbit ; the teeth also are formed like those of the rat kind, there being two cutting teeth in each jaw ; has a very long tail, tufted at the end; the head, the back, and sides, are covered with long ash-coloured soft hair; the breast and belly is whitish; but what most deserves our attention in the formation of this little animal, is the legs; the fore legs are not an inch long, with four claws and a thumb upon each, while the hinder

stroked with great composure, and never made a noise or quarrelled among themselves, even when food was scattered among them. No distinguishing symptoms of joy, fear, or gratitude, were discoverable; and even their gentleness was by no ineaus eitlıer ainiable or interesting; it appeared the effect of a cold and complete indifference, approaching to stupidily. Three of these died before he left Alexandria; two died on a rough passage to the isle of Rhodes; and the last was lost, and, as he supposes, devoured by cats while he was on the island.

He observes, that they do not ruminate, and that it is difficult to transport them, on account of the quickness and facility with which they guaw through the thickest and strongest boards. 
legs are two inches and a quarter, and exactly resemble those of a bird, there being but three toes, the iniddlemost of which is longest. The jerboa is found in Egypt, Barbary, $\mathrm{Pa}$ lestine, and the deserts between Bussorah and Aleppo; its hind legs, as was said before, are only used in running, while the fore paws, like those of a squirrel, grasp its food, and in some measure perform the office of hands. It is often seen by travellers as they pass along the deserts, crossing their way, and jumping six or eight feet at every bound, and going so swiftly, that scarcely any other quadruped is able to overtake them. They are a lively harmless race of animals, living entirely upon vegetables, and burrowing like rabbits in the ground. Mr. Pennant tells us of two that were lately brought to London, that burrowed almost through the brick wall of the room where they were kept; they came out of their hole at night for food, and, when caught, were much fatter and sleeker than when confined to their burrows. A variety of this animal is found also in Siberia and Circassia, and is, most probably, common enough over all Asia. They are more expert diggers than even the rabbit itself; and when pursued for a long time, if they cannot escape by their swiftnesa, they try to make a hole instantly in the ground, in which they often bury themselves deep enough to find security before their pursucrs come up. Their burrows, in some places, are so thick, as to be dangerous to travellers, the horses perpetually falling in them. It is a provident little animal, and lays up for the winter. It cuts grass in heaps of a foot square, which, when dried, it carries into its burrow, therewith to serve it for fond, or to keep its young warm during the rigonrs of the winter.

But of all animals of this kind, that which was first discovered and described by Mr. Banks, is the most extraordinary. He calls it the kanguroo; and though from its general outline, and the most striking peculiarities of its figure, it greatly resembles the jerboa, yet it entirely differs, if we consider its size, or those minute distinctions which direct the makers of systems in assorting the general ranks of nature."

The largest of the jerboa kind which are to be found in the ancient continent, do not exceed the size of a rabbit. The kanguroo of New Holland, where it is only to be found, is often known to weigh above sixty pounds, and must consequently be as large as a sheep. Although the skin of that which was stuffed and brought home by Mr. Banks, was not much above the size of a hare, yet it was greatly superior to any of the jerboa kind that have been bitherto known, and very different in many particulars. The snout of the jerboa, as has been said, is short and round, that of the discovered animal long and slender; the teeth also entirely differ; for as the jerboa has but two cutting teeth in each jaw, making four in all, this animal, besides its cutting teeth, has four canine teeth also; but what makes a more striking peculiarity, is the formation of its lower jaw, which, as the ingenious discoverer supposes, is divided into two parts, which open and shut like a pair of scissors, and cut grass, probably this animal's principal food. The head, neck, and shoulders, are very small in proportion to the other parts of the body; the tail is nearly as long as the body; thick near the rump, and tapering towards the head and ears, which bear a slight resemblance to those of the hare. We are not told, however, from the formation of its stomach, to what class of quadrupeds it belongs: from its eating grass, which it has been seen to do, one would be apt to rank it among the ruminating animals; but from the canine teeth which it is found to have, we may on the other hand suppose it to bear some relation to the carnivorous. Upon the whole, however, it can be classed with none more properly, than with animals of the jerboa kind, as its hind legs are so much longer than the fore; it moves also precisely in the same manner, taking great bounds of ten or twelve feet at a time, and thus sometimes escaping even the flectest graylound, with which Mr. Banks pursued it. One of them that was killed proved to be good food; but a second, which weighed eighty-four pounds, and was not

a In order to supply some deficiencies in our author's description of this animal, the reader is referred to p. 413, under the head of the "Oppossum and its kinds," to which class naturalists now consider this creature to be uearly allied. 
yet come to its full growth, was found to be much inferior.

With this last described and last discovered animal, I shall conclude the history of quadrupeds, which of all parts of natural knowledge seems to have been described the most accurately. As these, from their figure, as well as their sagacity, bear the nearest resemblance to man, and from their uses or enmities are the most respectable parts of the inferior creation; so it was his interest, and his pleasure, to make himself acquainted with their history. It is probable therefore that time, which enlarges the sphere of our knowledge in other parts of learning, can add but very little to this. The addition of a new quadruped to the catalogue already known, is of no small consequence, and happens but seldom; for the number of all is so few, that wherever a new one is found, it becomes an object worthy our best attention. It may take refuge in its native deserts from our pursuits, but not from our curiosity.

But it is very different with the inferior ranks of the creation; the classes of birds, of fishes, and of insects, are all much more numerous, and more incompletely known. The quadruped is possessed of no arts of escaping, which we are not able to overcome; but the bird removes itself by its swiftness, the fishes find protection in their native element, and insects are secured in their minuteness, numbers, and variety. Of all these, therefore, we have but a very inadequate catalogue; and though the list be already very large, yet every hour is adding to its extent.

In fact, all knowledge is pleasant only as the object of it contributes to render man happy; and the services of quadrupeds being so very necessary to him in every situation, he is particularly interested in their history : without their aid, what a wretched and forlorn creature would he have been! the principal part of his food, his clothing, and his annusements, are derived wholly from them; and he may be considered as a great lord, sometimes cherishing his humble dependents, and sometimes terrifying the refractory, to contribute to his delight and conveniences.

The horse and the ass, the elephant, the camel, the lama, and rein-deer, contribute to ease his fatigues, and to give him that swiftness which he wants from nature By their assistance, he changes place without lisbour; he attains health withont weariness; his pride is enlarged by the elegance of equipage, and other animals are pursued with a certainty of success. It were happy indeed for man, if, while converting these quadrupeds to his own benefit, he had not turned them to the destruction of his fellow creatures; he has employed some of them for the purposes of war, and they have conformed to his noxious ambition with but too fatal an obedience.

The cow, the sheep, the deer, and all their varieties, are necessary to him, though in a different manner. Their flesh makes the principal luxuries of his table, and their wool or skins the chief ornament of his person. Even those nations that are lorbid to touch any thing that has life, cannot wholly dispense with their assistance. The milk of these animals makes a principal part of the food of every country, and often repairs those constitutions that have been broken by disease or intemperance.

The dog, the cat, and the ferret, may be considered as having deserted from their fellow quadrupeds, to list themselves under the conduct and protection of man. At his command they exert all their services against such animals as they are capable of destroying, and follow them into places where be bimself wants abilities to pursue.

As there is thus a numerous tribe, that he has taken into protection, and that supplies his necessities and amusements, so there is also a still more numerous one, that wages an equal combat against him, and thus calls forth his courage and his industry. Were it not for the lion, the tiger, the panther, the rhinoceros, and the bear, he would scarcely know his own powers, and the superiority of human art over brutal fierceness. These serve to excite, and put his nobler passions into motion. He attacks them in their retreat, faces them with resolution, and seldom fails of coming off with a victory. He thus becomes hardier and better in the struggle, and learns to know and to value his own superiority.

As the last mentioned animals are called forth by his boldest efforts; so the numerous tribe of the smaller vermin kind excite his 
continual vigilance and caution; his various arts and powers have been 110 where more manifest, than it the extirpation of those that multiply with such prodigions fecundity. Neither their agility nor their minuteness can secure them from his pursuits; and though they may infest, they are seldom found materially to injure him.

In this manner we see, that not only human want is supplied, but that human wit is sharpened, by the humbler partners of man in the creation. By this we see, that not only their benefits, but their depredations, are useful, and that it has wisely pleased providence to place us like victors in a subdued country, where we have all the benefit of conquest, without being so secure as to run into the sloth and excesses of a certain and undisturbed possession. It appears, therefore, that those writers who are continually fuding immediate benefit in every production, see but half way into the general system of nature. Experience must every hour inform us, that all animals are not formed for our use; but we may be equally well assured, that those conveniences which we want from their friendship, are well repaid by that vigilance which we procure from their enmity.

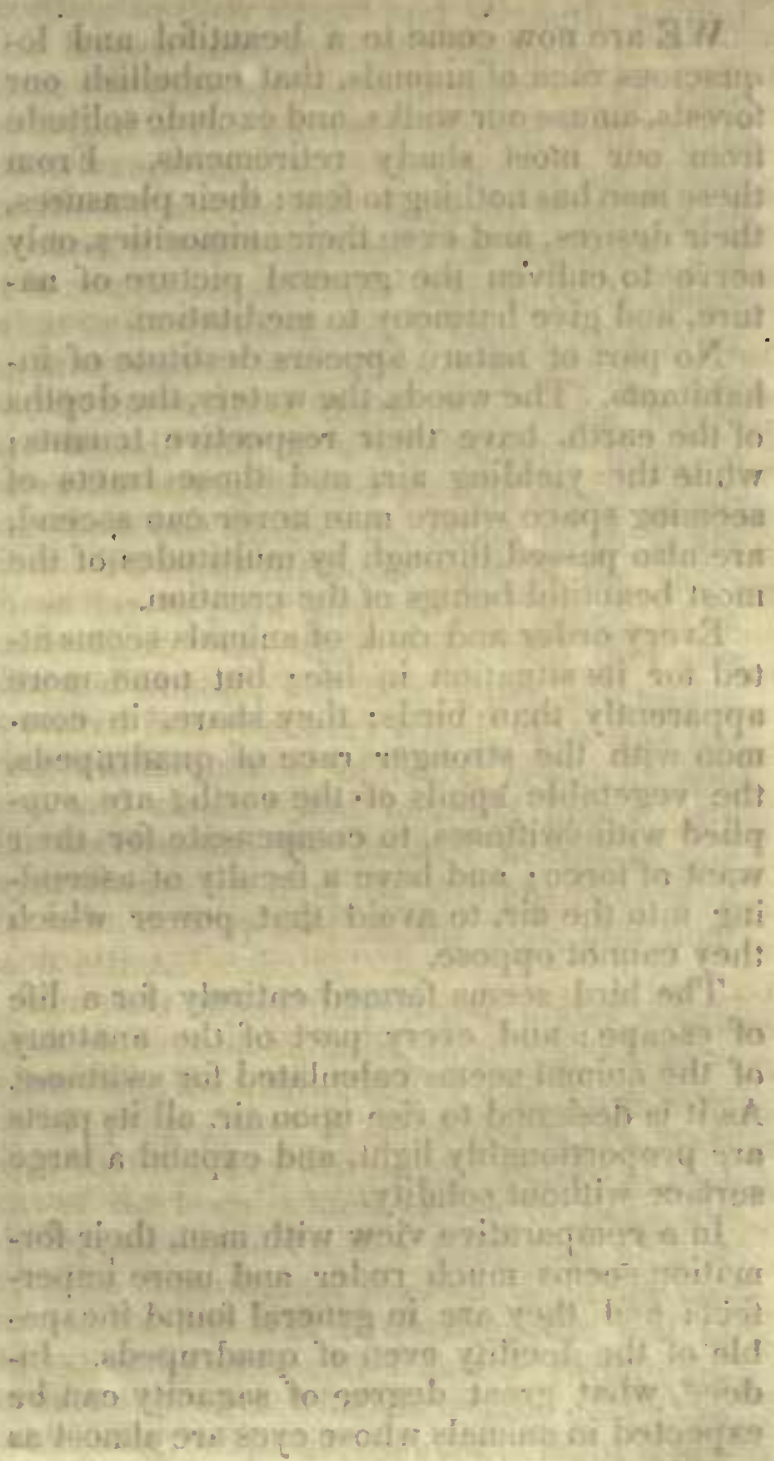




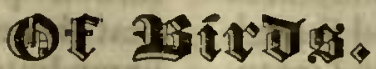

\section{OF BIRDS IN GENIRAT.}

\section{CHAPTER LXXIV.}

\section{INTRODUCTION.}

WE are now come to a beautiful and loquacious race of animals, that embellish our forests, amuse our walks, and exclude solitude from our most shady retirements. From these man has nothing to fear; their pleasures, their desires, and even their animosities, only serve to enliven the general picture of nature, and give harmony to meditation.

No part of nature appears destitute of inhabitants. The woods, the waters, the depths of the earth, have their respective tenants; while the yielding air, and those tracts of seeming space where man never can ascend, are also passed through by multitudes of the most beautiful beings of the creation.

Every order and rank of animals seems fitted for its situation in life; but none more apparently than birds: they share, in common with the stronger race of qnadrupeds, the vegetable spoils of the earth; are supplied with swiftness, to compensate for their want of force; and have a faculty of ascending into the air, to avoid that power which they cannot oppose.

The bird seems formed entirely for a life of escape; and every part of the anatomy of the animal seems calculated for swiftness. As it is designed to rise upon air, all its parts are proportionably light, and expand a large surface without solidity.

In a comparative view with man, their formation seems much ruder and more imperfect; and they are in general found incapable of the docility even of quadrupeds. Indeed, what great degree of sagacity can be expected in animals whose eyes are almost as large as their brain? However, though they fall below quadrupeds in the scale of nature, and are less imitative of human endowments; yet they hold the next rank, and far surpass fishes and insects, both in the structure of their bodies and in their sagacity.

As in mechanics the most curious instruments are generally the most complicated, so it is in anatomy: The body of man presents the greatest variety upon dissection; quadrupeds, less perfectly formed, discover their defects in the simplicity of their conformation; the mechanism of birds is still less complex ; fishes are furnished with fewcr organs still; whilst insects, more imperfect than all, seem to fill up the chasm that separates animal from vegetable nature. Of man, the most perfect animal, there are but three or four species; of quadrupeds, the kinds are more numerous; birds are more various still; fishes yet more; but insects afford so very great a variety, that they clude the search of the most inquisitive pursuer.

Quadrupeds, as was said, have some distant resemblance in their internal structure with man; but that of birds is entirely dissimilar. As they seem chiefly formed to inhabit the empty regions of air, all their parts are adapted to iheir destined situation. It will be proper, therefore, before I give a general history of birds, to enter into a slight detail of their anatomy and conformation.

As to their external parts, they seem surprisingly adapted for swiftness of motion. The shape of their body is sharp before, to pierce and fnake way through the air; it then 
rises by a gentle swelling to its bulk, and falls off in an exparisive tail, that helps to keep it buoyant, while the fore parts are cleaving the air by their sharpness. From this conformation, they have often been compared to a ship making its way through water; the trunk of the body answers to the hold, the head to the prow, the tail to the rudder, and the wings to the oars; from whence the poets have adopted the metaphor of remigium alarum, when they describe the wavy inotion of a bird in flight.

What we are called upon next to admire in the external formation of birds is, the neat position of the feathers, lying all one way, answering at once the purposes of warmth, speed, and security. They mostly tend backward, and are laid over one another in an exact and regular order, armed with warm and soft down next the body, and more strongly fortified, and curiously closed externally, to fence off the injuries of the weather. But, lest the feathers should spoil by their violent attrition against the air, or imbibe the moisture of the atmosphere, the animal is furnished with a gland behind, containing a proper quantity of oil, which can be pressed out by the bird's bill, and laid smoothly over every feather that wants to be dressed for the occasion. This gland is situated on the rump, and furnished with an opening or excretory duct; about which grows a small tuft of feathers somewhat like a painter's pencil. When, therefore, the feathers are shattered or rumpled, the bird, turning its head backwards, with the bill eatches hold of the gland, and, pressing it, forces out the oily substance, with which it anoints the disjoined parts of the feathers; and drawing them out with great assiduity, recomposes and places them in due order; by which they unite more closely together. Such poultry, however, as live for the most part under cover, are not furnished with so large a stock of this fluid, as those birds that reside in the open air. The feathers of a hen, for instance, are pervious to every shower; on the contrary, swans, geese, ducks, and all such as nature has directed to live upon the water, have their feathers dressell with oil from the very first day of their leaving the shell. Thus their stock of fluid is equal to the necessity of its consumption.
Their very flesh contracts a flavour from it, which render's it in some so very rancid, as to make it utterly unfit for food; however, though it injures the flesh, it improves the feathers for all the domestic purposes to which they are usually converted.

Nor are the feathers with which birds are covered less an object of admiration. The shaft of every feather is inade proportionably strong; but hollow below for strength and lightness, and above filled with a pith to feed the growth of the vane or beard that springs from the shaft of the feather on either side. All these feathers are placed generally according to their length and strength, so that the largest and strongest feathers in flight have the greatest share of duty. The vane or beard of the feather is formed with equal contrivance and care. It consists not of one continued membrane; because, if this were broken, it could not easily be repaired; but it is composed of many layers, each some. what in itself resembling a feather, and lying against each other in close conjunction. Towards the shaft of the feather, these layers are broad, and of a semicircular form, to serve for strength, and for the closer grafting them one against the other when in action. Towards the outer part of the vane, these layers grow slender and taper, to be more light. On their under-side they are thin and smooth, but their upper outer-edge is parted into two hairy edges, each side having a different sort of hairs, broad at bottom, and slender and bearded above. By this mechanism, the hooked beards of one layer always lie next the straight beards of the next, and by that means lock and hold each other.

'The next object that comes under consideration, in contemplating an animal that flies, is the wing, the instrument by which this wonderful progression is performed. In such birds that fly, they are usually placed at that part of the body which serves to poise the whole, and support it in a fiuid that at first seems so much lighter than itself. They answer to the fore legs in quadrupeds; and at the extremity of this they have a certain finger-like appendix, which is usually called the bastard-wing. This instrument of flight is furnished with quills, which differ from the com- 
mon feathers only in their size being larger, and also from their springing from the deeper part of the skin, their shafts lying almost close to the bone. The beards of these quills are broad on one side and more narrow on the other, both which contribute to the progressive motion of the bird, and the closeness of the wing. The manner in which most birds avail themselves of these, is first thus: they quit the earth with a bound, in order to have room for flapping with the wing; when they have room for this, they strike the body of air beneath the wing with a violent motion, and with the whole under surface of the same; but then to avoid striking the air with equal violence on the upper side as they rise, the wing is instantly contracted; so that the animal rises by the impulse, till it spreads the wing for a second blow. For this reason, we always see birds choose to rise against the wiud, because they have thus a greater body of air on the under than the upper side of the wing. For these reasons also large fowls do not rise easily; both because they have not sufficient room at first for the motion of their wings, and because the body of air does not lie so directly under the wing as they rise.

In order to move the wings, all birds are furnished with two very strong pectoral muscles, which lie on each side of the breastbone. The pectoral muscles of quadrupeds, are trifling in comparison to those of birds. In quadrupeds, as well as in man, the muscles which move the thighs and hinder parts of the body are by far the strongest, while those of the arms are feeble: but in birds, which make use of their wings, the contrary obtains; the pectoral muscles, that move the wings or arms, are of enormous strength, while those of the thighs are weak and slender. $\mathrm{By}$ means of these, a bird can move its wings with a degree of strength which, when compared to the animal's size, is almost incredible: The flap of a swan's wing would break a man's leg; and a similar blow from an eagle has been known to lay a man dead in an instant. Such, consequently, is the force of the wing, and such its lightness, as to be inimitable by art. No machines, that human skill can contrive, are capable of giving such force to so light an apparatus. The art of flying, therefore, that has so often and so fruitlessly been sought after, must, it is feared, for ever be unattainable; since as man increases the force of his nying machine, he must be obliged to increase its weight also.

In all birds, except nocturnal ones, the head is smaller, and bears less proportion to the body than in quadrupeds, that it may more readily divide the air in flying, and make way for the body, so as to render its passage more easy. Their eyes also are more flat and depressed than in quadrupeds; a circle of small plates of bone, placed scalewise, under the outer coat of the organ, encompasses the pupil on each, to strengthen and defend it from injuries. Beside this, birds have a kind of skin, called the nictitating membrane, with which, like a vail, they can at pleasure cover their eyes, though their eyelids continue open. This membrane takes its rise from the greater or more obtuse corner of the eye, and serves to wipe, cleanse, and probably to moisten its surface. The eyes, though they outwardly appear but small, yet, separately, each almost equals the brain; whereas in man the brain is more than twenty times larger than the orbit of the eye. Nor is this organ in birds less adapted for vision by a particular expansion of the optic nerve, which renders the impressions of external objects more vivid and distinct.

From this conformation of the eye it follows, that the sense of seeing in birds is infinitely superior to that of other animals. Indeed this piercing sight seems necessary to the creature's support and safety. Were this organ blunter, from the rapidity of the bird's motion, it would be apt to strike against every object in its way; and it could scarcely find subsistence, unless possessed of a power to discern its food from above with astonishing sagacily. An hawk, for instance, perceires a lark at a distance which neither men nor dogs could spy; a kite, from an almost imperceptible height in the clouds, darts down on its prey with the most unerring aim. The sight of birds, therefore, exceeds what we know in most other animals, and excels them both in strength and precision.

All birds want the external ear standing out from the head; they are only furnished with holes that convey sounds to the audi- 
tory canal. It is true, indeed, that the horned owl, and one or two more birds, seem to have exterual ears; but what bears that resemblance are only feathers sticking out on each side of the head, but no way necessary to the sense of hearing. It is probable, however, that the feathers encompassing the earholes in birds, supply the defect of the exterior ear, and collect sounds to be transmitted to the internal sensory. The extreme delicacy of this organ is easily proved by the readiness with which birds learn tunes, or repeat words, and the great exactness of their pronunciation.

The sense of smelling seems not less vivid in the generality of birds. Many of them wind their prey at an immense distance, while others are equally protected by this sense against their insidious pursuers. In decoys, where ducks are caught, the men who attend tnem universally keep a piece of turf buruing near their mouths, upon which they breathe, lest the fowl should smell them, and consequently fly away. The universality of this practice puts the necessity of it beyond a doubt, and proves the extreme delicacy of the sense of sinelling, at least in this species of the feathered creation.

Next to the parts for flight, let us view the lcgs and feet ministering to motion. They are both made light, for the easier transportation through the air. The toes in some are webbed, to fit them for the waters; in others they are separate, for the better liolding objects, or clinging to trees for safety. Such as have long legs have also long necks, as otherwise they would be incapable of gathering up their food either by land or water. But it does not hold, however, that those who have long necks should have long legs, since we see that swans and geese, whose necks are extremely long, have very short legs, and these chiefly employed in swimming.

Thus every external part, hitherto noticed, appears adapted to the life and rituation of the animal; nor are the inward parts, though less inmediately appropriated to flight, less necessary to safety. The bones of every part of the body are extremely light and thin; and all the muscles, except that immediately moving the wings, extremely slight and feeble. The tail, which is composed of quill พn. $39 \& 40$. feathers, serves to counterbalance the head and neck; it guides the animal's flight, like a rudder, and greatly assists it either in its ascent or when descending.

If we go on to examine birds internally, we shall find the same wonderful conformation fitting them for a life in air, and increasing the surface by diminishing the solidity. In the first place their lungs, which are commonly called the sole, stick fast to the sides of the ribs and back, and can be very little dilated or contracted. But to make up for this, which might impede their breathing, the ends of the branch $s$ of the wind-pipe open into them, while these have openings into the cavity of the belly, and convey the air drawn in by breathing into certain receptacles like bladders, rumning along the length of the whole body. Nor are these openings obscure, or difficult to be discerned; for a probe thrust into the lungs of a fowl will easily find a passage into the belly; and air blown into the wind-pipe will be seen to distend the animal's body like a bladder. In quadrupeds this passage is stopped by the midriff; but in fowls the communication is obvious; and, consequently, they have a much greater facility of taking a long and large inspiration. It is sometimes also seen that the wind-pipe makes many convolutions within the body of a bird, and it is then called the labyrinth; but of what use these convolutions are, or why the wind-pipe should make so many turnings within the body of some birds, is a difficulty for which no naturalist has been able to accoust.

This difference of the wind-pipe often obtains in animals that, to all appearance, are of the same species. Thus in the tame swall, the wind-pipe makes but a straight passage into the lungs; while in the wild swan, which to all exterual appearance seems the same animal, the wind-pipe pierces through the breast-bone, and there has several turnings before it comes out again, and goes to enter the lungs. It is not to form the voice that these turnings are found, since the fowls that are without them are rocal; and those, particularly the bird just now mentioned, that have them, are silent. Whence, therefore, some birds derive that loud and various modulation in their warblings, is not easily to $3 \mathrm{X}$ 
be accounted for; at least the knife of the anatomist goes but a short way in the investigation. All we are certain of is, that birds have much louder voices, in respect to their bulk, than animals of any other kind; for the bellowing of an ox is not louder than the scream of a peacock.

In these particulars, birds pretty much resemble each other in their interual conformation; but there are some varieties which we should more attentively observe. All birds have, properly speaking, but one stomach; but this is very different in different kinds. In all the rapacious kinds that live upon animal food, as well as in some of the fish-feeding tribe, the stomach is peculiarly formed. The mosophagus, or gullet, in them, is found replete -with glandulous bodies, which serve to dilate and macerate the food, as it passes into the stomach, which is al ways very large in proportion to the size of the bird, and generally wrapped round with fat, in order to increase its warmth and powers of digestion.

- Granivorous birds, or such as live upon fruits, corn, and other vegetables, have their intestines differently formed from thosc of the rapacious kind. Their gullet dilates just above the breast-bone, and forms itself into a pouch or bag, called the crop. This is replete with salivary glands, which serve to moisten and soften the grain and other food which it contains. These glands are very numerous, with longitudinal openings, which cmit a whitish and a viscous substance. After the dry food of the bird has been maccrated for a convenient time, it then passes into the belly, where, instead of a soft moist stomach, as in the rapacious kinds, it is ground between two pair of muscles, commonly called the gizzard,covered on the inside with a stony ridgy coat, and almost cartilaginous. These coats rubbing against each other, are capable of bruising and attenuating the hardest substances, their action being often compared to that of the grinding teeth in man and other animals. Thus the organs of digestion are in a manner reversed in birds. Beasts grind their food with their teeth, and then it passes into the stomach, where it is softened and digested. On the contrary, birds of this sort first macerate and soften it in the crop, and then it is ground and comminuted in the sto- mach or gizzard. Birds are also careful to pick up sand, gravel, and other hard substances, not to grind their food as has been supposed, but to prevent the too violent action of the coats of the stomach against each other

Most birds have two appendices, or blindguts, which, in quadrupeds, are always tound single. Among such birds as are thus supplied, all carnivorous fowl, and all birds of the sparrow kind, have very small and short ones; water-fowl and birds of the poultry kind, the longest of all. There is still another appendix observable in the intestines of birds, resembling a little worm, which is nothing more than the remainder of that passage by which the yolk was conveyed into the guts of the young chicken, while yet in the egg and under incubation.

The outlet of that duct which conveys the bile into the intestines is, in most birds, a great way distant from the stomach; which may arise from the danger there would be of the bile regurgitating into the stomach in their various rapid motions, as we see in men at sea; wherefore their biliary duct is so contrived, that this regurgitation cannot take place.

All birds, though they want a bladder for urine, have large kidneys and ureters, by which this secretion is made, and carried away by one common canal. "Birds," says Harvey, "as well as serpents, which have spongy lungs, make but little water, because they drink but little. They therefore have no need of a bladder; but their urine distils down into the common canal, designed for receiving the other excrements of the body. The urine of birds differs from that of other animals : for, as there is usually in urine two parts, one more serous and liquid, the other more thick and gross, which subsides to the bottom; in birds, the last part is most abundant, and is distinguished from the rest by its white or silver colour. This part is found not only in the whole intestinal canal, but is seen also in the whole channel of the ureters, which may be distinguished from the coats of the kidneys by their whiteness. This milky substance they have in greater plenty than the more thin and serous part; and it is of a middle consistence, between limpid urine and 
the grosser parts of the freces. In passing through the ureters, it resembles milk curdled or lightly condensed; and, being cast forth, easily congeals into a chalky crust."

From this simple conformation of the animal, it should seem that birds are subject to few diseases; and, in fact, they have but few. There is one, however, which they are subject to, from which quadrupeds are, in a great measure, exempt; this is the annual moulting which they suffer; for all birds whatsoever obtain a new covering of feathers once a year, and cast the old. During the moulting season, they ever appear disordered; those most remarkable for their courage, then lose all their fierceness; and such as are of a weakly constitution, often expire under this natural operation. No feeding can maintain their strength; they all cease to breed at this season; that nourishment which goes to the production of the young is wholly absorbed by the demand required for supplying the nascent plumage.

This moulting-time, however, may be artificially accelerated; and those who have the management of singing-birds frequently put their secret in practice. They enclose the bird in a dark cage, where they keep it excessively warm, and throw the poor little animal into an artificial fever; this produces the moult; his old feathers fall before their time, and a new set take place, more brilliant and beautiful than the former. They add, that it mends the bird's singing, and increases its vivacity; but it must not be concealed, that scarcely one bird in three survives the operation.

The manner in which nature performs this operation of moulting is thus : the quill, or feather, when first protruded from the skin, and come to its full size, grows harder as it grows older, and receives a kind of periosteum or skin round the shaft, by which it seems attached to the animal. In proportion as the quill grows older, its sides, or the bony penpart, thicken; but its whole diameter shrinks and decreases. Thus, by the thickening of its sides, all nourishment from the body becomes more sparing; and, by the decrease of its diameter, it becomes more loosely fixed in its socket, till at length it falls out. In the mean time, the rudiments of an incepient quill are beginning below. The skiu forms itself into a little bag, which is fed from the body by a small vein and artery, and which every day increases in size till it is protruded. While the one end vegetates into the beard or vane of the feather, that part attached to the skin is still soft, and receives a constant supply of nourishment, which is diffused through the body of the quill by that little light substance which we always find within when we make a pen. This substance, which as yet has received no name that I know of, serves the growing quill as the umbilical artery does an infant in the womb, by supplying it with nourishment, and diffusing that nourishment over the whole frame. When, however, the quill is come to its full growth, and requires no further nourishment, the vein and artery become less and less, till at last the little opening by which they communicated with the quill becomes wholly obliterated ; and the quill, thus deprived, continues in its socket for some months, till in the end it shrinks, and leaves room for a repetition of the same process of nature as before.

The moulting season commonly obtains from the end of summer to the middle of autumn. The bird continues to struggle with this malady during the winter; and nature has kindly provided, that when there are the fewest provisions, that then the animal's appetite shall be least craving. At the beginning of spring, when food begins again to be plentiful, the animal's strength and vigour return. It is then that the abundance of provisions, aided by the mildness of the season, incite it to love, and all nature seems teeming with life, and disposed to continue it.

$$
3 \mathrm{X}^{*}
$$




\section{CHAPTER LXXV.}

\section{OF THE GENERATION, NESTLING, AND INCUBATION, OF BIRDS.}

THE return of spring is the beginning of pleasure. Those vital spirits, which seemed locked up during the winter, then begin to expand; vegetables and insects supply abundance of food; and the bird, having more than a sufficiency for its own subsistence, is impelled to transfuse life, as well as to maintain it. Those warblings, which had been hushed during the colder seasons, now begin to animate the fields; every grove and bush resounds with the challenge of anger, or the call of allurement. This delightful concert of the grove, which is so mueh adinired by man, is no way studied for his amusement: it is usually the call of the male to the female, his efforts to soothe her during the times of incubation; or it is a challenge between two males, for the affections of some common favourite.

It is by this call that birds begin to pair at the approach of spring, and provide for the support of a future progeny. The loudest notes are usually from the male, - while the hen seldom expresses her consent, but in a short interrupted twittering. This compact, at least for the season, holds with unbroken faith; many birds live with inviolable fidelity together for a constancy; and when one dies, the other is always seen to share the same fate soon after. We must not take our idea of the conjugal fidelity of birds from observing the poultry in our yards, whose freedom is abridged, and whose manners are totally corrupted by slavery. We must look for it in our fields and our forests, where nature continues in unadulterated simplicity; where the number of males is generally equal to that of females; and where every little animal seems prouder of his progeny, than pleased with his mate. Were it possible to compare sensations, the male of all wild birds seems as happy in the young brood as the female; and all his former caresses, all his soothing melodies, seem only aimed at that important occasion, when they are both to become parents, and to educate a progeny of their own producing. The pleasures of tove appear dull in their effects, when compared to the interval immediately after the exclusion of their young. They both seem at that season transported with pleasure; every action testifies their pride, their importance, and tender solicitude.

When the business of fecundation is performed, the female then begins to lay. Such eggs as bave been impregnated by the cock are prolific; and such as have not, for she lays often without any congress whatsoever, continue barren, and are ouly addled by incubation. Previous, however, to laying, the work of nestling becomes the common care; and this is performed with no small degree of assidnity and apparent design. It has been asserted, that birds of one kind always make their nests in the same manner, and of the same materials; but the truth is, that they vary this as the materials, places, or climates, happen to differ. The red breast, in some parts of England, makes its nest with oak leaves, where they are in greatest plenty; in other parts, with moss and hair. Some birds, that with us make a very warm nest, are less solicitous in the tropical climates, where the heat of the weather promotes the business of incubation. In general, however, every species of birds has a peculiar architecture of its own; and this adapted to the number of eggs, the temperature of the climate, or the respective heat of the little animal's own body. Where the eggs are numerous, it is then incumbent to make the nest warm, that the auimal heat may be equally diffused to them all. Thus the wren, and all the small birds, make the nest very warm; for having many eggs, it is requisite to distribute warmth to them in common: on the contrary, the plover, that has but two eggs, the eagle, and the crow, are not so solicitous 
in this respect, as thoir bodies are capable of being applied to the smali number upon which they sit. With regard to climate, water-fowl, that with us make but a very slovenly nest, fire much more exact in this particnlar in the colder regions of the north. They there take every precantion to make it warm; and some kinds strip the down from their breasts, to line it with greater security.

In gencral, however, every bird resorts to hatch in those climates and places where its fool is found in greatest plenty ; and always at that season when provisions are in the greatest abuudance. The large birds, and those of the aquatic kinds, choose places as remote from man as possible, as their food is in general different from that which is cultivated by human labour. Some birds. which have only the serpent to fear, build their nests depending from the end of a sinall bough. and forin the entrance from below; being thus secured either from the serpent or the monkey tribes. But all the little birds which live upon fruits and corn, and that are too often unwelcome intruders upon the firuits of human industry, in making their nests, use every precaution to conceal them from man. Ont the other hand, the great birds remote from human society, use every precaution to render theirs inaccessible to wild beasts or vermin.

Nothing can exceed the patience of birds while latching; ncither the calls of hunger; nor the near approach of danger, can drive them from the nest. They are often fat upon beginning to sit, yet before incubation is over the female is usually wasted to skin and bone. Ravens and crows, while the females are sitting, take care to provide them with food; and-this in great abundance. But it is diffe ent with most of the smaller kinds: during the whole tine, the male sits near his mate upon some tree, and soothes her by his singing: and often when she is tired takes her place, and patiently continues upon the nest till she returns. Sotnetimes, however, the eggs acquire a degree of heat too much for the purposes of hatching; in such cases, the hen leaves them to cool a little, and then returns to sit with her usual perseverance and pleasure.
So great is the power of instinct in animals of this class, that they seem driven from one appetice to another, and continue almost passive under its influence. Reason we cannot call it, since the first dictates of that principle would be self-preservation: "Take a brute." says Addison, "out of his instinct, and you find him wholly deprived of understanding. With what caution," continues he, " docs the hell provide herself a nest in places unfrequented, and free from noise and disturbance! When she has laid her eggs in such a manner that she can cover them, what care does she take in turning them frequent$1 y$, that all parts may partake of the vital warmth! When she leaves them, to provide for her necessary sustenance, how punctually does she return before they have time to cool, and become incapable of producing an animal! In the summer you see her giving herself greater freedoms, and quitting her care for above two hours together: but in winter, when the rigour of the season would chill the principles of life, and destroy the young one, she grows more assiduous in her attendance, and stays away but half the time. When the birth approaches, with how much nicety and attention does she help the chick to break the prison! not to take notice of her covering it from the injuries of the weather, providing it with proper nourishment, and teaching it to help itself; nor to mention her forsaking the nest, if, after the usual time of reckoning, the young one does not inake its appearance. A chymical operation could not be followed with greater art or diligence than is seen in the hatching a chick, though there are many birds that show an infinitely greater sagacity: yet at the same time the hen, that has all this seeming ingenuity, (which is indeed absolutely necessary for the propagation of the species, ) considered in other respects, is without the least glimmerings of thought or common sense: she mistakes a piece of chalk for an egg, and sits upon it in the same manner; she is insensible of any increase or diminution in the number of those she lays; she does not distinguish between her own, and those of another species; and when the birth appears of never so different a bird, will cherish it for her own. A hen, followed by a brood of ducks, 
shall stand affrighted at the edge of the pond, trembling for the fate of her young, which she sees venturing into so dangerous an element. $\Lambda$ s the different principle which aets in these different animals cannot be termed reason, so when we call it instinct, we mean something we have no knowledge of. It appears to me the immediate direction of Providenee; and such an operation of the Supreme Being, as that which determines all the portions of matter to their proper centres."

The production of the young, as was said, seems to be the great æra of a bird's happiness. Nothing can at that time exceed its spirit and industry: the most timid becomes courageous in the defence of its young. Birds of the rapacious kind, at this season, become more than usually fieree and active. They carry their prey, yet throbbing with life, to the nest, and early accustom their young to habits of slaughter and cruelty. Nor are those of milder natures less busily employed; the little birds then discontinue their singing, taken up with more important pursuits of common subsistence.

While the young are yet unfledged, and continue in the nest, the old ones take care to provide them with a regular supply; and, lest one should take all nourishment from the rest, they feed each of the young in their turn. If they perceive that man has been busy with their nest, or has handled the little ones, they abandon the place by night, and provide their brood a more secure, though less commodious, retreat. When the whole family is completely plumed, and capable of avoiding danger by flight, they are then led forth when the weather is fine, and taught the paternal art of providing for their subsistence. They are led to the places where their food lies; they are shown the method of discovering or carrying it away; and then led back to the nest, for a day or two longer. At length, when they are completely qualified to shift for themselves, the old ones take them abroad, and leading them to the accustomed places, forsake them for the last time; and all future connexion is ever at an end.

Those birds which are hatched and sent out earliest in the season are the most strong and vigorous; those, on the other hand, that have been delayed till the midst of summer, are more feeble and tender, and sometimes incapable of sustaining the rigours of the ensuing winter. Birls themselves seem sensible of this difference, and endeavour to produce carly in the spring. If, however, their efforts are obstructed by having their nests robbed, or some similar aceident, they still persevere in their efforts for a progeny; and it often happens that some are thus retarded till the midst of winter. What number of eggs any bird can lay in the course of a seasoll is not ascertained; but this is true, that such as would have laid but two or three at the most, if their nests be robbed, or their eggs stolen, will lay above ten or twelve. A common hen, if moderately fed, will lay above a hundred from the beginning of spring to the latter end of autumn. In general, however, it obtains, that the smallest and weakest animals are the most prolific, while the strong and rapacious are abridged by sterility. Thus, such kinds as are easily destroyed, are as readily repaired; and nature, where she has denicd the power of resistance, has compensated by the fertility attending procreation.

Birds in general, though they have so much to fear from man and each other, are seldom scared away from their usual haunts. Although they be so perfectly formed for a wandering life, and are supplied with powers to satisfy all thcir appetites, though never so remote from the object, though they are so well fitted for changing place with ease and rapidity, yet the greatest number remain contented in the districts where they have been bred, and by no means exert their desires in proportion to their endowments. The rook, if undisturbed, never desires to leave his native grove; the black-bird still frequents its accustomed hedge; and the red-breast, though seemingly mild, claims a certain district, from which he seldom moves, but drives out every one of the same species from thence without pity. They are exeited to migration by no other motives but those of fear, elimate, or hunger. It must be from one of these powerful motives that the birds, which are called birds of passage, every year forsake us for some time, and make their regular and expected returns.

Nothing has more employed the curiosity 
of mankind than these annual emigrations; and yet few subjects continue so much involved in darkness. It is generally believed, that the cause of their retreat from these parts of Europe, is either a scarcity of food at certain seasons, or the want of a secure asylum from the persecution of man, during the time of courtship and bringing up their young. Thus the starling, in Sweden, at the approach of winter, finding subsistence no longer in that kingdom, descends every year into Germany; and the hen chaffinches of the same country are seen every year to fly through Holland in large flocks, to pass their winter in a milder climate. Others, with a more daring spirit, prepare for journeys that might intimidate even human perseverance. Thus the quails, in spring, forsake the burning heats of Africa for the milder sun of Europe; and, when they have past the summer with us, steer their flight back to enjoy in Egypt the temperate air, which then begins to be delightful. This, with them, seems a preconcerted undertaking. They unite together in some open place, for some days before their departure, and, by an odd kind of chattering, seem to debate on the method to proceed. When their plan is resolved upon, they all take flight together, and often appear in such numbers, that to mariners at sea they seem like a cloud that rests upon the horizon. The boldest, strongest, and by far the greatest number, make good their intention; but many there are, who, not well apprised of their own force for the undertaking, grow weary on the way, and, quite spent by the fatigues of their flight, drop down into the sea, and sometimes upon deck, thus becoming an easy prey to the mariner.

Of the vast quantity of water-fowl, that frequent our shores, it is amazing to reflect how few are known to breed here. The cause that principally urges them to leave this country, seems to be not merely the want of food, but the desire of a secure retreat. Our country is too populous for birds so shy and timid as the greatest number of these are. When great part of our island was a mere waste, an uncultivated tract of woods and marshes, many species of birds which now migrate remained with us throughout the year. The great heron and the crane, that have now forsaken this country, in former times bred familiarly in our marshes, and seemed to animate our fens. Their nests, like those of most cloven footed water-fowl, were built on the ground, and exposed to every invader. But as rural economy increased, these animals were more and more disturbed. Before they had little to fear, as the surrounding marsh defended them from all the carniverous quadrupeds, and their own strength from birds of prey; but upon the intrusion of man, and by a long series of alarms, they have at length been obliged to seek, during the summer, some lonely habitation, at a safe distance from every destroyer.

Of the numerous tribes of the duck kind, we know of no more than five that breed here; the tame swan, the tame goose, the sheldrake, the eider duck, and a few of the wild ducks. The rest contribute to form that amazing multitude of water-fowl which annually repair to the dreary lakes and deserts of Lapland from the more southern countries of Europe. In those extensive and solitary retreats, they perform the duties of incubation and nutrition in full security. There are few of this kind that may not be traced to the northern deserts, to countries of lakes, rivers, swamps, and mountains, covered with thick and gloo$\mathrm{my}$ forests, that afford shelter during summer to the timid animals, who live there in undisturbed security. In those regions, from the thickness of the forests, the ground remains moist and penetrable during the summer season; the woodcock, the snipe, and other slender-billed birds, can there feed at ease; while the web-footed birds find more than sufficient plenty of food from the number of insects, which swarm there to an incredible degree. The days there are long; and the beauliful meteorous nights afford them every opportunity of collecting so minute a food, which is probably of all others the most grateful. We are not to be astonished, therefore, at the amazing number of fowl that descend from these regions at the approach of winter; numbers to which the army of Xerxes was but trifling in comparison; and which Linnæus has observed for eight whole days and nights to cover the surface of the river Calix.

This migration from the north usually begins in September, when they quit their retreats, and disperse themselves over all the 
southern parts of Europe. It:is not unpleasing to observe the order of their flight; they generally range themselves iu a long line, or they sometimes make their march angularly, two lines uniting in the centre like the letter $V$ reversed. The bird which leads at the point seems to cleave the air, to facilitate the passage for those which are to follow. When fatigued with this laborious station, it falls back into one of the wings of the file, while another takes its place. With us they make their appearance about the beginning of $\mathrm{Oc}$ tober, circulate first round our sliores, and, when compelled by severe frost, betake themselves to our lakes and rivers. Some, indeed, of the web-footed fowl, of hardier constitutions than the rest, abicle the rigours of their northern climate the whole winter; but when the cold reigns there with more than usual severity, they are obliged to seek for more southern skies. They then repair with the rest for shelter to these kingdoms; so that the diver, the wild swan, and the swallowtailed slueldrake, visit our coasts but seldom, and that only when compelled by the severity of their winters at home.

It Las been often a subject of astonishment, how animals to all appearance so dull and irrational should perform such long journcys, should know whither to steer, and when to set out upon such a great undertaking. It is probable that the same instiuct which governs all their other actions operates also here. They rather follow the weather than the country; they steer only from colder or warmer climates into those of an opposite nature; and finding the variations of the air as they proceed in their favour, go on till they find laud to repose on. It cannot be supposed that they have any memory of the country where they might have spent a former winter: it cannot be supposed that they see the country to which they travel, from their height in the air; since, though they mounted for miles, the convexity of the globe would intercept their view : it must therefore only be, that they go on as they contiuue to perceive the atmosphere more suitable to their present wants and dispositions.

All this seems to be pretty plain: but there is a circumstance attending the migration of swallows which wraps this subject in great obscurity. It is agreed on all hands, that they are seen migrating into warmer chinates, and that in amazing numbers, at the approach of the European winter. Their return into Europe is also as well attested about the beginning of gumner; but we have another account, which serves to prove that numbers of them continue torpid here during the winter, and, like bats, make their retreat into old walls, the hollow of trees, or even sink into the deepest lakes, and fiud security for the winter season by remaining there in clusters at the bottom. However this latter circumstance may be, their retreat into old walls is too well authenticated to remain a doubt at present. The dificulty, therefore, is to account for this difference in these animals thus variously preparing to encouuter the winter. It was supposed that in some of them the blood might lose its motion by the cold, and that thus they were rendered torpid by the severity of the season; but Mr. Buffon having placed many of this tribe in an ice-luouse, found that the same cold by which their blood was congealed was fatal to the auimal ; it remaius, therefore, a doubt to this hour, whether there may not be a species of swallows to all external appearance like the rest, but differently formed within, so as to fit them for a state of insensibility during the winter here. It was suggestel, indeed, that the swallows found thus torpid, were such only as were too weak to undertake the inigration, or were hatched too late to join the general convoy; but it was upon these that Mr. Buffon tried his experiment; it was these that died under the operation.

Thus there are some birds wlich by migrating make an habitation of every part of the earth; but in general every climate has birds peculiar to itself. The feathered inhabitants of the teruperate zone are but little remarkable for the beauty of their plumage; but then the smaller kinds make up for this defect by the melody of their voices. The birds of the torrid zone are very bright and vivid in their colours; but they have sereaming voices, or are totally silent. The frigid zous, on the other hand, where the seas abound with fish, are stocked with birds of the nquatic kind, in mucl greater plenty than in Europe; and these are generally clothed 
with a warmer coat of feathers; or they have large quantities of fat lying underneath the skin, which serves to defend them from the rigours of the climate.

In all countries, however, birds are a more long-lived class of animals than the quadrupeds or insects of the same climate. The life of man himself is but short, when compared to what some of them enjoy. It is said that swans have been known to live three hundred years; geese are often seen to live fourscore; while linnets and other little birds, though imprisoned in cages, are often found to reach fourteen or fifteen. How birds, whose age of perfection is much more early than that of quadrupeds, should yet live comparatively so mueh longer, is not easily to be accounted for: perhaps, as their bones are lighter, and more porous, than those of quadrupeds, there are fewer obstructions in the animal machine; and nature, thus finding more room for the operations of life, is carried on to a greater extent.

All birds in general are less than quadrupeds; that is, the greatest of one class far surpass the greatest of the other in magnitude. The ostrich, which is the greatest of birds, bears no proportion to the elephant; and the smallest humming-bird, which is the least of the class, is still far more minute than the mouse. In these the extremities of nature are plainly discernible; and in forming them she appears to have been doubtiul in her operations: the ostrich, scemingly covered with hair, and incapable of flight, making near approaches to the quadruped class; while the humming-bird, of the size of an humble-bee, and with a fluttering motion, seems nearly allied to the insect.

These extremities of this elass are rather objects of human curiosity than utility: it is the middle order of birds which man has taken care to propagate and maintain. Of those which he has taken under his protection, and which administer to his pleasures or necessities, the greatest number seem creatures of his formation. The varicty of elimate to which he consigns them, the food with which he supplies them, and the purposes for which he employs them, produce amazing varieties, both in their colonrs, shape, magnitude, and the taste of their flesh. Wild birds are, for the most part, of the same magnitude and shape; they still keep the prints of primæval nature strong upon them, except in a few; they generally maintain their very colour: but it is otherwise with domestic animals; they change at the will of man-of the tame pigeon, for instance, it is said they can be hred to a feather.

As we are thus capable of influencing their form and colour, so also is it frequent to see equal instances of our influencing their habitudes, appetites, and passions. The cock, for instance, is artificially formed into that courage and aetivity which he is scen to possess; and many birds testify a strong attachment to the hand that feeds them. How far they are capable of iustruction, is manifest to those who have the care of hawks. But a still more surprising instance of this was seen some time ago in London: a canary bird was taught to pick up the-letters of the alphabet, at the word of command, so as to spell any person's name in company; and this the little animal did by motions from its master, which were impereeptible to every other spectator. Upon the whole, however, they are inferior to quadrupeds in docility; and seem more mechanically impelled by all the power of instinct.

\section{CHAPTER LXXVI.}

\section{OF THE DIVISION OF BIRDS.}

THOUGH birds are fitted for sporting in air, yet as they find their food upon the surface of the earth, there seems a variety equal to the different aliments with which it tends

No. 39 \& 40 . to supply them. The flat and burning desert, the rocky eliff, the extensive fen, the stormy ocean, as well as the pleasing landscape, have all their peculiar inhabitants. The $3 \mathrm{Y}$ 
most obvious distinction therefore of birds, is into those that live by land and those that live by water; or, in other words, into land birds, and water fowl.

It is no difficult matter to distinguish land from water fowl, by the legs and toes. All land birds have their toes divided, without any membrane or web between them; and their legs and feet serve them for the purposes of running, grasping, or climbing. On the other hand, water fowl have their legs and feet formed for the purposes of wading in water, or swimming on its surface. ln those that wade, the legs are usually long and naked; in those that swim, the toes are webbed together, as we see in the fect of a goose, which serve, like oars, to drive them forward with greater velocity. The formation, therefore, of land and water fowl, is as distinet as their habits; and nature herself seems to offer us this obvious distribution, in methodizing animals of the feathered creation.

However, a distinction so comprehensive goes but a short way in illustrating the different tribes of so numerous a class. The number of birds already known, amounts to nearly three thousand; and every person who turns his unind to these kinds of pursuits, is every day adding to the catalogue. It is not enough, therefore. to be able to distinguish a laıd from a water fowl; much more is still required - to be able to distinguish the different kinds of birds from each other; and even the varieties in the same kiud, when they happen to offer. This certainly is a work of great difficulty; and perhaps the attainment will not repay the labour. The sensible part of mankind will not withdraw all their attention from more important pursuits, to give it entirely up to what promises to repay them only with a very confined species of amusement. In my distribution of birds, therefore, I will follow Linnæus in the first sketch of his system; and then leave him, to follow the most natural distinctions, in enumerating the different kinds that admit of a history, or require a description.

Limneus divides all birds into six classes; namely, into birds of the rapacious kind, birds of the pie kind, birds of the poultry kind, birds of the sparrow kind, birds of the duck kind, and birds of the crane kind. The four first com- prehend the varions kinds of land birds; the two last, those that belong to the water.

Birds of the rapacions kind, constitute that class of carnivorous fowl that live by rapine. He distinguishes them by their bcak, which is hooked, strong, and notched at the point; by their legs, which are short and muscular, and made for the purposes of tearing; by their toes, which are strong and knobbed; and thcir talons, which are sharp and crooked; by the make of their body, which is muscular; and their flesh, which is impure: nor are they less known by their food, which consists entirely of flesh; their stomach, which is membraneous; and their manners, which are fierce and eruel.

Birds of the pic kind have the bill differing from the former: as in those it resembled a hook, destined for tearing to pieces; in these it resembles a wedge, fitted for the purpose of cleaving. Their legs are formed short and strong, for walking; their body is slender, and impure, and their food miscellaneous. They nestle in trees; and the inale feeds the female during the time of incubation.

Birds of the poultry kind have the bill a little convex, for the purposes of gathering their food. The upper chap hangs over the lower; their bodies are fat and muscular, and their flesh white and pure. They live upon grain, which is moistened in the crop. They make their nest on the ground, without art; they lay many eggs, and use promiscuous venery.

Birds of the sparrow kind comprehend all that beautiful and vocal class that adorn our fields and groves, and gratify every sense in its turn. Their bills may be compared to a forceps that catches hold; their legs are formed for hopping along; their lodies are teuder; pure in such as feed upon grain, impure in such as live upon insects. They live chiefly in trees; their nests are artificially made, and their amours are observed with connubial fidelity.

Birds of the duck kind use their bill as a kind of strainer to their food; it is smooth, covered with a skin, and nervous at the point. Their legs are short, and their feet formed for swimming, the toes being webbed together. Their body is fnt, inclining to rancidity. They live in waters, and chiefly build their nests upon land. 
With respect to the order of birds that belong to the waters, those of the crane kind have their bill formed for the purposes of searching and examining the bottom of pools; their legs are long, and formed for wading; their toes are not webbed; their thighs are half naked; their body is slender, and covered with a very thin skin; their tail is short, and their flesh savoury. They live in lakes upon animals, and they chiefly build their nests upon the ground.

Such is the division of Linnæus with respect to this class of animals; and, at first sight, it appears natural and comprehensive. But we must not be deceived by appearances: the student, who should imagine he was making a progress in the history of nature, while he was only thus making arbitrary distributions, would be very much mistaken. Should he come to enter deeper into this naturalist's plan, he would find birds the most unlike in nature thrown together into the same class; and find animals joined, that entirely differ in climate, in habitudes, in manners, in shape, colouring, and size. In such a distribution, for instance, he would find the humming-bird and the raven, the rail and the ostrich, joined in the same family. If, when he asked what sort of a creature was the humming-bird, he were told that it was in the same class with the carrion-crow, would he not think himself imposed upon? In such a case, the only way to form any idea of the animal whose history he is desirous to know, is to see it; and that curiosity very few have an opportunity of gratifying. The number of birds is so great, that it might exhaust the patience not only of the writer, but the reader, to examine them all: in the present confined undertaking it would certainly be impossible. I will, therefore, now attach myself to a more natural method; and, still keeping the general division of Linnæus before me, enter into some description of the most noted, or the most worth knowing.

Under one or other class, as I shall treat them, the reader will probably find all the species, and all the varieties that demand his curiosity. When the leader of any tribe is described, and its history known, it will give a very tolerable idea of all the species contained under it. It is true, the reader will not thus have his knowledge ranged under such precise distinctions; nor can he be able to say with such fluency, that the rail is of the ostrich class; but, what is much more material, he will have a tolerable history of the bird he desires to know, or at least of that which most resembles it in nature.

However, it may be proper to apprize the reader that he will not here find his curiosity satisfied, as in the former volumes, where we often took Mr. Buffon for our guide. Those who have hitherto written the natural history of birds, have in general been contented with telling their names, or describing their toes or their plumage. It must often, therefore, happen, that instead of giving the history of a bird, we must be content to entertain the reader with merely its description. I will therefore divide the following history of birds, with Linnæus, into six parts; in the first of which I will give such as Brisson has ranged among the rapacious birds; next those of the pie kind; and thus go on through the succeeding classes, till I finish with those of the duck kind. But before I enter upon a systcmatic detail, I will beg leave to give the history of three or four birds, that do not well range in any system. These, from their great size, are sufficiently distinguishable from the rest; and, from their incapacity of flying, lead a life a good deal differing from the rest of the feathered creation. The birds I mean are the Ostrich, the Cassowary, the Emu, the Dodo, and the Solitaire. 


\section{CHAPTER LXXVII.}

\section{THE OSTRICH.}

IN beginning with the feathered tribe, the first animal that offers seems to unite the class of quadrupeds and of birds in itself. While it lias the general outline and properties of a bird, yet it retains many of the marks of the quadruped. In appenrance the ostrich resembles the camel, and is almost as tall; it is covered with a plumage that resembles hair much more nearly than feathers, and its internal parts bear as near a similitude to those of the quadruped, as of the bird creation. It may be considered, therefore, as an animal made to fill up that chasm in nature which separates one class of beings from another.

The ostrich is the largest of all birds. Travellers affirm that they are seen as tall as a man on horseback; and even some of those that have been hrought into England were above seven feet high. The head and bill somewhat resemble those of a duck; and the neck may be likened to that of a swan, but that it is much longer; the legs and thighs resemble those of a ben; though the whole appearance bears a strong resemblance to that of a camel. But to be more particular: it is usually seven feet high from the top of the head to the ground; but from the back it is only four; so that the head and neck are above three feet long. From the top of the head to the rump, when the neck is stretched out in a right line, it is six feet long, and the tail is about a foot more. One of the wings, without the feathers, is a foot and a half; and being stretched out, with the feathers, is three feet.

The plumage is much alike in all; that is, generally black and white; though some of them are said to be gray. The greatest feathers are at the extremities of the wings and tail, and the largest are generally white. The next row is black and white; and of the small feathers, on the back and belly, some are white and others black. There are no feathers on the sides, nor yet on the thighs, nor under the wings. The lower part of the neck, about half way, is covered with still smaller feathers than those on the belly and back; and those, like the former, also are of different colours.

All these feathers are of the same kind, and peculiar to the ostrich; for other birds have several sorts, some of which are soft and downy, and others hard and strong. Ostrich feathers are almost all as soft as down, being utterly unfit to serve the animal for flying, and still less adapted to be a proper defence against external injury. The feathers of other birds have the webs broader on one side than the other, but those of the ostrich have their shaft exactly in the middle. The upper part of the head and neck are covered with a very fine, clear, white hair, that shines like the bristles of a hog; and in some places there are small tufts of it, consisting of about twelve hairs, which grow from a single shaft about the thickness of a pin.

At the end of each wing, there is a kind of spur, almost like the quill of a porcupine. It is an inch long, being hollow, and of a horny substance. There are two of these on each wing; the largest of which is at the extremity of the bone of the wing, and the other a foot lower. The neck seems to be more slender in proportion to that of other birds, from its not being furnished with feathers. The skin in this part is of a livid flesh-colour, which some improperly would have to be blue. The bill is short and pointed, and two inches and a half at the beginuing. The external form of the eye is like that of man, the upper eye-lid being adorned with eye-lashes, which are longer than those on the lid below. The tongue is small, very short, and composed of cartilages, ligaments, and membranes, intermixed with fleshy fibres. In some it is about an inch long, and very thick at the bottom. In others it is but half an inch, being a little forked at the end. 
The thighs are very fleshy and large, being covered with a white skin, inclining to redness, and wrinkled in the manner of a net, whose meshes will admit the end of a finger. Some have very small feathers here and there on the thighs; and others again have neither feathers nor wrinkles. What are called the legs of birds, in this are covered before with large scales. The end of the foot is cloven, and has two very large toes, which, like the leg, are covered with scales. These toes are of unequal sizes. The largest, which is on the inside, is seven inches long, including the elaw, which is near three-fourths of an inch in length, and almost as broad. The other toe is but four inches long, and is without a claw.

The internal parts of this animal are formed with no less surprising peculiarity. At the top of the breast, under the skin, the fat is two inches thick; and on the fore part of the belly it is as hard as suet, and about two inches and a half thick in some places. It las two distinct stomachs. The first, which is lowermost, in its natural situation somewhat resembles the crop in other birds; but it is considerably larger than the other stomach, and is furnished with strong muscular fibres, as well circular as longitudinal. The second stomach, or gizzard, lias outwardly the shape of the stomach of a man; and, upon opening, is always found filled with a variety of discordant substances; hay, grass, barley, beans, bones, and stones, some of which exceed in size a pullet's egg. The kidneys are eiglit inches long and two broad, and differ from those of other birds in not being divided into lobes. The heart and lungs are separated by a midriff, as in quadrupeds, and the parts of generation also bear a very strong resemblince and analogy.

Sirch is the structure of this animal, forming the shade that unites birds and quadrupeds; and from this structure its habits and manners are entirely peculiar. It is a native only of the torrid regions of Africa, and has long been celebrated by those who have had occasion to mention the animals of that region. Its flesh is proseribed in scripture as unfit to be eaten; and most of the ancient writers describe it as well known in their times. Like the race of the elephant, it is transmit- ted down without mixture; and has never been known to breed out of that country which first produced it. It seems formed to live among the sandy and burning deserts of the torrid zone; and, as in some measure it owes its birth to their genial influence, so it seldom migrates into traets more mild or more fertile. As that is the peculiar country of the elephant, the rhinoceros, and camel, so it may readily be supposed capable of affording a retreat to the ostrich. They inhabit, from preference, the most solitary and horrid deserts, where there are few vegetables to clothe the surface of the earth, and where the rain never comes to refresh it. The Arabians assert that the ostrich never drinks; and the place of its habitation seems to confirm the assertion. In these formidable regions, ostriches are seen in large flocks, which to the distant spectator appear like a regiment of eavalry, and have often alarmed a whole caravan. There is no desert, how barren soever, but what is capable of supplying these animals with provision; they eat almost every thing; and these barren tracts are thus doubly grateful, as they afford both food and security. The ostrich is of all other animals the most voracious. It will devour leather, glass, hair, iron, stones, or any thing that is given. Nor are its powers of digestion less in such things as are digestible. Those substances which the coats of the stomach cannot soften, pass whole; so that glass, stones, or iron, are excluded in the form in which they were devoured. All metals, indeed, which are swallowed by any animal, lose a part of their weight, and often the extremities of their figure, from the action of the juices of the stomach upon their surface. A quarter pistole, which was swallowed by a duek, lost seven grains of its weight in the gizzard before it was voided; and it is probable that a still greater diminution of weight would happen in the stomach of an ostricl. Considered in this light, therefore, this animal may be said to digest iron; but such substances seldom remain long enough in the stomach of any animal to undergo so tedious a dissolution. However this be, the ostrich swallows almost every thing presented to it. Whether this be from the necessity which smaller birds are under of picking up gravel 
to keep the coats of their stomach asunder, or whether it be from a want of distinguishing by the taste what substances are fit and what incapable of digestion; certain it is, that in the ostrich dissected by Ranby there appeared such a quantity of heterogeneous substances, that it was wonderful how any animal could digest such an overcharge of nourishment. Valisnieri also found the first stomach filled with a quantity of incongruous substances; grass, nuts, cords, stones, glass, brass, copper, iron, tin, lead, and wood; a piece of stone was found among the rest, that weighed more than a pound. He saw one of these animals that was killed by devouring a quantity of quick-lime. It would seem that the ostrich is obliged to fill up the great capacity of its stomach, in order to be at ease; but that nutritious substances not occurring, it pours in whatever offers to supply the void.

In their native deserts, however, it is probable they live chiefly upon vegetables, where they lead an inoffensire and social life; the male, as Therenot assures us, assorting with the female with connubial fidelity. They al'e said to be very much inclined to venery; and the make of the parts in both sexes seems to confirm the report. It is probable also they copulate, like other birds, by compression; and they lay very large eggs, some of them being above five inches in diameter, and weighing above fifteen pounds. These eggs have a very hard shell, somewhat resembling those of the crocodile, except that those of the latter are less and rounder.

The season for laying depends on the climate where the animal is bred. In the northern parts of Africa, this season is about the beginning of July; in the south, it is about the latter end of December. These birds are very prolific, and lay generally from forty to fifty eggs at one clutch. It has been commonly reported that the female deposits them in the sand; and, covering them up; leaves them to be hatched by the heat of the climate, and then permits the young to shift for themselves. Very little of this, however, is true: no bird has a stronger affection for her young than the ostrich, nor none watches her eggs with greater assiduity. It happens, indeed, in those hot climates, that there is less necessity for the continual incubation of the fe- male; and she more frequently leares her eggs, which are in no fear of being chilled by the weather: but though slue sometimes forsakes them by day, she always carefully broods over them by night; and Kolben, who has seen great numbers of them at the Cape of Good Hope, affirms that they sit on their eggs like other birds, and that the male and female take this office by turns, as he had frequent opportunities of observing. Nor is it more true what is said of their forsaking their young after they are excluded the shell. On the contrary, the young ones are not even able to walk for several days after they are hatched. During this time, the old ones are very assiduous in supplying them with grass, and very careful to defend them from danger; nay, they encounter every danger in their defence. It was a way of taking them among the ancients, to plant a number of sharp stakes round the ostrich's nest in her absence, upon which she pierced herself at her return. The young, when brought forth, are of an ashcolour the first year, and are covered with feathers all over. But, in time, these feathers Irop; and those parts which are covered assume a difierent aud more hecoming plumage.

The beauty of a part of this plumage, particularly the loing feathers that compose the wings aud tail, is the chief reason that man has been so active in pursuing this harmless bird to its deserts, and hunting it with no small degree of expense and labour. The ancients used those plumes in their helmets; the ladies of the East make them an ornament in their dress; and, among us, our undertakers and our fue gentlemen still make use of thein to decorate their hearses and their hats. Those feathers which are plucked from the animal while alive, are much more valued than those taken when dead; the latter being dry, light, and subject to be worm-eaten.

Beside the value of their plumage, some of the savage nations of Africa hunt them also for their flesh, which they consider as a dainty. They sometimes also breed these birds tame, to eat the young ones, of which the female is said to be the greatest delicacy. Some nations have obtained the name of Struthophagi, or ostrich-eaters, from their peculiar fondness for this food; and eren the 
Romans themselves were not averse to it. Apicius gives us a rcceipt for making sauce for the ostrich; and Heliogabalus is noted for having dressed the brains of six hundred ostriches in one dish; for it was his custom never to eat but of one dish in a day, but that was an expensive one. Even among the Europcans now, the eggs of the ostrich are said to be well tasted, and extremely nourishing; but they are too scarce to be fer upon, although a single egg be a sufficient entertainment for eight men.

As the spoils of the ostrich are thus valuable, it is not to be wondered at that man has become their most assiduous pursuer. For this purpose, the Arabians train up their best and fleetest horses, and hunt the ostrich still in view. Perhaps of all other varieties of the chace, this, though the most laborious, is yet the most entertaining. As soon as the hunter comes within sight of his prey, he puts on his horse with a gentle gallop, so as to kcep the ostrich still in sight; yet not so as to terrify him from the plain into the mountaius. Of all known animals that make use of their legs in running, the ostrich is by far the swiftest; upon observing himself therefore pursued at a distance, he begins to run at first but gently; either insensible of his danger, or sure of escaping. In this situation he somewhat resembles a man at full speed; his wings, like two arms, keep working with a motion correspondent to that of his legs : and his speed would very soon snatch him from the view of his. pursuers; but, unfortunately for the silly creature, instead of going off in a direct line, he takes his course in circles; whilc the hunters still make a small course within, relieve each other, mect him at unexpected turns, and keep him thus still employed, still followed for two or three days together. At last, spent with fatigue and famine, and finding all power of escape impossible, he endeavours to hide himself from those enemies he cannot avoid, and covers his head in the sand, or the first thicket he mects. Sometimes, however, he attempts to face his pursuers; and, though in general the most gentle animal in nature, when driven to desperation, he defends himself with his beak, his wings, and his feet. Such is the force of his motion, that a man would be utterly unable to withstand him in the shock.
The Struthophagi have another method of taking this bird; they cover themselves with an ostrich's skin, and passing up an arm through the neck, thus counterfeit all the motions of this aninal. By this artitice they approach the ostrich, which becomes an casy prey. He is sometimes also taken by dogs and nets: but the most usual way is that mentioned above.

When the Arabians have thus Iaken an ostrich, they cut its throat, and making a ligature below the opening, they shake the bird, as one would rince a barrel; then taking off the ligature, there runs out from the wound in the throat a considerable quantity of blood, mixed with the fat of the animal; and this is considered one of their greatest dainties. They next flay the bird; and of the skin, which is strong and thick, sometimes make a kind of vest, which answers the purposes of a cuirass and a buckler.

There are others who, more compassionate or more provident, do not kill their captive, but endeavour to tame it, for the purposes of supplying those feathers which are in so great request. The inhabitants of Dara and Lybia breed up whole flocks of them, and they are tamed with very little trouble. But it is not for their feathers alone that they are prized in this domestic state; they are often ridden upon, and uscd as horses. Moore assures us, that at Joar he saw a man travelling upon an ostrich; and Adanson asserts, that, at the factory of Podore, he had two ostriches, which were then young, the strongest of which ran swifter than the best English racer, although he carried two negroes on his back. As soon as the animal perceived that it was loaded, it set off running with all its force, and made sevaral circuits round the village; till at length the peeple werc obliged to stop it, by barring up the way. How far this strength and swiftness may be useful to mankind, even in a polished state, is a matter that perhaps deserves inquiry. Posterity may avail themselves of this creature's abilitics; and riding upon an ostrich may one day become the favourite, as it most certainly is the swiftest, mode of conveyance.

The parts of this animal are said to be convertible to many salutary purposes in medicine. The fat is said to be cmollient and re. 
laxing; that while it relaxes the tendons, it fortifies the nervous system; and being applied to the region of the loins, it abates the pains of the stone in the kidneys. The shell of the egg powdered, and given in proper quantities, is said to be useful in promoting urine, and dissolving the stone in the bladder. The substance of the egg itself is thought to be peculiarly nourishing: however, Galen, in mentioning this, asserts, that the eggs of hens and pheasants are good to be eaten; those of geese and ostriches are the worst of all.

\section{CHAPTER LXXVIII.}

\section{THE EMU.}

OF this bird, which many call the Amevican Ostrich, but little is certainly known. It is an inhabitant of the New Continent; and the travellers who have mentioned it, seem to have been more solicitous in proving its affinity to the ostrich, than in describing those peculiarities which distinguish it from all others of the feathered creation.

It is chiefly found in Guiana, along the banks of the Oroonoko, in the inland provinces of Brasil and Chili, and the vast forests that border on the mouth of the river Plata. Many other parts of South America were known to have them; but as men multiplied, these large and timorous birds either fell beneath their superior power, or fled from their vicinity.

The Emu, though not so large as the ostrich, is only second to it in magnitude. It is by much the largest bird in the New Continent; and is generally found to be six feet high, measuring from its head to the ground. Its legs are three feet long; and its thigh is near as thick as that of a man. The toes differ from those of the ostrich; as there are three in the Americen bird, and but two in the former. Its neek is long, its head small, and the bill flatted, like that of the ostrich; but in all other respects it more resembles the Cassowary, a large bird, to be described hereafter. The form of the body appears round; the wings are short, and entirely unfitted for flying, and it wants a tail. It is covered from the back and rump with long feathers, which fall backward, and cover the anus; these feathers are gray upon the back, and white on the belly. It goes very swiftly, and seems assisted in its motion by a kind of tubercle behind, like an heel, upon which, on plain ground, it treads rery securcly; in its course it uses a very odd kind of action, lifting up one wing, which it keeps elevated for a time; till letting it drop, it lifts up the other. What the bird's intention may be in thus keeping only one wing up, is not easy to discover; whether it makes use of this as a sail to catch the wind, or whether as a rudder to turn its course, in order to avoid the arrows of the Indians, yet remains to be ascertained : however this be, the emu runs with such swiftness, that the fleetest dogs are thrown out in the pursuit. One of them, finding itself surrounded by the hunters, darted among the dogs with such fury, that they made way to aroid its rage; and it escaped, by its amazing velocity, in safety to the mountains.

As this bird is but little kuown, so travellers have given a loose to their imaginations in describing some of its actions, which they were conscious could not be easily contradicted. This animal, says Nierenberg, is very peculiar in the hatching of its young. The male compels trenty or thirty of the females to lay their eggs in one nest; he then, when they have done laying, chases thein away, and places himself upon the eggs; however, he takes the singular precaution of laying two of the number aside, which he does not sit upon. When the young ones come forth, these two eggs are addled; which the male having foreseen, breaks one, and then the other, upon which multitudes of flies are found to settle; and these supply the young brood with a sufficiency of pro- 
vision, till they are able to shift for themselves.

On the other hand, Wafer asserts, that he has seen great quantities of this animal's eggs on the desert shores, north of the river Plata; where they were buried in the sand, in order to be hatched by the heat of the climate. Both this, as well as the preceding account, may be doubted; and it is more probable that it was the crocodile's eggs whichWafer had seen, which are und oubtedly hatched in that manner.

When the young ones are hatched, they are familiar, and follow the first person they meet. I have been followed myself, says
Wafer, by many of these young ostriches; which, at first, are extremely harmless and simple: but as they grow older, they become more cunning and distrustful; and run so swift, that a grayhound can scarcely overtake them. Their flesh, in general, is good to be eaten; especially if they be young. It would be no difficult matter to rear up flocks of these animals tame, particularly as they are naturally so faniliar: and they might be found to answer domestic purposes, like the hen or the turkey. Their maintenance could not be expensive, if, as Narborough says, they live entirely upon grass.

\section{CHAPTER LXXIX.}

\section{THE CASSOWARY.}

THE Cassowary is a bird which was first brought into Europe by the Dutch, from Java, in the East Indies, in which part of the world it is only to be found. Next to the preceding, it is the largest and the heaviest of the feathered species.

The cassowary, though not so large as the former, yet appears more bulky to the eye; its body being nearly equal, and its neck and legs much thicker and stronger in proportion; this conformation gives it an air of strength and force, which the fierceness and singularity of its countenance conspire to render formidable. It is five feet and a half long, from the point of the bill to the extremity of the claws. The legs are two feet and a lualf high, from the belly to the end of the claws. The head and neck together are a foot and a half; and the largest toe, including the claw, is five inches long. The claw alone of the least toe, is three inches and a half in length. The wing is so small, that it does not appear; it being hid under the feathers of the back. In other birds, a part of the feathers serve for flight, and are different from those that serve for merely covering; but in the cassowary, all the feathers are of the same kind, and outwardly of the same colour. They are generally double; having two long shafts, which xo. $39 \& 40$. grow out of a short one, which is fixed in the skin. Those that are double, are always of an unequal length; for some are fourteen inches long, particularly on the rump; while others are not above three. The beards that adorn the stem or shaft, are, from about half way to the end, very long, and as thick as a horse hair, without being subdivided into fibres. The stem or shaft is flat, shining, black, and knotted below; and from each knot there proceeds a beard: likewise the beards at the end of the large feathers are perfectly black; and towards the root of a gray tawny colour; shorter, more soft, and throwing out fine fibres like down; so that nothing appears except the ends, which are hard and black; because the other part, composed of down, is quite covered. There are feathers on the head and neck; but they are so short and thinly sown, that the bird's skin appears naked, except towards the hinder part of the head, where they are a little longer. The feathers which adorn the rump are cxtremely thick; but do not differ, in other respects, from the rest, excepting their being longer. The wings, when they are deprived of their feathers, are but three inches long; and the fcathers are like those on other parts of the bodv. The ends of the wings $3 \mathrm{z}$ 
are adorned with five prickles, of different lengths and thickness, which bend like a bow; these are hollow from the roots to the very points, having ouly that slight substance within, which all quills are known to have. The longest of these prickles is eleveninches; and it is a quarter of an inch in diameter at the root, being thicker there than towards the extremity; the point seems broken off.

s. The part, however, which most distinguishes this animal is the head: this, though small, like that of an ostrich, does not fail to inspire some degree of terror. It is bare of feathers, and is in a manner armed with an helmet of homy substance, that covers it from the root of the bill to near half the head backwards. This helmet is black before and yellow behind. Its substance is very hard, being formed by the elevation of the bone of the skull; and it conisists of several plates, one over another, like the horil of an ox. Some have supposed that this was shed every year with the feathers; but the inost probable opinion is, that it only oxfoliates slowly like the beak. To the peculiar oddity of this natural armour may be added the colour of the eye in this animal, which is a bright yellow, and the globe being above an inch and a half in diameter, gives it an air equally fierce and extraordinary. At the bottom of the upper eye-lid, there is a row of small hairs, over which there is another row of black hair, which look pretty much like an cye-brow. The lower eye-lid, which is the largest of the two, is furnished also with plenty of black hair. The hole of the ear is very large and open, being ouly covered with small black feathers. The sides of the head, about the eye and ear, being destitute of any covering, are blue, except the middle of the lower eye-lid, which is white. The part of the bill which answers to the upper jaw in other animals, is very hard at the edges above, and the extremity of it like that of a turkey-cock. The end of the lower mandible is slightly notched, and the whole is of a grayish brown, except a green spot on each side. As the beak admits a very wide opening, this contributes not a little to the bird's menacing appearance. The neck is of a violet colour, inclining to that of a slate; and it is red behind in several places, but chiefly in the middle. About the middle of the neck before, at the rise of the large feathers. there are two processes formed by the skin, which resemble somewhat the gills of a cock. but that they are bluc as well as red. The skin which covers the fore part of the breast, on which this bird leans and rests, is hard, callous, and without feathers. The thighs and legs are covered with feathers, and are extremely thick, strong, straight, and covered with scales of several shapes; biut the legs are thicker a little above the foot than in any other place. The toes are likewise covered with scales, and are but three in number; for that which should be belind is wanting. The claws are of a hard solid substance, black without, and white within.

The internal parts are equally remarkable. The cassowary unites with the double stomach of animals that live upon vegetables, the short intestines of those that live upon flesh. The intestines of the cafsowary are thirteen timesshorter than those of the ostrich. The heart is very small, being but an inch and a halflong, and an inch broad at the base. Upon the whole, it has the head of a warrior, the eye of a lion, the defence of a porcupine, and the swiftness of a courser.

Thus formed for a life of hostility, for terrifying others, and for its own defence, it might be expected that the cassowary was one of the most fierce and terrible animals of the creation. But nothing is so opposite to its natural character, nothing so different from the life it is contented to lead. It never attacks others; and, instead of the bill, when attacked, it rather makes use of its legs, and kicks like a horse, or runs against its pursucr, beats him down, and trcads him to the ground.

The manner of going of this animal is not less extraordinary than its appearance. Instead of going directly forward, it seems to kick up behind with one leg, and then making a bound onward with the other, it goes with such prodigious velocity, that the swiftest racer would be left far behind.

The same degree of voraciousness which we perccive in the ostrich, obtains as strongly here. 'The cassowary sivallows cvery thing that comes within the capacity of its gullet. The Dutch assert, that it can devour not only glass, iron, and stones, but even live on burn- 
ing coals, without testifying the smallest fear, or feeling the least injury. It is said, that the passage of the food through its gullet is performed so speedily, that even the very eggs which it has swallowed whole, pass through it unbroken, in the same form they went down. In fact, the alimentary canal of this animal, as was observed above, is extremely short; and it may happen that many kinds of food are indigestible in its stomacls, as wheat or currants are to a man when swallowed whole.

The cassowary's eggs are of a gray ash colour, inclining to green. They are not so large nor so round as those of the ostrich. They are marked with a number of little tubercles of a deep green, and the shell is not very thick. The largest of these is found to be fifteen inches round one way, and about twelve the other.

The southern parts of the most eastern Indies seems to be the natural climate of the cassowary. His domain, if we may so call it, begins where that of the ostrich terminates. The latter has never been found beyond the
Ganges; while the cassowary is never seen nearer than the islands of Banda, Sumatra, Java, the Molucca Islands, and the corresponding parts of the continent. Yet even here this animal scens not to have multiplied in any considerable degree, as we find one of the kings of Java making a present of one of these birds to the captain of a Dutch ship, considering it as a very great rarity. The ostrich, that has kept in the desert and unpeopled regions of Africa, is still numerous, and the unrivalled tenant of its own inhospitable climate. But the cassowary, that is the inhabitant of a more peopled and polished region, is growing scarcer every day. It is thus that in proportion as man multiplies, all the savage and noxious animals fly before him : at his approach they quit their ancient habitations, how adapted soever they may be to their natures, and seek a morc peaceable, though barren, retreat: where they willingly exchange plenty for frcedom; and encounter all the dangers of famine, to avoid the oppressions of an unrelenting dcstroyer.

\section{CHAPTER LXXX.}

\section{THE DODO.}

MANKIND have generally made swiftness the attribute of birds; but the dodo has no title to this distinction. Instead of exciting the idea of swiftuess by its appearance, it seems to strike the imagination as a thing the most unwieldy and inactive of all nature. Its body is massive, almost round, and covered with gray feathers; it is just barely supported upon two short thick legs, like pillars, while its head and neck rise from it in a manner truly grotesque. The neck, thick and pursy, is joined to the head, which consists of two great chaps, that open far behind the eyes, which are large, black, and prominent; so that the animal, when it gapes, seems to be all mouth. The bill, therefore, is of an extraordinary length, not flat and broad, but thick, and of a bluish white, sharp at the end, and each chap crooked in opposite directions. They resemble two pointed spoons that are laid together by the backs. From all this results a stupid and voracious physiognomy; which is still more increased by a bordering of feathers round the root of the beak, and which gives the appearance of a hood or cowl, and finishes this picture of stupid deformity. Bulk, which in other animals implies strength, in this only contributes to inactivity. The ostrich, or the cassowary, are no more able to fly than the animal before 115 ; but then they supply that defect by their speed in running. The dodo seems weighed down by its own heaviness, and has scarcely strength to urge itself forward. It seems among birds what the sloth is among quadrupeds, an unresisting thing, equally incapable 
of Hight or defence. It is furnished with wings, covered with soft ash-coloured feathers, but they are too short to assist it in flying. It is furnished with a tail, with a few small curled feathers ; but this tail is disproportioned and displaced. Its legs are too short for running, and its body too fat to be strong. One would take it for a tortoise that had supplied itself with the feathers of a bird; and that thus dressed out with the instruments of flight, it was only still the more unwieldy.

This bird is a native of the Isle of France; and the Dutch, who first discovered it there, called it, in their language, the nauseous bird, as well from its disgusting figure as from the bad taste of its flesh. However, succeeding observers contradict the first report, and assert that its flesh is good and wholesome eating. It is a silly simple bird, as may very well be supposed from its figure, and is very easily taken. Three or four dodos are enough to dine a hundred men.

Whether the dodo be the same bird with that which some travellers have described under the bird of Nazareth, yet remains uncertain. The country from whence they both come is the same; their incapacity of flying is the same; the form of the wings and body in both are similar; but the chief difference given is in the colour of the feathers, which in the female of the bird of Nazareth are said to be extremely beautiful; and in the length of their legs, which in the dodo are short; in the other, are described as long. Time and future observation must clear up these doubts; and the testimony of a single witness, who shall have seen both, will throw more light on the subject than the reasonings of a hundred philosopliers. 


\section{OF RAPACIOUS BIRDS.}

\section{CHAPTER LXXXI.}

\section{OF RAPACIOUS BIRDS IN GENERAL.}

THERE seems to obtain a general resernblance in all the classes of nature. As among quadrupeds, a part were seen to live upon the vegetable productions of the earth, and another part upon the flesh of each other; so among birds, some live upon vegetable food, and others by rapine, destroying all such as want force or swiftness to procure their safety. By thus peopling the woods with animals of different dispositions, nature has wisely provided for the nuultiplication of life; since, could we suppose that there were as many animals produced as there were vegetables supplied to sustain them, yet there might still be another class of animals formed, which could find a sufficient sustenance by feeding upon such of the vegetable feeders as happened to fall by the course of nature. By this contrivance, a greater number will be sustained upon the whole; for the numbers would be but very thin were every creature a candidate for the same food. Thus, by supplying a variety of appetites, nature has also multiplied life in her productions.

In thus varying their appetites, nature has also varied the form of the animal; and while she has given some an instinctive passion for animal food, she has also furnished them with powers to obtain it. All land-birds of the rapacious kinds are furnished with a large head, and a strong crooked beak, notched at the end, for the purpose of tearing their prey. They

\footnotetext{
- The animals of this order are all carnivorous; they associate in pairs, build their nests in the most lofty siluations, and produce generally four young ones at a brood: and the female is mostly larger than the male. Thcy consist of vultures, eagles, hawks, and owls.
}

have strong short legs, and sharp crooked talons, for the purpose of seizing it. Their bodies are formed for war, being fibrous and muscular; and their wings for swiftness of flight, being well feathered and expansive. The sight of such as prey by day is astonishingly quick; and such as ravage by night, have their sight so fitted as to see objects in darkness with extreme precision.

Their internal parts are equally formed for the food they seek for. Their stomach is simple and membranous, and wrapt in fat to increase the powers of digestion; and their intestines are short and glandular. As their food is succulent and juicy, they want no length of intestinal tube to form it into proper nourishment. Their food is flesh; which does not require a slow digestion to be converted into a similitude of substance to their own.

Thus formed for war, they lead a life of solitude and rapacity. They inhabit by choice the most lonely places, and the most desert mountains. They make their nests in the clefts of rocks, and on the highest and most inaccessible trees of the forest. Whenever they appear in the cultivated plain or the warbling grove, it is only for the purposes of depredation; and are gloomy intruders on the general joy of the landscape. They spread terror wherever they approach: all that variety of music which but a moment before enlivened the grove, at their appearing is instantly at an end: every order of lesser birds seek for safety, either by concealment or flight ; and some are even driven to take protection with man, to avoid their less merciful pursuers.

It would indeed be fatal to all the smaller race of birds, if, as they are weaker than all, 
they werc also pursued by all; but it is contrived wisely for their safety, that every order of carnivorous birds seek only for such as are of the size most approaching their own. The eagle flies at the bustard or the pheasant; the sparrow-hawk pursues the thrush and the linnet. Nature has provided that each species should make war only on such as are furnished with adequate means of eseape. The smallest birds avoid their pursuers by the extreme agility, rather than the swiftness of their flight ; for every order would soon be at an end, if the eagle, to its own swiftness of wing, added the versatility of the sparrow.

Another circumstance which tends to render the tyranny of these animals more supportable, is, that they are less fruitful than other birds; breeding but few at a time. Those of the larger kind seldom produce above four eggs, often but two; those of the snialler kinds, never above six or seven. The pigeon, it is true, which is their prey, never breeds above two at a time; but then she breeds every montl in the year. The carnivorous kinds only breed annually, and, of consequence, their fecundity is small in comparison.

As they are fierce by nature, and are difficult to be tamed, so this fiereeness extend: even to their young, which they force from the nest somer than birds of the gentler kind. Other birds stidom forsake their young till able, completely, to provide for thenselves: the rapacious kinds expel them from the nest at a time when they still sloould protect and support them. This severity to their young proceeds fiom the necessity of providing for themselves. All animals that, by the conformaiion of their stomach and intestines, are obliged to live upon flesh, and support themselves by prey, though they may be mild when young, soon become fierce and mischierous, by the very liabit of using those arms with which they are supplied by nature. As it is only by the destruction of other animals that they can subsist, they become more furious every day; and even the parental feelings are overpowered in their general habits of cruelty. If the power of obtaining a supply be difficult, the old ones soon drive their brood from the nest to shift for theinselves, and often destroy them in a fit of fury caused by hunger.

Another effect of this natural and acquired severity is, that almost all birds of prey are unsociable. It lias long been observed by Aristotle, that all birds with crooked benks and talons are solitary : like quadrupeds of the cat kind, they lead a lonely wandering life, and are united only in pairs, by that instinet which overpowers their rapacious habits of enmity with all other animals. As the male and fernale are often necessary to each otlier in their pursuits, so they sometimes live together; but except at certain seasons, they most usually prowl alone ; and, like robbers, enjoy in solitude the fruits of their plunder.

All birds of prey are remarkable for one singularity, for which it is not easy to account. All the males of these birds are about a third less, and weaker than the fenales, contrary to what obtains among quadrupeds, anong which the males are always the largest and the boldest: from thence the male is called by falconers a tarcel; that is, a tierce or third less than the other. The reason of this difference caunot proceed from the necessity of a larger body in the female for the purposes of breeding, and that her volume is thus increased by the quantity of her eggs; for in other birds, that breed much faster, and that lay in much greater proportion, such as the hen, the duck, or the pheasant, the male is by much the largest of the two.

Whatever be the cause, certain it is, that the females, as Willoughby expresses it, are of greater size, inore beautiful and lovely for shape and colours, stronger, niore fierce and generous, than the males; whether it may be that it is necessary for the female to be thus superior, as it is incumbent upon her to provide, not only for herself, but her young ones also.

These birds, like quadrupeds of the carnivorous kind, are all lean and meagre. Their flesh is stringy and ill-tasted, soon corrupting, and tinctured with the flavour of that animal food upon which they subsist. Nevertheless, Belonius asserts, that many people admire the flesh of the vilture and falcon, and dress them for eating, when they meet with any accident that unfits them for the chase. He asserts, that the osprey, a species of the eagle, when young, is excellent foor; but lse contents himself with advising us to breed these birds up for our pleasure rather in the field, than for the table.

Of land birds of a rapacious nature, there 


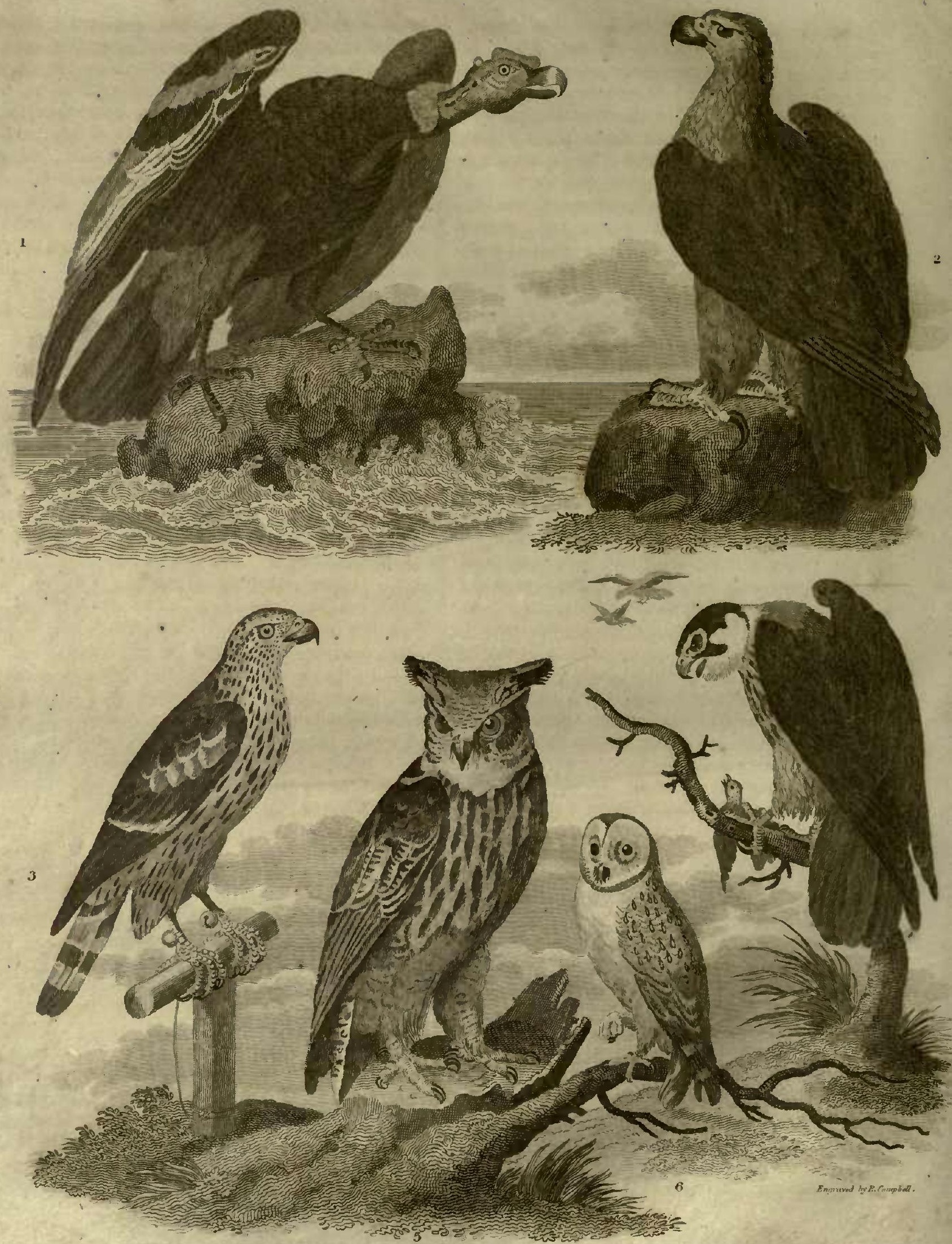

1. Genus Vulture. Conder of Mragellam .

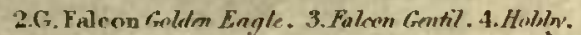

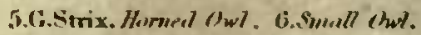


are five kinds. The eagle kind, the hawk kind, the vulture kind, the horned and the screecl owl kind. The distinctive marks of this class arc taken from their claws and beak: their toes are scparated: their legs are feathered to the heel: their toes are four in number; three bcfore, one behind: their beak is short, thick, and crooked.

The eagle kind is distinguished from the rest by his beak, which is straight till towards the end, when it begins to hook downwards.
The vulture kind is distinguished by the head and neck; which are witlout feathers.

The hawk kind by the beak; being hooked from the very root.

The liorued owl by the feathers at the base of the bill standing forwards; and by some feathers on the head that stand out, resembling horns.

The screech-owl by the feathers at the base of the bill standing forward, and being without horns. A description of one in each kind, will serve for all the rest.

\section{CHAPTER LXXXII.}

\section{THE EAGLE AND ITS AFFINITIES.}

THE Golden Eagle is the largest and the noblest of all those birds that have received the name of eagle. It weighs above twelve pounds. Its length is three feet; the extent of its wings, seven feet four inches; the bill is three inches long, and of a dcep blue colour ; and the eye of a hazel colour. The sight and scuse of smelling are very acute. The head and ncck are clothed with narrow sharp-pointed feathers, and of a deep brown colour, bordered with tawny; but those on the crown of the head, in very old birds, turn gray. The whole body, above as well as beneath, is of a dark brown; and the feathers of the back are finely clouded with a deeper shade of the sanic. 'l'he wings, when clothed, reach to the end of the tail. The quill-feathers are of a chocolate colour, the shafts white. The tail is of a deep brown, irregularly barred and blotched with an obscure ash-colour, and usually white at the roots of the feathers. The legs are yellow, short, and very strong, being three inches in circumference, and feathered to the very feet. The toes are covered with large scales, and armed with the most formidable claws, the middle of which are two inches long

In the rear of this terrible bird follow the ring-tailed eagle, the common eagle, the bald eagle, the white eagle, the kough-footed eagle, the erne, the black eagle, the osprey, the sea eagle, and the crowned eagle. These, and others that might be added, form different shades in this fierce family; but have all the same rapacity, the same general form, the same habits, and the same manner of bringing up their young.

In general, these birds are found in mountainous and ill-peopled countries, and breed among the loftiest cliffs. They choose those places which are remotest from man, upon whose possessions they but seldom make their depredations, being contented rather to follow the wild game in the forest, than to risk their safety to satisfy their hunger.

This fierce animal may be considered among birds as the lion among quadrupeds; and in many respects they have a strong similitude to each other. They are both possessed of force, and an empire over their fellows of the forest. Equally magnanimous, they disdain smaller plunder; and only pursue animals worthy the conquest. It is not till after having been long provoked, by the crics of the rook or the magpie, that this generous bird thinks fit to punish them with dcath: the eagle also disdains to share the plunder of another bird ; and will take up with no other prey but that which he has acquired by his own pursuits. How hungry soever he may be, he never stoops to carrion; and when satiated, he never returns to the same carcass, but leaves it for other animals, more rapacious and less delicate than he. Solitary, like the lion, he keeps the desert to himself alone; it is as 
extraordinary to sec two pair of eagles in the same mountain, as two lions in the same forest. They keep separate, to find a more anuple supply; and consider the quantity of their game as the best proof of their dominion. Nor does the similitude of these animals stop here: they have both sparkling eyes, and nearly of the same colour; their claws are of the same form, their breath equally strong, and their cry equally loud and terrifying. Bred both for war, they are enemies of all society: alike fierce, proud, and incapable of being easily tained. It requires great patience and much art to tame an eagle; and even though taken young, and brought under by long assiduity, yet still it is a dangerous domestic, and often turns its force against its master. When brought into the ficld for the purposes of fowling, the falconer is never sure of its attachment: that innate pride, and love of liberty, still prompt it to regain its native solitudes; and the moment the falconer sees it, when let loose, first stonp towards the ground, and then rise perpendicularly into the clouds, he gives up all his former labour for lost; quite sure of never beholrling his late prisoner more. Soinetinues, however, they are brought to have an attachment for theil. feeder; they are then highly serviceable, and liberally provide for his pleasures and support. When the falconer lets them go from his hand, they play about and hover round him till their gaine presents, which they see at an immense distance, and pursue with certain destruction.

Of all animals the eagle flies highest; and from thence the ancients lave given him the epithet of the bird of heaven. Of all others also, he has the quickest eye; but his sense of smelling is far inferior to that of the vulture. He never pursues, therefore, but in sight; and when he has seized his prey, he stoops from his leight, as if to cxamine its weight, always laying it on the ground before he carries it off. As his wing is very powerful, yet, as he has but little suppleness in the joints of the leg, he finds it difficult to rise when down; however, if not instantly pursued, he finds no difficulty in carrying off geese and cranes. He also carries away hares, lambs, and kids; and often destroys fawns and calves, to drink their blood, and carries a part of their flesh to his retreat. Infants themselves, when left unat- tended, have been dlestroyed by these rapacious creatures; which probably gave rise to the fable of Ganymede's being snatched up by an eagle to heaven.

An instance is recorded in Scotland of two children being carried off by eagles; but fortunately they received no hurt by the way; and, the eagles being pursued, the children were restored unhurt out of the nests to the affrighted parents.

The eagle is thus at all times a formidable neighbour; but peculiarly when bringing up its young. It is then that the femalc, as well as the male, exert all their force and industry to supply their young. Smith, in his history of Kerry, relates, that a poor man in that country got a comfortable subsistence for his family, during a sunmer of famine, out of an eagle's nest, by robbing the eaglets of food, which was plentifully supplied by the cld ones. He protracted their assiduity beyond the usual time, by clipping the wings, and retarding the fight of the young; and very probably also, as I have known myself, by so tying them as to increase their cries, which is always found to increase the parent's despatch to procure them provision. It was lucky, however, that the old eagles did not surprise the countryman as he was thus employed, as their resentment might have been dangerous.

It happened some time ago, in the same country, that a peasant resolved to rob the nest of an cagle, that had built in a small island in the beautiful lake of Killarney. He accordingly st i ped, and swam in upon the island while the old unes were away; and, robbing the nest of its young, lic was preparing to swim back, with the eaglets tied in a string; but while he was yet up to his chin in the water, the old eagles returned, and, missing their young, quickly fell upon the plunderer, and, in spite of all his resistance, despatched him with their beaks and talons.

In eider to extirpate these pernicious birds, there is a law in the Orkney Islands, which entitles any person that kills an eagle to a hen out of every house in the parish in which the plunderer is killed.

The nest of the engle is usually built in the most inaccessible cliff of the rock, and often slielded from the weather by some jutting crag that hangs over it. Sometimes, huwever, it is wholly exposed to the winds, as 
well sideways as above; for the nest is flat, though built with great labour. It is said that the same nest serves the eagle during life; and indeed the pains bestowed in forming it seems to argue as mueb. One of these was found in the P'eak of Derbyshire; which Willoughby thus describes. "It was made of great sticks, reating one end on the edge of a rock, the other on two birch trees. Upon these was a layer of rushes, and over them a layer of heath, and upon the heath rushes again; upon which lay one young one, and an addle egg; and by them a lamb, a hare, and three heath-poults. The nest was about two yards square, and had no hollow in it. The young eagle was of the shape of a goshawk, of almost the weight of a goose, rough footed, or feathered down to the foot, having a white ring about the tail." Such is the place where the female eagle deposits her eggs; which seldom exceed two at a time in the largest species, and not above three in the smallest. It is said that she hatches them for thirty days: but frequently, even of this small number of eggs, a part is addled; and it is extremely rare to find three eaglets in the same nest. It is asserted, that as soon as the young ones are somewhat grown, the mother kills the most feeble or the most voracious. If this happens, it must proceed only from the necessities of the parent, who is incapable of providing for their support; and is content to sacrifice a part to the welfare of all.

The plumage of the eaglets is not so strongly marked as when they come to be adult. They are at first white; then inclining to yellow; and at last of a light brown. Age, hunger, long captivity, and diseases, make them whiter. It is said, they live above a hundred years; and that they at last die, not of old age, but from the beaks turning inward upon the under mandible, and thus preventing their taking any food. They are equally remarkable, says Mr. Pennant, for their longevity, and for their power of sustaining a long abstinence from food. One of this species, which bas now been nine years in the possession of Mr. Owen Holland, of Conway, lived thirty-two years with the gentleman who made him a present of it; but what its age was when the latter received it from Ireland, is unknown. The same bird also พo. $41 \& 42$. furnishes a proof of the truth of the other remark; having once, through the neglect of servants, endured hunger for twenty-one days, without any sustenance whatever.

Those eagles which are kept tame, are fed with every kind of flesh, whether fresh or corrupting; and when there is a deficiency of that, bread, or any other provision, will suffice. It is very dangerous approaching them if not quite tame; and they sometimes send forth a loud piercing lamentable cry, which renders them still more formidable. The eagle drinks but seldom; and perhaps, when at liberty, not at all, as the blood of its prey serves to quench its thirst. The eagle's excrements are always soft and moist, and tinged with that whitish substance which, as was said before, mixes in birds with the urine.

Such are the general characteristics and habitudes of the eagle; however, in some these habitudes differ, as the Sea Eagle and the Osprey live chiefly upon fish, and consequently build their nests on the sea-shore, and by the sides of rivers on the ground among reeds; and often lay three or four eggs, rather less than those of a hen, of a white elliptical form. They catch their prey, which is chiefly fish, by darting down upon them from above. The Italians compare the violent descent of these birds on their prey to the fall of lead into water; and call them aquila piombina, or the Leaden eagle.

Nor is the bald eagle, which is an inhabitant of North Carolina, less remarkable for habits peculiar to itself. These birds breed in that country all the year round. When the eaglets are just covered with down, and a sort of white woolly feathers, the female eagle lays again. These eggs are left to be hatched by the warmth of the young ones that continue in the nest; so that the flight of one brood makes room for the next that are but just hatehed. These birds fly very heavily; so that they cannot overtake their prey, like others of the same denomination. To remedy this, they often attend a sort of fishing-hawk, which they pursue, and strip the plunderer of its prey. This is the more remarkable, as this hawk flies swifter than they. These eagles also generally attend upon fowlers in the winter; and when any birds 
are wounded, they are sure to be seized by the eagle, though they may fly from the fowler. This bird will often also steal young pigs, and carry them alive to the nest, which is composed of twigs, sticks, and rubbish; it is large enough to fill the body of a cart; and is commonly full of bones half eaten, and putrid flesh, the stench of which is intolerable.

The distinctive marks of each species are as follow :

The golden eagle: of a tawny iron colour; the head and neck of a reddish iron; the tail feathers of a dirty white, marked with cross bands of tawny iron; the legs covered with tawny iron feathers.

The common eagle: of a brown colour; the head and upper part of the neck inclining to red; the tail feathers white, blackening at the ends; the outer ones, on each side, of an ash colour; the legs covered with feathers of a reddish brown.

The bald eagle: brown; the head, neck, and tail feathers, white; the feathers of the upper part of the leg brown.

The white eagle: the whole white.

The rough-footed eagle: of a dirty brown; spotted under the wings, and on the legs, with white; the feathers of the tail white at the beginning and the point; the leg feathers dirty brown, spotted with white.

The white-tailed cagle: dirty brown; head white; the stems of the feathers black; the rump inclining to black; the tail feathers, the first half black, the end half white; legs naked.

The erne: a dirty iron colour above, an

- To these we may add, the bearded eagle of the Alps, a bird of vast size, measuring sometimes nearly ten feet from the tip of one wing to the tip of the other: below the throat is a beard-like appendage, consisting of very aarrow feathers. The legs are clothed with feathers quite down to the toes. One of these Mr. Bruce shot on the high mountains of Abyssinia. "Upon laying hold of his monstrous carcass, (says he) I was not a little surprised at seeing my hands covered and tinged with a yellow powder or dust. Upon turning him on his belly, and examining the feathers of his back, they also produced a iron mixed with black below; the head and neck ash, mixed with chesnut; the points of the wings blackish; the tail feathers white; the legs naked.

The black eagle: blackish; the head and upper neck mixed with red; the tail feathers, the first half white, speckled with black; the other half blackish; the leg feathers dirty white.

The sea eagle: inclining to white, mixed with iron brown; belly white, with ironcoloured spots; the covert feathers of the tail whitish; the tail feathers black at the extremity; the upper part of the leg feathers of an iron brown.

The osprey: brown above, white below; the back of the head white, the outward tail feathers, oll the inner side, streaked with white; legs naked.

The jean le blane: above, brownish gray; below, white, spotted with tawny brown; the tail fcathers, on the outside and at the extremity, brown; on the inside, white, streaked with brown; legs naked.

The eagle of Brasil : blackish brown; ash colour, mixed in the wings; tail feathers white; legs naked.

The Oroonoko cagle: with a topping; above, blackish brown; below, white, spotted with black; upper neck yellow; tail feathers brown, with white circles; leg feathers white, spotted with black.

The crouned African eagle: with a topping; the tail of an ash colour, streaked on the upper side with black.

The eagle of Pondicherry: chesnut colour; the six outward tail feathers black one half."

dust, the colour of the feathers there. The dust was not in small quantities; for, upon striking the breast, the yellow powder flew in full greater qualltity than from a hairdresser's powder-puff. What is the reason of this extraordinary provision of nature, it is not in my power to determine. As it is an unusual one, it is probably meant for a defence against the climate, in favour of the birds which live in those almost inaccessible heights of a country doomed, even in its lower parts, to several months excessive rain." 


\section{CHAPTER LXXXIII.}

\section{THE CONDOR OF AMERICA.}

WE might now come to speak of the vulture kind, as they hold the next rank to the eagle; but we are interrupted in our method, by the consideration of an enormous bird, whose place is not yet ascertained; as naturalists are in doubt whether to refer it to the eagle tribe, or to that of the vulture. Its great strength, force, and vivacity, might plead for its place among the former; the baldness of its head and neck might be thought to degrade it among the latter. In this uncertainty, it will be enough to describe the bird, by the lights we have, and leave future historians to settle its rank in the feathered creation. Indeed, if size and strength, combined with rapidity of flight and rapacity, deserve preeminence, no bird can bc put in competition with it.

The Condor possesses, in a higher degree than the eagle, all the qualities that render it formidable, not only to the feathered kind, but to beasts, and even to man himself. Acosta, Garcilasso, and Desmarchais, assert, that it is eighteen feet across, the wings extended. The beak is so strong as to pierce the body of a cow: and two of them are able to devour it. They do not even abstain from man himself: but fortunately there are but few of the species; for if they had been plenty, every order of animals must lave carried on an unsuccessful war against them. The Indians assert, that they will carry off a deer, or a young calf, in their talons, as eagles would a hare or a rabbit; that their sight is piercing, and their air terrible; that they seldom frequent the forests, as they require a large space for the display of their wings; but that they are found on the sea-shore, and the banks of rivers, whither they descend from their heights of the mountains. By later accounts we learn, that they come down to the sea-shore only at certain seasons, when their prey happens to fail them upon land; that they then feed upon dead fish, and such other nutritious substances as the sea throws upon the shore. We are assured, however, that their countenance is not so terrible as the old writers have represented it; but that they appear of a milder nature than cither the eagle or the vulture.

Coudamine has frequently seen them in several parts of the mountains of Quito, and observed them hovering over a flock of sheep; and he thinks they would, at a certain time, have attempted to carry one off, had they not been scared away by the shepherds. Labat acquaints us, that those who have seen this animal, declare that the body is as large' as that of a sheep; and that the flesh is tough, and as disagreeable as carrion. The Spaniards themselves seem to dread its depredations; and there have been many instances of its carrying off their children.

Mr. Strong, the master of a ship, as he was sailing along the coasts of Chili, in the thirtythird degree of south latitude, observed a bird sitting upon a high cliff near the shore, which some of the ship's company shot with a leaden bullet, and killed. They were greatly surprised when they beheld its magnitude; for when the wings were extended, they measured thirteen feet from one tip to the other. One of the quills was two feet four inches long; and the barrel, or hollow part, was six inches and three quarters, aud an inch and a half in circumference.

We have a still more circumstantial account of this amazing bird, by P. Feuille, the only traveller who has accurately described it: "In the valley of Ilo in Peru, I discovered a condor perched on a high rock before me: I approached within gun-shot, and fired; but, as iny piece was only charged with swan-shot, the lead was not able sufficiently to pierce the bird's feathers. I perceived, however, by its manner of flying, that it was wounded; and it was with a good deal of difficulty that it flew to another rock, about five hundred 
yards distant on the sea-shore. I therefore charged again with ball, and hit the bird under the throat, which made it mine. I accordingly ran up to seize it; but even in death it was terrible, and defended itself upon its back, with its claws extended against me, so that I scarcely knew how to lay hold of it. Had it not been mortally wounded, I should have found it no easy matter to take it; but I at last dragged it down from the rock, and, with the assistance of one of the seamen, I carried it to my tent, to make a coloured drawing.

"The wings of this bird, which I measured very exactly, were twelve feet three inches (English) from tip to tip. The great feathers, that were of a beautiful shining black, were two feet four inches long. The thickness of the beak was proportionable to the rest of the body; the length about four inches; the point hooked downwards, and white at its extremity; and the other part was of a jet black. A short down, of a brown colour, covered the head; the eyes were black, and surrounded with a circle of reddish brown. The feathers, on the breast, neck, and wings, were of a light brown; those on the back were rather darker. Its thighs were covered with brown feathers to the knee. The thigh bone was ten inches long; the leg five inches; the toes were three before, and one behind: that behind was an inch and a half; and the claw with which it was armed was black, and three quarters of an inch. The other claws were in the same proportion; and the legs were covered with black scales, as also the toes; but in these the scales were larger.

"These birds usually keep in the mountains, where they find their prey: they never descend to the sea-shore but in the rainy season; for, as they are very sensible of cold, they go there for greater warmth. Though these mountains are situated in the torrid zone, the cold is often very severe; for a great part of the year they are covered with snow, but particularly in winter.

"The little nourishment which these birds find on the sea-coast, except when the tempest drives in some great fish, obliges the condor to continue there but a short time. They usually come to the coast at the approach of evening; stay there all night, and fly back in the morning."

It is doubted whether this animal be proper to America only, or whether it may not have been described by the naturalists of other countrics. It is supposed that the great bird called the Rock, described by Arabian writers, and so much exaggerated by fable, is but a species of the condor. The great bird of Tarnassar, in the East Indies, that is larger than the eagle, as well as the vulture of Senegal, that carries off children, are probably no other than the bird we have been. describing. Russia, Lapland, and even Switzerland and Germany, are said to have known this animal. A bird of this kind was shot in France, that weighed eighteen pounds, and was said to be eighteen feet across the wings: however, one of the quills was described only as being larger than that of a swan; so that probably the breadth of the wings may have been exaggerated, since a bird so large would have the quills more than twice as big as those of a stvan. However this be, we are not to regret that it is scarcely ever seen in Europe, as it appears to be one of the most formidable enemies of mankind. In the deserts of Pachomac, where it is chiefly seen, men seldom venture to travel. Those wild regions are very sufficient of themselves to inspire a secret horror: broken precipicesprowling panthers-forests only vocal with the hissing of serpents-and mountains rendered still more terrible by the condor, the only bird that ventures to make its residence in those deserted situations. 


\section{CHAPTER LXXXIV.}

\section{OF THE VULTURE AND ITS AFFINITIES.}

THE first rank in the description of birds, has been given to the eagle; not because it is stronger or larger than the vulture, but because it is more generous and bold. The eagle, unless pressed by famine, will not stoop to carrion; and never devours but what he has earned by his own pursuit. The vulture, on the contrary, is indelicately voracious; and seldom attacks living animals, when it can be supplied with the dead. The eagle meets and singly opposes his enemy; the vulture, if it expects resistance, calls in the aid of its kind, and basely overpowers its prey by a cowardly combination. Putrefaction and stench, instead of deterring, only serves to allure them. The vulture seems among birds, what the jackal and hyæua are among quadrupeds, who prey upon carcasses, and root up the dead.

Vultures may be easily distinguished from all those of the eagle kind, by the nakedness of their heads and necks, which are without feathers, and only covered with a very slight down, or a few scattered hairs. Their eyes are more prominent; those of the eagle being buried more in the socket. Their claws are shorter, and less hooked. The inside of the wing is covered with a thick down, which is different in them from all other birds of prey. Their attitude is not so upright as that of the eagle; and their flight more difficult and heavy.

In this tribe we may range the golden, the ash-coloured, and the brown vulture, which are inhabitants of Europe; the spotted and the black vulture of Egypt; the bearded vulture; the Brasilian vulture, and the king of the vultures, of South America. They all agree in their nature; being equally indolent, yet rapacious and unclean.

The gOLDEN vULTURE seems to be the foremost of the kind; and is in many things like the golden eagle, but larger in every proportion. From the end of the beak to that of the tail, it is four feet and a balf; and to the claws' end, forty-five inches. The length of the upper mandible is almost seven inches; and the tail twenty-seven in length. The lower part of the neck, breast, and belly, are of a red colour; but on the tail it is more faint, and deeper near the head. The feathers are black on the back; and on the wings and tail of a yellowish brown. Others of the kind differ from this in colour and dimensions; but they are all strongly marked by their naked heads, and beak straight in the beginning, but hooking at the point.

They are still more strongly marked by their nature, which, as has been observed, is cruel, unclean, and indolent. Their sense of smelling, however, is amazingly great; and nature, for this purpose, has given them two large apertures or nostrils without, and an extensive olfactory membrane within. Their intestines are formed differently from those of the eagle kind; for they partake more of the formation of such birds as live upon grain, They have both a crop and a stomach; which may be regarded as a kind of gizzard, from the extreme thickness of the muscles of which it is composed. In fact, they seem adapted inwardly, not only for being carnivorous, but to eat corn or whatsoever of that kind comes in their way.

This bird, which is common in many parts of Europe, and but too well known on the western continent, is totally unknown in England. In Egypt, Arabia, and many other kingdoms of Africa and Asia, vultures are found in great abundance. The inside down of their wing is converted into a very.warm and comfortable kind of fur, and is commonly sold in the Asiatic markets.

Indeed, in Egypt, this bird seems to be of singular service. There are great llocks of them in the neighbourhood of Grand Cairo, which no person is permitted to destroy, The service they render the inhabitants, is 
the devouring of all the carrion and filth of that great city; which might otherwise tend to corrupt and putrefy the air. They are commonly seen in company with the wild dogs of the country, tearing a carcass very deliberately together. This odd association produces no quarrels; the birds and quadrupeds seem to live amicably, and nothing but harmony subsists between them. The wonder is still the greater, as both are extremely rapacious, and both lean and bony to a very great degree; probably having no great plenty even of the wretched food on which they subsist.

In America they lead a life somewhat similar. Wherever the hunters, who there only pursue beasts for the skins, are found to go, these birds are seen to pursue them. They still keep hovering at a little distance; and when they see the beast flayed and abandoned, they call out to each other, pour down upon the carcass, and, in an instant, pick its bones as bare and clean as if they had been scraped by a knife.

At the Cape of Good Hope, in Africa, they seem to discover a still greater share of dexterity in their methods of carving. "I have," says Kolben, "been often a spectator of the manner in which they have anatomized a dead body: I say anatomized; for no artist in the world could have done it more cleanly. They have a wonderful method of separating the flesh from the bones, and yet leaving the skin quite entire. Upon coming near the carcass, one would not suppose it thus deprived of its internal substance, till he began to examine it more closely ; he then finds it, literally speaking, nothing but skin and bone. Their manner of performing the operation is this : they first make an opening in the belly of the animal, from whence they pluck out, and greedily devour, the entrails: then entering into the hollow which they have made, they separate the flesh from the bones, without ever touching the skin. It often happens that an ox returning home alone to its stall from the plough, lies down by the way : it is then, if the vultures perceive it, that they fall with fury down, and inevitably devour the unfortunate animal. They sometimes attempt them grazing in the fields; and then, to the number of a hundred or more, make their attack all at once and together."

"They are attracted by carrion," says Catesby, "from a very great distance. It is pleasant to behold them, when they are thus eating, and disputing for their prey. An eagle generally presides at these entertainments, and makes them all keep their distance till he has done. They then fill to with an excellent appetite; and their sense of smelling is so exquisite, that the instant a carcass drops, we may see the vultures floating in the air from all quarters, and come sousing on their prey." It is supposed by some, that they eat nothing that has life; but this is only when they are not able; for when they can coine at lambs, they show no mercy; and serpents are their ordinary food. The manner of those birds is to perch themselves, several together, on the old pine and cypresstrees; where they continue all the morning, for several hours, with their wings unfolded: nor are they fearful of danger, but suffer peo ple to approach them very near, particularly when they are eating.

The sloth, the filth, and the voraciousness, of these birus, almost exceeds credibility. In the Brasils, where they are found in great abundance, when they light upon a carcass, which they have liberty to tear at their ease, they so gorge themselves that they are unable to fly; but keep hopping along when they are pursued. At all times, they are a bird of slow flight, and unable readily to raise themselves from the ground; but when they have over-fed, they are then utterly helpless: but they soon get rid of their burden; for they have a method of vomiting up what they have eaten, and then they fly off with greater facility.

It is pleasant, however, to be a spectator of the hostilities between animals that are thus hateful or noxious. Of all creatures, the two most at enmity, is the vulture of Brasil, and the crocodile. The female of this terrible amphibious creature, which in the rivers of that part of the world grows to the size of twenty-seven feet, lays its eggs, to the num. ber of one or two hundred, in the sands, on the side of the river, where they are batched by the heat of the climate. For this purpose, she takes every precaution to hide from all 
other animals the place where she deposits her burden: in the mean time, a number of vultures, or galinassos, as the Spaniards call them, sit silent and unseen in the branches of some neighbouring forest, and view the crocodile's operations, with the pleasing expectation of succeeding plunder. They paticntly wait till the crocodile has laid the whole number of her eggs, till she has covered them carefully under the sand, and until she is retired from them to a convenient distance. Then, all together, encouraging cach other with cries, they pour down upon the nest, hook up the sand in a moment, lay the eggs bare, and devour the whole, brood without remorse. Wretched as is the flesh of these auimals, yet men, perhaps when pressed by hunger, have been templed to taste it. No= thing can be more leau, stringy, nauseous, and unsavoury. It is in vain that, when killed, the rump has been cut off; in vain the body has been washed, and spices used to overpower its prevailing odour; it still smells and tastes of the carrion by which it was nourished, and sends forth a stench that is insupportable.

These birds, at least those of Europe, usually lay two eggs at a time, and produce but once a year. 'They make their nests in inaccessible cliffs, and in places so remote, that it is rare to find them. Those in our part of the world chiefly reside in the places where they breed, and seldom come down into the plains, cxcept when the snow and ice, in their native retreats, hàs banished all living animals but themselves: they then come from their heights, and brave the perils they must encounter in a more cultivated regiou. $\Lambda \mathrm{s}$ carrion is not found, at those seasons, in sufficient quantity, or sufficiently remote from man to sustain thein, they prey upon rabbits, hares, serpents, and whatever small game they can overtake or overpower.

Such are the manners of this bird in gene- ral; but there is one of the kind, called the King of the Vultures, which, from its extraordinary figure, deserves a scparate description. This bird is a native of America, and not of the East Indies, as those who make a trade of showing birds would induce us to believe. This bird is larger than a turkeycock; but is chiefly remarkable for the odd formation of the skin of the head and neck, which is bare. This skin arises froin the base of the bill, and is of an orange colour; from whence it stretches on each side to the head; from thence it proceeds, like an indented comb, and falls on either side, according to the motion of the head. The eyes are surrounded by a red skin, of a scarlet colour: and the iris has the colour and lustre of pcarl. The head and neck are without feathers, covered with a flesh-coloured skin on the upper part, a fine scarlet behind the head, and a duskier coloured skin before: farther down, behind the head, arises a little tuft of black down, from whence issues and extends beneath the throat, on each side, a wrinkled skin, of a brownish colour, mixed with blue, and reddish behind: below, upon the naked part of the neck, is a collar formed by soft longish feathers, of a deep ash-colour, which surround the neck, and cover the breast before. Into this collar the bird sometimes withdraws its whole neck, and sometimes a part of its head, so that it looks as if it had withdrawn the neck into the body. Those marks are sufficient to distinguish this bird from all others of the vulture kind; and it cannot be doubted, but that it is the most beautiful of all this deformed family : however, neither its habits nor instincts vary from the rest of the tribe; being like them a slow cowardly bird, living chiefly upon rats, lizards, and serpents; and upon carrion or excrement, when it happens to be in the way. The flesh is so bad, that even savages themselves can. not abide it. 


\section{CHAPTER LXXXV.}

\section{OF THE FALCON KIND, AND ITS AFFINITIES.}

EVERY creature becomes more important in the history of nature in proportion as it is connected with man. In this view, the smallest vegetable, or the most seemingly contemptible insect, is a subject more deserving attention than the most flourishing tree, or the most beautiful of the feathered creation. In this view, the falcon is a more important animal than the eagle or the vulture; and, though so very diminutive in the comparison, is, notwithstanding, from its connexion with our pleasures, a much more interesting object of curiosity.

The amusement of hawking, indeed, is now pretty much given over in this kingdom; for as every country refines, as its enclosures become higher and closer, those rural sports must consequently decline, in which the game is to be pursued over a long extent of country; and where, while every thing retards the pursuer below, nothing can stop the object of his pursuit above.

Falconry, that is now so much disused among us, was the principal amusement of our ancestors. A person of rank scarcely stirred out without his hawk on his hand; which in old paintings is the criterion of nobility. Harold, afterwards king of England, when he went on a most important embassy into Normandy, is drawn in an old bas-relief, as embarking with a bird on his fist, and a dog under his arm. In those days, it was thought sufficient for noblemen's sons to wind the horn, and to carry their hawk fair, and leave study and learning to the children of meaner people. Indeed, this diversion was in such high esteem among the great all over Europe, that Frederic, one of the emperors of Germany, thought it not beneath him to write a treatise upon hawking.

The expense which attended this sport was very great: among the old Welsh princes, the king's falconer was the fourth officer in the state; but, notwithstanding all his honours, he was forbid to take more than three draughts of beer from his horn, lest he should get drunk and neglect his duty. In the reign of James I. Sir Thomas Monson is said to have given a thousand pounds for a cast of hawks; and such was their value in general, that it was made felony in the reign of Edward III. to steal a hawk. To take its eggs, even in a, person's own ground, was punishable with imprisonment for a year and a day, together with a fine at the king's pleasure. In the reign of Elizabeth the imprisoument was reduced to three months; but the offender was to lie in prison till he got security for his good behaviour for seven years farther. In the earlier times the art of gunning was but little practised, and the hawk was then valuable, not only for its affording diversion, but for its procuring delicacies for the table, that could seldom be obtained any other way. Of many of the ancient falcons used for this purpose, we at this time know only the names, as the exact species are so ill described, that one may be very easily mistaken for another. Of those in use, at present, both here and in other countries, are the gyr-falcon, the falcon, the lanner, the sacre, the hobby, the kestril, and the merlin. These are called the long-winged hawks, to distinguish them from the goss-hawk, the sparrowhawk, the kite, and the buzzard, that are of shorter wing, and cither too slow, too cowardly, too indolent, or too obstinate, to be serviceable in contributing to the pleasures of the field.

The generous tribe of hawks, as was said, are distinguished from the rest by the peculiar length of their wings, which reach nearly as low as the tail. In these, the first quill of the wing is nearly as long as the second; it terminates in a point, which begins to diminish from about an inch of its extremity. This sufficiently distinguishes the generous breed from that of the baser race of kites, 
sparrow-hawks, and buzzards, in whom the tail is longer than the wings, and the first feather of the wing is rounded at the extremity. They differ also in the latter having the fourth feather of the wing the longest; in the generous race it is always the second.

This generous race, which have been taken into the service of man, are endowed with natural powers that the other kinds are not possessed of. From the length of their wings, they are swifter to pursue their game; from a confidence in this swiftness, they are bolder to attack it; and from an innate generosity, they have an attachment to their feeder, and, corisequently, a docility which the baser birds are strangers to.

The gyr-falcon leads in this bold train. He exceeds all other falcons in the largeness of his size, for he approaches nearly to the magnitude of the eagle. The top of the head is flat and of an ash-colour, with a strong, thick, short, and blue beak. The feathers of the back and wings are marked with black spots, in the shape of a heart; he is a courageous and fierce bird, nor ficars even the eagle himself; but he chiefly flies at the stork, the herbn, and the crane. He is mostly fiound in the colder regions of the north, but loses neither his strength nor his courage when brought into the milder climates.

'The falcon, properly so called, is the second in magnitude and fame. There are some varieties in this bird; but there seem to be only two that claim distinction; the falconzentil and the peregrine-falcon; both are inuch less than the gyr, and somewhat about the size of a raven. They differ but slightly, and perhaps only from the different states they were in when brought into captivity. Those differences are easier known by experience than taught by description. The falcon-gentil inoults in March, and often sooner: the peregrine-falcon does not moult till the middle of August. The peregrine is stronger in the shoulder, has a larger eye, and yet more sunk in the hrad; the beak is stronger, his legs longer, and the toes better divided.

Next in size to these is the lanner, a bird now very little known in Europe; then follows the sacre, the legs of which are of a bluish colour, and serve to distinguish that bird; to kn. 41 \& 42 . them succeeds the hobby, used for smaller game, for daring larks, and stooping at quails, The kestril wastrained for the same purposes; and lastly the merlin; which, though the smallest of all the hawk or falcon kind, and not much larger than a thrush, yet displays a degree of courage that renders him formidable even to birds ten times his size. He has often been known to kill a partridge or a quail at a single pounce from above.

Some of the other species of sluggish birds were now and then trained to this sport, but it was when no better could be obtained; but these just described were only considered as birds of the nobler races. Their courage in general was such, that no bird, not very much above their own size, could terrify them; their swiftness so great, that scarcely any bird could escape them; and their docility so remarkable, that they obeyed not only the commands, but the signs of their master. They remained quietly perched upon his hand till their game was flushed, or else kept hovering round his head, without everleaving him but when he gave permission. The common falcon is a bird of such spirit, that, like a conqueror in a country, he keeps all birds in awe and in subjection to his prowess. Where he is seen flying wild, as I often had an opportunity of observing, the birds of every kind, that seemed entirely to Jisregard the kite or the sparrow-hawk, fly with screams at his most distant appearance. Long before I could see the falcon, I have seen them with the utmost signs of terror endeavouring to avoid him; and, like the peasants of a country before a victorious army, every one of them attempting to shift for himself. Even the young falcons, though their spirit be depressed by captivity, will, when brought out into the field, venture to fly at barnacles and wild geese, till, being soundly brushed and beaten by those strong birds, they learn their error, and desist from meddling with such unwieldy game for the futnre.

'T'o train up the hawk to this kind of obedience, so as to hunt for his master, and bring him the game he shall kill, requires no small degree of skill and assiduity. Numberless treatises have been written upon this subject, which are now, with the sport 
itself, almost utterly forgotten: indeed, except to a few, they seem utterly unintelligible; for the falconers had a language peculiar to themselves, in which they conversed and wrote, and took a kind of professional pride in using no other. A modern reader, I suppose, would be little edified by one of the instructions, for instance, which we find in Willoughby, when he bids us "draw our falcon out of the mew twenty days before we enseam her. If she truss and carry, the remedy is, to cosse her talons, her powse, and petty single."

But, as it certainly makes a part of natural history to show how much the nature of birds can be wrought upon by harsh or kind treatment, I will just take lcave to give a short account of the manner of training a hawk, divested of those cant words with which men of art have thought proper to obscure their profession.

In order to train up a falcon, the master begins by clapping straps upon his legs, which are called jesses, to which there is fastened a ring with the owner's name, by which, in case he should be lost, the finder may know where to bring him back. To these also are added little bells, which serve to mark the place where he is, if lost in the chase. He is always carricd on the fist, and is obliged to keep without slecping. If he he stubborll, and attempts to bite, his head is plunged into water. Thus, by hunger, watching, and fatigue, he is constrained to submit to having his head covered by a hood or cowl, which covers his eyes. This troublesome einployment continues often for three days and nights without ceasing. It rarely liappens but at the end of this, his necessities and the privation of light make him lose all idea of liberty, and bring down his natural wilduess. His master judges of his being tamed when he permits his liead to be covered withont resistance, and when uncovered he seizes the meat before him contentedly. The repetition of these lessons by degrees ensures success. His wants being the chief principle of his dependence, it is endeavoured to increase his appetite by giving him litt]e balls of flannel, which he greedily'swallows. Having thus excited the appetite, care is taken to satisfy it; and thus gratitude at- taches the bird to the man who but just before had been his tormentor.

When the first lessons have succeeded. and the bird shows signs of docility, he is carried out upon some green, the head is uncovered, and, by flattering him with food at different times, he is taught to jump on the fist, and to continue there. When confirmed in this habit, it is then thought time to make him acquainted with the lure. This lure is only a thing stuffed like the bird the falcon is designed to pursue, such as a heron, a pigeon, or a quail, and on this lure they always take care to give him his food. It is quite necessary that the bird should not only be acquainted with this, but fond of it, and delicate in his food when shown it. When the falcon has flown upon this, and tasted the first morsel, some falconers then take it away; but by this there is a danger of daunting the bird; and the surest method is, when he flies to seize it, to let him feed at large, and this serves as a recompense for his docility. The use of this, lure is to flatter him back when he has flown in the air, which it sometimes fails to do; and it is always requisite to assist it by the voice and the signs of the master. When these Jessons have been long re. peated, it is then necessary to study the character of the hird; to speak frequently to him, if he be inattentive to the voice; to stint in his food such as do not come kindly or readily to the lure; to keep waking him, If he be not sufficiently familiar; and to cover bim frequently with the hood, if he fears darkness. When the familiarity and the docility of the bird are sufficiently confirmed on the green, he is then carried into the open fields, but still kept fast by a string which is about twenty yards long. He is then uncovered as before; and the falconer, calling him at some paces distance, shows him the lure. When he files upon it, he is permitted to take a large morsel of the food which is tied to it. The next day the lure is shown lim at a greater distance, till he comes at last to fly to it at the utmost length of his string. He is then to be shown the game itself alive, but disabled or tame, which he is desigued to pursue. After having seized this several times, with his string, he is then left entirely at liberty, and carried into the field for the 
purpose of pursuing that which is wild. At that he flies with avidity; and when he has seized it, or killed it, he is brought back by the voice and the lure.

By this method of instruction, an hawk may be taught to fly at any game whatsoever; but falconers have chiefly confined their pursuit only to such animals as yield them profit by the capture, or pleasure in the pursuit. The hare, the partridge, and the quail, repay the trouble of taking them ; but the most delightful sport is the falcon's pursuit of the heron, the kite, or the wood-lark. Instead of flying directly forward, as some other birds do, these, when they see themselves threatened by the approach of the hawk, immediately take to the skies. They fly almost perpendicularly upward, while their ardent pursuer keeps pace with their fight, and tries to rise above them. Thus both dininish by degrees from the gazing spectator below, till they are quite lost in the clouds; but they are soon seen descending, struggling together, and using every effort on both siles; the one of rapacious insult, the other of desperate defence. The unequal combat is soon at an end; the falcon comes off victorious, and the other, killed or disabled, is male a prey either to the bird or the sportsman.

As for other birds, they are not so much puraued, as they generally fly straight forward, by which the sportsman loses sight of the chase, and, what is still worse, runs a ehance of losing his falcon also. The pursuit of the lark by a couple of merlins is considered, to him only who regards the sagacity of the eliase, as one of the most delightful spectacles this exercise can afford. The amusement is to see one of the merlins climbing to get the ascendant of the lark, while the other, lying low for the best advantage, waits the success of its companion's efforts; thus while the one stoops to strike its prey, the other seizes it at its coming down.

Such are the natural and acquired habits of these birds, which of all others have the greatest strength and courage relative to their size. While the kite or the goss-hawk approach their prey sideways, these dart perpendicularly, in their wild state, upon their game, and devour it on the spot, or carry it off, if not ton large for their power of flying. They are sometimes seen descending perpendicularly from tlee clouds, from an amazing height, and darting down on their prey with inevitable swiftness and destruction.

The more ignoble race of birds make up by cunning and assiduity what these claim by force and celericy. Being less courageous, they are more patient ; and, having less swiftness, they are better skilled at taking their prey by surprise. The kite, that may be distinguished from all the rest of this tribe by his forky tail and his slow floating motion, seems alınost for ever upon the wing. He appears to rest himself upon the boson of the air, and not to make the smallest effort in flying. He lives only upon aceidental carnage, as alnuost every bird in the air is able to make good its retreat against him. He may be therefore considered as an insidious thief, who only prowls about, and, when he finds a small bird wounded, or a young elicken strayed too fur from the mother, instantly seizes the hour of ealamity, and, like a famished glutton, is sure to show no mercy. His hunger, indeed, often urges him to acts of sceming desperation. I have seen one of them fly round and round for a while to mark a clutcl of chickens, and then on a sudden clart like lightning upon the umresisting little aninal, and carry it off, the hen in vain crying out, and the boys hooting and casting stones to scare it from its plunder. For this reason, of all birds the kite is the good housewife's greatest tormentor and aversion.

Of all obscene birds, the kite is the best known; but the buzzard among us is the most plenty. He is a sluggish innetive bird, and often remains perched whole days together upon the same bough. He is rather an assassin than a pursuer; and lives nore upon frogs, mice, and insects, which he can easily seize, than upon birds whicl, he is obliged to follow. He lives in summer by robbing the nests of other birds, and sucking their eggs, and more resembles the owl kind in his countenance than any other lapacious bird of day. His figure implies the stupidity of his disposition; and so little is he capable of instruetion from man, that it is common to a proverh to call one who cannot be taught, or contimues obstinately ignorant, a buzzerd. The honcy-buzzard, the moor-buzzard, and the ben-harrier, are all of this stupid tribe, and differ chiefly in their size, growing less in the order I have 
nanied them. The goss-hawk and sparrowhawk are what Mr. Willoughby calls shortwinged birds, and consequently unfit for training, however injurious they may be to the pigeon-house or the sportsman. They have been indeed taught to fly at game; but little is to be obtained from thrir efforts, being difficult of instruction, and capricious in their obedience. It has been lately asserted, however, by one whose authority is respectable, that the sparrow-hawk is the boldest and the best of all others for the pleasure of the chase.

\section{CHAP'TER LXXXVI.}

\section{THE BUTCHER-BIRD.}

BEFORE I conclude this short history of rapacious birds that prey by day, I must take leave to describe a tribe of smaller birds, that seem from their size rather to be classed with the harmless order of the sparrow kind; but that from their crooked beak, courage, and appetites for slaughter, certainly deserve a place liere. The lesser butcher-bird is not much ahove the size of a lark; that of the smallest species is not so big as a sparrow ; yet diminutive as these little animals are, they make themselves formidable to birds four times their dimensions.

The greater butcher-bird is about as large as a thrush ; its bill is black, an inch loug, and looked at the end. This mark, together with its carnivorous appetites, ranks it annong the rapacious birds; at the same time that its legs and feet, which are slender, and its toes, formed somewhat differently from the former, would seem to make it the shade between such birds as live wholly upon flesh, and such as live chiefly upon insects and grain.

Indeed, its habits seem entirely to correspond with its conformation, as it is found to live as well upon flesh as upon insects, and thus to partake in some measure of a double

- The Secretary Falcon, an inhabitant of Asia and Africa, is a curious bird, for whose natural history we are cluiefly indebted to the indefatigable labours of $\mathbf{M}$. le Vaillant. Its body, when standing erect, is not much unlike the crane; but its head, bill, and claws, are precisely those of the falcon. The general colour of the plumage is a bluish-ash; the tips of the wings, the thighs, and the vent, being blackish : the tail is black near the end, but the very tip is white: the legs are long, so that it ineasures, when standing erect, full three feet from the top of the head to the ground. On the back of the head are nature. However, its appetite for flesh is the most prevalent; and it never takes up with the former when it can obtain the latter. This bird, therefore, leads a life of continual combat and opposition. As from its size it does not much terrify the smaller birds of the forest, so it very frequently meets birds willing to try its strength, and it never declines the engagement.

It is wonderful to see with what intrepidity this little creature goes to war with the pie, the crow, and the kestril, all above four times bigger than itself, and that sometimes prey upon flesh in the same manner. It not only figlits upon the defensive, bat often conies to thic attack, and always with advantage, particularly when the male and female unite to protect their young, and to drive away the more powerful birds of rapine. At that season, they do not wait the approach of their invader; it is sufficient that they see him preparing for the assault at a distance. It is then that they sally forth with loud cries, wound him on every side, and drive him off with such fury, that he seldom ventures to return to the charge. In these kinds of disputes, they generally come off with the victory; though it

several long dark-coloured feathers, hanging down behind, and which it can erect at pleasure. This crest lias induced the Dutch at the Cape to give it the name of the Secretary, from the resemblance they fancy it has to the pen of a writer, when in the time of leisure it is stuck behind the ear.

In the craw of one of this kind, M. le Vaillant found eleven tolerable large lizards, three serpents as long as his arm, eleven small tortoises of about two inches in diameler, and number of locusts and other insects, some of which were so eutire, that he added them to his collection. 
sometimes happens that they fall to the ground with the bird they have so fiercely fixed upon, and the combat ends with the destruction of the assailant as well as the defender.

For this reason, the most redoubtable birds of prey respect them ; while the kite, the buzzard, and the crow, seem rather to fear than seek the engagement. Nothing in nature better displitys the respect paid to the claims of courage, than to see this little bird, apparently so contemptible, fly in company with the lanner, the falcon, and all the tyrants of the air, without fearing their power, or avoiding their resentment.

As for small birds, they are its usual food. It seizes them by the throat, and strangles them in an instant. When it has thus killed the bird or insect, it is asserted by the best authority, that it fixes them upon some neighbouring thorn, and, when thus spitted, pulls them to pieces with its bill. It is supposed, that as nature has not given this bird str.ngth sufficient to tear their prey to pieces with its feet, as the hawks do, it is obliged to have recourse to this extraordinary expedient.

During summer, such of them as constantly reside here, for the sunaller red butcher-bird migrates, remain among the mountainous parts of the country : but in winter they descend into the plains, and nearer human habitations. The larger kind make their nests on the highest trees, while the lesser build in bushes in the fields and hedge-rows. They both lay about six eggs; of a white colour, but encircled at the bigger end with a ring of brownish red. The nest on the outside is composed of white moss, interwoven with long grass; within it is well lined with wool, and is usually fixed among the forking branches of a tree. The female feeds her young with caterpillars and other insects while very young; but sonn after accustoms thein to flesh, which the male procures with surprising industry. Their

a The great Butcher-bird of America makes use of a curious stratagem to decoy and seize its prey. A gentleman accidentally observing that several grasshoppers were stuck upon some sharp thorns, inquired of a person, who lived close by, the cause of this appearance; and was informed, that they were placed there by this bird, which is nature also is very different from other birds of prey it their parental care ; for, so far from driving out their young from the nest to shift fur themselves, they keep them with care; and even when adult they do not forsake them, but the whole brond live in one family together. Each family lives apart, and is generally composed of the male, female, and five or six young ones; these all maintain peace and subordination anıong each other, and hunt in concert. Upon the returning season of courtship, this union is at an end, the family parts for ever, each to establish a little household of its own. It is easy to distinguish these birds at a distance, not only fronı their going in companies, but also from their manner of flying, which is always up and down, seldom direct or sideways.

Of these birds there are three or four different kinds; but the greater ash-coloured butcher-bird is the least known among us. The red-backed butcher-bird migrates in autumn, and does not return till spring. The woodclat resembles the former, except in the colour of the back, which is brown, and not red as in the other. There is still another, less than either of the former, found in the marshes near London. This too is a bird of prey, although not much bigger than a titmouse; an evident proof that an animal's courage or rapacity does not depend upon its size. Of foreign birls of this kind there are several; but as we know little of their manner of living, we will not, instead of history, substitute mere description. In fact, the colours of a bird, which is all we know of them, would afford a reader but small entertainment in the enumeration. Nothing can be more easy than to fill volumes with the different shades of a bird's plumage; but these accounts are written with more pleasure than they are read; and a single glance of a good plate or a picture imprints a justeridea than a volume could convey.

there called the nine-killer, from the supposition that nine are always stuck up in succession. On further inquiry, he was led to suppose, Ibat this was an instinclive stratagem, arlopted for the purponse of tempting the smaller birds iuto a situation where he could easily dart out upon them and seize them. 


\section{CHAPTLR IXXXVII.}

\section{OF RAPACIOUS BIRDS OF THE OWL KIND, THAT PREY BY NIGHT.}

HITHERTO we have been describing a tribe of animals who, though plunderers among their fellows of the air, yet wage war boldly in the face of day. We now cume to a race equally cruel and rapacious; but who add to their savage disposition, the further reproach of treachery, and carry on all their depredations by niglit.

All birds of the owl kind may be considered as nocturnal robbers, who, unfitted for taking their prey while it is light, surprise it at those hours of rest, when the tribes of nature are in the least expectation of an enemy. Thus there seems no link in nature's chain broken: no where a dead inactive repose; but every place, every season, every hour of the day and night, is bustling with life, and furnishing instances of industry, selfdefence, and invasion.

All birds of the owl kind have one common mark, by which they are distinguished from others; their eyes are formed for seeing better in the dusk than in the broad glare of sun-shine. As in the eyes of tigers and and cats, that are formed for a life of nocturnal depredation, there is a quality in the retina that takes in the rays of light so copiously as to permit their seeing in places almost quite dark; so in these birds there is the same conformation of that organ, and though, like us, they cannot see in a total exclusion of light, yet they are sufficiently quick-sighted, at times when we remain in total obscurity. In the eyes of all animals, nature hath made a complete provision, either to shut out too much light, or to admit a sufficiency, by the contraction and dilatation of the pupil. In these birds the pupil is capable of opening very wide, or shutting very close: by contracting the pupil, the brighter light of the day, which would act too powerfully upon the sensibility of the retina, is excluded; by dilating the pupil, the animal takes in the more faint rays of the night, and thereby is enabled to spy its prey, and catch it with greater facility in the dark. Beside this, there is an irradiation on the back of the eye, aud the very iris itself has a faculty of reflecting the rays of light, so as to assist vision in the gloomy places where these birds are found to frequent.

But though owls are dazzled by too bright a day-light, yet they do not see best in the darkest nights, as some have been apt to imagine. It is in the dusk of the evening, or the gray of the morning, that they are best fitted for seeing, at those seasons when there is neither too much light, nor too little. It is then that they issue from their retreats, to hunt or to surprise their prey, which is usually attended with great success: it is then that they find all other birds asleep, or preparing for repose, and they have only to seize the most unguarded.

The nights when the moon shines are the times of their most successful plunder; for when it is wholly dark, they are less qualified for seeing and pursuing their prey : except, therefore, by moonlight, they contract the liours of their chace; and if they come out at the approach of dusk in the evening, they return before it is totally dark, and then rise by twilight the next morning to pursue their gaine, and to return in like manner, before the broad day-light begins to dazzle them with its splendour.

Yet the faculty of seeing in the night, or of being entirely dazzled by day, is not alike in every species of these nocturnal birds: some see by night better than others; and some are so little dazzled by day-light, that they perceive their enemies, and a void them. The common White or Barn Owl, for instance, sees with such exquisite acuteness in the dark, that though the barn bas becn shut at night, and the light thus totally excluded, yet it perceives the smallest mouse that peeps from its hole: on the contrary, the Brown 
Horned Owl is often seen to prowl along the hedges by day, like the sparrow-hawk; and gometimes with good success.

All birds of the owl kin! may be divided into two sorts; those that have horns, and those without. These horns are nothing more than two or three feathers that stand upon each side of the head over the ear, and give thi animal a kind of horned appearance. Of the horned kind is, the Great Horned O wl, which at first view appears as large as an eagle. When he comes to be observed more closely, however, he will be found much less. His legs, body, wings, and tail, are shorter; his head much larger and thicker: his horns are ciuposed of feathers that rise above two incles and a half high, and which he can crect or depress at pleasure: his eyes are large and transparent, encircled with an orange-coloured iris: his ears are large and deep, and it would appear that no animal was possessed with a more exquisite sense of hearing: his plumage is of a reddish brown, marked on the back with black and yellow spots, and yellow only upon the belly.

Next to this is the Common Horned Owl, of a much smaller size than the former, and with horns much shorter. As the great owl was five feet from the tip of one wing to the other, this is but three. The horns are but about an inch loug, and consist of six feathers, variegated with black and yellow.

There is still a smaller kind of the homed owl, which is not much larger than a blackbird; and whose horns are remarkably short, being composed but of one feather, and that not nbove half an inch high.

vo these succeeds the tribe withont horns. The HOWLET, which is the largest of this kind, with dusky plumes and black eyes; the SCREECH OWL, of a smaller size, with blue eyes, and plumage of an iron gray; the wHIT ows, about as large as the former, with yellow eyes and whitish plumage; the GREAT uROW OW., less than the former, with brown plumage and a brown beak; and, lastly, the LiTTLE Brown owl, with yellowish coloured cyes, and an orange-coloured bill. To this catalogue night be alled others of foreign denominatious, which differ but little from our own, if we except the HARFANG, or GREAT HUDSOx's BAY OWL of Edwards, which is the largest of all the nocturnal tribe, and as white as the snows of the country of which he is a native.

All this tribe of animals, however they may differ in their size and plumage, agree in their general characteristics of preying by liight, and having their eyes formed for nocturnal vision. 'Their bodies are strong and inuscular; their feet and claws unade for tearing their prey; and their stomachs for digesting it. It must be remarked, however, that the digestion of all birds that live upon mice, lizards, or such like food, is not very perfect; for though they swallow then whole, yet they are always seen some time after to disgorge the skin and bones, rolled up in a pellet, as being indigestible.

In proportion as each of these animals bears the day-light best, he sets forward earlier in the evening in pursuit of his prey. The great horned owl is the foremost in leaving his retreat; and ventures into the woods and thickets very soon in the evening. The horned, and the brown owl, are later in their excursions: but the barn-owl seerns to see best in profound darkness, and seldom leaves his hiding-place till midnight.

As they are incapable of supporting the light of the day, or at least of then seeing and readily aroiding their danger, they keep all this time concealed in some obscure retreat, suited to their gloomy appetites, and there continue in solitude and silence. The cavern of a rock, the darkest part of a hollow tree, the battlements of a ruined and unfrequented cástle, some obscure hole in a fariner's out-house, are the places where they are usually found: if they be seen out of these retreats in the day-time, they nay be considered as having lost their way; as having by some accident been thrown into the midst of their enemies, and surrounded with danger.

Having spent the day in their retreat, at the approach of evening they sally forth, and skim rapidly up and down along the hedges. The barn-owl, indeed, who lives chielly upon mice, is contented to be more stationary: he takes his residence upon some sliock of corn, or the point of some old house; and there watches in the dark, with the utmost perspicacity and perseverance.

Nor are these birds by any means silent; 
they all have an lideous note; which, whilc pursuing their prey, is seldom heard ; but may be considered rather as a call to courtship. There is something always terrifying in this call, which is often heard in the silence of midnight, and breaks the general pause with a horrid variation. It is different in all; but in each it is alarming and disagreeable. Father Kircher, who has set the voices of birds to music, has given all the tones of the owl note, which make a most tremendous melody. Indeed, the prejudices of mankind are united with their sensations to make the cry of the owl disagreeable. The screech-owl's voice was always considered among the people as a presage of some sad calamity that was soon to ensue.

They seldom, however, are heard while they are preying; that important pursuit is always attended with silence, as it is by no means their intention to disturb or forewarn those little animals they wish to surprise. When their pursuit has been successful, they soon return to their solitude, or to their young, if that be the season. If, however, they find but little game, they continue their quest still longer; and it sometimes happens that, obeying the dictates of appetite rather than of prudence, they pursue so long that broad day breaks in upon them, and leaves them dazzled, bewildered, and at a distance from hoine.

In this distress they are obliged to take shelter in the first tree or hedge that offers, there to continue concealed all day, till the returning darkness once more supplies them with a better plan of the country. But it too often happens that, with all their precautions to conceal themselves, they are spied out by the other birds of the place, and are sure to receive no inercy. The blackbird, the thrush, the jay, the bunting, and the red-breast; all come in file, and employ their little arts of insult and abuse. The smallest, the feeblest, and the most contemptible of this unfortunate bird's er emies, are then the foremost to injure and torment him. They increase their cries and turbulence round him, flap him with their wings, and are ready to show their courage to be great, as they are sensible that their danger is but small. The unfortunate owl, not knowing where to attack or where to fly, patiently sits and suffers all their insults. Astonished and dizzy, be only replies to their mociseries by awkward and ridiculous gestures, by turning his head and rolling his eyes with an air of stupidity. It is enough that an owl appears by day, to set the whole grove into a kind of uproar. Either the aversion all the small birds have to this animal, or the consciousness of their own security, makes them pursue him without ceasing, while they encourage each other by their mutual cries to lend assistance in this laudable undertaking.

It sometimes happens, however, that the little birds pursue their insults with the same imprudent zeal with which the owl himself had pursued his depredations. They hunt him the whole day until evening returns; which restoring him his faculties of sight once more, he miakes the foremost of his pursuers pay dear for their former sport. Nor is man always an unconcerned spectator here. The bird-catchers have got an art of counterfeiting the cry of the owl exactly; and having before lined the branches of a hedge, they sit unseen, and give the call. At this, all the little birds flock to the place where they expect to find their well-known eneny; but istead of finding their stupid antagonist, they are stuck fast to the hedge themselves. This sport must be put in practice an hour before niglte-fall, in order to be successful ; for if it is put off till later, those birds which but a few ninutes sooner came to provoke their eneny, will then fly from him with as much terror as they just before showed insolence.

It is not unpleasant to see one stupid bird made, in some sort, a decoy to deceive another. The great horned owl is sometinies made use of for this purpose to lure the kite, when falconers desire to catch him for the purposes of training the falcon. Upon this occasion they clap the tail of a fox to the great owl, to render his figure extraordinary; in which trim he sails slowly along, flying low, which is his usual manner. The kite, either curious to observe this odd kind of animal, or perluaps inquisitive to see whether it may not be proper for food, flies after, and comes nearer and nearer. In this manner he continues to hover, and sometimes to descend, till the falconer setting a strong-winged hawk against him, seizes him for the purpose of training his young ones at home.

The usual place where the great horned owl breeds is in the cavern of a rock, the hollow of 
a tree, or the turret of some ruined castle. Its nest is near three feet in diameter, and composed of sticks, bound together by the fibrous roots of trees, and lined with leaves on the inside. It lays about three eggs, which are larger than those of a hen, and of a colour somewhat resembling the bird itself. The young ones are very voracious, and the parents not less expert at satisfying the call of hunger. The lesser owl of this kind never makes a nest for itself, but always takes up with the old nest of some other bird, which it has often been forced to abandon. It lays four or five eggs ; and the young are all white at first, but change colour in about a fortnight. The other owls in general build near the place where they chiefly prey; that which feeds upou birds, in some neighbouring grove; that which preys chiefly upou mice, near some farmer's yard, where the proprietor of the place takes care to give it perfect security. In fact, whatever mischief one species of owl may do in the woods, the barn owl makes a sufficient recompense for, by being equally active in destroying nice nearer home; so that a single owl is said to be more scrviceable than half a dozen cats, in ridding the barn of its domestic vermin.

a Mr. Constedt, in the Transactions of the Philosophical Sociely of Stockbolm, gives a pleasing instance of their attaclument to their young. A young owl having quitted the nest, in the month of July, was caught by his servants, and slut up in a large ben-coop. The next morning a ynung partridge was fuund lying dead before the door of the coop. For fourteen successive nights the same cir-
"In the year 1580," says an old writer, "at Hallontide, an army of mice so over-run the marshes near Southminster, that they eat up the grass to the very roots. But at length a great number of strange painted owls came and devoured all the mice." The like happened again in Essex about sixty years after.

To conclude our account of these birds, they are all very shy of man, and extremely indocile and difficult to be taned. The white owl in particular, as Mr. Buffon asserts, cannot be made to live in captivity; I suppose he means, if it be taken when old. "They live," says he, "ten or twelve days in the aviary where they are shut up; but they refuse all kind of nourishment, and at last die of hunger. By day they remain without moving upon the floor of the aviary ; in the evening they mount on the highest perch, where they continue to make a noise like a man snoring with his mouth open. 'This seems designed as a call for their old companions without; and, in fact, I have 'seen several others come to the call, and perch upon the roof of the aviary, where they made the samc kind of hissing, and soon after permitted themselves to be taken in a net."

cumstance was repeated; plainly proving that it had been brought there by the old owls as a provision for the young one. Till the month of August, various articles of food, as young partridges, muor-fowl, pieces of lamb, and other substances, wcre regularly brought; after which time the parents discontinued their attendance. 


\section{OF BIRDS OF THE POULTHX TIND.}

\section{$-000$ \\ CHAPTER LXXXVII. \\ OF BIRDS OF THE POULTRY KIND IN GENERAL.}

FROM the most rapacious and noxions tribe of birds, we nuake a transition to those which of all others are the most harmless, ind the most serviceahle to man. He may force the rapacious tribes to assist his pleasures in the field, or induce the sinaller warblers to delight him with their singing: but it is from the poultry kind that he derives the inost solid advantages, as they not only make a considerable addition to the necessaries of life, but furnish ont the greatest delicacies to every entertainnent.

Almost, if not all, the domestic birds of the poultrv kind that we maintain in our yards, are of foreign extraction; but there are other's to be ranked in this class that are as yet in a state of nature; and perhaps only wait till they become sufficiently scarce to be taken under the eare of man, to multiply their propagation. It will appear remarkable enough, if we consider how much the tame poultry which we have imported from distant climates has increased, and how much those wild birds of the poultry kind that have never yet been taken into keeping have been diminished and destroyed. They are all thinred; and nuany of the species, especially in the more cultivated and populous parts of the kingdom, are utterly unseen.

Ulider birds of the poultry kind I rank all those that have white flesh, and, comparatively to their head and limbs, have ibulky bodies. They are furnished with short strong bills for picking up grain, which is their chicf and often their only sustenance. Thir wings are short and concave; for which resson they are not able to fly far. They lay a great many eggs; and, as they lead their young abroad the very day they are hatched, in ruuest of food, which they are shown by the mother, and whicls they pick up for theniselves, they generally make their nests on the ground. The toes of all these are united by a membrane as far as the first articulation, and then are divided as in those of the former class.

Under this elass we may therefore rank the commion cock, the peacock, the turkey, the pintada or Guinea-hen, the pheasant, the bustard, the grouse, the partridge, and the quail. These all bear a strong similitude to each other, being equally granivorous, flesliy, and delicate to the palate. These are anıng birds what bensts of pasture are among quadrupeds, peaceable tenants of the field, and shrunning the thicker parts of the forest, that abound with numerous animals, who carry on unceasing hostilities against them.

As nature has formed the rapacious class for war, so she seems equally to have fitted these for peace, rest, and society. Their wings are but short, so that they are ill formed for wandering from one region to another; their bills are also short, and incapable of annoying their opposers; their legs are strong, indeed, but their toes are made for scratching up their food, and not for holding or tearing it. These are sufficient indications of their harmless nature; shile their bodies, which are fat and fleshy, rencler them unwieldy travellers, and incapable of straying far from each other.

Accordingly we fincl them chiefly in society; they live together; and though they may have their disputes, like all other animals, upon some uccusions, yet when kept in the same district, or fed in the same yard, they learn the arts of subordination; and, in proportion 
as each knows his strength, he seldom tries a second time the combat where he has once been worsted.

In this manner, all of this kind seem to lead an indolent voluptuous life; as they are furnished internally with a very strong stomach, commonly called a gizzard, so their voraciousuess scarcely knows any bounds. If kept in close captivity, and scparated from all their former companions, they still have the pleasure of eating left; and they soon grow fat and unwieldy in their prison. To say this more simply, many of the wilder species of birds, when cooped or caged, pine away, grow gloomy, and some refuse all sustenance whatever; none, except those of the poultry kind, grow fat, who seem to lose all remembrance of their former liberty, satisfied with indolence and plenty.

The poultry kind may be considered as ensual epicures, solely governed by their appetites. The indulgence of these seems to influence their other habits, and destroys among them that connubial fidelity for which most other kinds are remarkable. The eagle and the falcon, how fierce soever to other animals, are yet gentle and true to each otlier; their connexions, when once formed, continue till death; and the male and female, in every exigence, and every duty, lend faithful assistance to each other. They assist each other in the production of their young, in providing for them when produced; and even then, though they drive them forth to fight their own battles, yet the old ones still retain their former affection to cach other, and seldom part far asunder.

But it is very different with this luxurions class I am now describing. Their courtship is but short, and their congress fortuitous. The male takes no heed of his oflspring; and satisfied with the pleasure of getting, leaves to the female all the care of providing for posterity. Wild and irregular in his appetites, he ranges from one to another; and claims every female which he is strong enough to keep from his fellows. Though timorous whell opposed to birds of prey, yet lie is in- credibly bold among those of his own kind; and but to see a male of his own species is sufficient to produce a combat. As his desires extend to all, every creature becomes his enemy that pretends to be his rival.

The female, equally without fidelity or attachment, yiclds to the most powerful. She stands by, a quiet meretricious spectator of their fury, ready to reward the conqueror with every compliance. She takes upon herself all the labour of hatching and bringing up her young, and chooses a place for hatching as remote as possible from the cock. Indeed, she gives herself very little trouble in making a nest, as her young ones are to leave it the instant they part from the shell.

She is equally unassisted in providing for her young, that are not fed with meat put into their moutlis, as in other classes of the feathered kind, but peck their food, and, forsaking their nests, run here and there, following the parent whercver it is to be found She leads them forward where they are like ly to have the greatest quantity of grain, and takes care to show, by pecking, the sort proper for them to seek for. Though at other times voracious, she is then abstemious to an extreme degree; and intent only on providing for, and showing her young clutch their food, she scarcely takes any nourishment herself. Her parental pride scems to overpower every other appetite; but that decreases in proportion as her young ones are more able to provide for themselves, and then all her voracious habits return.

Among the other habits peculiar to this class of birds is that of dusting themselves. Thicy lie flat in some dusty place, and with their wings and feet raise and scatter the dust over their whole body. What may be their reason for thus doing, it is not easy to explain. Perhaps the heat of their bodies is such, that they require this powder to be interposed between their feathers, to keep them from lying too close together, and thus increasing that heat with which they are incommoded. 


\section{CHAPTER LXXXIX.}

\section{OF THE, COCK.}

ALL birds taken under the protection of man lose a part of their natural figure, and are altered, not only in their habits, but their very form. Climate, food, and captivity, are three very powerful agents in producing these alterations; and those birds that have longest felt their influence under human direction, are the most likely to have the greatest variety in their figures, their plumage, and their dispositions.

Of all other birds, the cock seems to be the oldest companion of mankind, to have been first reclaimed from the forest, and taken to supply the accidental failure of the luxuries or necessities of life. As he is thus longest under the care of man, so of all others perhaps he exhibits the greatest number of varieties, there being scarce two birds of this species that exactly resemble each other in plumage and form. The tail, which makes such a beautiful figure in the generality of these birds, is yet found entirely wanting in others; and not only the tail, but the rump also. The toes, which are usually four in all animals of the poultry kind, yet in a species of the cock are found to amount to five. The feathers, which lie so sleek and in such beautiful order in most of those we are acquainted with, are in a peculiar breed all inverted, and stand staring the wrong way. Nay, there is a species that comes from Japan, which, instead of feathers, seems to be covered over with hair. These, and many other varieties, are to be found in this animal, which seem to be the marks this early prisoner bears of his long captivity.

It is not well ascertained when the cock was first made domestic in Europe, but it is generally agreed that we first had him in our western world from the kingdom of Persia. Aristophanes calls the cock the Persian bird, and tells us he enjoyed that kingdom before some of its earliest monarchs. This animal was in fact known so early, even in the most savage parts of Europe, that we are told the cock was one of the forbidden foods among the ancient Britons. Indeed, the domestic fowl seems to have banished the wild one. Persia itself, that first introduced it to our acquaintance, seems no longer to know it in its natural form; and if we did not find it wild in some of the woods of India, as well as those of the Islands in the Indian ocean, we might begin to doubt, as we do with regard to the sheep, in what form it first existed in a state of nature.

But those doubts no longer exist : the cock is found in the island of Tinian, in many others of the Indian ocean, and in the woods on the coast of Malabar, in his ancient state of independence. In his wild condition, his plumage is black and yellow, and his comb and wattles yellow and purple. There is another peculiarity also in those of the Indian woods; their bones, which when boiled with us are white, as every body knows, in those are as black as ebony. Whether this tincture proceeds from their food, as the hones are tinctured red by feeding upon madder, I leave to the discussion of others : satisfied with the fact, let us decline speculation.

In their first propagation in Europe, there were distinctions then that now subsist no longer. The ancients esteemed those fowls whose plumage was reddish as invaluable; but as for the white, it was considered as utterly unfit for domestic purposes. These they regarded as subject to become a prey to rapacious birds; and Aristotle thinks them less fruitful than the former. Indeed, his division of those birds seems to be taken from their culinary uses; the one sort he calls generous and noble, being remarkable for fecundity; the other sort, ignoble and useless, from their sterility. These distinctions differ widely from our modern notions of generosity in this animal; that which we call the gamecock being by no means so fruitful as the 
ungenerous dunghill-cock, which we treat with contempt. The Athenians had their cock-matches as well as we: but it is probable they did not enter into our refinement of choosing out the most barren of the species for the purposes of combat.

However this be, no animal in the world has greater courage than the cock, when opposed to one of his own species; and in every part of the world where refinement and polished manners have not entirely taken place, cock-fighting is a principal diversion. In China, India, the Philippine islands, and all over the East, cock-fighting is the sport and amusement even of kings and princes. With us it is declining every day; and it is to be hoped it will in time become only the pastime of the lowest vulgar. It is the opinion of many, that we have a bolder and more valiant breed than is to be found elsewhere; and some, indeed, have entered into a serious discussion upon the cause of so flattering a singularity. But the truth is, they have cocks in China as bold, if not bolder, than ours; and, what would still be considered as valuable among cockers here, they have more strength with less weight. Indeed, I have often wondered why men who lay two or three hundred pounds upon the prowess of a single cock, have not taken evcry method to improve the breed. Nothing, it is probable, could do this more effectually than by crossing the strain, as it is called, by a foreign mixture; and whether having recourse even to the wild cock in the forests of India would not be useful, I leave to their consideration. However, it is a mean and ungenerous amusement, nor would I wish much to promote it. The truth is, I could give such instructions with regard to cock-fighting, and could so arm one of these animals against the other, that it would be almost impossible for the adversary's cock to survive the first or second blow; but, as Boerhaave has said upon a former occasion, when he was treating upon poisons," to teach the arts of cruelty is equivalent to committing them."

This extraordinary courage in the cock is thought to proceed from his being the most salacious of all other birds whatsoever. A single cock suffices for ten or a dozen hiens; and it is said of him, that he is the only ani- mal whose spirits are not abated by indulgence. But then he soon grows old; the radical moisture is exhausted; and in three or four years he becomes utterly unfit for the purposes of impregnation. "Heus also," to use the words of Willoughby, "as they for the greatest part of the year daily lay eggs, cannot suffice for so many births, but for the most part after three years become effete and barren: for when they have exhausted all their seed-eggs, of which they had but a certain quantity from the beginning, they must necessarily cease to lay, there being no new ones generated within.

The hen scldom clutches a brood of chickens above once a season, though instances have been known in which they produced two. The number of eggs a domestic hen will lay in the year are above two hundred, provided she be well fed, and supplied with water and liberty. It matters not much whether she be trodden by the cock or no; she will continue to lay, although all the eggs of this kind can never, by hatching, be brought to produce a living animal. Her nest is made without any care, if left to herself; a hole scratched into the ground, among a few bushes, is the only preparation she makes for this season of patient expectation. Nature, almost exhausted by its.own fecundity, seems to inform her of the proper time for hatching, which she herself testities by a clucking note, and by discontinuing to lay. The good housewives, who often get more by their hens laying than by their chickens, artificially protract this clucking season, and sometimes entirely remove it. As soon as their hen begins to cluck, they stint her in her provisions; and if that fails, they plunge her into cold water: this, for the time, effectually puts back her hatching; but then it often kills the poor bird, who takes cold, and dies under the operation.

If left eintirely to herself, the hen would seldom lay above twenty eggs in the same nest, without attempting to liatcli them: but in proportion as she lays, her eggs are removed; and she contirlues to lay, vainly hoping to increase tlie number. In the wild state the hen seldom lays above fifteen egos; but then her provision is more difficultly obtained, and she is perhaps sensible of 
the difficulty of maintaining too numerous a family.

When the hen begins to sit, nothing can exceed her perseverance and patience; she continues for some days immoveable; and when forced away by the importunities of hunger, she quickly returns. Sometimes, also, her eggs become too hot for her to bear, especially if she be furnished with too warm a nest within doors, for then she is obliged to leave thein to cool a little: thus the warnith of the nest only retards incubation, and often puts the brood a day or two back in the shell. While the hen sits, she carefully turns her eggs, and even removes them to different situations; till at length, in about three wecks, the young brood begin to give signs of a desire to burst their confinement. When by the repeated efforts of their bill, which serves like a pioneer on this occasion, they have broke themselves a passage through the shell, the hen still continues to sit rill all are excluded. The strongest and best chickens generally are the first candidates for liberty : the weakest come behind, and some even dic in the shell. When all are produced, sle then leads them forth to provide for themsclves. Her affection and her pride seem then to alter her very nature, and correct her imperfections. No longer voracious or cowardly, she alsstains from all fond that her young can swallow, and flies boldly at every creature that she thinks is likely to do them mischief. Whatever the invading animal be, she boldly attacks him; the horse, the hog, or the mastiff. When marching at the head of her little troop, she acts the commander, and has a variety of notes to call her numerous train to their food, or to warn them of approaching danger. Upon one of thcse occasions, I have seen the whole brood run for security into the thickest part of a hedge, when the hen herself ventured boldly forth, and faced a fox that came for plunder. With a good mastiff, however, we soon sent the invader back to his retreat; but not before he had wounded the hen in several places.

Ten or twelve chickens are the greatest number that a good hen can rear and clutch at a time; but as this bears no proportion to the number of her eggs, schemes have been imagined to clutch all the eggs of a hen, and thus turn her produce to the greatest advantage. By these contrivances it has been obtained that a hen, that ordinarily produces but twelve chickens in the year, is found to produce as many chickens as eggs, and consequently often above two hundred. The contrivance I mean is the artificial methor of hatching chickens in stoves, as is practised at Grand Cairo; or in a chymical elaboratory properly graduated, as has been effected by Mr. Reaumur. At Grand Cairo, they thus produce six or seven thousand chickens at a time; where, as they arc brought forth in their mild spring, which is warmer than our summer, the young ones thrive without clutching. But it is otherwise in our colder and unequal climate; the little animal may, without much difficulty, be hatched fiom the shell; but they almost all perish when excluded. To remedy this, Reaumur has made use of a woollen hen, as he calls it; which was nothing more than putting the young ones in a warm basket, and clapping over them a thick woollen canopy. I should think a much better substitute might be found; and this from among the species themselves. Capons may very easily be taught to clutcli a fresh brood of chickens throughout the year; so that when one little colony is thus reared, another may be brought to succeed it. Nothing is more common thau to sce capons thus enIployed; and the manner of teaching them is this : first the capon is made very taine, so as to feed from one's hand ; then, about evening, they pluck the feathers off his breast, and rub the bare skin with nettles; they then put the clickens to him, which presently run under his breast and belly, and probably rubhing his bare skin gently with their heads allay the stinging pain which the nettles had just produced. This is repeated for two or three nights, till the animal takes an affection to the chickens that have thus given him relief, and continues to give them the protecrion they seek for: perhaps also the querulous voice of the chickens may be pleasant to him in inisery, and invite him to succour the distressed. He from that time brings up a brood of chickens like a hen, clutching them, feeding them, clucking, and performing all the functions of the tenderest parent. A eapon once accustomed to this service, will not give over; but when one brood is grown up he shay have another nearly hatched put under hin, which he will treat with thesame tenderness he did the fornner:

The cock, from his salaciousness, is allow- 
ed to be a short lived-animal; but how long these birds live, if left to themselves, is not yet well ascertained by any historian. As they are kept only for profit, and in a few years become unfit for generation, there are few that, from mere motives of curiosity, will make the tedious experiment of maintaining a proper number till they die. Aldrovandus hints their age to be ten years; and it is probable that this may be its extent. They are subject to some disorders, which it is not our business to describe; and as for poisons, besides nux vomica, which is fatal to most animals except man, they are injured, as Linnzeus asserts, by elder-berries, of which they are not a little fond.

\section{CHAPTER XC.}

\section{OF THE PEACOCK.}

THE Peacock, by the common people of Italy, is said to have the plumage of an angel, the voice of the devil, and the guts of a thicf. In fact, each of these qualities mark pretty well the nature of this extraordinary bird. When it appears with its tail expanded, there is none of the feathered creation can vie with it for beauty; yet the horrid scream of its voice serves to abate the pleasure we find from viewing it; and still more, its insatiaable gluttony, and spirit of depredation, make it one of the most noxious domestics that man has taken under his protection.

Our first peacocks were brought from the East Indies; and we are assured, that they. are still found in vast flocks, in a wild state, in the Islands of Java and Ceylon. So beautiful a bird, and one esteemed such a delicacy at the tables of the luxurious, could not be permitted to continue long at liberty in its distant retreats. So early as the days of Solomon, we find in his navies, among the articles imported from the east, apes and peacocks. Alian relates, that they were brought into Greece from some barbarous country, and were held in such ligh esteem among them, that a male and female were valned at above thirty pounds of our money. We are told also, that when Alexander was in India, he found them tlying wild, in vast numbers, on the banks of the river Hyarotis, and was so struck with their beauty, that he laid a severe tine and punishment on all who shoult kill or disturb them. Nor are we to be surprised at this, as the Greeks were so much struck with the beauty of this bird, when first brought among them, that every person paid a fixed price for seeing it; and several people came to Athens, from Lacedamon and Thessaly, purely to satisfy their curiosity.

It was probably first introduced into the West, merely on account of its beauty; but mankind, from contemplating its figure, soon came to think of serving it up for a different entertainment. Aufidius Hurco stands charged by Pliny with being the first who fatted up the peacock for the feast of the luxurious. Whatever there may be of delicacy in the flesh of a young peacock, it is certain an old one is very indifferent eating; nevertheless, there is no mention made of choosing the youngest; it is probable they were killed indiscriminately, the beauty of the feathers in some measure stimulating the appetite. Hortensius, the orator, was the first who served them up at an entertainment at Rome; and from that time they were considered as one of the greatest ornaments of every feast. Whether the Roman method of cookery, which was much higher than ours, might not have rendered them more palatable than we find them at present, I cannot tell; but certain it is, they talk of the peacock as being the first of viands.

Its fame for delicacy, however, did not continue very long; for we find in the times of Francis the First, that it was a custom to serve up peacocks to the tables of the great, with an intention not to be eaten, but only 
to be seen. Their manner was to strip off the skin; and then preparing the body with the warmest spices, they covered it up again in its former skin; with all its plumage in full display, and no way injured by the preparation. The bird thus prepared, was often preserved for many years without corrupting; and it is asserted of the peacock's flesh, that it keeps longer unputrefied than that of any other animal. To give a higher zest to these entertainments, on weddings particularly, they filled the bird's beak and throat with cotton and camphire, which they set on fire, to amuse and delight the company. I do not know that the peacock is much used at our entertainments at present, except now and then at an alderman's dinner, or a common-council feast, when our citizens resolve to be splendid; and even then it is never served with its cotton and camphire.

Like other birds of the poultry kind, the peacock feeds upon corn, but its chief predilection is for barley. But as it is a very proud and fickle bird, there is scarcely any food that it will not at times covet and pursue. Insects and tender plants are often eagerly sought at a time that it bas a sufficiency of its natural food provided more nearly. In the indulgence of these capricious pursuits, walls cannot easily confine it; it strips the tops of houses of their tiles or thatch, it lays waste the labours of the gardener, roots up his choicest seeds, and nips his favourite flowers in the bud. Thus its beauty but ill recompenses for the mischief it occasions; and many of the more homely looking fowls are very deservedly preferred before it.

Nor is the peacock less a debauchee in its affections, than a glutton in its appetites. $\mathrm{He}$ is still more salacious than even the cock; and though not possessed of the same vigour, yet burns with more immoderate desire. He requires five females at least to attend him; and if there be not a sufficient number, he will even run upon and tread the sitting hen. For this reason, the peahen endeavours, as much as she canl, to hide her nest from the male, as he would otherwise disturb her sitting, and break her eggs.

The peahen seldom lays above five or six eggs in this climate before she sits. Aristotle describes her as laying twelve; and, it is probable, in her native climate, she may be thus prolific; for it is certain, that in the forests where they breed naturally, they are numerous beyond expression. This bird lives about twenty years; and not till its third year has it that beautiful variegated plumage that adorns its tail.

"In the kingdom of Cambaya," says Taverner, "near the city of Baroch, whole flocks of them are seen in the fields. They are very shy, however, and it is impossible to come near them. They run off swifter than the partridge; and hide themselves in the thickets, where it is impossible to find them. They perch by night upon trees; and the fowler often approaches them at that season with a kind of banner, on which a peacock is painted to the life on cither side. A lighted torch is fixed on the top of this decoy; and the peacock, when disturbed, flies to what it takes for another, and is thus caught in a noose, prepared for that purpose."

There are varieties of this bird, some of which are white, others crested: that which is called the Pcacock of Thibet, is the most beautiful of the feathered creation, containing in its plumage all the most vivid colours, red, blue, yellow, and green, disposed in an almost artificial order, as if merely to please the eye of the beholder. 


\section{CHAP'TER XCI.}

\section{THE TURKEY.}

THE natal place of the cock and the peacock is pretty well ascertained, but there are stronger doubts concerning the turkey; some contending, that it has been brought into Europe from the East Indies inany centuries ago; while others assert, that it is wholly unknown in that part of the world, that it is a native of the New Continent, and that it was not brought into Europe till the discovery of that part of the world.

Those who contend for the latter opinion, very truly observe, that among all the descriptions we have of eastern birds, that of the turkey is not to be found: while, on the contrary, it is very well kuown in the New Continent, where it runs wild about the woods. It is said by them to have been first seen in France in the reign of Friucis $I$. and in England in that of Henry VIII. which is about the time when Mexico was first conquered by Spain. On the: other hand it is asserted, that the turkey, so far from being unknown in Europe before that time, was known even to the ancients; and that Eliau has given a pretty just description of it. They allege, that its very name implies its having been brought from some part of the east; and that it is found anong other dainties served up to the tables of the great, before that time among ourselves. But what they pretend to be the: strongest proof is, that thongh the wild turkey be so very common in $\Lambda$ merica, yet the natives cannot contrive to tame it; and thongh hatched in the ordinary manuer, nothing can render it domestic. In this diversity of opinions, perhaps it is best to suspend assent, till more lights are thrown on the subject: however, 1 ain inclined to concur with the former opinion.

With us, when young, it is one of the tenderest of all birds; yet, in its wild state, it is found in great plenty in the forests of Canada, that are covered with snow above thrce parts of the year. In the natural woods, they are found much larger than in their state of doNo $43 \& 44$. mestic captivity. They are much more beautiful also, their feathers being of a dark gray, bordered at the edges with a bright gold colour. These the savages of the country weave into cloaks to adorn their persons, and faslion into fans and unbrellas, but never once think of taking into keeping animals that the woods furnish them with in sufficient abundance. Savage nuan seems to find a delight in precarious possession. A great part of the pleasure of the chase lies in the uncertainty of the pursuit, and he is unwilling to abridge himself in any accidental success that may attend his fatigues. The hunting the turkey, therefore, makes one of his principal diversions; as its nesh contributes chiefly to the support of his family. When he has discovered the place of their letreat, which, in gencral, is near fields of nettles, or where there is plenty of any kind of grain, he takes his dog with him, which is trained to the sport, (a faithful rough creature, supposed to be originally reclaimed from the wolf,) and he sends him into the midst of the flock. The turkeys no sooner perceive their enemy, than they set off running at full speed, and with such swiftness, that they leave the dog far behind thens; he follows, nevertheless, and sensible they must soon be tired, as they cannot go full speed for any length of time, he at last firces them to take shelter in a tree, where they sit quite spent and fatigued, till the hunter comes up, and, with a long pole, knocks thein down, one after the other.

This manner of suffering themselves to be destroyed, argues no great instinct in the animal; and, indeed, in their captive state, they do not appear to be possessed of nuch. They seem a stupid, vain, querulous tribe, apt enough to quarrel among thenselves, yet without any weapons to do each other any injury. Every body knows the strange antipathy the turkey-cock has to a red colour; how he bristles, and, with his peculiar gobbling sound, flics to attack it. But there is another method of increasing the animosity of these birds $4 \mathrm{D}$ 
against each other, which is often practised by boys, when they have a mind for a battle. This is no more than to smear ovel the licad of one of the turkeys with dirt, and the rest run to attack it, witl all the spced of impotent animosity: nay, two of them, thus disguised, will fight each other till they are almost suffocated with fatiguc and anger.

But though so furious anong themselves, they are weak and cowardly against othel aninals, though far less powerful than they. The cock oftén makes the turkey keep at a distance; and they seldoin venture to attack him but with united force, when they ratlice oppress him by their weight, than annoy him by their arms. There is no animal, how contemptible soever, that will venture boldly to face the turkey-cock, that he will not fly from. On the contrary, with the insolence of a bully, he pursues any thing that seems to feal him, particularly lap-dogs and children, against both which he secuis to have a peculiar aversion. On such occasions, after he lias made them scamper, lie returns to his fenale train, displays his plumage aromnd, struts about the yard, and gobbles out a note of self-approbation. ${ }^{\mathrm{a}}$

The female secms of a milder, gentler disposition. Rather querulous than bold, she hunts about in quest of grain, and pursuit of insects, being particularly delighted with the eggs of ants and caterpillars. Slue lays eiglteen or twenty eges, larger than those of a hen, whitish, lutt marked with spots resembling the freckles of the face. Her young arc extremely tender at first, and must be carefully fed with curd chopped with dock leaves; but as they grow. older, they beconie more hardy; and follow the mother to considerable distances, in pursuit of insect food, which they prefer to any other. On these occasions, howcver, the female, though so large, and, as it

- In the American Medical Repository, an instance is recorded, where the turkey-cock seemed to show a considerable share of courage and prowess. A gentleman of New-York received from a distant part a turkey-cock and hen, and with them a pair of bantans : these he put all together into the yard with his other poultry. Some time afterwards, as he was feeding them from the bain door, a large hawk suddenly turned the corner of the loaru, and made a pounce at the bantam lien : she immediately gave would seem, so powerful a bird, gives them b!tt very little protection against the attacks of any rapacious animal that cones in her way. She rather warns her young to shift for themselves, than prepares to defend them. "I have heard," says the Abbe la Pluche, "a turkeyhen, when at the head of her brood, send forth the most hideous screans, without knowing as yet the cause: however, her young, inmediately when the warning was given, skulked under the bushes, the grass, or whatever else uffired for shelter or protection. They even stretched themselves at their full length upon the ground, and continued lying as motionless as if they wcre dead. In the mean time the mothes", with her eyes directed upwards, contimued her cries and screaming as before. Upon looking "1) to where she scemed to gaze, I discovered a hlack spot just under the clouds, but was unable at first to determine what it was; however, it soon appeared to be a lird of prey, though at first at too great a distance to be distinguished. I have secn one of these animals continue in this violent agitated state, and her whole brond pimed down as it were to the gromel, for four hours together; whilst their formidable foe has taken his circuits, lias mounted, and hovered directly over their heads: at last, upon disappearing, the parent began to change her note, and sent forth another cry, which, in an instant, gave life to the whole trenibling tribe, and they all flocked round her with expressions of pleasure, as if conscious of their happy escape from clanger."

When once grown up, turkeys are very hardy hirds, and feed themselves at very little expense to the farmer. Those of Norfolk are saitl to be the largest of this kingdom, weighing fiom twenty to thirty pounds. There are places, however, in the East Indies, where they are known only in their domestic state, in which they grow to the weight of sixty pounds.

the alarm, by a noise which is natural to her on sucl nccasions; when the turkey-cock, who was at the distance of alsoul two yards, and without doubt understood the hawk's intentions, and the immediate danger of his old acquaintance, flew at the tyrant with such violence, and gave lim so severe a stroke with his spurs, as to knock fiim from the lien to a considerable distance; and the timely aid of this fiendly auxiliary, completely saved the bantam from being devoured. 


\section{CHAPTER XCII.}

\section{THE PHEASANT.}

IT would surprise a sportsman to be old, that the pheasant, which lie finds wild 'n the woods, in the remotest parts of the kingdom, and in forests whicls can scarcely be said to have an owner, is a foreign bird, and was at first artificially propagated amongst us. They were brought into Europe from the banks of the Pliasis, a river of Colchis, in Asia Minor; and from whence they still retain their name.

Next to the peacock, they are the most beautiful of birds, as well for the vivid colour of their plumes, as for their happy mixtures and variety. It is far beyond the powcr of tlie pencil to draw any thing so glossy, so bright, or points so finely blended into each other. We are told that when Crosus, king of Lydia, was seated on his throne, adorued with royal magnificence, and all the barbarous poinp of eastern splendour. he asked Solon if he had ever belield any thing so fine? The Greek philosoplıer, no way moved by the objects before him, or taking a pride in his uative simplicity, replied, that after having seen the beautiful plumage of the pheasant, he could be astonished at 110 other finery.

In fact, nothing can satisfy the eye with a greater variety and richness of ormament than this beautiful creature. The iris of the eye is yellow; and the eyes themsclves are surrounded with a scarlet colour, sprinkled with small specks of black. On the forcpart of the head there are blackish feathers mixed with a shining purple. The top of the liead and the upper part of the neck are tinged with a darkish green, that shines like silk. In some, the top of the head is of a shining blue, and the head itself, as well as the upper part of the neck, appears sometimes blue and sometimes green, as it is differently placed to the eye of the spectator. Tlue feathers of the breast, the shoulders, the midthe of the back, and the sides under the wings, liave a blackish ground, with edges tinged of an exquisite colour, which appears sometimes black and sometimes purple, according to the different lights it is placed in; under the purple there is a transverse streak of gold colour. The tail from the middle feathers to the root is about eighteen inches long; the legs, the feet, and the toes, are of the colour of horu. There are black spurs on the legs, shorter than those of a cock; there is a membrane that connects two of the toes together; and the male is much more beautiful than the femalc.

This bird, though so beautiful to the eye, is not less delicate when served up to the table. Its flesh is considercd as the greatest dainty; and when the old physiciaris spoke of the wholesomeness of any viands, they made their comparison with the flesh of the pheasant. However, notwithstanding all these perfections to tenpt the curiosity or the palate, the pheasant has multiplied in its nild state; and, as if disdaining the protection of man, has left him to take shelter in the thickest woods and the remotest forests. All others of the domestic kind, the cock, the turkey, or the pintada, when once reclaimed, have still continued in their domestic state, and persevered in the habits and appctites of willing slavery. But the pheasant, though taken from its native warm retreats, where the woods supply variety of food, and the warm sun suits its tender constitution, has still continued its attachment to native freedom; and now wild among us, makes the most enviec ornament of our parks and forests, where he feeds upon acoris and berries, and the scanty produce of our clilling climate.

This spirit of independence seems to attend the pheasant even in captivity. In the woods, the hen pheasant lays from eighteen to twenty eggs in a season; but in a domestic state she seldom lays above ten. In the same manner, when wild she hatches and leads up her brood with patience, vigilance, 
and courage; but when kept tame, she never sits well; so that a lien is generally her substitute upon such occasions; and as for leading her young to their food, she is utterly ignorant of where it is to be found; and the young birds starve, if left solely to her protection. The pheasant therefore, on every account, seems better left at large in the woods, than reclaimed to pristine captivity. Its fecundity when wild is sufficient to stock the forest; its beautiful plumage adorns it ; and its flesh retains a higher flavour from its unlimited freedom.

However, it has been the aim of late to take these birds once more from the woods, and to keep them in places fitted for their reception. Like all others of the poultry kind, they have no great sagacity, and snffer themselves easily to be taken. At night they roost upon the highest trees of the wood; and by day they come lown into the lower brakes and bushes, where their food is clitictly found. They generally make a kind of flapping noise when they are with the fernales; and this often apprises the sportsman of their retreats. At other times he tracts them in the snow, and frequently takes them in springes. But of all birds they are shot most easily, as they always inake a whirring noise when they rise, by which they alarm the gunner, and being a large mark, and flying very slow, there is scarcely any missing them.

Ah ! what avail his glossy, varying dyes,

II is purpled crest, and scarlet-circled eyes,

The vivid green his shining plumes unfold,

II is painted wings, and breast that flames with gold ?

Pope.

When these birds are taken young into keeping, they become as familiar as chickcus; and when they are designed for breeding, they are put together in a yard, five hens to a cock; for this bird, like all of the poultry kind, is very salacious. In her natural state the female makes her nest of dry grass and leaves; the same must be laid for her in the pheasantry, and she herself will sometimes properly dispose them. If she refuses to hatch her eggs, then a common hen must be got to supply her place, which task she will perform with perseverance and success.
The young ones are very difficult to be reared; and they must be supplied with ants' eggs. which is the food the old one leads them to gather when wild in the woods. To make these go the farther, they are to be chopped up with curds, or other meat; and the young ones are to be fed with great exactness, both as to the quantity and the time of their supply. This food is sometimes also to be varied, and woodlice, earwigs, and other insects, are to make a variety. The place where they are reared must be kept extremely clean, their water must be changed twice or thrice a day; they must not be exposed till the dew is off the ground in the morning; and they should always be taken in before sun-set. When they become adult, they very well can shift for themselves, but they are particularly fond of oats and barley.

In order to increase the breed, and make it still more valuable, Longolius teaches us a method that appears very peculiar. The pheasant is a very bold bird, when first bronght into the yard among other poultry, not sparing the peacock. nor even such young cocks and heus as it can master; but after a time it will live tamely among them, and will at last be bronght to couple with a common ben. The breed thus produced take much stronger after the pheasant than the hen; and in a few successions, if they be left to breed with a cock-pheasant, (for the mixture is not barren,) there will be produced a species more tame, stronger, and more prolific; so that he adds, that it is strange why most of our pheasantries are not stocked with birds produced in this manner.

The pheasant, when full grown, seems to feed indifferently upon every thing that offers. It is said by a French writer, that one of the king's sportsmen shooting at a parcel of crows, that were gathered round a dead carcass, to his great surprise upon coming up, found that he had killed as many pheasants as crows. It is even asserted by some, that such is the carnivorous disposition of this bird, that when scveral of them are put together in the same yard, if one of them happens to fall sick, or seems to be pining, that all the rest will fall upon, kill, and devour it. Such is the language of books: those who have frequent opportunities of examining the 
manners of the bird itself, know what credit ought to be given to such an account.

Of the pheasant, as of all other domestic fowl, there are many varieties. There are white pheasants, crested pheasants, spotted pheasants; but of all others, the golden pheasant of China is the most beautiful. It is a doubt whether the peacock itself can hear the comparison. However, the natives of China would not have us consider it as their most beautiful bird, though covered all over with eyes, resembling in miniature those of the peacock. By their accounts, it is far exceeded by the fongwang, an imagnary bird, of which they give a most fantastic description. It is thus that the people of every country, though possessed of the greatest advantages, have still others that they would persuade strangers they enjoy, which have existence only in the imagination.

\section{CHAPTER XCIII.}

\section{THE PINTADA, OR GUINEA-HEN.}

THIS is a very remarkable bird, and in some measure unites the characteristics of the pheasant and the turkey. It has the fine delicate shape of the one, and the bare head of the other. To be more particular, it is about the size of a common hen, but as it is supported on longer legs, it looks much larger. It has a round back, with a tail turned down. wards like a partridge. The head is covercd with a kind of casque; and the whole plumage is black or dark gray, speckled with white spots. It has wattles under the bill, which do not proceed from the lower chap as in cocks, but froin the upper, which gives it a rery peculiar air; while its restless gait and odd chuckling sound distinguish it suffciently from all other birds whatever.

It is well known all over Europe, and even better than with us, as the nations that border on the Mediterranean probably had it before us from those parts of Africa which lay nearest. Accordingly we find it in different countries called by different names, from the place whence they had it. They are by some called the Barbary-hen; by others, the Tamis bird; and by others, the bird of Numidia. We have given it the name of that part of Africa from whence probably it was first brought. In many parts of their native country, they are seen in vast flocks together, feeding their young, and leading them in quest of food. All their habits are like those of the poultry kind, and they agree in every other respect, except that the male and female are so much alike, that they can hardly be distinguished asunder. The only difference lies in the wattles described above; which in the cock are of a bluish cast; in the hen they are more inclining to a red. Their eggs, like their bodies, are speckled; in our climate, they lay but five or six in a season: but they are far more prolific in their sultry regions at home. They are kept among us rather for show than use, as their flesh is not much esteemed, and as they give a good deal of trouble in the rearing 


\title{
CHAPTER XCIV.
}

\author{
THE BUSTARD.
}

THE Bustard is the largest land-bird that is a native of Britain. It was once much more numerous than it is at present; but the increased cultivation of the country, and the extreme delicacy of its flesh, has greatly thinned the species; so that a time may come when it may be doubted whether ever so large a bird was bred among us. It is probable that long before this the bustard would have been extirpated, but for its peculiar malner of feeding. Had it continued to seek shelter among our woods, in proportion as they were cut down, it must have been destroyed. If in the forest, the fowler might approach it without being seen; and the bird, from its size, would be too great a mark to be easily missed. But it inhabits only the open and extensive plain, where its food lies in abundance, and where every invader may be seen at a distance.

The bustard is much larger than the turkey, the male generally weighing from twenty-five to twenty-seven pounds. The neek is a foot long, and the legs a foot and a half: The wings are not proportionable to the rest of the body, being but four feet from the tip of the one to the other; for which reason the bird flies with great difficulty. The head and neck of the male are ash-coloured; the back is barred transversely with black, bright, and rist colour. The greater quill feathers are black; the belly white; and the tail, which consists of twenty feathers, is marked with broad black bars.

It would seem odd, as was hinted before, how so large a land-bird as this could find shclter in so cultivated a country as England; but the wonder will cease when we find it only in the most open countries, where there is scarce any approaching without being discovered. They are frequently seen in flocks of fifty or more, in the extensive downs of Salisbury Plain, in the heaths of Sussex and Cambridgeshire, the Dorsetshire uplands, and so on as far as East Lothian in Scotland. In those extensive plains, where there are no woods to screen the sportsman, nor hedges to creep along, the bustards enjoy an indolent security. Their food is composed of the berries that grow among the heath, and the large earth-worms that appear in great quantities on the downs before sun-rising in summer. It is in vain that the fowler creeps forward to approach them, they have always centinels placed at proper eminences, which are ever on the watch, and warn the flock of the smallest appearance of danger. All therefore that is left to the sportsman, is the comfortless view of their distant security. He may wish; but they are in safety.

It sometimes happens that these birds, though they are seldom shot by the gun, are often run down by grayhouids. As they are voracious and greedy, they often sacrifice their safety to their appetite, and feed themselves so very fat, that they are unable to fly without great preparation. When the grayhound, therefore, comes within a certain distance, the bustard runs off flapping its wings, and endeavouring to gather air enough under them to rise; in the mean time, the enemy approaches nearer and nearer, till it is too late for the bird even to think of obtaining safety by flight; for just at the rise there is always time lost, and of this the bird is sensible; it continues, therefore. on the foot, until it has got a sufficient way before the dog for flight, or until it is taken.

As there are few places where they can at once find proper food and security, so they generally continue near their old haunts, seldom wandering above twenty or thirty miles from home. As their food is replete with moisture, it enables them to live upon these dry plains, where there are scarcely any springs of water, a long time without drinking. Besirles this, nature has given the males an admirable magazine for their security 
against thirst. This is a pouch, the entrance of which lies immediately under the tongue, and capable of holding near seven quarts of water. ${ }^{\text {a }}$ This is probably filled upon proper occasions, to supply the hen when sitting, or the young before they can fly.

Like all other birds of the poultry kind, they change their mates at the season of incubation, which is about the latter end of summer: They separate in pairs, if there be a sufficiency of females for the males: but when this happens to be otherwise, the males fight until one of them falls. In France, they often find some of those victins to gallantry dead in the fields, and no doubt are not displeased at the occasion.

They make their nests upon the ground, only just scraping a liole in the earth, and sometimes lining it with a little long grass or straw. There they lay two eggs only, al- most of the size of a goose egg, of a pale olive brown, marked with spots of a darker colour. They hatch in about five weeks, and the young ones run about as soon as they are out of the shell.

The bustards assemble in flocks in the month of October, and keep together till April. In winter, as their food becomes more scarce, they support themselves indiscriminately, by feeding on moles, mice, and even little birds, when they can seize them. For want of other food, they are contented to live upon turnip leaves, and such like succulent vegetables. In some parts of Switzerland, they are found frozen in the fields in severe weather; but when taken to a warm place, they again recover. They usually live fifteen years, and are incapable of being propagated in a domestic state, as they probably want that food which best agrees with their appetite.

\section{CHAPTER XCV.}

\section{THE GROUSE, AND ITS AFFINITIES.}

THE Cock of the Wood, the Black Cock, the Grouse, and the Ptarmigan-these are all birds of a similar nature, and chiefly found in heathy mountains and piny forests, at a distance from mankind. They might once indeed have been common enough all over England, when a great part of the country was covered with heath; but at present their numbers are thinned; the two first of this kind are utterly unknown in the south, and have taken refuge in the northern parts of Scotland, where the extensive heath: afford them security, and the forests shelter.

The cock of the wood is sometimes of the size of a turkey, and often weighs near fourteen pounds; the black cock; of which the male is all over black, though the female is of the colour of a partridge, is about the size of a hen, and, like the former, is only found

\footnotetext{
a The size of this reservoir seems sometling exaggerated : for with an addition of nearly fourteen pounds weight thrown forwards, the centre of gravity must be so
}

with us in the highlands of Scotland; the grouse is about half as large again as a partridge, and its colour much like that of a woodcock, but redder; the ptarmigan is still somewhat less, and is of a pale brown or ashcolour. They are all distinguishable from other birds of the poultry kind by a naked skin of a scarlet colour, above the eyes, in the place and of the figure of eye-brows.

It seems to be something extraordinary, that all the larger wild animals of every species choose the darkest and the inmost recesses of the woods for their residence, while the smaller kinds come more into the open and cultivated parts, where there is more food and more danger. It is thus with the birds I am describing: while the cock of the wood is seldom seen, except on the inaccessible parts of heathy mountains, or in the

much overbalanced, as to destroy its power of flight, and impede its running. About half this quantity seems a probable sufficiency for all its wants. 
midst of piny forests, the gronse is found in great numbers in the neighbourhood of cornfields, where there is heath to afford retreat and shelter. Their food too some what differs; while the smaller kind lives upon heath blossoms, cranberries, and corn, the larger feeds apon the cones of the pine-tree; and wili sometimes entirely strip one tree, before it ollers to touch those of another, though just beside him. In other respects, the manners of these birds are the same; being both equally simple in their diet, and licentious in their amours.

The cock of the wood, for it is from him we will take our description, is, as was said, chiefly fond of a mountainous and woody situation. In winter he resides in the darkest and inmost part of the woods; in summer be ventures down from his retreats, to make short depredations on the farmers' corn. The delicacy of his tlesh in some measure sets a high price upon lis head; and as he is greatly sought after, so he continues, when he comes down from the hills, always on his guard. Upon these occasions, he is seldom surprised; and those who would take him, must venture up to find him in his native retreats.

The cock of the wood, when in the forests, attaches himself principally to the oak and the pine-tree; the cones of the latter serving for lis food, and the thick boughs for a habitation. He even makes a choice of what cones he shall feed upon; for he sometines will strip onc tree bare before he will deign to touch the cones of another. He feeds also upon ants' eggs, which seem a high delicacy to all birds of the poultry kind: cranberries are likewise often found in his crop; and his gizzard, like that of domestic fowls, contains a quantity of gravel, for the purposes of assisting his powers of digestion.

At the earliest return of spring, this bird begins to feel the genial influence of the season. During the inonth of March, the approaches of courtship are continued, and do not desist till the trees have all their leaves, and the forest is in full bloom. During this whole season, the cock of the wood is seen at sunrise and setting, extrcmely active, upon one of the largest branches of the pine-tree. With his tail raised and expanded like a fan, and the wings drooping, he is seen walking backward and forward, his neck stretehed out, his head swollen and red, and making a thousand ridiculous postures: his cry upon that occasion is a kind of loud explosion, which is instantly followed by a noise like the whetting of a scythe, which ceases and commences alternately for about an hour, and is then terminated by the same explosion.

During the time this singular cry continues, the bird seems entirely deaf and insensible of every danger; whatever noisc may be made near him, or even though fired at, he still continues bis call; and this is the time that sportsmen generally take to shoot him. Upon all other occasions, he is the most timorous and watchful bird in nature; but now he seems entirely absorbed by his instincts; and seldom leaves the place where he first begins to feel the accesses of desire. This extraordinary cry, which is accompanied by a clapping of the wings, is no sooner funished, than the fernale, hearing it, replies, ápproaches, and places herself under the tree, from whence the cock descends to impregnate her. The number of females that, on this occasion, resort to his call, is uncertain; but one male generally suffices for all.

The female is much less than her mate, and entirely unlike him in plumage, so that she might be mistaken for a bird of another species: she seldom lays more than six or seven eggs, which are white, and marked with yellow, of the size of a common hen's egg; she generally lays them in a dry place, and a mossy ground, and hatches them without the company of the cock. When she is obliged, during the time of incubation, to leave her eggs in quest of food, she covers them up so artfully, with moss or dry leaves, that it is extremely difficult to discover them. On this occasion, she is extremely tame and tranquil, however wild and timorous in ordinary. She often keeps to her nest, though strangers attempt to drag her away.

As soon as the young ones are hatched, they are seen running with extreme agility after the mother, though sometimes they are not entirely disengaged from the shell. The hen leads thein forward, for the first time, into the woods, shows them ants' eggs, and the wild mountain-berries, which, while young, are their only food. As they grow older, 
their appetites grow stronger, and they then feed upon the tops of hether, and the cones of the pine-tree. In this mamner they soon come to perfection: they are a hardy bird, their food lies every where before them, and it would seem that they should increase in great abundance. But this is not the case; their numbers are thinned by rapacious birds and beasts of every kind ; and still more by their own salacious contests.

As soon as the clutching is over, which the fernale performs in the manuer of a hell, the whole brood follows the mother for about a month or two; at the end of which the young males entirely forsake her, and keep in great harmony together till the beginning of spring. At this scason they begin, for the first time, to feel the genial access; and then adieu to all their former friendships! They begin to consider each other as rivals; and the rage of concupiscence quite extinguishes the spirit of society. They fight each other like game-cocks; and at that time are so inattentive to their own safety, that it often happens that two or three of them are killed at a shot. It is probable that in these contests, the bird which comes off victorious takes possession of the female seraglio, as it is certain they have no faithful attachments.

\section{CHAPTER LCVI.}

\section{OF THE PARTRIDGE, AND ITS VARIETIES.}

THE Partridge may be partieularly considered as belonging to the sportsman. It is a bird which even our laws have taken under protecrion; and, like a peacock or a hen, may be ranked as a private property. The only difference now is, that we feed one in our farms, the other in our yards: that these are contented captives; those, servants that have it in their power to cliange their master, by changing their habitation.

"These hirds," says Willoughby, " hold the principal place in the feasts and entertainments of princes; without which their feasts are esteemed ignoble, vulgar, and of no account. The Frenchmen do so highly value, and are so fond of, the partridge, that if they be wanting, they utterly sligits and despise the bestspread tables; as if there could be no feast without them." But however this night be in the times of our historian, the partridge is now too common in France to be considered as a delicacy : and this, as well as every other simple dish, is exploded for luxuries of a more compound invention.

In England, where the partridge is much

\footnotetext{
a This account is from the Journal Economique, and may be relied on.
}

xo. $43 \& 44$. scarcer, and a great deal dearer, it is still a favourite delicacy at the tables of the rich; and the desire of kecping it to theniselves, has induced them to nake laws for its preservation, no way harmonizing with the general spirit of English legislation. What call be more arbitrary than to talk of prescrving the game; which, when defined, means no more than that the poor shall abstain from what the rich have taken a fancy to kecp for themselves? If these birds could, like a cock or a hen, be made legal property, could they be taught to kecp within certain districts, and only feed on those grounds that belong to the nian whose entertainments they improve, it then might, with some show of justice, be admitted, that as a man fed them, so he night claim them. But this is not the case; nor is it in any uran's power to lay a restraint upon the liberty of these birds, that, when let loose, put no limits to their excursions. They feed ercry where ; upon cvery man's ground; and no man can say these birds are fed only by me. Those birds which are nourished by all, belong to all; nor can any ouc man, or any set of men, lay claim to them, when still continuing in a state of nature.

I never walked out about the environs of $4 \mathrm{E}$ 
Paris, that I did not consider the immense quantity of game that was running almost tame on every side me, as a batige of the slavery of the people; and what they wished me to observe as an object of triumph, I al ways regarded with a kind of secret compassion: yet this people have no game-laws for the remoter parts of the kingdôm ; the game is only preserved in a few places for the king, and is fiee in most places else. In England, the prohibition is general; and the peasunt has not a right to what even slaves, as he is taught to call them, are found to pussess.

Of partridges there are two kinds ; the gray anil the red. The red partridge is the largest of the two, and often perches upon trees; the gray, with which we are best acquainted in England, is most prolific, and always keeps on the ground.

The partridge seems to be a bird well known all over the world, as it is found in every country, and in every climate; as well in the frozen regions about the pole, as the torrid tracts under the equator. It even seems to adapt itself to the nature of the climate where it resides. In Greenland, the partridge, which is boivn in summer, as soon as the icy winter sets in, begins to take a covering suited to the season: it is then clothed with a warm down heneath; and its outward plumage assumes the colvur of the snows amongst which it seeks its food. Thus it is doubly fitted for the place, by the warmth and the colour of its plumage; the one to defend it liom the cold, the oth re to prevent its being noticed by the enemy. Those of Barakonda, on the other hand, are longer-legged, much swifter of foot, and choose the highest rocks and precipices to reside in.

They all, however, agree in one character, of being immoderately addicted to venery; and, as some writers affirm, often to an unnatural degree. It is certain the male will pursue the hen even to her nest; and will break her eggs, rather than not indulge his inclinations. Thougl the young ones have kept together in flocks during the winter, when they begin to pair in spring, their society disperses, and combats, very terrible with respect to each other, ensue. Their manners, in other circumstances, resemble all those of poultry in general ; but their cumning and instincts seem superior to those of the larger kinds. Perlaps, as they live in the very neighbourhood of their encmies, they have more frequent occasion to put their little arts in practice; and learn, by linbit, the means of evasion or safety. Whenever, therefore, a dog, or other formidable animal, approaches their nest, the female uses every means to draw him away. She keeps just before him, pretends to be incapable of flying, just hops up, and then falls down before him, but never goes off so far as to discourage her pursuer. At length, when she has drawn him entircly away from her secret treasure, she at once takes wing, and fairly leaves hin to gaze alter her in despair.

After the rlanger is over, and the dog withdrawn, she then calls her young, who assemble at once at her ery, and follow where she leads them. There are generally from ten to fifteen in a covey; and, if unnulested, they live from fifteen to seventeen years.

There are several niethods of taking them, as is well known: that by which they are taken in a net with a setting-dog, is the most pleasant, as well as the most secure. The dog, as every body knows, is trained to this exercise by a long course of education : by blows and caresses he is taught to lie down at the word of command; a partridge is shown him, and he is then ordered to lie down: he is hrought into the field, and when the sportsinan perceives where the covey lies, he orders his dog to crouch: at length the dog, from habit, crouches wherever he approaches a covey; and this is the signal which the sportsman reccives for unfolding, and covering the birds with his net. A covey thus caught, is sometimtes fed in a place proper for their reception; but they can never be thoroughly tamed, like the rest of our domestic poultry. 


\section{CHAPTER XCVII.}

\section{THE QUAIL.}

THE last of the poultry kind that I shall mention, is the quail; a bird much smaller than any of the former, being not above half the size of a partrilge. The feathers of the head are black, edged with rusty browil; the breast is of a pale ycllowish red, spotted with black; the feathers on the back are marked with lines of a pale yellow, and the legs are of a pale hue. Except in the colours thus described, and the size, it every way resembles a partridge in shape; and, except that it is a bird of passage, all others of the poultry kind, in its habits and nature.

The quail is by all known to be a bird of passage; and yet if we consider its heavy mamuer of flying, and its dearth of plumage, with respect to its corpulence, we shall be surprised how a bird so apparently ill qualified for migration, should take such extensive journeys. Nothing, however, is more certain: "When we sailed from Rhodes to Alexandria." says Bellonius, "about autumn, many quails, flying from the north to the south, were taken in our ship; and sailing at spring-time, the contrary way, from the south to the north, I obscrved them on their return, when many of them were taken in the same manner." This account is confirmed by many others; who aver, that they choose a north wind for these adventures; the south wind being very unfavourable, as it retards their flight, by moistening their plumage. 'They then fly two by two; continuing, when their way lies over land, to go faster by night than by day : and to fly very high, to avoid being surprised or set upon by birds of prey. However, it still remains a doubt whether quails take such long journeys as Bellonius has made them perform. It is now asserted by some, that the quail only migrates from one proviuce of a country to another. For instance, in England, they fly from the inland counties, to those bordering on the sea, and continue there all the winter. If frost or snow drive them out of the stubble-fields or marshes, they then retreat to the sca-side, shelter themselves among the weeds, and live upon what is thrown up from the sea upon shore. Particularly in Essex, the time of their appearance upon the coasts of that country exactly coincides with their disappearance from the more internal parts of the kingdom; so that what has been said of their long flights, is probably not so well founded as is generally supposed.

These birds are much less prolific than the partridge; seldom laying more than six or seven whitish eggs, marked with ragged rustcoloured spots. But their ardour in courtship yields searcely to any other bird, as they are fierce and cruel at that seison to each other, fighting most desperately, and (a punishment they richly deserve) being at that time very easily taken. Quail-fighting was a favourite amusement among the Athenians: they abstained from the flesh of this bird, deeming it unwholesome, as supposing that it fed upon the white hellebore; but they reared great numbers of them, for the pleasure of seeing them fight; and staked sums of money, as we do with regard to cocks, upon the success of the combat. Fashion, however, has at present changed with regard to this bird; we take no pleasure in its courage, but its flesh is considered as a very great delicacy.

Quails are easily caught by a call: the fowler, early in the morning, having spread his net, hides himself under it among the corn; he then imitates the voice of the female with his quail-pipe, which the cock hearing, approaches with the utmost assiluity; when he has got under the net, the forler then discovers himself, and terrifies the quail, who attempting to get away, entangles him- 
self the more in the net, and is taken. The quail may thus very well serve to illustrate

[In this place it may be proper to mention a curious bird of South America, called the Trumpeter, as it seems, both in its formation and manners, to approach nearest to the poultry kind. It is about the size of a large fowl. Its general plumage is black; the neck and breast glossy changeable green; the bill yellowish green, the upper mandible a little convex; the legs are greenish. The the old adage, that every passion, carried to an inordinate excess, will at last lead to ruin.

Trumpeter is so called from the singular noise it makes. It is easily domesticatcd, and discovers a great degree of attachment to those who take notice of it and feed it, and follows them like a dog; but bites the legs of those to whom it takes a dislike, following them to a great distance, and showing every mark of displeasure.] 


\section{OF BIRDS OF TIE PIS IIND.}

\section{CHAP'TER XCVIII.}

\section{OF BIRDS OF THE PIE KIND.}

IN marshalling our army of the feathered crcation, we have placed in the van a race of birds loug bred to war, and whose passion is slaughter; in the centre we have placed the slow and heavy laden, that are usually brought imto the field to be destroyed; we now come to a kind of light infantry, that partake something of the spirit of the two former, and yet belonging to neither. In this class we nust be content to marshal a numerous irregular tribe, variously armed, with different pursuits, appetites, and manners; not formidably formed for war, and yet generally delighting in mischief, not slowly and usefully obedient, and yet without any professed enmity to the rest of their fellow tenants of air.

To speak without metaphor; under this class of birds we may arrange all that noisy, restless, chattering, teazing tribe, that lies between the hen and the thrusli, that, from the size of the raven down to that of the woodpecker, flutter round our habitations, and, rather with the spirit of pilferers than of robbers, make frec with the fruits of human industry.

Of all the other classes, this seems to be that which the least contributes to furnish out the pleasures, or supply the necessitics, of man. The falcon hunts for him ; the poultry tribe supplies him with luxurious food; and the little sparrow race delight him with the melody of their warblings. The crane kind make a studied varicty in his entertainments; and the class of ducks are not only many of them delicate in their flesh, but extremely useful for their feathers. But in the class of the pie kind, there are few, except the pigeon, that are any way useful: They serve rather to tcaze man, than to assist or amuse him. Like faithless ser- vants, they are fond of his neighbourhood, because they mostly live by his labour; hut their chief study is what they can plunder in his absence, while their deaths make him no atonement for their depredation.

But though, with respect to man, this whole class is rather noxious than beneficial; , though he may consider them in this light, as false, noisy, troublesome neighbours, yet, with respect to each other, no class of birds are so ingenious, so active, or so well fitted for society. Could we suppose a kind of morality among birds, we should find that these are by far the most industrious, the most faithful, the most constant, and the most connubial. The rapacious kinds dive out their young before they are fit to struggle with adversity : but the pic kind cherish their young to the last. The poultry class are faithless and promiscuous in their courtship; but these live in pairs, and theil attachments are wholly confined to each other. The sparrow kind frequently overleap the bounds of nature, and make illicit varieties; but these never. They live in harmony with each other; every species is true to its kind, and transmits an unpolluted race to posterity.

As other kinds build in rocks or upon the ground, the chief place where these build is in trees or bushes; the male takes his share in the labours of building the nest, and often relicres his mate in the duties of incubation. Both take this office by turns; and when the young are excluded, both are equally active in making them an ample provision.

They sometines live in societies; and in these there are general laws observed, and a kind of republican form of government established among them. They watch not only for 
the general safety, but for that of every other bird of the grove. How often have we seen a fowler, stealing in upon a flock of ducks or wild geese, disturbed by the alarming note of a crow or a magpie: its single voice gave the whole thoughtless tribe warning, and taught them in good time to look to their safety.

Nor are these birds less remarkable for their instincts than their capacity for instruction. There is an apparent cumning or archness in the look of the whole tribe; and I have seen crows and ravens taught to fetch and carry with the docility of a spaniel. Indeed, it is often an exercise that, without teaching, all this tribe are but too fond of. Every body knows what a passion they have for shining substances, and such toys as some of us put a value upon. A whole family has been alarmed at the loss of a ring; every servant has been accused, and every creature in the house, conscious of their own innocence, suspected each other, when, to the utter surprise of all, it has been found in the nest of a tame magpic or a jackdaw, that nobody had ever thought of.

However, as this class is very numerons, it is not to be supposed that the manners are alike in all. Some, such as the pigeon, are gentle and serviceable to man; others are noxious, capricious, and noisy. In a few general characters they all ngree; namely, in having hoarse voices, slight active hodies, and a facility of flight, that baffles even the boldest of the rapacious kinds in the pursuit. 1 will begin with those bi:ds which most properly may be said to belong to this class, and go on till I finish with the pigeon, a harmless bird, that resembles this tribe in little else except their size, and that seems to be the shade uniting the pie and the sparrow kind into one general picture.

It is not to be expected that in this sketch of the great magazine of nature, we can stop singly to contemplate every object. To describe the number that offers would be tedious, and the similitude that one bears to another would make the history disgusting. . As a historian in relating the actions of some noble people does not stop to give the character of every private man in the army, but only of such as have been distinguished by their conduct, courage, or treachery; so should the historian of nature only seize upon the most striking objects before him; and having given one common account of the most reinarkable, refer the peculiarities of the rest to their general description.

\section{CHAP'TER XCIX.}

\section{OF THE RAVEN, THE CROW, AND THEIR AFFINITIES.}

THE Raven, the Carrion-crow, and the Rook, are birds so well known, that a long description would but obscure our ideas of them. The Raven is the largest of the three, and distinguished from the rest not only by his size, but by his bill being somewhat more hooked than that of the rest. As for the carrion-crow and the rook, they so strongly resemble each other, both in make and size, that they are not easily distinguished asunder. The chief difference to be found between them lies in the bill of the rook; which, by being frequently thrust into the ground to fetch out grubs and earth-worms, is bare of feathers as far as the eyes, and appears of a whitish colour. It differs also in the purple splendour or gloss of its feathers, which in the carrion-crow are of a more dirty black. Nor is it amiss to make these distinctions, as the rook has but too frequently suffered for its similitude to the carrion-crow; and thus a harmless bird, that feeds only upon insects and corn, has been destroyed for another that feeds upon carrion, and is often de. structive among young poultry.

The manners of the raven and the carrion. crow are exactly similar; they both feed upon carrion; they fly only in pairs; and will destroy other birds, if they can take them by surprise. But it is very different with the 
rook, the daw, and the Cornish chough, which may be all ranked in this order. They are sociable and harmless; they live only upon insects and grain; and wherever they are, instead of injuring other birds, they seem centinels for the whole feathered creation. It will be proper, therefore, to describe these two sorts according to their respecive appetites, as they have nothing in common but the very strong similitnde they bear to each other in their colour and formation.

The raven is a bird found in every region of the world; strong and hardy, he is uninfluenced by the changes of the weather; and when other birds seem numbed with cold, or pining with famine, the raveu is active and healthy, busily employed in prowling for prey, or sporting in the coldest atmosphere. As the lieats at the line do not oppress him, so he bears the cold of the polar countries with equal indifference. He is sometimes indeed seen milk white; and this may probably be the effect of the rigorous climates of the north. It is most likely that this change is wrought upon him as upon most other animals in that part of the world, where their robes, particularly in winter, assume the colour of the country they inhabit. As in old age, when the natural heat decays, the bair grows gray, and at last white; so among these animals the cold of the climate may produce a similar languishment of colour, and may shut up those pores that conveyed the tincturing fluids to the extremest parts of the body.

However this may be, white ravens are often shown among us, which I have heard some say, are rendered thus by art; and this we could readily suppose, if they were as easily changed in their colour, as they are altered in their habits and dispositions. A raven may be reclaimed to almost every purpose to which birds can be converted. He may be trained up for fowling like a hawk; he may be taught to fetch and carry like a spaniel; he may be taught to speak like a parrot; but the most extraordinary of all is, that he can be taught to sing like a man. I

A At the seat of the earl of A ylesbury in Wiltshire, a tame raven, that had been taucht to speak, used to ramble about in the park; there he was commonly attended and beset with crows, rouks, and others of his inquisitive tribe. Wluen a considerable number of these were collected round have heard a raven sing the Black Joke with great distinctness, truth, and humour."

lndeed, when the raven is taken as a domestic, he has many qualities that render him extremcly amusing. Busy, inquisitive, and impudent, he goes every where; affronts and drives off the dogs, plays his pranks on the poultry, and is particularly assiduous in cultivating the good-will of the cook-naid, who seems to be the favourite of the family. But then, with the amusing qualities of a favourite, he often also has the vices and defects. He is a glutton by nature, and a thief by habit. He does not confine himself to petty depredations on the pantry or the larder; he soars at more maguificent plunder; at spoils that he can neither exhibit nor enjoy; but which, like a miser, he rests satisfied with having the satisfaction of sometimes visiting and contemplating in secret. A piece of money, a tea-spoon, or a ring, are always tempting baits to his avarice ; these he will slily seize upon, and, if not watched, will carry to his favourite hole.

In his wild state, the raven is an active and greedy plunderer. Nothing comes amiss to him; whether his prey be living or long dead it is all the same, he falls to with a voracious appetite; and, when he has gorged himself, flies to acquaint his fellows, that they may participate of the spoil. If the carcass be already in the possession of some more powerful animal, a wolf, a fox, or a dog, the raven sits at a little distance, content to continue a humble spectator till they have done. If in his flights he perceives no hopes of carrion, and his scent is so exquisite that he can smell it at a vast distance, he then contents himself with more unsavoury food, fruits, insects, and the accidental dessert of a dunghill.

This bird cliefly builds its nest in trees, and lays fire or six eggs of a pale green colour, marked with small brownish spots. They live sometimes in pairs, and sometimes they frequent, in great numbers, the neighbourhood of populous cities, where they are useful in devouring those carcasses that would

him, he would lift up his head, and with a loarse and lollow voice slrout out the word Ilolla! This would instantly put to flight and disperse his suble brethren; while the raveu seemed to enjoy the fright he had occasioned. 
otherwise putrefy and infect the air. They build in high trees or old towers, in the beginning of March with us in England, and sometimes sooner, as the spring is more or less advanced for the season. But it is not always near towns that they fix their retreats; they often build in unfrequented places, and drive all other birds from their vicinity. They will not permit even their young to keep in the same district, but drive them off when they are sufficiently able to shift for themselves. Martin, in his description of the Western Isles, avers, that there are three little islands among the number, which are occupied by a pair of ravens each, that drive off all other birds with great cries and impetuosity.

Notwithstanding the injury these birds do in picking out the eyes of sheep and lambs, when they find them sick and helpless, a vulgar respeet is paid them, as being the birds that fed the prophet Elijah in the wilderness. This prepossession in favour of the raven is of very ancient date, as the Romans theinselves, who thought the bird ominous, paid it, from motives of fear, the most profound veneration. One of these that liad been kept in the temple of Castor, as Pliny informs $1 \mathrm{u}$. flew down into the shop of a tailor, who took much delight in the visits of his new acquaintance. He taught the bird several trieks; but particularly to pronounce the names of the emperor Tiberius, and the whole royal family. The tailor was begiuning to grow rich by those who came to see this wonderful raven, till an envious neighbour, displeased at the tailor's success, killed the bird, and deprived the tailor of his future hopes of fortune. The Romans, however, took the poor tailor's part; they punished the man who offered the injury, and gave the raven all the honours of a magnificent interment.

Birds in general live longer than quadrupeds; and the raven is said to be one of the most long-lived of the number. Hesiod asserts that a raven will live nine times as long as a nnan; but though this is fabulous, it is certain that some of them have been known to live near a hundred years. This animal seems possessed of those qualities that generally produce longevity, a good appetite, and great exercise. In clear weather, the ravens fly ill pairs to a great height, making a deep loud noise, different from that of their usual croaking.

The carrion-crow resembles the raven in its appetites, its laying, and manner of bringing up its young. It only differs in being less bold, less docile, and less favoured by inairkind.

The rook leads the way in another, but a more harmless train, that have no carnivorous appetites, but only feed upon inseets and corn. The Royston crow is about the size of the two former. The breast, belly, back, and upper part of the neck, being of a pale ashcolour; the head and wings glossed over with a fine blue. He is a bird of passage, visiting this kingdom in the heginning of winter, and leaving it in the spring. He breed, however, in different parts of the British dominions; and his nest is common enough in trees in Ireland. The jackdaw is black, like all the former, but ash-coloured on the breast and belly. He is not above the size of a pigeon. He is docile and loquacious. His head is large for the size of his body, which, as has been remarked, argues him ingenious and crafty. He builds in steeples, old castles, and high rocks, laying five or six eggs iin a season. The Cornish chough is like a jackdaw, but bigger, and almost the size of a crow. The bill, feet, and legs, are long like those of a jackdaw, but of a red colour; and the plumage is black all over. It frequents rocks, old eastles, and churches by the sea-side, like the daw; and w th the same noisy assiduity. It is only seen along the western coasts of Eugland. These are birds very similar in their manners, feeding on grain and insects, living in society, and of ien suffering general castigation from the flock for the good of the commnnity.

The rook, as is well known, builds in woods and forests in the neighbourhood of man, and sometimes makes choice of groves in the very midst of eities for the place of its retreat and security. In these it establishes a kind of legal constitution, by which all intruders are excluded from coming to live among them, and none suffered to build but acknowledged natives of the place. I have often amused myself with observing their plan of policy from my window in the Temple, 
that looks upon a grove where they have made a colony in the midst of the city. At the commencement of spring, the rookery, which during the continnance of winter seemed to have been deserted, or only guarded by about five or six, like old soldiers in a garrison, now begins to be once more frequented; and in a short time all the bustle and hurry of business is fairly commenced. Where these numbers resided during the winter is not easy to guess; perhaps in the trees of hedge-rows, to be nearer their food. In spring, however, they cultivate their native trees; and, in the places where they were themselves hatched, they prepare to propagate a future progeny.

They keep together in pairs; and when the offices of courtship are over, they prepare for making their nests and laying. The old inhabitants of the place are all already provided; the nest which served them for years before, with a little trimming and dressing, will serve very well again; the difficulty of nestling lies only upon the young ones, who have no nest, and must therefore get up one as well as they can. But not only the inaterials are wanting, but also the place in which to fix it. Every part of a tree will not do for this purpose, as some branches may not be sufficiently forked; others may not be sufficiently strong; and still others may be too much exposed to the rockings of the wind. The male and female upon this occasion are. for some days, seen examining all the trees of the grove very attentively; and when they have fixed upon a branch that seems fit for their purpose, they continue to sit upon and observe it very sedulously for two or three days longer. The place being thus determined upon, they begin to gather the materials for their nest; such as sticks and fibrous roots, which they regularly dispose in the most substantial manuer. But here a new and unexpected obstacle arises. It often happens that the young couple have made choice of a place too near the mansion of an older pair, who do not choose to be incommoded by such troublesome neighbours. A quarrel therefore instantly ensues, in which the old ones are always victorious.

The young couple, thus expelled, are obliged again to go through the fatigues of พо $43 \& 44$. deliberating, examining, and choosing; and having taken care to keep their due distance, the nest begins again, and their industry deserves commendation. But their alacrity is often too great in the hegiming; they soon grow weary of bringing the materials of their nest from distant plices; and they very easily perceive that sticks may be provided nearer lome, with less honesty, indeed, but some degree of address. Away they go, therefore, to pilfer, as fast as they can; and wherever they see a nest unguarded, they take care to rob it of the very choicest sticks of which it is composed. But these thefts never go unpunished; and probably upon complaint being made there is a general punishment inflicted. I have seen eight or ten rooks come upon such occasions, and, setting upon the new nest of the young couple all at once, tear it in pieces in a moment.

At length, therefore, the young pair find the necessity of going more regularly and honestly to work. While one flies to fetch the materials, the other sits upon the tree to guard it; and thus in the space of three or four days, with a skirmish now and then between, the pair have fitted up a commodious nest, composed of sticks without, and of fibrous roots and long grass within. From. the instant the female begins to lay, all hostilities are at an end; not one of the whole grove, that a little before treated her so rudely, will now venture to molest her; so that she brings forth her brood with patient tranquillity. Such is the severity with which even native rooks are treated by each other; but if a foreign rook should attempt to make himself a denizen of their society. he would ineet with no favour; the whole grove would at once be up in arms against him, and expel him without mercy.

In some countries these birds are considered as a benefit, in others as a nuisance : their chief food is the worm of the dor-beetle, and corn; thus they may be said to do as much service by destroying that noxious insect, as they do injury by consuming the produce of the husbandman's industry.

To this tribe of the erow-kind, some foreign sorts might be added: I will take notice only of one, which, from the extraordi$4 \mathrm{~F}$ 
nary size and fashion of its bill, must not be passed in silence. This is the Calio, or horned Indian raven, which exceeds the common ravell in size, and habits of depredation. But what he differs in from all other birds is the beak, which by its length and curvature at the end, appears designed for rapine; but then it has a kind of horn standing out from the top, which looks somewhat like a second bill, and gives this bird, otherwise fierce and ugly, a very formidahle appearance. The liorn springs out of the forehead, and grows to the upper part of the bill, being of great bulk; so that near the forehead it is four inches broad, not unlike the horn of the rhinoceros, but more crooked at the tip. Were the body of the bird answerable in size to the head, the calao would exceed in magnitude cren the vulture or the eagle. But the head and beak are out of all proportion, the body being not much larger than that of a hell. Yet even here there are varieties; for in such of those birds as come from different parts of Africa, the body is proportionable to the beak; in such as come from the Molucca Islands, the beak bears no proportion to the body. Of what use this extraordinary excrescence is to the bird, is not easy to determine; it lives, like others of its kind, upon carrion, and seldom has a living enemy to cope with: Nature seems to sport in the production of many animals, as if she were willing to exhibit instances as well of variety as economy in their formation.

\section{CHAP'TER C.}

\section{OF THE MAGPIE, AND ITS AFFINITIES.}

THERE are such a variety of birds that may be distributed under this head, that we must not expect very precise ideas of any. To have a straight strong bill, legs formed for hopping, a body of about the size of a magpie, and party-coloured plumage, are the only marks by which I must be contented to distinguish this numerous fantastic tribe, that add to the beanty, though not to the harmony, of our landscapes. In fact, their chattering every where disturbs the melody of the lesser warblers; and their noisy courtship not a little damps the song of the linnet and the nightingale.

However, we have very few of this kind in our woods compared to those in the neighbourhood of the line. There they not only paint the scene with the beauty and the variety of their plumage, hut stun the ear with their vociferation. In those luxurious forests, the singing birds are scarcely ever heard, but a hundred varieties of the pie, the jay, the roller, the chatterer, and the toucan. are continually in motion, and with their illusive mockeries disturb or divert the spectator, as he happens to be disposed.
The magpie is the chief of this kind with us, and is too well known to need a description. Indeed, were its other accomplishments equal to its beauty, few birds could be put in competition. Its black, its white, its green, and purple, with the rich and gilded combination of the glosses on its tail, are as fine as any that adorn the most beautiful of the feathered tribe. But it has too many of the qualities of a beau, to depreciate these natural perfections: vain, restless, loud, and quarrelsome, it is an unwelcome intruder every where; and never misses an opportunity, when it finds one, of doing mischief.

The magpie bears a great resemblance to the butcher-bird in its bill, which has a sharp process near the end of the upper chap, as well as in the shortness of its wings, and the form of the tail ; each feather shortening from the two middlemost. But it agrees still more in its food, living not only upon worms and insects, but also upon small birds when they can be seized. A wounded lark, or a young chicken separated from the hen, are sure plunder; and the magpie will even sometimes set upon and strike a blackbird. 
The same insolence prompts it to teaze the largest animals, when its insults can be offered with security. They often are seen perched upon the back of an ox or a sheep, pecking up the insects to be found there, chattering, and tormenting the poor animal at the same time, and stretching out their necks for combat, if the beast turns irs head loackward to reprehend him. They seek out also the nests of birrs: and, if the parcnt escapes, the eggs make up for the deficiency : the thrush and the blackbird are but too frequently robbed by this assassin, and this in sone measure causes their scarcity.

No food scems to come amiss to this bird; it shares with ravens in their carrion, with rooks in their grain, and with the cuckoo in birds' eggs : but it seems possessed of a providence seldo:n usual with gluttons; for when it is satisfied for the present, it lays up the remainder of the feast for another occasion. It will even in a tame state hide its food when it has done eating, and after a time return to the secret hoard with renewed appetite and vociferation.

In all its habits it discovers a degree of instinct unusual to other birds. Its nest is not less remarkable for the manner in which it is composerl, than for the place the magpie takes to build it in. The nes is asually placed conspicuous enough, either in the middle of some haw thorn bush, or on the top of some high tree. The place, however, is always found difficult of access; for the tree pitched upon usually grows in some thick hedge-row fenced by brambles at the root; or sometimes one of the ligher bushes is fixed upon for the purpose. When the place is thus chosen as inaccessible as possible to men, the next care is to fence the nest above so as to defend it from all the various rnemies of air. The kite, the crow, and the sparrow-hawk, are to be guarded against; as their nests have been sometimes plundered by the magpie. so it is rcasunably feared that they will take the first opportunity to retaliate. To prevent this the magpie's nest is built with surprising labour and ingenuity.

The body of the nest is composed of hawthorn branches, the thorns sticking outward, set well united together by their mutual insertions Within it is lined with fibrous roots, wool, and long grass, and then nicely plastercd all round with mud and clay. The body of the nest being thus made firm and commodions, the next work is to make the canopy which is to defend it above. This is composerl of the sharpest thorns, wove together in such a manner as to deny all entrance except at the door, which is just large enough to permit egress and regress to the owners. In this fortress the male and female hatch and bring up their brood with security, sheltered from all attacks but those of the climbing school-boy, who ofien finds his torn and bloody hands too dear a price for the eggs or the young ones. The magpie lays six or seven eggs, of a pale green colour, spotted with browll.

This hird, in its domestic state, preserves its natural character with strict propriety. The same noisy mischievous habits attend it to the cage that marked it in the woods; and being more cunning, so it is also a more docile bird than any other taken into kefping. Those who are desirous of teaching it to speak, have a foolish custom of cutting its tongue, which only puts the poor animal to pain, without insproving its speech in the smallest degree. Its speaking is sometimes very distinct; but its sounds are too thin and sharp to be an rxact imitation of the human voice, which the hoarse raven and parrot can counterfeit more exactly.

To this tribe we may refer the jay, which is one of the most beautiful of the British birds. The forchead is white, streaked with black; the head is covered with very long feathers, which it can erect into a crest at pleasure; the whole neck, back, breast, and belly, are of a faint purple, dashed with gray; the wings are IIost beautifully barred with a lovely blue, black, and white; the tail is black, and the feet of a pale brown. Like the magpie, it feeds upon fruits, will kill small birds, and is extremely docile.

The Chatterer also, which is a native of Germany, may be placed in this rank; and is somewliat less than the former. It is variegated with a beautiful mixture of colours ; red, ash-colour, chesnut, and yellow: but what distinguishes it from all other birds, are the horny appendages from the tips of seven of the lesser quill feathers, which stand bare of beards, and have the colour and gloss of the best red sealing-tvax.

The Roller is not less beautiful than any of the former. The breast and belly are blue; the head green; and the wings variegated 
with blue, black, and white. But it may he distinguished from all udhers by a sort of naked tubercles or warts near the eyes, which still farther contribute to increase its beauty.

To this class may be added a numerous list from all the tropical lorests of the east and west; winere the birds are remarkable for discordant voices and brilliant plumage. I will fix only upon one, which is the most singular of all the feathered creation. This is the Toucan, a bird of the pie kind, whose bill is nearly as large as the rest of its whole body.

Of this extraordinary bird there are four or five variecies. I will only describe the redheaked toucan; and as the figure of this bird mukes the principil part of its history, I will follow Edwards through all the minutiae of its singular conformation. It is about the size of and shaped like a jackdaw, with a large head to support its monstrous bill; this bill, from the angles of the mouth to its point, is six inches and a half; and its breadth, in the thickest part, is a little more than two. Its thickness near the hearl, is one inch and a quarter; and it is a little rounded along the top of the upper chap, the under side being round also ; the whole of the bill is exuremely slight, and a little thickes than parchment. The upper chap is uf a loright yellow, except on each side, which is of a fine scarlet colour; as is also the lower cliap, except at the base, which is purple. Between the head and the bill there is a black line of separation all round the base of the bill; in the upper part of which the nostrils are placed, and are alnıost covered with feathers; which has occasioned some writers to say, that the toucan has no nostrils. Round the eyes, on each side of the head, is a space of bluish skin, roid of feathers, above which the head is black, except a white spot on each side joining to the base of the upper chap. 'The hinder part of the neck, the back, wings, tail, belly, and thighs, are black. The under side of the head, throat, and the beginning of the breast, are white. Between the white on the breast, and the black on the belly, is a space of red feathers in the form of a new moou, with its horus upivards. The legs, feet, and claws, are of an ash-colour; and the toes stand like those of the parrot, two before, and two behind.

It is reported, by travellers, that this bird, though furnished with so formidable a beak, is harnless and gentle, being so easily made tauce, as to sit and hatch its young in louses. It feeds chiefly upon pepper, which it devours very greedily, gorging itself in such a manner, that it voits it crude and unconcocted. 'This, however, is no objection to the natives from using it again ; they even prefer it before that pepp:r which is fresh gathered from the tree: and seem persuaded that the strength and heat of the pepper is qualified by the bird, and that all its noxious qualities are thus exhausted.

Whatever be the truth of this report, nothing is more certain than that the toucan lives only upon a vegecable diet; and in a domestic state, to which it is frequently brought in the warm countries where it is bred, it is seen to prefer such food to all other. Pozzo, who bred one tame, asserts, that it leaped up and down, wagged the tail, and cried with a voice resembling that of a magpie. It fed upon the sime things that parrots do; but was most greedy of grapes, whicl, being plucked off one liy one, and thrown into the air, it would most dexterously catch before they fell to the ground. Its liill, he adds, was hollow, and upon that account very light, so that it had but little strength in so apparently formidable a weupon; nor could it peck or strike smartly therewith. But its tongue seemed to assist the efforts of this unwieldy nachine: it was long, thin, and flat, not unlike one of the feathers on the neck of a dunghill cock; this it moverl up and down, and often extended five or six iuches from the bill. It was of a flesh colour, and very remarkably fringed on each side with very small filaments, exactly resembling a feather.

It is probable that this long tongue has greatur strength than the thin hollow beak that contains it. It is likely that the beak is only a kind of sheath for this peculiar instrument, used by the toucan, not only in ınaking itself a nest, but also in olntaining its provision. Nothing is more certain, than that this bird builds its nest in holes of trees, which have bern previously scooped out for this purpose; and it is nut very likely that so feeble a bill could be very serviceable in working upon such hard materials.

Be this as it will, there is no bird secures its young better from exterual injury than the toucan. It has not only birds, men, and serpents, to guard against, but a numerous tribe of munkeys, still more prying, mischiev. 
ous, and hungry, than all the rest. The toucan, however, scoops out its nest in the hollow of some trees, leaving only a hole large enough to go in and out at. There it sits, with its great beak, guarding the entrance, and if the monkey ventures to offer a visit of curiosity, the toucan gives him such a welcone, that he presently thinks proper to pack off, and is glad to escape with safety.
This bird is only found in the warm climates of South Amcrica, where it is in great request, both for the delicacy of its flesh, which is tender and nourishing, and for the beauty of its plumage, particularly the feathers of the breast. The skin of this part the Indians pluck off, and, when dry, glue to their cheeks; and this they consider as an irresistible addition to their beauty.

\section{CHAPIER CI.}

\section{OF THE WOODPECKER, AND ITS AFFINITIES.}

WE now come to the numerous tribe of Woodpeckers; a class easily distinguished from all others, both for their peculiar formation, their method of procuring food, and their manner of providing a place of safety for their young. Indeed, no other class of birds seems more immediately formed for the method of life they pursue, being fitted by nature, at all points, for the peculiarity of their condition. They live chiefly upon the insects contained in the body of trees; and for this purpose are furnished with a straight, hard, strong, angular, and sharp bill, made for piercing and boring. They have a tongue of a very great length; round, ending in a sharp, stiff; bony thorm, dentated on each side, to strike ants and insects when dislodged from their cells. Their legs are short and strong, for the purposes of climbing. Their toes stand two forward, and two backward; which is particularly serviceable in holding by the branches of the trees. They have hard stiff tails to lean upon when climbing. They feed only upon insects, and want that intestine, which anatomists call the cecum; a circumstance peculiar to this tribe only.

Of this bird there are many kinds, and many varieties in cach kind. They form large colonies in the forests of every part of the world. They differ in size, colour, and appearance; and agree only in the marks above inentioned, or in those habits which result from so peculiar a conformation. Instead, therefore, of descending into a minute discrimination of every species, let us take one for a pattern, to which all the rest will be found to bear the strongest affinity. Words can but feebly describe the plumage of a bird ; but it is the province of history to enter into a detail of every animal's pursuits and occupations.

The Green Woodspite, or Woodpecker, is called the rain-fowl in some parts of the country; because, when it makes a greater noise than ordinary, it is supposed to foretel rain. It is about the size of a jay; the throat, breast, and belly, are of a pale greenish colour; and the back, neck, and covert feathers of the wings, are green. But the tongue of this little animal makes its most distinguished characteristic, as it serves for its support and defence. As was said above, the woodpecker feeds upon insects; and particularly on those which are lodged in the body of hollow or of rotting trees. The tongue is its instrument for killing and procuring this food; which cannot be found in great plenty. This is round, ending in a stiff, sharp, bony tip, dentated on both sides, like the beard of an arrow; and this it can dart out threc or four inches from the bill, and draw in again at pleasure. Its prey is thus transfixed, and drawn into the bill, which, when swallowed, the dart is again launched at fresh game. Nothing has employed the attention of the $\mathrm{cu}$. rious in this part of anatomy, more than the contrivance by which the tongue of this bird performs its functions with such great celeri ty. The tongue is drawn back into the bill 
by the help of two small round cartilages, fastened into the fore-mentioned bony tip, and running along the length of the tongue. 'These cartilages, from the root of the tongue, take a circuit beyond the ears; and being reflected backwards to the crown of the liear, make a large bow. The muscular spongy flesh of the tongue encloses these cartilages, like a sheath; and is so made that it may be extended or contracted like a worm. The cartilages indeed have muscles accompanying them along their whole length backwards. But there is still another contrivance; for there is a broad inuscle joining the cartilages to the bones of the skull, which, by contracting or dilating, forces the cartilages forward through the tongue, and then forces the tongue and all through the bill, to be cmployed for the animal's prescrvation in piercing its prey.

Such is the instrument with which this bird is provided; and this the manner in wluich this instrument is employed. When a woodpecker, by its natural sagacity, finds out a rotten hollow tree, where there are worms, ants' eggs, or insects, it iumediately prepares for its operations. Resting by its strong clavs, and leaning on the thick feathers of its tail, it begins to bore with its sharp strong beak, until it discloses the whole internal habitation. Upon this, either through pleasure at the sight of its prey, or with a desire to alarm the insect colony, it sends forth a loud cry, which throws terror and confusion into the whole insect tribe. They creep hither and thither, sceking for safety; while the bird luxuriously feasts upon them at lcisure, darting its tongue with uncrring certainty, and devouring the whole brood.

The woodpecker, howerer, does not confine its depredations solcly to trees, but sometimes liglits upon the ground, to try its fortune at an ant-hill. It is not so sccure of prey there as in the former case, although the numbers are much greater. They lic generally too deep for the bird to come at them; and it is obliged to make up by stratagem the defect of power. The woodpecker first goes to their lills, which it pecks, in order io call them abroad; it then thrusts out its long red tongue, which being like a worm, and resembling their usual prey, the ants come out to settle upon, in great numbers; however, the bird watching the properest opportunity, withdraws its tongue at a jerk, and devoures the devourers. This stratagem it continues vill it has alarmed their fears; or till it is quite satisfied.

As the woodpecker is obliged to make looles in trees to procure food, so is it also to nuake ravities still larger to form its nest, and to lay in. This is performed, as usual, with the bill; although some have affirmed that the animal uses its tongue as a gimblet to bore with. But this is a mistake; and those that are curious, may often hear the noise of the bill making its way in large woods and forests. The woodpecker chooses, however, for this purpose, trees that are decayed, or wond that is soft, like beach, elm, and poplar. In these, with very little trouble, it can make holes as exactly round as a mathematician could with compasses. One of these holes the bird generally chooses for its own use, to nestle and bring up its young in; but as they are ensily made, it is delicate in its choice, and often makes twenty before one is found fit to give entire satisfaction. Of those which it has inade and deserted, other birds, not so good borers, and less delicate in their choice, take possession. The jay and the starling lay their eggs in these looles; and bats are now and then found in peaceable possession. Boys sometimes have tlirust in their hands with certail bopes of plucking out a bird's egg ; but, to their great nortification, have had their fingers bitten by a bat at the bottom.

The woodpecker takes no care to line its nest with feathers or straw; its eggs are deposited in the hole, withont any thing to keep them warm, except the heat of the parent's body. Their number is generally five, or six; always white, oblong, and of a micldle size. When the young are excluded, and before they lcave the nest, they are arlorned with a scarlet plumage under the throat, whicl adds to their beauty.

In our clinate, this bird is contented with such a waiuscor habitation as has been described for its young; but in the warmer regions of Guiuca and Brasil, they take a very different method to protect and hatch their mascent progeny. A traveller who walks into the forests of those countries, among the first strange objects that excite curiosity, is struck with the nultitude of birds' nests hanging at the extremity of alinost every branch. Many otleer kinds of lirds build in this manner, but 
the chicf of them are of the woodpecker kind; and indeed there is not, in the whole history of nature, a more singular instance of the sagacity of those little animals in protecting themselves against such enemies as they have most occasion to fear. In cultivated countries, a great part of the caution of the feathered tribe is to hide or defend their nests from the invasions of man; as he is their most dreaded enemy. But in the depth of those remote and solitary forests, where man is but seldom seen, the little bird has nothing to apprehend from mall. The parent is careless how much the nest is exposed to general notice; satisfied if it be out of the reach of those rapacious creatures that lire by robbery and surprise. If the monkey or the snake can be guarded against, the bird has no other enemies to fear; for this purpose its nest is built upon the depending points of the most outward branches of a tall tree, such as the banana, or the plantain. On one of those immense trees, is seen the must various and the most inimical assemblage of creatures that can be imagined. The top is inhabited by monkeys of some particular tribe, that drive off all others; lower down twine about the great trunk numbers of the larger snakes, patiently waiting till some unwary animal comes within the sphere of their activity, ant at the edges of the tree hang these artificial nests, in great abundance, inliabited by birds of the most delightfil plumage.

The nest is usually formed in this manner: when the time of incubation approaches, they Ay busily about, in quest of a kind of moss, called by the English inhabitants of those

- This bird constructs a curious nest with the long fibres of plants and grass, and suspends it by a kind of cord, nearly half an ell long, from the end of a slender brancli of a tree, that it may he inaccessible to snakes, and secure from the intrusion of the numerous munkeys which inhabit those regions. At the end of this cord, is a gourd-shaped countries, old man's beard. It is a fibrous sub: stance, and not very unlike hair, which bears being moulded into any form, and suffers being glued together. This therefore the little woodpecker, called by the natives of Brasil, the guiratemga, first glues, by some viscous substance gathered in the forest, to the extremest branch of a tree; then building downward, and still adding fresh materials to those already procured, a nest is formed, that depends, like a pouch, from the point of the branch : the hole to enter at, is on the side; and all the interior parts are lined with the liner fibres of the same substance, which compose the whole.

Such is the general contrivance of these hanging nests; which are made, by some other birds, with still superior art. A little bird of the Grosbeak kind, in the Philippine islands, makes its nest in such a manner that there is no opening but from the bottnm. At the boltom the bird enters, and gnes up through a funnel like a chimney, till it comes to the real door of the nest, which lies on one side, and only opens into this fumel."

Some birds glue their nest to the leaf of the banana-tree, which makes two sides of their little habitation; while the other two are artificially composed by their own industry. But these, and all of the kind, are built with the same precautions to guard the young against the depredations of monkeys and serpents, which abound in every tree. The nest hangs there before the spoilers, a tempting object, which they can only gaze upon, while the bird flies in and out, without danger or molestation from so formidable a vicinity.

nest, divided into three apartments; the first of which is occupied by the male, the second by the female, and the third contains the young; and in the first apartment, where the male keeps watch, is placed on one side a little tough clay, and on the top of this clay is fixed a glow-worm, to afford its inhabitants light in the night. 


\section{CHAPTER CH.}

\section{OF THE BIRD OF PARADISE, AND ITS VARIETIES}

THERE are few birds that have more deeeived and puzzled the learned than this. Some have described it as an inhabitant of the air, living only upon the dew of heaven, and never resting below; others have acquiesced in the latter part of its history, but have given it flying insects to feed on. Some have asserted that it was without feet, and others have ranked it among the birds of prey.

The great beauty of this bird's plumage, and the deformity of its legs, seem to have given rise to most of these erroneous reports. The native savages of the Molneca Islands, of which it is an inhabitant, were very little studious of natural history; and, perceiving the inclination the Europeans had for this beautiful bird, carefully cut off its legs before they brought it to market; thus concealing its greatest deformity, they considered themselves entitled to rise in their demands when they offered it for sale. One deceit led on to another; the buyer finding the bird without legs, naturally inquired after them; and the seller as naturally began to assert that it had none. Thus far the European was imposed upon by others; in all the rest he imposed upon himself. Seeing so beautiful a bird without legs, he concluded that it could live only in air, where legs were unnecessary. The extraordinary splendour of its plumage assisted this deception; and, as it had beavenly beauty, so it was asserted to have a heavenly residence. From thence its name, and all the false reports that have been propagated concerning it.

Error, however, is short-lived; and time has discovered that this bird not only has legs, but very large strong ones for its size. Credulity, when undeceived, runs into the opposite extreme; and soon after this harm. less bird was branded with the character of being rapacious, of destroying all those of smaller size, and from the amazing rapidity of its flight, as qualified peculiarly for exten- sive rapine. The real history of this pretty animal is at present tolerably well known; and it is found to be as harmless as it is beautiful.

There are two kinds of the bird of Paradise; one about the size of a pigeon, which is more common; the other not much larger than a lark, which bas been described more imperfectly. They are both sufficiently distinguished from all other birds, not only by the superior vivacity of their tints, but by the feathers of the tail, there being two long slender filaments growing from the upper part of the rump; these are longer than the bird's body, and bearded only at the end. By this mark the bird of Paradise may be easily known, but still more easily by its gaudy livery, which, being so very brilliant, demands to be minutely described.

This bird appears to the eye as large as a pigeon, though in reality the body is not much greater than that of a thrush. The tail, which is about six inches, is as long as the body; the wings are large, compared with the bird's other dimensions The head, the throat, and the neck, are of a pale gold colour. The base of the bill is surrounded by black feathers, as also the side of the head and throat, as soft as velvet, and changeable like those on the neck of a mallard. The hinder part of the head is of a shining green, mixed with gold. The body and wings are chiefly covered with beautiful brown, purple, and gold feathers. The uppermost part of the tail-feathers are of a pale yellow, and those under them white, and longer than the former; for which reason the hinder part of the tail appears to be all white. But what chiefly excites curiosity are, the two long naked feathers above mentioned, which spring from the upper part of the rump above the tail, and which are usually about three feet long. These are bearded only at the beginning and the end; the whole shaft, for above 


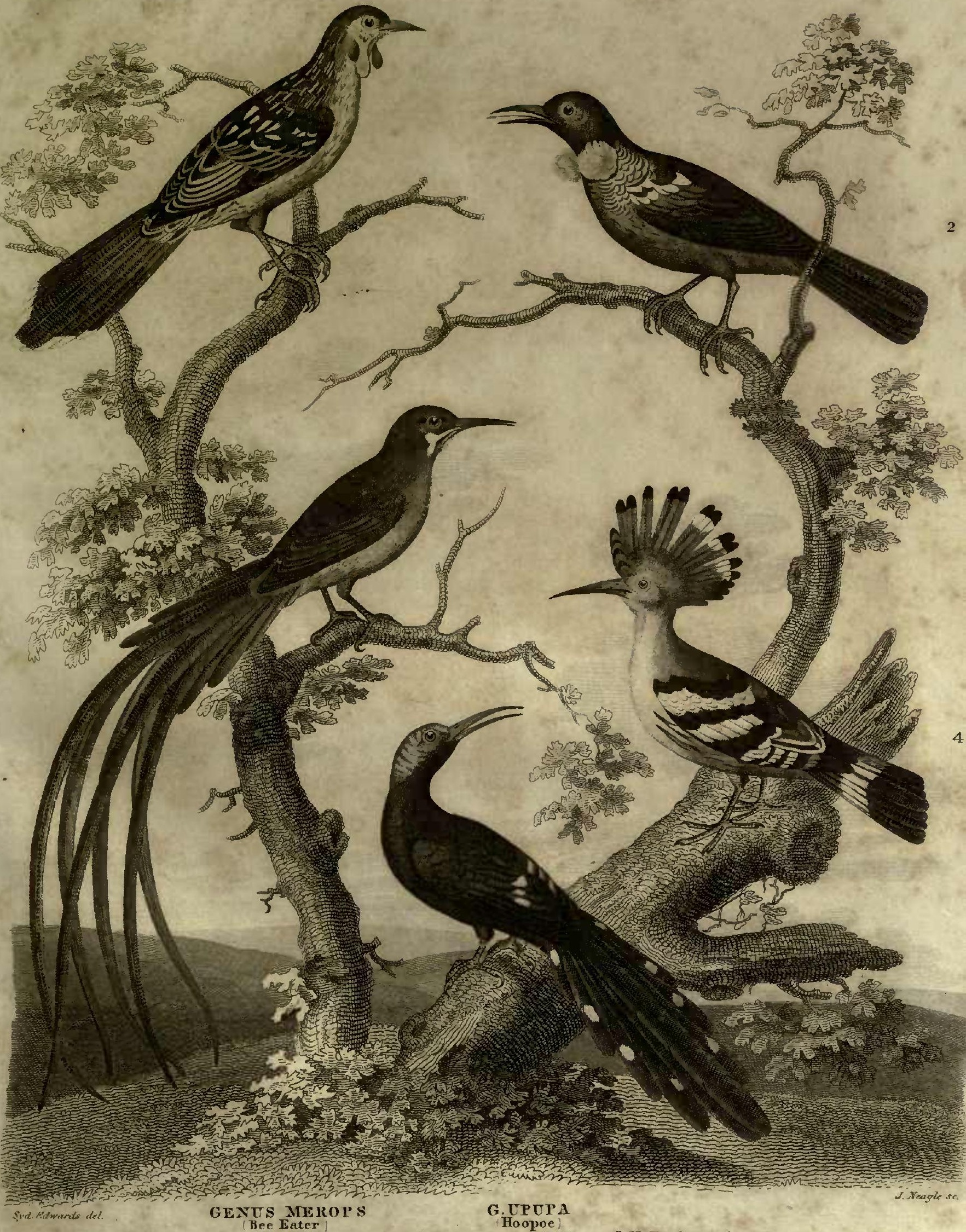

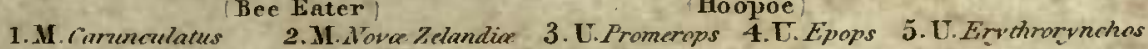
WATTLED B.E. NEW ZEALAND D.E. CATE R. 

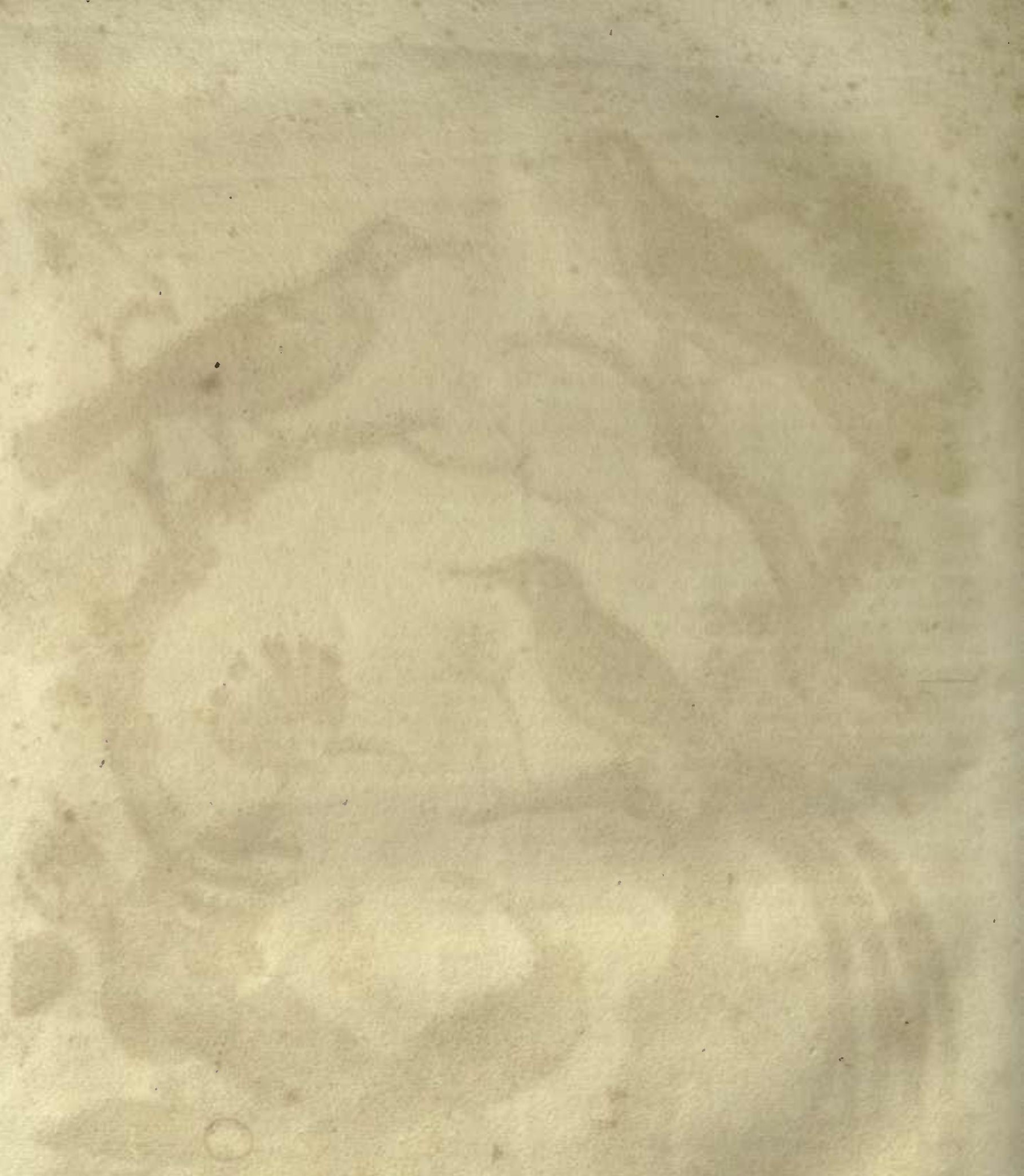

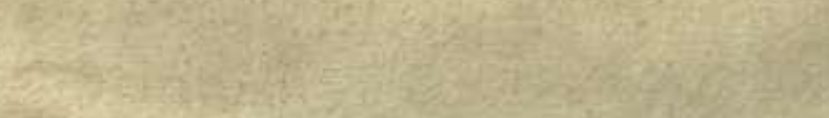


two feet nine inches, being of a dcep black, while the feathered extremity is of a changeahle colour, like the mallard's neck.

This bird, which for beauty exceeds all others of the pie kind, is a native of the Molucea lslinds, but found in greatest numbers in that of Aro. There, in the delighifil and spicy woods of the country, do these beautiful creatures fly in large flock ; so that the groves which produce the richest spices produce the finest birds also. The inhabitants themselve's are not insensible of the pleasure these afford, and give them the name of God's birds, as being superior to all others that he has made. They live in large flocks, and at night generally perch upon the same tree. They are called by some, the swallows of Ternate, from their rapid flight, and fiom sheir being continually on the wing in pursuit of insects, their usual prey.

As the country where they are bred has its tempestuous season, when rains and thunders continually disturb the atmosphere, these birds are then but seldom seen. It is thought that they then fly to other conntries, where their food appears in greater abmudance; for, like swallows, they have their stated times of return. In the begiuning of the month of August, they are seen in great numbers flying together; and, as the inhabitants would have us believe, following their king, who is distinguished from the rest by the lustre of his plumige, and that respect and veneration which is paid him. In the evening they perch upun the highest trees of the forest, particularly one which bears a red berry, upon which they sometines feed, when other food fails them. In what manner they breed, or what may be the number of their young, as yet remains for discovery.

The natives, who make a trade of killing and selling these birds to the Europeans, generally conceal theinselves in the trees where they resort, and having covered themselves up fro.n sight in a bower marle of the branches, they shoot at the birds with recdy arrows; and, as they assert, if they happen to kill the king, they then have a good chance for killing the greatest part of the flock. The chief marks by which they know the king is by the ends of the feathers in his tail, which have eyes like those of a peacock. When they liave taken a number of these birds, their usual method is to gut them, and cut off their legs; they then run a hot iron into the body, which dries up the internal moisture; and, filling the cavity with salts and spices, they sell them to the Europeans for a perfect trifle.

\section{CHAPTER CIII.}

\section{THE CUCKOO, AND ITS VARIETIES.}

FROM a bird of which many fables have been reported, we pass to another that has not given less scope to fabulous invention. The note of the cuckno is known to all the world; the history and nature of the bird itself still remains in great obscurity. That it devours its parent, that it changes its nature with the season, and becomes a sparrow-liawk, were fables invented of this bird, and are now sufficiently refuted. But where it resides in winter, or how it provides for its supply during that season, still continues undiscovered.

This singular bird, which is somewhat less than a pigcon, shaped like a magpie, and of

xo. $45 \& 46$ a grayish colour, is distinguished from all other birds by its round prominent nostrils. Having disappeared all the winter, it discovers itself in our country carly in the spring, by its wellknown call. Its note is heard earlier or later, as the season seems to be more or less forward, and the weather more or less inviting. From the checrful voice of this bird the farmer niay be instructed in the real advancement of the year. The fallibility of human calendars is but too well known; but frum this bird's note, the husbandman may be taught when to sow his most useful seeds, and to do such work as depends upon a certain tenperatur 
of the air. These feathered guides come to us heaven-taught, and point out the true commencement of the season.

The cuchoo, that was silent some time after its appearance, begins at first feebly, and at very distant intervals, to give its call, which, as the summer advances, improves both in its frequency and londness. This is an invitation to courtship, and used only by the male, who sits generally perched upou some dead tree, or hare bough, and repcats his song, which he loses as soon as the genial season is over. His note is pleasant, though uniforn ; and, from an association of ideas, seldon vccurs to the meenory without reminding us of the sweets of summer. Custom too has affixed a more Iudicrons association to this note; which, however, we that are bachelors need be in no piin about. This reproach seems to arise from this bird's making use of the bed or nest of unother to deposite its own brood in.

However this may be, nothing is more certain than that the female nuakes non $s$ fher own. She repairs for that purpose to the nest of some other bird, generally the watcr-wagtail or hedge-sparrow, and having devoured the eggs of the owner, lays her own in their place. She usually lays but one, which is speckled, and of the size of a blackbird's. This the fond foolish bird hatches with great assiduity, and, when excluded, fiuds no difference in the great ill-looking changeling from her own. To supply this voracious ereature, the credulous nurse toils with unusual labour, no way sensible that she is feeding up an cnemy to her race, and one of the most destructive robbers of her future progeny.

It was once doubted whether these birds were carnivorous; but Reaumur was at the pains of breeding up several, and found that they would not feed upon bread or corn; but flesh and insects were their favourite nourishment He found it a very difficult task to teach them to peck; for he was obliged to feed them a full month after they were grown as big as the motlier. Insects, however, seemed to be their peculiar food when young; for they devoured flesh by a kind of constraint, as it was always put into their mouths; but mealworm insects they flew to, and swallowed of their own accord most greedily Indeed, their gluttony is not to be wondered at, when we consider the capacity of their stomach, which is enormous, and reaches from the breast-bone to the vent. It is partly membranous, partly muscular, and of a prodigious capacity; yet still they are not to be supposed as birds of prey, for they have neither the strength nor the courage. On the contrary, they are naturally weak and fearful, as appcars by their flying from small birds, which every where pursue them. The young birds are brown, mixed with black; and in that state they liave been deseribed by some authors as old ones.

The cuckoo, when fleclged and fitted for flight, follows its supposed parent but for a little time ; its appetites for insect food increasing, as it finds 110 great chance for a supply in imitating its little instructor, it parts good friends, the step-rhild seldom offering any vio'ence to its nurse. Nevertheless, all thie little birds of the grove seem to consider the young cuckoo as all enemy, and revenge the cause of their kind by their repeated insults. 'They pursue it wherever it flies, and oblige it to take shelter in the thickest branches of some neighbouring tree. All the smaller birds form the train of its pursuers; but the wry-neck, in particular, is found the most active in the chase; and from thence it has been called by inany, the cuckoo's sttendant and provider. But it is very far from following with a friendly intention; it only pursues as an insulter, or a spy, to warn all its little coinpanions of the cuckoo's depredations.

Such are the manners of this bird while it continues to reside, or to be seen amongst us. But early, at the approach of winter, it totally disappears, and its passage can be traced to no other country. Some suppose that it lies hid in hollow trees; and others that it passes into warmer climates. Which of these opinions is true is very uncertain, as there are no facts related on either side that can be totally relied on. To support the opinion that they remain torpid during the winter, at home, Willonghby introduces the following story, which lie delivers upon the credit of another. "The servants of a gentleman, in the country, having stocked up in one of thcir meadows some old, dry, rotten willows, thought proper, on a certain occasion, to carry them home. In heating a stove, two logs of this timber were put into the furnace beneath, and fire applied as usual. But soon, to the great surprise of the family, was heard the voice of a cuckoo, sing- 
ing three times from under the stove. Wondering at so extraordinary a cry in winter tine, the servants ran and drew the willow logs from the furnace, and in the midst of one of them saw something move! wherefore, taking an axe, they opened the hole, and thrusting in their hands, first they plucked out nothing but feathers; afterwards they got hold of a living animal; and this was the cuckoo that had waked so very opportunely for its own safety. It was, indeed," continues our historian, "brisk and lively, but wholly naked and bare of feathers, and without any winter provision in its hole. This cuckoo the boys kept two years afterwards alive in the stove; but whether it repaid thein with a second song, the author of the tale has not thought fit to inform us."
The most probable opinion on this subject is, that as quails and woodcocks shift their habitations in winter, so also does the cuckoo; but to what country it retires, or whether it has been ever seen on its jouruey, are questions that I am wholly incapable of resolving.

Of this bird there are many kinds in various parts of the world, not only differing in their colours, but their size. Brisson makes not less than twenty-eight sorts of them; but what analogy they bear to our English cuckoo, I will not take upon me to determine. He talks of one, particularly of Brasil, as making a most horrible noise in the forests; which, as it should seem, must be a very different note from that by which our bird is distinguished at home.

\section{CHAPTER CIV.}

\section{OF THE PARROT, AND ITS AFFINITIES.}

THE Parrot is the best known among us of all foreign birds, as it unites the greatest beauty with the greatest docility. Its voice also is more like a man's than that of any other; the raven is too hoarse, and the jay and magpie too shrill, to resemble the truth; the parrot's note is of the true pitch, and capable of a number of modulations that even soine of our orators might wish in vain to imitate.

The ease with which this bird is taught to speak, and the great number of words which it is capable of repeating, are no less surprising. We are assured by a grave writer, that one of these was taught to repeat a whole sonnet from Petrarch; and that I may not be wanting in my instance, I have seen a parrot belonging to a distiller, who had suffered pretty largely in his circumstances from an inforiner who lived opposite him, very ridiculously employed. This hird was taught to pronounce the ninth commandment, Thou shalt not bear false voitness against thy neighbour, with a very clear, loud, articulate voice. The bird was generally placed in its cage orer against the informer's house, and delighted the whole neighbourhood with its persevering exhortations.

Willoughhy tells a story of a parrot, which is not so dull as those usually brought up when this bird's facility of talking happens to be the subject. "A parrot belonging to King Henry the Seventh, who then resided at Westminster, in his palace by the river Thames, had learned to talk many words from the passengers as they happened to take the water. One day, sporting on its perch, the poor bird fell into the water, at the same time crying out, as loud as he could, $A$ boat! twenty pounds for a boat! A waterman, who happened to be near, hearing the cry, made to the place where the parrot was floating, and taking him up, restored him to the king. As it seems the bird was a favourite, the man insisted that he ought to have a reward rather equal to his services than his trouble: and, as the parrot had cried twenty pounds, he said the king was bound in honour to grant it. The king at last agreed to leave it to the parrot's own deternaination, which 
the bird hearing, cried out, Give the knave a groat."

The parrot, which is so common as a foreign bird with us, is equally so as an indigenous bird in the climates where it is produced. The forests swarm with them; and the rook is not better known with us than the parrot in almost every part of the East and West Indies. It is in vain that our naturalists have attempted to arrange the various species of this bird; new varieties daily offer to puzzle the system-maker, or to demonstrate the narrowness of his catalogues. Limneus makes the number of its varieties amount to fortyseven; while Brisson doubles the number, and extends his catalogue to ninety-five. Perhaps even this list might be incrensed, were every accidental change of colour to be considered as constituting a new species. But, in fact, natural history gains little by these discoveries; and as its dominions are extended it becomes more barren. It is asserted, by sensible travellers, that the natives of Brasil ean change the colour of a parrot's plumage by art. If this be true, and I am apt to believe the information, they can make new species at pleasure, and thus cut out endless work for our nomenclators at home.

Those who usually bring these birds over, are content to make three or four distinctions, to which they give names; and with these distinctions I will content myself also. The large kind, which are of the size of a raven, are called maccaws; the next size are simply called parrots; those which are entirely white, are called lories; and the lesser size of all are called parakeets. The difference between even these is rather in size than any other peculiar conformation, as they are all formed alike, having toes, two before and two hehind, for climbing and holding; strong looked bills for breaking open nuts, and other hard substances, on which they feed; and loud harsh voices, by which they fill their native woods with elamour.

But there are further peculiarities in their conformation: and first, their toes are contrived in a singular manner, which appears when they walk or climb, and when they are eating. For the first purpose they strutch two of their toes forward, and two backward; hut when they take their meat, and bring it to their mouths with their foot, they dexterously and nimbly turn the greater hisd toe forward, so as to take a firmer grasp of the nut or the fruit they are going to feed on, standing all the while upon the other leg. Nor even do they present their food in the usual inanner; for other animals turn their meat inwards to the mouth; but these, in a seemingly awkward position, turn their meat outwards, and thus hold the hardest nuts, as if in one hand, till with their bills they break the shell, and extraet the kernel.

The bill is fashioned with still greater peculiarities; for the upper chap, as well as the lower, are both moveable. In most other birds the upper chap is comected, and makes but one piece with the skull; but in these, and in one or two species of the feathered tribe more, the upper chap is connected to the bone of the head by a strong membrane, placed on each side, that lifts and depresses it at pleasure. By this contrivance they can open their bills the wider; which is not a little useful, as the upper ehap is so hooked and so over-hanging, that, if the lower chap only had motion, they could scarcely gape suthciently to take any thing in for their nourishment.

Such are the uses of the beak and the toes, when used separately; but they are often employed both together, when the bird is exercised in climbing. As these birds cannot readily hop from bough to bough, their legs not being adapted for that purpose, they use both the beak and the feet; first catching hold with the beak, as if with a hook, then drawing up the legs and fastening them, then advancing the head and beak again, and so putting forward the body and the feet alternately, till they attain the height they aspire to.

The tongue of this bird somewhat resembles that of a man; for which rcason some pretend that it is so well qualified to imitate the human speech; but the organs by which these sounds are articulated lie farther down in the throat, being performed by the great motion which the os hyoides has in these birds above other's.

The parrot, though common enough in Europe, will not, however, breed here. The climate is too cold for its warn constitution; and though it bears our winter when arrived 
at maturity, yet it always seems sensible of its rigour, and loses both its spirit and appetite during the colder part of the season. It then becomes torpid and inactive, and seems quite changed from that bustling loquacious animal which it appeared in its native forest, where it is almost ever upon the wing. Notwithstanding, the parrot lives even with us a considerable time, if it be properly attended to; and, indeed, it must be owned, that it employs but too great a part of some people's attention.

The extreme sagacity and docility of the bird may plead as the best excuse for those who spend whole hours in teaching their parrots to speak; and, indeed, the bird, on those occasions, seems the wisest animal of the two. It at first obstinately resists all instruction; but seems to be won by perseverance, makes a few attempts to imitate the first sounds, and when it has got one word distinct, all the succeeding come with greater facility. The bird generally learus most in those families where the master or mistress have the least to do; and becomes more expert, in proportion as its instructers are idly assicluous. In going through the towns of France some time since, I conld not help observing how much plainer their parrots spoke than ours, and how very distinctly I understood their parrots speak French, when I conld not understand our own, though they spoke my native language. I was at first for ascribing it to the different qualities of the two languages, and was for entering into an elaborate discussion on the vowels and consonants : but a friend that was with me solved the difficulty at once, by assuring me that the French women scarcely did any thing else the whole day than sit and instruct their feathered pupils; and that the birds were thus distinet in their lessons in consequence of continual schooling.

The parrots of France are certainly very expert, but nothing to those of the Brasils, where the education of a parrot is considered as a very serious affair. The history of Prince Maurice's parrot, given us by Mr. Locke, is too well known to be repeated here; but Clusius assures us that the parrots of that country are the most sensible and cunning of all animals not endued with rea- son. The great parrot, called the aicurous, the head of which is adorned with yellow; red, and violet, the body green, the enils of the wings red, the feathers of the tail long and yellow; this bird, he asserts, which is seldom brought into Europe, is a prodigy of understanding. "A certain Brasilian woman, that lived in a village two miles distant from the island on which we resided, had a parrot of this kind which was the wonder of the place. It seemed endued with such understanding, as to discern and comprehend whatever she said to it. As we sometimes used to pass by that woman's house, she used to call upon us to stop, promising, if we gave her a comb, or a looking-glass, that she would make her parrot sing and dance to entertain us. If we agreed to her request, as soon as she had pronounced some words to the bird, it began not only to leap and skip on the perch on which it stood, but also to talk and to whistle, and imitate the shoutings and exclamations of the Brasilians when they prepare for battle. In brief, when it came into the woman's head to bid it sing, it sang; to dance, it danced. But if, contrary to our promise, we refused to give the woman the little present agreed on, the parrot seemed to sympathize in her resentment, and was silent and immoveable; neither could we, by any means, provoke it to move either foot or tongue."

This sagacity, which parrots show in a domestic state, seems also natural to them in their native resilence among the woods. They live together in flocks, and mutually assist each other against other animals, either by their courage or their notes of warning. They generally breed in hollow trees, where they make a round hole, and do not line their nests within. If they fiml any part of a tree beginning to rot from the breaking off of a branch, or any such accident, this they take care toscoop, and to make the hole sufficiently wide and convenient; but it sometimes happens that they are content with the hole which a woodpecker has wrought out with greater ease before them; and in this they prepare to hatch and bring up their young.

They lay two or three eggs; and probably the smaller kind may lay more; for it is a rule that universally holds through nature, 
that the sinallest animals are always the most prolific; for being, from their natural weakness, more subject to devastation, nature finds it necessary to replenish the species by superior fecundity. In general, however, the number of their eggs is stinted to two, like those of the pigcon, and they are about the same size. They are always marked with little specks, like those of a partridge; and some travellers assure us, that they are always found in the trunks of the tallest, straightest, and the largest trees. The natives of those countries, who have little else to do, are very assiduous in spying out the places where the parrot is seen to nestle, and generally come with great joy to inform the Europeans, if there be any, of the discovery. As those birds have always the greatest docility that are taken young, such a nest is often considered as worth taking some trouble to be possessed of; and, for this purpose, the usual method of coming at the young is, by cutting down the tree. In the fall of the tree it often happens that the young parrots are killed; but if one of them survives the shock, it is considered as a sufficient recompense.

Such is the avidity with which these birds are sought when young; for it is known they always speak best when their ear has not been anticipated by the harsh notes of the wild ones. But as the natives are not able upon all occasions to supply the demand for young ones, they are contented to take the old; and for that purpose shoot them in the woods with heary arrows, headed with cotton, which knock down the bird without killing it. The parrots thus stunned are carried home: some die, but others recover, and, by kind usage and plentiful food, become talkative and noisy.

But it is not for the sake of their conversation alone that the parrot is sought after anong the savages; for though some of them are but tough and ill-tasted, yet there are other sorts, particularly of the small parakeet tribe, that are very delicate food. In general it obtains, that whatever fruit or grain these birds mustly feed upon, their llesh partakes of the flavour, and becomes good or ill-tasted, according to the quality of their particular diet. When the guava is ripe, they are at that season fat and tender; if they feed upon the seed of the acajou, their flesh contracts an agreeable flavour of garlic; if they feed upon the seed of the spicy trees, their flesh then tastes of cloves and cinnamon; while, on the contrary, it is insupportably bitter if the berries they feed on are of that quality. Their seed of the cotton-tree intoxicates them in the same manner as wine does man; and even wine itself is drunk by parrots, as Aristotle assures us, by which they are thus rendered more talkative and amusing. But of all food, they are fondest of the carthamus, or bastard saffion; which, though strongly purgative to man, agrees perfectly with their constitution, and fattens them in a very short time.

Of the parakeet kind in Brasil, Labat assures us, that they are the most beautiful in their plumage, and the most talkative birds in nature. They are very tame, and appear fond of mankind; they seem pleased with holding parley with him; they never have done; but while he continues to talk, answer him, and appear resolved to have the last word: but they are possessed of another quality, which is sufficient to put an end to this association; their flesh is the most delicate imaginable, and highly esteemed by those who are fonder of indulging their appetites than their ears. The fowler walks into the woods, where they keep in abundance, but as they are green, and exactly the colour of the leaves anong which they sit, he only hears their prattle, without being able to see a single bird; he looks round him, sensible that his gane is within gun-shot in abundance, but is mortified to the last degree that it is impossible to see them. Unfortunately for these little animals, they are restless, and ever on the wing, so that in flying from one tree to another, he has but too frequent opportunities of destroying them; for as soon as they have stripped the tree on which they sat of all its berries, some one of them flies off to another; and, if that be found fit for the purpose, it gives a loud call, which all the rest resort to. That is the opportunity the fowler has long been waiting for; he fires in among the flock, while they are yet on the wing; and he seldom fails of bringing down a part of them. But it is singular enough to 
see them when they find their companions falten. They set up a loud outcry, as if they were chiding their destroyer, and dn not cease till they see him preparing for a second charge.

But though there are so many inotives for destroying these beautiful birds, they are in very great plenty; and in some countries on the coast of Guinea, they are considered by the negroes as their greatest tormentors. The flocks of parrots persecute them with their unceasing screaming, and devour whatever fruits they attempt to produce by art in their little gardens. In other places they are not so destructive, but sufficiently cominon; and, indeed, there is scarce a country of the tropical climates that has not inany of the common kinds, as well as some peculiarly its own. Travellers have counted inore than a hundred different kinds on the cuntinent of Africa only: there is one country in particular, north of the Cape of Good IIope, which takes its name from the multitude of parrots which are seen in its woods. There are white parrots seen in the burning regions of Ethiopia : in the East Indies they are of the largest size; in South America they are docile and talkative ; in all the islands of the Pacific Sea and the Indian Ocean, they swarm in great variety and abundance, and add to the splendour' of those woods which nature has dressed in eternal green.

So generally are these birds known at present, and so great is their variety, that no- thing seems more extraordinary than that there was but one sort of them known amoung the ancients, and that at a time when they pretended to be masters of the world. If nothing else conld serve to show the vanity of a Roman's hoast, the parrot tribe unight be an instance, of which there are a hundred kinds now known; not one of which naturally breeds in the comntries that acknowledged the Roman power. The green parakeet, with a red neek, was the first of this kind that was brought into Europe, and the only one that was known to the ancients, from the time of Alexander the Great to the age of Nero: this was brought from India; and when afterwards the Romans began to seek and rummage through all their dominions, for new and unheard-of luxuries, they at last found out others in Gaganda, an island of Ethiopia, which they considered as an extraordinary discovery.

Parrots have usually the same disorders with other birds; and they have one or two peculiar to their kind. They are sometimes struck by a kind of apoplectic blow, by which they fall lrom their perches, and for a while seein ready to expire. The other is the growing of the beak, which becomes so very inuch hooked as to deprive thein of the power of eating. These infirmities, however, do not hinder them from being long-lived; for a parrot, well kept, will live five or six and twenty years.

\section{CHAPTER CV.}

\section{THE PIGEON, AND ITS VARIETIES.}

THIS is one of the birds which, from its great fecundity, we have, in some ineasure, reclaimed from a state of nature, and taught to live in habits of dependence. Indeed, its fecundity seems to be increased by human cultivation; since those pigeons that live in a wild state, in the woods, are by no means so fruitful as those in our pigeon-houses near-. er home. The power of increase in most birds depends upon the quantity of their food; and it is seen, in more than one instance, that man, by supplying food in plenty, and allowing the animal at the same time a proper sliare of freedom, has brought some of those kinds which are known to lay but once a year, to become much more prolific.

The tame pigeon, and all its beautiful varieties, derive their origin from one species, the Stock-Dove only; the English name, implying its being the stock or stem from whence 
the other domestic kinds have been propagated. This bird, in its natural state, is of a deep bluish ash-colour; the breast dashed with a fine changeable green and purple; its wings marked with two black bars; the back white, and the tail barred near the end with black. These are the colours of the pigeon in a state of nature; and from these simple tints has man by art propagated a variety that words canuot describe, nor even fancy suggest. However, nature still perscveres in her great outline; and though the form, colour, and even the fecundity, of these birds, may be altered by art, yet their natu. ral manners and inclinations continue still the same.

The stock-dove, in its native woods, differs from the ring-dove, a bird that has never been reclained, by its breeding in the holes of rocks and the hollows of trees. All other birds of the pigeon kind build, like rooks, in the topmost branches of the forest, and choose their habitation as remote as possible from man. But this species soon takes to build in artificial cavities; aud, from the temptation of a ready provision and numerous society, easily submits to the tyranny of man. Still, however, it preserves its native colour for several generations, and becomes more variegated only in proportion as it removes from the original simplicity of its colouring in the woods.

The Dove-house Pigeon, as is well known, breeds every month; but then it is necessary to supply it with food when the weather is scvere, or the fields arc covered with suow. Upon other occasions, it may be left to provide for itself, and it generally repays the owner for his protection. The pigeon lays two whitc eggs, which most usually produce young ones of different sexes. For the laying of each egg, it is necessary to have a particular congress with the male; and the egg is usually deposited in the afternoon. When the cgus are thus laid, the female, in the space of fifteen days, not including the three days during which she is employed in laying, continues to hatch, relieved at intervals by the male. The turns are usnally regulated with great exactuess. From three or four o'clock in the evening till nime the next day, the femalc continues to sit; she is then relieved by the male, who takes his place from ten till three, while his mate is feeding abroad. In this manner they sit alternately till the young are excluded. If, during this term, the fernale delays to return at the expected time, the male follows, and drives her to the nest; and should he in his turn be dilatory, she retaliates with equal severity.

The young ones, when hatched, require no food for the three first days, only wanting to be kept warm. which is an employment the female takes entirely upon herself. During this period, she never stirs out, except for a few minutes to take a little food. From this they are fed for eight or ten days with corn or grain of different kinds, which the old ones gather in the fields, and keep treasured up in their crops, from whence they throw it up again into the mouths of their young ones, who very grcedily demand it.

As this method of fecding the young from the crop is different in birds of the pigeonkind from all others, it demands a more detailed explanation. Of all birds, for its size, the pigeon has the largest crop, which is also made in a manner quite peculiar to the kind. In two of these that were dissected by a member of the Royal Academy of Sciences, it was found that if the anatomist blew air into the wind-pipe, it distended the crop or gullet to a prodigious size. This was the more extraordinary, as there seemed to be no communication whatever between these two receptacles; as the conduit by which we breathe, as every one kiows, leads to a very different receptacle from that where we put our food. By whit apertures the air blown into the lungs of the pigeon makes its way into the crop, is unknown; but nothing is more certain than that these birds have a power of filling the crop with air; and some of them, which are called croppers, distend it in such a mamer, that the hird's breast seems bigger than its body. The peculiar mechanism of this part is not well k:1own: but the necessity for it in these animals is pretty obvious. The pigeon, as we all !now, lives entirely upon grain and water: these are mixed together in the crop; and in the ordinary way are dige-ted in proportion as the hird lays in its provision. But io ferd its young, which are very voricions, it is neccssary to lay in a store greater than ordinury, and to give the 
food a kind of half maceration, to suit their tender appetites. The heat of the bird's bo$\mathrm{dy}$, assisted by air, and numerous glands separating a milky fluid, are the most necessary instruments for this operation: but, in proportion as the food macerates, it begins 10 swell also; and the erop must, of consequence, be considerably dilated. Still, however, the air which is contained in it gives the hird a power of contraeting it at pleasure; for if it were filled with more solid substances, the bird could have no power to compress it. But this is not the case, the birl can compress its crop at pleasure; and driving out the air, can thus drive out the food also, which is forced up the gullet, like a pellet from a pop-gun. The young ones, open-mouthed, receive this tribute of affection, and are thus fed three times a day. In feeding, the inale u-trally supplies the young female, while the old fenale supplies the young of the opposite sex. 'The food with which they are supplied, is more macerated at the beginning; but as they grow older, the parents give it less preparation, and at last drive thein out to shift for themselves. When well fed. however, the old ones do not wait for the total dismission of their young; but in the same nest are to be found young ones almost fit for tlight, and eggs hatching at the saine time.

The fidelity of the furtle-dove is proverhial, and makes the usual comparison of such poets as are content to repeat what others have said before them; but the pigeon of the dovehouse is not so faithful; and having been subjected to man, it puts on licentiousness among its other domestic habits. Two males are often seen quarrelling for the same mistress; and when the female admits the addresses of a new gallant, her old compauion seems to bear the contempt with some marks of displeasure, abstaining from her company; or if he approaches, it is only to chastise her. There have been instances when two males, being displeased with their respective mates, have thought proper to make an exchange, and have lived in great harmony with their new companions.

So great is the produce of this bird in its domestic state, that near fifteen thousand may, in the space of four years, be produced พ0. $45 \& 46$. from a single pair. But the stock-dove seldom breeds above twice a year; for when the winter months come, the whole employment of the fond couple is rather for selfpreservation, than transmitting a posterity They seem, however, to have a stronger attacliment to their young than those who are found to breed so often; whether it be that instinct acts more powerfully upon them in their state of nature, or that their affections are less divided by the multiplicity of claims.

It is from a species of these, therefore, that those pigeons which are called Carriers, and are used to convey letters, are produced. These are easily distinguished fiom all others by their eyes, which are compassed about with a broad circle of naked white skin, and by being of a dark blue or blackish colour. It is from their attachment to their native place, and particularly where they have brought up their young, that these birds are employed in several countries as the most expeditious carriers. They are first brought from the place where they were bred, and whither it is intended to send them back with information. The letter is tied under the bird's wing, and it is then let loose to return. The little animal no sooner finds itself at liberty, than its passion for its native spot directs all its motions. It is seen, upon these occasions, flying directly into the clonds to an amazing height; and thell, with the greatest certainty and exactness, directing itself, by some surprising instiuct, towards home, which lies sometimes at many miles distance, bringing its message to those to whom it is directed. By what marks they discover the place, by what chart they are guided in the right way, is to us utterly unkıown: certain it is, that in the space of an hour and a half they perform a journey of forty miles; which is a degree of despatch three times greater than the fleetest quadruped can perform. These birds are not brought up at present with as much care as formerly, when they were sent from governors in a besieged city to generals that were coming to relieve it without; when they were sent from princes to their subjects with the tidings of some fortunate event ; or from lovers to their mistresses with expressions of their passion. 'The only use we now see made of them is to be 
let fly at Tyburn, when the cart is drawn away; pretty mucl as when some ancient hero was to be interred, an eagle was let off from the funeral pile, to complete his apotheosis.

The varieties of the tame pigeon are so numerous, that it would be a vain attempt to mention them: so much is the figure and colour of this bird under human control, that pigeon-fanciers, by coupling a male and female of different sorts, can breed them, as they express it, to a feather. From hence we have the various names of croppers, carriers, jacobines, powters, mints, and turbits: all birds that at first might have accidentally varied from the stock-love; and then, by having these varieties still heightened by food, climate, and paring, different species have been produced. But there are many species of the wild pigeon, which, though bearing a strong affinity to the stock-dove, are, nevertheless, sufficiently different from it to deserve a distinct description. The ring-dove is of this number; a good deal larger than the former, and building its nest with a few dry sticks, in the boughs of trees. This seems a bird much fonder of its native freedom than the former; and attempts have been frequently made to render it domestic; but they have hitherto proved fruitless, for though their eggs have been hatched by the tame pigeon in a dove-house, yet, as soon as they could fly, they always betook themselves to the woods where they were first produced. In the beginning of winter these assemble in great flocks in the woods, and leave off coo-

a In the Annual Register for the year 1765, we read of an experiment which was made, by which the velocity of flight in these birds was pretty well ascertained. A gentleman, for a trifling wager, sent a carrier-pigeon from London by the coach, to a friend at St. Edinondsbury; and along with it a note, desiring that the pigeon, two days after its arrival there, might be thrown up precisely when the town clock struck nine in the morning. This was accordingly done; and the pigeon arrived in London, and flew into the Bell Inn in Bishopsgate-street, at half an hour past eleven o'clock of the sams morning; laving flown 72 miles in the space of two lıurs and a half.

Sume years ago this animal was made use of for a very extraordinary purpose. During the drawing of the Lot- ing; nor do they resume this note of courtship till the beginning of March, when the gerial season, by supplying them with food, renews their desires.

The turle-dove is a smaller, but a much shyer bird, than any of the former. It may easily be distingnished from the rest by the iris of the eye, which is of a fine yellow, and by a beautiful crimson circle that encompasses the eye-lids. The fidelity of these birds is noted; and a pair being put in a cage, if one dies the other will not survive it. The turtle-dove is a bird of passage, and few, or none, remain in our northern climates in winter. They tly in flocks when they cone to breed here in summer, and delight in open, mountainous, sandy eountries. But they build their nests in the midst of woods, and choose the most retired situations for incubation. They feed upon all sorts of grain, but are fondest of millet-seed.

To this short list might be added a long catalogue of foreign pigeons, of which we know little more than the plumage aud the names. Indeed, the variety of their plumage is as beautiful, as the names by which they are known are harsh and dissonant. The ocotzimtzcan, for instance, is onc of the most splendid tenants of the Mexican forests; but few, I believe, would desire to learn the name, only to be informed that it is covered with purple, green, and yellow, plumage. To describe such birds, the historian's pen is not half such a useful implement as the painter's pencil.

tery, a gang of sharpers, distrihuted in various places, devised a scheme for making this bird the instrument of their plunder. One of these was to bring with him a carrier-pigeon, and wait in the Guildlaall till a large prize was drawu, and with all possible despatch to place the fortunate number under the wing of the pigeon, and let him loose. This intelligence was faithfully conveyed to his associate, in a much more speedy nuanner than by the usual node, and he was directed to ensure the number to whatever amount he thought proper. It is probable, that from this circumstance miglit arise the application of the common cant term pigcon, to any one who had been overreached and cheated. 


\section{OE BIRDS OI THE SPARROW IITD.}

\section{CHAPTER CVI.}

\section{OF BIRDS OF THE SPARROW KIND.}

STILL descending from the larger to the smaller, we come to birds of the sparrow kind; or thit class of beautiful little animals that, being less than the pigeon, go on timinishing till we arrive at the humming-bird, the smallest of the feathered creation.

The birls which coinpose this class chiefly live in the neighbourhood of man, and are his greatest lavourites. The falcon may be inore esteemed, an t the turkey more useful; but these he consilfers as servants, not as firiends; as animals reclaimed merely to supply him with some of the conveniences of life: but these little painterl songsters have his affections, as well from their beauty as their melody; it is this rlelightful class that fill his groves with harmony, and lift his heart to sympatbize with their raptures. All the orber classes are either mute or screaning; it is this diminutive tribe only that have voices equal to the beauty of their figures; equally adapted to rejoice man, and delight each other.

As they are the favourites of man, so they are chiefly seen neal him. All the great birds dread his vicinity, and keep to the thickest darkness of the forest, or the brow of the most craggy precipice: but these seldom resort to the thicker purts of the rood; they keep near its edpes, in the neighbourhood of cultivated fields, in the hedge-rows of farm grounds, and even in the yard, mixing with the poultry.

It must be owned, indeed, that their living near man is not a society of affection on their part, as they approach inhabited grounds mercly because their chief provision is to be found there. In the depth of the desert, or the gloom of the forest, there is no grain to be picked up; none of those tender buds that are so grateful to their appetites: insects themselves, that make so great a part of their food, arc not found there in abundance; their natures being unsuited to the moisture of the place. As we enter, thercfore, deeper into uncultivated woods, the silence becomes more profound; every thing carries the look of awful stillness; there are none of those warblings, nome of those murmurs, that awaken attention, as near the habitations of mell; there is nothing of that confused buzz, formed by the united, though distant, voices of quadrupeds and birds; but all is profoundly dead and solemn. Now and then, indee $\mathrm{l}$, the traveller may be ronsed from this lethargy of life, by the voice of a heron, or the screan of an eagle; but his sweet little friends und warblers have totally forsaken him.

There is still another reason for these little birds avoiding the depths of the forests; which is, that their most formidable enemies usually reside there. The greater birds, like robbers, choose the most dreary solitudes for their retreats; and if they do not find, they make a desert all around them. The snuall birds fly from their tyramny, and take protection in the vicinity of man, where they kuow their more unmerciful foes will not venture to pursue them.

All birds, even those of passage, scem eontent with a certain district to provide food and centre in. The red-breast or the wren soldom leaves the field where it has been lorought up, or where its young have been excluded; even though hunted it flics along the hedge, and seems fond of the place with an imprudent perseverance. The fact is, all these small birls mark out a territory to themselves, which 
they will permit none of their own species to remain in; they guatrd their dominions with the most watchiul resentment; and we seliom find two male tenants in the same hedge together.

'Thus, though fitted by nature for the inost wandering life, these little animals do not make such distant excursions, during the season of their stay, as the stag or the leveret. Food seems to be the only object that puts them in motion, and when that is provided for them in sufficient plenty, they never wander. But as that is seldom permanent through the year, almost every bird is then obliged to change its ahode. Some are called 1 irds of passage, because they are obliged to take long journeys for this purpose; but, strictly speaking, almost every other kind are birds of passage, though theil migration may not be to places so remote. At sone particular season of the year, all small birds migrate either from onc country to another, or from the more inland provinces towards the sliore.

There are several persons who get a livelihood by watching the seasons when our small bircls begin to migrate from one country to another, and by taking them with nets in their passage. The birds are found to fly, as the bird-catchers term it, chiefly during the month of October, and part of September and November. 'There is also another' flight in March, which is much less considerable than that in autumm. Nor is it less remurkable, that several of these species of flight-birds make their appearance in regular succession. The pippet, for instance, begins its flight every year about Mlichacluas, when they are caught in greatest number. To this the wood-lark succeeds, and continues its flight till towards the middle of October; other birds follow, but are not so punctually periodical; the green-finch does not begin till the frost obliges it to seek for a change. These birds, during those months, fly from day-break till tivalve at noon; and there is afterwards a small flight from two till night. Such are the seasons of the migration of the birds, which have been usually considered as stationary, and on these occasions they are cauglit in great abundance, as they are on their journcy. But the same arts used to allure them upon other occasions would be utterly fruitless, as they avoid the nets with the most prudent circumspection. The au- tumnal flight probably consists of the parcnt: conducting their new-fledged young to those places where there is sufficient provision, and a proper temperament of the air during the winter season; and their return in spring is obviously from an attachment to the place which was found so convenient before for the purposes of nestling and incubation

Antumn is the principal season when the bird-catcher enıploys his art to catch these wanderers. His nets are a most ingenious piece of mechanism, being generally twelve yaris and a half long, and two yards and a half wide, and so contrived as from a flat position to rise on each side, and clap over the birds that are decoyed to come between them. The birds in their passage are always observed to fly against the wind; hence there is a great contention among the bird-catchers which shall gain the wind; for example, if it is westerly, the bird-catclier who lays his nets most to the east, is sure of the nost plentiful sport, if his call-birds are good. For this purpose, he generally carries five or six linnets, two gold-finches, two green-finches, one woodlark, one red-poll, and perliaps a bull-finch, a yellow-hammer, a tit-laik, and an aberdavine: these are placed at small distances from the nets in little cages. He has besides what he calls his flur-birds, which are placed upon a moveable perch, which the bird-catcher can raise at pleasure by means of a string; and these he always lifts gently up and down as the wild bird approaches. But this is not enongh to allure the will bird down; it must be called by one of the call-birds in the cages; and these, by being made to moult prematurely in a warm cage, call louder and better than those that are wild and at frecdom. There even appears a malicious joy in these call-birds to bring the wild ones into the same state of captivity. while at the same time their call is louler, and their plumage brighter, than in a state of nature. Nor is their sight or hearing less exquisite, far exceeding that of the bird-catcher; for the instant the wild birds are perceived, notice is given by one to the rest of the call-birds, who all unite in the same tumultuous ecstacy of pleasure. The call. birds do not sing upon these occasions as a bird does in a chamber, but incite the wild ones by short jerks, which, when the birds are good, inay be lieard at a great distance. The 
"l...nmmant of this call is so great, that the will bird hearng $14,2-$...nod it its most rapid flight; and, if not already acyumost with the nets, lights boldly within twenty yards perhaps of the bird-catcher, and on a spot which it would otherwise have quite disregarted. This is the opportunity wished for, ant the bird-catcher pulling a string, the nets on each side rise in an iustant, and clap directly down on the poor little unsuspecting visitant. $\mathrm{Nay}$, it frequently happens, that if half a flock only are caught, the remaining half will immediately afterwards light between the nets, and share the fate of their companions. Should only one bird escape, this unhappy survivor will also venture into danger till it is caught; such a fascinating power have the callbirds.

Indeed, it is not easy to account for the nature of this call, whether it be a challenge to combat, an invitation to food, or a prelude to courtship. As the call-birds are all males, and as the wild birds that attend to their voice are most frequently males also, it does not seem that love can have any influence in their assiduity. Perhaps the wild females, in these flights, attend to and obey the call below, and their unale companions of the flight come down to bear then company. If this be the rase, and that the females bave unfaithfully ied their mates into the nets, they are the first that are punished for their infidelity: the males are only made captives for singing; wlile the females are indiscriminately killed, and sold to be served up to the tables of the delicate.

Whatever be the motives that thus arrest a fock of birds in their flight, whether they be of gallantry or of Ivar, it is certain that the small birds are equally remarkable for both. It is, perhaps, the genial desire that inspires the courage of most animals; and that being greatest in the males, gives them a greater degree of valour than the females. Small birds being extremely amorons, are remarkably brave. However contemptible these little warriors are to larger creatures, they are often but too formidable to each other; and sometimes fight till one of them yields up his life with the victory. But their contentions are sometimes of a gentler nature. Two male birds shall strive in song, till, after a long struggle; the loudest shall entirely silence the other. During these contentions, the female sits an attentive silent auditor, and often rewards the loudest songster with her company during the scason.

DHes... - manm hirds is almost universally the prerogative of the Imne. ixr:h thrm it is the reverse of what occurs in the human kino. Among the feathererl tribe, the heaviest cares of life fall to the lot of the female. Her's is the fatigue of incubation, and to her devolves the principal fatigue of mursing the helpless brood. To alleviate these fatigues, and to support her under them, nature has given the solng to the male. 'Ihis serves as a note of blandishment at first to attract her affections; it serves as a note to delight her during the time of her incubation; but it serves still farther as a note of security, to assure her that no danger threatens to molest her. The male, while his mate is hatching, sits upon some neighbouring tree, continuing at once to watcl and to sing. While his voice is heard, the fenuale rests in conficlent security; and, as the poet expresses it, appears most bless' $d$ when most unseen : but if any appearance of danger uffers to intrude, the male, that a monent before was so loud and sportive, stops all of a sudden; and this is a most certain signal to his mate to provide for her own security.

The nest of little birds secuns to be of a more delicate contrivance than that of the larger kinds. As the volume of their bodies is smaller, the materials of which their nests are composed are generally warmer. It is easy to conceive that small things keep heat a sholter time than those that are large. The eggs, therefore, of small birds require a place of more constant warmth than those of great oues, as being liable to cool nıore quickly; and accordingly their nests are built warner and deeper, lined on the insicle with softer substances, and guarded above with a better covering. But it sometimes liappens that the little architects are disturberl in their opera. tions, and then they are obliged to make a nest, not such as they wish, but such as they can. The bird whose nest has been robbed several times, builds up her last in a very slovenly manner, conscious that, from the near approach of winter, she must not take time to give her habitation every possible advantage it is capable of receiving. When the nest is finished, nothing can exceed the cunning which the male and female employ to conceal it. 
If it is built in bushes, the pliant branches are so disposed as to hide it entirely from the view; if it be built among moss, nnthino outwardly appears to at always built near those places where food is found in greatest abundance; and they take care never to go in or out while there is any one in sight. The greater birds continue from their nest for some time, as their eggs take no damage in their absence; but the little birds are assiduous while they sit, and the nest is always occupied by the male when the female is obliged to seek for sustenance.

The first food of all birds of the sparrow kind is worms and insects. Even the sparrow and the gold-finch, that when adult feed only upon grain, have both been fed upon insects while in the nest. The young ones, for some time after their exclusion from the shell, require no food; but the parent soon finds, by their chirping and gaping, that they begin to feel the approarhes of humger, and flies to provide them a plentiful supply. In her absence they continue to lie close together, and cherish each other by their mutual warmth. During this interval also, thry preserve a perfect silence, uttering not the slightest note, till the parent returns. Her arrival is always announced by a chirrup, which they perfectly understand, and which they answer all together, each petitioning for its portion. The parent distribntes a supply to each by turns, cantiously avoiding to gorge them, but to give them often, though little at a time. The wren will in this manlner feed seventeen or eighteen young ones, without passing over one of them.

Such is the manuer in which these birds bring forth and hatch their young; but it yet remains to usher them from the nest into life, and this they very assiduously perform. When they are fully fledged, and fitted for short 'nights, the old ones, if the weather be fair, lead them a few yards from the nest, and then compel them to return. For two or three succeeding days they are led out in the same manuer, but each day to seek more distant adventures. When it is perceived that they can dy, and shift for themselves, then the parents forsake them for ever, and pay them no more attention than they do to other birds in the same flock. Indecd, it wnild s.... axnony these littl these littl. ceases between the male and the female; they go separate ways, each to provide for itself during the rigours of winter; and, at the approach of spring, each seeks for a new associate.

In general, birds, when they come to pair in spring, associate with those of their own age and place of abode. Their strength or courage is generally in proportion to their age : the oldest females first feel the accesses of desire, and the oldest males are the holdest to drive off all younger pretenders. Those next in courage and desire become pretenders, till they are almost all provided in turn. The youngest come last; as, in fact, they are the latest in their inclinations. But still there are several, both males and females, that remain unprovided for; either not happening to meet with each other, or at least not during the genial interval. Whether these mix with small hirds of a different species, is a doubt which naturalists have not been able thoroughly to resolve. Addison, in some beautiful Latin lines. inserted in the Spectator, is entirely of opinion that birds observe a strict chastity of manners, and never admit the caresses of a different tribe.

Chaste are their instincts, faithful is their fire,

No foreign heauty tempts to false desire:

The snow-white vesture, and the glittering crown,

The simple plumage, or the glossy down,

Prompt not their love. The patriot bird pursues

His well acquainted tints, and kindred hues:

Hence thro' their tribes no inix'd polluted flame,

No monster-breed to mark the groves with shame:

But the chaste blackhird, to its partner true,

Thinks black alone is Beauty's fav'rite bue:

The nightingale, with mutual passion blest, Sings to its mate, and nightly charms the nest :

While the dark owl, to court his partner flies,

And owns his offspring in their yellow eyes.

But whatever may be the poet's opinion, the probability is against this fidelity among the smaller tenants of the grove. The great birds are much more true to their species than these; and, of consequence, the varicties among them are more few. Of the ostrich, the eassowary, and the engle, there are but few species; and no arts that man can use, could probably induce them to mix with cach other. 
But it is otherwise with the small birds we are describing; it requires very little trouble to make a species between a gold-finch and a canary-bird, between a linnet and a lark. They breed frequently together; and produce a race, not, like the mules among quadrupeds, incapable of brecding again; for this motley mixture are as firuitfil as their parents. What is so easily done by art, very probably often happens in a state of nature; and when the male cannot find a mate of his own species, he flies to one of another, that, like lim, has been left out in pairing. This, some listorians think, may have given rise to the great variety of small birds that are seen among us; some uncommon mixture might first have formed a new species, and this might have been continued down, by birds of this species choosing to breed together.

Whether the great variety of our small birds may have arisen from this source, cannot now be ascertained; but certain it is, that they resemble each other very strongly, not only in their form and plumage, but also in their appetites and manner of living. The gold-finch, the linnet, and the yellow-hammer. though obviously of different species, yet lead a very similar life; being equally an active, lively, salacious tribe, that snbsist by petty thefts upon the labours of mankind, and repays them with a song. Their nests bear a similitude; and they are all about the same time in hatching their young, which is usually fiftcen days. Were I therefore to describe the manners of these with the same minuteness that I have done the greater birds, I should only present the reader with a repetition of the same accounts; animated neither by novelty nor information. Instead, therefore, of specifying each sort, I will throw them into groupes; uniting those together that practise the same manners, or that are remarkable for similar qualifications.

Wilioughby has divided all the smaller birds into those that have slender bills, and those that have short and thick bills. Those with slender bills, chiefly live upon insects; those with short strong bills, live mostly upon fruits and grain. Among slender-billed birds, he enumerates the thrush, the blackbird, the fieldfare the starling, the lark, the titmouse, the water-wagtail, the nightingale, the red- start, the robin-red-hreast, the beccatigo, the stonc-chatter, the whinchat, the gold-finch, the white-throat, the hedge-sparrow, the pettichaps, the golden-crowned wren, the wren, the liunming-bird, and several other small birds of the sparrow-kind, unknown in this part of the world.

All these, as was said, live for the most part upon insects; and are consequently of particular benefit to man. By these are his grounds cleared of the pernicious swarms of vermin that devour the budding leaves and flowers; and that even attack the root itself, before ever the vegetable can come to maturity. These seek for and destroy the eggs of insects that would otherwise propagate in numbers beyond the arts of man to extirpate: they know better than man where to scek for them; and thus at once satisfy their own appetites, and render him the most essential services.

But this is not the only merit of this tribe: in it we have the sweetest songsters of the grove; their notes are softer, and their manner more musically soothing, than those of hard-billed birds. The foremost in musical fame are the nightingale, the thrush, the blackbird, the lark, the red-breast, the blackcap, and the wren.

Birds of the sparrow-kind, with thick and short bills, are the gross-beak, the green-finch, the bull-finch, the crossbill, the house-sparrow, the chaffinch, the brambling, the goldfinch, the linnet, the siskin, the bunting, the yellow-hammer, the ortolan, the wheat-ear, and several other foreign birds, of which we know rather the names than the history. These chiefly feed upon fruits, grain, and corn. They are often troublesome to man, as they are a numerous tribe; the harvest often suffers from their depredations; and while they are driven off from one end of the field, they fly round, and come in at the other. But these also have their uses: they are frequently the distributors of seeds into different districts; those grains which they swallow, are sometimes not wholly digested; and these, laid upon a soil congenial to them, embellish the face of nature with that agreeable varicty, which art but vainly attempts to imitate. The mistletoe plant, which we often see growing on the tops of elm and 
other trees, has been thought to be propagated in this manner; yet, as it is often scen growing on the under side of the branch, and sometimes on a perpendicular shoot, it seems extraordinary how a seed conld be deposited in that situation. However this be, there are many plants propagated from the depositions of birds; and some seeds are thought to thrive the better for first having undergone a kind of maceration in the stomach of the little animal, before it is roided on the ground.

There arc some agreeable songsters in this tribe also; and those who like a loud piercing pipe, cndued with great variety and perseverance, will be pleased most with their singing. The songsters of this class are the canarybird, the linnet, the chaffinch, the gold-finch, the green-finch, the bull-finch, the brambling, the siskin, and the yellow-hammer. The note of these is not so generally pleasing as that of the soft-billed birds, but it usually holds longer; and, in a cage, these birds are more easily fed, and more hardy.

This class of small birds, like all the greater, has its wanderers, that leave us for a season, and then return, to propagate, to sing, or to embellish the landscape here. Some of this smaller kind, indeed, are called birds of passage, that do not properly come under that denomination; for though they disappear in one place, they never leave the kingdom, but are seen somewhere else. But there are many among them that take longer flights, and go to a region colder or warmer, as it suits their constitutions. The ficldfarc and the red-wing breed pass their summers in Norway, and other cold countries, and are tempted hither to our mild winters, and to those various berries which then abound with us, and make their principal food. The hawfinch and the crossbill are uncertain visitants, and have no stated times of migration. Swallows of every species disappear at the approach of winter. The nightingale, the blackcap, the fly-catcher, the willow-wren, the wheat-ear, the whin-chat, and the stone-chatter, leave us long before the approach of winter; whilc the siskin and the limnet only forsake us when our winters are more than usually severe. All the rest of the smaller tribe never quit this country; but support the severest rigours of the climate.

Yet it must not be supposed that the man. ners of our little birds prevail in all other countries; and that such kinds as are stationary with us, never wander in other parts of Europe: on the contrary, it happens that many of those kinds which are birds of passage in England, are seen, in other places, never to depart, but to make one conntry their fixed residence, the whole year round. It is also frequent, that some birds, which with us are faithful residents, in other kingdoms put on the nature of birds of passage, and disappear for a season.

The swallow, that with us is particularly remarked for being a bird of passage, in Upper Egypt, and in the island of Java, brecds and continues the whole year, without ever disappearing. Larks, that remain with us the year throughout, are birds of passage in Sweden; and forsake that climate in winter to return again with the rcturning spring. The chaffich, that with us is stationary, appears during the winter in Carolina and Virginia; but disappears totally in summer, to breed in the more northern regions. In Sweden, also, these little birds are seen returning, at the approach of spring, from the warmer climates, to propagate; which being accomplished by the latter end of autumn, the males and females separate; the males to continue among their native snows, the females to seek a warmer and gentler winter. On this occasion, they are seen in flocks, that darken all the air, without a single male among them, making their way into the more southern regions of Denmark, Gerumany, and Holland. In this Amazon-like retreat, thousands fall by the way; some by fatigue, somc by want; but the greatest number by the nets of the fowler; the taking them being one of the chief amusements among the gentry where they pass. In short, the change of country with all this little tribe, is rather a pilgrimage than a journey; a migration rather of necessity than of choice.

Having thus given a general idea of the birds of this class, it will be proper to give some account of the most remarkable among them. 


\section{CHAP'TER CVII.}

\section{OF THE THRUSH, AND ITS AFFINITIES.}

WITH the Thrush we may rank the redwing, the fieldfare, the blackbird, the ringouzel, and the water-ouzel. 'These are the largest of the sparrow kind, and may be distinguished from all others of this class, as well by their siz", which is well known, as by their bills, whi $/ \mathrm{t}$ are a little bending at the point; a small notch near the end of the upper chap; and the outmost toe adhering as far as the first joint of $\mathrm{t}$ e middle toe. To this tribe may be also ad ed the stare or starling, which, though with a flat bill, too much resembles these birds to be placed any where else.

The missel-thrush is distinguished from all of the kind by its superior size, being much larger than any of them. It differs scarcely in any other respect from the throstle, except that the spots on the breast are larger. It builds its nest in bushes, or on the side of some tree, as all of this kind are found to do, and lays four or five eggs in the season. Its song is very finc, which it begins in spring, sitting on the summit of a ligh tree. It is the largest bird of all the feathered tribe that has music in its voice; the note of all greater birls being either screaning, chattering, or croaking. It feeds on insects, hiolly, and mistletoe-bcrries; and sumetimes sends forth a very disagreeable screain when frighted or disturbed.

'The blackbird, which in cold countries, and particularly upon the Alps, is sometimes seen all over white, is a beautiful and canorous bird, whistling all the spring and summer time with a note, at a distance, the most pleasing of all the grove. It is the deepest toned warbler of the woods; but it is rather unpleasant in a cage, being loud and deafening. It lays four or five bluish eggs, in a nest usually built at the stump of some old hawthorn, well plastered on the inside with elay, straw, and hair.

Pleasing, however, as this bird may be, the Blue-bird, describerl by Bellonius, is in every respect far superior. This beautiful anina! sc. $45 \& 46$. entirely resembles a blackbird in all but its blue colour. It lives in the highest parts of the Alps, and even there chooses the most craggy rocks and the most frighteful precipices for its residence. As it is rarely caught, it is in high estimation even in the countries where it breeds, but still more valuable when carried from home. It not only whistles in the most delightful manner, but speaks with an articulate distinct voice. It is so docile, and obscrves all things with such diligence, that though waked at midnight by any of the family, it will speak and whistle at the word of commanit. Its colour, about the beginning of winter, from blue becomes black, which changes to its original hue on the first approaches of spring. It makes its nest in dleep Inoles, in very high and inacessible solitudes, and removes it not only from the accesses of man, but also hides it with surprising cumning from the shammoy and other wild beasts that might annoy its young.

The manner of taking this heautiful bird is sairl to be this. The fowlers, cither by cliance or by lying in wait, having found out the place where it builds, take with them a strong stilt or stake, such as the climbers of rocks niake use of to assist them in their ascent. With the assistance of this, they mount where an indifferent spectator would think it impossible to ascend, covering their hoads at the same time to ward off any danger of the failing of pebbles or stones from above. At length, with extreme toil and danger, having arrived at the nest, they draw it up fiom the hole in which it is usually buried, and cherish the young with an assiduity equal to the pains they took to obtain them. It produces for the most part five young, and never more; it seldom descends into the plain country, flies swifter than a blackbird, and uses the same food.

The fieldfare and the redwing make but a short stay in this country. With us they are insipid tuneless bircls, flying in flocks, and excessively watchful to preserve the general 
safety. All their season of music and pleasure is employed in the more northern climates, where they sing most delightfully, perched among the forests of maples, with which those countries abound. They build their nests in hedges; and lay six bluishgreen eggs spotted with black.

The stare, distinguishable from the rest of this tribe by the glossy green of its feathers in some lights, and the purple in others, breeds in hollow trees, eaves of houses, towers, ruins, cliffs, and often in high rocks over the sea. It lays four or five eggs of a pale greenish ash-colour, and makes its nest of straw, small fibres of roots, and such like. Its voice is rougher than the rest of this kind; but what it wants in the melody of its note, it compensates by the facility with which it is taught to speak. In winter these birds assemble in vast flocks, and feed upon worms and insects. At the approach of spring, they assemble in fields as if in consultation together, and for three or four days seem to take no nourishment: the greater part leave the country; the rest breed here, and bring up their young.

To this tribe might be added above a a hundred other birds of nearly the thrush size, and living like them upon firuit and berries. Words could not alford variety enough to describe all the beautiful tints that adorn the foreign birds of the thrush kind. The brilliant green of the emerald, the flaming red of the ruby, the purple of the amethyst, or the bright blue of the sapphire, could not, by the most artful combination, show any thing so truly lively or delightful to the sight, as the feathers of the chilcoqui or the tauto- tal. Passing, therefore, over these beautiful, but little-known, birds, I will only mention the American mock-bird, the favourite songster of a region, where the birds excel rather in the beauty of their plumage than the sweetness of their notes.

This valuable bird does not seem to vie with the feathered inhabitants of that country in the beauty of its plumage, content with qualifications that endear it to mankind much more. It is but a plain bird to the eye, about the size of a thrush, of a white and gray colour, and a reddish bill. It is possessed not only of its own natural notes, which are musieal and solemn, but it can assume the tone of every other animal in the wood, from the wolf to the raven. It seems even to sport itself in leading them astray. It will, at one time, allure the lesser birds with the call of their males, and then terrify them, when they have come near, with the screarns of the cagle. There is no bird in the forest but it can mimic; and there is none that it has not at times deceived by its call. But, not like such as we usually see famed for mimicing with us, and who have no particular merit of their own, the mock-bird is ever surest to please when it is most itself. At those times it usually frequents the houses of the American planters; and, sitting all night on the chimney-top, pours forth the sweetest and the most various notes of any bird whatever. It would seem, if accounts be true, that the defieiency of most other song-birds in that country, is made up by this bird alone. They often build their nests in the fruit-trees about houses, feed upon berries and other fruits, and are easily rendered domestic.

\section{CHAPTER CVIII.}

\section{OF THE NIGHTINGALE, AND OTHER SOFT-BILLED SONG-BIRDS.}

The Nightingale is not only famous among the moderns for its singing, but almost every one of the ancients, who undertook to describe beautiful nature, has contributed to raise its reputation. "The nightingale," says
Pliny, "that for fifteen days and nights, hid in the thickest shades, contiuues her note without intermission, deserves our attention and wonder. How surprising that so great a voice can reside in so small a body! such 
perseverance in so minute an animal! With what a musical propriety are the sounds it produces mudulated! The note at one time drawn out with a long breath, now stealing off into a different carlence, nisw incerrupted by a break, then changing intu a new note by an unexpected transition; now secming to renew the same strain, then deceiving expcctation! She sometimes seems to murmur within herself; full, deep, sharp, swift, drawliıg, treinbling; now at the top, the midrlle, und the bottom of the scale! In short, in that little bill seems to reside all the melody which man has vainly laboured to bring from a variety of musical instruments. Some even seem to be possessed of a different song from the rest, and contend with each other with great ardour. The bird overcome is then seen only to discontinue its song with its life."

This most fanous of the feathered tribe visits England in the beginning of April, and leaves us in August. It is found but in some of the southern parts of the country, being totally unknown in Scotland, Ireland, or North IVales. They frequent thick herlges and low coppices, and generally keep in the middle of thi bush, so that they are rarely seen. They begin their song in the evening, and generally continue it for the whole night. For weeks together, if undisturbed, they sit upon the same tree; and Sirakspeare rightly describes the nightingale sitting nightly in the same place, which I have frequently observed she seldom departs from.

From Pliny's description, we should be led to believe this bird possessed of a persevering strain; but thougl it is in fact so with the nightingale in Italy, yet in our hedges in England the little songstress is by no means so liberal of her music. Her note is soft, various, and interrupted; she seldon holds it without a pause above the time that one can count twenty. The nightingale's pausing song would be the proper epithet for this bird's music with us, which is more pleasing than the warbling of any other bird, because it is heard at a time when all the rest are silent.

In the begiuning of May, the nightingale prepares to make its nest, which is formed of the leaves of trees, straw, and moss. The nest being very eagerly sought after, is as cunningly secreted; so that but very few of them nse found by the boys when they go upon these pursuits. It is built at the bottom of hedges, where the bushes are thickest and best covered. While the female continues sitting, the male at a good distance, but always within learing, cheers the paticnt hour with his voice, and, by the short interruption of lis song, often gives her ivarning of aprroaching dallger. She lays four or five egrs ; of which but a part in our cold clinuate come to maturity.

The delicacy, or rather the fame, of this hird's music, las induced many to abridge its liberty, to be secured of its song. Indeed, the greatest part of what has been written concerning it in our country, consists in directions how to manage it for domestic singing; while the history of the bird is confined to dry receipts for fitting it for the cage. Its song, however, in captivity, is not so very alluring; and the tyranny of taking it from those hedges where only it is most pleasing, still more depreciates its imprisoned efforts. Gesner assures us, that it is not only the most agreeable songster in a cage, but that it is possessed of a most admirable faculty of talking. He tells the following story in proof of his assertion, which he says was communicated to hin by a friend. "Whilst I was at Ratisbon," says his correspondent, "I put up at an inn, the sign of the Golden Crown, where my host had three nightingales. What I am going to repeat is wonderful, almost incredible, and yet is true. The nightingales were placed separately, so that each was shut up by itself in a dark cage. It happened at that time, being the spring of the year, when those birds are wont to sing indelatigably, that I was so afflicted with the stone, that I could sleep but very little all night. It was usual then about midnight, when there was no noise in the house, but all still, to hear the two nightingales jangiug and talking with each other, and plainly initating men's discources. For my part I was almost astonished with wonder; for at this time, when all was quiet else, they held conference together, and repeated whatever they hat heard among the guests by day. Those two of them that werc most notable, and masters of this art, were scarcely ten feet distant fron one another. The third hung more remote, so that I could not so well hear it as I lay a-bed. But it is wonderful to tell how those two provoked each other; and by answering, invited and drew one another to speak. Yet did they not con 4. I* 
found their words, or talk both together, but rather utter them alternately and of course. Besides the daily discourse of the guests, they chaunted out two stories, whicis generally held them from midnight till morning; and that with such modulations and inflexjous, that no man could have taken to come from such little creatures. When I asked the host if they had been tanght, or whether he observed their talking in the night; he answered, no: the same said the whole family. But I, who could not sleep for nights together, was perfectly sensible of their discourse. One of their stories was concerning the tapster and his wife, who refused to follow him to the wars, as he desired her: for the husband endeavoured to persuade his wife, as far as I understood by the birds, that he would leave his service in that inn, and go to the wars in hopes of plunder. But she refused to follow him, resolving to stay either at Ratisbon, or go to Nuremberg. There was a long and earnest contention between them; and all this dialogue the birds repeated. They even repeated the unseemly words which were cast out between them, and which ought rather to have been suppressed and kept a secret. But the birds, not knowing the difference between modest, immodest, honest, and filthy words, did out with them. The other story was concerning the war which the emperor was then threatening against the Protestants; which the birds probably heard from some of the generals that had conferences in the house. These things did they repeat in the night after twelve o'clock, when there was a deep silence. But in the daytime, for the most part they were silent, and seemed to do nothing but meditate and revolve with themselves upon what the guests conferred together as they sat at table, or in their walks. I verily had never believed our Pliny writing so many wonderful things concerning these little creatures, had I not myself seen with my eyes. and heard them with my ears uttering such things as I have related. Neither yet can I of a sulden write all, or call to remembrance every particular that I have heard."

Such is the sagacity ascribed to the nightingale: it is but to have high reputation for any one quality, and the world is ready cnough to give us fame for others to which we have very small pretensions. But there is a little bird, rather celebrated for its affection to mankind than its singing, which, however, in our climate, has the sweetest note of all others. The reader already perceives that I mean the RED-BREAST, the well-known friend of man, that is found in every hedge, and makes it vocal. The note of other birds is louder, and their inflexions more capricious, but this bird's voice is soft, tender, and well supported; and the more to be valued, as we enjoy it the greatest part of the winter. If the nightingale's song has been compared to the fiddle, the red-breast's voice has all the delicacy of the flute.

The red-breast, during the spring, haunts the wood, the grove, and the garden; it retires to the thickest and shadiest hedge-rows to breed in. But in winter it seems to become more domestic, and often to claim protection from man. Most of the soft-billed birds, the nightingale, the swallow, and the tit-mouse, leave us in the winter, when their insect food is no longer offered in plenty; but the red-breast continues with us the year round, and endeavours to support the famine of winter by chirping round the warm habitations of mankind; by coming into those shelters where the rigour of the season is artificially expelled, and where insects themsclves are found in greater numbers, attracted by the same cause.

This bird breeds differently in different places : in some countries its nest is usually found in the crevice of some mossy bank, or at the foot of a hawthorn in hedge-rows; in others it chooses the thickest coverts, and hides its nest with oak leaves. The eggs are from four to five, of a dull white, with reddish streaks.

The Lark, whether the sky-lark, the wood, or the tit-lark, being all distinguishable from other little birds by the length of their heel, are louder in their song than either of the former, but not so pleasing. Indeed, the music of every bird in captivity produces no very pleasing sensations; it is but the mirth of a little animal. insensilile of its unfortunate situation: it is the landscape, the grove, the golden break of day. the contest upon the hawthorn, the fluttering from brauch to 
branch, the soaring in the air, and the answering of its young, that gives the bird's song its true relish. These, united, improve each other, and raise the mind to a state of the highest, yet most harmless, exultation. Nothing ean, in this situation of mind, be more pleasing than to see the lark warbling upors the wing; raising its note as it soars, until it seems lost in the immense heights above us; the note continuing, the bird itself unseen; to see it then descending with a swell as it comes froin the clouds, yet sinking by degrees as it approaches its nest, the spot where all its affections are centred, the spot that has prompted all this joy.

The lark builds its nest upon the ground, beneath some turf that serves to hide and shelter it. The female lays four or fire eggs, of a dusky hue in colour, somewhat like those of a plover. It is while she is sitting that the male thus usually cutertains her with his singing; and while he is risen to an imperceptible height, yet he still has his loved partner in his eye, nor once loses sight of the nest, either while he ascends or is descending. This harmony continues several months, beginning early in the spring on pairing. In winter they assemble in flocks, when their song forsakes them, and the bird-catchers destroy them in great numbers for the tables of the luxurious.

The Black-cap and the Wren, though so very diminutive, are yet prized by some for their singing. The former is called by some the mock nightingale; and the latter is admired for the loudness of its note, compared to the little borly from whence it issues. It must be confessed, that this disproportion between the voice of a bird and its size, in some measure demands our wonder. Quadrupeds in this respect may be considered as mutes to them. The peacock is louder than the lion, and the rabbit is not so loud as the wren. But it inust be considered, that birds are very differently formed; their lungs in some measure are extended through their whole body, while in quadrupeds they lie only in the breast. In birds there are a variety of cells which take in the air, and thus pour forth their contents at the little animal's command. The black-cap and the wren, therefore, are as respectable for their voices as they might be deemed inconsiderable for their size.

All these soft-billed birds, thus prized for their singing, are rendered domestic, and brought up with assiduity by such as are fond of their voices in a cage. The same inethod of treatment serves for all, as their food and their liabits are nearly the same. The manner of taking and treating them, particnlarly the nightingale, is this: A nightingale's nest may be found by observing the place where the male sings, and then by sticking two or three meal-worms (a kind of maggot found in flour) on some neighbouring thorn, which when he sees he will infallibly bear away to his young. By listening, he then may be heard with the female chirping to the young ones while they are feeding. When the nest is found, if the young ones are not fledged enough to be taken, they must not be touched with the hands, for then the old ones will perceive it, and entice them aray. They should not be taken till they are almost as full of feathers as the old ones; and, though they refuse their meat, yet, by opening their bills, you may give them two or three small bits at a time, which will make them soon grow tame, when they will feed themselves. They should be put nest and all into a little basket which should be covered up warm: and they should be fed every two hours. Their food should be sheep's hearts, or other raw flesh-meat, chopped very fine, and all the striugs, skins, and fat, taken away. But it should always be mixed with hard hen's eggs, upon which they will feed and thrive abundantly.

They should then be put in cages like the nightingale's back cage, with a little straw or dry moss at the bottom; but when they are grown large, they should have ant's mould. They should be kept very clean, as indeed should all singing-birds whatsoever; for otherwise they will have the cramp, and perhaps the claws will drop off. In autumn they will sometimes abstain froin their food for a fortnight, unless two or three meal-worms be given them twice or thrice a week, or two or three spiders in a day; they must likewise have a little saffion in their water. Figs chopped small among their meat will help them to recover their flesh. When their legs are 
cramped, they should be anointed with freshbutter, or capon's fat, three or four days together. If they grow melancholy, pit white sugar-candy into their water, and feed them with sheep's heart, giving them three or four meal-worms in a day, and a few ants with their eggs.

With regard to adult birds, those that are taken before the twenty-third of April are accounted the best, because after that they begin to pair. They usually haunt woods, coppices, and quickset hedges, where they may be laken in trap-cages baited with meal-worms. They should be placed as near the spot where the bird sings as possible; and before you fix the trap, turn up the earth twice the breadth of the cage, because they will there look for food. They are also taken with lime twigs, placing them upon the bedge where they usually sing; and there should be meal- worms stuck at proper places to draw them into the snare. After they are taken, their wings should be gently tied with thread, to prevent their beating themselves against the cage. This should be first hung in a private place, that the bird may not be disturbed; and it should be fed every two hours, at farthest, with sheep's heart and egg minced very fine, mixing it with meal-worms. However, the first food must be worms, ants, caterpillars, and flies. You must, to feed the bird, take it in your hand, and open the bill with a stick made thick at one end, giving it the insects, or four or five bits of food as big as peas, to entice it to eat. Its common food should be mixed with ants, so that when the bird goes to pick up the ants, it may pick up some of that also. The nightingale, when caged, begins to sing about the latter end of November, and continues its song till June.

\section{CHAPTER CIX.}

\section{OF THE CANARY-BIRD, AND OTIIER HARD-BILLED SINGING-BIRDS.}

THE Canary-bird is now become so common, and has continued so long in a domestic state, that its native habits, as well as its native country, seem almost forgotten. Though by the name it appears that these birds came originally from the Canary Islands, yet we have it only from Germany, where they are bred up in great numbers, and sold into different parts of Europe. At what period they were brought into Europe is not well known; but it is certain that about a century ago they were sold at very high prices, and kept only for the amusement of the great. They have since been multiplied in great abundance; and their price is diminislied in proportion to their plenty.

In its native Islands, a region equally noted for the beauty of its landscapes and the harmony of its groves, the Canary-bird is of a dusky gray colour, and so different from those usually seen in Europe, that some have even doubted whether it be of the same species. With us, they have that variety of colouring usual in all domestic fowls; some white, some mottled, some beautifully shaded with green; but they are more esteemed for their note than their beauty, having a high pierciug pipe, as indeed all those of the finch tribe have, continuing for some time in one breath without intermission, then raising it higher and ligher by degrees, with great variety.

It is this that has rendered the Canary-bird, next to the nightingale, the most celebrated songster; and as it is more easily reared than any of the soft-billed birds, and continues its song throughout the year, it is rather the most common in our liouses. Rules, therefore, have been laid down, and copions instructions given, for breeding these birds in a domestic state; which, as a part of them may conduce towards the natural history of the bird, I will take leave to transcribe.

In cloosing the Canary-bird, those are best that appear with life and boldness, standing upright upon the perch, like a sparrowhawk, and not apt to be frighted at every 
thing that stirs. If its eyes look cheerful, and not drowsy, it is a sign of health; but, on the contrary, if it hides its head under the wing, and gathers its body up, these are symptoms of its being out of order. In choosing them, the melody of the song should also be minded: some will open with the notes of the nightingale, and, running through a variety of modulations, end like the tit-lark. Others will begin like the sky-lark, and, by a soft melodious turn, fall into the notes of the nightingale. These are lessons taught this bird in its domestic state, and generally taught it by others; but its native note is lond, shrill, piercing, and enough to deafen the hearers. There are persons who admire each of these songs, but the second is in the most general estimation.

Canary-birds sometimes breed all the year round; but they most usually begin to pair in April, and to breed in June and August. Those are said to be the best breeders that are produced between the English and the French.

Towards the latter end of March, a cock and a hen should be put together in a small eage, where they will peck at each other in the beginning, but will soon become thoronghly reconciled. The room where they are liept to breed should be so situnted as to let the birds have the benefit of the morning sun, and the windows should be of wire, not glass, that they mny enjoy the benefit of the air. The floor of the room should be kept clean, and sometimes there should be dry gravel or sand sifted upon it. There should also be two windows, one at each end, and sereral perches at proper distances for the birds to settle on, as they fly backwards and forwards. A tree in the middle of the room would be the most convenient to divert the birds, and sometimes to serve for building their nests upon.

In Germany they prepare a large room, and build it in the manuer of a barn, being much longer than broad, with a square place at each end, and several holes to go into those square places. In those outlets they plant several sorts of trees, in which the birds take great delight to sing and breed. The hottom of the place they strew with sand, and upon it cast rape-seed, chick-weed, and groundsel, which the old birds feed upon while breeding. In the body of the house they put all soits of stuff for building the nest, and brooms, one under the other, in all the corners, for the birds to build in. These they separate by partitions from each other, to prevent those above flying down upon, or otherwise incommoding, such as breed below. The light also is excluded, for no bird is ford of having light come to its nest.

With us the apparatus for breeding is less expensive; a little breeding-eage sometimes suffices, but seldom any thing more extensive than a small room. While the birds are pairing, it is usual to feed them with soft meat; that is, bread, maw-seed, a little scalded rapeseed, and near a third part of an egg. The room should be furuished with stuff for making their nests; such as fine hay, wool, cotton, and hair. These materials should be thoronghly dry, and then mixed and tied together in such a manner that the birds may readily pull out what they want. This should be hung in a proper part of the room, and the male will take his turn in building the nest, sitting upon the eggs, and feeding the young. They are generally two or three days in building their nests; the hen commonly lays five eggs; and in the space of fourteen days the young will be excluded. So prolific are these birds sometimes, that the female will be ready to hatch a second brood before the first are able to quit the nest. On these occasions she leaves the nest and the young, to provide herself with another to lay her new brood in. In the mean time the male, more faithful to the duties of his trust, breeds up the young left behind, and fits them for a state of independence.

When the young ones are excluded, the old ones should be supplied with a sufficiency of soft food every day, with likewise fresh greens, such as cabbage, lettuce, and chickweed; in June, shepherd's purse; and in July and August, plantain. They are never to have groundsel after the young are excluded. With these different delicacies the old ones will take particular care to feed and bring up their young; but it is usual when they cau feed themselves, to be taken from the nest and put into cages. Their meat then is the yolk of an egg boiled hard, with 
an equal quantity of fine bread, and a little scalded rape-seed : this must be bruisecl till it becomes fine, and then it may be mixed with a little maw-seed; after which blend all together; which is to be supplied them fresh every day.

The canary-birl, by being kept in company with the limnet or the gold-fincli, pairs and produces a mixed breed, more like the canarybird, and resembling it chicfly in its song. Indeed, all this tribe with strong bills and piercing notes, and feeding upon grain, have the most strong similitude to each other, and may justly be supposed, as Mr. Buffon imagines, to come from the saine original. They all breed about the same time; they frequent the same vegetables; thry build in the same herlges and trees; and are broughr up for the cage with the same food and preautions. The linnet, the bull-fiuch, aud the goli-finch, whet, we know the history of the canary-bird, have scarcely any peculiarities that can attract our curiosity, or require our care. The only art necessary with all those that have no very fiue note, is to breed them up under sone more pleasing harmonist. The gold-finch learns a finc song from the niglitingale; and the linnet and bull-finch inay be taught, forgetting the wild notes of nature, to. whistle a long and regular tune.

\section{CHAPTER CX.}

\section{OF THE SWALLOW, AND ITS AFFINITIES.}

AN idea of any one bird in the former classes will give us some tolerable conception of the rest. By knowing the linnct or the canarybird, we have some notion of the manners of the gold-finch; by exhibiting the listory of the nightingale, we sce also that of the blackcap or the tit-mouse. But the swallow tribe seems to be entirely different from all the former; different in their form, different in their habits, and unlike in all the particulars of their listory.

In this tribe is to be found the Goat-sucker, which may be styled a nocturnal swallow; it is the largest of this kind, and is known by its tail, which is not forked, like that of the cominou swallow. It begins its flight at evening, and makes a loud singular noise, like the whur of a spinning-whecl. To this also helongs the House-swallow, which is too well known to need a description : the Martin, inferior in size to the former, and the tail much less forked; it differs also in its nest, which is covered at top, while that of the house-swallow is open: and the Swift, rather larger than the honseswallow; with all the toes standing forward; in which it differs from the rest of its kintl. All these resemble each other so strongly, that it is not without difficulty the smaller kinds are knowu asunder.
These are all known by their very large mouths, which, when they fly, are always kept open; they are not less remarkable for their short slender feet, which scarcely are able to support the weight of their bodies; their wings are of immoderate extent for their lulk ; their plumage is glossed witl a rich purple; and their note is a slight twittering, which they seldom exert but upon the wing. This peculiar conformation seems attended with a similar peculiarity of manners. Their food is insects, which they always pursue flying. For this reason, during fine weather, when the insects are most likely to be aloroad, the swallowe are for ever upon the wing, an seem pursing their prey with anazing swiftuess and agility. All smaller animals, in some measure, find safety by winding and turning, when they endeavour to avoid the greater: the lark thus evades the pursuit of the hawk, and mais the crocodile. In this manner, inserts upon the wing endeavour to avoid the swallow; but this bird is admirably fitted by nature to pursue them through their sliortest turnings. Besides a great length of wing, it is also provided with a long tail, which, like a rudder, urns it in its most rapirl motions ; ant thus, while it is possesscel of the greatest swiftness, it is also possessed of the most extreme agility. 
Early, therefore, in the spring, when the reiuruing sun begins to rouse the insect tribe from their annual state of torpidity; when the guat and the beetle put of their earthly robes, and venture into air; the swallow then is seen returning from its long migration beyond the occan, and making its way fecbly to the shore. At first, with the timidity of a stranger, it appears but seldom, and flies but slowly and heavily along. As the weather grows warmer, and its insect supply increases, it then gathers greater strength and activity. But it sometimes loppens that a rainy season, by repelling the insects, stints the swallow in its food; the poor bird is then seen slowly skimming along the surface of the ground, and ofte $n$ resting after a flight of a few minutes. In general, however, it keeps on the wing, and moving with a rapidity that nothing can escape. When the weather promises to be fair, the insect tribe feel the genisl influence, and make bolder flights; at which time the swallow follows them in their aerial journeys, and often rises to inperceptible heights in the pursuit. When the weather is likely to be foul, the insects feel the first notices of it; and from the swallow's following low we are often apprized of the approuching change.

When summer is fairly begun, and more than a sufficient supply for sustaining the wauts of nature cvery where offers, the swallow then begins to think of forming a progeny. The nest is built with great industry and art, particularly by the common sivallow, which builds it on the tops of chimneys. The martiu sticks it to the eaves of houses. The goatsucker, as we are told, builds it on the bare ground. 'This nest is built with mul from some neighhouring brook, well tempered with the bill, moistened with water, for the better adhesion; and still farther kept firm, by long grass and fibres: within it is lined with goose feathers, which are ever the warmest and the neatest. The martin cover's its nest at top,

a Sir George Staunton, in his account of the embassy to Clina, says, that in the Cass, a small island near Sumatra, were found two eaverns, running horizontally inlo the side of the ruck; in which were a number of these nests so much prized by the Chinese epicurcs. "They secmed to be composed of fine filaments eemented together by a transparent viscous inatter, not unlike wlsat is left by the foam of the sea, or those gelatinous animal substances found floating on every coast. The nests adhere together, No. $47 \& 48$. and has a door to enter at; the swallow leaves her's quite open. But our European nests are nothing to be compared with those the sival. low builds on the coasts of China and Coro. mandel; the description of which I will give in the plain honest plurase of Willunghby. "On the sea-coast of the kingdum of China," says he, "a sort of party-coloured birds, of the shape of swallows, at a certain season of the year, which is their breeding time, come out of the midland country to the rocks, and from the foam or froth of the sen-water, dashing against the bottom of the rocks, gather a certain clainmy glutinous matter, perchance the spawn of whules and other young fishes, of which they build their nests, wherein they lay their egrgs and hatch their young. 'These nests the Chinese pluck from the rocks, and bring them in great numbers into the East Indies to sell. They are esteemed, by gluttons, as great delicacies; who, dissolving them in chicken or mutton broth, are very fond of them ; far before oyster's, mushrooms, or other dainty and liquorish morsels." What a pity this luxury hath not been introduced among us, and then $0 m 1$ great feasters might be cnabled to eat a little more!

The swallow usually lays from five to six eggs, of a white colour, speckled will red; and sometimes breeds twice a year. When the young brood are excluded, the swallow supplies them very plentifully, the first brood particularly, when she finds herself caprable of producing two broods in a year. This liappens when the parents come early, when the season is peculiarly mild, and when they begin to pair soon. Sumetimes they find in difficulty in rearing even a single nest, particularly when the weather has been severe, or their nests have been robbed in the beginuing of the season. By these accidents, this important task is sometimes deferred to the middle of Septeinber.

At the latter end of September, they leave

and to the sides of the cavern, mostly in rows without any break or interruption. The birds that build these nests are sinall gray swallows, with bellies of a dirty white. These nests are a considerable ohject of traffic among the Javanese, many of whom are employed in it from their infancy; and as the operation of taking them is atlended with much danger, many lives are lost in that employment. 
us ; and for a few days previous to their departure assemble in vast locks, on house tops, as if deliberating on the fatiguing journey that lay before them. This is no slight undertaking, as their flight is directed to Congo, Senegal, and along the whole Morocco shore. 'There are some, lowever, left behind in this general expedition, that do not depart till eight or ten days after the rest. These are chielly the latter weakly broods, which are not yet in a condition to set out. They are sometimes even too fecble to venture, till the setring in of winter; while their parents vainly exhort them to efforts which instinct assures them they are incapable of performing. 'Thus it often happens, that the wretehed little families, being coinpelled to stay, perish the first cold weather that coines; whil the tender parents share the fate of their offspring, and die with the new-fledged brood.

Those that migrate, are first observed to arrive in Africa, as Adanson assures us, about the beginning of October. They are thought to have performed their fatiguing joursey in the space of seven days. They are sometimes seen, when interrupted by contrary winds, wavering in their course far off at sea, and lighting upon whatever ship they find in their passage. They then seem spent with famine and fatigue; yet still they boltly venture, when refieshed by a few hours rest, to renew their flight, and continue the course which they had been steering before.

These are facts, proved by incontestable authority; yet it is a doubt whether all swallows migrate in this manner, or whether there may not be some species of this animal that, though cxternally alike, are so intermally different, as to be very differently affected by the approich of winter. We are assured from nany, and these not contemptible wituesses, that swallows hide themselves in holes under ground, joined close together, bill against bill, and feet igninst feet. So:ne inform us, that they have seen them taken ont of the water, and even from under the ice, in bunches, where they are asserted to pass the winter, without motion. Reaumur, who particularly interested himself in this inquiry, received several accounts of bundles of swallows being thus found in quarries, and under the water. These men, therefore, have a right to some degree of assent, and are not to lose all credit fiom our ignorauce of what they aver.

All, however, that we have hitherto dissected, are formed within like other biris; and seem to offer no observable variery. Indeed, that they do not hide themselves under ivater, has been pretty well proved, by the noted experiment of Frisch, who tied several threads, dyed in water-colours, round the legs of a great number of swallows that were preparing for their departure : these, upon their return the ensuing summer, brought their threads back with them, no way dainaged in their colour: which they most certainly would, if, during the winter, they had been steeped in water: yet still this is a subject on which we must suspend our assent, as Klein, the naturalist, luas brought such a number of proofs in defence of his opinion, that swallows are torpid in winter, as cven the most incredulous must allow to have some degrec of probability.

\section{CHAPTER CXI.}

\section{THE HUMMING-BIRD, AND ITS VARIETIES.}

HAVING given some history of the manners of the nost remarkable hirds of which accounts can be obtained, I night now go to a very extensive tribe, renarkable for the splentour and the variety of their plumage : but the deseription of the colours of a beautiful bird, bas nothing in it that can iuform or enrertain; ut rather excites a longing, which it is impossible for worls to satisfy. Naturalists, indeed, have endeavoured to satisfy this desire by coloured prints; but, beside that these at best give only a faint resemblance of nature, and are a vely indifferent kind of painting, the bird itself has a thousand beauties, 

that the most exquisite artist is incapable of initating. They, for instance, who imagine they have a complete idea of the beauty of the little tribe of inanikin birds, from the pictures we have of them, will find themselves deceived, when they compare their draughts with nature. The shining greens, the changeable purples, and the glossy reds, are beyond the reach of the pencil; and very far beyond the coloured print, which is but a poor substitute to panting. I have therefore declined entering into a minute description of foreign birds of the sparrow kind; as sounds would never convey an adequate idea of colours.

There is one species, however, that I will conclude the history of this class with; as, though the least, it will certainly be allowed the inost beautiful of all others. In quadrupeds, the smallest animals are noxious, ugly, and loathsome; the smallest of birds are the most beautiful, innocent, and sportive. Of all those that flutter in the garden, or paint the landscape, the humming-bird is the most delightful to look upon, and the most inoffensive.

Of this charming little animal, there are six or seven varieties, from the size of a small wren, down to that of an humble-bee. An European could never have supposed a bird exintung so very small, and yet completely furnished out with a bill, feathers, wings, and intestines, exactly resembling those of the largest kind. A bird not so big as the end of one's little finger, would probably be supposed but a creature of imagination, were it not seen in infinite numbers, and as frequent as butterflies in a summer's day, sporting in the fields of America, from flower to flower, and extracting their sweets with its little bill.

The smallest humming-bird is about the size of a hazel-nut. The feathers on its wings and tail are black; but those on its body, and under its wings. are of a greenish brown, with a fine red cast, or gloss, which no silk or velvet can imitate. It has a small crest on its head, green at the bottom, and, as it were, gilded at the top; and which sparkles in the sun like a little star in the middle of its forehead. The bill is black, straight, slender, and of the length of a small pin. The larger humming-bird is near half as big as the common wren, and without a crest on its head; but, to make amends, it is covered, from the throat half way down the belly, with changenble crimson-coloured feathers, that, in different lights, change to a variety of beautiful colours, much like an opal. The heads of both are small, with very little round eyes, as black as jet.

It is inconceivable how much these add to the high finishing and beauty of a rich luxurious western landscape. As soon as the sun is risen, the humming-birds, of different kinds, are seen flutering about the flowers, without ever lighting upon them. Their wings are in such rapid motion, that it is inpossible to discern their colours, except by their glittering. They are never still, but continually in motion, visiting flower after flower, and extracting its honey as if with a kiss. For this purpose they are furlushed with a forky tongue, that enters the cup of the flower, and extracts its nectared tribute. Upon this alone they subsist. The rapid motion of their wings brings out a humining sound, from whence they have their name; for whatever divides the air swiftly, must thus produce a murmur.

The nests of these birds are not less curious than the rest; they are suspended in the air, at the point of the twigs of an orange, a pomegranate, or a citron-tree; sometimes even in houses, if they find a small and convenient twig for the purpose. The female is the architect, while the male goes in quest of materials; such as cotton, fine moss, and the fibres of vegetables. Of these materials a nest is composed, of about the size of a hen's egg cut in two, admirably contrived, and warmly lined with cotton. They lay two eggs at a time, and never more, about the size of small peas, and as white as snow, with here and there a yellow speck. The male and the female sit upon the nest by turns; but the female takes to herself the greatest share. She seldom quits the nest, except a few minutes in the morning and evcring, when the dew is upon the flowers, and their honey in perfection. During this short interval, the male takes her place; for, as the egg is so small, the exposing it ever so short a time to the weather, would be apt to injure its contents, the surface exposed being so 
great in comparison to the bulk. The time of incubation continues twelve days; at the end of which the young ones appear, much about the size of a blue-bottle fly. They are at first bare; by degrees they are covered with down; and, at last, feathers succeed, but less beautiful at first than those of the old ones.

"Father Labat's companion in the mission to America, found the nest of a lummingbird, in a shed that was near the dwellinghouse, and took it in at a time when the young ones were alsout fifteen or twenty days old; he then placed them in a cage at lis chamber-window, to be amused by their sportive flutterings; but he was soon surprised to see the old ones, that came and fed their brood regularly every hour in the day. By these means they themselves soon grew so tame that they seldom quitted the chamber; but, without any constraint, came to live with their young ones. All four have frequently come to perch upon their master's hand, chirruping as if they had been at liberty abroad. He fed them with a very fine clear pastc, made of wine, biscuit, and sugar: they thrust their tongues into this paste, till they were satisfied, and then fluttered and chirruped about the room. I never beheld any thing more agreeable," continues he, "than this lovely little family that had taken possession of my companion's chamber, and that flew out and in just as they thought proper; but were ever attentive to the voice of their master, when he called them. In this manuer they lived with him for above six months; but at a time when he expected to see a new colony formed, he unfortunately forgot to tie up their cage to the ceiling at night, to preserve them from the rats, and he found they were devoured in the morning."

These birds, on the contiuent of America, continue to flutter the year round; as their food, which is the honey of flowers, never forsakes thein in those warm latitudes where they are found. But it is otherwise in the islands of the Antilles, where, when the winter season approaches, they retire, and, as some say, continue in a torpid state during the severity of that season. At Surinam and Jamaica, where they constantly have flowers, these beautiful birds are never known to disappear.

It is a doubt whether or not these birds have a continued note of singing. All travellers agree, that, beside the liumming. noise produced by their wings, they have a little interrupted chirrup; but Labat asserts, that they have a most pleasing melancholy melody in their voices, though small, and proportioned to the organs which produce it. It is very probable that, in different places, their notes are also different; and as there are some that continue torpid all the winter, there may likewise be some with agreeable voices, though the rest may in general be silent.

The Indians formerly made great usc of this pretty bird's plumage, in adorning their belts and head-dress. The children take them in the fields upon rings smeared with bird-lime: they approach the place where the birds are flying, and twirling their rings in the air, so allure them, either by the colour or the sound, that the simple little creature comes to rest upon the ring, and is scized. They are then instantly killed and gutted, and liung up in the chimncy to dry. Those who take greater care, dry them in a stove, which is not so likely to injure the plumage as the foregoing method. Their beautiful feathers were once the ornament of the lighlest rank of savage nobility: but at present they take the bird rather for the purpose of selling it as a curiosity to the Europeans, than that of ornament for themselves. All the taste for savage finery is wearing out fast, even among the Americans. They now begin to adopt, if not the dresses of Europe, at least the materials of which they are composed. The wandering warrior is far from thinking himself fine at present with his bow and his feathered crown: lis ambition reaches to higher ornaments; a gun, a blue shirt, and a blanket. 


\section{OF IIRDS OF FIAT CRANE IIIND.}

\section{$\rightarrow$ \\ CIAPTER CXII. \\ OF BIRDS OF THE CRANE KIND IN GENERAL}

TIIE progressions of nature from one elass of beings to another, are always by slow and almost imperceptible degrees. She has peopled the woods and the fields with a variery of the most beautiful birds; and, to leave no part of her extensive territories untenanted, she has stocked the waters with its feathered inhabbitants also: sle has taken the same care in providing for the wants of her auimals in this element, as she has. done with respect to those of the other ; she has used as much precaution to render water-fowl fit for swimming, as she ditl in forming land-fowl for flight ; she has defended their feathers with a natural oil, and united their toes liy a webbed membrane; by which contrivances they lave at once security and motion. But between the elasses of land-birds that shun the water, and of waterfowl that are made for swimming and living on it, she has formed a very numerous tribe of birds, that seem to partake of a middle nature; that, with divided tocs, seeningly fitted to live upon land, are at the same time furnished with appetites that chiefly attach them to the waters. These can properly be called neither land-birds nor water-fowl, as they provide all their sustenance from watery places, and yet are unqualified to seck it in those depths where it is often found in greatest plenty.

This elass of birds, of the crane kind, are to be distingnished from others rather by their appetites than their conformation. Yet even in this respect they seem to be sufficiently aiscriminated by nature: as they are to live amoing the waters, yet are incapable of swimming in them, most of them have long legs, fitted for wading in shallow waters, or long bills proper for groping in them.
Every bird of this kind, habituated to marshy plares, may be known, if not loy the length of its legs, at least by the scaly surface of them. Those who have ubserved the legs of a snipe or a woodcock, will easily perceive my meaning; and how different the surface of the skin that covers them is from that of the pigeon or the partridge. Most birds of this kind also, are bare of feathers half way up the thigh; at least, in all of them, above the knee. Their loug habits of wading in the waters, and having their legs continually in moisture, prevents the growth of feathers on those parts; so that there is a surprising difference hetween the $\mathrm{leg}$ of a crane, naked of feathers almost up to the body, and the falcon, booted alınost to the very toes.

The bill also is very distinguishable in most of this class. It is, in general, longer than that of other birds, and in some finely fluted on every side; while at the point it is possessed of extreme sensibility, and furnislied with nerves, for the better feeling their food at the bottom of marshes, where it cambot be seen. Some birds of this class are thus fitted with every convenience: they have long legs, firr wading; long neeks, for stouping; long bills, for searching ; and nervous points, for fecling. Others are not so anply provided for ; is some have loug bills, but legs of wo grent length ; and others lave long necks, lut very short legs. It is a rule which universally holds, that where the bird's legs are long, the neck is also long in proportion. It would indeed be an incuralle defect in the bird's conformation, to be lifted upon stilts above its food, without being furnished with an instrument to reach it. 
If we consider the natural power of this class, in a comparative view, they will secm rather inferior to those of every other tribe. Their nests are more simple than those of the sparrow ; and their methorls of obtaining food less ingenious than those of the falcon; the pie exceeds them in cunning; and though they have all the voraciousness of the poultry tribe, they want their fecundity. None of this kind, therefore, have been taken into man's socicty, or under his protection; they are neither caged, like the nightingale; nor kept tame, like the turkey ; but lead a life of precarious liberty, in fens and marshes, at the edges of lakes, and along the sea-shore. They all live upon fish or insects, one or two only excepted; even those that are called mudsuckers, such as the snipe and the woodcock, it is more than probable, grope the bottom of marshy places only for such insects as are deposited there by their kind, and live in a vermicular state, in pools and plashes, till they take wing, and become flying insects.

Ali this class, therefore, that are fed upon insects, their food b ing easily digestible, are good to be eaten; while those who live entirely upon fish, abounding in oil, acquire in their flesh the rancidity of their diet, and are, in general, unfit for our tables. To savages, indeed, and sailors on a long voyage, every thing that has life seems good to be eaten; and we often fint them recommending those animals as dainties, which they thenselves would spurn at after a course of goud living. Nothing is more common in their jourmals than such accounts as these $\longrightarrow$ "This day we shot a fox-pretty good eating: this lay we shot a heron-pretty good eating: and this day we killod a turtle"__ which they ras,k with the heron and the fox, as "pretty good eating." Their accounts, therefire, of the flesh of these birds, are not to be depended upon; and when they cry up the heron or the stork of other countries as luxurious food, we must always attend to the state of their appetites who give the character.

In treating of this class of birls, it will be best to observe the simplest method pussible; neither to load the memory with numerous distiuctions, nor yet confuse the imagination by a total want of arrangement. I will therefore describe some of the larger sorts scparately; as, in a history of birds, each of these demands peculiar distinction. The crame, the stork, the Balearic crane, the heron, the bittern, with some others, inay require a separate history. Sone particular tribes may next offer, that may very naturally be classed together; and as for all the smialler and least remarkable sorts, they may be grouped into one gencral description.

\section{CHAPTER CXIII.}

\section{THF CRANE.}

'THERE is something extraordinary in the different accounts we have of this bird's size and dimensions. Willoughby and Pennant make the crane from five to six feet long, from the tip to the tail. Other accounts say, that it is above five feet high; and others, that it is as tall as a man. From the nıany which I myself had seen, I own this imputed magnitude surprised me; as, from meniory I was convinced, they could be neither so long nor so tall. Indeed, a bird, the body of which is not larger than that of a turkey-hen, and acknowledged on all liands not to weigli above ten pounds, cannot easily be supposed to be almost as long as an ostrich. Brisson, however, seems to give this bird its real dinensions, when he describes it as sumething less than the brown stork, abont three feet high, and about four from the tip to the tail. Still, however, the numerous testimonies of its superior size are not to be totally rejected; and, perhaps, that from which Brissin look his dimensions, was one of the smallest of the kind.

The crune, taking its dimensions from him, is exactly three feet four inches from the tip to the tail, and four feet from the head to the toe. 
It is a tall slender bird, with a long neck and long legs. The top of the head is covered with black bristles, and the back of it is bald and red, which sufficiently distinguishes this bird from the stork, to which it is very nearly allied in size and figure. The plumage, in general, is ash-coloured; and there are two large tufts of feathers, that spring from the pinion of each wing. These bear a resemblance to hair, and are finely curled at the ends, which the bird has a power of erecting and depressing at pleasure. Gesner says, that these feathers, in his time, used to be set in gold, and worn as omaments in eaps.

Such are the dimensions of a bird, concerning which, not to mention modern times, there have been more fables propagated than of any other. It is a bird with which all the ancient writers are familiar; and, in describing it, they have not failed to mix imagination with history. From the policy of the cranes, they say, we are to look for an idea of the most perfect republic amongst ourselves; from their tenderuess to their decrepit parents, which they take care to nourish, to cherish, and support when flying, we are to learn lessons of filial piety ; but particularly from their conduct in fighting with the pigmies of Ethiopia. we are to receive our maxjms in the art of war. In early times, the bistory of nature fell to the lot of poets only, and eertainly none could describe it so well; but it is a part of their province to embellish also; and when this agreeable science was claimed by a more sober class of people, they were obliged to take the accounts of things as they found them; and, in the present instance, fable ran down blended with truth to posterity.

In these aceounts, therefore, there is some foundation of truth; yet much more has been added by fancy. The erane is certainly a very social bird, and they are seldom seen alone. Their usual method of flying or sitting is in flocks of fifty or sixty together; and while a part feed, the rest stand like centinels upon duty. The fable of their supporting their aged parents, may have arisen from their strict connubial affection; and as for their fighting with the pigmies, it may not be improbable but that they have boldly withstood the invasions of monkeys coming to rob their nests; for, in this ease, as the crane lives upon vegetables, it is not probable that it would be the first aggressor.

However this be, the crane is a wandering, soeiable bird, that, for the most part, subsists upon vegetables; and is known in every country of Europe, except our own. There is no part of the world, says Bellonius, where the ficlds are eultivated, that the crane does not come in with the husbandman for a share in the harvest. As they are birds of passage, they are seen to depart, and return regularly at those seasons when their provision invites or repels them. They generally leave Europe about the latter end of autumn, and return in the beginning of summer. In the inland parts of the continent, they are seen erossing the conntry in floeks of fifty or a hundred, naking from the northern regions towards the soutl. In these migrations, however, they are not so resolutely bent upon going forward, but that if a field of corn offers in their way, they will stop a while to regale upon it: on such oceasions they do incredible damage, chiefly in the night; and the husbandman, who lays down in joyful expectation, rises in the morning to see his fields laid entirely waste by an enemy, whose march is too swift for his vengeance to overtake.

Our own country is free from their visits; not but that they were formerly known in this island, and held in great estimation for the delicacy of their flesh; there was even a penalty upon such as destroyed their eggs; but, at present, they never go so far out of their way. Cultivation and populousness go hand in hand; and though our fields may offer them a greater plenty, yet it is so guarded that the birds find the venture greater than the enjoyment; and probably we are much better off by their absence than their company. Whatever their flesh might once have been, when, as Plutarch tells us, eranes were blinded and kept in coops, to be fattened for the tables of the great in Rome: or, as they were brought up, stuffed with mint and rue, to the tables of our nobles at home; at present, they are considered all over Europe as wretched eating. 'The flesh is fibrous and dry, requiring much preparation to make it 
palatable; and even after every art, it is fit only for the stomachs of strong and labouring people.

The cold Aretic regionseems to be this bird's fuvourite abode. They come down into the more southeru parts of Europe, rather as visitants than inhahitants: yet it is not well known in what manner they portion out their time, to the different parts of the world. The migrations of the fieldfare or thrnsh, are obvious and well known; they go northward or southward, in one simple track; when their food fails them here, they have but one region to go to. But it is otherwise with the crane; he changes place, like a wanderer: he spends the autunn in Europe; he then flies off, probably to some more southern climate, to enjoy a part of the winter; returns to Europe in the spring; crosses up to the north in summer; visits those lakes that are never dry; and then comes down again, to make depredations upon our cultivated grounds, in autumn. Thus, Gesner assures us, that the cranes usually begin to quit Germany, from about the eleventh of September to the seventeenth of October; from thence they are seen flying southward by thousands; and Redi tells us, they arrive in Tuscany a short time after. There they tear up the fields, newly sown, for the grain just committed to the ground, and do great mischief. It is to be supposed that, in the severity of winter, they go southward, still nearer the line. They again appear in the fields of Pisa, regularly about the twentieth of February, to anticipate the spring.

In these journeys, it is amazing to conceive the heights to which they ascend when they fly. Their note is the loudest of all other birds; and that is often heard in the clouds, when the bird itself is entirely unseen. As it is light for its size, and spreads a large expanse of wing, it is capable of floating at the greatest height, where the air is lightest; and as it secures its safety, and is entirely out of the reach of man, it flies in tracts which would be too fatiguing for any other birds to move forward in.

In these aerial journeys, though unseen themselves, they have the distinctest vision of every object below. They govern and direct their flight by their cries; and exhort each other to proceed or to descend, when a fit opportunity offers for depredation. Their voice, as was ohserved, is the loudest of all the feathered tribe; and its peculiar clangor arises from the very extraordinary length and contortion of the windpipe. In quadrupeds, the windpipe is short, and the glottis, or cartilages that form the voice, are at that end of it which is next the mouth; in water-fowl, the windpipe is longer, but the cartilages that form the voice are at the other end, which lies down in their belly. By this means they have much louder vorces, in proportion to their size, than any other animal whatever; for the note when formed below, is reverberated through all the rings of the windpipe, till it reaches the air. But the voice of the duck or the goose, is nothing to be compared to that of the cranc, whose windpipe is not only made in the same manner with theirs, but is above twenty times as long. Nature seems to have bestowed much pains in lengthening out this organ. From the outside, it enters through the flesh into the breast-bone, which hath a great cavity within to receive it. There being thrice reflected, it goes out again at the same hole, and so turns down to the lungs, and thus enters the body a second time. The loud clangorous sound which the bird is thus enabled to produce, is, when near, almost deafening: bowever, it is particularly serviceable to the animal itself, either during its migrations, or its stay; by it the flock is encouraged in their journeys; and if, while they are feeding, which is usually performed in profound silence, they are invaded on any side, the bird that first perceives the danger is sure to sound the alarm, and all are speedily upon the wing.

As they rise but heavily, they are very sliy. birds, and seldom let the fowler approach them. Their depredations are usually made in the darkest nights; at which time they enter a field of corn, and trample it down, as if it had been crossed over by a regiment of soldiers. On other occasions, they choose some extensive solitary marsh, where they range themselves all day, as they were in deliheration; and not having that grain which is most to their appetites, wade the marshes for insects and other food, which they can procure with less danger. 
Corn is their favourite food; but there is scarcely any other that comes amiss to them. Redi, who opened several, found the stomach of one full of the herb called dandelion; that of another was filled with beans; a third had a great quantity of elover in its stomach; while that of two others was filled with earthworms and beetles; in some he found lizards and sea-fish; in others snails, grass, and pebbles, swallowed perhaps for medicinal purposes. It seems, therefore, that these birds are easily supplied; and that they are noxious to corn-fields but on some particular occasions.

In general it is a peaceful bird, both in its own society, and with respect to those of the forest. Though so large in appearance, a little falcon pursues, and often disables it. The method is, with those who are fond of hawking, to fly several lowks logether against it; which the crane endeavours to avoid, by flying up perpendicularly, till the air becomes too thin to support it any higher. The hawk, however, still bears it company; and though less fitted for floating in so thin a medium, yet, possessed of greater rapidity, it still gains the ascendancy. They botl often rise ont of sight; but soon the spectator, who keeps his eye fixed above, perceives then, like two specks, beginning to appear: they gather on his eye for a little space, and shortly after come tumbling perpend icularly together, with great animosity on the side of the hawk, and a loud screaming on that of the cranc. Thus driven to extremity, and unable to fly, the poor animal throws itself upon its back, and, in that sitnation, makes a most desperate defence, till the sportsman coming up, generally puts an end to the contest with its life.

It was once the barbarous custom to breed up cranes to be thus baited; and young ones were taken from the nest, to be trained up for this cruel diversion. It is an animal easily tamed; and, if we can believe Alburtus Magvo. $47 \& 48$. nus, has a particular affection for man. This quality, however, was not sufficient to guard it from being made the victim of his fierce amusements. The female, which is easily distinguished from the male, by not being bald behind as he is, never lays above two eggs at a time; being like those of a goose, but of a bluish colour. The young ones are soon fit to fly, and then the parents forsake them to shift for themselves; but, before this time, they are led forth to the places where their food is most easily found. Though yet unfledged, they run with such swiftness that a man cannot easily overtake them. We are told, that as they grow old, their plumage becomes darker; and, as a proof of their longevity, Aldrovandus assures us, that a friend of his kept one tame for above forty years.

Whatever may have been the disposition of the great, the vulgar of every country, to this day, bear the crane a compassionate regard. It is possible the ancient prejudices in its favour, which once having been planted are eradicated but slowly, may still continue to operate. In some countries, it is considered as an heinous offence to kill a crane; and though the legislator declines to punish, yet the people do not fail to resent the injury. The crane, they, in some measure, consider as the prophet of the season: upon its approach or delay they regulate the periods of their rural economy. If their favourite bird comes carly in the season, they expect a plentiful summer; if he is slow in his visits, they then prepare for an unfavourable spring. Whatever wisdom there may be in despising the prejndices of the vulgar, there is but little in condemning them. They have generally had their origin in good motives; and it should never be our endeavours to suppress any tender emotions of friendship or pity, in those hard breasts that are, in general, unsusceptible of either.

$4 \mathrm{~L}$ 


\title{
CHAP'TER CXIV.
}

\author{
THE STORK.
}

IF we regard the Stork externally only, we shall be very apt to confound it with the crane. It is of the same size; it has the same formation as to the bill, neck, legs, and body, except that it is something more corpulent. Its differences are but very slight; such as the colour, which, in the crane, is ash and black, but in the stork is white and brown. The nails of the toes of the stark also are very peculiar; not being clawed like those of other birds, but flat like the nails of a man.

These, however, are but very slight differences; and its true distinctions are to be taken rather from its manners than its form. The crane has a loud piercing voice; the stork is silent, and produces no other noise than the clacking of its under-chap against the upper: the crane has a strange convolution of the wind-pipe through the breast-bone; the stork's is formed in the usual manner: the crane feeds mostly upon vegetables and grain; the stork preys entirely upon frogs, fishes, birds, and serpents: the crane avoids towns and populous places; the stork lives always in or near them: the crane lays but two eggs; and the stork generally four. These are distinctions fully sufficient to mark the species, notwithstanding the similitude of their form.

Storks are birds of passage, like the former; but is is hard to say whence they come or whither they go. IWhen they withdraw from Europe, they all assemble on a particular day, and never leave one of their company behind them. They take their flight in the night; which is the reason the way they go

- Stor]:s take their departure from Europe in the autumn, and pass into Egypt and the marslses of Barbary : there they enjoy a second summer, and there they pair, lay again, and bring up a sccond brood. Mrs. Starke, in her Letters on Italy, mentions a singutar instance of the sagacity of these birds. " $\Lambda$ wild stork was brought by a farmer, in the neighbourlood of Ilamburg, into his poultry-yard, to be the companion of a tane one lie had long has never been observed. They generally return into Europe in the middle of March, and make their nests on the tops of chimneys and houses, as well as of high trees. The females lay from two to four eggs, of the size and colour of those of geese; and the male and female sit upon them by turns. They are a month in hatching; and when their young are excluded, they are particularly solicitous for their safety. ${ }^{\mathrm{a}}$

As the food of these birds consists in a great measure of frogs and serpents, it is not to be wondered at that different nations have paid them a particular veneration. The Dutch are very solicitous for the preservation of the stork, in every part of their republic. This bird seems to have taken refuge among their towns; and builds on the tops of their louses without any molestation. There it is seen resting familiarly in the streets, and protected as well by the laws as the prejudices of the people. They have even got an opinion that it will only live in a republic; and that story of its filial piety, first falsely propagated of the crane, has in part been ascribed to the stork. But it is not in republics alone that the stork is seen to reside, as there are few towns on the continent, in low marshy situations, but have the stork as an inmate among them; as well the despotic princes of Germany, as the little republics of Italy.

The stork seems a general farourite even among the moderns; but with the ancient Egyptians their regard was carried even to adoration. This enlightened people, who worshipped the Deity in his creatures, paid

kept there: but the tame stork disliking a rival, fell upon the poor stranger, and beat him so unmercifully, that he was compelled to take wing, and cscaped with difficulty. About four months afterwards, however, he returned to the poultry-yard, recovered of his wounds, and attended by three other storks; who no sooner alighted, than they all together fell upon the tame stork, and killed him. 
divine honours to the ibis, as is universally knowu. It has been usually supposed that the ancient ibis is the same with that which goes at present by the same name; a bird of the stork kind, of about the size of a curlew, all over black, with a bill very thick in the beginning, but ending in a point, for the better seizing its prey, which is caterpillars, locusts, and serpents. But however useful the modern ibis may be in ridding Egypt, where it resides, of the vermin and venomous animals that infest it; yet it is much doubted whether this be the same ibis to which the ancients paid their adoration. Maillet, the French consul at Cairo, observes, that it is very hard to determine what bird the ancient ibis certainly was, because therc are cranes, storks, hawks, kites, and falcons, that are all equally enemies to serpents, and devour a vast number. He farther adds, that in the month of
May, when the winds begin to blow from the internal parts of Africa, there are several sorts of birds that corne down from Upper Egypt, from whence they are driven by the rains, in search of a better habitation, and that it is then they do this country such signal services. Nor does the figure of this bird, hieroglyphically represented on their pillars, mark it sufficiently to make the distinction. Besides, the modern ibis is not peculiar to Egypt, as it is to be seen but at certain seasons of the year; whereas we are informed by Phiny, that this bird was scen no where else. It is thought, therefore, that the true ibis is a bird of the vulture kind, described above, and called by some the capon of Pharaoh, which not only is a devourer of serpents, but will follow the caravans that go to Mecea, to feed upon the offal of the animals that are killed on the journey.

\section{CHAPTER CXV.}

\section{OF THE BALEARIC AND OTHER FOREIGN CRANES.}

HAVING ended the last chapter with doubts concerning the ibis, we shall begin this with doubts concerning the Balearic Crane. Pliny has described a bird of the crane kind with a topping resembling that of the green woodpecker. This bird for a long time continued unknown, till we became acquainted with the birds of tropical climates, when one of the crane kind with a topping was brought into Europe, and described by Aldrovandus as Pliny's Balearic Crane. Hence these birds, which have since been brought from Africa and the East in numbers, have received the name of Balearic Cranes, but without any just foundation. The real Balearic Crane of Pliny seems to be the lesser ash-coloured heron, with a topping of narrow white fea-

a The true ibis of the ancients differs from the stork, in having a long, awl-shaped, slightly curved bill, without the furrow from the nostrils observable in the stork: the face is likewise destitute of feathers; and it has a naked jugular pouch. The body is of a whitish rufous colour, with black quill-feathers; the face is red, and the bill pale thers; or perhaps the egret, with two long feathers that fall back from the sides of the head. The bird that we are about to describe under the name of the Balearic Crane, was unknown to the ancients, and the heron or egret ought to be reinstated in their just title to that name.

When we see a very extraordinary animal, we are naturally led to suppose that there must be something also remarkable in its history, to correspond with the singularity of its figure. But it often happens that history fails on those occasions where we most desire information. In the present instance, in particular, no bird presents to the eye a more whimsical figure than this, which we must be content to call the Balearic Creme. It is pretty

yellow. It inhalits, in vast flocks, the lower parts of Eypt, which, after the inundation of the Nile, is infested with swarms of reptiles and noxious insects: hese it destroys with great expedition, and is for this reason held sacred by the Egyptians. It is nearly forty incles long, and rests in an erect posture. 
nearly of the shape and size of the ordinary crane, with long legs and a long neck, like others of the kind; but the bill is shorter, and the colour of the feathers of a dark greenish gray. The head and throat form the most striking part of this bird's figure. On the lead is seen, standing up, a thick round crest, made of bristles, spreading every wray, and resembling rays standing out in different directions. The longest of these rays are about three inches and a half, and they are all topped with a kind of black tassels, which give them a beautiful appearance. The sides of the head and cheeks are bare, whitish, and edged with red; while underneath the throat hangs a kind of bag or wattle, like that of a cock, but not divided into two. To give this odd composition a higher finishing, the eye is large and staring; the pupil black and big. surrounded with a gold-coloured iris, that completes the bird's very singular appearance.

From such a peculiar figure, we might be led to wish for a minute history of its manners; but of these we can give but slight information. This bird comes from the coast of Africa, and the Cape de Verd Islands. As it runs, it stretches out its wings, and goes very swiftly, otherwise its usual motion is very slow. In their domestic state, they walk very deliberately among other poultry, and suffer - themselves to be approached (at least it was so with that I saw) by every spectator. They never roost in houses; but about night, when they are disposed to go to rest, they search out some high wall, on which they perch in the manner of a peacock. Indeed, they so much resemble that bird in manners and disposition, that some have described them by the name of the sca peacock: and Ray has been inclined to rank them in the same family. But though their voice and roosting be similar, their food, which is entirely upon greens, vegetables, and barley, seems to make some difference.

In this chapter, of foreign birds of the crane kiud, it will 'se proper to mention the Jabiru and the Jabiru Guacu, both natives of Brasil. of these great birds of the crane kind we know but little, except the general outline of their figure, and the enormous bills which we often see prescrved in the cabinets of the curious. The bill of the latter is red, and thir- teen inches long; the bill of the former is black, and is found to be eleven. Neither of them, however, are of a size proportioned to their immoderate length of bill. The jabiru gnacu is not above the size of a common stork, while the jabiru with the smallest bill exceeds the size of a swan. They are both covered with white feathers, except the head and neck, that are naked; and their principal difference is in the size of the body and the make of the bill; the lower chap of the jabiru guacu being broad, and bending upwards.

A bird still more extraordinary may be added to this class, called the anhima, and, like the two former, a native of Brasil. This is a water-fowl of the rapacious kind, and bigger than a swan. 'The head, which is small for the size of the body, bears a black bill, which is not above two inches long: but what distinguishes it in particular, is a horn growing from the forehead as long as the bill, and bending forward like that of the fabulous unicorn of the ancients. This horn is not much thicker than a crow-quill, as round as if it were turned in a lathe, and of an ivory colour. But this is not the only instrument of battle this formidable bird carries; it seems to be armed at all points; for at the fore-part of each wing, at the second joint, spring two straight triangular spurs, about as thick as one's little finger: the foremost of these goads or spurs is above an inch long; the hinder is shorter, and both of a dusky colour. The claws also are long and sharp; the colour is black and white; and they cry terriby loud, sounding something like $V y h o o, V y h o o$. They are never found alone, but always in pairs: the cock and hen prowl together; and their fidelity is said to be such, that when one dies, the other never departs from the carcass, but dies with its companion. It makes its nest of clay, near the bodies of trees, upon the ground, of the shape of an oven.

One bird more may be subjoined to this class, not for the oddity of its figure, but the peculiarity of its manners. It is vulgarly called by our sailors the buffon bird, and by the French the demoiselle or lady. 'The same qualities have procured it these different appellations from two nations, who, on more occasions than this, look upon the same objects 
in very different lights. The peculiar gestures and contortions of this bird, the proper name of which is the Numidian Crane, are extreinely singular; and the French, who are skilled in the arts of elcgant gesticulation, consider all its motions as lady-like and graceful.

Our English sailors, however, who have not entered so decply into the dancing art, think, that while thus in motion, the bird cuts but a very ridiculous figure. It stoops, rises, lifts one wing, then another, turns round, sails forward, then back again; all which highly diverts our seamen; not imagining, perhaps, that all these contortions are but the awk- ward expression, not of the poor animal's pleasures, but its fears.

It is a very scarce bird; the plumage is of a leaden gray; but it is distinguished by fine white feathers, consisting of long fibres, which fall from the back of the head, about lour inches long; while the fore-part of the neck is adorned with black feather's, composed of very finc, soft, and long fibres, that hang down upon the stomach, and give the bird a very graceful appearance. The ancients have described a buffoon hird; but there are many reasons to believe that theirs is not the Numidian cranc. It comes from that country from whence it has taken its name.

\section{CHAPTER CXVI.}

\section{OF THE HERON, AND ITS VARIETIES:}

BIRDS of the Crane, the Stork, and the Heron kind, bear a very strong affinity to each other: and their differences are not easily discernible. As for the crane and the stork, they differ rather in their nature and internal conformation, than in their external figure; but still they may be known asunder, as well by their colour as by the stork's claws, which are very peculiar, and more resembling a man's nails than the claws of a bird. The heron may be distinguished from both, as well by its size, which is inuch less, as by its bill, which in proportion is much longer; but particularly by the middle claw on each foot, which is toothed like a saw, for the better seizing and holding its slippery prey. Should other marks fail, however, there is an anatomical distinction, in which herons differ from all other birds; which is, that they have but one crecum, and all other birds have two.

Of this tribe, Brisson has enumerated not less than forty-seven sorts, all differing in their size, figure, and plumage; and with talents adapted to their place of residence, or

a Cranes are distinguished by having the head bald; Storks have the orhits round the eyes naked; and Herons have the mildle claw serrated internally. their peculiar pursuits. But, how various soever the heron kind may bc in their colours or their bills, they all seem possessed of the same manners, and have but one character of cowardice, rapacity, and indolence, yet insatiable liunger. Other birds are found to grow fat by an abundant supply of food; but these, though excessively destructive and voracious, are ever found to have lean and carrion bodies, as if not even plenty were sufficient for their support.

The common heron is remarkably light, in proportion to its bulk, scarcely weighing three pounds and a half, yet it expands a breadth of wing which is five feet from tip to tip. Its bill is very long, being five inches from the point to the base; its claws are long, sharp, and the middlemost toothed like a saw. Yet, thus armed as it appears for war, it is indolent and cowardly, and even flies at the approach of a sparrow-hawk. It was once the ainusement of the great to pursuc this timorous creature with the filcon: and heronhawking was so favourite a diversion among our ancestors, that laws were enacted for the preservation of the species; and the person who destroyed their eggs was liable to a penalty of twenty shillings for each offence. 
At present, liowever, the defects of the illjudged policy of our ancestors, is felt by their posterity; for, as the amusement of hawking has given place to the more useful method of stocking fish-ponds, the heron is now become a most formidable enemy. Of all other birds, this commits the greatest devastation in fresh waters; and there is scarce a fish, though never so large, that he will not strike at and wound, though unable to carry it away. But the smaller fry are his clief subsistence; these, pursued by their larger fellows of the deep, are obliged to take refuge in shallow waters, where they find the heron a still more formidable enemy. His method is to wade as far as he can go into the water, and there patiently wait the approach of his prey, which, when it comes within sight, he darts upon with inevitable aim. In this manner he is found to destroy more in a week than an otter in three montlis. "I have scen a heron," says Willoughby, "that had been shot, that had seventeen carps in his belly at once, which he will digest in six or seven hours, and then to fishing again. I have seen a carp," continues he, "taken out of a heron's belly, vine inches and a half long. Several gentlemen who kept tame herons, to try what quantity one of them would eat in a day, have put several smaller roach and dace in a tub; and they have found him eat fifty in a day, one day with another. In this manner a single heron will destroy fifteen thousand carp in half a year.

So great are the digestive powers of this fresh-water tyrant, and so detrimental to those who stock ponds with fish. In general, he is seen taking his gloomy stand by the lake's side, as if meditating mischief, motionless, and gorged with plunder. His usual attitude on this occasion is to sink his long neck between his shoulder's, and keep his head turned on one side, as if eyeing the pool more intently. When the call of hunger returns. the toil of an hour or two is generally sufficient to fill his capacious stomach; and he retires long hefore night to his retreat in the woods. Farly in the moruing, however, lie is seen assiduous at his usual occupation.

But, though in seasons of fine weather the heron can always find a plentiful supply; in cold or stormy seasons, his prey is no longer within reach : the fish that before came into the shallow water, now keep in the deep; as they find it to be the warmest situation. Frogs and lizards also seldom renture from their lurking places; and the heron is obliged to support himself upon his long habits of patience, and even to take up with the weeds that grow upon the water. At those times he contracts a consumptive disposition, which succeeding plenty is not able to remove; so that the meagre glutton spends his time between want and riot, and feels alternately the extremes of fanine and excess. Hence, notwithstanding the care with which lie takes his prey, and the amazing quantity he devours, the heron is always lean and emaciated; and though his crop be usually found full, yet his flesh is scarcely sufficient to cover the bones.

The heron usually takes his prey by wading into the water; yet it must not be supposed that he does not also take it upon the wing. In fact, much of his fishing is performed in this manner; but he never hovers over deep waters, as there his prey is enabled to escape him by sinking to the bottom. In shallow places he darts with more certainty; for though the fish at sight of its enemy instantly descends, yet the heron, with his long bill and legs, instantly pins it to the bottom, and thus seizes it securely. In this manner, after having been seen with his long neck for above a minute under water, he rises upon the wing, with a trout or an eel struggling in his bill to get free. The greedy bird, however, llies to the shore, scarcely gives it time to expire, but swallows it whole, and then returns to fishing as before.

As this bird does incredible mischief to ponds newly stocked, Willoughby has given a receipt for taking him.- "Having found his haunt, get three or four small roach or dace, and having provided a strong hook with a wire to it, this is drawn just within-side the skin of the fish, beginuing without-side the gills, and running it to the tail, by which the fish will not be killed, but continue for five or six days alive. Then having a strong line made of silk and wire, about two yards and a balf long, it is tied to a stone at one end, the fish with the Look being suffered to swim about at the other. This being properly dis- 
posed in shallow water, the heron will seize upos the fisis to its own destruetion. From this method we may learlu, that the fish must be alive, otherwise the heron will not cuch them, aud that this bird, as well as all those that feed upon fish, must be its own caterer; for they will not prey upon such as die naturally, or are killed by others before them."

Though this bird lives chiefly among pools and nuarshes, yet its nest is built on the tops of the highest trees, and sometimes on cliffs hanging over the sea. They are never in flocks when they fish, committing their depredations in solitude and silence; but in making their nests they love each other's society; and they are seen, like rooks, building in company with flocks of their kind. Their nests are made of sticks, and lined with wool; and the female lays four large eggs of a pale green colour. The observable indolence of their nature, however, is not less scen in their nestling than in their habits of depredation. Nothing is more certain, and I have seen it a hundred times, than that they will not be at the trouble of building a nest, when they can get one made by the rook, or deserted by the owl, already provided for them. This they usually enlarge and line within, driving off the original possessors, should they happen to renew their fruitless claims.

The French seem to have availed themselves of the indolence of this bird in making its nest; and they actually provide a place with materials fitted for their nestling, which they call heronries. The heron, which with us is totally unfit for the table, is more sought for in France, where the flesh of the young ones is in particular estimation. To obtain this, the natives raise up high sheds along some fishy stream; and furnishing them with materials for the herons to nestle with, these birds build and breed there in great abundance. As soon as the young ones are supposed to be fit, the owner of the heronry comes, as we do into a pigeon-house, and carries off such as are proper for cating; and these arc sold for a very good price to the neighbouring gentry. "These are a delicacy which," as my author says, "the French are very fond of, but which strangers have not yet been taught to relish as they ought." Nevertheless, it was formerly much esteemed as food in England, and made a faromrite dish at great tables. It was then said that the tlesh of a heron was a dish for a king; at present nothing about the house will touch it but a cat.

With us, thercfure, as the heron, both old and young, is thought detestable eating, we seldom trouble these animals in their heights, which are for the most part sufficiently inaccessible. Their nests are often found in great numbers in the middle of large forests, and in some groves nearer home, where the owners have a predilection for the bird, and do not choose to drive it from its accustomed habitations. It is certain that by their cries, their expansive wings, their bulk, and wavy motion, they add no small solemnity to the forest, and give a pleasing variety to a finished improvement.

When the young are excluded, as they are numerous, voracious, and importunate, the old ones are for ever upon the wing to provide them with abundance. The quantity of fish they take upon this occasion is amazing, and their size is not less to be wondered at. I remember a heron's nest that was built near a school-house ; the boys, with their usual appetite for mischief, climbed up, took down the young ones, scwed up their vents, and laid them in the nest as before. The pain the poor little animals felt from the operation increased their cries; and this lut served to increase the diligence of the old ones in enlarging their supply. Thus they heaped the nest with various solts of fish, and the best of their kind; and as their young screamed, they flew off for more. The boys gathered up the fish, which the young ones were incapable of eating, $t i$ I the old ones at last quitted their nest; and gave up their brood, whose appetites they found it impossible to satisfy.

The heron is said to be a very long-lived bird; by Mr. Keyslel's account, it may exceed sixty years; and by a recent instance of one that was taken in Holland, by a hawk belonging to the Stadtholder, its longevity is again confirmed, the bird having a silver plate fastened to one leg, with an inscription, importing that it had been struck by the elector of Cologne's hawlss thirty-five ycars be fore. 


\section{CHAPTER CXVII.}

\section{OF THE BITTERN, OR MIRE-DRUM.}

THOSE who have walked in an evening by the sedgy sides of unfrequented rivers, must remember a variety of notes from different water-fowl: the loud scream of the wild-goose, the croaking of the mallard, the whining of the lapwing, and the tremulous neigling of the jack-snipe. But of all those sounds, there is none so dismally hollow as the booming of the bittern. It is impossible for $w$ ords to give those who have not heard this evening-call an adequate idea of its solemnity. It is like the interrupted bellowing of a bull, but hollower, ant louder, and is heard at a mile's distance, as if issuing from some formidable being that resided at the bottom of the waters.

The bird, however, that produces this terrifying sound, is not so big as a heron, with a weaker bill, not above four inches long. It differs from the heron chiefly in its colour, which is in general of a paleish yellow, spotted and barred with black. Its wind-pipe is fitted to produce the sound for which it is remarkable; the lower part of it dividing into the lungs, is supplied with a thin loose membrane, that can be filled with a large body of air, and exploded at pleasure. These bellowing explosions are chiefly lieard from the beginning of spring to the end of autumn; and, however awful they may seem to us, are the calls to courtship, or of connubial felicity.

From the loudness and solemnity of the note, many have been led to suppose, that the bird made use of external instruments to produce it, and that so sinall a body could never eject such a quantity of tone. The comınon people are of upinion, that it thrusts its bill into a reed, that serves as a pipe for swelling the note above its natural pitch; while others, and in this number we find Thomson the poet, imagine that the bittern puts its head under water, and then violently blowing produces its boomings. The fact is, that the bird is sufficiently provided by nature for this call; and it is often heard where there are neither reeds nor waters to assist its sonorous invitations.
It hides in the sedges by day, and begins its call in the evening, booming six or eight times, and then discontinuing for ten or twenty minutes, to renew the same sound. This is a call it never gives but when undisturbed, and at liberty. When its retreats amoung the sedges are invaded, when it dreads or expects the approach of an eneny, it is then perficuly silent. This call it has never been heard to utter when taken or brought up in domestic eaptivity; it continues under the control of man a inute forlorn bird, equally incapable of attachment or instruction. But though its boomings are always perforned in solitude, it has a scream which is generally heard upon the seizing its prey, and which is sometimes extorted by fear.

This bird, though of the heron kind, is yet neither so destructive nor so voracious. It is a retired timorous animal, concealing itself in the midst of reeds and marshy places, and living upon trogs, insects, and vegetables; and though so nearly resembling the heron in figure, yet differing much in manners and appetites. As the heron builds on the tops of the higliest trees, the bittern lays is nest in a sedgy margin, or amidst a tuft of rushes. The heron builds with sticks and wool; the bittern composes its simpler habitation of sedges, the leaves of water-plants, and dry rushes. The heron lays four eggs; the bittern gemerally seven or cight, of an ash-green colour. The heron feeds its young for niany days; the bittern in three days leads its little ones to their fond. In short, the heron is lean and cadaverous, subsisting ehiefly upon aninal food; the littern is lilump and fleslyy, as in feeds upon vegetables, when more nourishing food is ivanting.

It cannot he, therefore, from its voracious appetites, but its hollow boom, that the bittern is held in such detestation by the vulgar. I reineinber, in the place where I was a boy, with what terror this bird's note affected the whole village; they considered it as the pre- 
sage of some sad event ; and generally found or mate one to succeed it. I do not speak ludicrously; but if any person in the neighbourhorsl died, they supposed it could not be otherwise, for the night-raven had foretold it; but if no body happened to die, the death of a cow or a sheep gave completion to the prophecy.

Whatever terror it may inspire among the simple, its flesh is greatly esteemed among the luxurious. For this reason, it is as eagerly sought after by the fowler, as it is shunned by the peasant; and, as it is a heavy-rising slowwinged bird, it does not often escape him. Indeed, it seldom rises but when almost trod upon, and seems to seek protection rather from concealment than flight. At the latter end of autumn, however, in the evening, its wonted indolence appears to forsake it. It is then seen rising in a spiral ascent, till it is quite lost from the view, making at the same time a singular noise very different from its former boomings. Thus the same animal is often seen to assume different desires; and while the Latins have given the bittern the name of the star-reaching bird, (or the stellaris,) the Greeks, taking its character from its more constant habits, have given it the title of the oxos, or the lazy bird.

\section{CHAP'TER CXVIII.}

\section{OF THE SPOONBILL, OR SHOVELER.}

AS we proceed in our description of the crane kind, birds of peculiar forms offer, not entirely like the crane, and yet not so far different as to rank more properly with any other class. Where the long neck and stilt-like legs of the crane are found, they make too striking a resemblance not to admit such birds of the number; and though the bill, or even the toes, should entirely differ, yet the outlines of the figure, and the natural habits and dispositions, being the same, these are sufficient to mark their place in the general groupe of nature.

The Spoonbill is one of those birds which differs a good deal from the crane, yet approaches this class more than any other. The body is more bulky for its height, and the bill is very differently formed from that of any other bird whatever. Yet still it is a comparatively tall bird; it feeds among waters; its toes are divided; and it seems to possess the natural dispositions of the crane. The European spoonbill is of about the bulk of a crane; but as the one is above four feet high, the other is not more than three feet three inches. The common colour of those of Europe is a dirty white; but those of America are of a beautiful rose colour, or a delightful crimson. Beauty of plumage seems to be the prerogative of all the birds of that continent; and we here see the most splendid tints bestowed on a bird, mo. $47 \& 48$. whose figure is sufficient to destroy the effects of its colouring; for its bill is so oddly fashioned, and its eyes so stupidly staring, that its fine feathers only tend to add splendour to deformity. The bill, which in this bird is so very particular, is about seven inches long, and running out broad at the end, as its name justly serves to denote, it is there about an inch and a half wide. This strangely fashioned instrument in some is black; in others of a light gray; and in those of America, it is of a red colour, like the rest of the body. All round the upper chap there runs a kind of rin, with which it covers that beneath; and as for the rest, its cheeks and its throat are without feathers, and covered with a black skin.

A bird so oddly fashioned might be expected to possess some very peculiar appetites; but the spoonbill scems to lead a life entirely resembling all those of the crane kind; and nature, when she made the bill of this bird so very broad, seems rather to have sported with its form, than to aim at any final cause for which to adapt it. In fact, it is but a poor philosophy to ascribe every capricious variety in nature to some salutary purpose: in such solutions we only inipose upon each other, and often wilfully contradict our own belief. There must be imperfections in every being, as well as capacities of enjoyment. Between both, $4 \mathrm{M}$ 
the animal leads a life of moderate felicity; in part making use of its many natural advantages, and in part necessarily conforming to the imperfections of its figure.

The shoveler chiefly feeds upon frogs, toads, and serpents; of which, particularly at the Cape of Good Hope, they destroy great numbers. 'The inhabitants of that country hold them in as much esteem as the ancient Egyptians did their bird ibis: the shoveler runs tamely about their houses; and they are content with its society, as an useful, though a hornely, conıpanion. They are never killed; and, indeed, they are good for llothing when they are dead, for the flesh is unfit to be eaten.

This bird breeds, in Europe, in company with the heron, in high trees; and in a nest formed of the same materials. Willoughby tells us, that in a certain grove, at a village called Seven Huys, near Leyden, they build and breed yearly in great numbers. In this grove, also, the heron, the bittern, the cormorant, and the shag, have taken up their residence, and annually bring forth their young logether. Here the crane kind secm to liave formed theil general rendezvous; and, as the inhabitants say, every sort of bird has its several quarter, where none but their own tribe are permitted to reside. Of this grove the peasants of the country make good profit. When the young ones are ripe, those that farm the grove, with a hook at the end of a long pole, catch hold of the loough on which the nest is built, and shake out the young ones; but sometimes the nest and all tumble down together.

The shoveler lays from three to five eggs, white, and powdered with a few sanguinc or pale spots. We sometimes see, in the cabinets of the curious, the bills of American shovelers, twice as big and as long as those of the common kind among us; but these birds have not yet made their way into Europe.

\section{CHAPTER CXIX.}

\section{THE FLAMINGO.}

THE Flamingo has the justest right to be placed among cranes; and though it happens to be web-footed, like birds of the goose kind, yet its height, figure, and appetites, entirely remove it from that groveling class of animals. With a longer neck and legs than any other of the crane kind, it seeks its food by wacling among waters, and only differs from all of this tribe in the inanner of seizing its prey; for as the heron makes use of its claws, the flamingo uses only its bill, which is strong and thick for the purpose, the claws being useless, as they are fecble, and weblued like those of water-fowl.

The flamingo is the most remarkable of all the crane kind, the tallest, bulkiest, and the most beautiful. The body, which is of a beautiful scarlet, is no bigger than that of a swan; but its legs and neck are of such an cxtraordinary length, that, when it stands crect, it is six feet six inches high. Its wings, extended, are five feet six inclies from tip to tip ; and it is four feet eight inches from tip to tail. The head is round and small, with a large bill, seven inches long, partly red, partly black, and crooked like a bow. The legs and thighs, which are not much thicker than a man's firger, are about two feet eight inches high; and its neck near tluree feet long. The feet are not furnished with sharp claws, as in others of the crane kind; but feeble, and united by membranes, as in those of the goose. Of what use these niembranes are does not appear, as the bird is never seen swimming, its legs and thighs being sufficient for bearing it into those depths where it seeks for prey.

This extraordinary birct is now chiefly found in America; but it ri as once known on all the coasts of Europe. Its hemuty, its size, and the peculiar delicacy of its flesh, have been such temptations to destroy or take it, that it has long since deserted the shores frequenterl by man, and taken refuge in countries that are as yet but thinly peopled. In those 
desert regions, the flamingos live in a state of society, and under a better polity than any other of the feathered creation.

When the Europeans first came to America, and coasted down along the Africanshores, they found the llamingos on several shores, on either continent, gentle, and no way distrustful of mankind. ${ }^{a}$ They had long been used to security, in the extensive solitudes they had chosen; and knew no enemies but those they could very well evade or oppose. The Negroes and the native Americans were possessed but of few destructive arts for killing them at a distance; and when the bird perceived the arrow, it well knew how to avoid it. But it was otherwise when the Europeans first came among them: the sailors, not considering that the dread of fire-arms was totally unknown in that part of the world, gave the flamingo the character of a foolish bird, that sulfered itself to be approached and shot at. When the fowler had killed one, the rest of the flock, far from attempting to $f y$, only regarded the fall of their companion in a kind of fixed astonishment; another and another shot was discharged; and thus the fowler often levelled the whole flock, before one of them began to think of eseaping.

But at present it is very different in that part of the world: and the flamingo is not only one of the scarcest, but of the shyest birds in the world, and the most difficult of approach. They chiefly keep near the most deserted and inhospitable shores; near salt-water lakes and swampy islands. They come down to the banks of rivers by day; and often retire to the inland mountainous parts of the country at the approach of night. When seen by mariners in the day, they always appear drawn up in a long close line of two or three hundred together; and, as Dampier tells us, present, at the distance of half a mile, the exact representation of a long. brick wall. Their rank, however, is broken when they seek for food; but they always appoint one of the number as a watch, whose only employment is to observe and give notice of danger, while the rest are feeding. As soon as this trusty centinel perceives the remotest appearance of danger, he gives a loud scream,

2 Albin's New Ilistory of Birds. with a voice as shrill as a trumpet, and instantly the whole cohort are upon the wing. They feed in silence; but, upon this occasion, all the flock are in one cliorus, and fill the air with intolerable screamings.

From this it appears, that the flamingos are very difficult to be approached at present, and that they avoid mankind with the most cautious timidity; loowever, it is not from any antipathy to man that they shun his society, for in some villages, as we are assured by Labat, along the coasts of Africa, the flamingos come in great numbers to make their residence among the natives. There they assemble by thousands, perched on the trees. within and about the village; and are so very clamorous, that the sound is heard at near a mile's distance. The Negroes are fond of their company ; and consider their society as a gift of Heaven, as a protection from accidental evils. The French, who are admitted to this part of the coast, cannot, without some degree of discontent, see such a quantity of game untouched, and rendered useless. by the superstition of the natives: they now and then privately shoot some of them, when at a convenient distance from the village, and hide them in the long grass, if they perccive any of the Negroes approaching; lor they would probably stand a chance of being ill used, if the blacks discovered their sacred birds thus unmercifully treated.

Sometimes, in their wild state, they are shot by mariners; and their young, which run excessively fast, are often taken. Labat has frequently taken them with nets, properly extended round the places they breed in. When their long legs are cntangled in the meshes, they are then unqualified to make their escape: but they still continue to combat with their destroyer; and the old ones, though seized by the head, will scratch with their claws; and these, though seemingly inoffensive, very often do mischief. When they are fairly disengaged from the net, they nevertheless preserve their natural ferocity ; they refuse all nourishment; they peck, and combat with their claws, at every opportunity. The fowler is, therefore, under a necessity of destroying them, when taken; as they would only pine and dic, if left to themselves in captivity. 
The flesh of the old ones is black and hard; though, Dampier says, well-tasted : that of the young ones is still better. But of all other delicacies, the flamingos' tongue is the most celebrated. "A dish of flamingos' tongues," says our author, "is a feast for an emperor." II fact, the Roman emperors considered them as the highest luxury; and we have an account of one of them, who procured fifteen humdred flamingos' tongues to be served up in a single dish. The tongue of this bird, which is so much sought after, is a good deal larger than that of any other bird whatever. The bill of the flamingo is like a large black box, of an irregular figure, and filled with a tongue which is black and gristly; but what peculiar flavour it may possess, 1 leave to be determined by such as understand good eating better than I do. It is probable, that the beauty and scarcity of the bird might be the first inducements to studious gluttony to fix upon its tongue as meat for the table. What Dampier says of the goodness of its flesh, cannot so well be relied on; for Dampier was often hungry, and thought any thing good that could be eaten : he avers, indeed, with Labat, that the flesh is black, tough, and fishy; so that we can hardly give him credit, when he asserts, that its flesh can be formed into a luxurious entertainment.

These birds, as was said, al ways go in flocks together; and they move in rank, in the manner of cranes. They are sometimes seen, at the break of day, flying down in great numbers from the mountains, and conducting each other with a trumpet cry, that sounds like the word Tococo, from whence the savages of Canadla have given them the name. In their flight they appear to great advantage; for they then seem of as bright a red as a burning coal. When they dispose themselves to feed, their cry ceases; and then they disperse over a whole marsh, in silence and assiduity. Their manner of feeding is very singular: the hird thrusts down its head, so that the upper convex side of the bill shall only touch the ground; and in this position the animal appears, as it were, standing upon its head. In this manner it paddles and moves the bill about, and seizes whatever fish or insect hap. pens to offer. For this purpose the upper chap is notched at the edges, so as to hold its prey with the greater security. Catesby, however, gives a diflerent account of their feeding. According to him, they thus place the upper chap undermost, and so work about, in order to pick up a seed from the bottom of the water, that resembles millet: but as in picking up this they necessarily also suck in a great quantity of mud, their bill is toothed at the edges in such a manner as to let out the mud while they swallow the grain.

Their time of breeding is according to the climate in which they reside: in North America they breed in our summer; on the other side the line, they take the most favourable season of the year. They build their nests in extensive marshes, and where they are in no danger of a surprise. The nest is not less curious than the animal that builds it: it is raised from the surface of the pool about a foot and a half, formed of mud scraped up together, and hardened by the sun, or the heat of the bird's body: it resembles a truncated cone, or one of the pots which we see placed on chimneys; on the top it is hollowed out to the shape of the bird, and in that cavity the fenale lays her eggs, without any lining but the well-cemented mud that forms the sides of the building. She always lays two eggs, and no more; and, as her legs are immoderately long, she straddles on the nest, while her legs hang down, one on each side, into the water.

The young ones are a long while before they are able to fly; but they run with amazing swiftness. They are sometimes caught; and, very different from the old ones, suffer themselves to be carried home, and are tamed very easily. In five or six days they become familiar, eat out of the hand, and drink a surprising quantity of sea-water. But though they are easily rendered domestic, they are not reared without the greatest difficulty: for they generally pine away, for want of their natural supplies, and die in a short time. While they are yet young, their colours are very different from those lively tints they acquire with age. In their first year they are covered with plumage of a white colour, mixed with gray: in the second year the whole body is white, with here and there a slight tint of scarlet; and the great covert feathers of the wings are black: the third 
year the bird acquires all its beauty; the pluimage of the whole body is scarlet, except some of the feathers in the wings, that still retain their sable hue. Of these beautiful plumes the savages make various ornanients; and the bird is sometimes skinned by the Europeans, to make muffs. But these have diminished in their price, since we have obtained the art of dying feathers of the brightest scarlet.

\section{CHAPTER CXX.}

\section{OF THE AVOSETTA, OR SCOOPER; AND THE CORRIRA, OR RUNNER.}

THE extraordinary shape of the Avosetta's bill might incline us to wish for its history ; and yet in that we are not able to indulge the reader. Natural historians have hitherto, like ambitious monarchs, shown a greater fondness for extending their dominions, than cultivating what they possess. While they have been labouring to add new varieties to their catalogues, they have neglected to study the history of animals already known.

The avosetta is chiefly found in Italy, and now and then comes over into England. It is about the size of a pigeon, is a pretty upright bird, and has extremely long legs for its size. But the most extraordinary part of its figure, and that by which it may be distinguished from all others of the feathered tribe, is the bill, which turns up like a hook, in an opposite direction to that of the hawk or the parrot. This extraordinary bill is black, flat, sharp, and flexible at the end, and about three inches and a half long. From its being bare a long way above the knee, it appears that it lives

- The Avoset breeds in the fens of Lincolnshire, and on Romney marsh in Kent. In winter they assemble in small flocks of six or seven, and frequent our shores, especially the mouths of large muddy rivers, in search of worms and marine insects. These they scoop out of the inud with their recurved bills, which are admirably adapted for that purpose, being tough and flexible like whalebone. The feet seem calculated for swimining, but they and wades in the waters. It has a chirping pert note, as we are told; but with its other habits we are entirely unacquainted. I have placed it, from its slender figure, among the cranes; although it is web-footed, like the duck. It is one of those birds of whose history we are yet in expectation."

To this bird of the crane kind, so little known, I will add another, still less known; the Corrira, or Runner, of Aldrovandus. All we are told of it is, that it has the longest legs of all web-footed fowls, except the flamingo and avosetta ; that the bill is straight, yellow, and black at the ends; that the pupils of the eyes are surrounded with two circles, one of which is bay, and the other white : below, near the belly, it is whitish ; the tail, with two white feathers, black at the extremities: and that the upper part of the body is of the colour of rusty iron. It is thus that we are obliged to substitute dry description for instructive history; and employ words, to express those shadings of colour which the pencil alone can convey.

are never observed to take the water: it is therefore probable, that they are furnished with a web merely to preveut their sinking into the mud. The female lays two eggs about the size of those of a pigeon, of a white colour tinged with green, and marked with large black spots. It is said to be very tenacious of its young, and when disturbed at this season, will fly round in repeated circles, uttering a note that resembles the word twit twice repeated. 


\section{CHAPTER CXXI.}

\section{OF SMALL BIRDS OF THE CRANE KIND, WITH THE THIGHS PARTLY BARF OF FEATHERS.}

AS I have taken my distinctions rather from the general form and manners of birds, than from their ininuter though perhaps more precise discriminations, it will not be expected that I should here enter into a particular history of a numerous tribe of birds, whose manners and forms are so very much alike. Of many of them we have scarcely any account in our historians, but tedious descriptions of their dimensions, and the colour of their plumage; and of the rest, the history of one is so much that of all, that it is but the same account repented to a most disgusting reiteration. I will therefore group then into one general draught; in which the more eminent, or the most whimsical, will naturally stand forward on the canvass.

In this group we find an extensive tribe of native birds, with their varieties and affinities; and we might add a hundred others, of distant climates, of which we know little more than the colour and the name. In this list is exhibited the Curlew, a bird of about the size of a duck, with a bill four inches long: the Woodcock, about the size of a pigeon, with a bill three inches long: the Godwit, of the same size; the bill four inches: the Green Shank, longer legged; the bill two inches and a half: the Red Shank, differing in the colour of its feet from the former: the Snipe, less by half, with a bill three inches. Then with shorter bills-The Ruff, with a collar of feathers round the neck of the male: the Knot, the Sandpiper, the Sanderling, the Dunlin, the Purre, and the Stint. To conclude with bills very short-The Lapwing, the Green Plover, the Gray Plover, thie Dottrel, the Turnstone, and the Sea-lark. These, with their affinities, are properly natives or visitants of this country; and are clispersed along our shores, rivers, and watery grounds. Taking in the birds of this kind, belonging to other countries, the list would be very widely cxtended; and the whole of this class, as described by Brisson, would amount to near a hundred.

All these birds possess many marks in common; though some have peculiarities that deserve regard. All these birds are bare of feathers above the knee, or above the heel, as some naturalists choose to express it. In fact, that part which I call the knee, if compared with the legs of mankind, is analogous to the heel; but, as it is-comnonly conceived otherwise, I have conformed to the general apprehension. I say, therefore, that all these birds are bare of feathers above the knee; and in some they are wanting half way up the thigh. The nudity in that part, is partly natural, and partly produced by all birds of this kind habitually wading in water. The older the bird, the barer are its thighs; yet even the young ones have not the same downy covering reaching so low as the birds of any other class. Such a covering there would rather be prejudicial, as being continually liable to get wet in the watcr.

As these birds are usually employed rather in running than in flying, and as their food lies entirely upon the ground, and not on trees or in the air, so they run with great swiftness for their size, and the length of their legs assists their velocity. But, as in seeking their food, they are often obliged to change their station; so also are they equally swift of wing, and traverse immense tracts of country without much fatigue.

It lias been thought by some, that a part of this class lived upon an oily slime, found in the bottoms of ditches and of weedy pools; they were thence termed, by Willoughby, Mudsuckers. But later discoveries have shown that, in these places, they hunt for the caterpillars and worms of insects. From hence, therefore, we may generally assert, that all 
birds of this class live upon animals of one kind or another. 'The long-billed birds suck up worms and insects from the bottom; those furvished with shorter bills, pick up such insects as lie nearer the surface of the meadow, or among the sands on the sea-shore.

Thus the curlew, the woodcock, and the snipe, are ever seen is plashy brakes, and under covered hedges, assiduously employed in seeking out insects in their worm state; and it seems, from their fatness, that they find a plentiful supply. Nature, indeed, has furnished them with very convenient instruments for procuring their food. Their bills are made sufficiently long for searching; but still more, they are endowed with an exquisite sensibility at the point, for feeling their provision. They are furnished with no less than three pair of nerves, equal almost to the optic nerves in thickness; which pass from the roof of the mouth, and run along the upper chap to the point.

Nor are those birds with shorter bills, and destitute of such convenient instruments, without a proper provision made for their subsistence. The lapwing, the sandpiper, and the redshank, run with surprising rapidity along the surface of the marsh or the seashore, quarter their ground with great dexterity, and leave nothing of the insect kind that happens to lie on the surface. These, however, are neither so fat nor so delicate as the former; as they are obliged to toil more for a subsistence, they are easily satisfied with whatever offers; and their flesh often contracts a relish from what has been their latest, or their principal food.

Most of the birds formerly described, have stated seasons for feeding and rest; the eagle kind prowl by day, and at evening repose; the owl by night, and keeps unseen in the day-time: but these birds, of the crane kind, seem at all hours employed; they are selfom at rest by day; and, luring the whole night-season, every meadow and marsh re- counds with their different calls, to courtship or to food.

This seems to be the time when they least fear interruption from man; and though they fly at all times. yet, at this season, they appear more assiduously employed, both in providing for their present support, and continu- ing that of pasterity. This is usually the season when the insidions fowler steals in upon their occupations, and fills the whole meadow with terror and destruction.

As all of this kind live entirely in waters, and among watery places, they seem provided by nature with a warmth of constitution to fit them for that cold element. They reside, by choice, in the coldest climates: and as other birds migrate here in our summer, their migrations hither are mostly in the winter. Even those that reside among us the whole season, retire in summer to the tops of our bleakest mountains; where they breed, and bring down their young, when the cold weather sets in.

Most of them, however, migrate, and retire to the polar regions; as those that remain behind in the monntains, and keep with us during summer, bear no proportion to the quantity which in winter haunt our marshes and low grounds. The snipe sometimes liuilds here; and the nest of tlse curlew is sometimes found in the plashes of our hills; but the number of these is very small; and it is most probnble that they are only some stragglers who, not having strength or courage sufficient for the general voyage, take up from necessity their habitation here.

In general, during the summer, this whole class either choose the coldest countries to retire to, or the coldest and the moistest part of ours to breed in. The curlew, the woodcock, the snipe, the godwit, the gray plover, the green and the long-legged plover, the knot, and the turnstone, are rather the guests than the natives of this island. They visit us in the beginning of winter, and forsake us in the spring. They then retire to the mountains of Sweden, Poland, Prussia, and Lapland, to breed. Our country, during the summer season, becomes uninhabitable to them. The ground parched up by the heat; the springs dried away; and the vermicular insects already upon the wing; they have no means of subsisting. Their weak and delicately pointed bills are unfit to dig into a resisting soil; and their prey is departed, though they were able to reach its retreats. Thus, that season when nature is said to teem with life, and to put on her gayest liveries, is to them an interval of sterility and 
famine. The coldest mountains of the north are then a preferable habitation; the marshes there are never totally dried up; and the insects are in such abundance, that, both above ground and underneath, the country swarms with them. In such retreats, therefore, these birds would continue always; but that the frosts, when they set in, have the saine effect upon the face of the landscape, as the heats of summer. Every brook is stiffened into ice; all the earth is congealed into one solid mass; and the birds are obliged to forsake a region where they can no longer find subsistence.

Such are our visitants. With regard to those which keep with us continually, and breed here, they are neither so delicate in their food, nor perhaps so warm in their con. stitutions. The lapwing, the ruff, the redshank, the sandpiper, the sea-pie, the Norfolk plover, and the sea-lark, breed in this country, and, for the most part, reside here. In suminer they frequent such marshes as are not dried up in any part of the year; the Essex hundreds, and the fens of Lincolnshire. There, in solitudes formed by surrounding marshes, they breed and bring up their young. In winter they come down from their retreats, rendered uninhabitable by the flooding of the waters, and seek their food about our ditches and marshy meadow-grounds. Yet, even of this class, all are wanderers upon some occasions; and take wing to the northern climates, to breed and find subsistence. This happens when our summers are peculiarly $\mathrm{dry}$; and when the fenny countries are not sufficiently watered to defend their retreats.

But though this be the usual course of nature, with respect to these birds, they often break through the general habits of their kind; and as the lapwing, the ruff, and the sandpiper, are sometimes seen to alter therr manners, and to migrate from hence, instead of continuing to breed here; so we often find the woodcock, the snipe, and the curlew, reside with us during the whole season, and breed their young in different parts of the country. In Casewood, about two miles Prom Tunbridge, as Mr. Pennant assures us, some woodcocks are seen to breed annually. The young have been shot there in the beginning of August; and were as healthy and vigorous as they are with us in winter, though not so well tasted. On the Alps, and other high mountains, says Willoughby, the woodcock continues all summer; I myself have flushed them on the top of Mount Jura, in June and July. The eggs are long, of a pale red colour, and stained with deeper spots and clouds. The nests of the curlew and the snipe are frequently found; and some of these perhaps never entirely leave this island.

It is thus that the same habits are, in some measure, common to all; but in nestling, and bringing up their young, one method takes place universally. As they all run and feed upon the ground, so they are all found to nestle there. The number of eggs generally to be seen in every nest, is from two to four; never under, and very seldom exceeding. The nest is made without any art; but the eggs are either laid in some little depression of the earth, or on a few bents and long grass, that scarcely preserve them from the moisture below. Yet such is the heat of the body of these birds, that the time of incubation is shorter than with any others of the same size. The nagpie, for instance, takes twenty-one days to hatch its young; the lapwing takes but fourteen. Whether the animal oil, with which these birds abound, gives them this superior warmth, I cannot tell; but there is no doubt of their quick incubation.

In their seasons of courtship, they pair as other birds; but not without violent contests between the males, for the choice of the fe. male. The lapwing and the plover are often seen to fight among themselves; but there is one little bird of this tribe, called the ruff, that has got the epithet of the fighter, merely from its great perseverance and animosity on these occasions. In the beginning of spring, when these hirds arrive amorig our marshes, they are observed to engage with desperate fury against each other: it is then that the fowlers, seeing them intent on mutual destruc. tion, spread their nets over them, and take them in great numbers. Yet even in captivity their animosity still continues: the people that fat them up for sale, are ohliged to shut them up in close dark rooms; for it they let ever so little light in among them. the turbulent prisoners instantly fall to fighting 
with each other, and never cease till each has killed its antagonist, especiully, says Willoughby, if any body stands by. A similar animosity, though in a less degree, prompts all this tribe; but when they have paired, and begun to lay, their contentions are then over.

The place these birds chiefly choose to breed in, is in some island surrounded with sedgy moors, where men seldom resort; and in such situations l have often seen the ground so strewed with eggs and nests, that one could scarcely take a step, without treading upon some of them. As soon as a stranger intrudes upon these retreats, the whole colony is up, and a hundred different screams are heard from every quarter. The arts of the lapwing, to allure men or dogs from her nest, are perfectly amusing. When she perceives the enemy approaching, she never waits till they arrive at her nest, but boldly runs to meet them: when she has come as near them as she dares to venture, she then rises with a loud screaming before them, seeming as if she were just flushed from hatching; while she is then probably a hundred yards from the nest. Thus she flies, with great clamour and anxiety, whining and screaming round the invaders, striking at them with her wings, and fluttering as if she were wounded. 'To add to the deceit, she appears still more clamorous, as more remote from the nest. If she sees them very near, she then seems to be quite unconcerned, and her cries cease, while her terrors are really augmenting. If there be dogs, she flies heavily at a little distance before them, as if maimed ; still vociferous and still bold, but never offering to move towards the quarter where her treasure is deposited. The dog pursues, in hopes every moment of seizing the parent, and by this means actually loses the young; for the cunning bird, when she has thus drawn bim off to a proper distance, then puts forth her powers, and leaves her astonished pursuer to gaze at the rapidity of her flight. "The eggs of all these birds are highly valued by the luxurious; they are boiled lard, and thus served up without any further preparation.

As the young of this class are soon hatched, so, when excluded, they quickly arrive at งo. $49 \& 50$. maturity. They run about after the mother as soon as they leave the egg; and being. covered with a thick down, want very little of that clutching which all birds of the poultry kind, that follow the mother, indispensably require. They come to their adult state long before winter; and then flock together till the breeding season returns, which for a while dissolves their society.

As the flesh of almost all these birds is in high estimation, so many methods have been contrived for taking them. That used in taking the ruff, scems to be most adrantageous; and it may not be amiss to describe it. The rulf, which is the name of the male, the reeve that of the female, is taken in nets about forty yards long, and seven or eight feet high. These birds are chiefly found in Lincolnshire and the Isle of Ely, where they come about the latter end of April, and disappear about Michaelmas. The male of this bird, which is known from all others of the kind by the great length of the feathers round his neck, is yet so various in his plumage, that it is said, no two ruffs were ever scent totally of the same colour. The nets in which these are taken, are supported by sticks, at an angle of near forty-five degrees, and placed either on $d r y$ ground, or in a very shallow water, not remote from reeds : among these the fowler conceals bimself, till the birds, enticed by a stale or stuffed bird, come under the nets; he then, by pulling a string, leis them fall, and they are taken; as are godwits, knots, and gray-plover also, in the same manner. When these birds are brought from under the net, they are not killed iminediate$1 y$, but fattened for the table with bread and milk, hemp-seed, and sometimes boiled wheat; but if expedition be wanted, sugar is added, which will make them a lump of fat in a fortnight's time. They are kept, as observed be. fore, in a dark room; and judgment is required in taking the proper time for killing them, when they are at the highest pitch of fatness : for if that is neglected, the birds are apt to fall away. They are reckoned a very great delicacy; they sell for two shillings, or half-a-crown, a piece; and are served up to the table with the train, like woodcocks, where we will leave them.

$$
4 \mathrm{~N}
$$




\section{CHAPTER CXXII.}

\section{OF THE WATER-HEN, AND THE COOT.}

BEFORE we enter upon water-fowls, properly so called, two or three birds claim our attention, which seem to form the shade between the web-footed tribe and those of the crane kind. These partake rather of the form than the habits of the crane; and, though furnished with long legs and necks, rather swim than wade. They camot properly be called web-footed; nor yet are they entirely destitute of membranes, which fringe their toes on each side, and adapt them for swimming. The birds in question are, the Water-Hen and the Bald-Coot.

These birds have too near an affinity, not to be ranked in the same description. They are shaped entirely alike, their legs are long, and their thighs partly bare; their necks are proportionable, their wings short, their bills short and weak, their colour black, their foreheads bald and without feathers, and their habits entirely the same. These, however, naturalists have thonght proper to range in different classes, from very slight distinctions in their figure. The water-hen weighs but fifteen ounces; the coot twenty-four. The bald part of the forehead in the coot is black; in the water-hen it is of a beantiful pink colour. The toes of the water-hen are edged - with a straight membrane; those of the coot have it scolloped and broader.

The differences in the figure are but slight; and those in their manner of living still less. The history of the one will serve for both. As birds of the crane kind are furnished with long wings, and easily change place, the water-hen, whose wings are short, is obliged to reside entirely near those places where her food lies: she cannot take those long journeys that most of the crane kind are seen to perform; compelled by her natural imperfections, as well perhaps as by inclination, she never leaves the side of the.pond or the river in which she seeks for provision. Where the stream is selvaged with sedges, or the pond edged with shrubby trees, the water-hen is generally a resident there: she seeks her food along the grassy banks, and ofien along the surface of the water. With Shakspeare's Edgar, she drinks the green mantle of the standing pool; or, at least, seems to prefer those places where it is seen. Whether she makes pond-weed her food, or hunts among it for water-insects, which are found there in great abundance, is not certain. I have seen them when pond-weed was taken out of their stomach. She builds her nest upon low trees and shrubs, of sticks and fibres, by the waterside. Her eggs are sharp at one end, white, with a tincture of green, spotted with red. She lays twice or thrice in a summer; her young ones swim the moment they leave the egg, pursue their parent, and imitate all her manners. She rears, in this manner, two or three broods in a season: and when the young are grown up, she divives them off to shift for themselves.

As the coot is a larger bird, it is always seen in larger streams, and more remote from mankind. The water-hen seems to prefer iuhabited situations: she keeps near ponds, moats, and pools of water near gentlemen's houses; but the coot keeps in rivers, and amoug rushy margined lakes. It there makes a nest of such weeds as the stream supplies, and lays them among the reeds, floating on the surface, and rising and falling with the water. The reeds anong which it is built keep it fast; so that it is seldom washed into the middle of the stream. But if this happens, which is sometimes the case, the bird sits in her nest, like a mariner in his boat, and steers with her legs her cargo into the nearest harbour: there, having attained her port, she continues to sit in great tranquillity, rega. dles- of the impetuosity of the current; and though the water penetrates her nest, 


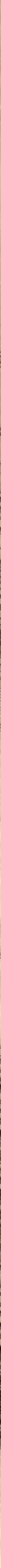




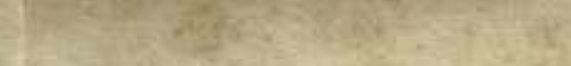

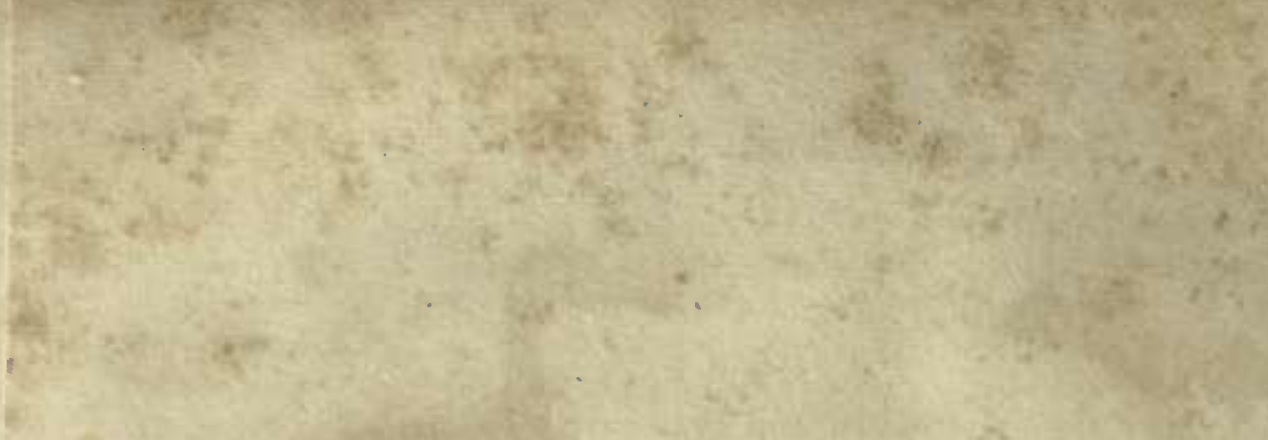

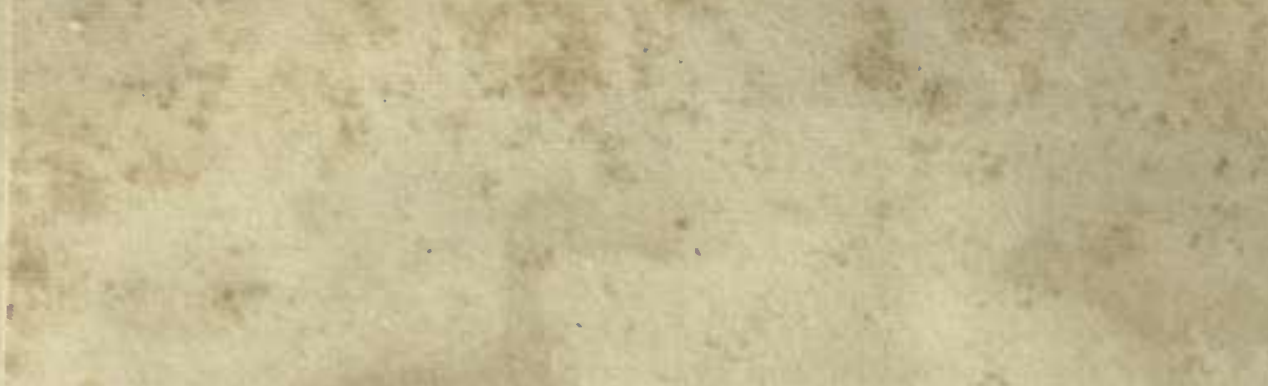

(1)

Q 192

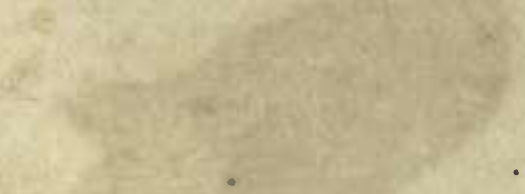
10.

$+2$

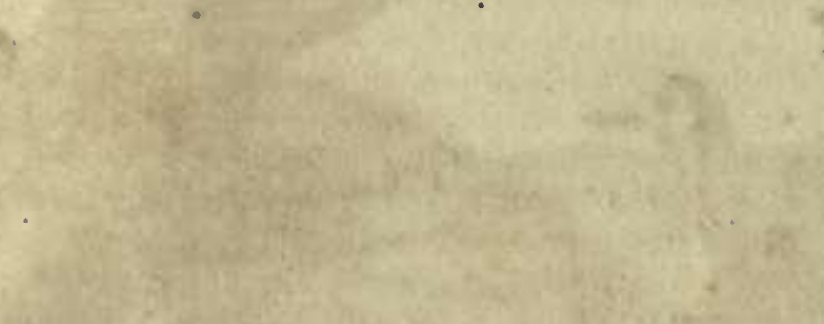

(⿻i, $5, y$

(4⿻)丨 3

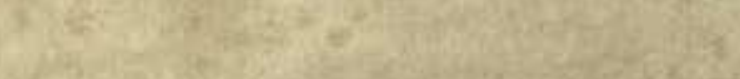

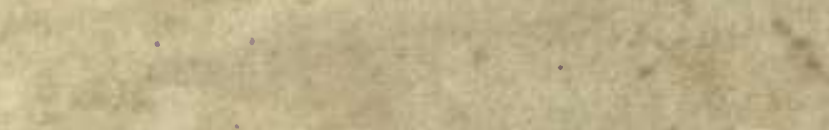

48

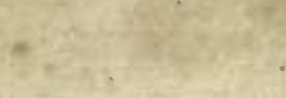

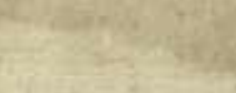

48

s.

$x^{4}+x^{2}$

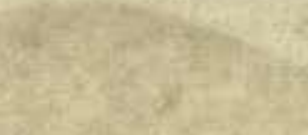

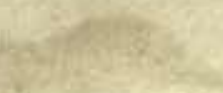

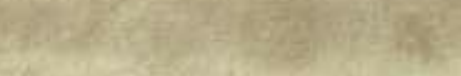

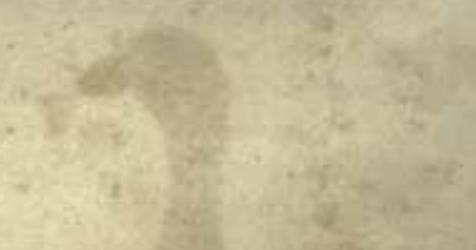

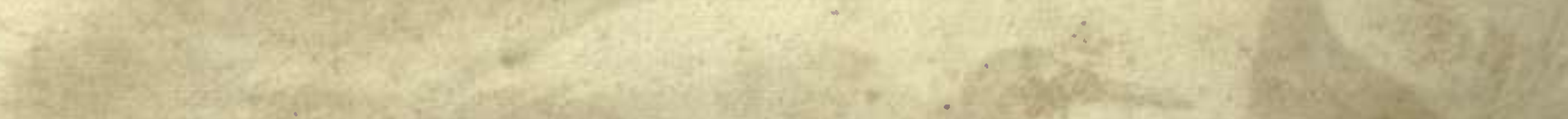

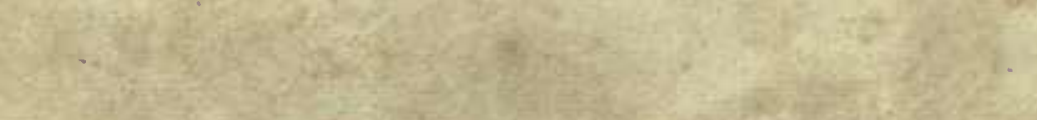

$\cos ^{2} \cos ^{2} \sin ^{2}$

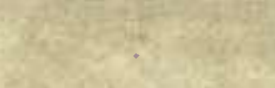

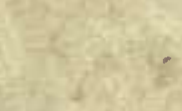

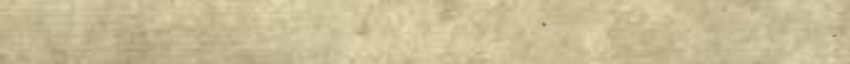

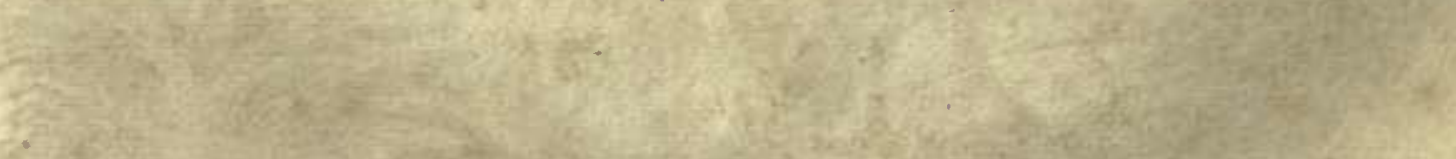

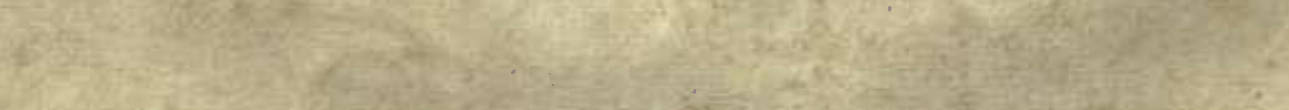

H. 
she hatches her eggs in that wet condition. -The water-hen never wanders; but the coot sometimes swims down the current, till it even reaches the sea. In this voyage these birds encounter a thousand dangers: as they cannot thy far, they are hunted by dogs and men; as they never leave the stream, they are attacked and destroyed by otters; they are preyed upon by kites and falcons; and they are taken in still greater numbers in weirs made for catching fish; for these birds are led into the nets, while pursuing small fish and insects, which are their principal food. Thus animated nature affords a picture of universal, invasion! Man destroys the otter, the otter destroys the coot, the coot feeds upon fish, and fish are universally the tyrants of each other!

To these birds, with long legs and finny toes, I will add one species more, with short legs and finny toes; I mean the Grebe. The entire resemblance of this bird's appetites and manners to those of the web-footed class, might justly induce me to rank it among them; but as it resembles those above described, in the peculiar form of its toes, and bears some similitude in its manners also, I will for once sacrifice method to brevity. The grebe is much larger than either of the former, and its plumnge white and black; it differ's also entirely in the shortness of its legs, which are made for swimming, and not walking: in fact, they are from the knee upward hid in the belly of the bird, and have consequently very little motion. By this mark, and by the scolloped fringe of the toes, may this bird be easily distinguished from all others.

As they are thus, from the shortness of their wings, ill formed for flying, and from the uncommon shortness of their legs utterly unfitted for walking, they seldom leave the water, and chiefly frequent those broad shallow pools where their faculty of swimming can be turned to the greatest advantage, in fishing and secking their prey.

They are chiefly, in this country, seen to frequent the meres of Shropshire and Cheshire; where they breed among reeds and flags, in a floating nest, kept steady by the weeds of the margin. The female is said to be a careful nurse of her young, bcing observed to feed them most assiduously with small eels; and when the little brood is tired, the mother will carry them either on her back or under her wings. This bird preys upon fish, and is almost perpetually diving. It does not show much more than the head above water; and is very difficult to be shot, as it darts down on the appearance of the least danger. It is never seen on land; and, though disturbed ever so often, will not leave that lake, where alone, by diving and swim. ming, it can find food and security. It is chiefly sought for the skin of its breast, the plumage of which is of a most beautiful silvery white, and as glossy as satin. This part is made into tippets; but the skins are out of scason about February, losing their bright colour; and in breeding-time their breasts are cntirely bare. 


\section{OF WATHR-FOWL.}

\section{$\rightarrow 00$ \\ CHAPTER CXXII.}

\section{OF WATER-FOWL IN GENFRAL.}

IN settling the distinetions among the other classes of birds, there was some difficulty ; one tribe encroached so nearly upon the nature and habitudes of another, that it was not easy to draw the line which kept them asunder: but in water-fowl, nature has marked them for us by a variety of indelible characters; so that it would be almost as unlikely to mistake a land-fowl for one adapted for living and swimming among the waters, as a fish for a bird.

The first great distinction in this class appears in the toes, which are webbed together for swimming. Those who have remarked the feet or toes of a duck, will easily conceive how admirably they are formed for making way in the water. When men swim, they do not open the fingers, so as to let the fluid pass through them ; but closing them together, present one broad surface to beat back the water, and thus push their bodies along. What man performs by art, nature has supplied to waterfowl; and, by broad skius, has webbed their toes together, so that they expand two broad oars to the water; and thus, moving them alternately, with the greatest case paddle along. We must observe also, that the toes are so contrived, that, as they strike backward, their broadest hollow surface beats the water; but as they gather them in again, for a second blow, their front surface contracts, and does not impede the bird's progressive motion.

As their toes are webbed in the most convenient manner, so are their legs also made most fitly for swift progression in the water. The legs of all are short, except the thrce birds described in a former chapter; namely, the flamingo, the avosetta, and the corrira: all which, for that reason, I have thought proper to rank among the crane kind, as they make little use of their toes in swimining. Except these, all web-footed birds have very short legs; and these strike, while they swim, with great facility. Were the leg long, it would act like a lever whose prop is placed to a disadvantage; its motions would be slow, and the labour of moving it considerable. For this reason, the very few birds whose webbed feet are long, never make use of the $m$ in sivimming: the web at the bottom seems only of service as a broad base, to prevent them from sinking while they walk in the mud; but it otherwise rather retards than advances their motion.

The shortness of the legs in the web-footed kinds, renders them as unfit for walking on land, as it qualifies them for swimming in their natural element. Their stay, therefore, upon land, is but short and transitory; and they seldom venture to breed far from the sides of those waters where they usually remain. In their breeding seasons, their young are brought up by the water-side; and they are covered with a warm down, to fit them for the coldness of their situation. The old ones, also, have a eloser, warmer plumiage, than birds of any other elass. It is of their feathers that our beds are composed; as they neither mat, nor imbibe humidity, but are furnished with an animal oil that glazes their surface, and keeps each separate. In some, however, this animal oil is in ton great abundance; and is as offensive from its smell, as it is serviceable for the purposes of bousehold economy. The feathers, therefore, of all the penguin kind are tntally useless for domestic purposes; as neither 
boiling nor bleaching can divest them of their oily rancidity. Indeed, the rancidity of all new feathers, of whatever water-fowl they be, is so disgusting, that our upholsterers give near double the price for old feathers that they afford for new : to be free from smell, they must all be lain upon for some time; and their usual method is to mix the new and the old together.

This quantity of oil, with which most waterfowl are supplied, contributes also to their warmth in the moist element where they reside. Their skin is generally lined with fat; so that, with the warmth of the feathers externally, and this natural lining more internally, they are better defended against the changes or the inclemencies of the weather, than any other class whatever.

As, among land-birds, there are some found fitted entirely for depredation, and others for an harmless method of subsisting upon vegetables, so also, among these birds, there are tribes of plunderers that prey, not only upon fish, but sometimes upon water-fowl themselves. There are likewise more inoffensive tribes, that live upon insects and vegetables only. Some water-fowls subsist by making sudden stoops from above, to seize whatever fish come near the surface; others again, not furnished with wings long enough to fit them for flight, take their prey by diving after it to the bottom.

From hence all water-fowl naturally fall into three distinctions. Those of the Gull kind, that, with long legs and round bills, fly along the surface to seize their prey : those of the Penguin kind, that, with round bills, legs hid in the abdomen, and short wings, dive after their prey : and, thirdly, those of the Goose kind, with flat broad bills, that lead harmless lives, and chiefly subsist upon insects and vegetables.

These are not speculative distinctions, made up for the arrangement of a system; but they are strongly and evidently marked by nature. The Gull kind are active and rapacious ; constantly, except when they loreed, keeping upon the wing; fitted for a life of rapine, with sharp straight bills for piereing, or hooked at the end for holding their fislyy prey. In this class we may rank the Albatross, the Cormorant, the Gannet or Soland Goose, the Shag, the Frigate-bird, the Great Brown Gull, and all the lesser tribe of gulls and sea-swallows.

The Penguin kind, with appetites as voracious, bills as sharp, and equally eager for prey, are yet unqualitied to obtain it by flight. Their wings are short, and their bodies large and heavy, so that they can neither run nor fly. But they are formed for diving in a very peculiar manner. Their feet are placed so far backward, and their legs so hid in the abdomen, that the slightest stroke sends them head foremost to the bottom of the water. To this class we may refer the Penguin, the Auk, the Skout, the Sea-turtle, the Bottlenose, and the Loon.

The Goose kind are easily distinguishable, by their flat broad bills, covered with a skin; and their manner of feeding, which is mostly upon vegetables. In this class we may place the Swan, the Goose, the Duck, the Teal, the Widgeon, and all their numerous varieties.

In describing the birds of these three classes, I will put the most remarkable of each class at the beginning of their respective tribes, and give their separate history; then, after having described the chiefs of the tribe, the more ordinary sorts will naturally fall in a body, and come under a general description, behind their leaders. But before I offer to pursue this methodical arrangement, I must give the history of a bird, that, from the singnlarity of its conformation, seems allied to no species; and should, therefore, be separately described-I mean the Pelican. 


\section{CHAP'TER CXXIV.}

\section{OF THE PELICAN.}

THE Pelican of Africa is much larger in the body than a swan, and somewhat of the same sliape and colour. Its four toes are all webbed together; and its neck, in some measure, resembles that of a swan: but that singularity in which it differs from all other birds, is in the bill and the great pouch underneath, which are wonderful, and demand a distinct description. This enormous bill is fifteen inches from the point to the opening of the mouth, which is a good way back behind the eyes. At the base, the bill is somewhat greenish, but varies towards the end, being of a reddish-blue. It is very thick in the beginning, but tapers off to the end, where it liooks downwards. The under chap is still more extraordinary; for to the lower edges of it hangs a bag, reaching the whole length of the bill to the neck, which is said to be capable of containing fiftcen quarts of water. 'This bag the bird has a power of wriukling up into the hollow of the under chap; but by opening the bill, and putting one's hand down into the bag, it may be distended at pleasure. The skin of which it is formed will then be scen of a bluish ash-colour, with many fibres and veins running over its surface. It is not covered with feathers, but a short downy substance, as smooth and as soft as sntin, and is attached all along the under edges of the chap, to be fixed backward to the neck of the birl by proper ligaments, and reaches near half way down. When this bag is cinpty it is not seen; but when the hird has fished with success, it is then incredible to what an extent it is often seen dilated. For the first thing the pelican does in fishing is to fill up the bag; and then it returns to digest its burden at leisurc. When the bill is open to its widest extent, a person may run his head into the bird's mouth, and conceal it in this moustrous pouch, thus adapted for very singular purposes. : Yet this is nothing to what Ruysch assures.us, who avers, that a man has been seen to hide his whole leg, boot and all, in the monstrous jaws of one of these animals. At first appearance this would seem impossible, as the sides of the under chap, from which the bag depends, are not above an inch asunder when the birl's bill is first opened; but then they are capable of great separation; and it must necessarily be so, as the bird preys upon the largest fishes, aud hides them by dozens in its pouch. Tertre affirms, that it will hide as many fish as will serve sixty hungry men for a meal.

Such is the formation of this extraordinary bird, which is a native of Africa and America. The pelican was once also known in Europe, particularly in Russia; but it seems to have deserted our coasts. This is the bird of which so many fabulous accounts have been propagated; such as its feeding its young with its own blood, and its carrying a provision of water for them in its great reservoir in the desert. But the absurdity of the first account answers itself; and as for the latter, the pelican uses its bag for very different purposes than that of filling it with water.

Its amazing pouch may be considered as analogous to the crop in other birds, with this difference, that as theirs lies at the bottom" of the gullet, so this is placed at the top. Thus, as pigeous and other birds macerate their food for their young in their crops, and then supply them, so the pelican supplies its young by a more ready contrivance, and macerates their food in its bill, or stores it for its own particular sustenance.

The ancients were particularly fond of giving this bird admirable qualities and parental affections ; struck, perhaps, with its extraordinary figure, they were willing to supply it with as extraordinary appetites; and having found it with a large reservoir, they were pleased with turning it to the most tender and parental uses. But the truth is, the pelican is a very heavy, sluggish, voracious 


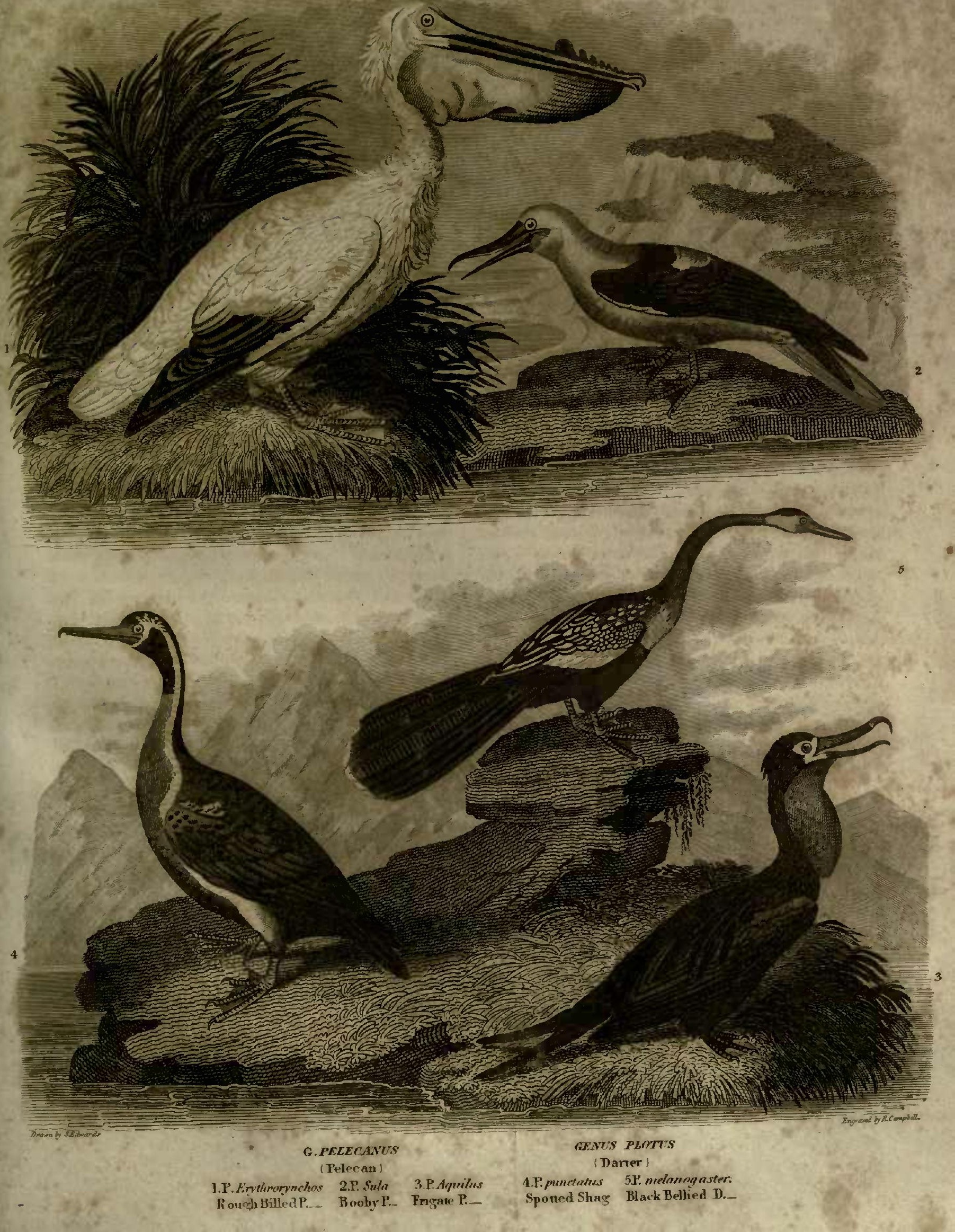


bird, and very ill fitted to take those flights, or to make those cautious provisions for a distant time, which we have been told they do. Father Labat, who seems to have studied their manuers with great exactness, has given us a minute listory of this bird, as found in America; and from him I will horrow iniue.

The pelican, says Labat, has strong wings, furnished with thick plumage of an ash-colour, as are the rest of the feathers over the whole body. Its eyes are very small, when compared to the size of its liead; there is a sadness in its countenance, and its whole air is melancholy. It is as dull and reluctant in its motions, as the flamingo is sprightly and active. It is slow of flight; and when it rises to fly, performs it with difficuliy and Jabour. Nothing, as it would seem, but the spur of necessity could make these birds change their situation, or induce them to ascend into the air; but they must eitber starve or fly.

They are torpid and inactive to the last degree, so that nothing can exceed their indolence but their gluttony; it is only from the stimulations of hunger that they are $\mathrm{cx}$ cited to labour; for otherwise they would continue always in fixed repose. When they liave raised themselves about thirty or forty feet above the surface of the sea, they turn their luead with one eye downwards, and continue to fly in that posture. As soon as they perceive a fish suflicicutly near the surface, they dart down upon it with the swiftness of an arrow, seize it with unerring certainty, and store it $u_{i}$, in their pouch. They then rise again, though not witlout great labour, and continue liovering and fishing, with their head on one side as before.

This work they continue with great effort and industry till their bag is full, and then they fly to land, to devour and digest at leisure the fruits of their industry. This, however, it would appear, they are not long in performing; for towards night they have another hungry call, and they again reluctantly go to labour. At night, when their fishing is over, and the toil of the day crowned with success, these lazy birds retire a little way from the shore; and, though with the welsbed feet and clumsy figure of a goose, they will be contented to perch no where but upon trees, among the light and airy tenants of the forest.
There they take their repose for the night; and often spend a great part of the day, except such times as they are fishing, sitting in dismal solemnity, and, as it would seem, hall asleep. Their attitude is, with the bead resting upon their great bag, and that resting upon their breast. There they remain without notion, or once changing their situation, till the calls of hunger break their repose, and till they fund it indispensably necessary to fill their magazine for a fiesh meal. 'Ilsus their' life is spent between slecping and eating; and our author adds, that tice are as foul as they are voracious, as they are every moment voiding excrements in heaps as large as one's fist.

The same indolent babits seem to attend them even in preparing for incubation, and defending their young when excluded. The female makes no preparation for hel nest, nor seemis to choose any place in preference to lay in; but drops her eggs on the bare ground to the number of five or six, and there continues to hatch them. Attached to the place, without any desire of defending her eggs or her young, she tamely sits, and suffers them to be taken from under her. Now and then she just ventures to peck, or to cry out when a person offers to beat her off.

She feeds her young with fish macerated for some time in her bag; and when they cry, flies off for a new supply. Labat tells us, that lue took two of these when very young, and tied them by the leg to a post stuck into the ground, where he had the pleasure of seeing the old one for several days come to feed them, remaining with them the greatest part of the day, and spending the night on the brauch of a tree that hung over them. By these means they were all three become so familiar, that they suffered themselves to be handled; and the young ones very kindly accepted whatever fish he offered them. These they always put first into their bag, and then swallowed at their leisure.

It seems, however, that they are but disagreeable and useless domestics; their glultony can scarcely be satisfied; their flesh smells very rancid; and tastes a thousand times worse than it smells. The native Americans kill vast numbers; not to eat, for they are not fit even for the banquet of a savage; but to convert their large bags into purses 
and tobacco poucles. Thicy bestow no small pains in dressing the skin with salt and ashes, rubbing it well with oil, and then forming it to their purpose. It thus becomes so soft and pliant, that the Spanish women sometimes adorn it with gold and embroidery to make work-bags of.

Yet, with all the seeming hebetude of this bird, it is not entirely incapable of instruction in a domestic state. Father Raymond assures us, that he has seen one so tame and well educated among the native Americans, that it would go off in the morning at the word of command, and return before night to its master, with its great pouch distended with plunder; a part of which the savages would make it disgorge, and a part they would permit it to reserve for itself.

"The Pelican," as Faber relates, " is not destitute of other qualifications. One of those which was brought alive to the duke of Bavaria's court, where it lived forty years, seemed to be possessed of very uncommon sensations. It was much delighted in the company and conversation of men, and in music both vocal and instrumental: for it would willingly stand," says he, "by those that sung, or sounded the trumpet; and stretching out its head, and turning its ear to the music, listened very attentively to its harmony; though its own voice was little pleasanter than the braying of an ass." Gesner tells us, that the eniperor Maximilian had a tame pelican, which lived for above eighty years, and that always attended his army on their march. It was one of the largest of the kind, and had a daily allowance by the $\mathrm{em}$ peror's orders. As another proof of the great age to which the pelican lives, Aldrovandus makes mention of one of these birds that was kept several years at Mechlin, was verily believed to be fifty years old. We often sce these birds at our shows abuut town. 


\section{CHAPTER CXXY.}

\section{OF THE ALBATROSS, THE FIRST OF THE GULL KIND.}

THOUGH this is one of the largest and most formidable birds of Africa and America, yet we have but few accounts to enlighten us in its history. The figure of the bird is thus described by Edwards: "The body is rather larger than that of a pelican; and its wings, when extended, ten feet from tip to tip. The biil, which is six inches long, is yellowish, and terminates in a crooked point. The top of the head is of a bright brown; the back is of a dirty deep spotted brown; and the belly and under the wings is white; the toes, which are webbed, are of a flesh colour."

Such are the principal traits in this bird's figure: but these lead us a very short way in its listory; and our naturalists have thought fit to say nothing more. However, I am apt to believe this bird to be the same with that described by Wicquefort, under the title of the Alcatraz; its size, its coluurs, and its prey, incline me to think so. He describes it as a kind of great gull, as large in the body as a goose, of a brown colour, with a long bill, and living upon fish, of which they kill great numbers.

This bird is an inhabitant of the tropical climates, and also beyond them as far as the Straits of Magellan in the South Seas. It is one of the most fierce and formidable of the aquatic tribe, not only living upon fish, but also such small water-fowl as it can take by surprise. It preys, as all the gull kind do, upon the wing; and eliefly pursues the flyingfish, that are forced from the sea by the dolphins. The ocean in that part of the world presents a very different appearance from the seas with which we are surrounded. In our scas we see nothing but a dreary expanse, rumled by winds, and seemingly forsaken loy every class of animated nature. But the tropical seas, and the distant southern latitudes beyond them, are all alive with birds and fishes, pursuing and pursued. Every various species of the gull kind are there seen hovering on the wing, at a thousand miles distance xo. $49 \& 50$. from the shore. The flying-fish are every moment rising to escape from their pursuers of the decp, only to encounter equal dangers in the air. Just as they rise the dolphin is seen to dart after them, but generally in vain; the gull has more frequent success, and often takes them at their rise; while the albatross pursues the gull, and obliges it to relinquish its prey; so that the whole horizon presents but one living picture of rapacity and evasion.

So much is certain; but how far we are to credit Wiequefort, in what he adds concerning this bird, the reader is left to deternine. "As these birds, except when they breed, live entirely remote from land, so they are often seen, as it should seem, sleeping in the air. At night, when they are pressed by slumber, they rise into the clouds as high as they can; there, putting their head under one wing, they beat the air with the other, and seem to take their ease. After a time, however, the weight of their bodies, only thus half supported, brings them doivn; and they are seen descending, with a pretty rapid motion, to the surface of the sea. Upon this they again put forth their efforts to rise; and thus alternately ascend and descend at their case. But it sometimes happens," says my author, "that in these slumbering flights, they are off their guard, and fall upon deck, where they are taken."

What truth there may be in this account I will not take it upon me to determine: but certain it is, that few birds float upon the air with more ease than the albatross, or support themselves a longer time in that element. They seem never to feel the accesses of fatigue; but, night and day upon the wing, are always prowling, yet always emaciated and hungry.

But though this bird be one of the most formidable tyrants of the deep, there are some associations which even tyrants themselves form, to which they are induced either by caprice or necessity. The albatross seenis to have a peculiar affection for the penguin, and 40 
a pleasure in its society. They are always seen to choose the same places for breeding; some distant uninhabited island, where the ground slants to the sea, as the penguin is not formed either for flying or climbing. In such places their nests are seen together, as if they stood in need of mutual assistance and protection. Captain Hunt, who for sone time commanded at our settlement upon Falkland Islands, assures me, that he was often amazcd at the union preserved between these birds, and the regularity with which they built together. In that bleak and desolate spot, where the birds had long continued undisturbed possessors; and no way dreaded the encroachment of men, they seemed to makc their abode as comfortable as they expected it to be lasting.
They were seen to build with an amazing degree of uniformity; their nests covering fields by thousands, and resembling a regular plantation. In the middle, on high, the albatross raised its nest, on heath, sticks, and long grass, about two feet above the surface: round this the penguins made their lower settlements, rather in looles in the ground, and most usially eight penguins to one albatross. Nothing is a stronger proof of Mr. Buffon's fine observation, that the presence of man not only destroys the society of meaner animals, but their instincts also. These nests are now, $I$ am told, totally destroyed; the society is broke up; and the albatross and penguin lave gone to breed upon more desert shores, in greater security ${ }^{2}$

\section{CHAPTER CXXVI.}

\section{THE CORMORANT.}

THE Cormorant is about the size of a large Muscovy duck, and may be distinguished from all other birds of this kind, by its four toes being united by membranes together; and by the middle-toe being toothed or notched like a saw, to assist it in holding its fishy prey. The head and neck of this bird are of a sooty blackness; and the body thick and heavy, more inclining in figure to that of the goose than the gull. The bill is straight, till near the end, where the upper chap bends into a hook.

But notwithstanding the seeming heaviness of its make, there arc few birds more powerfully predaceous. As soon as the winter ap. proaches, they are secn dispersed along the sea-shore, and ascending up the mouths of fresh-water rivers, carrying destruction to all the finny tribc. They are most remarkably voracious, and have a nost sudden digestion.

a The Alhatross, or man of war bird, luas a straight bill, the upper mandible of which is crooked at the point, and the lower one truncated : the nostrils are qval, wide, prominent, and placed on each side the bill : the feet have three toes, all placed forwards. In the West Indies these birds are said to foretell the arrival of ships: which is frequently true, and may. arise from a very uatural cause.
Their appetite is for ever craving, and never satisfied. This gnawing sensation may probably bc increased by the great quantity of small worms that fill their intestines, and which their unceasing gluttony contributes to engender.

Thus formed with the grossest appetites, this unclean bird has the most rank and disagreeable sinell, and is more foetid than even carrion, when in its most healthful state. Its form, says an ingenious modern, is disagreeable; its voice is hoarse and croaking; and all its qualities obscene. No wonder then that Milton should make Satan personate this bird, when he sent him upon the basest purposes, to survcy with pain the beauties of Paradise, and to sit devising death on the tree of life. It has been remarked, however, of our poet, that the making a water-fowl perch upon a tree, inplied no grcat acquaintance with the

They always fish in fine weather ; sn that, when the wind is rough at sea, they retire into the harbours, where they are protected by the land; and the same wind that blows themin, brings likewise whatever vessels may be exposed to its firy, to seck a retrcat froin it.

b Vide Pennant's Zoology, p. 47\%. 
history of nature. In vindication of Milton; Aristotle expressly says, that the cormorant is the only water-fowl that sits on trees. We have already seen the pelican of this number; and the cormorant's toes seem as fit for perching upon trees as for swinmming; so that our epic bard scems to have been as deeply versed in natural history as in criticism.

Indeed this bird seems to be of a multiform nature; and wherever fish are to be found, watches their migrations. It is seen as well by land as sea; it fishes in fresh-water lakes, as well as in the depths of the ocean; it builds in the cliffs of rocks, as well as on trees; and preys not only in the day-time, but by night.

Its indefatigable nature, and its great power in catching fish, were probably the motives that induced some nations to breed this bird up tame, for the purposes of fishing; and Willoughby assures us, it was once used in England for that purpose. The description of their manner of fishing is thus delivered by Faber. "When they carry them out of the rooms where they are kept, to the fish-pools, they hoodwink them, that they may not be frighted by the way. When they are come to the rivers, they take off their hood; and having tied a leather thong round the lower part of their necks, that they may not swallow down the fish they catch, they throw them into the river. They presently dive under water; and there for a long time, with wonderful swiftness, pursue the fish; and when they have caught them, rise to the top of the water, and pressing the fish lightly with their bills, swallow them; till each bird hath, after this manner, devoured five or six fishes. Then their keepers call them to the fist, to which they readily fly; and, one after another; vomit up all their fish, a little bruised with the first nip, given in catching them. When they have done fishing, setting the birds on some high place, they loose the string from their necks, leaving the passage to the stomach free and open; and, for their reward, they throw them part of their prey; to each one or two fishes, which they will catch most dextcrously, as they are falling in the air."

At present, the cormorant is trained up in every part of China for the same purpose, where there are inany lakes and canals. "To this end," says Le Compte, "they are edu- cated as men rear up spaniels or hawks, and one man can easily manage a hundred. The fisher carries them out into the lake, perched on the gunnel of his boat, where they continuc tranquil, and expecting his orders with patience. When arrived at the proper place, at the first signal given each flies a different way to fulfil the task assigned it. It is very pleasant, on this occasion, to behold with what sagacity they portion out the lake or the canal where they are upon duty. They hunt about, they plunge, they rise an hundred times to the surface, until they have at last found their prey. They then seize it with their beak by the niddle, and carry it without fail to their master. When the fish is too large, they then give each other mutual assistance : one seizes it by the head, the other by the tail, and in this manner carry it to the boat together. There the boat-man stretches out one of his long oars, on which they perch, and being delivered of their burden, they fly off to pursue their sport. When they are wearied, he lets them rest for a while; but they are never fed till their work is over. In this manner they supply a very plentiful table; but still their natural gluttony cannot be reclaimed even by education. They have always, while they fish, the same string fastened round their throats, to prevent them from devouring their prey, as otherwise they would at once satiate theinselves, and discontinue their pursuit the moinent they had filled their bellies."

As for the rest, the cormorant is the best fisher of all birds; and though fat and heavy with the quantity it devours, is nevertheless generally upon the wing. The great activity with which it pursues, and from a vast height drops down to dive after its prey, offers one of the nost amusing spectacles to those- who stand upon a cliff on the shore. This large bird is seldom seen in the air, but where there are fish below; but then they must be near the surface, before it will venture to souse upon then. If they are at a depth beyond what the inmetus of its flight makes the cormorant capable of diving to, they certainly escaje him; for this bird cannot move so fast under water, as the fish can swim. It seldom, however, makes an unsuccessful dip; and is often seen rising heavily, with a fish larger than it can readily devour. It sometimes also happens, that the cormorant has caught the 
fish by the tail; and consequently the fins prevent its being easily swallowed in that position. In this case, the bird is seen to toss its prey above its head, and very dexterously to catch it, when descending, by the proper end, and so swallow it with ease."

\section{CHAPTER CXXVII.}

\section{OF THE GANNET, OR SOLAND GOOSE.}

THE Gannet is of the size of a tame goose, but its wings much longer, being six feet over. The bill is six inches long, straight almost to the point, where it inclines down, and the sides are irregularly jagged, that it may hold its prey with greater security. It differs from the cormorant in size, being larger; and its colour, which is chiefly white; and by its having no nostrils, but in their place a long furrow that reaches almost to the end of the bill. From the corner of the mouth is a narrow slip of black bare skin, that extends to the hind part of the head; beneath the skin is another that, like the pouch of the pelican, is dilatable, and of size sufficient to contain five or six entire herrings, which in the breeding season it carries at once to its mate or its young.

These birds, which subsist entirely upon fish, chiefly resort to those uninhabited islands where their food is found in plenty, and men seldom come to disturb them. The islands to the north of Scotland, the Skelig islands off the coasts of Kerry in Ireland, and those that lie in the north sea off Norway, abound with them. But it is on the Bass island, in the Frith of Edinburgh, where they are seen in the greatest abundance. "There is a small island," says the celebrated Harvey, "called the Bass, not more than a mile in circumference. The surface is almost wholly covered during the months of May and June with their nests, their eggs, and young. - It is scarcely possible to walk without treading on them: the flocks of birds upon the wing are so numerous, as to darken the air like a cloud; and their noise is such, that one cannot with-

\footnotetext{
a These birds build their nests on the highest parts of the cliffs that hang over the sea: they lay three or more pale green eggs, about the size of those of a goose. In
}

out difficulty be heard by the person next to lim. When one looks down upon the sea from the precipice, its whole surface seems covered with infinite uumbers of birds of different kinds, swimming and pursuing their prey. If, in sailing round the island, one surveys its hanging cliffs, in every crag, or fissure of the broken rocks, may be seen innumerable birds, of various sorts and sizes, more than the stars of heaven, when viewed in a serene night. If they are viewed at a distance, either receding, or in their appproach to the island, they seem like one vast swarm of bees."

They are not less frequent upon the rocks of St. Kilda. Martin assures us, that the inhabitants of that small island consume annually near twenty-three thousand young birds of this species, besides an amazing quantity of their eggs. On these they principally subsist throughout the year; and from the number of these visitants, make an estimate of their plenty for the season. They.preserve both the cggs and fowls in small pyramidal stone buildings, covering them with turf ashes, to prevent the evaporation of their moisture.

The gannet is a bird of passage. In winter it seeks the more southern coasts of Cornwall, hovering over the shoals of herrings and pilcliards that then come doivn from the northern seas; its first appearance iil the northern islands is in the beginning of spring; and it continues to breed till the end of summer. But, in general, its motions are determined by the migrations of the immense shoals of herrings that come pouring down at that season through the Britisl Channel, anil supply all

winter they disperse themselves along the shores, visiting the fresh-water ponds and lakes, where they commit great depredations among the fish. 
Europe, as well as this bird, with their spoil. The gannet assiduously attends the shoal in their passage, kceps with them in their whole circuit round our island, and shares with our fishermen this exhaustless banquet. $A s$ it is strong of wing, it never comes near the land; but is constant to its prey. Wherever the gannet is seen, it is sure to announce to the fishermen the arrival of the finny tribe: they ther, prepare their nets, and take the herrings by millions at a draught; while the gannet, who came to give the first information, comes, though an unbidden guest, and often snatches its prey from the fisherman even in his boat. While the fishing season continues, the gannets are busily employed; but when the pilchards disappear from our coasts, the gannet takes its leave to keep them company.

The cormorant has been remarked for the quickness of his sight; yet in this the gannet scems to exceed him. It is possessed of a transparent membrane under the eye-lid, with which it covers the whole eye at pleasure, without obscuring the sight in the smallest degree. This seems a liecessary provision for the security of the eyes of so weighty a creature, whose method of taking its prey, like that of the cormorant, is by darting headlong down from a height of a hundred feet and more into the water to seize it. These birds are sometimes taken at sea, by fastening a pilchard to a board, which they leave floating. The gannet instantly pounces down from above upon the board, and is killed or maimed by the shock of a body where it expected no resistance." -

These birds breed but once a year, and lay but one egg, which being taken away, they lay another; if that is also taken, then a third; but never more for that season. Their egg is white, and rather less than that of the common goose; and their nest large, composed of such substances as are found floating on the surface of the sea. The young birds, during the first year, differ greatly in colour from the old ones; being of a dusky hue, speckled with numerous triangular white spots; and at that time resembling the colours of the speckled diver.

The Bass island, where they chiefly breed, belongs to one proprietor; so that care is ta: ken never to fright away the birds when lay. ing, or to shoot them upon the wing. By that means, they are so confident as to alight and feed their young ones close beside you. They feed only upon fish, as was observed; yet the young gamet is counted a great dainty by the Scots, and is sold very dear; so that the lord of the islet makes a considerable annual profit by the sale.

\section{CHAPTER CXXVII.}

\section{OF THE SMALLER GULLS AND PETRELS.}

HAVING described the manners of the great ones of this tribe, those of the smaller kinds may be easily iuferred. They resemble the more powerful in their appetites for prey, but have not such certain methods of obtaining it. In general, therefore, the industry of this tribe, and their audacity, increase in proportion to their imbecility; the great gulls live at the most remote distance

ar. Pennant says, that one of these birds flying over Penzance in Cornwall, saw some pilchards lying on a fir plank, where they had been placed for curing; and dart- from man; the smaller are obliged to reside wherever they can take their prey; and to come into the most populous places, when solitude can no longer grant them a supply. In this class we may place the Gull, properly so called, of which there are above twenty different kinds; the Petrel, of which there are three; and the Sea-swallow, of which there are as many. The gulls may be distinguish-

ing itself down with great violence, it struck its bill quite through an inch and quarter plank it was killed on the spot. 
ed by an angular knob on the lower chap; the petrels by their wanting this knob; and the sea-swallow by their bills, which are straight, sleuder, and sharp-pointed. They all, however, agree in their appetites, and their places of abode.

The gull, and all its varieties, is very well known in every part of the kingdom. It is seen with a slow-sailing flight, hovering over rivers to prey upon the smaller kinds of fish; it is seen following the ploughman in fallow fields to pick up insects; and when living animal food does not offer, it has been known to eat carrion, and whatever else of the kind that offers. Gulls are found in great plenty in every place; but it is chiefly round our boldest rockiest shores that they are seen in the greatest abundance; it is there that the gull breeds and brings up its young; it is there that millions of them are heard screaming with discordant notes for months together.

Those who have been much upon our coasts know that there are two different kinds of shores; that which slants down to the water with a gentle declivity, and that which rises with a precipitate boldness, and seems set as a bulwark to repel the force of the invading deeps. It is to such shores as these that the whole tribe of the gull-kind resort, as the rocks offer them a retreat for their young, and the sea a sufficient supply. It is in the cavities of these rocks, of which the shore is composed, that the vast variety of sea-fowls retire to breed in safety. The waves beneath, that continually beat at the base, often wear the shore into an impending boldness; so that it seems to jut out over the water, while the raging of the sea makes the place inaccessible from below. These are the situations to which sea-fowl chiefly resort, and bring up their young in undisturbed security.

Those who have never observed our boldest coasts, have no idea of their tremendous sublimity. The boasted works of art, the highest towers, and the noblest domes, are but ant-hills when put in comparison: the single cavity of a rock of ten exhibits a coping higher than the ceiling of a Gothic Cathedral. The face of the shore offers to the view a wall of massive stone, ten times higher than our tallest stceples. What should we think of a precipice three quarters of a mile in height? and yet the rocks of St. Kilda are still higher! What must be our awe to approach the edge of that impending height, and to look down on the unfathomable vacuity below; to ponder on the terrors of falling to the bottom, where the waves that swell like mountains are scarcely seen to curl on the surface, and the roar of an ocean a thousand leagues broad appears softer than the murmur of a brook! it is in these formidable mansions that myriads of sea-fowls are for ever seen sporting, flying in security down the depth, half a mile beneath the feet of the spectator. The crow and the chough avoid those frightful precipices; they choose smaller heights, where they are less exposed to the tempest; it is the cormorant, the gannet, the tarrock, and the terne, that venture to these dreadful retreats, and claim an undisturbed possession. To the spectator from above, those birds, though some of them are above the size of an eagle, seein scarcely as large as a swallow; and their loudest screaming is scarcely perceptible.

But the generality of our shores are not so formidable. Though they may rise two hundred fathoms above the surface, yet it often happens that the water forsakes the shore at the departure of the tide, and leaves a noble and delightful walk for curiosity on the beach. Not to mention the variety of shells with which the sand is strewed, the lofty rocks that hang over the spectator's head, and that seem but just kept from falling, produce in him no unpleasing gloom. If to this be added the fluttering, the screaming, and the pursuits of myriads of water-birds, all either intent on the duties of incubation, or roused at the presence of a stranger, nothing can compose a scene of more peculiar solemnity. To walk along the shore when the tide is departed, or to sit in the hollow of a rock when it is come in, attentive to the various sounds that gather on every side, above and below, may raise the mind to its highest and noblest exertions. The solemn roar of the waves swelling into and subsiding from the vast caverns beneath, the piercing note of the gull, the frequent chatter of the guillemot, the loud note of the hawk, the scream of the heron, and the hoarse deep periodical croaking of the cormorant, all unite to furnish out the 
grandeur of the scene, and turn the mind to нIм who is the essence of all sublimity.

Yet it often happens that the contemplation ol a sea-shore produces ideas of an humbler kind, yet still not unpleasing. The various arts of these birds to seize their prey, and sometines to elude their pursuers, their society among each other, and their tenderness and care of their young, produce gentler sensations. It is ridiculous also now and then to see their various ways of imposing upon each other. It is common enough, for instance, with the arctic gull, to pursue the lesser gulls so long, that they drop their excrements through fear, which the hungry lunter quickly gobbles up before it ever reaches the water. In breeding too they liave frequent contests; one bird who has no nest of her own, attempts to dispossess another, and puts herself in the place. This often happens among all the gull kind : and I have seen the poor bird, thus displaced by her more powerful invader, sit near the nest in pensive discontent, while the other seemed quite comfortable in lier new habitation. Yet this place of pre-eminence is not easily obtained; for the instant the invader goes to snatch a momentary sustenance, the other enters upon her own, and always ventures another battle before she relinquishes the justness of her claim. The contesnplation of a cliff thus covered with hatching-birds, affords a very agrecable entertainment; and as they sit upon the ledges of the rocks, one above another, with their white breasts forward, the whole group has not unaptly been conpared to an apothecary's shop.

These birds, like all others of the rapacious kind, lay but few eggs; and hence, in many places, their number is daily seen to diminish. The lessening of so many rapacious birds may, at first sight, appear a benefit to mankind; but when we consider how many of the natives of our islands are sustained by their flesh, either fresh or salted, we shall find no satisfaction in thinking that these poor people may in time lose their chief support. The gull, in general, as was said, builds on the ledges of rocks, and lays from one egg to three, in a nest formed of long grass and sca-weed. Most of the kind are fishy tasted, with black stringy flesh; yet the young ones are better food: and of these, with several other birds of the penguin kind, the poor inhabitants of our northern islands make their wretched banquets. They have been long used to no other food; and even salted gull can be relished by those who know no better. Almost all delicacy is a relative thing; and the man who repines at the luxuries of a well-served table, starves not for want, but from comparison. The luxuries of the poor are indeed coarse to us, yet still they are luxuries to those ignojant of better; and it is probable enough that a Kilda or a Feroe inan may be found to exist, outdoing Apicius himself in consulting the pleasures of the table. Indeed, if it be true that such meat as is the most dangerously carned is the sweetest, no men can dine so luxuriously as these, as none venture so hardily in the pursuit of a dimier. In Jacobson's History of the Feroe islands, we have an account of the method in which those birds are taken; and $I$ will deliver it in his own simple manner.

"It cannot be expressed with what pains and danger they take these birds in those high steep cliffs, whereof many are two hundred fathoms high. But there are men apt by nature, and fit for the work, who take them usually in two manners: they either climb from below into these high promontories, that are as steep as a wall; or they let themselves down with a rope from above. When they climb from below, they have a pole five or six ells long with an iron hook at the end, which they that are below in the boat, or on the cliff, fasten unto the man's girdle, helping him up thus to the highest place where he can get footing; afterwards they also help up another man; and thus several climb up as high as they possibly can; and, where they find difficulty, they help each other up, by thrusting one another up with their poles. When the first bath taken footing, he draws the other up to him, by the rope fastened to his waist; and so they proceed, till they come to the place where the birds build. They there go about as well as they can in those dangerous places; the one holding the rope at one end, and fixing himself to the rock; the other going at the other end from place to place. If it should happen that he chan. 
ceth to fall, the other that stands firm kecps him up, and helps him up again. But if he passeth safe, he likewise fastens himself till the other has passed the same dangerous place also. Thus they go about the cliffs after birds as they please. It often liappeneth, however, (the inore is the pity) that when one doth not stand fast enough, or is not sufficiently strong to hold up the other in his fall, that they both fall down, and are killed. In this manuer some do perish every year."

Mr. Peter Clanson, in his description of Norway, writes, that there was anciently a law $\cdot$ in that country, that whosocver climbed so on the cliffs that he fell down and dicd, if the body was found before burial, his next kinsman should go the same way; but if he durst not, or could not do it, the dead body was not then to be buried in sanctified eartl, as the person was too full of temerity, and his own destroyer.

"When the fowlers are come, in the manner aforesaid, to the birds within the cliffs, where people seldom come, the birds are so taine, that they take them with their liands; for they will not readily leave their young. But when they are wild, they cast a net, with which they are provided, over them, and entangle, them thercin. In the mean time, there lieth a boat beneath in the sea, wherein they cast the birds killed; and, in this manner, they can in a short time fill a boat with fowl. When it is pretty fair weather, andthere is good fowling, the fowlers stay in the cliff seven or eight days together; for there are here and there holes in the rocks, where they can safely rest; and they have meat let down to them with a line from the top of the mountain. In the mean t im some go every day to them, to fetch home what they have taken.

"Some rocks are so difficult, that they can in no manner get unto them from below; wherefore they seek to come down thereunto from above. For this purpose they have a rope eighty or a hundred fathoms long, made of hemp, and three fingers thick. The fowler maketh the end of this fast about his waist, and between his legs, so that he can sit thereon; and is thus let down, with the fowlingstaff in his hand. Six men hold by the rope, and let him easily down, laying a large piece of wood on the brink of the rock, upon which the rope glideth, that it may not be worn to pieces by the hard and rough edge of the stone. 'They have, besides, another small line, that is fastened to the fowler's body; on which he pulleth, to give then notice how they should let down the great rope, either lower or higher; or to hold still, that he may stay in the place whereunto he is come. Here the man is in great danger, because of the stones that are loosencd from the cliff, by the swinging of the rope, and he cannot avoid them. To remedy this, in some measure, he hath usually on his head a seaman's thick and shaggy cap, which defends him from the blows of the stones, if they be not too big; and then it costeth him his life : nevertheless, they continually put themselves in that danger, for the wretched body's food sake, lıoping in God's mercy and protection, unto which the greatest part of them do devoutly recommend themselves when they go to work: otherwise, they say, there is no other great danger in it, except that it is a toilsone and artificial labour; for he that hath not learned to be so let down, and is not used thereto, is turned about with the rope, so that he soon growerh giddy, and can do nothing; lut he that hath learned the art, considers it as a sport, swings himself on the rope, sets his fect against the rock, casts himself some fatloms from thence, and shoots himself to what place lie will : he knows where the birds are, lie understands how to sit on the line in the air, and how to hold the fowling-staff in lis hand; striking therewith the birds that come or fly away: and when there are looles in the rocks, and it stretches itself out, making underneath as a cciling under which the birds are, he knoweth how to slioot himself in among then, and there take firm footing. There, when he is in these boles, he maketh himself loose of the rope, which he fastens to a crag of the rock, that it may not slip from him to the outside of the cliff. He then goes about in the rock, taking the fowl either with his hands or the fowling-staff. Thus, when he hath killed as many hirds as he thinks fit, lie ties them in a bundle, and fastens then to a little rope, giving a sign, by pulling, that they should draw them up. When he has wrought thus the whole day, and desires to get up again, he siteth once more upon the grent rope, giving a new sign that they should pull hiul $11 \mathrm{p}$; ol else lue worketh himself up, climbing along the rope, with his girdle full of birds. It is 
also usual, where there are not folks enough to hold the great rope, for the fowler to drive a post sloping into the earth, and to make a rope fast therefore, by which he lets himself down without any body's help, to work in the manner aforesaid. Some rocks are so formed that the person can go into their cavities by land.

"These manners are more terrible and dangerous to see than to describe; especially if one considers the steepness and height of the rocks, it seeming impossible for a man to approach them, much less to climb or descend. In sone places, the fowlers are seen climbing where they can only fasten the ends of their toes and fingers; not shunning such places, though there be a hundred fathom between them and the sea. It is a dear meat for these poor people, for which they must venture their lives; and many, after long venturing, do at last perish therein.

"When the fowl is brought home, a part thereof is eaten fresh; another part, when there is much taken, being hung up for winter provision. The feathers are gathered to make merchandise of, for other expenses. The inhabitants get a great many of these fowls, as God giveth his blessing and fit weather. When it is dark and hazy, they take most; for then the birds stay in the rocks: but in clear weather, and hot sun-shine, they seek the sea. When they prepare to depart for the season, they keep themselves most there, sitting on the cliffs towards the seaside, where pcople get at them sometimes with boats, and take them with fowling-staves."

Such is the account of this historian; but we are not to suppose that all the birds caught in this manner are of the gull-kind: on the contrary, numbers of them are of the penguin kind; auks, puffins, and guillemots. These all come, once a season, to breed in these recesses; and retire in winter to fish in more southern climates.

\section{CHAPTER CXXIX.}

\section{OF THE PENGUIN KIND: AND FIRST, OF THE GREAT MAGELLANIC PENGUIN.}

THE gulls are long-winged, swift flyers, that hover over the most extensive seas, and dart down upon such fish as approach too near the surface. The penguin kind are but ill fitted for flight, and still less for walking. Every body must have seen the awkward manner in which a duck, cither wild or tame, attempts to change place: they must recollect with what softness and ease a gull or a kite waves its pinions, and with what a coil and flutter the duck attempts to move them; low many strokes it is obliged to give, in order to gather a little air; and even when it is thus raised, how soon it is fatigued with the force of its exertions, and obliged to take rest again. But the duck is not, in its natural state, half so unwieldy an animal as the whole tribe of the penguin kind. Their wings are much shorter, more scantily furnished with quills, and the whole pinion placed too forward to be usefully employed

พo. $49 \& 50$.
For this reason, the largest of the penguin kind, that have a thick heavy body to raise, cannot fly at all. Their wings serve them rather as paddles to help them forward, when they attempt to move swiftly, and in a manner walk along the surface of the water. Even the smallest kinds seldom fly by choice; they flutter their wings with the swiftest efforts without making way; and though they have but a small weight of body to sustain, yet they seldom venture to quit the water, where they are provided with food and protection.

As the wings of the penguin tribe are unfitted for flight, their legs are still nore awkwardly adapted for walking. This whole tribe have all above the knee hid within the belly: and nothing appears but two short legs, or feet, as some "would call them, that scem stuck under the rump, and upon which the animal is very awkwardly supported.

$4 P$ 
They seem, when sitting, or attempting to walk, like a dog that has been laught to sit up, or to move a minuet. Their short legs drive the body in progression from side to side; and were they not assisted by their wings, they could scarcely move faster than a tortoise.

This awkward position of the legs, which so unqualifies them for living upon land, adapts them admirably for a residence in water. In that, the legs placed behind the moving body, pushes it forward with the greater velocity; and these birds, like Indian canoes, are the swiftest in the water, by having their paddles in the rear. Our sailors, for this reason, give these birds the very homely, but expressive, name of arse-feet.

Nor are they less qualified for diving than swimming. By ever so little inclining their bodies forward, they lose their centre of gravity; and every stroke from their feet only tends to sink them the faster. In this manner they can either dive at once to the bottom, or swim between two waters; where they continue fishing for some minutes, and then ascending, catch an instantaneous breath, to descend once more to renew their operations. Hence it is, that these birds, which are so defenceless, and so easily taken by land, are impregnable by water. If they perceive themselves pursued in the least, they instantly sink, and show nothing more than their bills, till the enemy is withdrawn. Their very internal conformation assists their power of keeping long under water.' 'Their lungs are fitted with numerous vacuities, by which they can take in a very large inspiration; and this probably serves them for a length of time.

As they never visit land, except when they come to breed, their feathers take a colour from their situation. That part of them which has been continually bathed in the water, is white; while their backs and wings are of different colours, according to the different species. They are also covered more warmly all over the body with feathers, than any other birds whatever; so that the sea seems entirely their element: and but for the necessary duties of propagating their spccies, we should scarcely have the smallest opportunity of seeing them, and should be utterly unacquainted with their listory.
Of all this tribe, the Magellanic Penguin is the largest, and the most remarkable. In size it approaches near that of a tame goose. It never flies, as its wings are very short, and covered with stiff hard feathers, and are always seen expanded, and hanging uselessly down by the bird's sides. The upper part of the head, back, and rump, are covered with stiff black feathers; while the belly and breast, as is common with all of this kind, are of a snowy whiteness, except a line of black that is seen to cross the crop. The bill, which from the base to about half way is covered with wrinkles, is black, but marked crossway with a stripe of yellow. They walk erect, with their heads on high, their fin-like wings hanging down like arms; so that to see them at a distance, they look like so many children with white aprons. From hence they are said to unite in themselves the qualities of men, fowls, and fishes. Like men, they are upright; like fowls, they are feathered; and like fishes, they have fin-like instruments, that beat the water before, and serve for all the purposes of swimming, rather than flying.

They feed upon fish; and seldom come ashore, except in the breeding-scason. As the seas in that part of the world abound with a variety, they seldom want food; and their extreme fatness seems a proof of the plenty in which they live. They dive with great rapidity, and are voracious to a great degree. One of them, described by Clusius, thongh but very young, would swallow an entire herring at a mouthful, and often three successively before it was appeased. In consequence of this gluttonous appetite, their flesh is rank and fishy; though our sailors say, that it is pretiy good eating. In some the flesh is so tough, and the feathers so thick, that they stand the blow of a scimetar without injury.

They are a bird of society; and, especially when they come on shore, they are seen drawn up in rank and file, upon the ledge of a rock, standing together with the albatross, as if in consultation. This is previous to their laying, which generally begins, in that part of the world, in the month of November. Their preparations for laying are attended with no great trouble, as a small depression in the earth, without any other nest, serves for this purpose. The waruth of their fea- 
thers and the heat of their bodies is such, that the progress of incubation is carried on very rapidly.

But there is a difference in the manner of this bird's nestling in other countries, which I can only ascribe to the frequent disturbances it has received from man or quadrupeds in its recesses. In some places, instead of contenting itself with a superficial depression in the earth, the penguin is found to burrow two or three yards deep:- in other places it is seen to forsake the level, and to clamber up the ledge of a rock, where it lays its egg, and hatches it in that bleak exposed situation. These precautions may probably have been taken, in consequence of dear-bought experience. In those countries where the bird fears for her own safety, or that of her young, she may providently provide against danger, hy digging, or even by climbing; for both which she is but ill adapted by nature. In those places, however, where the penguin has had but few visits from man, her nest is made, with the most confident security, in the middle of some large plain, where they are seen by thousands. In that unguarded situation, neither expecting nor fearing a powerful enemy, they continue to sit brooding; and even when man comes among them, have at first no apprehension of their danger. Some of this tribe have been called, by our seamen, the Booby, from the total insensibility which they show when they are sought to their destruction. But it is not considered that these birds have never been taught to know the dangers of a human enemy : it is against the fox or the vulture that they have learned to defend themselves; but they have no idea of injury from a being so very unlike their natural opposers. The penguins, therefore, when our seamen first came among them, tamely suffered themselves to be knocked on the head, without even attempting an escape. They have stood to be shot at in flocks, without offering to move, in silent wonder, till every one of their number has been destroyed. Their attachment to their nests was still more powerful; for the females tamely suffered the men to approach and talie their eggs, without any resistance. But the experience of a few of those unfriendly visits, has long since taught them to be more upon their guard in choosing their situations; or to leave those retreats where they were so little able to oppose their invaders.

The penguin lays but one egg; and, in frequented shores, is found to burrow like a rabbit : sometimes three or four take possession of one hole, and hatch their young together. In the holes of the rocks, where nature has made them a retreat, several of this tribe, as Linnæus assures us, are seen together. There the females lay their single egg, in a common nest, and sit upon this, their general possession, by turns; while one is placed as a centinel, to give warning of approaching danger. The egg of the penguin, as well as of all this tribe, is very large for the size of the bird, being generally found bigger than that of a goose. But as there are many varieties of the penguin, and as they differ in size, from that of a Muscovy duck to a swan, the eggs differ in the same proportion.

\section{CHAPTER CXXX .}

\section{OF THE AUK, PUFFIN, AND OTHER BIRDS OF THE PENGUIN KIND.}

OF a size far inferior to the penguin, but with nearly the same form, and exactly of the same appetites and manners, there is a very numerous tribe. These frequent ourshores, and, like the penguin, have their legs placed behind. They have short wings, which are not totally incapable of flight; with round bills for seizing their prey, which is fish. They live upon the water, in which they are continually seen diving; and seldom venture upon land, except for the purposes of continuing their kind. 
The first of this smaller tribe is the Great Northern Diver, which is nearly the size of a goose: it is beautifully variegated all over with many stripes, and differs from the penguin, in being much slenderer, and more elegantly formed. The Gray Speckled Diver does not exceed the size of a Muscovy Duck; and, except in size, greatly resembles the former. The Auk, which breeds on the islands of St. Kilda, and chiefly differs from the penguin in size and colour, is smaller than a duck; and the whole of the breast and belly, as far as the middle of the throat, is whitc. The Guillemot is about the same size; it differs from the auk, in having a longer, a slenderer, and a straighter bill. The ScarletThroated Diver may be distinguished by its name; and the Puffin, or Coulterneb, is one of the most remarkable birds we know.

Words cannot easily describe the form of the bill of the puffin, which differs so greatly from that of any other bird. Those who have seen the coulter of a plough, may form some idea of the beak of this odd-looking animal. The bill is flat; but, very different from that of a duck, its edge is upwards: it is of a triangular figure, and ending in a sharp point, the upper chap bent a little downward, where it is joined to the head; and a certain callous substance encompassing its base, as in parrots. It is of two colours; ash-coloured near the base, and red towards the point. It has three furrows or grooves impressed in it; one in the livid part, two in the red. The eyes are fenced with a protuberant skin, of a livid colour; and they are gray or. ashcoloured. These are marks sufficient to distinguish this bird by; but its value to those in whose vicinity it breeds, renders it still more an object of curiosity.

The puffin, like all the rest of this kind, has its legs thrown so far back, that it can hardly move without tumbling. This makes it rise with difficulty, and subject to many falls before it gets upon the wing: but as it is a small bird, not much bigger than a pigeon, when it once rises, it can continue its flight with great celerity.

Both this and all the former build no nest: but lay their eggs either in the crevices of rocks, or in holes under ground near the shore. They chiefly choose the latter situation; for the puffin, the auk, the guillemot, and the rest, cannot easily rise to the nest when in a lofty situation. Many are the attempts these birds are scen to make to fly up to those nests which are so high above the surface. In rendering them inaccessible to mankind, they often render them almost inaccessible to themselves. They are frequently obliged to make three or four efforts, before they can come at the place of incubation. For this reason, the auk and guillemot, when they have once laid their single egg, which is extremely large for the size, seldom forsake it until it is excluded. The male, who is better furnished for flight, feeds the female during this interval; and so bare is the place where she sits, that the egg would often roll down from the rock, did not the body of the bird support it.

But the puffin seldom chooses these inaccessible and troublesome heights for its situation. Relying oni its courage and the strength of its bill, with which it bites most terribly, it either makes or finds a loole in the ground, where to lay and bring forth its young. All the winter these birds, like the rest, are absent; visiting regions too remote for discovery. At the latter end of March, or the beginuing of April, come over a troop of their spies or harbingers, that stay two or three days, as it were to view and search out for their former siluations, and see whether all be well. This clone, they once more depart; and, about the beginning of May, return again with the whole army of their companions. But if the season happens to be stormy and tempestuous, and the sea troubled, the unfortunate voyagers undergo incredible hardships; and they are found, by hundreds, cast away upon the shores, lean and perished with

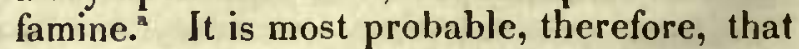
this voyage is performed more on the water than in the air; and as they cannot fish in stormy weather, their strength is exhausted before they can arrive at their wished-for harbour.

The puffin, when it prepares for breeding, which always happens a few days after its arrival, begins to scrape up a hole in the ground not far from the shore, and when it has some way penetrated the earth, it then throws itself

ailloughby's Ornith. p. 326. 
apon its back, and with bill and claws thus burrows inward, till it has dug a hole with several windings and turnings, from eight to ten feet deep. It particularly seeks to ilig under a stone, where it expects the greatest security. In this fortified retreat it lays one egg; which, though the bird be not much bigger than a pigeon, is of the size of a hen's.

When the young one is excluded, the parent's industry and courage is incredible. Few birds or beasts will venture to attack them in their retreats. When the great searaven, as Jacobson informs us, comes to take away their young, the puffins boldly oppose him. Their meeting affords a most singular combat. As soon as the raven approaches, the puffin catches him under the throat with its beak, and sticks its claws into his breast, which makes the raven, with a loud screaming, attempt to get away; but the little bird still holds fast to the invader, nor lets bim go till they both come to the sea, where they drop down together, and the raven is drowned; yet the raven is but too often successful; and, invading the puffin at the bottom of its hole, devours both the parent and its family.

But were a punishment to be inflicted for immorality in irrational animals, the puffir is justly a sufferer from invasion, as it is often itself one of the most terrible invaders. Near the isle of Anglesey, in an islet called Priesholm, their flocks may be compared, for multitude, to swarms of bees. In another islet, called the Calf of Man, a bird of this kind, but of a different species, is seen in great abundance. In both places, numbers of rabbits are found to breed; but the puffin, unwilling to be at the trouble of making a hole, when there is one ready made, disposesses the rabbits, and it is not unlikcly destroys their young. It is in these unjustly acquired retreats that the young puffins are found in great numbers, and become a very valuable acquisition to the natives of the place. The old ones (I am now speaking of the Manks puffin) early in the morning, at break of day, leave their nests and young, and even the island, nor do they return till night-fall. All this time they are diligently employed in fishing for their young; so that their retreats on land, which in the morning were loud and clamorous, are now still and quiet, with not a wing stirring till the approach of dusk, when their screams once more announce their return. Whatever fish, or other food, they have procured in the day, by night begins to suffer a kind of half digestion, and is reduced to an oily matter, which is ejected from the stomach of the old ones into the mouth of the young. By this they are nourished, and become fat to an amazing degree. When they are arrived to their full growth, they who are entrusted by the lord of the island, draw them from their holes; and, that they may more readily keep an account of the number they take, cut off one foot as a token. Their flesh is said to be excessively rank, as they feed upon fish, especially sprats, and sea-weed; however, when they are pickled and preserved with spices, they are admired by those who are fond of high eating. We are told, that formerly their flesh was allowed by the church on Lenten days. They were, at that time, also taken by ferrets, as we do rabbits. At present, they are either dug out, or drawn out, from their burrows, with an hooked stick. They bite extremely hard, and keep such fast hold of whatsoever they seize upori, as not to he easily disengaged. Their noise, when taken, is very disagreeable, being like the efforts of a dumb pcrson attempting to speak.

The constant depredation whicl these birds annually suffer, does not in the least seem to intimidate them, or drive them away; ou the contrary, as the people say, the nest must be robbed, or the old ones will breed there no longer. All birds of this kind lay but one egg; yet if that be taken away, they will lay another, and so on to a third; which seems to imply, that robbing their nests does not much intimidate them from laying again. Those, however, whose riests have been thus destroyed, are often too late in bringing up their young: who, if they be not fledged and prepared for migration when all the rest llepart, are left at land to shift for themselves. In August the whole tribe is seen to take leave of their summer residence; nor are they observed any more till the return of the cnsuing spring. It is probable that they sail away to more southern regions, as our mariners frequently see myriads of water-fowl npon their return, and steering usually to the north. In- 
deed the coldest countries secm to be their most favoured retreats; and the number of water-fowl is much greater in those colder climates, than in the warmer regions near the line. The quantity of oil which abounds in their bodies, serves as a defence against cold, and preserves them in vigour against its severity; but the same provision of oil is rather detrimental in warm countries, as it turns rancid, and many of them dic of disorders which arise from its putrefaction. In general, however, water-fowl can be properly said to be of no climatc; the element upon which they live, being their proper residence. They necessarily spend a few months of summer upon land, to bring up their young; but the rest of their time is probably consumed in their migrations, or near some unknown coasts, where their provision of fish is found in greatest abundance.

Before I go to the third general division of water-fowls, it may not be improper to observe, that there is one species of round-billed waterfowl, that does not properly lie within any of the former distributions. T'his is the Gooseander; a bird with the body and wings shaped like those of the penguin kind, but with legs not hid in the belly. It may be distinguished from all others by its bill, which is round, hooked at the point, and tonthed, both upper and under chap, like a saw. Its colours are various and beautiful: however, its manners and appetites entirely resemble those of the diver. It feeds upon fish, for which it dives; and is said to build its nest upon trees, like the heron and the cormorant. It seems to form the shade between the penguin and the goose kind; having a round bill like the one ; and unembarrassed legs, like the other. In the shape of the head, neck, and body, it resembles them both.

\section{CHAPTER CXXXI.}

\section{OF BIRDS OF THE GOOSE KIND, PROPERLY SO CALLED.}

THE Sivan, the Goose, and the Duck, are leaders of a numerous, useful, and beautiful tribe of birds, that we have reclaimed from a state of nature, and have taught to live in clependence about us. To describe any of these, would be as superfluous as definitions usually are when given of things with which we are already well acquainted. There are few that have not had opportunities of secing thenı, and whose ideas would not anticipate our description. But, though nothing be so easy as to distinguish these in general from each other, yet the largest of the duck kind approach the goose so nearly, that it may be proper to mark the distinctions.

The inarks of the goose are, a bigger body, large wings, a longer neck, a white ring about the rump, a bill thicker at the base, slenderer towards the tip, with shorter legs, placed more forward on the body. They both have a waddling walk; but the duck, from the position of its legs, has it in a greater degree. By these marks, these similar tribes may be known asunder; and though the duck should be found to equal the goose in size, which sometimes happens, yet there are still other sufficient distinctions.

But they all agree in many particulars; and have a nearer affinity to each other than the neighbouring kinds in any other department. Their having been tamed, has produced alterations in each, by which they differ as much from the wild ones of their respective kinds, as they do among themselves. There is nearly as much difference between the wild and the tame duck, as between some sorts of the duck and the goose; but still the characteristics of the kind are strongly marked and obvious; and this tribe can never be mistaken.

The bill is the first great obvious distinction of the goose kind from all of the feathered tribe. In other birds it is round and wedgelike, or crooked at the end. In all the goose kind it is flat and broad, made for the purpose of skimming ponds and lakes of the mantling weeds that stand on the surface. The bills of other birds are made of a horny substance throughout; these have their inoffensive bills 
sheathed with a skin which covers them all over. The bill of every other bird seems, in some measure, formed for piercing or tearing; theirs are only fitted for shovelling up their food, which is chiefly of the vegetable kind.

Though these birds do not reject animal food when offered them, yet they can contentedly subsist upon vegetables, and seldom seek any other. They are easily provided for; wherever there is water, there seems to be plenty. All the other iveb-footed tribes are continually voracious, continually preying. These lead more harmless lives: the weeds on the surface of the ivater, or the insects at the bottom, the grass by the bank, or the fruits and corn in cultivated grounds, are sufficient to satisfy their easy apperites: yet these, like every other animal, will not reject flesh, if properly prepared for them; it is sufficient praise to them that they do not eagerly pursue it.

As their food is chiefly vegetables, so their fecundity is in proportion. We have had frequent opportunities to obscrve, that all the predatory tribes, whether of birds or quadrupeds, are barren and unfruitful. We have seen the lion with its two cubs; the eagle with the same number; and the penguin with even but one. Nature, that has supplied them with powers of destruction, has denied them fertility. But it is otherwise with these harmless animals I am describing. They seem formed to fill up the chasins in animated nature, caused by the voraciousness of others. They breed in great abundance, and lead their young to the pool the instant they are excluded.

As their food is simple, so their flesh is nourishing and wholesome. The swan was considered as a high delicacy among the ancients; the goose was abstained from as totally indigestible. Modern manners linve inverted tastes; the goose is now become the favourite; and the swan is seldom brought to table, unless for the purposes of ustentation. But at all times the flesh of the duck was in high esteem; the ancients thought even more highly of it than we do. We are contented to eat it is as a delicacy; they also considered it as a medicine; and Plutarch assures us, that Cato kept his whole family in health, by feeding then with duck whenever they threatened to be out of order.

These qualities, of great fecundity, easy sustenance, and wholesone nourishment, have been found so considerable, as to induce man to take these birds from a state of nature, and render them domestic. How long they have been thus dependents upon his pleasures is not known; for, from the earliest accounts, they were considered as familiars about him. The time $m$ ust have been very remote; for there have been many changes wronght in their colours, their figures, and even their internal parts, by human cultivation. The different kinds of these birds, in a wild state, are simple in their colourings: when one has seen a wild goose or a wild duck, a description of its plumage will, to a feather, exactly correspond with that of any other. But in the tame kinds no two of any species are exactly alike. Different in their size, their colours, and frequently in their general form, they seem the mere creatures of art; and having been so long dependent upon man for support, they seem to assume forms entirely suited to his pleasures or necessities.

\section{CHAPTER CXXXII.}

\section{OF THE SWAN, TAME AND WILD.}

NO bird makes a more indifferent figure upon land, or a more beautiful one in the water, than the Swall. When it ascends from its favourite element, its motions are awkward, and its neck is stretched forward with an air of stupidity; but when it is seen sinoothly sailing along the water, commanding a thousand graceful attitudes, noving at pleasure without the smallest effort; "when it proudly rows its state," as Milton has it, "with arched neck, between its white wings mantling," there is not a more beautiful figure in all na- 
ture. In the exhibition of its form, there are no broken or harsh lines, no constrained or catching inotions; but the roundest contours, and the easiest transitions; the eye wanders over every part with insatiable pleasure, and every part takes a new grace with a new motion.

This fine bird has long been rendered domestic; and it is now a doubt whether there be any of the tame kind in a state of nature. The wild swan, though so strongly resembling this in colour and form, is yet a different bird; for it is very differently formed within. The wild swan is less than the tame by almost a fourth; for as the one weighs twenty pounds, the other only weighs sixteen pounds and three quarters. The colour of the tame swan is all over white; that of the wild bird is, along the back and the tips of the wings, of an ash-colour. But these are slight differences compared to what are found upon dissection. In the tame swan, the windpipe sinks down into the lungs in the ordinary manner; but in the wild, after a strange and wonderful contortion, like what we have seen in the crane, it enters through a hole formed in the breast-bone; and being reflected therein, returns by the same apcrture; and being contracted into a narrow compass by a broad and bony cartilage, it is divided into two branches, which, before they cnter the lungs, are dilated, and, as it were, swollen out into two cavities.

Such is the extraordinary difference between these two animals, which externally seem to be of one species. Whether it is in the power of long-continued captivity and domestication to produce this strange variety, between birds otherwise the same, I will not take upon me to determine. But certain it is, that our tame swan is no where to be found, at least in Europe, in a state of nature.

As it is not easy to account for this difference of conformation, so it is still more difficult to reconcile the accounts of the ancients with the experience of the moderus, concerning the vocal powers of this bird. The tame swan is one of the most silent of all birds; and the wild one has a note extremely loud and disagreeable. It is probahle, the convolutions of the windpipe may contribute to increase the clangor of it; for such is the harshness of its voice, that the bird from thence has been called the hooper. In neither is there the smallest degree of melody; nor have they, for above this century, been said to give specimens of the smallest musical abilities; yet, notwithstanding this, it was the general opinion of antiquity, that the swan was a most melodious bird; and that even to its death, its voice went on improving. It would show no learning to produce what they have said upon the music of the swan: it has already been collected by Aldrovandus; and still more professedly by the Abbe Gedoyn, in the Transactions of the Academy of Belles Lettres. From these accounts it appears, that, while Plato, Aristotle, and Diodorus Siculus, believed the vocality of the swan, Pliny and Virgil seem to doubt that received opinion. In this equipoise of authority $\mathrm{Al}$ drovandus seems to have determined in favour of the Greek philosophers; and the form of the wind pipe in the wild swan, so much resembling a inusical instrument, inclined his belief still more strongly. In aid of this also, came the testimony of Pendasius, who affirmed, that he had often heard swans sweetly singing in the lake of Mantua, as he was rowed up and down in a boat; as also of Olaus Wormius, who professed that many of his friends and scholars had heard them singing. "There was," says he, " in my family, a very honest young man, John Rostorph, a student in divinity, and a Norwedian by nation. This man did, upon his credit, and with the interposition of an oath, solemnly affirm, that once, in the territory of Dronten, as he was standing on the sea-shore, early in the morning, he heard an unusual and sweet murmur, composed of the most pleasant whistlings and sounds; he knew not at first whence they came, or how they were made, for he saw no man near to produce them; but, looking round about him, and climbing to the top of a certain promontory, he there espied an infinite number of swans gathered together in a bay, and making the most delightful harmony; a sweeter in all his life-time he had never heard." These were accounts sufficient at least to keep opinion in suspense, though in contradiction to our own experience : but Aldrovandus, to put, as he supposed, the ques. 
tion past all doubt, gives us the testimony of a countryman of our own, from whom he had the relation. This honest man's name was Mr. George Braun, who assured him, that - nothing was more common in England, than to hear swans sing; that they were bred in great numbers in the sea near London; and that every fieet of ships that returned from their voyages from distant countries, were met by swans, that came joyfully out to welcome their return, and salute them with a loud and cheerful singing! It was in this manner that Aldrovandus, that great and good man, was frequently imposed upon by the designing and the ncedy : his unbounded curiosity dretv round him people of every kind, and his generosity was as ready to reward falsehond as truth.-Poor Aldrovandus! after having spent a vast fortune, for the purposes of enlightening mankind; after having collected more truth, and more falsehood, than any man ever did before him, he little thought of being reduced at last to want bread, to feel the ingratitude of his country, and to die a beggar in a public hospital!

Thus it appears that our modern authorities, in favour of the singing of swans, are rather suspicious, since they are reduced to this $\mathrm{Mr}$. G. Braun, and John Rostorph, the native of a country remarkable for ignorance and credulity. It is probable the ancients had some mythological meaning in ascribing melody to the swan; and as for the moderns, they scareely deserve our regard. The swan, therefore, nıust be content with that share of fame which it possesses on the score of its beauty; since the melody of its voice, without better testimony, will scarcely be adinitted by even the credulous.

This beautiful bird is as delicate in its appetites, as elegant in its form. Its chicf food is corn, bread, herbs growing in the water, and roots and seeds, which are found near the margiı. It prepares a nest in some retired part of the bank, and chiefly where there is an islet in the streant. This is composed of

a species has lately been discovered in New Holland, which at once puts an end "to the proverbial point of a black swan. This rare and eleyant bird, in its general appearance, bears the most striking resemblance to the tame swan, aud has all those gracefully-varying attitudes which so eminently distinguish it from all other inhabi. พо. $51 \& 52$. water-plants, long grass, and sticks; and the niale and female assist in forming it with great assiduity. The swan lays seven or eight eggs, white, mucls larger than those of a goose, with a hard, and sometimes a tuberous, shell. It sits near two montlss before its young are excluded; which are ash-coloured when they first leave the shell, and for some months after. It is not a little dangerous to approach the old ones, when their little family are feeding round them. Their fears, as well as their pride, seem to take the alarm; and they have sometimes been known to give a blow with their pinion, that has broke a man's leg or arm.

It is not till they are a twelvemonth old that the young swans cliange their colour with their plumage. All the stages of this bird's approach to maturity are slow, and seem to mark its longevity. It is two months hatching; a year in growing to its proper size : and if, according to Pliny's observation, that those animals that are longest in the womb are the longest lived, the swan is the longest in the shell of any bird we know, and is said to be remarkable for its longevity. Some say, that it lives three hundred years; and Willoughby, who is in general diffident enough, seems to believe the report. A goose, as he justly observes, has been known to live a hundred; and the swan, from its superior size, and from its harder, firmer flesh, may naturally be supposed to live still longer.

Swans were formerly held in such great esteem in England, that by an act of Edward the Fourth, none, except the son of the king, was permitted to keep a swan, unless possessed of five marks a year. By a subsequent act, the punishment for taking their eggs was inprisonment for a ycar and a day; and a fine at the king's will. At present they are but little valued for the delicacy of their flesh; but many are still preserved for their beanty. We see nultitudes on the Thames and Trent; but uo where greater numbers than on the salt water inlet of the sea near Abbotsbury, in Dorsetshire. ${ }^{a}$

tants of the waters: but the plumage is of a full deep black, with a bill of the finest red, and white quilled feathers. The tip of the upper beak is blackish; and thero is a yellow spot near it: the legs are black, and the feet somewhat paler. 


\section{CHAPTER CXXXIII.}

\section{OF THE GOOSE, AND ITS VARIETIES.}

THE Goose, in its domestic state, exhibits a variety of colours. The wild goose always retains the same marks; the whole upper part is ash-coloured; the breast and belly are of a dirty white; the bill is narrow at the base, and at the tip it is black ; the legs are of a saffron colour, and the claws black. These marks are seldom found in the tame; whose bill is entirely red, and whose legs are entirely brown. The wild goose is rather less than the tame; but both invariably retain a white ring round their tail, which shows that they are both descended from the same original.

The wild goose is supposed to breed in the northern parts of Europe; and, in the beginning of winter, to descend into more temperate regions. They are often seen flying at very great heights, in flocks from fifty to a hundred, and seldom resting by day. Their cry is frequently heard, when they are at an imperceptible distance above us; and this seems bandied from one to the other, as among hounds in the pursuit. Whether this be the note of mutual encouragement, or the necessary consequence of respiration, is doubtful; but they seldom exert it when they alight in these journeys.

Upon their coming to the ground by day, they range themselves in a line, like cranes; and seem rather to have descended for rest, than for other refreshment. When they have sat in this manner for an hour or two, I have heard one of them, with a loud long note, sound a kind of charge, to which the rest punctually attended, and they pursued their journey with renewed alacrity. Their flight is very regularly arranged: they either go in a line abreast, or in two lines, joining in an angle in the middle. I doubt whether the form of their flight be thus arranged to cut the air with greater ease, as is commonly believed ; I ain more apt to think it is to present a smaller mark to fowlers from below. A bullet might easily reach then, if huddled together in a flock, and the same discharge might de- stroy several at once; but, by their manner of flying, no shot from below can affect above one of them; and from the beight at which they fly, this is not easy to be hit.

The Barnacle differs in some respects from both these; being less than either, with a black bill, much shorter than either of the preceding. It is scarcely necessary to combat the idle error of this bird's being bred from a shell sticking to ships' hottoms; it is well known to be hatched from an egg in the ordinary manner, and to differ in very few particulars fiom all the rest of its kind.

The Brent Goose is still less than the former, and not bigger than a Muscovy duck, except that the body is longer. The head, neck, and upper part of the breast, are black ; but about the middle of the neck, on each side, are two small spots or lines of white, which together appear like a ring.

These, and many other varieties, are found in this kind; which agree in one common character of feeding upon vegetables, and being remarkable for their fecundity. Of these, however, the tame goose is the most fruitful. Having less to fear from its enemies, leading a securer and a more pleutiful life, its prolific powers increase in proportion to its ease; and though the wild goose seldom lays above eight eggs, the tame goose is often seen to lay above twenty. The female hatehes her eggs with great assiduity; while the gander visits her tivice or thrice a day, and sometimes drives her off to take her place, where he sits with great state and composure.

But beyond that of all animals is his pride when the young are excluded: he seems then to consider himself as a champion, not only obliged to defend his young, but also to keep off the suspicion of danger; he pursues dogs and men that never atiempt to molest him: and, though the most harmless thing alive, is then the most petulant and provoking. When, in this manner, he has pursued the calf or the mastiff, to whose contempt alone he is indebted 


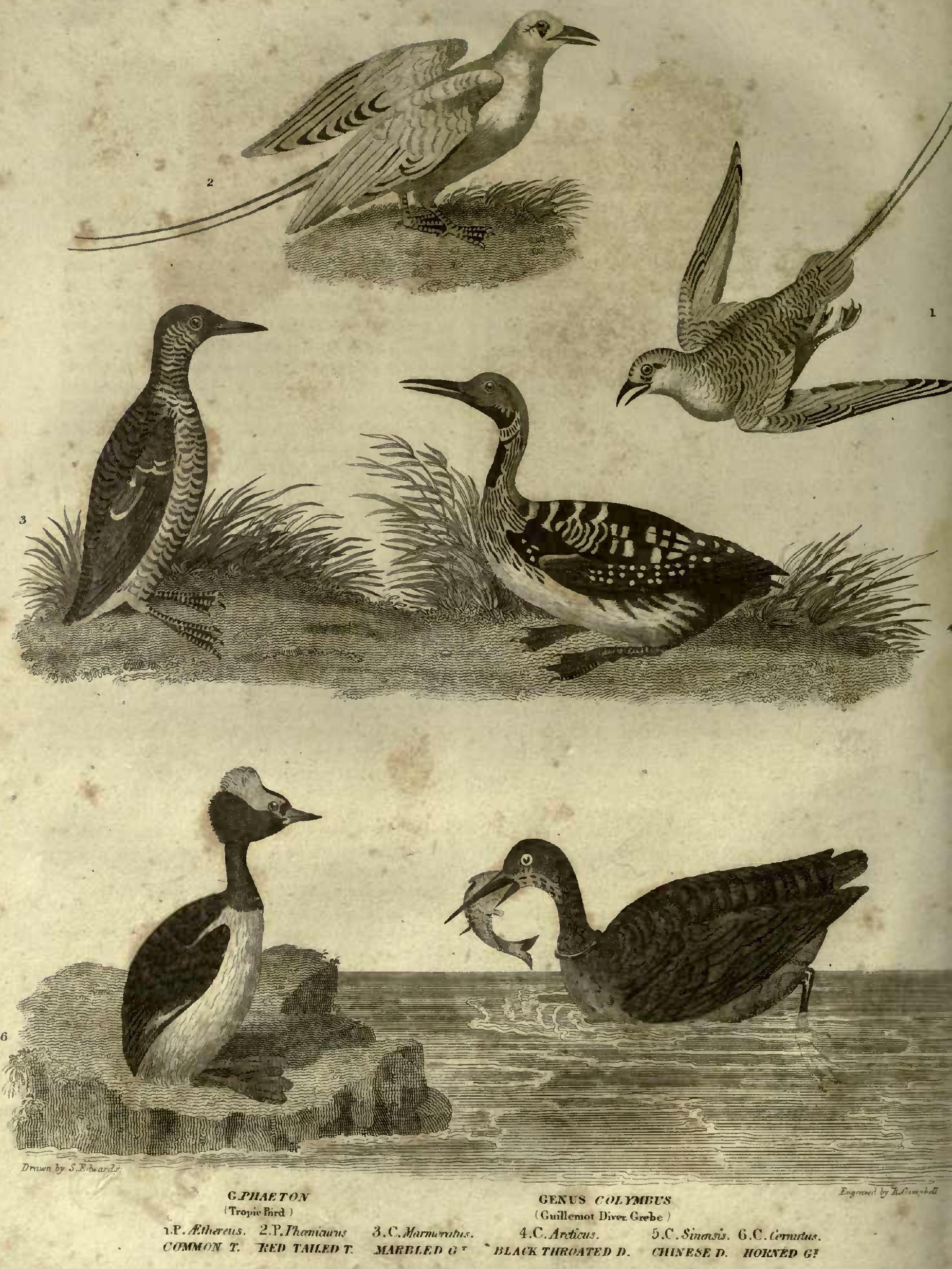


for safety, he returns to his female and her brood in triumph, clapping his wings, screaming, and showing all the marks of conscious superiority. It is probable, however, these arts succeed in raising his importance among the tribe where they are displayed; and it is probable there is not a more respectable aniinal on earth to a goose than a gander!

A young goose is generally reckoned very good eating; yet the feathers of this bird still farther increase its value. I feel my obligations to this animal every word I write; for, however deficient a man's head may be, his pen is nimble enough upon every occasion: it is happy indeed for us, that it requires no great effort to put it in motion. But the feathers of this.bird are still as valuable in another capacity, as they make the softest and the warmest beds to sleep on.

Of goose-feathers most of our beds in Europe are composed; in the countries bordering on the Levant, and in all Asia, the use of them is utterly unknown. They there use mattrasses, stuffed with wool, or camel's hair, or cotton; and the warmth of their climate may perhaps make them dispense with cushions of a softer kind. But how it happens that the ancients lod not the use of featherbeds, is to me surprising: Pliny tells us, indeed, that they made bolsters of feathers to lay their heads on; and this serves as a proof that they turned feathers to no other uses.

As feathers are a very valuable commodity, great numbers of geese are kept tame in the fens in Lincolnshire, which are plucked once or twice a year. These make a considerable article of commerce. The feathers of Somersetshire are most in esteem; those of Ireland are reckoned the worst. Hudson's Bay also furuishes very fine feathers, supposed to be of the goose kind. The down of the swan is brought from Dantzic. The same place also sends us great quantities of the feathers of the cock and hen; but Greenland, Iceland, and Norway, furnish the best feathers of all: and in this number we may reckon the Eider down, of which we shall take notice in its place. The best method of curing feathers, is to lay them in a room, in an open exposure to the sun, and when dried to put them into bags, and beat them well with poles to get the dust off. But, after all, nothing will prevent, for a time, the heary smell which arises from the putrefaction of the oil contained in every feather; no exposure will draw this off, how long soever it be continued; they must be lain upon, which is the only remedy ; and for this reason, old feathers are much more valuable than new.

\section{CHAPTER CXXXIV.}

\section{OF THE DUCK, AND ITS VARIETIES.}

THE Tame Duck is the most easily reared of all our domestic animals. The very instincts of the young ones direct them to their favourite element; and though they are conducted by a heri, yet they despise the admonitions of their leader.

'This serves as an incontestable proof that all birds have their manners rather from nature than education. A falcon pursues the partridge, not because it is taught by the old one, but because its appetites makr their importunate call for animal food: the cuckoo follows a very different trade from that which its nurse endeavoured to teach it; and, if we may credit Pliny, in time destroys its instructor: animals of the duck kind also follow their appetites, not their tutor, and come to all their various perfections without any guide. All the arts possessed by man, are the result of accumulated experience; all the arts of inferior animals are self-taught, and scarcely one acquired by imitation.

It is usual with the good women to lay duckeggs under a hen, because she hatches them better than the original parent would have done. The duck seems to be a heedless in- 
attentive mother; she frequently leaves her eggs till they spoil, and even seems to forget that she is intrusted with the charge: she is equally regardless of them when excluded; she leads them to the pond, and thinks she has sufficiently provided for her offspring when she has shown them the water. Whatever advantages may be procured by coming nearer the house, or attending in the yard, she declines them all; and often lets the vermin, who haunt the waters, destroy them, rather than bring them to take shelter nearer home. The hen is a nurse of a very opposite character; she broods with the utmost assiduity, and generally brings forth a young one from every egg committed to her cliarge; she does not lead her younglings to the water indeed, but she watchfully guards them when there, by standing at the brink. Should the rat, or the weasel, attempt to seize them, the hen can give them protection; she leads them to the house when tired with paddling, and rears up the suppositious brood, without ever suspecting that they belong to another.

The wild duck differs in many respects from the tame; and in them there is still greater variety than among the domestic kinds. Of the tame duck there are not less than ten different sorts; and of the wild, Brisson reckons above twenty. The most obvious distinction between wild and tame ducks is in the colour of their feet: those of the tame duck being yellow, those of the wild duck black. The difference between wild ducks among each other, arises as well from their size as the nature of the place they feed in. Sea-ducks, which feed in salt-water, and dive much, have a broad bill, bending upwards, a large hind-toe, and a long blunt tail. Pondducks, which feed in plashes, have a straight and narrow bill, a small lind-toe, and a sharppointed train. The former are called, by our decoymen, foreign ducks; the latter are supposed to be natives of England. It would be tedious to enter into the minute varieties of such a number of birds; all agreeing in the same general figure, the same luabits and mode of living, and differing in little more than their size and the colours of their plumage. In this tribe, we may rank as natives of our own European dominions, the Eider Duck, which is double the size of a common duck, with a black bill; the Velvet Duck, not so large, and with a yellow bill; the Scoter, with a knob at the base of a yellow bill; the Tulted Duck, adorned with a thick crest; the Scnup Duck, less than the common duck, with the bill of a grayish blue colour; the Golden Eye, with a large white spot at the corners of the mouth, resembling an eye; the Sheldrake, with the bill of a bright red, and swelling into a knob; the Mallard, which is the stock from whence our tame breed has probably been produced; the Piutail, witls the two iniddle feathers of the tail three inches longer than the rest; the Pochard, with the head and neck of a bright bay; the Widgeon, with a lead-coloured bill, and the plumage of the back marked with narrow black and white undulated lines, but best known by its whistling sound; lastly, the Teal, which is the smallest of this kind, with the bill black, the head and upper part of the neck of a bright bay. These are the most common birds of the duck kind among ourselves: but who can describe the amazing variety of this tribe if he extends his view to the different quarters of the world? The most noted of the foreign tribe are the Muscovy Duck, or, imore properly speaking, the Musk Duck, so called from a supposed musky smell, with naked skin round the eyes, and which is a native of Africa; the Brasilian Duck, that is of the size of a goose, all over black except the tips of the wings; the American Wood Dıck, with a variety of beautiful colours, and a plume of feathers that falls irom the back of the head like a friar's cowl. These, and twenty others, might be added, were increasing the number of names the way to enlarge the sphere of our comprehension.

All these live in the manner of our domestic ducks, keeping together in flocks in the winter, and flying in pairs in summer, bringing up their youtig by the water-side, and leading them to their food as soon as out of the shell. Their nests are usually built among heath or rushes, not far from the water, and they lay twelve, fourteen, or more eggs, before they sit: yet this is not always their method; the dangers they contiuually encounter from their ground situation, sometimes obliges them to change their manner of building; and their awkward nests are often seen exalted on the tops of trees. This must be a 
very great labour to perform, as the duck's bill is but ill formed for building a nest, and giving the materinls of which it is composed a suffieient stability to stand the weather. The nest, whether high or low, is generally composed of siugular materials. The longest grass, mixed with heath, and lined with the bird's own feathers, usually go to the composition : however, in proportion as the climate is colder, the nest is more artificially made, and more warmly lined. In the Arctic regions, nothing can exceed the great care all of this kint take t) protect their eggs fiom the intenseness of the weather. While the gull and the penguin kind seem to disregard the severest cold, the duck, in those regious, forms itself a liole to lay in, shelters the approach, lines it with a layer of long grass and clay; within that another of moss; and, lastly, a warm coat of feathers, or down. The eider duck is particularly remarkable for the warmth of its nest. 'This bird, which, as was said, is above twice as large as the common duck, and resides in the culder climates, lays from six to eight egys, making her nest among the rocks or the plants along the sea-sluore. The external nıaterials of the nest are such as are in common with the rest of the kind; lout the inside lining, on which the eggs are immediately deposited, is at once the softest, warmest, and the ligitest substance, with which we are acquainted. This is no other than the inside down which covers the breast of the bird in the breeding season. This the fenıale plucks off with her bill, and furnishes the inside of her nest with a tapestry nore valuable than the most skilfinl artists can produce. The natives watch the place where she begins to build, and, suffering her to lay, take away both the eggs and the nest. The duck, how-

The Eider duck is principally found in the western Islands of Scotland, and on the coasts of Norway, Iceland, and Greenland. Its bill is black, and its plumage is a varied mixture of black and white; the feinale lowever is of a reddish brown colour, marked with black and dusky streaks. They generally build on small islands, not far from the shore, and the male continues on the watch near the shore while the female is sitting; but he leaves them when the brood is hatched. As soon as they are able to creep from the shell, the mother entices them to the water side, and taking them on her back, she swims a short distance with then; when she has got them a little way from the land, she dives suddenly, leaving them floating on the surface of the water to shift for themselves. After this they are seldom found on land. ever, not discouraged by the first disappointment, builds and lays in the same place a second time; and this they in the same manner take away: the third time she builds, but the drake nust supply the down from his breast to line the nest with; and if this be robbed, they both forsake the place, and breed there wo more. This down the natives take care to separate from the dirt and moss with which it is nixed; and though no people stand in more need of a warm covering than themselves, yet their necessities compel them to sell it to the more indolent and luxurious inhabitants of the south for brandy and tobacco."

As they possess the faculties of flying and swimming, so they are in general birds of passage, and, it is most probable, perform their journeys across the ocean, as well on the water as in the air. Those that migrate to this country, on the approach of winter, are seldom found so well tasted or so fat as the fowls that continue with us the year round: their flesh is often lean, and still oftener fishy; which flavour it has probably contracted in the journey, as their food in the lakes of Lapland, from whence they descend, is generally of the insect kind.

As soon as they arrive among us, they are generally seen flying in flocks to nuake a survey of those lakes where they intend to take up their residence for the winter. In the choice of these they liave two objects in view; to be near their food, and yet remote from interruption. Their chief aim is to choose some lake in the neighbourlıood of a marsh, where there is at the same time a cover of woods, and where insects are found in great abundance. Lakes, therefore, with a marsh on one side, and a wood on the other, are seldom without

But that which renders this bird so highly valued, is the celebrated Eider down, used for the beds and couches of the luxurious and the effeminate. This is plucked from the breast by the birds, in order to line their nests; and during the time that the female is sitting, those who are concerned in the traffic, remove her, and rake away the down and superflunus eggs, and then carefully replace her. This is done several times, and the down is again produced by the birds, and she begins to lay afresh; and when the young ones leave the nest, it is completely plundered. One fentale will give about half a pound of down; which, when properly cleaned, is reduced to one half of that quantity. 
vast quantities of wild-fowl; and where a couple are seen at any time, that is a sufficient inducement to bring liundreds of others. The ducks flying in the air, are often lured down from their heights by the loud voice of the millard from below. Nature seems to have furnished this bird with very parlicular faculties for calling. The windpipe, where it begins to enter the lungs, opens into a kind of bony cavity, where the sound is reflected as in a musical instrument, and is heard a great way off. To this call all the stragglers resort; and in a week or a fortnight's time, a lake, that before was quite naked, is black with water-fowl, that have left their Lapland retreats to keep company with our ducks who never stirred from home.

They generally choose that part of the lake where they are inaccessible to the approach of the fowler, in which they all appear huddled together, extremely busy, and very loud. What it is can employ them all the day is not easy to guess. 'There is no food for them at the place where they sit and cabal thus, as they choose the middle of the lake; and as for courtship, the season for that is not yet come; so that it is wondereul what can so busily keep them occupied. Not one of then seems a noment at rest. Now pursuing one another, now screaming, then all up at once, then down again ; the whole seems one strange scene of bustle, with nothing $10 \mathrm{do}$.

They frequently go off in a more private manuer by night to feed in the adjacent meadows and ditches, which they dare not venture to approach by day. In these nocturial adventures they are often taken; for, though a timorous bird, yet they are easily deceived, and every spring seems to succeed in taking them. But the greatest quantities are taken in decoys; which, though well known near London, are yet untried in the remoter parts of the country. The manner of making and managing a decoy is as follows.

A place is to be chosen for this purpose far remote from the common highway, and all noise of people. A decoy is best where there is a large poind surrounded by a wood, and beyond that a marshy and uncultivated country. When the place is chosen, the pool, if possible, is to be planted round with willows, unless a wood answers the purposes of shading it on every side. On the south and north side of this pool are two, three, or four ditches or channels, made broad towards the pool, and growing narrower till they end in a point. These channels are to be covered over with nets, supported by hooped sticks bending from one side to the other; so that they form a vault or arch growing narrower and narrower to the point, where it is terminated by a tunnelnet, like that in which fish are caught in weirs. Along the banks of these channels so netted over, which are called pipes, many hedges are made of reeds slanting to the edge of the channel, the acute angles to the side next the pool. The whole apparatus, also, is to be hidden from the pool by a hedge of reeds along the margin, behind which the fowler manages his operations. The place being fitted in this manner, the fowler is to provide himself with a number of wild ducks made tame, which are called decoys. These are always to be fed at the mouth or entrance of the pipe, and to be accustomed to come at a whistle.

As soon as the evening is set in, the decoy rises, as they term it, and the wild-fowl feed during the night. If the evening be still, the noise of their wings, during their flight, is heard at a very great distance, and produces no unpleasing sensation. The fowler, when he finds a fit opportunity, and sees his decoy covered with fowl, walks about the pool, and observes into what pipe the birds gathered in the pool may be enticed or driven. Then casting hemp-seed, or some such seed as will float on the surface of the water, at the entrance, and up along the pipe, he whistles to his decoy-ducks, who instantly obey the summons, and come to the entrance of the pipe, in hopes of being fed as usual. Thither also they are followed by a whole flock of wild ones, who little suspect the danger preparing against them: Their sense of smelling, however, is very exquisite; and they would soon discover their enemy, but that the fowler always keeps a piece of turf burning at his nose, against which he breaths, and this prevents the effluvia of his person from reaching their exquisite senses. The wild-ducks, therefore, pursuing the decoy-ducks, are led into the broad mouth of the channel or pipe, nor have the least suspicion of the man, who keeps hidden behind one of the hedges. When they have got up the pipe, however, finding it grow mure and more narrow, they begin to suspect 
danger, and would return back; but they are now prevenied by the man, who shows limself at the broad end below. Thither, therefore, they dare not return; and rise they may not, as they are kept by the net above from ascending. The only way left them, therefore, is the narrow-funnelled net at the bottom; into this they fly, and there they are taken.

It often happens, however, that the wildfowl are in such a state of sleepiness or dozing, that they will not follow the decoyducks. Use is then generally made of a dog, who is taught his lesson. He passes backward and forward between the reed-hedges, in which there are little holes, both for the decoy-man to see, and for the little dog to pass through. This attracts the eye of the wildfowl; who, prompted by curiosity, advance towards this little animal, while he all the time kecps playing among the reeds, nearer and nearer the funnel, till they follow him too far to recede. Sometimes the dog will not attract their attention till a red handkerchief, or something very singular, be put about him. The decoy-ducks never enter the funnel-net with the rest, being taught to dive under water as soon as the rest are driven in.

The general season for catching fowl in decoys is from the latter end of October till February. The taking them earlier is prohibited by an act of George the Second, which imposes a penalty of five shillings for every bird destroyed at any other season.

The Lincolnshire decoys are commonly let at a certain annual rent, from five pounds to twenty pounds a year; and some even amount to thirty. These principally contribute to supply the markets of London with wild-fow]. The number of ducks, widgeon, and teal, that are sent thither is amazing. Above thirty thousand have been sent up in one season from ten decoys in the neighbourhood of Wainfleet. "This quantity makes them so cheap on the spot, that it is asserted, that several decoy-men would be glad to con- tract for years to deliver their ducks at the next town for ten-pence the couple.

To this manner of taking the wild-fowl in England, I will subjoin another, still more extraordinary, frequently practised in Clina. Whenever the fowler sees a number of ducks settled in any particular plash of water, he sends off two or three gourds to float among them. These gourds resemble our pompions; but, being made hollow, they swin on the surface of the water; and on one pool there may sometimes be seen twenty or thirty of these gourds floating together. The fowl at first are a little shy of coming near them; but by degrees they come nearer; and as all birds at last grow familiar with a scare-crow, the ducks gather about these, and amuse themselves by whetting their bills against them. When the birds are as familiar with the gourds as the fowler could wish, he then prepares to deceive them in good earnest. He hollows out one of these gourds large enough to put his head in; and, making holes to breath and see through, he claps it on his head. Thus accoutred, he wades slowly into the water, keeping his body under, and nothing but his head in the gourd above the surface; and in that mauner moves imperceptibly towards the fowls, who suspect no danger. At last, however, he fairly gets in among them; while they, having been long used to see gourds, take not the least fright while the enemy is in the very midst of them: and an insidious enemy he is; for ever as he approaches a fowl, he scizes it by the legs, and draws it in a jerk under water. There he fasteus it under his girdle, and goes to the next, till he has thus loaded himself with as many as he can carry away. When he has got his quantity, without ever attempting to disturb the rest of the fowls on the pool, he slowly moves off again; and in this manner pays the flock three or four visits in a day. Of all the various artifices for catching fowl, this seems likely to be attended with the greatest success, as it is the most practised in China. 


\section{CHAPTER CXXXV.}

\section{OF THE KING FISHER.}

I will conclude this history of birds with one that seems to unite in itself somewhat of every class preceding. It seems at once possessed of appetites for prey like the rapacious kinds, with an attachment to water like the birds of that element. It exhibits in its form the beautiful plumage of the peacock, the shadings of the humming-bird, the bill of the crane, and the short legs of the swallow. The bird I mean is the King-fisher, of which many extraordinary falsehoods have been propagated; and yet of which many extraordinary things remain to be said that are actually true.

The King-fisher is not much larger than a swallow; its shape is clumsy; the legs disproportionably small, and the bill disproportionably long; it is two inches from the base to the tip; the upper chap black, and the lower yellow: but the colours of this bird atone for its inelegant form; the crown of the head and the coverts of the wings are of a deep blackish green, spotted with bright azure; the back and tail are of the most resplendent azure; the whole under-side of the body is orange-coloured; a broad mark of the same passes from the bill beyond the eyes; beyond that is a large white spot: the tail is short, and consists of twelve feathers of a rich deep blue; the feet are of a reddish yellow, and the three joints of the outmost toe adhere to the middle toe, while the inner toe adheres only by one.

From the diminutive size, the slender short legs, and the beautiful colours of this bird, no person would be led to suppose it one of the most rapacious little animals that skims the deep. Yet it is for ever on the wing, and

a Mr. Montague, who paid much attention to the manners of this bird, says, that they never suspend themselves on the wing, and dart on their prey, like the osprey; but that they sit patiently on a bough over the water, and when a small fish comes near the surface, they dart on it, feeds on fish, which it takes in surprising quantities, when we consider its size and figure. It chiefly frequents the banks of rivers, and takes its prey after the manner of the osprey, balancing itself at a certain distance above the water for a considerable space, then darting into the deep, and seizing the fish with inevitable certainty. While it remains suspended in the air, in a bright day, the plumage exhibits a beautiful variety of the most dazzling and brilliant colours. It might have been this extraordinary beauty that has given rise to fable; for wherever there is any thing uncommon, fancy is always willing to increase the wonder."

Of this bird it has been said, that she built her nest on the water, and thus in a few days hatched and produced her young. But, to be uninterrupted in this task, she was said to be possessed of a charm to allay the fury of the waves; and during this period the mariner might sail with the greatest security. The ancient poets are full of these fables; their historians are not exempt from them. Cicero has written a long poem in praise of the halcyon, of which there remain but two lines. Even the emperor Gordian has written a poem on this subject, of which we have nothing remaining. These fables have been adopted each by one of the earliest fathers of the church. "Behold," says St. Ambrose, " the little bird, which in the midst of the winter lays her eggs on the sand by the shore. From that moment the winds are hushed; the sea becomes smooth; and the calm continues for fourteen days. This is the time she requires; seven days to hatch, and seven days to foster her young. Their Creator has taught

and seize it with their bill. He never could observe the old birds with any thing in their bills, when they went in to feed lheir young; from which he concludes that they eject it from their stomachs for this purpose. 
these little animals to make their nest in the midst of the most stormy season, only to inanifest his kindness by granting them a lasting calm. The seamen are not ignorant of this blessing; they call this interval of fair weather their halcyon days; and they are particularly careful to seize the opportunity, as then they need fear no interruption," 'This, and a hundred other instances, might be given of the credulity of mankind with respect to this bird; they entered into speculations concerning the manner of her calming the deep, the formation of her nest, and her peculiar sagacity; at present we do not speculate, because we know, with respect to our king-fisher, that most of the facts are false. It may be alleged, indeed, with some show of reason, that the halcyon of the ancients was a different bird from our king-fisher; it may be urged, that many birds, especially on the Indian ocean, build a floating nest upon the sea; but still the history of the ancient halcyon is clogged with endless fable; and it is but an indifferent method to vindicate falsehood, by showing that a part of the story is true.

The king-fisher with which we are acquainted at present, has none of those powers of allaying the storm, or building upon the waves; it is contented to make its nest on the banks of rivers, in such situations as not to be affected by the rising of the stream. When it has found a place for its purpose, it hollows out with its bill a hole about a yard deep; or if it finds the deserted hole of a rat, or one caused by the root of a tree decaying, it takes quiet possession. This hole it enlarges at the bottom to a good size; and lining it with the down of the willow, lays its eggs there without any further preparation.

Its nest, or rather hole, is very different from that described by the ancients, by whom it is said to be made in the shape of a longnecked gourd of the bones of the sea-needle. 'The bones, indeed, are found there in great quantities, as well as the scales of fishes; but these are the remains of the bird's food, and by no means brought there for the purposes of warmth or convenience. The king-fisher, as Bellonius says, feeds upon fish, but is incapable of digesting the bones and scales, which he throws up again, as eagles and owls are seen to do a part of their prey. These พо. $51 \& 52$. fill the bird's nest of course; and although they seem as if designedly placed there, are only a kind of nuisance.

lin these holes, which, from the remains of fish brought there, are very foetid, the kingfisher is often found with from five eggs to nine. There the female continues to hatch, even though disturbed; and though the nest be robbed, she will again return and lay there. "I have had one of those females brought me," says Reaumur, "which was taken from her nest about three leagues from my house. After admiring the beauty of her colours, I let her fly again, when the fond creature was instantly seen to return back to the nest where she had just before been made a captive. There, joining the male, she again began to lay, though it was for the third time, and though the season was very far advanced. At each time she had seven eggs. The older the nest is, the greater quantity of fish-bones and scales does it contain: these are disposed without any order; and sometimes take up a good deal of room."

The fomale begins to lay early in the season; and excludes her first brood about the beginning of April. The male, whose fidelity exceeds even that of the turtle, brings her large provisions of fish while she is thus employed; and she, contrary to most other birds, is found plump and fat at that scason. The male, that used to twitter before this, now enters the nest as quietly and as privately as possible. The young ones are hatched at the expiration of twenty days; but are seen to differ as well in their size as in their beauty.

As the ancients have had their fables concerning this bird, so have the modern vulgar. It is an opinion generally received among them, that the flesh of the king-fisher will not corrupt, and that it will even banish all vermin. This has no better foundation than that which is said of its always pointing, when hung up dead, with its breast to the north. The only truth which can be affirmed of this bird, when killed, is, that its flesh is utterly unfit to be eaten; while its beantiful plumage preserves its lustre longer than that of any other bird we know.

Having thus given a short history of birds, I own I cannot take leave of this most beau-. tiful part of the creation without reluctance. 
These splendid inhabitants of the air possess.all those qualities that can sooth the heart, and cheer the fancy. The brightest colours, the roundest forms, the most active manners, and the sweetest music. In sending the imagination in pursuit of these, in following them to the chirping grove, the screaming precipice, or the glassy deep, the mind naturally lost the sense of its own situation, and, attentive to their little sports, almost forgot the TASK of describing them. Innocently to amuse the imagination in this dream of life is wisdom; and nothing is useless that, by furnishing mental employment, keeps us for a while in-oblivion of those stronger appe- tites that lead to evil. But every rank and state of mankind may find something to imitate in those delightful songsters, and we may not only employ the time, but mend our lives, by the contemplation. From their courage in defence of their young, and their assidnity in incubation, the coward may learn to be brave, and the rash to be patient. The inviolable attachment of some to their companions may give lessons of fidelity; and the connubial tenderness of others, be a monitor to the incontinent. Even those that are tyrants by nature never spread capricious destruction; and, unlike man, never inflict a pain but when urged by necessity. 


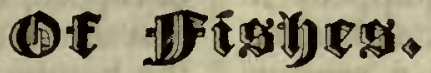

\section{OF IISHES IN GINERAI.}

\section{CHAPTER CXXXVI.}

\section{INTRODUCTION.}

THE ocean is the great receptacle of fishes. It has been thouglit, by some, that 11 fish are naturally of that salt element; and that they have mounted up into fresh water by some accidental migration. A few still swim up rivers to deposit their spawn ; but of the great borly of fishes, of which the size is enormous and the shoals are endless, those all keep to the sea, and would quickly expire in fresh water. In that extensive and undiscovered abode, millions reside, whose manners are a secret to us, and whose very form is unknown. The curiosity of mankind, indeed, has drawn some from their depths, and his wauts many more: with the figure of these at least he is acquainted ; but for their pursuits, migrations, societies, antipathies, pleasures, times of gestation, and manner of bringing fortl, these are all hidden in the turbulent element that protects them.

The number of fish to which we have given naines, and of the figure, at leasl, of which we know something, according to Linnæeus, are above four hundred. Thus to appearance, indeed, the history of fish is tolerably copious; but when we come to examine, it will be found that of the greatest part of these we know very little. Those qualities, singularities, or advantages, that render animals worth naming, still remain to be discovered. The history of fishes, therefore, has little in it entertaining: for our plilosophers hitherto, instead of studying their nature, have been $\mathrm{em}$ ployed in increasing their catalogues; and the reader, instead of observations or facts, is presented with a long list of names, that disgust him with their barren superfluity. It must displease him to see the language of science increasing, while the science itself has nothing to repay the increasing tax laid upon his memory.

Most fish offer us the same external form; sharp at either end, and swelling in the middle; by which they are enabled to traverse the fluid which they inhabit, with greater celerity and ease. That peculiar shape which nature has granted to most fishes, we endeavour to initate in such vessels as are designed to sail with the greatest swiftness; however, the progress of a machine moved forward in the water by human contrivance, is nothing to the rapidity of an animal destined by nature to reside there. Any of the large fish overtakea ship in full sail with great ease, play round it without effort, and outstrip.it at pleasure. Every part of the body seems exerted in this despatch ; the fins, the tail, and the motion of the whole back-bone, assist progression; and it is to that flexibility of body at which art cannot arrive, that fishes owe their great velocity 
The chief instruments in a fish's motion, are the fins; which, in some fish, are much more numerous than in others. A fish completely fitted for sailing, is furnished with not less than two pair; also three single fins, two above and one below. 'Thus equipped, it migrates with the utmost rapidity, and takes voyages of a thousand leagues in a season. But it does not always happen that such fish as have the greatest number of fins have the swiftest motion: the shark is thought to be one of the swiftest swimmers, yet it wants the ventral or belly fins; the haddock does not inove so swift, yet it is completely fitted for motion.

But the fins serve not only to assist the animal in pregression, but in rising or sinking, in turning, or even leaping out of the water. To answer these purposes, the pectoral fins serve, like oars, to push the animal forward; they are placed at some little distance behind the opening of the gills; they are generally large and strong, and answer the same purposes to the fish in the water, as wings do to a bird in the air. With the help of these, and by their continued motion, the flying-fish is sometimes scen to rise out of the water, and to fly above an hundred yards: till, fatigued with its exertions, it is obliged to sink down again. "These also serve to balance the fish's head, when it is too large for the body, and keep it from tumbling prone to the bottom, as is secn in large-hended fishes, when the pectoral fius are cut off. Next these are seen the ventral fins, placed towards the lower part of the body, under the belly; these are always seen to lie flat on the water, in whatever situation the fish may be; and they serve rather to raise or depress the fish in its element, than to assist progressive motion. The dorsal fin is situated along the ridge of the back; and serves to keep it in equilibrio, as also to assist its progressive motion. In many fishes this is wanting; but in all flat fishes it is very large, as the pectoral fins are proportionably small. The anal fin occupies that part of the fish which lies between the anus and the tail; and this serves to keep the fish in its upright or vertical situation. Lastly, the tail, which in some fishes is flat, and upright in others, seems the grand instrument of motion; the fins are but all subservient to it, and give direction to its great impetus, by which the fish seems to dart forward with so much relocity. To explain all this by experiment; a carp is taken, and put into a large vessel. The fish, in a state of repose, spreads all its fins, and secms to rest upon its pectoral and ventral fins near the bottom: if the fish folds up (for it has the power of folding) either of its pectoral fins, it inclines to the same side: folding the right pectoral fin, the fish inclines to the right side; folding the left fin, it inclines to that side in turn. When the fish desires to have a retrograde motion, striking with the pectoral fins, in a contrary direction, effectually produces it. If the fish desires to turn, a blow from the tail sends it about; but if the tail strikes both ways, then the motion is progressive. In pursuance of these observations, if the dorsal and ventral fins be cut off, the fish reels to the right and left, and endeavours to supply its loss by keeping the rest of its fins in constant employment. If the right pectoral fin be cut off, the fish leans to that side; if the ventral fin on the same side be cut away, then it loses its equilibrium entirely. When the tail is cut off, the fish loses all motion, and gives itself up to where the water impels it.

From hence it appears, that each of these instruments has a peculiar use assigned it; but, at the same time, that they all conspire to assist each other's motions. Some fish are possessed of all, whose motions are yet not the swiftest; others have but a part, and yet dart in the water with great rapidity. The number, the size, and the situation of the fins, therefore, seem rather calculated to correspond with the animal's figure, than solely to answer the purposes of promoting its speed. Where the head is large and heavy, there the pectoral fins are large, and placed forward, to keep it from oversetting. Where the head is small, or produced out into a long beak, and therefore not too heavy for the tail, the pectoral fins are small, and the ventral fins totally wanting.

As most animals that live upon land are furnislied with a covering to kecp off the injuries of the weather, so all that live in the water are covered with a slimy glutinous matter, that, like a sheath, defends their bo- 
dies from the immediate contact of a surrounding fluid. This substance may be considered as a secretion from the pores of the animal's body; and serving not only to defend, but to assist the fish's easy progress through the water. Beneath this, in many kinds, is found a strong covering of scales, that, like a coat of inail, defeud it still more powerfully; and under that, before we cone to the muscular parts of the body, an oily substance, which supplies the requisite warmth and vigour.

T'he fish thus protected and fitted for motion in its natural element, seems as well furnished with the means of happiness as quadrupeds or birds; but if we come to examine its faculties more nearly, we shall find it very much their inferior. The sense of touching, which beasts and birds have in a small degree, the fish, covered up in its own coat of inail, can have but little acquaintance with.

The sense of sinelling, which in begsts is so exquisite, and among birds is not wholly unknown, seems given to fishes in a very moderate pioportion. It is true, that all fishes have one or more nostrils; and even those that have not the holes perceptible without, yet have the proper formation of the bones for smelling within. But as air is the only medium we know for the distribution of odours, it cannot be supposed that these animals, residing in water, can be possessed of any power of being affected by them. If they have any perception of smells, it must be in the same manner as we distinguish by our taste; and, it is probable, the oltactory membrane in fish serves them instead of a distinguishing palate: and by this they judge of substances, that, first tincturing the water with their vapours, are thus sent to the nostrils of the fish, and no doubt produce some kind of sensation. This most probably must be the use of that organ in those animals, as otherwise there would be the instruments of a sense provided for them, without any power in them of enjoyment.

As to tasting, they seem to make very little distinction; the palate of most fish is hard and bony, and consequently incapable of the powers of relishing different substances. This sense among quadrupeds, who possess it in some degree, arises from the soft pliancy of the organ, and the delicacy of the skin which covers the instruments of tasting; it may be cousidered, in them, as a more perfect and delicate kind of feeling: in the bony palate of fish, therefore, all powers of distinguishing are utterly taken away; and we have accordingly often seen these roracious animals swallow the fisherman's plummet instead of the bait.

Hearing in fishes is found still inore imperfect, if it be found at all. Certain it is, that anatomists have not been able to discover, except in the whale kind, the smallest traces of an organ, either within or without the head of fishes. It is true, that in the centre of the brain of some fishes are found now and then some little bones, the number and situation of which are entirely accidental. These bones Mr. Klein has supposed to constitute the organ of hearing; but if we consider their entire dissimilitude to the bones that serve for hearing in other animals, we shall be of another opinion. The greatest number of fishes are deprived of these bones entirely: some fish have them in small numbers, and others in abundance; yet neither testify any excellence or defect in hearing. Indeed, of what advantage would this sense be to animals that are incapable of making themselves heard? They have no voice to communicate to each other, and consequently have no need of an organ for hearing. Mr. Gouan, who kept some gold fishes in a vase, informs us, that whatever noise he made, he could neither disturb nor terrify them; he halloed as loud as he could, putting a piece of paper between his mouth and the water, to prevent the vibrations from affecting the surface, and the fishes still seemed insensible: but when the paper was removed, and the sound had its full play upon the water, the fishes seemed instantly to feel the change, and shrunk to the bottom. From this we may learn, that fishes are as deaf as they are mute: and that when they seem to hear the call of a whistle or a bell at the edge of a pond, it is rather the vibrations of the sound that affect the water, by which they are excited, than any sounds that they hear.

Seeing seems to be the sense fishes are possessed of in the greatest degree; and yet even this seems obscure, if we compare it to that of other animals. The eye, in almost all fish, 
is covered with the same transparent skin that covers the rest of the head; and which, probably, serves to defend it in the water, as they are without eye-lids. The globe is more depressed anteriorly, and is furnished behind with a muscle, which serves to lengthen or flatten it, according to the necessities of the animal. The crystalline humour, which in quadrupeds is flat, and of the shape of a button-mould, in fishes is as round as a pea; or sometimes oblong, like an egg. From all this it appears, that fish are extremely near-sighted; and that even in the water they can see objects at a very small distance. This distance might very easily be ascertained, by comparing the refraction of bodies in the water, with that formed by a lens that is spherical. Those unskilled in mathematical calculations, will have a general idea of this, from the glasses used by near-sighted people. Those whose crystalline humour is too convex, or, in other words, too round, are always very near-sighted; and obliged to use concave glasses, to correct the imperfections of nature. The crystalline humour of fish is so round, that it is not in the power of any glasses, much less of water, to correct their vision. This crystalline humour in fishes all must have seen; being that little hard pea-like substance which is found in their eyes after boiling. In the natural state it is transparent, and not much harder"than a jelly.

From all this it appears how far fish fall behind terrestrial animals in their sensations, and consequently in their enjoyments. Even their brain, which is by some supposed to be of a size with every animal's understanding, shows that fish are inferior even to birds in this particular. It is divided into three parts, surrounded with a whitish froth, and gives off nerves as well to the sense of sightas of smelling. In some fish it is gray, in others white; in some it is flatted, in others round; but in all extremely small, compared to the bulk of the animal.

Thus Nature seems to have fitted these animals with appetites and powers of an inferior kind; and formed them for a sort of passive existence in the obscure and heavy element to which they are consigned. To preserve their own existence, and to continue it to their posterity, fill up the whole circle of their pursuits and enjoyments; to these they are impelled rather by necessity than choice, and seem mechanically excited to every fruition. Their senses are incapable of making any distinctions; but they drive forward in pursuit of whatever they can swallow, conquer, or enjoy.

A ceaseless desire of food seems to give the ruling impulse to all their motions. This appetite impels them to encounter every danger; and indeed their rapacity seems insatiable. Even when taken out of the water, and almost expiring, they greedily swallow the very bait by which they were allured to destruction.

The maw is, in general, placed next the mouth, and though possessed of no sensible heat, is, however, endued with a surprising faculty of digestion. Its digestive power seems, in some measure, to increase with the quantity "of food it is supplied with; a single pike having been known to devour a hundred roaches in three days. Its faculties also are as extraordinary ; for it digests not only fish, but much harder substances; prawns, crabs, and lobsters, sleells and all. These the cod or the sturgeon will not only devour, but dissolve down, though their shells are so much harder than the sides of the stomach which contains them. This amazing faculty in the cold maw of fishes, has justly excited the curiosity of philosophers; and has effectually overturned the system of those, who supposed that the heat of the stomach was alone a sufficient instrument for digestion. The truth seems to be, and some experiments of the skilful Dr. Hunter seem to evince, that there is a power of animal assimilation lodged in the stomach of all creatures, which we can neither describe nor define, converting the substances they swallow into a fluid fitted for their own peculiar support. This is done neither by trituration, nor by warmth, nor by motion, nor by a dissolving fluid, nor by their united efforts; but by some principle in the stomach yet unknown, which acts in a different manner from all kinds of artificial maceration. The meat taken into the stomach or maw is often seen, though very near being digested, still to retain its original form: and ready for a total dissolution, while it appears to the eye as yet. untouched by the force of 
the stomach. This animal power is lodged in the maw of fishes, in a greatel degree than in any other creatures; their digestive powers are quick, and their app:tites ever are craving.

Yet though fish are thus hungry, and for ever prowling, no animals can suffer the want of food for so long a time. The gold and silver fish we keep in vases, scem never to want any nourisliment at all: whether it be that they feed on the water insects, too minute for our observation, or that water alone is a sufficient supply, is not evident; but they are often seen for months without apparent sustenance. Even the pike, the most voracions of fishes, will live in a pond where there is none but himself; and, what is more extraordinary, will be often fonnd to thrive there.

Still, however, fishes are of all other animals the most voracious and insatiable. Whatever any of then is able to swallow, possessed of life, seems to be considered as the inost desirable food. Some that liave very small mouths feed upon worms nod the spawn of other fish; others, whose moutlis are larger, seck larger prey; it matters not of what kind, whether of another or their own. Those with the largest mouths pursue almost every thing that has life; and often incet cach other in fieme opposition, when the fish with the largest swallow comes off with the victory, and devours its antagonist.

Thus are they irritated by the continual desire of satisfying their hunger; and the life of a fish, from the smallest to the greatest, is but one scene of hostility, violence, and evasion. But the smaller fry stand no chance in the unequal combat; and their usual way of escaping is by swimming into those shallows where the greater are inable, or too heavy, to pursue. There they become invaders in turn, and live upon the spawn of larger fish, which they find floating upon the surface of the water; yet there are dangers attending them in every place. Even in the shallows, the mussel, the oyster, and the scallop, lie in ambush at the hottom, with their shells open, and whatever little fish inadvertently approaches into contact, they at once close their shells upon him, and devour the imprisoned prey at their leisure.

Nor is the pursuit of fishes, like that of terrestrial animals, confined to a single region, or to one effort: shoals of one species follow those of auther through vast tracks of ocean, from the vicinity of the pole, even down to the equator. Thus the cod, from the banks of Newfoundland, pursues the whiting, which flies before it even to the southern shores of Spain. The cachalot is said, in the same manner, to pursue a shoal of herrings, and to swallow thousands at a gulp.

This may be one cause of the annual migration of fishes from one part of the occan to the other; but there are other motives which come in aid of this also. Fishes may be induced to change the place of their residence, for one more suited to their constitutions, or more adapted to depositing their spawn. It is remarkable that no fish are fond of very cold waters, and generally frequent those places where it is warmest. Thus, in summer, they are seen in great numbers in the shallows near the shore, where the sun has power to warm the water to the bottom; on the con. tlary, in winter, they are found towards the buttom in the deep sea; for the cold of the atmosphere is not sufficiently penstrating to reach them at those great depths. Cold produces the same effect upon fresh-water fishes; and when they are often seen dead after severe frosts, it is most probable that they have been killed by the severity of the cold, as well as by their being excluded by the ice from air.

All fish live in the water; yet they all stand in need of air for their support. Those of the whale kind, indeed, breatl air in the same manner as we do, and come to the surface every two or three minutes to take a fiesh inspiration; but those which continue entirely under water, are yet under a necessity of being supplied with air, or thcy will expire in a very few nimutes. We sometimes see all the fish of a pond killed, when the ice every where covers the surface of the water, and thus keeps off the air from the subjacent fluid. If a hole be made in the ice, the fish will be seen to come all to that part, in order to take the benefit of a fresh supply. Should a carp, in a large vase of water, be placed under an air-pump, and then be deprized of its air, during the operation a number of bubbles will be seen standing on the surface of the fish's body; soon after the animal will appear to breath swifter, and with greater difficulty ; it will then be seen to rise towards the surface, 
to get more air; the bubbles on the surface begin to disappear; the belly, that was before swollen, will then fall of a sudden; and the animal sinks expiring and convulsed at the bottom.

So very necessary is air to all animals, but particularly to fish, that, as was said, they can live but a few minutes without it ; yet nothing is more difficult to be accounted for than the manner in which they obtain this necessary supply. Those who have seen a fish in the water, must remember the motion of its lips and its gills, or at least of the bones on each side that cover them. This motion in the animal is, without doubt, analogons to our breathing; but it is not air, but water, that the fish actually sucks in and spouts out through the gills at every motion. The manner of its breathing is thus: the fish first takes in a quantity of water by the mouth, which is driven to the gills; these close and keep the water so swallowed from returning by the mouth; while the bony covering of the gills prevents it from going through them, until the unimal has drawn the proper quantity of air from the body of water thus imprisoned: then the bony covers open, and give it a free passage ; by which means also the gills again are opened, and admit a fresh quantity of water. Should the fish be prevented from the free play of its gills, or should the bony cover's be kept from moving, by a string tied round them, the animal would soon fall into convulsions, and die in a few minutes.

But though this be the general method of explaining respiration in fishes, the difficulty remains to know what is done with this air, which the fish in this manner separates from the water. There seems no receptacle for containing it ; the stomach being the chief cavity within the body, is too much filled with aliment for that purpose. There is indeed a cavity, and that a pretty large one, I mean the airbladder or swim, which may scrve to contain it for vital purposes; but that our philosophers have long destined to a very different use. The use universally assigned to the air-bladder, is the enabling the fish to rise or sink in the water at pleasure, as that is dilated or compressed. The use assigned by the ancients for it was to come in aid of the lungs, and to remain as a kind of store-house of air to supply the animal in its necessities. I own my attachment to this last opinion; but let us exhibit both with their proper share of evidence, and the reader must be left to determine.

The air-bladder is described as a bag filled with air, sometimes composed of one, sometinies of two, and sometimes of three divisions, situated towards the back of the fish, and opening into the maw or the gullet. Those who contend that this bag is designed for raising or depressing the fish in the water, build upon the following experiment: A carp being put into the air-pump, and the air exhausted, the bladder is said to expand itself to such a degree, that the fish swells in an extraordinary manner, till the bladder bursts, and then the fish sinks, and ever after continues to crawl at the bottom. On another occasion, the airbladdler was pricked and wounded, which let out its air; upon which the fish suuk to the bottom, and was not seen to rise after. From thence it is inferred, that the use of the airbladder must be by swelling, at the will of the animal, thus to increase the surface of the fish's looly, and thence dininishing its specific gravity, to enable it to rise to the top of the water, and keep there at pleasure. On the contrary, when the fish wants to descend, it is, say they, but to exhaust this bladder of its air; and the fish being thus rendered slinuter and heavier, consequently sinks to the bottom.

Such is the account given of the use of the air-bladder; no part of which seems to me well supported. In the first place, though nothing is more certain, than that a carp put into the air-pump will swell, yet so will a mouse or a frog; and these we know to have 1 o air-bladders. A carp will rise to the surface; but so will all fish that want air, whether they have an air-bladder or not. The air-bladder is said to burst in the experiment; but that I deny. The air-bladder is indeed found empty, but it has suffered no laceration, and may be distended by being blown into like any other bladiler that is sound. The fish after the experiment, I grant, continues to creep at the bottom; and so will all fish that are sick and wounded, which must be the case with this after such an operation. Thus these facts prove nothing, but that when the fish is killed in an air-pump the air-liladder is found exhausted, and that it will naturally and necessarily be; for the drain of air by which the fish is supplied in the natural 
way will necessarily oblige it to make use of all its hidden stores; and, as there is a communication between the gullet and the airbladder, the air which the latter contains will thus be obviously drawn away. But still farther, how comes the air-bladder, according to their hypothesis, to swell under the experiment of the air-pump? What is it that closes the aperture of that organ in such a manner as at last to burst it? or what necessity has the fish for dilating it to that violent degree? At most, it ouly wants to rise to the surface; and that the fish can easily do without so great a distention of the air-bladder. Indeed, it should rather seem that the more the air was wanted without, the less necessity there was for its being uselessly accumulated within; and, to make the modern system consistent, the fish under the air-pump, instead of permitting its bladder to be burst, would readily give up its contents; which, upon their supposition, all can do at pleasure.

But the truth is, the fish can neither increase nor diminish the quantity of air in its air-bladder at will, no more than we can that which is contained in our stomachs. The animal has no one muscle, much less a pair of muscles, for contracting or dilating this organ; its aperture is from the gullet; and what air is put into it must remain there till the necessities, and not the will, of the animal call it forth as a supply.

But, to put the matter past a doubt, many fish are furnished with an air-bladder, that continually crawl at the bottom; such as the eel and the flounder; and many more are entirely without any bladder, that swim at ease in every depth; such as the anchovy and fresh-water gudgeon." Indeed, the number of fish that want this organ is alone a sufficient proof that it is not so necessary for the purposes of swimming; and as the ventral fins, which in all fish lie flat upon the water, seem fully sufficient to keep them at all depths, I see no great occasion for this internal philosoplical apparatus for raising and depressing them. Upon the whole, the airbladder seems adapted for different purposes than that of keeping the fish at different

- Redi.

No. 51 it 52 . depths in the water: but whether it be to supply them with air when it is wanted from without, or for what other purpose, I will not take upon me to determine.

Hitherto we have seen fish in every respect inferior to land animals : in the simplicity of their conformation, in their senses, and their enjoyments; but of that humble existence which they have been granted by nature, they have a longer term than any other class of animated nature. "Most of the disorders incident to mankind," says Bacon, "arise from the changes and alterations of the atmos. phere; but fishes reside in an element little subject to change; theirs is an uniform existence; their movements are without effort, and their life withont labour. Their bones also, which are united by cartilages, admit of indefinite extension; and the different sizes of animals of the same kind, among fishes, is very various. They still keep growing; their bodies, instead of suffering the rigidity of age, which is the cause of natural decay in land animals, still continue increasing with fresh supplies; and as the body grows, the conduits of life furnish their stores in greater abundance. How long a fish, that seems to have scarcely any bounds put to its growth, continues to live, is not ascertained; perhaps the life of a man would not be long enough to measure that of the smallest.

There have been two methods devised for determining the age of fishes, which are more ingenious than certain; the one is by the circles of the scales, the other by the transverse section of the back-bone. The first method is this: When a fish's scale is examined through a microscope, it will be found to consist of a number of circles, one circle within another, in some measure resembling those which appear upon the transverse section of a tree, and supposed to offer the same information. For as in trees we can tell their age by the number of their circles, so in fislies we can tell theirsby the number of circles in every scale, reckoning one ring for every year of the animal's existence. By this method, Mr. Buffon found a carp, whose scales he examined, to be not less than a hundred years old; a thing almost incredible, had we not several accounts in other authors which tend to confirm the is 
discovery. Gesner brings us an instance of one of the same age; and Albertus of one more than double that period.

The age of the skate and the ray, that want scales, may be known by the other method; which is, by separating the joints of the backbone, and then minutely observing the number of rings, which the surface where it has joined exhibits. By this the fish's age is said to be known; and perhaps with as much certainty as in the former instance.

But how unsatisfactory soever these marks may be, we have no reason to doubt the great age of some fishes. Those that have ponds, often know the oldest by their superior size. But the longevity of these animals is nothing when compared to their fecundity. All sorts, a few of the larger ones excepted, multiply their kind, some by hundreds, and some by millions. There are some that bring forth their young alive, and some that only produce eggs: the former are rather the least fruitful; yet even these are scen to produce in great abundance. The viviparous blenny, for instance, brings forth two or three hundred at a time, all alive and playing round the parent together. Those who exclude their progeny in a more imperfect state, and produce eggs, which they are obliged to leave to chance, either on the bottom at the edge of the water, or floating on the surface where it is deeper, are all much more prolific; and secm to proportion their stock to the danger there is of its consumption. Of these eggs thus deposited, scarcely one in a hundred brings forth an animal; they are devoured by all the lesser fry that frequent the shores; by aquatic birds near the margin; - and by the larger fish in deep water. Still, however, there are enough for supplying the deep with inhabitants; and, notwithstanding their own rapacity, and that of the fowls of rarions tribes, the numbers that escape are sufficient to relieve the wants of a very considerable part of mankind. Indeed, when we consider the numbers that a single fish is capable of producing, the amount will seem astonishing. If, for instance, we should be told of a being so very prolific, that in a single season it could bring forth as many of its kind as there are inhabitants in England, it would strike us with surprise; yet a single cod produces full that number. The cod spawns in one season, as Lewenhocck assures us, above nine million of eggs or peas, contained in one single roe. The flounder is commonly known to produce above one million; and the inackarel above five hundred thousand. Such all amazing increase, if permilted to come to maturity, would overstock nature, and even the ocean itself would not be able to contain, much less to provide for, the half of its inhabitants. But two wise purposes are answered by this amazing increase; it preserves the species in the midst of numberless enemies, and serves to furnish the rest with a sustenance adapted to their nature.

Fishes seem, all except the whale kind, entirely divested of those parental solicitudes which so strongly mark the manners of the more perfect terrestrial animals. How far they copulate, remains as yet a doult ; for though they seem to join, yet the male is not furnished with any external instrument of generation. It is said, by some, that his only end in that action is to emit his impregnating milk upon the eggs that at that time fall from the female. He is said to be seen pursuing them as they float down the stream, and carefully impregnating them one after another. On some occasions also the fernales dig holes in the bottom of rivers and ponds, and there deposit their spawn, which is impregnated by the male in the same marner. All this, however, is very doubtful; what we know with certainty of the matter, and that not discovered till very lately, is, that the male has two organs of generation that open into the bladder of urine, and that these organs do not open into the rectum as in birds, but have a particular aperture of their own." These organs of generation in the male are emply at some seasons of the year; but before the time of spawning they are turgid with what is called the milt, and emit the fluid proper for impregnation.

Fish have different seasons for depositing their spawn: some, that live in the depths of the ocean, are said to choose the winter months; but, in general, those with. which we are acquainted, choose the hottest months in summer, and prefer such water as is some-

- Vide Gaman de Generatione Piscium. 
what tepified by the beams of the sun. They then leave the deepest parts of the ocean, which are the coldest, and shoal round the coasts, or swim up the fresh-water rivers, which are warm as they are comparatively shallow. When they have deposited their burdens, they then return to their old stations, and leave their nascent progeny to shift for themselves.

The spawn continues in its egg-state in some fish longer than in others, and this in proportion to the animal's size. In the salmon, lor instance, the young auimal continues in the egs from the beginning of December till the begiming of April ; the carp continues in the egg not above three weeks; the little gold fish from China, is produced still quicker. These all, when excluded, at first escape by their minuteness and agility. They rise, sink, and turn, inuch readier than grown fish; and they can escape into very shallow waters when pursued. But, with all their advantages, scarcely one in a thousand survives the numerous perils of its youth. The very male and female that have given them birth, are equally dangerous and formidable with the rest, forgetting all relation at their departure.

Such is the general pieture of these heedless and hungry ereatures: but there are some in this class, living in the waters, that are possessed of finer organs and higher sensations; that have all the tenderness of birds or quadrupeds for their young; that nurse them with constant care, and protect them from every injury. Of this class are the $C_{e-}$ taceous tribe, or the fishes of the whale kind. There are others, though not capable of nursing their young, yet that bring them alive into the world, and defend them with courage and activity. Tliese are the Cartulaginous kinds, or those who have gristles instead of bones. But the fierce unmindful tribe we have been describing, that leave their sp awn without any protection, are called the Spinous or bony kinds, from their bones resembling the sharpness of thorns.

Thus there are three grand divisions in the

- Though fishes live in a salt element, they do not subsist on it. All the water they take into their mouths is again discharged through the gills, after retaining the air fish kind; the cetaceous, the cartilaginous, and the spinous; all differing from each other in their conformation, their appetites, in their bringing forth, and in the education of their young. These three great distinctions are not the capricious differences formed by a maker of systems, but are strongly and firmly marked in nature. These are the distinetions of Aristotle; and they have been adopted by mankind ever since his time. It will be necessary, therefore, to give the history of each of these in particular; and then to range, under each head, those fishes whose history is the most remarkable; or, more properly speaking, those of which we have any listory. For we shall find, when we come to any of the species in particular, how little can be said of their habits, their stations, or method of propagation.

Much, indeed, can be said of them if considered relatively to man; and large books have been written of the manner of taking fish; or of dressing them. Apicius is noted for having first taught mankind to suffocate fish in Carthaginian pickle ; and Quin, for giving a sauce to the Johndory: Mrs. Glasse is famous for her eel-pie, and Mr. Tull for his invention of spaying carp, to give it a finer flavour. In this manner our cooks handle the subject. On the other hand, our physicians assure us that the flesh of fishes yields little nourishment, and soon corrupts; that it abounds in a gross sort of oil and water, and hath but a few volatile particles, which render it less fit to be converted into the substance of our bodies. They are cold and moist, and must needs, say they, produce juices of the same kind, and consequently are improper to strengthen the body. In this diversity of opinion, it is the wisest way to eat our fish in the ordinary manner, and pay no great attention to cooks or doctors.

I cannot conclude this chapter without putting a question to the learned, which, I confess, I am not able to resolve. How comes it that fish, which are bred in a salt element, have yet no salt to the taste, or that is capable of being extracted from them?a

contained in it for the purposes of life. The medium of water answers the precise purpose to fishes, that the medium of air does to man and otber land animals. In in- 


\section{CHAPTER CXXXVI.}

\section{OF CETACEOUS FISHES IN GENERAL.}

AS on land there are some orders of animals that seem formed to command the rest, with greater powers and more various instincts, so in the ocean there are fishes which seem formed upon a nobler plan than other's, and that, to their fishy form, join the appetites and the conformation of quadrupeds. These are all of the cetaceous kind; and so much raised above their fellows of the deep, in their appetites and instincts, that alınost all our moderu naturalists have fairly excluded them from the finny tribes, and will have them called, not fishes, but, great beasts of the ocean. With them it would be as improper to say men go to Greeuland fishing for whale, as it would be to say that a sportsman goes to Blackwall a fowling for mackarel.

Yel, notwithstanding philosophers, mankind will always have their own way of talking; and, for my own part, I think them here in the right. A different formation of the lungs, stomach, and intestines; a different manner of breathing or propagating; are not sufficient to counterhalance the great obvious anlogy which these animals bear to the whole finny tribe. They are shaped as other fishes; they swim with fins; they are entirely naked, without hair; they live in the water, though they come up to breath; they are only seen in the depths of the ocean, and never coine upon shore but when forced thither. These, surely, are sufficient to plead III favour of the general denomination, and acquit mankind of error in ranking them with their lower companions of the deep.

But still they are many degrees raised above other fishes in their nature, as they are in general in their size. This tribe is com-

spiration the element is received into the lungs or gills, and in expiration is relurned deprived of its purer parts, which are retained for the purpose of animal economy. And whatever salt may be taken ints the stomachs of fishes with their food, is decomposed and separated into posed of the Whale and its varieties, of the Cachalot, the Dolphin, the Grampus, and the Porpoise. All these resemble quadrupeds in their internal structure, and in some of their appetites and affections. Like quadrupeds, they have lungs, a midriff, a stomach, intestines, liver, spleen, bladder, and parts of generation; their heart also resembles that of quadrupeds, with its partitions closed up as in them, and driving red and warm blood in circulation through the body. In short, every internal part bears a most striking similitude; nnd to keep these parts warn, the whole kind are also covered between the skin and the muscles with a thick coat of fat or blubber, which, like the bacon-fat of a hog, keeps out the cold, renders their muscles glib and pliant, and probably makes them lighter in swimming.

As these animals breath the air, it is obvious that they cannot bear to be any long time under water. They are constrained, therefore, every two or three minutes, to come up to the surface to take breath, as well as to spout out through their nostril (for they have hut one) that water which they sucked in while gaping for their prey. This conduit, by which they breath, and also throw out the water, is placed in the head, a little before the brain. Though externally the hole is but single, it is internally divided by a bony partition, which is closed by a sphincter muscle on the inside, that, like the mouth of a purse, shuts it up at the pleasure of the animal. There is also another muscle or valve, which prevents the water from going down the gullet. When, therefore, the animal takes in a certain quantity of water, which is necessary to be discharged and

its component parts of acid and soda. The sailor that feeds for twelve months together on salted meats, has not his own flesh mare salt; bit a decomposition taking place during the process of digestion, he becomes corrupted and scorbulic by the excess of soda and magnesia. 
separated from its food, it shuts the mouth, closes the valve of the stomach, opens the sphincter that kept the nostril closed, and then breathing strongly from the lungs, pushes the water out by the effort, as we see it rise by the pressure of air in a fire-engine.

The senses of these animals seem also superior to those of other fishes. The eyes of other fishes, we have observed, are covered only with that transparent skin that covers the rest of the head; but in all the cetaceous kinds, it is covered by eye-lids, as in Inan. This, no doubt, keeps that organ in a more perfect state, by giving it intervals of relaxation, in which all vision is suspended. The other fishes, that are for ever staring, must see, if for no other reason, more feebly, as their organs of sight are always exerted.

As for hearing, these also are furnished with the internal instruments of the ear, although the external orifice no where appears. It is most probable that this orifice may open by some canal, resembling the Eustachian tube, into the mouth; but this has not as yet been discovered.

Yet nature sure lias not thus formed a complete apparatus for hearing, and denied the animal the use of it when formed. It is most likely that all animals of the cetaceous kind can hear, as they certainly utter sounds, and bellow to each other. This vocal power would be as needless to animals naturally deaf, as glasses to a man that was blind.

But it is in the circumstances in which they continue their kind, that these animals show an eminent superiority. Other lish deposit their spawn, and leave the success to accident: these never produce above one young, or two at the most; and this the female suckles entirely in the manner of quadrupeds, her breasts being placed, as in the human kind, above the navel. We have read many fabulous accounts of the nursing of the demigods of antiquity, of their feeding on the marrow of lions, and their being suckled by wolves: one tnight imagine a still more heroic systern of nutrition, if we supposed that the young hero was suckled and grew sirong upon the breast-milk of a she-whale!

The whale or the grampus are terrible at any time; but are fierce and desperate in the defence of their young. In Waller's beautiful poem of the Summer lslands, we have : story, founded upon fact, which shows the maternal tenderness of these animals for their offspring. A whale and her cub had got into an arm of the sea, where, by the desertion of the tide, they were enclosed on every side. The people from shore soon saw their situation, and drove down upon them in boats, with such weapons as the urgent occasion offered. The two animals were soon wounded in several places, and the whole sea round was tinetured with their blood. The whales made several attempts to escape; and at last the old one, by its superior strength, foreed over the shallow into the depths of the ocean. But though in safety herself, she could not bear the danger that awaited her young one; she therefore rushed in once more where the smaller animal was imprisoned, and resolved, when she could not protect, at least to share its danger. The story ends with poetical justice; for the tide coming in, brought off both in safety from their enemies, though not without sustaining an infinite number of wounds in every part.

As to the rest, the distinctive marks of this tribe are, that the number of their fins never exceed three; namely, two pectoral fins, and one back fin; but in some sorts the last is wanting. These fins differ very much from those of other fishes, which are formed of straight spiues : the fins of the cetaceous tribe are made up of bones and muscles; and the skeleton of one of their fins, very much resembles the skeleton of a man's hand. Their tails also are different from those of all other fish: they are placed so as to lie flat on the surface of the water; while the other kinds have them, as we every day see, upright or edgeways. This flat position of the tail in cetaceous animals, enables them to force themselves suddenly to the surface of the water to breath, which they are continually constrained to do.

Of these enormous animals, some are without teeth, and properly called whales: others have the teeth only in the lower jaw, and are called, by the French, cachalots: the narwhal has teeth only in the upper jaw: the dolplin's teeth, as well as those of the porpoise and grainpus, are both above and below. These are the marks that serve to distingnish the kinds of this enormous tribe from each other; and these shall serve to guide us, in giving their history, 


\section{CHAPTER CXXXVIII.}

\section{OF THE WHALE PROPERLY SO CALLED, AND ITS VARIETIES.}

IF we compare land animals, in respect to magnitude, with those of the deep, they will appear contemptible in the competition. It is probable, indeed, that quadrupeds once existed much larger than we find them at present. From the skeletons of some that have been dug up at different times, it is evident, that there must have been terrestrial animals twice as large as the elephant; but creatures of such an immense bulk required a proportionable extent of ground for subsistence, and, by being rivals with men for large territory, they must have been destroyed in the contest.

But it is not only upon land that man has exerted his power of destroying the larger tribes of animated nature, he has extended his efforts even into the midst of the ocean, and has cut off numbers of those enormous animals that had perhaps existed for ages. We now no longer hear of whales t:vo hundred, and two hundred and fifty feet long, which we are certain were often seen about two centuries ago. They have all been destroyed by the skill of mankind, and the species is now dwindled into a race of diminutive animals, from thirty to about eighty feet long.

The northern seas were once the region to which the greatest of these animals resorted; but so great has been the slaughter of whales for more than two ages, that they begin to grow thinner every day; and those that are now found there, seein, from their size, not to come to their full dimensions. The greatest whales resort to places where they have the least disturbance; to those seas that are on the opposite side of the globe, near the south pole. In that part of the world, there are still to be seen whales that are above a hundred and sixty feet long; and perhaps even longer might be found in those latitudes near the south pole, to which we have not as yet ventured.

Taking the whale, however, at the ordinary size of eighiy fret long and twenty feet high, what an enormous animated mass must it ap- pear to the spectator! With what amazement must it strike him, to behold so great a creature gamboling in the deep, with the ease and agility of the smallest animal, and making its way with incredible swiftness! This is a sight which is very common to those who frequent the northern or southern ocean. Yet though this be wonderful, perhaps still greater wonders are concealed in the deep, which we have not had opportunities of exploring. These large animals are obliged to show themselves in order to take breath; but who knows the size of those that are fitted to remain for ever under water, and that have been increasing in magnitude for centuries! To believe all that has been said of the Sea-Serpent, or the Kraken, would be credulity; to reject the possibility of their existence, would be presumption.

The Whale is the largest animal of which we have any certain information; and the various purposes to which, when taken, its different parts are converted, have brought us tolerably acquainted with its history. Of the whale, properly so called, there are no less thall seven different kinds; all distinguished from each other by their external figure, or internal conformation. The Great Greenland Whale, without a back-fin, and black on the back; the Iceland Whale, without a back-fill, and whitish on he back; the New-England Whale, with a hump on the back; the Whale, with six liumps on the back; the Fin-fish, with a fin on the back near the tail; the Pikeheaded Whale, and the Round-lipped Whale. All these differ from each other in figure, as their names obviously inply. They differ also some what in their manner of living; the fin-fish having a larger swallow than the rest, being more active, slender, and fierce, and living chiefly upon herrings. However, there are none of them very voracious; and, if compared to the cachalot, that enornous tyrant of the deep, they appear harmless and gentle. The history of the rest, therefore, may be 
comprised under that of the Great Common Greenlanil Whale, with which we are best acquainted.

The Great Greenland Whale is the fish, for taking which there are such preparations made in different parts of Europe. It is a large heavy aninal, and the head alone makes a third of its bulk. It is usually found from sixty to seventy feet long. The fins on each side are from five to eight feet, composed of bones and muscles, and sufficiently sirong to give the great mass of body which they move, speed and activity. The tail, which lies flat on the water, is about twenty-four feet broad; and, when the fish lies on one side, its blow is tremendous. The skin is smooth and black, and, in sone places, marbled with white and yellow; which, running over the surface, has a very beautiful effect. This marbling is particularly observable in the fins and the tail. In the figures which are thus drawn by nature, fancy often forms the pictures of trees, landscapes, and houses. In the tail of one that was thus marbled, Ray tells us, that the number 122 was figured very evenly and exactly, as if done with a pencil.

The whale makes use only of the tail to advance itself forward in the water. This serves as a great oar to push its mass along; and it is surprising to sce with what force and celerity its enormous bulk cuts throngh the ocean. The fins are only made use of for turning in the water, and giving a direction to the velocity impressed by the tail. The female also makes use of thrm when pursued, to bear off lier young, clapping them on her back, and supporting them by the fins on each side from falling.

'The outward or scarf skin of the whale is no thicker than parchment; but this removed, the rcal skin appears, of about an inch thick, and covering the fat or blubber that lies beneath; this is from eight to twelve inches in thickness; and is, when the fish is in health, of a beautiful yellow. The muscles lie beneath; and these, like the ficsh of quadrupeds, are very red and tough.

The cleft of the mouth is above twenty feet long, which is near one-tlird of the animal's whole length; and the upper jaw is furnished with barbs, that lie like the pipes of an organ, the greatest in the middle, and the smallest to the sides. These compose the whalebone; the longest spars of which are found to be not less than eighteen feet ; the shortest, being of no value, are thrown away. The tongue is almose immoveably fixed to the lower jaw, sceming one great lump of fat ; and, in fact, it fills several hogshcads with blubber. The eyes are not larger than those of an ox; and when the crystalline humour is dried, it does not appear larger than a pea. They are placed towards the back of the head, being the most convenient situation for enabling them to see both before and behind; as also to see over them, where their food is principally found. They are guarded by eye-lids and eye-lashes, as in quadrupeds; and they scem to be very sharp-sighted.

Nor is their sense of hearing in less perfection ; for they are warned at great distances, of any danger preparing against them. It would seem as if nature liad designedly given them these advantages, as they multiply little, in order to continue their kind. It is true, indeed, that the external organ of hearing is not perceptible, for this might only embarrass them in their natural element : but as soon as the thin scarf-skin above mentioned is removed, a black spot is discovered behind the eye, and under that is the auditory canal, that leads to a regular apparatus for hearing. In short, the animal bears the smallest sounds at very great distances, and at all times, except when it is spouting water; which is the time that the fishers approach to strike it.

These spout-holes or nostrils, in all the cetaceous tribe, have been already described: in this whale there are two, one on each side the head before the eyes, and crooked, somewhat like the holes on the belly of a violin. From these holes this animal blows the water very fiercely, and with such a noise, that it roars like a hollow wind, and nay be heard at three miles distance. When wounded, it then blows more fiercely than ever, so that it sounds like the roaring of the sea in a great storm.

We have already observed, that the substance called whalebone, is taken from the upper jaw of the animal, and is very different from the real bones of the whale. The real bones are hard, like those of great land animals, are very porous, and filled with marrow. Two great strong bones sustain the under lip, lying against each other in the shape of a 
half-moon: some of these are twenty feet long; they are seen in several gardens set up against each other, and are usually mistaken for the ribs of this animal.

Such is the general conformation and figurc of this great inhabitant of the deep, the precise anatomy of which has not been yet ascertained. In those places where they are caught in greatest abundance, the sailors are not very curious as to the structure of the viscera; and few anatomists care to undertake a task, where the operator, instead of separating with a lancet, must cut his way with an axe. It is as yet doubted, therefore, whether the whale, that in most points internally resembles a quadruped, may not have one great bowel fitted entirely for the reception of air, to supply it, when constrained to keep longer than usual at the bottom. The sailors universally affirm that it has; and philosophers have nothing but the analogy of $\mathrm{jts}$ parts to oppose to their general assertions.

As these animals resemble quadrupeds in conformation, so they bear a strong resemblance in some of their appetites and manners. The female joins with the male, as is asserted, more humano, and once in two years feels the accesses of desire.

Their fidelity to each other exceeds whatever we are told of even the constancy of birds. Some fishers, as Anderson informs us, having struck one of two whales, a nıale and a female, that were in company together, the wounded fish made a long and a terrible resistance: it struck down a boat with three men in it, with a single blow of the tail, by which all went to the bottom. The other still attended its companion, and lent it every assistance; till, at last, the fish that was struck sunk under the number of its wounds; while its faithful associate, disdaining to survive the loss, with great bellowing, stretched itself upon the rlead fish, and shared its finte.

The whale goes with young nine or ten months, and is then fatter than usual, particularly when near the tine of bringing forth. It is said that the enibryo, when Grst perceptible, is about seventeen inches long, and white; but the cub, when excluded, is black, and about ten feet long. She generally produces one young one, and never nbove two. When she suckles her young, she throws herself on one side on the surface of the sca, and the young one attaches itself to the teat. The breasts are two, generally hid within the belly; but she can produce them at pleasure, so as to stand forward a foot and a half, or two feet; and the teats are like those of a cow. In some, the breasts are white; in others, speckled; in all, filled with a large quantity of milk, resembling that of land animals.

Nothing can excerd the tenderucss of the female for her offspring; she carries it with her wherever she goes, and when hardest pursued, kecps it supportcd between her fins. Even when wounded, she still clasps her young one; and when she plunges to avoid danger, takes it to the botton; but rises sooner than usual, to give it breath again.

The young ones continue at the breast for a year; during which time they are called by the sailurs, short-heads. They are then extremely fat, and yield above fifty barrols of blubber. The mother, at the same time, is equally lean and emaciated. At the age of two years they are called stunts, as they do not thrive much immcdirtely after quitting the breast ; they then scarcely yield nbove twenty, or twenty-four, harrels of blubber: from that forward, they are called skull-fish, arid their age is wholly unknown.

Every species of whale propagates only with those of its own kind, and does not at all mingle with the rest; however, they are generally seen in shoals, of different kinds together, and muke their migrations in large companies, from one ocean to another. They are a gregarious aninal, which implies their want of mutual defence agaiust the invasions of smaller, but more powerful fislies. It serms astonishing, therefore, how a shoal of these enormous animals find subsistence together, when it would seem that the supplying cven one with food would require greater plenty than the ocean could furnish. To increase our wonder, we not ouly see tlicm herding together, but usually find them fatier than any olher animals of whatsocver elcment. We likewise know that they cannot swallow large fishes, as their throat is so narrow, that an animal larger than a herring could not enter. How then do they subsist and grow so fat? A small insect, which is seen floating in those seas, and which Linureus terus the Medusa, is sufficient for this supply. These insects are bluck, and of the size of a small bean, and 
are sometimes seen floating in clusters on the surface of the water. They are of a round form, like snails in a box, but they have wings, which are so tender, that it is scarcely possible to touch them without breaking. 'These serve rather for swimming than flying; and the little animal is called by the Icelanders, the Walfizchoas, which signifies the whale's provender. They have the taste of raw muscles, and have the smell of burnt sugar. These are the food of the whale, which it is seen to draw up in great numbers with its huge jaws, and to bruise between its barbs, which are always found with several of these sticking among them.

This is the simple food of the great Greenland whale; it pursues no other animal, leads an inoffensive life in its element, and is harmless in proportion to its strength to do mischief. There seems to be an analogy between its manners and those of the elephant. They are both the strongest and the largest animals in their respective elements; neither offer injury, but are terrible when provoked to resentunent. The fin-fish indeed, in some measure, differs from the great whale in this particular, as it subsists chiefly upon herrings, great shoals of which it is often seen driving before it. Yet even the swallow of this fish is not very large, if compared to the cachalot tribe; and its ravages are but sports in comparison. The stomach and intestines of all these animals, when opened, seldom have any thing in them, except a soft unctuous substance of a brownish colour; and their excrements are of a shining red.

As the whale is an inoffensive animal, it is not to be wondered that it has many enemies, willing to take advantage of its disposition, and inaptitude for combat. There is a small animal, of the shell-fish kind, called the Whalelouse, that sticks to its body, as we see shells sticking to the foul bottom of a ship. This insinuates itself chiefly under the fins; and whatever efforts the great animal makes, it still keeps its hold, and lives upon the fat, which it is provided with instruments to arrive at.

The sword-fish, however, is the whale's most terrible enemy. "At the sight of this little animal," says Anderson, "the whale seems agitated in an extraordinary manner; ro. $53 \& 54$. leaping from the water as if with affright: wherever it appears, the whale perceives it at a distance, and flies from it in the opposite direction. I have been myself," continues he, " a spectator of their terrible encounter. The whale has no instrument of defence except the tail; with that it endearours to strike the enemy; and a single blow taking place, would effectually destroy its adversary: but the sword-fish is as active as the other is strong, and easily avoids the stroke; then bounding into the air, it falls upon its great subjacent enemy, and endeavours not to pierce with its pointed beak, but to cut it with its toothed edges. The sea all about is seen dyed with blood, proceeding from the wounds of the whale; while the enormous animal vainly endeavours to reach its invader, and strikes with its tail against the surface of the water, making a report at each blow louder than the noise of a cannon."

There is still another and more powerful enemy, called by the fishermen of New-England, the Killer. This is itself a cetaceous animal, armed with strong and powerful teeth. A number of these are said to surround the whale, in the same manner as dogs get round a bull. Some attack it with their teeth behind; others attempt it before, until, at last, the great animal is torn down, and its tongue is said to be the only part they devour when they have made it their prey. They are said to be of such great strength, that one of them alone was known to stop a dead whale that several boats were towing along, and drag it from among them to the bottom.

But of all the enemies of these enormous fishes, man is the greatest : he alone destroys more in a year than the rest in an age, and actually has thinned their numbers in that part of the world where they are chiefly sought. The great resort of these animals, was found to be on the inhospitable shores of Spitzbergen; where the distance of the royage, the coldness of the climate, the terrors of the icy sea, and, still more, their own formidable bulk, might have been expected to protect them from human injury. But all these were but slight barriers against man's arts, his courage, and his necessities. The European ships, soon after the improvement of navigation, found the way into those seas; and as early $4 T$ 
as the beginning of the fourteenth century, the Biscayneers were in possession of a very considerable trade to the coast of Greenland. The Dutch and the English followed them thither, and soon took that branch of commerce out of their hands. The English commenced the business about the begimning of the seventeenth century; and the town of Hull had the honour of first attempting that profitable branch of trade. But, at present, it seems upon the decline, as the quantity of fish are so greatly reduced, by the constant capture for such a vast length of time. It is now said that the fishers, from a defect of whales, apply themselves to the seal-fishery; yet, as these animals are extremely timorous, they will soon be induced to quit those shores, where they meet such frequent disturbance and danger. The poor natives of Greenland themselves, who used to feed upon the whale, are diminishing, in proportion as their sustenance is removed; and, it is probable, that the revolution of a few years will see that extensive coast totally deserted by its inhabitants, as it is already nearly deserted by the whales.

The art of taking whales, like most others, is much improved by time, and differs in many respects from that practised by the Biscayneers, when they first frequented the icy sea. But as the description of their method is the least complicated, and consequently the easiest understood, it will be best suited to our purpose.

For this navigation, the Biscayneers, in favourable seasons, fitted out thirty ships, of two hundred and fifty tons each, with fifty choice men apiece, and a few boys. These were stored with six months' provision; and each ship had its boats, which were to be serviceable when come to the place of duty. When arrived at the part where the whales are expected to pass to the southward, they always keep their sails set, and a sailor is placed at the mast head, to give information when he spies a whale. As soon as he discovers one, the whole crew are instantly in employment: they fit out their boats, and row away to where the whale was seen. The harpooner, who is to strike the fish, stands at the prow of the boat, with an harpoon or javelin in his hand, five or six feet long, pointed witl steel like the barb of an arrow, of a triangular shapc. As this person's place is that of the greatest dexterity, so also it is of the greatest dauger: the whale sometimes overiurns the boat with a blow of its tail; or drives against it with fury. In general, however, the animal seems to sleep on the surface of the water: while the boat is approacting, the harpooner stands aloft, and with his harpoon tied to a cord of several hundred falhom length, darts it into the animal, aud then rows as fast as possible away. It is some time before the whale seems to feel the blow; the instrument has usually pierced no deeper than the fat, and that being insensible, the animal continues for a while motionless; but soon roused from its seeming lethargy, as the shaft contirues to pierce deeper and deeper into the muscular tlesh, it flies off with amazing rapidity. In the mean time, the harpoon stieks in its side, while the rope, which is coiled up in the boat, and rums upou a swivel, lengthens as the whale recedes, but still shows the part of the deep to which it has retreated. The cord is coiled up with great care; for such is the rapidity wjth which it rums off, that if it was but the least checked, as it yields witb the animal's retreat, it would infalliby overset the boat, and the crew would go to the bottom. It sorretimes happens also, that the rapidity with which it runs over the swivel at the edge of the boat, lieats $\mathrm{jt}$, and it would infallibly take fire, did not a man stand continually with a wet mop in his hand, to cool the swivel as the cord runs. The whale luaving dived to a considerable depth, remains at the bottom, sometimes for near half an hour, with the harpoon in its body, and then rises to take breath, expecting the danger over; but the instant it appears, they are all with their boats ready to recejve it, and fling the harpoons into its body; the animal again dives and again rises, while they repeat their blows. The ship follows in full sail, like all the rest, never losing sight of the boats, and ready to lend them assistance; the whole ocean seems dyed in blood. Thus they renew their attacks, till the whale begins to be quite enfeebled and spent, when they plunge their longer spears into various parts of its body, and the cnormous animal expires When it is dead, to prevent it from sinking 
they tie it with a strong iron chain to the side of the boat, and either cut it up in pieces, and carry it home in that manner, or cxtract the oil from the blubber on ship-board.

Such is the manner in which these fish were taken in the beginning; but succeeding arts have improved the method, and the harpoon is now thrown by; a machine being used which inflicts a deeper wound, and strikes the animal with much greater certainty : there are better methods for extracting the oil, and proper machines for cutting the animal up, than were used in the early fisheries. But as an account of this belongs to the history of art, and not of nature, we must be contented with observing, that several parts of this animal, and all but the intestines and the bones, are turned to a very good account; not only the oil, but the greaves from which it is separated. The barbs also were an article of great profit; but have sunk in their price, since wonsen no longer use them to swell out their petticoats with whale-bone. The flesh of this animal is also a dainty to some nations, and even the French seamen are now and then found to dress and use it as their ordinary diet at sea. It is said, by the English and Dutch sailors, to be harl and ill-tasted; but the French assert the contrary; and the savages of Greenland, as well as those near the south pole, are fond of it to distraction. They eat the flesh, and drink the oil, which is a first-rate delicacy. The finding a dead whale is an adventure considered among the fortunate circumstances of their wretched lives. They make their abode beside it; and seldom remove till they have left nothing but the bones.

Jacobson, whom we quoted before in the History of Birds, where he described his countrymen of the island of Feroe as living a part of the year upon salted gulls, tells us also, that they are very fond of salted whale's flesh. The fat of the head they season with bay salt, and then hang it up to dry in the chimney. He thinks it tastes as well as fat bacon; and the lean, which they boil, is, in his opinion, not inferior to beef. I fancy poor Jacobson would make but an indifferent taster at one of our city feasts!

\section{CHAPTER CXXXIX.}

\section{OF THE NARWHAL.}

FROM whales that entirely want teeth, we come to such as have them in the upper jaw only; and in this class there is found but one, the Narwhal, or Sea-unicorn. This fish is not so large as the whale, not being above sixty feet long. Its body is slenderer than that of the whale, and its fat not in so great abundance. But this great animal is sufficiently distinguished from all bthers of the deep by its tooth or teeth, which stand pointing directly forward from the upper jaw, and are from nine to fourteen feet long. In all the variety of weapons with whicis nature has armed lies various tribes, there is not one so large or so formidable as this. This terrible weapon is generally found single, and some are of opinion that the animal is furnished but with one by nature; but there is at present the skull of a narwhal at the Stadthouse at Anssterdam, with two teetlı; which plainly proves that in some animals, at least, this instrument is double. It is even a doubt whether it may not be so in all; and that the narwhal's wanting a tootl is only an accident which it has net with in the encounters it is obliged daily to be engaged in. Yet it must be owned, of those that are taken only with one tooth, there seems no socket, nor no remains of any other upon the opposite side of the jaw, but all is plaiin and even. However this be, the tooth, or, as somie are pleased to call it, the horn of the narwhal, is the most terrible of all natural instruments of destruction. It is as straight as an arrow, about the thickness of the small of a man's leg, wreathed in the manner we sometimes see twisted bars of iron; it tapers 
to a sharp point; and is whiter, heavier, and harder, than ivory. It is generally seen to spring from the left side of the head directly forward in a straight line with the body; and its root enters into the socket above a foot and a half. In a skull to be seen at Hamburgh there are two teeth, which are each above seven feet long, and are eight inches in circumference. When the animal, possessed of these formidable weapons, is urged to employ them, it drives directly forward against the enemy with its teeth, that, like protended spears, pierce whatever stands before them.

The extreme length of these instruments have induced some to consider then rather as horns than teeth; but they in every respeet resemble the tusks of the boar and the elephant. They grow, as in them, from sockets in the upper jaw; they have the solidity of the hardest bone, and fal surpass ivory in all its qualities. The same error has led others to suppose, that as among quadrupeds the female was often found without horus, so these instruments of defence were only to be found in the male: but this has been more than once refuted by actual experience; both sexes are found armed in this manner; the horn is sometimes found wreathed, and sometinses smooth; sometimes a little hent, and sometimes straight; but always strong, deeply fixed, and sharply pointed.

Yet, notwithstanding all these appointments for combat, these long and pointed tusks, amazing strength, and unmatchable celerity, the narwhal is one of the inost harnuless and peaceful inhabitants of the ocean. It is scen constantly and inoffensively sporting among the other great monsters of the deep, no way attempting to injure them, but pleased in their company. The Greenlanders eall the narwhal the forerunner of the whale; for wherever it is seen, the whale is shortly after sure to follow. This may arise as well from the natural passion for society in these animals, as from both living upon the same.fuod, which are the insects described in the preceding chapter. These powerful fishes make war upon no other living creature; and though furnished with instruments to spread general destruction, are as innocent and as peaceful as a drove of oxen. Nay, so regardless are they of their own weapons, and so utterly unmindful to keep them in repair for engagement, that they are constantly seen covered over with weeds, slough, and all the filth of the sea; they seem rather considered as all impediment than a defence.

The manners and appetites both of the narwlial and the great whale are entirely similar; they both alike want teeth for chewing, and are obliged to live upon insects; they both are peaceable and harmless, and always rather fly than seek the combat The narwhal, however, has a much narrower gape than the great whale, and, therefore, does not want the use of barbs to keep in its food when once sucked into the mouth. It is also much swifter, and would never be taken by the fishermen but for those very tusks which at first appear to be its principal defence. These animals, as was said, being fon.l of living logether, are always seen in herds of several at a time; and whenever they are attacked they crowd together in such a manner, that they are mutually embarrassed by their tusks. By these they are often locked together, and are prevented from sinking to the hottom. It seldom happens, therefore, but the tishermen make sure of one or two of the hindmost, which very well reward their trouble.

It is from the extraordinary circumstance of the teeth, thercfore, that this fish demands a distinct history; and such luas been the curiosity of mankind, and their desire to procure them, that a century ago they were considered as the greatest rarity in the world. At that time the art of catching whales was not known; and mankind saw few, except such as were stranded on the coasts by accident. The tooth of the narwhal, therefore, was ascribed to a very different animal from that which really hore it. Among other fossil substances, they wore sometimes dug up; and the narwhal being ntterly unknown, naturalists soon found a terrestrial owner. They were thought to be the horus of unicorus, an animal described by Pliny as resembling a horse, and with one straight horn darting forward from the middle of its forehead. These teeth were, therefore, considered as a strong testimony in favour of that historian's veracity, and were shown among. 
the most precious remains of antiquity. Even for some time after the narwhal was known, the deceit was continued, as those who were possessed of a tooth sold it to great adrantage.
But at present they are too well known to deceive any, and are only shown for what they really are; their curiosity increasing in proportion to their weight and their size.

\section{CHAPTER CXL.}

\section{OF THE CACHALOT, AND ITS VARIETIES.}

THE Cachalot, which has generally gone under the name of the spermaceti-whale, till Mr. Pennant very properly made the distinction, by borrowing its name from the French, has several,teeth in the under jaw, but none in the upper. As there are no less than seven distinctions among whales, so also there are the same number of distiuctions in the tribe we are describing. The cachalot with two fins and a black back; the cachalot with two fins and a whitish back; that with a spout in the neck; that with a spout in the snout; that with three fius and sharp-pointed teeth; that with three fins and sharp-edged teeth; and, lastly, the cachalot, with three fins and flatted teeth.

This tribe is not of such enormous size as the whale, properly so called, not being above sixty feet long, and sixteen feet high. In consequence of their being more slender, they are much more active than the common whale; they remain a longer time at the bottom; and afford a smaller quantity of oil. As in the common whale the head was seen to make a third part of its bulk, so in this species the head is so large as to make one half of the whole. The tongue of this ani$\mathrm{mal}$ is small, but the throat is very formidable; and with very great ease it could swallow an ox. In the stomach of the whale scarcely any thing is to be found; but in that of the cachalot there are loads of fish of different kinds; some whole, some half digested, some sinall, and others eight or nine feet long. The cachalot is, therefore, as destructive

a A species is mentioned by Fabricius, as being found on the shores of Grcenland, much smaller, of a black colvur, witl two obtuse teeth from the upper jaw, a litile among lesser fishes, as the whale is harmless; and can at one gulp swallow a shoal of fishes down its enormous gullet. Linnæus tells us that this fish pursues and terrifies the dolphins and porpoises so much, as often to drive them on shore.

But, how formidable soever this fish may be to its fellow's of the deep, it is by far the most valuable, and the most sought after by man, as it contains two very precious drugs, spermaceti and ambergris. The use of these, either for the purposes of luxury or medicine, is so universal, that the capture of this animal, that alone supplies them, turns out to very great advantage, particularly since the art has been found out of converting all the oil of this animal, as well as the brain, into that substance called spermaceti.

This substance, as it is naturally formed, is found in the head of the animal, and is no other than the brain. The outward skin of the head being taken off, a covering of fat offers about three inches thick; and under that, instead of a bony skull, the animal has only another thick skin that serves for a covering and defence of the brain. The first cavity or chamber of the brain, is filled with that spermaceti which is supposed of the greatest purity and highest value. From this cavity there is generally drawn about seven barrels of the clearest spermaceti, that thrown upon water coagulates like cheese. Below this there is another chamber just over the gullet, which is about seven feet high; and this also contains the drug,

curved at the tips, very weak, and measuring not above an incl in length: it las likewise a small fin on the back, which is wanting in the common narwhal. 
but of less value. It is distributed in this cavity like honey in a hive, in small cells, separated from each other by a membrane like the inner skin of an egg. In proportion as the oily substance is drawn away from this part, it fills anew from every part of the body; and from this is generally obtained about nine barrels of oil. Besides this, the spinal-marrow, which is as thick as a man's thigh, and reaches all along the back-bone to the tail, where it is not thicker than one's finger, affords no inconsiderable quantity.

This substance, which is used in the composition of many medicines, rather to give them consistence than efficacy, was at first sold at a very high price, both from the many virtues ascribed to it, and the small quantity that the cachalot was capable of supplying:'at present, the price is greatly fallen; first, because its efficacy in medicine is found to be very small; and again, because the whole oil of the fish is easily convertible into spermaceti. This is performed by boiling it with a ley of pot-ash, and hardening it in the manner of soap. Candles are now made of it, which are substituted for wax, and sold much cheaper; so that we need not fear having our spermaceti adulterated in the man- ner some medical books caution us to beware of; for they carefully guard us against having our spermaceti adulterated with virgin wax.

As to the ambergris, which is sometimes found in this whale, it was long considered as a substance found floating on the surface of the sea; but time, that reveals the secrets of the mercenary, has discovered that it chiefly belongs to this animal. The name, which has been improperly given to the former substance, scems more justly to belong to this; for the ambergris is found in the place where the seminal vessels are usually situated in other auimals. It is found in a bag of three or four feet long, in round lumps from one to twenty pounds weight, floating in a fluid rather thinner than oil, and of a yellowish colour. 'There are never seen more than four at a time in one of these bags; and that which weighed twenty pounds, and which was the largest ever seen, was found single. These balls of ambergris are not found in all. fishes of this kind, but chiefly in the oldest and strongest. The uses of this medicine for the purposes of luxury, and as a perfume, are well known; though upon some subjects ignorance is preferable to information.

\section{CHAPTER CLXI.}

\section{OF THE DOLPHIN, THE GRAMPUS, AND THE PORPOISE, WITH THEIR VARIETIES.}

ALL these fish have teeth both in the upper and the lower jaw, and are much less than the whale. The Grampus, which is the largest, never exceeds twenty feet. It may also be distinguished by the flatness of its head, which resembles a boat turned upside down. The Porpoise resembles the grampus in most things except the snout, which is not above eight feet long; its snout also more resembles that of a hog. The Dolphin has

\footnotetext{
a The perfume called Ambergris, is found in large masses, in the intestines, and is now known to be nothing more han the excrements of the animal. Spermaceti is found
}

a strong resemblance to the porpoise, except that its snout is longer and more pointed. They have all fins on the back; they all have heads very large, like the rest of the whalekind; and resemble each other in their appetites, their manners, and conformations; being equally voracious, active, and roving.

The great agility of these animals prevents their often being taken. They seldom remain a moment above water; sometimes, in-

in a vast cavily in the upper part of the head: while fresh, and in its naturat receptacle, it is nearly fluid; but it concretes into opake masses soon after it is exposed to the air. 


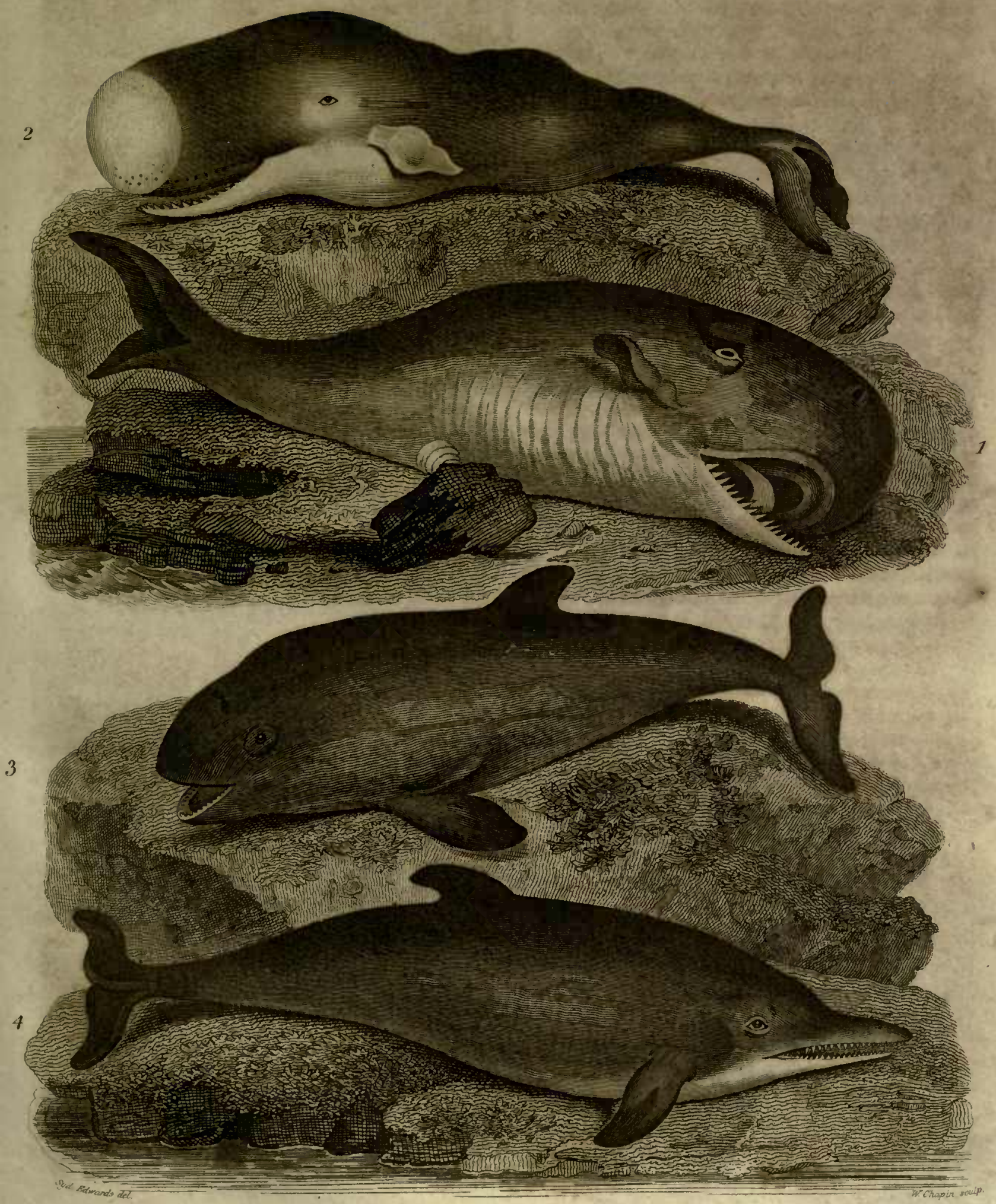

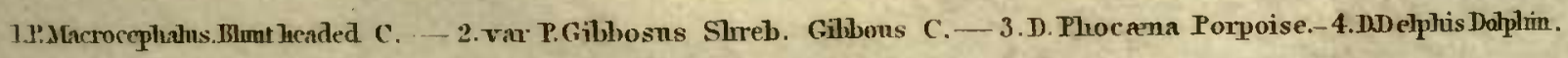


The

*

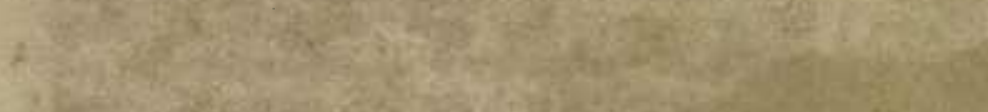

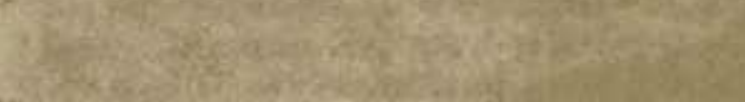

6y

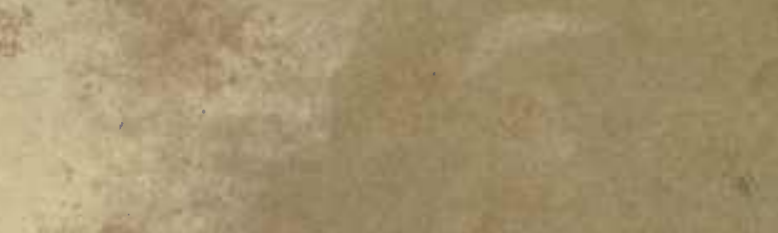

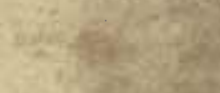

(c)

ate $\frac{1}{3}-4=0$

(istist

in

$\left(x, x^{2}\right)^{2}$

दै4

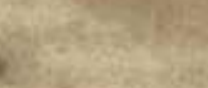

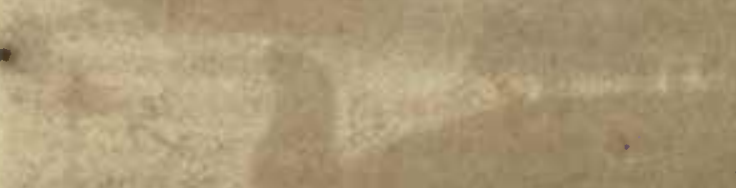

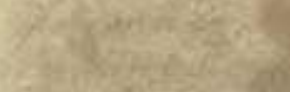

ane

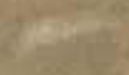

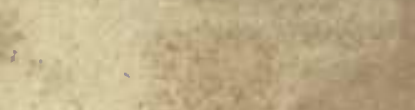

$3 \times 19$

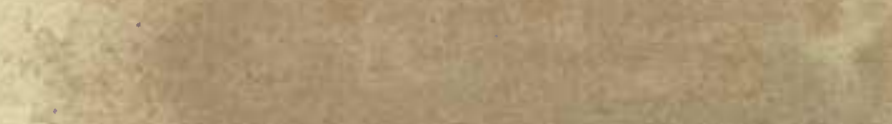

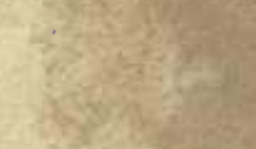

$x^{2}=3$

y.

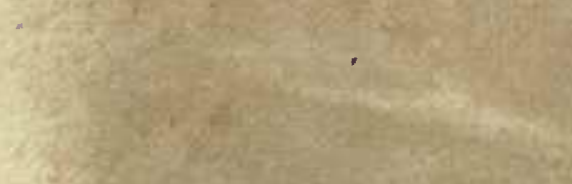

38

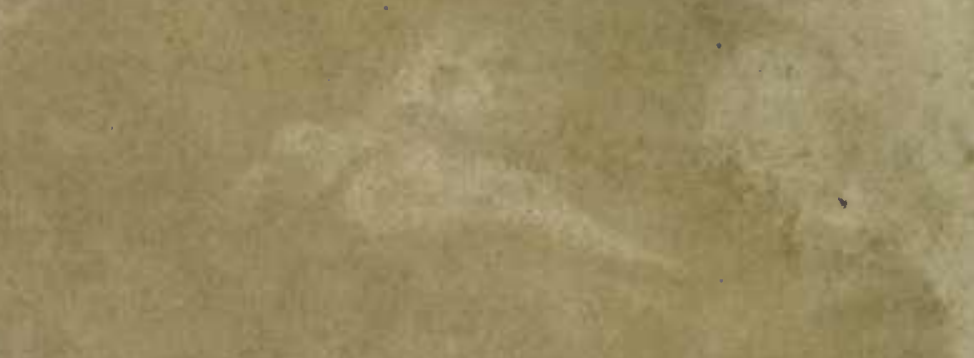

y 
deed, their too eager pursuits expose them to danger; and a shoal of herrings often allures them out of their depth. In sueh a case, the hungry animal continues to flounder in the shallows till knoeked on the head, or till the returning tide seasonably comes to its relief. But all this tribe, and the dolphin in particular, are not less swift than destructive. No fish could escape them, but from the awkward position of the mouth, which is placed in a manner under the hend: yet, even with these disadvantages, their depredations are so great, that they have been justly styled the plunderers of the deep.

What eould induce the ancients to a predilection in fivour of these aumals, particularly the dolphin, it is not easy to aecount for. Historians and philosophers seem to have contended who should invent the greatest number of fables concerning them. The dolphin was eclebrated in the earliest time for its fonduess to the human raee, and was distinguished by the epithets of the boy-loving and philanthropist. Seareely an accident could happen at sea, but the dolphin offered himself to convey the unfortunate to shore. The inusician flung into the'sea by pirates, the boy taking an airing in the midst of the sea, and returning again in salety, were obliged to the dolpinin for its services. It is not easy, I say, to assign a cause why the aneients should thus have invented so many fables in their favour. The figure of these animals is far from prejudicing us in their interests; their extreme rapacity tends still less to eudear them; I know nothing that can reconeile them to man and exeite his prejudices, exeept that when taken they sometimes have a plaintive moan, with which they eontinue to express their pain till they expire. This, at first, might have exeited human pity; and that might have produeed affeetion. At present, these fishes are regarded even by the vulgar in a very different light; their appearance is far from being esteemed a favourable omen by the seamen; and from their boundings, springs, and frolics in the water, experience has taught the mariners to prepare for a storm.

But it is not to one circumstance only that the ancients have eonfined their fabulous reports concerning these animals; as from their leaps out of their element, they assume a temporary curvature, which is by no means their natural figure in the water, the old painters and sculptors have universally drawn them wrong. A dolphin is scareely ever exhibited by the aneients in a straight shape, but curved, in the position whieh they sometimes appear when exerting their force; and the poets too have adopted the general error. Even Pliny, the best naturalist, has asserted, that they instantly die when taken out of the water; but Rondelet, on the contrary, assures us that he has seen a dolphin carried alive from Montpelier to Lyons.

The moderns have more just notions of these animals; and have got over the many fables, which every day's experience eontradicts. Indeed their jumbers are so great, and, though shy, they are so often taken, that sucls peeuliarities, if they were possessed of any, would have been long sinee ascertained. They are found, the porpoise especially, in such vast numbers. in all parts of the sea that surrounds this kingdom, that they are sometimes noxious to seamen, when they sail in small vessels. In some plaees they almost darken the water as they rise to take breath, and particularly before bad weather are much agitated, swimming against the wind, and tumbling about with unusual violence.

Whether these motions be the gambols of pleasure or the agitations of terror, is not well known. It is most probable that they dread those seasons of turhulence, when the lesser fishes shrink to the bottom, and their prey no longer offers in such abundance. In times of fairer weather they are seen herding together, and pursuing shoals of various fish with great impetuosity. Their method of hunting their game, if it may be so called, is to follow in a pack, and thus give each other mutual assistance. At that season, when the maekarel, the herring, the salmon, and other fish of passage, begin to make their appearance, the cetaceous tribes are seen fierce in the pursuit; urging their prey from one creek or bay to another, deterring them from the shallows, driving them towards each other's ambush, and using a greater variety of arts than hounds are seen to exert in pursuing the hare. However, the porpoise not only seeks for prey near the surface, but often descends to the 
bottom in search ot sand-eels, and sea-worms, which it roots out of the sand with its nose, in the manner hogs harrow up the fields for food. For this purpose, the nose projects a little, is shorter and stronger than that of the dolphin; and the neck is furnished with very strong muscles, which enable it the readier to turn up the sand.

But it sometimes happens, that the impetuosity, or the hunger, of these animals, in their usual pursuits, urges them beyond the limits of safety. The fishermen, who extend their long nets for pilchards, on the coasts of Cornwall, have sometimes an unwelcome eapture in one of these. Their feeble nets, which are calculated only for taking smaller prey, suffer an universal laceration from the efforts of this strong animal to escape; and if it be not knoeked on the head, before it has had time to flounder, the nets are destroyed, and the fishery interrupted. There is nothing, therefore, they so much dread, as the entangling a porpoise; and they do every thing to intimidate the animal from approaching.

Indeed, these creatures are so violent in the pursuit of their prey, that they sometimes follow a shoal of small fishes up a fresh-water river, from whence they find no small difficulty to return. We have often seen them taken in the Thames at London, both above the bridges and below them. It is curious enough to observe with what activity they avoid their pursuers, and what little time they require to fetch breatlu above the water. The manuer of killing them is for four or five boats to spread over the part of the river in which they are seen, and with fire-arms to shoot at them the instant they rise above the water. The fish being thus for some time kept in agitation, requires to come to the surface at quicker intervals, and thus affords the marksmen more frequent opportunities.

When the porpoise is taken, it becomes no inconsiderable capture, as it yields a very large quantity of oil; and the lean of some, particularly if the animal be young, is said to be as well tasted as veal. The inhabitants of Norway prepare, from the eggs found in the body of this fish, a kind of carier, which is said to be a very delicate sauce, or good when even eaten with bread. There is a fishery for porpoise along the western isles of Scotland during the summer season, when they abound on that shore; and this branch of industry turns to good advantage.

As for the rest, we are told, that these animals go with young ten months; that, like the whale, they seldom bring forth above one at a time, and that in the midst of summer: that they live to a considerable age; though some say not above twenty-five or thirty years; and they sleep with the snout above water. They seem to possess, in a degree proportioned to their bulk, the manners of whales; and the history of one species of cetaceous animals, will, in a great measure, serve for all the rest. 


\section{OT CARTHAGITOUS IUSIERS.}

\section{$\rightarrow 000$ \\ CHAP'TER CXLII. \\ OF CARTILAGINOUS FISHES IN GENERAL.}

WE have seen that fishes of the cetaceous kind bear a strong resemblance to quadrupeds in their conformation; those of the cartilaginous kinds are one remove scparated from them; they form the shade that completes the imperceptible gradations of nature.

The first great distinction they exhibit is, in having cartilages or gristles instead of bones. The cetaceous tribes have their bones entirely resembling those of quadrupeds, thick, white, and filled with marrow; those of the spinous kind, on the contrary, have small slender bones, with points resembling thorıs, and generally solid throughout. Fishes of the cartilaginous kinds have their bones always soft and yielding; and age, that hardens the bones of other animals, rather contributes still more to soften theirs. The size of all fishes increases with age; but from the pliancy of the bones in this tribe, they seem to have no bounds placed to their dimensions; and it is supposed that they grow larger every day till they die.

They have other differences, more obviously discernible. We have observed, that the cetaceous tribes had lungs like quadrupeds, a heart with its partition in the same manner, and an apparatus for hearing; on the other hand, we mentioned that the spinous kinds had no organs of hearing, no lungs to breath through, and no partition in the heart; but that their cold red blood was circulated by the means of the impulse made upon their gills by the water. Cartilaginous fishes unite both these systems in their conformation: like the cetaceous tribes, they พ0. $53 \& 54$. have organs of hearing, and lungs; like the spinous kinds, they have gills, and a heart without a partition. Thus possessed of a twofold power of breathing, sometimes by means of their lungs, sometimes by that of their gills, they seem to unite all the advantages of which their situation is capable, and drawing from both elements every aid to their necessities or their enjoyments.

This double capacity of breathing in these animals, is one of the most remarkable features in the history of nature. The apertures by .which they breath, are some where placed about the head; either beneath, as in flat fish; on the sides, as in sharks; or on the top of the head, as in pipe-fish. To these apertures are the gills affixed, but without any bone to open and shut them, as in spinous fishes; from which, by this mark, they may be easily distinguished, though otherwise very much alike in appearance. From these are bending cylindrical ducts, that run to the lungs, and are supposed to convey the air, that gives the organs their proper play. The heart, however, has but one valve; so that their blood wants that double circulation which obtains in the cetaceous kinds; and the lungs seem to be rather as an internal assistant to the gills, than fitted for supplying the same offices as in quadrupeds, for they want the pulmonary vein and artery.

From this structure, however, the animal is enabled to live a longer time out of water than those whose gills are more simple. The cartilaginous shark, or ray. live some hours after they are taken; while the spinous herring or mackarel expire a few minutes $4 U$ 
after they are brought on shore. From hence this tribe secms possessed of powers that other fishes are wholly deprived of; they can remain continually under water, withont ever taking breath; while they can venture their heads above the deep, and continue for hours out of their native element.

We observed, in a former chapter, that spinous fishes have not, or at least appear not to have, externally any instruments of generation. It is very different with those of the cartilaginous kind, for the male always has these instruments double. The fish of, this tribe are not unfrequently seen to copulate; and their manner is belly to belly, such as may naturally be expected from animals whose parts of generation are placed forward. They in general choose colder seasons and situations than other fish for propagating their kind; and many of them bring forth in the midst of winter.

The same duplicity of character which marks their general conformation, obtains also with regard to their manner of bringi::g forth. Some bring forth their young alive; and some bring forth eggs, which are afterwards brought to maturity. In all, however, the manner of gestation is nearly the sane; for upon dissection, it is ever found, that the young, while in the body, continue in the egg till a very little time before they are cxcluded: these eggs they may properly be said to hatch within their body; and as soon as their young quit the shell, they begin to quit the womb also. Unlike to quadrupeds, or the cetaceous tribes, that quit the egg state in a few days after their first conception, and continne in the womb several months after, these continue in the body of the fermale, in their egg state, for weeks together; and the eggs are found linked together by a membrane, from which, when the foetus gets free, it continues but a very short time till it delivers itself from its confinement in the womb. The eggs themselves consist of a white and a yolk, and have a substance, instead of shell, that apily may be compared to softened born. These, as I observed, arc sometimes hatched in the wornb, as in the shark and ray kinds; and they are sometimes excluded, as in the sturgeon, before the animal coines to its time of disengaging. Thus we see that there seems very little difference. between the viviparous and the oviparous kinds, in this class of fishes: the one hatcl their eggs in the womb, and the young continue uo long time there; the others exclude their eggs before hatching, and leave it to time and accident to bring their young to maturity.

Such are the peculiar marks of the cartilaginous class of fishes, of which there are many kinds. To give a distinct description of every fish is as little my intention, as perhaps it is the wish of the reader; but the peeuliarities of each kind deserve notice, and the most striking of these it would be unpardonable to omit.

Cartilaginous fish may be divided first into those of the shark kind, with a body growing less towards the tail, a rough skin, with the moush placed far beiseatls the end of the nose, five apertures on the sides of the neek for breathing, and the upper part of the tail longer than the lower. This class chiefly comprehends the Great White Shark, the Balance Fish, the Hound Fish, the Monk Fish, the Dog Fish, the Basking Shark, the Zygæna, the Tope, the Cat Fish, the Blue Shark, the Sea Fox, the Swooth Hound Fish, and the Porbeagle. These are all of the same nature, and differ more in size, than in figure or conformation.

The next division is that of flat fish; and these their bruad, flat, thin shape, is sufficiently capable of distinguishing from all others of this kind. They nay be easily distinguished also from spinous flat fish, by the holes through which they breath, which are uncovered by a bone; and which, in this kind, are five on each side. In this tribe we may place the Torpedo, the Skate, the Sharp-nosed Ray, the Rough Ray, the Thornback, and the Fire Flare.

The third division is that of the slender suake-shaped kind; such as the Lamprey, the Pride, and the Pipe-fish.

The fourth division is of the Sturgeon and its variery, the Ising-glass Fish.

The last division may comprise fish of different figures and natures, that do not rank under the former divisions. These are the Sun Fish, the Tetrodon, the Lump Fish, the Sea Snnil, the Chimara, and the Fishing Frog. Earh of these has somewhat peculiar in its powers or its forms, that destrves to be remarked. The description of the figurcs of these at least may compensate for our general ignorance of the rest of their history. 


\section{CHAPTER CXLIII.}

\section{OF CARTILAGINOUS FISHES OF THE SHARK KIND.}

OF all the inhabitants of the deep, those of the shark kind are the fiercest and the most voracious. The sumallest of this tribe is not less dreaded by grenter fish, than niany that to appearance seem more powerful; nor do any of them seem fearful of attacking animals far above their size: but the Great White Shark, which is the largest of the kind, joins to the most amazing rapidity, the strongest appetites for mischief: as he approaches nearly in size to the whale, he far surpasses him in strength and celerity, in the fornidable arrangement of his teeth, and his insatiable desire of plunder.

The White Shark is sometimes seen to rank even anong whales for nagnitude; and is found from twenty to thirty feet long. Some assert that they have seen them of four thousand pound weight; and we are told particularly of one, that had a human corpse in his belly. The head is large, and soniewhat flatted; the snout long, and the eyes large. The mouth is enormously wide, as is the throat, and capable of swallowing a man with great ease. But its furniture of teeth is still more terrible; of these there are six rows, extremely hard, sharp-pointed, and of a wedge-like figure. It is asserted that there are seventytwo in each jaw, which make an bundred and forty-four in the whole; yet others think that their number is uncertain ; and that in proportion as the animal grows older, these terrible instruments of destruction are found to increase. With these the jaws, both above and below, appear planted all over; but the animal has a power of erecting or depressing them at pleasure. When the shark is at rest, they lie quite flat in his mouth; but when he prepares to seize his prey, he crects all this dreadful apparatus, by the help of a set of muscles that join them to the jaw ; and the animal he seires, dies, pierced with a hundred wounds, in a moment.

Nor is this fish less terrible to behold as to the rest of his form : his fins are larger in pro- portinn; he is furnished with great goggle cyes, that he turns with ease on every side, so as to see his prey behind him as well as before; and his whole aspect is marked with a cliaracter of malignity : his skin also is rough, hard, and prickly; being that substance which covers instrument cases, called shagreen.

As the shark is thus formidable in his appearance, so is he also dreadful from his courage and activity. No fish can swin so fast as he; noue so constantly employed in swimming: he outstrips the swiftest ships, plays round then, darts ont before them, returns, seems to gaze at the passengers, and all the while does not seem to exhibit the smallest symptom of an effort to proceed. Sucl amazing powers, with such great appetites for destruction, would quickly unpeople even the ocean, but providentially, the shark's upper jaw projects so far above the lower, that he is obliged to turn on one side, (not on his back, as is generally supposed,) to seize his prey. As this takes some small time to perform, the animal pursued seizes that opportunity to make its escape.

Still, however, the depredations he commits are frequent and formidable. The shark is the dread of sailors in all hot climates; $w$ here, like a greedy robber, he attends the ships, in expectation of what may drop over-buard. A man who unfortunately falls into the sea at such a time, is sure to perish, without inercy. A sailor that was bathing in the Mediterranean, near Antibes, in the year 1744, while he was swimming about fifty yards from the ship, perceived a monstrous fish making towards him, and surveying him on every side, as fish are often seen to look round a bait. The poor man, struck with terror at its approach, cried out to his companions in the vessel to take him on board. They accordingly threw him a rope with the utmost expedition, and were drawing him up by the ship's side, when the shark darted after him from the deep, and snapped off his leg. 
Mr. Pennant tells us, that the master of a Guinea-ship, finding a rage for suicide prevail among his slaves, from a notion the unhappy creatures had, that after death they should be restored again to their families, friends, and country; to convince them at least that some disgrace should attend them here, he ordered one of their dead bodies to be tied by the heels to a rope, and so let down into the sea; and, though it was drawn up again with great swiftness, yet, in that short space, the sharks had bit off all but the feet. Whether this story is prior to an accident of the same kind, which happened at Belfast in Ireland, about twenty years ago, I will not take upon me to determine; but certain it is, there are some circumstances alike in both, though more terrible in that I am going to relate. A Guinea captain was, by stress of weather, driven into the harbour of Belfast, with a lading of very sickly slaves, who, in the manner above mentioned, took every opportunity to throw themselves overboard when brought up upon the deck, as usual, for the benefit of the fresh air. The captain perceiving, among others, a woman slave attempting to drown herself, pitched upon her as a proper example to the rest. As he supposed that they did not know the terrors attending death, he ordered the woman to be tied with a rope under the arm-pits, and so let her down into the water. When the poor creature was thus plunged in, and about half way down, she was heard to give a terrible shriek, which at first was ascribed to her fears of drowning; but soon after the water appearing red all round her, she was drawn up, and it was found that a shark, which had followed the ship, had bit her off from the middle.

Such is the frightful rapacity of this animal; nothing that has life is rejected. But it seems to have a peculiar enmity to man: when once it has tasted human flesh, it never desists from haunting those places where it expects the return of its prey. It is even asserted, that along the coasts of Africa, where these animals are found in great abundance, numbers of the negroes, who are obliged to frequent the waters, are seized and devoured by them every year. The people of these coasts are firmly of opinion, that the shark loves the black man's flesh in preference to the white, and that when men of different colours are in the water together, it always makes choice of the former.

However this be, men of all colours are equally afraid of this animal, and have contrived different methods to destroy him. In general, they derive their success from the shark's own rapacity. The usual method of our sailors to take him, is by baiting a great hook with a piece of beef or pork, which is thrown out into the sea by a strong cord, strengthened near the hook with an iron chain. Without this precaution, the shark would quickly bite the cord in two, and thus set himself free. It is no unpleasant amusement to observe this voracious animal coming up to survey the bait, particularly when not pressed by hunger. He approaches it, examines it, swims round it, seems for a while to neglect it, perhaps apprehensive of the cord and chain: he qnits it for a little; but his appetite pressing, he returns again; ap. pears preparing to devour it, but quits it once more. When the sailors have sufficiently diverted themselves with his different evolutions, they then make a pretence, by drawing the rope, as if intending to take the bait away: it is then that the glutton's hunger excites him; he darts at the bait, and swallows it, hook and all. Sometimes, however, be does not so entirely gorge the whole, but that he once more gets free; yet even then, thongh wounded and bleeding with the hook, he will again pursue the bait until he is taken. When he finds the hook lodged in his maw, his utmost efforts are then excited, but in vain, to get free; he tries with his teeth to cut the chain; he pulls with all his force to break the line; he almost seems to turn his stomach inside ont, to disgorge the hook : in this manner be continues lis formidable though fruitless efforts: till, quite spent, he suffers his head to be drawn above water, and the sailors, confining his tail by a noose, in this manner draw him on ship-board, and despatch him. This is done by beating lim on the head till he dies; yet even that is not effected without difficulty and danger; the enormous creature, terrible even in the agonies of death, still struggles with his destroyers; nor is there an animal in the world that is 
harder to be killed. Even when cut in pieces, the muscles still preserve their motion, and vibrate for some minutes after being scparated from the body. Another method of taking them, is by striking a barbed instrument, called a fizgig, into his body, as he brushes along by the side of the ship. As soon as he is taken up, to prevent his flouncing, they cut off the tail with an axe, with the utmost expedition.

This is the manner in which Europeans destroy the shark; but some of the Negroes along the African const, take a bolder and more dangerous method to combat their terrible enemy. Armed with nothing more than a knife, the Negro plunges into the water, where he sees the shark watching for his prey, and boldly swims forward to meet him: though the great animal does not come to provoke the combat, he does not avoid it, and suffers the man to approach him; but just as he turns upon his side to seize the aggressor, the Negro watches the opportunity, plunges his knife into the fish's belly, and pursues his blows with such success, that be lays the ravenous tyrant dead at the bottom: he soon however returns, fixes the fish's head in a noose, and drags him to shore, where he makes a noble feast for the adjacent villages.

Nor is man alone the only enemy this fish has to fear: the Remora, or Sucking-fish, is probably a still greater, and follows the shark every where. This fish has got a power of adhering to whatever it sticks against, in the same manner as a cupping-glass sticks to the human body. It is by such an apparatus that this animal sticks to the shark, and drains away its moisture. The seamen, however, are of opinion, that it is seen to attend on the shark for more friendly purposes, to point him to his prey, and to apprise him of his danger.

- Sharks, as well as the Ray tribe, bring forth their young alive, more than one at a time, and each enclosed in a square horny case, terminated at the four corners by slender filaments. After being in the water some time, these natural pouches npen at one end, and the young fish escapes from his confiuement. These receptacles are, in the shark, of a pellucid horn-colour, terminated at the
For this reason it has been ca!led the Shark's Pilot.

The shark so much resembles the whale in size, that some have injudiciously ranked it in the class of cetaceous fishes; but its real rank is in the place here assigned it, among those of the cartilaginous kind. It breaths with gills and lungs, its bones are gristly, and it brings forth several living young: Bellonius assures us, that he saw a female shark produce eleven live young ones at a time. But I will not take upon me to vouch for the veracity of Rondeletius, who, when talking of the blue shark, says, that the female will permit her small brood, when in danger, to swim down her mouth, and take shelter in her belly. Mr. Pennant, indeed, seems to give credit to the story, and thinks that this fish, like the oppossum, may have a place fitted by nature for the reception of her young. To his opinion much deference is due, and is sufficient, at least, to make us suspend our dissent; for nothing is so contemptible as that affectation of wisdom which some display, by universal incredulity."

Upon the whole, a shark, when living, is a very formidable animal; and, when dead, is of very little value. The flesh is hardly digestible by any but the Negroes, who are fond of it to distraction: the liver affords three or four quarts of oil ; some imaginary virtues bave been ascribed to the brain; and its skin is, by great labour, polished into that substance called shagreen. Mr. Penuant is of opinion, that the female is larger than the male in all this tribe; which would, if confirmed by experience, make a striking agreement between them and birds of prey. It were to be wished that succeeding historians would examine into this observation, which is offered only as a conjecture!

corners by very long slender filaments, which are generally found twisted round coral, sea-weeds, and other substances, to prevent their being driven on sliore before the young is excluded : those of the Ray tribe are black, with the filaments hardly longer than the case, and are frequently cast on our shores in great abundance. 


\section{CHAPTER CXLIV.}

\section{OF CARTILAGINOUS FLAT-FISH, OR THE RAY KIND.}

THE same rapacity which impels the shark along the surface of the water, actuates the flat fish at the bottom. Less active, and less formidable, they creep in security along the bottom, seize every thing that comes in their way ; neither the hardest shells nor the sharpest spines give protection to the animals that bear them; their insatiable hunger is such that they devour all; and the force of their stomach is so great, that it easily digests them.

The whole of this kind resemble each other very strongly in their figure; nor is it easy, without experience, to distinguish one from another. The stranger to this dangerous tribe may imagine he is only handling a skate, when he is instantly struck numb by the torpedo; he may suppose he has caught a thorn-back, till he is stung by the fire-flare. It will be proper, therefore, after describing the general figure of these animals, to mark their differences.

All fish of the ray kind are broad, cartilaginous, swimming flat on the water, and having spines on different parts of their body, or at the tail. They all have their eyes and mouth placed quite under the body, with apertures for breathing either about or near them. They all have teeth, or a rough bone, which answers the same purpose. Their bowels are very wide towards the mouth, and go on diminishing to the tail. The tail is very differently shaped from that of other fishes; and at first sight more resembling that of a quadruped, being narrow, and ending either in a bunch or a point. But what they are chiefly distinguished by, is, their spines or prickles, which the different species have on different parts of their body. Some are armed with spines both above and below; others have them on the upper part only; some have their spines at the tail; some have three rows of them, and others but one. These prickles in some are comparatively soft and feeble; those of others, strong and piercing. The smallest of these spines are usually inclining towards the tail; the larger towards the head.

It is by the spines that these animals are distinguished from each other. The skate has the middle of the back rough, and a single row of spines on the tail. The sharpnosed ray has ten spines that are siluated towards the middle of the back. The rough ray has its spines spread indiscriminately over the whole back. The thorn-back has its spines disposed in three rows upon the back The fire-flare has but one spine, but that indeed a terrible one. This dangerous weapon is placed on the tail, abont four inches from the body, and is not less than five inclies long. It is of a flinty harduess, the sides thin, sharp-pointed, and closely and sharply bearded the whole way. The last of this tribe that I shall mention is the torpedo; and this animal has no spines that can "ound; but in the place of them it is possessed of one of the most potent and extraordinary faculties in nature.

Such are the principal differences that may enable us to distinguish animals, some of which are of very great use to mankind, from others that are terrible and noxious. With respect to their uses, indeed, as we shall soon see, they differ much; but the similitude among them, as to their nature, appetites, and conformation, is perfect and entire. They are all as voracious as they are plenty; and as dangerous to a stranger as is useful to him who can distinguish their diflerences.

Of all the larger fish of the sea, these are the most numerous; and they owe their numbers to their size. Except the whic shark and cachalot alone, there is no other fish that has a swallow large enough to take them in; and their spines make thein a still more dangerous morsel. Yet the size of some is such, that even the shark himself is unable to devour them: we have seen some of them in England weigh above two hundred pounds; but that is nothing to their enormous bulk in 
other parts of the world. Labat tells us of a prodigious ray that was speared by the negroes at Gradaloupe, which was thirteen feet eight inches broad, and above ten feet from the snout to the insertion of the tail. The tail itself was in proportion, for it was no less than fifteen feet loug, twenty inches broad at its insertion, and tapering to a point. The body was two feet in depth; the skin as thick as leather, and marked with spots; whieh spots, in all of this kind, are only glands, that supply a inucus to lubricate and soften the skin. This enormous fish was utterly unfit to be eaten by Europeans; but the negroes chose out some of the nicest bits, and carefully salted them up as a most favourite provision.

Yet, large as this may seem, it is very probable that we have seen only the smallest of the kind; as they generally keep at the bottom, the largest of the kind are seldom seen; and, as they may probably have been growing for ages, the extent of their magnitude is unknown. It is generally supposed, however, that they are the largest inhabitants of the deep; and, were we to eredit the Norway Bishop, there are some above a mile over. But to suppose an animal of such a magnitude is absurd; yet the over-stretching the supposition does not destroy the probability that animals of this tribe grow to an enormous size.

The ray generally chooses for its retreat such parts of the sea as have a black muddy bottom; the large ones keep at greater depths; but the smaller approach the shores, and feed upon whatever living animals they can surprise, or whatever putrid substances they meet with. As they are ravenous, they easily take the bait, yet will not touch it if it be taken up and kept a day or two out of water. Almost all fish appear much more delicate with regard to a baited hook than their ordinary food. They appear by their manner to perceive the line, and to dread it; but the impulse of their hunger is too great for their caution; and, even though they perceive the danger, if thoroughly hungry they devonr the destruction.

These fish generate in March and April; at which time only they are seen swimming near the surface of the water, several of the males pursuing one female. They adhere so fast together in coition, that the fishermen frequently draw up both together, though only one has been hooked. The females are prolific to an extreme degree; there having been no less than three hundred eggs taken out of the body of a single ray. These eggs are covered with a tough horny substance, which they aequire in the womb; for before they descend into that, they are attached to the ovary pretty much in the same manner as in the body of a pullet. From this ovary, or egg-bag, as it is vulgarly called, the fish's eggs drop one by one into the womb, and there receive a shell by the concretion of the fluids of that organ. When come to the proper maturity, they are excluded, but never above one or two at a time, and often at intervals of three or four bours. These eggs, or purses, as the fishermen call them, are usually cast about the beginning of May, and they continue casting during the whole summer. In October, when their breeding ceases, the $y$ are exceedingly poor and thin; but in November they begin to improve, and grow gradually better till May, when they are in the highest perfection.

It is chiefly during the winter season that our fishermen take them; but the Dutel, who are indefatigable, begin their operations earlier, and fish with better success than we. The method practised by the fishermen of Scarborough is thought to be the best among the English; and as Mr. Pennant has given a very succinct account of it, I will take leave to present it to the reader.

"When they go out to fish, each person is provided with three lines: eaeh man's lines are fairly coiled upon a flat oblong piece of wicker-work; the hooks being baited and placed very regularly in the centre of the coil. Each line is furrished with two hundred and eighty hooks, at the distance of six feet two inches from each other. The hooks are fastened to lines of twisted horse-hair, twenty-seven inches in length.

"When fishing, there are always three men in each coble; and consequently nine of these lines are fastened together, and us r d as one line, extending in length near three miles, and furnished with above two thousand five hundred hooks. An anchor and a buoy 
are fixed at the first end of the line, and one more at each end of each man's lines; in all, four anchors, and four buoys made of leather or cork. The line is always laid across the current. The tides of flood and ebb continue an equal time upon our coast; and, when undisturbed by winds, run each way about six hours. They are so rapid that the fishermen can only shoot and haul their lines at the turn of the tide; and therefore the lines always remain upon the ground about six hours. The same rapidity of tide prevents their using hand-lines; and, therefore, two of the people commonly wrap themselves in the sail and sleep, while the other keeps a strict look-out, for fear of bcing run down by ships, and to observe the weather: for storms often rise so suddenly, that it is sometimes with extrene difficulty they escape to the shore, though they leave their lines behind then.

"The colle is twenty feet six inches long, and five feet extreme breadth. It is about one ton burden, rowed with three pair of oars, and admirably construeted for the purpose of encountering a mountainous sea. They hoist sail when the wind suits.

"The five-men-boat is forty feet long, fifteen broad, and twenty-five tous burden. It is so called, though navigated by six men and a boy; because one of the men is hired to cook, and does not share in the profits with the other five. All our able fishermen go in these boats to the herring fishery at Yarmouth, the latter end of September, and return about the middle of Noveniber. The boats are then laid up until the beginning of Lent, at which time they go off in them to the edge of the Dogger, and other places, to fish for turbot, cod, ling, skate, \&r. They always take two cobles on board, and when they come upon their ground, anchor the boat, throw out the cobles, and fish in the same manner as those do who go from the shore in a coble ; with this difference only, that here each man is provided with double the quantity of lines, and, instead of waiting the return of the tide in the coble, return to the boat, and bait their other lines; thus hauling one ser and shooting another, every turn of tide. They commonly run into the harbour twice a week, to deliver their fish. The fivemen-boat is decked at eaclı end, but open in the middle, and has two long sails.

"The best bait for all kinds of fish, is fresh herring cut in pieces of a proper sizc; and, notwithstanding what has been said to the contrary, they are taken there at any time in the winter, and all the spring, whenever the fishermen put down their nets for that purpose: the five-men-boats always take some nets for that end. Next to herrings are the lesser lampreys, which come all winter by land carriage from Tadeaster. The next baits in esteem are small haddocks cut in pieces, sand-worms, muscles, and limpets; and, lastly, when none of these can be found, they use bullock's liver. The hooks used there are much smaller than those employed at Iceland and Newfoundland. Experience has shown that the larger fish will take a living small one upon the hook, sooner than any bait that can be put on; therefore they use such as the fish can swallow. The hooks are two inches and a half long in the shank; and near an inch wide between the sliank and the point. The line is made of small cording, and is always tanned before it is used. All the rays and turbots are extremely delicate in their choice of baits : if a piece of herring or haddock has been twelve hours out of the sea, and then used as a bait, they will not touch it."

Such is the manner of fishing for those fish that usually keep near the bottom on the coasts of England; and Duhamel observes, that the best weather for succeeding, is a halfcalm, when the waves are just curled with a silent breeze.

But this extent of line, which runs, as we have seen, three miles along the bottom, is nothing to what the Italians throw out in the Mediterranean. Their fishing is carried on in a tartan, which is a vessel much larger than ours; and they bait a line of no less than twenty miles long, with above ten or twelve thousand hooks. This line is called the parasina : and the fishing goes by that of the pielago. This line is not regularly drawn every six hours, as with us, but remains for some time in the sea, and it requires the space of twenty-four hours to take it up. By this apparatus they take rays, sharks, and other fish; some of which are above a thousand pound weight. When they have caught any of this magnitude, they strike them throngh with a harpoon to bring them on board, and kill them as fast as they can. 
This method of catching fish is obviously fatiguing, and dangerous; but the value of the capture generally repays the pains. The skate and the thorn-back are very good food, and their size, which is from ten pounds to two hundred weight, very well rewards the trouble of fishing for them. But it sometimes happens that the lines are visited by very unwelcome intruders; by the rough ray, the fire-flare, or the torpedo. To all these the fishermen have the most mortal antipathy; and, when discovered, shudder at the sight: however, they are not always so much upon their guard, but that they sometimes feel the different resentments of this angry tribe; and, instead of a prize, find they have caught a vindictive enemy. When such is the case, they take care to throw them back into the sea with the swiftest expedition.

The rough ray inflicts but slight wounds with the prickles with which its whole body is furnished. To the ignorant it scems harmless, and a man would at first sight venture to take it in his hand, without any apprehension; but he soon finds, that there is not a single part of its body that is not armed with spines; and that there is no way of scizing the animal, but by the little fin at the end of the tail.

But this animal is harmless, when compared to the fire-flare, which seems to be the dread of even the boldest and most experienced fishermen. The weapon with which nature has armed this animal, which grows from the tail, and which we described as barbed, and five inches long, hath been an instrument of terror to the ancient fishermen as well as the modern: and they have delivercd man tremendous fables of its astonishing eflects. Pliny, Ælian, and Oppian, have supplied it with a venom that affects even the inanimate creation: trees that are struck by it instantly lose their verdure, and rocks themselves are ineapable of resisting the potent poison. The enchantress Circe armed her son witli a spear headed with the spine of the trygon, as the most irresistible weapon she could furnish him with; a weapon that soon after was to be the death of his own father.

"That spears and darts," says Mr. Pennant,

The account of the venomous properies of this spine, as well as chat it is shed aunually, appears to be altogether No. $53 \& 54$. might in very early times have been headed with this bone instead of iron, we have no doubt. The Americans bead their arrows with the bones of fishes to this day ; and, from their hardness and sharpness, they are no contemptible weapons. But that this spine is possessed of those venomous qualities ascribed to it, we have every re:ison to doubt; though some men of high reputation, and the whole body of fishermen, contend for its venomous effects. It is, in fact, a weapon of offence belonging to this animal and capable, from its barbs, of inflicting a very terrible wound, attended with dangerous symptoms; but it cannot be possessed of any poison, as the spine has no sheath to preserve the supposed venom on its surface; and the animal has no gland that separates the noxious fluid: besides, all those animals that are furnished with envenomed fangs or stings, seem to have them strongly connccted with their safety and existence; they never part with them; there is an apparatus of poison prepared in the body to accompany their exertions; and when the fangs or stings are taken away, the animal languishes and dies. But it is otherwise with the spine of the fire-flare; it is fixed to the tail, as a quill is into the tail of a fowl, and is annually slied in the same manner: it may be necessary for the creature's defence, but it is noway necessary for its existence. The wound intlicted by an animal's tail, has something terrible in the idea, and may from thence alone be supposed to be fatal. From hence terror might have added poison to the pain, and called up imagined dangers: the negroes universally believe that the sting is poisonous; but they never die of the wound; for by opening the fish, and laying it to the part injured, it effects a speedy cure. The slightness of the remedy proves the innocence of the wound."

The Torpedo is an animal of this kind, cqually formidable and well known with the former; but the manner of its operating is to this hour a mystery to mankind. The body of this fish is almost circular, and thicker than others of the ray kind; the skin is soft, smooth, and of a ycllowish colour, marked, as all the kind, with large annular spots; the eyes very

fabulous. It is probable lhat, by its great strength, it may be able to inflict a painfully lacerated wound.

$$
4 \mathrm{X}
$$


small; the tail tapering to a point; and the weight of the fish from a quarter to fifieen pounds. Redi found one twenty-four pounds weight. To all outward appearance, it is furnished with no extraordinary powers; it has no muscles formed for particularly great exertions; no internal conformation perceptibly differing from the rest of its kind; yet such is that unaccountable power it possesses, that, the instant it is touched, it numbs not only the hand and arm, but sometimes also the whole body. The shock received, by all accounts, most resembles the stroke of an electrical machine; sudden, tingling, and painful. "The instant," says Kempfer, "I touched it with my hand, 1 felt a terrible numbuess in iny arm, and as far up as the shoulder. Even if one treads upon it with the shoe on, it affects not only the leg, but the whole thigh upwards. Those who touch it with the foot, are scized with a stronger palpitation than even tlose who touch it with the hand. This numbness bears no resemblance to that which we feel when a nerve is a long time pressed, and the foot is said to be asleep; it rather appears like a sudden vapour, which passing through the pores in an instant, penetrates to the very springs of life, from whence it diffuses itself over the whole body, and gives real pain. The nerves are so affected, that the person struck imagines all the bones of his body, and particularly those of the limb that received the blow, are driven out of joint. All this is accompanied with an universal tremor, a sickness of the stomach, a general convulsion, and a total suspension of the faculties of the mind. In short," continues Kempfer, "such is the pain, that all the force of our promises and authority could not prevail upon a seaman to undergo the shock a second time. A negro, indeed, that was standing by, readily undertook to touch the torpedo, and was seen to handle it without feeling any of its effects. He informed us, that his whole secret consisted in keeping in his breath; and we found, upon trial, that this method answered with ourselves. When we beld in our breath, the torpedo was harmless; but when we breathed ever so little, its efficacy took place."

Kempfer has very well described the effects of this animal's slock; but succeeding experience has abundantly cosviuced us, that holding in the breath no way guards against its violence. Those, therefore, who depending on that receipt, should play with a torpedo, would soon find themselves painfully undeceived: not but that this fish may be many times touched with perfect security; for $i t$ is not upon every occasion that it exerts its potency. Reaunur, who made several trials upon this animal, has at least convinced the world that it is not necessarily, but by an effort, that the torpedo numbs the hand of him that touches it. He tried several times, and could easily tell when the tish intended the stroke, and when it was about to continue liarmless. Always before the fish intended the stroke, it flattened the back, raised the head and the tail, and then, by a violent contraction in the opposite direction, struck with its back against the pressing finger; and the body, which before was flat, became humped and round.

But we must not infer, as he lias done, that the whole effect of this animal's exertions arise from the greatness of the blow which the fingers receive at the instant they are struck. We will, with him, allow that the stroke is very powerful, equal to that of a musquet-ball, since he will have it so; but it is very well known, that a hlow, though never so great, on the points of the fingers, diffuses no numbress over the whole body: such a blow might break the ends of the fingers indeed, but would hardly numb the shoulder. Those blows that numb, must be applied immediately to some great and leading nerve, or to a large surface of the body; a powerful stroke applied to the points of the fingers will be excessively painful indeed, but the numbiess will not reach beyond the fingers themselves. We must, therefore, look for another cause producing the powerful effects wrought by the torpedo.

Others have ascribed it to a tremulous motion which this animal is found to possess, somewhat resembling that of a hor'se's skin, when stung by a fly. This operating under the touch with an amazing quickness of vibration, they suppose produces the nieasy sensation described above; something similar to what we feel when we rub plush cloth against the grain. But the cause is quite dis. proportioned tc the effect; and so much be- 
yond our experience, that this solution is as difficult as the wonder we want to explain.

The most probable solution seems to be, that the shock proceeds fron an animal electricity, which this fish has some hidden power of storing up, and producing ou its nost urgent occasions. The shocks are entirely similar; the duration of the pain is the same; but low the animal contrives to renew the charge, how it is prevented from evaporating it on contiguous objects, how it is originally procured, these are difficulties that time alone ean elucidate.

But to know even the effects is wisdom. Certain it is, that the powers of this animal seem to decline with its vigour; for as its strength ceases, the force of the shock seems to diuninish ; till, at last, when the fish is dead, the whole power is destroyed, and it may be handled or eaten with perfeet security: on the contrary, when immediately taken ont of the sen, its force is very great, and not only affects the halld, but if even touched with a stick, the person finds himself sometimes affected. This power, however, is not to be extended to the degree that some would have us believe; as reaching the fishermen at the end of the line, or numbing fishes in the sane pond. Godignus, in his History of Abyssinia, carries this quality to a most ridiculous excess; he tells us of one of these that was put into a basket among a number of dearl fishes, and that the next morning the people, to their utter astonishrusent, perceived, that the torpedo had actually numbed the dead fishes into life again.

To conclude, it is generally supposed that the female torpedo is nuch more powerful than the niale. Lorenzini, who has made

\footnotetext{
- From a series of experiments maile by Mr. Walsh, and communicated to the Royal Society, it appears that the powers of this animal are purely electric; though no spark could ever be discovered to proceed fron it, nor were pith-balls ever affected hy it. "A live Torpedo," says this ingenious experimentalist, "was placed on a table; round another.table stood five persons insulated; two brass wires, each thirteen feet long, were suspended from the ceiling by silken strings; one of these wires rested by nne ent on the wet napkin on which the fish lay; the other end was immersed in a basin foll of water, p'aced on a second table, on which stnod four other basius likewise full of water; the first person put a finger of one hand in the basin in which the wire was iminersed, and a finger of the other hand in a second basin: the second person put a finger of one hand in this last basin, and a f.nger of the other hand in the third; and so on succes-
}

several experiments upon this animal, seems convinced that its power wholly resides in two thin muscles that cover a part of the back. These he calls the trembling fibres; and he asserts that the animal may be touched with safety in any other part. It is now known also that there are more fish, than this of the ray kind, possessed of the numbing quality, which has acquired them the nane of the torpedo. These are deseribed by Atkins and Moore, and fuund in great abundance along the coast of Africa. They are shaped like a mackarel, except that the head is much larger; the effects of these seem also to differ in some respects. Muore talks of keeping his hand upon the animal; which in the ray torpedo it. is actually impossible to do. "There was no nıas in the company," says he, "that could bear to keep his hand on this animal the twentieth part of a minute, it gave him so great pain; hut upon taking the hand away: the numbness went off, and all was well again. This numbing quality continued in this torpedo even after it was dead; and the very skin was still possessed of its extraordinary power till it became dry." Condamine informs us of a fish possessed of the powers of the torpedo, of a shape very different from the former, and every way resembling a laniprey. This animal, if touched by the hand, ur even with a stick, iustantly benumbs the hand and arm to the very shcuulder; and sometimes the man falls down under the blow. These animals, therefore, must affect the nervous system in a different manner from the former, both with respect to the manner and the intention; but how this effect is wrought, we must be content to dismiss in obscurity."

sively, till the five persons communicated withone another by the water in the basine. In the last basin, one end of the second wire was immersed, and with the other end. Mr. Walsh touched the torpedo; when five persons felt a coinmotion, which differed in nothing from that of the Leyden experiment, except in the degree of force. Mr. Walsh, who was not in the circle of conduction, received no shock. The aetion of the torpedo is comınunicated by the same incliums as that of the electric fluid; and the bodies which intercept the action of the one, intercept likewise the action of the other. The effeet produced by the torpedo, wheil in air, appeared, on many repeated experiments, to be ahout four times as strong as when in water. The numloness produced by the shock of the torpedo was imitated by artificial eleetricity, and shown to be producible by a quick coneussion of minute shocks. This, in the torpedo, may be effected by the successive $4 \mathrm{X}$ * 


\section{CHAPTER CXLV.}

\section{OF THE LAMPREY, AND ITS AFFINITIES.}

THERE is a species of the Lamprey served up as a great delicacy anıong the modern Romans, very different from ours. Whether theirs be the maræna of the ancients I will not pretend to say; but there is nothing more certain than that our lamprey is not. The Roman lamprey agrees with the ancient fish in being kept in ponds, and considered by the luxurious as a very great delicacy.

The lamprey, known among us, is differently estimated, according to the season in which it is caught, or the place where it has been fed. Those that leave the sea to deposit their spawn in fresh waters are the best: those that are entirely bred in our rivers, and that have never been at sea, are considered as much inferior to the former. Those that are taken in the months of March, April, or May, just upon their leaving the sea. are reckoned very good; those that are caught after they have cast tleir spawn, are found to be flabby, and of little value. Those caught in several of the rivers in Ireland, the pcople will not venture to touch; those of the English Severn, are considered as the most delicate of all other fish whatever.

The lamprey much resembles an eel in its general appearance, but is of a lighter colour, and rather a clumsier make. It differs however in the mouth, which is round, and placed rather obliquely below the end of the nose. It more resembles the mouth of a leech than an eel; and the animal has a hole on the top of the head through which it spouts water, as in the cetaceous kind. There are seven holes on each side for respiration; and the fins are formed rather by a lengthening out of the skin, than any set of bones or spines for that purpose. As the mouth is formed resembling

discharges of his numerous cylinders, the organs of its power, in the nature of a running fire of musquetry; the strong single shock may be his general volley. In the continued effect, as well as the instantaneous, his eyes, which are usually prominent, are withdrawn into their cockets. A coated vial was applied to it, but could not that of a leech, so it has a property resembling that animal, of sticking close to and sucking any borly it is applied to. It is extraordinary the power they have of adhering to stones; which they do so firmly, as not to be drawn off without some difficulty. We are told of one that weighed but three pounds; and yet it stuck so firmly to a stone of twelve pounds, that it remained suspended at its mouth, from which it was separated with no small difficulty. This amazing power of suction is supposed to arise from the animal's exhausting the air within its bociy by the bole over the nose, while the mouth is closely fixed to the object, and permits no air to enter. It would be easy to determine the weight this animal is thus able to sustain; which will be equal to the weight of a column of air of equal diameter with the fish's mouth.

From some peculiarity of formation, this animal swims generally ivith its body as near as possible to the surfuce; and it might easily be drowued by being kept by force for any time under water. Nuralto las given us the anatorny of this aninal; but, in a very minute description, makes no mention of lungs. Yet I am very apt to suspect, that two red glands tissued with nerves, which he describes as lying towards the back of the head, are no other than the lungs of this animal. The absolute necessity it is under of breathing in the air, convinces me that it must have lungs, though I do not know of any anatomist that has described them.

The adhesive quality in the lamprey may be in some measure increased by that slimy substance with which its body is all over smeared; a substance that serves at once to keep it warm in its cold element, and also to

be charged. Two other fishes are known to possess this extraordinary power : the electrical Eel, which is able to give a shock even greater than the torpedo; and the electric Silurus, whose shock is much less vigorous than either of the others. 
keep its skin soft and pliant. This mueus is separated by two long lyınphatic canals, that extend on each side from the head to the tail, and rhat furnish it in great abundance. As to its intestines, it seems to have but one great bowel running from the mouth to the vent, narrow at both cuds, and wide in the middle.

So simple a conformation secms to inply an equal simplicity of appetite. In fact, the lamprey's food is either sline and water, or sueh sinall water-insects as ure scarecly perceivable. Perhaps its appetite may be more active at sea, of which it is properly a native; but when it cones up into our rivers, it is hardly perceived to devour any thing.

Its usual time of leaving the sea, whieh it is anmually seen to do in order to spawn, is about the beginning of spring; and after a stay of a few months it returns again to the sea. Their preparation for spawning is peculiar; their manner is to make looles in the gravelly bottom of rivers; and on this occasion their sucking power is particularly serviceable; for if they meet with a stone of a considerable size, they will remove it, and throw it out. Their young are produced from eggs in the manner of flat fish; the female remains near the place where they are excluded, and continues with them till they come forth. She is sometimes scen with her whole family playing about her; and after some time she conducts them in triumph back to the ocean.

But some have not suffieient strength to return; and these continue in the fresh water till they die. Indeed the life of this fish, according to Rondeletius, who has given its history, is but of very short continuance; and a single brood is the extent of the female's fertility. As soon as she has returned after casting her eggs, slie seems exhausted and flabby.
She becomes old before her time; and two years is generally the limit of her existence.

However this may be, they are very indifferent eating after they have cast their eggs, and particularly at the approach of hot weather. The best season for them is the months of March, April, and May; and they are usually taken in nets with salnion, and sometimes in baskets at the bottom of the river. It has been an old custom, for the city of Gloucester annually to present the king with a lampreypie; and as the gift is made at Christmas, it is not without great difficulty the corporation can procure the proper quantity, though they give a guinea a-piece for taking them.

How much they were valued among the ancients, or a fish bearing some resemblance to them, appears from all the classics that have praised good living, or ridiculed gluttony. One story we are told of this fisl, with which I will conclude its history. A senator of Rome, whose name does not deserve being transmitted to posterity, was famous for the delicaey of his lainpreys. Tigelinus, Manucius, and all the celebrated epicures of Rome, were loud in his praises: no man's fish had such a flavour, was so nicely fed, or so exactly pickled. Augustus, hearing so much of this man's entertainments, desired to be his guest; and soon found that fame had been just to his merits; the man had indeed very fine lampreys, and of an exquisite flavour. The emperor was desirous of knowing the method by which he fed his fish to so fine a relish; and the glutton, making no secret of his art, informed him that his way was to throw into his ponds such of his slaves as had at any time displeased him. Augustus, we are told, was not much pleased with his receipt, and instantly ordered all his ponds to be filled up. The story would have ended better, if he had ordered the owner to be flung in also. 


\section{CHAPTER CXLVI.}

\section{THE STURGEON, AND ITS VARIETIES.}

THE Sturgeon, with a form as terrible, and a body as large, as the shark, is yet as harmless as the fish we have been just describing; incapable and unwilling to injure others, it flies from the sinallest fishes, and generally falls a victim to its own timidity.

The sturgeon in its general form resembles a fresh-water pike. The-nose is long; the mouth is situated beneath, being small, and without jaw-bones or tecth. But though it is so harmless and ill provided for war, the body is formidable enough to appearance. It is long, pentagonal, and covered with five rows of large bony knobs, one row on the back and two on cach side, and a number of fins to give it greater expedition. Of this fish there are three kinds; the Common Sturgeon, the Caviar Sturgeon, and the Huso or Isinglass Fish. The first lias eleven knobs or scales on the back; the second has fifteen; and the latter thirteen on the back, and fortythree on the tail. : These differences seem slight to us who only consider the animal's form; but those who consider its uses firid the distinction of considerable importance. The first is the sturgeon, the flesh of which is sent pickled into all parts of Europe. The second is the fish from the roe of which that noted delicacy called Caviar is made; and the third, besides supplying the caviar, furnishes also the valuable commodity of isinglass. They all grow to a very great size; and some of them have been found above eighteen feet long."

There is not a country in Europe but what this fish visits at different seasons; it annually ascends the largest rivers to spawn, and propagates in an amazing number. The inhabitants along the banks of the $\mathrm{Po}$, the $\mathrm{Da}$ nube, and the Wolga, make great profit yearly of its incursions up the stream, and have

- Isinglass is prepared from various other fishes, but principally from the White Dolphin, or Belluga of North their nets prepared for its reception. The sturgeon also is brought daily to the markets of Rome and Venice, and hey are known to abound in the Mediterranean sca. Yet those fish that keep entirely either in salt or fresh water are but comparatively small. When the sturgeon enjoys the vicissitude of fresh and salt water, it is then that it grows to an enormous size, so as almost to rival even the whale in magnitude.

Nor are we without frequent visits from this much esteemed fish in England. It is often accidentally taken in our rivers in salmon-nets, and particularly in those parts that are not far remote from the sea. The largest we have heard of, caught in Great Britain, was a fish taken in the Eske, where they are most frequently found, which weighed four hundred and sixty pounds. An enormous size to those who have only seen our freshwater fishes!

North America also furnishes the sturgeon; their rivers in May, June, and July, supply them in very great abundance. At that time they are seen sporting in the water, and leaping from its surface several yards into the air. When they fall again on their sides, the concussion is so violent, that the noise is heard in still weather at some miles distance.

But of all places where this animal is to be found, it appears no where in such numbers as in the lakes of Frischehatf and Curischaff, near the city of Pillau. In the rivers also that empty themselves into the Euxine sea, this fish is caught in great numbers, particularly at the mouth of the river Don. In all these places the fishermen regularly expect their arrival from the sea, and have their nets and salt ready prepared for their reception.

As the sturgeon is a harmless fish, and no way voracious, it is never caught by a bait

A merica. This well-kuown substance is made from the sound, or air-bladder. 
in the ordinary manner of fishing, but always in nets. From the description given above of its month, it is not to be supposed that the sturgeon would swallow any hook capable of holding so large a bulk and so strong a swimmer. In fact, it never attempts to seize any of the funiy tribe, but lives by rooting at the bottom of the sea, where it makes insects and sen-plants its whole subsistence. From this quality of flomdering at the bottom it has received its name; which comes from the German verb floeren, signiifying to wallow in the mut. That it lives upon no large animals is obvious to all those who cut it open, where notling is found in its stomach but a kind of slimy substance, which has induced some to think it lives only upon water and air.Froun hence there is a German proverb, which is applied to a man extremely temperate, when they say, he is as moderate as a sturgeoll.

As the sturgeon is so temperate in its appetites, so is it also equally timid in its nature. Tliere would be searcely any method of taking it, did not its uatural desire of propagation induce it to incur so great a variely of dangers. The smallest fish is alone sufficient to terrify a shoal of sturgeons; for, being unfurnished with any weapon of defence, they are obliged to trust to their swiftuess and their caution for security. Like all animals that do not make war upon others, sturgeons live in society among themselves; rather for the purposes of pleasure than from any power of mutual protection. Gesner even asserts, that they are delighted with sounds of various kinds; and that lie has scen them shoal togetlier, at the notes of a trumpet.

The usual time, as was said before, for the sturgeon to come up rivers to deposit its spawn, is about the beginning of summer, when the fishermes of all great rivers make a regular preparation for its reception. At Pillau, parieularly, the shores are formed into distriets, and allotted to companies of fislsermen, some of which are rented for about three hundred pounds a year. The nets in which the sturgeon is cauglit, are made of small cord, and placed across the mouth of the river; but in such a manner that, whether the tide ebbs or flows, the pouch of the net goes with the stream. The sturgeon thus caught, while in the water, is one of the strongest fishes that swims, and often breaks the net to pieces that encloses it; but the instant it is raised with its head above water, all its activity ceases; it is then a lifeless, spiritless lump, and suffers itself to be tamely dragged on shore. It has been found prudent, however, to draw it to shore gently; for if excited by any unnecessary violence, it has been found to break the fishermen's legs with a blow of its tail. The most experienced fishers, therefore, when they have drawn it to the brink, keep the head still elevated, which prevents its doing any mischief with the hinder part of the body: others, by a noose, fasten the head and the tail together; and thus, without immediately despatching it, bring it to the market, if there be one near, or keep it till their number is completed for exportation.

The flesh of this animal, pickled, is very well known at all the tables of Europe; and is even more prized in England than in any of the countries where it is usually caught. The fishermen have two different methods of preparing it. The one is by cutting it in long pieces lengthwise, and, having salted thein, by hanging them up in the sun to dry: the fish thus prepared is sold in all the countrics of the Levant, and supplies the want of hetter provision. The other method, which is usually practised in Holland, and along the shores of the Baltic, is to cut the sturgeon crosswise, into short pieces, and put it in small barrels, with a pickle made of salt and saumure. This is the sturgeon which is soltl in Eugland; and of which great quantities came from the North, until we gave elleouragement to the importation of it from North America. From thence we are very well supplied; but it is said, not with such good fish as those imported from the North of Europe.

A very great trade is also carried on with the roe of the sturgeon. preserved in a particular manner, and called Caviar: it is made from the roe of all kinds of sturgeon, but particularly the second. This is much more in request in other countries of Europe than with us. 'To all these high-relished meats, (he appetite must be formed by degrees; and though formerly even in England it was very much in request at the politest tables, it is at present sunk entirely into disuse. It is still, 
however, a considerable merchandise among the Turks, Greeks, and Venetians. Caviar somewhat resembles soft soap in consistence; but it is of a brown, uniform colour, and is eaten as cheese with bread. The manner of making it is this: they take the spawn from the body of the sturgeon-for it is to be observed, the sturgeon differs from other cartilaginous fish, in that it has spawn like a cod, and not eggs like a ray. They take the spawn, I say, and freeing it from the small membranes that connect it together, they wash it with vinegar, and afterwards spread it to dry upon a table; they then put it into a vessel with salt, breaking the spawn with their hands, and not with a pestle; this done, they put it into a canvas bag, letting the liquor drain from it; lastly, they put it into a tub, with holes in the bottom, so that, if there be any moisture still remaining, it may run out : then it is pressed down, and covered up close for use.

But the Huso or Isinglass fish furnishes a still more valuable commodity. This fish is caught in great quantities in the Danube, from the month of October to January : it is seldom under fifty pounds weight, and often above four hundred: its flesh is soft, glutinous, and flabby ; but it is sometimes salted, which makes it better tasted, and then it turns red like salmon. It is for the commodity it furnishes that it is chiefly taken. Isinglass is of a whitish substance, inclining to yellow, done up into rolls, and so exported for use. It is very well known as serviceable, not ouly in medicine, but many arts. The varuisher, the wine-merchant, and even the clothier, know its uses; and very great sums are yearly expended upon this single article of commerce. The manner of making it is this: they take the skin, the entrails, the fins, and the tail of this fish, and cut them into small pieces; these are left to macerate in a suffcient quantity of warm water, and they are all boiled shortly after with a slow fire, until they are dissolved and reduced to a jelly; this jelly is spread upon instruments made for the purpose, so, that drying, it assumes the form of parchment, and, when quite dry, it is then rolled into the form which we see it in the shops.

This valuable commodity is principally furnished from Russia, where they prepare great quantities surprisingly cheap. Mr. Jackson, an ingenious countryman of our own, found ont an obvious metliod of making a glue at home that answered all the purposes of isinglass; but what with the trouble of making it, and perhaps the arts put in practice to under-sell him, be was, as I am told, obliged to discontinue the improvement of his discovery. Indeed, it is a vain attempt to manufacture among ourselves those things which may be more naturally and cheaply supplied elsewhere. We have many trades that are unnaturally, if I may so express it, employed among us; who furnish more laboriously those necessaries with which other countries could easily and cheaply supply us. It would be wiser to take what they can thus produce; and to turn our artizans to the increase and mallufacture of such productions as thrive more readily among us. Were, for instance, the number of hands that we have now employed in the manufacture of silk, turned to the increase of agriculture, it is probable that the increased quantity of corn thus produced, would be more than an equivalent for the diminution of national wealth in purchasing wrought silk from other countries.

\section{CHAPTER CXLVII.}

\section{OF ANOMALOUS CARTILAGINOUS FISHES.}

OF all others, the Cartilaginous class seems to abound with the greatest variety of ill-formed animals; and, if philosophy could allow the expression, we might say, that the cartilaginous class was the class of monsters; in fact, it exhibits a variety of shapeless be- 
ings, the deviations of which from the usual form of fishes are beyond the power of words to describe, and scarcely of the pencil to draw. In this class we have the Pipe Fish, that almost tapers to a thread, and the Sun Fish, that has the appearance of a bulky head, but the body cut off in the middle; the Hippocampus, with a head somewhat like that of a horse, and the Water Bat, whose head can scarcely be distinguished from the body. In this class we tind the Fishing Frog, which from its deformity some have called the Sea Devil; the Chimæra, the Lump Fish, the Sea Porcupine, and the Sea Suail. Of all these the history is but little known; and naturalists supply the place with description.

The Sun Fish sometimes grows to a very large size; one taken near Plymouth was five hundred weight. In form it resembles a bream, or some deep fish cut off in the middle: the mouth is very small, and contains in each jaw two broad teeth, with sharp edges: the colour of the back is dusky and dappled, and the belly is of a silvery white. When boiled, it has been observed to turn to a glutinous jelly, and would most probably serve for all the purposes of isinglass, were it found in sufficient plenty.

The Fishing Frog in shape very much resembles a tadpole or young frog; but then a tadpole of enormous size, for it grows to above five feet long, and its mouth is sometimes a y:rd wide. Nothing can exceed its deformity. The head is much bigger than the whole body ; the under jaw projects beyond the upper, and both are armed with rows of slender sharp teeth: the palate and the tongue are furnished with teeth in like manner: the eyes are placed on the top of the head, and are encompassed with prickles: immediately above the nose, are two long beards or filaments, small in the beginning, but thicker at the end, and round : these, as it is said, answer a very singular purpose; for being made somewhat resembling a fishing-line, it is asserted, that the animal converts them to the purposes of fishing. With these extended, as Pliny asserts, the fishing frog hides in muddy waters, and leaves nothing but the beards to be seen: the curiosity of the smaller fish brings them to view these filaments, and their hunger iuพo. $55 \& 56$. duces them to seize the bait; upon which the animal in ambush instantly draws in its filaments, with the little fish that had taken the bait, and devours it without mercy. This story, though apparently improbable, has found credit among some of our best naturalists; but what induces me to doubt the fact is, that there is another species of this animal, that has no beards, which it would not want if they were necessary to the existence of the kind. Rondeletius informs us, that if we take ont the bowels, the body will appear with a kind of transparence; and that if a lighted candle be placed within the body, as in a lantern, the whole has a very formidable appearance. The fishermen, however, have in general a great regard for this ugly fish, as it is an enemy to the dog-fish, the bodies of those fierce and voracious animals being often found in its stomach: whenever they take it, therefore, they always set it at liberty.

The Lump Fish is trifling in size, compared to the former: its length is but sixteen inches, and its weight about four pounds; the shape of the body is like that of a bream, deep, and it swims edgeways; the back is sharp and elevated, and the belly flat; the lips, mouth, and tongue of this animal, are of a deep red; the whole skin is rough, with bony knobs; the largest row is along the ridge of the back; the belly is of a bright crimson colour: but what makes the chief singularity in this fish, is an oval aperture in the belly, surrounded with a lleshy soft substance that seems bearded all round; by means of this part it adheres with vast force to any thing it pleases. If flung into a pail of water, it will stick so close to the bottom, that on taking the fish by the tail, one may lift up pail and all, though it holds several gallons of water. Great numbers of these fish are found along the coasts of Grcenland in the beginning of summer, where they resort to spawn. Their roe is remarkably large, and the Greenlanders boil it to a pulp for eating. They are extremely fat, but not admired in England, being both flabby and insipid.

The Sea Snail takes its name from the soft and unctuous texture of its body, resembling the snail upon land. It is almost transparent, and soon dissolves and melts away. It is but a little animal, being not above five inches $4 \mathrm{Y}$ 
long. The colour, when fresh taken, is of a pale brown, the shape of the body round, and the back fin reaches all the way fron the head to the tail. Beneath the throat is a round depression, of a whitish colour, surrounded by twelve brown spots, placed in a circle. It is taken in England at the mouth of rivers, four or five miles distant from the sea.

The body of the Pipe Fish, in the thickest part, is not thicker tlian a swan-quill, while it is above sixtcen inches long. This is angular, but the angles being not very sharp, they are not discernible until the fish is dried. lis general colour is an olive-brown, marked with numbers of bluisl liuses, pointing from the back to the belly. It is viviparous; for on crushing one that was just taken, hundreds of very minute young ones were observed to craivl about.

The Hippocampus, which, from the form of its head, some call the Sea-horse, never exceeds nine inches in lengtl. It is about as thick as a mau's thumb, and the body is said, while alive, to have hair on the fore-part, which falls off when it is dead. The snout is a sort of a tube with a holc at the botton, to which there is a cover, which the animal can open and shut at pleasure. Belıind the eyes there are two funs which look like ears; aud above them are two holes which serve for respiration. The whole body seems to be composel of cartilaginous rings, on the intermediate membranes of which several small prickles are placed. It is found in the Mediterranean, and also in the Western Ocean; and, upon the whole, more resembles a great caterpillar than a fish. The ancients considered it as extremely venomous; probably induced by its peculiar figure.

From these harmless animals, covered with a slight coat of mail, we may proceed to others, more thickly defended, and more formidably armed, whose exact station in the scale of fishes is not yet ascertained. While Liunæus ranks them ainong the cartilaginous kinds; a later naturalist places them among the spinous class. With which tribe they most agree, succeeding observations must determine. At present we seem better acquainted with their figure than their history: their deforinity is obvious; and the venornous nature of the.greatest number, lias been confirmed by fatal experience. This circumstance, as well as the happy distance at which they ale placed from us, being all found in the Oriential or American seas, nay have prevented a more critical inquiry; so that we know but little of the nature of their nalignity, and still less of their pursuits and enmities in the deep.

In the first of this tribe we may place the Sea Orb, which is almost round, has a mouth like a frog, and is from seven inches to two feet long. Like the porcupine, from whence it sometimes takes its name, being also called the Sea Purcupiose, it is covered over with long thorns or prickle's, which point on every side; and, when the anjmal is enraged, it can blow up its body as round as a bladder. Of this extracolinary creature there are nony kinds: sonue threatening only with spines, us the Sea Hedgchog; olliers defended with a bouy helmet that covers the hrad, as the Ostracion; others with a coat of nuail from the head to the tail, where it terninates in a point, as the Centriscus; and others still arnied offensively and delensively with bones and spines, as the Shield Orb.

Of these scarcely one is without its peculiar weapon of offence. The centriscus wounds with its spine; the ostrncion poisons with its venom ; the orb is impregnable, and is absolutely poisonous il eaten. Indeed, their figure is not such as would tempt one to make the experiment; and the natives of those countries where they are found, are careful to inform foreigners of their danger: yet a certain sailor at the Cape of Good Hope, not believing' what the Dutch told him concerning their venom, was resolved to make the experiment, and break through a prejudice, which, he supposed, was founded on the animal's deformity. He tried, and ate one; but his rashness cost hin his life; lie instantly full sick, and died a few days after.

These frightful animals are of different sizes; some not bigger than a foot-bnll, and others as large as a bushel. They almost all flatten and erect their spines at pleasure, and increase the terrors of their appearance in proportion to the approach of danger. At first they seem more inoffensive; their body oblong, with all their weapons pointing towards the tail; but, upon being provoked or alarmed, the body, that before seemed small, swells to the view; the animal visibly grows rounder and larger, and all its prickles stand upright, 
and threaten the invader on every side. The Amcricans often amuse themselves with the barren pleasure of catching these frightful creatures by a line and hook, baited with a piece of sea-crab. The animal approaches the bait with its spines flattened; but when hooked and stopped by the line, straight all its spines are ereeted; the whole body being armed in such a mamer at all points, that it is impossible to lay hold of it on any part. For this reason it is dragged to some distance from the water, and there it quickly expires. In the middle of the belly of all these there is a sort of bag or bladder filled with air, and by the inflation of which the animal swells itself in the manner already mentioned.

In describing the deformed animals of this class, one is sometimes at a loss whether it be a fish or an insect that lies before him. Thus the hippocampus and the pipe-fish bear a strong resemblancento the caterpillar and the worm; while the lesser orb bears some likeness to the class of sea-eggs to be described after. I will conclude this account of cartilaginous fishes with the description of an animal which I would scarcely call a fish, but that Father Labat dignifies it with the name. Indeed, this class teems with such a number of odd-shaped animals, that one is prompted to rank every thing extraordinary of the finny species among the number; but besides, Labat says, its bones are cartilaginous, and that may entitle it to a place here.

The animal I mean is the Galley Fish, which Linnæus degrades into the insect tribe, under the title of the Medusa, but which I choose to place in this tribe, from its habits, that are somewhat similar. To the eye of an unmindful spectator, this fish seems a trausparent bubble swimming on the surface of the sea, or like a bladder variously and beautifully painted with vivid colours, where red and violet predominate, as variously opposed to the beams of the sun. It is, however, an actual fish; the body of which is composed of cartilages, and a very thin skin filled with air, which thus keeps the animal floating on the surface, as the waves and the winds happen to drive. Sometimes it is seen thrown on the shore by one wave, and again washed back into the sea by another. Persons who happen to be walking along the shore often happen to tread upon these animals; and the bursting of their body yields a report like that when one treads upon the swim of a fish. It has eight broad feet, with which it swims, or which it expands to catch the air as with a sail. It fastens itself to whatever it meets by means of its legs, which have an adhesive quality. Whether they move when on shore, Labat could never perceive, though he did every thing to make them stir; he only saw that it strongly adhered to whatever substances he applied it. It is very common in America, and grows to the size of a gooseegg, or somewhat more. It is perpetually seen floating; and no efforts that are used to hurt it can sink it to the bottom. All that appears above water is a bladder, clear and transparent as glass, and shining with the most beautiful colours of the rainbow. Beneath, in the water, are four of the feet already mentioned, that serve as oars, while the other four are expanded above to sail with. But what is most remarkable in this extraordinary creature, is the violent pungency of the slimy substance with which its legs are smeared. If the smallest quantity but touch the skin, so caustic is its quality, that it burns it like hot oil dropped on the part affected. The pain is worst in the heat of the day, but ceases in the cool of the evening. It is from feeding on these that he thinks the poisonous quality contracted by some West Indian fish may be accounted for. It is certain these animals are extremely common along all the coasts in the Gulf of Mexico; and whenever the shore is covered with them in an unusual manner, it is considered as a certain forerunner of a storm. 


\section{OF SPINOUS FISFrmS.}

\section{CHAPTER CXLVIII.}

\section{THE DIVISION OF SPINOUS FISHES.}

THE third general division of fishes is into that of the spinous or bony kind. These are obviously distinguished from the rest by having a complete bony covering to their gills; by their being furnished with no other ncthod of breathing but gills only; by their bones, which are sharp and thorny; and their tails, which are placed in a situation perpendicular to the body. This is that class which alone our later naturalists are willing to admit as fishes. The cetaceous class with them are but beasts that have taken up their abode in the ocean; the cartilaginous class are an amphibious band, that are but ball denizens of that element: it is fishes of the spinous kind that really deserve the appellation.

This distinction the generality of mankind will hardly allow; but whatever be the justice of this preference in favour of the spinous class, it is certain that the cetaceous and cartilaginous classes bear no proportion to them in number. Of the spinous classes are already known above four hundred species; so that the numbers of the former are trifling in comparison, and make not above a fifth part of the finny creation.

Frons the grcat variety in this class, it is obvious how difficult a task it must have been to describe or remember even a part of what it contains. When six hundred different sorts of animals offer themselves to consideration, the mind is bewildered in the multiplicity of objects that all lay some claim to its attention. To obviate this confusion, systems have been devised, which, throwing several fishes that agree in many particulars into one group, and thus uniting all into so inany particulin bodies, the mind that was incapable of separately con- sidering each, is enabled to comprehend all, when thus offered in larger masses to its consideration.

Indeed, of all the beings in animated nature, fishes most demand a systematical arrangement. Quadrupeds are but few, and can be all known; birds, from their seldom varying in their size, can be very tolerably distinguished without system; but among fishes, which no size can discrininate, where the animal ten inches, and the animal ten feet long, is entirely the same, there nust be some other critcrion by which they are to be distinguished; something that gives precision to our ideas of the animal whose history we desire to know.

Of the real history of fishes, very little is yet known; but of very many we have fill and sufficient accounts, as to their external form. It would be unpardonable, therefore, in a history of these animals, not to give the little we do know; and, at least, arrange our forces, though we cannot tell their destination. In this art of arrangement; Artedi and Linnæus have long been conspicuous : they have both taken a view of the animal's form in different lights; and, from the parts which most struck them, have founded their respective systems.

Artedi, who was foremost, perceiving that some fishes had hard prickly fins, as the pike; that others had soft pliant ones, as the herring; and that others still wanted that particular fin by which the gills are opened and shut, as the eel, madc out a system from these varieties. Linnæus, on the other hand, rejecting dis system, which be found liable to too many exceptions, considered the fins, not with regard to their substance, but their position. The 
ventral fins seem to be the great object of his systenı; he considers them in fishes supplying the same offices as feet in q!tadrupers ; and from thcir total absence, or from their being situated nearer the head or the tail, in different fishes, he takes the differences of his system.

These arrangements, which are totally arbitrary, and which are rather a method than a science, are always fluctuating; and the last is generally preferred to that which went before. There has lately appenred, however, a system composed by Mr. Gouan, of Montpellier, that deserves applause for more than its novelty. It appears to me the best arrangement of this kind that ever was nade; and in it the divisions are not only precisely systematical, but, in some measure, adopted by nature itsclf. 'This learned Frenchman has united the systems of Artedi and Linnæus together; and, by bringing one to correct the other, has made out a number of tribes, that are marked with the utnıost precision. A part of his system, however, we have already gone through, in the cartilaginous, or, as he calls a part of them, the branchiostegous tribe of fishes. In the arrangement of these, I have followed Linnaus, as the number of thein was but sinall, and his methor simple. But in that which is more properly called the spinous class of fishes, I will follow Mr. Gouan's system; the terms of which, as well as of all the former systems, require some explanation. I do not love to multiply the technical terms of a science; but it often happens that names, by being long used, are as necessary to be known as the science itself.

If we consider the substance of the fin of a fish, we shall find it composed, besides the skin, either of straight, hard, pointed, bony prickles or spines, as in the pike; or of solit, crooked, or forked loones, or cartilages, as in the herring. 'The fich that have bony prickly fins, are called prickly-finned fish; the latter, that have soft or cartilaginous fins, are called soft-finned fish. The prickly-finned fish have received the Greek new-formed name of Acanthopterigii; the soft-finned fish have likewise their barbarous Greek name of Malacopterigii. Thus far Artedi has supplied Mr. Gouan with names and divisions. All spinous fish are divided into prickly-finned fish and soft-finned fish.
Again, Linnæus has taught him to remark the situation of the fins; for the ventral or belly-fins, which are those particularly to be remarked, are either wholly wanting, as in the eel, and then the fish is called Apodal, (a Greek word signifying without feet ;) or the ventral-fins are placed more forward than the pectoral-fins, as in the haddock, and then the animal is called a Jugular-fish; or the ventralfins are placed directly under the pectoralfins, as in the father-lasher, and then it is called a Thoracic-fish; or, lastly, the ventral-fins are placed nearer the tail than the pectoralfins, as in the minnow, and then it is an $A b$ dominal-fish.

Possessed of these distributions, the French naturalist mixes and unites them into two grand divisions. All the prickly-finned fish make one general division; all the soft-finned fish another. These first are distinguished from each other, as being either apodal, jugular, thoracic, or abdominal. Thus there are prickly-finned apodal fishes; prickly-finned jugular fishes; prickly-finned thoracic fishes ; and prickly-finned abdominal fishes. On the other hand, the soft-finned fishes fall under a similar distribution, and make the other general division. Thus there are soft-finned apodal fishes, soft-finned jugular fishes, soft-finned thoracic fishes, and sofi-finned abdominal fishes. These gencral characters are strongly niarked, and easily remembered. It only remains, therefore, to divide these into such tribes as are inost strongly marked ly nature; and to give the distinct characters of eacl, to form a complete system with great simplicity. This Mr. Gouan has done; and the tribes into which he has distributed each of these divisions, exactly amount to fifty. Thus the reader, who can contain in his memory the characteristic marks of fifty kinds, will have a tolerable idea of the form of every kind of spinous fish. I say, of the fornı; for as to the history and nature of the animal itself, that can only be obtained by experience and information.

SECT. I.

PRICKLY-FINNED FISHES.

Prickly-finned Apodal Fish.

1. The Trichurus. The body of a swordform; the head oblong; the teeth sword- 
like, bearded near the points; the fore-teeth largest; the fin that covers the gills with seven spines; the tail ending in a point with out fins; an inhabitant near the Oriental and American shores; of a silvery white; frequently leaping into the fishermen's buats in China.

2. The Xiphias, or Sivord-fish. The body round; the head long; the upper jaw terminating by a long beak, in form of a sword; the fin that covers the gills with eight spines; an inhabitant of Europe; an eneny to the whale.

3. The Ophidium or Gilthead. The body sword-like; the head blunt; the fin covering the gills with seven spines; the opening of the mouth side ways; the fins of the back, the anus, and the tail, all joining together; the most beautiful of all fishes, covered over with green, gold, and silver; it is by sailors called the dolphin, and gives chace to the flying fish.

\section{Prickly-finned Jugular Fish}

4. The Trachinus or Weever. The body oblong; the head obtuse; the bones covering the gills jagged at the bottom; the fins covering the gills with six spines; the anus near the breast; buries itself in the sands, leaving only its nose out; and if trod upon, immediately strikes with the spines that form its dorsal fins, which are venomous and dangerous.

5. The Uranoscopus. The body wedgelike; the head almost round, and larger than the body; the month flat; the eyes on the top of the head; the fin covering the gills with six spines; the anus in the middle of the body ; an inbabitant of the Mediterranean Sea.

6. The Callyonymus or Dragonet. The borly almost werlge-like; the head broad, and larger than the body; the mouth even with the body; the bony covering of the gills close shut; the opening to the gills behind the hear; the fin covering the gills with six spines; an inhabitant of the Atlantic Ocean.

7. The Blennius or Blenny. The body oblong; the head obtusely bevel; the teen a single range; the fin covering the gills with six spines; the ventral fins have two small blunt bones in each; a species of this animal is viviparous.
Prickly-finned T'horacic Fish.

8. The Gobius or Gudgeon. The body round and oblong; the head with two little holes between the eyes, one before the other; the fin covering the gills with four spines; the ventral fins joined together.

9. The Cepola. The body sword-like; the head blunt; the mouth flat; the fin covering the gill with six spines; the fins distinct; an inhabitant of the Mediterranean Sea.

10. The Coryphana or Razor fish. The body wedge-like; the head very bevel; the fin covering the gills with five spines.

11. The Scomber or Mackarel. The body oblong; the line running down the side rigzagged towards the tail; the head sharp and small; the fins covering the gills with seven spines; several false fins towards the tail.

12. The Labrus or Wrasse. The body oval; the head middling; the lips doubled inward; both cutting and grinding teeth; the covers of the gills scaly; the fin covering the gills with five spines; the pectural fins pointed.

13. The Sparus or Sea-bream. The body oblong; the head middling; the lips not inverted; the teeth cutting and grinding; the cover of the gills scaly; the fins covering the gills with five rays; the pectoral fins pointed.

14. The Chatodon or Cat-fish. The body oblong; the head small; the teeth slender and bending; the fin covering the gills with three to six spines; the fins of the back and anus scaly.

15. The Scicena. The body nearly elliptical; the head bevel, the covers of the fins scaly ; the fin covering the gills with six rays; the fins of the back jagged, and hidden in a furrow in the back.

16. The Perch. The body oblong; the head bevel; the covers of the gills scaly and toothed; the fin covering the gills $w$ ith seven spines; the fins in some jagged.

17. The Scorpcena or Father-lasher. The body oblong; the head great, with beards; the covers of the gills armed with prickles; the fin covering the gills with seven spines.

18. The Mullus or Surmulet. The body slender; the head almost four-cornered; the fin covcring the gills with three spines; some 
of these have beards; a fish highly prized by tive Romans, and still considered as a very great delicacy.

19. The Trigla or the Gurnard. The body slender; the head nearly four-cornered, and covered with a bony coat, the fin covering the gills with seven spines; the pectoral and ventral-fins, strengthened with additional muscles and bones, and very large for the aniinal's size.

20. The Cottus or Bull-head. The body wedge-like; the head flat and broader than the body; the fin covering the gills" with six spines; the head furnished with prickles, knobs, and beards.

21. The Zeus or Dorce. The body oblong; the head large, bevel; the fin covering the gills with seven rays; the fins jagged; the upper jaw with a loose floating skin depending into the mouth.

22. The Thrachipterus or Sabre. The body sword like; the head bevel; the fin covering the gills with six spines; the lateral line straight; the scales in a single order; a loose skin in both the jaws.

23. The Gasterosteus or Stickleback. The body broadest towards the tail; the head oblong; the fin covering the gills with three, six, or seven spines; prickles starting backward before the back fins and the fins of the anus.

\section{Prickly-finned Abdominal Fish.}

24. THE Silurus or Sheath-fish. The body oblong; the head large; the fin covering the gills from lour to fourteen spines; the leading bones or spines in the back and pectoral fins toothed.

25. The Mugil or Mullet. The body oblong; the head almost conical; the upper jaw with a furrow, which receives the prominence of the under; the fin covering the gills with seven rays.

26. The Polynemus. The body oblong; the head with a beak; the fin covering the gills with from five to seven spines: the bones that move the pectoral fins not articulated to those fins.

27. The Teuthys. The body alınost elliptical; the head abruptly shortened; the fin covering the gills with five rays; the teeth in a single row, close, strong, and even.

28. The Elops or Sea-Serpent. The body slender; the head large; the fin covering the gills double, with thirty spines, and armed externally with five bones resembling teeth.

\section{SECT. II.}

SOFT-FINNED FISIIES.

Sofi-finned Apodal Fish.

29. The Murcena or Eel. The body round and slender; the head tcrminating in a beak; the fin covering the gills with ten rays; the opening to the gills pipe-fashion, placed near the pectoral fins; the fins of the back, the anus, and the tail, united in one.

30. The Gymnotus or Carapo. The body broadest on the back, like the blade of a knife; the head small; the fin covering the gills with five rays; the back without a fin; two beards or filaments from the upper lip; an inhabitant of Brasil.

31. The Anarlicas or Wolf-fish. The body roundish and slender; the head large and blunt; the fore-teeth above and below conical; the grinding teeth and those in the palate round; the fin covering the gills hasseven rays.

32. The Stromateus. The body oblong; the head small; the teeth moderately sharp; the fin covering the gills with five or six rays.

33. The Ammodytes or Lannce. The body slender and roundish; the head terninated by a beak; the teeth of a hair-like fineness; the fin covering the gills with seven rays.

\section{Soft-finned Jugular Fish.}

34. The Lepaulogaster. The body wedgelike; the head oblong, forwarder than the body, flattish, the beak resembling that of a duck; the pectoral fins double, two on each side; the ventral fins joined together; a kind of bony breast-plate between the pectoral fins; the fin covering the gills with five rays; the opening to the gills pipe-fashion.

35. The Gadus or Cod-fish. The body oblong; the liead wedge-like; the fin covering the gills with seven rays; several back and anal fins

\section{Soft-finned Thoracic Fish.}

36. The Pleuronectes of Flat-fish. The body 
elliptical; the head small; both eyes on one side of the head; the fin covering the gills with from four to seven rays.

37. The Echineis or Sucking-fish. The body almost wedge-like, moderately round; the head broader than the body; the fin covering the gills with ten rays; an oval breast-plate, streaked in form of a ladder, toothed.

38. The Lipidopus or Garter-fish. The body sword-like; the head lengthened out; the fins covering the gills with seven rays; three scales only on the whole body; two in the place of the ventral fins; the third from that of the anus.

\section{Soft-finned Abdominal Fish.}

39. The Loricaria. The body crusted over; the head broad with a beak; no teeth; the fin covering the gills with six rays.

40. The Atherina or Atherine. The body oblong; the head of a middling size; the lips indented; the fin covering the gills with six rays; the line on the sides resembling a silver band.

41. The Salmo or Salmon. The body oblong; the head a little sharp; the fin covering the gills from four to ten rays; the last fin on the back, without its correspondent muscles, fat.

42. The Fistularia. The body angular, in form of a spindle; the head pipe-fashion, with a beak; the fin covering the gills with seven rays; the under jaw covering the upper.

43. The Esox or Pike. 'The body round; the head with a beak; the under jaw pierced longitudinally with small holes; the fin covering the gills with from seven to twelve rays.

44. The Argentina or Argentine. The body a little round and slender; the head with a beak, broader than the body; the fin covering the gills with eight rays; a spurious back-fin.

45. The Clupea or Herring. The body a little oblong; the head with a small beak; the fin covering the gills with eight rays.

46. The Exocetus or Flying-fish. The body oblong; the head almost three-cornered; the fin covering the gills with seven rays; the pectoral fins placed ligh, and as long as the whole body; the back-fin at the extremity of the back.

47. The Cyprinus or Carp. The body elon- gated, almost round; the head with a small beak; the hinder part of the bone covering the gills, marked with a crescent; the fin covering the gills with three rays.

48. The Cobitis or Louch. The body oblong; almost equally broad throughout; the head small, a little clongated; the cyes in the hinder part of the head; the fin covering the gills from four to six rays; the covers of the gills closed below.

49. The Amia or Bonito. The body round and slender; the head, forehead, and breast, without skin; the fin covering the gills with twelve rays; two beards from the nose.

50. The Mormyrus. The body oblong; the head elongated; the fin covering the gills with a single ray; the opeuing to the gills is linear, and has no bone covering them.

Such is the system of Mr Gouan; by reducing to which any fish that offers, we. can know its rank, its affinities, and partly its anatomy, all which make a considerable part in its natural history. But, to show the use of this system still more apparently, suppose I meet with a fish, the name to me unknown, of which I desire to know something more. The way is first to see whether it be a cartilaginous fish, which may be known by its wanting fins to open and shut the gills, which the cartilaginous kinds are wholly without. If I find that it has them, then it is a spinous fish; and in order to know its kind, I cxamine its fins, whether they be prickly or soft : I find them soft; it is therefore to be ranked among the soft-finned fislues. I then examine its ventral or belly fins, and finding that the fish has them, I look for their situation, and find they lie nearer to the tail than the pectoral fins. By this I find the animal to be a soft-finned abdominal fish. Then, to know which of the kinds of these fishes it is, I examine its figure and the shape of its head: I find the body rather oblong; the head with a small beak; the lower jaw like a saw; the fin covering the gills with eight rays. This animal must thereforc be the herring, or one of that family, such as the pilchard, the sprat, the shad, or the anchovy. To give another instance: Upon examining the fins of a fish to me unknown, I find them prickly; I then look for the situation of the ventral fins, I find them 
entirely wanting ; this then must be a pricklyfinned apodal fish. Of this kind there are but three: and by comparing the fish with the description, I find it either of the trichurus kind, the sword-fish, or the gilthead. Upon examining also its internal structure, I shall find a very great similitude between my fish and that placed at the head of the family.

\section{CHAPTER CXLIX.}

\section{OF SPINOUS FISHES IN GFNERAL.}

HAVING given a method by which Spinous Fishes may be distinguished from each other, the history of each in particular might naturally be expected to follow; but such a distinct acconnt of each would be very disgusting, from the unavoidable uniformity of every description. The history of any one of this class very nuch resemble's that of all the rest: they breath air and water through the gills; they live by rapine, each devouring such animals as its mouth is capable of adtnitting; and they propagate, not by bringing forth their young alive, as in the eetaceous tribes, nor by distinct eggs, as in the generality of the cartilaginous tribes, but by spawn, or peas, as they are generally called, which they produce by hundreds of thousands. Thest are the leading marks that run through their whole history, and which have so much swelled books witl tiresome repetition.

It will be sufficient therefore to draw this numerous elass into one pint of view, and to mark how they cliffer from the former classes; and what they possess peculiarly striking, so as to distingnish them from each other. The first objeet that presents itself, and that by which they differ from all others, are the bones. These, when exainined but slightly, appear to be entirely solid; yet, when viewed more closely, every bone will be found hollow, and filled with a substance less raneid and oily than marrow. These bones are very numerous, and pointed; and, as in quadrupells, are the props or stays to which the muscles are fixed which move the different parts of the body.

The number of bones in all spinous fishes of the same kind, is always the same. It is a vulgar way of speaking to say, that fishes are at soine seasons more bony than at others; พ⿳. 55 \& 56. but this scarcely requires comtradiction. It is true indeed, that fish are at some seasons much fatter than at uthers; so that the quantity of the flesh bcing dimitished, and that of the bones remaining the same, they appear to increase in number, as they actually bear a greater proportion.

All fish of the same kind, as was said, have the same number of bones: the skeleton of a fish, however irregularly the bones may fall in our way at table, has its members very regularly disposed; and every bone has its fixed place, with as much precision as we find in the orders of a regular fabric. But then spinous fish differ in the number of bones according to the species: for some have a greater number of fins by which they move in the water. The number in each is always in proportion to the number and size of these fins: for every fish has a regular apparatus of bones and muscles, by which the fins are moved; and all those fish, where they are numerous or large, must, of consequence, be considerably bony. Indeed, in the larger fish, the quantity of flesh is so much, and the bones themselves are so large, that they are easily seen and separated; but in the smaller kinds with many fins, the bones are as numerous as in the great; yet being so very minute, they lurk almost in every part of the flesh, and are dungerous as well as troublesome to be eaten. In a word, those fish which are large, fat, and have few fins, are found to be the least bony; those which are small, lean, and have many fins, are the most bony of all others. Thus, for instance, a roach appears more bony than a carp, bccause it is leaner and smaller; and it is actually more bony than an ecl, because it has a greater number of fins.

As the spinous fish partake less of the quad- 
ruped in their formation than any others, so they can bear to live out of their own element a shorter time. In general, when taken out of the water they testify their change by panting more violently and at closer intervals, the thin air not furnishing their gills the proper play; and in a few mimutes they expire. Some indeed are more vivacious in air than others; the cel will live several hours out of water; and the carp lias been known to be fattened in a damp cellar. The nuechod is by placing it in a net well wrapped up in wet moss, the mouth only out, and then hung up in a vault. The fisls is fed with white bread and milk; and the net now and then plunged into the water. The animal, thus managed, has been known not only to live for a fortnight, but to grow exceedingly fat, anil of a superior flavour. From this it would seem that the want of mojsture in the gills is the chief cause of the death of these animals; and could that be supplied, their lives might be prolonged in the air, almost as well as in their own element.

Yet it is impossible to account for the different operations of the same element, upon animals that, to appearance, have the same conformation. To sone fishes, bred in the sea, fresl w water is inmediate destruction : on the other hand, some fishes, that live in our lakes and ponds, caniot bear the salt water. Whence this difference can arise, is not casily to be accounted for. The saline quality of the water eannot properly be given as the cause; since no fishes irubibe any of the sea's saltness with their food, or it respiration. The flesh of all fishes is cqually fresh, both in the river, and in the saltest depths of the ocean; the salt of the element in which they live un way mixing with their constitution. Whence then is it that animals will live ouly there, and will quickly expire when carricd into fresh water? It may probably arise frum the sup rior weight of the sea-water; as from the great quantity of salt dissolved in its composition, it is much heavier than fresh water, so it is probable it lies with greater force upon the organs of respiration, and gives them their proper and necessary play: on the other hand; those fish which are used only to fresh water, cannot bear the weight of the saline fluid, and expire in a manner suffocated in the grossness of the strange clement.
But though there are some tribes that live only in the sea, and others only in fresh water, yet there are some whose organs are equally adapted to either element; and that spend a part of their season in one, and a part in the other. Thus the salınon, the shad, the smelt, and the flounder, annually quit their native ocean, and corre up our rivcrs to deposite their spawn. This seems the most important business of their lives; and there is no danger which they will not encounter, even to the surmounting precipices, to find a proper place for the deposition of their future offspring. The sálnon, upon these occasions, is seen to aseend rivers five hundred miles fiom the sea; and to brave not only the danger of various enemies, but also to spring up cataracts as high as a house. As som as they come to the botton of the torrent, they seem disappointed to mect the obsiruction, and swim sunc paces back: they then take a view of the dauger that lies before them, survey it notionless for some nimutes, advance, and again retreat; till at last sumnoning up all tlieir force, hiy take a leap from the bottom, their body straight, und strongly in ntotion; and thus most fiequenty clear every obstrnction. It sometimes happens, how ever, that they want strength to make the leap; and then, in our fisheries, they are takes in their descent. But this is one of the surallest dangers that attend these adventuring animals in their progress: numberless are the methods of taking thent; as well by the hook, as by nets, baskets, and other inventions, which it is not our business here to describe. Their capture makes, in several countries, a great article of commerce; and being cured in several different manners, either by salting, pickling, or drying, they are sent to all the markets of Europe.

As these mount up the rivers to deposite their spawn, others, particulary the eel, descend the fresh water stream, us Redi assures us, to bring forth lleir young in the sea. About the month of August, anmually, these animals take the opportunity of the most obscure nights, and when the rivers are flooded by accidencal rains seel the ocean. When they have reached the sea, and produced their young, for they are viviparous, they again ascend the stream, at different tinies, as opportunity offers, or as the season is favourable or 
tempestuous. Their passage luegins usually about the end of January, and continues till towards ché end of May, when they are taken in the river. Amo by millions, and so small that a thousand of them goes to $n$ pound. There is nothing more certain than that they descend in oir own rivers after floods, in great abusdance, and are thus caumht in nets, to very great advantage. They are possessed alsu of a power of climbing over any obstacle; for, by applying their glutinous and slimy bodies to the surface of the object they desire to summount, they. can thus creep up locks, weirs, and every thing that would prevent their ascending the current of the stream.

But the length of the voyage performed by these fishes, is sport, if compared. to what is anmually undertaken by soure tribes, that constantly reside in the ocean. These are known to take a conrse of three or four thousand iniles in a season, serving for prey to whales, sharks, and the numerous flocks of water-fowl, that regularly wait to intercept their progress. These may be called fish of passige, and bear a strong an ilogy to birds of passage, both from their sorial disposition, and the immensity of their numbers. Of this kind are the cot, the haddlock, the whiting, the mackarel, the tunny, the herring, and the pilchard. Other fish live in our vicinity, and reside on our coasts all the year round; or keep in the depths of the ocean, and are but seldoin seen: but these, at stated seasons, visit their accustomed haunts with regular certainty, generally returning the same week in the succeeding year, and often the same day.

The stated returns, and the regular progress of lhese fish of passage, is one of the most extranrdinary circunstances in all the history of nature. What it is that impels them to such distant voyages; what directs their passage ; and what supports them by the way; and what sometimes prompts them to quit, for several seasons, one shore for another, and then return to their accustomed harbour: are questions that curiosity may ask, but philosophy can bardly resolve. We must dismiss inquiry, satisfied with the certainty of the facts.

The corl sciems to be the forenuost of this wanderine tribe, and is only found in our northers part of the world. This animal's chief place of resolt is on the banks of Newfoundland, and the other sand-banks that lie off Cape Breton. That extensive flat seems to be no other than the broad top of a seamountain, extending for above five hundred miles long, and surrounded with a deeper sea: Hither the cod annually repair in numbers beyond the power of calculation, to feed on the quautity of worms that are to be found there in the sandy botton. Here they are taken in such quantities, that they supply all Europe with a considerable share of provision. The English have stages erected all along the shore for salting and drying then; and the fishermen, who take them with the hook and line, which is their method, draw them in as fast as they can throw out. This inmense capture, however, makes but a very snall diminution, when compared to their numbers; and when their provision there is exhausted, or the season for propagation returns, they go off to the polar seas, whire they deposite their roes in full security. From thence want of food forces them, as soon as the first mole southern. seas are open, to repair soutluward for subsistence. Nor is this fish an unfrequent visitant upon our own shores: but the returns are not so regular, nor does the capture bear any proportion to that at Newfoundland.

The haddock, the whiting, and the mackarel, are thought by some to be driven upon our coast rather by their fears than their appetites; and it is to the pursuic of the larger fishes we owe their welcome visits. It is much more probable, that they come for that food which is found in more plenty near the shore than farther out at sea. One thing is remarkable, that their migrations seem to be regularly conducted. The grand shoal of haddocks that conıes periodically on the Yorkshire coasts, appeared there in a body on the tenth of Decermber, 1766 ; and exactly on the same day in the following year. This shoal exteuded from the shore near three miles in breadth: and in length for more than forty. The linits of a slioal are precisely known; for if the fishermen put down their lines at the distance of more than three miles from shure, they catch nothing but dog-fish : a proof that the haddock is nol there.

But of all inigrating fish, the herring and the pilchard take the most arlventurous voyages. Herrings are, found in the greatest 
abundance in the highest northern latitudes. In those inaccessible seas, that are covered with ice for a great part of the year, the herring and pilchard find a quiet and sure retreat from all their numerous enemies : thither neither man, nor their still more destructive enemy, the fin-fish, or the cachalot, dares to pursue them. The quantity of insect food which those seas supply, is very great; whence, in that remote situation, defended by the icy rigour of the climate, they live at ease, and multiply beyond expression. From this most desirable retreat, Anderson supposes, they would never depart, but that their numbers render it necessary for them to migrate; and, as with bees from a hive, they are compelled to seek for other retreats.

For this reason, the great colony is seen to set out from the icy sea abont the middle of winter; composed of numbers, that if all the men in the world were to be loaded with herrings, they would not carry the thousandtl part away. But they no sooner leave their retreats, but millions of enemies appear to thin their squadrons. The fin-fish and the cachalot swallow barrels at a yawn; the porpoise, the grampus, the shark, and the whole numerous tribe of dog-fish, find them an easy prey, and desist from making war upon each other: but, still more, the umumbered flocks of sea-fowl, that chiefly inhabit near the pole, watch the outset of their dangerous migration, and spread extensive ruin.

II this exigence the defenceless emigrants find no other safety but by crowding closer together, and leaving to the outmost bands the danger of being the first devoured; thus, like sheep when frighted, that always run together iu a body, and each finding some protection in being but one of many that are equally liable to invasion, they are seen to separate into shoals, one body of which moves to the west, and pours down along the consts of America, as faj soutlı as Carolina, and but seldom farther. In Chesapeak Bay, the allnual inundation of these fish is so great, that they cover the shores in such quantities as to become a nuisance. Those that hold more to the east, and come down towards Europe. endeavour to save themselves from their merciless pursuers, by approaching the first shore they can find; and that which first offers in their descent, is the coast of Iceland, in the beginning of March. Upon their arrival on that coast, their phalanx, which has already suffered considerable diminutions, is, nevertheless, of amazing extent; depth, and closeness, covering an extent of shore as large as the island itself. The whole water seems alive; and is seen so black with them to a great distance, that the number seems inexhaustible. There the porpoise and the shark continue their depredations; and the birds devour what quantities they please. By these enemies the herrings are cooped up into so close a body, that a shovel, or any hollow vessel, put into the water, takes them up without farther trouble.

That bolly which comes upon our coasts, hegins to appear off the Slietland Isles in April. These are the forerumners of the grand shoal which descends in June; while its arrival is easily announced, by the number of its greedy attendants, the gannet, the gull, the shark, and the porpoise. When the main body is arrived, its breadth and depth is such as to alter the very appearance of the ocean. It is divided into distinct columns, of five or six miles in length, and three or four broad; while the water before them curls up, as if forced out of its bed. Sometimes they sink for the space of ten or fifteen minutes, then rise again to the surface; and, in bright weather, reflect a variety of splendid colours, like a field bespangled with purple, gold, and azure. The fishermen are ready prepared to give them a proper reception; and, by nets made for the occasiou, they take sometimes above two thousand barrels at a single draught.

From the Shetland Isles, another body of this great army, where it divides, goes off to the western coasts of Ireland, where they meet with a second necessity of dividing. The one takes to the Atlantic, where it is soon lost in that extensive ocean; the other passes into the Irish sea, and furrishes a very considerable capture to the natives.

In this manuer, the berrings, expelled from their native seas, seek those bays and shores where they can find food, and the best defence against their unmerciful pursuers of the deep. In general, the most inhabited slores are the places where the larger animals of the deep 
are least fond of pursuing; and these are chosen by the herrings as an asylum from great dangers. Thus, along the coasts of Norway, the German shores, and the northern shores of France, these animals are found punctual in their visitations. In these different places they produce their young; which, when come to some degree of inaturity, attend the general motions. After the destruction of such numbers, the quantity that attempts to return is but small; and Anderson doubts whether they ever return.

Such is the account given of the migration of these fishes, by one who, of all others, was best acquainted with their history; and yet many doubts arise, in every part of the migration. The most obrious which has been made is, that though such numbers perish in their descent from the uorth, yet, in comparison to those that survive, the account is trifling: and it is supposed, that of those taken by man, the proportion is not one to a million. Their regularly leaving the shore also at a stated tine, would imply that they are not in these visits under the impulse of necessity. In fact, there seems one circumstance that shows these animals are governed by a choice with respect to the shores they pitch upon; and not blindly drove from one shore to another. What I mean is, their fixing upon some shores for several scasons, or, indeed, for several ages together; and, after having regularly risited them every year, then capriciously forsaking them, never more to return. The first great bank for herrivigs was along the shores of Norway. Before the year 1584, the nuinber of ships from all parts of Europe that resorted to that shore, exceeded some thousands. The quantity of herrings that were then assembled there, was such, that a man who should put a spear in the water, as Olaus Magnus ascerts, would see it stand on end, being prevented from falling. But soon after that period, these animals were seen to desert the Norway shores, and took up along the German coast, where the Hanse-Towns drove a very great trade by their capture and sale; but for above a century, the herrings have, in a great measure, forsaken them; and their greatest colonies are seen in the British Channel, and upon the lrish shores. It is not easy to assign a cause for this seemingly ca- pricious desertion: whether the number of their finny enemies, increasing along the northern coasts, may have terrified the herring tribe from their former places of resort; or, whether the quantity of food being greater in the British Channel, may not allure them thither; is not easy to determine.

The pilchard, which is a fish differing little from the herring, makes the coast of Cornwall its place of principal resort. Their arrival on that coast is soon proclaimed by their attendants the birds, and the larger fishes; and the whole country prepare to take the advantage of this treasure, providentially thrown before them. The natives sometimes enclose a bay of several miles extent with their nets called saines. To direct them in their operations, there were some years ago (but I believe they are discontinued) several men placed on eminences near the shore, callcd huers, who, with brooms in their hands, gave signals where the nets were to be extended, and where the shoals of fishes lay: this they perceived by the colour of the water, which assumed a tincture from the shoals beneath. By these means, they sometimes take twelve or fifteen hundred barrels of pilchards at a draught; and they place then in heaps on the shore. It often happens, that the quantity caught exceeds the salt or the utensils for curing them; and they then are carried off to serve for the purposes of manure. This fishery employs not only great numbers of men at sea, training them to naval affiirs, but also numbers of women and children at land, in salting and curiug the fish; in making boats, nets, ropes, and casks, for the purposes of taking or fitting them for sale. The poor are led with the superfluity of the capture; the land is manured with the offials; the merchant finds the gain of commission, and lionest commerce; the fisherman a comfortable subsistence from his toil. "Ships," says Dr. Borlase, "are often freighted hither with salt, and into foreign countries with the fish, carrying off at the same time a part of our tin. The usinal produce of the number of hogsheads exported for ten yenrs, from 1747 to 1756 inclusive, amounted to near thirty thousand hogsheads each year; every hogshead has amounted, upon an average, to the price of one pound thirtecn shillings and 
threepence. Thusthe money paid for pilchards exported, has annually amounted to near fifty thousand pounds."

Whence these infuite numbers are derived, still remains obscure; but it will increase our wonder to be told, that so small a fish as the sticklehack, which is seldom above wo inches long, and that one would think conld easily find support in any water, is yet obliged to colonize, and leave its native fens in search of new habitations. Once every seventh or eighth year, amazing shoals of these appear in the river Welland, near Spalding, and come up the stream, forming one great column. They are supposed to be multitudes collected in some of the fens, till overcharged with numbers, they are periodically obliged to migrate. An idea may be had of their numbers, when we are informed, that a man, employed by a farmer to take them, for the purpose of manuring his grounds, has got, for a considerable time, four shillings a day, by selling them at a halfpenny a bushel!

Thus we see the amazing propagation of fishes along our own coasts and rivers; but their numbers bear no proportion to the vast quantities found among the islands of the Inclian ocean. The inhabitants of these countries are not under the necessity even of providing instruments for fishing; it is but going down to the shore, and there the fish are found in great numbers in the plashes that still continue to have water in them. In some of these places the quantity is so great, that they are left in shoals on those swamps, drierl up by the sun, and their putrefaction contributes to render the country unhealthful.

This power of increasing in these animals, exceeds our ideas, as it would, in a very short time, outstrip all calculation. A single herring, if suffered to multiply unmolested and undiminished for twenty years, would show a progeny greater in bulk than ten such glohes as that we live upon. But happily the balance of nature is exaetly preserved; and their consumption is equal to their fecnudity. For this reason we are to consider the porpoise, the shark, or the cod-fish, not in the light of plunderers and rivals, but of benefactors to mankind. Without their assistance, the sea would soon becoine overeharged with the burden of its own productions; and that element, which at present distributes health and plenty to the shore, would but load it with putrefaction.

In the propagation of all fish, some degree of warnith scems absolutely necessary, not only to their preservation, but to the advancement of their posterity. Their spawn is always deposited in those places where the sun-beanis may reach them, either at the bottom of shallow shores, or floating on the sirfice in deeper waters. A small degree of heat answers all the purposes of inculation, and the animal issues from the egg in its state of perfect formation, never to undergo any succeeding change.

Yet, still I have sone doubts whether most fish come from the egg con pletely forned. We know that in all the frog tribe, and many of the lizard kind, they are produced from the egg in an imperfect formi. The tadpole, or young frog, with its enormous head and slender tail, are well known; a species of the lizard also, which is excluded from the shill without legs, only acquires them hy degrees, and not till after some time dloes it put off its serpent form. It is probable that sume kinds of fish in like manner suffer a cliange; and though it be too inconsiderable to strike the fisherinan or the inattentive spectator, yet it makes a very material difference to the naturalist, and wuuld perhaps disarrange his most favourite systems. A slight alteration in the fins or bones that cover the gills would overturn the whole fabric of the most applauded ichthyologist; and yet, as I observed, it is most probable that these minute alterations often take place.

As a proof of this, during the month of July, there appear near Greenwich innumerable shoals of small fishes, which are known to the Londoners by the name of White Bait. It is universally agreed that they are the young of some fish; they are never seen but at this time of the year, and never found to have any roe, a circumstance that proves their not being come to maturity. The quantity is amazing; and the fish that produces them in such numbers must be in plenty, though it is not yet known what that fish is, as they correspond with no other species whatever. They most resemble the smelt in form; and yet they want a fin, which that animal is never without. They cannot be the bleak, as they are never found in other rivers where 
the bleak breed in great abundance. It is most probable, therefore, that they are the young of some animal not yet cone to their perfect form, and therefore reducible to no present system.

The time that spinous fishes continue in the pea is in proportion to the size of the kind. It is a rule that chiefly holds through nature, that the larger the animals are, the longer they continue before exelusion. This I say holds generally through all nature, though it is not easy to assign a cause for so well known a truth. It may probably be, that as all large bodies take a longer time to grow hot than small ones, so the larger the egy, the longer influence of vital warmth it requires to reach through all its recesses, and to unfold the dormant springs that wait to be put into motion.

The manner in which the eggs of fishes are impregnated is wholly nukuown. All that obviously offers is, that in ponds the sexes are often seen together among the loug grass at the edge of the witer; that there they seem to struggle; and that during this time they are in a state of suffering: they grow thin; they lose their appetite, and their flesh becomes flabby; the scales of some grow "rough, and they lose their lustre. On the contrary, when the time of coupling is over, their appetite returns; they reassume their natural agility, and their scales become brilliant and beautiful.

Although the usual way with spinous fishes is to produce by spawu; yet there are some, such as the eel and the blenny, that are known to bring forth their young alive. Bowlker, who has written a treatise upon fishing, seems to determine the question relative to the viviparous produetion of eels, upou the authority of one or two eredible witnesses. An eel, opened in the presence of several persons of eredit, was found to have an infinite number of little ereatures, closely wrapped up together in a lump, about the size of a nutmeg, which being put into a

a The Eel, it is known, is viviparous. It produces its numerous young during the decline of summe: : these are very small at their first exclusion. This fisl often wantders about meadows in search of snails and other food; and, according to Dr. Anderson, young eels will often basin of water, soon separated, and swam about : yet still, whether these may not have been worms generated in the animal's body, remains a doubt; for there are scarcely any fishes that are not infested with worms in that manner. ${ }^{\mathrm{a}}$

With respeet to the growth of fishes, it is observed, that among carps, particularly the first year, they grow to about the size of the leaf of a willow-tree; at two years, they are about four inches long. They grow but one inch more the third season, which is five inches. Those of four years old are about six inches; and seven after the fifth. From that to eight years old they are found to be large in proportion to the goodness of the pond, from eight to twelve inches. With regard to sea-fish, the fishermen assure us, that a fish must be six years old before it is fit to be served up to table. They instance it in the growth of a mackarel. They assure us that those of a year old are as large as one's finger; that those of two years, are about twice that length; at three and four years, they are that small kind of maekarel that have neither milts nor roes; and between five and six, they are those full-grown fish that are served up to our tables. In the same manner, with regard to flat fishes, they tell us, that the turbot and barbel at one year are about the size of a crown-piece; the second year as large as the palm of one's hand; and at the fifth and sixth year, they are large enough to be served up to table. Thus it appears, that fish are a cousiderable time in coming to their full growth, and that they are a long time destroyed before it comes to their turn to be destroyers."

All fish live upon each otlier, in some state of their existence. Those with the largest mouths, attack and devour the larger kinds; those whose mouths are less, lie in wait for the smaller fry; and even these chiefly subsist upon spawa. Of those which live in the ocean, of the spinous kiuds, the Dorado is the most voracious. This is chiefly found in

migrate across land, in great shoals, from one part of a river to another.

b Traité des Pêclıes, par Monsieur Duhaınel. Sect. 3. p. 10. 
the tropical climates; and is at once the most active and the most beantiful of the finny region. It is about six feet long; the back all over enamelled with spots of a bluish green and silver; the tail and fins of a gold colour; and all have a brilliancy of tint, that nothing but nature's pencil can attain to: the eyes are placed on each side of the head, large and beautiful, surrounded with circles of shining gold. In the seas where they are found, these fish are always in motion, and play round ships in full sail, with ease and security : for ever either pursuing or pursued, they are seen continually in a state of warfare; either defending themselves against the shark, or darting after the smaller fishes. Of all others, the Flying-fish most abounds in these seas; and as it is a small animal, seldom growing above the size of a herring, it is chiefly sought by the dorado. Nature has furnished each respectively with the powers of pursuit and evasion. The dorado being above six feet long, yet not thicker than a salmon, and fiurnished with a full complement of fins, cut its way through the water with amazing rapidity: on the other hand, the flying-fish is furnished with two pair of fins longer than the body, and these also moved by a stronger set of muscles than any other. This equality of power seems to furnish one of the most entertaining spectacles those seas can exhibit. The efforts to seize on the one side, and the arts of escaping on the other, are perfectly amusing. The dorado is seen, upon this occasion, darting after its prey, which will not leave the water, while it has the advantage of swimming, in the beginning of the chase. But, like a hunted hare, being tired at last, it then has recourse to another expedient for safety by flight. The long fins, which began to grow useless in the water, are now exerted in a different manner and different direction to that in which they were employed in swinming: by this means, the timid little animal rises from the water, and flutters over its surface, for two or three hundred yards, till the muscles employed in moving the wings are enfeebled by that particular manner of exertion. By this time, however, they have acquired a fresh power of renewing their efforts in the water, and the animal is capable of proceeding with some velocity by swin- ming: still, however, the active enemy keeps it in view, and drives it again from the deep; till, at length, the poor little creature is seen to dart to shorter distances, to flutter with greater effort, and to drop down at last into the mouth of its fierce pursuer. But not the dorado alone, all animated nature seems combined against this little fish, which seems possessed of double powers, only to be subject to greater dangers. For though it should escape from its enemies of the deep, yet the tropic bird and the albatross are for ever upon the wing to seize it. Thus pursued in either element, it sometimes seeks refuge from a new enemy; and it is not unfrequeut for whole shoals of them to fall on shipboard, where they furnish man with an object of useless curiosity.

The warfare in fresh water is not carried on with such destructive activity; nor are the inhabitants of that element so numerous. It would seem that there is something more favourable to the fecundity of fishes in the ocean, than in an element less impregnated with salt. It has been the opinion of some philosophers, that all fish are natives of that great reservoir; and that only colonies have been sent up rivers, either through accident, or the necessity of procuring subsistence. They have been led to this opinion by the superior fecuudity of sea-fish, which breed twenty to one; as well as by their superiority in strength and size, over those of the same kind found in lakes and rivers. This is a matter too remotely speculative to be worth pursuing; but certain it is, that, in fresh water, fishes seem to abate much of their coulrage and rapacity; pursue each other with less violence, and seem to be less powerfully actuated by all their appetites. The greediness with which sea-fish devour the bait is prodigious, if compared with the-manner they take it in fresh water. The lines of such fishermen as go off to sea, are coarse, thick, and clumsy, compared to what are used by those who fish at land. Their baits are seldom more than a piece of a fish. or the flesh of some quadruped, stuck on the hook in a bungling manner; and scarcely any art is employed to conceal the deception. But it is otherwise in fresh water: the lines must often be drawn to a hair like finencss; they must be 
tinctured of the peculiar colour of the stream; the bait must be formed with the nicest art, and even, if possible, to exceed the perfection of nature: yet still the fishes approach it with diffidence, and often swim round it with disdain. The cod, on the banks of Newfoundland, the instant the hook, which is only baited with the guts of the animal last taken, is dropped into the water, darts to it at once, and the fishermen have but to pull up as fast as they throw down. But it is otherwise with those who fish in fresh waters, they must wait whole hours in fruitless expectation: and the patience of a fisherman is proverbial among us.

This comparative neglect of food, which is found in all the tribes of fresh-water fishes, renders them less turbulent and less destruc tive among each other. Of all these the pike is the most active and voracious; and our poets, whose business it is to observe the surface of nature, bave called it the tyrant of the watery plain. In fact, in proportion to its strength and celerity, the pike does some mischief; but what are its efforts compared to those of the cachalot or the shark! they resemble the petty depredations of a robber, put in competition with the ravages of a conqueror! However, the pike will attack every fish less than itself; and it is sometimes seen choaked, by attempting to swallow such as are too large a morsel. It is immaterial of what species the animal it pursues appears to be, whether of another or its own, all are indiscrininately devoured; so that every fish owes its safety to its minuteness, its celerity, or its courage: nor does the pike confine itself to feed on fish and frogs; it will draw down the water-rat and the young ducks, as they are swimming about. Gesiler tells us of a mule that stooped to drink in the water, when a famished pike, that was near, seized it by the nose, nor was it disengaged till the beast flung it on shore. So great is their rapacity, that they witl contend with the otter for his prey, and even endeavour to force it from him. For this reason it is dreaded by all other fish; and the small ones show the same uneasiness and detestation at the presence of their tyrant, as the little birds do at the sight of a hawk or an owl. When the pike lies asleep near the surface, as is frequently the case, the lesser fish are often obNo. $\$ 5 \& 56$. served to swim around it in vast numbers, with a mixture of caution and terror.

The other tribes of fresh-water fish are much inferior to this animal in courage and rapacity: they chiefly subsist upon worms and insects, pursuing them at the bottom, or jumping after them to the surface of the water. In winter also, their appetite seems entirely to forsake them; at least they continue in so torpid a state, that few baits will tempt them to their destruction. At that season, they forsake the shallow waters, and seek those deep holes to be found in every river, where they continue for days together, without ever appearing to move. The cold seems to affect them; for at that time they lie close to the bottom, where the water is most warm, and seldom venture out, except the day be peculiarly fine, and the shallows at the edges of the stream become tepified by the powerful rays of the sun. Indeed, I have been assured, that some fishes may be rendered so torpid by the cold, in the northern rivers, as to be frozen up in the great masses of ice, in which they continue for several months together, secmingly without life or sensation, the prisoners of congelation, and waiting the approach of a warmer sun, to restore them at once to life and liberty. Thus that cheerful luminary not only distributes health and vegetation to the productions of the earth, but is ardently sought even by the gelid inhabitants of the water.

As fish are encmies one to another, so each species is infested with worms of different kinds, peculiar to itself. The great fish abound with them; and the little ones are not entirely free. These troublesome vermin lodge themiselves either in the jaws and the intestines internally, or near the fins without. Wheu fish are healthy and fat, they are not much annoyed by them; but in winter, when they are lean or sickly' they then suffer very mucl.

Nor does the reputed longevity of this class secure them from their peculiar disorders. They are not only affected by too much cold, but there are frequently certain dispositions of the element in which they reside unfavourable to their lealth and propagation. Some ponds they will not breed in, however artfully disposed for supplying them with fresh $5 \mathrm{~A}$ 
recruits of water, as well as provision. In some seasons they are found to feel epidemic disorders, and are seen dead by the water side, without any apparent cause : yet still they are animals of all others the most vivacious, and they often live and subsist upon such substances as are poisonous to the more perfect classes of animated nature.

It is not easy to determine whether the poisonous qualities which many of them are found to possess, either when they wound our bodies externally with their spines, or when they are unwarily eaten at our tables, arises from this cause. That numbers of fishes inflict poisonous wounds, in the opinion of many, cannot be doubted. The concurrent testimony of mankind, they think sufficient to contradict any reasonings upon this head, taken from anatomical iuspection. The great pain that is felt from the sting given by the back fin of the weaver, bears no proportion to the smallness of the instrument that inflicts the wound. How the poison is preserved, or how it is conveyed by the animal, it is not in our power to perceive; but its actual existence has been often attested by painful experience. In this instance we must decline conjecture, satisfied with history.

The fact of their being poisonous when eaten, is equally notorious; and the cause equally inscrutable. My poor worthy friend Dr. Grainger, who resided for many years at St. Christopher's, assured me, that of the fish caught, of the same kind, at one end of the island, some were the best and most wholesome in the world; while others taken at a different end were always dangerous, and most commonly fatal. We have a paper in the Philosophical Transactions, giving an account of the poisonous qualities of those found at New Providence, one of the Bahama islands. The author assures us, that the greatest part of the fish of that dreary coast are all of a deadly nature: their smallest effects being to bring on a terrible pain in the joints, which, if terminating favourably, leaves the patient without any appetite for several days after. It is not those of the most deformed figure, or the most frightful to look at, that are alone to be dreaded; all kinds, at different times, are alike dangerous; and the same species which has this day scrved for nourishment, is the next, if tried, found to be fatal!

This noxious quality has given rise to much speculation, and many conjectures. Some have supposed it to arise from the fishes on these shores eating of the manchineel apple, a deadly vegetable poison, that sometimes grows pendent over the sea: but the quantity of those trees growing in this manner, bears no proportion to the extensive infection of the fish. Labat has ascribed it to their eating the galley fish, which is itself most potently poisonous: but this only removes our wonder a little farther back; for it may be asked, with as just a cause for curiosily, how comes the galley fish itself to procure its noxious qualities? Others have ascribed the poison of these fishes to their feeding upon copperas beds: but I do not know of any copper mines found in America. In short, as we cannot deseribe the alembic by which the rattlesnake distils its malignity, nor the process by which the seorpion, that lives among roses, converts their sweets to venom, so we cannot discover the nanner by which fishes become thus dangerous; and it is well for us of Europe that we can thus wonder in security. It is certain that, with us, if fishes, such as carp or tench, acquire any disagreeable flavour from the lakes in which they have been bred, this ean be removed, by their being kept some time in finer and better water: there they soon elear away all those disagreeable qualities their flesh had contracted, and become as delieate as if they had been always fed in the most cleanly manner. But this expedient is with us rather the precaution of luxury, than the effect of fear: we have nothing to dread from the noxious qualities of our fish; for all the animals our waters furnish are wholesome.

Happy England! where the sea furnishes an abundant and Inxurious repast, and the fresh waters an innocent and harmless pastime; where the angler, in cheerful solitude, strolls by the edge of the stream, and fears neither the coiled snake, nor the lurking crocodile; where he can retire at night, with his few trouts (to borrow the pretty description of old Walton) to some friendly cottage, where the landlady is good, and the daughter innocent and beautiful; where the room 
is cleanly, with lavender in the sheets, and twenty ballads stuck about the wall! There he can enjoy the company of a talkative brother sportsman, have his trouts dressed for supper, tell tales, sing old tunes, or make a catch! There he can talk of the wonders of nature with learned admiration, or find some harmless sport to content him, and pass away a little time, without offence to God, or injury to man! 


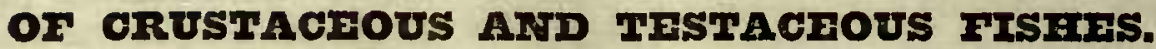

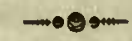

\section{CHAPTER CL.}

\section{THE DIVISION OF SHELL FISH.}

IN describing the inhabitants of the water, a class of animals occur, that mankind, from the place of their residence, have been content to call fish; but that naturalists, from their formation, have justly agreed to be unworthy of the name. Indeed, the affinity many of this kind bear to the insect tribe, may very well plead for the historian who ranks them rather as insects. However, the common language of a country must not be slightly invaded; the names of things may remain, if the philosopher be careful to give precision to our ideas of them.

There are two classes of animals, therefore, inhabiting the water, which commonly receive the name of fishes, entirely different from those we have been describing, and also very distinct from each other. These are divided by naturalists into Crustaceous and Testaceous animals : both, totally unlike fishes to appearance, seem to invert the order of nature; and as those have their bones on the inside, and their muscles hung upon them for the purposes of life and motion, these, on the contrary, have all their bony parts on the outside, and all their muscles within. Not to talk mysteriously-all who have seen a lobster or an oyster, perceive that the shell in these bears a strong analogy to the bones of other animals; and that, by these shells, the animal is sustained and defended.

Crustaceous fish, such as the crab and the lobster, have a shell not quite of a stony hardness, but rather resembling a firm crust, and in some measure capable of yielding. Testaceous fishes, such as the oyster or cockle, are furnished with a shell of a stony hardness; very brittle, and incapable of yielding. Of the crustaceous kinds are the Lobster, the Crab, and the Tortoise : of the testaceous, that numerous tribe of Oysters, Muscles, Cockles, and Sea-Snails, which offer with infinite variety.

The crustaceous tribe seems to hold the middle rank between fishes, properly so called, and those snail-like animals that receive the name of testaceous fishes. Their muscles are strong and firm, as in the former; their shell is self-produced, as among the latter. They have motion, and hunt for food with great avidity, like the former. They are incapable of swimming, but creep along the bottom, like the litter: in short, they form the link that unites these two classes, that seem so very opposite in their natures.

Of testaceous fishes we will speak hereafter. As to animals of the crustaceous kind, they are very numerous, their fignre offers an liundred varieties: but as to their nature, they are obviously divided into two very distinct kinds, differing in their habits and their conformation. The chief of one kind is the Lobster; the chief of the other, the Tortoise. Under the Lobster we rank the Prawn, the Craw-Fish, the Shrimp, the SeaCrab, the Land-Crab, and all their varieties. Under the Sea-Tortoise, the Turtle, the Hawksbill-Turtle, the Land-Tortoise, and their numerous varieties. 


\section{CHAPTER CLI.}

\section{CRUSTACEOUS ANIMALS OF THE LOBSTER KIND.}

HOWEVER different in figure the lobster and the crab may seem, their manners and conformation are nearly the same. With all the voracious appetites of fishes, they are condemned to lead an insect life at the bottom of the water; and, though pressed by continual hunger, they are often obliged to wit till accident bring them their prey. Though without any warmth in their bodies, or even without red blood circulating through their veins, they are animals wonderfully voracious. Whatever they seize upon that has life, is sure to perish, though never so well defended; they even devour each other: and, to increase our surprise still more, they may, in some measure, be said to eat themselves; as they change their shell and their stomach every year, and their old stomach is generally the first morsel that serves to glut the new.

The lobster is an animal of so extraordinary a form, that those who first see it are apt to mistake the head for the tail; but it is soon discovered that the animal moves with its claws foremost; and that the part which plays within itself by joints, like a coat of armour, is the tail. The two great claws are the lobster's instruments of provision and defence; these, by opening like a pair of nippers, have great strength and take a firm hold; they are usually notehed like a saw, which still more inereases their tenacity. Besides these powerful instruments, which may be considered as arms, the lobster has eight legs, four on each side, and these, with the tail, serve to give the animal its progressive and sideling motion. Between the two claws is the animal's head, very small, and - furnished with eyes that seem like two black horny speeks on each side; and these it has a power of advancing out of the socket, and drawing in at pleasure. The mouth, like that of insects, opens the long way of the body, not crossways, as with man, and the higher race of animals. It is furnished with two teeth for the comminution of its food; but, as these are not sufficient, it has three more in the stomach; one on each side, and the other below. Between the two teeth there is a fleshy substance, in the shape of a tongue. The intestines consist of one long bowel, which reaches from the mouth to the vent, but what this animal differs in from all others, is, that the spinal-marrow is in the breast-bone. It is furnished with two long feelers or horns, that issue on each side of the head, that seem to correct the dimness of its sight, and apprize the animal of its danger, or of its prey. The tail, or that jointed instrument at the other end, is the grand instrument of motion : and with this it can raise itself in the water. Under this we usually see lodged the spawn in great abundance; every pea adhering to the next by a very fine filament, which is searcely perceivable. Every lobster is a liermaphrodite, and is supposed to be self-impregnated! The ovary, or place where the spawn is first produced, is backwards towards the tail, where a red sub. stance is always found, and which is nothing but a cluster of peas, that are yet ton small for exelusion. From this receptacle there go two canals, that open on each side at the jointures of the shell, at the belly; and through these passages the peas descend to be excluded, and placed under the tail, where the animal preserves them from danger for some time, until they come to maturity; when being furnished with limbs and motion, they drop off into the water.

When the young lobsters leave the parent, they immediately seek for refuge in the smallest clefts of rocks, and in such like crevices at the bottom of the sea, where the entrance is but small, and the opening can be easily defended. There, without seeming to take any food, they grow larger in a few weeks time, from the mere accidental sub- 
stances which the water washes to their retreats. By this time, also, they acquire a hard firm shell, which furnishes them with both offensive and defensive armour. They then begin to issue from their fortresses, and boldly creep along the bottom, in hopes of mecting with more diminutive plunder. The spawn of fish, the snialler animals of thcir own kind, but chicfly the worms that keep at the bottom of the sca, supply them with plenty. They keep in this manner close among the rocks, busily employed in scratching up the sand with their claws for worms, or surprising such heedless animals as fall within their grasp: thus they have little to apprehend, except from each other; for in them, as among fishes, the large are the most formidable of all other enemics to the small.

But this life of abundance and security is soon to have a most dangerous interruption; for the body of the lobster still continuing to increase, while its shell remains unalterably the same, the animal becomes too large for its habitation, and imprisoned within the crust that has naturally gathered round it, there comes on a necessity of getting free. The young of this kind, therefore, that grow faster, as I am assured by the fishermen, change their shell oftener than the old, who come to their full growth, and who remain in the same shell often for two years together. In general, however, all these animals change their shell once a year; and this is not only a most painful operation, but also subjects them to every danger. Their moulting season is generally abont the beginning of summer, at which time their food is in plenty, and their strength and vigour in the bighest perfection. But soon all their activity ceases; they are seen forsaking the open parts of the deep, and secking some retired situation among the rocks, or some outlet where they may remain in safety from the attacks of their various enemics. For some days before their change the animal discontinues its ustual voraciousness; it is no longer seen laboriously larrowing up the sand at the bottom, or fighting with others of its kind, or bunting its prey; it lies torpid and motionless, as if in anxious expectation of the approaching change. Just before casting its shell, it throws itself upon its back, strikes its claws against each other, and every limb seems to tremble; its feclers are agitated, and the whole body is in violent motion: it then swells itself in an unusual manner, and at last the shell is seen beginning to divide at its junctures; particularly, it opens at the junctures, of the belly, where, like a pair of jumps, it was before but secmingly united. It also seems turned inside out, and its stoniach comes away with its shell. After this, by the same operation, it disengages itself of the claws, which burst at the joints; the animal, with a tremulous motion, casting then off as a man would kick off a boot that was too big for him.

Thus, in a short time, this wonderful creature finds itself at liberty ; but in so wenk and enfeebled a state, that it continues for several hours motionless. Indeed, so violent and painful is the operation, that many of them die under it; and those who survive are in such a weakly state for some time, that they neither take food nor venture fron their retreats. Inmediately after this change, they have not only the softness but the timiclity of a worm. Every animal of the deep is then a powerful enemy, which they can nejther escape nor oppose; and this, in fact, is the time when the dog-fish, the cod, and the ray, devour them by hundreds. But this state of defenceless imbecility continues for a very sloort time: the animal, in less than two days, is seen to have the skin that covered its body grown almost as hard as before; its appetite is seen to increase; and, strange to behold! the first olject that tempts its gluttony, is its own stomach, which it so latcly was disengaged from. This it devours with great eagerness; and sometime after eats even its former shell. In about forty-eiglit hours, in proportion to the animal's health and strength, the new shell is perfectly formed, and as hard as that which was but just thrown aside.

To contribute to the speedy growth of the shell it is supposed by some, that the lobster is supplied with a very extraordinary concretion within its body, that is converted into the shelly substance. It is a clualky substance, found in the lower part of the stomach of all lobsters improperly called crab's eyes, and sold under that title in the shops. About the time the lobster quits its shcll, the teeth in its stomach break these stones to pieces, and the fluids contained therein dissolve them. This fluid, which still renıains in the new stomach, 
is thought to be replete with a petrifying quality, proper for forming a new shell: however, the concreting power that first formed these, shows a sufficient power in the animal to produce also the shell; and it is going but a short way in the causes of things when we attempt to explain one wonder by another.

When the lobster is conspletely equipped in its new shell, it then appears how much it has grown in the space of a very few days; the dimensions of the old shell being compared with those of the new, it will be found that the creature is increased above a third in its size; and, like a boy that has outgrown his clothes, it seems wonderful how the deserted shell was able to contain so great an animal as entircly fills up the new.

The creature thus furnished, not only with a complete covering, but also a greater share of strength and courage, ventures more boldly among the animals at the bottom; and not a week passes, that, in its combats, it does not suffer some mutilation. A joint, or even a whole claw, is sometiınes snapped off in these encounters. At certain seasons of the year these animals never meet each other without an engagement. In these, to come off with the loss of a leg, or even a claw, is considered as no great calanity ; the victor carries off the spoil to feast upon at leisure, while the other retires from the defeat to wait for a thorough repair. This repair it is not long in procuring. From the place where the joint of the claw was cut away, is seen in a most surprising manuer to bourgeon out the beginning of a new claw. This, if observed, at first, is small and tender, but grows, in the space of three weeks, to be almost as large and as powerful as the old one. I say almost as lurge, for it never arrives to the full size; and this is the reason we generally find the claws of lobsters of unequal inagnitude.

After what has been thus described, let us pause a little, to reflect on the wonders this extraordinary creature offers to our imagination! An animal without bones on the inside, yet furnished with a stomach capable of digesting the hardest substances, the shells of muscles, of oysters, and even its own ; an animal gaining a new stomach and a new shell at stated intervals! Furnished with the instruments of generation double in both sexes; and yet with an apparent incapacity of uniting! Without red blood circulating through the body, and yet apparently vigorous and active! But, most strange of all, an animal endowed with a vital principle that furnishes out such limbs as have been cut away, and keeps continually combating it, though in constant repair to renew its engagements! These are but a small part of the wonders of the decp, wherc nature sports without a spectator!

Of this extraordinary yet well known animal there are many yarieties, with some differences in the claws, but little in the habits or conformation. It is found above thrce feet long; and if we may admit the shrimp and the prawn into the class, though unfurnished with claws, it is seen not above an inch. These all live in the water, and can bear its absence for but a few hours. The shell is black when taken out of the water, but turns red by boiling. The most commion way of taking the lobster is in a basket, or pot, as the fishermen eall it, made of wickerwork, in which they put the bait, and then throw it to the bottom of the sea, in six or ten fathoms water. The lobsters creep into this for the sake of the bait, but are not able to get out again. The river craw-fish differs little from the lobster, but that the one will live only in fiesh water, and the other will thrive only in the sea.

The crab is an animal found equally in fresh and salt water; as well upon land as in the ocean. In chape it differs very much from the lobster, but entirely resembles it in habits and conformation. The tail in this animal is not so apparent as in the former, being that broad flap that scens to cover a part of the belly, and when lifted discovers the peas or spawn, situated there in great abundance. It resembles the lobster in the number of its claws, which are two, and its legs, which are eight, four on cither side. Like the lobster, it is a bold voracious animal; and such an enmity do crabs bear each other, that those who carry them for sale to market, often tie their claws with strings to prevent their fighting and mainiug themselves by the way. In short, it resembles the lobster in every thing but the amazing bulk of its body compared to the size of its liead, and the length of its intestines, which have many convolutions.

As the crab, however, is found upon land as well as in water, the peculiarity of its situa- 
tion produces a difference in its habitudes, which it is proper to describe. The Land $\mathrm{Crab}$ is found in some of the warmer regions of Enrope, and in great abundance in all the tropical climates in Africa and America. They are of various kinds, and endued with various properties; some being healthful, delicious, and nourishing food; others, poisonous or malignant to the last degree; some are not above half an inch broad, others are found a foot over; some are of a dirty brown, and others beautifully mottled. That animal called the Violet Crab of the Carribbee Island, is the most noted both for the shape, the delicacy of its flesh, and the singularity of its manuers. The violet crab somewhat resembles two hands cut through the middle and joined together; for each side looks like four fingers, and the two nippers or claws resemble the thumbs. All the rest of the body is covered with a shell as large as a man's hand and bunched in the middle, on the fore-part of which there are two long eyes of the size of a grain of barley, as transparent as crystal, and as hard as horn. A little below these is the mouth, covered with a sort of barbs, under which there are two broad sharp teeth as white as snow. They are not placed, as in other animals, crossways, but in the opposite direction, not much uslike the blades of a pair of scissors. With these teeth they can easily cut leaves, fruits, and rotten wood, which is their usual food. But their principal instruments for cutting and seizing their food is their nippers, which catch such a hold, that the animal loses the limb sooner than its grasp, and is often seen scampering off, having left its claws still holding fast upon the enemy. The faithful claw seems to perform its duty, and keeps for above a minute fastened upon the finger while the crab is making off:a In fact, it loses no great matter by leaving a leg or an arm, for they soon grow again, and the animal is found as perfect as before.

This, however, is the least surprising part of this creature's history; and what I am going to relate, were it not as well known and as confidently confirmed as any other circumstance in natural history, it might well stag-

- Brown's Jainaica, p. 423. ger our belief. These animals live not only in a kind of orderly society in their retreats in the mountains, but regularly once a year march down to the sea-side in a body of some millions at a time. As they multiply in great numbers, they choose the months of April or May to begin their expedition; and then they sally out by thousands from the stumps of hollow trees, from the clefts of the rocks, and from the holes which they dig for themselves under the surface of the earth. At that time the whole ground is covered with this band of adventurers; there is no setting down one's foot without treading upon them." The sea is their place of destination, and to that they direct their march with right-lined precision. No geometrician could send them to their destined station by a shorter course; they neither turn to the right nor left, whatever obstacles intervene; and even if they meet with a house, they will atteinpt to scale the wálls to keep the unbroken tenor of their way. But though this be the general order of their route, they upon other occasions are compelled to conform to the face of the country; and if it be intersected by rivers, they are then seen to wind along the course of the stream. The procession sets forward from the mountains with the regularity of an army, under the guidance of an experienced commander. They are commonly divided into three hattalions; of which, the first consists of the strongest and boldest males, that, like pioneers, march forward to clear the route and face the greatest dangers. These are often obliged to halt for want of rain, and go into the most convenient encampment till the weather changes. The main body of the army is composed of females, which never leave the mountains till the rain is set in for some time, and then descend in regular battalia, being formed into columns of fifty paces broad and three miles deep, and so close that they almost cover the ground. Three or four days after this the rear-guard follows; a straggling, undisciplined tribe, consisting of males and females, but neither so robust nor so numerous as the former. The night is their chief time of proceeding; but if it rains by day, they do not fail to profit by the occasion; and they

b. Lebat. Voyage aux Isle Françoises, vol. ii. p. 221. 
continue to move forward in their slow uniform manner. When the sum shines and is hot upon the surface of the ground, they then make an universal halt, and wit till the cool of the evening. When they are terrified, they march back in a confused disorderly manner, holding up their nippers, with which they sometimes tear off a piece of the skin, and then leave the weapon where they inflicted the wound. They even try to intimidate their enemies; for they olien clatter their nippers together, as if it were to threaten those that come to disturb them. But though they thus strive to be formidable to man, they are inuch more so to each other; for they aue possess. cd of one most unsocial property, which is, that if any of them by accident is maimed in such a manuer as to be incapable of procceding, the rest fall upon and devour it on the spot, and then pursue their journey.

When after a fatiguing march and escaping a thousand dangers (for they are sometimes three months in getting to the shore) they have arrived at their destined port, they piefrare to cast their spawn. The peas are as yet within their bodies, and not excluded, as is usual in animals of this kind, under the tail; for the crealure waits for the benefit of the sea-water to help the delivery. For this purpose, the crab has no sooner reached the shore, than it engerly goes to the edge of the water, and lets the waves wash over its body two or three times. 'This secms only a preparation for bringing the spawn to maturity; for without farilier delay they withdraw to seck a lodging upon land: in the inean time, the spawn grows larger, is excluded out of the boily, and sticks to the barbs under the llap, or more properly the tail. This bunch is seen as big as a hen's egg, and exaclly resembling the roes of herrings. In this state of yreguancy, they once more seck the shore for the last tine, and shaking of their spawn into the water, leave accident to bring it to maturity. At this time whole shoals of humgry Gish are at the shore in expectation of this annual supply; the sea to a great distance seems black with them; and about two-thirds of the crabs-eggs are inmediately devoured by these rapacious invaders. The eggs that escape are hatched under the sand; and soon after millions at a time of these little crabs พั0. $57 \& 58$. are seen quitting the shore, and slowly travelling up to the mountains.

The old ones, however, are not so active to return; they have become so fecble and lean, that they can hardly creep along, and the flesh at that time changes its colour. "The most of them, therefore, are obliged to continue in the tlat parts of the country till they recover, makiug holes in the carth, which they cover at the mouth with leaves and dirt, so that no air inay enter. There they throw off their old shells, which they leave as it were quite whole, the place where they opened on the belly being unscen. At that time they are quite naked, and almost without motion for six days together, when they become so fat as to be dcliciums food. They have then under their stomachs four large white stones, which gradually decrease in proportion as the shell hardens, and when they come to perfection are not to be found. It is at that time that the animal is seen slowly making its way back; and all this is most commonly performedin the space of six weeks.

This animal when possessed of its retrents in the mountains is impregnable; for only subsisting upon regetables, it seldom ventures out; and its habitation being in the most inaccessible places, it remaius for a great part of the season in perfect sceurity. It is only when impelled by the desire of bringing forth its young, and when compelled to descend into the flat country, that it is taken. At that time the natives wait for its descent in eager expectation, and destroy thousands; but disrcgarding the bodies, they only seek for that small spawn which lies on each side of the stomach within the shell; of about the thickness of a man's thumb. 'They are much more valuable upon their returi after they have cast their shell; for being covered with a skin resembling soft parchment, almost every part except the stomach, may be eaten. They are taken in their holes by feeling for them in the ground with an instrument: they. are sought after by night, when on their journey, with flambeaux. The instant the animal perceives itself attacked, it throws itself on its back, and with its claws pinches most terrbly whatever it happens to fasten on. But the dexterous crab-catcher takes them by the hinder legs in such a manner, that its nippers 
cannot rouch inm, aut tius he turows it into his bag. Sometimes also shcy are canght when they take refiuge at the hottom of holes, in rocks by the: sea-side, by clapping a stick at the movils of the hole, which prevents their getting out; and then soon alion the tide coming, enters the hole, and the animal is found, upon its retiring, lrownerl in its retreat.

These crabs ale of eomsiderable advantage to the natives; and the slaves very often fied entirely upon them. In Jamaica, where they are foumd in great plenty, they are consinlered as one of the greatest delicacies of the place. Yet still, the eating of them is attented with some danger, for cren of this kind many are fouml poisonous, being terl, as it is thought, npon the machincel apple; and whenever they are fouml under that noxious plant, they are always rejected with caution. It is thus with almost all the productions of those luxurious climates; however tempting they may he to the appectite, they but ton often are found destructive; and scarce a delicacy among theul that does not carry its own alloy.

The descent of these creatures for such important purposes, descrves or admiration; but there is an animal of the lobster kind that nnnually descends from its mountains in like manncr, and for purposes still nore iumportant and various. Its descent is not only to produce an offipring, but to provide itself a covering; not only to secure a fanily, but to furnish a house. The animal I mean is the soldier-crab, which has some similitide to the lobster, if divested of its shell. It is usually ahout four inches long, has no shell behind, but is covered down to the tail with a rough skin, terminating in a point. It is, however, rrmed with strong hard nippers before, like the lobster; and one of them is as thick as a man's thumb, and pinches most powerfully. It is, as I said, without a shell to any part exrept its nippers; but what nature has denied this animal, it takes care to supply by art; and taking possession of the deserted shell of soine other animal, jt resides in it, till, $b y$ growing too large for its hahitation, it is under a necessity of change. It is a native of the West India Islands; end, like the former, it is seen every year descending from the mountains to the sea-shore, to deposite its spawn, and to provide itself with a new shell. This is a most bustling time with it, having so many things to do : and, in foct, very busy it appears. Ir is very probable that its first care is to provide for its offipring before it attends to its own wants; and it is thought, from the mumber of little shells which it is seen examining, that it deposites its spawn in thens, which thus is placed in perfeet securily till the time of exclusion.

Howerer this be, the soldicr is in the end by no means unmindfil of itself. It is still seen in its old shell, which it appears to have consirlerably ontgrown; for a part of the naked body is seen at the month of it, which the habitation is too snall to licle. A shell, therefore, is to be found large enough to cover the whole body; and yet not so large as to be unmanageable and unwieldy. To answer both these cunls it is no casy nuatter, nor the attainment of a slight inquiry. The little soldier is scen busily parading the shore along that line of pebbles amd shells that is forned by the extremest wave ; still, however, dragging its old incommodioms habitation at its tail, unwilling to part with one sh(ll, even though a troublesome appendage, till it can find another more comvenicut. It is scen stopping at one shell, turning it and passing it by, going on to another, contemplating that for a while, and then slipping its tail from its old habitation, to try on the new. 'This also is found to be inconvenient; and it quickly returns to its old shell again. In this manner it frequently changes, till at last $\mathrm{jt}$ finds one light, roomy, and comnodious; to this it adheres, though the shell be sometimes so large as to hide the body of the animal, claws and all."

Yet it is not till after many trials, but many combats also, that the soldier is thus completely equipped; for there is often a contest between two of them for some well-looking favourite shell for which they are rivals. They both endeavour to take possession; they strike with their claws, they bite each other, till the weakest is olliged to yield, hy giving up the object of dispute. It is then that the victor immediately takes possession, and parades it in his new conquest three or four rimes back and forward upon the strand before his envious antagonist.

When this animal is taken, it sends forth a fecble cry, endeavouring to seize the enemy

- Peru du Testre. 
with its nippers; which if it fastens upon it will sooner die than quit the grasp. The wound is very painful, and not easily curce. For this reason, and as it is not much estecmed for its flesh, it is generally permitted to re- turn to its old retreat to the mountains in snfety. There it continues till the necessity of changing once more, and the desire of producing an offspring, expose it $t \theta$ fresh dangers the year ensuing.

\section{CHAPTER CLII.}

\section{OF THE TORTOISE AND ITS KINDS.}

HAVING described the lobster and the crab as animals in some measure approaching to the insect tribes, it will appear like injustice to place the Tortoise among the number, that, from its strength, its docility, the warm red bloot that is circulating in is veins, descrves to be ranked even above the fishes. But as this animal is covered, like the lobster, with a shell; as it is of an amphibious mature, and brings forth its young from the egg without hatching, we must be content to degrade it among annuals that in every respect it infinitely surpasses.

Tortoises are usnally divided into, those that live upon land, and those that subsist in the water; and use has malle a distinction even in the name; the one being called Tortuises, the other Turtles. However, Scha has proved that all tortoises are amphilioms; that the land-tortnise will live in the water, and that the sea-turtle can be fed upon land. A landtortoise was bronght to hiun that was caunght in one of the canals of Amsterdam, which lie kept for half a year in his honse, where it lived very well eontented in both elements. When in the water it remained with its hear above the-surface; when placed in the sun, it seemcd delighted with its heans, and contmued immoveable while it felt their warmth. The difference, therefore, in these animals, arises rather from their habits than thrir conformation; ankl, upon examination, there will be less varicty found between them than between birds that live upon land, and those that swim upon the water.

Yet, though nature scems to have madc but fow distinctions among these animals, as to their conformation, yet, in their habits, they are very dissimilar; as these result from the different qualities of their food, and the different sorts of encmies they have to avoid or encounter. I will, therefore, exhilsit their figure and conformation muder one common description, by which their slight differences will be more obvions; and then I will give a scparate history of the manners of each, as naturalists and travellers have taught us.

All tortoises, in their extcrnal form, pretty much resemble each other; their outward covering being composed of two great shells, the one laid upon the other, and only touching at the edges: however, when we come to look chiser, we shall find that the upper shell is composed of no less than thirteen pieces, which are laid flat upon the ribs, like the tiles of a house, by which the shell is kept arched and supported. The shells both above and below, that, which secm, to an inattentive ulsserver, to make each but one piece, are bound tugether at the edges by very strong and hard ligaments, yet with some small share of motion. There are iwo holes at either edge of this vauled botly; one fior a very small heast, shonlders, and arms to peep through; the uther at the opposite edge, for the feet and the mil. These shells the animal is never lisengaged firem; and they serve for its delence against crery creature but maн.

The. torroise has but a small head, with no teeth; having only two bony ridges in the place, serrated and harl. "These serve to gather and grind its foot; and such is the amazing strength of the jaws, that it is impossible to open them where they have once fastenetl. Even when the heal is cut off, the jaws still keep their hold; and the muscles, in iteath, preserve a tenacious rigillity. Indeed, the animal is possessed of cqual strength in all 
other parts of its body : the legs, though short, are inconceivably strong: and torpid as the tortoise may appear, it has been known to carry five men standing upon his back, will, apparent ease and unconcern. Its manner of going forward is by moving its legs one atter the other; and the claws with which the toes are furnished, sink into the ground like the nails of an iron-shod wheel, and assist its progression.

With respect to its internal parts, not to enter into minute anatomical disquisitions, it may not be imploper to observe, that the blood circulates in this animal as in some cartilaginous fishes, and something in the manner of a child in the wonb. The greatest quantity of the biood passes directly from the vena cava into the left ventricle of the heart, which communicates with the right ventricle by an openiug; while the auricles only receive what the ventricles seem incapable of adınitting. 'Ihus the blood is driven by a very short passage through the circulation; and the lungs seem to lend only occasional assistance. From this conformation the auimal can subsist for some time, without using the lungs or breathing; at least, the lungs are not so necessary an instlument for driving on the circulation as with us.

Sucl is the general structure of this animal, whether found to live by land or water. With regard to the differences of these aninials, the land-tortoise, from its habits of making use of its feet in walking, is muel, more nimble upon land than the sea-turtle: the landtortoise, if thrown upon its back, by rocking and balancing its body, like a cliild rocking in a cradle, at last turns itself upon its face again; but the turtle, when once turned, continues. without being able to move from the spot. In comparing the feet also of these animals, the nails upon the toes of one that has been used to scratch for subsistence upoll lanil, are blunt and worn; while those that have only been employed in swimming, are sharp and long, and have more the similitude of fins. The brain of the land-tortoise is but small; and yet it is three times as large as that of the turtle. There is a difference also in the shape of their eggs, and in the passage hy which they are excluded; for, in the land-tortoise, the passage is so narrow, that the egg conforms to the shape of the aperture, and tlougly round when in the body, yet becomes much more oblong than those of fowls, upon being excluded; otherwise they would never be able to pass through the bony canal by which they are protruded; on the cuntrary, the passige is wider in the turtle, and therefore its eggs are romul. These are the nost striking distinctions; but that which is most linown is their size; the land-tortoise often not excecding three feet long, by wo feet broad; the sca-turtle being sometimes from five to seven feet long. The size, however, is hut a fallacious distinction; since land-tortoises, in some parts of India, grow to a very great magnitude; though probably not, as the ancients affirm, big enough for a singlc shell to serve for the covering of a house.

But if the different kinds of tortoises are not sufficiently distinguished by their figure, they are very obviously distinguishable by their methods of living. The land-tortoise lives in. holes dng in the nountains, or near marsliy lakes; the sea-turtle in cavities of rocks, and extensive pastures at the bottom of the sea. The tortoise makes use of its feet to walk with, and burrow in the ground; the turtle chiefly uses its feet in swimming, or ereeping at the bottom.

The land-toltoise is gencrally found, as was observed above, firom one foot to five feet long, frout the end of the snout to the cnd of the tail; and from five inches to a foot and a half across the back. It has a small head, somewhat resembling that of a serpent; an eye without the upper lid; the under eye-lid serving to cover and keep that organ in safety. It has a strong scaly tail, like the lizard. Its head the animal can put out and hide at pleasure, under the great penthouse of its shell : there it can remain secure fiom all attacks; there, defended on every side, it call fatigue the patience of the most formidable aninal of the forest, that makes use only of natural. strength to destroy it. As the tortoise lives wholly upon vegetable food, it never seeks the encounter; yet, if any of the smaller animals attempt to invade its repose, they are sure to suffer. The tortoise, impregnably defended, is furnished with such a strength of jaw, that, though armed only with bony plates instead of teeth, wherever it fastens, it infallibly keeps its loold, until it has taken out the piece.

Though peaceable in itself, it is formed for 
war in another respect, for it scems almost endued with immortality. Nothing can kill it ; the depriving it of one of its nnembers, is but a slight injury; it will live, though deprived of the brain; it will live, though deprived of its head. Rhedi informs us, that in making some experiments upon vital motion, he, in the beginning of the numtb of November, took a land-tortoise, made a large opening in its skull, and drew out all the brain, washed the cavity, so as not to leave the smallest part remaining, and then, leaving the loole open, set the animal at liberty. Notwithstanding this, the tortoise marched away without sceming to have received the smallest injury; only it shut the eyes, and never opened them afterwards. Soon after the hole in the skull was seen to close; and, in three days, there was a complete skin covering the wound. In this nunner the animal lived without a brain, for six months; walking about unconcernedly, and moving its limbs as before. But the Italian philogopher, not satisfied with this experiment, carried it still further; for he cut off the head, and the animal lived twentythree days after its separation from the body. The heal also continued to rattle the jaw's, like a pair of castanets; for above a quarter of an hour.

Nor are these animals less long-lived than difficult in destroying. Tortoises are commonly known to exceed eighty years old; and there was one kept in the Archbishop of Canterbury's garden, at Lambeth, that was remembered alove a hundred and twency. It was at last killed by the severity of a frost, from which it had not sufficiently defended itself in its winter retreat, which was a hea! of sand, at the bottom of the garden.

The usual food of the land-tortoise seems not so nourishing as to supply this cxtraordinary principle of vitaliey. It lives upon vegetables in its retreats in the mountains or the plain; and seldom makes its prey of snails or worms, but when other food is not found in grateliul plenty. It is fond also of fruits; and when the forest affords them, is generally found not far from where they grow. As it can move but slowly, it is not very delicate in the choice of its food; so that it usually fills itself with whatever offers. Those that are kept in a domestic state, will eat any thing; leaves, fruits, corn, bran, or grass.
From the smallness of its brain, and the slowuess of $j$ ts motion, it obviously appears to be a torpid, heavy animal, requiring rest and slecp; and, in fact, it retires to some cavern to sleep for the winter. I already observed that is blund circulated through the heart by a short passage; and that it did not, as anatomists express it, go through the great circulation. With us, and quadrupeds, the lolood goes from the veins to the heart; from the lieart it is sent to be spread over the lungs: from the lungs it returns to the heart again; and from thence it goes to the arteries to be distributed through the whole body. But its passage in the tortoise is much shorter; for, from the veins it goes to the heart; then leaving the lungs entircly out of its course, it takes a short cut, if I may so say, into the beginning of the arteries, which send it round the unimal, frame. From hence we see the lungs are left out of the circulation; and, consepuently, the animal is capable of continuing to live without continuing to breath. In this it resembles the bat, the serpent, the mole, and the lizard; like them it takes up its dark residence for the winter; and, at that time, when its food is no longer in plenty, it happily becomes insensible to the want. Nor is it unmindful to prepare its retreat, and nuke it as convenient as possible; it is sometimes buried two or three feet in the ground, with its hole furnished with moss, grass, and other substances, as well to keep the retreat warm, as to serve for fond, in case it should prematurely wake from its state of stupefaction. But it unust not be supposed that, while it is thus at rest, it totally discontinues to breath; on the contrary, an animal of this kind, if put into a close vessel, without air, will soon be stifled; though not so readily as in a state of vigour and activity:

From this dormant state the tortoise is awakened by the genial return of spring; and is thought not to be much wasted by its long confinement. To animals that live an hunlled and fifty years, $n$ sleep of six months is but as the nap of a night. All the actions of these long-lived creatures seem formed upon a scale answering the length of their existence; their slumbers are for a season; their motions are slow, and require time in every action: even the act of procreation, which among other animals is performed in a very few. 
minutes, is with them the business of days. About a month after their enlargement from a torpid state, they prepare to transinit their posterity; and both continue joined for near a mouth together. The eggs of the female are containcd in the orary, above the bladder, which is extremely large; and these are, beiore their exclusion, round and naked, with some spots of red: after they are laid, however, they assume another form, being smaller and lenger than those of a hen. This alteration in the figure of the eggs most probably proceeds from the narrowness of the bony passage through which they areexcluded. Swannerdan, who compared the size of the egres taken out of this animal's body with the diameter of the passage through which they were excluded, was of opinion that the bones themselves separated from each other, and ciosed again; but, in my opinion, it is more probable to suppose, that the eggs, and not the bones, alter their form. Certain it is, that they are round in the body, and that they are oval upon being protruded.

The eggs of all the tortoise kind, like those of birls, are furnished with a yolk and a white; but the shell is different, being somewhat like those soft eggs that heus cxclude licfore their time: however, this shell is much thicker and stronger, and is a longer time in coming to maturity in the womb. The landtortoine lays but a few in number, if compared to the sen-turtle, who deposits from a bundred and fifty to two hundred in a season.

The amount of the land-tortoise's eggs I bure uot been able to learn; but, from the scarceness of the animal, I am apt to think they cannot be very numerous. When it prepares to lay, the female scratehes a slight depression in the earth, generally in a warm situation, where the beams of the sun have thrir full effeet : there depositing her eggs, and covering them with grass and leares. she forsakes them, to he hatched by the heat of the season. The young tortoises are generally excluded in about twenty-six days ; lut, as the heat of the weather assists, or its coldness retards incubation, sometimes it happens that there is a difference of two or three days. The little animals no sooner leare the exg than they seek for their provision, entirely self-taught; and their shell, with which they are covered from the beginning. expands and grows larger with age: as it is composed of a variety of pieces, they are all capable of extension at their sutures, and the shell admits of increase in every direction. It is otherwise with those aninals, like the lobster, whose shell is composed all of one piece, that admits of no increase; which, when the tenant is too big for the habitation, must burst the shell, and get anotber. But the covering of the tortoise grows larger in proportion as the internal parts expand; in some measure resembling the growth of the luuman skull, which is composed of a number of bones, increasing in size in proportion to the quantity of the brain. All tortoises, therefore, as they never change their shell, must have it formed in pieces; and though, jn some that have been described by painters or historians, these marks have not been attended to, yet we ean have no doubt that they are general to the whole tribe.

It is common enough to take these animals into gardens, as they are thought to destroy insects and snails in great abundance. We are even told that in hot countries, they are admitted into a domestic state, as they are great destroyers of hugs. How so large and heavy an animal is capable of being expert at such petty prey, is not easy to couceive; but $I$ have seen sereral of them about gentlemen's houses, that, in general, appear torpid, harmless, and even fond of employment. Children have sometimes got upon the back of a tortoise; and such was the creature's strength, that it never seemed overloatled, but moved off with its burden to where it expeeted to be fed, but would earry them no further. In winter they regularly. find out a place to sleep in ; but in those warm countries in which the tortoise is found larger, and in greater plenty than in Europe, they live, without retiring, the whole year round.

The Sea-Tortoise, or Turtle, as it is now called, is generally found larger than the former. This element is possessed with the property of inereasing the magnitude of those aninals, which are common to the land and the nceall. The sea-pike is larger than that of fresh water; the sea-bear is larger than that of the mountains; and the sea-turtle cx 
ceeds the land-tortoise in the same proportion. It is of different magnitudes, according to its different kinds; some turtles being not above fifty pounds weight, and some above eight hundred.

The Great Mediterranean Turtle is the largest of the turtle kind with which we are acquainted. It is found from five to eight feet long, and from six to nine liundred pounds weight. But, muluckily, its utility bears no proportion to its size; as it is unfit for food, and sometimes poisons those who eat it. The shell also, which is a tough, strong integunent, resembling an hide, is unfit for all serviceable purposes. One of these animals was taken in the year 1729, at the month of the Loire, in nets that were not designed for so large a capture. 'This turtle, which was of enormous strength, by its own struggles involved itself in the nets in such a manner as to be incapable of doing mischief: yet, even thus shackled, it appeared terrible to the fishermen, who were at first for flying; but finding it impotent, they gathered courage to drag it on shore, where it madc a most horrible bellowing; and when they began to knock it on the head with their gaffs, it was to be heard at half a mile's distance. They were still further intimidated by its nanscous and pestilential breath, which so powerfully affected them, that they were near fainting. This animal wanted but four inches of being eight feet long, and was above two feet orer: its shell more resembled leather than the shell of a tortoise; and, unlike all other animals of this kind, it was furnished with teeth in each jaw, one rank behind another, like those of a shark: its feet also, different from the rest offthis kind, wanted claws; and the tail was quite disengaged from the shell, and fifteen :nches long, more resembling that of a quadruped than a tortoise. This animal was then unknown upon the coasts of France, and was supposed to have been brought into the European seas, in some India ship that might be wrecked upon her return. Since that, however, two or three of these animals have been taken upon the coasts; two in particular upon those of Cornwall, in the year 1756, the largest of which weighed eight hundred pounds; and one upon the isle of Rhe, but two years before that, weighed between seven and eight hundred. One, most probably of this kind also, was caught about thirty years ago near Scarborough, and a good deal of company was invited to feast upon it: a gentleman, who was one of the guests, told the company that it was a Mediterranean turtle, and not wholesome; but a person, who was willing to satisfy his appetite at the risk of his life, ate of it: he was seized with a violent vomiting and purging; but his constitution overpowered the malignity of the poison.

These are a formidable and useless kind, if compared to the turtle caught in the Souths Seas and the Indian Ocean. These are of different kinds; not only unlike each other in form, but furnishing man with very diflerent advantages. They are usually distinguished by sailors into four kinds; the T'runk Turtle, the Loggerhead, the Hawksbill, and the Green Turile.

The Trunk Turtle is commonly larger than the rest, and its back higher and rounder. The nesh of this is rank, and not very wholesome.

The Loggerhead is so called from the largeness of its head, which is much bigger in proportion than that of the other kinds. The llest of this is also very rank, and not eaten but in case of necessity.

The Hawksbill Turtle is the least of the four, and has a long and small mouth, somewhat resembling the bill of a hawk. The flesh of this also is very indifferent eating; but the shell serves for the most valuable purjoses. This is the animal that supplies the tortoise-shell, of which such a variety of beautiful trinkets are made. The substance of which the shells of other turtles are composed, is thin and porous; but that of the hawksbill is firm, and, when polished, is beantifully marbled. They generally carry about three pounds; but the largest of all six pounds. The shell consists, as in all the kind, of thirteen leaves or plaits, of which eight are flat, and five hollow. They are raised and taken off by means of fire, which is made under the shell after the flesh is taken out. "As soon as the heat affects the leaves, they start from the ribs, and are easily raised with the point of a knife. By being scraped and polished on both sides, they become beantifully transparent, or are easily cast into what form the workman thinks proper, by making them soft 
and pliant in warm wates, asud then screwing them in a mould. like a medal: howerer, the shell is most beautiful before it undergoes this last operation.

But of all animals of the tortoise kind, the green turtle is the most noted, and the inost valuable. The delicacy of is flesh, and its nutritive qualities, together with the property of being easily digested, were, for above a century, known only to our seamen and the iuhabitants of the cossts where lhey were taken. It was not till by slow degrees the distinction came to be made between such as vere inalignant and such as were wholesome. 'The controversies and contradictions of our old travellers were nutnerous upon this head: some asserting, that the turtle was delicious tood; and othicrs, that it was actual poison. Dampier, that rough seaman, who has added more to natural history than half of the philosophers thint went before him, appears to be the first who informed us of their distinctions; and that, while the rest might be valuahle for other purposes, the green turtle alone was chicfly prized for the delicacy of its flesh. He never imagined, lowever, that this animal would make its way to the luxurious tables of Furope; for he seems chiefly to recommend it as salted up for ship's provision, in case of necessity.

At present the lurtle is very well known among us, and is become the favourite food of those that are desirous of ealing a great deal without the danger of surfeiting. This is a property the flesh of the turtle seems peculiarly possessed of; and by the importation of it alive among is, gluttony is freed from one of its greatest restraints. The llesh of the turtle is become a branch of commerce; and therefore ships are provided with conreniences for supplying them with water and provision, to bring them over in health from Jamaica and other West India islands. This, however, is not always effected ; for though they are very viracious, and scarcely require any provision upon the voyage, yet, by the working of the ship, and their beating against the side of the boat that contains them, they become battered and lean: so that to eat this animal in the highest perfection, instead of bringing the turtle to the epicure, he ought to be transported to the turtle.
The animal is called the green turtle, from the colour of its shell, which is rather greener than that of other's of this kind. It is gene. rally found about two hund red weight; though some are five lumdred, and others not above fifty. Dampier tells us of one that was seen at Port-Royal in Jamaica, that was six feet broad across the back; he does not tell us its other dimensions; but says, that the son of Caprain Roach, a boy about ten years old, sailed in the shell, as in a boat, from the shore to his father's ship, which was above a quarter of a mile from land. But this is nothing to the size of some turtles the ancients speak of. Alian assures us, that the houses in the island of Taprobane are usually covered with a single shell. Diodorus Siculus tells us, that n people neighbouring on Ethiopia, called the T'urtle-cuters, coasted along the sliore in boats marle of the upper shell of this animal; and that in war, when they had eaten the flesh. the covering served them as a tent. In this account, Pliny, and all the rest of the ancients agree; and as they had frequent opportunities of knowing the truth, we are not lightly to contradiet their testimony.

At present, however, they are not seen of such amazing dimensions. We are told, by. Laet, that on the isle of Cuba they grow to such a size, as that five men can stand on the back of one of them together; and, what is more surprising still, that the animal does not seem overloaded, but will go off with them upon its back, with a slow steady motion, towards the sea.

They are found. in the greatest numbers on the island of Ascensicn; where, for several year's, they were taken to be salted to feed the slaves, or for a supply of slip's provision. Their value at present seems to be better known.

This animal sel(lom comes from the sea but to deposite their eggs, and now and then to sporl in fresh water. Its clief food is a submarine plant, that covers the bottom of several parts of the sea not far from the shore. Therr the turtles are seen, when the weather is fair, feeding in great numbers, like flocks of sheep, several fathoms deep upon the verdant carpet below. At other times they go to the mouths of rivers; and they seein to find gratification in fresh water 
After some time thus employed, they scek their former stations: and when done feeding, they generally float with their heads ahove water, unless they are alarmed by the approach of hunters or birds of prey, in which case they suddenly plunge to the bottom. They ofien seek their provision among the rocks, feeding upon moss and sea-wecd: and it is probable will not disdain to prey upon insects and other small animals; as they are very fond of flesh when taken and led for the table.

At the time of treeding, they are seen to forsake their former haunes and their food, and to take sometimes a voyage of nine hundred miles to deposite their eggrs on some favourite shore. The coasts they always resort to upon these occasions are those that are low, flat, and sandy ; for being heavy animals, they cannot climb a bold shore; nor is any bed so proper as sand to lay their eggs on. They couple in March, and continue mited till May; cluring a great part of which tine they are scen locken together, and almost incapable of scparation. The femalc seems passive and reluctant; but the male grasps lier with his claws in such a manner, that nothing can influce him to ruit his hold. It would seem that the grasp, as in frogs, is in some ineasure convulsire, and that the animal is unable to relax its efforts.

When the time for laying approaches, the female is seen towards the setting of the sun drawing near the shore, and looking earncsily about her, as if afraid of being discorered. When she perceives any person on shore, she seeks for another place; but if othervise, she lands when it is lark, and goes to take a survey of the sand where she designs to lay. Having :marked the spot, she goes back, without laying for that night, to the ocean ngnin: but the next night returns to deposite a part of her burden. She begins by working and digging in the sand with her fore-fett till she has naade a round hole, a foot broad and a font and a half decp, just at the place a linte above where the water reaches highest. This done, she lays eighty or ninety eggs at a time, each as hig as a hen's egg, and as round as a ball. She continues laying about the space of an hour, during which time, if a cart were drivell over her, slie would not be induced to stir. The eggs are covered with a tough . ง. $57 \& 58$. white skin, like wetted parcliment. When she has done laying she covers the hole so dexterously, that it is no easy matter to find the place; and these must be accustomed to the scarch to make the discovery. When the turtle has done laying she returns to the sca, and leaves her eggs to be hatched by the heat of the sun. At the end of fifteen days she lays about the same number of eggs again; and at the end of another fifteen days she repeats the same; thrce times in all, using the same precautions every time for their safety.

In about twenty-four of twenty-five days after laying, the eggs are hatched by the heat of the sun; and the young turtes, being about as big as quails, are seen bursting from the sand, "ns if earth-born, and runuing directly to the sea, with instinet only for their guide: but, to their grent misfortulic, it often happens that, their strength being small, the surges of the sea, for sone few days, beat then back upon the shore. Thus exposed, they remain a prey to thousands of birds that then haunt the coasts; and these stooping down upon them, carry off the greatest part, and sometimes the wiole brood, before they have strength sufficient to withstand the waves, or dive to the bottom. Helligins informs us, that they have still another enemy to fear, which is no other than the parent that produced then, that waits for their arrival at the edge of the deep, and devomrs as many as she can. 'This circumstance, however, denands further confirmation; though nothing is more certain than that the crocodile acts in the same unnatural manner.

When we turtles have done laying, they then return to their accustomed places of feeding. Upon their out-set to the shore, where they breed, they are always found fat and healihy ; but upnn their seturn, they are weak, lean, and unfit to be caten. They are seldom, therefore, molested upon their retreat; but the great art is to seize them when arrived, or to intercept their arrival. In these uninhabited islands, to which the green-turtle chiefly resorts, the inen that go to talic them land about niglit-fall, and without making any noise (for those animals, though without any external opening of the ear, hear very distinctly, there being an auditory conduit that opens into the mouth) lie close while they see the female turtle coming on shore. They let 
her proceed to her greatest distance from the sea; and then, when she is most busily employed in scratcling a hole in the sand, they sally out and surprise her. 'Their manuer is to turn her upon her back, which utterly incapacitates her fiom moving; and yet, as the creature is very strong, and struggles very hard, two inen find it no easy matter to lay hicr oves. When thus secured they go to the nex!; and in this nuanucr, in less than three hours, they have becn known to turn forty or fifty turtles, each of which wcighs from a hundred and fifiy to two hundred pounds. Labat nssures us, that when the animal is in this helpless situation, it is heard to sigh very lieavily, and even to slied tears.

At present, from the great appetite that inan has discovered for this animal, they are not ouly thinned in their numbers, but are also growi much more shy. There are several other ways, therefore, contrived for taking them. Otie is, to seize them when coupled together, at the breeding season, when they are very easily approached, and as easily seen; for these animals, thongh capable of living for some time under water, yet rise every eight or ten minutes to breath. As goon as they are thus perceived, two or three people draw near them in a canoe, and slip a noose either round their necks or one of their feet. If they have no line, they lay hold of them by the neck, where they have no shell, with their lands only; and by this means they usually catch them both together. But soinetimes the fermale escapes, being more shy than the male.

Another way of taking them is by the harpoon, either when they are playing on the surface of the water, of feeding at the bottom; when the larpoon is stillully darted, it sticks fast in the shell of the back; the wood then disengages from the iron, and the line is long enough for the animal to take its range: for if the harpooner should attempt at once to draw the animal into lis. boat till it is weakened by its own strugdiug, it would probably get free. Thus the turtle struggles hard to get loose, but all in vain; for they take care the line fastened to the harpooi shall be strong enough to liold it.

There is yet another way which, though secmingly awkward, is said to be attended with very great success. A good diver places himself at the head of the boat; and when the turtles are observed, which they sometimes are in great numbers, asleep on the surface, he immediately quits the vessel, at about fifty yards distance, and keeping still under water, directs his passage to where the turtle was seen, and coming up beneath, seizes it by the tail; the animal awaking, struggles to get free; and by this both are kept at the surface until the boat arrives to take them in.

\section{CHAPTER CLIII.}

\section{OF THE SHELL OF TESTACEOUS FISHES.}

ONE is apt to combine very dissimilar objects in the same group, when hurried into the vortex of method. No two animals are inore unlike each other than the whale and the limpet, the tortoise and the oyster. Yet, as these animals must find some place in the picture of Animated Nature, it is best to let them rest in the station where the generality of mankind have assigned them; and as they have bren. willing to give them all from their abode the name of fishes, it is wisest in us to conform.

But before I enter into any history of shellfish, it may not be improper to observe, that naturalists who have treated on this part of history, have entirely attended to outward forms; and, as in many other instances, forsaking the description of the animal itself, have exhausted all their industry in describing the habitation. In consequence of this 
radical.error, we have volumes written upon the subject of shells, and very little said on the history of shell-fish. The life of these industrious creatures, that for the most part crecp along the bottom, or immoveably wait till driven as the waves happen to direct, is almost entirely unknown. "The wreathing of their shells, or the spots with which they are tinctured, have been described with a most disgnsting prolixity; but their appetites and their combats, their escapes and humble arts of subsistence, have been utterly neglected.

As I have only undertaken to write the history of Animated Nature, the variety of shells, and their peculiar spots or blemishes, do not come within my design. However, the manner in which shells are formed is a part of natural history connected with my plan, as it pre-supposes vital force or industry in the animal that forms them.

The shell may be considered as a habitation supplied by nature. It is a hard stony substance, made up somewhat in the manner of a wall. Part of the stony substance the animal derives from outward objects, and the fluids of the animal itself furnish the cement. These united make that firm covering which shell-fish generally reside in till they dic.

Bnt, in order to give a more exact idea of the manner in which sea-shells are formed, we must have recourse to an animal that lives upon land, with the formation of whose shell we are best acquainted. This is the garden5mail, that carries its box upon its back, whose history Sivammerdam lias taken such endless pains to lescribe. As the manner of the forination of this animal's shell extends to that of all others that have shells, whether they live upon land or in the water, it will be proper to give it a place before we enter upon the history of testaccous fishes.

To begin with the animal in its. earliest state, and trace the progress of its shell from the time it first appears. The instant the young snail leaves the egg, it carries its shell or is box on its back. It does not leave the egg till it is arrived at a certain growth, when its little habitation is sufficiently hardened. This beginning of the shell is not much bigger than a pin's head, but grows in a very rapid manner, having at first but two circumvolutions, for the rest are added as the snail grows larger: In proportion as the animal increases in size, the circumvolutions of the shell increase also, until the number of those volutes corne to be five, which is never exceeded.

The part where the animal enlarges its shells is at the mouth, to which it adds in proportion as it finds itself stinted in its habitation below. Being about to enlarge its shell, it is scen with its little teeth biting and clearing away the scaly skin that grows at the edges. It is sometimes seen to eat those bits it thus takes off; at other times it only cleans away the margin when covered with films, and then adds another rim to its shell.

For the purposes of making the shell, which is natural to the animal, and without which it could not live three days, its whole body is furnished with glands, from the orjfices of which flows ont a kind of slimy fluid, like small spiders'threads, which join together in one common crust or surface, and in time condense and acquire a stony hardness. It is this slimy humour that grows into a membrane, and afterwards a stony skin; nor can it have escaped any who have observed the track of a suail, that glistening substance which it leaves on the floor or the wall, is no other than the materials with which the animal adds to its shell, or repairs it when broken.

Now to exhibit in a more satisfactory manner the method in which the shell is formed. The snail bursts from its egg with its shell upon its back; this slicll, though very simple, is the centre round which every succecding convolution of the shell is formed, by new circles added to the first. As the body of the snail can be extended no where but to the aperture, the mouth of the shell only can, of consequence, receive augmentation. The substance of which the shell is composed is chiefly supplied by the animal itself, and is no more than a slimy fluid which hardens into bone. This fluid passes through an infinite number of little glands till it arrives at the pores of the skin; but there it is stopped by the shell that covers the part below; and therefore is sent to the mouth of the shell, where it is wanted for its cnlargement. There the first layer of slime soon hardens; and 
then another is added, which hardens also, till in time the shell becomes as thick as is requisite for the animal's preservation. Thus every shell may be considered as composed of a number ot layers of slime, which have entirely proceeded from the animal's own body.

But though this be the general opinion with regard to the formation of shells, I cannot avoid thinking there are still other substances besides the animal's own sline which go to the composition of its shell, or at least to its external coat, which is ever different from the interral. The substances 1 mean are the accidental concretions of earthy or saline parts, which adhere to the slimy matter upon its first emission. By adopting this theory, we cau inore satisfactorily account for the various colours of the shell, which cannot be supposed to take its tincturc from the animal's body, as is the usual opinion; for all the internal parts of the shell are but of one white colour; it is only the outermost layer of the shell that is so beautifully varied, so richly tinctured with that variety of colours we bebold in the cabincts of the curious. If the external coat be scaled off, as Mr. Angenville asserts, all the inuer substance will be found but of onc simple colouring; and consequently the animal's own juices can give only one colour; whercas we see some shells stained with a liundred.

The usinal way of accounting for the different colouring of shells, which seems to me erroneous, is this: In the body of every one of these animals, several-streaks are discerned of a different colour from the rest. "This varicty," say they, "is an incontestable proof that the juices flowing from those parts will be also of a different hue; and will consequently tinge that part of the shell which their slime composes of a different colour." But this system, as was olserved before, is overthrown by the fact, which discovers that only the outer surfice of the shell is tinged; whereas by this it would have leen coloured throughout; nay, by this system, the internal parts of the shell wonld be stained with the most vivid colauring, as being least exposed to the external injuries of the element where it is placed. But the truth is, the animal residing in the shell has none of these various colours thus talked of: its slime is a simple, pellucid substance; and the only marblings which appear in its body, are the colour of the food which is seen through its transparent intestines. IVe must, therefore, account for the various colouring of its shell upon a different principle.

If, as I said, we examine the cabinets of the curious, we shall fund shells with yarious and beautiful colouring; we shall find them generally furnished with a white ground, tiuctured with red, yellow, brown, green, and several other shades and lovely mixtures, but never blue. Shells are of almost all colours but blue. The reason seems to be obvious; for blue is the colour which sea-water clianges. A piece of silk, or a feather, of this colour, put into an infusion of salt, urine, or nitre, lose their tint entirely. Now, may not this give us a hint with respect to the operation of uature in colouring her shells? Micy we not from lience conclude, that sea-water is efficacious in giving colour or taking it away? That, to produce colour, the animal not unly furnishes its juices, but the sea or the earth that mixture of substance which is to unite with them. Neither the animal slime alone, nor the external earthy or saline substances alone, could producc colours; but both united, produce an effect which neither separately were possessed of. Thus shells assume every colonr but biue; and that sea-water, instead of producing, would be apt to destroy.

From hence, therefore, it appears, that the animal does not alone incture its own shell; but that external causes co-operate in contributing to its beauty. It is probable, that, from the nature of its food, or from other circumstances unknown to us, the external layers of its slime may be of different consistences; so as, when joined with the particles of earth or salt that al'c accidentally united with them from without, they assume various and beautiful hues. But the internal layers, which reccive no foreign admixture, still passerve the natural colour of the animal, and cortinue white without any variation.

Thus far we sec that the animal is not wholly the agent in giving beauty and colouring to its shell: but it seems otherwise with respect to its convolutions, its prominences, and general form. Tliese entircly depend upon 
the art of the animal; or rather upon its instincts; which, in the same kinds, are ever. invariable. The shell generally bears some rude resemblance to the body upon which it lias been moulded. Thus, it is observable in all sea-shells, that if the animal has any tumour or excrescence on its body, it creates likewise a swelling in that part of the incrustation to which it corresponds. When the animal begins to alter its position, and to make new additions to its apartments, the same protuberance which liad raised the shell before in one part, swells it again at some little distance; by which means we see the same inequality, in a spiral line, all -round the shell. Sometimes these tumours of the animal are so large, or so pointed, that those which rise over them in the incrustation, appear like horns: after this the animal disengages itself from its first cavities, and then, by fresh evacuations, asșumes a new set of horns; and so increases the number in proportion to its growth. If, on the other hand; the body happens to be channelled, the shell that covers it will be channelled likewise; if there be any protuberances in the body, which wind in a spiral line about it, the shell will likewise have its tumours and cavities winding round to the end.

In this manuer, as the animals are of various forms, the shells exhibit an equal variety. Inleed, the diversity is so great and the figures and colonrs so very striking, that several persons, with a kind of harmless indolence, hare made the arrangement of them the stully and the business of their lives. Those who consult their benuty alone, take care to have them polished, and to have an external crust, or periosteum, as Swammerdam calls it, scoured off froun their surfaces by spirit of salt. But there are others that, with more learned affectation, keep them exactly in the state in which they have been found, with their precious crust still ronnd them. The expesise men have sometimes been at in making snch collections, is amazing; and some shells, such as the Stairs-shell, or the Admiral-sliell, are not more precious for their scarceness, than pearls are for their beauty. Indeed, it is the scarcity, and not the beauty of the object, that determines the value of all natural curiosities. Those shells that offer but little beauty to the igmorant, are often the most precious; and those shells which an unlearned spectator would stop to observe with admiration, one accustomed to the visitation of cabinets, would pass over with disdain. These collections, however, have their use; not only by exhibiting the vast varjety of nature's operations, but also by exciting our curiosity to the consideration of the animals that form them. A mind that can find inno. cent entertainment in these humble contemplations is well cmployed; and, as we say of children, is kept from doing mischief. Althongh there may be nobler occupations than that of considering the convolutions of a shell, yet there may be some who want the ambition to aspire after such ardnous pursuits; there may be some unfit for them; there may be some who find their ambition fully gratified by the praise which the collectors of shells bestow upon cach other. Indeed, for a day or two, there is no mind that a cabinet of sbells cannot furnish with pleasing employment. "What can be more gratifying," as Pliny says," "than to view nature in all her irregularities, and sporting in her variety of shells! such a difference of colour do they exhibit! such a difference of figure! flat, concave, long, lunated, drawsi round in a circle, the orbit cut in two! some are seen with a rising on the back, some smooth, some wrinkled, toothed, streaked, the point variously intorted, the mouth pointing like a dagger, folded back, bent inwards! all thesc variations, and many more, furnish at once novelty, elegance, and speculation."

With respect to the fignre of shells, Aristotle has dividled them into three kinds: and his method is, of all others, the most conformable to nature. These are, first, the univalve, or turbinated; which consist of one piece, like the box of a snail; secondly, the bivalve, consisting of two pieces, united by a hinge, like an oyster; and, thirdly, the multivalive, consisting of more than two pieces, as the acorn-shell, which has not less than twelve pieces that go to its composition. All these kinds are found in the sea at different depths, and are valuable in proportion to their scarceness or beauty.

\footnotetext{
- Plin. ix. 33.
} 
From the variety of the colours and figure of shells, we may pass to that of their place and simation. Some are fombl in the sea; some in liesh-watel rivers; some alive upon lund; and a still greater. quamity dead in the bowels of the earth. But wherever shells are foumd, they are universally known to be composed of one anl the same substance. They are formed of an animal or calcarious carth, that lemments with vinegar ant otlıce acids, and that burns into lime, and will not easily melt into glass. Such is the substance of which they are composed: and of their spoils, muny philosophers think that a great part of the surlince of the earth is comprosed at present. It is supposed by them, that chalks, nuils, and all such earths as ferment with vinegrar, are nothing more than a composition of shells, decayed, and crumbled down to one imilom IIass.

Sea-shells are cither found in the deprlis of the ocean, or they are cast empty and forsalien of their animals upon shore. "Those which are fished up from the deep, are called by the I atin name Pelcoii ; thoss: that are cast upon shore, are called Littorcles. Many of the pelagii are never seen upon slore; they convinue in the deptlis where they are lsred ; and we owe their capture only to accident. 'These, therefore, are the most scarce shells, and consequently the most valuable. The littorales ure more fiequent, and such as are of the sime lind with the pelagij are not.so beautilul. As they are often empty and forsaken, and as their animal is dead, and perhaps putrid in the bottom of the shell, they by this means lose the whiteness and the brilliancy of their colouring. They are not unfrequently also found eaten through, either by worms or by each other; and they are thus rendered less valuable: but what decreases their price still more is, when they are scaled and worn by lying too long empty at the botton, or exposed upon the shore. Upon the whole, however, seashells exceed cither land or fossil shells in beanty; they receive the highest polish, and exhibit the most brilliant and various colouling.

Fresh-water shells are neither so numerous, so various, nor so beautiful, as those belonging to the sea. They want that solidity which the others have; their clavicle, as it is called, is neither so prominent nor so strong; and not having a saline substance to tinge the surface of the shell, the colours are obscure. In freshwater there are but two kinds of shells, namely, the bivalred and the turbinated.

Living land-shells are more heautiful, though not so varions as those of fresh-water; and some not inferior to sea-shells in beauty. There are, indecd, but of one kind, namely, the turbinated; but in that there are found four ur five very beautiful varieties.

Of lossil, or, as they are called, extrancous shells, fonud in the howels of the earth, there are great mmbers, and as great a variety. In his class there are as many hinds as in the sea itself: There are found there turlinated, the bivalve, and the multivative kinds; and of all these, many at presint mot to be found even in the ocenu. Indeed, the mumber is so great, and the varieties so many, that it was Fong the opinion of naturalists, that they were merely the capricious productions of nature, ant had never given reirst to animals whose habitations they resembled. 'They were found, inot only of various kinds, but in different states of prescrvation: some had the shell entire, composed, as in its prinitive state, of a white calcarious earth, and filled with earth, or even empty; others were found with the shell enure, but filled with a substance which was petrified by time; others, and these in great numbers, were found with the shell entirely unouldered away, but the petrificd substance that filled it still exhiljiting the figure of the shell; other's still, that had bee'n lodged near earth or stone, impressed their print upon these substances, nind left the inmpression, thongh they themselves were decayed: lastly, sone shells were found half mouldered away, their parts scaling off from each other in the same order in which they were originally formed. However, these different stages of the shell, and even their fermenting with acids, were at first insufticient to convince those who had before assigned them a different origin. 'They were still considered as accidentally and sportively formed, and deposited in the various reposituries where they were found, but no way appertaining to any part of Animated Nature. This put succeeding inquiries upon more minute researches; and they soon began to find, that often where they dug up petrified shells or teeth, they could discover the petrified remains of some other bony parts of 
the body. They found that the shells which were taken from the earth, exhibited the usual defects and mischances, which the same kind are known to receive at sca. They showed them not only tinctured with a salt-water crust, but pierced in a peculiar manner by the sea worms, that make the shells of fishes ilieir fovourite food. These denunstrations were sufficient at last to convince all but a few philosophers who died away, and whose crooncous systems died with theml.

Every shell, thercfore, wherever it is found, is now considered as the spoil of sone animal, that once found shelter therein. It matters not by what unaccountable ineans they may have wandered from the sea; but they exhibit all, and the most certain marks of their origin. From their numbers and situation, we are led to conjecture, that the sen reached the places where they are found; and from their varietics, we learn low little we know of all the sca contains at present; as the earth finruishes many kinds which our most exact and industrious shell-collectors have not been able to fish up from the deep. It is most probable that thousands of different forms still remain at the botton unknown; so that we nay justly say with the philosopher: Ea qua scimus sunt pars minima eorum qua ignorainus.

It is well, however, for mankind, that the defect of our knowledgc on this subject is, of ail parts of learning, that which may be most easily dispensed with. An increase in the number of shells, would throw but very few lights upon the history of the animals that inhabit them. For such information we are obliged to those mcn who contemplated something inore than the ontside of the ohjects before then. To Reaumar we are obliged for examining the manners of some with accuracy; but to Swamuerdan for more. In fact, this Dutchman has lent attention to those animuls. that almost cxceerl credibility: he has excellecl even the insects he dissected, in patience: industry, and perseverance. It was in vain that this poor man's father dissuaded liu from what the world considered as a barreu pursuit; it was in vain that an habitual disorder, loronght on by his application, interrupted his efforts; it was in vain that naukind treated him with ridicule while living, as they suffered his works to remain long umprinted and neglected when dead; still the Dutch philosopher went oll, peeping into unwholesome ditches, wading through fens, dissceting spiders, and enmmerating the blood-vesscls of a snail: like the bee, whose heart he could not only distinguish, but dissect, he seemed instinctively impelled by his ruling passion, althougli he found nothing but ingratitude from man, and though his industry was apparently becoming fatal to himself. From him I will take some of the leading features in the history of those animals which breed in shells; previously taking iny division from Aristotle, who, as was said above, divides them into three classes; the T'urbinated, or those of the Suail kind; the Bivalved, or those of the Oystey kind; and the Multivalved, or those of the Acorn-shell kind. Of each I will treat in distinct chapters.

\section{ĆHAPTER CLIV.}

\section{OF TURBINATED SHELL-FISH OF THE SNAIL KIND.}

TO conccive the manner in which those animals subsist that are hid from us at the bottom of the dcep, we must again have recourse to one of a similar nature and formation, that we know. The history of the garden-snail has been more copiously considered than that of the elephant; and its anatomy is as well, if not better known : however, not to give any one object more room in the general picture of nature than it is entitled to, it will be sufficient to observe, that the snail is surprisingly fitted for the life it is formed to lead. It is furnished with the organs of life in a manner almost as complete as the largest animal; with a tonguc, brain, salival ducts, glands, nerves, stomach, and intestines; liver, 
beart, and blood-ressels: besides this, it has a purple bag that furnishes a red matter to different parts of the body, together with strong muscles that hold it to the shell, and which are bardened, like tendons, at their insertion.

But these it possesses in common with other animals. We must now see what it has peculiar to itself. The furst striking peculiarity is, that the animal has got its eyes on the points of its largest homs. When the suail is in motion, four horns are distinctly seen; but the two uppermost and loigest deserve peculiar consideration, both ou nccount of the various motions with which they are endued, as well as their having their eyes fixed at the extreme ends of them. These appear like two blackish points at their ends. When considered as taken out of the boly, they are of a bulbons or turnip-like figure; they liave but one coat; and the three humours which are common in the eyes of other auimals, samely, the vitrcous, the aqueous, and the crystallinc, are in these very indistinctly seen. The eyes the animal can direct to different oljects at pleasure, by a regular motion out of the boly ; and sometimes it bides them, by a very swift contraction into the belly. Under the small horns is the animal's mouth; and thougl it may appear too soft a substance to be furnished with teeth, yet it has not less than eight of them, with which it devours leaves, and other substances. scemingly harder than itself; and with which it sometimes bites off pieces of its own shell.

But what is most surprising in the formation of this animal, are the parts that serve for generation. Every snail is at once male and female; and while it impregnates another, is itself impregnated in turn. The ressels supplying the fluid for this purpose, are placed chielly in the fore part of the neck, and extend themselves over the body; but the male and female organs of generation, are always found united, and growing together. There is a large opening on the right side of the neck, which serves for very different purposes. As an anus it gives a passage to the excrements; as a mouth it serves for an opening for a respiration; and also as an organ of generation, it dilates when the desire of propagation begins. Within this each ani- mal has those parts, or something similar thereto, which continue the kind.

For some days before coition, the snails gather together, and lie quite near each other, eating very little in the mean time; but they settle their borlies in such a posture, that the neck and head are placed upright. In the mean time, the apertures on the side of the neck being greatly dilated, two organs, resembling intestines, are seen issuing from them, which some luave thought to be the instruments of generation. Beside the protrusion of these, each animal is posscssed of another peculiarity; for, lirom the same apesture, they launch forth a kind of dart at each other, which is pretty liard, barbed, and ending in a very sharp point. This is performed when the apertures approach cach other; and then the one is secu to shoot its weapon, which is received by the other, though it sometimes falls to the ground; some minutes after, the snail which received the weapon, darts one of its own at its antagonist, which is received in like manner. They then softly approach still nearer, and apply their bodies one to the other, as closely as the palms and fingers of the hands, when grasped together. At that time the horns are seen variously moving in all directions; and this sometimes for three days together. The coupling of these animals is generally thrice repeated, at intervals of fifteen days eaclı; and at every time, a new dart is mutually emitted.

At the expiration of eighteen days, the snails produce their eggs, at the opening of the neck, and hide them in the earth with the greatest solicitude and industry. These eggs are in great numbers, round, white, and covered with a soft shell: they are also stuck to each other by an imperceptible slime, like a bunch of grapes, of about the size of a small pea.

When the animal leaves the egg, it is seen with a very small shell on its back, which has but one convolution; but in proportion as it grows, the shell increases in the number of its circles. The shell always receives its additions at the mouth; the first centre still remaining: the animal sending forth from its body that slime which hardens into a stony substance, and still is fashioned into similar volutions. The garden-snail seldom exceeds 
four rounds and a half; but some of the seasnails arrive even at ten.

The snail, thus fitted with its box, which is light and firm, finds itself defended in a very ample manner from all cxternal injury. Whenever it is invaded, it is but retiring into this fortress, and waiting patiently till the dan(5er is over. Nor is it pussessed only of a power of retreating into its sliell, lut of mend. ing it whem broken. Sometimes these animals are crushed seemingly to pieces; and, to all appearance, utterly destroyed : yet still they set themselves to work, and, in a few days, mend all their numerous breaches. The same substance by which the shell is originally made, goes to the re-establishment of the ruined habitation. But all the junctures are very easily seen, for they have a fresher colour than the rest, and the whole shell in some measure resembles an old coat, patched with new pieces. They are sometimes seen with eight or ten of these patches; so that the damage must have been apparently irreparable. Still, however, though the animal is possessed of the power of mending its shell, it cannot, when come to its full growth, make a new one. Swammerdam tried the experiment: he stripped a snail of its shell, without hurting any of the bloot-vessels, retaining that part of the shell where the muscles were inserted; but it died in three days after it was stripped of its covering: not, however, without making efforis to build up a new shell ; for, before its death, it pressed out a certain nienıbrane round the whole surface of its body. This membrane was entircly of the shelly nature, and was intended, by the animal, as a supply towards a new one.

As the snail is furnished with all the organs of life and sensation, it is not wonderful to see it very voracious. It clicfly subsists upon the leaves of plants and trees; but is very delicate in its choice. When the animal moves to seck its food, it goes forward by means of that broad muscular skin which is sometimes seen projecting round the month of the shell; this is expanded before, and then contracted with a kind of undulating motion, like a man attempting to inove hinself forward by one arm, while lying on his belly. But the snail has another advantage, by which it not only smooths and planes its way, but also can ascend in the most perpendicular direction. พก. $57 \& 58$.
This is by that slimy substance with which it is so copiously furnisled, and which it emits wherever it moves. Upon this slime, as upon a kind of carpet, it proceeds slowly along, without any danger of wounding its tender body against the asperites of the pavement; by means of this it moves upivards to its food upon trees; and by this descends without danger of falling, and breaking its shell by the shock.

The appetite of these animals is very great; and the damage gardeners in particular sustain from them, makes them employ every method for their destruction. Salt will destroy them, as well as soot; but a tortoise in a garden is sail to banish then nuclı more effecinally.

At the approach of winter, the snail buries itself in the earth; or retires to some hole, to coutinue in a torpid state, during the severity of the season. It is sometimes seen alone; but more frequently in company in its retreat; several being usually found together, apparently deprived of life and scnsation. For the purposes of continuing in greater warmth and security, the snail forms a cover or lid to the mouth of its sleell with its slime, which stops it up entirely, and thus protects it from every external danger. The matter of which the cover is composed, is whitish, somewhat like plaster, pretty hard and solid, yet at the same time porous and thin, to admit air, which the animal cannot live without. When the cover is formed too thick, the snail then breaks a little hole in it, which corrects the defect of that closeness, which proceeded firom too much caution. In this manner, sheltered in its hole fiom the weather, defended in its shell by a cover, it sleeps during the winter; and, for six or seren momlse, contimues without food or motion, until the genial call of spring breaks its slumber, and excites its activity.

The snail liaving slept for so long a season, wakes one of the first fine days of April, breaks open its cell, and sallies forth to seck for nourishment. It is not surprising that so long a fast should have thinned it, and rendered it very voracious. At first, therefore, it is not very difficult in the choice of its food; almost any vegetable that is green seems welcome; but the succulent plants of the garden are chiefly grateful; and the various kinds of pulse are, at some seasons, almost wholly destroyed by their numbers. So great is the SD 
muliplication of snails at some years, that gardeners imagine they burst from the carth. $\AA$ wet season is gencrally favourable to their nroluction; for this animal cannot bear very tiry seasons, or dry places, as they cause too great a cousumption of its slime, without plenty of which it cannot subsist in health and vigoni.

Such are the most striking particulars in the history of this animal; and this may serve is a general picture, to which the manners and hitbitudes of the other tribes of this class may be conipared and referred. These are, the sea-snail, of which naturalists luave, from the apparent difference of their shells, mentioned fiteen kinds ; ${ }^{\mathrm{a}}$ the fresh-water snail, of which there are cight kinds; and the landsnail, of which there are five. These all bear a strong resemblance to the garden-snail, in the formation of their shell, in their hermaphrodite natures, in the sliny substance with which they are covered, in the formation of their intestines, and the disposition of the hole on the rightit side of the neck, which serves at once fur the discliarge of the faxces, for the lodging the instruments of generation, and for respiration, when the animal is under a necessity of taking in a new supply.

But in nature, no two kinds of animals, however like each other in figure or conforluation, are of manners entirely the same. 'Though the common garden-snail bears a very strong resemblance to that of fresh-water, and that of the sea, yet there are differences to be found, and those very considerable ones.

If we compare them with the fresh-water snail, though we shall find a general resemhlance, yet there are one or two rensarkable distinctions: and first, the fresh-water snail, and, as I should suppose, all snails that live in water, are peculiarly furnished with a contrivance by nature, for rising to the surface, or sinking to the bottom. The manner in which this is performed, is by opening and shutting the orifice on the right side of the neck, which is furnished with nuscles for that purpose. The snail sometimes gathers this aperture into an oblong tube, and stretches or protends it above the surface of the water, in order to draw in or expel the ajr as it finds occasion. This may not only be seen, but heard also by

a D'Argenville's Conchylioligie. the noise which the snail makes in moving the water. By dilating this it rises, by compressing it the animal sinks to the bottom. This is effected sonsewhat in the manner in which little images of glass are made to rise or sink in water, by pressing the air contained at the moutli of the tubes, so that it shall drive the water into their lyollow bodies, which before were filled only with air, and thus nıke them heavier than the clensent in which they swim. In this manner does the fresh-water snail dive or swim, by properly managing the air contained in its loorly.

But what reuders these animals far more worthy of notice is, that they are viviparous, and bring forth their young not only alive, lut with their shells upon their backs. This seems surprising: yet it is incontestably true! the young come to some degree of peifection in the womb of the parent; there they receive their stony coat; and from thence are $\mathrm{c} x$ cluded, with a complete apparatus for subsistence.

"On the twelfth of Marcl,," says Swammerdam, "I began my observatious upon this snail, and collected a great number of the kind, which I put into a large basin filled with rain-water, and fed for a long time with potter's earth, dissolved in the water about them. On the thirteenth of the same month I opened one of these snails, when I found nine living suails in its womb: the largest of these were placed foremost, as the first candidates for exclusion. I put them into fresh-water, and they lived till the eighteenth of the same month, moving and swimming, like snails full grown; nay, their manner of swimming was much more beautiful." Thus, at whatever time of the year these snails are opened, they are found pregnant with eggs, or with living snails; or with both together.

This striking difference between the freshwater and the garden-snail, obtains also in some of the sea kind; among which there are some that are found viviparous, while others lay eggs in the usual manner. Of this kind are one or two of the Buccinums; within which living young liave been frequently found, upon their dissection. In general, however, the rest of this numerous class bring forth eggs; from whence the animal bursts at a proper state of maturity, completely equipped with a house, which the moistness of the 
element where it resides does not prevent the inbabitant from enlarging. How the soft slime of the suail hardens, at the bottom of the sea, into the stony substance of a shell, is not easy to conceive! This slime must at least be possessed of very powerful petrifying powers.

All animals of the snail kind, as was ob. served before, are hermaphrodites; each containing the instruments of generation double. But some of the sea kinds copulate in a different manner from those of the garden. The one impregnates the other; but, from the position of the parts, is incapable of being impregnated by the same in turn. For this reason it is necessary for a third to be admitted as a partner in this operation: so that, while one impregnates that before it, another does the same office by this; which is itself impregnated by a fourth. In this manner, Mr. Adanson has seen vast numbers of sea-snails united together in a chain, impregnating each other. The Bulin and the Coret perform the oflices of male and female at the same time. The orifices in these are two, both separate from each other: the opening by which the animal performs the office of the inale, being at the origin of the horns; that by which it is passive, as the feinale, being farther down upon the neck. It may also be observed as a general rule, that all animals that have this orifice, or verge, as some call it, on the right side, have their shells turised from the right to the left; on the contrary, those which have it on the left side, have their shells turned from left to right, in a contrary direction to the former.

But this is not the only difference between land and sea-suails. Many of the latter entirely want horrss; and none of them have above two. Indeed, if the horns of snails be furnished with eyes, and if, as some are willing to think, the length of the horn, like the tube of a telescope, assists vision, these animals that chiefly reside in the gloomy bottom of the decp, can have no great occasion for them. Eyes would be unnecessary to creatures whose food is usually concealed in the darkest places; and who, possessed of very little motion, are obliged to grope for what they subsist on. To such, l say, eyes would rather be an olsstruction than an advantage; and, perhaps, even those that live upon land are without them.
Those that have seen the shells of seasnails, need not be told, that the animal which produces them is larger than those of the same denomination upon land. The sea scems to have the property of enlarging the magnitude of all its inhabitants; and the same proportion that a trout bears to a shark, is often seen to obtain between a shell bred upon the Jand, and one bred in the ocean. Its convolutions are more numerous. The gardensnail has but five turus at the most; in the sea-snail the convolutions are sometimes seen amounting to ten.

There is a difference also in the position of the month, in the garden and the watersnail. In the former, the mouth is placed crosswise, as in quadrupeds; furnished witl jaw-bones, lips, and teeth. In most of the sca-suails, the mouth is placed longitudinally in the head; and in some obliquely, or on one side. Others, of the Trochus kind, have no mouth whatsoever; but are furnished with a trunk, very long in some kinds and shorter in others.

Snails of the Trochus kind, furnished thus with an instrument of offence, deserve our par ticular attention. The trunk of the Trochus is fleshy, muscular, supple, and hollow. Its extremity is bordered with a cartilage, and toothed like a saw. The snails that are provided with this, may be considered as the predacious tribe among their fellows of the bottom. They are anong suails, what the tiger, the eagle, or the shark is among beasts, birds, or fishes. The whole race of shelled animals avoid their approach; for their habitations, however powerfully and strongly built, though never so well fortified, yield to the superior force of these invaders. Though provided with a thick, clumsy shell themselves, yet they move with greater swiftuess at the bottom than most other shell-fish, and seize their prey with greater facility. No shell so large but they will boldly venture to attack; and, with their piercing augre-like trunk, will quickly bore it through. No efforts the other animal makes can avail : it expands itself, and rises to the surface: but the enemy rises with it: it again sinks to the bottom, but still its destroyer closely adheres. In this manner the carnivorous shell-fish, as some naturalists call it, sticks for several days, nay weeks, to 
its prey, mutil, with its trunk, it has sucked out all substance, or until it drops off when the other begins to putrefy.

'Thus it would seem throughout nature, that no animal is so well defended, but that others are found capable of breaking in upon its entrenchments. 'The garden-snail seems tolerably well guarded; but the wall of its shell is paper itself, in comparison with that which fortifies some of the sea-snail kind. Beside this thick shell, many of them are also furnished with a lid, which covers the mouth of the shell, and which opens and shuts at the animal's pleasure. When the creature hunts for food, it opens its box, gropes or swims about; and, when satisfied, drops its lid, and sinks to the boltom: there it might besupposed to remain in perfect security; but the trochus soon finds the way to break into the thickest part of its enclosure, and quickly destroys it with the most fatal industry.

Their being liable to the attacks of the trochus seems to be a calamity to which most of this tribe are subject. Scarce a shell is met with entirely and sound to the end of its convolutions; but particularly the thiunest shells are the most subject to be thus invaded. As their shells are easily pierced, the predatory shell-fish, or the sea-worm, chiefly seek thein for subsistence; and of those thin, paper-like shells, not one in a hundred is found that has not suffered some disaster. As they are lighter than other shell-fish, they swim with greater ease; and this is the chief inethod of avoiding their heavier thick-shelled pursuers. The food of all snails properly lies at the bottom; when, therefore, the nautilus, or other thin-shelled fish, are seen busily swimming at the surface, it may be, that, instead of sporting or sunning themselves, as some are apt to suppose, they are actually labouring to escape their most deadly pursuers.

Of all sea-snails, that which is most frequently seen swimming upon the surface, and whose shell is the thinnest and most easily pierced, is the nautilus. Whether, upon these occasions, it is employed in cscaping its numerous enemies at the botlom, or seeking for food at the surface, I will not venture to decide. It seems most probable, that the former is the cause of its frequently appearing; for, upon opening the stomach, it is found to contain chienly that food which it finds at the bottom. 'This animal's industry, therefore, may be owing to its fears: and all those arts of sailing which it lıs taught matıkind, may have been originally the product of necessity. But the mautilus is too famous not to demand a more ample description. Al. though there be screral species of the nautilus, yet they all may be diviled into two: the one with a white shell, as thin as paper, which it is often secn to quit, and again to resume; the other with a thicker shell, sometimes of a beantiful mother-of-pearl colour, and that quits its shell but rarely. This shell outwardly resembles that of a large snail, but is generally six or eight inches across: within it is divided into forty partitions, that communicate with each other by doors, if I may so call them, throngh which one could not thrust a goose-quill: almost the whole internal part of the shell is lilled by the anianimal; the body of which, like its habitation, is divided into as many parts as there are chambers in its shell : all the parts of its body communicate with each other, through the doors or openings, by a long blood-vessel, which runs from the head to the tail: thus the body of the animal, if taken out of the shell, may be likened to a number of soft bits of flesh, of which there are forty threaded upon a string. From this extraordinary conformation, one would not be apt to suppose that the nautilus sometimes quitted its shell, and returned to it again; yet nothing, though seemingly more impossible, is more certain. The manner by which it contrives to disengage every part of its body from so intricate a habitation; by which it makes a substance to appearance as thick as one's wrist, pass through forty doors, each of which would scarcely admit a goose-quill, is not yet discovered; but the fact it is certain; for the animal is often found without its shell; and the shell more frequently destitute of the aniinal. It is most probable, that it has a power of making the substance of one section of its body remorc up into that which is next; and thus, by multiplied removals, it gets frce.

But this, though very strange, is not the peculiarity for which the nautilus has been the most distinguished. Its "spreading the thin oar," and "catching the flying gale," to use the 
poet's description of it, has chiefly excited human curiosity. These animals, particularly those of the white, liglt kind, are chiefly found in the Mediterranean; and scarce any who have sailed on that sea, but unust often have seen them. When the sea is calm, they are observed floating on the surfice; some spreading their little sail; some rowing with their feet, as if for life and death; and others still, floating upon their mouths, like a ship with the keel upward. If taken while thus employed, and examined, the extraordinary mechanism of their limbs for sailing will appear more manifest. The nantilus is furnished with eight feet, which issue near the mouth, and may as properly be called barbs: these are connected to each other by a thin skin, like that between the toes of a duck, but much thinner and more transparent. Of these eight leet thus connected, six are short, and these are held up as sails to catch the wind in sailing: the two others are longer, and are kept in the water; serving, like paddles, to steer their course by. When the weather is quite calm, and the animal is pursued from below, it is then seen expanding only a prart of its sail, and rowing with the rest: whenever it is interrupted, or fears danger from above, it instantly furls the sail, catches in all its oars, turns its shell mouth downward, and instantly sinks to the bottom. Sometimes, also, it is seen pumping the water from its leaking hulk; and, when unfit for sailing, deserts its shell entirely. The forsaken hulk is seen floating along, till it dashes, by a kind of shipwreck, upon the rocks or the shore.
From the above description, I think we may consider this animal rather as attempting to save itself from the attacks of its destroyers, than as rowing in pursuit of food. Certain it is, that no creature of the decp lias more numerous and more powrrful enemics. Its shell is scarcely ever lound in perfect preservation; but is generally scen to bear some marks of hostile invasion. Its little arts, therefore, upon the surface of the water, may have been given it for protection; and it may thus be endued with comparative swiftness to avoid the crab, the sea-scorpion, the troclus, and all the slower predacions reptiles that lurk for it at the bottom of the water.

From this general view of snails, they appear to be a much more active, animated tribe, than fiom their figure one would at first conceive. They seem to an inattentive spectator, as mere inert masses of soft flesh, rather loaded than covered with a shell, scarcely capable of motion, and insensible to all the objects around them. When viewed more closely, they are found to be furnished with the organs of life and sensation in a tolerable perfection: they are defended with armour, that is at once both light and strong; they are as active as their necessities require; and are possessed of appetites more poignant than those of animals that seem much more perfectly formed. In short, they are a fruitful, industrious tribe; furnished, like all other animals, with the powers of escape and invasion; they have their pursuits and their enmities; and, of all creatures of the deep, they have most to fear from each other.

\section{CHAPTER CLV.}

\section{OF BIVALVED SHELL-FISH, OR SHELLS OF THE OYSTER KIND.}

IT. may seem whimsical to make a distinction between the animal perfections of turbinated and bivalved shell-fish; or to grant a degree of superiority' to the snail above the oyster. Yet this distinction strongly and apparently obtains in nature; and we shall find the hivalved tribe of animals in every respect inferior to those we have been describing.
Inferior in all their sensations; inferior in their powers of motion; but particularly inferior in their system of animal generation. The snail tribe, as we saw, are hermaphrodite, but require the assistance of each other for fecundation; all the bivalve tribe are hermaphrodite in like manner, but they require no assistance from each other towards impregna- 
tion; and a single muscle or oyster, if there were no other in the world, would quickly replenish the ocean. As the land-snail, from its being best known, took the lead in the former class, so the fresli-water muscle, for the same reason, may take lead in this. The life and manners of such as belong to the sea will be best displayed in the comparison.

The muscle, as is well known, whether belonging to fresh or salt-water, consists of two equal shells, joined at the back by a strong, muscular ligament, that answers all the purposes of a hiinge. By the elastic contraction of these the animal can open its shell at pleasure, about a quarter of an inch from each other. 'The fish is fixed to either shell by four tendons, by means of which it shuts them close, and keeps its body firm from being crushed by any shock against the walls of its own luabitation. It is furuished, like all other animals of this kind, with vital organs, though these are situated in a very extraordiuary manmer. It has a mouth furnished with two fleshy lips; its intestine begins at the bottom of the mouth, passes through the brain, and makes a number of circumvolutions through the liver; on leaving this organ, it goes on straight into the heart, which it penetrates, and ends in the anus; near which the lungs are placed, and through which it breaths, like those of the snail kind; and in this manner its languid circulation is carried on. ${ }^{\circ}$

But the orgaus of generation are what most deserve to excite our curiosity. These consist in each muscle of two ovaries, which are the female part of its furniture, and of two seminal vessels, resembling what are found in the male. Each ovary and each seminal vessel, has its own proper canal; by the ovarycanal the eggs descend to the anus; and there, also, the seminal canals send their fluids to impregnate them. By this contrivance, one single animal suffices for the double purposes of generation; and the eggs are excluded and impregnated by itself alone.

As the muscle is thus furnished with a kind of self-creating power, there are few places where it breeds, that it is not found in great abundance. The ovaries usually empty them-

^ M. Mery. Anal, de Moules d'Etang. selves of their eggs in spring, and they are replenished in aulumn، For this reason they are found empty in summer and full in winter. They produce in great numbers, as all bivalved shell-fish are found to do. The fecundity of the snail kind is trifling in comparison to the fertility of these. Indeed it may be asserted as a general rule in nature, that the more helpless and contemptible the animal, the more prolific it is always found. Thus all creatures that are incapable of resisting their destroyers, have nothing but their quick multiplication, for the continuation of their existence.

The multitude of these animals in some places is very great; but, from their defenceless state, the number of their destroyers are in equal proportion. The crab, the cray-fish, and many other animals, are seen to devour them; but the trochus is their most formidable enemy. When their sluells are found deserted, if we then observe closely, it is most probable we shall find that the trochus has been at work in piercing them. There is searce one of them without a hole in it; and this probably was the avenue by which the enemy entered to destroy the inhabitant.

But notwithstanding the number of this creature's animated enemies, it seems still more fearful of the agitations of the element in which it resides; for if dashed against rocks, or thrown far on the beach, it is destroyed without a power of redress. In order to guard against these, which are to this animal the commonest and the most fatal accidents, although it has a power of slow motion, which I shall presently describe, yet it eudeavours to become stationary, and to attach itself to any fixed object it happens to be near. For this purpose, it is furnished with a very singular capacity of binding itself by a number of threads to whatever object it approaches; and these Reaumur supposed it spun artificially, as spiders their webs which they fasten against a wall. Of this, however, later philosophers have found very great reason to doubt. It is therefore supposed that these threads, which are usually called the beard of the nusele, are the natural growth of the animal's body, and by no means produced at pleasure. lndeed, the extreme length of this beard in some, which far exceeds the length. 
of the bodiy, seems impossible to be manufuctured by the thrusting ont and drawing in of the tongue, with the glutinous matcer of "which the French philosopher supposed those threads were formed. It is even found 10 increase with the growtls of the anim.s]; and as the muscle becomes larger and olter, the hearrl becomes longer and its filaments more strong." Be this as it will, nothing is more certain thitil that the muscle is found attached by these threads to every fixed object; sometimes, indeed, lor want of such an ohject, these animals are found united to each other; and though thrown into a lake separately, they arc taken out in bunches of many togetlier.

To have some fixed resting place where the muscle can continue, and take in its accidental foot, scems the state that this animal chiefly desires. Its instrunent of motion, by which it contrives to reacls the object it wants to bind itself to, is that muscular substance resembling a tongue, which is found long in proportion to the size of the muscle. In some it is two inches long, in others not a third part of these dimensions. This the animal has a powver of thrusting out of its shell; and with this it is capable of nuaking a slight furrow in the sand at the bottom. By neans of this furrow it can erect itself upon the edge of its shell; and thus continuing to make the furrow in proportion as it gocs forward, it reaches out its tongue, that answers the purpose of an artu, and thus carries its slicll edgeways, as in a groove, until it reaches the point intended. There, where it determines to take up its residence, it fixes the ends of its beard, which are glutillous, to the rock or the object, whatever it be; and thus, like a ship at anchor, braves all the agitations of the water. Sometimes the animal is attached by a large number of threads; sometimes but hy three or four, that secm scarce able to retain it. When the muscle is fixed in this manner, it lives upon the little earthy particles that the water transports to its shells, and perhaps the flesh of the most dininutive animals. Huwever, it does not finil to grow considerably; and some of this kind have been found a foot loug. I have seen the beards a foot and a lualf; and

a Mercier du Paly, sur le bouchots à moules. HAcademie de la Rochelle. of this substance the natives of Palermo sometimes make gloves and stockings.

These shell-fish are found in lakes, rivers, and in the sea. Those of the lake often grow to a very large size; but they seen a solitary animal, and are found generally separate from each other. 'Those of livers are not so large', but yet in greater alundauce; but the seamuscle of all others is perhaps the most plenty. These are often breal artificially in salt-water Imarshes that are overflowed by the tide; the fishermen throwing then in at the proper seasons; and there being undisturbed by the agitations of the sea, and not preyed upon by their powerful enenies at the hottom, they cast their eggs, which soon become perfect animals, and these are generally lound in clusters of several dozens together. It requires a year for the peopling a muscle bed; so that, if the number consists of forty thousand, a tenth part may annually be left for the peopling the bed anew. Muscles are taken from their beds from the month of July to October; and they are sold at a very moderate price.

From this animal the oyster differs very little, except in the thickness of its slecll, and its greater imbecility. The oyster, like the muscle, is formed with organs of life and respiration, with intestines which are very voluminous, and liver, lungs, aud lieart. Like the muscle, it is self-impregnated; and the shell, which the animal soon acquires, scrves it for its future habitation. Like the muscle, it opens its shell to receive the influx of water; and like that animal is strongly attached to its sliells both above aud below.

But it differs in many particulars. In the first place its shells are not equal, the one being cupped, the other flat; upon the cupped shell it is always scen to rest ; for if it lay upon the flat side it would then lose all its water. It differs also in the thickness of its shells, which are so strongly lined and defended, that no animal will attenıpt to pierce them. But though the oyster be secured from the attacks of the small reptiles at the bottom, yet it often serves as an object to which they are attached. Pipe-worms, and other little animals, fix their habitation to the oyster's sides, and in this manner continue to live in security. Among the number of these is a little red worm, that is often found upon the shell; which some. 
from never seeing oysters copulate, erroneously supposed to be the male by which their spawn was impregnated.

The oyster differs also from the muscle in being utterly unable to clange its situation. 'The muscle, as we luave observed, is capable of erecting itself on an edge, and going forward with a slow laborious motion. 'The oyster is wholly passive, and endeavours by all its powers to rest fixed to one spot at the bottom. It is entirely without that tongue which we saw answering the purposes of an arm in the other animal; but nevertheless is often attached very firmly to any object it Jappeus to approach. Roeks, stones, pieces of timber, or sea-weeds, all seem proper to give it a fixture, and to secure it against the agritation of the waves. Nothing so common in the rivers of the tropical climates as to see oysters growing even amidst the branches of the forest.. Many trees which grow along the banks of the stream often bend their Jranclies into the water, and particularly the mangrove, which chiefly delights in a moist siturtion. 'To these the oysters hang in cluster's, like apples upon the most fertile tree; and in proportion as the weight of the fish sinks the plant into the water, where it still continues growing, the number of oysters increase, and hang upon the branches. Thus there is nothing that these shell-fish will not stick to; they are often even found to stick to each other. This is effected by means of a glue proper to themselves, which, when it cements, the joining is as hard as the shell, and is as difficulty broken. The joining substance, however, is not always of glue; but the animal grows to the rocks, somewhat like the muscle, by threads; although these are only seen to take root in the shell, and not, as in the muscle, to spring from the body of the fish itself.

Oysters usually cast their spawn in May, which at first appear like drops of candlegrease, and stick to any hard substance they fall upon. These are covered with a shell in two or three days; and in three years the animal is large enought to be brought to market. As they invariably remain in the places where they are laid, and as they grow without any other seeming food than the afflux of seawater, it is the custom at Colchester, and other parts of the kingdom, where the tide settles in marshes on land, to pick up great quantities of small oysters along the shore, which, when first gatliered, seldom exceed the size of a sixpence. These are deposited in beds where the tide comes in, and in two or three years grow to a tolerable size. They are said to be better tasted for being thus sheltered fiom the agitations of the deep: and a mixture of fresh water entering into these repositories, is said to improve their flavour, and to increase their growth and fatness.

'The oysters, however, which are prepared in this manner, are by no means so large as those found sticking to rocks at the bottom of the sca, usially called rock-oysters. These are sometimes found as broad as a plate, and are admired by some as excellent food. But what is the size of these compared to the oysters of the Liast Indies, some of whose shells I have seen two feet over! The oysters found along the coast of Coromandel are capable of furnishing a plentiful meal to eight or ten men; but it seens universally agreed that they are no way comparable to ours for delicacy or flavour.

Thus the muscle and the oyster appear to have but few distiuctions, except in their shape, and the power of motion in the former. Other hivalved shell-fish, such as the cockle, the scallop, and the razor-shell, have differences equally minute. The power of changing place, which some of them effect in a namner quite peculiar to themselves, makes their greatest difference. The scallop is particularly remarkable for its mcthod of moving forward upon land, or swinıning upon the surfice of the water. When this animal finds itself deserted by the tide, it makes very remarkable efforts to regain the watel, noving towards the sea in a nost singular nınuer. It first gapes with its shell as widely as it can, the edges being often an inch asumder; then it shuts them with a jerk, and by this the whole animal rises five or six inches from the ground. It thus tumbles any how forward, and then renews the operation until it has attained its journey's cnd. When in the wate it is capable of supporting itself upon the surface; and there opening and shutting its shells, it tumbles over and over, and makes its way with some celerity.

The Pivot, or Razor-shell, has a very different kind of motion. As the former moves 
laboriously and slowly forward, so the razorshell has only a power of sinking point downward. The shells of this inimal resemble nothing so much as the haft of a razor; and hy this torm it is better enabled to dive into the soft sand at the bottom. All the motions of this little animai are confined to sinking or rising a foot downwards or upwards in the sand, for it never 'eaves the spot where first it was planted. From time to time it is seen to rise about half way out of its hole; but if any way disturhed, it sinks perpendicularly down again. Just over the place where the razor buries itself, there is a small bole like a chimney, through which the animal breatlss, or imbibes the sea-water, $\mathrm{U}_{1}$ on the llesertion of the tide, these holes are easily distinguished by the fishermen who seek for it; and their methorl of ensicing the rarot up firom the deptly of its retreat is hy sprinkling a little seasalt upon the hole. This, meling, no sooner reaches the razor below than it rises instancly straight upwards, and shows about hali its length above the surface. This appearance, lowever, is instantaneous; and if the fisher does not seize the opportunity, the razor louries itself with great ease to its former (lepth. 'There it continues secure; no salt can allure it a second time; but it remains unmolested, unless the fisher will be at the tronble of digging it out sometimes two feet below the surface.

Such are the mimute differences between bivalved shell-fish; but in the great outlines of their nature they exactly resemble each other. "It is partirularly in this elass of shellfish that pearls are fomm in great abundance; and it is in the internal parts of those shells thit are of a slining silvery colour that these gems are ustally generated; but the pearl is also funnd in breed as well in the muscle or the seallop as in the oyster. In fact, it is fommel in all bivalved sluells, the insirles of which resemble that well-known substance called mother-of-pearl.

Whetler pearle be a disease or an accident in thr mimal is scarcely worthy inquiry. The com nou opinion is, that they are a kind of ealenlus coneretion in the borly of the animal, some what resimbling a stone in the bladder, and are comsecfuently to be considered as a disorder. It is said, in confirmation of this opinion, that those coasts upon which pearls งo. $59 \& 60$. are fisherl, are very unhealthy; and therefore most probably oysters share the general influenee of the climate; it is also added, that those oysters in which pearls are found are always ill-tasted, which is a sign of thoir being unsound; and lastly, it is assetted that the peall grows sometimes so big as 10 krep the shells of the animal from shuting, and that thus it dies by being exposed. It is easy to see the weakness of these assertions, which seem neither true nor anusing. To answer them in their own way: If a stone in the bladiler be a disorler, a stone in the stomach of an ostrich is a benefit, and so it may be in the shell of an oyster. If the shores where the pearls are fisherl be unwholesoure to mall, that, insteat of being disatvintageous, is so mucls the more lineky for the oyster. If the pearl oysters are the worst tasted, so are kjtes and ravens among birds; and yet we know that they are healdry and long-lived animals : if the oyster hatd ever its shell kept asunder by the pearl within it, that would be a disease indeed: but this, in reality, never happens; for the oyster that breeds a large pearl always breeds a large shell, and the shell itself indents to receive its impression. The pearl upon the whole seens bred from no disorder in the animal, but accidentally produced by the same matter that goes to form the shell. The substance, which is soft at first, quickly liardens; and thus, by successive conts, layer over layer, the pearl arquires its dimensions. If cut through it will he foumer to consist of several coats, like an ouion; and sometimes a small speck is seen in the midrlle, uperm which the coats were originally formed.

All oysters, and most shell-fish, are found to contain penrls; but that which particularly obtains the name of the pearl oyster, has a large strong whitish shell, wrinkled and rough without, and within smootl and of a silver colour. From these the mother-of-pearl is taken, which is nothing noore than the internal coats of the sholl, resembling the pearl in colour and consistence. This is taken out and shaped juto the variety of utensils which are found so beautiful, but the pearl itself is chiefly prized; being fonnd but in few oysters, and generally adlıering, sometimes making a print in the body of the shell, sometimes at large within the substaince of the fish.

There are a great number of pearl fisheries $5 \mathrm{E}$ 
in America and Asfa; but as pearls bear a worse price than formerly, those of America are in a great measure discontinued. The most famous of all the Asiatic fisheries is in the Persian Gulf, near the Isle of Bahren. There is another between the coast of Madura and the Island of Ceylon; and there was a third on the coasts of Japan: but as these noble islanders have a contempt for jewels, and an abhorrence for such Europeans as come in pursuit of them, that fishery, which is thought to be the most valuable of all others, is discontinued. The diving business is now carried on only in those countries where the wretchedness of one part of maukind goes to support the magnificence of the other.

The chief tishery, as was said, is earried on in the Persian Gulf, and the most valuable pearls are brought from thence. The value of these jewels increases not only in proportion to their size, but also their figure and colour; for some pearls are white, others are yellowish, others of a lead colour; and some affirm they have been found as black as jet. What it is that gives these different tinctures to pearls is not known; Taverner ascribes it to their lying two or three weeks upon shore after the oyster is taken; Reaumur thinks it proceeds from the colour of that part of the fish's body upon which the pearl lies. It is most probable that this colour proceeds. like the spots frequently found on the internal surface of the shell itself, from some accident while the pearl is growing

The best coloured pearls, and the roundest, are brought from the East; those of America are neither so white nor so exactly oval. All pearls, however, in time beome yellow; they may be considered as an animal substance converted into a stony hardness, and like ivory taking a tincture from the air. They have been even found to decay when in damp or vaulted places, and to moulderinto a substance scarce harder than elanlk. When the daughters of Stilicon, who were both hetrothed. one after the other, to the emperor Honorius, were buried, much of their finery was also deposited with them in the same tomb. In this manner they remained buried for above eleven hundred years, till the foundations of the church of St. Peter were laying. Their tomb was then discorered, and all their finery was found in tolerable preservation except their pearls, which were converted by time and damps into a chalky powder.

The wretched people that are destined to fish for pearls, are either Negroes or some of the poorest of the natives of Persia. The inhabitants of this country are divided into tyrants and slaves. The divers are not only subject to the dangers of the deep, to tempests, to suffocation at the bottom, to being devoured by sharks, but from their profession universally labour under a spitting of blood, occasioned by the pressure of air upon their lungs in going down to the bottom. The most robust and bealthy young men are chosen for this employment, but they seldom survive it above five or six years. Their fibres become rigid; their eye-balls turn red; and they usually die consumptive.

It is amazing how very long they are seen to continue at the bottom. Some, as we are assured, have been known to continue three quarters of an hour under water without breathing; and to one unused to diving, ten minutes would suffocate the strongest. Whether from some effort the blood bursts the old passage which it had in the foetus, and circulates without going through the lungs. it is not easy to tell; but certain it is that some bodies have been dissected with this canal of communication open, and these extraordinary divers may be internally formed in that manner.

Be this as it may, no way of life seems so laborious, so dangerous, or so painful. They fish for pearls, or rather the oysters that con. tain them, in boats twenty-eight feet long; and of these there are sometimes three or four hundred at a time, with each seven or eight stones, which serve for anchors. There are from five to eight divers belonging to each, that dive one after another. They are quite naked, except that they have a net hanging down from the neck to put their oysters in, and gloves on their hauds to defend them while they pick the oysters from the holes in the rocks; for in this inanner alone ean they be gathered. Every diver is sunk by means of a stone, weighing fifty pounds, tied to the rope by whieh he descends. He places his foot in a kind of stirrup, and laying hold of the rope with his left hand, with his right he 
stops his nose to keep in his breath, as upon going down he takes in a very long inspiration. They are no sooner come to the bottom, but they give the signal to those who are in the boat to draw up the stone; which done, they go to work, filling their net as fast as they can; and then giving another signal, the boats above pull up the net loaded with oysters, and shortly after the diver himself to take a new inspiration. They dive to the depth of fifteen fathoms, and seldom go deeper. They generally go every morning by break of day to this fatiguing einployment, taking the land wind to waft them out to sea, and returning with the sea-brecze at night. The owners of the boats usually hire the divers, and the rest of the boats crew, as we do our labourers, at so much a day. All the oysters are brought on shore, where they are laitl in a great heap, till the pearl fishery is over, which continues during the months of November and December. When opportunity serves, they then examine every oyster, and it is accidental whether the capture turns out ad. vantageous. Indeed no human being cau wish well to a commerce, which thus chains such a number of fellow creatures to the bottom, lo pluck up a glittering, inouldering pebble.

\section{CHAPTER CLVI.}

\section{OF MULTIVALVE SHELL-FISH.}

MULTIVALVE SHELL-FISH may be considered as animals shut up in round boxes. To view their habjtations externally, one would be little apt to consider them as the retreats of living creatures; and still less, to suppose that some of them carry their boxes with a tolerable share of swiftness, so as to escape their pursuers. Of these there are principally two kinds; such as move, and such as are stationary: the first are usually known in our cabinets by the name of Seaeggs; the oihers are as often admired, from the cavities which they scoop out for their habitation in the hardest marble. The first are called, by naturalists, Echini, or Urchins : the latter are called Pholarles, or File-fisls. Of both there are several sorts; but, hy describing these two, we shall have a competent idea of all the rest.

To a slight view, the sea urchin may be compared to the husk of a chesnut; being like it round, and with a number of bony prickles standing out on every side. To exhibit this extraordinary aninal in every light, if we could conceive a turnip sturk full of pins on every side, and running upon these pins with some degree of swiftness, we should have some idea of this extraordinary creature. The mouth is placed downwards; the vent is above; the shell is a hollow vase, resembling a scooped apple; and this filled with a soft muscular substance, through which the intestines wind from the bottom to the top. The mouth, which is placed undermost, is large and red, furnished with five sharp teeth, which are easily discerned. The jaws are strengthened by five small bones, in the ccutre of which is a small fleshy tongue; and from this the intestines make a winding of five spires round the internal sides of the shell, ending at top, where the excrements arc excluded. But what makes the most extraordinary part of this animal's conformation, are its horns and its spines, that point from every part of the borly, like the horns of a snail, and that serve at once as legs to move upon, as arms to feel with, and as instrunients of capture and defence. Between these horns it has also spines that are not endued with such a share of motion. The spines and the horns issue from every part of the body ; the spines being hard and prickly; the horns being soft, longer than the spines, and never seen except in the water. They are put forward and withdrawn like the horns of a snail, and are hid at the bases of the spines, serving, as was said before, for procuring food and motion. All this apparatus, however, is only seen when the ani 
mal is hunting its prey at the bottom of the water; for a few ninutes after it is taken, all the horns are withdrawn into the body, and most of the spines drop off.

It is generally said of the insects, that those which have the greatest number of legs, always move the slowest: but this animal seerns to be an exception to the rule; for though furnished with two thousand spines, and twelve hundred horns, all serving for legs, and from their number seeming to impede each other's motion, yet it ruus with some share of swifiness at the bottom, and it is sometimes no easy matter to overtake it. It is often taken upon tle elsb, by following it in shallow water, either in an osier basket, or simply with the haud. Both the spines and the horns assist its motion; and the animal is usually seen running with the mouth downward.

Some kinds of this animal are as good eating as the lobster ; and its eggs, which are of a deep red, are consilered as a very great delicacy. But of other's the taste is hut indifferent; and in all platces, except the Mediterranean, they are litlle sought for, except as objects of curiosity.

Very different in motion, though not much different in shape from these, are the Acorn Shell-Fish, the Thumb-footed Shell-Fish, and the Imaginary Barnacle. These are fixed to one spor, and apprear to vegetate from a stalk. Indeed, to aninaltentivespectator, each actually seems to be a kiud of fungus that grows in the deep, destitute of animbl life as well as motion. But the inquirer will soon change his opinion, when he comes ta observe this nushromlike figure more minutely. He will then see that the animal residing within the shell has not only lile, but some degree of voraciousness; that it has a cover, by which it opens and shuts its shell at pleasure; that it has twelve long cronked arms, lurnished with hair, which it thrusts forth for its prey ; and eight smaller, which are generally kept in the shell: These are seen adhering to every substance that ic to be met with in the ocean; rocks, ro ts of trees, ships' bottoms, whales, lobsters, and even crabs, like bunches of grapes, clung to each other, It is amusing

\footnotetext{
* Andęrson's History of Greeuland.
}

enough to behold their operations.' They for some time remain motionless within their shell; but when the sea is calm, they are seen opening the lid, and peeping about them. They then thrust out their long neck, look round them for some time, and then abrupily retreat back into their box, shut their lid, and lurk in darkness and security, Some people eat thenı; but they are in no great repute at the tables of the luxurious, where their deformed figure would be no oljection to their being introduced.

Of all animals of the shelly tribr, the Pholades are the most wonderful. From the ir great powers of penetration, compared witls their apparent inbecility, they justly excite the astonishment of the curious observer. These animals are found in tifferent places; sometimies clothed in their proper shell, at the bottom of the water; sometines concealed in lumps of marly earth; and somftimes lodged, shell and all, in the body of the hardest narble. In their proper shell they assume different figures; but, in general, they somewhat resemble a muscle, except that their shell is found actually composed of five or more pieces, the sunaller valves serving to close up the opening left by the irregular meeting of two principal shells. But their penetration into rocks and their residence there, nakes up the nost wouderful part of their history.

This aninal, when divested of its slorll, resembles a roundish soft purding, with vo instrument that seems in the least fittrd fir boring into stones, or even penetrating the suftest substances. It is furnished with two teeth indeed; but these arr placed in such a situation as to be incapalle of touching the hollow surface of its siony dwelling: it has also two covers to its shrll, that open and shut at either end; but these are totally unserviceable to it as a miner. The instrument with which it performs all itsoperations, and buries itself in the hardest rocks, is only a broad fleshy substance, sonewhat resembling a tongue, that is seen issuing from the bottom of its shell. With this soft, yielding instru. nemt, it perforates the most solid marbles; and having, while yet little and young, made its way, by a very narrow entrance, into the substance of the stone, it then begins to 
grow bigger, and thus to enlarge its apartment.

The seeming unfitness, however, of this animal for penetrating into rocks, and there forming an labitation, has induced many philosophers to suppose that they entered the rock while it was yet in a soft state, and from the petrifying quility of the water, that the whole rock afterwards luardened round them by degrees. Thus any peuetrating quality, it was thought, was unjustly ascribed to them, as they ouly hored into a soft substance, that was hardened by time. This opinion, however, has been confuted, in a very satisfactory manuer, by Doctor Bohads, who observed, that many of the pillars of the teinple of Serapis at Puteoli were penetrated by these animals. From thence be very jusily concludes, that the pholas must bave pierced into them since they were erected; for no workmen would have laboured a pillar into form, if it had been honey-combed by worms in the quarry. In short, there can be no doubt but that the pillars were perfectly sound when crected; and that the pholades have attacked then, duriug that time in which they continued buried under water, by means of the carthquake that swallowed up the city."

From heuce it appears, that, in all nature, there is not a greater instance of perseverance and patience than what this animal is seen to exhibit. Furnished with the bluntest and softest anger, by slow successive applications, it effects what other animals are incapable of performing by force; penetrating the hardest bolies ouly with its tongue. When, while yet naked and very small, it has effected an entrance, and has buried its borly in the stone, it there continues for life at its ease; the sea-water that enters at the little aperture supplying it with luxurious plenty. When the animal has taken ton great a quantity of water, it is seen to spurt it out of its hole with some violence. Upon this seemingly thin diet, it quickly grows larger, and sonu finds itself under a necessity of enlarging its babitation and its shell. The motion of the pholas is slow heyond conception; its

a Bohadsch de Animalibus Marinis, p. 153. progress keeps pace with the growth of its body; and, in proportion as it becomes larger, it makes its way farther into the rock. When it has got a certain way in, it then turns from its former direction, and hollows downward; till, at last, when its habitation is completed, the whole apartment resembles the loole of a tobacco pipe; the hole in the shank being that by which the animal entered.

Thus immured, the pholas lives in darkness, indolence, and plenty; it never removes from the narrow mansion into which it has penetrated; and seems perfectly content with being enclosed in its own sepulchre. The influx of the sea-water, that enters by its little gallery, satisfies all its wants; and, without any other food, it is found to grow from seven to eight inches long, and thick in proportion.

But they are not supplied only with their rocky habitation; they have also a shell to protect them: this shell grows upon them in the body of the rock, and seems a very unnecessary addition to their defence, which they have procured themselves by art. These shells take different forms, and are often composed of a different number of valves: sometimes six; sometimes but three; sometimes the shell resembles a tube with holes at either end, one for the mouth, and the other for voiding the excrements.

Yet the pholas, thus shut up, is not so solitary an animal as it would at first appear; for though it is immured in its hole without egress, though it is impossible for the animal. grown to a great size, to get out by the way it made iin, yet many of this kind often meet in the heart of the rock, and, like miners in a siege, who sometimes cross each other's galleries, they frequently break in upon each other's retreats. Whether their thus meeting be the work of accident or of choice, few can take upon them to determine: certain it is, they are most commonly found in numbers in the same rock; and sometines above twenty are discovered within a few inches of each other.

As to the rest, this animal is found in greatest numbers at Aucona. in Italy : it is found along the shores of Normandy and 
Poitou, in France; it is found also upon some of the coasts of Scotland: and, in general, is

a Most of these animals contain a phosphorescent fluid, of great splendour and brilliancy in the dark, and which illuminates whatever it touches, or happens to fall upon. They are generally on rocky shores, with a bed of sand, considered as a very great delicacy at the tables of the luxurious."

just below high water mark, with their heads a little lifted above the surface, by which they may be easily drawn from their holes. 


\section{OF

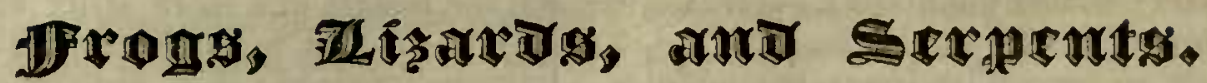

\section{OF FROGS AITD TOADS.}

\section{CHAPTER CLVIT.}

\section{OF FROGS AND TOADS IN GENERAL.}

IF we emerge from the deep, the first and most obvious class of amphibions animals that occur upon land are frogs and toads. These, wherever they reside, seem equally adapted for living upon land and in the water, having their hearts furmed in such a mauner as to dispense with the assistance of the lungs in carrying on the circulation. The frog and the toud therefore can live several days under water, without any danger of suffocation; th: $y$ want but little air at the boltum; and what is wanting is supplied by lungs, like blalder's, which are generally distended with wind, and a iswer all the purposes of a reservoir firorn whence to breath.

To describe the form of animals so well known would be superfluous; to mark those difierences that distinguish them from each other inay be necessary. The frog moves by leaping; the toad crawls along the ground: the frog is in general less than the toad, its colour is brighter, and with a more polished surface; the toad is hrown, rough, and dusty. The frog is light and active, and its belly comparatively small; the toad is slow, swollen, and incapable of escaping. The frug, when taken. coutracts itself so as to have a lunip on its back; the toad's back is straight and even. Their internal parts are nearly the same, except that the lungs of the toad are more compact than those of the frog; they have fewer air-bladders, and of consequence the animal is less fitted for living under water. Such are the differences with respect to figure and conformation; their habitudes and manners exhibit a greater variety, and require a separate description.

\section{CHAPTER CLVIII.}

\section{OF THE FROG, AND ITS VARIETIES.}

THE external figure of the Frog is too well known to need a descripuion. Its power of laking large leaps is remarkably great, compared to the bulk of its body. It is the best swimmer of all four-footed animals; and nature hath finely adapted its parts for those ends, the arms being light and active, the legs and thighs long, and furnished with very strong muscles.

If we cxumine this animal internally, we 
shall find that it has a very little brain for its size; a very wide swallow; a stomach 6eemingly small, but capable of great disteistion. The heart in the frog, as in all other animals that are truly amphibious, has but one ventricle; so that the blood can circulate without the assistance of the lungs, while it kecps under water. The lungs resenble a number of small bladders joined together, like the cells of a honey-comb: they are connected to the back by muscles, and can be distended or exhausted at the animal's pleasure. The male has two testiculi lying near the kidneys; and the female has two ovaries, lying near the same place: but ueither male nor female have any of the exterual iustruments of generation; the anus serving for thet purpose in both. Such are the most striking peculiarities in the anatomy of a frog; and in these it agrees with the toad, the lizard, and the serpent. They are all formed internally pretty much in the same manner, with spongy lungs, a simple heart, and are destitute of the external instruments that serve to continue the kind.

Of all those who have given histories of the frog, Mr. Ræsal, of Nuremberg, seems the most accurate and entertaining. His plates of this animal are well known; his assiduity and skilfulness in observing its manners are still more deserving onr esteem. Iustead, therefore, of following any other, I will take him for my guide; and though it be out of my power to amuse the reader with his beautiful desigus, yet there will be some merit in transcribing bis history.

The Common Brown Frog begins to eouple early in the season, and as soon as the icc is thawed from the staguating waters. In some places the cold protracts their genial appetite till April; but it generally begins about the middle of March. The male is nsually of a grayish brown colour; the female is more inclining to yellow, speckled with brown. When they couple, the colours of both are nearly alike on the back; but as they change their skins alumost every eighth day, the old one falling off in the form of mucus, the male grows yellower, and the female more brown. In the males the arms and legs are much stronger than in the females; and at the time of coupling, they have upon their thumbs a kind of fleshy excrescence, which they fix firmly to the breast of the female. This Linnæus supprsed to be the male instrument of generation; but, by closer inspection, it is tound only of service in holding tise female in a more strict enbrace. It may be eut off, and the inipregnation continue mimpaired: it is sometimies fonnd in the opposite sex; and some of the males are found entirely without it: however, when it is cut off, the male cannot hold the female so strongly as before.

The sex couple only once a year; and then continue united sometimes for four days together. At this time they both have their bellies greally swollen; that of the female being filled with eggs; the male having the skin of the whole body distended with a limpid water, which is ejected in impregnation. As soon as the male has leaped upon the female, he throws his fore legs round her breast, and closes them so frmly, that it is imp:ssible with the naked hands to loose them. The male clasps bis fingers between each other, in the same manner as people when they are praying; the thumbs press with their thickest sides against the breast of the female; and though she should struggle ever so much, nothing can induce him to let go his hold. The grasp seems involuntary and convulsive; they cannot be easily torn asunder; and they swim, creep, and live united, for some days successively, till the female lias shed her sparn, which at length she does almost in an instant. But how the impregnation is performed, without any apparent instruments of generation, las long been an object of inquiry; and still continues in grent obscurity. To investigate the difficulty as carefully as possible, our German philosopher continued to examine their mutual congress for three yenrs together, and availed himself of all the lights that the knife, or analogy, could furnish.

After having chosen twelve couple of frogs that were thus joined to each other, and having placed each couple in a glass vessel with water, he scarcely let them out of his sight day or night, and even sat up two nights together to examine their operations. The first day he observed nothing that deserved remark; but the sccond they began to be 
agitated more than before; the males made a noise somewhat resembling the grunting of a hog; the females only keptsinking and rising in the water. 'The male of the first couple ejected the humidity with which his body was swollen, by which the water in the glass was inarle muddy; and he soon after quitted the fomale. Our philosopher continued for twelve hours to observe whether the female would cast her spawn; but fuding her tardy, he dissected both lier and the male: in the latter, the spermatic vessels were quite empty, as might naturally have been supposed; but, for the female, ber spawn still remained in her body. Upon its being extracted, and put into water, it perished without producing any animal whatever. From hence he justly concluded, that it required that the eggs should be ejected from the body of the female before they could be at all prolific. In another pair the male quitted the female, who did not eject her spawn till sixteen days after; and these, like the former, came to nothing. But it was very different with some of the rest. The fernales ejected their spawn, while the male still remained in his station, and impreguated the masses at different intervals as they fell from her; and these all brought forth animals in the usual course of generation. From these observations it was easy to infer, that the female was inpregnated neither by the month, as some philosophers imagined, nor by the excrescence at the thunns, as was the opinion of Linnæus, but by the inspersion of the male seminal fluid upon the eggs, as they proceeded from the body.

A single female produces from six to eleven hundred eggs at a time; and, in general, she throws thern all out together, by a single elfort; though sometimes she is an hour in performing this task. While she is llues bringing forth, it may be observed, that the male acts the part of a mid wife, and promotes the expulsion of the eggs by working with his thumbs, and compressing the female's body more elosely. The eggs which were compressed in the womb, upon being cmitted, expand themselves into a round form, and drop to the hottom of the water: while the

- The tadpole is furnished with a sinall tube beneath the knwer jas, which acts as a sucker, and by means of which it can at pleasure attach itself to the under surface of พo. $59 \& 60$. male swims off, and strikes with his arms as usual, though they liad continued so long in a state of violent contraction.

The egg, or little black globe, which produces a tadpole, is surromided with two different kinds of liquor. That which immediately surrounds the globe is clear and transparent, and contained in its proper mem. brane; that which surrounds the whole is muddy and inucus. The transparent liquor serves for the nourishment of the tadpole from time to time; and answers the same purposes that the white of the egg does to birds. The tadpoles, when this membrane is broken, are found to adhere with their mouth to part of it; and when they get free, they immediately sink to the bottom of the water, never being able to get to the top after, while they continue in their talpole lorm.

But to return-When the spawn is emitted and impregnated by the male, it drops, as was said, to the bottom, and there the white quickly and sensibly increases. The eggs, which during the four first hours suffer no perceptible change, begin then to enlarge and grow lighter; by which means they mount to the surface of the water. At the end of eight hours, the white in which they swim grows thicker, the eggs lose their blackuess, and, as they inerease in size, somewhat of their spherical form. The twenty-first day, the egg is seen to open a little on one side, and the begimning of a tail to peep out, which becomes more and more distinet every day.

The thirty-ninth day the little animal begins to have motion; it moves at intervals its tail; and it is perceived that the liquor in which it is circumfused, serves it for nourishment. In two days more, some of these little creatures fall to the botton; while others remain swimming in the fluid around them, while their vivacity and motion is seen to increase. Those which fall to the bottom remain there the whole day; but having lengthened themselves a little, for hitherto they are doubled up, they mount at intervals to the mucus which they had quitted, and are seen to feed upon it with great vivacity. The next day they acquire iheir tadpole form." In three

aquatic plants : from these plants it can also suspend itself, when very young, by a kind of glutinous thread, in the same manner as spiders drop from the ceiling to the ground. 
days more they are perceived to have two little fringes, that serve as fins, beneath the head; and these, in four days after, assume a more perfect form. It is then, also, that they are seen to feed very greedily upon the pond-weed with which they are to be supplied; and, leaving their former food, on this they continue to subsist till they arrive at maturity. When they come to be ninety-two days old, two small feet are seen beginning to bourgeon near the tail: and the head appears to be separate from the body. The next day, the legs are considerably enlarged: four days after they refuse all vegetable food; their mouth appears furnished with teeth; and their hinder-legs are completely formed. In two days more the arms are completely produced; and now the frog is every way perfect, except that it still continues to carry the tail. In this odd situation the animal, resembling at once both a frog and a lizard, is seen frequently rising to the surface, not to take food, but to breath. In this state it continues for about six or eight hours, and then, the tail dropping off by degrees, the animal appears in its most perfect form.

Thus the frog, in less than a day, having changed its figure, is seen to change its appetites also. So extraordinary is this trans. formation, that the food it fed upon so greedily but a few days before, is now utterly rejected; it would even starve if supplied with no other. As soon as the animal acquires its perfect state, from having fed upon vegetables, it becomes carnivorous, and lives entirely upon worms and insects. But as the water caunot supply these, it is obliged to quit its native element, and seek for food upon land, where it lives by hunting worms, and taking insects by surprise. At first, being fecble and unable to bear the warmth of the sun, it hitles among bushes and under stones; but when a shower comes to refresh the earth, then the whole multitude are seen to quit their retreals, in order to enjoy the grateful humidity. Upon many occasions the ground is seen perfectly blackened with their numbers: some hunting for prey, and some seeking secure lurking places. From the myriads that offer on such occasions, some have been induced to think that these animals were generated in the clouds, and thus showered down on the earth. But lad they, like Derham, traced them to the next pool, they would have found out a better solution for the difficulty.

The frog lives for the most part out of the water; but when the cold nights begin to set in, it returns to its native element, always choosing stagnant waters, where it can lie without danger concealed at the bottom. In this manner it continues torpid, or with but very little motion, all the winter: like the rest of the dormant race, it requires no food; and the circulation is slowly carried on without any assistance from the air.

It is at the approach of spring that all these animals are roused from a state of slumber to a state of enjoyment. A short time after they rise from the bottom they begin to pair, while those that are as yet too young come upon land before the rest. For this reason, while the old ones continue concealed in the beginning of spring, the small ones are more frequently seen; the former remaining in the lake to propagate, while the latter are not yet arrived at a state of maturity.

The difference of sexes, which was mentioned above, is not perceivable in these animals, until they have arrived at their fourth year; nor do they begin to propagate, till they have completed that period. By comparing their slow growth with theirotherhabitudes, it would appear that they live about twelve years; but having so many enemies, both by land and water, it is probable that few of them arrive at the end of their term.

Frogs live upon insects of all kinds; but they never eat any unless they have motion. They continue fixed and immoveable till their prey appears; and just when it comes sufficiently near, they jump forward with great agility, dart out their tongnes, and seize it with certainty. The tongue, in this animal, as in the toad, lizard, and serpent kinds, is extremely long, and formed in such a manner, that it swallows the point down its throat; so that a length of tongue is thus drawn out, like a sword from its scabbard, to assail its prey. This tongue is furnished with a glutinous substance; and whatever insect it touches, infallibly adheres, and is thus held fast till it is drawn into the mouth.

As the frog is thus supplied with the power 
of catching its prey, it is also very vivacious, and able to bear bunger for a very long time. I bave known one of them continue a month in summer without any other food than the turf on which it was placed in a glass ressel. We are told of a German surgeon, that kept one eight years in a glass ressel, covered with a liet. Its food was at all times but sparing: in summer be gave it fresh grass, which it is said to have fed upon; and, in the winter, hay, a little moistened: he likewise, now and then, put tlies into the glass, which it would follow with an open mouth, and was very expert in catching them. In winter, when the flies were diflicult to be found, it usually fell away, and grew very leals; but in the suminer, when they were plenty, it soon grew fat again. It was kept in a warm room, and was always lively and ready to take its prey : however, in the eighth winter, when there were no flies to be found, it fell away and died. It is not certain how long it might have lived, had it been supplied with proper nourishment; but we are certain, that a very little food is capable of sufficing its necessitics.

Nor is the frog less tenacious of life. It will live and jump about several hours after its head has been cut off. It will continue active, though all its bowels are taken out; and it can live some days, though entirely stripped of it skin. This cruel trick, which is chicfly practised among school-boys, of skinning trogs, an operation which is done in an instant, seems for some hours no way to abate their vigour. I am assured that some of them get a new skin, and recover, after this painful experinent.

The croaking of frogs is well known; and, from thence, in some conntries, they are distinguished by the ludicrous title of Dutch Nightingales. Indeed, the aquatic frogs of Holland are loud beyond what one would imagine. We could hardly conceive that an animal, not bigger than one's fist, should be able to send forth a note that is heard at three miles' distance; yet such is actually the case. The large water-frogs have a note as loud as the bellowing of a bull; and, for this purpose. puff up the cheeks to a surprising magnitude. Of all frogs, however, the male only croaks; the female is silent, and the voice in the other seems to be the call to courtship. It is certain, that at these times when they couple, the loudness of their croaking is in some places very troublesome; for then the whole lake seems vocal; and a thousan!l dissonant notes perfectly stun the neighbourhoad. At other times, also, before wet wenther, thicir voices are in full exertion; they are then heard with unceasing assiduity, sending forth their call, and welcoming the approaches of their favourite moisture. No weather-glass was ever so true as a frog in foreteling an approaching change; and, in fact, the German surgeon, mentioned above, kept his trog for that puipose. It was always heard to croak at the approach of wet weather: but was as mute as a fish when it threatened a contiuuance of fair. This may probably serve to explain an opinion which some entertain, that there is a month in the year, called Paddock Moon, in which the frogs never croak : the whole seems to be no more than that, in the hot season, when the moisture is dried away, and consequently, when these animals neither enjoy the quantity of health or food that at other times they are supplied with, they show, by their silence, how much they are displeased with the weather. All very dry weather is hurtful to their health, and prevents them from getting their prey. They subsist chicfly upon worms and snails; and as drought prevents these from appearing, the frog is thus stinted in its provisions, and also wants that grateful humidity which moistens its skin, and renders it alert and active.

As frogs adhere closely to the backs of their own species, so it has bcen found, by repeated experience, they will also adhere to the backs of fishes. Few that have ponds, but know that these animals will stick to the backs of carp, and fix their fingers in the corner of each eye. In this manuer they are often caught together: the carp blinded and wasted away. Whether this proceeds from the desires of the frog, disappointed of its proper mate, or whether it be a natural enmity between frogs and fishes, I will not take upon me to say. A story told us by Walton, might be apt to incline us to the latter opinion.

"As Dubravius, a bishop of Bohemia, was $5 \mathrm{~F}$ * 
walking with a friend by a large pond in that country, they saw a frog, when a pike lay very sleepily and quiet by the shore side, leap upun his head, and the frog having expressed malice or anger by his swollen cheeks and staring eyes, did stretch out his legs, and embraced the pike's head, and presently reached them to his eyes, tearing with then and his teeth those tender parts; the pike, irritated with anguish, moves up and down the water, and rubs himself against weeds, and whatever he thought inight quit him of his enemy; but all in vain, for the frog did continue to ride tritunphantly, and to bite and torment the

[Another tribe of this fanily, is the Tree-frog: these unimals have a much slenderer and more elegant shape than the cominon frog, and have the linubs longer. At the end of each toe is a round, fleshy, concave substance, pike till his strength failed, and then the frog sunk with the pike to the bottour of the water: then presently the frog appeared again at the top, and croaked, and seemed to rejoice like a conqueror; after which he preseutly retired to his secret hole. The bishop, that had beheld the battle, called his fisherman to ferch his nets, and by all means to get the pike, that they might declare $n$ hat had happened. The pike was drawn forth, and botb his eyes eaten out ; at which when they began to wonder, the fisherman wished them to forbear, and assured them he was certain that pikes were often so served."

which exudes an unctuous matter, which enables it to adhere to the leaves and branclies of trees, \&c. in search of insects. They are found in France, Germany, Italy, and America.]

\section{CHAPTER CLIX.}

\section{OF THE TOAD, AND ITS VARIETIES.}

IF we regard the figure of the toad, there seems nothing in it that should disgust more than that of the frog. Its form and proportions are nearly the same; and it chiefly differs in colour, which is blacker; and its slow and heavy motion, which exhibits nothing of the agility of the fiog: yet such is the force of habit, begun in early prejudice, that those who consider the one as a harmless playful animal, turn from the other with horror and disgust. The frog is considered as an useful assistant, in ridding our grounds of vermin ; the toad, as a secret enemy, that only wants an opportunity to infect us with its venom.

The imagination, in this manner biassed by its terrors, paints out the toad in the most hideous colouring, and clothes it in more than natural deformity. Its body is broad; its back flat ; covered witl a dusky pimpled hide; the belly is large and swagging; the pace laboured and crawling; its retreat gloomy and filthy; and its whole appearance calculated to excite disgust and horror: yet, upon my flrst seeing a toad, none of all these deformities in the least affected me with sensations of loathing: born as I was, in a country where there are no toads, I had prepared my imagination for some drearlful object; but there scenied nothing to me more alarning in the sight, than in that of a conmon frog ; and, indeed, for some time, I mistook and handled the one for the other. When first informed of my mistake, I very well remember my sensations: I wondered how I had escaped with safety, after handling and dissecting a toad, which I had mistaken for a frog. I then began to lay in a fund of horror against the whole tribe, which, though convinced they are harmless, I shall never get rid of. My first inaginations were two strong not only for my reason, but for the conviction of my senses.

As the toad bears a general resemblance of figure to the frog, so alsu it reseubles that animal in its nature and appetites. Like the frog, the toad is amphibious; like that animal, it lives upon worms and insects, which it seizes by darting out its length of tongue; and in the same inanner also it crawls about in moist weather. The male and feniale 
couple as in all the frog kind; their time of propugation being very early in the spring. So:metimes the females are seen upon land oppressed by the mules; but more frequently they are coupled in the water. They continue together some hours, and adhere so fast as to tear the very skin from the parts they stick to. In all this they entirely resemble the frog; but the assistance which the male lends the fensale, in bringing forth, is a peculiarity in this species that must not be passed over in silence. "In the evening of a summer's day, a French gentleman, bing in the king's gardens at Paris, perceived two tonds coupled together, and he stopped to examine them. Two facts equally new surprised him; the first was the extreme difficulty the female had in laying her eggs; the second was the assistance lent her by the male for this purpose. The eggs of the finale lie in her body, like beads on a string; and after the first, by great effort, was excluded, the male caught it with his hinder paws, and kept working it till he had thus extracted the whole chain. In this manner the animal performed, in some measure, the functions of a midwife; impregnating, at the same time, every egg as it issued fioun the body."

It is probable, however, that this difficulty in bringing forth olstains ouly upon land; and that the toad, which prodices its spawn in the water, performs it with as inuch ease as a frog. They propagate in England exactly in the manner of frogs; and the female, instead of retiring (1) dry holes, goes to the bottont of ponds, and there lies torpid all the winter, preparing to propagate in the heginning of spring. On these vecasions, the number of mal's is found greatly to surpass that of the other sex, there being above thirty to one; an! twelve or fourteeu are often seen clinging to the saine feinale.

When, like the frog, they have undergone all the variations of their tadpole state, they forsake the water; and are ifien scen, in a moist summer's evening, crawling up, by myriads, from fenny places, into dryer situatinus. There, having found out a retreat, or haviug dug themselves one with their inouth an! liands, they lead a patient solitary life, seldom venturing out, except when the moisture of a sumner's evening invites them abroad. At that time the grass is filled with snails, and the pathways covered with worms, which make their priucipal food. Insects also of every kind they are fond of ; and we have the authority of Linnæus for it, that they sometimes continue immoveable, with the mouth open, at the botton of shrubs, where the butterflies, in some mieasure fascinated, are seen to fly down their throats."

In a letter from Mr. Arscott, there are some curious particulars relating to this animal, which throws great light upon its history. "Concerning the toad"" says he, "that lived so many years with us, and was so great a favourite, the greatest curiosity was its becoming so remarkably tame; it had frequented some steps before our hall-door some years before my acquaintance conımenced with it, and had been admired by my father for its size, (being the largest I ever met with,) who constantly paid it a visit every evening. I knew it myself above thirty years; and by constantly feeding it, brought it to be so tame, that it always came to the candle, and looked up, as if expecting to be taken up and brought upon the table, where I always fed it with insects of all sorts. It was fondest of flesh maggots, which I kept in bran; it would follow them, and when within a proper distance, would fix his eyes, and remain notionless for near a quarter of a minute, as if preparing for the stroke, which was an instantaneous thirowing its tongue at a great distance upon the insect, which stuck to the tip by a glutinous matter. The motion is quicker than the eye can follow. I cannot say how long my facher had been acquainted with the toad, before I knew it; but when I was first acquainted wirh it, he used to mention it as the old toad I have known so many years; I can answer for thirty-six years. 'This old toad nade its appearance as soon as the warm weather. came; and I always concluded it retired to some dry bank, to repose till spring. When we new layed the steps, I had two holes made. in the third step, on each, with a hollow of more than a yard long for it; in which I inagine it slept, as it came from thence at its. first appearance. It was seldom provoked. Neither that toad, nor the multitudes I have seen tormented with great cruelty, ever showed the least desire of revenge, by spitting:

- Amzenit. vol. vi. p. 201. 
or emitting any juice from their pimples. Sometimes, upon taking it up, it would let out a great quantity of clear water, which, as I have often seen it do the same upon the steps when quite quict, was certainly its urine, and no more than a natural evacuation. Spillers, millipeds, and flesh maggots, seem to be this animal's favourite fool. I imagine if a bee was to be put before a toad, it would certainly eat it to its cost; but as bees are seldon stiring at the same time that toads are, they rarely come ii their way; as they do not appear after sun-rising, or before sunset. In the heat of the day they will come to the inouth of their hole, I belicve for air. I once, froin my parlour window, observed a large toad I had in the bauk of a bowlinggreen, about twelve at noon in a very hot day, very busy and active upon the grass. So uncominon an appearance made me go out to see what it was; when I found an innumerable swarm of winged ants had dropped round his hole; which temptation was as irresistible as a turtle would be to a luxurious alderman. In respect to its end, had it not been for a tame raven, I make no doubt but it would have been now living. This bird, one day seeing it at the mouth of its hole, pulled it out, and, although I rescued it, pulled out one eyc, and hurt it so, that notwithstanding its living a twelvemonth, it never enjoyed itself, and had a difficulty of taking its food, missing the mark for want of its eye. Before tluat accident, it had all the appearance of perfect health."

To this account of the toad's inoffensive qualities, I will add another from Valisnieri, to show that, even taken internally, the toad is no way dangerous. "In the year 1692, some German soldiers, who had taken possession of the castle of Arceti, finding that the peasants of the country often amused themselves in catching frogs, and dressing them for the table; resolved to provide themsclves with a like entertainment, and made preparations for frog fishing, in the same manner. It may easily be supposed that the Italians and their German guests were not very fond of each other; and indeed it is

\footnotetext{
* Rresel tried a frog; it swallowed the bee alive : its ttomach was stung, and the animal vomited it up again.
}

natural to think that the soldiers gave the poor people of the country many good.reasons for discontent. They were not a little pleased, therefore, when they saw them go to a ditch where toads instead of frogs werc found in abundance. 'The Germans, no way distinguishing in their sport, caught them in great numbers; while the peasants kept looking on, silently flattering theinselves with the hopes of speerly revenge. After being brought home, the toads were dressed up after the Italian fashion: the peasants were quite happy at seeing their tyrants devour them with so good an appetite, and expecter every moment to see thein drop down dead. But what was their surprise to fiud, that the Germans continued as well as ever, and only complained of a slight excoriation of the lips, which probably arose from soine other cause than that of their repast."

I will add another story, from Solenander; who tells us, that a tradesman of Rome and his wife had long lived together with mutual discontent; the man was dropsical, and the woman amorous: this ill-matched society promised soon, by the very infirm state of the man, to have an end; but the woman was unwilling to wait the progress of the disorder; and therefore concluded that, to get rid of her husband, nothing was left her but poison. For this purpose, she chose out a dose that she supposed would be the most effectual; and having calcined some toads, mixed their powder with his drink. The man, after taking a hearty dose, found no considerable inconvenience, except that it greatly promoted urine. His wife, who considered this as a beginning symptom of the venom, resolved not to stint the next dose, but gave it in greater quantities than before. This also increased the former symptom; and, in a few days, the woman had the mortification to see her detested husband restored to perfect health; and remained in utter despair of ever heing a widow.

From all this it will appear with what injustice this animal has hitherto been treated. It has undergone every kind of reproach; and mankind have been taught to consider as an enemy, a creature that destroys that insect tribe which are their real invaders. We are to treat, therefore, as fables, those 
accounts that represent the toad as possessed of poison to kill at a distance; of its ejeeting its venom, which burns wherever it tonches; of its infecting those regetables near which it resides; of its excessive fondness for sage, which it renders poisonous by its approach; these, and a hundred others of the same kind, probably took rise from an antipathy which some have to all animals of the kind. It is aı harmless, defenceless creature, torpid and unvenomous, and seeking the darkest retreats, not from the malignity of its nature, but the multitude of its enemies.

Like all the frog kind, the toad is torpid in winter. It chooses then for a retreat either the hollow root of a tree, the eleft of a rock, or sametimes the bottom of a pond, where it is found in a state of seeming insensibility. As it is very long-lived, it is very difficult to be killed; its skin is tongh, and cannot be easily pierced; and, though covered with wounds, the animal continues to show signs of life, and every part appears in motiou. But what shall we say to its living for centuries lodged in the bosom of a rock, or eased within the body of an oak tree, without the smallest access on any side either for nourishnent or air, and yet taken out alive and perfect! Stories of this kind it would be as rash to contradict, as difficult to believe; we have the highest authorities bearing wituess to their truth, and yet the whole analogy of nature seems to arraign them of falsehood. Bacon asserts, that toads are found in this manner; Dr. Plot asserts the same: There is to this day a inarble climuey-piece at Cliatsworth with the prist of a toad upon it, and a tradition of the manner in which it was found. In the Memoirs of the Academy of Sciences, there is an account of a toad found alive and healthy in the heart of a very thick elm, without the smallest entrance or egress." In the year 1731, there was another found near Nantes in the heart of an old oak, without the sinallest issue to its cell; and the discoverer wits of opinion, from the size of the tree, that the animal could not have been confined there less than eighty or a hundred years, without sustenance and ivithout air. To all these we can only oppose the strangeness of the facts;

- Vide the year 1719 . the neccessity this animal appears under of receiving air; and its dying like all other animals in the air-punp, when deprived of this all-sustaining fluid. But whether these be objections to weigh against such respectahle and disinterested authority, I will not pretend to determine; certain it is, that il kept in a damp place, the toad will live for several months without any food whatsoever.

To this extraordinary account, which is doubtful, I will add another not less so; which is, that of toads sucking cancerous breasts, and thus extracting the venom, and perlorming a cure. The first account we have of this, is in a letter to the Bishop of Carlisle from Doctor Pitfield, who was the first person of consequence that attended the experiment. His letter is as follows:

"Your lordship must lave taken notice of a paragraph in the papers with regard to the application of toads to a cancered breast. A patient of mive has sent to the neighbourhood of Hungerford, and brought down the very woman on whom the cure was done. I have, with all the attention I am capable of, attended the operation for eighteen or twenty days, and ain surprised at the phenomenon. I am in no expectation of any great service from the application; the age, constitution, and thoroughly cancerous condition, of the person, beiug unconquerable barriers to it. How all ailment of that kind, absolutely local, in an otherwise sound babit and of a likely age, might be relieved, I cannot say. But as to the operation, thus much I eail asscrt, that there is neither pain nor nauseousuess in it. The animal is put into a linen bag all but its head, and that is held to the part. It bas generally instantly laid hold of the foulest part of the sore, and sucked with greediness until it dropped off dead. It has frequently happened that the creature has swollen immediately, and from its agonies appeared to be in great pain. I lave weighed them for several days together, before and after the application, and found their increase of weight, in the different degrees, from a drachn to near an ounce. They frequently sweat exceedingly, and turn quite pale; sometimes they disgorge, recover, and become lively again: I think the whole scene is surprising, and a very remarkable piece of natural his" 
tory. From the constant inoffensiveness which I have observed ia them, I almost question the truth of their poisonous spitting. Many people here expect no great good from the applieation of toads to cancers; and where the disorder is not absolutely local, none is to be expected. When it is seated in any part not to be well come at for extirpation, I think it is hardly to be imagined, but that the having it sucked clean as often as you please, must give great relief. Every body knows that dogs licking of sores cures them, which is I suppose chiefly by keeping them clean. If there be any credit to be given to history, poisous have been sucked out. Pallentia vulnera lambit ore venena trahens, are the words of Luican on the occasion. If the people to whom these words are applied did their cure by immediately following the iujection of the poison, the lncal confinement of another poison brings the case to a great degree of similarity. I hope I have not tired your Lordship with my long tale : as it is a true one, and in my apprehension a curious piece of natural history, I could not forbear communicating it to you. I own I thought the story in the papers to be an invention; and when I considered the instinctive principle in all animals of self-preservation, I was confirmed in my disbelief: but what I have related I saw; and all theory must yield to fact. It is only the Rubeth, the land-toad, which has the property of sucking: I cannot fud any the least mention of the property in any one of the old naturalists. My patient cal bear to have but one applied in twentyfour hours. The woman who was cured had them on day and night without intermission for five weeks. Their time of hanging at the breast has been from one to six hours."

Other remarks made upon their method of prrforming this extraordinary operation are as follow. "Some toads die very soon after they have sucked; others live about a quarter of an hour, and some much longer. For example, one that was applied about seven o'clock sucked till ten, and died as soon as it was taken from the breast; another that immediately succeeded continued till three o'clock, but dropped dead from the wound: each swelled exceedingly, and of a pale colour. They do not seem to suck greedily, and often turn their heads away; but during the time of their sucking, they were heard to smack their lips like a young child."'a

From this circumstantial account of the progress of this extraordinary application. one could hardly suppose that any doubt could remain of the ingenious observer's accuracy; and yet, from information which I have received from authority still more respectable, there is much reason as yet to suspend our assent. A lady, who was under the care of the present president of the college of physicians, was induced by her friends to try the experiment; and as he saw the case was desperate, and that it would quiet her mind as as well as theirs, he permitted the trial. During the whole contiuuance of their application, she could never thoroughly perceive that they sucked her; but that did not prevent their swelling and dying, as in the former instances. Once indeed, she said, she thought that one of them seemed to suck; but the physician, and those who attended, could not rerceive any appearance of it. Thus, after all, it is a doubt whether these animals die by the internal or the external application of the cancerous poison.

Of this animal there are sereral varieties; such as the Water and the Land Toad, which probably differ only in the ground-colour of their skin. In the first, it is more inclining to ash-colour, with brown spots; in the other, the colour is brown, approaching to black. The water toarl is not so large as the other; but both equally breed in that element. The size of the toad with us is generally from two to four inches long; but in the fenny countries of Europe, I have seen them much larger, and not less than a common crab, when brought to table. But this is nothing to what they are found in some of the tropical climates, where travellers oftell, for the first time, mistake a toad for a tortoise. Their usual size is from six to seven inches; but there are some still larger, and as broad as a plate. Of these some are beautifully streaked and coloured; some studded over, as with pearls; others bristled with horns or spines; some have the head distinct from the body, while others have it so sunk in, that the animal appears without

a British Zoology, vol. iii. p. 338. 
a head: All these are found in the tropical climutes, in great abuudance; and particularly after a shower of rain. It is then that the streets seem entirely paved with them; they then cratwl from their retreats, and go into all places to enjoy their favourite moisture. With ts the opinion of its raining toads and frogs has long been justly exploded; but it still is entertained in the tropical countries; and that not only by the savage natives, but the more refined settlers, who are apt enough to add the prejudices of other nations to their owis.

It would be a tedious, as well as useless task, to enter into all the minute discriminations of these animals, as found in different conntries or places; but the Pipal, or the Surinan Toad, is too strange a creature not to require an exact description. There is not, perhaps, in all nature, a more extraordinary phenomenon, than that of an animal breeding and hatching its young in its back; from whence, as froun a kind of lot-bed, they crawl one after the other, when come to maturity.

The pipal is in form more hideous than even the cominon toad; uature seeming to have marked all those strange-mannered animals with peculiar deformity. The body is flat and broad; the head small; the jaw's, like those of a mole, are extended, and evi. dently formed for rooting in the ground: the skin of the neck forms a sort of wrinkled collar: the colour of the head is of a dark chesnut, and the eyes are small : the back, which is very broad, is of a lightish gray, and seems covered over with a number of small eyes, which are round, and placed at nearly equal distauces. These eyes are very different from what they seem; they are the animal's eggs, covered with their shells, and placed there for hatching. These eggs are buried deep in the skin, and in the begimning of incubation but just appear; and are very visible when the young animal is about to burst from its contfinement. They are of a reddish shining yel-

a Among this numerous family there is one, which, for horrid and deformed appearance, probably excceds all other created beings. This is the liorned Toad of South America. The colonr is cinerous, with brown stripes. The eye-lids project in a singular manner, and give it the appearance as if the eyes were placed at the bottom of a No. $59 \& 60$. low colour ; and the spaces between them are full of small warts, resembling pearls.

This is their situation, previous to their coming forth; but nothing so much demands our admiration, as the manner of their production. The eggs, when formed in the ovary, are sent by some interual cauls, which anawomists have not hitherto described, to lie and come to maturity under the bony substance of the back; in this state they are im. pregnated by the male, whose seed finds its way by pores vely singularly contrived, and pierces not only the skin but the periosteunt. The skin, however, is still apparently entire, and forms a very thick covering over the whole brood ; but as they advance to nıaturity, at different intervals, one after another, the egg seems to start forward and bourgeon from the back, becomes more yellow, and at last breaks, when the young one puts forth its head: it still, however, keeps its situation, until it has acquired a proper degree of strength, and then it leaves the slrell, but still continues to keep upon the back of the parent. In this manner the pipal is seen travelling with her wondrous family on her back, in all the different stages of maturity. Some of the strange progeny, not yet come to sufficient perfection, appear quite torpid, and as yet without life in the egg: others seem just beginning to rise through the skin ; here peeping forth from the shell; and there, having entirely forsaken their prison, some are sporting at large upon the parent's back; and others descending to the ground, to try their own fortune below.

Such is the description given of this strange production by Seba, in which he differs fiom Ruysch, who affirms, that the young ones are bred in the back of the male only, where the female lays her eggs. I have followed Seba, however, not because he is better authority, but because he is more positive of the truth of his account, and asserts, assuredly, that the eggs are found on the back of the female only. Many circumstances, however, are

pair of sharp-pointcd horns : the head is very large, and the moutl is so enorinous, as to exceed half the length of its body. To add to its loathsome appearance, it is likewise clothed all over, except the head and feel, with short sharp spines. 
wanting towards completing his information; such as a deseription of the passage by which the egg finds its way into the baek; the manner of its fecundation; the time of gestation; as also a history of the manners of this strange animal itself: but, by a prolixity that too much prevails among naturalists at present, he leaves the most interesting object of curiosity, to give us a detailed deseription of the legs and claws of the pipal, about which we have very little concern.

The miale pipal is every way larger than the female, and has the skin less tightly drawn lound the bodv. The whole body is covered with pustules resembling pearls ; and the bel$\mathrm{ly}$, which is of a bright yellow, seems as if it were sewed up from the throat to the vent, a seam being seen to run in that direction. This animal, like the rest of the frog kind, is most probably harmless; though we are told of the terrible effects resulting from its powder when calcined. This, however, nust certainly be false; no creature whatever, when calcined, can be poisonous; for the fire burns away whatever might have been dangerous in their composition : all animal substances, when calcined, being entirely the same. 


\section{OP TII IIZARD IIIND.}

\section{CHAPTER CLX.}

\section{OF LIZARDS IN GENERAL.}

THERE is scarcely a naturalist, who has treated of lizards, but has a particular manner of ranking them in the scale of aninated nature. Ray, rather struck with the number of their legs, than their habits and conformation, has exalted them among quadrupeds; whike Linnæus, attentive only to their long slender forms, has degraded then anıong serpents. Brisson gives them a distinct class by themselves, under the name of reptiles. Klein gives them a class inferior to beasts, under the name of naked quadrupeds. Some, in short, from their scaly covering, and fonduess for the water, have given them to the fishes; while there have not been wanting naturalists who have classed them with insects, as the snaller kinds of this class seem to demand.

It is indeed no easy nuatter to tell to what class in uature lizards are chiefly allied. They are unjustly raised to the rank of beasts, as they bring furtli cggs, dispense with breathing, and are not covered with hair. They cannot be placed among fishes, as the najority of them live upon land: they are excluded from the serpent tribe, hy their feet, upon which they run with some celerity; and from the insects, by their size; for though the Newt nay be looked upou in this contemptible light. a Crocollile would be a terrible insect indeed. Thus lizards are, in sume measure, excluded from every rank; while they exhibit somewhat of the properties of all; the legs and celerity of the quadruped ; a facility of creeping through narrow and intricate ways, like the serpent; and a power of living in the water, like fishes: however, though endued with these various powers, they have no real advantages over any other class of animated nature ; for what they gain in aptitude for one elenient, they lose in their fitness for another. Thus, between both, they are an awkward ungninly tribe; neither so alert upon land, nor so nimble in the water, as the respective inluabitants of either abode: and, indeed, this holds throughout all nature, that in proportion as the sceming advantages of inferior animals are multiplied, their real ones are abridged; and all their instincts are weakened and lost by the variety of chanucls into which they are divided.

As lizards thus differ fronı every other class of auimals, they also differ widely from each other. With respect to size, no class of beings has its ranks so opposite. What, for instance, can be more removed than the small Chameleon, an inch long, and the Alligator of the river Amazons, alove twenty-seven feet? To an inattentive observer, they would appear entirely of different kinds; and Seba wonders how thicy ever came to be classed together.

The colour of these animals also is very various, as they are found of a hundred different hues-green, blue, red, chesuut, yellow; spotted, streaked, and marbled. Were colour alone capable of constituting beanty, the lizard would often please; but there is something so repressing in the animal's figure, that the brilliancy of its scales, or the variety of its spots, only tend to give an air of more exquisite venom or greater malignity. The figure of these animals is not less various: sousetimes swollen in the belly; sometimes pursed up at the throat; sonetimes with a rough set of spines on the back, like the tceth of a saw ; sometimes with teeth, at others with none: sometimes venomous at others harmless, and even $5 \mathrm{G}^{*}$ 
philanthropic; sometimes smooth and even; sontimes witls a long slender tail; and often with a shorter blunt one,

But their grcatest clistinction arises from the unanner of bringing forth their young. First, some of them are viviparous. Secondly, some are oviparous; and which may be considered in three distinet ways. Thirdly, some bring forth small spawn, like fishes. The Crocodile, the Iguana, and all the larger kinds, bring forth eggs, which are hatched by the heat of the suu; the animals that issue from them are complete upon lcaving the shcll; and their first efforts are to run to seek food in their proper element. The viviparous kinds, in which are all tie salamanders, come forth alive fiom the body of the lemale, perfect and active, and suffer no succeeding change. But those which are bred in the water, and, as we lave reason to think, from spawn, suffer a very considerable change in their forn. They are. produced with an external skin or covering, that sometimes encloses their feet, and gives them a serpentine appearance. To this false skin fins are added, above and below the tail, that serve the animal for swimming; but when the false skin drops off, these drop off also; and then the lizard, with its four feet, is completely formed, and forsakes the water.

From hence it appears, that of this tribe there are three distinct kinds, differently pinduced, and inost probably very different in their formation. But the history of these animals is very ohscure ; and we are as yet incapable of laying the line that separates them. All we know, as was said before, is, that the great animals of this kind are mostly produced perfect from the egg; the salamanders are generally viviparous; and some of the water lizarls imperfectly produced. In all these

a The whole of this tribe is perfectly destitute of poison, and, except the crocodile and alligator, quite inofien- most unfinished productions of nature, if I may so call them, the varieties in their structure increase in proportion to their imperfections. A poet would say, that nature grew tired of the nauseous formation, and left accident to finish the rest of her handy-work.

However, the three kinds have many points of similitude; and, in all their varieties of figure, colour, and production, this tribe is easily distinguished, and strongly nıarked. They have all four short legs; the two forefeet somewhat resembling a man's hand and arm. They have tails almost as thick as the body at the begiming, and that generally run tapering to a point. They are all amphibious also ; equally capable of living upon land and water; and formed internally in the same manner with the tortoise, and other animals, that can continue a long time without respiration: in other words, their lungs are not so necessary to continue life and circulation, but that their play may be stopped for some considerable time, while the blood performs its circuil round the body by a shorter communication.

These are differences that sufficiently separate lizards from all other anjmals; but it will be very difficult to fix the limits that distinguish the three kinds from each other. The crocodile tribe, and its affinities, are sufficiently distinguished from all the rest by their size and fierceness; the salumander tribe is distinguished by their deformity, their frog-like heads, the shortness of their snouts, their swollen bellies, and their viviparous production. With regard to the rest, which we may denominate the chameleon or lizard kind, some of which bring forth from the egg, and some of which are imperfectly formed from spawn, we must group them under one head, and leave time to unravel the rest of their history.

sive to mankind. Those that are bred in waters underga a inetamorphosis, and pass through a tadpole state. 


\section{CHAP'TER CLXI.}

\section{OF THE CROCODILE, AND ITS AFFINITIES.}

THE Crocodile is an animal placed at a happy distance from the inhabitants of Europe, and formidable only in those regions where men are scarce, and arts are but little known. In all the cultivated and populous parts of the world, the great animals are entirely banished, or rarely seen. The appearance of such raises at once a whole country up in arms to oppose their force; and their lives generally pay the forfeit of their temerity. The crocodile, therefore, that was once so terrible along the banks of the river Nile, is now neither so large, nor its numbers so great, as formerly. The arts of mankind have, through a course of ages, powerfully operated to its destruction; and, though it is sometimes seen, it appears comparatively timorous and feeble.

To look for this anımal iı all its natural terrors, grown to all enormous size, propagated in surprising numbers, and committing unceasing devastations, we must go to the uninhahited regions of Africa and America, to those immense rivers that roll through extensive and desolate kingdoms, where arts have nerer penetrated, where force only makes distinction, and the most powerfil animals exert their strength with confidence and security, Those that sail up the river Amazons, or the river Niger, well know how numerous and terrible those animals are in such parts of the world. In both these rivers, they are found from eighteen to twenty +seven feet long; and sometimes lying as close to each other as rafts of timber upon one of our streams. There they indolently bask on the surface, no way disturbed at the approach of an enemy, since, from the repeated trials of their strength. they found none that they were not able to subdue.

Of this terrible animal there are two kinds; the Crocodile, properly so called, and the Cayman or Alligator Travellers, however, have rather made the distiuctions than nature; for in the general outline, and in the nature of these "wo animals, they are entirely the same.
It would be speaking more properly to call these animals the Crocodiles of the eastern and the western world; for in books of voyages, they are so entirely confounded together, that there is no knowing whether the Asiatic animal be the crocodile of Asia, or the alligator of the western world. The distinctions usually made between the crocodile and alligator are these: the body of the crocodile is more slender than that of the alligator; its snout runs off tapering from the forehead, like that of a greyhound; while that of the other is indented. like the nose of a lap-dog. The crocodile has a much wider swallow, and is of an ash-colour; the alligator is black, varied with white, and is thought not to be so mischievous. All these distinctions, however, are very slight; and can be reckoned little more than minute variations. ${ }^{2}$

This animal grows to a great length, being sometimes found thirty feet long, from the tip of the snout to the end of the tail: its most usual length, however: is eighteen. One which was dissected by the Jesuits at Siam, was of the latter dimeusions; and as the description which is given of it, both externally and internally, is the most accurate known of this noted animal, I must beg leave to give it as I find it, thongh somewhat tedious. It was eighteen feet and a half, French measure, in length; of which the tail was no less than five feet and a balf, and the head and neck above two feet and a half. It was four feet nine inches in circumference, where thickest. The fore legs had the same parts and conformation as the arms of a man, both within and without. The hands, if they may be so called, had five fingers; the two last of which had no nails, and were of a conical figure. The hinder legs, including the thigh and paw, were

a The Crocodile has a scaly mail round its neck: but the neck of the Altigator is naked : the tail of the Croco dile is likewise furnished with two lateral crested prucesses 
two fect two inches long; the paws, from the joint to the extremity of the longest claws, were above nine inches: they were divided into four toes, of which three were armed with large claws, the longest of which was an inch and a half; these toes were united by a membrane, like those of a duck, but much thicker. The head was long, and had a little rising at the top; but the rest was flat, and especially towards the extremity of the jaws. It was covered by a skin, which adliered firmly to the skull and to the jaws. The skull was rough and unequal in several places: and about the middle of the forehead there were two bony crests, about two inches high: the skull between these two crests was proof against a nusket-ball; for it oniy rendereci the part a little white that it struck against. The eye was very small, in propertion to the rest of the body, and was so placed within its orbit, that the outward part, when the lid was closed, was only an inch long, and the line running parallel to the opeuing of the jaws. It was covered with a donble lid, one within and one without: that within, like the nictitating membrane in birds, was folded in the great corner of the eye, and had a motion towards the tail, but being transparent, it coverel the eye without hindering the sight. The iris was very large in proportion to the globe of the cye, and was of a yellowish gray colour. Above the eye the ear was placed, which opened from above downwards, as if it were by a kind of spring, by means of a solid, thick, cartilaginous substance. The nose was placed in the middle of the upper jaw, near an inch from its cxtremity, and was perfectly round and flat, being near tivo inches in diameter, of a black, soft, spongy substance, not unlike the nose of a dog. The jaws seemed to shut one within another; and nothing can be nore false than that the animal's under jaw is without motion; it moves like the lower jaw in all other animals, while the upper is fixed to the skull, and absolutely immoveable. 'The animal had twenty-seven cutting teeth in the upper jaw, and fifteen in the lower, with several void spaces between them: they were thick at the buttom, and sharp at the point, being all of different sizes, except ten large booked ones, six of which were in the lower jaw, and four in the upper. The mouth was fifteen inches in length, and eight and a half in breadth, where broadest. The distance of the two jaws, when opened as wide as they could be, was fifteen inches and a half; this is a very wide yawn, and could easily enough take in the body of a man. The colour of the body was of a dark brown on the upper part, and of a whitish citron below, with large spots of both colours on the sides. From the shoulders to the extremity of the tail, the animal was covered with large scales, of a square form, disposed like parallel girdles, and fiftytwo in number; but those near the tail were not so thick as the rest. The creature was covered not only with these, but all over with a coat of armour; which, however, was not proof against a musket-ball, contrary to what has been conmmonly asserted: lrowever, it must be cunfessed, that the attitude in which the animal was placed, might contribure to render the skin more penetrable; for, probably, if the ball hail struck obliquely against the shell, it would have flown off. Those parts of the girdles underneath the belly were of a whitish colour, and were made up of seales of divers shapes, but not so hard as those on the back.

With respect to the internal parts of the animal, the gullet was large in proportion to the month; and a ball of wood as large as one's head, readily ran down, and was drawn up again. The guts were but short, in comparison, being not so long as the animal's body. The tongue, which some have erroneously asserted this animal was without, consisted of a thick spongy soft flesh, and was strongly connected to the lower jaw. The heart was of the size of a calf's, of a bright red colour, the blood passing as well from the veins to the aorta as intu the lungs. There was no bladder; but the kidneys sent the urine to be discharged by the anus. There were sixty-two joints in the back-bous, which, though very closely united, had sufficient play to enable the animal to bend like a bow to the right and the lefr; so that what we hear of escaping the creature by turning out of the right line, and of the animal not being able to wheel readily after its prey, seems to be fabuluus. It is most likely the crocodile can turn with ease, for the juints of its back are not stiffer than those of other animals, which we know, by experience, can wheel about very nimbly for their size.

Such is lhe figure and conformation of this 
formidable animal, that unpeoples countries, and makes the most navigable rivers desert and dangerous. They are seen, in some places, lying for whole lours, and even days, stretched in the sun, and notionless; so thit one not used to thein might mistake them for trunks of trees, covered with a rough and dry bark; but the mistake would soon be fatal, if not prevented: for the to:pirl nuimal, at the near approach of any living thing, darts upon it with instant swifuess, and at once drags it down to the bottom. In the times of an inundation, they sometimes enter the coltages of the natives, where the dreadful visitant seizes the first aninal it meets with. There have been several examples of their taking a man out of a canoe in the sight of his companions, without their being able to lend him any assistance.

The strength of every part of the crocodile is very great; and its a:ms, both offensive and defensive, irresistible. We have seen, from the shortness of its legs, the amazing strength of the tortoise: but what is the strength of such an animal, compared to that of the crocodile, whose legs are very short, and whose size is so superior! The back-bone is jointed in the firınest manner; the muscles of the fore and hinder legs are vigorous and strong; and its whole form calculated for force. Iis tecth are sharp, numerous, and forinidable; its claws are long and tenaceous; but its principal instrument of destruction is the tail: with a single blow of this it has often overturned a canoe, and scized upon the poor savage its conductor.

Though not so powerful, yet it is very terrible even upon laud. The crocodile seldom, except when pressed by hunger, or with a view of depositing its eggs, lcaves the water. Its usual method is to float along upon the surface, and seize whatever animals come within its reach; but when this method fails, it then goes closer to the bank. Disappointed of its fishy prey, it there waits covered up amung the sedges, in patient expectation of some land animal that comes to drink; the dog, the bull, the tiger, or inan himself. Nothing is to be seen of the insidions destroyer as the animal approaches; nor is its retreat discovered, till it be too late fur safety. It seizes the vietim with a spring, and goes at a bound much farther than so unwieldy an ani- mal could be thought capable of exerting, then having secured the creature with both teeth and claws, it drags it into the water, instantly sinks with it to the bottom, and, in this manner, quickly drowns it.

Sometimes it happens that the creature the crocodile has thus surprised escapes firom its grasp wounded, and makes off from the river sidle. In such a case the tyrant pursurs "ilh all its force, and often seizes it a second line; for, though seemingly heavy, the croconlic runs with great celerity. In ihis manner it is sometimes seen above half a nile from the bank, in pursuit of an animal wounded beyond the power of escaping, and then diagging it back to the river-side, where it feasts in security.

It often happens, in its depredations along the bank, that the crocorlile seizes on a creature as formidable as itself, and meets with a most desperate resistance. We are told of frequent combats between the crocodile and the tiger. All creatures of the tiger kind are continually oppressed by a parching thirst, that keeps them in the vicinity of great rivers, whither they descend to drink very frequently. It is upon these occasions that they are seizid by the crocodile; and they die not unrevenged. The instant they are scized upon, they turn with the greatest agility, and force their claws into the crocodile's eyes, while he plungrs with his fierce antagonist into the river. There they continue to struggle for some time, till at last the tiger is drowned.

In this manner the crocodile seizcs and destroys all animals, and is equally dreaded by all. There is no aninnal but man alone that can combat it with success. We are assured by Labat, that a Negro, with no other weapons than a knife in his right hand, and his left arm wrapped round with a cow-hide, ventures boldly to attack this animal in its own element. As soon as he approaches the crocodile, he presents his left arm, which the animal swallows most greedily; but sticking in its throat, the Negro has time to give it several stabs under the throat; and the water also getting in at the mouth, which is held involuntarily open, the creature is soon bloated up as big as a tun, and expires.

To us who live at a distance from the rapacity of these animals, these stories appear strange, and yet most probably are 
true. From not having scen any thing so formidable or bold in the circle of our own exflerience, we are not to determine upon the wonderful transactions in distant climates. It is probable that these, and a number of more dreadful cncounters, happen every day anıong those forests and in those rivers where the most formidable animals are known to reside; where the elephant and rhinoceros, the tiger and the lippopotamus, the shark and the crocodile, have frequent opportunities of meeting, and every day of renewing their engagements.

Whatever be the truth of these accounts, certain it is that crocodiles are taken by the Siamese in great abundancc. The natives of that cmpire seem particularly fond of the capture of all the great animals with which their country abounds. We liave already seen their success in taking and taning the elephant; nor are they less powverful in exerting their dominion over the crocodilc. The manuer of taking it in Siam, is by throwing three or four strong nets across a river, at proper distances from each other; so that if the animal breaks through the first, it may be caught by one of the rest. When it is first taken, it employs the tail, which is the grand instrument of strengrh, with great force; but after inany unsuccessful struggles, the animal's strength is at last exhausted. Then the natives approach their prisuner in boats, and pierce him with their weapons in the most tender parts, till he is weakencd with the loss of blood. When he las done stirring, they begiu by tying up his mouth, and with the same cord they fasten his head to his tail, which last they bend back like a bow. However, they are not yet perfectly sccure from his fury; but, for their greater safety, they tie his fore-fcet, as well as those behind, to the top of his back. These precautions are not useless: for if they were to onit them, the crocodile would soon recover strength enough to do a great deal of mischief.

The crorodile, thus brought into subjection, or hred up young, is used to divert and entertain the great men of the East. It is often maulaged likc a horse; a curb is put into its month, and the rider directs it as he thinks proper. Though awkwardly formed, it does not fail to proceed with some degree of swiftlless; and is thought to move as fast as some of the most unwieldy of our own animals, the hog or the cow. Some, indeed, assert, that no animal could escape it, but for its lifficuliy in uming; but to this resource we could wish none would trust who are so unhappy as to find themselves in danger.

Along the river's of Africa this animal is sometimes taken in the same manner as the sliark. Scveral European's go together in a large boat, and throw out a piece of beef upon a hook and strong fortified liue, which the crocodile seizing and swallowing, is drawn along, floundering and struggling until its strength is quite exhausted, when it is pierced in the belly, which is its tenderest part; and thus, after numberless wounds, is drawu ashore. In this part of the world also, as well as at Sian, the clccodilc nuakes an object of savage pomp near the palaces of their monarchs. Philips informs ns, that at Sahi, on the slave coast, there are two pools of ivater, neal the royal palace, where crococliles are bred, as we breed carp in our ponds in Europe.

Hitherto I have been describing the crocodile as it is found in unpeopled comutries, and undisturbed by frequent encounters with mankind. In this state it is ficrce and cruel, attacking every object that scens endued with notion: but in Egypt, and other countries long peopled, where the inliabitants are civilized, and the rivers frequented, this ani$\mathrm{mal}$ is solitary and fearful. So far from coming to attack a man, it sinks at his npproach with the utmost precipitation; and, as if scnsible of superior power, ever declines the engagement. We have scen more than one instance in animated nature of the contenupt which at first the lower orders of the creation have for man, till they have expericuced his powers of destruction. The lion and the tiger among beasts, the whale among fishes, the albatross and the penguin among birds, nincet the first encounters of man without dread or apprehension : but they soon learn to ackliowledge his superiority, and take rofige from his powel in the deepest fastnesses of nature. This may account for the diffrent characters which have been given us of the crocodile and the alligator, by travellers at different timies; some describing them as barmless and fearful, as ever avoiding the sight of man, and preying: only upon fishes: others ranking them among the destroyers of nature; describing 
them as furnished with strength, and impelled by malignity, to do mischief; representing them as the greatest enemies of mankind, and particularly desirous of human prey. The truth is, the animal has been justly described by both; being such as it is tound in places differently peopled or differently civilized. Wherever the crocodile has reigned long unmolested, it is there fierce, bold, and dangerous; wherever it has been harassed by mankind, its retreats invaded, and its numbers destroyed, it is there timorous and inoffensive.

In some places, therefore, this animal, instead of being formidable, is not only inoffensive, but is cherished and admired. In the river San Domingo, the crocodiles are the most inoffensive animals in nature; the children play with them, and ride about on their backs; they even beat them sometimes, without receiving the smallest injury. It is true the inhabitants are very careful of this gentle breed, and consider them as harmless domestics.

It is probable that the smell of musk, which all these animals exhale, may render them agreeable to the savages of that part of Africa. They are often known to take the part of this animal which contains the musk, and wear it as a perfume about their persons. Travellers are not agreed in what part of the body these musk-bags are contained; some say in the ears; some, in the parts of generation; but the most probable opinion is, that this musky substance is amassed in the glands under the legs and arms. Froin whatsoever part of the body this odour proceeds, it is very strong and powerful, tincturing the flesh of the whole body with its taste and smell. The crocodile's flesh is at best very bad, tough eating; but unless the musk-bags be separated, it is insupportable. The Negroes themselves cannot well digest the flesh; but then, a crocodile's egg is to them the most delicate morsel in the world. Even savages exhibit their epicures as well as we; and one of true taste will spare neither pains nor danger to furnish himself with his favourite repast. For this reason, he often watches the places where the female comes to lay her eggs, and upon her retiring, seizes the booty.

All crocodiles breed near fresh waters; and though they are sometimes found in the sea, พо. $61 \& 62$. yet that may be considered rather as a place of excursion than abode. They produce their young by eggs, as was said above; and for this purpose the female, when she comes to lay, chooses a place by the side of a river, or some fresh-water lake, to deposite her brood in. She always pitches upon an extensire sandy shore, where slie may dig a bole without danger of detection from the ground being fresh turned up. The shore must also be gentle and shelving to the water, for the greater convenience of the animal's going and returning; and a convenient place must be found near the edge of the stream, that the young may have a shorter way to go. When all these requisites are adjusted, the animal is seen cautiously stealing upon shore to deposite her burden. The presence of a man, a beast, or even a bird, is sufficient to deter her at that time; and if she perceives any creature looking on, she infallibly returns. If, however, nothing appears, she then goes to work, scratching up the sand with her fore-paws, and making a hole pretty deep in the shore. There she deposites from eighty to a hundred eggs, of the size of a tennis-ball, and of the same figure, covered with a tough white skin like parchment. She takes above an hour to perform this task; and then covering up the place so artfully that it can scarcely be perceived, she goes back to return again the next day. Upon her return, with the same precaution as before, she lays about the same number of eggs; and the day following also a like number. Thus having deposited her whole quantity, and having corered them close up in the sand, they are soon vivified by the heat of the sun; and at the end of thirty days, the young ones begin to break open the shell. At this time the female is instinctively taught that her young ones want relief; and she goes upon land to scratch away the sand, and set them free. Her brood quickly avail themselves of their liberty; a part run unguided to the water; another part ascend the back of the female, and are carried thither in greater safety. But the moment they arrive at the water, all natural connexion is at an end: when the female has introduced her young to their natural element, not only she, but the male, become among the number of their most formidable enemies, and de$5 \mathrm{H}$ 
vour as many of them as they can. The whole brood seatters into different parts of the bottom; by far the greatest number are destroyed, and the rest find safety in their agility or minuteness.

But it is not the crocudile alone that is thus found to thin their numbers; the eggs of this animal are not only a delicious feast to the savage, but are eagerly songht after by every beast and bird of prey. 'The ichneumon was erected into a deity among the ancients for its success in destroying the eggs of these monsters: at present that species of the vulure called the Gallinazo is their most prevailing enemy, All along the banks of great rivers, for thousands of miles, the crocodile is seen to propragate in numbers that would soon overrun the earth, but for the vulture, that seems appointed by Providence to abridge its fecundity. These birds are ever found in greatest numbers where the crocodile is nost numerous: and, liding themselves within the thick, branches of the trees that shade the banks of the river, they watch the female in silence, and permit her to lay all her eggs ivithout interruption. Then when she has retired, they encourage each other with cries to the spoil; and flocking all together upon the bidden treasure, tear up the eggs, and devour them in a much quicker time than they wcre deposited. Nor are they less diligent in attending the female while she is carrying her young to the water; for if any one of them happens to drop by the way, it is sure to receive no mercy.

Such is the extraordinary account given us hy late travellers of the propagation of this animal; an account adopted by Linuæus and the most learned naturalists of the age." Yet,

a Uloa. b What the author means here by the openbellied crocodile, we are at a loss to make out: but it is certain that not one of the lizard tribe have any thing like an if one might argue from the general analogy of nature, the crocodile's devouring lier own young when she gets to the water seerus doubtful. This may be a story raised from the general idea of this animal's rapacious cruelty; when, in fact, the crocodile only seems more cruel than other animals, because it has nore power to do mischief. It is probable that it is not more divested of parental tenderness than other creatures, and I am the more led to think so from the peculiar formation of one of the crocodile kind. This is called the OpenBellied Crocodile, and is furnished with a false belly like the oppossum, where the young creep out and in, as their dangers or necessities require. The crocodile thus furnished at least cannot be said to be an enemy to her own young, since she thus gives them more than parental protection. It is probable, also, that this open-bellied crocodile is viviparous, and fosters her young that are prematurely excluded in this second womb, until they come to proper maturity. ${ }^{b}$

How long the crocodile lives we are not certainly informed: if we may believe Aristotle, it lives the age of a man; but the ancients so much amused themselves in inventing fables concerning this animal, tliat even truth from them is suspicious. What we know for certain from the ancients is, that among the various animals that were produced to fight in the amphitheatre at Rome, the combat of the crocodile was not wanting. Marcus Scaurus produced them living in his unrivalled exhibitions; and the Romąns considered him as the best citizen, because he furnished them with the most expensive entertainments. But entertainment at that corrupt time was their only occupation.

abdominal pouch for the safety of their young. - Plin. lib. viii. c. 26 . 


\section{CHAP'TER CLXII.}

\section{OF THE SALAMANDER.}

THE ancients have described a lizard that is bred from heat, that lives in the flames, and feeds upon fire as its proper nourishment. As they saw every other element, the air, the earth, and water, inhabited, fancy was set to work to find or make an inhabitant in fire; and thus to people every part of nature. It will be needless to say that there is no such animal existing; and that of all others, the modern salamander has the smallest affinity to such an abode.

Whether the animal that now goes by the name of the Salamander be the same with that described by Pliny, is a doubt with me; but this is not a place for the discussion. It is sufficient to observe, that the modern salamander is an animal of the lizard kind, and under this name is comprehended a large tribe that all go by the same name. There have been not less than seven sorts of this animal described by Seba; and to have some idea of the peculiarity of their figure, if we suppose the tail of a lizard applied to the body of a frog, we shall not be far from precision. The common lizard is long, small, and taper; the salamander, like the frog, has its eyes towards the back of the head; like the frog, its snout is round, and not pointed, and its belly thick and swollen. The claws of its toes are short and feeble; its skin rough; and the tongue, unlike that of the smallest of the lizard kind, in which it is long and forked, is short, and adhering to the under jaw.

But it is not in figure than this animal chiefly differs. from the rest of the lizard tribe; for it seems to differ in nature and conformation. In nature it is unlike, being a heavy torpid animal; whereas the lizard tribe are active, restless, and ever in motion : in conformation it is unlike, as the salainander is produced alive from the body of its parent, and is completely formed the moment of its exclusion. It differs from them also in its general reputation of being venomous : however, no trials that have been hitherto made seem to confirm the truth of the report.

Not only this, but many others of the lizard tribe, are said to have venom; but it were to be wished that mankind, for their own happiness, would examine into the foundation of this reproach. By that means many of them, that are now shunned and detested, might be found inoffensive; thcir figure, instead of exciting either horror or disgust, would then only tend to animate the general scene of nature; and speculation might examine their manners in confidence and security. Certair it is, that all of the lizard kind, with which we are acquainted in this country, are perfectly harmless; and it is equally true that, for a long time, till our prejudices were removed, we considered not only the Newt, but the Snake and the Blind-worm, as fraught with the most destructive poison. At present we have got over these prejudices; and, it is probable, that if other nations made the same efforts for information, it would be found, that the malignity of most, if not all, of the lizard tribe, was only in the imagination.

With respect to the Salamander, the whole tribe, from the Moron to the Gekko, are said to be venomous to the last degree; yet, when experiments have been tried, no arts, no prorocations, could excite these animals to the rage of biting. They seem timid and inoffensive, only living upon worms and insects; quite destitute of fangs, like the viper, their teeth are so very small that they are hardly able to inflict a wound. But as the teeth are thus incapable of offending, the people of the countries where they are found have recourse to a vellomous slaver, which, they suppose, issues from the animal's mouth; they also tell us of a venom issuing from the claws: even Linnæus seems to acknowledge the fact; but thinks it a probable supposition that this venom may proceed from their urine. 
Of all rnimals, the Gekko is the most notorious for its powers of Inischief; yet we are told by those who load it with that calunny, that it is very friendly to man, and though supplied with the most deadly virulence, is yet never known to bite. It would be absurd in us, withont experience, to pronounce upon the noxious or inoffensive qualities of animals: yet it is most probable, from an inspection of the teeth of lizards, and from their inoffensive qualities in Europe, that the gekko bas been unjustly accused; and that its serpent-like figure has iurolved it in one common reproach with serpents.

The salamander best known in Europe, is from eight to eleven inches long, usually black, spotted with yellow; and, when taken in the hand, feeling cold to a great degree. 'There are several kinds. Our Black WaterNewt is reckoned among the number. The idle report of its being inconsumable in fire, has caused many of these poor animals to be burnt; but we cannot say as philosophical martyrs, since scarcely any philosopher could think it necessary to make the experiment. When thrown into the fire the animal is seen to burst with the heat of its situation, and to cject its fluids. We are gravely told, in the Philosophical Transactions, that this is a method the animal takes to extinguish the flames!

When examined internally, the salamander exhibits little difference from other animals of the lizard kind. It is furnished with lungs that sometimes serve for the offices of breathjng; with a heart that has its communications open, so that the animal cannot casily be drowned. 'The ovary in the female is double the size of what it is in others. of this tribe; and the male is furnished with four testiculi instead of two. But what deserves particular notice is the manner of this animal's bringin forth its young alive." "The salamander," says my author, "begius to show itself in spring, and chiefly during heavy rains. When the warm weather returns, it disappears; and never leaves its hole, during either great heats or severe colds, both which it equally fears. When taken in the hand, it appears

Acta Hafniénsia, ann. 1676, Observ. 11. Memoires de l'Acadęmie Royale des Sciences, tom, iii. part 3. p. 80. like a lump of ice; it consequently loves the shade, and is lound at the leet of old trees surrounded with brushwood at the bottom. It is fond of running along new ploughed grounds; probably to seek for worms, which are its ordinary food. One of these," continues iny author, "I took alive some years ago in a ditch that had been lately made. I laid it at the foot of the stairs upon coming home, and there it disgorged from the throat a worm three inches long, that lived for an hour after, though wounded as 1 suppose by the teeth of the animal. I afterwards cut up another of these lizards, and saw not less than fifty young ones, resembling the parent, come from its womb, all alive, and actively running about the room." It were to be wished the author had used another word beside that of worm; as we now are in doubt whether he means a real worm, or a young animal of the lizard species: had he been more explicit, and had it appeared that it was a real young lizard, which I take to be his meaning, we might here see a wonder of nature brought to the proof, which many have asserted, and many have thought proper to deny: I mean the refuge which the young of the shark, the lizard, and the viper kinds, are said to take, by running down the throat of the parent, and there finding a temporary security. The fact, indeed, seems a little extraordinary; and yet it is so frequently attested by some, and even believed by others, whose authority is respectable, among the number of whom we find Mr. Pennant, that the argument of strangeness must give way to the weight of authority.

However this be, there is no doubt of the animal's being viviparous, and producing above fifty at a time. They come from the parent in full perfection, and quickly leave her to shift for themselves. These animals, in the lower ranks of nature, want scarcely any help when excluded; they soon complete the little circle of their education; and in a day or two are capable of practising all the arts of subsistence and evasion practised by their kind.

They are all amphibious, or at least are found capable of subsisting in either element, when placed there: if those taken from land are put into water, they continue there in 
seeming health; and, on the contrary, those takeu from the water will live upon land. In water, however, they exhibit a greater variety in their appearance; and what is equilly wonderful with the rest of their history, during the whole spring and summer this waterlizard changes its skin every fourth or fifth day; and during the winter every fifteen days. This operation they perform by means of the mouth and the claws; and it seems a work of no small difficulty and pain. The cast skins are frequently seen floating on the surface of the water: they are sometimes seen also with a part of their old skiı still sticking to one of their limbs, which they have not been able to get rid of; and thus, like a man with a boot half drawn, in some measure crippled in their awn spoils. This also often corrupts, and the leg drops off; but the animal does not seem to feel the want of it, for the loss of a limb to all the lizard kind is but a trifling calamity. They can live several hours even after the loss of their head: and for some time under dissection, all the parts of this animal seem to retain life: but the tail is the part that longest retains its motion. Salt seems to be much more efficacious in destroying these animals than the knife; for upon being sprinkled with it, the whole body enits a viscous liquor, and the lizard dies in three minutes, in great agonies.

The whole of the lizard kind are also - tenacious of life in another respect, and the salamander among the number. They sustain the want of food in a surprising manner. One of them, brought from the Indies, lived nine months, without any other food than what it received from lieking a piece of earth on which it was brought over: $:^{n}$ another was kept by Seba in an enpty vial for six months, without any nourishment; and Rhedi talks of a large one, brought from $A$ frien, that lived for cight months, without taking any nourishment whatever. Indeed, as many of this kind, both salamanders and lizards, are torpid, or nearly so, during the winter, the loss of their appetite for solong a time is the less surprising.

\section{CHAPTER CLXIII.}

\section{OF THE CHAMELEON, THE IGUANA, AND LIZARDS OF DIFFERENT KINDS.}

IT were to be wished that animals could be so classed, that by the very mentioning their rank, we slrould receive some insight into their history. This I have endeavoured in most instances; but in the present ehapter all method is totally unserviceable. Here distribution gives no general ideas: for some of the animals to be here mentioned produce by eggs; some by spawn; and some are viviparous. The peculiar manner of propagating in each, is very indistinctly known. The Iguana and the Chameleon, we know bring forth eggs; some others also produce in the same manner; but of the rest, which naturalists make amount to above fifty, we have but very indistinet information.

In the former divisions of this tribe, we had to observe upon animals, formidable from their size, or disgusting from their frog-like head and appearance; in the present division, all the animals are either beautiful to the eye, or grateful to the appetite. The lizards, properly so called, are beautifully painted and mottled; their frolicksome agility is amusing to those who are familiar with their appearance; and the great affection which some of them show to man, should, in some measure, be repaid witli kindness. Others, suel as the Iguana, though not possessed of beauty, are very serviceable, furnishing one of the most luxurious feasts the tropical elimates ean boast of. Those treated of before were objects of euriosity, because they were apparently objects of dan-

2. Phil. Trans ann. 1661. N. 21, art. 7. 
ger: most of these here mentioned have either use or beauty to engage us.

Directly descending from the crocodile, we find the Cordyle, the Tockay, and the Tejuguacu, all growing less in order, as I have named them. These fill up the chasm to be found between the crocodile and the African Iguana.

The Iguana, which deserves our notice, is about five feet long, and the body about as thick as one's thigh : the skin is covered with small seales, like those of a serpent; and the back is furnished with a row of prickles, that stand up, like the teeth of a saw : the eyes seem to be but half opened, except when the animal is angry, and then they appear large and sparkling: both the jaws are full of very sharp teetl, and the bite is dangerous, though not venomous, for it never lets loose till it is killed. The male has a skin hanging under his throat, which reaches down to his breast; and, when displeased, he puff's it up like a biadder: he is one-third larger and stronger than the female; though the strength of either avails them little towards their defence. The males are ash-coloured, and the females are green.

The flesh of these may be considered as tne greatest delicacy of Africa and America; and the sportsmen of those climates go out to hunt the iguana, as we do in pursuit of the pheasant or the hare. In the beginning of the season, when the great floods of the tropical climates are past away, and vegetation starts into universal verdure, the sportsmen are seen, with a noose and a stick, wandering along the sides of the rivers to take the iguana. The animal, though apparently formed for combat, is the most harmless creature of all the forest: it lives among the trees, or sports in the water, without ever offering to offend; there, having fed upon the flowers of the mahot, and the leaves of the mapou, that grow along the banks of the stream, it goes to repose upon the branches of the trees that hang over the water. Upon the land the animal is swift of foot; but when once in possession of a tree, it seems conscious of the security of its situation, and never offers to stir. There the sportsman easily finds it, and as easily fastens his noose round its neck: if the liead be placed in sucb a man- ner that the noose cannot readily be fastened, by hitting the animal a blow on the nose with the stick, it lifts the head, and offers it in some measure to the noose. In this manner, and also by the tail, the iguana is dragged from the trees, and killed by repeated blows on the head.

The Chameleon is a very different animal; and as the iguana satisfies the appetites of the epicure, this is rather the feast of the philosopher. Like the crocodile, this littie animal proceeds from an egg; and it also nearly resembles that formidable creature in form: but it differs widely in its size and its appetites; being not above eleven inches long, and delighting to sit upon trees, being afraid of scrpents, from which it is unable to escape on the ground.

The head of a large chameleon is almost two inches long; and from thence to the beginning of the tail, four and a half: the tail is five inches long, and the feet two and a half: the thickness of the body. is different at different times; for sometimes, from the back to the belly, it is two inches, and sometimes but one; for it can blow itself up, and contract itself at pleasure. The swelling and contraction is not only of the back and belly, but of the legs and tail.

These different tumours do not proceed from a dilatation of the breast in breathing, which rises and falls by turus; but are very irregular, and seem adopted merely from caprice. The chameleon is often seen, as it were, blown up for two hours together; and then it continues growing less and less insensibly; for the dilatation is always more quick and visible than the contraction. In this last state the animal appears extremely lean; the spine of the back seems sharp, and all the ribs may be counted; likewise the tendons of the legs and arms may be seen very dis: tinctly.

This method of puffing itself up, is similar to that in pigeons, wliose crops are sometimes greatly distended with air. The chameleon has a power of driving the air it breaths over cvery part of the body : however, it only gets between the skin and the muscles; for the muscles themselves are never swollen. The skin is very cold to the touch; and though the animal seems so lean, 
there is no feeling the beating of the heart. The surface of the skin is unequal, and has a grain not unlike shagreen, but very soft, because each eminence is as smooth as if it were polished. Some of these little protuberances are as large as a pin's hend, on the arms, legs, belly, and tail; but on the shoulders and head they are of an oval figure, and a little larger: those under the throat are ranged in the form of a chaplet, from the lower lip to the breast. The colour of all these eminences, when the chameleon is at rest in a shady place, is of a bluish gray, and the space between is of a pale red and ycllow.

But when the animal is removed into the sun, then comes the wonderful part of its his: tory. At first it appears to suffer no change of colour, its grayish spots still continuing the same: but the whole surface soon seems to imbibe the rays of light; and the simple colouring of the body clianges iuto a variety of beautiful hues. Wherever the light comes upon the bady, it is of a tawny brown; but that part of the skin on which the sun does not shine, changes into several brighter colours, pale yellow, or vivid crimson; which forms spots of the size of half one's finger: some of these descend from the spine half way down the back; and others appear on the sides, arms, and tail. When the sun has done shining, the original gray colour returns by degrees, and covers all the body. Sometimes the animal becomes all over spotted with brown spots, of a greenish cast. When it is wrapt up in a white linen cloth for two or three minutes, the natural colour becomes much lighter; but not quite white, as some authors have pretended: however, from hence it must not be concluded that the chameleon assumes the colour of the objects which it approaches; this is entirely an error, and probably has taken its rise from the continual changes it appears to undergo.

Le Bruyn, in his Voyage to the Levant, has given us a very ample description of the chameleon. During his stay at Smyrna, he bought severul of this kind; and to try how long they could live. kept four of them in a cage, permitting them at times to run about the house. The fresh sea-breeze seemed to give them most spirits and vivacity; they opened their mouths to take it in; lue never perceived that they eat any thing, except now and then a fly, which they took half an hour to swallow: he observed their colour of ten to change, three or four times successively, without being able to find out any cause for such alterations; their common colour he found to be gray, or" rather a pale mouse colour; but its most frequent changes were into a beautiful green, spotted with yellow; sometimes the animal was marked all over with dark brown; and this often changed into a lighter brown: some colours, however, it never assumed; and, contrary to what was said above, be found red to be among the number.

'Though our traveller took the utmost care, he was unable to preserve any of them alive above five months; and many of them died in four. When the chameleon changes place, and attempts to descend from an eminence, it moves with the utmost precantion, advancing one leg very deliberately before the other, still securing itself by holding whatever it can grasp by the tail. It seldom opens its mouth, except for fresh air; and when that is supplied, discovers its satisfaction by its motions, and the frequent changes of its colour. The tongue is sometines dirted out after its prey, which is flies: and this is as long as the whole body. The cyes are remarkably little, though they stand out of the head: they hare a single cye-lid; like a cap with a hole in the middle, through which the sight of the eye appears, which is of a shining brown; and round it there is a little circle of a gold colour: but the most extraordinary part of their conformation is, that the animal often moves one eye, when the other is entirely at rest; nay, sometimes one eye will seem to look directly forward, while the other:looks backward; and one will look upward, while the other regards the earth,

To this class of lizards, we may refer the Dragon, a most terrible animal, but most probably not of nature's formation. Of this deatlsdealing creature all people have read; and the most barbarous countries, to this day, paint it to the imagination in all its terrors, and fear to meet it in every forest. It is not enough that nature has furnished those countries with poisons of various malignity; with serpents forty feet long; with clephants, lions, and tigers; to make their situation really danger- 
ous, the capricious imagination is set at work to call up new terrors; and scarce a savage is found that does not talk of winged scrpents of immoderate length, flying away with the camel or the rhiuoceros, or destroying mankind by a single glare. Happily, however, such ravages are no where found to exist at present; and the whole race of dragons is dwindled down to the Flying Lizard, a little haimless creature, that only preys upon insects, and even seems to embellish the forest with its beauty.

The Flying Lizard of Java perches upon fruit-trees, and feeds upon flies, ants, butterflies, and other small insects. It is a very harmless creature, and does no mischief in any respect. Gentil, in his Voyage round the World, affirms, that he has seen these lizards at the Island of Java, in the East Indies. He observed they flew very swifly from tree to tree; and having killed one, he could not but admire the skin, which was painted with scveral beautiful colours: it was a foot in length, and had four paws, like the common lizards; but its head'was flat, and had a small hole in the middle; the wings were very thin, and resembled those of a flying-fish. Ahout the neck were a sort of wattles, not unlike those of cocks, which gave it no disagreeable appearance. He intended to have preserved it, in order to bring it into Europe; but it was corrupted by the heat, before the close of the day: however, they have since been brought into England, and are now

[Besides these, it may be necessary to mention one more, the Basilisk, so dreadful to the imagination of our ancestors. It is, however, an inoffensive animal, a native of South America. It is distinguished by a long, conic, cap-like protuberance on the head, and a kind of fin like common enough in the cabinets of the curious.

The last animal of the lizard kind that I shall mention, is the Chalcidian Lizard of Aldrovandus, very improperly called the Seps by modern historians. This animal seems to make the shade that separates the lizard firom the serpent race. It has four legs, like the lizard; but so short, as to be utterly unscrviceable in walking: it has a long slendet body, like the serpent; and it is said to have the serpent's malignity also. The fore legs are very near the head; the hind legs are placed far backward; but before and belind they seem rather useless incumbrances, than instruments serving to assist the animal in its motions, or in providing for its subsistence. These animals are found above three feet long, and thick in proportion, with a large head and pointed snout. The whole body is covered with scales; and the belly is white mixed with blue. It has four crooked teeth, as also a pointed tail, which, however, can iuflict no wound. Whether the teeth be similar to the viper's fangs, we are not told; though Volateranus says, they are covered with a menubrane; by which 1 am apt to think he means a venom-bag, which is found at the root of the teeth of all serpents that are poisonous. It is viviparous; fifteen young ones having been taken alive out of its belly. Upon the whole, it appears to bear a strong affinity to the viper; and, like that animal, its bite may be dangerous.

a fish along the back, which it can elevate or depress at pleasure; and is about a foot and a half in length, of great agility, and is said to be able occasionally to swim with perfect ease.] 


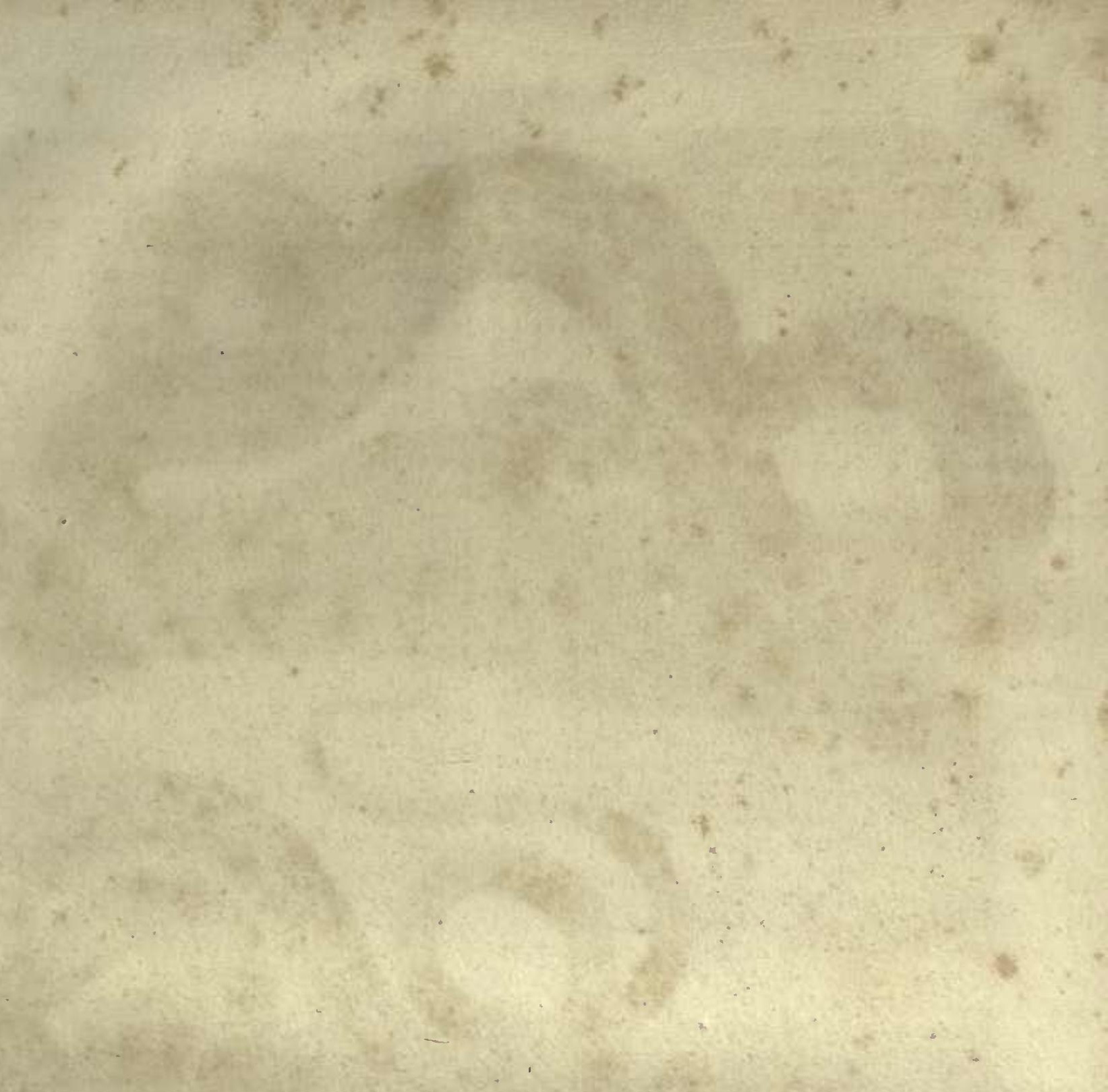

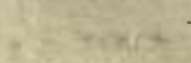

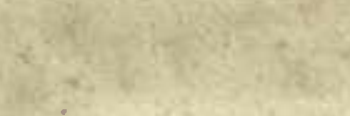

$\sin ^{2} x+2 y$

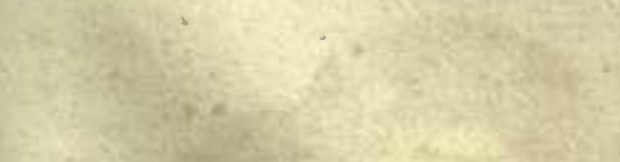

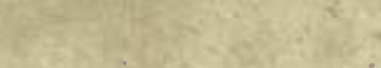

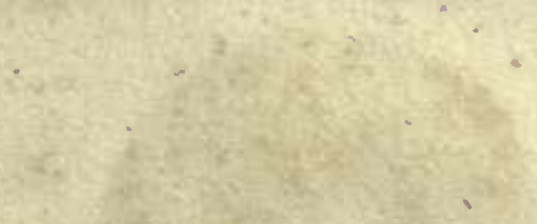

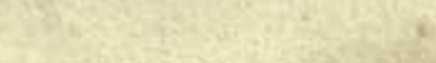

S.

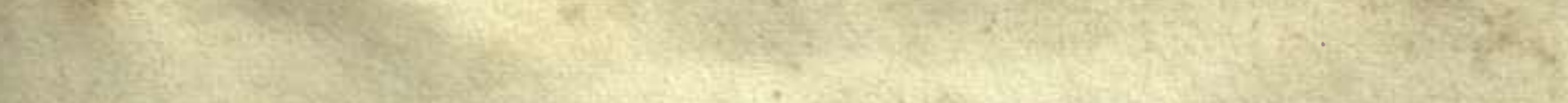

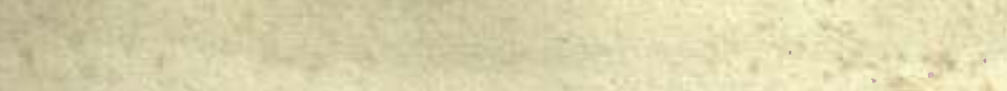




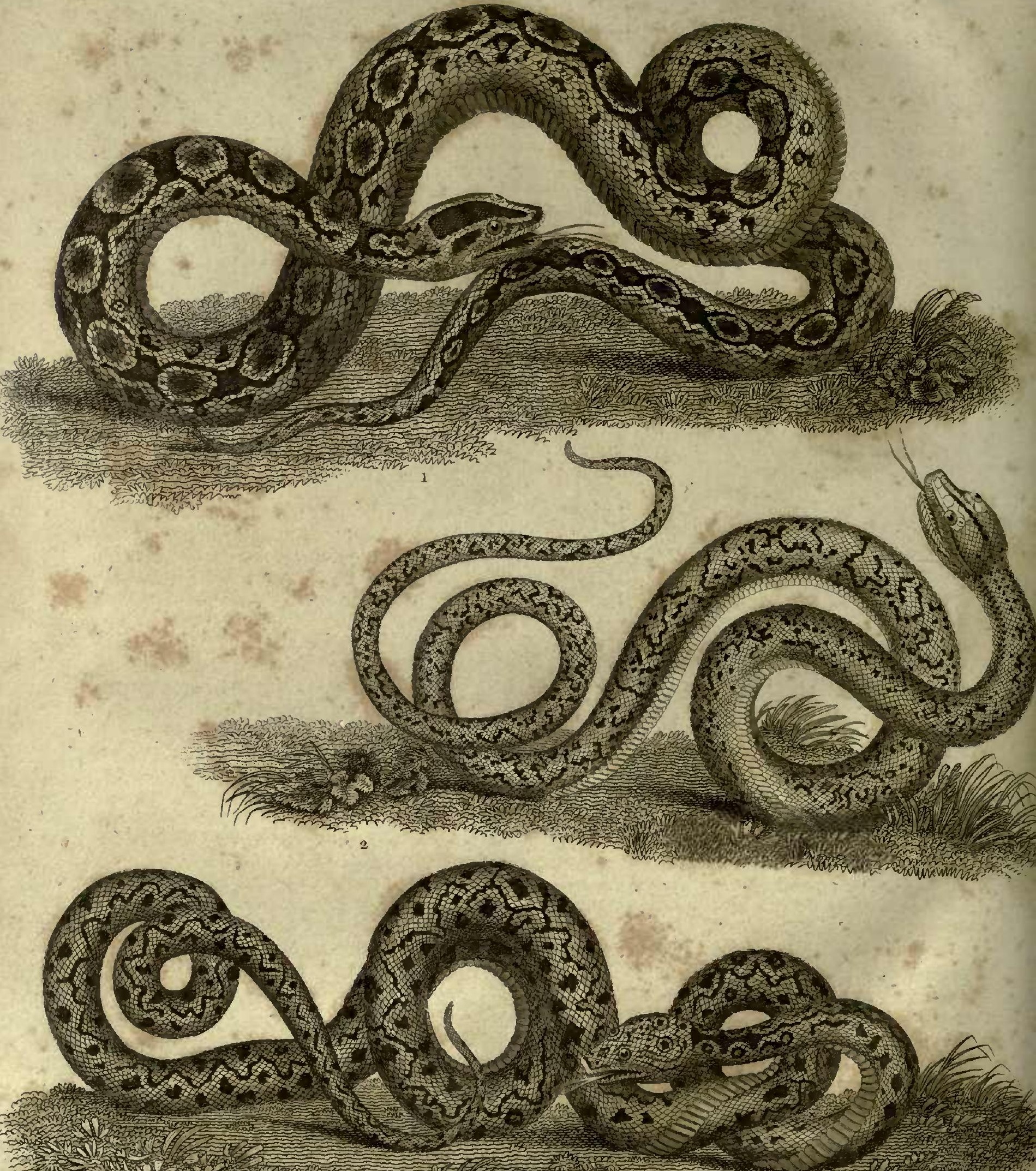
3 


\section{OF SERPFNTS.}

\section{$\rightarrow 009-$ \\ CHAPTER CLXIV. \\ OF SERPENTS IN GENERAL.}

WE now come to a trihe that not only their deformity, their venom, their ready malignity, but also our prejudices, and our very religion, have taught us to detest. The serpent has from the beginning been the enemy of man; and it has hitherto continued to terrify and annoy him, notwithstanding all the arts that have been practised to destroy it. Formidable in itself, it deters the invader from the pursuit; and from its figure capable of finding shelter in a little space, it is not easily discovered by those who wonld venture to try the encounter. Thus possessed at once of potent arms and inaccessible or secure retreats, it baffles all the arts of man, though never so earnestly bent upon its destruction.

For this reason, there is scarce a country in the world that does not still give birth to this poisonous brood, that seem formesl to quell luman pride, and repress the boasts of security. Mankind have driven the lion, the tiger, and the wolf, from their vicinity; but the snake and the viper still defy their power, and frequently punish their insolence.

Their numbers, however, are thinned by human assiduity; and it is possible some of the kinds are wholly destroyed. In none of the countries of Europe are they sufficienily nunerous to be truly terrible; the philosopher can inclitate in the fields without danger, and the lover seck the grove without fearing any wounds but those of metaphor. Thic various malignity that has been ascribed to European serpents of old, is now utterly unknown; there are not above three or four kinds that are dangerous, and their poison operates in all in the same mamner. A hurning pain in the part, easily removable by timely applications, ะo. $61 \& 62$. is the worst effect that we experience from the bite of the most renomous serpents of Europe. The drowsy death, the starting of the blood from every pore, the insatiable and burning thirst, the melting down the solid mass of the whole form into one heap of putrefaction, these are horrors with which we are entirely unacquainted.

But thougls we have thus reduced these dangers, having been incapable of wholly removing them, in other parts of the world they still rage with all their ancient malignity. Nature secms to have placed them as centinels to deter mankind from spreading too widely, and from secking new abodes till they have thoroughly cultivated those at home. In Ilse warm countries that lie within the tropic, as well as in the cold regions of the north, where the inhabitants are $\mathrm{fe} w$, the serpents propagate in equal proportion. But of all cuuntries, those regions have then in the greatest abundance where the fields are unpeopled and fertile, and where the clinate supplies warnith and humidity. All along the swampy banks of the river Niger or Oroonoko, where the sun is hot, the forests thick, and the nien but few, the serpents cling anong the branches of the trees in infinite uumbers, and carry on an unceasing war against all orber animals in their vicinity. Travellers have assured us, that they have often seen large suaks twining round the trunk of a tall tree, cncompassing it like a wreath, and thus rising and descending at p'ensure. In these countries, therefore, the serpent is too formidable tn becone an object of curiosity, for it excites much more violent sensalions.

We are not, therefore, to reject as wholly 
fabulous, the accounts lef( us by the ancients of the terrible devastarions committed by a single serpent. It is probable, in early times, when the arts were little known, and mankind were but thinly scattered over the earth, that serpents, continuing undisturbed possessors of the forest, grew to an amazing magnitule; and every other tribe of animals fell before them. It then might have happened, that serpents reigned the tyrauts of a district for centuries together. To animals of this kind, grown by ti ne and rapacity to a lundred or a hundred and fifty feet in length, the lion, the tiger, an I even the elephant itself, were but feeb!c opponents. The dreadful monster spread desolation round him ; every creature that had life was devoured, or fled to a distance. That horrible feetor, which even the commonest and the most harmless snakes are still found to diffuse, might, in these larger ones, become too powerful for any living being to withstand; and while they preyed without distinction, they might thus also have poisoned the atmosphere around them. In this manner, having for ages lived in the hillden and unpeopled forest, and fiuding, as their appetites were more powerful, the quantity of their prey decreasing, it is possible they might venture boldly fron their retreats, into the more cultivated parts of the comtry, and carry consternation among mankind, as they had before desulation among the lower rasks of nature. We have many histories of antiquity, pres nting us such a picture; and exhibiting a whole nation sinking under the ravages of a single serpent. At that time man had not learned the art of uniting the efforts of many, to effect one great purpose. Opposing multitudes only added new victinis to the general calamity, and increased mutnal embarrassment and terror. The animal was therefore to be singly opposed by him who had the greatest strength, the best armour, and the most undaunted courage. In such an encounter hundrei's nust have fallen; till one, more lucky than the rest, by a fortunate blow, or by taking the monster in its. torpid interval, and surcharged with spoil, might kill, and thus rid his country of the destroyer. Such was the original occupation of heroes: and those who first abtained that name, from their destroying the ravagers of the earth, gained it usurh nore deservedly than their successors, who ac- quired their reputation only for their skill in destroying each other. But as we descend into more enlightened antiquity, we find these animals less fornidable, as being attacked in a more successful mamer. We are told, that wbile Regulus led his army along the banks of the river Bagrada, in Africa, an enormous serpent disputed his passage over. We are assured by Pliny, who says that he himself saw the skin, that it was a hundred and twenty feet loug, and that it had destroyed many of the army. At last, however, the battering engines were brought out against it; and these assailing it at a distance, it was soon destroyed. Its spoils were carried to Rome, and the general was decreed an ovation for lis success. There are, perhaps, few facts better ascertained in history than this: an ovation was a remarkable lionour; and was giren only for some signal exploit, that did not deserve a triumph: no listorian would offer to invent that part of the story at least, without being subject to the most shameful detection. The skin was kept for several years after in the Capitol; and Pliny says, he saw it there: now, though Pliny was a credulous writer, he was liy no means a false one; and whatever he says. he has seen, we may very safely rely on. At present, indeed, such raviges from serpents are scarcely seen in any part of the world; not but that in Africa and America, some of them are powerfill enough to brave the assaults of men to this day.

But happily for us, we are placed at such a distance as to take a view of this tribe, without fearing for our safety ; we can survey their impotent malignity with the same delight with which the poet describes the terrors of a dead monster.

Nequeant expleri corda tuendo

Terribiles oculus villosaque setis pectore.

To us their slender form, their undulating motion, their vivid colouring, their horrid stench, their finky tongue, and ibeir envenomed faugs, are rotally harmless; and in this conntry their uses even serve to counterbalance the mischicf they sometimes occasion.

If we mke a survey of serpents in general, they have marks by which they are distin- 
guished from all the rest of animated nature. They have the length and the suppleness of the cel, but want funs to swim with: they bave the scaly covering and pointed tail of the lizard, but they want legs to walk with: they have the crawling motion ef the worm, but, unlike that animal, they have lungs to breath with: like all the reptile kind, they are resentful when offended; and uature las supplied them with terrible arms to reveage every injury.

Though they are possessed of very differeut degrees of maliguity, yet they are sill formidable to man, and have a strom similitule of form to each otiser; and it will be proper to mark the geneml characters before we descend to parliculars. With respect to their conformation, all serpents bave a very wide mouth, in proportion to the size of the head; and, what is rery extraordinary, they can gape and swallow the head of another animal which is three times as big as their own. I lave seen a load taken ont of the belly of a suake, at Lord Spencer's, near Loudou, the horly of which was thrice the diameter of the animal that swallowed it. However, it is no way surprising that the skin of the snake should stretch to receive so large a morsel; the wonder secms how the jaws could take it in. To explain this, it must be observed that the jaw's of this auimal do not open as ours, in the manner of a pair of hinges, where bones are applied to bones, and play upon one another; on the contrary, the serpent's jaws are held together at the roots by a stretching muscular skin; by which means they open as widely as the animal chooses to stretch them, and admit of a prey much thicker than the snake's own body. The throat, like stretching leather, dilates to admit the morsel; the stomach receives it in part; and the rest remains in the gullet, till putrefaction and the juices of the serpent's body mite to dissolve it.

As to the teeth, I will talk more of them when I come to treat of the viper's poison; it will be sufficient here to observe, that some serpents have fangs, or canius teeth, and others are without them. The teeth in all are crooked and hollow ; and, by a peculiar contrivance, are capable of being erected or depressed at pleasure.

The eyes of all serpents are small, if com- pared to the length of the body; and though differently coloured in difterent kinds, yet the appearance of all is malign and heavy; nud from their known qualities, they strike the imagination with the idea of a creature mediating mischief. In some, the upper eyelirl is wanting, and theserpont wiuks ouly with that below; in others, the animal has a nictitating nembranc or skin, resembling that which is found in birds, which lieeps the eyc clean, nud preserves the sight. 'The substance of the eye $\mathrm{i}$ : all is hard and homy ; the crystalline humour oceupying a great part of the globe.

The holes for hearing are very visible in all: but there are no conduits for smelling; though it is probable that some of them enjoy that sense in tolerable perfection.

The tongue in all these animals is long and forky. It is composed of two long flestyy substances, which terminate in sharp points, and are very pliable. At the root it is connected very strongly to the neck by two tendons, that give it a variety of play. Some of the viper kind have tongues a fifth part of the length of their bodies; they are continually darting them out, but they are entirely harmless, and only terrify those who are ignorant of the real situation of their poison.

If from the jaws we go on to the gullet, we shall find it very wide for the animal's size, and capable of being distended to a great degree; at the bottom of this lies the stomach, which is not so capacious, aud receives onily a part of the prey, while the rest continues in the gullet for digestion. When the substance in the stomach is dissolved into chyle, it passes into the intestines, and from thence goes to nourishment, or to be cxcluded by the vent.

Like most other animals, serpents are furnished with lungs, which I suppose are serviceable in breathing, though we cannot perceive the manner in which this operation is performed; for though serpents are often seen apparently to draw in their breath, yet we camnot find the smallest sigus of their ever respiring it again. Their lungs, however, are lorg and large, and doubtless are necessary to promote their languid circulation. The heart is formed as in the tortoise, the frog: and the lizard kinds, so as to work without the 
assistance of the lungs. It is single, the greatest part of the blood flowing from the great vein to the great artery by the shortest course. By this contrivance of nature we easily gather two consequences - that snakes are amphibious, being equally capable of living on land and in the water; and, that also they are torpid in winter, like the bat, the lizard, and other animals formed in the same manner.

The vent in these animals serves for the emission of the urine and the freces, and for the purposes of generation. The iustruinent of generation in the male is double, being forked like the tongue; the ovaries in the temale are double also; and the aperture is very large, in orler to receive the double instrument of the male. They copulate in their retreats; and it is said by the ancients, that in this situation they appear like one serpent with two lieads: but how far this remark is founded in truth, I do not find any of the moderns that can resolve me.

As the body of this animal is long, slender, and capable of bending in every direction, the number of joints in the back-bone are numerous beyond what one would imagine. In the generality of quadrupeds, they amount to not above thirty or forty; in the serpent kind they amount to a hundred and forty-five from the head to the vent, and twenty-five more from that to the tail." "The number of these joints must give the back-bene a surprising degree of pliancy; but this is still increased by the manner in which each of these joints are locked into the other. In man and quadrupeds, the flat surfaces of the bones are laid one against the other, and bound tight by sinews; but in serpents, the bones play oue within the other, like ball aud socket, so that they have full motion upon each other in every direction." 'Thus, if a man were to form a machine composed of so many joints as are found in the back of a serpent, he would find it no easy matter to give it such strength and pliancy at the same time. The chain of a watch is but a bungling piece of workmanship in comparison.

Thaugh the number of joints in the backbane is great, yet that of the ribs is still great-

\footnotetext{
4. Vide Charat. Anatom. Derlaam, p. 396
}

er; for, from the head to the vent, there are two ribs to every joint, which makes their number two hundred and ninety in all. These ribs are furnished with muscles, four in number; which being juserted into the head, run along to the end of the tail, and give the animal great strength and agility in all its motions.

The skiu also contributes to its motions, being composed of a number of scales, united to eaclı other by a transparent membrane. which grows harder as it grows older, until the animal changes, which is generally donc twice a year. 'This cover then bursts near' the head, and the serpent creeps from it, by an undulatory motion, in a new skin, much more vivid than the former. If the old slough be then viewed, every scale will be distinctly seell, like a piece of net-work, and will be found greatest where the part of the body they covered was largest.

There is much geometrical neatness in the disposal of the serpent's scales, for assisting the animal's sinuous motion. As the edges of the foremost scales lie over the ends of their following scales, so those edges, when the scales are erected, which the animal has a power of doing in a small degree, catch in the ground, like the nails in the wheel of a cliariot, and'so promote and facilitate the animal's progressive motion. The erecting these scales is by means of a multitude of distinct muscles, with which each is supplied, and one end of which is tacked each to the middle of the foregoing.

In some of the serpent kind there is the $\mathrm{cx}$ actest symmetry in these scales; in others. they are disposed more irregularly. In some there are larger scales on the belly, and often answering to the number of rilss; in others, however, the animal is without them. Upon this slight difference, Linnæus has founded his distinctions of the various classes of the serpent tribe. Human curiosity, however, and even human interest, scem to plead for a very different method of distribution. It is not the number of scales on a formidable animal's belly, uor their magnitude or variety, that any way excite our concern. The first question that every man will naturally ask, when he hears of a suake, is, whether it he large? the second, whether it be venomous? In other words, the strongest lines in the ani- 
mal's history are those that first excite our attention; and these it is every historian's business to display.

When we come to compare serpents with each other, the first great distinction appears in their size; wo other tribe of animals differing so widely in this particular. What, for instance, can be so remotely separated as the Great Liboya of Surinam, that grows to thirtysix feet long; and the Little Serpent, at the Cape of Good Hope, and the north of the river Senegal, that is not above three inches, and covers whole sandy deserts with its multitudes! This tribe of animals, like that of fishes, seems to have no bounds put to their growth : their bones are in a great measure cartilaginous, and they are consequently capable of great extension : the older, therefore, a serpent becomes, the larger it grows; and as they seem to live to' a great age, they arrive at an enormous size.

Leguat assures us, that he saw one in Java, that was fifty feet long. Carli mentions their growing to above forty feet; and we have now the skin of one in the Museum, that measures thirty-two. Mr. Wentworth, who had large concerns in the Berbices in America, assures me, that, in that country, they grow to an enormous length. He one day sent ont a soldier, with an Indian, to kill wild fowl for the table; and they accordingly went some miles from the fort: in pursuing their game, the Indian, who gencrally marched before, beginning to tire, went to rest himself upon the fallen trunk of a tree, as he supposed it to be; but when he was just going to sit down, the cnormous monster began to move, and the poor savage perceiving that he had approached a Liboya, the greatest of all the serpent kiud, dropped down in an agony. The. soldier who perceived at some distance what had happened, levelled at the serpent's head, and, by a lucky aim, slot it clead: however, he continued his fire until he was assured that the animal was killed; and then going up to rescue his companion, who was fallen untionless by its side, he, to his astonishment, found him dead likewise, being killed by the fright. Upon his return to the fort, and telling what had happeued, Mr. Wentworth ordered the animal to be brought up, when it was measured, and found to he thirty-six feet long. He had the skin stuffed, and then sent to Europe, as a present to the Prince of Orange, in whose cabinet it is now to be seen at the Hague; but the skiu has shrunk, by drying, two or three feet.

In the East Indies they grow also to an enormous size; particularly in the island of Java, where, we are assured, that one of them will destroy and devour a buffalo. In a letter, printed in the German Ephemerides, we have an account of a combat between an enormous serpent and a buffalo, by a person, who assures us that he was himself a spectator. The serpent had for some time been waiting near the briuk of a pool, in expectation of its prey; when a buffalo was the first that offered Having darted upon the affrighted animal, it instantly began to wrap it round with its voluminous twistings; and at every twist the bones of the buffalo were heard to crack alınost as loud as the report of a cannon. It was in vain that the poor animal struggled and bellows ; its enormous.enemy entwined it too closely to get free; till at length, all its bones being mashed to pieces, like those of a malefactor on the wheel, and the whole body reduced to one uniform mass, the scrpent untwined its folds to swallow its prey at leisure. To prepare for this, and in order to make the body slip down the throat more glibly, it was seen to lick the whole body over, and thus cover it with its nucus. It theu began to sivallow it at that end that offered lcast resistance; while its length of body was dilated to receive its prey, and thus took in at once a morsel that was three times its own thickness. We are c-ssured by travellers, that these animals are often found with the body of a stag in their gullet, while the horns, which they are unable to swallow, keep sticking ont at their mouths.

But it is happy for mankind that the rapacity of these frightful creatures is often their punishment; for whenever any of the serpent kind have gorged themselves in this manuer, whenever their body is seen particularly distended with food, they then become torpid, and may be approaclied and destroyed with safety. Patient of hunger to a surprising degree, whenever they seize and swallow their prey, they seem, like surfcited gluttons, unwieldy stupid, helpless, and sleepy : they at that time seek some retreat, where they inay lurk for several days together, and digest their 
ineal in safety: the smallest effort at that time is capable of destroying them; they can scarcely make any resistance; and they are equally unqualified for Alight or opposition: that is the loappy opportunity of attacking them with success: at that time the naked Indian himself does not fear to assail them. But it is otherwise when this sleepy interral of digestion is orer; they then issue, with famished appetites, from their retreats, and with accumnlated terrors, while every animal of the forest flies betore them.

Carli describes the Long Serpent of Congo, making its track through the tall grass, like mowers in a stimmer's day. He could not without terror behold whole lines of grass lying levelled under the sweep of its tail. In this manner it moved forward with great rapidity, until it found a proper situation frequented by its prey: there it contiused to lurk, in patient expectation, and would have remained for weeks together, had it not been disturbed by the natives.

Other creatures have a choice in their provision; but the serpent indiscriminately preys upon all; the buffalo, the tiger, and the gazelle. One would think that the porcupine's quills might be sufficient to protect it; hut wliaterer has life, serves to appease the hunger of these devouring creatures : porcupines, with all their quills, have frequently been found in their stomachs, when killed and opened; nay, they most frequently are seen to devour each other.

A life of savage hostility in the forest, offers the imagination one of the most tremendous pictures in nature. In those burning conntries, where the sun dries up every brook for hundreds of miles round; when what had the appearance of a great river in the rainy season, becomes, in summer, one dreary bed of sand-in those countries, I say, a lake that is never dry, or a brook that is perenial, is considered by every animal as the greatest convenience of nature. As to food, the luxuriant landscape supplies that in sufficient abundance: it is the want of water that all animals endeavour to remove; and inwardly parched by the heat of the climate, traverse whole deserts to find out a spring. When they have discovered this, no dangers can deter them from attempting to slake their thirst. Thus, the neighbourhood of a rivulet, in the lieart of the tropical contiuents, is generally the place where all the hostile tribes of nature draw up for the engagement. On the banks of this little envied spot, thousands of animals of various kinds are seen venturing to quench their thirst, or preparing to seize their prey. The elcplants are perceived, in a long line, marching from the darker parts of the lorest; the buffalocs are there, depending upon numbers for security; the gazelles, relying solely upon their swiftness; the lion and tiger, waiting a propes opportunity to seize; but chiclly the larger scrpents are upon gnard there, and defend the accesses of the lakc. Not an lıour passes without some dreadful combat; but the serpent, defended by its scales, and naturally capable of sustaining a multitude of wounds, is, of all others, the most formidable. It is the most wakeful also; for the whole tribe sleep with their eyes opeu, and are, consequently, for ever upon the watch: so that, till their rapacity is satisfied, few other animals will venture to approach their station.

But though these animals are, of all other: the inost voracious, and though the morsel which they swallow without chewing, is greater than what any other creature, either by land or water, the wluale itsell not excepted, can devour, yet no animals upon earth bear abstinence so long as they. A single meal, with many of the snake kind, seems to be the adventure of a season; it is an occurrence for which they have been for weeks, nay, sometimes for months, in patient expectation of. When they have seized their prey, their industry for several weeks is entirely discontinued: the fortunate capture of an hour, often satisfies them for the remaining period of their annual activity. As their blood is colder than that of most other terrestrial animals, and as it circulates but slowly through their bodies, so their powers of digestion are but feeble. Their prey continues, for a long tine, partly in the stomach, partly in the gullet, and a part is often seen hanging out of the mouth. In this manner, it digests by degrees; and in proportion as the part below is dissolved, the part above is taken in. It is not, therefore, till this tedious operation is entirely performed, that the serpent renews its ap- 
petite and its activity. But should any accident prevent it from issuing once more from its cell, it still can continue to bear famine for weeks, months, Day, for years together. Vipers are often kept in boxes for six or eight months, without any food whatever; and there are little serpents sometimes sent over to Europe from Grand Cairo, the name of which I have not been able to learn, that live for several years in glasses, and never eat at all, nor even stain the glass with their excrements. Thus the serpent tribe unite in themselves two very opposite qualities; wonderful abstinence, and yet incredible rapacity.

If, leaving the consideration of their appetites, we come to eompare serpents as to their voices, some are found silent, some have a peculiar cry; but hissing is the sound which they most commonly send forth, either as a call to their kind, or as a threat to their enemies. In the countries where they abound; they are generally silent in the middle of the day, when they are obliged to retire from the heat of the climate; but as the cool of the evening approaches, they are then heard issuing from their cells, with eontinued hissings; and such is the variety of their notes, that some have assured me they very much resemble the music of an English grove. This some will hardly credit-at any rate, such notes, however pleasing, can give but very little delight, when we calt to mind the malignity of the minstrel. If considered, indeed, as they answer the animal's own occasions, they will be found well adapted to its nature, and fully answering the purposes of terrifying such as would venture to offend it.

With respect to motion, some serpents. particularly those of the viper kind, move slowly; while others, such as the Ammodytes, dart with amazing swiftness. The motion in all is similar; but the strength of body in some gives a yery different appenrance. The viper, that is but a slow fécble-bodied animal; makes way in a heavy undulating manner: advaneing its head, then drawing up its tail behind, and bending the body into a bow; then from the spot where the head and tail were united, advancing the head forward as before. This, which is the motion of all serpents, is very different from that of the earth-worm or the naked snail. The serpent, as was said above, has a back-bone with numerous joints, and this bone the animal has a power of bending in every direction, but without being able to shorten or lengthen it at pleasure. The earth-worm, on the other hand, has no backbone; but its body is composed of rings, which, like a barber's puff, it can lengthen or shorten as it finds necessary. The earth-worm, therefore, in order to move forward, lengthens the body; then, by the fore part clings to the ground, where it has reached, and then contracts and brings up its rear: then when the body is thus shortened, thie fore part is lengthcned again for another progression; and so on. The serpent, instead of shortering the body, bends it into an arch; and this is the prineipal difference between serpentine and vermicular progression.

I have instanced this motion in the viper, as most easily discerned; but there are many serpents that dart with such amazing swiftuess, that they appear rather to leap than crawl. It is most probable, however, that ho serpent can dart upon even ground farther than its own length at one effort. Our fears, indeed, may increase the force of their spced, which is sometimes found so fatal. We are told by some, that they will dart to a very great distance; but this my inquiries have never been able to ascertain. "The manner of progression in the swiftest serpent we know, which is the jaculus, is by instantly coiling itself uponits tail, and darting from thence to its full extent; then carrying the tail as quick as lightning to the head, coiling and darting again; and by this means proceeding with extreme rapidity, withont ever quitting the gromnd. Indeed, if we consider the length and the weakness of the baek-bone in all these animals; if we regard the make of their vertebre, in which we shall find the junctures all formed to give play, and none to give power; we cannol be of opinion that they have a facully of springing from the ground, as they entirely want a fulcrum, if I may so express it, from whence to take their spring; the whole hody locing composed of unsupported muscles and joints that are yiclding. It must be confessed, that they dart down from trees upon their prey; but their weight alone is sufficient for that purpose. without much effort of their own.

Though all serpents are amphibious, som 
are much fonder of the water than others; and, though destitute of fins $\left(\mathrm{P}^{\circ}\right.$ gills, remain at the bottom, or swim aiong the surface with great case. Fron their internal structure, just sketched above, we see how well adapted they are for either elenient; and how capable their blood is of circulating at the bottom, as freely as in the frog or the tortoise. They can, however, endure to live in fresh-water only; for salt is an effectual bane to the whole tribe. The greatest serpents are most usually found in fresh-water, either choosing it as their favourite element, or finding their prey in such places in the greatest abundance. But that all will live and swim in liquids, appears from the experiment of Rhedi; who put a serpent into a large glass vessel of wine, where it lived swimming about six hours; though, when it was by force immersed and kept under that liquid, it lived only one hour and a laalf. He put another in common water, where it lived three days; but when it was kept under water, it lived only about twelve liours. ${ }^{a}$ Their motion there, however, is perfectly the reverse of what it is upon land; for, in order to support themselves upon an element lighter than their bodies, they are obliged to increase their surface in a very artificial manner. On earth their windings ale perpendicular to the surface; in water they are parallel to it: in other words, if I should wave uny hand up and down, it will give an idea of the animal's progress on laud; if I should wave it to the right and left, it will give some idea of its progress on the water.

Some serpents liave a most horrible fætor attending then, which is alone capable of intimidating the brave. This proceeds from two glands near the vent, like those in the wea.el or polecat; and, like those animals, in proportion as they are excited by rage or by fear, the scent grows stronger. It would seem, however, that such serpents as arc most venomous, are least offensive in this particular; since the rattle-snake and the viper have no sinell whatever: nay, we are told that at $\mathrm{Ca}$ licut and Cranganon, in the East Indies, there are some very noxious serpents, who are so far from being disagrceable, that their excrements are sought after, and kept as the most

ahedi, Exper. p. 170. pleasing perfumc. The Esculapian Serpent is also of this number.

Some serpents bring forth their young alive, as the viper; some bring fortl eggs, which are hatched by the heat of their situation; as the common black snake, and the majority of the serpent tribe. When a reader, ignorant of anatomy, is told, that some of those animals produce their young alive, and that some produce eggs only, he is apt to suppose a very great difference in the internal conformation, which makes such a variety in the inanner of bringiug forth. But this is not the case : these animals are internally alike, in whatever manner they produce their young; and the variety in their bringing forth, is rather a slight than a real discrimination. The only difference is, that the viper hatches lier eggs, and brings them to maturity within her body; the suake is more premature in her productions, and sends her eggs into the light some time before the young ones are capable of leaving the shell. Thus, if either are opened, the eggs will be found in the womb, covered with their membranous shell, and adhering to each other like large beuds on a string. In the eggs of both, young ones will be found, though at different stages of maturity: those of the viper will crawl and bite the inoment the shell that encloses them is broke open; those of the snake are not yet arrived at their perfect form.

Father Labat took a serpent of the viper kind, that was nine feet long, and ordered it to be opened in his presence. He then sav the manner in which the eggs of these animals lie in the womb. In this creature there were six eggs, each of the size of a goose egur, but longer, more pointed, and covered witl a membranous skin, by which also they were united to each other. Each of these cagss contained from thirteen to fifteen young ones, about six inches long, and as thick as a goosequill. Though the female from, whence they were taken was spotted, the young séeıned to liave a variety of colours very different from the parent; and this led the travellep to suppose that the colour was no characteristic mark among serpents. These little mischievous animals were no sooner let loose from the shell, than they crept about, and put themselves into a threatening posture, coiling themselves up, and biting the stick with which lie was destroying them. In this manner he kill- 
ed seventy-four young ones; those that were contained in one of the eggs escaped at the place where the female was killed, by the bursting of the egg, and their getting anong the bushes.

The last distinction that I shall mention, but the most material among serpents, is, that some are vellomous, and some inoffensive. If we consider the poison of serpents as it relates to man, there is no doubt but that it is a scourge and an affliction. The various calamities that the poison of serpents is capable of producing, are not only inflicted by the animal itself, but by men, more mischicvous than even serpents, who prepare their venom to destroy each other. With this the savages poison their arms, and also prepare their revengeful potions. The ancicnts were known to preserve it for the purposes of suicide; and even among semi-barbarous countries at this day, the venom of snakes is used as a philter.

But, though the poison be justly terrible to us, it has been given to very good purposes for the animal's own proper support and defence. Without this, serpents, of all uther animals, would be the most exposed and defenceless: without fect for escaping a pursuit; without teeth capable of inflicting a dangerous wound, or without strength for resistance ; incapable, from their size, of finding security in very small retreats, like the earth-worm, and disgusting all from their deformity, nothing was left for them but a speedy extirpation. But furnished as they are with powerful poison, every rank of ani:nals approach them with dread, and never seize them but at an advantage. Nor is this all the advantage they derive from it. The malignity of a few serves for the protection of all. Though not above a tenth of their number are actually venonous, yet the similitude they all bcar to each otlicr excites a general terror of the whole tribe; and the uscertainty of their enemies in which the poison chiefly resides, makes even the most harmless formidable. Thus Providence scems to have acted with double precaution; it has given some of them poison for the general defence of a tribe naturally feeble; but it has thinned the numbers of those which are venomous, lest they should become too powerful for the rest of Animated Nature.

From these noxious qualities in the serpent kind, it is no wonder that not only man, but so. 61 \& 62 . beasts and birds, carry on an unceasing war against them. The ichneumon of the Indians, and the peccary of Anierica, destroy them in great numbers. These aninials liave the art of seizing them near the head; and it is said that they can skin them with great dexterity. The vulture and the eagle also prey upon them in great abundance; and often sousing down from the clouds, drop upon a long serpent, which they snatch up struggling and writhing in the air. Dogs also are bred up to oppose them. Father Feuillec tells us, that being in the woods of Martinico, he was attacked by a large serpent, which he could not easily avoid, when his dog immediately came to his relief, and seized the assailant with great courage. The serpent entwined him, and pressed lim so violently, that the blood came out of his mouth, and yet the dog never ceased till he had tore it to pieces. The dog was not sensible of lis wounds during the fight; but soon after lis head swelled prodigiously, and he lay on the ground as dead. But his master having found hard by a banana tree, he applied its juice, mixed with treacle to the wounds, which recovered the dog, and quickly healed his sores.

But it is in man that these venomouscreatures find the most dangerous eneiny. The Psylli of old were famous for charning and destroying serpents. Some moderns pretend to the same art. Cassaubon, says, that lie knew a man who could at any time summon a hun. dred serpents together, and draw them into the fire. Upon a certain occasion, when one of them biggel than the rest would not be. brouglit in, he only repeated his charm, and it came forward, like the rest, to submit to the flames. Philostralus describes particularly how the Indians charm serpents. "They take a scarlet robe, embroidered with golden letters, and spread it before a serpent's hole. The golden letters have a fascinating power; and by looking steadfastly, the scrpent's eyes are overcome and laid aslecp." These, and many other feats, have been often practised upon these aninals by artful men, who had first prepared the serpents for their exercise, and then exhibited them as adventitiously assembled at their call. In India there is nothing so common as dancing serpents, which are carried about in a broad flat vesscl, somewhat resembling a sieve. These erect and put 
themselves in motion at the word of command. When their ketper sings a slow tune, they seen by their lieals to keep time; when he sings a quicker measure, they appear to move brisk and lively. "All animals have a certain degree of docility ; and we find that serpents themselves can be bronght to move and appronch at the voice of their master. From this trick, successfully praclised before the ignorant, it is most probable has arisen all the bossted pretensions which some have made to charming of serpents; an art to which the native Americans pretend at this very day. One of Limnans's pupils, we are told, purchased the secret from an Indian, and then discovered it to his master; but, like all secrets of the kint, it is probable this onded in a fer unmeaning words of no efficacy.

Though the generality of mankind regard this formidable race with horror, yet there have been some natinns, and there are some at this day, that consider them with veneration and regarcl. The adoration paid by the ancient Egyptians to a serpent is well known: many of the nations at present along the western coast of Africa retain the same uıaccountable veneration. Upon the gold and slave coasts, a stranger, upon entering the cottages of the natives, is often surprised to see the roof swarming with serpents, that cling there without molesting and unmolested by the natives. But his surprise will increase upon going farther sauthward to the kingdom of Widah, when he finds that a serpent is the god of the country. This aninal, which travellers describe as a huge, overgrown creature, has its habitation, its temple, and its priests. 'These impress the vulgar with an opinion of its virtues ; and nunibers are daily seen to offer not only their goods, their provisions, and their prayers, at the shrine of their hideous deity, but also their wives and daughters. These the priests readily accept of, and alter some days of penance, return them to their suppliants, much benefited by the serpent's supposed embraces. Such a complicated picture of ignorance and imposture gives no very favourable impressions of our fellow-creatures; but we may say in defence of Human Nature, that the most firightful of reptiles is worshipped by the most uncultivated and barbarous of mankind.

From this general picture of the serpent tribe, one great distinction obviously prescnts itself; namely, into those that are venomous, and those that are wholly destitute of poison. To the first belong the viper, the rattlesnake, the cobra di capello, and all their affinities: to the other, the common black snake, the liboya, the boiguacu, the amphisbrena, and various others, that, thongh destitute of venon, do not cease to be formidable. I will, therefore, give their history separately, beginning with the venomous class, as they have the strongest claims to our notice and attention,

\section{CHAPTER CLXV.}

\section{OF VENOMOUS SERPENTS IN GENERAL.}

THE poison of serpents lias been for ages one of the greatest objects of human consideration. To us, who seldom feel the vengeful wound, it is merely a subject of curiosity; but to those placed in the midst of the serpent tribe, who are every day exposed to some new disaster, it becomes a matter of the most serious importance. To remedy the bite of a serpent is considered arnong our physicians, as one of the slightest operations in medicine: but among the physicians of the East, the anti- dotes for this calamity make up the bulk of their dispensaries. In our colder climates, the venom does not appear with that instantaneous operation which it exhibits in the warmer regions; for either its powers are less exquisite, or our fluids are not carried round in such rapid circulation.

In all countries, however, the poison of the serpent is sufficiently formidable to deserve notice, and to excite our attention to its nature and effects. It will, therefore, in the first 
place be proper to describe its seat in the animal, as also the instrument by which the wound is made, and the poison injected. In all this venomous class of reptiles, whether the viper, the rattlesnake, or the cobra di capello, there are two large teeth or fangs that issue from the upper jaw, and that hang out beyond the lower. "The rest of the snake tribe are destitute of these; and it is most probable that wherever these fings are wanting, the animal is harmless; on the contrary, wherever they are found it is to be aroided as the most pestilent encmy, These are the instruments t!at seem to place the true distinetion between animals of the serpent kind; the wounds which these fangs inflict produce the most dangerous symptoms; the wounds inflicted hy the teeth only are attended with nothing more than th:c ordinary consequences attending the bite of any other animal. Our first great attention, therefore, upon sccing a serpent, shonld be directed to the tceth. If it has the fang tcetl, it is to be placed among the venomous clnss; if it wants them, it may be set down as inoficnsive. I am not ignorant that many serpents are said to be clangerous whose jaws are unfurnished with fangs; but it is most probable that our terrors only have furnished these ani. inals with venom; for of all the tribe whose teeth are thus formed, not one will be found to have a bag for containing poison, nor a conduit for injecting it into the wound. The Black Snake, the Liboya, the Blind Worm, and a hundred others that night be inentioned, have their tectlı of an equal size, fixed into the jaws, and with no other apparatus for inflicting a dangerous wound than a dog or a lizard; but it is otherwise with the venomous tribe we are now describing; these are woll furnished, not only with an elaboratory where the poison is formed, but a canal by which it is conducted to the jaw, a bag under the tooth for kceping it ready for every occasion, and also an aperture in the tooth itself for injecting it into the wound. To be more particnlar, the glands that serve to fabricatc this venomous fluid are situated on each side of the head behind the eyes, and have their canals leading from thence to the bottom of the fangs in the upper jaw, where they empty into a kind of bladder, from whence the faugs on each side are seen to grow. The venom contained in this bladder is a yellowish thick tasteless liquor, which injected into the blood is death, yet which may be swallowed without any danger.

The fangs that give the wound come next under observation ; they are large in proportion to the size of the anmal that bears them; crooked, yet sharp cnough to inflict a rcady wound. They grow one on ench sirle, and sometimes two, from two moreable boucs in the upper jaw, which by sliding bachward or forward, have a power of erecting or cepressing the tecth at pleasure. In these homes are a'so fixed many'teeth, but no way venonons, and only scrving to take and hold the animal's prey. Besides this apt clisposition of the linigs, they are hollow within, and have an ropening towards the point like the slit of a pen, through which, when the fang is pressed down npon the bladder where it grows, there is secil to issue a part of the venom that lay below. To describe this operation at once, when the scrpent is irritated to give a venomous wound, it opens its formidable jaws to the widest rxtent; the moveable bones of the upper jaw slide forward; the fangs that lay before inclining are thus erected; they are struck with force into the flesh of the obnoxious person; by meeting resistance at the points, they press upon the bladders of vessom from whence they grow; the venom issues tp through the hollow of the tooth, and is pressed out through its slit into the wound, which by this tine the tooth has made in the skin. Thus from a slight puncture, and the infusion of a drops of venom scarce larger than the head of a pin, the part is quickly inflamed, and, witlout a proper antidote, the whole frame contaminated.

The appearances which this venom produces are different, according to the serpent that wounds, or the season, or the strength of the animal that strikes the blow. If a viper inflicts the wound, and the remedy be neglected, the symptoms are not without danger It first. causes an acute pain in the place affected, attended with a swelliug, first red, and afterwards livid. This by degrees spreads to the neighbouring parts; great faintness and a quick, though low and interrupted, pulse ensues: to this succeed great sickness at the stomach, bilious and convulsive vomitings, cold sweats, pains about the navel, and death itself. But the violence of the symptoms depend much on the season of the year, the difference of $5 \mathrm{~K}^{*}$ 
the climate, the size or rage of the animal, and the depth and situation of the wound. These symptoms are much more violent, and succeed each other more rapidly after the bite of a rattlesnake; but when the person is bit by the cobra di capello, he dies in an hour, his whole frame being dissolved into a putrid mass of corruption.

Nothing surely can more justly excite our wonder, than that so sinall a quantity of venom should produce such powerful and deadly effects. If the venom jtself be examined through a microscope, it will be found to shoot into little crystals, that, to an inagination already impressed with its potency, look like so many darts fit for entering the blood-vessels, and wounding their tender coats. But all these darts are wholly of our own making; the softest millest fluid whatever, possessed of any consistency, will form crystals under the eye of the microscope, and put on an appearance exactly like the venom of the viper. In fact, this venom has no acrid taste wliatever; and to all experiments that our senses can make upon it, appears a slimy insipid fluit. Charas, who often tasted it, assures us of the faot; and asserts, that it may be taken inwardly without any sensible effects, or any prejudice to the constitution. But the famous experiments that were tried by Rhedi and others, in the presence of the Great Duke of Tuscany and his court, put this beyond any doubt whatsoever. By these it appeared, that the serpent having once bitten, exhausted-for that time the greatest part of its poison; and though the wound caused by its biting a second time was attended with some malignant symptoms, yct they were much milder than before. It appeared that the serpent biting upon a sponge, or a piece of soft bread, and then biting a dog immediately after, did not inflict a wound more dangerous than the prick of a needle. It appeared that the venom being collected, and a needle dipped thercin, this produced almost as painful effects as the tooth of the animal itself.

But what caused the greatest surprise in the court was, the seeming rashness of one Tozzi, a viper-catcher; who, while the philosophers were giving elaborate lectures on the danger of the poison when taken internally, boldly desired a large quantity of it might be put together; and then, with the utmost confidence, drank it off before them all. The court was struck with astonishment, and expected that the man would instantly fall dead; but they soon perceived their mistake, and found that taken in this manner the poison was as harmless as water; so true is that famous passage of Lucan,

Noxia serpentum est admixto sanguine pestis: Morsu virus habent, et fatum in dente minantur: Pocula morte carent.

What then shall we say to the speedy effect of so seemingly harmless a liquid taken into the circulation? Let us first observe, that milk is one of the most mild and nourishing of all fluids, and seemingly the most friendly to the human constilution; yet if milk be injected into a vein, it will quickly become fatal, and kill with more certain destruction than even the venom of the viper. From hence then we may infer, that the introducing not only the serpentine venom, but also a quantity of any other mixture, into the circulation, will be fatal; and that, consequently, serpents kill as well by their power of injecting the wound as by the potency of their poison. Some indeed may inject a more acrimonious mixture, and this may produce more speedy effects; but any mixture thus inject ed would be dangerous, and many would be fatal.

Ray gives us an instance of the potency of the serpent-poison; which though it has all the air of a fable, I cannot help transcribing. "A gentleman who went over to the East Indies, while he was one day sitting among some friends, was accosted by an Indian juggler, who offered to show him some experiments respecting the venom of serpents; an exhibition usual enough in that country. $\mathrm{Ha}$ ving first, therefore, produced a large serpent, he assured the company that it was harmless; and to convince them of what he said, he tied up his arm, as is usual with those who are gaing to be bled, and whipped the serpent till it was provoked to bite him. Ha-t ving drawn in this manner about half a spoonful of blood from his arm, he put the congealed clot upon his thigh. He then took out a much smaller serpent, which was no other 
than the cobra di capello; and having tied up its neck, he procured about half a drop. of its venom, which he sprinkled on the clot of blood on his thigh, which instantly began to ferment and bubble, and soon changed colour from a red into a yellow."

This, he pretended, was caused by the extreme malignity of that animal's venom; however, I have no doubt that the whole is either a fable, or a trick of the Indian's; who, while he seemed to mix the serpent's venom, actually infused some stronger ingredient, some mineral acid, into the mass of blood, which was capable of working such a change. It cannot be supposed that any animal poison could act so powerfully upon the blood already drawn and coagulated; for a poison that could operate thus instantaneously upon cold blood, could not fail of soon destroying the animal itself.

Be this as it will, the effects of serpent-poison are too well known, though the manuer of operation be not so clear. As none of this malignant tribe grow to a great size, the longest of them not exceeding nine feet, they seldom seek the combat with larger animals, or offend others till they are tirst offended. Did they exert their malignity in proportion to their power, they could easily drive the ranks of nature before them; but they secm unconscious of their own superiority, and rather fly than offer to meet the ineanest opposer. Their food chiefly consists of small prey, such as birds, moles, toads, and lizards; so that they never attack the more formidable anjmals that would seldom die unrevenged. They lurk therefore in the clefts of rocks, or among stony places; they twine round the branches of trees, or sun themselves in the long grass at the bottom. There they only seek repose and safety. If some unwary traveller invades their retreats, their first effort is to fly ; but when either pursued or accidentally trod upon, they then make a fierce and fatal resistance, For this purpose, they raise themselves according to their strength upon their tail, erect their head, seize the limb that presses them, the wound is given, and the head withdrawn in a moment. It is not therefore without reason, that the Asiatics, who live in regions where serpents greatly ahound, wear boots and long clothes, which very well protect their lower parts from the accidental resentment of their reptile annoyers.

In the eastern and western Indies, the num ber of noxious serpents is various; in this coun try we are acquainted only with one. Thic viper is the only animal in Great Britain from whose bite we have any thing to fear. In the tropical climates, the rattlesilake, the whipsnake, and the cobra di capello, are the most formidable, though by no means the most common. From the general notoriety of the particular serpents, and the universal terror which they occasion, it would seen that lew others are possessed of such powerful malignity.

Vipers are found in many parts of this island; but the dry, stony, and particularly the claalky countries, abound with them. This animal seldom grows to a greater length than two feet; though sometimes they are found above three. The ground colour of their bo. dies is a dirty yellow; that of the female is deeper. The hack is marked the whole length with a series of rhomboid black spots; touching cach other at the points; the sides with triangular ones, the belly entirely black. It is chiefly distinguished from the common black snake by the colour, which in the latter is more beantifully mottled, as well as by the head, which is thicker than the hody; but particularly by the tail, which in the viper, though it ends in a point, does not run tapering to so great a length as in the other. When, therefore, other distinctions fail, the difference of the tail can be discerned at a single glance.

The viper differs firon most other serpents in being nuch slower, as also in excluding its young completely formed, and bringing them forth alive. The kindness of Providence seems cxerted, not only in ditninishing the speed, but also the fertility; of this dangerous creature. They copulate in May, and are supposed to be about three months before they bring forth, and have seldom above eleven eggs at a time. These are of the size of a blackbird's egg, and chained together in the womb like a string of beads. Each egg contains from one to four young ones; so that the whole of a brood nay amount to about twenty or thirty. They continue in the womb till they come to such perfection as to be ahle to burst from the shell; and they are said by their own efforts to creep from the confinement into the open air, where they continue for several days with- 
out taking any food whatsocver. "We have been ofien assured," says Mr. Pennant, "by intelligent people, of the truth of a fict, that the young of the viper, when terrified, will run down the throat of the parcint, and seek shelter in its belly in the sane manner as the young of the oppossum retire into the ventral pouch of the olil one. From this," contimues lic, "some lave jmagined that the viper is so unnatural as to devour its own young; but this deserves no credit, as these animals live upon frogs, toads, lizards, and young birds, which they olten swallow whole, though the morsel is often three times as thick as their own body."

The riper is capable of supporting very long abstinence, it being known that some have been kept in a box six months without food; yet during the whole time they did not abate of their vivacity. They feed only a small part of the year, but uever during their confinement; for if mice, their favourite diet, should at that lime be thrown isto their hox, though they will kill, yet they will never eat them. When at liberty, they remain torpid throughout the winter; yet, when confined, have never been observed to take their annual repose. Their poison, however, decreases in proportion to the length of their confinement; and it is thought that the virtues of the auimal's flesh are, by the same restraints, considerably lessened.

T'hey are usually taken with wooden tongs, by the end of the tail, which may be done without danger; for, while lıeld in that position, they are unable to wind themselves up to hurt their enemy : yet, notwithstanding this precaution, the viper-catchers are frequently bit by them; but, hy the application of oliveoil, the bite is effectually cured.

One William Oliver, a viper-catcher at Bath, was the first who discovered this admirable remedy. On the first of June, 1735, in the presence of a great number of persons, he suffered himself to be bit by an old black viper, (brouglut by one of the company,) upon the wrist and joint of the thumb of the right hand, so that drops of blood came out of the wound: he immediately felt a violeut pain both at the top of his thumb, and up his arm, eren before the viper was loosened from his liand; soon after he felt a pain, resembling that of buming, trickle up lis arm; in a few minutes his eyes began to look red and fiery, and to water much; in less than an hour he perceived the resom scize his heart; with a pricking pain, which was attended with faintness, shortness of hreath, and cold sweats; in a few minutes after this, his belly began to swell, with great gripings, and pains in lis back, which were attended with vomitingsand purgings: during the violence of these symptoms, his sight was gone for several minutes, but he could hear all the while. He said, that in his former experiments he had never deferred making use of lis remedy longer than he perceived the effects of the venom reaching his heart; but this time, being willing to satisfy the company thoroughly, and trusting to the speedy cffects of his remedy, which was nothing more than olive-oil, he abstained to apply any thing, till he found himself exceeding ill and quite giddy. About an hour and a quarter after the tirst of his being bit, a chafing-dish of glowing charcoal was brought in, and his naked arn was held over it, as near as he could bear, while his wife rubbed in the oil with her hand, turning his arm continually round, as if she would have roasted it over the coals: he said the poison soon ahated, but the swelling did not diminish much. Most violent-purgings and vonitings soon ensued; and his pulse became so low, and so often interrupted, that it was thought proper to order him a repetition of cordial potions: he said he was not sensible of any great relief from these; but that a glass or two of olive-oil drank down, seemed to give him case. Continuing in this dangerous condition, he was put to bed, where his arm was again bathed over a pan of charcoal, and rubbed with olive-oil, heated in a ladle over the charcoal, by Dr. Mortimer's direction, who was the physician that drew up the account. From this last operation he declared that he found immediate ease, as thougl by some charm: he soon after fell into a profound sleep, and, after about nine hours sound rest, awaked about six the next morning, and found himself very well; but in the afternoon, on drinking some rum and strong beer, so as to be almost intoxicated, the swelling returned, with much pain and cold sweats, which abated soon, on bathing 
the arm, as before, and wrapping it up in brown paper soaked in the oil.

Such are the effects of the viper's bite; yet its flesh has long been celebrated as a noble medicine. A broth, made by boiling one viper in a quart of water till it comes to a pint, is the uspal method in which it is given at present; and it is said to be a very powerful restorative in battered constitutions: the salt of vipers is aiso thought to exceed any other animal salt whatever, in giving vigonr to the languid circulation, and prompting to venery.

The Rattlesnake is bred in America, and in no part of the old worlu. Some are as thick as a man's leg, and six feet in length; but the most usial size is from four to five feet long. In most particulars it resembles the viper: like that animal, having a large head and a small neck, being of a dusky colour, and furnished with fangs that inflict the most terrible wounds. It differs, however, in having a large scale, which hangs like a penthouse over each eye. The eye also is furnished with a nictitating membratye, that preserves it from dust; and its scales are of a considerable degree of hardness, They are of an orange, tawny, and blackish eolour, on the back; and of an ash-colour on the belly, inclining to lead. The male may be readily distinguished from the female, by a black velvet spot on the head, and by the head being smaller and longer. But that which, besides their superior malignity, distinguishes them from all other animals, is.their rattle, an instrument lodged in their tail, by which they make such a loud, rattling noise, when they move, that their approach ina y readily be perceived, and the danger aroided. 'This rattle, which is placed in the tait, somewhat resembles, when taken out of the body, the curb chain of a brille: it is composed of several thin, hard, hollow bones, liuked to each other, and rattling upon the slightest motion. It is supposed by some, that the snake acquires an additional bone every year; and that, from hence, its age may be precisely known: however this may be, certain it is, that the young snakes, of a year or two old; have no rattles at all: while many old ones have been killed, that had from eleven to thirteen joints each. They shake and make a noise with these rattles with prodigious quickness when they are disturbed; however, the peccary and the vulture are no way terrified at the sound, but hasten, at the signal, to seize the snake, as their most favourite prey.

It is very different with almost every other animal. The certain death which ensues from this torrible creature's bite, makes a solitude wherever it is heard. It mores along with the most majestic rapidity; neither seeking to offend the larger animals, nor fearing their insults. If unpror oked, it nerer ineddles with any thing but its natural prey; but when accidentally trod upon, or pursuen to be destroyed, it then makes a dreadful and desperate defence. It ereots itself upon its tail, throws back the head; and inflicts its wound in a moment; then parts, aud inflicts a second wound : after which, we are told, by some, that it remains torpid and innctive, withant even atteinpting to escape.

The very instant the wound is inflicted, though small in itself, it appears more painful than the sting of a bee. This pain, which is so suldenly felt, far from abating, grows every moment more excrucialing and dangerous: tho limb swells; the renom reaches the head, which.is.soon of a monstrous size; the eyes are rect and liery; the heart beats quick, with frequent interruptions; the pain becomes insupportable, and some expire under it in five or six hours; but others, who are of stronger constitutions, survive the agony for a few hours longer, only to sink under a geueral mortification, whioh ensues, and corrupts the whole body.

As a gentleman in Virginia was walking in the fields for his amusement, he accidentally trod upon a rattlesnake, that had been lurking in a stony place; wlrich, enraged by the pressure, reared up, bit his band, and shook his rattles. The gentleman rearlily perceived that he was in the most dreadful danger; but unwilling to die nurevenged, he killed the snake, and carrying it home in his hand, threw it on the grounil before his family, crying out, "I am killed, and there is my murderer!"' In such an cxtremity, the specdiest remedies were the best. His arm, which was beginning to swell, was tied up near the shoulder, the womnd was anointed with oil, and every precaution taken to stop the infec- 
tion. By the help or a very strong constitution he recovered; but not without feeling the most various and dreadful symptoms for several weeks together. His arm, below the ligature, appeared of several colours, with a writhing amoug the muscles, that, to his terrified imagination, appearcd like the motions of the animal that had wounded him. A fever ensued; the loss of his hair, giddiness, drought, weakness, and nervous faintings: till, by slow degrees, a very strong habit overpowered the latent malignity of the poison.

Several remedies have been tried to alleviate this calamity. A decoction of the Virginian snake-root is considered as the most effectual; and at the same time the head of the animal bruised and laid upon the part affected, is thought to assist the cure. In general, however, it is found to be fatal; and the Indians, sensible of this, take care to dip their arrows in the poison under the rattlesnake's fangs, when they desire to take a signal revenge of their enemies.

Thus much concerning this animal is agreed upon by every naturalist: there are other circumstances in its history, which are not so well ascertained. And first, its motion, which some describe as the swiftest imagiuable; asserting, that its Indian name of Ecacoalt, which signifies the windserpent, implies its agility: others, on the contrary, assert that it is the slowest and the most sluggish of all serpents; and that it seldom moves from one place. In this opposition of opinions, there are others, who assert, that on even ground it moves but slowly; but then, among rocks, that it goes at a great rate. If we may argue from analogy, the opinion of those who contend for its slow motion, seems the most probable; as the viper, which it so very much resembles, is remarkable among scrrents for its inactivity.

It is said also by some, that the rattlesnake has a power of charming its prey into its mouth; and this is as strongly contradicted by others. The inhabitants of Pennsylvania are said to have opportunities of observing this strange fascination every day. The snake is often seen basking at the foot of a tree, where birds and squirrels make their residence. There, coiled upon its tail, its jaws extended, and its eyes shining like fire, the rattlesnake Ie- vels its dreadful glare upon one of the little animals above. The bird, or the squirrel, which ever it may be, too plainly perceives the mischief meditating against it, and hops from branch to branch, with a timorous, plaintive sound, wishing to avoid, yet incapable of breaking through the fascination: thus it continues for some time its feeble efforts and complaints, but is still seen approaching lower and lower towards the bottom branches of the trec, until, at last, as if overcome by the potency of its fears, it jumps down from the tree directly iuto the throat of its frightful destroyer.

In order to ascertain the truth of this story, a mouse was put into a large iron cage, where a rattlesnake was kept, and the effect carefully observed. The mouse remained motionless at one end of the cage; while the snake, at the other, continued fixed, with its eyes glaring full on the little animal, and its jaws opened to their widest extent: the mouse for some time seemed eager to escape; but every effort only served to increase its terrors, and to draw it still nearer the enemy; till, after several ineffectual attempts to break the fascination, it was scen to run into the jaws of the rattlesnake, where it was instantly killed.

To these accounts the incredulous oppose the improbability of the fact: they assert, that such a power ascribed to serpents, is only the remnant of a vulgar error, by which it was supposed that serpents could be charmed, and had also a power of charming. They aver, that animals are so far from running down the throat of a rattlesuake in captivity, that the snake will eat nothing in that state, but actually dies for want of subsistence.

A serpent, called the Whipsnake, is still more venonwus than the former. This animal, which is a native of the east, is about five feet long, yet not much thicker than the thong of a coachman's whip. It is exccedingly venomous; and its bite is said to kill in about six hours. One of the Jesuit missionaries, happening to enter into an Indian pagoda, saw what he took to be a whipcord lying on the floor, and stooped to take it up; but, upon handling it, what was his surprise to find that it was animated, and no other than the whipsnake, of which he had heard 
such formidable accounts: fortune, however, seemed favourable to him, for he grasped it by the head, so that it had no power to bite him, and only twisted its folds up his arm. In this manner he held it, till it was killed by those who came to his assistance.

To this formidable class might be added the Asp, whose bite however is not attended with those drowsy symptoms which the ancients ascribed to it. The Jaculus of Jamaica also, is one of the swiftest of the serpent kind. The Hainorrhois, so called from the hamorrhages which its bite is said to produce; the Seps, whose wound is very venomous, and causes the part affected to corrupt in a very short time; the Coral Serpent, which is red, and whose bite is said to be fatal. But of all others, the Cobra di Capello, or Hooded Serpent, inflicts the most deadly and incurable wounds. Of this formidable creature there are five or six different kinds; but they are all equally tangerous, and their bite followed by speedy and certain death. It is from three to eight feet long, with two large fangs hanging out of the upper jaw. It has a broad neck, and a mark of dark brown on the forehead; which, when viewed frontwise, looks like a pair of sueetacles; but behind like the head of a cat. The eyes are fierce and full of fire; the head is small, and the nose flat, though covered with very large scales, of a yellowish ash-colour; the skin is white, and the large tumour on the neek is flat, and covered with oblong, smooth scales. The bite of this animal is saicl to be incurable, the patient dying in about an hour after the wound; the whole frame being dissolved into one putrid nıass of corruption.

To remedy the bite of all these animals, perhaps salad-oil would be very efficacious: however, the Indians make use of a composition, which is called, in Europe, Petro de $\mathrm{Co}$ bra, or the Serpent-stone; and which applied to the wound, is said to draw out the venom. The composition of this stone, for it is an artificial substance, is kept a secret; and perhaps its effects in extracting the venom may be inaginary : nevertheless, it is certain that it has a power of sticking to the skin, and sucking a part of the blood from the wound. This it may do sonewhat in the same manner as we see a tobacco-pipe stick to the lips of a man who is smoking: yet still we are ignorant of the manner; and the secret might probably be of some use in medicine. It were to be wished, therefore, that those who go into India would examine into this composition, and give us the result of their inquiries: but I fear that it is not to benefit mankind, that our travellers now go to India.

\section{CHAPTER CLXVI.}

\section{OF SERPENTS WITHOUT VENOM.}

THE class of serpents without poison, may be distinguished fiom those that are venonous, by their wanting the fang-teeth : their heads, also, are not so thick in proportion to their bodies; and, in general, they taper off to the tuil more gradually in a point. But notwithstanding their being destitute of venom, they do not cease to be formidable: some grow to a size by which they become the nust powerful animals of the forest; and even the smallest and nost harmiless of this slender tribe, find protection from the similitude of their form.

The fangs make the great distinction among พо. $63 \& 64$. serpents; and all this tribe are without them. Their teeth are short, numerous, and, in the smaller kinds, perfectly inoffeusive : they lie in either jaw, as in frogs and fishes, their points bending backivarls, the better to secure their prey. They want that artificial mechanism by which the poisonous tribe inflict such deadly wounds: they have no gland in the head for preparing venom ; no conduits for conveying it to the teeth; no receptacles there; no hollow in the instrument that inflicts the wound. Their bite, when the teeth happen to be large enough to penetrate the skin, (for, in general, they are too small for this purpose,) 
is attended with no other symptoms than those of an ordinary puncture; and many of this tribe, as if sensible of their own impotence, canmot be provoked to bite, though never so rudely assaulted. They hiss, dart out their forky tongues, erect thenselves on the tail, and call up all their terrors to intimidate their aggressors; but seem to consider their teeth as unnecessary instruments of defence, and never attempt to usc them. Even amongst the largest of this kind, the tecth are never employed, in the most desperate engagements. When a hare or a bird is caught, the teeth may serve to prevent such small game from escaping; but when a buffalo or a tiger is to be encountered, it is by the strong folds of the body, by the fierce verberations of the tail, that the enemy is destroyed: by this twining round, and drawing the knot with convulsive cnergy, this enormous reptile breaks every bo:se in the quadruped's body, and then, at one morsel, devours its prey.

From lience we may distinguish the unvenomous tribe into two kinds: first, into tionse which are seldom found of any considerable magnitude, and that never offend animals larger or more powerful than themselves, but which find their chief protection in flight, or in the doubtfulness of their form; secondly, into such as grow to an enormous size, fear no enemy, but indiscriminately attack all other animals and devour them. Of the first kind is the Conmon Black Snake, the Blind Worın, the Esculapian Serpent, the Amphisbrena, and several others. Of the second, the Liboya, the Boiguacu, the Depona, and the Boiquatrara.

The Black Snake is the largest of English scrpents, sometimes exceeding four feet in length. The neek is slender; the middle of the body thick; the back and sides covered with small scales; the belly with oblong, narrow, transverse plaits : the colour of the back and sides are of a dusky brown; the middle of the back marked with two rows of small black spots, running from the head to the tail; the plaits on the belly are dusky; the seales on the sides are of a bluish white; the teeth are small and serrated, lying on each side of the jaw in two rows. The whole species is perfectly inoffensive; takiug shelter in dunghills, and among bushes in moist places; from whence they seldom remove, unless in the midst of the day, in summer, when they, are called out by the heat to bask themselves in the sun. If disturbed or attacked, they move away among the brambles with great swifuess; but if too closely pursued, they hiss and ihreaten, and thus render thenisclyes formidable, though incapable of offending.

The black snake preys upon frogs, insects, worms, micc, and youmg birds : and, considering the smalluess of the neck, it is amazing how large an aninnl it will swallow. The black snake of Virginia, which is larger than ours, and generally grows to six feet long, takes a prey proportionable to its size; partridges, chickens, and young duclis. It is generally found in the rieighbourhood of the lien-roost, and will devour the cggs even while the hen is sitting upon them: these it swallows whole, and often after it has done the mischief will coil itself round in the nest.

'The whole of this tribe are oviparous, excluding eighty or a lundred eggs at a tine, which are laid in dunglills or hotbers; the heat of which, aiderl by that of the sun, brings them to maturity. During winter they lie torpid, in banks of edges, and under old trees.

The Blind Worm is another harmless reptile, with a formidable appearance. The usual length of this species is eleven inclies. The eyes are red; the head sniall; the neck still more slender; from that part the body grows suddenly, and continues of an cqual bulk to the tail, which ends quite blunt: the colour of the back is cinereons, marked with very small lines, composed of mimute black specks; the sides are of a reddish cast; the belly dusky, and marked like the back. The motion of this serpent is slow; from which, and from the smalness of the eyes, are derived its names; some calling it the slow and sone the blind worm. Like all the rest of the kind in our climates, they lie torpid during winter; and are sometimes found in vast numbers, twisted twgether. This animal, like the former, is perfectly innocent; however, like the viper it brings forth its young alive. Gesner tells us, that one of these being struck on the head when it was pregnant, it immediately cast forth its young.

The Amphisbaena, or the Double Headed Serpent, is remarkable for moving along with either the head or the tail foremost; and from 
thence it has been thought to have two heads. This error took its rise from the thickness of the tail, which, at a distance, may be mistaken for another head. Upon a nearer view, however, the error is easily discovered, and the animal will be found formed according to the usual course of nature. It is as thick at one end as at the other; and the colour of the skin is like that of the earth, being rough, hard, and variously spotted. Some have affirmed that its bite is dangerous; but this unust be a mistake, as it wants the fangs, and, consequently, the elaboratory that prepares the poison.

These animals are only formidable from their similitude to the viper tribe; and, in some countries, where such reptiles are conmon, they make the distinction so exactly, that while they destroy serpents of one kind with great animosity, they take others into their houses, and even into their bosoms, with a kind of unaccountable affection. The Esculapian Serpent of Italy is among this num. ber. It is there suffered to crawl about the chambers; and often gets into the beds where people lie. It is a yellow serpent, of about an ell long; and, though innocent, yet will bite when exasperated. They are said to be great destroyers of mice; and this may be the reason why they are taken under human protection. The Boyuna of Ceylon is equally a favourite among the natives; and they consider the meeting it as a sign of good luck. The Surinam Serpent, which some improperly call the Ammodytes, is equally harmless and desirable among the savages of that part of the world. They consider themselves as extremely happy if this animal comes into their huts. The colours of this serpent are so many and beautiful, that they surpass all description; and these, perhaps, are the chief inducements to the savages to consider its visits as so very fortunate. A still greater favourite is the Prince of Serpents, a native of Japan, that has not its equal for beauty. The scales which cover the back are reddish, finely shaded, and marbled with large spots of irregular figures mixed with black. The fore part of the head is covered with large beautiful scales, the jaws bordered with yellow, the forehead marked with a black marhled streak, and the cyes handsome and live- 1y. But of all others, the Gerenda of the East Indies is the most honoured and esteem. ed. To this animal, which is fincly spotted with varions colours, the natives of Calicut pay divine honours; and while their deity lies coiled up, which is its usual posture, the people fall upon their laces before it with stupid adoration. The African Gerenda is larger, and worshipped in the same manuer by the inhabitants of the east of Mosambique. The skin is not so finely spotted as the former; but it is rariegated all over the body with very tine, white, ash-coloured, and black: spots. The brilliancy of colouring in these reptiles would only serve with us to increase onr disgust; but in those countries where they are, common distinctions are made; and even in this horrid class, there are some eyes that can discover beauty.

But in the larger tribe of serpents, there is nothing but danger to be appreliended. This formidable class, though without venom; bave something frightful in their colour, as well as their size and form. They want that vivid hue with which the savages are so much pleased in the lesser kinds; they are all found of a dusky colour, with large teeth, which are more formilable than dangerous.

The first of this class is the Great Liboya of Javi and Brasil, which Legaut affirms, he has seen fifty feet long. Nor is lie singular in this report, as many of the missionaries affirm the same; and we have the concurrent testimony of historians as a further proof. The largest animal of this kind which has been brought into Europe, is but thirty-six feet long; and it is probable, that much greater have been seen and destroyed, before they were thought worth sending so far to satisly European curiosity. The inost usual length, however, of the liboya, is about twenty feet, and the thickness in proportion. The teeth are small in proportion to the body; nor are they used, but when it seizes the sinallest prey. It lies in wait for wild animals near the paths, and when it throws itself upon them, it wraps them round so closely as to break all the bones; then moistening the whole body over with its slaver, it makes it fit for deglutition, and swallows it whole.

The Boiguacu is supposed to be the next in magnitude, and has often been seen to swal- 
low a goat whole. It is thickest in the middle of the body, and grows shorter and smaller towards the head and the tail : on the middle of the back, there is a chain of small black spots running along the length of it; and on each side, there are large, round, black spots, at some distance from each other, which are white in the centre: between these, near the belly, there are two rows of lesser black spots, which run parallel to the back. It has a double row of sharp teeth in eacls jaw, of a white colour, and shining like mother-of-pearl. "The hend is" broad; and over the eyes it is raised into two prominences: near the extremity of the tail there are two claws, resembling those of birds.

These serpents lie hid in thickets, from whence they sally out unawares, and raising themselves upright on their tails, will attack both men and beasts. They make a loud, hissing noise when exasperated ; and sometimes winding up trees, will dart down upon travellers, and twist themselves so.closely round their bodies, as to despatch them in a very few minutes. Condamine, however, affirms, that their bite is not dangerous; for though the teeth are so large as to inspire the beholder with terror, yet the, wound they make is attended with no dangerous consequences whatever. Dellon affirms, that they generally haunt desert places; and though they are sometimes seen near great towns, or on the banks of rivers, yet it is generally after some great inundation: he never saw any but what were dead; and they appeared to him like the trunk of a great tree lying on the ground.

To this class of large serpents, we may refer the Depona, a native of Mexico, with a very large head and great jaws. The mouth is armed with cutting, crooked teeth, among which there are two longer than the rest, placed in the fore part of the upper jaw, but very different from the fangs of the viper. All round the mouth there is a broad scaly border; and the eyes are so large, that they give it a very terrible aspect. The forehead is covered with very large scales; on which are placed others, that are smaller, curiously ranged: those on the back are grayish, and along it runs a double chain, whose ends are joined in the manner of a buckler. Each side of the belly is marbled with large square spots, of a chesnut colour, in the middle of which is a spot, which is round and yellow. They aroid the sight of man; and, consequently, never do much harm.

Such are the most noted animals of the serpent tribe; but to recount all, would be a vain, as well as a useless endeavour. In those countries where they abound, their discriminations are so numerous, and their colours so various, that every thicket seems to produce a new animal. The same serpent is often found to bring forth animals of eight or ten different colours: and the naturalist who attempts to arrange them by that mark, will find that he has made distinctions which are entirely disowned by nature: however, a very considerable number might be added to enlarge the catalogue; but having supplied a general history, the mind turns away from a subject where every object presents something formidable or loathsome to the imagination. Indeed, the whole tribe - resemble each other so nearly, that the history of one may almost serve for every other. They are all terrible to the imagination, all frightful to behold in their fury, and have long been considered as a race of animals between whom and man there is a natural antipatby. 


\section{(1) Nomerts.}

\section{OF INSFCTS OF THE TIRST ORDER.}

\section{CHAPTER CLXVII.}

\section{OF INSECTS IN GENERAL.}

HAVING gone through the upper ranks of nature, we descend to that of insects, a subject almost inexhaustible from the number of its tribes and the variety of their appearance. Those who have professedly written on this subject scem to consider it as one of the greatest that can occupy the human mind, as the most pleasing in Animated Nature. "After an attentive examination," says Swammerdam, " of the nature and anatomy of the smallest as well as the largest animals, I cannot help allowing the least an equal, or perhaps a superior, degree of dignity. If, while we dissect with care the larger animals, we are filled with wonder at the elegant disposition of their parts, to what a height is our astonishment raised, when we discover all these parts arranged in the least in the same regular manner! Notwithstanding the smallness of ants, nothing hinders our preferring them to the largest animals. If we consider either their unwearied diligence, their wonderful strength, or their inimitable propensity to labour. Their amazing love to their young is still more unparalleled among the larger classes. They not only daily carry them to such places as may afford them food; but if, by accident, they are killed, and even cut into pieces, they, with the utmost tenderness, will carry them away pieceneal in their arms. Who can show such an exainple among the larger animals which are dignified with the title of perfect? Who can find an instance in any other creature that can come in competition with this?"

Such is the language of a man, who, by long study, became enamoured of his subject; but to those who judge less partially, it will be found that the insect tribe, for every reason, deserve but the last and lowest rank in Animated Nature. As in mechanies the most complicated machines are required to perform the nicest operations, so in anatomy the noblest animals are most variously and wonderfully made. Of all living beings, man offers the most wonderful variety in lis internal conformation; quadrupeds come next, and other animals follow in proportion to their powers or their excellencies. Insects seem of all others the most imperfectly formed: from their minuteness, the dissecting knife can go but a short way in the investigation; but one thing argues an evident imperfection, which is, that many of them can live a long time, though deprived of those organs which are necessary to life, in the higher ranks of nature. Many of them are furnished with lungs and a heart, like nobler animals; yet. 
the caterpillar continues to live, though its heart and lungs, which is often the case, are cntirely eaten away.

But it is not from their conformation alone that insects are inferior to other animals, but from their instincts also. It is true that the ant and the bee present us with very striking instances of assiduity; but how far are their's beneath the marks of sagacity exhibited in the hound or the stag! a bee, taken from the 6warm, is totally helpless and inactive, incapable of giving the sinallest variation to its instinets: it has but one single method of operating, and, if put from that, it can turn to no other. In the pursuits of the hound, there is something like a choice; in the labours of the bee, the whole appears like necessity or compulsion.

If insects be considered as bearing a relation to man, and as assisting him in the pleasures or necessities of life, they will, even in this respect, sink in the comparison with the larger tribes of nature. It is true that the bee, the silk-worm, the cochineal fly, and the cantharides, render him signal services; but how many others of this class, are either noxious or totally unserviccable to lim. Even in a country like ours, where all the noxious animals have been reduced by repeated assiduity, the insect tribes still maintain their ground, and are but too often unwelcome intruders upon the fruits of human industry. But in more uncultivated regions, their annoyance and devastations are terrible. What an uncomfortable life must the natives lead in Lapland, and some parts of America, where it a candle be lighted, the insects swarm in such abundance, as instantly to extinguish it with their numbers; where the inhabitants are obliged to smear their bodies and faces with tar, or some other composition, to protect them from the puncture of their minute cicemies; where, though millions are destroyed, famished millions are still seen to succecd, and to make the torture endless!

Thcir amazing numlier is also an argument of their imperfection. It is a rule that obtains through all nature, that the nobler animals are slowly produced, and that nature acts with a kind of dignified economy; but the meaner births are lavished in profusion. and thousands are brought forth merely to supply the necessities of the more favourite ohjects of Creation. Of all other productions in nature, insects are the most numerous. Vegetables that cover the surface of the earth bear no proportion to their multitudes; and though, at first sight, herbs of the field seem to be the parts of organized nature produced in the greatest abundance, yet upon minuter iuspection, we shall find every plant supportii:g a number of scarce perceptible creatures, that fill up the rarions stages of youth, vigour, and age, in the compass of a few days existence.

All other animals are capable of some degree of education; their iustincts may be suppressed or altered; the dog may be taught to fetch and carry; the hird to whistle a tune; and the serpent to dance; but the insect has but one invariable method of operating; no arts can turu it from its instincts; and, indeed, its life is too short for instruction, as a single season often terminates its existence.

For these reasons, the insect tribe are deservedly placed in the lowest rank of Animated Nature; and, in general, they seem more allied to the vegetables on which they feed, than to the noble classes abore them. Many of them are attached to one vegetable, often to a single leaf; there they increase: with the flourishing plant, and die as it decays; a few days fill up the measure of their contemptible lives; while the ends for which they were produced, or the pleasures they enjoyed, to us, at least, are utterly unknown.

Yet while I am thus fixing the rank of a certain class of animals, it secms necessary to define the nature of those animals which are thus degraded. Definitions in general produce little knowledge; but here, where the shades of nature are so intimately blended, some discrimination is necessary to prevent confusion. The smallness of the animal, for instance, does not constitnte an insect; for then, many of the lizard kind, which are not above two inches long, would come under this denomination. and if the smaller lizards, why not the crocodile? which would be a terrible insect indeed! In the same manner, smallness, with a slow creeping motion, does not constitute an insect; for, though snails might be called insects, with the same propriety the whole tribe of sea shell-fish would then have 
equal pretensions; and a very troublesome innovation would be brought into our language, which is already formed. Excluding such animals, therefore, from the insect tribe, we may define insects to be little animals without red blood, bones, or cartilages, furnished with a trunk, or else a mouth, opening lengthwise, with eyes which they are incapable of covering, and with lungs which have their oponings on the sides. This delinition comprehends the whole class of insects, whether with or without wings; whether in their caterpillar or butterfly state; whether produced in the ordinary method of generation between male and fenale, or from an animal that is itself both male and female, or from the same animal cut into several parts, and each part producing a perfect animal.

From hence it appears, that in this class of animals there are numerous distinctions, and that a general description will by no means serve for all. Almost every species has its own distinct history; and exhibits manners, appetites, and modes of propagation, peculiarly its own. In the larger ranks of existence, two animals that nearly resemble each other in form will be found to have a similar history; but here insects almost entirely alike will be often found perfectly dissimilar, as well in their manner of bringing forth and subsisting, as in the changes which they undergo during their short lives. Thus as this class is prolific beyond computation, so are its varieties multiplied beyond the power of description. The attempt to enumerate all the species of a fly or a moth would be very fruitless; but to give a history of all would be utterly impracticable; so various are the appetites, the manners, and the lives of this humble class of beings, that every species requires its distinct history. An exact plan, therefore, of nature's operations in this minute set of creatures is not to be expected; and yet such a general picture may be given, as is sulficient to show the protection which Providence affords its smallest as well as its largest productions, and to display that admirable circulation in nature by which one set of living beings find subsistence from the destruction of another; and by which life is continued without a pause in every part of the Creation.
Upon casting a slight view over the whole insect tribe just when they are supposed to rouse from their state of annual torpidity, when they hegin to feel the genial influence of spring, and again exhibit new life in every part of nature, their numbers and their varieties seem to exceed all powers of calculation, and they are indeed too great for deseription. When we look closer, however, we shall find some striking similitudes, either in their propagation, their manners, or their form, that give us a hint for grouping several of them into one description, and thus enabling us to shorten the labour of a separate history for every species. Swammerdan, Reaumur, and Limnus, have each attempted to abridge the task of description, by throwing a number of similar animals into distinct classes, and thus making one general history stand for all. I will avail myself of their labours; and uniting their general distinctions, throw the whole class of insects into four separate clistributions, giving under each the history of every species that seems to me considerable enough to deserve our notice. Thus our labour will be shortened; and the very rank in which an insect is placed, will, in some measure, exhibit a considerable part of its history.

In our cursory inspection of the insect tribe, the first anims ls that offer themselies are those which want wings, that appear crawling about on every plant, and on every spot of earth we regard with any degree of attention. Of these, some never obtain wings at any period of their existence, but are destined to creep on the regetable, or the spot of earth where they are stationed for their whole lives. On the contrary, others are only candidates for a more happy situation; and only wait their growing wings, when they inay be said to arrive at their state of full perfection.

Those that never have wings, but creep about till they die, may be considered as constituting the rrrst chass of insects. All these, the flea and the wood-louse only excepted, are produced from an egg; and when once they break the shell, they never suffer any further change of form. but continue to grow larger till they die. Thus the louse or the spider are produced from an egg, never suffering any alteration when once they are excluded; but, like the chicken or the duck 
remaining invariably the same, from their birth to their dissolution.

The SFCOND ORDER of insects consists of such as have wings; but which, when produced from the egg, have those wings cased up in such a manner as not to appear. This casing up of the wing, however, does not prevent the animal's running, leaping, and moviug with its natural celcrity; but when the case bursts, and the wings have a power of expanding, all the animal's motions become more extensive, and the animal arrives at full perfection. Thus the grasshopper, the dragonfly, and the ear-wig, have their wings at first bound down; but when the skin that, like a pair of stays, kept them confined, bursts, they are then expanded, and the animal pursues the purposes for which it was produced.

The THIRD ORDER of insects is of the moth and butterfly kind. These all have four wings, each covered with a mealy substance of various colours, which when handled comes off upon the fingers; and, if examined by the microscope, will appear like scales, with which the wing is nicely, embroidered all over. These insects also are produced in a manner peculiar to themselves. They are first hatched from an egg, from whence proceeds a caterpillar that eats, and often casts its skin; the caterpillar having divested itself for the last time, assumes a new covering, which is called a chrysalis, or the cone in the silk-worm, in which it continues hidden till it comes forth a perfect moth, or butterfly.

The FOURTH ORDER is of those winged insects which come from a worm instead of a caterpillar, and yet gothrough changes similar to those which moths and butterflies are seen to undergo. They are first excluded from the egg as a worm, and then become a chrysalis; in some, their wings and legs are seen; in others, the animal is quite detached from the cone in which it is concealed; but all at length break their prison, and come out perfect winged animals; some furnished with two wings and some with four. The wings of all these differ from those of the butterfly and moth kind, by not having the mealy scales which are ever found on the wings of the former. In this class we may place the numerous tribes of gnats, beetles, bees, and flies.

To these I will add, as a FIFTH oRDER, a numerous tribe lately discovered, to which naturalists have given the name of Zoophytes. These do not go through the ordinary forms of gencration, but may be propagated by dissection. Some of these, though cut into a hundred parts, still retain life in each, and are endued with such a vivacious principle, that every part will in a short time become a perfect animal. They seem a set of creatures placed between animals and vegetables, and inake the shade that connects Aunmated and Insensible Nature. To this class belong the polypus, the earth-worm, and all the varieties of the sea-nettle.

Having thus given a generel distribution of insects, I will proceed to describe each class in the order I have mentioned them; beginning with insects without wings, as they more nearly resemble the higher ranks of nature, as well in their habits as their conformation.

\section{CHAPTER CLXVIII.}

\section{OF INSECTS WITHOUT WINGS.}

EVERY moment's ohservation furnishes us with instances of insects without wings; but the difficulty is to distinguish those which are condemned continually to lead reptile lives, from such as only wait the happy moment of transmutation. For this, nothing hut a long and intimate acquancance will suffice; but, in general, all animals resembling the flea, the louse, the spider, the bug, the wood-louse, the water-louse, and the scorpion, never acquire wings, but are produced from the egg in that form which they never change afterwards. 
If we consider this class as distinct from others, we slaall find them in general longer lived than the rest, and often continuing their term beyond one season, which is the ordinary period of an insect's existence. They secus also less subject to the influence of the weather; and often 'ndure the rigours of winter without being numbed into torpiclity. The whole race of inoths, butterfies, bees, and flies, are rendered lifeless, by the return of cold weather; but we need not be told, that the lonse, th. Hed, ant many of these wingless ereatures that seem formed to teaze mankind, continue their painful depredations the whole year round.

They come to perfection in the erge, as was said belore; and it sometimes happens, that when the animal is intermpted in perioning the offices of exclusion, the young ones harst the shell within the parent's body, and are thus bronght forth alive. 'This not unfieguently happens with the wood-louse, and achers of the kind, which are sometimess seen producing egges, and so.netimes young ones perfectly formed.

Though these crcatures arc perfect from the beginning, yet they are often, during their existence, seen to change their skin: this is a faculty which they gorsess in common with many of the higher ranlss of nnimats, and which answers the same purposes. How ever tender their skins may srem to our feel, yet, if compared to the animal's strength and size, they will be found to resemble ni coat of inail, or, to talk more closely, the slicll of a lobster. By this skin these animals are delended from aecisientil injuries, and particularly from the attacks of each other. Within this they continue to grow, till tbeir bosdies become so large as to be intisprisoned in their own covering, and then the shell bursts, but is quickly replaced by a new one.

Lasily, these animals are condued with a degree of strength for their size, that at first might exceed credibility. Llad a man an equal degree of strength, bulk for bulk, with a louse, ir tlea, the lisțtory of Sanson would be no longer niraculous. A flea will draw a chain a hundred times heavier than itself; an! to compensate for this force, will eat ten times its own size of provision in a singlc day.

\section{CHAPTER CLXIX.}

\section{OF THE SPIDER AND ITS VARIETIES.}

THE animal that deserves our first notice in this principal order of insects is the spider, whose mamers are, of all others, the most sulule, and whose instincts are most various. Formed for a life of rapacity, and incapahle of living upon any other than insect food, all its habits are calculated to deceive and surprise ; it spreads tuils to entangle its prey ; it is endued with patience to expect its coming ; and is possessed of arms and streugth to dcstroy it when fallen into the smare.

In this country, where all the insect mibes are kept unler hy hunan assiduity, the spiders are but small and harmless. We are acquainted with few, but the house-spider, which weaves its web in neglected rooins; the garden-spider, that spreads its toils from tree to tree, and rests in the centre; the wanderingspicler, that lias no abode like the rest; and жо. $63 \& 64$. the field-spider, that is sometinies scen mourting, web and all, into the clouds. These are the chief of our native spiders; which, though reputed veuomous, are entirely inoffensive. But they form a mucli more terrible tribe in Afiica and Anerica. In those regions, where all the insect species acquire their greatest growth, where the butterfy is seen to expand a wing as broad as our sparrow, and the ant to build a habitation as till as a man, it is not to be wondered at that the spiders are seen bearing a proportionable magnitude. In fact, the hottom of the Martinicu spider's body is as large as a hen's egg, and covered all over with bair. Its web is strong, and its bite dangerous. It is happy for us, however, that we are placed at a distance from these formidable creatures, and that we can examine their his. tory without fecling their resentment. 
Every spiller has two divisions in its body. 'The fore part, containing the head and breast, is sepurated from the linder part or belly by a very slenter thread, llirough which, however, there is a communication from one part to the other. The fore part is covered witls a liaril shell, as well as the legs, which adhere to the breast. 'The hiuder part is clorhed will a supple skin, beset all over with bait. 'liey have scveral eyes all round the head, brilliant and acute; these are sometimes eiglit jI number, somerines but six; two behind, two hefore, and the rest on each side. Like all oner insects, cheir 'yes are inmorcable, and they want eye-lids; but this organ is fircified with a triusparent horny substance, which at once sceures and assists their vision. As the animal procures its subsistence by the inost warchiful artention, so large a number of eyes was necessary to give it the cat liest informarion of the capture of its prey 'They have two pincers or: the fore part of the head, rough, witlı strong points, toorhed like a saw, and rerminating in claws like those of a cat. A little below the point of the claw there is a small hole, through which the animal emits a proison, which, though harmless to us, is sufficiently capable of instantly destroying its prey. This is the most powertul weapon they. have against their enemies; they can open or extend these pincers as occasion may require; and when they are undisturbed, they suffer them to lie one upon the other, never opening them but wlien there is a necessity for their exertion. 'They have all eight legs, jointed like those of lobsters, and similar also in another respect; for if a leg be torn away, or a joint cut off, a new onc will quickly grow in its place, and the animal will find irself fitted for combat as before. At the end of each leg there are three crooked moveable claivs; namely, a small one, placed higher up, like a cock's spur, by the assistance of which it adheres to the threads of its web. There are two others larger, which meet together like a lohster's claw, by which they can catch hold of the smallest depressions, walking up or down the very polished surfaces, on which they can find inequalities that are imperceptible to onr grosser sight. But when they walk upon such borlies as are perfectly smooth, as looking-glass or polished marble, they squeeze a little sponge, which grows near the extremity of their claws, and thus diffusing a glutinous substance, adhere to the surface until they make a second step. Besides the eight legs just mentioned, these animals have two others, which may more properly be called arms, as they do not serve to assist motion, but are used iulolding and nuanging their prey.

The spider, though thus formidably equipped, would seldon prove successful in the capture, were it not equally furnished will other instruments to assist its depredations. As it lives wholly upon flies, and is without wings to pursue them, it is obvious they nust fol ever escape so inıpotent an adversary ; lut the spider is a nost experienced hunter, and sprearls irs nets to ('atch those animals it is unable to pursue. The spider's web is generally laid in those places where flies are must apt to come and shelter; in the corners of roons, round the edges of wiudows, and in the open air anong the branches of trees. There the little animal remains for days, nay, wecks togetler, in patient expectation, seldom clianging its situation though never so unsuccessliul.

For the purposes of nuking this web, nature has supplied this animal with a large quantity of glutinous matter within its bonly, and five dugs or teats for spinning it into thread. This substanee is contained in a little bag, and at first sight it resembles soft glue; but when examined more aceuratcly, it will be found twisted into nuny coils of an agate colour, and upon breaking it, the contents may be easily drawn out into threads, from the tenacity of the substance, not from those threads being already furmed. Those who have scen the machinc by which wire is spun, will have an idea of the manner in which this animal forms the tlureads of its little net, the orifices of the five teats above mentioned, throngh which the thread is drawn, contracting or dilating at pleasure. The threars which we sce, and appear so fine, are, notwithstanding, composed of five joined, together, and these are many times doubled when the web is in formation.

When a house-spider nroposes to begin a web, it first makes choice of some conımodions spot, where there is an appearance of plunder and sccurity. The animal then distils one little diop of its glutinous liquor, which is very tenacious, and then ereeping up the wall, and joining its thread as it proceeds, it darts itself in a very surprising inanner, as I 
have often seen, to the opposite place, where the other end of the web is to be fastened. The first thread thus formed, drawn tight, and fixed at each end, the spider then runs upou it backward and forward, still assiduously employed in doubling and strengthenitg it, is upon its force depends the strength and stability of the whole. The scaffolding thus completed, the spider makes a number of threads parallel to the first, in the same mamner, and then crosses them with others; the (lammy substance of which they are formed, strving 10 bind them, when newly nade, to each other. 'The insect, after this operation, doubles and trebles the thread that borders its web, by opening all its teats at once, and secures the edges, so as to prevent the wind from blowing the work away. The edges being thus fortified, the retreat is next to be attended to; and this is formed like a funnel at the bottom of the web, where the litcle creature lies concealed. To this are two passages, or ontlets, one above and the other below, very artfully cuntriverl, to give the animal an opportunity of inaking excursions at proper sensons, of prying into every corner, and cleaning those parts which are observed to be clogged or encumbered. Still attentive to its web, the spider, from time to time, cleans away the dlust that gathers round it, which might otherwise clog and incommode it: for this purpose, it gives the whole a shake with its paws; still, however, proportioning the blow so as not to endanger the labric. It often happens also, that from the main web there are several threads extended at some distance on every side; these are, in some measure, the outworks of the fortification, which, whenever toucbel from without, the spider prepares for attack or sell-defence. If the insect impinging be a fly, it springs forward with great agility ; if, on the comtrary, it be the assautc of an enemy stronger than itself, it keeps within its fortress, and never ventures out till the danger be over. Another advantage which the spider reaps firom this contrivance of a cell or retreat behind the web, is, that it serves for a place where the crealure can feast upon its game with all safety, and conceal the fragments of those carcasses which it has picked, without exposing to public view the least trace of barbarity, that might create a suspicion in any insects that their enemy was near.
It often happens, however, that the wind, or the rustling of the branches, or the approach of some large animal, destroys in a mimus lise. labours of an age. In this case, the spider is obliged to remain a patient spectator of the universal ruin; and when the danger is passed away, it sets about repairing the calamity. For this purpose, it is furnished with a large store of the glutinous substance of which the web is made; and with this, it either makes a new web, or parches up the old one. In gencral, however, the animal is nuch fonder of mending than making, as it is furnished originally with hut a certain quantity of glutinous matter, whirh, when exhausted, nowhing can renew. The time seldom fails to come, when their reservoirs are entirly dried up, and the poor animal is left to all the ehances of irretrievable necrssity. An old spicler is thus firequently reduced to the grealest extremity; is web is destroyel, and it wants the materials to make a new one. But as these animals have been long accustomed to a life of shifing, it hunts about to find out the web of another spider, younger and weaker than itsclf, with whon it veutures a battle. The invader generally succeeds; the young one is driven out to make a new web, and the old one remains in quiet possession. If, however, the spider is unable to dispossess any other of its web, it then endeavours, for a while, to subsist upon accidental deprcdation; but in two or three months it inevitably dies of hunger.

The garden-spider seems to work in a differcut manner. The method with this insect is to spin a great quantiry of thread, which floating in the air in various dirccions, happens from its glutinous quality, at last to stick to some object near it, a lofity plant or the branch of a tree. The spider only wants to have one end of the line fasi, in orter to secitre and tighten the other. It accordingly draws the line when thus fixed, and then hy prssing and repassing upon it, strengtheus the thread in such a manner as io answer all its intentions. The first cord being thus stretehed, the spider walks along a part of it, and there fastens another, and dropping from thence, fastens the thread to some solid body helow, then climbs up again and begins a third, which it fastens by the same contrivance. When three threads are thus fixed, it forms a square, 
or something that very ncarly resembles one, and in this the animal is genterally seen to reside. It ofien happens, however, when the young spider begias spinming, that is web becomes too baloyat, and not omly the threat hoats in the air, but cvell the littic spinster. In this manney we have ofien seen the threads of spiclers floariug in the nir ; and what is still more surprising, the young spiders theinselves attached to their own web. The reison is obvious; for as even gold itself may be so finely drawn out as to float in the air, so the finer thread of a spider is so huoyant as not only to swin in the air, but also to lift the spider itsell; which, like the tail of a kite, rises with its own :manufacture.

Thé spicler's wel, being thus completed, nud fixed in a propel place, its next care is to seize. and secure whatever insect happens to be caught in the toil. For this purpose, it remains for wceks and rven months upon the watch, without ever catching a single fly ; for the spider, like monst other insects, is surprisingly patieut of hunger. It sometimes happens that too stiong a fiy strikes itself agaiust the web, and thus, instead of being caught, tears the net to pieces. In general, however, the butterfly or the hornet, when they touch the web, fly off again, and the spider seems no way disposed to interrupt their retreat. The large blue-bottle-fly, the ichneumon-fly, and the common meat-fly, seems to be its favourite gaine. When one of these strike into the toils, the spider is instantly seen alert and ivatchful at the mouth of its hole, careful to observe whether the fly be completely immeshed: if that be the case, the spider walks leisurely forward, seizes its prey, and instantly kills it by instilling a venomous juice into the wound it makes. If, however, the fly be not entirely inmeshed, the spider patiently waits, without appearing until its prey has fatigued itself by its struggles to obtain its liberty; for if the ravager shmuld appear in all his terrors while the prey is but half involved, a desperate effort inight give it force enough to get free. If the spicler has fasted for a long time, it then drags the fly inmediately into its hole and devours it; but if there has been plenty of game, and the animal be no way pressed by hunger, it then gives the fly two or three turns in its web, so as completely to immesh it, and there leaves it imputently to struggle until the little tyrant comrs to its appetite. Why the spider should at one time kill its prey, and at another suffer it to struggle in the toils for several hours togather, I am not able to say; perhaps it only likes its prey newly killed, and themfure delays to put the caprive to death until it is to be caten.

It lias been the opinion of sone philosnphers, that the spiller was in itselt both mele aud female; but Lister has been able to distinguish the sexes, and to perceive that the males were nuch less in size than the fonales. But this is not the chief peculiarity; for, different from all oiher animals, except the fish called the $R r y$, it has its instruments of generation placed in the fore-arms, which lave been already rlescribed. When these animals copulate, they for some time tease each other with their legs and arms, then appear the instruments of generation in the male, as if bursting out from the points of its fore feet, and are iuserted into the receptacle bencath the body of the feinale.

The fenale gencrally lays from nine hundred to a thousand eggs in a season; they are of a bluish colour, speckled with black, and separated from each other by a glutinous substance, not unlike firog spawn water. These eggs are large or small in proportion to the size of the auinal that produces them. In some they are as large as a grain of mustardseed; in others, they are searcely visible. The female never begins to lay till she he two years old at the least, and her first brood is never so numerous as when she has corric to her greatest maturity.

When the number of eggs which the spider has brought forth, have remained for an bour or two to dry after exclusion, the litte animal then prepares to make them a bag, where thi'y are to be hatched until they leave the shell. For this purpose, she spins a web four or five times stronger than that marle for catching flies; and besides, lines it wishin side by a down, which she plucks from her uw breast. This bag, when completed, is as lhick as paper, is smooth within side, lut rouglier without. Within this they deposice their eggs; and it is almost incredible to relate the crincern and inclustry which they bestow in the preservation of it. They stick it by means of their glutinous fluid in the end of their body; so that the aninual, when thus loaded, appears 
as if she had one body placed behind another. If this bag be separated from her by any accident, she cinploys all her assiduity to stick it again in its forner situation, ant seldom abonduns her treasure but with here life. When the young ones are excluded from their shells, within the bag, they remain for some tine in their confinement, intil the female, instinctively knowing their inaturity, bites open their prison, and sets them free. But her parental care does not terminate with their exclusion; she receives them upon lier back for some time, until they lave strength to provide for themselves, when thoy leave ber never to return, and each begius a separate ununfactory of its own. The young ones begin to spiu when they can scarcely be discerned; and prepare for a life of plunder before they have strength to overcome. Indeed, nature sefnss to bave formed them in every respeci for a lite of hostility. No ofber insect is possessed of such various powers of assault and defence; and they are able to destroy animals ten times bigurer than thenselves. Even after a severe defeat, they quickly recover of their wounds; and as for their lege, they consider the loss of them as but a small misfortune, as they grow again very. speedily to their forner magnitudle.

Thus there is no insect to which they are not an enemy; but what is more barbarrus still, spiders are the enemies of each onther. Mr. Reaunur, who was lond of making experiments upron insects, tricel to turn the labours of the spider to human advantage, and actuatly made a pair of gloves frrm their webs. Fur this purpose, he collected a large number of those insects together: he took care to have then constantly supplied with Hies, and the crids of young feathers, lresh picked from chickens and pigeons, which beinir liul of bloosl, are a diet that spiders are particularly fond of. But, notwitlistandiug all his cure, he was som convinced timat it was impraciicable to rear them, since they were of such a maliguant nature, that they could never ba brought to live in society ; but instearl of their usual forl, chose to devour each other. Indeed, were it pracieable to reconcile them to each other, it would require ton much attendance to rear up a sufficicnt number to make the project any way useful. Their threarl is four, if not five times finer than that of the silk- worm; so that upon the smallest calculation, there must have been sixty thousand spiders to make a single pound of silk. That which Reaumur made use of was only the web in which they deposited their eggs, which is five times stronger than their ordinary manufacture.

$\mathrm{OI}^{\circ}$ this aninal, there arc scveral kinds, slightly differing from each other, cither in habits or conformation. 'The Water spider is tiie most remarkable of the number. This insect resembles the common spider in its appearonce, except that its hinder part is nıade ruther in the shape of a ninc-pin than a ball. They differ in being able to live as well by land as water; and in bring capable of spinming as well in one elencut as the other. Their appearance under water is very remarliabic; for though they inbabit the bottom, yet lhey are never touched by the elenment in which they reside, but arc cnclased in a bubble of air that, like a box, surromnds then on every side. This bubble has the bright appearance, at the bottom, of quicksilver; and within this they perfurm thejr several funclions of eatiug, spinniug, and slerping, without its ever busting, or in the least disturling their operations: sumetimes, the bubble is secn divided into three discinct apartments; and it the spring, the male cuters oue of those to impreguate he femule in the namuer mentioned above, while the bubble in which he was comtained unites with the other, like two drops of water, when approached to each otler. They spin their webs as well in the water as upon land; atid it is most probahle that they make their food of the snall insects of citluev element.

The Tarantula is also of this species, and deserves particular notice, not for any remarkable properijes that loally atcond it, but for the numero:s falsehoods which liave been propagated concerning it. What may be said nith trush conceming it is, that it is the largest of the spider kingl kuown in Europe, and is a native of $A$ pulin in Italy. Its body is three quarters of an iucl long, and about as thick as one's little finger; the colnur is generally an olive hrown, variegated with one that is nore dusky; it has eight legs and eight cyes, like the rest, and nippers, which are sharp and scrrated: between these and the fore legs, there are two little loorns, or feelcrs, which it is 
observed to move very briskly when it approaches its prey. It is corered all over the body with a soft down, and propagates, as other spiders, by laying eggs. In the summer inonths, particularly in the dog-days, the tarantula creeping among the corn, bites the mowers and passengers: but in winter, it lurks in holes, and is seldom seen.

Thus far is true; but now the fable begins: for though the bite is attended with no dangerous symptoms, and will easily cure of itself, wonderful stories are reported concerning its virulence. The part which is bitten, as we are told, is soon after discoloured with a livid black, or yellowish circle, attended with an inflammation. At first the pain is scarcely felt; but a few liours after, come on a violent sickness, difliculty of breathing, fainting, and sometimes trembling. The person bit after this does nothing but laugh, dance, skip about, putting himself into the most extravagant postures, and sometimes also is seized with a most frightful melancholy. At the return of the season in which he was bit, his madness begins again; and the patient always talks of the same things. Sometimes he fancies himself a shepherd: sometimes a king; appearing entirely out of his senses. These troublesome symptoms sometimes return for several years successively, and at last terminate in death. But so dreadful a disorder has, it seems, not been left without a remedy; which is no other than a well played fiddle. For this purpose the medical musician plays a particular tune, fitnous for the cure, which he begins slow, and increases in quickness as lie sees the patient affected. The patient no sooner hears the musie, but he begins to dance; and continues so doing till he is all over in a sweat, which forces out the venom that appeared so dangerous. This dancing sometimes continues for three or four liours, before the patient is weary, and before the sweating is copious enough to cure the disorder. Such are the symptoms related of the tarantula poison; symptoms which some of the best and gravest physicians have credited, and attempted to account for. But the truth is, that the whole is an inposition of the peasants upon travellers who laappen to pass through that part of the country, and who procure a trifle for suffering themselves to be bitten by the tarantula. Whenever they find a traveller willing to try the experiment, they readily offer themselves, and are sure to counterfeit the whole train of symptoms which music is supposed to remove. A friend of mine, who had passed through that part of the country, had a trusty servant bitten, without ever administering the musical cure : the only symptoms were a slight inflammation, which was readily removed, and no other consequence ever attended the bite. It is thus that falsehoods prevail for a century or two; and mankind at last begin to wonder how it was possible to keep up the delusion so long.

\section{CHAPTER CLXX.}

\section{OF THE FLEA.}

THE history of those animals with which we are the best acquainted, are the first objects of our chiefest curiosity. There are few but are well informed of the agility and blood-thirsty disposition of the flea; of the caution with which it comes to the attack; and the readiness with which it avoids the pursuit. This inseect, which is not only the enemy of mankind, but of the dog, cat, anc several other animals, is found in every part of the world, but bites with greater severity in some eountries than in others. Its numbers in Italy and France are much greater than in England; and yet its bite is much more troublesome here, than I have found it in any other place. It would seem that its 
force increase with the coldness of the climate; and, thougl less prolific, that it became more predaceous.

If the flea be examined with a microscope, it will be observed to have a small head, large eyes, and a roundish body. It has two feelers, or horus, which are short, and composed of four joints; and between these lies its trunk, which it buries in the skin, and through which it sucks the blood in large quantities. The hody appears to be all over curiously adorned with a suit of polished sable armour, neatly jointed, and beset with inultitudes of sharp pins, almost like the quills of a porcupine. It has six legs, the joints of whiclı are so adapted, that it can, as it were, fold them up one within another; and when it leaps, they all spring out at once, whereby its whole strength is exerted, and the body raised above two hundred times its own diameter.

The young fleas are at first a sort of nits or eggs, which are round and smooth; and from these proceed white worms, of a shining pearl colour : in a fortnight's time they come to a tolerable size, and are very lively and active; but if they are touched at this time, they roll themselves up in a ball: soon after this they begin to creep like silk-worms that. have no legs: and they seck a place to lie hid in, where they spin a silken thread from their mouth, and with this they enclose themsclves in a small round bag or case, as white within as writing-paper, but dirty without: in this they continue for a fortnight longer: after which they burst from their confinement perfectly formed, and armed with powers to disturb the peace of an emperor.

\section{CHAPTER CLXXI.}

\section{OF THE LOUSE, AND ITS VARIETIES.}

THE antipathies of mankind are various; some considering the toad, some the serpent, some the spider, and some the beetle, with a strong degree of detestation: but while all wonder at the strangeness of each other's aversions, they all seen to unite in their dislike to the louse, and regard it as their natural and most nauseous enemy. Indeed, it seems the enemy of man in the most odious degree, for wherever wretchedness, disease, or hunger seize upon him, the louse seldom fiails to add itself to the tribe, and to increase in proportion to the number of his calamities.

In examining the human louse with the microscope, its external deformity first strikes us with disgust; the shape of the fore part of the head is somewhat oblong; that of the hind part somewhat round: the skin is hard, and being stretched, transparent, with here and there several bristly liairs: in the fore part is a proboscis or sucker, which is seldom visible : on each side of the head are antennæ, or horns, each divided into five joints. covered with bristly hair; and several white res- sels are seen throngh these horns: behind these are the eyes, which seem to want those divisions observable in other insects, and ap. pear encompassed with some few hairs: the neck is very short, and the breast is divided into three parts; on each side of which are placed six legs, consisting of six joints, covered also with bristly hairs; the ends of the legs are armed with two smaller and larger ruddy claws, serving those insects as a funger and thumb, by which they catch hold of such objects as they approach: the end of the body terminates in a cloven tail, while the sides are all over hairy; the whole resembling clear parclıneıt, and, when roughly pressed; cracking with a noise.

When we take a closer view, its white veius, and other interual parts appear, as likewise a most wonderful motion in its intestines, from the transparency of its external covering. When the louse feeds, the blood is seen to rush, like a torrent, into the stomach; and its greediness is so great, that the excrements contained in the intestines are ejected at the 
same time, to make room for this new supply.

The louse has meither beak, teeth, nor any kind of mouth, as Dr. Hooke described it, for the entrance into the gullet is absolutely closed. In the place of all these, it has a proboscis or trunk; or, as it miay be otherwise called, a pointed, hollow sucker, with which it pierces the skin, and sucks the human blood, taking that for food ouly. The stomach is lodged partly in the breast and back; but the greatest portion of it is in the abdomen. When swollen with blood, it appears of a dark brown colour, which is visible through the skin; and is either a faint red, or a full or bright brown, as the contents of the stomach are more or less changed. When it is empty, it is colourless; bnt when filled, it is plainly discernible, and its motion seems very extraordinary. It then appears working with very strong agitations, and somewhat resembles an animal within an animal. Superficial observers are apt to take this for the pulsation of the lucart; but if the animal be ohserved when it is sucking. it will then be found that the food takes a direct passage from the trunk to the stomach, "here the remainder of the old aliment will be seen mixjing with the new, and agitated up and lown on crery side.

If this animal be kept from food two or threc days, and then placed on the back of the hand, or any soft part of the body. is will immediately seck for food; which it will the more readily find, if the hand be ruhbed till it grows red. The animal then turns its liend, which lies between the two fore legs, to the skin, and diligently searches for some pore: when fomd, it fixes the trunk therein; and soon the microscope discovers the blood ascending throngh the head, in a very rapid. and even friglitiul stream. The louse has at that time suflicient appetite to feed in a:ty posture; it is then secn sucking withits head downward. and its tail elevated. If, luring this operation. the skin be drawn light, the trunk is bound fast, and the animal is incapable of disengaging itself; hut it more frequen:ly suffers from its gluttony, since it gorges to such a degree, that it is crushed to rieces by the sligbtest impression.

Whether lice are distinguished by the parts of generation into males and females is not yet discovered: Swanmerdam is inclined to think that they are hermaplurodites, having found an ovary in all those lie exomined; and he dissected not less than forty-iwo. In one of these animals were found ten large cggs; and forty-four smaller, that were not yet come to their full perfection.

There is scarce any animal that multiplies so fast as this unwelcome intruder. It has been pleasautly said, that a louse becomes a grandiather in the space of twenty-four hours; this fact cannot be ascertained; but nothing is more true than the moment the nit, which is 10 other than the egg of the louse, gets rid of its superfluous moisture, and throws ofl its shell, but it then begins to breed in its turn. Nothing so inucl prevents the increase of this nanseous animal as cold and want of humidity; the nits must be laid in a place that is warm, arm morlerately moist, to produce any thing. This is the reason that many nits laid on the hairs in the vight-time, are destroyed by the cold of the succeeding day; and so stick for several months, till they at last come to lose even their external forni.

The louse is found upon every part of the humna body; but particularly in the heads of children. Those found upon the miners in Swellen, are said by Linnaus to be very large; and he is of opinion that the head and the body-louse liffer in no respect from each other. The pthiriasis, or lousy disease, 1lsough very little known at present, was frequent enough amoug the ancients: Herou, Antiochus. Epiphanes. Aleman. the joet, Pherecydes. Cassander, Callisthenes, and Sylla, all died of this disorder. The use of mercury. which was unknown among the ancients, may probibly fave banished it from among the moderns; for certain it is, that these animals seldom attack any in our climate, but such as fro'n sloth or fimine invite their company.

Such is the history of the human louse, which, fron its connection with mankind, deserves first notice: but it would be condless to describe the various tribes that go under this name, aud swarm upon every part of nature. There is scarce an animnl, and scarce even a vegetable, that cloes not suffer under its own peculiar louse. The sheep, the horse, the hog, and the elephant, are all 
teased by them; the whale, the shark, the salinon, and the lobster, are not without their company ; while every hot-house, and cvery garden is infested with some peculiarly destructive. Linneus tells us, that he once found a vegetable-louse upon some plants newly arrived from America; and, willing to trace the little animal through its varions stages, he brought it with him from London to Leyden, where he carefully preserved it during the winter, until it bred in the spring; but the louse it seems did not treat him with all the gratitude he expected; for it becane the parent of so numerons a progeny, that it soon overrun all the physic-garden of that beautiful city; and leaves, to this day, many a gardener to curse the Swede's too indulgent curiosity.

The animal which some have ealied the Leaf-louse, is of the size of a flea, and of a bright green, or bluish-green colour; the body is nearly oval, and is largest and most convex on the hinder part ; the breast is very small, and the head is blunt and green: the eyes may be seen very plainly, being prominent on the fore part of the head, and of a shining black colour; near these there is a black line on each side; and the legs are very slender.

These animals are usually found upon the leaves of the orache, and other plinits; and the weaker the leaves and buds are, these insects swarm upon them in greater abunlance. Some plants are covered over with lhein: though they are not the causc of the plant's weakness, but the sign: howerer, by wonnding and sucking the leaf, they increase the disease. They generally assume their colour from the plant on which they reside. Those that feed npon pot-herbs and plumtrees, are of an ash-colour; only they are urcenish when they are young: those that belong to the alder and cherry-tree, are hlaek; as also those upon beans, and some other plants: those on the leaves of apples and rose-trees, are white; but as they leap, like grasshoppers, some place them in the number of the flea kind. The most uncommon colour is reddish; and lice of this sort may be found on the leaves of tansey; and their juice, when rubbed in the hauds, tinges them with no disagreeable red. All these No. $63 \& 64$. live upon their respective plant; and are often engendered within the very substance of the leaf.

All these bring forth their young alive; and the foetus, when it is ready to be brought forth, entirely fills the belly of the female; its fore parts being excluded first, and then the hinder. The young one does not begin to move till the horus or feelers appear out of the body of the old one; and by the motion of these it first shows signs of life, moving them in every direction, and bending all their joints. When the horns and head are excluded, the two fore feet follow, which they move with equal agility; after this follow the iniddle feet, aud then the hinder: still, lowever, the young one conlinues sticking to its parent, supported only at one extremity, and lsanging, as it were in air, until its sinall and soft niembers becone hardened and fitted for self-support. The parent then gets rid ol its burden; by moving firom the place where she was sitting, and forcing the young one to stand upon its legs, leaves it to shilt for itself.

As the animal has not far to go, its provisions lying belleath it, during the summer it continues to eat and creep about with great agility. But as it is viviparous, and must necessarily lurk somewhere in winter, where its body may be defended from the cold, it endeavours to secure a retreat. near the trees or plants that serve to nourish it in the beginning of spring. They never lide themselves in the earth, like many other insects, because they have no part of their bodies fitted to remove iisc earth; nor can they creep into every chink. as their legs are too long: besides, their bodies are so tender, that the least rough particle of the earth would hurt thein. 'They, therefore, get into the deep chinks of the bark, and into the cavities of the stronger stalks, from whence they sally out upon the branches and leaves, when the warmth of the sun begins to be felt. Neither the cold in the autumnal season, nor the lesser degree of heat in the spring, ever lints them; they seldom, therefore, seek for hiding-places before the fall of the leaf, and are alert enough to take the earliest advantage of the returning spring.

Like many other insects, they east their $5 \mathrm{~N}$ 
skins four several times; and, what is very remarkable, the males have four wings, but the females never have any. They all have long legs, not only to enible them to creep over the long hairs of plants or leaves, but also to travel from one tree to another when they happen to stand at a clistance. 'Their trunk or suout lies under their breast; and this they thrust into the pores of the plant to suck out the juice, for they do not gnaw them, like the caterpillar; but so hurt them by sucking, that the leaves become spotted, and as it were overrun with scabs; for which reason their edges always turn up towards the middle.

It has been said, that these insects nee often corricil away and devoured by ants; but this Frysch, from whom this description is taken, could never observe. The ants, indeed, are fond of those trees where there is a great number of those insects ; but then it is only to suck the juice which flows from the lenves that have been just wounded. 'This more parti- cularly happens in the heat of summer, when other moisture is wanting: however, he never found them hurting or carrying away any of these insects while alive; nor, indeed, were they able, for the leaf-louse is more than a inatcli for the ant at single combat. Whenever they perceive the ant approaching behind then, they kick back with their hinder feet; and thus drive off the invader, as a borse would a lion.

The three principal and constant enemies to these insects are, first, the fire-fly, which lays its eggs where thesc insects are in greatest number, which, producing a worm, seizes and devours all the leaf-lice that come near it: another enemy is the worm of a peculiar kind of beetle, which destroys them in great numbers : but the most formidable of all cuemies, is the ichneumon fly, that seizes upon one of the largest females, and laying its egg upon her, this is hatched into a worm, which soon devours and destroys the animal from whose body it sprung.

\section{CHAPTER CLXXII.}

\section{OF THE BUG, AND ITS VARIETIES.}

THE Bug is another of those nauseous iusects that intrude upon the retreats of mankind; and that often banish that sleep, which even sorrow and anxiety permitted to approach. This, to many inen, is of all other insects the most troublesome and obnoxious. The night is usually the season when the wretched have rest from their labour; but this seenıs the only season when the bug issues from its retreats, to make its depredations. By day it lurks, like a robber, in the most secret parts of the bed; takes the advantage of every chink and cranny, to make a secure lodgment; and contrives its habitation with so much art, that searce any industry can discover its retreat. It scems to avoid the light with great cunuing; and even if candles be kept burning, this formidable insect will not issue from its hiding-place. But when darkness promises security, it then issues from cvery corner of the bed, drops from the teas- ter, crawls from behind the arras, and travels with great assiduity to the unhappy patient, who vainly wishes for rest and refreshment. It is generally vain to destroy one only, as there are hundreds more to revenge their companion's fate; so that the person who thus is subject to be bitten, remains the whole night like a centinel upon duty, rather watching the approach of fresh invaders, than inviting the pleasing approaches of sleep.

Nor are these insects less disagreeable from their nauseous stench, than their unceasing appetites. When they begin to crawl, the whole bed is infected with the smell : but if they are accidentally killed, then it is insupportable.

These are a part of the inconveniences that result from the persecution of these odious insects: but happily for Great Britain, they multiply less in these islands than in any part of the continent. In France and Italy the 
beds, particularly in their inns, swarm with them ; and every piece of furniture secnis to afford them a reireat. They grow larger also with them than with us, and bite with more cruel appetite.

This animal, if examined minutely, appears to consist of three principal parts; the head, the corselet, and the belly. It has two brown eyes, that are very sinall, and a little prominent, besides two feelers, with three joints: underneath these there is a crooked trunk, which is its instrument of torture, and which, when in motion, lies close upon the breast. 'The breast is a kind of ring, in which are pliced the two first pair of legs. The belly consists of nine rings; under which are placed (wo) pair of legs inore, making six in all. Each leg has thrce joints, which forn the thigh, the leg, and the foot, which is armed with a crooked claw, like a liook. The body is sinooth, except a few short hairs, that may be seen by the microscope, about the vent, and on the two last rings. Its notion is slow and unwieldy; yet its sight is so exquisite, that the instant it perceives the light, it generally makes good its retreat; and they are seldoin caughi, though the bed swarms with thein.

If we examine this insect internally, we shall find the great artery, which in all insects performs the functions of the heart; we shall find the apertures of the lungs on the right side and the left, through which the animal breaths; we sluall find a stomach and intestines, which, as in other animals, run from the month to the anus. If the insect has been kept long fasting, there will be a mucus found in its body, like the white of an egg; but if crushed afier a liull meal, the human blood which it has sucked in, will appear a litrle darkened, by having passed through the insect's body.

The malc and female of these animals are plainly distinguishable from each other; and the pirts of generation are olvvious enough. Tron.. nmo nfrow found rounling tail to tail; and in this state are very ensily destroyed. The female has an ovary filled with eggs, joined together like a bunch of grapes; cach cgg being oblong, almost cylindrical, inclining (1) white, and pretty transparent. In about two days after impregnation by the male, she deposites her eggs to the number of about a hundred and fifty, in some convenient place where they are likely to receive no disturbance. There they continue for some months; during which time, neither cold nor heat, neither moisture nor fumigation, can in the lenst retard their exclusion; but they come forth active, and rearly for mischief. It is this hardiness in the shell that seems to continue the breed; as the old ones die every winter, or are casily destroyed by any fumigation that is used fur that purpose. But the eggs seem incapable of destruction; evell those men who make a livelihood by killing these vauseous insects, though they can answer for the parent, can never be sure of the egg. For this reason they usually pay those bouses to which they are called, a second or a third visit, and at lass. exterminate them by perseverance.

The manner of destroying thenı scenıs rathe! the effects of assiduity than antidote; for the men called in upon this occasion, take every part of the furniture asunder, brush every part of it with grent assiduity, anoint it with a liquid which I take to be a solution of corrosive sublimate, and having performed this operation twice or thrice, the vermin are most usually destroyed.

Cleanliness, therefore, seenıs to be the best antidote to remove these nauseous insects; and wherever that is wanting, their increase scems but a just punishment. Pudeed, they are sonetimes found in such numbers anıng old furniture, and neglected chambers, exposed to the south, that, wanting other sustcnance, they devour each other. They are also enemies to other vermin, and destroy fleas very effectual$\mathrm{ly}$; so that we seldoun have the double persecution of different vermin in the same bed. Of the bug kind Linnæus reckons up forty. 


\section{CHAP'TER CLXXIII.}

\section{OF THE WOOD-LOUSE, AND ITS VARIETIES.}

THE common wood-louse is seldom abore half an inch long, and a quarter of an inch broad. The colour is of a livid black, especially when found about dunghills, and on the ground; but those that are to be met with under tiles, and in drier places, are of the colour of the hair of an ass. It has fourteen feet, seven on each side; and they have only one joint each, which is scarcely perceivable. It has two short feelers, and the body is of an oval shape. When it is touched, it rolls itself up into a sort of a ball; and the sides near the feet are dentated like a s.uw. It is often found among rotten timber, and on decayed trces; in winter it lies hid in the crevices of walls and all sorta of huild- ings. The male is easily distinguishable from the female, being less and nore slender. The eggs they lay are white and shining. like seed pearls, and are very numerous: however, more properly speaking, although, when excluded, the young have all the appearance of all egg, yet they are alive, and without throwing of any shell, stir and move about with great vivacity; so that this animal may properly be said to be viviparous. The little worms at first seem scarce able to stir; but they soon feed, and become very brisk. These animals are of great use in medicine: being impregnated with a saline quality, which is diuretic and stimulating. Of this insect, Linnæus makes three species.

\section{CHAPTER CLXXIV.}

\section{OF THE MONOCULUS; OR, ABORESCENT WATER.FLEA.}

THIS animal, which is of the size of a flea, appears to the sight, unassisted by the microscope, to have but one eye; for the eyes, by reason of the smallness of the head, seem to be joined to each other: they are situated in the trunk of this insect, and the beak is likewise very small and sharp-pointed. The structure of the eye is seen, by the microscope, to be reticulated, or made like a net; and the trunk of this insect, by which it feeds, is not only small and sharp, but also transparent. The insects are of a blood-red colour; and sometimes are seen in such multitudes on the surface of standing water, as to make them appear all over red, whence many fanciful people have thought the water to be turned into blood.

Swammerdam tells us of a celebrated professor of Leyden, who was at first astonished by an appearance of this kind. Being once intent upon his studies, he beard a noise, of which, as it increased by degrees, he was desirous to know the cause. The maid-servant attending to his summons, appeared quite petrified with fear, and told him with a tremulous voice, that all the waters of Ley. den were turued into blood! Upon this he went directly, in a small bark, to the place where the water was thus changed, and put some of the bloody water into a glass; but upon viewing it with attention, he observed, that it abounded with infinite numbers of these little red insects, which tinged the whole body of the fluid with that seemingly formidable colour. Thus his sudden fright was changed into lasting admiration.

Of all parts of this animal, its branching arms, and the motion it makes with them in 
the water, deserve our greatest attention. By these the little creature can move in a straight line; waving its arms, as a bird does its wings in the air, sometimes upward, sometimes dowuward, sometimes to the right, sometimes to the left, yet still eontinuing to proceed in a right linc. By striking the water with its arms, it car ascend with great velocity; and by striking in a contrary direction, it dives with equal ease. As these motions are very rapid, the little animal appears to jump in the water, its head always tending to the surface, and its tail stretched downward. This insect is produced from an egg, which, when excluded, is carried on the back of the female, and soon is scen floating in the water round her. Its appearance at first is that of a very small whitish insect, endued with a very nimble motion. Except in colour, it suffers no change, only continuing to grow larger and redder, as it grows old. They sometimes remain several days on the. surface of the water; and sometimes are seen at the bottom only; but they are never at rest. They change their skin, like most other insects; and the cast skin resembles the insect itself so exactly, that one might mistake the mask for the animal.

\section{CHAPTER CLXXV.}

\section{OF THE SCORPION, AND ITS VARIETIES.}

THERE is searee an insect withont wings that is not obnoxious to man: the smallest have the power of annoying him, either by biting or stinging him; and though each is in itself contemptible, they become formidable from their numbers. But of all this elass, there is none so terrible as the Scorpion, whose shape is hideous, whose size among the insect tribe is enormous, and whose sting is generally fatal. Happy for England, the scorpion is entirely a stranger among us! In several parts of the continent of Europe it is but too well known, though it seldonn grows above four inches long: but in the warm tropical climates, it is scen a foot in length, and in every respect as large as a lobster.

The scorpion is one of the largest of the insect tribe, and not less terrible from its gize than its malignity. It resembles a lobster somewhat in shape, but is infinitely more hideous. There have been enunerated nime difrerent kinds of this dangerous insect, chiefly distinguished by their colour, there being scorpions yellow, brown, and ast-coloured; others that are the colour of rusty iron, grcen, pale yellow, black, claret-colour, white, and gray.

There are four principal parts distingnishable in this animal; the head, the brcast, the belly, and the tail. The scorpion's head seems, as it were, jointed to the breast; i! the middle are seen two eyes; and a little more forward, two cyes more, placed in the fore part of the head: these cyes are so small, that they are searcely perceivable; and it is probable the animal has but little occasion for seeing. The month is furnished with two jaws; the undermost is dirided into two, and the parts notehed into each other, which scrves the animal as teeth, and with which it breaks its food, and thrusts it into its mouth: these the scorpion can at pleasure pull back into its mouth, so that no part of them can be seen. On each side of the liend are two arms, each composed of four joinls: the last of which is large, with strong muscles, and made in the mamer of a lobster's claw. Below the breast are eight articulated legs, each dirided into six joints; the two hindmost of which are each provided with two crooked claws, and here and there covered with hair. The belly is divided into seven little rings; from thir lowest of which is continued a tail composed of six joints, which are bristly and formed like little globes, the last being armed with a crooked sting. This is that fatal instrument which renders this insect so formidable: it is long, pointed, hard, and hollow; it is pierced 
near the base by two small holes, through which, when the animal stings, it ejects a drop of poison, which is white, caustic, and fatal. The reservoir in which this poison is kept, is in a small bladder near the tail, into which the renom is distilled by a peculiar apparatus. If this blardder be gently pressed, the venom will be seen issuing out through the two holes ahove mentioned; so that it appears, that when the animal stings, the hadfer is pressed, nud the vellom issues througl, the two apertures into the wound.

There are few animals more formidalile, or more truly mischievous than the scorpion. As it takes refuge in a small place, and is generally found sheltering in houses, so it cammot be otherwise than that it inust frequently sting those anong whom it resides. ln some of the towns of Iialy, and in France, in the province of Languedoc, it is one of the greatest pests that torment mankind: but its unalignity in Europe is tritling, when compared to what the natives of Africa and the East are known to experience. In Batavia, where they grow twelve inches long, there is no removing any piece of furniture, without the utınost danger of being stung hy them. Bosunan assures us, that, along the Gold Coast, they are often found larger than a lobster; and that their sting is inevitubly fatal. In liurope, however, they are by no means so large, so venomons, or so plentitul. T'he general size of this animal does not exeecd fivo or threc inches; and its sting is very selflom foumel to loc fatal. Maupertuis, who inade several experinents on the scorpion of Languedoc, found it ly no inenus so imvariably dangerous as lind till then been represented. He provoked one of them to sting a log, in three places of the belly, where the animal was without hair: in ubout no hour nffer the poor animal secmed greally swollen, and became very sick: he then cast up whatever he had in his bowels; and for about three honrs continned romiting a whitish liquid. 'The belly was always greatly swollen, when the animal began to vomit; but this operition always seemed to abate the swelluig; which alternately swelled, and was thus cinptied, for threc hours successively. The poor animal, after this, fell into convulsions, bit the gromed, dragged himself along upou his fore feet, and at last died, five hours after being bitten. He was not partially swollen romil the place which was bitten, as is usual after the sting of a wasp or a bee; but his whole bolly was inflated, and there only ap. peared a red spot on the places where he had been stung.

Some days after, lowever, the same experiment was tried upon another dog, and even with more aggravated cruelty; yet the dog scerned no way affected hy the wounds, but howling a little when he received them, continued alert and well after them; and soon after was set at liberty, withont showing the smallest symptoms of pain. So far was this poor creature from being terrificel at the experiment, that he left his own master's liouse, to come to that of the philosopher, where lic had received inore plentifil entertaimment. The same experiment was tried by fresh scorpions, "pon seven other dogs; and upon three hens; but not the smallest deadly syinptoms were secu to ensue. From lience it appears that many circumstances, which are utterly unknown, must contribute to give etlieacy to the scorpion's venom. Whether its food, long fisting, the season, the nafure of the vessels it wounds, or its state of maturity, contribute to, or retard its inaliguity. is yet to be ascertained by succeeding experiments. In the trials made by our philosopher, he employed scorpions of both scxes, newly canglit, and seemingly vigorous and active. The success of this experiment may serve to show, that many of those hoasted antidotes which are given for the cure of the scorpion's sting, owe their success rather to accident than their own efficacy. They ouly happened to cure, when their sting was no) way dangerous; but in cases of actual Inaliguity, they might probably be utterly unservicenble.

The scorpion of the tropical climates being much larger than the former, is probably inuch more venomous. Helbigius, huwever, who resided for many years in the East, assures us, thant he was often stung by the scorpion, and never received any material injury fiom the wound: a painful tumour generally ensued: but he nlways cured it, by rubbing the part with a picce of iron or stone, as he bad seen the Indians practise before 
liim, until the fesh became insensible. Sebn, Moore, and Bosman, however, give a very different acconnt of the scorpion's inalignity: and assert that, unless speedily relieved, the wound becomes fatal.

It is certain that no animal in the creation seems endued wilh such an irascible nature. I have often seen them taken and put into a place of security, exerting all their rage against the sides of the ghass ressel that contained them. I have seen them attempt to sting a stick, when put near them; and attack a mouse or a frog, while those animals were far from offering any injury. Manpertuis put three scorpions and a mouse into the same vessel together, and they soon stung the little aninal in different places. The mouse, thus assaulted, stood for some time upon the defensive, and at last killed them all, one after another. He tried this experiment, in order to see whether the mouse, after it had killed, would eat the scorpions; but the little quadruped seemed entirely satisfied with the victory, and even survived the severity of the wounds it had receired: Wolkaner tried the courage of the scorpion againgt the large spider, and enclosed several of both kinds in glass vessels for that purpose." The success of this combat was very remarkable. The spider at first used all its elforts to immesh the scorpion in its web, which it immediately began spinning; but the scorpion rescued itself from the danger, by stinging its adversary to death; it soon after cut off; with its clars, all the legs of the spicler, and then sucked all the internal parts at its leisure. If the seorpion's skin had liot been so hard, Wolkaner is of opinion that the spider would have olntained the victory; for he had olten scen one of these spiders destroy a toad.

The fierce spirit of this animal is equally dangerous to its own species; for scorpions are the cruelest enemies to each other. Mnupertuis put about a hundred of them together in the same glass; and they scarce cane into contact, when they began to exert all their rage in mutual destruction: there was nothing to be seen but one universal carnage, without any distinction of age or or sex; so that in a few days there remained

(a) Ephemerides Dec. II. 1687. Observ. 224. only fourteen, which had killed and devoured all the rest.

But their unnatural malignity is still more apparent in their cruelty to their offspring. He enclosed a female scorpion, big with young, in a glass vessel, and she was seen to devour them as fast as they were exelucled: there was but one ouly of the number that escaped the general destruction, by taking refuge on the back of its parent; and this soon after revenged the cause of its brechren, by killing the old one in its turn.

Such is the terrible and unrelenting nature. of this insect, which neither the bonds of sociely, nor of nature can reclain: it is even asserted that, when driven to aI extremity, the scorpion will often destroy itsell: Thie following experiment was inclfectually tried by Maupertuis: but I am so well assured of it by many eye-wituesses, who have seen it both in Italy and America, that I have no doubt remaining of its veracity. A scorpion, newly canght, is placed in the inidst of a circle of burning charcost, and lhus an egress prevented on every side : llo scorpion, us I am assured, runs for ghout $n$ uninute round the eircle, in lopes of escaping: but finding that impossible, it stings itsclf on the lack of the head, and in this manner the undaunted suicicle instantly expires.

It is happy for mankind that these animals are thus destructive to each other: since otherwise they would multiply in so great a degree as to render some countries uninhabitable. The male and female of this insect are very easily distinguishable; the male being smaller and less hairy. The female brings forth her young alive, and perfect in their kind. Rhedi having bought a quantity of scorpions, selected the firmales, which by their size and ronghness were easily distinguishable from the rest, and putting them in separate glass vessels, he kept them for some days without food. In abont fire days onc of them brought forth thirly-eight young ones, well shaped, and of a milk-white colour, which changed every day more and unore into a lark rusty hue. Anoher female, in a different vessel, brought forth twenty-seven of the same colour: and the day following the young ones seemed all fixed to the back and belly of the female. For near a fortnight all these con- 
tinued alive and well; but afterwaris some of them died daily: until, in about a month, they all died except two.

Were it worth the trouble, these animals might be kept living as long as curiosity should think proper. Their chief food is worns and insects; and upon a proper sup. ply of these, their lives might be lengthened to their natural extent. How long that may be, we are not told; but if we may argue froin analogy, it camnot be less than s:ven or eight years; and perhaps, in the larger kind, double that duration. As they have somewhat the form of the lobster, so they resemble that animal in casting their shell, or more properly their skin; since it is softer by far than the covering of the lobster, and set with hairs, which grow from it in great abundance, varticularly at the joinings. The young lie at the womb of the narent, each corered up in its own membrane, to the number of forty or fifty, and united to each other by an oblong thread, so as to exhibit altogether the form of a chaplet.

Such is the mauner in which the common scorpion produces its young; but there is a scorpion of America, produced from the egg, in the manner of the spider. The eggs are no larger than pin-points; and they are deposited in a web, which they spin from their bodies, and carry about with them, till they are hatched. As soon as the young ones are cxcluded from the shell, they get upon the back of the parent, who turns her tail orer them, and defends them with her sting. It seens probable, therefore, that eaptivity prodnces that unnatural disposition in the scorpion, which induces it to destroy its young; since, at liberty, it is found to protect them with such unceasing assiduity.

\section{CHAPTER CLXXVI.}

\section{OF THE SCOLOPENDRA AND GALLY-WORM.}

OF these hideous and angry insects we know little, except the figure and the noxious qualities. Though with us there are insects somewhat rescmbling them in form, we are pliced at a happy distance from such as are really formidable. With us they seldom grow above an inch long; in the tropical climates they are ofien found above a quarter of a yard.

The Scolopendra is otherwise called the Centipes, from the number of its feet; and it is very common in many parts of the world, especially between the tropics. Those of the East Indies, where they grow to the largest size, are about six inches long. of a rudily colour, and as thick as a man's finger: they consist of many joints; and from each joint is a leg ou cach side : they are covered with hair, and seem to have no eyes: but there are two feclers on the head. which they make use of to find out the way they are to pass: the head is very round, with two small sharp teeth, with which they inflict wounds that are very painful and dangerous. A sailor that was bit by one on board a ship, felt an excessive pain, and his life was supposed to be in danger: however, he recoverel, by the application of three roasted onions to the part, aud was soon quite well. Of this animal there are different kinds: some living, like worms, in boles in the earth: others under stoners, and among rotten wood: so that nothing is more dangerous than removing those substances, in the places where they breed.

The Gally-worin differs from the scolopendra, in haring double the number of feet: there being two on each side, to every joint of the body. Some of these are smooth, and others hairy: some are yellow, some black, and some brown. They are found among decayed trees. lietween the wood and i!? bark; as also among stones that are covered with inoss. They all, when touched. contract themselves, rolling themselves up like a ball. Whaterer may be their qualities in the tropical parts of the world, in Europe they are 
perfectly harmless; having been often handled and irritated, without any vindictive consequences.

All these, as well as the scorpion, are supposed to be produced perfect from the parent, or the egg; and to undergo no changes, after their first exclusion. 'They are seen of all sizes; and this is a sufficient inducement to suppose, that they preserve their first appearance through the whole of their existence. It is probable, however, that like most of this class, they often change their skins; but of this we have no certain information.

\section{CHAPTER CLXXVII.}

\section{OF THE LEECH.}

THE last of this wingless tribe that I shall mention is the Leech, which, like all the former, undergoes no varieties of transformation; but when once excluderl from the body of the parent, preserves its first figure to the end. I place the history of the leech among the first class of animals; while I have degraded the Earth-worm, the Tænia, and the Polypus, into the class of Zoophytes, or that imperlect tribe which serves to make the shade between animal and vegetable nature. Not but that the earth-worm or the polypus have their motions, their appetites, and their vital principles, as complete as the leech, and, to a cursory view, appear every way as complete animals. But there is one circumstance that lays the line between them; that exalts the one and degrades the other. The earthworm and the polypus may be cut in two pieces, and each piece will produce a new and perfect animal : the leech caunot suffer this dissection, but dies when cut in two; an evident instance that it is possessed of a more perfect organization than those animals which it otherwise very much resembles.

The leech, from its uses in medicine, is one of those insects that man hns taken care to provide; but of a great variety, one kind only is considered as servicenble. The horse-leech, which is the largest of all, and grows to four inches in length, with a glossy, black surface, is of no use, as it will not stick to the skin; the suail-leech is but an inch in length: and though it will stick. is not large enough to extract a sufficient quantity of blood from the patient; the broad-tailed No. $65 \& 66$. leech, which grows to an inch and a half in length, with the back raised into a sort of ridge, will stick but on very few occasions: it is the large brown leech, with a whitish belly, that is made use of in medicine, and whose history best merits our curiosity.

The leech has the general figure of a worm, and is about as long as one's middle finger. Its skin is composed of rings, by means of which it is possessed of its agility, and swims in water. It contracts itself, when out of water, in such a manner, that when touched it is not above an inch long. It has a small head, and a black skin, edged with a yellow line on each side, with some yellowish spots on the back. The belly also, which is of a reddish colour, is marked with whitish yellow spots. But the inost remarkable part of this animal is the mouth, which is composed of two lips, that take whatever form the insect finds convenient. When at rest, the opening is usually triangular; and within it are placed thrce very sharp teeth, capable of piercing not only the human skin, but also that of a horse or an ox. Still deeper in the head, is discovered the tongue, which is composed of a strong fleshy substance, and which serves to assist the animal in sucking, when it has inllicted its triple wound; for no sooner is this voracious creature applied to the skin, than it buries its teeth therein, then eloses its lips ronnd the wound which it has made; and thus, in the manner of a cupping-glass, extracts the blood as it flows to the different oritices.

II examining this animal's form farther to50 
wards the tail, it is seen to have a gullet and an intestinal canal, into which the blood llows in great abundance. On each side of this are seen running along several little bladders, which, when the animal is empty, seem to be filled with nothing but water; but when it is gorging blood, they seem to communicate with the intestines, and receive a large portion of the blood which flows into the body. If these bladders should be considered as so many stomachs, then every leech will be found to bave twenty-four. But what is most extraordinary of all in this animal's formation is, that though it takes so large a quantity of food, it has no auus or passage to eject it from the body when it has been digested. On the contrary, the blood which the leech has thus sucked remains for several months clotted within its body, blackened a little by the change, but no way putrefied, and very little altered in its texture or consistence. In what manuer it passes through the animal's body, or how it contributes to its nourishment, is not easily accounted for. The water in which they are kept is very little discoloured ly their continuance; they cannot be supposed to return the blood by the same passage through which it was taken in; it only remains, therefore, that it goes olf through the pores of the body, and that these are sufficiently large to jermit its exclusion.

But it is not in this instance alone that the leech differs from all other insects. It was remarked in a former cliapter, that the whole insect tribe had the opening into their lungs placed in their sides, and that they breathed through those apertures as other animals through the mouth. A drop of oil poured on the sides of a wasp, a bce, or a worm, would quickly suffocate them, by stopping up the passages through which they breath; but it is otherwise with the leech, for this animal may be immersed in oil without injury; nay, it will live therein; and the only damage it will sustnin is, that, when taken ont, it will be seen to cast a fine pellucid skin exactly of the shape of the animal, after which it is as alert and rigorous as before. It nppears from hence that the leech breaths through the mouth: and, in fac, it has a motion that secms to resenble the act of respiration in more perfect animals: but concerning all this we are very much in the dark.

This animal scems to differ from all others in several respects: the rest of the reptile tribe are brought forth from eggs; the leech is viviparous, and produces its young one after the other, to the number of forty or fifty at a birth. It is probable that, like the suail, each insect contains the two sexes, and that it impregnates and is impreguated in the same manner. The young ones are chiefly found in the month of July, in shallow rumuing waters, and particularly where they are tepified by the rays of the sun. The large ones are chiefly sought after; and being put into a glass vessel filled with water, they remain for montlss, nay for years, without taking any other subsistence. But they never breed in this confunement; and, consequently. what regards. that part of their history still remains obscure.

In this part of the world they sclilom grow to above four inches; but in America and the East they are found from six to seven. Their pools there abound with tlem in such numbers, that it would be dangerous bathing there, if for no other consideration. Our sailors and soldiers, who the last war were obliged to walk in those countries through marshy grounds, talk with terror of the number of leeches that infested them on their march. Even in some parts of Europe they increase so as to become formidable. Sedelius, a German physician, relates, that a girl of nine years old, who was keeping sheep near the city of Bomst in Poland, perceiving a soldier making up to her, went to hide herself in a neighbouring marsh amoug some bushes; but the number of leeches was so great in that placc, and they stuck to her so close, that the poor creature expired from the quantity of blood which she lost by their united efloris. Nor is this much to be wondered at, since one of those insects that, when empty, generally weighs but a scruple, will, when gorged, weigh more than two drachins.

When lceches are to be applied, the best way is to take them from the water in which they are contained about an hour before, for they thus become more voracious and fisten more readily. When saturated with blood, 
they generally fall off of themselves; but if it be thonght necessary to take them from the wound, care should be used to pull them very gently, or even to sprinkle them with salt if they continue to adhere: for if they be plucked rudely away, it most frequently happens that they leave their teeth in the wound, which makes a very troublesome inflammation, and is often attended with danger. If they be slow in fixing to the part, they are often enticed by rubbing it with milk or blood, or water mixed with sugar. As salt is a poison to most insects, many people throw it upon the lecch when it has dropped from the wound, by which means it disgorges the blood it has swallowed, and it is then kept for repeated application. They seldom, however, stick after this operation; and as the price is but small, fresh lecches should always be applied whenever such an application is thought necessary. 


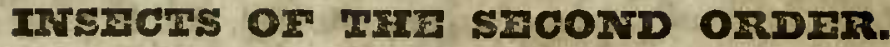

\section{CHAPTER CLXXVIII.}

\section{OF THE SECOND ORDER OF INSECTS.}

IN the former part we gave a concise history of the 11 ost considerable insects that, without wings, were produced in a perfect state; either from the body of the parent alive, like quadrupeds, or from the egg, in the manner of birds. We come now to a second order of insects, that are produced from the egg, like the former, but not in a perfect state; for when first excluded, they are without wings. This, however, does not hinder the exercise of their animal functions : the insect, although not yet come to perfection, walks, leaps, and eats; nor is it ever deprived of motion, ouly that it rests a little when it is about to cast that part of its skin previous to its state of perfection. It is then seen to assume two wings, which, like a budding flower, burst through the case that contained then, and ihe animal becones a winged insert in its state of highest perfection. To this order we may refer the Libella, or Dragon-Fly ; the Formica Leo, or Lion-Ant ; the Grasshopper; the Locust; the Cricket; the Wood-Cricket; the Mole-Cricket; the Flea-Locust ; the FlyingBug; the Tipula; the Water-Scorpion; the Notonecta, or Water-Fly; and many others.

\section{CHAPTER CLXXIX.}

\section{OF THE LIRELLA, OR DRAGON-FLY.}

$\mathrm{OF}$ all the flies which adorn or diversify the face of nature, these are the most various and the most beantiful; they are of all colours; green, blue, crimson, scarlet, white; some unite a variety of the most vivid rints, and extibir in one animal more different shades than are to be foumd in the rainbow. 'They are called, in different parts of the kingdoun, by difierent names; hut none can be at a loss in knuw them, ns they are distinguished from all other flies by the length of their bodies, by the largeness of their eyes, and the beautiful transparency of their wings, which are four in number. They are seen in summer fleing wich great la!nility near every hedge, and by every running brook; they sometimes settle on the leaves of plants, and sometimes keep for hours together on the wing.

Dragon-flies, though there are three or four different kinds, yet agree in the most striking parts of their history, and one account niay serve for all. The largest sort are generally frumd firm two to three inches long; their tail is forked; their body divided into eleven rings; their eyes are large, horny, and transparent, divided by a number of intersections; and their wings, that always lie flat when they are at rest, are of a beautiful glossy transparency; somerimes shiming like silver, and sometimes glistening like gold. Within the 
mouth are to be seen two teeth covered with a beautifil lip; wilh unese the creatures bite fuercely when they are: taken: hut their bite is perfectly harmless, as I lave experionced more than once.

'These insects, beautiful as they are, are produced from eges, which are dipusitud in the water, where hey remain for some time without seeming life or mutiun. They are rjected by the female into the water in clisters, like a bunch of grapes, whore thry sink to the hotto $n$ by their natural weinht, and comtinue in that state till the young ones find strength enough to break the shell, and to separate from each other. The furm in which they first show life, is that of a worn with six legs, bearing a strong resemblance to the dragon-fly in its winged state, except that the wings are yet concealed within a sheath peculiar (1) this animal. The rudiments of these appear in buisches on the back, within which the wings are folled up into each other, while all the colours and varieties of painting appear transparent through the skin. These aninals, upon quitting the egg, still continue in the water, where they creep and swim, but donot move swiftly. They have likewise a sharp sight, and immediately sink to the bottom, if any one comes to the places wherein they live, or whenever they perceive the least uicommon nbject. Their food at that time is soft mul and the glutinous earthy substances that are found at the bottom.

Whem these animals prepare to change from their reptile to their flying state, they then muve ont of the water to a dry place; ins into glinss; to pieces of wool, stone, ol any thing clie they meet with. They thre firmly fix thrir acute claws; and, for a short time, contimue quite immoveable, as if meditating (u) the cliange they are 10 umlergo. It is then observed, that the skin first opens on the hear an I back; aud out of this opening they exhibit their real hend and eyes, and at Imoth their six legs; whilst, in the mean time, ilic ho!hw and empty skin, or slough of their legs, re nains firmly fixel in its place. Afrel this, the enclosed creature creeps forwaril lyy degrees; and by this means draws lirst its inings

(a) During the Erib-stale of Itis animal, it preys with the most savage forociv on all aquatic insects. It is, likewise, at this period, furnislued with an apparatus at the and then its body ont of the skin; and procreoling a little farther, sits at rest for some time, as if immoveahle. During this time, the wings, which were inoist and folled, begin by regrees to expand themselves, and to nuke smonth aucl even all those plaits which were lairl against each other, like a closed fan. The burly is likewise insensibly ext. nded, until all the limbs have obtained their propuer size and dimensions. All these surprising und difficult operations are accomplished by the foree of the blool and the circulating hunours. The creature canuot at first make use of its new wings, and therefore is forced to stay in the same place until all its limbs are dried by the circumamhient air. It soon, however, begins to enter upon a nore noble life thm it had hitherto lied in the bottom of the brook; and from creeping slowly and living accidentally, it now wings the uir, and makes choice fiom ausidst the variety of its provisions. ${ }^{2}$

Indeed, no animal is more amply fitted for morion, subsistence, and enjoyment. As it haunts and seeks aftel its food flying in the air, nature has provided it with two large eyes, which make almost the whole head, and which resemble glittering mother-of-pearl. It has also four expansive silver-coloured wings, with which, as with oars, it can turn itself with prodigious velocity; and to assist these, it is furuished with a very long body, which. like a ruclder, directs its motions. As the wings are long, and the legs short, they seldom walk, but ale ever seen either resting or flying. For this reason, they always choose dry brauches of trees or sturubs to remain on; and when they liave refieslied theniselves a litule, they renew theil night. Thus they are seen aroming the summer with a profision wi henty, lightly traversing the air in a thunsand directions, and cxpanding the nost beautitul colours to the sun. 'The garden, the fircst, the hedges, and the rivulets, are aniunater! by their sports; and there are few who have been bronglit up in the comntry, who liave not rmployed a part of their childhood in the pursuit.

Bnt while these beaniful fies appear to us

end of the body, by which it can suck up and eject water with considerable forec. 
so illy and innocently employed, they are in fact the greatest tyrants of the insect tribe; and, like the luawk ainong birds, are only hovering up and down to seize their prey. 'I'iney are the strongest and the most conrageous of all winged insects; nor is there one, how large soever, that they will not attack and devour. The blue-fly, the bee, the wasp, and the hornet, make their constant prey; and even the butterfly, that spreads so large a wing, is often caught and treated without mercy. Their appetite secms to know no bounds; they spend the whole day in the pursuit, and have been seen to devour three times their own size in the capture of a single hour. 'They seize their prey flying with their six claws, and tear it easily to pieces with their teeth, which are capable of inflicting troublesome wounds.

But the nales are upon the wing for another purpose beside that of food, as they are very salacious, and seek the females with great ardour. The sun no sooner begins to warm the fields, than the males are found assiduously employed each in seeking its mate; and no sooner does a female appear, but two or three males are seen pursuing, and endeavouring to seize her with all their arts and agility. The instrument of generation in the male is placed very different from that of any other insect, being not at the end of the tril, as in others, but immediately under the breast, and consequently, at first view, incapable of being united to the sexual part of the female; which, as in other insects, lies in the tail. To perform this junction, nature has provided the male with a very peculiar manner of proceeding. As soon as he perceives the fenale, and finds himself sufficiently near, he seizes upon the back of her head by surprise, and fastening his claws upon her, turns round his forky tail, which he fastens round her neck, and in this manner fixes himself so closely and firmily, that no efforts can remove him. It is in vain that she flies from one branch to another, and settles upon them, he still keeps fixed, and often continues in this situation for three or four hour's successively. When he flies, she is obliged to fly with him; but he still directs the way: and though she moves her wings, she seems entirely guided by his motion. As yet, however, the business of impregnation is not performed; for to this the female must contribute; and she at last seems, by the continuance of her constraint, to comply : for, turning up the end of her tail to that part of the breast of the male in which lies the part proper for generation, both instruments meet, and the eggs of the female receive the necessary fecundation. An hour or two after this, she flies to some neighbouring pool, where she deposites her eggs, as was already mentioned. There they continue in a reptile state for a year; and then are changed into a beautiful fly, resembling the parent.

\section{CHAPTER CLXXX.}

\section{OF THE FORMICA LEO, OR LION-ANT.}

ALTHOUGH this animal properly belongs to no order of insects, yet as it is changed into a fly very much resembling that described in the preceding chapter, it niay not he inproper to give its history here. If we consider the life of this animal, in its different stages of $\mathrm{ex}$ istence, we shall find it equally wonderful in all; but as it changes to a dragon-fly, what we have said of that animal above, need not be repeated here. The lion-ant, when it becomes an inhabitant of air, in every respect resembles that which has been already described; its glossy wings, its voracious appetites, its peculiar manner of generation, are entirely the same. It is in its reptile state that it differs from all other insects; and in that state it will be amusing to pursue its history.

The lion-ant, in its reptile state, is of the size of a common wond-louse, but somewhat broader. It has a pretty long head, and a roundish body, which becomes a little nar- 
rower towards the tail. The colour is a dirty gray, speckled with black, and the borly is composed of severdal thit rinus, which slip one upon another. It has six feet, four of which are fixed to the breast, and two to the neck. The head is sinall and flac, and bufore there are two little smouth horus or feelers, which are hard, about a quarter of an inch long, and crooked at the ends. At the basis of the feelers there are two smill black lively eyes, by which it can see the smallest object, as is easily discovered by its starting fiom every thinir that approaclies.

'Po a forll so unpromising, and so ill provided for the purposes of rapacity, this animal unites the most ravennus appetites in nature; but to mark its imbecility still stronger, as other animals have wings or fiet to enable them to advance towards their prey, the lionant is unprovided with such assistance firom either. It lias legs, indeed; but these ouly enable it to run backward, so that it could as som dic as make the smallest progressive motion. Thus famished and rapacious as it ever seems, its prey must come to it, or rat er into the snare provided for $i t$, or the insidions assassin must starve.

But nature, tliat loas denicil it strength or swifuess, has given it an equivalent in cunning, so that no ani ual fares more sumptuously, ivithout ever stirring from its retreat. For this purpose, it chooses a diy sandy place at the foot of a wall, or under some shelter, in order to preserve its machinations from the rain. The driest and nost sandy spot is the most proper for it ; because a lienvy clogged earth would defeat its labunr. When it goes about to dic the hole where it takes its prey, it begins to bund the hinder part of its borly, which is pointed, and tluss works hackward; making, after several attenpts, a circular furrow, which serves to mark out the size of the hole it intends mukiug, as the ancients nuarked out the limits of a city with a plough. Within this first furrow it digs a second, then a third, and afterwarls others, which are always less than the precelling. Then it begins to deepen its hole, sinking lower and luwer into the saill, which it throws with its horns or feelers fowards the edges, as we see men throw up sand in a gravel-pit. Thus, by repeating its lab urs all round, the sand is thrown 11 in a circle about the edge of the pit, until the whole is quite completed. This hole is always formed in a perfect circle; and the pit itself resembles the insicle of an inverted funnel. When this insect first leaves the egg and is newly hatched, the first pit it makes is very smali; but as it grosvs bigger, it makes a larger hole; which Is destined, like a pit-fall, to entrap its prey. It is generally about two inches deep, and as much in diameter.

The work being thus, with great labour, funished, the insidious insect places itself in ambush, hiding itself in the bottom under the sand, in such a manner, that its two horns encircle the hottom of the pit. All the sides of this pit-fall are made of the most loose and crumbling materials; so that scarcely any insect can climb up that lias once got down to the bottom. Conscious of this, the lion-ant remains in patient expectation, ready to profit by that accident which throws some heedless little animal into its den. If then, by nisfortune, an ant, a wood-louse, or a small caterpillar, walks ton near the edge of the precipice, the sand gives way beneath them, and they fall to the bottom of the pit, where they meet inevitable destruction. The fall of a single grain of sand gives the murderer notice at the botton of its cave; and it never fails to sally forth to seize upon its prey. It happens sometimes, however, that the unt or the wood-lonse is too nimble, and runs up the sides of the pitfall before the other can make ready to seize it. The lion-ant has then another contrivance, still more wonderful than the former; for, by means of its broad head and feelers, it has a methol of throwing "I] a shower of sand, which fulls upon the struggling eaptive with trumendous weight, and once more crushes it down to the botton. When the insect is once fallen thus low, no efforts can retrieve or release it; the lion-ant scizes it with its feelers, which are hollow, and darting them both into its body, sucks out all the little animal's juices with the utmost rapacity.

Wh'n the prey is thus reduced to a husk, and nothing but the external form remaius, the next care of the murderer is to remove the body from its cell; since the appearance of dear carcasses might forewarn orher insects of the danger of the place. The insect, therefore, takes up the wasted trunk with its feelers, and throws it, with wonderful strength, at least six inches from the edge of its hole; and 
then patiently sets about mending the breaches which its fortifications had receivel in the last engagement. Nothiug can abate its industry, its vigilance, its patience, ol its rapacity. It will work fol a week together to make its pitfall; it will continue upon the watch for more than a month, patiently expecting the approach of its prey; and if it comes in greater quantities than is needful, yet still the little voracious creature will quit the insect it has newly killed, and leave it half eaten, to kill and attack any other that happens to fall within the sphere of its malignity: thomgh so voracions, it is surprisingly patient of hunger ; some of them having been kept in a box with sand, for six months and upivards, wilhout feeding at all.

When the lion-ant attains a certain age, in which it is to change into another form, it then leaves off its usual rapacious habits, but keeps on its industry. It no longer continues to make pits, but furrows up the sand all round in an irregular "nanuer; testifying those workings and violent agitations which most insects exhibit previous to their transformation. These animals are produced in autumn, and generally live a year, and perhaps two, before they assume a winged form. Certain it is, that they are found at the end of winter of all sizes; and it would seem that many of the smaller kinds had not yet attained sufficient maturity for transformation. Be this as it may, when the time of change approaches, if the insect finds its little cell convenient, it secks no other; if it is obliged to remove, after furrowing up the sand, it hides itself under it, horns and all. It there spins a thread, in the manner of the spider; which being made of a glutinous subsiance, and being humid from the moisture of its body, sticks to the little particles of sand among which it is spun ; and in proportion as it is thus excluderl, the insect rolls up its web, sand and all, into a ball, of which itself is the centre. This ball is about hall an inch in diameter; and within it the insect resides, in an apartment sufficiently spicions for all its motions. The outside is composed of sand and silk; the inside is lined with silk only, of a fine pearl-colour, extremely delicate, and perfectly beauriful. But thongh the work is so curious within, it exhibits nothing to exterual appearance but a lump of sand; and thus escapes the seatch of birds, that might otherwise disturb the inhabitant within.

The insect continues thus shut up for six weeks or two months; and gradually parts with its eyes, its feelers, its feet, and its skin; all which are thrust into a corner of the inner apartnent, like a rag: The insect then appears almost in its winged state, except that there is a thin skin which wraps up the wings, and that appears to be nothing else but a liquor dried on their outside. Still, however, the little animal is too delicate and tender to venture from its retreat; but continues enclosed for some time longer: at length, when the members of this new insect have acquired the necessary consistence and vigour, it tears oper its lodging, and breaks through its wall. For this purpose it has two teeth, like those of grasshopper's, with which it eats through, and enlarges the opening, till it gets out. Its body, which is turned like a screw, takes up no more than the space of a quarter of an inch; but when it is unfolded, it becomes half an inch in length; while its wings, that seemed to occupy the smallest space, in two minutes' time unfold, and becomr longer than the body. In short, it becomes a large and beautiful fly, of the libcllula kind, with a long slender body, of a brown colour; a small head, with large bright eyes, long slender legs, and four large transparent reticulated wings. 'The rest of its hatits resemble that insect whose form it bears ; except, that instead of dropping its eggs in the water, it deposites them in sand, where they are soon hatched into that rapacious insect so justly aduired for its method of catching its prey. 


\section{CHAPTER CLXXXI.}

\section{OF THE GRASSHOPPER, THE LOCUST, THE CICADA, THE CRICKET, AND THE MOLE-CRICKET.}

BELONGING to the second order of insects, we find a tribe of little animals, which, though differing in size and colour, strongly resemble each other in figure, appetites, nature, and transformation. But though they all appear of one family, yet man has been taught to hold them in different estimation; for while some of this tribe amuse him with their chirpings, and banish solitude from the fielis, others come in swarms, cat up every thing that is green, and in a single night convert the most delightful landscape into a dreary waste. However, if these animals be separately considered, the devouring locnst is not in the least more mischievous than the musical grasshopper; the only difference is, that one species comes for food in a swarm, the other feeds singly.

That animal which is called the grasshopper with us, differs greatly from the cicada of antiquity; for as our insect is active cnough in hopping through the long grass, from whence it has taken its name, the cicada lind not this power, but either walked or flew. The little hissing note also of our grasshopper is very different from the song of the cicada, which was louder, and far more musical. The manner in which this note is produced by the two animals is very different; for the cicada makes it by a kind of buckler, which the male has beneath its belly; the grasshopper by a transparent membrane that covers a hole at the base of its wings. There is still a greater variety in all these with regard to shape and colour. Sume are green, some black, some livid, and some variegated; but many of themilo not show all their colours till they fly. Some have long legs, some short, some with more joints, others with fewer. Some sing, others are mute: some are innocent, doing no damage to the husbandinan; while others do such prodigious mischief, that they are looked upon in some so. $65 \& 66$. countries as one of the terrible scourges of the incensed Divinity.

Of this variegated tribe, the little grasshopper that breeds in such plenty in every meadow, and that continues its chirping through the summer, is best known to us; and by lhaving its history, we shall be possessed of that of all the rest. This animal is of the colour of green leaves, except a line of brown which streaks the back, and two pale lines under the belly and behind the legs. It may be divided into the head, the corselet, and the belly. The head is oblong, regarding the earth, and bearing some resemblance to that of a horse. Its mouth is covered by a kind of round buckler jutting over it, and armed with teeth of a brown colour, hooked at the points. Within the mouth is pereeivable a large reddish tongue, and fixed to the lower jaw. The feelers or horus are very long, tapering off to a point; and the eyes are like two black specks, a little prominent. The corselet is elevated, narrow, armed above and below by two serrated spines. The back is armed with a strong buckler, to which the muscles of the legs are firmly bound, and round these muscles are seen the vessels by which the animal breaths, as white as snow. The last pair of legs are much longer and stronger than the first two pair, fortified by thick inuscles, and very well formed for leaping. It lias four wings; the anterior ones springing from the secoud pair of legs, the posterior from the third pair. The hiuder wings are much finer and more expansive than the forcmost, and are the principal instruments of its flight. The belly is considerably large, composed of cight rings, and terminated by a forky tail, covered with down, like the tail of a rat. When examined internally, besides the gullet, we discover a small stomach; and belind that a very large one, wrinkled and furrowed within side: $5 \mathbf{P}$ 
lower down there is still a third; so that it is not without reason that all the animals of this order are said to chew the cud, as they so much resemble ruminant animals in their interual conformation.

A short tiue after the grasshopper assumes its wings, it fills the meadow with its note; which, like that among birds, is a call to courtship. The male only of this tribe is vocal; aud, upon examining at the base of the wings, there will be found a little hole in its body, covered with a fine transparent membranc. This is thought, by Linnaus, to be the instrument it employs in singing: but others are of opinion the sound is produced by rubbing its hinder legs against each other: however this be, the note of one male is seldom licard, but it is returued by another; and the two little animals, after many mutual insults of this kind, are seen to meet and fight desperately. The female is generally the reward of victory; for, after the counbat, the male seizes her with his teeth behind the neck, and thus keeps her for several hours till the business of fecundation is performed. They are at that tine so strongly nuiled, that they can scarcely be separated without tearing asunder. Towards the latter end of autumu the female prepares to deposite her burden; and her body is then seen greatly distended with her eggs, which she carries to the number of an hundred and fifty. In order to make a proper lodgment in the earth for them, nature has furnished her with an instrument at her tail, somewhat resemhling a twoedged sword, which she can sheath and un. sheath at pleasure: with this she pierces the earth as deep as she is able; and into the hole which her instrument has made, she deposites her eggs, one after the other.

Having thus provided for the continuation of her posterity, the animal herself does not long survive; but as the winter approaches, she dries up, seems to feel the effects of age, and dies from a total decay. Some, however, assert, that she is killed by the cold; and others, that she is eaten by worms: but certain it is, that neither the male nor female are ever seen to survive the winter. In the mean time, the eggs which have been deposited continue unaltered, either by the severity of the season or the retardation of the spring. They are of an oval figure, white, and of the consistence of horn: their size nearly equals that of a grain of anise: they are enveloped in the body within a corering, branched all over with veins and arteries; and when excluded they crack, on being pressed between the fingers; their substance within is a whitish, viscous, and transparent fluid. In this manner they remain deposited beneath the surface of the earth, during the whole winter; till the genial retum of spring begins to vivify and hatch them. The sun, with its warmth, beginning to animate all nature, the insect eggs feel its benign influeuce; and, generally, about the beginuing of May, every egg produces an insect, about the size of a flea. These, at first, are of a whitish colour; at the end of two or three days they turn black; and soon after they become of a reddish brown. They appear, from the beginning, like grasshoppers, wanting wings; and hop among the grass, as soon as excluded, with great agility.

Yel still they are by no means arrived at their state of full perfection; although they bear a strong resemblance to the animal in its perfect form. They want, or seem to want, the wings, which they are at last seen to assume; and can only hop among the grass, without being able to fly. The wings, however, are not wanting, but are concealed within four little bunches, that seem to deform the sides of the animal : there they lie rolled up in a most curious manner; and occupying: a smaller space than one could conceive who saw them extended. Indeed, all irsects, whatever transmutations they seem to undergo, are yet brought forth with those very limbs, parts, and wings, which they afterwards seem to acquire. In the most helpless caterpillar, there is still to be seen the rudiments of that beautiful plumagre which it afterwards expands when a butterfly: and though many new parts seem unfolded to the view, the animal arcquires none but such as it was from the beginning possessed of. The grasshopper, therefore, though seemingly without wings, is, in reality, from the first, possessed of those instruments, and only waits for sufficieut force to break the bonds that hold them folded up, and to give them their full expansion. 
The grasshopner, that for above twenty days from its exelusion has continued without the use of its wings, which were folded up to its body, at length prepares for its emancipation, and for a life of greater liberty and plcasure. 'To make the proper dispositions tor the approaching change, it ceases from its grassy food, and secks about for a convenicnt place, beneath some thorn or thistle, that may protect it from an accidental shower. T'he same laborious writhings and workings, heavings and palpitations, which we have remarked in every other insect upon an approaching change, are exhibited in this. It swells up its head and ncek; it then seems to draw them in again; and thus alternately, for some time, it exerts its powers to get free. At lenglh, the skin covering the head and breast is seen dividing above the neck; the head is seen issung out first from the bursting skin; the efforts still continuing, the other parts follow successive. ly; so that the little animal, with its long feelers. Jegs and all, works its way from the old skin, that reinains fixed to the thisıle or the thorn. It is, indeed, inconceivalsle how the insect can thus extricate itself from so cxact a slieath as that which corercth every part of its body.

The grasshopper, thus disengaged from its outer skin, appears in its perfect form; but then so feeble. and its body so soft and teruder, that it may be moulded like wax. It is no longer of that obscure colour which it exhibited before, but of a greellish white, which becomes more vivid as the moisture on the surface is dried away. Still, however, the animal continues to show no sigus of life, but appears quite spent and fatigued with its labour for more than an hour together. During this time, the body is drying, and the wings unfolding to their greatest expausion; and the curious observer will perceive them, fold after fold, opening to the sun, till at last they become longer than the two hinder legs. The insect's body also is lengthened during this operation, and it becomes much more beautiful than before.

These insects are generally vocal in the midst of suinmer, and they are heard at sunsetting much londer than during the beats of the day They are fed upon grass; and, if their belly be pressed, they will be seen to return the juices of the plants they have last fed upon. Though unwilling to fly, and slow in Hight, particularly when the weather is inoist or cool, they are sometimes seen to fly to considerable distances. If they are cauglit by one of the hinder legs, they quickly disengage themselves from it, and leave the leg behind them. This, however, does not grow again, as with crabs or spiders; for as they are animals but of a single year's continuance, they have not sufficient time for repairing those accidental misfortunes. The loss of their leg also prevents them from flying; for being uuable to lift themselves in the air, they have not room upon the ground for the proper expansion of their wings. If they be handled roughly, they will bite very fiercely; and when they fly, they make a noise with their wings. They generally keep in the plain, where the grass is luxuriant, and the ground rich and fertile: there they deposite their eggs, particularly in those cracks which are formed by the heat of the sun.

Such are the habits and nature of those little vocal insects, that swarm in our meadows, and enliven the landscape. The larger kinds only differ from them in size, in rapidity of night, and the porrers of injuring mankind, by swarming upon the productions of the eartl. The quantity of grass which a few grasshoppers that sport in the fields can destroy is trifling; but when a swarm of locusts, two or three miles long, and several yards deep, settle upon a field, the consequences are frightful. The annals of every country are marked with the devastation which such a mullitude of inseets produces; and though they seldom visit Europe in such dangerous swarms as formerly, yet, in some of the southern kingdoms, they are still formidable. Those which have at uncertain intervals visited Europe, in our memory, are supposed to have come from Africa. and the aninal is called the Great Brown Locust. It was secu in several parts of England in the year 1748, and many dreadful consequences were apprehended from its appearance. This insect is about three inches long; and has two horus or feelers, an inch in length. The head and horns are of a brownish colour; it is blue about the mouth, as also on the in- 
sile of the larger legs. The shield that covers the back is greenish; and the upper side of the hody brown, spotted with black, and the under' side purple. 'The upper wings are brown, with sinall dusky spots, with one Inrger at the tips; the unter wings are more trinsparent, and of a light brown, tinctured with green, but there is a darls cloud of spots near the tips. 'This is that iusect that has threatened us so often with its visitations; and that is so truly terrible in the countries where it is bred. There is no animal in the creation that multiplies so fast as these, if the sus be warm, and the soil in which their eggs are deposited be dry. Happily for us, the coldness of our climate, and the humidity of our soil, are no way favourable to their production; and as they are but the animals of a year, they visit us and perish.

The Scripture, which was written in a country where the locust made a distinguished feature in the picture of nature, has given us several very striking images of this animal's numbers and rapacity. It compares an army, where the numbers are almost infinite, to a swarm of locusts: it describes them as rising out of the earth, where they are produced; as pursuing a settled march to destroy the fruits of the earth, and co-operate with Divine indignation.

When the locusts take the field, as we are assured, they have a leader at their head, whose llight they observe, and pay a strict attention to all bis motions. They appear, at a distance, like a black cloud, which, as it approaches, gathers upon the horizon, and almost hides the light of the day. It ofien happens that the husbandman sees this imminent calamity pass away without doing him any mischief; and the whole swarm proceed onward, to settle upon the labours of some less fortunate country. But wretched is the slistrict upon which they settle: they ravage the meadow and the pasture ground; strip the trees of their leaves, and the gardell of its beauty : the visitation of a few minutes destroys the expectations of a year; and a famine but too frequently ensues. In their native tropical climates they are not so dreadful as in the more southern parts of Europe. There, though the plain and the forest be stripped of their verdure, the power of vegetation is so great, that an interval of three or four days repairs the calamity: but our verdure is the livery of a season; and we Inust wait till the ensuing spring repairs the damage. Besides, in their long lights to this part of the world, they are famislied by the tedionsness of their journey, and are therefore more voracious wherever they happen to settle. But it is not by what they devour that they do so much damage, as by what they destroy. Their very bite is thought to contaminate the plant, and to prevent its vegetation. To use the expression of the husbandman, they burn whatever they touch, and leave the marks of their devastation for two or three years ensuing. But if they be noxious while living, they are still more so whel dead; for wherever they fall, they infect the air in such a manner, that the smell is insupportable. Orosius tells us, that in the year of the world 3800 , there was an incredible number of locusts which infected Africa; and, after having eaten up every thing that was green, they flew off, and were drowned in the African sea; where they caused such a stencl, that the putrefying bodies of hundreds of thousands of men could not equal it.

In the year 1690 , a cloud of locusts was secn to enter Russia in three different places; and from thence to spread themselves over Poland and Lithuania, in such astonishing multitudes, that the air was darkened, and the earth covered with their numbers. In some places they were seen lying dead, heaped upon each other four feet deep: in others, they covered the surface like a black cloth: the trees bent beneath their weight; and the damage which the country sustained exceeded computation. In Barbary their numbers are formidable, and their visits are frequent. In the year 1724 , Dr. Shaw was a wituess in that country of their devastations. Their first appearance was about the latter end of March, when the wind had been southerly for some time. In the beginning of A pril, their numbers were so vastly increased, that in the heat of the day they formed themselves into large swarms, which appeared lik' clouds, and darkened the sun. In the middle of May they began to disappear, retiring into the plains to deposite their eggh 
In the next month, being June, the young brood began to make their appralance, formin, many eompact bodies of several hundred yards square; which afterwards marching for vart, elimbed the trees, walls, and houses, cating every thing that was green in their way. The inhabitants, to stop their progress, laid trenches all over their fields and gardens, filling them with water. Some placed large quatutities of beath, stubble, and such like coubustible inutter, in rows, and set them on fire on the approach of the locusts. But all this was in no purpose; Ji the trenches were quickly filled up, and the fires put out by the vast number of swarins that succeeded each other. A day or two after one ol these was in motion, others that were just hatched came to glean after them, gnawing off the young branches and the very lark of the trees. Having lived near a month in this manner, they arrived at their full growth, and threw off their worm-like state, by casting their skins. To prepare themselves for this change, they fixed their hinder feet to some bush or twig, or corner of a stone, when immediately, by an undulating motion used on this occasion, their heads would first appear, and soon after the rest of their bodies. The whole transionmation was performed in seven or eight minutes' time; alter which, they were a little while in a languishing condition ; but as soon as the sun and air hail hardened their wings, and driel up the moisture that remained after casting off their slonghs, they returned again to their limner greediness, with an addition both of strength and agility. But they did not coutinne long in this state before they were entirely lispersed; after laying their eggs, directing their course northward, they problably perished in the sea. It is said that the holes these animals make, to deposite their eggs, are four feet diep in the ground; the eges are about fourscore in number, of the size. of caraway comfits, and bundled up tugether in clusters.

It would be endless to recount all the mischiefs which these famished insects have at diff'rent times occasioned; but wh.t can have induced them to take such distant flights, when they come into Europe, is not so easy to be arcounted for. It seems most probable, that by means of a very diy season in the heart of Africa, they are propagated in such numbers, that the vegetables of the spot where they are produced are not sufficient to sustain them. 'Thus heing obliged to find out other countries, they traverse the sandy deserts, where they can find no sustenance : still neeting with nothing to allure them from their height, they proceed forward across the sea, and thus cone into Europr, where they alight upon the first green pastures that ocent.

In some parts of the world, the inbabitants turn what seems a plague to their own advantage. Locusts are eaten by the natives in many kingtoms of the East; and ure caught in suall nets provided for that purpuse. They purch then over the fire in an earloen pan; and when their wings and legs are fullen ofi, they turn reddish, of the colour of boiled slurimps. Dampier has eaten them thus prepared, and thioks them a tolerable dish. The uatives of Burbary also ent them fried with salt; and they are snid to taste like crayfish.

There is a locust in Tonquin, about the bigness of the top of a man's finger, and as long as the first joint. It breeds in the earth, in low grounds; nnd in the months of January and February, which is the season for taking them, they issue from the earth in vast swarms. At first they can hardly fly, so that they ofien fall into the rivers in great numbers: however, the natives in these nonths watch the rivers, and take them up in multitudes in small nets. They eihler eat thom fresh, broiled on the coals, or pickle then for keeping. They are considered as a great delicacy in that part of the world, as well by. the rich as the poor. In the countries where they are eaten, they are regularly brought to market, and sold as larks or quails in Europe. They must have been a common food with the Jews, as Moses, in the bouk of Levitieus, permits them to eat four different kinds of this animal, which he takes care to specily. This dish, however, has not yet made its way into the kitchens of the luxurious in Europe; and though we may admire the delicacies of the Easi, we are as yet happily deprived of the power of imitation.

OI all animals, however, of this noxious irily, the Great West Indian Locust, undividually considered, is the most formidable. It is about the thickness of the barrel of a goose-quill, and the body is divided into nine 
or ten joints, in the whole about six or seven inches long. It has two simall eyes standing out of the head like those of crabs, and rwo feclers like long hair. The whole body is studded with small cxcrescences, which are not unch bigger than the points of pins. The shape is roundish, and the body diminishes in circumference to the tail, which is forkerl into two horns. Between this, there is a sort of a shcath contnining a small daugerous sting. If any person happens to touch this insect, he is surc to he stung; and is immerliately taken with a shivering and trembling all over the body; which, however, may soon be put a stop to, by rubbing the place tluat was affected with a litile palm oil. ${ }^{a}$

Froni the locust we descend to the Cricket, which is a very inoffensive and pretty animal. Though there be a species of this insect that lives entirely in the woods and fields, yet that witl which we are best acquainted is the House-cricket, whose voice is so well known behind a country fire in a winter's evening. There is something so unusual in hearing a sound while we do not sec the animal producing it, nor discover the place from whence it comes, that among the country pcople the chirping of the cricket is always held oninous; and whether it deserts the fire-side, or pays au unexpected visit, the credulous peasantry alvays find something to be afiaid of. In general, however, the killing of a cricket is considered as a most unlucky omen: and though their company is not nuch desired, yet no metliods must be taken to remuve them.

The cricket vely much resembles the grasshopper in its shape, its manner of ruminating, its voice, its leaping, and methods of propagation. It differs in its colour, which is uniformly of a rusty brown; in its food, which is more various; and in its place of residence, which is most usually in the warmest chinks belind a country hearth. 'They are, in son:e measure, obliget to the bad masoniy employed in making peasants' houses for their retreats. The smallest chink serves to give them shelter; and where they once make their abode, they are sure to propagatc. They are of a most chilly nature, seldom leaving the fire-side; and, if undisturbed, are seen to hop fronı their

(a) It is now known that every insect of this tribe is perfecrly harmless. retreats in climerip at the blaze in the chimney. The wood-cricket is the most timorous animal in nuture; but the chimney-cricket, being used to noises, disregards not ouly those, but the appearance of people near it. Whether the voice of rhis auimal is formed in the same nianuer with that of the grasshopper, by a fine inembrane at the base of the wings, which is moved by a nuscle, and which being coiled up, gives a sound like a quail-pipe, is not yet ascertuined; nor do we well know the use of this voice, since nuatomical inspection has not yet been able to discover the smallest organs of hearring. Still, however, we can minke no doubt of their power of distinguishing sounds, though probably not in the sane manner with the more perfect ranks of nature. Certain it is, that I have often heard thrm call, and this call was as ricyularly answered by another, althougli nome but the males are vocal.

As the cricket lives chiefly in the dark, so its eyes seem formed for the gloominess of its abolle; and those who would surprise it, have. only to light a candle unexpectedly; by which it is dazzled, and cannot find the way back to its retreat." It is a very voracious little aninul, ant will eat bread, flour, and meat; but it is purticularly fond of sugar. They never link, hut keep fow nunths together at the back of the rhimury, where they could possilsly have had no moisture. The warmeth of thrir situation only serves to increase their mirth anul loquacity. Except in the very coldest weather, they never cease their chirruping, but continue that little piercing note, which is pleasing to some as it is disagrecable to others. The great Scaliger was padticularly delighted with the chirruping of crickets, and kept several of them for his anusement, enclosed in a box, which he placed in a warm simation. Others, on the contraty, think there is something ominous and ficlanclooly in the sound, and use every endeavour to banish this insect from their houses. Ledelins tells us of a woman who was very much incommoded by crickets, and tried, but in vain, every methnd of hanishing then fion her house. She at last accidentally succeeded; for having one day invited several guests to her house, where there was a wedding, in order to increase the festivity of the entertainment, she procured drums and trumpets to entertain then. The noise of 
these was so much greater than what the little animals were used to, that they instantly forsook their situation, and were never heard in that mansion more.

But of all the cricket kind, that which is calied the Mole-Cricket is the most extraordinary. This animal is the largest of all the insects with which we are acqnainted in this country, being two inches and a half in length, and three quarters of an inch in breadth. The colour is of a dusky brown; and at the extremity of the tail there are two hairy excrescences, resembling in some sense the tail of a mouse. The body consists of eight scaly joints or separatr. folds, is brown on the upper part, and more deeply tinged below. The wings are long, narrow, and terminate in a sharp point, each having a blackish line running down it: however, when they are extended, they appear to be much broader than could at first sight be supposed. The shield of the breast is of a firm texture, of a blackish colour, and hairy. The fore feet, which are this animal's principal instruments of burrowing into the earth, are strong, webbed, and hairy; it generally, however, runs backward; but it is cominonly under ground, where it burrows even faster than a mole. It is thought also to be amphibious, and capable of living under water, as well as under ground.

Of all insects this is the most detested by gardeners, as it chiefiy resides in that ground which lies light, and where it funds aufficient plenty under the surface. Thus, in a single night's time, it will run along a furrow which has been newly sown, and rob it of all its contents. Its legs are formed in such a manner that it can penetrate the earth in every direction; before, behind, and above it. At night it ventures from its under-ground habi-

(a) Among this tribe may be numbered the Great Lantern Fly of Peru, an insect the most splendid and luminous of all that ere yet known. In the head is contained a phosphnrescent light, sufficiently vivid to serve the purposes of a candle in a dark room; or, when two or three tation, and, like the cricket, has its chirping call. When the female is fecundnted, she makes a cell of clammy earth, the inside of which is large enought to hold two hazel-nuts; and in this she lays her eggs. The whole nest is about the size of a common hen's egg, closed up on every side, and well defended from the smallest breath of air. The eggs generally amount to the number of a hundred and fifty, being white, and about the size of a caraway comfit. They. are thus carefully covered, as well to defend them from the injuries of the weather, as from the attacks of the black beetle; that being itself an underground inhabitant, would, but for this precaution, devour or destroy then. To prevent this, the female mole-cricket is often posted as a centinel near the nest, and when the black invader plunges in to seize its prey, the guardian insect seizes him behind, and instantly bites him in two.

Nothing can exceed the care and assiduity which these animals exhibit in the preservation of their young. Wherever the nest is placed, there seems to be a fortification, avenues and entrenchments, draws round it: there are numberless winding-ways that lead to it, and a ditch drawn about it, which few of its insect enemies are able to pass. But their care is not confined to this only; for at the approach of winter they carry their nest entirely away, and sink it deeper in the ground, so that the frost can have no influence in retarding the young brood from coming to maturity. As the weather grows milder, they raise their magazine in proportion; till, at last, they bring it as near the surface as they can, to receive the genial influence of the sun, without wholly exposing it to view; yet should the frost unexpectedly return, they sink it again as before."

are put together at the end of a stick, to light travellers on the road like a lantera. It is about the size of the larger kind of locust, and the wings and whole body are. beautifully variegated. 


\section{CHAPTER CLXXXII.}

\section{OF THE EARWIG, THE FROTH INSECT, AND SOME OTHERS BELONGING TO THE SECOND ORDER OF INSECTS.}

WE should still keep in memory, that all insects of the second order, though not produced quite perfect from the egg, yet want very little of their perfection, and require but a very sinall change to arrive at that state which fits them for llight and generation. The natural functions in these are never suspended; from the instant they leare the egg, they continue to eat, to move, to leap, and pursue their prey: a slight change ensues; a skin, that enclosed a part of their body and limbs, bursts behind, like a woman's stays, and gires freedom to a set of wings, with which the animal expatiates, and fies in pursuit of its mate.

Of all this class of insects, the Earwig undergoes the smallest change. This animal is so common that it scarce needs a description: its swiftuess in the reptile state is not less remarkable than its indefatigable velocity when upon the wing. That it must be very prolific, appears from its numbers; and that it is very liarmless, every one's experience can readily testify. It is provided with six feet, and two feelers; the tail is forked ; and with this it often attempts to defend itself against every assailant. But its attempts are only the threats of impotence; they draw down the resentment of powerful animals, but no way serve to defend it. The deformity of its figure, and its slender make, have also subjected it to an imputation, which, though entirely founded in prejudice, has more than once procured its destruction. It is supposed, as the name imports, that it often enters into the ears of people sleeping; thus causing madness from the intolerable pain, and soon after death itself. Indeed, the French name, which signifies the Ear-piercer, urges the calumny against this harmless insect in very plain terms; yet nothing can be more unjust: the ear is already filled with a substance which prevents any insect from entering; and besides, it is well lined, and defended with membranes, which would keep out any little animal, even though the ear-ivax were away. These reproaches, therefore, are entirely groundless: but it were well if the accusations which gardeners bring against the earwig were as slightly founded. There is nothing more certain than that it lives among flowers, and destroys them. When fruit also has been wounded by flies, the earwig generally comes in for a second feast, and sucks those juices which they first began to broach. Still, however, this insect is not so noxious as it would seem; and seldom is found but where the mischief has been originally begun by others. Like all of this class, the earwig is hatched from an egg. As therc are various kinds of this animal, so they choose different places to breed in: in general, however, they lay their eggs under the bark of plants, or in the clefts of trees, when beginning to decay. They proceed from the egg in that reptile state in which they are most commonly seen; and, as they grow larger, the wings bound under the skin begin to bourgeon. It is amazing how very little room four large wings take, up before they are protruded; for no person could ever conceive such an expansion of natural drapery could be rolled up in so small a paciet. The sheath in which they are enveloped, folds and corcrs them so neatly, that the animal seems quite destitute of wings ; ${ }^{\mathrm{a}}$ and even when they are burst from their confusement, the animal, by the power of the muscles and joints which it has in the middle of its wings, can closely fold them into a very narrow compass. When the earwig has become a winged insect, it flies in pursuit of the female, ceasing to feed, and is wholly employed in the business of propagation. It lives in

(a) Swammerdam, p. 114. 
its winged state but a few days; and having taken care for the continuance of posterity, dries up, and dies to all appearance consumptive."

To this order of insects we may also refer the Cuckow-Spit, or Froth-WVorm, that is often found hid in that frothy natter which we find on the surface of plants. It has an oblong obtuse body; and a large head with small eyes. The external wings, for it has four, are of a dusky brown, marked with two white spots: the head is black. The spume in which it is found wallowing, is all of its own formation, and very much resembles frothy spittle. It proceeds from the vent of the animal, and other parts of the body ; and if it be wiped away, a new quantity will be quickly seen ejected from the little animal's body. Within this spume it is secn in time to acquire four tubercles on its back, wherein the wings are enclosed: these bursting, from a reptile it becomes a winged animal; and thus rendered perfect, it flies to meet its mate, and propagate its kind.

The Water-Tipula also belongs to this class. It has an oblong slender body, with four feet fixed upon the breast, and four feelers near the mouth. It has four weak wings, which do not at all scem proper for fiying, but leaping only. But what this insect chiefly demands our attention for is, the wonderful lightness wherewith it runs on the surface of the water, so as acarce to put it in motion. It is somelimes seen in rivers, and on their banks, especially under shady trees; and generally in swarms of several together.

The Common Water-Fly also breeds in the same manner with those above mentioned.

(a) The indefatigable M. de Geer has discovered that the female earwig sits over her eggs, and fosters her young, in the same manner as a hen does her chickens.

ก०. $65 \& 66$.
This animal is by some called Notonecta, because it does not swim, in the usual manner, upon its belly, but on its back : nor can we help admiring that fitness in this irsect for its situation, as it lecds on the under-side of plants which grow on the surface of the water; and therefore it is thus formed with its mouth uprards, to take its food with greater convenience and ease.

We may also add the IVater-Scorpion, which is a large insect, being near an inch in length, and ahout half an inch in breadth. Its body is nearly oval, but very flat and thin; and its tail long and pointed. The head is small; and the feelers appear like legs, resembling the claws of a scorpion, but without sharp points. This insect is generally found in ponds; and is, of all others, the most tyrannical and rapacious. It destroys, like a wolf among sheep, twenty times as many as its hunger requires. One of these, when put into a basin of water, in which were thirty or forty worms of the libellula kind, each as large as itself, destroyed them all in a few minutes; getting on their backs, and piercing with its trunk through their body. These animals, however, though so formidable to others, are nevertheless themselves greatly overrun with a little kind of louse, about the size of a nit, which very probably repays the injury which the water-scorpion inflicts upon others.

The water-scorpions live in the water by day; out of which they rise in the dusk of the evening into the air, and so flying from place to place, often betake themselves, in quest of food, to other waters. The insect, before its wings are grown, remains in the place where it was produced; but when come to its state of perfection, sallies forth in search of a companion of the other sex, in order to continue its noxious posterity.

$5 Q$ 


\section{CHAPTER CLXXXII.}

\section{OF THE EPHEMERA.}

THE last insect we shall add to the second order, is the Ephemera; which though not strictly belonging to it, yet secms more properly referred to this rank than any other. Indeed, we must not attend to the rigour of method, in a history where nature seems to take delight to sport in variety.

That there should be a tribe of flies whose duration extends but to a day, secms at first surprising; but the wonder will increase, when we are told, that some of this kind seem to be born and to die in the space of a single hour. The reptile, however, from which they are bred, is by no means so short-lived; but is sometimes seen to live two years, and many times three years together.

All ephemeras, of which there are various kinds, are produced from the egg in the form of worms; from whence they change into a more perfect form; namely, that of aurelias, which is a kind of middle state between a worm and a fly; and from thence they take their last mutation, which is into a beantiful fly, of longer or shorter duration, according to its kind.

'The ephemera, in its fly state, is a very beantiful winged insect, and has a strong similitude to the butterfly, both from its shape and its wings. It is about the size of a middling butterfly; but its wings differ in not being covered with the painted dust with which those of butterflies are adorned, and rendered opake, for they are very transparent and tery thin. These insects have four wings, the uppermost of which are much the largest: when the insect is at rest, it generally lays its wings one over the other, on the back. The body is long, being formed of six rings, these are larger at the origin than near the extremity; and from this a tail proceeds, that is longer than all the rest of the fly, and consists sometimes of three threads of an equal length, or sometimes of two long and one short. To acquire this beautiful form, the insect has been obliged to undergo several transmutations; but its glory is very short-lived, for the hour of its perfection is the hour of its death; and it seems scarcely introduced to pleasure, when it is obliged to part with life.

The reptile that is to become a fly, and that is granted so long a term, when compared to its latter duration, is an iuhabitant of the water, and bears a very strong resemblance to fishes, in many particulars; having gills by which it breaths at the bottom, and also the tapering form of aquatic animals. These insects have six scaly legs, fixed on their corselet. Their bead is triangular: the eyes are placed forward, and may be distinguish-: ed by their largeness and colour. The mouth is furnished with teeth; and the body consists of six rings; that next the corselet being largest, but growing less and less to the end: the last ring is the shortest, from which the, three threads proceed, which are as long as the whole body. Thus we see that the reptile bears a very strong resemblance to the fly; and only requires wings, to be very near its perfection.

As there are several kinds of this animal, their aurelias are consequently of different colours; some yellow, some brown, and some cream-coloured. Some of these also bore themselves cells at the bottom of the water, from which they never stir out, but feed upon the mud composing the walls of their habitation, in contented captivity; others. on the contrary, range about, go from the bottom to the surface, swim between two waters, quit that element, entirely to feed upon plants by the river side, and then return to their favourite element, for safety and protection.

The reptile, however, though it lives two or three years, offers but little, in its long duration, io excite curiosity : it is hid at the bottom of the water, and feeds almost wholly within its narrow habitation. The most 
striking facts command our attention during the short interval of its fly state; into which it crowds the most vitrious transactions of its little life. It then may be said to be in a hurry to live, as it has but so sinall a time to exist. The peculiar sign whereby to know that these reptiles will change into flies in a short time, consists in a protuberance of the wings on the back. Abont that time the smooth and depressed form of the upper part of the body is changed into a me swollen and rounder shape; so that the wings are in some degree visible through the external sheath that covers them. As they are not natives of England, he who would see them in their greatest abuudance, must walk, about sun-set, along the banks of the Rhine, or the Seine near Paris; where, for abont three days, in the midst of sumner, he will be astonished at their numbers and assiduity. The thickest descent of the flakes of snow in winter seems not to equal their number: the whole air seems alive with the new horu race; and the earth itsell is all over covered with their remains. The aurelias, or reptile insects, that are as yet beneath the surlace of the water, wait ouly for the approach of evening to begin their transformation. The most industrious shake off their old garments about eight o'clock; and those who are the most tardy, are transformed before nine.

We have already seen that the operation of change in other insects is laborions and painful: but with these nothing seems shorter. or performed with greater ease. The aurelins are scarcely lifted above the surface of the water, than their old sheathing skiı bursts; and through the cavity which is thus formed, a fly is-ues, whose wings, at the same instant, are unfolded. and at the same time lift it into the air. Millions and millions of aurelias rise in this manner to the surface: and at once hecome flies, and fill every quarter with their flutterings. But all these sports are shortly to have an end; for as the little strangers live but an hour or two, the whole swarm soon falls to the gronud, and covers the earth, like a deep snow, for several hundred yards, on every side of the river. Their numbers are then incredible, and every object they touch becomes fatal to them; for they instanlly die, if they hit even against each other.

At this time the males and females are very differently employed. The males, quite inactive, and apparently without desires, seem only born to die: no way like the males of other insects; they neither follow the opposite sex, nor bear any enmity to each other: after fluttering for an houl or two, they drop upon land, withont seening to receive wings fir scarce any other purpose but to satisfy an idle curiosity. It is otherwise with the females; they are scarce risen from the surface of the water, and have driegd their wings, but they hasten to drop their eggs back again. If they happen also to flutter upon land, they deposite their burden in the place where they drop. But then it may be demanded, where, and in what manner, are these eggs fecundated, as no copulation whatever appears between the sexes, in their tiansitory visits in air? Swammerdam is of opinion, that they are inpregnated in the manner of fish-sparwn, by the male, after being ejected by the female; but, heside that, this doctrine is explocled even from the history of fishes, it is certain that the males have not time for this operation, as the eggs drop to the bottom the instant they are litid on the water. Reauinur is of opinion that they copulate; lut that the act bears a proportion in shortness to the small duration of their lives; and, consequently, must be so soon performed, as to be scarcely visible. This, however, is at best forcing a theory; and it is probable, that as there are many insects known to breed without any impregnation from the male, as we have already seen in muscles and oysters, and shall herealter see in the guat, and a species of the beetle, so the ephemera inay be of this number. Be this as it inay, the females are in such haste to deposite their $\mathrm{eggs}$, that multiturles of them fall to the ground; but the greatest part are laid in the water. As they flutter upon the surface, two clusters are seen issuing froin the extremity of their body, each containing about three hundred and fifty eggs, which make seven hundred in all. Thus. of all insects, this appears to be the most prolific; and it would seem that there was a necessity for such a supply, as in its reptile state it is the favourite food of 
every kind of fresh-water fish. It is in vain that these little animals form galleries at the bottom of the river, from whence they seldoun remove; many kinds of fish break in upon their retreats, and thin their numbers. For this reason fishermen are careful to provide themselves with these insects, as the most grateful bait ; and thus turn the fish's rapacity to its own destruction.

But though the usual date of those flies is two or three hours at farthest, there are some kinds that live several days; and one kind in particular, after quitting the water, has another case or skin to get rid of. These are often seen in the fields and woods, distant from the water; but they are more frequently found in its vicinity. They are often found sticking upon walls and trees; and frequently with the head downwards, without clanging place, or having any sensible motion. They are then waiting for the moment when they shall be divested of their last incommodious garment, which sometimes does not happen for two or three days together. 


\section{OF INSFCTS OF THE TITRD ORDER.}

\section{CHAPTER CLXXXIV.}

\section{OF CATERPILLARS IN GENERAL.}

IF we take a cursory view of insects in general, caterpillars alone, and the butterflies and moths they give hirth to, will make a third part of the number. Wherever we move, wherever we turn, these insects, in one shape or another, present themselves to our view. Some, in every state, offer the most entertaining spectacle; others are beautiful only in their winged form. Many persous, of which number I an one, have an invincible aversion to caterpillars and worms of every species: there is something disagreeable in their slow crawling motion, for which the variety of their colouring can never compensate. But others feel no repugnance at observing, and even handling, them with the most attentive application.

There is nothing in the butterfly state so beautiful or splendid as these insects. They serve, not less than the birds themselves, to banish solitude from our walks, and to fill up our idle intervals with the most pleasing speculations. The butterfly makes one of the principal ornaments of oriental poetry; but in those countries, the insect is larger and more beautiful than with us.

The beauties of the fly may, therefore, very well excite our curiosity to examine the reptile. But we are still more strongly attached to this tribe from the usefulness of one of the number. The silk-worm is, perhaps, the most serviceable of all other animals; since, from its labours, and the manufacture attending it, near a third part of the world are clothed, adorned, and supported.

Caterpillars may be easily distinguished from worms or maggots, by the number of their feet; and by their producing butterflies or moths. When the sun calls up vegetation, and vivifies the various eggs of insects, the caterpillars are the first that are seen upon almost every vegetable and tree, eating its leaves, and preparing for a state of greater perfection. They have feet both before and behind; which not only enable them to move forward by a sort of steps made by their fore and binder parts, but also to climb up vegetables, and to stretch themselves out from the boughs and stalks to reach their food at a distance. All of this class have from eight feet, at the least, to sixteen; and this may serve to distinguish them from the worm tribe, that never have so many. The animal into which they are converted is always a butterfly or a moth; and these are always distin- guished from other flies, by having their wings covered over with a painted dust, which gives them such various beauty. The wings of flies are transparent, as we see in the common flesh-ny; while those of beetles are hard, like horn: from such the wing of a butterny may be easily distinguished; and words would obscure their differences.

From hence it appears, that caterpillars, whether in the reptile state, or advanced to their last state of perfection into butterfies, may easily be distinguished from all other insects; being animals peculiarly formed, and also of a peculiar natuie. The transmutations they undergo are also more numerous than those of any insect hitherto mentioned; and. in consequence, they have been placed in the third order of changes by Swammerdam, who has thrown such lights upon this 
part of natural history. In the second order of changes, menrimed before, we saw the grassmpper and the earwig, when cxcluded firm the egg, nssume a fom very like thit which they were affer to proserve; and seemed arriver at a state of perfectim, in all respects, excepr in not having Ivings; which did not bud forth until they were come to maturity. But the insects of this third order, that we are now about to describe, go throngh a much greater variety of tra sformanions; for when they are excluded from the egg, they assume the form of a small caterpillar, which feeds and grows larger every day, ofecn changing its skin, but still prescrving its form. When the animal has come to a certain lisanitude in this state, it discontinues cating, makes itsclf a covering or husk, in which it rimains wrapped up, scemingly without life or morim ; and after having for some time contimed in lhis state, it once nore bursts its confincment, and comes firth a beautiful butterfly. Thus we sec this animal put on no less than three different appeatances, from the time it is first rxeluded from the ego. It appears a erawling caterpillar; then an insensible aurelia, as it is called, witheut life ol motion; and, lastly, a butterfly, variously painted, according to its difierent kind. Having thus distinguished this class of insects from all others, we will first survey their history in general; aud then enter particularly into the manners and nature of a few of them, which most deserve our curiosity and attention.

\section{CHAPTER CLXXXV.}

\section{OF THE TRANSFORMATION OF THE CATERPILLAR INTO ITS CORRESPOND ING BUTTERFLY OR MOTH.}

WHEN winter has disrobed the trees of their leaves, nature then seems to have lost her insects. There are thousands of different kinds, with and without wings, which, though swarming at other seasons, then entirely disappear. Our fields are re-peopled, when the leaves begin to bud, by the genial influence of spring; and caterpillars of various sorts are seen feedling upon the promise of the year, even bcfore the leaves are completely unfolded. Those catcripilars, which we then see, may serve (1) give us a view of the general means which nacure einploys to preserve such a number of insects during that season, when they can no longer find subsistcuce. It is known, by mited experience, that all these anjmals are histched from the eggs of butterflies: and those who observe them nore closely, will find the fly very careful in depositing its eggs in those places where they are likcly to be hatched with the greatest safety and success. During winter, therefore, the greatest number of caterpillars are in an egg state; and in this lifeless situation brave all the riguirs and the humidity of the climate; and though often ex posed to all its changes, still preserve the la- tent principles of life, which is more fully exerted at the approach of spring. That same power that pushes forth the budding leaf and the opening flower, impels the insect into animation; and nature at once seerns to furnish the guest and the banquet. When the insect has found furce to hreak its shell, it always finds its favourite aliment provided in abundance before it.

But all caterpillars are not sent off from the egg in the beginning of spring; for many of them have subsisted during the winter in iheir aurelia state; in which, as we have brieny observed above, the animal is seemingly aleprived of life and notion. In this state of insensibility, many of these insects fontimue during the rigours of winter; -ome enclosed in a kind uf shell, which they have spun for themselves at the enit of autumn; - some concealed under the bark of trees; others in the chinks of old wells; and many buried under ground. From all these, a variety of butierfies are seen to issue in the beginning of spring; and adorn the earliest part of the year with their painted flut terings.

Some caterpillars do not make any change 
whatsoever at the approach of winter; but continue to live in their reprile state through all we severity of the season. 'They chunse themselves some retreat, where they may remain undisturbed for months together; and there they continue motionless, and as insensible as if they were aetually dead. Their constitution is such, that food at that time would be useless; and the cold prevents their making those dissipations which require restoration. In general, caterpillars of this kind are found in great numbers together, enclosed in one common web, that covers them all, and serves to protect them from the injuries of the air.

Lastly, there are sume of the caterpillar kind, whose butterflies live all the wiuter; and who, having fluttered about for some part of the latter end of autumn, seck for some retreat during the winter, in order to answer the ends of propagation at the approach of spring. These are often found lifeless and motionless in the hollows of trees or the clefts of timber ; but by being approached to the fire, they recover life and activity, and seem to anticipate the desires of the spring.

In gencral, however, whether the animal lias subsisted in an egg state, during the winter; or whether as a butterfly, bred from an aurelia, in the begiuning of spring; or a butterfly that has subsisted during the winter, and lays eggs as soon as the leaves of plants are shot forward; the whole swarm of caterpillars are in motion to share the banquet that nature has provided: There is scarcely a plant that has not its own peculiar insects; and some are known to support several of different kinds. Of these, many are hatched from the egg, at the font of the tree, and climb up to its leaves for subsistence; the eggs of others have been glued by the parent hutterfly to the leaves; and they are no somer exclucled from the shell, but they find themselves in the midst of plenty.

When the caterpillar first bursts from the egg, it is small and ferble; its appetites are in proportiou to its size, and it seems to make no great costumption; but as it increases in magnitude, ir improves in its apperires; so that, in its adult caterpillar state, it is the most ravenous of all animals whatsoever. A single catcrpillar will eat double its own w ight of leaves in a day, and yet seens no way disor- dered loy the meal. What would mankind do, if their oxen or their horses were so voracious?

'These voracious habits, with its slow crawling motion, but still more a stimging like that of nettes, which follows upon loandling the greatest number of them, make these inseets not the most agreeable objects of hmman curiosity. However, there are many philosophers who have spent years in their contemplation; and who have not only attended to their habits and labours, but ininutely exanined their structure and internal conformation.

'The body of the caterpillar, when aratomically considered, is found composed of rings, whose circumference is pretty near circular ol oval. 'They are generally twelve in number, and are all nembranaceous; by which caterpillars may be distinguished from many other insects, that nearly resemble them in form. The head of the caterpillar is conneeted to the first ring by the neck; that is generally so short and contracted, that it is scarce visible. All the covering of the head in caterpillars seenis to consist of a shell; and they have neither upper nor under jaw, for they are both placed lather vertically, and each jaw armed with a large thick tooth, which is singly equal to numbers. Witl these the animals devour their food in such annazing quantities; and with these, some of the kind defend themselves against their enemies. Though the nouth be kept shut, the teeth are always uncoveied; and while the insect is in bealth they are seldom without employment. Whatever the caterpillar devours, these teeth serve to chop it into small pieces, and render the parts of the leaf fit for swallowing. Many kinds, while they are yet young, eat only the succulent part of the leaf, and leave all the fibres $u n$. touched; others, however, attack the whole leaf, and eat it clean away. One may be amuscd, for a little time, in observing the avidity with which they are seen to feed; some are secn eating the whole day; others have their hours of repast; some choose the nierlst, and others the day. When the caterpillar artacks a leaf, it places its body in such n mann: $r$ that the edge of the leaf shall fall hetweeu its feet, which kecps it stearly while the teetis are enployed in cutting it: these fall upon the leaf somewhat in the manner of a 
pair of gardener's shears; and every morsel is swalluwed as soon as cut. Some caterpillars feed upon leaves so very narrow, that they are not broader than their nuouths; in this case the animal is scen to devour it from the poini, as we would eat a radish.

As there are various kinls of eaterpillars, the number of their feet are various; some having eight, and some sixteen. Of these, feet the six foremost are covered with a sort of shining gristle; and are therefore called the shelly legs. The hindnost feet, whatever be their number, are soft and flexible, and are called membranaceous. Caterpillars also, with regard to their external figure, are eirher smooth or hairy. The skin of the first kind is soft to the touch, or hard like shagreen; the skin of the latter is hairy, and as it were thorny; and generally, if handled, stings like nettles. Some of them even cause this stinging pain if but approached too nearly.

Caterpillars, in general, have six small black spots placed on the circumference of the fore ring, and a little to the side of thc head. Three of these are larger than the rest, and are convex and transparent: these Reaumul takes to be the eyes of the caterpillar; howcver, most of these reptiles have very little occasion for sight, and seem only to be directed by their feeling.

But the parts of the caterpillar's body which most justly demand our attention, are the stignata, as they are called; or those holes on the sides of its body, through which the animal is supposed to breatl. All along this insect's body, on. each side, these holes are casily discoverable. They are eighteen in number, nine on a side, rather nearer the belly than the back; a hole for every ring, of which the animal's body is composed, except the second, the third, and the last. These oval openings may be considered as so many mouths, through which the insect breaths; but with this difference, that as we have int one pair of lungs, the caterpillar has no less than eighteen. It requires no great anatomical dexterity to discover these lungs in the larger kind of caterpillars : they appear, at first view, to be hollow cartilaginous tubes, and of the colour of mother-of-pearl. These tubes are often seen to unite with each other; some are perceived to open into the intestines; and some go to different parts of the surface of the hody. That these vessels serve to convey the air, appears evilently, from the famous experiment of Malpighi; who, by stopping up the mouths of the stigmata with oil, quickly suffucated the animal, which was secn to die convulsed the instant after. In order to ascertain his theory, he rubleri nil upon other parts of the insect's body, leaving the stirmata frec; and this scenied to lave no effect upon the animal's health, but it continued to nove nud eat as usual: he rubbed oil on the stignata of one side, and the animal undement a partial convulsion, but recovered soon after. However, it ought to be observed, that air is not s") nec'ssary (1) these as to the nobler ranks: of aniuals, since catcrpillars will live in an exhansted receiver for several days together: and though they secm dead at the botton, yet, when taken out, recover, and resunse their former vivacity.

If the caterpillar be cut open longitudinally along the back, its intestines will be perceived rumning rlirectly in a straight line from the mouth to the anus. They resemble a number of small hags oncuing into each other; and strengtheued on both silles by a nesliy cord, by which they are united. These insects are, upon many occasions, seen to cast forth the interual coat of their intestincs with their food, in the changes which they so fiequently undergo. But the intestined take up but a small part of the animal's hody, if compared to the fatty substance in whicl they are involved. The substance changes its colour when the insec:'s metamorphosis begins to approach; and from white it is usualiy seen to become yellow. If to these parts we add the caterpillsr's inplements for spinning, (fur all caterpillars spin at one time or another,) we shall have a rude s'retch of this animal's conformation: huwever, we shall ieserve the description of those parts, till we come to the history of the silk-worm, where the manner in which these insects spin their webs, will most properly find a place.

The life of a caterpillar seems one continued succession of changes, and it is seen to throw off one skia only to assume another; which also is divested in its turn : and thus for eight or ten times successively. We must not, however, confound this changing of the skin with the great metamonphosis which it is afterwards to undergo. The throwing off one skin, and 
assuming another, seems, in comparison, but a slight operation among these auimals: this is but the work of a day; the other is the great adrenture of their lives. Indeed, this faculty of changing the skin, is not pecuiliar to caterpillars only, but is cornmon to all the insect kind; and even to some animals that clain a higher rank iti nature. We lave already seen the lobster and the crab outgrowing their first shells, and then bursting from their confinement, in order to assume a covering inore roomy and convenient. It is probable that the louse, the flea, and the spider, change their covering fiom the same necessity; and growing too large for the crust in which they liave been for some time enclosed, burst it for another. This period is probably that of their growth; for as soon as their new skin is hardened round them, the animal's growth is necessarily circumscribed, while it remains within it. With respect to caterpillars, many of them cliange their skins five or six times in a scason; and this covering, when cast off, often seems so complete, that many inight mistake the empty skin for the real insect. Among the hairy caterpillars, for instance, the cast skin is covered with hair; the feet, as well gristly as membraneous, remain fixed to it; even the parts which nothing but a microscope can discover, are visible in it; in short, all the parts of the head; not only the skull, but the teeth.

In proportion as the time approaches in which the caterpillar is to cast its old skin, its colours becone more feeble, the skin seems to wither and grow dry, and in some measure resembles a leaf, when it is no longer supplied with moisture from the stock. At that time, the insect begins to find itself under a necessity of changing; and it is not effected without violent labour, and perhaps pain. A day or two before the critical hour approaches, the insect ceases to cat, loses its usual activity, and seems to rest immoveable. It seeks some place to remain in security; and no longer timorous, scems regardless even of the touch. It is now and then seen to bend itself and elevate its back; again it stretches to its utmost extent: it soinetimes lifts up the head, and then lets it fall again; it sometimes waves it three or four times from side to side, and then remains ม. $67 \& 68$. in quiet. At length, some of the rings of its body, particularly the first and second, are seen to swell considerably, the old skin distends and bursts, till, by repeated swellings and contractions in every ring, the animal disengages itself, and creeps froun its inconvenient cavering.

How laborious soever this operation may be, it is performed in the space of a minute; and the animal, having thrown off its old skin, seems to enjoy new vigour, as well as acquired colouriig and beauty. Sometimes it liapens that it takes a new appearance, and colours very different from the old. Those that are hairy still preserve their covering; although their ancient skin seems not to have lost a single hair: every hair appears to have been drawn like a sword from the scabbard. However, the fact is, that a new crop of hair grows between the old skin and the new, and probably lielps to throw off the exterual covering.

The caterpillar luaving in this manner continued for several days feeding, and at intervals casting its skin, begins at last to prepare for its change into an aurelia. It is most probable that, from the beginning, all the parts of the butterfly lay hid in this inseet, in its reptile state; but it required time to bring them to perfection; and a large quantity of food, to enable the animal to undergo all the changes requisite for throwing off these skins, which seemed to clog the butterfy form. However, when the caterpillar has fed sufficiently, and the parts of the future butterfly have formed themselves beneath its skin, it is then time for it to make its first great and principal change into an aurelia, or a chrysalis, as some have chosen to call it; during whicl, as was observed, it seems to remain for several days, or even months, without life or motion.

Preparatory to this important cliange, the caterpillar nost usually quits the plant, or the tree on which it fed: or at least attaches itself to.the stalk or the stem, more gladly than the leaves. It forsakes its food, and prepares, by fasting, to undergo its transmutation. In this period, all the food it has taken is thoroughly digested; and it often voids even the iuternal membrane which lined its intestines. 
Some of this tribe, at this period also, are seen entirely to change colour; and the vivacity of the tints, in all, seems faded. T'ıose of them which are capable of spinning themselves a web, set about this operation; those which have already spun, await the change in the best manner they are able. The web or cone, with which some cover themselves, hides the aurelia contained wilbin from the view; but in others, where it is more transparent, the caterpillar, when it hirs done spinning, strikes into it the claws of the two feet under the tail, and afierwards forces in the tail itself, by contractirng those claws, and violently striking the feet one against the other. If, however, they be taken from their web at this time, they appear in a state of great languor; and, incapable of walking, remain on that spot where they are placed. In this condition they remain one or two days; preparing to change into an aurelia; somewhat in the manner they made preparations for changing their skin. They then appear with their bodies bent into a bow, which they now and then are scen to straighten: they make no use of their legs; but if they attempt to change place, do it by the contortions of their body. In proportion as their change into an aurelia approaches, their body becomes more and more bent; while their extensions and convulsive contractions become more frequent. The hinder end of the boly is the part which the animal tirst disengages from its caterpillar skin; that part of the skin remains empty, while the body is drawn up contractedly towards the head. In the same manner they disengage themselves from the two succeeding rings; so that the animal is then lodged entirely in the fore part of its caterpillar covering: that half which is abandoned, remains flaccid and empty; while the fore part, on the contrary, is swollen and distended. The animal, loving thus quitted the hinder part of its skiu, to drive itself up into the fore part, still continues to heave and work as before; so that the skull is soou seen to burst into three pieces, and a longitudinal opening is made in the three first rings of the body, througls which the insect thrusts forth its naked body with strong efforts. Thus at last it entirely gets free from its cateruilla! skin, and for ever forsakes its most odious reptile form.
The caterpillar, thus stripped of its skin for the last time, is now become: an aurcha; in which the parts of the future butterfly are all visible; but in so solt a state, that the smallest toucls can discompose them. The animal is now become helpless and motionless; but only waits for the assistance of the air to dry up the moisture on its surfice, and supply it with a crusi capable of resisting external injuries. Immediately alter being stripped of its caterpillar skm, it is of a green colour, especially in those parts which are distended by an extraordinary afllux of animal moisture; but in ten or twelve hours after being thus exposed, its parts barlen, the air forms its external covering into a firm crust, and in about four and twenty hours the aurelia may be handled, whout endangering the little animal that is thus lefi in so defenceless a situation. Such is the history of the little pod or cone that is found so common hy every pathway, sticking to nettles, and sometimes shining like polished gold. From the beautifisl and resplendent colour, with which it is thus sometimes adorned, some authors have called it a Chrysalis, implying a creature made of gold.

Such are the efforts by which these little animals prepare for a state of perfection; but their care is still greater to provide thrm. selves a secure retreat, during this season of their imbecility. It would seem like erecting themselves a monument, where they were to rest secure, until nature had called them into a new and more improved existence. For this purpose, some spin themselves a cone or web, in which they lie secure till they bave arrived at maturity : others, that cam spin so copious a covering, suspend themselves by the tail, in some retreat where they are not likely to meet disturbances. Some mix sand with their gummy and moist webs, and thus make themselves a secure incrustation; while others, before their change, bury themselves in the ground, and thus avoid the unmerous dangers thit inight attend them. One would imagine that they were conscions of the precise time of their continuance in their aurelia state; since their litte sepulchres, with re. spect to the solidity of the building, are proportioned to such duration. Those that are. to lie in that state of existence but a few days 
make choice of some tender leaf, which they render still more pliant by diffusing a kind of glne upon it : the leaf thus gradually curls up, and withering as it infolds, the insect wraps itself within, as in a mantle, rill the genial varmth of the sum enables it to struggle for new life, and burst from its confinement. Others, whose time of trausformation is alsu near at hand, fast n their tails to a tree, or to the first worm-hole they meet in a beam, and wait in that delenceless situation. Such caterpillars, on the other hand, as are secn (1) lie several months in their aurelia state, act with much greater circumspection. Must of them mix their web with sand, and thuts make thenselves n strong covering: others build in wood, which serves them in the nature of a coffin. Such as have made the lenves of willows their favoulite food, break the tender twigs of them first into small pieces, then pound thein as it were to powder; and, by means of their glutinous silk, make a kind of paste, in which they wrap themselves up. Many are the forms ivhich these animals assume in this helpless state; and it often happens, that the most deformed butterflies issue from the most beautiful nurelias.

In general, however, the aurelin takes the rucle ontline of the parts of the animal which is contained within it; but as to the various colours which it is seen to assune, they are rather the effect of accident; for the same sirecies of insect does not at all tinies assume the same hue, when it becomes an aurelia. In some, the beautiful gold colour is at one time found; in others, it is wanting. This brilliant lue, which does not full short of the b : gilding, is formed in the same manner in which we see leather obtain a gold colour, though nouse of that metal ever enters into the tincture. It is only formed by a beautiful brown varnish, laid upon a white gromnd; and the white thus gleaming through the transparency of the brown, gives a charming gollen yellow. These two colours are found, ous over the other, in the aurelia of the little aninal we are describing; and the whole appears gilled, without any real gilding.

The aurelia thus formed, and lefi to time to expand into a butterfly, in some measure resenubles an animal in als ego, that is to wait for externdl warmih to hatch it into life and vigour. As the quantity of moisture, that is enclosed within the covering of the anrelia, continues (1) keep its body in the most tender state, so it is. requisite that this hmmidity should be lried away, before the little buttertly can burst its prison. Many have been the experiments to prove that nature may in this respect be assisted by art; and that the life of the insect may be retarded or quickenced, without doing it the smallest injury. For this purpose, it is only requisite to continue the insect in its anrelia state, by preventing the evaporation of its bumidity; which will consequently add some days, nay weeks, to its life: on the other hand, by evaporating its moisture in a warm simation, the animnl assumes itswinged siate before its ustial time, and goes through the offices assigned its existence. To prove this, Mr. Reaumur enclused the aurelin in a glass tube; and found the evaporated water, which exhaled from the body of the inseri, collected in drops at the bottous of the tube: he corered the aurelin with varnish; and this making the ctaporation more difficult and slow, the butterfy was two months longer than its natural teim, in coming out of its case: he found, on the other hand, that hy laying the animal in a warm roum, he hastenced the disclosure of the butterfly, and by keeping it in an ice-house, in the same manner he delayed it. Warmth acted, in this case, in a double capacity; invigo. rating the animal, and evaporating the nooisture.

The aurelia, though it bears a different exterual appearanee, nevertleless contains within it all the parts of the butterfy in perfect formation; and lying each in a very orderly manner, though in the smallest compass. These, however, are so fast and tender, that it is impossible to visit without discomposing them. When either by warnith, or increasing vigonr, the parts have acquired the necessary force. and solidity, the butcrfly then seeks to disembarrass itself of those bands which kept it so long in confinement. Some insects continue under the form of an aurelia not above ten days; some twenty; sone several months; and even for a year together.

The butterfly, however, does not continue so long under the form of an aurelia, as one would be apt to imagine. In general those caterpillars that provide themselves with cones, continue within them but a few days after the 
cone is completely finished. Some, however, remain buried in this artificial covering for eight or nine months, without taking the smallest sustenance during the whole time: and thongh in the caterpiliar state no animals were so volacions, when thus transformed they appear a iniracle of abstinence. In ill, sooner or later, the butterfly buists from its prison; not only that natural prison which is formed by the skiu of the autelia, but also from chat artificial one of silk, or any other substance in which it has cuclosed itscli.

The effurs which the butterfly makes in get free from its aurelia state, are by no means so violent as those which the insect had in changing fiom the caterpillar into the aurelia. The quanticy of moisture surrounding the butterfly is by no means so great as that attending its former change; and the shell of the aurelia is so dry, that it may be cracked between the fingers,

If the animal be slut up within a cone, the butterfly always gets rid of the natural internal skin of the aurelia, before it eats its way through the external covering which its awn industry has formied round it. In order to observe the manner in which it thus gets rid of the aurelia covering, we must cut open the cone, and then we shall have an opportunity of discovering the insect's efforts to emancipate itself from its natural shell. When this operation begius, there seems to be a violent agitation in the humours contained within the litcle animal's body. Its fluids seem driven, by an hasty fermentation, through all the vessels; while it labours violently with its legs, and makes several other violent struggles to get fiee. As nll these motions concur with the growth of the insect's wings and body, it is impossible that the brittle skin which covers it should longer resist : it at length gives way, by bursting into four distinct and regular pieces. The skin of the head and legs first separates; then the skin at the back flies open, and dividing into two regular portions, disengages the back and wings: then there likewise happens another rupture, in that por-

(a) These red drops, which several of the Butterfly tribe discharge immediately upon their transformation, have been recorded by ancient writers, as shnwers of blood, portending some convulsion of nature, or national calamity. In the year 1608 , the inliabitants of the town af Aix were in the utmost consternation, in consequence tion which covered the rings of the back of the aurelia. After this, the butterfly, as if farigued with its struggles, remains very quiet for some time, with its wings pointed downwards, and irs legs fixerl in thr skin which it had just thrown off. Ar first sight the animal, just set free, and permitted the finture use of its wings, seerns ro want then cntirely; they take up such litale room, that one would wonder where they were hidden. But soou after they expand so rapidly, that the rye can scarce attend their unfolding. From reaching scarce half the length of the body, they acquire, in a most .wouderful manner, their full extent and bigness, so as to be each five tiunes larger than they were before. Nor is it the wings alone that are thus increased; all their spots and paintings, before so minut: as to be scarce discruluble, are propurtionably cxtended: so that what a few numutes before seemed only a number of confused ummeaning points, now became distinct and rimost beantiful oruaments. Nor arc the wings, when they are thus expanded, unfolled in the manner in which earwigs and grasshoppers display theirs, who unfirt them like a lady's fan: on the contrary, those of butterflies actually grow to their natural size in this very short space. The wing, at the instant it is frecd from its late confinement, is considerably thicker than afterwards; so that it spreads in all its dimensious, growing thinuer as it becomes broarler. If one of the wings be plucked from the animal just set free, it may be spread by the fingers, and it will soon become as broad as the other which has been left behind. As the wings extend themselves so suddenly, they have not yet harl time to dry; and according. ly appear like pieces of wet paper, soft and full of wrinkles. In about half an hour they are perfectly dry, their wrinkles entirely disappear, and the little animal assumes all its splendour. The transmutation being thus perfectly finished, the butterfly ilischarges three or four drops of a blood-coloured liquid, which are the last remins of its superfluous moisture. " Those aurelias which are enclused

of a discharge of this kind, which fell in the suburbs, and for soine miles round. But the philosopher Pieresc soon quieted their alarms, by showing them that the whole of this wonder originated in a fight of harniless butterflics, that had just taken wing from their chrysalis state. 
within a cone, find that exit more difficult, as they have still another prison to break through: this, however, they perform in a short time; for the butterfly, freed frou its aurelia skiu, butts with its head violently against the walls of its artificial prison; and probibly with its eyes, that are rough and like a file, it rubs the internal surface awily; till it is at last seen bursting its way into open light ; and, in less than an quirter of an hour, the animal acquires its full perfection.

Thus, to use the words of Swammerdam, we see a little insignificant creature distinguished, in its last birtl, with qualifications and ornoments, which tuan, duriug his stay upon earth, can never even hope to acquire.
The butterfly, to enjoy life, needs no other food but the dews of heaven, and the honeyed juices which are distilled from every flower. The pageantry of princes cannot equal the ornaments with which it is invested; nor the rich colouring that embellishes its wings. The skies are the butterfly's proper habitation, and the air is its element: whilst man comes into the world naked, and often roves about without habitation or shelter; exposed on one hausl to the heat of the sun, and, on the other, to the damps and exhalations of the earth; both alike enemies of his happiness and existence. A strong proof that, while this little animal is raised to its greatest height, we are as yet in this world only candidates for perfection!

\section{CHAPTER CLXXXVI.}

\section{OF BUTTERFLIES AND MOTHS.}

IT has been alrcady shown, that all butterflies are bred from caterpillars; and we have exhibited the various eircumstances of that surprising change. It has been remarked, that butterflies may be easily distinguished from flies of every other kind, by their wiugs: for, in others, they are either transparent, like ganze, as we see in the common flesh-fly; $T$ they are hard and crusted, as we see in the wings of the beetle. But in the butterfly, the wings are soft, opake, and painted over with a beautiful dust, that comes off with handling.

The number of these beatiful animals is very great; and though Limuzus has reckoued ip above seven hundred and sixty different kinds, the catalogue is still very incomplete. Every collector of butterflies can show undescribed species: and such as are fond of minute discovery, can here produce animals that have been examined only by himself. In general, however, those of the warm climates are larger and more beantiful than such as are bred at home; and we: can easily admit the beautr of the bitterfly, since we are thus freed froin the tyinage of the caterpillar. It has been the anuse nent of some to collect these animals firou different parts of the world; or to breed them from caterpillars at home.
These they arrange in systematic order, or dispose so as to make striking and agreeable pictures; and all must grant, that this specious idleness is far preferable to that unhappy state which is produced by a total want of employment.

The wings of hutterflies, as was observed, fully distinguish them from flies of every other kind. They are four in number; and though two of them be cut off, the animal can fly with the two others remaining. They are, in their own substance, transparent; but owe their opacity to the beautiful dust with which they are covered; and which has been likened, by some naturalists, to the feathers of birds; by others, to the scales of fishes; as their imaginations were disposed to catch the resemblance. In fact, if we regard the wing of a butterfly with a good microscope, we shall perceive it studded over with a variety of little grains of different dimensions and forms, generally supported upon a footstalk, regularly laid upnn the whole surface. Nothing can exceed the beautifil and regular arrangement of these little sulstances; which thus serve to paint the butterfly's wing, like the tiles of a house. Those of one rank are a litule covered by those that follow: they are of many 
firures: on one part of the wing may be seen a succession of oval studs; on another part, a cluster of studs, each in the forin of a heart: in one place they resemble a hand open; and in another they are long or triaigular; while all are interspersed with taller studs, that grow between the rest, like mushrooms upon a stalk. The wing itself is composed of several thick nerves, which render the construction very strong, though light; and though it be covered, over with thousands of these scales or studs, yet its weight is very little increased by the number. The animal is with ease enabled to support itself a long while in air, although its flight be not very graceful. When it designs to fly to a coussiderable distance, it ascends and descends alternately; going sometimes to the right, sometimes to the left, without any apparent reason. Upon closer examination, however, it will be found that it flies thus irregularly in pursuit of its mate; and as dogs bait and quarter the ground in pursuit of their game, so these insects traverse the air in quest of their mates, whom they can discover at more than a mile's distance.

If we prosecule our description of the butterfly, the animal may be divided into three parts; the head, the corselet, and the body.

The body is the hinder part of the butterAy, and is composed of rings, which are gencrally concealed under long hair, with which that part of the animal is clothed. The corselet is more solid than the rest of the body, because the fore-wings and the legs are fixed therein. The legs are six in number, although four ouly are made.use of by the animal; the two fore-legs being often so much concealed in the long hair of the body, that it is sometines difficult to discover them. If we examine these parts internally, we shall find the same set of vessels in the butterfly that we observed in the caterpillar; but with this great difference, that as the blood or humours in the caterpillar circulated from the tail to the head, they are found in the butterfly to take a direct contrary course, and to cireulate from the head to the tail; so that the caterpillar may be considered as the embryo animal, in which, as we have formerly senn, the circulation is carried on differently from what it is in animals when excluded.
But leaving the other parts of the butterfly, let us turn our attention panticularly to the head. The eyes of hutterflies have not all the same form; for in some they are large, ii) others small; in some they are the larger portion of a spliere, in others. they are hut a small part of $\mathrm{it}$, and just appearing lrom the head. In all of them, however, the outward coat has a lustre, in which may be discovered the various colours of the rainhow. When cxamined a little closely, it will be found to have the appearance of a multiplying-glass; having a great number of sides or fucets, in the manner of a brilliant cut diamond. In this particular, the eye of the butterfly, and of most other insects, cntirely correspond; and Leuwenhoek pretends there are about six thousand facets ou the cornea of the flea. These animals, therefore, see not only with great clearuess, but view every object inultiplied in a surprising manner. Puget adapted the colnea of a fly in such a position, as to sec objects tlurough it by the niears of a microscope; and nothing conld exceed the strangeness ol its representations. A soldier, who was seen through it, appeared like an army of pigmies; for while it multiplied, it also dimiuished the object; the arch of a loridge exhibited a specticle inore magnifieent than human skill could perform; the flame of a candle seemed a beautiful illumination. It still, however, remains a doubt, whether the insect sees objects - singly, as with one eye; or whether every facet is itself a complei. eye, exhibiting jts own object distinct from all the rest.

Butterfies, as well as most other flying insects, have two instruments, like horns, on their heads, which are commonly called feelers. They differ fiom the horus of greater animals, in being moveable at their base; and in having a great number of joints, by whicli means the insect is enabled to turn them in every direction. Those of butterflies are placed at the top of the head, pretty near the external edge of eye. What the use of these instruments may be which are thus formed with so much art, and by a Workmas who does nothing without reason, is as yet unknown to man. They may serve to gurard the eye; they may be of use to clean it; or they may be the organ of some 
sense which we are jgnornnt of: but this is only explaining one difficuliy by annther. Wrare not so igmorant of the uses of the trunk. which lew inspets of the bntterfly kind are without. This instrument is placed exactly between the cyes; and when the animal is not einployed in seeking its nourishment, it is rolled up like a curl. A butterfly when $\mathrm{jt}$ is feediug, flies round some fower, and settles upon it. The trunk is then uncurled, and thrust out eitber wholly or in part; and is employed in searching the flower to its very bottom, let it be ever so deep. This search being repeated seven or eight times, the butterfly then passes to another; and contiuues to hover over those agreeable to its taste, like a bird over its prey. 'This trunk consists of two equal hollow tubes, nicely joined to each other, like the pipes of an organ.

Such is the figure and conformation of these beautiful insects, that cheer our walks, and give us the earliest intimations of summer. But it is not by day alone that they are seen fluttering wantouly from llower to flower, as the greatest number of them ny by night, and expand the most beautiful colouring at those hours when there is no spectator. This tribe of insects has, therefore, heen divided into Diurnal and Nocturnal Flies; or, more properly speaking, into Butterties and Moths: the one flying only by day, the other most usually on the wing in the night. They may be easily distinguished from each other, by their horns or feelers: those of the butterfly being clubbed or knobbed at the end; those of the moth taperiug finer and finer to a point. To express it technicallythe feelers of butterfies are clavated: those of moths are filiform.

The butterfies, as well as the motha, employ the short life assigned them in a variety of sujoyments. Their whole time is sperit either in quest of food. which every flower offers: or in pursuit of the frinsle. whose approach they can often perceive at two miles' distance. Their sagacity in this particular is not less astonishing than true: but by what senae they are thus capable of distirignish. ing each other at such distances. is not ensy to conceive. It cinnot he by the sight, silce such small objects as they are must be utter- ly imperceplible at half the distance a! which they perceive each ohter: it canscarcely be by the sense of smelling, since the animal has no organs for that purpose. Whatever be their powers of perception, certain it is, that the nuale, after having fluttered, as if carelessly about for some time, is seen to take wiug, aud go forward, sometimes for two iniles together, in a direct line, to where the. female is perclied on a flower.

The general rule among insects is, that the feinale is larger than the male; and this obtains particularly in the tribe I ain describing. The body of the male is smaller and slenderer; that of the female more thick and oval. Previous to the junction. of these atimals, they are seen sporting in the air, pursuing and flying from each other, and preparing, by a uock combat, for the more important business of their lives. If they be disturbel while united, the female flies off with the male on her back. who seems entirely passive upon the occasion.

But the females of many moths and butterflies seem to have assumed their airy form for no other reason but to fecundate their. eggs, and lay them. They are not seen fluttering about in quest of food or a mate: all that passes during their short lives, is a junction with the male of about half an hour; after which they deposite their eggs, and die, without taking any nourishment, or serking any. It may be observed, however, that ii all the females of this tribe, they are injregnated by the male by one aperture, and lay their eggs by another.

The eggs of lemale butterflies are disposed in the borly like a bed of chaplets; which. when excluded, are usually oval, and of a whitish colour: some, however, are quite round; and others, flatted, like a turnip. The covering, or shell of the egg, though solid, is thin and trunsparent; aud in proportion as the cuterpillar grows within the egg, the colours change, aisd are distributed difiprently. The butterfly seems very well instructed by mature in its chnice of the plant, or the leaf, where it shall deposite jts burden. E ch egg contajus but one caterpillar; and it is requisite that this litule animal. when exclude f. should be nearits peculiar provision. The buttertly, therefore, is careful to place 
her brood only upon those plants that afford good nourishment to its posterity. Though the little winged animal has been fed itselfupon dew, or the honey of flowers, yet it makes choice for its young of a very different provision, and lays its eggs on the most unsavoury plants; the rag-weed, the cabbage, or the nettle. Thus every butterlly chooses not the plant most grateful to it in its winged state; but such as it has fed upon in its reptile form.

All the eggs of butterflies are attached to the leaves of the favourite plant, by a sort of size or glue; where they continue unobserved, unless carefully sought after. The eggs are sometimes placed round the tender shoots of plants, in the form of bracelets, consisting of above two hundred in each, and generally surrounding the shoot like a ring upon a finger. Some butterflies secure their eggs from the injuries of air, by covering them with hair plucked from their own bodies, its birds sometimes are seen to make their nests; so that their eggs are thus kept warm, and also entirely concealed.

Ail the tribe of female moths lay their eggs a short time after they leave the aurelia; but there are many butterflies that tlutter about the whole summer, and do not think of laying, till the winter begins to warn them of their approaching end: some even continue the whole winter in the hollows of trees, and do not provide for posterity until the beginning of April, when they leave their retreats, deposite their eggrs, and dic. Their eggs soon begin to feel the genial influence of the season: the little animals burst from them in their caterpillar state, to becone aurelias and butterlies in their turn. and thus to continue the round of nature.

\section{CHAP'TER CLX:XVII.}

\section{OF THE ENEMIES OF THE CATERPILLAR.}

NATURE, though it has rendered some animals surprisingly fruitful, yet ever takes care to prerent their too great increase. One set of creatures is generally opposed to another: and those are chiefly the most prolific that are, from their imbecility, incapable of making any effectual defence. The caterpillar has, perhaps, of all other animals, the greatest number of enemies; and seems only to exist by its surprising fecundity. Some animals devour them by hundreds; others, more minute, yet more dangerous, mangle them in various ways: so that, how great soever their numbers may be, their destroyers are in equal proportion. Indeed, if we consider the mischiefs these reptiles are capable of occasioning, and the various damages we sustain from their insatiable rapacity, it is happy for the other ranks of nature, that there are thousands of fishes, birds, and even insects, that live chiefly upon caterpillars, and make them their most favourite repast.

When we described the little birds that live in ou" gardens, and near our houses, as destructive neighbours, sufficient attention was not paid to the services which they are frequently found to render us. It has been proved, that a single sparrow and its mate, that have young ones, destroy above three thousand caterpillars in a week; not to mention several butterflies, in which numberless caterpillars are destroyed in embryo. It is in pursuit of these reptiles that we are favoured with the visits of many of our most beautiful songsters, that amuse us during their continuance, and leave ns when the caterpillars disappear.

The maxim which has often been urged against man, that he, of all other animals; is the only creature that is an enemy to his own kind, and that the human species only are found to destroy each other, has been adopted by persons who never considered the history of insects. Some of the caterpillar kind in paricular, that seem fitted only to live upon leaves and plants, will, however, eat 
each other'; and the strongest will devour the weak, in preference to their vegetable food. That which lives upon the oak is found to seize any of its companions, which it convenicully can, by the first rings, and inflict a deadly wound: it then feasts in tranquillity on its prey, and leaves nothing of the animal but the husk.

But it is not from each other they have the most to fear, as in general they are inoffensive; and many of this tribe are found to live in a kind of society. Many kinds of tlies lay their eggs either upon, or within their bodies; and, as these turn iuto worms, the caterpillar is seen to nourish a set of intestine cnemies within its body, that must shortly be its destruction: nature having taught flies, as well as all other animals, the surest methods of perpetuating their kind. "Towards the end of August," says Reaumur, "I perceived a little fly, of a beautiful gold colour, busily employed in the body of a large caterpillar, of that kind which feeds upon cabbage. I gently separated that part of tlic lcaf on which these insects were placed, from the rest of the plant, and placed it where I might observe them more at my ease. 'The fly, wholly taken up by the business in which it was cmployed, walked along the caterpillar's borly, now and then remaining fixed to a particular spot. Upon this occasion, I perceived it every now and then dart a sting; which it carried at the end of its tail, into the caterpillar's body, and then drew it out again, to repeat the same operation in another place. It was not difficult for me to conjecture the business which engaged this animal so earucstly; its whole ain was to deposite its eggs in the caterpillar's body; which was to serve as a proper retreat for bringing them to perfection. The reptile thus rudely treated, seemed to bearall very patiently, only moving a little when stung too decply; which, however, the fly seemed entirely to disregard. I took particular care to feed this caterpillar; which seemed to me to continue as voracious and vigorous as any of the rest of its kind. In about ten or twelve days, it changed into an aurelia, which seemed gradually to decline, and died: upon examining its internal parts, the animal was entirely devoured by worms; which, however, did not come to per\$0. $67 \& 68$. fection, as it is prolsable they had not enough to sustain them within."

What the Frencl philosopher perceived upon this occasion, is every day to be seen in several of the larger kinds of caterpillars, whose bodies serve as a nest to various flies, that very carefully deposite their eggs within them. The large cabbage caterpillar is so subject to its injuries, that, at certain seasons, it is much easicr to find them with than without them. The ichneumon fly, as it is called, particularly infests these reptiles, and prevents their fccundily. This fly is of all others the most formidable to insects of various kinds. The spider, that destroys the ant, the moth, and the butterfly, yet ofien falls a prey to the iclineumon; who pursues the robber to his retrcat, and, despising his nets, tears him in pieces, in the very labyrinth he has made. This inseet, as redoubtable as the little quadruped that destroys the crocodile, has receiv. ed the same name; and from its destruction of the caterpillar tribe, is probably more serviccable to mankind. This insect, I say, makes the body of the caterpillar the place for depositing its eggs, to the number of ten, fifteen, or twenty. As they are laid in those parts which are not mortal, the reptile still continues to live and to feed, showing no signs of being incommoded by its new guests. The caterpillar changes its skin; and sometimes undergoes the great change into an aurelia: but still the fatal intruders work within, and secretly devour its internal substance: soon after. they are seen bursting through its skin, and moving away, in order to spin themselves a covering, previous to their own little transformation. It is indeed astonishing sometimes to see the number of worms, and those pretty large, that thus issue from the body of a single caterpillar, and eat their way through its skin: but it is more extraordinary still, that they should remain within the body, devouring its entrails, without destroying its life. The truth is, they seem instructed by nature not to devour its vital parts; for they are found to feed only upon that fatty substance which composes the largest part of the caterpillar's body. When this surprising appearance was first observed, it was supposed that the animal thus gave birth to a number of flies different from itself; 
and that the same caterpillar sometimes bred an ichneumon, and sometimes a butterfly; but it was not till after more careful inspec- tion it was discovered, that the ichneumon tribe were not the caterpillar's offspring, but its murderers.

\section{CHAP'TER CLXXXVII.}

\section{OF THE SILKWORM.}

HAVING mentioned, in the last chapter, the damages inflicted by the caterpillar tribe, we now come to an animal of this kind, that alone compensates for all the mischief occasioned by the rest. This little creature, which only works for itself, has been made of the utmost service to man; and furnishes him with a covering more beautiful than any other animal can supply. We may declaim indeed against the luxuries of the times, when silk is so generally worn; but were such garments to fail; what other arts could supply the deficiency?

Though silk was anciently brought in small quantities to Rome, yet it was so scarce as to be sold for its weight in gold; and was considered as such a luxurious refinement in dress, that it was infarnous for a man to appear in habits of which silk formed but half the composition. It was most probably brought among them from the remotest parts of the East; since it was, at the time of which I am speaking, scarcely known even in Persia.

Nothing can be more remote from the truth, than the manner in which their historians describe the animal by which silk is produced. Pausanias informs us, that silk came from the country of the Seres, a people of Asiatic Scythia; in which place an insect as large as the beetle, but in every other respect resembling a spider, was bred up for that purpose. They take great care, as he assures us, to feed and defend it from the weather; as well during the summer's heat, as the rigours of winter. This insect, he observes, makes its web with its feet, of which it has eiglit in number. It is fed for the space of four years upon a kind of paste, prepared for it; and at the beginning of the fifth, it is supplied with the leaves of the green willow, of which it is particularly fond. It then feeds till it bursts with fat; after which they take out its bowels, which are spun into the beautiful inanufacture so scarce and costly.

The real history of this animal was unkuown among the Romans till the time of Justinian; and it is supposed, that silkworms were nat brought into Europe till the beginning of the twelfth century; when Roger of Sicily brought workmen in this manufacture from Asia Minor, after his return from his expedition to the Holy Land, and settled them in Sicily and Calabria. From these the other kingdoms of Europe learned this manufacture; and it is now one of the most lucrative carried on among the southern provinces of Europe.

The silkworm is now very well known to be a large caterpillar, of a whitish colour, with twelve feet, and producing a butterfly of the moth kind. The cone on which it spins, is formed for covering it while it continues in the aurelia state; and several of these, properly wound off, and united together, form those strong and beautiful threads, which are woven into silk. The feeding these worms, the gathering, the winding, the twisting, and the weaving their silk, is one of the principal manufactures of Europe; ar:d, as our luxuries increase, seems every day to become more and more necessary to human happiness.

There are two methods of breeding silkworms; for they may be left to grow.. and to remain at liberty upon the trees where they are hatched; or they may be kept in a plare, built for that purpose, and fed every diny with fresh leaves. The first method is userl in China, Tonquin, and other hot countries s 
the other is used in those places where the animal has been artificially propagated, and still continues a stranger. In the warm climates, the silkworm proceeds from an egg, which has been glued by the parent moth upon proper parts of the mulberry-tree, and which remains in that situation during the winter. The manner in which. they are situated and fixed to the tree, keeps them unaffected by the influence of the weather; so that those frosts which are severe enough to kill the tree, lave no power to injure the silkworm.

The insect never proceeds from the egg till nature has provided it a sufficient supply; and till the budding leaves are furnished, in sufficient abundance, for its support. When the leaves are put forth, the worms seem to feel the genial summons, and, bursting from their little eggs, crawl upon the leaves, where they feed with a most voracious appetite. Thus they become larger by degrees; and after some months' feelling, they lay, upon every leaf, small bundles or cones of silk, which appear like so many golden apples, painted on a fine green ground. Such is the method of breeding them in the East; and without loubt it is best for the worms, and least troublesome for the feeder of them. But it is otherwise in our colder Europenn climates; the frequent changes of the weather, and the heavy dews of our evenings, render the keeping them all night exposed, subject to so many inconveniences, as to admit of no remedy. It is true, that, by the assistance of nets, they may be preserved from the insults of birds; but the seyere cold weather, which often succeeds the first heats of summer, as well as the rain and higli winds, will destroy them all: and, therefore, to breed them in Europe, they inust be sheltered and protected from every external injury.

For this purpose, a room is chosen, with a south aspect; aud the windows are so well glazed, as not to adnit the lenst air: the walls are well built, and the planks of the floor exceedingly close, so as to admit neither birds nor mice, nor even so much as an insect. In the midlle there should be four pillars erected, or four wooden posts, so placed as to form a pretty large square. Between these are different stories made with osier hurdles; and under each hurdle there should be a floor, with an upright border all round. These burdles and floors must hang upon pulleys, so as to be placed or taken down at pleasure.

When the worms are hatched, some tender mulberry leaves are provided, and placed in the cloth or paper-hox in which the eggs were laid, and which are large enough to hold a great number. When they have acquired some strength, they must be distributed on beds of mulberry leaves, in the different stories of the square in the middle of the room, round which a person may freely pass on every side. They will fix themselves to the leares, and afterwards to the sticks of the hurdles, when the leaves are devoured. They have then a thread, by which they can suspend themselves on occasion, to prevent any shock by a fall; but this is by no means to be considered as the silk which they spin afterwards in such abundance. Care must be taken that fresh leaves be hrought every inorning, which must be strewed very gently and equally over them; upon which the silkworms will forsake the remainder of the old leaves, which must be carefully taken array, and every thing kept very clean; for nothing lurts these insects so much as moisture and uncleanliness. For this reason their leaves must be gathered when the weather is dry, and kept in a dry place, if it be necessary to lay in a store. As these animals have but a short time to live, they make use of every moment, and almost continually are spinning, except at those intervals when they change their skins. If mulberry leaves be difficult to be obtained, the leaves of lettuce, or holyoak will sustain them; but they do not thrive so well upon their new diet; and their silk will neither be so copious, nor of so good a quality.

Though the judicious choice and careful management of their diet is absolutely necessary, yet there is another precaution of equal importance; which is, to give them air, and open their chamber windows, at such times as the sun shines warmest. The place also must be kept as clenn as possible; not only the several floors that are laid to receive their ordure, but the whole apart ments in general. These things well ob- 
served, contribute greatly to their health and increase.

"The worm, at the time it bursts the shell, is extremely small, and of a black colour; but the head is of a more shining black than the rest of the body: some days after, they begin to turn whitish, or of an ash-coloured gray. After the skin begins to grow too rigid, or the animal is stinted within it, the insect throws it off, and appears clothed anew : it then becomes larger, and much whiter, though it has a greenish cast : after some days, which are more or less, according to the different heat of the climate, or to the quality of the food, it leaves off eating, and seems to sleep for two days together: then it begins to stir, and put itself into violent morions, till the skin falls off the second time, and is thrown aside by the animal's feet. All these cluanges are made in three weeks or a montls's time; after which it begins to fecd once more, still in its caterpillar form, but a good deal difiering from itself before its change. In a few clays' time it seems to sleep again; and, when it awakes, it again cluanges its clothing, and continues feeding as before. When it has thus taken a sufficiency of food, and its parts are disposed for assuming the aurclia form, the animal forsakes, for the last time, all food and society, and prepares itself a retreat to defend it from external injuries, while it is seemingly deprived of life aud motion.

This retreat is no other than its cone, or ball of silk, which nature has taught it to compose witl] great art; and within which it buries itself, till it assumes its winged form. 'This cone or ball is spun from too little longish kinds of bags that lie above the intestines, and are filled with a gummy flujd, of a marigold colour. This is the substance of which the threads are formed; and the little animal is furnished with a surprising apparatus for spinning it to the degree of fineness which its occasions may require. This instrument in some ineasure resembles a wire-drawer's machine, in which gold or silver threads are drawn to any degree of nilnuteness; and through this the animal draws its thread with great assiduity, As every thread proceeds from two gum-bags, it is probable that each supplies its own; which, however, are united, as they proceed from the animal's body. If wo examine the thread with a microscope, it will be found that it is flatted on one side, and grooved along its length: from hence we may infer, that it is doubled just upon leaving the body; and that the two threads stick to each other by that gumny quality of which they are possessed. Previous to spinuing its web, the silkworm seeks out some convenient place to erect its cell, without any obstruction. When it has found a leaf, or a chink fitted to its purpose, it begins to wreatl its head in every direction, and fastems its thread on every side to the sides of its retreat. Though all its first essays seein perfectly confused, yet they are not altogether without design: there appears, indeed, no ordes or contrivance in the disposal of its first threads: they are by no means laid artfully over each other, but are tlirown out at random, to serve as an external shelter against raiı; for nature having appointed the animal to work upon trees in the open air, its habits remain, thougl it is brought up in a warm apartment.

Malpigli pretends to have observed six different layers in a single cone of silk; but what may casily be observed is, that it is composed extermally of a kind of rough cottonlike substance, which is called floss; within, the thread is more distinct and even; and next the body of the aurelia, the apartment seeins lined with a substance of the hardness of paper, but of a much stronger consistence. It must not be supposed, that the thread which goes to compose the cone, is rollcd round, as we roll a bottom; on the contrary, it lies upon it in a very irregular manner, and winds off now from one side of the cone, and then from the other. 'I'his whole thread, if measured, will be found about three hundred yards long; and so very fine, that eight or ten of them are generally rolled off into one by the manufucturers. The cone, when completed, is in form like a picgeon's egg, and more pointed at one end than the other: at the snialler end, the head of the aurelia is generally found; and this is the place that the insect, when converted into a moth, is generally secn to burst through.

It is generally a fortnight or three weeks before the aurelia is changed into a moth; but no sooner is the winged insect completely formed, than having divested itself of its aurelia skin, it prepares to burst through its cone, or outward prison: for this purpose it 
extends its head towards the point of the cone, butts with its eyes, which are rough, against the lining of its cell, wears it away, and at last pushes forward, through a passage which is small at first, but which enlarges as the animal increases its efforts for emancipation; while the tattered remnants of its aurelia skin lie in confusion within the cone, like a bundle of dirty linen.

The animal, when thus set free from its double confinement, appears exhausted with fatigue, and seems produced for no other purpose but to transmit a future brood. It neither flies nor eats; the inale only seeking the female, whose eggs he impregnates; and their union continues for four days, without interruption. The male dies immediately after separation from his mate; and she survives him only till she has laid her eggs, which are not hatehed into worms till the ensuing spring.
However, there are few of these animals suffered to come to a state of maturity; for as their bursting through the cone destroys the silk, the manufacturers take care to kill the aurelia, by exposing it to the sun, before the moth coines to perfection. This done, they take off the floss, and throw the cones into warm water, stirring them till the first thread offers them a clue for winding all off. They generally take eight of the silken threads together; the cones being still kept under water, till a proper quantity of the silk is wound off: however, they do not take all; for the latter parts grow weak, and are of a bad colour. As to the paper-like substance which remains, some stain it with a variety of colours, to make artificial flowers; other's let it lie in the water, till the glutinous matter which cements it is all dissolved: it is then carded like wool, spun with a wheel, and converted into silk stuffs of an inferior kind. 


\section{OF IUSECMS OF THE TOURTH ORDER.}

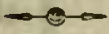

\section{CHAPTER CLXXX1X.}

\section{OF THE FOURTH ORDER OF INSECTS IN GENERAL.}

IN the foregoing part we treated of caterpillars changing into butterflies; in the present will be given the history of grubs changing into their corresponding winged animals. These, like the former, undergo their transformation, and appear as grubs or maggots, as aurelias, and at last as winged insects. Like the former, they are bred from eggs; they feed in their reptile state; they continue motionless and lifeless, as aurelias; and fly and propagate, when furnished with wings. But they differ in many respects : the grub or maggot wants the number of feet which the caterpillar is seen to have; the anrelia is not so totally wrapped up, but that its feet and its wings appear. The perfect animal, when emancipated, also has its wings either cased, or transparent like gauze; not coloured with that beantifully painted dust which adorns the wings of the butterfly.
In this class of insects, therefore, we may place a valious tribe, that are first laid as eggs, then are excluded as maggots or grubs, then change into anrclias, with their legs and wings not wrapped np, but appearing; and, lastly, assuming wings, in which state they propagate their kind. Some of these have four transparent wings, as bees; soine have two membranous cases to their wings, as bectles; and some have but two wings, which are transparent, as ants. Here, therefore, we will place the bee, the wasp, the humblebee, the ichmeumon fly, the gnat, the tipula or longlegs, the beetle, the may-bug, the glow-worm, and the ant. The transformations which all these undergo, are pretty nearly similar; and though very different auimals in form, are yet produced nearly in the same manner.

\section{CHAP'TER CXC.}

\section{OF THE BEE.}

TO give a complete history of this insect in a few pages, which some have exhausted volumes in describing, and whose nature and properties still continue in dispute, is impossible. It will be sufficient to give a general idea of the animal's operations; which, though they have been stadied for more than two thousand years, are still but incompletely known. The account given us by Reaumur is sufficiently minute; and, if true, sufficiently wonderful : but I find many of the facts which he relates, doubted by those who are most conversant with bees; and some of them actually declared not to have a real existence in nature.

It is unhappy, therefore, for those whose 
method demands a history of bees, that they are unfurnished with those materials which have induced so many observers to contradict so great a naturalist His life was spent in the contemplation; and it requires an equal share of attention, to prove the error of his discoveries. Without entering, therefore, into the dispute, I will take hin for my guide; and just mention, as I go along, those particulars in which succeeding observers have begun to think liin erroneous. Which of the two are right, time only ean discover; for iny part, I have only heard one side, for as yet none have been so bold as openly to oppose Reaumur's delightful researches.

There are three different kinds of bees in every live. First, the labouring bees, which make up the far greatest number, and are thought to be neither male ior female, but merely born for the purposes of labour, and continuing the breed, by supplying the young with provision, while yet in their helpless state. The second sort are the drones; they are of a darker colour, longer, and more thick by one-third than the former; they are supposed to be the males; and there is not above a hundred of them in a hive of seven or eight thousand bees. The third sort is much larger than either of the former, and still fewer in number; some assert that there is not above one in every swarm: but this later observers affirm not to be true, there being sometimes five or six in the same hive. These are called queen bees, and are said to lay all the eggs from which the whole swarin is hatched in a season.

In examining the structure of the common working bee, the first remarkable part that offers is the trunk, which serves to extract the honey from flowers. It is not formed, like that of other llies, in the manuer of a tube, by which the fluid is to be sucked up; but like a besom to sweep, or a tongue to lick it away. The animal is furnished also with teeth, which serve it in making wax. This substance is gathered fron flowers, like honey : it consists of that dust or farina which contribute to the fecundation of plants. and is moulded into wax by the little animal at leisure. Every bee, when it leaves the hive to collect this precious store enters into the cup of the flower, particularly such as seem charged with the greatest quantitie of this yellow farina. As the animal's body is covered over with hair, it rolls itself within the flower, and soon becomes quite covered with the dust, which it soon after brushes off with its two hind-legs, and kneads into two little balls. In the thighs of the hind-legs there are two cavities, edged with hair, and into these, as into a basket, the animal sticks its pellets. Thus employed, the bee flies from flower to flower, increasing its store, and addling to its stock of wax; until the ball upon each thigh becomes as big as a grain of pepper: by this time, having got a suflicient load, it relurns, making the best of its way to the hive.

The belly of the bee is divided into six rings, which sometimes shorten the body, by slipping one over the other. It contains within it, beside the intestines, the honey-bag, the venom-bag, and the sting. The honcybag is as transparent as crystal, containing the lioney that the bee has brushed from the flowers; of which the greater part is carried to the hive, and poured into the cells of the honey-comb, while the remainder serves for the bee's owi nourishment; for during sum. mer, it never tonches what has been laid up for winter. The sting which serves to delend this little animal from its enemies, is composed of three parts; the sheath and two darts, which are extremely small and penetrating. Bath the darts have several small points or barbs, like those of a fish-hook, which render the sting more painful, and makes the darts rankle in the wound. Still, however, this instrument would be very slight, did not the hee poison the wound. 'The sheath, which has a sharp point, makes the first impression; which is followed by that of the darts, and then the venomous liquor is ponred in. The sheath sometimes sticks so fast in the wound, that the animal is obliged to leave it behind; by which the bee soon after dies, and the wound is considerably inflamed. It might at first appear well for mankind, if the bee were without its sting: but, upon recollection. it will be found, that the little animal would then have too many rivals in sharing its labours. A humdred other lazy animals fond of honey, and hating labour, would intrude upon the sweets of the hive; and the treasure 
would be carried off for want of armed guardians to protect it.

Frum examining the bee singly; we now conle to consider it in society, as an animal not only subject to laws, but active, vigilant, laborious, and disinterested. All its provisions are laid up for the community; and all its arts in building a cell, designed for the benefit of posterity. The substance with which bees build their cells is wax; which is fashioned into convenient apartments for themselves and their young. When they begin to work in their hives, they divide themselves into four companies: one of which roves in the fields in search of materials; another employs itself in laying out the bottom and partitions of their cells; a third is employed in making the inside smooth from the corners and angles; and the fourth company bring food for the rest, or relieve those who return with their respective burdens. But they are not kept constant to one employment ; they olten change the tasks assigned them: those that have been at work, being permitted to go abroad; and those that have been in the ficlds already, take their places. They seem even to have signs, by which they understand each other; for when any of them wants food, it bends down its trunk to the bee from whom it is expected, which then opens its honcy-bag, and lets some drops fall into the other's mouth, which is at that time open to receive it. Their diligence and labour is so great, that in a day's time they are able to make cells, that lie upon each other, numerous ellough to contain three thousand bees.

If we examine their cells, they will be found formed in the exactest proportion. It was said by Pappus, an ancient geometrician, that, of all other figures, hexagons were the most convenient; for when placed touching each other, the most convenient room would be given, and the sinallest lost. The cells of the bees are perfect hexagons: these, in every honey-comb, are double, opening on either side, and closed at the bottom. The bottoms are composed of little triangular panes, which, when united together, terminate in a point, and lie exactly upon the extremities of other panes of the same shape, in opposite cells. These lodgings have spaces, like streets, between them, large enough to give the bees a free passage in and out; and yet narrow enough to preserve the necessary heat. The mouth of every cell is defended by a border, which makes the door a little less than the inside of the cell, which serves to strengthen the whole. These cells scrve for different purposes : for laying up their young; for their wax, which in winter becomes a part of their food; and for thejr honey, which makes their principal subsistence.

It is well known that the habitation of bees ought to be very close; and what their hives waut, from the negligence or unskilfulness of man, these animals supply by their own industry: so that it is their principal care, when first hived, to stop up all the cramies. For this purpose they make use of a resinous gum, which is more tenacious than wax, and diffcrs greatly from it. This the ancients called propolis: it will grow considerably hard in June; though it will in some measure soften by heat; and is often found different in consistence, colour, and smell. It has generally an agreeable aromatic odour when it is warmed ; and by some it is considered as a most grateful perfume. When the bees begin to work with $\mathrm{it}$, it is soft, but it acquires a firmer cousistence every day; till at length it assumes a brown colour, and becomes much harder than wax. The bees carry it on their linder legs; and some think it is met with on the birch, the willow, and poplar. However it is procured, it is certain that they plaster the inside of their lives with this composition.

If examined through a glass hive, from the hurry the whole swarm is in, the whole appear's at first like anarchy and confusion : but the spectator soon finds every animal diligently employed, and following one pursuit, with a settled purpose. Their teeth are the instruments by which they model and fashion their various buildings, and give them such symmetry and perfection. They hegin at the tup of the hive; and several of them work at a time, at the cells which have two faces. If they are stinted with regard to time, they give the new cells but half the depth which they ought to have; leaving them imperfect, till they have sketched out the number of cells necessary for the present occasion. The construction of their combs costs them a great deal of labour: they are made by iusensible additions; and not cast at once in a mould, as sonie are apt to imagine. There seems no end of their 
shaping, funishing, and turning them neatly up. The cells for their young are most carefully formed; those designed for loxtging the drones, are larger than the rest; and that for the queen-bee the largest of all. The cells in which the young brood are lodged, serve at diffrent times for containing honey; and this proceeds fiom an obvious cause : every worm, before it is transformed into an aurelia, hangs its old skin on the partitions of is cell; and thus, while it strengihens the wall, diminishes the capacity of its lute apartment. The same cell, in to single summer, is often tenanted by three or fonr worms in succession; and the next season by three or four more. Each worm takes particular care to fortify the pannels of its cell, by hanging up its spoils there: thus, the partitions being lined six or eight deep, become at last too narrow fur a new broot, and are converted into store-houses for honey.

Those cells where nothing but honey is deposited, are much deeper than the rest. When the harrest of honey is so piontiful that they have not suficient roos for it, they either lengihen their combs, or build more; which are much longer than th' former. Sometimes they work at three combs at a time; for when there are three work-houses, more bees may be thus cmployed, withont embarrassing each other.

But honey, as was before observel, is not the only food upon which these animals suhsist. 'The meal of flowers, of which their wax is formed, is one of their most favenrite repasts. This is a diet which hey live upon during the sumumer; and of which they lay up a large winter provision. The wax if which their combs are unade, is mo more than this meal digested, and wronght into a paste. When the flowers upon which hees generally feed, are not fully blown, and this ineal or dust is not offered in sufficient quantities, the bees pinch the tops of the staninit in which it is contained, with their teeth ; and thus anticipate the progress of vegetation. In April and Way, the bers are busy, from morning 10 evening, in gathering this meal; but when the weather becomes too hot in the midst of summer, they work only in the morning.

The hee is furnished with a stomach for its wax, as well as its honey. In the former of the two, their powder is altered, digested, and мо. $67 \& 68$. concocted into real wax; and is thus ejected by the same passage by which it was swallowed. Every comb, newly made, is whitc; but it becones yellow as it grows olel, and almost black when kept too long in the hive. Beside the wax thus digested, there is a large portion of the powder kneaded up for food in every hive, and licpt in separate cells, for winter provision. This is called by the country people bec-bread; and contributes to the health and strength of the animal during winter. Those who rear bees, may rols them of their honcy, and feed them, cluring the winter, with treacle; but no proper substitute has yet becn found for the bec-bread ; and, without it, the animals bccome consumptive, and die.

As for the honey, it is extracted from that part of the flower called the nectarcum. From the mouth this delicions fluid passes into the gullet; and then into the first stomach, or honey-bag, which, when filled, appears like an oblong bladder. Children, that live in comnery places, are well acquainted with this blarder; and destroy many bees; to come at their store of honey. When a bee lias sufficiently filded its first stomach, it returns back to the live, where it disgorges the honey into one of the cells. It often happens that the bec delivers its store to some other, at the mouth of the hive, and flies off for a fresh supply. Some honey-combs are always left open fir common use; but many others are stopped up, till there is a necessity of opening them. Each of these is covered carefully with wax; so close, that the covers secm to be made at the very instant the fluid is deposited within them.

Having thus given a cursory description of the insect, individually considered, and of the habitation it forms, we next come to its social habits and institutions: and, in considering this little animal attentivcly, after the necessary precautions for the inmediate preservation of the comnunity, its second care is turned to the continuance of postcrity. How numerous soever the multitude of hees may appenr in one swarm, yet they all owe their original to a single pareit, which is called the Queen-Bee. It is indeed surprising that a single insect shall, in one summer, give birth to abuve twenty thousand young: but, upon opening her body, the wonder will cense; as the number of eggs appearing, at one time $5 \mathbf{T}$ 
amounts to five thousand. This animal, whose existence is of such $\mathrm{j}$ :nportance to her subjects, may easily be distinguished from the rest by her size, and the shape of her body. On her safety depends the wliole welfare of the coinmonivealth; and the attentions paid her by all the rest of the swarı, evidintly show the dependence her subjects have upon her security. If this insect be carefully ohserved, sle will be seen at times attended with a numerous retinue, marching from cell to cell, plunging the extrenity of her body into many of them, and leaving a suall egg is each.

The bees which generally compose her train, are thought to be males, which serve to impregnate her by turns. These are larger and blacker than the common bees; without stings, and without industry. They seem for:ued only to transmit a posterity; and to attend the queen, whenever she thitiks proper to issue from the secret retreats of the hive, where she most usually resides. Upon the union of these two kinds depends all expectations of a future progeny; for the working bees are of no sex, and only labour for another offspring: yet such is their attention to their queen, that if she happens to die, they will leave off working, and take no farther care of posterity. If, however, another queen is, in this state of universal despair, presented then, thry immediately acknowledge her for their sovereign, and once more diligently apply io theil labour. It must he observed, however, that all this fertility of the queen-bee, and the great attentions paid to her by the rest, are controverted by more recent observers. 'They assert, that the common bees are parents themselves; that they deposite their eggs in the cells which they have prepared; that the females are impregnated by the males, and bring forth a progeny, which is wholly their own.

However, to go on with their history, as delivered us by Mr. Reaumur. When the queenbee has deposited the number of egus necessary in the cells, the working bees undertake the care of the rising posterity. They are seen to leave off their usual employments; to construct proper receptacles for eggs; or to complete those that are already formed. They purposely build little cells, extremely solid, for the young; in which they employ a great deal of wax : those designed for lodging the niales, as was alruady ohserved, are larger than the rest; and those for the queen-bees the largest of all. There is usually but tme egg deposited in every cell; but when the fecundity of the queen is such, that it exceeds the number of cells already prepared, there are sometimes three or four eggs crowded together in the same apartument. But this is an inconvenience that the working bees will by no means suffer. They seem seusible that two young ones, stuffed up in the same cell, when they grow larger, will but enıbariass, and at last destroy each other : they therefore take care to leave a cell to every egg; and renove or destroy the rest.

The single egg that is left remaining, is fixed to the botton of the cell, and touclies it but in a single point. A lay or two after it is deposited, the worm is excluded from the sliell of the egg, having the appearance of a nıaggot rolled up in a ring, and lying sofily on a bed of a whitish-coloured jelly; upon which also the little animal begins to feed. In the mean time, the instant it appears, the working bees attend it with the most anxious and parental tenderness; they furnish it every hour with a supply of this whitish substance, on which it feeds and lies; and watch the cell with unremitting care, They are nurses that have a greater affection for the offspring of others, than many parents have for their own children. They are constant in visitiug each cell, and seeing that rothing is wanting; preparing the white mixture, which is nothing but a composition of honey and wax, in their own bowels, with which they feed then. Thus attended, and plentifully fid, the worm, in less than six days' time, comes to its full growth, and no longer acespes the food offered it. When the bees perceive that it lias no further occasion for fceding, they perform the last offices of tenderuess, and shut the liule animal up in its cell: walling up the mouth of its apartment with wax: where they leave the worn to itself; having secured it from every external injury.

The worm is no sooner loft enclosed, but from a state of inaction, it begins to labour, extending and shortening its body; and by this means lining the walls of its apartment with a silken tapestry, which it spins in the manner of caterpillars, before they underga 
their last transformation. When their cell is thus prepared, the aninal is soon after transformed into an aurelia; but differing from that of the common caterpillar, as it exhibits not only the legs, but the wings of the future bee, in its present state of inactivity. Thus, in about twenty or one and twenty days after the egg was laid, the bre is completely formed, and fitted to undergo the fatigues of its state. When all its parts have acquired their proper strength and consistence, the young animal opens its prison, by piercing with its teeth the waxen door that confines it. When just freed from its cell, it is as yet moist, and inco:nmoded with the spoils of its former situation: but the otficious bees are soon seen to flock round it, and to lick it clean on all sides with their trunks; while another band, with equal assiduity, are observed to feed it with honey: others again begin immediately to cleanse the cell that has been just left; to carry the ordure out of the hive, and to fit the place for a new inhabitant. The young bee soon repays their care by its industry; for as soon as ever its exterual parts becone dry, it discovers its natural appetites for labour, and industriously begius the task, which it pursues unremittingly through life. The toil of man is irksome to him, and he earns his subzistence with pain; but this little animal seems happy in its pursuits, and finds delight in all its employments.

When just freed from the cell, and properly equipped by its fellow-bees for duty, it at once issues from the hive, and, instructed only by nature, goes in quest of flowers, chooses ouly those that yicld it a supply, rejects such as are barren of honey, or have been already drained by other adventurers; and when loaded, is never at a loss to find its way back to the common habitation. After this first sally, it beging to gather the mealy powder that lies on every flower, which is afterwards converted into wax; and with this, the very first day, it returns with two large balls stuck to its thiglıs.

When bees first begin to break their prisons, there are generally above a hundred excluded in one day. Thus, in the space of a few iveeks, the number of the inhabitants in one hive, of moderate size, becomes so great, that there is no place to contain the new comers; and they are scarcely excluded from the cell, when they are obliged, by the old bees, to sally forth in quest of new habitations. In other words, the hive begins to swarm, and the new progeny prepares for exile.

While there is room enough in the hive, the bees remain quietly together; it is necessity aloue that compels the separation. Sometimes, indeed, the young brood, with graceless obstinacy, refuse to depart, and even venture to resist their progenitors. The young ones are known by being browner than the old, with whiter hair, the old ones are of a lighter colour, with red hair. The two armies are therefore easily distinguishable, and dreadful battles are often seen to ensue. But the victory almost ever terminates with strict political justice in favour of the veterans, and the rebellious offspring are driven off, not without loss and mutilation.

In different countries, the swarms make their appearance at different times of the year, and there are several signs previous to this intended migration. The night before, an unusual buzzing is heard in the hive; in the morning, though the weather be soft and inviting, they seem not to obey the call, being intent on more important meditations within. All labour is discontinued in the hive; every bee is either employed in forcing, or reluctantly yielding, a submission; at length, after some noise and tumult, a queen-bee is chosen to guard rather than conduct the young colony to other habitations, and then they are marshalled without any apparent conductor. In less than a minute they leave their native abode, and forming a cloud round their protectress, they set off, without seeming to know the place of their destination; the world before them, where to choose their place of rest. The usual time of swarming is from ten in the morning to three in the aftermoon, when the sun shines brigbt, and invites them to seek their fortunes. They flutter for a while in the air, like flakes of snow, and sometimes undertake a distant journey, but more frequently are contented with some neighbouring asylum; the branch of a tree, a chimney-top, or some other exposed situation. It is, indeed, remarkable, that all those animals, of whatever kind, that have long lieen under the protection of man, seem to 
lose a part of their natural sagacity in providing for themselves. The rabbit, when domesticated, forgets to dig holes, the hen to build a nest, and the bee to seck a shelter. that shall protect it from the inclemencies of winter. In those countries where the bees are wild, and unprotected by man, they are always sure to build their waxen cells in the hollow of a tree; but with us, they seem improvident in their choice, and the first green branch that stops their flight, seems to be thought sufficient for their abode through winter. However, it does not appear that the queen choores the place where they are to alight, for inany of the stragglers, who seem to be pleased with a paricular branch, go and settle upon it; others are seen to succeed; and, at last, the queen herself, when she finds a sufficient number there before her, goes to make it the place of her head-quarters. When the queen is settled, the rest of the swarm soon follow; and in about a quarter of an hour, the whole body seem to be at ease. It sometimes is found, that there are two or three queens to a swarm, and the colony is divided into parties; but it most usually happens, that one of these is more considerable than the other, and the liees, by degrees, desert the weakest, to take shelter under the most powerful protector. The deserted queen does not long survive this defeat; she talses refuge under the new monarch, and is soon destroyed by her jealous rival. Till this cruel execution is performed, the bees never go out to work; and if there should be a queen-bee belonging to the new colony left in the old hive, she always undergoes the fate of the former. However, it must be observed, that the bees never sacrifice any of their queens, when the hive is full of wax and honey; for there is at that time no danger in maintaining a plurality of breeders.

When the swarm is thus conducted to a place of rest, and the policy of government is settled, the bees soon resume their former labours. The making cells, storing them vith honey, impregnating the queen, making proper cells for the reception of the rising progeny, and protecting them from exterual danger, employ their unceasing industry. But soon after, and towards the latter end of summer, when the eolony is sufficiently stored with inhabitants, a most cruel policy ensus. The drone bees, which are (as hins been sad) generally in a hive to the number of a liundred, are marked for slanghter. Fliese, which had hitherto led a life of undolence and pleasure, whose only employment was in impreguating the queeu, and rioting opou. the labours of the live, without riding in the general toil, now share the fate of nost voluptuaries, and fall a sacritice to the general resentment of society.

The working bees, in a body, declare wal against them; and in two or thee days' time, the gromul all round the hive is covered with their dead bodies. Nay, the working bees will even kill such drones, as are jet in the worm state, in the cell, and rject their bodies from the hive, among the general carnage.

When a hive sends out several swarms in the year, the first is always the best, and the most numerous. These, having the whole summer before them, have the more time for making wax and houey, and consequently their labours are the most valuable to the proprietor. Although the swarm chiefly consists of the youngest bees, yet it is often found, that bees of all ages compose the nultitude of emigrants, and it often happens, liat bees of all ages are seen remaining behiud. The number of them is always nore considerable than that of some populous cities, for sometimes upwards of forty thousand are found in a single hive. So large a body may well be supposed to work with great expedition; and, in fact, in less than twenty-four hours, they will make combs above twenty inches long, and seven or cight broad. Sometimes they will half fill thejr hives with wax in less than five days. In the first fifeen days, they are always found to make more wax than they do afterwards during the rest of the year.

Such are the outlines of the natural history of these animals, as usually found in our own conntry. How they are treated, so as to produce the greatest quantity of honey, belongs rather to the rural economist. than the natural historian; volumes have been written on the subject, and still more remains equally curious and new. One thing, however, it may 
be proper to observe, that a farm, or a country, may be over-stocked with bees, as well as with any other sort of animal; tor a certain number of bives always require a certain number of llowers to subsist oll. When the flowers near home are ritled, then are these industrious insects secu taking more extensire ranges: but their ahilities may be over taxed; ind if they are obliged, in quest of honey, to go too fir from home, they are over-wearied in the pursuit, they are devourert by birds, or beat down by the winds and rain.

From a knowledge of this, in some parts of France and Piedmont, they liave contrived, as I have often seen, a kiisd of floating bec-lionse.

They have on board one barge threescore or a hundred bee-hives, well defended from the inclemency of an accidental storm; aul with these the owners suffer themselves to float gently down the river. As the bees are continually choosing their flowery pasture along the banks of the strean, they are furnished with sweets before unrifled: and thus a single floating ber-house yields the proprictor a considerable incone. Why a metisod similar to this has never been adopted in Eugland, where we have more gentle rivers, and unore flowery banks, than in any other part of the world, I know not: certainly it miglst be turued to advantage, and yield the possessor a secure, though perliaps a molniate jucome.

H.wing mentioned the industry of these admirahle jusects, it will be proper to say something of the effects of their labour, of that w ix and houcy which are turned by man to such various uses. Bees gather two kiuds of wax; nne coase, and the other fine. The coarser sort is bitter, and with this, which is called propolis, they stop up all the boles and crevices of their hives. It is of a more resinous uature than the fine wax, and is conse. quently better qualified to resist the moistnre of the seasoll, and preserve the works warn and dry within. The fune wax is an necessary to the animal's preservation as the honey itself. With this they make their lorlgings, with this they cover the cells of their young, and in this they lay up their magazines of honey: This is marle, as has breen alpondy observed, from the dust of flowers, which is carefully kneaded by the little insect, then swalloned, and laving nudergonc a kind of digestion, is formed ino the cells, which aliswer such a variety of purposes. 'To collect this. the animal rolls itself in the flow it would rob, and thus takes up the vegetable dust with the hair of its body. Then carefully brushing it into a lump, with its forepatws it thrusts the composition into two cavities behind the thighs, which are male like spoons to receive the wax, and the hair that lines then serves to keep it from fillting.

As of wax, there are also two kinds of honey; the white and the yellow. "The white is taken withont fire from the honcycombs. The yellow is extracted by heat, airl squeezerl through bags, in a press. 'The best honey is new, llick, and granulated, of a clcar trausparent white colour, of a soli and aromatic smell, and of a sweet lively taste. Honey made in mountainous comstries, is preferable to that of the valley. The honey made in the spring is more highly esteemed than that gathered in summer; which last is still more valuahle than that of autmin, "lien the flowers begin to fade, and lose their tiagrance.

The bees are nearly alike in all parts of the world; yet there are differences worthy our notice. In Guadaloupe, the bee is less by one half than the European, and more black and round. 'They have no sting, and make their cells in hollow trees; where, if the hole they meet with is too large, they form a sort of waxen house of the shape of a pear, and in this they lorge and store their honey. and lity their eggs. They lay up their honey in waxen ressels, of the size of a pigcou's egg of a black or deep violet colour; and these are so joined together, that there is no space lefi between them. The honey never congenls, hut is tluid, of the consistence of oil, and the colour of amber. Resembling these, there are found little black bees, without at sting, in all the tropical climates; and thongh these countries are replete with bees like our own, yet those form the most usefinl and laborions tribe in that part of the world. The honey they proluce is neim ther so unpalatable nor so surfeiting as ours; and the w:ix is so soft, that it is only used for medicinal purposes, it being never found 
hard enough to form into candles, as in Europe.

Of insects that reccive the name of bees atnong us, there are several; which, however, differ very widely from that industrious social race we have been just describing. The Humble-Bee is the largest of all this tribe, being as large as the first joint of one's middle finger. These are seen in every field, and perched on every flower. They build their nest in holes in the ground, of dry leaves, mixed with wax and wool, defended with moss from the weather. Each humble-bee makes a separate cell about the size of a smalt nutmeg, which is round and hollow, containing the honey in a bag. Several of these cells are joined together in such a manner, that the whole appears like a cluster of grapes. The females, which have the appearance of wasps, are very few, and their eggs are laid in cells, which the rest soon cover over with wax. It is uncertain whether they have a queen or not; but there is one much larger than the rest, without wings and without hair, and all over black, like polished ebony. 'This goes and views all the works, from time to time, and enters into the cell, as if it wanted to see whether every thing was done right. In the morning the young humble-bees are very idle, and seem not at all inclined tolabour, till one of the largest, about seven o'clock, thrusts half its body from a hole designed for that purpose, and seated on the top of the nest, beats its wings for twenty minutes successively, buzzing the whole time, till the whole colony is put in motion. The humble-bees gather honey, as well as the cominon bees; but it is neither so fine nor so good, nor the wax so cleau, or so capable of fusion.

Beside the bees already mentioned, there are various kinds among us, that have much the appearance of honey-makers, and yet make only wax. The Wood-Bee is seen in every garden. It is rather larger than the common queen-bee; its body of a bluish black, which is smooth and shining. It begins to appear at the approach of spring, and is seen flying near walls exposed to a sunny aspect. This bee makes its nest in some piece of wood, which it contrives to scoop and hollow for its purpose. This, however, is never done in trees that are standing, for the wood it makes choice of is half rotten. The holes are not made directly forward, but turning to one side, and have an opening sufficient to admit one's middle finger, from whence runs the imer apartment. generally twelve or filteen inches long. The instruments nsed in boring these cavities, are their teeth; the cavity is usually branched into three or four apartments; and in each of these they lay their eggs, to the number of ten or twelve, each separate and distinct from the rest: the egg is involved in a sort of paste, which serves at once for the young animal's protection and nourishment. The grown bees, however, feed upon small insects. particnlarly a louse, of a reddish brown colour, of the size of a small pin's head.

Mason-Bees inake their cells with a sort of mortar made of earth, which they build against a wall that is exposed to the sun. The mortar, which at first is soft, soon becomes as hard as stone, and in this their eggs are laid. Each nest contains seven or eignt cells, an egg in every cell, placed regularly one over the other. If the nests remain unhurt, or want but little repairs, they make use of them the year ensuing : and thus they often serve three or four years successively. From the strength of their houses, one would think these bees in perfect security; yet none are more exposed than they. A worm with very strong teeth. is often found to bore into their little fortifications, and devour their young.

The Ground-Bee builds its nest in the earth, wherein they make round holes, five or six inches deep; the mouth being narrow, and only just sufficient to admit the little inhabitant.

It is amusing enough to observe the patience and assiduily with which they labour. They carry out all the earth, grain by grain, to the mouth of the hole, where it forms a little hillock; an alps, compared to the power of the artist by which it is raised. Sometimes the walks of a garden are found undermined by their labours; some of the holes running directly downward, others horizontally beneath the surface. They lay up in these cavities provisions for their young, which consist of a paste that has the appearance of corn, and in of a sweetish taste. 
The Leaf-cutting Bees make their nest and lay their ergs among bits of leaves, very artificially placed in hulus in the earth, of abont the lenuth of a tooth-pick case. They make the bits of leaves of a roundish form, and with them line the inside of their habitations. This tapestry is still further lined by a reddish kind of paste, somewhat sweet or acid. These bees are of various kinds; those that build their nests with chesnut leaves are as big as drones, but those of the rose-tree are smaller than the common bee.

The Wall-Bees are so called because they make their nests in walls, of a kind of silky menbrane, with which they fill up the vacuities betweeu the small stones which form the sides of their habitation. Their apartment comsists of several cells placed end to end, each in the shape of a woman's thimble. Though the web which lines this habitation is thick and warm, yet it is transparent, and of a whitish colour. This substance is supposed to be spun fiom the animal's body. The males and females are of a size, but the former are without a sting. To these varieties of the bee kind might be added several others, which are all different in nature, but not sufficiently distinguished to excite curiosity.

\section{CHAPTER CXXI.}

\section{OF THE WASP.}

HOWEVER similar many insects may be in appearance, this does not imply a similitude in their history. The bee and the wasp resemble each other very strongly, yet, in examining their manner and their duration, they differ very widely: the bee labours to lay up honey, and lives to enjoy the fruits of its industry : the wasp appears equally assiduous; but only works for posterity, as the habitation is scarcely completed when the inhabitant dies.

The wasp is well known to be a winged insect with a sting. To be louger in proportion to its bulk than the bee., to be inarked with bright yellow circles round its body, and to be the most swift and active insect of all the fly kind. On each side of the mouth this animal is furnisbed with a long tooth. notched like a saw, and with these it is enabled to cut any substance, not omitting meat itself, and to carry it to its nest. Wasps live, like bees, in community, and sometimes ten or twelve thousand are found inhabiting a single nest.

Of all other insects the wasp is the most fierce, voracious, and most dangerous, when enraged. They are seen wherever flesh is cutting up. gorging themselves with the spoil, and then flying to their nests with their reeking prey. They make war also on every other fly, and the spider himself dreads their approaches.

Every community among bees is composed of females or queens, drones or males, and neutral or working hees. Wasps have similar. occupations; the two first are for propagating the species, the last for nursing, defending; and supporting the rising progeny. Among bees, however, there is seldom above a queen or two in a hive; among wasps there are above two or three hundred.

As soon as the summer begins to invigorate. the insect tribes, the wasps are the most of the number, and diligently employed either in providing provisions for their nest, if already male; or in making one, if the former habitation be too small to receive the increasing community. The nest is one of the most curious ohjects in natural history, and contrived almost as artificiully as that of the bees themselves. Their principal care is to seek out a hole that has been begun by some other animal, a field-mouse, a rat, or a mole, to build their nests in. They sometimes build upon the plain, where they are sure of the dryness of their situation ; but most commonly on the side of a bank, to aroid the rain or water that would otherwise annoy them. When they have chosen a proper place, they. 
go to rork with wonderful assidnity. Their tirst labour is to enlarge and widen the hole, taking away the earth, and carrying it off to some distance. They are perfectly formed for labour, being furnished with a truuk above their mouths, two saws on each side, which play to the right and left agninst each other, and six strong muscular legs to support thern. 'They cut the carth into sinull parcels with their saws, and carry it out with their legs or paws. This is the work of some days; and at length the ontline of their habitation is formed, making a cavity of about a foot and a half every way. While soine are working in this manner, others are roving the fields to seck out materials for their building. To prevent the earth from falling down and crushing their rising city into ruin. they make a sort of roof with their gluey substance, to which they begin to fix the rudiments of their bnilding, working from the top downwards, as if they were hanging a bell; which, however, at length they close up at the bottom. The materials with which they build their nests are bits of wood and glue. The wood they get where they can from the rails and posts which they meet with in the fields and elsewhere. These they saw and divide into a multitude of small fibres, of which they take up little bundles in their claws, letting fall upon them a few drops of gluey matter, with which their bodies are provided, by the help of which they knead the whole composition into a paste, which serves them in theirfuture building. When they have returned with this to the nest, they stick their load of paste on that part where they make their walls and partitions; they tread it close with their leet, and trowel it with their trunks, still going backwards as they work. Having repeated this operation three or four times, the composition is at length flatted out until it becomes a sinall leaf of a gray colour, much finer tlan paper, and of a pretty firm texture. This done, the same wasp returns to the field to collect a second load of paste, repeating the same several times, placing layer upon layer, and strengthening every partition in proportion to the wants or convenience of the general fabric. Other working wasps come quickly after to repeat the same operation, laying more leaves upon the forme, till at length, after much toil, they have finished the large root, which is to secure thein from the tumbling in of the earth. This dome being finished, they make arother entrance to their habitation, designed either for letting in the warmth of the sun, or for escaping, in case one door be invaded by plunderers. Certain however it is, that by one of these they always enter, by the other they sally forth to their toil; esch hole being so sinall that they can pass but one at a time. The walls being thus composed, and the wholc somewhat of the shape of a pear, they labour at their cells, which they compose of the same paper-like substance that gocs to the formation of the outside works. Their combs differ from those of bees not less in the composition, than the position which they are always seen to obtain. The honey-comb of the bee is edgeways with respect to the hive; that of the wasp is flat, and the mouth of every cell opens downwards. Thus is their babitation contrived, story above story, supported by several rows of pillars, which give firmness to the whole building, while the upper story is flat-roofed, and as smooth as the pavelnent of a room, laid with squares of marble. The wasps can freely walk upon these stories between the pillars, to do whatever their wants require. The pillars are very hard and compact, being larger at each end than in the iniddle, not much nnlike the columus of a building. All the cells of the nest are only destined for the reception of the young, being replete with neitler wax nor honey.

Each cell is like that of the bee, hexagonal: but they are of two sorts; the one larger, for the production of the male and female wasps; the other less, for the reception of the working part of the commmity. When the females are inpregnated by the males, they lay their eggs, one in each cell, and stick it in with a kind of gummy matter to prevent its falling out. From this egg proceeds the insect in its worm state, of which the old ones are extremely careful, feeding it from time to time till it becomes large, and entirely fills up its cell. But the wasp community differs from that of the bee in this; that among the latter the working-bees take the parental duties upon them, whereas among the wasps 
the females alone are permitted to feed their young, and to nurse their rising progeny. For this purpose the female waits with great patience till the working-wasps have brought in their provisions, which she takes from them, and cuts into pieces. She then goes with great composure from cell to cell, and feeds every young one with her mouth. When the young worms have come to a certain size they leave off eating, and begin to spin a very fine silk, fixing their first end to the entrance of the cell ; then turning their heads, first on one side, then on the other, they fix the thread to different parts, and thus they make a sort of a door, which serves to close up the mouth of the cell. After this they divest themselves of their skins after the usual mode of transformation: the aurelia, by degrees, begins to emancipate itself from its shell; by little and little, it thrusts out its legs and wings, and insensibly acquires the colour and shape of its parent.

The wasp thus formed, and prepared for depredation, becomes a hold, troublesome, and dlangerous insect: there are no dangers which it will not encounter in pursuit of its prey, and nothingseems to satiate its gluttony. Though it can gather no honey of its own, no animal is more fond of sweets. For this purpose it will pursue the bee and the humblebee, destroy them with its sting, and then plunder them of their honey-bag, with which it flies triumphantly loaded to its nest to regale its young. Wasps are ever fond of making their nests in the neighbourhood of bees, merely to have an opportuuity of robbing their hives, and feasting on the spoil. Yet the bees are not found always patiently submissive to their tyranny, but fierce battles are sometimes scen to ensue, in which the bees make up by conduct and numbers what they want in personal prowess. When there is no honey to be had,-they seek for the best and sweetest fruits, and they are never mistaken in their choice. From the garden they fiy to the city, to the grocers' shops, and butchers' shambles. They will sometimes earry off bits of flesh half as big as themselves, with which they fly to their nest for the nourishment of their brood. Those who cannot drive them away, lay for them a piece of ox's liver, which being without fibres, they ผo. $69 \& \div 0$. prefer to other flesh; and whenever they are found, all other flies are seen to desert the place immediately. Such is the dread with which these little animals impress all the rest of the insect tribes, which they seize and devour without mercy, that they vanish at their approach. Wherever they tly, like the eagle or the falcon, they form a desert in the air around them. In this manuer the summer is passed in plundering the neighbourhood, and rearing up their young: every day adds to their numbers; and from their strength, agility, and indiscriminate appetite for every kind of provision, were they as long-lived as the bee, they would soon swarm upon the face of nature, and become the most noxious plague of man; but providentially their lives are measured to their mischief, and they live but a single season.

While the summer heats continue, they are bold, voracious, and enterprising; but as the sun withdraws, it seems to rob them of their courage and activity. In proportion as the cold increases, they are seen to become more donnestic; they seldom leave the nest, they make but short adventures from home, they flutter about in the noon-day heats, and soon after return chilled and feeble.

As their calamities increase, new passions soon begin to take place; the care for posterity no longer continues; and as the parents are no longer able to provide their growing progeny a supply, they take the barbarous resolution of sacrificing them all to the necessity of the times. In this manner, like a garrison upon short allowance, all the useless hands are destroyed; the young worms, which a little before they fed and protected with so much assiduity, are now butchered, and dragged from their cells. As the cold increases, they no longer find sufficient warmth in their nests; which grow hateful to them, and they fly to seek it in the corners of houses, and places that receive an artificial heat. But the winter is still insupportable; and, before the new year begins, they wither and die; the working-wasps first, the males soon following, and many of the females suffer in the general calamity. In every nest, however, one or two females survive the winter, and having been impregnated by the male during the preceding season, she begins in spring to $5 \mathrm{U}$ 
lay her eges in a little hole of her own contrivance. This bundle of eggs, which is clustered together like grapes, soon produces two worms, which the female takes proper precaution to defend and supply, and these, when hatched, soon give assistance to the female, who is employed in hatching two more; these also gathring strength, extricate themselves ont of the web that enclosed them, and become likewise assistants to their mother: fifeen days after, two more mike their appearance: thus is the community every diny increasing, while the female lays in every cell, first a male and then a feomale. These soon after become breeders in turı, till, from a single female, ten thousand wasps are seen produced before the month of Junc. Afrer lie fenule luas thus produced her progeny, which are distribnted in different districts, ilicy assemble from all parts in the middle of summer, and provide for themselves the large and commodious habitation which has been described alove.

Such is the history of the social wasp; but, as among bees, so also anong these insects, there are various tribes that live in solitude; these lay their eggs in a hrole for the purpose, and the parent dies long hefore the birth of its offopring. In the principal species of the Solitary-Wasps, the insect is snaller thon the working-wasp of the social kind. The filiment by which the corselet is joined to the body, is longer and nore distinctly scen, and the whole colour of the insect is blacker than in the ordinary kinds. But it is not thei figure, but the manuers of this extraordinary insect, that claim our priucipal regard.

From the end of May to the beginuing of July this wasp is seen unost diligently emploved. 'The whole purponse of its life seems to be in contriving and fitting up a commodious apartment for its young one, which is not to succed it till the your ensuing. For this end it is employed, with murearied assirluity, in boring a bole into the finest earth some inches deep, but not much willer than the diameter of its own body. - This is but a gallery leading to a willer apartment destined for the convenient lodgment of its young. As it always chooses a gravelly soil to work iii, and where the earlh is almost as hard as stone itself, the digging and hollowing this apartment is an enterprise of ro small labour : for effecting its. operations, this insect is furnished with two. tecth, which are strong and firm, but not sufficiently hard to penetrate the substance through which it is resolved to make its way. In order therefore to soften that earth which it is inable to pierce, it is furnished with a gummy liquor, which it emits upon the place, and which renders it more ensily separable from the rest, and the whole becoming a kind of soft paste, is removed to the mouth of the labitation. The animal's provision of liquor in these operations is however soon exhausted; and it is then seen taking up water either from some nrighbouring flowrr or strean, in order to supply the deficiency.

At length, after much toil, a hole some inclses deep is formed, at the bottun of which is a large cavity; and to this no mher hostile insect would venure to find its way, from the Irngth and the narrowness of the defile througl which it would be obligred to pass. In this the solitary wasp lays its egg, which is destined to continue the species; there the nascent animal is to continue for about nine months unatrended and immured, and, at first appearance, the nost helpless insect of the creation. But when we come to examine, new wonders offer; no other insect can boast so copiously luxurious a provision, or such confirmed security.

As soon as the mother wasp lias deposited her egg at the bottom of the hole, her next care is to furnish it wirh a supply of provisions, which may be: offered to the young insect as soun as it leaves the egg. To this end she procures a nunb of litrle green worms, generally from eight to twelve, and these are to serve as fool for the young one the instant it awakens into life. When this supply is regularly arrange(l and laid in, the old one then, with as much assiduity as it hefore worked out its hole, now closes the mouth of the passage; and thus leaving its young one-immured in perfect security, and in a copious supply of animal food, she dies satisfied with having provided for a future progeny.

When the young one Teares the egg, it is scarcely visible, and is seen immured among a number of insects, infinitely larger than itself, ranged in proper order around it, which, however, give it no manner of apprehension. Wliether the parent, when she laid in the in- 
sect provision, contrived to disable the worus from resistance, or whether they were at first incupable of any, is not known. Cerrain it is, that the young glutton feasts upon the living spoil without any control; his gane lies at lis hand, and he devours one after the other as the calls of ippetite incite him. The life of the young animal is therefore spent in the most luxurious manner, till its whole stock of worms is exhausted, when the time of its traustormation begins to approach; and then spinning a silken web, it continues fixed in its cell till the sun calls it from its dark abode the ensuing summ

The wisps of Europe are very mischievous, yet they are innocence itself when compared to those of the tropical climates, where all the insect tribes are not ouly nu nerons, but large, voracious, and formilable. 'Those of the W. st Indics are thicker, and twice as lo:g, as the common bee; they arc of a gray colour, striped with yellow, and armed with a very dangerous sting. They make their cells in the manner of a honey-comb, in which th. young ones are hatched and bred. They generally hang their nests by threads, compo ed of the same substance with the cells, to the branches of trees, and the eaves of houses. They are secu erery where in great abundiuce. descendiug like fruit, particularly pears, of which shape they are, and as large as ouse's hrat. The insirle is divided into three round storirs full of cells, each hexagonal, like those of a honey-comb. In some of the islands these insecis are so very numerous, that their uests are stuck up in this manter, scarce two feet asunder, and the inhubitants are in contiunal apprehension from their accidental resentment. It sometimes happons that no precautions can prevent their attacks, and the prin of their sting is almost insupportable. Those who have felt it, think it more terrible than event that of a scorpion; the whole visage swells, and the features are so disfignterl, that a person is searcely known by his most intimate acquaintance.

\section{CHAP'TER CXXII.}

\section{OF THE ICHNEUMON FLY.}

EVERY rank of insects, how voracious socver, have enemies that are terrible to thems, and that revenge upon them the injuries done upon the rest of the animated creation. The wasp, as we luave scen, is very tronblesome to man, and very formidable to the insect tribe; but the jelunemmon fly (of which there are many varieties) lears not the wasp itsclf; it enters its retreats, plunders its habitations, and takes possession of that coll for its own youmg, which the wasp had laboriously built for a dearer posterity.

Though there are many different kinds of this insect, yet the most formilable, and that best kuown, is called the common ichnemun, with four wings, like the bee, a long, slender, black boly, and a three-forked tail, consisting of bristles; the two outrmust black, and the middlemost red. This fly recrives its name from the little quadruped, which is found to be so destructive to the crocodile, as it bears a strong similitude in its courage and rapacitv.

Though this instrument is, to all appearance, slender and fecble, yet it is found to be a weapon of great force and efficacy. There is scarcely any substance which it will not pierce; and indeed it is scldom seen but employed in penetration. This is the weapon of ilefence; this is employed in destroying its Irey; and still more, by this the animal deposites her eggs wherever she thinks fit to lay them. As it is an instrument chicfly employed fir this purpose, the nıale is unprovided with such a sting, while the fernale uses it with great force and dexterity, braulishing it when caught, from side to side; and very uften wounding those who thought they held lier with the greatest security.

All the flies of this tribe are produced in the same inanner, and oive their birth to the destruction of some other insect, within whose 
body they have been deposited, and upon whose vitals they have preyed, till they came to maturity. 'There is no insect whatever, which they will not attack, in order to leave their futal present in its body; the catcrpillar, the gnat, and even the spicler himself, so forunidable to others, is often made the unwilling fosterer of this destructive progeny.

About the midule of the summer, , when other insects are found in great abundance, the ichneumon is seen fying busily about, and seeking proper oljjects upon whom to deposite its progeny. As there are various kinds of this fly, so they seem to have various appetites. Some are found to place their eggs within the aurelia of some nascent insect, others place them within the nest, which the wasp had curiously contrived for its own young: and as both are preduced at the same time, the young of the iclsneumon not only devours the young wasp, but the whole supply of worms, which the parent had carefilly provided for its provision. But the greatcst number of the ichneumon tribe are seen settling upon the back of the caterpillar, and darting, at different intervals, their stings into its body. At every dart they deposite an egg, while the wounded aninal seems scarcely sensible of the jujury it sustains. In this manner they leave from six to a dozen of their eggs within the fatty substance of the reptile's body, and then fly off to commit further depredations. In the mean time, the caterpillar, thus irreparably injured, seems to feed as voraciously as betore; does not abate of its usual activity; and, to all appearance, seems no way affecied by the internal enemies that are preparing its destruction in their darksome abode. But they snon burst from their egg state, and begin to prey upon the substance of their prison. As they grow larger, they require a greater supply; till at last the animal, by whose vitals they are supported, is no longer able to sustain them, but dics; its whole inside being almost eaten away. It often happens, hon ever, that it survives their worm-state, and then they change into a chrysalis, enelosed in the caterpillar's body till the time of their delivery approaches, when they burst their prisons, and fly away. The caterpillar, however, is irreparably destroyed, it never changes into a chrysalis, but dies shortly after from the injuries it had sus. tained.

Such is the history of this fly, which, though very terrible to the insect tribe, fails not to be of infinite service to mankind. The millions which it kills in a single sumner, are inconceivable; and without such a destroyer, the fruits of the earth would only rise to furnish a. banquet for the insect race, to the exclusion of all the nobler ranks of animated nature.

\section{CHAPTER CXCII.}

\section{OF THE ANT.}

THOUGH the number of two-winged flies be very great, and the naturalists have taken much pains to describe their characters and varieties; yet there is such a similitude in their forms and manners, that, in a work like this, one description must serve for all. We now, thereliore, come to a species of four-winged insects, that are famous from all antiquity for their social and industrious habits, that are narked for their spirit of subordination, that are offered as a pattern of parsimony to the profuse, and of unremitting diligence to the sluggard.
In the experiments, however, which have been more recently niade, and the observations which have been taken, mueh of their bonsted frugality and precaution seems denied them: the treasures they lay up are no longer supposed intended for future provision; and the choice they nake in their stores, seenis no way dictated by wisdom. It is, indeed, somewhat surprising, that almost every writer of antiquity should describe this insect, as labouring in the summer, and feasting upon the produce during the winter. Perhaps, in some of the warmer climates, where the win- 
ter is Inild, and of short continuance, this may take place; but in France and England, these animals can have no manner of occa sion for a supply of winter provisions, as they are actually in a state of torpidity during that season.

The commonants of Europe are of two or three different kinds; some red, some black; some with stings, and others without: such as have stings, inflict their wounds in that manner; such as are unprovided with tnese weapons of defence, have a power of spurting from their hinder parts an acid pungent liquor, which, if it lights upon the skin, inflames and burns it like nettles.

The body of an ant is divided into the head, breast, and belly. In the head the eyes are placed, which are eutircly black, and under their eyes there are two small horus or feelers, composed of twelve joints, all covered with a fine silky hair. The inouth is furnished with two crooked jaws, which project outwards, in each of which are seen incisures, that look like teetl. The breast is covered with a fine silky hair, from which project six legs, that are pretty strong and hairy, the extremities of each armed with two small claws, which the animal uses in climbing. The belly is more reddish.than the rest of the body, which is of a brown chesnut colour, shining as glass, and covered with extremely fine hair.

From such a formation, this animal seems bolder and more active, for-its size, than any other of the insect tribe, and fears not to attack a creature often above ten times its own inagnitude.

As soon as the winter is past, in the first fue day in Aprit, the ant-hill, that before seemed a desert, now swarms. with new life, and inyriads of these insects are seen just awaked from their annual lethargy, and preparing for the pleasures and fatigues of the season. For the first day they nevel offer to leave the hill, which may be considered as their citadel, but run over every part of it, as if to examine its present situation, to abserve what injuries it has sustained during the rigours of winter," while they slept, and

(a) Memoires pour servir a l'Hisloire des Insectes par Charles de Geer. to meditate and settle the labours of the day ensuing.

At the first display of their forces, none but the wingless tribe appears, while those furnished with wings remain at the bottom. These are the working ants that first appear, and that are always destitute of wings; the males and females, that are furnished with four large wings each, are more slow in making their appearance.

Thus, like bees, they are divided into males, females, and the neutral or the working tribe. These are all easily distinguished from each other; the females are much larger than the males; the working ants are the smallest of all. The two former have wings; which, however, they sometimes are divested of; the latter never have any, and upon them are devolved all the labours that tend to the welfare of the community. The female, also, may be distinguished by the colonr and structure of her brenst, which is a little more brown than that of the common ant, and a little brighter than that of the male.

In eight or tell days after their first appearance, the labours of the hill are in some forwarduess; the males and females are seen mixed with the working multitude, and pursucel or pursuing each other. They seem no way to partake in the common drudgeries of the state; the males pursue the females with great assiduity, and in a manner force them to eompliance. They remain coupled for some time; while the males; thus united, suffer themselves to be drawn along by the will of their partners.

In the mean time, the working body of the state take no part in their pleasures; they are scen diligently going from the ant-hill, in pursuit of food for themselves and their associates, and of proper materials for giving a comfortable retreat to their young, or safety to their habitation. In the fields of England, ant-hills are formed with but little apparent remularity. In the more southern provinces of Curope they are constructed with wonderful contrivance, and offer a sight highly. worthy a naturalist's curiosity. These are generally formed in the neighbourhoor of some large tree and a stream of water: 'The one is considered by the animals as the pro. per place for getting food; the other for sup. 
plying them with moisture, which they cannot well dispense with. The shape of the ant-hill is that of a sugar-loaf, about three feet high, composed of various substances; leaves, bits of wood, sand, earth, bits of gum, and grains of corn. These are all united into a compact botly, perforated with galleries down to the bottom. and winding ways within the body of the structure. From this retreat, to the water, as well as to the tree, in different directions, there are many paths worn by constint assiduity, and along these the busy insects are seen passing and repassing continually; so that from May, or the beginning of June, according to the state of the season, they work continually, till the bad weather comes on.

The chief employment of the working ants, is in sustaining not only the idlers at home, but also finding a sufficiency of food for themselves. They live upon varions provisions, as well of the vegetable as of the animal kind. Sinall insects they will kill and devour: sweets of all kinds they are particularly fond of. They seldom, however, think of their community, till they themselves are first satiated. Having found a juicy fruit, they swallow what they can, and then tearing it in pieces, carry home their load. If they mect with an insect above their match, several of them will fall upon it at once, and having mangled it, each will carry off a part of the spoil. If they meet, in their excursions, any thing that is too heavy for one to bear, and yet which they are unable to divide, several of them will endeavour to force it along, some dragging, and others pushing. If any one of them happens to make a lucky discovery, it will immediately give advice to others, and then, at once, the whole republic will pat themselves in motion. If in these struggles one of them happens to be killed, some kind survivor will carry him off to a great distance, to prevent the obstructions his body might give to the general spirit of industry.

But while they are thus employed in supporting the state in feeding abroad, and carrying in provisions to those that continue at liome, they are not unmindful of posterity. After a few days of fine weather. the female ants begin to lay their eggs, and those are as assiduously watched and protected by the working ants, who take upon themselves to supply whatever is wanting to the niscent. animal's convenience or necessity. They are carried, as soon as laid, to the safest situation, at the bottom of their hill, where they are carcfully defended from cold and moisture. We are not to suppose, that those white substances which we so plentifully find in every ant-hill, are the eggs as newly laid. On the contrary, the ant's egg is so very small, that, though laid upon a black ground, it can scarcely be discerned. The little white bodies we see are the young animals in their maggot state, endued with life, long since freed from the egg, and often involved in a cone, which it has spun round itself, like the silkworm. The real egg when laid, if viewed through a microscope, appears smooth, polished, and shining. while the maggot is seen composed of twelve rings, and is otten larger than the ant itselt: It is impossible to express the fond attachment which the working ants show to their rising progeny. In cold weather they take them in their mouths, but without offering them the smallest injury, to the very depths of their habitation, where they are less subject to the severity of the season. In a fine day they remove them with the same care nearer the surface, where their maturity may be assisted by the warm beams of the sun. If a formidable enemy should come to batter down their whole habitation, and crush them by thousands in the ruin, yet these wonderful insects, still mindful of their parental duties, make it their first care to save their offspring. They are seen running wildly about, and different ways, each loaded with a young one, often bigger than the insect that supports it. I have kept, says Swammerdam, several of the working ants in my closet, with their young in a glass filled with earth. I took pleasure in observing, that in proportion as the earth dried on the surface, they dug deeper and decper to deposite their eggs; and when I poured water thereon, it was surprising to see with what care, affeetion, and diligence, they laboured, to put their brood in safety, in the driest placc. I have seen also, that when water bas been wanting for several days, and when the earth was moistened after it a little, they immediately carried their young ones to 
have a share, who seemed to enjoy and suck the moisture.

When the young maggot is coine to its full growth, the breast swells insensibly, it casts its skin, aud loses all motion. All the ineinbers which were hidden before, then begin to appear; an aurelia is formed, which represents very distinctly all the parts of the animal, though they are yet without motion, and, as it were, wrapped up in swaddling clothes. When at length the little insect has passed through all its changes, and acquired its proper maturity, it bursts this list skin, to assume the form it is to retain ever atier. Yet this is not done by efforts of the little animal alone, for the old ones very assidnously break open with their teeth the covering in which it is enclosed. Without this assistance the aurelia would never be able to get free, as M. de Geer often found, who tried the experiment by leaving the aurelia to themselves. The old ones not only assist them. but know the very precise time for lending their assistance: for, il produced too soon, the young one dies of cold; if retarded too long, it is suffucated in its prison.

When the female has done laying, and the whole brood is thus produced, her labours, as well as that of the male, become umnecessary: and her wings, which she had but a short time hefore so actively einployed, drop off: IVhat becomes of her when thus divested of her onaments is not well known, for she is seen in the cells for some weeks afier. "The males, on the other hand, having no longer any occupation at home, make use of those wings with which they have been furnished by nature, and fly away, never to returis or be heard of more. It is prohable they perish with the cold, or are devoured by the birds, which are particularly fond of this pelty prey.

In the mein time, the working ants having probably deposed their queens, and being deserted by the males, that served but to clog the community, prepare for the severity of the winter, and bury their retreats as decp in the earth as they conveniently can. It is now found that the grains of com, and other substances with which they furnish their hill, are only meant as fences to keep off the rigours of the weather, not as provisions to sup- port them during its continuance. It is fomd generally to obtain, that every insect that lives a year after it is come to its full growth, is obliged to pass four or five months without taking any nourishment, and will seem to be dead all that time. It would be to no purpose, therefore, for ants to lay up corn for the winter, since they lic that time without motion, heaped upon each other, and are so far from cating, that they are utterly unable to stir. Thus, what authors have dignified by the name of a magazine, appears to be no more than a cavity, which serves for a continon retreat when the w eather forces them to return to their lechargic state.

What has been said with exaggeration of the European ant, is however true, if assertet of those of the tropical climates. They build an ant-hill with great contrivance and regularity, they lay up provisions, and as they probably live the whole year, they submit themselves to regulations entirely unknown anong the ants of Europe.

Those of Africa are of three kinds, the red, the green, and the black; the latter are above an inch long, and in every respect a most formidable insect. Their sting pioduces extreme pain, and their clepredations are sometimes extremely destructive. They build an ant-hill of a very great size, from six to twelve feet high; it is made of viscons clay, and ta pers into a pyramidal form. This habitation is constructed with great artifice; and the cells are so numerous and even, that a honey-conb scarce exceeds them in number and regularity.

The inlabitants of this edifice scein to be under a very strict regulation. At the slightitest warning they will sally out upon whatever disturbs them; and if they have line to arrest. their enemy, he is sure to find no mercy. Sheep, hens, and even rats, are often destroyed by these merciless insects, and their flesh devoured to the bone. No anatomist in the world can strip a síkeleton so completely as they; and no animal, how strong soever, when they have once seized upon it, has. power to resist thein.

It often happens that these insects quit. their retreat in a body, and go in. quest of alventures. "During iny stay," says Sinith, "at Cape Coast Castle, a body of these ants. 
came to pay us a visit in our fortification. It was about day-break when the advanced guard of this famished crew entered the chapel, where some negro servants were asleep upon the floor. The men were quickly alarmed at the invasion of this unexpected army, and prepared, as well as they could, for a defence. While the foremost battalion of insects had already taken possession of the place, the rear-guard was more than a quarter of a mile distant. The whole ground seemed alive, and crawling with unceasing destruction. After deliberating a few moments upon what was to be done, it was resolved to lay a large train of gunpowder along the path they had taken: by this means millions were blown to pieces; and the rearguard perceiving the destruction of their leaders, thought proper instantly to return and make back to their original habitation."

The order which these ants observe, seems very extraordinary; whenever they sally forth, fifty or sixty larger than the rest are seen to head the band, and conduct them to their destined prey. If they have a fixed spot where their prey continues to resort, they then form a vaulted gallery, which is sometimes a quarter of a mile in length; and yet they will hollow it out in the space of ten or twelve hours. ${ }^{2}$

\section{CHAPTER CXXIV.}

\section{OF THE BEETLE, AND ITS VARIETIES.}

HITHERTO we have been treating of insects with four transparent wings, we now come to a tribe with two transparent wings, with cases that cover them close while at rest, but which allow them their proper play when flying. The principal of these are the Beetle, the May-bug, and the Cantharis. These are all bred like the rest of their order, first from eggs, then they become grubs, then a chrysalis, in which the parts of the future fly are distiuctly seen; and, lastly, the animal leaves its prison, breaking forth as a winged animal in full maturity.

Of the Beetle there are various kinds; all, however, concurring in one common formation of having cases to their wings, which are the more necessary to those insects, as they often live under the surface of the earth, in holes which they dig out by their own indus-

(a) But far exceeding in wisdom and policy the Bee, the Ant, or the Beaver, is the White Ant, inhabiting the plains of East India, Africa, and South America. The animals of this extraordinary community consist of working insects or labourers, about half an inch long, having six feel, and no eyes; figliting insects or soldiers, about an inch long, with a large head, and no eyes; and the perfect male and female iusect, which alone are furnished with wings. Tliey build pyramidal stuctures, ten or try. These cases prevent the various injuries their real wings might sustain, by rubbing or crushing against the sides of their abode. These, though they do not assist flight, yet keep the internal wings clean and even, and produce a loud buzzing noise when the animal rises in the air.

If we cxamine the formation of all animals of the beetle kind, we shall find, as in shellfish, that their bones are placed externally, and their inuscles within. These muscles are formed very much like those of quadrupeds, and are endued with such surprising strength, that, bulk for bulk, they are a thousand times stronger than those of a man. The strength of these muscles is of use in digging the animal's subterraneous abode, where it is most usually hatched, and to which it most frequently returns, even after

twelve feet in height, and divided into nppropriate apartments. These are so firmly cemented together, that they will easily bear the weight of four or five men to stand upon them: and in the vast plains of Senegal, they appear like the huts of the natives. After impregnation, the abdoinen of the female grows to a prodigious bulk, and she actually protrudes to the amount of eight thoussand eggs in twenty-four hours. 
it becomes a winged insect, capable of flying.

Biside the difference which results from the shape and colour of these animals, the size also inakes a considerable one; some beetles bring nor larger than the head of a pin, while others, such as the elephant-beetle, are as big as one's fist. But the greatest difference among them is, that some arc produced in a month, and in a siugle season go through all th. stages of their existence; while others take near fimr years to their production, and live as winged insects a year inore. To give the histury of all these animals, that are hred pretty mnch in the same way, would be insipid and Pudless ; it will suffice to select one or two from the number, the origin of which muy serve as specimens of the rest. I will, therefore, offer the history of the May-bug to the reader's attention; premising that most other beetles, thongh not so loug-lived, are bred in the same mamner.

The May-bug, or dor-beetle, as some call it, lias, like all the rest, a pair of cases to its wings, which are of a redilish brown colour, sprinkled with a whitish dıst, which easily co.nes off. In some years their necks are seen covered with a red plate, and in other's with a black; these, however, are distiuct sorts, and their difference is by no means accidental. The fore-legs are very short, and the better calculated for burrowing in the ground, where this insect makes its retreat. It is well known, for its evening buzz, to chiliren; but still more formidably introduced to the acquaintance of husbandmen and gardeners; for, in some seasons, it has been found to swarm in such numbers, as to eat up every vegetable production.

The two sexes in the May-hug are easily distinguished from each other, by the superior lenuth uf the tufts, at the end of the horns, in the inale. They begin to copulate in summer; anl, at that season, they are seen joined together a considerable rine. The female being impregnated, quickly falls to boring a hole into the gromul, where to deposite her burden. This is generally abont half a foot deep, and in it slu: plares her eggs, which are of an oblons shape, with great regularity, one by the other. "Thry are of a bright yellow colour, and uo w : y wrapped up in a common covering, as some have imagined. When the No. $60 \& 70$ female is lightened of her hurden, she again ascends from ber hole, to live as before, upon leaves and vegetables, to buzz in the summer evening, and to lie hid anong the branches of trees in the heat of the day.

In about three unonths after these eggs liave been thus deposited in the earth, the contained insect begins to brak its shell, and a small grub or inaggot crawls forth, and feeds upon the roots of whatever vegetable it happens to be nearest.

All substances of this kind seem equally grateful, yet it is probalile the nother insect has a choice among what kind of vegetables she shall deposite her young. In this manner these voracious creatures continue in the worm state, for more than three years, devouring the roots of every plant they approach, and making theil way under ground, in quest of foorl, with great despatch and facility. At length they grow to above the size of a waluut, being a great thick white maggot with a red head, which is seen most frequently in new-turned earth, and which is so eagerly sought after by birds of every species. When largest, they are found an inch and a half long, of a whitish yellow colour, with a body consisting of iwelve segments or joints, on each side of which there are nine bteathingholes, and three red feet. The head is large in proporton to the body, of a reddish colour, with a pincer before, and a semi-circular lip, with which it cuts the roots of plants, and sucks out their moisture. As this insect lives entircly unter grounrl, it has no occasion for eyes, and accordingly it is found to have none; lut is furnislied with wo feelers, which, like the crutch of a blind nan, serve to direct its motion. Such is the form of this animal, that lives for years in the worm state under ground, still voracious, and every year changing its skin.

It is not till the end of the fourth year, that this extruordinary iusect prepares to energe from its subterraneous abode, and even this is not effected, but by a tedious preparation. About the latter end of autumn, $t$ e grub begins to perceive the approach of its transformation : it then buries itself deeper and deeper in the earth, sometimes six feet beneath the surface, and there forms itself a capacious apartment, the walls of which it renders very smooth and shining by the excretions of its $5 X$ 
body. Its abode being thus forned, it begins, soon after, to shortcu itself, to swell, and to burst its last skin, in order to assume the form of a clirysalis. This, in the begimning, appears of a yellowish colour, which heightens by degrees, tiil at last it is seen nearly red. Its exterior form plainly discovers all the vestiges of the future winged insect, all the fore-parts being distinctly seen; while, bebind, the animal scems as if wrapped in swaddling clothes.

The young May-bug continues in this state for about three months longer; and it is not till the begimning of January that the aurelia divests itself of all its impeliments, and beconses a winged insect, conpletely formed. Yet still the animal is fitr from attaining its natural strength, liealth, and appetite. It undergoes a kind of infant imbecility; and, unlike most other insects, that the instant they become flies are arrived at their state of full perfection, the May-bng continues feeble and sickly. Its colour is much brimhter than in the perfeet animal, all its parts are soft, and its voracious nature scems, for a while, to have entirely forsaken it. As the animal is very often found in this state, it is supposed, by those unacquainted with its real history, that the old ones, of the former season, have buried themselves for the winter, in order to revisit the sun the ensuing summer. But the fact is, the oltl one never survives the season, but dies, like all the other winged tribe of insects, from the severity of cold in winter.

About the latter end of May, these inscets, after having lived for four years under ground, burst from the earth, when the first mild evening invites them abroad. They are at that time seen rising from their loug imprisonment, fron living only upon roots, and inbibing only the moisture of the earth, to visit the milduess of the summer air, to choose the sweetest vegetables for their banquet, and to drink the dew of the evening. Wherever an attentive observer then walks abroad, he will see them bursting up before him in his pathway, like ghosts on a theatre. He will see every part of the earth, that had its surface beat into hardness, perforated by their cgression. When the season is favourable for them, they are seen by myriads buzzing along, hitring against every ubjeet that intercepts their flight. The mid-day sun, however, seems ton powerful for their constitutions; they then lurk under the leaves and branches of some sliady tree: but the willow seems particularly iheir most favourite food; there they lurk in clusiers, and seldom quit the tree till they have devom:ed all its verdure. In those seasons which are favourable to their propagation, they are seen in an evening as thick as flakes of snow, and hitting against every object wirl a sort of capricious blindness. Their duration, however, is bul short, as they ntvel survive the season. They begin to join shortly after they have been let loose from their prison, and when the female is impregnated, she cauriously bores a hole in the ground, with an iustrument fitted for that purpose, which she is furnished with at the tail, and there deposites her eggs, generally to the number of threeseore. If the season and the soil be adapted to their propagation, these soon multiply, as already describer, and go through the noxious stages of their contemptible existence. This iusect, horvever, in its worm state, though projudicial to man, makes one of the chief repasts of the feathered tribc, and is generally the first nourishment with which they supply their young. Rooks and hogs are particularly fond of these worms, and devour them in great numbers. The inhabitants of the county of Norfolk, some time since, went into the practice of destroying their rookeries; but in proportion as they destroyed one plague, they were pestercd with a greater; and these insects mulriplied in such an amazing abundance, as to destroy not only the verilure of the fields, but cven the roots of vegerables not yet shot forth. One farm in partirular was so injured by them in the year 1751 , that the occupier was not able to pay his rent, and the landlord was coutent not only to lose his inconic? for that year, but also gave money for the support of the farmer and his family. In Ircland they suffered so much by these inseets, that they canıe to a resolution of setting fire to a wood, of some niles in extent, to prevent their mischievous propagation.

Of all the leetle kind, this is the most numerous, and therefore deserves the chief atiention of history. The numcrous varieties of other kinds might repay the curiusity of the diligent observer, but we must be content in general o observe, that in the great outlines of their history, they resemble those of which 
we have just been giving a description ; like thein, ali other beeiles are bred from the egg, which is deposited in the ground, or so netimes, thougl: seldom, in the barks of irees; they change into a ivorm; they subsist in that state by liviı:g upmon the roots of vegetables, or the succulent parts of the bark round them. They generally live a year at least before they change into an aurelic; in that state the $y$ are not entirely inotion!ess, nor entirely swaddled up without form.

It would be tedious and endless to give a description of all ; and yet it would be an unpardotiable omission not to mention the particularities of sume beetles, which are singul ir rather from their size, their manners, or their forillation. That beetie, which the Americans call the Tumble-duing, particularly demands our attention; it is ali over of a dlusky black, rounder than those animals are generally finnd to be, and so strois, though not much larger than the coinnicn wlack beetle, that if one of them be put uniler a brass candlestick, it will cause it to nove baciswarls and forwards, as if it were by 51 invisille liand, to the admiration of those who are not accustomed (1) the sight; but this strength is given it fir much more useful purposes than those of exriting humar curiosity, for there is no creature more lahorious, either in seeking subsistence, or in provicling a proper retreat for its young. They are endowed with sagacity to discover subsistence by thejr excellent smelling, which lirects them in fiights to excrements just fallen from man or heast, on which they instantly drop, and fall unanimously to work in forming rruund balls or pellets thereof, in the middle of which they lay an egg. These pellets, in September, they convey three feet deep in the earth, where they lie till the approach of spring; when the eggs are liatched the nests burst, and the insects fiud their way ont of the earth. They assist each other with indefatigable industry, in rolling these globullar pellets to the place where they are to be buried. This they are to perform with the tail foremost, by raising up their hinder part, and shoving along the ball with their hind feet. They are always accoinpanied with

(a) The crepitating Beetle has a very singular method of defending itself, and annnying its enemies. Whenever it is touched it makes a report, not unlike the dis- other beetles of a larger size, and of a more elegant structure and colour. The breast of this is covered with a shield of a crimson colour, and shining like metal; the hear is of the like colour, mixed with green, and on the crown of the head stands a shiming black horn, bended hackwards. These are called the kings of the beetles: but for what reason is uncertain, since they partake of the same dirty drufgery with the rest.

The Elephant-Beetle is the largest of this kind hitherto known, and is found in South America, particularly Guinna and Surinam, as well as about the river Oromoko. It is of a black colour, and the whole body is covered with a very hard shell, full as thick and as strong as that of a small crab. Its length, from the hinder part to the eyes, is almost four inches, and from the same part to the end of the proboscis, or trunk, four iuclies and three quarters. The transverse diameter of the bondy is two inches and a quarter, and the breadth of each elytron, or case for the wings, is an inch and three-teuths. The attennæ, or feelers, are quite horny ; for which reason the proboscis, or trunk, is moviable at its insertion into the hearl, and seems to supply the place of feelers. The horns are eight-tenths of an inch long, and terminate in points. The proboscis is an inch and a quarter long, and turns upwards, making a crooked line, terminating in two horns, each of which is near a quarter of au inch long; but they are not perlirated at the end like the proboscis of other insects. About four-tenths of an inch above the head, or that side next the body, is a prominence or small horu, which, if the rest of the trunk ivere away, would cause this purt to resemble the horn of a rinoceros. There is indeed a bertle so called, but then the horns or trunk has no fork at the end, though the lower horn resembles this. The feet are all forked at the end, but not like lobsters' claws."

To this class we nay also refer the Glowworm, that little animal which makes such a distinguished figure in the descriptions of our poets. No two insects can differ more than the male and female of this species from each

charge of a musket in miniature; and this discharge is accompanied with a blue vapour highly acrimonious and pungent. 
other. The male is in every respect a beetle, having cases to its wings, and rising in the air at pleasure; the female, on the contrary, has none, but is entirely a creeping insect, and is obliged to wait the approaches of her capricious companion. The body of the female has eleven joints, with a shield breastplate, the shape of which is oval; the head is placed over this, and is very small, and the three last joints of her body are of a yellowish colour; but what distinguishes it from all other animals, at least in this part of the worid, is the shining light which it emits by night, and which is supposed by some philosophers to be an emanation which she sends forth to allure the male to her company. Most travellers who have gone through sandy countries, must well remember the little. shining sparks with which the ditches are studded on each side of the road. If incited by curiosity to approach more nearly, he will find this light sent forth by the glowworm: if he should keep the little animal for some time, its light continues to grow paler, and at last appears totally extinct. The manner in which this light is produced has hitherto continued inexplicable; it is probable the little animal is supplied with some electrical powers, so that by rubbing the joints of its body against each other, it thus supplies a stream of light, which if it allures the male, as we are told, serves for very useful purposes.

The Cantharis is of the beetre kind, from whence come cantharides, well known in the shops by the name of Spanish flies, and for their use in blisters. 'T'hey have feelcrs like bristles, flexible cases to the wings, a breast pretty plain, and the sides of the belly wrinkled. Cantharides differ from each other in their size, shape, and colour: those used in the shops also do the same. The largest in these parts are about an inch long, and as much in circumference, but athers are not above three quarters of an inch. Some are of a pure azure colour, others of pure gold, and others again have a mixture of pure gold and azure colours; but they are all very brilliant, and extremely beautiful. These insects, as is well known, are of the greatest benefit to mankind, making a part in many medicines conducive to human preservation.
They are chiefly natives of Spain, Italy, and Portugal; but they are to be met with al-o about Paris in the summer time. upon the leaves of the ash, the poplar, and the rosetrees, and also among wheat, and in meadows. It is very certain, that these inserts are tond of ash-leaves, insomuch that they will sonetimes strip one of these trees quite bare. Some alfirm that these flies delight in sweetsmelling herbs; and it is very certain, lliat they are fond of honeysuckles, lilac, and wildcherry shrubs; but some that liave sought after them declare they never could fund them on elder-trees, nut-trees, and among wheat. We are told, that the country people expect the returu of these insects every seven years. It is very certain, that such a number of these insects have been seen together in the air, that they appeared like swarms of hees; and that they have so disagreeable a smell, that it may be perceived a great way off: especially about sun-set, though they are not spell at that time. This bad snell is a guide for those who make it their business to catch them. When they are caught they dry them, after which they are so light, that fifty will hardly weigh a dram. Those that gather them tie them in a bag. or a piece of linen cloth, that has been well worn, and then they kill them with the vapours of hot vinegar, after which they dry them in the sun, and keep them in boxes. These flies, thus dried, being chymically analyzed, yield a great deal of volatile caustic salt, mixed with a little oil, phlegm, and earth. Cantharides are penetrating, corrosive, and, applied to the skin, raise blisters, from whence proceeds a great deal of serocity. They are made use of both inwardly and outwarlly. Howerer, it is somewhat strange that the effects of these flies should fall principally upon the urinary passages; for thongh some authors have endeavoured to account for this, we are still in the dark, for all they have said amounts to no more than that they affect these parts in a manner which may be very learnedly described, but very obscurely comprehended.

An insect of great, though perliaps not equal use in medicine, is that which is known by the name of the Kermes; it is produced in the excrescence of an oak, called the berry-bearing ilex, and appears at first wrapt 
up in a membranaceous bladder, of the size of a pea, smooth and shining, of a brownishred colour, and covered with a very finc ashcoloured powder. This bag teems with a number of reddish eggs or insects, which being rubbed with the tingers pour out a crimsoll liquor. It is ouly met with in warm countries in the months of May and June. In the month of April this insect becomes of the size and shape of a pea, and its eggs some tine after burst from the womb, and soon turning worms, run about the branches and leaves of the tree. They are of two sexes, and the females have be'nhitherto described; but the inales are very distinct from the former, and are a sort of small flies like gnats, with six feet, of which the four forward are short, and the two backward long, divided into four joints, and armed with three crooked nails. There are two teelers on the heal, a line and a half long, which are moveable, streaked, and articulated. The tail, at the back part of the body, is half a line long, and forked. The whole body is covered with two transparent wings, and they leap about in the manner of fleas. The liarvest of the kermes is greater or less in proportion to the severity of the winter, and the women gather them before sun-rising, tearing them off with their nails, for fear there should be any loss from the hatching of the insects. They sprinkle them with vincgar, and lay them in the sun to dry, where they acquire a red colour.

An insect, perhaps still more useful than either of the former, is the Cochineal, which has been very variously described by anthors: some have supposed it a regetable excrescence from the tree upon which it is lound; some have described it as a louse; some, as a bug; and some, as a bretle. As they appear in our shops when brought from Anerica, they are of an irregular shape, convex on one side, and a little concave on the other: but are both marked with tralisverse streaks or wrinkles. They are of a scarlet colour within, and without of a blackish red, and sometimes of a white, reddish. or ash-colour, which are accounted the best, and are brought us from Mexico. The cochineal insect is of an oval form, of the size of a small pea, with six feet, and a snout or trunk. It brings forth its young alive, and is nourished by sucking the juice of the plant. Its body consists of several rings, and when it is once fixed on the plant, it continues immoveable, being subject to no change. Some pretend there are two sorts, the one donestic, which is best; and the other wild, that is of a vivid colour: however, they appear to be the sanne, only with this difference, that the wild feeds upon uncultivated trees, without any assistance, whereas the domestic is carefully, at a stated season, removed to cultivated trees, where it feeds upon a purer juice. 'Those who take care of these insects, place them on the prickly-pear plant in a certain order, and are very industrious in defending them from other insects; for if any other kind come among them, they take care to brush thein off with toxes' tails. Towards the end of the year, when the rains and cold weather are coming on, which are fatal to these insects, they take off the leaves or branches coverect with cochineal, that have not attained their utmost degree of perfection, and keep them in their houses till winter is past. These leaves are very thick and juicy, and. supply them with sufficient nourishment, while they remain within doors. When the milder weather returus, and these animals are about to exclude theil young, the natives make them nests, like those of birds, but less, of tree moss, or soft hay, or the down of cocoamuts, placing twelve in every nest. These they fix on the thorus of the prickly-pear plant, and in three or four days' tinc they bring forth their young, which leave their nests in a few days, and creep upon the branches of the plait, till they find a proper place to rest in, and take in their nourishinent; and until the females are fecundated by the males, which, as in the former tribe, differ very widely from the fenales, being. winged insects, whereas the others only creep, and are at most stationaly. When. they are inpreguated, they produce a new olfspring, so that the propagator has a new. harvest thrice a year. When the native Americans have gathered the cochineal, they put them into holes in the ground, where they kill them with boiling water, and afterwards. dry them in. the sun, or in an oven, or lay. them upon hot plates. From the various. 
methods of killing them, arise the different colour" which they appear in when brought to $u$ - While they are living they seem te be sprinkled over with a white powder, which they lose as soon as the boiting water is poured upon them. Those that are dried upon hot plates are the blackest. What we call the cochineal are only the females, for the males are a sort of $1 l y$, e.s aiready observed $\mathrm{in}$ the kermes. They are used both for dying and Inedicine, and are said to have much the same virtue as the kermes, though they are now seldom used alone, but are mixed with other things for tha sa're of the colour.

I shall end this account of the beetie tribe with the history of ais animal which camnot properly be ranked under this species, and yet cannot be more methodically ranged under any other. This is the inseet that forms and resides in the gall-nut, the spoils of which are converted to such useful purposes. The gall-insects are bred in a sort of bodies adhering to a kind of oak in Asia, which differ with regard to their colour, size, roughness, smoothness, and shape, and which we call galls. They are not fruit, as some have imagined, but preternatural tumours, owing to the wounds given to the buds, leaves, and twigs of the tree, by a kind of insects that lay their eggs within them. This animal is furnished with an implement, by which the fernale penetrates into the bark of the tree, or into that spot which just begius to bud, and there sheds a drop of corrosive fluid into the cavity. Having thus formed a receptacle for her eggs, she depasites them in the place, and dies soon after. The heart of the bud being thus wounded, the circulation of the nutritive juice is interrupted, and the fermentation thereof, with the poison injected by the fly, burns the parts adjacent, and then alters the natural colour of the plant. The juice or sap, turned back from its natural course, extravasates, and flows round the egg.

(a) To the Beetle kind also belongs that little animal which causes such alarm to the superstitious hy its ticking noise, and which is often called the death-watch. It is found in decayel trees and furniture, or among hay and dried leaves. This noise is merely the call of one sex to
After which it swells and dilates by the assistance of some bubbles of air, which get admission through the pores of the bark, and which rut in the vessels with the sap. The external coat of this excrescence is dried by the air, and grows into a figure, which benrs some resemblance to the bow of an arch, or the roundness of a keruel. This little ball receives its autriment. growth, and vegelation, as the other parts of the tree. by slow degrees, and is what we rall the gall-nut. The worm that is hatched under this spacious vau!t, finds in the sulostance of the ball, which is as yet very tender, a subsistence suitalle to its nature; gnaws and digests it till the time comes lor its transformation to a ny mph, and from that state of existence clanges into a fly. After this, the insect, perceiving itself duly provided with all things requisite, disengages itself soon from its confunement, and takes its flight into the open air. The case, however, is not similar with respect to the gall-nut that grows in autumn. The cold weather frequently comes on before the worm is transformed into a fly, or before the fly can pierce throngh its enclosure. The unt falls with the leaves, and although you may imagine that the fly which lies within is lost, yet in reality it is not so: on the contrary, its being covered up so close, is the means of its reservation. Thus it spends the winter in a warm house, where every crack and cranny of the nut is well stopped up; and lies buried, as it were, under a heap of leaves, which preserves it from the injuries of the weather. This a partment, however, though so commodious a retrent in the winter, is a perfect prison in the spring. The fly, roused out of its lethargy by the first heats, breaks its way through, and ranges where it pleases. A very small aperture is sufficient, since at this time the fly is but a dimiuutive creature. Besides, the ringlets whereof its body is composed, dilate, and become pliant in the passage."

the other, and is caused by the a imal's beating on any hard subsiance with the shield or fore part of the head: which is always in scven, uine, or eleven distinct strokes. A little insecr, hardly the reorh of an inch long, ofien found in old books, is sometimes falsely charged with this alarm. 


\section{CHAP'TEK CXCV.}

\section{OF THE GNAT AND TIPULA.}

THERE are two insects which entirely resemble each other in their forn, and yet widely differ in their habits, manners, and propagarion. Those who have secn the Tipula, or Long-legs, and the larger kind of Gnat, have most probably mistaken the one for the other; they have often accused the tipula, a harmless insect, of depredations made by the gnat, and the innocent have suffered for the guilty ; indeed the differences in their form are so very minutc, that it often requires the assistance of a microscope to distingnish the one from the other: they are both mounted on long legs, both furnished with two wings and a slender body : their heads are large, and they scem to be hunp-backed; the chief and only difference, therefore, is, that the tipula wants a trunk, while the gnat has a large one, which it often exerts to very mischicvous purposes. The ripula is a harmless peaceful insect, that offers injury to nothing; the gnat is sanguinary and predaceous, ever sceking out for a place in which to bury its trunk, and puniping up the blood from the animal in large quantities.

The gnat proceeds from a little worm, which is usually seen at the bottom of standing waters. The manner in which the insect lays its eggs is particularly curious; after having laid the proper number on the surface of the water, it surrounds them with a kind of unctuous matter, which prevents them from sinking, but at the same time fastcus them with a thread to the bottom, to prevent their tloating away, at the mercy of every breeze, from a place, the warmtb of which is proper for their production, to any other, where the water inay be too cold, or the animals' enemies too numerous. Thus the insects. in their egg state, resemble a buoy, which is fixed by an anchor. As they come to maturity they sink deeper: and at last, when they leave the egg as worms, they creep at the bottom. They now make themselves lodg- ments of cement, which they fasten to some solid body at the very bottom of the wate', muless, by accident, they meet with a piece of chalk, which being of a soft and pliant nature, gives them an opportunity of sinking a retreat for themselves, where nothing but ihe claws of a cray-fish can possibly molest them. The worm alterwards changes its form. It appears with a large head, and a tail invested with hair, and moistened with an oleaginous liquor, which she makes use of as a cork to sustain her head in the air, and her tail in the water, anl to transport her from one place to another. When the oil, with which her tail is moistened, begins to grow dry, she discharges out of her mouth an unctuous humour, which she sheds all over her tail, by virtue where of she is enabled to transport herself where she pleases, withont being either wet or any ways incommoded by the water. The gnat, in her second state, is, properly speaking, in her form a nymph, which is an introduction or entrance into a new life. In the first place, she divests herself of her second skin; in the next, she resigns her eyes, her antennx, and her tail; in short, she actually seems to expire. However, from the spoils of the amphibious animal, a little winged insect cuts the air, whose every part is active to the last degree, and whose whole structure is the just object of our admiration. Its little head is adorned with a plume of feathers, and its whole body invested with scales and liair, to secure it from any wet or dust. She makes trial of the activity of her wings, by rul,bing them either against her body, or her broad sidebags, which keep her in an equilibrium. The fur below, or little horder of fine fenthers, which graces her wings, is very curious, and strikes the eye in the most agreeable manner. There is nothing, however, of greater importance to the gnat than her trunk. and that weak implement may justly be deemed one of nature's master-picces. It is so very 
small, that the extremity of it can scarcely bediscerned through the best microscope that can be procured. That part which is at first obvions to the cye, is nothing but a long scaly sheath under the thront. At near the distance of two-thirds of it, there is an aperture, through which the insect darts out four stings, and afterwards retracts them. One of which, however sharp and active it may be, is no more than the case in which the other three lie concealed, and run in a long groove. The sides of these stings are sharpened like two-edged swords; they are likewise barbed, and have a vast number of cutting leetl towards the point, which turus up like a hook, and is fine beyond expression. When all these darts are stuck into the flesh of animals, sometimes one after another, and sometimes all at once, the blood and humours of the adjacent parts must unavoidably be extravasated; upon which a tumour must consequently ensue, the little orifice whereof is closed up by the compression of the external air. When the gnat, by the point of her case, which she makes use of as a tongue, has tasted any fruit, flesh, or juice, that she has found out; if it be a fluid, she sucks it up, without playing her darts into it; but in case she finds the least obstruction by any flesh whatever, she exerts her strength, and pierces throngh it, if possibly she can. After this she draws back her stings into their sheath, which she applies to the wound in order to extract, as through a reed, the juices which she finds enclosed. This is the implement with which the gnat performs her work in the summer, for during the winter she has no manner of occasion for it. Then she ceases to eat, and spends all that tedious season either in quarries or in caverns, which she abaudons at the return of summer, and flies about in search after some commodious ford, or stanling water, where she may produce her progeny, which would be soon washed away and lost, by the too rapid inotion of any running stream. The little hrood are sometimes so numerous. that the very water is tinged according to the colour of the species, as, green. if they be green, and of a sanguine hue, if they be red.

These are circumstances sufficiently extraordinary in the life of this little animal; but it offers something still more curious in the method of its propagation. However similar insects of the gnat kind are in their appearance, yet they differ widely from each oilier in the manner in which they are brought forth, for some are oviparous, and are produced from eggs; some are viviparous, and come forth in their most perfect form; some are males, and unite with the female; some are females, requiring the impregnation of the male; some are of neither sex. yet still produce young, without any copulatiol, whatsoever. This is one of the strangest discoveries in all natural hislory! A gnat separated from the rest of its kind, and enclosed in a glass vessel, with air sufficient to keep it alive, shall produce young, which also, when separated from each other, shall be the parents of a numerous progeny. Thus, down for five or six generations, do these extraordinary animals propagate without the use of copulation, witlont any congress between the inale and the female, but in the manner of vegetables, the young hursting from the body of their parents, without any previous impregnation. At the sixth generation, however, their propagation stops; the gnat no longer produces itslike, from itself alone. but it requires the access of the male to give it another succession of fecundity.

The gnat of Europe gives but little uneasiness; it is sometimes heard to hum about our beds at night, and kceps off the approaches of sleep by the apprehension it causes; hut it is very different in the illpeopled regions of America, where the waters stagnate, and the climate is warm, and where they are produced in multitudes beyond expression. The whole air is there filled with clonds of those fanished insects, aid they are found of all sizes, from six inches long to a minuteness that even requires the microscope to have a distinct perception of them. The warmth of the mill-day sun is too powerful for their constitutions; but when the erening approaches, neither art nor flight can shield the wretched inhabitants from their attacks: though millions are destroyed, stiil millions more succeed, and produce unceasing torment. The native Indians, who anoint their bodies with oil, and who have from their infancy been used to their depredations, find them much lest 
inconvenient than those who are newly arrived from Europe; they sleep in their cottages covered all over with thousands of the gnat kind upon their bodies, and yet do not seem to have their slumbers disturbed by their cruel devourers. If a candle hapмо. $69 \& 70$. pens to be lighted in one of those places, a cloud of insects at once light upon the flame, and extinguish it: they are therefore obliged to keep their candles in glass lanterus; a miserable expedient to prevent an unceasing calamity! -

5 Y 


\section{OF THE ZOOPEYTYS.}

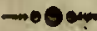

\section{CHAPTER CXCVI.}

\section{OF ZOOPHYTES IN GENERAL.}

WE now come to the last link in the chain of animated wature, to a class of beings so confined in their powers, and so defective in their formation, that some historians have been at a loss whether to consider them as a superior rank of vegetables, or the humblest order of the animated tribe. In order, therefore, to give them a denomination agreeable to. their existence, they have been called Zooplyytes, a name implying vegetable nature endued with animal life; and, indeed, in some the marks of the animal are so few, that it is difficult to give their place in nature with. precision, or to tell whether it is a plant or an insect that is the object of our consideration.

Should it be asked what it is that constitutes the difference between animal and vegetable life; what it is that lays the line that separates those two great kingdoms from each other; it would be difficult, perhaps we should find it impossible, to return an answer. The power of motion cannot form this distinction, since some vegetables are possessed of motion, and many animals are totally without it. The sensitive plant has obviously a greater variety of motions than the oyster or the pholas. The animal that fills the acoru-shell is immoveable, aud can only. close its lid to defend itself from external injury, while the ftower, which goes by the name of the fir-trap, seems to close upon the flies that light upon it, and that attempt to riffe it of its honey. The animal in this instance seems to have scarce a power of self-defence; the vegetable not only guards its possessions, but seizes upon the robber that would venture to invade them. In like manner, the methods of propagation give no superiority to the lower rank of animals. On the contrary, vegetables are frequently produced more conformably to the ligher ranks of the creation, and though some plants are produced by cuttings from others, yet the general manner of propagation is from seeds, laid in the womb of the earth, where they are hatched into the similitude of the parent plant or flower. But a most numerous tribe of animals have lately been discovered, which are propagated by cuttings, and this in so extraordinary a manner, that, though the original: insect be divided into a thousand parts, each, however small, shall be formed into an animal, entirely resembling that which was at first divided : in this respeet, therefore, certain races of animals seem to fall beneath vegetables, by their more imperfect propagation.

What, therefore, is the distinction between them? or are the orders so intimately blended as that it is impossible to mark the boundaries of each? 'In me it would seem, that all animals are possessed of one power, of which vegetables are totally deficient: I mean, either the actual ability, or an awtward attempt at self-prescrvation. However vegetables may seem possessed of this important quality, yet it is with them hut a mechanical impulse, resembling the raising one end: of the lever when you: depress the other: the sensitive plant contracts and hangs its. leaves indeed, when toucher, but this motion no way contributes to its safety the fly-trap flower acts entirely in. the same: 
manner; and though it seems to seize the little animal that comes to annoy it, yet, in reality, only closes mechanically upon $i t$, and this enclosure neither contributes to its preservation nor its defence. But it is very different with insects even of the lowest oriler; the earth-worm not only contracts, but hides itself in the earth, and escapes with some share of swiftness from its pursuers. The polypus hides its horns; the star-fish contracts its arms upon the appearance even of distant dangers; they not only hunt for their food, hut provide for their safety; and however imperfectly they may be formed, yet still they are in reality placed many degrees above the highest vegetable of the earth, and are possessed of many animal functions as well asthose that are more elaborately formed.

But though these be superior to plants, they are far beneath their aninated fellows of existence. In the class of zoophytes, we may place all those animals which may be propagated by cuttings; or, in other words, which, if divided into two or more parts, each part in time becomes a separate and perfect animal; the head shoots forth a tail, and, on the contrary, the tail produces a head; some of these will bear dividing but into two parts, such is the earth-worm; some may be divided into more than two, and of this kind are many of the star-fish; olhers still may be cut into a thousand parts, ench becoming a perfect animal; they may be turned inside out, like the finger of a glove; they may be moulded iuto all manner of shapes, yet still their vivacious principle remains, still every single part becomes perfect in its kind, and, after a few days' existence, exhibits all the arts and industry of its contemptible parent! We shall therefore divide zoophytes according to their several degrees of perfection, namely, into Worms, Star-fish, and Polypi; contenting ourselves with a short review of those nauseous and despicahle creatures, that excite our curiosity chiefly by their imperfections : it must not be concealed. however, that much has of late been written on this part of natural history. A new mode of animal production, could not fail of exciting not only the curiosity, but the astonishment of every philosopher: many found their favourite systems totally overthrown by the discovery; and it was not without a wordy struggle, that they gave up what had fornierly been their pleasure and their pride. At last, however, conviction became too strong for argument; and a question, which owed its general spread rather to its novelty than to its importance, was given up in favour of the new discovery.

\section{CHAPTER CXCVIl.}

\section{OF WORMS.}

THE first in the elass of zoophytes, are animals of the worm kind, which being entirely destitute of feet, trail themselves along upon the ground, and find themselves a retreat under the earth, or in the water. As these, like serpents, lave a creeping motion, so both, in grieral, go under the common appellation of reptiles; a loathsome, noxious, maliguant tribe, to which man by nature, as well as by religion, has the strongest antipathy. Bnt though worms, as well as serpents, are mostly without feet, and have been donmed to creep along the earth on their bellies, yet their motions are very different. The serpent, as has been said before, having a back-bone, which it is incapable of contracting, bends its body into the form of a bow, aud then shoots forward from the tail; but it is very different with the worm. which has a power of contracting or lengthening itself at will. There is a spiral muscle, that runs round its whole body, from the head to the tail, somewhat resembling a wire wound ronnd a walking-cane, which when slipped off, and one end extended and held fast, will bring the other nearer to it; in this manner $5 \mathrm{Y}^{*}$ 
the earth-worm, having shot out, or extended its body, takes hold by the slime of the fore part of its body, and sa contracts and brings forward the hinder part; is this manner it moves onward, not without great efforts; but the occasions for its progressive motion are few.

As it is designed for living under the earth, and leading a life of obscurity, so it secms tolerably adapted to its situation. Its body is armed with sinall stiff sharp burrs or prickles, which it can erect or depress at pleasure; under the skin there lies a slimy juice, to be ejected as occasion requires, at certain perforations, between the rings of the muscles, to lubricate its body, and hicilitate its passage into the earth. Like most other insects, it has breatling-tholes along the back, adjoining each ring; but is without bones, without eyes, without ears, and properly without feet. It has a montl, and also an atinentay canal, which runs along to the rely point of the tail. In some wolms, however, particularly such as are found in the bodies of animals, this canal opens towards the middle of the belly, at some distance from the tail. The intestines of the earthworm are always found filled with a very fine earth, which seems to be the only nonrishment these animals are capable of receiving.

The animal is entirely without a brain, but near the head is placed the heart, which is seen to beat with a very distinct motion, and round it are the spermatic vessels, forming a number of little globules, containing a milky nuid, which have an opening into the belly, not far from the head; they are also often found to contain a number of eggs, which are laid in the earth, and are hatched in twelve or fourteen days into life by the genial warmth of their situation; like suaik, all these animals unite in themselves both sexes at once; the reptile that impreguates, lacing impregnated in turn: few that walk out. but must have observed them, with their heads laid against each other, and so strongly attached, that they suffer themselves to be trode upan,

When the eggs are laid in the earth, which, in ahout fourteen days, as has been said, are hatched into maturity, the young ones come farth very small; but perfectly formed, and suffer no change during their existence: how long their life continues is not well known, but it certainly holds for more than two of three scasons. During the winter, they bury themselves deeper in the earth, and seem, in some ineasure, to share the general torpidity of the insect tribe. In spring, they revive with the rest of nature, and on those occisions, a moist or dewy erening brings them. forth from their retceats, for the universal purpose of continuing their kind. They chielly live in a light, rich, and fertile soil, moistened hy dews or accidental showers, but avoid those places where the water is apt to lie on the surface of the earth, or where the clay is too stiff for their easy progression under ground.

Helpless as they are formed, yet they seem. very vigilant in avoiding those animals that chiefly make them their prey; in particular, the mole, who feeds entirely upon theon beneath the surface, and who sektom zentures, from the dimness of its sight, into the open air; him they avoid, by darting up from the earth, the instant they feel the ground move; and fishermen, who are well acquainted with this, take them in what numbers they choose, by stirging the carth. where they expect to find them. They are also driven from their retreats under grouud, by pouring hitter or acrid water thereou, such as that water in which green walnuts have been steeped, or a ley made of pot-ashes.

Such is the general outline of the history of these reptiles, which, as it should scem, degrades them no way beneath the rank of other animals. of the insect creation: but naw-we come to a part of their history, which proves the imperfection of their organs, from the casiness witl which these little machiries may be damaged and repaired again. It is well known in mechanics, that the finest and most complicated instruments are the most easily put out of order, and the most difficultly set right; the same also obtains in the animal machine. Man, the most complicated machine of all others, whose nerves are more vumerous, and powers of action more various, is most easily destroyed : he is seen to die under wounds which a quadruped of a bird conld easily survive; and as we descend gradually to the lower ranks, the ruder the 
composition, the more difficult it is to disarrange it. Some animals live without their limbs, and often are secn to reproduce them; some are seen to live without their brain for many weeks together; caterpillars continue to increase and grow large, though all their nobler organs are entirely destroyed within; some animais continue to exist, thongh eut in two, their nobler parts preserving life, while the others perish that were cut away: but the earth-worm, and all the zoophyte tribe, continue to live in separate parts, and one animal, by the means of eutting, is divided into two distincf existences, sometimes inta a thousand!

There is no phenomenon in all natural history more astonishing than this, that man at pleasure should have a kind of ereative power, and out of one life make two, each completely formed, with all its apparatus and functions; each with its pereeptions, and powers of motion and self-preservation; each as complete in all respects as that from which it derived its existence, and equally enjoying the lumble gratifieations of its nature.

When Des Cartes first started the opinion, that brutes were machines, the discovery of this surprising propagation was unknown, which inight, in some measure, have strengthened his taneiful theory. What is life in brutes, he might have said, or where does it reside? In some we find it so diffused, that every part seems to maintain a vivacious principle, and the saine animal appears possessed of a thousantel distinet irrational souls. at the same time. But let us not, he would say, give so noble a name to such contemptible powers, but rank the vivifying principle in these with the sap that rises in vegetables, or the moisture that contracts a cord, or the heat that puts water into motion! Nothing, in fact, deserves the name of soul. but that which reasons, that which understands, and by knawing God, receives the mark of its currency, and is minted with the impression of its great Creater.

Such might have been the speculations of this pliilosopher: however, to leave theory, it will be sufficient to say, that we owe the

(a) Allied to these in their vermicular shape, are several ather kinds of woxms, cainmonly known by the nane first discovery of this power of reproduction in animals to Mr. Trembley, who first observed it in the Polypus, and after him, Spalanzani and others found it taking place in the earth-worm, the sea-worm, and several other ill-formed animals of a like kind, which were susceptible of this new mode of propagation. This last philosopher has tried several experiments upon. the earth-worm, many of which succeeded according to his ex pectation: every earth-worm, however, did not retain the vivacious principle with the same obstinacy; some, when cut in two, were elltirely destroyed; others survived only in the nobler part; and while the head was living, the tail entirely perished, and a new one was seen to bourgeon from the extremity. But what was most surprising of all, in some, particularly in the small red-headed earth-worm, both extremities survived the operation; the head produced a tail, with the anus, the intestines, the annular muscle, and the prickly beards; the tail part, on the otber hand, was seen to shoot forth the nobler organs, and in less than the space of three montlis sent forth a head, a heart, with all the apparatus and instruments of generation. This part, as inay easily be supposed, was produced much more slowly than the former, a new bead taking above three or four months for its completion; a new tail being shot forth in less than as many weeks. Thus two animals, by dissection, were made out of one, each with their separate appetites, cach endued with life and motion, and seemingly as perfect as that single animal from whence they derived their origin.

What was performed upon the earth-worm, was found to obtain also in many of the vermicular species. The sea-worm, the white water-worm, and many of those little worms with feclers, found at the bottom of dirty ditches; in all these the nobler organs are of such little use, that if taken away, the animal does not scem to feel the want of them; it lives in all its parts, and in every part; and by a strange paradox in nature, the most useless and contemptible life is of all otliers the most difficult to destroy."

of Thread-worms. The common Ilair-worm is found in fresh waters, or in a wet clayey soil, through which it per- 


\section{CHAPTER CXCVII.}

\section{OF THE STAR-FISH.}

THE next order of zoophytes is that of the star-tish, a numerous tribe, shapeless and deformed, assuming at different times different appearances. The same animal that now appears round like a ball, shortly after flattens as thin as a plate. All of this kind are formed of a semi-transparent gelatinous substance, covered with a thin membrane, and to an inattentive spertator often appear like a lump of inanimate jelly, floating at random upon the surface of the sea, or thrown by chance on shore at the departure of the tide. But upon a more minute inspection, they will be found possessed of life and motion; they will be found to shoot forth their arms in every direction, in order to seize upon such insects as are near, and to devour them with great rapacity. Worms, the spawn of fish, and even muscles themselves, with their hard resisting shell, have been found in the stomachs of these voracions animals; and what is very extraordinary, though the substance of their own bodies be almost as soft as water, yet they are no way injured by sivallowing these shells, which are almost of a stony hardness. They increase in size as all other animals do. In summer, when the water of the sea is warmed by the heat of the sun, they float upon the surface, and in the dark they send forth a kind of shining light resembling that of phospherus. Some have given these aminals the name of seanettles, beeause they born the hands of those that touch them, as nettles are found to do. They are olten seen fastened to the rocks,

furares. In size and appearance it exactly resembles the litir of a horse's tail; and, when touched, twists itself into a variety of knot-like contortions, for which reason it has been called the Gordius. The Guinea-worm is shaped something like this, except that the mouth is dilated, and has a roundish concave lip. It enters the naked arms and legs of the inhabitants of the East and West Indies, sinking deep into the inuscles, and frequently occasioning inflammation and fever. The Fury is a still more danger- and to the largest sea-shells, as if to derive their nourishment from them. If they be taken and put into spirit of wine, they will continue for many years entire; but if they be left to the intluence of the air, they are, in less than four and twenty hours, melted down into limpid and offensive water.

In all of this species, none are found to possess a vent for their excrements; but the same passage by which they devour their food, serves for the ejection of their freces. These animals, as was said, take such a variety of figures, that it is impossible to describe them under one determinate shape; but in general their bodies resemble a truncated cone, whose base is applied to the rock to which they are found usually attached, Though generally transparent, yet they are found of different colours, some inclining to green, some to red, some to white, and some to brown. In some, their colours appear diffused over the whole surface, in some they are often streaked, and in others often spotted. They are possessed of a very slow progressive motion, and in fine weather they are continnally seen, stretching out, and fishing for their prey. Many of them are possessed of a inumber of long slender filaments, in which they entangle any small animals they happen to approach, and thus draw them into their enormons stomachs, which fill the whole eavity of their bodies. The harder shells continue for some weeks undigested, but at length they niddergo a kind of maceration in the stomach, and become a part of the sub-

ous wurin, and has on each side a siugle row of closely pressed reflected prickles. It is fonnd in Finland and the uorlherı parts of Swerlen, in marslyy places, where it crawls up the stems of sedge-grass and low shrubs; and being wafted by the wind, darts into the naked parts of such as inay happen to be wear it. The celebrated naturalist, Sir Charles Linné, was so severely bitten by one of these drendful animals, that for some time it was doubtful whether lie would live or die. 
stance of the animal itself. The indigestible parts are returned by the same aperture by which they were swallowed, and then the star-fish begins to fish for more. These also may be cut in pieces, and every. part will survive the operation; each becoming a perfect animal, endued with its satural rapacity.

Of this tribe, the number is various, and the description of each would be tedions and uninstructing; the manners and nature of all are nearly as described : but I will just make mention of ane creature, which, though not properly belonging to this class, yet is so nearly related, that the passing it in silence would be an unpardonalile omission.

Of atl other animals, the Cuttle-fish, though in some respects superior to this tribe, possesses qualities the most extraordinary. It is about two feet long, covered with a very. thiu skiu, and its flesh composed of a gelatinous substance, which, loowever, within-side, is strengthened by a strong bone, of which such great use is made by the goldsmith. It is possessed of eight arms, which it extends, and which are probably of service to it in fishing for its prey; while in life, it is capable of lengthening or contracting these at pleasure; but, when dead, they contract, and lose their rigidity. They feed upon small fish, which they seize with their arms; and they are bred from eggs, which are laid upon the weeds along the sea-shore.

The cuttle-fish is found along many of the coasts of Europe, but are not easily caught, from a contrivance with which they are lurnished by nature; this is a black substance, of the colour of ink, which is contained in a bladder generally on the left side of the belly, and which is ejected in the manner of an exerement from the anus. Whenever, therefore, this fish is pursued, and when it finds a difficulty of escaping, it spurts forth a great quantity of this black liquor, by which the waters are totally darkened, and then it escapes by lying close at the bottom. In this manner the creature finds its safety; and men find ample cause for admiration, from the great variety of stratagems with which creatures are endued for their peculiar preservation.

\section{CHAPTER CXCIX.}

\section{OF THE POLYPUS.}

THOSE animals which we have described in the last chapter are variously denominated. They have been called the Star-fish, Seanettles, ami Sea-polypi. This last name has been peculiarly ascribed to them by the ancients, becanse of the number of feelers. or feet of which they are all possessed, and with which they have a slow progressive motion; but the moderus have given the name of Polypus to a reptile that lives in fresh water. by no means so large or observable. These are found at the bottom of wet ditches,or attached to the under surface of the broadleafed plants that grow and swim on the wa. ters. The same difference holds hetween these and the sea-water polypus, as between all the prortictions of the sea, and of the tank and the ocean. The marine vegetables and animals grow to a monstrous size. The eel, the pike, or the bream, of fresh waters, is hut small; but in the sea they grow to an enormous magnitude. The herbs of the ficld are at most but a few feet high; those of the sea. often shoot forth a stalk of a hundred. It is so between. the Palypi of hoth, elements. Those of the sea are fonnd from two feet in length to three or four, and Pliny. has even lescribed one, the arms of which were no tess than thirty feet long. Those in fresh waters. however. are comparatively inimute; at their ntmost size seldom ahove three parts of. an inch loug: and when gathered up into: their usual form, not, above - a third even of those dimensions.

It was unon these minute animals, that the power of disscction was first tried in multi. 
plying their numbers. They had been long considered as little worthy the attention of observers, and were consigned to that neglect in which thousands of minute species of insects remain to this very day. It is true, indeed, that Reaumur observed, classed, and named them. By contemplating their motions, he was enabled distinctly to pronounce on their being of the animal, and not of the vegetable kingdon; and he called them Polypi, from their great resemblance to those larger ones that were found in the ocean. Still, however, their properties were neglected, and their history unknown.

Mr. Trembley was the person to whom we owe the first discovery of the aniazing properties and power's of this little vivacious creature. He divided this class of animals into four clifferent kinds: into those inclining to green, those of a brownisl cast, those of a fleshcolour, and those which he calls the polype de panache. The differences of structure in these, as also of colour, are observable enough ; but the manner of their subsisting, of seizing their prey, and of their propagation, is pretty nearly the same in all.

Whocver has looked with care into the bottom of a wet ditch when the water is stagnant, and the sun has been powerful, may remensber to have seen many little transparent lumps of jelly, about the size of a pea, and flatted on one side; such also as have exnminel the under side of the broad-leafed weeds that grow on the surface of the water, must have observed them studded iwith a number of these little jelly-like substances, which were probably then distregarded, because their nature and history were unknown. These litule substances, however, were no other than living joly ji, gathered up into a quiescent stati, and sce.ningly inanimate, because either undisturberl, or not excited by the calls of appetite to action. Whicn they are seen exerting themselves, they put on a very different appearance firom that when at rest: to conceive a just idea of their figure, we may suppose the finger of a glove cut off at the botton ; we may suppose also several threads or horns planted round the edge like a fringe. The hollow of this finger will give us an idea of the stomach of the animal; the threads issuing forth from the edges may br considered as the arms or feclers, with which it hunts for its prey. The animal, at its greatest extent, is seldom seen abore an inch and a half long, but it is much shorter when it is contracted and at rest; it is furnished neither with musctes nor rings, and its manner of lengthening or contracting irself more resembles that of the snail, than worns, or any other insect. The polypus contracts itself more or less, in proportion as it is touched, or as the water is agitated in which they are scen. Warmth animites them, and cold benumbs them; but it requires a degree of cold approaching congelation before they are reduced to perlect inactivity: those of an inch have generally their arnıs double, often thrice as long as their bodies. The arms, where the animal is not disturbed, and the season not unfavourable, are thrown about in various directions, in order to seize and entangle its little prey; sometimes three or four of the arms are thus employed, while the rest are contracted like the horns of a snail, wirhin the animal's boily. It seens capable of giving what length it pleases to these arms; it contracts and extends them at pleasure, and stretclies them only in proportion to the renoteness of the object it would seize.

These animals have a progressive motion, which is performed by that power they have of lengthening and contracting themselves at pleasure; they go from one part of the botton to another; they mount along the margin of the water, and climb up the side of aquatic plants. They often are seen to come to the surface of the water, where they suspend themselves by their lower end. As they advance but very slowly, they employ a great deal of time in every action, and bind themselves very strongly to whatever body they chance to move upon as they proceed; their adbesion is voluntary, and is probably performed in the manner of a cupping-glass applied to the body.

All animals of this kind have a remarkable attachment to turn towards the light, and this naturally might induce an inquirer to look for their eyes; but however carefully this search has been pursued, and however excellent the microscope with which every part was examined, yct nothing of the appearance of this organ was found over the whole body; and it is most probable that, like several other insects which hunt their prey by their feeling, these creatures are unfurnished with advan- 
tages which would be totally useless for their support.

In the centre of the arms, as was said before, the mouth is placed, which the animal can open and shut at pleasure, and this scrves at once us a passage for food, and an opening for it after digestion. 'Tlie inwarl part of the animal's body seems to be one great stomach, which is open at both ends; but the purposes which the opening at the bottom serves are hitherto unknown, but certainly not for exeluding their excrements, for those are ejected at the aperture by which they are taken in. If the surface of the body of this little creature be examined with a microscope, it will be found studded with a number of warts, as also the arms, especially when they are contracted; and these tubercles, as we shall presently see, answer a very important purpose.

If we examine their way of living, we shall find rhes" inseets chiefly subsisting upon others, much less than themselves, particularly a kind of millepeles that live in the water, and a very small red worm, which they seize with great avidity. In shorl, no insect whatsoever, less than themsclves, seems to come amiss to them; their arms, as was said before, serve them as a net would a fisherman, or perhaps, inore exactly speaking, as a lime-twig does a fowler.

Wherever their prey is perceived, which the animal effects by its feeling, it is sufficient to tonch the object it wonld seize upon, and it is fistened without a power of escaping. The instant one of this insect's long arms is laid upon a mill pede, the little insect sticks without a possibility of retreating. The greater the distance at which it is tonched, the greater is the ease with which the polypus brings the prey to its mouth. If the lirtle object be near, thnugh irretrievably caught, it is not without great difficulty that it can be brought to the inouth to he sivallowed. When the polypus is unsupplied with prey, it testifies its hunger by opening its innuth; the aperture, however, is so small that it cannot be easily perceived; hut when, with any of its long arms, it has seized upon its prey, it then opens the mouth discinctly enongh, and this opening is alwyys in propurtion to the size of the animal which it would swallow; the lips dilate insensibly by small degrees, and adjust themselves precisely to the figure of their prey. Mr. Trem.0 $71 \& 72$. bley, who took a pleasure in freding this useless brood, found that thry could devour aliments of every kind, fish and flesh, as u insects; but he owns they did not thrive so well upon beef and veal, ns upon the little worns of their own providing. Whien he gave one of these fanished reptiles any substance which was iniproper to serve for aliment, at tirst it seized the prey with avillity, but after keeping it some time entangled ur ar the mouth, it dropt it again with distinguishing nicety.

When several polypi happen to fall upon the same worm, they dispute their common prey with each other. Two of them are ofien seen seizing the same worm nt different ends, and dragging it at opposite direclions with great force. II often linppens, that while one is swallowing its respecrive end, the other is also enployed in the same manner, and thus they continue swallowing each his part, until their nouths meet together; they then rest, each for some time in this situation, till the worm breaks between them, and each goes of with his share; but it ofien happens, that a seemingly more dangerous conibat ensues, when the mouths of both are thus jois ed upon one conmon prey together: the largest polypus then gapes and swallows his antagonist; but what is very wonderfil, the animal thus swallowed seems to be rather a gainer by the misfortune. After it has lain in the conqueror's body for about an hour, it issues unhurt, and often in posse-sion of the prey which had been the origiual cause of contention. How hapsy would it be for men, if they had as little to fear from each other!

These reptiles continue eating the whole year, except when the cold approaches in congelation; and then, like most others of the insect tribe, they feel the general torpor of nature, and all their faculties are for two or three months suspended: but if they abstain at one time, they are equally voracious at another, and, like snakes, ants, and other animals that are torpid in winter, the meal of one day suffices them for several months together. In general, however, they devour more largely in proportion to their size, and their growth: is quick exactly as they are fed; such as are best supplied, soonest acquire their largest size, but they diminish also in their growth with the samie fucility if their food be taken away. 
Such arc the more obvious properties of these little aninals, but the most wonderful still renuain behind: "Their manner of propagation, or rather multiplication, has for some rears been the astonishument of all the learned of Europe. 'They are produced in as great a variety of manners as cvery specics of vegetable. Some pulypi are propagater from eggs, as plants are firn their seed; some are produced by buts issuing from their bodies, as plants are produced by inoculation; while all may be multiplied by cuttings, and this to a degree of minuteness that exceeds even philosophical perseverance.

With respect to such of this kind as are hatched from the egg, little curious can be added, as it is a method, of propagation so common to all the tribes of insect nature; but with regard to such as are produced like buds from their parent stem, or like cuttings from an original root, their history requires a more detailed explanation. If a polypus be carefully observed in summer, when these animals are chiefly active, and more particularly prepared for propagation, it will be found to bourgeon forth from different parts of its body several tubercles or little knobs, which grow larger and larger every day: after two or three days' inspection, what at first appeared but a small excrescence takes the figure of a small animal, entirely resembling its parent, furnished with feelers, a mouth, and all the apparatus for scizing and digesting its prey. This little creature every day becomes larger, like the parent to which it continues attached; it spreads its arms to seize upon whatever insect is proper for aliment, and devours it for its own particular benefit: thus it is possessed of two sources of nourishment, that which it receives from the parent by the tail, and that which it receives from its own industry by the mouth. The food which these animals receive often tinctures the whole body, and upon this oceasion the parent is often seen communicating a part of its own fluids to that of its progeny that grows upon it; while, on the contrary, it never receives any tincture from any substance that is caught and swallowed by its young. If the parent swallows a red worm, which gives a tincture to all its fluids, the young one partakes of the parental colour; but if the latter should seize upon the same prey, the parent polypus is no way benefited by the capture, but all the advantage remains with the young one.

But we are not to suppose that the parent is capable of producing only one at a time; several young ones are thus seen at once, of different sizes, growing from its body, sone just budding forth, others acquiring their perfect form, and others come to sufficient maturity, and just ready to drop from the original sten to which they had been attached for several days. But what is more extraordinary still, those young ones themselves that continue attacherl to their parent, are seen to bourgeon, and propagate their own young ones also, each holding the same dependence upon its respective parent, and possessed of the same. advantages that have been already described in the first connexion. Thus we see a surprising cliain of existence continued, and numbers of animals naturally produced without any union of the sexes, or other previous disposition of nature.

This seems to be the most natural way by which these insects are multiplied; their production from the egg being not so common; and thougl some of this kind are found with a little bladder attached to their bodies, which is supposed to be filled with eggs, which afterwards come to maturity, yet the artificial method of propagating these animals is much more expeditious, and cqually certain. It is indifferent whether one of them be cut into ten, or ten hundred parts, each becomes as perfect an animal as that which was originally divided; but it must be observed, that the smaller the part which is thus separated from the rest, the longer it will be in coming to maturity, or in assuming its perfect form. It would be endless to recount the many experiments that have been tried upon this philosophical prodigy: the animal has been twisted and turued into all manner of shapes; it has been turned inside out, it has beell cut in every division, yet still it continued to move ; its parts adapted themselves again to each other, and in a short time it became as voracious and industrious as before.

Besides these kinds mentioned by $\mathrm{Mr}$. Trembley, there are various others which have been lately discovered by the vigilance of succeeding observers, and some of these so strongly resemble a flowering vegetable in their forms, that they have been mistaken by 
many naturalists for such. Mr. Hughes, the author of the natural history of Barbadoes, has described a species of this animal, but has mistaken its nature, and called it a sensitive flowering plant; he observed it to take refuge in the holes of rocks, and, when undisturbed, to spread forth a number of ramifications, each terminated by a flowery petal, which shrunk at the approach of the hand, and withdrew into the hole from whence before it had been seen to issue. 'This plant, however, was no other than an animal of the polypus kind, which is not only to be found in Barbadoes, but also on many parts of the coast of Cornwall, and along the shores of the continent.

\section{ChAP'TER CC.}

\section{OF THE LYTHOPHYTES ANU SPONGES.}

IT is very probable that the animals we see and are acquainted with, bear no manner of proportion to those that are concealed from us. Although every leaf and vegetable swarms with animals upon land, yet at sea they are still more abundant ; for the greatest part of what would seem vegetables growing there, are in fact nothing but the artificial formation of insects, palaces which they have built for their own habitation.

If we examine the bottom of the sea along some shores, and particularly at the mouths of several rivers, we shall find it has the appearance of a forest of trees under water, millions of plants growing in various directions, with their branches entangled in each other, and sometimes standing so thick as to obstruct navigation. 'The shores of the Persian Gulf, the whole extent of the Red-sea, and the western coasts of America, are so choaked up in many places with these coraline substances, that though ships force a passage through them, boats and swimmers find it impossible to make their way. These aquatic groves are formed of different substances, and assume varions appearances. The coral plants, as they are called, sometimes shoot out like trees without leaves in winter; they often spread out a broad surace Jike a fan, and not uncommonly a large sundling head like a faggot; sometimes they are found to resemble a plant with leaves and fowvers; and often the antlers of a stag, with great exactness and regularity. In other parts of the sea are seen sponges of various magnitude, and extraordinary appearances, assuming a variety of phantastic forms, like large mushrooms, mitres, fonts, and flowerpots. To an attentive spectator these various productions seem entirely of the vegetable kind; they seem to have their Jeaves and their fowers, and have been experimentally known to shoot out branches in the compass of a year. Plilosophers, therefore. till of late, thought themselves pretty secure in ascribing these productions to the vegetable kingdom; and Count Marsigli, who has written very laboriously and learnedly upon the subject of corals and sponges, lias not hesitated to declare his opinion, that they were plants of the aquatic kind, furnished with flowers and seeds, and endued with a vegetation entirely resembling that which is found upon land. This opinion, however, some time after, began to be shaken by Rum-. phius and Jussieu, and at last by the ingenious Mr. Ellis, who by a more sagacious and diligent inquiry into nature, put it past doubt, that corals and sponges were entirely the works of animals, and that, like the lioneycomb which was formed by the bee, the coral was the work of an infinite number of rep. tiles of the polypus kind, whose united labours were thus capable of filling whole tracts of the ocean with those embarrassing tokens of their industry.

If, in our researches after the nature of these plants, we should be induced to break off a branch of the coraline substance, and observe it carefully, we shall perceive its 
whole surface, which is very rugged and irregular, covered with a mucous tiuid, and ahmost in every part studded with little jellylike drops, which, when closely examined, will be found to be no other than reptiles of the polypus kind. These have their motions, their arms, their appetites, exactly resembling those described in the last chapter; but they soon expire when taken ont of the sea, and our curiosity is at once stopped in its career, by the animals ceasing to give any mark of their industry : recourse, therefore, has becn bad to other expedients, in order to determine the nature of the inhabitant, as well as the luabitation.

If a coraline plant be strictly observed, while still growing in the sea, and the animals upon its surface be not disturbed, either by the agitation of the waters, or the touch of the observer, the little poly pi will then be seen in infunite numbers, each issuing from its cell, and in some kinds the head covered with a little shell, resembling an umbrella, the arms spread abroad, in order to seize its prey. while the hinder part still remains attached to its habitation, from whence it never wholly removes. By this time it is perceived, that the number of inhabitants is intinitely greater than was at first suspected; and that they are all assiduously employed in the same pursuits, and that they issue from their respective cells, and retire into them at pleasure. Still, however, there are no proofs that those large branches which they inhabit, are entirely the construction of such feeble and minute animals. But chymistry will be fonud to lend a clne to extricate us from our doubts in this particular. Like the shells which are formed by snails, muscles, and oysters, these coraliue substances effervesce with acids; and may therefore well be supposed to partake of the same animal nature. But Mr. Ellis went still farther, and examined their operations, just as they were beginning. Observing an oyster-bed which had been for corne time neglected, he there perceived the first rudinents of a coraline plantation, and tufts of various kinds shooting from different parts of this favourable soil. It was upon these he tried his principal experiment. He took out the oysters which were thus furnished with coralines, and placed them in a large wooden vessel, covering them with sea-water. In about au hour be perceived the animals, which before had been contracted by handling, and had shown no signs of life, expanding themselves in every direction, and appearing employed in their own natural manner. Perceiving them, therefore, in this state, his next aim was to preserve them thus expandcd, so as to be permanent objects of curiosity. For this purpose, he poured, by slow degrees, an equal quantity of boiling water into the vessel of sea-water in which they were immersed. He then separated each polypus with pincers from its shell, and plunged each separately into small crystal vases, flled with spirit of wine mixed with water. By this means the animal was preserved entire, without having time to contract itself, and he thus perceived a variety of kinds, almost equal to that variety of productions which these little animals are seen to form. He bas been thus able to perceive and describe fifty different kinds, each of which is seen to possess its own peculiar mode of construction, and to form a coraline that none of the rest can imitate. It is true, indeed, that on every coraline substance there are a number of polypi found, no way resembling those which are the erecters of the building: these may be called a vagabond race of reptiles, that are only intruders upon the labours of others, and that take possession of habitations, which they have neither art nor power to build for themselves. But, in general, the same difference that subsists between the honey-comb of the bee, and the paper-like cells of the wasp, subsists between the different habitations of the coral-making poly pi.

With regard to the various forms of these substances, they have obtained differcut names from the nature of the animal that produced them; or the likeness they bear to some well-known object, such as coralines, fungi-madrepores, sponges, astroites, and keratophytes. Though these differ extremely in their outward appearances, yet they are all formed in the same manner by reptiles of various kinds and nature. When examined chymically, they all discover the marks of animal formation; the corals, as was said, dissolve in acids, the sponges burn with an odour strongly resembling that of burnt horn. 
We are left somewhat at a loss with regard to the precise manner in which this multitude of cells, which at last assume the appearance of a plant or flower, are formed.

If we may be led in this subject by analogy, it is innst probable, that the substance of coral is produced in the same manner that the shell of the suail grows round it; these little reptiles are each possessed of a slimy matter, which covers its body, and this hardening, as in the suail, becomes a habitation exactly fittel to the body of the animal that is to reside in it; several of these habitutions being joined together, form at length a considerable mass; and as most animals are productive in proportion to their minuteness, so these multiplying in a surprising degree, at length form those extensive forests that cover the bottom of the deep.

Thus all nature seems replete with life; almost every plant on land lias its surface covered with millions of these minute creatures, of whose existence we are certain, but of whose uses we are entirely ignorant; while numbers of what seem plants at sea, are not only the receptacles of insects, but also entirely of insect lormation. This might have led some late philosuphers into an opinion, that all nature was animated; that every, even the most inert mass of matter, was endued with life and sensation, but wanted organs to make those sensations perceptible to the observer: those opinions, taken up at randorn, are difficultly maintained, and as difficultly refuted; like combatants that meet in the dark, each party may deal a thousand blows without ever reaching the adversary. Those, perhaps, are wiser, who view nature as she offers; who, without searching too deeply into the recesses into which she ultimately hides, are contented to take her as she presents herself; and storing. their minds with effects rather than with causes, instead of the embarrassments of systems, about which few agree, are contented with the history of appearances, concerning which all mankind bave but one opinion. 
aty

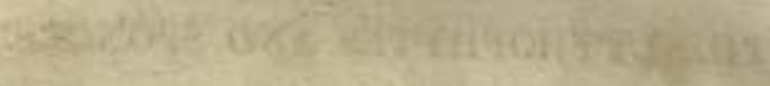

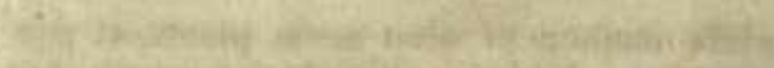

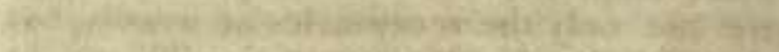

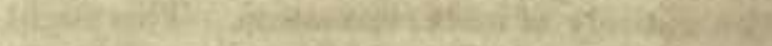

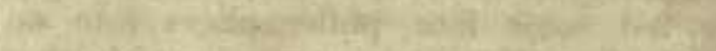
whathising

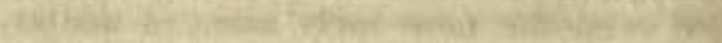

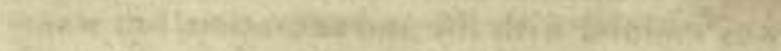

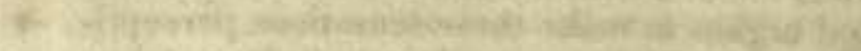

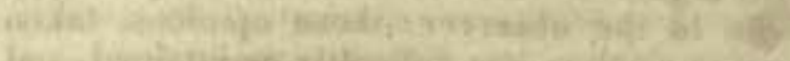

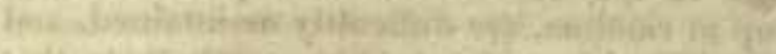

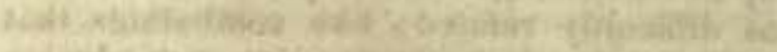

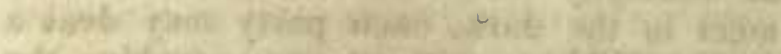

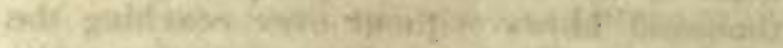

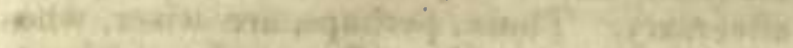

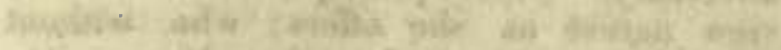

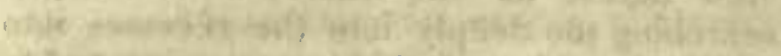

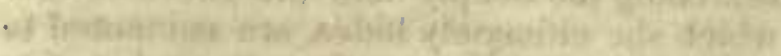

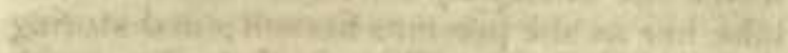

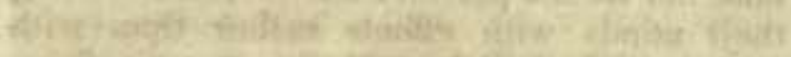

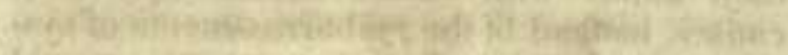

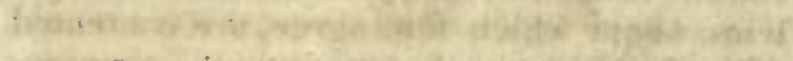

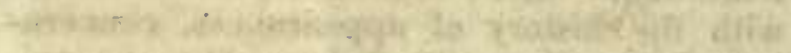

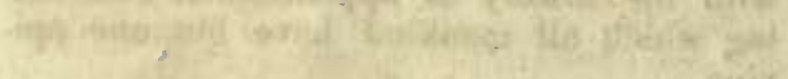
wirkt

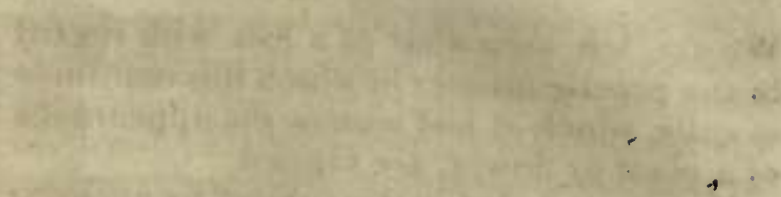

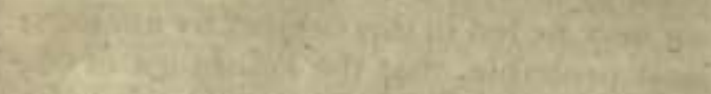
10

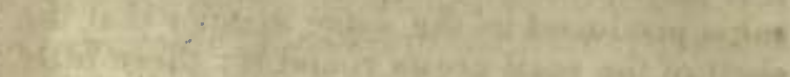
a.ting

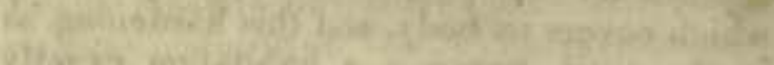

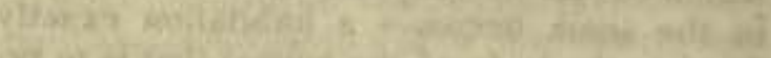

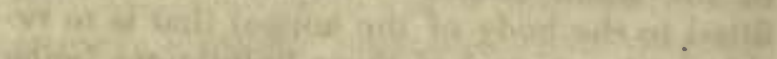

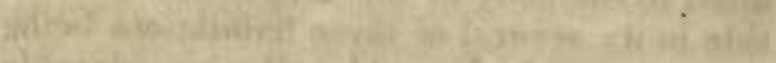

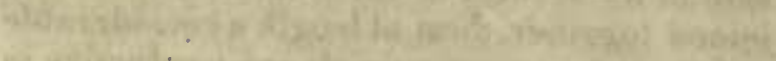

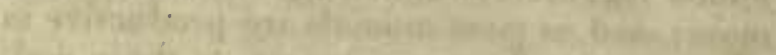

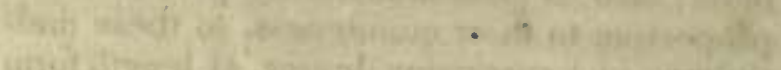

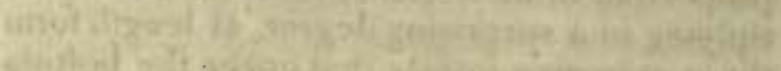

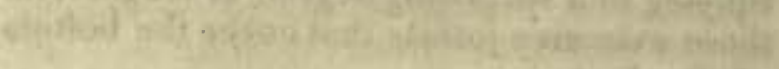

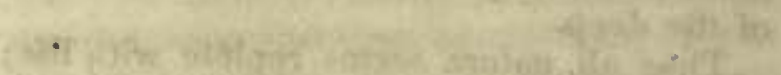

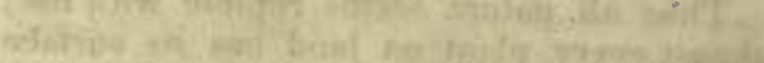

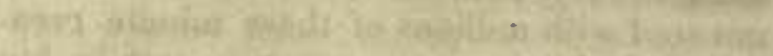

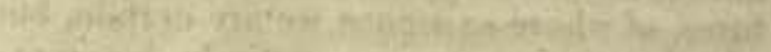

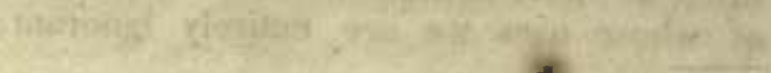
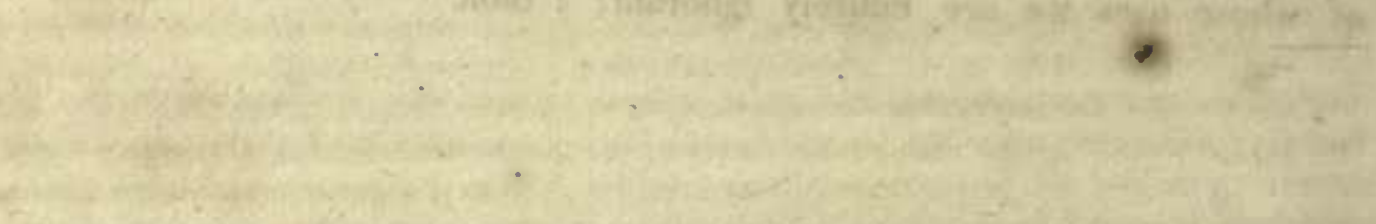

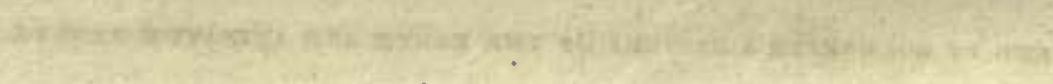
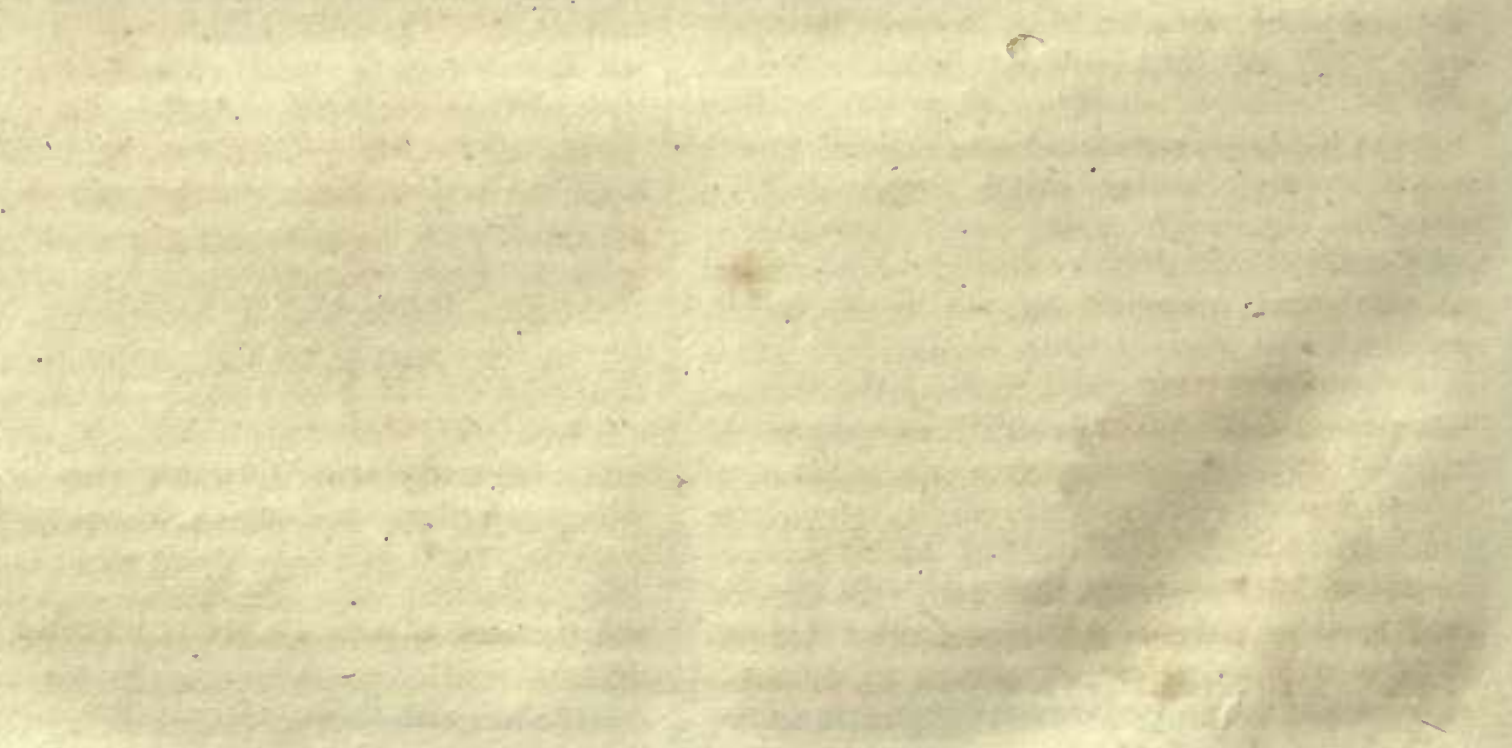
4 


\section{REV. HENRY GOLDSMITH.}

DEAR SIR,

I AMt sensible that the friendslip between us can acquire no new force from the ceremonies of a dedication; and perhaps it demands an excuse thus to prefix your name to iny attempts, which you decline giving with your own. But as a part of this poem was formerly written to you from Switzerland, the whole can now, with propriety, be only inscribed to you. It will also throw a light upon many parts of it; when the reader understands that it is addressed to 2 Inan, who, despising fame and fortune, has retircd early to happiness and obscurity, with an income of forty pounds a year.

I now perceive, my dear brother, the wisdoin of your humble choice. You have entered upon a sacred office, where the harvest is great, and the labourers are but few ; while you bave left the field of ambition, where the labourers are many, and the harvest not worth carrying away. But of all kinds of ambition, what from the refinement of the times, from different systeuns of criticism, and from the divisions of party, that which pursues poetical fame is the wildest.

Poetry makes a principal anusement among unpolished nations; but in a country verging to the extremes of refinement, painting and music come in for a share. As these offer the feeble mind a less laborious entertainment, they at first rival poetry, and at length supplant her; they engross all that favour once shown to her, and, though but younger sisters, seize upon the clder's birthright.

Yet however this art nay be neglected by the powerful, it is still in greater danger from the mistaken efforts of the learned to inprove it. What criticisms have we not heard of late in favour of blank verse, and pindaric odes, chom russes, anapests, and iambics, alliterative care, and happy negligence! Every absurdity has now a champion to de fend it; and as he is generally much in the wrong, so he has always much to say; for error is ever talkative.

But there is an enemy to this art still more dangerous; I mean party. Party entirely distorts the judgment, and destroys the taste. When the mind is once infected with this disease, it can only find pleasure in what contributes to increase the distemper. Like the tiger, that seldom desists from pursuing mad, after liaving once preyed upon human flesh, the reader, who has once gratified his appetite with calumny, makes ever after the most agreeable feast upon murdered reputation. Such readers generally admire some half-witted thing, who wants to be thought a bold man, having lost the character of a wise one. Him they dignify with the name of poet: his tawdry lampoons are called catires; his turbulence is said to be force, and his phrenzy fire. 
What roception a poem may find, which has neither abuse, party, nor blank verse to support it, I cannot tell, not ain I solicituus to know. My aims are right. Without espousing the cause of any party, I have attempted to moderate the rage of all. I have endeavoured to show, that there may be equal happiness in states that are difierently governed from our own; that every state has a particular principle of happiuess, and that this principle in each may be carried to a mischievous excess. There are few can judge better than yourself how far these positions are illus. trated in this poem. I ain, dear sir, your most affectionate brother,

OLIVER GOLDSMITH. 


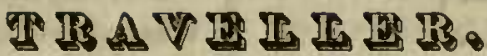

Reмоте, unfriended, melancholy, slow,

Or by the lazy Scheld, or wandering Po;

Or onward, where the rude Carinthian boor

Against the houseless stranger shuts the door;

Or where Campania's plain forsaken lies,

A weary waste expanding to the skies;

Where'er I roam, whatever realms to see,

My lieart, untravelled, fondly turns to thee ;

Still to iny brother turns, with ceaseless pain,

And drags, at each remove, a lengthening chain ;

Eternal blesshugs crown my earliest friend,

And round his dwelling guardian saints attend ;

Blessed be that spot, where cheerful guests retire,

To pause from toil and trim their evening fire;

Blessed that abode, where want and pain repair,

And every stranger finds a ready chair :

Blessed be tloose feasts, with simple plenty crowned,

Where all the ruddy family around

Laugh at the jests or pranks that never fail,

Or sigh with pity at some mournful tale;

Or press the bashful stranger to his food,

And learn the luxury of doing good!

But me, not destined such delights to share,

My prime of life in wandering spent, and care

Impelled, with steps unceasing, to pursue

Some fleeting good, that mocks me with the view;

That, like the circle, bounding earth-and skies,

Allures from far, yet, as I follow, flies;

My fortune leads to traverse realins alone,

And find no spot of all the world my owp.

พо. $71 \& 72$.
E'en now where Alpine solitudes ascend,

I sit me down a pensive hour to spend;

And placed on high, above the storm's career, Look downward where an hundred realms appear;

Lakes, forests, cities, plains, extending wide,

The pomp of kings, the shepherd's humbler pride.

Wlien thus creation's charms around combine, Amidst the store should thankless pride repine, Say, should the philosophic mind disdain

That good which makes each humbler bosom vain?

Let school-taught pride dissemble all it can,

These little things are great to little man;

And wiser he, whose sympathetic mind

Exults in all the good of all mankind.

Ye glittering towns, with wealth and splendour crowned;

Ye fields, where summer spreads profusion round;

Ye lakes, whose vessels catch the husy gale;

Ye bending swains, that dress the flowery vale;

For me your tributary stores combine:

Creation's heir! the world, the world is mine!

As some lone miser, visiting his store,

Bends at his treasure, counts, recounts it o'er;

Hoards after hoards his rising raptures fill,

Yet still he sighs, for hoards are wanting still;

Thus to my breast alternate passions rise,

Pleased with each good that heaven to man supplies;

Yet oft a sigh prevails, and sorrows fall,

To see the hoard of human bliss so sinall;

And oft I wish, amidst the scene, to find

Some spot to real happiness consigned, 
Where my worn soul, eacli waudering liope at rest,

May gather bliss to see my fellows blessed.

But where to find that happiest spot below,

Who can dircet, when all pretend to know?

The shuddering tenant of the frigid zone

Boldly proclaims that happiest spot his own;

Extols the treasures of his stormy seas,

And his long nights of revelry and ease;

'The naked uegro, panting at the line,

Boasts of his goldeı sands and palmy wine ;

Basks in the glare, or stems the tepid wave,

And thanks his gods for all the good they gave.

Such is the patriot's boast, where'er we roam;

Hlis first, best country ever is at home:

And yet, perhaps, if countries we compare,

And estimate the blessings which they share,

Tliough patriots flatter, still shall wisdoin find

An equal portion dealt to all mankind;

As different good, by art or nature given,

To different nations, makes their blessings even.

Nature, a inother kind alike to all,

Still grauts her bliss at labour's earnest call ;

With ford as well the peasant is supplied

On Id'a's cliffs as Arno's shelvy side;

And though the rocky-crested summit's frown,

These rocks by custom turn to beds of down.

From art more various are the blessings sent;

Wealth, commerce, honour, liberty, content :

Yet these each other's power so stronig contest

That either seems destructive of the rest.

Where wealth and freedom reign, contentment fails;

And honour siuks where commerce long prevails :

Hence every state, to one loved blessing prone,

Conforms and models life to that alone.

Each to the favourite happiness attends,

And spurns the plan that aims at other ends;

'Till, carried to excess in each domain,

This favourite good hegets peculiar pain.

But let us try these truths with closer eyes,

And trace thein through the prospect as it lies;

Here for a while my proper cares resigned,

Here let me sit in sorrow for mankind;

Like yon neglected shrub at random cast,

That shades the steep, and sighs at every blast.

Far to the right where Appennine ascends,

Bright as the summer, Italy extends;
Its uplands sloping, deck the mountain's side, Woods over woods in gay theatric pride;

While of some tcmple's mouldering tops between,

With venerable grandeur mark the scene.

Could nature's bounty satisfy the breast,

The sons of Italy were surely blest.

Whatever fruits in different climes are found,

That proudly rise, or humbly court the ground;

Whatever blooms in torrid tracts appear,

Whose bright succession decks the varied year;

Whatever sweets salute the northern sky

With vernal lives, that blossom but to die :

These, lyere disporting, own the kindred soil,

Nor ask luxuriance from the plante:'s toil,

While sea-born gales their gelid wings expand,

To winnow fragrance round the smiling land.

But sinall the bliss that sense alone bestows, And sensual bliss is all the nation knows.

In florid beauty groves and fields appear;

Man seems the only growth that dwindles here.

Contrasted faults through all his manners reign :

Though poor, luxurious; though submissive, vain :

Though grave, yet trifling; zealous, yet untrue;

And e'en in penance planning sins anew.

All evils here contaminate the mind,

That opulence departed leaves behind ;

For wealth was theirs; not far removed thu date,

When commerce proudly flourished through the state;

At her comniand the palace learned to rise,

Again the long-fallen colunn sought the skies;

The canvass glowed beyond e'en nature warm,

The pregnant quarry teemed with luman form;

Till, more unstcady than the soutliern gale,

Cominerce on other sluures displayed lier sail;

While nought remained of all that riches gave,

But towns ummanned and lords without a slave :

And late the nation found with fruitless skill

Its former strength was but plethoric ill.

Yet still the loss of wealth is here supplied

By arts, the splendid wrecks of former pride;

From these the feeble heart and long-fallen mind

An easy compensation seem to find.

Here may be seen, in bloodless poinj arrayed,

'The pasteboard triumph and the cavalcade;

Processions formed for piety and love,

A mistress or a saint in every grove. 
By sports like these are all their cares beguiled, The sports of children satisfy the child; Each nobler aim, repressed by long control, Now sinks at last, or feebly mans the soul; While low delights, succeeding fast belind, In happier meanness occupy the mind :

As in those domes, where Crsars once bore sivay, Defaced by time, and tottering in decay, There in the ruin, heedless of the dead, The sliciter-seeking peasant builds his shed; And, wondering man could want the larger pile, Exults, and owns his cottage with a smile.

My soul, turn from them-turn we to survey

Where rougher climes a nobler race display; Where the bleak Swiss their stormy mansion tread, And force a churlish soil for scanty bread.

No product here the barren bills afford, But man and steel, the soldier and his sword. No vernal blooms their torpid rocks array, But winter, lingering chills the lap of May ; No zephyr fondly sues the mountain's breast, But meteors glare, and stormy glooms invest.

Yet still e'en here, content can suread a charm, Redress the clime, and all its rage disarm. Though poor the peasant's hut, his feasts though small, He secs his little lot the lot of all;

Sees no contiguous palace rear its head, 'To shame the ineanness of his humble shed; No costly lord the sumptuous banquet deal, 'To make him loath his vegetable meal; But calm, and bred in ignorance and toil, Each wish contracting, fits him to the soil. Cheerful at morn, he wakes from short repose, Breaths the keen air, and carols as he goes: With patent angle trolls the finny deep, Or drives his venturous plongh-share to the steep; Or secks the den where snow-tracks mark the way, And drags the struggling savage into day. At night returning, every labour sped, He sits him down, the monarch of a shed; Smiles by lis cheerful fire, and round surveys His children's looks, that brighten at the blaze: While his loved partuer, boastful of her hoard, Displays her cleanly platter on the buard; And haply, too, some pilgrim thither led, With many a tale repays the nightly bed.
Thus every good his native wilds impart Imprints the patriot passion on his heart : And e'en those hills, that round his mansion rise, Enhance the bliss his scanty fund supplies. Dear is that shed to which his soul conforms, And dear that hill which lifts him to the storms; And as a child, when scaring sounds molest, Clings close and closer to the mother's breast, So the loud torrent, and the whirlwind's roar, But bind him to his native inountains more.

Such are the charms to barren states assigned, Their wants but few, their wishes all confined. Yet let them only share the praises due; If few their wants, their pleasures are but few ; For every want that stimulates the breast, Becomes a source of pleasure when redressed. Whence from such lands each pleasing science flies, That first excites desire, and then supplies; Unknown to them, when sensual pleasures cloy, To fill the languid pause witl finer joy; Unknown those powers that raise the soul to flame, Catch every nerve, and vibrate through the frame. Their level life is but a mouldering fire, Unquenched by want, unfanned by strong desire; Unfit for raptures; or, if raptures cheer, On soine high festival of once a year, In wild excess the vulgar breast takes fire, Till, buried in debauch, the bliss expire.

But not their joys alone thus coarsely flow;

Their morals, like their pleasures, are but low :

For, is refiument stops, from sive to son, Unaltered, unimproverl, the manners run; And tove's and friendship's finely-pointed dart Fall blunted from each indurated heart. Some sterner virtues o'er the mountain's breast May sit like falcons cowering on the nest; But all the gentler morals, such as play Through life's more cultured walks and charm the way, These far dispersed, on timorous pinions fly, To sport and flutter in a kinder sky.

To kinder skies, where gentler manners reign, I turn-and France displays her briglit domain. Gay sprightly land of mirth and social ease, Pleased with thyself, whom all the world can please, How often have I led thy sportive choir, With tuneless pipe, beside the murmuring Loire ! 
Where shading clins along the unargin grew, And, freshened from the wave, the zephyr flew ;

Aud haply, though my harsh touch faltering still, But mocked all tune, and marred the dancers' skill, let weuld the village praise my wonderous power, And dance, forgetful of the noon-tide hour!

Nike all ages. Dames of ancient days

Have led their children through the mirthful maze;

And the gay grandsire, skilled in gestic lore,

Has frisked beneatls the burden of threescore.

So blessed a life these thoughtless realms display, Thus idly busy rolls their world away:

Theirs are those arts that mind to mind endear,

For honour forms the social temper here.

Honour, that praise which real merit gains,

Or e'en imaginary worth obtains,

IIere passes current; paid from hand to hand.

It shifts in splendid traffic round the land;

From courts to camps, to cottages it strays,

And all are taught an avarice of praise;

They please, are pleased, they give to get esteem,

Till seeming blessed, they grow to what they seem.

But while this softer art their bliss supplies,

It gives their follies also room to rise;

For praise too dearly loved, or warmly sought,

Enfeebles all interaul strength of thought;

And the weak soul, within itself uoblessed,

Leans fur all pleasure on another's breast.

-Ience ostentation here with tawdry art,

Pants for the vulgar praise which fools impart :

Here vanity assumes her pert.grimace,

And trims her robes of frieze with copper lace;

Here beggar-pride defrauds her daily cheer,

To boast one splendid banquet once a year;

'The inind still turns where shifting fashion draws,

Nor weighs the solid worth of self-applause.

To men of ether minds my fancy flies,

Embosomed in the deep where Holland lies.

Methinks her patient sons before me stand,

Where the broad ocean leans against the land;

And sedulous to stop the coming tide,

Lift the tall rampire's artificial pride.

Onward, methinks, and diligently slow,

The firm connected bulwark seemis to grow

Spreads its long arms amidst the watery roar,

Scoops out an empire, and usurps the shore,
While the pent ocean, rising o'er the pile,

Sees an amphibious world beneath him smile;

The slow canal, tho ycllow-blossomed vale,

The willow-tufted bank, the gliding sail,

The crowded nuart, the cultivated plain;

A new creation rescued from his reign.

Thus while around the wave-subjected soil

Impels the native to repeated toil,

Industrious habits in each bosom reign,

And industry begets a love of gain.

Hence all the good from epulence that springs,

With all those ills superfluous treasure brings

Are here displayed. Their much-loved wealth imparts.

Convenience, plenty, elegance, and arts ;

But view them closer, craft and fraud appear,

E'en liberty itself is bartered liere.

At gold's superior charms all freedom flies,

The needy sell it, and the rich man buys;

A land of tyrauts, and a den of slaves,

Here wretches seek dishonourable graves,

And calmly bent, to servitude conform,

Dull as their lakes that slumber in the storm.

Heavens! how unlike their Belgic sires of old !

Rough, poor, content, ungovernably bold;

War in each breast, and freedom on each brow;

How much unlike the sons of Britain now!

Fired at the souad, my genius spreads ber wing, And flies where Britain courts the western spring; Where lawns extend that scorn Arcadian pride, And brigliter streams than fanied Hydaspis glide. There all around the gentlest breezes stray, There gentle music melts on every spray ; Creation's mildest charms are there combined;

Extremes are only in the master's mind!

Stern o'er cach bosom, reasen holds her state,

With daring aims irregularly great :

Pride in their port, defiance in their eye,

I see the lords of human-kind pass by ;

Intent on ligh designs, a thoughtful band,

By forms unfashioned fresh from nature's hand;

Fierce in their native hardiness of soul,

True to imagined right, above control,

While e'en the peasant boasts these rights to scan,

And learns to venerate himself as man.

Thine, Freedom, thine thre blessings pictured here, Thine are those charms that dazzle and endear; 
Too blessed, indeed, were such without alloy,

But fostered e'en by Freedom ills annoy;

That independence Britons prize too high,

Keeps man from man, and breaks the social tie;

'The self-dependent lordlings stand alone,

All claims that bind and sweeten life unknown;

IIere, by the bonds of nature feebly held, Minds combat minds, repelling and repelled;

Ferments arise, imprisoned factions roar,

Repressed ambition struggles round ber shore,

Till, over-wrought, the general systems feels

Its motions stop, or phrenzy fire the wheels.

Nor this the worst. As nature's ties decay,

As duty, love, and hunour fail to sway,

Fictitious bonds, the boinds of wealth and law,

Still gather strength, and force unwilling awe.

Hence all obedience bows to these alone,

And talent sinks, and merit weeps uuknown;

Till time may come, when, stripped of all her cliarms,

The land of scholars, and the nurse of arms,

Where noble stems transmit the patriot flame,

Where kings have toiled, and poets wrote for fame,

One sink of level avarice shall lie,

And scbolars, soldiers, kings, unhonoured die.

Yet think not, thus when freedom's ills I state,

I mean to flatter kings, or court the great:

Ye powers of truth! that bid my soul aspire,

Far from my bosom drive the low desire!

And thou, fair Freedom! taught alike to feeI

The rabble's rage, and tyrant's angry steel ;

Thou transitory flower! alike undone

By proud Contempt, or Favour's fostering sun,

Still may thy blooms the changeful cline endure,

I only would repress them to secure;

For just experience tells, in every soil,

That those who think must govern those that toil ;

And all that Freedom's highest aims can reach,

Is but to lay proportioned loads on each.

Hence, should one order dispruportioned grow ${ }_{2}$

Its double weight must ruin all below.

$O$ then, how blind to all that truth requires,

Who think it freedom when a part aspires!

Calm is my soul, nor apt to rise in arms,

Except when fast-approaching danger warms;

But when contending chiefs blockade the throne,

Coutracting regal power to stretch their own;
When I beliold a factious band agree

To call it freedom when themselves are free;

Each wanton judge new penal statutes draw,

Laws grind the poor, and rich men rule the law;

The wealth of elimes, where savage nations roam,

Pillaged from slaves, to purchase slaves at home;

Fear, pity, justice, indiguation start,

Tear off reserve, and bear my swelling heart;

Till half a patriot, half a coward grown,

I fly from petty tyrants to the throne.

Yes, brother, curse with me that baleful hour,

When first ambition struck at regal power;

And thus polluting honour in its source,

Gave wealth to sway the mind with double force.

Have we not seen round Britain's peopled shore,

Her useful sons exchanged for useless ore ?

Seen all her triumphs but destruction liaste,

Like flaring tapers, brightening as they waste;

Seen Opulence her grandeur to maintain,

Lead stern Depopulation in her train,

And over fields, where scattered luamlets rose,

In barren, solitary pomp repose?

Have we not seen, at Pleasure's lordly call,

The smiling long-frequented village fall?

Behold the duteous son, the sire decayed,

The modest matron, and the hlushing maid,

Forced from their homes, a nelancholy train,

To traverse climes beyond the western main;

Where wild Oswego spreads her swamps around,

And Niagara stuns witl thundering souud?

E'en now, perhaps, as there some pilgrim strays,

Through tangled forests, and through dangerous ways:

Where beasts with man divided enpire claim,

And the brown Indian marks with nurderous aim;

There, while above the giddy tempest llies,

And all around distrustful yells arise,

The pensive exile, bending with his woe,

To stop too fearful, and too faint to go,

Casts a long look where England's glories shine;

And bids his bosom sympathize with inine.

Vain, very vain, my weary sea:ch to find

That bliss which only centres in the mind !

Why have I strayed from pleasure and repose,

To seek a good each governinent bestows?

In every government thuing terrors reign,

Though tyrant kings, or tyrant laws restrain, 
How small, of all that human hearts endure, That part which laws or kings can cause or cure. Still to ourselves in every place consigned, Our own felicity we make or find;

With seeret course, which no loud storms annoy,
Glides the smootl curreut of domestic joy.

The lifted axe, the agonizing wheel,

Luke's iron erown, and Damien's bed of steel, To inen remote from power but rarely known, Leave reason, faith, and conscience, all our own. 


\section{SIR JOSHUA REYNOLDS.}

\section{DEAR SIE}

I caN have no expectations, in an address of this kind, either to add to your reputation, or to establish my own. You can gain nothing from my admiration, as I am iguorant of that art in which you are said to excel; and I may lose much by tne severity of your judgment, as few have a juster taste in poetry than you. Setting interest therefore aside, to which I never paid mucl attention, I must be indulged at present in following my affections. The only dedication I ever made was to my brother, because I loved him better than most other men. IIe is since deact. Permit me to inscribe this poem to you.

How far you may be pleased with the versification and mere mechanical parts of this attempt, I do net pretend to inquire; but I know you will. object (and indeed several of our best and wisest friends concur in the opinion) that the depopulation it deplores is no where to be scen, and the disorders it laments are only to be found in the poet's own imagination. To this I can scarce make any other answer, than that I sincerely believe what I have written; that I have taken all possible pains, in my country excursions, for these four or five years past, to be certain of what I allege, and that all my views and inquiries have led me to believe those miseries real which $I$ here attempt to display. But this is not the place to enter into an inquiry, whether tlje country be depopulating, or not; the discussion would take up much room; and I should prove myself, at best, an indifferent politician, to tire the reader with a long preface, when I want his unfatigued attention to a long poem.

In regretting the depopulation of the country, I inveigh against the increase of our luxuries; and here also I expect the shout of modern politicians against me: For twenty or thirty years past, it has been the fashion to consider luxury as one of the greatest national advantages; and all the wisdom of antiquity in that particular as erroneous. Still, however, I must remain a professed ancient on that head, and contioue to think those luxuries prejudicial to states, by which so many vices are introduced, and so many kingdoms have been undone. Indeed, so much has been poured out of late on the other side of the question, that, merely for the sake of novelty and variety, one would sometimes wish to be in the right.

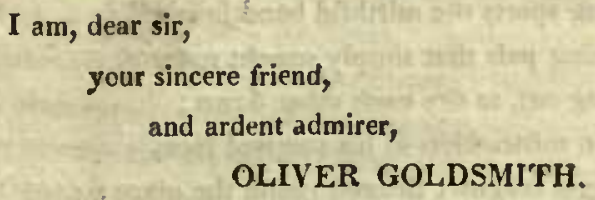




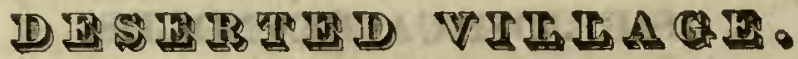

SweEt Auburn! loveliest village of the plain, Where health and plenty cheered the lab'ring swain, Where smiling spriog its earliest visit paid, And parting summer's lingering blooms delayed. Dear lovely bowers of innocence and ease, Seats of my youth, when every sport could please, How often have I loitered o'er thy green, Where humble happiness endeared each scene! How often have I paused on every charm, The sheltered cot, the cultivated farm, The never-failing brook, the busy mill, The decent church, that topt the neighbouring hill; The liawthorn bush, with scats beneath the shade; For talking age and whispering lovers made!

How often have I blest the coming day, When toil remitting lent its turn to play, And all the village train, from labour free, Led up their sports bencath the sprending tree, While many a pastime circled in the shade, The young contending as the old surveyed; And many a gambol frolic'd o'er the ground, And sleights of art and feats of strength went round. And still, as each repeated pleasure tired, Succeeding sports the mirthful band inspired; The dancing pair that simply sought renown, By holding out, to tire each other down; The swain mistrustless of his smutted face, While secret laughter tittered round the place; The bashful virgin's side-long looks of love, The matron's glance that would those looks reprove.
These were thy charms, sweet village sports like these, Witl sweet successlon, taught e'en toil to please; These round thy bowers their cheerful influence shed, These were thy charms-but all these charms are fied.

Sweet smiling village! loveliest of the lawn, Thy sports are fed, and all thy charms withdrawn; Amidst thy bowers the tyrant's hand is seen, And desolation saddens all thy green: One only master grasps the whole domain, And half a tillage stints thy smiling plain; No more thy glassy brook reflects the day, But chaked with sedges, works its weedy way; Along thy glades, a solitary guest, The hollow-sounding bittern guards its nest; A midst thy desert walks the lapwing flies, And tires their echoes with unvaried cries, Sunk are thy howers in shapeless ruin all, And the long grass o'ertops the mouldering wall; And, trembling, shrinking, from the spoiler's liand, Far, far away thy children leave the land.

Ill fares the land, to hastening ills a prey; Where wealth accumulates, and men decay: Princes and lords may flourish or may fade; A breath can make them, as a breath has made: But a bold peasantry, their country's pride, When once destroyed, can never be supplied. A time there was, ere England's griefs began, When every rood of ground maintained its man; For him light labour spread her wholesome store, Just gave what life required, but gave no more: 


\section{THF DESERTED VILLAGE.}

His best companions, innocence and liealth;

And his best riches, ignorance of wealth.

But times are altered : trade's unlecling train

Usurp the land, and dispossess the swain;

Along the lawn, where scattered hamlets rose,

Unwieldy wealth, and cumberous pomp repose;

And every want to lixury allied,

Aud every pang that folly pays 20 pride.

Those gentle hours that plenty bade to hloom;

Those calin desires that asked but little room;

Those healthful sports that graced the peaceful scene,

Lived in each look, and brightened all the green;

These, far departing, seek a kiuder shore,

And rural mirtlı. and manuers are no more.

Sweet Auburn ! parent of the blissful hour,

Thy glades forlurn confess the tyrant's power.

Here, as I take my solitary rounds,

Amidst thy tangling walks and ruined grounds,

And, many a year elapsed, returned to view

Where once the cuttage stood, the hawthorn grew,

Remembrance wakes, with all ber busy train,

Swells at my breast, and turns the past to pain.

In all my wanderings through this world of care,

In all my griefs-and God has given my share-

I still had hopes my latest hours to crown,

Amidst these humble bowers to lay me down;

To husband out life's taper at the close,

And keep the flame from wasting by repose:

I still had hopes, for pride attends us still,

Amidst the swains to show iny book-learned skill,

Around iny fire an evening group to draw,

And tell of all I felt, and all I saw ;

And as a hare, whom hounds and horns pursue,

Pants to the place from whence at first she flew,

I still had hopes, my long vexations past,

Here to return - and die at home at last.

O blest retirement ! friend to life's decline,

Retreat from cares, that never must be inine,

How blest is he who crowns, in shades like these,

A youth of labour with an age of ease!

Who quits a world where strong temprations try,

And since 'tis hard to combat, learas to fly !

For him no wretches, born to work and weep,

Explore the mine, or tempt the dangerous deep;

No surly porter stands in guilty state,

To spurn imploring famine froin the gate;

мo. $71 \& 72$.
But on he moves to minet his latter end, Angels around befriending virtue's friend; Sinks to the grave with unperceived decay, While resignation gently slopes the way; And all his prospects brightening to the last, His heaven commences ere the world be past! Sweet was the sound, when oft, at evening's close, Up yonder hill the village murmur rose;

There, as I passed with careless steps and slow, The mingling notes came softened from below; The swain responsive, as the milk-maid sung; The sober herd, that lowed to meet their young: The noisy geese, that gabbled o'er the pool; The playful children, just let loose from school ; The watcli-dog's voice, that bayed the whispering wind; And the loud laugh, that spoke the vaeant mind; These all in sweet confusion souglit the shade, And filled each pause the nightingale had made. But now the sounds of population fail, No cheerful murmurs fluctuate in the gale ; No busy steps the grass-grown foot-way tread, But all the bloomy flush of life is fled.

All but yon widowed solitary thing, That feebly bends beside the plashy spring; She, wretched matron, forced, in age, for bread, To strip the brook with mantling cresses spread, To pick her wintry faggot from the thurn, To seek her nightly shed and weep till morn; She only left of all the harmless train, The sad historian of the pensive plain.

Near yonder copse, where once the garden smiled, And still where many a garden flower grows wild; There, where a few torn shrubs the place disclose, The village preacher's modest mansion rose.

A man he was, to all the country dear, And passing rich with forty pounds a year; Remote from towns he ran his godly race, Nor e'er had clianged, nor wished to change his place; Unskilful be to fawn, or seek for power, By duetrines fashioned to the varying hour; Far other aims his heart had learned to prize, Nore bent to raise the wretched than to rise. His house was known to all the vagrant train, He chid their wanderings, but relieved their pain. The long remembered beggar was his guest, Whose beard descending swept his aged breast; 
The ruined spendthrift, now no lon rer proud,

Claimed kindred there, and load his claims allowed;

The broken soldier kiodly bade to stay,

Sat by his fire, and talked the night away;

Wept o'er his wounds, or tales of sorrow done,

Shoulder'd his crutch, and show'd how fields were won.

Plased with his guests, the goud man learned to glow,

And quite forgot their vices in their woe;

Careless their merits or their faults to scan,

His pity gave ere cloarity began.

Thus to relieve the wretched was his pride,

And even his failings leaned to virtue's side;

But in his duty, prompt at every call,

Ife watched and wept, he prayed and felt for all.

And, as a bird each fond endearment tries,

To tempt its new-fledged offspring to the skies,

He tried each art, reproved each dull delay,

Allured to brighter worlds, and led the way.

Beside the bed where parting life was laid,

And sorrow, guilt, and pain, by turns dismayed,

The reverend champion stood. At his control,

Despair and anguish fled the struggling soul ;

Comfurt came down the trembling wretch to raise,

And his last faltering accents whispered praise.

At church, with meek and unaffected grace,

His looks adorned the venerable place;

Truth from his lips prevailed with double sway,

And fools, who came to scoff, remained to pray.

The service past, around the pious man,

With ready zeal, each honest rustic ran;

E'en children followed with endearing wile,

And plucked his gown, to share the good man's smile.

His ready 'smile a parent's warmth exprest ;

Their welfare pleased hin, and their cares distrest ;

To them his heart, lis love, lis griefs were given,

But all his serious thoughts had rest in heaven.

As some tall cliff that lifts its awful form,

Sivells from the vale, and midway leaves the storm,

Though round its breast the rolling clouds are spread,

Eternal sunshine settles on its head.

Beside yon straggling fence, that skirts the way

With blossamed furze uaprofitably gay,

There, in his noisy mansion, skilled to rule,

The village master taught bis little school;

A man severe he was, and storn to view;

I knew him well, and every truant knew;
Well had the boding tremblers learned to trace

'The day's disasters in his morning face;

Full well they laughed, with counterfeited glee,

At all his jokes, for many a joke had he;

Full well the busy whisper, circling round,

Conveyed the dismal tidings when be frowned;

Yet he was kind, or if severe in aught,

The love he bore to learning was in fault;

The village all declared how mucls he knew,

'Twas certain he could write, and cipher too;

Lands he could measure, terms and tides presage;

And even the story ran, that he could guage :

In arguing too, the parson owned his skill,

For even though vanquished he could argue still ;

While words of learned strength, and thundering sound,

Amazed the gazing rustics ranged around;

And still they gazed, and still the wonder grew,

That one small head could carry all he knew.

But past is all his fame. The very spot

Where many a time he triumphed is forgot.

Near yonder thorn, that lifts its head on high, Where once the sign-post caught the passing eye,

Low lies that house where nut-brown draughts inspired,

Where gray-beard mirth, and smiling toil retired,

Where village statesmen talked with looks profound,

And news much older than their ale went round.

Imagination fondly stoops to trace

The parlour splendours of that festive place;

The white-washed wall, the nicely sanded floor,

The varnished clock that clicked behind the door;

'The chest, contrived a double debt to pay,

A bed by night, a chest of drawers by day;

The pictures placed for ornament and use,

The twelve good rules, the royal game of goose;

The hearth, except when winter chilled the day,

With aspen boughs, and flowers and fennel gay;

While broken tea-cups, wisely kept for show,

Ranged o'er the chimney, glistened in a row.

Vain transitory splendour ! could not all

Reprieve the tottering mansion from its fall ?

Obscure it sinks, nor shall it more impart

An loour's inportance to the poor man's heart:

Thither no more the peasant shall repair,

To sweet oblivion of bis daily care ;

No more the farmer's news, the barber's tale,

No more tlue woudman's ballad, shall prevail; 
No more the smith his dusky brow slıall clear,

Relax his ponderous strength, and lean to hear;

The host himself no longer shall be found

Careful to see the mantling bliss go round;

Nor the coy maid, half willing to be prest,

Sluall kiss the cup to pass it to the rest.

Yes! let the rich deride, the prond disdain, 'These simple blessings of the lowly train,

To ine inore dear, congenial to my heart, Oıe uative cliarin, than all the gloss of art ; Spontaneous joys, where nature has its play, The soul adopts, and owns their first-burn sway:

Lightly they frolic o'er the vacant inind, Unenvied, unmolested, unconfined.

But the long pomp, the midnight masquerade, With all their freaks of wanton wealth arrayed, In these, ere triflers half their wish obtain, The toiling pleasure sickens into pain; And, even while fashion's brightest arts decoy, Tlie heart distrusting asks, if this be joy?

Ye friends to truth, ye statesmen, who survey The rich man's joys increase, the poor's decay, 'Tis yours to judge, how wide the limits stand Between a spleudid and a happy land.

Proud swells the tide with loads of freighted ore, And shouting Folly hails them from her shore; Hoards, even beyond the miser's wish, abound, And rich men flock from all the world around.

Yet count our gains. This wealth is but a name That leares our useful product still the same.

Not so the luss. The man of wealth and pride Takes up a space that many poor supplied; Space for his lake, his park's extended bounds, Space for his horses, equipage, and hounds; The robe that wraps his limbs in silken sloth, IIas rubbed the neighbouring fields of half their growth; His seat, where solitary sports are seen, Indignant spurns the cottage from the green: Around the world each needful product flies, For all the luxuries the world supplies.

While thus the land adorned for pleasure, all In barren splendour feebly waits the fail:

As some fair female unadorned and plain, Secure to please while youth confirms her reign, Slights every borrowed charm that dress supplies, Nor shares with art the triumph of her eyes;
But when those charms are past, (for charms are frail,) When time advances, and when lovers fail, She then shines furth, solicitous to bless, In all the glaring inpotence of dress. Thus fares the land by luxury betrayed, In nature's sinplest charms at first arrayed, But verging to decline, its splendours rise, Its vistas strike, its palaces surprise; While senurged by famine from the smiling land, The mournful peasant leads his humble band; And while he sinks, without one arm to save, The conntry blooms - a garden and a grave.

Where then, ah! where shall poverty reside, To 'scape the pressure of contiguous pride? If to some commuı's fenceless linits strayed, He drives his flock to pick the scanty blade, Those fenceless fields the sons of wealth divide, And even the bare-worn common is denied.

If to the city sped-what waits him there? To see profusion that he must not share; To see ten thousand baneful arts combined To pamper luxury and thin mankind; To see eacli joy the sons of pleasure know Extorted from his fellow creature's woe. Here, while the courtier glitters in brocade, There the pale artist plies the sickly trade; Here, while the proud their long drawn pomps display, There the black gibbet glooms beside the way: The dune where Pleasure holds her midnight reign, Here, richly decked, admits the gorgeous train; Tumultuous grandeur crowds the blazing square, The rattling chariots clash, the torches glare. Sure scenes like these no troubles e'er annoy! Sure these denote one universal joy! Are these thy serious thoughts? $-\boldsymbol{\Lambda} \mathrm{h}$, turn thine eyes Where the poor houseless shivering fernale lies. She once, perhaps, in village plenty blest, Has wept at tales of innocence distrest; Her inodest looks the cuttage might adorn, Sweet as the primrose peeps beneath the thorn; Now lost to all; har friends, her virtue fled, Near her betrayer's dour she lays her liead; And, pinched with cold, and shrinking from the shower, Witl heavy heart deplores that luckless hour, When idly first, ambitious of the town, She left her wheel, and robes of country brown. 
Do thine, sweet Auburn, thine the lovelicst train,

Do thy fair tribes participate her pain?

Even now, perhaps, by cold and hunger led, At proud men's doors they ask a little bread !

Ah, no. To distant climes, a dreary scene,

Where half the convex world intrudes between,

Tlırough torrid tracks with failting steps they go,

Where wild Altama inurmurs to their woe.

Far different there from all that charmed before,

The various terrors of that horrid shore;

Those blazing suns that dart a downward ray,

And fiercely shed intolerable day ;

Those matted woods where birds forget to sing,

But silent bats in drowsy clusters cling;

Those poisonous fields with rank luxuriance crowned,

Where the dark scorpion gathers death around;

Where at each step the stranger fears to wake

The rattling terrors of the vengeful snake;

Where crouching tigers wait their hapless prey,

And savage men more murderous still than they;

While oft in whirls the mad tornado flies,

Mingling the ravaged landscape with the skies.

Far different these from every former scene,

The cooling brook, the grassy-vested green,

The breezy covert of the warbling grove,

That only sheltered thefts of harmless love.

Good heaven! what sorrows gloomed that parting day,

That called thein from their native walks away;

When the poor exiles, every pleasure past,

Hung round the bowers, and fondly looked their last,

And took a long farewell, and wished in vain

Fur seats like these beyond the western main;

And, shuddering still to face the distant deep,

Returned and wept, and still returned to weep.

The good old sire, the first prepared to go

To new-found worlds, and wept for others' woe ;

But for himself, in conscious virtue brave,

He only wished for worlds beyond the grave.

His lovely daugliter, lovelier in her tears,

The fond companion of his helpless years,

Silent went next, neglectful of her cliarns,

And left a lover's for a father's arms.

Witlı louder plaints the mother spoke her woes,

And blessed the cot where every pleasure rose;

And kissed her thoughtless babes with many a tear,

And clasped them close, in sorrow donbly dear;

Whilst her fond lusband strove to lend relief
In all the silent manliness of grief.

0 , luxury ! thou cursed by heaven's decree, How ill exchanged are things like these for thee !

Haw do thy potions, with insidions joy,

Diffuse their pleasures only to destroy !

Kingdoms by thee, to sickly greatuess grown,

Boast of a florid vigour not their own.

At every draught large and more large they grow,

A bloated mass of rank unwieldy woe;

Till sapped their strength, and every part unsound,

Down, down they sink, and spread a ruin round.

E'ell now the devastation is begun,

And half the business of destruction done;

E'en now, methinks, as pondering here I stand,

I see the rural virtues leave the land.

Down where yon anchoring vessel spreads the sail,

That idly waiting flaps with every gale,

Downward they move, a melancholy band,

Pass from the shore, and darken all the strand.

Contented toil, and hospitable care,

And kind connubial tenderness, are there;

And piety, with wishes placed above,

And steady loyalty, and faithful love.

And thou, sweet poetry, thou loveliest maid,

Still first to fly where sensual joys invade;

Unfit, in these degenerate times of shame,

To catch the heart, or strike for honest fame;

Dear charming nymph! neglected and decried,

My shame in crowds, my solitary pride.

Thou source of all my bliss, and all my woe,

That found'st me poor at first, and keep'st me so;

Thon guide, by which the nobler arts excel,

Thon nurse of every virtue, fare thee well;

Farewell, and $O$ ! where'er thy voice be tried,

On Torno's cliffs, or Pambamarca's side,

Whether where equinoctial fervours glow,

Or winter wraps the polar world in snow;

Still let thy voice, prevailing over time,

Redress the rigours of the inclement clime;

Airl slighted truth, with thy persnasive strain;

Teach erring man to spurn the rage of gain ;

Teach him, that states of native strength possessed,

Though very poor, may still be very blessed;

That trade's proud empire hastes to swift decay,

As ocean sweeps the laboured mole away;

While self-dependent power can time defy,

As rock resist the billows and the sky. 


\section{THE}

\section{I I III If:}

\section{OR, \\ EDWIN AND ANGELINA.}

- TURN, gentle hermit of the dale,

And guide my lonely way,

To where yon taper cheers the vale

With hospitable ray :

- For here forlorn and lost I tread,

With fainting steps and slow;

Where wilds immeasurably spread,

Seem lengthening as I go.'

- Forbear, my son,' the Hermit cries,

- To tempt the dangerous gloom;

For yonder faithless phantom flies

To lure thee to thy doom.

- Here to the houseless child of want

My door is open still;

And though my portion is but scant,

I give it with good will.

'Then turn to-night, and freely share

Whate'er my cell bestows;

My rushy couch and frugal fare,

My blessing and repose.

- No flocks, that range the valley free,

To slaughter I condemn;

Taught by that power that pities me,

I learn to pity them:
' But from the mountain's grassy side

A guiltless feast I bring;

A scrip with herbs and fruits supplied,

And water from the spring.

' Then, pilgrim, turn, thy cares forego ;

All earth-born cares are wrong :

Man wants but little here below,

Nor wants that little long.?

Soft as the dew from heaven descends,

His gentle accents fell :

The modest stranger lowly bends,

And follows to the cell.

Far in a wilderness obscure

The lonely mansion lay;

A refuge to the neighbouring poor,

And strangers led astray.

No stores beneath its humble thatch

Required a master's care;

The wicket, opening with a latch,

Received the harınless pair.

And now, when busy crowds retire

To take their evening rest,

The Herınit trimmed his little fire,

And cheered his pensive guest; 
And spread his vegetable store,

And gayly pressed and smiled;

And, skilled in legendary lore,

The lingering hours beguiled.

Around in sympathetic mirth,

Its tricks the kitten tries;

The cricket chirrups in the hearth,

The crackling faggot flies.

But nothing could a charm impart

To sooth the stranger's woe;

For grief was licavy at his heart,

And tears began to flow.

His rising cares the Hermit spied,

With answering care opprest :

'And whence, unhappy youth!' he cried,

' The sorrows of thy breast ?

' From better habitations spurned,

Reluctant dost thou rove:

Or grieve for friendship unreturned,

Or unregarded love?

'Alas! the joys that fortune brings,

Are trifing, and decay;

And those who prize the paltry things,

More trifling still than they.

- $A$ d what is friendship but a name,

A charm that lulls to sleep;

A shade that follows wealth or fame,

And leaves the wretch to weep?

- And love is still an emptier sound,

The modern fair-one's jest ;

On earth unseen, or only found

To warm the turtle's nest.

'For shame, fond youth! thy sorrows hush,

And spurn the sex!' he said :

But while he spoke, a rising blush

His love-lorn guest betrayed.

Surprised he sees new beauties rise,

Swift mantling to the view,

Like colours o'er the morning skies,

As bright, as transient too.
The bashful look, the rising breast, Alternate spread alarns:

The lovely stranger stands confest A maid, in all her charms.

'And, al, forgive a stranger rude, A wretch forlorn,' she cried;

- Whose feet unlalluwed thus intrude Where lieaven and you reside!

- But let a maid thy pity share, Whom love has taught to stray ; Who seeks for rest, but finds despair

Companion of her way.

'My father lived beside the Tyne,

A wealthy lord was he;

And all his wealth was marked as mine,

He had but only me.

- To win me from his tender arms, Unnumbered suitors came ;

Who praised me for imputed charms,

And felt, or feigned a flame.

' Each hour a mercenary crowd

With richest proffers strove :

Among the rest young Edwin bowed,

But never talked of love.

' In humble, simplest habit clad,

No wealth or power had he:

Wisdom and worth were all he had,

But these were all to me.

- The blossom opening to the day,

The dews of heaven refined,

Could nought of purity display,

To emulate his mind.

'The dew, the blossoms of the tree,

With charms inconstant shine;

Their charms were his, but, woe to me!

Their constancy was mine.

- For still I tried each fickle art,

Importunate and vain;

And while his passion touched my heart,

I triumphed in his pain : 
' Till, quite dejected with my scorn, He left me to my pride;

And sought a solitude forlorn

In secret, where he died.

But mine the sorrow, mine tlie fault, And well my life shall pay;

I'll seek the solitude be sought, And stretch me where he lay.

'And there forlorn despairing hid, I'll lay me down and die:

'Twas so for me that Edwin did, And so for him will I.'

'Forbid it, heaven!' the Hermit cried, And clasped her to his breast;
The wondering fair one turned to chide:

'Twas Edwin's self that prest.

- Turn, Angelina, ever dear,

My charmer, turn to see

Thy own, thy long-lost Edwin here,

Restored to love and thee.

- Thus let me hold thee to my heart, And every care resign.

And shall we never, never part, My life-my all that's mine !

' No, never, from this hour to part ; We'll live and love so true, The sigh that rends thy constant heart, Shall break thy Edwin's too.' 


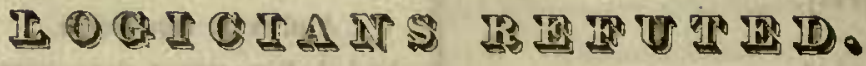

\author{
IN IMITATION OF DEAN SWIFT.
}

Logsctans have but ill defin'd

As rational the human mind :

Reason, they say, belongs to man,

But let them prove it if they can.

Wise Aristotle and Smiglesius,

By Ratiocinations specious,

Have strove to prove with great precision,

With difinition and division,

\section{Homo est ratione preditum;}

But for my soul I cannot credit 'em;

And must in spite of them maintain,

That man and all his ways are vain;

And that this boasted lord of nature ;

Is both a weak and erring creature.

That instinct is a surer guide,

Than reason-boasting mortals' pride;

And that brute beasts are far before 'em,

Deus est anima brutorum.

Whoever knew an honest brute,

At law his neighbour prosecute,

Bring action for assault and battery,

Or friend beguile with lies and flattery?

O'er plains they ramble unconfin'd,

No politics disturb their mind;

They eat their meals, and take their sport,

Nor know who's in or out at court :

They never to the levee go

To treat as dearest friend, a foe:

They never importune his grace,
Nor ever cringe to men in place;

Nor undertake a dirty job,

Nor draw the quill to write for Bob.

Fraught with invective, they ne'er go

To folks at Pater-noster-Row :

No judges, fiddlers, danciug masters,

No pick-pockets, or poetasters,

Are known to honest' quadrupeds;

No single brute lis fellow leads.

Brutes never meet in bloody fray,

Nor cut each other's throat for pay.

Of beasts, it is confess'd, the ape

Comes nearest us in human shape ;

Like man he imitates each fashion,

And malice is his ruling passion :

But both in malice and grimaces,

A courtier any ape surpasses.

Behold lsim humbly cringing wait

Upon the minister of state:

View him soon after to inferiors

Aping the conduct of superiors :

He promises with equal air,

And to perform takes equal care.

He in his turn finds imitators ;

At court, the porters, lackeys, waiters,

Their master's manners still contract,

And footmen lords and dukes call act.

Thus at the court, both great and small,

Behave alike, for all ape all. 


\section{ESS A Y S.}

\section{ESSAY I.}

\section{$\mathbf{T}$} is no easy matter to shake off. My little beau yesterday overtook me again in one of the public walks, and slapping me on the shoulder, saluted me with an air of the most perfect familiarity. His dress was the same as usual, except that he had more powder in his bair, wore a dirtier shirt, and had on a pair of temple spectacles, with his hat under his arm.

As I knew him to be an harmless amusing little thing, I could not return bis smiles with any degree of severity; so we walked forward on terms of the utmost intimacy, and in a few minutes discussed all the usual topics of a general conversation.

The oddities that marked his character, however, soon began to appear: he bowed to several well-dressed persons, who, by their manner of returning the compliment, appeared perfect strangers. At intervals he drew out a pocket-book, seeming to take memoranduins before all the company, with much importance and assiduity. In this manner be led me through the length of the whole Mall, fretting at his absurdities, and fancying mygelf laughed at, as well as he, by every spectator.

When we were got to the end of our procession, he cried, with an air of vivacity, - I never saw the Park so thin in my life before; there's no company at all to-day. Not a single face to be seen.' 'No company!' interrupted I, peevishly; ' no company, where there is such a crowd! Why, man, there is too much. What are the thousands that have been laughing at us but company!" 'Lord, my dear,' returned le, with the utmost No. $73 \& 74$. good humour, 'you seem immensely chagrined; when the world laughs at me, I laugh at the world, and so we are even. My lord Trip, Bill Squash the Creolian, and I, sometimes make a party ai being ridiculous. But I see you are grave; so if you are for a fine grave sentimental companion, you shall dine with my wife; I must insist on't; l'll introduce you to Mrs. Tibbs, a lady of as elegant qualifications as any in nature; she was bred, but that's between ourselves, under the inspection of the countess of Shoreditch. A charming body of voice! But no more of that, she shall give us a song. You shall see my little girl too, Carolina Wilhelmina Amelia Tibbs, a sweet pretty creature! I design her for my lord Drumstick's eldest son; but that's in friendship, let it go no farther; she's but six years old, and yet she walks a minuet and plays on the guittar immensely already. I intend she shall be as perfect as possible in every accomplishment. In the first place, l'll make her a scholar; I'll teach her Greek myself, and I intend to learn that language purposely to instruct her; but let that be a secret.'

Thus saying, without waiting for a reply, he took me by the arm, and hauled me along. We passed through many dark alleys and winding ways. From some motives to me unknown, he seemed to have a particular aversion to every frequented street; but, at last, we got to the door of a dismal looking house in the outlets of the town, where be informed me he chose to reside for the benefit of the air.

We entered the lower door, which seemed ever to lie most hospitably open; and began $6 \mathrm{C}$ 
to ascend an old and creaking staircase; when, as he inounted to show me the way, he demanded, whether I delighted in prospects; to which, answering in the affirmative, 'Then," says he, "I shall show you one of the most charming out of my windows, for 1 live at the top of the house; we shall see the ships sailing, and the whole country twenty miles round, tip top, quite high. My lord Swamp would give ten thousand guinens for such a one; but, as I sometimes pleasantly tell him, I always love to keep my prospects at home, that niy friends may come to see me the oftener.'

By this time we were arrived as high as the stairs would permit us to ascend, till we caine to what he was facetiously pleased to call the first floor down the chimney; and knocking at the door, a voice, with a Scotch accent, from within, demanded, 'Wha's there.' My conductor answered, that it was him. But this not satisfying the gnerist, the voice igain repented the demand; to which he answered louder than before, and now the loor was opened by all old maid-servant, with cautious reluctance.

When we were got in, he weleomed me to his liouse with great ceremony, and tuming to the old woman, asked where lier lady was. 'Good troth,' replied she in the northern dialect, "she's washing your twa shirts at the jext door, becanse they have taken all oath against lending ont the tub any longer.' 'My two slints!' cried be, in a tone that fallered witl, confusion, "what does the idiot mean?" 'I ken what I mean well enough,' replied the other, she's washing your twa shirts at the next door, because'- "Fire and fury, no more of thy stupid explanations,' cried he.-Go and inform lier we have got company. IVere that Scotch hag, continued he, turning to me, - to be for ever in my family, she would never learis politeness, nor forget that absurd poisomnis accent of her's, or testify the smallest specimen of breediug or high-life; and yet. it is very surprising too, as I bal her from a parliament-man, a friend of mine from the Highlands, one of the politest men in the world; lout that's a secret.

We waited some time for Mrs. Tibb's arrival, during which interval I liad a full opportunity of surveying the chamber and all its furniture; which consisted of four chairs with old wrought bottoms, that he assured me were his wife's embroidery; a square table that had been once japanned, a cradle in one corner, a lumbering cabinet in the other; " broken shepherdess, and a maudarine without a head, were stuck over the chimney; and round the wall several paltry, unframed pictures, which he observed were all his own drawing: "What do you think, Sir, of that head in the corner, done in the inamner of Grisoni? There's the true keeping in it; it's my own face; and, though there happens to be no likeness, a countess offered me a hundred for its fellow: I refused her, for hang it. that would be mechanical you know.'

The wife, at last, made her appearance; at once a slattern and a coquet; much emaciated, but still carrying the remains of beanty. She made twenty apologies for being seen in such an odious dishabille, but hoped to be excused, as she had staid out all night at Vauxhall Gardens with the countess, who was excessively fond of the horns. "And indeel, my dear, added slse, turuing to her husband, "his lordship drank your health in a bumper.' 'Poor Jack, cries lie. 'a dear good natured creature, I know he loves me; but I hope, my dear, you have given orders for diuner; you need make no great preparation neither, there are but Hree of us; something elegant, and a little will do; a turbot, an ortolan, or a-' "Or what do you think, my dear, interrupts the wife, 'of' a nice pretty bit of ox-clueek piping loot, and

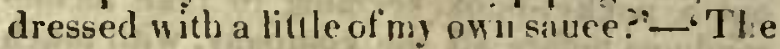
very thing,' rejlies he; 'it will eat best with some smait bottled beer; hut be sure to let's have the sauce his grace was so foud of. I bate your immense loads of meat; that is country all over: extreme diserusling in ilinse. who are in the least acquainted with figh-tifi.'

By this lime ny curiosity hegan to alater, and iny appretite to increase; the company of fonls may at first make us smile, hut int last wever tinils of rendering us miplancholy. I therefore pretended to peculiect a jrior allgagrinent, ald. after having shown my respect in the house, by giving the old servant a piece of money at the foor, I took my leave; Mrs. Tibbs assurlug me, that dinner, if lstaid, would be ready at least in less than two liours. 


\section{ESSAY II.}

AGE, that lossens the enjoyment of life, increases our desirc of living. Thuse dangers which, in the vigour of youth, we had learned to despise, assume new terrors as we grow old. Our caution increasing as our years increase, fear becomes at last the prevailing passion of the mind; and the small remainder of lite is taken up in useless efforts to kcep off our end, or provide for a contivesed existence.

Strange contradiction in our nature, and to which even the wise are liable! If I should judge of that part of life which lies before me by that which I have already seen, the prospect is hideous. Experience tells me, that my past enjoyments have brought no real felicity; and sensation assures me, that those I have felt are stronger than those which are yet to come. Yet experience and sensation iII vain persuade; hope, more powerful than either, dresses out the distant prospect in fincied beauty ; some happiness, in long perspective, still beckons me to pursue; and, like a losing gamester, every new disappointment ilscreases my ardour to continue the game.

Whence then is this increased love of life, which grows upon us with our years; whence comes it, that we thus make greater efforts to preserve our existence, at a period when it becomes scarce worth keeping? Is it that nature, attentive to the preservation of mankiud, increases our wishes to live, while slse lessens our enjoyments; and, as she robs the senses of every pleasure, equips imagination in the spoils? Life would be insupportable to an old man; who, loaded with infirmities, feared death no more than when in the vigour of manhood; the numberless calamities of decaying nature; and the consciousness of surviving every pleasure, would at once induce him, with his own hand, to terminate the scene of misery; but happily tie con-
Imint of deatl forsakes lim at a time when it could only be prejudicial; and lile requires an imaginary value, in proportion as its real value is no more.

Our attachment to every olrject around us increascs, in general, firom the length of our acpuaintance with it. 'I would not choose? says a French philosopher, 'to see an old post pulled up with which I had been long acquainted.' A mind long habituated to a certain set of objects, insensibly becomes fond of seeing them; visits them from babit, and parts from them with reluctance: from hence proceeds the avarice of the old in every kind of possession; they love the world and all that it produces; they love life and all its advantages; not because it gives them pleasure, but because they have known it long.

Chinvang the Chaste, ascending the throne of China, commanded that all who were unjustly detained in prison, during llue preceding reigns, should be set free. Among the number who came to thank their deliverer on this occasion, there appeured a majestic old man, who, falling at the emperor's feet, addressed him as follows: "Great father of China, behold a wretch, now eighty-five years old, who was shut up in a dungeon at the age of twenty-two. I was imprisoned, though a stranger to crime, or without being even confronted by my accusers. I have now lived in solitude and darkness for more than fifty years, and am grown familiar with distress. As yet. dazzled with the splendour of that smin to which you have restored me, I have been wandering the streets to find out some mence that would assist, or relieve, or remember nie: but my friends, my family, and relations, are all dead, and I am forgotten. Permit me then, $O$ Chinvang, to wear out the wretched remains of my life in former prison; the walls of my dungeon are to me more pleasing than 
the most splendid palace: I have not long to live, and shall be uuhappy except I spend the rest of my days where my youth was passed, in that prison from whence you were pleased to release me.

The old man's passion for confinement is similar to that we all have for life. We are habituated to the prison, we look round with discontent, are displeased with the abode, and yet the length of our captivity ouly increases our fonduess for the cell. The trees we have planted, the houses we have built, or the posterity we have begotten, all serve to bind us closer to the earth, and embitter our parting. Life sues the young like a new acquaintance; the companion, as yet unexhausted, is at once instructive and amusing; its company pleases, yet, for all this, it is but little regarded. To us, who are declined in years, life appears like an old friend; its jests have been anticipated in former conversation: it has no new story to make us smile, no new improvement with which to surprise, yet still we love it; destitute of every enjoyment, still we love it; husband the wasting treasure with increasing frugality, and fecl all the poignancy of anguish in the fatal separation.
Sir Plilip Mordaunt was young, beautiful, sincere, brave, an Englishman. He had a complete fortune of his own and the love of the king his master, which was equivalent to riches. Life opened all her treasures before hinı, and promised a long suecession of happiness. He came, tasted of the entertainnent, but was disgusted even at the beginning. He professed an aversion to living; was tired of walking round the same circle; had tried every enjoyment, and found them all grow weakel' at every repetition. 'If life be in youth so displeasing,' cried he to himself, ' what will it appear when age comes ou; if it be at present indifferent, sure it will then be exesrable.' This thought embittered every reflection; till, at last, with all the serenity of perrerted reason, he ended the debate with a pistol. Had this self-deluded man been apprized, that existence grows more desirable to us the longer we exist, he would have then faced old age without shriuking! he would have boldly dared to live; and served that society, by his future assiduity, which he basely injured by his desertion.

\section{ESSAY III.}

\section{THE STORY OF ALCANDER AND SEPTIMIUS.}

ATHENS, long after the decline of the Roman empire, still coutinued the seat of learning, politeness, and wisdom. Theodoric, the Ostrogoth, repaired the schools which barbarity was suffering to fall into decay, and continuel those pensions to men of learning, which avaricious governors bad monopolized.

In this city, and about this period, Alcander and Septimius were fellow-students together. The one, the most subtle reasoner of all the Lyceum; the other, the most eloquent speaker in the academic grove. Mutual admiration soon begot a friendship. 'Their fortunes were nearly equal, and they were natives of the most celebrated cities in the world; for Alcander was of Athens, Septimius came from Rome.

In this state of harmony they lived for some time torgether, when Alcander, after passing the first part of his youth in the indolence of philosophy, thought at length of entering into the busy world; and, as a step previous to this, placed his affections on Hypatia, a lady of exquisite beauty. The day of their intended nuptials were fixed; the previous cereinonies were performed; and nothing now remained but her being conducted in triumph to the apartment of the intended bridegroom.

Alcander's exultation in his own happiness, or being unable to enjoy any satisfaction without making his friend Septimius a partner, 
prevailed upon him to introduce Hypatia to his fellow-student; which he did with all the gayety of a man who found himself equally happy in fiendship and love. But this was an interview fatal to the future peace of both: for Septimius no sooner saw her, but he was smitten with an involuntary passion; and, though he used every effort to suppress desires at once so imprudent and minust, the emotions of his inind in a short time became so strong, that they brought on a fever, which the physicians judged incurable.

During this illuess, Alcander watched him with all the anxiety of fondness, and brought his mistress to join in those amiable oflices of friendship. The sagacity of the physicians, by these means, soon discovered that the cause of their patient's disorder was love; and Alcauder being apprized of their discovery, at length extorted a confession from the reluctant dying lover.

It would but delay the narrative to describe the conflict between love and friendship in the breast of Alcander on this occasion; it is enongh to say, that the Athenians were at that time arrived at such refinenent in morals, that every virtue was carried to excess. In short, forgetful of his own felicity, he gave up his intended bride, in all her charms, to the young Roman. They were married privately by his connivance, and this unlooked for change of fortune wrought as unexpected a change in the constitution of the now happy Septimius, In a few days he was perfectly recovered, and set out with his fair partner fol Rame. Here, by an exertion of those talents whicl he was so eminently possessed of, Septimius in a few years arrived at the highest dignities of the state, and was constituted the city-judge or prætor.

In the meau time Alcander not only felt the pain of being separated from his friend and his mistress, but a prosecution was also commeneed against him by the relations of Hypatia, for having basely given up his bride, as was suggested, for money. His innocence of the crime laid to his charge, and even his eloquence in his owı defence, were not able to withstand the influence of a powerful party. He was cast ancl condemued to pay an enormous fine. Ilowever, being unable to raise so large a sum at the line appointed, his possessions were confiscated, he himself was stripped of the hatit of freedom, exposed as a slave in the market-place, and sold to the highest bidder.

A merchant of "Thrace becoming his purchaser, Alcander, with some other companions of distress, was carried into that region of desolation and sterility. His stated $\mathrm{cm}$ ployment was to follow the herds of an imperious master, and his success in hunting was all that was allowed hin to supply his precarious subsistence. Every morning waked him to a renewal of faniue or toil, and every change of season served but to agyravate his unsheltered distress. After some years of bondage, however, an opportunity of escaping offered; he embraced it with ardour; so that travelling by night, and lodging in caverns by day, to shorten a long story, be at last arrived in Rome. The same day on which Alcauder arrived, Septimius sate administering justice in the forum, whither our wanderer came, expecting to be instantly known, and publicly acknowledged, by his former friend. Here lie stood the whole day among the crowd, watching the eyes of the judge, arid expecting to be taken sotice of; but he was so mucli altered by a long succession of hardships, that he continued unnoted among the rest; and in the evening, when he was going up to the prætor's chair, he was hrutally repulsed by the attending lictors. The attertion of the poor is generally driven from one ungrateful object to another; for uight coming on, he now found himself under a necessity of seeking a place to lie in, and yet knew not where to apply. All emaciated, and in rags as he was, none of the citizens would harbour so much wretchedness; and sleeping in the streets might be attended with interruption and danger: in short, he was obliged to take up his lodging in one of the tombs without the city, the usual retreat of guilt, poverty, asd despair. In this mansion of horror, lay. ing his head upon an inverted urn, he forgot his miseries for awhile in sleep : and found, oll bis flinty couch, more case than beds of down can supply to the guily.

As he continued here, about milinght, two robbers came to make this their retrent; but happening to disagree about the division of their plunder, one of them stabbed the other 
(1) the heart, and left him weltering in his biond it the entrance. In these circumstances he was found next morning dead at the month of the vault. This naturally induring a further iligury, an a!am was splond the cave, was rximined; and Alcanfler being fouml, was jilmediately apprehended and accused uf rohhery and murder. The circumstances against hin were strong, and the wretcheducss of his appearance confirmed suspicion. Misfortune ant he were now so long actuainted, that he at last became regardless of life. He detestcd a world where he had found ouly ingratitude, filselıond, and crueliy; he was determined to make no rlefence; and ums lowering with resolution, he was dagged, bound with cords, before the tribunal of Septimius. As the proofs were positive against him, and lie offered nothing.in his own vindication, the judge ivas proceeding to doom lium to a most cruel and ignominious death, when the attention of the multitude was soon divided by another olject. The rubber, wi:o had been really guily, was apprehended sclling his plunder, ant, struek with a paric, had ionlissed his crime. He nas brought bonud to the same tribunal, and acquited eren wher persun of ally parmership in lis guili. Alcander's inmocence therefore appeared, hut the sullon rashness of his conduft ronainf a wombler to the surrounding numbitule; but their astonishunent $w$ as still lurther increased, wheu thry saw there judge start from his tribunal to embrace the supposed criminal: S'ptimius recollected his friend and former bencfactor, and hung upon his neck with tears of pity and joy. Nerd the srquel be related; Alcander was acquitted; shared the fricudship and honours of the principal citizens of Rome; lived afterwards in happiness and ease; and left it to be engraved on his tomb, That no circumstances are so desperate, which Providence may not relieve.

\section{ESSAY IV.}

WHEN I reflect on the unambitious retirement in which I passed the earlier part of my life in the country, I cannot avoid feeling some pain in thinking that those happy days are never to return. In that retreat all nature seemed capable of affording pleasure; 1 then made no refinements on happiness, but could be pleased with the inost awkward efforts to rustic mirth; thought cross-purposes the highest stretch of human wit; and questions and commands the most rational way of spending the evening. Happy could so charming an illusion still continue! I find that age and kuoviledge only contribute to sour our dispositions. My present enjoyments may be more refined, but they are infinitely less pleasing. The plcasure the best actor gives, can no way collpare to that I have received froni a country wag who imitated a quaker's sermon. The music of the finest singer is dissonance to what I felt when our old dairy-maid sung me into tears with Johnny Armstrong's Last good night, or the Cruelty of Barbara Allen.
Writers of every age have endeavoured to show that pleasure is in us, and not in the objects offered for our amusement. If the soul be happily disposed, every thing becomes capable of affording entertainment; and distress will always want a name. Every occurrence passes in review like the figures of a procession ; some may be awkward, others ill dressed; but none but a fuol is for this enraged with the master of the ceremonics.

I remember to have once seen a slave in a fortification in Flanders, who appeared no way touched with his situation. He was maimed, deformed, and chained obliged to toil from the appearance of day till night-fall, and condemned to this for life: yet with all these circumstances of apparent wretchedness, he sung, would have danced, but that he wanted a leg, and appeared the merriest, happiest man of all the gartison. What a practical philosopher was here; an liappy consticuion supplied philosophy; and though seemingly destitute of wisdom, he was really wise. No reading or study had contributed to disenchant 
the fairy-land aromud hin. Every thing furnished him with an opportunity of mirth; and though some thought him, from his insensibility, a fool, he was such an illiot as philosophers should wish to imitute; for all philosophy is only forcing the trade of happiness, when nature seems to deny the means.

They who, like our slaves, can place themselves on that side of the world in which every thing appears in a pleasing light, will find something in every occurence to excite their good humour. Tilie inost calamitons events, either in themselves or others, cau bring no new affliction! the whole world is to them a theatre, on which comedies ouly are acted. All the bustle of heroism, or the rants of ambition, sclve only to heighten the absurdity of the scene, and make the humour more poigmant. 'They feel, in short, as liule anguish at their "wn distress, or the complaints of others, as the undertaker, though dressed in black, fieels sorrow at a funcral.

Of all the men I ever read of, the famous cardinal de lies possessed this happliness of teuper in the highest degrce. As lic was a man of gallantry, and despised all that wore the polanric appeartuce of philosophy, whereevel pleasure wiss to be solil, be was generally foremost to raise the auction, Being an universal alunirer of the hir six, when be found one lady cruel, be generally fell in love with another, from who.n he expected a more favinurable reception : if she too rejected his addresses, he never thought of reciring into desarts, or pining in hopeless distress. He persuaded li mself, that, instead of loving the lady, lee only lancied that he had loved her, and so all was well again. When fortune wore he: angriest look, he at last liell into the power of his most deally enemy, cardinal Mazarine, (being confincel a close prismer in the custle of Villencirnas s, he never attempted w supp. Me his distress hy wisdon or philosoplyy, for he presended to ricinher. He only laughed ut limself inul his persecuor, and seemorl iufinitely pleased at his new sifuation. In this mansion of ilistress, though secluded liom his firments, thounil denied all the amusements, and evern the cinveniences of life, he still retained his guat humour: laughed at all the little spire of his euture; alst carried the jest so far, as to be revenged, by writing the life of his gater.

All that the in isom of the proud can teach, is to be stubborn or sullen under misfortunes. The cardiual's rxample will instruct us to be merry in circumstances of the lighest afflictiou. It matters not whether our good humour be constiued by others into insensibility, or even idiotism; it is happiness to ourselves, and none hut a foul would measure his satisfaction by what the world thinks of it ; for my own part, I never pass by one of our prisons for debr, that I do not enry that felicity which is still going forward anong those people who forget the cares of the world by being sliut out firoun its ambition.

The happiest silly fellow I ever knew, was of the number of these good-naturid creatures that are said to do no harm to any but themselves. Whenever he fell into any misery, lie usually called it, Sceing Lic. If lis head was broke by a chairman, or his pocket picked by a sharper, he conforted hinseli hy imilating the Hibernian dialect of the one, or the more fashomable cant of the other. Nothing came amiss to him. His inattention to money matters had iucensed his father to such a degrer, that all the intercession of his fiends in his firvour was fruirless. Tine old gemeloumin wins on his deall-bed. 'The whole founily, and Dick anong the number, gathered around him. 'I leave iny second son, Andrew, said the expiring miser, 'my whole estate, and de'sire hinı to be frugal.' Andrew, in a solrowful tone, as is usual on these occasions, praycd Heaven to prolong his life and health to enjoy it himself: "I recommend Simon, my thind 'son, to the care of his eller bromber, and leav. 'hin beside four thousand pounds.' 'Ah! 'father,' cried Simou, (iu great affliction to by: sure) 'May heaven give you life and lowalu 'to enjoy it yourself? At last, turning to pon' Dick," As for you, you have always berol a sad "dug; you'll never come to gous!; you'll nevir 'be rich; l'Jl leave you a shilling to buy a l:al'tur.' 'Ah! father,' cries Dick, w illient any emulion, "may Heaven give you life and liealih

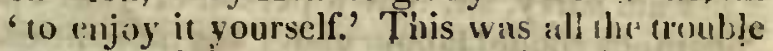
the loss of foptune gave this thrnglules immudent creature. Howevor, the tendemes of an uncle rccompensed the neglest of a father; and iny firiend is now not only excessively gruad humoured, but rompetemly lich.

Yes, let the wrorld cry out at a hankrupt who appears at a ball; at an author who linughs ut 
the public, which pronounces him a dunce; at a general who smiles at the reproach of the vulgar, or the lady who keeps lier goodlinuour in spite of scandal; but such is the wiscst behaviour that any of us can possibly assume; it is certainly a better way to oppose ealamity by dissipation, than to take up the arms of reason or resolution to oppose it : by the first method, we forget our miseries; by the last, we only conceal them from others; by struggling with misfortunes, we are sure to receive some wounds in the conflict; but a sure method to come off victorious, is by running away.

\section{ESSAY V.}

I AM fond of amusement in whatever company it is to be found; and wit, though dress. ed in rags, is ever pleasing to me. I went some days ago to take a walk in St. James's Park, about the hour in which company leave it to go to dinner. There were but few in the walks, and those who stayed, seemed by their looks rather more willing to forget that they had an appetite than gain one. I sat down on one of the benches, at the other end of which was seated a man in very shabby clothes.

We continued to groan, to hem, and to cough, as usual upon such occasions; and, at last, ventured upon conversation. 'I beg pardon, sir,' cried I, ' but I think I have seen you before; your face is familiar to me.' 'Yes, sir, replied he, 'I have a good familiar face, as my friends tell me. I am as well known in every town in England as the dromedary, or live crocodile. You must understand, sir, that I have been these sixteen years Merry Andrew to a puppet-show; last Bartholomew fair my master and l quarrelled, beat each other, and parted; he to sell his puppets to the pincushion-maker in Rosemary-lane, and I to starve in St. James's Park.

'I am sorry, sir, that a person of your appearance should labour under any difficulties.' ' $O$, sir,' returned he, ' $m y$ appearance is very much at your service; but though I cannot boast of eating much, yet there are few that are merrier: if $I$ had twenty thousand a year I should be very merry; and, thank the fates, though not worth a groat, I am very merry still. If I have three-pence in my pocket, I never refuse to be my three-laalf-pence; and, if I have no money, I never scorn to be treated by any that are kind enough to pay my reckoning. What think you, sir, of a steak and a tankard? You shall treat me now, and I will treat you again when I find you in the Park in love with eating, and without money to pay for a dinner.

As I never refuse a small expense for the sake of a merry companion, we instantly adjourned to a neighbouring alehouse, and, in a few moments, had a frothing tankard, and a smoking steak spread on the table before us. It is impossible to express how much the sight of such good cheer improved iny companion's vivacity. 'I like this dinner, sir,' says he, 'for three reasons; first, because I am naturally fond of beef; secondly, because I am hungry : and, thirdly and lastly, because I get it for nothing: no meat eats so sweet as that for which we do not pay.'

He therefore now fell to, and his appetite seemed to correspond with his inclination. After dinner was over, he observed, that the steak was tough: ' and yet, sir,' returns he, ' bad as it was, it seemed a rump-steak to me. $O$ the delights of poverty and a good appetite! We beggars are the very fondlings of nature; the rich she treats like an arrant step-ınother; they are pleased with nothing; cul a steak from what part you will, and it is insupportably tough; dress it up with pickles,-even pickles eannot procure them an appetite. But the whole creation is filled with good things for the beggar; Calvert's butt out-tastes Champaigne, and Sedgeley's home-brewed excels Tokay. Joy, joy, my blood, though our estates lie no where, we have fortunes wherever we go. If an inundation sweeps 
away half the grounds of Cornwall, I am content; I have no lands there: if the stocks sink, that gives me no uneasiness; I am no Jew.' The fellow's vivacity, joined to his poverty, I own, raised my curiosity to know something of his life and circumstances; and I entreated that he wonld indulge my desire. 'That I will, sir,' said he, 'and welcome; only let us drink to prevent our sleeping; let us have another tankard while we are awake: let us have another tankard; for, ah, how charming a tankard looks when full!

' You must know, then, that I am very well descended; my ancestors have made some noise in the world; for my mother cried ovsters, and my father beat a drum: I am told we have even had some trumpeters in our family. Many a nobleman cannot sliow so respectful a genealogy : but that is neither here nor there. As I was their only child, my father designed to breed me up to his own employment, which was that of a drummer to a puppet-sbow. 'Thus the whole employnent of iny younger years was that of interpreter to Punch and king Solomon in all his glory. But, though my father was very fond of instructing me in beating all the marches and points of war, 1 made no very great progress, because I naturally had no ear for music; so at the age of fifteen, I went and listed for a soldier. As I had ever hated beating a drum, so I soon found that I disliked carrying a musket also; neither the one trade nor the other were lo my taste, for I was by nature fond of being a gentleman: besides, 1 was obliged to obey my captain; he has his will, I have mine, and you have yours: now I very reasonably concluded, that it was much more comfortable for a man to obey his own will than another's.

- The life of a soldier soon therefore gave me the spleen; I asked leave to quit the service; but. as I was tall and strong, my captiiin thanked me for my kind intention, and said, becnuse he had a regard for me, we should not part. I wrote to my father a very dismal penitent letter, and desired he would raise money to pay for my discharge; but the good man was as fond of drinking as I was, (Sir, my service to yon.) and those who are fond of drinking never pay for other people's discharges: in short, he never answered my letter. What could be done? If I have not money, said I to myself, to pay for my discharge, I must find an equivalent some other way; and that must be by running away. I deserted, and that answered my purpose every bit as well as if I had bought my discharge.

'Well, I was now fairly rid of my military employment; I sold my soldier's clothes, and bought worse, and, in order not to be overtaken, took the most unfrequented roads possible. One evening, as I was entering a village, I perceived a man, whom I afterwards found to be the curate of the parish, thrown from his horse in a miry road, and almost smothered in the mud. He desired my assistance; I gave it, and drew him out with some difficulty. He thanked me for my trouble, and was going off; but I followed him home, for I loved always to have a man thank me at his own door. "The curate asked me an hundred questions; as, whose son I was, from whence I came, and whether I would be faitlful? I answered him greatly to his satisfaction; and gave myself one of the best characters in the world for sobriety, (Sir, I have the honour of drinking your health, discretion, and fidelity. To make a long story short, he wanted a servant, and hired me. With him I lived but two months; we did not much like each other; I was fond of eating, and he gave me but little to eat. I loved a pretty girl, and the old woman, my fellow-servant, was ill-natured and ugly. As they endeavoured to starve me between them, I made a pious resolution to prevent their committing murder: I stole the eggs as soon as they were laid; I emptied every unfinished bottle that I could lay my hands on; whatever eatable came in my way was sure to disappear: in short, they found I would not do : so I was discharged one morning, and paid three shillings and sixpence for two months' wages.

-While my money was getting ready, I employed myself in making preparations for my departure; two hens were hatcling in an out-honse, I went and habitually took the eggs, and, not to separate the parents from the children. I lodged hens and all in my knapsack. After this piece of frugality, I returned to receive ny money, and with my knapsack on my back, and a staff in my hand. I bid adieu, with tears in my eyes, to my old 
benefactor. I had not gone far from the house, when I heard behind me the cry of stop thief! but this only increased my despatch; it would have been foolish to stop, as I knew the voice could not be levelled at me. But liold, I think I passed those two months at the curate's without drinking: come, the times are dry, and may this be my poison if ever I spent two more pious, stupid montlss, in all my life.

-Well, after travelling some days, wliom should I light upou but a company of strolling players. The moment I saw them at a distance my heart warmed to them; I had a sort of natural love for every thing of the vagabond order: they were employed in settling their haggage, whirh had been overturned in a narrow way; I offered iny assistanee, which they accepted; and we soon became so well acquainted, that they took me as a servant. This was a paradise to me; they sung, danced, drank, eat, and travelled, all at the same time. By the blood of the Mirabels, I thought I had never lived till then; I grew as inerry as a grig, and laughed at every word that was spoken. They liked me as much as I liked them; I was a very good figure, as you see; and, though I was poor, I was not modest.

-I love a straggling life above all things in the world; sometimes good, sometimes bad; to be warm to-day, and cold to-morrow; to eat when one can get it, and drink when (the tankurd is out) it stands before me. We arrived that evening at Tenderden, and took a large room at the Grayhound; where we resolved to extribit Romeo and Juliet, with the funeral procession, the grave and the garden scene. Romeo was to be performed by a gentleman from the Theatre-Royal in Drury-lane; Juliet, by a lady who had never appeared on any stage before; and I was to snufr the candles: all excellent in our way. IVe had figures enough, but the difficulty was to dress them. The same coat that served Romeo, turned with the blue lining ontwards, served for his friend Mercutio: a large piece of erape sufficed at once for Juliet's petticoat and pall: a pestle and mortar, from a weighbouring apothecary's, answered all the purposes of a hell; and our landlord's own fanily, wrapped in white sleets, served to fill up the procession. In short, there were but three figures among us that might be said to be dressed with any propriety: I mean the nurse, the starved apothecary, and myself. Our performance gave universal satisfaction: the whole audience were enchanted with our powers, and Tenderden is a town of taste.

- There is one rule by which a strollingplayer may be ever secure of suecess; that is, in our theatrical way of expressing it, to Inake a great deal of the character. 'To speak and act as in common life, is not playing, nor is what people come to see: natural speaking, like sweet wine, runs glibly over the palate, and scarce leares any taste behind it; but being high in a part resembles vinegar, which grates upon the taste, and one feels it while he is drinking. To please the town or country, the way is, to ery, wring, cringe into attitudes, mark the emphasis. slap the pockets, and labour like one in the falling sickuess: that is the way to work for applause, that is the way to gain it.

- As we received mueh reputation for our skill on this first exhibition, it was but natural for me to ascribe part of the success to myself; I snuffed the caudles : and let me tell you, that, without a candle-snufier, the piece would lose half its embellishments. In this manner we continued a fortnight, and drew tolerable houses; but the evening before our intended departure, we gave out our very best piece, in which all our strength was to be exerted. We had great expectations from this, and even doubled our prices. when, behold, one of the principal actors fell ill of a violent fever. This was a stroke like thunder to our little company: they were resolved to go, in a hody, to scold the man for fitling sick at so inconvenient a time, and that too of a disorder that threatened to be expensive; I seized the moment, and offered to act the part myself in his stead. The case was desperate; they aecepted my offer ; and I accordingly sat down, with the part in iny hand and the tankard before me, (Sir, your liealth,) and studied the character, which was to be rehearsed the next day, and pliyed soon after.

I found my menory excessively helped hy drinking: I learnt my part with astonishing 
rapidity, and bid adieu to snuffing candles ever after. I found that nature had designed me for more noble employments, and I was resolved to take ber when in the humour. We got together in order to rehearse, and I informed iny companions, masters now no longer, of the surprising change I felt withiu me. Let the sick man, said 1 , be under 110 uneasiness to get well again; l'll fill his place to universal satisfaction : he may even die, if be thinks proper, l'll engage that he shall never he missed. I rehearsed before them, strutted, ranted, and received applause. They soon gave out that a new nctor of e:nituence was to appear, and immediately all the genteel places were bespoke. Before I ascended the stage, however, I concluded within myself, that, as I brought money to the house, I ought to have my share of the profits. Gentlensen, said I, addressing our company, I don't pretend to direct you; far be it from me to treat you with so much ingratitude; you have published my name in the bills with the utmost good nature; and as affairs stand, cannot act without me; so, gentlemen, to show you my gratitude, I expect to be paid for my acting as much as any of you, otherwise I declare off; I'll braudish my suuffers and clip candles as usual. This was a very disagreeable proposal, but they found that it was impossible to refuse it; it was irresistible, it was adamant: they consented, and I went on in king Bajazet: $m y$ frowning brows, bound with a stocking stuffed into a turban, while on my captived arms I brandished a jack-chain. Nature seemed to have fitted me for the part; I was tall, and hatl a loud voice, my very entrance excited universal applause; I looked round on the audience with a smile, and made a most low and graceful bow, for that is the rule among us. As it was a very passionate part, I inigrorated my spirits with three full glasses (the tankard is alinost out) of brandy. By Alla! it is almost inconceivalsle how I went through with it ; Tamerlane was but a fool to me, though he was sometimes loud enough too, yet Iivas still louder than lic; but, then, besides, I had attitudes in abundance: in gen ral I kept my arms folded up thus upon the pit of my stomach: it is the way at Druiy-lane, and has always a fine effect. The No. $75 \& 76$. tankard would sink to the bottom before I could get llirough the whole of my inerits. in short, I came off like a prodigy ; and, such was my success, that I could ravish the laurels even from a sirloin of beef. The principal gentlemen and liddies of the town came to me after the play was uver, to coinpliment me upon my success; onc praised my voice, another my person: upon my word, says the 'squire's lady, he will make one of the finest actors in Europe; I siny it, and I think I am something of a judge.-Praise in the beginning is agreeable enough, and we receive it as a favour; but when it comes in great quantities we regard it ouly as a debt, which nothing but our merit could extort: instead of thanking them, I internally applauded my self. We were desired to give our piece a second time; we obeyed, and I was applauded even more than before.

'At last we left the town, in order to be at a horse-race at some distance from thence. I shall never think of Tenderden witlout tears of gratitude and respect. The ladies and gentlemen there, take my word for it, are very good judges of plays and actors. Come, let us drink their healths, if you please, Sir. We quitted the town, I say; and there was a wide differeuce between my coming in and going out: I entered the town a candle-siuffer, and quitted it an hero!-such is the world; little to-day, and great to-morrow. I could say a great deal more upon that subject; something truly sublime upon the ups and downs of fortune; but it will give us both the spleen, and so I shall pass it over.

'The races were ended before we arrived at the next town, which was no small disappointment to our company; however, we were resolved to take all we could get. I played capital characters there too, and came off with my usual brilliancy. I sincerely believe I should have been the first actor of Europe, had my growing merit been properly cultivated: but there came an unkindly frost which nipped me in the bud, and levelled me once more down to the cominon standard of humanity. I played Sir Harry Wildair: all the country ladies were charmed: if I but drew out iny snuff-box, the whole house was in a roar of rapture; when I exercised my cudgel, I thought theywould have fallen into convulsions. 
- There was here a lady who had received an education of nine montlıs in London; and this gave her pretensious to taste, which rendered her the indisputable mistress of the ceremonies wherever she came. She was informed of my merits; every body praised me; yet she refused at first going to see me perform: she could not conceive, she said, any thing but stuff from a stroller; talked something in praise of Garrick, and amazed the ladies with her skill in enunciations, tones, and cadeuces: she was at last, however, prevailed upon to go; and it was privately intimated to me what a judge was to be present at my next exhibition: however, no way intimidated, I came on as Sir Harry, one lıand stuck in my breeches, and the other in my bosom, as is usual at Drury-lane; but, instead of looking at me, I perceived the whole audience had their eyes turued upon the lady who had been nine months in London: from ber they expected the decision which was to secure the general's truncheon in my hand, or sink me down into a theatrical letter-carrier. 1 opened my suuff-box, took snuff; the lady was solemn, and so were the rest; I broke'the cudgel on alderman Smuggler's back; still gloomy, melanelıoly all, the lady groaned and slurugged her shoulders; I attempted, by laughing mysclf, to excite at least a smile; but the devil a cheek could I perceive wrinkled into sympathy: I found it would not do; all my good liumour now became forced; my laughter was converted into hysteric grinning; and while I pretended spirits, my eye showed the agony of my heart; in sluort, the lady came with an intention to be displeased, and displeased she was; my fame expired; I am here, and (the tankard is no more!)

\section{ESSAY VI.}

NO observation is more common, and at the same time more true, than that one half of the world are ignorant how the other half lives. The misfortunes of the great are held up to engage our attention; are enlarged upon in tones of declamation; and the world is called upon to gaze at the noble sufferers; the great, under the pressure of calamity, are conscious of several others sympathizing with their distress : and have the comfort of admiration and pity.

There is nothing magnanimous in bearing misfortunes with fortitude, when the whole world is looking on; men in such circumstances will act bravely from inotives of vanity ; but he who, in the vale of obscurity, can brave adversity; who, without friends to encourage, acquaintances to pity, or even without hope, to alleriate his misfortunes, can behave with tranquillity and indifference, is truly grea! : whether peasant or courtier, he deserves admiration, and should be held up for our imitation and respect.

While the slightest inconveniences of the great are magnified into calamities, while tragedy mouths out their sufferings in all the strains of eloquence, the miseries of the poor are entirely disregarded; and yet some of the lower ranks of people undergo more real hardships in one day, that those of a more exalted station suffer in their whole lives. It is inconceivable what difficulties the meanest of our common sailors and soldiers endure without murmuring or regret; without passionately declaiming against Providence, or calling their fellows to be gazers on their intrepidity. Every day is to them a day of misery, and yet they entertain their hard fate without repining.

With what indignation do I hear an Ovid, a Cicero, or a Rabutin, complain of their misfortunes, and hardships, whose greatest calamity was that of being unable to visit a certain spot of eartl, to which they had foolishly attached an idea of happiness. Their distresses were pleasures, compared to what many of the adventuring poor every day endure without murnuring. They ate. drank, and slept: they hal slaves to attrud them, and were sure of subsistence for life; while 
many of their fellow creatures are obliged to wander without a friend to comfort or assist them, and even without shelter from the severity of the seasoll.

I have been led into these reflections from accidentally mecting, some days ago. a poor fellow whoin I knew when a boy, dressed in a suilor's jacket, and begging at onc of the outlets of the town, with a wooden leg. I knew him to have heen honest and industrions when in the country, and was curious to lean what had reduced him to his present situation. Wherefore, after having given him what I thouglit proper, I desired to know the history of his lile and misfortunes, and the manner in which he was reduced to his present distress. The disabled solulier, for such he was, thongh dressed in a sailor's habit, scrateling his head, and leaning on his crutch, put himself into an attitude to comply with iny request, and gave me his history as follows.

' Is for my misfortunes, master, I cannot pretend to bave gone through any more than other folks; for, except the loss of my limh, and my being obliged to beg, I don't know any reason, thank Heaven, that I have to complain; there is Bill Tibbs, of our regiment, he has lost both his legs and an eye to hoot; but, thank Heaver, it is not so bad with me yet.

- I was boru in Shropshire, my father was a labourer, and died when I was five years old; so I was put upon the parish. As he hal been a wandering sort of a man, the parishioners were not able to tell to what parish I belonged, or where I was borm, so they sent me to another parish, and that parish sent me to a third. I thought in my heart, they kept seuding me about so long, that they would not let me be born in any parish at all; but at last, however, they tixed me. I had some disposition to be a scholar, and was resolved, at least, to kuow my letters; hut the master of the work-house put me to business as soon as I was able to baudle a mallet; and here I lived an easy kind of life for five years. I ouly wrought ten bours in the day, and had iny meat and drink provided for my Intwour. It is true, I was not suffered to stir out of the house. for fear, as they said, I should run away; but what of that, I had the liberty of the whole house, and the yard before the door, and that was enough for me. I was then bound out to a farmer, where I was up both early and late: but I ate and drank well, and liked my business well enough, till he died, when I was obliged to provide lor myself; so I was resolved to go scek my fortune.

'In this mamuer I went from town to town, worked when I could get einployment, and starved when I could gel none: when happening one day to go through a field belonging to a justice of peace, I spyed a hare crossing the path just before me; and I believe the devil put it in my head to tling my stick at it:-Well, what will you have on't? I killed the hare. and was bringing it away, when the justice himself met me: he called me a poacher and a villain; and collaring me, desired I would give an account of myself; I fell upon my knees, hegged his worship's pardon, and began to give a full account of all that I kuew of my breed, seed, aud generation: but, though I gave a very true account, the justice said I could give no account; so I was indicted at the sessions, found guilty of being poor, and sent up to London to Newgate, in order to be transported as a vagabond.

- People may say this and that of being in jail; but, for iny part, I found Newgate as agreeable a place as ever I was in, in all my life. I had my belly full to eat and drink, and did no work at all. This kiud of life was too good to last for ever; so I was taken out of prison, after five mouths, put on board a ship, and sent off, with two hundred more, to the plantations. We had hut an indifferent passage, for, being all confined in the hold, more than a hundred of our people died for want of sweet air; and those that remained were sickly enough, God knows. Whell we cane a-shore, we were sold to the planters, and I was bound for seven years more. As I was no scholar. for I did not know my letters, I was obliged to work among the negroes; and I served out my time, as in duty bound to do.

' When my time was expired. I worked my passage home, and glad I was to see old England again, hecause I loved my country. I was afraid. however, that I should he indicted for a vagabond once more, so did not 
much care to go down into the country, but kept about the town, and did little jobs when I could get them.

-I was very happy in this manner for some time, till one evening, coming lome from work, two men knocked me down, and then desirell me to stand. They belonged to a press-gang; I was carried before the justice, and, as I could give no account of inyself, I had my choice left, whether to go on boarl a man of war, or list for a soldier. I chose the latter; and, in this post of a gentleman, I served two campaigns in Flanders, was at the battles of $\mathrm{Val}$ and Foutenoy, and received but one wound, through the breast here; but the doctor of our regiment soou made me well again.

Vhen the peace came on I was discharged; and, as I could not work, because my wound was sometimes troublesome, I listed for a landsman in the East-India company's service. I have fought the French in six pitched battles: and I verily believe, that if I could read or write, our captain would have made ne a corporal. But it was not my good fortune to have any promotion, for I soon fell sick, and so got leave to return home again with forty pounds in my pocket. 'This was at the beginning of the present war, and I hoped to be set on shore, and to have the pleasure of spending my money; but the government wanted men, and so I was pressed for a sailor, before ever I could set foot on shore.

- The boatswain found me, as he said, an obstinate fellow: he swore he knew that I understood my business well, but that I shammed Abraham, to be idle: but God knows, 1 knew nothing of sea business, and he beat me without considering what he was about. I had still, however, my forty pounds, and that was some comfort to me uuder every beating; and the moncy I might have had to this day, but that our ship was taken by the French, and so I lost all.

- Our crew was carried into Brest, and many of them died, because they were not used to live in a jail; but, for my part, it was nothing to me, for I was seasoned. One night, as I was asleep on the bed of boards, witlı a warm blanket about me, for I always loved to lie well, I was awakened by the boatswain, who had a dark lantern in his hand; "Jack," says he to me, "will you knock out the French sentry's brains?" "I don't care, says I, striving to keep myself awake, 'if I lend a hand." "Then follow me," say's he, "and I hope we shall do business." So up I got, and tied my blanket, which was all the clothes I had, about iny middle, and went with him to fight the Frenchman. I hate the French, because they are all slares, and wear woolen shoes.

- Though we had no arms, one Englishman is able to beat five French at any time; so we went down to the door, where both the sentries were posted, and rushing upon them, seized their arms in a monent, and knocked them down. From thence, nine of us ran together to the quay, and seizing the first boat we met, got out of the harbour and put to sea. We had not been here three days hefore we were taken up by the Dorset privateer, who were glad of so many good hands; and we consented to run our chance. However, we had not as much luck as we expected. In three days we fell in with the Pompadour privateer, of forty guns, while we had but twenty-three; so to it we went, yard-arm and yard-arm. The light lasted for three hours, and I verily believe we should have taken the Frenchman, had we but had some more men left behind; but, uufortunately, we lost all our men just as we were going to get the victory.

-I was once more in the power of the French, and I belicve it would have gone hard with me had I been brought back to Brest; but, by good fortmue, we were retaken by the Viper. I had almost forgot to tell you, that in that engagement, I was wounded in two places: I lost four fingers off the left hand, and my leg was shot off. If I had had the good fortune to have lost my leg and use of my hand on board a king's ship, and not a-board a privateer, I should have been cutitled to clothing and maintenance during the rest of $\mathrm{my}$ life: but that was not $\mathrm{my}$ chance: one man is boru with a silver spoon in his mouth, and another with a wooden ladle. However, hlessed be God, I enjoy good health, and will for ever love liberty and old England. Liberty, property, and old England, for ever, huzza!" 
Thus saying, he limped off, learing me in admiration at his intrepiclity and content; nor could 1 avoid acknowledging, that an habitual acquaintance with misery serves better than philosophy to teach us to despise it.

\section{ESSAY VII.}

AN alehouse-keeper, near Islington, who had long lived at the sign of the French king, upon the commencement of the last war, pulled down his old sigu, and put up that of the queen of Hungary. Under the influence of her red face, and golden sceptre, he continued to sell ale, till she was no longer the favourite of his customers; he changed her, therefore, some time ago, for the king of Prussia, who may probably be clianged, in turu. tor the next great man that shall be set up for vulgar admiration.

In this inantier the great are dealt out one after the other, to the gazing crowd. When we have sufficiently wondered at one of them, he is taken in, and another exhibited in his room, who selılom holds his station long; for the mob are ever pleased with variety.

I must own I have such an iudifferent opinion of the vulgar, that I am ever led to suspect that merit which raises their shout; at least 1 an certain to find those great and sometimes good men, who find satisfaction in such acclamations, made worse by it; and history has too frequently taught ine, that the head which has grown one day giddy with the roar of the million, has the very next been fixed upon a pole.

As Alexander VI. was entering a little town in the neighbourhood of Rome, which had been just evacuated by the enemy, he perceived the townenen busy in the marketplace in pulling dow from a gibbet a figure which had been designed to represent limself. There were some also knocking down a neighbouring statue of one of the Orsini family, with whom he was at war, in order to put Álexander's effigy in its place. It is possible a man who kuew less of the world, would have condenned the arlulation of those bare-faced flatterer's; but Alexander seemed pleased at their zeal; and turning to Borgia, his son, said with a smile, 'Vides, mi fili quam leve discrimen patibulum inter et statuam.' 'You see, my son, the sinall difference between a gibbet and a statue.' If the great could be taught any lesson, this might serve to teach them upon how weak a foundation their glory stands; for, as popular applause is excited by what seems like merit, it as quickly condemns what has only the appearance of guilt.

Popular glory is a perfect coquet; her lovers must toil, feel every iıquietude, indulge every caprice; and, perhaps, at last be jilted for their pains. True glory, on the other haud, resembles a woman of sense: her admirers must play no tricks; they feel no great anxiety, for they are sure, in the end, of being rewarded in proportion to their merit. When Swift used to appear in public, he generally had the mob shouting in lis train. 'Pox take these fools,' he would say, 'how much joy might all this bawling give my lord-mayor. We have seen those virtues, which have, while living, retired from the public eye, generally transmitted to posterity, as the truest objects of admiration and praise. Perhaps the character of the late durke of Marlborough may one day be set up, eren above that of his more talked-of predecessor; since an assemblage of all the mild and amiable virtues, are far superior to those vulgarly called the great ones. I must be pardoned for this sliort tribute to the inemory of a man, who, while living, would as much detest to receive any thing that wore the appearance of flatte. $r y$, as I should to offer it.

I know not how to turn so trite a subject out of the heaten road of conmon-placr, except by illustrating it, rather by the assistance of my memory than judgnient; and instead of making reflections. hy telling a story.

A Chinese, who had long studied the works 
of Confucins, who knew the characters of fourteen thousand words, and could read a great part of every book that came in his way, once took it into his head to travel into Enrope, and observe the customs of a people which he thought not very much inferior, even to his own countrymen. Upon his arrival at Amsterdain, his passion for letters naturally Jed him to a bookseller's shop; and, as he could speak a little Dutch, be civilly asked the bookseller for the works of the immortal Xixofou. The bookseller assured him he had never heard the book mentioned before; 'Alas!' cries our traveller, 'to what purpose, then, has he fasted to death, to gain a renown which bas never travelled beyond the precincts of China!'

There is scarce a village in Furope, and not one university, that is not thus furnished with its little great men. The head of a petty corporation, who opposes the designs of a prince, who would tyrannically force his subjects to save their best clothes for sundays; the puny pedant, who finds one undiscovered quality in the polype, or describes an unbeeded process in the skeleton of a mole; and whose mind, like his microscope, perceives nature only in detail; the rhymer, who makes sinooth verses, and paints to our imagination, when he should only speak to our hearts; all equally fancy themselves walking forward to immortality, and desire the crowd behind them to look on. The crowd takes them at their word. Patriot, philosopher, and poet, are shonted in their train. Where was there ever so much merit -seen; no tines so important as our own; ages, yet unborn, shall gaze with wonder and applause!' To such music, the important pigmy moves forward; bustling and sinelling, and aptly compared to a puddle in a storm.

I lave lived to see generals who once had crowds hallooing after them wherever they went, who were bepraised by newspapers and magazines, those echoes of the voice of the vulgar, and yet they have long sunk into merited obscurity, with scarce evenan epitaph left to flatter. A few years ago the herringfishery employed all Grub-street; it was the topic in every coffee-house, and the burden of every ballad. We were to drag up oceaus of gold from the bottom of the sea; we were to supply all Europe with herrings upon our own terms. At present we hear no more of this. We have fished up very little gold that I can learn; nor do we furnish the world with herrings, as was expected. Let us wait but a few years longer, and we shall find all our expectations an berring-fishery.

\section{ESSAY VIII.}

THOUGH naturally pensive, yet I am fond of gay company, aud take every opportunity of thus dismissing the mind from duty. From this motive 1 an often found in the centre of a crowd; and wherever pleasure is to be sold, am always a purchaser. In those places, without being remarked by any, I join in whatever goes forward, work my passions into a similitude of frivolous earnestuess, shout as they shout, and condemn as they happen to disapprove. A mind thus sunk for a while below its natural standard, is qualified for stronger flights; as those first retire who would spring forward with greater vigour.

Attracted by the serenity of the evening, a friend and I lately went to gaze upon the company in one of the public walks uear the city. Here we sauntered together for some lime, either praising the beauty of such as were handsome, or the dresses of such as had nothing else to recommend them. We had gone thus deliberately forward for some time, when my friend stopping on a sudden, caught me by the elbow, and led me out of the pullic walk; I could perceive by the quickness of his pace, and by his frequently looking behind, that he was attempting to avoid somebody who followed; we now turned to the right, then to the left: as we went forward, he still went faster, but in vain; the person 
whom he attempted to cscape, liunted us through every doubling, and gained upon is each moment; so that, at last, we fairly stood still, resolving to face what we could not avoid.

Our pursuer soon came up, and joincd us with all the familiarity of an old acquaintance. - My dear Charles,' cries he, shaking my friend's hand, 'where have you been hiding this half a ccntury? Positively, I had fancied voul were gone down to cultivate matrimony and your estate in the country.' During the reply, I had an opportunity of surveying the appearance of our new companion. His hat was pinched up with peculiar smartness; his looks were pale, thin, and sharp; round his neck he wore a brond black ribbon, and in his bosom a buckle studded with glass; his coat was trimmed with tarmished twist; he wore by his side a sword with a black hilt; and his siockings of silk, though newly washed, were grown yellow by long service. I was so much engaged with the peculiarity of his dress, that I attended only to the latter part of my friend's reply; in which he complimented Mr. Tibbs on the taste of his clothes, and the bloom in his countenance. 'Psha, psha, Charles,' cried the figure, ' no more of that if you love me; you know 1 hate flattery, on my soul 1 do; and yet to be sure an intimacy with the great will improve one's appearance, and a course of venison will fatten; and yet, faith, I despise the great as much as you do; but there are a great many honest fellows among them; and we inust not quarrel with one half because the other wants breeding. If they were all such as iny lord Mudler, one of the most goodnatured creatures that ever squeezed a lcmon, I should myself be among the number of their admirers. I was yesterday to dine at the duchess of Piccadilly's. My lord was there. 'Ned,' says he to ine, 'Nod', says he, 'I'll hold gold to silver I can tell where you were poaching last night.' 'Poaching, my lord,' savs I; 'faith, you have missed already; for 1 staid at hune, and let the girls poach for me. That's my way ; I take a fine woman as some animals do their prey; stand still, and swoop, they fall into my mouth.'

'Al, Tibbs, thou art an happy fellow, cried iny companion with looks of infinite pity, - I hope your fortune is as much improved as ve. $75 \& 76$. your understanding in such company ?" 'Improved,' replied the other; 'you shall know, but let it go no farther, - a great secret-live lundred a year to begin with-My lord's wort of homour for it- His lordship touk ne down in his own churiot yesterday, and we had a tete-a-tete diunce in the counury; where we talked of notling else," "I fancy you furgot, Sir,' cried I, 'you tolel us but this moment of your dining yesterday in town!' 'Did I say so,' replied he cooly. 'To be sure, if I said so it was so.-Dined in town: egad, now I do remember 1 did dine in town: bnt I dined in the country too: for you must know, my boys, I eat two diumers. By the by, I am grown as nice as the devil in my eating. 1'll tell you a pleasant affair about that: we were a select party of us to dine at lady Grogram's, an affected piece, but let it go no fatther; a secret: Well, says I, I'll hold a thousand guineas, and say done first, that-But dear Charles, you are an honest creature, lend me half a crown for a minute or two, or so, just till-But hark'c, ask me for it next time we meet, or it may be. twenty to one but. I forget to pay you.'

When he left us, our conversation naturally turned upon so extraordinary a character ' His very dress,' cries my friend, 'is not less extraurdinary than his conduct. If you meet him this day, you find him in rags; if the next, in embroidery : with those persons of distinction, of whom he talks so familiarly, he has scarce a coffee-house acquaintance. However, both for the interest of society, and perhaps for his own, Heaven has made him poor; and, while all the world perceives his wants, be fancies thicm concealed from every eye. An agreeable companion, bccause he inderstands flattery : and all nust be pleased with the first pait of his conversation, though all are sure of its ending with a deniand on their pursc. While his yourh commenances the lcviry of his conduct, he may thus earn a precarious subsistence; but when ace comes (m, the gravity of which is incompatible wilh huffoonery, then will he find liniself torsaken by all. Condemued in the decline of life to hang upon sone rich fanily whom he once despised, there to undergo all the ingenuity of stulied contempt; to he employed mily as a spy upon the servants, or a bug-bear to frighten children into duty.'

GE 


\section{ESSAY IX.}

WHEN Catharina Alexowna was made empress of Russia, the women were in an acturil state of bundage, but she indertook to introduce mixed assemblies, as in other parts of Europe: she altered the women's dress, by substituting the fashions of England! instead of furs, she brought in the use of taffeta and damask ; and corouets and commodes, instead of caps aud sable. The women now found themselves no longer shut up in separate apartments, but saw company, visited each other, and were present at every entertainment.

But as the laws to this effect were directed to a savage people, it is amusing enough the manner in which the ordinances ran. Assemblies were quite unknown among them, the czarina was satisfied with introducing them, for she found it was impossible to render them polite. An ordinance was therefore published according to their notions of breeding, which, as it is a curiosity, and has never before been printed, that we know of, we shall give our readers.

'I. The person at whose house the assembly is to be kept, shall signify the same by hanging out a bill, or by giving some other public notice, by way of advertisement, to persons of both sexes.

- II. The assembly shall not be opened sooner than four or five o'clock in the afternoon, nor continue longer than ten at night.

'III. The master of the house shall not be obliged to meet his guests, or conduct them out, or keep them company; but, though he is excmpt from all this, he is to find them chairs, candles, liquors, and all other neressaries that the company may ask for; he is like- wise to provide them with cards, dice, and every necessary for gaming.

'IV. There shall be no fixed hours for coming or going away; it is enough for a person to appear in the assembly.

' $V$. Every one shall be free to sit, walk, or game as he pleases; nor shall any one go about to hinder him, or take exceptions at what he does, upon pain of rmptying the great cagle, (a pint bowl full of brandy:) it shall likewise be sufficient, at entering or retiring, to salute the company.

'VI. Persons of distinction, mollemen, superior officers, nutrchants, and tradesunen of note, head-workmen, especially carpenters, and persons employed in chancery, are to have the liberty to enter the assemblies: as tikewise their wives and children.

- VII. A particular place shall be assigned the footmen, except those of the liouse, that there may be room enough in the apartunents designed for the assembly.

- VIII. No ladies are to get drunk upon any pretence whatsocver, nor slıall geutlemen be drunk before niue.

'IX. Ladies, who play at forfeitures, questions and commands, \&c. shall not be riotous: no gentleman shall attempi to force a kiss, and no person sluall ofler to strike a woman in the assembly, under pain of futmre exclnsion.'

Such are the statutes upon this occasion, which, in their very apprearance, carty an air of ridicule and satire. But politeness must enter every country by degrees; and these rules resemble the breeding of a clown, awk. ward but sincere. 


\section{ESSAY X.}

WHERE Tauris lifts its head above the storm, and presents nothing to the sight of the distant traveller, but a prospect of nodeling rocks, falling torrents, and all the variety of tremendous nature; on the bleak busom of this frightful mountain, secluded from society, and derestiug the ways of men, lived Asem the Man-hater.

Asem had spent his youth with men; had shared in their amusements; and had been taught to love his fellow-creatures with the noost ardent affection: but from the tenderness of his disposition, he exhausted all his formue in relieving tne wants of the distressed. The petitioner never sued in sain; the weary traveller never passed his door; he only desisted from doing good when he had no longer the power of relieving.

Froull a fortume thus spent in benevolence, he expected a grateful return from those he hall formerly relieved; and made his application with confidence of redress; the ungrateful world soon grew weary of his importunity ; for pity is but a short-lived passion. He soon, therefore, began to view mankind in a very different lighif from that in which he had before beheld then; he percived a thousand vices he bad never before suspected to exist: wherever he turned, insrationde, dissimulation, and treachery, contributed to increase his detestation of them. Resolved, therefore, to continue no longer in a world which he hated, and which repaid his detestation with contempt, he retired to this region of sterility, in order to brood over his resentment in solitude, and converse with the only honest heart he knew ; namely, with his own.

A cave was his only shelter from the inclemency of the weather; fruits gathered with difficulty from the mountain's side, his only foud; and his drink was ietched with danger and toil from the headlong torrent. In this manner he lived, sequestered from socip'y, passing the hours in meditation and some- times exulting that he was able to live independently of his fellow creatures.

At the foot of the mountain, an extensive lake displayed its glassy busoun; reflecting on its brond surfare the inupending horrors of the mountain. To this capacious nuirror he would sometimes descend, and, reclining on its stecp bauk, cast an rager look on the smooth $\mathrm{x}$ panse that lay before him. 'How beautiful,' he often cried, 'is nature! how lovely, even in her wildest scenes! how finely contrasted is the level plain that lies beneatl me, with yon awful pile that hides its tremendous head in clouds! But the beauty of these scenes is no way comparable with their utility; from hence an hutidred rivers are supplied which distribute health and verdure to the various countries through which they flow. Every part of the universe is beautiful, just, and wise; but man, vile man, is a solecism in nature: the ouly monster in creation. Tempests and whirlwinds have their use; but vicious, un. grateful man, is a blot in the fair page of universal beauty. Why was I born of that detested specics, whose vices are alınost a reproach to the wisdom of the divine Creator? Were men entirely free from vice, all would be uniformily, harnony, and order. A world of moral rectitude shiuld be the result of a perfectly moral agent. Why, why then, $O$ Alla! must I be thus confined in darkness, doubt, and despair?"

Just as be ottered the word despair, he was going to plunge into a lirke beneath him, at once to satisfy his doubts, and to put a period to his anxiety; when he perceived a most majestic briug walking on the surface of the water, and approaching the bank on which he stood. So unexpected an object at once cherked his purpose; he stopped, contenuplated, and fancied he saw something awful and divine in his aspect.

'Son of Adam,' cried the genius. 'stop thy rash purpose; the father of the faithful has 
seen thy justice, thy integrity, thy niseries, and hath sent me to afford and administer relief. Give me thine hand, and follow without trembling, wherever 1 shall lead; in me behold the genius of conviction, kept hy the great prophet, to turn from their errors those who go astray, not from curiosity, but a rectitude of intention. Follow me, and be wise.'

Asem immediately descended upon the lake, and his guille conducted him along the surface of the water; till coming near the centre of the lake they both began to sink; the waters closed over their heads; they descended several hundred fathoms, till Asem, just ready to give up his life as inevitably lost, found himself with his celestial guide in another worli, at the botton of the waters, where hmman foot had never trod before. His astonishment was beyond description, when he saw a sun like that he had left, a serene sky over his head, and blooming verdure under his feet.

'I plainly perceive your amazement,' said the geuius; 'but suspend it for a while. This world was formed by Alla, at the request and under the inspection of our great prophet, who once entertained the sane doubts which filled your mind when I found you, and from the consequence of which you were so lately rescued. The rational inhabitants of this world are forined agreeable to your own ideas; they are absolutely without vice. In other respects it resembles your earth, but differs from it in being wholly inhabited by men who never do wrong. If you find this world more agrecable than that you so lately left, you have free permission to spend the remainder of your days in it; but permit me, for some time, to attend you, that I may silence your doubts, and make you better acquainted with your company and your new habitation.'

'A world without vice! Rational beings without imnorality!' cried Asem, in a rapture: 'I thank thee, O Alla, who hast at length heard my petitions; this, this indeed will produce happiness, ectasy, and ease. O for an immortality to spend it anong men who are incapable of ingratitude, injustice, fraud, violence, and a thousand other crincs, that render society miserable!"

'Cease thine acclamations,' replied the genius. 'Look around thee; reflect on every object and action before us. and communicate to me the result of thine observations. Lead wherever you think proper, 1 shall be your attendant and instructor.' Asem and his companion travelled on in silence for sonie time, the former being entirely lost in astonishment; but at last, recovering his former serenity, he could not help observing, that the face of the country bore a near rescmblance to that he had left, except that this subterranean world still seemed to retain its primæval wildness.

'Here,' cried Asem, 'I percrive animals of prey, and others that seen only designed for their subsistence; it is the very same in the world over our hearls. But had I been permitted to instruct our prophet, I would have removed this defect, and formed no unracious or destructive animals, which ouly prey on the other parts of the creation.' 'Your tenderness for inferior animals is, 1 find, remarkable,' said the genius, smiling, 'but, with regard to meaner creatures, this world exactly resembles the other; and, indeed, for obvious reasons: for the earth can support a more considerable number of animals, by their thus beconing food for each other, than if they had lived entirely on the vegetable productions. So that animals of differeni natures thus formed, instead of lessening their multitude, subsist in the greatest numbrr possible. But let us hasten on to the inhabited comntry before us, and see what that offers for instruction.'

They soon gained the utmost verge of the forest, and entered the country inliabited by men without vice; and Asem anticipated in idea the rational delight he hoped to experience in such an innocent society. But they had scarce left the confines of the wood, when they beheld one of the inhabitants flying with hasty steps, and terror in his comitenance, from an army of squirrels that closely pursued him. 'Heavens!' cried Asem, ' why does he fly? What cau he fear from animals so conttemptible!' He had scarce spoke when he perceived two dogs pursuing another of the human species, who with equal terror and haste attempterl to avoidl them. 'This,' cried Asem to his guirle, 'is truly surprising; nor can I conceive the reason for so strange an action.' 'Every species of animals,' 1eplied the genitus, "has of late grown very powerful in this country; for the imbabitants, at first, thinking it unjust to use either fraud or force in destroying them, they have insensibly 
increased, and now frequently ravage their harmless fiontiers.' 'But they shouid have been destroyed,' cried Asein; 'you see the consequence of such neglect.' - Where is then that tenderness you so lately expressed for subordinate animals?" replied the genius, smiling; "you seem to have forgot that buanch of justice.' 'I must acknowledge my mistake,' returned Asem; 'I am now convinced that we must be guilty of cyranny and injustice to the brute creation, it we would enjoy the world ourselves. But let us no longer observe the duty of men to these irrational creatures, but survey their commections with one another.'

As they walked farther up the country, the more he was surprised to see no vestiges of handsome louses, no cities, nor any inark of elegant design. His conductor perceiving his surprise, observed, that the inhabitants of this new world were perfectly content with their ancient sinplicity; each had an house, which, though homely, was sufficient to lodge his little family; they were too good to build houses, which could only increase their own pride, and the envy of the spectator; what they built was for convenience, and not for show. 'At least then,' said Asem, - they have neither arclitects, painters, or statuaries in their society; but these are idle art-, and may be spared. However, before 1 spend much more time bere, you should have iny thanks for introducing ine into the society of some of their wisest men: there is scarce any pleasure to me equal to a refined conversation; there is nothing of which I ain so enamoured as wisdom.' 'Wisdom,' replied his instructor, 'how ridiculous! We have no wisdom here, for we have no occasion for it; true wisdom is only a knowledge of our own duty, and the duty of others to us; but of what use is such wisdom here? each intuitively performs what is right in himself, and expects the same from others. If by wisdom you should mean vain curiosity, and einpty speculation, as such pleasures have their origin in vanity, luxury, or avarice, we are too good to pursue thein.' 'All this may he right,' says Asem, 'but methinks I olıserve a solitary disposition prevail among the people; each family keeps separately within their own precincts, without society, or without intercourse.' 'That indeed, is true,' replied the other; 'here is no established society; nor should there be any: all societies are made either through fear or friendship; the people we are among, are too good to fear each other; and there are no motives to private friendship, where all are equally meritorious.' 'Well then,' said the sceptic, ' as I am to spend my time here, if I am to have neither the polite arts, nor wisdom, nor friendship, in such a world, I should be glad at least of an easy companion, who may tell me his thoughts, and to whom I may communicate mine.' 'And to what purpose should either do this?" says the genius: "flattery or curiosity are vicious motives, and never allowed of here; and wisdom is out of the question.'

'Still, however,' said Asem, 'the inhabitants must be happy; each is contented with his own possessions, nor avariciously endeaours to heap up more than is necessary for his own subsistence: each has therefore leisure to pity those that stand in need of his compassion.' He had scarce spoken whel his ears were assaulted with the lamentatious of a wretch who sat by the way-side, and, in the most deplorable distress, seemed gently to murmur at his own misery. Asem immediately ran to his relief, and found him in the last stage of a consumption. ' Strange,' cried the son of Adam, 'that men who are free from vice should thus suffer so much misery without relief!' 'Be not surprised,' said the wretch who "ras dying; "would it not he the greatest injustice for beings, who have only just sufficient to support themselves, and are content with a bare subsistence, to take it from their own mouths to put it into mine? They never are possessed of a single meal inore than is necessary; and what is barely necessary cannot be dispensed with.' 'Tliey should have been supplied with more than is necessary,' cried Asem: 'and yet I contriclict my own opinion but a moment before: all is doubt, perplexity, and confusion. Even the want of ingratitude is no virtue liere, since they never received a layour. They luave, however, another excellence, yet behind; the love of their country is still, I hope, ons or their darling virtues.' 'Peace, Asem,' rejlied the guardian, with a countenance not less 
severe than beautiful, 'nor forfeit all thy pretensions to wisdom; the saine selfish motives by which we prefer our own interest to that of others, induce us to regard our country preferable to that of another. Nothing less than universal benevolence is free from vice, and that you see is practised here.' 'Strange!' cries the disappointed pilgrim, in an agony of distress; " what sort of a world am I now introduced to? There is scarce a single virtue but that of temperance, which they practise; and in that they are no way superior to the very brute creation. 'There is scarce an amusement which they enjoy; fortitude, liberality, friendship, wisdoin, conversation, and love of country, all are virtues entirely unknown here; thus it seems, that, to be acquainted with vice is not to know virtue. Take me, $O$ my genius, back to that very world which I have despised; a world which has Alla for its contriver is much more wisely formed than that which has been projected by Mahomet. Ingratitude, contempt, and hatred, I can now suffer, for perhaps I have deserved then. When I arraigned the wisdom of Providence, I only showed my own ignorance; henceforth let me keep from vice myself, and pity it in others.'

He had scarce ended, when the genius, assuming an air of terrible coinplacency, called all his thunders around him, and vanished in a whirlwind. Asem, astonished at the terror of the scene, looked for his imaginary world; when, casting his eyes around, he perceired himself in the very situation, and in the very place, where he first began to repine and despair; his right foot had been just advanced to take the fatal plunge, nor had it yet been withdrawn: so instantly did Providence strike the series of truths just imprinted on his soul. He now departed from the water-side in tranquillity, and, leaving his horrid mansion, travelled to Segestan, his native city; where he diligently applied himself to conmerce, and put in practice that wisdom he had learnt in solitude. The frugality of a few years soon produced opulence; the number of his domestics increased; his friends came to him from every part of the city; nor did he receive them with disdain; and a youth of misery was concluded with an old age of elegance, affluence, and ease. 


\section{INDEX.}

ABDO.MIN.AL FISH, has the ventral nearer the tail than the pecteral fins, 649 .

Abstemiaus life, its great benofit, 174 .

Abstinence, religinusly observed long after the Reformation; Queon Elizabeth's injunction upon this head; a lieavenly institution, from its benofit to individuals and advantage to society, 155 ; remarkable instance of it in the sloth, 444

Acanthopterigii, a name of the prickly-finned fish, 647 .

Acurn, a sluell-fish, 644 ; the shell of the acorn filled by an inmeveable animal, 8zo.

Adriatic, its onpire claimed by the republic of Venice, 68 .

Alian, his account of the dreadful cavern called the Gulf of Pluto, 18. See E. ephant, 417 .

Atru, volcano in Sicily ; remarkable eruption in 1537; an account of it ; the burning seon at Malta, 26; the quantity el matter discharged, supposed to exceed twenty times the original bulk of the mountain, walls built of materials thrown up by it, 30 .

Nolipie, an instrument to preduce artificial wind; ite deacription, and the manner of generating viulent blasts, 94.

Africn, its sundy storms, 106 ; destroy villages and armies, 107; see Animals, 207; has the largest and the smallest of the cow kind, 235 ; the ferret originally from Africa, 351.

Age, the mountains of Scotland, Wales, Auvergne, and Switzerland, furnish mure instances of old age, than the plains of Holland, Flanders, Germany, or Poland, 175. See Fishes, til1. See Trees, 612 .

Agauti, an animal found in great abundance in South America, and by some called the rabbit of that continent; it resembles the rabbit, yet is different from ours, and peculiar to the new wnrld; its description; its ordinary food; it has the hair and the vuraciousness of the hog; eats greedily, and hides the reluainder ; burrows in hollow trees; its manner of feeding and walking; sight and hearing; its flesh how dressed; how hunted and forced out of its hole ; it turns in its own defence upon the hunters; its bite and cry; how tamed; bears two young at each litter; breeds at least twico a year; carrioe its young about like a cat; and ledges then in a troe, where they soon become able to provide for themselves, 357 .

Agricola, has seen hats ingde of mole skins, most beantiful, 372 .

Agriculture, the number of hands employed in the manufacture of silk, turned to agriculture, would increase the quantity of corn to more tlian equivalent lor the diminution of national wealth in purcliasing wrought silk from other ceuntries. See Silk-worm.

$A i$, a name of the sloth; its description, 412 .

Aicuraus, a great parrot; its sagacity and docility, 527.

Aigues-martes, town in France, a port in the time of St. Louis now remeved mere than four miles frem the sea, $\forall \mathbf{l}$.

Air, the only active agent in earthquakes, 30 ; Amenton's calculation of a moderate dogree of heat sulicient $t$ o give the air amazing pewers of expansien, 31 ; too fine for our sight, is very obvious to our touch; its elasticity; a cubic foot of air weighs more than an onnce, 87,83 ; a hand upon the moutls of a vessel from which the air has been exhausted, is violently sucked inwards, and why, so; the mouth of such vessel inverted being immersed, the water will rise into the empty space, and fill the glass; the manner in which this is done; water never ascends higher than thirty-two fcet; our ordinary load of air amounts nearly to forty thousand pounds, 83 ; four thousand pounds weight of air carried at one time more than at another, and why; the air contained in a nut-shell, may be dilated intounknowndimensions; the air contained in a heuse, may be cempressed into a cavity equal to the eye of a needle; the increasing el asticity of cempressed air augmented by hoat wonld, when expanded, be sufficient for the explesion of a werld, 89 ; one of the mest cempounded bodies in nature, 1 ; scarcely any substance resisting its correding qualities, ?I ; factitious air produced in great quantities frem vegeLable, a nimal, or mineral substanees; proves a greater enemy to animals than a vacuum; a bird enclosed in artificial air, from raisins, died in a quarter of a ininute; a frog, in seven minutes ; a snail put into the receivor, with air of paste, died in four uninutes, 93; to be wholeseme, should not be of ene kind, but a coinpound of severa ubstances, 94 ; how air centributes to the support of our lives; dispute upon it, 97 ; gives life and bedy to flame, 97 ; kindles fire into No $75 \& 76$. flame, moderates the rays of light, and dissipates their violence; convoyance of seund; all tho pleasure received from conversation or from music, depends entirely upon the air ; oduurs are difiused by the air, 98 ; vegctablee, or the bodies of animals, left te putrefy, produce air in a very copious manner; it finds admission into wine or other fermented liquers, and inost easily inte spirits of wine; mountains, minerals, vegetables, anituals, and fires, contribute to inorease a current of air, 99 ; a tide of air produced by the sun and moon; a current of air, driven through a contracted space, grews mere violent and irresistible, 104. Air-bladder, in fishes, described, 610. Seo Fishes, Scc. 610.

Air-pump, the exporiment on a Carp, 610.

Albatross, a bird of the gull kind; its description by Edwards; is an inhabitant of the tropical climates, and othor regions, as far as the straits of Magollan in the Sonth Seas; is the must fiorce and formiduble of the aquatick tribe; it chiefly pursues the flying-fish, forced from the sea by the dolphins: Wiquefort's account of this bird; it scems to have a peculiar affection for the penguin, and a pleasure in its socioty; its nest, $578,5.9$.

Aibouras, a famous volcane near Mount Taurus, 29.

Aider, hares will not feed on the bark of it, 346.

Algazel, the seventh variety of gazelles with Mr. Buffon, 251.

Aidrorand us, places the bats anong birds, $3<3$; he, having spent a fortune te enlighten mankind, and collocted more trnth and falsehood than any man, was reduced to want, to suffer ingratitude, and to die in an liospital, 595.

Alexunder's soldiers agitated by curiesity and apprehension at the tides in the river Indus, 76.

Alligular, er the Cuyman, a kind of crocodile, 712 .

Alps, dreadful chasms found in them, 17; Pope's doscription of a traveller straining up the Alps, 42 ; the lighest peint of them not above sixteen hundred toises above the surface of the eea, 44

Amuzons, the greatest river in the world, has its source ameng the Andes, 42 ; its course from its erigin in the lake of Lauricocha, to ite discharge in the Western Ocean, is mere than twelve hundred leagues: its discharge is through a channel of a hundred and fifty miles broad, after receiving above sixty considerable rivers, 63.

Ambergris, long considered as a substance found floating on the eea, but since discovered to belong to the cachalot: the balls of ambergris found in all fishes of this kind, but chicfly in the eldest and strengest, 624

Ambrose, (St.) his credulity cencerning the halcyon, 602.

America, exceeds in the size of its reptiles, but is inforier in its quadrupeds, 211; that part of the American centinent which lies under the line, is cool and pleasant, 183; the cause of the tawny celour of the North American Indians; they paint their sking with red ochre, and annint them with the fat of beare, 184; the original cause of their flat heads, 185; A merican wood-duck described, 598 . See Tapir, 214. See Quadrupeds, ib. See Dag, 387. See Rats, 366. See Rabbits, (Syrian) 351. See Bats, 205. Sce Sarages, who suppose menkies to be mien, 410. See Pacaes, 434. See Mocklird, 540 .

Amin, or Bonito, description of this fish, 650 .

Animodytes, or the Lance, a fish; its description, 649.

Anmodytes, a kind of viper; it darts with amazing swifness, 729. Amontons. See Air, 31 .

Amour, a river of Eastern Tartary, 62 ; it receives about forty lesser rivers, ib.

Ampliesbenn, or the double-headed serpent, 740 .

Anarchicas, the welf-fish, its deseription, 649 .

Anatomists. Sec Apes, 205. See Lamprey, 638

Anchovy, has no bladder, 611 .

Andaiusin, gennete of that province the best, 218 .

Andes, amazing chasms or fissuree in them; seme of these are a mile wide, and others running under ground, resemble a province, 17 ; the highest mountains of the world, 29; excellent description of them by Ullea; the Andes are by measure three thousand one hundred and thirty-six toises or fathoms, above the surface of the gea, 45 ; at the top no difficulty of breathing perceived, ib.; nxonner of mules going down the precipices, 227. 
Anemometer, an instrument to measure the veloeity of the wind; gives no certain information of the force of a storm, 104.

Angnra, the eat of Angora, 2 $2:$; the goat of Angora; a number of animals about Angora, affording liair for trade; the camblet made of such hair, 247 .

Anhima, a bird of the crane kind, of Brazil, 258 ; deseribed; the cock and the hen prowl together; when one dics, the other stays by it, and dies also, ib.

Animals, hold the first rank amidst the infinitely different produetions the earth offers; are endowed with powers of motion and defence, even those fixed to one apst; organized beinga, provided with some defence for their own aecurity; endued with life and vigour; some by nature, violent; have their enmities and affections; ultimately supported upon vegetables; those in a dry sunny climate strong and vigerous; different vegetables appropriated to the different appetites, and why; of domestic kinds, carried from milder countries into the northern climates, quickly degenerate and grow less; in the internal parts of South Ameriea and Africa grow to a prodigious size, and why; not so in the cold frozen regions of the North; the most perfect races lave the least similitude to the vegetable productions on which they are ultimately fed ; the meaner the animal, the more local; assume different habits as woll as appearanees, and why; some peculiar to every part of the vegetable system; there are that live upon other animals; this wisely so constituted; to diminish the number of animals, and increase that of vegetables, the general scope of human induatry; of the vast variety, very few serviceable to man; in a catalogue of more than twenty thousand kand animals, gearcely a hundred are any way useful to man; expedieney of man's living upon animals as well as vegetables; little inore known than that the greatest number require the concurrenee of a male and fermale to reproduee their kind; and these distinetly and invariably found to beget ereatures of their own species, 119 to 123 ; usnal distinetion, with reapect to their manner of generation, inte oviparous and viviparous kinds, 125 ; the warmth of the sun, or of a stove, efficacious in bringing the animal in the egg to perfeetion, 126; such parts as the animal has double, or witliont which it can live, are the latest in production, 128; De Graaf las attended the progress and increase of various animals in the womb, and minutely marked the ehanges they undergo, 129 ; that which, in proportion to its bulk, takes the longest time for preduction, the most complete when finished; of all others, man the sloweat in coining into life, the most formidable are the least fruitful; and why those which bring forth many engender before they liave arrived at half their natiral gize ; approach more to perfection, whose generation nearly resembles that of man, 132 to 133 ; men and apes only have eye-lashes upon the upper and lower lids, all others want them un the lower lid, 142; that which has most desires appears eapable of the greatest variety of happiness, 153 ; those of the forest remain without food several weeks; all endure the want of sleep and hunger with lesa injury to health than man; nature contraets the stomachs of carnivorous animals of the forest to suit them to their preearions way of living; but the meaner tribes are still more capable of snstaining life without food, ib.; some lower animals scein to apend the greatest part of their lives in sleep, 156; some affected by music ; instances of it, 157; those furnished with hands hive more understanding than others, 170 ; in general the large animals live longer than the little, 174; difference between animuls in a state of nature and domestic tameness, so considerable that $\mathrm{Mr}$. Buffon makes it a principal distinetion of classea, 399; their teeth fitted to the nature of their tood; and their legs as well fitted to their respective wants or enjoyments; those who chew the cud have four stomachs; several that with us have four stomachs, have but two in Afriea : no carnivoroua animal, except the $\mathrm{dog}$, makes a voluntary attack but with superiority; the stomach generally proportioned to the nature of the food, or tize ease with which it is obtained; the size of the intestines proportioned to the nature of the food; few of the wild sort geek their prey in the day time ; in proportion as each earrivorous animal wants strength, it usea all the asslstance of patience, nssiduity, and eunning; some animals carefully avoid their enemies by placing sentinels to warn of the approach of danger, and know hovv to punish such as have neglected their post, or been unmindful of the common aafety; the wild sort subject to few alterations, and in the savage state continue for ages the same, in size, shape, and colour; is otherwise when subdued and taken under the protection of man; the tame kind bears no resernblanee to its ancestors in the woods ; animals feeding only upon grass, rendered carnivorous; two ingtances, 206 to 210: Afriea ever remarkable for the fierceness of its animals; the smallest multiply the fastest; the larger sort bring fow at a time; seldom generate till they be near their full growth; those which bring many reproduce bofore they arrive at half their natural size; with all animals, the time of their pregnancy is pro- portioned to their size; in all kinds the intermediate litters the most fruitful; the first and last generally produce the fervest in number and worst of kind; natural instinct to choose the proper tinies of copulation; whatever the natural disposition of animals, they have all eournge to defend their young: instances of it; milk in the carnivorous animals more sparing than in others; choice of situntion in bringing forth, remarkable in animals, 210 to 213 ; the ass, in a state of tameness, the most gentle and quiet of all animals, 225; of all aninals covered with hair, the ass the least subject to vermin, 226 ; the zebra, the most beautiful, but the wildest animal in nature, 22: ; perfeetly know their encmies, and low to a void them ; instances of it, 220); best method of classing animals adopted by Ray, Klien, and Jinneus, 201; the author's method of classing them, $2(12$ to 204 ; the earnivorous seek their food in gloomy solitudo; they are sharper than the ruminating kind, and why; ruminating animals most harmless, and most easily tamed; generally go in lierds for their mutual security; live entirely upon vegetables; the meanest of them unite in each others defence; carnivorous animals have small stonacls and short intestines; ruminating animals naturally more indolent and less artful than the earnivorous kinds, and why; their howels considered as an elaboratory, with proper vessels in it; nature enlarges the capacity of their intestines, to take in a greater supply; and furnishes them with four stomachs; the names of these four stomaciss; the intestines of carnivorous animals are thin and lenn: but those of the runinating sort strong, fleshy, and well covered witl fat; of all others, man spends the least time in eating; of all ruminant aninals the cow kind descrve the first rank, 2:31 to 232 ; naturalists give various names to the same, only differing in accidental cireumstances; of all, exeept man, the cow nost extensively propagated; greatest variety among cows; none more humble and pliant of disposition; the large kind of the torrid zone ; very fond of the water; some void their dung, when pursued; this arises rather from fear, than a desire of defence; the number of the cow kind, by naturalists extended to oight or ten sorts, reduced to two; one animal of the eow kind, no naturalist has hitherto deseribed; it may be added as a third species; deseription of it ; all the ruminant internally much alike; these that take refuge under the protection of man, in a few generations become indolent and helpless; the sheep, in a domestie state, the most defenceless and inffensive; also the most stupid, $2: 37$ to 241 ; a great number and variety about Angora; the inhabitants drive a trade with their hair, 247; the kinds actually not distinguished by the horns, colour, position of the ears, or tineness of the hair, ib. ; the fat, urine, beak, and even dung, of various animals, officacious in some diserders, 250 ; of all in the world, the gazelle has the most beautiful eye, 251 ; scarcely one animal, except the carnivorous, that does not produce coneretions in the stomach, intestines, kidncys, bladder, or in the heart, 252 ; no naturalists inform us whether that which bears tlie musk be a runinant, or of the hog kind, $256^{\circ}$; by a general rulf every animal lives about seven or eight times the number of years it continues to grow, 25y; of all natives of this climate, none have sueh a beantitiful eye as the stag, 260; no two mere nearly allied than the stag and the fallow deer, yet form distinct families, and never engender together, 265; many that once flourished in the world, may now be extinet, 268; of all the deer kind the rein-deer the most extraordinary, and most useful, 272 ; of all, when young, none more prettily playful than the kitten, 28t); many in Syria and Pereia, renarknble for long sof hair; most terrestrinl are larger, fiercer, and stronger, in warm, than in cold or temperate elimates, 292 ; the only not afraid singly to make oppesition to the lion, are the elephant, the rhinoceros, the tiger, and the hippopotamus. 2.25; of all Anterican, the tiger the mest formidable and unischicvous, 301; the generality have greater agility, greater swiftaess, and noore formidable arms, from nature, than man; and their senses, particularly that of smelling, are far moro perfect ; those living upon flesh hunt by nature, 303 ; all under the influence of man, are subject to great variations, 310 ; many in this country bred between a dor and a fox, 315 ; all savage, that have once tasted hunan flesh, never rofrain from purguing mankind, 326; those of the north, in winter, are more hairy, than those of miller climates; and what the cause, 331 ; of the aretie climates, have their winter and summer garments, except as far north as Greenland, ib. ; of the weasel kind, the martin the most pleasing, 334 ; feeding entirely upon vegetables, are inoffengive and timorous, 345 ; remarkable for speed; except the horse, have the hind feet longor than the fore feet; none receives the inale when pregnant except the liare, 346 ; hares the only that have hair on the inside of their mouths, 347; few of the wild kind have so many varieties as the aquirrel, 351; al] are tamed more ditficultly in proportion to their cowardice, 365 ; in all coun. tries, civilized and improved, the lower ranks of animals repressed and degraded, 389 ; the beaver the only that in its fore parts re- 
semblea a quadruped, and in its hinder parts approaclice the nature of fishes, ib.; the lori of all others the longest, in proportion to size, 413 ; the camel the most temperate of all, 430 ; the ostrich the most voracious, 463 ; of sll that use their wings and lega in running, the ostrich ia the awiftest, 465; none has greater conrsge than the cock, opposed to one of bia own speeies, 405 ; the presence of man destroys the secicty of meaner animsls, and their instinets also, 580 ; those longest in the womb, are the lengest lived, aceording to Pliny, 595 ; none barder to he killed than the slisrk, 630 ; the snail kind are hermaphrodites, 684 ; of all four-footed, the frog the best swimmer, $69 \%$; whatever kind, long under the protection of inan, lose part of their nstural sagaeity in providing for themselves, 576 ; that which fills the scorn-shell is immoveable, 828; a most numerous tribe lately discovered, propagated by euttings; many entirely without motion ; all seem possessed of one power, of which vegetables are totally defieient; certain races of animals fall benesth vegetables, by their nore imperfect propagation, 828 ; some live without limbs, and often reproduce them; some live without brain for many weeks together; some increase snd grow large, thutigh al their nobler organs sre entirely destroyed; soine continue to exist though cut in two, their nobler parta preserving life, while the others perish that were eut away; the zoophyte tribe, continues to live in separate parts, and one animal, by means of eutting, is divided into two distinct existences, sometimes into $\mathbf{s}$ thousand, 831 the first discovery of the power of reproduction in suinals owing to Mr. Treinbley, 831 .

Antelope, tentlı variety of gazellea by Mr. Buffon; ita description; the lndisn antelope, $252,253$.

Antilles. See Negroes, 169.

Antiers, their distinct naines, 262.

Intiparos, its grotto most remarkable, 20.

Antipathy, many have it to some snimals, whose presence they instantly perceive by the smell, 16.1 ; no animals more alike than the cow and the buffilo, yet none have stronger dislikes to eseh other 23 ; digs and wolves so diffierent in their dispositions, that no snimals can have a more perfect antipathy, 313 ; the same subsiats between the jacksl and the dog, 326 ; of the marmount to the dog, 354 ; quadrupeds which have natural sntipathy against the Norwsy rat, 363 ; between the porcupine sud serpent ao irreconcileable as never to meet without a mortal engagement, 376 .

Antiquity, mest naturally looked up to with reverential wonder, 191 .

Anthony, (St.) lived a hundred and five years, 155.

Ants, every writer of antiquity describes this insect, as labouring in the summer, and feasting upon the produce during the winter in some of the warmer climates this may be so; but in Franee snd England they are in a sfate of torpidity during winter; common ants of Europe; their description ; fcars not to sttack a creature ten times its own mannitude; sre divided into males, females, and neutral or working tribe; in whst manner distincuished from eael other; males and females seem no way to partake in the commen drudgeries of the state; males pursue the feinales with great assiduity, and force them to compliance; remain coupled for some time; deseription of the ant-lills in the sonthern parts of Europe, constructed with wonderful contrivsnce ; their food and excursions; their eggs so very sinall, thst uuon a bluck ground thoy cans seareely be diseerned; fond attachment of the working ants to their progeny ; the aurelia state, and efforts to get rid of their skins; experiment of Mr. De Geer to this purpose ; state of the fenale after slie his done laying, not known; the males then fly away, snd sre heard of no more; ants of the tropicsl climates build a hill with great contrivance and regularity, lay up provisions, and, living the whole year, submit to regulations entirely different from tbe ants of Europe; three kinds of Africsn anta ; their hills from six to twelve feet high; sinazing number and regularity of their cella ; depredations snd adventures; they live under strict regulations; oriler in which they sally forth; often quit their dwelling in a body, and go in quest of adventures; an instance of it given by Smith : their sting produces extrcme pain, 814 to 818 ; drive the hair from its form, 247; many animala live upon ants in Africa and Anerica, 441.

Ant-rater, or Ant-beor, deacription and habita, 441 ; their art to catch the snts; manner of defence againat its enemiea; kills the invader, and remains fagtened upon him with vindictive deaperation.

Ant-lion, the, 768 .

Antiuch, buried by an earthquake, 32

Aurta, the great srtery, 131

Aperea, by sone the Brazilian tabbit ; ita description, 359 .

Apes, have eye-lashes upon the upper and lower lids, 142; the only animal possessed of hands and arms, 243 ; in aome of the kinds the resenblance to man so striking, that anatomists are puzzled to find in what part of the liuman body man's superiority consiats; enjey many advsntages in common with men, above the lower tribes of nsture, 205; the forcmoat of the kind is the ouran-outsng or wild man of the woods, 399; description of this animal by Dr. Tyson; comparative view of this creature with man; another de. scription of it by Mr. Buffon; two young ones, only a yesr old, discovered an astonishing power of initstion, 399,400 ; a kind ealled baris, properly instructed when young, serve aa useful domestics: Le Conto's aecount of sn ape in the Straits of Molueea, 4111; the long-armed ape an extraordinary and remarkable ereature, 403 ; its description; s native of the Fast Indies, and found along all the coaats of Coromandel, 404; fling themselves from one rope to another, at thirty, forty, and fifty leot distance, $40 \mathrm{~J}$; instances of amszing ninzbleness ; in a state of noture they run upon all fuura; certain proofs of it, 403 ; in the navica of Solomon, among the articles imported from the East, are spes and peacueks, 4.7 .

Apicius, noted for having taught mankind to suffocate fish in Carthaginian pickle, 613; manner of dressing a hare in true Roman taste, 349

Apodal, the name of the fish without ventral fins, 647 .

Appendices in the intestines of birds, 45\%.

Appetite, Nature, by supplying a variety, haa multiplied life in her productions, 471

Arabiv, its sandy tempests described, 106; men and snimals buried in the sands of Arabia, preserved from corruptien for several ages, as if actually embalned, 195 ; the ass originally a native of Arabia, 226. See Horses, 214 to 227 . See Cumel, 430.

Archimedes, diacovered the method of detcrmining the purity of gold, by weighing in water, 55 .

Archipelogo, very good horses in ita islanda, 219 ; the wild ass found in those islands, particularly in Cerigo, 224.

Ardebil, the pastures in those plains exccllent for rearing horses, 219.

Arequipa, a celebrsted burning mountain in Peru, 29.

Argentine, deseription of this fish, 650 .

Arion, his harp gathered the dolphins to the ahip's side, 165 .

Aristotle's opinion about the formation of the incipient animal, 118; and mules being aometimca prolific, 223 .

Arlotto, an Italian Franciscan friar; for his sleeping tranagressions taken before the Inquisition, and like to be condemned for them, 158

Armadillo, or Trtou, generally referred to the tribe of insects or ansils, 206; an inhabitant of South America; a harmleas creature, furnislied with a peculiar covering for its defence ; attacked without danger, and liable to persecution; is of differcnt sizca; in all, however, the animal is partinlly covered with a coat of mail; : striking curiosity in natural history; has the same method of protecting itaclf as the hedgehog or pangolin; when attacked, rolls itself $\mathrm{np}$ in its shell like a bsll, and continues ao till the dangcr is over; the Indiana take it in this form, lay it elose to the fire, and oblige it to unfold; this animal utterly unknown before the discovery of America ; does mischief in gardens; bears the cold of our climate without inconvenience; the mole does not burrow swifer than the armsdillo; burrows deep in the esrth; expedients used to force them out ; manner of tsking the in alive; sometines in anarea by the sides of rivers, and low moist places which they frequent; never found at a distance from their retreats; escapes by rolling itself up, and tumbling down from rock to rock, without danger or inconvenienee; $i t s$ food; scarcely any that do not root the ground like a hog; a kind friendship between thom and the rattlesnake; they sre frequently found in the aame bole; they all resenble each other, as elothed with s shell, yet differ in size, and in the division of their shell ; the various kinda ; the pighesded sort, the weaselheaded, the kabasson, and the encoubert, are the largest, $3-30$ to $3: 2$. Arno, the river, a considersble piece of ground gained at the mouth of it, 81 .

Aro, numbers of birds of paradise seen there, 523 .

Arsenius, tutor to the einperor Arcudiua, lived an hundred and twenty years, 155.

Aris, faults that have infected most of onr dictionariea and com. pilations of natural history, $2 \mathrm{~m}$; teaching the arts of cruelty equivalent to committing them, $4 ! 5$.

Asia, aim of the $\bar{A}$ siaties to pessess many women, and to furnish a seraglio their only ambition, 138 ; lustre of jewels and aplendour of brilliant colours eagerly sought sfter by all conditiona of men, 145 . Asin Minor, description of ita inhabitants, 183.

Asintic, the olive-coloured, clainia the hereditary reeemblance to our common parent ; an argument to prove the contrary, 185.

$A s p$, a kind of serpent, $7: 3 \%$.

Asphatum, an injection of petreoleum and an application of asphalturn auffice to muke a mummy, 198. 
Ass and horee, though nearly alike in form, are distinct kinds, different in natures; with only one of each kind, both raccs weuld be extinguished; in the state of nature entirely different; wild ass in greater abundance than the wild horse; wild ass and the zebra a different species; countries where the wild ass is found ; gome run so awift, few coursers can overtake them; caught with traps; taken chiefly for the flesh and skins, which make that leather called ehagreen ; entertainment of wild asses in Persia seen by Olearius ; the delicacy of its flesh a proverb there; Galen deema it unwhelesome; asaes originally imported inte America by the Spaniards, have run wild, and nultiplied in auch numbers as to be a nuisance; chase of them in the kingdom of Quito; have all the awiftness of horses; declivities and precipices do not retard their career; after the first load their celerity leaves them, their dangerous ferocity lost, and they contract the stupid look and dulness peculiar to the assinine species; will net permit a herse to live anong thein; always feed together; and herae straying where they graze, they fall upon, bite, and kick him, till he be dead ; their preference to any vegetable is to the plantain; they drink as aoberly as they eat, and never dip the nose into the stream; fear to wet their feet, and turn eut to avoid the dirty parts of a read; shew ne ardour but for the female, and often die after covering; scent an owner at a distance, and distinguigh him in a crowd ; with eyes covered, they will not stir a step; when laid down, one eye covered with the grass, and the other hidden with a stone, or other contiguous body, they will not atir or attempt to rise, to get free from impedimenta ; several brought up to perform, and exhibited at a show; suffered to dwindle every generation, and particularly in England; bulk for bulk, an ase stronger than a horse, and surer-footed; also lesa apt to start than the horse; mere healthy than the horse; Persians cleave their nostrils to give them more room for breathing; Spaniards alone know the value of the aas; the Spanish jack-ass above fifteen hands high; the ass eriginally a native of Arabia; warm climates produce the largest and best; entirely lost among us during the reign of queen Elizabeth; Hollingghead pretends our land yields no asses, yet they were common in England before that time ; in Sweden they are a aort of rarity; by the last history of Norway, they had not reached that country; in Guinea, they are larger and Inore beautiful than the harsce of that country; in Persia, are two kinds, aome suld for forty or fifty pounda; no animal covered with hair less aubject to vermin ; live till twenty or twenty-five; sleeps lesa than the horse, and never lies down for it, unless much tired; she-ass creages fire and water to protect her young; the gimerro bred between the ass and the bull; the size and atrength of our asses improved by importation of Spanish jack-assea, 223 to 227 . destroyed by the South-American bat, called vampyre, 385 .

Assafatidn, gavare nations delighted with the smell, 169.

Assiniboils lake, where the river $\mathrm{St}$. Lawrence takes ita rise, 63 Astroites, among coral substances, 838.

Atalantes, an island submersed, was as large as Asia Minor and Syria ; the fruits of the earth offered without cultivation, 39.

Alhanatus, instance of his atrength, 151 .

Athclstan, prohibited the exportation of mares and stallions, except as presents, 222.2.

Alhewians had thcir cock-matches, 495. See Quail-fighting, 509. Atherine, description of this fish, 650 .

Atmosphere, most disorders incident to mankind, saya Bacon, arise from changes in the atmesphere, 611

Attructivi, defined; the sun possessed of the greatest ahare, 2.

Acosetta, or acooper, a bird found in ltaly; now and then comes over into England ; its description, and extraordinary shape of its bill, 567 .

Aurelia, one of the appearances of the caterpillar, 784 to 787 ; luying it in a warm room, Mr. Reaumur hastened the disclosure of the butterfy, and by keeping it in an ice-house, retarded it ; though it bears a different appearance, it contains all the parts of the butterfly in perfect formation; gome insecta continue under that form not above ten daya, gome twenty, gome geveral montha, others for a year together, 789 ; how the butterfly gets rid of that covering, ib.; aurelia of the bee different from that of the conmon caterpillar, 805

Anrura Borealis, or nerthern light, atreame with peculiar lustre, and a variety of colours, round the pole; its appearance almost constant in winter; and when the sun departs for half a year, this metcor aupplies its beams, affording light for all the purposes of exiatence, 113.

Aurora, or the aamiri, the smallest and most beautiful of the sapajou monkeys; its description; is very tender, delicate, and beld in high price, 412 .

197.
Auk, a bird bred in the ialand of St. Kilda, 589.

Axis, a kind of beautiful stag ; its deacription, 265.

Azores, serpents, adders, and anakes, seen about these islands by sir Robert Hawkins in 1590,70

\section{B.}

Baboon, survey of the baboon kind, 404 ; fierce, malicious, ignorant, and untractalle; its description; impelled by a hatred for the malea of the human species, and a desire for women; the Chevalier Forbin relates, that in Siam, whele troopa will sally forth, plunder the houses of provisions, and endeavour to force the women; manner of robbing an orchard or vineyard at the Cape of Good Hope; the female brings forth one at a time, carries it in lyer arms, clinging to her brcast; at the Cape of Good Hope, the young of these animals are taught to guard houses, and perform the duty with punctuality; they geem insensible of the miachief they do; a baboon described by Mr. Buffon; lasciviousness predominant; their food; are not found to breed in our climate; are not carnivorous; their liver, like that of a dog, divided into six lobes; the largest of the kind is the mandril ; ita description; displeased, it weeps like a child; is a native of the Gold Const; that called Wanderow chiefly seen in the woods of Ceylon and Mala. bar; its description; the Maimon of Buffon, by Edwards called the pig-tail, the last of the sart; its description; a native of Sumatra, 406 .

Baby, the name of a dwarf, whose complete history is very accurately related by Mr. Daubenton, 189.

Babyrouessa, the Indian log; ita description; travellera call it the hog of Borneo; in what manner it escapes the pursuera; has enormous tusks of fine ivory; less dangerous than the wild boar the tusks have points directed to the eyes, and aometimes grow inte them; these animals, in a bedy, are seen with the wild boars, with which they are not known to engender; are easily taned have a way of reposing different from other animals of the larger kind, by litching one of their upper tusk on the branch of a tree, and suffering their whole body to swing down at ease; they are fierce and terrible when offended, and peaceable and harmless when unmolcated; their flesh good to be eaten, but aaid to putrefy in a short time; they chiefly live upon vegetablea and the leaver of trees; are found in the island of Borneo, and in other parts of Asia and Africa, 285 to 287.

Bacon's observations upon fishes, 611.

Budger, a solitary, stupid animal ; forms a winding hole, and remains in anfety at the bottom; the fox takes poasession of the bole quitted by the badger, or forces it from the retreat by wiles; surprised by the dogs at a diatance from its hole, it fights with desperate resolution; all that has life is its food; it sleeps the greatest part of its time, and though not voracious, keeps fat, particularly in winter; it keeps the hole very clean; the female makes a bed of hay for her young; bringa forth in summer, three or fuur young; how she feeds them; the young are easily tamed; the old are savage and incorrigible; are fond of fire, and often burn themselves dangerously; are subject to the mange, and have a gland under the tail, which scents strongly; its fleah rank and ill-tasted, 438 .

$B a g$, name of the false belly of the opposaum; ita description, 414

$B a g$, or pouch, of the civet. See Civet, 341 .

Bait, the best for all kinds of fish is fresh herring; the larger gort will take a living sinall fish upon the hook oooner than any other bait, 634

Balance, to determine the specific gravity of metala, 55 .

Balearic crane, its deacription; the real crane of Pliny ; comea from the coast of Africa and Cape de Verd Islanda; has been described by the name of aea-peacock; foreign birda of the crane kind described, the jabiru, the jabiruguacu, the anhima, and the buffoon-bird, 557,558 .

Ball of fire of the bigness of a bomb; its effects, 111.

Bunks of a river, after inundations, appear above water, when all the adjacent valleye are overflown, and why, 59.

Bunana, the elephant eats the plant to the roots, 418 .

Barb, an Abrabian horge bred in Barbary, 218.

Barbs of the whale, or whale-bone, 617.

Barbary hen, ita description, 503.

Barble, a flat figh, ita growth, 657 .

Barja, in South America, cattle destrayed at that place by the Ainerican bats, called vampyrea, 386

Baris. See Apes, 401.

Barnacle, inaginary, a shell-fiah, 694 . 
Barometer, servicealte in measuring the height of mountains, 45; ; measures the wcight of the air ; in what manner, 89 ; frequent changes in the sir without any sensible alteration in the barometer, 90; when it marks a peculiar lightness in the air, no wonder thst it foretells a storm; and why, 103.

Barretiere, a famous youth, considered as a prodigy of learning at the age of fourteen; slept regularly twelve hours in the twenty. four, 157 .

Bass, a rocky island in the Frith of Forth. See Birds, 582 .

Bath, persons coming out of a warm bath several ounces heavier than when thcy went in; warm bath of sea water, a kind of relief to inariners, upon a fajlure of fresh wster at sea, 78 .

Bat,-bats as big ss rabbits, 120 ; by some reckoncd among birds, 206 ; douhtful among nsturalists whether beast or bird, now universally tske place among quadrupeds, 352; Pliny, Gesner, and Aldrovsndus, placed it among birds ; scarcely in any particular resembles the bird, except in the powcr of sustaining itself in the air ; description of the common sort in England ; its intestines and skeleton, in some measure, resemble those of mankind; makes its first sppearance early in summer, snd begins its flight in the evening; is seen to skim along the surface of waters; feeds upon gnats, noths, and nocturnal insects of every kind, which it pursues open-mouthed; its flight laborious, irregular, and, if interrupted, not readily followed by a sccond elevation; usually taken when striking against an object it falls to the ground; even in the sunmer, it sleeps the greatest psrt of the time; its retreat; contiuues in a terpid state during winter; is usually hanging by its hooked claws to the roofs of caves; unaffected by all change of weather; is destroyed particularly by the owl; the hat couples and brings forth in summer from two to five young at a time; the female has two nipples forward on the breast, as in the human kind; and this is a motive for Linnæus to give it the title of a primas, to rank it in the same order with mankind; the female inakes no nest for her young; when she begins to grow hungry, and finds a necessity of stirring abrosd, she takes lier little ones and sticks them by their hooks against the sides of her apartment, and there they inmoveably cling, and patiently wait her return; less similitude to the rsce of birds than of quadrupeds; grest lishour in flying, soon fatigues, and tires it in less than an hour; its petty thefty upon the fat of bacon; long-eared bat; lorse-shoe bat; rhinoceros bat; a large race of bats in the East and West Indies truly formidable; a dangerous enemy; when united in flocks they becoune dreadful; are eaten; the Negroes of the African const will not cat then though starving; on the African const they fy in such numbers, as to obscure the setting oun; the rousette, or great bat of Madagascar, is found along the coasts of Africa and Malabar ; where it is often seen abeut the size of a large hen; destroys the ripe fruits, and sometimes settles upon animals, and man himself; destroys fowls and domestic aninsls, unless preserved with the utmost care, and often fasten upon the inhabitants, attack them in the face, and make terrible wounds; the ancients have taken their idea of harpies from these fierce and voracious crestures, equally deformed, greedy, uncleanly, and cruel ; the bat called the American vampyre; its description by Ulloa; purport of his account confirmed by various travellers, who all sgree that it has s faculty of drawing bleod from persens sleeping, and destroying them before they swake; a strong difficulty remains how they mske the wound; Ulloa and Buffor's opinions; suppose the smimal endewed with a strong power of suction; and that, witheut inflicting any wound, by continuing to draw, it enlarges the pores of the skin, so that the blood at length passes; they are one of the great pests of South America, 380 to 388 ; found in the holes deserted by the woodpecker, 520 .

To bay, said of a stsg when he turus his head against the hounds, 262.

Bergle. See Hound, 311.

Beak, how that of a imals is produced, 147.

Benm, by liunters meant that part which bears the antlers, 262.

Beams, those of the sun shining upon the fire put it out, and why; darting directly upon us, without the medium of the air, would burn us up at once, or blind us with effulgence, 98 .

Bears, in cold frozen regirms of the North, not smaller than in milder countries, 120 ; the Nortl American Indians anoint their skins with fat of bears, 184, the beurs now and then make depredations upen the rein-deer, 277; in Greenland do not change colour, 278; thrce different kinds; the black of Ainerica does not reject animal food, as believed; places where they are found; retrcat of the brown hear; a rulgar error, that during winter the brown bear lives by sucking its paws; it seeme rather to exist upon the exuherance of its former flesh, 436; the male and fernale do not inlabit the same den, and seldom are seen together, but on the ac- cesses of genial desire; care of the female for her young; the bear, when tamed, scems gentle and placid, yet still to be distrusted and msnaged witls caution, heing often treacherous and resentful without a cause; is capable of a degree of instruction; when come to maturity, can never be tamed; methods of taking them; their paws and hsuns 8 grest delicacy; the white placed in the coldest climates, grows larger than in the temperate zones, and remains master of the icy mountains in Spitzbergen and Greenland; unable to retreat, when attacked witl fire-arms they make a fierce and long registance; they live upon fish and seals; their flesh is too strong for food; sre often secn on ice-floats several Icagues st sea, though bad swimmers; the white sometimes jumps into a Greenlander's bost, and if he does not overset it, sits down calmly, and like a passenger suffers itself to be rowed aleng; hunger makes it swim after fish; often $\mathrm{s}$ battle ensues between a bear snd a morse, or a whale, and the latter generally proves victorious, 436,437

Beards, Americans taking grest pains to pluck theirs up by the roots, the underpart, and all but the whiskers, therefore supposed to lave no hair growing on tliat part; Linneus himself has fallen into this inistake ; different customs of men, in the manner of wearing their beards, $145,146$.

Beasts sre more ficrce and cruel in all countries where men are most barbarous, 22.

Beasts of chase, in the reign of William Rufus, and Henry the First, it was lcss criminal to destroy one of the human species than a beast of chase; sacred cdifices thrown down, and turned to wsste, to make room for bcasts of chase, 261 .

Beasts of prey scldom devour each other; they chiefiy scek after the deer or the goat; their usual method of hunting, 208.

Beaver, known to build like an srchitect, and rule likc a citizen, 210 ; its fore parts taste like flesh, snd the hinder like the fish it feeds on, 285; a remaining monument of brutal society; its qualities, taken from its fellows, and kept in solitude or domestic tameness ; resists only when driven to extremity, and fights whien its speed cannot avail; the only quadruped that has a flat broad tail, covcred with scales, gerving as a rudder to direct its motions in the watcr; the sole quadruped with membranes between the tocs on the hind fect, and none on the fore feet; the only animal in its fore parts entircly resembles a quadruped, and in its hinder parts approaches the nature of fishes, having a scaly tail; its description; has but one vent for the emission of excrements and urine; they asscmble sbout the months of June and July; make a society to continue the greatest part of the year; form a company of above twe hundred; fix their abode by the side of a lake or river; cut with their teeth $\mathrm{a}$ tree thicker than a man's body; amazing works and mansion-houses; cenvey their materials by water; mix clay and dry grass together, work it into a mortar, and with their tails plaster their work within and without; their walls perpendicular, and two feet thick; their piers fourscore or a hundred feet long, and ten or twelve feet thick at the bssc; their dykes ten snd twelve feet thick at the foundation; their apartments round or oval, and divided into threc stories, one abeve the ather; visited too often by men, they work only in the night time, or abandon the place, and scek a safer situation; four hundred reside in one msnsion-house, divided into a number of apartments, having communication with each other; their works in the nortlern parts finished in August or September; in summer they aro epicures; their provisions for the winter season; they drive piles inte the earth, to fence and fortify their habitation against the wind and water; cut down branclies three to ten feet in lengtl.; the largest are conveyed to their nugazines by a whole body; the smallest hy one only; each taking a different $w^{*} s y$, and having a walk assigned him, that no one should interrupt another in his werk; wood-yards larger or smaller, in proportion to the number in the family; Inanner of catching them in snares or hy surprise; they swim with their mortar on their tsils, and their stakes between their teeth; their works darnaged hy force of water, or fect of huntsmen, instantly repaired, 389 to 391

Beauty, every country has peculiar idcas of beauty; extraordinary tastes for beauty, 139 ; every nation, how barbarous soever, has peculiar arts of lieightening benuty; several of these arts, 140; a modern lady's face formed exactly like the Venus of Medicis, or the sleeping Vestal, would scircely be considered as a bcauty, except by the lovers of antiquity; less in the object than in the cye of the beholder; superior beauty of our ancestors not easily comparsble, 102.

Beccafigo, a bird of the sparrow kind, 357.

$B e d$, of a river, an increase of water there increases its rapidity, except in cases of inundation, and why; such bed left dry for eome hours by a violent storm blowing directly against the strean, 60,61 . 
Beds, the earth crery where in beds over beds, and each of them maintaining exactly the same thickness, 17.

Bee, a ruminating inseet, or seeningly so ; its stomach is composed of muscular fibres, 232; operations studied lor two thousand yesrs, are still incompletely known; Renumur's account suflieiently wonderful; many of the facts held dubious by those conversant with the subject; somo declared not to have existence in nature; three different kinds of bees; common working bees neither male nor female; queen bees lsy all the eggs that sre hatched in a season; strueture of the working bee, particularly of its trunk, which extracts the honey from flowers; manner of building their cells; in one day, they make eells upon each other enough to contain three thousand bees; deseription of those cells; the coinbs made by insensible degrees, not at once, as some inagine; the cells tor the young and for the drones; that for the queen bee the largest of all ; those for honey sre deeper than the rest; that not the only food upon which they subsist; manner of anticipating the progress of vegetation; the bee has s stomach for wax as well as honey; hee bread; treacle for food of bees in winter; what part of the flower hus the honey; sting of the bee; any wanting tood, bends down its trunk to the bee from whom it is expected, which then opens its honeybag, and lets some drops fall into the other's mouth; numerous as the multitude of bees appears in a swarm, they all owe their origin to one parent, ealled the queen-bee ; opening the body of a queen, the eggs at one time found to amount to five thousand; the queen easily distinguished from the rest; great fertility of the queen, and the great attention paid to her, controverted by recent observers; they leave a cell to every egg, and destroy the rest; great care and affection for the young; in about twenty days after the egg was laid, the bee was completely formed, and fitted to underge the fatigues of its state; the cell being prepared, the snimal soon transformed into an aurelia different from that of the counmon caterpillar; when they begin to break their prisons, above a hundred are excluded in one day; dreadful battles often ensue between the young breed and the progenitors; signs previous to their migrations; aiter the migration, the queen being settled, the swarm follows, and in a quarter of an hour the whole body is at ease; sometimes sacrifice their queen, but never when the hive is full of wax and honey; the working 8ort kill the drones in the worm-state, in the cell, and eject their bodies from the hive among the general carnage; upwards of forty thousand bees found in a single hive; instances of expedition in working; in the first fifteen days, they make more wax than during the rest of the year; a hive sending out several swarms in the year, the first always the best and most numerous; a kind of floating bee-bouse used in Franee, 800 to 807 .

Bees, in other countries; in Guadaloupe are less by half than in Eurepe, and have no sting; sometimes there are two or three queens to a sivarm ; then the weaker deserted for the more powerful protector; the deserted queen dues not survive the defeat; is destroyed by the jealous rival; and till this be done, the bees never go out to work; at Guadaloupe their eells are in hollow trees, sometimes with a sort of waxen-house, shaped like a pear, in which they lodge their honey, and lay thair eggs; their honey never congeals, is fluid as oil, and has the colour of amber; in the tropical elimates are black bees without a sting; their wax is soft, and only used for medicinal purposes, not being hard enough for candles, as in Europe; whether the humble-bees have a queen or not, there is one much harger than the rest, without vings, without hair, all over blsck, like polished ebeny; this views all the works from time to timo; their habits the lioney gathered by the humble-bees neither so fine, so good, nor the wax so elear, or so capable of fusion, as those of the common bees, 807,808 .

Bces, Lcaf-cutting, make thoir nest, and lay their eggs, ameng bits of leaves, 808 .

Bees, Wall, so ealled, beeause they make their nests in walls; the male and females are of a size; the former without a sting, 809 .

Bee, Wood, 808; Bee, Masun, Bec, Ground, builds its nest in the earth; the patienee and assicinity of their labour, ib.

Beetles, a ruminating insect, or seems to ruminate, 232 ; their general characteristies; their kinds distinguished from esch other; deseription of the sexes; dor-beetle, or the May-bug ; how the two in the May-bug are distinguished from each other; season of their coupling; the female beres a hole into the ground, where to deposit her hurden ; and when lightened of it, ascends from the hole to live as before; their eggs; deseription of the insect, and of its manner of life in the worm-state; continues in that state fur more than three years, changing every year its skin; and living under the ground without eyes; in what manner it sssunes the form of a chrysalis ; time when it beeomes winged, and eompletely formed; the old one never survives the season; and dies from the severity of eold in vinter; its habits and food, when completely formed; number of their eggs ; rooks and hogs particularly fond of them, and devour them in great numbers; instances of great devastations made by the May-bug; description and habits of that beetle which the Anericsns eall the tumble-dung; the insect ealled the king of the beetles; description of the eleplant-beetle, the largest of this kind hitherto known, 018 to $0: 21$.

Begrgars, a question in the schools, which the most happy man, tho beggar by night, and the king by day ; or the beggar by day, and king by night, 157 .

Belcher, (Mr.) See Blond, 173.

Bell, the great diving-bell improved by Dr. Jalley; he could write or read in it when the sea was clear, and especially when the sun shone, 85 .

Bell, when the sting cries, he is said to bell, 262 .

Bells, their vibrations not heard under the receiver of an airpump, 98.

Belly, a ninute description of the filse belly of the oppossum, 414 . Berries, the Laplanders drink water, in which juniper-berries have been infused, $17 \%$.

Bewailer, or the sai, a monkey of the new eontinent, 412.

Bezoar, German bezoar, 252.

Bezuar-goat, the oriental bezoar, 251 ; cow-bezonr, monkey-bezoar, snd hog-bezoar, $25 \%$.

Billiting, a name given by the huntsmen to the exerement of the fox, 323 .

Birch, hares are particularly fond of it, 346.

Birds, all produced from the egg, 126 ; their lower eye-lid alone has motion, 142; have the neck longer than any other kind of animals; those which have short elaws have also short necks, those that have long elaws have the neck in proportion, 147; have \& power of discharging food to feed their young; ruminating birds, 232 ; many kinds which the dog will not touch, 317 ; hunters often informed by the hirds of the place of retreat of the tox, 324; a fluck of small birds often alarnıs every thicket, and directs the hunter to the martin, 336 ; tornıed for a life of escape; surpass fishes snd insects in the structure of their bodies, and in sagacity ; their anatomy and conformation; compared to a ship making way through water; are lurnished with a gland behind containing a proper quantity of oil; to what purpose ; description of their leathers; the pectoral muscles of yuadrupeds trifling to those of hirds; choose to rise against the wind, and why; all except the nocturnal have the heads smaller, and less in proportion to the body, than quadrupeds; their sight exceeds most other animals, and excels in strength and precision; have no external ear standing out from the head; the feathers encompassing the ear-holes supply the defect of the exterior ear ; the extreme delicacy of their sense of hearing is easily proved by their readiness in learning tunes, or repeating wordy, and the exaetness of their pronunciation; their delicacy in the sense of smelling; instances of it in ducks; the tail guides their flight like a rudder, and assists them either in the ascent or deseent; wonderful internal conformation; the wind-pipe often makes many convolutions within the body of the bird, and is then called the labyrinth; of what use these convolutions are, no naturalist has been able to aceount; this difference obtains in birds to all sppearance of the same species; whence some derive that loud and varions modulation in their warbling is not easily aecounted for; birds have much louder voiees in respect to their bulk than animals of other kinds; all have properly but one stomach, but different in difierent kinds; the organs of digestion in a manner reversed in birds; why they pick up sand, gravel, and other hard substances; most have two appendices or blind-guts; in quadrupeds always fuund single; all birds want a bladder for urine; their urine differs from that of other snimsls; effects of the annual moulting which hirds suffer; their moulting. time artificially accelerated, and how ; the manner in which nature performs the operation of moulting; their nıoulting-season; nany live with fidelity together for a length of time; when one dies, the other shares the same fate soon sifter; the male of wild birds as happy in the young brood as the female; nothing exceeds their patience while hatching; Addison's observations to this purpose; great care and industry in providing subsistence for their young; they feed each of the young in turn, and why; perceiving their nests or young to have been handled, they abandon the plaee by night, and provide a more secure, though less connodious retreat; the young taught the art to provide for their subsistence; those hatehed and sent out earliest in the season the most strong and vigorous, 448 to 461 ; they endeavour to produce early in the spring, and why ; ef forts for a progeny when their nests are robbed; such as would have laid but two or three eggs, if their eggs bo stolen, will lay ten or twelve; the greatest nuniber remain in the distriets where they have been bred; and are excited to migration only by fesr, elimate, or hunger; cause of the annual emigrations of birds; times of mi- 
grations; in what order performed; follow the weatlier rather than the country, and go on as they pereeive the atmosphere more suitable to their wants and dispositions; in all countries, longer-lived thas quadrupeds or insects of the same climato; surprising age of swans ind geesc; plumage and voice of birds in different zones; all less than quadrupeds; the grcatest of one class surpass the greatest of the other in magnitude; calises of the great variety in the middle order of birds; the ostrich is the greatest of lirds; the hummingbird the smallest; wild birds generally of the same magnitude and shape; inferior to quidrupeds in docility; the number already known above eight liundred; differenec betwcen land-birds and water-fowls; description of birds of the rapacious kind; the pic kind ; the poultry kind; the sparrow kind ; the duck kind ; the crane kind, 456 to 461 ; the eormorant the best fisher ; the nauseous bird, or dodo; powers of land-birds of the rapacious kind to obtain their food; sight of such as prey by day surprisingly quick; such as ravage by night have their siglit fitted to see in darkness with precision; inhalit the most lonely places and desert mountains; appearing in cultivated plains, or the warbling groves, is for depredation; every order of carnivorons birds seek fur those of the size approaching their own; the carnivorous kinds only breed annually, and are less fruitful than others; breed but few at a time; where supplics of food are difficult, the old soon drive the brood from the nest to shift for themselves, and often destroy them in a fury causce by hunger; almost all birds of prey unsociable; the malc and fenule, when necessary to each other, live together, but they most nsually prowl alone; birds with crooked beaks and talons are solitary; all males of prey sre less and weaker than the fermales; the females are of a greater size, more beautiflal and lovely for shape and eolours, stronger, more fierce, and generous, than the males; it may be neeessary to be thus supcrior, to provide for herself and her young; these birds are lean and meagre ; their flesh is stringy and inl-tasted, soon corrupting, and flavoured of that animal upon which they subsist ; Belonins asserts, many people like the flesh of thic vulture and falcon, and dress them for eating; and that the osprey, when young, is excellent food ; five kinds of land-birds of the rapacious nature; whence thcir distinctive mark ; bird of licaven, name given by the ancients to the eagle ; two children carried off by cagles, 470 to 474 ; the most formidable birds of prey respect the butcher-bird, 486 ; the digestion of such $8 \mathrm{~s}$ live upon mice, lizards, or the like food, not very perfect, 489 ; Father Kircher set the voice of birds to music, 490 ; domestic birds of the poultry kind, maintained in our yards, are of foreign extraction, 492 ; the wilder species, cooped or caged, pine awsy, grow gloomy, and eome refuse all sustenance; the poultry kind alone grow fat, 493 ; climate, food, and captivity, three very powerful agents in the alteration of the hsbits, and the very form of birds; of all birds the cock the oldest companion of mankind, and the first reclaimed from the forest, 494 ; slso the Persian bird of Aristophanes, $\mathrm{ib}$.; description of the tamis, or the bird of Numidia, 503; the bustard the largest land-bird, native of Britain, 501; none secures its young better from external injury than the toncan, 519; God's bird, the bird of paradise, 523; parakeets the most beautiful in plnmagc, and the most talkative birds in nature, 528; the pigeon, for its size, has the largest crop, 530; small birds tho greatest favouritea of man; mark out a territory to theinsclves, which they permit none of their own species to remain in; at some seasons of the year, all small birds nigrate from one country to another, or from more in. land provinces towards the shore; months of their migrations; autumn the principal season for catching these wandercrs; the nets, and the method of catcling them; flur-birds; singing among birds universally the prerogative of the male; small birds fight till one yields his life witlı the victory; two male birds strive in song, till the loulest silences the other; during the contention, the femsle sits an attentive silent auditor, and often rewards the loudest songster with her company during the season; the male, while his mute is hatching, sits upon some neighbouring tree, to watch and to sing; the nest of small birds warmer than of larger ; small birds having finished their nests, nothing exceeds the cunning they employ to conceal it ; wornis and insects the first food of all birds of the sparrow kind; how birds of the sparrow kind bring forth and hatch their young; manner of life during the rigours of winter; the inale of small birds not finding a mate of his bwn species, flies to one of anotlier, like him, leit out in pairing; a rixed species between a gold-finch and a cansry-bird, betwa $n$ a linnet and a lark; these breed frequently together, and produce not, likc the mules among quadrupeds, a race incspable of breoding again, but one as fruitfisl as their parents; various hirds of the sparrow kind; many plants propacsted from the depositions of birds; many of those kinds, which are of passage in Englsnd, permsnent in other countries : and some with us constaut residents, in other kingdoms have tho nature of birds of passage ; instances of it, 533 to 538 ; the heren commits the greatest devastation in fresh waters, $5 b^{\circ 0}$; the flamingo luas the largest tongue, 566 ; birds of various sorts snd sizes, nore than the stars in a serenc night, scen in the rock of the Bass and in the Frith of Forth, 5\&2; none make a more indifferent figure upon land, or a more beitutiful in the water, than the swan, 593 ; of all birds knowu it is the longest in the shell, 595 ; the duek, reared under a hen, despises the admonitions of its leader; an incontestible proof that birds have their unanners ratluer from natire than education, 597 .

Bird-catchers sport by counterfeiting the cry of the owl, 490 ; nets for, and method of taking small hirds, 5.4 .

Bison and Urus, names of descendants of one common stock; crror of the naturalists upon this point; the cow and bison are animals of the same kind; deseription of the bison; it is supposed by Klein and Buffon no morc than another nane for the bonasus; the breed found in all the southern parts of the world; that breed more expert and docile than ours; many bend their knees to take burdens up, or sct them down; the respect for them in India degenerated into adoration; it is nimble of foet; it is esteemed by the Hottentuts; assists them in sttending their flocks, and guarding then against invaders; is taught to combat the encmies of the nation, and every army of the Hottentats is furnished witls a lierd of them; they procure the Hottentots an casy victory before they strike a blow; lives in the same cottage with jts mastcr, and when it dies, a nev one is chosen to succeed it by a council of the old men of the village, and is then joined with a veteran of its uwn kind, from whom it learns, becomes sacial and diligent, and is taken for life into friendship and protection; the bisons are found to differ from each other in several parts of the world; some have horns, and some are witl:out; they are equally tractable and rentle when tamed, and sre furnished with a finc, lustrous, soft hair, inore Leautiful than that of our own breed; their hump of different sizcs, weighing from forty to fifty pounds, more or less; cuts and tastes somewhat like a dressed udder; the bisons of Malibar, Abyssinia, Madagasear, Arabia, Asia, Afriea, and Amcrica ; in the course of a few generations, the hump wesrs away; its description; the bison and the cow brced anong each other; the grunting or Siberian cow, and the little African cow, or zcbu, are differcnt races of the bison, $22 \pi$ to 237 .

Bitch, a pregnant bitch, so placed by Mr. Buffon that her puppies were brought torth in warm water, 133; one forgotten in a colutry house lived forty days without any other nourishment than the wool of a quilt she had torn to pieces, 317.

Bittern, or mire-drum, the solemnity of its evening-call cannot $\mathrm{l}_{\mathrm{H}}$ described by words; they are calls to eourtship or of connubial telicity; it differs from the heron cliefly in colour; its wind-pipe fitted for the sound ; opinions concerning the cause of its bomings never utters its call in domestic coptivity; its residence; a retired tinıorous animal; its food, nest, snd eggs; in three dr.ys, leads its little ones to their food; differences betwcen the bittorn and tho heron; its hollow boom considered by the vulgar as the presage of some sad event; instance of it; its flesh greatly esteemed by the luxurious; it seldom rises but when slmost trode upon; at the lat. ter cnd of antumn, in the evening, its wonted indulence forsakes it ; is then scen rising in a spiral ascent, till ruite lost from the vicw, making a singulnr noise ditlerent from its former boomings; names given to this bird by the Greeks and Latins, 56\%, 563.

Biralre shells, 679 ; all the kinds hermaphrodite, yet require no assistance towarda impregnation, b8 7 ; it is particularly in these shell-fish that pearls are found, 691 .

Blackbird, of the sparrow kind, 537 ; sometimes seen all over white; its eggs and nest, 539 .

Black-cap, bird of the sparrow kind, 538 ; prized by some for its singing, and is also called the mock nightingale, 543.

Biacks, conjeetural opinien that tho blacks are a race of people bred from one man accidentally black. 1E3; the climate a cause obvious and sufficient to produce blackness; nothing satisfuctory discovered upon the cause of producing it in human complexions; opinion of Sir Thomas Brown upon the subjet. 124; whence originally thcir flat nosc8, 185 ; black parents have procreated two white Yegroes, ib.

Bladder, birds have no bladder for nrine, 452. Sec Fisles, 611,612 . Blcnnius, or blenny, deseription of this fish, 6I?.

Biind, such as live in countries generally covered with suow become blind, 163 ; the niole not blind, 371 .

Blindicorm, its description, 740 .

Blood, arterial blood immediately mixed with air in the lungs, is of a fine tlorid scarlet colonr; that of the veins returning to the heart, is of a blackish crimson hue; whenee this difierence of colvur proceds not well understood, 97 ; the blood circulates through the 
bones, as through every ather part of the body; Mr. Beleher the first who discovered it; his experiment to this purpose, 17:3; blood of the rein-deer prescrved in small casks for sauce with the marrow in spring, 277 ; the heat of the blood in man snd other animals above thirty degrees above congelation; in the marmout, and other animals which slcop the winter, it is not above ten degrees, 357 .

Blue-bird described; its residence ; is rsrely caught; it doeility ; speaks and whistles at the word of command manner of taking it, 539 .

Blue Cat described, 291 .

Blushing, whence it procesds, 144.

Boar, wild, varies not his colour as dogs of the domestic kind; description; he ploughs the ground like a furrow; his tusks seen almost a foot long; they differ from those of the elephant in that they never fall; when the hosrs come to a state of naturity, they dread no single crcature; their position when attacked, $27 \%$; the msnner of hunting them: when kilted, the testicles cut off to provent their tainting the flesl, 280; was formerly a native of our country; William the Conqueror punished with the loss of their eyes such as killed it in his forests; at prosent the wild bresd is axtinct, 2৬2; the Canary boar describod; the tusks being broken away, the snimal abates its fierceness and venery, and nearly the same effect as csstration is produced, 257 ; does not fly at the $s p$ prosch of the lion; combat of a lion and a wild boar, in a meadow near Algiers, 295 .

Bobak, name of the marmout in Poland, 358.

Bodies, why some light bodies swim, and ponderous bodies sink; the deeper a body sinks, the greater the resistance of the depressed fluid benesth; low then, after it has got a certain wsy, it does sink at all, 55,56 ; animal bedies left to putrefy, produce air copiously, 98; syminetry of the liuman body; the body of a wellshaped man ought to be square, 140; human body often found to differ from itself in size ; instance of it ; the cause ; differs also from itsclf in weight, 149 ; those parts furnislicd with the greatest quantity of nerves, are first in formation, 159; the tone of a sonorous body made to depend upon the number of its vibrations, and not the force, is taking an effect for a cansc, 164 ; suffering is but to a certain degree; torture becoming excessive, destroys itself; and the mind cesses to perceive, when the body can no longer endure, 176 .

Boerhaave taxed with marking out to his pupils a little ridge of

hills in Holland, ss mountains of no small consideration, 40.

Boiguacu, the largest of the serpent kind in South Americs; sometimes forty feet in length, 120 ; description of this creature, 741 .

Bonasus, ouppesed by Klein and Buffon another name for the bison, 236.

Bones, in the embryo, slmost sa soft as the muscles and flesh, 173 ; lard as the bones saem, the blood holds its current through them, as through other parts of the body; in old age more solid, also mere brittle, and why, ib.; fossil bones found on the banks of the Ohio, in Peru and Brazil, 424. See Blood, 173. Seo Bread, 179. See Fish, 651.

Bonet-Chinois, Mr. Buffon's name of a monkey, supposed to be a variety of that called malbrouk, 411

Bonito, description of this fish, 650 .

Booby, name given by our seamen to birds of the penguin tribe, 589.

Barandians, description of them, 178.

Boristhenes, or Nieper, a river, its course and source, 61.

Borneo, the natives hunt the ouran-outang in the same msnner

as the elephant or the lion, 403.

Boroch, in the kingdom of Cambaya, flocks of peacecks seen in the fields near that eity, 498 .

Bospharus, (the Thracian) was the first appropriated, by granting to such as were in possession of its shore the right of fishing in it, 68 .

Bottom of the Red Sea, a forest of submarine plants, 85 ; tbat of the sea in some parts not found, and why; that of the sea near America covered with vegetables; a map of the bottom of the sea between Africa and America, by M. Buache, ib.

Bornea, island in the East. Indies, where the babyrouessa, or Indian hog, is principally found; hog of Borneo, the name given by travellers to the babyronessa, 285.

Bowels, of the ruminating animals considered as an elaboratory with vessels in it, 231

Boyuna, of Ceylon, a kind of serpent, a great favourite among the natives, 741 .

Brain and spiral marrow the first seen in the embryo, 159; esrthworin entirely without it, 829 ; some animals live without their brains for many wceks together, 830 .

Brambling, a bird of the sparrow kind, 537,538 .
Bramins of India lave a power of emelling equal to most cres. tures; they smell the water they drink, though to us quite inodorous, $16 \%$.

Brasil, black clothes worn there soon turn of an iron-colour; kept in the shops, prescrve their proper hue, 92; duck described, 598.

Bread, twelve ounces of it, snd nothing but water, the common allowance for four and twenty lours, aung the primitive Christians of the East, 15.5; that of the Laplanders composed of bones of fishes, pounded and mixed with the inside tender bark of the pine-tree, 179.

Brcam, description of the sea bream, 648 .

Breasts in woinen larger than in men; milk found in the breasts of men as well as of women, 147 ; black women's breasts, efter bearing one child, hang down below the navel; it is customary anroug them to suckle the child at their backs, throwing the bressts over the shoulder, 182 .

Breuth of the lion is very offensive, 295 ; manner of breathing in fishes, 609 .

Brecze, constant breeze produced by the melting of snows, 101 ; from ses increases gradually till twelve, sinks away, and totally hushed at five ; upon its ceasing, the land breeze begins, increases till twelve at night, and is succeeder in the morning by the sea-brocze; cause of these two breczc: ; sometines the sea snd land-breczes come at sll hours; the land and sea-breezes on the coast of Malabar and at Congo, 102.

Brisson, his method of classing animals, 201

Bristal, a citizen of it who ruminsted his food, 232.

Britons, the sncient, considered ths lare as an unclean animsl, and religinusly abstainod from it, 348; the cock a forbidden food among them, 494.

Broches, the horns of the stag the first year, 262.

Brock, the sting of the third year, 262 .

Brovon (Sir Thomas) hoped one day to produce children by the same method as trees, 126 ; his opinion upon the cause of blsckness in huinan complexinns, 184.

Brun (Le) giving a painter directions about the passions, place the principal expressions of the face in the eye-brows, 142 .

Brush, the name given by luntsmen to the tail of the fox, 323 .

Brutcs, in those cuuntries where men sre nost barbarous and stupid, are most sctive and sagacious, $35 \%$.

Bubulus, an animal partaking of the mixed natures of the cow, the goat, and the deer; its description; has often been called the Barbary cow, from whieh it differs widely, 253.

Bubalus, properly \& gazelle of Africa, 272.

Bubalus of the sncients, supposed of the cow kind by Buffon, placed among the lower class of ruminant quadrupcds, 230 .

Buccinums, one or two of them viviparous, 684 .

Buck, capable of propagating at the age of one year; one buck sufficient for a luundred snd fifty gaats ; is enervated in four years st mast; becomes old before his seventh year, 246; hunting the buck snd the stag performed in the same manner in England, 262; number of names invented by liunters for this animal; dues not change his laycr like the stag; nanner of hunting him is much the same as that of stag liunting, 266 .

Buck-goat produces with the ewe an animal that, in two or three generations, returns to the sheep, retaining no marks of his ancient progenitor, 241 .

Buffala, of the varieties of the cow kind, but two are really distinct, the cow and the buffslo; they bear sntipathy to each other; they do not breed among each otlicr, and no animals are more distinct snd like each other less; are in abundance in Guinea and Malabar; it is areat swimmer; description of it; the vesl of the young is not better eating than the beef of the old; thicy are natives of the warmer climstes; yet are bred in several parts of Europe, particularly in Italy; the female produces one at a time; continues pregnant for twclve months; is sfraid of firs; leatlier made of its hide is well-known for thickness, softness, snd impenetrability; guided by a ring thrust through the nose; milk of the female not so good as that of the cow; two buffaloes yoked draw more thon four strong horses; its flesh hard and blackish, disngreeable to taste and smell ; this animal wild in niany parts of India, and dangerous; manner of hunting them; when tsmed, no aninal more patient or humble; inferior in size only to the elephant, the rhinoceros, or hippopotamus; the camelopard, or camel, if taller, neither so lng, nor so corpulent; is fond of the water, and crosses the largest rivers without difficulty; has an aversion to red colours that resemble flame; in those countries whcre they are in plenty no person dresses in scarlet; they make most use of their feet in conibat, and rather tread their enemies to death than gore thera, 236 to 239 . 
Bufiom, (M.) his theory of the earth, and a detail of it, 10, 11; questions that night be askerl this mast ingenious philosopher concerning his theory of the earth; he has brought together a multitude of facts relative to the history of the earth, 11 ; his system about the rudiments of animals, 121; objeetions against it, ib.; thinks that women never beeome bald, 142; his deseription of the first sensations of a man just brought into existence, pointing out the steps by which he arrived at reality, 171, 172 .

Buffoon-bird, name our sailors gave the Numidian crane; its peculiar gestures and contortions; the Freneh eall it demoiselle; is a very searee bird; the aneients have described a buffoon-bird, but not meant the Numidian erane, 559.

Bug, the May-bur. See Beetles.

Bngs, their habits; deseribed; are often found eoupling tail to tail; manner of destroying them; they devour fleus, and devour euch other, $75,5,75 \%$

Bulbous, hair is sa at the root, 143

Eu'tin, a sea-snail, performs the office of male and female at the same time, lis5.

Bull, the gimerro asserted to be between the ass and tho bull, 226 . Bulfinch, bird of the sparrow kind, 538, 539; may be taught to whistle to a regular tune, 540 .

Bull-herd, description of this fish, 206 .

Bulls, the wild, in Spain mean despicable animals; have nothing of that stermess of aspect remarkable in our bulls, ?30.

Jiull's-tye, the name given by suilors to a terriblo hurricune; deseribed, 105

Bunting, bird of the sparrow kind, 537

Burnct, his theory of the eartli; a detail of that work, 7,8 .

Bustard, the largest land-bird that is a nativo of Britain; inhabits the open and extensive plain; is much larger than the turkey, the male generally weighing from twenty-five to twenty-seven pounds; its deseription; places where frequently seen in noeks of tifty or unure; its tood; they have sentinels always placed at proper eminences, ever on the watch, to warn the flock ol the appearance of dunger ; are often run-down by greyhounds; in what manIter; they suldom wander above twenty or thirty miles from home; the mles have a pouch, holding near sevon quarts of water; they change their mates at the season of incubation, about the latter end of summer; separate in pairs, if there be a sulticiency of females fur the males; otherwise the males figlnt until one of them falls; in France, some of those vietims of gallantry found dead in the fields; their nests made upon the ground; they lay two eggs almost of the size of a goose-egg; hatch in about five weeks; the young run about as sum us out of the sliell; they assemble in floeks in Oetoher, and keep torether till April ; their toorl in winter ; in some parts of Switzerland they are tound frozen in the fields in severe weather: when taken to a warm place, they again reeover; usull1y live fiftecn years, and are incapable of being propagated in a domestic state. 504,505 .

Burcher-bird, its description, with its habits; leads a life of eontinual combat; intrepiclity of this little creature, in going to war with the pie, the crow, and the kestril, all above four timies birger than itself; it fights upon the defensive, and nften comes to the attack with advantage, particularlv wlien the male and fernale unite to protect thoir young, a: al to drive a way the more powerful birds of rapine; in what manucr they sally furth a gainst them; sometimes the combat ends with the destruction of the assialant, and slsn of the defender; the most redoubtable birds of prey respeet them, and they fly in their enuprany without fearing their power or avniding their resentment; small birds are its usual food; and when it las killed the bird or inseet, as asserted by the best authority, it fixes them upon some neighbonring thorn, and when thus spitted, pulls them to pieces with its bill; the smaller red butcher-bird unigrates; the places where they are to be found ; their nests, and the number of their coggs; tho femnle feeds her young with caterpillars and other inseets, but soon after aceustoms them to flesh procured by the male vitl 1 great industry; their nature very difierent from other birds of prey in their parental care; for instend of driving out their young from the nest to shift for themselves, they keep them with care, and even when adult do not forsake them; the whole brood thus live in a family together; each family afterwards live ap:rt, and build in concert ; upon the return. ing season of courtship, this union is at an end; the manner of fying is nlways up and down, selden clirect or sideways ; different kinds of this birl, $1 \geqslant 6,4 \%$

Futler, the fat of the manati serves in all eases instead of Intter, $3 i r$.

Butterfy, some kinds actually live upon little or nothing, 153. one of tho prineipal ornaments of oriental poetry; in those countries, the insect is larger and more beautiful than with us; easily xo $77 \& 73$. distinguished from thes of every other kind ly then wings: Linnous has reckoned up above seven lumdrerl and sixty different kinds, yet the catalngne is ineomplete; number and heautiful colours of its wingy; butlerfies can discover their mates at more than a mile distanee; description of the head, eorselet, and body; the eyes lave not all the same lorm; hut the outward coat has a lustre. in which may be diseovered all thu colours of the rainbow ; when examined closely, it has the appearance of a nmltiplying glass; the use of their horns or feelers, as yet unknown; the nse of their trunks ; dificrence between buttertlies and moths; they often pereeive the approach of the fomale at about turo miles distanco; by what sense is not easy to conceive; it has nu organs for smelling; ; the female is larger tlian the male; if disturbed while united, the female flies off with the male on her back, entirely passive on the occrsion ; after junction they deposit their eggs and die ; all females of this tribe are impregnated by the male by one aperture, and lay their eggs hy anothor; every butterfy chooses for her brond, instead of tho plant most gratelul in its winged state, that which it Las fed upon in its reptile form; low they kecp their eygs warm, and also entirely ennealed; inany do not lay till the winter warns thein of their approaching end; sorne continue the wholo winter in hollows of trees, and do not provide tor posterity until the heginning of April, then lenve their retreats, deposit their eggs, and die, 791 to 794 . Seo Jurclia, $7<8$.

Buttuck, in man, difierent from that of all nther animals, 148 .

Buzzerd, a sluggish, inactive bird; often remains perehed whole days upon the same bough; lives more upon frogs, nuce, and in sects, thin upon birds; linore troublesome to seize; its manner of living in snumer; resembles the owl kind in his countenance more thun any other rapacious bird of prey; so little eapable of intruc. tion that it is a proverb to eall one obstinately ignorant, a buzzard : the honey-buzzard, the moor-buzzard, and the hen-barrier, are of this stupid tribe, and differ cliefly in their size, 4:5.

Byron (Commodure) our last voyager that has seen the gigantic race of mankind, 191.

Cubbai, the sane animal as the capibara, 22-1.

Cachulat, a fish said to pureue a shes] of herrings, and to swallow thousands at a gulp, (009: it las generally gone under the name of the spermaceti whule, till Mr. l'enmant male the distinetion, horrowing its nune from the Freneh; seven distinctions in this tribe; description; the throat of this animal very formidalu? with easo it could swallow an ox; it terrifies the dolphins and porpoises so much, as often to drive them on shore; it contains two precious drugs, spermaceti and ambergris; the oil of this fish is ensily convertible into sperrnaceti, by boiling it with a ley of pot-ash, and lrardening it in the manner of soap; candles are now nade of it; the balls of ambergris not found in all fishes of this kind, but chieny in the oldest and sironmest, (io3, (i24.

Congi, or the sali, is the largest monkey of the sagoin kind; its description, 412 .

Cucretu, a mountain near it, was split by nn marthouake, 46 .

Chiro, in what manner they produce their six or scren thousand ehickens at a tinie, 406 .

Calco, the lrorned ludian raven, 516.

Culrination, all animal substances when calcined are the same, 708 .

Culf, name given to the young of the hink, ar the female of the stam, 260

Calf, or lind-calf; the stag ealled so the first year, 262 .

Callitrix, the green monkey of $\$$ t. Jare, of the ancient continent; its deserjption. 111.

Callyomymas, the diagonet; description of this fisli, 643 .

Calvas, attended witle a deluge of rain; why, and where, 101.

Cumbict, made of hair of animals ulout Angora, 247.

Camel, a ruminating animnl. 2:?; cumel and dromedary not two distinet kinds, only a variet of the sane, wirich has subsisted time inmemorial; the only sensible diflerence between thoso two races, they produce with each other, and the mixed breed is considered the best; of the two the dromedary is far the most numerous; countries wlere the camel and dronedury are found; neither can subsist or propagit to in the climates towards the north; Arabia the most adapted to the support and production of this animal; the caucl the most temperate of all animals ; it can eontinue to travel several days without drinking, and is ofter. six or seven days without any sustenance ; its feet formed to travel upon sand, and utterly unfit for moist or marsliy places; many vain efforts tried to propagate the camel in Spain; they have been transported into 
America, but have multiplied in neither; they miglt perhaps produce in these countries, but would in a few years degenerate; their strength and their patience would forsake them; and instead of enriching become a burden to their keepers; uses to which this animal is put among the $A$ rabians; its education; it has a fifth stomach, which serves as a reservoir to hold a greater quantity of water than immediately wanted; when the camel finds itself pressed with thirst, it throws up a quantity of this water by a simple contraction of the muscles, into the other stemachs; travellers, when straitened for water, liave often killed their camels for what they expected to find within them; countries where connerce is carried on by means of camels ; trading journeys in caravans ; capable of carrying a thousand weight; their foed; pursue their way when the guides are utterly astray ; its patience and docility wlien leaded; Buffon considers the camel to be the most domesticated of all other creatures; in what manncr the female receives the male; one malc left to wait on ten females, the rest castrated; they live from forty to fifty yeurs; evcry part of this aninual converted to some useful purpose ; its very excrements are not useless, 4:30 to 433 .

Caneleon, its dimensions and appetites; has a power of driving the air it breathes over every part of the body, 719; changes of its colour; it is an crror that it assumes the colour of the object that it approaches; description of it by Le Brun, 720; it often moves oue eye, when the other is at rest; sometimes one eye seems to look directly forward, while the other looks backward; and one looks upward, while the other regards the earth, ib.

Camelopard described; dimensions of a young one; inhabits the deserts of Africa; no animal, from its disposition or its formation, less fitted for a state of natural hostility; it lives entirely upon regetables, and when grazing, spreads its fore-legs wide to reach the pastare; known to the ancients, but rarely seen in Europe : often seen tame at Grand Cairo, in Egypt; Pompey exhibited at one time ten upon the theatre, 499 .

Camerarius, his description of the perfections a horse ought to pessess, 222.

Canuda, above thirty thonsand martins' skins usually imported from that country into England, 336 .

Cunal. See Blood, 173.

Cinury-bird taught to pick up the letters of the alphabet at the werd of cemmand, to spell any person's name in company, 459 ; by the name originally from the Canary Islands; comes to us from Germany, where they are bred in numbers; at what peried brought into Europe is not known; about a century ago they were sold at very high prices, and kept only for the amusement of the great ; in its native islands it is of a dusky gray colour, and so different from those seen in Europe, as to raisc a doubt about its species : rulcs and instructions for breeding them in a domestic state; apparatus for breeding in Germany ; food the old ones must be supplied with, when the young ones are excluded; so prolific are these birds sometimes, that the female will be ready to hatch a second time before the first is able to quit the nest; this bird kept in company with the linnet, or the geld-finch, pairs and produces a mixed brecd, most jike the canary-bird, and resembling it in its song, $544,545$.

Canary-boar described, 287.

Cancerous breasts conred by the sucking of the rubeth, or the land-toad, 705. 97.

Candle quickly extinguishes in an exhausted receiver, and why;

Cannons filled with water, and left to freeze, burst, 52 .

Cantharides, well known in the shops by the name of Spanish flies, and for their use in blisters ; their description, with the differcnces from each other; the countries where, and trees on which, they are seen; it is reported, that the country poople expect the rcturn of these inscets every goven years; their bad smell is a guide for those who catch them; they smell so disagrecable, as to be perceived at a great distsnce, especially about sunset, though not seen at the time; they yicld a deal of volatile caustic salt; their qualities; the effects fall principally upon the urinary passages; in what unanner they are killed, $822,823$.

Cape de Verde islands; a south wind prevails in them during the month of July, 10].

Cape of Good Hopc, a narth-wcst wind blows there during tlie month of September, 101: at the Cape of Good Hope it is customary to hunt the elcphant for its teeth; in what manner; account of an unhappy huntsman, 424.

Capibara, or cabiai, an animal resembling a hog of abont two years old; its description; some naturalists have called it the yater-hog, and why; a native of South America, and chiefly frequenting the borders of lakes and rivers, like the otter; it - eizes the fish, upon which it preys, with its hoofs and teeth; lives also upon fruits, corn, and sugar-canes; is often scen sitting up like a dog that is taught to beg; its cry resembles the braying of an ass, morc than the grunting of a hog; its only place of safety is the water, into which it plunges when pursued, and keeps so long at the bottom, that the hunter ean have no hopes of taking it there; when young is easily tamed; its flesh has a fishy taste, but its head is said to be excellent, 484,485 .

Capons taught to clutch a fresh brood of chickens thronghont the year, 496 .

Cupon of Pharawh, supposed the true ibis ; is a devourer of serpents, and follows the caravans that go to Mecca, to feed upen the offal of the animals killed on the journey, $55 \%$.

Caracal, or the siagush, a native of the East Indies, resembles the lyn $x$ in size and form, 304 .

Caracol, a town situated at the font of the Andes, 43.

Caraguata, a plant in the West Indies, which clings round the tree it happens to be near; it keeps away that nourishment dc. signed to feed the trunk, and at last entirely destroys its supporter, 160.

Carapo, description of this fish, 649.

Carassa, a volcano in South America, 29

Carazun, a single lion of the desert often attacks an entire cara. van, 293 ; the assemblage called a cararan sometimes compesed of numbers amounting to ten thousand, 43I.

Curcajou, name given by the North Americans to the glutton; its manner of killing the rein-deer, 277 .

Caribou, name the North Americans give the rein-deer, 273.

Carli, (Father) See Monkey, 410.

Carnicorous animals, there is one class that pursue in a pack and encourage each other by their mutual cries ; generally lead a life of famine and fatigue; suppert a state of famine for seversl weeks together, 208, 209; milk in those animals is more sparing than in others, 212. See -9nimals, 23I, 232.

Carnirotous birds seek for such as are of the size most approaching their own, 476. See Birds.

Carp, an experiment made with this fish in a large vase of water, under an air-pump, 609 ; one found by Buffon not less than a hundred years old; this discovery cenfirmed by other authors, $6 I I$; continues in the egg net above three weeks, 613 ; Mr. Tull famous for his invention of spaying carp to give it a fine flavour, ib.; its description, 650 ; the nuctlod of fattening it in a daunp cellar; it has been known thus to live for a fortnight, to grow exceedingly fat, and to get a superior flavour, 652 .

Carriers, pigcons used to carry letters, 532

Carrion-erow, resenbles the raven in its appetites, its laying, and manner of bringing up its young, $5 \mathrm{I} 4$.

Cartcsius, his theory to explain the invariable motion of the winds, not quite so absurd as that of Dr. Lyster, 100.

Carthagena, in America; the heat of the hottest day ever known in Europe is continual there; the heat of its elimate affects the speech of its inhabitants, which is sof and slaw, and their words generally broken ; nore than three parts of our army destroyed by the olimate, in our unsuccessful attack upon it, 94.

Carthamus, or bastard-saffron, strongly purgative to man ; parrots very fond of it, 528 .

Cartilage, the thyroid cartilage, 147 ; cartilages in youth elastio and pliant, in age become at last hard and bony, and why, 173.

Cartilaginous fishes; their general confurmation; supposed they grow larger every day till they die ; their internal structure; are possessed of a two-fold power of breathing; apertures by which they breatle ; the cartilaginons sliark, or ray, live for some hours after they are taken; fishes of this tribe possessed of powers that other fishes are wholly deprived of ; can remain under water, without taking breath; and can venture their heads above the doep, and continue for hours out of their native element; their season and manner of copulating, and of bringing forth; little difference between the viviparous and the oviparous kinds in this class of fiehes; five divisions of the cartilaginous fish, 627,628 .

Cassazoary, a bird first brought into Enrope by the Dutal from Java, in the East Indies, where only it is found; its description; the part which most distinguishes this animal is the lead, which inspires some derree of terror; its internal parts described ; their intestines are thirteep times shorter tlian those of the Ostric b; it has the head of a warrior, the oye of a lion, the defence of a por. cupine, and the swiftness of a courser; is not fierce in its natural character; how it defends itself; extraordinary manner of going; swallows evory thing that comes within tlie capacity of its gullet; the Dutch assert that it can devour glass, iron, and stones, and can cven live on burning coals, without the smallest fear, or the least injury ; the largest of its eggs is fifteen inches round one way, and twelve the other; places where this animal is found, it bas nat 
multiplied in any considerable degree, as a king of Java made a present of one to the captain of a Duteh ship, as a rarity, $462,468$. Catacombs of Egypt, 196.

Catamountain lunts for the hare or the rabbit, 207 ; the oeelet of Mr. Buffon; its description, 304 ; is one of the fiercest, and, for its size, one of the most destruetive animals in the world; no arts can tame or soften their naturea, 305 .

Catanea, a eity utterly overthrown by an earthquake, 33 .

Cataphracius, or kabassou, is one of the largest kinds of the armadillo, $3 \pm 2$

Cataracts of the Rhine, and of the Nile; the cataract of the river Velino, in Italy, is above a hundred and fifty feet perpendicular; a eataract near the city of Gottenburg in Sweden; other eataraets, 365

Cataruet of the eye; Mr. Cheselden having couched a boy of thirteen, who to that time had been blind, and at once having restered him to sight, curiously marked the progress of his mind upon the occasion, 161 .

Caterpillars, their differenees from all other insects; all these animals are hatelod from the egga of butterflies; during the winter, the greatest number of eaterpillars are in an egg state; in the aurelis state, they are seemingly deprived of life and motion; some do not inake any change at the approach of winter, but ehoose themselves some retreat, and there remain quite motionless, and as insensible as if actually dead ; caterpillars of this kind are feund in great numbers together, enclosed in one common web that eovers them all; there are some of this kind, whose butterfies live all the winter, and where; a single eaterpillar eats double its own weight of leaves in a day, and seems no way disordered by the meal; the body of the eaterpillar anatomieally considered; avidity with which they feed; number of their stigmata, or those holes through which the animal is supposed to breathe; it has eighteen lungs ; the experiment of Malpighi to ascertain their use; all eaterpillars spin at one time or another; many of them change their skins five or six times in a scason; and in what manner; change into an aurelia ; their retreats in that state, 782 to 789 ; there are thousands of fishes, birds, and insects, that live ehiefly upon eaterpillars; a single sparrow and its mate, that have young ones, destroy above threo thousand caterpillars in a week; some of the kind, fitted only to live upon leaves and plants, will eat each otler, in preference to their vegetable food; the bodies of the larger kinds serve as a nest to various flies, that very carefully deposit their roggs in them; number of worms remain within the body of the caterpillar, devouring its entrails withont destroying its life; the jehneunnon tribe is not the enterpillar's offispring, as supposed, but its murderers, 794, 795.

Cut-fish, its description, 648 .

Cuts, the wild hunt for the squirrel or the mouse, 207; lead a solitary ravenous life; the whole tribe seek their food alone, and never unite for mutual support; and, except at eertain seasons, are enemies to each otlier; all of the cat kind devour nothing but flesh; and starve upon any other provision; are fieree, rapacious, subtle, and eruel; their greatest foree lies in their elaws; the eat goes with young lifty-six days, and seldom bringrs fortls above five or six at a ime; the inale often devotrs the kittens; before they are a year old they are fit to engender; the fomale seeks the male with cries; nor is their copulation performed without groat pain, and why ; when young are very playful and amusing; eats hunt the serpents in the Isle of Cyprus; any animal weaker than themselves, is to them an indiscriminate objeet of destruction; the mouse is their favourite game, and they pationtly watch a whole day until the mouse appears; a flagrant mark by which the eat discovers its natural inalignity; their eyes aee better in darkness than in light, and why; if the inhabitant quits the house, the cat still remains; is particularly fearful of water, of cold, and of ill smells; is excessively fond of some plants, such as varelian, marum, and cat-mint ; particularly loves fish; its sleep is very light; its hair sends forth shining sparks, if rubbed in the dark; the wild breed with the tane ; deseription of the wild eat ; inhabits the most mountainons and woody parts; lives ninstly in -trees, and feeds only by niglat; the eat waa much higher in esteen among our ancestors than it is at present; laws of Howel, concerning the price of cats; cats were not naturally bred in our forests; of all quadrupeds, the wildcat is, perluaps, that whose intestines are proportionably the sinallest and the shortest, and why; conmon to the new continent as well as the old; the blue-cat, the lion-cat, or more properly, the cat of Angora; the cats in Syria and Persia remarkable for their long soft hair, 238 to 292 ; all the cat kind are kept off by the fires, which the inhabitants light to preserve their floeks and herds; and they hunt rather by the sight than the smell; it happens that the tion pursues the jackal, or the wild dog, while they are bunting upon the seent and mercly for themselvea; the lion is tiven an unwolcome intruder upon the fruits of their toil; from thenee, proba. bly, has arisen the story of the lion's provider, 29:4; the linn de. vours a great deal at a time, and generally fills limself for two or three days to eome ; in the deserts and foresta, his most usual prey are the gazelles aud the monkeys, 245 ; the race of eats noxious in proportion to their power to do inisclief; inluabit the must torrid latitudes of India, Africa, and Ainerica, and lave never been able to multiply beyond the forrid zone, they seldom attaek man, though provoked; of all animals these are thie most sullen, and, to \& proverb, untameable; they still preserve their fieree and treacherous spirit, 305; different elasses of the kind from the lion to the eat, 307 ; the wild cat and the martin seldom meet withunt a combat it is not a nateh for the martin, 237; the ielneumon iujudiciously ealled the cat of Pharioh, 33\% ; cata of Constantinople, a name of the genet, and why, 340 .

Cattle, we lave the best breel of liorned eattle in Europe; the large hornless breed in some parts of Englind, originally from Poland, 234; the Dutch bring great quantitios of lean eattle from Denmark to fatten on their own rioh grounds; that of Uhraine he. comes fat, and is considered the lirgest breed of all Enrope; in Switzerland these animals grow to a large size; not so in Franee: size in Barbary, Ethiopia, Persia, and Tartary, 2036; leather. mouthed eattle, 243; liablo to be destroyed by the South Amorican bat, vampyre, $3 \$ 6$.

Caverns, the amazing carern of Eldenhole in Derbyshire; the dreadful oavern in the eountry of the Arrian Indians, ealled the gulf of Pluto, described by $\mathbb{F}$ lian ; the famous eavern of Candia, suppoaed to be entirely the work of art ; eavern of Maestricht; its deseription; no part of the world has a greater number of artifieial caverns than Spain ; in those countries where the climate ia very severe, still made use of as houses; in general deserted by every raee of meaner animals, exeept the bat ; the caverns called Oakeyhole, the Devil's-hole, and Penpark-loole, in England; description of them; the eavern of Antiparos, and its discovery; Magni's amusing account of it; how natural caverns formed; two liundred feet as much as the lowest of them is found to sink, 17 to 21 ; one in Africa, near Fez, continually sends forth smoke or flames, 29.

Cavier, the inliabitants of Norway prepare from eggs found in the body of the porpoise, a savoury liquor, which makes a delicate sauce, and is good when eaten with bread, $626^{\circ}$; it ia made with the roe of the sturgcon; more in request in other countries of Eurepe than with us; formerly in much request at the politest table in England, now sunk entirely into disuse; is a considerable nerelrandise among the 'I'urks, Greeks, and Venetians; manter of making it, 641, 64:.

Causes, the investigation of final causes a barren study; and, like a virgin dedicated to the Deity, brings forth nothing, 6 .

Caustic, eantharides yield a great deal of volatile caustic salt, 822 . Cayman, s sort of erocodile, 711 .

Cayopolin, a kind of oppossum; its description, 415.

Cea, an island waalned a way with several thousand inhabitants, 39. Cells, made by the bees, 812.

Cenere, a mount of recent appearanee, 47.

Centincl. Sec Animals, 209. See Murnouts, 356. See Bustard, 504. Centipes, the acolopendra, 761.

Centriscus, a kind of eartilaginous fish, 644 .

Cephns, name given by the ancients to the monkey now ealled mona, 411 .

Cepola, the deseription of this fish, 643 .

Cerig", an island of the Arelipelago, where many wild asses are found, 224.

Cctaceaus fishes, the whale and its varictios resemble quadrupeds in their internal strueture, and in some of their appotites and affeetions; they are constrained every two or three minutes to come up to the surfice to take breath, as well as to spout out through their nostril (for they have but one) that water which they sucked in while gaping for their prey; the senses of these animals superior to those of other fishes ; and it is most likely that all animals of the kind can hear; they never produce above one young, or two at the most; and this the female suekles in the manner of quadrupeds, lrer breasts being placed as in the human kind, above the navel ; interesting story founded upon fact from $W_{a}$ aller ; distinetive marks of this tribe, $6+4,615$.

Chacrelas, white men go by that name in the East Indies, 186.

Chatodon. See Cat-fish, 648 .

Chafinch, a bird of the sparrow kind, 537,538 ; time of emigration of the hen, 457

Chapatanudas, a distemper in Ameriea, 96.

Charles XII. when shot at the siege of Frederickshlall, was seen to clap his hand on the hilt of his sword, 176 .

$6 \mathrm{G*}$ 
Charossi, the only sort of horses for hunting lions, 296.

Charyludis, a gulf; Nichola Pesce jumped into it, continued for three quarters of an hour below, and st last appeared holding a golden cup in one hand, and making his way anong the waves with the other; description of this gulf, 86,87 .

Chase, men of every age and nation litve made that of the stag a faveurite pursuit ; in our country it was ever esteemed a principal diversion of the great, 260 ; these eports reserved by sovereigns for partieular amusement, and when; in the reigns of William liufas and Henry the First, it was less eriminal to destroy a lunuan being than a beast of chase; sacred edifices thrown down for rona to beasts of cliase, 2ti1; chase of the stag, as performed in lingland; terms used by burters in that elase, 262; the same in Sicily; and in China, 10: ; clase of the fox ; eant terms nsed by the liuntsmen in it, 323; of all varieties, that of the ostrich the most laborivus, is also the most entertaining; deseription of it, $4(i 5$.

Chasms, aunazing in the $A \mathrm{Jps}$, and still more in the Andos, 17 ; causes that produce cliasnis or fissures, 18.

Chatterer, a bird, nitive of (1ermany; its description, 517, 513 .

Cheesc, the inluabitants of Canada usc no other than the milk of the hind, or the female of the stag, 205 ; those of Lapland little and well tasted; never breed mites, 266

Cheops, the oldest measure of the human figure in lis monument, in the first pyramid of Egypt, 192.

Cheselden. Sec Cutaruct, 161, 162

Cherrotin, or little Guinea 1)cer, the least of all cloven-footed quadrupeds, and perhaps the most beautifu? ; is most delicately shaped; its description; native of ludia, Guinea, and the warm climates between the tropics; the male in Guinea has horns, but the fomale is without any; they chiefly abound in Java and Ceylon, 253, 254.

Cheney, suspected the ruantity of water on the carth daily decreasing, 53.

Clicken, an amazing history of it in the egg, by Malpighi and Haller, 126; in what manner six or seven thousand are produced at a time, at Grand Cairo; capons cluteh a fresh broed of chickens throughout the year, 496 .

Child, listory of tlie child in the womb, 129 to $13 \mathrm{~J}$; cliildren of Negroes able to walk at two montlis old, at least to move from one place to another; in our own country scldom able to walk under a twelvemonth; skin of clildren newly brought tortli, is always red, and why; the size of a new-born intant about twenty inches, and its weight twelve pounds, 134 ; when newly born, pass mest of their tine in slceping, and awake with erying; in cold eountries eontinue to be suckled for four or five years togcther; in Canada and Greenland motherg are often scen sucluling twe or three elildren of different ages at a time, 135 ; ehild's growth less every ycar till the tinie of puberty, whien it seems to start up of a sudden, ib.; in some countrios speak sooner than in others, and why; children of the Italians speak sooner than those of the Germans; various methods pointed out to improve the intelleets of elildren, 188,189 ; inherit the aceidental deformities of their parents; instances of it, 105 ; white children frequently produced from black parents; hut never Flack ehildren from two whites, 136 ; many instances of the ehild in the wornb being marked by the strong affeetions of the mother; how performed is not known; hard to coneeive tliat the child in the womb should take the print of the father's features, $187,188$.

Chimboruzo, a remarkablo mountain in Soutls Ameriea, 44

Chinese, have neither flats nor slanjes in their musie, 161 ; their horses weak, littlo, ill-ahaped, and cowardly, 220; description of that people, 150,181 .

Chorosan, in Persia, bodies previously embalmed, and burifd in the sands of that coustry, preserved from corruption a thousand rears, 195 .

Chough, description of the Cornish Chough, 514 .

Christopher (St.) See Fish, 620.

Chrysalis, or the aurelia, 78\%.

Chryses, an island sunk near Lemnos, 39.

Cicero, a long poem of his in praise of the haleyon, of which but

two lines renisin, 602 .

Cireassians, deseribed, 183.

Circe, an enchantress, armed her sor: with a spear headed with

the spine of the trygon, 635 .

Circulation of the blood. See Blond, 173.

Cicet, the speeies distinguished into two kinds; Mr. Buffon ealls one the civet, the other the zibet; distinetions between the two kinds; the civet thirty inches long; both civet and zibet considered as varieties of the same animal, as former naturalists have done; the eivet resembles the weasel kind, in what; differs from then, in what; the opening of the pouch or bag, the receptacle of the eivet; manncr of taking the eivet from the pouch; although a native of the warmest climates, this animal lives in teraperate and even oold countries, the quantity of perfume which a single animal affords, menerally depends upon its health and nourishment; kinds of food it likes best; drinks rarely, yet it makes urine often; snd, upon such occasions, the male is not distinguishable from the femsle; numbers of these animals bred in Jollind, and the perfume of Amsterdam reckoned the purest of any; the quantity greater proportionably to the quality and abundance of the food; this perfume so strong that it conmunieates to all parts of the snimal's body, to its fur and skin: a person shut up witl ono of them in a close room, cannot support the perfume; manner of elonsing the perfime; the places of considerable traffic in it: the animal irritated, its secnt becomes grenter; and tormented, its swent is etill stronger, and serves to adulterate or increase what is otherwise obtained from it ; civet a more grateful perfume than musk ; solel in Iollinel for fifty shillings an ounce; its eyes sline in the night; sees better in the dark than by day; brceds very fast in climates where heat conduces to propa. gation; thought a wild ficrce aninal; never thoroughly familiar lives by prey ; birds, and snimals it can overcome; its teeth strong and cutting ; its olaws feeble and inflexible; this perfume cuite discontinued in prescription; persons of taste proscribe it from the toilet, 340 to 342

Clacicles, or collar-bones, what animals have them; MIr. Bufon says none but monkeys, but this is an oversight, 147 .

Clazos of the lion give a fulse idea of its power; we ascribe to its force the efiects of its arins, 149; the weascl kind neither draw in nor extend their claws, as cats do, 328; those of the civet feeble and inflexible, 341 .

Climates, calanities in those where the air is contensed by cold, 95 ; eause obvious, and sutheient to produce blackness of Negroes, 184 ; coniplexions of different eauntries darken in proportion to the beat of the region; next to human influence, the climate has the strongest eflects upon the naturo and form of quadrupeds, 408 ; those excessively hot, unfavourable to horses, 220 ; in general, water-fowls of no particular climate, 537.

Cloth now made worse tlian some years past ; Flemings possessed the art of cloth-working in a superior degree, 243.

Clore-trecs crit down by the Dutcl at Ternate to raise the price of the spice; soon had reason to revent of their avarice, 95 .

Clonds, tho forerunners uf a terrible hurricanc, called by the saiIors the bull's eye, 105 ; dashing a gainst each other, produce electrical fire; water evaporates, and rising forms clouds; the theory upon it; that of Dr. Hamilton; the author's theory of evaporation, 107 108; at onee pour down their contents, and produce a deluge; rcfleeting bock innges of things on earth, like mirrors; during the winter nontlis, under the line, usually about MIay, the whole hori: zon seems wrapt in a muddy eloud, 110 .

Clupea, or herring, its description, 650 .

Couiti, a monkey of the new continent, described, 412 .

Coan, the name of a dwarf lately dead at Chelsea, 189

Coast of Italy is bordered with rocks of unarble of different kinds; quarries of which may easily be distinmuislied at a distance from sea; those of France from Brest to Bourdeanx, and Spain, composed of rocks, 79; of the sea, have peculiar winds, 102 ; deadly winds all along those of the Persian Gulf, and those of India, 105.

Coatimondi, extrene length of its snout; its description; very subject to eat its own tai]; its habits, 440 .

Colitis, the loach, description of this fish, 6.50 .

Colira di Capello, a kind of serpent, 732, 73\%).

Cochineal, a description of this insect, as in our shops brought from America; difference between the donestie and the wild cochineal; precautions used by those who tako care of those insects; the propagator has a new harvest thrice a ycar; various methods of killing them; produce different colours as broucht to us; our cochineal is only the fermales, used both for dying and inedicine, \$23.

Cock, of all birds the coek the oldest compinion of man, and first reclaimed from the furest; seareely two in the whole species that exactly resenble each otlier in plumage and form; species of cock from Japan, eovered over with hiir instead of feathers; the wostern world had the cock from Persia ; Aristophanes' cock the Persian bird; it was one of the forbidden foods among the ancient Britons; Persia, that first introduced it to us, no loncer lnows it in its natural form: eountries where it is wild; peeuliarities, in a wild condition; another peculiarity in those of the Indian wonds, their boncs, when boiled, are as black as ebony; the Athenians had eock-matches ae we; no animal of greater eourage, whin olpused to one of its own species; in China, India, tho Plilippine islands, and over the East, cock-fighting the sport and amusement of kings and princes; coeks in China as bold, or bolder, than ours; and of more strength with less weight; its great eourage procecds from beinr tho tnost sala. cious of all birds; a single eock suftices for 2 dozen hens; and is the only animal whose spirits aro not abated by judulgence; soon grows 
old, and in three or four years becomes unfit for the purposes of inzpregnation; llow long eoeks live, loft to themselves, not well ascertained; Aldrovandus makes their age to be ten years; are injured, as Linnxus asserts, by elder borries, 494 to $496 ;$; the black oliefly found in heathy mountains, and piry furests, 502; cock ol the wood. See Woodcock.

Cockle, a bivalved she!l-fish, $69 n$.

Coena, the elephant eats the plants to the roots, 360 .

Cod, from the banks of Newfrmalsnt, pursues the whiting, which flies before it to tho southern sheres of Spain, 609 ; spawn in one season, as Lewenlrcek asserts, above nine millions of eggs or peas, contained in a single roo, (11\%; its desoription, (44'); fishery in Newfoundland; where tiaken in such large quantities, that they supply all Europe with a eonsideralulo share of provision; when their provision is exhansted, they go to the polar ses.s, where they deposit their roes in full sccurity, (hi3.3.

Cald promotes exoporation, altiough diminishing the foree of other menstruums, 10d; extrenity of it not less produetive of tawny complexions than that of hent, 144 ; excessive, preserves bodica from corruption, 1!5; sone fishes rendered so torpid by cold in the northern rivers, as to bo frozer up in the masses of iee, where they continue, for montlis together, without life or sensation, prisoners of congelation, waiting a warmer sun tu restore then to life and liberty, 6.59 .

Collar-banes, what animals have them, 147

Colliers, eight dropped down dead by the vapour of the mines in Scotland, as if shot, 21 .

Colour, nono refreshes the sight so well as green, 5 ; of the sea not from any thing fioating in it, but from diftcrent reflections of rays of light; the proot; 85 ; different colours of the eye, 141; whence proeeeds the tawny of the North Ameriean Inditns. 184, 185 ; different of the waters of the same sea, 80 ; hair takes its colour from juices fowing throngh it, 143 ; that of the objeet contrihutes to form an idea of the distance at which it appears, 1(i2; of all those by which mankind is diversified, ours most heautiful to the eye, and most advantagcons, 183 ; those ehanges the Afriean, the Asiatie, or the Anerican, undergo in their colour, are but nceidental deformities, which might probably be renoved, leb; nothing exceeds the delicate recrilarity of those of the zebra, 22] ; thange of eolonr in the hair obtains, in sume degree, in all quadrupeds, 331 ; difterent in several parts of tile fur of the sable, 336 .

C'nmcts, their appearance tormerly terrible to mankind; their number much greater thin that of the planets; they roll in orbits; experience lias not sufficiently eonfirned the truth of the investigation about their returuing periods, 2 .

Complexion, extrenity of culd nut less produotive of a tawny than that of heat; not easy to coneeive how the sum whitenis witx and linen, and darkens the human eomplexion; the sun not the only eanse of darkening it ; the sun tinges the eomplexion in proportion to its vicinity, $134,135$. 401.

Compte's (Le) aecount of an ape he saw in the straits of Molncea,

Concrctions, searce an animal, or a part of their bodies, in which eoncretions are not formed; experience las found but few eares by the effieacy of these concretions; often prove fatal to the animal that bears thern, 25.

Condonine $(L \Omega)$ knuw's a fish possessed of the powers of the torpedo, and every way resemlilinu a lamprey, $6: 37$. 253.

Condoma, anomalous animal of the goat kind; its descrijtion,

Condar, possesses, in a highes degree than the earle, all the qualities that render it formidable to the feathered kind, to beasts, arol to man himself; is cighteen feet ceross the wings cxtended, aecordiny to Acosta, Garoilasso, and Desmarehais; the beak so s:rong as to pieree the boly of a cow; two of them able to devour it; licy do not abstain from man himself; furtumately there are fow of the species; the Indians believe that they will earry off a cleer, or a young ealt in their talons, as earles would a hare or a rabbit; and that their sight is piereing and their air terrible; that they seldom frequent the forests, as they require a large spaec for the display of their wings; they come down to the sea-shore at eertain seasons; when their prey fitils upon land, they then feed unon dead fish, and such nutritious sabstances as are thrown upon the shore; their eountenanees not so terrible as old writers have ropresented; those who have seen this animal, say the body isas large as that of a sheep; many instanees of its earrying away elildren; circumstantial aceonnt of this bird by $P$. Feuilee, the only traveller who has aceurately described it; it is supposed that the great Bird ealled the Roek, deseribed by Arabian writers, and so mueh exaggerated by fable, is but a species of the condor; countries where it is found; in the deserts of Pachomae, unen seldon venture to travel; its flesh as disagrceable as carrion, 477,478 .

Concpate, an animal resembling the skink in all things except size, 3.5 .

Cougar of America, resembles the tiger in natnral ferocity, thougl for inferior in its dimensions, 43!).

Congrelation. See Bloorl, 357 .

Congo, the land and sea-breezes there, 103 ; the inlualuitants of that eountry desire ardently to prostitute their wives and dauglyters to strangers for trifling advantares, 100.

Constantinople, its eats; mane given to the genets, and why, 340.

Continent of Ameriea; that part under the line is enol and pleasant; either shaded by mountains, or refreshed by breezes from the sea, $1=1$.

Coot, deseription of that bird, 57.2; residence and nost; rears two or three broods in a season; sometimes swims down the cur. rent, till it reaches the sen; dangers encountered in this voyage, ilı.

(inpel, manner of making that vessel, 49.

Copulufion, natural instinct for the proper times; instanees of it.

212 ; gnats produce roung without copulation, $8 \% 6$.

Coquallin the Bazilian squirrel, so eslled by Buffon, 3-2.

Curnl, the common red never inet with in the fossil world, 13. Corul-serient, described, $7: 30$.

Corat-plants, thoir various appenrances; opinion of count Marsigli upon errals; Mr. Fillis proves it the work of reptiles of the polypus kind; principal experiment to this purpose, 837,838 .

Coralines ealled fungr mutrepores: $8: 38$.

C'uret, a sea snail, porforms tlie oflice of male and female, 685 .

Coriander used in dressing a liare in the true Roman taste, 349.

Corin, name of the third variety of gazelles, by Mr. Buffon, 251.

Cormorant, its description and food ; remarkably voracious, with a sudden digestion; lias a rank and disagreeable smell; and is more foetid than even earrion; its forn disagreeable; its voiee hoarse and croaking; al] its qualities olseene; no womeler Mlilton makes Satait personate this bird; objeetion against this passege of Miltan's. Paradise Lost vindieated; fishes in fresh water, and in the dejaths of the oeean; builds in clitl's of rueks, and in trees; preys in the day time, and by night; once ased in Fingland for fishing, anl in what manner; how edneated in Chinn, for the purpeses of fisbing; tho best fisher of all birds; a most amusing spectaele, standing upon a eliff on the shore to see it dive after its prey; sometimes bas eaught the fish by the tail ; the fins prevent ity being swallowed in thas position, how it manages the fish in this case, 580, 501; reinarked for the quickness of its sight, is?3.

Corn, the flying squirrel is apt to do a great deal of damage in the eorn-fields, 3 is.

Cornaro, lived a hundred years with a constitution naturally feeble, 174 .

Corncall, pilehards make that coast a place of resort; thei: arrival proclaimed by the birds, and the larger fishes, 65.5.

Cormmandsl, dreadful tempests wholly unknown along its coasts, 102 ; anzazing size of oysters along that coast, 6030.

Corrira, or the Runner, a bird of tlic erane lind; its descrip. tion, $56 \%$.

Corruptian, exeessive eolil proserves holies from it ; and a great degree of dryness groduecd lyy hent; earth, if drying and astringent, produees the same efleet; bedies never corrupt at Spitzbergen, thongh burjed for thirty years; men and animals burjed in the sands of Arabia, preserved from cormution for ages, as if aetually embalmed; eorruption of lead bedies ontirely cansed by the fermentation of the humours; bodies buried in the monastery of the Cordeliers at Thoulouse, preserved from corruption; hodies previously embahmed buried in the sonds of Cliorosan, in Yersia, preserved from corruption for a tlunsand years; anazis preservation from it, in a mummy lately dug up in France, 195 to $19 \%$. Caryphacu, the razor fish. its deseription, 400 .

Cotopaxi, voleano in South America, deserihed ly Ulloa, 29. more than three geographical miles above the surface of the sea, 44 . 524. Cottan-trec, the seed intoxicates parrots, as wine does man,

Cottus, the bull-head; description of this fivh, 649.

Counulo, mueh less than the pereupine, its deseriptioh, $3 \%$.

Cougar, the red tiger. by Mr. Bufton, 300 ; extremely enmmon in South America; make frequent ineursions by night into the midst of the streets, carrying off dogs and other domestic crea. tures; in what manner the Indians encounter it sol.

Coulterneb, remarkable bird of the Penguin kind. See $P u f i r$, 
Cows, allured by music, 16f; ; of ruminamt animals, the cow kind deserves the first runk; meanest peasunis in Germuny, Poland, and Switzerland, kill one cow at least for their own table; salted and hung up, is preserved as a delicacy the year round; cows want the upper lore-teetli ; in no part of kulupe cows grow so large, yield inure milk, or nore readily lat'en, than in England ; make no par ticular distinctiun in their lerbage, indiscriminately devouring the proper quantity; it givos back mare tluin it takis from the soil : the auro of the cow known liy the teeth and liorns; the number of is tceth; Inve eigult cutting teeth in the lower jaw; manner of r newing thein; the horns nure surely determine this animal's atre, and low; while this animal lives, the horus lengthen; wants in ulder wliat it has in neck; the larizer the dew-lap, the sinaller the quantity of its milk; tho kind to be found in every part of the world ; laruer in proportion to tho richness of the pasture; Africa remarkable tor the lajigast and s:mallest cuttle of this kind; as alse India, Poland, and Switzerland; among the Eluth Tartars, the eow so lerue, that a tall man can mily ramch the tip of its shoulder; of all quadrupeds, the cow nost liavle to alteration from its pasture the breed of the Isle of $\mathrm{Man}$, and most parts of Scotland, much les: than in England, also ditferently shaped; the breed improved by forcign mixture, adapted to supply the impertections of our own such as purely British, far inferior in size to llose of the Continent the cow, the urus, and the bison, animals of the same kind; difference in size not so remarkable as those in its form, hair, and herns many considered as a difterent kind, and nanes given to them as a distinct species, when in reality all the sime; only two varieties of the kind really distinet, the cow and the buflale; they bear an antipatly to each other; scarce a part of the world where tlie cow kind is not found; variety of the lorns; those in Iceland, are without horns; the Barbary cow, or zebu; of all animals, the cow most extensively propagated; an inlabitant of the frozen ficlds of lceland and the burning deserts of Lybia; otlor animals preserve their na. ture or their form with inflexible perseverance; the cows suit themselves to the appetites and convenience of mankind; no animal has a greater variety of kinds, none more lumble and pliaut; the cow and bison breed among eacli otlier; the cow does not breed with the buffule; no animals nore distinct, or have stronger antipathies to each other; the cow goes nine menths with young; the grunting or Siberian cow, and the little $\Lambda$ frican or zebu, are difierent races of the bison; animals of the cow kind by naturalists extended to eight or ten sorts, reduced to two; an animal of the cow kind no naturalist has deseribed; the description of it, 233 to 240 ; the Greeks compared the ejes of a bcautiful wonian to those of a cow, 251; it eats two hundred and seventy-six plants, and re. jects two hundred and eighteen, 280

Cow bezour, a factitious sart, 252.

Crab, a ruminating fish, 39; surprising manner in which the monkeys draw crabs from the watcr, $409^{\circ}$; found in fresh and salt water, and upon land; description; its intestines lave many convolutions; land-crabs of various kinds; some healthful and nourishing; others poisonous or malignant to a great degree; places where found, 665 .

Crab (riolet) of the Cariblue islands, described; most noted both for sluape and dclicacy of its flesh; their food; their nippers the principal instruments for seizing and cutting their food; catch such hold, tliat the limb is lost seoner than the grasp; thus it gets off, leaving its elaw fastencd upon the cnemy; the claw performs its luty, and keeps a miuute lastened uyon the finger, while the crab wakes ofi; it loses no great matter by a leg or an arm; as they grow again, the animal becomes perfect as befure; live in a kind of orderiy suciety in retreats in the mountains; fatiguing and anizing unarch from the mountains to the sea-shere, to deposit the spawn, from which soon after milions of little crabs are seen slowly travelling up the mountains; wait the benefit of sea-water for their delivery; change their shells, at which period they becone quite naked, and almost without mution for six days, when they becone so fat as to be delicious food; liave under their stomachs four white stones, which gradually decrease, as tlie shell hardens, and wlien cume to perfection are not to be found; season and manner in which they are cauglit; in Jamaica they are in great plenty, and considered as one of the greatest delicacies; nnany of this kind found poisonous, 605 to $66 \%$.

Crab (soldier) a native of the West Indies; its description; seen every ycar descending from the mountains to the sea-shore, to deposit its spawn, and to provide itself with a new shell; contest biween them for some well-looking favourite sliell, for which they are rivals; strike with their claws; bite aach other, till the weakest is obliged to yield and give up the object of dispute; when laken sends forth a feeble ery, endeaveuring to seize the enemy with its nippers; not nuch esteemed for its flesh, $668,669$.
Crane, hred faniliarly in our marshes formerly; not now, anj why, 457 ; general characteristics and liabits of birds of the cranekind; their food and flesh; description of the crane; their nest are more simple than the sparrow's; Gesner says, its featliers, in his tine, were set in gold, and worn as ernaments in caps; description of this bird fronl ancient writers, whohave mixedinagination with history; whence have arisen the fables of supporting their aged parents, and fighting with pignies; the crane a social bird, and seldom seen alone; usual method of fiying or sitting, in flocks of filty ur sixty together; wlile part feed, the rest keep guard; subsists mostly upon vegetables; are known in erery country of Furope, except our own; are hirds of passage ; seasons of their niurations, during which they do incredible damage, chiefly in the niglit; were formerly knowu, and held in great estimation here fur the delicacy of their flesh; there was a peualty upon destroying their eggs; Plutarch says cranes were blinded, kept in coops, and fattened for the tables of the great in Rome; at present they are considered all over Eurepe as wretched eating; qualities of its flesh; the cold Aretic region this bird's favourite abode; their note the loudest of all other birds; and often heard in the clouds, when the bird itself is unseen; anazing lieights to which they ascend when they tly; though unseen themselves, they liave distine: vision of every object below; govern and direct their flight by their cries; extruordinary length aud contortion of its windpipe; use made of their clangorous sound; they rise but heavily, are shy birds, and seldom let the fowler appreach them; their depredations usually in the darkest nights, wlien they enter a field of corn, and trample it down, as if crossed over by a reginent of soldiers; corn their favourite food, scarce any otber comes amiss to them; Redi" experiments to this purpose; a little falcon pursues, and often disables it; method used on such occasions by those fond of hawking; barbarous customs of breeding up the cranes to be thus baited; easily tamed; Alhertus Magnus says, it has a particular affection for man; the female distinguished from the nuale, by not being bald behind; never lays above two eggs at a tine; the young are soon fit to fly, and then the parents forsake tlem to shift for themselves; when unfledged, they run with such switness that a man cannot easily overtake them; Aldrovandus assures us one was kept tano for above forty years; the vulgar bear the crane a compassionate regard; prejudices in its favour; a lieinous offence in some countries to kill a cranc; distinctions between the crane and the stark, 551 to $55 \overline{5}$.

Crane, the Belearic, from the coast of Africa, and the Cape ce Verdo islands, its description; habits; has been described by the name of the sea-pencech ; real Belearic crane of Pliny; foreign birds of the crane kind, deseribed; the jabiruguacu; the anhima; the buffoon-bird or Numidian crane, described, $55 \%$, 558 ; place where the crune kind seem to have forned their gencral rendezvous, 564 ; the flamingo tíe nost remarkable of all the kind, the tallest, bulkiest, and most beautiful, described, 565 ; small birds of the crane kind, 568 .

Cresus, (king of Lydia) seated on his throne witl all the barbarous poinp of Eastern splendour, asking Sulon if he had ever beheld any thing so fine? was auswered. that after the beautiful plumege of the pheasant, he could be astoninhod at no other finery, 501 .

Cricetus, the German rat, by Mr. Bufion called the hamster, its description; is the greatest pest in the countries where found, and every methed made use of to destroy it; its hole a curious olject for contemplation; shows a skill superior to the rest of the rat kind; description of it; their storehuuses; contain two bushels of good grain in each apartment; means of finding out their retreats; produce young twice or thrice a year, and bring five or six at a time ; their devastations preduce a famine; thty destroy eacl ot:e.:; their fur very valuable, 368

Criclict, a ruminating insect, or seemingly so, 232; difference from the grasshopper; their voice; fond, 776 ; never drink; sound of drums and trumpets make tlien forsuke their situation, ib. Crichet (mole) descriljed, tlought to be amplibious, if7; the number of their eges; a most detested inseet by gardeners; its de. vastations; precauitions of the fenale against the black bectle; their care and assiduity in the preservation of their young, ib.

Croches, in the head of the star, $26^{\circ} 2$

Crocodile, extraerdinary combat between this aumal and the tiger, 301 ; the iclincumon discovers and destroys its eggs; kills its young, and sometimes entering, the mouth of the crocodile, when sleeping on the shore, effectually destroys it, 337 ; the eggs it lays in the sand uften amount to three or four hundred, 338 ; the places where found, together with their dimensions; description; during an inundation, it sometimes enters the cottages of the natives, and seizes the first animal it meets with; several examplea of taking a man out of a sanoe from his companions, notwithatand- 
ing all opposition and resistance; ean overturn a canoe with a singlo blow of its tail; terrible ever upon land; its depredations; combats between the crocodile and the tiger; in what manner it seizes its prey; there is no aninul but man alone that can combat it with success; how a negro ventures to attack this animal in its own element; manner of taking it st Siam; often managed like a horse ; a curb put into its mouth, and the rider directs it as he likes; makes an object of savage pomp near the palaces of their monarchs; unsuner of taking it along the rivers of Africa; pnols of water where bred, as we breed carp in our ponds; in ligypt, and other long-peopled countries, this animal solitary and fuarful; in the river San Douningo, they are nost inuttensivo, ohildren play with them, snd ride about on their backs; beat thom without regeiving the smallest injury; probable opinion, its musky substance annassed in glands under the legs and arms; its flesh; the eggs to the savages most delieate morsels; all breed near frush waters; precautions in laying their eggs; the female having introducer lier young to their natural element, she and the male beeome their most formidable enemies; their eggs eagerly sought afer by every bird and beast of prey; the Gallinazo (a species of the vulture) their greatest enuny; the open-bellied crocodile, thought viviparous; hrs a false belly like the oppossum, for the young to creep out and in, as danger or neeessity requires; their age; produeed to fight at the ainphitlieatro at Rome, 711 to 716 .

Croppers, a kind of pigeons, 530

Crossbill, a bird of the sparrow kind, 537.

Cross-fox, animal between the dug and fox, 320 .

Crown, in the head of a stag, 362 .

Crows fetch and carry with the docility of a spaniel, 512; the carrion-crow resembles tho raven in appetites, laying, and manner of bringing up its young; the Royston-erono, 514 .

Cruelty, teaching the arts of cruelty, equivalent to committing them, 495.

Crustaceous, animals of the lobster kind, 663 .

Cuh, the fox is so called during the hirst year, 323 ; born blind, likn those of the dog, 324 .

Cuckoo, fubles invented of tlis bird now sufficiently refuted; where it resides in winter, or how provides for its supply during that season still undiseovered; this bird somewhat less than a pigenn, shaped like a marpie, and of a grayish colour; is distinguished from all nther by its round prominent nostrils ; discovers itsolf in nur country early in the spring, by its well kuown eall; its note heard earlier or later as the season is more or less forward, and the weather inviting; from the clieerful voice of this bird the farmer instrueted in the real advancement of the year; from this bird's note, the lusehaulnian may he taught when to sow his most useful seeds; history and nature of this bird still in great obscurity; its eall an invitation to courtship, used only by the nuale, generally perehed upon a dead irec, or bare bourh, repeating his song, which he loses when the genial season is over; his note pleasant though uniform; the female makes no nest; repairs to the nest of some other bird, generally the water-wagtail or hedre-sparrow, and, after devouring the eggs of the owner, Jays her's in their place; usually lays but one, and this the little foolish bird hatches with great assiduity, and when excluded fondly thinks the ill-looking changeling her own; to supply this voracions ereature, the eredulous nurse tuils with unwedried labour, not sensible she is fecding up an enemy to her race; the stomach of this bird is enormous, and reaches from the breast-bone to the vent; its food; naturally weak and fearful ; the smaller birds consider tho young cuckoo as an enerny; revenge the enuse of their kind by repeated insults, and form in train of pursuers; the wryneck in partieular, the most aetive in the chace; supposed, in winter, to Jie hid in hollow trees, or to pass into warmer elimates; story of a euckoo found in a willow log, in winter; probable opinion concerning its residenee in winter; Brisson makes not less than $t$ wentyright sorts of this bird; and talks of one of Brazil, as making a horrible noise in the forests, 523,524 ; follow's a vory different trado form what its nurse endeavoured to teach it; and, aceording to Pliny, in time destroys its instructer, 597.

Cuckoo-spit, or froth-worm, its description, 779.

Curl, the hare, the rabbit, and the squirrel, placed by Pycrius among those that chew the eud; how far true is not dotermined, 345 . Cugucte aparu, name in Brazil for the roe-buck, $26 \%$.

Cummin-seed, formerly used in dressing a hare in true Roman toste, 349.

Cur, the cur-fox, 325 .

Curlezo, a small bird of the crane kind; its dimensions; places where found ; manner of procuring its food; its babits; its nest, and number of eggs; a bird of passage; our country, during the summer season, becomes uninhabitable to them ; season of courtship, 568 to 570 .
Currents of rivers well explained by the Italians, 50 ; side current ; Jaek eurrent, 60 ; somctimes the current at botton swifter than at top, and when; double eurrent, ib. ; found to run in all dircetions ; manner in whiel mariners judge of the setting and rapidity of the current; eurrents are generally found most violent under the equa. tor; along the easts of Guinea, if a ship haprens to overshoot the mouth of any river it is bound to, the enrrent prevents its return; a passage, with the current, gone in two days, with difliculty performed in six weeks against it; eurrents do not extend above twenty leagues from the coast; the currents at Sumatra extremely rapid, run from south to nortli; also strnug evrrents betwecn Madngasear and the Cape of Good Hope; on the westcrn coasts of America, the current always runs from the south to the north ; but the most remarksble are those continually flowing into the Ylediterrsnean sen; between the North and the South Foreland, the current runs one way at top, and the elb another way at bottom, 76 to $7 \times$.

Current of air, driven through a contracted space, grows more vinlent, 10.1 .

C'usco, Crareilasso de la Vego asserts tlic air is so dry and so cold there, that tlesh dries like wood without corrupting, 195.

Ciestom, the form of the face secms ratlier the result of cugtom, 125.5 .

Cullle-fish, its description ; oontrivanee with which it is furnished by nature, when under a difficulty of escaping, 833 .

Cybotus, a lofy mountain swallowed by sn earthquake, 47 .

Cynocephalus, the Magot of Buffon, the last of the ape kind; it description; is a native of Africa and the East, 404

Cyprinus, or the carp. See Curp, 650 .

\section{D.}

Dam, in the rapaoions lrinds, leads lier young forth for months together; it is not so with those of the hare kind, 346 .

Dampier, has added noore to natural history than half the plrilo. sophers before him, 674 .

Damps, of various natures in mines; the fulminating sort, 23,21

Dance, hares taught to dance to music, 347 .

Dane, the tallest dog lored in Fingland, 312, 313 .

Danube has seven openinurs int.n the Euxine Sea, 39 ; proceeds from the Alps, 42 ; its cmurse; the Turks and Christians lave fleets of men of war upon it, 61 ; it receives thirty lesser rivers, 64 ; the luso, or isinglass-fish, eaught in great quantities in the river, 642.

Dara, its inhabitants use ostriches as lorses, 46 .

Darliness, surprising how far the eye accommodates itself to it, 163; resnarkable instance of it in a gentlenau, a major undes Charjes the First, 163.

Dubluton gives a complete history of a dwarf: 18.9.

Deaf men often found to see the foree of those reasonings which they could not hear, understanding every word as it was spoken, 168 ; one born deaf, must necessarily be fumb; instances of two young men, who, born deaf, were restored to hearing, 167 ; a person born deaf, by time and pains tauglat to write, read, speak, and by the mo. tion of the lips to understand what is said; instances of it, 163 .

Deafness one of the most eommon disorders in old age; way to know this defeet either internal or external, $16 \%$.

Death, a young mun born deaf and dumb, knew nothiug of death, and never thought of it till the age of twenty-four, when he begars to speak of a sudden, 167 ; a spectre, which frights us at a distance, but disappears when we cone to approach it, 166 ; uncertainty of the signs of death, 17\%.

Deer, annually shedding horns, and their permanenee in the sheep, draws a distinet line between their kinds, 2.1 ; the little Guineadeer, the least of all eloven-footed quadrupeds, and most beautiful; its description, 253 ; the male in Guinea has horns, but the femala is without ; they abound in Java and Ceylon, ib.; sll of the deerkind want the gall-bladder, 257 ; a downy substanec, like velvet, upon the skin, eovering the skull of a deer, when the ols horn is fallen off; their horns grow differently from those of shecp or cows; they are furrowed along the sides, and why, 257; the bran-deer, or the brown-deer, ealled by the ancients trauglaphus, found in the forests of Germany ; the new continent of Aneriea produces animals of the deer-kind in suflieient plenty, 265.

Deer (Fallow, no animals more nearly sllied than the stag and fallow-deer, yet they never lierd nor engender together, nor form a mixed breed ; each form distinet families, and retain an unnlterable aversion; the fallow-deer, rarely wild in the forests; are in genoral bred in parks, and their flesh is preferred to that of any other ani$\mathrm{mal}$; a herd of them divides into two parties, and engiges each other with great ardour and obstinacy ; botlt desirous of gitining a favourito f) spot of the park for pasture, and of driving the vanumisbed into tho 
reore disngrcenble ports; nunner of their enmbata : ara casily tuned; and browse closer than the stur; they suek the fomale at their second year; tlieir strength, cunniug, and courage inferior to those of the stag; a more delicate inimal th an the stag; we hitve in England two varieties of the fullow-deer, one brownht from Bengal, the other from Norway; flesh of the French fitlow-doer, has pot the fatiness or the thavour of that fed upun Lnglish paiture: Syanish and Virginia fullow-deor larget and strongrer than ours; daer without horns, their description, $24,5,266$.

Deer (Rein,) the most extraordinary aud most useful : native of q1:e icy regions of the North; it answers the purposes of a lorse; witempts made to accustom it to a nuore sobthorn climate, in a few months it declines and dies; answers the purpose of a cow in giving r:yilk, and of the sheep in furnishing warm clothing to the people of Lapland and Greenlind; description of the rein-cleer; its ruttingsime, and that of shedling its liorns; difierence between this deer and the stag; it is not known to the natives of Siberia; $\Lambda$ mericans call it caribou ; herdsmen of Lapland known to possess a thousand rein-deer in a single herd; it subsists upon mosa; and makes the riches of the people of Lapland; guats and gadflies very formidable to this deer in Laplund; temale brings forth in May ; its milk thinner than that of the cow; sweeter and more nourishing; is of two kinds in Lapland; it draws sledges; can go about thirty miles without halting, and without dancerous effort ; general!y castrated by the Japlandors; one male left for six females; begin to breed when two years old; go with youmg eiglit months, and bring two at a time; Condness of the dan remarkable; livo but fitteen or sixteen years; mamer in which the Japlanders kill them; scarce any part of this auinal not converted to peculiar uses; the Laplanders find their necessities supplied from the rein-cleer alone; in what manner; diseases of this animal; the blnod of the rein-deer preserved in suall casks, for sauee with the marrow in spring ; the lorns converted into glue ; the ainews nuake the strongest sewingthread; the tongues a great delieacy; the intestines, washed like our tripe, in high esteen among the Lnplanders; bears make dle. predations upon the rein-deer; gluttan its most dangerous and specessful persecutor; only method ol escape from this creature, 272 to 278 ; in what mamner the rein-deer is killed by it, 3.13 ; the wolf vever attacks a rein-deer that is haltered in liapland, and why, 321 .

Deformity, children often inherit even the accidental defornities of their parents; instances ol it ; accidental deformities become natural ; by assiduity continu ed and increased, through suc. cessive generations, 185 ; all those cliances the $\Lambda$ frican, the Asiatic, or the Amcrican, undergo in their colour, are aceidental deformities probably to be removed, $18 t$.

Demoiselle, name given by the French to the Numidian bird, 558 . Depona, a large serpent, native of Hexico, 742 .

Derbent, pastures in these plains excellent for rearing horses, 219. Derbyshire, inscription of the nesi of an eagle found in the peak of Derbyshire, 475 .

Derham, by a mieroscupe, discovered in the cye of a mole, the parts known in otler animals, 351 .

Desman, one of the three distinctions of the musk-rat; a native of Laplund, 367 .

Deri', the Swedish Laplanders consult liim, 178.

Devil (Sea,) or fishing-frog deseribed, 643 .

Dcto compensates the want of showers in Exypt, 105.

Diableret, a mountain of France suddenly fallen down; its ruins covered an extout of a large square, 46 .

Dietionaries of Arts and Seiences, a fault that lras infected most of them, 204 .

Diet, of a thin sparing kind remarkable among quadrupeds, as well as the human species, to produce hair, 331 .

Digester, an instrument ; meat and bones put into it, dissolved into a jelly in six or eight ninutes, 90 .

Digrstion, these organs in birds are in a manner revorsod, 452 ; is not perfect in all birds that live npon mice, lizards, or sueh like food, 489 ; performed by some unknown principle in the stomach, acting in a manner difierent from all kinds of artificial masecration; this tuimal power lodged in the maw of fishes, 609.

Diseuses of the rein-deer; the manner in which the Laplanders eure them, 277.

Disordcrs, infectious, propagated by the efluvia from diseased bodies, 95 ; most of these incidents to mankind, says Bacon, arise from tho changes of the atmospliere, 611 ; fishes have their disordors, 659.

Diner (the great northern, a bird of the smaller tribo of the penguin kind; the gray-speckled diver ; the searlet-throated diver, 590 . Divers known to descend from twenty to thirty fathom, 85 ; $\mathrm{af}_{\mathbf{f}}$ all those who have brought information from the bottom of the Leep, Nicola Pcsce the most celcbrated; account of his perform- ances lyy Kircher, 8f; some known to continue three quarters of an hour uncler water, without brenthing; they usually die consumptive: manner of fisling for pearls, $6, j$.

Dodo, its description, 46\%; ammg birds, as the sloth among quadropeds, an unresisting aninal, equally ineapable of flight or defenec; native of the lsle of France; the Dutch first diacovered it, and called it the nauseous bird; travellers deem its flesh good and wholesone; it is easily taken; three or four dodos enough to dine a lundred men; whether the dodo be the same bird with that deseribed under the name of the bird of Nazareth, remains uncertain, 470 .

Due, the female of the deer kind, 266.

Dngs, always running witl tlicir noses to the ground, supposed of old the first that felt infection, 93 ; no othor animal of the carnivorous kind will make a voluntary attack, but with the odds on their sicie, 207; the Arabian horses outmm them, 9; in the dog kind the elief power lies in the under jaw, 2-2; in Syria, remarkable for the fine glossy length and softness of their hair, 2,2 ; in tropical climates, lose the delieacy of their scent, and why: the lion, tiger, panther, and ounce, all natural enemies to tlie dor, 305 : dog kind not so solitary as those of the eat; their proper prey are anmals unfitted for elimbing; they can live for some tims upon fruits and vegetalles, 308 ; deseription of the dog; knows a beggat by lis elothes, by his voice, or his gestures, and forbids his approach, ib.; the dog most susecptible of change in its form, $3 \mathrm{ho}$; all dngs are of one kind; which the original of all the rest, which the savage dog, whenees such a variety of descendants, is no easy matter to determine; the slieplierd's the primitive animal of his kind; those wild in Anerica and Congo, as those of Sibcria, Lapland, Iceland, of the Cape of Good IIope, of Madagasear. Madura, Calieut, and Malabar, resemble the shepherd's dog; those in Guinen, at tlis: second or thiil generation, forget to bark; dogs of Aibany, of Grecce, of Demnark, and of lreland, larecer and stronger than any other; shepluord's dog, transported into temperate climates, and among penple entirely civilized, from influence of climate and food aloue, becomes a matin, a mastiff, or a hound ; Turlish dog ; grat Dunish dog ; greot wolf dog, or Irish r.nlf dog ; the liutle Dunish dog; their variety now in Englaul much greater than in the reign of queen Elizabeth; Dr. Cains Eivides the whole race into three kinds; the generous, the farm-kind, the mongrel, 309 to 312 ; three sheplierd's dogrs reckoned it matcl for a bear, and four for a lion; three of them overeane a linn in the time of king James the First; the famous poet Lord Surry, the first who taught dogs io set; the pup dog; the English bull dog; the lion dog, originally from Malta; its deseription; the Molossion dogs of the aneients. according to Mr. Buffon; Epirotic liggs, mentioned by Pliny; $I h$ dion $\operatorname{logs}$, nientioned by Alian; his description of a combat betwoen a dog and a lion; the bravest of the kind; the nobler kinds of dogs, of which such beautiful ancient deseriptions, now utterly unknown, 313, 314; puppies eyes not open till ten or twelre days old; dog's teeth amount to forty-two; this animal capable of reproducing at the age of twelve months; goes nine weeks with young; and lives abnut twelve years; other particulars concerning dogs; many kinds of hirds the dous will not touch; dogs and vultures living wild ahout Grand Cairo in Egypt, continue together in an amicable mannor, and are linown to bring up their young in the same nest; dogs bear lunger fir a long time; a biteh forgotten in a country liouse, lired forty days without any other shistenance than the wool of a quilt she had torn in pieces, 311, 31\%; the wild lunt in packs; unknown, such as ho was before tho protection of man; some from a domestic state, lave turned savage, and partaken of the disposition of the wolf, and attuck the most formidable animals of tho forest; are easily tamed, and quickly be. come familiar and subuissive, 309 ; experiments to prove the volf and the fox not of the same nature with the dog, but" of a miture perfectly distinct; animals in this country bred between a dog and a fox; a digg set at liberty in his savige fury flow upnn every animal, fowls, dogs, and men, 316 ; the dog and the wolf so much alike internally, that anatonists can scarce percoive tho difference 317 ; a young dog shudders at the sight of a wolt; dogs and wolves so different in this dispositions, that no animals have a more perfect antipathy, 315; by instinct, witlunt oducation, dogs take care of flocks and herds, ib.; show no appetite to enjoy their victory when the wolf is killed. but leaves him where he fills, 321 ; Catesby asserts the wolf was the only dog used by the Americans, before the Europeans came among them, and they lave since procreated together; thus proving the dog and tho wolf of the same suecies; unsurmountable antipathy between the dog and the jackall; they never part without an engagement, 326 ; famished doga more hairy than thoae whose food has been more plentiful, 331; all kinds pursue the laare by instinet, and follow it more eagerly than other animals; 
few dogs dare to encounter the atter; some purpesely trained for discovering the retreat of the otter, 388 .

Dog-butchers all over China, and shsmbles for selling their flesb; wherever a deg-butcher appears, all the dogs in the place are in full cry after him; along the cosst of Gninea their flesh is estemed a delicacy by the Negrocs; they give a cow for a dog, 315.

Dolphin caught in the Red Sea, known by a ring to be the seme taken before in the Mediterrancan, 77 ; allured by music, 165 ; not easy to assign a cause why the ancients have invented so meny fables on the subject; thcir boundings in the water, have taught mariners to prepare for a storm ; old painters and sculptors have drawn them wrong; the poets have adopted the error; Pliny has asserted, they instantly die when taken out of the water Rondelet assures us, he has seen a dolphin carried alive froun Montpelier to Lyons; found in such vast numbers in all parts of the sea that surrounds this kingdom, as to be noxious to the fishermen; their motions the gambols of pleasure, or the agitations of terrar, not well known; in fair weather they herd together, and pursue shoals of various fish with impetuesity ; method of killing them, 624,625

Doiphin is also the name of the ophidium, or the gilt-hesd, 648 .

Don, or Tanois, a river, its course, 61 ; the sturgeon is caught in great quantities at the mouth of that river, 640 .

Dorodo, suppossd a ruminating fish, 232 ; a fish of the spinous kind, the most voracious; the most active and most beautiful of the finny region; its description; the flying fish is chiefly sought by it ; warfare carried on between thern, 658 .

Doree, description of this fish, 649 .

Dormouse, the mercury of the thermometer plunged into the bndy of a living dormouse never rose beyond its pitch in air, and sometimes sunk above a degrec, 357 ; the greatsr sort Mr. Buffon ealls the loir, the middle size he calls the lerot, and the less he denominates the muscordin; thcir descriptions; agree in being stupified like the marmout during winter; their nest and provisions ; they bring forth three or four young at a time, but once a sear, in spring, 366.

Dorr-beetle, or Afoy-bug, 819. See Beetle.

Dottrel, small bird of the crane kind, 568 .

Doves, the stock-dore, 529 ; the turtle-dore, 531 ; the ring-dore 532. See Pigeon

Douc, a monkey of the sncient continent, so called in CochinChina, where it is a native ; its description; forms part of the chain by which the monkeys of one continent are linked with those of the other, 411

J)uco rolans, a flying ball of fire, 111.

Drog, name given by the huntsmen to the tail of a fox, 323 .

Dragons, the whole race dwindled down to the flying lizard, 721 Drogon- $\Re y$, or the libella, described, 766

Dragonet, description of this fish, 648.

Dress, the first impression generally made, arises from dress, 146 .

Orill, of Purchas, an ape of the kind of the ouran-outang, 399.

Dromedary, a sort of cainel, 430.

Drone, a ruminating insect, or seemingly 80,232

Drones, the second sort of bees, supposed to be the males, 798; their cells, 803; the working-bees kill the drones in the worm-state in the cell, and eject them from the hive among the general carnage, 806

Drugs, in the tropical climates lose their virtue, and become verminaus, 92.

Drum, among the Swedish I aplanders every family lass one for consulting the devil, 178; hares tauglat to beat the drum, 347 .

Dryness, a great degree of it produced by heat, preserves from oorruption, 195 .

Duck, when ducks are canght, the men keep a piece of turf burning near their mouths, and breatlie upon it, lest the fowl smelling them should escape, 451 ; of the numerous tribes of the duck kind, no more than five breed here, 457 ; Plutarch assures us Cato kept his family in health, fceding them with duck whenever they threatened to be out of order, 593 ; its eggs often laid under a han; seems a haedless inattentive mother; of the tame duck, ten different sorts; and of the wild, Brisson reckons above twenty ths most obvious distinction between the wild and tanie ducks ? difference between wild ducks among each other; sea and pond ducks ; names of the mast common birds of the duck kind, anong ourselves, and of the most noted of the foreign tribe; the American wood-duck ; their habits, nests, and number of eggs; are, in general, birds of passage; their flesh ; the ducks flying in the air, often lured down from their beights by the loud voice of the mallard from below; what part of the lske they generally choose; what can employ them all day, not easy to guess; manner of No. $77 \& 78$. making and managing a decoy to the then : greneral season for catching them in decoys, from the end of Oetuter till February taking them earlier prohibited by an act of Canrge the Siccond, imposing a penalty of five shillings for every bird cestrover at any otlier soason; amazing quantity of ducks sent to supjly tho markets of London: manuer of taking ther frequently practised in China, 597 to 601

Dung, some animals vaid it wlyen pursued; this arises rather from fear than a desire of defence, 239

Dunlin, a emall bird of the orane kind, 568 .

Dutch, solicitous about the preservation of the stork, in every part of their repulslic, 556 .

Dicorf, in England, ss late ss the times of King James thr First, the court was furnished with one; and he was cslled Littl Jeflirey ; Peter of Russia celcbrated a marriage of dwarfs, 188, 182 ; they seem to have faculties resembling those of children; histery of a dwarf accurately related by Mr. Daubenten, ib.

Duina, a river ; its courke and source, 61 .

E.

Foglc-kind, the flap of an eagle's uing known to lay a man dead in an instant, 450 ; it flies at the bustard or the pheasent, 471 distinctive marks from the other kinds of carnivorous birds; the golden eagle is the largest and noblest of all those birds designated by the name of eagle; its description; its sight and sense of smelling very acute; breed among the loftiest cliffs, and choose those places most reinote from man; considered ameng birds ss the lion among quadrupeds; strong similitude to eacls other great patience, and much art, required to tame an eagle; though taken young, and brought under by long assiduity, yet it is a dangerous domestic, and often turns its force against its master sometimes has an attacliment for its feeder; it is then serviceable and will provide for his pleasure and support; flies the highest of all birds, and from thence has by the ancients been called the bird of heaven; it has also the quickest eye; but its sense of smelling is far inferior to that of the vulture; it never pursues, but in sight; finds difticulty in rising when down; carrics awsy geese, cranes, hares, lambs, and kids, and often destroys fawns and calves; to drink their blood, and carries a part of their flesh to its retreats ; infants when left unattended, have been destroyed by these rapscious creatures; the eagle is pecnliarly formidabls when bringing up its young; a poor man got a comfortable subsistence for his family, during a summer of famine, out of an eagle's nest, by robbing the eaglets of food; eagles killed a pcasant who had robbed their nests; there is a law in the Orkney islands, which entitles sny person that kills an eagle to a hen out of every house in the parish in which the plunderer is killed; the nest of the eagle is usually built in the most inaccessible eliff of the rock; description of one found in the Peak of Derbyshire; it hatches its eggs for thirty days ; very rare to find thrce eaglets in the same nest; and it is asserted, that the mother kills the most feeble, or the most yoracious; it is believed they live about an hundred years, and that they die, not of old age, but from the beaks turning inward upon the under jaw, and preventing their taking any food; an eagle endured hunger for twenty-one days, without any sustensnce whatever; they are first white, then inclining to yellow, and at last. light brown; age, hunger, captivity, and diseases, make them whiter; those kept tame are fed with every kind of flesh, fresh or corrupting; and upon a deficiency of that, bread, or any other provision, will suffice; it is dangerous approaching them, if not quite tame, and they sometimes scnd forth a loud piorcing lamentable cry, which renders them still more formidable ; they drink but seldom, and perhaps, when at liberty, not at all; the bald eagle an inhabitant of North Carolina; breeds in that country all the year round; manner in which the egrs are batched; characteristics and habitudes of this animal ; its ncst is large enough to fill the body of a cart, and commonly full of bones, half eaten, and putrid fiesh, the stench of which is intolerable, 473 to 476 .

Eagle, the sea-cogle called aquila poimbina by the Italians; they often lay three or four eggs, of a less size than those of a lien of a white elliptical form ; distinctive marks of the goldeneagle, of the common eogle, of the bald eagle, of the rehite cagle 475,476 ; of the rough-footed cagle, of the rohite-tailed cagle, of the erne, of the blacliengle, of the sea cagle, of the osprey, of the jean le blanc, of the Brasil eogle, of the Oroonoko eogle, of the cronened African eagle, of the eogle of Pondicherry, 476 .

Ears, distinruishing features in quadrupeds; serve in them as principal marks of the passions; smallest ears in men said to be mest beautiful; the largest the best for hearing; some savage na. 
tions borc their ears, and draw that part down, till the tip of the ear rests upon the shoulder, 145; "the richest jewels in an Éthiop's ear," a proverb, ib. ; undulations, which strilie the ear, supposed but one continued sound, by their quick successions, though in sealit $y$ they make many, 364 ; persons hoar differently with one car from the other; these have what musicians eall a bad ear; and, as hearing false, also sing false; such persons also deceived as to the side whence the sound comes, 167 ; from what eause the long ears of the Tartars and Chinese, 185 ; those of the liare moveable, and capable of direction to every quarter, 346 ; are remarkibly good, 347; birds have not the external ear standing out from the head; probably the feathers encompassing the ear-holes, supply the defect of the exterior ear, 451.

Earth, its globe a million of times less than the sun, 1 ; placed at a happy distance from the centre, in our solar systen; ;ess distant from the sun than Saturn, Jupiter, and Mars, and less parched np than Venus and Mercury, situated too near the violence of its pewer; the earth, like a chariot-wheel, has a compound motion; its rotundity proved, 3 ; is rather flatted at the poles, and its form resembles that of a turnip, ib.; considered as one scene of extensive desolation, 7 ; supposed by Buffon a globe of glass; by Whiston a sphere of heated iron; by Kircher one dresdful volcano; by Burnet a great mass of water; composed of different lnyers or beds, lying horizontally one over the other, like the leaves of a book, 15 .

Earth (garden) or mound-earth, a kind of mother, never found an enemy to man, 15; black earth formed by decayed leaves and branches in Burgundy, 16; drying and astringent earth preserves bodies from corruption, $1: 15$; all such earths as ferment with vinegar, are a cemposition of shells, decayed, and crumbled down to one uniform mass, $6 \varangle 0$.

Earthquakes frequent through a whole region wherc a volcano is situated, 26 ; various kinds of them distinguished by philosophers, and by Mlr. Buffon; air the only active operator in them; several opinions upon the cause of them; activity of internal heat alone sufficient to nceount for every appearsnce attending eartliquakes; twelve eities in Asia Minor swallowed up in one night; extraordinary earthquake related by Pliny; the city of Antioch, and a great part of the adjacent country, buried by an earthquake; in 1594 an earthquake at Puteoli caused the sea to retire 200 yards from its former bed; account of that in the year 1693, extending to a cireum. ference of two thousand six lundred leagues; minute description of that in Jumaiea in 1692,30 ta 33 ; account of the dreadful shock in Calabria in 1638, 34 ; coneonutant circumstances attending carthquakes, 35.

Earth-2eorm of America often a yard in length, and as thick as a walking-cane, 120 ; multiplied by being cut in pieces, 125 ; its description, 829. See Worms.

Earnig, its habits; repreaches gronndless about this animal ; its food, 778; general eharaeteristies of the kind; lives in its winged state a few days ; dies to all appearance consumptive, $i b$.

East-Indies, favourable months of embarking for them, 101.

Echineis, the sueking fish, its description, 6000 .

Echini, or urehin, a multivalve shell fish, 693. Soe Urchins.

Echo, no art can make an echo, 167.

Edgur, King of England, the first who attempted to rid this king. dom of wolves, and in what manner, 321.

Edicard I. issued his mandate to Peter Corbet to superintend and assist in the destruction of wolvcs, 321 .

Edwourd III. made it felony to steal a hawk, 482.

Edvard $I V$. his act concerning swans, 595.

Eel described, 649.

Effuvia from diseased bodies propagate disorders called infectious, 96 .

$E v g$, all birds, most fishes, and many of the insect tribes, breught forth from eggs; warmth of the sun, or of a stove, efficaeious in bringing the animal in the egg to perfection; its deseription; history of the chicken in the egg to its complete formation, 126 to 128 ; quadrupeds brought forth from the egg, above two hundred at a time, 213 ; the ichneumon discovers and destroys the eggs of the crocodile, 337 ; the crocodile lays in the sand, at a time three or four hundred, 338; some eggs only addled by incubation, 454 ; such birds as undisturbed lay but two or three eggs, when their eggs are stolen, lay ten or twelve; a common ben, muderately fed, lays above one hundred from the beginning of spring to the latter end of autunn, 456 ; some of the ostrich's weigh above fifteen pounds, 164; Gialen thought the oggs of hens and pheasants good to be eaten; those of gecse and nstriches are the worst of all, 466 ; and those hatched in the hot sand, where laid, 70 ; taking the eggs of a hawk, even in a person's own ground, punislicd with imprisonment for a year and a day, and a fine at the king's pleasure, in the reign of Ldward III. 482 ; inhabitants of Norway prepare from the eggs of the porpoise a kind of caviar, or delicate sauce, and good when eaten with bread, 626 ; manner in which the eggs of fishes are impregnated, wholly unknown, 657 ; doubts whether fish come from the egg completely formcd, ib.; those of the turtle hatehed by the sun, 675 .

Eggs (Sea) name given in our eabinets to a multivalve shell-fish called echini, or urehins, by naturalists, 693 ; those of the sea.urchin a great delieacy, 694; opening the body of a queen-bee, there appeared in it five thousand eggs, 803 .

Eglantine, found at a well dug at Marly, 17.

Ligypt has south winds so hot during summer, that respiration is almast stopped by then; they are eharged with such quantities of sand, that they durken the air, as with a clood; continuing for any length of time, they produce epidenic diseases; it rains very seldom in that country; but the want of showers is compensated by the copiousness of their dews, 104, 105; the catacombs, 196; mummy, not long sinee dug up in France, shows the art of embalming was morc coinpletely understood in the western world, than in Egypt itself, 197; the Tingitanians and Egyptians lave now the fame of rearing the fincst horses, both for size and beauty, 218; the iclineumon used in this kingdom, for the same purposes that cats are in Europe, 337.

Egyptian. See Embalming. See Ibis.

Eider duck, 598; remarkable for the warmth of its nest, 599.

Elaboralory, bowcls of ruminating aninals considered as an elaboratory, with vessels in it, 38 ; the chemical apparatus for hatehing chickens, 496.

Elasticity of the air, 87

Elder-berries hurtful to cocks, 497.

Elephant, not afraid singly to make opposition to the lion, 295; not less remarkable for its size than its docility ; all historians concur in giving it the eharacter of the most sagacious animal next to man; its heiglit from seven to fifteen feet; impossible to give an idea of this a nimal's figure by description; assisted by the art of the engraver, it will but confusedly represent the original; general observations about its conformation; of all quadrupeds, the elephant the strongest and largest, yet neither fieree nor formidable; in its native deserts seldom alone, being a social friendly creature; the oldest conducts the band; the next in seniority brings up the rear; order maintained in dangerous marehes; never so far asunder as to be incapable of reciprocal assistance; their invasions the more disagreeable, there being no means of repelling them, since an attempt to molest a drove would eertainly be fatal ; manner of going against him who offers the insult; do no personal injury when suffered to feed uninterrupted; molested by man, they seek all oecasions to be revenged; where they like best to live in this natural state; cannot live far from water, and always disturb it before they drink; often fill their trunk with water to cool it, or by way of plsy to spurt it out like a fountain ; equally distressed by the extremes of heat and cold; swim from the eontinent into islands some leagues distant; frequently migrate from one country to another, and why; their food of the vegetable kind, loathing all sort of animal diet; one finding a spot of good pasture, invites the rest to partake of it; precautions by Negroes and Indians against them; they often break through their fence, destroy the harvest, overturn their babitations, and then retreat in order, as they made the irruption; leoks with attention and friendship at its master; its ears wipe its eyes, and cover them against the flies and dust; it likes musie, learns to beat time, moves in measure, and joins its voiee to the sound of drum and trumpet; is pleased with the odours that delight man; the orange flower partieularly grateful to its taste and smell; picks up flowers, and is pleased with the seent; seeks the most odoriferous plants for food; prefers the cocoa, the banana, the palun, and tho sago tree, to all others; eats plants to the rnots; thieir sense of touching most delicate; description of its trunk; serving all the purposes of a hand; breathes, drinks, and smells through the trunk; takes a pin from tho ground, and unties the knots of a rope, unlocks a doar, and writes with a pen; Ellian saw an elephant write Latin charaeters on a board, his keeper only showing him the figure of each letter, 416 to 418 ; an object too large for the trunk to grasp, is sucked up by its breath, lifted, and sustained; the trunk its orgsn of smelling, of touching, of suction, of ornament, and defence; its neek is so short that it nust turn about to discover what is behind; how the hunters escape its resentinent; a description of its legs; while young it bends the legs, but when old or siekly, it wants humaul assistance, and chaoses to sleep standing; a description of its feet, and of its tusks; these with age become so heavy, that it is obliged to rest them in.holes in the walls of $\mathrm{jts}$ stall; they are two; their amazing siza; they proeeed from the upper jaw, not from the froutal-bones; and are not horns, as some linve supposed; nor ever sled in a domestic state; extraordinary manner of eating; 
is not a ruminating nnimal; its stemach and intestines resemble those of a horse; opinion that the young elephant sucks with its trunk, not with its mouth, referred to future discoveries; the skin not covered with hair; a fow bristles in the scars and wrinkles of the body, and thinly scattered over the skin; the lide resembles the bark of an old tree more than the skin of an animal; is subject to that disorder known by the namo of the eleplantiasis, or Arabian leprosy; in what manuer the Indians endeavour to prevent it ; the flies torment this animal incessantly; what arts it tries to keep them off; in a state of nature, it rarely quits the river, and often stands in water up to tho belly, $4 \mathrm{I} 3,420$; from time imnemorial emplnyed for the purposes of labour, of war, to increase the grandeur of Eastern princes, or to extend their doninions; is a na. tive of Africa and $A$ sia, still rotains its natural liberty in Africa during the splendour of the Carthaginian empire they were used in the wars; no elephant found on this side Nount Atlas; places where they are in great numbers; the groatest olcphants found in Asia ; their price increases in proportion to their size ; the largest kept for princes ; their colour ; that appropriated for the monarch's own riding, kept in a palace, attended by nobles, and almost adored by the people ; opinions concerning the white elephant; the Eastorn princes maintain as many elephants as they are able, and place great confidence on their assistance in an ongagenent ; the never breed in a state of servitude, and the generative powers fail when it comes under the dominion of man; duration of pregnancy in the fenale still a secret; what Aristotle and others say concerning this and their young is doubtful; method of taking them wild in the woods; Negroes of Africa who hunt this animal for its flesh, take it in pit-falls; its attachment to the person who attends it ; it counprehends scveral of the signs made to it; distinguishes the tone of command from that of anger or apprnhation, and acts accordingly ; executing orders with prudence, eagerly, yet withnut precipitation; is taught to kneel down to receive its rider, usually mounted upon its neck; caresses those it knows; salutes such as ordered to distingrish, and helps to take up part of its load; takes a pleasure in the finery of its trappings; draws cliariots, cannon, or shipping with strength. perseverance, and satisfaction, provided it be not corrected without a cause, and that its master be pleased with its exertions; in what manner the conductor guides it ; frequently takes such an affection to its keeper, as to obey no other; has been known to die of grief for killing its conductor in a fit of madness surprising instance of moderation in its fury; a word sufficient to put it in motion, 420,421 ; a century or two ago, the Indian generals made great dependence upon the number and the expertness of their elephants; of late they are little used, except for drawing cannon, and transporting provisions; still they are used in war in Siam, in Cochin-China, in Tonquin, and Peru; in what manne arned and led to battle; effects of its fury in the field; those placed upon its back, in a square tnwer, conbat as from an eminence, and fling down their weapons with dnuble force; nothing more dreadful or more irresistible than such moving inachines to men unacquainted with the modern arts of war; Romans quickly learned the art of opening their ranks to admit the elephant, and scparating it tron assistance, compelled its conductors to sooth the animal's tury, and to subnit ; sonnetimes, instesd of obeying, turned upon those it was employed to assist; one elophant is known to consum as much as forty men in a day; they are now chiefly employed in carrying or drawing burdens throughout the Peninsula of India ; it can with ease draw more than six harses can remove; it carries upon its back three or four thousand weight, and upon its tusks it can support near a thousand; when pushed, it moves as swiftly as a horse at full gallep; it travels finty or sixty miles a day, and hard pressed, almost deuble that quantity; heard trotting on at a great distance; its track is deeply impressed nn the ground, and from fifteen to eighteen inches in diameter; used in India as executioners, and with what dexterity they perform the horrid task sometimes they impale the prisoner on their enormous tuslse; two surprising instances how sensible it is of neglect; the keeper desuising its endeavours when launching a ship, the animal redoubled its efforts, fractured its skull, and died upon the spot; revenge one of them took upon a tailnr who pricked its trunk with a needle in Delli ; is mindful of benefits ; instance of it ; at the Cape of Good Hope they are hunted for the sake of their teeth; in what manner an account of an unhappy liuntsman; teeth of the elephant fousd in a fossil state : two crindinc teeth, and part of the tusk of an elephant, discovered at the depth of forty-two yards in a lead-mine in Flutshire; tusks of the elephants thit come from Africa, seldom exceed two hundred and finy pounds; it is defeated by llie rhinoceros; tusks of the Mammoth, often found fossil in Siberia, generally eupposed to belong to the elcphant, $423,424$.

Flephantiasis, or tho Arabian leprosy, a disease to which man and the elephant are equally subject; in whitt manner the Indians endeavour to preserve the elcphant from it, 4 : 2 ).

Elizabcth (Quecn,) her injunction upon fasting ; in the anthor's opinion very unwise, 155; in her times, tho whole kingdom could not supply two thousand horsos to form the cavalry, 2azz.

Ellis, his principal experiment upon corolinc sulustances; he put it past doubt, that corale and spunges were entirely the work of animals of the reptile or polypus kind, 837 .

$E l k$, its size equal to thit of the elephant; is an animal rather of the buck than the stag kind; known in America by the name of the moose-de:er; is sometimes taken in the Germun and Tussian forests, but extremely enminen in North Anterica ; its loorns fortuitously dug up in many parts of lreland, nensuring ten feet nims inches from tip to tip; a small one the size of a horse, and the horns a little larger than those of a common stag; Jocelyn and Dudley describe this animal above eleven feet hight; others extend their accounts to twelve and fourteen feet; never disturlss any other aninal, when supplied itselt; ; a female of this kind shown at Paris in the year 174\%; its deseription; they gave it thirty pounds of bread every day, besides hay, and it drank eight buckety of water, $269,220$.

I:lk ( 9 merican, ) two kinds, the gray and the black; descrihed; they prefer cold countries, feedino upon grass in sununer, and the bark of trees in winter; time and manner of hunting them; it flesh very well tasted, and very nourisling; its hide strong, and so thick ns to turn a masket-ball ; yet is yott and pliable; the horns applied to all the purposes for which lartshorn is beneficial; this anjmal troubled with the epilepsy; is but very indifierently and con. fusedly described by travellers; their varions descriptions, 2\%0, 27I; in what manner killed by the glutton, 343 .

Elops, or Sea-serpent, its description, 649

$E l y$, an island, the country round it was once a most delightfu? spot; produced grapes tliat afiorded excellont wine; the sea breaking in, overwhelmed the whole country, 16:2.

Emanuel, (ling of Portugal,) to try the strength of the elephant and rhinoceros, inade them figlit, and the elephant was deteated, 426.

Enbalmiag, the Egyptians carried this art to perfection; copious detail of this art as practised annong them; in Genesis, Joseph see. ing his father expire, ordered his physicians to enbalm the body, 193; various mathods of embalining, ib.; the art still among the Guanches, aneient inlabitants of the island of Teneriffe, when the Spaniardy conquered it ; particulars of their method of embalming ; the Peruvians also understood this art, according to Father Acasto, 194; a mummy lately dug up in France, shows the art more com. pletely understood in the western than the eastern world, 197.

Embroidary, done in India with poreupine quills, as belts, baskets and necessary pieees of furniture, 37 t.

Einbryo, its first rudiments; in a month an inch long; the male developes sooner than the female; progress and increase of it, 130 to 132 ; in the human, the under-jaw much advanced before the upper, 144; brain and spinal marrow, first seen begun, 54; the bones as soft as the flesh, 170 .

Emigration, causes of emigration of birds, 457 ; manner performed, 458,459

Emu, an inhahitsnt of the New Continent, called also the American ostrich ; description and places where found ; runs so swifly, the dogs lose the pursuit; one surrounded by hunters, the dogs avoided its rage ; peculiar in liatching its young; the young at first familiar; fnllow any person; as they grow older, become cunning and distruetful; their flesh good to be eaten; they live entircly upon grass, 466,467

Encoubert of Buffon, the tatou of Ray, a shelly quadruped, 382.

Fistgland elains dominion over the sens encompassing Great Britain and Ireland; losing its superiority upon the ocean, its safo ty becomes precarious, 68; late as King James I. the court still furnislied with a dwarf, a giant, and a jester, 188 ; the ass entirely lost under queen Elizabeth, 226; more fanous for its renison than any other country in the world, 207 ; not infested with wolves, 321 the viper the only venomens animal there, 735 .

Enquiries most intrieate generally most useless, 125.

Entry, a term in the chase of the stag, 262.

Eplecmera, various kinds of this insect; its description, celours of their aurelias; their transmutations; places where found in abundance ; short duration ; their impregnation, 780, 781 .

Epicure, the greatest has the most depraved taste, 170.

F.piphanius (St.) lived a hundred and fifteen yeare, I55.

Equator, deseription of the regions under it, 4 .

Ermine, its description; alike in figure to the weasel; its fur the most valuable of any; the time in which it is called the stoat; manner of moulting its hair ; one ate honey, and died shertly after: proof of a distinct species from the pole-cat or the uartin; one of 
these, fed with eggs and flesh, let them pntrefy before it touched either ; in Siberia taken in traps baited witl flesli, and in Norway shot with blunt arrows, or taken in traps; their skins a valuable article of commeree in Siberia; sometimes found white in Great Britain, and is then called the white weasel; its fur among us of no value, 330 to 332 ; preys upon the leming, 370

Erne, kind of eagle; its distinetive marks, 476.

Eruption of a volcano, remarkable, in 1537, 26 ; of Vesuvius, in which Pliny the naturalist was suffoeated, and the city of IIereulaneum was overwhelmed; another of the same mountain, in 1707, described; of Cotopaxi, in 1743, described by Ulloa; matter thus exploded lies a little below the bed of the mountains, in Mr. Buffon's system; but supplied from the deeper regions of the earth; the greatest part of Sicily seems eovered with the eruptions of mount Etna, 27 to 30 .

Esculapian serpent of Italy; its excrement a plcasing perfume, 730 ; a domestic creature, 741 .

Esox, or the pike, deseription of this fish, 650 .

Esquimaux Indians deseribed, 178.

Exaporation, cold dininishing the force of menstruums, promotes evaporation ; theory for the formation of the cleuds, 108 ; prevented by moist weather; dry frost assists evaporation, ib.

Evils, thousands of natural evils permitted to exist in the world, and why, 6.

Eunuchs, of two kinds, the white and the black, 139; made in Italy to improve the voice; instance, in our country, of a very fine wornan married to an eunuch, ib.

Euphamia, a city in Calabria, sunk by an earthquake, 35.

Eitphrates, a river, its sources, 62 ; receives eleven rivers, 64 .

Lurites, a city swallowed by an earthquake, 47 .

Europeans resemble our common parent more than any of the rest of his ehildren; 185; argument which suffices to prove it, 186.

Eustuehiun tube a passage from the car into the mouth; its use, $16 \%$.

Eve. See Buck-goot, 241.

Excrcments of some serpents kept as the most pleasing perfune

at Calieut and Crangsnon, in Eust India, 730.

Executioner, elephants in India used as such; impale the criminals on their tusks, 424.

Exercise (Afunual, hares taught to go through it, 347.

Exhalations, mineral, raised by subterranean heat, 168 ; when copious every where fatal, 95 .

Exocetus, the flying fish, its deseription, 650 .

Experienre, repeated, shows how selden pains are suffered, or pleasures enjoyed, to the utmost, 177.

Experiment, by Mr. Beleher, upen the cireulation of the hlood through the bones, 173 ; made by approaching a looking-glass to the montl to discover breathing, very uneertain, 177; of a carp placed under an air-pump, li10; the famous cxperinent of Malpighi, concerning the stigmata of the caterpillar, 786 .

Extrancous, or fossil shells, found in the bowels of the earth; in this class there are as many kinds as in the sea itself, 680 .

Eyes, opened by the infant the moment of its birth, 133; particularly in them the passions are painted, 141 ; sinall and nearly elosed, are liked in China and $\mathrm{J}_{a p a n, 140}$; different colours of the eye, whence they arise; eyes of oxen are brown; those of sheep of a water-eolour; of geats are gray; and those of most white animals are red; distance between the eyes less in man than in any other aninual, 142; Mentaigne disliked those men who shut one eye in looking upun any object, 145 : in what circumstances women with child are said to be all mouth and eyes; the lower eye-lids, in wonen witl child drawn downwards, 148 ; of all parts the animal has double, the eyes produeed soonest, and appear the most prominent, 159 ; priration of feeling and sight would misrepresent the situation and number of all things around us, ib.; two contribute to distinct and extensive vision, 160; both eyes see round the olject, and give it that heightened relief which no painting does attain to; in either if there be a point which has no vision, the defcet is corrected by having the organ double; easy experiment to be convinced of it, 160 ; objects at a distance rarely equal in beth eyes; the best eyes sees objects larrest ; infants having their eyes less, must see objects -maller in proportion; when we look at an object extremely brilliant, vision becomes indistinct, and why; how far the eye can accommodate itself to darkness, 163 ; remarkable instanee of it in a major under King Charles the First, ib.; whenee have arisen the small eyes of the Tartars and Chinese, 185 ; Eastern poets compare the eyes of their mistresses to those of the gazelle; the Greeks resemble the eyes of a beautifil woman to those of a cow, 76 ; of all animals, natives of this climate, nohe have an eye so beautiful as the stag, 260; that of the wolf opens slantingly upwards in the same direction with the nose, 317 ; of the fox placed obliquely, like those of the wolf, 222; of the civet shine in the night, 342; these of the hare placed backwards, to see behind it as it runs, and these are never wholly closed, 346 ; peeuliar advantares of the smallness of the eyo in the mole, 371 ; deseription of the cyes of birds of the owl kind; in the eyes of all animals, a complete provision to shut out too much light, or to admit a suffieiency, by eontraction and dilation of the pupil, 488; those of the great Greenland whale not larger than those of an ox, 617 ; of the snail on the points of its largest horns, 682 ; peculiarities in the eyes of the chamelion, 721 ; eyes of the butterfly have not all the same form; the outward coat las a lustre displaying the various colours of the rainbow; examined a little elosely, it will be found to liave the appearance of a multiplyingglass, 792 ; the beetle, in its worm state, has no eyes, 819 .

Eye-brous, joining in the midale, eonsidered a peenliar grace by Tibullus, and by the Persians, I40; Le Brun's directions regarding the passions, place the principal expression in them; sueh as hare them most at command are the best aeters, 142; the Talapoins of Siam sliave the eye-brows of the children committed to their care, 145.

Eye-lushes, man and apes only have them upon the upper and the lower lids, all other animals want them on the lower lid, 142.

Eye-lids, in birds and amphibious quadrupeds, the lower lid alone has motion; fishes and insects have vo eye-lids, 14?.

\section{F.}

Frec, its lorm, the result of custom, 185. See Beanty, 192.

Falcon-gentle, a kind of hawk ; it pursues the gazelle, 254 ; many pcople admire its flesh, and dress it for eating, says Bellonius, 472; method of training up this bird; falcomry, much disused among us, was a principal amusement of our ancestors; among the Welsh, the king's faleoner the fourth officer of the state, was forbid 'to take more than three draughts of beer from his lorn, lest ho should neglect his duty; the falcon-gentle and the peregrine much less than the gyr-falcon, which exceeds all others in largeness; de. scription of the gyr-falcon; a courageous and fierce bird, not fearing the eagle; it chiefly flies at the stork, the heron, and the crane; is ehiefly found in the northern regions, but loses neither strength ner courage when brought into the milder elimates; the falcon-gentle moults in March or sooner; the peregrine does not moult till August; the common falcon is of such spirit, that, like a conqueror of a country, he keeps all in awe and subjection to his prowess; young falcons, though depressed by captivity, will, when brought out, fly at barnacles and wild geese; the faleon's pursuit of the heron, kite, or woodlark, the most delightful sport; names of the faleons in use here and in other conntries, 482 to 486 .

Faleoners, by means of the grent owl, eatch the kite for the purposes of training the falcon, and how, 490 .

Fullopius, the two tubular vessels perceived by him, 123 .

Famine supported by carnivorous animals for several weeks together, 208

Fut of the shamois, its medicinal virtue; fat of animals found eflicacious in some diserders, 250 ; of the manati, exposed to the sun, has a fine smell and taste, and exceeds the fat of any sea. animal; the lieat of the sun will not spoil it, nor make it raneid; several other qualities of this fat, $39 \%$.

Futher-lasher, description of this fish, 648 .

Faicn, name of the buek and the doe the first year, 266.

Feathers of birds deseribed, 449 ; of the ostrich aimost as soft as down, 462 ; difierent uses made of goose-feathers, 597.

Feather-beds, utterly unknown in countries bordering on the Le. vant, and all Asia; ancients did not use feather-beds; Pliny spealss of bolsters of feathers for their lieads; feathers inake a considera. ble article of commerce ; different qualities; best method of curing them; old feathers more valuable tlian new, 597.

Fecundity of the rabbit greater than the hare, 349

Feeling, deprived of feeling, our eyes would misrepresent the situation and the number of all things around us, 159; blind men have their senses finer than otlicrs, and why; the grossest and most useful of the senses; no total deprivation of it but with life; those parts most exercised in it, acquire the greatest accuracy ; the fingers, by habit, greater in the art than others, not from their having more nerves; fisles having no organs for feeling, must be the most stupid of all animals ; fceling, the guardian, the judge, and the examiner of all the senses, is never found to deceive, 170,171 .

Ferret has eyes of a red colour, 141; not found at present here, but in the domestie state; its description; a native of the torrid zone; naturally such an enemy of the rabbit, that a young ferret, although unacquainted with the kind, will fiercely attack and bite even a dead one; use of ferrets in warrens to enter tho holes muzzled, and drive the rabbits into the nets at the mouth; to 
bring the ferret from his hole, straw and other substances burnt st the mouth; the female less than the male, whom she seeks with great ardour, and often dies without being admitted; they sleep almest centinually, and the instant they awake seem eager for food; are usnally fed with bread and milk; breed twice a year; senie devour their young as seon ss brought forth, and thon booome fit for the unale again; they litter usually from five to six young, and these consist of more feinales than males; its seent foetid; its nature voracious; has attacked and killed ehildren in the eradle; is easily irrituted, and then smells more offensively; its bite dificult of eure; las eight grinding teeth ; to the ferret kind may by added an animal called by Mr. Buffon, the vansire, 332,333 ; comes originally trom Afriea, $3 \overline{3} 1$.

Fever, opinion that the lion is in a continual fever, 295.

Funce, name of the exerement of the stag, 262.

Fibres, muscular, eampose the stomaclis of inseets, 232.

Ficldfare, bird of the sparrow kind, 537.

Fielding. Sce Smile.

Figure, little known exaetly of the proportion of the human figure, 143 ; different opinions coneerning it, 149; whenee proeeed the variations in the human figure, 134 ; the oldest measure at the human figure in the monument of Clieops, in the first pyramid of Eigypt, 141.

Finder, a dog of the generous kind, 312.

Fins, different purposes they answer in fishes, 606 ; those of the whale; their use, 617,618 .

Firt-fish, 616 ; its food, 619.

Fingers, by habit, and not from a greater number of nerves, become exaeter in the srt of feeling than any other part even where sensstion is more delieate and fine, 170 .

Fire, perpetual in the kingdom of Persia, 25; advantages arising from the subterranean fires, 36 ; put out by the sun shining upon it, and why, 98; fleeting balls of fre, 110; great globe of fire seen at Bononia in ltaly, not less than a mile long, and half a mile broad, 111, 112; lighted to preserve herds and floeks from animals of the eat kind, 294

Fireflare, the dread of the boldest and most experienced fishermen; Plioy, Elian, and Oppian, supply the weapon of this fish with a venom affecting even inanimate creation; reasons to doubt of it, 635 .

Fishes, petrified, found in the mountains of Castravan, 13; fish in abundanee found in a new formed island ; those who eat of them died shortly after, 37 ; cannot live in water whence the air is exhausted, 9:3; showers of fishes raised in the air by tenpests, 114; most of them produced from the egg, 12t; ; have no eye-lids at all, 14:; nor any neek, 147; aro allured by music, 165; having no organs for feeling, must be stupid, 170 ; a rumiuating eort, 232; opinion that all fish are naturally of the salt element, and have mounted up into fresh water by aecidental migration; some swim up rivers to deposit their spawn, of which the size is enormous, and the shoals endless; all keep to the sea, and would expire in fresh water; the number to which names are given, and of the figure of which something is known, aecording to Linnæus, are above four hundred; their pursuits, migrations, soeieties, antipathies, pleasures, times of gestation, manner of bringing forth, are all hidden in the turbulent element that protect them; the history of fishes can have little in it entertaining; for instead of studying their nature, pains have been taken to increase their eatu. logues; that shape granted to most fishes, is imitated in such vesseis as are designed to sail with the greatest swiftness; any large fish overtakes a ship in full sail, with great ease; takes vayages of a thousand leagues in 8 season; the shurk one of the swiftest swimmers; the chicf instruments in the motion of a fish are the fins; in solne they are more numerous than in others; it is not always the fish with the greatest number of fins that has the swiftest motion; how the fins assist tlue fish in rising or sinking, in turning or leaping out of the water; all this explained by the expcriment of a earp put into a large vessel ; all fishes eovered with a slimy glutinous matter that defends their bodies from the iminediate eontact of the surrounding fluid; they fall behind terrestrial animals in their sensations; their sense of touching and smelling; their sense of tasting; hearing is funnd still more imperfect, if found at all; Mr Gouan's experiment to this purpose; trom it is learned they are as deaf as mute; their sense of seeing their brain; a ceaseless desire of food gives the ruling impulse to all their motions; their rapaeity insatiable; when out of water, and almost expiring, they greedily swallow the bait by which they were allured to destruction; the maw placed next the mouth, and though possessed of no sensible heat, is endued with a faculty of digestion, contrary to the system, that the heat of the stomach is atone sufficient for digestion; though for ever prowling, can suf- fer want of food very long; instances of it; life of a fish but ono scene of lostility, violence, and evasion; the causes of snimal migration; all stand in need of air for support; these of the whale kind eome to the surface of the sea overy two or three minutes to breathe fresh air ; experiment of a earp in a large vase of water placed under an air-pump ; general method of explaining respiration in fishes; the deseription and uses of their sir-bladder; full play of the gills prevented, or the bony covers kept from moving, the animal weuld fall into cenvulsions, snd dic, 605 to 611 ; some fishes liave no air-bladder ; ean live but a few minutes without air nothing more difficult to aeceunt for than the manner of getting this supply; no part of the aecount of the use of the air-bladder well supported; Bacon's observations upon their growth and age two mothods for determining the age of fislies, more ingenious than certain; a earp found to be a hundred years old ; the diseovery confirıed by autliors; longevity of these animals, nothing compared to their feeundity; some multiply by millions; some uring ferth their young alive, and some produce eggs; the former rather the least fruitful ; the viviparous blenny brings forth two or three hundred at a time, all alive, and playing round the parent the cod spawns in one seasen above nine milliens of eggs, the fleunder above ene million, and the nrackarel above five hundred thousand; different seasons for depositing spawn; sone fishes have the tenderness of birds or quadrupeds for their young; their copulation as yet a doubt; the flesh of fishes; question to the learned concerning the fiesh of fishes ; cetaceous fishes, 611 to 615 . eartilaginous fishes, 627 ; sucking fish sticks to the shark; ealled the shark's pilot, and why, 631; all fish more delicate about a baited hook than their ordinary foed, 633 ; best bait for all is fresh herring ent in pieees of a proper size; experience slows, the larger fish take a living small one upon the hoek sooner than any other bait, 634 ; more than those of the ray kind possessed of the numb. ing quality; Condanine informs us of a fish with the powers of the torpedo, and resembling a lamprey; lsmprey of the English Severn the most delicate fish whatever, 637 ; sun-fish described, 643 ; lump-fish, ib. ; pipe-fish, 614; galley-fish, 645 ; spinous fishes, ib. ; Mr. Gouan's systen of spineus fislies, 647 to 651 ; use of it; all fish of the same kinds have the same number of bones; the small, lean, and with many fins, the most bony ; vulgar expression, that fishes at seme sessons are mare bony than at others, searee deserves contradietion; none imbibe the sea-sultness with their food, or in respiration; whence then do some fishes live there, and quickly expire in fresl w water ; some tribes live only in the sea; others only in fresh water; seme part of the season in one, and a part in the other, as the salmon, the shad, the amelt, and the flounder; some fish, as the eel, deseend the fresh water stream, to bring forth their young in the sea; in what reason, long voyages undertsken by some tribes that eonstantly reside in the ocean, and may be ealled the fish of passage ; the stated returns and regular progress of these fish of passage, the mest extraordinsry eireumstanees in the history of nature; the names of several migrating fishes; of all such, the herring and pilchard take the most adventurous roysges; places where found in abun. dance, 651. to 654 ; in the islands of the Indian Oeean, an overquantity, in shoals, on the swamps, dried up by the sun; the putrefaction renders the eountry unhealthful ; amazing propagation along our ceasts and rivers not proportionate to the quintities among the islands of the Indian Ocean; places where the spawn is deposited; denbts whether most fish eome from the egg completely formed; manner in which the eggs of fishes are impreg. nated wholly unknown; the eel and the blenny bring forth their young alive; growth of fishes; instances in the growth of the earp and maelkarel ; all live upon each other, in some stute of their existence; of those in the oeean of the spinous kinds, the dorado the most voraeious; flying fish ehiefly sought by the dorsdo; their warfare; opinion that all fishes are natives of the sea, founded upon their superior fecundity of breeding twenty to one; certainly fresh-water fishes abate of their courace and rapaeity; greediness of the sea-fish to devour the bait prodigious eompared with the manner it is taken in fresh water; differenee of bait. with which they are cauglit; some fishes rendered so torpid in the northern rivers, as to be frozen up in the masses of ice, and eontinue there several months, seemingly without lifo or sensation, waiting the approach of a warmer sun, to invite them to life and liberty; each species of fish infested with worms of different kinds ; most vivaeious animsls; often live upon substanees poisonous to the more perfect classes of animated nature; numbers of fishes making poisonous wounds seareely to be doubted; some fishes being poisonous is notorious; the eause inserutable; Dr. Grainger, after residing many years at St. Christopher's, affirms, that of fish eaught at one end of the island, some were good and wholesome, while 
others of the sann kind, taken at a different end. were dangerous, | snd commonly fatal; the Plilosoplical Transations givo an acsount of poisonons qualities of fish at New Providence; all kinds, at different times, alike dangernus; the same speeios this daj serving ns nourishment, the next found tatal; speculations and conjectures to which these prisonous qualities liave given rise, 655 to 680 .

Filc-fish, most wonderfil of the shelly tribe, 694. See Pholades.

Fishcry of pearls, seversl; chiefly earried on in the Persian Gulf, 602; the people destined for the pearl-fisheries; they die consumpive; in what manner they fish for pearls, $6 ! 12,693$.

Fishing-frog, from its deformity called the sea-deril; conceit that this fish uses its two long beards or filaments for fishing; liondeletius says, that the bewels taken out, the body appears transparent; and with a lighted candle in it, has a formidable appeicrance; fishermen have a great regard for this ugly fish, as an enemy to the dog-fish; when taken they set it at liberty, 643 .

Fissures, perpendicular, found in every field and evory quarry; their eauses, 18.

Fistularia, deseription of this fish, 650 .

Flame will burn under water; none found continuing to burn witlout air, 97 .

Flamingo, the mast remarkable of the crane kind, the tallest, bulkiest, and most beautiful; its description; ehiefly found in Ameriea; once known on all the coasts of Europe; its beauty and the poculiar delicacy of its flesh, have been such temptations to dostroy or take it, that it has long since deserted the shores frequented by men; in deserted regions, the flamingos live in a state of socioty, and under a better polity than others of the feathered creation ; delicacy of its flesh; when the first Europeans in Amcrica killed onc, the rest rogarded the fall in fixed astonishment; thus the fowler levelled the flock, belore any began to escape ; it is now one of the ecarcest and shyest birds in the world; plaees it chiefly inhabits; always appoints ons as a wateh, who gives notice of danger with a voice shrill as a trumpet; Negroes fond of their company, and think thoir saciety a gift of heaven, and protection from evils; these killed are hidden in the long grass, to prevent ill treatment from the blacks discavering the murder of their sacred birds; are frequently taken with nets; refuse all nourishment when taken pine and dic, if left to themselves in captivity; its tongue is the most colebrated delicacy ; a dish of them, says Labat, is a feast for an emperor; a Roman omperor had fifteen liendred flamingo's tangues eerved up in a dish; their tongue larger than any other bird; its flesh; they move in rank like eranes; appear in fight of a bright red a a burning coal; manner of feeding very singular savages of Canada call it tococo, and why; time of breeding, and their nests; number of their eggs; colour when young ; they become faniliar in five or six dnys, eat out of the hand, and drink sea-water ; but generally pine away, wanting their natural supplies, and die in a short time; savages make ornaments of their plumes and the skin sometimes serves the Eurepeans to make muffs, 564 to 567.

Flea, persecutes the hare, 348 ; it can draw a chain a liundred times lieavier than itself, and eat ten times its own size of provisions in one day, 747; its description, 753; aborescent water-flea, or monoculus, described, 598 ; Lewenhoeck has discovered above six thousand facets on the cornea of a flea, 792.

Flcmings possessed the art of cloth-working in a superior degree; were invited to settle here, 243.

Flesh dries at Cusco like wood, withont corrupting, 195; the Persians esteem that of the wild ass so highly, that its delicacy is a proverb among them, 224; of the fallow-deer preferred to any other, 265 ; of the roe-buck, between ons and two years old, allowed the greatest delieacy known, 269; of the tiger, is good for food, some hold it superior to mutton, 302 ; of dogs, sold in shambles all over China; and the Negroes of the coast of Guinea esteen it a delicncy, as likewise that of toads, lizards, and tigers, 315 ; that of tho wolf very indifferent; no ereature known to eat it but the wolf himself, 322 ; of the squash, tolerable food, 339 ; that of the glutton, not fit to be eaten, 344; of the hare, religiously abstained from by the Jews, ancient Britons, and Mahometans, 348 ; of the paca, considered a great delicacy, 359; of the tendrac, thought by the Indisns a great delicacy, 375; of the pangolin, considered a vory great delicacy by the Negrees of Africa, 379; of the armsdillo, or tatou, aaid to be delicate eating, 381; of the seal, formerly found place at the tables of the great, 396 ; of the monkey, liked by the Negroes, 498; of the ostrich, proscribed in scripture unfit to bo eaten, 463; of the emu, or the Ameriean ostrich, gead to be eaten, 467; of the dodo, gaad and wliolesome eating, 76 ; of the vulture, falcon, and osprey, when young, excellent food, according to Bellonius; that of carnivorous birds, stringy and ill-tasted, soon cormapting, and tinctured with that animal food upon which they sub. sist, 472 ; of the bird candor, as disagreeable as carrinn, 477; of thie peacoek, keeps unputrified louger than of any other animal, 498 ; that of the partridge, so valued by the French, nccording to Willoughly, that no feast could he complete without it, 507 ; of the pheasant, eonsidered as the grcutest dainty, 501 ; of the quail, a very great delicacy, $50 \%$; of the toucan, tender and nourishing, 519 ; of the young herous, in partieular estination in France, 561 ; of the bittern, greatly enteemed among the luxurious, 563; of the puffin, formerly by the ehurch allowed on Lenten days, 591 ; of fishes, yicld little nourishment; questions wroposed to the learned conceruing it, 613; of tho young porpoise; said to he as well tasted as veal, (\%20; of the shark, hardly digestible by any but Nogroes, who are fond of it to distraction, 631 ; of the turtle, is become a branch of commerce, 674 ; that of some erabs is poisonous, 663 ; of the great Mediterranean turtle sometimes poisonous, 673.

Flies torment the elephant unceasingly; arts the elephant tries to keep them off, 420 ; dragon-fly, or the libella, 7,60 ; cainmon wa. ter-fly swims on its back, 779; the cornea so adaptod by Puget, as to see objects througl it with a microscope; strangeness of its re. presentations; does the fly see objects singly, as with one eye, or is every facet a complete eyc, exhibiting its objects distinet from the rest, 792 ; the Spanisl fly? 822 See Canthorides.

Flintshire, in a lead-mine there, two great grinding-teeth, and part of the tusk of an elephant, discovered at the depth of forty-two yards, $42 i$.

Flounder, known to produce in one season above one million of eggs, 612 .

Fluits, ascending in vessels emptied of air ; rising in capillary tubes, and how this comes to pass, 56 .

Flux of the sea, 73 ; not equal in the straits of Magellan, 76 .

Fly-catcher, bird of the sparrow kind, 53.38 .

Flying-fish, its description, 650 ; ehiefly sought by the dorado, 658 . Fly-trap, naine of a flower, closing upon the flies that light upon it, 823.

Fatus, the canal of communication thrangh which the blood circulates in the fotus, without going through the lungs, has been found open in some bodies that liave been dissected, 602 .

Fongrang, natives of Clina give a fantastic deseription of this imaginary bird, 503.

Fontrnclle, a celebrated writer, of a weak and delicate habit of body; the remarkable equality of his temper lengthened out his life to above a lundred; nothing could vex or make him uneasy, $174,173$.

Food, man can live without it for seven days; a Scotchman for the space of six weeks took no foad at all, 15.

Foot, hares lave the sole of it furnished with hair, 347. See Hare and Hoir.

Foramen oxalc, opening in the lheart of the foetus, 131 ; in the seal's heart never eloses, 393 .

Forbin (Cheralier) his account of baboons forcing women in Siam, 404.

Forchead, narrow, liked by the Romans, 140.

Forest, generally divided between mnnkeys and scrpents, 407.

Formica leo, the lion-ant. described; its habits; its retreat; its contrivances for catcling other insects; when attaining a certaiu age, changes its form; description when become a large and beautiful fly of the libellula kind; equally wonderful in all its different stages of existence, 768 to 770 .

Fossil, teeth of elephants oflen found in that state, 425 ; bones found in Peru and Brasil, which when cut and polished appear liks ivory, ib.; shells in the bowcls of the earth, not found in the ocean, 680 .

Fouinc, animal of tlic weasel kind, 33.5.

Fowls, large do not rise easily, and why, 450; few water-fowls known to breed in England, snd why, 457; those of reddish plumage the ancients beld invaluable; the white, as unfit for domestic purposes, and fit as prey to rapacious birds; Aristotle thinks them less fruitful than the former, $4: 14$; sea-fowls ever sporting on formidable sea-coasts, 584; general characteristies of water-fowls; their food; the gull kind; the penguin kind; the goose kind, 574,575 ; water-fowls properly of no climate, $50 \%$.

Foxes hunt in packs; taken young are gentle only while cubs, growing older discover their natursl appotites of rapine and cruelty, 309 ; their cubs born blind, like those of the dog; the fox lives about twelve or fourtcen years; remarkable instance of parental affection of a she-fox; all animals make war upon the fox; even tho birds; refuses to engender with the dog; brings forth fewer than the dog, and but once a year; the femalo goes with young six weeks, and seldom stirs out while pregnant ; various colours of them; three varieties of this animal in Great Britain; greyhound fox, mastiff fox, and cur fox; round the pole they are all colours; 
jackal taken for the fox; skin of the black fox most esteemed, a single skin selling for forty or fifty crowns, the hair ae disposed; impossible to tell which way the grain lies, 323, 324; in Greenland do not ehango colour st all, 331 ; many animals in this country bred between 8 dog and a fox; experiments prove neither the wolf nor the fox of the same nature with the doe; each a species perfeetly distinct, 315 ; nothing eatable comes aniss to them, rats, mice, sorpents, toads, and lizards; insects, erabs, slirimps, and shell-fish; carrots, wax, and honey; even the hedgehog, 323 ; chaso of the fox; their offensive sinell often the cause of their death; way they find to subsist; name given by huntsmen to a tox of the second yoar; old fox the name for the third year, 32: 32:3; exactly resembles the wolf and the dog internally, 322; dewcription; eyes obliquely situated like the wolf, 213; often takes possession of the hole quitted by the badger, or forces it from its re'treat by art, $\mathbf{4 3 8}$.

Fox (crost) name of the isatis, when turning white, 827 .

Fox-tailed monkey, of tho sagoin kind, 412 .

France, its kings of the first race had whiskers knotted and buttoned with gold, 145; under Franeis I. peacocks served up at the tables of the great, not to be eaten, but seen, 497 . Fr:

rederic, emperor of Germany, wrote a trcatise upon hawking

Friczland, great inundations lappened in it, 82 6.10 .

Frog, designedly introduced inte Ireland before the Norway rat, 363 ; the rat pnt a stop to their increase, and the frog is almost extinet in that kingdom, 36.1 ; differences between it and the toad, in figure and conformation; the frog the best swimmer of all fourfoted animals ; its description; malc or female lave nn external instruments of generation; the anus serving for that purpose in both; coupling of the common brown frog; experiments to discover how their impregnation is performed; the female not inprognater by the mouth, as conjectured, nor by the thumbs, as imagived by Linneus, but by inspersion of male seminal fluid upon the cggs proceedling from the body; how the female hrings forth eggs; various clanges in the eggs after impregnation by the snale; tho animal in its perfeet state, from feeding upnn vegetables, becnues carnivorous; lives upon worms and inseets, and secks for frod upon land; myrinds seen on such nccasions, lave been fancied to be generated in the clonds, and showered down on earth ticir habitudes and food ; differences of sexes not perceivable, $\mathrm{mn}$ til their fourth year; do not begin to propagate till that period; live about twelve years; a German surgeon kept one eight years in a glass covered with a net, fed it often, but sparingly; instances nf tenaciousness of life; the male only croaks; from their croaking in some countries distinguished by the ludierons name of Dutch Nightingales; large water-frog's note as loud as the bellowing of a bull, and heard at three miles distanee; times of their croaking; no weather-glass so true in foretelling chsnges; adhere to the backs of fishes; story of Walton to this purpose; dry weather hurtful to frogs, 697, 698 . See Fisling-frog.

Frost, dry, auginents evaporation, 168.

Frost-smolie, fogs near the pole from halos, or Juminons circles, 113. Froth-zoorni, its description, 779.

Fumes of hot iron, copper, or otlier metal, blown into the place where an animal is confined, instantly destroys it, 93.

Fur, the colder the conntry, the larger and wariner the fur instances of it, 210; of the white fox not esteemed, and why, 32.5 the isatis of no value, unloss killed in winter, 327 ; the ermine the most valuable of any, 331 ; no easy matter to account for warmth of furs of northern qiuadrupeds, or how they come to have suel abundant eovering; partienlars on this subject, ib.; white weasel, found in Great Britain, of no value; ermine in every country changes by time, 332 ; of the pole cat in less estimation than some of inferior kinds, from its offensive smell, which ean never be removed, 334; of the yellow-breasted martin more valuable and beautiful than the white, 335 ; different colours of the sable, 336 ; of the genet valuable, 340 ; of the civet imprognated with the perfirme, 341 ; of the glutton has the most beautiful listre, and is preferred to all except the Siberian sable, 344 ; of the lisre forms a considerable article in the liat manufacture, 348 ; of the crieetus, or German rat, very valuable, 368 ; inside down of the vulture's wing makes a warm and comfortable kind of fur, 479.

G.

Gad-fly, formidable in Lapland; brings on an incurable disorder upon the reip-deer; precantions used amainat them, 274.

Gadus, the cod-fish, its description, 650 .
Gugandu, island of Ethiopia ; parrots found there by the Romans, 529

62. Galan, a place 900 miles up the Sencgal, taken from the French,

Galen asscrts the eggs of hens and pheasants good to be enten; those of geese and ostriehes worst of all, 466 .

Galinassos, Spanish name of vultures in Anerica, 481.

Gall of the shannoy held useful to strcigthen the sight, 250; the deer kind have none, 257.

Gall-nuts, descriptinn of the insect forming and residing in them, and its transformations, 824

Galley-fish, its description; its legs adhesive; common in America, perpetually flosting; no efiorts made to lurt, can unake it sink; never pereeived to move on shore, 80 strongly adluering to whatover substances spplied; the smallest quantity of sliny substanee from its legs, burns the skin like hot oil ; extremoly conımon alnng all the coasts in the Gulf of Mexico; the shore covered with them, a forerumner of a storm, 645 .

Galley-rorm, its difference from the scolopendra, 762 .

Game, sanguinary laws to preserve it, 261 .

Ganges, a river visited amually by a hundred thousand pilgrims, who pay their devotions to it as to God, 62 ; in its course ree eivea twenty rivers, 63 .

Gannet, the soland gnose, its description; subsists upnn fish; places abounding with them; manner of preserving them and their eggs, in the island of St. Kilda; the inhabitants of that island prineipally sulusist on them throughont the year; twenty-threo thousand of this kind of young birds consumed annually there; a bird of passage; its nigrations; never comes near the land; where seen, it announces the arrival of herringa; exceeds the cormorant in quickness of sight ; method of taking its prey ; manner of taking them at sea ; number of their eggs; their young counted a croat daint $y$, and sold vory dear, 582,583 .

Garter-fish, the lipidopus, its description, 650 .

Gasterosteus, or the stickleback, description of this fish, 649.

Gazelles, neither goat nor deer; partake of hoth natures; they form a distinet kind; their deseription; of all animals it has tho most licautiful cye; Eastern poets compare the eyes of their mistresses to those of the gazello; Buffon makes but twelve varieties; their names and desoriptions; comparing them torether, we find but slight distinetions; are inhabitants of the warnier climates; no animals, but of tho winged kind, can overtake them; are pursucd by falcons, and this lsumting is a principal amusement among the great in the East; alse hunted with the ounce; another n:sy of taking them; keep in solitary and inaccessible places, 250 to 253 ; the bubalua. more properly one of Africa, 272; the mnst usual prey for the lion, in deserts and forest.s. 205 ; the prey of the panther, 304 ; pursued by the jackal, makes towards houaes and towns, 326 .

Gekko, a kind of salamander, 717 .

Gencration most complete where fewest snimals are produced, 132; late discovery that male fishes have two organs of genera. tion, 612; all animals of the snail kind are hermaphrodites, each containing the instiuments of generation double, 685 ; these orgsns in the rnussel, 688 ; the male or female frogs have no external instruments for that use. 698 .

Genet, its odour more faint than eivet; description of this animal; resembles the martin; more easily tamed; Bellonius has seen them at Constantinople tame as cats; glands open differently from others of its kind; calied the cat of Constantinople; never found in mountains or dry places; its fur vahuable; species not much diffused ; cnuntries where it is found ; the most besutiful, cleanly, and industrious animal; keeps a house free from mice and rats by its smell, 340 .

Genatte, of the province of Andalusia the best, 218 .

Georgians, their description, 183.

Gerenda, a serpent, to which the natives of Calicut and these of the Nozanibique cosst pay divine honours, 741.

Germeny, the meanest peasant kills a cow for his table, salts and hangs it up, and preserves it ss a delicacy all the year round, 281. Gestuer, minutely describes a variety of mouse-traps, 365 ; places bats smong birds, 381 . 88.

Giant, in England, as late as King James I. the court had one,

Giants, probability of the race affirmed, possibility of their ex istence denied; Grew's opinion; Ferdinand Magellsn, a Portuguese, first diseovered a race of sueb people, towards the extreme coast of South America; assent to the existence of this gigantic rsec of mankind; trsvellers confirm it; seen here. liave the same defeets of understanding as dwarfs; are heavy, plulegmatic, atupid. and inclined to sadness, 190 to 192 . 
Gibbon, the lonerarmed ape, its description, 4U3.

Gills, their free play prevented, the animal lidls into convulsions and dies in a fow noments, 60 ?

Gilthead, called dolyhin by sailors ; its deseription, 648 .

Gimerro, inagined a breed between an ass and a hull, 226 .

Glands, furnish the fretil substances in animals of the weasel kind, 330 ; of the genet open differently from others, 393 ; unctuous in birds to preserve their featliers, 37 ; salivary in the gullet and crop of birds, 43 .

Glass, a looking-glass beld to the moutl of a person supposed to be dead, an uucertain experiment for determining latent life, 177.

Glitters, little impressions an called in the heads of stags, $26^{\circ} 2$.

Globe of fire rising from the side of the mountain Pichinea; a great one seen st Bononia, in Italy, In the year 1676 ; past westward at the rate of a hundred and sixty miles in a minute : could not be less than a mile long, and lialf a inile broad, 111 .

Globe of glass, filled with water, assumes successively all the colours of the rainbow, 112 .

Gloucester, its corporation luad an old custom annually 20 present the king with a lamprey pye, 585 .

Glow-2oorm, male and female of this species difier entirely from each other; low and in what manner the light sent forth by the glow-worm is produced, hitlerto inexplieable; the light continues to grow paler, and at last is totally extinct, if the worm be kept for some time, $821,822$.

Glue, made of the horns of the rein-deer, 277; Mr. Jackson found out a method of making glue to answer the purposes of isinglans, 642 .

Glutton, the most dangerous and most successful persecutor of the rein-deer; its manner of killing that deer, 277 ; belongs to the weasel-kind; there is no precise deseription of it, some resembling it to a badger, some to a fox, otliers to a hyma; one brought alive from Siberia, was three feet long, and about a foot and a lialf high, 342 ; so called from its voracious appetite; countries where found called carcajon in North Ameriea; general description; Ray and others doubt of its existence; endued with great patience; watches for its prey for several days together; takes its prey by surprise, and in what manner; darts down from the branclies of trees npon the elk or the rein-deer, sticks its claws between their shoulders and remains there firm, eating their neeks, and digging to the great blood vessels that lie in tlist part; amazing quantity one of theso nnimals can eat at a time; that seen by Mr. Klein, withont exer eise or air, taken from its native climate, and enjoying but indifieren sealth, ate thirteen pounds of flesh every dny, and was not satisfied continues eating and sleeping till its prey, bones and all, be devoured; prefers putrid flesh to that newly killed; it is so slow that sny quadruped can escape it, except tlie beaver; pursues it npon and; but the beaver taking water, the glutton has no chance to ucceed; called the vulture of the guadrupeds; in what manner it nakes up by stratagem the defects of nature; the female goes with roung four months, and brings forth two or three; the malo and male cqually resolute in defence of their young; is difficult to be -kinned; does not fear man; is a solitary animal, and nover in company but witl its female; conples in the midst of winter; the flesh not fit to be eaten; the fur has the most beautiful lnstre, and preferred to all, except the Siberian-fox, or the sable, 343,344 .

Gnats, in Lapland, fill the air like clonds of dust ; are chiefly enemies to the rein-deer; remedies used against them, 273; proceed from a little worn ; usually seen at the bottom of standing waters; curious inanner in which their eggs are laid; in their egg state it resembles a buoy, fixed by an anchor; different states of the insect; in its last transformation divested of a second skin, in the next it rcsigns its eyes, its antenne, and its tail, and seems to expire; from the spoils of the amphlbious animal appears a littlo winged insect, whose structure is an object of admiration; deseription of this insect, and of its trunk, justly deemed one of Nature's master-pieces implement with which the gnat performs its work in sumuner places where it spends the winter; the little brood so numerous that the water is tinged with the colour of the speeies; some gnats oviparous, others viviparous, and come forth in a perfect form; some are males, and unite with tho female; some are females requiring the male; others are of neither sex, and produee young without copulation; at the sixth generation the propagation stops, the gnat no longer reproduces its likeness, but requires the male to renew its fecundity; produced in multitudes beyond expreasion in Amcrica ; and found of all sizes, from six inches long, to a minuteness beyond the perception of the common eye; native Indians, anointed with oil, sleep in cot tages covered with thousands of gnats, and have not their slumbers interrupted by these cruel devourere, 625, 826 .

Goat, its eyes are gray, 142 ; from Europe imported into South
Ameriea, sonn degencrates; as it grows less it becomes more uro. lific; imported to the African ceast, it scems to improve, 21I geat and sheep propagato together, and may he considered ss of one family; the buek-goat produees witl the ewe an animal in two or three generations returning to the sheep, and retaining no marks of its ancient progenitor, 56; more fitted for a life of savsge liberty than the slieep; more lively ind mere possessed of animal instinct; it is not easily confined. its flock, but ehooses its own pasture, and loves to stray from the rest; delights in climbing precipices; walks ss securely on the ridgo of a house, as on the level gromnd ; is eapricious and vagrant ; is not terrified st storms, or incommoded by rain ; immoderate cold affects it, and produces a vertigo, to which this animal is subject; a hardy animal, and very easily sustained, for which reason chiefly the property of the poor its favourite food is the tops of boughs, or the tender bark of young trees; proof of its being naturally the friend of man, snd that it seldon resumes its forest wildness, when once reduced into the state of servitude; in some places they bear twice a year; in warmer elimates generally bring forth three, four, and five, at onee; one buck sufficient for a hundred and fifty gosts; milk of gosts medicinal; not apt to curdle on the stomach; in several parts of Ireland and the highlands of Scotland the goat the chief pessession of the inhabitants; flesh of the geat, properly prepsred, ranked by some not inferior to venison; is never so goed and so sweet in our climate as mutton; no man can attend above fifty goats st a time; flesh of the goat found to improve between the tropies; remarkable varieties in this kind; that of Natoli, by Mr. Bufion ealled goat of Angora; its description; the Assyrian goot of Grsner; elnefiy kept about Aleppo; little goat of Africa, the size of a kid, has hair as long as the ordinary breed; Juda goat, not much lsrger than a hare; common in Guinea, Angola, and the coast of A friea; blue gont, at the Cape of Good Hope ; its deseription, 245 to 217 boundaries between tlie goat and the deer lsind diflicnlt to fix, 250 . Bezonr gant, the pazan, found in the mountains of Egypt, 251 ; African wild goat of Grimmius, fourth anomalous of the kind; its deseription, 253; goats eat four hundred and forty-nine plauts, snd rejeet a hundred and twenty-six, 230 ; in Syria, reinarkable for their fine, glossy, long, soft hair, 292.

Goat-sucker, a nocturnal swallow ; deseription and liabits, 546.

Gobius, the gudgeon, deseription of this fish, 648 .

Godignus, in his history of Abyssinia, exaggerates the effects of the slioek of the torpedo, to an ineredible degree, 637.

Godwit, its dimensions, 563 ; a bird of passage, 570 .

Gojam, kingdom, where the Nile takes its rise, 62.

Gild never contracts rust, and why; except in places where mueh salt is used, 92 .

Golden-eye, bird of the duck kind, 598

Goldfinch, bird of the sparrow liind, 537 ; learns a song from the nightingale, 546.

Goosc, marks of the goose kind; abstained from by the ancients as indigestible, 592, 5.33; one known to live a hundred years; marks of the tsme and wild sort; wild supposed to breed in the nortliern parts of Eurove ; flight regularly arranged, 596 .

Goose (Brent,) most harmless, but for their young pursue dogs and men; use of its feathers in beds unknown in countries of the Levant and Asia; feathers a considerable article of commerce ; different qualities of them; the best method of euring them, 596, 597 . Gouse (Soland) described. See Gannel, 582.

Gonseander, a round-billed water-fowl, its description; feeds upon fish, 296.

Gordian, the emperor, wrote a poem upon the halcyon, of which are no remains, 602 .

Goss-hnuk, of the baser race of hawhs, $4 \in 2$; tauglit to fly at game; littlo obtained from its eflorts, 481 .

Gottenlurg, in Sweden, a cataract near it, 65.

Gouan, a learned Frenelunan, his system deserves spplanse for more than its novelty; how followed in arranging the spinous classes of fishes, 647 .

Graaf, his observations npon the progress and increase of animals in the womb, 129 .

Grampus, fieree and desperate in defenee of its young; remarkable instance, 615 ; deseription and liabits, 624 .

Grasshopper, a ruminating inseet, or seemingly so, 232; differences between ours snd tlie eicada of the aneients; great varieties of this animal in shape and colour; description of the little grasshopper that breeds plentifully in meadows, and continues chirping through the summer; the male of this tribe only vocal; how their fecundation is performed; the male or female never survive the winter ; their eggs from first appearing, possessed of wings; how it gets rid of the outer skin; their food; places where they deposir their cggs, 771 to 773 . 
Grare, the greatest cere recommended not to commit thos dearest to us to the grave, before real signs of cortain death be ascertained, $17 \%$.

Gretah, river in Yorkshire running under ground, and rising again, 66 .

Grebe, description of this bird; residence and habits; pcrpetually diving, and very difficult to be shot; never seen on land; chiefly sought for the skin of its breast, and why; in breeding-time their breasts are bare, 573 .

Greenfinch, bird of the sparrow kind, 53\%.

Greenland, Crantz's account of the formation of ice-montains in that country, 72, 73; aurora borealis, its appearancs a]most constant in winter; the inhabitants not entirely forsaken in the midst of thoir tedious night, this aurora affording them light for the purposes of existence, 113; thcy live mostly upon seals ; their number claily diminishing, and why, 396.

Grechlunders, described, 178; eustomary among them to turn Europeans into ridieule ; a quiet, or a modest stranger, thoy deem almost as well bred as a Grcenlander, 179

Grew, his opinion concerning dwarfs and giants, 190.

Greyhound kind, 312; greyhound fox, 325.

Gris, the petit gris, Mr. Buflon's name for the gray Virginian squirrel. $33:$

Grussbcuk, bird of the sparrow kind, 538 .

Grotla of -1utipuros, in the Archipclago, the most remarkible schterraneous cavern new known ; description, 23.

Grottn del Cane, near Niules, situation and description; noxious effects, 2:-

Grous, chiefly found in heathy mountains and piny forests, 505 .

Growth of the child less every year, till the time of puberty, when it starts up of a sudden; growth of the mind in children corresponds with that of the body, and why, 135, 136; of some young peoplc ceases at fourteen or fiftecn; ol others continues till two or three and twenty, 149; of fislies irregular and tardy, 657.

Guudulquiver, river in Spain buried in sand, 66.

Guunacues, a kind of camcl in America, 434.

Guenclues, ancient inhabitants of the island of Teneriff; art of embalming still preserved ameng them, when the Spaniards conquered the island, 194.

Guarilut, Brasilian guariba, or warine, the largest of the monkeykind in Anerica, described, 412.

Gituyaquil, river in Senth America, 43.

Guilgeon, fiesli-water sort, as well as the anchovy, has no bladder 611; description of this fish, 648.

Guibu, aninal resembling the gazelle ; its description, 253.

Guillemat, bird of the smaller tribe of the penguin kind, 590 .

Fuincu, the natives kill numbers of hares at a tinc, and in what manner, 348

Guinen-oss, larger and more beautiful than the horse, 226.

Guinea-hen, described, 503 .

Guinea-horse, remarkable exercise and sports with it among the grandees of that country, 220 .

Guinee-pig, by Brisson placed among the rabbit kind; native of the warmer climates; rendered doinestic, and now become common every where; its deseription; in some places a principal lavourite often displacing the lap-dor; manner of living anoong us; most lielpless and inoffensive, scarce possesse 3 of any courage ; their animosity exerted against each other; often fight obstinatcly, and the stronger destroys the weaker; no natural instinct, the female sees her young destroyed without attempting to protect them; suffer themselves to be devoured by cats ; fed upon recent vegetables, thoy seldoin drink; sometimes crnaw clothes, papcr, or other thing of the kind, drink by lapping; confined in a room, scldom cross the floor, but keep along the wall; never move abreast together chicfly seck the most intricate retreats, and venture out only when all interruption is removed, like the rabbits ; in cold weather mare active; a very cleanly animal; their plice nust be regularly cleaned, and a new bed of hay provided for them once a week; the young falling into the dirt, or other ways discompased, the female takes an aversion to them, and never permits them to visit her more; her employment and that of the malc, consists in smoothing their skins, disposing their hair, and improving its gloss, and take this office by turns; do the same to their young, and bite them when refractory; reared without any artificial heat; no keeping them from tirs in winter if once pernitted to approach it; manner of sleeping; the malo and femalc wateh one another by turns never seen both asleep at the sane time; generally capable of coupling st six weeks old; tine of their gestation; the femalo brings forth from three to five at a tine; not without pain; the female admits the male the very day sho has brought forth, and again No. 77 \& 78 . becomes prognant; suckles her young alsout twelve or fifteen days, and suffers the young of others, though older, to drain her, to the disadvantage of her own; produced with eyes open, and in twelvo hours equal to the dam in acility; capable of feeding upon vegetables from the beginning; thieir disputes for the xirmest place, or most agreeable fuod; manner of fighting; mest timorons creature upnn eartli, a finling leaf disturbs tliem, and every animal overenmes them ; flesh indifterent food ; difficultly tamed; suffer no spproaches but of the person who breeds them; manner of eating; drink selden, and nake water often; grunt like a yeung pig; appear to cliew the cad, 3011 to 30.2

Guivea-shorp, lave a lind of dewlap under the chin; breed with ether sheep, therefore not aninals of another kind, 244 .

Guiratemga, name given by the natives of Brasil to the little roood-pecker, $5 \div 1$.

Gulis, places where fonnd in plenty; their food, 584 ; various ways of imposing upon each otler; contests in breeding; residence, with their nests and eoces; their flusla: method of taking then in the Feroe islands; anciently a law in Norway concerning these who died in taking then, $585,586$.

Gulf, the Persian; deadly wind alung its coasts, 195; chicf pearl fislıery carried on there, 6!tiz

Gun, wind-gun, instrument determining the clasticity of the air ; a ball from it picress a thick board, 90 ; treat guns, in climater near the equator, with every prceantion, after suno years becone useless, and why, $9 \cdot 2$.

Grunpuoder, readily fires with a spark, not with the flame, 24 will not go of in an cxhansted recciver; a train of gunpowder laid, oue part in open air, the other part in vacue, the latter will remain untouched, 97

Gurnurd, description of this fish, 649 .

Gustums . Adulphus, attenpted in vain to form a reciment of Lsplanders, ss they can live but in their own country, and in their own manner, 178 .

Guts, unost birds have two blind guts, which in quadrupeds aro found single, $45 \%$

Gymnotus, the Carupo, deseription of this fish, 649 .

Gyr-fnlcon, exceeds all others in largeness of size; its descrip. tien, 483.

Gyrle, name given by hunters to the reebuck, the second year, 268

11.

Ifabit, contracted during life, to make out pleasures and pains in extremes, though either can lardly be suficred or enjoyed to the utmost, 177.

Inddock, a periodical shoal appeared on the Yorkshire coasts, on December 10,1766 , and exactly on the same day in the following year, 653 .

Henorrhois, a kind of serpent, 739.

Hail, Cartesians say, is a frozen cloud half-melted and frezen again in its descent; the most injurious meteor in our climate hail-stones fourteen inches round; struck out an eye of a young man, and killed him on the spot; $n$ dreadful shower recorded by Mezeray, fell in 1510; the hail-stones were of a blueish colour, and sone weighed a hundred pounds; the fislies were general sufferers in that great calamity, 109,110

Huir of the Roman ladies praised for the redness of its shade, 140 ; the hair under the temples and at the back of the head seldom known to fail ; found most different in different climates; marks the country and the disposition of the man; by the ancients held a sort of excrement, prodoced like the nails; according to moderns, every hair lives, receives nutriment, fills and distends, like other parts of the body ; takes colour from the juices flowing through it; each, viewed with a microscope, consists of five or six lesser, wrapped up in one common covering, and sends forth branches at the joints; suitable to the size or slape of the pore through which it issues; bulbous at the root, and its ends resemble a brush; length and strenoth of hair a mark of a good constitution: Americans and the A siatics have it thick, black, straight. and shining; inhabitants of the torrid climates of Africa have it black, shert, and woolly; the poople of Scandinavia have it red, long, and curled; opinion that every man has dispositions resembling these of the inhabitants of cauntries he resembles in tbe colour and nature of his bair; curled hair anong us a beauty; the Greeks have taken one of their na tiona] distinctions from the length and straightness of the hair, 142, 143; Americans take the greatest pains in cutting their hair the Tartars waged a long and bloody war with the Persians be- 
cause they would not give their whiskers the orthodox cut; variety in cuetoms and manner of cutting hair, 145; trade of the inhabitants of Angora with the hair of animals of their country; camblet and the other atuffs mado of it, 247; bair of the cat rubbed in the dark, sends forth shining sparks, 290 ; Syria and Persia noted for long Boft hair to the animals bred in them, 292 ; each hair of the lynx of three different colours; of the black fox bo disposed as impossible to tell which way the grain lies, 325 ; cuats of hair seem to thicken at the approach of winter; among quadrupeds, as among men, thin spare diet produces hair, 331 ; on the soles of the fcet, and on the inside of the mouths of hares, 347 .

If

Halley (Dr.) his plausible theory to explain the invariable motion of the winds, 100,101 .

Hallontide, in 1580 ; an army of mice $s 0$ over-run the marshes near Southminster, that they oat up the grass to the roots, 491.

Halos, or luminous circlce, oftener secn in countries near the poles, than any other part of the earth, 113.

Hommer, the ycllow, bird of the sparrow kind, 539 .

Honister, the cricetus or German rat of Mr. Buffon, 368.

Hand, sufficient to vindicate the dominion of man over other animals, a poor assertion; a man without hands or legs, converts his stumps to most convenient purposes, and performs astonishing feata of dexterity, 415,416 .

Harbour of a stag, in covert or thicket, 262.

Hare, gregarious animal, where it has no enemies but beasts of the forest, $23 \mathrm{t}$; the swiftest animal for the time it continues to run, 345 ; animals of the hare-kind inoffensive and timorous; being the prey of every voracious animal, are ineessantly pursued; placed by l'yerius amoug those that chew the cud; whether or not, certainly the lips continually move sleeping or waking; they use their fore-paws like hands; that hind remarkably salacious, and furnished by nature with ampler powers than otlors for propagation; if not thinned by constant depredations, would over-run the earth; of these, the lare the larrest and most timorous; lias large prominent eyes placed backwards to see behind as it runs; these never closed; it slceps with them onen; the ears moveable, and capable of direc tion to every quarter; nuuscles of its body strong and without fat ; hinder feet longer than the fore on account of spced; persceuted by dogs, cats, weasels, and birds of prey; in a state of engendering very early; females go with young thirty days, and bring forth three or four at a time; has young of ditrerent ages in her womb together; though already impregnated she admits the male, and receives a sccond impregnation; reason of this extraordinary circumstance; the young brought forth with their eyes open; the dam suckles them twenty days; food they are fond of ; sleep or repose in their form by day, and live only by night; the rutting seaon begins in February; the male puraues and discovers the temale by the eagacity of its nose; the slightest brecze or falling of a leaf disturbs their revels; they instantly fly off, each taking a separate way; are more easily taken than the fox, a much slower animal than they, and why; always choose to run up a hill, and wby; have the eole of the foot furnished with hair, and seem the only animal with hair on the inside of the inouth; live seven or eight vears, and come to perfection in one year; females live longer; Mr. Bnffon makes a doubt of it; seldom heard to ery, except when seized or wounded; their cry nearly like the squalling of a child; are easily tamed, but are incapable of attachment to any person; thougb never so young, regain their native freedom at the first opportunity; have a good ear, and been taught to beat the drum, dance to measure, and go through the manual excrcise; make themselves a form where the colour of the grass resembles that of their skin, open to the south in winter, and to the north in summer ; sore hunted, will start a freeb hare, and squat in its form; sometimes will hide among a flock of eheep, and no vigilance can drive them from it; some enter holes like the rabbit, by hunters termed going to vault; ae it tires, treads heavier, and its scent is stronger ; young hares tread heavier than the old; male unakes doublinge of greater compase than the female; divided by hunters into mountain and measled hares; mode of expression, the more you hunt, the more luares you ohall have, and why; what aninals persecute the hare; it enemies so various, that it seldom reaches the short term limited to it by nature; in countries near the north pole, they become white, and are often in great troops of four or five hundred; their skins sold for less than seven shillinge a bundred; the fur known to form a considerable article in the hat manufacture; found also entirely black, in much less quantity than the former; eome have been seen with horns, but rarely; those in hot countries smaller than wr: those in the Milanese the best in Europe; ecarce a country where not found, from the torrid zone to the polar circle; natives of G ninea till numbers at a time; in what manner; the Jew日, ancient Britons, and Mahometans, all considered it as an unclean animal, and religiously abstained from it ; A picius shows the manner of dressing a hare in true Roman taste; hare and rabbit distinet kinds, refuse to mix with each other; an instauce of it, Mr. Buffon having in vain tried to make them engender witl each other; law made for the preservation of them, 345 to 349 .

Ilarfang, or great Iludson's Bay owl, the largest of thę nocturnal tribe, and as white as snow, 599 .

IIarlequin, a kind of a dog, 312 ; sn useless animal, somewhat between an Italian greyhound and a Dutch mastiff, 313.

Ilarmany of our planetary вyetem, 2.

Harold. See Ilark, 492.

IIarp, the story of Arion's gathering the dolphins about the ship, 165.

Ifarpies, that ancient idea taken from the rousette, or the great bat of Madagascar, 385.

Harricr, hound, and beagle, all of the same kind, 311; a dog of the generous kind, 312 .

llart, name of the stag the sixth year, 262.

Ilartshorn, and musk, the only medicines of reputation of eeveral procurable from quadrupeds, 250.

Ilarvey, his opinion abont the formation of the incipient animal; altercations against his system, I23.

Hatching, notbing cxceeds the patience of birds hatehing, 455 ; Mr. Addison's observations to this purpose, ib.; the emu very peculiar in the batching of its young, 466 ; the crocadile's eggs hatched in the sand, 715 .

Hatfield, in Yorkshire, description of one of those spouts called typhans, observed there in $1687,115$.

Iarannah, in the fortunate expedition which gave us that placo, the climate left not a fifth part of the army survivors of the victory, 94.

Haufinch, a bird of the sparrow kind, 538 .

Hazck-kind, destroys mice, 365 ; perceives lark at a distance which neither men nor dogs could spy, 450 ; distinctive marks from other carnivorous birds, 473 ; in old paintings, the eriterion of nobility; no person of rank stirred without his hawk on bis hand Harold, afterwards king of England, going on an important embassy into Normandy, is drawn in an old bas-relief, embarking with a hawk on his fist, and a dog under hie arm; in thaee days, it was sufficient for noblemen's sons to wind the horn and carry the hawk fair; this diversion in such high esteem among the great all over Europe, that Frederick, Emperor of Germany, wrote a treatise upon hawking; this smusement now much given over in this kingdom, and why; this sport attended with very great expense; in the reign of James I. Sir Thomas Monson gave a thousand pounds for a caet of hawks; in the reign of Edward 1II. it was made fclony to steal a hawk; to take its eggs was punished by inprisonment for a year and a day, with a fine at the king's pleasure; in the reign of Elizabeth, the imprisonment reduced to three months, the offender to lie in prison till he got security for his good bohaviour during seven years ; in earlier times the art of gunning was but little uscd, and the hawk was then valuable for its affording diversion and pro. curing delicacies for the table not otherwise to be abtained; of such spirit that he kecps all birds in awe and subjection to his prowess distinctive niarks of the tribo called the long-winged hawk ; their names and description; have attachment to their feeders, and docility the baser race are strangers to ; names of hawks of the baser race; those of the generous breed remarkable for courage, ewiftness, and docility, in obeying the commands and the signs of their master; to train up the hawk so as to hunt for his master, and bring him the game he ohall kill, requires great skill and assiduity; account of the manner of training a hawk; falconers had a language peculiar, in which they conversed and wrote, 482 to 486 .

Hawk, (sparrow) pursues the thrush and the linnet, $4: 2$; said to be the boldest and the best of all others for the chase, 486 .

Have, (goss) and eparrow-hawk, unfit for training; taught to fly at gane, but little obtained from them, 486 .

Hawkins (Sir Robert.) See Azores, 70.

Head of man externally and internally different from that of all other animals, the monkey-kind excepted, 146; whence originally the flat-heads of the American Indians, 185; of quadrupeds different from other, but adapted to their several ways of living, and bow, 206 ; in all birds, except nacturnal, the head smaller and less proportioned to the body than in quadrupeds, 450 ; of the great Greenland whale makes a tbird of its bulk, 617 .

Hearing, extreme delicacy of this sense in birds, 451 ; that sense in whales in great perfection, 617 .

Hrarse, name of the female of the stag, the second year, 262.

Heart, a broken heart, in common language, in reality a dieorder caused by hunger, 154 . 
Heat, Boerhave considered it so prejudicial to health, that he never went near a fire, 95 ; of the blood in man and other animals about thirty degrees abovc congelation; in animals which slcep the winter, not above ten, 357 .

Hecla, the bellewinga of that volcano, believed by the inhabitants of Iceland to be the cries of the damned, 26.

Hedge-hog, with an appearance the most formidable, the most harmless of animals; destitute of either cunning or swittness; hes but one expedient for safety, and from this alone it finds protection; the cat, the weasel, the ferret, and the martin, decline combat with it; even the dog attacks it ineffectually; its description; usual appearance on the approach of danger; to disgust its eneny from pursuit, sheds its urine, the smell of which is sufficient to send him off; sleeps by day, and ventures out by night; places where found; its food; does not suck eattle; are not lurtful in gar. dens or orehards; the spines so disposed, that no fruit will stick upon them; appcars serviceable in ridding the fields of insects and worms; Mr. Bufion accuses it of tricks, of which, from its form and habits, one would not be led to suspeet it ; he kept males and females together, but they never coupled; time of their coupling ; slecp during winter, but do not lay ip provlsions for that stason; at no time eat nuch, and remain long without food; blood cold, and their flesh not good lor food; their skins cenverted to no use, cxcept to muzzle calves from sucking, 373, 374; destroyed and devoured by the fox; in what manner, 323.

Hctge-hag of the sea, a cartilaginous fish of the sea-orb kind, 644 . IIedge-spurrow, a slender billed bird, 5337 .

Height, Maximin, the Enperor, above nine foet in stature, 151.

IJ.liogabalus, noted for liaving the brains of six lundred ostrichos dressed in one dish, $46 \%$.

IIcllebore, a quantity of the black sort pounded carelessly purged several persons who were present, and the operator strengly, 96.

Helmo's (SL.) fire, or the mariner's light, 111.

Jlclmont, his experiment to show all things made of watcr, 49 .

Jlemisphere, half illuminated by northern lights, 110 .

Hemiorl, eat by the horse without injury, 214.

Hemuse, name lunters give the rocbuck the third year, 268 .

$H e n$, in the Museum at Brussels, a creature covered with feathers and hair, said to be bred between a rabbit and a hen, 34 ?

Ifen of the conumon sort, moderately fed, lays above an hundred egirs from spring to autumn, 456 ; after three years become effete and harren; clutches one brood of chickens in a scason; instances of two, very rare; number of cggs of a domestic hen in the year above two hundred, beiner woll fed, supplied witl watcr, and at liherty; trodden by the cock or not, sho continues to lay; $\operatorname{cggs}$ of this kind never by hutehing produce livirg animals; her nest made without care; clucking scason artificially protracted, and entirely removed, in wlat manner; left to herself, would seldom lay above twenty eggs without attempting to hatch them; as slie lays, her eggs being removed, she continues to increase the number; in the wild state, seldam lays above fiftcen eggs; particularities of incubation; affection and pride after producing chickens; every in. vading aninal she boldly attacks, the horse, the hog, or the mastiff; inarehing before her little tronp, by a varicty ol notes calls her train to their food, or warns them of danger; instance of the broed running for security into a liedge, while the hen stood beldly forth, and faced a fox that came for plunder; twelve chickens arc the greatest number that a hen can rear and clutch at a time; artificial inethod of hatching ehickens in stoves practised at Grand Cairo, or in a laboratory with gratuated heat, effected with woollen hens, by Mr. Reaumur; by these contrivances, from a hen naturally producing tivelve chickens in the yenr, are obtained artificially above two hundred, 495,496 ; common lien supplies the placc of the hen-pheasant, when refusing to hatch her eggs, and performs the task with perseverance and success, but the young ones very difficult to be reared, 502 .

Hen (Guinea) or Barbary hen, described, 503.

Hen (water) described, residence and food; nest and habits, 572,573

Henry $J V$. King of Deninark, desirous of trying the skill of a musicall, who boasted he could excitc men to madness, submitted to the operation, becante mad, and killed four of his attendants, 166.

Herculaneum overwhelmed in that eruption of Vesuvius in which Pling the naturalist waa suffucated; its ruins lately discovered at sixty feet below the surtace, and forty below the bottom of the sea, 27 .

Hermaphrodites, such are all animals of the snail kind, 685; the bivalve tribe are so too; they require no assistance from each other towards impregnation, 687 .

Hermetical-sealing, a glass vessel, the meaning of it, 49 .

Heron, a ruminating bird, 232 ; the great heron, in former times, bred familiarly in our marshes; not now, and wliy, 457 ; anstnmical distinction in which herons differ from other hirds; of this tribo Brissen has euumerated forty-seven eorts; excessively destructive and voracieus; ever have lesn and carrion bodics; description of the common licron; indolent and cownrdly, and flies at the approach of the sparrow-liawk; commits the greatest devastations in fresh waters; destroys morc in a wcek than the otter in three months; a fish ever so large he will strike at, and wound, though unable to carry it away; one licron, says Willougluby, will destroy fifteen thousand carp in half a year; usual attitude, waiting for prey; food in eold and stormy seasons; manner of fisbing; Wil. lougliby's reccipt for taking then; their nests; never in flocks when ticy fish, but making nests, they love each other's socicty ; ficsh of the young estccucd in France ; formerly mueh estcenied in England; at present nothing domestic but a cat will toucl jt; method used to obtain them; the young onco excluded, the old incessantly provide them with an anazing quantity of fish; instance of it; by Mr. Keysler's account, this bird nuy exceed sixty years; recent instance of one taken in Holland, witl a silver plate to one $\log$, and an inscription, that it had been struck by the electer of Cologne's hawks thirty-five years before; they contract a consump. tive dispasition, 559 to 561 .

Herou-hawking, a favourite diversion among onr ancestors; had laws cnacted for the prescrvation of the species; he who destroyed their eggs was liable to a perilty of twenty shillings for each offence, 559 .

Herrara confirms the existence of giants, 1?

Herring, its description, (6i)(1); of inigrating fish, this and the pilcliard take the most adventurous voyages; places where the herrings are in the greatest abundance; numerous enemies met in their nigrations ; in Chesapeak bay, the shoals ao great as to cover the shores, and become a uuisance; that body upon our coast begins to appear off the Shetland isles in April; forerunners, the grand shoal descending in June, and announced by the gannet, gull, ic.; the main body divided into distinct celumns of five or six mile: in length, and three or four broad ; in bright weather reflect a variety of splendid colours; fishernicn take two thousend barrels at a single drauglit; places of Europe where herrings are punctual in their visitations; doubts in every part of their migration; first great bank fer herrings was along the Norway shore; before 1584, the number of ships from varieus parts ef Turope reserting thither exceeded some thousands; quantity of herringe then assembled there was such, that a spear stuck in the water, as Olaus Magnus asserts, would stand on end; soon after that period, they deserted the Norivay sliores, and took up along the German ceasts; no causc assigned for this seeningly capricious descrtion; their greatest colonics now in the British cliannel, and upon the Irish shores; a herring suffered to multiply unmolested, and undimi nished for twenty years, would show a progeny greater in bulk than ten such globes as that we live upon, 653.to 656 .

Hertfardshire, a dreadful storm which happened in it, in 1697, described, 109

Hcxagons, with Pappus, the most convenient figures in building ; cells of bees are perfect hexagons, $80 \%$.

Hicle of the elk, oflen know'n to turn a nusket ball, 271.

Heiru island, in the Meditcrrcanean, risen and formed by subterraneous explosions, 37 .

Jeira. See Archimedes, 55.

Hind, or fcmalc of tle stag, has no horns; time of gestation, and usual season of bringing forth; lides her young in obscure thickets; obliged to use all arts to conceal them from the stag, the most danrernus of her pursuers; low she defenda her young, 260, 261; the femalc stag, still so called the third year, 262; manner of knowing the track of a hind, 26\%2; inhabitants of Canada have no other milk but that of the hind; and no other cheese but that made of it, 265 ; the hunter's name for tlie roc-buck, the first year, 268.

Hippocampus, the sco-liorse, its description, 644.

Hippocrates, his opinion about the formation of the incipient animal, 123.

Hippopotamus not afraid singly to oppose the lion, 295; its dimensiena ; places where it reaides; its food; swims with much force, and remains at the bottom for thirty or forty minates; it commits dreadful havock among the plantations; method the Africans uee to frighten it back to its element; inoffensive in arts and disposition; never attacks mariners in their boats, unless inadvertently struck against, or otherwise disturbed, then it would gend them at once to the bottom; instances of its grcat strength; never goes beyond the mouth of fresh-water rivers; attacked on shore, and incapable of vengeance upon a flying enemy, returns to the river, and plunges in head foremost; the princes of Africa amuse themselven with combats on their lakes, between this and other 
formidable animals; the negroes, apprized of its foree, do not engage it; continues uncontrolled master of the river, all other fly its approach, or become sn easy prey; moves slowly upon land; seldom goes from the river side, unless pressed by necessities of hunger, or of bringing forth its young; lives upon fish and vegetables; natives of Africa say it often devours children, and other creatures surprised upon land; the young are cxeellert eating; the female seldom produces above one at a time; hearing the slightest noise, she dashes into the stream, and the young one fol. lows her with equal alacrity; Dr. Pococke has seen their flesh sold in shambles like beef; their breast thought as delieate eating as veal; this creature, ence numerous at the mouth of the Nile, now wholly unknown in Lower Egypt, and no where found but above the eataracts, 427 to 429 .

Ifistorian, (natural) what lus proper business, 2; going too much into speculation certainly wrong, and why, 6 ; nietliod lis principal help, 199; faults of systenatic writers, 200.

History, (natural) of all otler eciences has the least danger of obscurity, and why, 202 ; best set forth, as Mr. Locke has olsserved, by drawings of animals, taken from life, 204 ; rule in natural history, that neither horns, colour, fineness or length of hair, or positien of ears, make aetual distinctions in the kinds, 217 ; aecounts of fishes little entertaining; philosophers not studying their nature, but employed in increasing their eatalogue, 605 ; Dampier has added more to it than half the philosophers before him, 674; one of the strangest discoveries in all natural history, 826.

Hobby, bird of the generous breed of hawks, for sinaller game, daring larks, and stooping at quails, 493 .

Hog $s$, animals of this kind resomble those of the herse as well as the corv kind, and in what; this kind partakes of the rapacious and the peaceful kinds; offends no animal of the forost; remarkable that none of this kind cver shed their tectls; any animal dying in the forest, or so wounded as to make no resistanee, is the prey of the hog, who refuses no animal foed, however putrid; in a state of wildness, most delicate in the choice of ite vegetables, rejects a greater nuinbor than any other: they eat but seventy-two plants, and reject a hundred and seventy; indelicacy of this animal more in our spprchensions than in its nature, and why ; in orchards of peaeh-trees in North Amcrica, rejects the fruit that has lain a few hours on the ground, and watcli hours for a fresh wind-fall ; have had mice burrowing in their backs while fattening in the sty, without seeming te perceive it; scent the hounds at a distance by nature stupid, inactive, and drowsy; its whole life a round of sleep and gluttony; has passions more active only when incited by venery, or when the wind blows with vebernence; foresees the approach of bad weather; much agitated on learing any of its kind in distress; have often gathered round a dog that teazed them, and killed him upon the spot; their various diseases; generally live, when pernitted, to eighteen or twenty years; the females produce to the age of fiftcen; produce from ten to twenty at a litter, and that twice a year; in the wild state less prolifie, 279 to 282.

Hog (Guinea) and that about Upsal, described, 252.

Ing (zoater.) See Copibara, 284.

Hog of Borneo. See Babyrouessa, 285.

IIog of the isthmus of Darien, deseribed by Wafer, 286.

Hohanho, a river of China, in Asia; its course, 62; receives lhirty-five lesser rivers, 64 .

Holland, a conquest from the sea, and rescued from its besom; the surfaee of its earth below the level of tlle bottom of the sea; upen approaching the coast, it is looked down upon from the sea, as into a valley; is every day rising higher, and by what means; those parts which formerly admitted large men of war, are now too shallow to reeeive ships of moderate burden, 81 .

Honcy, the polecat and the martin foed upon honey, 332 ; from what part of the flower it is extracted, 803; two kinds of it ; which to be prefersed, 807 ; that gathered by the humble-bee, 808 ; gathered by the black hees in the trepical climates, neither so unpalatable nor so surfeiting as curs; produced by the bees at Guadaloupe, 808. See Bees, 808 , 809 .

Honeycorab, name of the second stomach of ruminating anirnals, 673 . 666.

Hoof of the Persian mares, so hard that shoeing is unnecessary,

Hooper, name of the wild ewan, on account of the harshness of its voice, 594.

Horizon, seems wrapt in a usiddy clond, upon the approach of winter, under the line, 110.

Horr, to wind it, and to carry the hawk fair, formerly sufficient sccomplishrients for noblemen's sons, 482 .

Horns, in what manner those of animals are produced, 147; now differently in deer from those of sheep or oows; deers' homs furrowed along the sides, and why ; in crery respect resembling a vegetable substance, grafted upon the head of the stag; beauty and size of those of a stag, mark their strength and their vigour; the time of shedding them; severe winters retard the shedding the horns in stags; generally increase in thiekness and height from the seeend year to the eighth; partake of the nature of the soil; their horns shed, they seck the plainer part of the country, remote from those animals they are then unable to oppose, and walk with their lreads stooping down, to prevent strilking against the branehes at a tree, 257,258; of a stag. called his hoad; their names according to the different ages of the stag. 262 ; the author has seen the horns of the elk ten feet nine inches from one tip to the other; 270 ; applied to the same purposes as hartshorn, 271 ; rein-deer converted into glue, 277 ; of the rhineeeros, sometimes frem three to three feet and a half long, composed of the most solid substance, and pointed to inllict the most fatal wounds, 426 ; of owls nothing more than two or three feathers that stand up on each side of the licad, over tho enr, 48 ?.

Horses, characteristic marks given by Linnæus; eats hemleck without injury, 214; near as the ape spproaches man in external conformation, so the horse is the nost remote; wild horses berd together, and feed in droves of five or six hundred; one among their number always stands as sentinol, and after having alarmed his fellows to flight, remains the lindermost, 215 ; there are but three snimals of the horse kind, the horse, ass, and zebra, 227; a horse will not carry upon its back a weight of more than two or three hundred pounds, 150 ; to estimate the strength of a horse, is not to try what he can earry, but what he can draw; he draws a load ten men cannot move; and in some cases a draught horse draws better being somewhat loaded, ib. ; allured by inusic, 165; not readily attacked by the lion; the eombats between them in Italy, 207 ; one fond of oysters, 209; from what country the horse came originally, uncertain; according to the ancients, wild loorses once in Europe; the eolder climates do not agree with them. how wild herses aro caught; set at liberty they never beome wild again; the Buceaneers agreeably surprised to see their faith. ful horses prescnt themselves arain with their usirl assiduitr, and receive tho rein; this amimal in a state of nature in the eld, not the new world, 215 ; wild horses finding a tame horse to associate with them, gather round him, and oblige him to seek safety by flight; countries where wild horses are found ; the natives of An. gola, or Cafraria, eateh a horse only to eat him. Arabian will horscs, the most beautiful breed, the most generous, swift, snd persevering; the negroes show terror and surprise when first they see a horse, ib.; no Arabian, however poor, lut has lis horse tame Arabian horses, some valued at a thousand dneats; different classes among the Arsbians; they know the race of a horse by his appesranee; Arabians preserve the pedigree of their horses with eare, for severa] ages, 217; countries into which the race of their horses has spread itself, ib.; they take the wild horses with traps; the young horse considered by them ss a great delieacy; they feast upon him while any part is remaining; the usual manner of trying the swiftness of Arabian horses, by hunting the ostrieh; and a horse of the first speed is able to out-run it, 216 ; treat their horses gently; hold a discourse with them; permits thern to sleep indiseriminately with his family; written attestations given to per. sons who buy Arabian horses; they stand stock still in the midst of their career, the rider happening to fall ; keep them saddled at their tonts from morning to night, to prevent surprise; wlien the Arabians begin to break their horses; hew the Arubians drees and feed their horses, 217; first began the management of horses in the time of sheque Ishmael; the rapidity of the flight of Arabian horses is sueh, that the dogs give up the pursnit, 216 ; upon computation, the speed of the English horse is one-fourth greater carrying a rider, than that of the swiftest barb without one; in Persia, aceording to Marcus Paulus, there are studs of ten thousand white msres altogether, very fleet, and with the hoof so hard that shoeing is unnecessary; Numidian race much degenerated; the Tingitanians and Egyptians have the fame of rearing the finest herses for size and beauty, 218; horses of Barbary; an Jtalian poculiar sport, in which horses of this breed run against each other, ib.; Spanish genette described, ib.; those of Andalusin paes for the best, and preferred as war horses to every other country, Italian horses have a particular aptitude to prance, $\mathrm{ib}$.; the horses of India, weak and washy; fed with peas, sugar; and butter; one brought to England not much larger thnn a common mastiff; climates exccssively hot scen unfavourable to horses, remarkable sports on horsebick; the horses of the Gold Ceast and Guinea extremely little, but very manageable; of Chine, weak, little, illshaped, and cowardly; those of Corea timorous, as not to be serviceable in war, 220; Tartar horsee very serviceable in war; they 
were properly the conquerors of Clina; march two or three days without atopping ; continne five or six, withont eating more than a handful of grass at every eight houra ; and remain without drinking four and twenty hours; lose all their strength whon bronght into China or the Indies; thrive pretty well in Persia and Torkey; the Tartara towards the north have a breed of little horsea whicli they set auch a value upon that it is forbidden to sell them to strangers; aneiont opinions on the nature and qualitiea of the horses of Thessaly, Achaia, Ethiopia, Arabia, Afriea, Italy, and partieularly of Apulia; of Sicily, Cappadoeia, Syria, Armenia, Media, Persia ; of Sardinia, and Corsiea ; of Spain, Wallachia, Transylvssia ; of Denmark, Scandinavia, Flanders ; of the Ganlisli horses ; of tho German, Swiss, llungarian, and lastly, of the Englishl lorses, 221; Doush horses of such exeellent size and strong make, that they are preferred to all others for draught; some streaked hilie the tiger, ir mottled like the leopard; Germun and Ilungarian horses; Duteh horses are good for dranglit, the best eone from the provinee of Friezlind ; the Flunders horses, 219; few French horses good; in general are heavy aliouldered; the best of that eonntry eume from Limosin, and Normindy furnishes the next; Americun tame horses admirable; method of hunting with then, ib.; islands of the Archipelage have very good horses; those of Crete were in great reputation among the ancienta, 3t present seldom used in the country itself, beeause of the unevemess of the ground; the original horses of Morocco, smaller than the Arabian breed; in Turkey there are horses of all races; Persiun horseg, in general, the most heautiful and most valuable of all the kast, ib.; goue greatly esteemed in the Ukraine, in Wallachia, Poland, Sweden, 220 ; English horses excel the $\Lambda$ rabians in aize and swiftness; are more durable than the barb, and more hardy than the Persian; one instanee of their great rapidity, in the admirable Childers, frequently know'n to nove eight $y$-two leet and a halt in a seeond, 221 ; fault of our manner of breaking horses; the Frenel-managed horse never falls before, but more usually on one side; the Einglish are tor speed and despatch, tlie French and other nations are nnore for parade and spirit; English lunters considered the neblest and most useful horses in the world, 222, Iinger de Belerme, the first reeorded to lave attempted mendinir our native lored; number of lorses in London in $\mathrm{J}$ e reign of $\mathrm{King}$ Stephen, sidid to have anicuoted to twenty thousand; in the tinnes of Queen Elizaboth, the kingdem could not supply two thousand horses to form. the cavalry; Powisland, in Wales, for many agea funous for a swift and generous raee of horses, and why, 222 ; perfeetions which a horse ought to have, nceordin to Camerarius, ib. ; a ruminating animal, 252; in a course of years inpoverish tle ground, 233 ; the horse and the aas differ not so nuch in form as the cow and the hison, yet the former are distinet animals, and the latter animals of the sane kind, 235 ; eata two hundred and sixty-two planta, and rejeeta two hundred and twelve, : $\$ 0$; fumished horseg more hairy than those led plentifully, 331 ; for hunting lions, must be of that sort ealled chnrossi; all others fly at the sight of the lion, 296; are killed by wild asses, 225; destroyed by the Ameriean bat called vampyre, in South Ameriea, 385.

Hurse (Sea,) described, 644.

Hortensius, the orator, the first who had peacecks served up at a:n entertainment in Rome, 447.

Hospituls ereeted in India for the msintenanee of all kinds of rermin, 181 ; tor monkers, erected by the Bramins, 410 .

IIotlentots outstrip lions in the chase, as travellers report, 150 ; make much and very extraordinary use of the bison, 237 .

Hound, hurrier, and leug/e, all of the same kind; grey matin hound, transported to the North, beeomes a great Danish dog, and this sent into the South, becomes a greyhouid of different sizes; the saune transported into Ireland, the Ukraine, Tartary, Epirus, and Albania, becoines the great woll dug known by the name of the Irisk wulf-dog; the bload-hound, a dog of the generous kind; and likewige the gaze-fumd, and the greyjuund; all used for hunting; the blood-iround a dog of grat use and in high esteem amony our aneesturs; formerly employed in liunting thievea and robbers, whom they traeed by their footsteps; the gaze-lound hunted, like wir greyhound, by the cye, not by the scent; the greyhound formerly held in sueh estimation that it wss the peculiar companion of a gentleman; by some game-laws, persong under a certain rank in lite are forbid from keeping this animal, 31], 312. Greyhound fox, the largest, tallest, and boldest of the kind, 325 .

Hozolet, a kind of owl without horns, 489 .

Hudson's Bay, above twelve thousand marting' sking annually imported from thence into England, 336.

Huers, name given to the inen employed to give signals where to oxtend the nets in the pilehard-fishery, 655 .

Hughes. See Polypus, 837.
Ifull had the honour of first attempting that proftalule braneb of trade, the whale-fishery, 620

Humber, a new island formed at the mouth of this river; it is about nine miles in eircumferenee, and worth to the proprietor about eight hundred pounds a year, 39.

Hhmming-bird is the arnallest of birds, and seems nearly allied to the insect, 259 ; helongs to the sparrow-kind, 557 ; found in great numbers, during the summer seasen, in America; the smallest of them about the size of a lazel-nut; ita description; the larger hnoming-bird is near half as big as the common wren; its description; are seen fluttering about the flowers, witlout ever ligliting upon them; their wings in auch rapid motien, it is impossible to diseern their culours, exeept by their glittering; but only'extracting the loney as with a kiaa ; their nests and the number of orgs their tisne of incubation; instanee of their docility; countries where found; in the Leeward Islands, they eantinue in a terpir state during the severity of winter; Labst asserts, that hesidea the humming noise produeed by the wings, they have a pleasing nuelan. choly melody in their voices, small and propurtioned to their organs; the lndians make use of this pretty bird's plumage; in what manner the ehildren take thern; when taken, they are instantly kilied, and hung up in the chinney to dry; soine dry them in stoves; at present this bird is taken rather for selling as a euriosity to Eurapeans than an ornament for themselvea, 548 to 550 .

Itump, of the bison at difierent sizes, weighing from forty to fifty pounds, sonetimes less; cuts and taster like a dressed udder; in a few generations it wears away, 2337,238 .

Hunger, every nnimal endures the wants of sleep and hunger with less injury to health than man; hunger kills man sooner than watchfulncss; more dreadful in its approaches than eantinuanee; so terrible to man, that rather than endure its tortures he exehanges them fer inimediate destruetion; dreadfil effecta of hunger related to the auther by the esptain of a ship, who was one of six that en. dured it in its extremities; diflerent epinions eencerning the causo of hunger; few instances of men dying, except at sea, of absolute hunger; those men whose disorder is caused by hunger; the number of sueh as die in London of liunger supposed not less than two thousand in a year; method of palliating hunger among the Ameriean Indians, 153,154; inatances of anazing patience in hunger, 179.

Huniers, the English ennsidered the noblest and most useful horses in the world, 227 ; terms used by hunters in pnisuing the stag ; names invented by them for the stag, 202; for the fallowdeer, 266.

Huntiag, the natural rights of hunting made royal, and when, 261 ; the stag and the buck performed in the same manner in England, and how, 262 ; aneient manner of hunting the stam, 264 ; the manner in Sicily, and in China, ib.; the wolf, 321 ; wolves used in hunting, 322 ; hunting of the fox, 323 ; hunting the sable chiefly the lot of the exiles in Siberia, 380 ; of the ouran-outang, or wild man in Borneo, a favourite amusement of the king, 40:; of the elephant at the Cape of Good Hope, 423 ; the method used to take it alive, 42J ; manner of hunting, the ostrieh by the Arabians, and by the Struthophagi, 465 ; manner of hunting the turkey, 499 .

Hurco (Anfidius, ) eharged by Pliny with being the first who fatted peaeocks for the feasts of the luxurious, 497.

Hurrieune, the eloud preecding a liurricane, called by asilors lnill's eye, deseribed; houses nrade of timber, bend to the llast of the burrieane like osiers, and reeover their reetitude; hurricanea offensive to the sense of sunelling; maggots brought with them, 105 ; common in all tropieal climates; on the enasts of Guinea frequently three or four in a day ; their seasons upon those eonsts, at Loango and the opposite coast of Africa ; the hurricane called tornado; ita dreadful effeets, 106.

Hus, in Greek signifies a sow, and hnoinn derived from it, 327.

Huso, the isinglass fish, eaught in grest quantities in the Danube, from Oetober to January; furnishes the cormmodity ealled isinglass: method of naking it; often above four hundred pounds weight; its flesh salted is better tasted, and turns red like sulmon, Git2.

Hyano, no words give an idea adequate to this snimal's ficure, defornity, and fiercenese; more savage and untameable than any quadruped; for ever in a state of rige or rapaeity; its description; for its size, the most terrible of all quadrupeds; defends itself againat the lion, is a mateh for the panther, and attack the ounce, which it seldem fails to conquer; an olsseene and solitary animal; its first howl sonietinies mistaken for the voice of a man mourning; ita latter liko the violent efforts of retehing; whenee it first took its name; native of the torrid zone; resides in the eaverns of mountains, the clefts of roeka, or dess it has formed under earth; taken ever so young, it never ean be tamed; sometimes attacks man, and carries off cattle; its eyea shine by night, 
and it is asserted that it sees better by night than by day; scrapes up graves, and devours dead bodies, how putrid soever; absurditics of the ancients about this animal, 327,328 .

\section{I \& $J$.}

Jabiru and jabiru-guacu, birds of the crane kind, watives of Brisil ; their descriptions, $55 \%$.

Jackals, hunt in a pack, and escourage each other by mutual crics; what has given rise to the report of its being the lion's provider, 208; trayellers have mistaken the jackal for the fox; one of the commonest wild aniusals in the East, yet scarce any less known in Europe, or loss distinctly described by nziuralists; its description; in most parts of Africa takes up the place of the wolf, which in that country is not so common; its cry a lanjentation resembling that of human distress; is more noisy in its pursuit than a dog, more voracious than the wolf; never goes alone, but always in a pack of furty or fiaty torether; scens little afraid of man; take up with the smallest animals, and yet, wlicn uuited, liave courage to face the largest; pursues its game to the doors without apprehension; enters insolcntly into sliecp-folJs, yards, and stables, and finding pothing else, devours leather harness, boots, and sloes; scratches up new-miade graves, and devours the corpse, how putrid soever the corpse how dug up; follows armies, and keeps in the rear of earavans; the most putrid substances it greedily devours; hides in holes by day, and appears abroad at night-lall; hunts by the scent; irreconcileable antipatlyy between it and the dog; no wonder it be voracious, and why; is as stupid as impudent; instanees of it ; Indian peasants often cliase it as we do foxc8, $272,273$.

Jackdan, its description; builds in steeplos, old eastles, and high rocks, 514; rings found in the nest of a tane jackdaw, 512.

Jacolines, a kind of pigeons, 532 .

Jaculus, the swiftest serpent, its manner of progression by coiling, 729 .

Jaguar, or the panther of America, 303.

James, the hermit, eaid to have lived a hundred and four years, 155 .

Japanese, description of that people, 180.

Juro, the upper, thought by many quite immoveable; that it moves in unan, an easy exporiment will evince; las its proper muscles bchind the had for thus raising and depressing it; the under jaw in the embryo much advanced befure the upper, and in the adult hangs more backward; in a Chinese face it falls still more hackward than with us, the difference is thought half an inch, the moutl boing shut naturally; M'Laurin, a professor at Edinburgh, was subject to have his jaw dislocated; the under jaw has often an involuntary quivering motion; and often a state of languor produccs another; that of yawning, a very sympathetic kind of languid motion; ridiculous instance of this sympathetic affection cornmonly practiscd upon the same famous M Laurin, 143, 144

Jay, one of the most. beautiful of the British birds; its description; feeds upon fruits, kills small birds, and is extremely docile, 517; lays its eggs in the hole deserted by the woodpecker, 520 .

lbex, a native of the Alps, the Pyrennees, and the mountains of Greece ; its description, 243 .

lbis, the Egyptials paid divine bonours to this bird : different opinions concerning the aneient and modern ibis; Mailer's observation to this purpose ; the true ibis thought a bird of the vulture kind, called by some the capon of Pharaoh; follows the earavans that go to Mecea, to feod upon the offal of the animals that are killed on the journcy; held sacred by the Egyptians, 5.56, 557 .

Ice, very elastic, 53 ; floats of it diffused into plains of above two hundred loagues in length, and mountains of it rising amidst them; flat ice and mountain ice, $7 l$; their formation; mountains of it presenting the resemblance of trees in blossom, a glory, \&c. 72.

lekncumon, by some injudiciously donominated the cat of $\mathrm{Ph}$ araoh, one of the boldest and most useful animals of the weasel kind; used in Egypt for the sanc purposes as cats in Europe, but is more serviceable, being more expert in catcluing mice ; description; discovers and destroys the eggs of the crocodile; serpents its most natural food; grows fast and dies soon; easily strangles a cat stronger and larger than itself; countries where found; attacks every living thing it is able to overcome, and fears not the force of the dog, ner the claws of the vulture; takes the water like an otter, and will continue under much longer; not able to support the rigour of our winters; one corne from the island of Ceylen, climbed up the walls and the trees with very great ease; this animal one of those formerly worshipped by the Egyptians, 337, 338 .

Ichneumon $f y$, its weapon of defence; flies of tbis tribe owe their

birth to the destruction of some othor insect, within whose body they lave been deposited, and upon whose vitals they have preyed, till they came to mattrity; of all others the most formidable to insects of various kinds; it makes the body of the caterpillar the place for depositing its eggs; the tribe is not the euterpillar's offspring, as was supposed, but its murderers; description; whence its name; fears not the wasp, and plundors its habitations; various appetites of the several kinds of this fly; the millions of insects this fly kills in a sumuer inconceivable, 813, 814.

Ichncumon, a root the Indians believe an antidote for the bite of the asp or the viper, 337

Idrn, deplorahle infirmities of the workmen in the quicksilrer mincs near it, 23.

Jean-le-Llanc, a kind of cagle; its distinctire marks, 476.

Jenisca, in Tartary, a river, 62 ; receives above sixty lesser rivers, 64 .

Jenliens, a pcasant, lived to a hundred and sixty-five years, without much regularity, 125 .

Jerboa, has four feet, uses only the hinder in running or resting the swiftest creature in the world; description; countries where found; lives upon vogetables, and burrows like rabbits, 444, 445 .

Jester, in England, as late as the times of King James 1 . the court was furnished with a jester, 188 .

Jenels, the richest jewels found in an Ethiop's ear, a proverb, 146 Isnis futuus, or wandering fire, 111.

irmuna, description of this aninal; its flesh the greatest delicacy of Africa and America; its food; in what manner it is taken, 719,720 .

Jiboyu, the great, of Java and Brazil, the dimensions of this serpent; method of killing its prey, 741 .

luagination, by dny as well as by night, always employed, 158 ; very remarkable instiuces of its power in women, 157 .

Impaling, in some courts of the more barharous princes of India, they employ the elophant to impale the criminals on its cnormous tusks, 424

Impregnation, the lare, though already impregnated, admits the male, and reccives a second impregnation, $246 ;$ in what manner the sea and girden-snails impregnate each other respectively, 682 to 685 ; the bivale shell-fish requirc no assistanec from each other towards impregnation, 688 ; frogs impregnated without any apparent instrument of generation, an olject of inquiry ; continues iu great obscurity ; experiments made to this purpose, 698.

Incas, Father $\Lambda$ eosta and Gareilasso de la Vega have seen the bodies of several incas perfectly preserved from corruption, 194.

Indiu (Enst) in the warm eountries of India, tlse women are mar riageable at nine or ten, and the men at twolve or thirteen, 138 ; description of the inhabitants of the islands that lie scattered in the Indian ocean; over all India, children arrive sooner at maturity than in Europe; they often n:arry and consummate, the husband at ten years old, and the wife at eight, and frequently have children at that age; Indians have long been remarkable tor cowardice and effeminacy; are slothful, submissive, and luxurious; they may be considered as a feeble race of sensualists; from the times of Alexander to the present day, scarcely any instances to be found of their euccess in arms ; their dress, 181, 182; tho horses of India are weak and washy, 200 ; lions are found to dininish in their number in this country, 21:2; the Indians eagerly pursue the porcupine, in order te nuke embroidery of its quills, and to eut its flesh, 376 ; they eat bats in the Eist Indies, 384. See Elephunt, 422 .

India (Wcst) whence originally come the fiat lieads of the Anerican Indians, $1 \times 5$.

Indus, river, its course, 62 ; its water and that of the Thames, the most light and wholesome in the world, 50 ; the tide at the mouth of this river the greatest known, 75 .

Infants, just born, inay be said to come from one element into another, and why; open their eyes the instant of their birth; more capable of sustaining hunger, and more patient of cold, than grown persons; and why; infuits lrave inilk in their own breasts; their life very precarions till the age of three or four; instances of it ; the comparative progress of the understanding grcater in infants, than in children of three or four years old, 133, 134.

Inundations generally greater towards the source of rivers, than farther down, and why, 61; some distribute health and plenty; others cause discases, fumine, and death, 64 ; every inundation of the sea attended with some correspondent dereliction of another ehore; one of the most considerable inundations in history, is that which happencd in the reign of Henry the First; an inundation in the territory of Dort, destroyed a bundred thousand persons, and yet a greater number round the Dullart; remarkable inundations in Friezland and Zealand, in which more than three hundred villages were overwhelmed; their remains continue visible at the bottom of the water in a clcar day; some in which tbe sea bas overflowed the 
country, and afterwards retired, 81 ; inundation of the Thames at Dagenham in Essex, 83 ; instantly produced by land spouts, 115 .

Insects, in the internal parts of South America and Africa, tlicy grow to a prodigious size, and wlyy; those of the minuto kind in the northern climates not half so large as in the temperate zone; the ocean has its insects; their feet are placed upon their backs, and almost all without eyes, 120 ; in some countries almost darken the air, and a candle cannot bo lighted without their instantly flying upon it, and putting out the flime, 122; and 827 ; many may be multiplied by boing cut in pieces, 125; inany of the tribes brought forth from the ega, 126: have no eye-lids whatsoever, 142 ; tle Indians are fearful of killing the meanest, 181 ; quickly brought to change and adapt thenselves to the elimate, 205 ; have their stomachs enmposed of muscular fibres; of \& ruminating kind, 232; afford so great a varioty as to elude the search of the most inquisitive pursuer, 448 ; those with the greatest number of legs nove the slowest, 693 ; the general definition of insects, 741 ; the different classes, 745 ; general characteristics of inseets without wings, 746 ; of those that have wings, 766 ; some continue under the form of an aurelia not ten days; sone twenty; some several nionths, and oven for a vear, 789 ; general rule, that the fomale is larger than the male, 79:; every insoct that lives a year after its full growth, is obliged to pass fnur or five months without nonrishment, and will seen to be dead all that time, 817 ; duscription of that which forms and resides in the gall-nut, 821.

Instinct of all animals in choosing the proper times of copulation, 212; the Guinea-pig has not that natural instinct so common in almost every other creafure, 360 .

Intestines, in all animals the size of the intestines proportioned to the nature of the food, 207 ; intestines of ruminating aninals enlarged by nature, to take in a greater supply; those of the carnivorous kind are short, 231 ; also thin and lean; but of the ruminating are strong, fleshy, and covered witir fut, 232; of sheep found to be alove thirty times the length of the body; those of the wild cat not above three times the length of its body, 291; this sliortness still unaccounted for, 212; of the rein-deer washed like nur tripe, in high esteem among the Laplanders, 277 ; of the bat, in snne measure resemble those of man, 323 ; those of the manati Innger, in proportion. than those of any other creature, the horse execpted, 396 ; the tribe of woodpeckers want that intestine called the cancum, 519; the lauprey seems to liave but one, 639; those of the crab have many convolutions, 666 .

Jahndory, Quin noted for a sauce to this fish, 613.

Joints, hair in its growth sends forth branches at the juints, 143.

Jinelin has obliged the curious with the first accurate description of the form and nature of the sable, 336 .

Ireland not infested witl wolves, 321 ; froge designedly introduced into that kingdom some years before the Norway rat, 363 ; that rat put a stop to their increase, and the frog is once more almost extinct in that kingdom, 364 ; the mole ntterly a stranger there, $37 \mathrm{l}$.

Iron extracted from all the substances upon earth, 22J.

Isutis, an animal very common in all the northern countries bordering upon the iey sea, and seldom found in warm climstes; deseription; burrows like the fox, and when with young, the femsle retires to her kennel, in tho same manner as the fox; its kennel very narrow, and extremely deep, has niany outlets; inanner of coupling, time of gestation, and number of young, all similar to what is found in the fox; brings forth at the end of Mlay, or the heginning of June; considered as between the dog and the fox; shanges its colour, and is at one time brown, at another white; some naturally blue, which never change colour; its fur is two inches lone; of no value cxeept the animal is killed in winter; time in which it is called the crost-fax, $326,327$.

lsinglass, serviceable in medicine, and many arts; rery great sums yearly expended upon this article of commerce; manner of making it ; principully furnished from Russia, where great quantities sre prepared surprisingly cheap; Mr. Jackson found out a method of making a glue that answered the purposes of isinglass, 642.

Is'auds, new, formed in two ways; eitler suddenly by the sction of subterraneous fires, or more slowly by the deposition of mud, earried down by rivers, and stopped by some accident; thirteen islands in the Mediterranean appearing at once emerging from the water; one new formed in the year 1720 near that of Tercera; formed st the inouths of many rivers, and how; a benutiful sod large one formed at the mouth of the river Nanquin, in China, not less than sixty roiles long, snd about twenty broad, 36, 37; sppear, at first, infinitely greater than they naturally are; seem to trave to the shore, and represent a wood; the scene then shifted, represents curious figures, ships with sails, stresmers, and flags, antique levated castles, and at length vanish into nothing, 113. 1smael. (Sheque in his time the Arabians first began the maarement of horses, 216 .

Ispahan, the prince's messengers go on foot 36 leagnes in fourteen hours, 150 .

Italy, the horses there have a pirticular aptitude to prance, 218. Jucatun, s peninsula in the Gulf of Mexico, formerly a part of the sea, 81 .

Judu-goot common in Guinea, Angola, and all alung the coasts of Africa, not much larger than a hare, 247.

Jugular fish, name given to that fish which has the ventral fins placed more forward than the pectoral; 647

Julian's Bay, (St.) an American harbour, forty-nine degrees snuth of the line; Ferdinand Magellan happeried to winter in it, 191.

Juniper, its shade was fatal, if we credit the ancients, 96 ; the Iaplanders drink water in which these berries have been infused, 179.

Irory, the Insks of the babyroulessa are a very fine ivory smoother and whiter than that of the elephant, but not so hard and ser viccalle, 286 ; that of the morse more estcemed than that of the elephant, being whiter and harder, 396 ; almost all our ivory comes from Africa, where the greatest part is found in the forests; the tusks of the Mammoth converted tn purposes of ivory; fossil bones found in Peru and the Brazils, which when cut and polished, appear in every respect similar to ivory, 425 ; teeth of the narwhale far surpass ivory in all its qualitios, 622 .

Justinian, the emperor, till his time the sea was open to all nations. $6 \mathrm{R}$.

Iry-berries, showers of them raised by tempests in one country, and falling in another, 114.

K.

Kobasson, or cataphractus, one of the largest kinds of the armadillo, 382.

Kamtschatka, description of its natives, 178

Kanguroo, an aninial first discovered and described by $\mathrm{Mr}$

Banks, 4.15 .

Keratnphites, smong the coraline fungi, 838 .

Kermes, an insect of great use in medicine snd dying; its description; the difference of the male from the female; the harvest of the kermes greater or less in proportion ta the severity of the winter; women gather them before sun-rising, tearing them off with their nails, 822,823 .

Kestril, a bird of the generons breed of bawks, $4 \$ 3$.

Kevel, name of a second variety of gazelles, ruade by Mr. Buffon $2 i 1$

Kilda, (St.) a rocky island; its shores to the West six hundred fathom perpendicnlar above the surface of the sea, 80 ; the inhabitants consume annually near twenty-three thousand young gannets, and a great quantity of tljeir cgggs, 582 ; its rocks more than three quarters of a mile high. 584 .

Killer, a cetaceous animal of surprising strength, which sttacks the whale, 619 .

Kinds of animals not sctually distinguished by homs, colour, position of the ears, or fineness of hair, 247: dificult to fix precise boundaries between the goat kind and the deer; the gazelles form a distinet kind, 250; all of the deer-kind have no gall-bladder, 257.

Kine, in Iceland, sre without horns; 236.

King, a question in schools, which man most happy, the beggar by night, and king by day; or the beggar by day, and king by night? 157.

King-fisher, a remarkable bird ; its description; one of the most. rspacious little animals that skims the deep; places it frequents, and how it takes its prey ; the plunage a beantiful variety of brilliant colours; instances of credulity with respect to this bird; its nest, or rather hole, very different from that described by the ancients; instances of the eredulity of nankind wit] respect to this bird ; feeds upon fish in tbat hole; fotid from tlie remains of fish; the king-fisher is found with from five to nine eggs, which the female continues to hatch ; thongh disturbed and robbed, sho returns and lays again; Reaumur's account of this ; season for excluding the broad; the ruale faithful beyond the turtle, brings the female large provisions of fish, and keeps her plump and fat ; he used to twitter before, now enters the nest quietly and privately; the young hatched in twenty days; differ in their sizo and beauty, 602,603 .

King-fisher, the Halcyon.-Cicero has written a long poem in praise of this bird, of which but two lines remain; the emperor 
Cordian has also writen a long nocm on it, rothing of which is left; St. Autbrose is eredulity conceruing this bird; tahles the modern vulgar lave of it: its flesh unfit to le caten, and its beautilul plumage prezerves its lustre longer than any other, $602,603$.

Fircher, his ralculation of the lieights of the mountains nee incredible, and wlyy, 45 ; has sot the voiees of birds to music, 490 .

Kilc, from the greatest beight darts down on its prey with unerriner ainu 1,0): one of the baser ruce of hawlis, 401; distinguished by its forky tail, and slow fronting motion; seens ever upon the vine, and to unke no effor: in 11 ,ing; lives upon accidental carrame, every bird in the air being iille to malie its retreat from it; curall birds woulded, or straving rhickous, it seizes with rapacity; if all birds, tloo gond houscwife's greatest tormentor and aversion, 185 ; used fir training faiens, and how lured with the great horned -wl, when caught for that purpose, 4:0

Kitten, of all young animals nore inore prettily playful, 283.

Klein, his nretlod of classing animals, ?(1).

Knoi, small bird of the crane kind, 568 ; a bird of passage, 569 .

Kralirn, all thut has been said of this great fish seems fietitious, yet there is a possibility of its cxistence, 626 .

Krantz's account of the origin and fermation of the ice-rnountains of Greenland, \%2.

L.

Labrus, the wrasse, deseription of this fish, 6.18

Labyrinth of Candia, a subterranean wonder; supposed the work of art, 18.

Labyrinth, convolutions in the windpipe and lungs of some birds, 451 .

Lama, the camel of the new world; countries where fourd; their flesh an exeollent food; their lair, or rather wool, spun into beautiful cloathing; earry their burdens nver precipices and craggy rocks, where men can scarce accompany them ; often dies under, but never resists his driver's eruelty ; deseription and age ; manner of coupling; $i$ ts food; exceeds the camel in temperance; requires little water, being supplied with guantities of saliva, the only offensive weapon it.has to testify its resentnent; the Indians say, where this saliva falls, it will, from its acrimonious nature, burn the skin, or eause dangerous eruptions; colour and wool; labits and marks of agility in the state of nature; the stag scarcely more swift, or the goat a better elimber; scens the largest of the camel kind in Aneriea; the natives hunt the wild lnma for its fleece; a smaller weaker sort of the cancl kind, ealied also guanacoe and paco ; the manufucture of stuffs, carpets, and quilts, made of the wool of the preo, form a considerable branch of commerce in South America, and miglit usefully be cxtended to Europe, $433,4: 4$

Lambs, how to be produced all the year round, 212 ; the third an ewe brings fortl eupposed the best, 2J:3.

Lamprcy, a fish, every way resembling the lamprey, was possessed of the numbing quality of the torpedo; people will not venture to touch those of Ireland; a specics very different from ours werved up as a delieacy among the modern Romans; doubtfu] whether it be the murena of the ancients, whieh our lamprey is not; ours differently estinated aceording to the season; those of the river Severn the most delicate of all fish ; deseription of this fish's extraordinary power of adhering to stones; instance of it ; Muralto giving the anatomy of this fish, makes no mention of the Jungs, for which it has absolute necessity to breathe in the air; its time of leaving the sea annually, in order to spawn, is the beginning of spring; after a few montlis it returns to the sea; peculiar preparution for spawning; the young from eggs; the female reinains at the place where produced; has her family playing about her, and conducts them in triumpli to the ocean; its food; some not having suficient strength to return, continue in fresh water 'till they die; a single brood the extent of the female's fertility, two years being the limits of her existenee; very indifferent eating at the approach of hot weather; best season for them in the inonths of Mareh, April, and May ; are usually taken in nets with salmon, sometimes in baskets at the botton of the river; old custon for the city of Gloucester anuually to present the king witl a lamprey pie; a senator of Rome used to throw into the ponds such of his slaves as displeased him, to feed the lampreys, 637,638 .

Lands, new, produced from the sea, and in what manner, 81 .

Ianner, bird of the generous breed of hawks, now little known in Europe, 483.

Lapland, its division, 273; mountains there preferred to the woods; the country abounds more than others with marshy bottons and weedy lakes; gnats and gad-flies formidable there, 274 ; the manner of travelling in it; laplanders castrate the rein-deer with their treth, 215,240; the wolf never attacks a rein-deer that is lialtered, and why, $32 t$; the istis tound in this country, 327 ; in the forests. squirrels obscrved to clange their habitation ; they remove in nuubers from one country to anntlier, 353.

Inplanders, one of the first distinet races of men r.urd the polar regions; deseription of their persons and nanners; have in every fumily a drom for consulting the devil; Gustarus Adolphus ai templen in vain to form a reginent of Laplanders; use skates to run and slide, and how; ars all hunters; affer their wives and daughters to strangers, 177,178 ; manner of life, 60; wants supplied, and riches derived from the rein-decr; laub their faces with pitel mixed with milk, to shield their skins from the dreadtiol depredations of the gants, 274; boil milk, with wood-sorrel, and kecp it in casks moler ground to be eaten in winter, 277 ; when the lemings draw up to fight, they form orninous prognostics from their arrangeuent, 370 ; litppy whicn an army of lemings eomey dowu among then ; they then feast upon their flesh, which cats and dogs detest, ib.

Lameiur, a small bird of the crane kind, 563 ; its arts to lead off men and degs from their nests; their seisons of cuurtship, 570 .

Lark, bird of the sparrow kind, 537 ; the sky, the wood, or tho tit lark, distinguishable from other little birds by leugth of heel, and loud song; nest, number of eggs, and habits; wlien risen to an imperecptible hoight, does not lose sight of its nest, either asecnding or deseending, 543 ; those that remain with us the year throughout are birds of yassage in Swede $1,538$.

Lark, (Sea) a small bird of the crane kind, 568 ; breeds in thir country, 570.

Laxa, matter discharged by the eruptions of volcanoes, 30 .

Lunghter, in what manucr produced, 144.

Launce, description of this fish, 649 .

Lauricocha, a lake wherein the river Amazons las its source, 63.

Laurcnce, (St.) a river; its rige and suurce; receives about forty rivers, 63 ; its cataraet, 65 .

Laws, one of the Orkney islands, entitling any person that kills an eagle to a hen from every houge in the purish where killed, 474. Laycr, the impression on the place where the stag hats lain, 262 .

Layers of the earth regularly disposed, but nut of the same kind in every place ; enumeration of liners of earth in a well dug at Ansterdam, and of another dug at Marly; a layer, as far as it extends, always maintains the same thickness; proceeding to considerable depths, every layer is thicker; are sometimes very extensive, and often found to sprear over a space of some leagues in cireumference, 17; remarkable layers of earth round the city of Modena, 83.

Lcad-mine, teeth of the elepliant found in one in Flintshire, 424.

Leather called shammui, made of the skin of that animal, and also from those of the tame goat, the slieep, and the deer, 250 .

Leather-harness dovoured by the jackal, 326 .

Leares, two of a fig-tree, by experiment, imbibed from the eartl two ounces of water in five linurs and a half, 57.

Lecch, different kinds; its description; takes a large quantity of food; has no anus or passn re to eject it from the body when digested in what it differs from the rest of the reptile tribe; produces forty or fifty at a birth; uever brecds in confinement; the leech used in medicine; a girl of nine years old killcd by leeclues; best way of applying leeches, 763,764 .

Lews, a man without them performed estonishing feats of dexterity, 416 .

Leming, a bold animal of the rat kind, native of Scandinavia often pours down in myrials from the northern nountains, and, like a pestilence, destrays all the productions of the earth; they are often secu covering the ground a mile brond; Laplanders believe they drop from the clonds; their deseription; they move, in a square, forward by night, and lying still by day; whither their motions are turned nothing can stop them; a fre, a deep well, a torrent, does not turn thein out of their direction; they never re treat; interrupted by a boat across a river, they go over it ; stopped by a stack of bay or corn, they gnaw their way through; and obstructed by a liouse they cannot get through, continue before it till they die; eat nothing prepared for luman subsisteneo; never enter a house to destroy provisions; passing tlurough a meadow, destroy it in a short time, and leave it with the appearance of being burnt up and strewed over with ashes; a man imprudently attacking one of then, the animal furiously flies at him, barking something like a puppy, fastens, and does not easily quit his hold; their leader forced out of the line after a long defenee, and separated from the rest, sets up a plaintive cry, not of anger, and hangs itself on the fork of a tree; they destroy and devour ench other; after incredible devastations, they separate into armies, opposed with deadly hatred, and nove along the cossts of the larger lakes and rivers; 
the Laplanders form pregnosties from the manner of their arrangement; what prognosties; the divisions continue their engagementa and animosity until one party be overeome, then they disappear; and it is supposed, that having nothing to subsist on, they devour each other; their carcasses aonetimes infeet the air for iniles round, and produce malignant disorders; they seem also to infeet the plants, the cattle often dying in the plaees where they passed; the male larger, and more beautifully apotted than the fomale; are extremely prolifie; breeding does not hinder their nuarch, aome carrying one young in their month, and anotluer on their back; sre greatly preyed upon by the ermine, and even by the rein-deer; dogs and eate detest their flesh, but the Laplanders esteem it good eating, and devour it greedily, 369,370 .

Leo, the emperor, granted the nations in possession of the shore the aolo right of fisbing before their respective territories, 68 .

Leopord, the American, is neither so fieree nor so valiant as that of Afrien and Asia, 211; the leopard will not fly at the appraach of the lion, 205; the great panther and the leopard or panther of Senegal ; differenees between these animals, 303.

Lepodogaster, deseription of this fish, 649.

Leprosy, in what manner the Indians endeavour to prevent the Arabian leprosy, or the elephantiasis; a disease to which man and the elephant are equally subjeet, 420 .

Lerol, the middle dermouse, aecording to Mr. Buffon, 366 .

Libellu, the dragon-fly ; general characteristics; eygs ; food of the young; how they prepare to change from the reptile to the flying state; deseription; the strongest and most courageous of all winged insects; their appetite so great that they have been seen to devour three times their own aize in the eapture of a single hour; the business of inpregnation how performed, 766,767 .

Liboya, the grestest of the serpent kind, $72 \%$.

Lichen rang iferimus, the food of the rein-deer, a moss in Lapland of two kinda, the white in the fielda, and the black on the trees, 273,274 .

Life, formerly supposed producible only by oviparous and viviparoua generation, but later diseoveries induec many to doubt whether animal life may not be prodnced merely from putrefaction, 125; the beginning of our lives, as well as the end, is marked with anguish, 133 ; that of infants very preearious till the age of three or four; instances of it, 138; the duration of life in general noarly the same in most countries, 175 ; the most useless and contemptible, of all others the most diffioult to destroy, 831 .

light, the hand exposed to broad day-light some time, then immediately snatehed into a dark room, will be luninous, and remain ao for some time, and why; dangerous to the aiglit to look ateadily upon bright and luminous olyoets, and why; such peraons as read or write for any continuawee should choose a moderate light, 163.

Light sent forth by the glow-worm, how produced litherto inexplicable, 821 ; sent forth by the star-fish, resenibles that of phosphorus, 832 .

Lightning, is an electrical flasl produced by the apposition of two clouds, 109; of the torrid zone not go fatal or an dangerous as with us, otherwise those regions would be uninlabitable, 111 ; flasl.ing without noise, illuminates the oky all round in the torrid zone, 110.

Lights, northern lights illuminato half the hemispherc, 110.

Limbs, of the inliabitants near the poles are sometiues frozen and drop off, 113; some animals live without, and often are geen to roproduce them, 831 .

Lime, manner of making it in Persia, 25.

Line, upon the approach of the winter months under the line, the whole horizon geems wrapt in a muddy cloud, 110 ; in Aneriea, all that part of the continent which lies under the line is enol and pleasant, 184; in general, as we approach the line, we find the inhabitanta of each country grow browner, until the colour deepens into perfeet blackness, ib.

Linncus, the eelebrated naturalist, supposes man a ustive of the tropical climates, and only a snjourner more to the north; argument to prove the contrary, 185; hia inethod of elassing animals, 201 ; makes tho female of the bat a primas, to rank in the anme order with man, 384 .

Linnet, a bird of the sparrow kind, 837 ; taught to whistle a long and regular tune, 546 .

Lion, to compare the atrength of the lion with that of msn, jt should be considered that the claws of this animal gire a false idea of its power, aseribing to ita foree what is the effeet of its arms, 149; does not willingly attaek the horse, and only when compolled by the keenest hunger; combats between a lion and a horse in Italy; the lion stunned and left sprawling, the horse escapes, but the lion succeeding, sticks to its prey, and tears the horse to pieces instantNo. $79 \& 80$.
$1 y$; leaps twenty feet at a spring, 207, 208; produced under the burning sun of $\Lambda$ frica, is the mnst torrible and undaunted creature; he degeneratus when removed from the torrid zone, 293 ; deacription of this noblo animal; a single lion of the descrt often attacks an entire caravan; lie erouches on his belly, and continues so with patient expectation, until his prey eomes within a proper distance ; the female has no mano; his roaring is so lnud, that when heard in the night, and re-echood by the mountains, it resembles distant thunder ; lis most usual prey aro gazellos and monkeys, 294, 2015; in countrios tolorably inhabited, tho lion is eowardly, and often seared by the cries of women and children, 289 ; attends to the eall of the jackal, 326 .

Lions, thinse of mount $\Lambda$ tlas liave not the strength or feroeity of those of Bilodulgerid or Zatara; apeeies of this animal diminishing daily; Mr. Shaw observes, the Rnmans earricd fifty timea a many lions lrom I,ybia in one year, for their amphitheatres, as are in tho whole country at thie timo; the same remark made with regard to Turkey, Persia, and the Indice, where lions diminish in their number daily ; those inhabiting the peopled countriog of Morocee, or India, searod away with a shout; the keepers play with him, plague and chastise lim, without a eanse, he bears it with composure; but his anger once exoited, the ennaequences are terrible ; an instance from Labat; numberless acenunts nssure his anger noble, hia courage magnanimous, and his natural forocity seldom exerted against his henofactors; ho lias spared the lives of those thrown to be devoured by lim, aflirded them part of his subsistenee, and ometimos abstains from food himselr to support them; necessity alone makes him eruel; the nianner of hunting hin by Hottentots and others; reported that he sustnins himger a long time, but thirst he cannot aupport ; some lelieve lint in a continual fever; he drinks as often as lio finds water, and laps it ; he roquires about fifteen pounda of raw flesh in a duy; ho rather hunts for a fresh spoil, than returns to that he hitd betore; his breatls is offensive, and his urine insupportablo; horses for hunting them of that aort ealled elarossi, all others fly at the sight of him, 292, 293; the lion prefers the fesh of eamols to other food; is also fond of that of young eleplants; when old, finding men and quadrupeds togetlier, he attacks the latter, and never meddles with men, unless provoked; manner of eopulation, tinse of gestation, number brouglit forth, and time taken to come to perfection, all known; his internal otructuro in almost every respeet resombles that of a eat; a lion in the Tower of London aljove seventy years; the lioness fearing her retreat diseovered, hides her tracks by running back, or brushing them ont with her tail; becnues terrible witl young onea to provide for ; lions, incited by desire, fight bleody battles, till one becomes victorious over the rest ; the size of the lion between three and four feet; the female, in all dimensions, about one-third lear; there are properly no lions in America ; the puma las reeeived the namo of the American lion, but when compared, is a very contemptible animal; the ancients all concurred in denominating the liou the king of beasts, 296,297 .

Lion-cat or Angora-cat, a beautiful animal, a native of Syria and Persia, 291, 292

Lion, (Sea) deseribed in Anson's voyages, regarded as the largeat of the aeal family, 395 .

Lipidopas, the garter fish, its description, 650 .

Lips, thoee of the hare and of the squirrel continually move, whether slooping or waking, 345.

Litters, in all animals, intermediate litters most fruitful; first and last generally produce fewest and weakest of the kind, 212 .

Littoralcs, Jatin name for those shells that are east upon shore, 680 Lirer of a shark aflords three or four quarts of oil, 631 .

Lizurds, along the eossts of Guines thoir flesh esteemed a delieacy, 315; differ from every other elass of animals and from each other, 709, 710 ; whenee the greatest distinetion; general eharacteristies; the water-kind changes its skin every fourth or fifth day; sprinkled with salt, the whole body emits a viseous liquor, and tho lizard dies in three minutes in great agonies; whole of the kind sustain the want of iood in a surprising manner, 719.

Lizard (Chalcydon) of Aldruvindus deseribed, 722

Lizurd (Aying) of Java, acount of it by Gentil, 722.

Loach, a deseription of thia fish, 650

Lobstcr, a ruminating fish, 232 ; very roracious, though without warmth in its body, or red blood in its veins; whatever it seizes upon and has life perishes, however well dofended; thoy dovour each otlier, and, in some neasure, eat themselves; ehanging their shell and stomach every year, tho old stomach is the first morsel to glut the new; at first sight the head may be mistaken for the tail ; ita doseription; the food of the young; the monlting geasn ; how they ehange their shells; many dio under this operation; speedy growth of the new shell; and of itself after the change; the claws of $6 \mathrm{~K}$ 
unequal magnitude, and why: at certain seasons they never meet without an engagement; wonders this extruordinary crenture offers to the imagivation; are endowed witl a vital principle that furnishes out such limbs as have been eut away; varieties of this animal with difterenees in the claws, little in the habits or conformation; the shell black when taken, but turns red by boiling; common way of taking the lobster, 663 to 666 .

Loeust, the great brown locust seen in several parts of England in 1748; in some southern kingdoms they are still formidnble; description of this insect; in what manner they take the field; their devastations; are still more noxious when dead; instance of it ; account of their devastations in Russia, Poland, Lithuania, and Barbary ; transformations; eaten by the natives in many kingdoms of the East, and caurbt in small nets for that purpose; their taste ; are considered as a great delicacy in Tonquin, by the rich and the poor; must have been a common food with the Jews; deseription of the great West Indian Lecust, the most formidable, 773 to 776.

Leir, the great dormeuse, so ealled hy Mr. Buffon, 366 .

Longevity, persons remarkable for it, 205 .

Lori, the longest of all animals in preportion to its size; descriptien; a native of the island of Ceylon, 413.

Loricaria, description of this fislı, 650 .

Lories, a kind of parrot, 526 .

Louse, its deseription; whether distinguished by the parts of generation into males and females, not yet disenvered; the lousy disease frequent among the ancients, many of whom died of this diserder, 753,754

Louse (wood,) the description; of great use in medicine, 758.

Lowenhoeck, his opinion about the rudiments of animals, 123.

Luminous appearance of the waves in the night, the cause, 73 .

Lump-fish, its description; flung into a pail of water, will stick so close to the bottom, that on taking the fisl by the tail, the pail and several gallons of water may be lifted; their flesh, 643, 644 .

Lungs, snimals before birth make no use of their lungs, 393 ; no anatomist has described the lungs of tle lamprey, 638; caterpillars have eighteen lungs, and live several days in the exllausted receiver of the air-pump, 786 .

Lybia, its inhabitants use ostriches as horses; also at Joar ; instance of it at the factery of Podore, 465 .

Lyboya, of Surinam, a kind of serpent, thirty-six feet long, 727.

Lynx, distinguished from the ounce, and deseribed ; first striking distinction between it and these of the panther-kind is the tail; cach hair of this animal is of three different colours; it is not above the size of the ounce; chiefly met with in the cold countries bordering on the pole, in the north of Germany, 1,ithuania, Muscovy, Siberia, and North Ameriea ; those of the New Continent are smaller than in Kurope; this animal has been called the lupus cervarius; but for what reason hard to guess; in its nature it exaetly resembles the cat, is bigger, and near two feet long, is a.lso bolder and ficreer; more delicate than the cat; resembles the wolf in nothing exeept its cry ; several reports of the lynx, propagated by ignorance or imposture, 304 to 306 .

Lyster, strangeness of his theory to explain the invariable notion of winds, 100.

Lytleophytes and coraline substances, 837.

\section{II}

Macnguo, a kind of monkey described by Mr. Buffon, 411 . Maecow, the large kind of parrot, the size of a raven, 526 . Manehinel-tree, in Ameriea, its shade fatal, 95; no plant will grow under it, 128 .

Machines, the invention of many has rendered human strength less valusble, 152.

Markiarel produces five hundred tlousand eggs in one season, (j1:2 ; deseribed, 648 ; its growth, 657.

Maduguseur, its natives desire nothing so ardently as to prostitute their wives or daughters to strangers, and for the most trifling advantages, 139 ; the great bat of that island deseribed, 385 .

Mudder. See blwod, 173

Madness, produeed by want of sleep, 156 ; cured by music, and also caused by it. Sec Henry IV.166.

Maelstroem, Dutch name for a whirlpool; one upon the coast of Nerway, considered as most dreadful and destructive; the bedy of water forming this whirlpool, extended in a circle of above thirteen miles, 78

Magelian (Fcrilinand, a Portuguese of noble extraction, first discovered the gigasitic race of maukind, towards the extremity of South America; account of this discovery; he was slain upen one of the Molucea islands, 191.

Magni, an lialian traveller, diseovered the remarkable grotto of Antiparos, in the Archipelago, 20.

Hagot of Bufion, the Cynueephalus, the last of the ape kind, deseribed, 404

Mogpie, thievish; rings found in the nest of a tame magpie, 512; habits and food; when satisfied for the present it lays up the remainder for another time; places where it builds, and nest deseribed; number of eggs in its demestie state; preserves its natural cliaracter strictly; foolish custem of cutting its tongue to teach it to speak; puts the animal to pain, and balks the intention, $516,51 \%$.

Mahometuns, considering the hare as an unclean animal, religionsly alustain from its flesh, 343 .

Muimon, the last of the baboons, Edwards calls it the pigtail ; its description; native of Sumatra; does not well endure the rigours of our clinate, 406 .

Maire (James Le,) a traveller who confirms the existence of giants in Amcriea, 1!1.

Mfaki, the last of the monkey kind, 398 ; their description; many different kinds of these animals, 411,412 .

Mululiar, land and sea breezes upon those coasts, 103

Melacopterigii, the barbarous Greek nome given to the seft finned fish; the prickly-finned sort termed Acanthopterigii, 647.

Malahnllo, a very considerable volcano in South Ameries, 29.

Malbranche, grounds his beautiful theery of monstrous produc. tions upon a famous instance related by him, and some theory from which he deduees the effects of imagination upon the fortus, 187.

Malbrouk, a monkey of the sncient continent; its description; the Bramins have hospitsls for such as are sick or disabled, 638 .

Maldivia Islonds have land in them at one time covered with water, and at another free, 82 .

Mallurd, a kind of duck, 598 ; with very particular faculties for alling, 600 .

Malpighi, his famous experiment upon the stigmata of cater. pillars, 786 .

Nammuth, its tusks, which are used as jvory, and supposed to belong to the elephant, often weigh four hundred pounds, 425 .

Man endures a greater variety of elimates than the lower ordars are able to do, and why, 93 ; on comparing the minute differences of mankind, it will be found that there is scarce one nation upon eartlı that entirely resembles another; differenees in his speeies less than in animals, and rather taken from the tincture of the skin than variety of figure; there are not in the world sbove six distinct varieties in the race of men; first race in the polar regions, deep brown, short, oddly shaped, savage; second, the Tartar race, olive-coloured, middle-sized, ugly, robust; third, the southern Asiaties, dark olive, slender shaped, straight black hair, feeble fourth, the Negrnes of Africa, black, smooth skin, woolly hair, well shaped; fifth, the Americans, copper colour, straight black hair, small eyes, slight linbed, not strong ; sixth, the Europeans and bordering nations, white and of different tints, fine hair, large limbed, vigorous, 177 to 183 ; may be called the animal of every climate, 121; intended naturally to bo white, 184; white men resemble our common parent more than the rest of his ehildren a native of the tropical climates, and only a sojourner more to the north, according to Linnæus; argument sufficient to prove tho contrary, I85; marriageable in the warm countries of India at twelve and thirteen years of age, 189; just come into the world gives a pieture of conplete imbecility, 133; a vain man ventures to excite an auditor's attention at the risk of incurring his dislike, 146 ; as man bas a superiority of powers over other animals, so is he proportionably inferior to them in his necessities; nature has mado him subject to more wants and infirmities than other ereatures, but all these wants seem given to multiply the number of his enjoyments; and in what manner, 153 ; frst sensations of a man newly brought into existence, and the steps by which he arrives at reality, pointed out by Mr. Buffon, 171; the only animal that supports bimself perfectly ereet; the buttoek in man different from all other animals; man's feet alse different from those of other animals, the apes not excepted; the nails lese in man than in any animal, 148; said to be tall when from five feet eight inches to six feet high, 149 ; probability that men have been, in all ages, much of the same size they are at present, 192; proportionably stronger for his size than any other animal; to compare the strength of the lion with that of man, it must be considered the claws of the animal give a false idea of its power. and ascribe to its force the effects of its arms; another manner of comparing the strength of man with that of animals, is by the 
weights which either can carry; Dr. Desnguliers speaks of a man able to raise two thousand pounds, by distributing the weiglits in such a manner that every part of his body bore its share, 150 exercised in running outstrips horses; a stout walker, in a journey, walks down a horse; those employed as messengers at Ispahan in Persia, rumers by profession, go thirty-six leagues in fourteen hours, 150; every animal endures the want of sleep and hunyer with less injury to lealth than man, 153; he cannot, uninjured, live many days without enting, drinking, and sleeping. ib.; one said to live without food for seven days, 155 ; requires sleep for double motives, the refreshment of the mental as well as the bodily frame, 156 ; more difficult for man than any other animal to proeure sleep, ib.; has a lump upon the windpipe not to he seen in women, 147; a young man deaf and dumb from his birth, knew nothing of death, and never throglit of it till the age of twentyfour, when he began to speak all of a sudden, 167 ; aceount of a man ruminating, 232 ; in those countries where men are most harbarous and stupid, their brutes are most active and sagacious, 410 one, without hands or legs, by practice used his stumps for the most convenient purposes, and performed astonishing feats of dexterity, 416; nuan dies under wounds which a quadruped or bird could easily survive, 830 .

Manufuctures, the woollen inanufacture not carried on here till several ages after sheep were propugated in England; unavailing eflorts of our kings to introduce and preserve it; the Flemings possessed the art to a superior decree; the inhabitants of the Netherlands improved us in this art, and when; the wonllen-manufacture supposed for some time decaying among us, 243; of stufis of the wool of the pacos, a considerable braneh of commeree in South America, 434

Munati, may indiscriminately be the last of beasts, or tho first of fishes; its description; the female has breasts placed forward like those of women; holds lier young ones with her paws to her bnson, where it sticks and aecompanies her wherever she goes; the tongue so short, some have pretended it lias none; never entirely leaves the water; only advances the head out of the stream, to reach the rrass on the river sides; it feeds entirely on veretables; places where found; graze among turtles and other crustaceous fishes, giving or fearing no disturbance; nnmolested they keep together in large companies, and surround their young; bring forth in autumn; and supposed to ro with young eigliteen inonths; the manati has no voice nor ery; its intestines are Innger in proportion than thase of any other creature, the horse excepted; the fat which lies under the skin, exposed to the sun, has a fine smell and taste, and exceeds the fat of any sea animul; the heat of the sun does not make it rancid; it tastes like the oil of sweet almonds, and serves every way instead of butter; any quantity may be taken inwardly, having no other effect than to keep the body open; the fat of the tail boiled. more delieate than the former; the lean takes, a long time in boiling, and eats like beef; may be kept a long time in the hottest deys withont tainting; the fat of the young like pork, and the lean like veal; upon the whole this animal's flesh resembles turtle, 396 .

Mandril, the largest of the brboon kind; its deseription; when disploased, weeps like a child; Is a native of the Gold Coast, 406.

Mangabcy, a inonkey of the ancient continent; its description, 411 .

Mancrovetrec, that grows down in the water of the Senegal river, 64 .

Manks-puffin, or coulternel, a small water-fowl, described, 590,591 .

Marcusites, their compesition ; experiment by way of proof, 23.

Mares, their exportation prolibited by law in Arabia, 217 ; studs in Persia of ten thousand white mares, with hoofs so hard, that shoeing is unnceessary, 218; a law in England, prohibiting the exportation of mares and stallions; and one similar to this obtained 80 early as the time of $\Lambda$ thelstan, 229 .

Marikina, a monkey of the sagnin kind, with a mane round the neck, and a bunch of hair at the end of the tail, like a lion, 412

Mfarmase, only differs in size from the oppossum, being less; in stead of the bag to reccive the young, has only two longitudina] folds, within whicb the premalure young continue to suck; when first produced, not above the size of a bean; but stick to the teat until they arrive at maturity, 415

Marmout, or marmotte, a ruminating animal, 232 ; a native of the Alps; its deseription; is easily tamed, readily taught to dance, wield a stick, and obey the voice of its master; it has an antipathy to the dog; and when become familiar, and is supported by its master, it attacks and bites the largest mastiff; strength and agility; exeept its enmity to dogs, lives in friendship with every ereature, unless provoked; ludicrous saying that the Savoyards, the only chimney-sweepers of Paris, have learned their art from the marmotte they earry about for show; is apt to knaw the furniture; other aftections of this animal; its food; is cleanly, but has a disagreeable seent; sleeps during winter; though a native of the lighest mountains, and whero the snow is never wholly melted, yet fuels the influence of cold unore than any other animal; form of its hole resembles the letter $\mathbf{Y}$; manner of nuaking it; they live togrether, and work in eommon to make their labitations snug and convenient; whan they venture abroad, one is placed as sentinel upon a lofty rock; Mr. Butron says it does not sleep during winter, is rather in a torpor, a stagnation of all its fuculties; its heat not more than ten degrees above congelation; the flesh said to have a wild taste, and to eause vomiting : countries where it is fonnd; inhabitants of the Alps on not till winter open its hole; produces but onee a year, and brings forth 1 liree or four at a time; they grow fast, and their lives not above nine or ten vears, $35.5,35.5$.

Mnrringe and consummation of the Indians, the husband at ton years old, and the wife at eight; frequently have ehildren at that age, $18 \mathrm{I}$.

Huriotte, his experiment proves tlat water acts as a menstruum upon air, 168.

Marran, spinal, and the brain, the first seen as becun in the mbryo, 159

Murtin, its description; the most boautiful of all British beasts of prey; its scent a pleasing perfume; the yellow-breasted martin; its fur more valuable than the white-breasted enrt; Mr. Buffon sup. poses them a distinct species; that distinction unneeessary; of all the weasel-kind the most pleasing, 334, 335; is fond of honey, 332 ; scldom meets the wild cat without a combat; the wild eat not a match for the martin; there is seareely an animal in our wonds that will venture to oppose it ; kept tame by Gesner and Mr. Buffon ; often slept for two days, and then was two or three days without sleeping; the yellow-breasted more common in France than England; in their retreat the female brings forth her young, three or four at a time, and they eome with their eyes closed; how sho compensates for her defieieney of milk; this animal more common in North America than Europe; found in all northorn parts of the world, from Siberia to China and Canada; small birds alarm tho spot, where the dam keeps her young, and direet the lunter in his pursuit; the white-breasted keeps near houses and villages; the yellow in woods; Jends a snvage life, 335 ; its nest generally tho tenement of the squirrel, taking possession, and killing the owner, 353 ; seizes also the flying-squirrel, 354 .

Murtin, a bird of the swallow-tribe, 546 .

Mustiff, one of the threc deseendants of the shepherd's dog; chiefly a native of England; when transported into Denmark, becomes the little Danish dor, 311 ; the Duteh mastiff, 312.

Mastiff-fox, seeond variety of foxes less than the groyhound for, 325 .

Miaturity, attairied to by slow steps, announces a slow mareh to old age; as true to other animals as to man and vegetables, 174; sooner arrived at in India than in Europe, 181.

Mave, in fishes possesses the power of digesting, 608 .

Maximin, (the Emperor) a prodigy of strength; several instances of it ; by birth a Thracian; from being $n$ siniple herdsman he rose by the gradations of office, until lue became Emperor of liome; was above nine feet in height, and the best proportioned man in the empire; was killed by his own soldiers, while sleeping, 151, 152.

Mny-ung, or dor-bcetle, described, 819. Sce Bectle.

Measled-hares, disting uished from mountain hares, 343 .

Mrchanism, which reonlates the number of our years, admits no elange in its laws, and can be affected only by long fasting, or great excess, 175

Mcdaura, the brass helmet dug up there fits a common man, yet is allowed to have been left there at the overthrow of Asdrubal, 192 Media has pastures in its plains excellent for rearing horses, 220 . Medlicrunen sca, always receiving, and never discharging water, is no way fuller than before ; in what manner some account for this, 77; water-spouts seen in it; deseription of them by Tournefort; salutions offered for this phenomenon by Mr. Butfon and Dr. Strart, 114; this ser one of the smoothest and most gentle in the world, 78.

Medusa, name given by Linnæus to a small insect, thonght tho simple food of the Greenland whale, 613 .

Meibanius has collected sonic fow remains of aneient music, which do not leave room to regret what is lost, 166 .

Mi mbrane the nictitating membrane in birds; vails the eye at pleasure, 450

Hendip Mines, in Somersetshire, aecount of them by Mr. Locke, 23. Menstruum, that body which is most fluid and penetrating, Is likely to be the menstruum of one less so; Mariotte's experiment of $\mathrm{K}$ * 
shows that water will aet as a menstruum upon air; cold diininishes the force of rnenstruums, and often promotes evajorition, 168 .

Mfrlin, the smallest of the hawk or falcon-kind; scarce larger than a thrush; displays a degree of courage rendering him formidable to birds far above his size ; kills a partridge or a quail at a single pounce from above, 483 .

Mctals, the richest in their native state, nueh less glittering and splendid than uscless marcusites; the basest ores are generully the mast beautiful to the eye ; description of one by Mr. Condamine, 22 ; those trades that deal in their preparations, always unwholecone, 59 ; all pieces swallowed by animals lose part of their weight, and often the extrenities of their figure, 463.

Neteors, between the tropics, and near the poles, assume dreadful and various appesrances, 110 ; in those countries where the sun exerts the greatest force in raising vapours, there are the greatest quantity of netenrs, ib. ; one of a very uncommon kind, seen by Ulloa, at Quito, 1 I2.

Method, the prineipal help in natural history; without it, little progress made in this science; the most applauded of classing animals; the author's method of classing thens ; that of describing all things by words alone, a fault that has infected nost of our dictionaries, and bodies of arts and sciences; Mr. Locke lins observed, that a drawing of an aniual taken from life, is the best method of advaneing natural history, 199 to $20 \%$.

Mew, said of stags when they cast their heards, $\mathbf{2 6 2}$

Mice, lave burrowed in the backs of hogs, while fattening in the sty, without being felt, 281 ; in 1580 , at IJallontide, an army of mice over-run the inarshes near Southminster, and est up the grass to the roots; but soon after they were all devoured by a number of strange-painted owls; the like happened again in Lssex about sixty years afterwards, 491 .

Mico, the least and most beautiful monkey of the sagoin kind, 412 .

Microscope increases the magnitude of an object, and that of jts motion also, 124; the pupil and lum nours of the eye of the mole discovered by it, 371 .

Migrating fishes. See Fishes, 653.

Migration, causes of inigration of hirds; in what manner they perform them; at what times; rather follow the weather than country, and go on as they perceive the stmosphere more suitable to their wants and dispositions; some birds by migrating make an halitation of every part of the earth; migration of some swallows, and retreat of others into old walls, to avoid the rigour of winter, wrap this subject in great obscurity, 456,457 ; of bees several signs pro. vious to it, 803 .

Milk, infants have it in their own breasts, 137 ; sometimes found in the breasts of men, as well as in those of women, 147 ; in carnivorous animals more sparing than in others, 212 ; of goats inedicinal, and not apt to eurdle upon the sthmach as that of the $\mathrm{cow}$, 246 ; of the rein-deer thinner than that of the cow, but sweeter and more nourishing, 274 ; boiled up with wood-sorrel, by the Laplanders, kept in casks under ground, to be caten in winter, 276 ; injected into a vein, kills witl more certainty than the venom of a viper, 734

Millepedes multiplied by being cut in pieces, 125.

Milo, an instanco of his strength, when stood upright, 151.

Nilton nakes Satan personate the cormorant, a most nauseous bird, 275 .

Minerals, mere inactive and insensible bodies, 119.

Mincrs first beconne paralytic, then die colsumptive, for the trifling reward of seven-pence a day, 23; peculiar contrivanee for to supply lisht for their opcrations, 24.

Mines, the deepest that at Cotteberg in Hungary, not more than thrce thinusand feet deep, 15; a coal-mine of the North of England said to be eleven lrundred yards deep, 22 ; air different in them, proportionably us the macrazines of fire lay nearer the eentre; otler eauses of this difference; Mendip lead-mines in Snmersetshire; their description, ib.; mines of eoal generslly less noxious than those of in; tin than those of copper; but none are so dreadfully destructic as those of ouicksilver; deplorable infirmitics of workmen in the mines near the vilinge of Idra, 23 ; metallic, often desitroys all vecretoticn by their volatile corrosive funes; salt mines nuturally cold, 25; nitives of eountries abounding in mines too often experienef the naxurs effets of their vicinity, 95 ; in a leadmine in Flintshire were found two grinding teeth and part of ths tusk of an elepinnt, at tisty-tu'o 'yrds depth, 424.

Mingreliurs among the sixtl varicty of the human spccies, deacribed, 15:3.

Mirs-druti, the littern, descrihed, 50\%. See Bittern. $\operatorname{rin}$

Mestlutue, i prist. thought propagated by sceds voided by birds,
Mississippi, a great river in North America; its source and length, 63

Mists continually rise upon the anproach of the winter months undur the line, $110^{\circ}$; called frost smoke ; raises blisters on the body, in the regions round the poles, 113.

Hite-tly, not found in Lapland, 276 .

Minime, a river in America; cnormous skeletons lately discavered near it, 425.

Mock-bird, desctiption of the American mock-bird; its habits; can assume the tone of every animal in the wond, from the wolf to the raven, 540.

Nock-suns, meteors, and other phænomena, in the northern regions, 110.

Mucoco, first of the maki-kind, which is the last of the monkeys; its description ; a native of Nadagascar; its qualities, 412, 413; eats its own tail, 440 .

Modenu, a city in Italy; its remarkable wells; other rarities round it, 83

Mould, black, or garden-earth, the first layer on the surface of the globe ; is lorined from animal and vegetable bodies decayed; soil fertile in proportion to the quantity that putrificd mould bears to tle gravelly mixture; and as the former predominates, so far is the vegretation upon it inore luxuriant, 15.

Mule, a ruminating insect, or scemingly so, 232 ; no quadruped fatter, none with a more sleek, glossy skin;; an utter stranger in Ireland; formed to live under the earth; its description; the ancients, and some moderns, of opinion that the mole was blind, but Derham, by a microscope, discovered all the parts of the eye known in other animals; mole let loose in the midst of a field, like a ghost on a theatre, instsntly sinks into the earth; peculiar advantage of the smallness of its eyes; when once buried in the earth, it scldom stirs out; it chooses the looser softer grounds; chiefly preys upon worns and insccts; is most active snd casts up most earth immediately before rain, and in winter before a thaw ; in dry weather it seldom forms lilloeks; readily evades the pursuit of animals stronger and swifter than itself; their grestest calanity is an inundation, which whenever it happens destroys great numbers of them; description of the mole-lill in which the fenale has brouglit forth her young ; is scarcely found, except in cultivated countries; the varieties are but few; that of Virginia is black, mixed with a deep purple; that of Poland is'white; Agrieola says, lie saw hats made of mole-skins, the finest and most beautiful imaginable, 370 to 372 .

Molossinn hreed of dogs, and its perfeetions, set forth by Nemegianus, 314 .

Moniling, annually suffered by birds; its effects, 453 ; artificially aceelerated, and how; the manner in which nature performs the operation, ih.; moulting soason, from the end of suminer to the middle of autumn, ib. 191 .

Molucea Islands, Ferdinand Magellan slain upon one of them,

Mono, the cephus of the ancients, a monkey of the ancient continent, 411.

Monax, name given to the marmout in Canada, 358 .

Mangoz, nne of the maki kind, the last of the nonkeys; its description, 413.

Monkey, they sometimes fall a prey to the lion in deserts and forests, 295 ; one genersl description will not serve for sll animals of the monkey kind, 398; La Condamine asserts that it would take up a valume to describe the difference of monkeys found along the river of Amazons; and ws are sure that every one of thess is different from those on the Africall coast; there is scarcely a country in the tropical clinates that does not swarm with them, and scarcely a forest that is not inhabited by a race distinct from all others ; those of two cantons never found to mix ; of all kinds less than the baboon, have less power of doing mischief, and their ferocity diminishes with their size; in their native wonds, are tle pests of other snimals, and the masters of the forest where they reside; the tiger, nor the lion, will not venture to dispute dominion with creatures, who from the tops of troes with impunity carry on an offensive war, and by their agility escape all pursuit; birds have not less to fear from their corstinual depredations; such being their petulant delight in inischisf. that they fling the eggs against the ground when wanting appetite to devour then; one only animal in the forest ventures to opnose then; that is the serpent; lsrge snakes olten wind up the trees, where they reside, and happening to surprise them sleeping, swallow them whole, before they can make a defence; they generally inhabit the tops of trees, and the snakes cling to the branches near the bottom; in this mauner they are near each other, like enemies in the same field of battle; some suppnse their vicinity rather argued mutual friendship; Father Labat bas seen theun playing 
their gambols upon those branches on which the snakes were reposing, and jumping over them without receiving any injury; they provoke the sinake as the sparrows twitter at a cat; when attacked, they show perfect skill in defending and assisting each other, 406, 407; they regularly begin hostilities against those who enter their woods ; one being wounded, the rest come round, put their fingers into the wound, as desirous of sounding its depth; the blood ftowing in any quantity, some stop it, while others get leaves, chew, and thrust them into the opening; are often killed in numbers before they make a retreat; in this retreat the young are clinging to the back of the female, who jumps away, seemingly unembarrassed by the burclen; usual way of taking them alive ; skinned and served up at negro feasts, so like a child, an European is shocked at the sight ; the megroes seeing Europenus buy young and tame monkeys, with equal cure brought rats to the facters for sale, and were greatly distappointed at finding no purcliaser; they carry oft what they are able, and destroy ten times nore; Hinner of their plundering ; sre under a kind of diseipline, exercised among themselves; accounts to this purpose by Margrave; one species, by Mr. Buffon, called the uuarine, remarkable for loudress and distinctness of voice; use to which they convert it; are generally together in companies, niarch in exuct order, and obey the voice of some chieftain, remarkable for his size and gravity; chief food of the tribe; extraordinary manner of munaging an oyster; manser of drawing erabs fron the water; no snare, liowever nicely baited, takes a monkey of the West Indian islands; females bring forth one, and sometimes two at a time; rarely breed when brought into Europe; the male and female never tire of fondling their young, and instructing it with no little assiduity ; ofen severely correct it, if stubbern, or disinclined to profit by their example, 408,409 ; manner of carrying their young in the woods; dexterity in passing from one trec to another, by forıning a kind of chain, locking tail to tail, or hand in hand; one amused itself for hours imposing upon the gravity of a cat, and playing its pranks among rabbits; faithful services which Father Carli received from the monkeys in Angola, where he went to convert the savage natives to Christianity; savages of Africa and America suppose monkeys to be men, idle, slothful, rational beings, capable of speech and conversation, but obstinately dumb, for fear of being compelled to labour; monkeys of Africa most expert and entertaining; show a greater degree of cunning and activity; three marks by which monkeys of the new continent are distinguished from those of the old; Mr. Buffon makas but nine species of monkeys belong to the ancient continent, and eleven to the new; their names, with their descriptions; the red Africun, the patus, second sart of the ancient continent; the zrhite nosc, or moustoc, of the ancient continent, most beautiful its description; the grcen of St. Jago, also called callatrix, is of the ancient continent; its description; some of the kinds eat their own tail, and seem to foel no pain; the Braming have hospitals for those that happen to be sick or disahled; thuse monkeys of the new continent, with muscular holding trils, are called sapajous, and those with feeble useless tuils, are called sagoins; the fox-tailed monkey; makies, the last of the kind; their description, 410 to 413 Monkey-bezoar, a factitious concrete, 25:. See Bczonr.

Honuculus, the arborescent water-flea; its description; are of a blood-red colour; and sometinnes in stch multitudes on standing waters, as to make them sppear all over red, whence the water has been tbought turned into bloud, 758 .

Monsoons, so called from a fumous Pilot of that name, who first used them in navigation with succuss; in that part of the ocean between Africa and Indin those of the east winds begin in January, and end at the commencement of June ; in August, or Soptember, the contrary takes place; and the west winds blaw for three or four months ; these winds are always subject to their greatest variations as they approach the lund, so that on one side of the great peninsula of India the coasts are for near half the yeur harassed by violent hurricanes, while on the opposite side thesi drealful teinpests are wholly unknuwn, 102 ; monsoons prevail at defiurent seasons throughout the Indies, ib.

Minsters, after a cattloure of them, Limants particularly adds the slender waists of the women of liurope, list.

- kiunstrons productions. Father Malhranche's ingenious theory of ; renarkable instince related by lim, 157 .

Mnosc-decr, name in Antrica for the elk, 270 ; its description, 271.

Minmyrus, description of this fish, 651

Murocro, tise original horses there, much smuller than the Arabian breed, 219.

S.run, a kird of salamander, thought venomous. 717 .

. W. s. an animal of the seal-kind, might be ranked among tho

fishes, 216 ; generally frequents the same pluce where seals reside in ; different from the rest in a very particalar formation of the teeth; resembles at seal, except that it is much larger; are rarely found but in the frozen regions near the pole; the Greenlanders who formerly had great plenty, and who inade them their prineipal food, now find them very scarce, and are obliged to toil more assiduously for a subsistence ; its teetil generally trom two to three feet long ; the ivory morc estecmed than that of the elephant; the fishers have formerly killed three or lour hundred morses at once; their bones are still lying in prodigious quantitios along those shores they chiefly trequented, $395,34 \%$.

Moschetoes, excessive torinents caused by them, 43 . 278

Mother-of-pearl, taken from the pearl oyster, 691

Moths, difference from butterflies, 79.3.

Motion keeps the water of the sea sweet, 73; destroys numbere of viler creatures, ib.; constant motion of the waters of the sea westward, 76; principal difference between serpentine and vermicular notion, 729 ; some vegetables possessed of motion, 820; and many animals totally without it ; in what manner animals of the worin kind inove, 8 ?

Mouglon, the, sheep in a savage state, a bold fleet creature, able to escape from greater animals, or oppose the smaller; its description, 242 .

Mountains, rising from places once level, 10 ; give direction to the course of the air, 195; how formed and for what designed; upon our globe considered as angles of small lines in the circumference of a circle, 40, 41 ; countries most mountainous, are most barren and uninbabitable, 43 ; some valleys are fertilized by eartly washed down from great heights, 47; the more exteosive the mountain, the greater the river, 42 ; tops of the highest mountains bare and pointed, and why, 45 ; tops of land-mountsins sppear barren and rocky, of ses-mountains verdant and fruitful, 85 ; the higliest in Africa, those called of the moon, giving source to the Niger and Nile in Africa ; the greatest and highest under the line; some rise three miles perpendicular above the bottom of the ocean, 42, 43; highest in Asia; Mount Caucasus makes near approaches to the Andes in South America, 45; burning mountains in Europe, 26; in Asia ; in the Molucea Islands; in Africa; in America ; those of the Andes; those of Arequipa, Carasso, Malahallo, and Cotopaxi, 29; description of the latter by Ulloa, and an eruption of it, ib.

Mouse, the most feeble and most timid of all quadrupeds, except the Guinea-pig; never leaves its hole but to seek provision; never rendered quite familiar; though fed in a cage retains its apprehen sions ; no animal has more enemies, and few so incapable of resistance; the owl, cat, snake, hawk, weasel, and rat, destroy them by millions; brings forth at all seasuns; and several times in the year; its usual number from six to ten; these in a fortnight strong enough to shift for themselves; places where chiefly found; Aristotle, having put a mouse with young into a vessel of corn, some time after found a hundred and twenty sprung from that original its life lasts two or three years; the species found in all parts of the ancient continent, and has been exported to the new; although enernies to man, are never found but near those places where ho bas fixed his habitation; Gesner ninutely describes the variety of nouse-traps; lony-tailed field-mouse; short-tailed field-mouse has a store against winter, a bushel at a time; a description of the shrew-mouse, 365,366 .

Moustoc, or White-nose, monkey of the ancient continent, description, 411 .

Mouth of hares lined with hair; the only animals that have it on the inside, 347 ; the snails of the trochus kind have none, 655 . Mucous linuor, giving the joints an easy and ready play, 149 .

Mugil, the mullet, description of this fish, 649 .

Mnie, reputed barren, though Aristotle says it is sometimes prolific, 2is; ; engendered between a horse and a she-ass, or a jackass and a mare; inhabitants of mountainous countries cannot do withont them; how they go down the precipices of the Alps and Andes; a fine mule in Spain worth fifty or sixty guineas; common mule very healthy; lives thirty years and more, 226 ; in Soutl America destroyed by a bat called vampyre, 306.

Mfulus or surmulet, a description of this fish, 421.

Multiculve shells, third division of slells by Aristotle, 679; two principal kinds of inultivalve shell-fish, Inoving and stationary, 693 . Hummy, formerly a considerable article in medicine; Parmus wrinte a teatise on the inefiercy of munny in physic; counterfeited by the Jews, and how; the inethod of seeking for munmies; tound in the sands of Arsbia, in Egypt, in wooden coffins, or in eloths covered with bitumen, 196 ; reinarkable munny dug up at Auvergne, in France, 197; an injection of petreoleum in- 
wardly, and a layer of asphaltum witlıout, suffice to make a mummy, 198.

Afurena, the ecl, its description, 649.

Murena of the aneients, not cur lamprey, 637 .

Maralto. Sce Lamprey, 638.

Muscardin, name of the lesser dormouse, by Mr. Buffon, 366 .

Muscles, if we compare the largeness and thickness of our inuscles witl those of any other animal, we shall find that we have the advantage; to judge of the strength of animals by the thickness of their museles, inconclusive, 152 ; those of the hare are strong and wlthout fat, 345; the pectoral museles of quadrupeds trifing in comparision to those of birds; in quadrupeds, as in man, the muscles moving the thighs and hinder parts are strongest, while those of the srms are feeble ; in birds the contrary abtains, 450 ; those of the shark preservo their notion after being separated from the body, 631 .

Mussel, the shell-fish, its description; its organs of generation are what most deserve to excite our euriosity; the crab, snd the cray-fish, are seen to devour them, but the trochus is their most formidable enemy; it endeavours to become stationary, snd to attach itself to any fixed object it bappens to be near; its enemies; it is supposed that those threads, which sre usually called the beard of the mussel, are the natural growtl of the animal's body, and by no means produced at pleasure, as Reaumur supposes; its instrument of motion, by which it contrives to reach the object it wants to bind itself to; its food; some of this kind have been found a foot long; the natives of Palermo sometimes make gloves and stockings of its beards; the places where found; it requires a year for the peopling a nussel bed, 687,683 .

Muscory duck, or musk duck, so called from a supposed musky smell, 598.

Music, said by the ancients to have been invented from the blows of different hammers on an anvil; in all countries, where musie is in its infancy, the half tones are rejected; the Chinese have neither flats nor sharps in their musie; many barbarous nations have their instruments of music ; and the proportion between their notes is the saing as in ours; all countries pleased with music, and whers they have no skill to produce harmony, they substitute noise; its effects; the ancients give us many strangs instances of them upon men and animals; and the moderns likewise ; madness eured by it ; and also excited by it; remakable instance in Henry IV. of Denmark; fishes are allured by music; horses and cows likewise, 161,165 ; the elephant appeurs delighted with music, 418 ; Father Kircher has set the voices of birds to music, 490 .

Musl, among the numerous medicines procurable from quadrupeds, nong, except the musk and hartshorn, have preserved a degree of reputation, 250; a doubt whether the animal producing it be a hog, an ox, a goat, or a deer; no animal so justly the repreach of natural historians as that which bears the musk; it has been variously described, and is known very imperfectly; the deseription given by Grew; formerly in high request as a perfume; has for more than a century been imported from the East; is a dusky reddish substance, like coagulated blood; a grain of it perfunes a whole room; its odour continues for days, without diminution, and no substance known has a stronger or more permanent smell; in larger quantities it continues for years, and scarce wasted in weight, although it has filled the atmosphere to a great distance with its parts; the most porverful remedy now in use, in nervous and hysteric disorders; the bags of musk from abroad supposed to belong to some other animal, or taken from some part of the same, filled with its blood, and enough of the perfume to impregnate the rest; it conies from China, Tonquin, Bengal, and often from Muscovy ; that of Thibet reckoned the best, and of Muscovy the worst, 255, 256 .

Musk-rat, three distinctions of it, 367 .

Musky-smell does not properly make the characteristic marks of any kind of animals, 240.

Masmon or meuflan, rescmbles a ram ; its description, 244

Myoides, a brond thin skin, covering the whole upper fore-part of the body, its effect in women with child, 147.

\section{N.}

Vails, how formed in man; those of some of the learned men in China longer than their fingers; savages that let them grow long, use them in flaying animals, 147, 148 .

Nanquin, a river in Asia, receives thirty rivers, 64.

Narzchal, the sea unieorn; its description; errors concerning the teeth of this animal; the most harmless and peaceful inhabitant of tho ocean; the Greenlanders call it the fore-runner of the whale, and why ; its food; is a grenarious animal ; a century ago, its teeth considered the grcatest rarity in the world; they far surpass ivory in its qualities, 621,622

Natolian Goat, a remarkable variety in the goat kind, 246

Nuturc, lavish of life in the lower orders of the ereation, 132; has brought man into life with more wants and infirmities than the rest of her creatures, 153 ; in a course of ages shapes herself to constraint, and assurnes hereditary deformity ; instanees of it, 185 has contracted the stomachs of animals of the forest, suitable to their precarious way of living, 153; has left no part of her fabric destitute of inlubitants, 448 ; what might bave led some late philosophers into the opinion that all nature was animated, 839 .

Nautilus, a sea-snail, most frequently seen swinming ; its shell very thin, and essily piereed; its description, $6 \leq 6$.

Nuzareth hird: whether the dodo or not is uneertain, 470 .

Neck, fishes and other animuls that want lungs have none: birds, in general, have it longer than any other kind of animals, 148 ; in women it is proportionably longer than in men, ib.

Nectareum, that part of a flower from which the honey is extracted, 803

Niegroes of the Leeward Islands, by the smell alone distinguish the footsteps of a Freneluman from those of a Negro, 169 ; several of them have white beards and black hair; deseribed; their fea. tures not deformed by art; they are in general found to be stupid, indolent, and misehievous; the women s breasts, after bearing ons child, hang down below the navel, and are thrown over the shoulders to suck]e tlie child at their bucks, 181, 182; the jet black claim the honour of hereditary resemblance to our common parent; an argument suffieient io prove the contrary; two white Negroes the issue of blaek parents, 185, 186; show their terror and surprise when they first see a horse, 215 ; of the African coasts regard the bat with liorror, and will not ent it though ready to starve, 385 happy to see numbers of monkeys destroyed, because they dread their devastations, and love their flesh; cannot eomprehend advantages arising to Europeans from edueating or keeping menkeys ; and having seen young and tame monkeys bought, have offered rats for ale to our factors, and been greatly disappointed at finding no purchaser, 408 ; their manner of killing the shark; are distract. edly fond of its flesh, 631, 632.

Nicgroland, or Nigritiu, the plague not known in it, 96 .

Neres, wherever they go, or send their branches in number, thesc parts are soonest begun, and most completely finished, 159.

Niess, or Nithe, a river near Bruges, in Flunders; great quantities of trees found in its mouth, at the depth of fifty feet; in such perfeet preservation, that the particular kind of each tree may be instant]y known, 82 .

Nicst of every species of birds has a peculiar arehitecture; where eggs are nnmerous, the nest must be warn, 454 ; different places which birds choose for their nests, 435 ; description of the nest of an earle found in the Peak of Derbyshire, 475 ; of the bald eagle, Jarge enough to fill the body of a cart, 476 ; hanging nests in Brazil, 165 nests in the Plilippine islands; mada in such a manner, as to have no opening but at the bottom, 520; the Chinese get those of the swallows troin the rocks, and sell them in great numbers in the East Indies, where they are esteemed great delicacies, and eat dissolved in chicken or mutton broth, 447 ; that of the wasp one of the most curious objects in natural history; its description, $409,410$.

Netherlands, their inhabitants greatly inproved us in the woollen nianufacture, 243.

Nettles, how used to teach capens to clutch a fresh broed of chickens throughout the year, 496 .

Nittles of the sea, name given by some to the star-fish, 832 .

Nicola Pesce, a celebrated diver; his performances related by Kircher; he often swam over from Sicily into Calabria, carrying lettcrs from the king; frequently known to spend five days in the nidst of the waves, 80 .

Nieper, or Boristheres, a river rising in the middle of Muscovy, and running three hundred and fifty leagues to empty itself in the Black Søa, 61 .

Niger, this river has a course of several hundred miles from its souree, at the Mountains of the Moon, 42; confidently asserted that it is lost before it reaches the ocean, 66 .

Nightingale, a bird of the sparrow kind, 538 ; description of its melody by Pliny; its residence; for weeks together undisturbed, it sits upon the same tree; its nest and eggs; its song in captivity not so alluring ; Gesner says it is possessed of a faculty of talking; story related by him in proof of this assertion; its food, and in what manner they must be kept; manner of eatching the nightingale, and of managing when caught, 540 to 544

Nile, its course; its sources aseertained by missionaries; takes ite rise in the kingdom of Gojam; receives many lcsser rivers; Pliny 
mistaken, in saying that it received none; the cause of its annual overflowings; time of their increaso and decrease more inconsiderable now than in the time of the ancients, $62,(i)$

Noise, the mind predisposed to joy, noise fails not to increase it in to rapture; and those nations wlich have not skill enough to prodnee harmony, readily substitute noise; lond and uncxpected disturbs the whole frame, and why, 16.5.

Nuse, that of the Grecian Venus, such as would appear at present an actual deformity, 140 ; the form of the nose, and its advanced position, peculiar to the human visage; among the tribe of savage men, the nose is very flat; a Tartar seen in Furope with little more than tivo holes throngh which to breathe, 143 ; whence originally may have conie the flat noses of the blacks, 185.

Nostrils, wide, add a great deal to the bold and resolute air of the countenance; narrow ones, though supposed to constitute benuty, seldom improves expression, 143 ; of the certaceous tribe, 614 ; two in tho great Greenland whale, 617 .

Vutonecto, the common witer-fly; swims on its back, to fecd on the under side of plants growing in water, 779.

Nimmidiun bird, or Guinea-hen, described, 503 .

Numidlun crane; its peculiar gestures and contortions, 559

Nux romisa, ground and mixed with meal, supposed to be the most certain poison, and least dangerous, to kill rats, 365 ; futal to most aniunals, except man, 497 .

Niyl-ghavo, an animal between the cow and the deer, native of India ; its description; dispositions and manners of one brought over to this country; its manner of fighting; at all our settlements in India, considercd as a rarity; estee med good and delicious food, 435.

\section{o.}

Onks, of Intfield Chase Levels, as black as ebony, very lasting, and close grained, sold for fifteen pounds a-piece, 83 .

Objects. See Eye.

Oby, in Tartary a river of five hundred leagues, running from the lake of Kila, into the Northern Sea, 62 ; receives about sixty rivers, 6.1 .

Orean, occunies considerably more of the globe than the land; its different names; all the rivers in tho world flowing into it, would, upon a rude computation, take eight hundred years to fill it to its present height, 67 ; savages consider it as an angry deity, and pay it the homage of submission; the bays, gulfs, currents, and shnllows of it, much better known and examined than the provinces and kingdoms of the earth, and why; when England loses its suporiority there, its safety begins to be precarious, 68 ; opinions concerning its saltness, and that of Boyle particularly, 69; winds never change between the tropics in the Atlantic and Ethiopic Oceans, nor in the great Pacific sea, 100; eacl has its insects and vegetables, 120

Ocelot, or catamountain, its description, 304 ; of the panther kind; one of the fiercest, and, for its size, one of the most destructive animals in the world; no arts can tame or soften their manners, 305.

Ocutzimtzcan, a kind of pigeon, one of the most splendid tenants of the Hexican forests, 532 .

Ohin, several enormous skeletons, five or six feet beneath the surface on the banks of that river, lately discovered, 425 .

Oil, the oil of that fish called cachalot is very easily convcrted into spermaceti, 623 ; the porpoise yields a large quantity of it, 626 ; by the application of olive oil, the viper's bite is effectually cured, 736

Olive colour, the Asiatic, of that colour, claims the honour of the hereditary resemblunce to our common parent, 185.

Olirer, (Willium) the first who discovered that the application of olive oil, cured the viper's bite effectually, 736 .

Onuger, or the wild ass, is in still greater abundance than cren the wild horse, 223 .

Ondatra, one of the three distinctions of the musk-rat; a native of Canada; can contract and enlarge its body at pleasure; creeps into holes where others seciningly less cannot follow; the female has two distinct apertures, one for urine, the other for propagation; this animal, in some measure, resembles the beaver; its manner of life during winter, in houses covered under a depth of eight or ten feet of snow ; savages of Canada cannot abide its scent; call it stinkard; its skin very valuable, 367,363 .

O $t z a$, or ounce, of the panther kind; the onza of Linnaus, 303.

Ophidium, the gilthead, by sailors called tho dolphin, its description, 643.

Oppossum, the fernale's belly found double; when pursued, sho instantly takes lier yound into a false belly nature has given her, and carries them off, or dies in the endeavour, 212 ; an animal in North and South America, of the size of a small cat, and of the monkey kind ; its description, 413 ; a minute description of its bag; the young when first produced are very small, and immediately on quitting the real womb they creep into the false one, but the time of continuing there is uncertain; Ulloa has found five young hidden in the belly of the dam, alive and clinging to the teat three days aner she was dead: chiefly subsists upon birds, and hides anong the leaves of trees to seize them by surprise; caunot run with any swifness, but climbs trees with great ease and expedition; it often langs by the tail, and for hours together with the liead downwards, keeps watcling for its prey ; by means of its tail, flings itself from one tree to another, hunts insects, and cscapes its pursuers; eats veretable as well as animal substances; is casily tamed, but a disagreeable domestic, from its stupidity, figure, and scent, which, though fragrant in small qantities, is unfrateful when copious; during its gestation, the bag in which the young arc concealed may be opened and examined without inconvenience; the young may bo counted and handled; they keep fixed to the teat, and cling as firm as if they made a part of the body of the motlier, 414,415

orb, deseription of the sea-orb, also called the sea-porcupine; is absolutely poisonous if eaten, 644 .

Ore of tin is heavier than that of other metals, 22.

Organs of digestion in a manner reversed in birds, 452 .

OT gans of gencration in fishes, 612 .

Orifices, or different verges in snails, 685 .

orkney Islands, on their shores, the sea, when agitated by torms, rises two hundred feet perpendicular, 80.

Oroonoka, a river in South America, its source and length, 63.

Ortolan, a bird of the sparrow kind, 537 .

Osprcy, its flesh liked by many, and, when young, an excellent food, according to Belonius, 472 . 179

Ostiac Tartars, a race that have travelled down from the north,

Ostracion, a fisln of the cartilaginous kind; is poisonous, 614.

Ostrieh, manner in which the Arabians hunt them, 216, and 465 ; an Arabian horse of the first speed scarcely outruns them, 216 ; its flesh proscribed in Scripture as unfit to be eaten; the greatest of birds; makes near approaches to the quadrupod class; its description; appenrs as tall as a man on horseback; ons brought into England above seven feet high ; surprising conformation of its internal parts; a native only of the torrid regions of Africa; not known to breed elsewhere than whore first produced; places they inhabit; the Arabians say it never drinks; are seen in large flocks, which to the distant spectator appear like a regiment of cavalry, and have often alarmed a whole caravan; will devour leather, glass, lair, iron, stones, or any thing given; in native deserts, leads an ineffensive social life; Thevenot affirms the male keeps to the female with connubial fidelity; thought much inclined to vencry; some of their eggs above five inches in diameter, and weigh fifteen pounds; ls y from forty to fify eggs at one clutch; none has a stronger affection for her young; assiduous in supplying the young with grass, and careful to defend them, encountering every danger boldly; way of taking them among the ancients; the plumes used in their helmets; feathers plucked from the animal while alive more valued than those taken when dead; sone savage nations of Africa hunt them for their flesh; the young female said to be the greatest delicacy of the natives of Africa; a single egg sufficient entertainment for eight men; eggs well tasted, and extremaly nourisling; of all clases, that of the ostrich, though most laborious, the most entertaining; use they make of its skin ; its blood mixed with the fat a groat dainty with the Arabians ; inhabitants of Dara and Lybia breed flocks of thein; tamed with little trouble; prized for more than feathors in their domestic state ; often ridden upon and used as horses; Moore assures us lie saw a man at Joar travelling upon an ostrich; and Adanson asserts that lie had two young ostriches, the strongest of which ran swifter than the hest English racer, with two Negroes on his back; of all animals using wings with legs in running, these are by far the swiftest; tlie American ostrich, 462 to 466 .

ottar of roses, a modern perfume, valued for its vegetable fragrance, 342 .

otter, the link between land and amphihious animals, resembles terrestrial in make, and aquatic in living; swims faster than it runs ; is brown, and like an overgrown weascl; differs in no respect from the weasel kind, except in having the feet webbed, and in living almost constantly in the water ; its description ; voracious animal, found near lakes; not fond of fishing in running water, and why ; wlen in rivers, always swims against the stream, to meet rather 
than pursue the fish it preys upon; in lakes, destroys more than it devours, and spoils a pond in a fow niglits ; tears to pieces the nets of the fishers ; twe different methods of fishing practised by it: infects the edges of lakes with the dead fish it leaves; often distressed for provisions in winter, when lakes are frozen, and then obliged to live upon grass, wceds, and bark of trees; its retreat the hollow of a bank made by the water; there it forms a gallery several yards along the wster; description of its habitation; wsy of training it up to hunt fish, and, at the word of commund, driva thein up to the corner of a pond, seize the largest, and bring it in its moutl to its master; marks of its residence; bites with great fiercencss, and never lets go its hold; brings forth its young under hollow banks upon beds of rushes, fisgs, or weeds; manner of taking the young alive; how fed when taken; some dogs trained up to discover its retreat; otters met with in most parts of the world; in North America and Carolina found white, inclining to yellow; description of the Brasilian otter, 386 to 339 .

Ooaria, two glanduls bodies near the womb, resembling the cluster of small eggs found in fowls, 123 .

Ouarine, species of the monkeys so called by Mr. Buffon, remarkable for the loudness of their voice, and the use to which they apply it, $409,410$.

Oviparous animals, distinguished from the viviparous, the two classes for generation; all other modes held imaginary and erroneous, 125.

Ourang-outang, the wild man of the wood, an animal nearly approaching the human race; is the foremost of the ape kind; this name given to various animals walking upright, but of different countries, proportions, and powers ; the troglodyte of Bontius, the drill of Purchas, and the pigmy of Tyson, have received this general name; its description in a comparative view with man; gigantic races of it described by travellers truly formidable; in the gloomy forests where only found, they hald undisputed dominion; many ars taller than man, active, streng, intrepid, cunning, lascivious, and cruel ; countries where found; in borneo, the quality course him as we do the stag, and this hunting is a favourite amusement of the king; runs with great celerity; its description; Bettel calls him pongo; assurcs us that in all he resembles nian, but is larger to a gigantic state; a nutive of the trepical climates; he lives upon fruits, and is not carnivorous; goes in companies, and this troop meeting one of the humen species without succour, show him no mercy; they jointly attack the elephant, beat him with clubs, and force him to leave that part of the forest they claim as their own; is so strong that ten men are not a match for him; none of the kind taken but very young; ons of them dying, the rest cover the body with loaves and branches; a Negro boy taken by one of these, and carried into th: woods, continued there a whole year without any injury; they often attempt the female Negroes going inte the woods, and kecp them against their wills for their cempany, feeding them plentifully all the time; a traveller aseures that he knew a woman of Loango that lived among them for three years; they build sheds, and use clubs for their defence; sometimes walk upright, and sometimes upon all-fours, when fantastically disposed; though it resembles man in form, and imitates his actions, it is inferior in sagacity cven to the elephant or the beaver; two of these creatures brought to Europe discovered an astonishing power of imitation, sat at table like men, ate of every thing without distinction, made use of knife, fork, and spoon, drank wine and other liquors; the male of these two creatures being seasick, was twice bled in the arm, and afterwsrds, when out of order, he showed his arm, as desirous of relief by bleeding; another was surprisingly well behaved, drank wine mederately, and gladly left it for milk, or other sweet liquers; it had a defluxion upon the breast, which increasing caused its death in the space of one year from its arrival; these animals naturally run on all-four, 399 to 403 .

Ounce, or onza, remarkable for boing easily tamed, and employed all over the East for the purposes of hunting, 304; distinguished from the panther, the ounce of Linnæus, 303 ; does not pursus by the smell like those of the dog kind; a natural enemy to the dog, 305.

O vol, description of the common horned owl ; the screech-owl, and its distinctivs marks, 473 ; commen mark by which all birds of this kind are distinguished from others; gencral characteristics of birds of the owl kind; thongh dazzled by a bright day-light, they do not see best in darkest nights, as imagined; moonlight nights are the times of their most successful plunder; seeing in the night, or being dazzled by day, not alike in every species of this kind; description of the great herned owl; names of several owls without horns; these horns nothing more than two or three feathers that stand up on each side over the ear; father Kircher, having set the voices of birds to music, has given all the tones of the owl- note, which make a most tremendous melody; sometimes bewit dered; what they do in that distress; aversion of the small birds to the owl; how they injure and terment him in the day-time; sport of bird-catchers by counterfeiting the cry of the owl; in what manner the great horned ow] is used by falconcrs to lure the kite, when wanted for training the falcon; places where the great lorned owl breeds; its nest, and number of eggs; the lesser owl takes by force the nest of sone otlier bird; number of eggs; the otlier owls build near the place where thcy chiefly prey; a single owl more serviccable than six cats, in ridding a barn of mice; an army of mice deveured at Hallontide by a number of strsnge painted owls; are shy of man, extremely untructable, and difticult to tame; the white owl in captivity refuses all nourishment, and diss of lunger; account of Mr. Buffon to this purpose, 488 to 491 .

$0 x$, its eyes are brown, 142 ; on the fertile plains of India it grows to a size four times ss large as the sauc kind bred on the Alps, 185.

Oxney, an island near Romney Marsh, in what manner produced, 81 .

Oysters, a horse known to be fond of oysters, 209; surprising msnner in which menkeys manage an oyster, 409 ; bivalved shel]fish are self-impregnated; they are deposited in beds where the tide comes in, at Colchester, and other plaees of the kingdom; these said to be better tasted; amazing size of oysters along the cessts of Coromandel, $(89), 690$; the pearl oyster bas a large whitish shell, the internal coat of which is the mother-of-pcarl, 691 .

\section{P.}

Paca, improperly called American rabbit, an animal of South America ; its cry, snd manner of cating; is most like the sgonti, yet differs in several particulars; its deseription; places where generally found; a very fat unimal; its flesh considered as a delicacy, and often enten, skin and all, like a young pig; is seldom takcn alive, defending itself to the last extremity; persecuted not only by man, but by every beast and bird of prey; breeds in such numbers, the diminution is not perceptible, 359,360 .

Parhomoc descrts, where the formidable bird conder is chiefly secn, men seldonz venture to travel, 478.

Pacific sea, the winds never change in it, 100 .

Pacoes, a kind of camel in South Anerica; its wool very valuable, 434.

Paddock-moon, the silence of frogs in dry weather, may serve to cxplain an opinion whicl seme entertain, that there is a month in the year so called, in which tley never croak, 701 .

Pain, nothing but repeated experience shows how seldom pain can be suffered to the utmost, 177 .

Paleness, often effect of anger, 144.

Palm-tree, the elepliant eats the shoots and branch to the stump, 418.

Pambumatca, mountsins st Quito in Peru; a very uncommon metear seen upon it by Ulloa, $11 \%$.

Pangolin, vulgarly the scaly lizard, is a native of the torrid climates of the ancient contincnt; of all animsls the best protected from external injury ; its description; at the approach of an enemy, it rolls itself up like the hedge-hog; its scales so hard, when the animal has acquired ifs full growth, ss to turn a musket-ball; the tiger, panther, and hyæna, make vain attempts to force this animal, when it rolls itself up like the hedge-hog; its flesh is considered by the Negroes of Africa as a great delicacy; it has no teeth; lives entirely upon insects; there is not a more harmlese inoffensive creature than this, unmolested; countries where found, 378,379 .

Panther, the foremost of the mischievous spotted kind, by many naturalists mistaken for the tiger; the panther of Soncgsl; the large pantlier; difference between these two; that of Anierica, or jaguar, compared with the two former, 302, 303; sometimes employed in hunting; the gazells or leveret are its prey; it sometimes attacks its employer, 305.

Parr, a pesant, lived to a hundred and forty-four, without being abstemious, 175.

Paradise-bird, few have more deceived and puzzled the learned than this; it is an inhabitant of the Molucca Islands; erroneous reports concerning this bird, and what has given rise to them; the native savages of these islands carefully cut of its legs before they bring it to market, and why; two kinds of the bird of paradise their distinction from other birds; the description of this bird; found in great numbers in the island of Aro, where the inhabitants call it God's bird ; live in large flocks, and at night perch upan the samo tree; arc callod by some the swallows of Ternate, and, liko 
them, have their stated times of return; their king distinguished from the rest by the lustre of his plunage, snd the respeet and veneration paid to him; killing the king, the best chance of getting the flock ; the chief mark to know the king is by the ends of the feathers in the tail, having eyes liko those of the peacock; how this bird breeds, or what the number of its young, remains for discovery ; for beauty it excecds all others of the pie-kind; the natives of the isle of Aro make a trade of killing and selling them to the Europeans, $5: 2$ to 525.

Paralitet. See Parrot.

Parana, a river in South Anerica, from which the Plata runs eight hundred leagues from its souree to its month, 63.3.

Parasina, name given by the Italians to a fisling line, not lese t. lan twenty miles long; baited with above ten or twelve thousand looks, and sunk to the bottom along the coist in the Meditcranuan, for that fishing ealled the pieligo, 634 .

Parasile plants, not able to support themselves, grow and fix upon some heighbouring tree, 1'22.

Parrot, the middle or second size of the kind deseribed; the ease with which this bird is taught to speak, and the number of words it is capable of repeating, are surprising; a grave writer allirms, that one of these was tiught to repeat a whole sonnet from Petrarch; the author has seen one taught to pronounce the ninth commandment articulately; account of a parrot lelonging to Henry VlI. Linnreus makes its varioties amount to forty-seven; Brisson extends his catalogue to nincty-five; and the author thinks them numberless ; peculiarities observed in their conformation; common enough in Europe; will not, however, breed here; the rook is not better known with us than the parrot in almost every part of the Enst and West Indies; instanees of sagacity and docility. particularly of the great parrot called aicurous; their nests and the number of eggs ; usual method of taking the young; always speak hest when not accustomed to harsh wild notes; in France very expert, but nothing to those of Brazil, which, Clausius says, are most sensible and cunning; nstives of Brazil shoot them with heavy arrows, headed with cotton, which knoek down the lird without killine it ; those of the parakeet tribe are duclicate eating : of this kind in Brazil, Labat assures these are the most beitutifil in plumage, and the most talkative possible; are restless, and ever on the wing; their habits; their outery when their companions fall; are very destructive on the const of Guinea, and are considered by the negroes as their greatest tormentors; nore than a hundred different kinds comnted on the coast of Africa; the white sort called lories; countries where found: one, north of the Cape of Guod Hope, takes its name from the multitude of parrots in its woods; a hundred kinds now known, not one of which naturally loreeds in countries that acknowledged the Roman power; the grcen parakeet, with a red neck, was the first of this kind broughtint into Finrope, and the only one known to the ancients from Alexander the Great to Nern; disorders peculiar to the parrot kind; one well liept will live five or six and twenty years, 525 to 529 .

Partridges, in England, a fuvourite delicacy at the rables of the rich, whose desire of keoping them to themsclves has been gratified with laws for their preservation, no way harneonizing with the general spirit of English legislation, and why; there are two kinds the gray and the red; the gray is most prolific, and always kuejs on the ground; the red less common, and porches upmi trees; the partridge is found in every country, and chimate; in Greenlend, where it is brown in summer, becomes white in winter; those of Baraconda are larger legged, swifter of foot, and reside in the lighest rocks; partridges of all sorts agrce in one charicter, beiner ininoderately addicted to venery, often to un uanaturil derree; the wale pursues the hen to her nest, and brealss hor egess rather than be disappointed; the young laving kept in liveks during winter, lreak society in spring, when they begin to pair, and terrible eonbats ensue; their manners ollerwise rasomble those of poultry, lut their cunning and instincts are superior; menss tlue female uses to draw away any formidalle animal that approaches her nest the covies arc from ten to fifteen, and, umnolosted, they live from fifteen to seventeon years; method of taking then in a liet, with a setting-dog, the most pleasant, and most securs; they are never so tame as our domestic poultry, $5,07,508$.

Passions, nost of the furious sort characterized from the eleva. tion and depression of the eyc-brows, 14:2 freedon from passions not only adds to the happiness of the mind, but proserves the beauty of the face, 17.1.

Pustures, thoso of Great Britain excellently adapted to the cow kind, 233.

Patas, by some called the red African monkcy; its description, $4 \mathrm{~J}$.

Paul (St.) in Lower Brittany. See Send.

No. $79 \& 80$.
Petuch, name of the first stomael, of ruminating animals, 231.

Puzm, name of the eighth variety of gazelles, by Mr. Buffon, $25 \mathrm{I}$

Peacock, a saying a mong the ancients, As beautiful ss is the peacock among birds, so is the tiger among quadrupeds, 297 ; varicties of this hird; some white, others crested; that of Thibet the most beautiful of tle feathered creation; our first were brought from the Eiast Indies, and they are still found in fincks in a wild state in the islands of Java and Coylon; the common people of Italy say it his the phunage of an angel, the voice of a devil, and the guts of a thief; in the days of Solonion we tind his navies imported from the East apes and pencoeks; Aliun relates they were brought into Greece from some barbarous country, and that a male and female were valued at thirty pounds of our money; it is said also, that when Alexitnder was in ludia, he saw them flying wild on the banks of the river Hyarotis, and was so struck with their beauty, that ho livid a fine and punishnent on all who should kill or disturb them the Greeks were so nuch taken with the beauty of this bird, when first brought among them, that it was shown for money, and many came to Athens from Iacedainon and Thessaly to seo it; once extecmed a delicacy at the tubles of the rich and great; Aufidius Hurco stands ehargod by Pliny with being the first who fatted up pencorlss for the feasts of the luxurious; IIortensius, the orator, was the first who served them up at an enteriainment at Rome, and they are talked of as the first of viunds; in the fimes of Francis I. it was a custom to serve up peacocks to the tables of the great, not to be eaten, but seen; in what manner they sorred them; its flesh is said to lseep longer unputrefied than any other; has a predilection for barley; litt as a proud and fiekle bird, there is scarec any fond it will at all times like; it strips the tops of houses of tiles or thateh, lays waste the labours of the gardener, roots up the choicest seeds, and nips favourite thwers in the bud; is still more salacious than the coek; requires five femsles at least to attend him, snd, the munler not sulficient, will run upon and tread the sitting hen; the pea-lıen, as much as possible lides her nest from him, that he may not disturb her sitting ; she seldom lays above five or six cggs in this clinate; Aristotlo describes her laying twelve; in forests where they breed naturally they are rery numerous; this bird lives ahout twenty years, and not till the third year hus that boautiful variegated plumage of its tail; in the hingdom of Cambaya, says Taverner, near the city of Baroch, whole flocks of them are in the fields; description of their habits; decoy unade use of to eatel them there, $497,4 ! 3$

Pcacuck (seu) a uame given to the Balearie crane, 558 .

Peali of Teneriffe, its volcano seldun free from eruptions, 29.

Perk, nountain in the Molucca islands, swallowed lyy an eartls. quake, 47.

Pearl, an animal substance eoncreted and taking a tincture from the air; found in all bivalved shells, the inside of which resembles that substance called moller-of-pcarl; prarl-ayster, from which the mother-of-poarl is taken; several pearl fisheries ; the chief of them in the Persian Gulf, and the most valuable pearls brought from thence; the wretched people destined to fish for pearls, nsuully die consumptive; in what manner they fish for them, 691, 6!?

Ptarls, in stags, are parts rising from the crust of the beam, 262.

Pecrary or tajacn, an animal, a native of America; found there in such numbers, that they are secn in herds of several hundreds together; at fist view resensbling a small hog; its description; has upon the back a himp like the navel in other animn's; goes in herds of two or three hundred, snd unites, like bogs, in each other's defence; delights not in marshes or mud likc our hogs ; an unceasing encmy to the lizard, the toad, and the serpent kinds; also foeds injon toads and serpents, 232 to 244

Pedigruc, the Arahians preserve that of thair best horses, 216 .

Pegh, a river called the Indian Nile, lecause of its overflow. ing, 64 .

Pelugii, the Intin name for those shells fished up from the deep, $6>0$.

Yelican, ruminating bird, $2: 2$; a native of Afrien and America; its description; the description of this bird from Futher Labat; their flesh rancid, and tastes worse than it smells; use made by the Amcricans of their pouches; is not entirely incenpable of instruetion in a domestic state: instanees of it; Gesner tells us that the Kinperor Maximilian had a tame one wbich lived eighty years ; Aldrovandus mentions one believed tu be fifty years old, 576 to 578 . Penguins, a heavy water-fowl; the wings of this tribe unfit for flight ; and their legs still more atwkwardly adapted for walking; they dive to the bottom; or swim between two waters; they never visit land but when coming to breed; their colour; are covered more wsinly with feathers than vther birds; description of the Magellanic penguin; they unite in thern the qualities of men, $6 \mathrm{I}$. 
fowls, and fishes; instances of its gluttonous apyetite; their food and flech; are a bird of society, $50 ;$ to 509 .

Peninsula of India, on one side the consts are near half the year harassed by violent hurricanes and northern tempests, 102.

Penpark-hoic, in Glouccstershire; its description, from Captain Sturmey, 19.

People, so young as fourteen or fifteen, often found to ccase growing, 140.

Pepper, the Indians prefor that devoured and voided unconcocted by the toucsn, 518 .

Perch, s prickly-finned thoracic fish, its description, 648.

Perfumes, no perfume has a stronger or more permanent smell than musk, 255 ; the scent of the martin a most pleasant perfume, 334 ; some of the weasel kind have a smell approaching to perfume, 333 ; that of the musk or the civet, $33: \%$; in what nanner taken from the pouch; civet a more grateful perfume than musk; is communicsted to all parts of the animal's body; the fur impregnsted, and the skin also; a person shut up with one of them in a close room cannot support the scent; this perfume sold in Holland for about fifly shillings an ounce, 340,341 .

Pcrsepolts, its pastures excellent for the purpose of rearing horses, 219 .

Persia, the horses of that country the most heautiful and most vajuable of all in the East, 219 ; there are studs of ten thousand white mares together, with hoofs so hard that shoeine is unnecessary, 218; description of the Persian horses by Pietro de la Valle, 219; the flesh of the wild ass 80 nuch liked that its delicacy is a proverb there : an entertainment ol' wild asses exhibited by the monarch to Olearius, 224; two kinds of asses there, and some of then worth forty or fifty pounds, 226 .

Persiaa Gulf, a very dangernus wind prevails, by the natives called the Sameyel; it suddenly kills all those it involves in its pasrage, and frequently assumes a visible form, darting in a blueish vapour along the surface of the country, 105 .

Perspiration, an experiment from which the learned may infer npon what foundation the doctrine of "Sanctorian perspiration is built, 149 .

Peruvians understood the art of preserving their dead for a long time, 194.

Peter the Great, of Russis, celebrated a marrisge of dwarfs; the preparations for this wedding were grand, yet in a style of barbarous ridicule, 188,18 ?.

Petreoleum, an injection of this bituminous oil inwardly, and sn application of asphaltum without, sufficient tn make a muniny, 188 . Pcttichays, a bird of the sparrow kind, 537.

Phalanger, a kind of oppossum ; its description; called the rat of Surinam, 415 .

Pharaok (the cat of ) name given to the ichneumon, 337.

Plaraoh (the capon of) thought to be the true ibis; a devourer of serpents, 557

Pliasis, a river of Colchis, in Asia Minor, from the banks of which the pheasants were brought into Europe, snd still retain their name, 501 .

Phatugin, an animal less than the pangolin; where to be found 380.

Phensants, at first propagsted among ns, brourht into Europe from the banks of the Phasis a river of Colchis, in Asia Minor, where they still retain thcir name; description of this benutiful bird; wild among us, is an envied ornament of our parks and forests, where he feeds upon acorns and berries; in the woods the hen pheasant lays from eightecn to twenty eggs in a sesson; but in a domestic state seldorn above ten; it is bettcr. left at large in the woods than reduced to its pristine captivity; its fecundity, when wild, is sufficient to stock the forest, and its flesh acquires a higher favour from its unlimited freednn ; many varictics of pheasants of sll others, the golden pheasant of Clina the most beautiful, $50 \mathrm{I}$ to 503 .

Phle gium a high mountain of Ethiopia, swallowed by an earthquake, 47

Pholus, the file-fish, places where these nnimals are found ; their power of penetrsting; the pillars of the temple of Serapis at $\mathrm{Pu}$ teoli were penetrated by them; they pierce the hardest bodies with their tongue, 694,695 . 48

Pie, no class of birds so ingenious, active, and well-fitted for society; they live in puirs, and their attachments are confined to each other; they build nests in trees or bushes; the male shares in the labour of building, and relieves his mate in the duties of ineubation; and the young once excluded, bnth are equally active in making theu auple provision; general laws prevail, and a ro- publican form of government is established smong them; they watch for tho general safety of every bird of the grove ; they are remarkable for instinct, and mapacity for instruction; instances of it ; the few general characters in which thcy all agree, 511,512 . 569 .

Pigcons, are ruminating hirds, 232; those that live in a wild state by no means so fruitful as those in our pigeon-houses near home; the tame pigeon, and all its beautiful varieties, owe their origin to one species, the stock-dove; various names of tame pigeons: attempts made to render domestic the ring-dove, but fruitless; the turtle-dove a bird of passage; a pair put in a cage and one dying, the other does not survive; the pigenn called ocotzimizcan, is onc of the splendid tenants of the Mlexican forests; pigeon of the dove-honse is not so faitluful as the turtle-dove; near fitteen thousand pireons may in four years be produced from a single pair; the stock-dove scldom breeds above twice a year; the dove-house pigeon breeds every month; have a strongcr attachment to their young than those who breed so often; the pigeons called carriers used to convey letters; not trained with as much care as formerly, when sent from a besieged city to those coming to relieve it; in an lour and a lialf they perform a journey of forty-milos, 529 to 532

Pigmy, the existence of a pigmy race of mankind is founded in error $n \mathrm{r}$ in fable, 188.

Pigtail, is the last of the baboons ; its description, 406. 650

Pitie, the description of this fish, 659 ; instances of its rapacity,

Pilchards, little differing from the herring; make the coast of Cornwall their place of resort; advantages of this fishery ; money paid for pilchards exported has annually amounted to near fifty thousand pounds, 655,656

Pillau, on the Baltic, the shores there divided into districts for the sturgeon-fishery, 641 .

Pills, of calcined shells and tobacco, used by the American Indians to palliate hunger, 155 .

Pilori, one of the three distinctions of the musk-rat; a native of the West Indies, 367 .

Pilot of the shark, nsme given the sucking-fish or remora, and why, 631.

Pinch, name of a monkey of the ssgoin kind; its description, 412

Pintadal, or the Guinea hen, its description; difforent nsmes given to this bird, 503 .

Pintail, a kind of duck, 598.

Pipal, the Surinam toad, sn extraordinary and hideons creature; its description, 707 .

Pipe-fish, cartilaginous, and not thicker than a swan's quill; its description, 644 .

Pipe-zearms, and other little animals, fix their habitations to the oyster's sides, and live in security, 609 .

Pit-fnlls, a wolf, a friar, snd a woman, taken in one all in the same night; the woman lost her senses, the friar his reputation, and the wolf his life, 321

Pithekns, a name given by the ancients to the ape properly so called, 403 .

Pivot, the razor-shell, its motion, and habits; is allured by salt, 690

Placcnta, that body by which the animal is supplied with nourishment, 130.

Plague, not well known whence it has its beginning; is propagated by infection: some cnuntries, even in the midst of Africa, never infected with it ; others generally visited by it once 8 year, as Eygpt; not known in Nigritis ; Numidia it molests not once in a hundred years; plague sprend over the world in 1346, after two years travelling from the great kingdom of Cathay, north of China, to Europe; the plague desolated the city of London in 1665 ; for this lsst age, it has abated its violence, even in those cnuntries where most common, and why; a plague affected trees and stones, $96,97$.

Plaisue en Anjou, a village in France, particular account of a dwarf born there, 18 ?

Plaster of Paris, finely powdered, boils and heaves in great wares, like water, 53.

Planets exceed the esrth one thnusand times in magnitude; at first supposed to wander in the heavens without fixed paths; perform their circuits with great exactness, and strict regularity, 1 .

Plants and vegetables, will not grow so fast in distilled as undistilled water, 49 ; smell of some so powerful ss hardly to be endured, 64 ; do not vegetate in an exbausted receiver, 92 ; but thus ceasing to vegetate, keep longer sweet than when exposed to ex 
fernal air, ib.; their juices rarefied principally by the aun, to give an escepe to their imprisoned air, 99; a certain plant in Ireland 60 strongly affected the person who beat it in a mortar, and the pliysician present, that their hands and faces swelled to an enorinous size, and continued tumid for some time after, 96 ; compared witl animals ; sinilitude; how assimilated in different climates and soils, 119,120 ; the sensitive, that noves at the touch, has as much perception as the fresh-water polypus, possessed of a still slower share of motioo, 119. See Caraguata, 120. See Parnsite, 121.

Plate, or Plata, a great river in South Ameriea; its sourec and length, 63.

Plutina, or white gold, the most obstinate of all substances, 22 .

Pleurs en Champayne, a town in France, buried beneath a rocky mountain, 46.

Pliny, in his arrangements, placed the bats among birds, 383.

Plocer, the green and gray, are birds of passuge; tlie Norfolk

plever for the most part resides here, 569,570 .

Pochard, a kind of duck, 598 .

Poetry, our ancestors excel us in the poetic arts, 192.

Pointer, a kiud of dog, 312.

Poison, the inost deadly poisons are eften of great use in medicincs, 168; fishes oflen live and cubsist upon euch substances as are poisonous to the more perfect classes of animeted nature; the many speculations and conjectures to which this poisonous quality in some fishes has given rise, 660 ; some erabs found poisonous, 668 ; the seat where the poison in venomous serpents lies, 733 ; the serpent-poison may be taken inwardly, without any sensible effects, or any prejudice to the constitution; if milk be injected iuto a vein, it will kill with more certain destruction than even the poisen of the viper, 734. See Fire-flare. See vicu Providence

Polar regions, deseription of them, 3,4 ; and of the inbabitants round them; are of short stature, and savage appearance, 178.

Pole-cat, a distinet species from the ermine; resemblee the ferret so much, that somo have thought them the came animal; there are many distinctions between them; description of the pole-cat very destructive to young gane; the rabbit its favourite prey ; and one pole-cat destroys a whole warren by a wound hardly perceptible; it kills much more than it can devour; generally reside in woods or thick brakes, making holes two yards deep under ground female brings forth in summer five or six young at a time, aud supplies the want of milk with the blood of such animuls as she ean seize; the fur is in less estimstion than of inferior kinds, and why an inhabitant of temperate climates, being afraid of cold as well as heat; the species confined in Europe to a range froun Poland to Italy, 333, 334; pole-cat of America and Virginia are names for the squash and the skink; distinctions of tliese animals, 338,339 ; seizes the ffying-squirrel, 354

Poles, trade winde continually blow from them towards the equator, 191; the winter beginning round the poles, the sane misty appearance produced in the southern elimates by heat is there produeed by cold; the sea smokes like sn oven there, 113 ; the strength of the natives round polar regions is not less amazing than their patience in hunger, 179

Polyncmus, description of this fish, 619.

Polypus, very voracious; noted for its amazing fertility; its description; uses its arms as a fisluerman his net; is not of the vegetable tribe, but a real animal; every polypus has a colony sprouting from its body; and these new ones, even whise attached to the parent, become parents themselves, with a sinaller colonv also budding from them; though cut into thousands of parts, each still retains its vivacious quality, and shortly beconses a distinct and complete polypus, fit to reproduce upon cutting in piees; it lunts for its food, and possesses a power of choosing it, or retresting from danger, 125, 126; dimensions of the sea-polypus, and of that which grows in fresh water; the power of dissection first tried unon thesa animals to multiply their numbers; Mr. Trenbley has the lionour of the first discovery of the amazing properties and powers of this little vivacious ereature; their way of living; arms serve them as lime twigs do a fowler; how it seizes upon its prey ; the cold approaclıing to congelation, they feel the general torpor of nature, and their freulties are for two or three montlıs suspended; sucl as are best supplied soonest acquire their largest sizc, but they diniuish also in their growth with the same facility if their food be lessened some propagated from eggs; come produced by buds issuing from the body, as plants by inoeulation; while all nay be multiplied by cuttings, to an amazing degrae of minuteness; of those produced like buds from the parent stem, should the parent swallow a red worm, it gives a tineture to all its fluids, and the young partake of the psrental colour; but if the latter should seize upon the same prey, the parent is no way benefited by the capture, all the advantage thus remains with the young; several young of different sizes are growing from its body; some just budding forth, otliers acquiring periect form, and othere ready to drop from the original stem; those young still attached to the parent, bud and propagato also, each holding dependence upon its parent; srtificisl method of propsgating these snimals by cuttings; Mr. 1luglies describes a species of this animal, but mistskes its nature, and calls it a genditive flowering plant, 833 to 836 .

Polypus-carul, the work ol en infinite number of reptiles of that kind, 837 .

Pomerania, a large part of it covered by the sea, 82 .

Pongo, name given by Battel to the ouran-outang, 402.

Poppies affect with drowsiness those who walk through fields of thein, 96.

Purceluin, an srtificial composition of earth and water, united by lieat, 49

Porcupine, as to quills might be classed among the birds, $20 \mathrm{~b}^{\circ}$; its deseription, 375; of ull those brought into Europe, not one ever seen to luuneh its quills, though sufficiently provoked; their manner of defence; directs its quills pointing to the enemy; and Kolben relates, the lion then will not venture an attack; feeds on ser. pents and other reptiles; poreupine of Cansda subsists on vegetables; those brought to this country for show usually fed on bread, milk, and fruits; do not refuse meat when ofiered; is extremely hurtful to gardens; the Americans who hunt it, believe it lives fron twelve to fitcen years; time of their gestation; the femalo brings ferth one at a time; slie suekles it about a month, and accustoms it to live like herselt upon vegetables and the bark of trees; the porcupine never atteripts to bite or any way injure its purcuers; inanner of escaping, when husted by a dog or a wolf; circumstances conceraing it remaining to be known; little known with preeision, exeept what offers in a state of eaptivity; description of one kept in an iron cage; the porcupine of America differs nuch from that of the ancient continent; two kinds, the couanda and the urson; deseription of both 1,375 to 377 .

Poriupinc of the sea, described, 505.

Pork, unpalatable with us in sumuer, is the finest eating in the warmer latitudes, 224.

Purpoisc, or porpesse, a fish lese than a grampus, with the snout of a hog; its deseription and habits, 515,516 ; possess, proportionably to their bulk, the manners of whales; places where they seek for prey; manner of killing them in the Thames; yield a large quantity of oil ; the lean of some, not old, said to bo as well tasted as veal; caviar prepared from the egge of this fish, 626,627 .

Ports ehoked up with and by the vehemence of the wind, 102.

Pouch, or bag, receptacle of the civet, 341. See Bustard, 504. See Pelican, 576

Poultry, general characteristies of the poultry kind; nearly all do. mestic birds of thls kind nuaintained in our yards, are of foreign extrac. tion; the courtship of this kind is short, and the congress fortuitous; the inale takes no heed of his offspring; though tinorous with birds of prev, he is ineredibly bold among his own kind; the sight of a male of his own species produces a conbat; the female takes all the labour of hatching and bringing up her young, choosing a place re. mote from the cock, $492,493$.

Porcis Lond, in Wales, for many ages famous for a swift and generous race of horses, 222 .

Pouters, a variety of the tame pigeons, 532.

Pregnancy of some women found to continue a month beyond the usual time, 132; of all animals, in point of time, is proportioned to their size. 212 ; in that state no animals, except the hare, receive the male, 346 ; the duration in the fenale of the elephant still unknown, 421.

Prcssures, perpendicular in rivers, always in exact proportion to the depth, 59 .

Prcy, all the males of these birds less and weaker than the fomales, 472. See Birds.

Pricliet, name hunters give the buck the second year, 266.

Propagation of gnate, one of the strangest discoveries in natural history, $\times 26$; a new kind lately diseovered in a most numerous tribe of animals, propagated by euttings, 820 ; different manner of that operation in the polypi, 836 .

propolis, a re.inous gum, with which bees plaster the inside of their hives, 802.

Proportion of the human figure, very little known with precisian in regard to it, $14 x$

Provider, of the lion, what has given rise to the jackal's being so called, 208.

Psulmodi, an islaod in France, in A. D. 815 , now six milcs from the shore, 81

Ptarmigan, sort of grouse, chiefly found in heathy zoountain and piny forests, 505,506 . 
Pthiriasis, the lousy disease, frequent among the ancients; principal people who died of this disorter; plants and animals are infested with diseases of this kind; a vegetable louse from America over-run all the physic-garden of Leyden; the leaf-louse described; three principal and constant cremies to those insects, 754 to 756

Puffin, or Coulterneb, marks that distinguish this bird; its residence; migration; found by liundreds, cast away upon shores, lean and perished with famine; lays one egg; few birds or bcasts venture to attack its retreat ; in what manner it defends itself against the raven; the Manks' puffin is itself one of the ninst terrible invaders ; instances of it ; places which abound with them; in what manner their young are fed; their food, 589 to 502 .

Puget adapted the cornea of a flea in sizch a position, as to see objects throngh it by means of a microscope; strangeness of the representations, 792 .

Puraa, an animal decorated with the name of American linn, thougb, when compared, so contemptible as to be inferior to that called the American tiger, 519 .

$P u m p$, an experiment upon a carp put under a receiver, 610 .

Purre, a small bird of the crane kind, with a shorter bill, and thiohs bare of feathers, 568 .

Puteoli, a city swallowed up by an earthquake, had a temple of Serapis, the pillars of which, while under water, were penetrated by the pholas, or file-fish, $6 ! 5$.

Putrefaction, a new ciuse of animal life, 125

Pyraaids of Egypt, one of them entirely built of a kind of freestone, in which petrified shells are found in great abundance, 14.

Pyrard, his account of a kind of apes ealled baris, which, properly instructed when young, serve as useful domestics, 401.

Pyrites, their composition, 23.

\section{Q.}

Quodrupels, they bear the nearest resemblance to man, 205; the weaker races exert all efforts to avoid their iuvaders; next to huunan influence, the clinnate seems to liave the strongest effects upon tbeir nature and form; both at the line and the pole, the wild are ficrce and untameable. America inferior to us in these produetions; opinion that all in South America are a different species from those most resembling them in the old world; such as pcculiarly belong to the new continent are without any mirks of the perfection of their species; the large and formidable produce but one young at a time, while the mean and contemptible are prolific; it has been wisely ordered so by Providence, 208 to 212 ; those that ruminate are harmless and easily tamed, $2: 31$; they are chiotly the cow, the sheep, and the deer kind, 232; the largest are found in the torrid zone, and these are all fond of the water, 2:33; elicvrotin, or little Guinea-dcer, the least of all cloven-footed aninuals, and perhaps the most beautiful ; its description, 253 ; none ean be noro beautiful than the tiger, 207; change of colour in the lutir obtain in them all to a degree plainly observable, 330 ; the carnivorous have not milk in plenty, 334; are not fond of engaging each other, 335 ; general description of amphibious quadruneds, 386

Qunil, a bird of passage ; description of it, $5(0)$.

Querry of Macstrichi, 40,000 people may tako shelter in it ; its description, 19

Quiclisiler, remarkable effects of it at the mines near Idra, related by Dr. Pope in the Plilosophical Transactions, 23.

Quills. See Purcupine, 275.

Quito, in South America, onc of the most charming regions unon earth, 44

\section{R.}

Rabbit, a ruminating animal, 232; rabhit and hare distinct kinds a crcature covered with feathers and hair said to be bred between a rabbit and a hen; breed seven times a year, and bring cight young each time, 263,264 ; various colours of raljits; the inousecoloured kinds originally from an island in the river Humber, still continuing their gencral colour after a number of successive generations; acconnt of their production; the rabbit generally fatter, and lives longer, than the hare; native of the warmer climutes; it has been imported into England from Spain ; in some of the islands of the Nediterrane:n they multinlied in such numbers, that military aid mas demanted to destroy them; love a warm climate; de. light in grounds of a sandy soil; the fur a very useful coinmodity in England, 349 to 357.
Rubbit (Syrian) remarkable for the length, gloss, and softness of the hair, 240,351

Rubbit (Brasilian) shaped like the English, but without a tail, 35 ?

Ruroou, with some the Jamaica rat; its deseription and habits; do more injury in one niglit in Jamaica than the labours of a month ean repair ; capable of being instructed in amusing tricks; drinks by lapping as well as by sncking; its food, $4 ; 9,440$.

liainducs, circular rainbows in the Alps, 42 ; and between the tropies, and near the poles, 110 ; one of the three rainbows seen by Ulloa, at Quito, was real, the rest only reflections there of ; a glass globe filled with water, will assune successively all the colours of the rainbow, 112 .

Rainforol, the naine riven in some parts of the country to the wondpecker, 519 .

Rams, it is no uncommon thing, in the counties of Lincoln and Warwick, to give 50 guineas for a ram, 243 .

Ranguer, name of the ninth variety of gazelles, made by $\mathrm{Mr}$ Buffon, 252 .

Rarefaction of the air produced by the heat of the sun in countries under the line, 101

Rats, musk-rat, three distinctions of that species, the ondntra, desmnu, and pilori; in what they resemble each other; the savages of Canada think the musk-rat intolerably fotid, but deen its flesh good eating; great rat, called also rut of Norway, though unknown in all northern cuuntries; originally from the Levant, and a new-eomer into this country ; first arrival upon the coasts of Ire. land, with ships trading in provisions to Gibraltar; a single pair enough for the numerous progeny now infesting the British Einpire called by Mlr. Butfon the surmalot; its description; the Norway rat has destroyed the black rat or comaion rat, as once called; and being of an amplibious nature, has alsn destroyed the frogs in Ireland; the feeble animals do not escape the rapacity of the Norway rat, except the mouse; they eat and destroy each other; produce from fitteen to thirty at a time, and bring forth three timcs a year the blucls rut has propagated in America in great numbers, introduced from Europe, and are become the most noxious animals there black vouter-rat not web-footed, as supposed by Ray; the German rut. See C'ricetus, 362 to 363 .

Rut of Surinam. See Phalonger, 415.

Rut of Jumaica, a name by some given to the racoon, 439 .

knttlesnate, kind of friendship between it and the armadillo, or tatou, frequently found in the same hole, 382 ; its description and dimensions ; effects of its bite ; the remedies against it ; power of charning its prey into its mouth; facts related to this purpose, 736 to 739 .

Ravens, how distinguished from the carrion-crow and rook; manners and appetites; ravens found in every region of the world; white ravens often shown, and rendered so by art; amusing qualities, vices, and defeets; food in the wild state ; places for building nests; number of eggs; will not permit their young to keep in the same district, but drive them off, when sufficiently able to shift for themselves; the Romans thought it oininous, and from fear paid it profound veneration; Pliny's aceount of one kept in the temple of Castor, that flew down into the shop of a tailor; some have lived near a liundred years, 512, 513; the horned Indian raven, 516 .

Rarente, once stood by the sea-sidc, and is now removed from it, 81

Ray, his method of classing animals, 200.

Rut, figure of the fish of this kind, and their differences; amazing dimeirsions of one speared by Negroes at Guadaloupe; to credit the Norway bislon, there are some above a mile over; sup. posed to be the largest inhabitants of the deep; three liundred eggs taken out of the body of a ray; in what manner the eggg drop in to the womb from the ovary or egr-bag, 632,633

kays of light noderated, and their violcnce dissipated, by the air, 98 .

Ruys of the sun, darted directly upon the surface of the water, compared to so many bars of red-hnt iron, 108.

Razar-shell, the pivot; its motion and habits; is allured by salt, 690 .

Reaumur, his chemical elaboratory for hatching chickens, 196.

Rcd-breast. See Rabin Red-breast.

Red-start, hird of the sparrow kind, 537.

Red-roing, or fieldfare, bird of passage ; its nest and eggs, 539.

liecd, stuck into the ground in Persia continues to burn like a flambean, 25

lieeve, name given to the female of the ruff, 571 .

Reflection of saund, its laws not as well understood as those of light, 167.

Regions, the highest region in the world, 44. 
Rein-deer. Sce Deer, 272.

hemorn, the sucling-fish, it sticks to the shark, and drains uwny its moisture, $6: 31$.

Repradaction. Sue Trambley, 831.

hiplies grow to a prodigious sizo in the internal parts of South Americia and Afriea, and why ; infinite numbers of them not seen in this part of the world, and why, 120, 121.

fiesembiance to the common parent of all; the olive-coloured Asiatic, and the jet black Negro, claim the honour of hereditary resemblance to lim ; argument sullicient to prove the contrary, 165 ; dificult to rive a reason why the elild should rescmble the fither or the nother, 187 .

Respiration in fishes, general metled of explaining it, 609 .

Rhinc, a great river proceeds frou the Alps, $4:$; part of it lost in the sands, not far from Leyden; the greatest part arrives at the ocean, 66.

Rhinoceros, a ruminuting animal, 232 ; not afraid singly to oppose the lion, 295 ; next to the elephant the most powerful of animals ; general outline of it ; the elephant defeated by it; its liern sometimes tound from three feet to three feet and a half long; this horn composed of the most solid substance, and pointed so as to inflict the most fatal wounds; a rhinoceres sent from Bengal to London, not above two years old, cost near $£ 1000$ for his conveyance and tood; in some parts of Asia, these animals are tamed, and led into the field to strike terror into the enemy, but are as dunverous to their eniployers ; method of taking them; some found in Africa with a donble horn, one above the other; many inedicinal virtues aseribed to this horn, when taken in powder, without any foundation, $425,4: 6$

Riocrs, all our greatest find their souree nmong mountains, 42 . their production according to De la Hire, 57 ; other lyypotheses upon the sume subjeet, 58; make their own beds, and level tho bottom of their channels; their sinuosities and turnings more numerous as they proceed; a certain sign with the savages of North America, they are near the sea, when they find the rivers winding and often ehanging their direction; w little river received inte a large, without augmenting either width or depth, and why ; instanee of it ; a river tending to cuter another either perpendieularly or in an opposite direction, will be diverted by degrees from that direction, and obliged to make itself a mere favaurable entrance with the stream of the former; wlatever direction the ridge of the mountain has, the river takes the opposite course, 5.7 , 60 ; every great river, whose source lies within the tropies, has its stated inundations, 64 ; those of countries least inlanbited are very rneky and bruken into cataructs, and why, 65 ; nt the poles necessarily sinall, and why; the rivers of Lurope more navigable and more managenble thun those of Afriea and of the torrid zone; all rivers in the world Howing into the sen witl a centinuance of their present stores, would take up, at a rude computation, 800 years to till it to its present height, 67 .

Rotin Red-breast, a slender-billed bird of the sparrow kind, liviog upon insects, 537

Rucle, great bird deseribed by Arabian writers, and exargerated by fable, but a species of the Condor, $470^{\circ}$.

Rocks. See St. kildu, 544.

Roebuek. See Dier, 267.

Rorrer de Belegme, the first whe attempted to mend our breed of horses, 2ite.

hinger of Sicily. See Silk Mfmmufuetures, ron6.

Rinller, a beautiful bird of the pie kind; its deseription, 517

lim:anns cut down all the woeds and forests in Britain, and why, 84: the vanity of their boazts best shown by the parrot lind; in a hunired species now known, not one of tlunse birds naturally breeds in any of the countries that acknowledged the lRuman puwer, 5i?!; a Roman enperor hitd fitteen hundred flamingos' innrues served up in a single dish at a feast, 566 ; a Roman sena. tor tised to throw into his ponds such of lais slaves as offerded him, to feed the lanipreys, 634).

Rombald, it holy temperate man, snid to lave lived 120 yenrs, 155 .

liools, of the pie kint; not carniverous; their plan of policy; their chief food, 514,515 .

Fousette, the great bat of Madagasear. See But, 385 .

Ruysion-cruio, a bird of passage, deseribed, 514.

Rulicth, the land toad. See Toud, 706.

Rist ,uall bird of the erane kind; manner of ialsing it, 571.

Rumimunt quadrupeds, birds, fishes, insects; mea known to ruminate; instance in a young man at Bristol; those of the cow kind loold the first rank, 232; all of this class internally much slike; litve oot the upper foreteetl, 243 ; the stang perliruns this with inore diffieulty than the cow or sheep, 26io. See Animal, $231,232$.
Runner, the corrira, hird of the erane kind, its deseription, 567 . Runts, a varicty of tune pigeens preduced by cross coupling,

Rust, copper and iron quickly covered with it ; gold contracts no rust, 92.

Rut, time when the stig feels the desire of copulating, 259.

S.

Salle, its descriptien from Mr. Jenelin, the first accurate ebserver of this animal ; sables leap with ease from tree to tree, and are afraid of the sun; different colours of their fur ; hunting the sable chiefly the lot of soldiers and condemined crininals; how directed to shoot them, 336

Sabre, the trachepterus, deseription of this spinous fish, 649 .

Sacre, bird of the generous breed of hawks, $4 \times 3$.

Sog" tree, ate by the elephant to the stump, 418.

Sui, the bewailer, a monkey of the new continent, 412 .

Sail, a stag hard liunted, taking to the water, is said to go sail, 262.

Suines, name of the nets used in the pilchard fishery, on the coast of Cornwall, 0.55 .

Siujou, third sort of the sapajou, a monkey of the new continent,

Solki, the eagui, the largest monkey of the sagoin kind; its doseription, 412

Sal Ammoniae made of the urine of eamels, 432.

Salamunder, there is no such aninal existing as that described by the ancients ; the modern salamander a lizard; there are many kinds; its conformation and habits; reports concerning their venen; ; idle netien of its being inconsumahle in fire, 717,713 .

Suliru, in the lama, or Auerican camel, supplied by nature in such abundance, that it spits on all occasions, and seens the only elfensive weapon of this hamless creature, 494.

Salmon, a ruminating fisl, 232 ; a soft finned abdoninal fish, 650. Salt-zouter. See Sea and Sert-zouter.

Salt, Bay salt, brought frem the Bay of Biscay, a streng kind made by evaperation in the sun, 71 ; volatile caustic salt obtained in great quantities frem the eantharides fly, 822 .

Samari, the aurora, the smallest and most benutiful menkey of the sapajou kind, $41 \%$.

Sameid Tartars, deseription of that people, 177.

Sanctorian statieal experiments upon a weak foundation, 149.

Sund, rolling in waves like a troubled sea, and overwhelming all with incvitable destruction, 4 ; tract of a country, lying along the sea-side in Lower Brittany, inhabited before the year 1666, now lies desert, being covered with sand to the height ef twenty feet, 106 .

Sanderling, small hird of the erane kind, 568

Sandpiper, small bird of the crane kind, 508 .

Suntoriz, an earthquake there in 1707 ; a volcano near it, 37.

Sapajou, name given to the monkies of the new eontinent, 411.

Suzages more diffieult in point of dress than the most fashionable er tawdry European; instanee of it, 14\%; perform a journey of twelve hundred leagues in less than six weeks, 150; oblige their women to a life of eontinual labour; is surprised an European walks forward for his anusement und returns back again, 152.

Sinuce, made with the bleod and narrow of the rein-deer by the Laplanders, 277

Scallop, in its shell moves forward upen land, and swims upen the surface of the witer, by eontrivance in a singular manner, 690 .

Sear, a child distinetly marked similar to one the father received in battle, 185 .

Scarus, if we believe Ovid, is, like the salmen, a ruminating (isli, 2332 .

Scrne duck, a variety of the duek-kind, 598.

Sermt, the Negrees of Guinea have an insupportable seent, 182.

Siclottens assures us, he saw an instanee et fisbes being allured by music, 160.

Sciom, a spinous fish; deseription of this fish, 648 . $76 \%$.

Scomber, the mackarel, a prickly-finned theracic fish; its de scription, $64 \mathrm{~s}$.

s.t.

Seorpion, four principal parts distinguishable in this animal; the reservair where its poison is kept; etlect of its sting upon a dog, in an experiment made by M. Maupertius; experiments made upon other dags; instances of its iraseible nature and malignity; when driven to extremity, destroys itself; instanco of it ; captivity 
makes it destroy its young; a scorpion of America produced from the egg, 759 to 762 .

Scorpion (Water) an inseet with wings, described, 779.

Scoter, an European duck, 598 .

Scotland has land in it at one tine covered with water, at another free, 82 .

Scotchman, in the Tower, took not the least sustenance during six weeks, 155.

Sea was open to all till the time of the emperor Justinian, 68; sensihly retired in many parts of the coasts of France, England, Holland, Germany, and Prussia, 81; Norwegian sea has formed several little islands from the main land, and still daily advances upon the contincnt, 82 ; its colour not from any thing floating in it, lut from the different reflections of the rays of light; a prool of it; the sea grows colder in proportion as divers deseend, 85; smokes like an oren near the poles, when the winter begins, 113; no fish imbibe any of the sea-saltness with food or in respiration, 522 .

Sca $(R c d)$ choked up with coraline substances, 85 .

Sea-eggs, name given to the multivalve shell-fish of the echini, which move, 693 .

Sea-nettles, name given by some to the star-fish, 832 .

Sea-water, various methods proposed to render it fresh for the use of seamen in long voyages, 70 ; about a forty-fifth part heavier than fresh-water; is heavicr, and consequently salter, the nearer we approach the line, 71 .

Sca-200rm may be multiplied by being cut to pieces, 125 . Sce Polypus.

Seal, its description; the varieties innumerahle; the brain largest of any animal ; the foramen ovale in its heart never elosing, fits it for continuing under water; the water its labitation; seldon at a distance from the shore; found in the Nortl and Icy Seas, and on those shores in floeks; gregarious and migrant; direct their course to northern coasts, and seas free of ice, in two departures, observing time and track; how and by what passages they return unknown; females in our climate bring forth in winter; where they rear their young; hunt and herd together, and have a variety of tones like dogs and cats, to pursue prey, or warn of danger; neither length of time in prognancy, nor duration of these animals' lives, yet known; two taken young, after ten years had the narks of age; how the Europeans and Greenlanders destroy them ; in our climate they are wary, and suffer no approaeh ; never sleep witlout noving, and seldom more than a minute; taken for the skin and oil the tat yields; the flesh formerly at the tables of the great; an instanee of it; sea-lion in Anson's Voyages, the largest of the scal fauily, 392 to 395 .

Seeds, some thought to thrive better for maceration in the stomach of birds, before they be voided on the ground, 538 .

Scuegal, a river in Africa; its course; is navigable for more than three liundred leagues, 62 ; reccives more than twenty rivers, 64 ; the natives consider forty years as a very advanced time of life, and generally die of old age at finty, 94.

Sensations, their illusions at first when man is newly brought into existence, described by Wir. Bution, 171 ; tisls fall belind terrestrial animals in their sensations, 608 .

Senses, of all senses man is most inferior to other animals in that of smelling; and it seems not to offend then, 169; the grossest, and most useful of all, is that of feeling, 170 .

Sensitice plant has as much perception as the fresh-water polypus, 129. 722.

Seps, improper name of the Chalcidian lizard; its description,

Seraglio, to be able to furnish one the only ambition of an Asiatic, 133 .

Serpents, the sea about the islands of Azores replenished with them for want of motion, 70 ; the various hissings at the close of the evening, make a louder symplony in Africa, than birds in European groves in a thorning, 208; to believe oll sid of the sea-serpent is eredulity, to refuse assent to its existence is presumption, 616; eea-serpent, the elopr described, ib. ; marks distinguishing them from the rest of animals ; their conformation ; progressive motion; the only animal in the forest that opposea the monkey; entwines and devours the buffalo; account of a combat between a serpent and a buffalo; no animals bear abstinence so long as they; little serpents live for several years in glasses, never eat at all, or stain the glass with excrements; little serpent at the Cape of Good Hope, and north of the river Senegal; long serpent of Coniro; some bring forth their young alive, some bring forth eggs; some venomous, and some inoffensive; animals which destroy them; boasted pretensions of charning serpents; have docility ; Egyptians paid adoration to a serpent, and the inhabitants of the western coast of Africa retain tho ame veneration; all waphibious; their motion, swinmming in liquids; the Ksculapian serpent, 724 to 730 ; seat of poison in venonious serpents; instrument by which the wound is made ; those destitute of fangs are larmless ; various appearsnces the venon produces; inay be taken inwardly without sensible effeets or prejudice to the constitution ; instance of the force of serpents' poison from Ray ; their principal food birds, moles, toads, lizards, 732 to 735 ; the prince of gerpents, a native of Japan, the greatest favourite of savages, 741 . 304.

Serral, a native of Malabar, resembling the panther in spots,

Settcr, a dog of the generous kind, 312.

Serern, lamprey of this river the most delieate of all fish, 638 .

Shagrecn made of the skin of the wild ass, 224 ; also the shark. 632.

Shammoy, a kind of goat, in the mountains of Dauphiny, Piedmont, Savoy, Switzerland, and Germany; its description; their flesh good to eat ; in cases of danger, its hissing noise is heard at a great distance ; by smell discovers a man at balt' a league; admircd for the beituly of its eyes; not found in summer except in eaverns of rocks, anidst fiagnients of iee, or under the sliades of spreading trees; during winter, it sleeps in the thicker forests, and foeds upon shruhs and buds of pine-trees, and scratches up the snow for herbage ; manner of hunting it; akin of the shammoy when tanned, liked for softness and warinth; the leather now ealled shammoy, inade from the tame guat, sheep, and deer, 248 to 250 . See Bezoar, 250.

Shank, the red and green shank, varieties of the crane kind, 263.

Shark, deseription of the great white shark; no fish swims so fast; outstrips the swittest ships; instanees of frightful rapacity in this fish; its enoity to nian; usual method of sailors to take thenı; no animal harder to kill; liow killed by the African negroes; the remora, or sucking fish, sticks to it ; for what purpose ; brings forth living young; Roudeletius says, the female of the blue shark lets her brood, when in danger, swim down lier throat, and shelter in her belly, ti24 to $(i 31$.

Sheldrulie, a variety of the pond-duck; supposed a native of England, 598.

Shruth-fish, the silurus, of the priekly-finned abdominal kind, 649. Sheep, the author saw one that would eat flesh, 200 ; proper care taken of the animul, produces favourable alterations in the feeces here and in Syria, ib.; in eourse of tine inopoverisl the pasturage, 233 ; in the domestic state, stupid, most defenceless, and inoftensive; those without horns, more dull and heavy than the rest; those with longest and finest feeces most suhject to disorders; the goat, resembling them in miany respects, much their superior; they propagate together, as of one family ; distinguished from deer, 240,211 ; do not appear from old writers to have been bred in early times in Britain; du country produces such sheep as England, larger fleees, or better for clothing; silcepl without horns the best sort; the sheep in ity noblest state is in the African desert, or the extensive plaine of Sileria; sheep in the savage state; the woolly sheep is only in Europe, and in the temperate provinees of $A$ sia; subsists in cold countries, but not a natural inliabitant of them; the lceland sheep have four, and sometimes eight horns; with broad tails, common in Tartary. Arabia, Persia, Barbary, Syria, and Egypt; the tail often weighs from twenty to thirty pounds; those called strepsichoroe, natives of the Archipelago; Guinea sheep deseribed; bring forth one or two at a time, sometimes thrce or four; bear their young five months, 242, 243; the intestines thirty times the length of their body, 291; in Syria and Persiá, remarkable for fine gloss, length, and softness of hair, $2 z_{2}$. See Mouflin.

Shells, (fossil) found in all places near to and distant from the sea, upon the surface of the earth, on the tops of mountains, or at different depths, digging for marble, clialk, or other terrestrial matters, so compact is to preserve these shells from decay, 6 ; various kinds found at a liundred miles from the sea, at Touraine in France; a continued bed of oyster-shells found through the whole cireum. ferenee of five or six acres of ground near Reading, in Berkshire; shells found petrified in all the Alpine rocks, in the Pyrenees, on the hills of France, England, and Flandera; a floor or pavement of petrified shells found in Kent, near the Medway; shells always remaining in the deep; easier to believe fossil shells bred in fresh water, than that the sea for a long time covered the tops of high mountains, 12 to 14 ; methods of conveying a just idea of the formation of sea-shells and garden-shells; usual way of secounting for different colouring in shells; they assume every eolour but blue; stairs-shell, or admiral-shell, not more precious for their scarceness, than pearls for their beauty; collections of shells have their use; naturally classed by Aristotle; places where shells are found, and substances of which they are composed; supposition 
that all earths fermenting with vinegar, are composed of shells orumbled down to one mass; what sliells most valuablc; sea-shells exceed land or fossil sleclls in benuty; some livirng land-shells not inierior in beasty to fresh-wator shells; great variety of fossil or extraneous shells ; different states of preservation; every shell the spoil of some unimal; na malter how parted from the sea, 676 to 631

Shells of the sea, of all sea-sliclls, that of the nautilus the thinnest and inast easily piereed, fiษ ; all bivalved shells furnish pearls, and their insides resemble and afford that substance ealfed notherof-pearl, 641 .

Shells (animal) of the armadillo or tatou, one of the most striking curiosities in natural history, 380 ; turtle shells of an amazing marnitude, 674.

Shrtand Isles, amazing quantities of herrings appearing off these is!nucls, 6.54. 618.

Short-fecads, name given by sailars to the young of the whale,

Shareller, speeies of the erane kind; inhabitants of the Cape of Good llope respect it as the ancient Ergyptians did their lbis; its nest and eggs, 563.

Shoulders, high in sickly persans; neople dying are seen with their shoulders drawn up; shoulders in women narrower than in men, 14\%, 145 .

Showers, shower of hail in 1510 ; its description, 110 ; af stones, fislies, and ivy-berries, raised into the air by tempests in one coun try, and falling at a distance like rain to astanish another, 114

Siberia, the isatis found in this eountry, and geldom in milder climates, 326 ; the suble resembling the martin found in it, 336 enormous tusks found lodged in the sandy banks of ita rivers, 424 .

Sighs, in what manner produced; when invigorated produee sobbing, 144.

Sight, of old men indistinct for bodies close to them, but more precise for abjeets at a distance from thom, and why, 162 ; of birds exeeeds that of other animals, and excels in strength and precision a kite, from an insperceptihle height in the clouds, sces its prey, and darts on it with unerring ains, 450 ; of lirds that prey hy day astonishingly quiek, and in such as ravage by night, so fitted as to discern objeets in darkness with precisinn, 471 .

Signs of deuth, uncertainty of tliem ouglit to make every one cantious of giving up a fricnd as dead, and exposing him to real death, or a premature interment, 177.

Silks, brought to Jamaica, and there exposed to the air, rat while they preserve their colonr; but kept from air, retain their strength and gloss, 92

Silk Manujactures, established in Europe, in the beginning of the twelfth century, by Rager of Sicily, 737 .

Silk:norm, the most serviceable of all such ereatures, 733 ; its real history unknown among the Ronians to the time of Justinian, and supposed only brought inte Europe in the twelfh eentury: two methads of hreeding them ; Pausanias's description of this worm ; eluanges its skin in lluree weeks or a month; gummy fluid forming the threads; preparations made befure spinning the web; the cone or ball of silk described; efforts to burst the cone; free from confucment, it neither flies nor eats ; few of these animals suffered to come to a state of maturity, and why, $791 ;$ to 799

Silurus, the sheath-fish, of the prickly finned abdominal kind, 649

Simean, said to have lived a hundred and twelve years, 155

Sineres of the rein-deer. the stronuest kind af sewing thread, 225.

Single, name of the tail of the stag. $21 \% 2$

Sislin, singing bird of the sparrow-kind, with a thiek and shart bill, 537 .

Size of men varies ennsiderahly; the human bedv often differs fram itself; the same person taller in the morning than at niglit; sumetimes the differenee is an inch: this first vereeived in Enoland by a recruiting officer; men are tall fram five feet eight inches to six feet live : midule size from five feet to five feet eipht 144 . M I ximin. the emperox, above nine feet in height, 151 ; approacling $t$ (1) wirds the north pole, the natives diminish proportionably, growing less and less in ligher latitudes, 179

Slicleton of the bat, in some measure, resembles that of man, 610 ; of the elcphint, sonie lately discovered of an enormous size, ou the banks of the Ohio, in America. 42.5.

Slin, the only part of the body that age does not landen; whenee its wrinkles proceed, 174 ; of the rein-deer, 277 ; of tle tiger, 300 of the black fox..325; nost valuable part of the martin's skin: all, that of the sable most coveted, and held in higliest esteem, the fur surpassing all, 336 ; of the civet, 341 ; of the ondatra also very valuatie, 367 ; of the mole, 372 ; of the hedgehog, 374 ; of the cle phant, 420 ; of the rhinoceros, 425 ; of the astrich, 465 ; of the great Greenland whale, 61\%.
Shink, an animal called one of the polecate of America, 338.

Sliull-fish, name of the whale aluove two years old, 618 .

Siatherg, in lceland, (in the lands af) there staod a declivity, and the earth of $j$ t was found sliding dawn the hill upan the subjacent plain, 47

Slecp, with same of the lower animals, takes up the greatest part of their lives; man the only creature requiring sleep from double matives, for the refreshment of the mental and of the badily frame; want of it produces madness; procured to man with more diffieulty than to otlier animals; in what manner sleep fettcrs us for houre together, according to Rahault ; bodily labour demsnds a less quantity of it than mental; the famous Philip Barrotier slept twelve lrours in the twenty-four; numberless instances of persens, who asleep, performed many ardinary duties of their ealling ; snd, with ridiculaus industry, completed by night what they failed doing by day; remarkable instanee related in the German Ephemerides. See Arlotto, 15i5, 156

Sloth, two different kinds of that animal, the si snd the unan ; both seem the meanest and most ill-formed of all animsls that chew the cud; formed by nature to climb; they get up a tree with pain, but utterly unable ta deseend, drop fram the branches to the ground; strip a tree of its verdure in less than a fortnight, afterwards devaur the bark, and in a short time kill what might prave their sup. part; every step taken, sends forth a plaintive melanehaly ery like birds, have but one vent for propagstion, exerement, and urine; their look piteous, to inove campassion, accompanied with tears, that dissuade injuring so wretehed $\mathrm{a}$ being; ane fastened by its fcet to a pole, suspended aeross two heams, remained forty dars without meat, drink, or sleep ; an smazing instance of strength in the feet instanced, 442 to 444 .

Slot, term for the print of the haof of the stag, 262

Slown, name given by some to the blind worm, 740 .

Smell, the musky not praperly a eharaeteristie mark of any kind of animal, 240 ; none more permanent than musk, 255 ; streng of fensive smell of foxes often the cause of their death, 322 ; of the genet, not endured by mice and rats, 340

Smelling, Bramins of India have a power of smelling equal to what is in other erestures; ean smell the water they drink, to us quite inodoraus; negraes of the Antilles by smell distinguish the footsteps of a Freneliman from those of a negre; gives often false intelligenee; natives of different eauntries, or different natives of the same, differ widely in that sense; instanees of it; mixtures of badies vaid of adour produee powerful smells; s slight cold blunts all smelling; smallest elanges in unan make great slterations in this sense, 169 ; delicacy of smelling in birds instaneed in dueks, 451 . See Senses.

Smile, Fielding asserts, a person with a steady glavering amile, never failed to prove himself a rogue, 145 .

Snail (Garden) is surprisingly fitted for the life it is to live; or gans of life it passesses in cammon with animals; and what peeuliar to itself; every snail at once male and fenale; and while it impregnates snather, is impregnated in turn; coupling of these animals; possessed of the power of mending the sliell; and cume to full growth they esnnot make s new one; Swammerdam's experiment to this purpose; salt destroys them, so dees soot; eontinue in a torpid state during the severity of winter; sa great their nultiplieution in some years, that gardeners imagine they burst from the earth; wet seasons favourable to their production; sea snail, fresh-acater snail, and land snail, eoumon garden snail eompared with the fresh-water snnil and sea snail; fresh-water snall brings farth youn alive, with shells upon their backs; st all times of the year, fresh-water snails apen, are pregnant with eggs, or with living snails, or with both together; ses snails found viripa. rous, ethers lay eggs; manner in which the sea snails impregnate each other ; different orifices or verges of snails; the differenee between land and sea snails; of the trachus kind, have no mauth; their trunk; are among snails, as the tiger, the eagle, or the shark, anıong beasts, birds, and fishes; food of all sea snails lies at the bottom; of sea susils, that most frequently swimming upon the surface, whose shell is thinnest, and most easily picreed, is the nautilus; its descriptian; peculiarity by which the nautilus is mast distinguished, 681 to 687 .

Snail-sea, a eartilaginaus fish, deseribed, 643

Sruke (black) its deseription and food ; are oviparous, 740. See Serpents.

Snipe, a water-bird of passage : its deseription, $5 \% 4,575$.

Snow, inhabitants of jlaces where fields are centinually white with snow, generally become blind before their usual course of nature, 5 .

Snow-slips, a family in Germany lived for a fortnight bencath 
Sobbing is a sigh still more invigorated, 144 .

Soland goose, 582 . See Bass and Gannet.

Soldier-crab, 668. See Crab.

Solfatara, a valley ncar Naples; exhibits the appearance of an earthquake, 36 .

Soot, as well as sait, will destroy snails, 683 .

Sore, name the hunters give the buck the fourth year, 366 .

Sorel, the hunter's name for the buck the third year, 366 .

Sound conveyed by air is Jost in vacuo, 98 ; solinding bodies of two kinds, unelastic returning a single sound, and elastic rendering a succession of sounds; laws of the reflection of sound not so well understood as those of light; persons of a bad ear of deceived as to the side whence sound comes; trumpets inade to increase sounds, 167 59.

Source, rivers have their source in mountains, or elevated lakes,

Soutliminster narshes over-run with an army of mice, 491.

Spalanzani, his experiments concerning the power of reproductions in animals, 831 .

Spaniards, the only people in Europe acquainted with the value of the ass, 226 .

Spaniels, land and water, the offspring of the beagle, transported into Spain or Barbary, so altered, and converted there; a dog of the generous kind; the land-spaniel; the water-spaniel, 311, 312.

Spanish flies, described; their use in medicine, and as blisters.

See Cantharides, 822.

Spnrrows, house sparrow; various birds of the sparrow kind; their food; songsters of this class; their migrations, 537,538 ; a male and its mate, tliat have young, destroy ahove three thousand caterpillars in a week, 794

Sparrov-hazok, one of the baser race of hawks, 482 ; taught to fly at gane, but little obtained from its efforts; lately asserted. upon respectable authority, the boldest of all for the pleasures of the chase, 486

Sparus, the sea-bream, its deseription, 648

Spnzon, different seasons for fisly to deposit their spawn, 612 . Spazoning, peculiar preparation of the lamprey for spawning,
638 .

Spears (burning) a peeuliar kind of aurora borealis, 113 .

Spears, the liorns of the stag the third year, $26^{\circ}$.

Spermaceti, the whole oil of the cachalot casily converted into that conerete; efficacy of spermaceti in medicine very small, 624. Spernaceti whale, the cachalot, described, 623 .

Spiders, in South America and Africa, as large as sparrows, 120 ; the spider for several months together subsists upon a single meal, 153 ; chief of our native spiders not venomous; Martinico spider's body as large as a hen's egg ; manner of making their webs; Lister has distinguished the sexes of this animal; experiunent made by Mr. Reaumur to turn their lahours to the advantage of man; gloves made from their webs; found it inpracticable to rear them, 747 to 751 .

Spiders (water) inhabit the bottom, yet never wet, but enclosed in a bubble of air surrounding them on all sides, 751 .

Spinal marrow and the brain, the parts first seen begun in the embryo, 159.

Spinous elass of fishes already extended to four hundred sorts, 646; Gouan's system and arrangement of the various sorts of spinous fishes, 647 ; their gencral leading marks and difference from others, 651

Spirits of wine flame with a candle, not with a spark, 24 .

Spitzbergen, bodies never corrupt there, though buried for 30 years, 195.

Sponges, opinion of count Marsigli and others about them; that of Rumph and Jussien set in a clearer light by Mr. Ellis, 837. 563 .

Sports, one peculiar to the Italians, in which horses without riders run against each other, 217; remarkuble on liorseback, among the grandees of Guinea, 22 ; of wild asses exlibited in Persia, 221; of the bird-catchers counterfeiting the cry of the owl, 490 ; of liunting the turkey in Canada, 499. See Coek, 494.

Spouts of water at sea cominon in the tropical seas, and some- times in our own; description of one in the Mediterranean by Tournefort; solutions offered for this phrenomenon; those called typhons, sometimes seen at land, differ from these at sea deseribed by mariners; description of that observed at Hatfield in Yorkshire, in 1687 ; land-spouts sometimes drop in a column of water at once upon the earth, and produce an inundation; they appear in the calmest weather at sea; facts still wanting to form a rational theory of them, 114, 115.

Spoutholes in the cetacoous tribe, described, 614.
Springs of water, expcrience alone can deternine the useful or noxious qualities of every spring, 50 ; one mentioned by Derham, wlich he never perceived to diminish in the greatest drought, when all ponds in the country were dry for several inonths, 58 .

Squash. See Folecat. See Stinkard, 338.

Squinting, instances of squinting communicated by a father to his off'spririg, 18\%,

Squirrel, a ruminating animal, 232 ; classed as sueh by Pierius, 2.94 ; the kind has as nuany varieties as any wild animal; enunueration of some; its way of moving is by bounds; few animals so tender, or so unfit for a change of abode; some live on the tops of trees, others feed on vegetables below, where also they tako shelter in storms; description of its qualities, food, and mansion; the martin destroys the squirrel, then takes possession of its mansion, 351 to 353.

Squirrels, Nature particular in the formation of these aninals for propagation; in Lapland vast numbers remove from one part to another; method of crossing broad rivers or extensive lakes; the Laplanders eat their fiesh; description of the common sort and of the gray Virginian kind: the Barbary; Siberian white; Carolina biaele; Prasilian; little ground Carolina, and Nizo Sprin squirrel; flying squirrel more common in America than in Europe; its fuod and inansion, 351 to 354.

Stug, first in rauk among quadrupeds; its elegant form descril). ed; no obvious difference between the internal structure of the stag and the bull, but to a nice observer; ruminutes not so easily as the cow or sheep; reason why; manner of knowing its age; differs in size and horns from a frllow-deer; seldom drinks in winter, and less in spring; different colours of stags; of animals, natives of this climate, none lave such a beautiful eye as the stag; horns increase in thickness and height from the second year of age to the eighth; grow differcntly in stags from sheep and cows; stag eastrated when its horns are off, they never grow auain; the sume operation performed when they are on, they never fall off; one testicle only tied up, lie loses the horn of the opposite side; horns resembled to a vegetable substance, grafted upon the liead of the stag ; tinic of feeling impressions of rut, or desire of copulation; effects the rut cuuses; stag lives about forty years; voice in the time of rut terrible; and then keeps dogs of intrepidly; a stag and a tiger enclosed in the snine arca, thie stag's defence so bold, the tiger was obliged to fly; the stag in rut ventures out to sea from one island to another, and swims best when fattest, 257 to 260 ; the hind, er female, uses all her arts to conceal her young from him, the niost dingerous of her pursuers; stag remaining wild in Hingland, called red-deer, found on moors bordering on Cornwall and Devonshire; different names given them according to their ages ; terms used by hunters pursuing the stag; the manner of knowing the track of a stag, and that of a hind; he changes his manner of feeding every month; in what manner; swims igainst the stream; the ancient manner of pursuing bim ; that of hunting him; and in China; stag of Corsica; a kind called by the ancients tregelaphus; Germans call it bran-deer, or brown-deer; a beautiful stag, thouslst a native of Sardinia, though perlaps of Africa or the East-Indies ; its description; stag royal in Mexico ; of Canada, brought into the state of domestic tameness, as our sheep, goats, and black cattle, 200 to 265.

Stuggarl, name of the stag the fourth year, 262.

Strlitions, law prohibiting exportation of stallions and mares, 222 189.

Stare, bird classed with the thrush, distinction from the rest of its tribe; its residence; its egigs; it is easily taught to speak; its food, 240 .

Star-fisl, general deseription of the tribe; are also called seanettles; cut in pieces, every part survives the operation, becoming a perfect animal, endered with its natural rapacity, $832,833$.

Starling, slender-billed bird of the sparrow kind, living upon insects, 537 .

Sturs (fixed) supposed by philosophers suns, 2

Stars (fulling) meteors or unctuous substances raised from the earth, 114 .

Statues of untiquity, first copied after the human form, now models of it, 148.

Stature, middle in men from five feet five to five feet eight inclies, $149 ; \mathrm{Mr}$. Derharn observes, probably the same now as at the beginning, 192 .

Stellaris, name given by the Latins to the bittern, 563 .

Steno, his opinion about the formation of the incipient animal, 123.

Stigmntn, holes through which esterpillars breathe, 786 .

Stickleback, the gasterosteus of the prickly-finned thorecic sort, 
description of this fish, 649; this fish sppears in great quantities every seven or eight years in the river Welland, near Spalding; a man employed by a farmer tu take them, for manuring lis grounda, got for a considerable time four shillings a-daj, selling them at a halfpenny a hushel, 656 .

Stillicon, bis two daughters, buried with mueh finery, found eleven hundred years after in good preservation, excepting the pearls, 692 .

Stinkard, name given by our sailers to ono or two snimals of the wessel kind, chiefly found in America, 288; and by the savages of Canada to the musk-rst, 367 .

Stint, smaller and shorter billed water-bird of the ersne kind, 568 . Stoat, the ernine, its description, 330 .

Stamach, Nature has contracted the stomseh of animals of the forest, suitable to their preearious way of living, 153 ; proportioned to the quality of the animsl's food, or the esse of obtaining it ; those who ehew the cud have four stomsehs; yet several of those have but two in Africa, 207; the camel hss a fifth stomach, as a reservoir of water for aceasional use, 431 ; birds have properly but one stomach, yet this is different in different kinds, 452 .

Stark, true difference botween it snd the erane; are birds of passsge, returning into Europe in Mareh; the Duteh sttentive to the preservation of the stork in their republie, the bird protected by lawe and the prejudiees of the people; countries where found; ancient Egyptiang' regard for this bird earried to aderation; the ancient ibis supposed the same which at present besrs the same name, 556,557 .

Storms, foretold by the barometer; above their region all is calm and serene; rise to the tops of the higliest mountains; confirmed by those whe have bean on the Andes, and by the deep snows that crown thom; with powerful effects, do not show great speed, 103, 104; one most dresdful in Herefordshire, in 1697; description of it, I10; do not terrify goats, 245 .

Stones, showers of stones raised by storms in one country, earried to snother, 114.

Stone-chatter, slender-billed bird of the sparrow-kind, 537; migrates, 538.

Stove, expeditious in bringing the animsl in the egg to perfeetion, 126.

Strabism, an inequality of sight, and particular cast of the eye; whenee it proceeds, 162

Stream of rivers mere rapid in proportion as its clannel is diminished, and why, 60 .

Strength, a just way of estimsting humsn strength, by perseverance and agility of motions; not liereditary ; prodigies of it; Maximin the emperor deseribed; instanees of it in Milo, and also in Athanatus; estimation of strength in animals by the bulk of their museles very fallacious; thin and raw-boned men being generally stronger and more powerful than those seemingly more inuscular; women much inferior in strength to men; of man less valuable since the invention of gunpowder, of new machines, and the applieation of the power of animals to the purposes of life; the comparative strength of 8 horse, measured, not by what he can carry, but by what he can draw, 150 to 152; of the inliabitants round the poles is amazing, 179 .

Stromateus, a soft-finned apodal fish, deseribed, 649.

Struthophagi, nations so called from their fundness of the flesh of the ostrich, 465 .

Stuffs, made of hair of snimals sbout Angors, 247 ; half composed of silk forbid to be worn at home, as s luxurious refinement, 796.

Stunts, name given to whales at the age of two years, 618 .

Sturgeon, s cartilaginnus fish, of a considerable size, jet flies terrified from the smallest fishes; its deseription; three kinds of it; the largest eaught in Great Britain taken in the Eske, where frcquently found weigling four hundred and fifty pounds; live in society among themselves; and Gesner lras seen them shoal together at the notes of a trumpet; in the water it is one of the strongest fishes, and often bresks the nets that encloso it ; but its hesd once raised above wster, its activity ceases; two methods of preparing it ; that from America not so good \&s from the north of Europe eaviar made with the roe of sll kinds of sturgeen; manner of making it, 640 to 642 .

Sucking-fish, the remora, sticks to the shark; called the shark's pilot, 631 .

Sucking-fish, the echineis, a soft-finned thoraeic fish; its deacription, 650 .

Suction, from whence that amazing power in the lamprey arises, 638 .

Sugar, the white sort in the tropical climate sometimen full of maggots, 92. No. $79 \& 80$.
Sulphur, with iron filings kneaded together into a paste, with water, when heating, produce flame, 23.

Sun, mock suns and other meteors seen in the $A l p s, 42 ;$ in the polar regions, 110; retlected upon opposito clouds, appear like three or tour real suns in the firnisment; real sun always resdily known by superior brightness; the rainbow alse different in those countries, 112; not easy to conceive how it whitens wax and linea, and darkens the humsn complexion, 184

643.

Sun-fish, an aromalous cartilaginous fish, like a bulky head,

Surf of the sen, name the mariners givo waves, breaking againat the shore, 80 .

Surius $m$ rat, the phalanger, a small monkey, deseribed, 415 .

Surinam taud, the pipal, s hideous toad ; its deseription, 707.

Surmalat, with Mr. Buffon, the great rat, a hateful rapaciou ereature, 363

Surmulet, the mullus, a spinous fisin ; its deseription, 648 .

Sucullows, time of their naigrations; departure of some, and retreat of others into old walls, from the inclenencies of winter, wrap the migrstions of birds in great obseurity, 458; experiment of Mr. Buffon to this purpose, ib.; with 11 s birds of passage; breed in Upper Egypt snd the land of Java, snd never disappoar, 538; hause-swallaw; cliaracteristics of the swallow tribe; st the end of September they depart; those migrating first seen in Afriea, in the beginning of Oetober, having performed their journey in seven days; sometimes seen, interrupted by contrary winds, wavering in their course st sea, and lighting upon the ships in their passage; a doubt whether all su'allows thus migrate, or sonie others of this species exteruslly alike, and internslly different, be differently affected by the approsch of winter; observations made to this purpose by Reaunur, Friseh, and Klein; Chinese pluck their nests from rocks, and send great numbers into the East-Indies for sale; gluttons esteem them great delicacies, dissolved in chicken or mutton broth ; the number of their eggs, 546 to 543 .

Szoullaw of Ternate, or Gud's bird, the bird of parsdise, described, 523

Swammerdam lent attention to testaceous animsls, almost ex. ceeding eredibility, 681 .

Suran, a stately web-footed water-fowl; doubt whether the tame kind be in s state of nature; none found in Europe; the wild owan, thougb strongly resembling it in colour and form, yet another bird; differences betwoen wild and tame swans; the tame nost silent, the wild has a loud and disagreeable note; from thence called the hooper; sccounts sufficient to suspend an opinion of its musical abilities; two month bstching, and a year growing to proper size; longest in the shell of any bird; said to live three hundred years by an act of Edward IV. the son of the king was allowed to keep a swan, and no others, unless possessed of five marks a year; pu. nishment for taking their eggs, imprisonnent for a yesr and a day and a fine st the king's will; plaees which abound with them, 593 to 595 .

Swarms, (bec-hive) seversl swarms in the year, the first alway. the best, 806 .

Sueden, asses a sort of rarity in Sweden, 226 .

Sucetmeats, in tropical cliniates, exposed by day in the sun, to prevent their putrefying by the niglit sir, 92.

Swift, a bird of the swallow kind; peculiar position of the toos, 546 .

Siviftness of saroges, many surprising storieg about it, 150 .

Sword-fish, eneounters the whale, 619 ; its deseription, 647, 648 .

Syagushes, carnivoroiss animals, like the jackal snd wolf, hunt in packs, 208.

Symmetry and proportion of the human body, 140 .

Sympatletic affection of yawning; a ridieulous instance of it practised upon professor M'Laurin, at Edinburgl, 144.

Synuria, a lubrieating liguor in the joints, so called by anatomists, 149 .

Syria, most of its eities destroyed in 1182 by sn earthquake, 32 . System, in what manner the harmony of our planetary system is preserved, 2; very useful in natural history; books centaining them, useful to be consulted, but unnecessary to be read; that of Linneus deserves the preferenee; faults of systemstic writers in natural history, 199, 200; what has given birth to the variety of systems in natural listory, 202. See Gouan, 647 .

\section{T.}

Tabbies, streaked cats, to which the civet's colonr is compared, 341 .

Tajucu. See Peccary, 282 
Tails of sheep a foot brosd, and weighing from twenty to thirty pounds, sometimes supported by a board upon whesls, 244 . $41 \mathrm{I}$

Talapoin, eighth division of monkeys of the ancient continent,

Talons, in what manner produced in animals, 147.

Tamain, a monkey of the second sort of the sugoin kind; description, 412.

'Tamandua, sn snt-bear, larger snd smaller, lives upon ants, 441

Tamis-bird, one of the names of the Guinea-hen, described, 503 .

Tanais, a principal river in Europe, parting it from Asia, 61

Tanrec, of the hedge-hog kind, different enough to constitute another species; covered with prickles, though uixed with hair; only found in the East Indies; Indians consider its flesh a delicacy, 375 .

Topeti, the Brssilian rabbit. -See Rabbit, 349

Tupir, the largest animal of America, not comparsble to the elephant of Africa in size, 211 ; considered as the hippopotamus of the new continent; its description, 439

277.

Tarantula, the bite of this animsl, and its cure by music, all a deception; instance of it, 166 ; native of Apulia in Italy; description, 751 .

472

Tarcel, nsme falconers give the male bird of prey; and why,

Tariguagua, ruggedness of road from it up to the Andes, 43.

Tarnassar, grest bird in the Esat Indies, no other than the condor, 478.

Tarsier, a monkey, lsst of the elass of the oppossum kinds, 415.

Tarters, their religion consists in part by managing their whis kers; they wared a bloody war with the Persians as infidels, for not giving the whiskers the orthodox cut, 145, 140; Samoeid, first distinct race of men round the pole, described, 178; the Ostiac, a race travelled down from the north, and originslly sprung from $\mathrm{mi}$ nute savsges, 179 .

Tartary comprehends great part of Asia; natives end manners, $179,180$.

Taste, in sll substances, on mountain tops, and valley bottoms, 98 ; to determine somewhst upon the nature of tastes, bodies to be tasted must be moistened, or dissolved by saliva, to produce a sensation; the tongue and body to be tasted, being dry, no taste ensues; relish of tastes stronger in children than in persons advanced in life, 170 .

Totou, or armadillo, a quadruped ; covered with shells, 380 .

Tatu-apara, first of the kinds of the armadillo; the second, the tatou of Ray, or the encoubert of Buffon; the third, the tatuette; their diversities described, 382.

Teul, smallest bird of the duck-kind distinguished, 598 .

Teats, great variety of them in snimals; their form, and how placed, I 47 .

Teeth in cows, eight cutting tecth in their lower jsw, 234.

Teeth, coloured, the passion for them in China and Japan; in some parts of Indis black teeth desired with ardour, 140; teeth of animals vsrious; how formed in man, 147; of the elephant, shed like horns of deer, or obtained, after death, not yet known; natives of Africa find them in their forests ; of the narwhale surpass ivory; ascribed to a different animal; curiosity, and the desire of scarce things, msde them very valuable a century ago, 622 ; the white shark is said to have one hundred snd forty-four teeth, 629 .

Tegg, what the hunters c8ll the doe the second year, 266 .

Tejuguacu, tockey, and cordyle, sll of the lizard kind, graduslly less, fill up the chasin between the crocodile and the African iguana, 720 .

Tempests, loudest formed by united contributions of minerals, vegetables, and animals, increasing the streams of air fleeting round the globe, 99; frequent under the tropics, and a space beyond them, $104^{\circ}$ in Arabia and Africa described, 106.

Teneriffe (the peak of) a mile and a half perpendicular from the sea, 45.

Tendrac, an animal les than a mole, different from the hedgehog, and a different species; description; grunt like logs, and love to be near water, 374 .

Ternate, a Molucca island, its swallow taken for the bird of paradise, 523 .

Terrier, first division of dogs of the generous kind, used for bunting, 312

Testaceous substances on the tops of inountains, and in the heart of msrble, 6 .

Thales, the philosopher, held all things made of water, 42

Thames wster, and thst of the 1ndus, inost liglit and wholesome, 50 .

Theories of the earth, those of the most celebrated authors, 7 .
Theory of evaporstion, for the formation of clouds, 107, 108; other theories upon that subject; theory of sympathy, of Fathet Malbranche, beautiful upon nionstrous productions, 187 .

Therusia, an island, a pleared unexpectedly to mariners, 37.

Thermometer neasures hest and cold by a fixed standard; description, 52.

Theutys, a prickly-finned abdominal fish, description of it, 649 .

Thibet, the musk from thence reckonod the best; sells st $14 \mathrm{~s}$. the ounce, 256 ; the peacock there the nost beautiful of the festhered creation, 498

Tharacic fish, that which has the ventral fins directly under the pectorsil fins, 647 .

Throat of the great Freenland whale is so narrow, that any animal larger then a lierring could not enter, 618 ; but that of the cachalot can with great ease swallow an $0 x, 623$; that of the shark most annazing, 629

Thrush, \& slender-billed bird of the sparrow kind, 537 ; its distinction from all of the kind; its song very fine; the largest of the kind with a musical voice ; its food, 539 .

Thumb-footed shell-fikh, testaccous, described, 694 .

Thunder, Ulloa heard it rolling beneath him, when upon the Andes, 44 ; its cloud slways moves against the wind, 103 ; a sound produced by the opposition of two clouds, and continued by rever. berated echo; thunder clesrs the air and kills insects noxious to vegetation, 109.

Thyroid cartilage forms a lump upon the wind-pipe in men, not seen in women, 147.

Tides, with Pliny, were influenced partly by the sun, and in a greater degrae by the moon; Kepler first conjectured sttraction the principal cause of them; the precise manner discovered by Newton; high tides happen at the same tiune, on opposite sides of the globe, whers waters ars farthest from the moon; solar and lunar tides; grestest in siziges, least in quadratures ; flows strongest in narrowest places; Mediterranean, Baltic, and Black Sea, no sensible tides, the gulf of Venice excepted, and why; higher in the torrid zone, than in the rest of the ocesn; greatest in the river Injus, rising thirty feet ; remsrkably high on the coasts of Malay, in the otraits of Sunds, the Red Sea, the gulf of St. Lawrence, along the coast of China and Jspan, st Panams, and in the gulf of Bengal ; those at Tonquin most remarkable in the world; one tide and one ebb, in twenty-four hours; twics in each wonth no tide at all; in the straits of Magellan it rises twenty feet, flows six hours, and the ebb lasts but two hours, 73 to 76 .

Tiger leaps twenty feet at a spring, 208; defested by a stag, 260 ; taught to defend herds, 288 ; attacks the lion, 295 ; often bigger than the lion; nothing tames it ; perfsctly resembles the cat; thres sorts in Sunda Rajsh's dominions; the royal tiger cerrics a buffalo over its shoulder to its den; said to follow the rhinoceros for its excrements; other tales about it; under Augustus, a tiger an oxtraordinary sight; the species scarce; opinion of Varro, that it was never taken slive; the sncisnts commended it for beauty among quadrupede, equal to that of the peacock among birds; supposed to bring forth four or five young st a time ; expresses his resentment at the lion; the skin estecrned in the esst. particularly in Chins; battle of one tiger and three elephants at Siau described; another between \& crocodile; the red tiger, Mr. Buffon's cougar; common in Guinea, Brasil, Parsguay, and other parts of South America; the flesh superior to mutton, 297 to 302 ; and esteemed by the negroes as a dainty, 315

Tiger-cat, or cat-8-mountain, s beautiful animal of its kind, 304 . Tigris, a great river in Asia, lost under mount Taurus, 66 . Tingitanians, and Egyptiuns, famous for fine horses, 218 .

Tipula (voater) of the second order of insects; description of it, 779 . Tipu! $n$, long-legged gnat, description of this insect, 825 .

Titmouse, a slender-billed bird of the sparrow kind, 537 .

Toad, some bigger than ducks, 120 ; their flesh is s delicacy on the coast of Guines, 315 ; differences between the frog and it, as to figure and conformation, 697 ; their nature, appetites, and food; coupling; difficulty in bringing fortl $;$; curious particulars relating to this animal; one swallowing a bes alive, the stomsch stung, and the insect vomited up again; toads not venomious; accounts of toads taken inwardly; ditficult to be killed; lives for centuries in a rock, or within an oak, without access, nourishment, or sir, and yet found alive and perfect; scconnts of this; toads suck cancerous brensts, and perform a cure; progress of this operation; the rubeth, the land toad, alone has the property of sucking; doubtful whether they dis by interns] or external application of the cancerous niatter; description of the Surinam tesd, called pipal, 702 to 707 . 506. 
Toes, usually four in all animala of the poultry kind ; in a species of cock amount to five, 494 .

Tune, a continuing tone produced from a non-elastic body, repeating blows quick and often; of a sonorous body made to depend upon the number of vibrations, not the impelling force, is miataking an effect for a cause; half tones rejected in all countries where mueic is in its infancy, as in China, $164,165$.

Tongres, a city in the eounty of Liege formerly encompassed by the sea, and at present thirty-five leagues distant from it, 81 .

Tougue of the rain-deer a great delieacy, 277; the flaningo's much celebrated, and larger than that of any bird, s6t; of the great Greenland whale, fills severa] hogsheads with blubber, $61 \%$.

Tonquin, tides there the noat remarkable in the world, 76 .

Tormudo, a formidable tempest, so called by the Spaniards, 106.

Torpedo, its description; by an unaccountable power, the instant touched even with a stick, when immediately taken ovt of the sea, it numbs the hand and arm, or whole body; the shoek resembles an electrical struke; sudden, tingling, and painful; accounts by Keupfor of numbuess produced by it; be believes holding in the breath prevents the violence; implicit belief of efficucy would be painfully undeceived; thia power not exerted upon every occasion; trials by Reaumur to this purpose; opinions concerning the cause of this strange effect; the fish dead, the power destroyed, then handled or eaten with security ; the power not extended to the degree some believe, reaching fishermen at the end of a line, or numbing fiales in the same pond; ridiculous excess of this numbing quality in the hiatory of Abysainia, by Godignua; Lorenzini, fron experinents, is convinced the power residea in two thin musclea of the back; several fishes have acquired the name of the torpedo possessed of the sa. e quality; Maore's and Condamine s accounts of them, 6,25 to 637 .

Tortoise ranked among crustaceous fiahcs, though superior to thern all; amphibious, according to Seba; distinguished into two clasaes, the laad tortoise, and the sea turtle; differ more in habita than conformation; deacription; principal distinctions ; varieties are, trunk-turtle, loggerhcud, havcks-bill, and green turtle; all generally found in warm countries, without retiring; the shell never clianges, and growing with the body, is formed in picces; a defence against dingerous attacks; the blood warm and red; how circulated; turtle larger than tortoise; weighs from fifty to five hundred pounds; ancients speak of some of amazing sizes; live to 80 and 120 years; can live without limbs, head, or brais, proved by experiments of Rhedi ; movea with great weight upon it; hears distinctly by means of an auditory conduit opening into the pouth; sighs when ill aituated, and slieds tears when distressed; torpid during winter, sleeping in sone cave, and breathing impereeptibly; aecount of a land-tortoise caught in a canal at Amsterdam; and of a turtle in the 1,oire, in 1729); the food ehiefly vegetables, though believed to eat insecta, snila, and buga, 66 ? to 676 .

Toucan, a bird of the pie kind, has a bill aa large aa ita body; of five varieties; the red-bealsed deseribed; its food; has birds, men, wronkeya, and serpents, to guard against ; seoops out its nest into the hollow of some tree; leaves scaree room to go in and uut, and with its great beak guards that entrance; found only in the warm parta of South Anurica, where it is valued for its tender and nouriahing flegh, and the beauty of ita pluniage, particularly the breast, the skin of which the Indians dry, and glue to their cheeka for beauty, 518,519 .

Touch, those parts of the body most excrcised in touching, acquire the greatest aecuracy; the fingers, by long habit, not from a greater quantity of nerves, become mastera in the art, 170.

Tournefort deseribes a apout seen in the Mediterranean, 114.

Trachinus, the weaver, a prickly-finned jugular fish, described, 648 .

Trachipterus, the sabre, a priekly-finned theracic fish; its deaeription, 649

Truck of a atag, manner of knowing it, and that of a hind, 262.

Tragelaphus, name of the atag with the ancients, 264.

Trups for horses, used by the Arabians for the wild sort, 216 ; for wild asses, used in the Archipelago, 224

Treocle, food for bees during winter, when robbed of their honey, 803 .

Trees (fossit) in the body of aolid rocks, and decp under the earth upon which they onee grew; eonjeetures upen this subjeet, 14; fond in quantitiea at tho mouth of the river Ness in Flanders, at the deptli of fifty feet, 82 ; laying twenty feet deep under ground for many ages, beeome hard and tough, proofs of alternate overflowings and desertions of the sea, 83 ; usually of the largest kinds in wild uncultivated wilderness, in the state of rude nature, 121 the banuma and plantain, so immense, as to be inimically inhabited by monkeys, snakea, and birda of the moat delightful plumage, 521 ; aige known by the number of their circles, 612 .
Trembley, first discevered in the polypus the power of reproduction, 831 .

Trichurus, a prickly-finned apodal fish, of a awerd-like form, 647 . 648 .

Trochus. See Sea-snail.

Troglodyte of Bontius, is the ouran-outang, or wild man of the woods, 399 .

Troglodytes, the mountain of that name in Arabia, has a pasago made through it by a disruption, as if artificia], 46.

Tropical seas, under them, and for a good space beyond, tempest. are frequent, and their effects ontieipated, 104 ; are those in which spouts are aeen very conmonly, 114; tropics supposed by Linnæu: the native spot of man, and the northern elimates only places of sojourning for them; an argument suffieient to prove the contrary 157 ; the elimater so liot, the dogs in procesa of time lose the delicacy of their sceot entirely, and why, 305 .

Trumpets, increase solunds in the same manner as the teleacope does bodies; persons hard of hearing fad the same advantage in the trumpet inade for this purpose, that ahort-aighted persona do from glasses; were they farther enlarged, they could be uaed to advantage only in a place of solitude and stillness, as the multitude of sounda would produce tumult and eonfusion, 167

Trunks of animals, that of the elepliant described, 418; that of the gnat may justly be deemed one of Nature's master-piceea, 825 . Trygon, the fire-flare, the enchantresa Circe armed lier son with apear headed with the spine of this fish, $6: 35$.

Tules of glass, drawn as fine as a hair, still preserve their hollow withiv. 56

Tubular ressels, discovered by Fallopiua, and called his tubes, $12: 3$.

Tufted duck, a variety of the kind, native of Europe, 598

Tumb/e-dung, a strong beetle, remarkable for nake and man ners, 821

Tumbler, in the division of Dr. Caius, a dog of the first claaa, or generous kind ; aupposed the lurcher, and described, 312.

Turbinuted shells are univalvea, and the first kind of Ariatotle'a divisiona, 679 .

Turbits, varicty of the tame pigeons, obtained by cross breed, 3.32

Turbots (and rays) extremely delicate in their choice of bait. ; a piece of herring or haddock, twelve houra out of the sea, and used as a bait, will not be touched, 634 .

Turliey, bird of the poultry kind; ita native country diaputed; arguments for the old and new continent ; first seen in France in the reign of Francia I. and in England in the reign of Henry VIII.; ita tenderneas with ua ; when young, arguea not for our elimate; in the wild atate, hardy and numeroua in the snowy foreata of Canada also larger and more beautiful than in the domestic atate; the savages weave the featbera into cloaks, and fashion them into fans and unbrellas; hunting the turkey a principal diversion with them, it flesh chicfly aupporting their families; manner of hunting ; the cock's antipathy to red; manner of increasing their animoaity for diversion; the female gentler, and particularly fond of egga of ants and caterpillars; lnya eighteen or twenty eggs; the young very tender at first; the hen's care of her young at the sigbt of a hird of prey ; in Norfolk weigh thirty pounda ; in the East Indies grow to weigh sixty ponpds, 499,500 .

Turkey, in Asia, has in difforent parta horses of almost all races, 219 ; lions found to diminish in number in this country, 292.

Turnings of riners, more numeroua as they approach the aea, bo. come indications through trackleas lands; the bends increasing, form diflerent channels and moutlis into the sea, as the Danube, Nile, Wolga, 60

Turnspit, a dog of the mongrel kind, 312

Turnstone, a amall bird of the crane kind, 568 .

Turtle-dore, one of the ruminating birds, 232. See Pigeon.

Turtle, prepares for laying, and deposits her eggs in the and, where in twenty-six days they are hatched by the sun; laya from 1511 to 200 in the senaon; the young run by instinct into the sea, ignorant of all danger; propagated on shore only; comes from sea un purpose in coupling season; female is passive and reluetant the nale is slow, hut grasps so faat nothing can loose the bold, 675

Tusks, those of a boar sometimes a foot long, 279 ; of the babyrouessa a fine ivory, sinootler and whiter than the elephant'a, but not so hard ; of enormous size, $286^{\circ}$; of eastrated animala scarce appear without the lips; those of a boar broken, abate his fierceness and venery; produeing nearly the aame effect as eastration, ib.; of the mammoth weigh four hundred pounda; those of the olephant from Africa, two hundred and fify; aome remarkable lately found near the Obio, and Miunse, in America; Dr. Hunter thinks them 
of a larger animal than the elephant, 425 ; of the narwhale, or seaunicorn, a cetacoous fish witli teeth, from nine to fourteen feet long, 621 .

Twins, never, while infants, so large or strong aa children that come aingly into the world, and why, 132.

Typhons, apouts so called seen at land; differ in several respects from those at sea, 115 .

Tyson, $(D r$.$) his description of an ouran-outang, by the name$ of pigmy, the best and most exact. See Ouran-outang, 400 .

\section{V.}

Valerian, a plant of which cats are exceseively fond, 290.

Valle, (Pietro) his description of Persian horses, 219.

Vainpyre, a foreign bat having the reputed faculty of drawing blood from parsons asleep, and thus destroying them before they awake. See Bat, $38 \overline{\text { s. }}$ 333.

Vunsire, a sort of ferret of Madagascar, according to Mr. Buffon,

Vapour of metala in mines not so noxious as those of substances with which ores are usually united, such an arsenic, cimnabar, \&c. ; fragrance of their smell ; warnings about them, 23; disengaged from water, and attenuated, ascends into the atmosphere, where condensed and acquiring weigbt as it rolls, falls down in a shape suitable to the temperature of its elevation, 108 ; most foetid, breathed from the jaws of the wolf, 322.

Varenius, his opinion upon the formation of rivers, 58.

Vari, a kind of maki, last of the monkey kind, its description, 413.

Voult, go to rault, phrase used by hunters when the hare enters

holea like the rabbit, 347 .

Vegetables, vegetable earth; the bed of it, in an inhabited country, must be alwaye diminishing, and why, 16 ; plant with a round bulbous head, which, when dried, becornes of amazing elasticity, grews near the extremity of that region, on mountains where continual snow reigns, 44 ; like fluids and mineral substances, produce air in a copious manner, 93 ; totally unprotected, and exposed to every assailant, 119; those in a dry and sunny soil, are strong and vigorous, not luxuriant; and those the joint product of heat and mois. ture, are luxuriant and tender ; different kinds appropriated to different appetites of animals, and wly ; birds distribute the seeds of vegetablea where they fly; vegetables cover the bottom of many parts of the sea, 120 ; but few noxious; that life as inuch promoted by human industry, as animal life is diminished, 122 ; the ass gives preference over othere to the plantain, 225 ; the sole foud of ruminating animals, 231 ; animals feeding on regetableo most inoffensive and timorous, 345 ; gome possessed of motion; what constitutes the difference between animal and vegetable life, difficult, if not impossible, to answer, 828; not pessessed of one power which animals have, the actual ability, or awkward attempt at self-preservation, ib. ; thiose called marine grow to a monstrous size, 83:3.

Vegetation anticipated in its progress by bees, 803 .

Velino, a river in ltaly, has a cataract of 150 feet perpendicular in height, 65.

Velocity, not alone the actuating force of winds, but also the decree of density, 104.

Velvet-like downy substance upon the akin covering the skull, when the born of a deer is fallen off, 257 .

Velvet-duck, a variety of the common duck, a native of the European dominions, 598.

Venery, partridges immoderately addicted to it, to an unnatural degree, 508 .

Venom, given to the fire-flare by Pliny, Falian, and Oppian, in a regrec to affect the inanimate creation; many reasons to doubt of it, 635 .

Venus. See Nose, 140. See Face, 192.

V'erges, or orifices of the suala, are two, one active, the other passive, 685.

Vermin, hespitals erected by the Bramins in India for the maintenance of all kinds of vermin, 181 ; less found with asses, than with other animals covered with hair, 226.

Vertigo, in goata, produced by an immoderate cold, 246

Vesuvius, its eruptions, the most remarkable described by Valetta; account of another by bishop Berkeley, 27 to 29.

Vibrations. Seo Tone, 164.

Vineta, a port of Pomerania, overflowed and destroyed by the Baltic, 82 .

Violet-crah of the Curibhes islands, most noted for shape, delicacy of flesh, and singularity of manners, 665,666 .

Viper, most vivacious of reptiles; experiment on a viper in the seceiver of the air-pump, by Mr. Boyle, $93 ; \mathrm{kept}$ in boses for $\mathrm{eix}$ or eight mouths, without any lood; its progressive motion, 729; the only animal in Great Britain, whose hite is feared ; do not de vour their young; their food; by tho application of olive oil, the bite of the viper effectually cured; who first discovored this remody ; effects of the viper's bite, 735,736 .

Vision, its errors; objects represented upside down and double; the point without sensation; and want of measure for distance, 159,160 .

Viriparous and oviparous animals, the two classes for generation and production; all other modes held imaginary and erroneous 125 ; the bl:nny, a spinous fish, brings forth two or three hundred young at a time, alive and playing around their parent, 612.

Ukruine, the cattlo there become very fat, and considered the largest of all Europe, 2:6.

Ulloa, his description of South America, of Cotopaxi, of Quite, of the Andes, and a volcano, 29 .

Umbuical vessels, those of the placenta to the foetns, 131.

UTun, ne of the two kinds of the sloth, an animal about the size of a badger, $44 \%$.

Underhung, expression among painters, meaning a prominent under-jaw, 144.

Cuderstanding, comparative progress of it; greater in infanta than in children of tliree or four years old, 136 .

lindulations, in elastic budios supposed by the ear one continued sound, though in reality many, 164

Unicorn, of the sea, a whale with teeth in the upper-jaw; its deseription, 349. See Narvohale.

Unirulve shells, tirst division by Aristotle, as to figure, 679.

Voicuno, opinions of philosophers and ignorant men about it; three very remarkable in Europe, 26; Albouras most famous in Asia; one in the island of Ternate; in the Nolucca islands, in Japan, in Java and Sumatra, in the Cape de Verde islands, the peak in Teneriffe, and also in Anerica, 29; marino ones not very frequent, and why, 38 .

Urunoscopus, a prickly-finned apodal fish ; description of it, 648 .

Urchins, or echini, a multivalve shell-fish; nanner of exhibiting this extraordinary animal in every light; its description; some kinds as good eating as the lobster, and its eggs considered as a great delicacy, 693,694 .

Urinary passages, effects of the cantharidea falling principally upon thein, $3 \% 2$.

Urine of animals found efficacious in some disorders, 250; of the lion insupportable, 205; of camels, an ingredient in sal ammoniac, 432 ; of birds difier from that of other animals, 452 .

Urson or Hudson, of the hedgehog kind, a native of Hudson's bay; its description; aleeps much, and feeds upon the bark of juniper ; in winter, snow serves it as drink, and in summer it laps water like a dog, 377.

Urus and bison in fact descendants of one common stock, and naturalista assigning them different classes, have separated what is really united; this wild bull chiefly met with in Lithuania; deseription of it ; generally taken by pit-falls; the breed clicfly occupies the cold and temperate zones, $235,236$.

Vulture kind, vulture and dog, about Grand Cairo in Egypt, keop together in a sociable friendly manner, and bring up their young in the same nest, 317 ; its distinctive marks from other kinds of carnivorous birds; the flesh liked, and dress for eating, according to Bellonius, 472 ; of Senegal, said to carry off children, probably no otler than the condor, 478 ; seldem attacks living aniuals when supplied with dead, 479 ; description of the golden vulture, ib.

Vuiture, bird of prey, next in rank to the eagle, less generous and bold, 47, countries where found; unknown in England; flocka of them near Grand Cairo, not permitted to be destroyed, as they devour all the filth and carrion there; in company with wild dogs, teur and devour together without quarrelling; wonderful methed of separating $\mathrm{t}_{\mathrm{i}}$ flesh from the bones, and lecing the skin entire; smell carrion from afar; follow those that hunt for skins alone, and so voraciously till thensulves as merely. to waddle, and to want diagrorging before they fly away ; are little apprehenaive of danger, and allow themselves to be approached: an eagle falling in upon their meals, keeps them at a distance till he be satiated; an ox returning holle alone, lying down by the way, becones their prey, and is devoured alive; attempt oxen grazing; destroy lambs, and feed much upon serpents, rabbits, hares, and whit game they can overpower; also demolish whole broods of crocodiles; lay two eggs at a time, and produce but once a year; mako nests in inaccessible cliffs and remotest places; their flesh, lean, stringy, nauaeous, tasting and smelling of earrion; the down of their wing makéa a protty kind of fur, commonly aold in Aaiatic markets, 479 to 481.

Vultures, (King of) description of this bird, 481. 
W.

Wulfischoes, whales' provender, insects flosting in clusters on the surface of the gea, and called Medusa by Linnæus, 619 .

Walnut-tiees, with walnuts on the stem, leaves, and branches, in exact preservation, found at twenty-six feet deptl round the city of Modena in Italy, 83 406.

Wandcrow, a baboon, less than the mandril; its description,

Wappe, dog of the mongrel kind, in the third division of $\mathrm{Dr}$ Caius, 313

Warbling of birds, so loud and various in modulation, not easily to be accounted for, 451 .

Warine, the Brasilian guariba, largest of the monkey kind in Alnerica, 412.

Waree, hog of the isthmus of Darien, described by Wafer, 286.

Wasps, ruminating insccta, or sceiningly such, 232 ; their description und habits; their habitation scarcely completed when the inhabitant dies; have two or three liundred quecns in a hive; their nest a most eurious object; the social waspe gather no honey themolves, though fond of awects; fierce battles with the bees, who make up by conduct and numbers the deficiency of prowess ; their depredationa; where found, other flies desert the place ; live but one seaaon; caonot endure winter; before new-year they wither and die, having butchered their young; in every nest one or two females aurvive; impregnated the preceding season, she begins in epring to lay eggs; and belore June produces ten thougand young, which are nursed and fed by her alone; solitary wasp, its mannerg; provisions made for the young at leaving the egg; the proviaions arranged and laid in, the old one closes the hole and dies; the young leaving the egg are scarcely visible; bow the life of the young is spent; waspy of Europe innocent compared to those of the tropical climates; description of those of the West Indies, and their liabita ; paina of their sting insupportable, more terrible than that of a scorpion, the part $\mathrm{swells,}$ and people are so disfigured $\mathrm{as}$ ecarce to be known, 809 to 813 .

Water, its parts infinitely sinall; driven through the pores of gold; penetrating through all substances, except glass; enter the composition of all bodies, veyetable, animal, and fossil ; birds, beasta, fishes, insecty, trees, and vegotables, with their parts, have growth from it, and by putrefaction become water; gives all other bodiey firıness and durability; a phial, hermetically sealed, kep fifty years, deposed no tedinent, and continued transparent gathered after a thunder-clap, in sultry w'tather, deposits a real salt ; spring water collected from the air; of river waters, the Indus and the Thames offer the must light and wholosome; lightness, and not transparency, the test of purity ; purest waters distilled froun snow on tops of highest mountains; different kinda, and adapted to different coostitutioos; very transparent; fresh-water at sea, putrefies twice, sometimea thrice, in a voyage; a month at sea, senda up a noisome and dangerous vapour, which takea fire from a flame; elenentary water not compounded is ice kept in fusion; dilates in bulk by cold; confirmed by experiments, 43 to 52; very conpreasible and elastic; made to resemble air; a drop of water converted into yteam, capable of raising twenty ton weight; keeps its surface level and even; a single quart atuficient to burst a hogshead. and how, 52 to 55 ; water of the aea heavier and more buoyant than fresh-water, 7 I.

W'aler-spouts burst from the sea, and join miats immediately ahove thein, 110 ; most aurpriaing pliænomena, dreadful to mariners, and astonishing to observers of nature; comuson in the tropical seas, anietimes in our own; description of thuse seen by Tournefort in the Mediterranean, 114; solutions offered for this surprising phæenomenon, $11 \%$.

Water-iongtail, alender-billed bird of the sparrow kind. 5.37 . 70,73

$s$, their luminous appearance in the niglit, and the cause,

Wax, the first fifteen daya the bees make more wax than during the regt of the ycar. 806; of two kinds gathered by cunmon bees; tb't produced by black bees in tropical elinates only used for nedicinal purposes, being too aoft for candlex, as in Europe, c07.

Weasel, a small carnivorous animal; marks common to the kind these differ from the eat kind in the formation and disposition of claws; differ from the dog kind in a clothing of fur rather than hair; one of the species is like all the reat; this the smalleyt of the whole kind; its description; untameable and untractable; lides and aleeps three parts of the day, and sallies forth for prey in the ovening; attacks animals much above its own size; catchea rats and aice better than cats; also ainall birds; destraya youny poultry, and sucks the eggs; so nimbly runs ap high walls, no place is accure frow it ; in eultivated lands. it thins the number of hurtful vermin; never cries but when struck; all the kind have glands near the anus, secreting a substance foetid in some, and a perfume in others; this most offensive in summer, and insufferable when ir. ritated ; one sort in Anerica is by sailors called the atinkard; confined to a cage, is ever in uneasy egitations; must have leave to hide itself; eats only by stealth, and will not touch the foot until it begins to putrefy ; the female makes an easy bed for her young, and generally brings forth from three to five at a time, and with cloaed eyes; account of a weasel's forming her nest, and bringing forth licr young, in the putrid careass of a welf; the white ermine found in Great Britain is called the whitc weasel; its fur among us of no value, 328,329 ; of the wcasel kind, the martin most pleasing, 334 ; the boldest and most useful of all is the ichneumon, 337. See Stinkerd, 338 .

Weather, the meist alone prevents evaporation, 108.

Weathercoelis, often erroneous with Derham in regard to upper regions, 103

Weever, the trachinus, a prickly-finned jugular fiah, its descrip. tion, 648; the ating given by its back-fin is poisonous, 660 .

Weed, floating over great tracts of the aea, aerve as austenance for many fish, bearing similitude with such vegetables, 120 .

Weight of the human body often found to differ from itgelf; instances of it; the differeuce often aniount to a pound, or sometimes to a pound and a half: not easy to conceive whence this adventitious weight is derived; the portera of Constantinople carry burdens of nine hundred pounde weight; a men able to raise a weight of two thousand pounds; a horse will not carry upon his beck abeve two or three hundred pounds; whence this seeming superiority comes, 149 .

Well, burning, at Brosely, now stopped, had a fire-damp in it, which would kindle with the flame of a candle, 55 ; some continue full, noither affected by rain or drouglite, 83 .

656.

clland, river near Spalding, has amazing shoals of aticklebacks,

Wert (Sebald) a traveller, confirms the existence of gianta, on a coast of Soutl, America, towards the atraita of Magellan, 191.

Whale, the largest animal known; no precise anatomy of thie fish yet given; two centuriea sgo, they were described two hundred and fifty feet long; Biscayneera practised the whale-fishery near Greenland soon after the year 1300 ; seven different kinds distinguished by external figure or internal conformation; are gregarious animals; make migrations from one ocean to another, and generally resort where they have the least disturbance; great Greenland whale ; its description ; from sixty to seventy fcet long; the head one-third of ite bulk, it hearing is acute; breathes air at the surface of the water, and cannot remain under it like other fishes; it blows loudly throngh the spout-holes, and most tiercely when wounded; whalebone different from the bones of the bady; the fins are from five to eight feet long; the throat is narrow nothing larger than a herring can be swallowed; the tail, its only weapon of defenee, is twent y-four feet broad, and strikes hard blows one seen by Ray marbled, with the figures 122 distinetly narked upon it; the blubber and other parts turn out to very good acrount; the flesh palatable to anme nations; the female and male keep much together; their fidelity exceeds that of birds; do not cruse breeds; she goes witl young nine months, is theo fatter than at other times; produces two breasts and teats at pleasure; auckles her young a year, and how; is very tender of them; defends thens fiercely when purnued; instance of it ; dives with them, and conies up soon to give them breath; during the first year called sbortheads, and then yieldy fifty barrela of blubber; at two yeara they are ealled stunts, and after that akull-fish; the foor of this animal an insect called medusa by Linnaus, and walfischua by the lcelanders; pursues no other fish, and is inoffensive in its element; the whale-louse, of the shell-fish kind, zticks to its body as to the foul bottom of a ship, gets under the finy, and eats through the skin into the fat; the sword-fish affrights the whale, avoids the stroke of its tail, bounde upon its back, and cuts into it with the tootlued edges' of ita bill; the killer, a cetaceour fish of great strength, with powerful teath, boset the whale as dogs do a bull, tear it down, and then devour only its tongue; old manucr of taking the whale ; improvemeats hinted. 614 to 621 .

Whale (Spermenceti.) Sec Cachulot.

Wheat and currants, awallowed whole, indigestible to man, 469 .

Wheat-ear, a sliort-billed bird of the sparrow kind, thought foreign, 537 .

Whin-chot, a slender-billed bird of the sparrow kind, 537 .

Whip-snake, a very venomous gerpent of the East, is five feet long, and its bite kills in six hours time; happy preservation from one of them, 738 .

Whirlpool, the central point always lowcst, and why, 60 ; man. 
ner in which it is formed, 78; those of the ocean particularly dangerous; extraordinary one upon the consts of Norway, called the Maelstroom, 78, 79 .

Whirlwind, the most rapid formed by united contributions of minerals, vegetables, and animals, increasing the current of air, 99.

Whiskers, a man without them formerly considered as unfit for company in Spain; Nature denying, Art supplied the deficiency; a Spanish General borrowing money of the Venetians, pawned his whiskers, and took care to release them; part of the religion of the Tartars consists in the management of their whiskers, and they waged war with the Persians as infidels, whose whiskers had not the orthodox cut; the kings of Persia wore then matted witls gold thread, and the kings of France, of the first races, had then knotted and buttoned with gold, 145 .

Whiston, his reasoning concerning the theory of the earth, 8, 9; finds water enough in the tail of a comet for the universal deluge, 10.

White, the natural colour of man, all other tints proeed from greater or lesser heat of climate; among the white races of people, our own country bids fairest for pre-eminence, 184

White-bait, shoals appear near Greenwich in July, 656 .

White-nose, the inoustoc, monkey of the anciunt continent, a beautiful little animal; its description; a native of the Gold Coast, 411.

White-throat, a slender-billed bird of the sparrow kind, living upon insects, 537.

Widgeon, a variety of the European duck, described, but best known by its whistling sound, 5.5 .

Wild man of the woods. See Ourun-outung, 399.

Wind, a current of air ; artificial ; causes assigned for the variety, activity, continual change, and uncertain duration of it; in what manner to foretel the certainty of a wind, as the return of an eclipse ; to account for variations of wind upon land, not at present expected; recourse to be had to the ocean, and why; in many parts of the world the wind pays stated visits; in some places they blow one way by day, and another by night; in others, for one hali-year they go in a direction contrary to their former course ; in solle places the winds never change; the wind which nover varies is the great universal wind, blowing from the east to the west, in all exteusive oceans, where the land does not break the general current; the other winds are deviations of its current; many theories explain the inotion of the winds; that of Dr. Lyster; theory of Cartesius ; Dr. Halley's more plausible, $99,100$.

I"inds (Trude) blow from the poles towards the equator; were the surface of the globe sea, the winds would be constant, and blow in one direction; various cireurnstanees break its current, and drive it back against its general course, forcing it upon coasts that face the west ; want of a true system of trade winds, supplied by an imperfect history of them; north wind prevails during October, November, December, and January, in the Atlantic, under the temperate zone; north wind reigns during the winter in Nova Zembla, and other arctic countries; south wind prevails during July in the Cape do Verd Islands; nortl 1 -west wind blows during September at the Cape of Good Hope; regular winds produced by various causes upon land; ancient Greeks first observed them; in general, wherever a strong current of water, there is a wind to attend it ; regular winds produced by the flux and reflux of the sea; winds called monsoons; some peeuliar to certain coasts ; south wind constant upon those of Chili and Peru; other winds peculiar to various coasts, 100 to 102 .

Winds at land puff by intervals, and why; not so at sea ; east wind more constant than any otlıer, and generally nost powerful ; wind blowing one way and clouds moving anotlıer, forerunners of thunder; cause of this surprising appearance remains a secret; from sea, generally moister than those over tracts of land; morg boisterous in spring and autumn than at other seasons; their force does not depend upon velocity alone, but slso upon density; refleeted from sides of mountains and towers, often more powerful than in direct progression; rsise sandy deserts in one country, to deposit them upon some other; south winds in summer so hot in Egypt as almost to stop respiration, snd produce epidemic disorders, continuing for any length of time; deadly along the coasts of the Persian Gulf, and of India; assume a visible form, 103 to 105.

Wind-pipe in inen has a lump not scen in women, 147; nakes convolutions within a bird, and is called the labyrinth, this difference obtains in birds seemingly of the same species, 451 ; strange in the tluroat of the crane, 554 ; of the bittern, 562 ; in the wild swan, 594

Wings of birds, their description; bastard wing, 449 ; flap of a awan's wing breats a man'a leg; a similar blow from an cagle lays a man desd instantly, 450; of butterflies, distinguish them from flies of other kinds; their number and beautifinl colours, 79]

Winter beginning round the poles, the misty appearance of heat in southern climates is there produced by cold, 113

W'istiti, a nonkey of the sagoin kind, remarkable for the tufts of hair upon its fice, snd its annulated tail, 412.

Wolga, its length; abounds with water in May and June; at other times very shallow; the English disappointed in a trade into Persia through it, 61 ; receives thirty -three lesser rivers in its course. 64 ; and has seventy openings into the Caspian sea, 39.

Holf, wild dogs partake of the disposition of the wolf; the wolf taken young is grontls only while a $\mathrm{eub}$; as it grows older, discovers its natural appetite of rapine and cruelty, 309; experiments prove neither wolf nor fox of the same nature witb the dog, but each a distinet species, 315; a fierce, strong, cunning, carnivorous quadruped, exterually and interually so nearly resembling the dog, they seem modelled alike, yet have a perfect sntipathy to each other; deseription of the wolf; principal distinction from the dog is the eye, whieh opens slantingly upwards in the same direction with the nose; slso the tril is long, busliy, hanging lank; the wolf lives about twenty years; it is not much with those of his kind, yet hunts in packs with them; quarrelling, they devour each other; is watchful and easily waked; supplied with water, lives four or five days without food ; carries off a slieep without touching the ground, and runs with it swifter than his pursuers; smells a carcass at a great distance; leaving the wood, goes out against the wind; particularly fond of human flesh; follow armies, and arrive in numbers upon a field of battle; two or three wolves keep a province for a tine in continual alarm; distinguished by huntsnien into joung, old, and great wolf; minner of hunting then ; young dogs shudder at their sight ; the molf killed, no dogs show an appetite to enjoy their victory ; the fiesh so very indifferent, no creature eats it but the kind itself; breathe a nost foetid vapour from their jaws; often die of liunger after running inad by furious sgitations; season for coupling lasts but fifteen days; no strong attachment appears between male and female; seek eael other only once a year; couple in winter, several males then follow one female, dispute cruelly, growl, and tear each other, and sometines kill that preferred by the fomale; she flies trom all with the chosen when the rest are asleep; males pass from one female to another; time of pregnancy about three months and a half; couple like the dorg, and the separation hindered by the same eallse; bring forth from five to six, or nine at a litter; the cubs biought forth with eyes closed; young wolves play with hares or birds brought by their dams, and end by killing them; able to engender when two years old; lranco, Spain, and Italy, much infested with them; England, lreland, and Scotland, happily free ; King Edgar first attempted to rid this kingdom, and in what manner Edward 1. issued a mandate to Peter Corbet for the destruction of them; some quite black, some white all over; found in Asia, Africa, and America ; in the Fast trained up for show, taught to dance and play tricks; one thus educated sells for four or five hundred crowns; in Lipland the wolf never altucks a rein-deer when baltered; wolves of North America used in hunting ; caught in pit-falls; a wolf, friar, and a womall, taken in ong the same night, 317 to 322 .

Wolf, (Golden) the Latin name for the Jackal, 325. 649.

Wolf-fish, the anarbicas; a soft-finned apodal fish; its description,

Womb, history of the ehild in the womb, 129 to 132 ; of the hare dirided in two, as a double organ, one side of which may bo filled, while the other remains empty, 346 ; description of the false womb of the oppossuin, 414 .

Women, snme continue pregnant a month beyond the usual time; those of Africa deliver thenselves, and are well a few hours after, 132; in barbarous countries, the laborious duties of life thrown upon the women; the chief and only aim of an Asiatic is possession of many women; iustance, in our own eountry, of a fine woman narried to an eunucli; a principal employment of those of Thibet, is reddening the teeth with herbs, and making their hair white, 138, 139; the body arrives at perfection sooner than in men; the persons of women as complete at twenty ss those of men st thirty, 141 ; lass apt to beeome bald than men; Mr. Buffon thinks they never become bald; there are too unany instances to the contrary, 142; lower eyelids drawn downwards when with child; the corners of the mnuth also; then likewise high shouldered; circuinstances under which the midwifes eall them all mouth and eyes, 148; the shoulders narrower, and the neck proportionably longer than in men, ib. ; first impulse of savage nature confirms wounen's slavery; the next of half barbarous nations, appropriates their beauty; and that of the perfectly polite engages their affections, 152 ; the boncs, cartilages, museles, snd other parts of the body, softer than in men; a woman of aixty lias a better chance than a man of that age to live to eighty; 
women longer in growing old than men, 205 ; in the pelar regions as defarmed st the men, 178; women of India deseribed; marry and eonsummate at eight, nine, or ten years old, and have children at that age ; cease bearing hefore the age of thirty; those of savage nations in a great measure exempt from painful laboura, 181 ; sfter a eatalogue of deformities, Linneus puts down the slender waists of women in Europe, by strait laeing destroying their health, through a mistaken notien of inıproving their beauty, 186; remarkable inatance of the power of imagination upon the tectus, 187.

Woods, in Britain, cut down by the Romans, and for what reason, 84 .

W'oodcack, or cock of the vood, of the grouse kind; plaees which this bird inhahits; how distinguished from the other birda of the poultry kind; the delieacy of its Hesh; its food and habitation; amorous desires first felt in spring; keeps to the place where he first courts, and continues till the trees have their leaves, and the forest is in bloom; its ery, clapping of wings, and ridiculous postures in this season; during which the females, attending his call, are impregnated; sportsmen use this time to fire st them, and take many while thus tame, though at others it is most timorous and watchful; the female much less than her mate, and so unlike him in plunage, she might be mistaken for another speeies; number and size of the eggs ; she hatehes thein without the cock, and when obliged to leave them in quest of food, go covers them with moss or leaves, it is diffienlt to hind them; she is then extremely tame and quiet; keepa her nest, though attempted to be driven away; the young being batched, they run with agility after the mother, though scareely disengaged from the shell ; their food ant's eggs, and wild mountain berries; older, they feed upon the topa of bether, and cones of pine-trees; are hardy; the clutehing time over, the young males forsake the mother, keep together till spring, when the first genial aceess sets them at variance for ever; fight each other like game-eoks, and easily fall a prey to the fowler, 505 to 507 .

Woolcock, bird of the crane kind ; ita dimensions, food, 568.

Woulchut, a rapacious bird ; third kind of the buteher bird, 487 .

Woodlouse, its deseription; bas three varieties, $75 \mathrm{H}$.

Woodpecker, of this bird are many kinds and varieties in each ; general characteristies; deseription of the green voodpecker, or woodspite; called the rain-foun in some parts; its food; its tongue, the instrument for killing and procuring food; want that intestine which anatomists call the creum; in wliat nianner they make nests, and how delieate in the ehoice; number of eggs; nests in warmer regiens of. Guinea and Brasil; little woodpecker, called by the natives of Brasil guiratemgn, 519 to 521 .

Woodicard, his essay towards a natural history ; detail of it, 8 .

Wool, the Spanish finer than ours; but in weight not comparable to that of Lineoln or Warwickshire; sorne Spanish wool required to work up with it, 243.

Werms of different kinds infest each speeies of fish 659 ; worns make the shells of fishes their food, 681 ; within the body of the eaterpillar, deveur its entrails without destroying its life, 795.

Worm (blind) of the serpent kind: lies torpid all winter, 796.

Worm (froth) an insect in that sert of sulustance on the surfaee of plants, 789

Worm lind, general deseription of the eartli-worm, 929.

Wrusse, the Jabrua, of the priekly-finned thoracic kind, (j48.

Wren and golden-crozoned vren, slender-billed birds of the sparrow kind, 537; villow wern, a wandering bird of the sparrow kind, 538 .
Wrinkles, whence those of the body and face proceed, 174.

Wryncek, or enekoo's sttendant, a little bird mort active in the ehase of the young cuckoo, 524 .

$\mathbf{x}$.

Xiphias, or the sword-fish, of the prickly-finned apodal kind, 648.

\section{Y}

Yellow-hnmmer, a small bird of the aparrow kind, 537, 538 . 140

Young People sometimos cease growing at fourteen or fifteen,

\section{Z.}

Zenland, inundations there, in which many villages were and remain overflowed, 82 .

Zebra, the mest beautiful, but wildest animal; a native of the aouthern parts of Africa ; nothing exeeds the delicate regularity of its colour; description; watehful and swift; its speed a proverb among Spaniards and Portuguese; stands better upon its legs than a horse; in what countriea found; the Portuguese pretend to have taned, and sent four from Africa to Lisbon, to draw the king'a coach; some sent to Brasil could not be tamed; Merolla asserts when tamed, they are still as estimable for swiftness as beauty; their noise resembles the confused barking of a mastiff dog; in two, the author saw, the skin below the jaw, npon the neek, hung loose in a kind of dewlap; they are easily fed ; some in England eat bread, meat, and tobaeco; the Emperor of Japan made a present of sixty thousand erowns value, for one received from the governor of Batavia; the great Mogul gave two thonsand ducats for another; African Ambassadors to the eourt of Constantinople, bring some witl them, as presents for the Grand Seignior ; zebra and wild ass of a very different species, 445,446 .

$Z c b u$, the barbary cow, and the grunting and Siberian cow, are but different races of the bison, 240 .

Zeiran, name of the fourth variety of gazelles, by Mr. Buffon, 251.

Zembla (Nova) north wind reigns there during winter, 101 ; a deseription of its inhabitants, 178 .

Zeus, or doree, of the prickly-finned thoracic kind; ita deserip. tion, 649 .

Zibet, ane of the twa species of the civet, according to Mr. Buffon ; distinction between them, 341 .

Znne (Temperate) properly speaking the theatre of natural bistery, 5 .

Zone (Torrid) in the centre the heat very tolerahle, in other places the cold painful; temperature and advantagez of perpetual spring under it, 44 ; lightning there not fatal or dangerous, 111 ; has the largest quadrupeds; all fond of the water, 239 .

Zoophytes, name of vegetable nature endued with animal life, 828 ; first elass of zoophytes, 829 ; all the tribe continue to live in separate parts; one animal by cuttings divided into distinct existences, sometimes into a thousand, 831 ; second class, 832

Zorille, a stiukard of the weasel kind ; resembles tlie skink; is smaller, and more beautifilly coloured, 338 . 


\section{DIRECTIONS TO THE BINDER.}

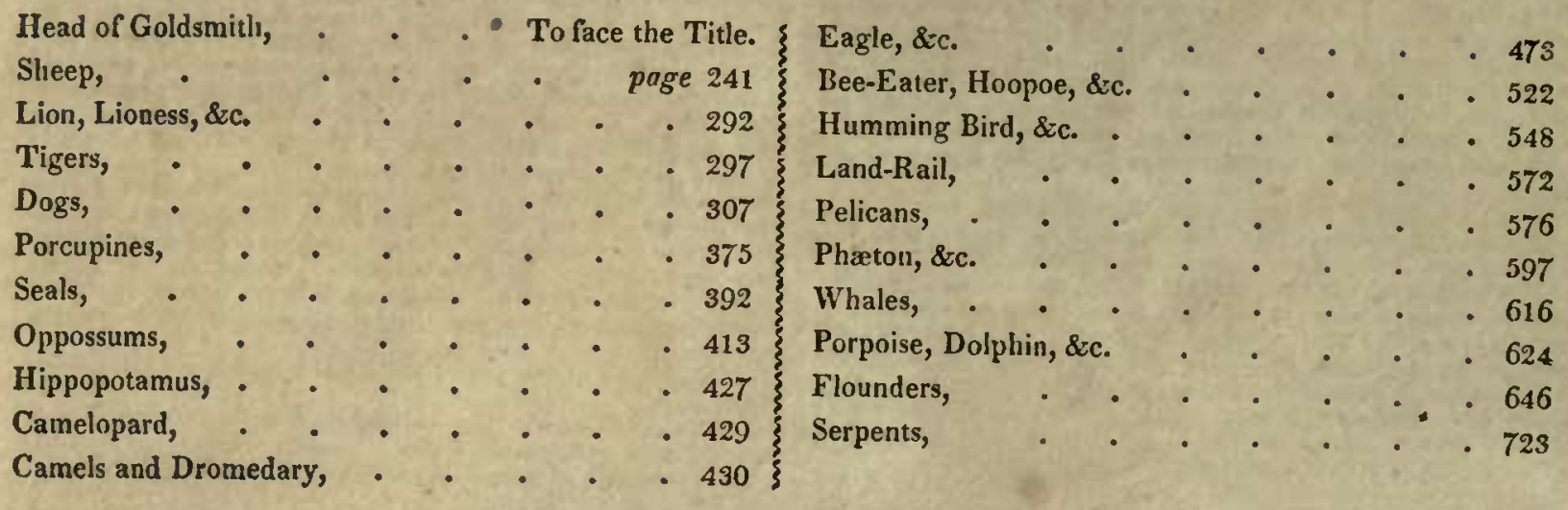





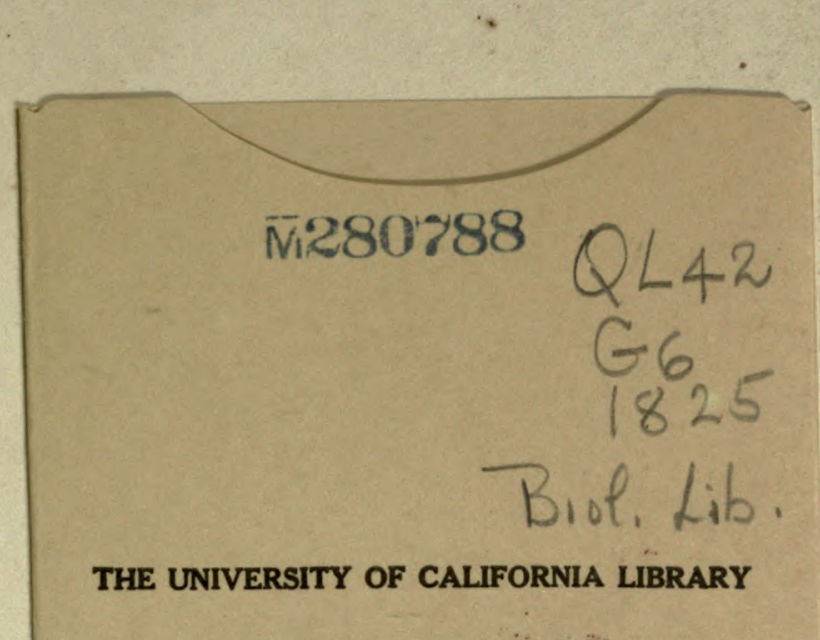


